
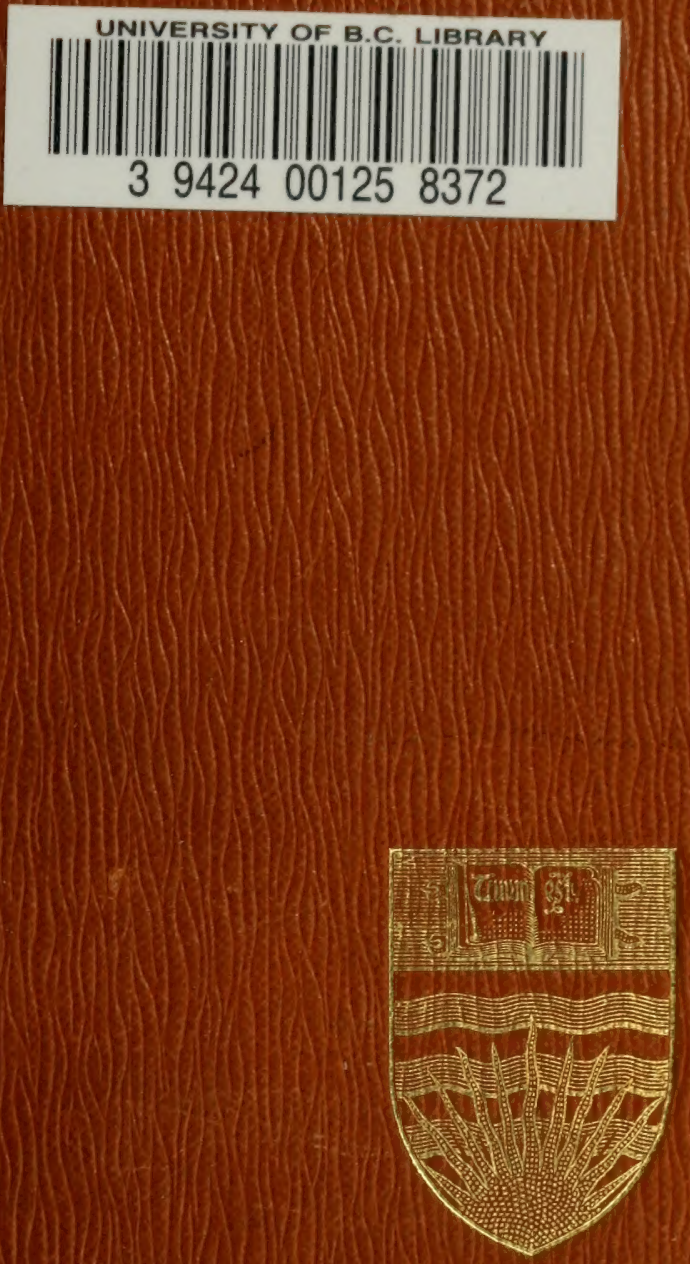

STORAGE ITEW

PROCESSING-CNE

L p 1-F $18 \mathrm{C}$

U.B.C. LIBRARY 


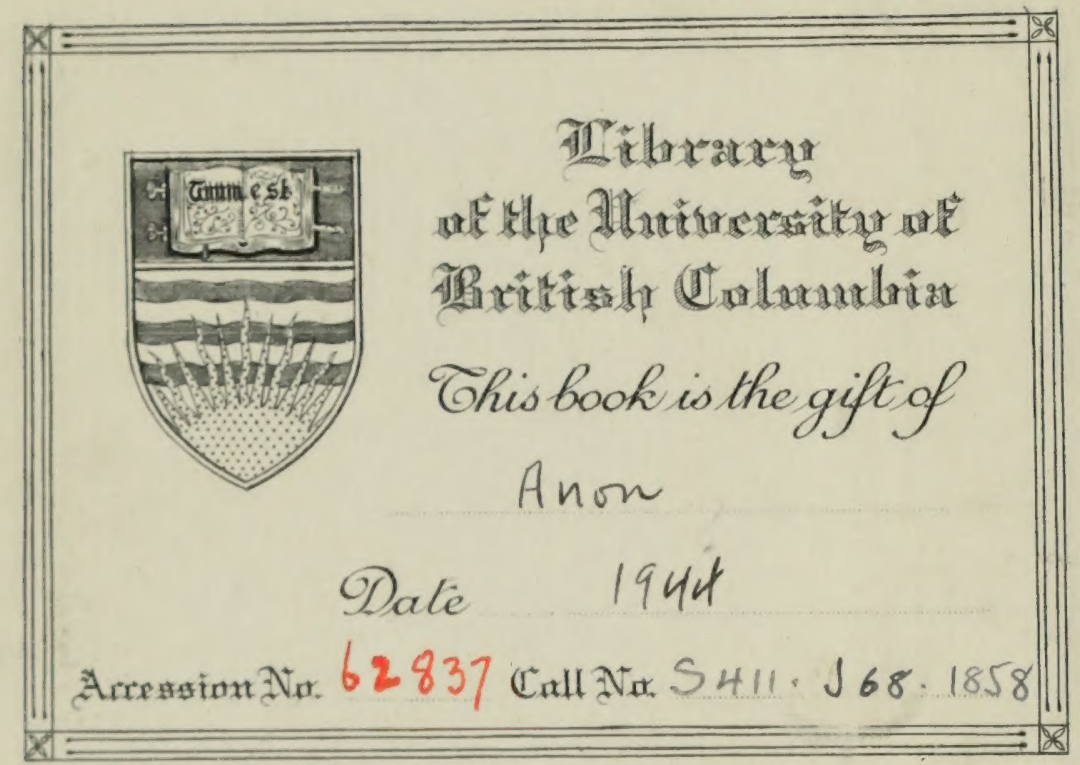




$$
6-17112
$$



(5) 

Digitized by the Internet Archive in 2010 with funding from University of British Columbia Library 


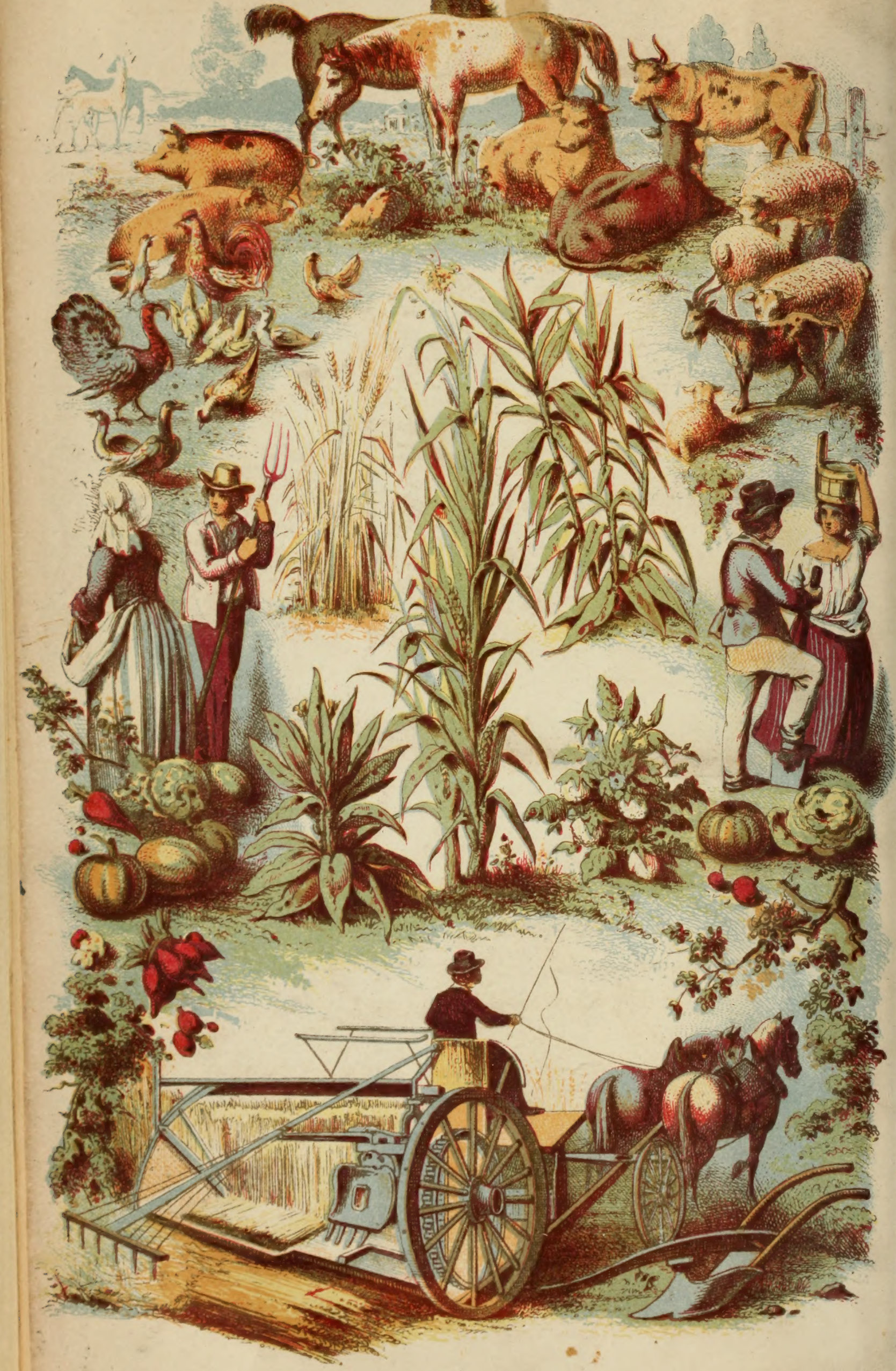




\title{
AMERICAN FARMER'S
}

\section{E N C Y C L O P E D I A ;}

вивндетхе

ALL THE RECENT DISCOVERIES IN AGRICULTTRAL CHEHISTRY, AKD THE USE OF MINERAL, VEGETABLE AND ANIMAL MaNURES,

W I T Y

DESCRIPTIONS AND FIGURES OR AMERICAN INSECTS,

INJERTOUS TO VNGETATION.

\section{BEING A COMPLETE GUITE} FOR THE CULTIVATIOX OF

EVERY VARIETY OF GARDEN AND FIELD CROPS.

\author{
I L L U S T R A T E D
}

BY NUMGROUS KNCRAF' GS OF GRASSES, GRAINS, ANTMALS, IMPLEMGNTS, INSECTS, ETC.

BY GOUVERNEUR EMERSON, OF PENNSYLVANIA, UPON THE BASIS OF

JOHNSON'S FARMER'S ENCYCLOPEDIA.

NEW YORK :

IL BOOK PUBLISHER,

STREET 



\section{PREFACE}

\section{or \\ THE AMERICAN EDITOR.}

The Farmers' Encyclopadia, as originally published in England, containe much matter not particularly interesting to those living on the western side of the Atlantic. In the American edition, the localisms and irrelevant portions have been supplanted by the introduction of much information more immediately relating to rural affairs in the United States. In effecting these alterations, the matter introduced by the American editor amounts to about thirty per cent., all of which has been derived from the best sources of intelligence. The main objects which interest the American farmer, such as cattle, and the great crops of maize, cotton, tobacco, hemp, and other staples of the north and south, have received the most particular attention.

In treating of farm-stock, implements, \&c., the editor has had no individual interests to serve, and no prejudices to bias him. He has, therefore, doubtless, often failed to say all that partiality or predilection might have dictated in particular cases, and the discussion of the relative merits or demerits of contested agricultural subjects he has left to be carried on in the most appropriate places, namely, the pages of the numerous excellent periodical publications, industriously employed in diffusing the lights of agricultural science through every part of the Lnion. To many of these the editor is deeply indebted for most valuable information, the particular sources of which he has been careful to acknowledge in the pripur nlaces. 



\section{EXPLANATION OF PLATES.}

\section{PLATE 1.}

\section{Short-Horned Covos.}

\section{PLATE 2. p. 1117 .}

Tarieties of Wheat, with the most destructive Enemies.

$a$, Summer or Spring Wheat.

$b$, Winter or Lammas Wheat.

$r$, Egyptian Wheat.

d, Turgid Wheat.

, Polish Wheat.

$f$, Spelt Wheat.

$g$, One-grained Wheat.

$h$, The Wheat Fly of Scotland, New Engiand, \&c., the larva or worm of which destroys the grain in the head or chaff.

$i$, One of the Worms magnified.

$k$, 'The Hessian Fly, which attacks the stem near its root.

l, A portion of Wheat Straw affected with Rust, magnified, to show the parasitic plant or fungus giving rise to the disease called Rust, Blight, and Mildew.

$m$, Another portion of a Diseased Stem in a green state, and before the fungus is quite ripe.

$n$, The small portion marked $1(l)$ is still more strongly magnified.

$o, p, q . r, s, t, u$, Very highly magnified representations of the Fungus Parasite in different stages of growth and maturity.

$o$, Showing it in the young state; $p$, fullgrown; $q$, two plants bursting and shedding their seeds when under water in the microscope; $r$, two plants bursting in a dry place; $s$, apparently abortive; $t$, seeds in a dry state; $u$, a small part of the bottom of a pore with some of the parasitic fungi growing upon it.

\section{PLATE 3. p. 139.}

Barley, Oats, Buckwheat, and Millet.

$a, b, c, d$, Varieties of Barley.

e, White, or Common Oat.

$f$, Siberian or Tartarian Oat.

$g$, Common Buckwheat.

$h$, Tartarian Buckwheat.

$i$, Emarginated Buckwheat.

$k$, German Millet.

l, Commrn Millet.

m, Italian Millet.

$n$, Polish Millet.

o, Indian Millet.

\section{PLATE 4. p. 1044.}

Rice, Sugar, Tobacco, \&ce.

$a$, Canary corn.

$b$, Rice Plant.

$c$, Wild Rice.

d, Sugar Cane.

e, Indigo Plant.

$f$, Virginian 'Tobacco Plant.

$g$, Common Green 'Tobacco.

h, Havanna Repanda Tobacco.

$i$, Quadrivalvis Tobacco of the Rocky Mo 1 tains.

$k$, Mana Tobacco of the Rocky Mountains.

PLATE 5. p. 575.

Hay-Grasses adapted to particular Soils and Situations.

The first group exhibits the Tall Hay-Grasses of temporary duration; the second group, Tall Hay-Grasses of permanent duration; the third group, Grasses adapted to particular soils and situations.

a, Ray or Rye-Grass (Lolium perenne), Perennial Darnel, Perennial Rye-Grass.

b, Orchard Grass, or Cock's-foot (Dactylis glomerata).

c, Woolly or Creeping Soft Grass (Holcus mollis).

$c c$, Tall Oat-like Soft Grass, Andes Grass (Holcus avenaceus).

d, Meadow Barley-Grass (Hordeum pratense). $d d$, Meadow, or Fertile Fescue (Festuca pratensis).

$e$, Tall, or Infertile Fescue (Fesiuca elatior).

$f$, Spiked, or Darnel Fescue Grass (Festuca loliacea).

g, Meadow Foxtail (Alopecurus pratensis).

h, Great, or Smooth-stalked Meadow Grass. Spear-Grass (Poa pratensis).

$i$, Rough-stalked Meadow Grass (Poa tr vialis).

$k$, Timothy, or Meadow Cat's-tail (Phlewn pratense).

$l$, Floating Fescue (Festuca fiutans).

$m$, Water Meadow Grass (Poa aquatica).

n, Fiorin (Agrostis stolonifera).

PLATE 6. p. 576.

Grasses.

The first group exhibits the Early Pasture Grasses; the second and third groups Pastum 
Grasses adapted to particular soils and situations.

$a$, Sweet-scented Vernal Grass (Anthoxanthum odoratum).

$b$, Downy Oat-Grass (Avena pubescens).

c, Annual Meadow Grass (Poa annua).

d, Fine Bent (.Agrostis vulgaris mutica).

$\iota$, Narrow-leaved Meadow Grass (Poa anrenstifolia).

f, Dog's-tail Grass (Cynosurus cristatus).

g, Hard Fescue (Festuca duriuscula).

$h$, Srnooth Fescue (Festuca glabra).

$i$, Long-awned Fescue (Festuca hordeiformis).

$k$, sheep's Fescue (Festuca ovina).

l, Alpine Meadow Grass (Poa alpina).

m, 'Turfy Hair Grass (Aira cæspitosa).

n, Common Quaking Grass, or Ladies' Tresses (Briza media).

\section{PLATE 7. p. 577.}

Grasses, \&c., found in Fields and Meadows.

$a$, Field Brome Grass (Bromus arvensis).

$b$, Soft Brome (Bromus mollis).

c, Darnel (Lolium temulentum). The Chess ur Cheat of Europe.

a, White Darnel (Lolium arvense).

e, Welsh Fescue (Fcstuca Cambrica).

$f$, Crab, or Finger Grass (Digitaria sanguinalis).

g, Red Top (Tricuspis).

h, Blue Grass (Poa compressa).

¿, Creeping Soft Grass, or Couch Grass.

$k$, Creeping Dog's Tooth (Cynodon dactylon).

l. Upright Sea Lime Grass, Star, or Bent

Elymus arenarius).

mi, Matt Grass (Psamma arenarium).

u, Gama Grass.

o, Scott's Grass (Panicum hirtellum).

p, Guinea Grass (Panicum polygamum).

$q$, Cow Wheat (Melampyrum pratense).

$r$, Tare, or Common Vetch (Vicia sativa).

$s$, The Lentil (Ervum lens).

i, Chick-Pea (Cicer arietinum).

u, Spanish Lentil (Lathyrus sativus).

$v$, Canadian Lentil (Vicia pisiformis).

"', White Lupine (Lupinus albus.)

PLATE 8. p. 339.

Plants cultivated for Hay or Herbuge.

$a$, White, or Creeping Clover (Trifoliumrepens).

b, Common Red, or Biennial Clover (Trifolium pratense).

r, Meadow, or Cow Clover (Trifolium medium).

d, Yellow, or Shamrock Clover (Trifolium porumbens).

e. Lupuline Clover (Medicago lupulinu).

$f$, Flesh-coloured, or Roussillon Clover (Triiritum incarnatum).

g, Saintfoin (the Bourgogne or Esparcette of ine French).

h, Incern (Medicago sativa).

i, Yellow Lucern (Medicago falcala).

$k$, Long-rooted Clover (Trifolium marro lizum).

\section{PLATE 9. p. 619.}

luferior Herbage, Planls occasionally culliva!ed.

a, Burnet (Poterium Sanguisorba).

i. Spurry (Spergula arvensis). c, Furze or Whin (U.cx Europaus). d, Common Broom (Spartium sioparum). e, Spanish Broom (Spartium junceum).

$f$, Parsley (Apium petrosilinum).

g, Bird's-foot Trefoil (Lotus corniculatus).

$h$, Lotus Tetragonolobus (Lotier cultiva, Fr.).

i, Ripple Grass, or Ribwort Plantain (Plan tago lanceolata).

$k$, Yarrow (Millefeuille, Fr.).

PLATE 10. p. 1108.

Weeds and Plants troublesome to the Farmer.

$a$, Cockle, or Corn Campion (Agrostemina Githago).

b, Mellilot Clover (Trifolium officinalis).

c, Tares. Smooth Tare (Ervum tetraspermumi).

d, Black Bindweed (Polygonum Convolvulus).

e, Dodder (Cuscuía Europæa).

$f$, Mellilot trefoil of Switzerland.

g, Charlock, or Wild Radish (Raphans Raphanistrum).

h, Hariff, Cleavers, \&c. (Galium Aperine),

$i$, Couch Grass (Triticum repens).

$k$, Rest Harrow (Ononis spinosa).

l, Colt's-foot (Tussilago Farfara).

$m$, Corn Mint (Mentha arvensis).

n, Black Foxtail (Alopecurus agrestis).

o, Wild Carrot (Daucus Carota).

$p$, Hedge Parsley, or Dill (Torilis infesta).

$q$, Fool's Parsley (Aithusa).

$r$, Bawd-Money. Fennel. (Meum bunias).

$s$, Corn Poppy (Papaver Rhoras).

$t$, Buttercup (Ranunculus bulbosus).

$u$, Blue Bottle. Ragged Robin. (Centaurea Cyanus).

$v$, Mayweed. Stinking Chamomile. (Anthemis Cotuia).

$v$, v, St. John's Wort (Hypericum).

w, Ox-eye Daisy (Chrysanthemum Leucanthemum).

w $w$, Chamomile Feverfew (Matricaria Cha momilla).

$x$, Common Fumitory (Fumaria offunalis vel vulgaris).

$x x$, Yellow Toad-Flax (Linaria vulgaris).

$y$, Cinquefoil (Polentilla Pennsylvanica).

y $y$, Soap Wort. Bouncing Bet. (Saponaria offirinalis).

PLATE 11.p. 628.

Russian Bec-Hive and Echium vulgare, called in Russian Ciniak.

1, The Hive with the upper door removed so as to show the interior, and arrangement of the honey frames. $a$, Movable doors; $b$, wooden pegs; $c$, mnvable pieces on which the doors are supported; $d$, slats separating the comb from the doors; $e$, frames in which the honey is deposited; $f$, entrances with slides.

2, One of the Honey Frames drawn out.

3, Grating, or Adapter.

4, Movable Board for separating.

5, A Transverse Section of the Hive, showing, at $f$, the places of entrance; at $a$, the depth to which the frames extend; and at $c$, one of the combs.

6, The Echium vulgare, or Ciniuh, with its Root, Efforescence, and nut-like Fruit. 
PLATE 12. p. 292.

Cattle.

1, Short-Horned Bull.

2, Ayrshire Cow.

3, Devon Bull, 2 years old.

PLATE 13. p. 638.

\section{Horses.}

(1, Arabian.

1, English Racer.

', English Hunter.

d, English Improved Hackney.

$\therefore$ English Black Horse.

$f$, English Draught Mare.

«, Suffolk Punch.

$h$, Clydesdale Horse.

i, Irish Racer.

$k$, Shetland Pony.

PLATE 14. p. 421.

Grain Drills.

1, Couke's Grain Drill.

2, The same arranged as a Horse Hce, or Cultivator.

3, Suffolk Corn and Manure Drill.

4, Groundsell's Patent Drop Drill.

5, Pennock's Grain Drill.

PLATE 15. p. 603.

Harrows, Extirpators, and Scarifiers.

1, Gang of Harrows.

2, Berwickshire Harrow.

3, Biddell's Extirpating Harrow.

4, Harrow Tooth.

5, Finlayson's Self-cleaning Cultivator, or scarifier.

\section{PLATE 16. p. 667.}

Destructive Insects, \& c.

1, The Oak Pruner (Elaphidion putator). See Borers, page 205.

2, Locust Tree Borer (Clytus flexuosus). See page 206.

'Potato-vine Bug (Criociris trilineata).
4, Cucumber to (Hallica striolala). Mag nified. Nore pages 172 and 173 .

5, Mav Beetle, or Dor Bug (Phyllophngn quercina) See pages 172,173 .

6, Pin- Iree Weevil (Hylobius pules). A most destrucuve insect to the Southern pine forests. Sere WERILS.

7, Molh it the Corn Cut-Worm (Agrotia clandeslina). see (;uт-Won..

8 , Female fily if the Peach Tree Worm (Ageria orulosa) See Pean Tиве Вonви.

9, Bee, ur Wax Moth (Gallerea cereann). See page 168

The three insects which follow are to be regarded as friendly to the interests of man, as they prey upon those which are destructive.

10, Caravus (rorgi, one of a large family which preys upust caterpillars, \&c.

11, Lady Bird, or Lady Bug (Coccinella borealis). This insect lives upon plant-lice and other injurluus insects.

12, Trogus Fulvis, an insect of the Ichneumon Family, which commit great havoc among caterpillars and grubs. See Icuneumor Fufs.

N. B. Most of the subjects of this plate were furnished expressly for this work by Professor Haldeman, of Marietta, Pennsylvania, and drawn under his inspection by Miss Lawson, of Philadelphıa

$$
\begin{aligned}
& \text { PLAIE 17. p. 902. } \\
& \text { Ploughs. }
\end{aligned}
$$

$a$, The Huhand, ur Rotterdam Plough.

$b$, Small's ('hain Plough.

$c, d$, Eas Lothian Plough, two views, with scale of feet, \&c

$e$, Enghsh Swing Plough.

$f$, Skelpun Plough of Kent.

g, Subsull Plonghing.

$h$, Eng! ish Plough Head.

$i$, Scotch Pluugh Head.

$k$, Ploughshare frir Stony Ground.

$l$, Ploughshare fur Clear Ground.

$m, m$, skiın Coulters.

n, Whee: Coulters.

o, Smith'. Subsoil Plough. 



\section{THE A MERICAN EDITOR'S}

\section{INTRODUCTION.}

"To render Agriculture more productive and beneficial to all, it is necessary that its principles should be better understood, and that we should profit more from the experience of each other, and by the example of other countries which excel us in this great business." - BuEL.

Tre work upon husbandry now ushered before the American public is the production of an English gentleman of great intelligence, assisted by some of the best authorities upon rural subjects in his country. By collecting and condensing the most interesting details relative to farming, chiefly derived from living authors, such as Professors Liebig, Lowe, Sir J. E. Smith, Brande, Youatt, Stephens, 'Thompson, Lindley, I. F. Johnson, etc., etc., he has been enabled to present the very latest information, and furnish a fund of matter which cannot fail to attract all who take an interest in rural affairs, so long studied and so thoroughly understood as these must needs be in Great Britain.

The absence of speculative views, with the very practical and matter-of-fact character of the information given upon all subjects treated of, will perhaps be found to constitute the highest recommendation of " $C$. $W$. Johnson's Farmers' Encyclopædia, and Dictionary of Rural Affairs."

The comparatively limited range of English Agriculture is strongly contrasted with the diversity of culture met with in the United States. A work limited to an account of productions of the soil and climate of England would leave out many of the most important crops which exact the attention of the American farmer and planter. Hence the necessity of adapting a book of the kind to the new localities into which it is introduced. 'This, as may be well supposed, presents a task of no small labour.

It has been charged upon agriculturists, that improvements in husbandry encounter great opposition, and generally work their way very slowly; whereas inventions and improvements made in the manufacturing and mechanic arts are seized upon and put to profit almost as quickly as promulgated. 'The late and justly celebrated Mr. Coke, of Holkam, England, the great benefactor of his own country, and, indeed, of every other country where agriculture is cherished, succeeded, by the adoption of an enlightened course of tillage, in converting a sandy and comparatively sterile district into one of very great productiveness. But, though his improvements were on so large a scale, and the results so very striking to observers, such was the general ignorance, apathy, or prejudice prevailing in the neighbouring counties, that he estimated the rate at which his improved process spread around hins, at only about three miles a year. A better condition of things would seem to exist at present in the United States, doubtless owing to the extension of education. But a few months have passed since the treatise upon Agricultural Chemistry of the celebrated Dr. Liebig, reached this side of the Atlantic, and though much of it is couched in the abstruse phraseology of science, still has it been eagerly sought after in all directions, and gone through several editions. Can any stronger proof be furnished of the high state of intelligence pervading a large portion of the agricultural population of the United States?

The advances in agricultural improvement have, of late years, been in what mathematicians call a geometrical ratio, the pace increasing with great celerity at every successive step. In proportion as the influences of modern education become diffused, the savage characteristics of man are softened down, and the better feelings of his nature ac. 
quire predominance. Bloody and desolating wars are viewed in their true light, anc: the useful arts of peace appear the only proper sources of individual pleasure and national prosperity. As, among these arts, none possesses the vital importance of agriculture, from its furnishing the means of immediate subsistence, so it may fairly be said, no other excites at the present day a greater and more pervading interest throughout Europe and America, with all who seek independence or the gratification of the most rational of tastes.

The inhabitants of the United States possess advantages for the prosecution of agricultural pursuits, which, for variety and extent, surpass those enjoyed by any other people on the globe. 'They occupy the greatest portion of the North American continent, embracing all varieties of soil and surface, with a climate which in the southern parts admits the culture of many of the most valuable productions of the tropics, whilst the northern limits verge upon, but do not reach the less favoured regions where too severe and enduring frost entails a scanty vegetation.

Commencing nearest the tropical limits, the chief attention of the planter is direct. ed to the culture of the sugar-cane, rice, tobacco, indigo, and especially cotton, more of which last is raised in the Southern States than in all the rest of the world besides. In the amount of sugar procured from the cane, Louisiana takes the lead, though Florida, Alabama, and others of the extreme southern states produce considerable quantities. South Carolina yields the most rice, which is also raised to a greater or less extent throughout the southern states, and even as high as 'Tennessee, Kentucky, and southern Virginia. The cotton region is still more extensive, spreading throughout the extreme southern and south-western states, from the Atlantic far west of the Mississippi, and rising into middle Virginia. and even the lowest portion of Delaware In the quantity of tobacco produced, Virginia stands foremost, being followed succes sively by Kentucky, Tennessee, Maryland, North Carolina, etc.

'The Niddle States raise in the greatest abundance, maize or Indian corn, wheat, rye, barley and oats, whilst in a large portion of the Northern States, the wheat, rye, oat, potato, and especially grass crops, are extremely productive and valuable. Although maize is most extensively cultivated in the middle states, it is abundant in almost every section of the country, and from its affording so large an amount of the foor of man and animals, is universally regarded as the most valuable cereal crop of the United States. Besiues these there are many other rich products of the fields and forests, which enter largely into the aggregate of national wealth.

'The first history of American Agriculture differs from that of countries in the old world, where the advances in the arts were slow, and every acquisition marked by rudeness and simplicity. Not so, however, in America, whose intelligent European settlers came with all the appliances of advanced civilization, prepared to chop down the forests and clear away the thickets which had so long encumbered the ground and furnished a scanty subsistence to the savage hunter. For a time the roots obstructed the plough and prevented the deep turning of the soil: but they afforded no impediment to the raising of grain crops, since the light virgin mould, abounding in the alkalies and all other elements of fertility, required but the slightest stirring of the surface to answer the purposes of the plough and harrow. Here then commenced the career of the American planter and farmer, upon a capital accumulated by nature herself through the most gradual accessions. Rich harvests of grain, crops of tobacco and other products sent to Europe and sold at high prices, stimulated to renewed exertions, and the generous soil was subjected to a scourging course of tillage, by which many of the essential elements of its fertility were finally exhausted without any compensating additions. In Virginia, where the primitive settlements were made, large tracts of many hundreds and even thousands of acres, the once profitable culture of which is shown by the extensive ruins of stately mansions, now lie waste and uncultivated, or are covered with a new growth of the oak and pine, renewing forests to which the deer, once driven away, has returned.

The lands borlering on the Atlantic have thus been worn out by successive years of culture without adequate help, the thinnest soils first, and next the deeper moulds. But let not those whose lots are cast in other and more prosperous parts of the Union sympathize over the decayed fortunes of once flourishing districts, and overlook their own gradual decline. It is in vain for the farmers of the western valleys and praries to boast of the de th and inexhaustible productive powers of their lands. With every 
croy, some of the elements of fertility must of necessity be removed, and the greater the crops the speedier the exhaustion, unless some adequate compensation be inade. "The following fact, stated in the fifth volume of that valuable American periodical, "The Cultivator," shows the progress of deterioration in one of the finest wheat districts in the whole country.

"'Thomas Burrall, Esq., has a most excellent wheat farm in the neighbourhood of Geneva, (New York,) which he began to elear and improve twenty-one or twentytwo years ago, and on which he has made and applied much manure. Mr. Burrall informed us, in the summer of 1836, that he had noted down the average product of his wheat crop every year; that dividing the twenty years into three periods, he found that his wheat had averaged twenty-nine bushels per acre during the first of these periods; twenty-five bushels the acre during the second; and but twenty bushels the acre during the third period-thus showing a diminished fertility of nearly onethird, under what may there be denominated a good system of husbandry."

All, then, who are engaged in agricultural pursuits, and even those now luxuriating upon the most fertile soils, must, sooner or later, be reduced to the necessity of adding to their fields some of the agents of fertility, and of adopting new means by which they can obtain crops that may be compensating and profitable.

'The late Judge Buel, in referring to a picture drawn by the Hon. James M. Garnett, of the deteriorated condition of Virginia agriculture, says :- "Let not the Northerners take credit to themselves, from this outline of old Virginia husbandry, or from the ingenuous detail of the causes which brought it to so low a condition. 'Though not exactly the like causes have operated, the same deteriorating system of husbandry has prevailed with us, though perhaps to a more limited extent. Though we have personally attended more to the art--to the practice--yet we have been equally deficient in the science with our brethren in Virginia-equally indifferent to the study and application of the principles upon which good husbandry must ever be based. And although we may have begun earlier in the business of reform, whether from necessity or from choice we will not say, we are still too defective in practice to boast of our trivial acquirements. The truth is, we have regarded the soil as a kind mother, expecting her always to give, without regarding her ability to give. We have expected a continuance of her bounties, though we have abused her kindness, and disregarded her maternal admonitions. We have managed the culture of the soil as a business requiring mere animal power, rather than as one in which the intellect could be brought largely to co-operate."

"But," continues the judge, in the full fervour of his zeal for the promotion of agriculture, "there is a redeeming spirit abroad. The lights of science are beaming upon the agricultural world, and dissipating the clouds of superstitious ignorance which have so long shrouded it in darkness. The causes which have for some time been actively operating to improve the condition of the other arts, and to elevate the character of those who conduct them, are extending their influence to agriculture."

'The course of tillage followed in America since its first settlement, and with such exhausting and disastrous effects upon the soil, has been of late aptly styled the old system, to distinguish it from the New Husbandry, which last consists in the employment of means calculated not only to arrest and prevent the exhaustion of soils, but to increase their productiveness. It is indeed gratifying to know that in many parts of our country which have suffered from the impoverishment of the land; agriculture has for many years shown signs of progressive improvement, reduced farms having been brought into increased value, and the products of many of them being raised even above the amount afforded in the days of their first exuberant culture. 'This has occurred in New England, in the Valley of the Hudson, in New Jersey, Pennsylvania, the upper portion of the Peninsula including Delaware and Eastern Mary-. land, in several parts of Western Maryland, Old or Eastern Virginia, etc.

It is the chief object of the numerous and many admirable agricultural publications so extensively circulated at the present day, as well as of the active societies everywhere instituted, to set forth the principles and practical details of the new system of husbandry, and to demonstrate the advantages resulting from the judicious application of manures and all sorts of fertilizing agents ; - from good tillage; - from proper rotation of crops; - from the assistance to be derived from root-culture;-from the substitution for naked fallows, of clover and other good fallow crops. All these means are to be 
adopted in conjunction with ample draining, with or without the additional advantages derived from sub-soil ploughing.

Many of the processes which may be resorted to in carrying out the new system are in a great degree mysteries to thousands in the United States, although familiarly known and long employed in other countries, where with not half the natural advantages the labour of the husbandman is far better rewarded. Such has been the agricultural improvement effected in Flanders, that the whole country may almost be styled a garden, each acre being capable of supporting its man. Scotland, in little more than half a century, has changed from comparative unproductiveness, into one of the richest agricultural districts in Europe. In Great Britain, the products of the grain harvests have increased within sixty years, from one hundred and seventy to three hundred and forty millions of bushels. The system inculcated by the new principles, has even in some districts of our own country, where they have been well followed up, increased the value of farms, two, three, and four hundred per cent.from twenty and thirty dollars to one hundred dollars per acre. "It has," says Buel, "made every acre of arable land, upon which it has been practised ten years, and lying contiguous to navigable waters, or a good market, worth, at least, one hundred dollars, for agricultural purposes."

The zeal for the promotion of good husbandry which pervades the country at large; is displayed in the geological surveys which have been finished, or are in progress, in most of the states; in the agricultural surveys in several others, together with the liberal premiums appropriated by legislative authority, and innumerable societies, for the encouragement of every thing tending in improve and advance the agricultural interests. It is also shown by the extensive circulation of the many periodicals devoted in whole or in part to agricultural topics. Every section of our extensive country has more or less of these invaluable aids for the dissemination of useful information. Although wishing to avoid, as far as possible, all invidious distinctions, where there are so many just claims to notice, some of these publications cannot be suffered to remain without a passing notice. Such are, "The American Farmer," recently published in Baltimore by John S. Skinner and successors, the pioneer of American periodicals specially devoted to agriculture: "The Cultivator," published in Albany, N. Y., by the late Judge Buel and successors: "The New England Farmer," by Thomas G. Fessenden and successor, the Rev. H. Coleman: "The Southern Agriculturist," in Charleston, S. C., by B. R. Carroll; and "The Farm. єr's Register," by Edmund Ruffin at Petersburg, Virginia. These able works constitute the chief officials on agricultural subjects in the northern, middle, and southern states.

Book-farmers have long suffered under general discredit, and been exposed to abundance of taunt and ridicule, even from their own agricultural brethren. Doubtless the imperfection of much of the scientific data furnished and practised upon has often given occasion to unsatisfactory results. But the rapid progress of science has developed new facts, and furnished much more accurate information. Under the direction of Davy, agricultural chemistry made vigorous advances. His many splendid discoveries, and especially his demonstration that the common alkalies, potash and soda, and the alkaline earths, magnesia, lime, and alumine, were not simple clementary substances, but the oxides of metals, seemed to give a new impulse to those who sought to make chemistry subservient to agriculture. But even with the brilliant achievements of Davy and the subsequent valuable researches of Count Chaptal in France, agricultural chemistry remained very imperfect. 'Too exclusive attention had been devoted to the mineral constituents of soils. Most gratifying and important results have been since obtained through the able investigations of several eminent French chemists, among whom we may name, Raspail, De Saussure, Braconnot, and Bonssingault, all of whom have devoted special attention to ascertaining the nature and properties of organic substances entering into the composition of soils. What England commenced by Davy, and France followed up so ably by her distinguished chemists just named, Germany seems to have the honour of almost perfecting through the brilliant achievements of her chemist, Dr. Liebig, the highly important results obtained by whom have been quite recently placed before the world in a treatise entitled "Organic Chemistry." The interesting developements made in this work of the chemical agencies operating in the various stages and conditions of growth, 


\section{INTRODUCTION.}

maturity, and subsequent decomposition of vegetable and animal substances, and the mutual relations subsisting between these and the earth and atmosphere, have drawn upon Liebig the admiration of all Europe and America.

It must, nevertheless, be owned that though generally adopted, the accuracy of some of Liebig's results has been more than questioned by distinguished chemists in Europe and the United States. The particulars of these and the effects of the several agencies acting upon the life of vegetables and animals, will be found in the Encyclopredia of Agriculture, arranged under various heads, such as, Soils, Humus, Carbon, Oxygen, Azote or Nitrogen, Hydrogen, Ammonia, etc.

Whilst agriculture has, within the last few years, been thus receiving such rich tributes from abroad, many scientific investigators of the highest merit have been zealously and successfully engaged in the United States, in experimental researches which have added greatly to the stock of useful knowledge. Among these, it would be signal injustice to pass unnoticed the names of Professors Jackson and Dana of Massachusetts, who have devoted great attention to the analyses of soils, the chemical composition and properties of humus as found in ordinary mould, and in peats and bog-mud, the results of which have been published in the reports of the Agricultural and Geological Surveys of Massachusetts, and in separate essays. Professors Rogers and Booth of Philadelphia, the former in his Geological Report of New Jersey, and the latter of Delaware, have furnished numerous and highly accurate analyses of the valuable calcareous marls and green-sand deposits found so abundantly in the states named, as well as in others of the mirldle and southern regions, together with much information relative to the application of these inexhaustible agents of fertility;-Nor can we omit the name of Dr. Harris of Massachusetts, whose highly interesting and useful treatise upon destructive insects, is a most valuable acquisition to the stores of agricultural knowledge.

The success with which science has developed the agencies concerned in the various stages and processes of vegetation, and the certainty with which deficiences of soil can now be detected and remedied, have suddenly elevated agriculture from the condition of an art under the guidance of common observation and empirical experiment, to a science regulated by recognised principles of induction. We are indeed much mistaken if the day has not arrived when the successes of the book-farme: shall cause his incredulous brother farmer of the old routine system, to cease his taunts and spend some of his leisure hours in searching into books containing modern information in regard to matters of husbandry.

In preparing the work for the American farmer, the editor has had several objects to fulfil. Of these, one of the principal was the reduction of the price, the cost of the imported copy being so great as to prevent any extensive circulation of it in the United States. Much of the irrelevant and less important materials in the original have been omitted, their place being supplied by the addition of information connected with the interests of American husbandry. In the selection of such information, the editor has to acknowledge his great indebtedness to distinguished writers at home and abroad, who have contributed, by elaborate works, separate treatises and communications in periodicals, to promote the cause of agriculture.

The American edition will contain a far greater number of plates and figures illus. trating the various subjects; notwithstanding which, its cost will be only about one. fourth that of the imported work. 


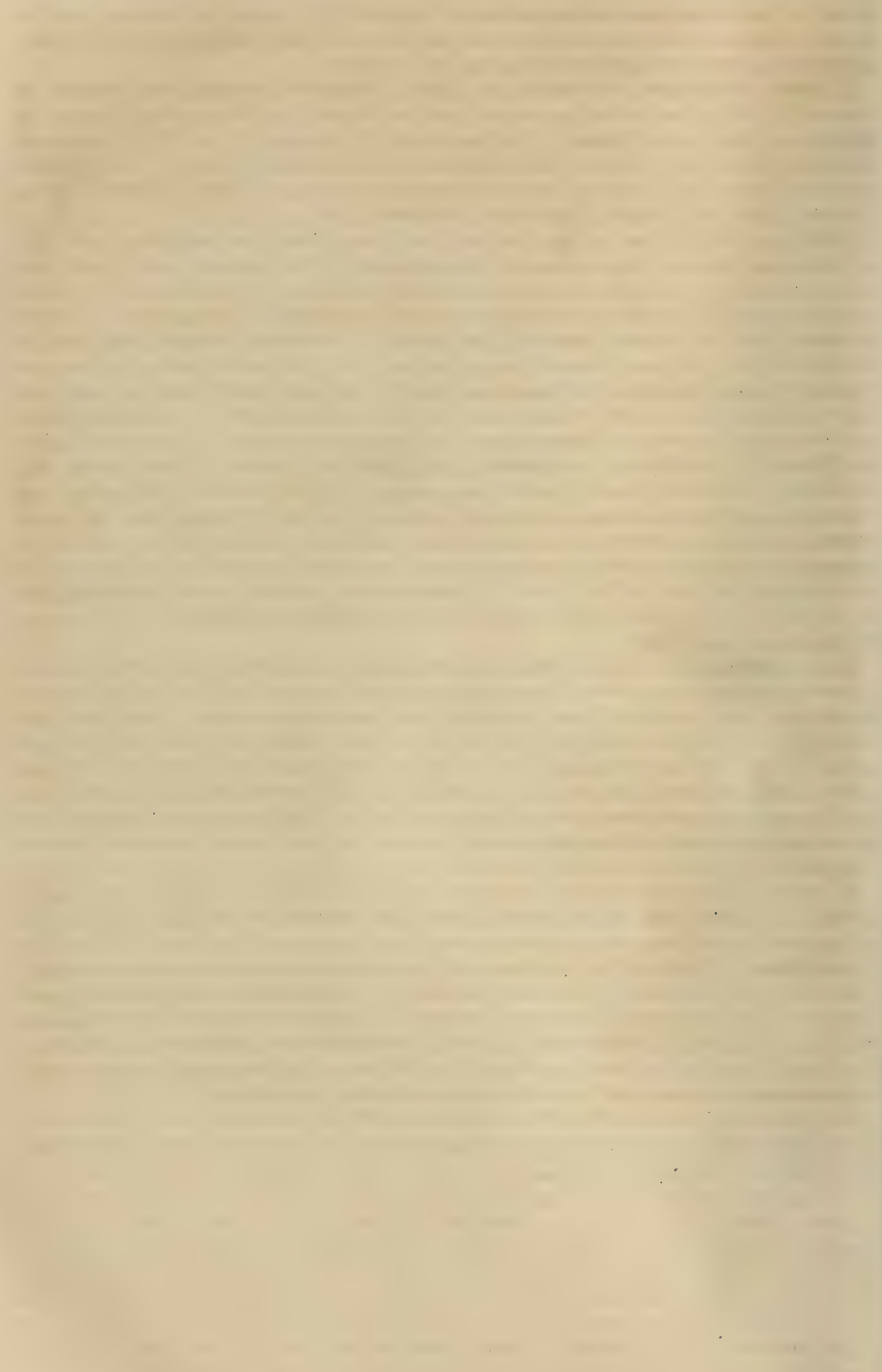




\title{
FARMER'S ENCYCLOPEDIA,
}

\author{
AND

\section{DICTIONARY OF RURAL AFFAIRS.}

A.

ABATE (French, abbatre; Spanish, $a b a-$ tir: Italian, abbatere); to beat down. In commerce, to let down the price in selling.

In law, means the beating down or removal of an obstruction or nuisance, which, accordIng to the common law of England, any person may remove, provided he does it in a peaceable manner, so as not to occasion a breach of the peace, such as the obstruction of an ancient light, which is a private nuisance, or the erection of a gate across a common road, which is a public nuisance, and which any one may beat down and remove.

ABELE TREE (Populus alba). European White Poplar, or Dutch Beech, otherwise called the Arbeel. The Abele is a tree of very rapid growth, but seldom exceeds forty or fifty feet in height. The leaves are large, and divided into three, four, or five lobes, which are indented on their edges.

This tree is not to be considered as a native of England. Hartlib, in his "Complete Husbandman," 1659, states that some years ago, there were ten thousand Abeles at once sent over into England from Flanders, and transplanted into many counties; that the timber is incomparable for all sorts of wooden vessels, especially trays; and that butchers' trays cannot be made without it, it being so exceedingly light and tough.

"A specimen of their advance," says EveIyn, "we have had of an Abele tree at Sion, which being lopped in Feb. 1651, did, by the end of October, 1652, produce branches as big as a man's wrist, and seventeen feet in length. As they thus increase in bulk, their value advances likewise, which, after the first seven years, is annually worth one shilling more. The Dutch, therefore," he continues, "look upon a plantation of these trees as an ample portion for a daughter." Besides the uses of the wood before stated, it is considered good for wainscoting, for floors, laths, and packing cases; and, from the boards of it not splitting ly nails, hut closing over the heads, it is esteemed siperior to deal for the latter purpose. It is found to answer for works under water. Peaty and low damp soils are the mos: proper for the Abele, and in these it is well worthy the attention of the forest planter. It should never be planted near the margins of, nor in grass fields, for it extends its roots under the grass to a great distance, and sends up numerous shoots. The Abele is propagated by layers, cuttings, and off-shoots or suckers. The month of February is the best season for planting the cuttings. In two years, many, if not all that have rooted, will be fit to plant out for good, on the sites where they are to remain for timber. The size of the plants considered the best for final transplantation, is from one and a half to three feet in length, but much larger plants will succeed very well by paying proper attention to leep the roots as perfect as possible.

The Abele is sometimes made a variety of the Gray Poplar (Populus canescens), and several British as well as foreign botanists have confounded the two species, but they are very distinct.

There are many varieties of the Abele, arising from local circumstances. The variety, called on the continent, Polan de Holland, is preferable for avenues and for landscape gardening, from its rapid growth, its majestic height and aspect, and from its fine white leaves contrasting well with the green of other leaves. There are some magnificent ones near the Hague, and more particularly exten. sive avenues of them along most of the highways in the lower districts of Belgium, near Bruges and Ghent. It is so common on the romantic banks of the Rhone, that some French authors call it Arbre du Rhone.

According to M'Intosh, the best cuttings, are taken from the wood of the preceding year: and when made, each cutting should be nine inches in length, and planted in nursery lines eighteen inches apart, and the cuttings about six inches distant from each other. When inserted in the ground, they should be put in deep enough to resist the drought; and if only two inches of the top appear above ground, it will be found sufficient. In two years, or three at most, these cuttings will be fully grow on fit them for being finally planted out: but if 
they are 10 remain the third year in the nursery, they ought to be taken up and re-planted at a greater distance. The Abele often sends up naturally vast numbers of suckers from its roots, and such are sometimes used for young plants; cuttings are, however, preferable. Langley asserts that he has known great quantities produced by chips only, where the trees have been hewed after felling; and one of our earliest authors has proposed ploughing down these chips, with a view to produce an economical coppice.

Amongst other uses of this tree, it may be mentioned that, on the Continent, the wood of the larger branches is prized, on account of its lightness, for maling wooden shoes; while the smaller twigs are used for fire-wood. By splitting the wood into thin shavings, like tape or braid, the stuff called sparterie used for hats, is manufactured. These shavings are always made from green wood. One workman can, with the aid of a child to carry off the shavings, keep several plaiters employed. The ancient Greek athletæ wore crowns made of the branches of this tree, because it was sacred to their patron deity, Hercules. (Julius Pollux, de Ludis. Miller's Dict.)

ABIES. In botany, the Fir or Pine tree genus, well known for the valuable timber obtained from many of the varieties. The origin of the Latin name is unknown, that of the English appellation is the Saxon Furh-wude, fir-wood. See Fin Tris.

ABLACTATION (Latin, ablacto). The weaning of an animal. Also a method of grafting, without cutting the scion from the stock.

ABORTION (Latin, abortio). In veterinary surgery, miscarriage, slipping, slinking, casting, or warping, all meaning the expulsion of the foetus at so early a period of pregnancy as to render it impossible for it to live. 'The immediate causes appear to be the death of the fœtus, or derangement in the functions of the womb or its dependencies, arising from some external cause or causes operating on the moiner. Amongst these operating causes may be reckoned too much, or too little food, producing plethora or emaciation; sudden fright acting on the nerves, or sympathy with certain smells or sights, such as the smell or sight of blood, of bones, of horns, and particularly of the aborted fœtus of another animal;-on a similar principle, perhaps, to that which causes even some strong-nerved men to faint away on witnessing a surgical operation. Accidents, also, such as falls, bruises, over-driving, or fatigue, and the like, may frequently bring on abortion.

The signs of approaching abortion are, great ianguor, uneasiness, and restlessness.- sometimes a discharge of bloody matter, and the sudden filling of the udder, similar to the signs of aproaching parturition.

Abortion in the Horse.-Abortions very freuluently happen among mares. This often arises in consequence of over-exertion during the latter period of pregnancy. Mares are liable, also, very frequently, to various accitents in their pastures, which may be the cause of their slipring their foal, such as kichs, tumbling into holes and ditches, over. exerting themselves to get over inces, and the like. On this account, when a mare is near her time, she should he kept by herself, in some convenient place. But there is another, aird we suspect a very general, cause of these accidents in mares; we mean a stinting of them in their food, either in quantity or quality. It appears, indeed, that some imagine that the mare, when she is in foal, may be turned out almost any where: but this opinion is ill founded; for although the mare does not require to be kept so high in condition as when she is at hard work, yet she is not to be turned out into a pasture where she may be in a manner starved: but how often do we see the mare-in-foal on the worst piece of ground in the whole farm, exposed, during the rigorous winter season, to endure the cold, as well as to put up with scanty food. Every well-informed farmer knows that the slinking of the foal is often the consequence of such treatment. On the other hand, when the mare is not worked at all, and indulged with too high keep, she is almost equally in danger of abortion, her high condition having a tendency to cause inflammation and other disorders; and these deranging the reproductive organs, frequently produce miscarriage. It would seem, then, that moderate exercise and diet are best suited as means to avoid the misfortune of the premature exclusion of the foal.

Abortion in the Cow.-Abortion occurs citener in the cow than in all other domestic animals put together. Perhaps it is one of the greatest annoyances the proprietor of cows has to encounter, and unfortunately, for aught we see to the contrary, it is likely so to continue; for in spite of the improved state of veterinary medicine, and the researches of skilful veterinary surgeons, both at home and abroad, abortion still continues as frequent and annoying as ever. The causes are frequently involved in obscurity; but it may be mentioned, that an extremely hot and foul cowhouse, a severe blow, violent exertion, starvation, plethora, an overloaded stomach, internal inflammations, constipated lowels, bad food or water, improper exposure, and the like, will now and then produce abortion. Any thing whatever, indeed, that seriously affects the health of the animal in general, or the state of the reproductive organs in particular, may do so. But abortion occurs again and again when no such causes as those enumerated can be traced. The disease, if such it may be called, as we think it may, is even said to be infectious. No sooner does it show itself in one animal than it is seen in another, and another, till it has spread over the most part of the cowhouse. Some say this is to be attributed to the odour arising from the things evacuated. Possibly it may he so, there is nothing unreasonable in the supposition; for although we cannot perceive the smeil, nor account for its peculiar influence, it is still quite within possibility that such an odour does exist, having the power attributed to it. There can be no grea: harm, however, in acting as if we were assured that the mischief has its origin in the source so commonly supposed, provided we do 
not shat our ey ss to any other which accident or investigation may reveal. In the meantime, the number of abortiors may be diminished by carefully avoiding all those causes which are known to be capable of producing it. Let the cows be regularly fed; let their fund be good, and in proper quantities; let them have water as often as they will take it; avoid sudden exposure to cold or heat; and, above all, let the cow-house be well ventilated. Prohibit all manner of rough usage on the part of those who look after the cows, whether they be pregnant or not. If any of them accumulate flesh too rapidly, gradually reduce their allowance; and, on the other hand, if any become emaciated, discover the cause, and remedy it, always by slow degrees. Sudden changes in the inatter or mode of feeding should also be avoided. The same sort of diet does not agree equally well with all the cows; and this, in general, is indicated by undue relaxation, or constipation of the bowels; this should be watched, and removed at once. Attention to these, and many other minor circumstances, u.ill amply repay the proprietor for the little additional trouble.

"That improper or too little food," says Mr. Lindsay, " is a prominent cause of abortion, is strongly indicated by the following facts. A friend of mine, a respectable grazing farmer, liept a dairy of twenty-two cows, ten of which slipped calf at different periods of parturition. The summer had been very unfavourable in every respect, both as regarded the ground where the cows were pastured, and in getting in the hay crop. He had little or no hay of the last year's growth, and the hay of that year when cut into was in a very bad state; but as he had no other, he was obliged to give it to his cattle. The consequence was as mentioned above; and besides, many of his stock died of various disorders; and many of those which recovered remained long weakly."

"The most common cause of abortion in cows," says White, "is improper feeding during winter and spring, before they are turned to pasture. The filthy pond-water they are often compelled to drink, and feeding on the rank fog-grass of October and Novem. ber, especially when covered with hoar-frost are likewise frequent causes of miscarriage. I remember a farm near Berkeley, in Gloucestershire, which afforded a striking proof of the injuries of stagnant pond-water, impregnated with dung and urine. This farm had been given up by three farmers successively, in consequence of the losses they sustainod through abortion in their cattle, their not being in season (that is, not conceiving), red water, and other diseases. At length a Mr. Dimmery, after suffering considerably in his live stock for the first five years, suspected that the water of his ponds, which was extremely filthy, might be the cause of the mischief. He therefore dug three wells upon his farm, and having fenced round the ponds to prevent his cattle from drinking there, caused them to be supplied with well-water, in stone troughs erected for the purpose; and from this moment his live stock began to thrive, became uncommonly healthy, and the quality of the butcer and cheese made on his farm was greaily im. proved. It should be observed, that on tis." farm the cattle were regularly fort with gisul hay during the winter, and kept in good plasture in summer: so that there cannot exist a Coubt that the losses sustained by $\mathrm{Mr}_{\mathrm{r}} \mathrm{M}_{\mathrm{m}} \mathrm{m}$. mery were entirely attributable to the un wiml.. some water the animals were compelled to drink."

"In order," adds Mr. White, "to show that the accident of warping may arise from a vitiated state of the digestive organs, I shall here notice a few circumstances tending io corrjborate this opinion. In January, 1782, all the cows in the possession of farmer D'Luruse, near Grandvilliers, in Picardy, miscarried. 'The period at which they warped was about the fourth or fifth month. The accident was attributed to the excessive heat of the preceding summer: but as the water they were in the habit of drinking was extrensely bad, and thry had been kept upon oat, wheat, and rye straw, it appears to me more probable that the greal quantity of straw they were obliged to eat in order to obtain sufficient nourishment, and the injury sustained by the third stomach in expressing the fluid parts of the masticated mass, together with the large quantity of water they probably drank while kept upon this dry food, was the real cause of their miscarrying. A farmer at Charentin, out of a dairy of twentyeight cows, had sixteen slip calf at different periods of gestation. 'The summer had been very dry, and during the whole of this season they had been pastured in a muddy place, which was flooded by the Seine. Here the cows were generally up to their knees in mud and water, and feeding on crowfoot, rushes, and the like. Part of the stock had recently been brought from Lower Normandy, where they had all been affected with indigestion by feeding upon lucerne, frorn the effects of which they had been relieved by the operation of paunching. In one, the opening made was large enough to admit the hand for the purpose of drawing out the food; the rest were operated on with a trocar. In 1789 , all the cows in the parish of Beaulieu, near Mantes, miscarried. All the land in this parish was so stiff as to hold water for a considerable time; and as a vast quantity of rain fell that year, the pastures were for a long time, and at several periods, completely inundated, on which the grass became sour and rank. These, and several other circumstances which have fallen under my own observation, plainly show that keeping cows on food that is deficient in nutrition, and difficult of digestion, is one, if not the principal, cause of their miscarrying. It is stated by Mr. Handwin, that feeding in pastures, when covered with white frost, has been. observed to occasion abortion in these animals."

If there be any probability of a cow miscarrying from exposure to any of the common causes already enumerated, let her by all means be put apalt from the others: and let a skilful person attend to the evil from which she is expected to suffer. If the approach of abortion be evident, bleeding may be had re. course to; for if it do not check abcrtion, it 
will yet do no harm though it take place. When there are any premonitory symptoms of abortion, they are precisely the same as those which present themselves in ordinary labour, with the exception of their being less marked.

Fumigation of the cow-house is resorted to as one of the means of preventing the spread of abortion: tar, sulphur, gunpowder, feathers, and the like, are burned for the purpose of destroying the odour. We have never seen a single instance of the practice being attended with the smallest success; while it is obvious that, if carried beyond a certain point, it may produce the very evil it is intended to remove or mitigate.

It is a remarkable feature in the history of this complaint, that those cows that have once miscarried are particularly liable to do so again at the same period of their succeeding pregnancy. Greater care is therefore requisite to guard against those causes which do, or are supposed to, excite it. The treatment of abortion, when it does take place, differs not from that adopted in cases of parturition, only that the cow which miscarries should be removed with all that belongs to her from among pregnant cows.

If the signs of approaching abortion be discovered early, the accident may sometimes be prevented. If the cow is in good condition, then immediately let it be bled to the extent of five or six quarts, and the bowels opened with half a pound of Epsom salts, three or four drams of aloes in powder, or as many ounces of castor oil, administered in a quart of gruel but if the cow is in very poor condition, and the miscarriage is anticipated from her having bee 1 exposed to cold, it would be more advantageous to avoid bleeding, and give her a warm gruel drink, with an ounce of laudanum in it. If after this abortion does take place, let her be kept in a comfortable place by herself; and if the after-birth has not passed off, let no injudicious and unnecessary administration of violent forcing medicines, such as capsicum or hellebore, be given. Nature, with a little assistance, is generaliy equal to the perfect restoration of the animal.

Abortion in the Sheep. Ewes are much subject to abortion, in consequence of the numerous accidents they are liable to, such as fright, overdriving, being worried or run with dogs, a remarkable instance of which came under my own observation. A pack of hounds, in pursuit of a hare, got among a flock of sheep belonging to a farmer, and so hurried and alarmed them, that thirty out of a flock of two hundred ewes prematurely dropped their lambs. It is the same in sheep as in the other cases of domestic animals, - scarcity of food, and exposure to severe cold, having a great tendency to make the ewes prematurely drop ineir lambs, or produce them weakly and crippled at the full time; and although there may De a little danger in giving too much food, such as allowing them to feed all the winter on turnips, the danger is trifling compared with the starving system. (Miller.)

ABORTIVE. A term applied by gardeners and larmers to flowers, seeds, and fruits, which do not come to maturity, in consequence of $e x$. ternal injury from the weather, from insects, or other causes affecting their growth. Thus fruit often becomes abortive, in consequence of cold winds or frosts in spring checking the flow of the nutritive juices; and after losing its healthy colour it shrivels, and falls. The same effects arise when the leaves of fruitbranches are devoured by caterpillars, or the fruit-stalks sucked by insects (Aphides, lucci, \&c.). The only preventives are sheltering from cold, and destroying the insects.

ABSCESS (Latin, ubscessus). In veterinary surgery, a circumscribed cavity in an animal, containing matter. [In common language, an imposthume or gathering.] The deposition of matter in a solid part of the body is always preceded, and in some degree accompanied, by inflammation. The local symptoms are, pain on pressure, heat, swelling, hardness, and, where it can be seen, redness. These are easily recognised, in proportion as the inflamed part is near the external surface. If the part in which an abscess is about to form be soft, yielding, and well supplied with blood, it soon softens and points, the pain diminishes, the skin becomes thin, a fluid is felt fluctuating under it, and by and by the skin bursts, or a portion of it drops out, and the matter escapes. What is called the process of granulation succeeds to this; and, provided the matter be completely evacuated, and the outlet be such as not to retain any that may form subsequently, the cavity soon fills up.

Such are the different stages of an ordinary abscess. The general health of the animal is rarely affected; but if an abscess form in a dense unyielding texture, in a part which cannot without much difficulty accommodate itself to an increase of volume, then the swelling may be less, but the animal will endure a great deal more pain, [as is often exemplified under similar circumstances in the disease called felon or whitlow in the finger or human hand.] The irritation, indeed, is sometimes so great, from this cause, as to induce fever, and even death; and hence the formation of an abscess in the foot of an irritable horse is not an unfrequent cause of death. During the deposition of the matter in such cases, we have general symptoms added to those termed local. There is loss of appetite, thirst, a hot skin, quick and hard pulse, constipated bowels; in short, the animal is fevered. When an abscess forms in a part remote from the surface, its presence is not easily recognised. The general practitioner has here an advantage over the veterinary surgeon. The expressed feelings of the patient, and the occasional slight shivering fits which accompany the formation of matter, are guides which the veterinary surgeon can rarely or never command. The shivering, if it occurs, passes unobserved, and the animal can give no account of himself; dissection, therefore, sometimes reveals large abscesses, whose existence was not even suspected during life. Fortunately these are not frequent.

It is a curious circumstance, and one that well illustrates the preservative principle of a living being, that, unless there be some me- 
chanical ubstacle, as in the case of the horse's foot, the matter always seeks its exit by an external opening. If this were not a law in the animal economy, and if the matter were to spread indiscriminately on all sides, it might not only accumulate to an enormous extent, and produce much destruction, but by encroaching upon vital organs, it might be a very frequent caluse of death. 'The instances of such a thing happening are rare; but they are easily accounted for by the presence of some mechanical obstacle which the absorbents could not overcome. Why an abscess should point at one part rather than another, is truly wonderful; but it is not more so than almost every other process of importance in the animal economy. We may attempt to explain it; but, in truth, to perceive that such is the case, and that because it would have been wrong had it been otherwise, is as far as we can proceed. We know that the absorbents remove a portion of that side of the cavity which is next to the external surface; but we do not know what urges them to act on that side in preference to any other; and, perhaps, in a practical point of view, we need not care to know.

The causes of abscess may in general be traced to an injury done to the texture of a part, or to the introduction of some foreign substance by which it is irritated. In the former, the formation of matter is a part of the process by which the injury is repaired; in the latter, it becomes necessary to interpose a bland insensible medium between the surrounding parts and the irritating substance, while the same means serve to expel it. Thus a severe bruise, the insertion of a thorn, a nail, or any similar agent, may be followed by an abscess.

The treatment of an ordinary abscess is very simple; as a general rule, the matter should be evacuated as soon as discovered. Let a broad-shouldered lancet be used, and let the opening be made sufficiently large; and, what is of still more consequence, let it be at the lowest part of the tumour, in order that the cavity may be completely and constantiy drained. The general practitioner has some scruple about making an artificial opening, often for good reasons. His patients drear the lancet more than a tedious cure; while the skin is thinner, and consequentiy the natural outlet is sooner formed. But in the horse, and the dog, and still more in the ox, the skin is thick, its removal proportionally slow, and the natural process is both tedious and painful. It is, therefore, better both for the animal and his owners, to have an artificial outlet made for the matter as soon as the abscess is brought to a head, either naturally, or by the application of a bran poultice. Little more is necessary than to keep the part clean; trim the hair from the edges of the orifice, and by applying hogs'-lard, prevent the acrid discharge from adhering to, and removing the hair from the skin beneath. Let no pretender stuff the cavity with a candle, or tent of tow, or rowels, or any thing else. All these interfere with nature's operations, prevent the escape of the matter, produce fistula, and other evils, often far more serious than the original abscess. If the cavity do not fill up so readily as might be expected, allow the animal a little more nourishing food than that recommended for invalids; and inject once, i $r$ even twice a day, a liniment composed of equal parts of spirits of turpentine and sweet oil; or, if the matter discharged, instead of being thick, pale yellow, and without smell, be dark-rolonred, variegated, and smell offensively, a solution of chloride of lime, or one to three drachms of nitre in six ounces of water, may be usce?

A hernial tumour [or rupture] has bern mistaken for an abscess: and, in conserpuence, the blacksmith has plunged a lancet into the gut, or inserted a rowel. This is a most unlikely mistake for a veterinary surgeon to make. 'The heat, the pain, the rigidity, and the situation of an abscess, would be sufincient to distinguish it from a hernial swelling. If there be met with a tumour without heat or pain, very compressible, elastic, and situated on the belly, the veterinary surgeon would pronounce it a rupture, or hernia; anci of course would never dream of touching it with the lancet.-Miller.

ABSORBENT SOILS. Such soils as imbibe water. See Eıктн, the use of, to vegetation.

ABSORBENTS. In veterinary medicine, those drugs are termed absorbents that are given internally for the purpose of neutralizing any acid which forms in the stomach and bowels, in consequence of impaired digestion. Prepared chalk is generally used for this purpose. Those medicines are likewise termed absorbents which are applied externally for absorbing moisture. Armenian bole, calamine, flour, and the like, are employed in this way. They are sometimes dusted between folds of the skin when galled, and raw from friction, blisters, or grease. They are likewise useful in canker of the horse's foot, foul in the foot of cattle, foot-rot in sheep, and sores between the toes of dogs; and they are beneficial in some forms of mange, in staying bleeding, and assisting the cure of a penetrated joint.

Absornerts. In veterinary physiology, a class of vessels whose office it is to convey the product of digestion, and the residue of nutrition into the circulation, to be mixed with and repair the waste of the blood. They are divided into lacteals and lymphatics. The former are all situated in the cavity of the belly; and by extremely minute mouths, opening on the inner surface of the stomach and intes. tines, they receive the nutritious portion of the food, and carry it to a vessel which runs along the left side of the spine, and which, in its turn, empties itself into the left jugular vein.

The lymphatics are distributed over every portion of the frame, at least over every po:tion that contains blood. Their different branches are so minute and su numerous, that a celebrated anatomist who attempted their dissection, is said to have thrown down his knife in despair, exclaiming, "that the hody is entirely composed of absorbents." The uses of the lymphatics are, to remore the residue of nutrition; and when the supply of fond is deficient, to remore such portions of the boty as can be spared and converted into blook. If 
is they that effect the removal of parts which / drought, so as to have had its leaves shriveldisappear without the action of external led up, the moisture will immediately begin to agents. The lymphatics ultimately empty penetrate the plant, which will thereby resume their contents into the same vessel as the lac- its original verdure; an experiment which teals; and they follow, in their distribution proves the fact of the entrance of moisture through the body, the same course as the into the plant through the outer bark (epides veins. In the horse they are liable to a dis- mis). ease termed farcy; and in all animals they are frequently inflamed in the neighbourhood of a sole. The absorbents, both lacteals and lymphatics, are very delicate in their sides, nearly transparent, have numerous valves which compel their contents to flow only in one direction; and their larger trunks have numerous glandular bodies on them. The use of these glands is not well known; but, from one or two circumstances, it would appear that they have to produce some change on the fluid which passes through them before it is fit to mingle with the blood.

ABSORPTION. An important process in vegetable physiology. As plants are not furnished with any individual organ similar to the mouth of animals, how, it may be asked, do they effect the introduction of food into their bodies; Is it by the general surface of their stem, leaves, or roots, or by any peculiar part of these? By whatever part it may enter, it must, at any rate, pass through the covering of the outer bark (epidermis), which the earlier physiologists thought it could not do, but by means of pores more or less visible. Yet some of them describe the outer bark as being so close and compact a texture, that the eye, aided even by the best microscopes, was unable to discover in it the slightest vestige either of pores or of apertures. But Hedwig and De Candolle detected superficial pores in the leaves, at least, of many plants; and so will any one else, who will be at the trouble of repeating their observations with lenses of similar powers.

The next difficulty was with regard to the outer bark (epidermis) of the flower, fruit, and root. No pores had been detected in the flower and fruit, though it was evident that they were refreshed and invigorated by the access of moisture and of atmospheric air; and no pores had been detected in the root, though it was evident that the whole of the nourishment which the plant derives from the soil must of necessity pass through the root. It was also evident that no aliment could be taken up by the plant, except in the state of a liquid, or of a gass-that is, by absorption or by inhalation, as the chyle is taken up into the animal lacteals, or the air into the cells of the lungs. The greediness with which plants absorb water was perceived and acknowledged even in the earliest times, and even by men who were not botanists. Anacreon, in one of his little triftes in honour of drinking, makes the very trees of the forest drink:

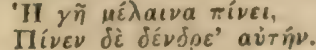

Ode $\mathrm{xix}$

"The black earth drinks, and the trees drink it ;"

that is the moisture which it contains.

By merely immersing in water a plant of almost any species of moss that has been some time gathered, or long exposed to
It might be doubted whether any of the moisture thus imbibed had passed throngh the root. But if the bulb of a hyacinth is placed on the mouth of a glass bottle filled with water, so as that the smaller roots (radicles) only shall be immersed, the water is imperceptibly exhausted, and the plant grows. The moisture must, consequently, have passed through the root. Plants seem, indeed, to be peculiarly well adapted for the absorption of fluids by the roots, from the infinite number of little absorbent fibulous sponges (spongiolx), in which the fine fibres of the root terminate. It is owing to this important property that the scientific gardener, in the transplanting of his young trees, or the scientific and ormamental planter, in the transplanting of his trees of full growth, is so extremely careful to preserve entire even the minutest fibres and extremities of the root. Sir Henry Steuart's Planter's Guide has taught him the great importance of these little organs.

Hales instituted a variety of experiments to show the absorbing power of roots, and the force with which it acted; as did also Duhamel and Marriotte, to show the absorbent power of leaves. But the most complete set of experiments upon the absorbent power of leaves is that of M. Bonnet, of Geneva, whose main object was to ascertain whether the apsorbing power of both surfaces of a leaf was alike. With this view he placed a number of leaves over water, so as that they only floated on it, but where not immersed; some with the upper surface, and others with the under surface, applied to the water. If the leaf retained its verdure the longer with the upper surface on the water, the absorbing power of the upper surface was to be regarded as the greater; but if it retained its verdure the longer with the under surface on the water, then the absorbing power of the under surface was to be regarded as the greater. Some leaves were found to retain their verdure the longer when moistened by the upper surface, and some when moistened by the under surface; and some were indifferent to the mode in which they were applied to the water. But the inference deducible from the whole, and deduced accordingly by Bonnet, was that the leaves of herbs absorb moisture chiefly by the upper surface, and the leaves of trees chiefly by the under surface. What is the cause of this singular difference between the absorbing surfaces of the leaf of the herb, and of the tree? The physical causs might be the existence of a greater, or of a smaller number of pores, found in the leaves of the herb and tree respectively. The chemical cause would be the peculiar degree of affinity existing between the absorbing organs and the fluid absorbed. Duhamel seems to have been content to look to the physical cause, merely regarding the lower surface of the leaf of the tree as being endowed with the greater 
capracity of absorbing moisture chiefly for the purpose of catching the ascending exhalations which must necessarily come in contact with it as thev rise, but which might possibly have escaped if absorbable only by the upper surface, owing to the increased rapidity of their ascent at an increased elevation; and regarding the upper surface of the leaf of the herb as being endowed with the greater absorbing power, owing to its low stature and the slow ascent of exhalations near the earth. This did not throw much light upon the subject; and the experiments were still deemed insufficient, as not representing to us the actual phenomenon of vegetation, though the fact of the absorption of moisture by the leaf is fully confirmed.

If, after a long drought, a fog happens to succeed before any rain falls, so as to moisten the surface of the leaves, plants begin to revive, and to resume their verdure long before any moisture can have penetrated to their roots. Hence it follows incontestibly, either that moisture has been absorbed by the leaf, or that exhalation has been suddenly stopped by closing the pores of the leaf, or both. The efficacy of rain and of artificial waterings may be accounted for partly on the same principle; for they have not always penetrated to the root when they are found to have given freshness to the plant by either or both of the processes just alluded to. The moisture, then, that enters the plant as an aliment, is taken up by means of the pores; or, in default of visible pores, merely by means of the absorbent power of the outer bark (epidermis), not only of the root and leai, but often, as it is to be believed, of the other parts of the plant also, at least when they are in a soft and succulent state.

It is to the modern improvements in pneumatic chemistry, and to them alone, that we are indebted for our knowledge of the real functions of the leaves of plants, and of their analogical resemblance to the lungs of animals, it being now proved indisputably that the leaves of plants not only contain air, but do both inhale and respire it. It was the opinion of Dr. Priestley that they inhale it chiefly by the upper surface; and it has been shown by Saussure that their inhaling power depends entirely upon the integrity of their organisation. A bough of Cactus Opuntia, detached from the plant and placed in an atmosphere of common air, inhaled in the course of a night four cubic inches of oxygen; but when placed in a similar atmosphere, after being cut to pieces and pounded in a mortar, no inhalation took place. The inhalation of air, therefore, is no doubt effected by the pores of the outer bark.(epidermis) of the leaf.

It is important to attend particularly to the distinction pointed out above, that it is not the whole of the root which is endowed with the pcwer of absorbing nourishment, but only the points of the root fibres, termed spongelets. The surface of the root whose outer bark has acquired a certain consistence does not absorb the moisture of the soil in contact with it; but the roots, and also the smallest rootlets, constantly lengthen at their extremities; and these extrenities are composed of a fine cellular tissue, compact, spongy, and the whole newly developed, possessing in a high degree the hygroscopical faculty proper to vegetable tissue.

M. Carradori (Degli Organi Assorluenti) has remarked that there is a slight absorption, either by the surface of the roots, or by the fugacious hairs with which the roots of young plants are often furnished: but this effret seems owing to general hygroscopicity; and he himself agrees that this absorption is $\mathbf{c x}$ tremely feeble, especially in old and woody roots, comparatively with that which takes place at their extremities. These experiments, however, are not made with such minute accuracy as to enable us to appreciate this comparison.

When we cut a branch of a tree and plunge it into water, its woody tissue thus laid bare quickly absorbs a quantity of water; and in this manner is the life of branches preserved which are kept for ornamental purposes, but this effect has a limit. The extremity which has been cut and plunged in the water is not renewed, as in the case of the root; and is, consequently, more or less quickly altered or deteriorated by being in contact with the water. We renew its action by cutting off the rotting extremity, and thus place a new and healthy surface in contact with the liquid. The water which in this manner penetrates into the woody tissue of vegetables, preserves their existence, at least for a certain time, as if it entered by the spongelets. This is the same thing, we may rest assured, in these phenomena, as is presented in the developement of the cuttings of trees, which are also nourished in general only through the water sucked up by the surface of their denuded wood. These means of nutrition are, however, accidental or artificial; and absorption is a natural operation by the spongelets in general, or by the suckers in some vegetable parasites. M. Sennebier observed that, if we divide a plant into three parts, the roots as far as the crown, the stem as far as the branches, and the leafy top, then plunge the lower ends of these into water, the whole three will pump up a certain quantity, but the leafy parts more than the others. This absorption particularly takes place at the cut surface, where the woody parts are laid bare.

A branch of raspberry put in water and ex posed to the sun has absorbed a hundred and fifty grains, but only imbibed eight grains when the division has been covered over with wax. It sucked up no more when, having the divided part covered, it was plunged in the whole of its length, than when only a short zone at the extremity was immersed. This proves that the outer bark is impenetrable to water.

The woody portion, when laid bare, sucks up moisture in every way; that is to say, when we cut a branch and place it in the water, it sucks it up, either when put into it by the upper or by the lower cut part. The habitual or upright direction, however, appears to offer certain facilities for this more than an inverse one. This, indeed, results, first, from the ob servation of M. Pollini (Elem. di Botan., i.281) for the watery juices mount a little less high 


\section{ABSORP'TION.}

in the branches placed in an inverse direciion; secondly, from the observation of common gardeners, and of Mr. T. A. Knight, that, in the cuttings made in an inverse manner, it is more frequently only the lower buds which are developed, and not the higher ones, as happens in those made in a direct manner. It is necessary, in order to render these experiments comparative, that the horizontal cuttings be made equal; and, as we were doubtiul whether this circumstance had been taken into consideration, we made the following experiment:-We placed two branches of willow in water, the one in a direct manner, the other inverted, and contrived in such a manner that these two absorbing bodies were equal; but the branch which was placed inverted pushed its roots a little slower than the direct one. (Mén. sur les Lenticelles, Anm. des Sc. Nut., 1825, Jan., pp. 18, 19.)

The wood tends not only to absorb the water by its transverse section, but also lengthways. Thus we placed in water (ibid., p. 4) a branch of willow, the section of which was covered with mastic, but which had the part immersed denuded of the bark by taking off a cortical ring of an inch in length. This branch pushed its buds and roots in a manner similar to the branches which are immersed by a transverse section.

The hygrometrical power of wood is such that when we expose it to the air it easily imbibes the surrounding moisture; and, when preserved in shady places, it never dries of itself. Count Rumford (Mém. sur le Bois et le Charbon: 8vo, Paris, 1812) dried in an oven a piece of wood taken from the interior of a beam which had been placed for one hundred and fifty years in a battlement, and observed that it lost about ten per cent. of its own weight; and he thinks that this is the greatest degree of natural desiccation which wood can attain in our climate. An oak faggot, exposed eighteen months in the air, and which might be regarded as excellent wood for burning, lost twenty-four per cent. The same experimenter observed that, when chips of wood have been well dried in a stove, on their exposure to the open air they very freely imbibe water. If these chips are placed for twenty-four hours in a room, the extremes of this power of absorption have proved to be, on one side, the Lombardy poplar, whose chips, five inches long by six lines broad, have sucked up 0.87 grains; and, on the other, a billet of oak of the same dimensions, which suclied up 1.40 grains. When the same chips were exposed for eight successive days, it was found that they did not iricrease in weight if the air had remained at the same temperature, but they lost in weight if the air became more heated. This experiment, then, proves that the absorption is rapid; and that the equilibrium it attains will be determined by the surrounding atmosphere, and certainly also by its own hygrometrical power.

These necessary conditions of existence have been effected by the organization of the spongelets as organs of suction, and by the vature of the water, which is abundantly dif- fused over nature, and also impregnated with their principal nourishment.

The nature of the action of the spongelets is remarkable in this, that the choice which they seem to make of the matter which they absorb does not appear to be determined by the natural wants of the plant, but the facility is less or more influenced by the nature of the liquids. Thus, M. Théodore de Saussure (Rech. Chirn., ch. 8) found, that if we place plants in water, with which is mixed sugar, gum, or the like, the spongelets will absorb a greater proportion of water than of the materials which are dissolved in it; for the water which remained after the experiment was more saturated than before the roots were put into it. Again, if we plunge the roots into different solutions, they will absorb so much the more of these in proportion to their fluidity, although at the same time such solutions may be injurious to the plant, and yet will they absorb a less proportion of viscous matter, although this may contain more nutritive materials. Thus, of blue vitriol (sulphate of copper), the most hurtful of the substances employed, they absorbed a large quantity, but a very small quantity of the gum, which is not injurious. When we placed plants in solutions of gum, of different degrees of thickness, we found that the quantity absorbed was smaller in proportion as the solution was more viscous. Sir H. Davy, also, observed that plants perished in those solutions in which there was a large quantity of sugar or gum; and prospered when the solutions had only a small quantity of either. (Agricullural Chem.)

The effect of the viscosity is obviated when we put the roots in water which holds organic matters in suspension. Thus, the drainings of dunghills, and impure waters, are taken up by the roots in smaller quantities than pure water. It should seem that these particles have a tendency to obstruct the imperceptible pores, passages, or cells of the spongelets. M. Th. de Saussure remarlis that analogous laws may be observed in the case of liquids in which different substances ale dissolved, the more fluid being absorbed in a greater quantity than others. It would accordingly appear that the roots exercise a kind of choice in the soil ; but that the choice, far from being relative to the wants of the plants, is a circumstance purely mechanical.

On the other hand, M. Pollini, who has repeated these experiments, found that of the solutions of different substances in water, the roots sucked up different quantities, withouı any apparent regard to their viscosity. Thus he constancly found, he says, that the roots absorbed more of common salt, or of potass, than of the acetate or of the nitrate of lime, and more of sugar than of gum. He found, on the other hand, that if he cut the extremity of a root, the water which entered by the wound contained indifferently all the calts which had been dissolved in the water; and the portion which remained after absorption did not contain more than before. (Srggin di Osserv. $e$ di Sperienze sulla Veget. degli Alber : Verona, 1815.)

Another circumstance remarkable in the 
experiments which we have before dotailed is; that the disorganized tissue of the spongelets appears to give a much freer passage to tho juices than that which had been uninjured. Thus plants can only live for two or threc days in a solution of blue vitriol (sulphate of copper), of which they ahsorb a large quantity: while they will live eight or ten days in a solution of gum, of which they absorb only a very little. Branches cut and plunged in the different solutions follow similar laws, and absorb both water and its solutions.

It is very probable that the spongelets of different species of plants are not all organized in a uniform manner, and that there are some which more easily admit of certain substances; but microscopical observations are still far from accounting for these differences, and the facts drawn from culture are equally obscure in directing our judgment upon the point.

The manner in which plants of different kinds exhaust the soil relatively to each other, the general action of manures, the prodigious number of different plants which we can cultivate in the same patch of a garden, tend to prove that the differences of absorption in vegetables are of great importance. Instead of the variety, however, of aliments which sustain the life of animals, we find among vegetables a great uniformity of the substances absorbed. The quantity of liquid absorbed at different epochs of the life of plants, and under the influence of different atmospherical circumstances, appear more intimately connected rith the ascent of the sap than with its suction.

Absorption varies according to the state of the plants and the periods of their growth; going on more rapidly in proportion as the leafing is rapid. At the time of flowering and fruiting, also, more nourishment is absorbed from the soil. We likewise know that absorption, as well as the progression of the fluids absorbed, depends greatly on the influence of heat and light; that it is most active in spring: that it diminishes in autumn, and is reduced almost to nothing, if it do not altogether cease, in winter.-Miller.

ABSTERGENT REMEDIES, in farriery, are those used for the purpose of resolving or discussing tumours and concretions on the joints and other parts of animals. They mostly consist of volatile, stimulant, and saponaceous matters.

ACACIA TREE (Rubinia Pseud-Acacia Linnæus). The Acacia tree is well known in America, from which it was introduced by the name of the Locust tree. It grows very rapidly in the early stages of its progress; so that in a lew years, from seeds, plants of eight and ten feet high may be obtained. It is by no means uncommon to see shoots of this tree eight or ten feet high in one season. The branches are furnished with very strong, crooked thorns; the leaves are winged with eight or ten pairs of leaflets, egg-oblong, bright green, entire, and without foot-stalks. The flowers come out from the branches in pretty long bunches, hanging down like those of the laburnum, or the still more lovely Wistaria sinensis. Each flower grows on a slender foot-stalk, smelling very sweet. It is of a white colour, but there a rose-red varietv. It hluws in Juhr, anr when the tree is full of bloom makes a hand. some appearance, and perfumes the whole ans around. 'The flowers are followed by sered. pods, oblong, flat, having a longitudinal rus next the seeding suture, on the rutsule if that being drawn out into a membranous margin; one-celled, and two-valved. 'The seeils are sometimes as many as sixteen, kidney-shajerl, ending in a hooked beak. like a lens, and are of a rusty colour.

In North America, where this tree grows to a very large size indeed, the wood is mucn valued for its duration. Most of the hruses which were built at Boston in New England, on the first settling of the English, were constructed of this wood; and since then it has been much used in America for various purposes.

The seeds of the Acacia tree were first brought to Europe by M. Jean Robin, nurseryman to the King of France, and author of a "History of Plants." M. Robin bronght the first seeds from Canada; in consequence of which, succeeding botanists have, in honour in his name, termed the genus Rubinia to which the Acacia tree belongs. Soon after its introduction into France, the English gardeners received seeds from Virginia, from which many trees were raised.

The wood, when green, is of a soft texture, but becomes very hard when dry. It is as durable as the best white oak of North America, and esteemed preferable tor axletrees of carriages, trenails for ships, and many other important purposes. The turner finds the wood of the Acacia hard and well suited to his purpose, and is delighted with its smooth texture and beautifully delicate straw colour.

The tree, when aged, abounds with certain excrescences or linots, which, when polished, are beautifully veined, and much esteemed by the cabinet-maker. It makes excellent fuel, and its shade is said to be less injurious than that of any other tree; while the leaves afford wholesome food for cattle. A gentleman in New England sowed several acres of it for this purpose alone.

It has been employed with signal success in Virginia for ship building, and is found to be very superior to American oak, ash, elm, or any other wood they use for that purpose. In New York it has been found, atter repeated trials, that posts for rail-fencing, made of the Acacia tree, stand wet and dry near the ground better than any other in common use, and will last as long as those of swamp cedar.

The Acacia tree seems happily adapted to ornamental plantirg. Whether as a single tree upon the gra.- , feathering to the ground line, or as a staiciard in the shrubbery, towering above a monotonous mass of sombre erergreens, the Acacia has great charms for us, and may justly be called a graceful tree; and although its light, loose, and pleasing foilage admits the light. and seems to harmonize so delightfully with the polished lawn, or tho highly cultivated shrubbery (and there is hardly a shrubbery to be found without them) yet we should like much to see the Acacia tree planted in the woods everywhere, where foreat timber is an object of attention. 
In France the Acacia tree appears to have been more generally diffused throughout the country than [in England]; for it does not only ornament their gardens, and shade their public walks, but the sprightly foliage of this beautiful tree shines through their woods and forests in every direction; so much so that it might be taken for an indigenous inhabitant of the soil.

In one of the Memoirs by the Agricultural Society at Paris, the properties of this tree are very highly extolled. Its shade, it is said, encourages the growth of grass. Its roots are so tenacious of the soil, and shoot up such groves of suckers, that when planted on the banks of rivers it contributes exceedingly to fix them as barriers to check the incursions of the stream. Acacia stakes, too, are more durable than any other known wood.

The choicest pieces only of the best oak timber are applied to the purpose of trenailmaking in ship-building; and, as the Sussex oaks are generally reckoned the best, most shipwrights, even in the north, have them from thence, and the demand for them is so great, that trenail-making is there become a very cunsiderable manufacture. If it be proved that the Acacia tree is equal to our best oak for this important purpose in our naval architecture, then do we strongly recommend (and we write practically) to every landed proprietor to plant the Acacia as a forest tree, more especially as it will grow upon almost any description of soil, but more particularly upon sandy or gravelly shallow soils, where the oak does not thrive.

In forty years the Acacia tree will grow sixty feet high, and will girth six feet, three feet from the ground; and, although brittle in a young state, the characteristics of the timber of a grown tree are toughness and elasticity.

As a durable timber, it has been proved that nothing can exceed the Acacia wood. when of proper age. But there is one important use to which these trees may be applied, which has 1itherto escaped the notice of the planter, namely, hedges. From its rapidity of growth it forms a fence capable of resistance in onefourth of the time of any other plant hitherto rsed for that purpose. Had we to fence in a whole estate, we should, in preference to all others, plant Acacias. They bear clipping, and may be raised to twenty or thirty feet high, if required, and are so strong that no animal can force through them. The only instance of an Acacia hedge we know of, on the continent of Eurnpe, is to be seen round part of the boulevars of the city of Louvain. Plants for this purpuse should be taken from the nursery lines four feet high. At every point where the stems cross one another, a natural union or grafting takes place, and, as the stems increase in size, the spaces between will gradually decrease; so that in the course of a few cears the fence becomes a complete wooden wall, not occupying a space more than twelve or fifteen inches, forming a barrier that no animal can force. Fences of this description snay either be made on the level ground, or concealed from the distant view.
It is difficult to account for the name com. monly given to this tree by the Americans, namely, Locust tree; for the Locust tree (Hymenza Courbaril) is a native of South America.

In the arboretum of the gardens of the Horticultural Society of London, there is a prooi, perhaps the very best proof that this country affords, of the great rapidity of growth, and also the beauty of this truly interesting and highly valuable tree. About twelve years ago. this aboretum was planted for the express purpose of introducing the trees of all countriesthe research of enterprising men. 'The Acacia was planted with the other individuals of this very splendid collection, and the result has been, that the Acacia has made greater progress than any of the oaks, the ash, the elm, the maple, or, indeed, any of the hardwooded timber trees within the wall of the gardens.

The Acacia trees, in their rapidity of growth, are exceeded only by a few of the poplar and willow tribes.

There is a singular character about the suckers of this tree. They are rarely seen to appear on the lawn, but in the shrubbery frequently. They rise singly, not like the elm, and other trees, in thick masses, choking one another, but they start out of the ground at once, with all the boldness and viguur of a healthy shoot from a powerful stool; and in a sheltered situation will grow, the same year, from twelve to fifteen feet long from the ground; and it is the more remarkable, that these suckers grow in this vigorous way immediately under the shade of the parent, and other large trees. What is also very singular, so strongly are they attached to the root below the ground, at the insertion, that they are very rarely from accident displaced.

Mr. William Lindsey mentions a very striking instance of the astonishing rapidity of the growth of this tree. He observed a strong shoot make its appearance in one of the woods at Chiswick, and he had the curiosity to see what would be the result by applying a stake to this sucker for protection. By the end of the season, it was twenty feet high, and measured three inches in circumference. When the full-grown old Acacia trees are felled, the following year hundreds of suckers will start up from the roots in all directions, and grow as freely as if a fresh plantation had been carefully made. So that, on the score of economy, we know of no tree that can be planted equal to the Acacia. As an underwood, it far exceeds any other tree in produce; and for stakes, arbour-poles, hop-poles, and for pale-fencing, there is no wood equal to the Acacia. In America, the use of the Acacia has been confined to trenails of ships, in consequence of its scarcity. But were it, either in that or this country, as plentiful as oak, it would be applied for more purposes in naval architecture, such as knees, floor-timbers, and foot-hooks, being far superior to oak for its strength and duration; and from the tree arriving much sooner at perfection, and spreading into so many branches, it affords full as 
larce a proportion of crooks and compassth..'jer as the oali tree.

A cubic foot of Acacia, in a dry state, weighs from forty-eight to fifty-three pounds' weight. If we compare its toughness, in an unseasoned state, with that of oak, it will not be more than 8-100 less. Its stiffness is equal to $99-100$ of oak; and its strength nearly

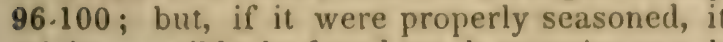
might, possibly, be found much superior to oak in strength, toughness, and stiffness. A piece of Acacia, unseasoned, two feet six inches long, and an inch square in the vertical section, broke when loaded with a weight of two hundred and forty-seven pounds avoirdupois. Its medium cohesive force is about $11-500$ pounds. (Dictionary of Architecture.)

We are not aware that this tree has added in any shape to the list of medicines. The Acacia of the shops was formerly made from the unripe pods of the true Acacia tree; but of later years, the Acacia Germanica of the shops is made from unripe sloes, and is preferred as an astringent medicine to the true Acacia.

The Acacia is easily propagated from seeds ur suckers. (Miller.)

[The following highly interesting account of this tree, and the mode of cultivating it in the United States, is given by Dr. S. Ackerly.

"The cultivation of the locust tree, on Long Island, and in other parts of the state of New York, has been attended to with considerable profit to the agricultural interest, but not with that earnestness which the importance of the subject demands. This may have arisen from the difficulty of propagating it by transplanting, or not understanding how to raise it from the seed.

"The locust is a tree of quick growth, the wood of which is hard, durable, and principally used in ship-building. To a country situated like the United States, with an extensive line of sea-coast, penetrated by numerous bays, and giving rise to many great rivers, whose banks are covered with forests of extraordinary growth, whose soil is fertile, rich, and variegated, and whose climate is agreeably diversified by a gradation of temperature; to such a country, inhabited by an industrious and enterprising people, commerce, both foreign and domestic, must constitute one of the principal employments. As long as the country possesses the necessary timber for shipbuilding, and the other advantages which our situation affords, the government will continue to be formidable to all other powers. We have within ourselves four materials necessary for the completion of strong and durable naval structures. These are the live-oak, licust, cedar, and pine, which can be abundantly supplied. The forther is best for the lower timbers of a ship, while the locust and cedar form the upper works of the frame. The pine supplies the timber for decks, masts, and spars. A vessel built of live-oak, locust, and cedar, will last longer than if constructed of any other wood. Naval architecture has arrived in this place and other parts of the United States, to as great perfection, perhaps, as in any other country on he globe. Our 'fir-built frigates' have been compared with the British oak, and stood the test; and in sailing, nothing bas equallest the fleetness of some of our sharp vessels. 'The preservation and cultivation of these necessary articles in ship-building, is a matter of serious consideration. It might not be amiss (1) su" gest to the Congress of the United Stitres to prohibit the exportation of them. 'I'he pine forests appear almost inexhaustible, and they will be so in all probability for many genera. tions to come; but the stately cedars of Mubile, and the lofty forests of Georgia, where the liveoak is of a sturdy growth, begin to disappear before the axe of the woodsman. The licush a native of Virginia and Maryland, is in such demand for foreign and domestic consumption, that it is called for before it can attain its full growth. It has been cultivated as far eastward as Rhode Island, but begins to depreciate in quality in that state. Insects attack it there, which are not so plentifully found in this state, or its native situations. These give the timber a worm-eaten appearance, and render it less useful. 'The locust has been extensively raised in the southern parts of the state of New York, but the call for it has been so great, that few trees have attained any size before they were wanted for use. Hence they are in great demand, and of ready sale, and no ground can be appropriated for any lind of timber with so much advantage as locust. Besides its application to ship-building, it is extensively used for fencing; and for posts, no timber will last longer, in or out of the ground. On Long Island, where wood is scarce and fencing tim. ber in great demand, the locust becomes of much local importance from this circumstance alone, independent of its great consumption in this city among the ship-builders. In naval structures it is not exclusively applied to the interior or frame. In many places where strength is wanting, locust timber will bear a strain which would break oak of the same size. Thus an oak tiller has been known to break near the head of the rudder in a gale of wind, which has never happened with a locust one. Tillers for large sea vessels are now uniformly made of locust in New York. It is the best timber also for pins or trenails (commonly called trunnels), and preferable to the best of oak. The tree generally grows straight with few or no large limbs, and the fibres of the wood are straight and parallel, which makes it split well for making trenails, with little or no loss of substance. These are made in considerable quantities for exportation.

"The locust tree does not bear transplanting well in this part of our country, but this in all probability arises from the custom of cutting off the roots, when taken up for that purpose. Most of the roots of the locust are long, cylin drical, and run horizontally not far under the surface. In transplanting, so few of the ronts are left to the body of the tree removed, that little or no support is given to the top, and it consequently dies. If care was taken not in destroy so much of the roots, a much larger proportion of those transplanted would live. and thrive. So great has been the difficulty in raising the locust in this $w a y$, that another 
method of propagating it, has been generally resorted to. Whenever a large tree was cut down for use, the ground for some distance around was ploughed, by which operation the roots near the surface were broken and forced up. From these roots suckers would shoot up, and the ground soon become covered with a grove of young trees. These, if protected irom cattle, by being fenced in, would grow most rapidly, and the roots continuing to extend, new shoots would arise, and in the course of a few years, a thrifty young forest of loeust trees be produced. The leaves of the locust are so agreeable to horses and cattle, that the young trees must be protected from their approach. When growing in groves they shoot up straight and slender, as if striving to nuttop each other, to receive the most benefit from the rays of a genial sun.

"Another difficulty has arisen in propagating the locust, from inability to raise it from the seed. The seed does not always come to perfection in this part of the state of New York, and if it does, it will not sprout, unless prepared before planting. 'The method best aclapted to this purpose was proposed by Dr. Samuel Bard; but it is not generally known, or if linown, is not usually attended to. When this shall be well understood and practised, the locust will be easily propagated, and then, instead of raising groves of them, the waste ground along fences, and places where the Lombardy poplar encumbers the earth, will be selected to transplant them, as, by having them separated and single, there will be an economy in using the soil, the trees will grow much better, and the timber be stronger.

"Doctor Bard's method of preparing the seeds was to pour boiling water on them, and let it stand and cool. The hard outer coat would thus be softened; and if the seed swelled by this operation, it might be planted, and would soon come up. This has been followed with success in Long Island; and on a late visit to North Hempsted, I was led to admire Judge Mitchell's nursery of young locust trees, planted in the spring.

" The judge took a quantity of seed collected on this island, and put it in an earthen pitcher, and poured upon it water near to boiling. This he let stand for twenty-four hours, and then decanted it, and selected all the seeds that were any ways swelled by this application of heat and moisture. To the remainder he made a second libation of hot water, and let it remain also twenty-four hours, and then made a second -selection of the swelled seeds. This was re:peated a third time on the unchanged ones, when nearly all were swelled, and then he prepared the ground and planted them. He planted the seeds in drills about four feet apart, and in - eight or ten days they were all above ground, and came up as regular as beans, or any other seeds that are cultivated in gardens. When I saw them, the middle of July, they were about a foot high, all thrifty and of a. good colour and condition.

"It is the judge's intention 10 leave them in their present situation about three years, and then transplant; and provided he does not muislate the roots in removing them, they will bear transplanting, live, and thrive, and be the most productive forest tree that a farm can have. This method of preparing the seeds and planting the locust, cannot be too warmly recommended to the farming interest. On Long Island, where fencing timber is growing scarce, the cultivation of the locust tree is of great moment. In the centre of the island, on and about Hempsted plains, where there no timber at all, it must be a most valuable acquisition; and from the trials made in raising it from the seed, all difficulty must be removed to its extensive cultivation."

After this account was written, Judge Mit. chell transplanted the young trees referred to, on a side hill of waste ground which had lain for many years uncultivated, and his farm was soon improved by the addition of a large grove of valuable locust trees, in the most thrifty condition.

When planted out from the nursery, the young trees must be protected from cattle, which are fond of the young buds.

Professor Henshaw lately made some experiments, with the view of determining how far the vitality of the seeds of the locust acacia was impaired by heat. He put some of these seeds into boiling water; others he actually boiled $1 \frac{1}{2}, 3,6$, and even 15 minutes; he planted them afterwards in the earth, and they all sprouted and grew in half the time that seeds did which had not been boiled or soaked.]

ACACIA. The Rose Acacia (Lat. Robinin hispida). This gracetul shrub is a native of North America. It grows twenty feet high, when the soil and situation agrees with it, and its beautiful rose-coloured drooping flowers bloom in June. It often blows again in July and August. Its branches are covered with prickles till they are two years old, when they fall off. This gives it the appellation of hispida, or hairy. It loves a good soil, and is very hardy. The flowers bloom on the wood of the same year; therefore the plants should be shortened every season, unless they are planted in a shrubbery, in which case cut away only the dead wood. The smooth tree Acaria (Lat Mimosa Julibrissin) is a green-house shrub, and a native of the Levant, but it succeeds in the open ground if carefully sheltered from frost and cold wind. It loves a fresh, light mould, and blows its beautiful rose-coloured flowers in August. It is multiplied by layers. The Sponge tree Acacia (Lat. Mimosa furnesiana) is also a green-house shrub; but it will thrive in the open air if very carefully protected. It comes originally from St. Domingo, and in August it throws out a small head of sweetscented yellow flowers. It loves a good rich soil, with a sheltered south aspect. It is raised by seed, and multiplied by layers. (L.Johnson.)

ACANTHA. The prickle of thorny p.ants. ACANTHIS. The plant called grouncsel.

ACANTHUS (Lat.). The name of the herb bear's breech, remarkable for being the model of the foliage on the Corinthian capital. Milton, in his Paradise Lost, iv. 696, speaks of it,

$$
\text { "On either side }
$$

Acanthns, and each odorous bushy shrub Fenced up the verdant wall."

Todd's Johnson. 
In modern botany, Acanthus is a genus of herbaceous plants found in the South of Europe. Asia Minor, and India, belonging to the natural order Acunthucex.

ACCLIMA'TION OF PLANTS. This term has been applied to the act of accustoming plants to support a temperature or a climate different from that in which they are found originally growing. This differs from naturalization, which is the act of transporting or transferring a plant into a country different from its native place of growth. Nobody can deny the possibility of these naturalizations; but there are some doubts upon the acclimations of plants, doubts which have been corroborated by M. Schubler (Linnæa, 1829, p. 16); and it renders this important question the more deserving of examination, that the facts which are reported are conuplex and somewhat contradictory.

On the one hand, we see wild plants appear fixed within the same climate from the epoch of which we have any knowledge, and cultivated trees, such as the olive, that have for many centuries kept within the same limit.

On the nther hand, we see certain trees, such as the horse-chestnut, which, although originally from the tropics, have reached as far north as Sweden. We see that in gardening, the Aucubajaponica and the Pronia Moutan, after having been cultivated in the hothouse, have passed into the greenhouse, and now flourish in the open air. But before we infer from these facts the possibility of acclimation, it will be necessary to analyze them more fully.

Taking the instance of a plant which may have been placed at the first in the hothouse, and afterwards cultivated in the open ground, what are we to conclude, but that, while ignorant of its nature, and while its rarity rendered it more precious, we vere unwilling to run the risk of losing it. There is not a gardener, or one who has had the management of a botanic garden, who has not made such calculation a hundred times, and who, doubtful of success, has been led to follow this prudent course with a multitude of plants. Those plants which are received from tropical countries are usually thus treated, on the supposition that they partake of the general nature of plants brought from those countries; and we afterwards try, by groping in the dark, those which form exceptions to the general law. We thus succeed in naturalizing some of them; but this does not yet prove that they have been acclimated, for they have not been exposed on their arrival in the climate they were afterwards seen to support. Even had this been done, the experiment would have been frequently doubtful; for when plants arrive in Europe they are for the most part weak, and too young to try the experiment with; while every one knows that young plants, such as those of the bead tree and the silk tree, will thrive in a temperate climate in their adult age, if they are very vigorous when planted, but which are easily destroyed by the frost when young.

An exact knowledge of the manner of living of each species tends to explain some of the illusions which we are apt to fall into on this subject. Thus, when a plant newly arrived in
Europe, and consequently little known, is cus? tivated in the open ground, it often happens that it is placed in a soil or a pesition contrary to its nature, that it is watered too much or too little, and that it is pruned unseasonably, and the like; it consequently perishes without the temperature of the climate being to blame Some years afterwards its nature becomes better known, and the management which it re quires; it is planted anew in the open ground is properly cultivated, and it succeeds, and w? then say it is acclimated, while it is simply naturalized.

The greater number of cultivators think that plants produced from seeds collected is the same country are much stronger than those produced from foreign seeds, and make this an argument to prove the doctrine of acclima. tion. Sir Joseph Banlss (Trans. Hort. Suc. i. 21 ), in particular, adduces in favour of this opinion the culture of Zizania aquatica, esta. blished by him at Spring Grove; but he also relates that the first seeds collected in England produced delicate plants, and the second strong plants, so that this example proves as much against as in favour of the theory. Dr. Macculloch, also (Journ. of Science, 1825, p. 20 ; Feruss. Bull., Sc. Agr., ix. p. 262), in his Essay on the Island of Guernsey, strongly doubts this pretended superiority of plants coming from seeds. We will nct stop to notice that this opinion is in opposition to the very generally received idea, that the changing of seeds is useful. We do not think it less probable that those seeds taken from trees supposed to be languishing, in consequence of not being yet properly acclimated, produce young plants much stronger than those which are taken from trees more healthy, and growing in their natal soil. We will not discuss that which certain cultivators, such as M. J. Street (Trans. Hort. Soc., viii. 1 ; Ferussac, Bull., Agr.), assert, that the individual plants coming from cuttings are much stronger than those coming from seeds; but we will ask whether this experiment has been made with any degree of certainty, that is to say, in a comparative manner; and when the fact is so, that native seeds have had better success, whether this may not have arisen from the circumstance that certain sorts of seeds do not succeed well when they are not sown immediately after maturity, as in the case of the coffee plant, or perhaps from their being a greater number of seeds to dispose of, and more of them sown? In fine, supposing that experiments are in accordance with the admitted opinion, does this prove any thing more than that a tree which produces good seed is of a nature to accommodate itself to the soil; and is not this rather a proof of naturalization than of acclimation? Let us see if there exist any clearer proofs of the reality of acclimation.

One of the principal results of culture is the formation of varieties which otherwise would have no existence in nature, and which have different degrees of susceptibility according to the temperature. We know that these varieties, in many instances, are much more delicate than the wild species. We may instance varieties of double flowers, which are 


\section{ACCLIMATION OF PLANTS.}

bardy than those of single varieties of the saine species; varieties of white flowers, which are generally less hardy than red or yellow varieties; and the varieties of the oleander, with double rose-red flowers, and with single white flowers, are often killed by the frost, while the common oleander, with single rosered flowers, may stand the winter.

It is, however, those species produced by culture, and chiefly by hybridizing, which are of a more hardy nature than the wild species. Now we conceive that the choice of these varieties affurds the means of introducing certain sorts into climates where the original species could not have succeeded. This effect is most apparent in such varieties as have undergone stume change in the season of vegetation: thus the late variety of the walnut tree, which we call St. John's walnut, will thrive in those localities where the frosts are felt late in the spring, and where the common walnut tree is soon killed by the cold. 'Thus the very early varieties of the vine will bear. fruit in certain climates, where either from there being little heat, or from the rapid approach of autumnal frosts, other varieties would not succeed.

There exists, in many species of plants, the remarkable phenomenon of certain individuals being more early or more late than others, without our being able to attribute the circumstance to the influence of locality; while, at the same time, we cannot perceive any sensible difference in the organization. Now, by car :ully collecting the seeds, or the layers, or the tubercles, or grafts, of such early and late varieties, we obtain artificially such agricultural sorts or varieties as present certain useful qualities, and such, in particular, as will thrive in climates where the original species would not succeed. For example, by gathering the tubers of such potatoes as ripen first, and by repeating the same, many times in succession, we may by this means obtain a variety which will ripen in three months. To us, such a variety is of no more advantage than in giving us an early vegetable; but if cultivated in climates farther north, it might introduce the useful culture of the potato in places where this was previously unknown. Attentive observation of such species and varieties may furnish means of advancing the culture of certain vegetables beyon their ordinary limits. For example, if the varieties of the olive brought from the Crimea, which appear less affected with cold than European varieties, should come to Le introduced on the shores of the Mediterranean; or if they should propagate extensively the variety called Caillou in Provence, we might be led to conclude that the olive is accustomed to a greater degree of cold, although there might only be the substitution of a hardier sort for a more delicate one.

In fine, although we are not authorized to observe that the vegetable tissue cannut, by the effects of habit, accustom itself to a different temperature than that of its native clinate; and although we are disposed to recognise, in many cases, this influence of habit, yet the preceding facts seem to lead to the following interences: 1. That if certain species of vege20

\section{ACCLIMATION OF PLANTS.}

tables are susceptible of being acclimated, this occurs within very narrow limits; and we fre. quently exaggerate these limits by confounding acclimation with naturalization. 2. That the cases in which acclimation appears to take place in reality, chieny, if not exclusively, comprise species where there is a formation of new varieties, or where we have managed to change the season of the regetation of plants, as arising from periodicity. 3. That practical results, almost as important as those of acclimation, more properly so called, are obtained by ably following up certain pro cesses of culture. (Miller's Dictionary.)

[A sensible and eloquent writer in tho American Jovirnal of Geology, has, in a paper upon the "Acclimating Principle of Plants," treated the subject in a highly interesting manner, and illustrated it by referring to many instances where plants have actually adapted their growth and habits to a great extent of country, and diversity of latitude. His views, it will be seen, are not in exact accordance with those contained in the preceding article upon a similar topic. 'They are, however, calculated to be particularly interesting in the meridian of the United States.

"Plants," observes the writer referred to, "have directly no locomotive powers, but indi. reclly, they have in a great degree the faculty of changing their places, and, consequently, their climate. The embryo germ wrapped in a kernel, or seed, is virtually a plant, ready to germinate when thrown upon its parent earth, and affected with heat and moisture. It is in a most portable shape, and can be transported with ease to an unlimited distance. Nature in many instances superadds to seels, wings, down, feathers, and chaff, by which they become buoyant, and are carried by the winds of heaven, by the storms that sweep the forest, and by the streams, and currents of rivers, and the ocean, to an immense distance, and through many degrees of latituile! They become finally deposited in sume genial soil, and at one remove, or through a succession, they occupy extensive regions. Nature manifests her great care of the embryo, by coating some of her seeds with shells, which protect them from the attacks of insects, and the action of the elements; others have bitter, narcotic, or poisonous qualities, which forbid animals eating them; and many are filled with oily, or resinous matter, which resists, for ages, and even centuries, the action of the elements, unless acted upon by the proper degree of heat and moisture. By such qualities they endure, and await a suitable time and conveyance to their destined place, in order to extend and vary their families.

Birds also convey the seeds of plants in their crops over a wide extent, before they become triturated and digested; and when these winged carriers die, or decay, from accident or age, the seeds are deposited, and take root in some distart land. Animals also convey them in their stomachs to a considerable distance, and pass them uninjured by the powers of digestion.

Man, more provident than all, to whow plants are necessary, whose support, whose 
comforts, and whose pleasures connect him with thein, carries their choice seeds, slips, and scions, far and wide. His interests foster their growth, his attentions enrich their products, and his skill and science preserve their existence, and adapt them to their new condition. In an improved community, man's wants multiply; he has occasion for the more varied and rich fruits; more abundant and luxurious clothing, and furniture of vegetable growth; odours to regale his senses, vegetable flavours to pamper his appetites, and all the medicinal plants to heal his various diseases, and invigorate his shattered constitution. Fie attaches himself to agriculture and horticulture: plants become his companions; te carries a creative resource into those departments, and $b y$ his attentions, forms new varieties and excellences, unknown to the wild state or vegetable existence. Such are the means nature has provided for the propagation and extension of plants; such are the indirect locomotive powers they possess. We must no longer, therefore, consider vegetables such inert and sluggish beings.

Human care, and the providences of nature, have given to many plants a great extent of climate and latitude, an enlarged growth, and an increased and improved product. Let us bring together such instances as are within the knowledge of all, and which ought to stimulate our cultivators to greater efforts.

The valley of the Euphrates was doubtless the native region of all those fine and delicious fruits which enrich our orchards, and enter so largely into the luxury of living. We thence derived all the succulent and nutritious vegetables that go so fur to support life; and even the farinaceous grains appertain to the same region. The cereal productions began in that same valley to be the staff of life.

Our corn, our fruit, our vegetables, our roots, and oil, have all travelled with man from Mesopotamia up to latitude $60^{\circ}$, and even farther, in favourable situations. The cares of man have made up for the want of climate, and his cultivation atoned for this alienation from their native spot. The Scandinavians of Europe, the Canadians of North America, and the Samoides of Asia, are now enjoying plants which care and cultivation have naturalized in their bleak climes. Melons and peaches, with many of the more tender plants and fruits, once almost tropical, have reached the 45 th degree of latitude in perfection, and are found even in $50^{\circ}$. Rice has travelled from the tropics to $36^{\circ}$, and that of North Carolina now promises to be better than that of more southern countries. The grape has reached $50^{\circ}$, and produces good wine and fruit in Hungary and Germany. The orange, lemon, and sugar-cane, strictly tropical, grow well in Florida, and up to $31 \frac{1}{2}^{\circ}$, in Louisiana, and the fruit of the former much larger and better than under the equator.

Annual plants grown for roots and vegetables, and grain, go still farther north in proportion, than the trees and shrubs, because their whole growth is matured in one summer; and we know that the developement of vegetation is much quicker when spring does open in countries far to the north, than in the tropics. In Lapland and on II uilson's Bay, the full leat is unfulded in one or $t w o$ weeks. when spring begins, although it requires six or eight weeks in the south. Nature makes up in despatch for the want of length in her seasons, and this enables us to cultivate the annual plants very far to the north, in full per. fection. 'The beans, pumpkins, potatues, peas, cabbages, lettuce, celery, beets, turnips, and thousands of others, seem to disregard climate, and grow in any region or latitude where man plants and cherishes them. The fig is becoming common in France; the banana, pineapple, and many other plants, have crossed the line of the tropics, and thousands of the plants valuable for food, clothing, and meaicine, and such as are cultivated for their beauty, fragrance, or timber, are extending their climates, and promise much comfort and resource to man. Plants lately introduced, whose cultivation has not run through many ages or years, have acquired but little latitude in their growth, and show but little capacity to bear various climates, because time has not yet habituated them to such changes, and human cares have not imparted to them new habits and new powers.

Nothing can be effected by suddenness in acclimating plants; too quick a. transition would shock them; it must be a very gradual process, embracing many years, and many removials. The complete success that has attended the plants first named, the earliest companions of man, proves this. In the inore recent plants, success is exactly in proportion to the length of time that a plant has been in a train of experimental culture.

The most striking method of lesting the effect of climate on plants, is to carry surdenly back to the south, such as have been extended far, and become habituated to a northern cli. mate. Such plants have so much vigour, and the habit of a quick and rapid growth so firmly fixed on them, by a long residence in the north, that when suddenly taken to the south, although the season be long and ample, they continue, from habit, to grow and mature quick, and obtain the name of rare-ripe; because they do not take half of the time to mature, that those of the same family require, which have never been so changed. Gardeners give us early corn, peas, fruit, and turnips, by getting seed from places far to the north; and cotton growers renew the vigour of the plant by getting the most northern seed. This practice is common in the case of most plants, and is founded on the supposition that planta do, and can acquire habits.

The fact supported in the first number of the American Journal of Geology and Naturai Science, "that plants are most productive near the northern limit in which they will grow," that they bear more seed or fruit, and have more vigour of constitution, offers much eucouragement to agriculturists. This proves that it is not a meager, stinted existence, devoid of profit or productiveness, that we give to plants, by pushing their culture far north, but a strong and healthful growth, one that repays the labour and attention, by a greater 
pr iduct than belongs to more southern situations.

Every view that we can take of this interesting subject, every fact within our knowledge, whether drawn from the actual state of cultivation, or from physiological investigations into the habits, nature, and construction of plants, goes to show that plants do become acclimated, both in the natural and artificial way, to a great extent. Enough has been witnessed to prove that plants have a physical conformation, that does accommodate itself to circumstances, and have capacities more extensive than are generally ascribed to them: enough has been realized to encourage farther efforts, and to give us hopes of much future benefit."

As allied to this subject see Climate, influence of, on the Fruitfulness of Plants.]

Accounts, Fanv. See Farm accounts.

ACER. The Roman name for a genus of trees, comprehending different species of the large deciduous kind, as the sycamore, \&c. See Maple Tref.

$\triangle C E T I C$ ACID, and ACETUM, terms employed to signify Vinegar, which see.

ACETOSA. See Sorrez.

ACHILLEA. A genus of plants consisting of sixty or seventy species, found exclusively in the colder climates of the northern hemisphere. They are all herbaceous, perennial weeds of little importance, except to botanists, and are only seen in cultivation in the collections of the curious.

ACIDS (Lat. acetum; Goth. aceit; Sax. mece). Liquids and other substances are called acids, which commonly, but not always, affect the taste in a sharp, piercing, and peculiar manner. The common way of trying whether any particular liquor hath in it any acid particles is by mixing it with syrup of [blue] violets, when it will turn of a red colour; but if it contains alkaline or lixivial particles, it changes that syrup green. [The blue liquor obtained by steeping purple cabbage leaves in hot water, is also a convenient test liquor for acids as well as alkalies.] They combine with various earths, alkalies, and metallic oxides, and form the peculiar class of bodies called salts. (Todd's Johnson.)

In agricultural chemistry, the acids are divided into the inorganic and organic. The first kind, or inorganic, are derived from sources wholly mineral. The second kind, or organic, are derived from animal or vegetable organized substances. The sulphuric acid, or oil of vitriol, is one example of a mineral or inorganic acid. It exists abundantly in nature, combined with mineral bases, as in plaster of Paris, where it is combined with lime, forming the sulphate of lime, or gypsum. Muriutic acid is another very abundant inorganic or mineral acid, and abounds in sea-salt, combined with soda, forming the muriate of soda or common salt. Nitric ucid, or upucufortis, is another of this class of acids, existing abundantly in the well known substance called saltpetre, or nitrate of potash. These three constitute the principal inorganic or mineral acids.

As all vegretables contain acids, these may be regarded as essential to their life. But these $\approx$ acids do not always exist in a free state, being generally combined with some of the alkalies or alkaline substances, such as potash, sora, lime, and magnesia. "These bases evidently regulate the formation of the acids, for the diminution of the one is followed by a decrease of the other: thus, in the grape, for example, the quantity of potash contained in its juice is less, when it is ripe, than when unripe; and the acids, under the same circumstances, are found to vary in a similar manner. Such constituents exist in small quantity in those parts of a plant in which the process of assimilation is most ac tive, as in the mass of woody fibre; and their quantity is greater in those organs whose of fice it is to prepare substances conveyed to them for assimilation by other parts. The leaves contain more inorganic matters than the branches, and the branches more than the stem. The potato plant contains more potash before blossoming than after it.

"Now, as we know the capacity of saturation of organic acids to be unchanging, it follows that the quantity of the bases united with them cannot vary, and for this reason the latter sub stances ought to be considered with the strict. est attention both by the agriculturist and physiologist.

"We haveno reason to believe that a plant in a condition of free and unimpeded growth produces more of its peculiar acids than it requires for its own existence; hence, a plant on whatever soil it grows, must contain an in. variable quantity of alkaline bases. Culture alone will be able to cause a deviation.

"In order to understand this subject clearly, it will be necessary to bear in mind, that any one of the alkaline bases may be substituted for another, the action of all being the same. Our conclusion is, therefore, by no means en. dangered by the existence of a particular alkali in one plant, which may be absent in others of the same species. If this inference be correct, the absent alkali or earth must be supplied by one similar in its mode of action, or in other words, by an equivalent of another base.

"Of course, this argument refers only to those alkaline bases, which, in the form of organic salts, form constituents of the plants. Now, those salts are preserved in the ashes of plants, as carbonates, the quantity of which can be easily ascertained.

"From these considerations we must perceive, that exact and trustworthy examination of the ashes of plants of the same kind growing upon different soils would be of the greatest importance to vegetable physiology, and would decide, whether the facts above mentioned are the results of an unchanging law for each family of plants, and whether an invariable number can be found to express the quantity of oxygen which each species of plant contains in the bases united with organic acids. In all prohability, such inquiries will lead to most important results; for it is clear, that if the production of a certain unchanging quantity of an organic acid is required by the peculiar nature of the organs of a plant, and is necessary to its existence, then potash or lime must be taken up by it, in order to form salts with this acid 


\section{ACIDS.}

that if these lo not exist in sufficient quantity II the soil, other bases must supply their place; and that the progress of a plant must be wholly arrested when none are present.

"Seeds of the Sulsola Kali, when sown in common garden soil, produce a plant containing both potash and soda; while the plants grown from the seeds of this contain only salts of potash, with mere traces of muriate of soda. (Cadet.)

"The existence of vegetable alkalies in combination with organic acids gives great weight to the opinion, that alkaline bases in general are connected with the developement of plants.

"If potatoes are grown where they are not supplied with earth, the magazine of inorganic bases, (in cellars for example,) a true alkali, called Solanin, of very poisonous nature, is formed in the sprouts which extend towards the light, while not the smallest trace of such a substance can be discovered in the roots, herbs, blossoms, or fruits of potatoes grown in fields. (Otlo.)

"When roots find their more appropriate base in sufficient quantity, they will take up less of another."-(Liebig's Organic Chem.)]

Vegetable acids abound in most plants; thus, che Acetic acid (vinegar) is found in the chick pea (Cicer arietinum), in the elderberry (Sımbucus nigra), in the date palm tree (Phœnix dactylifera), and in numerous others.

The Oxalic acid is found combined with potash in the Oxalis Acetosella, or wood-sorrel (whence its name), and many other plants; united with lime, it is detected in the root of the rhubarb, in parsley, fennel, soapwort, squills, \&c.; and in an uncombined state in the liquid which exudes from the Cicer arietinum, [chick pea, or Spanish Garbanza.]

Tartaric Acid [or Cremor tartar] is commonly procured from turtar or tartrate of potash (whence its name). It has been detected in many plants, such as in grapes, tamarinds, bilberries, white mulberries, the Scotch fir, couch grass, dandelion, \&c. \&c.

Citric Acid has been found in oranges and lemons, cranberries, red whortleberry, birdcherry, woody nightshade, the hip, and the onion.

Malic Acid is the only acid existing in the apple, [pear,] barberry, p'um, sloe, elder, service, \&c. It is found with tie citric acid in the gooseberry, currant, bleaberry, cherry, strawberry, raspberry, \&c.; combined with lime, it is found in the house-leek, wakerobin, \&c.; and with potash and lime, in rue, garden purslane, madder, spinach, lilac, mignionette, \&c.

Benzoic Acid.-This acid is found in benzoin, balsam of Tolu, storax, \&c.; and in marjoram, clary, chickpea, Tonkin bean, \&c.

The Prussic, or Hydrocyanic Acid, exists in laurel leaves, peach blossoms, bitter almonds, flowers of the sloe, leaves of the bay-leaved willow, \&c.; there is little doubt but that all the bitter almond kernels contain this acid.

Gallic Acid abounds in the barks of many plants, such as the elm, oak, chestnut, beech, willow, elder, plum tree, sycamore, birch, cherry tree, sallow, mountain ash, poplar, hazel crmmon ash, sumach, \&c.
AtIDS.

These are the chicf vegetable acids. There are others which have been detected sccasionally; such as the moroxylic, in the Morus albu, or white mulberry; the boletic, in the Boletus pseudo-igniarius; [a species of mush. room,] the meconic, in opium; the kinic, in the bark of the Cinchona officinulis; the cam. phoric from camphor; the suberic fron cork. \&c.; but none of these are of that importance to the cultivator to require a particular notice in this place. The composition of the principal vegetable acids is much more similar than the intelligent farmer might be inclined $w$ suspect, as will be readily seen from a comparison of the following table of their composi. tion, chiefly by M. Berzelius :-

$\begin{array}{lcccc} & \text { Hydrogea. } & \text { Carboa. } & \text { Oxyren } \\ \text { Acetic acid } & - & -6.35 & 46.83 & 46.82 \\ \text { Oxalic acid } & - & -0.244 & 33.622 & 66.534 \\ \text { Tartaric acid } & - & -3.951 & 36.167 & 50.852 \\ \text { (itric acid } & - & -3.800 & 41.369 & 54.831 \\ \text { Benzoic acid } & - & -5.16 & 74.41 & 2043 \\ \text { Gallic acid } & - & -5.00 & 56.64 & 38.36\end{array}$

[The organic acids of animal origin are, like those obtained from vegetables, very numerous. As examples, there are, the furmic acids, first obtained from ants, but now ascertained to exist in sugar and some other vegetable substances: Lactic acid, obtained from milk;Uric acid, procured from human urine, and Hippuric acid, from the urine of the horse and other animals when stall-fed: Margaric and Steuric acids from fat, etc. The Phosphoric acid, though found combined with minerals, is very abundant in the animal system, heing combined with lime to form the bones, and existing in the urine and other fluids and solids, in union with alkaline bases, forming phosphates of soda, potash, lime, and magnesia.

Phosphoric acid has also been found in all plants, the ashes of which have been examined by chemists, always, however, in combination with potash, soda, magnesia, or lime. Most seeds contain certain quantities of the phosphates formed by the union of phosphoric acid with some one or more of the allralies just named. In the seeds of diffc...... '.: inds of grain, there is abundance of phosphate of magnesia.

Phosphoric acid, in one or other of its com. binations, plays indeed an important part in agriculture, and is an indispensable constituent of all good land.

"The soil in which plants grow furnishes them with phosphoric acid, and they in turn yield it to animals, to be used in the formation of their bones, and of those constituents of the brain which contain phosphorus. Much more phosphorus is thus afforded to the body than it requires, when flesh, bread, fruit, and husks of grain are used for food, and this excess in them is eliminated in the urine and the solid excrements. We may form an illea of the quantity of phosphate of magnesia contained in grain when we consider that the concretions in the scum of horses consist of phos. phate of magnesia and ammonia, which must have been obtained from the hay and oats cous sumed as food. Twenty-nine of these stones were taken after death from the rectum of a horse belonging to a miller in Eherstadt, the total weight of which amounted to 3 lhs. 
"6 It is evident that the seeds of wheat could however; every farmer collecting his own, or not be formed without phosphate of magnesia, letting his pigs feed upon them.

which is one of their invariable constituents; the plant could not, therefore, under such circumstances attain its proper developement, so far as its fructification was concerned."']

The Crenic, is another organic acid lately discovered by Berzelius. From its containing nitrogen and being a constituent in all fertile soils, it is believed to exercise a beneficial action on vegetation. It is always accompanied by the Apocrenic acid, changed from the crenic by oxydation.

ACINUS. The stone of any berry.

ACONITF. See Wolfsiane.

ACORNS. The seed or fruit of the oak; ecejn, Saxon, from ac, an oak, and conn, corn or grain; that is, the grain or fruit of the oak.

The Greeks had a tradition, that the oals was the first created tree; and hence, having a similar idea as to the Arcadians being the first created men, they compared them to the oak. Virgil tells us to

Foresh the wond,

For masts of oak, your father's homely food."

\section{And Ovid corroborates their use :-}

"Coutent with fond which nature freely bred, On wildings and on strawberries they fed, Cornils and hramble trerries gave the rest, And fallen acorus furnish'd out a feast.'

Turner, who is the earliest English author on this subject, writes, "Oke, whose fruit we call "curn, or an eykorn (that is, the corn or fruit of an cyke), are hard of digestion, and nourish very much, but they make raw humores. Wherefore, we forbid the use of them for meates." They were long the food of the early Greeks, as they are of the lower order of Spaniards, even to this day; but then it must be remembered, that the acorns of Spain are more sweet and nutritious than those of England. And yet the early Britons certainly eat them: their priests, or Druids, taught them, that every thing that was produced on the oak, even to the parasitical mistletoe, was of heavenly origin, a superstition which was common, also, to the Persians and the Massagetæ.

The Saxons valued them chiefly for fattening swine. Their king Ina, in the seventh century, gave them a law, respecting the fatlening of their swine in the oak woods, which privilege was called a pawnage, or pannage.

The oak is often mentioned in Holy Writ, as the oal of Ophra, Judges vi. 11; of Shechem, Gen. xxxv. 4 ; and of Deborah's Grave, Gen. Xxxv. 8. See OAK.

Although acorns are said to have been the primitive food of mankind, at present they are only used in raising young oaks, or for the purpose of fattening deer and hogs, for which last they are said to be a very proper and useful kind of food.

In Gloucestershire, according to Mr. Marshall, they are in high esteem among the farmers, who seem to be as anxious about them as their apples. They consider them as the best means of fatting hogs, and think they make the bacon firm, and weigh better than bean-fed bacon. The price of acorns there is from 1s. $6 d$. to $2 s$. per bushel, according to the season and the price of beans. Few are sold,
Some care is necessary to be talken when hogs are fed upon acorns, for otherwise they will be subject to constipation, and the disease called the garget. These may, however, be avoided, by mixing laxative substances with them, and not allowing them to have too many at a time; at first a few, twice a day is often enough; afterwards three times a day. The hogs, while they eat this food, should not be confined to the stye, but be suffered to run at large; for if their liberty be too much abridged, they never thrive well, or grow fat on this sor of food.

In Hertfordshire, and the New Forest in Hampshire, it is no uncommon thing, with the management above directed, and the assistance of a little wash, and a few grains now and then, for a farmer to kill several hogs in a season, which weigh from eight to ten score. and sometimes even more. Hogs fed in this way make very good well-flavoured meat; but it is not thought by some so fine as when thcy are taken up, and four or five bushel of pease or barley-meal given to each to complete their fattening.

"The pigs are gone acorning," is a very coin. mon provincialism (see Mr. Wilbruham's Che. shive Glossary); and the expression is also confirmed by Shakspeare's "full-acorn'd boar."

Acorns are sometimes given to poultry, and would be found an advantageous food for them, when dried and ground into meal.

Tusser, speaking of acorns, says,

"Some left among bushes shall pleasure thy swine,
For fear of a mischief, keep acorns from kine"

They are considered injurious to cows, because they swell in their stomachs, and will no: come up to the cud again; which causes them to strain as it were, to remit, and to draw their limbs together.

In medicine, a decoction of acorns is repuled good against dysentaries and colics. Pliny states, "that acorns beaten to powder, and mixed with hog's lard and salt, heal all hard swell. ings and cancerous ulcers; and when reduced into a liniment, and applied, stays hæmorrhage." (Phillip's Fruits.)

When employed for raising oak timber from, the method of planting the acorns, which is practised by some, is to make holes to recerve them, at the distance of 12 or 15 inches from each other, in an oblique direction, so as to raise up a tongue of turf under which they are to be deposited, and where they require no farther kind of nursing. In the course of from twenty to thirty years, in this mode of planting, the spot, it is said, will be fit to be coppiced, that is, partially cut down as underwood, leav. ing the most healthy plants. The thinnings may be sold for railing, and generally fetch a good price. A better method is, however, to dibble them on land that has been properly prepared by ploughing or digging, which may be done by women, three or four within a square yard; or they may be sown broad-cas when the surface is fine and moist, and rolles in with a light roller. The former is probably the better practice. They may likewise be ses about the middle of November, by a land chain. 
a quarter of a rod asunder, and six inches apart in the rows; dibbling them in, zigzag, alternately on either side a line stretched tightly on the surface, with blunt-pointed dibbles, letting a little mould fall down to the bottoms of the holes, to prevent water lodging round them, and burying them about two inches beneath the surface. Each squarc rod, when planted in this way, takes 132 acoms, nearly a pint, when they are middle-sized, which is equal to two statute bushels and a half on an acre. 'The expense, in England, of planting acorns in this manner is about $5 s$. an acre. See Planting.

ACORUS, from the Greek $u$, privative, and xaph, the pupil of the eye. The botanical name af a plant of the thistle kind, that produces the drug called in the shop C'ulamus uromuticus. It is found abundantly in the neighbourhood of freshwater marshes. The ancient practice of s'rewing the floors with the leaves of these sweet rushes is still kept up in some of our cathedral churches upon certain high festivals. The plant, which belongs to the natural order Aroidex, flourishes luxuriantly in loose, moist soils, and sends forth many deep-green, long sword-shaped leaves from its perennial, creeping, and horizontal stems. It seldom flowers, but the blossoms which it sends furth are of a greenish colour. The root, or more properly the stem, is the part which, when dried, is used medicinally, occasionally as a stimulant. It is slightly acrid and aromatic. (Thomson's Dispensary.)

ACRE (aecne, Sax. Acre, Lye says, is common to all the European languages. $S_{i} x$. Dic.). He might have added further, that it is an Eastern word: and that $a g r$, akoro, and akkoran, denote in the Hebrew, Syriac, and Arabic, a field, a husbandman. So the Saxon aeccenmon, a husbandman. Wachter, in his Glossary, gives ukermnn, a day-labourer. (Todd's Johnsun.) In Shakspeare's King Lear, we have-

\section{"Search ev try acre in the high grown field, And bring him to our eye."}

The prevai ing and standard measure of land in Britain. In acre in England contains 4 squara ruod; ; a rood, 40 perches, rods, or poles, $5 \frac{1}{2}$ yar is, or $16 \frac{1}{2}$ feet each, according to the statute ir the act passed in 1824, for the equalization of weights and measures throughout the Unired Kingdom, which is in this instance confirmatory of the old law of England. But in some parts of England there are nther measures under the same designation of acre. For example, in Devonshire, and part of Somerset, 5 yards (instead of $5 \frac{1}{2}$ ) have been reckoned to a perch; in Cornwall, 6 yards (anciently called the Woodland perch); in Lancashire, 7 yards ; in Cheshire and Staffordshire 8 yards; in the Isle of Purbeck, and some parts of Devonshire, 15 feet and 1 inch. In the common fields of Wiltshire and the neighbouring counties, 120 poles, or 3 roods, were reckoned to an acre.

The Irish acre is 7840 square yards, and is equal to 1 acre, 2 roods, and 19 poles, nearly, of English measure.

The Scorch acre contains 5760 square Scotch ells, and is equal to 1 acre, 1 rood, 2 poles nearly, of Linglish measure.

The following 'Table shows the comparative quantity of each of the above measures:-

A. R. P.

120320 Devonshire custonary measure, ?

119226 Inle uf Purbeck, dulto.

8404 Cornish or Wondlaud litto.

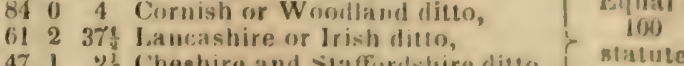

$4712 \%$ Cheahire and staffurdshire dito, f statute

13320 Wiltshire tenantry ditto,

$16 \frac{1}{8}$ seotch measure,

The French acre, or arpent, according to Mr. Greave's calculation, consists of 100 perches, of 22 feet each, amounting to 48,400 square French feet, which are equal to 51,691 square English fleet, or very near one acre, and three quarters of a rood, English measure. The Strasburg acre is about hall an English acre.

Table exhibiting the Number of Plants which may be raised on a Perch of Land, at different distances:-

In a perch are $272 \frac{1}{2}$ square feet, or 39,204 square inches. A perch will contain

\begin{tabular}{|c|c|c|c|c|}
\hline $\begin{array}{l}\text { Trees or } \\
\text { Plants. }\end{array}$ & $\begin{array}{l}\text { Inches } \\
\text { over. }\end{array}$ & $\begin{array}{r}\text { Number of } \\
\text { asunde }\end{array}$ & $\begin{array}{l}\text { Iuches } \\
\text { er. }\end{array}$ & $\begin{array}{l}\text { Square Inches } \\
\text { to each. }\end{array}$ \\
\hline 2450 & 4 & 4 by & 4 & 16 \\
\hline 1960 & . & $5-$ & 4 & 20 \\
\hline 1633 & 12 & $6-$ & 4 & 24 \\
\hline 1069 & - & $6-$ & 6 & 36 \\
\hline 816 & 36 & $8-$ & 6 & 48 \\
\hline 612 & 36 & $8-$ & 8 & 64 \\
\hline 490 & 4 & $10-$ & 8 & 80 \\
\hline 392 & 4 & $10-$ & 10 & 100 \\
\hline 272 & 36 & $12-$ & 12 & 144 \\
\hline 261 & 54 & $15-$ & 10 & 150 \\
\hline
\end{tabular}

An acre will contain

\begin{tabular}{|c|c|c|c|}
\hline $\begin{array}{l}\text { Trees or } \\
\text { Plants. }\end{array}$ & $\begin{array}{l}\text { Inches } \\
\text { over. }\end{array}$ & $\begin{array}{c}\text { Number of feet } \\
\text { asunder. }\end{array}$ & $\begin{array}{c}\text { Square feet } \\
\text { to each. }\end{array}$ \\
\hline 108 & 360 & 20 & 400 \\
\hline 160 & - . & $16 \frac{1}{2}$ & $272 \frac{1}{4}$ \\
\hline 134 & 144 & 18 & 324 \\
\hline 302 & 72 & 12 & 144 \\
\hline 435 & 60 & 10 & 100 \\
\hline 680 & 40 & 8 & 64 \\
\hline 888 & 48 & 7 & 49 \\
\hline 1089 & . . & 8 by 5 & 40 \\
\hline 1210 & - . & 6 & 36 \\
\hline 1361 & 8 & $8-4$ & 32 \\
\hline 1452 & . . & $6-5$ & 30 \\
\hline 1555 & 20 & $7-4$ & 28 \\
\hline 1815 & . : & $6-4$ & 24 \\
\hline 2178 & . . & $5-4$ & 20 \\
\hline 2722 & 8 & $4-4$ & $16 \frac{1}{2}$ \\
\hline 2904 &. & $5-3$ & $15^{2}$ \\
\hline 3630 & . & $4-3$ & 12 \\
\hline 4840 & . . & $3-3$ & 9 \\
\hline 5445 & . . & $4-2$ & 8 \\
\hline 7260 & .. & $3-2$ & 6 \\
\hline 8712 & . . & $2 \frac{1}{2}-2$ & 5 \\
\hline 10,890 & . . & $2-2$ & 4 \\
\hline 19,305 & . . & $1 \frac{1}{2}-1 \frac{1}{2}$ & $2 \frac{1}{2}$ \\
\hline 21,780 & . . & $2-1$ & 2 \\
\hline 43,560 & - . & 1 & 1 \\
\hline
\end{tabular}


A Table for reducing Square Yards into Acres, Roods, and Perches.

\begin{tabular}{|c|c|c|c|c|c|c|c|c|c|c|c|c|c|c|c|}
\hline $\mathrm{Sq} . \mathrm{Yds}$. & A. & R. & P. & Sq. Yds. & A. & n. & P. & Sq. Y ds. & A. & n. & P. & Sq. Yds. & A. & n. & P. \\
\hline 30 & 0 & 0 & 1 & 5,400 & 1 & 0 & 19 & 11,100 & 2 & 1 & 7 & 6,900 & 3 & 1 & 39 \\
\hline 60 & 0 & 0 & 2 & & 1 & 0 & 22 & & 2 & 1 & 10 & 17,000 & 3 & 2 & 2 \\
\hline 91 & 0 & 0 & 3 & 5,600 & 1 & 0 & 25 & 11,300 & 2 & 1 & 14 & & & & \\
\hline 121 & 0 & 0 & 4 & 5,700 & 1 & 0 & 29 & 11,400 & 2 & 1 & 17 & 7,100 & 3 & 2 & 5 \\
\hline 151 & 0 & 0 & 5 & 5,800 & 1 & 0 & 32 & 11,500 & 2 & 1 & 20 & & 3 & 2 & 9 \\
\hline & & & & & 1 & 0 & 35 & 11,600 & 2 & 1 & 23 & 300 & 3 & 2 & 12 \\
\hline 200 & 0 & 0 & 7 & 6,000 & 1 & 0 & 38 & 11,700 & 2 & 1 & 27 & 17,400 & 3 & 2 & 15 \\
\hline 300 & 0 & 0 & 10 & & & & & 11,800 & 2 & 1 & 30 & 17,500 & 3 & 2 & 19 \\
\hline 400 & 0 & 0 & 13 & 6,100 & 1 & 1 & 2 & 11,900 & 2 & 1 & 33 & 17,600 & 3 & 2 & 22 \\
\hline 500 & 0 & 0 & 17 & & 1 & 1 & 5 & 12,000 & 2 & 1 & 37 & 17,700 & 3 & 2 & 25 \\
\hline 600 & 0 & 0 & 20 & 300 & 1 & 1 & 8 & & & & & 17,800 & 3 & 2 & 28 \\
\hline 700 & 0 & 0 & 23 & & 1 & 1 & 12 &, 100 & 2 & 2 & 0 & 17,900 & 3 & 2 & 32 \\
\hline 800 & 0 & 0 & 26 & 500 & 1 & 11 & 15 & 00 & 2 & 2 & 3 & 8,000 & 3 & 2 & 25 \\
\hline 900 & 0 & 0 & 30 & 6,600 & 1 & 1 & 18 & 00 & 2 & 2 & 7 & & & & \\
\hline 1,000 & 0 & 0 & 33 & 6,700 & 1 & 12 & 21 & 2,400 & 2 & 2 & 10 & 8,100 & 3 & 2 & 38 \\
\hline & & & & 6,800 & 1 & $1:$ & 25 & 500 & 2 & 2 & 13 & & 3 & 3 & 2 \\
\hline 1,100 & 0 & 0 & 36 & 6,900 & 1 & 12 & 28 & 2,600 & 2 & 2 & 17 & 00 & 3 & 3 & 5 \\
\hline 1,200 & 0 & 1 & 0 & 7,000 & 1 & 1 & 31 & 12,700 & 2 & 2 & 20 & 00 & 3 & 3 & 8 \\
\hline 1,300 & 0 & 1 & 3 & & & & & 12,800 & 2 & 2 & 23 & 00 & 3 & 3 & 12 \\
\hline 1,400 & 0 & 1 & 6 & 7,100 & 1 & $1:$ & 35 & 12,900 & 2 & 2 & 26 &, 600 & 3 & 3 & 15 \\
\hline 1,500 & 0 & 1 & 10 & & 1 & $1:$ & 38 & 13,000 & 2 & 2 & 30 & 700 & 3 & 3 & 18 \\
\hline 1,600 & 0 & 1 & 13 & 300 & 1 & 2 & 1 & & & & & 8,800 & 3 & 3 & 21 \\
\hline 1,700 & 0 & 1 & 16 & 00 & 1 & 2 & 5 & 0 & 2 & 2 & 33 & 8,900 & 3 & 3 & 25 \\
\hline 1,800 & 0 & 1 & 20 & 00 & 1 & 2 & 8 & & 2 & 2 & 36 & 19,000 & 3 & 3 & 28 \\
\hline 1,900 & 0 & 1 & 23 & 7,600 & 1 & 21 & 11 & & 2 & 3 & 0 & & & & \\
\hline 2,000 & 0 & 1 & 26 & 7,700 & 1 & 21 & 15 & & 2 & 3 & 3 & & 3 & 3 & 31 \\
\hline & & & & 7,800 & 1 & 21 & 18 & 13,500 & 2 & 3 & 6 & & 3 & 3 & 35 \\
\hline 2,100 & 0 & 1 & 29 & 7,900 & 1 & 22 & 21 & 13,600 & 2 & 3 & 10 & & 3 & 3 & 38 \\
\hline 00 & 0 & ] & 33 & 8,000 & 1 & 22 & 24 & 13,700 & 2 & 3 & 13 & 00 & 4 & 0 & 1 \\
\hline 00 & 0 & 1 & 36 & & & & & 13,800 & 2 & 3 & 16 & 9,500 & 4 & 0 & 5 \\
\hline 00 & 0 & 1 & 39 & 00 & 1 & 22 & 28 & 13,900 & 2 & 3 & 20 & 9,600 & 4 & 0 & 8 \\
\hline 2,500 & 0 & 2 & 3 & 0 & 1 & 23 & 31 & 14,000 & 2 & 3 & 23 & 9,700 & 4 & 0 & 11 \\
\hline 2,600 & 0 & 2 & 6 & 0 & 1 & 23 & 34 & & & & & 9,800 & 4 & 0 & 15 \\
\hline 2,700 & 0 & 2 & 9 & 8,400 & 1 & 23 & 38 & & 2 & 3 & 26 & 9,900 & 4 & 0 & 18 \\
\hline 2,800 & 0 & 2 & 13 & 8,500 & 1 & 3 & 1 & & 2 & 3 & 29 & 0,000 & 4 & 0 & 21 \\
\hline 2,900 & 0 & 2 & 16 & 8,600 & 1 & 3 & 4 & 0 & 2 & 3 & 33 & & & & \\
\hline 3,000 & 0 & 2 & 19 & 8,700 & 1 & 3 & 8 & & 2 & 3 & 36 & & 4 & 0 & 24 \\
\hline & & & & 800 & 1 & $3 \quad 1$ & 11 & 0 & 2 & 3 & 39 & & 4 & 0 & 28 \\
\hline 90 & 0 & 2 & 2 & 8,900 & 1 & $\begin{array}{ll}3 & 1\end{array}$ & 14 & 0 & 3 & 0 & 3 & & 4 & 0 & 31 \\
\hline 0 & 0 & 2 & 21 & 9,000 & 1 & $\begin{array}{ll}3 & 1\end{array}$ & 18 & & 3 & 0 & 6 & & 4 & 0 & 34 \\
\hline & 0 & 2 & 29 & & & & & 00 & 3 & 0 & 9 & 0 & 4 & 0 & 38 \\
\hline 00 & 0 & 2 & 32 & & 1 & 32 & 21 & 0 & 3 & 0 & 13 & & 4 & 1 & 1 \\
\hline 00 & 0 & 2 & 36 & & 1 & 32 & 24 & 15,000 & 3 & 0 & 16 & 0 & 4 & 1 & 4 \\
\hline 0 & 0 & 2 & 39 & & 1 & 32 & 27 & & & & & & 4 & 1 & 8 \\
\hline 3,700 & 0 & 3 & 2 & & 1 & 33 & 31 & & 3 & 0 & 19 & 0 & 4 & 1 & 11 \\
\hline & 0 & 3 & 6 & & 1 & 33 & 34 & & 3 & 0 & 22 & 1,000 & 4 & 1 & 14 \\
\hline 3,900 & 0 & 3 & 9 & 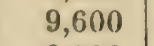 & 1 & $\begin{array}{ll}3 & 3\end{array}$ & 37 & & 3 & 0 & 26 & & & & \\
\hline $4,0 \cap 0$ & 0 & 3 & 12 & 9 & 2 & 0 & 1 & & 3 & 0 & 29 & & 4 & 1 & 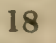 \\
\hline & & & & $\mathbf{9 , 8}$ & 2 & 0 & 4 & & 3 & 0 & 32 & & 4 & 1 & 2 \\
\hline & 0 & 3 & It & & 2 & 0 & 7 & & 3 & 0 & 36 & & 4 & 1 & 24 \\
\hline & 0 & 3 & 19 & 10,000 & 2 & $\begin{array}{ll}0 & 1\end{array}$ & 11 & & 3 & 0 & 39 & & 4 & 1 & 27 \\
\hline & 0 & 3 & 22 & & & & & 0 & 3 & 1 & 2 & & 4 & 1 & 31 \\
\hline & 0 & 3 & $2:$ & & 2 & $\begin{array}{ll}0 & 1\end{array}$ & 14 & & 3 & 1 & 6 & & 4 & 1 & 34 \\
\hline 00 & 0 & 3 & 29 & & 2 & $\begin{array}{ll}0 & 1\end{array}$ & 1 & 16,000 & 3 & 1 & 9 & 0 & 4 & 1 & 37 \\
\hline & 0 & 3 & 3 & & 2 & 02 & 2 & & & & & & 4 & 2 & 1 \\
\hline 4,700 & 0 & 3 & 35 & & 2 & 02 & 2 & & 3 & 1 & 12 & & 4 & 2 & 4 \\
\hline & 0 & 3 & 39 & & 2 & 02 & 2 & & 3 & 1 & 16 & 2,000 & 4 & 2 & 7 \\
\hline 4,900 & 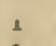 & 0 & 2 & 10,000 & 2 & 03 & 3 & & 3 & 1 & 10 & & & & \\
\hline 5,000 & 1 & 0 & $\Rightarrow$ & & 2 & 03 & 34 & & 3 & 1 & 22 & & 4 & 2 & 11 \\
\hline & & & & & 2 & $\begin{array}{ll}0 & 3\end{array}$ & 37 & & 3 & 1 & 2 & & 4 & 2 & 14 \\
\hline & 1 & 0 & & & 2 & 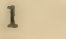 & & & 3 & 1 & 25 & & 4 & 2 & 17 \\
\hline & 1 & 0 & 12 & 11,000 & 2 & 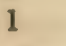 & 4 & & 3 & 1 & 32 & & 4 & 2 & 20 \\
\hline (i) & 1 & 0 & 15 & & & & & 6 & 3 & 1 & 35 & 22,500 & 4 & 2 & 4 \\
\hline
\end{tabular}




\section{ACRIMONY.}

\section{Table of Land Measure.}

In an acre are

4 roods, each rood forty perches.

160 perches, sixteen feet and a half each. 4,840 square yards, nine feet each.

43,560 square feet, 144 inches each.

174,240 squares of six inches each, thirty-six inches each.

6,272,640 inches, or squares, of one inch each.

ACRIMONY (Acrimonia, Lat.). A sharp property in some plants and vegetables, by which they excoriate and blister the tongue, mouth, or other parts of the body, on being applied to them. The nature of this sort of acrimony has not yet been sufficiently examined by chemical investigation. It seems to differ in some measure according to the nature of the plants; as in the common onion, watercresses, cabbages, \&c., a part of their acrimony is lost, by their being exposed to a boiling heat; while other kinds, as ginger, capsicum, arum, \&c., do not become much milder by undergoing that process.

The juice of the fungous excrescences of some trees possess so much acrimony as to be capable of blistering; and some kinds of fungi contain a juice or liquor of a very corrosive quality; and it is probably on this account that many of those which are commonly procured disagree so much with the patient, when made use of as articles of diet. By being more perfectly stewed, or otherwise prepared by means of heat, they might most likely be rendered safe and nutritious. Much caution should, however, he used, even when thus prepared, in eating such kinds as are un known. "There be some plants," says Bacon, in his Nut. Hist., "that have a milk in them when they are cut; as figs, old lettuce, sowthistles, spurge. The cause may be an inception of putrefaction: for those milks have all an acrimony, though one would think they should be lenitive."

ADAPTER (Adapto, Lat.). In the management of bees, is a board used to place the hives or glasses upon.

ADDER (Aerren, aerron, naobne, as it seems, from eitzen, Sax. poison; Mœs-Goth. nadr, vipera; Teut. adder). A viper, a poisonous reptile, perhaps of any species. In common language, however, adders and snakes are not the same, the term adder being generally understood to imply a viper. See Animat Poisons.

ADEPS. In veterinary science, animal oil or fat. The fat differs in different animals; and hence it has received different names. In the horse it is called grease; in the ox and sheep, tallow, fat, suet; and in the hog, hog's lard. At a low temperature all these possess various degrees of consistence; but in the living aniInal, they all exist in a fluid state, and are distributed over various parts of the body. An immense quantity of fat is often found in the belly, all deposited in extremely small cells, which have no communication with each other. No fat is ever found within the skull.

Fat performs important functions in the animal economy. When the supply of ali-

\section{AEROLITES.}

ment, for example, is greater than the demand, the surplus is stored away in the form of fat; and when the demand, either from deficiency of food, over-exertion, or disease, becomes greater than the supply, then the absubents carry the fat into the circulation, and thus, for a time, the evils that would very sun arise from a defect in the quantity of blood are pre. vented. Some animals accumulate fat nore readily than others. Health, a round chest, a short back, and tranquil temper are highly favourable to its formation; and when to these qualities are added inaction, clean litter, and a plentiful supply of nourishing food, the animal is soon fit for the butcher. A warm atmor sphere, provided it be a pure one, is also favourable to fattening. [See LARn OIL, \&c.] (Miller's Dictionary).

AERATION. The process by which the soil is exposed to the air and imbued therewith, air being indispensable to the healthy growth of plants. When a flower-pot is filled with rather dry earth, if it be plunged under water a profusion of air-bubbles will be seen to rise, owing to the water penetrating between the particles of the dry earth, and forcing out the air previously lodged there. As the more loose and porous a soil is, the greater quantity of air it will contain, it will follow, that the more a soil is ploughed and harrowed, or dug and ralsed, the better it will be aerated-one of the chief beneficial effects of frequently repeating these operations.

Besides the direct influence of the atmosphere, the agency of water is all-important in the process of aeration. All water openly exposed contains more or less atmospheric air; and, in consequence of this, it acquires an agreeable taste, always destroyed by boiling, which renders it vapid and disagreeable, by expelling the air. The importance of air contained in water to the growth of plants appears from water being found beneficial in proportion as it has had opportunities of becoming mixed with air. But the best water, with respect to the properties of the air it contains, is rain, which, falling in small drups, often tossed about by the wind, has an opportunity of collecting a large proportion of air, and, according to Liebig (Organic Chem.), ammonia, during its descent to the earth; and hence the smaller the bore of the holes in a garden watering-pot, the better; and the more minutely the garden-engine scatters the water, the more advantageously, so far as the air is concerned.

There is another point of view in which aeration appears beneficial, arising from the excrementitious matters thrown into the soi! by growing plants, as ascertained by M. Màcaire; for as these matters become decomposed in the processes of fallowing, irrigation, and draining, the gases there produced would not so readily be carried off from the snil, but for a due circulation of the common air through the earth. See Gases, their use to vegetation. (Miller's Dictionary).

AEROLITES (From the Greek anp, air, and $\lambda_{1} \theta$ os, a stone). Meteoric stones, bodies that fall from the heavens. The origin of these remarliable bodies is still a mystery. 
AFRICAN MARIGOLD.

AFRICAN MARIGOLD (Tugites erecta, J,in.). A favourite hardy annual, which does not come from Africa, as its name would indicate, but from Mexico. See Marigozn.

AF'TER-GRASS, or AFTERMATH. The second crop of grass, or that which springs after mowing, or the grass cut after some kinds of com crops.

The composition of the after-grass generally varies considerably from that of the first or spring crop. The nutriment of the latter, from most of the grasses, is materially less than that of the former. 'This was clearly ascertained by the elaborate experiments of the late Mr. G. Sinclair, the results of which are dispersed throughout his valuable work on the Grasses. To give a few instances only-

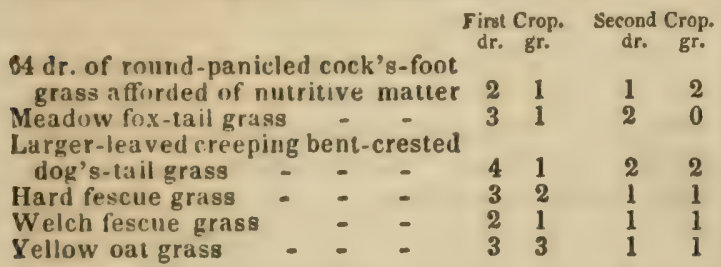

And the same remark applies to the rye-grass (Lolium perenne), not only of upland pastures but of meadows. Thus, Sinclair found (Hort. Gram. Wob. 381) that this grass when flowering, taken from a water meadow that had been fed off with sheep till the end of April, yielded of nutritive matter 72 grs.

But the same grass from the same meadow which had not been fed off, yielded 100 grs.

The same weight of this grass, from a rich old pasture that had been shut up for hay at the same time, yielded of nutritive matter 95 grs. But the grass from the same field, which had not been depastured, yielded 120 grs.

Some of them, however, contain exactly as much nutritive matter in the aftermath as in the first crop: thus, $64 \mathrm{drs}$. of the

\begin{tabular}{|c|c|c|c|c|c|c|}
\hline \multirow{2}{*}{\multicolumn{3}{|c|}{ Bweet-scented soft grass yiehled }} & \multicolumn{2}{|c|}{ First Crop. } & \multicolumn{2}{|c|}{ Latter Crop. } \\
\hline & & & $\begin{array}{l}d \\
4\end{array}$ & gr." & $\begin{array}{l}d r \\
4\end{array}$ & $g r$. \\
\hline Smonth-stalked me & eadow & & 1 & 3 & 1 & 3 \\
\hline Short blue meadou & $v$ grass & - & 2 & 0 & 2 & 0 \\
\hline Cow grass & - & - & 2 & 1 & 2 & 1 \\
\hline Creeping fescue & - & - & 1 & 2 & 1 & 2 \\
\hline
\end{tabular}

and one or two were found to contain more nutritive matter in the aftermath than in the first crop: thus $64 \mathrm{drs}$. of the

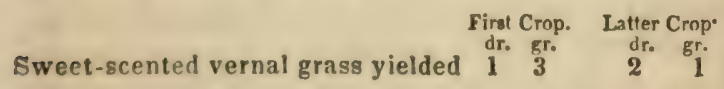

In the vicinity of London most of the aftergrass, or second crop, was formerly made in to hay, and was considered of considerable value for the ewes of sucl-ling lambs, and milch cows; but in harvesting this crop, so as to make it sell well, gr:at nicety is requisite, the nature $0^{\circ}$ dfter-grass being more soft, spongy, and porous than the first growth, and consequently more liable to be hurt by rains. 'The practice is therefore on the decline.

In the midland counties their management of the feeding off the after-grass is in general judicious. It is commonly suffered to get up to a full lite before it is broken, and not turned in upon as .von as the hay is off, or suffered to stand unti. much of it becomes improper for the food of animals. Farmcrs, however, make
AFTER-GRASS.

a point of saving autumnal grass for spring feed, and contend that it is the most certain, and, on the whole, the best spring feed yet known. This would seem to be a wastelul practice, at least in respect to the more forward after-grasses. These ought certainly to be broken sufficiently early to be eaten, without waste, before winter sets in; and the latest, that is to say, the shortest, may be shut in for spring feed. If after-grass be too long and gross, it is apt to lodge, and rot upon the ground in winter; therefore, on rich lands, it ought always to be more or less off before Michaelmas, in order to prevent its being wasted or lost in the winter.

It is remarked by the author of "Practical Agriculture," that, "In some districts much of the after-grass is frequently cut and made into a green soft sort of hay, as has heen already mentioned; but in others it is fed off by live stock in the autumn." And that "both modes may be useful under different circumstances. In situations where plenty of manure can be procured, as near large towns, and where the chief dependence is upon the sale of hay, or where lamb-suckling prevails, it may frequently be a beneficial practice to take a second crop of hay, as the first may by that means be more fully spared for sale, the aftercrop supplying the cows or other cattle that may be kept on the farm. But in cases where manure cannot easily be obtained, and there is no local practice carried on which requires such sort of hay, it is better to let it be fed off by stock than run the risk of exhausting and injuring the ground by taking off repeated crops. There is also another circumstance," he says, "to be considered in this business, which is, that of the state of the land in respect to dryness, as where it is low, wet, and very retentive of moisture, it may be often more hurt by the poaching of the cattle in feeding off the herbage than by a second crop of hay." But that, "independent of these considerations, it may, in general, be a more safe and usual practice to eat off the after-grass by stock, and only take one crop of hay, as by such means a more abundant annual produce may be afforded, and the land sustain less injury."

It is, however, added, that "where a crop of rowen is made into hay, the most profitable application of it is probably in the foddering of such cows as are in mill; as it is well suited, by its grassy quality, and its not heating so much, when well made, as other sorts of hay in the stack, to afford a large flow of milk. It is this reason that induces the cow farmers to cut their grass so many times in the summer. Another beneficial application of this hay is, as has been seen, in the feeding of such ewes as are employed in the suckling of house-lambs during the winter season; the intention in this case is the same as in that of the preceding instance. There is another advantageous use to which this sort of produce may be applied, which is that of supporting young calves, and all sorts of young cattle that are kept as store stock." And that, "where sheep require the support of hay in the winter season, it is also well adapted to that use."

In the manner of feeding after-grass, there is 
also much variety in different districts. "It has," the same author says, "been observed by a farmer in Midcllesex, that the condition on which he rents his farm is that of taking out the cattle at Michaelmas, but that sheep remain till February." In that county the practice is to turn on the cattle immediately after nowing; but in the northern districts, this grass, to which they have given the name of eddish, is kept till November, or even a later period, for the purpose of furnishing fat stock, or for the pasturage of milch cows, from which a superior quality of cheese is made, and by which time it has attained a considerable head: however, this latter practice would seem to be attended with some loss, as has been shown from its being trodden and trampled under foot. In the stocking of after-grass, Marshall found the midland graziers of opinion, that one cow to an acre, on well-grown after-grass, was an ample stock. Good grass-land may, however, admit something more; and instead of pusturing of rowen, or after-grass, by heavy cattle in the autumn, to avoid poaching the ground, particularly at a late period in that or the winter season, it has been recommended by $\mathrm{Dr}$. Wilkinson, "to confine the consumption of this grass principally to the support of sheep, unless in very favourable seasons, or where the soil is uncommonly dry; in which cases milch cows, or other heavy cattle, may be admitted without inconvenience."

In some placies it is the practice, as "where there is a great scarcity of spring feed, to reserve after-grass in the autumn for spring use." Some, on the basis of experience, contend that it is the most certain, and, on the whole, the best spring feed yet known. It would seem, however, as has been shown, to be a wasteful practice, at least in respect to the more forward after-grasses. The forwardest ought certainly to be eaten without waste before winter sets in; and the latest, that is, the shortest, be shut up for spring feed. Arthur Young, it is stated, found, from repeated experiments, as suggested above, "that old after-grass feeds sheep that give milk better than turnips, which are more adapted to the fattening of stock; and that this grass holds to a period, if wanted, when most other resources fail, the last half of April and the first half of May-periods always of want and difliculty, where rye-grass is not sown." Marshall also assures us, that as a certain and wholesome supply of food for ewes and lambs in the early spring, the preserved pasture is to be depended on as "the sheet anchor, in preference to turnips, cabbages, or any other species whatever, of what is termed spring feed:" and the same thing has been experienced by 10r. Wilkinson, who has observed, that "this food with him afforded a more nutritive and healthful quality of milk from the ewes to their tender lambs than turnips, even in their best state." But however useful after-grass pastures may be under this management, there is evidently a great loss of food incurred by it, especially in severe winters. (Sinclair's Hort. Gram.; Lowe's Prac. Agr.)

AGARIC OF THE OAK. [Spunk, or touch- ood.] In farriery, a substance sometimes employed for restraining the bleeding of s mall vessels.

AGARICUS. See Musnnon.

AGAVE. In botany, comprehends those plants which gardeners call American aloes.

AGE OF ANIMAIS. 'The age of a horse may be ascertained by his mouth, and the examination of his teeth, till he is eight years old, after which the usual marks commonly wear out. 'These are usually forty in all; of which twenty-four are double teeth, and from their office, denominated grinders, four tushes, or corner teeth, and twelve fore-teeth.

The first which appear are the foal-teeth, which generally begin to show themselves a month or two after foaling; they are twelve in number, six above and six below, and are easily distinguished from the teeth that come afterwards, by their smallness and whiteness, having some resemblance to the incisores, or fore-teeth of man.

When the colt is about two years and a half old, he commonly sheds the four middlemost of his foal-teeth, two above and two below; but sometimes none are cast till near three years old. The new teeth are readily distinguished from the foal-teeth, being much stronger, and always twice their size, and are called the nippers or gatherers, being those by which horses nip off the grass when they are feeding in the pastures, and by which, in the house, they gather their hay from the rack. When horses have got these four teeth com plete, they are reckoned to be three years old.

When they are about three and a half, or in the spring before they are four years old, they cast four more of their foal-teeth, two fit the upper and two in the lower jaw, one on each side the nippers or middle teeth; so that when you look into a horse's mouth, and see the two middle teeth full grown, and none of the foalteeth, except the common teeth, remaining, you may conclude he is four that year, about April or May. Some, indeed, are later colts, but that makes little alteration in the mouth.

The tushes appear near the same time with the four last-mentioned teeth, sometimes sooner than these, and sometimes not till after a horse is full four years old; they are curved like the tushes of other animals, only in a young horse they have a sharp edge all round the top and on both sides, the inner part being somewhat grooved and flattened, so as to incline to a hollow.

When a horse's tushes do not appear for some time after the foal-teeth are cast, and the new ones come in their room, it is generally owing to the foal-teeth having been pulled ous before their time, by the breeders or dealers in horses, to make a colt of three years old ap. pear like one of four that he may be the more saleable; for when any one of the foal-teeth have been pulled out, the others soon come in their places; but the tushes having none that precede them, can never make their appear ance till their proper time, which is when a horse is full four, or coming four; and therefore one of the surest marks to know a fouryear old horse is by his tushes, which are ther. very small, and sharp on the tops and edges.

At the time when a horse comes fire. 
rather in the spring before he is five, the corner teeth begin to appear, and at first but just equal with the gums, being filled with flesh in the middle. The tushes are also by this time grown to a more distinct size, though not very large: they likewise continue rough and sharp on the top and edges. But the corner teeth are now most to be remarked; they differ from the middle teeth in being more fleshy on the inside, and the gums generally look rawish upon their first shooting out, whereas the others do not appear discoloured. The middle teeth arrive at their full growth in less than three weeks, but the corner teeth grow leisurely, and are seldom much above the gums till a horse is fall five; they differ also from the other fore-teeth in this, that they somewhat resemble a shell; and thence are called the shellteeth, because they environ the flesh in the middle half-way round; and as they grow, the flesh within disappears, leaving a distinct hollowness and openness on the inside. When a horse is full five, the teeth are generally about the thickness of a crown-piece above the gums. From five to five and a half they will grow about a quarter of an inch high, or more : and when a horse is full six, they wili be near half an inch, and in some large horses a full half-inch above the gums.

The corner teeth in the upper jaw fall out before those in the under, so that the upper corner teeth are seen before those below; on the contrary, the tushes in the under gums came out before those in the upper.

When a horse is full six years old, the hollowness on the inside begins visibly to fill up, and that which was at first fleshy grows into a brownish spot, not unlike the eye of a dried garden-bean, and continues so till he is seven; with this difference only, that the teeth are gradually more filled up, and the marks, or spots, become fainter, and of a lighter colour. At eight, the mark in most horses is quite worn out, though some retain the vestiges of it a longer time; and those who have not had a good deal of experience may sometimes be deceived by taking a horse of nine or ten years old for one of eight. It is at this time only, when a horse is past mark, that one can easily err in knowing his age; such practices are used to make a very young horse or colt appear older than he really is, by pulling out the foal-teeth before their time, which may be discovered by feeling along the edges where the tushes grow, for they may be felt in the gums before the corner teeth are put forth; whereas, if the corner teeth come in some months before the tushes rise in the gums, we may reasonably suspect that the foal-teeth have been pulled out at three years old.

It is not necessary to mention the tricks that are used :o make a false mark in a horse's mouth, by hollowing the tooth with a graver, and burning a mark with a small hot iron; because those who are acquainted with the true marks will easily discover the cheat by the size and colour of the teeth, by the roundness anc uluntness of the tushes, by the colour of the false tuark, which is generally blacker and more impressed than the true mark, and hw other circumstances which denotc the ad vanced age of horses.

After the horse has passed his eighth vear, and sometimes at seven, nothing certain can be known by the mouth. It must, however. be remembered, that some horses have but indifferent mouths when they are young, and soon loose their mark; others have their mouths good for a long time, their teeth being white, even, and regular till they are sixteen years old and upwards, together with many other marks of freshness and vigour; but when a horse comes to be very old, it may be discovered by several indications, the constant attendants of age; such as his gums wearing away insensibly, leaving his teeth long and naked at their roots; the teeth also growing yellow, and sometimes brownish. The bars of the mouth, which in a young horse are always fleshy, and form so many distinct ridges, are in an old horse, lean, dry, and smooth, with little or no rising. The eye-pits in a young horse are generally filled up with flesh, look plump and smooth; whereas, in an old one, they are sunk and hollow, and make him look ghastly. There are also other marks which discover a horse to be very old, as gray horses turning white, and many of them being all over flea-bitten, except thefr joints. This, however, happens sometimes later, and sometimes sooner, according to the variety of colour and constitution. Black horses are apt to grow gray over their eyebrows, and very ofter
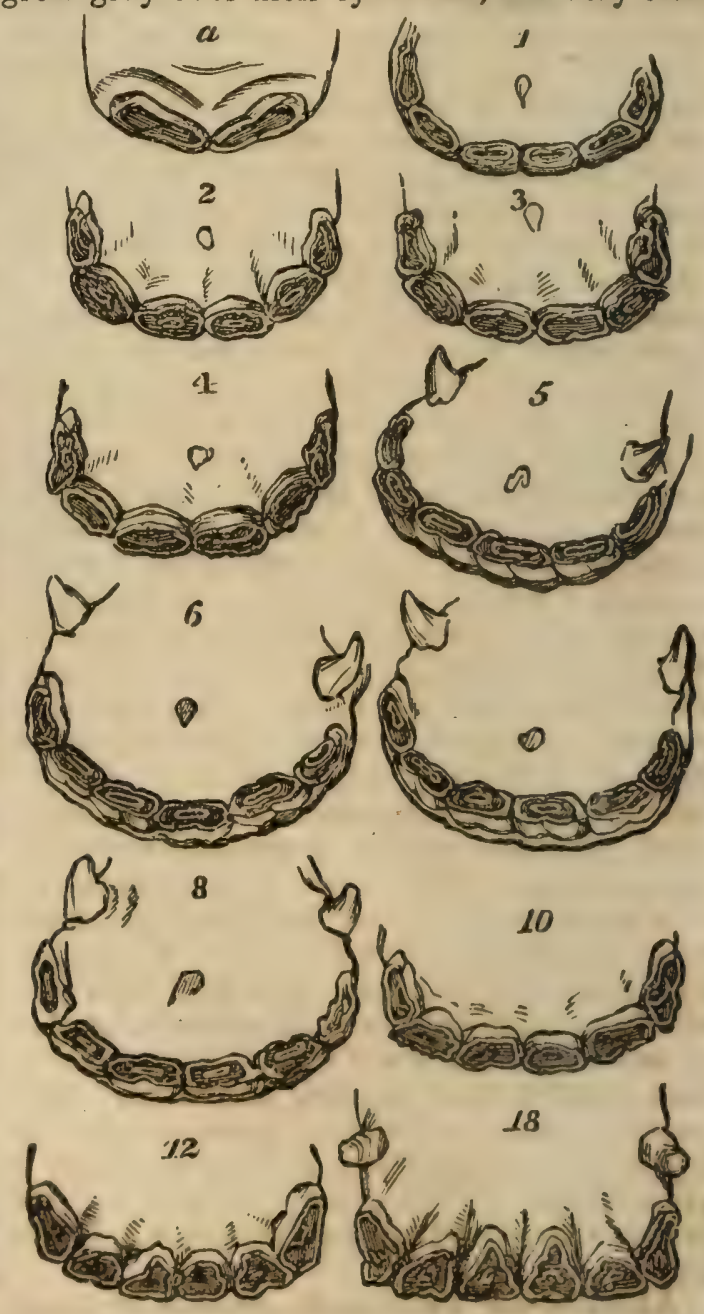
nver a great part of their faces; and all horses, when very ofd, sink more or less in their backs; and sume horses that are naturally longbacked, grow so hollow with age, that it is scarcely possible to fit them with a saddle.

The varicus progressive changes that take place in the appearance of the teeth of horses at different ages, from a few weeks old (marked $a$ in $f g$. .) to $1,2,3,4,5,6,7,8,10,12$, and 18 years, may be seen in the foregoing deutal map, constructed by Mr. Blaine (Encyc. of Rurul Sports, 273).

Age of Neat Cattle. The age of cows, oxen, and bulls, is known by the teeth and horns. At the end of abnut two years they shed their first fore-teeth, which are replaced by others, larger, but not so white; and before five years all the incisive teeth are renewed. These teeth are at first equal, long, and pretty white; but as the animals advance in years, they wear down, become unequal and black. When three years old, neat cattle also experience a considerable change in the structure of their horns, after which period these aprendages, like the second or permanent teeth, preserve the same character. During the first year of the animal's age, two small, smooth, pointed, and neatly formed horns make their appearance attached to the head by a kind of button. This conformation continues during the first three years, after which the bution moves from the head, being impelled by a horny cylinder. Thus the horns continue growing as long as the animal lives, as is indicated by the annual joints, which are easily distinguished in the horn, and by which the age of the creature may be easily known; counting three years for the point of the horn, and one for each of the joints or rings. Dishonest dealers sometimes obliterate these rings by shaving or filing the horns, in order to conceal the age of the beast.

Age of Shecp.-The age of these animals is known by their having, in their second year, two broad teeth ; in their third year, four broad teeth; in their fourth year, six broad teeth; and in their fifth year, eight broad teeth before. After which, none can tell how old a sheep is while their teeth remain, except by their being worn down.

About the end of one year, rams, wethers, and all young sheep, lose the two fore-teeth of the lower jaw; and they are known to want the incisive teeth in the upper jaw. At eighteen months, the two teeth joining to the furmer also fall out; and at three years, being all replaced, they are even and pretty white. But as these animals advance in age, the teeth become loose, blunt, and afterwards black. The age of the ram, and all horned sheep, may also be known by their horns, which show themselves in their very first year, and often it the birth, and continue to grow a ring annually to the last period of their lives.

Age of Goals. -The age of these animals is known by the same marks as those of sheep, as, by their teeth, and the annular rings on their horns.

Age of Plant:-This, however difficult to ascertain, may be attempted in various ways, as from th-ir general appearances and growth. The continuance of life is extremely different in plants, and from this difference, they are generally divided into anuual, biennial, and perennial.

The infancy of plants, like that of animals, is marked by the characters of weakness and tenderness; in the youthful state they accuire beanty and size, the vessels attract and convey their juices; the full growth is crowned with the robust fibre, and full exercise of all its functions; the fruit therefore ripens; but old age advancing, the vessels begin gradually to harden and lose their tone, they droop, the juices move $n$ o longer with equal celerity as in youth, the vital powers cease, and they die.

Agre of Trees.- The age of some trees may be determined from the number of ligneous annuli or rings. In many sorts of trees it is, however, very difficult to distinguish these, and in others, utterly impossible. Some trees arrive to an astonishing age; thus, the cedars of Lebanon have existed for 2000 years. In Eng. land, the oak is the most durable.

Many instances of the extreme old age of trees exist in [England and elsewhere.] At Ellerslie, three miles from Paisley, at the birthplace of William Wallace, is an oak, in which, according to the tradition of the neighbourhood, that celebrated chieftain once shel. tered hirnself with many of his followers. And many others either till lately or still abound in England; for instance, there was one at Lang. ley Wood, near Downton (Dodsley, An. Reg. $1758, p .116)$, supposed to be of 1000 years? growth; then there is the oak of William Rufus, in the new Forest; the Fairlop oak of Hainault Forest; Fisher's oak on the road to Tonbridge; Hern's oak in Windsor Forest . Queen Elizabeth's oak at Heveningham, in Suffolk; the Whinfield oak, near Appleby, al! of great antiquity. (Phillip's Fruits; Withers on Planting.)

At Ankerwyke, near Staines, is a yew tree, that has certainly been growing there since the time of King John; and at Fountain's Abbcy, in Yorkshire, there are yew trees that are probably some centuries older; and the celebrated Spanish chestnut tree, growing in Tord Ducie's park, at Tortworth, in Gloucestershıre, which in the reign of Iohn was called the Great Chestnut of Turtworth, was certainly growing there in the days of Willian of Normandy.

At Trons, in the Grisons, there existed in 1798 , a lime tree which was a celebrated plant in the year 1424, and which, when last measured, was 51 feet in circumference. The age of this specimen could not have been less than 580 years.

In the year $\mathbf{1 7 7 6}$ there existed in the palace garden of Granada some famous cypresses, which were thought to have been at least 800 or 900 years old.

Some of the trees of oriental countries, how ever, attain to still greater ages than any of these: thus the Baobab trees of Africa, accord ing to Adanson, are 5150 years old; and De candolle considers the deciducus cypress treen of Chapuitepec in Mexicn to be still older.

I: would seem, that, after a certain age, all trees decrease in their rapidity of grow $h$, a fact of some importance to be known to plan: 
ers; the oak, for instance, befween its fortieth and sixtieth years; the elm after its fiftieth; the spruce after its fortieth; the yew after its sixtieth : of this rate of growth, Decandolle has constructed an interesting table, showing the rate of increase in diameter of certain trees, such as the Oak, Larch, Elm, Spruce, Yew, every 10 years from 1 to 150 years.

Mr. Waistell has constructed tables respecting the growth of timber, showing every fourth year, from 12 to 100 , the progressive annual increase in the growth of trees, and gradual decrease in the rate per cent. per annum, that the annual increase bears to the whole tree.

AGEN'TS. [In England.] Land agents, are very commonly persons of the legal profession, little conversant with the ordinary details of farming affairs. This is not always a desirable state of things-it often leads to oppression, to discord, and to very bad farming.

An agent cannot bind his principal beyond the extent of his limited authority (Fenn v. Harrison, 3 T. R. 575). For although a principal is bound by all the acts of his general agent, yet where he appoints an agent for a particular purpose, he is only bound to the extent of the authority given.

"Agreements for a lease, made with an agent who acts under a power of attorney, and a lease executed by such agent in pursuance of the agreement, shall bind the principal." milton v. Clinicarde, 1 Bro. P. C. 341 .)

AGISTMENT. A term seemingly from the the old law French word giste, which signifies a lying-place, and therefore, as applied to catfle, supposes pasturing. Agistment accordingly is the pasturing of cattle, the property of another, on the payment of a certain sum of money, or other valuable consideration; and the animals thus grazed are sumetimes called gistments. "If," says Blackstone, "a man takes in a horse or other cattle to graze and depasture in his grounds, which the law calls agistment, he takes them upon an implied contract to return them on demand to the owner. (Cro. Car. 271.) But he cannot like an innkeeper retain them till payment." Agistment also means the profit arising from this practice. 'The tithe of agistment is the tenth part of the value for the keeping or depasturing such cattle as are liable to pay it; but it may be avoided by cutting the grass for stall-feeding.

AGREEMENT. A very considerable proportion of the lands of England are held by agreements between the landlord and the tenant. See I,rases.

These are best made in writing, although not absolutely necessary for terms not exceeding three years. (Crusby v. Wurdsworlh, 6 East, 602.) An agreement to make a lease is, in equity, a good lease. (Harnilton v. Card. ness, 2 Bro. P. C. 125.) But whether an instrument shall amount to a present lease or only as an agreement for a future lease, will depend on the intention of the parties, to be collected from the instrument itself. (Morgan v. Bissett, s Taunton, 65. Buxler v. Browne, 2 W. Black. v73.) [Seo Cus roms of Counties.]

AGRICULTOK (I,at. a husbandman). The

ad in our language is modern, but is getting 32 into common use. It is, however, more generaliy written agriculturist, and is intended to imply one who is skilled in the art of cultivating the ground. (Todd's Johnsun.)

AGRICULTURE, HISTORY OF (Lat. agricultura). The art of cultivating the ground; tillage, husbandry, as distinct from pasture. (Todd's Jihnson.)

I shall, in the present article, limit myself to a brief historical sketch of agriculture, which became one of the sustaining arts of life as soon as man was ordained to earn his bread by the sweat of his brow. In the crarden of Eden, whose fertile soil and genial clime ap. pear to have combined in maturing a continued variety and unfailing succession of vegetable sustenance, agricultural operations were unknown; for that which came spontaneously to perfection required no assistance from human ingenuity; and where there is no deficiency there can be no inducement to strive for improvement. 'That period of perfection was but transitory; and the Deity that had placed man in the garden "to dress it and keep it," eventually drove him thence "to till the earth from whence he was taken," (Gen. ii. 15 ; iii. 23.)

From that time to the present, agriculture has been an improving art; and there is no reason to doubt but that it will go on advanc. ing as long as mankind continues to increase.

Man, in his greatest state of ignorance, is always found dependent for subsistence uporı the produce of the chase; but, as population increases, recourse must be had to other sources of food. And we find in the shepherd's life of the early ages, the first step to agriccltural art, the domestication of animals, which it was found to be more convenient to have constantly at hand, rather than to have to seek precariously at the very time they were re. quired. As the increase of population still went on, and the flocks and the herds had proportionately to be enlarged, one favourite spot would be found too small for the subsistence of the whole; and, as in the case of Abraham and Lot, they would have to separate and find pasturage in different districts. This separation into tribes could not proceed beyond a certain extent; and when the land was fully occupied, recourse would by necessity be hail to means of increasing the produce of given surfaces of soil instead of enlarging their extent. With Abraham and Isaac it is very evident that wheat and the other fruits of the earth were the rare and choice things of their country; but when such nations once learned, as they might from the example of Egypt, the resource such products were in periods of famine, arising from mortalities among their cattle, they would soon pursue their interests by cultivating them. This completed, the acquirement of property in land for the space not only long occupied, but upon which the occupier had bestowed his labour, built his habitation, and had enclosed from injury by vagrant animals, would be acknowledged to be his without any one stopping to inquire what right he had to make the enclosure.

When once thus localed, experience and olservation would soon teach the employment 


\section{AGRICULTURE.}

of thanures, irrigation, times of suwing, and other necessary operations; and every generation would be wiser in the art than that which preceded it. 'This especially has occurred in these more northern climates, where art and industry has to compensate for a deficiency of natural advantages. "Enlarging numbers," observes Mr. Sharon Turner, "only magnify the effect; for mankind seem to thrive and civilize in proportion as they multiply; and, by a recurrent action, to multiply again in proportion as they civilize and prosper." In this manner improved modes of cullivation, the introduction of new species, and of more fruitful varieties of agricultural prod'uce, have universally kept pace with an increasing population. 'This resting upon a basis of facts, vindicates the wisdom of Providence, and refutes Mr. Malthus's superficial theory of over-production. The agricultural produce of England has gradually increased from the insignificant amount that was its value in the time of the Roman invasion, to the enormous annual return of $200,000,000 \%$; and it is very certain that in this country, and much more in other parts of the world, the produce is a mere fraction of what the total soil is capable of returning.

Agriculture is the art of obtaining from the earth food for the sustenance of man and his domestic animals; and the perfection of the art is to obtain the greatest possible produce ai the smallest possible expense. Upon the importance of the art, it is needless, therefore, to insist; for by it every country is enabled to support in comfort an abundant population. On this its strength as a nation depends; and by it its independence is secured. An agriculiural country has within itself the necessaries and comforts of life; and, to defend these, there will never be wanting a host of patriot soldiers.

Of the pleasure attending the judicious culsivation of the soil, we have the evidence of lacts. The villa farms sprinkled throughout our happy land, the estahlishments of Holkham, Woburn, \&c., would never have been formed if the occupation connected with them was not delightful. We have an unexceptionable witness to the same fact in the late $\mathrm{Mr}$. Roscoe, the elegant, talented author of the Lives of Lorenzo de Medici and of Leo the Tenth. Mr. Roscoe was the son of an extensive potato grower, near Liverpool. In the cultivation of that and other farm produce, he had been an active labourer; and he who thus had enjoyed the delights that spring from literary pursuits, and from the cultivation of the soil, has left this recorded opinion, "If I was asked whom I consider to be the happiest of the human race, I should answer, those who cultivate the earth by their own hands."

We have but little information to guide us as to the country in which man first cultivated the soil; nor of that in which he first settled after the deluge. Thus much, however, is certain, that we have the earliest authentic account of the state of agriculture as it existed among the Egyptians and their bond-servants, the Israelites. From the former, probably, the Greeks were descended. The Romans, at a later period, were a colony from Greece; and from the Romans the other cuuntries of Europe derived their earliest marlied improvement in the arts.

Our brief history of the progres of acricul. ture, then, will be divided into, 1. The agriculture of the Egyptians and other eastern nations; 2. The agriculture of the Greeks: 3. The agriculture of the Romans; 4. 'The agriculture of the Britons, including a cursury notice of its present state among the chief nations of Europe.

I. The Africultune of the Eayptias, Istaelites, and other early Eastens NATIONB.

Every family of these primitive 1itic.zs had its appointed district for pasturage, is it pursued a pastoral life; or its allotted enclosure, if it was occupied by tilling the earth. There was no distinction in this respect between the monarch and his people: each had a certain space of land from which he and his family were to derive their subsistence.

The Egyptians, as well as the Israelites, were flock-masters. The latter were particularly so; and, as Joseph's brethren said to Pharaoh, "their trade was about cattle from their youth." (Gen. xlvi. 34.) When, therefore, they came into Egypt, they desired the low-lying land of Goshen, as producing the most perennial of pasture. (Gen. xlvii. 4.) It is true that the same authority says, "Every shepherd is an abomination unto the Egyptians;" but this was because, about a century before the arrival of Joseph among them, a tribe of Cushite shepherds from Arabia had conquered their nation, and held them in sla. very; till, after a sanguinary contest of thirty years, they regained their liberty about twentyseven years before Joseph was promoted by Pharaoh. That the Egyptians were flockmasters is certain, from many parts of the Scriptures. Thus, when l'haraoh gave permission to the Israelites to dwell in Goshen, he added, as he spoke to Joseph, "And if thou knowest any men of activity among them, then make them rulers over my cattle" (Gen. xlvii. 6.); and when the murrain came into Egypt, it was upon their horses, asses, camels, oxell, and sheep. (Exod. ix. 3.)

The attention and care necessary to be paid to their domestic animals were evidently well known and attended to; for when they pro posed to settle in a land, their first thought was to build "sheepfolds for their cattle." (Numb.xxxii. 16.) They had stalls for their oxen (Hab. iii. 17), and for all their beasts Thus King Hezeliah is said to have made "stalls for all manner of beasts, and cotes for flocks; moreover, he provided him possessions of flocks and herds in abundance" ( 2 Chron xxxii. 28); and that this abundance exceeded the possessions of the greatest of our moder. flock-masters, we may readily acknowledge, when we read that "Mesha, king of Moab, was a sheep-master, and rendered unto the king of Israel 100,000 lambs, and 100,000 rams, wit/s the wool." (2 Kings, iii. 4.)

They prepared the provender for their horses and asses of chaff, or cut stra anil 
barley. (Judges, xix. 21; 1 Kings, iv. 28.) Our translation does not explicitly state this, but it is clear in the Hebrew original. ( $D r$. Kennicoll's xxivth Codex; Harmer's Observations, i. 423.) It is also certain, from the Hebrew original, that they tied up calves and bullocks for the purpose of fattening them (Jerem. xlvi. 21 ; Amos, vi. 4, \&c., Parkhurst's Hebrew Lexicon, 673); and that they were acquainted with the arts of the dairy "Surely the churning of milk," says Solome, , "bringeth forth butter" (Prov. xxx. 31); and Samuel speaks of the "cheese of kine." (2 Sam.xxvii. 29.) The chief vegetable products cultivated by these eastern nations were, wheat, barley, beans, lentils, rye, the olive, and the vine. (Exod. ix. 31; Levit. xix. 10; 2 Sam. xvii. 28, \&c.)

The scanty notices which we have of their tillage, give us no reason to doubt that they were skilful husbandmen. The name for tillage (Obed.) emphatically expresses their idea of it; for it literally means to serce the ground. (Parkhurst, 508.) And that the cares and attention necessary were well sustained, is evidenced by the fact, that Darid, for his extensive estate, had an overseer for the storehouses in the fields; another over the tillage of the ground; a third over the vineyards; a fourth over the olive trees; two to superintend his herds; a seventh over his camels; an eighth to superintend his flocks; and a ninth to attend similarly to the asses. (1 Chron. xxvii. 2531.)

Of their ploughing, we know that they turned up the soil in ridges, similarly to our own practice; for the Hebrew name of a husbandman signifies a man who does so. (Parkhurst, 93.) 'That they ploughed with two beasts of the same species attached abreast to the plough. (Deut.xxii.10.) That the yole, or collar was fastened to the neck of the animal; and that the plough, in its mode of drawing the furrows, resembled our own; for we read of their sharpening the conlter and the ploughshare. (1 Sam. xiii. 20, \&c.) Ploughing was an operation that they were aware might be beneficially performed at all seasons; for Solomon mentions it as a symptom of a sluggard, that he will not plough in the winter (Prov.xx.4); and that too much care could not be devoted to it, they expressed, by deriving their name for ploughing from a Hebrew root, which signifies silent thought and attention. (l'arkhurst, 244.)

Their sowing was broadcast, from a basket (Amos, xi. 13; Psalm cxxvi. 6); and they gave the land a second superficial ploughing to cover the seed. It is true that harrowing is mentioned in our translation (Job, xxxix. 10); but Schultens and other Hebraists agree that harrowing was not practised by them. Rus. rell, in remarking upon the mode of cultivation I.ow practised near Aleppo, says, "No harrow is used, but the ground is ploughed a second lime after it is sown, to cover the grain." (Puthhur:t, 720.)

The affer-cultivation apparently was not neglected; they had hoes or mattocks, which they employed for extirpating injurious plants. "On all hills," says the prophet, "that shall digged with the mattock, there shall not 34 come thither the fear of briers and thorns."

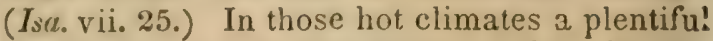
supply of moisture was necessary for a healthful vegetation; and the simile of desolation, employed by the same prophet, is "a garden that hath no water." (Isa. i. 30.) In Egypt they irrigated their lands; and the water thus supplied to them was raised by an hydraulic machine, worked by men in the same manner as the modern tread-wheel. To this practice Moses alludes, when he reminds the Israelites of their sowing their seed in Egypt, and watering it with their feet, a practice still pursued in Arabia. (Deut. xi. 10; Niebuhr, Voyage en Arabie, i. 121.)

When the corn was ripe, it was cut with either a sickle or a scythe (Jer. 1. 16; Joel, iii. 13), was bound into sheaves (Psalm cxxix. 7; Deut. xxiv. 19, \&c.), and was conveyed in carts (Amos, ii. 13), either immediately to the threshing-floor or to the barn. They never formed it into stacks as we do. These pas. sages in the Scriptures (Exod.xxii. 6; Judg. $\mathrm{xv} .5 ; J o b, \mathrm{v} .26$ ) refer exclusively to the thraves or shocks in which the sheaves are reared as they are cut. (Harmer's Observ iv. 145, \&c.) The threshing-floors, as they are at the present day, were evidently level plats of ground in the open air. (Jitg. vi. 37; 2 Sam. xxiv. 18-25, \&c.) They were so placed that the wind might, at the time of the operation, remove the chief part of the chaff. They, perhaps, had threshing-floors under cover, to be used in inclement seasuns; for Hosea (ii. 35), speaking of "the summer threshing-floors," justifies such surmise. The instruments and modes of threshing were various. They are all mentioned in these two verses of the prophet; "Fitches are not threshed with a threshing instrument, neither is a cart-wheel turned upon the cummin, but the fitches are beaten out with a staff, and the cummin with a rod. Bread-corn is bruised because he will not ever be threshing it, nor break it with the wheel of his cart, nor bruise it with his horsemen." (Isaiah, xxviii. 27, 28.) When the seed was threshed by horses, they were ridden by men; and when by cattle, al. though forbidden to be muzzled (Deut. xxv. 4) yet they were evidently taught to perform the labour. (Hosea, x. 11.) The "instrument" was a kind of sledge made of thick boards, and furnished underneath with teeth of iron. (Isuiah, xli. 15; Parkhurst, 242, 412.) The revolving wheels of a cart, and the various sized poles employed for the same purpose, need no further comment. To complete the dressing of the corn, it was passed through a sieve (Amos, ix. 9), and thrown up against the wind by means of a shovel. The fan was, and is still, unknown to the eastern husbandmen; and where that word is employed in our translation of the Scriptures, the original seems to intend either the wind or the shovel. (Isaiuh, xxx. 24; Jer. xv. 7; Purkhurst, 183, 689.)

Of their knowledge of manures we know little. Wood was so scarce that they con. sumed the dung of their animals for fuel. (Purlchurst, 764.) Perhaps it was this deficiency of carbonarens matters for their lands 
that makes an attention to fallowing so strictly enjoined. (Levil. xix. 23; xxv. 3; Huseu, x. 12, \&ce.)

The landed estates were large, both of the kings and of some of their subjects; for we read that Uzziah, king of Judah, "had much both in the low country and in the plains; husbandmen also, and vine-dressers in the mountains and in Carmel, for he loved husbandry" (2 Chron. xxvi. 10); that Elijah fuund Elisha with twelve yoke of oxen at plough, himself being with the twelfth yoke ( 1 Kings, xix. 19); and that Job, the greatest man of the east, had 14,000 sheep, 6000 camels, 1000 yoke of oxen, and 1000 she-asses. (Job, i. 3 ; xlii. 12.) In the time of Isaiah, the accumulation of landed property in the hands of a few proprietors was so much on the increase, that a curse was uttered against this engrossment. "Wo unto them," says the prophet, "that join house to house, that lay field to field, till there be no place, that they may be placed alone in the midst of the earth." (Isaiah, v. 8.)

\section{The Agriculture of the Grens.}

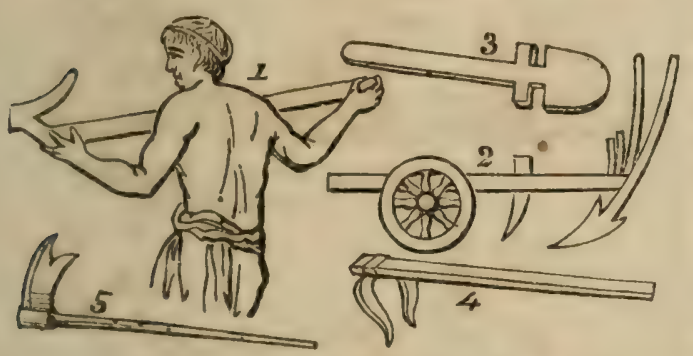

1. Ancient implement from a tombstone at Athens 2. The Greek plough. 3. The spade. 4.and 5. Hoes.

Revelation has taught us to offer up our prayers and thanksgivings for all berefits to the one omni-beneficent Creator and provider of the universe. The less enlightened ancients, whose religion was mythological, equally conrinced with ourselves of the existence of some divine first cause and providence, like us offered up their votive petitions and hymms of praise, though the objects of their worship were as many as the benefits or the evils to which man is subject.

Agriculture was too important and too beneficial an art not to demand, and the Greeks and Romans were nations too polished and discerning not to afford to it, a very plentiful series of presiding deities. They attributed to Ceres-as their progenitors, the Egyptians, did to Isis-the invention of the arts of tilling the soil. Ceres is said to have imparted these to Triptolemus, of Eleusis, and to have sent him as her missionary round the world to teach mankind the best modes of ploughing, sowing, and reaping. In gratitude for this, the Greeks, about 1356 years before the Christian era, established, in honour of Ceres, the Eleusinian mysteries, by far the most celebrated and enduring of all their religious ceremonies; for they were not established at Rome till the close of the fourth century. Superstition is a prolific weakness; and, consequently, by degrees, every operation of agriculture, and every period of the growth of crops, obtained its presiding and tutelary deity. The goddess, Terra, was the guardian of the soil; Stercutius pre- sided over the manures; Volulia guarded the crops whilst evolving their leaves; Flura received the still more watchful duty of sheltering their blossom; they passed to the guatrianship of Lactantia when swelling with milky juices; Rubigo protected them from blight; and they successively became the care of IIortilina, as they shot into ears; of Mulura as they ripened; and of Tutelina when they were reaped. Such creations of polytheism are fables; but they are errors that should even now give rise to feelings of gratification rather than of contempt. They must please by their elegance; and much more when we reflect that it is the concurrent testimony of anterior nations, through thousands of years, that they detected and acknowledged a Great First Cause.

Unlike the arts of luxury, Agriculture has never been subject to any retrograde revolutions; being an occupation necessary for the existence of mankind in any degree of con. fort, it has always continued to receive their first attention; and no succeeding age has been more imperfect, but in general more expert, in the art than that which has preceded it. The Greeks are not an exception to this rule; for their agriculture appears to have been much the same in the earliest brief notices we have of them, as it was with the nation of which they were an offset. The early Grecians, like all new nations, were divided into but two classes; landed proprietors, and Helols, or slaves; and the estates of the former were little larger than were sufficient to supply their respective households with necessaries. We read of princes among them; and as we dwell upon the splendid details of the Trojan war, associate with such titles, unreflectingly, all the pageantry and luxury of modern potentates, that are distinguished by similar titles. But in this we are decidedly wrong; for there was probably not a leader of the Greeks whe did not, like the father of Ulysses, assist with his own hands in the farming operations. ( $H_{n}$ mer's Odyss. 1. xxiv.) Hesiod is the earliest writer who gives us any detail of the Grecian agriculture. He appears to have been the contemporary of Homer; and, in that case, to have flourished about nine centuries before the Christian era. His practical statements, however, are very meager ; we have, therefore, preferred taking Xenophon's Economics as our text, and introducing the statements of other authors, as they may occur, to supply deficien. cies or to afford illustrations.

Xenophon died at the age of ninety, 359 years before the birth of Christ. The following narrative of the Greek agriculture is from his "Essay," if not otherwise specified.

In Xenophon's time the landed proprietor no longer laboured upon his farm, but had a steward as a general superintenclunt, and numerous labourers, yet he always advises the master to attend to his own affairs. "My ser. vant," he says, "leads my horse into the fields, and I walk thither for the sake of exercise in a purer air; and when arrived where my workmen are planting trees, tilling the ground, axa the like, I observe how every ining is performed, and study whether any of these operations may be improved." After his ride, his 
servant took his horse, and led him home, " iaking with him," he adds, "to my house, such things as are wanted, and I walk home, wash my hands, and dine off whatever is prepared for me moderately." "No man," he says, "can be a farmer, till he is taught by experience; observation and instruction may do much, but practice teaches many particulars which no master would ever have thought to remark upon." "Before we commence the cultivation of the soil," he observes, that, "we should notice what crops flourish best upon it; and we may even learn from the weeds it produces, what it will best support."

"Fallwwing, or frequent ploughing in spring or summer," he observes, "is of great advantage;" and Hesiod advises the farmer (Works and Days, 50) always to be provided with a spare plough, that no accident may interrupt the operation. The same author directs the ploughman to be very careful in his work. "Let him," he says, " attend to his employment. and trace the furrows carefully in straight lines, not looking around him, having his mind intent upon what he is doing." Ilid. 441-443.

Theophrastus evidently thought that the soil could not be ploughed and stirred about too much, or unseasonably; for the object is to let the earth feel the cold of winter and the sun of summer, to invert the soil, and render it free, light, and clear of all weeds, so that it can most easily afford nourishment. (De Causis Plant. lib. iii. cap. 2, 6.)

Xenophon recommends green plants to be ploughed in, and even crops to be raised for the purpose; "for such," he says, "enrich the soil as much as dung." He also recommends earth that has been long under water to be put upon land to enrich it, upon a scientific principle which we shall explain under IRRIGAriox. Theophrastus, who flourished in the fourth century n.c., is still more particular upon the subject of manures. He states his conviction that a proper mixture of soils, as clay with sand, and the contrary, would produce crops as luxuriant as could be effected by the agency of manures. He describes the properties that render dungs beneficial to vegetation, and dwells upon composts. (Hist. of Plants, ii.cap.8.) Xenophon recommends the stubble at reaping time to be left long, if the straw is abundant; "and this, if burned, will enrich the soil very much, or it may be cut and mixed with dung." "The time of sowing," says $\mathrm{Xenophon,} \mathrm{"must} \mathrm{be} \mathrm{regulated} \mathrm{by} \mathrm{the}$ season; and it is best to allow seed enough."

Weeds were carefully eradicated from among their crops; "for, besides the hindrance they are to corn, or other profitable plants, they keep the ground from receiving the benefit of a free exposure to the sun and air." Homer describes Laertes as hoeing, when found by his .on Ulysses. (Odyss. xxiv. 226.)

Water-courses and ditches were made to drain away "the wet which is apt to do great damage to corn."

Homer describes the mode of threshing corn by the trampling of oxen (lliad, $\mathrm{xx}$. lin. 495 , sc.) - and to get the grain clear from the straw, Xenophon observes, "the men who have the care of the work take care to shake up the straw as they see occasion, flinging into the way of the cattle's feet such corn as they observe to remain in the straw." From Theo. phrastus and $\mathbf{X e n o p h o n ~ c o m b i n e d , ~ w e ~ c a n ~ a l s o ~}$ very particularly make out that the Greeks separated the grain from the chaff by throwing it with a shovel against the wind.

\section{The Agricultere of the Romang.}
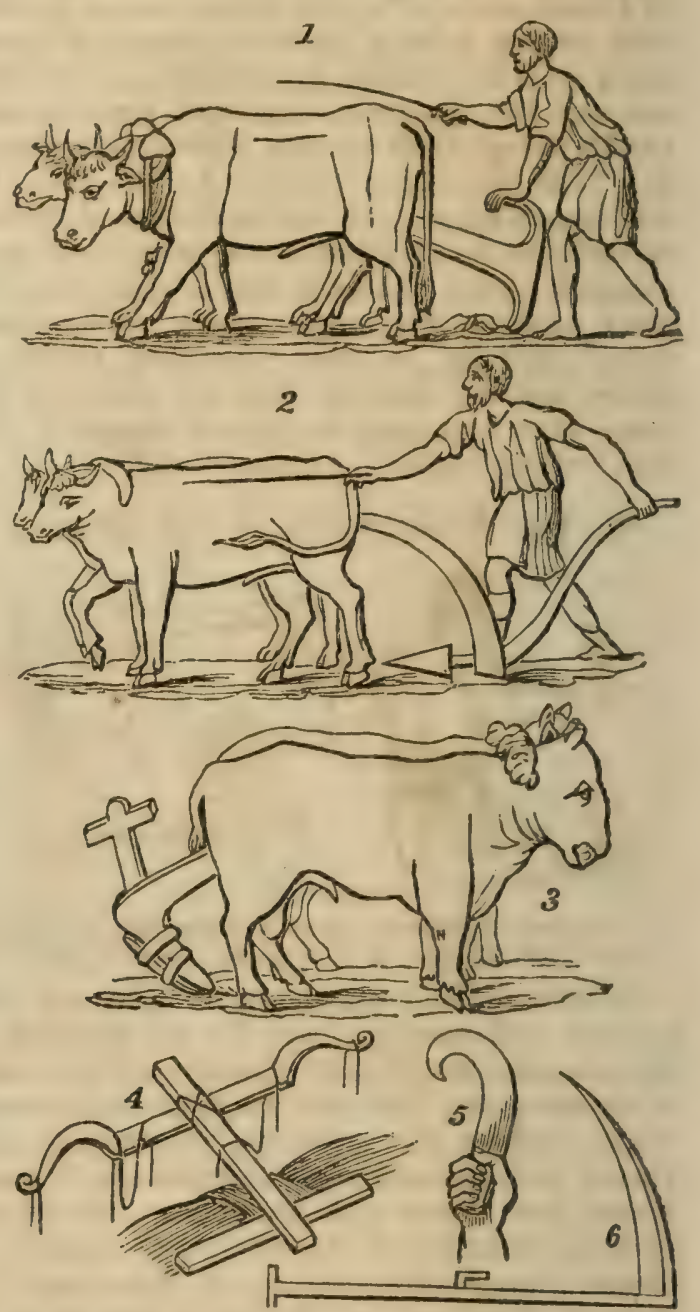

$1,2,3$, Ploughs used by the Ronans in different ages 4. The yoke for fixing the cattle. 5. The reaping hook 6. The scythe.

It is certain, that at a very early age Italy received colonies from the Pelasgi and Arcadians; and that, consequently, with them the arts of Greece were introduced; and we may conclude that there was then a similarity in the practice of agriculture in the two countries.

About 753 years before the nativity of Christ, Romulus founded the city of Rome, whose inhabitants were destined to be the conquerors and the improvers of Europe. The Roman eagle was triumphant in Egypt, Persia, Greece, Carthage, and Macedon; and the warriors who bore it on to victory, in those and other countries, being all possessors of land of a larger or smaller extent, naturally introduced, upon their return, any superior vegetable, or improved mode of culture, which they observed in those highly civilized seats of their victories.

Thus the arts of Rome arrived at a degree of superiority that was the result of the accumulated improvements of other nations: and. 


\section{AGRICULTURE.}

finally, when Rome became in turn the conquered, the victors became acquainted with this accumulated knowledge, and difiused it over the other parts of Europe.

Of the agriculture of the early Romans we know but little; but of its state during the period of their greatest prosperity and improvement, we fortunately have very full informafion. Cato in the second, and Varro in the first century before the Christian era, Virgil, at the period of that event, Columella and Pliny but few years subsequently, and Palladius in the second or fourth century, each wrote a work upon agriculture, which, with the exception of that by Columella, have come down to us entire.

From these various authorities we derive full information; and we are convinced that many of our readers will be surprised at the correct knowledge of the arts of cultivation. possessed by that great nation.

1. Size "f the Roman Farms.-When Romulus first partitioned the lands of the infant state among his followers, he assigned to no one more than he could cultivate. This was a space of only two acres. (Varro, i. 10 ; Pliny, xvii. 11.) After the kings were expelied, seven acres were allotted to each citizen. (Pliny, xviii. 3.) Cincinnatus, Curius Dentatus, Fabricius, Regulus, and others, distinguished as the most deserving of the Romans, had no arger estates than this. Cincinnatus, accord.ng to some authorities, possessed only four acres. (Ibid.; Culumella, i. 3, \&c.) On these limited spaces they dwelt, and cultivated them with their own hands. It was from the plough that Cincinnatus was summoned to be dictator (Livy, iii. 26); and the Samnian ambassadors tound Curius Dentatus cooking his own repast of vegetables in an earthen vessel. (Plutarch, in vita Cato. Cens.)

Some of the noblest families in Rome derived their patronymic names from ancestors designated after some vegetable, in the cultivation of which they excelled, as in the examples of the Fahii, Pisones, Lentuli, Cicerones, and the like. (Pliny, xviii. 1.) In those days, "when they praised a good man, they called him an agriculturist and a good husbandman: he was thought to be very greatly honoured who was thus praised." (Cat", in Præf.) As the limits of the empire extended, and its wealth increased, the estates of the Roman proprietors became very greatly enlarged; and, as we shall see more particularly mentioned in our historical notices of gardening, attained to a value of 80,000\%. (Pluturch in vit. Murius et Lucullus.) Such extensive proprietors let portions of their estates to other citizens, who, if they paid for them a certain rent, like our modern tenants, were called Culoni (Columella, i. 7; Pliny, Epist.x. 24) and I'olitores, or Parliarii, if they shared tine produce in stated proportions with the proprietor. (Iliny, Epist. vii. 30, and ix. 37 , \&c.) Leases were occasionally granted, which appear to have been of longer duration than five years. (Ibid. ix. 37.)

2. Distinction of Suils.-Soils were characterized by six different qualities, and were described as rich or poor, free or stiff, wet or dry. (Colum. ii. 2.)

\section{AGRICUITURE.}

The best soil they thought had a blackish coloul, was glutinous when wet, and friable when dry; exhaled an agreeable surbll when ploughed, imbibed water readily, retaining a sufficiency, and discharging what was super. Aluous; not injurious to the plough irons by causing a salt rust; frequented by crows and rooks at the time of ploughing; and, when at rest, speedily covered with a rich turf. (Virg. Georg. ii. 203, 217, 238, 248; P'liny, xvii. 5.)

Vines required a light soil, and corn a heavy, deep, and rich one. (Virg. Georg. ii. 29; Culi), vi.)

3. Manures.-The dung of animals was particularly esteemed by the Romans for enrich. ing their soil. "Study," says Cato, "to harea large dunghill." (Cuto, v.) They assiduously collected it and stored it in covered pits, so as to check the escape of the drainage. (Colum. i. 6; Plimy, xvii. 9, and xxiv. 19.) They sowed pulverized pigeons' dung and the like over their crops, and mixed it with the surface soil by means of the sarcle or hoe. (Colum.i. 16; Cato, xxxvi.) 'They were aware of the benefit of mixing together earth of opposite qualities (Ibid.), and of sowing lupines and ploughing them in while green. (Vurro, $\mathrm{i}$. 23.) They burnt the stubble upon the ground, and even collected shrubs and the like for the similar purpose of enriching the soil with their ashes. (Virg. Georg. i. 81; Pliny, xvii $6,25$.

Pliny also mentions that lime was employed as a fertilizer in Gaul, and marl in the same country and Britain; but we can only surmise hence that they were also probably employed by the Romans. (Pliny, xvii. 8, and xvii. 5.)

4. Droining.-The superfluous water of soils was carried off by means both of open and covered drains. (Colum. ii. 2, 8; Pliny, xvii. c.; Virg. Georg. i. 109.) Cato is very particular in his directions for making them. (Cato, xliii. $\left.c l x_{0}\right)$

5. Crops.-They cultivated wheat, spelt, barley, oats, flax, beans, pease, lupines, kidney. beans, lentils, tares, sesame, turnips, vines, olives, willows, and the like. To cite the authorities who mention each of these would be needless, for they are noticed in all the Roman writers upon agriculture. Of the relative im. portance or proportion in which the crops were profitable to the Romans, we have this judgment of Cato:- "If you can buy 100 acres of land in a very good situation, the vineyard is the first object if it yields much wine: in the second place, a well-watered garden; in the third, a willow plantation; in the fourth, an olive ground; in the fifth, a meadow; in the sixth, corn ground; in the seventh, an underwood, a plantation yielding stout poles for training the vine; and in the ninth, a wpod where mast grows." (Cato, i.)

They made hay, and the process appears to have been the same as in modern times. After being cut it was turned with forks, piled into conical heaps, and finally into stacks or under cover. But the mowing was imperfectly performed; for, as soon as the hay was removed from the field, the motrers had to go over it again. (Vurro; Colum. ii. 22.)

6. Implements.--The plough consisted of s 
veral parts: the beam to which the yoke of the "xen was fastened; the tail or handle terminated in a cross bar, with which the ploughman guided the instrument; it had a ploughshare, the share-beam to which it was fixed, and two mould-boards, a coulter, and a plough-staff for cleaning the ploughshare. (Ovid. Punt. i. 8, 57 ; Virg. (. i. 170 ; Pliny, xvii. 18, 19.) Some of their ploughs had wheels, and some were without coulters and earth-boards. Besides this, they had spades, rakes, hoes, with plain and with forked blades, harrows, mattocks, and similar implements.

7. Operations.-Ploughing was usually performed by two oxen, though three were sometimes employed. They were yoked abreast, and trained when young to the employment. (Cicern, in Verr. iii. 21 ; Col. vi. 2, 10 ; Pliny, xviii. 18; Virg. G. iii. 163, \&c.) They were usually yoked by the neck, but sometimes by the horns. (Pliny, viii. 45; Colım. ii. 2.) There was but one man to a plough, which he guided, and managed the oxen with a goad. (Pliny, Epist. viii. 17.)

They sometimes ploughed in ridges, and sometimes not. They did not take a circuit when they came to the end of the field, as is our practice, but returned close to the furrow. They were very particular in drawing straight and equal sized furrows. (Pliny, xviii. 19, s.49.)

They seem to have ploughed three times always hefore they sowed (Vurro, i. 29); and to stiff soils even as many as nine ploughings were given. (Virg. G.i.47; Pliny, xviii. 20 ; Pliny, Epist. v. 6.) The furrows in the first ploughing were usually nine inches deep. When the soil was only stirred about three inches, it was called scarification. (Pliny, xviii. 17-19.) They usually fallowed their land every other year. (Virg. G. i. 71.)

Sowing was performed by hand, from a basket; and that it might be performed regularly, the hand moved with the steps. (Colum. ii. 9; Pliny, xviii. 24.) The seed was either scattered upon the land and covered by means of rakes and harrows, or more commonly by sowing it upon a plain surface, and covering by a shallow ploughing, which caused it to come up in rows, and facilitated the operation of hoeing. (Pliny, xviii. 20.) They were particular as to the time of sowing, the choice of seeds, and the quantity sown. (Varro, i. 44; Pliny, xviii. 24, s. 55 ; Virg. G. i. 193, \&c.)

Weeding was performed by hoes, hooks, and by hand.

In dry seasons the crops were watered. (Virg. G. i. 106.) If they appeared too luxuriant they were fed off. (7bid. 193.)

Reaping and mowing were the usual modes of cutting down the corn crops, but the cars were sometimes taken off by a toothed machire, called butilium, which seems to have been a wheeled cart, pushed by uxen through the corn, and catching the ears of corn between a low of teeth fixed to it, upon the principle of the modern daisy rake. In Gaul, the corn was cut down by a machine drawn by two horses. (Vurro, i. 50; Virg. G. i. 317; Colum. ii. 21; Pliny, xviii. 30.) They do not seem to have ver bound their corn into sheaves.

1.)
Threshing was performed by the trampling of oxen and horses, by flails, and by means of sledges drawn over the corn. (Pliny, xvii. 30 ; Colum. i. 6; Virg. G. iii. 132; Tibullus, i. 5, 22; Varro, i. 52.) The threshing-floor was circular, placed near the house, on high ground, and exposed on all sides to the winds. It was highest in the centre, and paved with stones, or more usually with clay, mixed with the lees of the oil, and very carefully consolidated. (Colum. i. 6; Varro, i. 2; Virg. G. i. 178; Cato, xci. and cxxix.)

Dressing was performed by means of a seive or van, and by a shovel, with which it was thrown up and exposed to the wind. (Varro, i. 52; Colum. ii. 21.) It was finally stowed in granaries or in pits, where it would keep fifty years. (Pliny, xviii. 30 ; Varro, i. 57.)

8. Animals.-Oxen, horses, asses, mules, sheep, goats, swine, hens, pigeons, pea-fowls, pheasants, geese, ducks, swans, guinea-fowls, and bees, are mentioned by various authors as products of the Roman farms. Directions for breeding many of these are given in the third and fourth books of the Georgics.

Such is an outline of the Roman agriculture; and in it our readers will doubtless find sufficient evidence to warrant them in agreeing with us, that it was but little different from that pursued by the present farmers of England. We are superior to them in our implements, and consequently in the facility of performing the operation of tillage; we perhaps have superior varieties of corn, but we most excel them in our rotation of crops, and in the management of stock. We differ from them, also, in not practising the superstitious rites and sacrifices which accompanied almost all their operations (see Cato, cxxxiv.c.); but of the fundamental practices of agriculture, they were as fully aware as ourselves. No modern writer could lay down more correct and comprehensive axioms than Cato did in the following words; and whoever strictly obeys them will never be ranked among the ignorant of the art. "What is good tillage?" says this oldest of the Roman teachers of agriculture; "to plough. What is the second? to plough. The third is to manure. The other part of tillage is to sow plentifully, to choose your seed cautiously, and to remove as many weeds as possible in the season." (Cato lxi.)

Such is an epitome of their agricultural knowledge; a knowledge which has since increased, and can only in future be added to by attending to this advice of another of their writers. "Nature," he observes, "has shown to us two paths which lead to a knowledge of agriculture-experience and imitation. Preceding husbandmen, by making experiments, have established many maxims; their posterity generally imitate them; but we ought not only to imitate others, but make experiments, not directed by chance, but by reason." (Varro, i. 18.)

\section{The Agriculture of Eiggrant.}

The historian of English agriculfure has not the least trace of authority from which he can obtain information of its state beyond the pe 
rivd when the Romans invaded this island, and the annals of even that period are meager and unsatisfactury.

When Cixsir arrived in Encrland, about 55 н. $\mathbf{c}$, he describes the Cantii, or inhabitants of lient, and the Belgx, inhabiting the modern counties of Somerset, Wilts, and Hants, as much more advanced than the rest of the people in the habits of civilized life. They cultivated the soil; employed marl as manure; stored their corn unthreshed, and freed it from the chaff and bran only as their daily demands required. The interior inhabitants lived chiefly upon milk and flesh, being fed and clothed by the produce of their herds. "The country," adds Cæsar, " is well-peopled, and abounds in buildings resembling these of the Gauls, and they have a great abundance of cattle. They are not allowed to eat either the hen, the goose, or the hare, yet they take pleasure in breeding them." (Cærs. v. c. 10 ; Strabo, iv. 305 ; Diodor. Sic. v. 301 ; Pliny, xvii. 4.) Cicero, in one of his letters, says, "There is not a scruple of money in the island; nor any hopes of booty, but in slaves; (Lib. iv. Ep. 17); a description, that the industry and intelligence of succeeding ages has rendered singularly inapplicable. The first steps in that improvement were owing to the Romans themselves. Rutilius has elegantly and correctly said, that Rome filled the world with her legislative triumphs, and caused all to live in one common union, blending discordant nations into one country, and, by imparting a companionship in her own acquirements and laws, formed one great city of the world.

Agricola was the chief instrument in imparting to the Britons the improved arts and civilization of the Romans. "To wean them from their savage habits, Agricola held forth the baits of pleasure, encouraging the natives, as well by public assistance as by warm exhortations, to build temples, courts of justice, and commodious dwelling-houses. He bestowed encomiums on such as cheerfully obeyed; the slow and uncomplying were branded with reproach; and thus a spirit of emulation diffused itself, operating like a sense of duty. To establish a plan of education, and give the sons of the leading chiefs a tincture of letters, was part of his policy. By way of encouragement he praised their talents, and already saw them, by the force of their natural genius, rising superior to the attainments of the Gauls. The consequence was, that they who had always disdained the Roman language began to cultivate its beauties. The Roman apparel was seen without prejudice, and the toga became a fashionable part of dress. By degrees, the charms of vice gained admission to their hearts; baths, porticos, and elegant banquets grew into vogue; and the new manners, which in fact served only to sweeten slavery, were by the unsuspecting Britons called the arts of polished humanity." (Tacitus, Agricola, xxi.) Thus eloquently does Tacitus describe the diffusion of the Roman arts among the early natives of England; and that agriculture was one of those in which they so rapidly improved, is attested by the fact that in the fourth century the Emperor Julian, having erected here gra- uaries in which to store the tributary corn thas he exacted from the natives, at one lime sent a fleet of 600 large vessels to convey away the store they contained. Julian himself particu. larizes the transaction. "If," says Gibbon. "we compute those vessels at only seventy tons each, they were capable of exporting 120,000 quarters; and the country which could bear so large an exporiation must have altained an improved state of agriculture." (Dec. and Fall of Rom. Emp. c. xix.)

Possessing this improved agriculture, Eng. land was successively subdued by the Saxons, the Danes, and the Normans; but as these all came to improve their fortunes, and to win the comforts of life, agriculture continued to Hourish: her operations were interrupted, her products destroyed, in whichever direction swept the tide of war; but no sooner was peace restored than the inhabitants, though of varied extraction, united their knowledge in the pursuit of this art, on which not only their com. fort, but their existence chiefly depended. $\mathbf{A}$ similar summary observation applies to al! succeeding ages; and our agriculture has continued slowly to improve in spite of every obstacle that has occasionally delayed, or that has permanently retarded its advance.

1. Tenures-Size of Estates.-The native Britons, it is very certain, approfriated but small portions of the land for raising corn, or other cultivated vegetables, and the rest of the country was left entirely open, affording a common pasturage for their cattle, and pan. nage for their swine. Under the Roman government, we have seen that the extent of cultivated ground must have considerably increased, yet the oldest writers agree, that by far the greatest proportion of the country was occupied by heaths, woods, and other unreclaimed wastes.

When the Saxons established themselves in the island, an almost total revolution in the proprietorship of the lands must have occurred. The conquest was only accomplished after a bloody struggle; and what was won by the sword was considered to possess an equitable title, that the sword alone could disturb. In those days it was considered that the lands of a country all belonged to the king: and on this principle the Saxon monarchs gave to their followers whatever districts they pleased, as rewards for the assistance afforded in the conquest, reserving to themselves certain portions, and imposing cer'ain burdens upon each estate granted. (Cukc's Litllton, I. 58. 2 ; Blackstone's Corrm. 45, \&c.) This was only a continuance of that feudal system that prevailed upon the Continent.

As this feudal system declined, and was finally extinguished in the twelfth year of Charles II., so proportionally did the landed interest increase in prosperity. Freed from the burden of furnishing a soldier and hi's armour for every certain number of acr , and all restrictions as to lands changing hanils being removed, and the numerous impositions being got rid off, with which the lords op. pressed their sub-infeudatories, it soon becams a marketable species of property; and, as money and merc..-andisi increased, and the 
proprietor lived less upon his estate, it soon became the most eligible plan for both landlord and tenant, that the whole rent should be paid in money.

Of the size of these early farms we have no precise information; but, from the laws of Ina we may perhaps conclude that a hide of land, equal to about 100 or 120 acres, was the customary size; for, in speaking of the produce to be given to the lord for ten hides, the law speak:; of the smallest division of each county of which it was particularly cognisant; namely, of ten families, or a tithing, as they were collectively called. Again, Bede expressly calls a hide of land fumilio, and says it was sufficient to support a family. It was otherwise called mansum, or manerium, and was considered to be so much as one could cultivate in a year.

War succeeded war, and chivalry and the chase were the engrossing occupations of the landed proprietors during the whole of the midrle ages; yet amid all these convulsions, and all this neglect, agriculture continued to obtain a similar degree of attention, and its practitioners to occupy a similarly humble, yet more independent station of life. Bishop Latimer flourished in the first half of the sixteenth century; and his father was among the most respectable yeomen of his time, yet his farm evidently did not exceed 100 acres. "My father," says Latimer, "was a yeoman, and had no lands of his own; he had only a farm of three or four pounds by the year, at the utmost; and hereupon he tilled as much as kept half a dozen men. He had a walk for 100 sheep; and my mother milked thirty kine," \&c. (Latimer's Sermons, p. 30.) But that this class of society was then not very refined, is proved by Sir A. Fitzherbert, in his Bork of Husbandry, declaring, "It is the wife's occupaiion to winnow all manner of corn, to make malt, to wash and wring, to make hay, to shear corn, and in time of need to help her husband io fill the muckwain, or dung-cart; to drive ihe plough, to load corn, hay, and such other; and to go or ride to the market; to sell butter, cheese, milk, eggs, chickens, capons, hens, pigs, geese, and all manner of corn."

This race of farmers, and this extent of farm, continued much the same till the closing years of the eighteenth century. The wife, indeed, had long previously ceased to participate in the above-mentioned drudgery, but she still attended the dairy, and sold its products at market, as her husband still participated in the usual labours of his farm; but in the latter half of that century, and thence to the present time, a different class of men have engaged in the cultivation of the soil. The accumulation of wealth from the vast increase and improvement of manufactures and commerce, the diffusion of better information, and the inrreased population, have all contributed to this effect. Individuals engage in the pursuit whose education and habits require a larger income for their indulgence than can be ufforded by the profits of a small farm; and, consequently, in districts having the most fertue soils, farms of from 300 to 500 acres are very common; whilst in less productive dis40) iricts they extend even to 1000 arr $\$ 000$ acres. With the present expenditure of rent, tithe, taxes, rates, and labour, and the reduced prices of agricultural produce, farms, even of those extents, cannct yield a profit sufficient to support the farmer of refined habits. And if the present artificial system of corn laws is removed, we do not see any possible result bus a return to smaller farms, and a more labouring class of tenants; for it admits of perfect demonstration, that small farms, having that manual labour, and that careful tillage which small plots obtain, return a more abundant produce than those which are too large to be so attentively cultivated.

Enclosure of Land.-It is a rule, founded upon general observation, that the most enclosed country is always the best cultivated: for, as Sir Anthony Fitzherbert observed, in the reign of Henry VIII., live stock may be better kept, and with less attendance, closes be better alternately cropped, and the crops better sheltered in inclement seasons, "if an acre of land," he concludes, "be worth sixpence an acre before it is enclosed."

We have seen, already, that hedges, ditches, and other fences, marked the boundaries of the early Saxon estates; and these were certainly not adventitious distinctions, for they are mentioned in most of the Saxon grants of which we are aware, and are strictly regulated and protected by law. If a tenant omitted to keep his farm enclosed, both in winter and summer, and to keep his gate closed, if any damage arose from his hedge being broken down, or his gate being open, he was declared to be legally punishable. (Wilkins, Leges Sax. 21.) If a freeman broke through another's hedge he was fined $6 s$. (Ibid.)

As woollen manufactures improved, the demand for broad cloths became excessive, not only in England but in the continental nations; and the consequent consumption of wool was so large, and the price was so enhanced, that self-interest dictated to the landed proprietors, even in the reign of Henry III., that the enclosure of their manorial wastes, on which to feed sheep upon their own account, or to let out as pasture farms, would be a source of extensive emolument. The statutes of 20 Hen. 3, 13 Edw. 1, and others, were consequently passed for sanctioning and regulating the practice. The demand for woollens continued, and became so great, that rapidity of manufacture was the chief consideration. "Yet as ill as they be made," says King Edward VI., in his private journal, "the Flemings do at this time desire them wonderfully." The consequences are depicted by the same genuine authority. "The artificer will leave the town, and for his mere pastime will live in the coun. try ; yea, more than that, will be a justice of the peace, and will scorn to have it denied him, so lordly be they now-a-days; for they are not content with 2000 sheep, but they must have 20,000 . or else they think themselves not well. They must have twenty miles square their own land, or full of their farms: four or five crafts to live by is too little. Such hell-hounds be they." (Edward the Sixth's Remains, p. 101.) The rents of land were consequently enormously 
raised, and the corn farmers were ruined. "They everywhere," says Roger Ascham, "labour, economize, and consume themselves to satisfy their owners. Hence so many fanilies dispersed, so many houses ruined. so many tables common to every one, taken away. Hence the honour and strength of England, the noble yeomanry, are broken up nnd destroyed." (Aschum's Epistles, 293-295.) Bishops story, latimer, and others, raised their voices in their behalf, and hurled their invectives from the pulpit upnn those who oppressed them. "Let them," said Isatimer, in a sermon preached before the king, "let them have sufficient to maintain them, and to find them in necessaries. A plough land must have sheep to dung their ground for bearing corn; they must have swine for their fond, to make their bacon of ; their bacon is their venison, it is their necessary food to feed on, which they may not lack; they must have other cattle, as horses to draw their plough, and for carriage of things to the markets, and line for their milk and cheese, which they must live upon, and pay their rents."

The short-sighted executive of that period endeavoured to prevent these enclosures by a prohibitory proclamation, as the legislature had done by the statutes 4 Hen. 7, c. 16,19 . There doubtless was great distress, and always will be upon any sudden change in the direction of the national industry, and in none more extensively than in the return from an agricultural to a pastorai mode of life. But, as is observed by one of the most impartial of our historians, "every one has a legal and social right of employing his property as he pleases; and how far he will make his use of it compatible with the comforts of others, must be always a matter of his private consideration, with which no one, without infringing the common freedom of all, can ever interfere. That no national detriment resulted from this extensive enclosure-no diminution of the riches, food, and prosperity of the country at large, is clear to every one who surveys the general state and progress of England with a comprehensive impartiality." (Turner's History of Edward the Sixih, \&c.) "The landlord," he further observes, "advanced his rent, but the farmer also was demanding more for his produce."

The evil of converting arable to pasture land cured itself. The increased growth of wool in other countries, and the improvement of their manufactures, by degrees caused the production of it in England to diminish : and as dearths of corn accrued, and the consequent enormous increase of its value rendered its growth more lucrative, pasture-land gradually returned to the dominion of the plough.

Since that period enclosures have gone on with various, but certainly undiminished, degrees of activity. More than 3000 enclosure bills were passed in the reign of George III. The land so enclosed was, and is, chiefly dedicated to the growth of corn; but since the field culture of turnips was introduced in the seventeeth, of mangel wurzel in the nineteenth century, and other improvements in agricultural practice, every farm is enabled to combine the autvantages of the stock and tillage husbandry.

Implemen/s.-It is very certain that the state of any art is intimately connected with that of its instruments. If these are imperfect it cannot be much advanced; and this is so universally the case, that agriculture, of course, is nos exception.

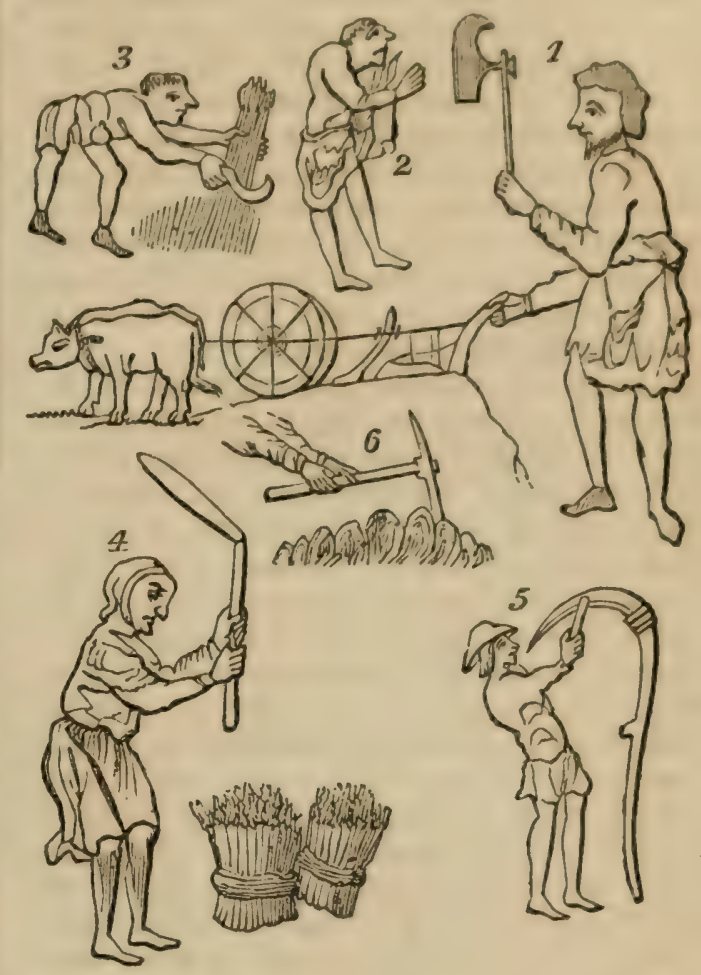

1. Norman plough, with the hatchet carried by the ploughman for breaking the clods. 2. Sowing, as represented by strutt. 3. Reaping. 4. Threshing. 5. Whetting. 6. Beating hemp.

We find, in the earliest of our national records, that the plough, the most important implement of husbandmen, was then of a very rude construction. In general form it rudely resembled the plough now employed, but the workmanship was singularly imperfect. This is no matter of surprise ; for among the early inhabitants of this country there were no artificers. The ploughman was also the ploughwright. It was a law of the early Britons that no one shou!d guide a plough until he could make one; and that the driver should make the traces, by which it was drawn, of withs or twisted willow, a circumstance which affords an interpretation to many corrupt terms at present used by farming men to distinguish the parts of the cart harness. Thus the womb willy has degenerated into wambtye or wantye; withen trees into whipping or whipple trees; besides which we have the tail withes, and some others still uncorrupted. (Leges Wollicr, 283 -288.) We read, also, that Easterwin, Abbot of Wearmouth, not only guided the plough and winnowed the corn grown on the abbey lands. but also with his hammer forged the instruments of husbandry upon the anvil. (Bede, Hist. Al,b. Wearmoth, 296.) Whether the early British or Saxon ploughs had wheels is uncertain, but those of the Normans certainly hail such appendages. Pliny says that wheels were first applied to ploughs by the Gauls 
The Britons were forbidden to plough with hoeing, not merely to extirpate weeds, but for any other animal than the ox; and they attached the purpose of pulverizing the soil, by which iny requisite number of oxen to the plough. The Normans had been accustomed, in their light soils, to employ only one, or at most two. (Leges Wullicx, 288; Montfaucon's Momumens de Monarchie Frunçois I. Planche, 47; Giraldus Cambrensis, c. 17.)

The gigantic and universal impulse that seemed simultaneously to affect the human mind in the sixteenth century, tended to the improvement of sciences which could not be benefitted without agriculture sharing in the good. Metallurgy and its subservient arts, and applied mathematics, were thus assistant to improving the plough. It received the first improvement among the Dutch and Flemings in the sixteenth century; and still more so in Scotland in the following one.

The common wooden swing-plough is the state to which it was brought in the last-named country, in the eighteenth century, and still is known in many countries, as the improved Scotch plough. The first author of the improved form is differently stated. A man of the name of Lummis has by one writer this credit assigned to him, though he learned the improvement in Holland. He obtained a patent for his form of construction; but another ploughman, named Pashley, living at Kirkleathem, pirated his invention. The son of Lummis established a manufactory at Rotherham in Yorkshire, whence it is sometimes called the Rotherham plough; but in Scotland it was known as the Dutch or Putent Plough. On the other hand, the Rotherham plough is said to have been made at that town in 1720 , or ten years before Lammis's improvements. The grandmother of the Earl Buchan, Lady Stewart of Goodtrees, near Edinburgh, is also named as an improver. She invented the Rutherglen plough, formerly much employed in the west of Scotland. Mr. Small, in 1784, and Mr. Bailey, in 1795, published upon the proper mathematical form of this implement. In the fourth volume of the Transactions of the Highland Society, and in the Quarterly Jonirnal of Agriculture for February, 1829, there are also two valuable Essays upon the same subject. In 1811 this plough came very generally to be made of cast iron. (Amos's Essay on Agricullural Machines, Survey of W. Riding of Yoikshire, \&c.)

Wheel ploughs have been commensurately improved. The objects to be attended to in the formation of a plough, and that is the best which attains to them most effectually, are, first, that it shall enter and pass through the soil with the least possible resistance; secondly, that the furrow-slice be accurately turned over; and, thirdly, that the moving power or team shall be placed in the most heneficial line of draught.

Scarifiers and horse hoes are implements which were unknown till within about a century ago. Hoeing by manual labour had, in very early ages, been partially practised; for the earliest writers, we have seen, recommended particular attention to the cutting down and destroying of weeds. But to Jethro Tull, is indisputably due the honour of having iirst demonstrated the importance of frequent process the gases and moisture of the atmosphere are enabled more freely to penetrate to the roots of the crop. The works of 'Tull ap. peared between the years 1731 and 1739 .

Drills.-We noticed, when considering the Roman agriculture, that the Romans endeavoured to attain the advantages incident to row-culture by ploughing in their seeds. A rude machine is described in the Transactions of the Board of Agriculture, as having been used immemorially in India for sowing in rows. The first drill for this purpose introduced into Europe seems to have been the in. vention of a German, who made it known tc the Spanish court in 1647. (Harle's Essays on Husbandry.) It was first brought much into notice in this country by Tull, in 1731; but the practice did not come into any thing like general adoption till the commencement of the present century. There are now several improved machines adapted to the sowing of corn, beans, and turnips. See Duruss.

Draining, as we have seen, was attenled to by the Romans, and it was unquestionably practised in Britain during the middle ages: for where lands were too retentive of moisture, or abounded in springs, the obvious remedy was to remove it by drains. This, however, and far simpler operations, are seldom performed in the most correct mode without a knowledge of the sciences connected with their success. Draining was never correctly understood till the scientific observations of Dr. Anderson, and the practical details of $\mathbf{M r}$. Elkington, about the year 1761, placed it upon a more enlightened and correct system. The important benefits that have arisen from the adoption of this system are very extensive; and the acknowledgment of $1000 \mathrm{l}$, voted to Mr. Elkington, was a just testimony that the landed interest appreciated the boon, and that the benefiter of this country is duly estimated by its legislature.

There are numerous kinds of drain ploughs. The mole plough was invented by a Mr. Adam Scott, and improved by a Mr. Lumley of Gloucestershire during the present century.

The past and the present century have also given birth to machines totally unknown in previous ages; of these are rollers, machines for haymaking, reaping, threshing, and dressing; and if to these be added the immense improvement that has taken place in the form and quality of all other agricultural implements, the saving of labour, and the power to pursue the necessary operations neatly and well, will be found to be incalculably promoted.

Crops.-It is probable that wheat was not cultivated by the early Britons; for the climate, owing to the immense preponderance of woods and undrained soil, was so severe and wet, that in winter they could attempt no agricultural employments; and even when Bede wrote, early in the eighth century, the Anglo. Saxons sowed their wheat in spring. (Bede's Works, p. 244.) The quantity cultivated in the reign of Henry III. does not appear to have exceeded the quantity necessary for the year's 


\section{AGRICULTURE.}

consumption; for in a very wet, inclement year, 1270, wheat sold for six pounds eight shillings per quarter, which, calculating for the difference of the value of money, was equal to twenty-five pounds of our present currency. It continued an article of comparative luxury till nearly the 17 th century commenced; for in the household books of several noble families it is mentioned that manchets, and other loaves of wheat flour, were served at the master's table, but there is only notice taken of coarser kinds for the servants. That the cultivation of wheat was very partial in the reign of Elizabeth is attested by Tusser, who, writing at that period, says,-

"In Sufolk again, whereas wheat never grew,

food husbandry used, good wheat-land 1 knew."

As the climate has improved by the clearing and drying of the surface of the country, so proportionally, has the cultivation of wheat extended.

It was probably owing to the fickle and inclement climate of England rendering the successful completion of harvest a much rarer and more hazardous event than now, that our forefathers made on the occasion such marked and joyous festivities. We do not know the motive that actuated the farmer, but no dread of an uncertain harvest could have made him more prompt and vigorous, who, in 1289 , cut and stored 200 acres of corn in two days. J'he account is given in "The History of Hawstead." About 250 reapers, thatchers, and others, were employed during one day, and more than 200 the next. The expenses of the lord on this occasion are thus stated:-Nineteen reapers, hired for a day at their own board, $4 d$. each; eighty men one day, and kept at the lady's board, $4 d$. each; 140 men, hired for one day, at $3 d$. each; wages of the head reaper, $6 s_{.} 8 d$.; of the brewer, $3 s_{.} .4 d$. ; of the cook, $3 s_{.} 4 d_{0}$; thirty acres of oats, tied up by the job, 1.. $8 d$.; three acres of wheat, cut and tied up by the job, 1s. 11d.; five pair of gloves," \&c.

Barley is probably the grain which was most cultivated by the early Britons. The representation of it occurs upon their coins. (Camden's Britannia, by Gibson, lxxxviii.) It was not only the grain from which their progenitors, the Cymri, made their bread, but from which they made their favourite beverage, leer.

Oats being well-known and cultivated by the Germans and other continental nations when Pliny wrote, they were probably known also to this island in the earliest ages. In all periods, even to the present time, bread made of oatmeal has been a very prominent part of the food of the inhabitants of the northern parts of Britain. "In Lancashire," says Gerarde, in 1597, "it is their chiefest bread-corn, for jamrocks, haver-cakes, thorffe-cakes, and those which are called generally oaten-cakes; and for the most part they call the grain haver, whereof they do likewise make drink for want of barley." It is so hardy that it is admirably calculated for a cold climate, and there is scarcely any soil in which it will not be productive. In southern climates it will not flourish.
AGRICUITURE.

"Rye," says Gorarle, gr. welh very plenti. fully in the most parts of Germany and Polonia, as appeareth by the great quantity brought into England in times of scarcity of corn, as happened in the year 1596 ; and at other times, when there was a general want of bread-corn, by reason of the abundanes of rain that fell the year before, wherchy erreat penury ensued, as well of cattle, and all other victuals, as of all manner of grain. It groweth, likewise, very well in most places of England, especially towards the north."

Its hardiness probably rendered it a principal grain with the early Britons; but as it is a great impoverisher of the soil upon which it grows, and the grain makes very inferior bread, it is now cultivated to a very small extent.

Peas have been extensively cultivated in England from a very early period; but they have been much less since the bean has become a more general field crop, which it did not till within the present century. Lentils were brought to England about 1548. Gerarda says he had heard they were cultivated as fodder near Waterford. Maize, or Indian corn, was made known in England in 1562. It is commonly cultivated in the south of France as a field crop, and for the same purpose was tried in England in 1828, at the recrimmendation ol Mr. Cobbett, but it has not succeeded. Tares, in 1566, according to Ray, were grown as a seed crop, and given to horses, mixed with oats and peas, though they were sometimes cut green as fodder. This is now their chief use.

Potatoes were introduced from South America, by Sir Walter Raleigh, about 1586. Sir Robert Southwell, President of the Royal Society, informed the Fellows, in 1693, that his father introduced them into Ireland, having received them fiom Sir Walter. (MS. Jumrna of Royal Society.) It long continued to be neglected by gardeners. In 1663, however, attention was drawn to its extensive culture. But notwithstanding the exertions of the Royal Society to effect this purpose, potatoes did not become a field crop till the early part of the last century. They became so in Scotland about 1730, a day-labourer of the name of Prentice having the honour of first cultivating them largely two years previously. Every county of England now grows them extensively. ancashire and Cheshire are particularly celebrated for them. In the counties round London, especially in Essex, about two thousand acres are annually cultivated for supplying the metropolis with this root.

Turnips and clover, though known in Eng. land during time immemorial, were never much cultivated in the field before the early part of the seventeenth century, and we mention them together, because their introduction among the farmer's crops caused the greatest improvement in the art that it ever received. In 1684, it is observed as a modern discovery. " sheep fatten very well on turnips, these prov. ing an excellent nourishment for them in hard winters, when fodder is scarce; for they will not only eat the greens, but feed on the roots in the ground, scooping them out even 
to the very skin." This is the first notice we have of feeding off turnips; and the same authority adds, "ten acres sown with clover, turnips, \&c., will feed as many sheep as one hundred acres would have done before." (Houghton's Collections on Husbundry, \&c., iv. 142-144.) Brown, Donaldson, and all other writers upon agriculture, agree, that the introduction of the improved mode of cultivating these crops revolutionized the art of husbandry. Previously, light soils could not be cropped with advantage; there was no rotation that the judgment could approve. Tusser, in the sixteenth century, in the following homely ines, teils us that two corn crops were grown consecutively and then a fallow; and many authorities could be quoted to show that some soils were fallowed on alternate years, so that they afforded only one crop in two years.

\footnotetext{
"First rie and then barlie, the champinn saies, Or wheat before barlie, be champion waies:

But drink before bread-corn, with Middlesex men,

Then laie on more compas, and fallow agen."
}

But now, by the aid of green crops, a fallow usually occurs but once in four years. "Clover and turnips," it has been observed, "are the two main pillars of the best courses of British husbandry; they have contributed more to preserve and augment the fertility of the soi. for producing grain, to enlarge and improve brzeds of cattle and sheep, and to afford a regular supply of butcher's meat all the year, than any other crops." It was previously a difficult task to support live stock through the winter and spring months; and as for feeding and preparing cattle and sheep for market during these inclement seasons, the practice was hardly thought of, and still more rarely attempted.

Mangel wurzel has only been cultivated by the farmer for a few years past. Its chief advantage is, that as it will succeed upon tenacious soils which will not produce turnips, it enables farms in which such soils predominate to support a larger quantity of live stock. Its cultivation seems on the increase, its fattening qualities being good, the produce heavy, and liability to failure small.

Hops, although indigenous to England, were little attended to, and never employed in brewing till the sixtcenth century; and then, when they began to be more used, the citizens of London petitioned parliament to prevent them as a nuisance. "It is not many years since," says Walter Blith, writing in the year 1653, "the famous city of London petitioned against :wo nuisances, and these were Newcastle coals, in regard of their stench, \&c., and hops, in regard they would spoil the taste of drink and endanger the people." (English Improver Improved, $3 \mathrm{~d}$ ed. 240.)

There are many other crops occasionally cultivated by the farmer which may be enumerated here, and most of them first extensively cultivated within the last 150 years, but which in this place will require no further notice-such as the artificial grasses, rape, inustard, caraway, coriander, flax, hemp, buckwheat or brank, teasel, madder, saintfoin, incerne, cabbage, carrots, and others.

General cullivation.-We have no informa. tion as to whether the early inhabitants of Britain varied their modes of ploughing with the nature of their soil. They sometimes ploughed with two oxen, sometimes with more; some ploughmen, represented in very old pictures, evidently drove the team as well as guided the plough; but it was usual for them to have a driver. There is a very old Saxon dialogue extant, in which a ploushman, in stating his duties, says, "I go out at day-break, urging the oxen to the field, and I yoke them to the plough-the oxen being yoked, and the share and coulter fastened on, I ought to plough one entire field or more. I have a boy to threaten the oxen with a goad, who is now hoarse through cold and bawling. I ought, also, to fill the bins of the oxen with hay, and water them, and carry out their soil." (Turner's Anglo-Saxons, ii. 546, ed. 5.) Repeated ploughings and fallowings, to prepare the soil for wheat, was the common practice; for Giral. dus Cambrensis, speaking of the Welsh, says, with astonishment, " they ploughed their lands only once a year, in March or April, in order to sow them with oats; but did not, like other farmers, plough them twice in summer and once in winter, to prepare them for wheat." (Descript. Cambriæ, c. viii.)

In a law tract, called Fleta, and written early in the fourteenth century, are given several agricultural directions, especially upon dressing and ploughing fallows. In summer, the ploughing is advised to be only so deep as to bury and kill the weeds; and the manure not to be applied till just before the last ploughing, which is to be deep. (Fleta, lib. ii. c. 73.)

Sowing was anciently peiformed in all cases by hand. In the famous antique tapestry of Bayeux, a man is represented sowing. The seed is contained in a cloth fastened round his neck, is supported at the other extremity by his left arm, and he scatters the seed with his right hand.

All agricultural writers, from the earliest era to the present, have recommended the seed to be soaked in some medicament or other previously to sowing. Virgil recommends oil and nitre for beans; others direct the employment of urine; and Heresbachius, who wrote in 1570 , mentions the juice of the houseleek. "Sow your ridges," says the same author, "with an equal hand, and all alike in every place, letting your right foot, especially, and your hand go together. Wheat, rye, barley, oats, and other large seeds must be sown with a full hand, but rape seeds only with three fingers." (Googe's Heresbachius, 246.)

The tapestry of Bayeux, already mentioned, represents a man harrowing; one harrow only being employed, and one horse. In the time of Heresbachius, though harrowing was the usual mode of covering the seed, yet he says, "in some places it is done with a board tied to the plough." Rakes seem to have been employed by the Anglo-Saxons; for the accurate researches of $\mathrm{Mr}$. Turner do not appear to have discovered any mention of other im plements that were employed by them for the purpose. (Hist. Anglo-Sax. ii. 544.)

We find no very early mention made of hoeing by any English agricultural writer. 


\section{AGRICULTURE.}

Though there is generally some directions for "plucking up the naughty weeds." Heresbachius is the first that we have met with who notices the advantage of loosening the surface of the soil about growing crops. "Sometimes," he says, "raking is needful, which, in the spring, loosens the earth made clung by the cold of winter, and letteth in the fresh warmth. It is best to rake wheal, barley, and beans twice. Moreover, they break asunder with a roller the larger and stiffer clods." (Gunge's Heresbachius, [printed in 1578,] 256.) It was not till the time of Tull, 1731, that the due importance of this was appreciated.

Of the other operations of agriculture, as reaping, mowing, stacking, and the like, there seems no need of making mention: they were performed much in the same way as now. "Corn," says the author last quoted, "should be cut before it is thorough hard; experience teacheth that if it be cut down in due time, the seed will grow to fulness as it lieth in the barn." (Grogge's Heresbuchius, 406.) According to Henry, the practice with our ancestors was for the women to thresh and the men to reap. (Hist. of Brituin, vi. 173.)

Irrigation seems to have been practised in a few places in Britain from the time of the Romans, there being meadows near Salisbury which have been irrigated from time immemorial. Lord Bacon mentions it as a practice well understood in his time $(1560-1626)$; and at the same period, 1610 , appeared a work by Robert Vaughan, detailing the mode of "summer and winter drowning of meadows and pastures, thereby to make those grounds more fertile ten for one." It was not, however, till the close of the last century that the attention of agriculturists was much aroused to the subject. The writings of Boswell, Wright, West$\mathrm{ern}$, and others, hetween the years 1780 and 1824 , partially awakened the farmers to the importance of the practice. The best examples of it are to be observed in Gloucestershire and Wiltshire; but it is now one of the practices of farming that is the most undeservedly neglected. Mr. Welladvise was its great promoter in Gloucestershire.

Live Stock.-Cattle and sheep were the chief riches of the Britons when they became first known to the Romans (Cæsar, v. c. x.), and they are still a great source of our agricultural riches.

Sheep.-In a very early Anglo-Saxon MS. a shepherd is represented as saying, "In the first part of the morning I drive my sheep to their pasture, and stand over them in heat and in cold with dogs, lest the wolves destroy them. I lead them back to their folds, and milk them twice a day; and I move their folds and make cheese an.i butter." (Turner's Anglo-Sax. ii. 546.)

'I'his attention to sheep was attended with so mich success that they became an object of acquirement by the continental nations; and in the reign of Edward IV. at the time a treaty of peace was concluded with Spain (1466), a lieense was granted by that monarch "for certain Coteswold sheep to be transported to Spain, as people report, which have there so multiplied and increased, that it hath rurned

\section{AGRICULTL゙RE.}

the commodity o: England much to the Spanish profjt, and to the no sinall hinderance of the gain which was beforetimes in England raised of them." (Hall's Chrunicle, 266. Holinshed, 668.) The sheep thus exported were probably improved by attention and climate till they harl become that breed of Merinos which was reimported to this country early in the present century. 'The statute 3 H. 6, c. 2 , forbids the exportation of sheep. The fears which old chroniclers may have ignorantly entertained, that the exporting of sheep would be injurious to our native commerce, have in all succeering years been proved to be fallacious. The demand for our wool was so large, and the consequent increase of the breed of sheep was so great, that an impolitic legislature in 15:33 endeavoured to check it. The preamble of the act states, that "divers of the king's subjects, to whom God of his goodness hath disposed great plenty and abundance of moveable substance, now of late, within few years, have daily studied, invented, and practised ways and means to accumulate into few hands, as well great multitudes of farms as great plenty of cattle, and in especial sheep, putting such lands as they can get to pasture and not to tillage, whereby they have not only pulled down churches and towns, and enhanced the old rates of the rents, and that no poor man is able to meddle with it, but also have raised the prices of all manner of corn, cattle, \&c., almost double ahove the prices accustomed, to the great injury, \&cc., of his majesty's subjects; and as it is thought that the greates? occasion of this accumulation is the profit that cometh of sheep, which now be come to a few persons' hands of this realm, that some have 24,000 , some $20,000, \&$ c., by which a good sheep for victual, that was accustomed to be sold for $2 s .4 d$., \&c., is now sold for $6 s$. , \&c. ; which things thus used be principally to the high displeasure of Almighty God, to the decay of the hospitality of this realm, to the diminish. ing of the king's people, and to the let of clothmaking," \&c. It then enacts, that no one shall have more than 2000 sheep; though, as a subsequent section declares every hundred to consist of six score, the limited number was $\mathbf{2 4 0 0}$. And it further enacts, that no man shall have above two farms. ( 25 H. 8, c. 13.)

Harrison, who died in 1593, describes our sheep as very excellent, "sith for sweetness of flesh they pass all other. And so much are our wools to he preferred before those of Milesia and other places, that if Jason had known the value of them that are bred and to be had in Britain, he would never have gone to Colchis to look for any there." (Description of England, prefixed to Hulinshed, 220.) Heresbach, who" was a contemporary, gives such a description of the best form and qualities of sheep, that is evident that the excellence of the breed was not the mere effect of chance. (Gonge's Heres. bach. 1376.) From that period till the latter half of the eighteenth century, we are nct ac: quainted with any efforts further to improve it. This last-mentioned period was he era of the improvements effected by Mr. Bakewell and his pupils, the Messrs. Culley.

Bakewell was born in 1726, at Ditchley iu 
Ieicestershirc, and about the year $1755 \mathrm{com}$ menced those experiments which finally effected a greater improvement in our sheep than was ever effected in any species of agricultural produce by the exertions of one individual. He travelled over England, Ireland, Holland, and other places, for the purpose of examining the various breeds of cattle, and by careful selections, and judicious crosses, succeeded in procuring a stock that obtained for the Ditchley sheep a previously unheard of excellence. Fortunately the English agriculturists appreciated the importance of his success; and it is a fact that, in 1789 , three of his rams, the produce of one birth, were let for the breeding season, for 1200 guineas, and the whole produce of his letting was at least 3000 guineas. One of his rams obtained for Mr. Bakewell, in one season, 800 guineas; and when it is taken into the calculation, that the same animal served for his own flock, it produced for its owner in that year 1200 guineas. Mr. Bakewell died in 1795 .

Messrs. Culley introduced these improvements into Northumberland, and the other northern counties of this island. When they first settled in that district, the sheep kept there were large, slow-feeding, long-woolled animals; and a breed between those and the Cheviot sheep. These breeds rarely became fat before they were three years old; but the Leicesters introduced by the Messrs. Culley were sold fat at little more than a year old. They at first met with much opposition; but as it was soon seen they were improvers, and not mere innovators, the flocks have generally been made to improve by their example. They became the general patrons of improvement, and their great attention to minutiæ, unremitting industry, and superior cultivation, gave birth to a spirit of emulation, and their own merits were rewarded with a liberal success. For several years they occupied farms to the amount of about $8000 l$. per annum. They had pupils with liberal premiums from all parts; and these again were the means of making known, not only their enlightened husbandry, but the encouraging illustration they afforded of industry, economy, and intelligence duly rewarded.

Merino sheep were imported by George III. in the years 1788 and 1791 . This breed attracted much atterition in 1804, when his majesty commenced his annual sales. Dr. Parry, Lord Somerville, and others have paid considerable attention to them; but the climate of England has a considerable effect in deteriorating their fleeces, and the flesh is too indifferent to permit them to be much encouraged in a country where mutton is so considerable an article of food. (Hunt's Agricullural Memoirs; Gent's Magazine; Enc. Brit.)

Mr. Ellman, of Sussex, during an enlightened practice of more than fifty years has brought the South Down variety of sheep to a state of the highest improvement. Perhaps the best description of the varieties of the sheep reared in England has been written by this gentleman for "Baxter's Agricultural Litrary."

Cattle, a: we have already noticed, have al- ways been a prominent production of Great Britain. They were mentioned by Cæsar, Strabo, and other ancient writers. They have ever since continued, more or less, particularly to engage the attention of the husbandman, not only for the dairy and the plough, but also as a source of food. The breeding of cattle, however, had been so much neglected for the more profitable pasturage of sheep, that in 1555 , an act of parliament was passed to remedy the evil. The preamble states that, "Forasmuch as of late years a great number of persons in this realm have laid their lands, farms, and pastures, to feeding of sheep, oxen, runts, scrubs, steers, and heifers, \&c., having no regard or care to breed up young beasts or cattle, whereby is grown great scarcity of cattle and victual;" and, therefore it is enacted that a cow shall be kept wherever are sixty sheep, and a calf reared where there are one hundred and twenty, \&c. (2 \& 3 Phil. \& Mary, c. 3.) Many other legislative enactments occur in the records of that and contiguous periods; but reason and interest are better promoters of im. provement than acts of parliament. A due attention to the breeding of cattle was first aroused by Mr. Bakewell, who has just been mentioned as an improver of sheep. He let bulls for 150 guineas during four months, and 5 guineas per cow was no uncommon charge. Pedigrees have been preserved of different animals with as much care as those of race-horses. 'The attention and care that have thus been paid to their breeding have met with an appropriate recompense. In no other country is there in be found such breeds of cattle; and that none are so highly estimated, is proved by the prices that have been given for individuals. (Marshall's Midland Counties, i. 334 ; Parkinson on Live stock, ii. 469.)

Horses.-That the ancient Britons had horses with which they impelled their war chariots, we know upon the authority of those who had seen them--Cæsar, Stralo, and others. In the epitome of Dion Cassius, by Xiphelin, those horses are described as small and swift. They appear not to have been usually employed in the operations of agriculture ; and their employment was not considered desirable; for in tbe old Cambrian laws, oxen are exclusively directed to be employed. (Leges Wallicx, 288.) Under the Saxons, and still more under the Normans, who flourished here in an age that, from its excelling in noble horsemanship, has been distinguished as the chivalric, the breed of horses was undoubtedly improved. "Richard De Rulos, Lord of Brunne and Deeping, was much addicted to agriculture, and delighted in breeding horses and cattle." (Ingulphus's Chron. lib. i.)

In the year 1494, the exportation of horses was so extensive, and the price of them so much enhanced, that an act of parliament ordained that none should go out of the realm without the king's license $(2 \mathrm{H} .8, \mathrm{c} .6 ; 32, \mathrm{c}$. 13 ; 33, c. 5 ); but these being evidently intended for the improvement of war horses, "for the defence of the realm," would only collaterally benefit those employed by the husbandman. II was provided by the second of the acts jusi quoted, tnat no stallion should be kept that did 


\section{AGRICULTITE.}

not measure fifteen hands from the sole of the hoof to the highest part of the wither; each hand to be four standard inches. We find, however, that at this period draught horses were fine and powertul animals, for Harrison, who lived at this era, and whose appendix to Holinshed we have before quoted, after expressing his admiration of them, says, that five or six of them would draw with ease three thousand weight of the greatest tale for a long journey. We must remember, too, that in those days the roads were totally different from what they are at present. It is within the memory of persons still living in the hundreds of Essex, that no more than a load of wheat was ever sent out in a wagon, the roads there being, until within less than a half a century, exceedingly bad.

We have already noticed that in the tapestry of Bayeux a man is represented harrowing with a horse. This tapestry was woven in the year 1066, and this representation is the first notice, of which we are aware, of the horse being employed in agriculture. The first attempt that historians notice, to improve the breed of our husbandry horses, was in the reign of King John. Tyrant and despot as he was, yet his evil qualifications gave two benenits to England. His tyranny gave birth to Magna Charta; and his pride, rendering it hateful to him to see foreigners surpass him in the excellence of their horses, induced him to import 100 stallions from Flanders; and from that era may be dated the improvement of our draught horses. His object did not entirely succeed; for a century subsequently, in the reign of Edward II., we find that horses were still imported from Lombardy and Flanders. We have already noticed some of the enactments to improve the breed of horses, but these shared the fate of most other compulsory measures; for when Elizabeth summoned her forces to defend her realm, in the prospect of a Spanish invasion, she could obtain no more than 3000 cavalry.

Sir A. Fitzherbert, who wrote in the reign of Henry VIII., says, in his Boke of Husbandry, - A husbande may not be without horses and mares, and specially if he goe with a horseplough, he must have both; his horses to droive, and his mares to brynge colts to upholde his stocke, and yet at many times these may droive well if they be well handled." The roguery of horsedealers was an early sin; for one of the old Cambrian laws provides, that the purchaser of a horse shall have three nights to ascertain whether he is infected with the staggers; three months to prove his lungs; and twelve months to discover whether he is infected with the glanders. For every blemish not disccvered before purchasing, if it was not in the ears or tail, one third of the price was to be returned. (Laws of Howell Dhu.) The deceptions practised by the dealers in horses is still proverbial; and there does not appear with their fraternity to have been any intermediate age of innocence; for Sir A. Fitzherbert says, "Thou grayser, that mayest fortune to he of myne opinion or condytion to love horses, and young coltes and foles to go among
AGRICLI,TIRE.

thy cattle, take hede that thou be not begrilud as I have been a hundred times and mure. Ard first, thou shalt knowe that a good horse has fifty-four properties; that is to say two of a man, two of a badger, four of a lion, nine of an oxe, nine of a hare, nine of a fox, nine of an asse, and ten of a woman."

Since the days of Elizabeth, every variety of horses has been gradually improving, in England, and four kinds, the Suffulk Punch, the Cleveland bays, the Clydesdale, and the Lincolnshire or dray, are surpassed by no country in the world. The numerous cart stallions attending every market town during the covering season, is an attestation that this care is not on the decrease. It is stated, as a further proof, that a few years since a Suffolk cart-mare and her offspring sold at $\mathbf{W}^{\top}$ oodbridge Lady-day fair for $1000 l$.

Pigs have been among the usual animals fostered by the farmer in times at least as early as the Anglo-Saxons. In those days they were evidently the most numerous of their live stock; scarcely an estate is mentioned without its being stated that it afforded pan. nage, or mast in its wood, for such a number of swine. They were a very prominent portion of their wealth; and, indeed, a chief necessary, for they were in winter obliged to use almost exclusively salted meat, and the great preponderance of woodland supported best this kind of stock. (Turner's Angli-Saxons, iii. 22.) Heresbach is particularly earnest in commending the pig; and after mentioning it as abominable to the Jews, says, with a boastful feeling that made him forget its impiety, "I bclieve, verily, they never tasted the flitches of Westphaly."

Enactments occur in our statute book, in 1225 and 1534, regulating the rannage of swine. There are now a great many varieties of pigs, every district of England varying in the size and qualities of those it prefers. Some attention has of late years been f aid to improve the stock, but in general they have been too much neglected. We have not particu. larized the progress of husbandry in Scotland, because previously to the time of its union with this country, Lord Kames and Mr. Fletcher agree that its agriculture was deplorable; and since then the improvement of the art in that most generally enlightened part of twe island has, in many districts, outstripped, and, in most, at least kept pace with that of England; and its future advance will probably surpass that of England, because good education is more completely diffused among its inhabj. tants.

Ireland is in general deplorably behind in all the arts of life; nor will this be obviared until the effect of education and wealth is mure generally felt and appreciated by its gineruus and hospitable, but far from wealthy irliabitants.

Wales, for the most part, has an agriculture as bad as that of Ireland; and we cannot have much hope of its improvement, when Mr. Adam Murray, in his evidence before the Com mittee of Agriculture in 1833, stated that the Welsh have a great antipathy against u. 
Saxons, or Sassenachs; and that they take every advantage of any Englismon that settles among them.

\section{Continentai Agnicultur.}

We have now brought to a conclusion our iketch of the progress of agriculture. The limits of our work preclude us from giving here more of the ample details that have come under our notice in the research for the materials, of which we have given the abstract. We have not withheld our attention from the husbandry of other nations, but have found little concerning the history of their progress in the art; and the examination of their present operations made it so apparent, that with the exception of Flanders, they were all so much behind in general practice, that the conviction is forced upon us, that little instruction could be obtained from its detail. Several of them, however, excel us in some particular points: and in noticing these we shall avail ourselves of the opportunity to enfore the importance of extra attention to them upon our own agriculturists.

Flanders.--This country was certainly the first of modern countries to improve the practice of agriculture. Its farmers were the first tutors of England; and from the time of Sir Richard Weston, who published an account of their husbandry, in 1645, till that of the Rev. T. Radcliff in 1819, the Flemish husbandmen have continued models of neat and economical farming. In this respect we fall short of them. It is a leading principle with them to make their farms closely resemble gardens. Conscquently, to effect this, they have small farms, and devote their efforts to these three grand points--the accumulation of manure-the destruction of weeds-and the frequent and deep pulverization of the soil. We recommend for the perusal of our readers the work (Tour in Flanders) published by Mr. Radcliff, and the Flemish Husbandry of the Society for the Diffusion of Useful Knowledge, and we are convinced that they will benefit by the time so occupied. We do not expect that they will induce them to try to cultivate a large surface of land with the minute accuracy of a garden; but it might pursuade them to adopt that more cleanly system of cultivation which is the only one that is permanently profitable.

We shall only remark more particularly upon the assiduous care the Flemish farmers bestow upon the collection of manures.

They were the first among the moderns to raise crops for the sake of pluughing them in whilst growing; and they contunue it more extensively inan any other nation. 'This practice, we may say, is entirely neglected by our farmers; but if they knew sufficient of chemist $y$ to understand how much fertilizing materials such green crops impart to the soil, it would we a practice more extensively adopted. Fivery fragment of animal and vegetable matter is preserved by the Flemish farmers for the fertilizing of their lancs; and the ready *ale which all such decomposable substances meet, is one cause of the broom and the bar-

$\checkmark$ succecding in keeping their town so scru$1 \mathrm{~A}$ pulously neat. Saw-dust, chips, and similar refuse all tend to increase their composts; and on their barren lands trees are frequently planted for the purpose of creating in time a fertile soil by the agency of their falling leaves.

Their dunghills are so constructed that all the drainage is collected in cisterns, with which liquid is mixed the emptyings of privies, pulverized rape cakes, and the like; and this most fertilizing compound is conveyed to their fields by means of barrels fixed on wheels, and is spread by means of a scoop, 2840 gallons per acre being allowed for their flax crop. (Johns. on Liq. Manure.)

The slovenly management of his dunghill is one of the most general specimens of the ignorance or carelessness of a farmer. He allows the most soluble and valuable portions to drain away; and treats with ridicule the idea of carrying out manure in a liquid form. As this arises from ignorance and bigoted attachment to old practice, it should excite our pity more than our anger. Liquid manures, notwithstanding stupidity and prejudice, are amongst the best of fertilizers, and will, in a coming age, be generally employed, since it is a fallacy to argue that they cannot be employed on a large scale; for the comparative expense of preparation and application is unquestiona. bly smaller on a large scale than on a less.

Holland.-The husbandry of this country is almost exclusively confined to the dairy and to stall feeding. There are two points in their practice in which other farmers would do well to imitate them.

It is a common prejudice that a cow for the dairy should never be fat. 'This is thus far true, namely, that if a cow inclines to fatten easily, she does not yield so much milk as one that generates fat less readily. But a good dairy cow, that is, one that secretes mills abundantly, will not fatten whilst in that condition, and therefore the abstain:ng from giving them nutritive food is an erroneous conclusion. The Hollanders know that the contrary is the correct practice, and once a day, or oftener, they give their cows rape cake, and other nutritious preparations. 'The ignorance of the common English practice is evident from this fact, that without one exception, other animals, when suckling, are always kept much higher than at other periods.

The other point of their practice that merits imitation is the cleanliness with which they ireep all their animals, "It will excite a laugh with some of our agricultural readers, when we recommend not only the most scrupulous daily cleaning and washing out of cow-sheds, pig-styes, and the like, but that the animals themselves should be cleaned. Whis, however, is not a mere speculative precept, for the national example of Holland attests its utility. We have known the beneficial effects of such treaiment upon the health of cows and pigs in this country. But in the absence of all facts, if the farmer would but allow his own common sense to direct him; if he would but reflect that no animal will thrive that is not healthy; that his horse becomes diseased if not kept clean; and that by no possibility can it be 
otherwise but that fetid stenches, and encumbering filth must tend to breed disease, he would not allow so baleful a neglect to continue. It is fulile to uge that where stock is large, the attendance to such treatment is impossible; for if it is beneficial it will pay to adopt it; and no one should engage in a larger concern than he can manage in the most beneficial mode.

Germany-The inhabitants of the different districts of this extensive empire pay particular attention to the cultivation of timber trees. The number of German books on the subject is excessive.

It is a subject which has of late years been gaining much attention also in England, and planting will probably be still further extended over many of the poorer soils that at present will not pay whilst producing corn.

The careless and ignorant manner in which the labaurer is allowed to mutilate timber trees that grow upon most farms, cannot be too severely deprecated. To train trees correctly, requires as much judgment as any operation in which the gardener or forester is concerned. Not an unnecessary wound should be inflicted upon them; for the process of healing each wound not only deducts so much from the growth of the tree, but is usually the introducer of decay. Yet the hedger, with no other instrument than his bill, is generally allowed an unguided use of so unfit and mutilating a tool.

Lombardy.-In this, and most of the other Italian states, all rivers, and in some, even all springs, are considered to be the property of the government, for they are the source of a considerable revenue. Any one desiring a canal from a river has to pay for it to the government; and he may cut it through another person's ground without the latter having the power to prevent it, upon paying the value of the land. Such canals are considered as improving the value of an estate, for they irrigate not only their grass lands, but their corn, vines, and other crops, numerous little channels being cut for the purpose down the ridges. The water from a river is purchased at a certain price for so many hours' or days' run in the year, through a sluice of a stated dimension. Arthur Young mentions that the fee-simple of an hour's run per week through a particular sized sluice at Turin, sold in 1788, for 1500 livres. Watered lands usually let for one third more than lands that are unwatered.

We have already noticed, and shall again have to recur to the subject of irrigation; but we could not but notice the above national evidence in favour of what we know to be one of the most beneficial practices neglected by our agriculturists.

Tuscany.-Sismondi informs us that it is the practice in this country, where he was himself for five years a cultivator, to trench one-third of the farm every year with the spade, bringing the lower soil to the top. This mode of culture bringing a new soil for the promotion of vegetation, for it has been in a manner lying two years fallow, is sanctioned by reason as well as confirmed by practice. We are not the advocates of a general system of spade husbandry. There are objections to it that at present are insuperable. But we do recommend, and that from our own experience, its partial adoption. There is no parish in England in which many of the labourers are not out of employ during a considerable portion of the year. Perhaps the average of the poor's rates were 108 . in the pound upon the farmer's rental; and this night have been reduced more than one half, if every farmer had employed one man in spade husbandry for every thirty acres he cultivated. Thus he would have had some return for the money he expended; and the saving of horse labour, and the benefit of the extra cultivation, would hare turned the balance in his favour, and he wou!l thus have got rid, in a great degree, of the worst of all outlays-an outlay without a pos. sibility of a return.

I have searched various statements of the agriculture of the other European countries: but though I am gratified by the conviction that they are all more or less improving, yet in almost all their practices, except the culture of the vine, they are very far behind England. For that reason I leave them unnoticed, because there is no instruction to be extracted from a detail of deficiencies that have already been overcome. Upon a revision of the whole, I may remark that agriculture, in common with all other kinds of knowledge, is always flourishing, in proportion to the freedom of the people. Spain, subjugated by its despotis monarchy and priesthood, has an agricultare imperfect and degraded beyond that of any other European nation. Flanders has always had a liberal government, and its agriculture imploved before our own, and is its equal now.

By freedom, I mean security of property and person, unrestricted discussion of every virtuous opinion, and an untainted distribution of justice. With us, the era that introduced such freedom into England was that of the Reform. ation, confirmed and strengthened by the exclusion of the Stuarts in 1688.

The introduction of the scholastic philosophy, which revived that activity of mind which the Grecian vanity had so much abused, and the Romans, by their gross habits, had so long paralysed; the mathematical sciences which the Grecians had imported from Alexandria and had forgotten; that natural and experimental knowledge which neither the Grecians nor Romans had ever much or permanently pursued; the reformation of religion, wnich removed from the mind that incubus that forbad man to trust to his own reason, but made it the bond-slave of interested ignorance. the invention of printing, which became the mighty engine of diffusing accumulated know. ledge; were all events that preceded the seven. teenth century, and rendered it an era splendid by the general improvement which it afforded in all the arts and sciences. These have justly been represented as forming a circle, for they are so united, so blended together, and so co. assistant, that one cannot be improved withous the benefit being shared in some way by the others.

Agriculture participated in the general pro. 
gress; and the impetus that was given to the human mind, tutoring it to follow reason rather than habit, was felt by the cultivators of the soil. The eighteenth and present centuries have been those in which the improvement has been marked, and the instances of which have already been noticed. The reason of this is to be found in its having then very generally engaged the attention of a more enlightened class of society. The noblemen, the gentry, and even the monarch of Ergland, became practical agriculturists; and under the patronage of George III., the Duke of Bedford, Lords Sheffield, Suffield, and Albemarle, Coke, Western, and inany others, it was sure to obtain the benefit of all the improved knowledge of the day. In 1723 was instituted the Society of Improvers in the Knowledge of Agriculture in Scotland; in 1749, the Dublin Agricultural Society; in 17r7, the Bath and West of England Society; in 1784, the Highland Society of Scotland; in 1793, the London Board of Agriculture, and the Royal Agricultural Society of England in 1838. The last chiefly through the exertions of Mr. W. Shaw and Mr. Handley, Lord Spencer and the Duke of Richmond. This, although supported eritirely by voluntary subscriptions, promises to be of the highest advantage to agriculture, and by its excellent arrangements, of which carefully avoiding all political discussions is a prominent feature, it now includes in its copious list of members, men of all parties, who are united not for the sake of indirectly forwarding party objects, but for the improvement in all its imfortant branches of practical agriculture. The fate of the Board of Agriculture, which expired about the year 1812, from the withdrawal by government of the annual parliamentary grant for its support, should operate as a warning to all other agricultural societies; for this society failed, not from a want of talent or of industry, but from its efforts being paralysed, and its resources curtailed by its being considered the society of a party, and made the arena for the discussion and promulgation of political doctrines. From none of these have arisen any splendid discoveries, for such are not to be made in agriculture: there can never arise, so far as we can foresee, any Newton or Watt in this art; but they have elfected and are accomplishing all that such associations can be expected. They have occasioned the collision of opinion, they have stimulated the desire of improvement, and they have promoted the general communication of its acquirements. The general improvements introduced into agriculture, under the auspices of these valuable societies, have been, amongst several others, 1. The general introduction of green crops; 2 . The improveinent of agricultural machinery, such as the drill, the thrashing-machine, the plough, \&c.; 3. Better breeds of all kinds of live stock; 4. Better and more numerous varieties of seeds.

Of the benefits conferred by other sciences upon agriculture, by chemistry, botany, and physiology. I shall hereafter have much to - say. They are branches of knowledge hitherto inu seldom combined with practical skill to have yet accomplished much; but of what they are capable of achieving, an estimate may be formed from the perusal of De Cal. dolle's Physiologie Végútale. "It is certain," as the writer of this has elsewhere observed, "that a cultivator of the soil should have a knowledge of botany and of chemistry. Without the first he will be unable to understand terms and observations that must occur in every well-written work on his art; unable to comprehend the nature and habits of the objects of his culture, or to render observations which he makes intelligible to others or even to himself. Chemistry is of as much, if not greater, importance to him. The nature of soils, of manures, of the food and functions of plants, would all be unknown but from the analyses which chemists have made. Science can never supersede the dung-hill, the plough, the spade, and the hoe; but it can be one of their best guides-can be a pilot even to the most experienced." (Baxter's Agricultural Library, 110.)

of the literature of agriculture, I have little to say in this place. From the days of Hesiod until the sixteenth century, the authors upon this art were very few; but from that period to the present, they have continued to increase; and its literature, if now collected, would form a copious library.

There have been professorships of agriculture for some time proposed at the Universities of Oxford and Cambridge. There was one appointed at Edinburgh in 1790, and the chair is now (1811) filled by Mr. Low; another at Oxlord in 1840, of which Mr. Daubeny is the present holder.

A prejudice too generally existed amongs? farmers against the agricultural knowledge contained in books; but now they are generally better educated, this prejudice will cease. Ignorance is always bigoted and obstinate; and it is the same mental sterility which made the $m$ jealous of all new practices, that made the Irish persist in fastening their horses to the plough by their tails, until it was absolutely prohibited by the government. The Irish said in defence of their practice what some English farmers say in defence of theirs, however erroneous, "My grandfather did well enough this way." Such foolish observations - amount to no more than this, "We will not try to improve." This race of stagnant cultivators is gradually disappearing; and those who are succeeding them, we see reason to believe, are more enlightened, and consequentiy more read: to adopt improvements. We most heartily rejoice at this; and we hope to see them more and more a class of reading men. Practice must ever be their chief tutor, as in all other arts; but likewise, as in all other arts, that practice will always be the most correct in its details which is founded upon scientific knowledge. (G. W. Johnsun. Miller's Gurd. Dict. by Orr \& Co.)

\section{[AgRiculture in The UNiten States.}

A glance into the agricultural history of the United States has been given in the introduction to this work. It will not therefore be 
nesessary to say much upon that topic here, where the agricultural resourses of the Republic will be mainly dwelt upon.

Notwithstanding the desolation to which a scourging course of tillage has reduced so many of the once rich acres in the Atlantic states, the agricultural productions of the country are exceedingly abundant. Until very recently, the value of these products has been a subject for conjecture and approximate computation. The act of Congress for taking the Census of 1840 , provided that the persons engaged in enurnerating the population, should collect facts so as to show the amount of the products of husbandry, as well as of every other branch of industry pursued throughout the country. A fund of authentic information of the highest interest has been thus obtained, exhibiting not only the aggregate value, but the relative proportions the several products of agriculture, commerce, the forests, and the manufactures, bear to each uther.

As the agriculture of the country yields the immediate means of subsistence, so does it furnish the basis of commerce, and the various branches of industry, all of which must prosper or languish according to the good or bad success attending rural affairs.

"Land and trade," says a quaint old English writer, "are twins, and ever will wax and wane together. It cannot be ill with trade but lands will fall, nor ill with lands, but trade will feel it." (Sir Juseph Child.)

"In the pursuit of agriculture," says a sensible writer in Hunt's Magazine, "we are, in effect, advancing the other great interests of the country, a fact which we are too apt to forget in discussing any single interest with ex-parte views. We will take the mere subject of commerce, which is supposed to be inimical to the other interests of the nation, and what a mighty spring is given to the internal trade of the country by agricultural enterprise, looking at the actual condition of the transportation of agricultural products upon the principal lines of commercial communication, both at the east and west. How large a portion of the freights is furnished by the agriculture of the south to the ships which are continually plying from its ports to the inland ports of our own territory, and to the prominent cotton markets abroad. Of the vessels that are daily taking in their cargoes in the harbours of Charleston and New Orleans, and the intervening ports, it is safe to say that the principal portion of those freights is derived from the cotton, sugar, tobacco, and rice, as well as the other agricultural staples of the surrounding territory. The same is the case with the commerce of the Mississippi: and we find the numerous steam ships and flat boats which ply upon that river during the season of navigation, are laden with the agricultural products of the states that border its banks, or that are sent down through the interior by the Ohio. The commerce of the lakes is maintained, moreover, in a great measure by the transportation of the agricultural produce of the great states of Ohio, Illinois and Michigan, lying upon their borders, to the eastern markets : and the same may be said of the canal and rail-road trans- portation of the greater number of the states as well as our coastwise trade. Furthermore, if we examine the decks and holds of the ships which are constantly setting sail from our commercial towns both at the east and south, we find that agriculture supplies the great bulk of the cargoes which are exported abruad. It is agriculture indeed which gives life-blood to the trade and commerce of the country, and is doubtless as important to the solid vigour of commercial enterprise as nutritious food to the health of the human body. Withdraw this re. source from our commerce, and the veins and arteries of the commercial system would sink into a state of collapse, exhibiting the cadaverous and pallid hue of disease and starvation. Of the amount of the several species of agricultural products yielded by the country, we are furnished with the following statements, made in one of the late reports of the United States Commissioner of Patents.

An Estimate of the products of labour and crap:tal in the United States for the year 1818.

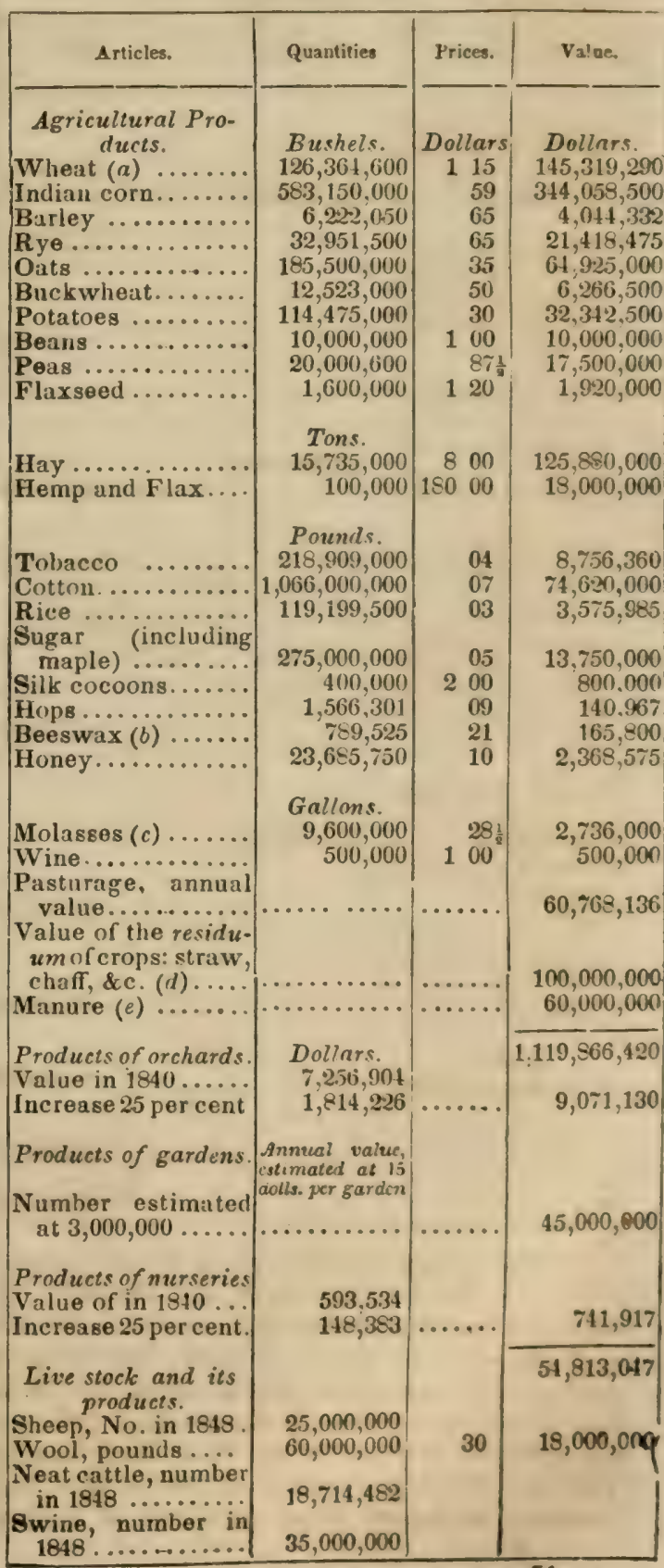


Estimnte-continued.

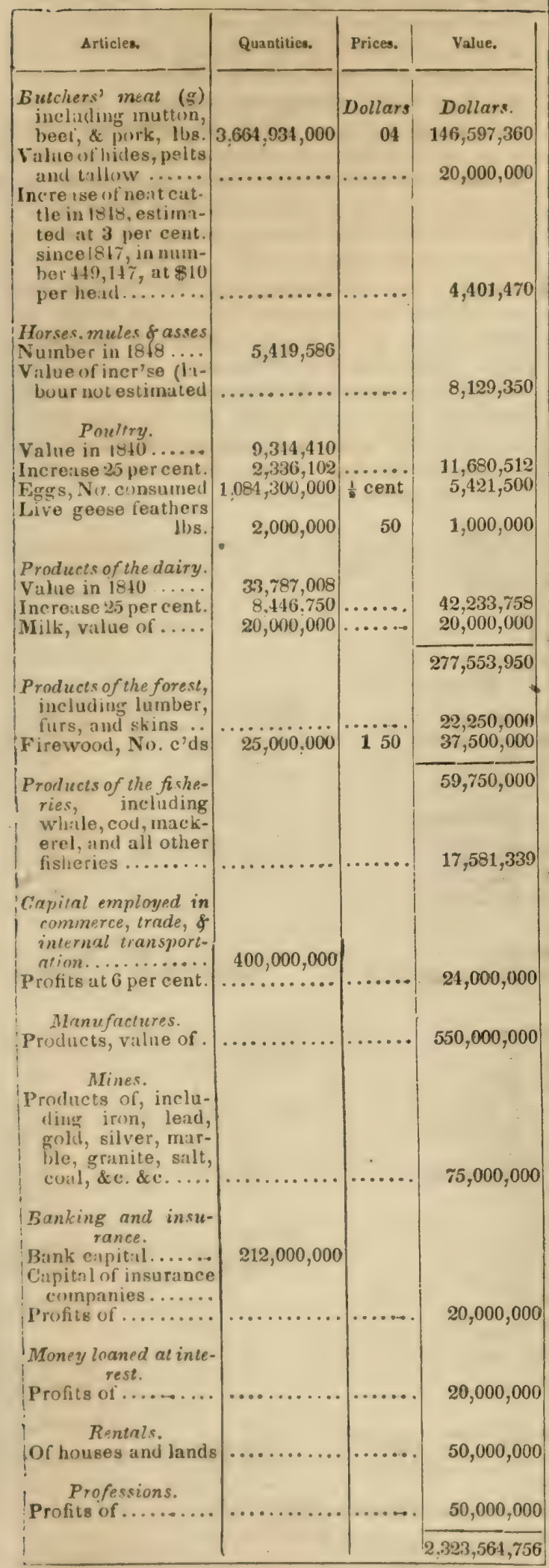

(a) The estimates above given by the Commissioner of Patents, for 1848 , are founded upon the bases furnished in the census returns for 1810 , with the addition of 22 per cent., that being the computed increase of population since that period. The prices are generally the average prices of the different articles in the New York market. The quantities and values of hemp, flax, hops, beeswax, molasses, wine, products of orchards and nurseries; have 25 per cent. allowed for increase, except where later information justifies a departure from this rule.

(b) The census of 1840 contains no returns of horiey. Bevan estimates 30 pounds of honey for each pound of wax produced, and this is taken as the basis of the present estimate.

(c) A little more than 45 gallons of molasses are allowed by authors treating on the subject of sugar-growing and manufacture, for every $1000 \mathrm{lbs}$. of cane sugar.

(d) In France $11 \frac{1}{2}$ per cent. upon the value of the products of the land and forest is allowed for the refuse of crops. From the returns of estimates made by farmers in various parts of the Union in 1848, it appears that many allow 1 ton of straw to 20 bushels of wheat and other small grain produced, and 1 ton of fodder for about 25 bushels of Indian corn. The straw is valued at $\$ 2.50$, and the fodder at $\$ 2$ per ton: very low prices. If to hese be arlded the refuse of the cotton, sugar, rice, and other crops, it will make the total value exceed $\$ 100,000,000$. In England, the annual value of straw alone, used for thatching, \&c., is, estimated at about $\$ 40,000,000$.

(e) The average price of manure in the present estimate is $66_{\frac{2}{3}} \mathrm{cts}$. per cord. The value of the manure produced in England was computed, in 1835, at $329,300,000$ loads, valued at about $\$ 295,000,000$, exclusive of the droppings from grazing stock, equal to about $\frac{1}{3}$ more.

$(g)$ See Food and Ventilation.

[AGRICULTURAL PRODUCTS, ConsUMPrION OF. To one who examines statements of the agricultural products of various kinds every year yielded in such immense quantities, it seems, at first glance, difficult to imagine how these can all be consumed, before fresh crops would glut the markets and do away, for a time, with the labours and profits of the husbandman. It is, however, only necessary for one to inquire into the consumption of the products of the soil constantly going on in some of the most populous countries and cities, to give him courage to persevere in his productive efforts, even with renewed ardour. It has, for example, been estimated that the daily consumption of corn in England and Ireland, is, $1,238,096$ bushels of wheat and barley; besides annually, 100,000 bags of rice, and 450,000,000 lbs. of sugar. The immediate products of the grasses, which, consumed by animals, forms the food of man, constitutes an amount almost inconceivable. In London alone there is annually consumed $155,000,000$ lbs. of butcher's meat. Of cheese, another production of yrass, 11,500 tons are annually. introduced irta Loh don, from Cheshire, about 20,000 tons from Warwickshire, besides that imported from many other countries. Of butter, the annual consumption is about $50,000,000 \mathrm{lbs}$, the produce of 300,000 cows; and in London, between 9 and 10,000 cows are kept for the supply of milk to the inhabitants, which produce annually about 30,000,000 qts. (Johnson's Leetures on Bata'y.)]

AGROSTIS. The bent grass. An extelsive genus of grasses, which, from the marshy soil on which they flourish best, are of comparatively small value to the farmer.

Agrostis alba, or white bent, in Finglana flowers in the first week in Aagust, and the 
need is ripe about the beginning of September. This grass is late, unproductive, and contains but little nutritive matter. Its creeping roots greatly exhaust the soil; in this variety they are smaller than in the other varieties of Agrostis, but equally difficult to extirpate when once in possession of tenacious clays. 'This propesty of the roots is the best character of distinction for the purpose of the agriculturist, as it may be found at any season or stage of growth of the plant.

'The Agrostis canina, var. mutica, Awnless variety of brown bent; Trichodium caninum muticum (Schrader), Creeping-stalked brown bent, is the most common grass on cleep bogs, even where they are subject to be under water for six months in the year. It is a diminutive plant, very unlike the produce of such soils: the leaves seldom attain to more than two or three inches in length. The smallness of the produce, even when cultivated in the most favourable circumstances, affords a sufficient proof of its unworthiness to be regarded by the farmer in any other light than that of a weed which indicates a soil capable of being improved, so as to produce the most valuable grasses by irrigation. It differs but little firom the Agrostis nivea, except in the want of awns and the length of the culms. The structure varies almost imperceptibly in the Agrostis canina, Agrostis niver, and in this species. The like gradual shades of difference may be perceived in the colour of the plants; the canina is of a brownish-green colour; this awnless variety is of a pale green; the nivea of a greenish straw colour. The knots or bundles of leaves attached to the decumbent shoots show it to be connected with the Agrostis canina fuscicularis. It flowers in England the second and third weeks of July, and ripens the seed about the middle of Aligust.

Agrustis canina capillaris. Fine-panicled brown bent. This variety is nearly akin to the Agrostis canina fascicularis, bundle-leaved bent; tufted bent. In old pastures, or light soils, this bent may be readily distinguished in the autumn by its shoots, which are furnished with leaves in tufts or bundles, that generally run along on the surface of the rest of the herbage, and is occasioned, apparently, by the cattle, which eat the other herbage, and leave the scattered shoots of the tufted-leaved bent untouched. It is a very common grass on poor, light, but moist soils, incumbent on clay, that have long been under pasture. This and the woolly soft grass in some parts of England are termed winter fog. From the above details it will appear to be the least valuable of the bent grasses that have been mentioned. The cultivation of a grass of this value is out of the question; the point of most importance to be ascertained respecting it is, how to remove it from the soil, and to substitute more valuable grasses in its place. I have witnessed the beneficial effects of coal ashes, as a top diessing, when spread on the pasture in sufficient quantity. The ashes favour the growth of the superior grasses, and the pasture being in consequence closely cropped by the cattle, which now find the pasture more palarable, the tufted bent disappears; it will, how. ever, be found by no means destroyed, Lus only checked in its growth. This grass flowers in England the first and second weelis of August, and ripens the seed in the end of the same rnonth.

Agrostis lubuta. Lobed bent; sea-side bent. The general appearance of this plant indicates its inferior comparative value. It appears, according to the information afforded by $\mathrm{Mr}$. Curtis, to be chiefly confined to the sea cuasts. It grows wild on a stiff wet, clayey loam, part of the London blue clay, in the parish of Cuddington, near Epsom, Surrey. It does not appear to be of much value to the agriculturish although its nutritive powers are far from being inconsiderable.

Agrustis mexicuna, the Mexican bent grass, is, as its name implies, a native of South America, and was introduced into England, by Mr. Gilbert Alexander, in 1780. It delights more in calcareous or clayey soils than in those that are of a silicious sandy nature. It perfects an abundance of seed, which when sown produces plants that soon arrive at perfection. So far, therefore, it possesses the requisite properties of a grass adapted for the alternate husbandry; but it is late in the produce of foliage in the spring, and that herbage is not distinguished by any superior nutritive powers. It is perfectly haldy. Being a native of a warmer climate, its defects may possibiy be greatly lessened by being naturalized, and by frequently raising it from seed successively ripened in England. At present it does not offer any strong reasons to recommend it further to the notice of the agriculturist. It flowers in the third week of August, and the seed is ripe towards the end of September.

Agrostis nivea. Snowy bent; straw-coloured bent grass.

Agrostis palustris, or marsh bent. This is considered only a variety of the Agrostis stolonifera. This grass is properly a sub-aquatic: it will grow on tenacious clays, but it seems only to thrive in very moist soils, or in such as are for the most part covered with water. In moist woods it is more frequent than any other of the creeping-stemmed bent grasses: here the culms often attain to five feet in height, when supported by bushes. The above details show the inferior nature of this grass compared to the larger, and even to the lesser leaved varieties of the Agrostis stulonifera. It cannot, therefore, as yet be considered in any other light than a weed that chokes up drains and underwoods.

Agrostis ramosissima. Lateral-branching bent grass. This is nearly allied to the Agrostis mexicana, and is one of the latest fluwering grasses. It is remarkable for the number of branches that issue from the joints of the stem; and the woody substance of the culms makes it approach to the nature of a shrub. It affords little herbage till the beginning of summer, and flowers at so late a period of the season (the first or second week in October), that, the frost generally destroys the panicles before the seed is perfected. The herbage is killed by frost, but the roots suffer nothin from its effects; it is propagated by paring and planting the roots early in the spring $\mathrm{nr}$ 
late in the autumn. It is nesther very proluctive nor nutritive.

Agrostis repens. Creeping-rooted bent; white $\rightarrow 1$. The Agrostis nigru, or black couch uss of Withering. Though a later growing rass, it is less productive than the Agrostis alba. $I$ : is subject to the rust, a peculiar disease which dries up the extremities of the leaves and gives it an unsightly appearance. Simple ploughing will be found ineffectual to root out this weed in clayey soils. It will be found ultimately the cheapest and most expeditious mode of extirpating it to follow the plough and tork ont the roots. Burning, under such circumstances of soil, would doubtless be highly beneficial, but the roots of this couch grass penetrate so deep that a considerable part of them would escape; and the least particle of the root soon produces a plant. It flowers in England the second week of August, and the seed is ripe about the latter end of September.

Agroxtis stolonifera aristuta. Awned-creeping bent. 'This variety of creeping bent, which is allied to the Agrostis Canina or awned var. Agr. vulgaris of Dr. Smith, is greatly inferior to the larger-leaved variety (Agrostis stolonifera latifoliu, or fiorin); for the weight of nutritive matter per acre afforded by the lutifolia is twothirds greater than that of the awned variety. Cattle appear to eat this grass in common with the rough-stalked meadow-grass and meadow fox-tail grass. It flowers about a week later than the fiorin, but the seed is ripe about the same time.

Agrostis stolınifera angustifolia. Smallerleaved creeping bent. This is the most common variety of the creeping bent, on damp, tenaceous, clayey soils, and in moist woods. It stands next in value to the longer-leaved variety of creeping bent; but appears from all the observations that have been made on it, when growing in natural pastures, to be entirely neglected by cattle, while any of the superior pasture grasses presented a sufficiency for a bite. It flowers in the second and third weeks of July, and ripens the seed about the end of August.

Agrostis stolunifera (var. 1 latifolia). Longerleaved creeping bent; fiorin. [See Plate 5, n. Hay Grasses.]

The Rev. Dr. Wm. Richardson has introdiced this variety of the Aurostis stolonifera to the agricultural world, under the name of Fiorin, and has shown its merits and properties, deduced from his own experiments, in a variety of publications on the subject, to which the reader is referred. It is greatly superior in point of produce and nutritive powers to the ther varieties of Ayros/is stolonifera.

On comparing the specimens of these different varieties, their resemblance to each other is so great, that they may be easily mistaken for each other, without a close inspection, and sume knowledge of botany to assist it. This variety appears to be confined to rich ancient pasture land, as its natural place of growth, and the other varieties to various soils and situations; and that when taken from these tifferent soils, and cultivated together under the same circumstances, they retain their diseruminating characters. On damp, clayey soils, the second variety (smaller-leaved, creeping bent) is the most common. To moors and bog soils, the third variety (awned creeping bent grass) is chiefly or altogether confined. To light sandy soils, particularly when more or less shaded, the fourth variety (wood creep. ing bent grass) is peculiar; and the fifth variety (marsh creeping bent grass) is seldom found but in the bottoms of ditches, or by the side of rivulets. 'The first variety being therefore scarce, and the others very common, there is little room for surprise at the contradictory results of experiments that have been made, on one or other of these inferior varieties, by gentlemen equally eminent for agricultural knowledge under the conviction of their being one and the same grass as recommended by Dr. Richardson under the name of fiorin: whereas, though they agree in the general habit of Dr. Richardson's variety, and indeed in every respect except in the characters before described, their inferiority in every agricultural merit is so great, as to justify the opprobrious epithets that have been bestowed upon them, by those who, from the above causes have differed from Dr. Richardson's statements of the merits of the first variety of fiorin, and prevented that justice being done to the discovery which it may have deserved.

The above details will assist the farmer in deciding on the comparative merits of this grass as a constituent of a mixture of grasses for permanent pasture; from which it will doubtless appear worthy of attention, but its value not so great as has been supposed, if its habits or manner of growth be impartially taken into the account, when compared with the produce and nutritive powers of the other grasses. The chief advantage of this grass, in permanent pasture, is its late growth. It remains in a degree inactive, till other grasses have attained to perfection, and when their productive powers become exhausted, those of fiorin and its varieties begin; and it will be found, on inspection, that the latest mouthful of herbage, and sometimes the earliest, in those pastures, is principally afforded by this grass.

There has been much prejudice existing against the different species of Agrostis in general; but let the proprietor of a rich ancient pasture divest a part of it of this grass entirely, and the value of the plant will be demonstrated in the comparative loss of late and early herbage. The cock's foot grass is superior to the larger variety of the creeping bent, in the proportion nearly of 11 to 9 . The meadow fescue is also superior to fiorin in nearly the like proportion as cock's foot. The meadow fox-tail grass is inferior to fiorin in the proportion nearly of 6 to 7 . When cultivated separately, for the purpose of green food or hay, fiorin requires to be kept perfectly clear of weeds, its couchant habit of growth affording great encouragement for the health of upright growing plantsunder this circumstance, weeds. It flowers in England about the second and third weeks of July, and the seed is ripe about the second and third weeks of August. The mode of convert. ing fiorin into hay, during the winter months, is amply detailed in Dr. Richardson's publications on Fiorin. Full information will there 
be likewse found on the productive powers, uses, modes of cultivation, \&c., of this grass, deduced from the Doctor's own experiments.

Agrostis strictu. Rock bent; upright bent. Trichodiu in rupestre (Schrader). This species being inferior to the common bent in most points, its value to the agriculturist can be but little. 'The only property that renders it worthy of notice is, the small degree in which it impoverishes the soil : when cultivated on a poor, silicious, sandy soil, the produce, though somewhat inferior, continued for six years, without diminishing in the yearly quantity, and without any manure being applied; a circumstance which was not manifested in any other species of grass.

Agrostis vulgaris canina. Awned fine bent. (Brown bent, or Agrostis canina, Wither. Arr. Smith's Engl. Flora. Agrostis vulgaris var. f. Do. var. 1.) $\Lambda \mathrm{s}$ this is a much less common plant than the variety of Agrostis vulgaris before described, and as it differs so much from that variety in the properties which constitute the farmer's distinguishing characters of grasses, the name canina is here added. The vulgaris mutica is more common to sandy soils; the $v$. canina to clayey soils. The weight of nutritive matter in which the produce of one acre of the awnless variety of Agrostis vulgaris canina exceeds that of the awned variety is 151.8. The comparative merits of the Agrustis vulyaris exceed those of the Agrostis vulgaris canina nearly as 2 to 1 . The crop of the awnless variety is greater than that of the awned, but it is much less nutritive, being as 10 to 7 ; the spring and autumn produce is likewise superior. Neither of these varieties appears to be of much value to the farmer. The rust attacks the culms and leaves of both varieties which gives the plants a dirty brown appearance; the Agrostis vulsuris is always free from this disease. The brown berat flowers in the second and third weeks of Juls, and ripens the seed in the end of August.

Agrustis vulgaris muticu. Common bent; fiue bent grass. [See Plate $6, d$, of Hay Grasses.] This species has four varieties, according to Dr. Schrader. 'The first is distinguished by being awned (see Agrostis vulgaris curinu, and Trichodium caninum); the second by awnless and diseased flowers (see Agrostis pumilu of Willd. Spec. Plant. i. p. 371); the third by its diseased awned flowers; the fourth, by having the flowers viviparous, Agrostis sylvalica.

The common bent is one of the earliest of the bent grasses; in this respect it is superior to every other of this family; but inferior to several of them in the quantity of produce it affords, and the nutritive matter it consumes. It is the most common grass on natural sandy pastures; and even on more tenaceous soils, that are elevated and exposed, it is frequent. It flowers from the third week of June till the second week of July, and the seed is ripe the beginning of August.

The following tabulai arrangement shows at a glance the proportional value of the several varieties of Agrostis, in seed and in flower, and their yield per acre of green and dry frorduce on various soils, and comparative qualities of nutrition.

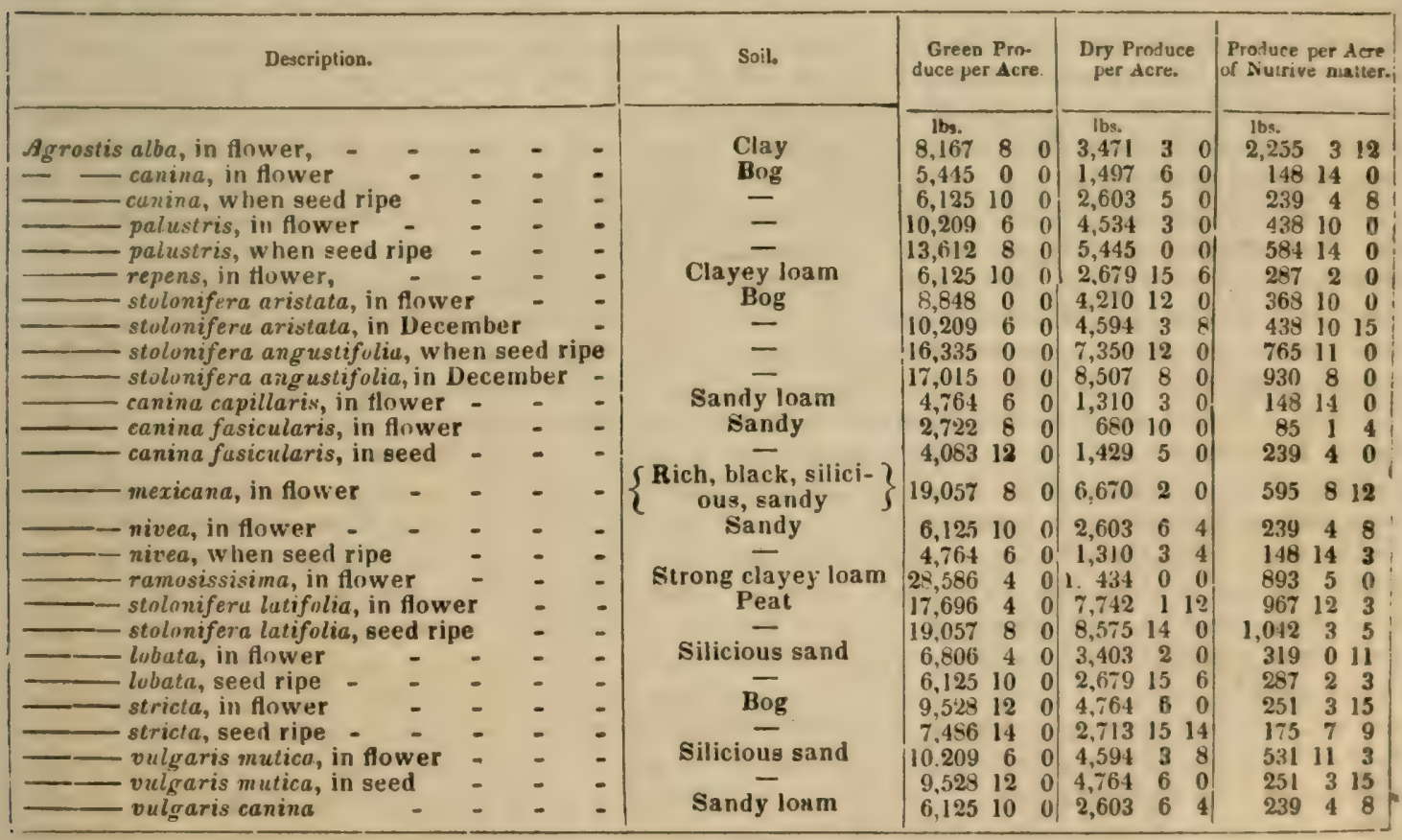

This family of grasses has been held in little esteem by farmers, principally on account of their lateness of flowering. (Sincluir's Hort. Gram.; S'mith's Eng. Bot.)

[Several of the species thus enumerated, as existing in England, have found their way to America, doubtless introduced mixed in grain and grass seeds. They are, however, so dry and wiry as to be esteemed of little or no value to the farmer, Among these are, the - A. vulgaris, which Pursh, the celebrated botanist, says, is common in all grassy field.., flowering in July. This is doubtless the species which gives name to the genera, de rived from Agros, a Greek word signifying a field. Dr. Darlington says it is the grass ex tensively known in the Middle States as Herds or Red-lup, and scmetimes in the Eastern States 
called Foul Meudow Grass. The last name being evidently derived from the great difficulty with which it is eradicated when it has once obtained a footing. 'The grass called white-top, appears to be a variety of Herds. There seems to be considerable obscurity and confusion in the descriptions given of this grass. The common characteristics of the plant, as seen in the meadows of Pennsylvania, Dr. Darlington says, resemble those of the $A$. alba, the White or Yellow 'Tops of the Eastern States. It affords a tolerably good pasture for cattle, and is valuable in swampy grounds, which its roots tend to consolidate; but it is not much esteemed for hay, and is now seldom, if ever, an object of special cultivation in the Middle States. The Pennsylvania farmers are so opposed to having Herds grass rooted in their fields and meadows that they reject clover and every other grass seed in which the least Herds appears. Among the species found in the United States, are the following-

A. pungens, or Virginian Agrostis, frequenting dry, sandy banks, and road-sides, flowering in the southern part of Pennsylvania, in August. This species differs much, in habit, from most others.

A. cinna, common on rivers and islands below tide-water, from Canada to the Carolinas, Rowering in June, \&c.

A. juncert, found in barren, sandy places, from New Jersey to Florida; flowering from July to August.

1. laterifulia, found in rich soil on the edges of woods from New York to Florida, especially in the western countries, where it appears to be of more value. In the southern parts of Pennsylvania it affords an indifferent pasture in the latter part of summer, but is not regarded as of much consequence, which may indeed be said of most, if not all, of the American species of agrostis.

The late Judge Peters introduced the fiorin into Philadelphia county, in 1812 , by importing a quantity of the strings or layers from which it is always propagated in Ireland. For some reason its cultivation has not been kept up, and at present it is difficult to be found in America. When once it has obtained a footing in a suitable soil, it is scarcely to be eradicated, for which reason it is not adapted to the alternate system of husbandry.]

AIR (Air, French, aër, Lat). 'The element or thin medium in which terrestrial animals move and breathe, and which surrounds the earth to a considerable height. See ArmoSPHERE and GASES.

AIRA. A genus of grasses, of which there are but few species capable of being cultivated to advantage as field grasses.

Aira aquuticr. Water hair-grass. This plant is an aquatic, found naturally growing in the mul of standing pools, or running waters in England. It is, therefore, unfit for cultivation. $\mathrm{Mr}$. Curtis says, that it is the sweetest of the British grasses; but there are several species which contain more sugar, in proportion to the other ingredients which compose their nutritive matter, as the Glyceria fluitans, Elymus arenarius. Pou nemoralis var. angustifolia, Poa "requatice
Aira cxpitosa. Turfy hair-grass; hassuck grass. [See Plate 6. of Pasture Grasses, m.] This grass is of a very innutritious nature; but even if it had greater nutritive powers, the extreme coarseness of the foliage would render it unfit for cultivation. It delights in moist clayey soils, where the water stagnates; but is found in almost every kind of soil, from the dry sandy heath to the bog. It forms dense tufts in pastures very disagreeable to the sight, which are termed hassocks, bull's faces, \&c. by farmers. It is a most difficult plant to extirpate, when in considerable quantity. Some persous, to get rid of it, dig up the tufts, and fill up the holes with lime compost; this, no doubt, would answer the end, at least for a few years, if all the roots were destroyed; but this is never the case: a circle of roots is left, which, in one or two seasons, produce larger hassocks than before; and besides, when the hassocks are numerous, the expense attending this process is considerable. Others depend on occasional mowings to keep the hassocks under; but this is productive of little good particularly if the mowing of the tufts be deferred till the autumn, which I believe is the common practice. I have found no treatment weaken or retard the growth of grass so much as cutting it closely, before and after the first tender shoots appear in the spring. But the only effectual and most profitable mode of extirpating this grass is by first paring and burning the surface of the land, and by making proper drains, to correct, as much as possible, the tenacious nature of the soil; in this case surface-drains are as necessary as those termed hollow. Sand should likewise be applied during the course of crops taken previous to returning the land again to permanent pasture, if such should be desirable, from its local situation; as that, for instance, of a park or policy. 'This grass flowers about the third week in July, and the seed is ripe towards the end of August.

Aira cristata. Crested hair-grass. Poa crislata. Crested meadow-grass. Hnst. ii. p. 54, t. 75. This native grass was formerly ranked by botanists under the genus $P u a$, but has since been referred to that of Aira, to which it is more closely allied. 'The produce of this species, and the nutritive matter it affords, are equal to those of the Festuca ovina at the time the seed is ripe; they equally delight in dry soils, though the Aira cristata will thrive well and remain permanent in soils of a moist and clayey nature. which is different from the Festuca ovina. The greater bulk of the produce of the Aira cristala, in proportion to its weight makes it of inferior value to the Festuca ovina. In some parts of the country it grows on dry pastures plentifully, where it appears to be but sparingly eaten by cattle, particularly if the pasture be not overstocked. Rye-grass (Lolium perenne), sheep's fescue (Festuca ovina), yellow oat-grass (Avena flavescens), crested dog's tail (Cynosurus cristatus), meadow barley (Hordeum pratense), flexuose hair-grass (Aira flexuosa), are all preferred by cattle to the crested hair-grass. The nutririve matter of this grass differs but little in its composition from those of the above: it approaches nearest 


\section{AIRING.}

to that of the Aira ficxuosa, differing only in having less bitter extractive matter and of more tasteless mucilage; but the soft hairy foliage of the grass appears at once the cause of this dislike in cattle to eat it. It flowers about the first week in July, and the seed is ripe about the beginning of August.

Aira flexuosa. Zig-zag hair-grass; wavy mountain hair-grass. The Aira flexuosa is much more productive on its natural soil than the Fes/uca ovina; but it requires a deeper soil though not a richer. The Festuce ovina is unore common among heath, the Aira flexunsa among furze, though both grasses frequently grow intermixed on the same soil. To those who attempt the improvement of such soils in a secondary manner only, this species of bair grass appears (o) be the best of thrse grassee natural to the soils in question, and may form a principal part of a mixture of seeds for that purpose of improvement. The produce of this grass on a heath soil is superior to that on a clayey loam in the proportion of 2 to 1. The proportional value in which the crrass at the time of flowering exceeds that of the litter. math, is as 8 to 7 . Flowers in the first weet of July. Seed ripens in August.

In England the proportionate value of the different varieties of Aira as deduced from experiments may be ascertained by reference to the following classified table of results:

\begin{tabular}{|c|c|c|c|c|c|c|c|c|c|c|c|c|}
\hline \multicolumn{3}{|l|}{ Description. } & \multirow[t]{2}{*}{ Soil. } & \multicolumn{3}{|c|}{$\begin{array}{l}\text { Green Produce } \\
\text { per Acre. }\end{array}$} & \multicolumn{3}{|c|}{$\begin{array}{l}\text { Dry Produce } \\
\text { per Acre. }\end{array}$} & \multicolumn{3}{|c|}{$\begin{array}{c}\text { I'moduce per Acie } \\
\text { of Nutritive } \\
\text { Malter. }\end{array}$} \\
\hline & & & & lbs. & & & lbs. & & & Its.s. & & \\
\hline Sira aqualica, in flower & - & - & $\left\{\begin{array}{c}\text { Mud covered with } \\
\text { water }\end{array}\right\}$ & 10,890 & 0 & 0 & 3,267 & 0 & 0 & 382 & 13 & 10 \\
\hline - caspitnsa, seed ripe & - & - & Clay & 10,209 & 0 & 0 & 3,318 & 0 & 0 & 319 & 0 & 11 \\
\hline - crisiala, in flower & - & - & Sandy loam & 10,890 & 0 & 0 & 4,900 & 8 & 0 & 340 & 5 & 0 \\
\hline - crislala, seed ripe & - & - & - & 6,806 & 4 & 0 & 3,403 & 2 & 0 & 127 & 10 & 0 \\
\hline — flexusa, in flower & - & - & Heath on clay & 10,209 & 6 & 0 & 3,318 & 0 & 12 & 319 & 0 & 11 \\
\hline - flexussa, seed ripe & - & - & - & 9,528 & 12 & 0 & 3,573 & 4 & 8 & 297 & 12 & 6 \\
\hline
\end{tabular}

(Sinclair's Hort. Gram. Wob.)

AIRING. In the management of horses, implies the exercising them in the open air, which is of the greatest advantage to them when performed with moderation, and according to the circumstances or state in which they are in respect to their health and the nature of their keep. By this means their legs are prevented from swelling, their stomachs improved, and their wind rendered more free and perfect.

AIR VESSELS, of vegetables, are certain horizontal vessels of large diameter, that pass through the bark of trees to the alburnum, [or white internal bark.] These horizontal vessels Dr. Darwin supposes to contain air, enclosed in a thin moist membrane, which may serve the purpose of oxygenating the fluid in the extrernities of some fine arteries of the embryo buds, in the same manner as the air at the broad end of the egg is believed to oxygenate the fluids in the terminations of the placental vessels of the embryo chicken.

ALBUMEN is the name given by chemists to the impure glossy viscid liquid, which forms the white of an egg. This white is composed chiefly of albumen mixed with some mucus, soda, and sulphur

Albumen unites readily with water, and when heated to $165^{\circ}$ it coagulates into a white solid mass; but when mixed with ten times its weight of water, it no longer is coagulated by heat. It is composed, according to the analysis of MM. Gay Lussac and Thénard, of

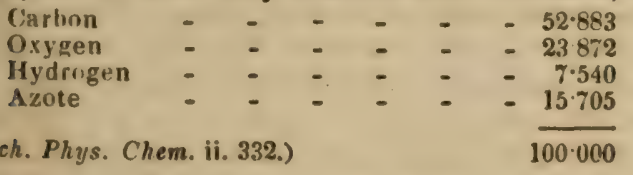

Albumen (which is nearly identical in composition with the gluten ol vegetables), is one of the most important and common of all the animal substances. It abounds in bones, mus- cle, the membrane of shells, sponges, dic.; and, according to the experiments of Hatchett, cartilage, nails, horns, hair, \&c., are almost entirely composed of it. (Thorrsun, vol. iv. p. 407.)

ALBURNUM. An integument composed of a soft white substance, scarcely perceptible in some sorts of trees, situated between the liber and the wood. In the oak and elm it is hard and very conspicuous. It is as it were an imperfect wood, not having acquired that state of consistence necessary to perfect wood; hence it may be compared to the cartilage in animals, which at length becomes bone. This state must necessarily be passed through before wood can be formed. The hardness of this substance is in proportion to the vigour of the plant or tree.

The vessels of the alburnum in their living state possess the property of conveying the sap-juice, which is propelled upwards in the early spring, by the absorbent terminations of the roots, as visible in decorticated oaks, the branches of which expand their buds like those of the birch and vine in the bleeding season. That the vessels of the alburnum in their living state occasionally act as capillary syphons, through which the sap-juice is first pushed upwards by the absorbent extremities of the roots, and afterwards returns downwards, partly by its gravitation, in branches bent below the horizon, appears from an experiment of Dr. Walker; and lastly, that the vessels of the alburnum, after their vegetable life is extinct, possess a power of capillary attraction of the sap-juice, or of permittin- it to pass through them occasionally, appears from the following experiment:- $A$ branch of a young apple-tree was so cankered, that the bark for about an inch round it was totally destroyed. To prevent the alburnum from becoming too dry by exnatation, this deraged 
part was covered with thick white paint: in a few days the painting was repeated, and this three or four times, so as to produce a thick coat of paint over the decayed part, or naked alburnum, extending to the ascending and descending lips of the wound; this was in spring, and the branch blossomed and ripened several apples.

ALCOHOL is the name first given by the alchemists (it came originally from Arabia) to the liquid obtained by the distillation of wine, beer, and other fermented spirits. These seem to have been known in the earliest ages: Noah, who planted a vineyard, drank wine; and the heathen writers deemed the invention worthy of being ascribed to their greatest kings and heroes. Beer, there is little doubt, was invented by the Egyptians. They certainly used it in the days of Herodotus. The Germans drank it extensively when Tacitus wrote. These were probably the purest varieties of alcohol then generally made; although they were known in the dark ages, and it is probable have been employed in the North of Europe from a very remote period. The process, however, of separating the impure alcohol from these is very easy: upon subjecting the wine or wash to a moderate heat, the spirit arises, and is easily collected in a worm surrounded by cool water. It is in this way that gin is procured from the distillation of fermented barley or other grain; rum from molasses; brandy from wine. It must not be supposed, however, that the product of these distillations is pure alcohol, for even the strongest brandy contains between forty and fifty per cent. of water. The first who procured alcohol in a state of tolerable purity is supposed to have been Arnold of Villa Nova, a celebrated alchernist of the fourteenth century. When impure alcohol is concentrated by repeated distillations, and by mixing it with sorne salt, like the salt of tartar, that has a strong attraction for water, it gradually parts with a considerable portion of its water, and becomes reduced in specific gravity to about 0.820 ; that of commerce, however, is rarely of less specific gravity than 0.8371 . At the greatest strength, however, at which it has been observed, such as that of 0.792 , which M. Lowitz obtained by repeatedly distilling rectified spirits from potash, it possesses the following properties:-it is transparent, colourless, of a strong agreeable penetrating taste, and produces when swallowed intoxication. It does not freeze, even by exposure to the most intense cold; it is very volatile, boiling at $176^{\circ}$ of Fahreaheit, and in a vacuum at $56^{\circ}$. It unites with water in all proportions, and is entirely combustible, burning without lcaving any residuum. Alcohol, according to the analysis of M. Saussure, is composed of

\begin{tabular}{|c|c|c|c|c|c|c|c|}
\hline Hydrogen & - & - & - & - & - & - & $13 \cdot 70$ \\
\hline Carhnn & - & - & - & - & - & - & $51 \cdot 98$ \\
\hline Oxyzen & - & - & - & - & - & - & $34 \cdot 32$ \\
\hline
\end{tabular}

The following table will show the ordinary proportirn of alcohol per cent. by measure in various fluids, according to the experiments of Professor Brande.

58

\begin{tabular}{|c|c|c|c|c|c|c|c|}
\hline Port & - & - & - & - & - & - & $21 \cdot 40$ \\
\hline Ditto & - & - & - & - & - & - & - 25.83 \\
\hline Madeira & - & - & - & - & - & & -19.34 \\
\hline Ditto & - & - & - & - & - & - & - $24 \cdot 42$ \\
\hline Sherry & - & - & - & - & - & - & - $18 \cdot 25$ \\
\hline Ditto & - & - & - & - & - & - & - $19 \cdot 83$ \\
\hline Claret & - & - & - & - & - & - & -12.91 \\
\hline Calcavell & a & - & - & - & - & - & $-\quad 18 \cdot 10$ \\
\hline lisbon & - & - & - & - & - & - & - 18.94 \\
\hline Malaga & - & - & - & - & - & - & $-17 \cdot 26$ \\
\hline Bucellas & - & - & - & - & - & 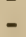 & - 18.49 \\
\hline Red Made & & - & - & - & - & - & -18.40 \\
\hline Malmsy & Madej & & - & - & - & - & -16.40 \\
\hline Marsala & - & - & - & - & - & - & -2587 \\
\hline Ditto & - & - & - & - & - & - & $-17 \cdot 26$ \\
\hline Red Chan & npagr & & - & - & - & - & $-11 \cdot 30$ \\
\hline White $\mathrm{Ch}$ & lampa & agne & - & - & - & - & -12.80 \\
\hline Burgundy & & - & - & - & - & - & -14.53 \\
\hline Ditto & - & - & - & - & - & - & $-11 \cdot 95$ \\
\hline White $\mathbf{H}$ & ermit & & - & - & - & - & $-17 \cdot 43$ \\
\hline Red Hern & nitage & & - & - & - & - & - 1232 \\
\hline Hock & - & - & - & - & - & - & $-14 \cdot 37$ \\
\hline Ditto & - & - & - & & - & - & 8.88 \\
\hline Vin de $\mathbf{G}$ & rave & - & - & & - & _ & $-\quad 12.80$ \\
\hline Frontigna & & - & - & & - & - & - 12.79 \\
\hline Coti-Roti & & - & - & & - & - & - 12.32 \\
\hline Roussillo & & - & - & - & - & - & - $17 \cdot 26$ \\
\hline Cape Ma & deira & - & - & - & - & - & $-18 \cdot 11$ \\
\hline Cape Mus & schat & - & - & - & - & - & - 18.25 \\
\hline Constant & & - & - & & - & 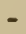 & $-\quad 17.75$ \\
\hline Tent & - & - & - & $=$ & - & - & $-13 \cdot 30$ \\
\hline Sheraz & - & - & - & - & - & - & $-15 \cdot 52$ \\
\hline Syracuse & - & - & - & & - & 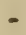 & $-\quad 15.28$ \\
\hline Nice & - & - & - & - & - & - & -14.63 \\
\hline Tokay & - & - & - & - & - & - & 9.88 \\
\hline Raisin & - & - & - & & - & - & $-25 \cdot 77$ \\
\hline Grape & - & - & - & & - & - & - 18.11 \\
\hline Currant & - & - & - & & - & - & -20.55 \\
\hline Gonseber & & - & - & & - & - & -11.84 \\
\hline Elder & - & - & - & - & - & - & $-\quad 9.87$ \\
\hline Cider & - & - & - & - & - & - & 9.87 \\
\hline Perry & - & - & - & & - & - & 987 \\
\hline Brown S & tout & - & _ & & 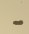 & & 6.80 \\
\hline Ale - & - & - & - & & - & - & $8 \cdot 88$ \\
\hline Brandy & - & - & - & & - & - & $-\quad 53.39$ \\
\hline $\mathrm{R}$ if $\mathrm{m}$ & & - & 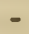 & & 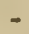 & . & - $\quad 53.68$ \\
\hline Hollands & or $\mathrm{Gi}$ & & - & - & - & - & $-51 \cdot 60$ \\
\hline
\end{tabular}

The spirits distilled from different fermented liquors, says Davy, differ in their flavour, for peculiar odorous matters or oils rise in most cases with the alcohol. The spirit from malt usually has an empyreumatic taste, like that of oil formed by the distillation of vegetable substances. The best brandies seem to owe their flavour to a peculiar oily matter, formed probably by the action of tartaric acid upon alcohol; and rum derives its characteristic taste from a principle in the sugar cane. 'The cogniac brandies contain prussic acid. (Davy, Chem. Phil. 135.)

ALCOVE (Span. alcoba; Dan. alkove; but originally from the Arab. alkibba). A recess in gardens or pleasure-grounds.

ALDER TREE (Alnus glutinosa, Gxrtner; Betula Alnus, Linn.). The common Alder [of England] appears generally as a shrub; but if allowed to attain maturity it will grow to a stately tree. The bark in old trees is blackish, and full of clefts; on the young shoots it is smooth, and of a purplish hue. The leaves have a dark green colour, and roundish shape, resembling those of the hazel, niclied on the margin, smooth, and clammy to the touch. The foot-stalk is about an inch long; the leaf ribs on the under side have spongy balls at the angles, as in the leaves of the lime tree. The male catkins are cylindrical, appear in autumn, and remain on the tree till spring. The female catkins are of a short conical fonn, like a small fir cone.

[In England] the alder is often planted as a coppice-wood in wet and boggy places where no other trees will thrive, and cut down every 


\section{AI.DER TREE.}

tenth or twelfth year for poles. It may also be often used to advantage on swampy ground for fences, and may be conveniently trained to any desired height. 'The young trees may be planted to great advantage for securing the banks of water-courses from the torrents. We certainly know of no tree so well adapted to this purpose as the alder; for, on account of the numerous suckers which it constantly sends up from the bottom, and the very fibrous nature of their roots, the banks become in time one mass of strongly interwoven roots.

Wherever it may be desirable to complete a prospect by extending plantations over sterile cold ground, water-galls, or boggy swamps, no Iree we know of is equal to the alder, even in a picturesque point of view.

The generality of trees acquire picturesque beauty by age. Some of the largest alders to be seen in England are growing in the Bishop of Durham's park at Bishop-Auckland, and some very fine ones are to be found in his Grace the Duke of Northumberland's grounds at Sion House. Mr. Beevor mentions an alder in his garden, which, at four feet from the ground, measured upwards of sixteen feet in circumference.

Sir Thomas Dick Lauder says, "In very many instances we have seen the alder put on so much of the bold resolute character of the oak, that it might have been mistaken for that tree except for the intense depth of its green colour.

The wood of the alder is used [in Europe] for making charcoal and heating ovens, and is valuable for piles, pumps, sluices, and in general for all works under water; "because," says Pliny, "it will endure for many years." It is said to have been used under the Rialto at Venicc; and we are told that the morasses about Ravenna were piled with it in order to lay foundations for building upon. In Flanders and Holland it is raised in great quantities for this purpose. It serves also many domestic and rural uses, such as for cart-wheels, spinning wheels, milk-vessels, bowls, spoons, and other turnery ware, troughs, handles of tools, clogs, pattens, and wooden heels. The roots and knots furnish a beautiful veined wood for cabinets. The Scottish Highlanders often made chairs of it, which are very handsome, and of the colour of mahogany.

Sir Thomas Dick Lauder tells us that the old trees, which are full of knots, cut up into planks, make very handsome tables. "We have seen some of these," says the baronet, "made from some enormous trees that grew at Dalwick, on the property of Sir John Nasmyth, in Peebleshire; and no foreign wood we have ever seen can match them for beauty."

The bark, though nearly superseded by logwood, is used by dyers, tanners, and leatherdressers; and also by fishermen for dyeing their nets. Both the bark and young shoots dye yellow, and with a little copperas, a yellowish grey, very useful in the demitints and shadows of flesh colour in tapestry. The shoots cut in March will dye a cinnamon colour; and a fine tawnv, if they be dried and powdered. The fresh wood yields a dye the colour of rappee snuff. The catkins dye green,

\section{ALDER TREE.}

and the bark is used as a basis for black. The bark and leaves have been sometimesemployed in tanning leather, the whole tree being very astringent.

The alder delights in a very moist soil, where few other trees will thrive:-

"The Alder, owner of each waterish soil."

F'uirfux's T'useo

It is also an old opinion that it does not in. jure grass, but rather nourishes its growth:-

"The Alder, whose fat shadow nourisheth;

Each plant set neere to him long flourisheth."

W. Browne.

Marshall is of a very different opinion. "In low swampy situations," he says, "where the ground cannot be drained but at ton great ar expense, the alder may be planted with pro priety and advantage; but wherever the soil is or can be made pasturable, the alder should by no means be allowed to gain a footing. Its suckers and seedlings poison the herbage; and it is a fact well known to the observant hus. bandman, that the roots of the alder have a peculiar property of rendering the soil they grow in more moist and rotten than it would be if not occupied by this aqueous plant Plantations of alders should therefore be confined to swampy, low, unpasturable places; except when they are made for the purpose of ornament; and in this case the native species ought to give place to its more ornamental varieties, of which Hanbury makes five, namely, the log-leaved alder, the white alder, the black alder, the hoary-leaved alder, and the dwarf alder." (On Plunting, ii. 37.) The cutleaved is a pretty variety.

It is propagated by layers, cuttings, or truncheons, about three feet in length. Such truncheons are often employed for securing the banks of rivers, either by planting them very close, or crosswise. For general pur. poses, however, we approve of raising the young trees by layers.

The distance at which these trees should be placed, if intended for a coppice, is a yard square; and at the expiration of seven years, when they may be felled for poles, every other stool may be taken away; and if the small lateral shoots be taken off in the spring, it will very much strengthen the upright poles, provided a few small shoots be left at certain distances upon the trunk, to detain the sap for the increase of its bulk.

The alder may be raised from seeds sown in beds in the same way as is usual for birch, but propagation by truncheons or layers is the most speedy process for obtaining young plants.

The best time for planting alder truncheon: is in February or March. They should be about three feet in length, sharpened at one end, and the ground loosened with an instru. ment before they are thrust into it, lest $\because$ the stiffness of the soil the bark should be torn nff, which may prevent their growing. They should be put into the earth about two feet, to prevent their being blown out of the ground by strong winds. After they have made stout shoots, the plantations should be cleared from all such weeds as grow tall, otherwise they will over. bear the young shoots; but when they hav 
made gond heads, they will keep down the weeds, and will require no further care.

If they be raised by laying down the branches, it must be performed in October; and by the October following, they will have taken root sufficiently to be transplanted out; which must be done by digring a hole, and loosening the earth in the place where each plant is to stand, planting the young trees at least a fort and a half deep, cutting off the top to about nine inches above the surface, which will occasion them to shoot out many branches.

Mr. South, in the sixth volume of the Letters and Papers of the Buth and West of Englund Sociely, has stated, that, on planting a wagonload of truncheons in such situations as have been described above, they all appeared to succeed by throwing out strong shoots the first summer, but that the year following they all died, not having struck a single root. Concluding that this did not depend on any defect in the soil, he planted it again with smallrooted slips, taken from old stubs, few of which failed, most of them having been since repeatedly cut for brush-wood, poles, and other purposes; and of those planted single, he observes, one has formed a conical top of great beauty, and that its bole is three feet seven inches in circumference midway between the branches and the ground. From this statement it would seem, that the best mode of securing the growth of those trees is the planting of the rooted slips, which can be easily done, as great juanitios of young shoots are annually throws un, fi.)m about the roots of this sort of irees.

Where there are plantations, or much of this sort of wood on a farm, Arthur Young advises that it should be cut when the bark will peel, and be immediately soaked in a pond for two months, as by this means the wood is so much hardened as to be greatly improved in its quality.

[Among the species of alder found in the United States Michaux describes only two species, the Almus serruluta, or Common Alder, abounding in the Northern, Middle, and Western States on the borders of streams and especially in places covered with stagnant water. Its ordinary size is eight or ten feet in height, seldom attaining more than two inches in the diameter of its stem. It blooms in January, the sexes being separate on the same stock. The barren flowers resembling those of the birch. The common alder is too small to be applicable to any use in the arts, and from its inferiority of size, it will probably one day give place to the European Alder.

The Alnus Glaucr, or Black Alder, is one of the most beautiful species of the genus. It is unknown in the Southern, rare in the Middle States, and in the North-eastern States, where it is more frequently found, much less multiplied than the common alder. It grows a third taller than the latter species, attaining sometimes eighteen or twenty feet in height and eight juches in diameter. Its leaves are similar in shape, nut a third larger. The bark of the trunk and of the secondary branches is smooth, glcossy, and of a deep brown colour sprinkled with white. It is employed by hatters for dying black. (Nirth American Sylva.)]

ALDERNEY COWS. This admired breed of cows is in general fine-boned, but small and ill-made, and of a light red or yellowish colour. Cows of this breed are most frequently met with in England about the seats of the opulent, from their milk, though smaller in quantity, being more rich in quality than that of most other kinds, and yielding from the same measure a larger proportion of cream and butter, which is of a beautiful yellow colour and fine flavour. They are much inclined to fatten, and their beef has a very fine grain, and is well tasted, but rather more yellow or high-coloured than that of other sorts.

Mr. Lawrence in his general treatise on cattle, however, supposes, "that the cattle of the islands on the French coast are collectively known by the name of Alderney;" and that "these are a variety of, and smaller than, the Norman; light red, yellow, dun, and fawncoloured; short, wild-horned, deer-necked, with a general resemblance to that animal; thin, hard, and small-boned; irregular, often very awkwardly shaped." But he considers this description to refer chiefly to the cows. He thinks "they are amongst the best milkers in the world as to quality, and in that respect are either before or immediately next to the long horn, but that in weight of butter for inches they are far superior to all. He has been assured by a respectable friend, that "an Alderney strayed cow during the three weeks she was kept by the finder made nineteen pounds of butter each week; and the fact was held so extraordinary, as to be thought worth a memorandum in the parish books." And it is added, that "the Norman and island cattle make fat very quick, and for their bulk arrive at considerable weight. The beef," in his opinion, "is of the first class, very fine grained, in colour yellow, or of a high colour, with a bluish cast and elastic feel, which denotes the closest grained, most savoury, and finest meat." It is in his recollection, that, "some years since, a heifer, bred between Alderney and Kentish home-bred stock, and fattened on calıbages and carrots, made one hundred and fifty stone, dying uncommonly fat." On this ground he supposes, that "this species is, in course, a proper cross for the large and coarse-boned, but in that view he would prefer the real Normans from the Continent, as generally better shaped than the islaniers." He likewise states, that "many persons near the metropolis, and along the south and western coast, make a trade of importing these cattle, which are extremely convenient for private families, and make a good figure in parks and lawns."

Mr. Culley, however, remarks, that they are a breed of cattle too delicate and tender to be much attended to by the British farmer, and not capable of bearing the cold of this island, especially the northern parts of it.

By an experiment which is stated in the $R e$ port for the County. of Kent, made between a large home-bred cow of eight years old and a small Alderney of two years old, it appears that the home-bred cow in seven days gave thirty-five gallons of milk, which made ten 
pounds and three ounces of butter, and the Alderney cow, in the same length of time, gave only fourteen gallons of milk, but which made six pounds and eight ounces of butter.

Very useful cattle may be bred by crossing these cows with short-horned bulls. The late Mr. Hunter also produced a very beautiful cow from the Alderney by a buffalo, which is said, in the Middlesex Report, to have lept plump and fat, both in summer and winter, on much less food than would be sufficient to support a beast of the same size of the ordinary breed.

ALE (Sax. eale). A liquor obtained from the infusion of malt and hops by fermentation. Ale differs from beer chiefly by having a smaller proportion of hops. There are different sorts of ale brewed, such as strong ale, table ale, pale ale, and brown ale. The pale ale is made from malt which has only been slightly dried, and is generally considered as of a more viscid quality than the brown ale, which is produced from malt that has been roasted, or very hard dried. (Miller.) See BeEn and Brewing. The fertility of the soil in grain, and its being not proper for vines, put the Egyptians upon drinking ale, of which they were the inventors. (Arbuthnot.)

A liquor made from fermented harley is mentioned by Herodotus (1. ii. c. 77): the earliest manufactured kind of intoxicating liquid was probably, however, mead. Tacitus notices the use of beer by the Germans. Pliny -lescribes it as common to all the nations of the west. It has long been a favourite beverage of the inhabitants of England. Our Saxon and Danish forefathers drank beer to excess. They regarded it as the drink allotted to those admitted into the Hall of Odin. Ale is named amongst the laws of King Ina; and it was long the custom, when the Norman princes were on the throne, to regulate its price by statute; thus, in 1272 , it was ordained that a brewer should sell two gallons of ale in a city for a penny, or three or four gallons for the same price in the country.

Hops were apparently first used for beer in Germany, and in the Dutch breweries about the year 1400 ; but they were not used generally in England until about the year 1600 . Henry VIII., in 1530, even forbade the brewers to mix hops in their beer; and yet, according to Beckmann (Hist. of Inv. vol. iv. p. 336), plantations of hops had begun to be formed in England, A. n. 1552: The distinction between ale and beer is thus stated by Dr. Thomson: "Both are obtained by fermentation fiom the malt of barley, but they differ from each other in several particulars, ale is light-coloured, brisk, and sweetish, or at least free from bitter; while beer is darli-coloured, bitter, and much less brisk. Porter is a species of beer, and is what was formerly called strong beer. The original difference between ale and beer was owing to the malt, from which they were prepared. Ale malt was dried at a very low heat, and consequently was of a pale colour; while beer or porter malt was dried at a higher tcmperature, and had in consequence acquired a brown colour. This incipient charring had developed a peculiar, and agreeable bitter taste, whici was communicated to the beer along with the dark colour. This bitter taste rendered beer more agreeable to the palate, and less injurious to the constitution than ale. It was manufactured in larger quantities, and soon became the common drink of the lower ranks in England. When, during the wars of the French Revolution, the price of malt was very materially increased, the brewers found out that a greater quantity of wort of a given strength could be procured from pale malt, than from brown malt; the consequence was, that pale malt was to a considerable extent substituted for brown malt in the brewing of porter and beer. The wort now, however, was paler, and wanted that agreeable bitter flavour which characterized porter. The por. ter brewers endeavoured to remedy these defects by several artificial additions, such as burnt sugar, quassia, \&c., and most of which the chief London porter brewers have, I believe, long since discontinued." Brewers are obliged, under the $6 \mathrm{Geo.} 4$, c. 81 , to take out an annual license, for which they pay, if brewers of strong beer,

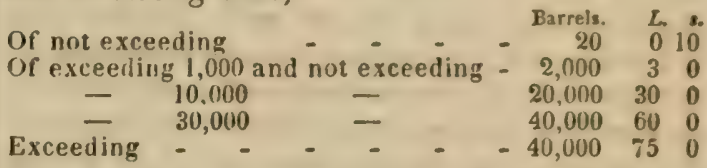

Considering the increase of population in England, the consumption of beer has not materially increased since 1787 , as the following table of the beer brewed in this country in various years will show.

\begin{tabular}{|c|c|c|}
\hline $\begin{array}{c}\text { Years ending } \\
\text { 5ih July. }\end{array}$ & Strong Beer. & Table Beer. \\
\hline & Barrels. & Barreis. \\
1787 & $4,426,482$ & $4 \times 5,620$ \\
1797 & $5,839,627$ & 584,422 \\
1807 & $5,577,176$ & $1,732,710$ \\
1817 & $5,236,048$ & $1,453,960$ \\
1825 & $\mathbf{6 , 5 0 0 , 6 6 4}$ & $\mathbf{1 , 4 8 5 , 7 5 0}$ \\
\hline
\end{tabular}

The number of barrels of beer exported from England is considerable and increasing, amounting in the years ending the

5 th of January, 1826 to 53,013 barrels.

$$
\begin{array}{ll}
- & 1828-59,471 \quad- \\
-\quad & 1830-74,902- \\
& \left(M^{\prime}\right. \text { Culloch's Dict. of Com.) }
\end{array}
$$

ALEHOOF (Hedera terrestris. From ale, and hoог, head). Ground-ivy, so called by our Saxon ancestors, as being their chief in. gredient in ale. This wild plant creeps upon hedge banks, at the foot of trees, and in every shady place, flowering in spring. It takes root at every joint, like the strawberry runners, and its leaves are roundish and notched at their edyes, becoming a purple colour as the spring advances. Its flowers are blue, and its roots fibrous. This plant has a peculiar and. strong smell; and it is best gathered when in flower. It is an excellent vulnerary or wcundherb, applied outwardly, and taken inwardly. An ointment made from alehoof, or groundivy, is very healing to ulcers and fistula. The decoction of the herb arank daily for a continuance is deemed useful for cleansing the stomach, promoting the proper secretions, and sweetening the blood. [The old writers are full of commendations of the medical vi:sue. of ground-ivy, which are extolled for a greas 
variety of ailments and "griefs," oparating as a diuretic, and being excellent in disorders of the lungs and breast.] It obtained its name of Alehoof among the poor, who infuse it in ale or beer, and drink it warm for all internal ailments. (L. Juhnson.)

ALEXANDER (Hipposelinumi). This garden vegetable has been superseded by celery, yet it is an excellent vegetable, and grows abundantly wild almost everywhere in England. The seeds and root are hot and drv 'ike those of parsley, and preparations of them are much in use as a popular medicine.

[Some wild species of Alexander are known in the United Stares. (See Flor. Ces.)]

ALIMENT (Lat. alimentum). That which nourishes, nutriment or food.

Of alimentary roots, some are pulpy and very nutritious, as turnips and carrots. These have a fattening quality. (Arbuth. on Aliments.) See Gases, Earth, Watrin, \&c.

The food of animals, whether of a solid or liquid kind, should be adapted to their different organs both in quantity and quality, in order that they may exist in the most perfect state. It is observed, that nature directs every animal, instinctively, to choose such substances for food as are best adapted to its health and support; but as some are withdrawn from their natural condition for the convenience of man, and, in their domesticated state, are fed on artificial productions, not of their own choice, it becomes a matter of serious importance to the owners of cattle, horses, \&c., to make themselves acquainted with their nature and habits, and also with the qualities of those substances which are usually designed as food for them, since there is no doukt but errors in the choice of the latter must be a fruitful source of disease. Besides, in the view of the grazier, sume sorts of food may be much more advantageous in the quality of fattening animals than othersa circumstance of vast importance. See Foon.

ALKALI. The word alkali comes from an herb alled by the Egyptians kali; by us glasswort. This herb they burnt to ashes, boiled the ashes in water, and after having evaporated the water, there remained at the bottom a white salt-this they called sal kali or alkali. (Todd's Johnson.) 'The word is of Arabic origin; according to Albertus Magnus it signifies "the dregs of bitterness." (Thomsun, vol. ii. p. 49.)

The chief alkalies found in plants are potash and soda; ammonia, it is true, is produced by the distillation of certain vegetables, but it is a product of the distillation; and again, morphia is obtained from opium, quinia from the Peruvian bark, \&c.; but these allaline substances are but rarely met with by the cultivator, and do not involve any very important facts of vegetahle chemistry.

Potash is found in all vegetables growing at n distance from the sea; that of commerce is procured by merely burning the vegetable, washing the ashes in water, and evaporating the solution of potash thus obtained to dryness. In this manner the potash of commerce is made. The proportion, however, of potash, existing in plants varies very ccusiderably, as may be seen from the following table of the quantities of ashes and potash obtained from 100 parts of various plants :-

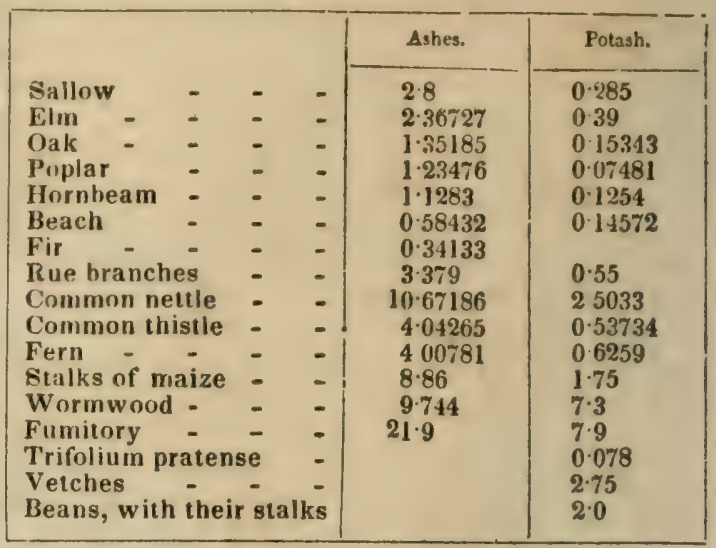

Thomson's Chem. iv. 189.

The potash thus obtained, however, must not be regarded as a pure alkali, for it contains almost always a small portion of various saits, such as the sulphate of potash, muriate of potash, sulphate of lime, phosphate of lime, \&c.

Soda abounds in marine plants generally to a much greater extent than potash does in the vegetables of inland districts; the barilla of Spair is extracted from the salsola sativa and vermiculata, and some of these plants yield nearly 20 per cent. of ashes, which contain about 2 per cent. of soda.

The union of alkalies with acids forms the class of bodies known as the alkaline salts.

[Plants, in their growth, derive certain ele. ments for their subsistence from the atmosphere, namely, carbonic acid, water, and ammonia, the decomposition of the last furnishing their nitrogen. They, however, require other materials for the perfection of certain organs or parts appropriated to the performance of special functions, such, for example, as the perfection of the seed, which is destined to renew the plant. These elements are furnished by the soil, and consist of salts or alkaline substances,"such as potash, soda, lime, alumine, magnesia, metallic oxids, and phosphates. The proportion of these contained in soils regulate, in a great degree, their capacities for the production of different plants.

Connected with agricuitural philosophy, the alkalies are subjects of the deepest interest. The salts of potash and soda, and of the a]kaline earths or minerals, lime, alumine, and even magnesia, can be obtained, by burning and certain chemical processes, from parts of the structure of all plants. This shows the great importance of alkalies, and alkaline substances, to the growth and welfare of every product of the soil. It follows also that with every crop removed, a portion of the potash, etc., must be removed from the land. To compensate for such losses, ashes, farm-yard manure, \&c., supply alkalies to the soil, along with other fertilizing substances. In rocky districts of country natural sources exist from whence the soil derives a regular supply of potash, namely, the disintegration of granite, and decomposition of its felspar and mir:a, both of which contain this alkali. 


\section{ALKALI.}

A few years after gypsum was introduced into general use, farmers began to observe a diminution of their hay crops, and to condemn it as an exhauster of the soil. But this charge against plaster was not well founded, at least in the sense it was made.

The numerous instances given by Liebig, of the importance of the alkalies and metallic nxides on vegetation, show that their influence has been too much overlooked. It has been thought remarkable by some vegetable physiologists, that those cereal grasses which furnish food for man, should, as it were, follow him wherever he goes. The reason is to be found in the fact, that none of our grain plants can produce perfect seeds, or seeds yielding farina, without a greater supply of phosphate of magnesia and ammonia than can be found in regions where these salts, resulting from organized vitality, are less abundant. (Cultivator.)

Plants growing on a soil, containing a due mixture of earthy ingredients, always select a proportion of each, according to their several capacities or wants. It is a fact of the highest practical value to the agriculturist to know, that where a soil which originally contained all the elements essential to the production of a crop, becomes exhausted of one alkaline or earthy element, another may be substituted so as to compensate for the privation. Where, for example, there is a deficiency in a soil of the alkaline earth-lime, the addition of potash, soda or magnesia, all of which exist in the ashes of wood and other vegetable substances, may be resorted to for the purpose of making it up. Thus, plants when growing in a soil where there is no potash will make up the deficiency by taking up soda, if this last allali be present.

Plants which grow on or near the sea-shore assimilate or take up soda instead of potash. Sea-salt consists almost entirely of soda, and the sea is therefore to be regarded as the great source of this alkali. It is, however, found in England and many other countries in the form of native rock salt, and also exists in most soils combined with potash. The soda of commerce is usually obtained from the ashes of plants growing on the sea coast, just as potash is procured from the ashes of trees and other vegetables growing inland. (See Soda, Kelp,\&c.)

The sowing of the earth with salt has from the earliest times been deemed an infallible means of producing total barrenness, and the excess of any salt in a soil is still known to be destructive of fertility.

The perfect developement of a plant is, nevertheless, according to Liebig, dependent on the presence of due proportions of the alkalies or alkaline earths, since, when these substances are totally wanting, its growth will be arrested, and when they are only deficient it must be impeded. "Let us compare," says this eminent chemist, " two kinds of trees, the wood of which contains unequal quantities of alkaline bases, and we shall find that one of these grows luxuriantly in several soils, upon which the others are scarcely able to vegetate. For example, 10,000 parts of oak wood yield 250
AI.KALI.

parts of ashes, tne same quantity of fir-wooul only 83 , of linden-wood 500 , of rye 440 , and of the herb of the potato-plant 1500 parts.

"Firs and pines find a sulficient quantity of alkalies in granitic and barren sandy suils, in which oaks will not grow; and wheat thrives in soils favourable for the linden-free, bucause the bases, which are necessary to bring it to complete maturity, exist there in sufficient quantity. The accuracy of these conclusions, so highly important to agriculture and to the cultivation of foresis, can be proved by the the most evident facts.

"All kinds of grasses, the Equisetacex, for example, contain in the outer parts of their leaves and stalk a large quantity of silicic acid and potash, in the form of acid silicate of potash. The proportion of this salt does not vary perceptibly in the soil of corn-fields, because it is again conveyed to them as manure in the form of putrefying straw. But this is not the case in a meadow, and hence we never find a luxuriant crop of grass on sandy and calcareous soils which contain little potash, evidently because one of the constituents indispensable to the growth of the plants is wanting. Soils formed from basalt, grauwackè, and porphyry are, cæeteris paribus, the best for meadow land, on account of the quan tity of potash which enters into their composi tion. The potash abstracted by the plants is restored during the annual irrigation.* That contained in the soil itself is inexhaustible in comparison with the quantity removed by plants.

"But when we increase the crop of grass in a meadow by means of gypsum, we remove a greater quantity of potash with the hay than can, under the same circumstances, be restored. Hence it happens, that after the lapse of several years, the crops of grass on the meadows manured with gypsum diminish, owing to the deficiency of potash. But if the meadow be strewed from time to time with wood-ashes, even with the lixiviated ashes which have been used by soap-boilers, (in Germany much soap is made from the ashes of wood, then the grass thrives as luxuriantly as before. The ashes are only a means of restoring the potash.

"A harvest of grain is obtained every thirty or forty years from the soil of the Luneburg heath, by strewing it with the ashes of the heath-plants (Erica vulgaris) which grow on it. These plants during the long period just mentioned collect the potash and soda, which are conveyed to them by rain-water; and it is by means of these alkalies, that oats, barley and rye, to which they are indispensable, are enabled to grow on this sandy heath.

* A very high value is attached in Germany to the cultivation of grass as winter provision for catte, and the greatest care is used in order 10 nbtain the greatest possible quantity. In the viciuity of Liegen (a town in Nassau), from three to five perfict crops ore ohtained from one meadow, and this is effected by covering the fields with river-water, which is conducted over the meadow in spring by numerous small canals. Thie is found to be of such advartage, that suppusing a meadow not so treated to yield 1,000 ibs. of hay, then from ono thus watered 4,500 lbs. nre prodnced. In respect to the
cultivation of meadows, the country arnund Liegen iv considered to be the best in all Germany. $-L$. 


\section{Al,KALI.}

"The woodsutter: in the vicinity of Heidelberg have the privilege of cultivating the soil for their own use, after felling the trees used for making tan. Before sowing the land thus obtained, the branches, roots, and leaves are in every case burned, and the ashes used as a manure, which is found to be quite indispensable for the growth of the grain. 'The soil itself, upon which the oats grow in this district, consists of sandstone; and although the trees find in it a quantity of alkaline earths sufficient for their own sustenance, yet in its ordinary condition it is incapable of producing grain.

"The most decisive proof of the use of strong manure was obtained at Bingen (a town on the Rhine), where the produce and developement of vines were highly increased by manuring them with such substances as shavings of horn, \&c., but after some years the formation of the wood and leaves decreased to the great loss of the possessor, to such a degree, that he has long had cause to regret his departure from the usual methods. By the manure employed by him, the vines had been too much hastened in their growth; in two or three years they had exhausted the potash in the formation of their fruit, leaves, and wood, so that none remained for the future crops, his manure not having contained any potash.

"There are vineyards on the Rhine, the plants of which are above a hundred years old, and all of these have been cultivated by manuring them with cow-dung, a manure containing a large proportion of potash, although very little nitrogen. All the potash, in fact, which is contained in the food consumed by a cow is again immediately discharged in its excrements.

"The experience of a proprietor of land in the vicinity of Güttingen offers a most remarkable example of the incapability of a soil to produce wheat or grasses in general, when it fails in any one of the materials necessary to their growth. In order to obtain potash, he planted his whole land with wormwood, the ashes of which are well known to contain a large proportion of the carbonate of that alkali. The consequence was, that he rendered his land quite incapable of bearing grain for many years, in consequence of having entirely deprived the soil of its potash.

"The leaves and small branches of trees contain the most potash; and the quantity of them which is annually taken from the wood, for the purpose of being employed as litter, contain more of that allsali than all the old wood which is cui down. The bark and foliage of naks, for example, contain from 6 to $\boldsymbol{9}$ per ceut. of this alkali; the needles of firs and pines 8 per cent.

"With every 2650 lbs. of fir-wood, which are yearly removed from an acre of forest, only from 0.114 to $0.53 \mathrm{lbs}$. of alkalies are abstracted from the soil, calculating the ashes at 0.83 per cent. The moss, however, which covers the ground, and of which the ashes are hnown to contain so much alkali, continues uninterrupted in its growth, and retains that potash on the surface, which would otherwise sc easily penetrate with the rain through the sandy soil. By its decay, an abundant provision of alkalies is supplied to the roots of the trees, and a fresh supply is rendered unnecessary.

"The supposition of alkalies, metallic oxides, or inorganic matter in general, being produced by plants, is entirely refuted by these wellauthenticated facts.

"It is thought very remarkable, that those plants of the grass tribe, the seeds of which furnish food for man, follow him like the domestic animals. But saline plants seek the sea-shore or saline springs, and the Chenopodium* the dunghill from similar causes. Saline plants require common salt, and the plants which grow only on dunghills, need ammonia and nitrates, and they are attracted whither these can be found, just as the dung-fly is to animal excrements. So likewise none of our corn-plants can bear perfect seeds, that is, seeds yielding flour, without a large supply of phosphate of magnesia and ammonia, substances which they require for their maturity And hence, these plants grow only in a soil where these three constituents are found combined, and no soil is richer in them, than those where men and animals dwell together; where the urine and excrements of these are found corn-plants appear, because their seeds cannot attain maturity unless supplied with the constituents of those matters.

"When we find sea-plants near our saltworks, several hundred miles distant from the sea, we know that their seeds have been carried there in a very natural manner, namely, by wind or birds, which have spread them over the whole surface of the earth, although they grow only in those places in which they find the conditions essential to their life.

"The first colonists of Virginia found a country, the soil of which was similar to that mentioned above; harvests of wheat and tobacco were obtained for a century from one and the same field without the aid of manure, but now whole districts are converted into unfruitful pasture land, which without manure produces neither wheat nor tobacco. From every acre of this land, there were removed in the space of one hundred years $1,200 \mathrm{lbs}$. of alkalies in leaves, grain, and straw; it became unfruitful, therefore, because it was deprived of every particle of alkali, which had been reduced to a soluble state, and because that which was rendered soluble again in the space of one year, was not sufficient to satisfy the demands of the plants. Almost all the cul. tivated land in Europe is in this condition; fallow is the term applied to land left at rest for further disintegration. It is the greatest possible mistake to suppose that the temporary diminution of fertility in a soil is owing to the loss of humus; it is the mere consequence of the exhaustion of the alkalies.

"Let us consider the condition of the country around Naples, which is lamed for its fruitful corn-land; the farms and villages are situated from eighteen to twenty-four miles distant from one another, and between them there are no

* Chenopodium album, called in the United States Lamb's Quarter, a troublesome weed about gardens and house. 


\section{ALKALI.}

roads, and consequently no transportation of manure. Now corn has been cultivated on this land for thousands of years, without any part of that which is annually removed from the soil being artificially restored to it. How can any influence be ascribed to humus under such circumstances, when it is not even known whether humus was ever contained in the soil?

"The method of culture in that district completely explains the permanent fertility. It appears very bad in the eyes of our agriculturists, but there it is the best plan which could be adopted. A field is cultivated once every three years, and is in the intervals allowed to serve as a sparing pasture for cattle. The soil experiences no change in the two years during which it there lies fallow, further than that it is exposed to the influence of the weather, by which a fresh portion of the allkalies contained in it are again set free or rendered soluble. The animals fed on these fields yield nothing to these soils which they did not formerly possess. The weeds upon which they live spring from the soil, and that which they return to it as excrements, must always be less than that which they extract. The field, therefore, can have gained nothing from the mere feeding of cattle upon them; on the contrary, the soil must have lost some of its constituents.

"Experience has shown in agriculture, that wheat should not be cultivated after wheat on the same soil, for it belongs with tobacco to the plants which exhaust a soil. But if the humus of a soil gives it the power of producing corn, how happens it that wheat does not thrive in many parts of Brazil, where the soils are particularly rich in that substance, or in our own climate, in soils formed of mouldered wood; that its stalk under these circumstances attains no strength, and droops prematurely? The cause is this, - that the strength of the stalk is due to silicate of potash, and that the corn requires phosphate of magnesia, neither of which substances a soil of humus can afford, since it does not contain them; the plant may indeed, under such circumstances, become an herb, but will not bear fruit.

"Again, how does it happen that wheat does not flourish on a sandy soil, and that a calcareous soil is also unsuitable for its growth, unless it be mixed with a considerable quantity of clay? It is because these soils do not contain alkalies in sufficient quantity, the gr 'wth of wheat being arrested by this circumstance, even should all other substances be presented in abundance.

"Trees, the leaves of which are renewed annually, require for their leaves six to ten times more alkalies than the fir-tree or pine, and hence, when they are placed in soils in which alkalies are contained in very small quantity, do not attain maturity.* When we see such trees growing on a sandy or calcare-

* One thousand parts of the dry leaves of naks yielded 55 parts of ashes, of which 24 parts consisted of alkulies coluble in water; the same quantity of pine leaves gave only 29 parts of ashes, which contained 4.6 parts of soluble salts. (De Saussure.) ous soil,- -the red-beech, the service-tree, and the wild-cherry, for example, thriving luxuriantly on limestone, we may be assured that alkalies are present in the soil, for they are necessary to their existence. Can we, then, regard it as remarkable, that such trees shculd thrive in America, on those spots on which forests of pines which have grown and collected alkalies for centuries, have been burnt, and to which the alkalies are thus at once restored; or that the Spartium scoparium, Erysimum latifulium, Blitum capitatum, Senecio viscosus, plants remarkable for the quantity of alkalies contained in their ashes, should grow with the greatest luxuriance on the localities of conflagrations.*

"Wheat will not grow on a soil which has produced wormwood, and, vice versâ, wormwood does not thrive where wheat has grown, because they are mutually prejudicial by appropriating the alkalies of the soil.

"One hundred parts of the stalks of wheat yield 15.5 parts of ashes $(H . D u v y)$; the same quantity of the dry stalks of barley, 8.54 parts (Schrader); and one hundred parts of the stalks of oats, only 4.42 ; -the ashes of all these are of the same composition.

"We have in these facts a clear proof of what plants require for their growth. Upon the same field, which will yield only one harvest of wheat, two crops of barley and three of oats may be raised.

"All plants of the grass kind require silicate of potash. Now this is conveyed to the soil, or rendered soluble in it by the irrigation of meadows. The equisetucere, the reeds and species of cane, for example, which contain such large quantities of siliceous earth, or silicate of potash, thrive luxuriantly in marshes, in argillaceous soils, and in ditches, streamlets, and other places, where the change of water renews constantly the supply of dissolved silica. The amount of silicate of potash removed from a meadow, in the form of hay, is very considerable. We need only call to mind the melted vitreous mass found on a meadow between Manheim and Heidelberg after a thunder-storm. This mass was at first supposed to be a meteor, but was found on examination (by Gmelin) to consist of silicate of potash; a flash of lightning had struck a stack of hay, and nothing was fuund in its place except the melted ashes of the hay.

"Potash is not the only substance necessary for the existence of most plants, indeed it has been already shown that the potash may be replaced, in many cases by soda, nagnesia, or lime; but other substances, besides alkalies, are required to sustain the life of plants.

The soil in which plants grow furnishes them with phosphoric acid, and they in turn yield it to animals, to be used in the formation of their bones, and of those constituents of the brain which contain phosphorus. Much more

* After the great fire in I.nndon, large quantities of the Erysimum latifolium were observed growing on the spots where a fire had iaken place. On a similar occasiom the Blitum capitatum was geen at Copentragen, the Senecio visensus in Nassau, and the Spartium senparium in Lan. guedoc. After the burnings of forests of pines in North America poplars grew on the same suil. (Frentins) 
phosphorus is thus afforded to the body than it requires, when flesh, bread, fruit, and husks of grain are used for food, and this excess in them is eliminated in the urine and the solid excrements. We may form an idea of the quantity of phosphate of magnesia contained in grain, when we consider that the concretions in the cœecum of horses consist of phosphate of magnesia and ammonia, which must have been obtained from the hay and oats consumed as food. Twenty-nine of these stones were taken after death from the rectum of a horse belonging to a miller in Eberstadt, the total weight of which amounted to $3 \mathrm{lbs}$; and Dr. F. Simon has lately described a similar concretion found in the horse of a carrier, which weighed $1 \frac{1}{2} \mathrm{lb}$.

"It is evident that the seeds of corn could not be formed without phosphate of magnesia, which is one of their invariable constituents; the plant could not under such circumstances reach maturity." (Organic Chemistry.)]

ALKANET (Anchusa, Lat.). This plant is a species of bugloss with a red root, brought from the southern parts of France, and used in medicine. It grows wild in Kent and Cornwall, but in other counties only in gardens. It flowers in summer, and its root becomes red in Autumn. The root is astringent: the leaves not so much so. [The puccoon (Batschia Canadensis) is called allanet in the United States. See Flor. Ces. p. 118, obs.]

ALliUM. See Orion, Garlic, Leek, Shaцот, Chives, \&c.

ALLOTMENT SYSTEM. This designation has been applied in England to a plan for bettering the condition of the poor, by allotting to each family in a parish an extent of ground for the purpose of cultivation with the spade.

Under the article Agricurture it is noticed, that in England, during the feudal times, an allotment system existed. Its object, however, was different; the lords of the soil, having an interest in obtaining as many tenants as they could, for their power was proportionate to their number, portioned their estates into as many small allotments as they could obtain family tenants, receiving in return certain days of military or other service.

When the feudal system was destroyed, the lords let their lands in a similar manner, receiving as rent certain quantities of labour from the tenant, or produce of the land he rented; although, it not being now an object to maintain the number of their tenants, but rather to acquire an increased return of produce, and to obtain a prosperous tenantry, no obstacle was thrown in the way of increasing the size of farms. Land was left like any other subject of investment, and a man obrained as much as his means of cultivating permitted, or as he found to be profitable. These were powerful limitations, for money was scarce, and the agriculturists were chiefly tenants, labourers for hire being few.

In the fourteenth century occurred the greatest revolution that ever happened to the agriculture of England. The increased demand ior wool in the Netherlands and at home, ren$\therefore$ red the breeding of sheep much inore profitable than the growing of corn, and conse66 quently the arable lands were converted inte pastures. England had been very closely cultivated, and the small or cotter farms were extremely numerous. These were now generally exterminated, and the land proprietor be. coming a great flock-master, converted them all into one breadth of grazing land. "Yo.ur sheep," says Sir Thomas More in his Utopia, "that were wont to be so meek and tame, and such small eaters, are now become such great devourers, and so wild, that they eat up and swallow down the very men themselves." "One covetous and unsatiable cormorant, and very plague of his native country, compasses about and encloses many thousand acres of ground together within one pale or hrdge, the husbandmen are thrust out of their own, or else, either by covin and fraud, or by violent oppression, they are put beside it, or by wrongs and injuries they be so wearied that they be compelled to sell all; by one means or other either by hook or by crook, they must needs depart away, poor, silly, wretched souls, men, women, husbands, wives, fatherless children, widows, woful mothers and their young babes, and their whole household, small in substance and much in number, as husbandry requireth many hands. For one shepherd or herdsman is enough to eat up that ground, to the occupying whereof about husbandry many hands were required."

Some few of the cotter farmers were reduced to the grade of hired shepherds; others became artisans, a still smaller number retained a plot of land, but a large portion (for even monastic support was now abolished) became beggars, who, as all records agree, infested England. This gave birth to the poor laws, and the same reign of Elizabeth was the era of an effort to remedy the evils which had arisen from this destruction of small farms.

It had been experienced that though the tenants of those small farms had been poor, yet none of them were paupers; it was therefore thought that every mode of recurring to such a system must be beneficial; and in ac. cordance with this opinion an act of parliament was passed, commanding that to every cottage that should be erected, four acres of ground should be allotted. This first suggestion of the allotment system failed. The quantity of ground allotted was too large, and from its interfering with the just liberties of the landed proprietors, this act was repealed in the last century.

As the value of all farming produce increased from various causes, the profits becoming commensurately large, cultivators required more extensive forms, consolidation proceeded, and in 1709 the first enclosure act passed; and from that time to the present the small occupiers have gradually further diminished, as their right of commonage and the like was taken away by the four thousand enclosure bills that have since been enacted.

When small farmers are deprived of their tenements, they became, if they continue agriculturists, farming labourers. It becomes a subject of very great political importance, therefore, to ascertain how the character 


\section{ALLOTMENT SYSTEM.}

and comfort of these, who are now by far the most numerous class in society, can be best promoted. It would be here misplaced to examine how the system of poor laws has served in various ways to debase and depress them; our present object must be to consider how the allotment system may be the best made to promote contrary effects.

This system, we have noticed, suggested itself to the legislature in the reign of Elizabeth, but it was of very limited operation.

On the Continent, a system of larger allotments was partially adopted in the year 1707 , in the Duchy of Cleves, but we are not aware that the example was followed, till, after the lapse of more than a century, the Dutch government, in 1818, divided tracts of poor soil at Frederick's Oord, and other places, into allotments of seven acres. The government provided overseers to notice the moral conduct and industry of the tenants; advanced capital when needed, which was to be repaid; and an annual rent was to be returned. Manual labour was exclusively adopted. The expense of establishing each individual was 22l. 6s.4d.; and the annual excess of produce over the subsistence of the family, after deducting the rent, twelve shillings per acre, was $8 l$. $2 s$. 4d. (M. de Kirchoff. Jacob on the Corn Trade, \&c.)

About the year 1800, Dr. Law, Bishop of Bath and Wells, commenced the allotment system; Sir H. Vavasour communicated to the Board of Agriculture, about the same period, some experiments demonstrating the great benefit of "the Flemish", or "field-gardening husbandry;" and, in 1802, Charles Howard, Esq. followed the example.

"On Pulley Common, in Shropshire," says Sir W. Pulteney, "there is, at least there was, a cottager's tenement of about 512 square yards, somewhat more than one-ninth of an acre. The spade and the hoe are the only implements used, and those chiefly by his wife, that he may follow his daily labour for hire. The plot of land is divided into two parcels, whereon she grows wheat and potatoes alternately. In the month of October, when the potatoes are ripe, she takes off the stalks of the plants, which she secures to produce manure by littering her pig. She then goes over the whole with a rake, to collect the weeds for the dunghill. She next sows the wheat, and then takes up the potatoes with a three-pronged fork; and by this operation the wheat seed is covered deep. She leaves it quite rough, and the winter frost mellows the earth; and by its falling down in the spring it adds vigour to the wheat plants. She has pursued this alternate system of cropping for several years without any diminution of produce. The potato crop only has manure. In 1804, a year very noted for mildew, she had fifteen Winchester bushels of wheat from 272 square yards, being four times the general averaging crop of the neighbouring farmers. It is to be wished such instances of cottage industry were more frequent; and more frequent they would be, were proper means made use of to invigorate the spirit of exertion in the labouing class."

\section{ALLUVIUM.}

Since that period the patrons of the sy:tern have been very numerous. The clergy have been especially promoters of this system.

Where this system, well regulated, has been tried, and the experience is now very extensive, the results have been most happy. The condition of the poor has been ameliorated; by rendering them more independent, they have become more contented and more careful; be:ter as citizens, and better as individuals.

If the allotments much exceed a quarter of an acre, or in any way approach to the nature of cotter farms, a proportionate blow is made at that employment of capital and talent in agriculture which has raised it to its presen: improved state.

"The advantages attending this system," says a clerical writer in the Christian Ob. server for 1832, "besides the comfort of the poor man, are the diminution of the poor's rate, and the moral improvement of the labourer. Since this plan has been in operation, the poor-rate has been steadily declining from about $320 l$. to about $180 l$. per annum, with the prospect of still further diminution. When the farmer's work is scarce, the poor man finds profitable employment on his patch of ground, which if he had not to occupy him, he would be sent to idle upon the roads at the expense of the parish. The system has the further and very important effect of improving his character. When the labourer has his little plot of ground, from which he feels he shall not be ejected as long as he conducts himself with propriety, he has ar. object on which his heart is fixed; he has something at stake in society; he will not hang loose on the community, ready to join those who would disturb it; so much so, that in the late riots, no man in the parish showed any disposition to join them."

From the year 1828 to the present time, numerous pamphlets upon this subject have appeared, and for further information readers are referred to those of Dr. Law, and of Messrs. Scobell, Scrope, Banfill, Denson, Blackistcn, Withers, \&c.

ALLOWANCES TO TENANTS. Such as are agreed to be made to them on their quitting farms, or under any other circumstances. See Customs of Counties and Appraisement.

ALLUVIUM, or ALLUVION (from the Latin Alluvio, "an inundation"), is a term which, in the English language, has no very defined meaning. Some authors use it to designate all those rocks which have been formed by causes now acting on the surface of the earth, including those of volcanic origin; while others, adhering to the literal meaning of the original term, confine its application to deposits, whatever be their character, that have resulted from inundations. Neither of these definitions convey the same meaning as is usually attached to the word, the one including tow much, the other too little. The term has been badly selected, but is used in its proper appl1cation to designate all those deposits recently formed, or now forming, by the agency of water, whether from an uninterrupted and constant stream, or from casual inundation.

All streams, lakes, rivers, seas, and the 


\section{ALLUVIUM.}

ocean itself, hold a large quantity of earthy matter in mechanical solution, which they deposit in their beds. The character of the sediment is governed by the nature of the rocks over which the waters flow; and the quantity depends partly upon the constitution of the rocks, and partly upon the power of the water. If the rock be easily destroyed, and a large body of water flow over it with a considerable velocity, the destructive effect will be great, and much worn materials (detritus) being formed, the stream will have a thick and turbid appearance. The same effect is frequently produced by the discharge of a number of tributary streams into a river, all of which accumulate a greater or less quantity of the earths over which they flow.

The distribution of water at the present time, and I more particularly refer to rivers, is very different from that of former periods. The majority of the valleys through which rivers are now flowing, have been produced by the action of water, which, running from higher lands, has not only scooped them out, but has spread over them the worn material which it accumulates in its passage. By the operations which have since been going on, the waters have been collected together in comparatively narrow channels of considerable permanency. On this account, the influence of water that flows over the portions of the earth inhabited by terrestrial animals is greatly restricted; and the production of new beds of rock or soil is rather an accidental than a necessary consequence.

But, although the influence oi water has been thus confined, all lands, and especially the surfaces of mountainous districts, are undergoing change, and the superficial covering of one district is conveyed to another. The showers of heaven are constantly sweeping away the soil and decomposed rocks of the uplands into the valleys, over which they are transported by strearns and rivers, the larger and heavier particles falling to the bottom, the smaller being united with the water in mechanical mixture. That portion of earthy matter which is carried away from a district by the running water, is, as far as the district itself is concerned, the most valuable, being the superficial covering or soil, and would be for ever lost to that portion of the earth inhabited эy man, were it not arrested in its passage to the ocean, by deposition in the bed of the river, or on those lands which the waters may happen to overflow.

It is well known to those who have visited elevated districts, that many mountains are already deprived of ineir soils, and are but the skeletons of the earth, without covering or life. By this action the valleys are in the process of elevation, and the mountains of depression; and if we coula conceive it to proceed without limitation, we may imagine a time when all the varieties of elevation and depression, which now give beauty to the surface, will be destroyed, and an entirely different condition of the distribution of land and water will be established. But, at the same time, it cannot be denied that these changes, as far as they have hitherto proceeded, have been advanta- geous to man, whatever might be their result under the conditions to which we have alluded. The mountainous regions are, from their ele. vation, less suited to the progression of society, so intimately connected with agricultural prosperity, than the plains. As we rise above the level of the sea, the atmosphere becomes more rarified, and the cold more intense, both of which are injurious to vegetation in general, and unsuited to promote the comfort of animal life. The plains are, therefore, preferred by men when they congregate together, and form societies. It cannot be considered an unwise or unfit result, that the lowlands should be enriched with alluvial soils, produced by the destruction of the rocks and natural soils of mountainous regions. It is reported of Dioclesian, that he told his colleague, Maximilian, he had more pleasure in the cultivation of a few potherbs which, in the gardens of Spalatro, grew in the soil that on the top of Mount Hremus had only produced moss and dittany, than in all the honours the Roman empire could confer. From the definition I have given of the word "alluvium," I must include the gravels and sands thatare of recent formation among the alluvial deposits; but our attention is chiefly directed to the soils, or those beds which are suited to sustain vegetable life. It is true that the gravels may be made available for the cultivation of some plants, but the beds which are so used belong rather to that class of rocks denominated diluvial by geologists, than to the deposits of which we are speaking.

If we trace the circumstances under which alluvial soils are formed to their cause, we shall find that they have their origin in the fall of heavy rains, and the melting of snows, in mountainous regions. The water, in its passage to the valleys, collects the superficial soil and decomposed earthy material that lies in its path, and transports them into the channels towards which it flows. The streams that are formed on the mountain slopes are generally united together before they reach the plains, and form impetuous torrents, overcoming all obstacles, until their velocity is lost, when, in their winding courses, they meet each other, and form rivers.

Rivers, in every part of their course, are subject to inundation; when, throwing their waters over a considerable space, they deposit the earthy materials they have accumulated. If such inundations had not occurred, the accumulated worn materials (débris) would have been deposited in the bed of the river, or carried into the lake or sea where the waters theinselves are discharged. There are abundant instances on record of the filling up of rivers by the worn materials (detritus), which have been carried into their courses; and any river of our own country will afford a limited example of this result. Many rivers and estuaries, which a few years since were navigable, have ceased to be so on account of the large amount of alluvial matter deposited in their beds; and many of our towns, which were once populous and wealthy, have on this account become poor and almost deserted. If we would see the effect of the transport of worm 


\section{ALLUVIUM.}

materials into lakes, we cannot have a more favourable opportunity than in Switzerland. Many of the lakes of this sublime and majestic country are rapidly filling from this cause; and in some of them water plants are seen above the surface of the water. But when a river suffers inundation, the earthy matter, which is held in mechanical mixture, is arrested, and deposited on the land that is overflowed, and a richly productive soil is formed. One or two examples may illustrate these remarks.

The Ganges annually overflows its banks, and deposits a rich alluvial soil over the country it inundates. This magnificent river was supposed to take its rise on the northern side of the Himalaya mountains, until it was proved, in 1819 , by Lieutenant Webb, that all the streams which unite to give its existence, take their rise on the south side of the Hindoo Coast, or Snowy Mountains. The melting of the snows, and the heavy periodical rains augment the volume of the water, and by the end of June, before the rainy season has commenced in the low country, the river has generally risen fifteen feet; but after the rains in Bengal it usually attains a height of thirty-two feet above its ordinary level. By the end of July all the low countries adjoining the Ganges and the Burrampooter are overflowed, and nothing but houses and trees are seen for many miles inward. The province of Bengal is divided into two nearly equal parts by the Ganges; and as a large portion of the country on the banks of the river is low, it is especially exposed to inundation, from which circumstance it probably derives its name, such districts being called beng. A deep bed of rich soil is deposited during the period of the overflow, and the vegetable productions are of the most varied and luxuriant character. Rice, wheat, barley, tobacco, indigo, cotton, the mulberry, and the poppy, are all cultivated with snccess on the alluvial soils.

It is well known that Egypt has been from time immemorial indebted to the overflow of the Nile for a rich alluvial soil, as well as for the means of irrigating the land. The ancients seem to have been altogether at a loss to account for the periodical overflow of this river; and when we consider the appearances before them, we are not surprised at the difficulties they experienced. They observed it in a country that was not moistened by a drop of rain, and where it was unaided by a single stream, and yet, at its stated period, it began to lift its waters from their bed, and rising higher and higher, overflowed its banks, and spread itself like a sea over Lower Egypt, refreshing the parched earth with moisture, and aiding its productiveness with the formation of a superficial covering of rich loam. The philosophers speculated without success upon its cause; but while they were disputing as to the origin of the phenomenon, year by year the Nile rose, and left the evidence of its beneficial sway in the richness of the crops and the luxuriance of the country. From the inrestigations that have now been made, we know that the rise of the Nile is occasioned by the rains which fall on the high mountains

\section{AI.I.UYIUM.}

in the interior and tropical regions, and not, as many of the ancients supposed, from the Etesian winds, which, blowing periodically from the north, prevent the waters from reaching the sea.

The great importance of rivers, as agents in the production of alluvial soils, cannot be more strongly proved by any positive evidence than by a consideration of the state of Austra. lia, a country remarkable for the fewness of its rivers, and the general poverty of its soil. Contrary to all precedents, the richest soils in this land, excepting the alluvial, are found on the summits of hills. The fires which so frequently happen on the plains, the peculiar character of the vegetation (chiefly consisting of ever-greens), and the sparing distribution of water, are the principal causes of the sterility of this otherwise desirable country. There are, however, spots which, covered with alluvial soil, can rival the richest and most cultivated districts of England; and the comparison of these with other lands impresses the observer the more strongly with the great importance of the natural provision for the restitution of that portion of the earth inhabited by man, by the deposition of new earthy matter and a virgin soil. The alluvial flats of the Nepean, the Hawksbury, and the Hunter rivers, are spoken of by all writers as remark able for their fertility. The rich valley in which the Lake Alexandrina is situated may be noticed as another example of the influence of alluvial soils. The country around this lake appears to be one of the most beautiful and fertile in Australia; and a glance at the map will immediately inform the inquirer of the cause. It is so situated as to receive the worn materials of the mountain chain that ranges along the promontory of which Cape Jervis is the southern point, and also to obtain moisture at all times from the lake, and a renovating suil whenever it may overflow its banks.

Alluvial soils are produced by the discharge of mountain streams into valleys, as well as by the overflow of rivers. We have already explained the manner in which they collect the superficial covering of mountainous districts, and being charged with earthy matter, bring it into the plains. This may be deposited before the streams are united together in an individual channel as well as after, and should this be done, the valley may be covered with alluvial products. The formation of a river is a process which requires time, and many changes must happen before the flowing waters can form for themselves a local habitation; obstacles must be removed, a bed must be scooped out, and an outlet must be formed, in the performance of which earthy matter must be accumulated, and extensive deposits be formed.

A third cause in the production of alluvial deposits may be mentioned. The sea is making great inroads upon many of its shores. carrying on a destructive war against the cliffs that vainly endeavour to oppose its force; while on the other hand it is in some instances receding from the shores against which it once beat; and thus, as though to recompense man for what it takes away, gives to him a portiov 


\section{ALLUVIUM.}

of its own territory. Those districts which are thus added to the land are usually superposed by a fine rich alluvial soil, as also are those which have at a former period been covered by the sea, and would be at the present day, were it not for the ingenuity and works of man.

The districts in which are situated New Orleans in America, and Missolonghi in Greece, are chiefly alluvial, and nearly the whole of Holland has the same character, and can only be described as a district of which man has robbed the ocean. That part of the coast of Germany which is bordered by the North Sea is alluvial, and additions are constantly made to the shores by the gradual depositions of earthy matter upon the immense flats which extend along them. The first sign of vegetation on these lands is the appearance of the saltwort (Nalicornia maritima), which is succeeded by the sea grass (Pou maritima), and when the land is very rich, by the marsh starwort (Aster Tripolium). The land is afterwards dyked, and used as pasture for sheep and cattle; so that the spot over which the sea has perhaps for ages exercised an undisputed control, is brought under the power of man in a state most admirably adapted to suit his wants.

In Lincolnshire and uther parts of the English coast, where the land is beneath the level of high-water mark, unfruitful districts are often restored to a state of fertility by the removal of the artificial banks that prevent the sea-water from flowing over it. In this way the land is thrown open to the sea, and as the tide rises, it is covered by water, which, being overcharged with earthy matter, deposits in two or three years a bed five or six feet thick of rich soil, which may be brought under cultivation by the exclusion of the agent that was instrumental in its production. (See Warpinf.)

But it may be asked, whence does the sea ubtain the earthy matter with which it abounds? Rivers discharge themselves into the ocean, and it has been already stated that their waters are charged, more or less, with the superficial soil of mountainous countries, and the destroyed materials of rocks. A part of this may be arrested by occasional or periodical inundations, and by deposition in the bed of the river, but a large quantity must still be carried into the ocean. It must also be remembered that the water which is conveyed in a channel is constantly endeavouring so to arrange its course as to suffer the least possible resistance. In this attempt, it attacks the banks that confine it, and widens its course, precipitating much earthy matter into the stream, to be removed by the flowing water. It frequently happens, and especially after the fall of heavy rains, that the water at the mouths of rivers is thick and turbid from the quantity of alluvial matter it holds in solution, and very many large rivers are rendered unsafe for navigation by the existence of large bars of sand or clay at their outlet.

But the sea is not mert.y a passive recipiunt of the product of destructive causes, but s itsel. a cause. Sea coasts are constantly suffering depredation by the action of the vaves that beat upon them. Whether we look 70 at the soft and almost unresisting rocks of the eastern coast of England, or the hard primary rocks of Devonshire, Cornwall, and the Shetland Isles, the same results will be observed. During the stormy months of winter, when the waves are tossed upon the coasts with an almost uncontrolled violence, no rock is sufficiently hard to resist its energy, and when unruffled by a passing breeze in the months of summer, its influence upon the softer rocks is hardly less destructive, though more insidious, for it then attacks the base of the cliffs, and removing the support of the superincumbent mass, causes the precipitation of large portions into the sea. By these two causes the sea is provided with the materials for the formation of alluvial soils. Some estimate may be formed of the violence and extent of these causes, by an examination of the present state of the German Ocean, one fifth of which is covered by banks that appear to have been produced in the same way as the alluvial soils on the northern coast of Germany.

Water, then, is a most powerful agent in the destruction and production of rocks, and were there no conservative principle, the changes that are going on would be more extensive than they are in the present day. The floods to which some rivers are subject are so impetuous that they frequently sweep away all opposing objects, and involve an entire district in ruin. These effects, however, are much more common in countries that are thinly covered by vegetation than in those where it is luxuriant, for it acts as a conservative agent, increasing the power of the resistance, by binding the soil more closely together. This, therefore, will account for the diminished influence of floods upon lowlands, and for the fre quent deposition of rich and fertile alluvial soils.

The composition of the alluvial soils that have been brought under cultivation is exceedingly various; but they are generally remarkable for their fertility, and are admirably suited for pasture lands. "In general," says Sir Humphry Davy, "the soils, the materials of which are most various and heterogeneous, are those called alluvial, or which have been formed by the deposition of rivers; many of them are extremely fertile. I have examined some productive alluvial soils, which have been very different in their composition. A specimen from the banks of the river Parret in Somersetshire, afforded me eighty parts of finely divided matter, and one part of silicious sand; and an analysis of the former gave the following result ;

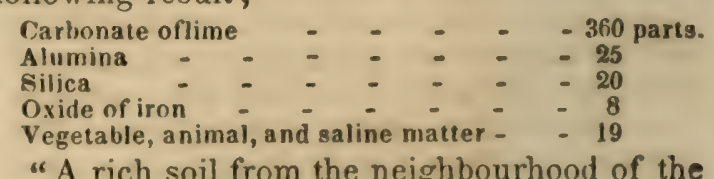
"A rich soil from the neighbourhood of the
Avon, in the valley of Evesham, in the WorAvon, in the valley of Evesham, in the Wor-
cestershire, afforded me three-fifths of fine sand and two-fifths of impalpable matter. This last consisted of-

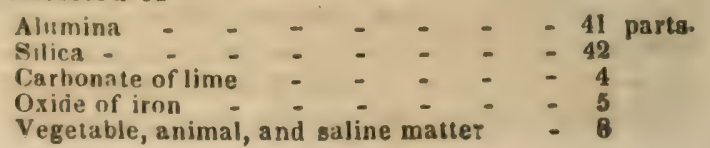


"A soil yielding excellent pasture, from the valley of the Avon, near Salisbury, afforded one eleventh of coarse silicious sand, and the finely divided matter consisted of -

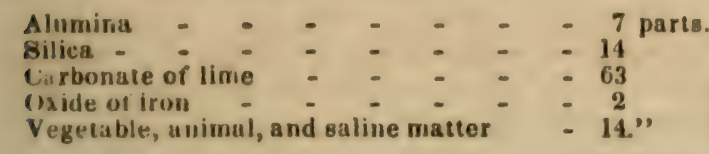

Another striking cause of the fertility of allurial soils will come more properly under Inrigation.-(Miller's Dictionary.)

ALMDND, Silver-leaved (Lat. Amygdalus argenteu). A beautiful shrub originally from the Levanto It grows from eight to ten feet high, and blows rose-coloured flowers in April. Its leaves are covered on both sides with a silvery-coloured down, but they do not appear till the flowers are gone. All the almond tribe are hardy, and will bear any situation, if the soil is tolerably good. Propagate by grafting upon the bitter almond or a plum stock. The double dwarf almond, Lat. Amygdalus pumila, is a smaller shrub, with pale, rose-coloured double flowers, blowing in May, and again in September. The common dwarf almond, Lat. Amygdalus nana, grows only three feet high, and is a native of Russia. It blows its pink flowers in March and April. Propagate by seed, or grafting upon the bitter almond or plum stocks. Trim away dead wood, but prune seldori, they rarely require pruning. (L. Johnsom.)

ALMOND TREE (Amygdalus, Linnæus; amand, $\left.\mathrm{Fr}_{0}\right)$. Derived by Mennge from amandala, a word in low Latin; by others from Allemand, a German, supposing that almonds came to France from Germany. But the Spanish have almendra; and perhaps amand, amandola, and this, are all referable to amygdalum, as that is to duvyderis\%. (Todd's Johnson.) More than one species, and several varieties of this well known genus are cultivated in England, chiefly for the beauty of their early spring flowers.

The common almond tree (Amygdulus communis, Linnæus) is a native of northern Africa, and so late as the time of Cato had not been introduced into Italy, as he calls the fruit Greek nuts (nuces Græc: $)$ ). It was introduced into Britain about 1548. It will grow to the height of twenty or thirty feet, dividing into a head of numerous spreading branches. The leaves very much resemble those of the peach, but they proceed from buds both above and below the flowers. There are also small glands on the lower saw-toothing of the leaves. The form of the flowers is not very different from those of the peach, but they come out usually in pairs, and vary more in their colour, from the fine blush of the apple blossom to a snowy whiteness. The chief obvious distinction is in the fruit, which is flatter, with a leather-like covering, instead of the rich pulp of the peach, and the nectarine, and it also opens spontaneously when the kernel is ripe. The shell of the almond is never so hard as a peach stone, and is sometimes even tender and exceedingly brittle. It is flatter, smoother, and the furrows or holes are more superficial than those of the peach stone.

Varieties of the common almond.-1. The nuts about an inch and a quarter long, with a hard smooth shell; the kernel not valuable. 'T'he seedlings are used in France to bud peaches upon.

2. Bitter : fruit of a large size.

3. Bitter: with a tender shell; fruit of a large size.

4. Bitter : with a hard shell; fruit of a laıge size.

5. Sultan: fruit of a small size.

6. Grand Sultan : fruit of a small size.

7. Sweet: with a tender shell, or tendershelled Sultan; fruit of a moderate size.

8. Sweet: with a half hard shell.

9. Sweet: with a hard shell.

10. Long-fruited: hard-shelled; fruit of a large size.

11. Peach almond: fruit of a large size.

12. Brittle: fruit of a moderate size.

We are not certain whether the French va. rieties, called, 1. Amande dinuce à coyue dure, 2. Amande douce à coque tendre; 3. Amande des dames; and 4. Amande princesse, coincide with any of the preceding.

The whole of the varieties generally produce a profusion of blossoms, which vary a little in colour from a fine rose to a pale blush. They closely resemble each other in foliage, the principal distinction being in the fruit, which differs either as to its form, its sizt, or its taste.

In the south of Europe, as in France, Spain, Portugal, and Italy, the almond is cultivated very extensively as a standard fruit tree, the varieties there being very numerous. They export the fruit to every quarter of the globe. The kernel of the almond is the part used, and when it is green, ripe, or dried, it furnishes a most agreeable addition to the dessert. It is also used to a very great extent in confectionary, perfumery, cookery, and medicine.

The general purpose of introducing the tree into gardens and pleasure grounds in England is for the great beauty of its blossoms, which are not only handsome, but being produced in such profusion as they usually are at so early a period of the spring season, before the foliage appears, become extremely conspicuous and highy ornamental; a circumstance which renders the tree a most desirable shrubby plant.

The common almond, and its varieties, blos. som earlier than the dwarf kinds, from which circumstance the blossoms of the latter are very rarely damaged by spring frosts, but the other kinds, when planted in situations sheltered from the east winds, are generally preserved from sustaining damage.

Propagation.-All the species and varietses are propagated by seeds, budding, grafting, layers, and occasionally they will produce suckers, which may be successfully planted out. When stocks for budding or grafting upon are wanted, or new varieties desired, these are obtained by sowing the fruit stones, though they may be budded or grafted on mussel-plum stocks.

The stones of the last season's produce should be sown in October, upon a bed of light rich soil, about three inches a part, and cuveres four inches deep with fine soil. This is indis. pensable; for when the soil is left in lumps, the 
shoots are often forced into a croolred direction, and this causes the trunk to be deformed, and unfit to become a fine tree. When the surface of the seed-bed has been smoothed, a covering of rotten tanner's bark, or leaf mould, to the depth of two inches, must be laid upon it, which being light, prevents the fruit-stones from being damaged by any severity of winter. At the beginning of May this covering of bark or leaves must be raked clean off the bed. The stones might be reserved till spring, and be sown at the end of March, but the plants do not come so certainly as when sown in autumn. An additional advantage of an autumn sowing is, that the plants come up about six weeks or two months earlier than those sown in spring; consequently the plants become vigorous and well rooted the first year, and thereby not liable to be thrown out of the ground by thaws succeeding frost in the following winter.

During summer, care must be taken to pull up all weeds, when very young, for if they be allowed to get strong before pulling out, this operation is apt to injure the roots of the almond plants.

When almond stones have been sown in spring, it will be necessary at the approach of the succeeding winter to have the beds covered with rotten tanner's bark, or leaf mould, scattering it an inch deep, or more, amongst the plants, a covering which will tend to prevent the plants being injured or thrown out by frost.

In the second spring after the sowing, the plants should be taken up, carefully preserving all the fibrous roots, a care which, as they are but sparingly produced, will be essentially necessary. The plants must be transplanted in rows, at two feet apart, row from row, and a foot and a half distant in the rows. Here they may be trained to form standards, half standards, or dwarfs, and be regulated and prepared either for wall training or shrubbery plantations. For both purposes, attention will be requisite during summer and winter, to thin out the branches, reserving only a suitable number for the future limbs of the tree, and these so far apart that they may not, in any future stage of growth, be liable to rub against each other, which standard trees would be liable to; for if this be not avoided, gum would be exuded at such injured parts, and the speedy decay of the tree be the consequence.

Almond plants intended for training against walls should have some stakes fixed in the form of a trelis, to which the branches should be secured in a proper form, so that they may be suited to the position of the wall on their final removal. (Miller's $D$ clionary.)

[In many parts of the Middle and Southern United States, the climate admits the almond tree to mature its fruit. The kind with a hard and smooth shell will ripen in New Jersey and the southern part of Pransylvania, near Philadelphia. A communication published in the 15 th vol. of the American Farmer states that the more tencier and valuable soft-shell kind have been brought to perfection at Cambden, Kent County, Delaware, which is about eighty miles south of Philadelphia.]
ALOPFCURUS. A genus of grasses of the foxtail kind, of which there are several species, some of which may be cultivated to advantage in the field.

Al pecurus agrestis. Slender foxtail-grass. (Alopecurus myosuroides, Curt. Lond.) One of the most inferior species of this grass. The herbage it produces is comparatively of nc value whatever. It appears to be left untouched by every description of cattle. The seed is produced in considerable abundance, and is eaten by the smaller birds, as well as by pheasants and partridges. This annual species of foxtail-grass is distinguished from the perennial meadow foxtail (Alopecurus protensis) by the total want of woolly hairs on the spike, so conspicuous in that of the $A$. pratensis. The Rev. G. Swayne observes, that it is a very troublesome weed in many places among wheat, and execrated by farmers under the name of black bent.

"I have always," says Mr. Sinclair, "found it prevalent in poor soils, particularly such as had been exhausted by avaricious cropping. It is most difficult to extirpate when once in possession of the soil ; for it sends forth flowering culms during the whole summer and autumn, till frost arrests it; so that it can bear to be repeatedly cut down in one season, without suffering essentially by the process. Indeed, it will be found a vain and unprofitable labour to attempt the removal of this grass by any other means than the opposite to that which gave it possession of the soil, which is judicious cropping. To return land, in this state, to grass, in the hope of overcoming this unprofitable plant, will be found of little avail. I have witnessed this practice, and the slender foxtail, instead of disappearing in these instances, re-appeared with the scanty herbage, and in greater health and abundance. The soil must first be got into good heart by very moderate and judicious cropping, which includes the proper application of manure, a skilful rotation of crops, and the most pointed attention to the destruction of weeds; which last can only be effected, in this sense, by adopting the drill or row culture for the crops After this the land may be returned to grass for several years with every prospect of success. It flowers in the first week of July, and successively till October.

Alopecurus arundinaceus. Reed-like foxtailgrass. The substance of the culms and leaves of this grass is coarser than that of the Alope. curus pratensis; and the root is so powerfully creeping as to render its introduction into arable land a matter of great caution. The produce and nutritive powers are very considerable: it is an early grass, producing culms at an early period of the spring, and continuing to vegetate vigorously through the summer and autumn. It cannot be recommended as a constituent of permanent pasture; but as a grass to cultivate by itself, to a certain extent, for green food, or for hay, it offers advantages in the superior produce and nutritive powers above stated. It grows stronger, and attains to a greater height, than the $A$. Tauntuniensis; but, owing to the roots spreading wide, being large, and requiring a consequent greater sup. 


\section{ALOPECURUS.}

ply of nourishment from the soil, the produce stands thinner and proves less weighty than the crops afforded by that variety. It flowers in April or early in May, and continues to produce flowering culms until the autumn.

Alopecurus bulbosus geniculatus. Bulbousrooted, knee-jointed, foxtail-grass. The produce and nutritive powers of this perennial grass are so inconsiderable as to justify a conclusion that it is comparatively of no use to the agriculturist. I have found it but seldom in a wild state: It grows on a soil of a drier sature than the fibrous-rooted variety, to be spoken of hereafter. When raised from seed on a moist soil, it still retains the bulbous root, which goes the length to prove, that if it is not a distinct species, it is at least a permanent variety.

Alopecurus geniculatus. Knee-jointed, foxtailgrass. There are two varieties of this species of foxtail-grass: the present, which is by far the more common, is distinguished from the other by its fibrous root and greater size; the less common variety has a bulbous root. The A. bullosus may be distinguished from the bulbous-rooted variety of the knee-jointed species, by its upright culms, which want the kneejointed form so conspicuous in the culms of the former. (Sm. Engl. Flora.) It is a perennial, and grows commonly in surface drains, and at the entrance of cattle ponds, particularly where the soil is clayey. It does not appear to be eaten with much relish by either cows, horses, or sheep. Its nutritive powers are not considerable, and its sub-aquatic natural place of growth excludes any recominendation of it for cultivation. Flowers in the first week of June, and during the summer. [This species is designated by Professor Dewey as the true fortail-grass, which in Massachusetts grows in wet, muddy bottoms, flowering in July.]

Alopecurus pratensis. Meadow foxtail-grass. [See Plate 5, of Pasture Grasses, g.] This grass is a native of Britain and most parts of Europe, from Italy, through France, Germany, Holland, to Denmark, Norway, Sweden, and Russia.

Under the best management, it does not attain to its fullest productive powers from seed till four years; hence it is inferior to the cock's-foot grass for the purposes of ultimate cropping, and to many other grasses besides. The herbage, however, contains more nutritive matter than that of the cock's-foot, though the weight of grass produced in one season is considerably less. It thrives well under irrigation, keeping possession of the crowns of the ridges; and is strictly permanent. Sheep are very fond of it; when combined with white clover only, the second season on a sandy loam, it is sufficient for the support of five couple of ewes and lambs per acre. As it only thrives in perfection on lands of an intermediate quality as to moisture and dryness, and also being somewhat longer in attaining to its full productive state than some other grasses, its merits have been misunderstood in many instances; and in others, as in the alternate husbandry, it has $\mathrm{I}$ en, by some persons, set aside altogether.

\section{ALOPECURUS.}

In many rich natural pastures, it constilates the principal grass. Though not so well adapted, therefore, for the alternate husbandry, it is one of the best grasses for permanent pasture, and should never form a less proportion than one-eighth of any admixture of different grasses prepared for that purpose; its merits demand this, whether in respect to early growth, produce, nutritive qualities, or permanency. It has been observed by the Rev. Mr. Swayne, (in his Grumina Pascua, a work which contains much valuable information on the subject of grasses), that nearly two-thirds of the seed is constantly destroyed by insects: according to my experiments, this evil may be almost entirely obviated by suffering the first culms of the season to carry the seed. It flowers in April, May, and June, according as it may have been depastured earlier or later. Seed ripe in June and July, according to the season of flowering. The meadow-foxtail constitutes part of the produce of all the richest pastures I have examined in Lincolnshire, Devonshire, and in the vale of Aylesbury. In Mr. Westcar's celebrated pastures at Creslew I found it more prevalent than in those of Devonshire and Lincolnshire.

Experiments tend to prove that there is nearly three-fourths of produce greater from a clayey loam than from a silicious sandy soil, and that the grass from the latter soil is of comparatively less value in the proportion of 3 to 2 . The culms produced on the sandy soil are deficient in number, and in every respect smaller than those from the clayey loam; which satisfactorily accounts for the difference in the quantity of nutritive matter afforded by equal quantities of the grass. It is not the strength and rankness of the grass that indicates the fitness of the soil for its growth, but the number and quality of the culms. The proportionate value in which the grass of the latter-math exceeds that of the flowering crof is as 4 to 3 ; a difference which appears extra. ordinary when the quantity of flowering culms is considered. In the Anthrxanthum odorat'sm the proportional difference is still greater, the latter-math being to the flowering crop in nutriment nearly as 9 to 4 . In the $P$ oa trivialis they are equal; but in all the later-flowering grasses that have culms resembling tho, e of the meadow-foxtail and sweet-scented vernal, the greater proportional value is always, on the contrary, found in the grass of the flowering crop. Whatever the cause may be, it is evident that the loss sustained by taking these grasses at the time of flowering is consider able. In ordinary cases, this seldom happens in practice, because these grasses perfect their seed about the season when hay-harvest generally commences, unless where the pasture has been stocked till a late period in the spring, which cannot, in this respect, be productive of any ultimate advantage, but rather loss. The proportional value which the grass, at the time the seed is ripe, bears to that at the time of flowering is as 3 to 2 . The superiority of the produce from a light loam over that from a clayey soil is as 4 to 3 .

Alupecurus Tuuntonensis Taunton's meadc 
fortail-grass. This holds a middle station be- $/$ veral species of Alopecurus, may eas ly be seen tween the Alupecurus pratensis and Alopecurus arundinaceus.

by a reference to the following analytical classification (Sinclair's Hort. Gram.) :-

The produce and nutritive powers of the se-

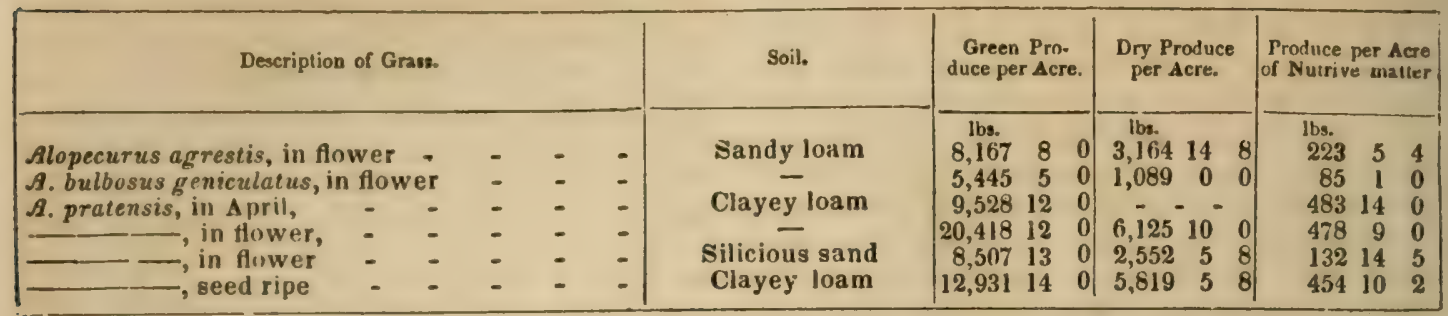

ALPACA. A peculiar breed of Peruvian sheep, for whose introduction into England considerable efforts have been recently made. A very excellent "Memoir" upon these interesting animals has recently (1841) been published by Mr. William Walton, from whose work are gathered the following interesting facts :-" When the Spanish adventurers under Pizarro crossed the isthmus of Panama and reached the shnrcs of the Pacific, they bent their steps ands Peru, and arriving there found the inhabitants in possession of two domestic animals, the beauty and utility of which excited their admiration. They also ascertained that two others, alike in species, although varying in properties, existed in a wild state. Struck with the analogy, and always disposed to see objects of comparison with the productions of their own land, the Spaniards called this new breed of cattle Carneros de la tierra, or country sheep, and in their use of them imitated the natives. Acosta, one of the earliest naturalists who embarked for the New World, wrote an account of these interesting animals, derived from personal observation; and that account, which made its appearance in 1590, is perhaps the best ever penned. He says (Historia Natural y Moral de los Indias, lib. iv. c. 41), "There is nothing in Peru more useful, or more valuable, than the country sheep called llamas, and they are as economical as they are profitable. From them the natives obtain both food and clothing, as we do in Europe from sheep, and besides use them as beasts of burden. They require no expense in either shoeing, packsaddles, bridles, or even barley, serving their masters gratuitously, and being satisfied wiih herbage picked up on the wastes. Thus did Providence provide the Peruvians with sheep and beasts of burden united in the same animal, and on account of their poverty, seems to have wished that they should enjoy this advantage, free from expense, as pastures in the highlands are abundant. These sheep are divided into two kinds; the one called prico bears a heavy fleece of wool, while the others have only a short coat, and are better adapted for carrying burdens. They have a long neck, similar to the camel, and this they require; for being tall and upright, they stand in need of an elongated neck to reach their food. The colours of both animals vary, some being entirely white, others entirely black, and occasionally particoloured. The meat is good, that of the fawn is best and most delicate, although the Indians use it spa- ringly, their principal object in rearing this breed of cattle being to avail themselves of its wool for clothing and of its services to carry loads. The wool they were accustomed to spin and weave into garments, one of their kinds of cloth, called huasca, being coarse and in more general use; while the other, known by the name of cumbi, was of a finer and more delicate quality. Of the latter they still make mantles, table-covers, quilts, and various articles of ornamental dress, which are durable, and have a gloss upon them, as if partly made of silk. Their mode of weaving is peculiar to themselves, each side of the web being alike; nor in a whole piece is it possible to discover an uneven thread or a knot. The Peruvian incas, or emperors, kept experienced master to teach the art of making the cumbi, or superfin: cloth, the principal part of whom resided in the district of Capachica, where they had public establishments, and with the aid of plants gave to it various colours, bright and lasting. The men and women in the highlands were mostly manufacturers, having looms in their own houses, which precluded the necessity of going to market to purchase clothing."

"The Indians still possess large droves, consisting of 400 , or 1000 head each, which they load, and with them perform journeys, travelling like a string of mules and carrying wine, coca, corn, chuño (a nutritive food made from potatoes, first frozen, and afterwards reduced to powder), quicksilver, and other articles of merchandise, and more especially that which, of all others, is the most valuable, viz., silver, ingots of which they bear from Potosi to Arica, a distance of seventy leagues, as they formerly did to Arequipa, more than twice as far. Often have I been astonished at seeing these droves carrying 1000 or 2000 ingots, valued at more than 300,000 ducats, journeying slowly on with no other guard than a few Indians, who chiefly served to load and unload, or, at mo: t, two or three Spaniards. They sleep in the open country; and though the journey is long, and the protection afforded so extremely weak, no part of the silver is ever missing. 'The load usually carried by each animal is from four to six arrobas, (each arruba has twenty-five lbs.); and if the journey is long they do not travel beyond three or four leagues per day. The drivers have their known resting-places, where they find pasture and water, and on arriving there, unload, pitch their tents, light a fire and dress their own food, while the bearers of their burdens are turned out loose." 


\section{ALPACA.}

He further remarks that the flesh of these animals was jerked and made into cusharqui, or, as the Spaniards call it, cecinu, which kept good for a considerable time, and was in very general request. "Both species," he says, " ure uccustomed to a cold climate, and thrive best in the highlands. Often does it happen that they are covered with snow and sparkling with icicles, and yet healthy and contented." speaking of the vicunas, the same author observes that they are wild and timid, inhabiting the punas, or snowy cliffs, and are affected by neither rain or snow. To this he adds that they are gregarious, extremely fleet, and that on meeting a traveller, or beast of the forest, they fly away, collecting and driving their young before them. He further affirms that the vicuna wool is as soft as silk, made into fine stuffs, and requires no dyeing; adding, that many persons also considered it medicinally useful in cases of pains in the loins and ather parts of the body, in consequence of which they had mattresses made of it.

Inca Garcilasso de la Vega, a native of Peru, was the next Spaniard of note who described the Carneros de la tierra, and subjoined are his leading remarks:- "The domestic arimals which God was pleased to bestow on the Indians, congenial to their character and like them in disposition, are so tractable that a child may guide them, more particularly those accustomed to bear burdens. Generally they are called llamas, and the keeper llama-michec. As a distinction, the larger kind is called huunacu-llama, owing to its resembling the wild one of that name, from which it only differs in colour, the tame breeds being seen of all hues, whereas the wild ones have only one, and that is a light brown. The height of the domestic breeds is that of a deer, and to no animal can they be likened so justly as the camel, excepting that they are smaller and have no hunch an the back. The skin was anciently steeped in tallow, in order to prepare it, after which the Indians used it for shoes, but the leather not being tanned, they were obliged to go barefooted in rainy weather. Of it the Spaniards now make bridles, girths, and cruppers for saddles. The llama formerly served to bear loads from Cusco to the mines of Potosi, in droves of 800 or 1000 , each animal carrying three or four arrobas. The paco was chiefly valued for its flesh, but more especially for its wool, long, but excellent, of which the natives made cloths, and gave to them beautiful and never-fading colours."

The Peruvian sheep are peculiar to that part of South America, bordering on the $\mathrm{Pa}$ cific, which extends from the equator beyond the tropic of Capricorn, that long and enormous range of mountains known as the Andes Cordilleras. Along this massive pile every imaginable degree of temperature may be found in successive gradation. Below stretches a narrow strip of land, washed by the sea, where the heat is intense and it never rains, but where, owing to heavy dews and filtration from the mountains, vegetation is luxuriant and an eternal spring reigns. As one ascends, the aspect of the country changes, and new plants appear; but no sooner are the middle
ALPACA.

summits gained, and the sun has lost his power, than those cold and icy regions rise up, one above the other, called by the natives punss, which are again crowned with rocky crests, broken by deep ravines and rugged chasms, and presenting a wilderness of crags and cliffs never trodden by the human footstep, and never darkened, except by a passing cloud, or the eagle's wing. In this land of mist and snow, or rather in the hollows which sur. round it, feed the guanaco and vicuña, at an elevation of 12,000 or 14,000 feet above the level of the sea; while in the lower regions, stretching immediately under the snowy belt, and where the Indian fixes his abode at a height from 8,000 to 12,000 feet, may be seen pasturing those flocks of llamas and alpacas which constitute his delight, and at the same time the principal part of his property.

Here, amidst broken and precipitous peaks, on the parapets and projecting ledges, slightly covered with earth, or in the valleys formed by the mountain ridges, like the Pyrenean chamois, the llama and alpaca pick up a precarious subsistence from the mosses, lichens, tender shrubs, and grassy plants which make their apppearance as the snow recedes; or, descending lower down, revel in the pajonales, or, as they are called in some parts of the country, ichualts-natural meadows of the ichus plant, the favourite haunts of the tame and wild kinds. Thus the hand of man never prepares food for either species-both readily find it on their native mountains. Besides the extremes of cold, these animals have equally to endure the severities of a damp atmosphere, for while below it seldom rains, in the summer months, when evaporation from the sea is abundant, clouds collect, and being driven over the lower valleys by strong winds from the south and west, and condensed by the cold, burst on the highlands, where the rain falls in torrents, amidst the most awful thunder and lightning.

However bleak and damp the situation, little does it matter for an animal requiring neither fold nor manger, and living in wild and desolate places, where the tender is often obliged to collect the dung of his flock to serve as fuel for himself. Although delicate in appearance, the alpaca is, perhaps, one of the hardiest anjmals of the creation. His abstinence has already been noticed. Nature has provided him with a thick skin and a warm fleece, and as he never perspires, like the ordinary sheep, he is not so susceptible of cold. There is, therefore, no necessity to smear his coat with tar and butter, as the farmers are obliged to do with their flocks in Scotland, a process which, besides being troublesome and expensive, injures the wool, as it is no longer fit to make into white goods, nor will it take light and bright colours. In the severest winter the alpaca asks no extra care, and his teeth being well adapted to crop the rushes and coarse grass with which our moors abound, he will be satisfied with the refuse left upon them. In a word, he would live where sheep must be is danger of starving.

The importations of sheep's wool from Pera into Liverpool, principally alpaca, have stead 
ily advanced since the article became known | from the ordinary kinds arriving fi.in Pera, to the manufacturer,-the best proof of its The total imports for the last five years of all worth. In 1835 they amounted to 8,000 bales; sheep's wool, distinguishing from Peru (includin 1836 , to 12,800 ; in 1837 , to 17,500 : in 1838 , ing alpaca) and other parts, and also of red, to 25,765 ; in 1839 , to 34,543 ; and in 1840 , to or vicuna wool, together with raw and thrown $\mathbf{3 4 , 2 2 4 - m o r e ~ t h a n ~ q u a d r u p l e d ~ i n ~ s i x ~ y e a r s . ~ s i l k s , ~ a n d ~ g o a t ' s ~ h a i r ~ o r ~ w o o l , ~ a n d ~ m o h a i r ~}$

In the Custom House returns, it is to be re- yarn, are here subjoined :gretted that alpaca wool is not distinguished

\begin{tabular}{|c|c|c|c|c|c|c|}
\hline & & 1836. & 1837. & 1638. & 1839. & 1840. \\
\hline $\begin{array}{l}\text { Sheep's wool : } \\
\text { From Peru } \\
\text { Other parts }\end{array}$ & $\overline{-}$ & $\begin{array}{l}162 . \\
953,974 \\
63,284,677\end{array}$ & $\begin{array}{c}\text { Ibs. } \\
1,914,137 \\
46,464,957\end{array}$ & $\begin{array}{r}\text { lbs. } \\
2,303,794 \\
50,289,846 \\
\end{array}$ & $\begin{array}{c}\text { Ibs. } \\
2,145,106 \\
55,228,349\end{array}$ & $\begin{array}{r}\text { Ibs. } \\
2,762,439 \\
46,630,638\end{array}$ \\
\hline Total & - & $64,238,651$ & $48,379,094$ & $52,593,640$ & $57,373,455$ & $49,393,077$ \\
\hline $\begin{array}{l}\text { Red Wnol: } \\
\text { From Peru } \\
\text { Other parts }\end{array}$ & - & $\begin{array}{r}1,248 \\
78\end{array}$ & $\begin{array}{c}614 \\
- \\
\end{array}$ & $\begin{array}{r}294 \\
421 \\
\end{array}$ & $\begin{array}{l}4,465 \\
2,003 \\
\end{array}$ & $\begin{array}{r}7,940 \\
34,377 \\
\end{array}$ \\
\hline Total & - & 1,326 & 614 & 715 & 6,468 & 42,317 \\
\hline $\begin{array}{l}\text { Raw silk } \\
\text { Thrown silk } \\
\text { Goat's hair or wool } \\
\text { Mohair yarn }\end{array}$ & - & $\begin{array}{r}4,453,081 \\
396,600 \\
1,117,629 \\
89,298\end{array}$ & $\begin{array}{r}4,146,481 \\
231,203 \\
602,373 \\
29,199\end{array}$ & $\begin{array}{r}3,458,959 \\
265,130 \\
942,770 \\
20,546\end{array}$ & $\begin{array}{r}3,746,248 \\
225,268 \\
992,188 \\
13,645\end{array}$ & $\begin{array}{r}3,758,841 \\
288,994 \\
989,257 \\
2,664\end{array}$ \\
\hline
\end{tabular}

With regard to the number of these sheep now in England, and their capability of being naturalized, Mr. Walton adds, "Mr. Bennett, of Farindon, had a pair of llamas sent to him from Peru twenty years ago, and fed them as sheep are usually fed, with hay and turnips in the winter. From his own experience he found that they are particularly hardy and very long-lived. He increased his stock, and has actually had six females at a time which have had young ones. Of these very few have died. The number of Peruvian sheep in the kingdom at present (July 1841) [is short of 100, chiefly distributed in parks]. The existence of this number among us, supported by their healthy appearance, as reported to me from every quarter where I have been able to institute inquiries, is a better proof of the capacity of Andes sheep to adapt themselves to our climate, than any further arguments or elucidations which I could adduce."

[The demand for alpaca wool in England, which the table indicates is rapidly increasing, certainly shows that it is well worthy the attention of North American farmers to make the experiment of raising Peruvian sheep. At a late meeting of the British Association for the Advancement of the Arts and Sciences, Mr. Dawson made a communication on the subject of the introduction into England, of a species of Auchenia, or Llama of South America, and presented specimens of alpaca wool, in its natural and manufactured states, resembling silk, and without being dved, as black as jet. Naturalists distinguish five species of the llama, all of which afford wool. But the alpaca alone has fine wool, from six to twelve inches long, and the vicuna wool, like the fur of the beaver, at the base of its coarser hair. It is capable of tire finest manufacture, and is especially adapted to such fabrics as the finest shawls. The yarns spun in England are mostly sold in France for the shawl trade, at from $\$ 1.50$ to $\$ 3.50$ per pound, according to quality, the price of the wool in a natural state being about fifty cents per pound. This wool is naturally free from grease, in which respect it differs materi76 ally from that of common sheep, and the animal requires no washing before shearing. $\mathrm{Mr}$. Dawson remarked, that it was not certain whe her the alpaca could be made to thrive in Great Britain. The last remark might raise a doubt whether it could be raised to advantage in the United States. Should it be proved that the alpaca was not adapted to any part of Great Britain, it would furnish no solid argument against their adaptation to the climate of the United States, especially the Northern States, and the mountainous districts everywhere. An interesting account of this animal will be found in the third volume of the American Farmer.]

ALTERATIVE MEDICINES. In farriery, are such medicines as possess a power of changing the constitution, without any sensible increase or diminution of the natural evacuations.

ALTERNATE HUSBANDRY. That sort of management of farms, which has one part in the state of grass or sward, while the other is under the plough, so as to be capable of being changed as there may be occasion, or as the nature of the land may require. This sys. tem of management is supposed to lessen the expense of manure, and keep the land more clean. (See Husbandry.)

ALTITUDE (Lat. alitudo, from altus, high). In vegetable physiology, altitude or elevation of surface above the level of the sea is equivalent to a receding, whether north or south, from the line of the equator, 600 feet of altitude being thought to be equal to a degree [of latitude.] Hence it follows that all varieties of climate, and consequently all varieties of vegetable habitat, may exist even in the same latitude, merely by means of variety in the altitude of the spot. This was found by Tournefort to be literally the fact, during his travels in Asia. At the foot of Mount Ararat he met with plants peculiar to Armenia; above these he met with plants which are found also in France; at a still greater height he found himself surrounded with such as grow in Sweden, and at the summit, with such as vegetate in 
the pular regions. Baron Humboldt, in his Personal Nurrative, gives us a similar account of the several zones of vegetation existing in a height of $\mathbf{3 7 3 0}$ yards on the ascent of Mount Teneriffe. The first zone is the region of vines, extending from the shores of the ocean to a height of from 400 to 600 yards, well cultivated, and producing date trees, plantains, olives, vines, and wheat. The second zone is the region of laurels, extending from about 600 to 1800 yards, producing many plants with showy flowers, and moss and grass beneath. The third zone is the region of pines, commencing at 1920 yards, and having a breadth of 850 yards. The fourth zone is the region Retama, or broom, growing to a height of nine or ten feet, and fed on by wild goats. The last zone is the region of grasses, scantily covering the heaps of lava, with cryptogamic plants intermixed, and the summit of the mountain bare.

This accounts for the great variety of plants which is often found in no great extent of country; and it may be laid down as a botanical axiom, that the more diversified the surface of the country, the richer it will be in species, at least in the same latitudes. It accounts, also, for the want of correspondence between plants of different countries, though placed in the same latitudes; because the mountains, or ridges of mountains, which may be found in the one and not in the other, will produce the greatest possible difference in the character of the genera and species. To this cause we may ascribe the diversity that often actually exists between plants growing in the same country and in the same latitudes; as between those of the north-west and north-east coasts of North America, as also of the south-west and south-east coasts; the former being more mountainous, the latter more flat. Sometimes the same sort of difference takes place between the plants of an island and those of the neighbouring continent; that is, if the one is flat and the other mountainous; but if they are alike in their geographical delineation, they are generally alike in their vegetable productions.

[Meteorologists generally compute, that as land rises above the level of the sea or tidewater, the temperature of its climate grows colder at the rate of $1^{\circ}$ Fahrenheit, for every 300 feet or 100 yards of elevation. It has however been found that the decline of temperature on rising above the common level of the sea, is less where large tracts of country rise gradually than when the estimate is made either by balloon ascension, or scaling the sides of isolated and precipitous mountains. A striking illustration of this is offered by the ridges and valleys of the great Himmaleh mountains of Southern Asia, where immense tracts, which theory would consign to the dreariness of perpetual congelation, are found richly clothed in vegetation and abounding in vegetable and animal life. At the village of Zonching, 14,700 feet above the level of the sea, in lat. $31^{\circ} 36 \mathrm{~N}$. Mr. Colebrook found flocks of sheep browsing on verdant hills; and at the village of Pui, at about the same elevation, there are produced, according to Captain Gerard, the most luxuriant crops of barley, wheat, and turnips, whilst a little lower the ground is covered with vineyards, groves of apricots, and many aromatic plants.

The effects of gradual elevation in lessening the falling off of temperature, is manifested upon a moderate scale in our own country. 'The [annual] mean temperature of Eastporh, Me., for example, is $42^{\circ} .95$, whilst that of Fort Snelling in the same latitude, but far in the interior, with an elevation of some 600 or 800 feet above the sea, is $2^{\circ} .88$ higher, namely, $45^{\circ} .83$, instead of being two or three degrees colder, to correspond with the law of elevation. (Amer. Med. Juur. July, 1842.)]

ALUM (Lat. Alumen). The sulphate of alumina and potash of the chemist, for common alum], is composed, according to the analysis of Berzelius (Ann. de Chim. 82-258), of

$$
\begin{aligned}
& \text { Sulphuric acid } \\
& \begin{array}{l}
\text { Alumina } \\
\text { Potash }
\end{array} \\
& \text { Water } \\
& 34.23 \\
& 1086 \\
& 981 \\
& 4500 \\
& \overline{99.90}
\end{aligned}
$$

In veterinary practice, alum in powder is sometimes used externally for destroying trifling excrescences, arresting bleeding, \&c. A little, very finely powdered, is occasionally blown through a quill into the eye for the purpose of removing specks of long standing.

Alum lotion is prepared by dissolving from six to eight drachms of alum powder in two pints of water. This forms an inexpensive and tolerably efficacious application for mild forms of grease, cracks in the heels of horses, and for superficial sores of all kinds. It should not be used till the surrounding inflammation has been subdued by time or proper remedies. In its weakest state, the alum lotion is serviceable in the cankered ear of dogs, and wounds or ulcers of the mouth in any animal.

Alum ointment is composed of one drachm of the powder to one ounce each of turpentine and hog's lard, incorporated by heating. This supplies the place of the lotion when the sores are apt to become dry and hard. It is, however, very little used.

Burnt alum is made by boiling a solid piece of the salt on an iron plate over a fire till it becomes quite dry and white, taking care not to make the heat so strong as to decompose it. This, in powder, is sometimes used for specks in the eye. (Miller's Dictionary.)

ALUMINA. The pure earth of clay, was so named from having been obtained in a state of the greatest purity from alum, in which salt it exists combined with sulphuric acid, and potash. This earth when pure has but little taste, and no smell. The earthy smell which clay emits when breathed upon, is owing to the presence of oxide of iron. Its specific gravity is $2 \cdot 00$. When heated it parts with a portion of water, and its bulk is considerably diminished. Hence most clay lands are apt to crack, by their contraction in dry weather. There is little doubt, from the experiments of Davy, but that alumina is the oxide of a metal, which has been denominated aluminum, although he did not succeed in procuring it in a separate state.

of all the earths alumina is found in plants in the smallest proportions, 32 ounces of the 


\section{ALVEARIUM.}

seeds of wheat only contain 0.6 of a grain, and those of the barley and the oat only aboul 4 grains.

If some clay be dissolved in water, and some nqua ammonia (hartshorn) be added to it, the mixture will assume a milky whiteness, and if left to stand awhile, a white substance will be precipitated, called in chemical language alumina. Prof. J. F. W. Johnston does not regard this as a nourishing element to plants. Its use in soils he considers entirely mechanical, binding the other materials together by its tenacity, so as to furnish that degree of stiffness necessary for the support of plants. Liebig takes a different view of the subject. "It is known," he says, "that the aluminous minerals are the most widely diffused on the suface of the earth, and, as we have already mentioned, all fertile soils, or soils capable of culture, contain alumina as an invariable constituent. There must, therefore, be something in aluminous earth which enables it to exercise an influence on the life of plants, and to assist in their developement. The property on which this depends is that of its invariably containing potash and soda.

"Alumina exercises only an indirect influence on vegetation, by its power of attracting and retaining water and ammonia; it is itself very rarely found in the ashes of plants, but silica is always present, having, in most places, entered the plants by means of alkalies." (Lie-

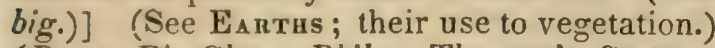
(Davy, El. Chem. Phil.; Thomson's System; Professor Schübler, Jour. Roy. Ag. Soc. vol. i. p. 177; [Liebig's Organic Chem.])

ALVEARIUM. A term sometimes employed to signify a bee-hive.

AMAUROSIS. In farriery, is a total blindness, without any altered appearance in the eye. [This irremediable affection proceeds from a paralysis of the nerve of sight, or optic nerve.]

AMBLE. In horsemanship, is a peculiar kind of pace, in which both the horse's legs of the same side move at the same time. In this pace the horse's legs move nearer to the ground than in the walk, and at the same time are more extended: but what is most extraordinary in it is, that the two legs of the same side, for instance, the off hin $\hat{i}$ and fore leg, move at the same time; and then the two near legs, in making another step, move at once; the motion being performed in this alternate manner, so that the sides of the animal are alternately without support, or any equilibrium between the one and the other, which must necessarily prove very fatiguing to him, being obliged to support himself in a forced oscillation, by the rapidity of a motion, in which his feet are scarcely off the ground. For if in the amhle he lifted his feet as in the trot, or even in a walk, the oscillation would be such, that he could not avoid falling on his side.

Those who are skilled in horsemanship observe, that horses which naturally amble, never trot, and that they are considerably weaker than others. Colts often move in this manner, especially wisen they exert themselves, and are not strung enough to trot or gallop. Most gond hnrses, which have been "ver-worked, and $n$, the decline, are also observed voluntarily tr. amlile, when forced to a 78
AMERICAN BLIGHT.

motion swifter than a walk. The amble may, therefore, be considered as a defective pace, not being common, and natural only to a very few horses, which, in general, are wealrer than others. Add to this, that such amblers as seem the strongest are spoiled sooner than those which trot or gallop.

AMEL-CORN. A diseased sort of grain, [resembling spelt.]

AMELIORATING CROPS. In husbandry, are such as are supposed to improve the lands on which they are cultivated. Carrots, turnips, artificial grasses, such as contain a large proportion of nutritious materials, and many other green vegetable products, especially if fed off, [or ploughed in,] are considered as ameliorating; but all kinds of crops, carried off the land, are in some degree or other exhausters of the ground; and green crops, such as have been just mentioned, are only less so than crops of grain or other ripe vegetables. The improvement of lands, therefore, by what are commonly termed ameliorating crops, depends, in a great measure, upon the culture which the ground receives while they are growing, and the returns which they make to it in the way of manure, after being consumed by animals.

AMELIORATING SUBSTANCES. In agriculture, are such substances, as, when applied to land, render it more fertile and productive.

AMERICAN BLIGHT. [A popular, but very inappropriate name used in England to designate the injurious effects upon apple trees caused by a species of plant-louse or Aphis, (the Eriosoma muli, of Leach, and the Aphis lanigera, of Illiger.) Its American origin is rendered dombtful from the fact that nurserymen in the Middle States have never witnessed the mischievous effects described as common in Europe from this kind of blight.] A de. tailed account of the insect is given in the Journal of a Naturalisl, which, with the correction of a few errors and oversights of the author, we shall now follow.

Early in summer, and even in spring, about March, a slight hoariness is observed upon the branches of certain species of our orchard fruit. As the season advances this hoariness increases, and becomes cottony; and toward the middle or the end of summer, the upper sides of some of the branches are invested with a thick, downy substance, so long as at times to be sensibly agitated by the air. Upon examining this substance, we find that it conceals a multitude of small, wingless creatures, which are busily employed in preying upon the limb of the tree beneath. This they are well enabled to do, by means of a beak terminating in a fine bristle; this being insinuated through the bark, and the sappy part of the wood, enables the creature to extract, as with a syringe, the sweet, vital liquor that circulates in the p.ant.

This terminating bristle is not observable in every individual, from being usually, when not in use, so closely concealed under the breast of the animal, as to be invisible. In the younger insects it is often manifested by protruding, like a fine termination, to the vent (amus); but as their bodies become lengthened, the bristle is not in this way observable. The pulp wood (alburnum) being thus wound- 
ed, rises up in excrescences and nodes all over the branch, and deforms it; the limb, deprived of its nutriment, grows sickly; the leaves turn yellow, and the part perishes. Branch after branch is thus assailed, until they become leafless, and the tree dies.

Plant lice (Aphides), in general, attack the younger and softer parts of plants; but this insect secms equily to wound the harder bark of the apple, and does not always make choice of the most conder branch. They give a preference to certain sorts, but not always the most rich fruits, as cider apples, and wildings, are greatly infested by them; and from some unknown cause, other varieties seem to be exempted from their depredations. The Wheeler's russet, and Crofton pippin, have never been observed to be injured by them; and the insect is so fastidious in its selections, that it will frequently attack the stock or the graft, leaving the one or the other untouched, should it consist of a kind not to its liking. This insect is viviparous, or produces its young alive, forming a cradle for them by discharging from the extremities of its body a quantity of long, cottony matter; which, becoming intcrwoven and entangled, prevents the young from falling to the earth, and completely envelopes the parent and the offspring. In this cottony substance, we observe, as soon as the creature becomes animated in the spring, and as long as it remains in vigour, many round pellucid bodies, which at the first sight look like eggs, only that they are larger than we might suppose to be ejected by the animal. They consist of a sweet glutinous fluid, and are not the eggs but the discharges of the insects. In the autumn, the winds and rains of the season partly disperse these insects; and we observe them endeavouring to secrete themselves in the crannies of any neighbouring substance. Should the savoy cabbage be near the trees whence they have been dislodged, the cavities of the under sides of its leaves are commonly favourite asylums for them. Multitudes perish by these rough removals, but numbers yet remain; and we may find them in the nodes and crevices, on the under sides of the branches, at any period of the year, the long, cottony vesture being nearly all removed; but still they are enveloped in a fine short downy clothing, to be seen by a magnifier, proceeding apparently from every suture or pore of their bodies, and protecting them in their dormant state from the moisture and frosts of our climate. This insect in a natural state, usually awakens and commences its labours very early in the month of March; and the hoariness on its body may be observed increasing daily; but if an affected branch be cut in the winter, and kept in water in a warm room, these creatures will awaken speedily, spin their cottony nests, and feed and discharge as accustomed to do in a genial season. [For further particulars relating to the habits of these and other similar insects, see Aphis and Aphidians.]

Remedies.-A considerable number of methods have been proposed for getting rid of the insect in question. White-washing, or washing with lime-water, has been tried, but is not so efficacious as the application of any gluti. nous substance, which may coyer the insects and dry over them. Double size or glue, liquefied by heat, and applied by me:tus of a brush, particularly in March, when the insects begin to show more cottony than in winter, is a very effectual remedy, if no crevicen of a tres is left unsized. This, however, mity be dissolved by the rain, and therefore a varnish is recommended by Mr. Knapp, as follows: "M : lt about three ounces of resin in an earthen pipkin, take it from the fire, and pour it into three ounces of fish oil; the ingredients perfectly unite, and when cold, acquire the consistence of honey. A slight degree of heat will liquefy it, and in this state paint over every node or infected part in ycur tree, using a common painter's brush. This I prefer doing in spring, or as soon as the hoariness appears. The substance soon sufficiently hardens, and forms a varnish, which prevents any escape, and stifles the individuals. After this first dressing, should any cottony matter appear round the margin of the varnish, a second application to these parts will, I think, be found to effect a perfect cure. The prevalence of this insect," adds this author, "gives some of our orchards here the appearance of numerous white posts in an extensive drying ground, being washed with lime from root to branch; a practice, I apprehend, attended with little benefit. A few of the creatures may be destroyed by accident; but as the animal does not retire to the earth, but winters in the clefts of the boughs, far beyond the influence of this wash, it remains uninjured, to commence its ravages again when spring returns."

All oily or resinous substances, however, being prejudicial to trees, Mr. George Lindley recommends vinegar as a wash for young trees; and, as less expensive for old trees, a sort of paint, composed of one gallon of quicklime, half a pound of flowers of sulphur, and a quarter of a pound of lamp-black, mixed with boiling water to the consistence of whitening for white-washing, and laying it on rather more than blood warm with a brush. This should be done in March, and again in Augusi when the winged insects spread from tree to tree.

$\mathrm{Mr}$. Couch, as a cheap and certain remedy, recommends three quarters of an ounce of sulphuric acid [oil of vitriol], by measure, to be mixed with seven ounces and a half of water. It should be applied all over the bark by means of rags, the only parts excepted being the present year's shoots, which it would destroy. This destroys moss and lichens, as well as insects; and if applied in showery weather, will be washed into every crevice in which they can harbour.

AMERICAN CRESS (Lepidium tirginicum). From $\lambda e \pi i s$, a scale, on account of the form of the seed-vessel. For the winter stand. ing crops, a light diy soil, in an cpen but warm situation, should be allotted to it, and for the summer, a rather moister and shady border ic to be preferred. In neither instance is it re. quired to be rich. It is propagated by seed. which must be sown every six weelis rom March to August, for summer and autumn, $r_{i: 1}$ 
on'y one sowing is necessary, either at the end of August, or beginning of September, for a supply during winter and spring. It may be sown broadcast, but the most preferable mode is in drills nine inches apart. Water may be given occasionally during dry weather, both before and after the appearance of the plants. If raised from broadcast sowings, the plants are thinned to six inches apart; if in drills, only to three. In winter they require the shelter of a little litter or other light covering; and to prevent them being injured by its pressure, some twigs may be bent over the bed, or some light bushy branches laid amongst them, which will support it. The only cultivation they require is to be kept clear of weeds.

In gathering, the outside leaves only should be stripped off, which enables successional crops to become rapidly fit for use. When the plants begin to run, their centres must be cut away, which causes them to shoot afresh. For the production of seed, a few of the strongest plants raised from the first spring sowing are left ungathered from. They flower in June or July, and perfect their seed before the commencement of autumn. (G.W. Jolenson's Kitchen Garden.)

[This plant in America is commonly called wild pepper-grass. It is frequent in fields and on roadsides in the Middle States.]

AMERICAN GRASS. A term sometimes applied [in England] to a species of agrostis.

AMMONIA. The name given by chemists to the volatile alkali, from its being first prepared in the East from camels' dung near to a temple dedicated to Jupiter Ammon. It is known in commerce under the name of hartshorn, sal volatile, \&c., and is prepared by the dry or destructive distillation of animal substances. It is formed also most commonly wherever animal substances undergo putrefaction. It is composed of

\section{Hydrogen}

Azote or nitrogen

0.125

Ammonia is usually produced in the state of carbonate of ammonia, or united with carbonic acid gas, and in this state, or in fact in combination with most other acids, it forms salts, which possess peculiarly fertilizing properties. This alkali fulfils, there is little doubt, a very important part in many organic manures. It is a very universally diffused substance, has been detected in rain-water and even in snow, and there is little doubt but that it exists, and prejudicially too, to the health of the inhabitants, in the atmosphere of many places crowded with animal life. (Liebig's Organic Chem. 76, 77.) Wherever this alkali is detecte $\cdot$ in a substance, such as it commonly is, for instance, in urine, gas-water, \&c., the most excellent effects may be anticipated to vegeta. tion by its use. Fresh urine contains phosphate of ammonia, muriate of ammonia, and lactate of ammonia, and there is perhaps no fertilizer more powerful in its effects than this.

[One of the most important discoveries bearing upon agriculture perhaps ever made, is that just promulgated by Liebig, of the existence in the atmosphere of ammonia. Davy and other chemists of the highest celebrity had analyzed the air collected from the most sicklv locations where impurities might certainly be expected to exist, but with their nicest tests and best conducted experiments they failed to detect any essential difference in the composi tion of the insalubrious air taken from the deadly coast of Africa, and that collected from the most elevated and healthy parts of Europe. The analyses of the air of the different places all gave the same proportions of the gaseous constituents, namely, oxygen, nitrogen, and carbonic acid. It was evident, therefore, that if other matters, in addition to the gases named and watery vapour, existed in the air, some other means must be found to demonstrate their presence; and happily, the genius of Liebig devised a plan by which this has been effected so far as the presence of ammonia is concerned. He knew that ammonia had a strong affinity for water, by which it is promptly absorbed, and that although it could be diffused through such a great bulk of air as to be placed beyond the reach of chemical tests, it might nevertheless be taken up by rain-water, and washed down in sufficient quantity to become apparent. Experiments made, in his laboratory at Geissen, with the greatest care and exactness, fully confirmed his views, and placed the presence of ammonia in rain-water, and consequently in the atmosphere, beyond a doubt. It had hitherto escaped detection because no one thought of searching for it in the same way. A single rounc? of rain-water contains as much of the gas of ammonia, as is diffused through $2 \varepsilon, 800$ cubic feet of air, namely, only one-fourth of a grain.

"All the rain-water employed in this inquiry," says Liebig, "was collected 600 paces southwest of Geissen, whilst the wind was blowing in $i$ ' e direction of the $10 \mathrm{wn}$. When several hundred pounds of it were distilled in a copper still, and the first two or three pounds evaporated with the addition of a little muriatic acid, a very distinct crystallization of sal-ammoniac was obtained; the crystals had always a brown or yellow colour.

"Ammonia may likewise be always detected in snow-water. Crystals of sal-ammoniac were obtained by evaporating in a vessel with muriatic acid several pounds of snow, which were gathered from the surface of the ground in March, when the snow had a depth of ten inches. Ammonia was set free from these crystals by the addition of hydrate of lime. The inferior layers of snow, which rested upon the ground, contained a quantity decidedly greater than those which formed the surface.

"It is worthy of observation, that the ammonia contained in rain and snow-wrater possessed an offensive smell of perspiration and animal excrements, - a fact which leaves no doubt respecting its origin.

"Any one may satisfy himself of the presence of ammonia in rain, by simply adding a little sulphuric or muriatic acid to a quantity of rain water, and evaporating this nearly to dryness in a clean porcelain basin. The ammonia remains in the residue, in combination with the acid employed; and may be detected either by the addition of a little chloride of platinum, or more simply by a little powdered lime, which 


\section{AMMONIA.}

separates the ammonia, and thus renders its peculiar pungent smell sensible. The sensation which is perceived upon moistening the hand with rain-water, so different from that produced by pure distilled water, and to which the term suftness is vulgarly applied, is also due to the carbonate of ammona contained in the former. A small quantity of ammunia water, added to what is commonly called hard water, will give it the softness of rain or snowwater.

"The ammonia which is removed from the atmosphere by rain and other causes, is as constantly replaced by the putrefaction of ani$\mathrm{mal}$ and vegetable matters. A certain portion of that which falls with the rain evaporates again with the water, but another portion is, we suppose, taken up by the roots of plants, and, entering into new combinations in the different organs of assimilation, produces albumen, gluten, quinine, morphia, cyanogen, and a number of other compounds containing nitrogen. The chemical characters of ammonia render it capable of entering into such combinations, and of undergoing numerous transformations. We have now only to consider whether it really is taken up in the form of ammonia by the roots of plants, and in that form applied by their organs to the production of the azotized matters contained in them. This question is susceptible of easy solution by well-known lacts.

"In the year 1834, I was engaged with Dr. Wilbrand, professor of botany in the university of Giessen, in an investigation respecting the quantity of sugar contained in the different varicties of maple trees, which grew upon soils which were not manured. We obtained crystallized sugars from all, by simply evaporating their juices, without the addition of any foreign substance; and we unexpectedly made the observation, that a great quantity of ammonia was emitted from this juice, when mixed with lime, and also from the sugar itself during its refinement. The vessels, which hung upon the trees in order to collect the juice, were watched with greater attention, on account of the suspicion that some evil-disposed persons had introduced urine into them, but still a large quantity of ammonia was again found in the form of neutral salts. The juice had no colour, and had no reaction on that of vegetables. Similar observations were made upon the juice of the birch-tree; the specimens subjected to experiment were taken from a wood several miles distant from any house, and yet the clarified juice, evaporated with lime, emitted a strong odour of ammonia.

"The products of the distillation of flowers, herbs, and roots, with water, and all extracts of plants made for medicinal purposes, contain ammonia. The unripe, transparent, and gelatinous pulp of the almond and peach emit much ammonia when treated with alkalies. (Robiquet.) The juice of the fresh tobaccoleaf contains ammoniacal salts. The water, which exudes from a cut vine, when evaporated with a few drops of muriatic acid, also yields a gummy deliquescent mass, which evolves much ammonia on the addition of lime. Ammonia exists in every part of plants,
AMMONIA.

in the roots (as in beet-root), in the stem (of the maple-tree), and in all blossoms and fruit in an unripe condition.

"The juice of the maple and birch contain both sugar and ammonia, and therefore aftord all the conditions necessary for the formation of the azotized components of the branchers, blossoms, and leaves, as well as of those which contain no azote or nitrogen. In propurtion as the developement of those parts advancers, the ammonia diminishes in quantity, and when they are fully formed, the tree yields no more juice.

"The employment of animal manure in the cultivation of grain, and the vegetables which serve for fodder to cattle, is the most convinc. ing proof that the nitrogen of vegetables is derived from ammonia. The quantity of gluten in wheat, rye, and barley, is very different; these kinds of grain also, even when ripe, contain this compound of nitrogen in very different proportions. Proust found French wheat to contain 12.5 per cent. of gluten; Vogel found that the Bavarian contained 24 per cent. : Davy obtained 19 per cent. from winter, and 24 from summer wheat; from Sicilian 21, and from Barbary wheat 19 per cent. The meal of Alsace wheat contains, according to Boussingault, $17 \cdot 3$ per cent. of gluten; that of wheat grown in the "Jardin des Plantes" $26 \cdot 7$, and that of winter wheat 3.33 per cent. Such great differences must be owing to some cause, and this we find in the different methods of cultivation. An increase of animal manure gives rise not only to an increase in the number of seeds, but also to a most remarkable difference in the proportion of the gluten which they contain.

"Animal manure, as we shall afterwards show, acts only by the formation of ammonia. One hundred parts of wheat grown on a soil manured with corvdung (a manure containing the smallest quantity of nitrogen), afforded only 11.95 parts of gluten, and 64.34 parts of amylin, or starch; whilst the same quantity, grown on a soil manured with human urine, yielded the maximum of gluten, namely $35 \cdot 1$ per cent. Putrefied urine contains nitrogen in the forms of carbonate, phosphate, and lactate of ammonia, and in no other form than that of ammoniacal salts.

"Putrid urine is employed in Flanders as a manure with the best results. During the putrefaction of urine, ammoniacal salts are formed in large quantity, it may be said exclusively; for, under the influence of heat and moisture, urea, the most prominent ingredient of the urine, is converted into carbonate of ammonia. The barren soil on the coast of Pern is rendered fertile by means of a manure called Guuno, which is collected from several islands on the South Sea. It is sufficient to aild a small quantity of guano to a soil, which consists only of sand and clay, in order to procure the richest crops of maize. The soil itself does not contain the smallest particle of organic matter, and the manure employed is formed only of urate, phosphate, oxalate, and carbnnate of ammunia, together with a few earthy salis. (Busssingault, Ann. de Chim. of de Phys. t. Ixv. p. 319.) 
"Ammonia, therefore. must have yielded the nitrogen to these plants. Gluten is obtained not only from corn, but also from grapes and other plants; but that extracted from the grapes is called vegetable albumen, although it is identical in composition and properties with the ordinary gluten.

"It is ammonia which yields nitrogen to the vegetable albumen, the principal constituent of plants; and it must be ammonia which forms the red and blue colouring matters of flowers. Nitrogen is not presented to wild plants in any other form capable of assimilation. Ammonia by its transformation, furnishes nitric acid to the tobacco plant, sunflower, Chenopodium, and Borago officinalis, when they grow in a soil completely free from nitre. Nitrates are necessary constituents of these plants, which thrive only when ammonia is present in large quantity, and when they are also subject to the influence of the direct rays of the sun, an influence necessary to effect the disengagement within their stem and leaves of the oxygen, which shall unite with the ammolia to form nitric acid.

"The urine of men and of carnivorous animals contains a large quantity of nitrogen, partly in the form of phosphates, partly as urea. Urea is converted during putrefaction into carbonate of ammonia, that is to say, it takes the form of the very salt which occurs in rain-water. Human urine is the most powerful manure for all vegetables containing nitrogen ; that of horses and horned cattle contains less of this element, but infinitely more than the solid exerements of these animals. In addition to urea, the urine of herbivorous animals contains hippuric acid, which is decomposed during putrefaction into benzoic acid and ammonia. The latter enters into the composition of the gluten, but the benzoic acid (fften remains unchanged; for example, in the Anthoxanthum odoratum. The late Professor Gorham obtained from Indian corn a substance to which he gave the name Zeine, according to whose analysis it contains no nitrogen; but ammonia has since been obtained from it."

It has always been a popular opinion among husbandmen, that snow contained some fertilizing salts, as winter crops were generally observed to thrive best after being long covered with snow. Common observation is here fully sustained by science, since ammonia, one of the greatest of fertilizers, may always be detected in snow-water, the inferior layers next the ground containing the largest proportion.

The following interesting ealculation is given by Liebig. "If," says he, "a pound of rain-water contain one-fourth of a grain of ammonia, then a field of 40,000 square feet must receive annually upwards of 80 pounds of ammonia, or 65 pounds of nitrogen; for, by the observations of Schüller, which were formerly alluded to, about 700,000 pounds of rain fall over this surface in four months, and consequently the annual fall must be $2,500,000$ pounds. This is much more nitrogen than is containcd in the form of vegetable albumen and g.uten, in 2,650 pounds of wood, 2,800 pounds of hay, or $200 \mathrm{cwt}$. of beet-root, which are the yearly produce of such a field, but it is less than the straw, roots, and grain of corn which might grow on the same surface would contain."

As to the source from which the ammonia diffused in the atmosphere is derived, it is sufficient to refer to the fact that ammonia is the last product of the putrefaction of animal bodies, all of which, whether large or infinitely small, yield their nitrogen to the atmosphere in the form of ammonia. This cannot remain long in the air, as every shower of rain must absorb and convey it to the earth. "Hence also, rain-water must, at all times, contain ammonia, though not always in equal quantity. It must be greater in summer than in spring or in winter, because the intervals of time between the showers are in summer greater; and when several wet days occur, the rain of the first must contain more of it than that of the second. The rain of a thunder-storm, after a long protracted drought, ought for this reason to contain the greatest quantity which is conveyed to the earth at one time."

Is it asked what direct proof exists that ammonia acts so favourably in promoting vegetation? The answer is furnished in the results of experiments made by Sir Humphry Davy, in which the beaks of retorts containing fermenting manures were introduced into the soil among the roots of grass, which was thus made to grow more luxuriantly than that in other places. The gases emanating from ro torts containing similar manure were examined and found to consist chiefly of ammonic. Sir Humphry considered such results as proving conclusively the advantage of applying manures to soils in a recent and fermenting state. (See Azote or Nitrog EN.)

Dr. Liebig's discovery of the great fertilizer ammonia in rain-water has led to a most simple and beautiful explanation of the manner in which gypsum or plaster of Paris acts in promoting the growth of plants, a matter which has been a subject of great speculation and controversy, but which would seem to be fully settled at last.

"The evident influence of gypsum upon the growth of grasses,-the striking fertility and luxuriance of a meadow upon which it is strewed,-depends only upon its fixing in the soil the ammonia of the atmosphere, which would otherwise be volatilized with the water which evaporates. The carbonate of ammonia contained in rain-water is decomposed by gypsum, in precisely the same manner as in the manufacture of sal-ammoniac. Soluble sulphate of ammonia and carbonate of lime are formed; and this salt of ammonia possessing no volatility is consequently retained in the soil. All the gypsum gradually disappears, but its action upon the carbonate of ammonia continues as long as a trace of it exists. The action of gypsum as well as that of chloride of lime (bleaching salts) really consists in their giving a fixed condition to the nitrogen, or ammonia which is brought into the soil, and which is indispensable to the nutrition of plants.

"Water is absolutely necessary to effect the decomposition of the gypsum, on account of its 
difncult solubility ( 1 part of gypsum requires 400 parts of water for solution), and also to assist in the absorption of the sulphate of ammonia by the plants; hence it happens, that the influence of gypsum is not observable on dry fields and meadows.

"The decomposition of gypsum by carbonate of ammonia does not take place instantaneously; on the contrary, it proceeds very gradually, and this explains why the action of the gypsum lasts for several years." (Org. Chem.)]

AMYLACEOUS. A term applied to such farinaceous seeds, grains, and roots, as contain inuch of the fine flour from which starch is made, and in which chiefly consists their nutritive principle.

ANALYSIS (Gr. ¿áádurıs). In a general sense, signifies the resolution of compound bodies into their original or constituent principles.

Analysis of Soils.-The means of ascertaining the nature, properties, and proportions of the different materials of which they are composed. The chemical examination of the soil affords perhaps more certain and more valuable information to the farmer, for the improvement of its fertility, than any other mode of investigation. The apparatus and the experiments, necessary for even the most accurate experiments, are by no means so difficult as it is often believed is the case. It is, in fact, a very erroneous conclusion, that an extensive or an expensive apparatus is necessary to carry on even the most valuable chemical researches. The laboratory of one of the most celebrated chemical philosophers of his day, that of Dalton of Manchester, contained apparently but a poor collection of glass bottles, retorts, crucibles, fragments of wine-glasses, \&c.

The following descriptions of the philosophically-accurate mode adopted by Sir Humphry Davy for the analysis of soils, [and of the more easily repeated plans of the Rev. W. Rham, of England, and Dr. Dana, of Massachusetts, are given nearly in their own words. The first is taken from his Elemenls of Agricultural Chemistry, the second from the first volume of the Journal of the Royal Agricultural Society of England, p. 46, and the last from Professor Hitchcock's Report of the Geological Survey of Massachusetls.] It may be well to premise that four earths are almost always the chief constituents of all cultivated soils, viz., silica (flint), alumina (clay), carbonate of lime (chalk), and carbonate of magnesia. These are mixed together in an endless variety of proportions, and are interspersed with animal and vegetable remains, salts, \&c., to an equally varying extent. It is to ascertain the presence and the extent of these substances that the analysis of soils is so necessary and so valuable to the farmer.

"The instruments required for the analysis of soils," said the illustrious Davy, "are few and but little expensive. They are a balance capable of containing a quarter of a pound of common soil, and capable of turning when loaded with a grain; a set of weights from a quarter of a pound troy to a grain; a wire sieve sufficiently coarse to admit a mustardseed through its apertures; an Argand lamp and stand; some glass bottles; Hessian cruci- bles; porcelain or queen's ware evaporaing basins; a Wedgewood pestle and mortar; some filters made of half a sheet of blotingpaper, folded so as to contain a pint of liquid, and greased at the edges; a bone knife, and an apparatus for collecting and measuring aëriform fluids.

"The chemical substances or re-agents required for separating the constituent parts of the soil are muriatic acid (spirit of salt), sulphuric acid (oil of vitriol), pure volatile (ammonia), dissolved in water, solution of prussiate of potash and iron, succinate of ammonia, soap-lye, or solution of potassa, solutions of carbonate of ammonia, of muriate of ammonia, of neutral carbonate of potash, and nitrate of ammonia.

"In cases when the general nature of the soil of a field is to be ascertained, specimens of it should be taken from different places, two or three inches below the surface, and exa. mined as to the similarity of their properties. I, sometimes happens that upon plains the whole of the upper stratum of the land is of the same kind, and in this case one analysis will be suffcient; but in valleys, and near the beds of rivers, there are very great differences; and it now and then occurs that one part of a field is calcareous, and another part silicious, and in this case, and in analogous cases, the portions different from each other should be separately submitted to experiment."

Soils, when collected, if they cannot be immediately examined, should be preserved in phials quite filled with them, and closed with ground glass stoppers. The quantity of soil most convenient for a perfect analysis is from two to four hundred grains. It should be collected in dry weather, and exposed to the atmosphere till it becomes dry to the touch.

The specific gravity of a soil, or the relation of its weight to that of water, may be ascertained by introducing into a phial, which will contain a known quantity of water, equal quantities of water and of soil, and this may be easily done by pouring in water till it is half full, and then adding the soil till the fluid rises to the mouth; the difference between the weight of the soil and that of the water will give the result. Thus if the bottle con. tains 400 grains of water, and gains 200 grains when half filled with water and half with soil, the specific gravity of the soil will be 2 , that is, will be twice as heavy as water; and if it gained 165 grains, its specific gravity would be 1825, water being 1000 . It is of importance that the specific gravity of a soil should be known, as it affords an indication of the quantity of animal and vegetable matter it contains; these substances being always most abundant in the lighter soils.

The other physical properties of soils should likewise be examined before the analysis is made, as they denote to a certain extent their composition, and serve as guides in directing the experiments. Thus silicious soils are generally rough to the touch, and scratch glass when rubbed upon it; ferruginous soils are of a red or yellow colour, and calcareous soils are soft.

1. Soils, though as dry as they can be ma? 
by co:linued exposure to air, in all cases contain a considerable quantity of water, which adheres with great obstinacy to the earths, and animal and vegetable matter, and can only be driven off from them by a considerable degree of heat. The first process of analysis is to free the given weight of soil from as much of this water as possible, without, in other respects, affecting its composition, and this may be done by heating it for ten or twelve minutes over an Argand lamp in a basin of porcelain to a temperature equal to $300^{\circ}$ Fahrenheit; and if a thermometer is not used, the proper degree may be easily ascertained by keeping a piece of wood in contact with the bottom of the dish; as long as the colour of the wood remains unaltered the heat is not too high, but when the wood begins to be charred the process must be stopped. A small quantity of water will perhaps remain in the soil, even after this operation, but it always affords useful comparative results; and if a higher temperature were employed, the vegetable or animal matter would undergo decomposition, and, in consequence, the experiment be wholly unsatisfactory. The loss of weight in the process should be carefully noted, and when in 400 grains of soil it reaches as high as $50^{\circ}$, the soil may be considered as in the greatest degree absorbent and retentive of water, and will generally be found to contain much vegetable or animal matter, or a large proportion of aluminous earth. When the loss is only from $20^{\circ}$ to $10^{\circ}$, the land may be considered as only slightly absorbent and retentive, and silicious earth probably forms the greatest part of it.

2. None of the loose stones, gravel, or large vegetable fibres should be divided from the pure soil till after the water is drawn off; for these bodies are often themselves highly absorbent and retentive, and in consequence infuence the fertility of the land. The next process, however, after that of heating, should be their separation, which may be easily accomplished by the sieve, after the soil has been gently bruised in a mortar. The weights of the regetable fibres or wood, and of the gravel or stones, should be separately noted down, and the nature of the last ascertained; if calcareous, they will effervesce with acids; if silicious, they will be sufficiently hard to scratch glass; and if of the common aluminnus class of stones, they will be soft, easily cut with a knife, and incapable of effervescing with acids.

3. The greater number of soils, besides gravel and stones, contain larger or smaller proportions of sand, of various degrees of fineness; and it is a necessary operation (the next in the process of analysis) to detach them from the parts in a state of more minute division, such as clay, loam, marl, vegetable and inimal matter, and the matter soluble in water. This may be effected in a way sufficiently accurate, by bnling the soil in three or four times its weight r,t water, and when the texture of the soil is broken down, and the water cool, by agitating the parts together, and then suffering them to rest. In this case, the coarse sand will generally separate in a minute, and the finer in two or three minutes, whilst the highly livided earthy, animal, or vegetable matter will remain in a state of mechanical suspension for a much longer time; so that by pouring the water from the bottom of the vessel, after one, two, or three minutes, the sand will be principally separated from the other substances, which, with the water containing them, must be poured into a filter, and after the water has passed through, collected, dried, and weighed. The sand must likewise be weighed, and the respective quantities noted down. The water of lixiviation must be preserved, as it will be found to contain the saline, and soluble animal or vegetable, if any exist in the soil.

4. By the process of washing and filtration, the soil is separated into two portions, the most important of which is generally the finely di. vided matter. A minute analysis of the sand is seldom if ever necessary, and its nature may be detected in the same manner as that of the stones or gravel. It is always either silicious sand, or calcareous sand, or a mixture of both. If it consist wholly of carbonate of lime, it will be rapidly soluble in muriatic acid, with effervescence; but if it consist partly of this substance, and partly of silicious matter, the respective quantities may be ascertained by weighing the residuum after the action of the acid, which must be applied till the mixture has acquired a sour taste, and has ceased to effervesce. This residuum is the silicious part; it must be washed, dried, and heated strongly in a crucible: the difference between the weight of it, and the weight of the whole indicates the proportion of calcareous sand.

5. The finely divided matter of the soil is usually very compound in its nature; it some times contains all the four primitive earths or soils, as well as animal and vegetable matter. and to ascertain the proportions of these with tolerable accuracy is the most difficult part of the subject.

The first process to be performed in this part of the analysis, is the exposure of the finf. matter of the soil to the action of muriatic acid. This substance should be poured upon the earthy matter in an evaporating basin, in a quantity equal to twice the weight of the earthy matter, but diluted with double its volume of water. The mixture should be often stirred and suffered to remain for an hour or an hour and a half before it is examined. If any carbonate of lime, or of magnesia, exist in the soil, they will have been dissolved in this time by the acid, which sometimes takes up likewise a little oxide of iron, but very seldom any alumina.

'The fluid should be passed through a filter, the solid matter collected, washed with rain. water, dried at a moderate heat, and weighed. Its loss will denote the quantity of solid matter taken up. The washings must be added to the solution, which, if not sour to the taste, must be made so, by the addition of fresh acid, when a little solution of prussiate of potassa and iron must be mixed with the whole. If a blue precipitate occurs, it denotes the presence of oxide of iron, and the solution of the prussiate must be dropped in, till no farther effect 
is produced. To ascertain its quantity. it must be collected in the same manner as uther solid precipitates, and heated red; the result is oxide of iron, which may be mixed with a little oxide of manganese.

Into the fluid freed from oxide of iron a solution of neutralized carbonate of potash must be poured till all effervescence ceases in it, and till its taste and smell indicate a considerable excess of alkaline salt. The precipilate that falls down is carbonate of lime: it must be collected on the filter, and dried at a heat below that of redness. The remaining fluid must be boiled for a quarter of an hour, when the magnesia, if any exist, will be precipitated from it, combined with carbonic acid, and its quantity is to be ascertained in the same manner as that of the carbonate of lime. If any minute proportion of alumina should, from peculiar circumstances, be dissolved by the acid, it will be found in the precipitate with the carbonate of lime; and it may be separated from it by boiling it for a few minutes with soap-lye, sufficient to cover the solid matter: this substance dissolves alumina, without acting upon carbonate of lime.

Should the finely divided matter be suficiently calcareous to effervesce very strongly with acids, a very simple method may be adopred for ascertaining the quantity of carboate of lime, and one sufficiently accurate in all common cases.

Carbonate of lime (chalk) in all its states contains a determinate proportion of carbonic acid, $i . e$. nearly 43 per cent.; so that when the quantity of this elastic fluid given out by any soil during the solution of its calcareous matter in an acid is known, either in weight or measure, the quantity of carbonate of lime may be easily discovered.

When the process by diminution of weight is employed, two parts of the acid and one part of the matter of the soil must be weighed in two separate bottles, and very slowly mixed together till the effervescence ceases. The difference between the weight before and after the experiment denotes the quantity of earbonic acid lost: for every $4 \frac{1}{4}$ grains of which 10 grains of carbonate of lime must be estimated.

6. After the calcareous parts of the soil have been acted upon by muriatic acid, the next process is to ascertain the quantity of finely divided insoluble animal and vegetable matter that it contains. This may be done with sufficient precision, by strongly igniting it in a crucible over a common fire till no blackness remains in the mass. It should be often stirred with a metallic rod, so as to expose new surfaces continually to the air: the loss of weight that it undergoes denotes the quantity of the substance that it contains destructible by fire and air.

It is not possible without very refined and difficult experiments, to ascertain whether this substance is wholly animal or vegetable matter, or a mixture of both. When the smell emitted during the incineration is similar to that of burnt feathers, it is a certain indication of some substance, either animal, or analogous to animal matter, and a copious blue flame at the lime of ignition almost always de- notes a considerable proportion of vegetable matter. In cases when it is necessary that the experiment should be very quickly performed, the destruction of the decomposible substances may be assisted by the agency of nitrate of ammonia, which at the time of ignition maty be thrown gradually upon the heated mass, in the quantity of 20 grains for every 100 of residual soil. It accelerates the dissijuation of the animal and vegetable matter, which it causes to be converted into elastic fluids, and it is itself, at the same time, decomposed and lost.

7. The substances remaining after the destruction of the vegetable and animal malter are generally minute particles of earthy matter containing usually alumina and silica, with combined oxide of iron or of manganese. 'To separate these from each other, the solid mai. ter should be boiled for two or three hours with sulphuric acid, diluted with four times its weight of water; the quantity of the acid should be regulated by the quantity of solid residuum to be acted on, allowing for every 100 grains two drachms, or 120 grains of acid.

The substance remaining after the action of the acid may be considered as silicious, and it must be separated and its weight ascertained, after washing and drying in the usual manner. The alumina, and the oxide of iron and manganese, if any exist, are all dissolved by the sulphuric acid: they may be separated by succinate of ammonia added to excess, which throws down the oxide of iron, and by soap-lye, which will dissolve the alumina, but not the oxide of manganese: the weights of the oxides ascertained after they have been heated to redness will denote their quantities.

Should any magnesia and lime have escaped solution in the muriatic acid, they will be found in the sulphuric acid: inis, however, is rarely the case; but the process for detecting them and ascertaining their quantities is the same in both instances. The method of analysis by sulphuric acid is sufficiently precise for all usual experiments; but if very great accuracy be an object, dry carbonate of potash must be applied as the agent, and the residuum of the incineration (6.) must be heated red for half an hour, with four times its weight of this substance in a crucible of silver, or of well baked porcelain. The mass obtained must be dissolved in muriatic acid, and the solution evapo. rated till it is nearly solid; distilled water must then be added, by which the oxide of iron and all the earths except silica will be dissolved in combination as muriates. The silica after the usual process of lixiviation must be heated red : the other substances may be separated in the same manner as from the muriatic anil sulphuric solutions. This process is the one usually employed by chemical philosopher's for the analysis of stones.

8. If any saline matter, or soluble vegetable or animal matter, is suspected in the soil, 1 will be found in the water of lixiviation used for separating the sand. This water must be evaporated to dryness in a proper dish, at a heat below its boiling point. If the solid matter obtained is of a brown colour and inflamma 
ANALYSIS.

ble, it may be considered as partly vegetable extract. If its smell when exposed to heat be like that of burnt feathers, it contains animal or albuminous matter; if it be white, crystalline, and not destructıble by heat, it may be considered principally as saline matter. The saline compoundș contained in soils are very various. The sulphuric acid combined with potash or sulphate of potash is one of the most usual. Common salt is also very often found in them; likewise phosphate of lime, which is insoluble in water, but soluble in muriatic acid. Compounds of the nitric, muriatic, sulphuric, and phosphoric acids, with alkalies and earths, exist in some soils. The salts of potash are distinguished from those of soda by their producing a precipitate in solutions of platina; those of lime are characterized by the cloudiness they occasion in solutions containing oxalic acid; those of magnesia by being rendered cloudy by solutions of ammonia. Sulphuric acid is detected in salts by the dense white precipitate it forms in solutions of baryta; muriatic acid, by the eloudiness it communicates to solution of nitrate of silver; and when salts contain nitric acid, they produce scintillations by being thrown upon burning coals.

9. Should sulphate or phosphate of lime be suspected in the entire soil, the detection of them requires a particular process upon it. A given weight of it, for instance, 400 grains, must be heated red for half an hour in a crucible, mixed with one third of powdered charcoal. The mixture must be boiled for a quarter of an hour in a half pint of water, and the fluid collected through the filtre and exposed for some days to the atmosphere in an open vessel. If any notable quantity of sulphate of lime (gypsum) existed in the soil, a white precipitate will gradually form in the fluid, and the weight of it will indicate the proportion.

Phosphate of lime, if any exist, may be separated from the soil after the process for gypsum. Muriatic acid must be digested upon the soil in quantity more than sufficient to saturate the soluble earths: the solution must be evaporated, and water poured upon the solid matter. This fluid will dissolve the compounds of earths with the muriatic acid, and leave the phosphate of lime untouched. It will not fall within the limits assigned to this article to detail any processes for the detection of substances which may be accidentally mixed with the matters of soils. Other earths and metallic oxides are now and then found in them, but in quantities too minute to bear any relation to fertility or barrenness, and the search for them would inake the analysis much more complicated, without rendering it more useful.

10. Where the examination of a soil is completed, the products should be numerically arranged and their quantities added together, and if they nearly equal the original quantity of soil, the analysis may be considered as accurate. It must, however, be noticed that when phosphate or sulphate of lime are discovered by the independent process just described (9), a correctior mist be made for the general process, by subtracting a sum equal to their weight fruns the quantity of carbonate of lime 86 obtained by precipitation from the muriatic acid. In arranging the products the form should be in the order of the experiments by which they were procured. Thus I obtained from $\mathbf{4 0 0}$ grains of a good silicious sandy soil from a hop garden near Tonbridge Kent,-

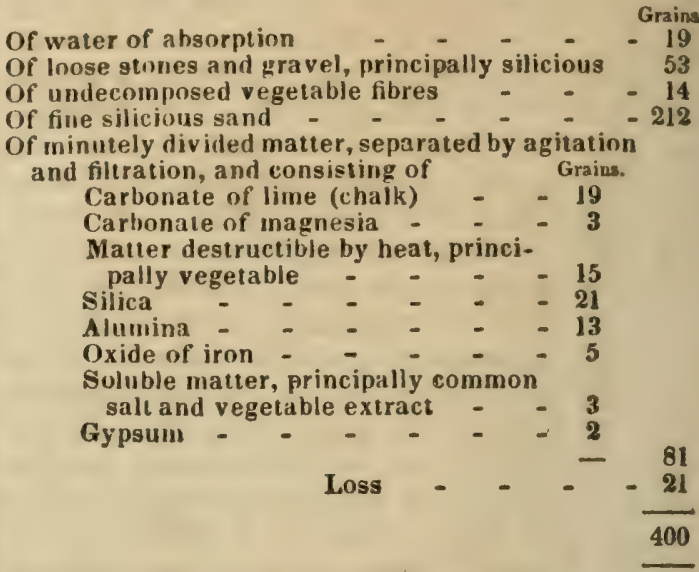

The loss in this analysis is not more than usually occurs, and it depends upon the impossibility of collecting the whole quantities of the different precipitates, and upon the presence of more moisture than is accounted for in the water of absorpiion, and which is lost in the different processes.

When the experimenter is become acquainted with the use of the different instruments, the properties of the re-agents, and the relations between the external and chemical qualities of soils, he will seldom find it necessary to perform, in any one case, all the processes that have been described. When his soil, for instance, contains no notable proportions of calcareous matter, the action of the muriatic acid (7.) may be omitted. In examining peat soils, he will principally have to attend to the operation by fire and air, and in the analysis of challss and loams, he will often be able to omit the experiment by sulphuric acid (9.).

In the first trials that are made (adds Davy) by persons unacquainted with chemistry, they must not expect much precision of result; many difficulties will be met with; but, in overcoming them, the most useful kind of practical knowledge will be obtained; and nothing is so instructive in experimental science as the detection of mistakes. The correct analyst ought to be well grounded in general chemical information; but perhaps there is no better mode of gaining it than that of attempting original investigations. In pursuing his experiments, he will be continually obliged to learn the properties of the substances he is employing or acting upon; and his theoretical ideas will be more valuable in being connected with practical operations, and acquired for the purpose of discovery.

Such were the excellent rules for analysis prescribed by Sir Humphry Davy. With the still more simple directions of the Rev. W. Rham, I shall conclude this paper.

A portion of the earth to be analysed may be dried in the sun or near a fire until it feels quite dry in the hand. It is then reduced to powder by the fingers, or by rolling it on a deal board with a wooden roller, so as to sepa- 


\section{ANAI.YSIS.}

rate the particles, but not to grind them: any small stones above the size of a pea must be taken out. If these form a considerable part of the soil, their proportion must be ascertained by weight; their nature and quality may be afterwards examined: this being a very simple operation, and obvious to the sight, need not be described. Where the stones and pebbles are evidently accidental, they may be overlooked, as having little influence on the fertility: the dry earth, cleared from stones, should be accurately weighed; and it is convenient to take some determined quantity of grains, as 1000,500 , or 250 , according to the accuracy of the instruments at hand. This portion shouid be put into a shallow earthen or metal vessel, and heated over the fire, or a lamp, for about ten minutes, stirring it with a chip of dry wood; the heat should not be so great as to discolour the wood. It may then be allowed to cool, and be weighed again; the loss of weight indicates the water which remained uncombined after the soil appeared quite dry. This is the first thing to be noted. The power of retaining water without any external appearance of moisture is greatest in humus (a modern term for very finely divided organic matter), next in clay, both of which readily absorb it from the atmosphere; carbonate of lime does so in a less degree, and silicious sand least of all. This moisture occupies the pores of the soil, and is very different from the water, which is combined with clay as a part of its substance, and to which it owes its ductility; for when this last is expelled by a great heat, the clay loses its quality, and approaches to the nature of sand. Pounded brick will not bird with water, and porcelain reduced to fine powder has all the properties of silicious sand in the soil. The finer the division of the particles of the soil, the greater will be its power of absorbing and retaining water; but in a soil where clay greatly predominates, the lumps sornetimes become so hard and baked by the sun that the moisture cannot penetrate; and in this case the power of absorption is much diminished. Hence loams in which there is a good proportion of humus have a greater power of absorption than the pure earths. Taking all circumstances into consideration, it will be found that the soils which most readily absorb moisture are also the most fertile, and therefore it is important to ascertain their power of absorption. This can be found by comparison. Equal portions of different soils, dried as before, are placed in the opposite scales of a good balance, and left exposed for some time to a moist atmosphere; that which preponderates has the greatest power of ahsorption; the degree is measured by the difference of the acquired weights. Another important circumstance is the specific gravity of a soil. The different earths have very different specific gravities; and humus being lighter than any mineral earth, the lightness of the soil is a sure indication of its richness, excepting where this lightness is occasioned by an excess of undecomposed vegetable matter, or peat. Humus, when nearly pure, has specific gravity varying from 1.2 to 1.5 ; fine porcelain clay, 2 ; chalk, about
ANAI,YSIS.

2.3 ; silicious sand from 2.5 to 2.7 ; mires soils have specific gravilies varyir.g according to the proportions of their component parts. 'Those in which clay, chalk, and humus abound, and which are generally the most fertile, are the lightest. 'The sandy soils are heavier, ard the more so if they contain oxides of iron, or of other metals; and it is well known that the ferruginous sands are the most barren. The common expression of lighl, when applied to a sandy soi!, has no reference to its specific gra. vity, but merely to the force required to plough it. No carrier would say that a loose sandy road was a light one. The easiest and readiest method of determining the specific gravity of earth, or any substance which is of a loose texture, is that described by Dr. Ure in his Philosiphy of Manufactures (p.97), as employed by him to ascertain the specific gravities of cotton, wool, silk and flax. It is as follows :Take a narrow-necked phial, capable of holding four or five ounces of water; mark a line round the middle of the neck with the point of a diamond, or a file; fill the phial up to the mark with river or rain water, and poise it with sand, or any other substance, in a scale; then put 1000 grains' weight in the same scale with the phial, and pour out water till the equilibrium is restored. In the vacant space, which is evidently equal to the bulk or 1000 grains of water, introduce the soil till the water rises to the mark in the neck; then put into the opposite scale grain weights sufficien to restore the equilibrium. The number of grains required for this purpose will denote the specific gravity of the soil compared to water as 1000. Suppose, for example, that silicious sand, which is $2 \cdot 7$ times denser than water, is poured into the vacant space, it will require $2 \cdot 700$ grains to fill the space occupied by the 1000 grains of water; and thus we have the specific gravity without any calculation. If, instead of 1000 grains, we use only 500 , or 250 , the result will be the same, if we multiply the grains in the other scale by 2 or 4.

We will give a few examples of soils, of which the specific gravity has been carefully determined.

A rich garden soil, which contained, per cent., -

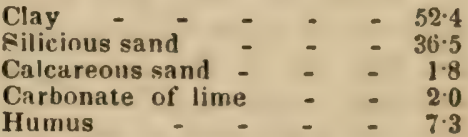

had a specific gravity of $2 \cdot 332$.

A good loam, consisting of-

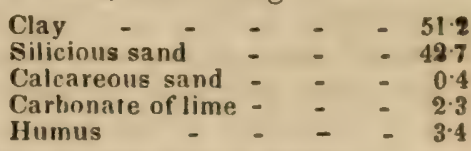

had a specific gravity of $2 \cdot 401$.

A poorer soil, of which the component rarts were,-

\begin{tabular}{|c|c|c|c|c|}
\hline Silicious & sand & & - & $=$ \\
\hline Clay & - & - & & \\
\hline Calcareo & us sand & 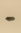 & - & - \\
\hline Carbonat & le of lime & - & . & - \\
\hline Humus & - & - & - & - \\
\hline
\end{tabular}

had a specific gravity of $2 \cdot 5 \approx 6$.

These examples suffice to show that the sre. cific gravity of a soil is some tolerable ind : a. 


\section{ANALYSIS.}

tion of its fertility. It cannot, however, be entirely relied upon in the absence of other proofs; for there may be many different mixtures of earths which will have the same specific gravity, although they may differ greatly in their fertility; bu. it will facilitate the analysis, and often detec nistakes in the process, if the result does not ac. ord with the specific gravity found. We proceed now to the analysis. The portion of soil which has been deprived of all its water, as described above, must be sifted through metallic sieves of different fineness; the first is made of a perforated tin plate, the holes of which are about onetwentieth of an inch in diameter: whatever does not go through this is put by. The remainder is successively passed through two or three more sieves, increasing in fineness to the last; which is of the finest wire-cloth, having from 150 to 170 threads in an inch: whatever passes through this is an impalpable powder. Thus we have already a division of the soil, according to the size of its particles:-1, the coarse grit left in the first sieve; 2 , the finer grit in No. 2; 3, fine sand in No. 3 ; and 4, impalpable powder, which has passed through the last sieve. To facilitate this part of the operation, the sieves may be made so as to fit into one another, like the filterers in a coffeebiggin, the last fitting into a tin pot which will hold about a pint of water; a cover being made to fit on the top sieve, the instrument is

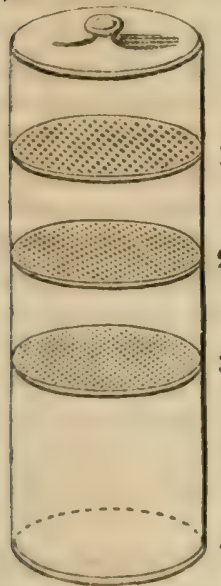
complete. (See fig.) Thus, all the sifting may be done at once without any loss. Any lumps which are not thoroughly pulverized must be broken. The coarser sand left in the sieve, No. 1, must 2 now be washed with purc water, to detach any fine dust adhering to it; what runs 3 through may be used to wash No. $\mathbf{2}$, in the same manner; and then may pass through No. 3 to the impalpable matter which passed through all 4 the sieves. A sufficient quantity of water must be used to render the whole of this last nearly fluid. There will then be three different portions of the washed soil left in the sieves, and a portion of impalpable matter diffused through the water in the lower division of the instrument. This last is the principal object of analysis, and that to which Sir Humphry Davy usually confined his attention, merely noticing the proportion of coarser sand in the soil. It contains, no doubt, the great principle of fertility and nutrition; and the effect of the coarser parts may be considered as chiclly mechanical; but they may much affect the fertility of the finer parts, and are of the greatest importance to the sos in which they are blended: they consequently deserve a more minute examination, in which we will return.

In the mean time, our attention shall be dilected to the composition of the finer earth in No. 4, which is mixed with water in a semi. Duid state. This is well shaken, and suddenly
ANALYSIS.

poured into a deep glass vessel, and allowed to settle for a few minutes, when the heavier earth, which is sand, will be deposited, and the lighter may be poured off suspended in the water. It requires some little practice to effect this at once, but a few trials will soon enable any one to do it. This operation may be repeated until all sand, of which the particles are visible to the naked eye, is separated. The earth and water decanted out of this last vessel are now poured into a glass tube, eighteen inches long, No. 1, the bore of which is less than an inch; one end is stopped with a cork fitted into it, and the other has a small lip for the convenience of pouring out the contents. In a short time, there will be a further deposition of earth, which will be principally alu. mina. What remains suspended in the water over it is gently poured off into another similar tube (No. 2); this will contain nearly the whole of the humus, which will take some hours to be deposited in the form of a fine brown mud. The contents of the tube No. I may now have a little more water added to them: after being well shalien, the tube may be set upright, and left for half an hour to scttle: what remains suspended in the water after this, must be added to the humus in the tube No.2. After some time, this will also be deposited, and the clear water may be decanted off. The mud which remains is put on filtering paper in a glass funnel; and when all the water has drained from it, it is dried over the fire, and weighed.

This is the most important portion of the soil. The fine earths deposited in the tube No. 1 will consist of very fine particles of sand, clay, and perhaps carbonate of lime. The sand will appear deposited in the bottom of the tube. The clay may be easily diffused in the water above it, by stirring it carefully with a small rod, without reaching the sand. It may then be decanted with the water into another tube (No. 3), and allowed to settle. This part of the operation may be carried to much perfection by great care, and by examining the results occasionally with a small $\mathrm{mi}$ croscope; but for all common practical purposes it is sufficient to separate the vegetable earth from the mineral, and the particles of sand from the finer. The contents of No. 1 having been collected, as well as those of No. 3, are dried over the fire, and accurately weighed. The same is done with the earth which remains on the sieves. All the water in which the earths have been diffused and washed is collected and passed through filtering paper, and then set over the fire in a common saucepan. It is boiled away gently, until it is reduced to a small portion, which begins to look turbid. The complete evaporation is finished in an evaporating dish as slowly as possible; and the residue is the soluble matter contained in the soil. It will be sufficient to dry and weigh this, as its further analysis would require more skill and chemical knowledge than we suppose in the operation. Salts may be detected by the taste, or by the crystals formed in the evaporation; but unless there is a decided saline taste, the whole may be consi 


\section{ANALYSIS.}

dered as soluble humus, and the immediate fertility of the soil depends greatly on the quantity of it.

To recapitulate what has been obtained, we shall have the coarse grit in sieve No. 1; the sand in Nos. 2 and 3 ; the fine earth separated in the tubes, Nos. 1 and 3 ; the humus in tube No. 2, and on the filtering paper, and on the soluble parts in the evaporating dish. All these substances must be well dried over the fire, as was done with the soil at first, and each separated part accurately weighed: the sum of them ought to be equal to the original portion of soil subjected to analysis after the water was drawn off; but there always is a loss, even with the most experienced analyser; this loss will be principally in the finer parts which are dissipated in the operation. But the analysis is not yet completed: we have separated the sand, clay, and humus, but there may be a portion of carbonate of lime in the form of sand, or of finely divided earth mixed with the other earths. 'T'o ascertain this, each portion, excepting the humus, is put into a separate cup, and a little muriatic acid, diluted with four tirnes its own weight of water, is poured on it: if there is any effervescence, it shows the presence of carbonate of lime; diluted acid is then added gradually, as long as the effervescence is renewed by the addition. When this ceases, and the water continues to have an acid taste, more pure water is added, and each portion separately filtered, dried, and weighed. The loss of weight in each of these gives the quantities of carbonate of lime dissolved by the muriatic acid, and which has passed with the water in the form of muriate of lime. The different weights being now cullected, the re. sult of the operations may be set down. There may be many mineral substances in the soil, which this mode of analysing will not detect; and some of these may materially affect the fertility. In most cases there will be something to indicate the presence of metals. Iron abounds in most soils: when the quantity is considerable, it will be detected by pouring a decoction of gall-nuts into the water which has washed the earth; it will immediately be come of a bluish dark colour. The other metals are not of frequent occurrence. Sulphate of lime or gypsum, and also magnesia, are found in some soils; but the separation of them can only be effected by those who are well acquainted with chemistry: they fortunately occur very seldom, and the places where they are found are generally well known. For all practical purposes it is sufficient to ascertain the proportion of sand, clays, carbonate of lime, and humus, which any soil contains. Many soils which have been highly manured, contain portions of undecomposed vegetable substances, and fibres of roots: these will be found mixed with the coarser earths separated by the sifting: not being a part of the natural soil, they need not be taken into the account; but they may be separated by washing the earths, as they are much lighter, and will come over in the first decantations They may be dried and weighed, and the quantity set down in the result, if it is desirable. Some very barren sauds, containing very little argillaceous earth or hurnus, may readily be known by the copious sandy deposit which they rapidly make when dif. fused through water. Good natural luams are not so easily judged of; but the preceding mode of analysis will in general detect their intrinsic value. When a soil contains peaty matter, it is easily discovered by the irregular black particles which are visible in it. Peat differs from humus only in being in a different state of decomposition, and containing a con. siderable portion of tannin: when acted upon by lime or alkalies, and brought into a state of greater decomposition, it is not to be distinguished from humus in its qualities. The only instruments absolutely required for the foregoing analysis are, in the first place, twc good balances, one capable of weighing a pound and turning with a grain, and one weighing two ounces and turning with the tenth part of a grain. Next, the combination of sieves which we have described, and which may easily be made by any tinsmith. But any sieves of the required fineness, whether of metal, horse-hair, or silk, provided they be of the proper texture, will answer the purpose for a trial. Some earthen or glass jugs, and two or three glass tubes, 18 inches long, open at both ends, which may be obtained at any glass-blower's or chemist's, a glass funnel, and some filtering paper, will complete the apparatus. The only chemical substance indispensable to the analysis is some muriatic acid, commonly called spirit of salt. A little test-paper to detect acids in the water with which the soil has been washed, and an infusion of gall-nuts to ascertain the presence of iron, may be useful. A small glass phial will serve for the specific gravities. The whole of these instruments and materials may be procured for a very small sum. If the foregoing process is carefully followed, any person, however unaccustomed to chemical operations, will soon be enabled to satisfy himself as to the composition of any soil of which he desires to know the comparative value. He must not be disheartened by a few failures at first. However simple every operation may appear, it requires a little practice and much patience, if we would come to a very accurate result. Every portion must be dried to the same degree before it is weighed: minute por. tions which adhere to the vessels when dried must be carefully collected by scraping and brushing off with a feather: pieces of filteringpaper and linen must be weighed before they are used, that small portions of matter adher. ing to them may be ascertained by the in. crease of weight. By attending to these parliculars, it is surprising how nearly the whote original weight is accounted for in the summing up of the separate parts. If this mechanical analysis should be thought lightly of hy experienced chemists, let them only carefully analvse a portion of soil by this process, and then another by any more perfect mode, and compare the importance of the results as regards practical agriculture. The object is in н 2 89 
ascertain the productive powers of the soils; and for this purpose the separation of the different earths is sufficient, in the present imperfect state of our knowledge of the mysteries of vegetation. The process which we have described, simple as it is, may yet be too tedious for the farmer who is desirous of speedily comparing different soils; and we will indicate a still simpler method of ascertaining, nearly, the composition of a soil, and a simple instrument by which it may be done. Take a glass tube, $\frac{3}{4}$ ths of an inch in diameter, and three ieet long; fit a cork into one end and set it upright; fill it half full of pure water; take nearly as much water as has been poured into the tube, and mix with it the portion of soil which is to be examined, in quantity not more than will occupy 6 inches of the tube; pour the mixture rapidly into the tube, and let it stand in a corner of a room, or supported upright in any way; in half an hour it may be examined. The earths will have been deposited according to the size and specific gravity of their particles. The portion still suspended in the water may be allowed to settle; and there will appear in the tube layers of sand, clay, and humus, which may be measured by a scale, and thus the proportion nearly ascertained. When a farmer is about to hire a farm of which the quality is not well known to him, he may be much assisted in his judgment by this simple experiment, if he has no time or opportunity for a more accurate analysis. For the glass tube may be substituted one of tin or zinc two feet in length, with a piece of glass tube a foot long joined to it by means of a brass collar or ferule with a screw cut in it, which is cemented to the glass, and screws on the metal tube; and thus the instrument may be made more portable. When the water has been poured off, and the earths only remain, the cork may be taken out and the contents pushed out on a plate, by means of a rod and a plug which exactly fits the internal diameter of the tube. They may thus be more particularly examined. The result of various accurate analyses of soils shows that the most fertile are composed of nearly equal quantities of silicious and argillaceous earths in various states of division, and a certain proportion of calcareous earth, and of humus in that state in which it attracts oxygen and becornes soluble, giving out at the same time some carbonic acid. No chemist has yet been able to imitate the process of nature in the formation of this substance; and the circum. stances which are most favourable to it are not yet fully ascertained. Here is the proper field for the application of science and accurate chemical analysis. As an example of an ana'ysis will be useful to those who may aesirc to try the proposed. method, we will add one actually made under very unfavourable circumstances, and without any apparatus; the only instrument at hand were scales and weights of tolerable accuracy, three glasses a foot long, and $1 \frac{1}{4}$ inch in diameter, belonging in French lamps, a tin coffee-strainer, a piece of fine gauze, and a very fine cambric pocketnandkerchief. A little muriatic acid was ob90 tained at the apothecary's. The soil to be analyzed was taken from a piece of good arable land on the south side of the slope of the Jura mountains in Switzerland. Its specific gravity was taken as described before, and found to be 2.358 nearly. 500 grains of the dry soil were stirred in a pint of water, and set by in a basin. To save time, 500 grains more of the same soil were weighed, after having been dried over the fire. It was well pulverized with the fingers, and sifted through the coffee-strainer, then through gauze, and, lastly, through the cambric handkerchiel. Some portion was left behind at each sifting. The two first portions were washed in the strainer and the gauze. The residue was sand of two different degrees of fineness, which, when dried, weighed, the coarser, 24 grains, the next, 20 grains. The earth and water which had passed through the strainer and the gauze were now strained through the cantbric, and left some very fine sand behind, which, dried, weighed, and added to what had remained on the cambric, when sifted in a dry state, weighed 180 grains. All that which had gone through the cambric was mixed with water in a jug and stirred about. The heavier earth subsided, and the lighter was poured in one of the lamp-glasses, which had a cork fitted into it, and was placed upright. In about two minutes there was a deposit, and the lighter portion was poured into a similar glass, where it was left some time to settle. In this a slower deposition took place, and in about a quarter of an hour the muddy water was poured off into the third glass. The three glasses were placed upright, and left so till the next day. In the first glass was some very fine earth, apparently clay; in the second the same, but more muddy; and in the third nothing but thin mud. The contents of Nu. 2 were divided between No. 1 and No. 3, by pouring off the muddy part into No. 3 after some of the pure water had been poured off, and the remaining earth into No. 1 ; they were then left to settle. As much water as appeared quite clear over the sediment was decanted off The sediment was poured on a plate by taking the cork out of the tube, which was cleaned with a piece of fine linen, which had been carefully dried and accurately weighed. The plates were examined, and some of the lighter part, which floated on the least agitation, was poured from one plate to another, until it was thought that all the humus had been separated. Most of the water could now be poured off the earths, by inclining the plates gently, without any muddiness. It was, however, passed through a piece of filtering-paper, which had been previously dried and weighed. The earth was slowly dried, by placing the plates on the hearth before a good fire, until they were quite dry, and so hot that they could not be easily held in the hand. The deposit left in the jug was poured on a plate, and a little muddy part, which was observed, was pourel off with the water on another. This was again transferred, and the finer added to that which was in the second plate. Collecting now all the separate portions, there were found 


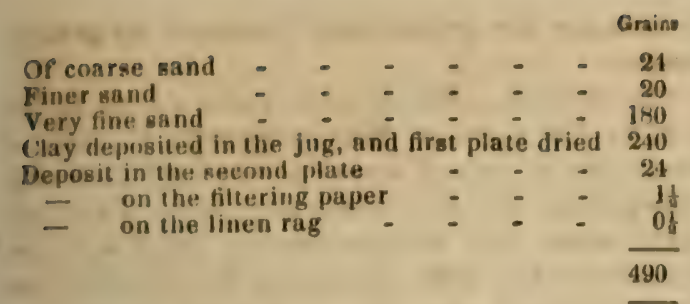

Leaving 10 grains to be accounted for.

Each portion, except the three last, was now put into a cup, and diluted muriatic acid poured over them: an effervescence appeared in ail of them, which continued on the addition of diluted acid, and when the contents of the cups were stirred with a piece of tobacco-pipe They were left till the next day, when all effervescence ceased, and the calcareous part seemed entirely dissolved: pure water was added to dissolve all the muriate of lime which had been formed. After some time, the clear liquor was poured off, and the remainder was strained through filtering-paper, and dried on plates before the fire. The earths were now found to weigh, respectively, 20, 17, 162, and 182.5 grains, having lost $4,3,18$, and $5 \% .5$ grains of calcareous earth dissolved by the acid. The soil and water which had been put by in a basin were now repeatedly stirred, and poured into a filter, and more water was passed through the earth to wash out all the soluble matter: all the water was boiled down and evaporated, and left two grains of a substance which had the appearance of a gum with a little lime in it. Thus the loss was reduced to eight grains, a very small quantity, considering the means used in analyzing the soil. The corrected account, therefore, is as follows :-
Qpecific gravity, 2:358

$\left\{\begin{array}{l}\text { Conare } \\ \text { Finter }\end{array}\right.$

$\left\{\begin{array}{l}\text { Finer - } \\ \text { Very fine }\end{array}\right.$

Conarae

$\{$ Finer

$\{$ Very fine

SClay

sand.

Impalpaible earth.

$\{$ Carb. of lime

(II)mus

sinlubie matter

Loss

Or, in round numbers,-

$$
\begin{aligned}
& 40 \text { per cent. Fand. } \\
& 36 \text { Clay. } \\
& 17 \text { Calcarenus earth. } \\
& 5.5=\quad \text { Vegetahle earth, or humus. } \\
& 0.5 \text { Soluble matter. }
\end{aligned}
$$

From the composition of this soil, it is evident that it is a most excellent loam, capable of producing with good tillage and regular manuring every kind of grain, artificial grasses, and roots commonly cultivated. The field from which the soil was taken was always considered to be of superior quality. This simple rule will suffice to enable any one to analyze any soil of which he desires to know the component parts, so far as they affect the general fertility. To ascertain minute portions of salts or metals, or any peculiar impregnation of the waters, must be left to practical chemists. 'To those who may be inclined to try the analysis of soils, it may be interesting to compare the results of their own experiments with some which have been obtained with great care. Thaër in his very excellent work on Rational Husbundry, written in German and translated into French, has given

\begin{tabular}{|c|c|c|c|c|c|c|}
\hline No. & Clay. & Sand. & $\begin{array}{l}\text { Carb. of } \\
\text { Lime. }\end{array}$ & $\begin{array}{l}\text { Finely divided } \\
\text { Organic Matter, } \\
\text { or Humus. }\end{array}$ & $\begin{array}{l}\text { Comparative } \\
\text { Value. }\end{array}$ & \\
\hline 1 & 74 & 10 & 4 & $11 \frac{1}{3}$ & 1007 & \\
\hline 2 & 81 & 6 & 4 & $8 \frac{1}{9}$ & $9^{2} \zeta$ & Rich alluvial soils. \\
\hline 3 & $\begin{array}{l}79 \\
40\end{array}$ & $\begin{array}{l}10 \\
22\end{array}$ & $\begin{array}{r}4 \\
36\end{array}$ & $6 \frac{1}{8}$ & 96 & Kich alluvial solls. \\
\hline 5 & 14 & 49 & 10 & 27 & & The value of tho could not be fixed, as it was \\
\hline 6 & 20 & 67 & 3 & 10 & 787 & grass land; perhaps bog-earth \\
\hline 7 & 58 & 36 & 2 & 4 & 77 & \\
\hline 8 & 56 & 30 & 12 & 2 & 75 & Good wheat and barley lands. \\
\hline 9 & $\begin{array}{l}60 \\
48\end{array}$ & $\begin{array}{l}38 \\
50\end{array}$ & {$\left[\frac{1}{2} e_{0}^{0}\right]$} & 2 & $\begin{array}{l}70 \\
65\end{array}$ & \\
\hline 11 & 68 & 30 & Ðீ. & 2 & 607 & \\
\hline 12 & 39 & 60 & 三气 & 2 & $60\}$ & Barley land not fit for wheat. \\
\hline 13 & 33 & 65 & $\Xi \Xi$ & 2 & $50)$ & 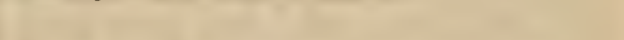 \\
\hline $\begin{array}{l}14 \\
15\end{array}$ & $23 \frac{1}{3}$ & $\begin{array}{l}70 \\
75\end{array}$ & $\frac{2}{5}$ & $2 \frac{2}{1}$ & $\left.\begin{array}{l}40 \\
30\end{array}\right\}$ & Poor sand, fit only for oats or buckwheat. \\
\hline 16 & $18 \frac{1}{8}$ & 80 & & $1 \frac{i}{3}$ & 205 & \\
\hline
\end{tabular}
a table in which different soils analyzed by him are classed according to their compara tive fertility, which is expressed in numbers, 100 being the most fertile.
The above table is the result of very patient investigation, the natural fertility of each soil being ascertained by its average produce with common tilla $\mathrm{e}$ and manuring.

[n describing his new method of analyzing soils, Dr. Dana, the distinguished American chemist, sets out by stating that geine constitutes the basis of all the nourishing part of vegetable manures. By the term geine, he means all the decomposed organic matter of the soil, chietly derived from decayed vegetable matter. Animal substances, he says, produce a similar compound containing azole or nitro. gen. There may be undecomposed vegetable fibres so minutely divided as to pass through the sieve, but as one object of this operation is to free the soil from vegetable fibre, the portion will be quite inconsiderable, and can only affect the amount of insoluble geine. When so minutely divided, it will probably pass into soluble geine in a season's cultivation. Geine, or the vegetable nourishing matter of soils, exists in two states, in one of which it is solu ble in water, \&c., whilst in the insoluble state it resists the solvent power of water. Soluble geine he considers the immediate food of grow. 


\section{ANALYSIS.}

ing plants, whilst insoluble geine becomes food after sufficient exposure to air and moisture. Hence the reason and result of tillage.

Rules of Analysis.- " 1. Sift the soil through a fine sieve. Take the fine part; bake it just up to browning paper.

"2. Boil 100 grains of the baked soil, with 50 grains of pearl ashes, saleratus or carbonate of soda, in four ounces of water, for half an hour; let it settle; decant the clear; wash the grounds with four ounces boiling water; throw all on a weighed filter, previously dried at the same temperature as was the soil, (1); wash till colourless water returns. Mix all these liquors. It is a brown-coloured solution of all the soluble geine. All sulphates have been converted into carbonates, and with any phosphates, are on the filter. Dry therefore that, with its contents, at the same heat as before. Weigh-the loss is soluble geine.

"3. If you wish to examine the geine; precipitate the alkaline solution with excess of lime-water. The geate of lime will rapidly subside, and if lime-water enough has been added, the nitrous liquor will be colourless. Collect the geate of lime on a filter; wash with a little acetic or very dilute muriatic acid, and you have geine quite pure. Dry and weigh.

"4. Replace on a funnel the filter (2) and its earthy contents; wash with two drachms muriatic acid, diluted with three times its bulk of cold water. Wash till tasteless. The carbonate and phosphate of lime will be dissolved with a little iron, which has resulted from the decomposition of any salts of iron, beside a little oxide of iron. The alumina will be scarcely touched. We may estimate all as salts of lime. Evaporate the muriatic solution to dryness, weigh and dissolve in boiling water. The insoluble will be phosphate of lime. Weigh-the loss is the sulphate of lime; (I make no allowance here for the difference in atomic weights of the acids, as the result is of no consequence in this analysis.)

"5. The earthy residuum, if of a grayish white colour, contains no insoluble geine-test it by burning a weighed small quantity on a hot shovel-if the odour of burning peat is given off, the presence of insoluble geine is indicated. If so, calcine the earthy residuum and its filter-the loss of weight will give the insoluble geine; that part which air and moisture, time and lime, will convert into soluble vegetable food. Any error here will be due to the loss of water in a hydrate, if one be present, but these exist in too small quantities in 'granitic sand' to affect the result. The actual weight of the residuary mass is ' granitic sand.'

"The clay, mica, quarłz, \&c., are easily distinguished. If your soil is calcareous, which may be easily tested by acids; then before proceeding to this analysis, boil 100 grains in a pint of water, filter and dry as before, the loss uf weight is due to the sulphate of lime, even the sulphate of iron mav ho so considered; ior the ultimate result in cultivation is to convert this into sulphate of lime.

"T'est the soil with muriatic acid, and having thus removed the lime, proceed as before, to 92 determine the geine and insoluble vegetable matter.

"In applying Dr. Dana's rules given in the text, to the soils of Massachusetts, I found it necessary to adopt some method of carrying forward several processes together. I accordingly made ten compartments upon a table each provided with apparatus for filtering and precipitations, also ten numbered flasks, ten evaporating dishes, and a piece of sheet-iron pierced with ten holes, for receiving the same number of crucibles. I provided, also, a sheetiron oven, with a tin bottom large enough to admit ten filters, arranged in proper order, and a hole in the top to admit a thermometer. The sand bath was also made large enough for receiving the ten flasks. In this manner I was able to conduct ten processes with almost as great facility as one could have been carried forward in the usual way."

As before stated, Dr. Dana regards geine as the basis of all the nourishing part of vegetable manures. The relations of soils to heat and moisture, he says, "depend chiefly on geine. It is in fact, under its three states of 'vegetable extract, geine, and carbonaceous mould, the principle which gives fertility to soils long after the action of common manures has ceased. In these three states it is essentially the same. The experiments of Saussure have long ago proved that air and moisture convert insoluble into soluble geine. Of all the problems to be solved by agricultural chemistry, none is of so great practical importance as the determination of the quantity of soluble and insoluble geine in soils. 'This is a question of much higher importance than the nature and proportions of the earthy constituents and soluble salts of soils. It lies at the foundation of all successful cultivation. Its importance has been not so much overlooked as undervalued. Hence, on this point the least light has been reflected from the labours of Davy and Chaptal. It needs but a glance at any analysis of soils, published in the books, to see that fertility depends not on the proportion of the earthy ingredients. Among the few facts, best established in chemical agriculture, are these : that a soil, whose earthy part is composed wholly, or chiefly, of one earth ; or any soil, with excess of salts, is always barren; and that plants grow equally well in all soils, destitute of geine, up to the period of fructification,-failing of geine, the fruit fails, the plants die. Earths, and salts, and geine, constitute, then, all that is essential; and soils will be fertile, in proportion as the last is mixed with the first. The earths are the plates, the salts the seasoning, the geine the food of plants The salts can be varied but very little in theil proportions, without injury. The earths admit of wide variety in their nature and proportions. I would resolve all into 'granitic sand;' by which I mean the finely divided, almost impalpable mixture of the detritus of granite, gneiss, mica-slate, sienite, and argillite; the last, giving by analysis, a compound very similar to the former. When we look at the analysis of vegetables, we find these inorganic principles constant constifuents-silica, lime, mag nesia, oxide of iron, potash, soda, and sulphurie 
and phosphoric acids. Hence, these will be found constituents of all soils. The phosphates have been overlooked from the known diffculty of detecting phosphoric acid. Phosphate of lime is so easily soluble when combined with mucilage or gelatine, that it is among the first principles of soils exhausted. Doubtless the good effects, the lasting effects, of bone manure, depend more on the phosphate of lime, than on its animal portion. 'Though the same plants growing in different soils are found to yield variable quantities of the salts and earthy compounds; yet I beliese, that accurate analysis will show, that similar parts of the same species, at the same age, always contain the inorganic principles above named, when grown in soils arising from the natural decomposition of granite rocks. These inorganic substances will be found not only in constant quantity, but always in definite proportion to the vegetable portion of each plant. The effect of cultivation may depend, therefore, much more on the introduction of salts than has been generally supposed. The salts introduce new breeds. So long as the salts and earths exist in the soil, so long will they form voltaic batteries with the roots of growing plants; by which, the 'grantic sand' is decomposed and the nascent earths, in this state readily soluble, are taken up by the abcorbents of the roots, always a living, never a mechanical operation. Hence, so long as the soil is granitic, using the term as above defined, so long is it as good as on the day of its deposition; salts and geine may vary, and must be modified by cultivation. The universal diffusion of granitic diluvium will always afford enough of the earthy ingredients. The fertile character of soils, I presume, will not be found dependent on any particular rock formation on which it reposes. Modified they may be, to a certain extent, by peculiar formations; but all our grantic rocks afford, when decomposed, all those inorganic principles which plants demand. This is so true, that on this point the farmer already knows all that chemistry can teach him. Clay and sand, every one knows: a soil too sandy, too clayey, may be modified by mixture, but the best possible mixture does not give fertility. That depends on salts and geine. If these views are correct, the few properties of geine which I have mentioned, will lead us at once to a simple and accurate mode of analyzing soils, - a mode, which determines at once the value of a soil, from its quantity of soluble and insoluble vegetable nutriment, - a mode, requiring no array of apparatus, nor delicate experimental tact,-one, which the country gentleman may apply with very great accuracy; and, with a little modification, perfectly within the reach of any man who can drive a team or hold a plough."]

ANALYSIS OF VEGETABLES. The process or means by which such bodies are resolved into their constituent or elementary principles. (See Chemistar, or Vegetabis Chismistr.)

ANBURY. In farriery, a kind of wen, or spongy soft tumour or wart, commonly full of blood, growing on any part of an animal's body. Substances of this kind may be removed either by means of ligatures heing passed round their bases, or by the hinife, and the subsequent application of some caustic material, in order to effectually destroy the parts from which they arise.

ANBURY, 'THE, AMBURY, II NBURY, or CJUUB-ROO'I. The anbury, the currect name, is evidently derived from the Saxon word ambre, a wart, suffused with blood, to which horses are subject. In Holderness, a district of Yorkshire, this disease is known as "fingers and toes," from its causing the top root of the turnip to be divided into swollen fibres, resembling those members of the human body. On this, Mr. Spence, the entomologist, wrote a very sensible pamphlet, entitled "Observations on the Diseases in 'Turnips, termed in Holderness Fingers and Toes, Hull, 1812." The deficiency of knowledge relative to the diseases of plants is well illustrated by the imperfect and inaccurate observations that have been adventured upon this disease. Where there is much difference of opinion there is little real knowledge, and both these are certainly the case, in the instance before us. Some cultivators assert that the disease arises from a variableness and unfavourable state of the seasons; a second party of theorists advance, that it is caused by insects; and a third, that it is owing to a too frequent growth of the same crop upon the same site. Every man having formed an opinion, usually clings to it pertinaciously, and sets its estimate far above its real value or correctness. "It is with our opinions as our watches, none go just alike, yet each believes his own." The chief error appears to be in considering any of the above enumerated causes as the exclusive one; for beyond doubt they each contribute, either immediately or remotely, to induce or exasperate the attacks of the anbury. [The disease attacks the hollyhock, and other plants, especially those belonging to the brassica or cabbage family.] Cabbage-plants are frequently infected with anbury in the seed-bed, and this incipient infection appears in the form of a gall or wart upon the stem, immediately in the vicinity of the roots; if this wart is opened it will be found to contain a small white maggot, the larva of a small insect called the weevil. If the gall and its tenant being removed, the plant is placed again in the earth where it is to remain unless it is again attacked, the wound usually heals, and the growth is little retarded. On the other hand, if the gall is left undisturbed, the maggot continues to feed upon the alburnum, or young woody part of the stem, until the period arrives for its passing into the other insect form, previously to which it gnaws its way out through the exterior bark. The disease is now almost beyond the power of remedies, the gall, increased in size, encircles the whole stem; the alburnum being so extensively destroyed, prevents the sap ascending, consequently, in dry weather, sufficient moisture is not supplied from the roots, to counterbalance the transpiration of the leaves, and the diseased plant is very discernible among its healthy compa nions, ky its pallid hue and flagging foliaf 
The disease now makes rapid progress; the swelling continues to increase; for the vessels of the alburnum and the bark continue to afford their juices faster than they can be conveyed away. Moisture and air are admitted to the interior of the excrescence through the perforation made by the maggot; the wounded vessels ulcerate, putrefaction supervenes, and death concludes the stinted existence of the miserable plant. The tumour usually attains the size of a large hen's egg, has a rugged, ichorous, and even mouldy surface, smelling strong and offensively. The fibrous roots, besides being generally thickened, are distorted and monstrous, from swellings which appear throughout their length, which apparently arise from an effort of nature to form receptacles for the sap, deprived as it is of its natural spissation in the leaves. These swellings do not seem to arise immediately from the attacks of the weevil, for 1 have never observed them containing its larva. Mr. Marshall very correctly describes the form which this disease assumes when it attacks the turnip. It is a large excrescence appearing below the bulb; growing to the size of both hands, and as soon as the hard weather sets in, or it is, by its own nature, brought to maturity, becoming putrid, and smelling very offensively. On the last day of August, when the bulbs of the turnips were about the size of walnuts in the husk, the anburies were as big as a goose's egg. These were irregular and uncouth in their form, with excrescences resembling the races of ginger hanging to them. On cutting them, their general appearance is that of a hard turnip; but on examining them through a magnifier there are veins, or string-like vessels, dispersed among the pulp. The smell and taste somewhat resemble those of turnips, but without their mildness, having an austere and somewhat disagreeable flavour resembling that of an old stringy turnip. The tops of those much affected turn yellow, and flag with the heat of the sun, so that in the daytime they are obviously distinguishable from those which are healthy. These distortions manifest themselves very early in the turnip's growth, even before the rough leaf is much developed. Observation seems to have ascertained, that if the bulbs have attained the size of a walnut unaffected, they do not subsequently become diseased. Mr. Spence has clearly shown, from established facts, that the anbury does not arise from any imperfection of the seed sown: for experience demonstrates that, in the same field and crop, the attacks are very partial; and crops in two adjoining fields, sown with seed from the same growth, will one be diseased, and the other healthy. Secondly, it does not arise from an unfavourable time of sowing, or from dry, unpropitious seasons, during their after-growth; for on this supposition we might expect that in all turnip districts the disease would occasionally make its appearance, in consequence of variations in the period and mode of sowing, or from following droughts; yet we know that, in many parts of the country, it has never been neard of. Thirdly, it does not arise from the quality of the soil, for Sir Joseph Banks suffered from its infecting thin stapled, sandy fields; whilst all IIolderness, which is generally a strong lnamy soil, was found equally liable to the disease. It is occasioned by the poisonous wound inflicted by an insect in an early stage of vegetation, or rather by its insinuating its egg into the tender plant. 'The maggot found in the turnip anbury, is the larva of a weevil called Curculio pleurostigma by Marsham, and Rhynchænus sulcicollis by Gyllenhal. "I have bred this species of weevil," says Mr. Kirby, from the linob-like galls on turnips, called the anbury, and I have little doubt that the same insects, or a species allied to them, cause the clubbing of the roots of cabbages." (Kirby and Spence's Introduction to Entomoligy.) Marsham describes the parent as a coleopterous insect, of a dusky, black colour, with the breast spotted with white, and the length of the body one line and two-thirds.

A very full description of this insect is in the Insecta Sverica descripta, of Gyllenhal, vol. iii. p. 229, under the name of Rhynch:nus sulcicollis.

The general experience of farmers and gardeners upon the subject, testifies that the anbury of the turnip and cabbage usually attacks these crops when grown for successive years on the same soil. This is precisely what might be expected; for the parent inseot always deposits her eggs in those situations where her progeny will find their appropriate food; and in the fragments of the roots, \&c., of preceding crops, some of these embryo ravagers are to be expected. That they never attack the plants upon a fresh site is not as. serted; Mr. Marshall's statement is evidence to the contrary ; but it is advanced that the obnoxious weevil is most frequently to be observed in soils where the turnip or cabbage has recently and repeatedly been cultivated. Another general result of experience is, that the anbury is most frequently observed in dry seasons. This is also what might be anticipated, for insects that inhabit the earth just beneath its surface are always restricted and checked in their movements by its abounding in moisture. Moreover, the piants actually affected by the anbury are more able to contend against the injury inflicted by the larva of the weevil by the same copious supply. The developement of their parts, their growth is more rapid; consequently the maggot has not to extend his ravages so extensively in search of food as in drier seasons, when the stem is less juicy and of a smaller growth. In wet periods, also, the affected plants show less the extent of the injury they have sustained, for their foliage does not flag; because their transpirations of watery particles is less, and their supply of nutriment from the soil is more free.

In considering the best modes of preventing the occurrence of the disease, and of palliating its attacks, it is apparent that any addition to the soil that renders it disagreeable to the weevil will prevent the visits of this insect. The gardener has this in his power with but little difficulty ; for he can keep the vicinity of his cabbage, cauliflower, and brocoli plants soaked with water. Mr. Smith, gardener to Mr. Bell, of Woolsington in Northumberland, expresses his conviction. after several vears' 
experience, that charcoal dust spread about half an inch deep upon the surface, and just mixed with it by the point of a sparle, efiectually prevents the occurrence of this disease. (Trans. of Lonn. Hort. Soc. vol. i. art. 2.) That this would be the case we might have surmised from analogy ; for charcoal dust is offensive to many insects, and is one of the most powerful preventives of putrefaction known. Soot, I have reason to believe, from a slight experience, is as effectual as charcoal dust. Judging from theoretical reasons, we might conclude that it would be more specific; for in addition to its being like charcoal, finely divid. ed carbon, it contains ammonia, to which insects have an antipathy. Mr. Drurey, a practical farmer at Erpingham, in Norfolk, considered marl a certain preventive of this disease. $\mathrm{He}$, and several other judicious farmers also, thought that tealhing, that is, giving sheep and cattle their green food, turnips, \&c.. upon the barley stubbles, intended for turnips as the succeeding crop, will cause the anbury. (Marshall's Rurul Economy of Norfilk, ii. 33, 35.) It is very evident that it would mix fragments with the soil that would be liable to contain the eggs of the weevil. The marl, approved by $\mathrm{Mr}$. Drurey, is probably the calcareous marl which occurs at Thorp Market, in the nundred of North Erpingham; but as there is a slight doubt, owing to the deficiency of accuracy in the statement, it affords me an opportunity to impress upon agriculturists in general, che great importance of employing more cerrain terms than they usually do. What can be more indefinite than the statement, that marl is a certain preventive of the anbury? For the very first question suggested to the reader's mind is, What marl is intended? Is it a chalky marl, or a clay marl? is it a mixture of chalk and clay, or of chalk and silicious sand? for all these varieties of marl are known to agriculture. The want of a correct nomenclature is one of the drawbacks and deficiencies checking the improving progress of agriculture. Few farmers ever thought upon this point, and still smaller is the number who duly appreciated its importance; yet it is an incontrovertible fact, that no art or science can advance rapidly until its technical terms are fixed, terse, expressive, and generally understood. Chemistry dttained a greater aid to its advancement by the introduction of its new nomenclature by Lavoisier, than by any series of discoveries that have since been made on its rapid and brilliant progress. If a sulphate, an acid, or a metal is mentioned, a chemist immediately has a definite idea of the nature and properties of the substance alluded to; but if a loam or marl is spoken of, would any two farmers agree in their idea of what description of earthy compound was intended! To make it well understood, a Inng detail must be added; and nothing checks the imparting of knowledge more, than the person capable of imparting it being conscious that he must define every term as he goes on, and that even then it is doubtful, if he shall succeed in making himself intelligible. The very name, anbury, usually applied to the disease, which is the subject of this paper, is another proof of the necessity of a reformed agricultural nomenclature; for in Sur ilk, the same title is given to another disease which merely affects the leaves of the turnip. Sir Joseph Banks, Mr. Baker of Norfolk, arul others, agree that marl is the best preventive of anbury. And another evirlence of the efficacy of applications to the soil is affirded ly a gentleman in Holderness, a Mr. Brigham, who had a highly manured clayey ridge, which he had levelled the year before, and this grew turnips entirely free of the disease, whilst in the natural rich loam of the field they were much infected. Francis Constable, Esq., of Burton Constable, had a field that had been in grass twenty years : this he pared, burned and sowed with turnips, obtaining a crop perfectly free from the disease. Two white crops were then taken, after which turnips were again sown; a considerable portion of the crop was then infected with the disease. (Spence's Ob. servations on the Disease of Turnips, termed in Holderness Fingers and Toes.) I have myself tried the efficacy of common salt in preventing the occurrence of this disease: its tendency to keep the soil moist, and to irritate the animal frame, certainly checks the inroads of the weevil; and its generally beneficial effects as a manure enables the plants better to sustain themselves under the weakening influence of the disease; but it is not a decisive preventive.

With regard to the use of salt as a cure for the disease, I am inclined to think, from the results of experiments which I have instituted, that unless the salt be applied very early, it would be useless; for the root soon becomes so diseased as to be entirely past recovery. (C.W. Johnson's Essay on Salt, p. 136.)

I have a strong opinion that a slight dress ing of the surface soil with a little of the dry hydro-sulphate of lime, that may now be obtained so readily from the gas-works introduced throughout England, would prevent the occurrence of the disease, by driving the weevils from the soil. It would probably as effertually banish the turnip-fly or flea, if sprinkled over the surface immediately after the seed is sown. I entertain this opinion of its efficacy in preventing the occurrence of the anbury, from an instance when it was applied to some broccoli, ignorantly grown upon a bed where cabbages had as ignorantly been endeavoured to be produced in successive crops; these had invariably failed from the occurrence of the anbury, but the broccoli was uninfected. The only cause for this escape that I could trace was, that just previously to planting, a little of the hydro-sulphuret of lime had been dug in. This is a very ietid, powerful compound, and must be used with great caution.

Where dry lime purifiers are. emplnyed at gas-works, it may be obtained in the state of a dry powder; but where a liquid mixture of lime and water is employed, the hydrn-sulphuret can only be had in the form of a thick cream. Of the dry hydro-sulphuret I would recommend eight bushels per acre to be spread regularly by hand upon the surface. after the turnip seed is somn, and before har. rowing. If the liquid is employed. I wn 
recommend thirty gallons of it to be mixed with a sufficient quantity of earth or ashes, to enable it to be spread over an acre in a similar manner. For cabbages twelve bushels, or forty-five gallons per acre, would not, probably, be too much, spread upon the surface, and turned in with the spade or last ploughing. Although I specify the quantities as those I calculate most correct, yet in all experiments it is best to try various proportions: three or four bushels may be found sufficient; perhaps twelve, or even twenty, may not be too much. Frequent hoeing has been recommended as a preventive of this disease; but I believe this to be unsustained either by reason or practice. (G,W. Johnson, Quar. Journ. Agric., vol. vii. p. 308, et seq.)

[ANDES GRASS. The Holcus avenaceus of some writers, and Avena elatior of others. Oat Grass, and sometimes Tall Meadow Grass. (Plate 5, ce.) A perennial cultivated grass, fowering in the Middle States in May, and ripening its seeds in July. (Flor. Cestrica.) Its name would imply that it came originally firn the mountains of South America, whereas the English botanists treat of the Holcus avenaceus, or Avena elatior, as a native of Britain. The Andes Grass was introduced to the notice of American farmers several years ago, when its merits were perhaps too highly extolled, which has contributed to its being now estimated much below its real worth. Perhaps, too, that those who have reported unfavourably of the value of Andes Grass, have mistaken some other plant for it, a very common sccurrence, leading to great discrepancy of "pinion. 'This grass is certainly highly prized by many persons in the Middle States, where, especially in the state of Delaware, it is frequently, though not very extensively, cultivated. It grows luxuriantly in soils of clay loam, even of a very light description, affording very early as well as late pasture. Even an open spell in winter, with a few warm days, will start this grass to vegetating so rapidly as to furnish a good bite to cattle. The grass grows very tall, and the hay, if left too late before cutting, is coarse. It grows in tufts, is very durable, and extremely difficult to eradicate from the soil when once well set. This last circurnstance perhaps constitutes the most common objection to its introduction into fields and meadows. It stands drought well, and would probably be found a highly valuable grass for southern pastures. It certainly deserves more attention than it now receives, and is, we think, destined to be much more extensively cultivated as a permanent pasture grass. Its durability renders it unfit for alternate husbandry.

From Colman's Foulch Report of the Agriculture of Massachusetts the following passage is extracted.

"The tall meadow oat (Avena elatior) has been cultivated in the county. This grass is not familiar to our farmers, but the success which nas attended its cultivation encourages its ex-ension. A Virginia farmer of the highest duthority speaks of it, after fifteen years' exnerience, as a hardy plant, bearing drought and frost, heat and cold, better than any other 96 grass known to him. A Pennsylvania farmer pronounces it of all other grasses the earliest, latest, and best for green fodder or hay. It blossoms about the middle of June, and is preferred to all others by horned cattle. It must be cut seasonably or it becomes hard like straw. A Middlesex farmer, who has cultivated it several years, and whose authority is of the highest character, confirms the above statements of its excellence both for grazing and hay. He says, from its early flowering it is adapted to be sown with red clover, and is fit to be cut about the first of June. His own account is as follows:

"IIn the spring he sowed with barley a field of four acres, and put on $2 \frac{1}{2}$ bushels of oatgrass seed, 5 lbs. of red clover, and $2 \mathrm{lbs}$. of white clover seed, to the acre. The soil was thin, and had been exhausted by long cropping. On the $3 \mathrm{~d}$ of June in the following year it was cut, and gave two tons to the acre of the finest and best hay, either for cattle or horses, he ever had in his barn.'

"He thinks three bushels of seed should be sown to the acre. It is well adapted for grazing on poor and exhausted lands, as well as on those of a richer quality. It is a fortnight earlier than the common grasses, and throughout the dryest weather exhibits a green appearance. From three-fourths of an acre, in good condition, he obtained over 20 bushels of well-cleaned seed.

"The late John Lowell, a man behind no other in his intelligent, successful, and disin. terested efforts to advance the cause of an im. proved agriculture in Massachusetts and New England generally, says that, 'under his cultivation, it has proved a most valuable grass, and fully sustained its high character. It is a very early and tall grass, yielding a good burden. It will start rapidly after cutting. It is a perennial and enduring grass, and on his first experiment it lasted seven years without the necessity of renewal.'

"A farmer in Waltham objects to sowing the tall meadow oats and the herdsgrass (Timothy) together, as they do not ripen at the same time. The tall meadow oats, when I visited him, would be ready for the scythe in ten days, or about the middle of June, while the herdsgrass, at the same time, had not begun to show its head.

" This grass-Avena elatior, tall oat grasssends forth flower-straws during the whole season; the latter math contains nearly an equal rumber with the flowering crop. It is subject to the rust, but the disease does not make its appearance ill after the period of flowering. It affects the whole plant, and at the time the seed is ripe the leaves and straws are withered and dry. This accounts for the superior value of the latter math over the seed crop, and points out the propriety of taking the crop when the grass is in flower. The nutritive matter afforded by this grass, when made into hay, according to the table is very small.' (Geo. Sinclair.)

"J. Buel speaks of his "field experiments with this grass not being so successful as he expected-owing partly to the seed not vegetating well; and partly, he supposed, to the 
soll (a light sandy loam) not being sufficientiy strong and tenacious."

"Taylor, of Virginia, says that, 'according to his experience, it will not succeed in lands originally wet, however well they are drained.' "The opinion of the farmers generally in this county is in favour of cutting herdsgrass (Timothy) early rather than late; perhaps for the reason that the hay is then of a bright green, and on this account commands in the city market a higher price. If we can rely upon chemical examination in determining the nutritive properties of grasses, it will be found that the grain in this respect, in cutling herdsgrass when its seed is ripe over cuting it when in flower, is as $86 \cdot 1$ to $37 \cdot 2 . "$ ]

ANETHUM. See DILL and FENNEL.

ANEURISM. In farriery, a throbbing tumour, produced by the dilatation of the coats of an artery in some part of the body of an animal. Aneurisms in the limbs may be cured by making an incision, exposing the artery, and tying it abuve and below the tumour with a proper ligature.

ANGELICA (Angelica Archangelica). This plant was formerly blanched and eaten like celery; but at present its tender stalks are the only part made use of, which are cut in May for candying.

It grows in gardens, and also wild. It fowers in July and August in England, and the roots perish after the seed has ripened. This plant grows as high as eight feet; the stalks robust, and divided into branches. 'The flowers are small, and stand in large clusters of a globular form. Two seeds follow each Alower.

It may be grown in any soil and exposure, but flourishes best in moist situations; consequently the banks of ponds, ditches, \&c., are usually alloted to it. It is propagated by seed, which is to be sown soon after it is ripe, about September, being almost useless if preserved until the spring, as at that season not one in forty will be found to have preserved its vegetative powers; if, however, it be neglected until that season, the earlier it is inserted the better. It may be sown either broadcast moderately thin, or in drills a foot asunder, and half an inch deep. When arrived at a height of five or six inches, they must be thinned, and those removed transplanted to a distance of at least two feet and a half from each other, either in a bed, or on the sides of ditches, \&c., as the leaves extend very wide. Water in abundance must be given at the time of removal, as well as until they are established; but it is better to discontinue it during their turther growth, unless the application is regular and frequent. In the May or early June of the second year they flower, when they must be cut down, which causes them to sprout again; and if this is carefully attended to, they will continue for three or four years, but if permitted to run to seed, they perish soon after. A little seed should be saved annually as a resource in case of any accidental destruction of the crop. (G.W. Johnsm's Kitchen Garden.)

Angelica is fragrant when bruised, and every part of it is medicinal. The bruised seeds are the most powerful. They are cordial and su13 dorific. Three table-spoonfuls of the distillec. water is a remedy for tlatulence and pains in the stomach. A paste of the fresh rout of angelica, beaten up in vinegar used to be carried by physicians in times of great contagion, w apply to the nose. Some preferred holding a dry piece in their mouths, to resist infection. It has always been celebrated against pestilen tial and contagicus diseases. The stalks if the angelica candied are much esteemed in winter desserts as a sweetmeat in Linglasd. The Laplanders boil or bake the stalks till extremely tender, and eat them as a delicacy. The seeds bruised are cordial, stomachic, and sudorific. (L. Johnson.)

ANGINA. In farriery, a name sometimes applied to the quinsy, or what in animals is termed anticor.

ANGLE-BERRY. In farriery, a sort of fleshy excrescence, to which cattle and some other animals are subject under different circumstances; and are supposed to proceed from a rupture of the cutaneous vessels, which give vent to a matter capable of forming a sarcomc, or fleshy excrescence. They frequently appear upon the belly and adjacent parts, hanging down in a pendulous manner.

ANGORA GOAT. A particular species of goat.

ANIMAL. A creature that is endowed with life, and commonly with spontaneous motion. though in some cases without it. 'They are distinguished in general from vegetables by having motion, though this gives us no perfect definition, as there are entire classes of animals which are fixed to a place, as the lithophytes and zoophytes, which are produced and die upon the same spot; and on the other hand. certain vegetables have as much motion in their leaves and flowers as certain animals. However, by attending to the most general characters, they may be defined to be bodies endued with sensation and motion necessary to preserve their life. They are all capable of reproducing their like: some by the union of the sexes, produce small living creatures; others lay eggs, which require a due temperature to produce young; some multiply without conjunction of the sexes; and uthers are reproduced when cut in pieces like the roots of plants. See Botany. For periods or Breeding

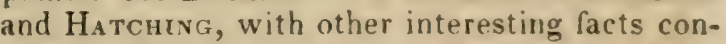
nected with the subject, see Gestation and IsCUBATION.

ANIMAI,S, DANGEROUS. See Nersayce. ANIMALS, WILD, STEAIING OF. In England no larceny at common law (says Mr. Archbold in his Crim. Law, p. 165) can be committed of such animals, in which there is no property either absolute or qualified; as of beasts that are feræ naturæ, and unreclaimed, such as deer, hares, and conies, in a forest. chase, or warren; fish, in an open river or pond; or wild fowls, rooks for instance (Hun. man v. Hocketl, 2 B. \& C. 934; 4 D. \& R. 518) at their natural liberty. (1 Hule, 511; Fost 366.) But if they are reclaimed or confined and may serve for food, it is otherwise $;$ for of deer so enclosed in a park that they may bo taken at pleasure, fish in a trunk or net, and pheasants or partridges in a mew, larceny ma 
be committed. (1 Hale, 511; 1 Hawk. c. 33, s. 39.) Swans, it is said, if lawfully marked, are the subject of larceny at common law, although at large in a public river (Dalt. Jus/. c. 156); or whether marked or not if they be in a private river or pond. (Ib.) So, all valuable domestic animals, as horses, and all animals domilæ naturæ, which serve for food, as swine, sheep, poultry, and the like, and the product of any of them, as eggs, milk from the cow while at pasture (Fuster, 99), wool pulled from the sheep's back feloniously ( $R$. v. Martin, 1 Leach, 171), and the flesh of such as are feræ nalurx, may be the subject of larceny. (1 Hale, 511.) But as to all other animals which do not serve for food, such as dogs, ferrets though tame and saleable ( $R$. v. Spearing, R. \& R. 250), and other creatures kept for whim and pleasure, stealing these does not amount to larceny at common law. (1 Hale, 512.) But now, to course, hunt, snare, or carry away, or kill or wound, or attempt to kill or wound, any deer kept or being in the enclosed part of any forest, chase, or purlieu, or in any enclosed land wherein deer are usually kept, is felony, punishable as simple larceny; and if committed in the unenclosed part of any forest, chase, or purlieu, the first offence is punishable upon summary conviction by fine not exceeding $50 \mathrm{l}$, and the second after a previous conviction is felony, and punishable as simple larceny. ( 7 \& 8 G. 4 , c. 29 , s. 27.) Summary punishment may also be imposed by fine, not exceeding $20 l$., upon any person who shall have in his possession, or upon his premises, with his knowledge, any deer, or the head, skin, or other part thereof, or any snare or engine for the taking of deer, without satisfactorily accounting for such possession $(7 \& 8 \mathrm{G} .4$, c. 29, s. 27) ; or who shall set or use any snare or engine whatsoever for the purpose of taking or killing deer in any part of any forest, chase, or purlieu, whether enclosed or not, or in any fence or bank dividing the same from any land adjoining, or in any enclosed land where deer are usually kept, or shall destroy any part of the fence of any land where deer are then kept. (7 \& 8 G.4, c. 29, s. 28.) To take or kill hares or coneys in the night-time, in any warren or ground lawfully used for the breeding or keeping of the same is a misdemeanor; and to take and kill them in any warren or ground in the day-time, or at any time to set any snare or engine for the taking of them, is punishable upon summary conviction by fine. ( $7 \&$ 3 G. 4, c. 29, s. 30.) Stealing dogs, or any beast or bird ordinarily kept in a state of confinement, not being the subject of larceny at common law ( $7 \& 8$ G. 4, c. 29, s. 31 ); knowingly being in possession thereof, or of the skin or plumage thereof (7\& 8 G. 4, c. 29, s. 32); killing, wounding, or taking any dovehouse pigeon, under such circumstances as shall not amount to larceny at common law (, te R. y. Brooke, 4 C. \& P. $131 ; 7$ \& 8 G. 4, (. 29, s. 33), is punishable upon summary conviction by nine, imprisonment, and whipping, according to the nature of the offence. So, to take or destroy any fish in any water which shall run through, or be in any land adjoining wr belonging to the dwelling-house of any per- son, being the owner of such water, and having a right of fishery therein, is a misdemeannr; and to take and destroy fish in any other water, being private property, or in which there shall be any private right of fishery ; and to destroy fish by angling, in the day-time, in either de. scription of water is punishable upon summary conviction by fine, varying according to the nature of the offence. ( $7 \& 8$ G. 4, c. 29, s. 34.) And, lastly, to steal any oyster or oyster brood from any oyster bed, laying, or fishery, being the property of another, and sufficiently marked out or known as such, is larceny; and to use any dredge or any net, instrument or engine whatsoever within the limits of such oyster fishery for the purpose of taking oysters or oyster brood, although none be taken, or to drag upon the soil of any such fishery with any net, instrument, or engine, is a misdemeanor. ( $7 \& 8$ G. 4 , c. 29 , s. 36. )

ANIMAL CHEMISTRY. See Chemistr.

ANIMAL MANURES. For the information I have to furnish with regard to animal manures, I must refer the farmer to other heads of this work, such as FanM-Yard Manure, Night-soil, Bones, Liquid Mavure, Fish, \&c. A very elaborate paper by Dr. C. Sprengel, translated by Mr. Hudson, will be found in the Journal of the Roy. Ag. Soc. of Eng., vol. i. p. 455, and to that I am indebted for most of the general observations on animal manures in this article. The excrements of animals vary with the age of the animal, its food, \&c. That of young animals is poorer than that of the aged, for the young and growing animal requires, for its nourishmeni and increase in size, a greater proportion of the phosphate of lime, and other solid ingredients of its fooc, than the more aged animal, because the excrements or refuse matters of the vegetables consurned are proportionately diminished in quanity and in richness. The richer the food, too, the better is the quality of the manure. That from animals fed upon oil-cake is the richest; then that from corn-fed animals; then that from green crops, hay; and, lastly, that from straw-yard cattle is decidedly the poorest. Then again the water consumed by animals to some extent influences the quantity of their manure. In the water usually drank by an ox, amounting daily to about $80 \mathrm{lbs}$., is often found from half an ounce to an ounce of saline matter. These consist of gypsum, common salt, carbonate of lime, and carbonate of magnesia. "It may be always regarded," as is observed by M. Sprengel, "as an indication that the excrements of animals contain many powerfully manuring substances when they pass quickly into the putrefactive state, and develope a large quantity of the offensive gases, ammonia; for in such cases they contain not only much sulphur, phosphorus, and nitrogen, but an abundance also of chlorine, soda, potash, lime, and magnesia, the whole of which are so much the more important in vegetation, as the soil manured with the excrements is deficient in these particular substances."

The mode in which animal fertilizers operate, varies, however, according to their chemi. cal composition. Some are enriching from possessing peculiar saline substances, which 
are direct food for plants. Thus bones abound with phosphate of lime. Night-soil and urine do the same. Farm-yard compost contains all the essential ingredients of the farmer's crops, and they all copiously yield, by their decomposition, the gases of putrefaction, such as the carburetted hydrogen, and carbonic acid gas, as well as various easily decomposible salts of ammonia; all of which are found to be highly nourishing when applied to the roots of the plants, or even to their leaves. And, in fact, some of the most powerful of the animal fertilizers, such as train-oil, whale-blubber, \&c., can yield the plant nothing else : they do not contain either saline or earthy matters. It is their gaseous elements only, therefore, which, when applied to the roots of vegetables, produces such a rankness of growth, such a dark green, as the farmer invariably finds to follow in moist seasons from their use.

The quantity of animal manures employed in England besides that produced by the farmer's live stock, is annually increasing, and it is a happy circumstance that it is so. Not only are sprats and other cheap fish bought up in every direction, but all northern Europe, and even the South Sea, is searched for bones; refuse train oil, and greaves are, to a considerable extent, also used, and there are several manufactories in the metropolis for the preparation of manure powders of an animal description, such as the urate of the London Manure Company, and the disinfected night-soil of M. Poittevin. These are both, especially the first, powerful enrichers, and are admirably adapted for application by the drill.

ANIMAL POISONS. Several animals are furnished with liquid juices of a poisonous nature, which, when injected into fresh wounds, occasion the disease or death of the wounded animal. Well known examples are furnished by the sting of serpents, bees, scorpions, spiders, \&c. The poison of the viper is a yellow liquid, which lodges in two small vesicles in the animal's mouth. These communicate by a tube with the crooked fangs which are hollow, and terminate in a small cavity. When the animal bites, the vesicles are squeezed, and the poison forced through the fangs into the wound. This poisonous juice occasions the fatal effects of the viper's bite. If the vesicles be extracted, or the liquid prevented from flowing into the wound, the bite is harmless. It has a yellow colour, resembling gum, but no taste; and when applied to the tongue occasions numbness. The poison of the viper, and of serpents in general, is most hurtful when mixed with the blood. Taken into the stomach, it kills if the quantity be considerable. Fontana has ascertained that its fatal efrects are proportional to its quantity compared with the quantity of the blood. Hence the danger diminishes as the size of the animal increases. Small birds and quadrupeds die immediately when they are bitten by a viper; but to an adult the bite seldom proves fatal. "Sweet oil," says Mr. Beckford, "has long been esteemed as a certain antidote to the bite of a viper; sume should be applied to the part, and some taken inwardly; but the common cheese-rennet, externally applied, is asserted to be a more efficacious remedy than oil. Ammonia, or spirits of hartshorn, has also been proposed as an antidote. It was introduced in consequence of the theory of Dr. Mead, that the poison was of an acid nature. The numerous trials of that medicine by Fontana robled is of all its celebrity; but it has been lately revived and recommended by Dr. Ramsay as a certain cure for the bite of the rattlesnake." (Phil. Mag. vol. xvii. p. 125.)

The venom of the bee and the wasp is also a liquid contained in a small vesicle, forced through the hollow tube of the sting into the wound inflicted by that instrument. From the experiments of Fontana we learn that it bears a striking resemblance to the poison of the viper. That of the bee is much longer in drying when exposed to the air than the venom of the wasp. 'The sting of the bee should be immediately extracted; and the best application is opium, and olive oil; one drachm of the former finely powdered, rubbed down with an ounce of the latter, and applied to the part affected by means of lint, which should be frequently renewed. (See BE.) The poison of the scorpion resembles that of the viper. But its taste is hot and acid, which is the case also with the venom of the bee and the wasp. No experiments upon which we can rely have been made upon the poison of the. spider tribe. From the rapidity with which these animals destroy their prey, and Even oise another, we cannot doubt that their poison is sufficiently virulent. (Mead and Fontana on Poisons; Thumson's Chem. vol. iv. pp. $531-$ 533.)

[Soft poultices of fresh flesh, bread and milk, or in the absence of these, even mud, are excellent applications to stings of insects and even the bites of the most venomous snakes. The vaunted specifics recommended in such cases for internal use, are not to be compared in effcacy with the timely application of a poultice of the flesh of a chicken or other animal recently killed. The flesh of the rattle-snake itself is in some parts of America reckoned to possess specific virtues, and doubtless will answer nearly, if not quite as well, as any other good soft and moist poultice, which will seldom fail to effect a cure when promptly applied and frequently renewed. In this way the irritation and inflammation induced by the poison in the part bitten is often arrested at once, and prevented from extending to vital parts. These conclusions are the results of experiments made with the poison of the rattle-snake, in which the most celebrated Indian and other specifics were used with little if any advantage.]

ANJOU CABBAGE. An excellent vegetable both for the kitchen and the food of cattle.

The great Anjou cabbage, said the Marquis de Turbilly, is one of the most useful legumiaous plants for country use. It will grow in almost any soil, not excepting even the most indifferent, provided it be sufficiently dung, 'd. The seeds of this cabbage are commonly sown in June, in a quarter of good mould, in the kitchen-garden, and watered from time to time in case of drought. The plants will rise pretty speedily, and should be thinned soon after 
wherever they stand too thick. The next care is to keep them free from weeds whilst they continue, by hoeing the ground between them. About the first of November (probably September or October would be better in this climate), they should be transplanted into the field where they are to remain. They should be planted there in trenches dug with a spade, pretty deep; that is, they should be buried almost up to the leaves. The distance between them should be two feet or two feet and a half every way, according to the soil. Particular care should be taken never to plant them with a dibble, as gardeners plant other sorts of cabbages. A layer of dung should be spread along the bottom of the trench, and the roots of the transplanted cabbages covered therewith. The mould taken out should then be returned back upon the dung; and, as the trench will then no longer hold it all, there will remain a ridge between each row of cabbages. Towards the middle of the ensuing May, the ground should be well stirred between the plants with a spade, or some other proper instrument, and its whole surface laid quite level. After this, nothing more remains to be done, except pulling up the weeds, from time to time, as they appear.

In the month of June, such of these cabbages as are already large, and do not turn in their reáves for cabbaging, but still continue green, hegin is ke fit for use, and soon arrive at their full perfection, which they retain till the next spring, when they begin to run up, and afterwarls blossom. Their seeds ripen towards the end of July, and what is intended for sowing should then be gathered. In Anjou, when these cabbages are entirely run up, they generally grow to the height of seven or eight feet; sometimes they reach to eight feet and a half, or nine leet; nay, some have even been seen of a greater height. From the month of June, when these cabbages begin to be fit for use, their leaves are gathered from time to time, and they shoot out again. They are large, excellent food, and so tender that they are diessed with a moment's boiling. They never occasion any flatulencies or uneasiness in the stomach; and are also very good for cattle, which eat them greedily. They likewise greatly increase the milk of cows. Such are the properties of this kind of cabbage, which is greatly esteemed in the districts formerly denominated Anjou, Poitou, Brittany, Le Maine, and some other neighbouring provinces. In the first, farmers were formerly bound by their leases to plant early a certain number of these cabbages, and to leave a certain number of them standing when they quitted their farms.

ANNONA (Trilobn). The Norlh American

Papaw. This is the only sort which will grow in the open air in England. [See PAPAw.]

ANNOTTA, or ARNOT'TA (Fr, rocou; Ger. orlean; It. oriana). In rural economy, anatto or arnatto, for it is written in various ways, is a colouring substance, or dye, obtained from the skin or pulp of the kernel of the Bixa orellana of South America and the West Indies.

of the preparation of this matter from the red pulp which covers the seeds, Mr. Miller gives the following acconnt:-The contents of 100 the fruit are taken out and thrown into a wooden vessel, where as much hot water is poured upon them as is necessary to suspend the red powder or pulp, and this is gradually washed off with the assistance of the hand, or of a spatula, or spoon. When the seeds appear quite naked, they are taken out, and the wash is left to settle; after which the water is gently poured away, and the sediment put into shallow vessels to be dried by degrees in the shade. After acquiring a due consistence, it is made into balls or calkes, (which are known in commerce as the flag, or cuke, and roll arnotta, and comes chiefly from Cayenne,) and set to dry in an airy place until it be perfectly firm. Some persons first pound the contents of the fruit with wooden pestles; then, covering them with water, leave them to steep six days. This liquor being passed through a coarse sieve, and afterwards through three finer ones, it is again put into the vat or wooden vessel, and left to ferment a week; it is then boiled until it be pretty thick, and when cool spread out to dry, and afterwards made up into balls, which are usually wrapped up in banana leaves.

Arnotta, when of good quality, is of the colour of fire, bright within, soft to the touch, and capable of being dissolved in water. But the substance commonly met with under this name is a preparation made by the druggists, in which madder is probably a principal ingredient; it is of a brick colour, and a hard compact texture. Arnotta is much used in Gloucestershire, and other cheese counties, and in the butter dairies. The method of using the soft, or genuine sort, is simply by dissolving such a quantity as is necessary in a small por. tion of milk; allowing such particles as will not dissolve to settle to the bottom. The milk thus coloured is then poured off, and mixed with that which is to be made into cheese. But when the hard preparation is used, pieces of it are frequently under the necessity of being rubbed against a hard, smooth, even-faced pebble, or other stone, being previously wetted with milk to forward the levigation, and to collect the particles as they are loosened. For this purpose, a dish of milk is generally placed upon the cheese-ladder; and, as the stone becomes loaded with levigated matter, the pieces are dipped in the milk from bime to time, until the milk in the dish appear to be sufficiently coloured. The stone and the "colouring" being washed clean in the milk, it is stirred briskly about in the dish; and, having stood a few minutes for the suspended particles of colouring-matter to settie, is returned into the cheese-cowl; pouring it of gently, so as to leave any sediment which may have fallen dow $\mathrm{n}$ in the bottom of the dish. The grounds are then rubbed with the finger on the bottom of the dish, and fresh milk added, until all the finer particles be suspended: and in this the skill in colouring principally consists. If any fragments have been broken off in the operation, they remain at the bcttom of the dish: hence the superiority of a hard closely-textured material, which will not break off or crumble in rubbing. The decoction of arnotta has a peculiar smell and a disagreeable flavour. An 
ounce of aruotta will colour about twenty cheeses of 10 or 12 lbs. each. The rolls usually weigh 2 or $3 \mathrm{oz}$. each. In Gloucestershire, it is usual to allow $1 \mathrm{oz}$. to a $\mathrm{cwt}$. of cheese; in Cheshire, 8 pennyweights to a cheese of 60 lbs. By the Spanish Americans, it is mixed with their chocolate. 'The average annual import of arnotta [into England] in the three years ending in 1831, was 128,528 Ibs. (Comp. Farm., M'Cullicli's Com. Dict.; Gray's Supplement; Loudon's Encyc.; Thomson's Chesn.)

ANNUAL MEADOW-GRASS. See Poa AN NUA.

ANNUAL PLAN'TS. Such as are only of one year's duration, or which come up in the spring and die in the autumn. They are frequently denominated simply anmuals. Wheat, oats, barley, beans, peas, \&c., are of this kind.

ANNULAR. Having the form or resemblance of a ring. This appearance is observed in the wood of some kinds of trees after they have been cut down; and in the horns of cattle and sheep, by which their ages may in some measure be ascertained.

ANODYNE. In farriery, a term applied to such medicines as ease pain and procure sleep.

ANOREXY. In farriery, a term applied to a want of appetite.

ANT. A sort of insect, extremely injurious to pasture lands and gardens; in the former by throwing up hills, and in the latter by feeding on the fruit, \&c. The best methods of keeping them from trees, are those of having the earth round them constantly dug up, and the application of saw-dust, coal-ashes, or other matters of the same kind, about their roots. The same purpose may be effected by covering the bottom part of the trees with tar; but, as it is prejudicial to the trees, night-soil may, perhaps, answer better; as it is lound to destroy them when spread upon or put into their hills. A liquor, prepared by boiling rainwater with black-soap and sulphur, has been made use of for destroying those animals, it is said, with considerable success. Where this liquor is employed, care should be taken that the ground where they inhabit be perfectly saturated with it.

ANT-HILLS. The habitations of ants, consisting of little eminences, composed of small particles of sand or earth, lightly and artfully laid together. These hills are very detrimental to the farmer, depriving him of as much land as the hills cover, which may often be computed at a tenth part, or more, of his grasslands. And in some places, where negligence has suffered them to multiply, almost half of it has been rendered useless, the hills standing as thick together as grass-cocks in a hay-field: and what is very surprising is, that, by some, this indolence is defended, by affirming, that the area or superficies of their land is thereby increased; whereas it is well known that very little or no grass ever grows thereon; and, therefore, if the surface be increased, the produce is proportionably decreased.

In order to remove the hills, and destroy the insects, it has been a custom in some places, at the beginning of winter, and often when the wealher was not very cold, to dig up the ant hills three or four inches below the surface of the ground, and then to cut them in pieces, and scatter the fragments abuut. But this practice only disseminates the ants, instead of destroying them, as they hide themselves among the roots of the grass for a little time, and then collect themselves together again upon any little eminence, of which there are great numbers ready for their purpose, such as the circular ridges round the hollows where the hills stood before. It is, therefore, a much better method to cut the hills entirely off, rather lower than the surface of the land, and to let them lie whole at a little distance, with their bottom upwards: by this means the ants, who continue in their habitations until the rains, running into their holes of communication, and stag. nating in the hollows formed by the removal of the hills and the frosts, which now readily penetrate, will be destroyed. If a little soot is sown on the places, it will contribute to the intended effect. The hills, when rendered mellow by the frosts, may be broken and dispersed about the land. By this method of cutting off the hills, one other advantage is gained: the land soon becomes even and fit for mowing, and the little eminences being removed, the insects are exposed to the rain, which is destructive to them. In wet weather these insects are apt to accumulate heaps of sandy particles among the grass, called by labourers sprout-hills, which quickly take off the edge of the scythe. These hills which are very light and compressible, may be removed by frequent heavy rolling.

ANTHELMINTIC. In farriery, a term applied to such remedies as are supposed to destroy or carry off the worms which lodge in the intestines of an animal.

ANTHOXANTHUM ODORATUM. The sweet-scented vernal grass. [See Plate 6,a.] This grass constitutes a part of the herbage of English pastures on almost every kind of soil, attaining its greatest perfection on the deep and moist, loving shady places, such as the skirts of woods. Its very early growth and hardiness, with the superior nutritive properties of its latter-math, give it high claims in the composition of all permanent pastures. In England it comes into flower about the middle of April, and in Pennsylvania about the middle of May, the seed ripening in both countries about the second week in June. In the moist climate of England it continues throwing up flower stalks till the end of autumn, but in Pennsylvania the effloreseence is confined to spring. When properly combined with other grasses, and mown at maturity, it gives to the hay a peculiarly delightful fragrance.

The cause of the high flavour for which Phi: ladelphia "May butter" is so highly celebruted, has hitherto been a matter of rague spec.lation. This superior flavour, like that distinguishing the Epping and Cambridge butter of the London market, has very naturally been ascribed to something eaten by the cows; but this something has never yet been defined or specified so as to enable persons in other localities to avail themselves of it for the improve ment of their own pastures and dairy product* I 2101 
The Anerican editor of the Farmer's Encyclopredia claims to have traced the source of the peculiar flavour of Philadelphia "May butter" to the sweet-scented vernal grass naturalized and abounding in the pastures withim marketing distance of the city. He assigns the following reasons for this conclusion. 1. In the dairy region around Philadelphia the vernal grass, with its vanilla fragrance, constitutes the predominant spring herbage on all pasture-fields and meadows left several years unploughed. The older the pasture the greater the proportion of the vernal grass, and the bigher flavoured the butter. 2. The flavour continues during the development of this grass, and invariably declines with its seeding, after which the cattle push its dry stems aside in search of fresher herbage. 3 . The sweetscented vernal grass is shown by chemical analysis to contain an aromatic essential oil, the basis of which is benzoic acid or flowers of benzoin. This is abundant, and can be distilled so os to furnish a delightful perfume. As the milk of animals is so very susceptible of acquiring disagreeable tastes from substances fed upon, it is natural to infer that it may be im- bued with agreeable flavours could the proper agents for this purpose be presented in their food. That the benzoic acid is the proximate cause of the peculiar fine flavour of butter made from pastures where the sweet-scented vernal grass abounds, he has shown by several experiments made in different places where the flowers of benzoin given to cows produced the characteristic flavour. From 20 to 30 grains of the benzoin was administered twice a day, previously mixed with a little rye or wheat flour, then stirred up with some hot water and mingled with the customary mess.

Hitherto, but little, if any, exact knowledge has been acquired in regard to the effects of particular grasses in improving the flavour of dairy products, or the meat of animals. The abundant presence of the sweet-scented vernal grass in pastures will, it is believed, not only contribute a rich flavour to dairy products, but to the mution and beef of cattle and sheep pastured upon it.

[See Dr. Emerson's communication to J. S. Skinner, on the subject of Philadelphia butter, originaliy published in the Farmer's Library for April, 1846.]

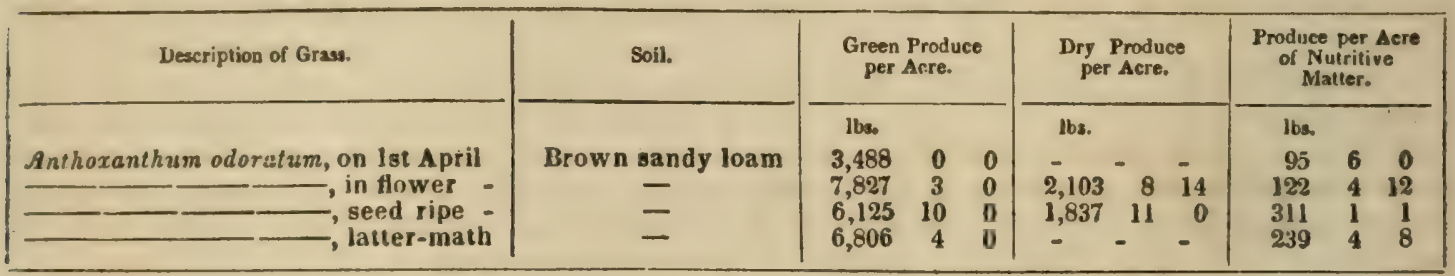

ANTICOR. In farriery, a disease among horses, arising from an inflammation in the gullet and throat, or a kind of quinsy. The swelling sometimes extends as far as the sheath; and is attended with fever, great depression, weakness, and a total loss of appetite.

ANTIDOTE. See Poisor, and Arimal and VEgeta hl: Poisons.

AN'TIMONY, SULPHURET OF. In farriery, a mineral substance, of a shining, striated appearance, hard, brittle, and very heavy. It is employed as a remedy in many diseases of horses and other animals, and is said to have been given to fattening cattle and hogs with advantage. An ounce is the common quantity for a full-grown animal, which may be repeated according to circumstances. It is composed according to Dr. J. Davy (Phil. Trans. 181\%, p. 231), of

\begin{tabular}{l} 
Antimnny \\
Sulphur $-\div-\div \quad-\quad 100$ \\
\hline-960
\end{tabular}

ANTISEPTIC SUBSTANCES. In agriculture, are such substances as have a tendency to resist the putrefaction and decay of animal and vegetable matters.

AN'TISPASMODICS. In farriery, are such medicines as are suited to cure spasmodic affections. Opium, assafœetida, and the essential oils of many vegetables, are the most powerful remedies of this kind.

ANTLER (Fr. andouiller). Properly the first brinches of a stag's horns; but, popularly and generally, any of his branches, and so used, by poetic license, in all our modern authors.
AORTAL ARTERIES, of vegetables. The large vessels destined to convey the elaborated juice or blood of plants to the leaves and extremities, are so denominated by Dr. Darwin.

APERIENTS. In farriery, are such remedies as are calculated to keep the bowels of animals in a gentle open state.

APHERNOUSLI, or ARKENOUSLI. A species of fir, pine, or pinaster, which grows wild on the Alps.

The timber of this tree is frequently large, and has many uses for internal work. The branches resemble those of the spruce-fir: but the cones are more round in the middle, being of a purplish colour, shaded with black. The bark of the trunk, or bole of the tree, is not reddish like the bark of the pine, but of a whitish cast like that of the fir. The husk, or sort of shell, which encloses the kernels, is easily cracked, and the kernels are covered with a brown skin, which peels off; they are about as large as a common pea, triangular like buckwheat, and white and soft as a blanched almond; of an oily agreeable taste, but leaving in the mouth that small degree of asperity which is peculiar to wild fruits, and is not unpleasant. These kernels sometimes make a part in a Swiss dessert; they supply the place of mushroom-buttons in ragouts, and are also recommended in consumptive cases.

Wainscoting, flooring, and other joiner's work, may be made with the planks of aphernousli, which is a wood of a finer grain, and more beautifully variegated than deal, and the smell is more agreeable. The aphernousli is a tree of a healthy, vigorous growth, and will bear removing when it is young, even in dry 


\section{APHIDIANS.}

warm weather. From this tree is extracted ahite odoriferous resin. 'The wood also makes excellent firing in stoves, ovens, and kilns.

[APHIDIANS. A group of minute insects, which includes those commonly called pluntlice. Some of these insects have the power of leaping, like the leal-hoppers, from which, however, they differ. 'These hoppers are by no means so prolific as other kinds of plant-lice, since they produce only one brood during the year. They live in groups, composed of about a dozen individuals each, upon the stems and leaves of plants, the juices of which they imbibe through their tubular beaks. The young are often covered with a substance resembling fine cotton arranged in flakes. This is the case with some which are found on the alder and birch in the spring of the year.

Another tribe of aphidians called Thrips, are very small and slender insects, exceedingly active in their motions. 'They live on leaves, flowers, buds, \&c. Their punctures appear to poison plants, and often occasion deformities in the leaves and blossoms. The peach tree sometimes suffers severely from their attacks, as from those of the true plantlice; and they are found beneath the leaves, in little hollows caused by their irritating punctures. The same applications that are employed for the destruction of plant-lice may be used with advantage upon plants infested with Thrips. (Dr. Harris's Report on Destructive Insects.)]

[APHIDES, or plant-lice, as they are commonly called, are found upon almost all parts of plants, and there is scarcely a plant which does not harbour one or two kinds peculiar to itself. They are exceedingly prolific, and Reaumur has proved that one individual, in five generations, may become the progenitor of nearly six thousand millions of descendants. It often happens that the succulent extremities and stems of plants will, in an incredibly short space of time, become completely coated with a living mass of little lice. These are usually wingless, consisting of the young and of the females only; for winged individuals appear only at particular seasons, usually in the autumn, but sometimes in the spring, and there are small males and larger females. After pairing, the latter lay their eggs upon or near the leaf-buds of the plant upon which they live, and, together with their males, soon afterwards perish. The genus to which plantlice belong is called Aphis, from a Greek word signifying to exhaust. They hatch out in the spring and immediately begin to pump up sap from the tender buds, stems, and leaves, increase rapidly in size and quickly come to maturity.

"Plant-lice seem to love society, and often herd together in dense masses, each one remaining fixed to the plant by means of its long tubular beak; and they rarely change their places till they have exhausted the part first attacked. The attitudes and manners of these little creatures are exceedingly amusing. When disturbed, like restive horses, they begin to kizk and sprawl in the most ludicrous manner. They may be seen, at times, sus-
APHIUES.

pended by their beaks alone, and throwisg up their legs as if in a high frolic, but too much engaged in sucking to withdraw their beaks. As they take in great quantities of sap, they would soon become gorged if they did not get rid of the superabundant fluid through the (wi) little tubes or pores at the extremity of their bodies. When one of them gets running-over full, it seems to communicate its uneasy sen. sations, by a kind of animal magnetism, to the whole flock, upon which they all, with one accord, jerk upwards their bodies, and eject a shower of the honeyed fluid. 'The leaves ant bark of plants much infested by these insects, are often completely sprinkled over with drops of this sticky fluid, which, on drying, becomes dark coloured, and greatly disfigures the foliage. This appearance has been denominated honey. dew; but there is another somewhat similas production observable on plants, after very dry weather, which has received the same name. and consists of an extravasation or oozing of the sap from the leaves. We are often apprized of the presence of plant-lice on plants growing in the open air by the ants ascending and descending the stems. By observing the motions of the latter we soon ascertain that the sweet fluid discharged by the lice is the occa. sion of these visits. The stems swarm with slim and hungry ants running upwards, and others lazily descending with their bellies swelled almost to bursting. When arrived in the immediate vicinity of the plant-lice, they greedily wipe up the sweet fluid which has distilled from them, and, when this fails, they station themselves among the lice, and catch the drops as they fall. The lice do not seem in the least annoyed by the ants, but live on the best possible terms with them; and, on the other hand, the ants, though unsparing of other insects weaker than themselves, upon which they frequently prey, treat the plant-lice with the utmost gentleness, caress. ing them with their antennæ, and apparently inviting them to give out the fluid by patting their sides. Nor are the lice inattentive to these solicitations, when in a state to gratify the ants, for whose sake they not only seem to shorten the periods of the discharge, but actually yield the fluid when thus pressed. A single louse has been known to give it drop by drop successively to a number of ants, that were waiting anxiously to receive it. When the plant-lice cast their skins, the ants instantly remove the latter, nor will they allow any dirt or rubbish to remain upon or about them. They even protect them from their enemies, and run about them in the hot sunshine to drive away the little ichneumon flies that are forever hovering near to deposit their eggs in the bodies of the lice."

Plant-lice differ much in form, colour, length of tubes, \&c. 'The Rose-louse (Aphis Rosa) has a long tube. The cabbage-louse (Aphrs Brassicæ) has also long honey-tubes, its body being covered with a whitish mealy substance. This species is very abundant on the lower side of cabbage-leaves in the month of $\mathrm{Au}$. gust. The largest species of plant-lice ob. served by Dr. Harris, he found in clusters beneath the limbs of the pig-nut hickory. He. 


\section{APHIDES.}

also found another large species living on the under side of the branches of various kinds of willows, and clustered together in great numbers. This species, the Doctor thinks, cannot be identical with the willow-louse described by Linnæus. When crushed, it communicates a stain of a reddish or deep orange colour.

Some plant-lice live in the grounil, and derive their nourishment from the roots of plants, which they often exhaust and destroy. Indian corn crops frequently suffer severely from their depredations, especially when the soil is light and reduced. They are generally of a white colour, and are closely clustered together on the roots. Dr. Harris, from whose Report all the information upon this subject is obtained, says that he never has been able to ascertain whether these are of the same species as the root-lice described by European writers. It is stated by those great entomologists, Kirby and Spence, that ants bestow the same care upon the root-lice as upon their own offspring, defending them from the attacks of other insects, bringing them in their mouths to the surface of the ground to give them the advantage of the sun, \&c. The sweet fluid which exudes from them whilst pumping in the sap of the ronts, forms the chief nourishment of the ants and their young.

"The injuries occasioned by plant-lice are much greater than would at first be expected from the small size and extreme weakness of the insects; but these make up by their numbers what they want in strength individually, and thus become formidable enemies to vegetation. By their punctures, and the quantity of sap which they draw from the leaves, the functions of these important organs are deranged or interrupted, the food of the plant, which is there elaborated to nourish the stem and mature the fruit, is withdrawn, before it can reach its proper destination, or is contaminated and left in a state unfitted to supply the wants of vegetation. Plants are differently affected by these insects. Some wither and cease to grow, their leaves and stems put on a sickly appearance, and soon die from exhaustion. Others, though not killed, are greatly impeded in their growth, and their tender parts, which are attacked, become stunted, curled, or warped. The punctures of these lice seem to poison some plants, and affect whers in a most singular manner, producing warts or swellings, which are sometimes solid and sometimes hollow, and contain in their interior a swarm of lice, the descendants of a single individual, whose punctures were the original cause of the tumour. I have seen reddish tumours of this kind as big as a pigeorn's egg, growing upon leaves, to which they were attached by a slender neck, and containing thousands of small lice in their interior. Naturalists call these tumours galls, vecause they seem to be formed in the same way as the oak-galls which are used in the making of ink. The lice which inhabit or profuce them generally differ from the others, in liavirg shorter antennæ, being without honeytubes, and in frequently being clothed with a 104 kind of white down, which, however, disapplears when the insect becomes winged.

"These downy plant-lice are now placed in the genus Eriosoma, which means woolly budy, and the most destructive species belonging to it was first described, under the name of $A p h$ is lanigera, by Mr. Hausmann, in the year 1801, as infesting the apple-trees in Germany. It seems that it had been noticed in England as early as the year 1787 , and has since acquired there the name of American blight, from the erroneous supposition that it had been import ed from this country. It was known, however, to the French gardeners for a long time previous to both of the above dates, and, according to Mr. Rennie, is found in the orchards about Harfleur, in Normandy, and is very de. structive to the apple-trees in the department of Calvados. There is now good reason to believe that the miscailed American blight is not indigenous to this country, and that it has been introduced here with fruit-trees from Europe. Some persons, indeed, have supposed that it was not to be found here at all; but the late Mr. Buel has stated that it existed on his apple-trees, and I have once or twice seen it on apple-trees in Massachusetts, where, how. ever, it still appears to be rare, and consequently I have not been able to examine the insects sufficiently myself. The best account that I have seen of them is contained in Knapp's 'Journal of a Naturalist,' from which, and from Hausmann's description, the following observations are chiefly extracted.

"The eggs of the woolly apple-tree louse are so small as not to be distinguished without a microscope, and are enveloped in a cotton-like substance furnished by the body of the insect. They are deposited in the crotches of the branches and in the chinks of the bark at or near the surface of the ground, especially if there are suckers springing from the same place. The young, when first hatched, are covered with a very short and fine down, and appear in the spring of the year like little specks of mould on the trees. As the season advances, and the insect increases in size, its downy coat becomes more distinct, and grows in length daily. This down is very easily removed, adheres to the fingers when it is touched, and seems to issue from all the pores of the skin of the abdomen. When fully grown, the insects of the first brood are one tenth of an inch in length, and when the down is rubbed off, the head, antennæ, sucker, and shins are found to be of a blackish colour, and the abdomen honey-yellow. The young are produced alive during the summer, are buried in masses of the down, and derive their nourishment from the sap of the bark and of the alburnum or young wood immediately under the bark. The adult insects never acquire wings, at least such is the testimony both of Hausmann and Knapp, and are destitute of honey-tubes, but from time to time emit drops of a sticky fluid from the extremity of the body. These insects, though destitute of wings, are conveyed from tree to tree by means of their long down, which is so plentiful and so light, as easily to be wafted by the winds of 
antumn, and thus the evil will gradually spread throughout an extensive orchard. The numerous punctures of these lice produce on the tender stinots a cellular appearance, and wherever a colony of them is established, warts or excrescences arise on the bark; the limbs thus attacked become sickly, the leaves turn yellow and drop off; and, as the infection spreads from limb to limb, the whole tree becomes discased, and eventually perishes. In Gloucestershire, England, so many apple-trees were destroyed by these lice in the year 1810 , that it was feared the making of cider must be abandoned. In the north of England the appletrees are greatly injured, and some annually destroyed by them; and in the year 1826 they abounded there in such incredible luxuriance, that many trees seemed, at a short distance, as if they had been whitewashed.

"Mr. Knapp thinks that remedies can prove efficacious in removing this evil only upon a small scale, and that when the injury has existed for some time, and extended its influence over the parts of a large tree, it will take its course, and the tree will die. He says that he has removed this blight from young trees, and from recently attacked places in those more advanced, by painting over every node or infected part of the tree with a composition consisting of three ounces of melted resin, mixed with the same quantity of fish oil, which is to be put on while warm with a painter's brush. Sir Joseph Banks succeeded in extirpating the insects from his own trees by removing all the old and rugged bark, and scrubbing the trunk and branches with a hard brush. The application of the spirits of tar, of spirits of turpentine, of oil, urine, and of soft soap, has been recommended. Mr. Buel found that oil sufficed to drive the insects from the trunks and branches, but that it could not be applied to the roots, where, he stated, numbers of the insects harboured. The following treatment, I am inclined to think, will prove as successful as any which has heretofore been recommended. Scrape off all the rough bark of the infected trees, and make them perfectly clean and smonth early in the spring; then rub the trunk and limbs with a stiff brush wet with a solution of potash, as hereafter recommended for the destruction of bark-lice; after which remove the sods and earth around the bottom of the trunk, and with the seraper, brush, and alkaline liquor cleanse that part as far as the roots can conveniently be uncovered. The earth and sods should immediately be carried away, fresh loam should be placed around the roots, and all cracks and wounds should be filled with grafting cement of clay or mortar. Small limbs and extremities of branches, if infected, and beyond reach of the applications, should be cut off and burned."

Dr. Harris found in Massachusetts several nther species of Eriosoma or downy lice, inhabiting various forest and ornamental trees, snme of which he thinks may have been iniroduced from abroad.

Remedips. With regard to the best means of destroying plant-lice, Dr. Harris recom. mends as follows: "Solutions of soap, or a mixture of soap-suds and tolucco water, used warm, and applied with a watering pot or with a garden engine, may be employed for the destruction of these insects. It is said that ho' water may also be employed for the same purpose with safety and success. The water, tobacco-tea, or sucis, should be thrown upon the plants with considerable force, and if they are. of the cabbage or lettuce kind, or nitice plants whose leaves are to be used as food, they should subsequently be drenched thoroughly with pure water. I,ice on the extremities of branches may be killed by bending over the branches and holding them for several minutes in warm and strong soap-suds. Lice multiply much faster, and are more injurious to plants, in a dry than in a wet atmosphere; hence in green houses, attention should be paid to keep the air sufficiently moist; and the lice are readily killed by fumigations wits. tobacco or with sulphur. 'To destruy subterranean lice on the roots of plants, I have founi that watering with salt water was useful, if the plants were hardy; but tender herbaceou. plants cannot be treated in this way, but may sometimes be revived, when suffering from these hidden foes, by free and frequent watering with soap-suds."

A solution of whale oil soap, in the proportion of two pounds of soap to fifteen gallons of water, is recommended as the best known means of destroying plant-lice, and other insects injurious to plants, flowers, and fruits. It was first made known by Mr. Haggerston, of Boston, who desis red it originally for the destruction of the rose slug, and received a pre. mium of $\$ 125$ from the Massachusetts Horticultural Society for his discovery. In preparing the solution of soap, the weight required for use is to be taken and dissolved in boiling water in the proportion of a pound to a quart. Strain this strong solution through a fine wire or hair sieve, which takes out the dirt, and prevents its stopping the valves of the engine, or rose of the syringe. Then add cold water to bring it to the proper strength, namely, about two pounds of the soap to fifteen gallons of water, and apply to the rose bush, or other plant, with a hand engine or a syringe, using as mucn force as practicable, saturating every part of the foliage. What falls on the ground will not be lost, but do much good in destroying worms and enriching the soil. From its tritling cost, it can be used with profusion, a hogshead of 136 gallons costing only about 45 cents. The soap sells for about 6 or 7 cents per pound. Early in the morning, or in the evening, is the proper time for making the application Among other insects mentioned by Mr. Hag gerston as destroyed by the solution of whale. oil soap, are the Aphis, or plant-louse, which goes by the name of the brown fly; an insect not quick in motion, very abundant on, and destructive to, the young shonis of the rose. peach trees, and many other plants; and the black fly, a very troublesome and destructive insect, that infests the young shoots of the cherry and the snowball tree. "I have never," he says, "known any positive cure for this insect until this timc." 
"Two varieties of insects that are destructive to and very much disfigure evergreens, the Balsam or Balm of Gilead fir in particular; one an aphis, the other very much like the rose-slug.

"The above insects are all destroyed by one application, if properly applied to all parts of the leaves; the eggs of most insects continue to hatch in rotation during their season; to keep the plants perfectly clean, it will be necessary to dress them two or three times."

As every plant has its insect destroyers, so have these their created enemies to keep them in check. If this was not so, the astonishing fecundity of plant-lice would make them far more formidable than at present. Indeed it is difficult to say where the plague might end. The destroyers of plant-lice described by $\mathrm{Dr}$. Harris are of three kinds.-The first are the young or larvæ of the hemispherical beetles amiliarly known by the name of lady-birds, and scientifically by that of Coccinella. These ittle beetles are generally yellow or red, with black spots, or black, with white, red, or yellow spots; there are many kinds of them, and they are very common and plentiful insects, generally diffused among plants, living upon plantlice, and thus performing a great service to the husbandman and gardener.

The second kind of plant-lice destroyers are the young of the golden-eyed lace-winged fly (Chrisopa perla), a fly of a pale green colour, with four wings resembling lace, and eyes of the brilliancy of polished gold, as its generic name implies. But, notwithstanding its brilliancy, it is extremely disgusting, from the offensive odour it exhales. It makes great bavoc among the plant-lice.

The third and last enemy are the maggots or young of various two-winged flies belonging to the genus Syrphus, many of which flies are black, with yellow bands on their bodies. The eggs are laid and the destructive maggot hatched immediately among the sluggish lice which become its victims.

The more minute account given by Dr. Harris, of the nature and habits of all these insects, is extremely interesting. (See his Report upon Destructive Insects submitted to the legislature of Massachusetts in 1841.)]

A PIUM. See Crentr and Parseer.

APOPLEXY. In farriery, is a disease which is often called the staggers, to which horses and other animals are subject, and by which they drop down suddenly, without sense or motion, except a working of the flanks. (See Shemp, Diseaseg of.)

APPE'TITE. Horses, more than most other creatures, are subject to diseases of the stomach, parucularly to a want of appetite, and a vitiated or voracious appetite.

Want of appetile is when a horse feeds poorly, and is apt to mangle his hay, or leave it in the rack, and at the same time gathers little fle..h, his dung being habitually soft, and of a pale colour. This state of the stomach evidently arises either from some error in respect of diet and management, want of grass, or from a relaxed constitution, in which the stomach 106 and bowels are more particularly affected with debility. This weakness of the digestive organs may be either accidental or constitutional; and it may proceed from the use of food administered in an improper state, such as too much scalded bran, or hot meat of any kind, which relaxes the tone of the stomach and bowels, and ultimately produces a weak $d_{\text {. }}$ gestion, and consequently a loss of appetite. The best method to strengthen and recover horses in this state, is to give them gentle exercise in the open air, especially in dry weather; never to load their stomachs with large feeds; and to keep them as much as possible to a dry diet, indulging them now and then with a handful of beans among their oats. But where the disorder has been caused by over-feeding with dry food, and the neglect of proper evacuation and exercise, mashes, with gentle saline purges, would seem to be the most suitable remedies; and where horses do not gain strength under the above management, a run at grass will most probably be the readiest method of removing their com. plaints.

APPLE. See Marus.

APPLES OF LOVE (Poma amoris; tomato). These apples are juicy, and large fruit, growing upon a low plant in gardens. The flowers are yellow and small; when the fruit ripens, it becomes red, containing soft juicy pulp and seeds. Its juice is cooling to the system, and is applied externally to remove eruptions upon the skin. (L. Juhnsan.) See Tомато.

[APPLE-TREE BLIGHT, and Apple-tree lice. See Aphides and Blight.]

[APPLE-TREE BORER. The larva of a kind of beetle. See BorERs.]

APPRAISEMENT. It is not only custom. ary, but essential to the maintenance of the good condition of a farm, that the outgoing tenant should be induced to carry on the proper course of husbandry up to the period of his quitting the farm; notwithstanding that much of the labour and manure he bestows is for the benefit of crops which a succeeding tenant will reap. Hence the good practice has arisen, that the outgoing tenant shall be allowed for these matters, according to agreement, or, in its absence, by the custom of the district, which varies considerably. (See Custom of тн. Counties.)

The following real appraisement of a farm in Surrey, by Mr. Hewitt Davis, an eminent appraiser of the Haymarket, London, will afford the young farmer a complete view of the matters usually included in such appraisements. It is usual for these valuations to be made by appraisers, one being appointed by the outgoing, and the other by the incoming tenants, who choose an umpire to decide in case of difference.

[The document cannot fail to be acceptable to the American farmer, since it communicates so many interesting facts relating to the estimates of putting in crops, the value of manures, various workings, rent, rates, taxes, \&c., in England.] 


\section{APPRAISEMENT.}

Appraisement of the Tenant's Property on the
From
of Surrey, mude this $29 t h$ September, 1841.

From
To
By
And
, outgoing tenant.
And
, incoming tenant.
, outgoing tenant's appraiser.
, incoming tenant's appraiser.

Farm, County

Made according to the terms of the Lease, which says, "at leaving the Landlord or Incoming Tenant shall pay for the Turnips, Leys, Seeds sown, and Crops in or on the Ground, Ploughings, Dressings, Half Dressings, Fallows, Half Fallows, and preparations of the Iand for the Manure and Underwoods, according to their growth, and all other Matters and Things accord. ing to the Custom of the County."

The farm is principally a light turnip soil, and consists of-

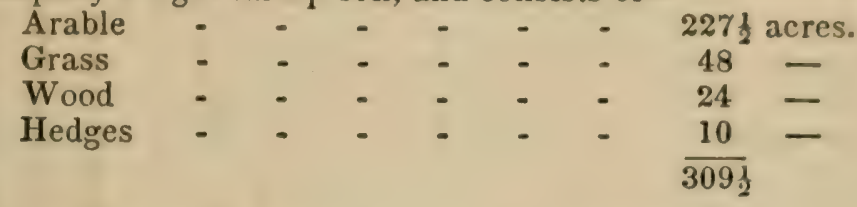

And has been very highly cultivated on the Scotch Drill system.

DRESSING AND TILLAGES, viz.,

Lodg Fiedd, 17 Acres._-Swedes.

Ploughed, 2 horses, three times

Ridging and splitting -

Ox harrowed, four times

Small harrowed, eight times

Rolled twice

Handpicking

Dung, 295 loads

Seed, 2 lb. per acre, per lb.

Drilling

Scuffling twice

Hand-hoeing .

Handpicking, rent, rates, and taxes, -

-
$:$
$:$
$:$
$:$
$:$
$:$
$:$
-

at $10 s$.

- $14 s$.

- $1 s .6 d$.

- $9 d$.

$-1 s$.

- $6 s$.

- 1s.

- 18.

- $2 s .6 d$.

- $8 s$.

- $30 s$.

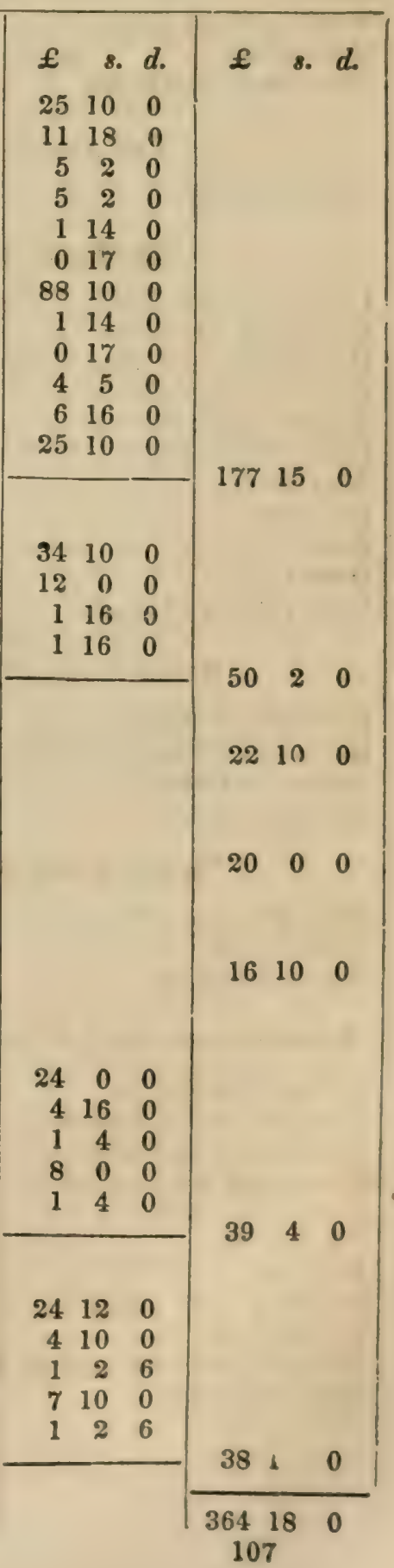

- $1 s .6 d$.

at 60 s.

at 40 s.

at $60 s$.

- $12 s$.

- $9 d$

$-10 s$.

- $3 s$.

Half dressing, 230 loads dung - $\quad-\quad$ - $\quad-\quad$ at $3 s$.

Harrowed, Finlayson $\quad-\quad-\quad: \quad-3 s$.

Ox harsowed twice

\section{Middle Loam Pit, $7 \frac{1}{2}$ Acres.-Seeds}

One year's ley

Upper Loam Pit, 10 Acres. - Seeds.

Two year's ley

Lower Blighs, 7 Acres.-Pea Stubble.

Half dressing, 110 loads dung - $\quad$ - $\quad$ at 3 s.

Nontr Blighs, 8 Acres.-Wheat after Clover.

Clover ley Ploughed, 3 horses -
Harrowed small, four times Seed, 16 bushels

Drilling

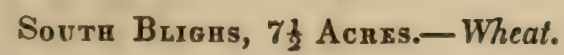

Compusition earth and lime, 164 loads

Ploughed, 3 horses

Harrowed small, four times -

Seed, 15 bushels

Drilling

\section{(1)}




\section{APPRAISEMENT.}

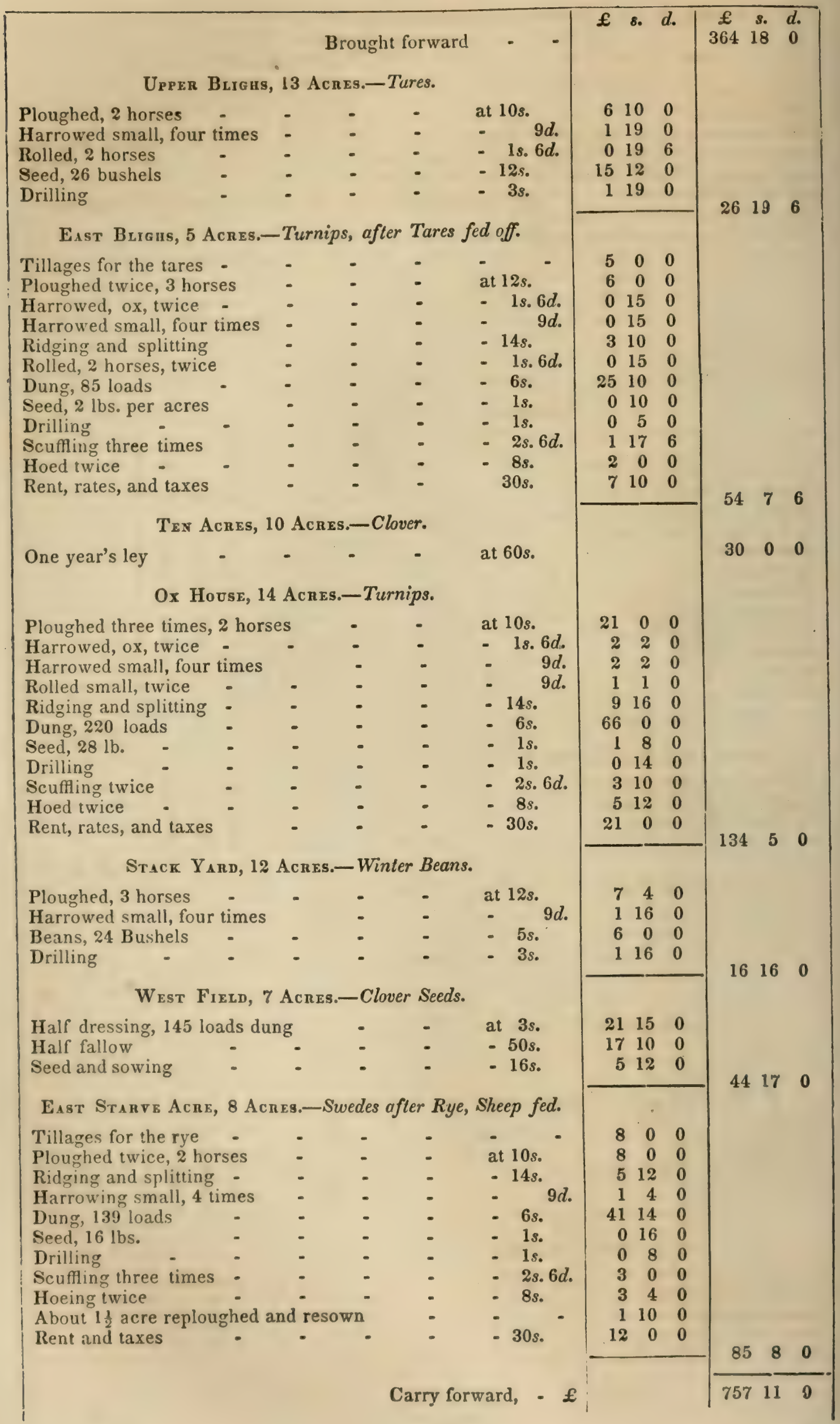




\section{APPRAISEMENT.}

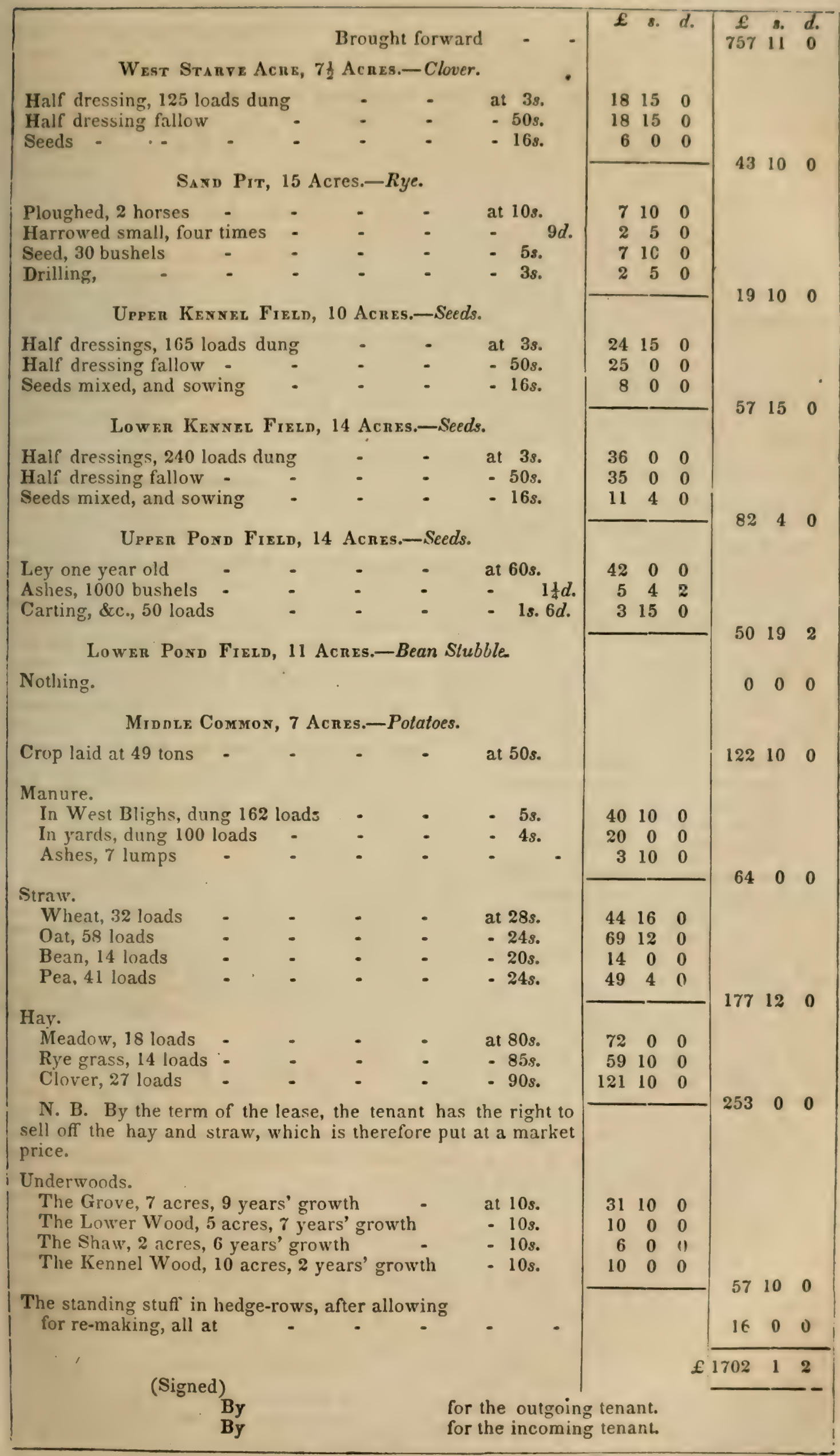


APRICOT (Armeniaca vulgaris). The name of the apricot has been thought to be derived from apricus, open and exposed to the sun, or from præcox, early ripe; but there can be no doubt that the word is a corruption of the Arabic name of the fruit. In England, it is one of the earliest wall-fruits, and held in the highest estimation. The fruit, when gathered young to thin the crop, makes an excellent tart; and when ripe, it is second to no fruit for preserves or jam: it gives an excellent flavour to ice, and makes a delicious liqueur: of all the fruits used in pastry, none is more beautiful or agreeable than the ripe apricot. To prolong the enjoyment of this fruit in its natural state, we should be careful to plant the earliest variety in the warmest situation, as the frost often injures the blossoms unless it is protected by a glass shutter. The apricot, as well as the plum, may be kept for our dessert two or three weeks later, by gathering it when half ripe, and placing it in an ice-house, a dairy, or any cool place, where it slowly ripens.

Apricots, if not too ripe, agreeably astringe and strengthen the stomach; but like all other perfumed watery fruit, it loses its aromatic and tempting flavour, becomes clammy, and is less easy of digestion, when over-ripe: they should therefore be gathered at least twentyfour hours before they acquire the last degree of maturity.

Of this excellent fruit, thirty-nine varieties have been described in the Horticultural Society's catalugue. For a small garden, Mr. Lindley recommends the following selection.

$\begin{array}{ll}\text { Breda } & \text { Peach apricot. } \\ \text { Brussels. } & \text { Red masculine. } \\ \text { Hemskirke. } & \text { Roman. } \\ \text { Large early. } & \text { Royal. } \\ \text { Moorpark } & \text { 'Turkey. }\end{array}$

The Moorpark and Turkey have been recommended where variety is not wanted, the former being fine, and a good bearer; the latter not a good bearer, but very fine. The apricot requires a rich soil, rather lighter than the apple and pear.

Budding is generally performed from the middle of June to the end of July, on mussel plum stocks two or three years old. The Breda, peach apricot, royal, and a few others are those generally budded upon the mussel, "and although," says Mr. Lindley, "the Moorpark is, for the most part, budded upon the common plum, on which it takes freely, yet I am persuaded that if it were budded on the mussel, the trees would be better, last longer in a state of vigour, and produce their fruit superior both in size and quality."

In planting out trees for training, young plants, or those called maiden plants, should be made chnice of, being far preferable to those which have been headed down, and stood two years in the quarters of the nursery; observing, in all cases, without exception, that the bud should stand outwards, and the wounded part where the stock has been headed down, inwards, or next the wall. The apricot in general bears chiefly upon the young shoots of the nreceding year, and also upon small spurs 110 rising on the two or three year old fruit branches. The pruning of wall-apricots comprehends both a summer and a winter course of regulation. In May, the summer pruning commences by the disbudding and removal of the superfluous shoots, and shortening the smaller shoots to half an inch, which will occasion many of them to form natural spurs for blossoms at the base. This should be carefully done with a sharp thin-bladed knife. Care must also be taken to select and train as many of the best placed young shoots as may be wanted to form the figure of the tree, proceeding thus from year to year, till it is com. pletely furnished, both in its sides and middle, for there ought not then to be a blank space in any part within its extent.

For the winter pruning of apricots, every shoot should be shortened according to its strength, none being permitted to exceed 18 inches, while a few will require to be even less than 6. By pruning thus short, and training the branches thus, the trees will be kept in vigour, the fruit will always attain its full size under favourable circumstances, and its quality will be good.

When the fruit is found to be too numerous and growing in clusters, thinning must be resorted to in May and June, leaving the most promising fruit singly, at three or four inches distance; or from about two to six on the respective shoots, according to their strength. The retained fruit should in all instances be situated at the sides of their respective shoots, and no fore-right fruit be suffered to remain; for these being exposed to the full power of the sun, will perish before they can arrive at maturity. The apricot is very liable to be attacked by wasps and large flies, which should be kept off by a net. The other insects and diseases of this tree are the same as in the peach tree; but it is not nearly so obnoxious to their attacks, probably owing to the comparatively hard nature of its bark and wood, and coriaceous leaves. [The apricot is the earliest and tenderest of American fruits, the blossoms coming so early as to be commonly nipped by frost. The position of the trees should be such as tends to retard flowering.] (Phillip's Pom. Brit.; Lindley's Guide to the Orchard and Kilchen Garden.)

ARBOR VIT $\mathbb{E}$ (Thuja). The generic name of this tree is a corruption from @úx of Theophrastus, or thya of Pliny, which were derived from the verb thyô, I perfume; as the thya of the ancients gave out an aromatic smoke when it was burnt. It is called arhor vilx, or tree of life, because it keeps in full leaf winter and summer; and not in allusion to the tree of life mentioned in the book of Genesis. The first mention we have of it in England is by Gerard, in his History of Plants, which was published in 1597. He tells us that it was then growing plentifully in his garden at Holborn, where it flowered about May, but it had not then ripened seed.

"The Thuja from China's fruitful lands,"

being of a brighter green and thicker verdure, has nearly superseded the arbor vitæ of Ca. nada in our plantations. It is well adapted to 


\section{ARBUTUS.}

\section{ARROW-IIEAD.}

screen private walks or low buildings, as it gives out flat spreading branches near the ground; but it has a sombre appearance, unless associated with more cheerful foliage, or ornamented by some gay climbing plant, as the everlasting pea, the flaming nasturtium, or our native bindweed.

'I'he arbor vitæ, which we have borrowed fiom the extremity of the east and of the west, as a mere ornament to our pleasure-grounds, forms an article of utility and profit to the inhabitants of its native soil. It is reckoned the most durable wood in Canada, where it is known by the name of the white cedar. All the posts which are driven into the ground, and the palisades round the forts, are made of this wood. 'The planks in the houses are made of it; and the thin narrow pieces of wood which form both the ribs and the bottom of the bark boats commonly made use of there, are taken from this wood, because it is pliant enough for the purpose, when fresh, and also because it is very light. The thuja wood is reckened one of the best for the use of limekilns. Its branches are used all over Canada for brooms, which leave their peculiar scent in all the houses where they are used. The arbor vitæ affords [a popular remedy for rheumatic and some other complaints among the Indians and settlers of North America.]

The finest trees are always raised by seed, but they are more easily propagated by layers or cuttings. (Phil. Syl. Flir.)

ARBU'TUS. A genus of evergreen shrubs which is characterized by its fruit being a berry, containing many seeds. The only variety necessary to be enumerated in these pages is the Arbutus unedo, or strawberry tree.

In Pliny's time, when Rome abounded in wine and oil, they called the tree unedo, which was an abridgment of unum edo, meaning, "You will eat but one." It has the name of strawberry-tree with us, because its berries so nearly resemble in appearance that delicious fruit. It is found growing spontaneously on rocky limestone situations in the west of Ireland, particularly in the county of Kerry, near the lake of Killarney, where the peasants eat the fruit. The arbutus is a native of the south of Europe, Greece, Palestine, and many other parts of Asia.

Horace celebrates the shade of this tree :-

\section{"Nunc viridi membra sub arbuto} Stratus."

But Virgil describes its foliage as rather thin (Ecl. vii.), and recommends the twig as a winter fond for goats.

The arbutus tree succeeds best in a moist soil, for when planted in dry ground it seldom produces much fruit. It is therefore recommended to place it in warm situations; and if the.earth is not naturally moist, there should be plenty of loam and rotten neat's dung laid about its roots, and in dry springs it should be plentifully watered.

The arbutus trees may be propagated by layers, but they are principally raised from seed; and they require to be kept in pots for several years before they are ready for the plantation. We meet with a variety of this tree in our shrubberies with double blossoms, and another with red flowers. Aiton enume: rates five different species of the artutus, an? there are several varieties of them in the Part. sian gardens not to be seen in our shrubberies. The leaves of the arbutus are said to be usefully employed by tanners in preparing their leather. (Phillips's Sylua Flumiferı.)

This beautiful evergreen grows to the height of ten and fifteen feet. Its flowers, which are of a yellowish white or red colour bloom in September, October, and November, and are succeeded by the fruit, which remain till the flowers of the following year are full blown, thus giving the tree a beautiful appearance.

ARCHED. A term employed among horsemen. A horse is said to have arched legs when his knees are bent archwise. This only relates to the fore-quarters, and the infirmity sometimes happens to such horses as have their legs spoiled in travelling.

\section{ARGILLACEOUS. [Clayey.] Containing} clay.

ARM OF A HORSE. A term applied to the upper part of the fore-leg.

ARNOTTO. See Anvotta.

AROMATIC. An epithet applied to such plants, and other bodies, as yield a fragrant odour, and have a warm spicy taste.

AROMATIC REED (Acorus calamus). The common sweet-flag. A marshy perennial plant of the easiest culture, flowering from June till August, which grows among rushes in moist ditches and watery places, about the banks of rivers, but not very general. Ront, thick, rather spongy; leaves, erect, two or three feet high, bright green, near an inch broad. It rarely flowers unless it grows in water, bu: when it does bloom, it puts forth a mass of very numerous, thick-set, brownish green flowers, which have no scent except when bruised. Every part of the herbage is stimu. lant, and very aromatic, but the roots are especially so. The dried root powdered is used by the country people of Norfolk, [England,] for curing the ague. It is affirmed to possess carminative and stomachic virtues, having a warm, pungent, bitterish taste, and is frequently used in preparing bitters, though it is said to impart a nauseous flavour. It is the Calamus aromaticus of the shops, and Linnæus says, the roots powdered might supply the place of foreign spices. (Eng. F/or. vol. ii. p. 157; Paxton's Bot. Dict.; Willich's Dom. Encyc.)

ARPENT. The French name for an acre. [The French arpent contains 51,691 square English feet, or very nearly one acre and threequarters of a rood English measure.]

ARROW-GRASS (Triglochin). Perennial marsh herbs, of which there are two hinds, the marsh arrow-grass and the sea arrow-grass, both perennials, flowering from May till August. They grow in wet boggy meadows and salt marshes, \&c., abundantly, and are very grateful to domestic cattle, the herbage containing a large proportion of salt. (Eng. Flor. vol. ii. p. 200.)

ARROW-HEAD (Sigittarin sngiltifulia, from sagitfa, an arrow; because of the resemblance of the leaves to the head of that weapnn) 
[In England,] an indigenous, aquatic, perennial herb, flowering in July or August. Root, suberous, nearly globular, with many long fibres. It is industriously cultivated in China for its esculent properties: its mealy nature rendering it easily convertible into starch or flour. It is much relished by most cattle. Nothing is more variable than the breadth and size of the floating leaves, which are diminished almost to nothing when deeply immersed in the water, or exposed to a rapid current. Hence has arisen the several varieties mentioned by authors, but which the slightest observation will discover to be evanescent. This plant, especially the seed, was formerly supposed to possess medicinal properties, which time and improved knowledge have demonstrated to be imaginary. The leaves, however, feel cooling when applied to the skin; hence they have been used and may be serviceable as a dressing to inflamed sores. (Eng. Flor. vol. iv. p. 144; Willich's Dom. Encyc.)

[ARROW-ROOT. This nutricious flour, which constitutes a very mild, light, agreeable and easily digested article of diet, so much resorted to for the sick and convalescent, and also for children, is the fecula or starch most commonly obtained from the root of a plant called Marania arundinacea. It is a native of South America, where, as well as in the West Indies, it is extensively cultivated. It grows also in Florida, in the southern parts of which it is manufactured at the very low price of 6 to 8 cents per lb. The low price at which arrow-root is sold at Key West and other parts of Florida, allows of its being used for the common purposes of starch, and also for the preparation of niceties for the table, being in fact often substituted for the ordinary breadstuffs. 'Though thus cultivated in the south, still most of that used is imported from the West Indies and Brazil, the best coming from Bermuda. The mode generally pursued in the West Indies for obtaining the fecula from the root and subsequently preparing it, is as follows:-The roots are dug up when a year old, washed, and then beat into a pulp, which is thrown into water, and agitated so as to separate the starchy from the fibrous or stringy portion. The fibres are removed by the hand, and the starch remains suspended in the water, to which it gives a milky colour. This milky fluid is strained through coarse linen, and allowed to stand that thr. fecula may subside, which is afterwards washed with a fresh portion of water and then dried in the sun. The powder is a light wnite colour, sometimes having small masses easily crushed. It is a pure starch like that obtained from wheat, potatoes, and several other vegetable substances, especially the plant called in the West Indies Jutropa Munilot, which yields the substance called Tapioca, used for similar purposes with arrow-root.]

[ARROW-WOOD. A name given in the United States to a shrub (Viburnum) the young and straight branches of which were, according to Marshall, formerly used by the nborgines for making arrows. The slender item:, when the pith is removed, afford good 112 fuse-sticks for blasting rocks. Ten or twelve species of Viburnum are enumerated in the United States. (See Darlington's Flor.Cestrica.)] ARSENIC. See Poison.

\section{ARTEMISIA. See Wonmwoons.}

ARTESIAN WELLS have been so named from the opinion that they were first used in Artois, in France. These wells have been found extremely beneficial in the low lands of Essex and Lincolnshire, and in some other districts where good water is scarce, and that of the surface of indifferent quality. Some practical knowledge of geology is necessary in order to fix with judgment upen the most eligible spot for sinking these wells, or else much labour and expense may be uselessly applied. They are formed by boring with a long auger and rod to such a depth into the earth, that a spring is found of sufficient power to rise to and run over the surface.

AR'TICHOKE (Cynara). From cinere, according to Columella, because the land for artichokes should be manured with ashes. ["A plant little cultivated in America, but very well worthy of cultivation. In its look it very much resembles a thistle of the bigblossomed kind. It sends up a seed stalk, and it blows, exactly like the thistle that we see in the Arms of Scotland. It is, indeed, a thistle upon a gigantic scale. The parts that are eaten are, the lower end of the thick leaves that envelope the seed, and the bottom out of which those leaves immediately grow. The whole of the head, before the bloom begins to appear, is boiled, the pod leaves are pulled off by the eater, one or two at a time, and dipped in butter, with a little pepper and salt, the mealy part is stripped off by the teeth, and the rest of the leaf put aside, as we do the stem of asparagus. The bottom, when all the leaves are thus disposed of, is eaten with knife and fork. The French, who make salads of almost every garden vegetable, and of not a few of the plants of the field, eat the artichoke in salad. They gather the heads, when not much bigger round than a dollar, and eat the lower ends of the leaves above mentioned raw, dipping them first in oil, vinegar, salt and pepper; and, in this way, they are very good. Articholes are propagated from seed, or from offsets. If by the former, sow the seed in rows a foot apart, as soon as the frost is out of the ground. Thin the plants to a foot apart in the row; and, in the fall of the year, put out the plants in clumps of four in rows, three feet apart, and the rows six feet asunder. They will produce their fruit the next year. When winter approaches, earth the roots well up; and, before the frost sets in, cover all well over with litter from the yard or stable. Open at the breaking up of the frost; dig all the ground well between the rows; level the earth down from the plants. You will find many young ones, or offsets, growing out from the sides. Pull these off, and, if you want a new plantation, put them out, as you did the original plants. They will bear, though later than the old ones, that same year. As to sorts of this plant, there are two, but they contain no difference of any con. sequence: one has its head, or fruit pod, round, and the other rather conical. As to the 
quantily for a family, one row across one of the plats will be sufficient." (Cobbetl's Ame-

\section{rican Gardencr.)]}

Those plants produce the finest heads which are planted in a soil abounding in moisture, but in such they will not survive the winter. Manure must be applied every spring, and the best compost for them is a mixture of three parts of well-putrefied dung, and one part of fine coal-ashes. They should always have an open exposure, and, above all, be free from the influence of trees; for, if beneath their shade or drip, the plants spindle, and produce worthless heads. For planting, these must be slipped off in March or early in April, when eight or ten inches in height, with as much of their fibrous roots pertaining as possible. Such of them should be selected as are sound and not woody. The brown, hard part, by which they are attached to the parent stem, must be removed; and if that cuts crisp and tender, it is evidence of the goodness of the plant; if it is tough and stringy, the plant is worthless. Further, to prepare them for planting, the large outside leaves are taken off so low, that the heart appears above them. If they have been some time separated from the stock, or if the weather is dry, they are greatly invigorated by being set in water for three or four hours before they are planted.

They produce heads the same year, from July to October, and will continue to do so annually, if preserved in succeeding years, from May until June or July; consequently, it is the practice, in order to obtain a supply during the remainder of the summer and gutumn, to make an annual plantation in some moist soil, as the plants are not required to continue.

As often as a head is cut from the permanent bed, the stem must be broken down close to the root, to encourage the production of suckers before the arrival of winter. In November or December they should receive their winter's dressing. The old leaves being cut away without injuring the centre or side shoots, the ground must be dug over, and part of the mould thrown into a moderate ridge over each row, close about the plants, but leaving the hearts clear. If this dressing is neglected until severe frosts arrive, or even if it is performed, each plant must be closed round with long litter or pea haulm : it is, however, a very erroneous practice to apply stabledung immediately over the plants, previous to earthing them up, as it in general induces decay. Early in February all covering of this description must be removed. In March, or as soon as the shoots appear four or five inches above the surface, the ridges thrown up in the winter must be levelled, and all the earth removed from about the stock to below the part from whence the young shoots spring. All of these but two, or at most three of the straightest and most vigorous, must be removed, care being taken to select from those which proceed from the under part of the stock; the strong thick ones proceeding from its crown, having hard wondy stems, are productive of indifferent heads. Those allowed to remain should be carefully preserved from injury. Every other sucker must be removed and every bud rubbed off, otherwise more will be produced, to the detrimeat of those purposely left. These must be separated as far apart as possible without injury, the tops of the pendulous leaves removed, and the mould then returned, sn as to cover the crowns of the stocks about two inches. Some gardeners recommend, as soon as the ground is levelled, a crop of spinach (o) be sown, which will be cleared off the ground before the artichokes cover it; but this mode of raising or stealing a crop is always in some degree injurious.

Although the articholie, in a suitable soil, is a perennial, yet after the fourth or fifth year the heads become smaller and drier. The beds, in consequence, are usually broken up after the lapse of this period, and fresh ones formed on another side.

If any of the spring-planted suckers should not produce heads the same year, the leaves may be tied together and covered with earth, so as just to leave their tops visible, and, on the arrival of frost, being covered with litter, so as to preserve them, they will afford heads either during the winter or very early in spring.

As a vegetable, the articholie is wholesome, but not very nourishing; and as a medicine, it is of little use. Sir John Hill, M. D., states having known patients cured of jaundice, by perseverance in this medicine alone, without combining its virtues with any other plant; but the statement of Sir J. Hill is of no value in the present day. The flowers of the artichoke have the property of rennet in curdling milk. The heads of the second crop of artichokes, when dried, are excellent baked in meat pies, with mushrooms, as they dress them in France. (G. W. Juhnsrn's Kitchen Garden.)

ARTICHOKE, JERUSALEM (Helianthus tuberosus, from 'Haws, the sun, and avbos, a flower). It flourishes most in a rich light soil, with an open enclosure. Trees are particularly inimical to its growth. As it never ripens its seeds in England, the only mode of propagation is by planting the middle-sized tubers or cuttings of the large ones, one or two eyes being preserved in each. These are best planted towards the end of March, though it may be performed as early as February, or even in October, and continued as late as the beginning of April.

They are planted by the dibble, in rows, three feet by two feet apart, and four inches deep. They make their appearance above ground about the middle of May. The only attention necessary is to keep them free from weeds, and an occasional hoeing to loosen the surface, a little of the earth being drawn up about the stems. Some gardeners, at the close of July or early in August, cut the stems off about their middle, to admit more freely the air and light; in other respects it may ve beneficial to the tubers.

' 1 'he tubers may be taken up as wanted dur. ing September; and in October, or as suon as the stems have withered, entire for preservation in sand, for winter's use. They should be raised as unbroken as possible, for the sinallest piece of a tuber will vegetate, and appear 
in the spring; for which reason they are often allotted some remote corner of the garden; but their culinary merits certainly demand a more favourable treatment. (C.W.Juhnson's Kitchen Garden).

The Jerusalem Artichoke thrives well in the United States on soft, moist, and it is said even on peaty soils. This root is abundant in the English and French markets, where it sells for a little more than the price of Irish potatoes. The fibres of the stems may be separated by maceration similar to hemp, so as to be capable of being manufactured into cordage or cloth, as is practised in some parts of Europe, where the plant is an object of field culture, especially on the poor and sandy soils. The articholie will yield, with similar culture, 30 per cent. more than the potato, and if the land be poor, they will yield at least double the quantity per acre that can be raised with the potato, and the expense of culture is no more. They are particularly adapted to the climate and soil of the Middle and Southern States, and being hardy, can be left during the fall and winter in the ground to be rooted up by hogs, great numbers of which may be thus fattened at little expense. Or they may be taken up and given to all kind of stock, for which purpose it is more requisite to steam them than potatoes. One of the chief objections urged against their culture is, that not being killed in winter by the frost, they grow among the crops which succeed them. But this is a comparatively trifling objection. The Jerusalem artichoke certainly deserves more attention from farmers than it now gets in the United States.

ARTIFICIAL GRASSES. See Grasstrs.

ARUM. Common Cuckow-pint, or WakeRobin (Arum maculatum). See W W $_{\text {A }}$-Roнis and INmian TURNip.

ARUNDO. A genus of grasses in which a number of useful species was once comprehended; but in consequence of the altered views of botanists regarding the limits of genera, it is now confined to the Arundo donux, and the species most nearly agreeing with it. These are grasses of considerable size, sometimes acquiring a woody stem, and found only in the warm parts of the world. The Arundo is closely allied to the genus Saccharum, the last of which includes the sugar-cane. (Penny (Cyclop.)

Arundo arenaria. Sea-reed, marram, starr, or bent. (See Plate 7, o.) The nutritive matter of this grass affords a large portion of saccharine matter when compared with the produce in this respect of nther grasses. The Elymus arenurius, however, affords about onethird more sugar than the present plant. The guantity of nutritive matter afforded by the Elymus arenarius is superior to that afforded by the Arundo arenaria, in the proportion of 4 to 5. From experiments as to the produce, it would appear that the $A$. arenaria is unworthy if cultivation as food for cattle, nut of the inHnence of the salt spray. But from the habit of the plant in its natural place of growth, it is of great utility, particularly when combined with the Elymus urenarius, in binding the lonse -ands of the sea-shure, and thereby raising a .1 .14 natural barrier, the most lasting against the encroachments of the ocean upon the land. So far back as the reign of William III., the important value of the Elymus arenurius and Arundo arencria was so well appreciated as to induce the Scottish parliament of that period to pass an act for their preservation on the sea-coasts of Scotland. And these provisions were, by the British parliament in the reign of George I., followed up by other enactments, extending the operation of the Scottish law to the coasts of England, and in passing further penal ties for its inviolability, so that it was rendered penal, not only for any individual, not even excepting the lord of the manor, to cut the bent, but for any one to be in possession of any within eight miles of the coast. This plant is likewise applied to many economical purposes; hats, ropes, mats, \&c., being manufactured from it. (Sinclair's Hirt. Gram. Wob.)

ASCARIDES. See Worms, Ivtrastival.

ASH (Fráxinus excélsior). This tree was called by the Greeks $\mu \varepsilon \lambda i 2$, and by some $\mu \varepsilon \lambda \varepsilon x_{0}$. The Latins, it is thought, named it Fraxinus, quia fucile frangitur, to express the fragile nature of the wood, as the boughs of it are easily broken. We are thought to have given the name of ash to this tree, because the bark of the trunk and branches is of the colour of wood-ashes, whilst some learned etymologists affirm that the word is derived from the Saxon ære. Virgil tells us that the spears of the Amazons were of this wood, and Homer celebrates the mighty ashen spear of Achilles. Many of the ancient writers highly extolled the ash. It has been asserted that serpents have such an antipathy to the ash, that they will not approach even within its morning or evening shadows; and Pliny tells us (he says upon experience), that if a fire and serpent be surrounded by ash boughs, the serpent will sooner run into the fire than into the boughs. There are many other superstitious notions, attached to the ash, which it would be foreign to our purpose to notice.

There are several varieties of the ash, among which are, 1 . The weeping, which forms a beautiful arbour when grafted upon a lofty stem - it is said to have originated incidentally in a tield at Garntingay, Cambridgeshire: 2. The entire leaved: 3. The curl-leaved, which has a dark aspect: and, 4 . The wasted.

Ash plantations have lately been formed in many parts of the kingdom to a very considerable extent. The Romans used the ash-leaves for fodder, which were esteemed better for cattle thars those of any other tree, the elm excepted: and they were also used for the same purpose, before agriculture was so well understood, and our fields clothed with artificial grasses. In Queen Elizabeth's time, the inhabitants of Colton and Hawkshead Fells remonstrated against the number of forges in the country, because they consumed all the loppings and croppings which were the sole winter food for their cattle. In the norih of Isancashire the farmers still lop the tops of the ash to feed their cattle in autumn, when the grass is on the decline; the cattle peeling off the bark as fond. The Rev. Mr. Gilpin tells us, that in forests the keepers make the dees 
browse on summer evenings on the sprays of ash, that they may not stray too far from the walk. The branches are frequently given to deer in time of frost. The ash-tree, in early days, served both the soldier and the scholar. It was also a principal material for forming the peaceable implements of husbandry, as it crntinues to be with us to this day, in the snape of carts, wagons, teeth and spokes of wheels, harrows, rollers, \&c. The gardener recognises it in his rake-stem, spade-tree, and other tool handles. The hop-planter knows its value for poles, the thatcher for spars, the ouilder for ladders, the cooper for hoops, the turner for his lathe, the shipwright for pulleys, the mariner for oars and ship-blocks, the fisherman for tanning his nets and drying his herrings; the wheelwright employs it usefully, and the coach-maker profitably, whilst the cabinet-maker palms it off upon us as green ebony. The ashes of this wood afford very good potash, and the bark is used in tanning calf-skins, and dyeing green, black, and blue. The ash-keys were formerly gathered in the green state, and pickled with salt and vinegar, and served to table for sauce.

Were we to transcribe all we have seen written on the medicinal virtues of this plant, it might naturally be asked how it happens that we do not meet our ancestors upon earth, who had in this tree a cure for every malady? The Arabian as well as the Greek and Roman physicians, highly extol the medicinal properties of the seed which the Latins named lingua avis, bird's tongue, which it resembles. Drs. Taner, Robinson, and Bowles, are amongst the later physicians who commend the good qualities of this little seed. The common ash propagates itself plentifully by the seed, so that abundance of young plants may be found in the neighbourhood of ash-trees, provided cattle are not suffered to graze on the land. It produces its leaves and keys in spring, and the seeds ripen in September. The foliage changes its colour in October. (Baxler's Lib. Ag. Kn.; Phillips's Syl. Flo\%.) [Michaux states that eight species of ash are mentioned by botanists as indigenous to Europe, whilst a much greater number exist in the United States. Probably more than thirty species can be found east of the Mississippi. A striking resemblance runs through the whole genus; but it is the white ash of America, the wood of which, by its strength and elasticity, is adapted to so many useful purposes, that bears the nearest resemblance to the common ash of Europe.]

ASHES (Goth. atzgo, azgo, dust; Sax. arca ; Dutch and Germ. asche; Su. Goth. aska). "Ashes contain a very fertile salt, and are the best manure for cold lands, if kept dry, that the rains doth not wash away their salt." (Mort. Husb.; Todd's Johnson.)

The use of ashes may be traced to a very early age. The Romans were well acquainted with paring and burning. Cato recommends the burning of the twigs and branches of trees, and spreading them on the land. Palladius says, that soils so treated would require no other manure for five years. They also burnt their stubbles, a practice common among the Jews. The ancient Britons, according to Pliny, used to burn their wheat-straw and stubble, and spread the ashes over the soil. And Conradus Heresbachius, a German counsellor, in his Treatise on I/usbandry, published in 1570 , which was translated by Googe, tells us, p. 20, that "in Lombardy, they like so well the use of ashes, as they esteem it farre aboue any doung, thinking doung not meete to be used for the unholsomnesse thereof."

It is the earthy and saline matters of the burnt soils, and combustibles employed, which constitute the substance of the ashes employed in agriculture. Their use as a manure is very general in most parts of England, although many errors are usually committed in their application, and much erroneous reasoning wasted in accounting for their unsuccessful application in some districts, or their general success in others. Those usually employed for agricultural and horticultural purposes in this country are, 1 . The ashes of coal ; 2. Ashes of wood; 3. Peat ashes; 4. The ashes from turf, as in paring and burning; 5. The ashes of burnt clay; 6 . The ashes from soap-boilers. I will remark upon these, in the order in which I have enumerated them.

1. Coul Ashes.-The only analysis of coal that I am acquainted with is that of earth-coal, by M. Klaproth : he found it to be composed of-

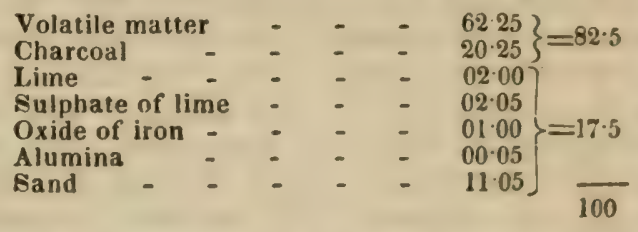

The combustion of the coals dissipates almost all the gaseous matters, and much of the charcoal; and the ashes, therefore, will consist almost entirely of the various earths, a small portion of charcoal, and the saline matters of which the sulphate of lime (gypsum) and lime constitute about a fourth.

The presence of these last-named substances gives to the coal-ash almost all its value as a fertilizer, for these ashes are always most beneficially applied to those crops which contain sulphate of lime in sensible quantities, such as to lucern, sainfoin, red-clover, \&c. In the garden, they are more often employed for the purpose of forming walks, and to prevent the ravages of garden-mice, than as a manure; or, when they are employed as an addition to the soil, it is generally in considerable quantities, on stiff clay soils, with the intention, by the mechanical operation of the cinders, of rendering the soil more friable and permeable by the gases of the atmosphere. As a top dressing for lucern, red clover, sainfoin, and other grasses, there is no application superior to coal ashes. This fact was clearly proved in some comparative experiments made by I.ord Albemarle, with a variety of manures, as a top dressing for sainfoin. He found roal ashes far superior in value to any other fertilizer. As a manure for gardens, it is generally employed in quantities much too large; and thence an idea has been entertained by many gardeners, that coal ashes are ininical to plants and trees. Mr. Loudon has given several experiments of this description. In these. 
ASHES.

one gardener imbedded his potted chrysanthemums, by placing a "large handful" at the bottom of each of his pots, and then was surprised that other pots, not thus partly filled, produced better plants. Another "horticultural friend" states the case of a Scotch gardener, who "coated over," for two successive years, his garden with coal ashes; and then our experimentalist, who was, doubtless, a persevering character, finding that, with this over-dose of cinders, the "fruit trees did not thrive so well as he expected," actually took them up, and placed them under a "substratum of ashes, in order to lay them," as he said, "dry and comfortable." The trees of crurse grew worse, and were taken up. (Gard. Mag. vol. vi. p. 224.) It is to be lamented that such trials as these are ever brought forward; they are merely sources of erroneous conclusions, and strong proofs of the ignorance of those who have thus been wasting their master's time and property.

Mr. Loudon has, in another place (Gard. Mag. vol. ii. p. 406), given some experiments of a very different character, which I shall give in his correspondent's own words :- "I sowed, on the 15th of May, 1826, three rows of Swedish turnips. No.1, was manured with well-rotted dung from an old melon bed. No. 2, with the tops of cabbages just come into bloom. No. 3, with coal ashes. They vegetated about the same time, but the row manured with the cabbage-tops seemed to suffer most from the drought; the season being hot and dry, they made little progress until the end of August, and in November they were a middling, or rather a bad crop. The row manured with coal ashes had, all along, a more luxuriant appearance than the other two. The rows were 20 yards in length, 3 feet apart, and 15 inches from plant to plant in the row. I took them up in February, and they weighed as follows:-No. 1, 78 lbs.; No. 2, 88 lbs.; No. 3, $121 \mathrm{lbs}$.; which is very much in favour of the coal ashes." It may be remarked, that sulphate of lime, which abounds in coal ashes, is found in very sensible quantities in turnips. In the garden, coal ashes are very useful when spread over the surface, to prevent the depredations of garden-mice; they cannot burrow through them; and, in the case of early sown peas, it will be found that the peas covered on the surface of the ground, with coal ashes, say a quarter, or half an inch in thickness, will be three or four days earlier than those to which the ashes have not been applied. This may he attributed to the greater heat absorbed from the sun by the black coal ashes.

Wiod Ashes.-The wood of various trees, \&c. lias been analyzed by M. Saussure, Jun.; the following was the result (Chem. Rec. Veg.) :-

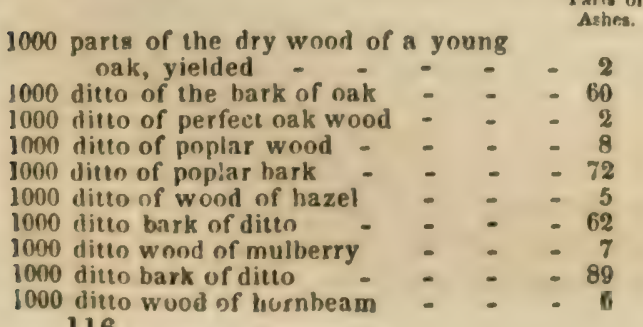

1000 ditto bark of ditto 1000 ditto wood of horse-chestnut 1000 ditto straw of wheat

1000 ditto branches of the pine -

100 parts of these ashes were found to consist of the following substances, in varying proportions. I have arranged the results in a tabular form, by which my readers will readily ascertain the composition of the ashes procured by the combustion of various woods, barks, \&c.:-

\begin{tabular}{|c|c|c|c|c|c|c|}
\hline & 产 & 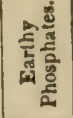 & 承产 & Silica. & 兰通 & Loss. \\
\hline $\begin{array}{l}100 \text { parts of ashes of } \\
\text { young oak dry wood, } \\
\text { contain - - - }\end{array}$ & 26.0 & 285 & $12 \cdot 25$ & 0.12 & 1. & .58 \\
\hline Bark of ditto, ditto - & $7 \cdot 0$ & $4 \cdot 5$ & $63-25$ & 0.25 & $1 \cdot 75$ & $22 \cdot 75$ \\
\hline Perfect oak wood, do. & $38 \cdot 6$ & $4 \cdot 5$ & 32. & 2 & $2 \cdot 25$ & 200 \\
\hline Poplar wood, ditto - & - & $16 \cdot 75$ & 27. & $3 \cdot 3$ & 1.5 & $24 \cdot 5$ \\
\hline Poplar bark, ditto - & 6. & $5 \cdot 8$ & $60^{\circ}$ & 4. & 1.5 & $23 \cdot 2$ \\
\hline Wood of the hazel, do. & $24 \cdot 5$ & 35 & 8. & (1.25) & 0.12 & $32 \cdot 2$ \\
\hline Bark, ditto, ditto - - & $12 \cdot 5$ & $5 \cdot 5$ & 54 & 0.25 & 1.75 & 26. \\
\hline $\begin{array}{l}\text { Mulberry wond, ditto } \\
\text { (Cut in Noveniber.) }\end{array}$ & 21 . & $2 \cdot 25$ & $56^{\circ}$ & 0.12 & 0.25 & $20 \%$ \\
\hline Burk of ditto, ditto - & 7 & $8 \cdot 5$ & $45^{\circ}$ & $15 \cdot 25$ & $1 \cdot 12$ & 1 \\
\hline Wood of hornbeam - & 22. & $23^{\circ}$ & $26^{\circ}$ & 012 & $2 \cdot 25$ & $26 \cdot 63$ \\
\hline Bark, ditto - - & $4 \cdot 5$ & $4 \cdot 5$ & 59. & J.5 & $0 \cdot 12$ & $30 \cdot 38$ \\
\hline Wood of chestnut - - & $9 \cdot 5$ & - & - & - & - & - \\
\hline $\begin{array}{l}\text { Straw of whod - - } \\
\text { Branches of the pine - }\end{array}$ & $22 \cdot 5$ & $6 \cdot 2$ & 1. & 61.5 & 1. & $7 \cdot 8$ \\
\hline
\end{tabular}

The soluble salts of these ashes are chiefly carbonate and muriate of potash. The earthy phosphates are the phosphates of lime and magnesia (or the principal salt of bones); the earthy carbonates are those of lime (chalk), and magnesia; silica is the pure earth of fint. and the oxides were those of iron and manganese.

The cultivator will readily see, by the results of these valuable investigations, the reason why wood ashes are so much superior to those from coal as a manure. The ashes from wood, he will notice, contain a very considerable proportion of the phosphates of lime and magnesia; those from the hazel, containing 35 per cent., and those from the wood of young oak 25 per cent., essential vegetable ingredients, of which the ashes from coal are entirely destitute. The phosphate of lime, it will be remembered, is the chief fertilizing constituent of bones, in which valuable manure it is invariably present, in proportion varying from $37 \frac{1}{2}$ per cent. in the bones of the ox, to 35 per cent. in those of the hare. Wood ashes also contain a considerable proportion of carbonate of potash, a salt which is more or less present in all vegetable substances, and for which, therefore, it must be highly serviceable as a food. The carbonate of potash, too, promotes the disso. lution of dead vegetable substances, and it also, from its attraction of moisture from the atmosphere, must promote an increased supply to the soil. Wood ashes are often very judiciously added to common manure, the quality of which is much improved by the mis. ture. The leaves of trees, when burnt, generally produce more ashes, or potashes as they are called, (from being formerly produced by burning vegetable substances in large open pots), than the branches, and the stem of the tree the least of all; herbs produce four or five times, and shrubs three or four times as much as either. All vegetables produce more 


\section{ASHES.}

ashes if burnt when green than when they are previously dried. Davy (Lectures, p. 113) has given a table of the quantity of potashes furnished by the combustion of various common vegetable substances, which I shall here insert, as the cultivator will see by it that there is a very remarkable difference in the quantity produced by equal weights of different trees and flants.

10,000 parts of the poplar produced
-

Parts of Pulashes.

$-7$

$-12$

$-15$

- 39

- 55

- 53

- 62

$-196$

$-200$

$-275$

$-730 *$

$-790$

Peat Ashes.-Peat ashes are made in many parts of England for the use of the farmer by burning peat in large heaps, after it has been sufficiently dried by the heat of the sun; and for grass lands and turnips they have been found a very valuable manure. They are usually applied as a top dressing. The composition of peat ashes more nearly resembles that of coal ashes than those from wood or vegetables-which is a result hardly to be expected, when we consider that the immense beds of peat, or turf, as it is sometimes called, which are dispersed over Britain, are evidently composed of the remains of vegetable substances; trunks of trees, leaves, fruits, stringy fibres, the remains of water mosses, \&c., and this in some places to a depth of 15 yards. Peat ashes were analyzed by Davy, with much care : he came to the conclusion that they owe most of their fertilizing properties to the presence of gypsum (or sulphate of lime). In the Berkshire and Wiltshire peat ashes, he discovered a considerable portion of it. The Newbury peat ashes he found to be composed of from one-fourth to one-third gypsum, and in the peat ashes of Stockbridge and Hampshire, a still larger proportion of the same substance. The other constituents of peat ashes are calcareous, aluminous, and silicious earths, with varying quantities of sulphate of potash, a little common salt, and occasionally oxide of iron, especially in the red varieties of peat ashes.

"These peat ashes," said Davy, "are used as a top dressing for cultivated grasses, particularly sainfoin, clover, and rye-grass. I found that they afforded considerable quantities of gypsum, and probably this substance is intiinately combined as a necessary part of their woody fibre; if this be allowed, it is easy to explain the reason why it operates in such small quantities; for the whole of a clover or sainfoin crop on an acre, according to my estimation, would afford, by incineration, only three or four bushels of gypsum. In examining the soil in a field near Newbury, which was taken from below a footpath, near the gate, where gypsum could not have been artificially furnished, I could not detect any of this sub-

- Hence potash was formerly called " salt of wormwood."
ASHES.

stance in it, and at the very time I collected the soil, the peat ashes were applied to the clover in the field. I have mentioned certain peats, the ashes of which afford gypsum : but it must not be inferred from this, that all prats agree with them. I have examined various peat ashes from Scotland, Ireland, Wales, and the northern and western parts of Eigland, which coutained no quantity that could be useful; and these ashes abound in silicious, aluminous earths, and in oxide of iron. Iord Charleville found in some Irish peat aslies, sulphate of potash. Vitriolic matter is usually found in peats; and if the soil or substratum is calcareous, the ultimate result is the production of gypsum. In general, when a recent potash emits a strong smell resembling that of rotten eggs (sulphuretted hydrogen), when acted upon by vinegar, it will furnish gypsum." (Agric. Chem. p. 336.)

In the valley of the Kennet, in Berkshire, where the peat ashes are made in very considerable quantities, and are used by the farmers as a manure for both grass and turnips, they are sold at three-pence per bushel, and are applied at the rate of 40 or 50 bushels an acre broadcast. On most grass lands there is no dressing equal to them; and on some soils, near to Hungerford, they produce the most luxuriant crops of grass, in cases where the effects of common farm-yard manure are hardly perceptible. As a manure for turnips, they answer best in wet seasons. In very dry weather, the crops growing on the ashed land are described by the farmers as putting on a "burned" appearance.

Peat ashes are extensively employed in Flanders as a manure; they are carefully preserved by the householders, who burn turf or peat, and are sold to the farmers by the bushel, in the same way that those of Newbury are in England. Their use is chiefly confined to clover, for which purpose they are an excellent top dressing. Mr. Radcliffe, in his Agriculture of Flanders, has given an analysis of these ashes, from which the farmer will see they owe nearly all their fertilizing properties to the presence of 12 per cent. of gypsum. 100 parts are composed of-

\begin{tabular}{|c|c|c|c|c|c|}
\hline Silicious earth & - & - & - & - & - \\
\hline Sulphate of lime & - & - & - & - & - \\
\hline Sulphate and mu & ria & of & da & 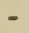 & - \\
\hline Carbonate of lim & & - & - & - & - \\
\hline Oxide of iron & - & - & - & - & - \\
\hline Loss & - & - & - & - & - \\
\hline
\end{tabular}

Paring and burning Ashes.-This is hardly the place to enter into the often argued and yet undecided question, as to the advantageis of paring and burning. It is pretty universaliy agreed, that the practice is highly injurious in sandy soils, beneficial to clay lands, and sti. more advantageous to those of a peaty destrip. tion; that is, to soils where there is an excess of inert vegetable remains. The cultivator of the soil will see, by the results of the analysis by Davy of the ashes produced by the paring and burning of three different descriptions of soil, the usual products of paring and burnum. 20n 
grains of the ashes from paring and burning a chalk soil in Kent, yielded that great chemist

\begin{tabular}{|c|c|c|}
\hline \multicolumn{3}{|c|}{80 grains of chalk, } \\
\hline 11 & - & gypsum, \\
\hline 9 & & charcoal, \\
\hline 15 & - & oxide of iron, \\
\hline 3 & 一 & $\begin{array}{l}\text { saline matter, consisting of sulphate of } \\
\text { potash, muriate of magnesia, and ve- } \\
\text { getable alkali, }\end{array}$ \\
\hline 82 & - & alumina (clay), and silica (flint). \\
\hline
\end{tabular}

200

According to the estimate of Mr. Boys, who has published a treatise upon paring and burning, it appears that on the chalk soils of Kent, about 2660 bushels of ashes are usually produced by paring and burning an acre of ground, and that this quantity of ashes, which he calculates will weigh $172,900 \mathrm{lbs}$, will contain

\begin{tabular}{|c|c|c|c|c|c|}
\hline Chalk - & - & - & - & - & - 69,160 lbs. \\
\hline Gypsum & - & - & - & - & - 9,509 \\
\hline Oxide of iron & - & - & - & - & $-12,967$ \\
\hline Saline matter & - & - & - & - & - 2,594 \\
\hline Charcoal & - & - & - & - & $-7,781$ \\
\hline
\end{tabular}

The second specimen of ashes was from a soil at Colerton, in Leicestershire, composed of three-fourths sand, one-fourth clay, and about 4 per cent. of chalk.

100 grains of the ashes yielded

6 graius charcoal,

3 - conımon salt, sulphate of potash, and a

9 - oxicle of iron,

82 - saud, clay, and chalk.

100

The third variety of ashes was produced by paring and burning a stiff clay soil at Mount's Bay, in Cornwall.

100 grains of these were found to contain

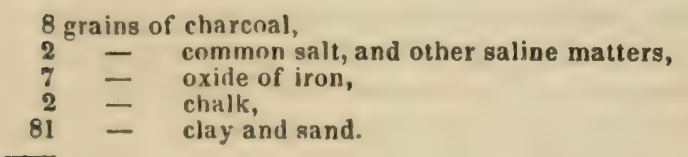

100

Such are the ashes from paring and burning. The cultivator of the soil will judge whether any of these products are required by his land, and whether all the good results of paring and burning might not be generally obtained by other means, without destroying that large portion of the vegetable matters of the turf, destroyed during combustion. In those cases, however, where it is practicable to transfer the ashes produced by paring and burning a chalk soil to a clay, or, vice versa, the ashes of a clay soil to a chalk, the result must, in general, be highly and permanently beneficial to both.

The Ashes of burnt Clay.-The composition of the ashes of burnt clay, although varying according to the earthy proportions of the soil, wil? be found pretty generally to accord with the analysis of the ashes from the clay soil, irnm Mount's Bay, given above under the head, Paring and hurning Ashes. Clay burning is practised with decided success in many districts of England, and, in every point of view, is by far the most eligible mode of producing ashes for manure; for the soil of the field is not thereby impoverished of its vegetable remains, the clar which is burnt being generally 118 procured from ditches, banks, hedgerows, \&c. The account of clay burning, given several years since by General Vavasour, of Melbourne Hall, in Yorkshire, is so practical and satisfactory, that I cannot do better than quote his own words:- "I would recommend to a beginmer, that the kiln should be made small, abou three yards wide, and six yards long in the inside; as he becomes more skilful, they nay be made larger. The walls of the kiln art $t()$ be made of sods, two feet thich at the bottom, and one foot thick at the top, leaving two flues on each side, and one at each end, about one foot square; these walls may be built at first four feet high. We then put in the wood, beginning with the larger pieces at the bottom, particularly near the flues, supported by sods to keep them open, adding tops of firs, or any brushwood, until the kiln is nearly filled. It might be burnt with coal or peat, if more convenient. Cover the wood with a layer of clay taken from some bank or ditch in the field, and which has been digged sometime before to dry; it is not necessary that it should be very dry. The fire is then to be lighted at the flue by means of straw previously placed there. The greatest care is required that the fire shall not escape at the top; but fresh clay constantly thrown on, wherever it seems likely to burn out, at the same time not overloading the kiln, so as to put out the fire. As the quantity of clay is increased, the walls should be raised, keeping them a foot higher than the clay. About six feet will be as high as can be conveniently burned. The chief art seems to be, to procure a great mass of fire at first, and to let the fire rise through the clay as you go, to let it smoke in every part at the top, but not to burn out. My men, who burnt by contract, watch the irilns by night and day. I have applied the ashes almost exclusively for wheat, upon a clay soil, spreading them on a fallow after the last ploughing, and harrowing them in with the seed, at the rate of 30 tons per acre, on 80 acres. The longer the ashes remain upon the land, before harrowing, the better, that the lumps may fall, and mix with the soil. If the walls are well made, one end may be taken down, and, after the kiln is emptied, rebuilt for a second burning; if not likely to stand, they may be entirely burned in a succeeding kiln. If the weather should not be moist, the kilns will burn for some weeks, as the clay will continue hot long after the wood is consumed."

Clay ashes have been used to a very considerable extent by Mr. Hewitt Davis, of Spring Park, near Croydon, on several of his farms, and with the most decided success. This excellent farmer and land-agent has the clay dug out in pits, that it may be more readily dried. He burns in heaps; and employs as fucl collections of hedge-clippings, furze, \&c.; and these he thinks it best not to use in ton dry a state, since one great object in clay-hurning, he is of opinion, is to produce a steady mouldering heat, not too fast. A fire, therefore, should not be suffered to flame. The fire in the heaps usually works against the wind, when those heaps are properly made. He applies about 150 bushels of the ashes per acre; pays $1 d$. to $1 \frac{1}{2} d$. per bushel for burning; dress- 


\section{ASHES.}

ing with them with great advantage all kinds of soil, for turnips, \&ec.

Mr. Popyy, of Witnesham, in a pamphlet published in 1830, after giving various directions for burning clay, adds:- "Salt (the only inexhaustible universal manure, besides burnt earth) does not increase the bulk of straw; and although it may be, and is, beneficial to corn, it will not be very extensively used, because its benefit is not apparent to the eye: burnt earth produces an abundance of straw. I have seen the corn so luxuriant on the sites of the heaps, where due caution was not used in laying a floor of earth under the fire, that it was rotted on the ground, and destroyed the clover plant. I have seen the beans on the site of a burnt-earth heap even too luxuriant; and potatoes and mangel wurzel a double produce to the rest of the crop. There is no limit to burning earth on stiff clay soils, because the most sterile subsoil, brought up purposely by the plough will, by the action of fire, be converted into useful manure. If it is converted into staple, it increases the depth of titheable soil, and acts both physically and mechanically." The Suffolk plan of clay-burning is similar to that adopted in Yorkshire. "The common mode of burning earth is to dig old borders, surfaces of banks, \&c.; turn it over, and, when dry, cart it to a heap, and burn; formerly much wood was used, but haulm, straw, dry weeds, and a few bushes, whins, or any thing of that kind, may be employed; then build a circular wall of turfs around it, cover the heap slightly with turfs and earth, and set fire to it in several places; feeding with the most inflammable materials at first, afterwards clay or any earth will burn; when all the earth is on the heap, the walls may be pulled down and thrown on, raising it by degrees as the fire ascends, in the shape of a cone, till all is consumed."

The expense of this kind of clay-burning is thus estimated by Mr. Poppy :-

Labour, digging, and burning 100 loads, at $9 d$. per load

Filling, 1s. $6 d$. per score-7s. $6 \bar{d}^{-}$; carting three

hing, 1s. $6 d$. per score-7s. $6 d$.; carting three

horses and iwo carts, 16s. - $-{ }_{-}-136$

Filling and spreading after burning, $3 d$. per acre 0150

Carting, and laying out over two acres

Total per 100 loads

Or $3 l .4 s .9 d$. per acre for 50 loads, or $1 s .4 d$. per load.

Clay-burning, according to Mr. Poppy, is certainly not a modern Suffolk improvement. "I have constantly seen it practised for half a century; and the oldest man I ever conversed with on the subject, spoke of it as common as long as he could remember. I have a workman on the farm who is, I think, upwards of eighty years of age, and has always followed the vocation of burning earth."

The Ashes from Surp Boilers.-Soap boilers' ashes are a mixture of a peculiar description; they are principally the insoluble portion of the barilla, potashes, or kelp, employed in soap-making, mixed with cinders, lime, salt, and other occasional additions; and also with muriate of potash, common salt, and other saline matters.
A.SHES.

The quantity of pearl and potashes imported into the United Kingdom is very consider. able; in 1837, it amounted to $147,329 \mathrm{cw}$ is.; in 1838, tu 127,101 cwts.: of barilla and alkali in the same year were imported $102,135 \mathrm{cw} / \mathrm{s}$. and $72,587 \mathrm{cwts}$. (M'Culluch's Dictionary of

\section{Commerce.)}

The insoluble portion of barilla consis? principally of lime, charcoal, sand, and oxide of iron. The insoluble portion of potash, or ashes, as they are denominated by the trade, will consist of a considerable portion of the same ingredients, added to a varying portion of phosphate of lime. Much difference of opinion has subsisted among farmers with regard to the advantages of soap-makers' ashes. It has been recommended as very useful upon strong, cold soils, on peat moss, and on cold, wet pastures. The quantity recommended to be applied per acre by Arthur Young, was 60 bushels for turnips; to be harrowed in with the seed. For wet grass lands, six loads per acre. For wet arable soils, seven loads per acre. He describes the immediate effects as very great. For poor loamy land, ten luads per acre: the effect very satisfactory. Dr. $\mathrm{C} c$ gan, who has written a paper on the use of soap ashes, has given this letter of one of his correspondents, whom he describes as a plain, sensible farmer:- "My experience of soaper's ashes is confined to the application of it as a top dressing on pasture land. About twelve years ago, I agreed with a soap boiler for 1500 tons of soapers' ashes. I used to apply abou: twenty wagon loads per acre, and a single bushing would let the whole in. I was laughed at, and abused by every body for my folly: these wiseacres alleging that my land would be burned up for years, and totally ruined; all which I disregarded, and applied my soaper's ashes every day in the year, reeking from the vat, without any mixture whatever.

"I tried a small quantity (say six acres), mixed up with earth; but I found it was only doing things by halves. My land never burned, but, from the time of the application, became of a dark green colour, bordering upon black, and has given me more, but never less than two tons per acre, ever since, upon being hayned, forty-two days, viz. from May 31 to Iuly 11. The ground I so dressed was twenty-four acres; and I have had 120 sheep (hogs of the new Leicester breed), upon the ground from last August to this day (March 2); but I allowed them plenty of hay: and although they were culled in August last, as the uorst I had out of 700 lambs, and selected for this ground on purpose to push them, they are now as good as the best I have."

As by far the most considerable portion of soap ashes is lime and chalk, wherever lime or calcareous matter is a fertilizer to the soil, soap-makers' ashes will generally, if not invariably, succeed; but they must be applied in quantities nearly as large as if lime was employed.

Such are the chief agricultural propertues of the various ashes hitherto employed in agriculture. The research is, however, by no means nearly exhausted, for these fertilizers have showed the fate generally attendant unon 
all agricultural or horticultural investigations: they have been lauded as equally beneficial to every description of soil, and in all situations; or they have been condemned, with equal folly, by the results of blundering trials-begun in ignorance, continued without care, and perhaps nearly forgotten in the hurry of a conclusion.

They furnish ingredients, such as the carbonate of lime, carbonate of potash, charcoal, phosphate of lime, sulphate of lime, \&c., which, in limited quantities, enter into the composition of all plants, as an absolute constituent part; and for these they must, according to the natural deficiency of the soil in ihese ingredients, be extremely useful. They absorb moisture from the atmosphere, too, in quantities much superior to what is generally believed, and in this property the ashes of burnt clay and coal ashes considerably exceed both chalk, lime, gypsum, and even crushed rock salt, as will be seen by the result of the experiments given under the head Manures.

Some very valuable comparative experiments on the influence of ashes upon the growth of potatoes were made by the Rev. Edmund Cartwright, of Hollenden House, in Kent. (Com. Buard of Agric., vol. iv. p. 370.) "The soil on which these experiments were made was previously analyzed: 400 grains gave-

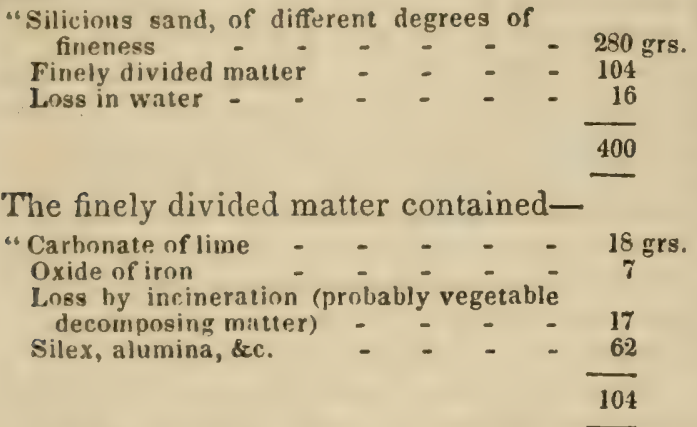

"It will appear," says Mr. Cartwright, "from the above analysis, that these experiments could not have been tried upon a soil better adapted to give impartial results; for of its component parts there is no ingredient (the oxide of iron possibly excepted) of sufficient activity to restrain or augment the peculiar energies of the substances employed." 'The beds were laid out and planted on the same day, the 14th of April; they were manured as in the following table. 'These beds were each forty yards in length, and one yard wide. Every bed was planted with a single row of potatoes, "and, that the general experiment might be conducted with all possible accuracy, each bed received the same number of sets." The potatoes were taken up on the 21 st of September wnen the produce of the beds were as follows :-

Land without any manure produced, per acre - - - 157

Pratnes in

- with 60 bushels of wond-ashes - 60 bushels of wood-ashes, salt 8

bushels - 60 bushels of wood-ashes, salt
- peat 363 bushuls -
- peat ashes 368 bushels, salt
bushels bushels - 120
Another series of experiments was made hy Dr. Cartwright, upon a cold, wet, tenacious clay, with burnt clay, wood-ashes, and soot; in all of which tre clay ashes had a decided supe. riority of effect. The following table shows the quantity of manure applied per acre, and the produce of the land thus fertilized. (Trans. Soc. Arts, vol. xxxvi.)

\begin{tabular}{|c|c|c|c|c|}
\hline \multirow{2}{*}{ Per Acre. } & \multicolumn{4}{|c|}{ Produce per Acre. } \\
\hline & Swedes. & Polatoes. & Barl & ley. \\
\hline & inns. civis. & bush. & qrs. & Jbs. \\
\hline Burnt clay, 400 bushels - & 252 & 480 & 4 & 4 \\
\hline Wood ashes, 100 bushels & $23 \quad 12$ & 456 & 4 & 2 \\
\hline Soot $-50 \longrightarrow$ & $16 \quad 12 \frac{1}{2}$ & 432 & 4 & 2 \\
\hline Soil simple - & 10 & 340 & 3 & 0 \\
\hline
\end{tabular}

The operation of burning clay produces but a slight chemical alteration in the composition of the clay; its tenacity is merely destroyed. and a portion of soot and of carbonized animal and vegetable remains are diffused through the ashes; added to which, the ashes of the wood employed for the burning, which usually contain a quantity of phosphate of lime and potash, are mixed up with the mass. (Johnson on Fertilizers, 296 ; Brit. Furm. Mag., vol. i. p. 58.)

ASPARAGUS (from the Greek as repryss, a young shoot before it expands). There are only two varieties, the red-topped and the green-topped; the first is principally cultivated. There are a few sub-varieties which derive their names from the places of their growth, and are only to be distinguished for superior size or flavour, which they usually lose on removal from their native place. The soil best suited to this vegetable is a black, fresh, sandy loam, made rich by the abundant addition of manure; it should be neither tenacious from the too great preponderance of clay, nor too dry from a superabundance of silica, but should be retentive of moisture chiefly by reason of its richness. To raise fine roots for hot-beds, they may be raised in a much moister soil (Miller's Dictimary); but for natural productions this will not answer, as such plants are much shorter lived. The site of the beds should be such as to enjoy the influence of the sun during the whole of the day, as free as possible from the influence of trees and shrubs, and, if choice is allowed, ranging north and south. The subsoil should be dry, or the bed kept so, by being founded on rubbish or other material to serve as a drain. The space of ground required to be planted with this vegetable for the supply of a small family is at least eight rods, if less, it will be incapable of affording one hundred heads at a time (Marshall says six rods will afford this quantity), so that part must be kept two or three days after it is cut, especially in ungenial seasons, to allow time for the growth of more to make a sufficient number for a dish. Sixteen rods will, in general, afford two or three hundred every day in the height of the season. To raise plants the seed may be sown from the middle of February to the beginning of April ; the most usual time is about the middle of March. The best mode is to insert them by the dibble, five or six inches apart and an inch below the surface, two seeds to be put in each 
hole; or they may be sown in drills made the same distance asunder, or broadesst. If dry weather, the bed should be refreshed with moderate, but frequent waterings, and if sown as late as April, shade is required by means of a little haulm during the meridian of hot days, until the seeds germinate. Care must be talien to keep them free from weeds, though this operation should never commence until the plants are well above ground, which will be in the course of three or four weeks from the tirne of sowing. If two plants have arisen from the same hole, the weakest must be removed as soon as that point can be well determined. Towards the end of October, as soon as the stems are completely withered, they nust be cut down, and well-putrefied dung spread over the bed to the depth of about two inches: this serves not only to increase the vigour of the plants in the following year, but to preserve them during the winter from injury by the frost. About March in the next year, every other plant must be taken up, and transplanted into a bed, twelve inches apart, if it is intended that they should attain another, or two years' further growth, before being finally planted out; or they may be planted immediately into the beds for production. It may be here remarked, that the plants may remain one or two years in the seed-bed; they will even succeed after remaining three, but if they continue four they generally fail: it is, however, nearly certain that they are best removed when one year old, for the earlier a plant can possibly be removed, the more easily does it accommodate itself to the change, and less injury is it apt to receive in the removal. Some gardeners sow the seed in the beds where they are to remain for production. This mode, too, has the sanction of Miller. The time for the final removal is from the middle of February until the end of March, if the soil is dry and the season warm and forward; otherwise it is better to wait until the commencement of April. The plan which some persons have recommended, to plant in autumn, is so erroneous, that, as Miller emphatically says, the plants had better be thrown away. Mr. D. Judd has mentioned (Trans. Hort. Soc. Lond., vol. ii. p. 236) a very determinate signal of the appropriate time for planting, which is, when the plants are beginning to grow: if moved earlier, and they have to lie torpid for two or three months, many of them die, or in general shoot up very weak.

Immediately that the buds begin to swell they should be removed, and this may easily be ascertained by occasionally opening the ground down to the stool. A successful experiment, tried by Mr.J. Smith, gardener to the Earl of Kintore, would evince that one year old asparagus plants may be removed even as late as June. The stems of his plants, at the lime of removal in that month, were twelve or fifteen inches high: they were removed and treated with the greatest care, the earth being gently pressed round the root, and water given plentifully; but although the experiment perfectly succeeded, for none of them died, and although they surpassed in growth those left in the seed-bed-so much so, that they might have been cul from-yet still, for many reasons, we are justified in considering that this must h: : been tried under accirlontal of very fiswoura... circumstances of soil and seasom, and it requires repeated experiments from different counties before the practice is confirmed. (Culed. Hort. Mem., vol. i. p. 71.) In forming the beds for regular production, it is customary to have them four or five feet wide. In the first instance, they have three rows of plints, in the latter four. 'The site of the bed being marked out, the usual practice is to trench the ground two spades deep, and then to cover it with well-rotted manure frum six to ten inches deep; the large stones being sorted out and care taken that the dung lies at least six inches below the surface. 'I') mix the manure with the soil effectually, Mr. D. Judd, before mentioned, trenches his ground two feet deep, three times successively during the autumn or winter, at intervals of a fortnight, and then lays it in ridges until wanted, performing the work in the absence of rain or snow: he justly observes, that the preparation of the suil is of more consequence to be attended to than all the after management. ('Trans. Hur\%. Suc. Lond., vol. ii. p. 234.)

In France, however, where the beds are celebrated for the number of years they continue in production, a pit is dug five feet in depth, and the mould that is raised from it sifted, care being taken to reject all stones, even as small as a filbert; the best part of the mould is laid aside for making up the bed. The bed is then formed as follows, beginning at the bottom; six inches deep of common manureeight of turf, very free from stones-six of manure-six of sifted earth-eight of turfsix of very rotten dung-eight of best earth ; finally, this last layer of mould is well incorporated with the adjoining one of dung. The bed is then ready for the reception of the plants. (Dr. M'Culloch, in the Culed. Hort. Mem.) The plants being taken from the seedbed carefully with a narrow, prolonged dungfork, with as little injury to the roots as posslble, they must be laid separate and even to gether, for the sake of convenience whilst planting, the roots being apt to entangle, and cause much trouble and injury in parting them. They should be exposed as short a time as possible to the air; and to this end it is advisable to keep them until planted in a basket, with a little sand, and covered with a piece of mat. The mode of planting is to form drills or narrow trenches, five or six inches deep and a foot apart, cut out with the spade, the line side of each drill being made perpendicular, and against this the plants are to be placed, with their crowns one and a half or two inches below the surface, and twelve inches asunder: in France eighteen are allowed. The roots must be spread out wide in the form of a fan, a little earth being drawn over each to retain it in its position whilst the row is proceeded with. If the plants have bcgun to shoot, it is the practice in France to remove the sprouts, and with this precaution the planting is successfully performed as late as July, and if any of those die which were first planted, they are replaced at that season. This is a practice to be avoided as much as 


\section{ASPARAGUS.}

possible, for it obviously must weaken the plants, and be particularly detrimental to such young plants. For the sake of convenience, one drill should be made at a time, and the plants inserted and covered completely before another is commenced; the two outside drills must be each six inches from the side of the bed. When the planting is completed the ber is to be lightly raked over, and its outline distinctly marked out. Care must be had never to tread on the beds-they are formed narrow to render that unnecessary-for every thing tending to consolidate them is injurious, as, from the length of time they have to continue without a possibility of stirring them to any considerable depth, they have a natural tendency to have a closer texture than is beneficial to vegetation. Water must be given occasionally in dry weather until the plants are established. The paths between the beds are to be two and a half feet wide. Throughout the year care must be taken to keep the beds clear of weeds. In the latter end of October or commencement of November the beds are to have their winter dressing: the stalks must be cut down and cleared away, and the weeds hoed off into the paths, care being taken not to commence whilst the stems are at all green, for if they are cut down whilst in a vegetating state, the roots are very prone to shoot again, and consequently are proportionably weakened. This habit might perhaps be taken advantage of in assisting our forcing this esculent; cutting down the summer-produced stems of such stools as are intended for the hotbed, a considerable time before they lose their verdant $\mathrm{co}$ lour, would give them a natural tendency to shoot again, and consequently assist the effect of the artificial heat employed. It is generally recommended not to add any manure until the bed has been two or three years in production, and then only to apply it every other year; but I consider it much more rational to manure regularly every year from the time of forming the bed, though in less quantity than if done every other year. I put on about two inches of well decayed hotbed. By this means a continued and regular supply of decomposing matter is kept up, which is not so perfectly effected by the usual mode; and from the experiments purposely instituted by Miller, we learn, that on the richness of the ground and warmth of the season the sweetness of asparagus depends; in proportion to the poverty of the soil it acquires a strong flavour. The dung needs merely to be laid regularly over the bed, and the weeds, as well as some manure, to be slightly pointed into the paths, some of the mould from which must be spread to the depth of two inches over the dung just laid ur,on the beds. In France the asparagus beds at this season are covered with six inches depth of manure and four of sea sand if procurable, otherwise, of river sand or fine earth. No forking is required; but the boundaries of the bed must be marked out distinctly, as they should be liept, indeed, at all times. In the end of March or early in April, before the plants begin to sprout, the rows are to be stirred between to a moderate depth with the - sparagus fork, running it slantingly two or three inches beneath the surface, as the object is merely to stir the surface and slightly mix it with the dung. Great care must be taken not in the least to disturb the plants. Some gardeners recommend that the beds should only be hoed again, so fearful are they of the injury which may be done to the stools; but if it be done carefully as above directed, the fork is the best implement to be employed, as by more effectually loosening the soil, it is by far the most beneficial in its effects upon the plants. 'I'his course of cultivation is to be continued annually, but with this judicious modification, that earth be never taken from the paths after the first year, but these merely be covered with dung, and which is only to be slightly dug in; for every gardener must have observed that the roots of the outer row extend into the alleys, and are consequently destroyed if they are dug over; and rather than that should take place, the beds should have no winter covering, unless mould can be obtained from some other source, as asparagus does not generally suffer from frost, as is commonly supposed. In May the beds are in full production of young shoots, which, when from two to five inches high, are fit for cutting, and as long as the head continues compact and firm. Care must be taken, in cutting, not $w$ injure those buds which are generally rising from the same root, in various grades of successional growth within the ground. The knife ought to be narrow-pointed, the blade about nine inches in length, and saw-edged: the earth being carefully opened round the shoot, to observe whether any others are arising, the blade is to be gently slipped along the stalk until it reaches its extremity, where the cut is to be made in a slanting direction. It almost always occurs that the same stool produces a greater number of small heads than large ones, but the latter only should be cut; for the oftener the former are removed, the more numerously will they be reproduced, and the stools will sooner become exhausted. Great attention must be paid to the seed. For the obtaining it, some shoots should be marked and left in early spring, for those which are allowed to run up after the season of cutting is over, are seldom forward enough to ripen their seeds perfectly. In choosing the shoots for this purpose, those only must be marked which are the finest, roundest, and have the closest heads; those having quick opening heads, or are small or flat, are never to be left More are to be selected than would be necessary if each stem would assuredly be fruitful; but as some of them only bear.male or unprom ductive blossoms, that contingency must be allowed for. Each chosen shoot must be fastened to a stake, which, by keeping it in its natural position, enables the seed to ripen more perfectly. The seed is usually ripe in September, when it must be collected, and left in a tub for four or six weeks, for the pulp and husk of the berry to decay, when it may be well cleansed in water. The sceds sink to the bottom, and the refuse floats and will pass away with the water as it is gently poured off. By two or three washings the seeds will be completely cleansed; and when perfectly dried 


\section{ASPARAGUS.}

exposure to the sun and air, may be stored use. Some gardeners lieep them in the ilp until the time of sowing, unless required be sent to a distance.

To furce Asparagus.- Such plants must be serted in hotbeds as are five or six years' d. and appear of sufficient strength to proce vigurous shoots: when, however, any old tural ground plantations are intended to be oken up at the proper season, some of the st plants may be selected to be plunged into hotbed or any spare corner of the stove rrk-beds. When more than ten years old, ey are scarcely worth employing. To plant d stools for the muin forcing crop, is, hower, decidedly erroneous; for, as Mr. Sabine marks, if plants are past production, and fit to remain in the garden, little can be excted from them when forced. The first antation for forcing should be made about e latter end of September: the bed, if it orks favourably, will begin to produce in the urse of four or five weeks, and will continue do so for about three; each light producing that time 300 or 400 shoots, and affording a thering every two or three days. To have regular succession, therefore, a fresh bed ust be formed every three or four weeks, the st crop to be planted in March or the early art of April : this will continue in production atil the arrival of the natural ground crops. he last-made beds will be in production a rtnight sooner than those made about Christas.

The bed must be substantial, and propor oned to the size and number of the lights, ad to the time of year-being constructed of able dung, or other material. The common ode of making a hotbed is usually followed; at, as Mr. Sabine remarks, the general apearance of forced asparagus in December ad the two following months, gives a suffient indication of defective management. The sual mode he considers erroneous, inasmuch that the roots of the plants come in contact ith, or are over, a mass of fermenting matter; ad the mode of raising potatoes practised by [r. Hogg, which will be hereafter stated, first aggested the plan for obviating this defect, and has been confirmed as correct by the sucessful practice of $\mathbf{M r}$. Ross, gardener to $\mathbf{E}$. Hice, Esq., of Brentford, who, by planting his sparagus in the tan of his exhausted pine its, which consist of eighteen inches of aves, and over that the same depth of $\tan$ nd applying hot dung, successively renewed, ound the sides, and thus keeping up a good eat, produced in five weeks asparagus so ne, and by admitting as much air as possible uring the day, of such good colour and so trong, as nearly to equal the natural ground rops. It is the best practice to plant the asaragus in mould laid upon the tan, which, or ome other porous matter, is indispensable for he easy admission of the heat from the linings. The bed must be topped with six or eight nches of light rich earth. If a small family s to be supplied, three or four lights will be uflicient at a time; for a larger, six or eight will not be too many. Several hundred plants nay be inserted under each, as they may be

\section{ASPARAGU}

crowded as close as possible mencher; from 500 to 900 are capable of being nersed uruler a three-light frame, according to their size. In planting, a furrow being drawn the whole length of the fiame, arrainst one sile of it the first row or course is to be placed, the crowns upright, and a little earth drawn on to the lower ends of the roots; then more plants again in the same manner, and so continued throughout, it being carefully observed to keep them all regularly about an inch below the surface; all round on the edge of the bed some moist earth must be banked close to the outside roots.

If the bed is extensive, it will probably ac. quire a violent heat ; the frames must therefore be continued off until it has become regular, otherwise the routs are liable to be destroyed by being, as it is technically termed, scorched or steam-scalded. When the heat has become regular the frames may be set on, and more earth be applied by degrees over the crowns of the plants, until it acquires a total depth of five or six inches. The glasses must be kept open an inch or two, as long and as often as possible, without too great a reduction of temperature occurring, so as to admit air freely and give vent to the vapours, for on this depends the superiority in flavour and appearance of the shoots. The heat must be kept up by linings of hot dung, and by covering the glasses every night with mats, \&c. The temperature at night should never be below $50^{\circ}$, and in the day its maximum at $62^{\circ}$. In gathering, for which the shoots are fit when from two to five inches in height, the finger and thumb must be thrust down into the earth, and the stem broken off at the bottom. This excellent vegetable possesses some diuretic properties. Its juice contains a peculiar crystallizable substance, which was discovered by Vauquelin and Robiquet, and named by them Asparagine. It is hard, brittle, colourless, and in the form of rhomboidal prisms: its taste is nauseous. The decoction of the plant is sometimes used on the Continent as a diuretic; but it is rarely or never prescribed in England. M. Dubois, of Paris, has submitted asparagus berries to fermentation, and procured a spirit from them by distillation, with which he makes an excellent liqueur. (Dict. des Drogues; G. W. Johnson's Kitchen Gurden, 81 ; Miller's Dictionary; Trans. Hort. Soc. Lond. vol. ii. pp. 234, 263, 361 ; Dr. Macculloch, Caled. Horl. Mem. vol. i.)

ASPEN TREE (Populas Tremula). This is a branch of the poplar family, which derives its Latin name from the incessant trembling of its leaves. The English name is from the German espe, which is the general name for all poplars. The heart-shaped leaves adhere to the twigs by a long and slender stalk, the plane of which is at right angles to that of the leaf, and consequently allows them a much freer motion than other leaves that have their planes parallel with their stalks. This, with their cottony lining below, and their hairy surface above, causes that perpetual motion and quivering, even when we cannot perceive by other means the least breath of air stirring in the atmosphere. This trepidation is attended of course with a rustling noise, on which ac- 
count country people often call it railer. The aspen tree may be planted so as to ornament large grounds, but its effect is lost when crowded. When it meets the eye as a foreground to plantations of firs, it has both a pleasing and singular appearance, as its foliage changes with the wind from a silver gray to a bright green, for when the sight goes with ihe wind, it catches only the under side of the leaves which are covered with a pale floss; but when it meets the current of air, the tree presents the upper surface of its foliage to the view; thus its tints are as changeable as its nature is tremulous. Like its relative, the poplar, this tree is of speedy growth, and will thrive in any situation or soil, but worst in clay. It is cultivated to the greatest advantage on such as are inclined to be moist, without having much stagnant surface water. In such situations they sometimes grow to a considerable size. It is accused of impoverishing the land, and its leaves are charged with destroying the grass, whilst its numerous roots, which spread near the surface, will not, it is said, permit any thing else to grow. The wood is extremely light, white, soft, and smooth, but it is of little value as timber, being chiefly used for making milk-pails, wooden shoes, clogs, and pattens, \&c. From its lightness it might, however, probably be used to advantage for the construction of common field-gates. The bark is the favourite food of beavers, whilst the leaves and the stalks form the nourishment and birthplace of the tipula juniperina, a species of long-legged fly. The aspen tree will not bear lopping, like other species of the poplar. (Phillip's Sylva Florifera.)

[ASPEN, AMERICAN (Populus Tremuloides). This species of poplar is common in the northern and middle sections of the United States, and Michaux thinks, still more common in Lower Canada. The same author remarks, that in the vicinity of New York and PhilaIphia, where he observed it, it appeared to fer open lands of a middling quality. Its dinary height is about 30 feet, and its diameter 5 or 6 inches. It blooms about the 20 th of April, 10 days or a fortnight before the birth of the leaves. Of all the American poplars, this species has the most tremulous leaves, the gentlest air being sufficient to throw them into great agitation.

'The wood of the American aspen is light, soft, and without either strength or durability. The most useful purpose which the wood subserves, is perhaps the furnishing of thin laminx, for the manufacture of women's hats, light baskets, \&c. The tree is considered very inferior to several species of the same genus, the Virginia poplar, for example, which is three times as large, more rapid in its growth, and of a more pleasing appearance.

The large American aspen (Populus grandidentalu), belongs rather to the Northern and Middle, than to the Southern States. In the most nor therly districts it is rather a rare tree, so that a person may perhaps travel several days without seeing one. For this reason, Michaux thinks it has been confounded with the preceding species, which is more multiplied. It surpasses the trembling aspen in height, on which 124 account it has received frcm Michaux its name. It grows as favourably on uplands as on the border of swamps, and attains a height of about 40 feet, with 10 or 12 inches in diameter. In the spring, the leaves are covered with a thick white down. The wood is light, soft, and unequal to that of the Virginia and Lombardy poplars. It possesses few, if any valuable qualities for the arts, and is only valuable for its agreeable foliage, which entitles it to a place in yards and ornamental gardens. (Michaux's Am. Sylva.)]

ASS (Fr. Ane; Ger. Esel; It. Asino ; Lat. Asinus). A well-known and useful domestic animal, whose services might be rendered even still more useful for various purposes of husbandry, if it were properly trained and taken care of. Buffon has well observed, that the ass is despised and neglected, only because we possess a more noble and powerful animal in the horse; and that if the horse were unknown, the care and attention which are lavished upon him being transferred to his now neglected and despised rival, would have increased the size, and developed the mental qualities of the ass, to an extent which it would be difficult to anticipate, but which Eastern travellers, who have observed both animals in their native climates, and among nations by whom they are equally valued, and the good qualities of each justly appreciated, assure us to be the fact.

Indeed the character and habits of these two quadrupeds are directly opposed in almost every respect. The horse is proud, fiery, and impetuous, nice in his tastes, and delicate in constitution; like a pampered menial, he is subject to many diseases, and acquires artificial wants and habits which are unknown in a state of nature.

The ass, on the contrary, is humble, patient, and quiet, and bears correction with firmness. $\mathrm{He}$ is extremely hardy, both with regard to the quantity and quality of his food, contenting himself with the most harsh and disagreeable herbs, which other animals will scarcely touch. In the choice of water he is, however, very nice; drinking only of that which is perfectly clear, and at brooks with which he is acquainted.

This animal is very serviceable to poor cottagers, and those who are not able to buy or keep horses; especially where they live near heaths or commons, the barrenest of which will keep the ass, who is contented with any kind of coarse herbage, such as dry leaves, stalks, thistles, briers, chaff, and any sort of straw. Animals of this sort require very little looking after, and sustain laboul, hunger, and thirst, beyond most others. They are seldom or never sick; and endure longer than most other kinds of animals. They may be made useful in husbandry to plough light lands, to carry burdens, to draw in mills, to fetch water, cut chaff, or any other similar purposes. They are also very serviceable in many cases for their milk, which is excellent for those who have suffered from acute diseases, and are much weakened; and they might be of much more advantage to the farmer, were they used, as they are in foreign countries, for the pur pose of breeding miles. 
The subjugation of the ass appears, from the records of the Bible, to have preceded that of the horse; and we infer from the same authority, that this subjugation took place prior to that of the dog.

The structural difference between the horse and the ass are trifling; perhaps that on which the very different tones emitted by the voice depends is one of the most striking. In all other essential points the organization of the horse and ass is the same; and, with the exception of the lengthened ears of the ass, their form, size, and proportions in a wild state, they differ but little; consequently, they possess conditions more favourable to the multiplication of species than those afforded by any other nearly allied animals. The ass is, properly speaking, a mountain animal; his hoof's are long, and furnished with extremely sharp rims, leaving a hollow in the centre, by which means he is enabled to tread with more security on the slippery and precipitous sides of hills and precipices. The hoof of the horse, on the contrary, is round and nearly flat underneath, and we accordingly find that he is most serviceable in level countries; and indeed experience has taught us that he is altogether unfitted for crossing rocky and steep mountains. As, however, the more diminutive size of the ass rendered him comparatively less important as a beast of burden, the ingenuity of mankind early devised a means of remedying this defect, by crossing the horse and ass, and thus procuring an intermediate animal, uniting the size and strength of the one with the patience, intelligence, and sure-footedness of the nther.

The varieties of the ass in countries favour$a b \varepsilon$ to their developement are great. In Guinea the asses are large, and in shape even excel the native horses. The asses of Arabia (says Chardin) are perhaps the handsomest animals in the world. 'Their coat is smooth and clean; they carry the head elevated, and have fine and well formed legs, which they throw out gracefully in walking or galloping. In Persia, also, they are finely formed, some being even stately, and much used in draught and carrying burdens, while others are more lightly propor- tioned, and used for the saddle by persons of quality, frequently fetching the large sum of 400 livres; and being taught a kind of easy ambling pace are richly caparisumed, and used only by the rich and luxurious mobies. With us, on the contrary, the ass unfortunately ex. hibits a stunted growth, and, appears rather to vegetate as a sickly exotic, than to riot in the luxuriant enjoyment of life like the horse.

The diseases of the ass, as far as they are known, bear a general resemblance to those of the horse. As he is more exposed, however, and left to live in a state more approaching to that which nature intended, he has few diseases. Those few, however, are less attended to than they ought to be; and it is for the veterninary practitioner to extend to this useful and patient animal the benefit of his art, in common with those of other animals. The ass is seldom or never troubled with vermin, probably from the hardness of its skin. (Bluine's Encyc. Rural Sports.)

ASTRINGENT (Astringo, Lat.). In farriery, a term applied to such remedies as have the property of constringing or binding the parts.

ATMOSPHERE. The name given to the elastic invisible fluid, which, to a considerable height, surrounds our globe. It is composed chiefly of two simple or undecomposed gases, viz.:-

$$
\begin{aligned}
& \text { Azote, or nitrogen - } \quad-\quad \text { - } 79.16 \\
& \begin{array}{l}
\text { Azote, or nitrogen } \\
\text { Oxygen }
\end{array}-\div \frac{2084}{100}
\end{aligned}
$$

It contains, also, about $\frac{1}{T+v 0}$ th of its weigh: of carbonic acid gas, or fixed air, a considerable portion of aqueous vapour (which is always the most considerable in amount in dry wea. ther), and occasionally foreign substances, called Aerolites. The average proportion in which these exist in the atmosphere, are-

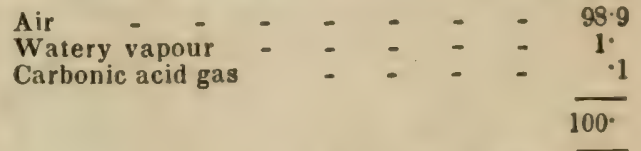

(Thomson's Chem. vol. iii. 181.) It fulfils a very essential office with regard to the growth of plants. (See Gases, tuirir Use to VEgE-

\section{Monthly Atmospherical Obsenvations.}

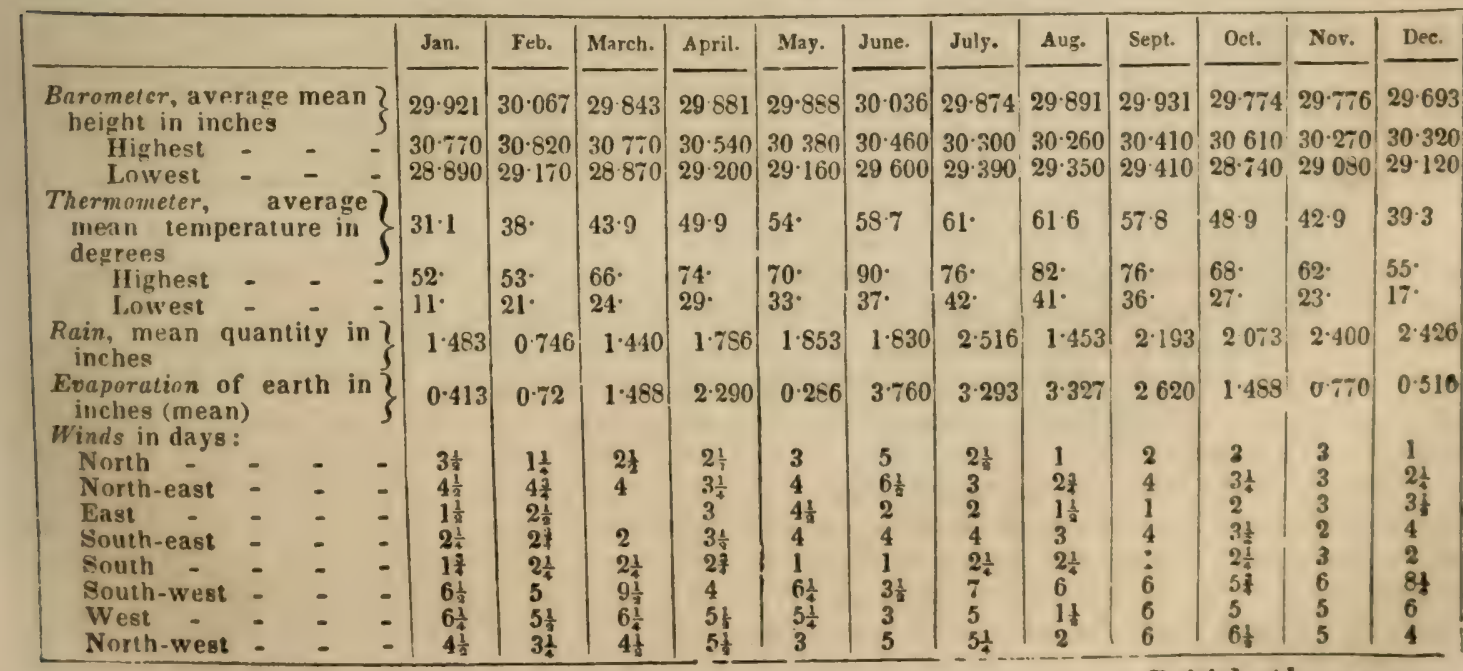


ration.) The composition of the atmosphere is always the same, although it has been analyzed when obtained from the most elevated mountains, the lowest marshes, from crowded cities, and the surface of the ocean, in all winds, and in all states of the barometer.

The following table exhibits the atmospheric mean temperatures in various parts of the United States and Territories, not only for the whole year, but for each month. It is abridged from Dr. Forry's Treatise upon the Climatology of the United States. 'The mean temperatures of some other celebrated places in the old world, are subjoined for the purpose of comparison.

The mean temperatures of the various military posts, are the results of 90 observations for each month, and 1095 for each year. 'The rule followed for computing the mean, was that adopted by the regents of the University of New York, viz.:-Take the lowest morning temperature, the highest afternoon temperature, and the temperature an hour after sunset. The mean of these observations for the day is found, by adding together the first, twice the second and third, and the first of the next day, and dividing the same by six. To most common observers this will appear rather an intricate mode of attaining an object which is so conveniently, and, in general, so satisfactorily accomplished by the very simple process of dividing the sum of the highest and lowest observations during the day. Strictly speaking the mean temperature of a day is equal to the sum of the temperature observed by the thermometer every hour or every minute, divided by the number of hours or minutes in the day. The hourly changes of atmospheric temperature have actually been observed for a continued year in some instances, among which we may mention that at the Arsenal at Frankford, near Philadelphia, in the year 1835-6, conducted under the superintendence of Capt. Mordecai, of the United States army. The results of these hourly observations are published in the 19th volume of the Journal of the Franklin Institute, New Series.

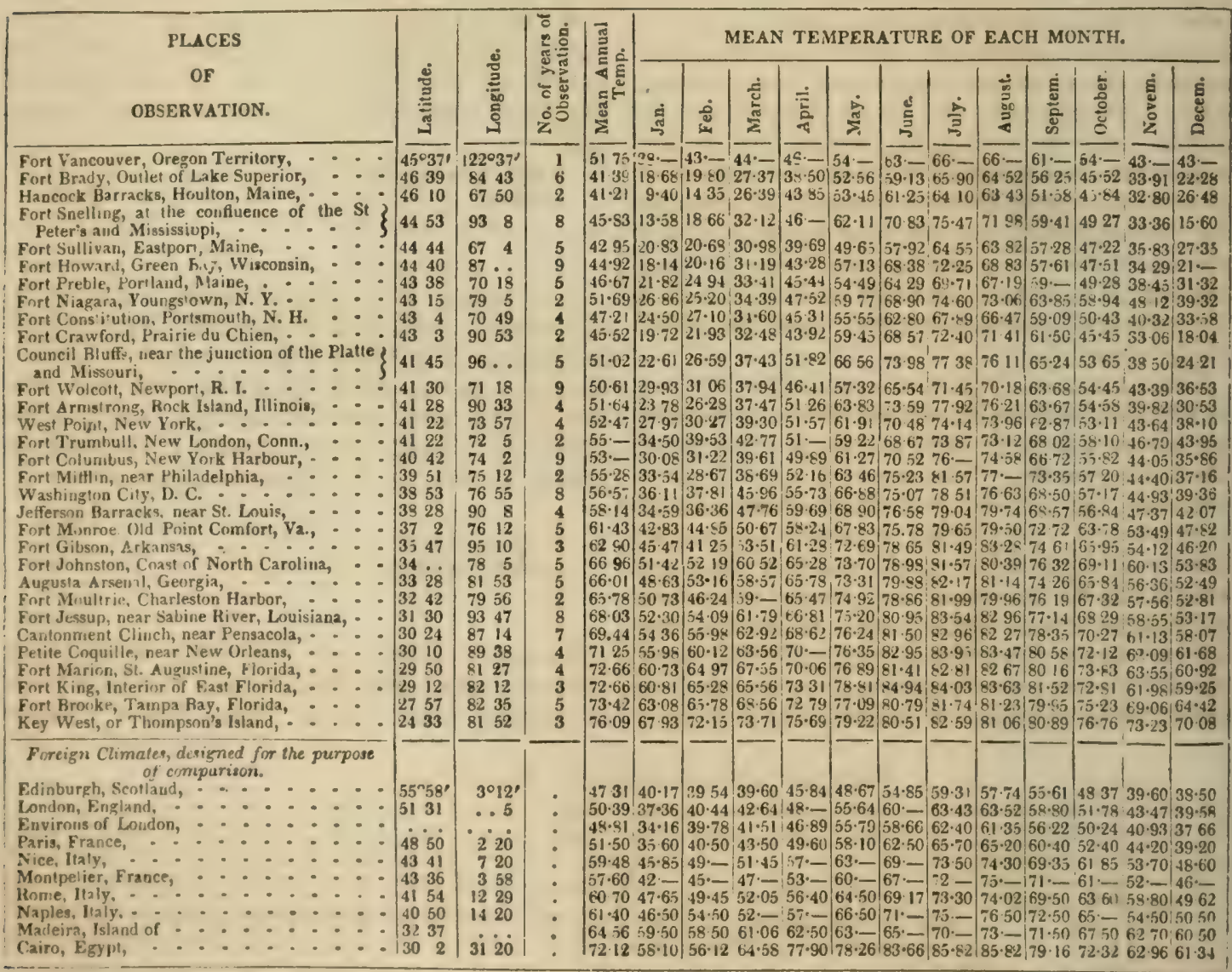

For further information relative to weather, and atmospheric conditions in general, see $\mathbf{B}_{\mathbf{A}}$ hometer, Climate, T'emperature, \&c.

A'TROPHY. In farriery, a morbid wasting and emaciation, attended with a great loss of strength in animals.

AUGER, BORING. An implement for boring into the soil. An auger of the above kind, when made of a large size, and with different pieces to fix on to each other, may be very lisefully applied to try the nature of the under soil, the discovering springs, and drawing off 26 water from lands, \&c. In order to accomplish the first purpose, three augers will be neces. sary; the first of them about three feet long, the second six, and the third ten. Their diameters should be near an inch, and their bits large, and capable of bringing up part of the soil they pierce. An iron handle should be fixed crossways to wring it into the earth, from whence the instrument must be drawn up as often as it has pierced a new depth of about six inches, in order to cleanse the bit, and examine the soil. 


\section{AUGFR, DRAINING.}

AUGER, DRAINING. An instrument $\mathrm{cm}$ ployed for the purpose of boring into the botioms of drains or other places, in order to discover and let off water. It is nearly similar (1) that made use of in searching for coal or other subterrancous minerals. The auger, shell, or wimble, as it is variously called, for excavating the earth or strata through which it passes, is generally from two and a half to three and a half inches in diameter; the hollow part of it one foot four inches in length, and constructed nearly in the shape of the wimble used by carpenters, only the sides of the shell coine closer to one another. The rods are made in separate pieces of four feet long each, that screw into one another to any assignable length, one after another as the depth of the hole requires. The size above the auger is about an inch square, unless at the joints, where, for the sake of strength, they are a quarter of an inch more.

There is also a chisel and punch, adapted for screwing on, in going through hard gravel, or other metallic substances, to accelerate the passage of the auger, which could not otherwise perforate such hard bodies. The punch is often used, when the auger is not applied, to prick or open the sand or gravel, and give a more easy issue to the water. The chisel is an inch and a half or two inches broad at the point, and made very sharp for curting stone; and the punch an inch square, like the other part of the rods, with the point sharpened also.

As it is remarked by Johnstone, in his account of Elkington's mode of draining, to judge when to make use of the borer is a difficult part of the business of draining. Many who have not seen it made use of in draining, have been led into a mistaken notion, both as to the manner of using it and the purpose for which it is applied. They think, that if by boring indiscriminately through the ground to be drained, water is found near enough the surface to be reached by the depth of the drain, the proper direction for it is along these holes where water has been found; and thus make it the first implement that is used. The contrary, however, in practice, is the case, and the auger is never used till after the drain is cut; and then for the purpose of perforating any retentive or impervious stratum, lying between the bottom of the drain and the reserroir or strata containing the spring. Thus it greatly lessens the trouble and expense that would otherwise be requisite in cutting the trench to that depth to which, in many instances, the level of the outlet will not admit. The manner of using it is simply thus:-in working it, two, or rather three men, are ne-
AVENA.

cessary. Two stand above, on each side of the drain, who turn it round by neans of the wooden handles, and when the auger is full they draw it out; and the man in the botwon of the trench clears out the earth, assists in pulling it out, and directing it into the hole, and who can also assist in turning with the iron handle or key when the depth and lerath of rods require additional force to perform the operation. The workmen should be cautious in boring not to go deeper at a time, without drawing, than the exact length of the shell, otherwise the earth, clay, or sand, through which it is boring, after the shell is full, makes it very difficult to pull out. For this purpose the exact length of the shell should be regularly marked on the rods, from the bottom upwards. Two flat boards, with a hole cut into the side of one of them, and laid alongside of one another over the drain, in the time of boring, are very useful for directing the rods in going down perpendicularly, for keeping them steady in boring, and for the men standing on when performing the operation.

AVENA. A genus of grasses; the oat grass. Some of the species may be cultivated to advantage in suitable situations, intermixed with a due proportion of other grasses.

Avena flavescens. Grolden oat, or yellow oat. grass. This is one of those grasses which never thrives when cultivated simply by itself: it requires to be combined with other grasses to secure its continuance in the soil, and to obtain its produce in perfection. It thrives best in England when combined with the Hordeum pratense (meadow barley), Cynosurus cristalus (crested dog's-tail), and Anthoxuntum odoratum (sweet-scented vernal-grass). It affects most a calcareous soil, and that which is dry. It grows naturally, however, in almost every kind of meadow: it is always present in the richest natural pastures in England where its produce is not, however, very great, nor its nutritive qualities considerable. The nutritive matter it affords from its leaves, (the properties of which are of more importance to be known than those of the culms, for a permanent pasture grass,) contains proportionally more bitter extractive than what is contained in the nutritive matters of the grasses with which it is more generally combined in natural pastures, and which have just now been mentioned. This latter circumstance is the chief claim it has to a place in the composition of the produce of rich pasture land; but more particularly, if the land be elevated, and without good shelter, this grass becomes more valuable, as it thrives better under such circumstances than most other grasses, and sheep

\begin{tabular}{|c|c|c|c|c|c|c|c|c|}
\hline \multicolumn{2}{|l|}{ Description of Grass. } & Soil. & \multicolumn{2}{|c|}{$\begin{array}{l}\text { Green Produce } \\
\text { per Acre. }\end{array}$} & \multicolumn{2}{|c|}{$\begin{array}{l}\text { Dry Produce } \\
\text { per Acre. }\end{array}$} & \multicolumn{2}{|c|}{$\begin{array}{c}\text { Produce per Acre } \\
\text { of Nulritive } \\
\text { Nialter. }\end{array}$} \\
\hline & & & lbe. & & Ibs. & & lbs. & \\
\hline Arewa flavescens, in flower. & - & Clayey loam & 8,1678 & 0 & $2.858 \quad 10$ & 0 & 4789 & 0 \\
\hline- , in seed ripe & - & - & $12,251 \quad 4$ & 0 & $4,900 \quad 8$ & 0 & 43011 & 5 \\
\hline , latter-math & - & - & 4,08312 & 0 & -5 & - & 7912 & 2 \\
\hline 9. praiensis, in flower - & - & Sandy loam & $6,806 \quad 4$ & 0 & 1,87111 & 8 & $239 \quad 4$ & 8 \\
\hline - in seed, ripe - & - & - & $9,528 \quad 12$ & 0 & $2,858 \quad 10$ & 0 & 14814 & 3 \\
\hline A. pubescens, ill flower - & - & - & $15,654 \quad 6$ & 0 & $5,8 \div 0 \quad 6$ & 4 & 36614 & 6 \\
\hline - in seed, ripe & - & - & $6,806 \quad 4$ & 0 & 1,3614 & 0 & 21211 & 2 \\
\hline
\end{tabular}

(Sinclair's Hort. Gram. Woh.! 


\section{AVENA.}

eat it as readily as they do most others. The seed is very small and light; but it vegetates freely if sown in the autumn, or not too early in the spring. I have sown the seeds of this grass in almost every month of the year, and after making due allowance for the state of the weather, the third week in May, and the first week of August to September, were evidently the best. It flowers in England in the first, and often in the second week of July, and ripens the seed in the beginning of August. The value of the grass, at the time of flowering, is to that at the time the seed is ripe, as 5 to 3 .

The value of the grass, at the time of flowering, exceeds that of the latter-math, as 3 to 1 ; and the value of the grass at the time the seed is ripe is to that of the latter-math, as 9 to 5 .

Avena pratersis. Meadow oat-grass. This species of oat-grass is much less common than the Avena pubescens, or Avena flavescens. It is found more frequent on chalky than on any other kind of soils: I have also found it in moist meadows as well as on dry heaths. This property of thriving on soils of such opposite natures is not common to the different species of grass. When this grass was planted in an irrigated meadow, the produce did not appear to exceed that which it afforded on a dry elevated soil, though it appeared more healthy, by the superior green colour of the ioliage; and it thus appears to thrive under irrigation. The produce and nutritive powers, however, seem to be inferior to many other species of the secondary grasses. The produce or value of the yellow oat is superior to that of the meadow oat in the proportion nearly of 7 to 3 . The downy oat-grass is also superior to the meadow oat-grass in the quantity of nutritive matter it affords from the crops of one season, in the proportion nearly of 3 to 2. From these facts and observations it cannot justly be recommended for cultivation in preference to either of the two species with which it has now been compared. Its nutritive matter contains a less proportion of bitter extractive and saline matters than any other of the oat-grasses that have been submitted to experiment. It flowers in July, and the seed is ripe in August.

Avena pubescens. Downy oat-grass. [See Plate $6,6$.$] This grass has properties which$ recommend it to the notice of the agriculturist, being hardy, and a small impoverisher of the soil; the reproductive power is also considerable, though the foliage does not attain to a great length if left growing. Like the Poa jratensis, it seldom or never sends forth any flowering culms, after the first are cropped, which is a property of some value for the purpose of permanent pasture, or dry soils, whinh are sooner impoverished by the growth of plants than those that are moist. Among the secondary grasses, therefore, I hardly know nne whose habits promise better for the purpuse now spoken of. The nutritive matter it affords contains a greater proportion of the bitter extractive principle than the nutritive inatter of those grasses that affect a similar soil, which lessens its merits in those respects and must prevent its being employed in any consicierable quantity as a constituent of a 128 mixtule of grasses for laying down such soils to grass. In one part of Woburn Park, where the soil is light and silicious, the downy oat grows in considerable abundance. 'The downy hairs which cover the surface of the leaves of this grass when growing on poor, dry, or chalky soils, almost disappear when cultivated on richer soils. The crop at the time of flower. ing is superior to that at the time the seed is ripe, in the proportion nearly of 5 to 3 . The grass of the latter-math, and that at the time the seed is ripe, are of equal proportional va. lue. It flowers in the second or third week of June, and the seed is ripe about the begin. ning or in the middle of July.

[Avena elatior. See Arnes Grass.

Avena sativa. Cultivated oats.

Avena sterilis. Animated oats, grown in gardens as a curiosity.]

AVENS, COMMON, or HERB BENNET (Geum urbanum). An indigenous perennial plant, which grows plentifully in woods and about shady dry hedges, producing small bright yellow flowers from May till August. The stalks of this useful plant attain two feet high, they are erect, round, finely, hairy branched at the upper part, bearing several flowers. The root consists of a root-stock and many stout brown fibres, which are astringent, and in some degree aromatic in spring. They are said to impart an agreeable clove-like flavour when infused in beer or wine. In medicine, the powdered root of the common avens has been employed with good effect in conjunction with Peruvian bark, or quinine, in cases of ague and intermittent fever, and it is also valuable in long-standing cases of diarrhœa, and in the last stage of dysentery. The dose is from thirty to sixty grains. Sheep are extremely fond of its herbage, which may likewise, when young, be used for culinary purposes, and especially in the form of salad. It is stated (Trans. of Swed. Acad.) that if a portion of the dried root be placed in a bag and hung in a cask of beer, it will prevent the beer from turning sour. There is a variety of this plant called the great-flowered avens. (Eng. Flora, vol. ii. p. 429 ; Willich's Dom. Ency.)

AVENS, WATER. A variety of the beforenamed plant, which is common in moist mea. dows and woods, especially in mountainous countries, and is not rare in the north of Eng land, Scotland, Wales, nor even in Norfolk It has drooping flowers, which distinguish it from the common avens. It is readily produced by transplanting the wild roots into a dry gravelly soil, by which the flowers become red, as well as double and proliferous, with many strange changes of leaves into petals, and the contrary. (Smith's Eng. Flora.)

AVENUE (Fr.). An alley or walk pianted on each side with trees. These kinds of walks were formerly much more the fashion than they are at present. When they are to be made, the common elm answers wery well for the purpose in most grounds, except such as are very wet and shallow, and is preferred to most other trees, because it bears cutting, heading, or lopping in any manner. The rough Dutch elm is approved by some, because of its quick growth; and it is a tree that will $\mathrm{nr}$ 
only bear removing very well, but that is green in the spring almust as soon as any plant whatever, and continues so equally long. It makes an incomparable hedge, and is preferable to all other trees for lofty espalicrs. The lime is very useful on account of its regular growth and fine shade; and the horse-chesnut is proper for such places as are not too much exposed to rough winds. The common chesnut does very well in a good soil, or on warm gravels, as it rises to a considerable height when planted somewhat close; but, when it stands single, it is rather inclined to spread than grow tall. The beech naturally grows well with us in its wild state, but it is less to be chosen for avenues than others, because it does not bear transplanting well. The abele may also be employed for this use, as it is adapted to almost any soil, and is the quickest grower of any forest tree. It seldom fails in transplanting, and succeeds very well in wet soils, in which the others are apt to suffer. The oak is but seldom used for avenues, because of its slow growth.

The old method of planting avenues was by regular rows of trees, a practice which has been adhered to till lately; but now, when they are used, a much more ornamental way of planting them is adopted, which is by setting the trees in clumps or platoons, making the opening much wider than before, and placing the clumps of trees from one to three hundred feet distant from each other. In these clumps there should always be planted either seven or nine trees; but it must be observed that this method is only proper to be practiced where the avenue is of considerable length, as in short walks such clumps will not appear so sightly as single rows of trees. The avenues made by clumps are the most suitable for large parks. The trees in the clumps in such should be planted thirty feet asunder; and a trench thrown up round each clump to prevent the deer from coming to the trees and barking them.

AVERAGES (Fr. aver; Lat. averagium). In the corn trade, is the average amount of the prices at which the several kinds of corn are sold in the chief corn markets of England, as ascertained by the returns of certain inspectors, according to the act of the 9 G. 4 , c. 60 . (See Cons I, aws.)

AVERDUPOIS, or AVOIRDUPOIS WEIGHT (Avoir du poid, Fr., Dr. Johnson says, but he should have added, averia ponderis, Lat., literally goods of weight, goods sold by weight; urer in old French, and avoir in modern, signifying goods, like the low Lat. averium, averum, avere). That kind of weight commonly made use of for weighing most kinds of large and coarse goods, as cheese, butter, salt, hops, flesh, wool, \&c. According to it, sixteen drachms make an ounce, sixteen ounces one pound, one hundred and twelve pounds one hundred weight, and twenty hundred weight one ton. It is most commonly written avoirdupois.

AVIARY (Lat. avis, a bird). A place set apart for the feeding and propagating birds.

AWNS (Goth. ahana; Sw. agri). The needie-like bristles which form the beards of wheal, barley, and other grasses. The word is in some parts of England pronounced ails and iles.

AXIS (Lat., axel, SW.), or axle-iree. The strong piece of wood or iron which supports the weight of wagons, carts, carriages, \&ec., and round the extremities of which the wheels turn.

AZALEA. American honey-suckle; the white-flowered (Lat. Azuler viscosu). A hardy shrub growing three feet high, and blowing its white flowers in June and July. Azuleu nudi. flura, also a native of North America, grows three feet high, with red flowers, blooming in May and June; and Azalea pontica, a native of the neighbourhood of the Black Sea, blooming yellow flowers in May: it grows three feet high. These hardy shrubs love shade and a moist soil. Propagate by layers and suckers: the seed does not ripen well in this climate. Do not prune, only cut out the dead wood. Remove the young well-rooted plants with a good ball of earth in the autumn or early in spring.

AZOREAN FENNEL (Anethum azoricum, or Finochio; from arntov, on account of its running up straight). A plant kept in kitchen gardens; it is not in much esteem here, its peculiar flavour being agreeable to few palates. In Italy, and some other countries, it is served with a dressing like salads.

AZOTE is as commonly known by the name of nitrogen. The name of azote (derived from the Greek $\alpha$, from, and $\zeta o k$, life), was given to it by the French chemists, from animals being unable to breathe it [in a state of purity.] 'This gas, which constitutes $79 \cdot 16$ parts per cent. of the air we breathe, was discovered in 1772 by Dr. Rutherford. Before his time there had been much confusion with regard to the composition of the atmospheric and other gases; they were chiefly regarded by the old chemists as. being all of the same kind, but mixed wits various unknown substances. When all tae oxygen is absorbed from a confined portion of atmospheric air, the remainder is nearty pure azote; it is known only in the state of gas. Azotic gas is invisible and elastic, and has no smell; its specific gravity is 0.969 . Animals cannot breathe it [in a pure state:] when they are placed in a jar of it, they die as rapidly as if immersed in water: neither will it support combustion. It unites with oxygen in various proportions: thus, -

Parts Parts.
1.75 azote and $\frac{2}{5}$ oxygen forms nitrous gas.
1.75

$1.75-5$ nitric acid, or aqua fortis. 1.75 - 4.178 - nitrousacid.

Azote, or nitrogen, abounds in animal sue stances, for it forms $\mathbf{1 6 . 9 9 8}$ per cent. of gela tine; 15.705 per cent. of albumen (white of egg), \&c., and these are commonly present in all animal substances. Azote unites also with hydrogen gas, and forms the volatile alkalk ammonia, which is composed of-

$$
\begin{aligned}
& \text { Azote - } \quad-\quad-\quad-\quad-26 \text { parts } \\
& \text { Hydrogen - } \quad-\quad-\quad-74
\end{aligned}
$$

Now, as both these substances exis on ar: mal matters, when such substances putrefy, or are subjected to the destructire distillation. 
they readily unite and form the volatile alkali ammonia.

Azote exists also in gluten; and wherever this substance is present in vegetable matter, there, in consequence, azote is to be found, but otherwise it does not often enter into the composition of vegetable substances. And yei it is worthy of remark, that although azote cannot be regarded as a direct food of plants, yet most of those substances which contain it are exceedingly grateful to them, such as ammonia, saltpetre, animal matter, \&c.; and again, vegetables certainly emit, and probably inhale, this gas. Thus some plants of Vinca minor being made to vegetate in a confined portion of air for six days, and the composition of the air being ascertained by M. Saussure (Rech. Chim. p. 40), the following were the results in cubic inches:-

Composition of atmosphere,
wzote
when put in.

The plants, therefore, had evidently increased the proportion of azote and oxygen, but had entirely exhausted the air of its carbonic acid gas.

Similar experiments made with the Mentha uqualica, Cuclus opuntir, Lythrum salacaria, and the Pinus genevensis, afiorded similar results.

Azote, therefore, evidently fulfils a more considerable office in vegetable economy than we are yet exactly aware of, and it is more than probable that considerable discoveries are yet to be made in the investigation of its uses to vegetable life. See Gasks, their use to vegetation. (Duvy's Chem. Phil. p. 255; Thomson's Chem.)

[The chief element contained in vegetable substances resorted to for the support of animals, is azote or nitrogen. On the other hand we see, in the vegetable kingdom, plants appropriating carbon as the prime element of their structure. The quantity of food which animals take for their nourishment diminishes or increases in the same proportion as it contains more or less of the substances yielding nitrogen. A horse may be kept alive by leeding it with potatoes, which contain a very small quantity of nitrogen; but life thus supported is a gradual starvation; the animal increases neither in size nor strength, and sinks under every exertion. The quantity of rice which an East Indian eats astonishes the Europear. or American; but the fact that rice contains less nitrogen than any other grain, at (ince explains the circumstance.

"We cannot suppose," says Liebig, "that a plant would attain maturity, even in the rich'st vegetable mould, without the presence of matter containing nitrogen; since we know that nitrogen exists in every part of the vegerable structure. The first and most important lliestion to be solved, therefore, is: How and in what form does nature furnish nitrogen to "pretable slbumen, aird gluten, to fruits and kreils?
"This question is susceptible of a very sim ple solution.

"Plants, as we know, grow perfectly well in pure charcoal, if supplied at the same time. with rain-water. Rain-water can contain nitrogen only in two forms, either as dissolved atmospheric air, or as ammonia. Now, the nitrogen of the air cannot be made to enter into combination with any element except nxygen, even by employment of the most powerful chemical means. We have not the slightest reason for believing that the nitrogen of the atmosphere takes part in the processes of assimilation of plants and animals ; on the contrary, we know that many plants emit the nitrogen, which is absorbed by their roots, either in the gaseous form, or in solution in water. But there are, on the other hand, numerous facts, showing that the formation in plants of substances containing nitrogen, such as gluten, takes place in proportion to the quantity of this element which is conveyed to their roots in the state of ammonia, derived from the putrefaction of animal matter.

"Ammonia is a compound gas, consisting of one volume of nitrogen and three volumes of hydrogen. It is produced during the decomposition of many animal substances. It is given off when sal-ammoniac and lime are rubbed together. It was formerly called volatile alkali.

"Ammonia, too, is capable of undergoing such a multitude of transformations, when in contact with other bodies, that in this respect it is not inferior to water, which possesses the same property in an eminent degree. It possesses properties which we do not find in any other compound of nitrogen; when pure, it is extremely soluble in water; it forms soluble compounds with all the acids; and when in contact with certain other substances, it com. pletely resigns its character as an alkali, and is capable of assuming the most various and opposite forms."

With regard to the sources from which vegetables draw those supplies of nitrogen, so essential to their growth and developement, Liebig makes the following observations:-

"Let us picture to ourselves the condition of a well-cultured farm, so large as to be independent of assistance from other quarters. On this extent of land there is a certain quantity of nitrogen contained both in the corn and fruit which it produces, and in the men and animals which feed upon them, and also in their excrements. We shall suppose this yuan. tity to be known. The land is cultivated without the importation of any foreign substance containing nitrogen. Now, the products of this farm must be exchanged every year for money, and other necessaries of life, for bodies therefore which contain no nitrogen. A cer. tain proportion of nitrogen is exported with corn and cattle; and this exportation talies place every year, without the smallest compensation; yet after a given number of years, the quantity of nitrogen will be found to have increased. Whence, we may ask, comes this increase of nitrogen? The nitrogen in the excrements cannot reproduce itself. and the 
earth cannot yield it. Plants, and consequently animals, must therefore derive their nitrogen from the atmosphere." (Org. Chem.)

\section{B.}

BACCIFEROUS (from bacca, a herry, and fero, to bear). A term applied to trees bearing berries.

BACK, the spine. 'The back of a horse should be straight, in order that it may be strong: when it is hollow, or what is termed sadille-brcked, the animal is generally weak.

Back sore. A complaint which is very com. mon to young horses when they first travel. To prevent it, their backs should be cooled every time they are baited, and now and then washed with warm water, and wiped dry with a linen cloth. The best cure for a sore back is a lotion of $1 \mathrm{oz}$. of Goulard's extract (sugar of lead and vinegar), $1 \mathrm{oz}$. of turpentine, $1 \mathrm{oz}$. of spirit of wine, and 1 pint of vinegar.

Buck sinews, sprain of the. This is often occasioned by the horse being overweighted, and then ridden far and fast, especially if his pasterns are long; but it may occur from a false step, or from the heels of the shoes being too much lowered. Sprain of the back sinews is detected by swelling and heat at the back of the lower part of the leg; puffiness along the course of the sinews; extreme tenderness, so far as the swelling and heat extend; and very great lameness.

The first object is to abate the inflammation, and this should be attempted by bleeding from the plate vein; by means of which blood is drained from the inflamed part. Next, local applications should be made to the back of the leg, in the form of fomentations of water sufficiently hot and frequently repeated. At the same time, as much strain as possible should be taken from the sinew, by putting a high callin on the heel of the shoe.

BACON. Probably from baken, that is, dried flesh. Dr. Johnson says, and Mr. Horne Tooke contends, that it is evidently the past participle of the Saxon bacan, to bake or dry by heat. (Div. of Pur. vol. ii. p. 71.) I may, however, refer perhaps as strongly to the old French bacon, which means dried flesh and pork. The Welsh also have bacwn. The flesh of the hog after it has been salted and dried, and it is either smoked or kept without smoking, when it is termed green bacon. (Todd.)

Such hogs as have been kept till they are full grown, and have then attained to a large size, are for the most part converted to the purpose of bacon. The seasons for killing hogs for bacon are between October and March, but it of course varies according to custom and circumstances in peculiar districts. The process of curing bacon is so well known throughout the country, that it is scarcely necessary to add any thing on the subject; but the following practical hints may not be withnut their utility. In order to have good bacon, the hair should be surealed off, not scalded, the flesh will be more solid and firm. The best method of doing this is to cover the hog thinly with straw, and to set light to it in the direction of the wind. As the straw is burnt off, it should be renewed, taking care, however, nct to burn or parch the skin. After both sides have been treated in this way, the hor is tn be scraped quite clean, but water must not be used. After the hog has been properly cut up, the inside, or flesh-side of each flitch is to be well rubbed with salt, and placed above each other in a tray, which should have a gutter round its edge to drain off the brine. Once in four or five days the salt should be changed, and the flitches frequently moved, putting the bottom one at top, and then again at the brittom. Some persons, in curing bacon, add for each hog half a pound of bay salt, and a quarter of a pound of saltpetre, and one pound of very coarse sugar or treacle. Very excel. lent bacon may, however, be made with common salt alone, provided it be well rubbed in, and changed sufficiently often. Six weeks, in moderate weather, will be time sufficient for the curing of a hog of twelve score. Smoking the bacon is much better than merely drying it. The flitches should, in the first place, be rubbed over with bran or fine saw-dust (not deal), and then hing up in a chimney out of the rain, and not near enough to the fire to melt. The smoke must be from wood, stubble, or litter. If the fire is tolerably constant and good, a month's smoking will be sufficient. The flitches are afterward frequently preserved in clear, dry wood ashes, or very dry sand.

The counties of England most celebrated for bacon, are York, Hants, Berks, and Wilts. Ireland produces great quantities, but it is neither so clean fed, nor so well cured as the English, and is much lower priced. Of the Scotch counties, Dumfries, Wigtown, and Kirkcudbright, are celebrated for the excellence of their bacon and hams, of which they now export large quantities, principally to the Liverpool and London markets. The imports of bacon and hams from Ireland have increased rapidly of late years. The average quantity imported during the three years ending the 25 th of March, 1800 , only amounted to 41,948 cwt.; whereas during the three years ending with 1820 , the average imports amounted to $204,380 \mathrm{cwt}$; and during the three years ending with 1825 , they had increased to $338,218 \mathrm{cwt}$.

In 1825 the trade between Ireland and Great Britain was placed on the footing of a coasting trade; and bacon and hams are imported and exported without any specific entry at the Custom-house. We believe the imports of bacon into Great Britain from Ireland amounts, at present, to little less than $500,000 \mathrm{cwt}$. a year. The quantity of bacon and hams exported from Ireland to foreign countries is inconsiderable, not exceeding 1500 or 2000 cwt. a year. The duty on bacon and hams being 8s. the cwt. is in effect prohibitary. See Provisions Trane.

BAIT (Sax. baran, German, baitzen). A fee? of oats, or any other material given to an ani. mal employed in travelling or labour. These should always be proportioned to the condition of the animal, and the nature of his labour. It also signifies any thing applied with the view of catching an animal.

BAKING. The application of heat in the preparation of bread. See BREAD. 


\section{BAKING OF LAND.}

BAKING OF LAND. A term applied to such kinds of land as are liable, from the large proportions of clayey or other matter which they contain, to become hard and crusty on the surface. In order to prevent this, the best practice is to lessen the tenacity of such soils by the application of substances capable of rendering them more open and friable, as lime, and other calcareous materials, rich earthy composts, sand, \&c.

BAI.L. Whatever was round was called by the ancients either bal, or bel, and likewise bol and bïl. In farriery, a well-known form of medicine, for horses or other animals, which may be passed at once in to the stomach. They should be made of a long oval shape, and about the size of a small egg, being best conveyed over the root of the tongue by the hand. This method of administering medicines is preferable in most cases to that of drenches. I subjoin the recipes for a few of those balls most commonly used by the farmer.

\section{Mild Physic Ball.}

$\begin{array}{lllll}\text { Barbadoeg aloes } & - & - & - & -6 \\ \text { Powdered ginger } & - & - & - & -2 \\ \text { Castile soap } & - & - & - & -2 \\ \text { Oil of cloves } & - & - & - & -20 \text { drops. } \\ \text { Syrup of buckthorn sufficient to form a balt. }\end{array}$

Strong Physic Ball.

Barbadoes aloes Ginger, powdered . Castile soap Oil of cloves 2
$-\quad 2$ 20 drops.

Syrup of buckthorn sufficient to form a ball.

\section{Calomel Ball for a Riding Horse.}

Caismel

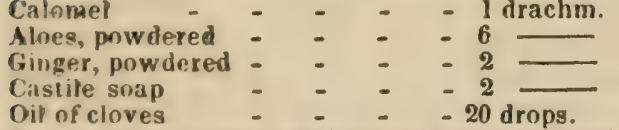

S̈yrup of buckthorn suficient to make into a ball.

\section{Calomel Ball for a Cart Horse.}

Ahes, powdered -

()therwise same as the last.

- 8 drachms.

\section{Diuretic Ball.}

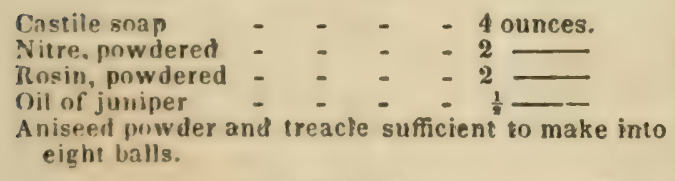

\section{Cordial Ball.}

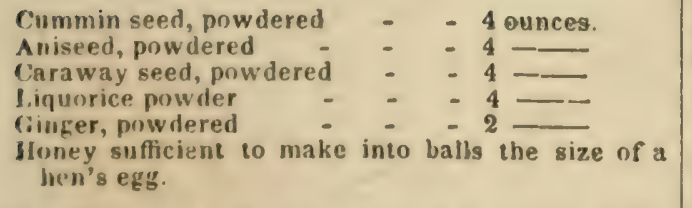

BALM, or BAUM (Melissa officinalis. From Cr. $\mu \wedge \lambda$, honey, on account of the bee being supposed to collect it abundantly from their Hcwers). Balm is used both as a medicinal and culinary herb. The leaves are employed green, or dried.

The soil best suited to its growth is any poor triable one, but rather inclining to clayey than silicious. Manure is never required. An eastern aspect is best for it. It is propagated 'y offsets of the roots, and by slips of the wung shoots. The first mode may be prac132 tised any time during the spring and autumn, but the latter only during May or June. If offsets are employed, they may he planted at once where they are to remain, at ten or twelve inches; but if by slips, they must be inserted in a shady border, to be thence removed, in September or October, to where they are to remain. At every removal, water must be given, if dry weather, and until they are established. During the summer they require only to be kept clear of weeds. In October the old beds require to be dressed, their decayed leaves and stalks cleared away, and the soil loosened by the hoe or slight digging.

Old beds may be gathered from in July, for drying, but their green leaves, from March to September; and those planted in the spring will even afford a gathering in the autumn of the same year. For drying, the stalks are cut with their full clothing of leaves to the very bottom, and the process completed gradually in the shade. (G.W. Jilinson's Kitchen Gar. den.)

This very common and well-known plant in our kitchen gardens is fragrant in smell, and its root creeps and spreads rapidly and abundantly. It flowers in July, and is best taken as an infusion when fresh, as it loses considerable power when dried. Its medicinal qualities are derived principally from the proportion of vola. tile oil, resin, and bitter extractive, which it contains. It is occasionally used in consequence of its moderately stimulant powers, in conjunction with more potent drugs, to produce profuse perspiration. Mixed with honey and vinegar, it forms a good gargle for an inflamed sore throat.

BALSAM (Impatiens Balsamina). This favourite flower is a native of the East Indies and Japan, where the natives, according to Thunberg, use the juice prepared with alum for dyeing their nails red. It is a tender annual, rising from one to two feet high, with a succulent branchy stem, serrated leaves, and various coloured flowers. It blows from July to October, and its flowers are single and double, red, pink, white, or variegated. It loves a good soil, and shelter from a hot sun. It blooms very handsomely in a window. Sow the seed early in March in a hot bed. Put the plants singly, and accustom them by degreez to the open air. Place them in larger pots, $n r$ put them out in the garden in May. They will require no watering, after being well rooted. Stir the earth round each plant frequently, and do it gently, with a small trowel.

The varieties are infinite, but not so marked or permanent as to have acquired names. The seed from one plant will hardly produce two alike.

This plant, which has been introduced into almost every flower-garden in the country, is commonly called Lady's Slipper. Several species of the genus are found in the United States, and have been described by Pursh, Nuttall, Darlington, and other botanists. One of these, the Pale Impaticns, known by the popular names of Yellow Balsam, Snap-weed, and Touch-me-not, is frequent in Pennsyiva. nia, and other states, in moist, shaded grounds and along streams, where its gamboge yellow 


\section{B. LSAM.}

Aowers appear from July to September. The most common species, however, is the F'ulums or Tuuny Impatiens, or Touch-me-not, the flowers of which are of a deep orange colour, with numerous reddish brown spots. 'The tender and succulent stems of this plant afford a domestic application to inflamed tumours, being bruised in the form of a poultice. It has sometimes been used for dying salmonred. (Nuttall's Genera, Darlington's Flora Cestricu.) The popular name of this plant must not lead to its being confounded with another, also called Lady's Slipper, the Stemless Cypripedium, a very different plant.

BAI.SAM TREE (Tacamahacea). This tree possesses considerable medicinal virtues. It is known among us as the Tacamahac tree, from its similitude to the real tree of that name, which is a native of the East and of America. The leaves of our balsam tree are long, of a dusky green on the outside, and brown underneath. "The buds of the tree in spring are very fragrant, and a sticky substance surrounds each bud, which adheres to the fingers on touching them. (See Tacamaнaccs.)

BAN-DOG. A corruption of band-dog, a large kind of fielee dog, which was formerly kept chained up as a watch-dog.

BANDS. The cords by means of which sheaves and trusses are tied. They are formed of twisted straw or hay.

Bands, where the straw is tender, should be made in the morning, that they may not crack; for the straw will not twist so well after the sun is up. The turning of three or four of the stubble or bottom ends of the straw to the ears of the band sometimes tend greatly to add to their strength and toughness.

The bands for the sheaves should not be spread out, except in fair weather, because they will grow sooner than any other part of the corn if rain should come; for they cannot dry, on account of their lying undermost. But though the bands may be made while the morning dew is upon them, the sheaves ought never to he bound up wet; for, if they are, they will grow mouldy.

BANE. The disease in sheep generally termed the rot.

BANE BERRIES (Actra), and BLACK BANE BERRIES (Herb Christopher). Perennial herbs, natives of cold countries, with compound or lobed cut leaves and clustered white flowers. The berries of the former are black, red, or white, of the latter, purplish, black, juicy, the size of currants, and have fetid, nauseous, and dangerous qualities. In England these herbs are found sometimes in bushy, monntainous, limestone situations.(Smith's Engl. Flora.)

Several species of Actæa, or Bane-berry are found in the United States. Among those inentioned by Dr. Darlington, as met with in Chester county, Pennsylvania, are the Racemose Actæa, commonly called Blıck Snakeroot, a pereunial, common in rich woodlands, in which the white flowers rising above most other surrounding plants, are very conspicuous in the month of June. The plant has an oppressive, disagreeable odour when bruised. The root is sjmewhat mucilaginous and as-
BARB.

tringent; and is a very popular melicise for man and beast. For the furmer, it is used in infusion or decoction, chinefly as a remedy in diseases of the breast. Many persuns consider it almost a panacea for a sicli cow. Its virtuc: however, are prohably overiated. Another species is the While Actra, or White Cirhosh, found in rocky woodlands, flowering in May, and not so common as the former. Its lierrices also differ from those of the Black Snalieront, being oval, about a fourth of an inch in diameter, milk white, or often tinged with purple when fully ripe. (Flor. Cestrica.)

BANE-WORT. See DEangr Nigutsuar.

BANGI.E-EARS. An imperfection in the ears of horses.

BANKS, of rivers and marshes, \&c., (banc, Sax.). In agriculture, are heaps or mounds of earth piled up to lieep the water of rivers, lakes, of the sea, from overflowing the grounds which are situated contiguous to them on the inside. (See Eмимкмитм.)

The common law of England is very severe against those who wantonly or maliciously injure or destroy embankments.

The $7 \& 8$ G. 4, c. 30 , s. 12 , enacts that if any person shall unlawfully and maliciously break down or cut down any sea-bank, or seawall; or the bank or wall of any river, canal, or marsh, whereby any lands shall be overflowed or damaged, or shall be in danger of being so, or shall unlawfully and maliciously throw down, level, or otherwise destroy any lock, sluice, or flcod-gate, or other work on any navigable river or canal, every such offender shall be guilty of felony; and, being convicted thereof, shall be liable, at the discretion of the court, to be transported beyond the seas for life, or for any term not less than seven years, or to be imprisoned for any term not exceeding four years; and if a male, to be once, twice, or thrice publicly or privately whipped (if the court shall so think fit), in addition to such imprisonment.

For protecting embankments exposed to water washing against them, a thick coat of the joint grass, or, as it is likewise called, the Bermuda grass, (Cymodon dactylon, Pl. 7, k, ) is one of the best means that can be adopted It is of a remarkably creeping nature, and grows very luxuriantly where no other grass will live, as on the sea-coast, and on poor loose soils. It is taken advantage of by the rice planters of the Southern States, whose exten. sive embankments are much exposed to the washing of water against them, and which are greatly protected from injury by the dense mat of joint grass made to grow upon them. Its extirpation is extremely difficult where it has once got possession. Mr. Nuttall says there is only one species (the $C$.dactylon) common to Europe, North America, and the West India Islands. (Nuttall's Genera.)

BANNOCK. The Scotch name for a small loaf or cake.

BARB. A general name for horses import ed from Barbary. The harb, one of the most celebrated of the African racers, is to be mer with throughout Barbary, Moroceco, Fez, Trlpoli, and Bornou. It sclidom exceeds fourteen hands and a half in height. The countenance 
of the barb is usually indicative of its spirit, and the facial line, in direct contradiction to that of the Arabian, is often slightly rounded; the eyes are prominent; the ears, though frequently small and pointed, are occasionally rather long and drooping : the neck is of sufficient length; the crest is generally fine and not overladen with mane; the shoulders are flat and oblique; the withers prominent, and the chest almost invariably deep; the back is usually straight; the carcass moderately rounded only; the croup long, and the tail placed rather high; the arms and thighs being commonly muscular and strongly marked; the knee and hock are broad and low placed; the back sinews singularly distinct and well-marked from the knee downwards; the pasterns rather long, and the feet firm, and but moderately open.

The barb requires more excitement to call out his powers than the Arabian; but when sufficiently stimulated, his qualities of speed and endurance render him a powerful antagonist, while the superior strength of his forehand enables him to carry the greater weight of the two. The Godolphin barb, which was imported from France into England, at the conclusion of the last century, about 25 years after the Darley Arabian, was one of those most worthy of note. The former appears to have rivalled the latter in the importance of his get. He was the sire of Lath, Cade, Babraham, Regulus, Bajazet, Tarquin, Dormouse, Sultan, Blank, Dismal, and many other horses of racing note; and without doubt, the English blood-breeds were more indebted to the Darley Arabian and the Godolphin barb than to all the other eastern horses which had previously entered the country. Among other barbs of some notoriety introduced in the $18 \mathrm{th}$ century, we may mention the Thoulouse, the Curwen Bay, Old Greyhound, St. Victor's, Tarran's Black, Hutton's Bay, Cole's Bay, and Compton's Barb. (Bluine's Encyc. Rural Sports, p. 243.

BARBERRY, COMMON, or PIPPERIDGE BUSH (Berberis vulgaris). In England an indigenous thorny shrub, bearing bunches of pale yellow drooping flowers in May, which are succeeded by nblong scarlet berries, ripening in September. The branches are flexible, covered with alternate tufts of deciduous, eggshaped, pinnated leaves, finely fringed on the edge. Sharp, three-cleft thorns rise at the base of each leaf-bud. The barberry likes any lind of soil, and makes good hedges. It may be propagated by seed, or by layers, which should remain two years before they are removed. The gross shoots, if the shrub stands singly, should be pruned away, and it will fruit better. The berries are gratefully acid, and the juice, when diluted with water, may be used as lemonade in fevers. The leaves, eaten in salad, are like sorrel. The fruit, made into conserve, is good. It is also excellent as a pickle and a preserve.

'I'he common barberry bush is a native of England; and notwithstanding the high state of cultivation that kingdom has now arrived $n t$, it is still to be found growing wild in manv parts of the northern counties. Gerarde says ill ni: time (1597), most of the hedges near
Colnbrook were nothing else but barberrybushes. It is now very properly introduced into our gardens and shrubberies, being both ornamenta! and useful; but it should not be planted near the house or principal walks, on account of its offensive smell when in blossom. The flowers are small, but beautiful; and, on their first appearance, have a perfume similar to that of the cowslip, which changes to a putrid and most disagreeable scent, particularly towards the evening, and at the decay of the flowers. Barberries are of an agreeable, cooling, astringent taste, which creates appetite. The fruit and leaves give an agreeable acid to soup. The Egyptians were used to employ a diluted juice of the berries in ardent and pestilential fevers; but it is merely an agreeable acidulous diluent. The inner bark, with alum, dyes a bright yellow, and in some countries is used for colouring leather, dyeing silk and cotton, and staining wood for cabinet and other purposes. Cows, sheep, and goats are said to feed on the leaves: but horses and swine refuse them. A very singular circumstance has been stated respecting the barberry shrub: that grain sown near it becomes mildewed, and proves abortive, the ears being in general destitute of grain; and that this influence is sometimes extended to a distance of 300 or 400 yards across a field. This, if correct, is a just cause for banishing it from the hedgerows of our arable fields, for which otherwise its thorny branches would have made a desirable fence.

I will cite a few instances which have been brought forward in proof of the injurious effects of this plant upon standing corn. Mr. Macro, a very respectable farmer at Barrow, in Suffolk, planted a barberry bush in his garden, on purpose to ascertain the disputed fact. He set wheat round it three succeeding years, and it was all so completely mildewed, that the best of the little grain it produced was only about the size of thin rice, and that without any flour. He adds, that some which he set on the opposite side of his garden on one of the years before mentioned, produced very good grain, although the straw was a little mildewed. From this observation, Mr. Phillips was induced to try the experiment by sowing clumps of canary seed in bis shrubbery. Those which were planted immediately under the barberry-bush certainly produced no seed; but other plants of this grass yielded seed, although not at many yards' distance. The celebrated Duhamel and M. Boussonet, who have paid such particular attention to agriculture, assure us that there is no just reason for ascribing this baneful effect to the barberrybush; and Mr. G. W. Johnson is of the same opinion. (See MrLnew.) On the other hand, we have it affirmed to be most destructive and injurious to all kinds of crops of grain and pulse, as proved by various observations, experiments, and testimonies, made in Brandenburgh, Hanover, Prussia, and Germany. (See Com. Board of Agr., vol. vii. pp. 18-126; and the writer there says, towards the conclusion of his article, "To those still inclined to regard the barberry as innocent, notwithstanding all the above proofs to the contrary, I would 


\section{BARILI.A.}

oniy make the request that they no longer urge their opinion on abstract and general grounds, until they have collected the result of impartial observation and careful experiment."

The Rev. Di. Singer, in the Truns. High. Suc., vol. vi. p. 340, in considering the barberry as the cause of rust or mildew on corn crops, says, when quoting the survey of Dumfriesshire, "On one farm alone, that of Kirkbank, the tenant lost about $100 \%$. in his oat-crops yearly; and altogether the annual damage in the county was considerably above $1000 l$. The views of Sir Joseph Banks, and of some intelligent practical farmers, relative to the evil influence of the Berberis vu/garis, induced the late Admiral Sir William Johnstone Hope to give orders for the total extirpation of the barberry bushes which grew intermixed with thorns in his hedgerows; and since that was done, and for above twenty years, no such distemper has appeared in these fields. The same thing has been done in some parts of Ayrshire, and the like result has followed. These facts," adds Dr. Singer, "appear to indicate some connection between the occurrence of rust or mildew on growing corn and the neighbourhood of barberry bushes." Phillips inquires (Pom. Brit.), whether the blighting effects of this shrub may not in some degree be accounted for by its May-flowers alluring insects, which breed on the branches, and then feed their progeny on the nutritious juices of the surrounding blades of young corn?

BARILI.A. See Soda.

BARING Rorts of Trees. A practice formerly much adopted, but which later experience has shown to be highly injurious and hurtful to their growth.

BARK (Dan. barck; Dutch, berck; from the Teutonic bergen, to cover). The rind or covering of the woody parts of a tree. The bark of trees is composed of three distinct layers, of which the outermost is called the epidermis, the next the prerenchyma, and the innermost, or that in contact with the wood, the cortical layers. The epidermis is a thin, transparent, tough membrane; when rubbed off, it is gradually reproduced, and in some trees it cracks and decays, and a fresh epidermis is formed, pushing outwards the old: hence the reason why so many aged trees have a rough surface. The parenchyma is tender, succulent, and of a dark green. The cortical layer, or liber, consists of thin membranes encircling each other, and these seem to increase with the age of the plant. The liber, or inner bark, is known by its whiteness, great flexibility, toughness, and durability: the fibres in its structure are ligneous tubes. It is the part of the stem through which the juices descend, and the organ in which the generative sap from whence all the other parts originate is received from the leaves. The bark in its interstices contains cells which are filled with juices of very varying qualities; some, like that of the oak, remarkable for their astringency; others, like the cinnamon, abounding with an essential oil: others, as the jesuits' bark, containing an alkali; some mucilaginous; many resinous. Sereral of these barks have been analysed by rarious chemists: they have found them to
13ARK.

consist chicfly of carbon, oxygen, and hydro, gen, with various saline and earthy substances. ('Ihum. Chem. vol. iv. p. 231.)

M. Saussure (Chem. Liec. Veg.) found in 1001 parts of the ashes of the barks of various trees the following substances:-

\begin{tabular}{|c|c|c|c|c|c|}
\hline & Oaks. & Hazel. & Poplar. & $\begin{array}{l}\text { Mul. } \\
\text { berry. }\end{array}$ & $\begin{array}{l}\text { Hur } 1 . \\
\text { beatn. }\end{array}$ \\
\hline Soluble salts - & $7 \cdot$ & 125 & 6. & 7. & $4 \cdot 5$ \\
\hline Earthy phosphates & 3. & 55 & $5 \cdot 3$ & $8 \cdot 5$ & $4 \cdot 5$ \\
\hline Eartliy carbonates & $66^{\circ}$ & 54. & 60. & 45. & 59 \\
\hline Silica - - & $1 \cdot 5$ & 0.25 & 4. & $15 \cdot 12$ & $1 \cdot 5$ \\
\hline Metallic oxides & $2 \cdot$ & 1.75 & 1.5 & 1.12 & 0.12 \\
\hline
\end{tabular}

From this analysis the farmer will see that the earthy and saline ingredients of the bark of forest trees must be considerable fertilizers : it is only to the slowness with which refuse tanner's bark undergoes putrefaction that its neglect by the cultivator must be attributed. It might certainly, however, be mixed with farm-yard compost with very considerable advantage, as has been often done with sawdust and peat, in the manner so well described by Mr. Dixon of Hathershew (Juiurn. of Roy. Eng. Agr. Soc. vol. i. p. 135), see FARM-Y ARD MANURE; and in its half putrefied or even fresh state it produces on some grass lands very excellent effects as a top dressing; and in instances where carriage is an object, even its ashes would be found, from the quantity of earthy carbonates and phosphates whtch they contain, a very useful manure.

The different uses of barks in tanning and dyeing are numerous and important. The strength or fineness of their fibres is also of consequence: thus, woody fibres are often so tough as to form cordage, as exemplified in the hark of the lime, the willow, and the cocoanut; the liber of some trees, as for example the lime and the paper mulberry, is manufactured into mats; and it is scarcely requisite to refer to hemp and flax for spinning and weav. ing. The bark of the papyrus, or flag of the Nile, was first used for paper; that of the mulberry is still employed in the cloth of Otaheite; that of the powdered Swedish pines, as bread for the poor peasants of Scandinavia. In England, the bark of the oak is used for affording tannic acid in the manufacture of leather; but other barks, such as that of the Spanish chestnut and the larch, are also employed. The following table of Davy will show the relative value of different kinds of bark to the tanner: it gives the quantity of tannic acid afforded by $480 \mathrm{lbs}$. of differen barks in that great chemist's own experiments (Lect. p. 83.)

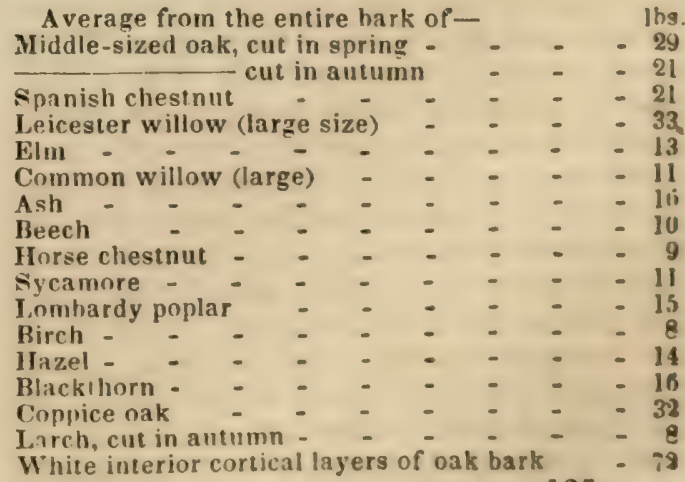


The difference of seasons makes a considerable variation in the produce of tannic acid; it is the least in cold springs. The tannic acid most abounds when the buds are opening, and least in the winter; 4 or $5 \mathrm{lbs}$. of good oak bark of average quality are required to form $1 \mathrm{lb}$. of leather. The consumption of oak bark in Great Britain is about 40,000 tons, more than one half of which is imported from the Netherlands.

Cork is the outer bark of a species of oak, which grows abundantly in the south of Europe. The average quantity imported annually is about $44,551 \mathrm{cwts}$.

The quantity of Quercilron bark, which is the production of black oak (Quercus nigra), is 22,625 cwts.

The quantity of Cinchuna, or Peruvian bark, is on an average about 300,000 lbs., but the consumption does not exceed 45,000 lbs. : the remainder is re-exported.

The bark of trees is best cleansed from the parasitical mosses with which it is wont to be infected, by being washed with lime-water or a solution of common salt in water $(4 \mathrm{oz}$. to a gallon), applied by a plasterer's brush.

Bark-BEE'lles, see Pine-tree Beetle, or W EEviL.

BARK-BOUND. A disease common to some fruit and other trees, which is capable of being cured by making a slit through the bark, from the top of the tree to the bottom, in February or March; where the gaping is pretty considerable, fill it up with cow-dung, or other similar composition.

BARKING IRONS, are instruments for removing the bark of oak and other trees. They consist of a blade or knife for cutting the bark, while yet on the trunk, across at regular distances, and of chisels or spatulæ, of different lengths and breadths for separating the bark from the wood.

BARKING OF TREES. the operation of stripping off the bark or rind. It is common to perform the operation of oak-barking in the spring months, when the bark, by the rising of the sap, is easily separated from the woor. This renders it necessary to fell the trees in these months. The tool commonly made use of in most countries is made of bone or iron. If of the former, the thigh or shinbone of an ass is preferred, which is formed into a twohanded instrument for the stem and larger houghs, with a handle of wood fixed at the end. The edge being once given by the grindingstone, or a rasp, it keeps itself sharp by wear.

In Europe, two descriptions of persons are usually employed in this business, the hagmen or cutlers, and the barkers. The latter chiefly consists of women and children. The cutters should be provided with ripping-saws, widely set, with sharn, light hatchets, and with shorthandled pruning-hooks. The barkers are provided with light, short-handled, ashen mallets, the head being about eight inches long, three inches diameter in the face, and the other end blunt, somewhat wedge-shaped; with sharp asher werlges, somewhat spatula-shaped, and which may either be driven by the mallet, or, bring furmed with a kind of handle, may be pushed with the hand; and with a smooth13 ? skinned whin, or other land-stone. The cut ters are divided into two parties; hatchet-men, who sever the stem, and hook-men, who prune it of small twigs, and cut it into convenient lengths. Small branches and twigs are held by one hand on the stone; the bark is then stripped off, and laid regularly aside, as in reaping of corn, till a bundle of convenient size be formed. The trunik and branches, as large as the leg, \&c. are laid along the ground; the bark is started, at the thick end, by thrusting or driving in the wedge, which, being run along the whole length, rips it open in an instant; the wedge is applied on both sides of the incision, in the manner of the knife in skinning a sheep. A skilful barker will skin a tree or branch as completely as a butcher a beast. But the point most particularly to be observed in this art is, to take off the bark in as long shreds or strands as possible, for the convenience of carriage to, and drying it on, the horses. These are formed of long branches; and pieces of a yard in length, sharpened at one end, and having a knag at the other to receive and support the end of the former.

The horses or supports may stand within four or five feet of each other, and are always to be placed on a dry, elevated spot, that the bark may have free air in drying. At the end of each day's work, the bark is carried to, and laid across, the horses, to the thickness of about six or eight inches. The large pieces are set up on end, leaning against the horses, or they are formed into smail pyramidal stacks. Due attention must be paid to turning the bark once, or perhaps twice a day, according to the state of the weather. Good hay weather is good barking weather. Gentle showers are beneficial; but long continued rains are productive of much evil; nor is the bark the better for being dried too fast. A careful hagman will take pains to lay the strong pieces of the trunk in such a manner as to shoot off the wet, in continued rains, from the smaller bark of the extremities; at the same time, preserving as much as possible the colour of the inner bark, and consequently the value of the whole, by turning the natural surface outwards. For it is chiefly by the high brown colour of the inner rind, and by its astringent effect upon the palate when tasted, that the tanner or merchant judges of its value. These properties are lost, if through neglect, or by the vicissitudes of the weather, the inner bark be blanched or rendered white.

After it becomes in a proper state, that is, completely past fermentation, if it cannot conveniently be carried off the ground and housed, it must be stacked. An experienced husbandman who can stack hay can also stalk bark. But it may be proper to warn him against building his stalk too large, and to caution him to thatch it well.

The method of drying bark in Yorkshire is generally the common one of setting it in a leaning posture against poles lying horizontally on forked stakes. But in a wet season, or when the ground is naturally moist, it is laid across a line of top-wond, formed into a kind of banklet, raising the bark about a foot from the ground. By this practice no part of the 

Plile \%.
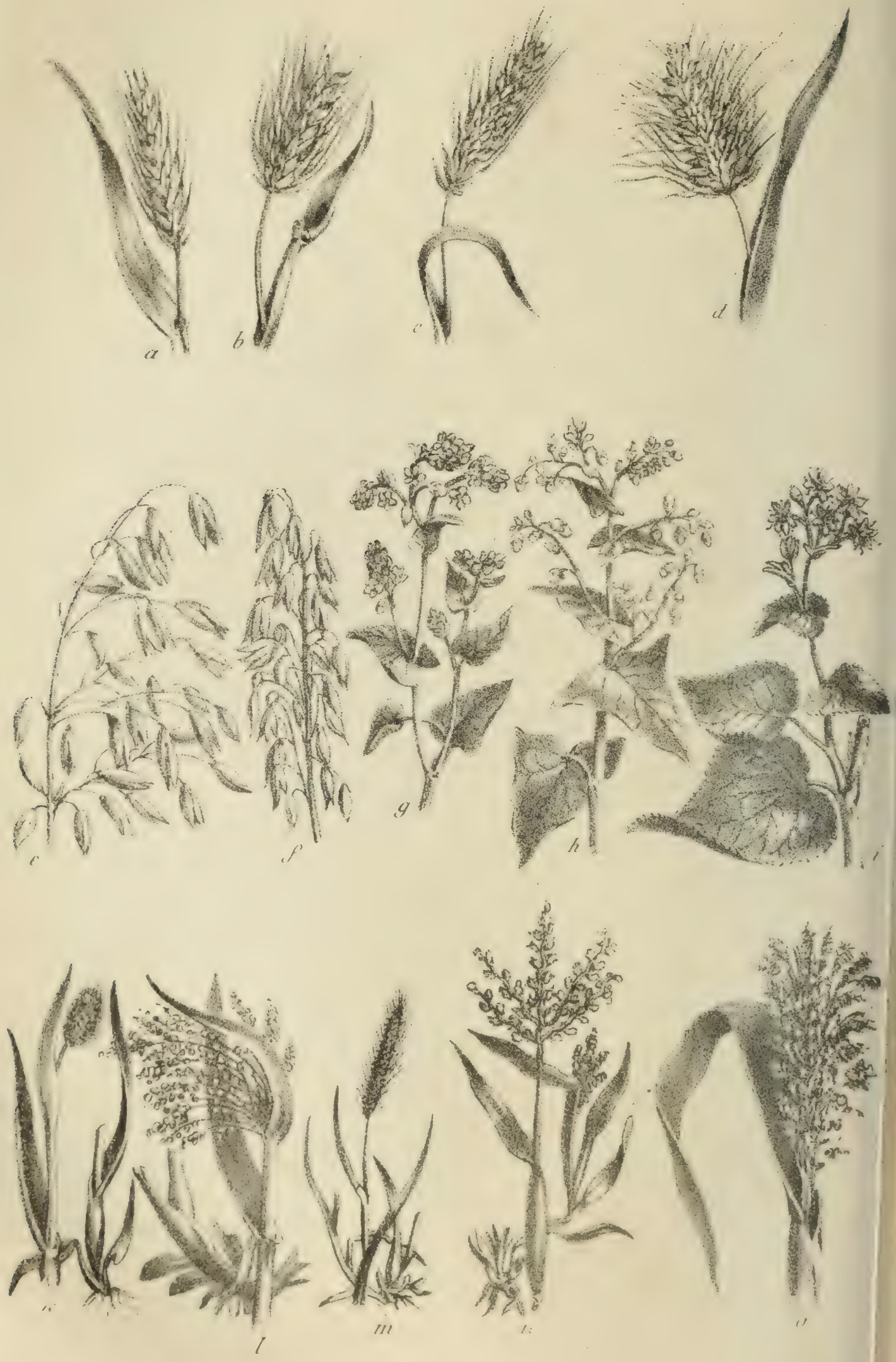
BARK-LICE.

Irk is suffered to touch the ground: and it is, rhaps, upon the whole, the best practice in I seasons and situations.

BARK-I.ICL. The mischiefs effected rough these minute insects, to fruit and other luable trees, are far greater than is generally pposed, and hence every farmer and garner must be interested in becoming intiately acquainted with the nature and habits so formidable an enemy. For the following ccedingly interesting account of bark-lice mmonly met with in the eastern states, we e indebled to our eminent countryman, Dr. hadeus William Harris of Massachusetts, ho was employed by that extremely liberal id enlightened state to write an account of e "Insects Injurious to Vegetulion," and made $s$ report to the legislature in 1841 . His eatise upon the subject forms a large octavo lume of 460 pages.

"The celebrated scarlet in grain, which has enployed in Asia and the South of Eupe, from the earliest ages, as a colouring aterial, was known to the Romans by the ame of Coccus, derived from a similar Greek ord, and was, for a long time, supposed to be vegetable production, or grain, as indeed its ame implies. At length it was ascertained at this valuable dye was an insect, and others rreeing with it in habits, and some also in roperties, having been discovered, Linnæus tained them all under the same name. Hence the genus Coccus are included not only the hula of the Phonicians and Jews, the Kermes the Arabians, or the Coccus of the Greeks ad Romans, but the scarlet grain of Poland, an the still more valuable Cochenille of lexico, together with various kinds of barkce, agreeing with the former in habits and ructure. These insects vary very much in rm; some of them are oval and slightly conex scales, and others have the shape of a uscle; some are quite convex, and either rmed like a boat turned bottom upwards, or re kidney-shaped, or globular. They live 1ostly on the bark of the stems of plants: some, owever, are habitually found upon leaves, nd some on roots. In the early state, the ead is completely withdrawn beneath the hell of the body and concealed, the beak or ucker seems to issue from the breast, and the egs are very short and not visible from above. he females undergo only a partial transformaion, or rather scarcely any other change than hat of an increase in size, which, in some pecies indeed, is enormous, compared with he previous condition of the insect; but the nales pass through a complete transformation efore arriving at the perfect or winged state. $\mathrm{n}$ both sexes we find threadlike or tapering intennæe, longer than the head, but much horter than those of plant-lice, and feet conisting of only one joint, terminated by a single law. The mature female retains the beak or ucker, but does not acquire wings; the male on the contrary has two wings, but the beak lisappears. In both there are two slender hreads at the extremity of the body, very short n some females, usually quite long in the males, which moreover are provided with a
BARK-LICE.

stylet at the tip of the abdomen, which is re curved beneath the body.

"The following account drawn up by me in the year 1828, and published in the seventh volume of the 'New England Farmer,' p. 186, 187 , contains a summary of nearly all that is known respecting the history and habits of these insects. Early in the spring the barklice are found apparently torpid, siluated longitudinally in regard to the branch, the head upwards, and sticking by their flattened inferior surface closely to the bark. On attempting to remove thein they are generally crushed, and there issues from the body a dark coloured fluid. By pricking them with a pin, they can be made to quit their hold, as I have often seen in the common species, Coccus heyperidum, infesting the myrtle. A little later the body is more swelled, and, on carefully raising it with a knife, numerous oblong eggs will be discovered beneath it, and the insect appears dried up and dead, and only its outer skin remains, which forms a convex cover to its future progeny. Under this prolecting shield the young are hatched, and, on the approach of warm weather, make their escape at the lower end of the shield, which is either slightly elevated or notched at this part. They then move with considerable activity, and disperse themselves over the young shoots or leaves. The shape of the young Coccus is much like that of its parent, but the body is of a paler colour and more thin and flattened. Its six short legs, and its slender beak are visible under a magnifier. Some are covered with a mealy powder, as the Coccus cocti, or cochenille of commerce, and the Coccus adoniduri, or mealy bug of our green-houses. Others are hairy or woolly; but most of them are naked and dark-coloured. These young lice insert their beaks into the bark or leaves, and draw from the cellular substance the sap that nourishes them. Réaumur observed the ground quite moist under peach-trees infested with bark-lice, which was caused by the dripping of the sap from the numerous punctures made by these insects. While they continue their exhausting suction of sap, they increase in size, and during this time are in what is called the larva state. When this is completed, the insects will be found to be of different magnitudes, some much larger than the others, and they then prepare for a change that is about to ensue in their mode of life, by emitting from the under-side of their bodies numerous little white downy threads, which are fastened, in : radiated manner, around their bodies to the bark, and serve to confine them securely in their places. After becoming thus fixed they remain apparently inanimate; but under these lifeless scales the transformation of the insect is conducted; with this remarkable difference, that, in a few days the large ones contrive to break up and throw off, in four or five tlakes, their outer scaly coats, and reappear in a very similar form to that which they before had; the smaller ones, on the contrary, continue under their outer skins, which serve instead of cocoons, and from which they seem to shrink and detach themselves, and then ho-

$$
\mathbf{x} 2
$$


come perfect pupæ, the rudiments of wings, antennæ, feet, \&c., being discoverable on raising the shells. If we follow the progress of these small lice, which are to produce the males, we shall see, in process of time, a pair of threads and the tips of the wings protruding beneath the shell at its lower elevated part, and through this little fissure the perfect insect at length backs out. After the larger lice have become fixed and have thrown off their outer coats, they enter upon the pupa or chrysalis state, which continues for a longer or shorter period according to the species. But when they have become mature, they do not leave the skins or shells covering their bodies, which continue flexible for a time. These larger insects are the females, and are destined to remain immovable, and never change their place after they have once become stationary. The male is exceedingly small in comparison to the female, and is provided with only two wings, which are usually very large, and lie flatly on the top of the body. After the insects have paired, the budy of the female increases in size, or becomes quite convex, for a time, and ever afterwards remains without alteration; but serves to shelter the eggs which are to give birth to her future offspring. These eggs, when matured, pass under the body of the mother, and the latter by degrees shrink more and more till nothing is lelt but the dry outer convex skin, and the insect perishes on the spot. Sometimes the insect's body is not large enough to cover all her eggs, in which case she beds them in a considerable quantity of the down that issues from the under or hinder part of her body. There are several broods of some species in the year; of the bark-louse of the apple-tree at least two are produced in one season. It is probable that the insects of the second or last brood pair in the autumn, after which the males die, but the females survive the winter, and lay their eggs in the following spring.

"Young appie-trees, and the extremities of the limbs of older trees are very much subject to the attacks of a small species of bark-louse. The limbs and smooth parts of the trunks are sometimes completely covered with these insects, and present a very singularly wrinkled and rough appearance from the bodies which are crowded closely together. In the winter these insects are torpid, and apparently dead. They measure about one-tenth of an inch in length, are of an oblong oval shape, gradually decreasing to a point at one end, and are of a brownish colour very near to that of the bark of the tree. These insects resemble in shape one which was described by Réaumur in 1738, who found it on the elm in France, and Geoffroy named the insect Coccus arborum lineuris, while Gmelin called it conchiformis. This, or one much like it, is very abundant upon apple-trees in England, as we learn from Dr. Shaw and Mr. Kirby; and Mr. Rennie states that he found it in great plenty on currant-bushes. It is highly probable that we have received this insect from Europe, but it is somewhat doubtful whether our apple-tree hark-louse be identical with the species found 138 by Réaumur on the elm; and the doubt saems to be justified by the difference in the trees and in the habits of the insects, our species being gregarious, and that of the elm nearly solitary. It is true, that on some of our indigenous forest-trees bark-lice of nearly the same form and appearance have been observed; but it is by nu means clear that they are of the same species as those on the apple-tree. The first account that we have of the occurrence of bark-lice on apple-trees, in this country, is a communication by Mr. Enoch Perley, of Bridgetown, Maine, written in 1794, and published among the early papers of the Massachusetts Agricultural Society. These insects have now become extremely common, and infest our nurseries and young trees to a very great extent. In the spring the eggs are readily to be seen on raising the little muscle-shaped scales beneath which they are concealed. 'These eggs are of a white colour, and in shape nearly like those of snakes. Every shell contains from thirty to forty of them, imbedded in a small quantity of whitish friable down. They begin to hatch about the 25th of May, and finish about the 10 th of June, according to Mr. Perley. The young, on their first appearance, are nearly white, very minute, and nearly oval in form. In about ten days they become stationary, and early in June throw out a quantity of bluish white down, soon after which their transformations are completed, and the females become fertile, and deposit their eggs. These, it seems, are hatched in the course of the summer, and the young come to their growth and provide for a new brood before the ensuing winter.

"Among the natural means which are provided to check the increase of these bark-lice, are birds, many of which, especially those of the genera Parus and Regulus, containing the chickadee and our wrens, devour great quan. tities of these lice. I have also found that these insects are preyed upon by internal parasites, minute ichneumon flies, and the holes (which are as small as if made with a fine needle), through which these little insects come forth, may be seen on the backs of a great many of the lice which have been destroyed by their intestine foes. The best ap. plication for the destruction of the lice is a wash made of two parts of soft soap and eight of water, with which is to be mixed lime enough to bring it to the consistence of thick white-wash. This is to be put upon the trunks and limbs of the trees with a brush, and as high as practicable, so as to cover the whole surface, and fill all the cracks in the bark. The proper time for washing over the trees is in the early part of June, when the insects are young and tender. These insects may also be killed by using in the same way a solution of two pounds of potash in seven quarts of water, or a pickle consisting of a quart of com. mon salt in two gallons of water.

"'There has been found on the apple and pear tree another lind of bark-louse, which differs from the foregoing in many important particulars, and approaches nearest to a species inhabiting the aspen in Sweden, of which a description has been given by Dalman in the 'Transactions of the Royal Academy of Sci- 
e's of Stuckholm.' for the year 1825, under name of Coccus cryptingurrus. This species f the kind in which the body of the fermale ot large enough to cover her eggs, for the tection whereof another provision is made, sisting, in this species, of a kind of memnous shell, of the colour and consistence ost of paper. In the autumn and throughthe winter, these insects are seen in a dorht state, and of two different forms and on the bark of the trees. The larger $s$ measure less than a tenth of an inch in rth, and have the form of a common oyster11, being broad at the hinder extremity, but ring towards the other, which is surmountyy a little oval brownish scale. The small $s$, which are not much more than half the th of the others, are of a very long oval pe, or almost four-sided with the ends nded; and one extremity is covered by a ute oval dark-coloured scale. These little l-like bodies are clustered together in great abers, are of a white colour and membrantexture, and serve as cocoons to shelter insects while they are undergoing their sformations. The large ones are the pupaes or cocoons of the fernale, beneath which eggs are laid; and the small ones are the es of the males, and differ from those of the ales not only in size and shape, but also in g of a purer white colour, and in having elevated ridge passing down the middle. minute oval dark-coloured scales on one he ends of these white cases are the skins he lice while they were in the young or a state, and the white shells are probably ned in the same way as the down which des from the bodies of other bark-lice, but ch in these assumes a regular shape, varyaccording to the sex, and becoming memnous after it is formed. Not having seen e insects in a living state, I have not been to trace their progress, and must therefore $r$ to Dalman's memoir above mentioned, such particulars as tend to illustrate the aining history of this species. The body the female insect, which is covered and cealed by the outer case above described, ninute, of an oval form, wrinkled at the s, flattened above, and of a reddish colour. means of her beak, which is constantly ist into the bark, she imbibes the sap, by ch she is nourished; she undergoes no nge, and never emerges from her habitaThe male becomes a chrysalis or pupa, - about the middle of July completes its isformations, makes its escape from its e, which it leaves at the hinder extremity, the wings with which it is provided are ersed over its head during the operation, are the last to be extricated. The perfect le is nearly as minute as a point, but a verful magnifier shows its body to be divided segments, and endued with all the imtant parts and functions of a living animal. the unassisted eye, says Dalman, it appears $y$ as a red atom, but it is furnished with a $r$ of long whitish wings, long antennæ or ns, six legs with their respective joints, and bristles terminating the tail. This minute ect perforates the middle of the case cover- ing the female, and thus celebrates its nuptials with its invisible partner. The litter subsequently deposits her eggs and dies. In due time the young are hatched and leave the case, under which they were fustered, by a little crevice at its hinder part. 'These young lice. which I have seen, are very small, of a pale yellowish brown colour, and of an oval shape, very flat, and appearing like minute scales. They move about for a while, at length becurne stationary, increase in size, and in due time the whitish shells are produced, and the included insects pass from the larva to the pupa state. The means for destroying these insects are the same as those recommended for the extermination of the previous species. (See Apнis, Тиния, \&c.)

"Many years ago, when on a visit from home, I observed on a fine native grape-vine, that was trained against the side of a house, great numbers of reddish brown bark-lice, of a globular form, and about half as large as a small pea, arranged in lines on the stems. An opportunity for further examination of this species did not occur till the last summer, when I was led to the discovery of a few of these lice on my Isabella grape-vines, by seeing the ants ascending and descending the stems. Upon careful search I discovered the lice, which were nearly the colour of the bark of the vine, partly imbedded in a little crevice of the bark, and arranged one behind another in a line. 'They drew great quantities of sap, as was apparent by their exudations, by which the ants were attracted. Further observations were arrested by a fire which consumed the house and the vines that were trained to it." (Hurris's Treatise on Insects.)

BARLEY (Lat. hordeum). A species of bread corn, which in Europe ranks next to wheat in importance, and of which there are several varieties. The generic name seems either hordeum, from horreo, on account of its long awns, or, as it was anciently written, fordeum, rather from whence oogin and forber, and, changing the $b$ into $d$, fordeum. (Vossius.) The name is, however, derived by Junius from the Hebrew בר. The plant belongs to the natural order Grominex, or grasses. It readily accommodates itself to any climate, bearing the heat of the torrid zone, and the cold of the frigid, and ripening in both equally well. Of the genus Hordeum, says Professor Low, the following species may be enumerated as cultivated for their seeds :-

1. Two-rowed barley (Hordeum distichum). Pl. 3, a.

2. Two-rowed naked barley (H. Gymnodistichum).

3. Two-rowed sprat, or battledore barley (H. disticho-zeocriton). Pl. 3, d.

4. Six-rowed winter barley ( $H$. hexastichum). P1. 3, b.

5. Six-rowed naked barley (H. Gymno-hexa. stichum).

6. Six-rowed sprat, or battlebore barley ( $H$ hexasticho-zeocriton).

The two leading species of this grain in cultivation are (No. 1.) the two-rowed, or common barley, and (No.4.) the six-rowed barley. Thu 
minor varieties of two-rowed barley are numerous, and are distinguished chiefly by the quality of the grain, and by their habit of early or later ripening; and some varieties are more productive than others: effects apparently dependent upon differences of climate and situation.

Barley is an annual plant, but like wheat it may be sown in autumn, and then it acquires the habit of later ripening, and is termed winter barley.

Two-lowed naked barley is said to have been introduced into England in the year 1768. It is now little cultivated, and is by some asserted, though without any evidence, to merge in to the common species.

The next species, two-rowed sprat, or battledore barley, is scarcely cultivated in England, the shortness of the straw being regarded as an objection; but it is much esteemed in Germany, where it is termed rice barley, owing to its smelling like rice in boiling, when it is decorticated.

The fourth enumerated species is six-rowed barley. When sown before winter, this species acquires the habit of late-ripening, and is then termed winter barley.

One of the kinds of six-rowed barley, and the best known in this country, is bere, bear, or bigg. Bigg ripens its seeds in a shorter period than the two-rowed barleys. It is cultivated very generally in the north of Scotland, in Denmark, Sweden, and other parts of $\mathbf{E u}$ rope, and in the south of England for green lood in spring, and for this purpose is sown early in the autumn. The number of its grains is greater than in the two-rowed kinds, but they do not weigh so heavy in proportion to their bulk. It is hence regarded as an inferior crop, and is only cultivated in the more elevated parts of the country. It ripens very early when sown in snring, thence the advantages which it possesses in a late climate. (Low's Prac. Agr. p. 240.)

The six-rowed naked barley is cultivated in various parts of Europe, and is greatly esteemed for its fertility. In some parts of Germany it is regarded as the most valuable kind of barley, and by the French, on account of its supposed productiveness, it has been termed orge céleste. An excellent variety of this naked barley has been produced by Mr. C. Alderman, of Kintbury, in Berkshire, and M. Mazucco, in a French paper, earnestly recommends the more general cultivation of naked barley, as he states that it weighs as much as the best wheats, and its quality resembles them so much that it may be used for the purpose of making good bread, and also for pearl barley. In mountainous countries, its produce is twentyfour to one. (Q'uart. Journ. of Agr. vol. iii. p. 373.) This and the other superior kinds of barley deserve more attention than they have yet received. Mr. Warren Hastings, (in an article in the Cum. to the Borard of $\mathrm{Agr}$. vol. vi. 1.304 ), after twelve years' experience in the cultivation of naked barley, very justly observes, "that it is of the greatest importance to promotc the culture of this sort of grain." "It is," he adds, "the corn that, next to rice, gives the greatest weight of flour per acre, and :40 may be eaten with no other preparation than that of boiling. It requires little or no dressing when it is sent to the mill, having no husk, and consequently produces no bran. It is gathered into the barn, and may even be consumed, when the seasons are favourable, in about eighty or ninety days after being sown; and there is no species of grain better calculated for countries where the summer is short, provided the vegetation be rapid."

The last of the species to be mentioned, says Professor Low, is six-rowed sprat, or battledore barley. This has been sometimes termed six-rowed barley; whereas the character of six-rowed barley does not belong to it alone. An examination of the plant will show that it is the common battledore barley, with all the florets entire. Much confusion has arisen in the arrangement by agriculturists of the cultivated barleys, and in an especial de. gree, by their speaking of four-rowed and six. rowed kinds. There is, however, no barley to which the term four-rowed can be applied. Barley is termed two-rowed, or six-rowed, according to the number of its fertile florets. In two-rowed barley, one row of florets on each of the two sides of the spike is fertile, and consequently one row of seeds on each side is perfected.

In six-rowed barley, three rows on each side are perfected. In this sense only it is termed six-rowed barley. But there is no species known to us in which only two rows on each side of the spike are fertile. Slightly examined, indeed, six-rowed barleys frequently present the appearance of four rows; but this is in appearance only, for such barleys have always the three rows on each side perfect. In poor soils and unfavourable situations, two of the rows run much into each other, and this has perhaps given rise to the mistake; but the two rows which thus run into each other in appearance are on the opposite sicles of the rachis. I have ventured, adds Professor Low (from whose work the above preliminary observations are taken), to propose a new arrangement of the cultivated barleys; under which it will be seen that the Hordeum vulgare of some botanists is Hordeum hexrstichum, and that of the Hordeum hexastichum, of some botanists is Hordeum hexasticho-zeocriton. Particular varieties have been in great repute at different times, when first introduced, and then seem to have, on many soils, lost their superiority. "Of this kind is the Moldavian barley, which was much sought after some years ago; and lately, the Chevalier barley, so called from the gentleman who first brought it into notice, has risen into great repute. It is said, that, having cbserved an ear of barley in his field, greatly superior to the rest, he carefully sowed the seed, and cultivated it in his garden, till he had a sufficient quantity to sow a field. It has since been extremely multiplied and diffused through the country. Some eminent maltsters and hrewers have declared, that it forms more saccharine matter than any other sort; and the trials hitherto made have convinced most agriculturists that it is not only heavier in the grain, but more productive. In 1832 Lord Jeicester, who was always foremost in all agri. 


\section{BARLEY.}

altural experiments and improvem: nts, sowed considerable portion of land with this $\mathrm{b}$.rley, and the result is said to have been perfortly tatisfactory. In 1833 two acres of Chevai, or arley were sown in the same field with som: of the best of the common barley. 'The soil vas poor, light sand, but in good order and rery clean. The produce of the whole was nearly he same, 4 quarters per acre; but the Chevaier barley weighed $57 \mathrm{lbs}$. per bushel, while he common barley weighed only 52. 'This ives the farmer an advantage of ten per cent. The sample was very fine, and the whole that he cultivator could spare was eagerly purhased by his neighbours for seed at his own rice. It is long in the ear, and very plump, ind the plant tillers so much, that half a bushel f seed may be saved per acre. 'This is probaly owing to its grains being all perfect, and egetating rapidly. The straw, like that of the ther long-eared barleys, appears weak in proortion to the ear; it is said also to be harder, ind not so palatable to cattle. These are cirumstances which experience alone can asertain. That hitherto it has a decided supeiority over the common sorts, no one who has ried it fairly in well-prepared lands seems to eny." (Penny Cyc.)

A new and seemingly very superior variety as lately been introduced, called the Annat arley. (See Quart. Journ. of Agr. vol.v. p. 18.) It is the produce of three ears which rere picked by Mr. Gorrie in a field in Perthhire, in the harvest of 1830 , since which peiod it has been grown at Annat Gardens, hence its name. In 1834, it was sown on a idge in the middle of a field, with common arley on the one side and Chevalier barley on he other. In bulk of straw it seemed to have he advantage of both these kinds; it was five ays earlier ripe than the former, and about a ortnight before the latter, and it was also $2 \frac{1}{2}$ bs. per bushel heavier than the Chevalier. At meeting of the Stoke Ferry Farmers' Club, n February of the present year (184l), it was tated by one of the members, that the Chevaier was decidedly the best stock for good barey land; but for very poor soils he preferred he Moldavian; though, probably even this was urpassed by the stock usually known as the id field barley. The Annat barley was alludd to by one gentleman who had tried it last eason; but not having thrashed it, he could only say that from its appearance it augured vell. He always adopted the drill system, asing wide, winged coulters, so as to disperse he grain in the rows as much as possible, givng the field the appearance of having been loughed in. Very little difference of opinion existed as to the superiority of the Chevalier ver any other variety, on the average of soils. Dne member had grown 15 coombs an acre on $t$; but he acknowledged it was on very excelent land. A curious fact was elicited in connection with this stock of barley; which was, hat however much the crop might be laid and beaten down, either by storms or its own weight, the grain did not receive that injury to which any other sort under similar circumstances would be liable. (Brit. Farm. Mag. vol.v.p. 190.)
BARLEY.

There can be no doubt of the general superiority of the Chevalier as a malting barley. Its introduction has occasioned a complete re. volution in certain districts, where formerly no such thing as malting barley was thought of. It is one of the greatest improvements of molern times, and now commands a higher price in the market than other barleys by two or three shillings a quarter.

Barley is evidently a native of a warmer climate than Britain; for in this moist atmosphere it is observed to degenerate, when either neglected or on a poor soil. We have the best authority for its having been cultivated in Syria so long back as 3153 years; therefore that part of the world may be fairly fixed as its native soil. We find that the Romans obtained barley from Egypt, and other parts of Africa, and Spain. It was also grown in France, as Columella calls one variety of barley Gulaticum.

Barley, like all grains, is liable to diseases, namely smut, the burnt ear, blight, and mildew : for an account of which I must refer the reader to these words. It is also apt to germinate in the ear even before it is reaped, in wer weather, giving the ear a singular appearance, and rendering the grain, even when kiln-dried, unfit for malting, and only of use to feed fowls or pigs. The diseases of barley are not so niz. merous or fatal as those of wheat. It is attacked by the larvæ of certain flies. The smut, which attacks it in a partial degree, ic generally the fungus uredo segetum.

Barley is now extensively cultivated in most European countries, in America, and in the temperate districts of Asia and Africa. It may also be raised between the tropics, but not at a lower elevation than from 3000 to 4000 feet, and then it is not worth cultivating. In Spain and Sicily it produces two crops in the year. Large quantities of barley have been for a lengthened period raised in Great Britain. Recently, however, its cultivation has been supposed, though probably on no good grounds, to be declining. In 1765, Mr. Charles Smith estimated the number of barley consumers in England and Wales at 739,000; and as a large proportion of the population of Wales, Westmoreland, and Cumberland continue to subsist chiefly on barley bread, I am inclined to think that this estimate may not, at present, be very wide of the mark. "Barley" (husked), says Pliny, "was the most ancient food in old times, as will appear by the ordinary custom of the Athenians, according to the testimony of Menander, as also by the surname given to the sword fencers, who, from their allowance or pension of barley, were called Hurdearii, bas: ley men." (Book xviii. chap. 7). It was not until after the Romans had learned to cultivate wheat, and to make bread, that they gave barley to their cattle. They made barley-meal into balls, which they put down the throats of their horses and asses, after the manner of fat tening fowls, which was said to make them strong and lusty.

There are no means of ascertaining whether barley was cultivated in Britain when the Romans discovered that country; but as Cæsar 
found corn growing on the coast of Kent, it is probable that this species of grain had been obtained from Gaul.

In the rotation of crops, barley may succeed to summer fallow, to potatoes, turnips, or any nther green crop, and to any of the pulse crops. It now generally follows turnips in England, and is a very important crop in the rotation, best adapted to light soils. The principal barley counties of England are Nurfolk, Suffolk, Cambridge, Bedford, Herts, Leicester, Nottingham, the upper parts of Hereford, Warwick, and Salop. The produce varies according to soil, preparation, season, \&c., from about 25 to 60 or 70 bushels an acre. The usual crop is from 28 to 36 or 38 bushels. The Winchester bushel of good English barley generally weighs about 50 lbs.; but the best Norfolk barley sometimes weighs 53 or 54 lbs. Its produce in flour is about $12 \mathrm{lbs}$. to $14 \mathrm{lbs}$. of the grain.

Barley is said to contain 65 per cent. of nutritive matter; wheat contains 78 per cent. A bushel of barley weighing 50 lbs. will therefore contain about 32 lbs. of nutriment; while a bushel of wheat weighing $60 \mathrm{lbs}$. contains 47 lbs. Good vats weighing 40 lbs. contain about $24 \mathrm{lbs}$. of nutritive matter; so that the comparative value of wheat, barley, and oats, in feeding cattle, may be represented by 47 , 32 , and 24 , the measure being the same. The experiments on which this calculation is founded were carefully made by Einhot, and confirmed on a lal'ge scale by Thäer, at his establishment at Mögelin, the account of the results being accurately kept.

Barley is a tender plant, and easily hurt in any stage of its growth. It is more hazardous than wheat, and is, generally speaking, raised at a greater expense, so that its cultivation should not be attempted except where the soil and climate are favourable for its growth. There is no grain perhaps more affected (says Baxter, in his Lib. of Agr. Knowledge, p. 36,) by soil and cultivation than barley, the same species exhibiting opposite qualities, modified by the nature of the soil from which it is produced; these opposite productions of the same individual will, if sown at the same period, on the same land, and under the same course of cultivation, exhibit corresponding differences, which are manifested during the growth of the crop, and subsequently in the quality of the sample when in hand. Thus the finest samples, the growth of suitable and well-cultivated lands, would, if sown on a poor and sterile soil, become alike coarse in appearance, and indifferent in quality. This fact, however important, has hitherto but little engaged the attention of the farmer; and the spring or early barley is therefore indiscriminately sown, as heing found more productive for the purpose of malting than any of the afore-mentioned varietics. The sprat, or battledore barley, makes good malt; and being short and erect lis the ear, and tapering in the stem, is, on otrong lands, less liable to injury from falling, and is consequently preferred by a few individuals. 'The common, or long-eared barley, being long in the ear and weak in the straw, 1, very liable to lodge early, whereby the grain 142 is rendered inferior in quality, and is, there. fore, not extensively cultivated. Naked bar. ley, or wheat barley, is so termed in consequence of the grain separating readily from the chaff when thrashed. It is a native of the north, and will bear sowing early in the season; it is not, however, in much estimation in the south of England, and is seldom cultivated, although it malies strong malt, and is excellent for fattening of hogs and cattle. Win. ter barley, or square-eared barley, is grown to a considerable extent in the north-western part of England, and in Scotland. It is usually sown for the feeding of sheep in the south of England, and mixed with tares for the soiling of cattle. As food for sheep, it is far more productive than rye, as it admits of being fed down every two or three days during summer; and if intended for seed, it may previously be fed off by sheep early in the season, without injury to the crop.

The land that produces the best barley is generally of a silicious, light, dry nature; for a good mellow preparation and free soil are essential to the growth of malting barleys. Cold, wet soils, which are peculiarly retentive of water, are ill adapted to the growth of this grain, both in reference to its weight and its malting qualities. The whole matter of barley and its straw contains more silicious particles than that of any other grain cultivated by the British farmer; and hence one reason why a sandy soil is most congenial to the growth of this plant. Barley is propagated by seed, sown either broadcast or in drills, the quantity varying according to the quality of the soil, cultivation, and time of sowing; less being required on rich mellow lands than on poor soils; early sowing, with good tillage, re. quiring less seed than the late sowing with indifferent tillage. 'The quantity of seed generally varies from $2 \frac{1}{2}$ to 4 bushels the acre (or sometimes more), when sown broadcast; but when drilled, the quantity of seed need not exceed two bushels to the acre.

Barley is an early ripening grain. It may be sown at a late period, but the sooner the better. The more early that barley can be sown, the produce in grain is the surer, though the bulk of the straw will be less. 'The com. mon sprat barleys may be sown from the second week in March, if the weather prove dry, until the 10th of May. The bigg, a variety of the winter barley, will stand against the wind, and may be sown either in tle autumn or the beginning of March. The bear, or square barley, should be sown as early in the autumn as the clearing of the harrest will admit, and may be sown after wheat, barley, oats, or any pulse crop, being a plant of sturdy growth. In the choice of seed, greal care should be taken that it is not of a reddish hue. as in that case it is more than probable that a great part of it will never vegetate; the sample. should be of a pale, lively colour, and uniform. Some farmers, not aware of its importance, are in the habit of sowing thin corn; but unless the land is quite adapted, from its nature and cultivation, for the fullest encouragement of the plant, it will in the end he found a "penny. wise and pound-foolish" speculation. In all 
cases it will be well for the farmer to select the finest samples and the plumpest grain; for in unfavourable seasons the crop from thin grain is always delicate, and assumes an unkindly hue, whilst, on the contrary, plump seed throws up strong, healthy stems, capable of resisting the effects of inclement seasons, and, in more congenial weather, pushing forth with renewed vigour and redoubled strength. In England, barley, for the most part, succeeds best after turnips, tares, potatoes, carrots, mangel wurzel, or other green ameliorating crops; but does not succeed so well after wheat or other white straw crops, nor after rape so well as other green crops, except on the South Downs of Sussex, and certain lands adjoining the sea-coast, where both the quantity of grain is greater, and the quality better, after wheat (particularly wheat sown upon a clover ley), and also after rape, than from any other course of tillage. The lands require more or less ploughing, according to the quality of the soil, and the state in which it is found after the season for the working of it commences. On retentive soils, as compact gravelly clay, if the urnips have been fed off during wet weather, he earth breaks up in large clods, and requires 0 be reduced by the roller, and at least a seeond ploughing should be given before the barley can be safely sown. On light soils of he best quality one ploughing may be sufficient; but if the land is twice ploughed in the spring, as soon as it is sufficiently dry for that purpose, it will be found amply to repay both he labour and expense. After the grass-seeds are sown, the barley-land admits of no further illage. Should any larger weeds appear, they may be pulled up by the hand; but it is the evidence of bad husbandry if a spring-sown oarley crop requires weeding during the comparatively short period in which it is on the ground. If weeding be necessary, it should be ittended to early, or the crop will be injured oy treading, and the roller should be used beore the blade becomes spindled.

In the harvesting of barley more care is requisite than in taking any other of the white crops, even in the best of seasons; and in bad vears it is often found very difficult to save it. When the period of harvest arrives, barley must be allowed to be sufficiently ripe, but not become what is termed "dead ripe." It may be cut either by the scythe or the sickle. Barey, says Professor Low, on account of the softness of its stem, and the tendency of its ears to vegetate, is more apt to be injured, and veren destroyed, by wet weather than any of he other cereal grasses. For this reason the safer course, in a humid climate like ours, is to place it when cut down in sheaves and shocks, and not to allow it, as is frequently practised, to lie loose upon the ground. $\mathbf{B y}$ some farmers, however. it is suffered to lie in the fields until the straw is quite dry, being turned over early in the morning while the lew is still upon it. This practice, they say, is found to improve the colour of the slin, and thereby render the grain of more value to the maltster. It should never be carried unless perfectly dry, otherwise it is in danger of being heated in the mow, which reduces the value very materially, for the undue action of the heat destroys the spear, or germination of the grain; the malting process is consequently very unequally performed, and as the duty has to be paid upon the whole bin, maltsters will scarcely purchase such samples, unless fur the purpose of grinding, and then always at an inferior price. It will be prudent, therr. fore, not to carry barley until the heat of the sun has evaporated the dew from it, when it should be carried in a perfectly dry state the remainder of the day, until the dew is again deposited in the evening. It is a very common practice to sow clover and other grass seeds with this crop; but great care must be taken that they are thoroughly harvested, for otherwise considerable fermentation will be created, and the sample injured. It not unfrequently occurs, that when it is supposed to be well harvested, heat is soon found to subsist in the mows, which should be daily examined, by placing a long iron spit, that should be kept for that purpose, deep into the mow; when, if the heat is found to increase, no delay should take place, but the middle should be instantly cut asunder, and taken out in proportion to the size of the mow, when it will generally escape without further injury. This operation, how. ever, must not be deferred. as the injury sustained rapidly increases. By heating in the stalk, it quickly becomes discoloured and injured. When barley is grown in large quantities, it is usual to tread the mows with horses or oxen, to get as much as possible into the barns, in which case more guarded caution is necessary than when thrown losely over the floor.

This grain should never be thrashed by a machine, as the injury done thereby is frequently of a very serious nature; it bruises the malting spear, which is as injurious to the maltsters as if heated in the mow, and, there. fore, should be guarded against. Care must also be taken not to have too large heaps lying together without frequent examination, as, until it has undergone a proper fermentation in the mow, it will be very apt to heat in the heap; in order to prevent which it requires to be moved daily, or every other day, till cleaned up from the chaff, which, from the fineness of its texture, scarcely admits the introduction of air, and consequently promotes fermentation.

The principal demand for barley in Great Britain is for conversion into malt, to be used in the manufacture of ale, porter, and British spirits; and though its consumption in this way has not certainly increased proportionally to the increase of wealth and population, still there does not seem to be any grounds for supposing that it has diminished.

But it is not only the most useful for making into malt, it is the best food for promoting the fattening of hogs, after they have been fed to a certain extent with beans, peas, \&c., from which it has been found that the meat is not only more tender, but increases in boiling whilst the meat of those fed on beans and peas alone has not only been hart, but has not yielded any increase. Barley is employed for various other purposes. It is excellent for fattening poultry. The flour is still nsed in 


\section{BARLEY.}

some parts for hread; but the bread, though sufficiently nutritious, is dark and strongtasted. Barley, in its green state, especially the Siberian wintermbarley, makes excellent spring food for milch cows, as is well known to the cow-keepers ahout London; it comes in early, and greatly increases the milk. For sheep it is more nourishing than rye, and is earlier. When fed off quite close in April, it will spring up again, and on good land produce a fair crop of grain in August; but, in general, it is ploughed up as soon as it is fed off, and succeeded by spring tares or turnips. It is also good food for horses, when given in the spring of the year in small proportion with oats, sparingly at first, and after being soaked in water, and allowed to vegetate. It is in general use in the south of Europe (Com. Buord of $\mathrm{Agr}$. vol. vi. p. 293). Mixed with other grain, in its ground state, it has been found an excellent food for fattening bullocks. The straw is employed partially for fodder, but chiefly for litter. It is lighter than the straws of oats and wheat, and less esteemed than either. The awns are given to stock, either in their natural state or boiled. Malt is the great purpose, however, to which barley is applied in this country. To understand the process of malting, it may be necessary to observe, that, in the germination of grasses and grains before the young plant is produced, the fecula of the seed is changed by the heat and moisture of the earth into sugar and mucilage. Malting grain is only an artificial mode of effecting this object. The grain is steeped in cold water during a certain period; the water is then allowed to drain off, the grain is spread out into a deep heap: it gradually heats, the rootlets begin to shoot out, afterwards the plumula begins to grow; and when this has grown to a certain extent within the grain, the further germination is checked by exposing the grain on a kiln, heated by fire to such a degree as extinguishes the vitality of the seed. At this period it is found that the starch is, in a great measure, converted into saccharine matter, and by subsequent fermentation, or distillation, either beer or spirits is obtained. (See FEnmevtation, Maltivg, and Brewing.) It is only necessary to add here that malt requires the best and heaviest barley, with its germinating powers entire.

Barley was formerly in general use in England as bread corn: it is still, for this purpose, much used on the Continent. It is generally used in the warmer climates as the food for horses, for which purpose, in fact, it appears to answer equally as well as oats. In this country, in some seasons, a considerable saving may be made by using for this purpose inferior barley. This was done in the season of 1840 by Mr. Hewitt Davis, of Spring Park, who sold his oats at the same rrice that he gave for the barley. And to this end the farmer should remember, that two parts of barley are iully equal, in feeding properties, to three parts if oats. In Germany they grind the barley, and form it into cakes, with which they feed their horses; and it is no unusual circumstance, in travelling in that country, to see the 144 driver take a slice of the loaf with which he baits his horses.

Wine made from malt, when kept to a pro. per age, has a good body, and a flavour nearly as agreeable as the generality of Madeira wines. The wort of malt is useful in scurvy, but it is apt to increase the diarrhøa which attends that disease. Barley was used by the ancients for many medicinal purposes. Pot barley, pearl barley, and French barley, are only barley freed from the husk by a mill; the distinction between them being, that the pearl barley is reduced to the size of small shot, all but the very heart of the grain being ground away. For a description of the mode of ma. nufacture, I refer the reader to the Penny $C y$. clop. vol. iii. p. 466. Barley-water is a decoc. tion of either of these, and is reputed soft and lubricating; a very useful cooling drink or gruel in many disorders, and is recommended to be taken with nitre in fevers. Its use is of great antiquity, as Hippocrates wrote a whole book on the merits of gruel made of barley. Barley-water is an admirable liquid to administer any medicine in, being pleasant, emollient, and cooling. The French or Scotch barley is principally used to thicken broth and soup.

The German chemist, Einhof, has analysed ripe barley, and found 100 parts to consist of 70.05 parts of meal, 18.75 of husk, and 11.20 of water. The meal he found to contain $67 \cdot 18$ parts of starch, $5 \cdot 21$ of uncrystallizable sugar, $4 \cdot 62$ of gum, 3.52 of gluten, 1.15 of albumen, 0.24 of superphosphate of lime, and 10.79 of water and loss, in 100 parts. The husk contains a bitter principle which is tasted in the decoction of entire barley.

M. Saussure has carefully analysed the ashes produced by burning barley and its straw, and the result of his experiments is given in $R e$ cherches Chem. sur la Veg., Paris, 1804.

The grain reduced to ashes, with its skin, gave, out of 100 parts, 18 of ashes, which contained:-

Potash -
Phosphate of potash
Sulphate of potash
Muriate of potash -
Earthy phosphates -
Silica -
Metallic oxides -
Loss -

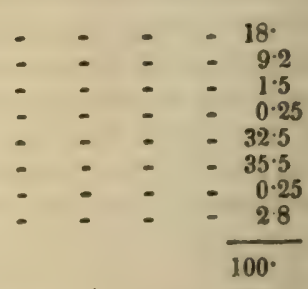

1000 parts of the straw produced 42 of ashes, containing:-

$$
\begin{aligned}
& \text { Potash - } \\
& \text { Sulphate of potash - } \\
& \text { Muriate of potash :- } \\
& \text { Earthy phosphates - } \\
& \text { Earthy carbonates - } \\
& \text { Nilica - } \\
& \text { Metallic oxides : } \\
& \text { Loss - }
\end{aligned}
$$

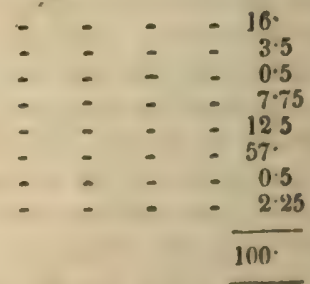

These products no doubt vary in different soils; but the proportion of silica in the straw and in the slin of barley is remarkable. 'This barley grew on a chalky soil. In addition to these the cubic saltpetre, or nitrate of soda, is usually found in minute proprortions in barley. 


\section{BARLEY GRASSES}

The average price in England, per Winchester quarter of barley, according to $\mathrm{M} \cdot \mathrm{Cul}$ ioch, was in

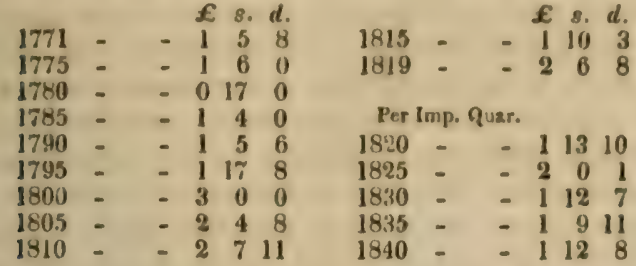

The account in imperial quarters of the foreign barley and barley-meal entered for home consumption every five years since 1815, was (M.Culloch's Com. Dict.) -

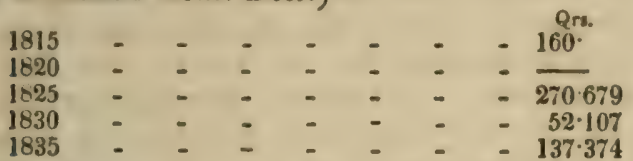

The annual average, from 1801 to 1825 , of barley imported into England, in Winchester quarters, was from

Russia

Sweden and Norway

Denmark

Prussia

Germany

France and Southern Europe

France and Sted Stares

British North America

Other countries

\begin{tabular}{l} 
Qrs. \\
$-\quad 7 \cdot 112$ \\
\hline
\end{tabular}

Ireland -
.987

$18 \cdot 808$

18.718

$24 \cdot 839$

0.500

1.097

31.

$51^{\circ}$

- $\quad 2 \cdot 194$

- $33 \cdot 331$
For further particulars as to its consumption and culture, see Smitl's Tracts on the Corn Trade, $2 d$ edit. p. 182 ; Penny Cyclop., vol. iii. p. 461 ; Brown on Rural Affairs, vol. ii. p. 42 ; and Elements of Pruc. Agr., by Prof. Low, p. 246 , \&c.; to which last-named valuable work I have, in this and other articles, been under very considerable obligation.

(Phillip's Cult. Veg.; M'Culluch's Com. Dict.; Corn. Buard of Ag. vol.vi.; Hitchin, in Baxter's Ag. Lib.; Professor Low's El. of Ag.; Brande's Jict. of Science.)

Barley, in the United States, is cultivated almost exclusively for the breweries, the grain being rarely given to cattle, and barley-bread being unknown to native Americans.

BARLEY GRASSES. Some coarse kind of grasses which are known under the several names of meadow barley grass (Plate $7, d$ ), wall barley grass, way-bennet, and mouse barley, and are of little use to the farmer. (Sec HonDEм murinum, and $H$. pratense.)

BARLEY HUMMEILER. This is an instrument worked by the hand, which is employed when the threshing machine is not in use, or performs its work imperfectly. It consists of a set of parallel iron plates fixed to a frame, and worked by the hand like a paver's instrument. The barley to be hummelled is laid upon the barn-floor, and by repeated strokes of the hummeller, is freed from its awns. Messrs. Grant, wheelwrights of Aberdeenshire, have described this instrument very fully, with some improvements, in Trans. High. Suc. vol. iv. p. 334.

BARM. The foam or froth of beer or any other liquor in a state of fermentation, which is used as a leaven in the making of bread, \&c. (See YwAsT.)

BARN. A covered building, constructed for the purpose of laying up grain, \&c. Farms should always be furnished with barns proportioned to the quantity of grain thry produce; but since the practices of stacking and thrashing by mills have become more general, there is much less need of large barns. They should have a dry situation, and be placed on the north or north-east side of the farm vard, si) that the sun at noonday may shine on the thrashing-floor, and the lean-toos for stock in the yard be thus open only to the south. Every farm should have at least two thrashing-flours, that different kinds of grain may be thrashing at the same time. Barns may either be constructed of timber, or be built of brick or stone, whichever the country affords in the greatest plenty, but wooden barns are the best for the corn; and in either case there should be such vent-holes or openings in their sides or walls as to afford free admittance to the air, in order to prevent the mouldiness that would otherwise occur from the least dampness lodging in the grain. The foundations, and for two feet out of the ground, are best made of brick or stone, on account of greater solidity, and the protec. tion from vermin; the whole may be roofed with either thatch, slate (which is the best of all), or tiles, as can be most conveniently procured. They should have two large double folding doors facing each other, one in each side of the building, for the convenience of carrying in or out wagon-loads; and these doors should be of the same breadth as the thrashing-floor, to afford the more light and air. Formerly, a much larger expenditure in the number and size of these buildings was incurred than is now requisite, since the practice of stacking has become general. It is found that all grain is a better sample from stacks than from barns; vermin have less chance of injuring it, indeed may be set at defiance, and at harvest the corn may admit of being carried two days sooner for stacking than for housing.

BAFNACLES. A name given to horsetwitchers or brakes, a sort of instrument used by farriers to put upon horses' noses, when they will not stand quietly to be shod, bled, or dressed.

BARN OWL (Strix flummea). The white, or screech owl, unlike some of the species, is resident in England throughout the year, and is so peculiar in the colour of its plumage, and so generally diffused, that it is probably the best known of all the British species of owls. It inhabits churches, barns, old malting kilns, or deserted ruins of any sort, and also holes in decayed trees. If unmolested, the same haunts.s are frequented either by parent birds or their offspring, for many years in succession. As a constant destroyer of rats and mice, and that to a very considerable extent, the services performed by barn owls for the agriculturists have obtained for these birds toleration at least, while by some they are, as they deserve to be, strictly protected in return for benefits received. Unless disturbed, these birds seldom leave their retreat during the day; and, if the place of concealment be approached with caution, and a view of the bird obtained, it will generally 


\section{BAROMETER.}

be observed to have its eyes closed as if asleep. About sunset, the pair of owls, particularly when they have young, issue forth in quest of food, and may be observed flapping gently along, searching lanes, hedgerows, orchards, and small enclosures near outbuildings. "In this irregular country," says White of Selborne, "we can stand on an eminence and see them beat the ficlds over like a setting dog, and often drop down in the grass or corn." Besides rats and mice, they feed on shrews, small birds, insects, \&c., and have sometimes been known to capture and eat fish. It is said of this owl, that when satisfied, it will hide the remainder of its meat like a dog. The barn owl lays from three to five eggs, which are oval and white, measuring one inch six lines in length, and one inch three lines in breadth. Young birds are found from July to September, and occasionally as late as December. The young birds are easily tamed, and live in harmony with other birds. The barn owl is common in most, if not all the counties of England, and, according to Mr. Thompson, it is also the most common owl in Ireland. In scotland, it is less numerous. Over the temperate part of the European continent, and in North America, it is generally diffused. Its form and colnur are too common to need description. The whole length of the bird is about fourteen inches. (Yurrell's Brit. Birds, rol. i.)

BAROMETER. The word is derived from two Greek words, which signify the measurer of weight. 'This, the most valuable instrument for meteorological observations in the farmer's possession, was invented about the middle of the 17th century, by Torricelli, an Italian philosopher. Some observations of Galileo had, perhaps, led the way to the discovery; the attention of this great philosopher, according to a well known story, having been drawn to the fact that water would not rise higher than 32 feet in a tube exhausted of air, by some workmen of the Duke of Florence, who had vainly endeavoured to construct a comon lifting pump to raise water a greater height. Galileo $e x$ plained the phenomenon, by saying that nature had a horror of a vacuum, but that this horror had its limits. It was found by Torricelli, that a column of water of about 32 feet exactly balanced the weight of the atmosphere which -urrounds our earth, and that this was equal to the weight of a column of mercury of about 28 inches. Now this column of mercury, under various outward shapes, forms the barometer, or weather-glass, so useful to the farmer. For as the pressure of the atmosphere commonly varies with isproaching changes in the weather, the consequent rise or fall of the mercury merely marks its amount : one end of the morcurial tube is hermetically sealed and is void of air, so that the quicksilver rises or 'alls in it unresisted; but the other end of the tube is open, and the atmosphere forces the meveary through this, by pressure on the surfice of the fluid mercury in the cistern. Thus, the atmosphere operates by its varying pres- ure. Winen. therefore, the quicksilver rises, the atmospheric pressure is increasing; when it falls, the pressure is diminishing.
The more dense the state of the aunosphere, the higher the mercury will rise in the instrument. It is a popular notion that the atmospheric pressure must be greatest when the air is thick and cloudy. The term density, when applied to the condition of the atmosphere and its relations with the barometer, means specific weight, without reference to its clearness or cloudiness. Vapour or moisture in the air a. ways lessens its weight, and the more vapour, whether this be invisible, or in the condensed states constituting fogs and clouds, the less the weight or density and pressure upon the barometer.

It is more from this rising and falling of the barometer, observes Mr. Forster, than from its height or lowness, that we are to infer fair or foul weather. In very hot weather the falling of the mercury indicates thunder: in winter, the rising indicates frost ; and in frosty weather, if the mercury fall three or four divisions, there will follow a thaw; but in a continued frost, if the mercury rises it will snow. When foul weather happens soon after the falling of the mercury, it will not continue; and, on the contrary, you may expect, if the weather becomes fair as soon as the mercury rises, that it will be of short duration. In foul weather, when the mercury rises much and high, and so continues for two or three days before the foul weather is quite over, then expect a con tinuance of fair weather to follow.

The words usually inscribed on the scale plates of barometers, such as "Very Dry," "Set Fair," "Fair," etc., etc., are extremely fallacious, and have tended to bring the instrument into great discredit as a weather glass. We may perhaps except "Stormy," for when the lowest falls happen, they are always the precursors of very high winds and storms. The words inscribed are, perhaps, better indications of the weather in England than on the American side of the Atlantic. It must be evident that when a barometer, with a scale plate marked as usual, is carried to high and mountainous positions, the mercurial column falls, and has its relations with the words on the scale plate entirely changed. The person who wishes to make the barometer useful in foretelling the changes of weather in the United States must throw aside all dependence upon inscriptions, with the exception mentioned, and study its fluctuations with reference to the prevailing winds, dew-point, and other conditions of the weather at the time. Rain or snow is frequently preceded by a rise, instead of a fall, of the mercurial column, and a fall of the barometer often indicates the cessation of rain.

The rise in the mercurial column generally indicates a northerly wind. The highest conditions of the barometer in the United States, near the Atlantic, commonly preceae north easterly storms of rain and snow. The very highest elevations have been atter_ded with very cold weather and a light wind from the north, followed by snow or rain within forty. eight hours. A subsidence of the mercury ge nerally indieates wind from a southerly point, and should this be so far round as to blow from land, the fall of rain or snow will commonly 
cease, for a while at least. When, during a may be regarded rather central and removed wet spell of weather, the wind has veered to the south-easterly points, with a cessation of rain, the wind rising to east and north-east is generally preceded or attended by a rise of the barometer and a renewal of the rain. When the wind has been from the south and southwest, with a moist condition of the atmosphere, or high dew-point, a rise of the barometer indicates that the wind is coming from a point north of west, and a clearing up shower about to ensue.

The following tabular view is intended to show the manner in which the mercurial column of the barometer fluctuates at Philadelphia, a position in the United States, which

from the extremes of more northerly and southerly situations. 'The higher north, the greater the fluctuations of the barometer. 'The observations were carefully made during the year 1842, by Mr. Owen Evans, a member of the Committee on Meteorology, of the Franklin Institute of Pennsylvania. The graduation of his barometer agrees with that of the standard constructed for the Committee on Meteorology, by which the instruments distributed to the various counties of Pennsylvania are regulated. The elevation of the place of observation is about 30 feet above high-water mark of the Delaware. The means are corrected for temperature to $42^{\circ} \mathrm{Fahr}$.

\begin{tabular}{|c|c|c|c|c|c|c|c|c|c|c|c|c|c|}
\hline & Jan. & Feb. & March & April & May. & June. & July & Aug. & Sept. & Oct. & Nov. & Dec. & Year. \\
\hline $\begin{array}{l}\text { Mean of Barnmeter for each month of } \\
\text { the year } 1842,\end{array}$ & $30 \cdot 04$ & $30 \cdot 00$ & 30.04 & $29 \cdot 95$ & 29.50 & 29.92 & 23.96 & 29.98 & 29.97 & 30.00 & 30.01 & 29.99 & $29.98 !$ \\
\hline $\begin{array}{l}\text { Greatesi height at the hours of obser- } \\
\text { vation, }\end{array}$ & & 30.47 & $\begin{array}{ll}30 & 51\end{array}$ & 30.42 & 30.31 & $30 \cdot 41$ & $30 \cdot 30$ & 30.37 & $30 \cdot 22$ & $30 \cdot 34$ & 30.43 & $30 \cdot 47$ & $30.63 \mid$ \\
\hline $\begin{array}{l}\text { Lowest falls at the hours of observa- } \\
\text { tion, - }\end{array}$ & $29 \cdot 5$ & $29 \cdot 12$ & 29.52 & 2957 & $=9.60$ & $25 \div 0$ & $29 \%$ & $29 \cdot 7$ & 29.63 & $29 \cdot 6$ & $29 \cdot 3 \pi$ & $29 \cdot 32$ & $29 \cdot 12$ \\
\hline
\end{tabular}

Many are the natural indications of vegetables which portend changes in the weather; thus, the Pimpernel, or Red Chickweed (Anagallis arvensis), is styled the poor man's weatherglass. This little plant blooms in June, in stubble fields and gardens, and continues in flower all the summer. When this plant is seen in the morning with its little red flowers widely extended, we may generally expect a fine day; on the contrary, it is a sign of rain when its petals are closed. (The Farmer's Almanac.)

The following table has been constructed from a long series of observations made in London; they will apply, however, to a considerable distance around the metropolis :-

\begin{tabular}{|c|c|c|c|}
\hline & $\begin{array}{c}\text { Barometer, } \\
\text { mean Height. }\end{array}$ & $\begin{array}{l}\text { Thermometer, } \\
\text { mean Tenipera- } \\
\text { ture. }\end{array}$ & $\begin{array}{l}\text { Mean quantity } \\
\text { of Ruin in } \\
\text { Inchea. }\end{array}$ \\
\hline January & $29 \cdot 921$ & $36 \cdot 1$ & $1 \cdot 483$ \\
\hline February & 30.067 & $38^{\circ}$ & 0.746 \\
\hline March & $29 \cdot 843$ & $43 \cdot 9$ & $1 \cdot 440$ \\
\hline April & 29.881 & $49 \cdot 9$ & 1.786 \\
\hline May & $29 \cdot 898$ & $54^{\circ}$ & 1.853 \\
\hline June & 30.020 & 587 & $1 \cdot 830$ \\
\hline July & $29 \cdot 874$ & $61^{\circ}$ & $2 \cdot 516$ \\
\hline August & $29 \cdot 891$ & $61 \cdot 6$ & $1 \cdot 453$ \\
\hline September & $29 \cdot 931$ & $57 \cdot 8$ & $2 \cdot 193$ \\
\hline October & $29 \cdot 774$ & $48 \cdot 9$ & $2 \cdot 073$ \\
\hline Novernber & $29 \cdot 776$ & $42 \cdot 9$ & $2 \cdot 400$ \\
\hline December & $29 \cdot 693$ & $39 \cdot 3$ & $2 \cdot 426$ \\
\hline
\end{tabular}

BARREL. A cask or vessel for holding liquids, particularly ale and beer. Formerly the barrel of beer in London, contained only 32 ale gallons $=32 \frac{1}{2}$ Imperial gallons. By a statute of 1 W. \& M., the ale and beer barrels were equalized for every part of England, except London, and ordered to contain $\mathbf{3 4}$ gallons; but it was enacted by 43 Geo. 3 , c. 69 , that 36 gallons of beer should be taken to be a barrel; and by the 6 Geo. 3 , c. 58 , it is enacted, that whenever any gallon measure is mentioned in any excise law, it shall always be deemed and taken to be a standard Imperial gallon. At present, therefore, the barrel contains 36 Imperial gallons. It may l,e worth while observing, that the barrel or cask is exclusively the pro- duce of European ingenuity, and that no such article is known to any nation of Asia, Africa, or America, who have not derived it from Europeans. The term barrel was formerly used to denote, in a rough way, other sorts of goods. Thus, a barrel of salmon was 42 gallons; a barrel of soap, 256 pounds. In common language, any hollow cylinder is called a barrel. Air and water-tight iron barrels coated with waterproof composition are now used in the navy, and might be made useful to the farmer. (M'Culloch's Com. Dict.; Brande's Dicl. of Science.)

A measure for Indian corn, in Maryland, Virginia, and other Southern States, containing 10 bushels in the ear $=$ to 3 flour barrels.

BARREN FLOWERS are those which either have stamens and no pistil, or which have neither stamens nor pistil. The latter are the production of art.

BARREN SOILS, in general, owe their sterility to the presence of too great a proportion of particular eartis-saline, or organic matters. No soil can be productive in which 19 parts out of 20 are composed of any one earth or other substance. The improvement of such soils constitutes the great art of all manuring and tillage. Lands containing an excess of calcareous matter may be improved by ture addition of clay or sand. Sands may be dressed with clay or marl, or vegetable matter. Where organic matters are in excess, the earths may be applied. Water must be removed by drain ing. (Davy's Lectures, p. 203.) See Sorus.

BARROWS. The common term for tumuli, or huge mounds of earth which were raised in former times over the bodies of heroes and warriors: many of which exist to the present day on the plains of $\mathbf{W}$ ilts and the downs of Dorset, Surrey, Sussex, and other counties. Barrow is also the name for a hog, and for any kind of carriage moved or borne by the hand. The most common barrows in use at present are the wheel-barrow, which is employed for the carriage of light loads, as of earth to short distances, lime for building, manure from the 
heaps for spreading, and the like. The handbarrow is, under certain circumstances, substisuted for the wheel-barrow. 'The load-barrow :s used for carrying filled sacks to and from the granary, \&c.

BARS. In farriery, a term applied to those portions of the crust or huof of horses that are reflected inwards, and which form the arches that are situated between the heels and the frog.

Bars of is Horse's Mouth.--The fleshy rows that run across the upper part of the mouth, and reach almost quite to the palate, very distinguishable in some young horses. They form that part of the mouth on which the bit should rest, and have its effect.

BAR-SHOE. A particular kind of shoe, which is sometimes of necessity used to protect a tender frog from injury, the hinder part of the shoe being thickened and hollowed over the frog; but unless it is made exceedingly heavy, it will soon be flattened down, and in the mean time it will most injuriously press upon the heels.

BARTER (Span. baratar; Fr. barrater; Ital. barrature, which signify to cheat as well as to barter: hence also our word barratry). The exchanging one commodity for another, without the payment of money. The term barter seems to have been derived from the languages of southern Europe. This rude mode of trade grows into desuetude as a country or nation advances in commercial knowledge, and progresses in civilization; and even where an actual exchange of commodities does take place between merchants and traders, their comparative value is expressed by certain current moneys, and balanced accordingly, and not by the proportionate value one article bears to another. The exchange of a civilized people amongst themselves, or with other countries, are principally carried on by bills of exchange. The actual money payments in a country, by no means represent the amount of its commercial transactions. (Penny Cyclop.)

BAR'TH. A provincial term, which signifies a warm enclosed place or pasture for calves, lambs, and other young animals.

BARTON, or BARKEN (Sax. bene-run, an area). A term employed in some districts to signify the yard of a farm-house. Blount describes this word as meaning the demesne lands of a manor; the manor-house itself, and sometimes the out-houses. Most of our old lexicngraphers explain it as an enclosed place, or inner yard, where poultry is kept, or husbandry used. Blount's is the provincialism of the west of England; the latter is still used in other places.

BASIL, SWEET (Ocymum. Probably from $x^{*} \omega$ and $\mu w \omega$, on account of its lasting fragrance). A culinary aromatic exotic used in salads and soups; the peculiar flavour of mock-turtle soups is chiefly derived from this valuable pot-herb. There are two species commonly cultivated, both annuals, and originally coming frcm the East Indies. 1. The sweetscented or larger basil ( $O$. basilicum), and, 2. The dwarf-busis pasil (O. minimum). They thrive most in a rich light soil, entirely free irum any overshadowing body; but they re148 quire, especially for the earliest plants, a she. tered border. In wet earth, the seed always rots.

BASIL, COMMON WILD (Chenopodium vulgare). This is also slightly aromatic, and is a perennial succulent herb, growing in bushy places, about hedges, and by road sides, on a gravelly or chalky soil. The herb rises about a foot high on a wavy, light green, hairy stem, with ovate leaves, an inch long, serrated, and the ribs beneath armed with bristly hairs. The whole of the flowers are also bristly, on branched hairy stallis, both arising from the axilla of the leaves and the top of the stem, of a light purple colour. The flowers blow in July and August. This plant flourishes abundantly in gardens. It is well known among kitchen herbs. Its very odour is fragrant and refreshing.

BASIL-Thyme. Field Thyme (Thymus acina). A leafy, small annual plant, much branched and spreading, but scarcely nine inches high, with acute, bluntly serrated leaves, rough at the edges, and slightly aromatic. The flowers are in axillary whorls of a bluish colour, variegated at the tip with white and dark purple; six on a whorl on simple stalks. It grows luxuriantly in cultivated fields, especially on a sandy, gravelly, or chalky soil. (Smith's Eng. Flor.)

BASIL. The skin of a sheep tanned.

BASILISK. (Lat.) The name for a serpent. BASIN, or BASON (Fr. bussin; It. bucino). In agriculture, a natural or artificial hollow or excavation in the ground, for the reception and preservation of water. See PoN1.

BASKETS (Basged, Welsh; bascauda, I,at. probably from bass, of which baskets were often made). They are made principally of the in terwoven twigs of willow, osier, and birch, \&c. but frequently also of grass, rushes, splinters of wood, straw, \&c. They are made to hold all sorts of dry goods, and constructed of every variety of quality and shape, from the small fruit-pottle to the bushel basket. For market baskets the osiers are used whole. Besides the vast quantities made in England, some of the finer kinds are imported under an ad valnrem duty of 20 per cent. In 1832 this duty produced $1044 l .7 s .9 d$., showing that the value of the foreign baskets entered for home consump. tion in the same year had been 5221 l. 18s. $9 d$. The fishing basket, pannier, or creel for the angler, should be made of wicker-work, with two openings for a leather strap to pass through, which sirap shouid encircle one shoulder and be bucliled, so that it may be let down or taken up as occasion may suit. There are great varieties of these panniers; some are made of sufficient width to carry a fish of four or five pounds at full length.

BASS. The material of which packing mats are made. It consists of the bark of the lime tree.

The American Bass wood, or American Lime, or Linden (Tilia Americana), abounds in the forests east of the Mississippi. It $\epsilon$ xists in Canada, but is most common in the more northern portions of the United States. It be. comes less frequent towards the south, and in Virginia, the Carolinas, and Georgia, is found 


\section{TASTARD ALKANET.}

oniy on the mountains. Michaux says he found this species of lime tree most abundant in the Genessee country, bordering on Lakes Erie and Ontario, where it frequently constitutes two-thirds, and sometimes the whole of the forests. 'The sugar maple, the white elm, and the white oak are the trees with which it most frequently associates. On newly cleared land its stump and roots frequently sprout, causing no little trouble to the settler

The presence of the lime tree indicates a loose, deep, and fertile soil. It is sometimes more than eighty feet high and four feet in diameter. Its straight and even trunk, terminating in an ample and tufted summit, forms a beautiful tree.

The wood is white and soft. In the Northern States, where the tulip poplar does not grow, it is used for the pannels of carriage bodies and the seats of Windsor chairs. It is, however, apt to split, and is not considered equal to poplar for such and other useful purposes. (North Amer. Sylva.) 'The American Lime tree or Linden is extensively cultivated in Europe, where its larger leaves easily distinguish it from the European Iime or Linden, which last bears such sweet blossoms, perfuming the air like the mock orange. The European Lin. den is so much the prey of insect borers and caterpillars as to make its preservation extremely difficult, especially in cities.

American Linden escapes much better.

The

BASTARD ALKANET (Corn Gromwell, Lilhospermum arvense). An annual weed common in waste grounds and corn-fields, especially among rye, flowering in May and June. It may be easily known by its tapering root, with a bright red bark, which communicates its colour to oily substances, as well as to paper, linen, and pale faces; and it is therefore occasionally used by the young girls in Sweden to colour their cheeks. This colouring matter is also used to tinge some ointments, especially lip-salves, of a red colour. From the root usually rises a single stem, about a foot high, rough, and generally branched and spreading at the top; sometimes decumbent. The flowers are small and white, surrounded with five long, narrow, hairy leaves. Wildenow says, he has seen a variety with blue flowers. (Smith's Eng. Flor.)

BASTARD-TOADFLAX (Thesium linophyllum). An English perennial wild plant, with terminal clusters of whitish or yellowish blossoms, many-flowered, erect, generally branched or subdivided, flowering in July. Its root is woody and yellowish, stems widely spreading, angular, leafy, a span or more in length; leaves turned to one side, rough-edged, light-green, an inch long at most. Found in high open chalky pastures. The only species of this genus known in the United States is the Thesium umbellatum. (See Darlington's Florn Cestrica.)

BAT, or FLITTERMOUSE (Cheiroptera, a hand and wing). A mammiferous animal which has a body like a mouse, with wings not feathered, but consisting of a membranous skin extended. These wings of the bat, osteologically considered, are hands; the bony stretchers of the cutaneous membrane being

\section{BAY OF A BARV.}

the digital platanges, or finerers; eztrrmely elongated; one digit or linerer of ear:h wang is tipped with a small nail. Bats are widely spread over the globe; they are to lie finsud in the Oid and New World, and in New Hulland. A tolerably temperate climate seems wecessary for them, and the greatest developernent of the form takes place in warm countries. (ienerally speaking, they remain in concealucent during the day in caverns, ruinous buildings, hollow trees, and such hiding places, anll ilf forth at twilight or sunset to take their jrey. They feed mostly on flies, insects, \&c., but do not refuse raw flesh, so that the notion that bats go down chimneys and gnaw men's bacorn is no improbable story.

Bats are dividerl into two classes, the omnivorous or fruit-eating, and the insectivorous. Those who are desirous of further investigating the subject will find ample particulars under the head "Cheiroptera" in the I'enny Cycls. vol. vii. p. 19.

BATEABLE HERBAGE. Provincially such herbage as has the tendency of readily fattening stock of different kinds.

BAT FOWLING. A particular manner of bird-catching in the night, while they are at roost under the eaves of harns, or upon trees or hedges. The fowler lights torches or straw, and beats the bushes, upon which the birds, dazzled by the light, fly into the flames, and are then knocked down with sticks, or caught either with nets or by other means.

BATING. An abbreviation of abating From bate, to iessen any thing, to retrench, to sink the price. Thus Locke says, "When the landholder's rent falls, he must either bate the labourer's wages, or not employ or not pay him." It is also used synonymously with barring, to except.

BATTEN (probably froin the French batôn, from its slender width). A name in common use for a slip or scantling of wood from two to four inches broad and one inch thick, the length inconsiderable, but undefined. If above seven inches wide, it is called deal.

It also signifies strong broad fencing rails. It is sometimes written batton.

BAY (Lat. badius; old Fr. baye, bai, rouge brun; Ital. baio). The term for a colour inclining to a chestnut. In reference to the horse this colour has various shades, from the very light bay, to the dark bay, which approaches nearly to the brown; but it is always more gay and shining. There are also colouted horses that are called dappled bays. All bay horses are commonly called brown. Bay horses have black manes, which distinguish them flom the sorrel, that have red or white manes. There are light bays, and gilded bays, which are somewhat of a yellowish colour. The chestnut bay is that which comes nearest to the colour of the chestnut.

The bay is one of the best colours of horses, and horses of all the different shades of bays are commonly good.

BAYARD. A provincial term for a baf horse.

BAY OF A BARN. That part where the mow is placed. Hence such barns as have the thrashing-floor in the midule, and a spact 
for a mow on each side, are called barns of two bays, \&e.

BAY-SALT. The salt made naturally on the sea-shore at St. Ubes and other bays, in the natural hollows of the sea-shore which are only overflowed at spring tides. The salt thus made at a low temperature by the action of the sun and wind is the strongest and best for butter and other agricultural purposes. (Brownrigg on Salt; Brande's Dict. of Science.)

Bay-salt is in large, moderately white cubes. St. Ubes' salt contains 960 parts of pure chloride of sodium in 1000 parts; the remainder consists of 28 parts of sulphate of lime and of magnesia; 3 parts of chloride of magnesia, or bittern; and 9 of insoluble matter. It is consequently very pure. Similar salt, but less pure, is made at St. Martin and Oleven. (For its dietetical use 3 and as a manure, see $\mathbf{S}_{\mathbf{A} \mathbf{L T}}$, Salting.)

BAY-TREE (Laurus nobilis). This plant, the laurel of antiquity, is a native of classical ground. We cannot ascertain at what exact period the bay-tree was first cultivated in this country; but in all probability it was planted by the Romans, and fell with their villas. Chaucer, who wrote in the time of Edward III., mentions it; and Turner, our oldest writer on plants, says, in 1564, "the bay-tre in England is no great tre, but it thryueth there many parts better, and is lustier than in Germany." We find that during the reign of Elizabeth it was common to strew the floors of distinguished persons in England with bay-leaves. And we may conclude that it was rare in this country, even so late as the beginning of the eighteenth century, for Bradley says, in 1716, "they (baytrees) should be put in pots or cases, and housed in the winter, that their beauty may be preserved." He states, that "he has seen pyramids and headed plants of bays introduced in parterre work, but he cannot advise the doing it, lest they should be injured by the weather." There need be no such care taken now, for they have become thoroughly hardy and acclimated. Bradley adds, the finest bay-trees he had ever seen, either abroad or in England, were then in the royal gardens of Kensington, and were of very great value.

The bay is a small tree, seldom exceeding fifteen to twenty feet in height. The bark is greenish, smooth, and aromatic: the leaves anceolate, sharp-pointed, wavy on the edge, and leathery and smooth on both sides. The flowers are four or six in a cluster, of a yelowish white, glandular, and dotted. The fruit is about the size of a large pea, black, and succulent.

Observation instructs us to place this tree in situations where it is sheltered from north and north-east winds, which affect its beauty, and often its growth. It thrives under the very wings of larger trees, where it is difficult to make other shrubs prosper, and this is of importance in our plantations. A warm, dry, sandy, or gravelly soil is recommended for the bay; but it thrives well on a rich loam. We are told by Mortimer, that bay-trees, whose branches are killed by the weather, or other accident, if cut down to the ground, will send up strong shoots, which we know by experi150 ence to be correct; therefore, the roots shruld not be grubbed up too hastily. This tree should never have a branch taken from it but in the spring. The directions for raising these trees from seed are given in the same manner by all writers on the subject, from Pliny down to Miller. It is, to gather the fruit when quite ripe, which is not before January or February. The berries are then to be preserved in dry sand until the middle of March, when they may be sown in a shady border of rich, loose, undunged earth. The berries, should be dropped in rows as French beans are planted, and covered with fine, rich mould about an inch thick. The young plants will require frequent but moderate watering for the first two years. The French nurserymen raise them inder glass, or in an orangery. The bay-tree will grow by cuttings, but these should be planted in a moderate hot-bed, and kept moist and covered from the heat of the sun during summer, and from the frost in winter. April is the proper time to plant cuttings, but layers may be laid down either in March or August, which, by the second spring, will make good plants.

'The variegated bay is increased by budding it on the common sort. Neither the broad nor the narrow-leaved varieties are so hardy as the common bay. The leaves and berries of the bay-tree have an aromatic, bitter, astringent taste, and a fragrant smell: and are ac. counted stomachic, carminative, and narcotic; but they are not much used in medicine at the present day, although old writers are very voluminous in describing their virtues. (Phillips's Syl. Flor.)

This well-known evergreen is always handsome in shrubberies, and grows well. It prefers a northern aspect: indeed, we may almosi consider the bay-tree a native of England, since gardens and shrubberies are now rarely formed without their presence. The leaves and berries are used as medicine; the leaves should be dried in the proper way, pounded, and kept in glass bottles; they are said to be cordial and beneficial in nervous complaints, and in paralysis: in large doses they prove emetic. The green leaves applied to the part allays the pain of the sting of bees. The berries of the bay-tree coniain both volatile and fixed oil, wax, resin, uncrystallizable sugar, gums, starch, some salts, and a peculiar sub. stance, which has been named laurin, and bears some resemblance to camphor. The dried berries are given in powder or infusion in fiatulent colic ; but they are of little value.

BEAGLE (Fr.bigle). A small well-proportioned hound, slow but sure, having an excellent nose and most enduring diligence ; formerly much in fashion for hunting the hare, but now comparatively neglected, its place being occupied, where hare-hunting is patronized, by the harrier. There are still several varieties of beagles, but formerly there appear to have been many more, from the deep-flewed diminutive tyne of the old southern hound, to the fleet and elegant fox-hound beagle, to which we may ard the pigmy breed called lap-dog beagles. Beagles were formerly distinguished into the rough and the smooth. The rough. wire-haired, or terrier beagle, is now seldom 


\section{BEAM.}

BE.ANS.

met with, although it was a hardy, and altogether a vermin-loving breed, and very strongly formed. (Bluine's Encyclopedia of Rurul Sports.s.)

BEAM. The principal piece of timber which supports a building.

BEAM OF A PLOUGH. 'The upper princroal timber into which the handles and all the other parts of the tail of the plough are fixed. It is most commonly made of ash wood, somewhat bent in its form, and of different lengths according to the nature of the plough. (See Ploughs.)

BEAM-TREE. The Pyrus aria of botanists. The white beam-tree or wild pear-tree, is a deciduous British tree of small growth inhabiting the mountainous parts of the country, and resembling a small apple-tree with berries like those of the mountain ash. Its leaves are strongly veined, in a plaited manner, and white underneath; the wood is hard, compact, and tough, and is used for axle trees, naves of wheels, and cogs of machinery. (Brande's Dict. Sicience.)

BEANS (Vicia Faba). A well-known vegetable of the pulse species, largely cultivated both in gardens and fields. Sax. bean; vicia is the Latin name for the tare or vetch; derived, according to Varro, a viciardo, because its tendrils entwine or bind round other plants. The bean was called in Greek Kúxuos; by the Falisci, a people of Etruria (now Tuscany), Haba, whence the name Faba seems to be taken. Martinius derives the word from $\pi$ aw, to feed, as if it were $\mathrm{Paba}$; Isidorus from qán, to eat. Its cultivation is of much importance in rural economy, inasmuch as it has gone far to supersede fallows on strong loams and clays. The bean is a plant of considerable importance to the farmer, as affording him a valuable food for both horses and swine; its varieties are numerous, but as it is cultivated both for agricultural and horticultural purposes, it will be necessary, in treating of its cultivation, to adopt the following arrangement:-1. Field beans; 2. Garden beans. The English growth of beans has or late years dininished, a large portion of the consumption of this country now coming from abroad; yet I am of opinion that beans or peas, according to the soil, should enter into the rotation of the crops of all English farms: for if drilled and well horse-hoed, it is one of the finest preparations for wheat. And it may be well to observe, that the Russian or winter bean may be successfully cultivated on moist soils.

The flowers of the bean emit a most agreeable perfume. Of all the pulse kind, this was held in the first rank in ancient times. We find the Athenians used beans sodden, in their feasts dedicated to Apollo; and the Romans presented beans as an oblation in their solemn sacrifice called Fabaria. Pliny informs us that they offered cakes made of bean meal unto certain gods and goddesses in these ancient rites and ceremonies. Lempriere states that bacon was added to the beans in the offerings to Cama, not so much to gratify the palate of the goddess, as to represent the simplicity of their ancestors. One of the most noble and powerful families of Rome derived the name of Fabii from some of their ancestory having cultivated the bean called fulu. The meal of beans is the heaviest made from pulse. and was called in Latin Lmentum. This was mingled with frumentii corn, whole, and so eaten by the ancients; but they sometimes bruised it first; it was considered a strung food, and was generally eaten with gruel or pottage. Many superstitious customs and notions were in olden times attached to this pulse. The ancients made use of beans in gathering the votes of the people, and for electing the magistrates. A white bean signified absolution, and a black one condemnation. From this practice, no doubt, was derived the plan of black-balling obnoxious persons. 'The Roman husbandman had a religious ceremony respecting this pulse, somewhat remarkable: when they sowed corn of any kind, they took care to bring some beans from the field for good luck's sake, superstitiously thinking that by such means their corn would return home again to them; these beans were then called Refrinæ or Referinx. The Romans carried their superstition even further, for they thought that beans mixed with goods offered for sale at the ports would infallibly bring good luck to the seller.

In some places bean meal is still mixed with other meal in making coarse bread; or the beans are boiled into a mess with fat meat, in which state they are very nutritious. Bean meal given to oxen soon makes them fat; mixed with water and given as a drink to cows, it greatly increases their milk. A small quantity of beans is generally mixed with new wheat when ground to flour: the millers pretend that soft wheat will not grind well without beans, and they generally contrive that there shall be no deficiency in the necessary proportion. Thus a quantity of beans is converted into what is considered as wheaten flour.

The bean came originally from the east, and was cultivated in Egypt and Barbary in the earliest ages of which we have any records. It spread thence into Spain and Portugal, from whence some of the best varieties have been introduced into this country. The proportion of nutritive matter in beans, compared with other grain, is, according to Einhof, as follows:-

\begin{tabular}{|c|c|c|c|c|c|}
\hline \multicolumn{4}{|c|}{ By weight. } & \multicolumn{2}{|r|}{ Or in a busbel. } \\
\hline Wheat & - & 74 per cent. & - & - & - about 47 ibs. \\
\hline Rye & - & 70 & - & - & $-\quad 39$ \\
\hline Barley & - & - & - & - & $-\quad 33$ \\
\hline Oats & - & - & - & - & -23 \\
\hline Beans & - & - & - & - & -45 \\
\hline Peas & - & - & - & . & -49 \\
\hline French & beans 8 & - & - & - & -54 \\
\hline
\end{tabular}

The same chemist obtained from 3810 parts of marsh beans (Vicia Faba), of

$$
\begin{aligned}
& \begin{array}{l}
\text { Starch } \\
\text { Albumen }
\end{array} \\
& \text { Other matters, nutritive, gummy, starchy, } \\
& \text { fibrous, analogous to animal matter }
\end{aligned}
$$

And from kidney beans (Phæseolus vulgaris) of

Starchy matters $\cdot 1805$

Albumen, and matter approaching to animal matter in its nature - $-\quad: \quad 851$ Mucilage 
Beans are best giver broken, especially to aged live stock. An excellent bean mill constructed by the Messrs. Ransome of Ipswich, will break one quarter of beans in an hour. It is also made with an extra roller and plate for malt; and is sometimes constructed so as to render it suitable for horse power.

Field Beans.-In England, the sorts usually cultivated in the fields are, the tick bean, the horse bean, and the small Dutch Heligoland, or prolific bean. In some situations the mazagon, longpod, and winter or Russian bean, have produced good crops in the field: the first three are, however, best suited for general cultivation. The last, a new and useful variety, has been more recently introduced, and has lately come into very general cultivation in various parts of the kingdom. It is planted in autumn in the usual manner, and is superior to the common bean, inasmuch as it is capable of resisting the severest frost, and is ready for harvesting two months earlier.

There are several varieties of beans, which differ but little in their appearance. Experience is the best guide in choosing the seed which suits particular soils and situations. The small, round, regular-shaped beans are generally preferred, as obtaining the best prices in the markets, especially in large towns where there is a great consumption of beans by hardworking horses.

All the varieties thrive best on strong clay soils, heavy marls, and deep loams of a moist description. In such soils the produce is sometimes 30 to 60 bushels per acre, but an average crop on moderate land is about half that quantity. The Heligolands, and especially the Russian bean, have been found very productive when grown upon hazel moulds, and deep chalk soils intermixed with loam, as they do not require so close a soil as the other varieties. The last-named varieties seldom succeed sufficiently to repay the grower, if attempted to be raised on light lands; indeed, sandy soils or late climates are ill adapted to the successful cultivation of the bean. On very rich land, beans have produced extraordinary crops, by being sown broadcast and very thick, the stems being brought up to a great height in favourable seasons. A small field of very rich land, in the county of Sussex, wats sown in the year 1832 with four bushels of the small tick bean, which came up so thick, that the proprietor thought of thinning ont the plants by hoeing; but he was advised :o see what the produce would be, and when they were thrashed out, there were ten quarters and one bushel of beans. He had the ground accurately measured, and it was found to be one acre and twenty-nine perches, which makes the crop above sixty-eight bushels per arre.

Beans are propagated by seed, which may be sown broadcast, drilled, or dibbled; if sown Lroadcast, three or four bushels of seed per ncre wili be required, which should be nls,ughed or harrowed in; if drilled, two and a half or three bushels per acre will be sufficient. Beans are tolerably hardy, and will bear moderate dry frosts; but they suffer much from alternate frosts and thaws, which in this climate are so common in February. The enc of February or the beginning of March is, therefore, generally preferred for bean sowing. When the season is remarkably mild, early sowing is a great advantage. As a general rule, spring beans may be sown from the middle of February to the middle of March. There are two modes of drilling beans. In one of these the lands or ridges are divided by the plough into ridgelets, or "one bout-stitches," at intervals of about twenty-seven inches.

If dung is applied to beans, the seed ought to be deposited first, as it is found inconvenient to run the drill machine afterwards. The dung may then be drawn out from the carts in small heaps. one row of heaps serving for three or five ridgelets; which is evenly spread and equally divided among them. The ridgelets are next split back or reversed, either by means of the common plough, or one with two mould-boards, which covers both the seed and the manure in the most perfect manner. When beans are sown by the other method in the bottom of a common furrow, the dung must be previously spread over the surface of the winter or spring ploughing. Three ploughs then start in succession, one immediately behind the other, and a drill-harrow either follows the third plough, or is attached to it, by which the beans are sown in every third furrow, or at from 24 to 27 inches asunder, according to the breadth of the furrow-slice.

Another improved mode of sowing beans when dung is applied at seed time, is to spread the dung and plough it down with a strong furrow; after this, shallow furrows are drawn, into which the seed is deposited by the drill machine. Whichever of these modes of sowing is followed, the whole field must be carefully laid dry, by means of channels formed by the plough, and when necessary, by the shovel; for neither then nor at any former period should water be allowed to stagnate on the land. It is a common practice with many farmers to mix and sow with beans a proportionate part of peas, about one-fourth, which, when growing, are called $P_{\text {olts, }}$ and are thus cultivated both on the drill and broadcast system. In either case the seed should be put into the ground by the latter end of January, or as soon after as the weather and state of the land will permit. By this intermixture of peas and beans, the straw or haulm is said to be greatly improved. In some places the peas are sown on the headlands, and the haulm is used to tie the beans with; but peas cling round the bean-stalks and impede the setting of the pods; they also interfere with the hceing and weeding, so that the practice is not to be recommended. Peas require a lighter soil, and are best sown separately, except when they are sown broadcast, mixed with beans, in order to be mown in a green state as fodder for cattle or pigs. Sowing beans for this last-mentioned purpose is not much practised in England, but is found very useful on the Continent, especially in Flanders; in this case they are mown like tares, soon fiter the pods are formed. In order to have a succession of this green food, they should be sown at different times within a week or a fortnight of each other. By this 
means a great deal of grass is saved, which may he reserved for hay. The cattle fed in the stables or yards thrive well on this food, and produce a quantity of rich manure, chiefly in a liquid state, which fills the tanks and reservoirs, which are indispensable appendages to every farm-yard. By having winter tares when the turnips are consumed, peas and beans after the first crop of clover, and suminer tares to succeed them, cattle may be fed in the stables all the year round with great adrantage; the land may be tilled at the best season of the year and prepared for wheat, as well as by a clear fallow, while the green crop will fully repay all the expenses. Three bushels of beans and two of peas, mixed together, are required per acre, when sown broadcast or drilled in each furrow after the plough. It is often advantageous to cut in a green state those beans which were sown for a general crop, when food for pigs is scarce. They will go nearly as far in this way in feeding store pigs, as the beans would have done when ripe: and the ground is left in a much better state for the following crop. (Penny Cyclop. vol. iv. p. 82.)

Many farmers have long and advantageously adopted the practice of dibbling in their beans, by which a great saving of seed is effected; neither are they required to be planted so early as by the old system. Besides being more evenly deposited in the soil, and properly covered over, they are better preserved from rooks, and other vermin that would destroy them. Drilling, however, is still preferred by most agriculturists, as being a less expensive course. Both drilling and dibbling have each great advantages over the broadcast system, as by the latter method the land cannot be kept clean.

Some parties recommend the topping of beans just as the blossoms are set, and assert that it not only improves the quality, but increases the quantity, and causes them to ripen sooner. They may be switched off with an old scythe-blade, set in a wooden handle, with which one man can easily top two acres a day. Others object, and with much justice, to this indiscriminate hacking and topping. The reason for doing this in garden culture is, that when a plant has borne pods a certain time, it is most advantageous to remove it, and the top blossums, of course, never come to perfection. In the field this is not the case, there being no succession of plants; and, unless the top blossoms are very late, or the black dolphin (aphis) begins to appear, which is shown by the honey-dew on the upper shoots, no advantage is gained by topping the plants, and the labour is thrown away. The bean crop is generally harrowed to destroy annual weeds: sometimes just before the plants make their appearance, and sometimes after the beans have got their first green leaves, and are fairly above ground. After the beans have made some growth, the horse-hoe is employed in the intervals between the rows, and followed by the hand-hoe, for the purpose of cutting down such weeds as the horse-hoe cannot reach; all the weeds that grow among the beans should be pulled up with the hands. The same ope- rations are repeated as ofien as the comisuon of the land in regard to cleanliness may require.

When the leaves of the benus lemin to lose, their green colour, and the poils w iurn black, the crop should be reaped with the sickle, and made into small sheaves, tied wish straw-bands or tarred twine, and set up in the field to dry. But if the haulm is short, as that of the long. pod and mazagan generally are, it is a more profitable course to pull them up by the rocits, and lay them in sheaves, the same as if cut, by which means the lowest and earliest pols are better preserved and harvesterl. Mr. J. C. Curwen, M. P. (Com. In) the Bourd of Agr., vol. iv. p. 390) gives some details of the result of experiments made in 1803 and 1804 , of cutting beans whilst in a perfectly green and fresh state. Forty acres of beans were drilled in February, 1804, and from May to the middle of July the ploughs and harrows were constantly at work in it. By the 10th of August, the beans had shot the black eye, which is the criterion of seeds being perfectly formed. The weather proving unfavourable, prevented their being reaped immediately, but they were eventually cut on the 20th of August, spread thinly, and exposed two days to the sun previous to binding and removing to an open pasture, where they remained three weeks, and were then found perfectly dry and fit for stacking. Mr. Curwen adds, as a strong proof of the benefit resulting from these early cuttings, that he was enabled, previous to drilling with wheat. to give the ground two ploughings, harrowings, \&c., and in some parts three (the extreme foulness of this piece of land requiring what in few instances would be necessary); and to cart and spread sixty loads of compost per acre, and to complete the whole by the $20 \mathrm{th}$ of September. Mr. Jolnn Sherif, of Haddington (Com. Bourd of $A g r$., vol. iv. p. 172), also says of harvesting beans, "This crop should be cut down as soon as the eye has attained its deepest dye, and instantly, if dry weather, sheaved. The sheaves of any grain or pulse ought not to exceed nine inches in diameter; and I think that sheaves from six to eight inches would be far safer in this variable climate. By cutting at this period of the state of the crop, the bean-straw will be of triple value of what stands till the leaves fall off; the grain too will be superior to that bleached by the weather for weeks, after the haulm and grain of the first is secured in the rick. Shocks of any crop of pulse or grain ought not to exceed six sheaves of the above-mentioned size." The Rev. John Ramsay, of Ayrshire, and Mr. John Boys, of Kent, also give the result of their observations on bean husbandry (Com. Board of Agr., vol. vi. p. 141-146), which, though valuable, are of too confined and local a na: ture for me to notice.

The diseases to which beans are subject ir. England, are the rust, or mildew, which is a minute fungus that grows on the stems of leaves, attributed to cold fogs and frequen! sudden transitions of weather, and the black dolphin or fly, also called the collier, an insec: of the aphis tribe. For the mildew no remedy has yet been found. Whenever it has attacke 3 
the plants, generally before the pods are filled, the best method is to cut down the crop in its green state; and if it cannot be consumed in the farm-yard, to plough it into the ground, where it will decay rapidly, and be an excellent manure for the succeeding crop of wheat. If allowed to stand, the crop will not only be unproductive, but the weeds will infest the ground, and spoil the wheat crop by their seeds and roots, which will remain in the soil. Whenever the tops of the beans begin to be moist and clammy to the feel, it is the forerunner of the aphis. They should then be immediately cut off, and this, if done in time, may save the crop from the ravages of the insects; but the most effectual way to prevent any disease from attacking the plants in their growth, is to have the ground in good heart, and well tilled; to drill the beans at a sufficient distance between the rows, to allow the use of the horse-hoe, and thus to accelerate the growth of the plants, and enable them to outgrow the effect of incipient disease, which seldom attacks any but weak plants. In the year 1831, there were imported fiom abroad 23,388 qrs. of beans. The largest proportion came from the following countries; Denmark, 1299 qrs.; Prussia, 1157 qrs.; Germany, 7664 ๆrs.; the Netherlands, 7070 qrs.; France, 1454 qrs.; Italy, 3691 qrs.; Malta, 1031 qrs. The total quantity of pulse (for beans and peas are included in the return) entered for home consumption in 1834, was 102,080 qrs.; in 1835, 94,540 qrs. (Appendix to Second Agr. Report for 1836, p. 282.; Phillips's Cultivated Vegetables; Penny Cyc. vol. iv.; Baxter's Agr. Lib.; Prof. Low's work on Agr.; Com. Board of Agr., vols. iv. and ri.; M'Culloch's Com. Dict.)

Garden Beans. - The following varieties are those principally cultivated:-Early mazagan, a great bearer, and a good sort. Early Lisbon, or Portugal bean, a small and sweet kind. Common sword, and other long-pods, the most abundant bearers, and consequently more generally found in the cottager's garden than any other sort. Small Spanish. Broad Spanish. Toker, a good bearer, middling large. White and black blossomed, good sorts, and bear well; middling size: the seed, when old, is apt to degenerate if not saved with care. Windsor, one of our best-tasted beans when young; but not a hardy kind. Green nonpareil, smallish. Besides these, there are the Munford, Dwarf-cluster, or Fan, and the Red blossomed, varieties of little value. In some places the Fan is, however, much grown. It grows only from six to twelve inches high; the branches spread out like a fan, and the pods are produced in clusters. The soil should vary with the season. For the winterstanding and early crops, a moderately rich and dry soil is best adapted to them, since, if oo moist, the seed is apt to decay, \&c., whilst a moist aluminous one is best for the spring and summer insertions. Although the bean $\mathbf{w}$ :ll succeed in much lighter soils than is gewerally imagined, yet, if such are allotted to it when thus late inserted, the produce is much diminished. The situation cannot be too unincumbered, but still a protection from violent winds is very beneficial, as no plant is more 154 liable to suffer if its leaves are much injured. It is propagated by seed. For the first production, in the following year, a small plantation may be made at the close of October, or during November, and a rather larger one in December. These should be inserted on a south border, in a row, about a foot from the fence, or in cross-rows. If intended for transplanting, the seed may be sown likewise during these months. Regular plantations may be continued to be made from the beginning of January to the end of June, once every three weeks. Early in July and August the two last crops nust be inserted. The Windsor, which is the principal variety then planted, should have a south border allotted; it comes into production about Michaelmas.

The experiments of Bradley serve as a guide in some respects, whereby to apportion the extent of the plantations. He found that a rod of ground, containing fourteen rows, in pairs, at two feet distance, the plants in which are six inches apart, or thirty-four in number, will yield forty-seven quarts of broad beans. Smaller varieties only from one-half to one. third as many. (General Treat. on Husband. and Garden., vol. iii. p. 16.) If the plants are intended to be transplanted, which is only practised for the early crops, the seed must be sown thick, about an inch apart, in a bed of light earth, in a sheltered situation, and of such extent as can be covered with a frame. If frames and hand-glasses are deficient, matting or litter, kept from pressing on and injuring the plants, by means of hooping, \&c., are sometimes employed.' These, however, afford such imperfect shelter, that there is scarce any advantage superior to the mode of sowing at once, where the plants are to remain, since the intention of this practice is to keep them in vigour, and to forward their growth, by securing them from ungenial weather. Care must be taken that they are not weakened from a deficiency of air or light; to guard against this, the lights should be taken entirely off every day that excessive wet or cold does not imperatively forbid their removal. The usual time for removing them into the open ground, in a south border, is February; if, however, the season is inclement, they may be kept under the frame until May; but then a week previous to their removal, Bradley informs us, they ought to be cut down within two inches of the ground. (Gen. Treat. on IIusband. and Garden.) When removed, as much earth as possible should be retained round the ruots of plants; and they must be set at similar distances as the main crops. No water is required, unless the season be very dry. When sown to remain, the seed may be inserted in rows, by a blunt dibble, or in drills, drawn by the hoe, from two and a half to three feet apart, from two to four inches apart in the row, and two deep, the earliest crops and shortest varieties being set at the smallest dis tances. These spaces may be considered as large by some gardeners; but the beans, Miller, from experience, asserts, are more productive than if set twice as close. Previous to sowing, in summer, if dry weather, the seed should be snaked for two or three hours in water, or if 


\section{BEAN, KIDNEY.}

sown in drills, these must be well watered immediately before the insertion. When advanced to a height of two inches, hoeing between, and drawing earth about the stems of the plants may commence. 'This must be often repeated, and even sooner begun to the early and late crops, as it affurds considerable protection from frost and wind. As soon as the various crops come into blossom, two or three inches length of each stem is broken off; this, by preventing its increase in height, causes more sap to be afforded to the blossom, consequently causing it to advance with more rapidity, and set more abuntantly. Some gardeners recommend the tops to be taken off when the plants are young, not more than six inches high, declaring it makes them branch, and be more productive. This may be ultimately the effect, but it is certainly incorrect to state that it brings them into production sooner: the effect in this respect is much the contrary. The winter-standing crops require, in the early stages of their growth, the shelter of diy litter, prevented touching the plants by small branches, \&c. This is only requisite during very severe weather; it must be constantly removed in mild open days, - therwise the plants will be spindled and weakened. For the production of seed, plantations of the several varieties should be made about the end of February, in a soil lighter than that their produce is afterwards to be grown upon. No two varieties should be grown near each other; and in order to preserve the early ones as uncontaminated as possible, those plants only which blossom and produce their pods the first should be preserved. Water ought to be given two or three times a week, from the time of their blossoming until their pods have done swelling. None of the pods ought to be gathered for the table from them; the after-production of seed is never so fine, and the plants raised from it are always deficient in vigour. They are fit for harvesting when the leaves have become blackish, which occurs at the end of August or early in September. They must be thoroughly dried, being reared against a hedge until they are so, before the seed is thrashed out and stored; and those only should be preserved that are fine and perfect. Some galdeners even recommend the pods from the lower part of the stem alone to be selected. Seed beans will sometimes vegetate after being kept for eight or ten years, but are seldom good for any thing when more than two. The plants arising from seed of this age are not so apt to be superluxuriant as from that produced in the preceding year.

BEAN, KIDNEY (Phaseolus vulgaris, from its pods resembling a species of ship, supposed first to have been invented at Phaselis, a town of Pamphylia): Of this vegetable there are two species, the one being a dwarf bușhy plant, the ather a lofty climbing one.

Of the Dwarfs there are twelve varieties:Early liver-coloured. Early red-speckled. Early white. Early negro, or black. Canterbury white. Battersea white.

\section{BEAN, KIDNEY.}

Of the Runners there are six varieties:-

Scarlet runner.

Large white.

Canterbury small whice.

Large white Dutch. Variable runner.

The soil for them may be any thing rather than wet or tenacious, for in such the grratr. part of the seed, in general, decays withoul germinating; whilst those plants which are produced are contracted in their produce and continuance. A very light mellow loam, ever inclining to a sand, is the best for the earliest sowings, and one scarcely less silicious, though moister, is preferable for the late sum. mer crops; but fi $r$ the later ones a recurrence must be made to a soil as dry as for the early insertions. In all cases the suissoil must be open, as stagna. $t$ moisture is inevitably fatal to the plants or seed. For the early and late crops a sheltered border must always be allotted, or in a single row about a foot from a south fence, otherwise the situation cannot be too open.

Dwarfs.-The sowing commences with the year. They may be sown :owards the end of January in pots, and placed upon the flues of the hot-house, or in rows in the mould of a hotbed, for production in March; to be repeated once every three weeks in simiiar situations during February and March, for supplying the table during April, May, and June. At the end of March and April a small suwing may be performed, if fine open weather, under a frame without heat, for removal into a sheltered border early in May. During May, and thence until the first week in August, sowings may be made once every three weeks. It. September, forcing recommences : at first merely under frames without bottom heat, but in October, and thence to the close of the year, in hotbeds, \&c., as in January. Sowings, when a removal is intended, should always be performed in pots, the plants being less retarded, as the roots are less injured, than when the seed is inserted in patches or rows in the earth of the bed. It is a good practice likewise to repeat each sowing in the frames without heat after the lapse of a week, as the first will often fail, when a second, although after so short a lapse of time, will perfectly succeed. In every instance the seed is buried one and a half or two inches deep. The rows of the main crops, if of the smaller varieties, may be one and a half, if of the larger, two feet apart, the seed being inserted either in drills or by the dibble four inches apart; the plants, however, to be thinned to twice that distance.

If any considerable vacancy occurs, it may always be filled by plants which have been carefully removed by the trowel from where they stood too thick. A general remark, however, may be made, that the transplanted beans are never so productive or continue so long in bearing (although sometimes they are earlier) as those left where raised. The rows of the earlier crops are best ranged north and south The seed inserted during the hottest period of summer, should be either soaked in water for five or six hours, laid in damp mould for a day or two, or the drills be well watered previous to sowing. The only after-cultivation requirec 
is the destruction of weeds, and earth to be drawn up round the stems.

The pods of both species are always to be gathered while young; by thus doing, and care being had not to injure the stems in detaching them, the plants are rendered as prolific and long-lived as possible.

Forcing.-The hotbed must be of moderate size, and covered with earth eight or nine inches thick. When the heat has become regular, the seed may be inserted in drills a foot apart, and the plants allowed to stand six inches asunder in the rows. Some gardeners erroneously sow thick in a hotbed, moulded over about six or seven inches deep, and remove the plants, when two or three inches high, to the above-mentioned distances in another for producing, water and shade being afforded until they have rooted. Air must be admitted as freely as to the melon. The same precautions are likewise necessary as to keeping up the temperature, taking the chill off the water, \&c., as for that plant. When the seed begins to sprout, the mould should be kept regularly moistened; and when grown up, water may be given moderately three times a week. The temperature should never be less than $60^{\circ}$, nor higher than $75^{\circ}$.

Some plants of the hotbed sowing at the end of March, are often, after being gradually hardened, planted in a warm border; this will at most hasten the plants in production a fortnight before those sown in the open ground in May.

Those sown under frames in March for transplanting into a border, when two or three inches in height, must in like manner be harlened gradually for the exposure, by the plentiful admission of air, and the total removal of the glasses during fine days. If any are raised in pots in the hot-house, they must in a like manner be prepared for the removal, by setting them outside in fine days, and there watering them with colder water. If the season is too ungenial after all to remove them even to a warm border, the plants are often inserted in patches, to have the protection of frames or hand-lights at night, or as the weather demands. It has been lately stated in a provincial paper, that kidney-beans appear of a perennial nature. In Somersetshire, they have been observed to vegetate for several years-the plants being in the vicinity of a steam-engine, and so situated that the frost could not penetrate to the roots. I have not yet had an opportunity of putting this statement to the test of experiment.

Runners.-As these are more tender, and the seed is more apt to decay than those of the Dwarfs, ru open ground crop must be inserted before the close of April, or early in May, to be continued at intervals of four weeks through June and July, which will ensure a supply from the middle of this last month until October. Some gardeners force them in a similar manner to the Dwarfs: they certainly require similar treatment; but they will endure a kigher temperature by a few degrees. They are so prolific, and such permanent yearers, that three open-ground sowing of a $15 t$ size proportionate to the consumption will, in almost every instance, be sufficient.

The runners are inserted in drills, either singly, three feet apart, or in pairs, ten or twelve inches asunder, and each pair four feet distant from its neighbour. The seed is buried two inches deep and four inches apart in the rows, the plants being thinned to twice that distance. If grown in single rows, a row of poles must be set on the south side of each, being fixed firmly in the ground; they may be kept together by having a light pole tied horizontally along their tops, or a post fixed at each end of a row, united by a cross-bar at their tops; a string may be passed from this to each of the plants. If the rows are in pairs, a row of poles must be placed on each side, so fixed in the ground that their summits cross, and are tied together. They are sometimes sown in a single row down the sides of borders, or on each side of a walk, having the support of a trellis-work, or made to climb poles which are turned archwise over it.

As the plants advance to five or six inches in height, they should have the earth drawn about their stems. Weeds must be constantly cleared away as they appear. When they throw up their voluble stems, those that straggle away should be brought back to the poles, and twisted round them in a direction contrary to that of the sun: nothing will induce them to entwine in the contrary direction, or from left to right.

For the production of seed, forty or fifty plants of the Dwarf species will be sufficient for a moderate-sized family, or thirty of the Runner. They must be raised purposely in May, or a like number from the crop in that month may be left ungathered from; for the first pods always produce the finest seeds, and ripen more perfectly. In autumn, as soon as the plants decay, they must be pulled, and, when thoroughly dried, the seed beaten out and stored. (G. W. Johnson's Kitchen Gaiden.)

BEAN-FLY. A beautiful bluish black fly, generally found on bean flowers. It is sometimes called the collier. The aphides of beans are invariably brought on by very dry weather; they are most prevalent on the summits of the plants. (See Bears.) The larvæ of the ladybird, or lady-cow (Coccinella seplempunctata), as well as the perfect insects, devour the aphis greedily, feeding almost entirely upon these insects. Several of the English summer birds also live upon them.

BEAR. A species of barley, called also winter barley, square barley, and big. It is sometimes written bere. This grain is chiefly cultivated in Scotland, the northern parts of England, and Yreland. It yields a very large return, but is not esteemed so gond for malting as the common barley, for which reason it is very little cultivated in the southern parts of England.

BEAR-BIND. See Brack Bind-Wend.

BEARD (Sax. beano). The same with the awn of a plant.

BEARD-GRASS (Polypogon). There are two sorts, the annual beard-grass ( $P$. monspeliensis) and the perennial beard-grass ( $\boldsymbol{P}$. litt 
ralis). They are found in moist pastures and near the sea, in muddy salt-marshes, but are not often met with.

BEARDED OAT-GRASS. See Win OATs. BEAR'S-FOO'T. See Her.виопи.

BEAST (Su. Goth. beest, Ger. bestie, Fr. beste, Lat. bestia). A term generally applied to all such quadrupeds, or four-footed animals, as are made use of for food, or employed in labour; but farmers apply the term more particularly to neat cattle.

BED-S'TRAW, YELI,OW, LADIES' ( $G(l$ lium verum). It is sometimes termed cheeserenning and maid's hair, or pelly muguet or mugucort, and yellou goose-grass. A perennial weed, flowering from June till October, more common in the hedges and waysides than in the body of pastures. Its slender stalks rise to about a foot in height. The leaves come out in whorls, eight or nine together. They are long, narrow, and of a green colour. Two little branches generally come out near the top of the stalk, supporting a considerable number of small golden yellow flowers, consisting of one petal divided into four parts, and succeeded by two large kidney-shaped seeds. The flowers of this plant are said to coagulate boiling millk, and the better sorts of Cheshire cheese are sornetimes prepared with them. A kind of vinegar is stated to have been distilled from the flowering tops. The French prescribe them in epileptic and hysteric cases; but they are of no value. Boiled in alumwater, they tinge wood yellow. 'The roots dye a fine red not inferior to madder, and are used for this purpose in the island of Jura. Sheep and goats eat the plant; horses and swine refuse it; cows are not fond of it. Smith enumerates seventeen species of bed-straw :1. C.uss-wort bed-straw, or mugweed; 2 . White water bed-straw; 3 . Rough heath bed-straw; 4. Smooth heath bed-straw; 5. Rough marsh bed-straw ; 6. Upright bed-straw; 7. Gray spreading bed-straw; 8. Bearded bed straw; 9. Warty-fruited bed-straw ; 10. Rough-fruited corn bed-straw, or three-flowered goose-grass; 11. Smooth-fruited corn bed-straw; 12. Least mountain bei-straw; 13. Yellow bed-straw; 14. Great hedge bed-straw; 15. Wall bed-straw ; 16. Cross-leaved bed-straw; 17. Goose-grass, or cleavers. (Hort. Grum. Wob. p. 329 ; Smith's Eng. Flora, vol. i.pp. 199-210.)

Dr. Darlington, in his Flora Cestrica, enumerates twenty-one species of this plant found in Chester county, Pennsylvania. Among these are the wild madder (Galium tinctorium), sometimes called Dyer's goose-grass, frequent in low grounds. The roots of this and another species of galium (boreale) are used by the Indians in dying their porcupine quills, and ther ornaments, of a red colour. Wild liquorice (Galium Circæzans), frequent in rich woodlands and having a sweet taste. Common sleavers, Robin-run-the-hedge, or Yellow goosegrass (Pl. 10, g), a troublesome weed.

BEECH (Fagus sylvatica, Sax. bece or boc). The beech is one of the handsomest of our native forest trees, and in stateliness and grandeur of outline vies even with the oak. Its silvery bark, contrasting with the sombre trunks of other trees, renders its beauties conspicuous in our woods; while the gracefully spreading pendulous brughs, with their glossy foliage, mark its elegance in the park or paddock. There is only one species, the difference in the wood arising from the effects of soil and situation. 'The beech is a native of the greater part of the north of Europe and America. The finest beeches in England are said to grow in Hampshire. The tree is also much grown in Wiltshire, Surrey, Sussex, and Kent. The forest of St. Leonard's, near Horsham, Sussex, abounds with noble beech trees. The shade of the beech tree is very injurious to most sorts of plants that grow near it, but it is believed by the vulgar to be very salubrious to human bodies. The wood of this tree, which is hard, and rather handsome, Brande tells us (in his Dict. of Science, p. 139), is brittle and perishable, and liable to become worm-eaten. Phillips admits, that it is subject to worms, when exposed to the air without paint; but says, that the timber of these trees, in point of actual utility, follows next to the oak and the ash, and is little inferior to the elm for water-pipes. It is used, he adds (Hist. of Fruits, p. 60), by wheelwrights and chairmakers, and also by turners for making domestic wooden ware, such as bowls, shovels, churns, cheese-vats, dressers, shelves for dairies, \&c. it being as white as deal, free from all disagreeable smell, and without any incon. venient softness. Bedsteads and other furniture are often made with this timber; and nc wood splits so fine, or holds so well together. as beech, so that boxes, sword-sheaths, and a variety of other things, are made from it. The baskets called pottles, in which strawberries or raspberries are usually sold in London, are made from beech twigs and cuttings, and the wood is also much in use for poles, stakes, hoops, \&c. Near large towns it is in great demand for billet wood. It affords a large quantity of potash and good charcoal. It is manufactured into a great variety of tools, for which its great hardness and uniform texture render it superior to all other sorts of wood. It is not much used in building, as it soon rots in damp places, but it is useful for piles in places which are constantly wet. The purple and copper beeches seen in plantations are seedling varieties of Fagus sylvatica. The beechtree thrives best and attains to a great size on clayey loams incumbent on sand: silicious sandy soils are also well adapted for its growth, and it will prosper on chalky, stony, and barren soils, where many other timber trees will not prosper; and it is found to resist winds on the declivities of hills better than most other trees. Where the soil is tolerably good, beech will become fit to be felled in about twenty-five years. The tree bears .opping, and may, therefore, be trained to form very lofty hedges.

The leaves of the beech, gathered in autumn before they are much injured by the frost, are said to make better mattresses than straw or chaff, as they remain sweet and continue sof for many years; they are also profitably employed in forcing sea-kale, asparagus, \&c. in hot-beds. The beech is propagated by sowing the nuts, or mast, which should be gathere? 


\section{BEECH.}

about the middle of September, when they are ripe, and begin to fall, and spread out on a mat in an airy place for a week to dry, when they may be sown. It is, however, recommersted to keep them dry in sand until the spring, as there is less danger of their being then destroyed by field mice and other vermin. These nuts do not require to be covered more than an inch deep in mould, and it will be observed that only a part of them germinates the first year. Two or three bushels of seed are sufficient for an acre, to be sown mixed with sand, in the same manner as the ash.

The flowers of this tree come forth in May, and its kernels ripen in September. The Romans used beech leaves and honey to restore the growth of hair which had fallen off; but the moderns have not found it efficacious.

The nuts or seed of this tree, termed beech masl, are the food of hogs, and of various small quadrupeds. They are often called buck-mast in England, from the eagerness with which deer feed on them.

An oil, nearly equal in flavour to the best olive oil, with the advantage of keeping longer without becoming rancid, may be obtained from the nuts by pressure. It is very common in Picardy, and other parts of France, where the mast abounds; in Silesia it is used by the country people instead of butter. And in the reign of George I. we find a petition was presented, praying letters patent for making buter from beech nuts.

The calies which remain from the pressure, after the oil is made, are given to fatten swine, oxen, or poultry. A bushel of mast is said to produce a gallon of clean oil; but the beech tree seldom produces a full crop of mast oftener than once in three years. 'This nut is palatable to the taste, but when eaten in great quantities occasions headache and giddiness; nevertheless, when dried and ground into meal, it makes a wholesome bread. Like acorns, the fruit of the beech was long the food of mankind before the use of corn. Roasted, the mast has been found a tolerable substitute for coffee. (Phillips's Hist. of Fruits, p. 56; M'Cullucli's Com. Dict.; Baxler's Agr. Library: Brande's Dict. of Science.)

In North America, as in Europe, the beech is one of the common trees of the forest. Two distinct species are found in the Northern States, which have been often treated by botatuists as varieties. Michaux, who makes this distinction, calls one the white beech, (Fagus sylvestris), and the other the red beech (Fagus ferruginca.), both the popular names being derived from the colour of the wood. In the Middle Western, and Southern States the red beech does not exist, or is very rare. A deep moist soil and a cool atmosphere are necessary to the utmost expansion of the white beech. In the Middle Statei, eas: of the mountains, it is insulated in the forests, whilst in the Northern parts of Pennsylvania, the Genessee district in New York, and in the states of Kentucky and Tennessee, it composes large masses of the primitive forests. The soils on which the heech mostly abounds have generally a stra1 um of clay or gravel, termed hard-pan, which jrevents any roots from descending. This
BEECH.

forces the trees to obtain their subsistence from the upper soil, and the roots spread around the trees to a distance sometimes of a hundred feet or more, and so numerous withal as to be greatly in the way of the settler when he first clears his grounds. But he has the satisfaction of knowing that they soon rot away and yield to his plough. The white beech is more slender and less branchy than the red beech; but its foliage is superb, the green being of the most agreeable shade, and its general appearance very beautiful. On the banks of the Ohio and in some parts of Kentucky, where the oak is too rare to furnish enough bark for tanning, the deficiency is supplied by that of the white beech. The leather made with this is white and serviceable, though avowedly inferior to what is prepared with the bark of the oak.

The red beech bears a greater resemblance to that of Europe than the white species. It equals the white beech in thickness, but not in height, has a more massive and spreading summit, and more tufted foliage. The leaves are very similar, but those of the white beech are not quite so thick and large, with rather shorter teeth. To these differences must be added a more important one in the wood. The red beech 15 or 18 inches in diameter consists of 3 or 4 inches of white wood and 13 or 14 inches of red wood or heart, the inverse of which proportion is found in the white beech. The wood of the red beech is stronger, tougher, and more compact. In the state of Maine and in the British Provinces where oaks are rare, it is employed with the sugar maple and yel. low birch for the lower part of the frame of vessels. As it is extremely liable to injury from worms, and speedily decays when exposed to alternate dryness and moisture, it is rarely used in the construction of houses. In the state of Maine the hickory is rare, and the white oak does not exist, and when the yellow birch and black ash cannot be procured in sufficient abundance the red beech is selected for hoops.

Experience has demonstrated the advantage of felling the beech in the summer, whilst the sap is in full circulation. Cut at this season it is very durable, but felled in winter, it decays in a few years. The logs are left several months in the shade before they are hewn, care being taken that they do not repose immediately upon the ground. After this they are hewn and laid in water for three months, which process, it is said, renders them inaccessible to worms.

The beech is very durable when preserved from moisture, and incorruptible when constantly in the water; but the white or exterior portion of the wood decays rapidly when exposed to alternations of dryness and dampness. The interior red wood, or heart, as it is usually called, is very durable. In the northern portion of the United States, the red beech consti tutes a large proportion of the fuel consumed, and, as in Europe, the wood of the beech subserves a great variety of useful purposes.

The ashes of both species of beech yield a very large proportion of potash.

Michaux, who describes the process of ex tracting the oil, says that it equals one-sixtb 
of the nuts veod. The quality of the oil depends upon the care with which it is made, and upon the purity of the vessels in which it is preserved. It should be twice drawn off during the first three months, without disturbing the dregs, and the third time at the end of six months. It arrives at perfection only when it hecomes limpid, several months after its exiraction. It improves by age, lasts unimpaired for ten years, and may be preserved longer than any other oil.

The manner of making beech nut oil most commonly pursued in the districts of the United States where the tree abounds, is somewhat different from that described in Michaux's Sylva. Instead of resorting to the rather tedious process of gathering the nuts and pressing them through screw-presses, the farmers turn out their hogs immediately after the first frost, who secrete the oil under their skin. In a favourable year they become perfect masses of blubber. Unless they be fed, sometime before killing, on Indian corn, the bacon has little solid consistency, becomes liquid upon the slighest application of heat, and keeps that state,-resembling in this respect the lard of hogs fed upon acorn mast. The nuts are only plentiful about every third or fourth year, and every farmer keeps a number of halfstarved swine in the intervening period to take advantage of the happy event.

BEEF (Fr. bœuf), is used either fresh or salted. Beef is also sometimes used for the name of an ox, bull, or cow, considered as fit for food. Formerly it was usual for most families, at least in England, to supply themselves with a stock of salt beef in October or November, which served for their consumption until the ensuing summer; but in consequence of the universal establishment of marhets where fresh beef may be at all times ohtained, the practice is now nearly relinquished, and the quantity of salted beef made use of as compared with fresh beef is quite inconsider. able. Large quantities of salted beef are, however, prepared at Cork and other places for exportation to the East and West Indies. During the war large supplies were also required for victualling the navy. The vessels engaged in the coasting trade, and in short voyages, use only fresh provisions. The English have at all times been great consumers of beef; and at this moment more beef is used in London, as compared with the population, than anywhere else in Europe.

BEELD, or BIELD (Sax. behlioan; Icel. boele, a dwelling). A term provincially applied in the north of England to any thing which affords shelter, such as a clump or screen of trees planted for the protection of live-stock.

BEER (Welsh, bir; Germ. bier; Sax. bean; Goth. bar, barley). A liquor made from malt and hops, which is distinguished from ale either by being older or smaller. It may be prepared from any of the farinaceous grains, out barley is most commonly employed.

Beer is, properly speaking, the wine of barley. The meals of any of these grains being extracted by a sufficient quantity of water, and remaining at rest in a degree of heat requisite for this fermentatinn. are changed into a vinous liquor. But as these matters renter the water mucilaginous, fermentation proceeds slowly and imperfectly. On the other hand, if the quantity of farinaceous matter be so diminished that its extract or decoction may have a convenient degree of fluidity, this liquor will be impregnated with so small a quantity of fermentable matter, that the beer or wine of the grain will be weak, and have little taste. These inconveniences are therefore remedied by preliminary operations which the grain is made to undergo. These preparations consist in steeping it in cold water, that it may soak and swell to a certain degree; and in laying it in a heap with a suitable degree of heat, by means of which, and of the imbibed moisture, a germination begins, which is to be stopped by a quick drying, as soon as the bud shows itself. To accelerate this drying, and to prevent the farther vegetation of the grain, which would impair its saccharine qualities, the grain is slightly roasted, by means of a kiln, or making it pass down an inclined canal sufficiently heated. This germination, and this slight roasting, change considerably the nature of the mucilaginous fermentable matter of the grain, and it becomes the malt of commerce. This malt is then ground; and all its substance, which is fermentable and soluble in water, is extricated by means of hot water. This extract or infusion is evaporated by boiling in cauldrons; and some plant of an agreeable bitterness, such as hops, is added to heighten the taste of the beer, and to render it capable of being longer preserved. Lastly, this liqun $r$ is put into casks, and fermented, assisted by the addition of barm.

Beer is nutritious from the sugar and mucilage it contains, exhilarating from the spirit, and strengthening and narcotic from the hops. Mr. Brande obtained the following quantities of alcohol from 100 parts of different beers:Burton ale, between 8 and 9; Edinburgh ale, 6 to 7 ; Dorchester ale, 5 to 6 . The average of strong ale being between 6 and 7 ; brows stout, 6 to 7 ; London porter about 4 (average); London brewers' small beer between 1 and 2 . (See Brewivg.) "The distinction between ale and beer, or porter, has been," says $\mathrm{Mr}$ $M^{\prime}$ Culloch, "ably elucidated by Dr. Thomas Thomson in his valuable article on brewing in: the supplement to the Encyc. Brit."

'Both ale and beer are in Great Britain ob tained by fermentation from the malt of barley but they differ from each other in several par ticulars. Ale is light-coloured, brisk, and sweetish, or at least free from bitter; while beer is dark-coloured, bitter, and much less brisk. What is called porter in England is a species of beer; and the term 'porter, at present signifies what was formerly called strong beer. The original difference between ale and beer was owing to the malt from which thev were prepared; ale malt was dried at a ver. low heat, and consequently was of a pale colour, while beer or porter malt was dried at a higher temperature, and had of consequence acquired a brown colour. This incipien: charring had developed a peculiar and agree. able bitter taste, which was communicated to the beer along with the dark colour. This hit 
ter taste rendered beer more agreeable to the palate and less injurious to the constitution than ale. It was consequently manufactured in greater quantities, and soon became the common drink of the lower ranks in England. When malt became high priced, in consequence of the heavy taxes laid upon it, and the great increase in the price of barley which took place during the war of the French revolution, the brewers found out that a greater quantity of wort of a given strength could be prepared from pale malt than from brown malt. The consequence was, that a considerable proportion of pale malt was substituted for brown malt in the brewing of porter and beer. The wort, of course, was much paler than before, and it wanted that agreeable bitter flavour which characterized porter, and made it so much relished by most palates. At the same time various substitutes were tried to supply the place of the agreeable bitter communicated to porter by the use of brown malt; quassia, cocculus indicus, and we believe even opium, were employed in succession; but none of them was found to answer the purpose sufficiently." The use of the articles other than malt, referred to by Dr. 'Thomson, has been expressly forbidden under heavy penalties by repeated acts of parliament. In England, the classification of the different sorts of beer according to their strength, originated in the duties laid upon them; and now that these duties have been repealed, ale and beer may be brewed of any degree of strength.

The duty on beer being repealed in 1830 , there are no later accounts of the quantity brewel.

The number of balcels of strong beer brewed in Scotland in the five years ending 1830, was 597,737; talul: beer, 1,283,490; amount of duty paid thereon, 393,136l. (Parl. Paper, No. 190, Sess. 1830.)

No account has been kept of the quantity of beer brewed in Ireland since 1809, when it amounted to 960,300 barrels. (Morewood on InInxicating Liquore, p. 353.) Perhaps it may How amount to from $1,000,000$ to $1,200,000$ barrels. Ale or beer exported to foreign parts is allowed a drawbacli of $5 s$. the barrel of 36 gallons, Imperial measure. The number of barrels of strong beer annually exported is, from England, about 70,000 barrels; Ireland, 15,000, and Scotland, 3,000. (M'Culloch's Com. Dict.)

BEES (Sax. veo, Lat. apies). These industrious and useful insects are worthy the attention of all classes, and will repay the utmost care that can be taken in their management.

No farm or cottage garden is complete without a row of these busy little colonies, with their warm, neat straw roofs, and their ewn particular, fragrant bed of thyme, in which they especially delight. Select a sheltered part of the garden, screened by a wall or hedge from the cutting north and easterly winds; let them enjoy a southern sun, but do not place them facing his early beams, because bees inust never be tempted to quit their hive in the heavy morning dew, which clogs their limbs and impedes their flight. Place them, if rossible, near a running stream, as they de166 light in plenty of water; but if none is within their easy reach, place pans of fresh water near the hives, in which mix a little cornmon salt; and let bits of stick float on the surface. to enable bees to drink safely, instead of slip. ping down the smooth sides of the vessel, and perish. Never place hives in a roofed stand: it heats them, and induces the bees frequently to form combs outside of their hives instead of swarming. Let the space before the hives be perfectly clear of bushes, trees, and every impediment to their movement, that they may wing their way easily to seek for food, and re. turn without annoyance. Bees, returning heavily laden and wearied, are unable to bear up against any object, should they hit them selves and fall. Let their passage to and from their hives be clear; but trees and bushes in the vicinity of their residence are advisable, as they present convenient spots for swarms to settle which might otherwise go beyond sight or reach. A swarm seldom goes far from home, unless the garden is unprovided with resting-places, to attract the queen, who takes refuge in the nearest shelter. In the month of November remove your hives upon their stools, into a cool, dry, and shady room, outhouse, or cellar, where they will be protect. ed as well from the winter sun as from the frosts. Warm days in winter often tempt bees to quit their cells, and the chilling air numbs and destroys them. Let then remain thus until February or March, should the spring be late and cold. Do not be satisfied with stopping the mouth of the hive with clay; the bees will soon make their way through it. Remive them. Bees are very subject to a disease in the spring, similar to dysentery. Before you place the hives in their summer quarters, examine the state of the bees by turning up the hive, and noticing the smell proceeding from it. If the bees are healthy, the odour will be that of heated wax; but if diseased, it will appear like that of putrefaction. In this case, a small quantity of port wine or brandy mixed with their food will restore them. In the early spring feed them, and do the same when the flowers pass away in autumn, until they are taken into the house; then disturb them no more. The proper food is beer and sugar, in the proportion of one pound to a quart; boil it five minutes only. In May, bees begin to swarm, if the weather is warm. New and dry hives must be prepared without any doorway; the entrance must be cut in the stool. This is recommended by "An Oxford Conservative Bee Keeper."

Sticks across the inside of the hive are useless, and very inconvenient. Let the hive be well washed with beer and sugar before you shake the bees into it. After swarming, place it upon a cloth with one side raised upon a stone; shade it with boughs, and let it alone till quite dusk, then remore it to the stool where it is to stand. The "Oxford Bee Keeper" advises food to be given to a swarm after hiving, for three or four days. Large hives are best: they do not consume more food than smail ones; this is a fact, and the same writer mentions it. Smarts and casts are the second and third swarms from a hive: they seldom 
Ive throush the winter, and ought to be united to each other, or to a weak hive. 'This is the plan recommended by several writers; as also returumg a smart or cast to the parent hive, if $y^{\prime} u$ have no hive weak enough to require an increase of numbers. In this last case, Huish recommends the following plan : Place the back of a chair parallel with the entrance of the hive, over which spread a sheet; then holding the hive containing the smart over it, give a few sharp knocks at the top, and the bees will immediately fall down on the cloth; proceed then, either with your finger or a stick, to guide a few of the bees to the entrance of the parent hive, and they will instantly crowd into it. The queen bee should be caught and secured as they proceed; if this is not done, they kill her, but in a less merciful way.

To form a junction of two weak hives, or a swarm and a hive, Huish discovered the following method: Smoke each hive, as if for taking, only with a less destructive fume, which will be mentioned presently. Spread all the bees of one hive upon a table, and search carefully for the queen; destroy her; sweep the bees of both hives together into one, sprinkling them with some beer and sugar mixed; replace the hive. The fungus used for smoking bees is that called frog's cheese, found in damp meadows; take the largest, and put it into a bag; squeeze it to half its size, then dry it in an oven or before the fire, but not by a very quick heat. Take a piece of this dried fungus, the size of two eggs, and put it in a stick split at one end, and sharp at the other, which is to be fixed into the bottom of an empty hive turned upside down, to receive the stupified hees as they fall.

To prevent swarming, the "Oxford Bee Keeper" recommends this treatment :-

"You see in the following figure a wooden
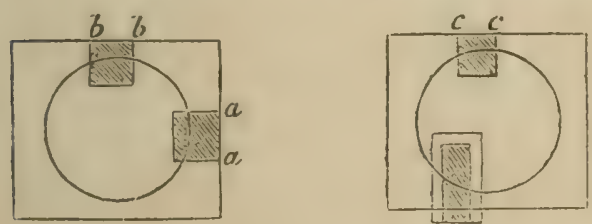

bottom board, with the doorway $a$ a cut in it. It has another doorway, $b \quad b$, on the right side. The ring is meant to show where a hive stands on it. The other bottom board is just like it, only the second doorway is on the left hand, so as to fit exactly to the side entrance of the first board, when pushed close together. As soon as the bees begin to hang out, in May, push the two boards close together. In the evening, when they are all in, stop up the entrance $a a$, and open the right hand one $b b$. Put an empty hive on the new board, with a glass worked into the back for observation. Each doorway has a bit of tin laid over as much of it as juts out beyond the hive. The bees must then find their way out by the new doorway; rub it with a little honey, and they will soon take to it. When the second hive is full, remove it thus: in the heat of the day, when many bees are out, s'ip a piece of tin or card between the two duorways, shui up the doorway $c$, and open the old doorway $a$ a. If the baresen on un oroit s quietly all day, you will be sure that the quee:n is in the old hive, and all is right. About haif an hour before dusk, open again the durway $c c$, and the bees, frightened by the ir long im. prisonment, will hurry from one domway if another to join the queen. $\Lambda \mathrm{s}$ sorm as they are gone, take away the full hive for yourself. If the old hive is very uneasy all dity, you may be sure the queen is shut up in the new hive: if so, draw out the card or tin to join thems again, and wait till another day."

Never destroy a bee; this is the first grrat principle in their treatment. Bees only live one year, therefore, by killing them in Septem. ber, you destroy the young vigorous mes ready to work the following spring: the yearold bees die in August. When a hive is to be taken, smoke the bees as directed for joining hives; replace them in a fresh hive, taking care to ascertain that the queen is safe among them, and feed them through the autumn and spring; they will be ready to work with the rest, and a hive is thus added to the general stock. The queen is easily known from the working bees, as the size is larger.

By fumigating the bees with tobacco smoke while operating upon a hive, they are rendered perfectly harmless. It is well to protect the face, neck, and hands, to prevent alarm or the chance of accident. When stung, extract the sting, and apply Goulard water immediately, or laudanum, or sweet oil. In February bees first begin their labours. May is their busiest month. In November their labours end, and they remain torpid for the winter. For more particular instructions, see Huish on Bces; The Conservative Bee Keeper's Letter to Cottagers; Wildiran's Trealise on Bees; The Honey Bee, by Dr. Bevan; Penny Cyclo.; Quurt. Juurn. of Agrr. vol. ii. p. 594; Baxter's Agr. Lit. pp. 46-53.

Several of these treatises have been repub. lished in the Uniter States, where, besides separate works upon the subjects, the agricultural periodicals and newspapers abound with suggestions and instructions relative to the unanagement of bees, \&c.

Loudon, in his lately published Encyclopædia of Agriculture, says, that after all that has been done in England, France, and Italy, the vee is still more successfully managed and finer honey produced in Poland, by persons who never saw a work on the subject, or heard of the mode of depriving bees of their honey without taking their lives. Much as has been written in France and England upon this subject, it is, he observes, still found the best mode to destroy the bee in taking the honey, a practice for which he thinlis unanswerable reasons are given by La Grenée, a French apiarian, and which is allowed to be conclu-. sive as to profit even by Huish.

"Suffocation is performed when the season of flowers begins to decline, and generally in October. The smoke of paper, or rag soaked or smeared with melted sulphur, is introduced to the hive, by placing it in a hole in tho ground where a few shreds of these articles are undergoing a smothering combustion; or the full hive may be placed on an empty one, inverted as in partial deprivation, and the sut 
phurous smoke introduced by fumigating bellows, \&c. The bees will fall from the upper to the lower hire in a few minutes, when they may be removed and burierl to prevent resuscitation. Such a death seems one of the easiest, both to the insects themselves and to human feelings. Indeed, the mere deprivation of life, to animals not endowed with sentiment or reflection, is reduced to the precise pain of the moment, without reference to the past or the future; and as each pulsation of this pain increases in effect on the one hand, so, on the other, the susceptibility of feeling it diminishes. Civilized man is the only animal to whom death has terrors, and hence the origin of that false humanity which condemns the killing of bees in order to obtain their honey, but which might, with as much justice, be applied to the destruction of almost every other animal used in domestic economy, as fowl. game, fish, cattle, \&c." (Encyc. of Agriculture, 7614.)

As to the best situation for bees during their working season, this must depend upon circumstances of climate and locality. In southerly latitudes and warm exposures,where the climate will admit of the hives remaining upon the stands during winter,-it may still be advisable to give some shelter, and the principal object should be to ward off the sun, the warmth from which invites the bees to fly abroad at an unprofitable season, and makes them sensitive to the sudden spells of cold experienced throughout the United States. In summer, the extreme heat of the sun should certainly be warded off by sheds and suitable shades, although it is improper to oblige the bees to pass through barriers of boughs and bushes. The heat accumulated by objects exposed to the direct rays of the sun often increases to $130^{\circ}$ or $140^{\circ}$ of Fahrenheit, a temperature which must be injurious, not only to the bees themselves, but to their honey and wax. Whitewashing the hives and stands will tend much to prevent the accumulation of heat. The hives may front the east, south-east, or south-west, according to circumstances.

In the northerly portions of the United States, means are generally used to protect the swarms in winter, by removal to some cool and dry out-house or cellar. Some bury the hives aither partly or entirely under ground, as is practised with many kinds of vegetables. The place should be very dry, and the hives set upon clean straw, without any bottom board to rest on, one side being raised about two inches by means of a stick or stone. An empty space must be left around, three times the size of the hive, covered over with bridging and earth, six, eight, or ten inches in depth, neaped up well so as to turn off water. They may remain thus covered about three months.

Whilst some persons contend for the necessity of protecting bees against the extreme coid of American winters, others deem it not only useless, but destructive to the health and welfare of swarms to remove the hives from their usual situations, however exposed these may be. Among apiarians who disapprove of - the removal of hives in the winter, is Dr.J. 362
V. C. Smith, of Boston, who, in a neat little duodecimo volume of about a hundred pages, "On the Practicability of Cultivating the $\mathrm{H}_{0}$. ney Bee in Maritime 'Towns and Cities, as a source of Domestic Economy and Profit," holds the following testimony:-

" During the season of rest, from the first of October to the first or middle of April, the quantity of honey consumed by such a hive as has been spoken of, as worth keeping, varies according to the average temperature of the weather, from ten to twenty pounds. It is better that the bees should have too much than too little in store. They are very economical in the expenditure of food, and therefore there is no risk in trusting them with well stocked granaries. All hives should have the weight marked on the back, which will enable the manager to judge pretty accurately of the quantity of honey and wax on hand. Taking five pounds as the standard weight of the bees, and a half pound of wax to every fifteen pounds of honey, almost the exact quantity of honey can thus be ascertained. My rule has invariably been, to let the bees remain in winter, wherever they have stood through the summer; all attempts on my part to prepare them for the inclemencies of approaching cold were invariably anticipated, and seasonably attended to by the bees themselves.

"Feeling peculiar commiseration for a swarm, two years since, whose bleak locality, I feared, would be the certain destruction of the hive before spring. they were placed in the lobby of an adjacent building for comfort. In the month of March, discovering that thousands of them were dead on the floor, and that the bees were sickly, they were carried back to their old stand in the open air, at the summit of a high, exposed hill, where they were per. fectly restored to health in about twelve days. If they are housed in winter, the torpidity which seems to be constitutionally requisite, both for the future health of the bee, and the saving of its honey, is obviated, and indisposition, in consequence of constantly feeding, without exercise, is the invariable result. The colder they are, the hetter: I am fully persuaded that bees, in their hive, cannot be frozen to death. Animation may be suspended several weeks or months with impunity-vitality may merely appertain to organized matter; but, when the genial warmth of spring cornes gently on, the little spark of life is again rekindled into vigorous flame.

"On the 21st of March, 1831, in company with Mr. J. S. C. Greene, we examined a hive of bees that had, probably, died for want of proper ventilation. There were two thousand two hundred bees. A common flint tumbler contained one thousand, weighing six ounces and a half. It was obvious they did not die of starvation, as there was a good supply of beautiful honey, which, together with the comb, weighed twenty-two pounds. Allowing one half pound of cell comb for holding every fifteen pounds of honey, the quantity was easily ascertained. Taking this in connection with that which was taken from them in the autumn. and at the same time admitting that five hun. dred bees were lost by high autumnal winds, 
storms, and early frosts, the whole colony consisted, originally, of thirty-two hundred bees, which, in eight weeks, or thereabouts, collected the wax, constructed the cells, and made over one hundred pounds of honey, in a garden on Pemberton's Hill, nearly in the centre of Boston! It should be remarked, that a bee answering the general description of the queen, as it relates to external appearance, was found in a cluster of dead ones. Not a drone was discovered, nor a young bee in any stage of infancy."

It is probable that bees can preserve their vitality in ordinary hives exposed to the most intense cold, so long as they remain in the torpid condition in which they are prepared for the worst. But when roused from this condition by the occurrence of a premature warm spell, they are then rendered sensitive to the effects of cold, and when this comes upon them suddenly and with severity, they perish under it. The great object therefore appears to be, to place the swarms during winter in some dry situation where they may be kept at a cool and equable temperature. A good dry and cool cellar must answer all the purposes admirably, and from such a situation it is easy to remove them oecasionally, in good mild weather, and give them an airing.

Loudon, who adopts the views of Howison and Huish, says that the best material and form for hives is a straw thimble, or flower-pot, placed in an inverted position. Hives made of straw, as now in use, have a great advantage over those made of wood and other materials, from the effectual defence they afford against the extremes of heat in summer and cold in winter. A full-sized straw hive will hold three pecks; a small-sized, from one and a half to two pecks. (Encyc. of Agric.)

The feeding of bees is generally deferred till winter or spring; but this is a most erroneous practice: hives should be examined in the course of the month of September, or about the time of killing the drones; and if a large hive does not weigh thirty pounds, it will be necessary to allow it half a pound of honey, or the same quantity of soft sugar made into syrup, for every pound that is deficient of that weight; and in like proportion to smaller hives. This work must not be delayed, that time may be given for the bees to make the deposit in their empty cells before they are rendered torpid by the cold. Sugar simply dissolved in water (which is a common practice), and sugar boiled in water into a syrup, form com. pounds very differently suited for the winter store of bees. When the former is wanted for their immediate nourishment, as in spring, it will answer equally as a syrup; but if to be laid up as a store, the heat of the hive quickly evaporating the water, leaves the sugar in dry crystals, not to be acted upon by the trunks of the bees. Hives may be killed with hunger while some pounds' weight of sugar remain in this state in their cells. The boiling of sugar into syrup forms a closer combination with the water, by which it is prevented from flying off, and a consistence resembling that of honey retained. Howison has had frequent experience of hives, not containing a pound of honey, preserved in perfect health through the wintep with sugar so prepared, when given in pruper time and in sufficient quantity.

In the article from looudon, from which we: are now quoting, it is recommended to protect hives from cold, by covering them with straw or rushes, about the end of September, or later, according to the climate and seisun. This perhaps only applies to buard hives, as those made of thick rye-straw or rushes will do without additional covering. Well protrce. ed hives always prosper better the following season than such as have not been covererl. In October, the aperture at which the bees enter should generally be narrowed, so that only one bee may pass at a time. Indeed, as a very small portion of air is necessary fot bees in their torpid state, it were better during severe frosts to be entirely shut up, as numbers of them are often lost from being enticed to quit the hive by the sunshine of a winter day. It will, however, be proper at times to remove, by a crooked wire or similar instrument, the dead bees and other filth, which the living at this season are unable to perform of themselves. To hives whose stock of honey ivas sufficient for their maintenance, or those to which a proper quantity of sugar had been given for that purpose, no further attention will be necessary until the breeding season arrives. This, in warm situations, generally takes place about the beginning of May; and in cold, about a month after. The young bees, for a short time previous to their leaving their cells, and some after, require being fed with the same regularity that young birds are by their parents; and if the store in the hive be exhausted, and the weather such as not to admit of the working bees going abroad to collect food in sufficient quantity for themselves and their brood, the powerful principle of affection for their young compels them to part with what is not enough for their support, at the expense of their own lires. To prevent such accidents, it is advisable, if during the breeding season it rain for two successive days, to feed all the bees indiscriminately, as it would be difficult to ascertain those only which require it.

The swarming of bees generally commences in June, in some seasons earlier, and in cold climates or seasons later. The first swarming is so long preceded by the appearance of drones, and hanging out of working bees, that if the time of their leaving the hive is not observed, it must be owing to want of care. The signs of the second are, however, more equivocal, the most certain being that of the queen, a day or two before swarming, at intervals of a few minutes, giving out a sound a good deal resembling that of a cricket. It frequently happens that the swarm will leave the oll hive, and return again several times, which is always owing to the queen not having accompanied them, or from having dropped on the ground, being too young to fly to a distance. Gooseberry, currant, or other low bushes, should be planted at a short distance from the hives, for the bees to swarm upon, otherwise they are apt to fly away; by attending to this, Howison has not lost a swarna by straying for 
several years. When a hive yields more than two swarms, these should uniformly be joined to others that are weak, as, from the lateness of the season, and deficiency in number, they will otherwise perish. This junction is easily formed, by inverting at night the hive in which they are, and placing over it the one you intend them to enter. They soon ascend, and apparently with no opposition from the former possessors. Should the weather for some days after swarming be unfavourable for the bees going out, they must be fed with care until it clears up, otherwise the young swarm will run a great risk of dying.

The honey may be taken from hives of the common construction by three modes, partial deprivation, total deprivation, and suffocation.

Purtiul deprivalion is performed about the beginning of September. Having ascertained the weight of the hive, and consequently the quantity of honeycomb which is to be extracted, begin the operation as soon as evening sets in, by inverting the full hive, and placing an empty one over it; particular care must be taken that the two hives are of the same diameter, for if they differ in their dimensions it will no be possible to effect the driving of the bees. The hives being placed on each other, a sheet or large table-cloth must be tied round them at their place of junction, in order to prevent the bees from molesting the operator. The hives being thus arranged, beat the sides gently with a stick or the hand, but particular caution must he used to beat it on those parts to which the combs are attached and which will be found parallel with the entrance of the hive. The ascent of the bees into the upper hive will be known by a loud humming noise; in a few minutes the whole community will have ascended, and the hive with the bees in it may be placed upon the pedestal from which the full hive was removed. The hive from which the bees have been driven must then be taken into the house, and the operation of cutting out the honeycomb commenced. Having extracted the requisite quantity of comb, this opportunity must be embraced of inspecting the hive, and of cleaning it of any noxious matter. In cutting the combs, however, particular attention should be paid not to cut into two or three combs at once, but having commenced the cutting of one, to pursue it to the top of the hive; and this caution is necessary for two reasons. If you begin the cutting of two or three combs at one time, were you to abstract the whole of them you would perhaps take too much; and secondly, to stop in the middle of a comb will be attended with very pernicious consequences, as the honey would drop from the cells which have been cut in two, and then the bees, on being returned to their native hive, might be drowned in their own sweets. 'The bees also, in their return to their natural domicile, being still under the impression of fear, would not give so much attention to the honey which flows from the divided cells; and as it would fall on the board, and from that on the ground, the bees belonging to the other hives would immediately scent the wasted treasure, and a general attack on the denrivated hive might be the consequence. The 164 deprivation of the honeycomb being effected, the hive may be returned to its former position, and reversing the hive which contains the bees, and placing the deprivated hive over it, they may be left in that situation till morning, when the bees wil: be found to have taken possession of their native hive, and, if the season proves fine, may replenish what they have lost. (Huish's Treatise on Bees.)

Total deprivation is effected in the same manner, but earlier in the season, immediately after the first swarm; and the bees, instead of being returned to a remnant of honey in their old hive, remain in the new empty one: which they will sometimes, though rarely, fill with comb. By this mode it is to be observed, very little honey is obtained, the bees in June and July being occupied chiefly in breeding, and one, if not two, swarms are lost. (Loudon's Encyc. of Agriculture.)

The mode of suffocation to be adopted by those who prefer destroying bees in taking honey, has already been given.

Particular attention should be paid to the culture of such plants as supply the bees with the best food and materials for making honey, such as thyme, clover, broom, and mustard, \&c.

As a good deal of difference of opinion exists relative to the construction of hives and management of bees, we have endeavoured to condense the views upon the subject entertained by the most respectable authorities. It is a great desideratum that honey be brought to market without removal from the hive in which it is originally deposited, which enables the purchaser to keep it in fine condition for any length of time. Few persons will purchase the contents of a very large hive, when honey in small boxes generally sells readily. Hence one great advantage of having the hives constructed in sections, which, being of the same size, can always be fitted over or under each other. According to the views of $\mathrm{Mr}$. Harasti, a skilful bee-cultivator, a good bethive ought to possess the following properties: First, it should be capable of enlargement or contraction according to the size of the swarm. Secondly, it should admit of being opened without disturbing the bees, either for the purpose of cleaning it from insects, increasing or dividing the swarm, \&c. Thirdly, it should be so constructed, that the produce may be removed without injury to the bees. Fourthlv.

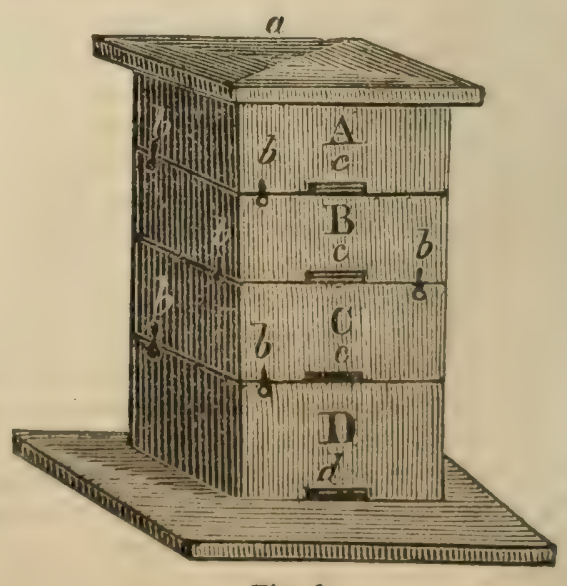

Nig. 1. 
it should be internally clean, smouth and free from cracks or flaws. All these properties seem best united in the section-hive, which is constiuted of two, three, four, or more square boxes of similar size as 10 width, placed over each other. Such hives are cheap, and so simple that almost any one can consitruct them. (See Fig. 1.)

The boxes A, B, C, D, may be made from ien to fourteen inches square and about five inches in depth, inside measure. Every beelieeper should have his boxes made of the same size, so as to fit on to each other. Every hive unust have a common top-board, $a$, which should project over the sides of the hive. 'The top-board of each section should have about sixteen holes bored through at equal distances from each other, and not larger than 4 or smaller than $\frac{5}{4}$ of an inch. Or, instead of such holes, chinks of proper size may be cut through to allow the bees to pass up and down. At the lower part of each box or section, in front, there must be an aperture or little door, $c, c, c, d$, just high enough to let the bees pass, and about an inch and a half wide. The lowermost apercure, $d$, is to be left open at first, and when the hive is filled the upper ones may be successively opened. By placing over the holes in the top of the upper section, glass globes, jars, tumblers, or boxes, the bees will rise into and fill them with honey. These may be removed at any time after being filled. The holes in the tops of the hive which do not open into the glasses or boxes should of course be plugged up. These glass jars, \&c. must be covered over with a box so as to keep them in the dark. Every box or section, on the side opposite the little door, should have a narrow piece of glass inserted, with a sliding shutter, by drawing out which the condition of the hive can always be inspected. To make the bees place their combs in parallel lines, five or six sticks or bars may be placed at the top of every section, running from front to rear. The bees will at-

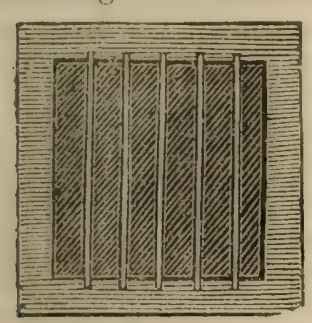

Fig. 2 . tach their combs to these bars, and the intermediate space will afford sufticient light to see them work. The slides covering the glasses should never be left open longer than is just necessary for purposes of inspection.

When one section is removed from the top, a wire or long thin knife must be previousiy run between this and the one immediately below, so as to destroy the attachments. Then remove the upper section, plaring the top upon the one below, which is now the highest division of the hive. Another section is to be placed beneath, lifting up the whole hive for the purpose. Sometimes a second section has to be put under during a good season. If the swarm is not very large three or even two boxes will be sufficient for its accommodation. The boxes or sections may be secured upon each other by buttons, $b, b$, or rabbits, and the joints closed with cement.

A good swarm of bees should weigh five or six pounds, and one weighing eight pounds is considered large. The weight diminishes in one pound. Such as are loss lisan fuur prounds weight should be strengthened by a small additional swarm. The hives oughe not in lee ino large, as bees are apt to lose time in filling up vacancies with wax instead of making luney.

Honey collected from flowers growing in meadows, pasture lands, trees, and cultivated crops, is almost as limpid as the purest oil, and the wax nearly as white as snow. Himey collected from buckwheat has a har hi tisir. When taken once in two years, it is considered richer and more solid, and will keep better than what is taken every year.

Some of the plants from which bees cullect their stores possess poisonous properties and impart these to the honey. The late Dr. B. S. Barton wrote an interesting and valuable paper upon this subject, which is published in the Transactions of the American Philosophical Sisciety, volume 5 th. The plants which, in the United States, most frequently, afford poisonous honey, are the dwarf laurel (Kulinin angustifolia), and the great laurel (Kalmia lalifolia), the mountain laurel (Rhododendron maximus), wild honey-suckle (Azalia nudifiora), Jamestown weed, and broad-leaved moorwort of the south (Andromeda marianu). Most of these plants are known to produce poisonous honey, whilst a few of them are only suspi. cious. Of the trees and shrubs resorted to by bees, some furnish them with the farina or flower-dust which yields the spring food for their young, - some, the gummy or resinous exudations or secretions from which they derive the propolis or wax for sealing the hives of fresh swarms, - whilst others yield them honey in greater or less purity. The willow is much resorted to by bees for all the objects mentioned, furnishing the farina, the propolis, and honey-dew (the last from their aphides), in regular succession. When swarms are in the vicinity of the American sweet gum or styrax, they make their propolis from its fragrant gum. At other times they resort to the Athenian poplar. The sweet box myrtle blooms very early in the spring, and its flowers are always thickly beset by bees. The European, or sweet-flowered linden or lime tree, is likewise greatly resorted to by bees when in bloom, and also various kinds of fruit trees, especially the cherry and apple. The sweet juice exuded by the hickory is eagerly sought after by bees, but there is no American forest tree which affords them such ample supplies of the most limpid honey as the tulip poplar of the Middle States. This stupendous tree sometimes rises, in fertile bottom lands, above one hundred feet in height, har ing a trunk five or six feet in diameter. Such a tree, with every branch from the ground to the summit covered with splendid tulips is a magnificent sight, and a most valuable acquisition when within reach of the apiary.

Among the very great variety of plans which have been adopted by American inge nuity to improve the bee culture, there is one which has acquired much celebrity frum its enabling the surplus honey to be taken without destroying the bees, which 110 st persons prefer doing. The plan referred to, is that of 
Mr. Luda, of Connecticut. By it the bees are made to build their cells and deposit their honey in the chamber of a dwelling-house appropriated for the purpose, in neat little drawers, from which it may be taken fresh by the owner, without killing the bees. 'The hive has the appearance of, and is in part, a mahogany bureau or sideboard, with drawers above and a closet below, with glass doors. 'This case or bureau is designed to be placed in the chamber of a house, or any other suitable building, and connected with the open air or outside of the house by a tube passing through the wall. The bees work and deposit their honey in drawers. When these or any of them are full, or it is desired to obtain honey, one or more of them may be taken out, the bees allowed to escape into the other part of the hive, and the honey taken away. The glass doors allow the working of the bees to be observed; and it is said that the spaciousness, cleanliness, and even the more regular temperature of such habitations, render them the more industrious and successful.

A recent plan called the "Kentucky Beehouse," has been highly commended for its successful adaptation, convenience and cheapness. One is described in the Farmer's Cabinet, for June, 1839, by Mr. F. C. Fisher.

"The building is twelve feet long, eight wide, and seven feet high from the floor to the plate or ceiling (the floor being eighteen inches from the ground), and consists of four posts, eleven feet six inches long, let in the ground three feet, which is weather-boarded round, and covered in so as to prevent the bees from getting in the house, they being confined in six boxes, three on either side of the house, placed fifteen inches one above another.

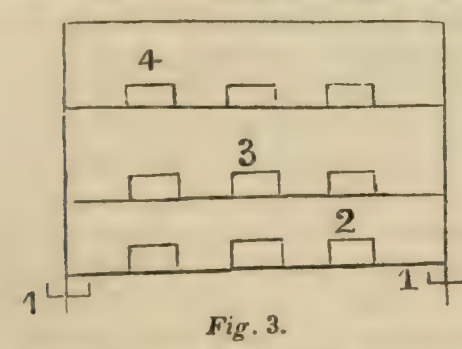

"The drawing (fig. 3) represents a side of the house, viewed from without. Nos. 1,1 , are copper troughs running round the post, halfway between the floor and ground, which are kept filled with water to prevent ants and other insects from getting in the house. Nos. 2, 3, and 4 are tubes eight inches wide, and one-eighth of an inch deep, to convey the bees through the wall into the long boxes, and entering them at the bottom, there being three to each long box. The drawing (fig. 4) represents one side of the house, viewed from the inside.

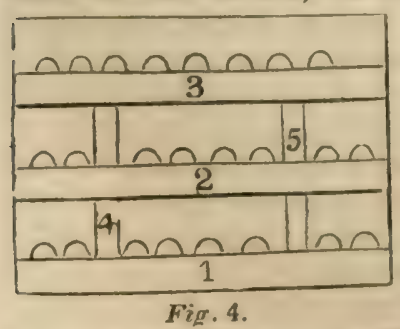

Nos. 1,2 and 3 are long boxes, eighteen inches wide and twelve deep, extending the whole length of the house, with eight holes, four inches square, in each box, upon which Is set two gallon caps, with two half inch holes in each, one near the top, the other about the rentre of the cap, in which the smoke of a murning rag is blown to drive the bees from 166 the cap into the long box. When they are all in the long box,-which can be known by strik. ing the caps,-a knife or wire should be drawn under the bottom of the cap to separate the comb from the box. The cap of honey may then be removed, and an empty one put in its place. Nos. 4 and 5 are tubes three inches square, to convey the bees from on bux to another, that one swarm of bees may do the whole work, or if one or more swarms be put in each box, that they may become as one, as they will not permit more than one queen when put together, by which they are prevented from destroying themselves by fighting. A house of this description, when the long boxes are filled, will afford, at a moderate calculation, ninety-six gallons of honey in the comb anrually."

A hive under the very pompous name of "Patent Fortified Transparent Royal Bee Pa. lace," invented a few years since by $\mathrm{Mr}$. William Groves, of Cleaveland, Ohio, is said to possess real merits, notwithstanding its unpromising and ridiculous name. It is so con. structed that the bees never swarm, and are enabled to reject and roll off all offensive matters, besides defending themselves against intruders. For the preservation of the bees it is said to be preferable to any other hive, and it admits of the convenient removal of honey in any desirable quantity, at all times without disturbing the bees, which are kept clean, wellventilated, and healthy.

A correspondent of the Farmer's Cabinet residing in Western Pennsylvania furnishes the following description of an improved hive, which he says embraces more advantages than any other he has ever seen. Among these are the following :-

" 1 . It prevents the ravages of the miller, whose worm is the bee's most fatal enemy. The miller deposits its eggs in the bee dirt; which in the common hive is constantly accumulating on the bottom. This difficulty is obviated by the slanting bottom of the stand; the dirt falling on this rolls out at $D$, and the bottom is kept clean.

"2. The cruel practice of destroying the bees is entirely superseded by the use of this hive. By blowing a small quantity of tobacco smoke into the upper box, through a hole made for that purpose, the bees will descend into the box next below; the upper box can be removed; fifty or sixty pounds of honey, entirely free from dead bees and dirt, can thus be taken from a good hive; and enough remain to winter the bees without any risk of loss.

"3. The swarming of the bees can be regulated by the rise of this hive, and the new swarms taken at the season of the year when they are most valuable. The bees can be prevented swarming again for the season, by additional boxes as the young bees increase.

"4. This hive is chenp and requires but little mechanical knowledge in its construction; any farmer with ordinary tools can make it from the following description:" -

Fig. 5, A, is the stand of Mr. Groves's hive, the legs of which are sixteen inches high, the stand itself eighteen inches square. $\mathbf{B}$ represents a three-cornered box, open on the top, witli a 
danting bottom $c, c$; a space is 10 be left open in the front of the hive the whole length at $D$, to admit the bees and allow the dirt to slide aff the slanting bottom.

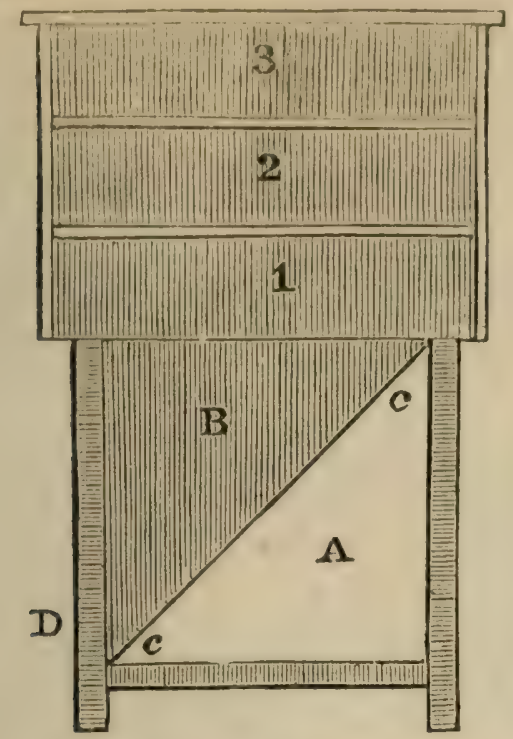

Fig. 5.

" 1,2 , and 3 , are boxes or hives, nineteen inches square, and seven inches high, with slats nailed across, a sufficient distance from each other to admit the free passage of the bees; bars are to be put across the hive to support the comb. The top is to be secured by a tight cover. The bees enter at $\mathrm{D}$, and pass up the slanting bottom of the stanc into the boxes above, and the boxes can be iccreased by adding others, always placıng the additional boxes nearest the stand."

Mr. ' $\Gamma$. Afflick, of Cincinnati, has recently published an interesting pamphlet on bees and their hives, entitled "Bee-Breeding in the West," which contains much useful information. His plan for constructing and placing hives seems to combine economy, simplicity, and durability, with the great desideratum of securing the bees against the moth.

The invention is called the Subtended hive, and may be constructed by any farmer who can handle a saw, a plane, and a hammer, by pursuing the following directions. "The boxes of which it is to be composed, must be formed of well-seasoned boards, free from knots and wind-shakes, one inch thick; they may be ten, eleven, or twelve inches square in the clear, well-dressed on each side, and joined on the edges, so as to fit close, without being tongued or grooved. Before nailing together at the sides, lay a strip of thick white-lead paint on the edge, which will render the joint impervious to the ovipositor of the moth. In the top. of each box cut two semicircular holes, at the front and back, one inch and a half in diameter, the straight side being in a line with the back and front of the box, so that the bees may have a straight road in their way from one story to the other; the top of the upper box must have an extra cover fixed with screws, that it may be easily removed in case of need, so as to form a second box when required: pour a littie melted bees-wax over the in- side of the top, which will enalile the bees ti. attach their comb more firmly. We will sip. pose the boxes thus made, to be a culne of twelve inches inside measure; in that case, the tunnel-stand will be made thus:-talic a piece of two-inch pine plank, frec from knuts and shakes, twenty-six inches long and righieen inches broad; now, ten inches from ine end, and two inches from the other and from each side, mark off a square of fourteen inches; from the outside of this square, the board is dressed off with an even slope until its thickness at the front edge is reduced to half an inch, and at the other three edges, ? about an inch. The square is then to bre re. duced to twelve inches, in the centre of whict. is bored an inch auger-hole, and to this hole the inner square is gradually sloped to the depth of an inch-thus securing the bees from any possibility of wet lodging about their hive, and affording them free ventilation. There will then be a level, smooth strip, of one inch in width, surrounding the square of twelve inches, on whicl) to set the box or hive. Two inches from the .ront edge of the stand, commence cutting a channel two inches in width, and of such a depth as to carry it out on an even slope half-way between the inner edge of the hive and the ventilating hole in the centre; and over this, fit in a strip of wood as neatly as possible, dressing it down even with the slope of the stand, so as to leave a tunnel two inches in width and a quarter of an inch deep. Under the centre hole, and over the outlet of the tunvel, hang small wire grates, the first to prevent the entrance of other insects, and the other to be thrown over to prevent the exit of the bees, or fastened down to keep them at home, in clear, sunshiny days in winter. For feet to the stand, use four or five inch screws, screwed in from below far enough to be firm; and the whole should have two coats of white paint, sometime before it is wanted, that the smell may be dissipated, as it is very offensive to the bees." (Farmer's Cabinet.)

A great variety of patent and fancy hives are from time to time vaunted for their very superior qualities, but in general the simplest construction answers best, and there is perhaps no hive which combines so many advantages as that composed of sections.

In most of the oldest settled parts of the United States, the larva or maggot of 'he beemoth (Phulana cereana), a small gray miller, commits great devastation among the swarms of bees. In many places in New England, the farmers have been induced to abandon the bee-culture entirely on account of the destruction caused by the bee-moth. These lay their eggs in the corners and other interior parts of the hive, which they enter at night. In due time these eggs are hatched out into maggots, and growing into worms with strong manclibles, they gnaw their way in any direction they choose to go, making destructive tracks through the honey-comb. After this destructive course, the worm envelopes itself in a thick, soft case or web, and there awaits the final change by which it is converted into the perfect winged miller. Numerous are the expedients resorteil to and recommended to obviate the destruction. 
produced through the moth. Some of the most intelligent apiarians put their chief trust in the strength of the swarms, and when these become reduced and weak, unite them so as to enable the bees to defend their hive against intruders. Placing buxes for wrens near the apiary is also strungly recommended, and with good reason, since these little birds are very active in catching all kinds of moths. To enable the wren to get under the hive, it has been recommended to raise these an inch or an inch and a half above the stand, by means of small blocks.

Another plan frequently adopted, and, it is said, with much success, consists in placing, early in the evening, a burning lamp in a pail, near the hive-stand. Some fresh honey or molasses and water may be spread upon the bottom as a bait. A keg with only one head is thought preferable to a pail for this purpose, owing to the curvature of the staves, which serves to prevent the insect from flying out so readily, and before it has met its destruction from the flame of the lamp. A small fire kept up early in the evening near the apiary is also frequently resorted to for attracting and destroying the night-flying miller. Placing shallow vessels containing sweetened water, with one gill of vinegar added for each pint, is said to attract and drown the moths in great numbers. Shutting up the apertures for the exit and entrance of the bees, early in the evening, is also advised, as the moth intrudes itself in the evening and night. But when this is done the apertures must be opened again very early in the morning. When millers are numerous, each hive should be raised at least twice a week, upon one side, and the worms sought for and destroyed. In this operation a puff of smoke under the hive keeps the bees quiet during the search, which should be performed with as little jarring or disturbance to the swarm as possible.

A correspondent of the Farmer's Register recommends, that as soon as the bees commence working in the spring, the hives are to be examined, and with a piece of hoopiron or other suitable implement, the stand well scraped immediately under the hive, especially around the inner edge of the box. The whole secret of keeping off the moth consists, he thinks, in keeping the hives free from the web formed by the moth. After this operation, four small blocks of wood are to be placed under each corner of the hive so as to raise it not quite half an inch from the stand. This will permit the hive and stand to be cleaned without raising the box. This scraping operation must be repeated every three or four days, especially if there be any appearance of web. In winter the blocks must be removed, and the hive let down upon the stand as a security against mice, and other depredators upon the honey. The person who recommends this plan as a certain security against the ravages of the worm, advises that an entrance le made for the bees, by cutting a perpendicular slit, one-eighth of an inch wide and two and a half inches long, situated about halfway from the bottom. Just under this a small sne If ic to be placed as a resting-place for the 168 bees in going out and returning to the hive. The bees soon get accustomed to this new place of entrance. The plan has, it is said, often proved an effectual security against the worm, after every wher remedy has failed.

Some persons have contrived drawers under the hives in to which the millers enter by night. The drawers are slipped out every morning, and the moths found in them destroyed.

In the western country and in the new sel. tlements of the Atlantic states, the bee-moth is rarely met with.

Some interesting views relative to the management of bees and construction of apiaries, by Henry Zollickoffer of Philadelphia, may be found in the Farmer's Cabinet for the year 1843.

BEE-MOTH. The following interesting details relative to the natural history of the beemoth or wax-moth, are from Dr. Harris's Treatise on Destructive Insects. This pernicious insect belongs to a group called Cambrians, and was well known to the ancients, as it is mentioned under the name of Tinea, in the works of Virgil and Columella. "In the winged state, the male and female differ so much in size, colour, and in the form of their fore-wings, that they were supposed, by Linnæus and by some other naturalists, to be different species, and accordingly received two different names. (Tortrix cereana, the male; Tinea mellonella, the female.) To avoid confusion, it will be best to adopt the scientific name given to the bee-moth by Fabricius, who called it Galleria cereana, that is, the wax Galleria, because in its caterpillar state it eats beeswax. Doubtless it was first brought to this country, with the common hive-bee, from Europe, where it is very abundant, and does much mischief in hives. Very few of the Tinex exceed or even equal it in size. In its perfect or adult state it is a winged moth or miller, measuring, from the head to the tip of the closed wings, from five-eighths to three quarters of an inch in length, and its wings expand from one inch and one-tenth to one inch and four-tenths. The male is of a dusty gray colour. The female is much larger than the male, and much darker coloured. There are two broods of these insects in the course of a year. Some winged moths of the first brood begin to appear towards the end of April, or early in May; those of the second brood are most abundant in August; but between these periods, and ever later, others come to perfection, and consequently some of them may be found during the greater part of the summer. By day they remain quiet on the sides or in the crevices of the bee-house; but, if disturbed at this time, they open their wings a little, and spring or glide swiftly away, so that it is very difficult to seize or to hold them. In the evening they take wing, when the bees are at rest, and hover around the hive, till, having found the door, they go in and lay their eggs. Those that are prevented by the crowd, or by any other cause, from getting within the hive, lay their eggs on the outside, or on the stand, and the little worm-like caterpillars hatched therefrom easily creep into the hive through the cracks, or gnaw a passage for themselves under the edges of it. These cater. 
pillars, at first are not thicker than a thread. they have sixteen legs. Their bodies are suft and tencler, and of a yellowish white colour, sprinkled with a few little brownish dots, from each of which proceeds a short hair; theil heads are brown and shelly, and there are brown spots on the top of the first ring. Weak as they are, and unprovided with any natural means of defence, destined, too, to dwell in the midst of the populous hive, surrounded by watchful and well-armed enemies, at whose cxpense they live, they are taught how to shield themselves against the vengeance of the bees, and pass salely and unseen in every direction through the waxen cells, which they break down and destroy. Beeswax is their only food, and they prefer the old to the new comb, and are always found most numerous in the upper part of the hive, where the oldest honey-comb is lodged. It is not a little wonderful, that these insects should be able to get any nourishment from wax, a substance which other animals cannot digest at all; but they are created with an appetite for it, and with such extraordinary powers of digestion that they thrive well upon this kind of food. As soon as they are hatched they begin to spin; and each one makes for itself a tough silken tube, wherein it can easily turn around and move backwards and forwards at pleasure. During the day they remain concealed in their silken tubes; but at night, when the bees cannot see them, they come partly out, and devour the wax within their reach. As they increase in size, they lengthen and enlarge their dwellings, and cover them on the outside with a coating of grains of wax mixed with their own castings, which resemble gunpowder. Protected by this coating from the stings of the bees, they work their way through the combs, gnaw them to pieces, and fill the hive with their filthy webs; till at last the discouraged bees, whose diligence and skill are of no more use to them in contending with their unseen foes, than their superior size and powerful weapons, are compelled to abandon their perishing brood and theil wasted stores, and leave the desolated hive to the sole possession of the miserable spoilers. 'These caterpillars grow to the length of an inch or a little more, and come to their full size in about three weeks. They then spin their cocoons, which are strong silken pods, of an oblong oval shape, and about one inch in length, and are often clustered together in great numbers in the top of the hive. Some time afterwards, the insects in these cocoons change to chrysalids of a light brown colour, rough on the back, and with an elevated dark brown line upon it from one end to the other. When this transformation happens in the autumn, the insects remain without further change till the spring, and then burst open their cocoons, and come forth with wings. Thos s which become chrysalids in the early part oi summer are transformed to winged moths fourteen days afterwards, and immediately pair, lay their eggs, and die.

Bees suffer most from the depredations of these insects in $\mathrm{h}, t$ and dry summers. Strong and healthy swarms, provided with a constant supply of food near home, more often escape 22 than small and weak ones. When the moth. worns have established them wlves in a hive, their presence is made known to us by the little fragments of wax and the black grains scattered by them over the flow."

BLESTING or BLESTING, written al BELSTNING (Flem. biest, biestmelite). T'Te first inilk taken from cows after calving. It is thick and yellow. 'This milk is commonly in pait taken away from the cow upon her firts calving, lest, when taken in too large a quantity by the calf, it should prove purritive.

BEET (Lat.beta; Celt.bell, red; asso said is tre so named from the Grcek character befw, which its seeds resemble when they begin (o) swe'l). 'The sweet succulent root of Betu vulsuri, a chenopodiaceous plant of biennial duration. It is used in the winter as a salad, for which purpose the red and yellow beets of Castelnandari are the best; for the food of cattle, that which is named mangel worzel being most used; and for the extraction of sugar, a whiterooted variety with a purple crown is the most esteemed. Sea beet (Betu maritima) is a well known and excellent substitute for spinach. (Brande's Dict. of Science, p. 139.)

The genus beta comprehends several biennial species. Miller enumerates five. 1. 'The common white beet. 2. The common green beet. 3. The common red beet. 4 . The turnip. rooted red beet. 5 . The great red beet. 6 . The yellow beet. 7. The Swiss, or chard beet. We have now nine varieties of this esculent, which are described with considerable discrimination by Mr. Morgan, gardener to H. Browne, Esq., Mimms Place, Herts. (Hort. Trans. vol. iii.) Of the red beet, Mr. Morgan enumerates seven varieties; of these, the three fol. lowing are generally chosen for cultivation: 1. The long-rooted, which should be sown in a deep sandy soil. 2. The short or turnip-rooted, better adapted to a shallow soil. 3 . The greenleaved, red-rooted, requiring a depth of soil equal to that of the long-rooted. There are two distinct species of beet comm.only cultivated, each containing several varjeties; the one called Cicla or Horlensis, or white beet, produc. ing succulent leaves only, the other the red beet (Beta vulgaris); distinguished by its large fleshy roots.

The white heet is chiefly cultivated in gardens as a culinary vegetable, and forms one of the principal vegetables used by agricultural labourers, and small occupiers of land in many parts of Germany, France, and Switzerland. A variety known by the name of Swiss chard produces numerous large succulent leaves, which have a very solid rib running along the middle. The leafy part being stripped off and boiled is useful as a substitute for greens and spinach, and the rib and italk are dressed like asparagus or scorzenera; they have a pleasant, sweet taste, and are more wholesome than the cabbage tribe. In a goud soil the produce is very abundant; and if $\mathrm{cu}_{\mathrm{i}}$ tivated on a large scale in the field, this specie. would prove a valuable addition to the plants raised for cattle. By cultivating it in rows, and frequently hoeing and stirring the inter vals, it would be an excellert substitute for a fallow on good light loams. All cattle are 
fond of the leaves of this beet, which add much to the milk of cows, without giving it that bad laste which is unavoidable when they are fed with turnips or cabbages, and which is chiefly owing to the greater rapidity with which the latter undergoes the putrefactive fermentation. If sown in May, in drills two feet wide, and thinned out to the distance of a foot from plant to plant in the rows, they will produce an abundance of leaves, which may be gathered in August and September, and will grow again rapidly, provided a bunch of the centre leaves be left on each plant. They do not sensibly exhaust the soil. These leaves when boiled or steamed with bran, cut with chaff or refuse grain, are an excellent food for pigs or bullocks put up to fatten. (Penny Cyclo. vol. iv. p. 158.)

The white beet is an excellent root, and is preferred by many to the larger and more common intermediate varieties. It has lately been in great repute in France and Belgium, and indeed all over the continent of Europe, for the manufacture of sugar. The process is given in detail by $\mathrm{Mr}$. Samuel Taylor in the sixth vol. of the Gardener's Maguzine; and there are some able articles, entering extensively into detail on the subject, in the Quart. Journ. Agr. vol. i. p. 624, and vol. ii. pp. 892 and 907. (For an account of the common field beet for cattle, see Manger Wurzel.)

BEE'T, WHI'T (Beta cicla). This is also known as the chard, or curde. We have two species in common cultivation, the green and the white. They receive their names from the colour of their footstalks; but the variation is considered by some as fugitive, and that both are produced from seed obtained of the same plant: but this the experience of Mr. Sinclair denies. The French have three varieties of the white-the white, the red, and the yellowwhich only differ from ours in having a larger foliage, and thicker, fleshier stalks, but they are less capable of enduring frost. They are cultivated for therr stalks, which are cooked as asparagus. Mangel wurzel is sometimes grown for the same purposes; but as it is much inferior, the notice that it may be thus employed, is sufficient. Beets require a rich, mouldy, deep soil; it should, however, be retentive of moisture, rather than light, without being tenacious, or having its alluminous constituent too much predominating. Its richness should preferably arise from previous application than from the addition of manure at the sime of sowing; and to effect this, the compartment intended for the growth of these vegetables is advantageously prepared as directed for celery. On the soil depends the sweetness and lenderness of the red and yellow beets, for which they are estimated; and it may be reinarked, that on poor, light soils, or heavy ones, the best solts will taste earthy. A gain, on some soils the better varieties will not attain any useful size, or even a tolerable flavour, whilst in the same compartment inferior ones will attain a very good taste. The situation should be open, and as free from the influence of trees as possible; but it is of advantage to have the bed shaded from the meridian sun in summer. I have always found it beneficial to dig the ground two spades drep for these deep170 rooting vegetables, and to turn in the whole or part of the manure intended to be applied, according to the richness of the soil near the surface, with the bottom split, so as to bury it ten or twelve inches within the ground. Salt is a beneficial application to this crop, one reason for which undoubtedly is, their being natives of the sea shore. Both species are propagat. ed by seed, and may be sown from the close of February until the beginning of April: it being borne in mind that they must not be inserted until the severe frosts are over, which inevitably destroys them when in a young stage. of growth. The best time for inserting the main crop of the beet root for winter supply is early in March; at the beginning of July or August, a successional crop of the white beet may be sown for supply in the winter and fol. lowing spring.

It is best sown in drills a foot asunder, and an inch deep, or by dibble, at the same distance each way, and at a similar depth, two or three seeds being put in each hole: it may, however, be sown broadcast and well raked in.

During the early stages of its growth, the beds, which, for the convenience of cultivation, should not be more than four feet wide, must be looked over occasionally, and the largest of the weeds cleared away by hand. In the course of May, according to the advanced state of their growth, the beds must be cleared thoroughly of weeds, both by hand and small hoeing; the beet roots thinned to ten or twelve inches apart, and the white beet to eight or ten. The plants of this last species which are removed may be transplanted into rows at a similar distance, and will then often produce a finer and more succulent foliage than those remaining in the seed bed. Moist weather is to be preferred for performing this operation: otherwise, the plants must be watered occasionally until they take root: they must be frequently hoed and kept clear of weeds through. out the summer.

It is a great improvement to earth up the stalks of the white beet in the same manner as celery, when they are intended to be peeled, and eaten as asparagus.

In October, the beet-root may be taken up for use as wanted, but not entirely for preser. vation during the winter until November or the beginning of December, then to be buried in sand in alternate rows, under shelter; or, as some gardeners recommend, only part at this season, and the remainder in February; by this means they may be kept in a perfect state for use until May or June. If prevented running to seed, they will produce leaves during the succeeding year; but as this second year's production is never so fine or tender, an annual sowing is usually made. For the production of seed some roots must be left where grown, giving them the plotection of litter in very severe weather, if unaccompanied with snow; or if this is neglected, some of the finest roots that have been stored in sand, and have not had the leaves cut away close, may be planted in February or March. Each species and variety must be kept as far away from the others as possible, and the plants set at least 
two feet from each other. They flower in August, and ripen their seed at the close of September. sied of the previous year is always to be preferred for sowing, but it will succeed, if carefully preserved, when two years of 1 .

As a medicine, the seed of the beet is diuretic. 'The juice of beet-root snuffed up into the nostrils promotes sneezing, and is beneficial in headache and toothache.

BEE'ILE (Scaruboidex; Sax. byxel). The generic name of a class of insects, of which there are a great many species, all of them having elytra or sheaths over their wings to defend them from hard bodies, which they may meet with in digging holes in the ground, or gnawing rotten wood with their teeth, to make themselves houses or nests. 'These insects are extremely destructive to many sorts of crops. The beetles most destructive to vegetables and animals are the ueevil beetle, the turnip-flea beetle, the wood-boring beetle, and some others, which are described at length by Mr. J. Duncan in the Quart. Journ. of Agr. vol. ix. p. 394.

American beetles.-Passing over many groups into which the extensive beetle family is divided, such as the ground-beetles, earth-borers, and dung-beetles, which last, in all their states, are found in excrement; the skin-beetles, which inhabit dried animal substances, and the gigantic Hercules-beetles, which live in rotten wood or beneath old dung-heaps, we come to those groups which require more particular notice from their depredations upon plants, fruits, and trees.

One of the most common, and at the same time most beautiful of the tree beetles of the United States, is the Woolly Areoda, sometimes called the goldsmith (Areoda lanigera), which is thus described by Dr. Harris, in his highly interesting and valuable "Treatise upon Insects injurious to Vegetation."-

"It is about nine-tenths of an inch in length, broad oval in shape, of a lemon-yellow colour above, glittering like burnished gold on the top of the head and thorax; the under side of the body is copper-coloured, and thickly covered with whitish wool; and the legs are brownishyellow, or brassy, shaded with green. These fine beetles begin to appear in Massachusetts about the middle of May, and continue genepally till the twentieth of June. In the morning and evening twilights they come forth from their retreats, and fly about with a humming and rustling sound among the branches of trees, the tender leaves of which they devour. Pear-trees are particularly subject to their attacks, but the elm, hickory, poplar, oak, and probably also other kinds of trees, are frequented and injured by them. During the middle of the day they remain at rest upon the trees, clinging to the under-sides of the leares; and endeavour to conceal themselves by drawing two or three leaves together, and holding them in this position with their long unequal claws. In some seasons they occur in profusion, and then may be obtained in great quantities by shaking the young trees on which they are lodged in the daytime, as the do not attempt to fly when thus disturbed out fall at once to the ground. The larvæ of these insects are not known; probably thry live in the ground upon the roots of plants."

Ansther member of the Rutilian tribe, (1) which the goldsmith belongs, is the spotted Pelidnota, a large beetle found on the cultivated and wild grape-vine, sometimes in great abundance, in the summer months. "It is," says Dr. Harris, "of an oblong oval shape, and about an inch long. The wine-cuvers are tile-coloured, or dull brownish yellow, with three distinct black dots on each; the thorax is darker, and slightly bronzed, with a black dot on each side; the body beneath, and the lews, are of a deep bronzed green colour. These beetles fly by day, but may also be seen at the same time on the leaves of the grape, which are their only food. They sumetimes prove very injurious to the vine. The only way to destroy them is to pick them off by hand, and crush them under foot. The larva live in rotten wood, stumps, and roots."

Among the tree-beetles, those commonly called dors, chafers, May-bugs, and rose-bugs, are the most interesting to the farmer and gardener, on account of their extensive ravages, both in the winged and larva states. Whilst the powerful and horny jaws possessed by most of these, are admirably fitted for cutting and grinding the leaves of plants upon which they subsist, their notched and double claws support them securely on the foliage; and their strong and jagged fore-legs, being formea for digging in the ground, point out the place of their transformations.

"The general habits and transformations of the common cock-chafer of Europe have been carefully observed, and will serve," says Dr. Harris, "to exemplify those of the other in. sects of this family, which, as far as they are known, seem to be nearly the same. This insect devours the leaves of trees anc shrubs. Its duration in the perfect state is very short, each individual living only about a week, and the species entirely disappearing in the course of a month. After the sexes have paired, the males perish, and the females enter the earth to the depth of six inches or more, making their way by means of the strong teeth which arm the fore-legs; here they deposit their eggs, amounting, according to some witers, to nearly one hundred, or, as others assert, to two hundred from each female, which are abandoned by the parent, who generally ascends again to the surface, and perishes in a short time.

"From the eggs are hatched, in the space of fourteen days, little whitish grubs, each provided with six legs near the head, and a mouth furnished with strong jaws. When ir a state of rest, these grubs usually curl them selves in the shape of a crescent. They subsist on the tender roots of various plants, committing ravages among these vegetable substances, on some occasions of the most deplorable kind, so as totally to disappoint the best founded hopes of the husbandman. Dur ing the summer, they live under the thin coat of vegetable mould near the surface, but, as winter approaches, they descend below the reach of frost, and remain torpid until the suc ceeding spring, at which time they change 
their skins, and reascend to the surface for food. At the close of their third summer, (or, as some say, of the fourth or fifth), they cease eating, and penetrate about two feet deep into the earth; there, by its motions from side to side, each grub forms an oval cavity, which is lined by some glutinous substance thrown from its mouth. In this cavity it is changed to a pupa by casting off its skin. In this state the legs, antennæ, and wing-cases of the future beetle are visible through the transparent skin which envelopes them, but appear of a yellowish white colour; and thus it remains until the month of February, when the thin film which encloses the body is rent, and three months afterwards the perfected beetle digs its way to the surface, from which it finally emerges during the night."

Some account of the destruction occasionally wrought by these insects may be found under the head of Соск-СнағER.

In their winged state, many species of treebeetles act as conspicuous a part in injuring trees as their grubs do in destroying herbage. "During the month of May they come forth from the ground, whence they have received the name of May-bugs or May-beetles. They pass the greater part of the day upon trees, clinging to the under-sides of the leaves, in a state of repose. As soon as evening approaches, they begin to buzz about among the branches, and continue on the wing till towards midnight. In their droning flight they move very irregularly, darting hither and thither with an uncertain aim, hitting against objects in their way with a force that often causes them to fall to the ground. They frequently enter houses in the night, apparently attracted, as well as dazzled and bewildered, by the lights. Their vagaries, in which, without having the power to harm, they seem to threaten an attack, have caused them to be called dors, that is, darers; while their seeming blindness and stupidity have become proverbial in the expressions 'blind as a beetle,' and 'beetleheaded.' Besides the leaves of fruit-trees they devour those of various forest-trees and shrubs, with an avidity not much less than that of the locust, so that in certain seasons, and in particular districts, they become an oppressive scourge, and the source of much misery to the inhabitants. Mouffet relates that, in the year 1574, such a number of them fell into the river Severn, as to stop the wheels of the water-mills; and, in the Philosophical Transactions, it is stated that, in the year 1688 , they filled the hedges and trees of Galway in such infinite numbers as to ciing to each other like bees when swarming; and, when on the wing, darkened the air, annoyed travellers, and produced a sound like distant drums. In a short lime the leaves of all the trees, for some miles round, were so totally consumed by them, that at midsummer the country wore the aspect of the depth of winter."

The animals and birds appointed to check the ravages of these and other insects so destructive to vegetation, are different in different countries. In Europe, according to the great French naturalist Latreille, they are the adger, weasel, martin, bats, rats, common dung-hill fowl, and the goat-sucker, or night. hawk. In the United States, various birds may be always seen in the spring of the year following the plough, among which the black bird family is by far the most numerous. These ought to meet with the utmost protection, and by no means to be stoned, shot at, killed, and frightened away, as is too often done by the idle and inconsiderate. The following view of the subject will serve to set the subject in the important light it deserves. In "Anderson's Recreations," it is stated that "a cautious observer, having found a nest of" five young jays, remarked that each of these birds, while yet very young, consumed at least fifteen of these full-sized grubs in one day, and of course would require many more of a smaller size. Say that, on an average of sizes, they consumed twenty a-piece, these for the five make one hundred. Each of the parents consume, say fifty; so that the pair and family devour two hundied every day. This, in three months, amounts to twenty thousand in one season. But, as the grub continues in that state four seasons, this single pair, with their family alone, without reckoning their descendants after the first year, would destroy eighty thousand grubs. Let us suppose that the half, namely forty thousand, are females, and it is known that they usually lay about two hundred eggs each; it will appear that no less than eight millions have been destroyed, or prevented from being hatched, by the labours of a single family of jays. It is by reasoning in this way that we learn to know of what importance it is to attend to the economy of na. ture, and to be cautious how we derange it by our short-sighted and futile operations." Our own country abounds with insect-eating beasts and birds, and without doubt the more than abundant Melolonthæ form a portion of their nourishment. (Harris.)

The very numerous varieties of the beetle family may be imagined from the fact taught us by naturalists, that of the genus Melolontha to which the beetles belong, more than two hundred have been described. Several of these found in the United States, produce injuries in the perfect grub state which rival those of the European cock-chafer. The Maybeetle, as it is generally called (Phyllophaga quercina), is the most common species.

"It is of a chestnut-brown colour, smooth, but finely punctured, that is, covered with little impressed dots, as if pricked with the point of a needle; each wing-case has two or three slightly elevated longitudinal lines; the breast is clothed with yellowish down. The knob of its antennæ contains only three leaf-like joints. Its average length is nine-tenths of an inch. In its perfect state it feeds on the leaves of trees, particularly on those of the cherry-tree. It flies with a humming noise in the night, from the middle of May to the end of June, and frequently enters houses, attracted by the light. In the course of the spring, these beetles are often thrown from the earth by the spade and plough, in various states of maturity, some ing soft and nearly while, their superabun. da. " juices not having evaporated, while others exhivit the true colour and texture of the per- 
feet insect. The grubs devour the roots of grass and of other plants, and in many places the turf may be turned up like a carpet in cornsequence of the destruction of the roots. The grub is a white worm with a brownish head, and, when fully grown, is nearly as thick as the little finger. It is eaten greedily by crows and fowls. 'There is a grub, somewhat resembling this, which is frequently found under old manure heaps, and is commonly called muckworm. It differs, however, in some respects from that of the May-beetle, or dor-bug, and is transformed to a dung-beetle called Scarabaus relictus by Mr. Say. The beetles are devoured by the skunk, whose beneficial foraging is detected in our gardens by its abundant excrement filled with the wing-cases of these insects. A writer in the 'New York Evening Post,' says that the beetles, which frequently commit serious ravages on fruit-trees, may be effectually exterminated by shaking them from the trees every evening. In this way two pailsful of beetles were collected on the first experiment; the number caught regularly decreased until the fifth evening, when only two beetles were to be found. The best time, however, for shaking trees on which the May-beetles are lodged is in the morning, when the insects do not attempt to fly. They are most easily collected in a cloth spread under the trees to receive them when they fall, after which they should be thrown into boiling water to kill them, and may then be given as food to swine." (Harris.)

In some parts of Massachusetts the beetle called the Georgian leaf-eater takes the place of the quercinu. It is extremely common in some places in May and June. Its colour is a bay-brown. The upper side is entirely covered with very short yellowish gray hairs, and measures seven-tenths of an inch, or more, in length. 'These beetles, with some others of the same genus, are commonly found in American gardens, nurseries, orchards, and fields, where they are more or less injurious depredators. They also devcur the leaves of various forest-trees, such as the elm, maple, oak, \&c. They are all nocturnal insects, never appearing, except by accident, in the day, during which they remain under shelter of the foliage of trees and shrubs, or concealed in the grass. (Harris.)

Of the American diurnal or day-flying beetles, which belong to the Melolonthians, one is described by Professor Gemar, which he proposes to call colebs. It resembles the vinechafer of Europe in its habits, and is found in the months of June and July on the cultivated and wild grape-vines, the leaves of which it devours. During the same period these chafers may be seen in still greater numbers on various kinds of sumach, which they often completely despoil of their leaves. They are very variable in colour. The head and thorax of the male are greenish black, margined with dull ochre or tile-red, and thickly punctured; the wing-covers are clay-yellow, with punctured furrows. The males are sometimes entirely black, and they commonly measure nearly, and the females rather more than seven-tenths of an inch in length. Should these beetles increase in numbers, Dr. Harris thinks they will be found as difficult to check and extirpate as the destructive vine-chafers of Europe.

An account of the natural history and habits of the Rose-hug or chafir, which belongs in the family of day-fliers, will be found urde: the head Rose-nug.

Very few of the beetle tribes which uswally subsist upon flowers are injurious to verpetio tion. Some of them are said to eat leaves, but the greater number live on the pollen and the honey of flowers, or upon the sap which oryes from the wounds of plants. The flower-beetles. belong chiefly to a group called Cetoniuns. They are easily distinguished from other bee. tles by their lower jaws, which are generally soft on the inside, and are often provided with a flat brush of hairs that serves to collect the pollen and juices on which they subsist. Most of the bright-coloured kinds are dayfliers; those of dark and plain tints are generally night-fliers. Some of them are of immense size, and have be:n styled the princes of the beetle tribes; such are the Incus of South America, and the Goliah beetle of Guinea, the latter being more than four inches long, two inches broad, and thick and heavy in proportion. (Harris.)

A family of beetles called the Lucanians, includes the insects called stag-beetles, hornbugs, and flying-bulls, vulgar names derived from the great size and peculiar form of their upper jaws, which are sometimes curved like the horns of cattle, and sometimes branched like the antlers of a stag. "These beetles," says Ur. Harris, "fly abroad during the night, and frequently enter houses at that time, somewhat to the alarm of the occupants; but they are not venomous, and never attempt to bite without provocation. They pass the day on the trunks of trees, and live upon the sap, for procuring which the brushes of their jaws and lip seem to be designed. They are said also occasionally to bite and seize caterpillars and other soft-bodied insects, for the purpose of sucking out their juices. They lay their eggs in crevices of the bark of trees, especially near the roots, where they may sometimes be seen thus employed. The larvæ hatched from these eggs resemble the grubs of the Scarabxians in colour and form, but they are smoother, or not so much wrinkled. The grubs of the large kinds are said to be six years in coming to their growth, living all this time in the trunks and roots of trees, boring into the solid wood, and reducing it to a substance resembling very coarse sawdust; and the injury thus caused by them is frequently very considerable. When they have arrived at their full size, they enclose themselves in egg-shaped pods, composed of gnawed particles of wood and bark, stuck together and lined with a lind of glue; within these pods they are transformed to pupæ, of a yellowish-white colour, having the body and all the limbs of the future beetle encased in a whitish film, which being thrown off in due time, the insects appear in the beetle form, burst the walls of their prison, crawl through the passages the larvæ had gnawed, and come forth on the outside of the trees. 
"The largest of these beetles in the New England States, was first described by Linnæus under the name of Lucanus capreslus, signifying the young roe-buck; but here it is called the horn-bug. Its colour is a deep mahogany-brown; the surface is smooth and polished; the upper jaws of the male are long, curved like a sickle, and furnished internally beyond the middle with a little tooth; those of the female are much shorter, and also toothed; the head of the male is broad and smooth, that of the other sex narrower and rough with punctures. The body of this beetle measures from one inch to an inch and a quarter, exclusive of the jaws. The time of its appearance is in July and the beginning of August. The grubs live in the trunks and roots of various kinds of trees, but particularly in those of old apple-trees, willows, and oaks.

"Several other and smaller kinds of stagbeetles are found in New England, but their habits are much the same as those of the more common horn-bug."

Another great tribe of beetles is described by naturalists under the name of serricurn, or sau-horned beetles, because the tips of the joints of their antennæe usually project more or less on the inside, somewhat like the teeth of a saw. The beetles belonging to the family of Buprestians have antennæ of this kind. The popular name for these in England is burncow, a very inappropriate appellation for a perfectly harmless insect. The French call them richards, on account of the rich and brilliant colours wherewith many of them are alcrned. Those beetles are frequently seen on the trunks and limbs of trees, basking in the sun. They walk slowly, and at the approach of danger, fold up their legs and antennæe and fall to the ground. Their flight is swift, and attended with a whizzing noise. They lieep concealed in the night, and are in motion only during the day. (Harris.)

The larvæ of these saw-horned beetles, are wood-eaters or borers, and orchards and forest trees are more or less subject to their attacks, especially after trees have passed the prime of life. The transformations of these insects take place in the trunks and limbs of trees. The larvæ that are known have a close resemblance to each other; a general idea of them can be formed from a description of that which attacks the pig-nut hickory. These grubs are found under the bark and in the solid wood of trees and sometimes in great numbers. They frequently rest with the body bent side-wise, so that the head and tail approach each other. They appear to pass several years in this larval state, before they cast off the pupa-coat and cut out through the bark in the form of a beetle.

"Some of these beetles are known to eat leaves and flowers, and of this nature is probably the food of all of them. The injury they may thus commit is not very apparent, and cannot bear any comparison with the extensive ravages of their larvæ. The solid trunks and limbs of sound and vigorous trees are uften bored through in various directions by these insects, which, during a long-coninued life, rerive their only nourishment from the woody fragments they devour. Pines and firs seem particularly subject to their attacks, but other forest-trees do not escape, and even fruit-trees are frequently injured by these borers. The means to be used for destroying them are similar to those employed against other borers, and will be explained in a subse. quent part of this essay. It may not be amios, however, here to remark, that wood-peckers are much more successful in discovering the retreats of these borers, and in dragging out the defenceless culprits from their burrows, than the most skilful gardener or nurseryman.

" Until within a few years the Buprestians were all included in three or four genera. A great number of kinds have now become known, prubably six hundred or more."

The largest of these beetles known to Dr. Harris, is called the Virginian Bupestris, or saw-horn beetle. It is of an oblong shape, brassy, or copper-coloured ; sometimes almost black, with hardly any metallic reflections. On each wing-cover are two small square impressed spots. It measures eight-tenths of an inch to one inch or more in length. This beetle appears in Massachusetts towards the end of May, and through the month of June, on pine trees and on fences. In the larvæ state, it bores into the trunks of the different kinds of pines, and is often times very injurious to these trees. (Harris.)

The wild-cherry tree (Prunus seritina) and also the garden cherry and peach trees, suffer severely from the attacks of borers, which are transformed to beetles called Buprestis divaricata, from the wing-covers parting a little at the tips. These beetles are copper-coloured, sometimes brassy above, and thickly covered with little punctures. They measure from seven to rine-tenths of an inch.

Other species of American wood-eaters or borers are described by Dr. Harris, among which are those attacking the hickory, oak, and white pine. When trees are found to be very much infested by borers, and are going to decay in consequence of their ravages, it will be better to cut them down and burn them immediately, rather than to suffer them to stand until the borers have completed their transformations and made their escape. (Harris.)

The family of Spring-beetles, or Elaters, are closely related to the Buprestians. They derive their name from the well known faculty of throwing themselves up with a jerk when laid on their backs, the legs being too short to enable them to turn over by their assistance.

"The larvæ or grubs of the Elaters," says Dr. Harris, "live upon wood and roots, and are often very injurious to vegetation. Some are confined to old or decaying trees, others devour the roots of herbaceous plants. In England they are called wire-worms from their slenderness and uncommon hardness. They are not to be confounded with the American wire-worm, a species of Iulus, which is not a true insect, but belongs to the class Myriapoda, a name derived from the great number of feet with which most of the animals included in it are furnished; whereas the English wire-worm has only six feet. The European wire-worm is said to live, in its feeding or larva state, not less than five 
years; during the greater part of which time it is supported by devouring the roots of wheat, rye, oats, and grass, annually cansine a large diminution of the produce, and sometimes destroyincr whole crops. It is said to be particularly injurious in gardens recently converted from pasture lands. We have several grubs allied to this destructive insect, which are quite common in land newly broken up; but fortunately, as yet, their ravages are inconsiderable. We may expect these to increase in proportion as we disturb them and deprive them of their usual articles of food, while we continue also to persecute and destroy their natural enemies, the birds, and may then be obliged to resort to the ingenious method adopted by European farmers and gardeners for alluring and capturing these grubs. This method consists in strewing sliced potatoes or turnips in rows through the garden or field; women and boys are employed to examine the slices every morning, and collect the insects which readily come to feed on the bait. Some of these destructive insects, which I have found in the ground among the roots of plants, were long, slender, worm-like grubs, closely resembling the common mealworm; they were nearly cylindrical, with a hard and smooth skin, of a buff or brownish yellow colour, the head and tail only being a little darker; each of the first three rings was provided with a pair of short legs: the hindmost ring was longer than the preceding one, was pointed at the end, and had a little pit on each side of the extremity; beneath this part there was a short retractile wart, or prop-leg, serving to support the extremity of the body, and prevent it from trailing on the ground. Other grubs of Elaters differ from the foregoing in being proportionally broader, not cylindrical, but somewhat flattened, with a deep notch at the extremity of the last ring, the sides of which are beset with little teeth. Such grubs are mostly wood-eaters, devouring the woody parts of roots, or living under the bark and in the trunks of old trees.

"After their last transformation, Elaters or spring-beetles make their appearance upon trees and fences, and some are found on flowers. They creep slowly, and generally fail to the ground on being touched. They fly both by day and night. Their food, in the beetle state, appears to be chiefly derived from flowers; but some devour the tender leaves of plants."

The largest of the American springingbeetles is of a black colour, covered with a whitish powder, and having a large oval velvetblack spot, like an eye, on each side of the middle, from which the insect derives its name of Oculatus, or eyed. This large beetle measures from one inch and a quarter to one inch and three quarters in length. It undergoes its transformations in the trunks of trees, and Dr. Harris has found many in old apple trees. These larvæ or worms are reddish yellow grubs. One of them found in April fully grown, measured no less than two inches and a half in length. Soon after this grub was found, it cast its slin and became a pupa, and in due time the latter was transformed to a beetle. (Hirris.)
Among the night-shining Elatr.r $i$, 1 ir ce? re brated Cucuriu, or fire-beetle, of the W W In. dies, from whence it is often brought alive to this country as a curiosity. It remmbles corl. siderably the insect just described, bring an inch or more in length. It gives put, eren by day, a strong light from two transparent cyelike spots on the thorax, and from the sergments of its body beneath. It limeds upon the sugar-cane, and its grub is said to be very injurious to this plant, by devouring its roots.

Dr. Harris states that above sixty different kinds of spring-beetles are now known to in. habit Massachusetts.

The utility of a knowledge of the natural history of insects in the practical arts of life, was perhaps never more strikingly and triumphantly displayed than by the great Lin. næus himself, who, while giving to natural science its language and its laws, neglected no opportunity to point out its economical advantages. On one occasion, this great natu. ralist was consulted by the King of Sweden, upon the cause of the decay and destruction of the ship-timber in the royal dock-yards, and, having traced it to the depredations of insects, and ascertained the history of the depredators, by directing the timber to be sunk under water during the season when these insects made their appearance in the winged state, and were busied in laying their eggs, he effectually secured it from future attacks. The name of these insects is Lymexylon navale, or the naval timber-destroyer, which Dr. Harris thinks cannot be far removed from the tribe of springbeetles. The odd-looking, long, and slender grubs of the Lymexylon, inhabit oaks, and make long cylindrical burrors in the solid wood. They are also found in some other kinds of trees. Dr. Harris considers insects of this family rather rare in New England, and describes only two kinds of American Timberborers. (See his Trentise.)

BEETLE. A large wooden instrument in the form of a mallet, with one, two, or three handles for as many persons, used in driving piles, wedges, hedge-stakes, and in splitting wood, \&c.

BEETLE, CLODDING. A sort of implement made use of in reducing the clods of tillage-lands, in clayey and other stiff tenacious soils, to a fine powdery condition. This business may be much sooner performed, and at less expense, by means of rollers constructed for the purpose. (See Rollen.)

BEEVES. The plural of beef. A general name employed by farmers for oxen or black cattle.

BEGGAR'S LICE (Echinaspernum Virginicum). An obnoxious weed found along the borders of woods, bearing a small bluish-white flower, frequent in pastures and along fencerows, the bur-like fruit or nuts of which are furnished with hooked prickles, and often form a matting in the fleeces of sheep, and the manes and tails of horses. (Flor. Cestrica.)

BELLADONNA (Atropa belladimna). In botany, the Deadly Nightshade. It is an acronarcotic poison. This name, belladimna (signifying Handsome Lady), according to Ray. 
was given to it by the Italians, because the Italian ladies make a cosmetic of the juice.

The belladonna, although perennial in reference to the root, is annual in its herbage, which is of quick growth, branching, and shrub-like. The leaves are lateral, generally two together, ovate, acute, entire, smooth, and clammy. The flowers are solitary, stalled, rising in the axillæ of the leaves, bell-shaped, and of a lurid purple colour. The fruit is a shining, black, sweetish berry, seated in the permanent calyx, about the size of a cherry. The plant is poisonous, having a peculiar alkali, named atropio, which, in combination with malic acid, is found in every part of the plant. Its influence is chiefly exerted on the brain and nervous system, causing delirium, movements of the body resembling intoxication, confused speech, uttered with pain, and other symptoms of narcotic poisoning. Buchanan, the Scotish historian, informs us, that the Scots under Macbeth intoxicated the Danes under Sweno by mixing their wine with the juice of the berries of belladonna during a truce, which enabled Macbeth readily to overcome them. Shakspeare alludes to it in the interview beiween Macbeth and the witches, when the former says-

Or have we drank

Of the insane root which takes the reason prisoner? Macbeth, Act l.

The beauty of the berries frequently entices children to eat them; and, although not often fatal, they cause very distressing effects to the little sufferers. In such cases, the stomach should be quickly emptied by an emetic, and afterwards vegetable acids and decoction of nut-galls should be given. Belladonna is an excellent medicine; but it should not be entrusted to the ignorant.

BELL-WETHER. A sheep which leads the flock, with a bell on his neck.

BELT. To belt, in some districts, signifies is shear the buttocks and tails of sheep.

BELT. In planting, a strip or portion of land planted with trees for the purpose of ornament, or warmth and shelter. Much advantage may be derived in this way in improving the climate of the district. (See Praver

BENE PLAN'T (Sesamum orientule). The bene or sesamum has been introduced into $\mathrm{Ja}$ maica and other West India islands, where it is quite extensively cultivated in many places. It is commonly called Vanglo or oil-plant, from the oil which it yields to pressure. The seeds are frequently used in broths, and by some introduced into cakes. Many of the Oriental nations look upon the seed as a hearty and wholesome food, and express an oil from them, not unlike, or inferior to, the oil of almonds. Attempts have even been made to manufacture oil from it in England, but with little success.

sesamum orientale, or bene, is frequently cultivated in the eastern parts of the Mediterranean as a garden vegetable. The seeds have been introduced into the Carolinas, and other southern States, by the African negroes. The seeds are used by the blacks for food; they parch them over the fire, then mix them with water, and then stew them up with other ngredients. A kind of pudding is also made of them, similar to such as are made of rice or millet. The oil pressed from the seeds will keep many years without acquiring any rancid taste, but in two years becomes quite nild, so that the warm taste of the oil when first drawn is worn off, and it can be used for salads and all the ordinary purposes of sweet oil. In $\mathrm{Ja}$ pan, China, and Cochin-China, where they have no butter, they use the oil for frying fish, and preparing other dishes; as a varnish, and for some medicinal purposes. Nine pounds of seed are said to yield upwards of two pounds of fine oil.

The sesamum is an annual plant. It grows like cotton, from three to six feet high, bearing numerous square pods about an inch and a half long, filled with seeds about the size of flaxseeds. In its growth it requires no sticks, or other support. The product of seed is about twelve or fifteen bushels per acre, and the proportion of ail yielded to pressure has been estimated as equal to one-half the measure of the seed, and some estimate the proportion as far greater. The oil may be extracted by bruising the seed and immersing them in hot water, when the oil rises on the surface and may be skimmed off. But the usual mode of extraction is similar to that practised in the expression of linseed oil. In the Southern States many planters cultivate the bene largely, sowing in drills about four feet apart, in the month of April, and gathering the crop of seed in September. The pods ripen successively, and not all at one time. Bene has been raised in Virginia, Maryland, and the lower part of the peninsula between the Dela. ware and Chesapeake Bays, just as far north as cotton admits of cultivation. In higher latitudes, even in the vicinity of Philadelphia, the plant will grow, but seldom ripens its seed. The leaves of the plant are in great repute as a remedy in dysentery, and especially the cholera infantum or summer complaint of children. The freshly gathered leaves are merely dipped into a tumbler of cold water, which immediately becomes ropy, without losing its transparency or acquiring any unpleasant taste, on which account it is readily and even gratefully received by the little sufferers, who are allowed to sip it in moderate quantities instead of other drinks. Sesamum is indeed a valuable plant, and should be cultivated wherever it will grow, for its medicinal and domestic uses, if not for its oil; which last, however, must, under proper management, prove a profitable product of the soil.

BENT, or STARR. Names applied in England to the common reed (the Arundo prasmites of Dr. Darlington, and the A. arenaria of some other botanists). Sinclair calls the upright sea lyme grass, starr, or bent. (See Plate 7, 1.) One of the chief uses this coarse grass is made to subserve in the United States, as well as in European countries, is to protect banks and sea-dykes exposed to the washings of waves and currents. See Arundo ARENARTA.

BENT-GRASS. A species of Agrostis very common in pasture grounds, the bent or creep. ing stems of which are very difficult to eradicate. (See Atrostis.) 


\section{BEN'TS.}

BFNTS. The withered stalks of grass standing in a pasture after the seeds have dropped. It also sometimes signifies a species of rush (Juncus squurrosus), which grows on moorland hills.

BERBEREN. A yellow bitter principle contained in the alcoholic extract of the root of the barberry tree.

BFRBERRY (Berberis). See Banaะnn.

BERE (Goth. bar; Sax. bene). The common name for a species of barley, which is also frequently termed big, bear, and square barley. Thus, in Huloet, an old writer, we find "beer-corn, barley-bygge, or moncorne."

BERGAMO'T (Fr. bergimolle). A species of citron, the fruit of the Citrus bergamia (Risso). This tree is cultivated in the south of Europe. It is a moderate-sized tree with oblong, acute, or obtuse leaves, with a pale underside, and supported on winged footstalks. The flowers are small and white; the fruit is pyriform, of a pale yellow colour, and the rind studded with oil vesicles; the pulp is slightly acidulous. The oil, which is procured from the rind, is imported from the south of Europe, under the name of oil ur essence of bergamot. It is of a pale greenish colour, lighter than water, and used merely as an agreeable perfume. A species of mint, having a highly agreeable odour (Mentha odorata, Smith), is popularly called bergamot in the United States.

BERRY (Bacea). A succulent pulpy fruit, which contains one or more seeds, or granules, imbedded in the juice.

BETHLEHEM, S'TAR OF (Ornithogalum). Smith points out four varieties of this flower: the yellow star of Bethlehem, O. luteum; the common star of Bethlehem, O. umbellatum, (commonly called ten o'clock); the tall star of Bethlehem, O. pyrenaicum; and the drooping star of Bethlehem, $O$. nutans. The first is met with sometimes, but not very frequently, in grove pastures. The second is found in meadows, pastures, and groves in various parts of England. The last is found mostly in fields and orchards, probably naturalized. All are elegant spring flowers. 'The last is common in country gardens, whence it may have escaped into the fields. Yet the plant may as well be a native of England as of Denmark, Austria, or other parts of Europe and America, where it is found in similar situations. One of the species, commonly called ten o'clock (Ornithogalum umbellatum), Dr. Darlington says, is a foreigner that has escaped from gardens, and has become a nuisance on many farms in the Middle States. Although it rarely perfects its seed, it propagates itself with great rapidity by means of lateral bulbs. These bulbs are extremely difficult to eradicate. ( F lor. Cestrica.) An American species of the star of Bethlehem ( 0 . virens) was found by Lindley on the Delaware Bay. The sea-squill, so extensively used in medicine, belongs to this bulbous-ronted family of plants. (Smith's Eng. Flora, vol. ii. p. $141-145$.

BEVER (Ital. bevere; old French, beivre). To drink: a word now almost obsolete, but from which we derive beverage. The provincial term amongst labourers for the meal between dinner and tea.
BLVD-WEED.

BIENNIAI, (I.at biemnis). Any thing that continues or endures two years. I'his terin is usually applied to plants whis:h grow one year and flower the next, after which thev prish. 'They only differ from annuals in requiring a longer period to fruit in. Mist hiemuals, if sown early in the spring, will flower in the antumn and then perish, thus actually becumin? annuals. (Brunde's Dict. "If Science.)

BIG. A term sometines applied in Ens. land $t o$ bere or square harloy.

BILBERRY, or BI.EABERRY. Sce WUn. TLEBERIR.

BILL (Bille; Sax. ribule, a two-edged axe). A kind of hatchet with a hooked point, and a handle shorter or longer, according to the particular uses for which it is intended. It is mostly employed by husbandmen for cutting hedges and felling underwood; and Johnson tells us it takes its name from its resemblance, in form, to the beak of a bird of prey.

BILLET (Fr. bilot). A small log of wood for the chimney.

BIN (Sax. binne). A small box or other contrivance in which grain of any kind is kept. It is sometimes written binn. Bin also signifies a sort of crib for containing straw or other bulky fodder in farm-yards.

BIN, CORN-. A sort of convenient box or chest fixed in the stable for the purpose of containing grain or other provender for horses. We have also hop-bins, wine-bins, \&c.

BIND-WEED (Lat. convolvulus). A trouble. some genus of weeds, of which there are in England three species, the smaller, the great, and the sea bind-weed. The climbing buckwheat ( Poly gonum convolvulus) is also known by the name of black bind-weed. The first or smaller bind weed ( $C$. urvensis), frequently called gravei bind-weed, is very common in hedges, fields, and gardens, and upon dry banks and gravelly ground in most districts, and is an almost un. conquerable weed. Its presence is generally a sign of gravel lying near the surface. Its branching, creeping roots penetrate to a great depth in the soil. The flowers are fragrant like the heliotrope, but fainter, very beautiful, of every shade of pink, with paler or yellowish plaits, and stains of crimson in the lower part; sometimes they are nearly white. They close before rain. The second kind, or great bind-weed (C. sepium), is also an equally troublesome and injurious weed to the husbandman. It grows luxuriantly in moist hedges, osier holts, and thickets. In an open, clear spot of ground, when the plants are kept constantly hoed down for three or four months, it may sometimes be effect ually destroyed; as when the stalks are broken or cut, a milly juice exudes, by which the roots are exhausted and decay. Every portion of the root will grow. The roots of this species are long, creeping extensively, and rather fleshy; the stems twining, several feet long leafy, smooth, and slightly branched. Flowers solitary, large, purely white for the most part, occasionally of a uniform flesh or rose colour. It is a perennial, flowering in July and Augus: in England, and a month earlier in Pennsylva. nia, where it is occasionally found. It is so injurious to crops that farmers should try all means to get rid of it. The black bind-w.'id, 
(Plate 10,d), called also climbing buck-whent, and hear-bind, is an annual, flowering in June and September. Its root is small and tapering, and the stem twines from left to right, round every thing in its way to the height of five or six feet. The flowers arc drooping, greenish white, or reddish.

Several plants of the convolvulus family are highly valuable for theod and medicines they furnish. That most active purgative scammony is obtained from C. scammonia, and jalap from a species of Ipomæa. Occasionally the purgative principle is so much diffused among the frecula of the root, as to be almost inappreciable, as is the case in the $C$. batatus, or sweet potato of America. The root of the great bind-weed is a strong purgative, fresh gathered and boiled in a little warm liquid, being near akin to the acrid and violent scammony. The humbler classes boil it in beer or ale, and find it a never-failing remedy. Among delicate constitutions it should be taken with caution, as its effects are very powerful. In Northamptonshire it grows most abundantly. A decoction of the roots also causes perspiration.

BiRCH (Sax. brnc; Lat. betula). The English word birch seems, however, to be derived from the Gierman birke, or the Dutch berk. All the European languages are similar in the pronunciation of the name of this tree. A very hardy, ornamental, and, in some respects, a useful tree, inhabiting the north of Europe, Asia, and America. There are many species of birch, but that best known, and most generally cultivated in this country, is the common birch (Betulis alla). The common birch is valuable for its capability of resisting extremes of both heat and cold: its timber is chiefly employed for fire-wood. Its bark is extremely durable: it consists of an accumulation of ter or twelve skins, which are white and thin like paper, the use of which it supplied to the ancients; and as a proof of its imperishable nature, we are told that the books which Numa composed, about 700 years before Christ, which were written on the bark of the birch tree, were found in a perfect state of preservation in the tomb of that great king, where they had remained 400 years. Although this species is not much valued for its timber, it is extremely useful for many other purposes. Russia skins are said to be tanned with its bark, from which the peculiar odour of such leather is derived; and it is said to be useful in dyeing wool yellow, and fixing fugacious colours. 'The Highlanders weave it into ropes for their wellbuckets. The poor people of Sweden were formerly accustomed to grind the bark to mingle with their bread corn. And in Denmark, Christopher III. received the unjust surname of Berka Kanung (king of bark), because in his reign there was such a scarcity, that the peasants were obliged to mix the bark of this tree with their flour. Cordage is obtained from it by the Laplanders, who also prepare a red dye from it; the young shoots serve to nourish their cattle, and the leaves are said to afford good fodder for horses, kine, sheep, and goats. The vernal sap of these trees is well known to have a saccharine quality, and from 1.78 the forest housewife makes an agreeable and wholesome wine. During the siege of Ham. burgh, in 1814, by the Russians, almost all the birch trees of the neighbourhood were destroyed by the Bashkirs and other barbarian soldiers in the Russian service, by being tapped for their juice. Vinegar is obtained from the fermented sap. 'The inhabitants of Finland use the leaves for tea ; and both in Lapland and Greenland, strips of the young and tender bark are used for food. From the timber are manufactured gates and rails, packingcases, hoops, yokes for cattle, turners' ware, such as bowls, wooden spoons, wooden shoes and clogs, and other articles in which light. ness without much durability is sufficient. Baskets, hurdles, and brooms are often made of part of its shoots. 'The broom-makers are constant customers for birch in all places in the vicinity of London, or where it is near watercarriage; but in most other parts the hoopbenders are the purchasers. 'The larger trees are often bought by the turners. In some of the northern parts of Europe, the wood of this tree is likewise greatly used for making of carriages and wheels, being hard and of long duration. The most general and the most profitable use to which birch at present can be turned is, unquestionably, the manufacture of small casks, as herring barrels, butter tubs, \&c. For the latter purpose it is admirably suited, because it is stout, clean, and easily wrought, and communicates no particular taste or smell to the butter. The timber of the birch was more used and more valued in former times. It was not so strong as the ash for harrows and other farming implements, but it was not so ready to split, and for roofing cottages it is still held in estimation. In Russia, Poland, and other northern countries, the twigs of this tree cover the dwellings of the peasant, instead of tile or thatch. It afforded our ancestors arrows, bolts, and shafts, for their war implements. The whole tree is adapted for burning into charcoal of the best quality, and suited for the manufacture of gunpowder.

The birch will grow in any soil, but best in shady places. It may, therefore, in some situations, be turned to good account, since it will grow to advantage upon land where other timber will not thrive. Miller says, it loves a dry barren soil, where scarcely any thing else will grow ; and will thrive on any sort of land, dry or wet, gravelly, sandy, rocky, or boggy, and those barren, heathy lands which will scarcely bear grass. It is said to attain sometimes the height of seventy feet, with a diameter of two feet; in England it does not acquire such considerable dimensions. The birch is propagated by seeds, which are easily taken from bearing trees, by cutting the branches in August, before they are quite ripe. The seed may be thrashed out like corn, as soon as the branches dry a little; they should be then kept in dry cool sand until they are sown, either in the autumn or spring. A great deal of nicety and attention is required in rearing the birch from the seed; they must be sown in the shade, and covered very lightly with soil made as fine as possible, and watered according to the wetness or dryness of the season. The planting out 
of this tree is performed in the same manner as in the ash. If planted for underwood, it should be felled before March to prevent its bleeding. 'The tree bears removing with safety, after it has attained the height of six or seven feet; and is ready to plash as hedges in four years after planting. When old they are trausplanted with considerable difficulty.

The other European birches are the weeping birch (Betula pendula), which is very common in different parts of Europe, along with the last, in the properties of which it appears to participate, and with which it is often improperly confounded. It differs from the common birch not only in its weeping habit, but also in its young shoots being quite smooth, bright chestnut brown when ripe, and then covered with little white warts. The Betula pontica of the nurseries is a slight variety, of a less drooping habit.

The third species is the downy birch ( $B e$ tula pubescens), a smaller species than the first, found in the bogs of Germany; a variety of it is called Betula urticifolia in gardens.

The fourth and last European species is the dwarf birch (Betula nana), a small bush found in Lapland and the mountainous parts of other northern countries. To the people of the south this plant has no value, but to the Laplanders it affords a large part of their fuel, and its winged fruits are reported to be the favourite food of the ptarmigan. The Asiatic species are the Indian paper birch ( $B$. Bhojpattra) tapering-leaved birch ( $B$. acuminata); shining birch (B. nitida); cylindrical spiked birch ( $\boldsymbol{B}$. cylindrostachya). The principal American birches are, 1. The poplar-leaved or white American birch (B. populifolia). It is very like the European B. pendula. 2. The red birch ( $B$. nigra). In this country it is generally called $B$. angulala, and by some $B$. rubra. The Messrs. Loddiges, of Hackney, were the first importers of this fine but little known species. 3. The yellow birch ( $B$. excelsu). 4. The paper or canoe birch (B. papyracea), which is employed by the North American Indians for a variety of useful purposes. 5. The soft black or cherry birch (B. lenta). None of the American birches produce timber so valuable as this, whence one of its American names is mountain mahogany. Its wood is hard, close-grained, and of a reddish brown; it is imported into England in considerable quantities, under the name of American birch, for forming the sides of dining tables, and for similar purposes. It is rarely seen in England, although it is perhaps one of the best suited to that climate. All the species of birches, except the common and weeping, are multiplied by layers in the usual way.

The juice of the birch tree, produced from punctures in the spring of the year, is diuretic. The wine made from this sap is said to be aperitive, and detersive. Old medical writers tell us that the wood was esteemed the best to burn in times of pestilence and contagious distempers; but, like many old medical saws, that opinion is of no value. (Phillips's Syl. Flor. vol. i. p. 123 ; Pen. Syc. vol. iv. p. 348 ; Baxter's Agr. Lib.)

BIRDS. A few of the feathered tribes may be regarded as mischievous depredators uprn the farmer and gardener, eating his fruit, as the robin; pulling up the corn when just spronterd, or eating it from the ear when nearly matured, as is so often done by the crow, the black-bird or grakle. But if account be marle of all the services derived from birds in destroying those insects which in their larva or worm state, or their more perfect winged state, commit such serious depredations upon orchards and fields, it will be found that we owe the feathered family a very large balance. Upon this subject we must refer for further illustration to the articles Befte, Borens, Aphis, and others relating to destructive insects. That distin. guished naturalist, Mr. Nuttall, has the following beautiful tribute to birds in his interesting Manual of the Ornithology of the United Siates.

"In whatever way we view the feathered tribes which surround us, we shall find much both to amuse and instruct. We hearken. to their songs with renewed delight, as the harbingers and associates of the season they accompany. Their return, after a long absence, is hailed with gratitude to the Author of all existence; and the cheerless solitude of inanimate nature is, by their presence, attuned to life and harmony. Nor do they alone administer to the amusements and luxury of life; faithful aids as well as messengers of the seasons, they associate round our tenements, and defend the various productions of the earth, on which we rely for subsistence from the destructive depredations of myriads of insects, which, but for timely riddance by unnumbered birds would be followed by a general failure and famine. Public economy and utility, then, no less than humanity plead for the protection of the feathered race, and the wanton destruction of birds, so useful, beautiful, and amusing, if not treated as such by law, ought to be considered as a crime by every moral, feeling, and reflecting mind."

BIRD-BOLT. A short arrow, having a ball of wood at the end of it, and sometimes an iron point, formerly used for shooting birds.

BIRD-CHERRY (Prunus padus). The berries are eagerly sought after by birds, and as the leaf and fruit resemble that of the cherry tree, hence the name of bird-cherry. In Scotland it is called hogberry. This aboriginal of our English woods possesses beauties that should oftener secure it a situation in the shrubbery, and more frequently a place in ornamental hedge-rows. The bird-cherry rises from ten to fifteen feet in height, spreading to a considerable distance its branches, which are covered with a purplish bark. It flowers in April and May, and the small black fruit, which hangs in bunches, ripen in August. Although the fruit is austere, and bitter to the taste, it gives an agreeable flavour to brandy, and many persons add it, for the same reason, to their made wines. Birds soon devour the fruit, which is nauseous and probably dangerous, though perhaps, like that of the cherry laurel, not of so deadly a quality as the essential oil, or distilled water of the leaves, which is highly dangerous from containing much Prussic acid. The wood is hard and closegrained, and is used for whip and knife handle 
Jinnæus says, that kine, sheep, goats, and swine eat the leaves, but that horses refuse thern. The scent of the leaves, when bruised, resembles rue. The variety with red fruit, commonly called the Cornish cherry, flowers two or three weeks earlier, and is therefore not so desirable for the shrubbery. The birdcherry may be propagated by layers, which should be performed in autumn, but the handsomest trees are raised from seed, which may be sown at the same season. A wet soil is not congenial to this tree. (Phillips's Syl. Flur. vol. i. p. 134; Smith's Eng. Flur. vol. ii. p. 354.)

BIRD'S EYE (Veronica chamædrys). The Germander Speedwell, or wild germander. A troublesome weed in fields. It is found very commonly in groves, meadows, pastures, and hedges. It is a perennial, flowering in May and June. Herbage light green. Flowers numerous, transient, but very beautiful, bright blue with dark streaks and a white centre; their outside pale and flesh coloured. The flowers expand in fine weather only. Some take this for the German "forget-me-not." It vies in beauty with the true one, Myosotis polustris. ('Mith's Eng. Flor. vol. i. p.23.) See SPEEDWELL.

BIRD'S FOOT, COMMON (Ornithopus perpusillus). A weed found most generally in sandy or gravelly pastures. Root fibrous, annual, though it is sometimes propagated by subterraneous lateral knobs in the manner of a potato, in which case the seeds are abortive. The stems, often numerous, are procumbent, from three to ten or twelve inches long. Leaves alternate, of from five to ten or twelve pair, of small uniform elliptical leaflets. Flowers three or four in each little head or tuft.

The species of bird's foot are curious on account of their jointed pods, but not worth culture as plants of ornament. O. sativus is, however, a most valuable agricultural plant.

BIRD'S-FOOT TREFOIL, or CLOVER (Lotus). The common name of a genus of plants that flourishes in a singular manner in the most exposed and dry situations. On bowlinggreens and mown lawns it forms a fine green close herbage, even in hot seasons; and in meadow and pasture grounds it is frequently abundant. Its very strong deep tap root is the cause of its resisting drought. Smith describes four species:-1. Common bird's-foot trefoil ( $L$. corniculatus), a perennial, flowering in the second week of June, and ripening the seed about the end of July, and successively to the end of autumn; common in open grassy pastures. [PI.9, g.] Some botanists have considered the following species ( $L$. major) to be a variety of the carniculatus, but the difference between them is obvious at first sight; and this difference remains permanent when the pant is raised from seed, and cultivated on different soils. What renders a specific distinction here of most importance to the farmer, is the difference which exists between them in an agricultural point of view. Heads depressed, of few flcwers, root branching, somewhat woody; the fibres beset with small granulacions; stems several, spreading on the 180 ground in every direction, varying in length from three to ten inches, simple or branched Flower stallis erect or recumbent, five times as long as the leaves, each bearing from two to five bright yellow flowers, dark green when dried, and they change to orange when verging towards decay. 'This species is recommended for cultivation, though under the erroneous names of milk-vetch and Astragalus glycyphyl los, by the late Dr. Anderson, in his Agriculiural Essays, as being excellent for fodder as well as for hay. Mr. Curtis and Mr. Wood also recommended it. Linnæus says that cows, goats, and horses eat it; and that sheep and swine are not fond of it. With regard to sheep (says the late Mr. G. Sinclair, Hurt. Gram. Wob. p. 310), as far as my observations have extended, they eat it in common with the herbage with which it is usually combined; the flowers, it is true, appeared, always untouched, ard in dry pastures little of the plant is seen or presented to the cattle, except the flowers, on account of its diminutive growth in such situations. This, however, is nearly the case with white or Dutch clover; sheep seldom touch the flowers while any foliage is to be found. Mr. Woodward informs us that it makes extremely good hay in moist meadows, where it grows to a greater height than the trefoils, and seems to be of a quality equal, if not superior, to most of them. Professor Martyn observes, that, in common with several other leguminous plants, it gives a substance to hay, and perhaps renders it more palatable and wholesome to cattle. The clovers contain more bitter extractive and saline matter than the proper natural grasses, and the bird's foot trefoils contain more of these vegetable principles than the clovers. In pastures and meadows, therefore, where the clovers happen to be in small quantities, a portion of the trefoil ( L. corniculatus) would doubtless be of advantage; but it appears to contain too much of the bitter extractive and saline matters to be cultivated by itself, or without a large intermixture of other plants. It does not spring early in the season, but continues to vegetate late in the autumn. In irrigated meadows, where the produce is generally more succulent than in dry pastures, this plant cannot with safety be recommended, at least in any considerable quantity. It is more partial to dry soils than the next species (L. major); it attains to a considerable height. when growing among shrubs, and seems to lose its prostrate or trailing habit of growth entirely in such situations. 2. The greater bird's-foot trefoil (L. mojor) fourishes in wet bushy places, osier holts and hedges; very different from the foregoing species in general habit, and now technically distinguished by several clear and sufficient characters. The stems are from one to two or three feet high, upright, clothed more or less with long loosely-spreading hairs. Leaves fringed with similar hairs; flowers from six to twelve in each head, of a duller orange than the former. The weight of green food or hay is triple that of the foregoing species, and its nutritive powers are very little inferior, being only as 9 to 8. These two species of bird's-foot trefoil may be compared to eacls 
other $w$ ith respect to habits in the same manner as the white clover and perennial red clover; and were the latter unknown, there appear to be no plants of the leguminous order, that, in point of habits, would so well supply their place as the common and gieater bird'sfoot trefoil. They are, however, greatly inferior to the clovers. The white clover is superior to the common bird's-foot trefoil in the quantity of nutritive matter it affords, in the proportion of 5 to 4 . It is much less productive of herbage, and is much more difficult of cultivation, the seed being afforded in much smaller quantities. The produce of the greater bird's-foot trefoil is superior to that of the perennial red clover on tenacious or moist soils, and on drier and on richer soils of the first quality; but the produce is inferior in the proportion of nutritive matter it contains as 5 to 4. The nutritive matter is extremely bitter to the taste. It does not appear to be eaten by any cattle when in a green state, but when made into hay, sheep, oxen, and deer, all eat it without reluctance, and rather with desire. It does not seem to perfect so much seed as the former species, but this is abundantly remedied in its propagation by the creeping or stoloniferous roots which it spreads out in all directions. In moist clayey soils it would doubtless be a most profitable substitute for red clover; but the excess of bitter extractive and saline matters it contains seems to forbid its adoprion without a considerable admixture of other plants. It flowers about the third week of June, and the seed is ripe about the end of the following month. The following analysis will show the comparative value of the two species :-

\begin{tabular}{|c|c|c|c|}
\hline & $\begin{array}{c}\text { Green Prod. } \\
\text { per acre. }\end{array}$ & $\begin{array}{l}\text { Dry Prod. } \\
\text { per acre. }\end{array}$ & $\begin{array}{l}\text { Nutriment } \\
\text { per acre. }\end{array}$ \\
\hline $\begin{array}{l}\text { Lotus corniculatus } \\
\text { - major }\end{array}$ & $\begin{array}{ccc}\text { 1tss. } & \\
10,209 & 6 & 0 \\
21,780 & 0 & 0\end{array} \mid$ & $\begin{array}{ccc}\text { Iths. } & & \\
3,190 & 6 & 0 \\
8,142 & 8 & 0\end{array}$ & $\begin{array}{lrl}\text { lbs. } & & \\
358 & 4 & 9 \\
680 & 10 & 0\end{array}$ \\
\hline
\end{tabular}

3. Spreading bird's-foot trefoil (L.decumbens) is, like the two preceding species, a perennial, flowering in England in July. It is found in fields and meadows. The flower-stalks are four or five times the length of the leaves, smooth, stout, and firm, each bearing an umbel of from three to six bright yellow flowers. 4. Slender bird's-foot trefoil ( $L$. angustissimus) is an annual flowering in May and June, found in meadows towards the sea on the south and western coasts of England. It is smaller, in general, than any of the foregoing species. A species of trifolium ( $\boldsymbol{T}$. ornithopodioides) also bears the name of bird's-foot trefoil; but Sir J. Smith very justly observes (Ingl. Flur. vol. iii. p. 298), it can scarcely, without violence, be retained in the genus Trifolium; yet no one has thought fit to make it a distinct one, however plausible might be the reasons for such a measure. It is an annual plant fowering in June and July, found in barren, gravelly, grassy pastures; root fibrous, stems several, spreading flat on the ground, flowers two or three, long, pale, reddish. (Smith's Eng. Flor. vol. iii. pp. 298, 312 ; Sinclair's Hort. Gram. Wob.)

Two species of lotus, not referred to in the preceding account, are a good deal cultivated in France, on light scils. 'These are the vi? lous (I. villosus) and the cultivated lotus (Latier cullivé, or Lotus telragronolubus, I'I. 9, h). The last is an annual sown in gardens.

BHRULIME. 'This glutinous vegetable product is procured either by boiling misletue berries in water until they break, pounding them in a mortar, and washing away the busky refuse with other portions of water; or, which is the chief mode in which it is made (chiefly in Scotland) for the purposes of bird-catching, \&ic., from the middle bark of the holly. 'The bark is stripped in June or July, and boiled for six or eight hours in water, until it becomes tender; the water is then separated from it, and it is left to ferment for two or three weeks, until it becomes a mucilage, which is pounded in a mortar into a mass, and then thoroughly rubbed by the hands in running water till all the branny matters and other impurities are washed away; the birdlime is then suffered to remain fermenting by itself in an earthen vessel for some weeks. (The bird-catchers, when they make their own, place the vessel in a dunghill.) The bark of the wayfaring tree is sometimes employed. The fragrant gum which exudes from the Styrax, or American Sweet Gum, a large tree, growing in the Middle and Southern States, also makes a good birdlime, being extremely tenacious. (Gray's Supplement, p. 226 ; Nich. Journ. b. xiii. p. 145; Thomson, vol. iv. p. 119.)

BIRD'S NEST, YELLOW (Monotropa hypopitys). A weed occasionally met with in poor and gravelly soils. It is also found sometimes about the roots of beeches and firs, in woods, frequent in all the midland counties. Rnot fibrous, much branched, and somewhat creeping, growing among dead leaves, or in half decayed vegetable mould. Stem solitary, five or six inches high, flowers in a drooping cluster. (Smith's Engl. Flor. vol. ii. p. 249.)

The species of this plant found in the Middle States, are, that called the Indian Pipe (M. unifora), and the woolly monotropa, Pine-sap, or False Beach-diops. Both these singular plants are called parasitic. (See Flor. Ces/ric.)

BIRD PEPPER. A species of small capsicum, which affords the best Cayenme pepper. See Capsicum.

BISCUIT (Lat. lis, twice; Fr. cuit, baked, Ital. biscuto). A kind of hard dry bread cake Biscuits are more easily kept than other kinds of bread, and as they contain no ferment, they are better fitted than loaf bread for persons of weak stomachs, and for the pap of infants, who are under the misfortune of being brought up by hand.

The best biscuits and the most wholesome. are those prepared for the use of the navy. They are of two kinds, captains' and seamen's biscuit. The latter are composed of wheaten flour, from which the bran only has been taken; consequently they are more nutritive than the finer sort. In the government bake-houses at Weevil and Deptford, the biscuits are preferable to those baked by ordinary bakers, owing to the extent of the operations, and the purity of the wheat-meal: 102 lbs. of perfectly dry biscuits are procured from $112 \mathrm{lbs}$. of meal.

BISHOPING. A cant term made usc o: 
among horse-jockeys, implying the practices employed to conceal the age of an old horse, or the ill properties of a bad one. See Agr of Honses.

BISON, AMERICAN (Bos Americanus). This species of the ox kind is peculiar to the temperate latitudes of North America, where it is universally, though incorrectly called the Buffalo, a name properly belonging to a different species of the ox tribe common to Eastern Asia. The bison was found by the first colonists of the Carolinas, and other of the Southern and Middle States, from which parts of the North American Continent they have long been exterminated or frightened away. So late as the year 1766 , they were seen in a wild state in Kentuchy. At present none are to be met with east of the Mississippi river, having retired beyond this great stream, and concentrated in the praries of the Missouri and other rivers of the far west. Here they often unite in immense flocks, some of which, travellers and hunters inform us, contain eight or ten thousand. Generally speaking, the bison is rather timid, flying from the hunter, except in the rutting season, about the middle of June, when the males become very fierce, and often kill each other in their terrible combats.

The qualities of buffalo beef are highly exlolled, and the hump upon the shoulders is regarded as a particularly choice morsel. The tongues, which constitute a regular article of trade, are exceedingly rich and tender. The thick and rough hairy skins of the bison are tanned by the Indians and trappers, and then sold to be formed into buffalo robes and other articles of comfort, so useful during the severe winters of the United States.

The following highly interesting account of the American Bison is taken from the American Farmer, (vol. vi. p. 260), under the head of Buffulo Oxen.

"The animal known by the name of the Buffalo throughout the valleys of Missouri and Mississippi differs materially from the buffalo of the Old World. At first view, his red fiery eyes, his shaggy mane, and long beard, the long lustrous hair upon his shoulders and fore-quarters, and the comparative nakedness of his hind-quarters, strongly remind a spectalur of the lion.

"In the size of his head, in bulk, in stature, and in fierceness, he resembles the buffalo of Buffon; but the humps or protuberance between his shoulders, the shape of his head, his curled forehead, short thick arms, and long hind legs, mark a much stronger affinity to the bison.

"He carries his head low like the buffalo, and this circumstance, together with his short muscular neck, broad ehest, and short thick arms, designate him as peculiarly qualified for drawing: the whole weight of his borly would thus be applied in the most advantageous manner to the weight drawn. The milk of the female is equal in quality to that of the cow, but deficient in quantity. It has been supposed that the smallness of the udders is more re. markable in those that have the hump large, and that the diminished size of the hump is evidence of a more aburidant secretion of milk 'The hump, when dressed, tastes like 182 the udder of a cow, and is deemed a delicacy by the Indians. But there is one other particu. lar which distingaishes the buffido of the New World from its eastern namesake more distinctly than any variety of conformation could do. The cow refuses to breed with the buffalo of Europe; and such is the fixed aversion between these creatures, that they always keep separate, although bred unde? the same roof and feeding in the same pas. ture. The American buffalo, on the contrary, breeds freely with the domestic cattle, and propagates a race that continues its kind. Many of the landholders in I.ouisiana, like the patriarchs of old, possess thousands of cattle which graze at liberty in the uncultivated prairies. These herds cost their owners little more than the trouble of marking them, and the expense of salting once or twice in a month, to prevent them from becoming wild. By occupying the same pastures, they have be come so much intermixed with the buffalo that it is difficult to say to which race they are most nearly allied.

"In procuring the cross, it is necessary to observe one precaution. The domestic breed must furnish the male, and the buffalo the female. The wild bull and the cow can be brought together without difficulty, and the irnpregnation is perfect; but the pelvis of the cow is not sufficiently capacious to allow the passage of the buffalo's fœtus with its hamp. The pelvis is the circular bone which connects the spine with the thigh bones, and when the fœtus, from disease or any other cause, is too large to pass through it, the female must necessarily die in labour. This fact constitutes the principal obstacle to the introduction of the half breed in the old setllements. It would be easy to catch and tame a single male of the wild breed, and to obtain any number of impregnations from him; but it is difficult to procure, and still more to confine a sufficient number of wild females. The amazing strength of the head and breast enables them to overset the strongest fences by running against them; and unless they are caught very young, they can never be effectually tamed. Nevertheless, some enterprising farmers in this state and Missouri are introducing the breed. Captain Jenkins of Rutherford county, has one three years old and one two years old of the half blood, and several calves of the quarter blood, all of which are large for their age, and promise well. The advantages proposed by the introduction of this breed are, that the oxen thus raised will be stronger, less sluggish, more hardy, and more easily kept, and (if it be true that the buffalo gnes twelve months with young) they will probably last longer than the common breed. In addition to these considerations, the hides are larger and applicable to a greater number of uses, and the leather is thicker, softer, and mnre impervinus to water. The full grown buffalo on the Missouri are said to be from sixteen to eighteen hands high, and as the body is larger in propertion to the height, than in the domestic cattle, they must greatly exceed the finest of the imported breed in strength and weight. In the neighbourhood of the settlements, the hunter's dogs and 
prairie flies conspire to prevent them from attaining either lull size or inature acze."

BISSIINGis. A provincial word, applied, like biestings, to the first milk of the newly calved eow. See Bristrivr.

BIT'TER PRINCII'I.L. 'This term has been applied to certain products of the action of nitric acid upon animal and vegetable matters of an intensely bitter taste. (Brunde's Dict. of Science.) 'The most important of the plants cultivated with us for their bitter principle are the hop, the common broom, mugwort, ground ivy, marsh trefoil or buck-bean, and the gentian family of plants. Quassia, the wood of a tree, is also a very intense bitter, and is used in medicine, and clandestinely in the brewing of beer. The chief combinations of the bitter principle used in medicine are narcotic, aromatic, astringent, acid, and purgative bitters. (Lowe's El. of Ag.pp. 371-373.)

BITTERS. A spirituous liquor in which bitter herbs of roots are steeped. An excessive habit of taking bitters may finally prove detrimental to the stomach, by over-excitement, or by inducing a kind of artificial demand for food in greater quantity than is salutary to the general health. Habitual drunkenness has often been the sequel of the insiduous practice of taking bitters.

BIT'IER-SWEET, or WOODY NIGHTBHADE (Solanum dulcamara). This wild plant loves moist places, therefore grows most freely in hedges and thickets, near ditches, rivers, and damp situations. It flowers in June and July, and ripens its berries in August, which are of a red colour, juicy, bitter, and poisonous. Its flowers are an elegant purple, with yellow threads in their middle, and the berries are oval or oblong in shape. The stalks are shrubby, and run, when supported, to ten feet in length; of a bluish colour, and when bruised or broken have an odour not very fragrant or desirable, savouring of rotten eggs. A decoction of its wood, and the young shoots sliced, is a valuable medicine, but not to be trifled with. (Eng. Flor., vol. i. p. 317.)

BIT'I'ERWORT. 'The old English name for the yellow gentian. See Gentian.

BIXA. See Anvotra.

BLACK. (Sax.) A common colour in horses. Horses of this colour are most esteemed when they are of a shining jet black, and well marked, without having white on their legs. The English black horses have generally more white about them than the black horses of other countries. Those that partake most of the brown are said to be the strongest in constitution; for the English black cart horses are found not to be so hardy as the bays or chestnuts.

\section{BLACKBERRY. See Bramule.}

BLACKBIRD. This is a species of bird so generally known, that but little need be said of its habits or its haunts. Numbers are bred in England every season, and those thus reared, it is believed, do not migrate. Its food varies considerably with the season. In spring and early summer, larvæ of insects, worms, and snails; as the season advances, fruit of various sorts. When the enormous number of insects and their larvæ, with the abundance of snails and slugs, all injurions to vegetation, be duly considered, it may fairly be doubud whether the value of the fruit is not counter. balanced by the services performed.

The American blackbird differs considerably from the European. The species found in the United States bear the names of the great crow, the common crow, the cow, the red-winged, and the rusty. The following in. teresting details relative to birds which so oftell occupy attention in rural life, are from $M r$. Nuttall's Manual of the Ornithology of the United States. Treating of the great crow blackbird, (The Quiscalis major of Bonaparte) Mr. Nuttall says:

"This large and crow-like species, som". times called the jackdaw, inhabits the southern maritime parts of the Union only, particularly the states of Georgia and Florida, where thev are seen as early as the close of January or beginning of February, but do not begin to pair before March, previously to which season the sexes are seen in separate flocks. But about the latter end of November, they quit even the mild climate of Florida, generally, and seek winter quarters probably in the West Indies, where they are known to be numerous, as well as in Mexico, Louisiana, and Texas; but they do not ever extend their northern migrations as far as the Middle States. Previous to their departure, at the approach of winter, they are seen to assemble in large flocks, and every morning flights of them, at a great height, are seen moving away to the south.

"Like most gregarious birds, they are of a very sociable disposition, and are frequently observed to mingle with the common crowblackbirds. They assemble in great numbers among the sea islands, and neighbouring marshes on the main land, where they feed at low water, on the oyster-beds and sand-1lats. Like crows, they are omnivorous, their food consisting of insects, small shell-fish, corn, and small grain, so that by turns they may be viewed as the friend or plunderer of the planter.

"The note of this species is louder than that of the common kind, according to Audubon. resembling a loud shrill whistle, often accom panied by a cry like crick crick cree, and in breeding season changing almost in to a war They are only heard to sing in the spring, their concert, though inclining to sadness, not altogether disagreeable. Their nests : built in company, on reeds and bushes, in $\mathrm{t}$ ! neighbourhood of salt marshes and ponds, they lay about three to five eggs which are whitish, blotched and lined nearly all over with dusky nlive. They begin to lay about the beginning of April; soon after which the males leave their mates not only with the care of in. cubation, but with the rearing of the young, moving about in separate floclis, like the cow birds, without taking any interest in the fate of their progeny.

"The general appearance of the male is black, but the head and neck have bluish-pur. ple reflections; the rest presents shades of steel-blue, excepting the back, rump, and middling wing coverts, which are glossed with cof ner-green; the vent, inferior tail coverts 
and thighs are plain black. The tail, wedgeshaped, is nearly eight inches in length, and like that of the common species, is capable of assuming a boat-shaped appearance. Iris pale yellow. The bill and feet black. The femule is of a light dusky brown, with some feeble greenish reflections, and beneath of a dull brownish white. The ymung, at first, resemble the female, but have the irids brown, and gractually acquire their appropriate plumage."

Of the Common Crow-Blackbird, (The Q'itscalis versicolor of Audubon), Mr. Nuttall says : "This very common hird is an occasional or constant resident in every part of America, from Hudson's Bay and the Northern interior to the great Antilles, within the tropic. In most parts of this wide region they also breed, at least from Nova Scotia to Louisiana, and probly farther south. In the states north of Vir. ginia they begin to migrate from the beginning of March to May, leaving those countries again in numerous troops about the middle of November. Thus assembled, from the north and west in increasing numbers, they wholly overrun, at times, the warmer maritime regions, where they assemble to pass the winter in the company of their well known cousins the redwinged troopials or blackbirds; for both, impelled by the same predatory appetite, and love of comfortable winter quarters, are often thus accidentally associated in the plundering and gleaning of the plantations. The amazing numbers in which the present species associate are almost incredible. Wilson relates that on the 20th of January, a few miles from the banks of the Roanoke, in Virginia, he met with one of those prodigious armies of blackbirds, which, as he approached, rose from the surrounding fields with a noise like thunder, and descending on the stretch of road before him, covered it and the fences completely with black: rising again, after a few evolutions, they descended on the skirt of a leafless wood, so thick as to give the whole forest, for a considerable extent, the appearance of being shrouded in mourning, the numbers amounting probably to many hundreds of thousands. Their notes and screams resembled the distant sound of a mighty cataract, but strangely attuned into a musical cadence, which rose and fell with the fluctuation of the breeze, like the magic harp of Eolus.

"Their depredations on the maize crop or Indian corn commence almost with the planting. The infant blades no sooner appear than they are hailed by the greedy blackbird as the signal for a feast; and, without hesitation, they descend on the fields, and regale themselves with the sweet and sprouted seed, rejecting and scattering the blades around as an evidence of their mischief and audacity. Again, about the beginning of August, while the grain is in the milky state, their attacks are renewed with the most destructive effect, as they now assemble as it were in clouds, and pillage the fields to such a degree that in some low and sheltered situations, in the vicinity of rivers, where they lelight to roam, one-fourth of the crop is devoured by these vexatious visitors. The gun, also, notwithstanding the havoc it preduces, has little more effect than to chase 184 them from one part of the field to the other. In the Southern States, in winter, they hover round the corn-cribs in swarms, and boldly peck the hard grain from the cob through the air-openings of the magazine. In consequenee of these reiterated depredations they are detested by the farmer as a pest to his industry; though, on their arrival, their food for a long time consists wholly of those insects which are calculated to do the most essential injury to the crops. They, at this season, frequent swamps and meadows, and familiarly following the furrows of the plough, sweep up all the grub-worms, and other noxious animals, as soon as they appear, even scratching up the loose soil, that nothing of this kind may escape them. Up to the time of harvest, I have uniformly, on dissection, found their food to consist of these larvæ, caterpillars, moths, and beetles, of which they devour such numbers, that but for this providential economy, the whole crop of grain, in many places, would probably be destroyed by the time it began to germinate. In winter they collect the mast of the beech and oak for food, and may be seen assembled in large bodies in the woods for this purpose. In the spring season the blackbirds roost in the cedars and pine trees, to which in the evening they retire with friendly and mutual chatter. On the tallest of these trees, as well as in bushes, they generally build their nests, which work, like all their movements, is commonly performed in society, so that ten or fifteen of them are often seen in the same tree, and sometimes they have been known to thrust their nests into the interstices of the fish. hawk's eyry, as if for safety and protection. Occasionally they breed in tall poplars near to habitations, and, if not molested, continue to resort to the same place for several years in succession. They begin their breeding operations from the commencement of April to May. The nest is composed outwardly of mud, mixed with stalks and knotty roots of grass, and lined with fine dry grass and horse-hair. The eggs, usually five or six, are of a dull green, like those of the crow, blotched and spotted with dark olive, more particularly towards the larger end. According to Audubon, the same species in the Southern States nests in the hollows of decayed trees, after the manner of the woodpecker, lining the cavity with grass and mud. They seldom produce more than a single brood in the season. In the autumn, and at the approach of winter, numerous fiocks after foraging through the day, return from considerable distances to their general roosts among the reeds. On approaching their station, each detachment as it arrives, in straggling groups like crows, sweeps round the marsh in waving flight, forming circles; amidst these bodies, the note of the old reconnoitring leader may be heard, and no sooner has he fixed upon the intended spot, than they all descend and take their stations in an in. stant. At this time they are also frequently accompanied by the ferruginous species, with which they associate in a friendly manner.

"The blackbird is easily tamed, sings in confinement, and may be taught to articulate some few words pretty distinctly. Among the 
variety of its natural notes, the peculiarly affected sibilation of the starling is heard in the woltishee, wottitsher, and whistle, which often accompanies this note. 'Their intestmes and stomach are frequently infested by long. cylindric, tapering worms, which probably increase sometimes in such numbers as to destroy the bird.

"The male is twelve inches long, and eighten in alar extent. The prevailing black colom of the body is relieved by glossy reflections of steel blue, dark violet, and green; the violet is most conspicuous on the head and breast, and the green on the hind part of the neck. The back, rump, and whole lower parts, with the exception of the breast, reflect a cupreous gloss. The wing-coverts, secondaries, and coverts of the tail, are light violet, with much of the red; the rest of the wings and rounded tail are black, with a steel-blue gloss. Iris silvery. The female is rather less, but very similar in colour, and glossy particoloured reflections."

The Rusty Blackbird. "This species," says Mr. Nuttall, "less frequent than the preceding, is often associated with it, or with the redwinged troopial or the cow-pen bird, and, according to the season, they are found throughout America, from Hudson's Bay to Florida and westward to the Pacific ocean. Early in April, according to Wilson, they pass hastily through Pennsylvania, on their return to the north to breed. In the month of March he observed them on the banks of the Ohio, near Kentucky river, during a snow-storm. They arrive in the vicinity of Hudson's Bay about the beginning of May, and feed much in the manner of ihe common crow-blackbird on insects, which they find on or near the ground. Dr. Richardson saw them in the winter as far as the latitude of $53^{\circ}$, and in the summer they range to the 68th parallel or to the extremity of the wooded region. They sing in the pairing season, but become nearly silent while rearing their young; though when their brood release them from care they again resume their lay, and may occasionally be heard until the approach of winter. Their song is quite as agreeable and musical as that of the starling, and greatly surpasses that of any of the other species. I have heard them singing until the middle of October.

"They are said to build in trees and bushes, at no great distance from the ground, making a nest similar to the other species, and lay five eggs, of a pale blue spotted with black. The young and old, now assembling in large troops, retire from the northern regions in September. From the beginning of October to the middle of November, they are seen in flocks through the Eastern States. During their stay in this vicinity, they assemble towards night to rnost. in or round the reed marshes of Fresh Pond, near Cambridge. Sometimes they select the willows by the water for their lodging, in preference to the reeds, which they give up to their companions the crow-blackbirds. Early in October they feed chiefly on grasshoppers and berries, and at a later period pay a transient visit to the corn-field. They pass the winter in the Southern States, and like their darker relatives, make familiar visits to the barn-yard and corn-crilss. Wilson remarks, that they are easily domesticaterl, and in a frow days become quite familiar, broug lecencibled to any quarters while supplied with plenty of food.

"The male is about nine inches in length,

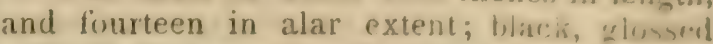
with dark green; with the tail soinewhat rounded; iris silvery. 'The femule is uf alumul the same size with the male, and the younis of the first season, of both sexes, are irearly of the same colour."

BLACK CANKER. $\Lambda$ disease in turnip and other crops, producerl by a species of caterpillar. See Bove Dust.

BLACK COUCH GRASS, or BLACK TWI'CH. Provincial names for the marsh bent grass, or Agroslis albu. See Agnostis.

BLACK DOLPHIN. A term applied to a small insect which is frequently very destructive to bean, turnip, and some other green crops.

BLACK FLY. An insect of the beetle tribe, very injurious to turnips in their early stage. See FLY.

BLACK GUM (Nyssa sylustica). This North American tree is variously designated in different parts of the United States by the names of the Black gum, Yellow gum, and Sour gum, the last of which appellation is doubtless derived from the extremely acid taste of its fruit. This consists of deep blue berries of an oval shape. Each stem has twin-berries, and each berry contains a very hard slightly convex stone. The leaves are five or six inches long, entire, of an elongated oval shape, with downy stems. The river Schuylkill, in the vicinity of Philadelphı, may be assumed as the northern limit of the black gum, which is very common in Delaware, Maryland, and other Middle and Southern States, both east and west of the Alleghany mountains. In Maryland, Virginia, and the Western States, Michaux informs us, it grows without any peculiar form on high and level grounds, with the oalis and walnuts. In the lower parts of the Carolinas and Georgia, where it is found only in wet places, with the small magnolia or white-bay, the red-bay, the loblolly-bay, and the wateroak, it has a pyramidal base resembling a sugar-loaf.

The black gum frequently attains a height of sixty or seventy feet, with a diameter of eighteen or twenty inches, being larger in the upper part of Virginia, in Kentucky and Tennessee, than in the marshy grounds of the maritime parts of the Southern states.

The bark of the trunk is whitish and similar to that of the young white oak. The wood is fine-grained but tender, and its fibres are in terwoven and collected in bundles; an arrarlge ment characteristic of the genus. 'The alburnum or sap part, as it is commonly designated, of stocks growing upon dry and elevated lands is yellow. This complexion is considered by wheel-wrights as a proof of the superior quality of the wood, and has probably given the tree one of its popular names. It is extensively employed in Richmond, Baltimore, and Philadelphia, for the naves or hubs of 
enach and wagon wheels, as well as for hatters' blocks, being so little liable to split; a quality which also causes it to be chosen by shipwrights for the cap, or piece which receives the top-mast.

Tupelo.-The black gum is often confounded with another tree of the same genus, the Tupelo or Nyssa uquaticu, also called gum tree, sour gum, and peperidge. The first of these appellations, Michaux says, is most common, the second is wholly misapplied, as no self-condensing fluid distils from the tree, and the third which more appropriately belongs to the common barberry-bush, is used only by the descendents of the Dutch settlers in the neighbourhood of New York. The tupelo extends much higher north than the black gum, appearing in the lower part of New Hampshire near the sea; but it is most abundant in the southern parts of New York, New Jersey, and Pennsylvania. It grows only in wet grounds. In Delaware, where the black gum and tupelo are found together, the former name is universally applied to both. In New Jersey it is constantly seen on the borders of the swamps with the sweet gum, the swamp white-oak, the chestrut white-oak, and the white elm. It rarely cxceeds forty or forty-five feet in height, and its limbs, which spring at five or six feet from the glound, grow in a horizontal direction. The trunk is of a uniform size from its base. While it is less than ten inches in diameter the bark is not remarkable, but on fullgrown and vigorous stocks it is thick, deeplyfurrowed, and, unlike the bark of any other tree, divided into hexagons, which are sometimes nearly regular.

The leaves are about half the length of those of the black gum, viz.: three inches long, oboval, smnoth, alternate, and often united in bunches at the extremity of the young lateral shoots. The flowers are small and scarcely apparent. The fruit, which is abundant, is, ilke that of the black gum, of a deep blue colour, about the size of a pea, and attacher in pairs. It is ripe towards the beginning of November, and remaining after the falling of the leaf, it forms a part of the nourishment of the robins and other birds in their auturnnal migration to the south. The stone is flattened on one side, a little convex on the other, and striated lengthwise. Bruised in water the berries yield an unctuous, greenish juice, of a slightly bitter taste, which is not easily mingied with the fluid.

The tupelo bolds a middle place between trees with soft and those with hard wood. When perfectly seasoned, the sap part is of a light raddish tint, and the heart, of a deep brown. Of trees exceeding fifteen or eighteen inches in diarneter more than half the trunk is generally hollow.

The woody fibres which compose the body wi trees in general are closely united, and usually ascend in a perpendicular direction. By a carice of nature, they sometimes pursue an undulating course, as in the red and sugar inaples, or, as in the last mentioned species, torm riplings so fine, that the curves are only nne, two, or three lines in diameter; or lastly, they ascend spirally, as in the twisted elm 186
(Orme tortillard) following the same bent for four or five feet. In these species, however, the deviation is only accidental, and to be sure of obtaining this form it must be perpetuated by grafting or by transplanting young stocks from the shade of the parent tree. The genus which we are considering exhibits, on the contrary, a constant peculiarity of organization; the fibres are united in bundles, and interwoven like a braided cord. Hence the wood is extremely difficult to split unless cut into short billets; a property which gives it a decided superiority for certain uses. In New York, New Jersey, and particularly at Philadelphia, the wood of the tupelo is almost exclusively employed for the hubs of wheels. In a very few places white oak is used for this purpose, probably because the tupelo is of a bad quality or cannot be readily obtained. Michaux thinks that from its limited size and strength, the tupelo can never be substituted for the twisted elm, where very large naves or hubs are required for wagons destined to support immense burdens. In France, he says, the wheels of their heavy vehicles have naves twenty inches in diameter at the insertion of the spokes, with an axle-tree of three hundred and fifty pounds weight, and are laden for distant transportation with nine thousand pounds. If, to its own organization, the tupelo joined the solidity of the elm, a more rapid vegetation and the faculty of growing on dry and elevated lands, and of expanding to three or four times its present size, it would be the most precious to the mechanical arts of all the forest-trees of Europe and North America. In Now Jersey and Pennsylvania, many farmers prefer the tulepo for the side-boards and bottom of carts, as experience has proved its durability. Wooden bowls are made of it, and also the mortars in which Indian corn is beaten with an iron pestle in the process of preparing ho. miny. It burns slowly and throws out a good heat, which makes it a favourite with those who keep wood fires, especially for the back $\log$, a purpose to which it is almost exclusively devoted. (American Sylia.) See Tupr.o.

BLACK LEGS. A provincial name given in some places to a disease frequent among calves and sheep. In Staffordshire it is called the wood evil. It is a bloody gelatinous humour, settling in their legs, and often in the neck between the skin and the flesh, making them carry their necks awry.

BL.ACK MUZZLE. See Shenp, Drseases of.

BLACK OA'TS. A species of oats much cultivated in some parts of England. The oats of this habit nave the corolla very dark, are awned, and the seeds are small. They are rather an inferior class of oats, but are hardy and ripen early, and it is this property which suits them for cultivation in cold and elevated climates. (Prof. Low. Ele. Ag., p. 256.) See OATs.

BLACK THORN, or SLOE (Prunus spinosa). This rigid bushy shrub is well known, growing commonly in hedges and thickets. It is frequently used in making fences, especially in exposed situations. But it is not reckoned so good for this purpose as the white thorn, because it is apt to run more into the ground. 


\section{BLACK TWITCH.}

and is not so certain of growing; however, when cut, the bushes are much the best, and most lasting of any for dead hedges, or to mend gaps; cattle are not so apt to crop fences of this kind as those of the white thorn.

The fruit is well known in the country, and from its acid, astringent, and very austere flavour, it is not eatable except when baked, or boiled with a large proportion of sugar, and then it is not good. The juice, when inspissated over a slow fire, is a substitute for the Egyptian acacia, or Indian catechu. In some form or other this juice is used in adulterating port wine. The leaves also are reckoned among the adulterated substitutes for tea in England. A water distilled from the blossoms of the sloe is said to be used medicinally in Switzerland and Germany.

The juice of sloes checks purgings when no inflammation is present. (Smith's Eng. Flor. vol. ii. p. 357.)

What is commonly called the black thorn in the United States is not the sloe or black haw, (a species of viburnum), but the yellow Cratægus of hotanists, one of the species of thorn commonly used for hedges. (See Flor. Cestrica.)

BLACK TWITCH (Agrostis alba). A noxious weed of the sub-aquatic marsh hent genus. It chokes up drains and underwood, and flourishes even in extremely dry situations, proving very injurious to many crops. It is also known under the names of black curch and black wrack. See Mansh Bert Grass.

BLACK WALNUT. See WALNoT.

BLACK WASH. A lotion composed of calomel and lime water.

BLACK WATER. See Shemp, Disfases of. BLADE (Sax. blaeo, bleo; Fr. bled; Low Lat. bludus). The spire of grass before it grows to seed; the green shoots of corn which lise from the seed. (Todd.)

BLADE-BONE. In farriery, the popular name for the shoulder-blade (scapula), of an animal.

BLAIN (Sax. blezene; Dutch, bleyne, from the Icelandic blina, a pustule). In farriery, inflammation of the tongue, a disease in cattle, which frequently affects them in the spring of the year or beginning of summer. The disease (says Clater) is neither so frequent nor so fatal in the horse as it is in cattle; but it does sometimes occur, and the nature of it is frequently misunderstood. The horse will refuse his food, hang his head, and a considerable quantity of ropy fluid will be discharged from the mouth. On examining the mouth, the tongue will be found considerably enlarged, and, running along the side of it, there will be a reddish or darkish purple bladder, and which sometimes protrudes between the teeth. The neighbouring salivary glands are enlarged, and the discharge of saliva is very great, while the soreness of the swelled and blistered part causes the horse obstinately to resist every motion of the jaws. The cure is very simple: the bladder must be deeply lanced from end to end: there will not be any great flow of blood. This will relieve or cure the horse in twenty-four hours. If he can be spared from his work, a dose of physic will romove the stomach affection and any slight

\section{BI.END.WATER.}

degree of fever that may have existed. If the disease is neglected, the swelling will at length burst, and corroding ulcers will eat deeply suto the tongue, and prove very difticult to heal. (Cluter's Farriery, p. 64.)

BI.AS'I. A vegetable disease, the same as blight. In farriery, it is also a vulgar name for any circumscribed swelling or inflamma tion in the body of an animal. See MrLw E.

BLAS'IING OF S'TONES. The operation of tearing asunder large stones or rocks which are in the way of the plough, or other instrument employed in breaking up ground, by means of gunpowder. Logs of wood, the roots of trees, and other obstructions, are removed by the same agent. In stone quarries, blasting is a necessary business. Perhaps one of the greatest and most successful blasts ever effected was at Craigleith quarry, Scotland, on the 18th of October, 1834, when, by $500 \mathrm{lbs}$. of Sir Henry Bridge's double-strong blasting powder, a mass of upwards of 20,000 tons of solid rock was displaced. (Quart. Journ. "f $A \mathrm{gr}$. vol. vi.p. 463.)

BLAZE. A white mark or star in the face of a horse.

BLEEDING (Sax. bleoan), An operation frequently necessary in the disorders of different kinds of cattle, particularly horses. Such horses as stand much in the stable, and are full-fed, require bleeding more than those which are in constant exercise; but especially when their eyes look heavy and dull, or red and inflamed; and when they look yellow, and the horse is inflamed in his lips and the inside of his mouth; or when he seems hotter than usual, and mangles his hay. These indications not only show that bleeding is required, but likewise the lowering of the diet. The spring is the common season for bleeding horses; but periodical bleeding, without its necessity being indicated, should never be practised. In summer, it is often necessary to prevent fevers, always choosing the cool of the morning for the operation, and keeping them cool the remaining part of the day. Some farriers bleed horses three or four times a year, or even oftener, by way of prevention, taking only a very small quantity at a time, as a pint or a pint and a half. There is, however, this inconvenience from frequent bleeding, that it grows into a habit, which, in some cases, can. not be easily broken off without hazard; and besides, horses become weak from frequent bleeding.

BLEMISH. In farriery, any kind of imperfection in a horse or other animal.

In horses, they consist of broken knees, loss of hair in the cutting places, mallenders and sallenders, cracked heels, false quarters, splents, or excrescences which do not occasion lamęness; and wind-galls and bog-spavins, where they prevail to any great degree.

In plunting, the knots on the outside of trees, and shakes internally, are termed blemishes.

BLENDINGS. A provincial word applied to mixed crops, such as peas and beans when grown together.

BLEND-WATER. In farriery, the name of a distemper incident to neat or black cattle, in which the liver is affected. 
BLIGH'T. The general name for various injuries received by, and diseases incident to, corn, fruit-trees, plants, \&c. 'The terms blight and blast, are indiscriminately applied to plants injured by fungi, insects, disease, frost, \&c. Blight originating in culd, which, congealing the sap of the tender shoots and leaves of plants, causes these to perish from the bursting of their sap-vessels. Blight sometimes results from causes the very opposite of this, namely during the prevalence of very sultry, or very dry winds, the effects of which are popularly termed fireblights, and are similar to those which sometimes injure the vineyards of Italy, and the hopgrounds of England. What is called in England the white blight is supposed to originate from want of nourishment. It is most commonly met with in grain fields during very dry spells of weather, especially on thin gravelly soils, when the plants get into head or blossom prematurely, and the head or seed-pod ripens without filling.

The mildew, one of the greatest enemies that the agriculturist has to contend with, is nothing more than several species of parasitical fungi, or very minute plants of the mushroom species, which attack different kinds of plants, grain, \&c. It varies in its nature and appearance, according to the plants attacked. (See Pl. $2, l, m, n, \& c$.

Blight originating in fungi, attacks the leaves or stems both of herbaceous and woody plants, such as the common barberry and buckthorn, but more generally grasses, and particularly our most useful grains, wheat, barley, and oats. It always appears in the least ventilated parts of a field and has generally been preceeded by cold, moist weather, which happening in the warm month of July, suddenly chills and checks vegetation. It generally assumes the appearance of a rusty-looking powder that soils the finger when touched. In March, 1807, some blades of wheat attacked by this species of blight were examined by Keith; the appearance was that of a number of rusty-looking spots or patches dispersed over the surface of the leaf, exactly like that of the seeds of dorsiferous ferns bursting their indusium. Upon more minute inspection, these patches were found to consist of thousands of small globules collected into groups beneath the epidermis, which they raised up in a sort of blister, and at last burst. Some of the globules seemed as if embedded even in the longitudinal vessels of the blade. They were of a yellowish or rusty brown, and somewhat transparent. But these groups of globules have been ascertained by Sir J. Banks to be patches of a minute fungus, the seeds of which, as they float in the air, enter the pores of the epidermis of the leaf, particularly if the plant is sickly; or they exist in the manure or soil, and enter by the pores of the root. (Sir J. Banks on Blight.) 'This fungus has been figured by Sowerby and by F. Bauer and Grew. It is known among farmers by the name of red rust, and chiefly affects the stallss and leaves. But there is another species of fungus known to the European farmer by the name of red gum, which attacks the ear only, and is extremely prejudicial. In the aggregate it consists of groups of minute glolules interspersed with 188 transparent fibres. The globules are filled with a fine powder, which explodes when they are put into water. It is very generally accompanied with a maggot of a yellow colour, which preys also upon the grain, and increases the amount of injury. Grisenthwaite conjectures that in many cases in which the blight and mildew attack corn crops, it may be for want of the peculiar food requisite for perfecting the grain; it being known that the fruit or seeds of many plants contain primitive principles not found in the rest of the plant. Thus the grain of wheat contains gluten and phosphate of lime, and where these are wanting in the soil, that is, in the manured earths in which the plant grows, it will be unable to perfect its fruit, which of consequence becomes more liable to disease. (New Theory of Agr.)

Smut is a disease incidental to cultivated corn, by which the farina of the grain, together with its proper integuments and even part of the husk, is converted into a black soot-like powder. If the injured ear be struck with the finger, the powder will be dispersed like a cloud of black smoke; and if a portion of the powder be wetted by a drop of water and put under the microscope, it will be found to consist of millions of minute and transparent globules, which seem to be composed of a clear and glairy fluid encompassed by a thin and skinny membrane. This disease does not affect the whole body of the crop, but the smutted ears are sometimes very numerously dispersed throughout it. Some have attributed it to the soil in which the grain is sown, and others have attributed it to the seed itself, alleging that smutted seed will produce a smutted crop; but in all this there seems to be a great deal of doubt. Wildenow regards it as originating in a small fungus, which multiplies and extends till it occupies the whole ear (Princip. of Bot.p. 356) : but F. Bauer, of Kew, seems to have ascertained it to be merely a morbid swelling of the ear, and not at all connected with the growth of a fungus. (Smith's Introd p. 282.) It is said to be prevented by steepins the grain, before sowing, in a weak solution of arsenic. But, besides the disease callerl smut, there is also a disease analogous to it. or a different stage of the same disease, known to the farmer by the names of bags or smui balls, in which the nucleus of the seed only is converted into a black powder, whilst the ovary, as well as the husk, remains sound. The ear is not much altered in its external appearance, and the diseased grain contained in it will even bear the operation of thrashing, and consequently mingle with the bulk; but it is always readily detected by the experienced buyer, and fatal to the character of the sample. It is said to be prevented as in the case of smut. This disorder, so very fatal to the character of wheat from the injury it does to flour, is known in some of the United States by the very homely name of bust.

Mildew is a thin and whitish coating with which the leaves of vegetables are sometimes covered, occasioning their decay and death, and injuring the health of the plant. It is frequently found on the leaves of hops, hazlenut, and the white and yellow dead-nettle. It is 
found also on wheat in the shape of a glutinous exudation, particularly when the days are hot and the nights without dew. J. Robertson (Hort. Truns. v. 178), considers it as a minute fungus, of which different species attack differrent plants. Sulphur he has found to be a specific cure.

In cultivated crops mildew is said to be pre. vented by manuring with soot; though by some this is denied, and soot, by rendering the crop more luxuriant, is said to be an encourager of mildew, the richest part of a field being al ways most infected by it. As it is least common in airy situations, thinning and ventilation may be considered as preventives. See MrLnew. (Loudon's Encyc. of Agricult.)

Mr. Haggerston, who obtained a premium from the Massachusett's Horticultural Society for the discovery of a mode of destroying the rose-slug, says - that a weak solution of whaleoil soap, in the proportion of two pounds of soap to about fifteen gallons of water, or weaker, will check and entirely destroy the mildew on the gooseberry, peach, grape vine, \&c. \&c. For further particulars in regard to the application of this remedy see Aphrs, Rust, and SMUT.

BLIND, MOON-. In farriery, a disease in the eyes of horses, which is commonly the forerunner of cataract, and generally ends in blindness.

BLINDNESS. A deprivation or want of sight, originating from various causes; a complaint more frequent in horses than in neatcattle or sheep.

Blindness in hores may be discerned by the walk or step being uncertain and unequal, so that they dare not set down their feet boldly; but when they are mounted by an expert horseman, the fear of the spurs will frequently make them go resolutely and freely, so that their blindness can hardly be perceived. Another mark by which horses that have lost their sight may be known, is, that when they hear anybody enter the stable, they prick up their ears, and move them backwards and forwards in a particular manner.

Blindness in sheep. A complaint that sometimes occurs in these animals, from their being much exposed to either great dampness or long continued snows.

BLIND NETrRE. A provincial term for the wild hemp plant.

BLINDWORM. A term sometimes applied to the slow-worm (Anguis fragilis). See Suow WORY.

BLINKERS. Expansions of the sides of the bridle of a horse, intended to prevent him from seeing objects on either side, but at the same time $n$ t to ohstruct his vision in front.

BLISTERING (Dutch, bluyster). In farriery, the operation of stimulating the surface of some part of the body of an animal, by means of acrid applications, so as to raise small vesications upon it. It is frequently employed for the purpose of removing local affections of different kinds, such as hard indolent tumours.

BLISTER FI,Y. The Cantharis, or Spanish fly.

BLISTER LIQUID is composed of pow- dered alkanet two ounces, and a gallon of spirit of turpentine; adding. on the finrth day, a pound of powdered Spanish flies; and inatere rating the whole for a month, when the clear fluid will form a strong liquid blister. If so powerful an external stimulant be not requirod, this liquid may be diluted with an equal part of spermaceti oil. (Clater's Farriery.)

BLIS'TER OINTMENT. One ounce of powdered Spanish flies; half an ounce of powdered euphorbium; four ounces of lard. One ounce of this well rubbed in is sulficicrit to blister a horse's leg. That commonly suld by farriers generally contains oil of vitriol. (sulphuric acid), to make it raise the blister without the trouble of rubbing in the ointment; and, in consequence, a blemish is producerl.

BLOOD (Sax. blod; old French, bloed). The fluid which circulates in the bodies of all ani. mals. Blood, when drawn from the body, and allowed to rest, speedily separates into two portions, viz. the fluid, or serum, and the solid clot, crassamentum, or cruor.

In quadrupeds, in general, the temperature of the blood is higher than in man. In the sheep, it ranges from $102^{\circ}$ to $103^{\circ}$; in man it is $98^{\circ}$ in a state of health. The equal distribution of the blood in the animal system is as essential to the health of quadrupeds as of man. When it is irregularly circulated, and more sent to any organ than it should share, that part becomes oppressed, diseased action is set up in it; and if the organ be a vital one, life is endangered or destroyed through the violence of inflammation.

Blood is an excellent manure for fruit trees; and, mixed with earth, forms a very rich com. post. (Ann. of Phil. vol. ii. p. 202.)

BLOOD-ROOT. See BLoonwont.

BLOOD-SHOT. In farriery, a popular term for that red appearance which the eye exhibits when inflamed. The best treatment is to bathe the eye with a lotion composed of one drachm of white vitriol (sulphate of zinc) dissolved in half a pint of water.

BLOOD-SPAVIN or BOG-SPAVIN. In farriery, a swelling of the vein that runs along the inside of the hock of the horse, forming a little soft tumour in the hollow part, often attended with weakness or lameness of the hock. Clater (Farriery, p. 272) says, a blister is the proper application.

BLOODWORT (Sanguinaria cunadensis). A hardy American perennial, flowering in April. It loves a shady situation and bog soil; and may be propagated by parting the roots in spring or autumn. The root of bloodwort throws out a bright red juice, when pressed, which the Indians paint themseives with. It operates as an emetic and narcotic.

BLOODWORT (Rumex sanguiners). This is a beautiful dock, growing wild in manv parts of England, but introduced lately into gardens, for its fine deep-red appearance. It grows from two to three feet high, and the stalks are firm, stiff, reddish, and branched. The leaves are long and nairow, heart-shaped at the base, and taper gradually towards their point. Sometimes the leaves are a deep green, only stained, or veined with red; sometimes they are entirely a deep blood colour. which 
gives them a beautiful appearance. The he makes a still earlier flitting visit, from the flowers are in terminal clusters, small and $3 \mathrm{~d}$ to the middle of March, he comes hither as numerous. They blow in June and July, and a permanent resident, and is now accompanied the seed ripens in August. The dried root, by his mate, who immediately visits the box in either in powder or in decoction, is astringent; the garden, or the hollow in the decayed and may be used in spitting of blood, and violent purgings.

BL.OOM or BLOSSOM. A general name for the flowers of plants, but more especially of fruit-trees. The office of the blossom is partly to afford protection, and partly to draw or supply nourishment to the fertilizing organs of the plant, for the perfecting of the embryo, fruit, or seed.

Bloom is a term applied to the delicate powder which coats the outer surface of such smooth-skinned fruits as the grape and plum. In gathering such fruits, care should always be observed to prevent this bloom from being removed by handling or otherwise, as it injures the appearance.

BLOsSOM. A colour in horses, formed by the intermixture of white hairs with sorrel and bay ones.

BLOW-BALL. A local name for the flower of the dandelion.

BLOW-FLY. The large flesh-fly (Musca carnaria).

BLOW-MILK. The milk from which the cream has been blown off.

BLOWN. In farriery, a diseased state of the stomach and bowels of cattle, caused by the sudden extrication of air in large quantities from some of the grosser kinds of green food. See Hover.

BLOWS. A provincial term used to signify the blossoms of beans, \&c.

BLUBBER. See Fish.

BLUE-BELLS (Scilla nutans). A common name given to a bulbous-rooted plant of the hyacinth kind, frequently met with in woods and other places. Its bulb is globular, white, and coated; its leaves linear, channelled, shining, and drooping in their upper half; the flowers form a cluster on an upright stalk, drooping in the upper half; they are blue, pendulous, nearly an inch long, and scented. The bulb is acrid, but loses its acrimony in drying, in which state it answers as a substitute for gum-arabic in the art of dyeing, by being simply dried and powdered.

BLUE-BIRD. Mr. Nuttall describes three species of the blue-bird (Sialia), found in America. That which is most familiarly known in the United States (the Sylvia siralis of Wilson), is an insectivorous bird, inhabiting almost every section of the continent east of the Rocky Mountains, from the forty-eighth degree of latitude to the tropics. Although they generally spend their winters in the Southern States, they sometimes remain in well-protected warm situations in the southern parts of Pennsylvania. They breed and pass the summer from Labrador to Natchez. "In the Middle and Northern States," says Mr. Nuttall, "the return of the blue-bird to his old haunts round the barn and the orchard is hailed as the first agreeable presage of returning spring, and he is no less a messenger of grateful tidings to the farmer, than an agreeable, familiar, and usefu] companion to all. Though sometimes orchard-tree, which has served as the cradle of preceding generations of his kindred. Affection and jealousy, as in the contending and related thrushes, have considerable influence over the blue-bird. He seeks perpetually the company of his mate, caresses and soothes her with his amorous song, to which she faintly replies; and, like the faithful rook, seeks occasion to show his gallantry by feeding her with some favourite insect. If a rival makes his appearance, the attack is instantaneous, the intruder is driven with angry chattering from the precincts he has chosen, and he now returns to warble out his notes of triumph by the side of his cherished consort. The business of preparing and cleaning out the old nest or box now commences; and even in October, before they bid farewell to their favourite mansion, on fine days, influenced by the anticipation of the season, they are often observed to go in and out of the box as if examining and planning out their future domicile. Little pains, however, are requisite for the protection of the hardy young; and a substantial lining of hay, and now and then a few feathers, is all that is prepared for the brood beyond the natural shelter of the chosen situation. As the martin and house-wren seek out the favour and convenience of the box, contests are not unfrequent with the parties for exclusive possession; and the latter, in various clandestine ways, exhibits his envy and hostility to the favoured blue-bird. The eggs are five or six, of a very pale blue, and without spots. As they are very prolific, and constantly paired, they often raise two and sometimes probably three broods in the season; the male taking the youngest under his affectionate charge, while the female is engaged in the act of incubation.

"Their principal foud consists of insects, particularly beetles, and other shelly kinds; they are also fond of spiders and grasshoppers, for which they often, in company with their young, in autumn, descend to the earth, in open pasture-fields or waste grounds. Like our thrushes, they, early in spring, also collect the common wire-worm, or Iulus, for food, as well as other kinds of insects, which they commonly watch for, while perched on the fences or low boughs of trees, and dart after them to the ground as soon as perceived. They are not, however, fycatchers, like the Sylvicolas and Muscicapas, but are rather industrious searchers for subsistence, like the thrushes, whose habits they wholly resemble in their mode of feeding. In the autumn, they regale themselves on various kinds of berries, as those of the sourgum, wild-cherry, and others; and later in the season, as winter approaches, they frequent the red cedars and several species of sumach for their berries, eat persimmons in the Middle States, and many other kinds of fruits, and even seeds, the latter of which never enter into the diet of the proper flycatchers. They have also, occasionally, in a state of confinement, 
been reared and fed on soaked brcad and vegetable diet, on which they thrive as well as the robin." (Nullull's Orinilholugy.)

The Western Blue-bird (Sialiu uccidentalis of Townsend), is found along the Pacific coast west of the Rocky Mountains. It possesses many of the habits of the common kind, his song being, however, described as more varied, sweet, and tender than that of the common blue-bird of the Atlantic states.

The Arctic Blue-bird (the Sialia artica of Audubon), is a beautiful species found in the highest latitudes of the North Western portions of the American continent. See Nuttull's Ornithology of American Lund Birds, Audubon, Wilson, \&c.

BLUE-BOT'TLE (Centaurea). This is a large herbaceous genus, which contains several species known as weeds; that, however, which is peculiar to corn-fields is the corn blue-bottle (Centaurea cyanus). It grows amongst corn, and its presence indicates careless farming. It is an annual, ripening its seeds in autumn. It is also known by the names of knapweed, matfellon, centaury, cornflower, and hurt-sickle. The expressed juice of its blue flower, when mixed with cold alumwater, may be used as a water colour for painting, being a permanent colour. See Centaury.

This pretty wild flower has been introduced into our gardens for its elegance. The bluebottle grows a foot high; the stalk is firm and white, and the leaves are narrow, and of a whitish-green. The root is hard and fibrous. A decoction of the flowers with galls and copperas affords a good writing ink. This plant is sometimes known among the common peop!e by the name of "wound herb." Any reliance on the styptic properties of the leaves might prove dangerous by losing time, and a consequent waste of blood, before proper assistance can be procured in extensive wounds. Small wounds can unite without its aid. An infusion of the flowers is slightly diuretic.

BLUE-GRASS, wire-grass (Poa compressa, compressed or flattened poa. Plate $7, h)$. A very common perennial grass in the United States, found in fields, pastures, \&c. It affords a good nutritious pasture for cattle, but is not so much esteemed as the green meadow-grass, (Poa pratensis). Its great tenacity of life makes it sometimes very troublesome in the tillage of certain crops. (Flor. Cæstrica.)

The famous Kentucky blue-grass, Dr. Darlington says, is the Poa pratensis, smoothstalked meadow-grass; green grass; (Plate $5, h$ ) decidedly the most valuable of all the American pasture grasses. It comes in spontaneously, in all rich, calcareous soils.

The best time for sowing, says a writer in the Western Farmer and Gardener, is as soon as you can get ready after October; or any time before the middle of March.

Old fields, on which the sun can exert full power, produce blue grass in the greatest abundance, and of the best quality. Animals feeding thereon without grain, keep better and become fatter than on any ither treatment; but even wood-lands will produce good grass.

If intended for old or permanent pasture, the fields should be broken up in February or March, and sown in oats. 'Then sow ten pound of blue-grass seed, half a rallon of red clover. seed, and if a little timothy or creinand-grass be sprinkled on, so much the belter. The: timothy or orchard-grass will give a quic:k pasture, and afford protection to the blue-erass until it gets a strong foot-hold, after which me other grass can contend with it. 'Tius rains will cover the seed sufficiently to insure vergetation.

The following account of the blue grass is from the Franklin Furmer.

"This grass, which constitutes the glory of Kentucky pastures, is esteemed superior to all others for grazing. It flourishes only on calcareous soils. Opinions and practice vary here, as to the best time of sowing it-some preferring September, for the same reasons, chiefly, which relate to timothy or other grasses, others preferring February or March, to obviate the danger of the tender roots being winter-killed. It is sown either on wood-land or open ground-in the latter case most generally after a succession of exhausting crops in old fields. If sown on woodland, the leaves, brush, and trash must be raked off or burnt. It is particularly important to burn the leaves, else the seed may be blown away with them by the wind, or if not blown away, the leaves may prevent the seed reaching the earth and thus defeat their germination. Many of those who sow in winter, prefer casting the seed on the snow, as it enables them to effect the operation with more neatness and uniformity. In woodlands, the grass must not be grazed the first year, or at all events till after the seeds have matured. In open land, the practice has been adopted by some, of mixing timothy and clover with blue grass, in which case, half a bushel of the latter seed to the acre is suffi cient. The advantage resulting from this is, that it secures at once, a well-covered pasture that will bear considerable grazing the first year. The blue grass, in a few years, expels the other grasses, and takes entire possession of the field. On open ground, it is frequently sown in March upon wheat, rye, or oats. If the season is favourable, it may be sown in April; but should the weather prove dry, a great portion of the seed will be lost. It is the practice, we believe, of most graziers, to put upon a given pasture as much stock as it will maintain, without shifting them during the season, as, besides saving labour, it renders the cattle more quiet and contented. Others, however, fence off their pastures into separate divisions, to undergo a regular succession of periodical grazings. This plan secures a constant supply of fresh grass, very grateful to the animals, and is believed to be more economical, as much less is trampled and rejected by the cattle. The number of animals to the acre must depend upon their size and the quality and quantity of grass. The grass on open ground is much more abundant, sweer and nutritious, than on woodland, and consequently will maintain much more stock, perhaps nearly twice as much; while open woodland will produce much more and better grass than tha! which is deeply shaded. The best grazierv 
extirpate, as fast as possible, every tree not valuable for timber or wanted for fuel, and some even prune the branches of those which are allowed to remain." (Furmer's Regiver.)

BLUE MILK. Milk that has been skimmed, or had the cream taken off. In large dairies it is chiefly used for feeding hogs.

BLUE STONE. The common name for blue vitriol, or sulphate of copper.

BOAR (Sax, ban; Dutch, beer). The male of the swine-tribe of animals. See Hog and Swive.

In horsemanship, a horse is said to boar when he shoots out his nose level with his ears, and tosses his nose in the wind.

BOARD OF AGRICULTURE. A society established in London in 1794, under the patronage of his Majesty, Geo. III., "For the Encouragement of Agriculture, and Internal Improvement," consisting of a president, and thirty ordinary members, with proper officers for conducting the business of the institution. The plan and design of this highly useful establishment, though previously suggested by several writers on rural improvements, was chiefly brought forward, and carried into execution by the unwearied efforts and persevering industry of Sir John Sinclair, to whom the nation is certainly under much obligation. It was discontinued about the year 1812, in consequence of the withdrawal by government of the annual parliamentary grant of $3000 l$. for its support, chiefly owing to the society's interference with political themes, foreign to the improvement of agriculture. A full account of the nature, origin, and plan, with the charter of incorporation of this excellent institution, may be seen in the first volume of the "Communications" published by the Board, which extended to seven vols.; and these contain some excellent papers on various important matters connected with husbandry and agriculture in general.

BOG, and BOG GRASSES. See PEAT Sorts.

BOG-BEAN. See Buck-reax.

BOG-RUSH, BIACK (Schœnus nigricans). Is found on turfy bogs. Root scarcely creeping, of very long, strong fibres, crowned with black, shining, erect, folded sheaths, a few of which bear very narrow, acute, upright leaves, and embracc the bottom of the otherwise nalied stem, which is from eight to twelve inches high. Head black. Anth. long, yellow. Stigm. three, dark purple. Seed white and polished. (Smith's Engl. Flur. vol.i. p. 50.)

Nuttall, in his Genera of North American Plants, mentions three species of the bog-rush or saw-grass. This remarkable grass, as he calls it, was discovered in the West Indies by Schwartz, and extends a considerable distance northward beyoud Wilmington, North Carolina, often almost exclusively occupying considerable ponds. The leaves are almost as snarply serrated as those of a Bromelia, and hence it is very properly called saw-grass. The genuine species of this genus are principally confined to Europe and Barbary.

BOG-SPAVIN. See Blood-Spavin.

BOII. (Sax. bile). In farriery, an inflaminatory suppurating tumour affecting cattle or 192 sheep. In order to cure this sort of tumour, it will be necessary to bring it to a head by the application of plasters composed of wheat. flour and tar; and when the boil feels soft under the finger, to open it with a lancet, and let out the matter or pus.

BOLE. A term signifying the body or trunk of a tree, and sometimes the stalk or stem of corn. This word is written and pronounced in the north of England boll, and "bollings" is the name for pollards, trees whose tops and branches are lopped off.

BOLE, or BOLL (Lat. brilla). In Scotland, a common measure of grain, containing four bushels. In the old measure of Scotland, for oats and barley,

$$
\begin{aligned}
4 \text { lippies } & =1 \text { peck. } \\
4 \text { pecks } & =1 \text { firlot. } \\
4 \text { firlots } & =1 \text { boll. } \\
16 \text { bolls } & =1 \text { chalder. }
\end{aligned}
$$

The boll of oatmeal weighs $140 \mathrm{lbs}$. For wheat, peas, and rye, three oat firlots make one boll. (Brit. Husb. vol. ii. p. 500.)

BOLE OF SALT. A measure that cortains two bushels.

BOLETUS. A genus of mushroom, of which several species have been subjected to chemical analysis, by the French chemists Braconnot and La Grange. They yield bolitic acid.

BOLSTERS. In horsemanship, those parts of a great saddle which are raised on the bows both before and behind, to rest the rider's thighs, and keep him in a posture to withstand the irregular motions of the horse.

BOLT and BOLTING. Terms provincially applied to the trussing of straw.

BOLTER. A sort of framed sieve, having its bottom made of linen stuff, hair, or wire, according to circumstances. The balkers employ bolters that may be worked by the hand, but millers have larger ones that move by the machinery of the mill. It is sometimes called boulter.

BOLTING, or BOULTING. The operation of separating flour or meal of any kind from the husks or bran, by means of a bolter.

BOLTING CLOTH. Linen or hair-cloth made for the purpose of sifting meal or flour through. They are made of different degrees of fineness, and numbered accordingly; hence we have cloths of No. 2, No. 3, \&c.

BOLTING FOOD. This is a very common vice in greedy horses, especially when they feed out of the same manger. The only remedy is not to let them fast too long, and to mix chaff in their corn. The teeth of such horses ought to be examined, to see whether the bolting of the corn arises from any unevenness of the grinders.

BOLTING MILL. A mill or machine having much lateral or circular motion, by which means the business of sifting meal or flour can be performed with great facility and expedition. The framed sieve that moves within $\mathrm{it}$ is termed a bolter.

BOI,US. See BarL.

BONASUS. A kind of buffalo, or wild bull. BONES (Sax. ban; Su. Goth. been; Germ. bein). The more solid parts of the body of animals. When crushed, a valuable manure. 
The introduction of bones as a fertilizer is perhaps one of the most important and successful agricultural efforts of modern days, and has been certainly one great means of sufficiently increasing the national production of corn to keep pace with an annually enlarging population. It required, however, like all other agricultural improvements, much perseverance and unshaken energy in the promoters of this manure, to induce its general adoption; many a long and stubborn argument had to be answered; many hundred loads of the bone refuse of Shefficld and Birmingham had to be given away, before the cautious and suspicious Yorkshire farmers could be generally persuaded of the fallacy of the assertion, that "there is no good in bones." To this tardy conviction the erroneous mode of employing them originally adopted mainly contributed, for they were at first used without even roughly breaking them, and, in consequence, they decomposed so very slowly in the soil that the farmer's patience was naturally exhausted: he sought in vain for immediate and striking results.*

The introduction of machinery, however, by enabling the cultivator to procure them in a crushed state, did away with this objection, for when crushed, they decompose with much greater rapidity; and this has long since induced a consumption of this manure more than adequate to the national produce of bones. It has been necessary, in consequence, to search in other countries for a supply; and for the last fifteen years the quantity of bones imported from abroad has been steadily increasing. Thus the declared value of all the bones imported into England-

In the year 1821 was 1824 1830

$1833=$

$1833-$

$1836=$
$£$ s. d. $\mathbf{1 5 , 8 9 8 \quad 1 2 \quad 1 1}$ $43,9910 \quad 17 \quad 11$ $77,956 \quad 6 \quad 8$ $58,223 \quad 16 \quad 8$ $\begin{array}{lll}57,900 & 6 & 4\end{array}$ $127,131 \quad 14 \quad 10$ $171,806 \quad 0 \quad 0$ $254,600 \quad 0 \quad 0$

Into the port of Hull alone, in 1815, were imported about 8000 tons; this had increased to 17,500 tons in 1833 , and to 25,700 tons in 1835. These came principally from the Netherlands, Denmark, and the Baltic, but they have been imported from much more distant places, such as Buenos Ayres and the Mediterranean; and I am confident that if the seal fishermen of North America and other distant stations were aware of the fact that the bones of fish are nearly, if not quite, as valuable for the farmer as those of other animals, they would not suffer any falling off in the supply. By the $3 \& 4$ W. 4, c. 56 , a duty of one pound per cent. on the declared value is payable on all bones imported for farming or other purposes.

The following table, extracted from one by Richard Tottie, Esq., of Hull, will show to the

* It is said, in the Doncaster Agricultural Society's Report upon the use of bones, "Colonel St. Leger, then residing at Warmsworth, was the first person who is known to have used them, and his introduction of them was in 1775; the early progress does not seem to have been rapid, from the practice of laving them on almost anbreken, and in very large quantities." armer from whence the great supply of fo. reign bones is derived. 'This table coutitins the imports during 1827, in which year the following number of vessels entered the port of Hull loaded with bones:-

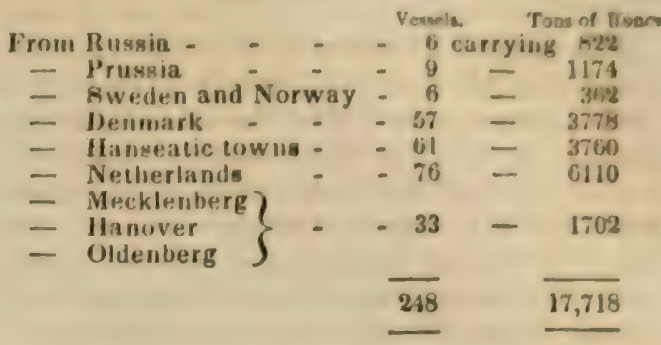

The import of bones into $\mathrm{Hull}$ has since been regularly increasing: it was, according to a letter with which Mr. Tottie favoured me, equal to 23,900 tons in 1834 , and to 25,700 in 1835 . It would certainly be well to look to other quarters besides the Continent for a future supply, since in some of the German states a duty on their export has been recently imposed. So considerable, indeed, has the demand become. that by many unprincipled deal. ers several kinds of adulterations are used. These, according to Mr. Halkett (Quar. Jisurn. of Agric. vol. ii. p. 181), are the lime that has been used in tan-works to take off the wool and hair, old plaster lime, soap boilers' waste, saw-dust, rotten wood, oyster-shells, \&c. The best remedy for these frauds is for the farmer to deal with only respectable crushers, and to pav a fair price for the bones.

There is, perhaps, no manure of whose powers the chemical explanation is more easy ; for of the earthy and purely animal matters of which bones are composed, there is not a silgle particle which is not a direct constituent or food of vegetables; thus, if carbon, hydrugen, and oxygen, are found in the abounding oil and cartilage of bones, they are equally common, nay, ever present, in all vegetable matters: and if carbonate and phosphate of lime are almost equally common in plants, they are still more universally present in all bones.

The bones of animals do not vary much in composition; they all contain phosphate and carbonate of lime, with a portior of cartilage or animal matter, with other minor ingredients. The bone of the ox has been analyzed by $\mathbf{M}$. Berzelius: he found that, by calcining these bones, every $100 \mathrm{lbs}$. lost $38 \mathrm{lbs}$. in weight. 100 parts of these bones, before calcination, consisted of-

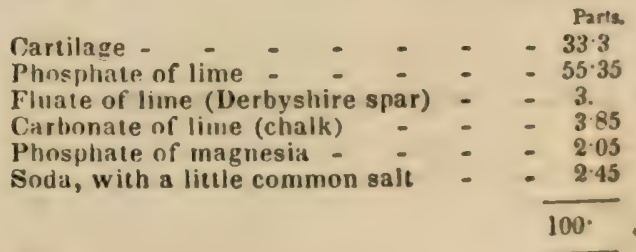

Bones, however, vary slightly in compos1tion, according to the age and condition of the animal, for MM. Fourcroy and Vauquelin found some ox bones which they analyws, (10) be composed of- 
Gelatine and oil

Phosphate of lime

Carbonate of lime
Phosphate of magnesia

The enamel of teeth is the only portion of bones hitherto analyzed, which is entirely destitute of cartilage. It is true that fossil bones contain none; but these have probably, in a former state of the earth, been acted upon by fire; for Mr. Hatchett found in some bones from Hythe in Kent, taken out of a Saxon tomb, the same proportion of cartilage as in a recent bone. Teeth have been analyzed by Mr. Pepys : he found them to be composed of

\begin{tabular}{llllr} 
Phosphate of lime & & & Adults'. & Children's. \\
Carbonate of lime & - & - & -64 & 62 \\
Cartilage - - & - & - & -20 & 6 \\
Loss - & - & - & -10 & 12 \\
& & & 100 & 100 \\
\hline
\end{tabular}

M. Merat Guillot has furnished us with a statement of the earthy constituents of 100 parts of the bones of different animals; from which the farmer will perceive that the composition of the bones of all animals is very similar.

\begin{tabular}{|c|c|c|c|c|}
\hline \multicolumn{2}{|l|}{ Bo e. } & $\begin{array}{l}\text { Phosphate of } \\
\text { Lume. }\end{array}$ & $\begin{array}{c}\text { Carbonate of } \\
\text { Lime. }\end{array}$ & $\begin{array}{l}\text { Animal } \\
\text { Matter. }\end{array}$ \\
\hline Calf & - & 54 & 一 & 46 \\
\hline Horse & - & $6 \% \cdot 5$ & 1.25 & $31 \cdot 25$ \\
\hline Shee, & - & r0 & 5 & 25 \\
\hline Elk & - & 90 & 1 & 9 \\
\hline Iog & - & 52 & 1 & 47 \\
\hline Hare & - & 85 & 1 & 14 \\
\hline Pulle? & - & $\tau^{2}$ & 1.5 & $26 \cdot 5$ \\
\hline Pike & - & 64 & 1 & 35 \\
\hline Carp & - & 45 & 5 & 50 \\
\hline Teeth of & the & & & \\
\hline Horse & - & 85.5 & 2.05 & - \\
\hline Ivory & - & 64 & 1 & $\cdot 35$ \\
\hline
\end{tabular}

Lobster shells, egg shells, \&c., are all com posed of the same ingredients as bone. The poor of Dublin are often employed for the purpose of pounding oyster shells for the use of the cultivators of the soil; and a similar plan might, I should imagine, be very advantageously adopted in some of the populous districts of this country: for, although such shells do not contain the same proportion of phosphate of lime as bone, yet they contain a sufficient quantity to render them highly valuable as fertilizing substances. 100 parts of lobster shells yield-

Carbonate of lime (chalk) - Parts,

$-\quad 60$

Cartilage of lime - - - - - $-\quad-24$

100

100 parts of cray-fish shells contain-

Carbonate of lime $\quad-\quad \ldots \quad \ldots \quad$ Parts

Phosphate of lime - _ _ - -

Cartilage - _ - - -

$\frac{-}{100}$

1C. 0 parts of hens' egg-shells contain-

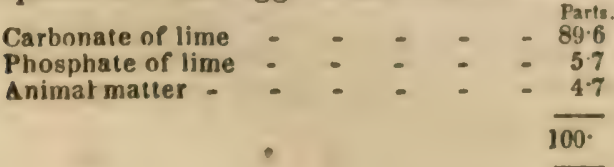

There is yet another source from whence the phosphate of lime might be obtained in iarge quantities for the use of the farmer, viz., the fossil bones or native phosphate of lime, which is found in various districts of this country, in very considerable quantities, and would only require crushing or powdering to render it nearly as useful to the farmer as the recent bones. That the cartilage or oily matter of the bone does not constitute the chief fertilizing quality is shown by the fact, that the farmers who use bone dust will as readily cmploy that which has first been steamed, and all its fatty portion extracted by the preparers of cart grease, as they will the unused fresh bones. It is acknowledged, says the Doncaster $A g r$. Soc. in their Report, to be a prevalent opinion amongst intelligent farmers, that manufactured bones are equal, in their effects, to the raw bones. Mr. Short, in the year 1812, "boned" twenty-four acres, at the rate of fifty bushels an acre. On one part of the field he put London bones, which had the oil stewed out of them; and another part was tilled with bones collected from Nottingham, which were full of marrow, and a third part with horses bones, having much flesh upon them. He could not see any difference in the turnips produced from these: they all produced a good crop. But the next crop was not so good where the fleshy bones had been laid." And Mr. Horncastle adds, "A strong fermentation takes place in the boiled bones; when thrown in a heap they become extremely offensive, and when they obtain this bad smell, I consider they are in a state to break up for manure."-And, says Mr. Halkett, of New Scone, in Perthshire, "After numerous trials between what we call green hones with all the marrow and fat in them, and dry ones free from it, I have always found that the latter raised by far the best crops. Therefore, I have arrived at the conclusion that the less animal fat in them the better, and that the boiling of them before crushing, instead of impairing them is a benefit." (Quar. Juurn. of Agric. vol. ii. p. 180.)

The mineral substance called the Apatite, found in the Cornish tin mines, is nothing but phosphate of lime: 100 parts bcing composed of-

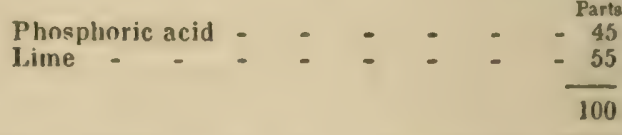

The phosphate of lime is also found in ma. ny parts of the north of England, in Hungary, and, in immense beds, in Spanish Estremadura, where it is said to be so common in many places, that the peasants make their walls and Pences of it. 100 parts of this substance, called by mineralogists the phosphorite, con. tain-

Phosphoric acid and lime -
Carbonate acid-
Muriatic acid - -
Fluoric acid -
Silica -
Oxide of iron - -

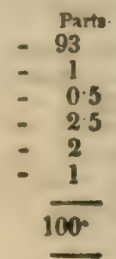


The horns of the deer are similar in composition to bones; but those of black cattle are totally different; they approach nearer in composition to animal muscle, as may be seen by the following analysis of Dr. John; 100 parts of the horns of black cattle yielding this chemist -

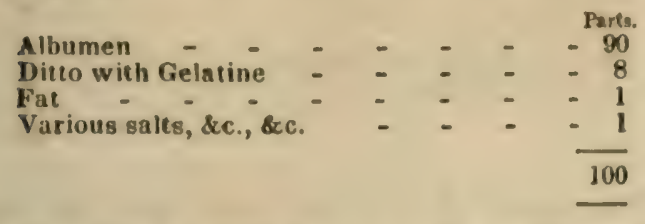

100 parts, however, of a fossil horn, analyzed by M. Braconnot, yielded-

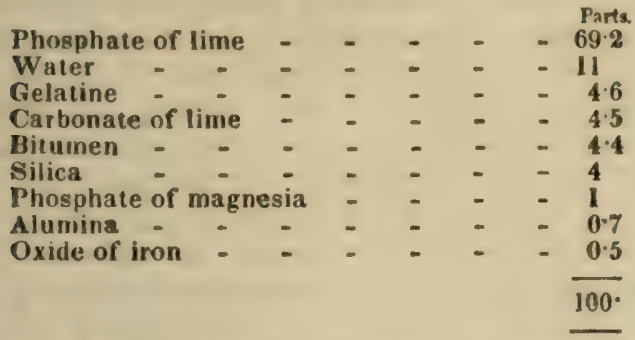

The excrements of those birds and animals which feed upon animal matters approach very nearly to bone in chemical composition; and I have little doubt but that the dung of sea birds might be profitably collected from some of the rocky islands on our coasts. This is actually done among the South Sea Islands by the Peruvian farmers, and to such an extent, that, according to M. Humboldt, fifty vessels, each carrying from fifteen hundred to two thousand cubic feet, are annually loaded with this manure at the island of Chinche alone. This manure is known in South America under the name of Guano, and is too powerful to be used in large quantities. It abounds in phosphate of lime. (A quantity has recently been imported into England : it contains 36 per cent. of phosphate of lime.) Some of the dung of sea-fowl collected on a rock on the coast of Merionethshire, was tried at the request of Sir Humphry Davy, at Nannau, by Sir Robert Vaughan, and produced a very powerful, though transient effect, on some grass land. The very soil of some of the rocks, which have been for so many ages tenanted by these water-fowls, must be completely impregnated with the earthy matters of bones. See Guaro.

All the constituent parts of bones are found in vegetable substances. The cartilage of bones is composed, according to the examinations of Mr. Hatchett, of a substance nearly identical in all its properties with solid albumen. Now, 100 parts of albumen are composed of -

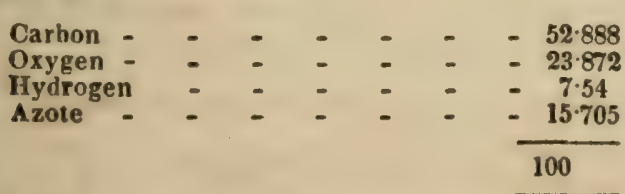

"The primary sources from which the bones of animals are derived, are the hay, straw, or other substances which they take as food. Now if we admit that bones contain 55 per cent of the phosphates of lime and magnesia
(Berzelius), and that hay contwins as much of them as wheat-straw, it will follow that 8 llus. of bones contain as much phosphate of lime as $1000 \mathrm{lbs}$. of hay or wheat-straw, and $2 \mathrm{lbs}$. of it as much as $1000 \mathrm{lbs}$. of the grain of wheat or oats. These numbers express pretty exactly the quantity of phosphates which a soil yields annually on the growth of hay and corn. Now the manure of an acre of land with $40 \mathrm{lbs}$. of bone dust is sufficient to supply three crops of wheat, clover, potatoes, turnips, \&c., with phosphates. But the form in which they are restored to a soil does not appear to be a matter of indifference. For the more finely the bones are reduced to powder, and the more intimately they are mixed with the soil, the more easily are they assimilated." (Liebig's Orgun. Chem.)

It is perfectly needless to specify any vegetable substances into which the three first of these substances enter, for the vegetable world is almost entirely composed of them, and $1 \mathrm{c}$. casionally a portion of azote is also found in vegetable substances, but the three first are invariably present. The flour of wheat, the poison of the deadly night-shade, the oxalic acid of the wild sorrel, the narcotic milk of the lettuce, the stinking odour of the garlic, and the perfume of the violet, are, by the contrivance of their divine architect, only sume of the results of the mixture of carbon, osygen, and hydrogen.

But the chief constituent present in all bones we have already seen is the phosphate of lime; and how absolutely necessary this substance is for the healthy vegetation of plants, will be apparent from the following table, which contains the results of the examination by MM. Saussure, Vauquelin, and a few other distinguished chemists, of the ashes or solid contents of a number of vegetable substances :-

100 parts of the ashes of the grain of the oat yielded of phosphate of lime _ _ _ 39.3 straw of wheat yielded of phosphates of lime and inagnesia - - 6.2 seeds of wheat - - _ - - 44.5

bran - - - - - - - 46.5 seeds of vetches _ _ _ $\quad$ - 27.98 golden rod (Solidago virgaurea) - 11. plants of turnsole (Helianthus annes), bearing ripe seeds - _ _ - 22.5 chaff of barley - _ _ _ _ $\quad 7.75$ seeds of harley - _ _ _ _ - 32.5

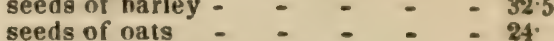
seeds of oats - $\quad-\quad-\quad-\quad-24$
leaves of oak - $\quad-\quad-\quad 4$ wond of nak - - $-\ldots$ bark of oak - - _ - - 4.5 leaves of poplar - $\quad-\quad \ldots 13$ $\begin{aligned} & \text { leaves of poplar } \\ & \text { wond of poplar }\end{aligned}-\quad-\quad-\quad-13.75$ leaves of harel - $\quad-\quad-\quad-23$ wond of hazel - _ _ _ $\quad-35$. bark of hazel - _ _ - - 5.5 wond of mulberry - - - - -2.25 wond of mulberry -
bark of mulberry wood of hornbeam - - - - 23. bark of hornbeam _ _ _ - 4.5 seeds of peas - _ _ _ _ 17.5 bulbs of garlic - - - $\quad$ - 8.9

Phosphate of lime has also been found in the marsh bean (Vicia faba), and in the peapod or husk, by Einhof; in rice, by Braconnot; in the Scotish fir, by Dr. John; in the quin quina of St. Domingo, by Fourcroy; in the fuci, by Gaultier de Claubry, and in many others; in short, as Dr. Thomson remarks 
(System of Chem. vol. iv. p. 319), "phosphate of lime is a constant ingredient in plants."

The cultivator of the soil will not be incredulous as to the power of vegetables to dissolve and feed upon the hard substance of the crushed bones of animals, when he is reminded that the ashes of the straw of wheat are composed of $61 \frac{1}{2}$ per cent. of silica (flint), a still harder substance than the hardest bone. And this is not a solitary instance; for the same earth abounds in a still greater proportion in the straw of other grain. Vauquelin found 603 per cent. of it in the ashes of the seeds of the oat; and the Dutch rush contains it in such abundance that it is employed by the turner to polish wood and even brass.

To the mode and effect of applying bones as a manure, either whole, broken, or in a state of powder, the Doncaster Agricultural Association paid considerable attention, and they have made a very valuable report of the result of their imquiries, in which they say:"The returns received by the Association satisfactorily establish the great value of bones as a manure. Our correspondents, with only two exceptions, all concar in stating them to be a highly valuable manure, and on light dry soils superior to farm-yard dung and all other manures. In copying the language of one of them, in reference to dry sandy soils, we express the opinions repeated in a far greater number-'I consider bone tillage one of the most useful manures which has ever been discovered for the farmer's benefit. The lightness of carriage, its suitableness for the drill, and its general fertilizing properties, render it peculiarly valuable in those parts where distance from towns renders it impossible to procure manures of a heavier and more bullky description.' For, as stated by another farmer, the carting of six, eight, or ten loads of manure per acre is no trifling expense. The ase of bones diminishes labour at a season of the year when time is of the first importance; for ore wagon load, or 120 bushels of small drill bone-dust is equal to forty or fifty loads of fold manure. Upon very thin sand land its value is not to be estimated; it not only is found to benefit the particular crop to which it is applied, but extends through the whole course of crops." The report adds, that bones have been found highly beneficial on the limestone suils near Doncaster, on peaty soils, and on light loams; but that on the heavy soils and on clay they produce no benefit. The late Mr. George Sinclair, of New Cross, has given (Truns. High. Soc. vol. i. p. 78), the analysis of :wo soils on which bone manure produced very opposite results. 400 parts of the soil on which the bone manure had very beneficial - ffects consisted of -

Silicious sand
Calcareous sand
Water of absorption -
Animal and vegetable matter
Carbonate of lime
Silica (tlint)

The soil on $\pi$ nich the bone manure had no sach beneficial effect, contained, in 400 parts,

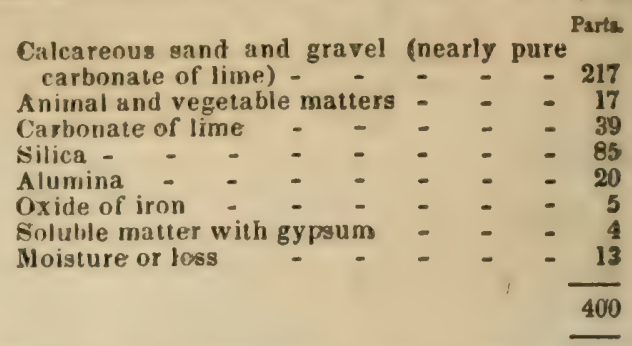

The mode of applying them, adds the Don. caster Report, is either by sowing broadcast or by the drill; either by themselves, or, what is much better, previously mixed with earth and fermented. Bones which have been thus fermented are decidedly superior to those which have not been so. Mr. Turner, of Tring, adopted the practice of mixing with his bone. dust an equal quantity of the dung of the sheep, collected for the express purpose, at an expense of $2 \frac{1}{2} d$. per bushel for labour. He prepared the mixture in winter, by laying the sheep-rung in heaps with the crushed bones, and allowing them to ferment together for some months. By this plan the two manures are thoroughly incorporated, and he considers that thirty-five bushels of the mixture are fully equal in effect to twenty-five bushels of the bones. (My Essay on Crushed Bones, p. 14.) The quantity applied per acre is about twenty. five bushels of bone-dust and forty bushels of large broken bones. The dust is best for immediate profit; the broken half-inch bones for more continued improvement. Mr. Birks says, "If I were to till for early profit, I would ust bones powdered as smali as saw-dust; if $J$ wished to keep my land in good heart, I would use principally half-inch bones, and in breaking these I should prefer some remaining considerably larger." "The reason for this is very obvious; the Iarger the pieces of bone, the more gradually will a given bulk dissolve in the soil.

Crushed bones are employed with decided success for turnips. The ease with which they are appiied by the drill, the ample nourishment they afford the young plants, on the very poorest soils, and the avidity with which the roots of the turnip encircle and mat themselves around the fragments of crushed bone, clearly evinces how grateful the manure is to this valuable crop. The evidence in its favour is copious, and decisive of its merits. In a recent report of the East Lothian Agricultural Society, Mr. John Brodie, of Aimsfield Mains, has given the result of his experiments upon the comparative cost of crushed bones and other commonly employed manure for turnips, which is worthy of attention:-

lst exp. -20 cart loads of street dung, per Scotch acre, at 5s. 6d. per Iord - - - - 510 $2 d$ exp.- - half a ion of rape-dust, at 110s. 215 three quarters crushed bones, at 19s. $\quad 217$ 3d exp.-16 loads of farm-yard dnng at is _ - 512

"The whole turnips," says Mr. Brodie, "brairded beautifully, and from the first to the time of lifting, it was impossible to decide which was the weightiest crop I therefor 
determined, in the last week in November, to takt: up alternate rows of the whole, and weigh each separately after the roots and tops were taken off, and the result was found to be as follows:-

Lst exp.-The portion examined of a Brotch acre, mamured with the street dung, produced of common globe turnip

$2 \mathrm{~d}$ exp.-The same quantity of ground manured with the rape and bone-dust, produced

3d exp.-1)itto with farm-yard dung

cwt. Ite

3018 30199 31230

"Mr. Watson, of Keilor," says the Hon. Capt. Ogilvy, of Airlie (Trans. High. Sıc. vol. iv. p. 238), "introduced the use of bone manure in Strathmore. The great deficiency of farm-yard dung in 1827 (consequent on the almost failure of the crop of the previous year), first induced me to try four acres of turnip without other manure, sown with fifteen bushels of bone-dust per acre: it cost 3s.per bushel, or $2 l .5 s$. per acre. The crop of turnips on these four acres was, at least, equal to the rest raised with farm-yard manure; but as the whr le of the turnips were pulled, and the land received some dung before the succeeding crop, much stress cannot be laid on the circumstance of the following white crop and grass being good.

"Next year, 1828, eight acres were sown with turnip, solely with hone-dust; the soil a light sandy loam; the subsoil gravel and sand, coming in some places nearly to the surface, which is very irregular, but in general has a south exposure. This field had been broken up with a crop of oats in 1827, after having been depastured six years, principally by sheep. The quantity of bone-dust applied was twenty bushels per acre, and cost 2s.6d. per bushel, or $2 \% 10$ s. per acre. The turnip crop was so heavy, that, notwithstanding the very light nature of the soil, it was judged advisable to pull one-third for the feeding cattle, two drills pulled, and four left to be eaten on the ground by sheep. The following year, 1829 , these eight acres were sown with barley and grass-seeds; and the produce was fiftyseven bolls one bushel, or seven bolls one bushel nearly per acre, of grain equal in quality to the best in the Dundee market, both in weight and colour. Next year, a fair crop of hay for that description of land was cut, about 150 stones an acre; and though I am now convinced that the field should rather have been depastured the first year, yet the pasture was better than it had ever been known before for the two following seasons, 1831 and 1832. It is worthy of remark, as a proof of the efficacy of the bone manure, that in a small angle of this field, in which I had permitted a cottager to plant potatoes, well dunged, and which, after their removal, was included in one of the flakings of sheep, and had (one might have supposed) thereby had at least an equal advantage with the adjacent bone-dust turnip land, both the barley and grass crops were evidently inferior, and this continued to be observable until the field was again ploughed up. A very bulky crop of oats has been reaped this season, probably upwards of eight bolls per acre, but no part of it is yet thrashed.

"Having detailed what may be considered a fair experiment, during the whote rotation of the above eight acres, I may add, that turnip raised with bone manure and fed off with sheep, has now become a regular part of the system on this farm. Fifteen, twenty, and last year twenty-five acres were fed off, and invariably with the same favourable results, with the prospect of being able to adopt a five-shift rotation, and to continue it without injury to the land. Every person in the least acquainted with the management of a farm, of which a considerable portion consists of light, dry, sandy loam, at a distance from town manure, nust be aware of the importance of this, from knowing the expense at which such land was formerly kept in a fair state of cultivation: in deed, the prices of corn, for some years past, would not warrant the necessary outlay; and large tracts of land, capable of producing barley little inferior to that of Norfolk, must speedily have been converted into sheep pas. ture, but for the introduction of bone manure." In the valuable experiments of $\mathrm{Mr}_{r}$ Robert Tuiner, of Tring, in Hertfordshire, the soil on which they were made, hitherto a ci rimon, producing only furze, is sandy, with a :ubstratum of clay, and then chalk. He began the use of bone manure in 1831 on this land, and has continued its employment for the last three years on a very bold scale, and with unvaried success. The quantity generally employed was from lwenty-four to thirty bushels per acre, of the description of half-inch and dust, and the bones were invariably applied to the turnip crop. The bones were usually drilled with the seed at a distance of eighteen inches, and the turnips were always horse-hoed. The year 1831 was a peculiarly goorl season for this crop generally. The turnips manured with bone-dust, like most others in the district, were very luxuriant. About 2000 bushels of bone manure were this year used by Mr. Tur ner. In 1832, the turnips were, in general, a very bad plant, the fly committing general devastation; many cultivators unsuccessfully sowing four or five times. On the turnip land of Mr.Turner, seventy-four acres were manured with bones, and of this breadth only the last sown four acres were a failure, and there was, in 120 instance, any necessity to repeat the sowing. The turnips were a much better crop than in 1831. In 1833, the turnips in the neighbourhood of Tring were a very partial crop. On the farm of Mr. Turner, about fifty acres were manured with bones. The effect, with the exception of the very last sown turnips, was again most excellent, the crop being very heavy, and that too on land now first cultivated. In 1835 and 1836 , Mr. Tumer continued the use of bones for his turnips, to the same extent, and with equal success. These experiments the cultivator will deem of the very first importance. The soil was zot manured with any other fertilizer except bones, and in drilling, every now and then, for the drill's breadth, the bones were omitted.

On the soil not boned, the failure of the tur nips was general and complete: they rege taled, it is true, and came up, but they were wretchedly small, and of no use. The turnips being fed off, and the sheep folded on the soi 
without any distinction between boned and anboned land, the comparative experiments upon the succeeding crop were rendered uncertain. The experience of two more years, Mr. Turner informs me (1836-7), has confirmed all his former experiments : he continues the use of this valuable fertilizer, with the most satisfactory results; his plot of turnips drilled with bones having been, in that dry season, most excellent.

In no part of England is the use of bone dust more extensive, and more absolutely essential to the growth of turnips than in Lincolnshire. A brief account of its introduction will be found in the following extract from a letter with which I was favoured in the spring of 1836, from Thomas Brailsford, Esq., of Barkwith.

"The use of bones crushed small enough to pass the drill, began in Lincolnshire about twenty or twenty-five years ago, and may now be considered as general over the greatest part of the county, and universul over the great natural divisions-the heath, and (the corn brash and upper oolite) the cliff, and the wolds (the chalk and green sand-stone measures of geologists). The effect produced has been wonderful: it has converted large tracts of thin-skinned and weak lands into the most fertile districts. The quantity now drilled varies from twenty strikes of half-inch bone, with the dust in it, per acre; and it is used almost exclusively for turnips, experience having proved that it is more profitably adapted to the caltivation of that crop than any other. It may be right to add, that, in this county, it is considered that the feeding quality of tarnips raised from bones exceeds that produced by dang. Last year," adds Mr. Brailsford, "I used sulphur with my crushed bones, mixing $7 \mathrm{lbs}$. of the former with $100 \mathrm{Ibs}$. of the latter: a few days before $\mathbf{I}$ drilled them with the turnip seed, a moderate fermentation took place, which rendered the sulphur active, and produced a pretty considerably smell of brimstone, and had the effect of most effectually defending the young turnip plants from the fly."

An opinion has been sometimes entertained, that the black grub or caterpillar, which has for the last two or three years been so destructive of the turnip crop, has been introduced in the bones imporied from abroad for manure; and many equally idle and learned papers have appeared to warn the farmer of the dangers he was incurring by their use. A more absurd supposition, perhaps, was never entertained; for, saying nothing of the total absence of every thing like proof of a single black grab being discovered in an imported bone, all the accurate experiments, and long experience of those who have used bones, render the supposition langhable.

In the numerous experiments at which 1 have assisted and witnessed, it has been always found that the black grub appeared equally numerous among the boned and anboned turnips: that in those portions of the field, or in the entire field, where bones were Irilled with the turnips, the grubs were not wore numerous than on those lands which 198 were manured with common manure, or drilled without any manure at all.

Again, the rery habits of this black grub betray the fact that he is not of animal origin; he lives, he feeds upon, he is composed of vegetable matter. The farmer well knows that the grub or caterpillar which is bred on a cabbage or turnip cannot sustain life, nay, cannot eat animal matters; it would perish if placed on the most dainty bone. And on the contrary, if a grub bred in a bone is placed, however cautiously and skilfully, on a turnip or cabbage, he dies of absolute starvation, for vegetable matters are not food for him; his habits, his very nature, make him revolt from the novel food presented to him.

And again, if he really be imported from Belgium in the bones, he must be able to resist a very considerable temperature; for it has been clearly established, that the turnip fields which have been manured with the refuse briled bones of the size and cart-grease makers have been just as much covered with the black caterpillars as those which have been manured with fresh bones. He can live, therefore, even in boiling hot water: or, if he come in the shape of caterpillar eggs, then the believers in this absurd doctrine must be convinced that caterpillar eggs can be hatched even after they have been boiled for hours in a temperature of $212^{\circ}$.

But grubs and black caterpillars are not the first living substances which have been supposed to have been imported in the foreign bones. Thus, the Nottingham and Lincolnshire farmers, many years since, found that, by the use of hones, the growth of white clover was surprisingly encouraged; and that, in fact, wherever a load of crushed bones was spread, in that place the clover sprang up as if by magic. "They appeared," says his Grace the Duke of Portland, in a letter with which he honoured me in Febraary 1836, "so much to encourage the growth of white clover, that $\mathbf{I}$ had almost formed the opinion that it was superffuous to sow the seed." The honest farmers of that fine district naturally had many a puzzling learned cogitation apon this strange yet regular appearance of the white clover, wherever bones were applied; but then, they recollected that the bones came from the very land of fine white clover seed; and that the seed must, therefore, as a natural consequence, come hid in the bones. The Lancasterian and Cheshire farmers, however, did not fall into this mistake, since they foand that the white clover sprung up just as copiously after the use of the boiled bones, as apon the lands manured with those in a fresh or green state.

The chemical explanation will oceur to every scientific farmer. The white clover abounds in phosphate of lime; it cannot, therefore, grow vigorously in soils which do not contain it. Bones sapply this necessary food, or constituent; and enable the white clover to contend successfully in the turf with other and caarser grasses, and finally extirpate them. There are few soils in England which do not contain the seeds of this plant; it has been noticed to spring up in the most unlikely situ- 
ations, even in London, afler a fire; and for precisely the same reason-the ashes of wood abound in phosphate of lime. Bones have been hitherto principally employed upon the turnip crop, but there is another, the potato plant, to which they seem admirably adapted; and of this opinion was Mr. Knight, the late President of the Horticultural Society; he observed to me in a communication dated March 26 , 1836, written with his usual anxious solicitude to assist on every occasion in any researches which tended to the improved cultivation of the earth,- "I have one large farm, upon which rises a sufficient quantity of spring water to work a thrashing machine and a bone mill, at all seasons; and upon that I have erected a machine for crushing bones, which my tenant has used largely. 'The soil is generally strong and argillaceous, but upon this the bone manure operates well, and it is applied by a drill to the turnip ground. My tenant finds that it acts according to the quantity of oleaginous matter which it contains; and I cannot help thinking, that taking away that part must destroy to a very great extent the operation of the manure during at least one year; particularly if the bones be crushed nearly to dust before boiling. I have tried other animal substances, such as hair,feathers, and the parings and dust of white leather, and none of these have operated till they have had some weeks to decompose. The white leather parings, being almost entirely composed of gelatine, I expect operate very soon, but I found that turnips drilled in over a very sufficient quantity of it did not begin to grow kindly till September; and I do not entertain a shadow of a doubt but that if bones, after being crushed, were mixed with four or five times their weight of earth, their operation, as a manure, immediately, would be greatly increased. It could not, however, then be conveniently drilled in with the seed, and that process, whenever the soil is poor, is very important, because by being placed close to the seedling plant, that gets well nourished while young. I cannot doubt but the bone manure must continue to operate as long as decomposition of the original substance continues, and under this impression I am willing to find capital to purchase it, upon the tenant's paying a fair amount of increased rent. Much would, of course, depend upon the bones being more or less crushed; but I cannot think that a good manuring of bone-dust can, under any circumstances, be soon entirely expended. I have seen bone-dust applied in considerable quantities in planting stone fruit trees, as peaches and plums, with good effect, though such are always greatly injured or destroyed by the application of stable-yard dung in the same way. My tenant applies his bone manure wholly to his turnips, and the stable-yard manure to the wheat field, in opposition certainly to my opinion; as I think wheat crops yield best when the soil is firm, and turnip crops best when it is hollow, and he purposes to try the effect of reversing the process. If the turnip plant is capable of deriving nourishment from fragments of bones, which have been boiled, after being crushed, their roots must, I conceive, have a power of ciecomposing the substance of the bone; which appears very improbable. though many plants appear to exercise such power on silicious earth. I have somewhere read an account of experiments, which appeared to prove that the silex found in the epidermis of the different species of Equisetum, grapes, $\& c$, is really dissolved and taken up from the soil, and subsequently deposited in an organic form; but as the plants which were subjected to experiment might, owing to having been feeble and sickly, not have deposited any, or the usual portion of silex, I am not satisfied that the remaining half of flint, after its oxygen has been driven off, is a simple substance. The number of simple elements (admitting the existence of matter) I suspect to be very small; such was the opinion of my late lamented friend, Sir H. Davy. I think it probable that quicklime, if applied to bones contain. ing much oily matter, would operate powerfully by reducing such oil to the state of soap, readily soluble in water; but a part of the ammonia might by this process be dissipated and lost. Valuable as bone-dust certainly is as a manure to the turnips, I doubt whether it may not be employed with more advantage as a manure for the potato; and my tenant is inclined to think that the potato crop, though wholly consumed upon the farm, will best repay him. The bone manure, when employed to nourish the potato plant, might be buried in the soil two months before it would be materially wanted; and the crops of barley and oats, upon all except light soils, are much better after potatoes than after turnips, both being carted off the ground. Early varieties which do not blossom are the most valuable, as they afford the most certain crops, and will be quite ready to be taken up in August, after which the ground may be well prepared for wheat. Of such potatoes I have obtained a produce equivalent to $963 \frac{1}{2}$ bushels of $80 \mathrm{lbs}$., and $1248 \frac{2}{3}$ bushels of $60 \mathrm{lbs}$. But early potatoes vegetate again late in autumn, and they then become much better food without being steamed, than previously."

The way in which bone-dust is usually employed as a manure for potatoes is decidedly wrong; it is used in much ton fresh a state. This error long deceived and perplexed the turnip growers of the east of England, who now invariably let the bone-dust ferment, either by itself, or mixed with earth, for some weeks before it is applied to the soil. And all my experiments have concurred in their result with those of my neighbours in Essex, that if the bones are mixed with five or six times their bulk of earth, and are turned over and mixed together some weeks before they are spread on the potato ground, the more valuable is the application. And this remark is not confined to its use for potatoes; oats and oarley are proportionally benefitted by the previous fermentation and partial dissolution of the bones in the mixed earth. The same observation must apply to Indian corn.

It is impossible, in any agricultural expers. ment, to give very minute directions for the farmer's guidance, since soil, climate, and situation, as regards temperature and easy acces; 


\section{BONES.}

to the proposed fertilizer, must be of necessity taken into the agriculturist's consideration; and these observations particularly apply to those manures of a purely animal nature, whose value I have been endeavouring to ilIustrate. Thus, with regard to bones, the quantity applied per acre must of necessity vary with circumstances; but, by many careiully conducted experiments, at some of which I have personally assisted, it has been found that the bones remain in the soil for a length of time proportionate to the size of the pieces, the dust producing the most immediate effect, the larger description showing the longest advantage; thus, on arable lands, the good efrects of the half-inch or inch bones are observable for four or five years; while, on pasture land, the advantage derived from their application is observable for eight or nine. But, as practical experience is alone the substitute for cur want of general scientific knowledge founded on experiments, the farmer should, in experimenting upon all manures, for the sake of correct information, apply them in varying quantities per acre, and on no account omit to leave, by way of comparison, a fair portion of the field without any manure.

There is no delusion more common than that a correct agricultural experiment is easily accomplished-that it may be taken up as a mere amusement, carried on without care, and concluded without any laborious attempts at accuracy. Some experience in these delightful pursuits, amongst some of the most talented farmers of the east of England, has long convinced me of the folly of such a conclusion, and of the extreme care and caution necessary for such valuable researches; for, otherwise, all kinds of errors are almost sure to arise. In applying weight and measure, also, to the crop, there is no need for the farmer to weigh and measure large plots; a square rod or two carefully examined, furnishes results nearly as accurate and valuable as the examination of acres.

The application of bones to grass land is very common in Cheshire and Lancashire. I have already noticed its effect in the production of white clover, a phenomenon well known to the farmers in the neighbourhood of Manchester, who are also fully aware of the amazingly increased produce of their grass lands by the application of the refuse bones of the size makers. The quantity which they employ is very large, varying from forty-five to eighty bushels per acre. 'The result, however, is fully commensurate with the outlay, for they calculate that the produce of their grass fields is nearly doubled by the application.

I cannot give a better account of its applica. tion for grass than that very kindly communicated to me in March, 1836, by Dr. Stanley, the present Bishop of Norwich. "Bone-dust has been used in Cheshire," said his lordship, "as is manure, to a very considerable extent, for the last seven years, but partially for a much longer period. Formerly, it was laid on pasture ground only, and in large quantities, and in large pieces, which rendered it very expensive, and the advantage comparatively $.0 w^{\cdot}$ but some pastures that were bone-dusted twenty years ago now show, almost to a yard, where this manure was applied. Bones are now used on every description of soil in England with the best results, provided the wet sands are first effectually drained. Some thousands of tons are annually consumed, and the demand is daily increasing. The quantity per statute acre varies; but the average may be, on pasture, from 30 to $40 \mathrm{cwt}$. of Manchester or calcined bones or $20 \mathrm{cwt}$. of raw or ground bones, to the statute acre. For turnips, from 20 to $30 \mathrm{cwt}$. of calcined bones. For oats or barley (of this latter, however, the quantity grown in Cheshire is very trifling), with clover and grass seeds, 20 to $30 \mathrm{cwt}$. of calcined bones, or one ton of raw or ground bones. Pasture ground should be well scarified or harrowed previous to sowing the bones, and immediately afterward rolled with a heavy roller. For turnips the bones should be pounded, or ground very small, and drilled in with the seed. With spring grain they should be rolled in with clover and seeds. It should be here remarked, that raw bones particularly should be allowed to remain for some days in heaps to ferment before they are applied. They have been used for potatoes; but experienced persons say they prefer dung. I am also informed, though my informant states his observations to be limited, that on old meadows the result has not been found to be so satisfactory as on pastures. On clover, bones have a most extraordinary effect. On old pastures that have been boned, although previously the clover was not to be seen, luxuriant crops have soon shown themselves. The best proof, indeed, of their beneficial effect, is the fact, that the farmers, six years ago, in this immediate neighbourhood, had so strong a prejudice against bones that it was with some difficulty they were induced to use them, although given by way of reduction of rent; but, for the last three years, they have been most anxious to obtain them, and are now quite willing to be at half the expense. The rents have latterly been well paid, and there is good reason for belieying that it is a great measure owing to the advantage they are deriving from the boned land. On some estates in the county, the proprietors have boned a considerable quantity of the pasture land, the tenants willingly agreeing to pay, as an increased rent, from eight to ten per cent. on the cost of bones. There is some difference of opinion as to the most advantageous sorts of bones for use, some preferring the dust to the ground bones. The dust, or calcined bones, are $3 l$. per ton, and the ground bones $7 l$. per ton. For turnips, the dust is generally preferred, as being more immediate in its effects. On a very poor peat soil, about $35 \mathrm{cwt}$. of bone-dust was applied to a statute acre for Swedish tnrnips. The crop was a fair average one. The turnips were carted off, and the ground sown with wheat, which produced nearly twenty-five measures (of $75 \mathrm{lbs}$. per measure) to the statute acre. Oats succeeded with seed, principally red clover, a most excellent crop of oats ensuing The clover, also, proved a very heavy full crop, and was mown twice. No manure was applied for this course, except the first set of 
bones for the turnips. The remainder of the field, of exactly the same description of soil, was well manured with farm-yard dung, for potatoes, mangel wurzel, and vetches, to be used for soiling. This was then sown with wheat; but, bcing first well set over with a compost of lime and soil, the wheat plant on this part during winter and spring looked much better than the boned part of the field, but did not prove so good a crop; but the difference in favoull of the bones was not much. Oats succeeded here, also, with seeds, but the oat crop bid not prove half so produclive anywhere as on the part boned; and the clover was still more inferior, and mowed only once, the second crop not being considered worth mowing, while the part boned, aiongside of it, was as much as could be well mown."

There appears to be on many grass soils some care requisite to ensure the greatest advantage from the application of the bones; and this observation is not confined to any particular district, since it is strongly alluded to in the following extract from a letter of Mr. William L.ewis, of Trentham in Staffordshire, transmitted to me in September last, in an rbliging communication of his Grace the Duke of Sutherland:-

"I have never," says this intelligent farmer, " applied less than one ton of crushed bones per acre for turnips drilled in, and have been generally successful in growing that crop; and their goud effects (I mean the bones) are most conspicuously shown and felt on the grass erop that follows the turnips, showing to an inch how far the ground has been manured with them. I have no genuine fertile land, it being nearly all of a light, dry, sandy, hungry nature; but I have now excellent pastures for sheep, which I greatly ascribe to the use of bones; for the pastures following barley which have been manured with dung I find very inferiog to that manured with bones-(the difference in the barley crop not being perceivable) -so much so, that I am upon the eve of breaking up some of my pasture fields which have lain three years, and were intended for permanent pasture; for those manured at the same time with bones are still looking beautiful, with a close, fine, even bottom. I have also applied bones to pastures, and they have generally improved the herbage and verdure very greatly. The top-dressing with the bones I would recommend to be done in moist weather, when the ground is pretty well covered with grass. I consider from one and a half to two tons per acre to be a fair dressing. After sowing them, the ground should be well brushed, harrowed length and breadthways, then heavily rolled, and all stock taken from the field for at least ten days. I have seen bones applied to bare pastures, with little or no covering, done in hot, dry weather, showing no beneficial effects whatever afterwards." There is no doubt of the superior advantage of rolling the bones into the soil; for fresh, or green bones, as they are called in Cheshire, when they are exposed to the atmosphere for some time, lose from one fifth to one fourth of their weight; and even boiled bones, under similar circumstances, ar a reduced one third in weight. bushel of crushed green bones, of the three quarter of an inch size, weighs about 45 liss.the same bulk of bone-dust 54 lbs.: 75 bushels of crushed green bones weigh about one in and a half, the same bulk of boiled bones about two tons. The average weight of the bones of an ox is about $2 \mathrm{cwt}$, or about one fourth of the carcase free from offal ; the bones of a sheer about 21 lbs., supposing the carcase (1) aberage 84 lbs. So that, according to this calculation, allowing twenty bushels of crushed bones to manure an acre, the bones of five bullocks of horses, or fifty sheep, are requisite to sujply the necessary dressing.

Liebig recommends the following method as the one by which the benefits may be most speedily derived from bone applications. "The most easy and practical mode of effecting their division is," he says, "to pour over the bones, in a state of fine powder, half of their weight of sulphuric acid diluted with three or four parts of water, and after they have been digested for some time, to add one hundred parts of water, and sprinkle this mixture over the field before the plough. In a few seconds, the free acids unite with the bases contained in the earth, and a neutral salt is formed in a verv fine state of division."

A convenient mode of preparing vitriolized bones, or super-phosphate of lime, is to make a hollow in the centre of a heap of fine mould, and place in this crater the bones to be dissolved. Upon these apply, gradually, sulphuric acid, in weight equal to half the weight of the bones. These will som be dissolved, after which the heap of mould and bones is to be thoroughly. mixed by shovelling together.

Another method is describel by Mr. Spooner, in which the ground bones, being placed in a hogshead, have poured upon them one-third of their weight of oil of vitriol; that is to say, $60 \mathrm{lbs}$. of the sulphuric acid, to $180 \mathrm{lbs}$. or about 4 bushels of bones. The acid, mixed with half its bulk or measure of water, previously to putting upon the bones, will suddenly produce very great heat, equal to about $300^{\circ}$ of Fahreuheit's thermometer. Too much care cannot be taken to prevent the acid from burning the clothes or skin of those employed in this work. After the bones are sufficiently dissolved, they are mixed with ashes, so as to bring them to a state convenient for application by the drill or otherwise. Prepared in this way, the fertilizing properties of bones are rendered much more soluble. Mr. Spooner cites a case in which two bushels of the vitriolized bones, with ashes, gave as good a crop as sixty busliels of common ground bones.

In manuring the light lands, cultivated on the four-course system, with bones and with bones only, for a long series of years, I would advise the farmer, whenever he finds any symptoms of his ground failing to produce clover so well as it was once used to do, to add in that case a dressing of gypsum, either with the bones or with the grass seeas. The value of this latter manure, which is amply suffcient, when applied in quantities of not $e x$ ceeding 2 cwt. per acre, being in most situa tions trifling. There is every reason to believe 
:hat i.l those cases which have puzzled some iarmers, where land, after a long course of suczessful bone-dressing, has at last refused to produce clover, the gradual exhaustion of sulphate of lime, and perhaps of potash and other elements of fertility, removed by previous crops, may account for the failure.

For ornamental plantations of trees there can be no manure more advantageous than bones. There is a considerable portion of phosphate of lime in all timber trees, and there is no manure of a mixed animal, earthy, and saline nature which remains so long in the soil, mixed with earth; and thus previously fermented bones are an excellent dressing for vines, and have been used with decided advantage. As a manure for the use of the conservatory and the flower-garden, there is no fertilizer more useful than bonedust; or, what is a still more elegant application, the turnings and chippings of the bone turners. Their use not only promotes the luxuriance of the plant, but the beauty of the flowers. The Sheffield florists are well aware of the value of bone turnings.

As it is desirable that American farmers should be instructed in the various and most simple modes of preparing vitriolized bones or superphosphate of lime-mentioned in a preceding pagraph-we subjoin a few more of the plans adopted in England.

The bones, in the form of bone-dust, or, where bone-mills are not at hand, simply broken in pieces with a hammer, may be put into a cast-iron, stone, earthenware, or strong wcoden trough, cask, or other vessel, mixed with half their weight of boiling water, and then with half their weight of the strong oil of vitriol of the shops, stirring constantly while the latter is slowly poured in. A powerful boiling up, or effervescence at first takes place, but which gradually subsides. By occasional stirring, the whole assumes the appearance of a thick paste; the pieces of bone disappear by degrees, and after a week or ten days the whole may be taken out and mixed with a little sawdust, charcoalpowder, charred peat, or fine dry earth, to make it dry enough to pass through the drill, and thus be immediately applied to the land. It would be better to prepare the bones a month at least before using them, and to lay them up in a heap for awhile, with a view to their more perfect decomposition. Where the pieces of bone are large this is especially desirable, as otherwise they will not be fully decomposed without a larger addition both of water and of acid. Or, the mixture of acid and bones, as above, may after a couple of days be further mixed with a quantity of light friable soil, and laid up into a heap for seven or eight weeks, with occasional turning; the bones thus heat, decompose, and dry up, so as to be ready for putting into the drill without further preparation. 'This method, however, requires more acid, and it is not unusual, in employing it, to take equal weights of acid and of bones. Professor J. F. W. Johnston recommends the following plan for preparing bones into a liquid manure: Take equal weights of bone-aust, of boiling water, and of acid, and mix together, occasionally stirring them for a week or ten days; when the particles of bone have nearly disappeared, from 50 to 100 times more water may be added to the mixture, and the , iquid thus diluted applied by a water cart. If 202 it is to be used upon grass land, in the spring, or to young grain, it will be safer to dilute it with 200 waters, but 50 waters (by weight) will be enough if it be applied to the turnip drills.

Mr. Tennant thus describes the method he adopts :- "I put 25 bushels into three old boilers, and next pour in two bottles of acid of about 170 lbs. each, and 36 Scotch pints (18 imperial gallons) of boiling water into each boiler. It boils away at a great rate for some time, and in a day or two we empty the boilers into two cart loads of light mould, and turn the mixture over. At this stage the bones are only partially dissolved, but they heat and decompose in the heap, after being turned over three or four times; and in the course of seven or eight weeks the compost becomes dry, and breaks down with a shovel."

It is important to know that oil of vitriol varies in strength, from water added purposely or attracted from the atmosphere, as will always be the case when left in open vessels, which, when partly empty, will soon become full again from the water attracted. The purest oil of vitriol has a specific gravity of about 1.85, one gallon weighing as much as 1.7 or 1.8 gallons of water. That of commerce ought to have a specific gravity of about 1.45 or 1.5 , that is to say, be about half as heavy again as water, so that one gallon of oil of vitriol shall weigh as much as a gallon and a half of water. More of it must be used if weak. The price varies with the strength, from $2 \frac{1}{2}$ to 3 cts. per $1 b$. The great heat produced by the mixing of oil of vitriol and water, acting on the animal portions of the bones, makes these of a dark colour; but, if a small quantity of acid only be employed, the mixture is white, from the carbonate of lime which then predominates. The fat, gristle, and other organic matter united with bones, in the state in which these are usually employed by farmers, constitutes about 1-3 of their weight. Mr. Hannum reckons the soft parts of bone, when very fresh, at 45 per cent. Four bushels of ground bones, which may be considered a fair allowance for an acre, will weigh, in a fine state, from 168 to $180 \mathrm{lbs}$. This last-named quantity contains $12 \frac{1}{2} \mathrm{lbs}$. of carbonate of lime, and the first action of the acid is to seize upon this, displace its carbonic acid, and convert the lime into sulphate of lime or gypsum. The quantity of the acid re. quired for this first change is $10 \mathrm{lbs}$. The acid having thus decomposed the carbonate of lime in the bones and converted it into plaster of $\mathrm{Pa}$ ris, next turns upon the phosphates, of which the 4 bushels contains about $106 \mathrm{lbs} ., 47 \mathrm{lbs}$. being lime and $59 \mathrm{lbs}$. phosphoric acid. $33 \mathrm{lbs}$. of the vitriolic acid unites with half the lime, or $23 \frac{1}{2} \mathrm{lbs}$., to form more gypsum. The other half of the lime unites with a double portion of phosphoric acid to produce the desired super-phosphate. Thus about $43 \mathrm{lbs}$. of acid will be required to effect the necessary changes in the 4 bushels of bones.

Instead of the sulphuric acid, muriatic acid has been substituted in similar quantity, diluted and treated in the same manner. The cost per acre and the produce obtained were very much the same. Where no manure was applied, and the produce per acre was only about 7 tons of turnips, the superphosphate of lime made from 4 bushels of bones increased the produce to $17 \frac{3}{3}$ tons. See Phosphates. 
It is hardly necessary for us to add more authorities in favour of bone manure. The reader may refer, however, to the experiments of Caplain Ogilvy, of Airlie Castle (Trums. of High. Soc. vol. iv. p. 238); of Mr. Watson, of Keillor, Cupar-Angus (Quart. Journ. of Agr. vis.. vi. p. 41-43); and of Mr. Boswell, of Kingcaussie (Trans. of High. Soc. vol. i. p. 73; Comparative 'Trial of Bones, Farm-yard Manure, and Rape Cake): to those of Mr. Billyse on their use for the pastures of Cheshire (Journ. of Kioy. Agr. Soc. of Eng. vol. ii. p. 91.) See also Johnson, On Fertilizers, p. 125. (Brit. Farm. Mug. vol.vi.p. 308.) The bone mill is described by Mr. Anderson, of Dundee (Trans. of High. Soc. vol. i. p. 401), and again in the Penny Cycloprdia.

BONE SPAVIN (Fr. espavent; Ital. spavano), in horses, is a disease of the hock joint, usually brought on by over-exertion, accelerated by bad shoeing. When this is forming, there is commonly lameness, but this diminishes or ceases when the bony matter, whose deposit causes the spavin, is completely formed, at least when the horse is warm with exercise. It impedes his rising when down, and in consequence spavined horses lie down with reluctance. A spavined horse generally does slow work well enough, and when used in the farm, his disease is commonly ameliorated or cured. Repeated blisters will either entirely remove or ameliorate the symptoms. It is only as a last resort that the hot iron - huuld be used.

BOOK-KEEPING. As the merchant, the manufacturer, and the tradesman all find it necessary to keep a set of account books which shall show them the amount of capital employed, the debts owing to and by them, and the profi: or loss arising from their different transactions, so to the farmer is this good practice equally essential. The Dutch have a proverb, that no one ever goes to ruin who keeps a correct set of accounts. There is great truth in this sagacious observation of the plodding Dutchmen; for by consulting correct accounts the farmer will be either warned to retrace his steps, or to persevere in the path he is pursuing. The time required for keeping these books is always to be found of an evening after the labours of the day are over. The necessary books to give him this informatuon are, first, a cash book, in which shall be entered on one side all the moneys received, and from whom; and on the other side, all payments, and to whom made; secondly; a journal, in which should be entered all deliveries, and articles received; and, thirdly, a stock book, in which should be every week entered all addition to or substraction from the stock of the farm; fourthly, an invoice book, to receive all bills of account; fifthly, a wages book, to keep each labourer's time and wages; and, sixthly, a ledger, which should contain every person's account with whom the farmer has transactions. With these statements carefully kept, and an account and valuation of his stock in trade made annually, as if he were about to quit the farm, no farmer's affairs can reasonably go wrong; for not only by good booking is fraud prevented, and economy pro- moted, but by this means the farmer always knows his real position. I am supported in these opinions by a very considerable farmer and land-agent, Mr. Hewitt Davis, of Spring Park, in Surrey.

BORAGE (Burago officinalis). Supposed to be derived from corag", or cur, the heart, and ago, to give, alluding to the renovating power of which it was supposed to be pussessed. This is a well-known plant in all gardens, growing two feet high, with large leaves, and bright blue flowers. 'The stalks are round, juicy, and thick, and so hairy that they are almost prickly to touch. The leaves are broad, rough, wrinkled, and hairy. The flowers have five bright blue petals or parts, with a black centre; they blow all through the summer, and continue till late in autumn. They will begin to flower about June, and when their seed is perfectly ripc, the stalks must be gathered and dried completely before it is rubbed out. ( $G$. W. Johnson's Kitch. Gard.) Borage was formerly considered cordial. The leaves and flowers tied in a bundle, and warmed up in beer, is a great remedy in England among the poor. They consider them corảial, opening, and cooling; and in many parts of England they make borage one of their materials in brewing. The whole plant, says Smith (Eng. Flor. vol. i. p. 265), has an odour approaching to cucumber and burnet, which gives a flavour to a cool tankard; but its supposed exhilarating qualities, which caused borage to be reckoned one of the four cordial flowers along with alkanet, roses, and violets, may justly be doubted. The flavour is nauseous in any other beverage.

BORDER (Germ. and Fr. bord; Sax. bono). A term which signifies the portion of land next the hedges in fields; but in ploughed grounds is mostly applied to the parts at the ends on which the teams turn.

BORECOLE (Brassicn oleracea fimbriata.) A species of winter cabbage, of which the follow. ing are the principal varieties commonly cultivated in the garden:-1. Brussels borecole. 2. Green borecole (Brassica oleracea selenisia). 3. Purple borecole ( $B$. o. laciniata). 4. Variegated borecole. 5. German, or curled kale or curlies. 6. Scotch or Siberan kale (B. o. sabellica). 7. Chou de Milan. 8. Egyptian, or Rabi kale. 9. Ragged Jack. 10. Jerusalem kale. 11. Buda, Russian, Prussian, or Manchester kale. 12. Anjou kale. Like the other member's of the cabbage tribe, it is propagated by seed. The first crop to be sown about the close of March, or early in April; the seedlings of which are fit for pricking out towards the end of April, and for final planting at the close of May, for production late in autumn and at the commencement of winter; the sow. ing must be repeated about the middle of May, for final planting during July, and lastly in August, for use during winter and tariy spring. If transplanting is adopted, their fitness for pricking out is known when their leaves are about two inches in breadth; they must be set six inches apart each way, and watered frequently until established. In four or five weeks they will be of sufficient growth for final re. moval. When planted, they must be set in 
rows two feet and a half apart each way; the last plantations may be six inches closer. They must be watered and weeded, as directed for the other crops; as they are of large spreading growth, the earth can only be drawn about their stems during their early growth. If, during stormy weather, any of those which acquire a tall growth are blown down, they must be supported in their erect posture by stakes, when they will soon firmly re-establish themselves. For the production of seed, such plants of each variety as are of the finest growth, and are true to the characteristics primarily given, must be selected, and either left where grown, or removed during open weather in November, or before the close of February, the earlier the better, into rows three feet apart each way, and buried down to their heads. The seed ripens about the beginning of August. (G.W. Johnson's Kitchen Garden.)

BORER. See Auger.

BORERS. The wood-eating worms called borers, are grubs of various species of the beetle tribe, several of which have been already referred to. Some live altogether in the trunks of trees, boring into the most solid wood; others take up their residence in the limbs. Some devour the wood, others the pith; some are found only in shrubs, some in stems of herbaceous plants, and others confine themselves to the roots. Certain kinds restrict themselves to plarits of one species, others live indiscriminately upon several plants, provided these belong to the same natural family; for the same borer is not known to inhabit plants differing essentially from each other in their natural characters. The beetles produced from these worm-borers are of very many kinds, nearly one hundred species having been already found by Dr. Harris in Massachusetts, belonging to the Capricorn fumily alone. This family of beetles derive their name from their long and tapering antennæ, which are curved like the horns of a goat. The head is short and armed with powerful jaws. Most of this family remain upon trees and shrubs during the daytime, and fly abroad at night. Some, however, fly by day, and may be found on flowers feeding on the pollen and even the blossoms. When annoyed or taken into the hands, they make a squeaking sound by rubbing the joints of the thorax and abdomen together. "The females are generally larger and more robust than the males, and have rather shorter antennæ. Moreover they are provided with a jointed tube at the end of the body, capable of being extended or drawn in like the joints of a telescope, by means of which they convey their eggs into the holes and chinks of the bark of plants.

"The larvæ hatched from these eggs are ong, whitish, fleshy grubs, with the transverse incisions of the body very deeply marked, so that the rings are very convex or hunched both above and below. The body tapers a little behind, and is blunt-pointed. The head is much smaller than the first ring, slightly bent downwards, of a horny consistence, and is provided with short but very powerful jaws, by means whereof the insect can bore, as with a cr ntre-bit, a cylindrical passage through the 2nd most solid wood. Some of these borers have six very small legs, namely, one pair under each of the first three rings; but most of them want even these short and imperfect limbs, and move through their burrows by the alternate extension and contraction of their bodies, on each or on most of the rings of which, both above and below, there is an oval space covered with little elevalions, somewhat like the teeth of a fine rasp; and these little oval rasps, which are designed to aid the grubs in their motions, fully make up to them the want of proper feet. Some of these borers always keep one end of their burrows open, out of which, from time to time, they cast their chips, resembling coarse saw-dust; others, as fast as they proceed, fill up the passages behind them with their castings, well known here by the name of powder-post. 'These borers live from one year to three, or perhaps more years before they come to their growth. They undergo their transformations at the furthest extremity of their burrows, many of them previously gnawing a passage through the wood to the inside of the bark, for their future escape. The pupa is at first soft and whitish, and it exhibits all the parts of the future beetle under a filmy veil which inwraps every limb. The wings and legs are folded upon the breast the long antennæe are turned back against the sides of the body, and then bent forwards be tween the legs. When the beetle has thrown off its pupa-skin, it gnaws away the thin coat of bark that covers the mouth of its burrow, and comes out of its dark and confined retreat to breathe the fresh air, and to enjoy for the first time the pleasure of sight, and the use of the legs and wings with which it is provided (Hurris's Treatise on Insec/s.)

One family of the capricorn or goat-horne? beetles, derives its name of Prionidæ from * Greek word signifying saw. It is said that some of these saw-beetles can saw off larga limbs by seizing them between their jaws, and flying or whirling sidewise round the encloser: branch, till it is completely divided. One of the largest species is the broad-necked pricm nus. It is from one inch and a quarter, to an inch and three-quarters in length, of an ovin form and pitchy black colour. The grubs $0^{\circ}$ this beetle, when fully grown, are as thick as man's thumb. They live in the trunks an? roots of the balm of Gilead, Lombardy poplat. and probably in other kinds of poplar.

In the second family of the Capricorn beetle called the Cerambycians, there is one whick inhabits the hickory, in its larva state forming long galleries in the trunk of this tree in the direction of the fibres of the wood.

"The ground beneath black and white oaks," says Dr. Harris, "is often observed to bs strewn with small branches, neatly severed from these trees as if cut off with a saw. Upon splitting open the cut end of a branch, in the autumn or winter after it has fallen, it will be found to be perforated to the extent of six or eight inches in the course of the pith, and a slender grub, the author of the mischief, will be discovered therein. In the spring this grub is transformed to a pupa, and in June or July it is changed to a beetle, and crirres out of the 


\section{BORERS.}

branch. The history of this insect was first made public by Professor Peck, who called it the oak-pruner, or Stenocorus (Elaphidion) putator. In its adult state it is a slender longhorned beetle, of a dull brown colour, sprinkled with gray spots, composed of very short close hairs; the antenna are longer than the body, in the males, and equal to it in length in the other sex, and the third and fourth joints are tipped with a small spine or thorn; the thorax is barrel-shaped, and not spined at the sides; and the scutel is yellowish white. It varies in length from four and a half to six-tenths of an inch. It lays its eggs in July. Each egg is placed close to the axilla or joint of a leafstalk or of a small twig, near the extremity of a branch. The grub hatched from it penetrates at that spot to the pith, and then continues its course towards the body of the tree, devouring the pith, and thereby forming a cylindrical burrow, several inches in length, in the centre of the branch. Having reached its full size, which it does towards the end of the summer, it divides the branch at the lower end of its burrow, by gnawing away the wood transversely from within, leaving only the ring of bark untouched. It then retires backwards, stcps up the end of its hole, near the transverse section, with fibres of the wood, and awaits the fall of the branch, which is usually broken off and precipitated to the ground by the autumnal winds. The leaves of the oak are rarely shed before the branch falls, and thus serve to break the shock. Branches of five or six feet in length and an inch in diameter are thus severed by these insects, a kind of pruning that must be injurious to the trees, and should he gitarded against if possible. By collecting the fallen branches in the autumn, and burning them before the spring, we prevent the developement of the beetles, while we derive some benefit from the branches as fuel.

"It is somewhat remarkable that, while the pine and fir tribes rarely suffer to any extent from the depredations of caterpillars and other leaf-eating insects, the resinous odour of these trees, offensive as it is to such insects, does not prevent many kinds of borers from burrowing into and destroying their trunks. Several of the Capricorn-beetles, while in the grub state, live only in pine and fir trees, or in timber of these kinds of wood. They belong chiefly to the genus Callidium, a name of unknown or obscure origin. The larva are of moderate length, more flattened than the grubs of the other Capricorn-beetles, have a very broad and horny head, small but powerful jaws, and are provided with six extremely small legs. They undermine the bark, and perforate the wood in various directions, often doing immense injury to the trees, and to new buildings, in the lumber composing which hey may happen to be concealed. Their burrows are wide and not cylindrical, are very winding, and are filled up with a kind of compact sawdust as fast as the insects advance. The larva state is said to continue two years, during which period the insects cast their skins several times. The sides of the body in the pupa are thin-edged, and finely notched, and the tail is forked.

\section{BORER9.}

"One of the most common knds of Cisllidium found here is a flattish, rusty black beetle, with some downy whitish spots across the middle of the wing-covers; the thorax is nearly circular, is covered with fine whitish down, and has two elevated polished black points upon it; and the wing-covers are very coarsely punctured. It measures from fourtenths to three-quarters of an inch in length. 'This insect is the Callidium brjulus; the second name, meaning a porter, was given to it by Linnaus on account of the whitish patch which it bears on its back. It inhabits fir, spruce, and hemlock wood and lumber, and may often be seen on wooden buildings and fences in July and August. We are informed by Kirby and Spence that the grubs sometimes greatly injure the wood-worls of houses in London, piercing the rafters of the roofs in every direction, and, when arrived at maturity, even penetrating through sheets of lead which covered the place of their exit. One piece of lead, only eight inches long and four broad, contained twelve oval holes made by these insects, and fragments of the lead were found in their stomachs. As this insect is now common in the maritime parts of the United States, it was probably first brought to this country by vessels from Europe." (Harris.)

The violet Callidium, is of a Prusslew a blue or violet colour, its length varying from four to six-tenths of an inch. It is found in great numbers on piles of pine wood, from the middle of May to the first of June, and the maggots and pupæ are often met with in splitting the wood. They live mostly just under the bark, where their broad and winding tracks may be traced by the hardened sawdust with which they are crammed. Just before they are about to be transformed, the larva or worms bore into the solid wood to the depth of several inches. In Maine and other places they are said to be very injurious to the sapling pines. Professor Peck supposed this species of borer to have been introduced into Europe in timber sent from this country, as it is found in most parts of that continent that have been much connected with North America by navigation. It is somewhat singular that Europe and America should have thus interchanged the porter and violet Callidium, which, by means of shipping, have now become common to the two continents. (Harris.)

Sugar Maple Borer.-The sugar-maple, cne of the most beautiful and noble trees of the American forest, suffers much from the attaclis of a borer, the largest known species of Clytus, by which it is sometimes entirely destroyed. In order to check the devastations of these borers they should be sought for in the spring, when they may be readily detected by the sawdust thrown out of their burrows; and, by a judicious use of a knife and stiff wire, they may be cut out or destroyed before they have gone deeply into the wood. (Harris.)

Locust-tree Borer.-The locust tree or acacia, is also preyed upon by a borer of the Clytus family, the larva of a painted beetle often seen in abundance feeding by day upon the blos. soms of the golden rod (Solidagu), in the month, 
of September. If the trunks of the common locust-tree are examined at this time, a still greater number of these beetles will be found upon them, and most often paired. This $\mathrm{Ca}$ pricorn-beetle has the form of the beautiful inaple Clytus. It is velvet-black, and ornamented with transverse yellow bands. The legs are rusty red, and the length of the insect is from about half an inch to three quarters of an inch. "In the month of September," says Dr. Harris, "these beetles gather on the locust trees, where they may be seen glittering in the sunbeams with their gorgeous livery of black velvet and gold, coursing up and down the trunks in pursuit of their mates, or to drive away their rivals, and stopping every now and then to salute those they meet with a rapid bowing of the shoulders, accompanied by a creaking sound, indicative of recognition or defiance. Having paired, the female, attended by her partner, creeps over the bark, searching the crevices with her antennæ, and dropping therein her snow-white eggs, in clusters of seven or eight together, and at intervals of five or six minutes, till her whole stock is safely stored. The eggs are soon hatched, and the grubs immediately burrow into the bark, devouring the soft inner substance that suffices for their nourishment till the approach of winter, during which they remain at rest in a torpid state. In the spring they bore through the sap-wood, more or less deeply into the trunk, the general course of their winding and irregular passages being in an upward direction from the place of their entrance. For a time they cast their chips out of their holes as fast as they are made, but after a while the passage becomes clogged, and the burrow more or less filled with the coarse and fibrous fragments of wood, to get rid of which the grubs are often obliged to open new holes through the bark. The seat of their operations is known by the oozing of the sap and the dropping of the sawdust from the holes. The bark around the part attacked begins to swell, and in a few years the trunks and limbs will become disfigured and weakened by large porous tumours, caused by the efforts of the trees to repair the injuries they have suffered. According to the observations of General H. A. S. Dearborn, who has given an excellent account (Mass. Agric. Repos. and Journ. vol. vi. p. 272), of this insect, the grubs attain their full size by the twentieth of July, soon hecome pupæ, and are changed to beetles and leave the trees early in September. Thus the existence of this species is limited to one year.

"Whitewashing, and covering the trunks of the trees with grafting composition, may prevent the female from depositing her eggs upon them; but this practice cannot be carried to any great extent in plantations or large nurseries of the trees. Perhaps it will be useful to head down young trees to the ground, with the view of destroying the grubs contained in them, as well as to promote a more vigorous growth. Much evil might be prevented by employing children to collect the beetles while in the act of providing for the continuation of their kind. A common black bottle, contain. ing a little water, would be a suitable vessel 206 to receive the beetles as fast as they were gathered, and should be emptied into the fire in order to destroy the insects. The gathering should be begun as soon as the beetles first appear, and should be continued as long as any are found on the trees, and furthermure, should be made a general business for several years in succession. I have no doubt, should this be done, that, by devoting one hour every day to this object, we may, in the course of a few years, rid ourselves of this destructive insect."

In noticing the locust-borer, Mr. Colernan states, that Allen C. Metcalf, of Lennox, Mas sachusetts, washed his locust trees with spirits of turpentine, and in that way, as he believes, compelled the borer to leave them, after they had made severe ravages. The trees were examined by Mr. Coleman, who found them much perforated, but without any signs indicating the presence of the worm. (See Mr. Coleman's Second Report.)

The poplar tribe of trees, both in Europe and America, are subject to the attacks of certain kinds of borers, differing essentially from all the foregoing when arrived at maturity. They belong to the genus Saperda. The largest kind found in America is the Saperda calcarata of Say, so called because the tips of the wing. covers end with a little sharp point or spur. It is covered all over with a short and close nap, which gives it a fine blue-gray colour; it is finely punctured with brown; there are four ochre-yellow lines on the head, and three on the top of the thorax. It is from one inch to an inch and a quarter in length. The grubs of this beetle, with those of the broad-necked Prionus, already mentioned, have in some parts of the United States, in the vicinity of Boston, for instance, almost entirely destroyed the Lombardy poplar. They also live in the trunk of American poplars. These grubs are of a yellowish-white colour, and, when fully grown, measure nearly two inches in length. The beetles proceeding from these may be found on the trunks and branches of the various kinds of poplars, in August and September; they fly by night, and sometimes enter the open windows of houses in the evening.

Apple-tree Borer.--"The borers of the apple tree," says Dr. Harris, "have become notorious, throughout the New England and Middle States, for their extensive ravages. They are the larvæ of a beetle called Saperdu bivit. tata by Mr. Say, the two-striped, or the brown and white striped Saperda ; the upper side of its body being marked with two longitudinal white stripes between three of a light brown colour, while the face, the antennæ, the underside of the body, and the legs are white. This beetle varies in length from a little more than one-half to three-quarters of an inch. It comes forth from the trunks of the trees, in its per. fected state, early in June, making its escape in the night, during which time only it uses its ample wings in going from tree to tree in search of companions and food. In the daytime it keeps at rest among the leaves of the plants which it devours. The trees and shrubs principally attacked by this borer are the apple tree, the quince, mountain ash, haw- 
thorn and other thorn bushes, the June-berry o1 shad-bush, and other kinds of Amelunclier and Aroniu. Our native thorns and Aronias are its natural food; for I have discovered the larvo in the stems of these shrubs, and have repeatedly found the beetles upon them, eating the leaves, in June and July. It is in these months that the eggs are deposited, being laid upon the bark near the root, during the night. 'The larvie hatched therefrom are fleshy whitish grubs."

The larva or grub state continues two or three years, during which the borer will be found to have penetrated eight or ten inches upwards in the trunk of the tree, its burrow, at the end approaching to, and being covered only by, the bark. Here its transformation from larva to pupa takes place, and its final change from pupa to beetle or winged insect, which occurs about the first of June, soon after which the beetle gnaws through the bark that covers the end of its burrow, and leaves its place of confinement in the night.

"Notwithstanding," says Dr. Harris, "the pains that have been taken by some persons to destroy and exterminate these pernicious borers, they continue to reappear in our orchards and nurseries every season. The reasons of this are to be found in the habits of the insects, and in individual carelessness. Many orchards suffer deplorably from the want of proper attention; the trees are permitted to remain, year after year, without any pains being taken to destroy the numerous and various insects that infest them; old orchards, especially, are neglected, and not only the rugged trunks of the trees, but even a forest of unpruned suckers around them, are left to the undisturbed possession and perpetual inheritance of the Saperda. On the means that have been used to destroy this borer, a few remarks only need to be made; for it is evident that they can be fully successful only when generally adopted. Killing it by a wire thrust into the holes it has made, is one of the oldest, safest, and most successful methods. Cutting out the grub with a knife or gouge is the most common practice; but it is feared that these tools have sometimes been used without sufficient caution. A third method, which has more than once been suggested, consists in plugging the holes with soft wood. If a little camphor be previously inserted, this practice promises to be more effectual; but experiments are wanting to confirm its expediency."

The zealous and able naturalist who has furnished the foregoing information relative to insects which so frequently carry destruction among the forest, fruit, and ornamental trees of the United States, has also described many others of the beetle tribe which attack trees and plants not yet named. Among these may be mentioned the borers which infest the pitch pine tree, and even the blackberry and raspberry bushes; together with various leafbeetles which prey upon the foliage of fruittrees, the linden-tree, potato, cucumber, and pumpkin vines, the leaves of turnips, horse. radish, milk-weed, \&c., most of which will be referred to in noticing the several trees and plants named. together with the best means known of destroying them or preventing their ravages.

BORING. A practice sometimes employed in order to ascertain the nature of the different strata that lie beneath the soil; and also for the purpose of discovering springs, and tapping them, so as to draw off the water, tha: injures the grounds below or in the ne!ghbourhood. See Drainixe.

BOS. The generic name for quadrupeds whose horns are in the form of a crescent. Sce

Catren.

BOSCAGE. A word borrowed from the French, signifying a woody grove, or woodland

BO'TANY (from the Gr. Brtávin, an herb), in the most confined sense of the term, is the science which teaches us the arrangement of the members of the vegetable kingdom in a certain order or system, by which we are enabled to ascertain the name of any individual plant with facility and precision. Such arrangement is only to be considered as useful in proportion as it facilitates the acquirement of a knowledge of their economical and medicinal qualities, which cannot be perfectly ascertained without an acquaintance with vegetable physiology, the parts of plants, their functions, and uses. Botany, in its most comprehensive form, teaches us the names, arrangement, parts, functions, qualities, and uses of plants.

This science may be consulted by the agriculturist with considerable benefit. For instance (and several other advantages wu readily suggest themselves to the intelligent farmer), the plants growing wild on a soil ever afford some tolerable indication of the nature of the soil and its subsoil. 'Thus, the heath on elevations indicates a dry soil; the fern that it is deep as well as dry. 'The deer hair (Scirpus caspitosus) grows commonly over bogs, resting on clay. In the lower situations the broom (Sprortium scoparium) tenants the deep light gravels. The whin, coarser gravels upon a clay subsoil. 'The rush (Juncus conglimeratus) tells the negligent farmer that good land is rendered useless for want of drainage. The common sprit (Juncus articulutus), that the land is not fertile. Sweet gale (Myrica Gule), that it is still worse. The rag weed (Senecio jacobra) in arable land betrays an ill-cultivated loam. The marsh marigold (Caltha pulustris) or the wild water-cress in water meadows, tells the owner that the land is fully irrigated. The common rattle (Rhinanthus christi), that a meadow is exhausted. The pry (Carer dioica), that water is stagnating beneath its surface, and these are only a few of the truths which wild flowers teach the intelligent cultivator. Botanists have, indeed, long been at work for the farmer-a fact no one will be willing to dispute who remembers that the sloe, the blackberry, and the crab are nearly all the fruits indigenous to England; and that hardly a grass, a flower, or a vegetable that is now cultivated is a native of the island.

In 1825 and $182 \%$, the Highland Society of scotland offered as a prize theme, "The indi. cations to be formed regarding the nature anc qualities of soils and subsoils, according ir the plants growing upon them, having regar. 
to elevatiun, exposure, climate, \&c." And in the first volume of their transactions will be found several valuable essays on the subject, by Mr. Macgillivray, p. 81 , Mr. Gorie, p. 113, Dr. Singer, p. 264, Mr. Hogg, p. 271, all ably illustrating the value of the study of plants to the cultivator.

The definition of a plant to a superficial observer may appear easy; but those who have studied natural history are aware of the diffculty of drawing a just line of distinction between the animal and the vegetable kingdoms. It is easy to distinguish a horse, or even a worm, from a rose-tree or a fungus; but to distinguish a sensitive plant, \&c., by descriptive marks from many zoophytes, has hitherto haffled the acutest botanists. Many plants, as will be presently seen, are gifted with spontaneous motion; whilst many animals, as the corallines, are devoid of locomotion; so that neither of these qualities avails us in distinguishing the two lingdoms. In short, whilst the zoophytes, most of which take root, grow up into stems, and multiply by buds and slips, must still be considered as animals, no one can correctly define how plants differ from them. It is, however, fortunate, that the student is seldom placed in a situation where these nice distinctions are to be made. Where specimens are to be examined which admit of the doubt whether they belong to the lower classes of animals or to the vegetable tribes, chemistry may be called to our aid; if, when burnt, they omit an ammoniacal smell resembling that of feathers, similarly treated, we need not hesitate to consider them as animal products; if that of burning wood, we may consider them as fit objects for our botanical researches.

A few facts will demonstrate that it is impossible to deny that vegetables possess some degree of sensation. The Venus's fly-trap (Dionæa muscipula) has jointed appendages to the leaves, which are furnished on their edges with a row of strong prickles. Flies, attracted by honey, which is secreted in glands on their surface, venture to alight upon them; no sooner do their legs touch these parts than the sides of the leaves spring up, and locking their rows of prickles together, squeeze the insects to death. The well-known sensitive plant (Mimosa sensitiva and pudica) shrink from the slightest touch. Oxalis sensitiva and Smithia sensitiva are similarly irritable; as also are the stamens of the flower of the barberry. One of this tribe (Hedysarum gyrans) has a spontaneous motion-its leaves are frequently moving in various directions without order or co-operation. When an insect inserts its proboscis between the converging anthers of a kind of dog's bane (Apocynum androsæmifolium), they close with a power usually suffi. cient to detain the intruder until his death. If frum these, and many other considerations which we shall notice as we pursue our study, we conclude that plants are endowed with a certain degree of sensation, or at least of irritability, we can pursue that path of the science no further. Such are the results of life; what constitutes the living principle no human eye can discover.
We gaze on a rose as it waves in the pleni tude of its vigour, admire the tints of its petals, the verdure of its foliage, the gracefulness of its form, the delicacy of its fragrance. We may come on the morrow, and it has been blasted-those petals are scattered on the borders-those leaves are withered and saplessand scarcely a vestive of its loveliness remains. Wherefore is this change? The same components remain - the same food was ready for its nourishment; but some invisible governing principle-some unknown agent-has silently departed, without one vacancy to point out where it had resided, but a total ruin, to show that it had pervaded the whole. Let a few more hours pass away, when the air, and moisture, and heat, external agents which were subservient to its welfare, now concur in completing its destruction-it is partly dissipated in pestilential exhalations, partly reduced to a few earthy and saline particles. Life, whilst it continued, prevented this ruin; but still, like its Great Author, "no one hath seen it at any time."

To explore our path satisfactorily, and that one step may naturally explain the way to the succeeding, we had bctter first consider the most obvious parts of plants, and their functions.

The root and its $u$ ses. - A rnot usually consists of two parts, the caudex or body, and the fibres or radicula. The last only are essential for the imbibing of nourishment, but the whole serves to steady or fix the plant firmly in a commodious situation and position. Roots are annual, biennial, or perennial. The first belong to those plants whose term of existence is confined to a portion of a year, as barley the second to such as, being raised during one year, survive its winter, and produce flower during a succeeding year, as wheat. Perennia roots belong to such plants as live for severa years. All plants are considered as biennials that are raised from seed one year, and flowe during another, whether that year is the next or whether the flowering is deferred during several, provided the flowers occur but once. This is often the case with the tree mallow (Lnvatera arborea), \&c. Attention must be paid to these circumstances, or we may often mis. take the natural term of a plant's existence. Mignionette (Reseda odorata), in our borders, is an annual; but in the shelter of a room or green-house, it may be made, by proper management, to blossom during several succes. sive seasons. The nasturtium (Tropæolum), naturally a shrubby perennial, is an annual in our gardens.

Plants search for food by means of their roots, and to obtain it have been known, by their aid, to overturn walls by piercing their foundations. A tree growing on the top of a wall has been observed to extend its roots down the sides, until they reached the earth at its bottom. If a flower-pot, divided by a perpendicular section, be on one side filled with common earth, and on the other with similar earth mixed with a little potass, the roots of a geranium or other plant, growing in it, will, by degrees, all move into the alkaline portion. It has also been proved that the root is gifted 
with the power of rejecting what is hurtful, and selecting what is berieficial to its parent plant, from any mixed solution of substances not corrosive or poisonous.

Botanists distinguish seven kinds of roots.

1. The fibrous root (radix fibrosa), consisiing of fibres alone, either branched or undivided, as that of the I'oa anmun, that species of grass so troublesome in gravel walks, \&c.

2. The creeping root ( $R$. repens). This spreads and branches horizontally, throwing out fibres in its course, as some kinds of mint (Mentha), and the couch-grass, or twitch (Triticum repens).

3. Tapering root ( $R$. fusifurmis), as that of the carrot, \&c.

4. Abrupt root (R. præmorsa), appears inclined to be a tapering one, but, from some natural decay or habit, becomes abrupt, or apparently bitten off: as in the devil's-bit scabious (Scabiosa succisa), and several of the hawk-weeds.

5. Tuberous root ( $R$. tuberosa), consists of fieshy tubers connected by fibres, as in the potato (Solanum tuberosum). It is the premature formation of the tubers which prevents the blooming of the Jerusalem artichoke, and some of the early varieties of the potato. If the tubers are removed as soon as they are formed, the plants blossom.

6. Bulbous root ( $R$. bulbusa), is solid, as in the crocus; tunicate, composed of concentric layers, as in the Onion (Allium cepu); or scaly, as in the lilies.

7. Jointed or granulated root $(R$. articulati or granulata), is a cluster of either little bulbs or scales, connected by a common fibre, as in the wood-sorrel (Oxalis acetosella), and white saxifrage (Saxifraga granulata).

The roots of plants sometimes change their form with the situation in which they grow. Those of some grasses are bulbous in a dry situation, and fibrous in a moist one. Thus we see the care of Providence is manifested even in providing for the welfare of a weed; bulbous roots being, as it were, reservoirs of moisture, enable such plants to perfect their seed in the driest season. Again, the fibrous roots of grasses growing in sandy sterile places are remarkably downy; by this means they retain firmly their hold in so yielding a medium, and their absorbing surfaces are likewise increased, not unnecessarily, where nourishment is so scanty.

Seven kinds of stalks or stems are distınguished by botanists;-1. A stem (caulis) is confined to such as bear both leaves and flowers, which is the case with the trunks of all trees. It is either simple, as in the white lily, or branched, as in most cases. In general it grows upright, but sometimes it is more or less recumbent. Some cling to other bodies by fibres for support, as the ivy (Hedera helix); or by tendrils, as the vine. Others twine round such plants as come in their way. A remarlsable distinction is to be observed in twining plants. Honeysuckles, \&c., twine from left to right; whilst others, as the kidney-bean, twine from right to left, nor can any art induce them to alter their course. Some trail along the ground; some are jointed, as in the samphire and Indian fig. They are of various forms, round, three-sided, square, \&c. 'T'heir surfaces are smooth, viscid, rough, bristly, hairy, \&c. Internally they are solid or hollow. Plants without stems are termed acauls.s.

2. $\Lambda$ culm or straw (culinus), is only a variety of the caulis, but, being peculiar to the grasses, rushes, and other plants nearly allied to them, has been deemed worthy of a separate name. It is without joints, as in the cummon rushes; jointed, as in wheat, \&c. ; bent like a knee, as in Alipecurus geniculatus. It varies in being hollow, solid, hairy, \&c.

3. A stalk (scupus), springing from the root, bears only flowers and fruit, as that of the primrose (Primula vulgaris), and cowslip ( $P$. veris). In the first it is simple, in the latver subdivided and many-flowered. It is sometimes scaly; in which case the scales are apt to sport into leaves, and thus render it a proper caulis. It greatly varies as to length, manner of growth, \&c.

4. A flower stalk ( $p$ cdunculus), springing from the stem, bears only fruit and flowers. A partial flower stalk (pedicellis), is the ultimate division of a general one, as in the cowslip before instanced. Flowers without stalks are termed sessile, as the dodders, \&c.

5. The leaf stalk (petiolus), signifies the stalk of a leaf only. It is solitary or simple, as in the lilac, and all other simple leaves. It is common in the rose, \&c. It is usually channelled on its upper side.

6. A frond (fruns), is now used only in describing the class Cryptogamia, and signifies a leaf which produces both flowers and fruit, as in the ferns, lichens, \&c.

7. A stipe (stipes), is the stem of a frond.

It will be better to defer the consideration of the functions of roots and stems until we talie a connected view of the phenomena of vegetable life.

I.eaves are a very general, but not a universal part of the vegetable body; they are wanting in the samphires, creeping cereus, \&c. Such plants are called plantæaphylla (leafless plants). The situations, forms, insertions, and surfaces of leaves are of great use in botanic descriptions; a few must at present suffice :-

Folia radiculia spring from the root, as in the primrose.

Folia caulina and ramea spring respectively from the stem or branch.

Folia bina terna, \&c., leaves in pairs, or three together, \&c.

Folia verticillata, whorled, several opposite, cr growing in a circle round the stem.

Folia peltata, peltate, having the foot-stalk in the centre, as the nasturtium.

Foliu sessilia, sessile, having no foot-stalk.

Folia perfuliata, perfoliate, when the stem runs through their centre.

Leaves are nearly circular, ruundish, ege shaped or ovate, oblong, lanceolate, \&c.; the terminate abruptly, or are sharp, jagged, point. ed, cirrhose ( $i$. e. tipped with a tendril), \&c. Their margins are entire, spinous, toothed, wavy, \&c. Their surfaces are dotted, rugged. veiny, coloured (i. e. tinted with any cclous 
but green, white, or yellow; in the two latter cases they are termed variegated), \&c. They are tubular, awl-shaped, three-edged, evergreen, \&c. Compound leaves consist of two or more leaflets, combined by a common footstalk, as in the rose; they are binate when they consist of two leaflets; ternate, of three, \&c.; pinnate when several proceed sideways or laterally from the common footstalk, as in the rose. Leaves are sometimes twice and thrice compounded.

'The flower is the most essential, yet the most transitory part of plants. By means of the seed, which it is the great agent in producing, plants may be indefinitely multiplied and perpetually renewed; whereas all other modes of propagation, by cuttings, grafts, \&c., are but extensions of an individual. Hence, though many plants, from unfavourable modes of cultivation, \&c., are seldom known to blossom, yet Providence has wisely ordained that no plant is incapable of producing and perfecting seed. As our systems of botany are founded chiefly upon the flower, we will proceed to consider it at large. A flower is divided into seven parts:-

1. The calyx, or outer covering, resembling leaves in texture; is not present in many flowers, as the tulip.

There are six kinds of calyx:-1. The perianth is close to, and forms part of, the flower, as in the rose, and is, in fact, the only true calyx. 2. The involucre is an appendage to the one form of inflorescence, namely the umbel. It is remote from the corolla, as in all the umbelliferous plants, carrot, \&c. 3. The spathe is a floral appendage which bursts longitudinally, being more or less remote from thr flower, as in the snow-drop, narcissus, \&c. 4. 'The glume, or husk, is the peculiar calyx or chaff of the grasses, as in wheat, \&c. 5. Perechatium, a scaly sheath, enclosing the fertile flowers of some mosses. 6. Volva is the membrane that covers the parts of fructification or gills of the fungi, as in the common mushroom; but it is also applied to the fleshy covering which encloses some fungi when young.

2. The curvlla, or more delicate coloured leaves or leaf, properly called petals, is situated within the calyx. This is absent in many flowers. It comprehends both the petul and the nictury. By petal is meant what are commonly called the coloured leaves of a flower. By nectary is meant an appendage to the corolla, supposed to be for the purpose of secreting honey. The little cells, for example, at the bottom of the flower of the crown imperial, each full of a sweet liquid, are called nectaries, but they vary in form and situation in different flowers. When a corolla is formed of one petal, it is said to be monopetalous. It may be bell-shaped, as in the Canterbury bell, funnel-shaped, as in lungwort (Pulmonaria); salver-shaped, as in the primrose; wheel-shaped, the same as the preceding, only with a short lube, as in the borage; ringent, like the mouth of an animal, as in the dead nettle; personate, like the mask of an animal, as in snap-dragon. ( Corollas of more than one petal are termed polypetalous. It is cruciform, as in the wallnower; rosaceous, as in the rose; papilionaccous, 210 as in the pea; incomplete, when some part, found in kindred flowers, is wanting.

3. The stamen or stamens are essential for the perfecting of the seed, and are only absent in double flowers, in which they are changed in to petals. They vary in different species, from a single one to several hundreds, and surround the pistil or pistils, which occupy the centre of the flower. A stamen usually consists of two parts; the filament, or slender stem, which is sometimes absent, bearing otherwise on its summit the anther, a cellular organ of various forms in different species of plants, being the part for holding the pollen.

4. The pistil or pistils are in the centre of the flower, and usually fewer in number than the stamens. They are sometimes situated in flowers distinct from the stamen, and even on different plants. No seed can be perfected without the pistil, which consists of the germen, or rudiment of the fruit and seed, and, of course, is never absent. The style, or little stem proceeding from the germ, which is not essential, serving chiefly to elevate the stigmathis must always be present: it varies in form and size, being either scarcely more than a point, or forming an orbicular head, or being variously lobed.

5. The seed-vessel is the germen enlarged, va. rying in form, texture, and size in almost every species. What old botanists called naked seeds are seed-vessels or carpels containing only one seed, ard which do not open when ripe; the strawberry, wheat, maize, are examples. 'The only naked seeds are those of the fir cones, and the Cycader.

There are seven kinds of seed-vessels:-1. A capsule is woody or membranous, containing one or more cells, as in the poppy. 2. A pod is long, dry, and solitary, formed of twro valves, divided by a linear partition into two cells, as in the wall-flower. 3. A legume is solitary, formed of two oblong valves without any partition, consequently is one-celled, as the pea. 4. A drupe has a fleshy coat, closely enclosed in a hard nut, as the cherry, peach, \&c. 5. A pome has a fleshy coat, enclosing a capsule, as the apple, pear; \&c. 6. A berry is fleshy, containing its seed or seeds within its pulp, without valves, as the currant. A compound berry is instanced in the blackberry, \&c. 7. A cone is a catkin hardened into a seed-vessel, as in the fir, birch, \&c.

6. The seed. To the perfecting of this part all the other parts of the fructification, and even of the whole plant, are subservient; annuals perish immediately aiter it is perfected, and in our climate even perennials begin todroop as soon as it is ripe. A seed consists of several parts:-1. The embryo is the part the welfare of which all the other parts unite in pro moting. It is the rudiment of the future plant. It is very apparent in the bean, pea, \&c., and has the form of a heart in the walnut. It is usually within the substance of the seed, as in the above instance; in the grasses, however, it is on the outside.

Upon removing the skin of a pea or bean, it divides easily into two parts; these are the cotyledons: this is the usual number. In the pine tribe they are four; in the grasses, \&c., 


\section{BOTANY.}

only one; hence the last are called monorolyledons. The cotyledons, when the seed has sprouted, usually rise, in the course of germination, out of the ground, and perform the functions of leaves for a while: this is never the case in wheat, or any other of the monocotyledons; their seeds consist chiefly of the albumen or white, which is either farinaceous, horny, or fleshy, and remains in the ground nourishing the embryo, until its leaves and roots are sufficiently perfected for that purpose. Athough the albumen is wanting in a distinct form in several tribes, as those with compound and cruciform flowers, \&c., yet the farinaceous matter lodged in the cotyledons is evidently intended to supply the embryo with nourishment during the first efforts of germination. Many plants have it distinct from the cotyledons. Vilellus, the yolk, like the albumen, serves to nourish the embryo in the com. mencement of germination. If the albumen, as a distinct organ, is present also, the vitellus is situated between it and the embryo.

Testa, the skin, envelopes all the preceding parts, and gives them their form, being itself of a permanent shape, whilst they are in a liquid state. It is of various textures and substance; sometimes single, but usually lined with a finer membrane. Hilum, or scar, marks where the seed was connected with the seedvessel or receptacle. In describing the form or external parts of a seed, it is always to be considered as the base.

There are several occasional appendages to seeds, which may as well be considered in this place. The pellicle closely adheres to some seeds, so as to conceal their actual skin. It varies, being downy, membranous, and mucilaginous, or not perceptible until moistened. The tunic envelopes the seed more or less loosely, being attached only at the base. The seed-down is the chaffy, bristly, or feathery crown, originating from the partial calyx remaining attached to the summit of a seed, somewhat resembling a parachute, which we see bearing along the seed of the dandelion, thistle, \&c. A tail is the permanent style which remains as an elongated, feathery termination to some seeds, as clematis. A wing, a membranous appendage, serving, as the seed-down, to transport the seed it is attached to through the air. It is solitary, except in some umbelliferous plants.

We may now proceed to the last division of the flower, which is, 7thly, the receptacle.This is the common base or point of connection of the other parts. In compound flowers it serves as a distinguishing mark, and therefore is of importance. In the daisy it is conical; in the chrysanthemum, convex; carduus has it hairy; chamomile, scaly; picris, naked; onopordum, cellular.

A compound flower is formed by the union of several sessile florets, or lesser flowers, within a common calyx; each, however, must possess five stamens, their filaments divided, but their anthers united into a cylinder, through which passes the style of a solitary pistil, much longer than the stamens, and having a stigma divided into two parts, which

\section{BOTANY.}

roll backwards. There are various forms, as the thistle, daisy, sunflower, icc.

When the flowers are collected round a stem in a complete ring, or merely on two of its sides, it is denominated a whorl, as in the dead nettle (Lamium). Flowers on their own stalks, standing somewhat distant from each other on a common one, or axis, are denominated a raceme, as a bunch of currants. When they are placed together on one common axis, they forın a spike, as in lavender (Lavandula). If flowers standing on a common stalk have, in proportion as they stand on it lower down, longer foot-stalks, so that the flowers all stand nearly on a level, it is denominated a corymb, as in Spirca opulifolia, common in our gardens; in the common cabbage, a corymb of flowers becomes a raceme of fruit. Flowers on partial stalks variously divided and inserted, collected closely together and level at top, is a fascicle, as in the Sweet William (Dianthus barbatus). Sessile flowers collected together in a globular figure form a head or tuft, as in Statice armeria. When several flowers on stalks of nearly equal length spring from a common centre on a general stalk, they form an umbel, as in the parsley. This is either general or partial; the latter is termed an umbellule. When flowers on separate foot-stalks, springing from a common centre, have their footstalks variously subdivided, it is termed a cyme, as in the elder (Sambucus). Flowers growing on partial foot-stalks without any order, but loosely spread on a common one, form a panicle, as in the oat (Avena). When the flowers of a panicle grow closely together, somewhat approaching an ovate form, as a bunch of grapes, the lilac, \&c., it is termed a thyrsus, or bunch. When the flowers are all barren and sessile upon a common axis, it forms the amentum.

The exterior covering of plants is called the epidermis or cuticle, answering the same purpose as the scarf-skin or cuticle of animals, viz. protecting the interior and more tender parts from the injuries that might arise from excessive heat, cold, \&c.; yet, being porous, it allows the absorption and emission of moisture and air, and the admission of light. It cannot but have been observed how the epidermis varies in different plants; how smooth it is over the petals of most flowers-how downy on the fruit of the peach--how rough on the the oak-on the nettle, clothed with perforated poisonous hairs. The cuticle peels off in some plants, as in the cork tree. In some plants, especially the Dutch rush (Equisetum hyemale), it is so impregnated with silicious or flinty matter as to serve as a polish for the cabinetmaker, \&c.

Immediately beneath the epidermis is the cellular integument; this is usually the seat "of colour, being red in the petals of the red rose, blue in the common violet, \&c. Leaves appear to be little else than masses of cellular integument, enclosed in a case of epidermis, and traversed by numeroas sap-vessels. Next to the cellular integument occurs the bark. In stems and branches but one year old this consists but of one layer; in older ones there are to be 
observed a layer for every year of age ; these, however, are of little import to the plant, the vital functions for the time being are carried on in the layer immediately in contact with the wood. This innermost ring is termed the liber. The bark is very conspicuous in some roots, as the parsnip, carrot, \&c.; the thick outer ring, observable when these are cut transversely, is the bark. The bark consists of woody fibres, chiefly running longitudinally, but beautifully interwoven. In one of the inezereon tribe, a native of Jamaica, and called the lace bark, it may be separated into elegant layers of lace-work. In the bark the peculiar properties of the plant principally reside; witness the resin in the pine, the fragrant oil of the cinnamon, \&c.

Next to the liber occurs the wood, which forms the chief bulk of trees. A layer or more of this occurs in all exogenous plants, for in the portion of it which adjoins the liber, and is named the alburnum, are the sap-vessels which convey the fluid from the root to the leaves, whence it descends into vessels situated in the liber, as we shall see hereafter. In trees, a fresh layer of wood is deposited every year adjoining the liber, from which it is formed or deposited; hence the age of a tree may be known by counting the concentric rings. In the middle of the wood occurs the medulla or pith, commonly a porous, juicy, yellowish or greenish substance; even the hollow stems of the onion, \&c., are lined with a film of it. It seems to be an extra reservoir of nourishment, required for the formation of the leaves and more recent parts of plants; at all events, in old stems and branches it is usually obliterated. Botanists are not determined as to its uses.

When a seed is committed to the ground, if moisture, air, and heat are not all present in certain favourable proportions, it refuses to germinate. (See WATER, its uses to vegetation.) No seed will vegetate in dry earth, nor in a temperature at or below the freezing point; all require a free admission of air. These circumstances being favourable, the seed swells-the skin bursts-and the radicle, or embryo root, makes its appearance, and sinks into the earth. The cotyledons, if the seed has more than one, by degrees develope themselves, and rise above the surface, affording nourishment to the embryo stem, situated between them, until the radicle has become sufficiently a root to supply food for its growth; when thus rendered useless, they decay.

Animal and vegetable matters rendered soluble in water by putrefaction, various salts and earths, and water, are the chief nourishment plants derive from the soil; but it is also sertain that the roots absorb air, which in part accounts for the benefit afforded to them by ioosening the soil about them, and for planting them near the surface. When a plant has got its leaves developed, it possesses another source of acauiring nourishment from the atmosphere. See GASEs, their use to vegetation.

The atmosphere, which to our eyes appears a siruple uniform fluid, has been demonstrated by chemists to be composed of three different gases or airs with which is constantly mixed 212 the vapour of water. The gases are known as oxygen, carbonic acid, and azote or nitrogen. Carbonic acid gas is carbon or charcoal com. bined with oxygen. Water is composed of hydrogen and oxygen gases. These facts, by a little attention, will be easily remembered, and render all that follows comprehensible. The nourishment which is absorbed by the roots being in a fluid state, proceeds alor-g the sap-vessels situated in the alburnum of the wood, and spreads through the leaves, flowers, \&c. Here, and during its course up the stem, by the varied absorption and decomposition of water and carbonic acid, and the emission of oxygen, the sap is converted into various substances, varying in every species of plants; gum is formed in the cherry, resin in the fir, \&c.; these are deposited as the sap descends through the vessels of the liber. From the sap likewise is derived the nourishment from whence is formed the wood, \&c.; in fact, it is the source of the growth of the parts. Our knowledge of chemistry and vegetable physio$\log y$ is yet too imperfect to enable us to mark the various shades of difference in the processes of each plant with any degree of precision. We know that in the light all plants absorb carbonic acid gas, and emit oxygen whilst in the dark; on the contrary, they absorb the latter and give out the former by the same surfaces; but we are utterly unable to point out how the same organs secrete a poison in the nightshade and a wholesome food in the potato, which so closely resembles the first in form. A few very simple experiments will serve to fix the above facts upon our memories. We may prove that the sap rises through the alburnum, and descends through the bark, by placing the cut end of a leafy twig of the fig tree in an infusion of Brazil wood; after some hours cut off about half an inch of the extremity, when a circle of red dots will mark where the infusion ascended, and an outer circle of white dots will show where the juices descend.

That leaves throw off moisture, or perspire, is demonstrated by inverting a tumbler over two or three leaves placed in the light; the inside of the glass will soon be perceptibly covered with dew.

That leaves throw off gas from their surfaces is demonstrated by plunging one in a vessel of water; air-bubbles will soon be perceived to be emitted by and attached to it.

In due course of time the flowers of a plant open; the anthers of the stamens swell, burst and scatter a dust, termed pollen, secreted by them, and which is caught immediately by the moist stigmas of the pistils, or is carried to them by the wind, or accidental contact of some insect. This contact of the pollen with the stigma is found to be absolutely necessary before the seed can be perfected. This course of vegetation is repeated for a series of years in perennials, but the plant decays as soon as the seed is perfected in annuals.

Botanists at present are acquainted with nearly 100,000 species of plants; and the care with which Providence has provided for the well-being of plants is an earnest of their im portance. That they may never become ex 
tinct, the number of their seeds is offen immense: Ray eounted 32,000 in one puppy-head! Where the seeds are less numerous, their safety is secured by the extra strength of the seed-vessel, their nausenus, poisonous nature, and other means. The various modes in which they are spread over the face of the conntry is equal evidence of a peculiar providential care. The seed-down bears some through the ait to a distance; some cling by their rough appendages to the coats of animals; others are borne by neighbouring streams, or by the winds, to an immense distance; cocon-nuts float from the tropics to the shores of Nolway; African seeds are blown over the southern coasts of Spain birds, animals, and even the seerl-vessels themselves, by an ejective power, all perform a part in the office of dissemination. Then, again, the various kinds of defence with which they are endowed: cuticles, woolly, and thorny, and Ainty, to preserve an equable temperature and to prevent injurious wounds. The buds which contain the embryo of leaves to appear the following year, how enveloped are they in scales, and often coated with resin or gum!

Independent of any general arrangement, piants are divided into species, genera, and varieties.

By species is to be understood a plant which by certain permanent signscan be distinguished from all others; for instance, every one can determine that the damask rose differs from every other; and botanists, having shown by what specific marks it may always be distinguished, have determined it to be a species: but there are many other roses which, though having specific points of difference, very closely resemble the damask rose; these, botanists have therefore collected into one family, which they term a genus, under the general name of Rosa. Rosa, then, is the generic or family name; but, to distinguish the species, every one has a separate second or specific name:thus, the damasik rose is Rosa centifolia; the dog rose, Rosa canina; these second names are therefore termed the specific names. By variety is meant a plant varying in an established species, but which cannot produce an exact resemblance of itself by seed. Thus, all our apples are varieties of one species, the erab (Pyrus); and all plants raised from their seed invariably differ from each other and their parent. The whole vegetable kingdom, then, is divided into families, or genera, composed of a greater or less number of species. In botany the varieties are little noticed. These genera are distributed by Linnæus into classes, in what, from him, is denominated the Linnæan System of Botany.

These classes are twenty-four in number, founded on the number, situation, or proportion of the stamens.

The plants of the twenty-four classes are further arranged in subdivisions, denominated orders. The orders of the first thirteen classes are founded on the number of pistils the plants belonging to them contain.

The orders of the 14th class are distinguished by their seed-vessels.

The two orders of the 15 th class are distinuished by the form of the seed-vessels.
Thro orders of the 16th, 17th, and 18th classets are founded on the number of the stamens, that is, on the characters of the first thirteen classes.

The orders of the 19th class (Syngenesia) are marked by the nuture of the florets.

'The orders of the 20 th, $2 \mathrm{lst}$, and $22 \mathrm{~d}$ classes are distinguished by the characters of some of the classes that preceded them: that is, by the number or proportion of the stamens, the union of the anthers not being attended to.

The orders of the $23 \mathrm{~d}$ class are distinguished upon the principles of the two preceding classes

The 24th class (Cryptogamia) is divided into five orders :-
1. Ferns,
3. Liverworts,
2. Mosses,
4. Algre,

5. Mushrooms.

The nalural system of M. Jussieu.-Every per son must have observed, that plants in many instances are arranged by nature in families: for instance, the grasses, liliaceous plants, the umbelliferous plants, mosses, sea-weeds, ferns, \&c., are composed of individuals bearing a very striking resemblance to each other in their forms. The same resemblance holds in their internal qualities, between such plants as resemble nne another in configuration. Thus the grasses are all nutritious; the liliaceous plants in general poisonous; umbelliferous plants growing on high dry soils are generally wholesome; those of wet situations are generally poisonous. The importance of keeping these families undivided in a botanical classification is evident; and if plants were universally separable into such distinct families as those above mentioned, a natural system would be easy and perfect. But plants are too diversified; they approach each other in such various shades, that it is certain a complete natural system can never be perfected, or must be too intricate for general use. Jussieu's system, with all its merit, is open to both these objections; it is imperfect, were it only from being founded upon the structure of the seed, that part of plants which is, perhaps, more seldom than any other capable of being observed by the botanist.

There are fifteen classes and one hundred orders. The classes have no particular names, but are distinguished by numbers, with a short statement of essential characters. The orders are named after some principal genus in each. There are some inaccuracies in the arrangement; many plants, considered by Jussieu as monocotyledonous, are now known to be without any cotyledons.

At the end Jussieu places a large assemblage of genera, consisting of plants, the construction of whose seed is undetermined. This, of course. is an imperfection, but not peculiar to Jussieu's system. It must be the case with all systems founded on nature, unless their contrivers could have at once before them a specimen of every species of plant that the various portions of our globe produce. This system has been greatly modified and improved by Decandolle, I.indley, and others; and it is now justly preferred to the artificial system of Linnaus. (G. W. Johnson; Dr.Lindley; G. Sinclair; Trane. High. Soc. vol. i. p. 81.)

BOTS. In farriery, a kind if worms very 
troublesome to horses. Bots are the larvæ or naggots of a species of gad-fly (the Estrus equi), which deposits its eggs on the legs, mane, or those parts of the horse that the animal is most apt to lick. The egg is immediately hatched by the warmth and moisture of the tongue, and the little worm conveyed into the mouth, whence it crawls down the œsophagus into the stomach. It adheres to the cuticular coat of the stomach by means of little hooks, with which its mouth is furnished; and there it remains from the summer of one year to the spring of the next, nourished by the mucus of the stomach, or the food which it contains. Then having attained its full size as a maggot, it loosens its hold, and is carried along the intestines with the other contents of the stomach, and evacuated with the frees. Before it drops, it generally clings for a while to the verge of the anus, and tickles and teases the horse to a very great degree. Except they exist in most unusual numbers, bots do neither good nor harm during their residence in the stomach of the horse. It is the habitation which nature has assigned to them; and the safety of so noble an animal as the horse would not have been compromised for the sake of a maggot and a tly. The best advice that can be given, therefore, is to let them alone, or at most to be content with picking them off when they appear under the tail. There are two good reasons for this. The first is, that there is not any medicine that will expel them; the strongest and even the most dangerous purgative is insufficient. The second reason is, that if the bots are let alone, they will, in due time, come all away without our help or meddling. (Clater's Farriery, p. 168-170.) Green food, however, expels them readily, as does common salt in the proportion of two to four ounces to a quart of water. 'The most simple and efficient reme$d y$ is a quart of milk, mixed well with a quarter of a pound of honey or brown sugar, given fasting. This is much better than aloes.

BO'T-FLIES. The various insects, improperly called bot-bees, are two-winged flies, belonging to the order Diptera and the family Estrida. Bot-flies do not seem to have any mouth or proboscis; for, although these parts do really exist in them, the opening of the mouth is extremely small, and the proboscis is very short, and is entirely concealed in it, su that these insects, while in the winged state, do not appear able to take any nourishment. The larvæ or young of bot-flies live in various parts of the bodies of animals. They are thick, lleshy, whitish maggots, without feet, tapering towards the head, which is generally armed with two hooks, and the rings of the body are surrounded with rows of smaller hooks or prickles. When fully grown, they drop to the ground and burrow in it a short distance. After this, the skin of the maggot becomes a nard and brownish shell, within which the insect turns to a pupa, and finally to a fly, and romes out by pushing a little piece like a lid rom the small end of the shell.

More than twenty different kinds of bot-flies are already known, and several of them are found in the United States. Some of them have boin brought here with our domesticated ani214 mals from abroad, and have multiplied as 1 increased. Three of them attack the horse. The large bot-fly of the horse (Gasterophilus equi) has spotted wings. She lays her eggs about his knees; the small red-tailed species (G.hamorrhoidalis), on his lips; and the brown farrier bot-fly (G. veterinus), under his throat, according to Dr. Roland Green. By rubbing and biting the parts where the eggs are laid, the horse gets the maggots into his mouth, and swallows them with his food. The insects then fasten themselves in clusters to the inside of his stomach, and live there till they are fully grown. The following are stated to be the symptoms shown by the horse when he is much infested by these insects. He loses flesh, coughs, eats sparingly, and bites his sides; at length he has a discharge from his nose; and these symptoms are followed by a stiffness of his legs and neck, staggering, difficulty in breathing, convulsions, and death. No sure and safe remedy has yet been found sufficient to remove bots from the stomach of the horse. The preventive means are very simple, consisting only in scraping off the eggs or nits of the fly every day. Bracy Clark, Esq., who has published some very interesting remarks on the bots of horses and of other animals, maintains that bots are rather beneficial than injurious to the animals they infest. (Dr. Harris.)

If a piece of the maw or stomach of a horse that has died while affected with bots be cut out, it may be held under the jet of the strongest fountain or hydrant, without the maggots or bots leaving go, or loosing their hooks. Experiments have been made to destroy them out of the body with spirits of tur pentine, alcohol, and a great many of the most stimulating and acrimonious substances, in liquid and other forms, all, however, with little apparent effect upon an insect so very tenacious of life. The bot-maggot is even said to live a considerable length of time in oil of vitriol and nitric acid or aquafortis. After such results, the chance of destroylng them in the body must be small, through means which would not destroy the horse. The following ingenious method has, however, been pursued with success. A full drench has been administered, consisting of a mixture of milk sweetened with molasses, followed soon after by an active purgative drench. The milk and molasses tempt the bot-maggots to let go their holds in order the better to partake of the milk, in which condition they are worked off quickly by the brisk operation of the medicine.

The maggots of the AEstrus bovis, or ox botfly, live in large open boils; sometimes called wornils or wurmals, that is, worm-holes, on the backs of cattle. The fly is rather smaller than the horse bot-fly, although it comes from a much larger maggot. The sheep bot-fiy (Cephalemyia ovis) lays its eggs in the nostrils of sheep, and the maggots crawl from thence into the hollows in the bones of the forehead. Deer are also afflicted by bots peculiar to them. Our native hare, or rabbit, as it is commonly called, sometimes has very large bots, which live under the skin of his back. The fly (OEstrus buccatus) is as big as our largest humble-bee, but is not hairy. It is of a reddisb.$$
\text { 218 }
$$ 
black colour; the face and the sides of the hind-body are covered with a bluish-white bloom; there are many small black dots on the latter, and six or eight on the face. 'This fy ineasures seven-eighths of an inch or more in length, and its wings expand about threequarters of an inch. It is rarely seen; and my only specimen was taken in the month of July, many years ago.

At the very end of this order is to be placed a remarkable group of insects, which seems to connect the flies with the true ticks and spiders. Some of these insects have wings; but others have neither wings nor poisers. Of the winged kinds there is one (Hippobosca equina) that nestles in the hair of the horse; others are bird-flies (Ornithomyia), and live in the plumage of almost all kinds of birds. The wingless kinds have sometimes been called spider-flies, from their shape; such are sheepticks (Mellophagus ovis) and bat-ticks (Nycteribia). These singular creatures are not produced from eggs, in the usual way among insects, but are brought forth in the pupa state, enclosed in the egg-shaped skin of the larva, which is nearly as large as the body of the parent insect. This egg-like body is soft and white at first, but soon becomes hard and brown. It is notched at one end, and out of this notched part the enclosed insect makes its way, when it arrives at maturity. (Dr.Harris.)

BOUND (Sax. hunde, from bindan, to bind). In veterinary medicine, a term of various application. Any part of an animal that is embraced with an unnatural force is said to be bound: thus horses are liable to be hoof-bound, hide-bound, \&c. Or the bowels may be constricted so as not to part with the freces, in which case the belly is said to be bound.

BOWEI, DISEASES (Mod. Fr. boyaux; old Fr. boailles). The horse and other quadrupeds are liable to various diseases affecting the bowels. Of inflammation of the bowels there are two kinds; that of the external and that of the internal coat. The former is a very frequent and fatal disease, and is recognised by the farier under the name of red colic. It is frequently caused by the application of cold to the belly of the horse, either by taking him into the water, or washing him about the belly with cold water, or suffering him to drink plentifully of it when he is heated, or by exposure to rain, over-exertion on a full stomach, \&c. From whatever cause it arises, it runs its course with fearful rapidity, and sometimes destroys the horse in less than twenty-four hours. The symptoms should be carefully studied. One of the earliest is the expression of very acute pain. The animal paws, rolls, struggles violently, lies upon his back, groans; his legs and mouth are cold, the flanks heave violently, the horse shivers and sweats, \&c. The violence of the symptoms soon abates, and the horse becomes weak, and scarcely able to stand. Prompt and copious bleeding should be at first resorted to, until fainting nearly or quite succeeds; and mild aperients may be next administered. The whole of the belly should be stimulated with the strong blistering liquid, or with spirit of turpentine; and these appliances should be rubbed in as hardly and thoroughly as the tomier state of the beelly will allow. The horse should be kerpt quieet, warmly clothed, and his legs bandaged. Inflammation of the imer coat of the bowels is usually the consequence of physic, either of bad quality or given in an over-drose; or the horse may have been ridden or driven far and fast with nothing but green meat in his belly. This disease can scarcely be confounded with the foregoing. The horse does not roll so vin lently nor kick so desperately, nor is there an heat nor much tenderness of the belly. At the same time he is purged, instead of exhibiting the obstinate costiveness which generally ac. companies the former. Plenty of tolerably thick gruel or starch should be forced down, which will possibly sheathe the coats of the stomach from the effect either of some portion of the physic or the acrimony of the secretion, and the purging will gradually stop. If this should have no effect, bleeding, carefully watched, and stopped when the pulse falters, must be resorted to; and thicker gruel and astringent medicine must be administered. As in the last species, warm clothing and bandages about the legs will be of essential service. (Clater's Farriery, p. 173-178.)

BOWLDERS, or BOULDERS. A term in geology, implying rounded masses of rock; it is also provincially applied to a kind of round stone, common in the soils of the midland districts. In the north of England it is pronounced sometimes bowder or booder, and also boother.

BOWLDER-WALL. A wall generally on the sea-coast, constructed of large pebbles or bowlders of flint, which have been rounded by the action of water.

BOW-LEGGED. In horsemanship, is a defective conformation or posture of the fore-legs of a horse.

BOWS OF A SADDLE are two pieces of wood laid archwise to receive the upper part of the horse's back, to give the saddle its due form, and keep it steady.

BOX DRAIN. An underground drain, re. gularly built, with upright sides, and a flat stone or brick cover; so that the close section has the appearance of a square box. See Drains and Draining.

BOX TREE (Sax. box; It. bosso; Fr. buis ; Lat. Buxus sempervirens). We consider the English name of this plant to be a corruption of the Latin word buxus, or from the Spanish $b o x$, and that it gave the name to the wooden cases made by the carpenter and turner, rather than derived its own from these cases. 'The box was formerly much more plentiful in England than at present. Boxwel, in Gloucestershire, was named from this tree, and it also gave the name of Boxhill to those delightful downs near Dorking, in Surry, where this shrub seems to have grown naturally, as it is known to have abounded there long before the time that the Earl of Arundel retired to that spot, and, as it is stated, planted the bor. In 1815 the box trees cut down on Boxhill produced upwards of $10,000 \%$. This evergreen bush, or small tree, is found all over Europe, as well as upon the chalk hills of England; but it acquires its largest dimensions in the south. The duty on box-wood is quite oppres. 
sive; being $5 l$. a ton if brought from a foreign country, and $1 l$. a ton if from a British possession. It is from Turkey that the principal part of the wood is imported into England; whether or not all this is really furnished by Buxus sempervirens is not known. It is not im. probable that Buxus balearica, a larger species, too tender to thrive in this country, may furnish a part, at least, of that which comes from the Mediterranean. It is said, that the wood of this species is coarser, and of a brighter yellow than that of the common species. At an average of the three years ending with 1831, the entries of box-wood for home consumption amounted to 382 tons a year. In 1832, the duty produced 1867l. 17s. 4d. Turkey boxwood sells in the London market for from $7 l$. to 14l. a ton, duty included. Box is a very valuable wood. It is of a yellowish colour, close-grained, very hard, and heavy; it cuts better than any other wood, is susceptible of a very fine polish, and is very durable. In consequence it is much used by turners and mathematical and musical instrument makers. It is too heavy for furniture. It is the only wood used by the engravers of wood-cuts for books: and, provided due care be exercised, the number of impressions that may be taken from a box-wood cut is very great. In France, boxwood is extensively used for combs, knife handles, and button moulds. The value of the box-wood sent from Spain to Paris is reported to amount to $10,000 \mathrm{fr}$. a year.

Where hox trees are required, they should be raised from seed, which should be sown soon after it is ripe, in a shady border of light loam, or sand; but it is generally propagated by cuttings planted in the autumn, and kept moist, until they have taken root. 'The box plant is best known for its use in gardens as hedgings to borlers; the kind so employed is a dwarf variety. It is very useful, as it grows freely under the drip and shade of trees. $\mathrm{D}$ warf box is increased by parting the roots, or planting the slips. The best time for transplanting this shrub is October; though it may be removed almost at any time, except summer, if it be taken up with a good ball of earth.

With respect to its medicinal properties, box-wood has been substituted for guaiacum as a sudorific in rheumatism; but is now seldom prescribed. Oil of box root is a popular remedy for the toothache, when dropped on cotton, and put into a carious tooth. (Phillips's Sylv. Flor. vol. i. p. 44 ; Brande's Dict. of Science; M'Culloch's Com. Dict.)

BOX of a Wheel. The aperture wherein the axis turns.

BOX of a Plough. The cross-piece in the head of the plough which supports the two crow-staves.

BRACE. The general name for a couple, or pair, of such animals as bucks, hounds, partridges, \&c. It is also applied to any thing that serves to strengthen or support.

BRACKEN. It is written also braken, and sometimes pronounced breckin in the north of England. The same with brake or fern. See FERN.

RRAIRD. In the agriculture and gardening 216 of Scotland, the term braird is applied to the springing up of seeds, which, when they come up well, are said to have a fine braird.

BRAKE. The name of a wooden instrument for dressing hemp and flax, used to bruise or break the bun or stem, \&c. in order to separate the cortical part or rind from it. It is sometimes applied to a thicket, or the place where fern grows; and is another name for the barnacles, or pincers, used by farriers. Brake is also a sharp bit, or snaffle for horses. A smith's brake is a machine in which horses unwilling to be shod are confined during that operation. Some species of large heavy harrows are frequently called brakes. See $H_{\mathbf{A R} \text { - }}$ now.

BRAMBIE, FLOWERING (Rubus odoratus). A hardy exotic shrub, five or six feet in height, blowing a pinkish violet-coloured flower in June and August. It loves shade and moisture, and is propagated by suckers. It is known also as the flowering raspberry.

BRAMBLE or BRAMBLE-BERRY (Sax. bræmbel, formerly written bremble; Lat. $R u$ bus). The bramble, or blackberry, the generic name of a large family of shrubs which creep along the hedge in every soil. The common bramble (Rubus fruticosus) derives both its Latin and English common name from the colour of its fruit at different stages of ripeness. However generally the bramble is reprobated as a troublesome weed, we must acknowledge that, when either in fruit or flower, it forms a principal among the numberless hedgerow beauties, and is not without its utility in particular soils, especially in poor sandy lands, where the growth of other hedges is slow, and where, by reason of the looseness of the soil, the ditch is no defence. When planted in such situations, it will, by its quick growth, soon entwine its thorny branches in the dead hedge, and form an almost impervious fence against the invasions of cattle, sheep, and other trespassers. Brambles mixed with other hedge plants will render them thicker and stronger. The objections urged against the more general adoption of bramble fences are, that, by the yearly decay of a portion of the shoots, they soon fill the hedge with dead wood, which has not only an unsightly appearance, but is also hurtful to the other plants; and again it is said, that the leaves are so broad and numerous as to smother every other plant, by depriving it of both sun and air. When brambles are in considerable abundance, as is often the case in waste and other lands that require to be brought into cultivation, they should always be grubbed or hoed up; and if the land be afterwards ploughed with a good furrow, the remaining roots will be torn up, and the plants at length destroyed. This shrub, which is only used by the chance passenger occasionally plucking its fruit, possesses, however, several advantages which deserve our attention. Its long branches can, in case of need, be employed as cords; and its fruit produces an excellent wine, the mode of making which is as follows:-Five mcasures of the ripe fruit, with one of honey and six of wine, are taken and boiled; the froth is skimmed off, the fire removed, and the mixture being 
passed through a linen cloth, is left to ferment. It is then boiled anew, and allowed to ferment in a suitable cask. In Provence bramble-berries are used to give a deep colour to particular wines. (Allgem. Forst und Jagd-Zcilung, Feb. 1828, p. 104.) The juice of the blackberry, mixed with raisin wine before it has fermented, will give it both the colour and flavour of claret. "The berries," says Pliny, "have a desiccative and astringent virtue, and are a most appropriate remedy for the gums and inflammition of the tonsils." The flowers as well as the berries of the bramble were ignorantly considered by the ancients as remedies against the most dangerous serpents. They are diuretic; and the juice pressed out of the tendrils, or young shoots, and afterwards reduced to the consistency of honey by standing in the sun, is, adds the above author, "a singularly efficacious medicine, taken inwardly or applied outwardly, for all the diseases of the mouth and eyres, as well as for the quincy, \&c." But Pliny has lost his celebrity as a medical authority, if he ever had any; and modern blackberries have also lost their virtue. Boerhaave affirms, that the roots taken out of the earth in February or March, and boiled with honey, are an excellent remedy against the dropsy.

Syrup of blackberries, picked when only red, is cooling and astringent in common purgings or fluxes. The bruised leaves, stalks, and unripe fruit, applied outwardly, are said to cure ringworm.

Billington, in his work on Planting, says, "To the poor in the vicinity of Newcastle it is of great importance; many of whom go a great number of miles to gather blackberries while they are in season, and carry them from ten to twenty miles, to Newcastle, Shields, and Sunderland, where they sometimes sell them as high as $3 d$. and $4 d$. per quart, for puddings, tarts, preserves, or jellies, and even making of wines." The fruit is, in particular, much esteemed and sought after by the wives and mothers of sailors, to send on board the ships, as it is found to be very healthful to the men to eat with their biscuits, as well as for puddings, much more so than their common fare of salt beef and pork. All through the season, after the gooseberries are over (for apples, plums, \&c., are often scarce and dear), the people are regaled with the fruit of the bramble as the greatest domestic luxury, and would probably lay in a store for future consumption if sugar were cheaper. The leaves of the dwarf crimson bramble (Rubus arcticus) are often used to adulterate tea. See Whon'xr. Eв ER

Of the Rubus fruticosus, or common bramble, we have (says Phillips) five varieties; and as one has been discovered in a hedge near $\mathrm{Ox}$ ford by Bobart which produces a white fruit, it will be necessary to adopt the proper name of bramble-berry for this fruit, to avoid the contradictory appellation of white blackberry. The variety with a double flower is now one of the ornaments of the shrubbery; the other varieties are, one with variegated leaves, one with cut leaves, and the bramble without thorns. Smith, in his English Flora, describes fourte $\mathbf{n}$ species of bramble (Rubus); which include the raspberry, cloudlerry, and dew. berry. Several reputed varieties of the common bramble have also been observed in Britain (says Smith, vol. ii. p. 400), differing in the shape and pubescence of their lraflets, not to mention other characters. These have recently been proposed as species in a very able work, with excellent plates partially coloured, by Dr. A. Weihe and Prof. Ch. (i. Nees ab Esenbeck of Bonn, under the title of liuli Germanica. Notwithstanding the colour of the llowers, I cannot suppose the British li. frut icosus to differ from theirs. (Smilh's Engl. Flora, vol. ii.; Phillips's Hist. of Fruits, p. 63; Quarterly Journ. of Agr. vol. i. p. 816; vol. iii. n 182.)

The Rubus brier, or bramble genus, consists of about fifty species, which are very widely dispersed over the various continents, extending from the arctic circle to the equatorial limits. Mr. Nuttall enumerates twenty species as found in America, among which are the following: Rubus Idcus, indigenous, according to Pursh and others, throughout Upper Canada and the northern parts of the United States. Dr. Darlington calls this the Antwerp raspberry, so advantageously known from its large and finely flavoured berries which are cultivated in most gardens. $\mathrm{He}$ doubts its being a native of America. There are several varieties of this species of Rubus. The Rubus occidentalis, common black raspberry, or thimble-berry, is common in the Middle States and other portions of the Union, growing along fence-rows, borders of woods, \&c. Rubus villosus, common brier, or blackberry bush, is often a great nuisance on farms, from the rapidity with which it spreads and takes possession of neglected fields. $R$. Cuneifolius, or wedge-leaved rubus or brier, bearing an oval-shaped, small, and well-flavoured blackberry, very common in New Jersey. $R$. Trivialis, dewberry, or running brier. The black, sweet, and succulent fruit of this species of rubus is a very great favourite. It is not, however, the same as the English dewberry, which is produced by the Rubus Ccosius. In treating of the American dewberry, or running brier, Dr. Darlington says, "the ploughboy is apt to get well acquainted with this species,-by the long trailing stems, with their recurved prickles, drawing across his naked ankles!" R. odoratus, found on the banks of the Wisahickon, near Philadelphia, abundant in mountainous districts, always among rocks.

The tall blackberry ( $R$. Villosus) is sometimes cultivated near Boston and other large cities, for the sake of its fruit, and richly repays the care bestowed upon it. Dr. Harris, in his report to the Massachusetts legislature upon destructive insects, says, that this plant and its near relation, the raspberry, suffer from borers that live in the pith of the stems, a fact which does not appear to be generally known. The beetle is a species of Saperdo, and finishes its transformations towards the end of July, laying its eggs early in August, one by one, on the stems of the blackberry and raspberry, near a leaf or small twig. The grubs proceed ing from these eggs burrow directly into the pith, which they consume as they proceed, si 
that the stem for several inches is completely deprived of its pith, and consequently withers and dies before the end of the summer. In Europe, one of these slender saperdas attack the hazle-nut bush, and another the pear tree in a similar manner.

The dewberry and blackberry are very pleasant fruits and make fine jelly. All the species are readily propagated both by seed and layers, and are wonderfully improved by culture.

There is a double white flowering bramble (Rubus albo-pleno) which is a beautiful and ornamental variety.

BRAN (Old Fr. bren; Ital. brenna). The thin skin or husks of corn, particularly wheat, ground and separated from the meal by a sieve or boulter. It is generally laxative; owing to the mechanical irritation it excites. An infusion of $j$ t, under the name of bran tea, is frequently used as a domestic remedy for coughs and hoarseness. Infusions of bran also remove scurf and dandriff. Calico-printers employ bran and warm water with great success, to remove colouring matter from those parts of their goods that are not mordanted. Bran is a useful ingredient, when well scalded, and employed occasionally in moderate quantities, in mashes for horses; but the constant use of it, whether raw or scalded, is prejudicial, as it is apt to weaken the horse's bowels, and thereby expose him to many disorders. It is also highly useful in stall-feeding cattle, and for sheep, when given as a dry food. According to the analysis of M. Saussure, 100 parts of the ashes of the bran of wheat contain (Chem. Rec.Veg.), -

Soluble salts -
Eartby phosphates
Silica - - -
Metallic oxides -

BRAND-GOOSE, or BRENT-GOOSE. A kind of wildfowl, less than a common goose, having its breast and wings of a dark colour. See Gons.

BRANK. A provincial name sometimes applied to buckwheat, which see.

BRAWN. The flesh of the boar, after being boned, rolled up, or collared, boiled, and pickled. Brawn is made of the flitches, and some other parts, the oldest boars being chosen for the purpose, it being a rule that the older the boar the more horny the brawn.

The method of making it is generally as follows:-The bones being taken out of the flitches, or other parts, the flesh is sprinkled with salt, and laid in a tray, that the blood may drain off; after which it is salted a little, and rolled up as hard as possible. The length of the collar of brawn should be as much as one side of the boar will bear; so that, when rolled up, it may be nine or ten inches in diameter. After being thus rolled up, it is boiled in a copper or large kettle, till it is so tender that you may almost run a stiff straw through it; when it is set by till thoroughly cold, and then puc into a pickle composed of water, salt, and wheat-bran, in the proportion of two handfuls of each of the latter to every gallon of water ; which, after being well boiled together, is strained off as clear as possible from the bran, and when quite cold, the brawn put into it (Willich's Dom. Encycl.)

BREACHY, or BREECHY WOOL, is the short coarse wool of a sheep, such as that which comes from the breech of the animal.

BREAD (Sax. bneoo; Ger. brod). This forms an important and principal article in the food of most civilized nations, and consists of a paste or dough formed of the flour or meal of different sorts of grain, mixed with water. with or without yeast or ferment, and baked.

Bread may be divided, in the first instance, in to leavened and unleavened bread. When stale dough or yeast is added to the fresh dough of flour and water to make it swell, it is said to be leavened; when nothing of this sort is added, the bread is said to be unleavened. These may again be subdivided into various kinds and qualities. The principal sorts in use are white, wheaten, household, and brown bread, which differ from each other in their degrees of purity. In the first, all the bran is separated from the flour; in the second, only the coarser parts of it; and in the third scarcely any at all; so that fine bread is made only of flour; wheaten bread of flour, with a mixture of fine bran; and household bread of the whole substance of the grain, without taking out scarcely any either of the coarse bran or the fine flour. We have also manchet or roll-bread, and French bread, which are fine white breads made of the purest flour; in roll-bread there is sometimes an addition of milk, and in French bread butter is used. There is likewise ginger-bread, maslin. bread, made of wheat and rye, or sometimes of wheat and barley; and other breads made with various substitutes for flour, as oat-bread, rye-bread, pea and bean-bread, \&c.

The President de Goguet has endeavoured (Origin of Laws, \&c., vol. i. pp. 95-105, Eng. trans.) to trace the successive steps by which it is probable men were led to discover the art of making bread; but nothing positive is known on the subject. It is certain, however, from the statements in the sacred writings, that the use of unleavened bread was common in the days of Abraham (Gen. xviii. 8); and that leavened bread was used in the time of Moses (Exod. xii. 15). The method of grinding corn by hand-mills was practised in Egypt and Greece from a very remote epoch; but for a lengthened period, the Romans had no other method of making flour than by beating roasted corn in mortars. The conquests of the Romans diffused, amongst many other useful discoveries, a knowledge of the art of preparing bread, as followed in Rome, through the whole south of Europe.

The use of yeast in the raising of bread seems, however, from a passage of Pliny (lib. xviii. c. 7), to have been taken advantage of by the Germans and Gauls before it was practised by the Romans; the latter, like the Greeks, having leavened their bread by intermixing the fresh dough with that which had become stale. The Roman custom seems to have superseded that which was previously in use in France and Spain; for the art of raising bread by an admixture of yeast was not practised in France in modern times till towards the end of the seventeenth century. 
For the formation of bread, a certain degree of fermentation, not unlike vinous fermentation, is requisite, care being taken to avoid the acetous fermentation, which renders the bread sour, and, to most persons, disagreeable. 'This fermentation is called panary. If dough be left to itself in a moderately warm place (between $80^{\circ}$ and $120^{\circ}$ ), a degree of fermentation comes on, which, however, is sluggish, or, if rapid, is apt to run into the acelous; sc that, to effect that kind of fermentation requisite for the production of the best bread, a ferment is added, which is either leaven, or dough in an already fermenting state, which tends to accelerate the process of the mass to which it is added, or yeast, the peculiar matter which collects in the form of scum upon beer in the act of fermentation. See Ykass. Of these ferments, leaven is slow and uncertain in its effects, and gives a sour and often slightly putrid flavour to the bread. Yeast is more effective, and, when clean and good, it rapidly induces panary fermentation; but it is often bitter, and sometimes has a peculiarly disagreeable smell and taste. Bread well raised and baked differs from unfermented bread, not only in being spongy, less compact, lighter, and of a more agreeable taste, but also in being more easily miscible with water, with which it does not form a viscous mass; and this circumstance is of great importance to health. All, then, that is essential to make a loaf of bread, is dough to which a certain quantity of yeast has been added. 'This mass, or sponge, in the language of the baker, is put into any convenient mould or form, or it is merely shaped into one mass; and, after being kept for a short time in rather a warm place, so that fermentation may have begun, it is subjected to the process of baking in a proper oven. Carbonic acid is generated, and the viscidity or texture of the dough preventing the immediate escape of that gas from the innumerable points where it forms, the whole mass is puffed up by it, and a light porous bread is the result. Along with the carbonic acid alcohol is evolved, but the quantity is so insignificant and the spirit so impure as not to be worth notice; thence the attempts which have been made to collect it upon a large scale have entirely failed in an economical point of view.

The general process of making household bread is this:-To a peck of meal or flour is to be added about three ounces of salt, half a pint of yeast, and three quarts of water, cold in summer, but warm in winter, and temperate between the two: the whole being then well kneaded in a bowl or trough, and being set by in a proper temperature, rises in about an hour, according to the season. It is then moulded into loaves, and put into the oven to be baked. In placing the dough aside, it is proper to cover it; this is termed setting the sponge, and it undergoes a second kneading before it is baked.

For French bread, take half a bushel of fine flour, ten eggs, a pound and a half of fresh butter (the eggs and butter, however, are very seldom used), and the same quantity of yeast used in making the finest rolls or manchet; and, tempering the whole mass with new milk, bretty hot, let it lie half an hour to rise; which done, make it into loaves or rolls, and wash these over with an egg beaten with milk, tak ing care that the oven is not too hot.

Other flour, besides that of wheat, will, under similar circumstances, undergo panary fermentation; but the result is a heavy, unpala. table, and often indigestible bread; so that the addition of a certain quantity of wheat flour is almost always had recourse to. It is the gluten in wheat which thus peculiarly fits it for the manufacture of bread, chiefly in consequence of the tough and elastic viscidity which it confers upon the dough.

Wheat flour is composed chiefly of starch and gluten; the proportion of these and other substances which it contains, according to Vogel, àre-

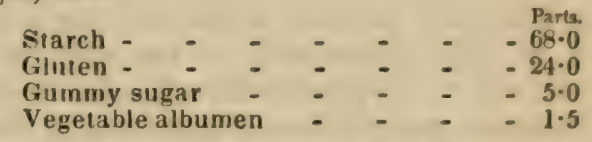

Sir H. Davy states, that wheat sown in autumn contains 77 per cent. of starch, and 19 of gluten; while that sown in spring yields 70 of starch and 24 of gluten. The wheat of the south of Europe contains a larger proportion of gluten than that of the north; and hence its peculiar fitness for making macaroni and vermicelii. Oats yielded, according to Davy's analysis, 59 of starch, 6 of gluten, and 2 of saccharine matter; while the same quantity of rye gave only $6 \cdot 1$ parts of starch, and half a part of gluten.

Like all other farinaceous substances, bread is very nourishing, on account of the gluten which it contains; but if eaten too freely, it is productive of acidity, which deranges the intestines, and lays the foundation of dyspepsia. Stale bread, in every respect, deserves the pre. ference over that which is newly baked; and persons troubled with flatulency, cramp of the stomach, or indigestion, should abstain from new bread, and particularly from hot rolls. Bread made from the best flour is necessarily costly, but is more wholesome for those persons who are liable to a relaxed state of the bowels. Brown bread, on the contrary, is the cheapest and most desirable for persons whose habit of body is of the contrary nature: but there is an intermediate kind made from flour, in which the finer portion of the bran is retain. ed, called locally "seconds," which is preferable to either of the above. (Quar. Jour. Agr. vol. ix. p. 585.) It is a prevailing idea that yeast reproduces itself, just as seeds reproduce similar seeds. But chemical investigation has shown that such an opinion is not to be entertained. See YEAst.

The species of bread in common use in a country depends partly on the taste of the inhabitants, but more on the sort of grain suitable for its soil. The superiority of wheat to all other farinaceous plants in the manufacture of bread is so very great, that wherever it is easily and successfully cultivated, wheaten bread is used to the nearly total exclusion of most others. Where, however, the soil or climate is less favourable to its growth, rye. oats, \&c., are used in its stead. A very great change for the better has, in this respect, taken piace in Great Britain within the last century. It is 
mentioned by Harrison, in his Description of England (p. 168), that in the reign of Henry VIII. the gentry had wheat sufficient for their own tables, but that their households and poor neighbours were usually obliged to content themselves with rye, barley, and oats. It appears from the household-book of Sir Edward Coke, that in 1596 rye bread and oatmeal formed a considerable part of the diet of servants, even in great families, in the southern counties. In 1626 barley bread was the usual ordinary food of the great bulk of the people. At the Revolution, the wheat produced in England and Wales was estimated by Mr. King and Dr. Davenant to amount to $1,750,000$ quarters. (Davenant's Works, vol. ii. p. 217.) Mr. Charles Smith, the very well informed author of the Tracts on the Corn Trade, originally published in 1758, states that in his time wheat had become much more generally the food of the common people than it had been in 1689 ; but he adds ( 2 d edit. p. 182. Lond. 1766), that, notwithstanding this increase, some very intelligent inquirers were of opinion that even then not more than half the people of England fed on wheat. Mr. Smith's own estimate, which is very carefully drawn up, is a little higher; for, taking the population of England and Wales, in 1760 , at $6,000,000$, he supposes that $3,750,000$ were consumers of wheat, 739,000 of barley, 888,000 of rye, and 623,000 of oat bread. He further supposed that they individually consumed-the first class, 1 qr. of wheat; the second, 1 qr. and 3 bushels of barley; the third, 1 qr. and 1 bushel of rye; and the fourth, 2 qrs. and 7 bushels of oats. About the middle of last century, hardly any wheat was used in the northern counties of England. In Cumberland the principal families used only a small quantity about Christmas. The crust of the goose-pie, with which almost every table in the county is then supplied, was, at the period referred to, almost uniformly made of barley meal. (Eden, On the Poor, vol. i. p. 564.)

Every one knows how inapplicable these statements are to the condition of the people of England at the present time. Wheaten bread is now almost universally made use of in towns and villages, and almost everywhere in the country. Barley is no longer used; oats are employed for bread only in the northern parts of the island; and the consumption of rye rread is comparatively inconsiderable. The juroduce of the wheat crops has been, at the very least, trebled since 1760. And if to this immense increase in the supply of wheat we add the still more extraordinary increase in the supply of butcher's meat (see CatruE), the fuct of a very signal improvement in the cordition of the population, in respect of food, will be obvious. When flour is converted into bread, it is found, on weighing it when laken from the oven, that it has increased from 28 to 34 per cent. in weight (3 lbs. of flour make $3 \mathrm{lbs} .10 \mathrm{oz}$. of dough); but when it has been kept thirty-six hours, that which had grained 28 will lose about 4 per cent. There are, however, several circumstances which influence the quantity of bread obtained from 2 given weight of flour, such as the season in which the wheat was grown and the age of the 220 four: the better the flour is, and the older, within certain limits, the larger is the quantity of the bread produced.

According to the assize acts, a sack of flour weighing $280 \mathrm{lbs}$. is supposed capable of being baked into 80 quartern loaves; one-fifth of the loaf being supposed to consist of water and salt, and four-fifths of flour. But the number of loaves that may be made from a sack of flour depends entirely on its goodness. Good flour requires more water than bad flour. Sometimes 82, 83, and even 86 loaves have been made from a sack of flour, and sometimes hardly 80: 96 are generally made, at 4 lbs. $6 \mathrm{oz}$. before going into the oven, by the London bakers.

It is well known that home-made bread and baker's bread are very different; the former is usually sweeter, lighter, and more retentive of moisture, and will keep well for three weeks, especially if a little rye meal is mixed with it; the latter, if eaten soon after it has cooled, is pleasant and spongy; but if kept more than two or three days, it becomes harsh and unpalatable, and mouldy. Small quantities of alum are invariably used by the London bakers, with the view of whitening or bleaching the bread; for it will be observed, that whatever may be the quality of the flour which is used, home-made bread is always of a comparatively dingy hue. By some respectable bakers it was formerly in extensive use, and might still be used, with perfect safety; for in so small a quantity as a quarter of a pound of alum to $1 \mathrm{cwt}$. of flour, it could not be in the least degree injurious. According to Mr. Accum (On the Adulteration of Food), the requisite quantity of alum for this purpose depends upon the quality of the flour. The mealman, he says, makes different sorts of flour from the same kind of grain. The best flour is chiefly used for biscuits and pastry, and the inferior kinds for bread. In London, no fewer than five kinds of wheaten flour are brought into the market; they are called fine flour, seconds, middlings, coarse middlings, and twentypenny.

Beans and peas are also, according to the same authority, frequently ground up with London flour. The smallest quantity of alum used is from three to four ounces to the sack of flour of $240 \mathrm{lbs}$. Alum may easily be detected in bread, by pouring boiling water on it, pressing out the water, boiling it away to onethird, allowing it to cool, filtering it through paper, and adding to the clear liquor some solution of muriate of lime (chloride of calcium). If considerable muddiness now appear, it is proof of adulteration, and none other can well be suspected than alum. Another article occasionally employed in bread and ginger-bread making is carbonate of ammonia. As it is wholly dissipated by the heat of the oven, none remains in the baked loaf. It renders the bread light, and perhaps neutralizes any acid that may have been formed (exclusive of carbonic acid); but it is too dear to be much employed. To some kinds of biscuits it gives a peculiar shortness, and a few of the most celebrated manufacturers use it largely. According to Mr. E. Davy, bread, especially that 
of indifferent flour, is materially improved by the addition of a little carbonate of magnesia, in the proportion of twenty to thirty grains to the pound of flour; it requires to be very intimately mixed with the flour. Salt, which, in small quantity, is absolutely necessary to the flavour of the bread, is used by fraudulent persons as an adulteration ; for a large portion of it added to dough imparts to it the quality of absorbing and retaining a much greater quantity of water than it otherwise would, thus making the loaf heavier. 'The taste of such bread is a sufficient index to its bad quality. It is rough in its grain. (Domestic Economy, vol. i.) A long list of other articles which are said to be used in the adulteration of bread might be given, but no advantage could result from such a statement.

Making bread at home is an operation very easy of acquirement; and, doubtless, most of our farming friends are fortunate in possessing worthy helpmates or experienced servants who provide the families with this daily necessary. To such a practical method of performing the art would be deemed needless; but others of our readers, who may not have considered the expediency of this bread, its superior salubrity, its decided economy, and the feasibility of its preparation, may be pleased to meet with its details. We may refer them, therefore, to the Quar. Journ. of $A g r$. (vol. ix. pp. 289 and 583), a work which is probably in the hands of the greater number of the British farmers; or they may consult with advantage any of the works cited at the end of this article, for our limits will not permit us to go into the palticulars. The writer there states, that the addition of potatoes is wholly unnecessary, unless it be the intention of a housewife that her product shall resemble that of the balier in insipidity and whiteness; both qualities will result from the use of that root, which enters largely into the composition of all bread that is purchased. Notwithstanding the prejudice in favour of the use of potatoes, it has been proved, by careful calculation, that although even a third part of the flour be exchanged for potatoes, so immense is the quantity of water which they contain, that the substitute would cause a loss rather than a gain.

Substitute for wheat flour.-Various substances have been used for bread, instead of wheat. In the year 1629-30, when there was a dearth in England, bread was made in London of turnips. And again in 1693, when corn was very dear, a great quantity of turnip bread was made in several parts of the kingdom, but particularly in Essex. The process is, to pat the turnips into a kettle over a slow fire, till they become soft; they are then taken out, squeezed, and drained as dry as possible, and afterwards mashed and mixed with an equal weight of flour, and kneaded with yeast, salt, and a little warm water. A series of interesting experiments were made some years ago by the Board of Agriculture to determine what were the best substitutes for wheaten flour in the composition of different kinds of bread. For this purpose, all the sorts of grain, \&c. commonly sold in the markets in London were procured, ground into meal, al d baked in various proportions into bread; such as wheat, rye, rice, barley, luckisheat, maize, oats, peas, beans, and potatues. Many of these form the principal nourishment of mankind in various countries. Buckwheat, made into thin cakes, is the chief article of foud in Bretagne and parts of Normandy. Rice nourishes, probably, more human beings in the East than all other articles of food taken together; and, for its bulk, is supposed to be the most nutritious of all the sorts of grain. Maize is a principal article throughout the south of Europe, and is made into bread in Italy and in America. Peas and beans have rarely, it is believed, been used alone as bread; but, it is suspected, they enter largely, though clandestinely, into its composition in various districts.

To ascertain the respective qualities of all these grains, and to discover their operation on each other, in correcting by means of one the defects of another, would be an inquiry deserving great attention, but it has not jet been experimentally investigated. With a!most all the several kinds of grain enumerated, experiments were made on seventy sorts of bread. But as all these sorts were made at once, by several bakers, in order to be examined at the same time, the execution, it is observed, was by no means such as gave the Board of Agriculture, who instituted the inquiry, satisfaction. One general result, however, was, that very few, if any, of the loaves then exhibited, were too bad for human food in times of scarcity; and it may be observed, that though at first a change may prove disagreeable, yet the practice of a few days soon reconciles the stomach to almost any species of food, by which, at least in the same country, other inlividuals can be supported. These experiments were followed by others, which I will explain under distinct heads.

Rice.-Of all the mixtures, nore has made bread equally good with rice, not ground, but boiled quite soft, and then mixed with wheaten flour. One-third rice and two-thirds wheat make good bread; but one-fourth rice makes a bread superior to any that can be eaten, better even than all of wheat; and as the gain in baking is more than of wheat alone (since rice contains 85 per cent. of starch), there can be no doubt of its nutritive quality. Rice bread thus formed is sweetish to the taste, and very agreeable; but, as the proportion of gluten is considerably less than in wheaten bread, it is less nutritive. Excellent biscuits are formed of the mixture.

Potatoes.-The experiments made with this root were similar. It makes a pleasant palatable bread with wheat in the proportion of one-third, but one-fourth still lighter and better. Specimens of barley and potatoes, and also of oats and the same root, made into bread, were submitted to the Board, which promise well. In some cases the potato was not boiled, but merely grated down into a falp and mixed with wheaten flour, in which mode it made excellent bread. It has been found sy other trials, that good bread may be made from equal quantities $\hat{f}$ flour and potato meal, which has been greatly the practice in thos 
countries most remarkable for the plentiful -ulture of the potato.

Various experiments have teen made to combine the meal of wheat, barley, oat, bean, and pea flour with vegetable substances, and which have been found to produce very wholesome and nutritive bread.

Using the potatoes after boiling, steaming, or baking, and reducing them into a sort of powder, seems, however, to be the most ready method of making them into bread.

Oats.-It appears, from some experiments made by Dr. Richard Pearson of Birmingham, that oats answer better mixed with potatoes than has been commonly apprehended.

He found that three pints (dry measure) of fine oatmeal, three pints of seconds flour, and one quart of potato pulp kneaded into a dough, with a proper quantity of yeast, salt, and milk and water, made a breal of excellent quality.

Barley.-Mixed with an equal proportion of wheat, or one-fourth potatoes and three-fourths barley, barley bread is good. The following method of making bread of wheat and barley flour has been strongly recommended. To four bushels of wheat ground to one sort of flour, extracting only a very small quantity of the coarser bran, add $3 \frac{1}{2}$ bushels of barley flour. The oven should be hotter than when bread is made of wheat alone; and the loaves should remain in the oven about two hours or more. The offal of the barley is good food for hogs. This bread appears to be improved by being baked in half-gallon loaves.

Rye.-In several parts of the kingdom a mixture of rye and wheat is reckoned an excellent species of bread. In Nottinghamshire even opulent farmers consume one-third wheat, one-third rye, and one-third barley; but their labourers do not relish it. As rye is well known to be a wholesome and nutritious grain, its consumption cannot be too strongly recommended. The astringent quality of rice, mixed with rye, corrects the laxative quality of the latter, and makes it equally strong and nourishing with the same weight of common wheaten bread. The principal objection to rye is the circumstance of the grain being sometimes ergotted, which renders the bread unwholesome.

Indian Corn.-The flour of maize or Indian corn, by itself, makes a heavy bread. The right mode of manufacturing it is to boil the flour to the consistency of paste, and then, when mixed with wheat flour, it makes a most excellent bread. If used by itself, it is said to have at first a laxative effect, but that diminishes by use, and at any rate can easily be corrected by a mixture either of barley or rice. It is stated, on very respectable authority, as the general opinion of the inhabitants of the United States, but more particularly of the people of Virginia, Maryland, Delaware, and Kentucky, where Indian corn is raised in the largest quantity, and applied to the greatest variety of uses, that rather more nutriment is contained in a bushel of Indian corn than of wheat. In the four states above-mentioned it constitutes the almost entire food of the labouring class of the people, and has supplantet the use of wheaten bread
There are several sorts of Indian corn in America. The yellow flinty corn is reckoned the sweetest and most nutritive. The white ground corn of the southern states makes the fairest, but considerably the weakest flour. of this last species there is one variety called the four-corn, which is scarce, but very valuable.

Buckwheat.-This is not kiln-dried, but dried in the sun, being reaped in October, a month remarkably dry and serene in America. The husk is taken off by what is called running it through the mill-stones. The farinaceous part of the grain is then easily separated from the husk by winnowing; and, being afterwards ground fine, forms an agreeable and nutritive aliment, and may be made into bread with wheat flour or other substances.

Eeans and peas.-When these are used as bread, in some places the flour is steeped in water to take off the harsh flavour, and afterwards, when mixed with wheat flour, the taste is hardly to be perceived. Specimens of very good bread have been produced, mixed as fol. lows :-1 lb. bean flour, $1 \mathrm{lb}$. potatoes, and 4 lbs. of wheat flour. The flour or meal both of beans and peas, by being boiled, previous to its being mixed with wheaten flour, incorporates more easily with that article, and is probably much more wholesome than it otherwise would be.

Eran may in times of scarcity be advantageously employed in the making of common household bread; this is effected by previously boiling the bran in water, and then adding the whole decoction in the dough; thus the bran will be sufficiently softened and divested of its dry husky quality, while the nutritive part, which is supposed to contain an essential cil, is duly prepared for food. It is asserted, that the increase in the quantity of bread, by the addition of one-fourth bran, or $14 \mathrm{lbs} .14 \mathrm{oz}$. of bran to $56 \mathrm{lbs}$. of flour, is from $34 \mathrm{lbs}$. to $36 \mathrm{lbs}$. of bread beyond what is produced by the common mode.

Dr. Davison considers that there are many vegetables which would afford wholesome nutriment either by boiling or drying and grinding them, or by both these processes. Amongst these may be reckoned, perhaps, the tops and bark of gooseberry trees, holly, haw. thorn, and gorse. The inner bark of the elm may be converted into a kind of gruel; and the roots of fern, and probably those of many other plants, such as some of the grasses, and clovers, might yield nourishment, either by boiling, baking, and separating the fibres from the pulp, or by extracting the starch from those which possess an acrid mucilage, such as the white bryony. If, in these days of im. proved chemical knowledge, a quartern loaf of very good bread can be made out of a deal board (see Quart. Rev. No. civ., quoted also in Quart. Journ. of $\mathcal{A g r}$. vol. v. p. 626), there is no reason why many of our native herbs and shrubs, which are now comparatively useless, should not, as their various nutritive properties become better known, be turned to consi derable advantage in the production of a greater or less proportion of cheap and wholesome food. There are many other substances 


\section{BREAD-ROOT.}

which may be formed, by a proportionate admixture of wheaten flour, into palatable bread, and advantageously employed in the manufacture of this indispensable article of human sustenance. (Brande's Dist. of Science and $\Omega r t$; M'Culloch's Com. Dict.; Penny Cyc. vol. V.; Willich's Domes. Encyc.)

BKEAD-ROO'T (Psoralea esculenta). A shrubby or herbaceous perennial plant found on the elevated plains of the Missouri. Its roots are eaten both raw and boiled, the latter being the most common way of cooking it adopted by the Indians. By cultivation it is made to produce abundant crops. The taste of the root is rather insipid, its texture being laminated, always tenacious, solid, but never farinaceous, like the potato. It is somewhat medicinal, operating as a diuretic.

Other species of Psoralea are also found on the Missouri and tributaries, among which are the $P$. canescens, and $P$. cuspidata, both of which are described as having large, tuberous, and ramified roots. The last species is known among the Canadian boatmen by the name of "Pomme de Prairie," or meadow potato. The $P$. lanceolata, or elliptica, grows in great quantities together on the sandy banks of the Misscuri, from the river Platte to the mountains, flowering in July and August. It sends up shoots in every direction through the sand, in which soil it is exclusively met with. The stem is about a foot high and the leaves aromatic when bruised. The $P$. lupinellus is found from South Carolina to Florida, though no: in abundance. It is a very singular plant, the leaves being so narrow as scarcely to be distinguished from the petiole, and two or three inches long, extremely deciduous when dry. The $P$. virgata is met with in West Florida. With very few exceptions, says Nuttall, this genus of plants proclucing esculent roots is indigenous to North America and the Cape of Good Hope.

BREAIKING (Goth. brikan; Sax. bneccœn). In rural economy, the bringing of an animal under subjection. The breaking of a colt is commonly, especially for race-horses, comunenced when he is much too young; for this, as for all other breeds of horses, too much caution and gentleness can hardly be used. (Darvill. On Training). Of dogs, spaniels should begin to be broken in at five or six months old. The water-spaniel, according to old Markham, as soon as "even when you first weane him;" and, according to Blaine (Encyc. of Rural Sports), the education of a pointer or a setter should commence at five or six months.

BREAKING UP. A term that is often applied to such lands as are ploughed from leys, or which are cut or pared for the purpose of being burned.

BREAST-PLATE. The strap of leather that runs from one side of the saddle to the other over the horse's breast, in order to keep the saddle tight, and hinder it from sliding backwards.

BREASTS. Part of the bows of a saddle. BREED (Sax. bræoan). A sort or variety of any kind of live-stock. The breeds of most domestic animals are numerous, and distinguished by certain invariable marks or ap-
BREEDING-IONDS.

pearances peculiar to each, ws in cattle, sherp. horses, and swine. See thesedifferent heals.

BREEUER. In agriculture, a fituer whor is much employed in lorerding and rearing animals of any of the domestice kimls.

BREEJING IN AND IN. The breedin' from clnse relations. "This plan," says Pro. fessor Youatt (Catlle, p. 525), "has many advantages to a certain extent. It may be pursued until the excellent form and quality of the breed are developed and established. $j_{t}$ was the source whence sprung the fine ca:tle and sheep of Bakewell, and the superior cattle of Colling; but disadvantages atterid breeding 'in and in,' and to it must be traced the speedy degeneracy, the absolute disappearance of the new Leicester cattle, and in the hands of many an agriculturist, the impairment of constitution and decreased value of the new Leicester sheep and the short-horned beasts. It has therefore become a kind of principle with the agriculturist to effect some change in his stock every second or third year: and that change is most conveniently effected by introducing a new bull or ram. These should be as nearly as possible of the same sort, coming from a similar pasturage and climate, but possessing no relationship, or at most a very distant one, to the stock to which he is introduced." These remarks apply to all descriptions of live-stock. In cattle, as well as in the human species, de. fects of organization and permanent derangements of function obtain, and are handed down when the relationship is close. In Spain the deformed and feeble state of the aristocracy arises from the alliances being confined to the same class; whilst in England, which can boast the finest aristocracy in the world, the higher classes are improved by constan! alliances being formed with the daughters of inferior classes, where wealth has been accumulated. See the heads, Catrue, Honse, SHFF, \&C.

BREEDING-PONDS. Such ponds as are employed for breeding fish. The qualities of a pond, to malie it profitable for breeding fish, are very different from those which are sufficient for the feeding of them; inasmuch as some particular ponds serve only for one of these purposes, and others for the other; and scarcely ever the same pond is found to answer for both. In general it is much more rare to find a good breeding-pond than a good feeding one. The indications of a gond breeding-pond are these,-a considerable quantity of rushes and grass about its sides, with gravelly shoals, such as horse-ponds usually have. The spawn of fish is prodigiously great in quantity ; and where it succeeds, one fish is able to produce some millions. Thus, in nne of these breeding-ponds, two or three melters and as many spawners will, in a very little time, stock the whole country. When these ponds are not meant entirely for breeding, but the owner wishes to have the fish grow to some size in them, the method is to thin their numbers; for they would otherwise starve one another. It may also be necessary to put in other fish that will prey upon the young, and thin them in the quickest manner. Eels and perch are the most useful on this account. ie 
cause they prey not only upon the spawn itself, but upon the young firy from the first hatching to the time they are of a considerable size. Some fish are observed to breed indiffercntly in all kinds of waters; of this nature are the roach, pike, and perch.

The introduction of certain voracious fish, such as the pike or pickarel, into ponds or lakes well stocked with trout, white and yellow perch, \&c., has been attended with serious consequences, and even led to the total extinction of some kinds and the diminution of all. The mischief in such cases has perhaps been less owing to the exceeding voracity of the pike or pickarel, than to its habits of thrusting itself into the shallows and retired breeding places of other fish, and there breaking up the spawn or devouring the small-fry, without allowing them a chance to live or increase. 'The trout contents itself with preying upon such bait as it can eatch away from the shallows, leaving the breeding places and spawn of other fish undisturbed. Hence, in lakes where plenty of bait is seen along the shores, trout may be found in abundance and in fine condition. Trout and perch both multiply in the same ponds or lales, provided no pike or pickarel be present.

BREWING. The process of obtaining the saccharine solution from malt, or other matters, and converting this solution into spirituous liquors, ale, porter, or beer. There is little doubt of the antiquity of this art. The Egyptians are said to have been the inventors of beer. The early Germans, and our Saxon forefathers, were as fond of beer as the modern citizens of Lubec and Rustock are now, or the English of all ages. It is hardly necessary, in this work, to go deeply into the description of a process which most country persons understand so well. The airections may be divided into several heads. 1. The grinding of the malt: in this there is, as in many other parts of brewing, considerable difference of opinion; some prefer it ground between stones, others crushed by rollers; some prefer a fine grist, others a coarse one. 2. The mashing is usually performed in a vessel of wood, with a false bottom pierced full of holes; on this bottom the malt is laid; the water is then admitted, which, for pale ale, or pale spirits, should be of the temperature of from $170^{\circ}$ to $185^{\circ}$, according to the quantity mashed; the heat being increased as the mass diminishes. For porter, not higher than $165^{\circ}$, or lower than $156^{\circ}$. For the second mash, an increased temperature of $15^{\circ}$ or $20^{\circ}$ will be advisable. For the first mash: for every quarter of malt, a barrel and a half of water may be used, and the grist well mixed with the water. The mash is permitted to rest for some time, and then allowed to run off into an auderback, whence it is pumped into the boiler, where it is raised to the boiling temperature. When the wort is sufficiently drained from the mash-tub, another portion of hot water is added for a second mash. The bops are next added, and the boiling is completed, which in general requires an hour and a half, "or until the wort breaks bright from the hops, when a sample is taken from the 224 copper." The wort is let off into coolers, either of wood or iron; where, when sufficient. ly cooled, or else in proper fermenting tuns, the yeast or barm is added. The fermentation speedily begins; and when it is thought that a sufficient quantity of alcohol is formed, the fermentation is stopped, and the yeast is separated by running it into smaller vessels, and skimming off the barm; or else by allowing it to run off from the bung-holes of the casks, which are, for this purpose, kept completely filled. A small portion of salt is commonly added, and, occasionally, especially by the professional brewer, a portion of isinglass or other finings. In all these operations, cleanliness is a most essential part, for without this it is impossible to have good beer.

The quantity of hops to be added varies with the quality of the beer. $4 \mathrm{lbs}$. to the quarter of malt is sufficient for beer for present use, and from this to $28 \mathrm{lbs}$. have been used for beer for long keeping, as for exportation, \&c.

The temperature of the fermentation should range between $56^{\circ}$ and $62^{\circ}$. Not more than $60^{\circ}$ for ale wort, nor more than $62^{\circ}$ for porter. Great care should be taken to have good, sound, healthy, and new yeast,-and of this about 2 lbs. per barrel are commonly needed. Good malt and hops, of course, are requisite; but the quality of the water is not of so much consequence as is very often considered to be the case. Some of the best ales in England are brewed either with soft or with hard water, and from rivers, or springs, or ponds. From those issuing from the limestones of Notting. hamshire, the chalks of Dorsetshire, the clays of Staffordshire, the gravels and sands of Sur. rey and Middlesex, is made some of the most excellent beer in the United Kingdom. Th quantity of alcohol, upon an average, in br.

stout is about $6 \cdot 80$, in ale $8 \cdot 98$, and in small beer from 2 to 3 per cent. (Erande.) B r came under the excise in the year 1643, wh the duties were repealed in 1830. The exportation of beer from England was in-

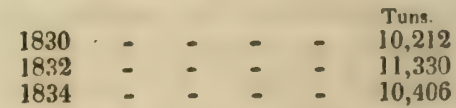

The specific gravity of the wort, when it is placed in the fermenting vessels, varies from $1 \cdot 060$, when it contains 14.25 per cent. of solid matter, to $1 \cdot 127$, when it contains 28.2 per cent. That of small beer varies from 1.015 to 1.040 , the first containing about 3.5 per cent. of solid matter, the latter about 9.5 per cent. The chief use of the hops (ground ivy and other herbs were used by our Saxon ancestors for this purpose) is to communicate the peculiar bitter flavour from the oil which is contained in them; partly to hide the sweetness of the saccharine matter, and partly to counteract the tendency which wort has to run into acidity. (Thomson's Chem. vol. iv. p. 376.)

"Hops," says Dr. Lardner (Domestic Econo $m y$, vol. i.), "are by no means the only bitter which may be made use of for preparing and flavouring ales; others can be inuch more conveniently procured in certain situations. Mixtures, in various proportions, of worm. 
wood, powdered bitter oranges, gentian root, and the rind of Seville oranges, will afford an excellent bitter, perhaps more wholesome than hops, and, if skilfully combined, to the full as palatable; in this position the brewers cannot refuse to bear me out." Strasburg beer, which is much prized on the continent, owes much of its excellence to the use of avens (Geum urbanum). It has been shown by Mr. Dubrunfault, that a good beer can be produced from potatoes grated to a pulp, mixed with barley malt. In Ireland, beer is made from parsnips. Cane sugar answers admirably (14 lbs. of cane sugar, dissolved in ten gallons of boiling water, with $1 \frac{1}{2} \mathrm{lbs}$. of hops). The beer made in this way is pale coloured, it is true; but colour may be given readily by scorched treacle, or the raspings of an over-baked loaf. (Quart. Journ. of Agr. vol. ii.p. 634.) Beer "which would not disgrace a nobleman's table" has also been made from mangel wurzel 150 Ibs., and $1 \mathrm{lb}$. of hops in sixteen gallons of water. (Mechanic's Mag.) It may also be made from the seeds of the Fiorin grass (Donovon, Domestic Economy), Indian and other corn. (Baxter's Lib. of Agriculture.)

BRICKS are building materials often employed by the farmer for the construction of drains, besides the ordinary purposes, for which they answer very well; but they are more expensive than draining tiles, which see. By the 17 G. 3, c. 42 , under a penalty of 20 s., and 10 s. per 1000 , all bricks made in England for sale shall be $8 \frac{1}{2}$ inches long, four inches wide, and $2 \frac{1}{2}$ inches thick; and all pantiles $13 \frac{1}{2}$ inches long, $9 \frac{1}{2}$ inches wide, and $\frac{1}{2}$ an inch thick. If the farmer wishes to make his own bricks, the I.ondon plan is to mix fifty chaldrons of coal ashes, or breeze, with 240 cubic yards of clay, which makes 100,000 bricks; and to burn these, fifteen chaldrons of coarse sifted breeze are required. The soils called brick earths vary much in their composition; they contain alumina in different proportions. Potters' clay is perhaps the richest in that earth, being composed, according to M. Vauquelin, (Bull. Phil.xxvi.) of -

\begin{tabular}{|c|c|c|c|}
\hline Silica (flint) & - & - & - \\
\hline Alumina & - & - & - \\
\hline lime & - & - & - \\
\hline Oxide of iron & - & - & - \\
\hline Water & - & - & - \\
\hline Loss & - & - & - \\
\hline
\end{tabular}

BRIDLE. A contrivance made of straps or thongs of leather, and pieces of iron, in order to keep a horse in subjection, and direct him in travelling. The several parts of a bridle are, the bit or snaffle; the head-stall, or leather from the top of the head to the rings of the bit; the fillet, over the forehead and under the fore-top; the throat-band, which buckles from the head-band under the throat; the nose-bands, going through the lonps at the back of the head-stall, and buckled under the cheeks; the reins, or long thongs of leather that come from the rings of the bit, and, being cast over the horse's head, the rider holds in his hand.

BRIDLE-HAND is the horseman's left 29 hand; the right being called the spear of sword hand; and that in which the whip is held.

BRIDON. A sort of snaffle, with a very slender mouth-bit, without any branches. They are much used in England. It is sometimes written bridoon.

BRILLS. In horsemanship, a vulgar name for the hair growing on the horse's eye-lids.

BRIM. A term applied to a sow when she goes to the boar, which is called going to brim. It is sometimes written brimme.

BRINING OF GRAIN is the practice of steeping it in pickle, in order to prevent smut or other diseases. The steep is made with common salt and water, of sufficient strength to float an egg; or of sea-water, with salt added to it till it is of the requisite strength. The seed is then put into it, and well stirred about: the light grains rise to the surface, and are skimmed off; the rest is put upon a sieve to drain, and new-slaked lime sifted upon it: after being carefully mixed, and when a little dried, it is put into the earth. Urine, when kept stale, is used in the same manner; and, if the seed be sowed directly, with good effect. Brining the seed wheat is commonly believed by the farmers to be a prevention of smut, a disease which has been shown by Sir Joseph Banks to be a parasitical fungus. Recent experiments have suggested that it may even be of use, when employed in larger quantities, as a preventive of mildew-the most dreadful of the numerous diseases to which the cultivated grasses are exposed. The experiments of the late Rev. E. Cartwright strongly evidence, that when salt and water are sprinkled with a brush upon diseased plants, it is actually a complete cure, even in apparently the most desperate cases. The proportion, one pound to a gallon of water, laid on with a plasterer's brush, the operator making his casts as when sowing corn : it is instant death to the fungus, but it also destroys some plants. The time and expense are trifling. It appeared, in the course of some inquiries made by the Board of Agriculture, that a Cornish farmer, Mr. Sickler, and also the Rev. R. Hoblin, were accustomed to employ refuse salt as a manure, and that their crops were never infected with the rust or blight. The farmer may see most of the authorities collected together on this important fact in Johnson, On Salt, p. 50. If potatoes are immersed in a solution of ammoniacal water for four or five days (one ounce of the common liquor ammoniæ to a pint of water), they will have, according to Mr. Webster, their vegetative power completely checked or destroyed, and may be in this way preserved throughout the year, without the least injury to their general qualities-the same effect is produced by immersing them in a strong brine. This merely requires subsequent ablution, and repeated changes of water. (Quart. Journ. of Agr. vol. vii. p. 438.)

BRISTLES (Dut. borstels; Ger.borsten). The strong glossy hairs growing upon tne back of the wild boar and the hog. Those $f: r$ the use of brushmakers, saddlers, shoemakers, \&c, are imported to a very considerable exten! from Russia, those of the Ukraine being the 
best. At an average of three years ending with 1831, says Mr. M'Culloch, the entries for home consumption in England amounted to $1,789,801$ lbs. annually. 'They contain a considerable quantity of gelatine, which may be separated from them by boiling water.

BRITTLE HOOF is an affection of the horse's hoof, very common, especially in summer, in England, from bad stable management. A mixture of one part of oil of tar and two of common fish oil, well rubbed into the crust and the hoof, will restore the natural pliancy and toughness of the horn, and very much contribute to the quickness of its growth. (Youatt, On the Horse, p. 282.)

BRIZA MEDIA. See Plate 6, n. Common quaking grass; ladies' tresses: a perennial grass, flowering in May and June. It is distinguished by the panicle of short spikelets, tinged with purplish brown. The spikelets are ovate, on very slender stems, which makes the panicle tremulous. This grass, says Sinclair, is best fitted for poor soils; its nutritive powers are considerable, compared with other grasses tenanting a similar soil. It is eaten by horses, cows, and sheep; and for poor sandy and tenacious soils, where improvements in other respects cannot be sufficiently effected, to fit them for the productions of the superior soils, the common quaking grass will be found of value.

BRIZE LANDS. A provincial term for lands which have remained long without tillage. Brize is also a name for the gad-fly, used commonly in the days of Shakspeare and Ben Jonson. (Tr. and Cress.: Poetasler, iii. 1.)

BROAD-CAST SOWIN( $y$. The primitive, rapidly diminishing method of putting grain, turnip, pulse, clover, grasses, \&c., into the soil, perforined by means of the hand. This mode of sowing seems better adapted to the stony and more stiff kinds of land than that by machines; as in such grounds they are liable to be constantly put out of order, and to deposit the seed unequally. In this way, however, the seeds are scattered over the ground, and not confined in regular rows, as is the case with the drill husbandry, which is in several ways more advantageous to the farmer. This mode of sowing, perhaps from its being that made use of in the infancy of agriculture, has often been called the old method.

In this method of sowing, the usual practice, especially where the ridges are equal in breadth, and not of too great a width, as five or six yards, is that of dispersing the seed regularly over each land or ridge, in once walking over; the seedsman, by different casts of the hand, sowing one-half in going and the other in returning. In doing this, it is the custom of some seedsmen to fill the hand from the basket or hopper which they carry along with them, as they make one step forward, and disperse the seed in the time of performing the next; while others scatter the seed, or make their casts, as they are termed by farmers, in advancing each step. It is evident, therefore, that in accomplishing this business with regularity and exaztness, upon which much of the success of the crop must depend, there is considerable difficulty, and the proper knowledge and habit 226 of which can only be acquired by experience This, however, by long practice, is done with surprising regularity and precision. The broad-cast system not only requires more seed, but it renders the hoeing, so essential to the most profitable growth of grain, much more difficult. Machines have been invented for distributing the seed broad-cast, which they perform with perfect precision: these are more especially useful for the grass seeds, and are simple and economical; a plate of one may be seen in Professor Low's Prac. Ag. p. 108, and another in British Husb. vol. ii. p. 14. These, however, require some attention in their working, to prevent the clogging of the seed.

BROAD-WHEELED WAGON. A fourwheeled carriage, in which the parts of the wheels that act upon the road are of considerable breadth. By the acts 3 G. 4, c. 126, s. 12, and $4 \& 5$ W. 4 , c. 81 , wagons, wains, and other four-wheeled carriages, whether on springs or not, whose wheels have their fellies of not less than four and a half inches at the bottom or soles, are considered to be broadwheeled.

BROCCOLI (Brassica oleracea botrytis). The varieties of this cabbage are now numerous, and are chiefly the fruits of the great attention which has been paid to its cultivation of late years. For an uninterrupted supply, scarce any of these varieties can be dispensed with: but the purple and white are those most generally cultivated. With respect to their quality, it has been remarked that they have less of the peculiar alkalescent taste, and are more palatable, in proportion as they approach a pale or white colour. (Transact. Hort. Soc. Lond. vol. i. p. 116.)

1. Purple cape, or autumnal broccoli. 2. Green cape, or autumnal broccoli. 3. Grange's early cauliflower broccoli. 4. Green, closeheaded winter broccoli. 5. Early purple broccoli. 6. Early white broccoli. 7. Dwarf brown close-headed broccoli. 8. Tall, large-headed purple broccoli. 9. Cream-coloured, or Portsmouth broccoli. 10. Sulphur-coloured broccoli. 11. Spring white, or cauliflower broccoli. 12. Late dwarf close-headed purple broccoli. 13. Latest green, Siberiar, or Spanish broccoli. Broccoli is propagated by seed. As all of the linds are not generally at command, the following times and varieties are specified as being those employed in general practice, and by which a supply nearly unfailing is accomplished. A first sowing may be made under a frame at the close of January, and a second at the end of February, or early in March, on an eastern wall-border, of the purple cape and early cauliflower varieties, for production at the close of summer and during autumn; the seedlings from these sowings are respectively fit for pricking out, if that practice is followed, in March and early in April, and for final planting at the close of the latter month and May. In April, another crop of the same varieties may be sown, for pricking out in May and planting in June, to produce at the close of autumn and in early winter. During the middle of May, a fourth and larger crop than any of the preceding, of the early purple and white varieties, to be pricked out in June and planted 
In July; and, finally, the last open-ground crop may be sown in June, to be pricked out in the succeeding month, and planted in August and September; the plants will follow from the others in succession throughout winter and spring. In a frame, however, they may be sown, like the cauliflower, in the last days of August, to remain until the following March, to be then planted out for production in early summer. By these repetitions, which, if for a family, should be small, an almost continued supply is afforded; but in general, for domestic use, especially if the establishment is small, three sowings of moderate extent will be sufficient; the first in the second week of April, the second in the third week in May, and the third in the middle of August, in a frame. Each variety should be sown separately, and the sowing performed thin; the beds not more than three or four feet wide, for the convenience of weeding, which must be performed as often as weeds appear, as they are very inimical to the growth of this vegetable. The seed must not be buried more than half an inch, and the beds be netted over to keep away the birds, which, especially in showery weather, are very destructive. The fitness of the plants for pricking out is intimated by their having five or six leaves, rather more than an inch in breadth; they are set four or five inches apart each way, and water given every right until they have taken root. They must have four or five weeks' growth before they are again moved; or not until they have leaves nearly three inches in breadth. When planted out, they must be set on an average two feet asunder each way, in summer a little wider, in winter rather closer. Water to be given at the time of planting, and occasionally afterwards, until they are established; during the droughts of summer it may be given plentifully with the greatest advantage. They must be hoed between frequently, and the mould drawn up about their stems. To force forward the winter standing varieties, it is a successful practice to take them up in November, and after trimming off the outer leaves, to lay them on their sides in a sloping position, in a bank or terrace of light earth, so much space being left between every two plants that their heads do not come in contact. To continue the supply uninterrupted, even in the mid-winter of the severest years, Mr. Maher recommends that when the crop sown about the third week in May has been planted out, the weaker plants which remain should be left eight or ten days to acquire strength, and then planted in pots (sixteens) filled with very rich compost; to be shaded, and watered until struck. 'These are to be plunged in the ground at similar distances as the main crops, and about three inches below the surface, so as to form a cup for retaining water round each; these cups are filled up by the necessary earthings, which must be pressed firmly down, to prevent the wind loosening them. A few of the plants generally flower early, and, to guard against the first frosts, must have the leaves broken over them: but on the approach of settled frost in December and January, the pots must be taken up and removed into a frame, shed, or any place of shelter from the extreme severity of the weather; but to have air when mild. (Tra. Hort. Soc. L. vol. i. p. 118.)

To those crops which have to withstand the winter in the open ground, salt is beneficially applied, as it preserves them from being frosted in the neck, and also their roots from being worm-eaten; which may also be effected, $\mathrm{Mr}$

Mackay of Errol House, N. B., informs us, by pouring soap-suds between the rows, which application is also very beneficial to the plants. (Mem. Caled. Hort. Soc. vol. i. p. 275.)

To preserve the winter standing crops from destruction by severe weather, it is also a practice, early in November, to take them up, injuring the roots as little as possible, and to lay them in a sloping direction in the soil, with their heads to the north. A modification of this plan, adopted by the distinguished president of the Horticultural Society, is, however, much preferable, as it obviates the defect of few roots being produced, and consequently diminutive heads. A small trench is made in the first week of September, at the north end of each row, in which the adjoining plant is laid so low, that the centre of its stems at the top is put level with the surface of the ground, the root being scarcely disturbed; it is then immediately watered, and its roots covered with more mould. Thus every plant is in succession treated; and by the beginning of November, it is scarcely perceptible that they have been thus treated, though it certainly checks their growth. Before the arrival of snow, a small hillock must be raised round each plant, to support its leaves, and prevent their being broken. (Trans. Hort. Soc. Lond. vol. ii.p. 304.) If snow accompanies severe frost, advantage should be taken of it, and the plants be heaped over with it, which will afford them an effectual protection.

For the production of seed, such plants of each variety must be selected, in March or April, as most perfectly agree with their peculiar characteristics, and are not particularly forward in advancing for seed. As the stems run up, some gardeners recommend the leaves to be taken away; but this must be injurious. Mr. Wood of Queensferry, North Britain, is particularly careful that no foliage appears on the surface of the flower; he always lifts his plants, and plants them in another bed, watering abundantly; as this, from his long experience, he finds, prevents their degenerating, or preducing proud seed; and when the head begins to open, he cuts out its centre, and leaves only four or five of the outside shoots for bearing. The sulphur-coloured he al ways finds the most difficult to obtain seed from. (Mem. Caled. Hort. Soc. vol. ii. p. 266.) As the branches spread, four or six stakes should be placed at equal distances round each plant, and hooped with string, to support them and prevent their breaking. When the pods begin to form, water should be given repeatedly, and occasionally some thrown over the whole plant, which :encs to prevent mildew. Before the pods begin to change colour, those from the extremity of every shoot must be taken away; as these yield seed which producc plants very apt to run to seed without heading, 
and by an early removal the others are benefited. The branches are to be gathered as soon as the pods upon them ripen. Varieties must never be planted near each other, or they will reciprocally be contaminated. The seed ripens in August or September; and it is often recommended to preserve it in the pod until wanted; but the general practice is to beat it out, and store it as soon as it is perfectly dry. The plants raised in frames are managed as directed for cauliflowers in the same situation. (G. W. Johnson's Kitchen Garden.)

BROKEN-KNEES, in horses. The best medical treatment, in slight cases, is to cleanse them from dirt and gravel by a sponge and warm water. In bad cases a veterinary surgeon is absolutely necessary, who will examine with his probe, and apply bandages, and even, in need, the hot iron.

BROKEN - WIND, in horses, is, says Professor Youatt, the rupture, dilatation, or running together of some of the air cells, - the inspiration by one effort, and the expiration by two; and is thus easily distinguishable from thick wind, in which the inspirations and the expirations are equal in amount. In healthy lungs, when the lungs are expanded, the air will rush in easily enough, and one effort of the muscles of expiration is sufficient for the purpose of expelling it; but when these cells have run into each other, the cavity is so irregular, and contains so many corners and blind pouches, that it is exceedingly difficult to force it out again, and two efforts are scarcely competent fully to effect it. A dry husky cough accompanies this disease, of a peculiar sound. Broken wind is usually caused by smart exercise on a full belly. We do not, therefore, find broken-winded horses on the race-course; for, although every exertion of speed is required from them, their food lies in a small compass; the stomach is not distended, and the lungs have room to play; and care is taken that their exertion shall be required when the stomach is nearly empty. Carriage and coach horses, from a similar cause, are not often broken-winded. The majority of brokenwinded horses come from those for whose use these pages are principally designed; the farmer's horse is the broken-winded horse, from being fed on bulky food; and because, after many hours' fasting, the horses are often suffered to gorge themselves, and then, with the stomach pressing upon the lungs, and almost impeding ordinary respiration, they are put again to work, and sometimes to that which requires considerable exertion. But the pressure of the distended stomach upon the lungs is sufficient to do this, without exertion; many a horse goes to grass or the straw-yard sound, and returns broken-winded. The cure of a broken-winded horse no one has witnessed, yet much may be done in the way of palliation; the food should consist of much nutriment in little compass; the oats should be increased, and the hay diminished; occasional mashes will be found useful; water should be given sparingly except at night, and the horse should never be exercised on a full stomach Carrots are excellent food for him.

Horse ; Lib. of Useful Know. p. 195.)

(The 228
BROMUS. The brome grasses; a genus of which the chief species are as follow:-

Bromus arvensis, taper field brome grass, has a spreading, drooping, compound panicle, with lanceolate, sharp-pointed spikelets. Each spikelet consists of eight imbricated, smooth florets, with two close ribs at each side. Th9 leaves are hairy, and the whole plant about three feet high. It is confined to rich pastures and meadows; while the next two, Bromus multiflorus and Bromus mollis, known by the leaves being soft and downy, abound most on poor or exhausted grass lands: they are all annuals. The farmer considers them to be bad grasses; the field brome grass, however, affords an early bite in the spring for sheep and lambs; it does not exhaust the soil; the roots do not extend to any depth; its seeds, which it sheds, readily and speedily take root and yield food; and it withstands the frost well: in England it flowers on the second week in August. At the time of flowering, the produce of its grass grown on a sandy loam per acre is 23,821 lbs.; of nutritive matter, $1488 \mathrm{lbs}$.

Eromus diandrus, upright annual orome grass.

Bromus erecius, apright perennial brome grass.

Bromus inermis, smooth awnless brome grass.

Bromus littoreus, sea-side brome grass.

Bromus mollis, soft brome grass.

Bromus multiflorus, many-flowered brome grass (named from the spikelets containing from ten to fifteen florets).

Bromus sterilis, barren brome grass. It grows principally under hedges in the shade; cattle refuse it.

Bromus tectorum, nodding-panicled brome grass.

These were all examined with much skill by Sinclair, but he had evidently a poor opinion of them as field grasses. (Hort. Gram. Wob.)

There are many other varieties of this family, the respective merits of which are pointed out by Sinclair in his Hort. Gram. Wob. That which is perhaps most interesting to the American farmer is the Bromus secalinus, commonly called cheat, so frequently found growing among the wheat or rye crops.

BRONCHITIS. A disease in horses. It is, says Professor Youatt, a catarrh extending beyond the entrance of the lungs. Symptoms, quicker and harder breathingthan catarrh, peculiar wheezing, coughing up mucus. Treatment, moderate bleeding, chest blistering, digitalis. Neglected bronchitis often leads to thick wind. (On the Horse, p. 189.)

BROOD MARES. Mares generally com. mence breeding at three or four years of age. Some commence at two years, which is much too early. A mare will, if only moderately worked, continue to breed till nearly twenty. She is in heat in the early part of the spring; averages about eleven months in foal; but this varies considerably; some have been known to foal four or five weeks before this time, others five or six later. In race-horses, the colt's age is calculated the same, whether he is born in January or May. It is desirable that the mare should go to the horse as earl. 
as possible. But in ordinary cases May is the best month; for then the mare foals at a period when there is an abundance of her natural food.

BROOKI.IME (Myositis palustris). This herb loves shallow streams and wet ditches, like the water-cress, which it resembles in taste. It flowers and seeds in June, July, and August. Brooklime is known by its thick stalk, roundish leaves, and its spikes of small bright blue flowers. It grows about a foot in height, and it strikes root at the lower joints, and the ronts are fibrous. The leaves are broad, oblong, slightly indented, round at their edges, and blunt at the point, to use an Irishism. The flowers stand singly upon short foot-stalks, one over another, forming a sort of loose spike. Brooklime possesses slight medicinal virtues; but it should be used fresh, as it loses its properties when dried. It is often eaten in salads, which is a pleasant mode of administering it; but its flavour is in any form warm and agreeable.

In many parts of the United States, the $M$. palustris is called Forget-me-not, Marsh scorpion grass. In French it is the Oreille de souris. In swampy places and spring heads, it remains vigorously green through the winter. It flowers from May to September. (Flor. Cestric.)

BROOM (the Spartium scoparium or Cyticus scoparius of botanists). Pl. 9, d. An evergreenbranched shrub, native of sandy soils throughout Europe. The broom, with its gay yellow Aowers, blooming from April to June, its tough stalks, and flat hairy pods, is well known on all barren and waste grounds, growing abundantly in dry gravelly thickets and fields, and is often admitted into shrubberies, for its delicate blooms and curious appearance. It is sown extensively in England as a shelter for game. Its branches, which are tough, are made up into brooms, to which they have given their name. The green stalks and tops of brooms are medicinally employed. They have a bitter nauseous taste, and a peculiai odour when green. The green twigs, when burned, yield a large quantity of carbonate of potash, and several other salts. Broom tops, administered in strong infusion, are emetic and purgative : in smaller doses they are diuretic; and as such have been long employed to excite the action of the kidneys in dropsy; but its efficacy depends on the nature of the dropsy, and its cause. When inflammation is present, broom tops do much harn ; and, therefore, like other remedies, its use should not be intrusted to non-professional persons. It may be useful to know that its action is promoted by dilution.

BROOM-GRASS. The Andropogon purpurescens, $\mathcal{A}$. furcatum, or forked spike-grass, and the $\mathcal{A}$. nutans, or beard-grass, are all known in the Eastern States, where they flower in August.

BROOM-RAPE (Orobanche major). This is a parasitical plant which is found amongst the red clover; "meaning, perhaps," says Mr. Main, "a robber of broom, from its being frequently found on waste grounds growing on the routs of the common broom, and in fields on the roots of clover." In its first appearance it resembles the ronts of asparagus, just as they break through the ground; the stems rise from six to ten inches high, and without proper leaves, having what are called bractes instead. The flowers are arranged on the stem like those of a hyacinth, but not so showy, being of a dingy brown colour, succeeded by oblong capsules of seeds. A straggling individual plant is sometimes met with amongst leywheat feeding on a clover plant, which has escaped destruction by the plough and harrow at wheat sowing; but it never appears again until the field is sown with clover. From a note by Mr. Rham, quoting Von Aelurock's Agriculture of Flanders, p. 283, it would seem that the minute seeds of the broom-rape, which can hardly be observed with the naked eye, exude a glutinous substance, by which they adhere to the seeds of the clover, and with which they are in consequence often sown. (Jourm. Roy. Eng. Ag. Soc. vol. i. p. 175.) Orobanche is a powerful astringent, and might be advantageously used in chronic diarrheas.

BROOM, SPANISH (Spartium junceum). Pl. 9, e. A handsome shrub, with fragrant yellow blossoms, which appear in July: Miller says, that in cool seasons it will keep blowing until September. It loves a sheltered situation. If raised by seed, sow it as soon as it is ripe, in a shady bed of common earth, kept free from weeds. Plant out the seedlings the following autumen. The white Spanish broom (Spartium monospermum) is more tender; therefore it should be sheltered during the winter. It grows well in shrubberies not exposed to a hot sun. Raised from seed. Phillips recommends the Spanish broom for shrubberies, from its long continuance in bloom, from July to October; and he adds, the common broom ( $S$. scoparium) may as judiciously be placed at the foot of towering trees, where it will shine as gay in the gloom as a cypress fire in a forest. (Shrubbery, vol. i. p. 151.)

BRYONY, BLACK (Tamus communis, Gr. fevow, I grow rapidly). This is a wild native plant, and climbs like the white bryony; but it wreathes its stalk around the bushes, having no tendrils. The stalk also runs fifteen feet in length. The leaves are broad, shaped like a triangle, smooth, polished, and of a black green colour. The flowers and berries re. semble the white bryony.

BRYONY, WHITE (Bryonia dioica). This plant, with its tendrils and leaves, somewhat resembles the vine, and clings like it around the trees and bushes in its progress. It grows in many parts of England under hedges and thickets. The leaves are hairy and broad. The flowers small, and of a greenish white colour, blowing from May till August. The berries are red, and full of seeds. The root is large, rough, and white, and the stalks from ten to twelve feet in length. The root contains a peculiar bitter principle, wh:ch has been termed bryonin. The root is poisonous, being both violently emetic and purgative, producing symptoms resembling those of cholera. It is sold by herbalists under the name of Manaran root. Many ignorant persons have been de stroyed by the employment of bryony root, in diseases in which it is said to be useful in olc 
herbals. Decoctions made with one pound of the fresh root are purgatives for cattle. This is a powerful medicine, and should be given cautiously in small doses, even to cattle.

BUCK. The male of the deer, hare, rabbit, \&c.

BUCK-BEAN (Menyanthes trifoliata). This is a beautiful wild flower, and deserving of cultivation. It naturally inhabits turbaries, and marshy places. In a garden it will live for many years, if planted in a pot filled with peat earth mixed with sphagnum or bog moss, and plunged in a pan of water; or better still, if planted out in rich soil, where it can be supplied with water from a pond or tank. It is not only a beautiful, but a valuable gift of Providence,-for it possesses powerful effects as a remedy against the fevers prevalent in marshy districts. (Gardener's Chronicle.) Withering, in speaking of this plant, says it is possessed of powerful medicinal properties; an infusion of the leaves is extremely bitter, and is prescribed in rheumatism and dropsies; it may be used as a substitute for hops in making beer, and is employed as a purgative for calves. It is easily recognised, possessing a very singular appearance. It grows a foot high; the leaf-stallss rise from the roots, and upon each stalk stand three large oblong leaves, somewhat resembling the garden bean leaves. The stalks themselves are round, thick, and smooth. The flowers are small, white, with a delicate tinge of purple, and hairy inside. They grow together, forming a short, thick spike, and stand upon thick, round, whitish, and naked stalks. The root is long, thick, and of a whitish colour. Buck-bean leaves should be gathered before the flowerstalks appear, and dried. Their powder, taken in tea, or any liquid, is considered excellent for rheumatism and ague.

BUCKEYE. Under this name, Michaux describes two species of trees in the United States, viz. the large buckeye or yellow pavia, (Pavia luteu); and the Ohio buckeye or Ohio horse-chestnut (Pavia ohioensis).

The yellow pavia, or large A merican buckeye, is first observed on the Alleghany Mountains in Virginia, near the 39 th degree of latitude. It becomes more frequent in following the chain towards the southwest, and is most profusely multiplied in the mountainous districts of the Carolinas and Georgia. It abounds, also, upon the rivers that rise beyond the mountains and flow through the western part of Virginia, and the states of Kentucky and Tennessee, to meet the Ohio. It is much less common along the streams which have their sources east of the Alleghanies, and may therefore be considered as a stranger to the Atlantic states, with the exception of a tract thirty or forty miles wide in the Southern States, as it were beneath the shadow of the mountains. It is here called big buckeye, to distinguish it from the Pavia rubra, which does not exceed eight or ten feet in herght, and which is called small buckeye.

Michaur states, that he had seen no situation which appeared more favourable to the developement of the big vuckeye, than the declivities of the lofty mountains in North Carolina, and particularly of the Great Father Mountain, the Iron Mountain, and the Black Mountain, where the soil is generally loose, deep, and fertile. The coolness and humidity which reign in these elevated regions, appear likewise to be necessary to its utmost expansion; it here towers to the height of sixty or seventy feet, with a diameter of three or four feet, and is considered a certain proof of the richness of the land.

The flowers of this tree are of a light, agreeable yellow, and the numerous bunches, contrasted with the fine dense foliage, lend it a highly ornamental appearance. The fruit is contained in a fleshy, oval capsule, the surface of which, unlike that of the horse-chestnut of Asia and Ohio, is smooth. Each capsule contains two seeds or chestnuts, of unequal size, flat upon one side and convex on the other. They are larger and lighter-coloured than those of the cornmon horse-chestnut, and, like them, are not eatable.

Of American trees, the large buckeye is one of the earliest to cast its leaves, which begin to fall near Philadelphia about the 15th of August, and whilst the other horse-chestnuts are still clothed with their finest verdure. Its foliation and flowering are also tardy, which is deemed an essential defect in a tree, the greatest merit of which is its beauty. The wood, from its softness and want of durability, cannot be made to subserve any useful purpose. In beauty, this species is reckoned inferior to that magnificent tree, the

Ohio buckeye, or common American horsechestnut, which is not a native of any of the Atlantic states, where, however, it is a favourite ornamental tree. The ordinary stature of the American horse-chestnut is ten or twelve feet, but it sometimes equals thirty or thirty-five feet in height, and twelve or fifteen inches in diameter.

The foliage of this tree appears very early in spring, being very quickly followed by its flowers, which almost cover the tree in white bunches, making a very brilliant appearance. The fruit is of the same colour with that of the foreign horse-chestnut and of the large buckeye, and of about half the size: it is contained in fleshy, prickly capsules, and is ripe the beginning of autumn. Horse-chestnuts are said to injure swine and other stock which eat them.

The bark of the larger trees is blackish, and endowed with a disagreeable odour and highly acrimonious properties. The wood is white, soft, and wholly useless. The value of the Ohio buckeye or American horse-chestnut consists mainly in the beauty of its abundant, precocious, and beautiful foliage and flowers, qualities which bring it into great request as an ornamental tree. (North Amer. Sylva.)

For some notice of the European or Asiatic horse-chestnut, see Cinsstrut, Horse.

BUCK-HEADING and BUCK-STALLING. Provincialisms applied to the cutting hedgefences off, fence-height.

BUCKHORN. See Prantain, Star of THE EARTH.

BUCK HUNTING. "In common parlarice," says Mr. Blaine, "the hunting of a faliow deer, whether male or female, is said to be 


\section{BUCKLE-HORNS.}

buck hunting." 'This, according to Mr. Chafing, in the reign of James II., was formerly practised after dinner; it was so fashionable, und so generally delighted in at that period, that even the judges on the circuit were accustomed to partake in it. (Srott's Ficld Sports, p. 435.)

BUCKLE-HORNS. A provincial name for short crooked horns turning inward in a horizontal manner.

BUCKTHORN, COMMON (Rhamnus catharlicus). A hardy indigenous prickly shrub, common in hedge rows in England; flowering in May, and ripening its fruit in September. The leaves have strong lateral nerves, are ovate, toothed, with linear stipules; the flowers are yellowish-green, and are succeeded by a black berry, which is glossy, and the size of a large pepper-corn, containing three or four seeds, and a violet-red pulp. The bark is glossy and dark-coloured. This shrub likes a sheltered situation, and succeeds in any soil. It is propagated by seed, layers, and grafts. The juice of the unripe berries is a deep green dye, if boiled with a little alum. The juice contains a purgative principle, which enables it to operate as a powerful cathartic; but its action is accompanied with much griping and thirst. It was formerly often used as a domestic purgative; but the frequent violence of its action has caused its disuse.

The Rhamnus or buckthorn genus of plants is very numerous, ten species being found in the United States, chiefly in the warmer parts. The leaves of a species found in China, the Rhamnus theezans, resemble those of the teaplant, and pass as a substitute for tea among the indigent population of that country. The buckthorn family of plants are all either very small trees or shrubs with the smaller branches often terminating in spines or thorns, qualities which fit them for hedges, for which purpose the common buckthorn (Rhamnus catharticus) is a favourite about Boston and other parts of New England, where the English and Virginia thorns will not stand the climate. The buckthorn, on the contrary, will grow in almost any climate and upon every variety of soil.

A species of rhamnus, called the broadleaved alaternus, a native of the south of Europe, is an ornamental evergreen, the blossoms of which are greatly frequented by the honeybee. It is a rapid growing shrub, and useful for thickening screens, clothing walls, \&c.

The sea or common sallow thorn, the Hippopha rhamnoides of I.innæus, is a very important shrub, growing wild on sandy shores, in various parts of the British coast, where it sometimes attains the height or eight or ten feet. Its bark is light brown, the wood white, the small leaves of a sea-green colour, but silvery white below. The leaves appear early in spring; the yellow flowers in June and July; the fine red berries late in autumn.

In situations contiguous to the sea-shore, or the banks of rivulets, this shrub eminently deserves to be cultivated, as it is well calculated to bind a sandy soil, and to prevent the water from penetrating through banks and fences. It may be raised from seeds, but more expeditiously by planting layers, or propagating it from the very abundant spreading roots.

\section{BUCKWHEAT.}

On account of its horny points, it affords excellent hedges, even on a sandy soil.

Although cows refuse the leaves of the sea. buckthorn, yet they are brow sed upi n by goats. sheep, and horses. The berries are strongly acid, with an austere vinous flavour: in Lap. land they are pickled and used as spice, but the fishermen of the (iulph of Bothnia prepare from them a rob, which, added to fresh fish, imparts a very grateful flavour.

From the leaves of this shrub, M. Suckow obtained an agreeable dark-brown dye for wooi and silk, first treated with vitriol of iron (copperas): Dambourney succeeded in producing a similar colour on cloth that had been pre. viously steeped in a solution of bismuth.

BUCKWHEAT (Germ. buchweizen). The name of a particular species of grain, of which, for the sake of their seeds, there are two species cultivated in Europe:-1. The common buckwheat (Polygonum fagopyrum), Pl. 3, g; 2. The Tartarian buckwheat (P.taturicum), $h$; and another in China and Tartary ( $P$. emarginatum), $i$. A new kind of buckwheat, known to the peasants of Germany by the name of Wild Italian buckwheat, they prefer to the common buckwheat, because it is more productive, hardier, and has whiter and more savoury meal. This is described in the Eull. des Scien. Agr., April, 1831. (Quart. Journ. Agr. vol. iii. p. 368.) Its flower is said to be deeper-coloured, and smaller.

Buckwheat is a plant known in almost every part of the world. It has been supposed to have been first known in Europe after the time of the Crusades. The French, in fact, call it blé Sarrazin. In China, Japan, and Russia, it forms a very considerable portion of the food of the inhabitants; it is likewise generally eaten in Switzerland and the southern parts of France, and in Flanders it is a considerable branch of husbandry. Gerard speaks of it as cultivated in England about the year 1597, particularly in the counties of Lancashire and Cheshire. It appears, however, to have made small progress in this kingdom, and has received less attention than it deserves. It thrives well in almost any dry soil, even those of the poorest kinds: and in most of the arable districts it is sown on the inferior sorts of land; as, when cultivated on the richer kinds of soil, it is found to run too much to straw. It is well adapted to light sandy lands. The quantity of seed sown varies from five to eight pecks per acre. Buckwheat is an annual. It has a strong, cylindrical, reddish, branching stem, about two feet in height, with alternate ivy-shaped leaves; the flowers, which are white, tinged with red, are in bunches at the end of the branches, and are succeeded by black angular seeds. Its flowers are very aitractive to bees. It begins flowering in July, and is generally fit to mow about the beginning of October. If put together, says Mr. Main, a little green or damp, it does not much signify ; for, although ever so mouldy, the grain is never damaged, and the more mouldy it is, the earlier it can be thrashed. It is the easiest of all barnwork for the thrasher. (Quart. Journ. Agr. vol vii. p. 180.)

In England, the proper time for sowing 231 
buckwheat is in May, when there is no longer any danger to be apprehended from the frosts; for so tender is this vegetable at its first appearance, as to be unable at an earlier period to withstand the vernal cold. The slightest frost in their infant state would infallibly cut off the young shoots; and as, from this circum. stance, it must be sown at a season when dry weather may be expected, the crop, on that account, not unfrequently fails. The produce, which varies with the seasons (and this is rather an uncertain crop), ranges from two to four quarters per acre. It is commonly grown in England in preserves, as food for pheasants and partridges. It is an excellent food for poultry; pigs thrive upon and are fond of it (it is commonly given to them mixed with potatoes); and when bruised, it is good food for horses, two bushels being equal, for this purpose, it is said, to three of oats (a bushel weighs about forty-six pounds). Cows, when fed with it, yield a large increase of mill. Sheep, when fed upon the plant when in blossom, stagger and tumble about as if drunk. I is sometimes made into hay, which is nutritive, but tedious to make, and should be consumed before the winter. It is often grown on poor exhausted soils, and ploughed in when in bloom; in this way it increases very materially the fertility of the soil, and is a mode often practised in Essex, Suffolk, Norfolk, and in Scutland. Mr. Ballingal has given an account of his experiments with it upon a clay loam recently limed; from the result of which he warns his brother farmers that it is "needless to attempt to grow it upon damp soils, or to expect full crops upon lands exhausted by uver-cropping." (Trans. High. Soc. vol. ii. p. 125.)

In reaping buckwheat, many farmers prefer pulling it, as less likely to shed the seed. The morning, or late in the evening, should be chosen for this purpose, when the dew is upon the plant. M. Vauquelin found 100 parts of its straw to contain 29.5 of carbonate of potash, 3.8 of sulphate of potash, 17.5 carbonate of lime, 13.5 carbonate of magnesia, 16.2 of silica, 10.5 earth of alum, and 9 of water.

Vast quantities of this grain, says Mr. Main, are annually imported into England from Holland and other northern countries, for the use of the gin-distilleries, who also consume considerable quantities of British growth, which, not being kiln-dried, as most of the Dutch grain is found to be, is more valued. 'The average quantity of buckwheat imported into England is about 10,000 quarters annually. It pays the same duty as barley. (M'Culloch's Com. Dict.) For illustrations of the varieties of buckwheat, see Pl. 3.

Buckwheat is extensively cultivated in the United States, the species usually sown being the Polygonum fagopyrum of botanists. The grain affords a favourite article of food. It is generally thought to be a severe crop upon lanद, and for this reason is seldom sown on highly improved ground. Rough and hilly districts are considered peculiarly favourable to the culture of buckwheat, which is admirably adapted to subdue new or wild lands. Besides the Climbing Buckwheat (Polygonum 232 scandens), found in the Middle States and else where, twining round bushes in moist thickets, $\& c .$, eight or ten additional varieties are enu. merated in the United States. (Flora Cestrica.)

Buckwheat comes to maturity so quickly, that it is usual to sow it upon the same ground from which wheat or other grain crops have been taken. It flourishes best in a mellow, dry, loose, sandy soil, but even on the poorest land, so that it be not moist, it will produce a tolerable crop in from three to four months after sowing. When intended for seed, it is best to put in the crop early enough to allow the grain to become perfectly matured before frost. For this purpose June or the first of July is soon enough in the Middle States. In the state of New York, buckwheat is frequently sown in August along with winter wheat, affording a ripe crop in the fall, without injury to the wheat, which grows along with and succeeds it. When sown broad-cast, the usual manner, a bushel of buckwheat is generally put upon the acre. Half the quantity is said to answer when put in with a proper drill machine. When harvested, it is usual to mow it with the scythe, and allow it to remain some time before it is taken from the field. Being very liable to heat, it is advisable to put it into small stacks of about four to six loads each. Larger stacks, or close housing, would subject it to spoiling. The quantity of produce varies greatly, according to circumstances of soil and season. In the northern part of Pennsylvania and still farther north, it is so often nipped before maturity by autumnal frosts, as to be a precarious crop. From thirty to forty-five bushels per acre may be considered an average yield in a favourable season, but sixty or eighty bushels are not unfrequently produced. Its flowers bloom and fade successively for a long time. It is thought that the crop would he much more productive, if the same uniformity in blowing and ripening existed that is observed with other grains. The buckwheat flour most preferred in the southern cities, where it commands a higher price, is that which comes from New Jersey and Pennsylvania. It is common, especially in New Jersey, to grind up with the buckwheat a fifth or sixth part of Indian corn, a peculiar kind of which, being very soft and white, is raised for the purpose. The form in which it is brought to the table is almost universally that of flat cakes, made of batter raised by means of yeast, or, what is still preferable, and requires but a few minutes in the preparation, adding a seidlitz powder to the mixture of flour and water, which causes the batter to rise at once, from the carbonic acid gas disengaged. These cakes are soft and spongy, and absorb a large quantity of butter, which is always put on while they are very warm. Considering the large amount of butter used, they cannot be regarded as economical food, except where butter is very cheap. Persons troubled with feeble digestion should never eat buckwheat prepared in this way. In Tuscany, buckwheat is mixed with barley, ground, and the flour made into bread, which possesses the property of retaining its moisture much longer than that of pure wheat; and, though of a darker colour, it is thought to be equally nou. 
rishing. In Germany, a very palatable grit, or coarse-grained meal, is made of it, which serves as an ingredient in pottage, puddings, \&c. In Brandenburg, not only ale and beer are brewed from buckwheat mixed with malt, but likewise a very excellent spirit, of a bluish shade, is obtained by distillation, in flavour resembling French brandy.

The seeds of buckwheat afford excellent fcod for cattle, and are very fattening to poultry and hogs, though it is said to make them liable to a scabby eruption. When cut in pro. per season, that is to say, about the time of flowering, when the stems and leaves are succulent and tender, it affords an excellent provender for cattle, especially for milch cows, which are very fond of it. Some intelligent farmers have thought it, for the last purpose, superior to timothy hay.

One of the purposes to which buckwheat has been applied, - and for which it appears, from the rapidity and exuberance of its growth, peculiarly adapted,-is the ploughing down to add fertility to the land. This can be done when the soil is too far exhausted to produce clover for a similar purpose. "We cannot," says the editor of the Theatre of Agriculture, " too much recommend, after our old and constant practice, the employment of this precious plant as a manure. It is certainly the most economical and convenient the farmer can employ. A small quantity of seed, costing a mere trifle, sows a large surface and gives a great crop. When in flower, first roll, and plough it in, and it is soon converted into manure." This crop is recommended by $\mathbf{M r}$. Taylor, in the Maine Farmer, as an effectual destroyer of that frequent pest of the field called couch-grass, quick-grass, \&c. For this purpose it must be sown as early in the season as frost will permit, and as soon as it gets into flower, rolled down and turned under with the plough. Another crop is then sown on top of the first, and harrowed in; and, if the season be not unfavourable, it will ripen and afford a harvest before frost sets in.

The fresh blossoms and succuleni stems of buckwheat have been applied in Europe to the purposes of dyeing wool, \&c. The infusion, by the addition of preparations of bismuth and tin, produces a beautiful brown colour. From the dried flower-bundles different shades of green are obtained. 'The Siberian species of buckwheat, in particular, yields a fine yellow, which, upon boiling the wool still longer in the dye, changes into a golden tint, and at length becomes a beautiful yellow.

BUD (Fr. bouton). The germ or first fruit of a plant, which is the organized rudiment of a branch or flower. Buds proceed from the extremities of the young shoots, and also along the branches, somerimes single, sometimes two and two, either opposite or alternate, and someumes collected in greater numbers. In general, we may distinguish three kinds of buds; the leaf-bud, the flower-bud, and mixed buds which contain both in one covering. The first species (foliferous buds) contains the rudiments of several leaves, which are variously folded over each other, and surrounded by scales. The second species, or flower-bud (floriferous buds), contains the rudiments of one or several flow. ers, folded and covered in a similar manner. The third sort, which is the most common of any, produces both flowers and leaves. A leaf-bud is constructed thus:-in its centre it consists of a minute conical portion of soft, succulent cellular tissue (the plumule or rudiment of the new twig), and over this are arranged rudimentary leaves, in the form of scales. These scales are closely applied to each other; those on the outside are the largest and thickest, and those in the interior are smaller and more delicate. In cold countries, the external scales are often covered with hair, or a resinous varnish, or some other contrivance, which enables them to prevent the access of frost to the young and tender centre which they protect, for they are strictly hybernacula; but in warm countries, where such a provision is not required, they are green and smooth, and much less numerous. 'The cellular centre of a bud is the seat of its vitality; the scales that cover $j$ are the parts towards the developement of which its vital energies are first directed. (Penny Cyclopadia, vol. v. p. 524.)

BUD. A term made use of in some districts for a weaned calf of the first year; probably from the horns then beginning to bud or shoot forth.

BUDDING, or grafting by germs, says $\mathrm{Mr}$. Loudon (Encyc. of Gard. p. 2050), consists, in ligneous plants, in taking an eye or bud attached to a portion of the bark of different sizes and forms, and generally called a shield, and transporting it to a place in another or a different ligneous vegetable. In herbaceous vegetables the same operation may be performed, but with less success. It may also be performed with buds of two or three years' standing, and on trees of considerable size, but not generally so. The object in view in budding is almost always that of grafting, and depends on the same principle, all the difference between a bud and a scion being, that a bud is a shoot or scion in embryo; in other respects, budding is conducted on the same principles as grafting. In every case, the bud and the stock must be botanically related. An apple may be budded on a pear or thorn, but not upon a plum or peach. Common budding is performed from the beginning of July to the middle of August.

It is indispensable that the bud to be inserted should be fully formed, or ripe. After the incision of the stock, great care must be taken in raising the bark that the cambium be not scraped or injured. The cambium is that soft portion between the wood and the bark destined to give support to the descending fibres of the buds, which fibres subsequently become embedded in it. In budding, therefore, the bark must be very carefully lifted up, and not forced from the wood with a bone or meta! blade as is too often done.

For propagating choice fruit, the operation of budding possesses several adrantages over that of grafting. "It is," says Buel, "more readily performed, with fewer implements, less preparation, and with greater success; it does not injure the stock if unsuccessful, and the operation may be twice or thrice repeated 
the same year, as the season for its performance is protracted, for some one or other of the varieties, for some three months. Although July and August constitute the ordinary season for budding, the plum and the cherry may often be budded in the latter part of June, and the peach, apricot, and nectarine as late as the middle of September. Youth may readily acquire the art, by little practice, under the directions we are about to give; and we know a young la ty who is an adept in it, and who practises it annually as a pleasant recreation, as well as a useful labour. We have often been treated with delicious peaches produced by the buds which she has inserted.

The first consideration is to provide stalks, if this provision has not already been made. Seeds may be collected the coming season in almost every family. Those of stone fruit may be mixed with earth, or deposited in a hole in the garden, and in the autumn buried superficially in the earth, to expose them to the expanding influence of the frost; and in the spring those of the peach and plum that have not burst the shell should be cracked, and the whole sown in a well-prepared seed-bed. The cherries may be sown immediately after they are taken from the fruit, and the apple, pear, and quince either in autumn or spring. All the kinds will generally grow the first season. The same rule applies to plants as to animals : the better condition they are kept in while young, the more profitable they will become at maturity. Thus two or three roods of grounc! will suffice a farmer for a nursery of choice fruit, from which he may replenish his orchard and his garden at pleasure, and readily appropriate to his use every new variety which comes under his observation. No one will regret the trifling labour and attention which he has bestowed on a little plantation of this kind, after he has begun to realize the fruits of it. Ornamental shrubs and trees, to embellish the grounds about his buildings, may be added without cost and with trifling labour.

A bud is an organized plant in embryo, with roots, branches, and foliage, and, like a seed, possesses individual vitality capable of developement and the reproduction of its species. The process of budding is the transferring this embryo plant from its parent tree to another tree, which must at least be of the same genus, if not of the same species. The apricot and nectarine may be, and generally are, budded upon the peach; the plum and the peach are budded on each other, and the pear and apple may be worked on the wild crab and hawthorn; and the former is put on the quince to produce dwarf trees. To render the transfer or budding successful, three things are requisite: 1 . That the bud be in a proper condition to transfer; 2. That the stalk be in condition to receive and nourish it; and, 3 . That the transfer he skilfully made. The bud ought to be matured, i. e., of full growth, and yet not so hard and firm as to cause injury in separating it from its parent. The stock must peel freely, as this is necessary for the insertion of the bud, and indicates the presence of whai is termed the cambium, which is the soft partially-formed woody matter us.terlaying the bark, and which ripens into indurated wood. It is the source of nourishment to the bud, and the bond of union between it and the stock. The operator must therefore use caution that he injures neither the bud, the bark, nor the cambium, as these all exercise important offices in effecting the union; and he must withal take care to apply his ligatures properly. It will be seen, from these remarks, that both the stock and the graft should be in a state of active growth, and the more vigorous the better, when the budding process is performed. It is also preferable to bud when the weather is cloudy, but not wet. Twigs for budding may be preserved for many days with care. They should be immediately divested of their leaves, but not wholly of their leaf-stalks or petioles, to prevent the exhaustion of moisture, and may then be wrapped in fresh grass, wet cloths, or with their butt ends preserved in moisture.

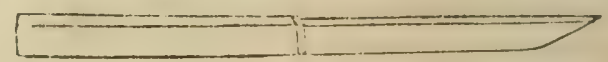

\section{Fig. 2.}

The only implement necessary is a buddingknife (fig. 2 ), and the only preparation some bass matting, or the inner bark of the basswood or linden. Filaments torn from the husk of Indian corn are also recommended.

Professor Thouin enumerates twenty species or varieties of grafting, most of which are only practised by amateurs and professional gardeners. We shall describe only the common mode, which is in general practice in nurseries. We take it from the Encyclopedia of Gardening.

Shield-budding, or $\mathrm{T}$ budding, is thus performed: Fix on a smooth part of the side of the stock, rather from than towards the sun, and of a height depending, as in grafting, on whether dwarf, half, or whole standard trees are desired; then, with the budding-knife, make a horizontal cut across the rind, quite through to the firm wood; from the middle of this transverse cut make a slit downward, perpendicularly, an inch or more lnng, going also quite through to the wood. This done, proceed with all expedition to take off a bud; holding the cutting or scion in one hand, with the thickest end outward, and, with the knife in the other hand, enter it about half an inch or more below a bud, cutting nearly halfway into the wood of the shoot, continuing it with one clear slanting cut about half an inch or more above the bud, so deep as to take a part of the bud along with it, the whole about an inch and a half long ( $\alpha$, fig. 1$)$; then directly with the thumb and finger, or point of the knife, clip off the woody part remaining to the bud; which done, observe whether the eye or germ of the bud remain perfect; if not, and a little hole appears in that part, it is improper, or, as gardeners express it, the bud has lost its root, and another must be prepared. This done, placing the back part of the bud or shield between your lips, expeditiously with the flat haft of the knife separate the back of the stock on each side of the perpendicular cut clear to the wood $(c)$, for the admission of the bud, which directly slip down, close between 
the wood and bark, to the bottom of the slit $(d)$. The next operation is to cut off the top part of the shield $(b)$ even with the horizontal firstmade cut, in order to let it completely into its place, and to join exactly the upper edge of the shield with the transverse cut, that the descending sap may immediately enter the back of the shield, and protrude granulated matter between it and the wood, so as to effect a living union. 'The parts are now to be immediately bound round with a ligament of fresh bass (e), or other suitable substance, previously soaked in water to render it pliable and
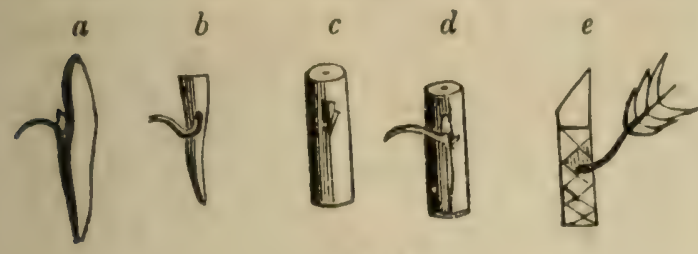

Fig. 1. and cross the broadest rivers without hesitation. 'Their gait is heavy, and they run almost always with the nose horizontal, being principally guided by the sense of smelling. They herd together in small flocks, or live in pairs, but are never strictly gregarious in a wild state. The females bear calves two years following, but remain sterile the third; they propagate at four and a half years old, and discontinue after twelve. "The common buffalo (says Professor Low) has come to us, beyond a question, from Eastern Asia. He seems to have been introduced into Italy about the sixth century, and is now an important animal in the rural economy of that country. He is used by the Italians as food and as the beast of labour, and may be said to form the riches of the inhabitants in many parts of the country. $\mathrm{He}$ is cultivated, too, in Greece and Hungary. The milk of the female is good, but the flesh is held in less esteem than that of the common ox. The pace of the animal is sluggish; but from the low manner in which he carries his head, throwing the weight of his great body forward when pulling, he is well suited for heavy draught. But this is not a property sufficiently important to cause the introduction of the buffalo into the agriculture of northern Europe, and he is not likely, therefore, to be cafried beyond the countries where he is now reared." Buffalo hunting on elephants is one of the field sports of the East; and this animal is also hunted on foot with avidity by the Caffres at the Cape of Good Hope, as well to get rid of a dangerous foe as to furnish themselves with food from his flesh and leather from his hide. (Brande's Dict. of Science; Blaine's Encyc. of Rural Sports; Elements of Practical Agriculture.) For American Buffalo, see Brsov.

BUFFALO BERRY TREE (Shepardia magnoides). Silver-leaved Sheperdia. A very beautiful tree, discovered by Mr. Nuttall in Missouri. The tree is of upright growth and thorny, the leaves small and of a delicate and silvery appearance. The fertile and barren flowers are produced on different trees. The fruit consists of berries about the size and ap. pearance of large currants, of a fine scarlet colour, and very beautiful, enveloping the branches in profuse clusters. It has a rich taste, and is considered valuable for making into tarts and preserves.

BUGLE, COMMON (Ajuga reptans). This very pretty wild plant grows in woods, copses, moist pastures, and shady places, flowering in April, May, and June. It is a perennial; has blue flowers, upright leafy stalks, and glossy leaves, of a deep purplish-green colour, oblong, broad, blunt at the point, and slightly indented round the edges, some growing immediately from the root. The flower-stalks rise eight or ten inches high, of a pale green-often purplish-and have two leaves at each joint, which joints are far apart from each other. The joint leaves are as large as those growing from the root. The scentless flowers are blue and white, sometimes entirely white, growing round the upper part of its stalk, forming a kind of loose spike. The cups remain, when the flower has fallen off, to hold its seed: This plant is often denominated sicklewort, an. 
hert carpenter. The roots (says Smith) are slightly astringent; but the herb has little taste or smell, and still less of any healing or vulnerary property. The white variety abounds in the Isle of Wight; and a flesh-coloured one has sometimes been observed. In dry mountainous situations the plant acquires a considerable degree of hairiness. The French, who are great herbalists, affirm, that "with bugle and sanicle, no one needs a surgeon."

Besides the common bugle, Smith, in his English Flora, (vol. iii. p. 65-67), enumerates three other species, the alpine bugle, pyramidal bugle, and ground pine or yellow bugle (Ajuga chamapitys).

BUGLE-HORN (from bucula, a heifer). A wind-instrument, much more commonly employed in the sports of the field formerly than at present. It has been, however, in our days, much improved for musical purposes by the introduction of keys.

BUGLE-WEED (Virginian lycopus), a creeping perennial found in the Middle States, frequenting swamps and moist woodlands, producing minute white flowers in June and July. It constitutes a prominent article in the materia medica of certain German empirics, in the city of Lancaster, and other parts of Pennsylvania,-who prescribe an infusion as a certain remedy for a "dry liver," an infirmity which, they allege, afflicts a large proportion of those credulous persons who consult them. (See Flor. Cestrica.)

BULB (Lat. bulbus; Gr. BunGas). A bud usually formed under ground, having very fleshy scales, and capable of separatinf from its parent plant. Occasionally it is produced upon the stem, as in some lilies. It contains the rudiments of the future plant, and partakes of the character of the bud (which see). In bulbous plants, as the tulip, onion, or lily, what we generally call the root is in fact a bulb or hybernaculum, or winter case, which incloses and secures the embryo or future shoot. At the lower part of this bulb may be observed a fleshy disk, knob, or tubercle, whence proceed a number of fibres or threads. 'This knob, with the fibres attached to and hanging from it, is, properly speaking, the true root; the upper part being only the cradle or nursery of the future stem, which, being replaced a certain number of times, the bulb perishes; but not till it has produced at its sides a number of smaller bulbs or cloves for perpetuating the species. In bulbous plants, where the stalk and former leaves of the plant are sunk below, into the bulb, the radicles or small fibres that hang from the bulb are to be considered as the root; that is, the part which furnishes nourishment to the plant: the several rinds and shells whereof the bulb chiefly consists successively perish, and shrink up into so many dry skins, betwixt which, and in their centre, are formed other leaves and shells, and thus the bulb is perpetuated. There are several kinds of bulbs; namely, 1. The tunicated bult (Bulbus tunicatus), formed of thin membranous layers, as, for example, the onion; 2. The scaly bulb (B. squammosus), formed of fleshy abortiv: leaves, not in layers, as in the lily. The cloves, which are produced between the scales of bulbs, are often, as it were, starved, when the bulb throws up a vigorous flowering stem; thence, in order to propagate bulbs, the flowering stem should be destroyed as soon as it appears.

BULLACE TREE, WILD (Prunus insititia). A small tree, chiefly growing in hedges and plantations, with irregularly-spreading round branches, for the most part tipped with a sharp straight thorn. There are several varieties of the black kind, differing in size and flavour, some good even in a fresh state, and of more or less excellence when dressed. (Smith's Eng. Flor. vol. ii. p. 356).

BULLEN. A provincial name applied to the hempstalk when the bark is stripped from it

BULRUSH (Scirpus lacustris). A perennial found commonly in clear ditches, ponds, and the borders of lakes and rivers; flowers in July and August. (Smith's Flora, vol. i. p. 56.) From this plant the bottoms of chairs, mats, \&c. are made. The common bulrushes of the English marshes, which bear masses of brown flowers, are the Typha latifolia and angustifolia. See Rusu.

BUNIAS. The oriental bunias (Bunias orientalis, $\mathrm{Pl} .9, k$ ) is a perennial plant, with leaves, branches, and its general habit of herbage, not unlike the wild chiccory. It is a native of the Levant or eastern shores of the Mediterranean, and has been cultivated by way of experiment in the grass garden at Woburn. It is less productive than chiccory, bears mowing well, and affords the same nutriment, in proportion to its bulk, as red clover. (Loudon's Ency. of Agr.)

BUR. The rough head of the burdock, \&c. BURDOCK (Arctium). There are two species, the $A$. lappa, common burdock or clotbur, and the $A$. lardana, woolly-headed burdock. 'This very cumbrous weed is removed the first year of its growth by stubbing, like other things comprehended by farmers under the name of docks, and paid for accordingly to the weeder. It is also very commonly found in waste ground, by waysides, and among rubbish. (Smith's Eng. Flora, vol.iii.p. 379.) It grows a yard high, with large leaves of a triangular shape, and of a whitish green colour. The stalks are round, solid, and tough. The florets are small and red, and they grow among the prickles of those heads called burs, which stick to the clothes of passers-by. The root is long and thick, brown outside, and whitish within. The plant is a biennial, and flowers in July and August. The root in decoction is a diuretic and sudorific; but it is of little value, except as a vehicle for more important medicines in some affections of the skin. This is a great remedy among village doctresses, who sometimes apply the bruised leaves to the soles of the feet in hysterics. Either the root or seeds decocted, or infused, are equally useful with the leaves. The root of the lesser burdock, or xanthium (Bardana minor), has a bitter and acrid flavour, and is useful in scrofulous disorders. A decoction of the root should be persevered in for a considerable length of time.

BURGLARY. The breaking into a dwelling-house in the night with a felonious intent 


\section{BURGOT.}

The 7 W. 4 , \& 1 Vict. c. 86, s. 2 , enact, that whosoever shall burglariously break and enter into any dwelling-house, and shall assault with intent to murder any person being therein, or shall stab, cut, wound, beat, or strike any such person, shall be guilty of felony, and being convicted thereof shall suffer death. S. 3 enacts, that whosoever shall be convicted of the crime of burglary shall be liable, at the discretion of the court, to be transported beyond the seas for the term of the natural life of such offender, or for any term not less than ten years, or to be imprisoned for any term not exceeding three years. S. 4 enacts, that, so far as the same is essential to the offence of burglary, the night shall be considered to commence at nine of the clock in the evening of each day, and to conclude at six of the clock in the morning of the next succeeding day. (Arrhbold's Crim. Lav.)

BURGO'T. A provincial word applied to yeast. It is sometimes pronounced burgood.

BUR-MARIGOLD (Bidens). This is an herbaceous, mostly annual, genus of plants, flowering in August and September. It is met with very frequently in watery places, and about the sides of ditches and ponds. There are two species, with one or two varieties in each. In the three-lobed bur-marigold ( $B$. tripartila), the root is tapering with many fibres; stem two or three feet high, erect, solid, smooth, leafy, with opposite axillary branches. Leaves dark green, strongly serrated, in three deep segments, sometimes five. Flower, terminal, solitary, of a brownish-yellow, somewhat drooping, devoid of beauty and of fragrance. Seeds with two or three prickly angles, and as many erect bristles; likewise prickly with reflexed hooks, by which they stick like burs to any rough surface, and are said sometimes to injure fish by getting into their gills. The herb of this species gives a yellow colour to woollen or linen. The nodding burmarigold ( $B$. cermua) has a root with many stout fibres, herb more erect and taller, with less extended branches than the foregoing species. Leaves undivided, pointed, and less deeply serrated. Flowers drooping, though their stalks are quite straight to the very summit; larger and handsomer than the last. (Smith's Eng. Flora, vol. iii. p. 398.)

Among the species of bidens or bur-marigold, found in the United States, are the following: the chrysanthemum-like bidens, commonly called beggar-ticks, an annual; and the bipinnate bidens, popularly called Spanish needles. These and the other American species of bidens or burweed are noted for mature akenes adhering, by their barbed awns, to the clothing of those who go among them in autumn. They are rather troublesome weeds along fence-rows, \&c., and bloom and ripen their seeds late in the season.

BURNET, COMMON (Pimpinella saxifraga). There are three species of burnet; namely, burnet saxifrage, dwarf burnet, and the greater burnet. The common burnet plant (Plate 9, $a$ ) was, a quarter of a century since, much cultivated as a green crop, from its being able to thrive on very poor, thin, and sandy soils, but it has been gradually super-

\section{BURNING.}

seded by better grasses. Its growth is rather slow. Cattle prefer it to clover and rye-grass, but sheep do not. (Ann. of $\mathcal{A g r}_{\mathrm{g}}$ vol, i. p. 394.) It is sown in spring-time, the same as other grass seeds, and withstands severe weather. It should be fed off when young (Ibid, vol. ii. p. 176); and then, says Arthur Young, "it is one of the best grasses for sheep" (Ibid.p. 369). who are at that stage of its growth exceedingly fond of it. About $7 \mathrm{lbs}$. of seed suffice for an acre (Ibid. vol. xvi. p. 355); and the produce is six or seven bushels per acre, on moderate land. (Ibil. vol. xx. p. 237.)

BURNET, SALAD, SMALL or UPLAND (Polerium sanguisorba, from the Greek $\pi: \tau$ нprov, a cup, used in cool tankards). The stem, which is angular, smooth, and leafy, rises one to two feet high, furnished with glaucous-green, smooth, pinnated leaves, with sharply cut stipules, in pairs at the base of the footstalk. The flowers are fertile and barren; the latter with crimson stamens resembling elegant silk tassels. (Smith.) It delights in a dry, poor soil, abounding in calcareous matter; any light compartment that has an open exposure, therefore may be allotted to it, the only beneficial addition that can be applied being bricklayers' rubbish or fragments of chalk. A small bed will be sufficient for the supply of a family. It may be propagated either by seed, or by slips and partings, or offsets of the roots. The seed may be sown towards the close of February, in open weather, and thence until the close of May; but the best time is in autumn, as soon as it is ripe; for if kept until the spring, it will often fail entirely, or lie in the cround until the same season of the following year, without vegetating. It may be inserted in drills, six inches apart, or broadcast ; in either mode, thin, and not buried more than half an inch. The plants must be kept thoroughly clear of weeds throughout their growth. When two or three inches high, they may be thinned to six inches apart, and those removed placed in rows at the same distance, in a poor, shady border, water being given occasionally until they have taken rool, after which they will require no further attention until the autumn, when they must be removed to their final station, in rows a foot apart. When of established growth, the only attention requisite is to cut down their stems occasionally in summer, to promote the production of young shoots, and in autumn to have the decayed stems and shoots cleared away. If propagated by partings, \&c. of the roots, the best time for practising it is in September and October. As it grows freely from seed, this is not usually practised. They are planted at once where they are to remain, and only require occasional watering until established. The other parts of their cultivation are as for those raised from seed. For the production of seed, some of the plants must be left ungathered from, and allowed to shcot up early in the summer; they flower in July, and ripen abun dance of seed in the autumn. The leaves taste and smell like cucumbers, thence the plant is used to flavour salads. (G.W. Johnson's Kitrhen Garder.)

BURNING. See Arsor. 
BURNING OF LIME. See LIME.

BURNS, in live stock, are best treated by a lotion composed of lime-water and linseed-oil, equal parts, applying it frequently; this allays the inflammation very rapidly.

BURN'T CLAY. See Ashes.

BUR-REED (Sparganium). Smith (Eng. Flora, vol. iv. p. 73) enumerates three species: 1. The branched bur-reed (S. ramosum); 2. The unbranched upright bur-reed (S. simplex); 3. The floating bur-reed (S. natans). They are all creeping-rooted, aquatic, juicy, smooth, upright, or floating herbs, and found in pools and ditches, and the margins of ponds and rivers: common: the last named principally in muddy fens, or slow rivers. 'The bur-reed is a perennial, flowering in July and August; the stems of some of the species attain to the height of three or four feet. The herbage of the branched bur-reed serves for package along with similar coarse grassy plants, and is softer and more pliant than most of them, not cutting the hand by any sharp edges, like carices or ferns. The unripe burs are very astringent. 4 strong decoction of the burs makes a wash or old ulcers. Dr. Darlington describes an American species of bur-reed, frequent in ditches, sluggish streams, \&c., in the Middle States. (Flor. Ces.)

BURROW (Teut. bergen, to cover). A provincial word, signifying a heap or hillock, hence stone-burrows, peat-burrows, \&c.

BUR-WEED (Xanthium strumarium). The broad-leaved bur-weed is an annual plant, fowering in August and September, found in rich moist ground, or about dunghills in the south of England; but rare. It is herbaceous or somewhat shrubby, rather downy, of a coarse habit, root fibrous; stem solitary, erect, branched, leafy, two feet high, solid; leaves on long stalks, heart-shaped, two or three inches wide; clusters of four or five fertile green flowers, and one or two barren ones, making no show. Old tradition reports that the xanthium is good for scrofulous disorders, as the specific name seems to indicate; but it is now out of use. The generic appellation alludes to a quality of dyeing yellow, which Dioscorides mentions. (Snith's Eng. Flora, vol. iv. p. 136.)

The scrofulous xanthium, clot-weed, or cockle-bur is an obnoxious weed, found in the United States about farm-yards, road-sides, \&c. It is an annual not much inclined to spread, and therefore, by a little attention, could generally be easily got rid off. The burs are a great annoyance in the fleeces of sheep. (Flor. Cestrica.)

BUSH (Teut. busch; Dan. busk). A thick shrub, or a collecion of shrubs or plants, growing close together, so as to form a sort of clump. It is also a provincial word, signifying the box of the nave of a wheel.

BUSH-DRAINING. A term applied to a kind of draining, which is done by putting in, or filling the drains with bushes. See DraisING.

BUSHEL (Old Fr. buschel; low Lat. bussellus). A measure of capacity for dry goods, as grain, fruit, pulse, and many other articles, conriining 1 pecks, 8 gallons, or 32 quarts, and is 238 the eighth of the English quarter. The name seems to be derived from an old English word, buss, signifying a box or vessel.

The bushel, by a statute made in the twelfth year of Henry the Seventh, is to contain 2150.42 cubic inches, or 8 gallons of wheat; the gallon of wheat to weigh 8 lbs. troyweight; the pound, $12 \mathrm{oz}$. troy-weight; the ounce, 20 sterlings; and the sterling, 32 grains. By 5 Geo. 4, c. 74, the imperial gallon is declared the standard measure of capacity, and is directed to be made such as to contain 10 lbs. avoirdupois of distilled water, weighed in air at the temperature of $62^{\circ}$ of Fahrenheit's thermometer, the barometer standing at 30 inches, or to contain 277 cubic inches, and 274 thousandth parts of a cubic inch; consequently, the imperial bushel contains $80 \mathrm{lbs}$. of distilled water, or 2218.192 cubic inches. By the same act $(\$ 7)$, the bushel is declared the standard measure of capacity for coals, culm, lime, fish, potatoes, or fruit, and all other goods or things commonly sold by heaped measure, and is prescribed to contain 2815 cubic inches, to be made round with a plain and even bottom, and being $18 \frac{1}{2} \frac{3}{4}$ inches in the interior diameter by 8 in depth, and $19 \frac{1}{2}$ inches from outside to outside; the goods to be heaped up in the form of cone, to a height above the rim of the measure of at least three. fourths of its depth.

Besides the standard or legal bushel, there are in England several local bushels, of different dimensions in different places. At Abingdon and Andover, a bushel contains 9 gallons : at Appleby and Penrith, a bushel of peas, rye, and wheat, contains 16 gallons; of barley, big malt, mixed malt, and oats, 20 gallons. A bushel contains, at Carlisle, 24 gallons : at Chester, a bushel of wheat, rye, \&c., contains 32 gallons, and of oats 40 ; at Dorchester, a bushel of malt and oats contains 10 gallons; at Falmouth, the bushel of stricken coals is 16 gallons; of other things 20 , and usually 21 gallons : at Kingston-upon-Thames, the bushel contains $8 \frac{1}{2}$; at Newbury, 9 ; at Wycomb and

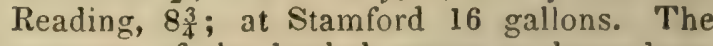
contents of the bushel seems to have been gradually increasing; the Winchester bushel, used in England from the time of Henry VII. to 1826 , contained 2150.42 cubic inches. The imperial bushel is therefore to the Win. chester bushel as $2218 \cdot 192$ to $2150 \cdot 42$, or as 1 to 969447 . Hence to convert Winchester bushels into imperial, multiply by 969447 . To convert prices per Winchester bushel into prices per imperial bushel, multiply by $1 \cdot 0315157$.

The heaped bushel was abolished by 4 \& 5 Will. 4 , c. 49 , an act which took effect from the first of January, 1835. (Brande's Dict. Science; Penny Cyclopadia; M'Culloch's Com. Dic.)

BUSH-HARROW. An implement constituted of any sort of bushy branches, interwoven in a kind of frame, consisting of three or more cross-bars, fixed into two end pieces in such a manner as to be very rough and brushy underneath. To the extremities of the frame before are generally attached two wheels, about twelve inches in diameter, upon which 


\section{BL'SH-HAIRIROWING.}

It иıves; sometimes, however, wheels are not impioyed, but the whole rough surface is applied $(0)$ and dragged on, the ground. See Hanew.

BUSH-HARROWING. The operation of harrowing with an instrument of the kind just described. It is chiefly necessary on grasslands, or such as have been long in pasture, for the purpose of breaking down and reducing the lumps and clods of the earth or manures that may have been applied, and thereby rendering them more capable of being washed into the ground, or for removing the wormcasts and mossy matter that may have formed on the surface.

BUSH-VE'TCH (Vicia sepium). A plant of the vetch lind, which may probably be cultivated to advantage by the farmer, where lucerne and other plants of a similar nature cannot be grown. Its root is perennial, fibrous, and branching; the stalks many, some of them shooting immediately upwards, others creeping just under the surface of the ground, and emerging, some near to, and others at a considerable distance from, the parent-stock. The small oval leaves are connected together by a mid-rib, with a tendril at the extremity; the flowers are in shape like those of the common vetch, of a reddish-purple colour; the first that blossom usually come in pairs, afterwards to the number of four at a joint; the pods are much shorter than those of the common vetch, larger in proportion to their length, and flatter, and are of a biack colour when ripe; the seeds are smaller than those of the cultivated species, some speckled, others of a clay colour. It yields, from a brown sandy loam, 17,696 lbs. per acre of grass, and of nutritive matter 976 Ibs. It flowers in the middle of May, and maintains its place when once in possession of the soil, but appears unfit for clayey soils. The seeds are sown in April or the beginning of May. (Hort. Gram. Wob. p. 210.) Being a perennial plant, Mr. Swayne deems it to be a proper kind to intermix with grass seeds for laying down lands intended for pasture; and that it is as justly entitled to this epithet as any herbaceous plant whatever, having observed a patch of it growing in one particular spot of his orchard for fourteen or fifteen years past. It is not only a perennial, but an evergreen: it shoots the earliest in the spring of any plant eaten by cattle with which he is acquainted; vegetates late in autumn, and continues green through the winter, though the weather be very severe: add to this, that cattle are remarkably fond of it. The chief reason that has hitherto prevented its cultivation has leen the very great difficulty of procuring good seed in any quantity. The pods, he finds, do not ripen altogether; but as soon almost as they are ripe, they burst with great elasticity, and scatter the seed around; and after the seeds have been procured, scarce one-third part of them will vegetate, owing, as he supposes, to an internal defect, occasioned by certain insects making them the nests and food for their young. It seems, also, that a crop of this kind of vetch may be cut three or four times, and in some cases even so early as the beginning of March-a circumstance of much
BUTYYLR.

importance to farmers who have a large stoc 2 of cattle. (Trans. Buth and West of Englond Soriety, vol, iii.)

BU'T'T. A provincial term applied to such ridges or portions of arable land as run out short at the sides or other parts of fields; also to a vessel holding 126 gallons of wine, 108 of beer: and to a measure of from 15 to $22 \mathrm{cwts}$. of currants. To bult, from Dutch bollen, to strike. Butl-land is the place where, in days of archery, the butts for practice were placed. It is also applied provincially to a closebodied cart: hence a dung-butt, or wheelcart, gurry-butt, or sledge-cart, ox-butt, horsebutt, \&c.

BU'T'TER (Ger, butter; Dut. boter). A well. known article of domestic consumption, com. monly procured by churning the milk of the cow. It was not an article employed by the early Greeks and Romans. "The ancient Romans," says Mr. Aiton (Quart. Journ. Agr. vol. v. p. 357), "knew nothing of making butter until they were taught by the Germans how to make it, and it was not used by them as food, but merely as oil." Herodotus says, that the Scythians formed butter by agitating mare's milk; and the poet Anaxandrides says, that the Thracians ate butter, at which the Grecians were surprised. When Julius Cæsar invaded England, he found that the inhabitants had abundance of milk, from which they made butter, but could not make cheese till they were taught that art by their invaders. The Arabs, it seems (Burckhardt's Travels in Nubia, p. 441), are very large consumers of fresh butter, and they are in the habit of drinking every morning a cupful of melted butter, or ghee, as it is called in the East. In India, ghee is made from the milk of the buffalo, and a very considerable traffic is carried on with it. It is usually conveyed in leather bottles or duppers, holding from ten to forty gallons; some are made of hide. The colour of butter is yellow; it possesses the property of an oil, and mixes readily with other oily bodies; it melts and becomes transparent at $96^{\circ}$ Fahrenheit, and if it is kept in this state for some time, it assumes exactly the appearance of oil, loses its peculiar flavour, and some curds and whey separate from it. Milk, in fact, is composed of cream, curd, and whey. The cream and the milk are merely united mechanically, and when, therefore, the new milk is allowed to rest, the cream, being the lighter of the two, rises gradually to the top; the curd separates from the milk, ton, with the assistance of a very slight degree of acidity. Butter may be made by the agitation of either cream or new milk: fresh cream is not commonly used, because it requires four times the churning that stale cream does. (Fourcroy, Ann. de Chém. tom. vii. p. 169.) The contact of the atmospheric air is not absolutely essential to the production of butter from cream, although the oxygen of the air is usually absorbed in churning: according to $\mathrm{Dr}$. Young, there is an increase in the temperature during the operation of four degrees. Buttermilk is merely milk deprived of its cream, in which it rapialy becomes sour, and the curdy or cheesy part is separated from the whey or serum. Cream of 239 
the specific gravity 1.0244 was found by Berzelius to contain-

\begin{tabular}{|c|c|c|c|c|c|c|}
\hline & & & & & & Parts \\
\hline Butter & - & - & - & - & - & \\
\hline Cheese & - & - & - & - & - & $-\quad 35$ \\
\hline Whey & - & - & - & - & - & -92.0 \\
\hline
\end{tabular}

Curd, which is easily separated from creamed milk by rennet, has many of the properties of coagulated albumen: it is composed, according to the analysis of MM. Gay Lussac and Thenard, of

\begin{tabular}{|c|c|c|c|c|c|c|}
\hline Carbon & - & - & - & - & - & $\begin{array}{r}\text { Parts. } \\
-59.781\end{array}$ \\
\hline Oxygen & . & - & - & - & - & -11.409 \\
\hline Hydrogen & - & - & - & - & - & $-7 \cdot 429$ \\
\hline Azote & . & - & - & - & - & $-21 \cdot 381$ \\
\hline . & & & & & & $100^{\circ}$ \\
\hline
\end{tabular}

Curd, adds Dr. Thomson (System of Chem. vol. iv. p. 499), as is well known, is used in making cheese, and the cheese is the better, the more it contains of cream, or of that oily matter which constitutes cream. It is well known to cheese-makers, that the goodness of it depends in a great measure on the manner of separating the whey from the curd. If the milk be much heated, the coagulum broken in pieces, and the whey forcibly separated, as is the practice in many parts of Scotland, the cheese is scarcely good for any thing; but the whey is delicious, especially the last squeezed out whey; and butter may be obtained from it in considerable quantities. But if the whey is not too much heated $\left(100^{\circ}\right.$ is sufficient), if the coagulum be allowed to remain unbroken, and the whey be separated by very slow and gentle pressure, the cheese is excellent, but the whey is almost transparent and nearly colourless. (Journal de Phys.)

When milk is deprived of its cream, it is composed, according to M. Berzelius, of

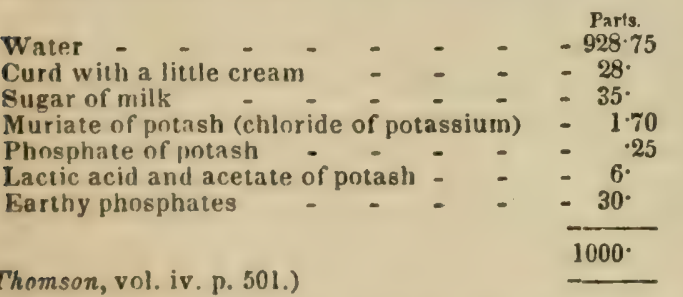

From some valuable experiments on the temperature at which butter may be best procured from crearn, by Dr. John Barclay and Mr. Allen, it appeared "that cream should not be kept at a high temperature in the process of churning. In the experiment when the temperature was !owest, the quantity of butter obtained was in the greatest proportion to the quantity of cream used; and as the temperature was raised, the proportional quantity of butter diminished; while, in the last experiment, when the mean temperature of the cream had been raised to $70^{\circ}$, not only was the quantity of butter diminished, but in quality it was found to be very inferiol, both with regard to taste and appearance. That the lowest possible temperature should be sought in churning, appears likewise from another result of these experiments, the specific gravity of the churned milk having been found to diminish as the temperature of the cream was increased; thus showing, that at the lower temperature, the butter, which is composed of the lighter parts of the cream, is more completely collected than at the higher temperature, in which the churned milk is of greater specific gravity." The conclusion to which they came therefore was, that the most proper temperature at which to commence the operation of churning butter is from $50^{\circ}$ to $55^{\circ}$, and that at no time of the operation ought it to exceed $65^{\circ}$; while, on the contrary, if at any time the cream should be under $50^{\circ}$ in temperature, the labour will be much in. creased, without any proportional advantage being obtained; and a temperature of a higher degree than $65^{\circ}$ will be injurious as well to the quality as the quantity of the butter. (Trans. High. Soc. vol. i. p. 194.) One of these experiments it may be well to abridge:-15 gallons of cream at the temperature of $50^{\circ}$ were churned; each gallon (equal to holding $8 \mathrm{lbs}$. $4 \mathrm{oz}$. of water) weighed $8 \mathrm{lbs} .4 \mathrm{oz}$; by churning for two hours, the temperature of the cream rose to $56^{\circ}$; at the end of the churning it was $60^{\circ}$. The butter obtained weighed $29 \frac{1}{2} \mathrm{lbs}$. avoirdupois, or nearly $2 \mathrm{lbs}$. for each gallon of cream: the butter was firm, rich, and pleasant. A gallon of the churned milk weighed 8 lbs. 9 oz.

Mr. J. Ballantyne found that the greatest quantity of butter from a given quantity of cream is obtained at $60^{\circ}$, and the best quality at $55^{\circ}$ in the churn just before the butter came; when the heat exceeded $65^{\circ}$, no washing could etach the milk from the butter without the aid f salt; but when a quantity of salt was wrought well into it, and the mass allowed to stand for twenty-four hours, and then well washed, the milk was separated. (Trans. High. Soc. vol. i. p. 198.)

The method of making the best butter all over the dairy district of Scotland, is thus described by Mr. Aiton (Quart. Journ. Agr. vol. v. p. 351): The milk, when drawn from the cow, is placed from six to twelve hours in coolers, the same as when set aside to cast up its cream; but this is merely to let the milk cool; and whenever it is divested of its natural heat, the whole meal of milk is emptied from the coolers into a stand vat or tub sufficient to contain the whole. If the vat is large, and a second meal of milk has become cold before the for mer meal of milk has begun to acidify, the second may be turned into the first. It is then placed in a vat, covered over, and allowed to remain undisturbed, till the milk has not only acidified, but until it has been formed into a coagulum (or lapper, in dairy language). It is now ready to be churned; and, proviled the lapper is not broken (which makes it ferment), it may remain, without injury, unchurned for some days.

Milk prepared in this way is churned in upright or plunge churns, of a size to suit the magnitude of the dairy. Where only a few cows are kept, the churns will hold about 100 quarts, from 200 to 240 quarts, and some still more. These large churns are on some large farms moved by machinery of various constructions, but in most dairy farms, churns of 200 quarts are wrought by hand-labour only. After the clotted milk is put into the churn, as much hot water is poured amongst the milk as to raise the temperature from $50^{\circ}$ or $55^{\circ}$, which 


\section{BUTTER.}

\section{BUTTER。}

is about the ordinary temperature of a good spring or milk-house. Experiments instituted for the purpose have determined this as the best temperature at which to commence the operation of churning, and that at no time during the operation ought it to exceed $65^{\circ}$. If the temperature be higher, it will be attended with injury to the quality and quantity of the butter. If lower than $50^{\circ}$, the butter will not "come." After the butter has formed, warm water may be gradually added, so as to raise the temperature to $70^{\circ}$ or $75^{\circ}$, one person agitating while another throws in the water. The temperature must be raised to or above $70^{\circ}$ before the butter can be separated from the milk; and this cannot be accomplished in any way so well as by pouring in boiling water after it has begun to be churned. If the milk is too cold, when churning it swells, has a pale white colour, throws upon the surface many air-bubbles, and emits a rattling noise; the time of churning is from $2 \frac{1}{4}$ to $2 \frac{3}{4}$ hours; the milk being of ordinary quality, 24 pints imperial yield 24 ounces of buiter.

In the making of butter, care and cleanliness are requisite. The cows should be milked in the cool of the morning and evening; they should be driven very gently, and if brought to the milking-place some little time previously, it will be all the better. In some countries they milk them in their pastures, a practice commonly followed in mountainous districts, and where they are distant from the dairy. The teats of the cow should be washed often with water, and the dairy floors (which are be:st of brick) and all the dairy utensils cannot be too frequently washed, not only because dirt is exceedingly noxious to the production of good butter, but from the coolness which it produces in the dairy.

When the milk is brought into the dairy, it is strained through a sieve, to remove any mechanically diffused matters, and then placed in shallow pans and coolers, or leaden troughs. Some are made of iron tinned, others of brass. There is, however, an objection to leaden troughs, for at the point of contact between the air and the cream, the latter aids the oxidizement of the lead; and carbonic acid being attracted, a carbonate of lead (white lead) is formed, and communicates a poisonous property to the cream. Painters' colic has been thus sometimes communicated to dairymaids. Zinc, or iron tinned, is preferable to lead for dairy vessels. The same objection applies to brass as to lead. Metal ones are regarded as the best, from their rapidity of cooling in summer, and from their being more easily warmed in the winter; they are besides (and the same remark applies to the milk pails, \&c.) more readily and completely cleaned than those of wood or earthenware. The dairy should be well ventilated by wire-gauze windows, and protected by either trees or buildings from the heat of the sun. In twelve hours the finest portion of the cream has risen to the surface, which, if then separated from the milk and churned, produces a very delicate butter. It is commonly left, however, for twenty-four hours, and then skimmed off and deposited in an earthen vessel. In the dairies of the usual 31 size, the cream collecied is churned every two days, and the formation of the butter is found to be materially accelerated by the creain ac. quiring a slight acidity; indeed, it has been sometimes contended that, without the presence of an acid, butter cannot be made. Isactic acid indeed is always present in buttermilk; an acid quality is even, in some cases, in parted to it by the dairywomen, who add a small quantity of vinegar or lemon-juice; this, however, does not improve the flavour of the butter, and it injures it considerably for salting. To effect the separation of the butter from the cream, a considerable degree of agitation is necessary, varying with the electrical state of the atmosphere, and other circumstances. Of the influence of electricity no one will doubt who has witnessed the effect of a thunder-storm on a dairy of milk. The agitation or churning is produced by various-sized churns, the most common shaped of which is the upright wooden churn, with an upright plunger; others are made of barrels, turning on an axle by means of a common winch; some are made like cradles, and rock much in the same manner: these are worked chiefly by hand. But it is sometimes done by horse power, and very commonly now in Cheshire by small portable high-pressure steam-engines: these last might easily be made to cut chaff, bruise corn for stock, crush bones, and a variety of other useful purposes.

In the course of a period varying from one hour to several hours, according to circum. stances, the butter begins to make its appearance in small lumps or kernels, which are gradually increased in number as the churning proceeds; these are collected and placed in a shallow wooden vessel, or washing-tub, and when all the butter is "come" or extracted, little else remains but the buttermilk. The butter placed in the washing-tub is worked by the hand into a mass, the butrermilk squeezed out, and the butter washed in , ater, an operation which, when it is intended for keeping, cannot be too carefully performed; and if the person who works it has not a very cool hand, it should be kept as cool as possible by fre. quent ablutions in cold water. A large portion of the butter made at a distance from large towns is salted and put into casks or firkins, which weigh about 56 lbs.; about 3 or 4 lbs. of salt are required for this purpose, which should be of the finest and purest description, totally free from the bitter deliquescing salts which commonly abound in that made by artificial heat from sea water. 'The casks also should be made of clean wood, and before the butter is placed in them they should be well washed with hot brine. "If," says a writer in the Penny Cyclopodia, "there is not a sufficient quantity to fill the cask at once, the surface is made smooth, some salt is put over it, and a cloth is pressed close upon it to exclude the air. When the remainder is added at the next churning, the cloth is taken off, and the salt which had been put on the surface is carefully removed with a spoon. The surface is then made rough with a small wooden spade and left so, and the newly salted butter is added, and incorporated completely. This 
prevents a streak which would otherwise appear at the place where the two portions joined. When he cask is full, some salt is put over it, and the head is put on. If the butter is well freed from all the buttermilk, and the salt mixed with it quite dry, it will not shrink in the cask, and it will keep its flavour for a long time." Dr. Anderson recommended for preserving butter a composition of salt 2 parts, saltpetre 1 part, sugar 1 part; $1 \mathrm{oz}$ of this mixture to $16 \mathrm{oz}$. of butter. It seems that butter thus treated will keep sweet for a lengthened period; but that for the first fortnight it does not taste well:

In Devonshire the method of making butter is peculiar to the county. The milk is placed in tin or earthen pans, and twelve hours after milking, these pans (each holding about eleven or twelve quarts) are placed on an iron plate, over a small furnace. The milk is not boiled, but heated until a thick scum arises to the surface; if when a small portion of this is removed bubbles appear, the milk is removed, and suffered to cool. The thick part is then taken off the surface, and this is the clouted rream of Devonshire, which is known all over England. By a gentle agitation this clouted cream is speedily converted into butter.

In Holland they churn the cream and milk together, after it has been kept sufficiently long for a slight acidity to appear. 'They churn, it scems, sometimes with a horse, sometimes by a dog, or turnspit, working on a wheel; a plan which I think might be well adopted, in many cases, in England, to the saving of the labour of many a poor dairy-maid. In the large dairies, however, about Dixmunde and Furnes, the cream only is churned three times a week. (Flemish Husb. p. 61.)

On an average, four gallons of milk produces a pound of butter, and a good cow should produce six pounds of butter per week in summer, and three pounds in winter. Of English butter, that of Cambridge and Epping is the most celebrated. But the consumption in England is much greater than the farmers can supply: very large quantities are in consequence annually imported into England; thus, in 1825, the import from Ireland amounted to $422,883 \mathrm{cwts}$, and from foreign countries $159,332 \mathrm{cwts}$; this last in 1835 was 134,346 cwts., of which $106,776 \mathrm{cwts}$. came from Holland. (M'Culloch's Com. Dict.; Trans. High. Soc.; Quart. Journ. Agr.)

To prepare Butter for a warm climate.-When butter is to be exposed to the heat of a warm climate, it should be purified by melting before it is salted and packed up. For this purpose let it be put into a proper vessel, and this im. mersed into another vessel containing water. Let the water be heated until the butter is thoroughly melted. Let it continue in this state for some time, when the impure parts will subside, leaving at the top a perfectly pure transparent oil. This, when it cools, will become opaque, and assume colour nearly resembling that of the original butter, being only somewhat paler, and of a firmer consistence. When tnis refined butter is become a little stiff, but while it is still somewhat soft, the pure part rinst be separated from the dregs, and be salted $242^{2}$ and paclied up in the same manner as other butter; it will continue sweet much longer in hot climates, as it retains the salt better than in its original state. It may also be preserved sweet, without salt, by adding to it a certain portion of fine honey, perhaps one ounce to a pound of butter, and mixing them together thoroughly, so that they may be perfectly in. corporated. A mixture of this sort has a sweet pleasant taste, and will keep for years without becoming rancid: there is no doubt, therefore, but that butter might thus be preserved in long voyages without spoiling.

As butter made in winter and even at other times is mostly pale or white, and at the same time of a poorer quality than that made during the summer months under the most favourable circumstances, various articles have been mixed with it in order to produce the rich yel. low colour associated with excellence. Those most commonly used are the juice of the carrot, or flowers of the marygold, carefully expressed and strained through a linen cloth, or a small portion of arnotta. When the juices of the carrot and marygold are used, a small quantity (to be determined by experience) is to be diluted with a little cream, and this mixture is added to the rest of the cream when put into the churn. The quantity of colouring matter required is so small as not to impart any particular taste to the butter. When arnotta is used instead of these vegetable juices a portion about the size of a pea is sufficient to colour sufficiently $25 \mathrm{lbs}$. of butter. It must be first mixed with a little water and put into the cream at the commencement of churning. The best Spanish arnotta should be used.

The butter most esteemed in London is that of Epping and Cambridge; the cows which produce the former feed during summer in the shrubby pastures of Epping forest, and the leaves of the trees and numerous wild plants which there abound are supposed to improve the flavour of the butter. It is brought to market in rolls from one to two feet long, weighing a pound each. The Cambridgeshire butter is produced from the mill of cows that feed one part of the year on challiy uplands, and the other in rich meadows or fens; it is made up into long rolls like the Epping butter, and generally salted, not cured, before brought to market. By washing it, and working the salt out of it, the London cheesemongers often sell it at a high price for fresh Epping butter.

The butter of the mountains of Wales an Scotland, and the moors, commons, and heath of England, is of excellent quality, when it is properly managed; and though not equal in quantity, it often is confessedly superior to thas produced from the richest meadows. Bad butter is more frequently the result of mismanagement, want of cleanliness, and inattention, than of any other cause. Ireland would produce the finest butter in the empire, were it not for the intolerably filthy state of their cows, and the want of cleanliness in their dairies.

In packing fresh butter, prepared for immo diate use or sale, the leaves of cabbage, white beet, or of the garden orache, are preferred in England. The bottom of the basket should be bedded with a thick cloth, folded two or three 


\section{BUTTER-CUP.}

rimes; then a thin gauze dipped in cold water, spread over it, on which the prints or rolls of butter are to be placed, each with one or more leaves beneath, and smaller ones over it. The lowermost layer being acljusted, fold half of the gauze cloth over it, put in another layer in the same way, and then cover with the remainder of the gauze. The butter should be put into and taken from the basket without being touched.

Whey butter, as its name implies, is butter made from the whey which is taken from the curd, after the milk is coagulated for the manufacture of cheese. It is chiefly made in those counties where cheese is manufactured, and where it forms no inconsiderable part of the profits of the dairy. In Derbyshire more butter is sdid to be made from whey than from the cream of milk, or from milk churned altogether.

Under the head of Anthoxanthum Odoratum, reasons are given for ascribing to its presence in pastures, a certain rich flavour for which the butter made in some districts is celebrated, such as the "May butter" of Philadelphia, and the Epping and Cambridge butter of London. The sweet-scented verual grass owes its aromatic qualities chiefly to the presence of benzoic acid or tlowers of benzoin, and this when administered to cows mixed with their food has been found to communicate the peculiarly pleasant flavour common to Philadelphia "May butter," not met with at present in the butter of any other part of the United States, and so highly prized by epicures that when good fresh butter sells in the Philadelphia market for 20 and 25 cents, the high-flavoured spring grass butter will bring 40 or 50 cents per pound. Very agreeable flavours may be given to butter by adding to cream, before churning, certain ngents, as flowers of benzoin, vanilla, etc. See axthoxanthum Odoratum, Dairy, Whey.

BUT'TER-CUP, butter-flower, or upriglıt meadow crow's foot (Ramunculus bulbosus, Smith). (Pl. 10, t.) A common perennial weed, abounding in meadows and pastures, and blooming in May. The whole plant is extremely acrid, so as often to be employed by country people to raise a blister. Bees are, however, very fond of it; it is eaten by sheep and goats; but horses, cows, and swine refuse it; drying destroys its acrimony. The roots are perennial, and bulbous; the stem rises a foot high, and bears its yellow flowers on the ends of its branches.

Dr. Darlington says that some fifteen or twenty species of ranunculus have been enumerated in the United States. (Flor. Cestrica.)

BUTTERFLY. The common English name, says Brande (Dict. of Science), of an extensive group of insects, as they appear in their last and fully developed state, when they constitute the most beautiful and elegant examples of their class. These insects belong to the order Lepidoptera, and to the section Diurna of Latreille, $O^{\prime}$ the genus Papilio of Linnæeus. The eggs of the butterfly are deposited on such plants as afford the nutriment most appropriate to the caterpillars, that are to be excluded from them; thus, the common white butterfly (Pieris brassica) and other species, oviposit upon cabbages, and hence have been termed brassicaria; the gaudy peacock butterfly lays

\section{BUTTERNUT.}

her eggs upon the netule. The eggs are coated with a glutinous secretion as they are excluded from the parent, and thus they are provided with the means of adhesion to the leaves or stems of the plants selected. See Cатв: PILLARs.

BUTTERNUT (Juglans calhartica vel Cinerea). A species of walnut growing in the United States, in different parts of which it is known by different names. In the New Enisland States it generally takes the narne of oilnut; in some of the Middle States it is called white walnut; but from New York to the Carolinas, and from Pennsylvania to Ohio, the most common name is butternut. The region of this tree is very extensive, as it is found from Upper and even Lower Canada to the Flo. ridas, and from the Atlantic to the Missouri. Even in Vermont and other cold regions its growth is so luxuriant that it attains a circumference of eight or ten feet. Michaux measured some in New Jersey nearly opposite New York, growing on the steep and elevated banks of the Hudson, where the soil was cold and unproductive, and found them, five feet from the ground, ten or twelve feet in circumference, and fifty feet high, with roots running along the surface of the ground in a serpentine direction, and with little variation in size, to the distance of forty feet. The limbs generally branch off at a small height above the base, and spread themselves widely, which gives the tree a striking appearance.

In the spring its vegetation is forward, and its leaves unfold a fortnight earlier than those of the hickory. The black walnut and butternut, when young, resemble each other, in their foliage, and in the rapidity of their growth; but when arrived at maturity, their forms are so different as to be distinguishable at first sight. Remarkable peculiarities are also found, on examining their wood, especially when seasoned. The black walnut is heavy, strong, and of a dark-brown colour; while the butternut is light, of little strength, and of a reddish hue. But they possess in common the great advantage of lasting long, and of being secure from the annoyance of worms. The wood of the butternut is used for the sleepers and posts of frame houses and barns, for post and rail fences, troughs for cattle, \&c. For corn-shovels and wooden dishes, it is preferred to the red-flowering maples, because it is lighter and less liable to split; consequently hollow ware and other articles made of it sell at higher prices. In Vermont the wood is used for the panels of coaches and chaises, being well adapted for this purpose, not only from its lightness, but because it is not liable to split. It receives paint in a superior manner. its pores being very open, more so than those of poplar and bass-wood.

The bark of the butternut possesses medicinal properties of a cathartic nature which have been highly recommended both by the testimony of the regular faculty and popular practice. An extract prepared from the bark is prescribed by American physicians in doses of from half a drachm to a drachm to aduits In the revolutionary war when supplies of foreign medicines were cut off, the extract of 
butternut was considered an admirable substitute for jalap. At present it is but little resorted to except in domestic practice in the country, where many of the farmer's wives make a preparation in the spring for the use of themselves and their neighbours. They usually boil the bark entire in water, till the liquid is reduced, by evaporation, to a thick, viscid substance, which is almost black. This is a faulty process; the exterior bark should first be removed, for by continuing the boiling, it soaks up nearly four-fifths of the liquid, already charged with rich extractive matter. In the country the bark is sometimes employed for dyeing wool of a dark-brown colour; but the bark of the black walnut is preferable for this purpose.

If the trunk of the butternut is pierced in the month which precedes the unfolding of the leaves, a pretty copious discharge ensues of a slightly sugary sap, from which, by evaporation, sugar is obtained of a quality inferior to that of the sugar maple. (Michaux's American Sylva.)

BUTTERWORT (Pinguicula vulgaris). A perennial weed growing in moist soils, as bogs and wet heaths. The viscid exudation of the leaves, which are thick and glutinous, says Smith (Eng. Flor. vol.i. p. 29), is reputed to be good for the sore teats of cows, whence the Yorkshire name of this plant, sanicle. The country people make it into a syrup as a purgative, and boil it with their garden herbs in broth as a remedy in colds. An ointment made from butterwort is also used for chapped hands, and to rub upon animals when bitten by an adder or slow-worm.

Mr. Nuttall enumerates four species of this plant found in the United States, all of which, he says, grow nearly on a level with the ocean, in moist pine-barrens. (Genera of North Am. Plants.)

BUTTONWOOD, or SYCAMORE, the Platanus accidentalis, or western plane tree, of naturalists.

Among trees with deciduous leaves, none in the temperate zones, either on the old or new continent, equals the dimensions of the planes. The species which grows in the Western World is not less remarkable for its amplitude and for its magnificent appearance than the plane of Asia, whose majestic form and extraordinary size was so much celebrated by the ancients.

In the Atlantic States this tree is commonly known by the name of buttonwood, and sometimes, in Virginia, by that of water-beech. On the banks of the Ohio, and in the states of Kentucky and 'Tennessee, it is most frequently called sycamore, and by some persons planetrec. The French of Canada and of Upper Louisiana give it the name of cotton tree.

The buttonwood is abundant and very vigorus along the great rivers of Pennsylvania and of Virginia; though in the more fertile valleys of the West, its vegetation is perhaps still more luxuriant, especially on the banks of the Ohio and rivers emptying into it. The bottoms watered by these rivers are covered with dark forests, composed of trees of extracrdinary size The soil is very deep, loose, of a brown 214 colour, and unctuous to the touch, formed ap parently of the slime deposited in the course of ages by the annual overflowing of the rivers. The fertility derived from this source is in. creased by accumulations of decayed vegetable matter furnished by leaves and the trees themselves. A degree of fertility is thus attained by the vegetable mould without example in Europe, and which is manifested by prodigies of vegetation. In such situations the buttonwood is found to be the largest tree in the United States, although in point of loftiness it is exceeded by the tulip poplar, and still more the white pine. Often, with a trunk of several feet in diameter, the plane tree begins to branch out at the height of sixty or seventy feet, near the summits of surrounding trees; and often the base divides itself into several trunks equally vigorous and superior in diameter to all other trees in the vicinity. "On a little island in the Ohio, fifteen miles above the mouth of the Muskingum, my father," says Michaux, "measured a buttonwood which, at five feet from the ground, was forty feet and four inches in circumference, and consequently more than thirteen feet in diameter. Twenty years before, General Washington had measured the same tree, and found it to be of nearly the same size." The same distinguished naturalist mentions another tree which he and his travelling companion had measured, and found, at the height of four feet above the ground, forty-seven feet in circumference This tree, which grew on the right bank of the Ohio, about thirty-six miles from Marietta, still exhibited the appearance of vigorous vegetation, and began to shoot out its limbs twenty. feet above the ground. A buttonwood of equa! size is mentioned, as existing in Tennessee. "The extraordinary dimensions of these trees recalls," says Michaux, "the famous plane tree of Lycia, spoken of by Pliny, the trunk of which, hollowed by time, afforded a retreat for the might to the Romars Consul Licinius Mutianus, with eighteen of his followers. The interior of this grotto was represented to be seventy feet in circumference, and the summit of the tree resembled a small forest."

The most striking resemblance, in the majesty of their form and in the enormous size of their trunk, thus appears to exist between the only two species of plane that have been discovered. It is difficult to mark any difference in the colour and organization of their wood. The American species is generally thought, in Europe, to possess a richer foliage and to afford a deeper shade than the Asiatic plane. Its leaves are of a beautiful green, alternate, from five to ten inches broad, less deeply lobed, and formed with more open angles than those of the plane of the Eastern continent. In some places where this tree is very abundant, it has been a source of alarm to the neighbouring inhabitants, who believe that the fine down from the leaves, floating in the air, produces an irritation of the lungs and predisposes to consumption. There appears to be little if any foundation for such an apprehension.

According to Michaux's observations, the buttonwood does not venture towards the north. 


\section{BUXUs.}

east, beyond Portland, in the latitude of $40^{\circ} 30^{\prime}$; but farther west, in $73^{\circ}$ of longitude, it is found two degrees farther north, at the extremity of Iake Champlain and at Montreal. Proceeding from Boston and the shores of Jake Champlain towards the west and the southwest, the buttunwood is continually met with over a vast tract, comprising the Atlantic and Western States, and extending beyond the Mississippi.

The wood of the plane tree speedily decays when exposed to the atmosphere. Hence it is only adauted for work that is sheltered from the weather, and when thoroughly seasoned, it may be usefully employed in the interior of houses for joists, \&c. Though never used in the construction of large vessels, it has been hollowed out into canoes, one of which, formerly on the river Wabash, made of a single tree, was sixty-five feet long, and carried nine thousand pounds. (Michaux's Am. Sylva.)

BUXUS. The boxwood, of which botanists commonly enumerate three species: 1. The arborescens, with oval leaves. 2. The angustifolia, with narrow leaves. 3. The suffruticosa, the species usually employed in the bordering of flower-beds. The first two, when allowed to grow in a natural manner, are deciduous shrubs of fine appearance. All the species are easily cultivated. The wood is extremely hard and capable of being wrought with great neatness by the turner. It is also used by the engravers on wood to cut figures upon.

BYRE. A term made use of in some places to signify a cow-house. It is commonly employed in the northern parts of England, and in Scotland; and they are differently denominated, according to the uses to which they are applied: thus, there are feeding-byres, turnipbyres, \&c.

BYSLINS. A provincial word signifying the first milk of a new-calved cow.

\section{C.}

CABBAGE (Fr. cabus; probably from cab, old Fr.for head, top, or extremity. Ital.cabuccio; Dutch, kabuys. "But the form of the cabbage, resembling a head, shows caput to be the original."-Todd's Johnson. Lat. brassica; from $\pi p \times \sigma i x^{n}$, a garden herb; or perhaps from brachia, from its numerous sprouts). A biennial genus of plants, of which there are a large number of species and innumerable varieties. Many are extensively cultivated in the vicinity of London; and several kinds are also grown by the farmer for the purpose of feeding his cattle and sheep. Our field and garden cabbages, with their varieties, have originated from the Brassica oleracea, or culinary cabbage, an indigenous sort of colewort growing principally on cliffs near the sea-coast. It is found abundantly at Dover. (Smith's English Flnra, vol. iii. p. 220.) The cabbage, says Mr. Amos (Comm. to Board of Agriculture, vol.iv. p. 178), is a most invaluable plant, very productive, accessible at all times, and is an infallible supply for sheep-feeding during the spring months, especially for ewes in lamb. Beasts and sheep are all exceedingly fond of cabbages. It may be of same importance to the farmer to lie informed that among all the plants of the natural order to which the cabbare belongs, nost one perhaps is possessed of any really deleterious property. Among nearly one thousand species (as Dr. Lindley observes), scallered over the face of the world, all are harmless, and many highly useful. 'The innumerable varieties arise from difference of soil and cultivation; and as all the cabbage tribe form hybrids, new varieties are continually produced. This is effected by the bees, when different sorts are in flower. Hence, only one variety should be in flower at the same time in any garden or field, when we wish to keep the sort unadulterated, particularly if some sorts have expanded leaves, and others close heads. It is thus only that the excellent small miniature cabbage, which grows on the stem of the Brussels sprout, can be kept in perfection. The different sorts of cabbage most prized for the garden are chiefly divided into the close-hearting and the spreading. Of the first, the York and the savoys are the most common; of the latter, the coleworts and Scotch kale. (Penny Cyclo. vol. vi. p. 92.) Of the genus brassica, or cabbage, the species chiefly interesting to the farmer, and the objects of cultivation, are, 1. Common turnip (B. Rapa);2. Wild navew (B. campestris); 3. Rape or cole (B. Nupus); 4. Early cole (B. precox); 5. Cabbage (B. oleracea). These species may be cultivated nearly in the same manner, but they may produce small fusiform roots when they are cultivated for their leaves, or for their seeds, which yield oils; or they may produce large esculent roots when they are cultivated chiefly for their roots. (Low's Elem. of Prac. Agric. p. 290.) The different kinds of cabbage in cultivation may, adds Professor Low (p. 307), be arranged in different classes, according to their general aspect and more popular characters :-1. Those which bear their leaves or stalks without their being formed into a head. Some of these have crisped leaves, and are a class of hardy pot. herbs everywhere familiar in the culture of the garden; others have smoothish leaves, with long branched stems. These comprehend the largest and most productive of all the cabbages, - the Jersey cole, the thousand-headed cabbage, ard others. 2. Those whose leaves are formed into a large head. These comprehend the larger cabbages cultivated in the fields. The savoys of our gardens are allied to this class. 3. Those whose roots become napiform, as the kohl-rabe. 4. Those in which the stem divides, and forms a corymbose lieal, as in the cauliflower and broccoli.

The cabbages of the first class, with crisped leaves, frequently termed greens, are very hardy. They are cultivated pretty extensively in some parts of the north of Europe; but in others they are chiefly regarded as potherbs, and confined to the garden. The branched kinds with smoothish leaves are the most prom ductive; but at the same time they demand a good soil and favourahle climate. Their leaves are stripped off as they are required for use ; and as these are constantly supplied by fresh leaves, the plants yield a succession of forage 
trroughout a great part of the season, and they remain growing for several years.

There are different varieties of these larger cabbages, which are more or less valued in the places where they are cultivated. The thousand-headed cabbage, chou ì mille têtes, is remarked as possessing a greater number of shoots; the cow cabbage, Cesarian cole or tree cabbage, as growing more to one stem, and producing cream-coloured flowers; the Jerscy cole, as being similar in its growth, and producing yellow flowers. In the Netherlands, and the Channel Islands, where the cultivation of these plants is well understood, they are sown in beds in autumn, and planted out in succession from November till February. About the month of April the farmers begin with the first sown, to strip off their under leaves for use. They give them to their cows, hogs, geese, and other stock, cutting them in small pieces, and mixing them with bran and other farinaceous substances. During the summer they continue this process of stripping off the leaves, the plant in the meantime rising to the height of several feet. (Gard. Mag. vol. vo) This plant requires a good soil and plentiful manure, and is regarded as a great exhauster of the soil. It perhaps yields a larger proportion of nutriment within the same period than any other forage plant. It may be presumed that it is not well fitted for general cultivation, and in England will only succeed in favourable situations, as the south of England and Ireland, and the beautiful little islands where it is now cultivated. When fed to milch cows, the decayed leaves should be carefully removed, as when eaten they impart an unpleasant taste to the milk.

The next class (continues Professor Low) consists of those in which the root becomes napiform. The principal variety is the kohlrabe or purple turnip cabbage (Brassica oleracea var. caulo-rapa). This plant is cultivated in Germany and the north of Europe. It is valued as a resource for cattle in winter. While it produces a ront like a turnip, it at the same time sends forth stems bearing leaves like a cabbage. It is not only hardy, but keeps better in store than any plant of the cabbage kind. It may be cultivated in the same manner as the Swedish and yellow turnips; but the experiments that have been made with it in this country lead to the inference that it is not equal to those turnips for the purpose of feeding. The cabbages of the last-mentioned class, as the cauliflower and the broccoli, are entirely limited to the garden. The kinds of the cabbage which are best suited for field-crops and the support of cattle, are the York, or large Scotch, the ox-head, the drum-head, the redveined, and the American, which commoniy produce heads of 10 to $20 \mathrm{lbs}$, and not unfrequently arrive to upwards of $30 \mathrm{lbs}$. weight. The above and other names, however, are frequently applied where there is no real distinction. The most productive of these are the drum-headed and American; but the red-veined and Scotch stand the winter best. They are all known by their large leaves, which, as the plant advances, collapse and form a dense liead. The large field cabbages are those which are generally considered as the best suited to farm culture, and are therefore those most commonly planted; but the species known as the sugar-loaf cabbage, and so called from its pointed form, though rarely exceeding from 5 to 7 lbs., may yet be in many casps, found more advantageous, for it can be grown on land of more ordinary quality than the other kinds; it is hardier in constitution, more solid and nutritive, and the inferiority of its weigh: may be in a great degree made up by the smallness of its size allowing of the plants being set closer together. (Brit. Husb. vol. ii. p. 255.) Of the different kinds, therefore, is appears that the large field cabbage, whatever name it may receive, is that which is best suited for common field culture. This plant impoverishes the soil very much. In collecting the produce for consumption, the plants (says the late Mr. Sinclair) should be drawn up by the roots, and not merely cut over, as is often practised to the detriment of the soil. The different varieties above enumerated afford about equal quantities of nutritive matter. The nutritive matter of the cabbage is wholly soluble in water; that of the potato only partially so, for a great proportion of the potato consists of starch. According to Mr. Sinclair's experiments-

\begin{tabular}{|c|c|c|}
\hline & $\begin{array}{l}\text { Nutr. } \\
\text { Matter, } \\
\text { grs. }\end{array}$ & $\begin{array}{l}\text { Woody } \\
\text { Fibre, } \\
\text { grs. }\end{array}$ \\
\hline $\begin{array}{l}7000 \text { grs. or } 1 \mathrm{lb} \text {. of the drum-head cab- } \\
\text { bage (B. oleracea capitata) contains } \\
7000 \text { grs. Early York cabbage }(B \text {. oler. }\end{array}$ & 430 & 280 \\
\hline var.) - - - - - - & -430 & 312 \\
\hline 7000 grs. Woburn perennial kale (B. oler & & \\
\hline fimbriata perennis) & -438 & 932 \\
\hline $\begin{array}{l}7000 \text { grs. Green curled kale (B.oler.viridis) } \\
\end{array}$ & 440 & 880 \\
\hline 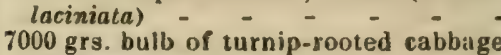 & -448 & 1120 \\
\hline apa, var.) - & -400 & 320 \\
\hline 000 grs. leaves or tops of ditto & -252 & 360 \\
\hline
\end{tabular}

And upon an analysis of the respective average nutritive qualities of each species of root, cabbages were generally found superior to common turnips, in the proportion of $107 \frac{1}{2}$ to 80 , and inferior to Swedes in that of $107 \frac{1}{2}$ to 110. Carrots are more nutritive than cabbages, in the proportion of 187 to $107 \frac{1}{2}$. (Hort. Gram. Wob. p. 407, 408.) It is, however, the opinion of an experienced farmer (Mr. Brown of Markle), that the culture of cabbage, taking into consideration the greater consumption of manure, and the superior nature of the requisite soil, does not afford advantages to be compared with the scourge it occasions to the land. (Brit. Husb. vol. ii. p. 258.)

It is no uncommon thing to raise singie cabbages that weigh $40 \mathrm{lbs}$ : : calculating the roots upon an acre to average each $20 \mathrm{lbs}$., and one to be planted on every square yard, the produce would yield 43 tons. Although it frequently averages $\mathbf{3 0}$ tons, few crops, except under very favourable circumstances, would reach to that extent. Cabbages are greatly esteemed by those farmers who have land capable of grow. ing them, from their forming a substitute for turnips during frosty weather, and also affording an admirable change of food for cattle, by whom they are much relished; and they are also found to be very nutritious for stall-feeding, or for the dairy, when used with the addition of sound hay. Hogs prefer them to turnips, 


\section{CABBAGE.}

and they are excellent for rouring calves and toothless crones. An acre of good cabbages is therefore considered by many as worth two of turnips, and is certainly equal to one and a half.

Woburn perennial kale is a valuable variety of the open-growing cabbage, which has been recently introduced, and appears far superior in amount of produce to either the green, purple, or borecole, and requires less manure. It has also this advantage, that it continues highly productive for many years, without further trouble or expense. Propagated by planting, in beginning of April, cuttings taken from the stems and branches of old plants. The seed is apt to produce spurious plants. For the table it is not inferior to the best kinds of greens or kale; and for the farm and cottage garden, its highly productive powers and cheapness of culture promise to render this plant highly valuable. Its perennial habit places it out of the reach of the yearly accidents of weather, bad seed, and depredations of insects, to which all other varieties sown annually are subject. (Trans. Hort. Soc. Lond. vol. v. art. 40.)

The turnip-rooted or bulb-stalked cabbage ( $B$. oleracea, var.) is distinguished by its irregularlyshaped root, and the swelling of the stalk in upper part, which forms a kind of round feshy head at the end of the stem on which the leaves are produced. It is a native of Germany, and was first introduced from thence by Sir'Thomas Tyrwhitt, under the name of kohl-rabe. (Decandolle, in Trans. Hort. Soc. vol. v. art. 1.) The produce is nearly the same as that of Swedish turnips, and the soil that suits the one is equally good for the other. Two pounds of the seed will produce a sutficiency of plants for one acre: 64 drs. of the bulb of kohl-rabe afford $105 \mathrm{grs}$. of nutritive matter. (Hort. Gram.Wob. p. 411.)

The turnip-rooted cabbage is a hybrid production between the cabbage and turnip, which both belong to the same genus; and the various kinds which have becomedisseminated throughout Europe are so confused in nomenclature, that it has become difficult to state their properties with any great degree of precision, or to draw any certain inferences to guide us in their use. (Brit. Husb. vol. ii. p. 259.)

These species of brassica are but little cultivated, and at most a very small quantity of each is in request. The bulbs, for which they are cultivated, must have their thick outer skin removed, and in other respects treated as turnips in preparing them for use. Of the turnip cabbage, which is so named on account of the round fleshy protuberance that is formed at the upper end of the stem, there are four varieties: 1. White turnip cabbage; 2. Purple turnip cabbage; 3. Fringed turnip cabbage; 4. Dwarf early turnip cabbage.

Of the turnip-rooted cabbage, which is distinguished from the above by its root having the protuberance near the origin of the stem, there are two varieties, the white and the red. (Trans. Hort. Soc. Lond. vol.v. p. 18-24.) They are propagated by seed, which may be sown broadcast or in drills, at monthly intervals, in small quantities, from the commencement of
CABBAGE.

April until the end of June. The best mode is to sow thin, in drills two feet anc a half aparh and allow the plants to remain where sown, the plants being thinned to a similar distance apart; or, if sown broadcast, to allow them to remain in the seed-bed until of sufficient size to be removed into rows at similar distances for production, rather than, as is the practice of some gardeners, to transplant them, when an inch or two in height, into a shady border, in rows three inches apart each way, to be thence removed as above stated.

Water must be given every night after a re. moval, until the plants are again established; and afterwards in dry weather occasionally, as may appear necessary.

Earth may be drawn up to the stem of the turnip cabbage, as to other species of brassica; but the bulb of the turnip-rooted must not be covered with the mould.

For direclions to obtain seed, \&c., see Broccolt, Tunnip, \&c. (G. W. Johnson.)

The red cabbage differs from the common cabbage in nothing but its colour, which is a purplish or brownish red. The varieties are three in number; the large, the dwarf, and the Aberteen red. It is chiefly used for pickling, and the dwarf red is considered the best sort. Cultivated precisely similar to the white cabbage. The cabbage is not nearly so extensively cultivated in this country as it ought to be. It is not only a valuable food for live stock, rarely misses plant, and is come-at-able in all weathers; but it is exceedingly useful to fill up the spaces on the ridges where the Swedes and common turnips have missed plant. 1000 parts of cabbage contain 73 parts of nutritive matters. (Erit. Husb. vol. ii.; Bax. ter's Agr. Lib.; Sinclair's Hort. Gram. Wob.; Low's El. Agr.; Com. Board of $A g r .$, vol. iv.; Quart. J. $A g r$. , vol. vii. p. 76.)

The cauliflower is considered the easiest to be digested of all the various species of cab. bage. It is not destitute of utility in a medicinal way; a decoction of red cabbage being supposed capable of relieving acrimonious hil. mours in some disorders of the breast, and also in hoarseness. (Willich's Dom. Encyc.) A cabbage leaf placed on any fleshy part acts in keeping open a blister; but it should be fre. quently changed, as it speedily becomes cor. rupt. The seed, bruised and boiled, is good in iroth.

Garden Cabbages.-For the seed-bed the soil should be moist, mouldy, and not rich; but for final production it should be a fresh, moderately rich, clayey loam, though very far removed from heavy, as they delight in one that is free and mouldy. Such crops as have to withstand the winter may have a lighter compartment allotted to them; the savoy, in particular, re. quires this, though it may be as rich as for the other crops, without any detriment: an extreme. of richness is, however, for all the crops to be avoided. The ground is advantageously dug two spades deep, and should be well pulverized by the operation. Stable manure is usually employed in preparing the ground for this genus; but Mr. Wood, of Queensferry, N. B., who has for the greater part of his life paid particular attention to the cultivation of bror. 
coli, recommends the following compositions in preference for that vegetable, and we are justified in concluding that they would be equally beneficial to all the other species. The manure collected from the public roads, used alone, causes the plants to grow strong, but with small heads. A mixture of road-rakings, sea-weed, and horse-dung is better. A manuring of the compartment on which they were intended to be planted with sea-weed in autumn, digging it up rough, repeating the application in spring, and pointing the ground before planting, produced the finest heads he had ever seen; but the compost of all others most suitable to them is one composed of the cleanings of old ditches, tree leaves, and dung. (Mem. Caled. Hort. Soc, vol. ii. p. 265.) The situation must in every instance be free and open, though, for the summer crops, it is advantageous to have them shaded from the meridian sun. They must never, however, be under the drip of trees, or in confined situations; for in such they, and especially savoys, are most subject to be infested with caterpillars, and to grow weak and spindling. In planting cabbage, it should be observed whether the roots of the plants are knotted or clubbed, as such should be rejected, or the excrescence entirely removed.

The numerous varieties of the cabbage, adds Mr. G. W. Johnson, may be divided into three classes, as most appropriate for sowing at an equal number of periods of the year. It may be here remarked, that, for family use, but few should be planted of the early varieties, as they soon cabbage, harden, and burst; on the contrary, the large York, and others that are mentioned in the middle class, though not far behind the others in quick cabbaging, never become hard, and continue long in a state fit for the table.

For First Crops.-Early dwarf; York; early dwarf sugar-loaf; early Battersea; early imperial; East Ham.

Midsummer Crops.-Large early York; large sugar-loaf; early Battersea; early imperial: these mentioned again as being valuable for successional crops also. Penton, this is valuable in late summer, when other varieties are strongly tasted. Antwerp, Russian; to have this in perfection, the seed must be had from abroad, as it soon degenerates in this country. Early London hollow. Musk is excellent at any period, but is apt to perish in frosty weather.

For Autumn, \&c.-Large hollow sugar-loaf; large oblong hollow; long-sided hollow, and any of the preceding; red Dutch for pickling.

The cabbage is propagated by seed, the sowing of which commences with the year. 'Towards the end of January, on a warm border, or under a frame, a small portion of the early and red cabbages may be sown, to come first in succession after those which were sown in the August of the preceding year. A sowing may be repeated after intervals of a month during February, and until the close of July of the secord or larger class, and from May to July of the third class of varieties. In August a full and last crop must be sown of the first class, as wcll as of the second, both to plant out in October, November, and December, as to remain in the seed-beds for final removal in the February and two succeeding months of the next year: this sowing is best performed during the first or second week of the month; if sown earlier, they are apt to run in the spring; and if later, will not attain sufficient strength to survive the winter. By these various sowings, which, of course, must be small ones for a private family, a constant supply is afforded throughout the year. The seed is inserted broadcast rather thin, and raked in evenly about a quarter of an inch deep. The bed is advantageously shaded with mats, and occasionally watered until the plants are well above ground; and the waterings may afterwards be beneficially repeated two or three times a week until they are ready for removal, if dry hot weather continues. The seedlings arising from these various sowings, when of about a month's growth, or when they have got four or five leaves an inch or so in breadth, are, by those who are advocates for transplanting, pricked out in rows four or five inches asunder each way; they must be shaded and watered until completely established: those of the August sowing that are pricked out are to remain until the next spring, and those which are left in the seed-bed are employed for planting in October and two following months.

When of six or eight week's growth, they are of sufficient size for planting, which they are to be in rows from one and a half to two and a half feet asunder each way; the smaller early kinds being planted the closest. The red cabbage, the principal plantation of which should be made in March for pickling in September, is benefited by having the distances enlarged to three feet. They must be well watered at the time of removal, and frequently afterwards, until fully established, in proportion as dry weather occurs. They must be frequently hoed to keep under the weeds, as perhaps no plant is more injured by them than the cabbage; and as soon as their growth permits it, the earth should be drawn round the stems of the plants. To promote the cabbaging of the plants, when requisite, it is useful to draw the leaves together with a shred of bass-mat, which forwards it about a fortnight. If any plants advance to seed whilst very young, the deficiencies should be immediately filled up. The stems of the summer and autumn crops, if left after the main head has been cut, will produce numerous sprouts during those seasons, and continue to do so throughout the winter. For the production of seed in October, which is the preferable season, and from thence until the close of February, some of the finest and best cabbage plants must be selected; or in default of these, though not by any means to be recommended, such of their stalks as have the strongest sprouts. They must have the large outer leaves removed, and then be inserted up to their heads, in rows three feet asunder each way. Each variety must be planted as far from any other as possible, as indeed from every other species of brassica; and this precaution applies equally to those which will be subsequently dwelt upon. The red cabbage especially must be 
kept distinct. Some plants of the early varieies should be planted in sheltered situations, as in severe winters thry are apt to run prematurely.

Frame Secdlings. - The first sowing of the year in a hotbed must be carefully attended to. The heat must never exceed $55^{\circ}$, nor sink more than $t w o$ or three degrees beneath $50^{\circ}$, which is the most favourable minimum; otherwise the plants will be weak and tender, or checked and stunted. Air should be admitted freely in the day, and the glasses covered, as necessity requires, at night with matting; the other offices of cultivation are the same as for plants raised in the open ground.

Colevorts. - One of the Latin names for cabhage is caulis, and from this is derived cale or cole and colewort. Coleworts now merely signify cabbages cut young, or previously to their hearts becoming firm, the genuine colewort or Dorsetshire cale being nearly extinct. The varieties of cabbage principally employed for the raising coleworts are the large York and sugar-loaf, as they afiord the sweetest; but the early York and East Ham are also employed, as also occasionally the Battersea, imperial, Antwerp, and early London hollow. When large coleworts are in request, the great spreading varieties should never be employed.

Sowings may be performed during the middle of June and Julv, to be repeated at the end of the latter month, for transplanting in August, September, and October, for a continual supply in September until the close of March. A fourth must be made the first week in August, for succeeding the others in spring; but, if of sufficient extent, these various plantations may be made frnm the seed-beds of the cabbage crops made at these several periods, as directed under that head; as the chief object in growing coleworts is to have a supply of greens sooner than can be obtained from the plantations of cabbages if left to form hearts.

The observations upon transplanting, and the directions for cultivating cabbages, apply without any modification to coleworts; but the distance at which the plants may be set is much less: if the rows are a foot apart, and the plants seven or eight inches distant from each other, an abundant space is allowed. As mentioned for cabbages, the heading is greatly forwarded by their leaves being drawn together so as to enclose the centre. They may be cut when the leaves are five or six inches in breadth. The most preferable mode of laking them is to pull up or cut every other one; these openings are beneficial to the remaining plants; and some, especially of the August-raised plants, may be left, if required, for cabbaging.

Colewort, or Dorsetshire cale, is now nearly superseded by the new cabbages of modern ames. The wild coleworts grow in ditches ard moist places.

Savoy - (Brassica oleracea sabauda). - The savoy, which is one of the best and chief of our vegetable supplies during the winter, derives its name either from being an introduction from that part of Europe with which it rears a similar name, or, otherwise, is a corrup icn from the French savourer. All its varieties may be denominated hardy, being generally rendered more sweet and tender by frost, though not all equally capable of withstanding the rigour of winter. There are three varieties of savoy, - the yellow, the dwarf, and the green: and of each of these there are likewise two sub-varieties, the round and the oval-headed, the first of which is the most permanent. Each variety has been described by Mr. Morgan, gardener to H. Brown, Esq̨., of North Mimms. Like the other members of this tribe, it is propagated by seeds; the first sowing to take place at the close of February, the plants of which are ready for pricking nut in Aprii, if that practice is adopted, and for final planting at the end of May for use in early autumn; this to be repeated about the middle of March, the plants to be pricked cut in May for planting in June, to supply the table in autumn and early winter; lastly, the main crops must be sown in April and early May, to prick out and plant after similar intervals for production in winter and spring. The seed is sown broadcast thinly, and raked in as mentioned for other species of brassica. The plants are fit for pricking out when they have four or five leaves about an inch in breadth; they must be set three or four inches asunder each way, being both here and in the seed-bet kept well cleared of weeds. When finally removed, the plants of the first crops should be set out two feet apart each way from one another; but the winter standing crops are better at two feet by eighteen inches. Both before and after every removal they should be watered abundantly, if the weather is at all dry; and this application to be continued until the plants are well established. The only after-culture required is the keeping them clear of weeds by frequent broad-hoeing and the earth drawn up two or three times about their stems. For the production of seed, such plants must be selected of the several varieties as are most true to their particular character. istics, and as are not the first to run. These, in open weather, from early in November to the close of February, (the earlier, however, the better, may be taken up with as little injury as possible to the roots, and the large under leaves being removed, planted entirely up to the head in rows two feet and a hall each way, each variety as far from the other as possible. They flower in May or June, and ripen their seed in July and August. (G. W. Johnson's Kitchen Garden.)

CABBAGE CATERPILLAR. This belongs to a genus of butterflies called the potherb pontia (Pontia oleracea). See Caterpillar.

CABBAGE-CUTWORM. See CuTworv.

CABBAGE-LICE. See Aruis.

CABBAGE TREE (Chamoops palmetto). See.

Palmetto.

CAG, or KEG. A vessel of the barrel bind, containing four or five gallons.

CAIRN (Welsh carn). A heap of stones.

CAKE. See Oat Cake and Rare Cake.

CALAMINT, COMMON (Thymus calamintha, Smith). This is a wild plant, growing in England in hedges and dry places, flowering from June till autumn. It is eight or ten inches high; has roundish dark-green leaves, and 
whitish flowers standing in whorls or luttle clusters surrounding the stalks, which are square and very much tranched. Calamint should be gathered and dried just as it is coming into flower. This herb is grown in almost every garden; it is strong-scented, and of an agreeable odour. Coles says it preserves meat from taint.

Pennyroyal calamint (Mentha pulegium, Eng. Flor. vol. iii. p. 87) is a medicinal herb, and should be planted in every herbalist's garden. It grows a foot high, with firm stalks, small leaves of a light green colour, and hairy, and small white purplish flowers. The pennyroyal calamint is more erect than its elder sister, and has a stronger but less pleasant smell. It must be dried with care, and given in infusion. It is a popular remedy for hysterics, and in deficiency of the periodical change in females; but the plant and its infusion is rarely ordered by professional men. A water arising from the distillation of the plant, to produce its volatile oil, is used as a vehicle for more important drugs; and the oil dropped on sugar and rubbed up with water as an oleosaccharum is sometimes employed as a carminative and an antispasmodic, in doses of two to five drops. There is, also, an officinal spirit of pennyroyal, which is used for the same purposes as the oil. This aromatic plant must not be confounded with the common pennyroyal of the United States. See Peyrumural.

CALANDRE. A name given by French writers to an insect of the scarabaus or beetle tribe, which frequently does great injury in granaries. It has two antennæe or horns, formed of a great number of round joints, and covered with a soft and short down; from the anterior part of the head there is thrust out a trunk, which is so formed at the end that the creature easily makes way with it through the coat or skin that covers the grain, and gets at the meal or farina on which it feeds; the inside of the grain is also the place where the female deposits her eggs. See Cornwervil.

CALCAREOUS MARL. A mineral fertilizer, exteusively used in many parts of Europe and the United States. See Maru.

CALCAREOUS SOILS (from the Latin calx) are soils which contain carbonate of lime (chalk of limestone) in such a proportion as to give it a determinate character. Calca. reous sand is merely chalk or limestone divided into pieces of the size of sand. This variety abounds on the seashore in some parts of the east of England, and is employed in Devonshire and Cornwall to a very large extent as a manure, especially about Padstow Harbour, from which bay many thousand tons are annually carted by the Cornish farmers, which they take free of toll, under a grant from Richard Duke of Curnwall, another of the 45th of Henry III., A. D. 1261. (Johison on Fertilizers, p 17 ) See Cнацк; Еаптнs, their Uses to Vegetation; and Sorus.

CALF, DISEASES OF (Sax. cealf, calf; Dutch, kalf). See Catrue. The most common diseases of calves are-

1. Navel Ill.-The best treatment for this da.1gerous disease is, 1st, to administer two or three doses (cach about a wine-glassful) of 250 castor oil (linseed oil does just as well, and is much cheaper); and, 2dly, cordials, which may be made of 2 drachms of caraway-seeds, 2 do. of coriander-seeds, 2 do. powdered gentian; bruise the seeds, and simmer them in beer or gruel for a quarter of an hour; give these once or twice a day.

2. Constipation of the Bowels.-For this doses of castor oil (or linseed oil), of 2 or $3 \mathrm{oz}$, are the best remedy.

3. Diarrhoa, or Scouring.-The farmer may rely on the following mixture. Let him keep it always by him; it will do for all sucking animals :-

Prepared chalk - - $\quad-\quad-4$ ounces
Canella bark, powdered
Laudanum - - - -1 - -1 -
Water - - -1 pint.

Give two or three table-spoonfuls, according to the size of the animal, two or three times a day. A table-spoonful or two of powdered chalk may be given daily or every other day, to calves whilst sucking, mixed in a little warm milk. It prevents the milk from turning acid, and thus checks the tendency to diarrhœa or looseness.

4. Hoose, or Catarrh.-Good nursing, bleed. ing, and then a dose of Epsom salts, with half an ounce of ginger in it. (Youatt on Caltle, p. 557.)

CALKERS. A name given to the prominent or elevated part of the extremities of the shoes of horses, which are forged thin, and turned downwards for the purpose of preventing their slipping. It is sometimes written calkins or cawkins.

CALLUNA VULGARIS. The common heath or ling. It abounds in peaty soils. (See Peat Sorls.) Its uses are considerable in some districts for litter, and, when young, sheep eat it. It is also shelter for grouse, and food for bees. See Ling.

CALVING OF COWS. The treatment before calving is to keep the cow moderately well, neither too fat nor too lean; remember that she commonly has the double duty of giving milk and nourishing the fœtus; dry her some weeks before calving; let her bowels be kept moderately open; put her in a warm sheltered place, or house her; rather reduce her food; do not disturb her when in labour, but be ready to assist her in case of need; let her have warm gruel; avoid cold drinks. A pint of sound good ale in a little gruel is an excellent cordial drink.

CALYCANTHUS FLORIDUS, the sweetscented shrub, or, as it is also sometimes called, Carolina allspice. See Swert-scenten Shrue.

CAM. A provincial term for a mound of made earth.

CAMELLIA JAPONICA. A beautiful evergreen greenhouse shrub; but if carefully attended to it will blow in the open air. It bears single, double, and semi-double flowers, in February and March; and they are red, white, blush-coloured, and various other tints. Plant it under a south wall, in good rich garden mould mixed with sand; and shelter it during winter with mats, or keep it in a large pot It cannot endure the broiiing mid-day sun. Propagate by cuttings, layers, and grafts; 


\section{CAMPHOR TREE.}

of camomile found in the shops is procured from this plant.

CAMPHOR TREE (Laurus camphora). Among the vegetable productions of the Old Continent which possess a high degree of interest for the United States, the camphor tree holds an eminent place. It especially deserves attention from the inhabitants of the Floridas, of the lower part of the Carolinas, and of lower Louisiana. Its multiplication in these climates would be so easy, that after a few years it might be abandoned to nature.

The camphor tree belongs to the same family as the common sassafras of the United States, though in its general character it is most nearly related to the red bay, so common thronghout the southern regions just referred to, both being evergreens of similar height, and at a small distance looking so much alike as to be easily mistaken for each other.

The camphor tree is a native of China, Japan, and some other parts of the East Indies, where it often attains forty or fifty feet in height, with a proportional diameter. The leaves are two or three inches long, pointed at their extremities, about an inch broad, with long petioles or stems. The young branches are green. The flowers are small and whitish. The leaves, bark, wood, and roots are all strongly impregnated with the odour of camphor. The roots especially yield this substance in greatest quantity. They are cut to pieces, boiled in water in large iron retorts, \&c. (See Michaux's Sylva.)

Camphor may likewise be obtained from certain plants or herbs of the class of labia, such as lavender and mint, out not in sufficient quantities to form an article of commerce.

CANADA ONION. See OnIon.

CANADA THISTLE (Carduns arvensis). This plant is widely spread in the northern part of the state of New York, and has been introduced into Pennsylvania and many other parts of the Middle States, the seeds having been sometimes mixed in timothy seed, and sometimes entangled in the fleeces of sheep driven from the North. The root of the $\mathrm{Ca}$ nada thistle is perennial, creeping and exceedingly tenacious of life, which, with its prolific character, for it springs up from the filaments of the roots as well as from seed, makes it the vilest pest in the form of a weed that has ever invaded American farms. It is a foreigner. The utmost vigilance will be required to prevent its spread wherever it may be discovered.

A great many devices have been resorted to for the eradication and destruction of the $\mathrm{Ca}$ nada thistle. Some aim at the entire removal of the root by means of extirpating machines, contrived to cut off and harrow up the roots. Others rely upon mowing down the thistles when they are in full bloom, as a most certain method. Not content with simply cutting down, some apply common salt to the stems or crowns of the roots which makes the destruction more sure. It is an admitted fact that the life of trees and plants, when these are not in the torpid state in which they are enabled to exist in winter, depends upon a funcion performed by their leaves. These are in 252

\section{CANARY-GRASS:}

fact their lungs, deprived of the use of which for a given time, during the season of their growth, trees and plants inevitably die. Low and frequent cutting down in summer abous the blooming period, will doubtless destroy plants however tenacious of life they may be, since the roots are as much indebted for life to their leaves or lungs as the leaves are to the roots. Neither can subsist long without the aid of the other important members of the system. The most usual methods, resorted to in England, for the eradication of thistles, couchgrass, and other weeds with creeping and tenacious roots, will be found mentioned under the head of Thistres. A highly interesting article upon this subject, originally published in that valuable agricultural periodical, The Genessee Farmer, and republished in Ruffin's Farm. Reg. vol. ii. p. 29, contains a great deal of information relative to the extermination of this pest of our plough fields.

CANARY-GRAS', CAT'S TAIl. See Cat's TaIL.

CANARY-GRASS (Phalaries canariensisPl. 4, a) is cultivated in a few parts of the south of England, and chiefly in the Isle of Thanet. The plant (says Prof. Low) is easily raised, but it is of little economical importance; it is a native of the Canary Islands, but is found frequently wild in cultivated and waste ground, and has probably become naturalized. It is an annual, with a stem from a foot to eighteen inches high, and lively green leaves about haif an inch in width. In England it flowers from June to August, and ripens its seed from September to October The seeds are sown in February, in rows about a foot apart, four or five gallons per acre. The reaping commences in September. The common yield is from thirty to thirty-four bushels per acre The chaff is superior to that of every : ther culminous plant for horse food, and the saw, though short, is also very nutritive. From Mr. Sinclair's experiments, it appears, that at the time of flowering, the produce of this grass per acre, from a rich clayey loam, on a tenacious

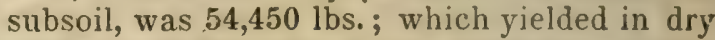
produce 17,696 lbs. 4 oz., nutritive matter $1,876 \mathrm{lbs} .2 \mathrm{oz}$. The herbage is but little nutritive, and the plant cannot be recommended for cultivation, but for the seeds only, which are principally in demand in the neighbourhood of large towns, as food for small singingbirds, particularly canaries, whence it derives its name. The produce is generally from three to five quarters an acre, and the actual price is from 40 s. to $42 \mathrm{~s}$. per quarter. The straw or haulm is a most excellent fodder for horses. (Hort. Gram. Wob. p. 399; Low's El. Prac. Ag. p. 266 ; Brit. Husb. vol. ii. p. 329.)

The reed canary-grass ( $P h$. arundinacea, Smith's Engl. Flora, vol. i. p. 74) is very common in ditches, pools, and the margins of rivers. At the time of flowering, the produce from a black sandy loam incumbent on clay was, -

Green produce per acre - $\quad$ - $27,225{ }^{16 z} 0$

Dry produce - - $-\quad-\quad-\quad 12,251$
Nutritive matter
-

On a strong tenacious clay, the produce was, - 


\section{CANCER IN CATTLE.}

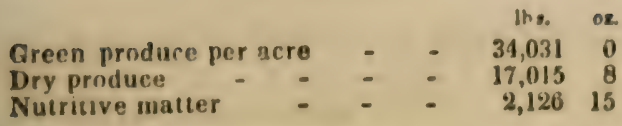

From this, it appears to be much more prouuctive on a tenacious clay soil than on a rich sandy loam; the superior nutritive powers which this grass possesses recommend it therefore to the notice of occupiers of such soils. The foliage cannot be considered coar3, when compared with other grasses which afford a produce equal in quantity. Dry straw is a much coarser food than the hay made from this grass, and the objection may i)e met by reducing this hay to chaff. The : triped reed canary-grass has not yet been found in a wild state; it is cultivated in gardens for the beauty of its striped leaves:-the common wild variety wants this distinguishing feature, it grows to a greater height than the striped-leaved variety, does not appear to be eaten by cattle, but birds are fond of the seeds. It comes into flower about the first and second weelss of July, and ripens about the middle of August. (Hort. Gram. Wob. p. 359.)

CANCER, IN CA'TTLE (Jat.; Sax. cancene.) A virulent swelling or sore. Cancer of the eye, or a perfect change of its mechanism into a fleshy half-decomposed substance, that ulcerates and wastes away, or from which fungous growths spring that can never be checked, is a disease of occasional occurrence in cattle. The remedy should be extirpation of the eyc; if it were deemed worth while to attempt it. (Lib. of Usef. Know., Cattle, p. 293.)

CANDLE (Lat. candela: Sax. canoul; Ital. candelle; Fr. chandelle; Welsh, camoyll). A taper or cylinder of tallow, wax, or spermaceti, the wick of which is commonly of several threads of cotton spun and twisted together. Candles in England were subject for a lengthened period to an excise duty of $3 \frac{1}{2} d$. per lb., but this was repealed in 1831. Good tallow candles ought to be made with equal parts of sheep and $0 x$ tallow; care being taken to avoid any mixture of hog's lard, which occasions a thick, black smoke, attended with a disagreeable smell, and also causes the candle to run.

The farmer, if far from any town, may make his own candles. The cotton for making the wicks is sold, ready prepared, in balls. When it is intended to be used for candles, a certain number of pieces of it of equal length are to be cut, and stripped through the hand to remove any knots or inequalities. They are next to be affixed by one end to a rod about three feet long, leaving about two inches between each wick. The whole is then to be dipped into a vessel, large enough, and filled with fluid tallow; and this is to be repeated three times for the first layer or coat. They are then to be suspended in a rack over the vessel to drain and solidify; after which they are to be dipped twice, and again hung up to drain; and so on, successively, until they acquire the desired degree of thicinness.

The first part of the process is the sorting of the tallow. Mutton suet with a proportion of ox-tallow is selected for mould candles, because it gives them gloss and consistence. Coarser tallow is reserved for the dipped can-
CANDLE.

dles. After being sorted, it is cut intn small pieces, preparatory to its being melted or ren dered; and the sooner this is done after the fat is taken from the carcase the better, because the fibrous and fleshy matters mixed with it promote its putrefaction. Tallow is too com monly melted by a naked fire applied to the bottom of the vessel, whereas it should be done either in a cold set pan, where the flame plays only round the sides a little way above the bottom, or in a steam-cased pan. After being fused a considerable time, the membraneous matters collect at the surface, constituting the cracklings used sometimes for feeding dugs, after the fat has been squeezed out of it by a press. The liquid tallow is strained through a sieve into another copper, where it is treated with water at a boiling temperature in order to wash it. After a while, when the foul water has settled to the bottom, the purified tallow is lifted out, by means of tinned iron buckets, into tubs of a moderate size, where it concretes, and is ready for use.

Wux Candles.-Next to tallow, the substance most employed in the manufacture of candles is wax. Wax candles are made either by the hand or with a ladle. In the former case, the wax, being kept soft in hot water, is applied bit by bit to the wick, which is hung from a hook in the wall; in the latler, the wicks are hung round an iron circle, placed immediately over a large copper-tinned basin full of melted wax, which is poured upon their tops, one after another, by means of a large ladle. When the candles have by either process acquired the proper size, they are taken from the hooks, and rolled upon a table, usually of walnut tree, with a long square instrument of box, smooth at the bottom.

In June, 1825, M. Gay Lussac obtained a patent in Eny. and for making candles from margaric and staric acids, improperly called stearine, by converting tallow into the above fat acids by the following process:-Tallow consists, by Chevreul's researches, of stearine, a solid fat, and elaine, a liquid fat; the former being in much the larger proportion. When tallow is treated with an alkaline body, such as potash, soda, or lime, it is saponified: that is, its stearine and elaine become respectively stearic and elaic acids, and, as such, form compounds with these bases. When by the action of an acid, such as the sulphuric or muriatic, these combinations are decomposed, the fats reappear in the altered form of stearic and elaic acids; the former body being harder than tallow, and of a texture sumewhat like spermaceti, the latter body beiıg fluid, like oil. "The decomposition of the soap should be made," says the patentee, "in a large quantity of water, kept well stirred during the operation, and warmed by steam introduced in any convenient way. When the mixture has been allowed to stand, the acid of the tallow or fat will rise to the surface, and the water being drawn off will carry the alkaline or saline matters with it; but if the acids of the tallow should retain any portion of the salts, fresh water may be thrown upon it, and the whole well agitated, until the acids have become perfectly free from the alkaline mai 
.ers; and when allowed to cuol, the acids will ve formed into a solid mass. This mass is now to be submitted to considerable pressure in such an apparatus as is employed in expressing oil from seeds; when the liquid acid will run off in the form of a substance resembling oil, leaving a solid matter, similar, in every respect, tc spermaceti, which is fit for making candles.

The wick to be used in the manufacture of these improved candles, and which forms one of the features of this invention, is to be made of cotton yarn, twisted rather hard, and laid in the same manner as wire is sometimes coiled round the bass strings of musical instruments. For this purpose, straight rods or wires are to be procured, of suitable lengths and diameters, according to the intended size of the candles about to be made; and these wires, having been covered with cotton coiled round them as described, are to be inserted in the candlemoulds as the common wicks are; and when the candle is made, and perfectly hard, the wire is to be withdrawn, leaving a hollow cylindrical aperture entirely through the middle of the candle. See Srearine.

For the process of making mould candles, which is even more simple than that for dipping, see Ure's Dictionary of Arts, \&c., art. CANILE: where also may be found a drawing and description of an ingenious machine for making dipped candles, much used in Edinburgh.

Candles ought never to be used until several weeks have elapsed after they are made; otherwise they are apt to gutter and run. (M'Cullock's Com. Dic.: Willich's Dom. Encyc.)

CANDLE-BERRY MYRTLE (Myrica gale). A hardy shrub, native of Britain, which grows ?o four feet high, and bears a smail red blossom in May and June. It loves heath mould, and is propagated by seed, or by dividing the roots.

The species called candle-berry myrtle in the United States, is the myrica cerifera of botanists. It grows on the lands bordering on the sea and bays of the Atlantic States, where the wax which surrounds the clusters of berries is often collected by the poor either for their own use in mixing with tallow to make candles, or to sell. The herries when gathered are put into hot water, which melts the wax by which each is enveloped, and which, rising to the top, is shimmed off. It is of an olive-green colour and fragrant odour. As a popular remedy in dysentery it has acquired considerable reputation.

Almost every region of the United States produces varieties of the wax myrtle. Michaux cunsiders them all as belonging to one species, a conclusion which is warranted by the great number of intermediate sizes and forms of leaf, which may be observed between the different extremes. Pursh, however, has chosen to distinguish three species which bear wax, and which he names cerifera after Linnæus, Carolnzenses from Willdenow, and Pennrylvanica from Lamarck. 'The wax myrtle or vayberry, as it is often called, which is cornmon in New England, varies in height from one to seven or eight feet. It is found in every kind of soil from the borders of swamps to the tops of barren hills, and is very much influenced in its size and appearance, by the place in which it happens to grow.

The wax myrtle is found bearing fruit at every size, from the height of one foot, to six or eight. In Louisiana, it is said, to grow to twelve feet. The top is much branched, and covered with a grayish bark. Every young part of the wax myrtle has a fragrarit, balsamic smell, which it communicates to the fingers when rubbed by them.

Dr. J. F. Dana has published, in Silliman's Journal, an account of some experiments made to ascertain the proportion of wax, and of the other parts which compuse the entire berry. He found the wax to constitute nearly a third of the whole, or thirty-two per cent; the kernels $47 \cdot 00$, the black powder $15 \cdot 00$, with about $5 \cdot 00$ of a resino-extractive matter.

The myrtle wax is useful for many of the purposes for which bees wax and tallow are employed, particularly for candles. It burns with a clear flame, though less vivid than that of common oil, and emits a considerable fragrance. It was formerly much in demand as an ingredient in a species of blacking ball, to which it communicated a temporary lustre and power of repelling water. It has occasionally been used in pharmacy in various compositions intended for external use, and is mild or stimulating according as it is more or less pure and freed from the colouring matter.

In some parts of Europe plantations of this shrub have been raised with a view to the profit to be derived from the wax. In this country, where the shrub abounds, the berries are often neglected, their collection and the separation of the wax being deemed too laborious to compensate the trouble. The bark of the wax myrtle considered medicinally is an acrid stimulant and astringent. (Dr. Bigclow's Am. Med. Botany.)

CANE. A provincial term used to signify a hollow place, where water stands. It also implies a wood of alder, or other aquatic trees, in a moist boggy situation.

In the South-western States of America there are extensive and almost impenetrable canebrakes, consisting of a rank growth of a subaquatic species of cane or reed (Arunto pragmites?). 'These cane-brakes resemble in many respects the jungles of the East Indies.

CANINE MADNESS. See Hínторнони.

CANKER, OR ULCER (Lat. canker; Sax. cancene, or cance). In the vegetable creation, a disease to which our apple, pear, elm, and other trees are subject.

"This disease," says Mr. G. W. Johnson, " is accompanied by different symptoms, accord ing to the species of the tree which it infects In some of those whose true sap contains a considerable quantity of free acid, as in the genus Pyrus, it is rarely accompanied by any discharge. To this dry form of the dis ease, it would be well to confine the term canker, and to give it the scientific name of Gangrana sicra, or dry gangrene. In other trees, whose sap is characterized by abounding in astringent or mucilaginous constituents, it is usually a:"rnord by a sanious discharge. In 


\section{CANKER.}

such instances, it might be strictly designated ulcer, or Gangrana saniosa. 'This disease has a considerable resemblance to the tendency to ossification, which appears in aged animals, arising from their marked appetency to secrete the calcareous saline compounds that chiefly constitute their skeletons. 'The consequence is an enlargement of the joints, and ossificaion of the circulating vessels, and other parts; phenomena very analogous to those attending the cankering of trees. As in animals, this tendency is general throughout their system; but, as is observed by Mr. Knight, "like the mortifications in the limbs of elderly people,' it may be determined, as to its point of attack, by the irritability of that part of the system. This disease commences with an enlargement of the vessels of the bark of a branch, or of the stem. This swelling invariably attends the disease when it attacks the apple tree. In the pear, the enlargement is less, yet is always present. In the elm and oak sometimes no swelling occurs, and in the peach I do not remember to have seen any; I have never $r b$ served the disease in the cherry tree, nor any of the pine tribe. The swelling is soon communicated to the wood; which, if laid open to view, on its first appearance, by the removal of the bark, exhibits no marks of disease beyond the mere unnatural enlargement. In the course of a few years, less in number in proportion to the advanced age of the tree, and the unfavourable circumstances under which it is vegetating, the swelling is greatly increased in size, and the alburnum has become extensively dead: the superincumbent bark cracks, rises in discoloured scales, and decays even more rapidly than the wood beneath. If the caries is upon a moderately sized branch, the decay soon completely encircles it, extending through the whole arburnum and bark. The circulation of the sap being thus entirely prevented, all the parts above the risease of necessity perish. In the apple and pear, the disease is accompanied by scarcely any discharge; but in the elm this is very abundant. The only chemists who have examined these morbid products are Sir H. Davy and Vauquelin; the former's observations being confined to the fact, that he often found carbonate of lime on the edges of the canker in apple trees. (Elcm. of Agr. Chemistry, 2d edit. p. 264.)

Vauquelin has examined the sanies discharged from the canker of an elm with much more precision. He found this liquor nearly as transparent as water, sometimes slightly coloured, at other times a blackish-brown, but always tasting acrid and saline. From it a soft matter, insoluble in water, is deposited upon the sides of the ulcer. The bark cver which the transparent sanies nows attains the appearance of chalk, becoming white, friable, crystalline, alkaline, and effervescent with acids. A magnifier exhibits the crystals in the forms of rhomboids and four-sided prisms : when the liquid is dark-coloured, the bark appears blackish, and seems as if coated with a. varnish. It sometimes is discharged in such quantities as to hang from the bark like stalactiles. The matter of which these are composed is alkaline, soluble in water, and with

\section{CANKER.}

acids effervesces. The analysis of this dark slimy matter shows it to be compounded of carbonate of potassa and ulmin, a product pe culiar to the elin. The white matter drposited round the canker was composed of-

\begin{tabular}{|c|c|c|c|c|}
\hline Vegetable matter - & - & - & - & - \\
\hline Carbonate of potassa & - & - & - & - \\
\hline Carbonate of lime & - & - & - & - \\
\hline Carbonate of magnesia & & - & - & - \\
\hline
\end{tabular}

Although young trees are liable to this dis. ease, yet their old age is the period of exist. ence most obnoxious to its attacks. It must be remembered, that that is not consequently a young tree which is lately grafted. If the tree from which the scion was taken is an old variety, it is only a multiplication of an aged individual. The scion may for a few years exhibit signs of increased vigour, owing to the extra stimulus of the more abundant supply of healthy sap supplied by the stock; but the vessels of the scion will, after the lapse of that period, gradually become as decrepid as th: parent tree. The unanimous experience ot naturalists agrees in testifying that every organized creature has its limit of existence. In plants it varies from the scanty period of a few months to the long expanse of as many centuries: but of all, the days are numbered; and though the gardener's, like the physician's slill, may retard the onward pace of death, he will not be permanently delayed. In the last periods of life they show every symptom that accompanies organization in its old age-not only a cessation of growth, but a decay of former developements, a languid circulation, and diseased órgans.

The canker, as already observed, attends especially the old age of some fruit trees, and of these, the apple is most remarkably a sufferer. "I do not mean," says Mr. Knight, " to assert that there ever was a lime when an apple tree did not canker on unlitvourable soils, or that highly cultivated varieties were not more generally subject to the disease than others, where the soil did not suit them; but I assert, from my own experience and observation within the last twenty years, that this disease becomes progressively more fatal to each variety, as the age of that variety beyoild a certain period increases; that all the varieties of the apple which I have found in the catalogues of the middle of the seventeenth century, are unproductive of fruit, and in a state of debility and decay." (Some Doubts relative to the Efficacy of Mr. Forsyth's Plaster, by 'T'. A. Kuight, Esq. 1802.)

Among the individuzls particularly liable "u be infected, are those which have been marked by an excessively vigorous growth in their early years. I have in my garden a maiden standard peach, which is now about sixteen years old. 'The size and abundance of ite annual shoots, until within the last quarter of its existence, were unnaturally large. It is now grievously affected by canlier. Trees injudiciously pruned, or growing upon an un genial soil, are more frequently attacked than those advancing under contrary circumstances The olde st trees are always the first attacked 
f those similarly cultirated. The golden pippin, the oldest existing variety of the apple, is more frequently and seriously attacked than any other. The soil has a very considerable influence in inducing the disease. If the subsoil is a ferruginous gravel, or if it is not well drained; if the soil is aluminous, and effective means are not adopted to free it of superabundant mojsture,-the canker, under any one of these circumstances, is almost certain to make its appearance among the trees they sustain. If an old worn-out orchard is replanted with fruit trees, the canker is almost certain to appear among them, however young and vigorous they were when first planted. How inducive of this disease is a wet, retentive subsoil, if the roots penetrate it, appears from the statement of Mr. Watts, gardener to R. G. Russell, Esq., of Chequer's Court, in Buckinghamshire. A border beneath a south wall had a soil three feet and a half in depth, apparently of the most fertile staple; twice remade under the direction of the late Mr. Lee, of the Vineyard, Hammersmith. In this the trees, peaches and nectarines, flourish for the next three or four years after they are planted, but then are rapidly destroyed by the canker and gum. The subsoil is a stiff sour clay, nearly approaching to a brick earth; and the disease occurs as soon as it is reached by the roots of the trees. (Gardener's Magazine, vol. vi. p. 617.) Pruning has a powerful influeuce in preventing the occurrence of canker. I remember a standard russet apple tree, of not more than twenty years' growth, with a redundancy of ill-arranged branches, that was excessively attacked by this disease. I had two of its three main branches removed, and the laterals of that remaining thinned carefully, all the infected parts, at the same time, being removed. The result was a total cure. The branches were annually regulated, and for six years the disease never reappeared. At the enc of that time the tree had to be removed, as the ground it stood upon was required for another purpose. John Williams, Esq., of Pitmaston, from long experience concludes that the golden pippin, and other apples, may be preserved from this disease by pruning away, every year, that part of each shoot which is not perfectly ripened. By pursuing this method for six years, he brought a dwarf golden pippin tree to be as vigorous and free from canker as any new variety. (Trans. Lordon Hort. Soc. vol. vi. art. 64.)

All these facts unite in assuring us that the canker arises from the tree's wealnness; from a deficiency in its vital energy, and consequent inability to imbibe and elaborate the nourishment necessary to sustain its frame in vigour, and much less to supply the healthy developement of new parts. It matters not whether its energy is broken down by an unnatural rapidity of growth, by a disproportioned excess of branches over the mass of roots, by old age, or by the disorganization of roots in an ungenial soil; they render the tree incapable of extracting sulficient r.surishment from the soil, consequently incapable of developing sufficient foliage, and therefore unable to digest and elaborate even the scanty sap that is supplied to them
The reason of the sap becomirg unnaturally saline appears to be, that in proportion as the vigour of any vegetable declines, it loses the power of selecting by its roots the nourishment congenial to its nature. M. Saussure found in his experiments that the roots of plants growing in saline solutions absorbed the most of those salts that were injurious to them, evidently because the declining plant lost the sensitiveness and energy necessary to select and to reject. Thus, when plants of Polygonum Persicaria and of Bidens cannabina were grown in a solution containing sulphate of soda (Glau. ber salt), acetate of lime, and chloride of sodium (common salt), they altogether rejected the acetate of lime; but when grown in a solution of sulphate of copper and acetate of lime, they imbibed the laiter abundantly. Now, sulphate of copper M. Saussure found to be the most deleterious to the plants of all the salts, in a solu. tion of which he plunged their roots. Suppos. ing the portion originally in solution to be $\mathbf{1 0 0}$, the proportions of each absorbed were as follows :-
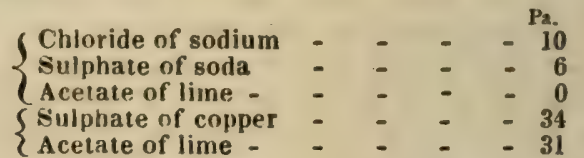

M. Saussure also found, that if the extremities of the roots were removed, the plants $a b$ sorbed all solutions indiscriminately. (Saussure's Récherches Chimiques sur la Vegetation, 260.) An ungenial soil would have a debilitatıng influence upon the roots in a proportionate, though less violent degree than the sulphate of copper; and these, consequently, would absorb soluble bodies more freely, and without that discrimination so absolutely necessary for a healthy vegetation; so the other most essen tial organs of nutrition, the leaves of the weak ened plant, would promote and accelerate the disease. These, reduced in number and size, do not properly elaborate the sap; and I have always found that, under such circumstances, these stunted organs exhale the aqueous particles of the sap very abundantly, whilst their power of absorption is greatly reduced. The sap, thus deficient in quantity and increased in acridity, seems to corrode and affect the vascular system of the tree in the manner already described. These facts afford us most important guides in attaining the desired objects, the prevention and cure of the disease. If superluxuriance threatens its introduction, the best remedy is for the cultivator to remove one of the main roots of the tree, and for him to be particularly careful not to add any fertile addition to the soil within their range. On the contrary, it will be well, if the exuberant growth shows its necessity, for the soil to be reduced in fertility by the admixture of one less fertile, or even of drift sand. If there is an excess of branches, the saw and the pruning-knife must be gradually applied. It must be only trees of weak vital powers, such as the golden pipnin, that will bear the general cutting of the annual shoots, as pursued by Mr. Williams. A new vigorous variety would exhibit itself in the following year in the production of new wood. Having completely headed down, if the can- 


\section{CANKER.}

ker is generally prevalent, or duly thinned the branches, entirely removed every small one that is in the least degree diseased, and cut away the decayed parts of the larger, so as not to leave a single speck of the decayed wood, I cover over the surface of each wound with a mixture, whilst in a melted state, of equal parts of tar and rosin, applying with a brush immediately after the amputations have been performed, taking care to select a fine dry day. I prefer this to any composition with a basis of cow-dung and clay, because the latter is always more or less absorbent of moisture, and is liable to injury by rain and frost, causing alternations of moisture and dryness to the wounds, that promote decay rather than their healing, by the formation of new wood and Dark. The resinous plaster seldom or never requires renewal. Mr. Forsyth, the arch-advocate of alkaline plasters, finding they promoted decay, if applied to the wounds of autumnpruned trees, recommends this important act of cultivation to be postponed to the spring. Such a procrastination, however, is always liable to defer the pruning till bleeding is the consequence. If a resinous plaster is employed, it excludes the wet, and obviates the objection to autumnal pruning. Mr. Forsyth's treatment of the trunks and branches of the trees, namely, scraping from them all the scaly, dry exuviæ of the bark, is to be adopted in every instance : he recommends them to be then brushed over with a thin liquid compound of fresh cow-dung, soapsuds, and urine. But I very much prefer a brine of common salt: each acts as a gentle stimulus, which is their chief source of benefit, and the latter is more efficacious in destroying insects, and does not, like the other, obstruct the perspiratory vessels of the tree. The brine is advantageously rubbed in with a scrubbing or large painter's brush. Some persons recommend a liquid wash, containing, as prominent ingredients, quicklime and wood-ashes; which, as the disease arises from an over-alkalescent state of the sap, cannot but prove injurious and aggravate the disease. Mr. Forsyth's composition, used as a plaster for the wounds made when cankered matter had been extracted, was -

1 bushel of fresh cow-dung,

$\frac{1}{2}$ bushel of lime rubbish,

$\frac{1}{2}$ bushel of wood ashes,

$\frac{1}{I^{3}}$ bushel of finely-sifted sand.

Mr. Knight well observed of this quackery (for which Forsyth was rewarded with a grant of money), that "it afforded a much better proof that he was paid for a discovery than that he made one." (G. W. Johnson; Quar. Journ. of $A g r$. vol. viii. p. 470 ; J. Pearson, ibid. vol. ii. p. 379; A. Drummond, On the Canker in the Larch, ibid. p. 231.)

Canker in horses is a separation of the horn from the sensible part of the fuot, and the sprouting of fungous matter instead of it, and occupying a portion of, or even the whole of the sole and frog. (The Horse, p. 308, Lib. of Useful Knowledge.) The whole secret of the treatment of canker consists in the use of superfirial caustics or stimulants,-pressure as
CAPERS.

firmly and as equably as it can be made, and the careful avoidance of all greasy applications, and all moisture, either applied imme. diately to the foot, or suffered to penctrate to it through the dressing. (Claler's Furriery, p. 324.)

CANKERED. A word sometimes used to signify mildewed or blighted.

CANKERS. A local name in some parts of England for caterpillars.

CANKER-WORM. The insects, called in the Eastern States canker-worms, are caterpillars with ten legs, the larvæ of a natural group of moths called hybernians. They belong to the tribe of geometers, commonly called earth-measurers, span-worms, and loopers. Sce SPAYwonms.

CANTER. (Said to be an abbreviation of Canterbury gallop, and derived from the pil. grims riding to Canterbury on easy ambling horses.-Todd's Johnson.) A well-known pace of the horse, which is not, generally, a natural pace. When the horse is excited to move his station from one place to another, he performs it with a velocity proportionate to the exciting cause. Thus, he changes from the walk to the trot, and from the trot to the gallop, according to his inclination. In each of these changes he acquires a addition of speed; but, as the trot is equal in speed to the canter, he seldom adopts the canter, but changes to the gallop, when he wishes to accelerate his motion. The horse is taught to perform the canter by shortening the gallop. The canter is to the gallop very much what the walk is to the trot, though probably a more artificial pace. The exertion is much less, the spring less distant, and the feet come to the ground in more regular succession: it is a pace of ease, quite in. consistent with any exertion of dranght. ( $L i$ b. Use. Know., The Horse, p. 413.) Some persons, and among them Nimrod, do not consider this pace injurious to horses. "A canter," he observes, "is much more easy, as well as safer to the rider, than a trot; the horse having his haunches more under him in the canter than when he trots, is hereby more likely to recover himself in case of making a mistake, which the best is sometimes subject to. Fast trotting also distresses a horse more than cantering, because, in the one, he is going at the top of his speed, and in the other much below it." (Blaine's Ency. of Rural Sports, p. 297.)

CAPERS. The caper is a small prickly shrub, cultivated in Spain, Italy, and the southern provinces of France. The flowers are large roses of a pretty appearance, but the flower-buds alone are the objects of this cultivation.

They are plucked before they open, and thrown into strong vinegar slightly salted, where they are pickled. The crop oi ach day is added to the same vinegar tub, so that, in the course of the six months during which the caper shrub flowers, the vessel gets filled, and is sold to persons who sort the capers (the smallest being most valued) by means of cop per sieves. This metal is attacked by the acid, wherefrom the fruit acquires a green coluur. much admired by ignorant connoisseurs.

$\times 2$ 


\section{CAPES.}

The capers, as found in the French market, are distinguished into five sorts; the nompareille, the capucine, the capote, the secand, and the third; this being the decreasing order of their quality, which depends upon the strength of the vinegar used in pickling them, as also the size and colour of the buds.

The caper shrub grows in the driest situations, even upon walls, and does not disdain any soil; but it loves a hot and sheltered exposure. It is multiplied by grafts made in autumn, as also by slips of the roots taken off in spring.

CAPES, or CAPPS, provincial words, applied to the ears of corn broken off, either wholly or in part, in thrashing; as well as to the grain to which the chaff adheres.

CAPITAL (Lat. capitalis). The capital required by a farmer, to a great extent, varies with the soil and country in which he is placed; all practical observations in this place, therefire, can only be of a general nature. The first and best direction, however, to a farmer must be, "do not take more land than your capital will enable you to farm well." For this purpose, the observations of the author of the iritish Huslandry, vol. i. p. 41, may very well be introduced in this place. "Most farmers are anxious for large occupations, and many are thus betrayed into the error of renting a greater quantity of ground than they have the means of managing to advantage; some, in the delusive hope of acquiring those means by future savings; others, from the vanity of holding more land than their neighbours: hence arises deficiency of stock, imperfect tillage, and scanty crops; with all the consequent train of rent in arrear, wages ill-paid, and debts unsatisfied-distress, duns, and final ruin. Whereas, he who is prudently content to commence with only such a number of acres as he has the power of cultivating with proper effect, is certain of obtaining the full return from the soil; while, not being burdened with more land than he can profitably employ, his engagements are within his means, and thus, while enjoying present ease of mind, he lays the surest foundation for his future prosperity." And, as it is well observed (Quart. Journ. of Agr. vol. iii. p. 452), "Or if, to save appearances, he borrows money to complete his necessary arrangements, his condition is not improved; because the interest he will have to pay for the borrowed money will operate as an additional yearly rent, and thus take from him all the advantages which he was led to expect he would enjoy under a moderate one." Under the head Ápraisemext will be found the amount of the valuation of the crops, and other things commonly paid by the incoming to the outgoing tenant on a farm of 309 acres, amounting to $1702 l$. This, however, varies r:onsiderably according to the Custom of Corntres, which see. To this must be added the expenses incurred of stocking the farm for the first year. Wages, seed, keep of family, rent, taxes, rates, \&c. On a farm of 500 acres, Professor Jow (Prac. Agr. p. 674) estimates the capital required for the first year to be (in (scotland) -
Implements

2. Live gtock

3. Seed -

4. Manure

5. Lahour, \&c.

6. Maintenance of horses

7. Burdens

Furniture of house

Family expenses, $1 \frac{1}{8}$ years

:

\& 9. 1.

47045
$-\quad 1423150$

27300

$51610 \quad 0$

$\begin{array}{lll}528 & 17 & 6\end{array}$

343711

$-18$

$3 4 8 8 \longdiv { 8 }$

$200 \quad 0 \quad 0$

$150 \quad 0 \quad 0$

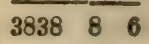

From this he deducts for produce sold

in this time

Required net capital

$-\overline{2542109}$

or $5 l .13 s .8 \frac{1}{2} d$. per acre. In this calculation, he supposes that no rent is paid till the crop is reaped. The estimate for the capital required for a Scotch farm of 500 acres (allowing nothing for payments to outgoing tenant) is, according to a statement in the Quart. Journ. of Agr. vol. iii. p. 475, as follows :-

\begin{tabular}{|c|c|c|c|c|c|c|}
\hline \multicolumn{7}{|c|}{ Value of implements for farm work } \\
\hline & do. & & & ive & tock & \\
\hline - & do. & & & arn & work & - \\
\hline - & Thrashing & machi & ine & - & - & 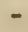 \\
\hline - & Horses & - & - & - & - & " \\
\hline - & Cattle - & - & - & - & - & 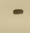 \\
\hline - & Sheep & - & - & - & - & - \\
\hline - & Other live & stock & - & - & - & - \\
\hline - & Grass seeds & & - & - & - & - \\
\hline - & Tares & - & - & - & - & - \\
\hline - & Peas - & - & - & - & - & - \\
\hline 一 & Turnips & - & - & - & - & - \\
\hline - & Potatoes & - & - & - & - & - \\
\hline- & Corn & - & - & - & - & - \\
\hline- & $\mathbf{L i}$ & - & - & - & - & 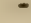 \\
\hline
\end{tabular}

$£$ s. $d$. 43194 $17 \quad 14 \quad 4$ $\begin{array}{lll}170 & 0 & 0\end{array}$ $\begin{array}{ccc}450 & 0 & 0\end{array}$ 51100 42000 $\begin{array}{lll}7 & 0 & 0\end{array}$ $8710 \quad 0$ 680 400 $\begin{array}{rrr}42 & 15 & 0\end{array}$ 2160 $\begin{array}{lll}215 & 6 & 3\end{array}$ 865610 $304117 \quad 11$

Rent 500 acres, at $40 s$. 100000

From $\mathrm{w}$ hich, however, dedrct the value of 40411711 the following articles, derived from the farm before the period of paying the second half year's rent, viz.

Profit on 20 fat cattle, $5 l$. each

$£ 100$

Wintering 20 kyloes for 24 weeks, at $2 s$. $6 d$. per week

Sold 30 dinmots an 1 gewmers at $25 \mathrm{~s}$.

each, and 20 draft ewes at 30 s. each

Profit on turniping 120 hogs 24 weeks, at $3 d$. per head per week Sold 14 pigs

Produce of 4 cows over what required

by family -

Wool sold

35691711

At p. 658, of Low's Prac. Agr. will be found a catalogue of the various implements of a farm of 500 acres, from a thrashing machine worth $100 l$. to a grease pot valued at $1 s .6 d$, amount ing altogether to $474 l$. $48.4 d$. And this includes hardly a single article that the young farmer can well do without. As a general rule on the chalks of Hampshire, they deem $5 l$. per acre to be a sufficient capital; but on some of the rich highly cultivated soils c: Surrey, Kent, and Essex, 10l. per arable acre is not too much. Grazing farms require less in proportion than arable lands.

CAPON (Sax. capun; Fr. chapon; Lat. capo). If cocks, when young, are emasculated, it has a prodigious effect upon their condition, and a similar effect may be produced upon young hens by the abstraction of their egg-bags. These operations have been practised upon 


\section{CAPON.}

poultry from the earliest antiquity, for the purpose of improving the flesh. In England, it is chiefly practised in the great poultry-breeding counties of Sussex, Essex, and Berks, but is little known anywhere else. There are, indeed, persons who make a trade of it, and it is best to employ one of those when they can be had; but it is not uncommon for the poultryfarmers' wives and daughters to acquire dexterity in performing the operation. This, indeed, seems to be no new thing, for Mascall, in his minute but very quaint directions, uses the feminine gender throughout. "To cut young cockrels," he says, "to make them capons, the time thereof best to cut and carve them is soone after their dam has left them, or when they cry or pule no more after her, as when they begin to crowe and waxe hote to tread the pullets. The common way of cutting or carving is not to be dispraysed, and is most knowne as this waye: they take them in the morning, commonly in the wane of the moone, and laye the cocke in her lappe, upon his back, trussing up his legges by his sides. Then the carver pluckes first awaye the feathers above the vent, and takes up the upper skin on the point of a needle, and slits it over-thwart an inche long, and then takes up the under thin skinne nexte the guts, and slits that likewise. Then the carver annoyntes her fore finger of her right hande with oyle or butter, and puts it gently to the raines of the cock, on the left side, and with her finger bringes forthe the stone. Then she annoyntes the fore finger of her left hande, and puts it into the stone on the right side of the cocke, and with her finger bringes it forthe. So done, she placeth the guts, and sowes the skinne up again with a threade, and then annoyntes that place with some fresh butter, and lets him go."

The art of caponing fowls forms a part of rural economy, and as the mode of operating is very little understood in the United States, we propose giving such ample and minute instructions upon the subject, as, with the aid of original drawings, will enable any one to succeed who possesses common dexterity.

The chickens intended for capons should be of the largest breed that can be obtained, and in the United States there is not perhaps one better suited in this respect than the celebrated large Buck's county breed, well known in the Philadelphia market, where capons made from these fowls have been sold weighing $25 \mathrm{lbs}$. the pair. As in breeding with a special view to making capons, male chickens alone are required, those eggs should be selected to set under hens which produce males, namely, such as have the sharpest points. The alteration of the chicken into a capon will, in about a twelvemonth, nearly double the size of the bird. Persons wishing to become expert in the operation of making capons would do well i) imitate surgeons, who always try their hand upon dead subjects before performing on the living. It is, however, quite simple, and in France and Italy is often allotted to mere children.

The Chinese mode of operating we think preferable not only to the old one described by Mascall, but to any other of which we have ever he ard.
CAPON.

Chickens intended for capons may be ope. rated upon at any age, though when between two and three months old is considered much the best time. Old fowls seldom survive the operation. Previous to cutting, the chickens must be kept entirely from food, and even water, for about thirty-six hours, as experiments have determined this time to insure the best chance of success by causing the bowels to be empty and lessening the tendency to bleeding. 'The fowl may be secured either in the Chinese mode, - that is to say, lying on its left side with its wings folded back till they meet, and pressed under the foot of the operator, whose other foot is placed upon the legs; - or, it may be held by an assistant in a similar position; or, what adds greatly to the convenience of the operator, especially in relieving him from the necessity of stooping low, the fowl may be confined by straps, \&c. to a table one of which, of a highly ingenious construction, has been invented by a Philadelphian, and will be subsequently described and delineated. (See Figs. 2 and 3.)

The chicken being secured with its left side downwards, wings clasped behind its back, legs extended backwards, the upper one being drawn the furthest back (see fig. 3), the head and neck left perfectly free, the feathers are next to be plucked from is right side near the hip joint, in a line between that and the shoulder joint; the space uncovered ( $a$, fig. 3) may be a little over an inch square. Having first drawn the skin of the part backward, so that when left to itself after the operation, it will cover the wound in the flesh, make an incision with the bevel-edged knife, (fig. $1, a$ ) between the last two ribs, commencing about an inch from the backbone, and extending obliquely downwards about an inch or inch and a half, just going deep enough to separate the ribs, and taking good care not to wound the intestines. A pair of broad blunt hooks (fig. 1, e, c) attached to a piece of elastic whalebone or ratan $(b)$ about six inches long are then applied, one hook to each side of the cul, and these being stretched apart by the spring bow, keep the wound open wide enough to give room for the operation. Then carefully cut open the skin covering the intestines, which last, if not sufficiently drawn up in consequence of the previous fasting, may be pushed forwards or towards the breastbone, by means of a flat instrument contrived for the purpose, or, what answers equally well, the handle of a teaspoon. When the testicles are exposed to view, they will be found to be connected with the back and sides by means of a thin skin which passes over them. This tender covering must be seized with the pincers $a, a$, and torn open with the assistance of the sharpedged hook $h$; after this, with the left hand, introduce the curved spoon under the lower or left testicle (which is generally a little nearer the rump than the right one): then take the tube $i$, and with the right hand pass the loop $n_{3}$ over the small hooked end of the spoon $h$, run. ning it down under the spoon and includer testicle, so as to bring the loop to act upon the part which fastens the testicle to he back Then by drawing the ends of the haur-locf 
backwards and forwards, and at the same time pushing the lower end of the tube towards the rump of the chicken, the cord or fastening of the testicle is sawn off. The same process is to be followed with the uppermost or right testicle, after which the separated testicles, together with any blood in the bottom of the wourd are to be scooped out with the crooked spoon. When performed properly, little or no blood of consequence is observed, neither does the fowl seem to experience any pain, after the first incision, but will eat if food be given to it. To enable the operator to produce the sawing movement, the hair or other ligature used may be tied in a knot so as to allow the index or fore finger of the operator's right hand to pass through it. This finger being then turned or rolled repeatedly from side to side, communicates to the loop below the sawing motion which contributes to cut off the testicle. The reason for cutting off the lowermost testicle first, is to prevent the blood which may issue, from covering the remaining one, and rendering it difficult to be seen. After this operation which, if skilfully performed, occupies very few minutes, the hooks are to be taken out, the skin drawn over the wound, and this covered with the feathers plucked off at the commencement of the operation. The chicken is then released, and as soon as let go will take grain or other food eagerly, and in a day or two be restored to its usual health. A person well skilled may operate on fifty chickens without killing more than one or two.

In some fowls the fore part of the thigh covers the last two ribs; in which case care must be taken to draw the fleshy part of the thigh well back, to prevent its being cut, as this might lame the fowl or even cause its death.

For ligatures nothing answers so well as that commonly employed by the Chinese, namely, the fibre of the cocoanut husk. This is rough, and makes a loop which saws off and separates the testicle very readily. The next best substance for this purpose is horse-hair. Experiments with fine wire, silk, silk-gut, \&c. show that these are all inferior to cocoanut fibr. and horse-hair.

Sometimes a portion of the testicle adheres and is left behind, in which case the fowls will not prove capons, as will soon be evident, and may be killed for use as soon as the head begrins to gruw large and get red, and they show a disposition to chase the hers. The real capon will make itself known by the head remaining small, the comb and gills losing their bright redness and appearing withered; the feathers of the neck and tail will also grow longer. They should be kept to the age of fffteen or eighteen months, which will bring them in the spring and summer, when poultry is scarce and bears a high price. But they should not be killed near moulting time, as all poultry then is very inferior. The operation fails principally in consequence of the bursung of the skin which encloses the soft matter of the testicle, some of which remains in the bird.

Fowls of five or six months are less liable

.6. have the testicles burst in the operation than 260 younger ones, but they are also more apt to bleed to death than those of from two to four months old. As the large vessel that supplies the entrails with blood passes in the neighbourhood of the testicles; there is danger that a young beginner may pierce this with the pointed instrument in taking off the skin of the lower testicle, in which case the chicken would die instantly. There are one or two smaller vessels to be avoided, which is very easy, as they are not difficult to be seen. If properly managed, no blood ever appears until a testicle is taken off: so that should any appear before that, the operator will know that he has done something wrong.

If a chicken die during the operation by bleeding, it is of course as proper for use as if bled to death by having its throat cut. They very seldom die after the operation unless they have received some internal injury, or the flesh of the thigh has been cut through, from not being drawn back from off the last two ribs, where the incision is made; all of which accidents may be liable to occur with young practitioners.

Where the testicles are found very large, the silver tube may be too small for the operation; in this case a larger one made of small bamboo or elder, about $\frac{3}{8}$ ths of an inch in diameter, may be substituted, with a strong cocoanut string or ligature. But for chickens of small and medium sizes, the silver tube, with a horse-hair in it, will answer perfectly well.

When a chicken has been cut, it is necessary, before letting it run, to put a permanent mark upon it; otherwise it would be impossible to distinguish it at first from others not operated on. Cutting off the outside or the inside. toe of the left foot, will enable one to distinguish them at a distance. Another mode is to cut off the comb, then shave off the spurs close to the leg, and stick them upon the bleeding head, where they will grow and become ornamental in the shape of a pair of horns. This last mode is perhaps the best, but it is not so simple and ready as the first. Whichever plan is adopted, the fowl should be marked before performing the operation.

It is very common, after the operation, and whilst the wound is healing, for the side to puff out with a windy swelling. This may be relieved by making a small incision or puncture in the skin, which will let the wind escape.

Those fowls make the finest capons which are hatched early in the spring; as they can be cut before the hot weather comes, which is a great advantage.

The operator should not be discouraged with the first difficulties; for with practice they will disappear; every year's experience will render one more expert, until the cutting of a dozen fowls before breakfast will be a small matter.

It may be well to give a warning against becoming dissatisfied with the instruments. A raw hand, when he meets with difficulties, is apt to think the tools are in fault, and sets about to improve them and invent others; but it may be only himself that lacks skill, which practice alone can give. Those who have devoted much time and attention to the subject say 


\section{CAPON.}

\section{CAPON.}

.nat they have found the old Chinese instru- / end in opposite directions. It is for the purments, a drawing of which is given in fig. 1 , preferable to all others.

In addition to these instruments, a regular Chinese set contains a flat kind of spatula something like the upper part of a spoon handle. This is about four inches long and half an inch wide, and slightly curved at each pose of pushing the intestines cut of the way. an office very well performed by the handle of a teaspoon.

Fig. 1 represents the instruments used in making capons, according to the Chinese mo. thod, reduced only about one-fourth their actua' sizes.
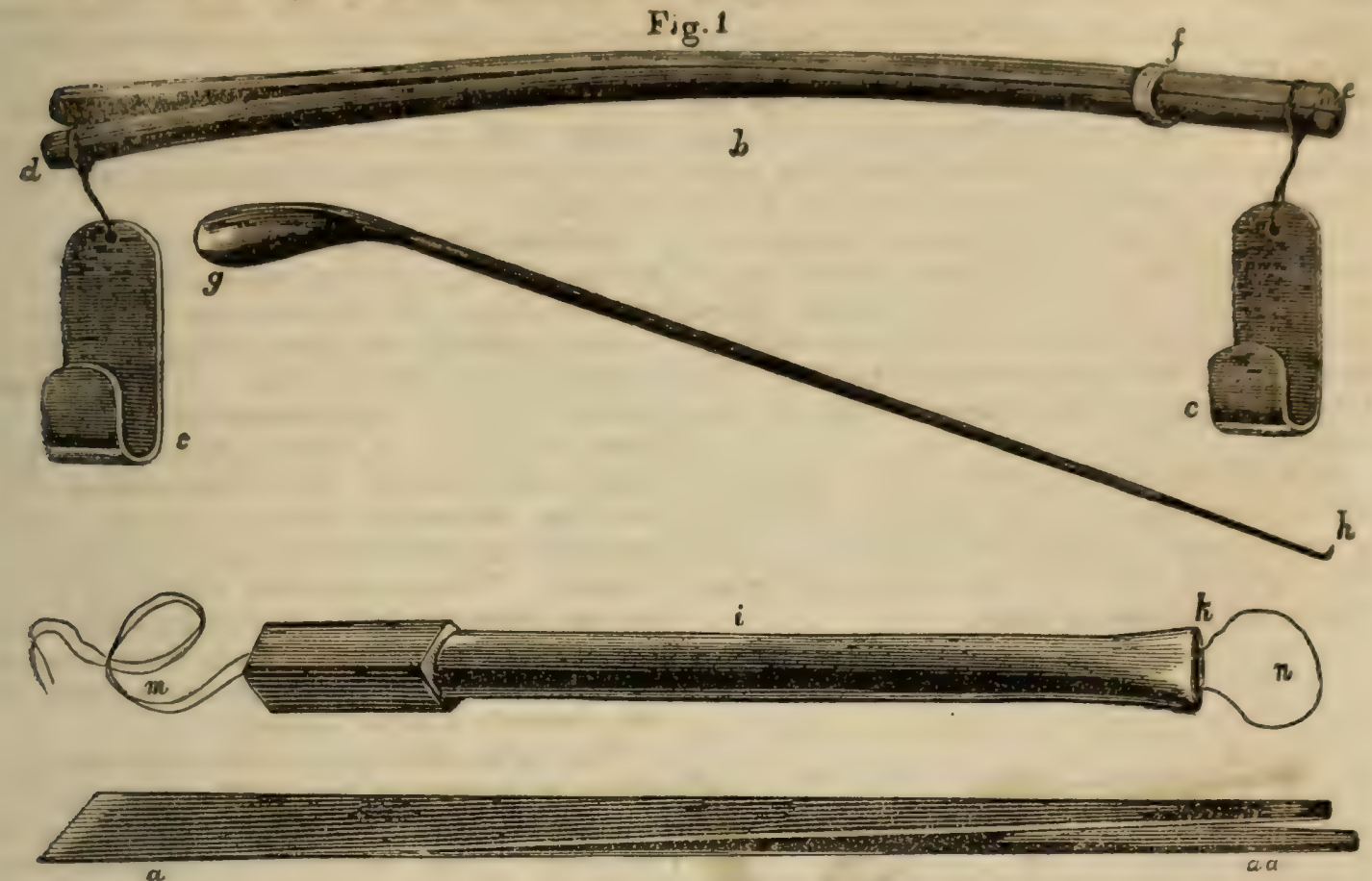

a, a knire, the edge of which resembles that of a chisel with a bevel or slanting edge, half an inch in the greatest width: the other end or handle consists of two forcep blades terminating at $a$, $u$, in slender points, and forming spring forceps. The whole length from the cutting edge to the end of the pliers is ahout six inches.

$c, c$, two hroad blunt hooks of silver or other metal, each haif an inch in width and one and a half in length.

$b$, an elastic bow, six inches Iong, made of whalebone or ratan, about the thickness of a large quill, and split horizontally inte two pieces. To the ends of this how the hroad hooks are attached hy strong cords about haif an inch inng. At the end $d$, the cord embraces only the lower lialf of the sptit bow, whilst both pieces are included in the string, at the end $e$

$f$, is a small ring which encircles hoth portions of the bow. When the honks are first mut in and only half the strength of the how is required to act upon them, this ring is slipped to the end $e$. But if the whole strength of the bow is needed to force the hooks apart and streich the wound open, the ring is passed towards the errd $d$. Thus, by means of the split bow and sliding ring, the strain upon the hooks can be increased or slackened at pleasure.

$i$, a tube of silver or other metal three or four inches inng, made square at the upper, and flattened at the fnwer end $k$, to the width of three-tenths of an ilich; this tube is for the purpose of passing the fibre or hais ligature $m$, forming the foop $n$.

$g$, a narrow curved spoon, the slender handle of which tapers off and has a steel mint ficted into it, furnished at the extremity with a very small hook, $h$; the inner edge of this hook is sometimes sharpened.

The operating table contrived in Philadelphia, and before referred to, is represented in the following cut, fig. 2 .

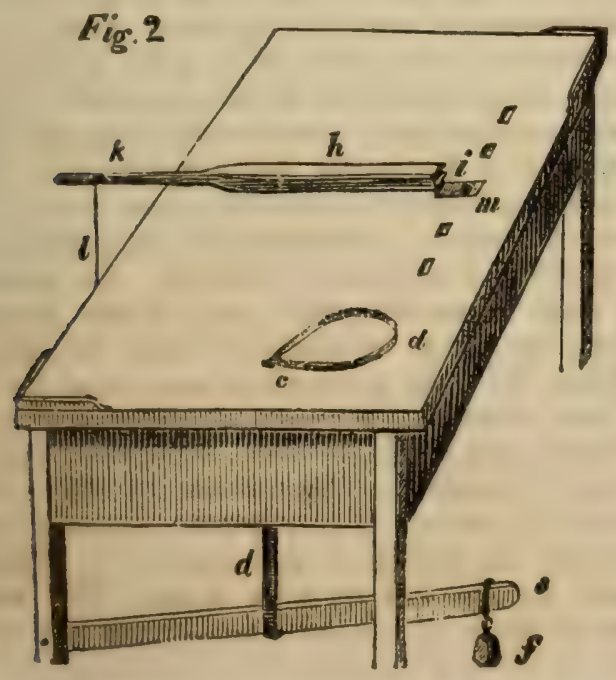

This table may be about $2 \frac{1}{2}$ feet long by $1 \frac{1}{2}$ feet wide, and $2 \frac{1}{2}$ feet high. At two of its corners it can have a raised moulding about $\frac{1}{2}$ an inch high, extending along the sides six or nine inches, for the purpose of placing the instruments at one corner and at the other some of the feathers under a stone, to keep them from being blown away. On one side there is a slit $c$ passing through the table, about $1 \frac{3}{1}$ inch long by an inch wide, running diagonally; being about three inches from the end and $6 \frac{1}{2}$ from the side. Through this slit the padded band or soft list, $d, d$, for confining the wings, passes below to be attached to the lever e. This lever has a 4 or $5 \mathrm{lb}$. weight hung to it, and works on a serew or pin, by which it is attached to the leg. When not in use the lever rests on a pin or ledge in the other leg. On being led down, the attached band clasps the wings of the chicken lying on the table, with greater or less force as the weight is drawn 10 or from the end of the lever. The next thing to be described is the lever, $h$, lipin the table, 
the olject of which is to hold down the legs as these are extended backwards. This lever is padded beneath, and is furnished with a hinge at $i$, which admits of being raised at the end $k$; it projects beyond the edge of the table, and has also a $5 \mathrm{lb}$. weight suspended by the string $l$, which increases or diminishes the pressure by being moved to or from the table. Through one portion of the hinge an iron screw, $m$, passes beneath the table where the end is secured by a nut. This screw or pin allows the lever to move sidewise, whilst the hinge admits of its being raised or let down. A range of holes, about $\frac{1}{3}$ of an inch wide, are made through the table to receive the pin of the lever, as this has to be placed nearer to or further from the slit $c$, according to the size of the chicken. The first hole is about eleven inches from the nearest end; the second, fourteen inches; the third, seventeen inches. The last is adapted to very large cocks or even surkeys.

In fig 3 , the position of the fowl when secured, lying upon its left side upon the table, is represented, $d$ being the wing-band, $h$ the lever placed over the legs, and $a$ the place where the incision is made.

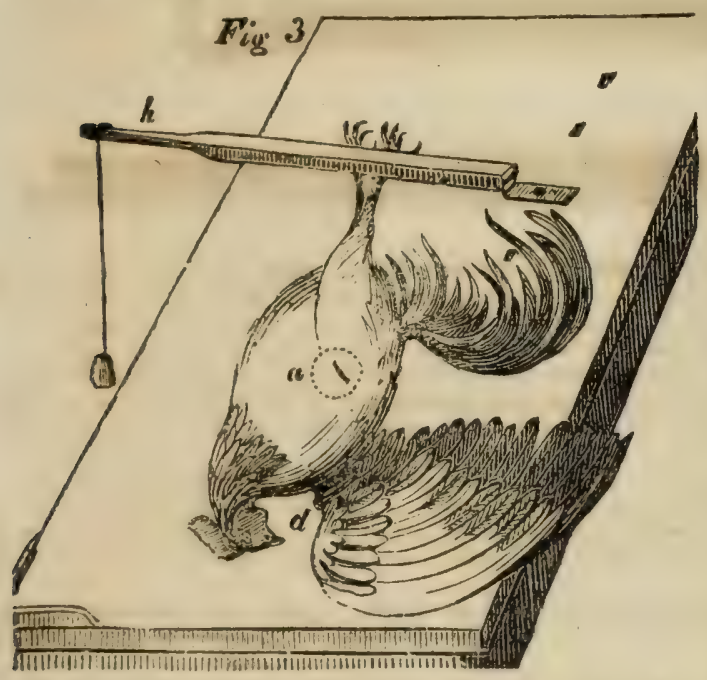

The table is a refinement in the art of caponing which we believe is altogether new, notwithstanding the thousands of years which have elapsed since the operation has been habitually practised. The difficulty of making a subject, apparently simple, well understood by persons to whom it is entirely new, is, we think, a sufficient apology for the length of the tetails given.

In France and other countries, besides furnishing a luxurious food, capons are made useful in taking care of broods of young chickens, ducklings, turkeys, and pheasants, which they are said to do much better than hens, owing to their larger size and thicker coats of feathers. The moment the chickens ire hatched they are taken from the hens and given to a capon, who rears them with all the care of a parent, often having a small bell attached to his neck, the tinkling of which serves the purpose of keeping the brood about him, ismilar to the clucking and maternal sounds of the mother. Should he show a disposition to treat the young chickens roughly 262 at first, he may be confined alone for a day or two in a dark place, after which if they be put with him he will be pleased with their com. pany and continue to take care of them. The hen is cooped, and well fed until she regains the flesh and strength lost whilst setting, and then turned out to lay again. In this way the poulterer is enabled to raise a large number of chickens from a few hens. The capon generally brings double or treble the price of common poultry.

CAPILIARY VESSELS OF VEGETA. BLES. The fine hair-like vessels that assist in the absorption and circulation of the juices of plants.

CAPSICUM. (Supposed either from $x a \pi \tau a$, mordeo, to bite; or from capsa, a chest.) Capsicum annurum. Of this there are five varieties. 1. Long-podded. 2. Heart-shaped. 3. Shortpodded. 4. Angular-podded. 5. Round shortpodded. Of the Capsicum cerasiforme there are three varieties. 1. Cherry-shaped. 2. Bellshaped, or Ox-heart. 3. Yellow-podded. The soil best suited for them is a rich, moist, mouldy loam, rather inclining to lightness than tenacity. When completely ripe, the pods are cut and hung up in the sun, or in a warm room, until completely dry, in which state they are kept until the seed is wanted for sowing. (G. W. Johnson's Kitchen Garden.)

The capsicum loses some of its aromatic odour by drying, its taste, both recent and dry, is hot and acrid, depending on a fixed acrid oil, not volatile and distinct from that oil which gives the odour to the fresh pod. Capsicum is used as a condiment in cookery; it is more excitant than pepper; but its effects are less permanent.

CARAWAY, or CARRAWAY (Fr. and It. carvi; Lat. carsm carui). A naturalized biennial plant, with a taper root like a parsnip, but much smaller; stem about two feet high, growing wild in meadows and pastures. This plant is extensively cultivated in several parts of Essex and some other counties, for the sake of its seeds, which are in daily use as a grateful and wholesome aromatic, and are largely consumed in confectionary and medicinal preparations; but its root was formerly much esteemed when boiled, and it is not easy to account for its falling into disuse. The seeds, which are grayish-brown, and ribbed, are too well known to need description. They should be chosen large, new, of a good colour, no: dusty, and of a strong agreeable smell. Caraway is sometimes sowed with coriander and teasel, and harvested the second year. The produce of this seed has often been very great; even as much as $20 \mathrm{cwt}$. per acre, which always finds a market in London. On accoun: of their aromatic smell and warm pungent taste, the seeds of caraway may be classed among the first stomachics and carminatives of our climate. To persons afficted with flatulency, and liable to colic, if administered in proper quantities, they generally afford considerable relief. Their virtue depends on a volatile oil, which is procured in a separate state, by distillation with water. The water retains some of the oil, and is used as a vehicle for other medicines. 
Caraway delights in a deep, rich, Mist loam. The ground for this, as well as other deep-rooting plants, is advantageously dug two spades deep. An open situation is most suitable to it; but in extensive orchards, where the trees are far apart, it may be grown with success. It is propagated by seed, which may be sown in March or April, either broadcast and raked in, or in drills six inches apart; in either case being performed thin, and buried about half an inch deep. When well distinguishable, the plants must be thinned to six inches apart, and carefully hoed. The hoeing must be several times repeated in the early stages of their growth, to extirpate the weeds, which at a later period cannot be conveniently got at. The plants flower in June, and ripen their seed at the close of summer. (G. W. Johnson's Kitch. Gard.; English Flora, vol. ii. p. 86; M'Culloch's Com. Dict.; Willich's Dom. Encyc.; Brande's Dict. Science.)

CARBON (Fr. carbone; Lat. carbo). A hitherto undecompounded combustible body, which enters into the composition, in some form or other, of all vegetable substances. In a perfectly pure state, carbon constitutes diamond. Carbonaceous substances are usually more or less compounded, containing hydrogen, or sometimes oxygen, and azote, along with earthy and metallic matters. Carbon, tolerably pure, abounds in the mineral kingdom; and, in a combined state, it forms a main constituent of vegetable and animal bodies. Anthracite is a mineral charcoal, differing from common pit-coal in containing no bitumen, and therefore burning without flame or smoke. Coke is the carbonaceous mass which remains after pit-coal has been exposed to ignition for some time out of contact of air; its volatile parts having been dissipated by the heat. It is a spongy substance, of an iron-black colour, a some what metallic lustre, and does not easily burn unless several pieces are kindled together. With a good draught, however, it produces a most intense heat. It is readily obtained in the form of charcoal by heating wood (and any kind of wood will answer the purpose) red-hot, covered with sand, in a crucible. The covering with sand is added to prevent the wood undergoing combustion by coming in contact with the atmosphere. In this state when reduced to powder, charcoal constitutes an excellent manure for most soils, either when applied by itself, or mixed with decomposing animal and vegetable substances. In such cases it absorbs a considerable volume of the gases which such substances constantly emit. Thus, reckoning the bulk of the charcoal to be 1 , it absorbs of

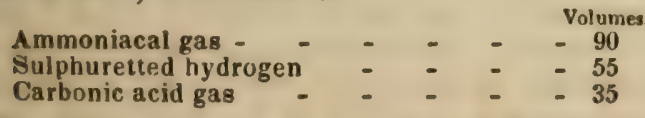

When burnt, charcoal unites with the oxygen of the atmosphere, and forms, in the state of carbonic acid gas, a very important portion of the gases required by all plants for their healthy vegetation. (See GASES, THeir UsE To VEgetation.) Carbon constitutes about 42.47 per cent. in sugar, 41.906 per cent. in gum, 43.55 per cent. in wheat starch, 52.58 per eent. in the wood of the oak, and 51.45 in that of the beech; 46.83 in pure acetic acid or vine. gar, 36.167 in tartaric acid, and 41.369 in the citric. In the state of carbonic acid gas, and in various organic malters, it is found in ali cultivated soils, in all waters, and in the atmon sphere; and in each situation, as will be more particularly described under the head Ganes. it is absorbed by and becomes the food of plants.

CARBONATES. A peculiar class of salis formed by the combination of carbonic acid gas with various earths, alkalies, and metallic oxides. The composition of those most commonly met with by the farmer is as follows:-

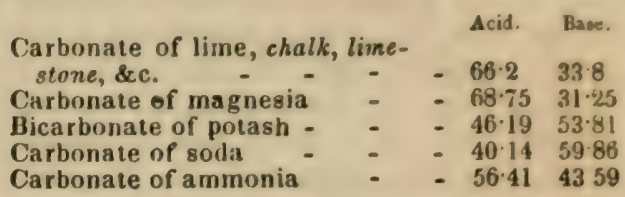

CARBONIC ACID GAS. A peculiar gas, the same as that emitted by fermenting beer, or other liquors; it is inhaled by, and its car. bon is the food of plants. It is composed of carbon 72.73, oxygen $27 \cdot 27$. See Gasks, their Use to Vegetation,

It is important to know, that carbonic acid gas is poisonous, if breathed. If, for example, a person descends into a tun where fermented liquor occupies the bottom, and an atmosphere of carbonic acid gas floating over it; as soon as his mouth is immersed in it, he is suffocated in the same manner as if his mouth and nostrils were closed. He dies from the defect of atmospheric air in the lungs, and the circulation of black blood through the brain. This is the manner also in which death occurs when persons descend into old wells and cellars that have been long closed. When the gas is diluted with air, as for instance, when a person dies by burning charcoal in a chafingdish in a bed-rnom, he is not suffocated; but he dies from the sedative influence of the diluted carbonic acid, which is breathed, on the nervous system. When such accidents happen, persons should not venture to bring out the bodies, until a quantity of pure lime mixed with water to the thickness of milk, has been thrown into the tun, well, or cellar; or in the event of death from burning charcoal, until a current of air has been sent through the apartment. The bodies should be laid on their backs, with the heads moderately elevated; cold water dashed on the chest, and frictions employed over the whole body; and the aid of a medical practitioner quickly procured.

This is the heaviest of all gases, its weight, compared with the common air of the atmosphere, being about one-half greater. This is the reason why it always subside: to the bottom of apartments, wells, sinks, \&c. where it may have been formed, or gained access. Its weight even admits of its being poured from one vessel to another. Hence it was at first called aërial acid. From its existing copiously, in a solid state, in limestones and the mild alkalis, it was styled fxed air by its proper discoverer, Dr. Black. About one volume of it exists in one thou sand volumes of common atmospheric air, which may be made manifest by the crust: 
carbnnate it occasions upon the surface of lime-water. Carbonic acid gas is found accumulated in many caverns of volcanic districts, and particularly in the grotto del cani at $\mathrm{Pau}$ silippo, near Puzzuoli; being disengaged in such circumstances by the action of subterranean fire, and, possibly, of certain acids, upon the limestone strata. It often issues from fountains in copious currents, as at Franzensbrumn, near Eger, in Polterbrunnen; near Trier; and Byrreshorn. This acid gas occurs also frequently in mines and wells, being called cholie damp, from its suffocating quality. Its presence may, at all times, be detected, by letting down a lighted candle, suspended from a string, into the places suspected of containing this mephitic air. It exists, in considerable quantities, in the water of every pumpwell, and gives it a fresh and pleasant taste. Water, exposed some time to the air, loses these aërial particles, and becomes vapid. Many springs are highly impregnated with carbonic acid gas, and form a sparkling beverage; such as the Selterswasser, from Selters, upon the I.ahn, in the grand duchy of Nassau; of which no less than two millions and a half of bottles are sold eve:y year. The amount in Saratoga water is very great. A prodigious quantity of a similar water is also artificially prepared under the name of aërated or soda water.

Carbonic acid occurs in nature, combined with many salifiable bases; as in the carbonates of soda, baryta, strontia, magnesia; the oxides of iron, manganese, zinc, copper, lead, \&c. From these substances it may be separated, generally speaking, by strong ignition, or more readily, by the superior affinity of muriatic, sulphuric, or nitric acid, for the earth or metallic oxyde. It is formed whenever vegetable or animal substances are burned with free access of air, from the union of their carbonaceous principle with atmospheric oxygen. It is also formed in all cases of the spontaneous decomposition of organic substances, particularly in the process of fermentation; and constitutes the pungent, noxious, heavy gas thrown off, in vast volumes, from beer vats. See Distillarios and Fermartarion. Carbonic acid is also generated in the breathing of animals; from 4 to 5 per cent., in volume, of the inhaled oxygen being converted, at each expiration, into this gas, which contaminates the air of crowded apartments, and renciers ventilation essential to health, and even to life; witness the horrible catastrophe of the Blackhole at Calcutta.

Carbonic acid gas is destitute of colour, has a sourish, suffocating smell, an acidulous pungent taste, imparts to moist, but not dry, litmus paper, a transient reddish tint, and weighs per 100 cubic inches, $46 \frac{1}{2}$ grains; and per cubic foct, $803 \frac{1}{2}$ grains; a little more than $33 \mathrm{oz}$., avoirdupris. A cubic foot of air weighs about two-thirds of that quantity, or 527 grains. It may be condensed into the liquid state by a pressure of 40 atmospheres, and this liquid may be then solidified by its own sudden :pontaneous evaporation. If the air contain inore than 15 per cent. in bulk of this gas, it lrcomes unfit for respiration and combustion, animal life and candles being speedily extinguished by it.

Before a person ventures into a deep well, or vault containing fermenting materials, he should introduce a lighted candle into the space, and observe how it burns. Carbonic acid being so much denser than common air, may be drawn out of cellars or fermenting tubs, by a pump furnished with a leather hose, which reaches to the bottom. Quicklime, mixed with water, may be used also to purify the air of a sunk apartment, by its affinity for, or power of, absorbing this aërial acid. (Ure's Dict. of Arts, \& $e^{\circ}$.)

CARBURETTED HYDROGEN. A compound of carbon and hydrogen gases, of which there are several species; such as oil gas, coal gas, olefiant gas, oil of lemons, otto of roses, oil or spirits of turpentive, petroleum, naphtha, naphtha. line, oil of wine, caoutchoucine, and caoutchouc or Indian rubber. (Ure's Dict. of Ar\%s, \&c:)

CARDINAI, SCARLET (Lobclia cardinalis). An herbaceous hardy plant, a native of Virginia. It blows its scarlet flowers in July, and again in October. It loves bog earth and shade, and the root should be parted every spring. Ripen the flower intended for seed under a glass hung over it, for it rarely ripens in this climate without assistance. This superb wild flower is worth a place in every garden. It continues blooming a long time. Five or six species are known in the United States.

CARDOON, or CHARDON (Span. cardo, an artichole; Isat. Cynara carlunculus). A kind of wild artichoke, which is principally confined to garden culture, as it has nc. yet been employed as an article of food for any sort of live stock.

The stalks of the inner leaves, when rendered tender by blanching, are used in stews, soups, and salads. A light rich soil is most suitable to this vegetable, dug deep and well pulverized. The situation must be open, and free from trees, for, like the artichoke, it is impatient of confinement. It is propagated by seed, which may be sown at the close of March; but, for the main crop, not until the early part of April; those plants raised from earlier sowings being apt to run at the close of autumn: for a late crop, a sowing may be performed in June. 'The best practice is to sow in patches of three or four rows, four feet apart each way, to be thinned finally to one in each place, the weakest being removed. The seedlings are nearly a month in appearing. If, however, they are raised in a seed-bed, they will be ready for transplanting in about eight or ten weeks from the tinie of sowing, and must be set at similar distances as are specified above. The plants of the first sc wing are generally three weeks before they rake their appearance; those from the later ones, about two. If, after a lapse of these times, they do not appear, it should be ascertained if the seed is decayed, and in that case the sowing may be renewed. The seed must be sown rather thin, and covered with about half an inch depth of mould. When about a month old, the seedlings, if too crowded, must be thinned to four inches apart; and those removed may 
be placed out at a similar distance, if there is any deficiency of plants. When of the age sufficient for their removal, they must be taken up carefully, and the long straggling leaves removed. The bed for their reception must be dug well and laid out in trenches as for relery, or a hollow sunk for each plant; but as they are liable to suffer from excessive wet, the best mode is to plant on the surface, and form the necessary earthing in the form of a tumulus. Water must be applied abundantly at the time of planting as well as subsequently, until they are established; and also in August, if dry weather occurs, regularly every other night, as this is found to prevent their running to seed. The only other necessary point to be attended to is, that they may be kept free from weeds during every stage of their growth. When advanced to about eighteen inches in height, which, according to the time of sowing, will be in August, and thence to October, the leaves must be closed together by encircling them with a hay-band, and earth placed round each plant, a dry day being selected for performing it. As they continue to grow, fresh bands and earth must be constantly applied, until they are blanched to the height of two feet, or about two-thirds of their stems. They will be fit for use in eight or ten weeks after the earthing first commences. Care must be had in earthing them up, to prevent the earth falling in between the leaves, which is liable to induce decay. The surface of the soil should likewise be beaten smooth, to throw off the rain. In severe weather their tops should be covered with litter, it being removed as invariably in mild weather: by this treatment, they may be preserved in a serviceable state throughout the winter. For the production of seed, which in England seldom con:es to maturity except in dry seasons, a few plants should be set in a sheltered situation, of the April sowing; of course not earthed up, but allowed the shelter of mats or litter in frosty weather. In the spring, the ground may be dug round them to destroy weeds, as well as to encourage the growth of the roots. The flowers make their appearance about the beginning of July, and the seed is ripe in September. (G. W. Johnson's Kitchen Garden.)

CAREX. A vast genus of grasses comprehending more than two hundred species, nearly all of which are indigenous to America. It includes sedges, and a vast variety of grasses found in salt-water marshes. See SEncE.

CARLICK. A provincial term applied in some places to charlock.

\section{CARNATION, or CLOVE PINK}

carnes; Dianthus caryophyllus). A beautiful and odoriferous perennial, blowing in July and August, and cultivated in beds or in pots. The wild $D$. caryophyllus is the origin of our fine garden carnations. (Smith's Eng. Flor. vol. ii. p. 287.) There are three distinct varieties; the flake, the bizarre, and the picotée. The flake has two colours only, with large stripes; the bizarre is variegated with irregular stripes and spots, or not less than three colours; and the picotée has a white ground, spotted with every variety of scarlet, red, purple, and pink. Thry love a light, rich earth mixed with sea. sand, and never bloom very handsomely with. out a proportion of the latter. Carnations are propagated by layers, pipings, and from seed. which produce new sorts. 'There is an irnmense collection of fine prize carnations, well known to the public, too lengthy to insert here; but they are easily procured at a reasonatle price. If you raise flowers from seed, sow it in pots of light earth in April; cover the seed very lightly with mould filtered through the fingers; shade the seedlings from the sun, and prick them out when each seedling has six leaves. Pot or plant for blowing in autumn. They will not blow well if moved in the spring. Carnations must be sheltered from excessive rains and hard frosts, and they should be placed in warm sunny borders.

CARNATION GRASS. In agriculture, a term applied to some grasses, as the hair grass (Aira), probably from their having this kind of colour in their flowers. Any coarse species of carex is so named in the north of England and Scotland.

CAROB (Ceraloria caroubier). A tree cul. tivated extensively in the south of Europe, the pods produced by which contain a sweet, eatable frecula. The tree attains a medium size, and the flowers, which are of a deep purple colour, are disposed in clusters. The fruitpcids are a foot long, contain a reddish pulp, of an agreeable sweet taste when dry; and are supposed to be "the husks ( $x$ sqaits) that the swine did eat," (Luke xv. 16). They are used as food for man and horse. The carob tree is raised from seeds.

CARPET (Dutch, karpet; Ital. carpetta). A covering for floors, \&c., manufactured of wool, or other materials, worked with the needle or by the loom. Carpets are generally composed of linen and worsted, but the Kidderminster or Scotch carpets are entirely fabricated of wool. Persian and Turkish carpets are the most esteemed. In England carpets are principally manufactured at Kidderminster, Wilton, Cirencester, Worcester, Axminster, \&c.; and in Scotland at Kilmarnock. Those made at Axminster are believed to be very little, if any thing, inferior to those of Persia and Turkey. (M'Culloch's Com. Dict.; Willich's Dom. Eircyc.; Brande's Dict. of Science.)

CARRIAGE (Fr. cariage). A general name applied to carts, wagons, and other vehicles, employed in conveying passengers, goods, merchandise, \&c., from one place to another, and which are usually constructed with two or four wheels. Wheel-carriages first came into use about 1381; they were called whirlicotes, and were little better than litters or cots (cotes) placed upon wheels.

Carriage, in irrigation, is a conduit made of timber or brick: if the latter, an arch is turned over the stream that runs under it, and the sides bricked up; if the former, which it commonly is, it is constructed with a bottom and two sides, as wide and as high as the main it lies in. It must be made very strong, close, and well-jointed. Its use is to convey the water in one main over another which runs at right angles with it; its depth and breadth are of the same dimensions with the main it belongs to; its length is in proportion to the 
breadth of the main it crosses. It is the most expensive conveyance belonging to the irrigating of land.

CARRIAGE DRAIN. See Drains.

CARROT (Fr. carote). A well-known annual or biennial root, common alike to the field and the garden. The wild carrot, from whence all those now commonly cultivated came, is a native of England, found chiefly on chalky hills. The kinds now preferred for field culture are the long red, the Altringham, and the orange. It is a crop which, for the heavier description of soils, is becoming more and more cultivated in this country; for its produce is not only large, but it can be grown on lands not suited to turnip culture; for although the soils best adapted to it are deep sandy loams, yet it can be grown successfully on sands and peats. The carrot delights, however, in a deep soil, and thus land intended for it can hardly be ploughed too deep. It is usual to trench plough or subsnil for it ; and in Holland they are even at the pains to deepen with the spade the furrows made by the plough. It may be sown, like the turnip, on ridges, by the drill or otherwise, or broadcast. 'The seed should be of the previous season's growth; if mixed a fortnight before sowing with two bushels of sand or mould, kept wetted and turned over once or twice, they will grow all the better (Com. to Loard of Agr. vol. vii. p. 70299); and it keeps the seed from clinging together. (Jour. of Roy. Agr. Soc. of Eng. p. 40.) The quantity proper to be sown per acre (April is the best period) is two pounds by the drill, and about five when sown broadcast. The plants should be hoed out like turnips, and dug up in October for storing; but they may be left in the ground if preferred, and dug up as they are wanted. They may be stored either in a building covered with straw or haulm, or in pits piled in heaps four feet deep. (Brit. Husb. vol. ii. p. 287.) The common produce is from 280 to 450 bushels per acre- $9000 \mathrm{lbs}$. (Com. Board of $A g r$. vol. vi. p. 141.) It is admirable food for all kinds of stock. (Low. Agr. p. 326.) Either the tops mown off green, which is said not to injure the roots (Com. Foard of $A g r$. vol. v. p. 211), or the roots, for horses, half a bushel a day, sliced in chaff, is admirable food. (Youatt on the Horse, p. 358, 392, 213; Brit. Husb. vol. i. p. 125.) 1000 parts of the carrot contain 98 of nutritive matter. (Davy's Lect.) It should be well manured with either farm-yard dung (20 cubic yards per acre); or pigeons' dung is excellent (Quar. Jour. of $\mathcal{A g r}$. vol.v. p. 144); or a mixture of salt, $6 \frac{1}{2}$ bushels, and soot $6 \frac{1}{2}$, trenched in (Sinclair; Johnson on Salt, 31, 146; Rev. E. Curturight, Com. Board of $A g r$. vol. iv. p. 376$)$; or sea-weed trenched in fresh as collected from the shore (Quar. Jour. of $A g r$. vol. vii. p. 268); or turf trenched in deep (Com. Board of Agr.vol. iv. p. 191); or street sweepings, mixed with one-third of pigs' dung and $\mathbf{2 0}$ hogshead of liquid manure. (Flem. Husb. 40.) The white or Belgian carrot has been recently tried as a field crop with consicerable success; Sir C. Burrell having grown - $f$ this variety in 1840 , "on a very indifferent neld," 1000 bushels per acre (Brit. Farm. Mag. vol. iv. p. 464); Lord Ducie, 26 tons 3 cwt.; 266 and from 20 to 32 tons by Mr. Harris; and in Jersey 38 tons per acre. It is described in the Report of the Yoxford Farmers' Club as well adapted for strong or mixed soil lands, as keep. ing well, and as excellent food for horses. (Journ. of Royal Agr. Soc. vol. ii. p. 42.)

CARROT, THE GARDEN (Daucus carota; as some imagine from duw, though its taste is far from being pungent. Perhaps from dxous, on account of the thickness (if its root). There are a considerable number $c^{s}$ varieties of the carrot, which are divided by horticulturists into two families: those with a regular fusiform root, which are named long carrots; and those having one that is nearly cylindrical, abruptly terminating, but continuing with a long slender tap-root, which are denominated horn carrots. The first are employed for the main crops; the second, on account of their superior delicate flavour, and are advantageously grown for early use. They are likewise commonly recommended for shallow soils. Horn carrots, - early red horn, common early horn, long horn: this last is the best for the summer crop. Long carrots, - white, yellow, long yellow, long red, Chertsey or Surrey, superb green-topped or Altringham: the last two are the best for main crops. Carrots should have a warm, light, sandy, fertile soil, dug full two spades deep, as they require to be deeper than any other culinary vegetable. With the bottom spit it is a good practice to turn in a little well-decayed manure; but no general application of it to the surface should be allowed in the year they are sown. A spot should be allotted them which has been made rich for the growth of crops in the previous year, or else purposely prepared by manuring and trenching in the preceding autumn. The fresh application of manure is liable to cause their growing forked, and to expend themselves in fibres, as well as to be worm-eaten. If, however, the want of manure must be obviated at the time of sowing, it should be used in a highly putrescent state, and but in small quantities, finely divided and well mixed with the soil. If the soil is at all binding, it should be well pulverized by digging very small pits at a time, \&c. Mr. Smith of Keith Hall, N. B., recommends pigeons' dung as the best manure for this crop: it not only prevents the maggot, but causes them to grow finer. He applies it in the same proportion as is usually done of stable manure. (Mem. Caled. Hort. Soc. vol. i. p. 129.) Carrots are propagated by seed. The first sowing for the production of plants to draw whilst young should take place in a moderate hotbed during January, and in a warm border at the conclusion of February or early in March. At the close of the last month, or more preferably in the early part of April, the main crop must be inserted; though, to avoid the maggot, it is even recommended not to do so until its close. In May and July the sowing may be repeated for production in autumn; and lastly, in August, to stand through the winter, and produce in early spring. For sowing, a calm day should be taken advantage of; and, previous to commencing, the seeds should be separated by rubbing them between the hands, with the admixture of a little sand; 


\section{CARROT.}

therwise, by reason of their adhering by the airs that surround their edges, they are cloted together, and cannot be sown regular. 'The urface of the bed should likewise be laid mouth; otherwise, in raking it, the seed will e drawn together in similar heaps. To avoid his, before raking, it may be gently trod in. The seed should be sown thin, and the beds ot more than four feet wide, for the conveience of after-cultivation. The larger weeds nust be continually removed by hand; and when the plants are seven or eight weeks old, or when they have got four leaves two or three nches long, they should be thinned; those inended for drawing young to four or five inches part, and those to attain their full growth to right or ten; at the same time, the ground must e small-hoed, which operation should be rerularly performed every three or four weeks, intil the growth of the plants becomes an efectual hinderance to the growth of the weeds. The crop to stand through the winter should, In frosty weather, be sheltered with a covering of litter, as, if frost occurs with much severity, t often destroys them. The hothed for the first owing of the year must be moderate, and arthed about sixteen inches deep; two or hree linings of hot dung, as the heat decreases, will be sufficient to bring them to a state fit for ase. These are the first in production, but are losely followed by those that have withstood he winter. The temperature must never exceed $70^{\circ}$, or fall lower than $65^{\circ}$ : if it rises aigher, it is a certain cause of weakness; if ower, it checks the advance of the root. They need not be thinned to more than three inches upart.

At the close of October, or early in Novem. er, as soon as the leaves change colour, the nain crop may be dug up, and laid in alternate ayers, with sand, in a dry outhouse; previous o doing which, the tops, and any adhering earth, must be removed. A dry day should always be chosen for taking them up.

For the production of seed, it is by much the Jest practice to leave some where raised. If, lowever, this is impracticable, some of the inest and most perfect roots should be select ed, and their tops not cut so close as those for storing; these likewise must be placed in sand antil February or March, though some gardeners recommended October or November, then to be planted out two feet asunder in a stiff loamy soil. Those left where grown, or those planted at the close of autumn, must, during frosts, have the protection of litter; being invariably removed, however, during mild weather. As the seed ripens in August which is known by its turning brown, abou the end of August each umbel should be cut for if it is waited for until the whole plant decays, much of the seed is often lost during stormy weather. It must be thoroughly dried by exposure to the sun and air, before it is rubbed out for storing. For sowing, the seed should always be of the previous year's growth; if it is more than two years old, it will not vegetate at all. (G. W. Johnson's Kitchen Garden.) The boiled carrot forms a good poultice in foul and cancerous ulcers.
CARROT.

Carrots, are much cultivated in many part of the United States, where many farmers pre. fer them over every other vegetable for fattening swine, cattle, and even as feed for horses. To fatten swine they should be given boiled, to store-hogs, raw.

The following remarks upon the culture anr use of carrots in New England, are extracted from Mr. Colman's Second Report on the Agriculture of Massachusetts.

"Jno. Merrill, of South Lee, has been a very successful cultivator of carrots. He states the yield on two acres at 600 bushels to the acre; and the cost of cultivation, exclusive of manure and rent of land, at twenty-five dollars per acre; or a little more than four cents per bushel. For feeding horses, he says, he should prefer one hundred bushels of carrots and one hundred bushels of oats to two hundred bushels of oats. He applied them in a raw state to the feeding of his ream horses, and horses in preparation for market; and they were kept by them in high health and spirits. Oats followed his carrot crop on the same ground with great success. The experience of J. C. Curwen, Eng., in the use of carrots fur horses, corresponds with that of Mr. Merrıll. The authority of Curwen is unquestionable; and he was in the habit of employing constantly as many as eighty horses on his farm and in his extensive coal mines.

" 'I cannot omit,' he says, 'stating the great profit of carrots. I have found by the experience of the last two years, that where eight pounds of oat-feeding was allowed to draft horses, four pounds might be taken away and supplied by an equal weight of carrots; and the health, spirit, and ability of the horses to do their work be perfectly as good as with the whole quantity of oats. With the drill husbandry and proper attention, very good crops of carrots may be obtained upon soils not generally supposed suitable to their growth.'

"He adds in another place. "The profits and advantages of carrots are in my opinion greater than any other crop. This admirable root has, upon repeated and very extensive trials for the last three years, been found to answer most perfectly as a part substitute for oats. Where ten pounds of oats are given per day, four pounds may be taken away; and their place supplied by five pounds of carrots. This has been practised in the feeding of eighty horses for the last three years, with the most complete success, and the health and condition of the horses allowed to be improved by the exchange. An acre of carrots supplies a quan tity of food for working horses equal to sixteel or twenty acres of oats.'

"My own experience of the value of carrots, which has not been small, fully confirms these statements. I have obtained at the rate of more than a thousand bushels to the acre on three quarters of an acre; but on several acres my crop has usually averaged 600 bushels in the acre.

Smith of Middlefield, Hampshire county, from three-fourths of an acre obtained 900 bushels.

"Charles Knowlton of Ashfield, Franklin 
sounty this year obtained 90 bushels on twelve rods of ground. This was at the rate of 1200 bushels to the acre.

"D. Moore, of Concord, Middlesex county, from six rods of land, obtained this year 56 bushels; or at the rate of 1493 bushels to the acre.

"According to Josiah Quincy's experience in Quincy, Plymouth county, charging labour at one dollar per day his carrots cost him eleven cents per bushel. David and Stephen Little, in Newbury, Essex county, in 1813, obtained, 961 bushels to the acre, at an expense of $\$ 79.50$ every expense included, excepting rent of land. This was at a rate less than nine cents to a bushel."

Mr. Colman subjoins, in an Appendix, an account of an experiment made in feeding swine, illustrating the value of this vegetable, upon the authority of Arthur Young.

"The great objection to the cultivation of carrots lies in the difficulty of keeping them while growing free from weeds. If sown without any preparation, the seed is a long time in germinating; and a plentiful crop of weeds is liable to get possession of the land before the carrots make their appearance. There is another difficulty. The carrot seed from its minuteness is liable to be sown too thickly. To obviate in a degree these objections, let the ground be ploughed deeply, well manured, and put in fine tilth; and let the first and perhaps the second crop of weeds be ploughed in. After this let the land be thrown into ridges two feet apart, and the seed sown on top of the ridges either in a single line, or the ridges be made so wide as to receive two rows of carrots, eight inches or one foot apart. In the mean time the seed should be freely mixed with fine sand; and the sand kept so moist that the seed shall germinate. As soon as it is sprouted it should be sown. This may he so arranged that the sowing shall take place about the first of June. They will then have the start of the weeds. The mixture with sand will prevent their being sown too thickly. After the first thinning and weeding is over, if done with care, the battle may be considered as won. Afterwards let them be cultivated with a plough or cultivator and kept clean. When the time of digging arrives, the work will be greatly facilitated by passing a plough directly along the side of the carrots; and they are easily thrown out by the hand."

CARROT, WILD (Daucus carota, Pl. 10,o). This common plant is abundant in pastures, and about hedges, in a gravelly soil. It is a biennial plant, flowering in June and July. Its root is small, slender, aromatic, and sweetish. It grows two feet high, branched, erect, leafy; the stalks are firm and striated; the leaves are divided into fine and numerous partitions, of a pale-green colour, being also hairy. The flowers are in large umbels, with large, pinnatifid involucres, and undivided involucels, small and white, except the central flower, which is red; and they are succeeded by rough seeds. This is one of those plants in which we are able to perceive design. The seeds -equire to be protected, to produce which all ho flower-stalks become incurvated, making 268 the umbel hollow, or giving it the aspect of a cup or nest. The seed is medicinally used; it is a powerful diuretic. An infusion of the seeds in white wine is very restorative in hysterical disorders.

The wild carrot is found in pastures, roadsides, \&c. in Pennsylvania and the Middle States. Although much esteemed in Europe as a food for milch-cows, it is regarded as rather a nuisance by the farmers in the United States, and requires great exertion to destroy and keep under when once introduced into fields. (Flor. Cest.)

CARRUCAGE (from caruca, an old name for the plough). In husbandry, denotes the ploughing of ground, either ordinary, as for grain, hemp, flax; or, extraordinary, as for woad, dyer's weed, rapeseed, \&c.

CARRUSATE. A term that anciently denoted the quantity of arable land capable of being tilled in one year with one plough.

CARRYING. A term used in horsemanship A horse is said to carry low, when, having naturally an ill-shaped neck, he lowers his head too much. This fault may be remedied by a proper bridle. A horse is said to carry well, when his neck is raised or arched, and he holds his head high and firm, without constraint. Carrying in the wind, is applied to horses which frequently toss their noses as high as their ears, and do not carry their heads handsomely.

CARSE. A provincial term applied to such lands as lie in the hollows near large rivers or estuaries of the sea, and have a deep rich soil The carse of Gowrie, in Scotland, yields the heaviest erops of grain north of the Tweed. Such lands are either of the deep clayey loamy kind, or alluvial soils in a state of aration.

CART. A vehicle constructed with two or more wheels, and drawn by one or more horses. Half a century since, Lord Robert Seymour advocated the cause of the single-horse cart: he observed, that the advantages of single-horse carts are universally admitted, wherever they have been attentively compared with carriages of any other description. By his own observation he was led to think that a horse when he acts singly, will do half as much more work as when he acts in conjunction with another; that is to say, that two horses will, separately, do as much work as three conjunctively: this arises, he believes, in the first place, from the single horse being so near the load he draws; and, in the next place, from the point or line of draught being so much below his breastit being usual to make the wheels of singlehorse carts very low. A horse harnessed singly has nothing but his load to contend with; whereas, when he draws in conjunction with another, he is generally embarrassed by some difference of rate, the horse behind or before him being quicker or slower than himself; he is likewise frequently inconvenienced by the greater or lesser height of his neighbour: these considerations gave, he conceived, a decided advantage to the sort of cart he recommended. If any other is wanted, that of the very great ease with which a low cart is filled may be added; as a man may load it with the help of a long-handled shovel or fork, by means 
is hands only: whereas, in order to fill a er cart, not only the man's back, but his is and whole person must be exerted. To use of single horses in draught he has rd no objection, unless it be the supposed essity of additional drivers created by it: fact, however, is, that it has no such effect; horses once in the habit of going singly, follow each other as uniformly and as idily as they do when harnessed together; accordingly we see, says he, on the most uented roads in Ireland, men conducting e, four, or five single-horse carts each, hout any inconvenience to the passengers: $\mathrm{h}$, likewise, is the case in England, in ich lime and coal are generally carried. ung's Ann. of $A g r$. vol. xxvii. p. 337.) And might likewise have added, the single-horse ts in some of the northern counties, where man manages two or three, and sometimes re.

The subject of carts has recently engaged attention of the Royal Agricultural Society England. Mr. Baker of Gloucestershire, $\mathrm{s}$, in their Journ. vol. i. p. 429, "My land is a stiff clay; my carts are on six-inch wheels, made to hold half the quantity that my ghbours carry in theirs. My land is hilly; carts generally go with one horse; but up - when loaded, another is put on before, ich comes down the hill with the next rening cart. Thus, on a level ground, with carts, and two or perhaps with three horses, ake out the same quantity of dung that my ghbours carry in their carts with never less n three horses, and sometimes with four." $d$ in the Journ. of the Roy. Agr. Soc. of Eng. . ii. p. 73, is a very good article by Mr. Han$m$ of Burcott, illustrated by engravings of the e-horse cart, and of a new one of his own istruction. "The counties of Cumberland Westmoreland," he observes, "have unirsally and immemorially used the one-horset. They have no other carriage for any ad of agricultural produce, and never is the dition of another horse on any occasion "n." The practice, apparently originating economy, has long since spread into Dumesshire; and, according to Mr. Wilkie of Idingston, it is all but universal at the present ment throughout the west of Scotland. Iy dung-carts," he adds, "are taken from the proved Cumberland cart, which measures inches long $\times 47 \frac{1}{2}$ inches wide $\times 17$ inches ep $=1$ cubic yard $=21$ bushels; and it tilts th a spring key-stick, which adjusts itself the horse moves forward; the wheels are out 4 feet 6 inches high, and are set so far art as to conveniently span two 27 -inch dges; it weighs $8 \mathrm{cwt.}$ " There are a variety carts peculiar to different counties, most of hich are described, and drawings given, in rit. Husb. vol. i. p. 159; from the heavy oneirse cart of the vicinity of London, to the ght simple Irish or Yarmouth car, as well as e improved car first introduced into Leices. rshire by Bakewell.

The carts of Pennsylvania are perhaps unIrpassed in the United States for neatness d strength. Either one, two, or three horses e used, as circumstances may require, and broad or narrow wheels, but the former are preferahle for farmwork.

CARTER. An inferior sort of farm servant, who has the care of driving and foddering the team. He should always be chosen as steady, regular, sober, and trustworthy as possible, and be perfectly gentle and humane in his disposition. It is of great importance to the farmer to have a carter with these qualifications; for otherwise his horses may be ill-treated, neglected, overworked, or overfed, and much fodder wasted. (Brit. Husb.vol. i. p. 170.) Leonard Mascal, nearly two centuries since, told the carter of his day to "have patience in moderate useing of his horses; and at all other times he ought to bear a love alwayes to his cattel, that his cattel may love him, not fearing him too much; let him never use to beat them with the stock of his whip, but whip them with the lash, and use them to the sound thereof, and yet not often for dulling of them."

CARTHAMUS, or SAFFLOWER (Charthamus tinctorius), an annual plant cultivated in Spain, Egypt, and the Levant, for its flower, which is used in dyeing silks, \&c., and in making rouge. See SAFrron.

CAR'T LODGE. A small outhouse for sheltering carts from the weather. Farmers should be very careful to place their carts, \&c. under proper shelter, when out of use, as they will last much longer by this means than if left exposed in the yard to the effects of the weather; for, as they are thus sometimes wet, and sometimes dry, they soon rot, and become unfit for use. The dust and dirt should also be constantly washed off before they are laid up. There are some excellent observations on the necessity of care in the preservation of agricultural implements by Mr. Crosskill of Beverley. (Journ. of Roy. Agr. Soe. vol. ii. p. 150.) He advises that the implements should all be placed under the care of one workman on the farm, who should be encouraged to feel a pride in showing his master's implements in fine order.

CARY'S CATTLE GAUGE. An instrument made in the form and on the principle of a slider rule, for ascertaining the weight of live cattle, which is indicated in stones of $8 \mathrm{lbs}$. and 14 lbs. (See Brit. Husb. vol. ii. foot note at p. 393.)

CASINGS. A provincial term, signifying dried cow's dung, which is used in several parts of England for fuel.

CASK. A vessel of capacity, for holding different sorts of liquids, or other matters. See Barret.

CASSAVA. See Tapioca.

CAST. A term applied to a swarm or flight of bees (see BrEs); and to poultry when they lose their feathers or moult. It is also used to denote the changing of the hair and hoofs of horses. Horses cast or shed their hair at least once a year. Every spring they cast the winter coat, and gain a summer one; and sometimes in the end of autumn they put on their winter hair, in case they have been ill-fed. curried, or clothed, or kept in a cold stable. Occasionally they cast their hoofs : when this happens, let them be turned out into a pas ture. 
CASTING. The operation of throwing a horse down, which should be performed with great care on straw. Take a long rope, double it, and cast a knot a yard from the bow; put the bow about his neck, and the double rope betwixt his fore legs, about his hinder pasterns, and under his fetlocks: when you have done this, slip the ends of the rope underneath the bow of his neck, and draw them quick, and they will overthrow him; then make the ends fast, and hold down his head.

CASTING A COLT. A term which implies a mare's proving abortive.

CASTOR OIL. The well known medicinal oil obtained from the seeds or beans of the Palma Christi, a plant indigenous to the West Indies. The cultivation of the Palma Christi and the manufacture of castor oil is extensively carried on in some parts of the United States, and continues on the increase. A single firm at St. I.ouis has worked up 18,500 bushels of beans in four months, producing 17,750 gallons of oil, and it is stated that 800 barrels have been sold at $\$ 50$ the barrel. This oil may be prepared for burning, machinery, soap, \&c., and is also convertible into stearin. It is more soluble in alcohol than lard-oil.

CASTRATION. In farriery, a term signifying, in regard to animals, the operation of gelding in males, and spaying in females. The operation may be performed at any age, but, in general, the earlier the better. For cattle, between two and eight months; for sheep, before they are twenty-one days old; in horses, between four and twelve months.

CAT (Felis catus, L.). A genus of animals comprising twenty-one species, and belonging to the same class as the lion and the tiger. Though originally a variety of the wild cat, one of the most ferocious brutes, this animal is now domesticated. The former inhabits hollow trees, especially the oaks of large forests, and in winter retreats to the deserted holes of foxes and badgers. Its skin is an excellent fur, but by no means compensates the damage done by wild cats to game and poultry.

The domestic cat, when suffered to retire to thickets, easily returns to a wild state. Its colour is uncommonly diversified; but the most beautiful varieties are the reddish Spanish cat, and that of Angora, with long silken hair. A tame cat generally attains the age of about twelve years; the female breeds in the first year, though it grows till eighteen months old; she usually produces from four to six blind kittens, after a gestation of fifty-five days; and carefully conceals them, apprehensive of the unnatural voracity of the male. It is further remarkable, that the female also has been observed to devour her offspring, when it happened to be deformed or monstrous.

The flesh of animals or fish is the most agreeable food to cats; 10r they partake of vegetable aliment only from necessity. As they chew with difficulty, frequent drink is intispensably requisite to the preservation of their health. There are, however, some plants of which they are excessively fond, and when indulged with them, present a variety of whimsical gesticulations; of this nature is the vale270 rian root, and the herb called nep, or catmint, the Nepeta cataria, L.; on the contrary, they shun other vegetables as their mortal enemies, for instance, the common rue, or Ruta graveolens, L. Any substance rubbed with the leaves of this plant is said to be perfectly secure from their depredations : for the communication of this useful fact in domestic life we are indebted to C. P. Funke, a German naturalist.

Cats enjoy a warm temperature and a soft couch ; moisture and filth, as well as water and cold, are equally repugnant to their nature; hence they are continually cleaning themselves with their paws and tongue. Another peculiarity is the purring of these animals, when they are cajoled or flattered, by passing the hand over their backs; this singular noise is performed by means of two elastic membranes in the larynx, or the upper part of the wind-pipe. Their hair is so electric that the expanded skin of a cat makes an excellent cushion for the glass cylinder or globe of an electrifying machine.

The flesh of cats is eaten by several nations, but the substance of the brain is said to be poisonous. From the intestines of these animals are manufactured the celebrated Roman chords for covering the violin.

They are manufactured out of the guts of rabbits and sheep also; they are cleaned, soaked in water, stretched by a machine, and dried. The name catgut comes from the circumstance of cats being used as food in many parts of Italy, and their guts applied to the making of strings. (Willich's Dom. Encyc.)

Several species of the cat kind are found wild in America. Dr. Harlan, in his "Fauna Americana," describes the following:

1. The Cougar of Buffon, the Pouma of some travellers, vulgarly called the American Lion. This is of a deep yellow colour, without a mane or a tuft at the end of the tail. Its total length is about three feet six inches, including the tail, which is over two feet long. The body is long and slender, head small, legs strong and short, tail long and trailing, colour grayish about the eyes, hairs within the ears white slightly tinged with yellow. This animal inhabits both American continents, from Paraguay and Brazil to Canada. Dr. Harlan thinks the Pennsylvania Cougar, Panther or Wild-cat a variety of the Pouma. The ferocity of these animals is familiarly known, and the pioneers often suffer from their depredations upon pigs, sheep, calves, and even colts.

2. The Jaguar, or South American panther, is also met with in the southwestern portions of the United States, and has occasionally been found east of the Mississippi. It is much larger than the North American panther, being four and a half feet long, including the tail, the length of which is two feet two inches. Their proportions are thicl and clumsy. The hairs are short, strong, compact, silky. The fur yellowish, and covered with spots either entirely black, or yellow encircled with black. Like all wild cats they rove by night, and retire into thick swamps by day.

3. The Spotted Mountain Cat, the Felis parda. lis of Linnæus, and Ocelet of Buffon, inhabits 


\section{CATAI.PA.}

\section{CATCH-WEED.}

Mexico and the southwestern parts of the United States, tl.jugh it has not been found east of the Mississippi. Its general colour is gray, marked with large fawn-coloured spots, bordered with black, forming oblique bands on the flanks. It is about two feet long from the end of the snout to the origin of the tail, which measures about two feet.

4. The Canadian Lynx, or Felis Canadensis of Buffon, inhabits the Canadas, Labrador, \&c. Its tail is very short, and black on the posterior alf. The ears are terminated by a small tuft of hairs. The colour of the body is grayish, with yellowish or pale brown points below, and some black lines on the head. Total ength two feet three inches, the included tail veing only three or four inches long.

5. Another species of wild cat, called by nauralists Felis rufa, or Red Cat, the Chat-cervier of furriers, is found in the forests of New York, Pennsylvania, and Ohio. 'This is rather smaller han the common lynx, the head and back beng of a deep red, with small spots of blackish rown, throat whitish, breast and belly of a lear reddish white.

6. Another lynx of large size, found on the orthwestern coast by Lewis and Clarke, has een called by naturalists Felis fasciata. This Or. Harlan thinks is probably the same as that lescribed by Mr. Nuttall in his Travels in Arransas. Its tail is very short, white, with the oint black. The ears are furnished with penils of hair, and black externally. The fur s very thick, of a brownish-red colour, with tripes and points above.

7. The common American Mountain Cat or Catamount (Felis montana), has been also Iamed the Mountain Lynx and Mississippi Lynx. $t$ is found in the Alleghany mountains, from New York to Florida. The tail is very short, nd in colour gray. The ears are destitute of encils of hair, and externally blackish, with vhitish or yellow spots within. Length three four feet including the tail.

8. Another species has been found on the orders of the Yellow Stone river, in size about ne half larger than the domestic cat, the tail eing only two inches long. It is the Lynx urens or Golden Lynx of Rafinesque, so named rom its clear, brilliant yellow colour. It is potted with black and white. The ears are vithout pencils.

CATALPA (Bignonia catalpa). A shrub rowing in England thirty or forty feet high; is beautiful pendulous flowers bloom in Aurust. It has a peculiarly large bright green eaf; loves heat, and does not blow in wet ummers. It is tolerably hardy; easily raised rom layers or seed.

The catalpa is an American tree which Michaux says begins to be found in the Atlantic States, on the banks of the Savannah river, near Augusta, Georgia, and west of the Alleshanies, on the banks of the Cumberland, beween the 35th and 36th degrees of latitude. Further south it becomes still more common, and abcunds near the borders of all the rivers which empty into the Mississippi, or which water West Florida. Michaux expresses surprise that this tree should not have been caturally distributed in the lower part of the
Carolinas and Georgia, and in East Floridi, which lie so near the country of its primitive growth. This is the more strange from the fact that the catalpa manifests a great iendency to spread itself abroad by means of its winged seeds, and has in so many instances left the vicinity of dwellings where it was planted as a shade tree and mixed with the natives of the forest. It may, for example, bo seen along the banks of the Schuylkill, and many other places, growing wild.

In the South it frequently exceeds fifty feet in height, with a diameter of eighteen to twentyfour inches. Its ample heart-shaped leaves, clusters of rich and beautiful flowers, long bean-shaped seed-pods, and wide spreading summit, give a strong character to this tree, which differs from all others in the fewness of 'its branches.

That the catalpa is a tree of rapid growth is proved by the distance of the annual concentrical circles. Its wood is of a grayish white colour, of a fine texture, very light, and very brilliant when polished. It resembles the butternut wood, with the exception that the butternut wood is of a reddish hue, and is less durable when exposed to the weather. Posts of the catilpa perfectly seasoned have been proved to be very lasting. In the spring, if a bit of the cellular integument of the bark be removed, a very offensive odour is exhaled. The honey collected from the flowers of this tree is somewhat poisonous, its effects, though less alarming, being similar to those produced by eating that collected by bees from the yellow jasmine (Geselminum nitidum).

In the Southern States the catalpa is called Catawba tree, after the name of the Indian tribe that formerly inhabited a iarge part of the country from which the tree was first procured. The French of Upper Louisiana call it Bois Shavanon, from the Shavanon or Shawnee nation which once existed in West Tennessee, watered by the Cumberland river. (Michaux.)

The rapid growth of the catalpa in almost every situation in which it can be placed in the Middle States, and the adaptation of its wood to posts and other useful purposes, make it deserving the attention of the farmer wherever other kinds of wood are scarce, especially the kinds suitable for fences.

CATARACT. In farriery, a disease in the eyes of horses, in which the crystalline humour is rendered opaque, and the vision impeded or destroyed. The only certain method of cure in these complaints is to remore the lens by means of extracting or couching. By the first mentioned operation, an incision is made into the eye, and the opaque lens taken out; by the second, it is depressed by the point of a couching needle thrust into the eye, and, being car ried to the lower part of the chamber of the eye or vitreous humour, it is left there to be absorbed. The first opera:icn is the more effective, but the more hazardous of the two. owing to the inflammation which succeeds. The second is tedious and sumetimes fails, bui it is free trom the risk of inflammation.

CATCH-WEED, CLEA VERS, or GOUSEGRASS (Galium Aparine, Eng. Flor. vol. i. p 
21). P1. 10, $h$. A weed growing in hedges and by roadsides. See Harifr.

CATCH-WORK. A term employed in irrigation for the works for throwing the water over such lands as lie on the declivities of hills.

CATCH-WORK MEADOW. That sort of meadow which is formed by turning the water of a spring or small rivulet along the side of a hill or declivity, so as to water the lands between the cut or main carriage and the original water-course, which in this case becomes the main drain. See Irrigation.

CATERPILLAR. The name given to the larva state of butterflies and moths.

The natural history of insects so universally destructive as caterpillars, which in voracity are only inferior to locusts, cannot fail to interest all, whether residents of town or country; and it is evident that persons acquainted with the precise nature and habits of destructive insects, their times and seasons of multiplication and transformation, must be enabled to devise the most effectual means of protection against their ravages. Thanks to the intelligent policy and liberal patronage of the Legislature of Massachusetts, the most exact and valuable information upon this branch of the history of destructive insects has been placed before the public, through the labours of the distinguished American entomologist, Doctor Harris.

Caterpillars are the larvæ or young of moths and butterflies, of which, Dr. Harris says, 500 species are already known to him as natives of Massachusetts; and he thinks there may be as many more yet undiscovered in the limits of that state. $\Lambda$ s each female usually lays from 200 to 500 eggs, 1000 different kinds of butterflies and moths will produce, on an average, 300,000 caterpillars. If one-half of this number, when arrived at maturity, are females, they will give $45,000,000$ of caterpillars in the second, and $6,750,000,000$ in the third generation. These data, whilst they suffice to show that the actual number of these insects existing at any one time is far beyond the limits of numerical calculation, explain their formidable capacity to destroy vegetation. Whilst most caterpillars feed upon the leaves of plants, some devour the solid wood of trees, some live only in the pith of plants, and some confine themselves to grains and seeds. Certain species attack woollens, furs, and other animal substances; for even leather, meat, wax, flour, and lard afford nourishment to particular kinds of caterpillars. "Some species herd together in great numbers, and pass the early period of their existence in society; and of these there are kinds which unite in their labours, and construct tents serving as a common habitation, in which they live, or to which they retire occasionally for shelter. Others pass their lives in solitude, either exposed to the light and air, or sheltered in leaves folded over their bodies, or form for themselves silken sheaths, which are either fixed or portable. Some make their abodes in the stems of plants, of mine in the pulpy substances of leaves; and others conceal themselves in the ground, from which they issue only when in search of food.

"Caterpillars usually change their skins 27.2 about four times before they come to their growth. At length they leave off eating entirely, and prepare for their first transformation. Most of them, at this period, spin around their bodies a sort of shroud or coconn, into which some interweave the hairs of their own bodies, and some employ, in the same way, leaves, bits of wood, or even grains of earth. Other caterpillars suspend themselves, in various ways, by silken threads, without enclosing their bodies in cocoons; and, again, there are others which merely enter the earth to undergo their transformations.

"When the caterpillar has thus prepared it. self for the approaching change, by repeated exertions and struggles it bursts open the skin on the top of its back, withdraws the forepart of its body, and works the skin backwards till the hinder extremity is extricated. It then no longer appears in the caterpillar form, but has become a pupa or chrysalis, shorter than the caterpillar, and, at first sight, apparently without a head or limbs. On close examination, however, there may be found traces of a head, tongue, antennæ, wings, and legs, closely pressed to the body, to which these parts are cemented by a kind of varnisn. Some chrysalids are angular, or furnished with little protuberances; but most of them are smooth, rounded at one end, and tapering at the other extremity. While in the pupa state, these insects take no food, and remain perfectly at rest, or only move the hinder extremity of the body when touched. After a while, however, the chrysalis begins to swell and contract, till the skin is rent over the back, and from the fissure there issues the head, antennæ, and body of a butterfly or moth. When it first emerges from its pupa skin, the insect is soft, moist, and weak, and its wings are small and shrivelled; soon, however, the wings stretch out to their full dimensions, the super. fluous moisture of the body passes off, and the limbs acquire their proper firmness and elasticity.

"The conversion of a caterpillar to a moth or butterfly is a transformation of the most com. plete kind. The form of the body is altered, some of the legs disappear, the others and the antennæe become much longer than before, and four wings are acquired. Moreover, the mouth and digestive organs undergo a total change; for the insect, after its final transformation, is no longer fitted to subsist upon the same gross aliment as it did in the caterpillar state: its powerful jaws have disappeared, and instead thereof we find a slender tongue, by means of which liquid nourishment is conveyed to the mouth of the insect, and its stomach becomes capable of digesting only water and the honeyed juice of flowers.

"Ceasing to increase in size, and destined to live but a short time after their final transformation, butterflies and moths spend this brief period of their existence in flitting from flower to flower and regaling themselves with their sweets, or in slaking their thirst with dew or with the water left standing in puddles after showers, in pairing with their mates, and in laying their eggs; after which they die a natu. ral death, or fall a prey to their numerous enemies. 
"These insects belong to an order called I.E.prnoprens, which means scaly wings; for the mealy powder with which their wings are covered, when seen under a powerful microscope, is found to consist of little scales, lapping over each other like the scales of fishes, and impianted into the skin of the wings by short stems. 'The body of these insects is also more or less covered with the same kind of scales, logether with hair or down in some species. The tongue consists of two tubular threads placed side by side, and thus forming an instrument for suction, which, when not in use, is rolled up spirally beneath the head, and is more or less covered and concealed on each side by a little scaly or hairy jointed feeler. The shoulders or wing-joints of the fore-wings are covered on each side by a small triangular piece, forming a kind of epaulette, or shouldercorer; and between the head and the thorax is a narrow piece, clothed with scales or hairs sloping backwards, which may be called the collar. The wings have a few branching veins, generally furming one or two large meshes on the middle. The legs are six in number, though only four are used in walking by some butterflies, in which the first pair are very short. and are folded like a tippet on the breast; and the feet are five-jointed, and are terminated, each, by a pair of claws.

"It would be difficult, and indeed impossible, to arrange the Lepidopterous insects according to their forms, appearance, and habits, in the caterpillar state, because the caterpillars of many of them are as yet unknown; and therefore it is found expedient to classify them mostly according to the characters furnished by them in the winged state.

"We may first divide the Lepidoptera into three great sections, called butterflies, hawkmoths, and moths, corresponding to the genera Papilio, Sphinx, and Phalana of Linnæus.

"The butterflies (Papiliones) have threadlike antennx, which are knobbed at the end; the fore-wings in some, and all the wings in the greater number, are elevated perpendicularly and turned back to back, when at rest; they have generally two little spurs on the hind-legs, and they fly by day only. Their caterpillars, when about to transform, suspend themselves by the tail, and are not enclosed in cocoons.

"The hawk-moths (Sphinges) generally have the antennæ thickened in the middle and tapering at each end, and most often hooked at the tip; the wings are narrow in proportion to their length, and are confined together by a bristle or bunch of stiff hairs on the shoulder of each hind-wing, which is retained by a corresponding hook on the under side of each fore-wing. All the wings, when at rest, are more or less inclined like a roof, the upper ones covering the lower wings: there are two pairs of spurs on the hind-legs. A few fly by day, but the greater number in the morning and evening twilight.

"In the moths (Phalance) the antennæ are neither knobbed at the end nor thickened in the middle, but taper from the base to the extremity, and are either naked, like a bristle, or are feathered on each side. The wings are confined together by bristles and hooks, the frst pair covering the hind-wings, and are more or less sloping when at rest; and lisere are two pairs of spurs to the hind-legs. These insects fly mostly by night."

Among A merican destructive caterpillars described by Dr. Harris, are the larvo of those butterflies called Asterias, seen in great abundance upon certain flowers in the month of July-particularly on the sweet-scented phlox. These flies, which are of a black colour with a double row of yellow dots on the back, lay their eggs, in this and the following month, on various umbellate plants, placing them singly on the different parts of the leaves and stems. The fly is large, its wings expanding from three and a half to four inches. The hinder wings are tailed, and have seven blue spots, with an eye-like spot of an orange colour near their hinder angle. The caterpillars of this tribe, Dr. Harris has found on various garden vegetables and plants, such as the carrot, parsley, celery, anise, dill, caraway, and fennel; also upon nightshade, hemlock, and other plants of the same poisonous family, which, he observes, constituted the appropriate food for these in. sects, before the exotics just named became abundant and furnished them in greater variety and profusion.

"Their injury to these cultivated plants," says the doctor, "is by no means inconsiderable; they not only eat the leaves, but are particularly fond of the blossoms and young seeds. I have taken twenty caterpillars on one plant of parsley which was going to seed. 'The eggs, laid in July and August, are hatched soon afterwards, and the caterpillars come to their growth towards the end of September, or the beginning of October; they then suspend themselves, become chrysalids, in which state they remain during the winter, and are nor transformed to butterflies till the last of May or the beginning of June in the following year."

"I know of no method so effectual for de. stroying these caterpillars as gathering them by hand and crushing them. An expert person will readily detect them by their ravages on the plants which they inhabit; and a few minutes devoted, every day or two, to a careful search in the garden, during the season of their depredations, will suffice to remore them entirely.

"In Europe there are several kinds of cater. pillars which live exclusively on the crucife. rous or oleraceous plants, such as the cabbage, broccoli, cauliflower, kale, radish, turnip, and mustard, and oftentimes do considerable injury to them. The prevailing colour of these cater pillars is green, and that of the butterflies pro duced from them, white. They belong to a genus called Pontia; in which the hind-wings are hot scolloped nor tailed, but are rounded and entire on the edges, and are grooved on the inner edge to receive the abdomen."

In the northern and western portions of Massachusetts, there is a white butterfly, the wings of which expand about two inches. This in all its states agrees with the character of the European insect. It is the potherb pontia (Pontia oleracea), a white butterfly, described by Dr. Harris in the New England Farmer in 
1829 (page 402). "About the last of May and beginning of June, it is" he say"s, "seen fluttering over cabbage, radish, and turnip beds, and patches of mustard, for the purpose of depositing its eggs. These are fastened to the undersides of the leaves, and but seldom more than three or four are left upon one leaf. The eggs are yellowish, nearly pear-shaped, longitudinally ribbed, and are one fifteenth of an inch in length. They are hatched in a week or ten days after they are laid, and the caterpiliars produced from them attain their full size when three weeks old, and then measure about one inch and a half in length. Being of a pale green colour, they are not readily distinguished from the ribs of the leaves beneath which they live. 'They do not devour the leaf at its edge, but begin indiscriminately upon any part of its under-side, through which they eat irregular holes. When they have completed the feeding stage, they quit the plants, and retire beneath palings, or ihe edges of stones, or into the interstices of walls, where they spin a little tuft of silk, entangle the horns of their hindmost feet in it, and then proceed to form a loop to sustain the forepart of the body in a horizontal or vertical position."

The next day after attaching itself it casts off its caterpillar skin and becomes a chrysalis, sometimes of a pale green, and sometimes of a white colour, regularly and finely dotted with black. 'The chrysalis state lasts eleven days, at the expiration of which comes out the whitewinged butterfly. The chrysalids produced from an autumnal brood of these insects surrive the winter, and the butterflies from them make their appearance in May or June. "In gardens or fields infested by the caterpillars, boards, placed horizontally an inch or two above the surface of the soil, will be resorted to by them when they are about to change to chrysalids, and here it will be easy to find, collect, and destroy them, either in the caterpillar or chrysalis state. 'The butterflies also may easily be taken by a large and deep bag-net of muslin, attached to a handle of five or six feet in length; for they fly low and lazily, especially when busy in laying their eggs. In Europe the caterpillars of the white butterflies are eaten by the larger titmouse (Parus major), and probably our own titmouse or chickadee, with other insect-eating birds, will be found equally useful, if properly protected.

"We have several kinds of small six-footed butterflies, some of which are found, during the greater part of summer in the fields and around the edges of woods, flying low and frequently alighting, and oftentimes collected together in little swarms on the flowers of the clover, mint, and other sweet-scented plants."

The heads of the common hop are frequently eater iy the small green and downy caterpilars $\therefore$ a very pretty little dusky brown butter

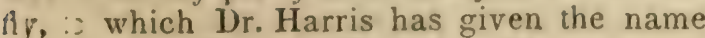
of $\mathrm{H}_{c_{-}}$-vine Thecla (Thecla humili).

The caterpillars of many of the four-footed : urterflies are spiny, or have their backs armed with numerous projecting points, beset all around with small stiff hairs, and sometimes long, hard, and sharp prickles disposed in isuriches.
The poplar, the willow, and the elm are infested with caterpillars in great numbers, produced by a butterfly called the Antiopa, the wings of which are purplish brown above, with a buff-yellow margin, near the inner side of which there is a row of pale blue spots. The wings of this Antiopa butterfly expand from three to three and a half inches. It comes out from its winter retreats with the first warmth of spring, and may be seen, even in Massachusetts, sporting in warm and shelterer. spots at the beginning of March, at which time its wings look ragged and faded. Wilson, the ornithologist, in his beautiful lines upon the well known American harbinger of springthe blue bird-alludes to its coming:

"When first the lone butterfly flits on the wing."

The caterpillars of the Antiopa butterfly are black, minutely dotted with white, with a row of eight dark, brick-red spots on the top of the back. When fully grown they measure an inch and three quarters in length, and appear very formidable with their thorny armature, doubtless intended to defend them from their enemies. It was formerly supposed that they were venomous, and capable of inflicting dangerous wounds, and poplar trees about dwellings have frequently been cut down from fear of these worms. "This alarm was unfounded; for although," says Dr. Harris, "there are some caterpillars that have the power of inflicting venomous wounds with their spines and hairs, this is not the case with those of the Antiopa butterfly. The only injury which can be laid to their charge, is that of despoiling of their foliage some of our most ornamental trees, ano this is enough to induce us to take all proper measures for exterminating the insects, short of destroying the trees that they infest. I have sometimes seen them in such profusion on the willow and elm, that the limbs bent under their weight; and the long leafless branches which they had stripped and deserted gave sufficient proof of the voracity of these caterpillars. The chrysalis is of a dark brown colour, with large tawny spots around the tubercles on the back. The butterflies come forth in eleven or twelve days after the insects have entered upon the chrysalis state, and this nccurs in the beginning of July. A second brood of caterpillars is produced in August, and they pass through all their changes before winter."

There is a species of caterpillar which comes from a butterfly called the Semicolon (Vanessa interrogationis). It lives on the American elm and lime trees, and also on the hopvine; and on this last they sometimes so abound as to destroy its produce. In the latter part of August the hop-vine caterpillars attain their full growth, and suspend themselves beneath the leaves and stems of the plant, and change into chrysalids. "This fact," says Dr. Harris, "affords a favourable opportunity for destroying the insects in this their stationary and helpless stage, at some loss, however, of the produce of the vines, which, when the insects have become chrysalids, should be cut down, stripped of the fruit that is sufticiently ripened, and then burnt. There is probably an early brood of eaverpillars in June or July 
but I have not seen any on the hop-vine before August, the former are therefore confined to the elm and other plants in all probability. The caterpillar is brownish, variegated with pale yellow, or pale yellow variegated with brown, with a yellowish line on each side of the body; the head is rust-red, with two blackish branched spines on the top; and the spines of the body are pale yellow or brownish and tipped with black. The chrysalis is ashen brown, with the head deeply notched, and surmounted by two conical ears, a long and thin nose-like prominence on the thorax, and eight silvery spots on the back. The chrysalis state usually lasts from eleven to fourteen days; but the later broods are more tardy in their transformations, the butterfly sometimes not appearing in less than twenty-six days after the change to the chrysalis. Great numbers of the chrysalids are annually destroyed by little maggots vithin them, which, in due time are transformed to tiny four-winged flies (Pteromalus vanessa), which make their escape by eating.little holes ihrough the sides of the chrysalis. They are ever on the watch to lay their eggs on the caterpillars of this butterfly, and are so small as easily to avoid being wounded by the branching spines of their victims."

The semicolon butterfly which produces this caterpillar expands its wings from two and a half to two and three-quarter inches, and even more. The colour of the wings is orange-taw. ny on the upper sides, with black spots in the middle. The under sides of the wings in some are rust-red, in others reddish white, with a pale gold-coloured semicolon on the middle of the hinder part, which last gives its specific name.

Another species of caterpillar living upon the hop, also proceeds from a butterfly having wings of an orange-tawny colour on the upper side; the hinder wings having a silvery comma in the middle of the under side. The wings expand from $2 \frac{1}{8}$ to $2 \frac{3}{4}$ inches. This comma butterfly, as it is called (Vanessa comma), resembles the white comma of Europe, for which it has probably been mistaken. In habits, \&c. the American comma resembles the preceding species.

Among American caterpillars, which attract the particular notice of the farmer, are several appertaining to the family of insects called hawk-moths, or sphinges, the latter name having been applied by Linnæus, from a fancied resemblance that some of the caterpillars, when ai rest, have to the Egyptian sphynx. The attitude of these caterpillars is indeed remarkable. Supporting themselves by their four or six hind legs, they elevate the fore part of the body, and remain immovably fixed in this posture for hours together. In the winged state, the true sphinges are known by the name of humming-bird moths, from the sound they make in flying, and hawk-moths from their habit of hovering in the air while taking their food. They may be seen during the morning and evening twilight, flying with great swiftness from flower to flower. Their tongues, when ancoiled, are, for the most part, excessively long, and with them they extract the honey from the blossoms of the honeysuckle and other tubular flowers, while on the wing. There are other sphinges which fy during the daytime only, and in the brightest sunshine. Then it is that the large clear-winged scrio make their appearance among the flowers, the fragrant phlox being their special favourite. From the size and form of these last, their fanlike tails, brilliant colours, and morle of taking their food whilst poised above the blossoms upon rapidly vibrating wings, they might readily be mistaken for humming-birds. (Harris.)

Among the caterpillars of the sphinges, is that commonly called the potato-worm, a large green caterpillar, with a kind of thorn upon the tail, and oblique whitish stripes on the sides of the body. "This insect, which devours the Ieaves of the potato, often to the great injury of the plant, grows to the thickness of the forefinger, and the length of three inches or more. It attains its full size from the middle of August to the first of September, then crawls down the stem of the plant and buries itself in the ground. Here, in a few days, it throws off its caterpillar-skin, and becomes a chrysalis, of a bright brown colour, with a long and slender tongue-case, bent over from the head, so as to touch the breast only at the end, and somewhat resembling the handle of a pitcher. It remains in the ground through the winter, below the reach of frost, and in the following summer the chrysalis-skin bursts open, a large moth crawls out of it, comes to the surface of the ground, and mounting upon some neighbouring plant, waits till the approach of evening invites it to expand its untried wings and fly in search of food. This large insect has generally been confounded with the Carolina sphinx (Sphinx Carolina of Linnæus), which it closely resembles. It measures across the wings about five inches; is of a gray colour, variegated with blackish lines and bands; and on each side of the body there are five round, orange-coloured spots encircled with black. Hence it is called by English entomologists Sphinx quinquemaculatus, the five-spotted sphinx. Its tongue can be unrolled to the length of five or six inches, but, when not in use, is coiled like a watch-spring, and is almost entirely concealed, between two large and thick feelers, under the head.

"A mong the numerous insects that infest our noble elms the largest is a kind of sphinx, which, from the four short horns on the forepart of the back, I have named Ceratomia quadricornis, or four-horned ceratomia. On some trees these sphinges exist in great numbers, and their ravages then become very obvious; while a few, though capable of doing considerable injury, may escape notice among the thick foliage which constitutes their food, or will only be betrayed by the copious and regularly formed pellets of excrement beneath the' 'rees. They are very abundant during the months oi July and August on the large elms which surround the northern and eastern sides of the common in Boston; and towards the end of August, when they descend from the trees for the purpose of going into the ground, they may often be seen crawling in the mall in considerable numbers. These caterpillars, at this period of their existence, are about three inches and 
$\boldsymbol{x}$ half in length, are of a pale green colonr, with seven oblique white lines on each side of the body, and a row of little notches, like saw-teeth, on the back." (Harris.)

The grape-vine suffers from the ravages of a sphinx caterpillar, which, not content with eating the leaves alone, in their progress from leaf to leaf, down the stem, stops at every cluster of food, nips off the stalks of the halfgrown grapes, and allows these to fall to the ground untasted. I have, says Dr. Harris, gathered under a single vine above a quart of unripe grapes thus detached during one night by these caterpillars. They are naked and fleshy, and generally of a pale-green colour, (sometimes, however, brown), with a row of orange-coloured spots on the top of the back, six or seven oblique darker green or brown iines on each side, and a short spine or horn on the hinder extremity. It is found on the vine and also upon the creeper in July and August. When fully grown it descends to the ground, conceals itself under fallen leaves, which it draws together by a few threads so as to form a kind of cocoon, or covers itself with grains of earth and rubbish in the same way, and under this imperfect cover changes to a pupa or chrysalis, to reappear in the winged state in the month of July of the following year. See Grape-vive Cateriluar.

Among this section of insects, naturalists have placed a group, many of which in the winged state bear a resemblance to bees, hornets, wasps, with their narrow wings. They fly only in the daytime, and frequently light to bask in the sunshine. Their habits, in the caterpillar state, are entirely different from those of the sphinges; the latter living exposed upon plants the leaves of which they devour, while the caterpillars of the agereans, as they are called, conceal themselves within the stems or roots of plants, and derive their nourishment from the wood and pitch. (Harris.)

The ash tree suffers very much from the attacks of borers of this kind, which perforate the bark and sap-wood of the trunk from the roots upwards, and are also found in all the branches of any considerable size. The trees thus infested soon show symptoms of disease, in the death of the branches near the summit; and then the insects become numerous, the trees no longer increase in size and height, and premature decay and death ensue. 'These borers assume the chrysalis form in the month of Iune, and the chrysalids may be seen projecting half way from the round holes in the bark of the tree in this and the following month, during which time their final transformation is effected, and they burst open and escape from the shells of the chrysalis in the winged or moth state.

"During the month of August, the squash and other cucurbitaceous vines are frequently found to die suddenly down to the root. The cause of this premature death is a little borer, which begins its operations near the ground, perforates the stem, and devours the interior. It afterwards enters the soil, forms a cocoon of a gummy substance covered with particles $\because f$ earth, changes to a chrysalis, and comes forth the next summer a winged insect. This is conspicuous for its orange-coloured body, spotted with black, and its hind legs fringed with long orange-coloured and black hairs. The hind wings only are transparent, and the fore wings expand from one inch to one inch and a half. It deposits its eggs. on the vines close to the roots, and may be seen flying about the plants from the tenth of July till the middle of August. This insect, which may be called the squash-vine xgeria, was first described by me in the year 1828, under the name of Ageria cucurbita, the trivial name indicating the tribe of plants on which the caterpillar feeds. See New England Farmer, vol. viii. p. 33; Dr. Harris's Discourse before the Massachusetts Horticultural Society, in 1832, p. 26 ; and Silliman's Journal, vol. xxxvi. p. 310." (Harris.)

The pernicious borer, which, during many years past has proved so very destructive to the peach trees throughout the United States, belongs to this group of the sphinx family. See Peach Tree Worm and Borer.

In Europe there is a species of ageria which has long been known to inhabit the stems of the currant-bush. There is an American insect, resembling this, found in the cultivated currant-bush, with which it may have been introdaced from Europe. See Cunnavr-push BorER.

Several caterpillars belonging to the family of tiger-moths are very destructive to vegetation, as, for example, the salt-marsh caterpillar, the yellow bear caterpillar of our gardens, and the fall web-caterpillur. These well-known insects are covered with coarse hairs, spreading out on all sides like the bristles of a bottlebrish. They creep very fast, and when handled roll themselves almost into a ball. When about to transform, they creep into the chinks of walls and fences, or hide themselves under stones, logs, or fallen leaves, where they enclose themselves in rough oval cocoons, made of hairs, plucked from their own bodies, interwoven with a few silken threads.

The caterpillars of the Arge, a species of tiger-moth, sometimes make great devastation among the young Indian corn in the Southern and Middle States. Their ordinary food consists of the leaves of the plantain and other herbaceous plants. It appears in Massachusetts, sometimes in large swarms, in the month of October. When fully grown they measure about an inch and a half in length. Their colour is a dark greenish-gray, although they appear almost black from the multitude of black spots with which they are dotted. They have three longitudinal stripes of fleshy white on the back, and a row of kidney-shaped spots of the same colour on each side of the body. The warts are dark gray, each one producing a thin cluster of spreading blackish hairs. The moth into which this caterpillar is finally con verted, has flesh-coloured wings which expand about from $1 \frac{3}{4}$ to 2 inches.

of all the hairy caterpillars frequenting American gardens, there are none so common and troublesome as that which Dr. Harris calls the Yellow Pear. "Like most of its genus," he observes, "it is a very general feeder, devour- 


\section{CATERPILLAR.}

ng aimost al! kinds of herbaccous plants, with qual relish, from the broad-leaved plantain at he door-side, the peas, beans, and even the lowers of the garden, and the corn and coarse rrasses of the fields, to the leaves of the vine, he currant, and the gooseberry, which it does lot refuse when pressed by hunger. This rind of caterpillar varies very much in its colours; it is perhaps most often of a pale yellow or straw colour, with a black line along ach side of the body, and a transverse line of he same colour between each of the segments or rings, and is covered with long pale yellow 1airs. Others are often seen of a rusty or brownsh yellow colour, with the same black lines on he sides and between the rings, and they are lothed with foxy red or light brown hairs. The head and ends of the feet are ochre-yellow, and the under side of the body is blackish in all the varieties. They are to be found of different ages and sizes from the first of June till October. When fuliy grown they are about wo inches long, and then creep into some convenient place of shelter, make their cocoons, in which they remain in the chrysalis state during the winter, and are changed to moths in he months of May or June following. Some of the first broods of these caterpillars appear to come to their growth early in summer, and are transformed to moths by the end of July or the beginning of August, at which time I have repeatedly taken them in the winged state; but the greater part pass through their last change in June. 'The moth is familiarly known by the name of the white miller, and is often seen about houses. Its scientific name is Arctia Viryinica, and, as it nearly resembles the insects coinmonly called ermine-moths in England, we may give to it the name of the Virginia ermine-moth. It is white, with a black point on the middle of the fore-wings, and two black dots on the hind-wings, one on the middle and the other near the posterior angle, much more distinct on the under than on the upper side; there is a row of black duts on the top of the back; another on each side, and ketween these a longitudinal deep yellow stripe; the hips and thighs of the fore-legs are also ochre-yellow. It expands from one inch and a half to two inches. Having been much troubled with the voracicus yellow bears in the little patch, (I cannot call it a garden,) where a few beans, and other vegetables, together with some flowers, were cultivated, I required my children io pick off the caterpillars from day to day and crush them, and taught them not to spare 'the pretty white millers,' which they frequently found on the fences, or on the plants, laying their golden yellow eggs, telling them that, with every female which they should kill, the eggs, from which hundreds of yellow bears would have hatched, would be destroyed. In some parts of France, and in Belgium, the people are required by law to écheniller, or uncaterpillar, their gardens and orchards, and are punished by fine if they neglect the duty. Although we have not yet become so prudent and public spirited as to enaet similar regulaions, we might find it for our advantage to offer a bounty for the destruction of caterpiliars: and though we should pay for them by the quart, as we do for berries, we shuuld be gainers in the end; while the children, whuse idle hours were occupied in the picking of them, would find this a profitable employment." (Hurvis.)

"The salt-marsh caterpillar, an insect by far too well known on our sea-board, and now getting to be common in the interior of the state, whither it has probably been introduccd, while under the chrysalis form, with the salt hay arnually carried from the coast by our inland farmers, closely resembles the yellow bear in some of its varieties. The history of this insect," says Dr. Harris, "forms the subject of a communication made by me to the "Agricultural Society of Massachusetts,' in the year 1823 , and printed in the seventh volume of the - Massachusetts Agricultural Repository ard Journal,' with figures representing the insect in its different stages. At various times and intervals since the beginning of the present century, and probably before it also, the salt marshes about Boston have been overrun and laid waste by swarms of caterpillars. 'These appear towards the end of June, and grow rapidly fiom that time till the first of August. During this month they come to their full size, and begin to run, as the phrase is, or retreat from the marshes, and disperse through the adjacent uplands, often committing very extensive ravages in their progress. Corn-fields, gardens, and even the rank weeds by the wayside afford them temporary nourishment while wandering in search of a place of security flom the tide and weather. They conceal themselves in walls, under stones, in haystacks and mows, in wood-piles, and in any other places in their way, which will afford them the proper degree of shelter during the winter. Here they make their coarse hairy cocoons, and change to chrysalids, in which form they remain till the following summer, and are transformed to moths in the month of June. In those cases where, from any cause, the caterpillars, when arrived at maturity, have been unable to leave the marshes, they conceal themselves aneath the stubble, and there make their ca rons. Such, for the most part. is the course aud duration of the lives of these insects in Massachusetts; but in the Middle and Southern States, two broods are brought to perfection annually; and even here some of them run through their course sooner, and produce a second brood of caterpillars in the same season; for I have obtained the moths between the 15th and 20th of May, and again between the 1st and the 10th of August. Those which were disclosed in May passe' the winter in the chrysalis form, while the miths which appeared in August must.have been produced from caterpillars that had come to their growt. and gone through all their transformations during the same summer. This, however, in Massachusetts, is not a common occurrence. for by far the greater part of these insects ap pear at one time, and require a year to complete their several changes. The full-grown ca terpillar measures one inch and three-quarters or more in length. It is clothed with long hairs, which are sometimes black and sometimes brown on the back and forepart of the

$$
2 \mathrm{~A} \quad 27^{\sim}
$$


body, and of a lighter brown colour on the sides. The hairs, like those of the other Arctias, grow in spreading clusters from warts, which are of a yellowish colour in this species. 'The body, when stripped of the hairs, is yeliow, shaded at the sides with black, and there is a blackish line extending along the top of the back. The breathing-tioles are white, and very distinct even through the hairs. These caterpillars, when feeding on the marshes, are sometimes overtaken by the tide, and when escape becomes impossible, they roll themselves up in a circular form, as is common with others of the tribe, and abandon themselves to their fate. The hairs on their bodies seem to have a repelling power, and prevent the water from wetting their skins, so that they float on the surface, and are often carried by the waves to distant places, where they are thrown on shore, and left in winrows with the wwash of the sea. After a little time most of them recover from their half-drowned condition, and begin their depredations anew. In this way these insects seem to have spread from the places where they first appeared to others at a considerable distance. Although these insects do not seem ever entirely to have disappeared from places where they have once established themselves, they do not prevail every year in the same overwhelming swarms; but their numbers are increased or lessened at irregular periods, from causes which are not well understood. These caterpillars are produced from eggs, which are laid by the moths on the grass of the marshes about the middle. of June, and are hatched in seven or eight days afterwards, and the number of eggs deposited by a single female is, on an average, about eight hundred. The moths themselves vary in colour. In the males, the thorax and upper side of the fore-wings are generally white, the latter spotted with black; the hind-wings and abdomen, except the tail, deep ochre-yellow, the former with a few black spots near the hind margin, and the abdomen with a row of six black spots on the top of the back, two rows on the sides, and one on the belly; the under-side of all the wings and the thighs are deep yellow. It expands from one inch and seven-eighths to two inches and a quarter. The female differs from the male either in having the hind wings white, instead of ochre-yellow, or in having all the wings ashen gray with the usual black spots. It expands two inches and three-eighths or more. Sometimes, though rarely, male moths occur with the fore-wings ash-coloured or dusky. Professor Peck called this moth psenderminea, that is, false ermine, and this name was adopted by me in my communication to the "Agricultural Society." (Harris.)

In order to lessen the ravages of the saltmarsh caterpillars, and to secure a fair crop of hay when these insects abound, Dr. Harris recommends that "the marshes should be mowed early in July, at which time the caterpillars are small and feeble, and being unable to wander tar, will die before the crop is gathered in. In defence of early mowing, it may be said that it is the only way by which the grass mav be saved in those meadows where 278 the caterpillars have multiplied to any extent; and, if the practice is followed generally, and continued during several years in succession, it will do much towards exterminating these destructive insects. By the practice of late mowing, where the caterpillars abound, a great loss in the crop will be sustained, immense numbers of caterpillars and grasshoppers will be left to grow to maturity and disperse upon the uplands, by which means the evil will go on increasing from year to year; or they will be brought in with the hay to perish in our barns and stacks, where there dead bodies will prove offensive to the cattle, and occasion a waste of fodder. To get rid of 'the old fog' or stubble, which becomes much thicker and longer in consequence of early mowing, the marshes should be burnt over in March. The roots of the grass wil! not be injured by burning the stubble, on the contrary, they will be fertilized by the ashes; while great numbers of young grasshoppers, cocoons of caterpillars, and various kinds of destructive insects, with their eggs, concealed in the stubble, will be destroyed by the fire. In the province of New Brunswick, the benefit arising from burning the stubble has long been proved; and this practice is getting into favour in New England.

"The caterpillars of all the foregoing Arctians (or harnessed moths) live almost entirely upon herbaceous plants; those which follow (with one exception only), devour the leaves of trees. Of the latter, the most common and destructive are the little caterpillars known by the name of fall web-worm,s, whose large webs, sometimes extending over eritire branches with their leaves, may be seen on oar native elms, and also on apple and other fruit trees, in the latter part of summer. The eggs, from which these caterpillars proceed, are laid by the parent moth in a cluster upon a leaf near the extremity of a branch; they are hatched from the last of June till the middle of August, some broods being early and others late, and the young eaterpillars immediately begin to provide a shelter for themselves, by covering the upper side of the leaf with a web, which is the result of the united labours of the whole brood. They feed in company beneath this web, devouring only the upper skin and pulpy portion of the leaf, leaving the veins and lower skin of the leaf untouched. As they increase in size, they enlarge their web, carrying it over the next lower leaves, all the apper and pulpy parts of which are eaten in the same way, and thus they continue to work downwards, till finally the web covers a large portion of the branch, with its dry, brown, and filmy foliage, reduced to this unseemly condition by these little spoilers. These caterpillars, when fully grown, measure rather more than one inch in length; their bodies are more slender than those of the other Arctians, and are very thinly clothed with hairs of a grayish colour, intermingled with a few which are black. The general colour of the body is greenish yellow dotted with black; there is a broad blackish stripe along the top of the back, and a bright yellow stripe on each side. The warts, from which the thin bundles of 
spreading, silky hairs proceed, are black on the back, and rust-yellow or orange on the sides. The head and feet are black. I have not observed the exact length of time required by these insects to come to maturity; but towards the end of August and during the month of September they leave the trees, disperse, and wander about, eating such plants as happen to lie in their course, till they have found suitable places of shelter and concealment, where they make their thin and almost transparent cocoons, composed of a slight web of silk intermingled with a few hairs. They remain in the cocoons in the chrysalis state through the winter, and are transformed to moths in the months of June and July. These moths are white, and without spots; the forethighs are tawny-yellow, and the feet blackish. 'Their wings expand from one inch and a quarter to one inch and three-eighths.

"During the months of July and August, there may be found on apple trees and rosebushes, and sometimes on other trees and shrubs, little slender caterpillars of a bright yellow colour, sparingly clothed with long and fine yellow hairs on the sides of the body, and having four short and thick brush-like yellowish tufts on the back, that is on the fourth and three following rings, two long black plumes or pencils extending forwards from the first ring, and a single plume on the top of the eleventh ring. The head, and the two little retractile warts on the ninth and tenth rings are coral red; there is a narrow black or brownish stripe along the top of the back, and a wider dusky stripe on each side of the body. These pretty caterpillars do not ordinarily herd toether, but sometimes our apple trees are

ch infested by them, as was the case in the

:mer of 1828. When they have done eating, they spin their cocoons on the leaves, or on the branches or trunks of the trees, or on fences in the vicinity. The chrysalis is not only beset with little hairs or down, but has three oval clusters of branny scales on the back. In about eieven days after the change to the chrysalis is effected, the last transformation follows, and the insects come forth in the adult state, the females wingless, and the males with large ashen-gray wings, crossed by wavy darker bands on the upper pair, on which, moreover, is a small black spot near the tip, and a minute white crescent near the outer hind angle. The body of the male is small and slender, with a row of little tufts along the back, and the wings expand one inch and three-eighths. The females are of a lighter gray colour than the males, their bodies are very thick, and of an oblong oval shape, and, though seemingly wingless, upon close examination two little scales, or stinted winglets, can be discovered on each shoulder. These females lay their eggs upon the top of their cocoons, and cover them with a large quantity of frothy matter, which on drying becomes white and brittle. Different broods of these insects appear at various times in the course of the summer, but the greater number come to maturity and lay their eggs in the latter part of August, and the beginning of September; and these eggs are not hatched till 279 the following summer. The name of this moth is Orgyia* leucostigma, the white-marke! Orgyia or tussock-moth. It is to the exers of this insect that the late $\mathbf{M r}$. B. H. Ives, of $\mathrm{S}_{3}$ lem, alludes, in an article on 'insects which infest trees and plants,' published in II,vey's 'Gardener's Magazine.' Mr. Ives states, tha! on passing through an apple orchard in Feb. ruary, he "perceived nearly all the trees speckled with occasional dead leaves, adhering so firmly to the branches as to require considerable force to dislodge them. Each leaf covered a small patch of from one to $t w^{\prime}$ hundred eggs, united together, as well as $t$ the leaf, by a gummy and silken fibre, peculiaı to the moth.' In March, he 'visited the same orchard, and, as an experiment, cleared three trees, from which he took twenty-one bunches of eggs. The remainder of the trees he left untouched until the tenth of May, when he found the caterpillars were hatched from the egg, and had commenced their slow but sure ravages. He watched them from time to time, until many branches had been spoiled of their leaves, and in the autumn were entirely destitute of fruit; while the three trees. which had been stripped of the eggs, were flush with foliage, each limb without exception ripening its fruit.' These pertinent remarks point out the nature and extent of the evil, and suggest the proper remedy to be used agains: the ravages of these insects."

In the New England States there is found a tussock or vaporer moth, seemingly the same as the Orgyia antiqua, the antique or rusty va. porer-moth of Europe, from whence, possibly its eggs may have been brought with importec fruit trees, for a description of which, anc other tussock moths, see Dr. Harris's treatise, and also Mr. Abbott's work on the insects of Georgia. Also communications by Miss Di. to Silliman's Journal, vol. xix. p. 62.

"To this group of hairy caterpillars belong those which swarm in the unpruned nurseries and neglected orchards of the slovenly and improvident husbandman, and hang their manycoated webs upon the wild cherry trees that are suffered to spring up unchecked by the way-side, and encroach upon the borders of our pastures and fields. The eggs from which they are hatched are placed around the ends of the branches, forming a wide kind of ring or bracelet, consisting of three or four hundred eggs, in the form of short cylinders, standing on their ends close together, and covered with a thick coat of brownish water-proof varnish. The caterpillars come forth with the unfolding of the leaves of the apple and cherry tree, dur. ing the latter part of April or the beginning of May. The first signs of their activity appear in the formation of a little angular web or tent, somewhat resembling a spider's web, stretched between the forks of the branches a little be-

* This name is derived from a word which sicnifies to stretch out the hands, and it is applied to this kind of moth on account of its resting with the Sore-legs extended. The Germans call these motlis streckfüssige Spinner, the French pattes ctendues, and the English va porer-moths, the latter protably because the males are seen flying about nstentatiously, or vaporing, by dav when most other moths keep concealed. 


\section{CATERPILLAR.}

low the cluster of eggs. Under the shelter of these tents, in making which they all work together, the caterpillars remain concealed at all times when not engaged in eating. In crawling from twig to twig and from leaf to leaf, they spin from their mouths a slender silken thread, which is a clue to conduct them back to their tents; and as they go forth and return in files, one after another, their pathways in time become well carpeted with silk, which serves to render their footing secure during their frequent and periodical journeys in various directions to and from their common habitation. As they increase in age and size they enlarge their tent, surrounding it from time to time with new layers or webs, till at length it acquires a diameter of eight or ten inches. They come out together at certain stated hours to eat, and all retire at once when their regular meals are finished; during bad weather, however, they fast, and do not venture from their shelter. These caterpillars are of a kind called lackeys in England, and livrées in France, from the party-coloured livery in which they appear. When fully grown they measure about two inches in length. Their heads are black; extending along the top of the back from one end to the other is a whitish line, on each side of which, on a yellow ground, are numerous short and fine crinkled black lines, that lower down become mingled together, and form a broad longitudinal black stripe, or rather a row of long black spots, one on each ring, in the middle of each of which is a small blue spot; below this is a narrow wavy yellow line, and lower still the sides are variegated with fine intermingled black and yellow lines, which are lost at last in the general dusky colour of ihe under side of the body; on the top of the eleventh ring is a small blackish and hairy wart, and the whole body is very sparingly clothed with short and soft hairs, rather thicker and longer upon the sides than elsewhere. The foregoing description will serve to show that these insects are not the same as either the Neustria or the camp lackey caterpillars of Europe, for which they have been mistaken. From the first to the middle of June they begin to leave the trees upon which they have hitherto lived in company, separate from each other, wander about a while, and finally get into some crevice or other place of shelter and make their cocoons. These are of a regular long oval form, composed of a thin and very loosely woven web of silk, the meshes of which are fille with a thin paste, that on drying is changed to a yellow powder, like flour of sulphur in appearance. Some of the caterpillars, either from weakness or some other cause, do not leave their nests with the rest of the swarm, but make their cocoons there, and when the webs are opened these cocoons may be seen intermixed with a mass of blackish grains, like gunpowder, excreted by the caterpillars during their stay. From fourteen to seventeen days after the insect has made its cocnon and changed to a chrysalis, it bursts its chrysalis skin, forces its way through the wet and softened end of its coconn, and appears in the winged or mii,er form. Many of them, how ever, are unable to finish their transformations 28) by reason of weakness, especially those remaining in the webs. Most of these will be found to have been preyed upon by !ittle maggots living upon the fat within their bodies, and finally changing to small four-winged ich. neumon wasps, which in due time pierce a hole in the cocoons of their victims, and escape into the air.

"The moth of our Amuerican lackey-caterpillar is of a rusty or reddish brown colour, more or less mingled with gray on the middle and base of the fore-wings, which, besides, are crossed by two oblique, straight, dirty white lines. It expands from one inch and a quarter to one inch and a half or a little more.

"The moths appear in great numbers in July, flying about and often entering houses by night. At this time they lay their eggs, selecting the wild cherry in preference to all other trees for this purpose, and next to these apple trees, the extensive introduction and great increase of which in this country afford an abundant and tempting supply of food to the caterpillars in the place of the native cherry trees that formerly, it would seem, sufficed for their nourish. ment. These insects, because they are the most common and most abundant in all parts of our country, and have obtained such noto. riety that in common language they are almost exclusively known among us by the name of the caterpillars, are the worst enemies of the orchard. Where proper attention has not been paid to the destruction of them, they prevail to such an extent as almost entirely to strip the apple and cherry trees of their foliage, by their attacks continued during the seven weeks of their life in the caterpillar form. 'The trees, in those orchards and gardens where they have been suffered to breed for a succession of years, become prematurely old in consequence of the efforts they are obliged to make to repair, at an unseasonable time, the loss of their foliage, and are rendered unfruitful, and consequently un. profitable. But this is not all; these pernicious insects spread in every direction from the trees of the careless and indolent to those of their more careful and industrious neighbours, whose labours are thereby greatly increased, and have to be followed up year after year without any prospect of permanent relief.

"Many methods and receipts for the destruc. tion of these insects have been published and recommended, but have failed to exterminate them, and indeed have done but little to lessen their numbers. Mr. Lowel has justly said that - the great difficulty is the neglect to do any thing, till after the caterpillars have covered the trees with their nests. Then the labours of the sluggard commence, and one tree, let his receipt be ever so perfect and powerful, will cost him as much time and labour as ten trees would have required three weeks sooner.' The means to be employed may be stated under three heads. The first is, the collection and destruction of the eggs. These should be sought for in the winter and early part of the spring, when there are no leaves on the trees. They are easily discovered at this time, and may be removed with the thumb-nail and forefinger. Nurseries and the lower limbs of large trees may thus be entirely cleared of eggs dur. 


\section{CATERPILIAR.}

ing a few visits made at the proper season. If a liberal bounty for the collestion of the egrs were to be offered, and continued for the space of ten years, these destructive caterpillars would be nearly exterminated at the end of that time. Under the second head are to be mentioned the most approved plans for destroying the caterpillars after they are hatched, and have begun to make their nests or tents. It is well known that the caterpillars come out to feed twice during the day time, namely, in the forenoon and afternoon, and that they rarely leave their nests before nine in the morning, and return to them again at noon. During the early part of the season, while the nests are small, and the caterpillars young and tender, and at those hours when the insects are gathered together within theircommon habitation, they may be effectually destroyed by crushing them by hand in the nests. A brush, somewhat like a bottle-brush, fixed to a long handle, as recommended by the late Colonel Pickering, or, for the want thereof, a dried mullein head and its stalk fastened to a pole, will be useful to remove the nests, with the caterpillars contained therein, from those branches which are too high to be reached by hand. Instead of the brush, we may use, with nearly equal success, a small mop or sponge, dipped as often as necessary into a pailful of refuse soap-suds, ley, strong white-wash, or cheap oil. The mop should be thrust into the nest and turned round a little, so as to wet the caterpillars with the liquid, which will kill every one that it touches. These means, to be effectual, should be employed during the proper hours, that is, early in the morning, at mid-day, or at night, and as soon in the spring as the caterpillars begin to make their nests; and they should be repeated as often, at least, as once a week, till the insects leave the trees. Early attention and perseverance in the use of these remedies will, in time, save the farmer hundreds of dollars, and abundance of mortification and disappointment, besides rewarding him with the grateful sight of the verdant foliage, snowy blossoms, and rich fruits of his orchard in their proper seasons. Under the third head, I beg leave to urge the people of this commonwealth to declare war against these caterpillars, a war of cxtermination, to be waged annually during the month of May and the beginning of June. Let every able-bodied citizen, who is the owner of an apple or cherry tree, cultivated or wild, within our border, appear on duty, and open the campaign on the first washing-day in May, armed and equipped with brush and pail, as above directed, and give battle to the common enemy; and let every housewife be careful to reserve for use a plentiful supply of ammunition, strong waste soap-suds, after every weekly wash, till the liveried host shall have decamped from their quarters, and retreated for the season. If every man is prompt to his duiy, I venture to predict that the enemy will be completely conquered in less time than it will take to exterminate the Indians in Florida.

"Another caterpillar, whose habits are similar to those of the preceding, is now and then met with, in Massachusetts, upon oak and walnut trees, and more rarely still upon apple trees.
According to Mr. Abbot, "it is sornetimes se plertiful in Virginia as to strip the oak-trees bare.' It may be called Clisiocumpa sylunticn, the tent-caterpillar of the forest. With us it comes to its full size from the tenth to the twentieth of June, and then measures about two inches in length." (Harris.)

Those who wish to become more intimately acquainted with the natural histrory of the cater. pillar tribe against which such incessant war is waged both in country and town, wherever a tree or a plant is found, will meet with abundant information in Dr. Harris's 'Treatise upon Insects destructive to vegetation.

Some others of the caterpillar tribe will be found noticed under the several heads of $\mathrm{C}_{\mathrm{ASE}}$ beafers, or Basket-Wonys, Curhast-besh Boner, Cutwonm Caterpillan, Leaf-rolleks, Appletree and Nursen Catempleans, Oak ani Warnut Catenpileals, Hopovive avil Grape-vine Caterpiluas, Locest Trep and other caterpillars infesting hichory and elm trees, \&c., 'Turpentive Motr, infesting the fir and pine, caterpillars living upon reals, flags, and other aquatic plants, Sparworms, Loopers, or Geometers, among which are the insects commonly called canker worms; GrEask-noru Caterpillars, \&c.

CATKIN. A name given to such amentaceous flowers as consist of a great number of chaffy scales and flowers, dispersed along a slender thread-like axis or rachis, hanging downward, in the form of a rope or cat's tail. It is the male flower of the trees which produce them, as the birch, beech, pine, fir, poplar, walnut, hazel, \&c. They drop as soon as the pollen is shed.

CATMIN'T, or NEP (Nepeta cataria, Smith, vol. iii.p. 70). This is a common plant, growing in borders of fields and in moist places, flowering in June and July. It grows a yard high, with broad whitish leaves, and white flowers, not unlike mint. The plant has a strong and rather unsavoury smell. It is easily recognised by its hoary, square, and erect stalks; its leaves slightly indented on the edges, of a whitish-green on their outside, and almost perfect white underneath; and its flowers growing in spiked clusters around the stalk at certain distances. Cats are exceedingly fond of rolling upon this plant, and they chew it eagerly. This has obtained for it the familiar name of catmint.

CAT'S-FOOT. A term sometimes provincially applied to ground-ivy.

CAT'S-MILK. A common name for the plant wartwort, which see.

CA T'S-TAIL, or TIMOTHY GRASS (Phleum pratense, Pl. 5, k). This grass flourishes best in moist deep loams. Perennial, native of Britain. At the time of flowerittg, in the end of June, Sinclair found the produce per acre was, from a clayey loam, 40,837 lbs.; of nutritive matter $1595 \mathrm{lbs}$. This is a great American grass, and is called timothy from Mr. Timothy Hanson, who first introduced its seeds into Maryland. Seeds ripe in July. It pro. duces an abundance of early feed, but its pruduct of aftermath is poor. See Grasses.

Timothy is undoubtedly one of the most valuable grasses linown to American farmers 
Mixed in the field with red clover, it affords excellent hay. The seed is usually sown in the autumn, among and immediately after wheat, and rye, though it succeeds very well when sown in the spring at the same time clover is sown. The clover dies out after the second year, leaving the ground in possession of the timothy, which requires a good soil and is considered an exhausting crop to land.

The smaller Meadow Cat's-tail (Phleum minus). Indigenous to England, on tenacious soils.

The Bulbous-jointed Cat's-tail Grass (Phleum nodosum). Perennial; native of Britain, but rare; found on a clayey soil at Woburn. Flowers in beginning of July. Seeds ripe at the end of the same month.

Purple-stalked Cat's-tail Grass (Phleum boehmeri). Indigenous and perennial; grows best on a sandy loam. Flowers in July.

In the New England States timothy, or $P$. pratense, is called herd's grass, a name applied in the Middle States exclusively to the Agrostis vulgaris or red-top, a kind of grass so very unpopular among Pennsylvania farmers, that in selecting clover and other grass seeds, they reject all samples containing herd's grass.

CATTLE. Under this head I propose to include the ox tribe, Lovida, of the class Mammalia, having teats or mamma; these are of the order Ruminantia, or ruminating, or cud-chewing animals. Of this tribe there are eight species:-1. Eos urus or Auroch, the ancient bison; 2. B.bison, the bison, or American buffalo; 3 . $B$. moschatus, or musk ox; 4. B. frontalis, or gayal; 5. B. grunniens, or grunting ox; 6 . B. iaffer, or buffalo of southern Africa; 7. B.bubulus, or common buffalo; 8. B.taurus, or common domestic ox. That the ox has been domesticated, and in the service of man from a very remote period, is quite certain. We learn from Gen. (iv. 20.) that cattle were kept by the eariy descendants of Adam. Preserved by Noah from the flood waters, the original breed oi our present ixen must have been in the neighbourhood of Mount Ararat; and from thence, dispersing over the face of the globe, altering by climate, by food, and by cultivation, originated the various breeds of modern ages. That the value of the ox tribe has been in all ages and climates highly appreciated, we have abundant evidence. The natives of Egypt, India, and of Hindostan seem alike to have placed the cow amongst their deities; and, judging by her usefulness to all classes, no animal could perhaps have been selected whose value to mankind is greater. Of the old race of British cattle, some remains of which are yet to be found in Chi'lingham Park, in Northumberland, in a state of tolerable purity, and in one or two other places in Great Britain, improved by judicious or accidental crossings, came most of our modern breeds. George Culley, in his valuable work on cattle, describes these aboriginals as being of a creamy white, with black muzzles, white horns with black tips bending upwards. The cows weighing from twenty-five to thirty-five stone. They hide for a week or ten days their calves, in some sequestered place; and these, when they are disturbed, put their heads to the ground, and lie close like a hare. Their wildness pre282 vents the introduction of them into any situation not surrounded by stone walls : and the mode in which they were wcnt to be killed by the keepers was by a rifle ball. See also two excellent papers by Dr. Knox on the wild ox of Scotland (Quart. Journ. of $A g r$. vol. ix. p. 367 ) ; and on the ox tribe, in connection with the white cattle of the Hamilton and Chillingham breeds, by the Rev. Dr. Patrick (Ibid. p. 514).

In nearly all parts of the earth cattle are employed for their labour, for their milk, and for food. In southern Africa they are as much the associates of the Caffres as the horse is of the Arab. They share his toils, and assist him in tending his herds; they are even trained to battle, in which they become fierce and cou. rageous. In central Africa the proudest ebony beauties are to be seen on their backs. They have drawn the plough in all ages; in Spain they still trample out the corn; in India raise the water from the deepest wells to irrigate the thirsty soils of Bengal. When Cæsar invaded England they constituted the chief riches of its inhabitants (Casar, lib. v. c. 10); and they yet form no inconsiderable item in the estimate of that country's abounding riches. According to the estimate of $\mathrm{Mr}$. Youatt, to whom in this and other articles on live stock I am so much indebted (On Cattle, p.9), it would seem that $1,600,000$ head of cattle are consigned to the butcher every year in the United Kingdom, and the value of the entire national stock of all kinds of cattle, sheep, and pigs, he is of opinion, amounts to nearly $120,000,000 l$. ster ling. An excellent paper on the origin and natural history of the domestic ox and its allied species, by Professor Wilson (Quart. Journ. of Agr. vol. ii. p. 177), may be consulted with advantage by those who wish for more information on this head.

The breeds of cattle in England are remarkable for their numerous varieties, caused by the almost endless crossings of one breed with another, often producing varieties of the most mongrel description, and which are rather difficult to describe. I will in this place touch upon the principal varieties; and in these we should, in looking for the chief points of excellence, regard, as Mr. Youatt well observes, "wide and deep girth about the heart and lungs; and not only about these, but above the whole of the ribs must we have both depth and roundness; the hooped as well as the deep barrel is essential. The beast should aiso be ribbed home; there should be little space between the ribs and the hips. This is indispensable in the fattening ox, but a largeness and drooping of the belly is excusable in the cow. It leaves room for the udder, and if it is also accompanied by swelling milk-veins, it generally indicates her value in the dairy. This roundness and depth of the barrel, however, is most advantageous in proportion as it is found behind the point of the elbow, more than between the shoulders and legs; or low down between the legs, than upwards towards the withers; for it diminishes the heaviness before, and the comparative bulk of the coarser parts of the animal, which is always a very great consideration. 


\section{CATTLE.}

"The loins should be wide, for these are the prime parts; they should seem to extend far along the back; and although the belly should not hang down, the flanks should be round and deep, the hips large, without being ragged, round rather than wide, and present, when handled, plenty of muscle and fat; the thighs full and long, and, when viewed from behind, close together; the legs short, for there is almost an inseparable connection between length of leg and lightness of carcass, and shortness of leg and propensity to fatten. The bones of the legs and of the frame generally should be small, but not too small; small enough for the well-known accompaniment, a propensity to fatten; small enough to please the consumer, but not so small as to indicate delicacy of constitution and liability to disease. Finally, the hide, the most important thing of all, should be thin, but not so thin as to indicate that the animal can endure no hardships, movable, mellow, but not too loose, and particularly well covered with fine and soft hair."

On the points by which live stock are judged, some very excellent papers have appeared in the Edin. Quart. Journ. of Agr., by Mr. James Dickson, cattle-dealer of Edinburgh. He very truly observes (vol.v.p. 159), that, "were an ox of fine symmetry and high condition placed before a person not a judge of live stock, his opinion of its excellences would be derived from a very limited view, and consequently from only a few of its qualities. He might observe and admire the beautiful outline of its figure, for that would strike the most casual observer. He might be pleased with the tint of its colours, the plumpness of its body, and the smoothness and glossiness of its skin. He might be even delighted with the gentle and complacent expression of its rountenance;all these properties he might judge of by the eye alone. On touching the animal with the hand, he could feel the softness of its body, xccasioned by the fatness of the flesh. But no man not a judge could rightly criticise the properties of an ox farther. He could not possibly discover without tuition those properties which had chiefly conduced to produce the high condition in which he saw the ox. He would hardly believe that a judge can ascertain merely by the eye, from its general aspect, whether the ox were in good or bad health; from the colour of its skin, whether it were of a pure or cross breed; from the expression of its countenance, whether it were a quiet feeder; and from the nature of its flesh, whether it had arrived at maturity. The discoveries made by the hand of a judge might even stagger his belief. He could scarcely conceive that the hand can feel a hidden property. The touch, which of all lests is the most surely indicative of fine quality of flesh and of disposition to fatten, can find whether that flesh is of the most valuable kind; and it can foretell the probable abundance of fat in the interior of the carcass. In short, a judge alone can discriminate between the relative values of the different points, or appre. ciate the aggregate value of all the points of an ox. These 'points' are the parts of an ox by which it is judged." The first point to be ascertained in examining an $\mathbf{O x}$, is the purity

\section{CA'T'TLE.}

of its breed, whatever that breed may be; fot that will give the degree of the dispusition to fatten of the individuals of that breed. The purity of the breed may be ascertained from several marks: the colour or colours of the skin of a pure breed of cattle, whatever those colours are, are always definite. The colour of the bald skin on the nose and round the eyes, in a pure breed, is always definite, and without spots. This last is an essential point. When horns exist, they should be smooth, small, ta. pering, and sharp-pointed, long or short, according to the breed, and of a white colour throughout in some breeds, and tipped with black in others. The shape of the horn is a less essential point than the colour. Applying these remarlss on the different breeds in Scotland, as illustrations of the point which we have been considering, we have the definite colours of white and red in the short-horns. The colour is either entirely white or entirely red, or the one or the other predominates in their mixture. The skin on the nose and around the eyes is uniformly of a rich cream colour. The Ayrshire breed, in its purity, is also distinguished by the red and white colour of the skin, but always mixed, and the mixture consists of spots of greater or smaller size not blended together. The colour of the skin on the nose and around the eye is not definite, but generally black or cream-coloured. In other points, these two celc.brated breeds differ from one another more th $: n$ in the characters which I have just describe l. In the West Highland, Angus, and Galloway breeds, the colour of the skin of the nose and around the eyes is indicative of the pure blood of black-coloured cattle, but a cream-coloured nose may frequently bo observed amongst the other colours of skin The characters above given will certainly apply to the purity of the blood in the short horn and Ayrshire breeds, if not to the Wes Highlanders.

"The second point to be ascertained in an ox is the form of its carcass. It is found that the nearer the section of the carcass of a fat $\mathbf{o x}$, taken longitudinally vertical, transversely vertical, and horizontally, approaches to the figure of a parallelogram, the greater quantity of flesh will it carry within the same measurement. That the carcass may fill up the parallelogram as well as its rounded form is capable of filling up a right-angled figure, it should possess the following configuration:-The back should be straight from the top of the shoulder to the tail. The tail should fall perpendicularly from the line of the back. The buttocks and twist should be well filled out. The brisket should project to a line dropped from the middle of the neck. The belly should be straight longitudinally", and round laterally, and filled at the flank: The ribs should be round, and should project norizontally, and at right angles to the back. The hooks should be wide and flat; and he rump, from the tail to the hooks, should a so be filled and well filled. The quarter from the itch-bone to the hook should be long. The loin bones should be long, broad, and flat, and weli filled; but the space betwixt the hooks and the short ribs should be rather short and weli arched over, with a thickness of beef letween 


\section{CATTLE.}

the hooks. A Jong hollow from the hooks to the short ribs indicates a weak constitution and an indifferent thriver. From the loin to the shoulder-blade should be nearly of one breadth, and from thence it should taper a little to the front of the shoulder. 'The neck-vein should be well filled forward to complete the line from the neck to the brisket. The covering on the shoulder-blade should be as full out as the buttocks. The middle ribs should be well filled, to complete the line from the shoulders to the buttocks along the projection of the outside of he ribs; these constitute all the points which are essential to a fat ox.

"The first of the points in judging of a lean $o x$, is the nature of the bone. A round thick bone indicates both a slow feeder and an inferior description of flesh. A flat bone, when seen on a side view, and narrow when viewed either from behind or before the animal, indicates the opposite properties of a round bone. The whole bones in the carcass should bear a small proportion in bulk and weight to the nesh, the bones being only required as a support to the flesh. 'The texture of the bone should be small-grained and hard. The bones of the head should be fine and clean, and only covered with skin and muscle, and not with lumps of fat and flesh, which always give a heavy-headed, dull appearance to an ox. 'The fore-arm and hock should also be clean and full of muscle, to endure travelling. Large joints indicate bad feeders. The neck of an ox should be, contrary to that of the sheep, small from the back of the head to the middle of the neck. A full, clear, and prominent eye is another point to be considered, because it is a nice indication of good breeding. It is always attendant on fine bone: the expression of the eye is an excellent index of many properties in the ox. A dull, heavy eye clearly indicates a slow feeder. A rolling eye, showing much white, is expressive of a restless capricious disposition, which is incompatible with quiet feeding. A calm, complacent expression of eye and face is strongly indicative of a sweet and patient disposition, and of course kindly feeling. The eye is frequently a faithful index of the state of health. A cheerful clear eye accompanies good health : a constantly dull one proves the probable existence of some internal lingering disease; the dullness of eye, however, arising from internal disease is quite different in character from a natural or constitutional phlegmatic dullness.

"The state of the skin is the next point to be ascertained; the skin affords what is technically and emphatically called the touch-a cri:erion second to none in judging of the feeding properties of an ox. The touch may be good or bad, fine or harsh, or, as it is often termed, hard or mellow. $\Lambda$ thick, firm shin, which is generally covered with a thick-set, hard, short hair, always touches hard, and indicates a bad feeaer. A thin, meager, papery skin, covered with thin, silky hair, being the opposite of the one just described, does not, however, afford a good touch. Such skin is indicative of weakness of constitution, though of good feeding properties. A perfect touch will be fourd with v thick, loose skin, floating, as it were, on

\section{CATTLE.}

a layer of soft fat, yielding to the least pressure, and springing back to the finger lik? a piece of soft, thick, chamois leather, and covered with thick, glossy, soft hair. It is not unlike a bed of fine soft moss, and hence such a skin is not unfrequently styled 'mossy.' A knowledge of touch can only be acquired by long practice; but after having acquired it, it is of itself a sufficient means of judging of the feeding quality of an ox, because, when present, the properties of symmetrical form, fine bone, sweet disposition, and purity of blood are the general accompaniments. These are the essential points in judging lean cattle, but there are other and important considerations in forming a thorough judgment of the ox. The head should be small, and set on the neck as if easily carried by the animal; this shows the animal to advantage in the market. The face long from the eyes to the point of the nose. The skull broad across the eyes, contracted a little above them, but tapering considerably below them to the nose. The muzzle fine and small; the nostrils capacious; the ears large, a little erect, and transparent; the neck short and light. A droop of the neck from the top of the shoulder to the head indicates a weakness of constitution, arising frequently from breeding too near akin. The legs below the knees should be rather short than long, and clean made; stand where they apparently bear the weight of the body most easily, and wide asunder. The tail rather thick than otherwise, as that indicates a strong spine, and a good weigher. It should be provided with a large tuft of long hair. The position of the flesh is important: that part called the spare rib in Edinburgh, and the fore and middle ribs in London, the loins and the rump, or hook-bone, are of the finest quality, and are generally used for roasts and steaks; consequently the ox which carries the largest quantity of beef on these points is the most valuable. Flesh of fine quality is actually of a finer texture than coarse flesh. The other desirable objects in a fat ox are a full twist, lining the division between the hams called 'the closing' with a thick layer of fat, a thick flank, and a full neck bend; these generally indicate internal tallow. The last points generally covered with fat are the point of the shoulder-joint and the top of the shoulder: if these parts are, therefore, felt to be well covered, the other and better parts of the animal may be considered ripe. It is proper, in judging of the weight of a fat ox, to view his gait while walking towards you, which will, if the ox has been well fed, be accompanied with a heavy rolling tread on the ground. In this way a judge can at once come very near to its weight." (Quart. Journ. of $\mathcal{A g r}$. vol.v.p. 167.) At the end of this paper will be found an account of the mode of ascertaining the weight of stock by admeasurement.

When we survey the frame of a short horn ox, adds Mr. Dickson (Ibid. vol. vi. p. 267), we have a straight, level back from behind the horns to the top of the tail, full buttocks, and a projecting brisket; we have, in short, the rectangular figure, as represented in a side view by fig. 1. We have also the level loin across the hook bones, and the level top of the 
shoulder across the ox, and perpendicu. lat lines down the hind and fore-legs on both sides, these constituting the square form when the $o x$ is viewed before and behind, as represented in figures 2 and 3 ; and we have straight parallel lines from the sides of the shoulders, along the outmost points of the ribs, to the sides of the hind quarters; and we have these lines connected at their ends by others of shorter and equal length, across the end of the rump and the top of the shoulder, thus constituting the rectangular form of the ox when viewed from above down upon the back, as represented by fig. 4 ; the form of the short ox and heifer, in perfect accordance with the diagrams of the rule. Farther, I should be inclined to assert, though I have not directed my attention sufficiently to the fact to be able to prove the assertion from examples, that the carcass of a full fed, symmetrical, short-horn ox, included within the rectangle, is in length double its depth, and in depth equal to its breadth; hence figures 2 and 3 are squares, and figures 1 and 4 each two similar squares, placed in juxtaposiiion. The form of the short-horn breed is perfect according to this rule.

The cow goes with calf about forty weeks, and is often capable of breeding when only a year old; but she should not be allowed to do so until she is above two years old. When the calves are intended for veal, January, February, and March are the best months for calving. On the question of breeding live stock in general, and upin the difficult question of the comparative influence of the male and female parents in impressing their offspring, a theme propounded by the Highland Society: there are some excellent papers by Mr. Boswell, Mr. Christian, and Mr. Mill (High. Sor. Trans. vol. i. p. 17), by the Rev. Henry Berry (Brit. Farm. Mag. vol. i.), and by Mr. Knight (Trans. Roy. Soc. 1809), in which they all seem to uphold the superior influence of the male; and on the selection of the male animal in breeding there is a paper by Lord Spencer (Journ. Roy. Agr. Soc. vol. i. p. 22); another on the gestation of cows (Itid. 165); and on the means of calculating the number of calves which will probably be produced by a herd of cows, by the same noble lord (Ibid. vol. ii. p. 112); and on the detection of pregnancy in the horse and cow by Professor Youatt (Ibid. p. $170)$; on a method of obtaining a greater number of one sex at the option of the owner in the breeding of livestock (Quart. Journ. of .Agr. vol. i. p. 63); on the rearing of calves, in which the writer recommends that skimmed milk should have a piece of red-hot iron plunged into it, not only to warm it, but to give an astringent quality (Com. Board of $A g r$. vol. iv. p. 382); on the mode of fattening them in Strathaven there is an account by Mr. Aiton in the Quart. Journ. of $\mathcal{A g r}$. p. 249; and of the mode of fattening them near London by Mr. Main (Ibid. vol. v. p. 608).

1.

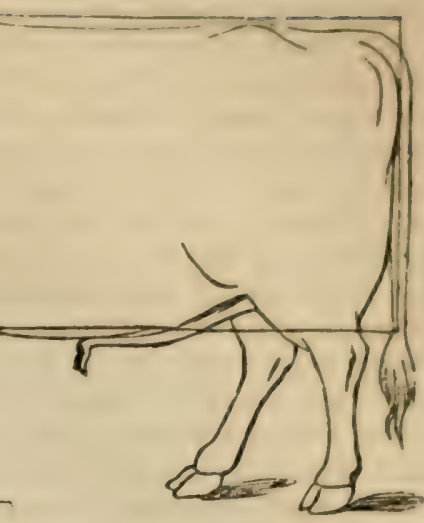

2.

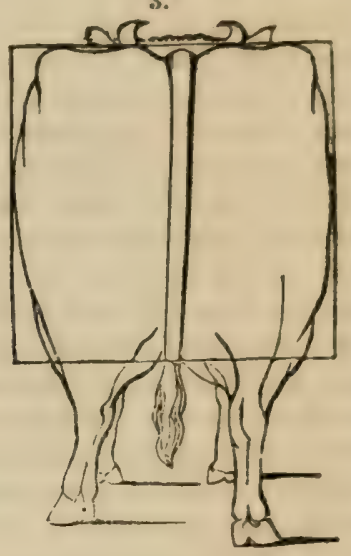

4.

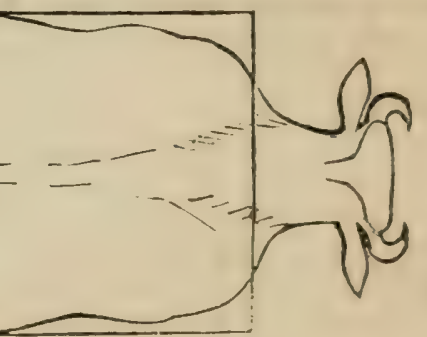

"Every cow is made to suckle her own calf three times a day for the first three or four days, and afterwards twice a day, and, in need, her bag is emptied by another calf. If a calf goes on thriving and well, it will be what is esteemed in England prime veal in about ten weeks, and weigh from 17 to 20 stones of $8 \mathrm{lbs}$. each."

The North Devon.-Of this breed the bull should have yellow horns, placed neither too low nor too high, nor be too thick, but growing gradually less towards the points; the eye clear, prominent, and bright; the forehcad small, flat, and indented; the muzzle fine; the cheek small; the nose of a clear yellow, the nostril high and open; the neck thick, and the hair about the head curled. The head of the $o x$ is smaller, otherwise he does not differ inaterially from the shape of the bull; his action is free, and he is quicker in his movements than any of our oxen; but his legs are apparently placed too much under his chest for speed, yet he possesses this pruperty in an eminent degree; his legs are straight; the forearm is large and strong; the bones of the leg, especially below the knee, very small; the tail is set on high, on a level with the back, rareiy much elevated, never depressed, is long and 
taper, with a bunch of hair at the end; the skin is very elastic, mellow, and rather thin; some have smooth hair, which should be fine and glossy; some curly, and these are rather the most hardy and fatten the best; red is the most favourite colour; many, however, are brown, and others are approaching to chestnut. Those of a yellow colour are reported to be subject to the steat (diarrhœa.) The drawing, Plate 12, fig. 3 , is taken from Low's splendid work upon British animals. It represents a young Devon bull, two years and nine months old, of a deep red colour.

The Devon cow is much smaller than the bull; she has a full, round, clear eye, the countenance cheerful, the muzzle orange or yellow, the jaws free from thickness, and the throat from dewlap. On all soils, except the very heavy, the Devon ox is very superior at the plough, for its quickness of action, docility, good temper, stoutness, and honesty. It is always worked in yokes. Four Devon oxen are considered equal in their work to three horses: they are commonly worked from two years old until they are four, five, or six, and then in ten or twelve months, on grass and hay, they are fit for market; neither corn, cake, nor turnips are needed for them during the first winter. They fatten faster and with less food than most others; their flesh is excellent. Some comparative experiments between the Devon and other cattle were made by the Duke of Bedford, of which the following table gives the result: they were fed from November 16, 1797, until December 10, 1798.

\begin{tabular}{|c|c|c|c|c|c|c|}
\hline \multirow[b]{4}{*}{ 1. Hereford } & \multirow{2}{*}{\multicolumn{2}{|c|}{$\begin{array}{c}\text { First } \\
\text { Weight. }\end{array}$}} & \multirow{2}{*}{ Gained. } & \multicolumn{3}{|c|}{ Consumed } \\
\hline & & & & $\begin{array}{c}0 i 1 \\
\text { Cake. }\end{array}$ & Turnips. & Hay. \\
\hline & cwt. & qrs. Ibs & & lbs. & Ibs. & Ibs. \\
\hline & -17 & $\begin{array}{ll}0 & 1\end{array}$ & 243 & - & $2 \% 00$ & 487 \\
\hline 2. - & -18 & 10 & 415 & 423 & 2712 & 432 \\
\hline 3. Devon & -14 & 17 & 454 & 438 & 2668 & 295 \\
\hline 4. - & -14 & 24 & 646 & 442 & 2056 & 442 \\
\hline 5. Sี11ssex & -16 & 20 & 454 & 432 & 2655 & 392 \\
\hline 6. Leicester & -15 & 214 & 402 & 434 & 2652 & 400 \\
\hline
\end{tabular}

There is much difference of opinion with regard to the fitness of Devon cows for the dairy, it being pretty generally asserted that their acknowledged grazing qualities render them unfit for the dairy, that their milk is rich, but deficient in quantity; but there are many very superior judges who prefer them even for the dairy. Of the calves, those which are dropped about Michaelmas time are preferred to those which are calved in January or February. They allow the calf to suck three times a day for a week; then new warm milk is given it for three weeks longer; then it has warm scalded milk mixed with a small portion of finely divided linseed cake, and its meals are gradually lessened, and at four months old it is entirely weaned. (Youatt On Cattle, p. 7-25.)

The Hereford.-The oxen of Herefordshire are much larger than the Devon, and of a darker red, some are dark yellow, and a few brindled; they generally have white faces, bellies, and throats. They have thicker hides than those of Devonshire, and they are more hardy, and shorter in the carcase and leg; are higher, heavier, and broader in the chine; have more fat, and are rounder and wider across the hips; the thigh is more muscular, the shoulders larger. (Ibid. p. 31.) Marshall long since described them pretty correctly as follows:-"The countenarice pleasant, cheerful, open; the forehead broad; eye full and lively; horns bright, taper, and spreading; head small; chap lean; neck long and tapering ; chest deep; bosom broad, and projecting forward; shoulder-bone thin, flat, no way protuberant in bone, but full and mellow in flesh; chest full; loin broad; hips standing wide, and level with the spine; quarters long and wide at the neck; rump even with the general level of the back, not drooping nor standing high and sharp above the quarters; tail slender, and neatly haired; barrel round and roomy, the carcase throughout deep and well spread; ribs broad, standing close and flat on the outer surface, forming a smooth even barrel, the hindmost large and of full length; round bone small, snug, not prominent; thigh clean, and regularly tapering; legs upright and short; bone below the knee and haugh, small; feet of middle size; cod and twist round and full; flank large; flesh everywhere mellow, soft, yielding pleasantly to the touch, especially on the chine, the shoulder, and the ribs; hide mellow, supple, of a middle thickness, and loose ; coat neatly haired, bright, and silky; colour of a middle red with a bald face, characteristic of the true Herefordshire breed."

"They fatten," says Mr. Youatt, "to a much greater weight than the Devons, and run from fifty to seventy score; a tolerable cow will average from thirty-five to fifty score; a cow belonging to the Duke of Bedford weighed more than seventy; an ox of Mr. Westcar's exceeded one hundred and ten score. The Hereford ox fattens speedily at an early age. They are not now much used for husbandry, although their form adapts them for the heavier work, and they have all the honesty and docility of the Devon ox, and greater strength, if not his activity.

"The Hereford cows are worse milkers than those of Devon, but then they will grow fat where a Devon would starve. The beef is sometimes objected to from the largeness of the bone, and the coarseness of some of the inferior pieces, but the best sorts are generally excellent. Mr. Youatt gives an account of an experiment in feeding, made in the winter of 1828-9, between the Herefords, and the improved short-horns, which, although by no means decisive of the merits of either breed, yet is worthy of notice by the grazier.

"Three Herefords and three short-horns were put together into a straw yard, December $2 d, 1827$, and each had, in the open yard, a bushel of turnips per day, besides straw, until May 2, 1828; they then were weighed, and sent to grass:-

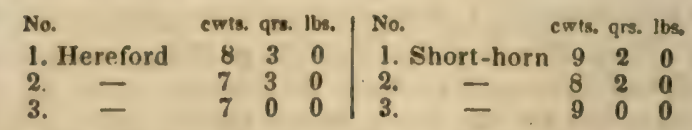

When taken from grass, November 3, they weighed- 


\section{CATTLE.}

\section{CATTLE.}

No. 1. Hereford crects ars tos 11 (1)

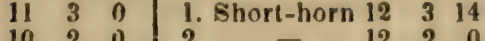
\begin{tabular}{lll|lllll}
10 & 2 & 0 & 2. & - & 12 & 2 & 0 \\
10 & 3 & 0 & 3. & - & 12 & 3 & 0
\end{tabular}

From this time till the 25th March, 1829, they consumed-

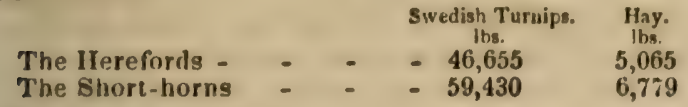

They then weighed-

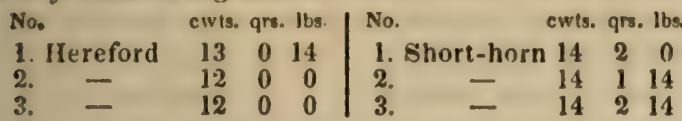

making a difference in favour of the shortlıorns of $3 \mathrm{cwts}$. 3 qrs. $14 \mathrm{lbs}$; but then they zonsumed more turnips by 12,775 lbs., and more hay by 1,714 lbs. When they were sold at Smithfield on the 30th of March, the shorthorns realized $97 \mathrm{l}$., and the Herefords 96l." (On Cattle, p. 34.)

The Sussex.-One of the best descriptions, says Mr. Youatt, that we have of the Sussex $n \mathrm{X}$ is given by that excellent agriculturist, $\mathrm{Mr}$. Ellman. He speaks of the Sussex ox as having a small and well-turned head; and so it has, compared with many other breeds, and even with the Hereford, but evidently coarser than that of the Devon, the horns pushing forwards a little, and then turning upwards, thin, tapering, and long, not so as to confound the breed with the long-horns, and yet in some cases a little approaching to them. The eye is full, large, and mild in the ox, but with some degree of unquietness in the cow. The throat clean; and the neck, compared with either the long or short-horns, long and thin, ye: evidently coarser than that of the Devon. The shoulder is the principal defect. There is more wideness and roundness on the withers; it is a straighter line from the summit of the withers towards the back; there is no projecting point of the shoulder when the animal is looked at from behind, but the whole of the fore-quarter is thickly covered with flesh, giving too much weight to the coarser and less profitable parts; but then the fore-legs are wider apart, straighter, and more perpendicular than in the Devon, and are placed more under the body than seeming to be attached to the sides. The fore-arm is large and muscular; the legs, though coarser than those of the Devon, are small and fine downwards, particularly below the fetlock. The barrel is round and deep. In the back, no rising spinal processes are to be seen, but rather a central depression; and the line of the back, if broken, is only done so by a lump of fat rising between the hips; the helly and flank are capacious; there is room before for the heart and lungs, and there is room behind in the capacious belly for the full exercise of its functions; yet the beast is well ribbed home; the space between the last rib an 1 the hip-bone is often very small, and there is no hanging heaviness of the belly or flank. The loins of the Sussex ox are wide ; the hipbone does not rise high, nor is it ragged externally; but it is large and spread out, and the space between the hips is well filled up. The tail fine, and thin, is set on lower than in the Devon, yet the rump is nearly as straight. 'The hind-quarters are cleanly made, and if the thighs appear to be straicht without, there is plenty of fulness within. The Sussex ox has all the activity of the Devon, and the strength of the Hereford, the propensity to fatten, and the beautiful fine-grained flesh of both. It possesses as many of the good qualities of both as can be combined in one frame. By crossing them with the Herefords, a heavier animal, but not fattening so profitably, or working so kindly, is produced. When the Sussex has been crossed with the Devon, a lighter breed has resulted, but not gaining in activity, while it is materially deteriorated in its grazing properties. The colour of the Sussex ox is a deep chestnut-red, or blood bay. The black, or black and white, generally indicate some strain in the breed, as a cross from the Welsh. 'The hide of the true Sussex ox is soft and mellow, the coat short and sleek. The Sussex ox does much of the farming labour of the Weald of Sussex. From ten to twelve of these are usually kept on a farm of 150 to 200 acres. These are fed with grass and straw till they begin to work, and then they have cut hay mixed with straw. There are, however, two breeds: the coarser Sussex is always slow; the lighter, or true Sussex is as light and fast as most cart-horses; of their speed proof was given by a Sussex ox which ran four miles against time, over the Lewes race-course, in sixteen minutes. Many farmers, if they have ten oxen at work, sell five or six every year, and break in an equal number to succeed them; the beasts will thus be broken in at three years old, and fatted at five or six. They are commonly taken from work when spring seed-time is over, and turned into the meadows, and thus prepared for winter stallfeeding. These are gradually accustomed to being constantly tied up. Some farmers, Mr. Ellman amongst the rest, are of opinion that there is a saving of one-fourth the food by stall-feeding, but many other farmers maintain that the cattle fatten faster when only confined to the yard. They average at Smithfield about one hundred and twenty stones; but they occasionally attain to much greater weights; one of Mr. Ellman's weighed two hundred and fourteen stones.

The Sussex cow is not a favourite with the generality of farmers. She does not answer for the dairy, for her milk, although of very good quality, is far inferior in quantity to either the Holderness or the Suffolk cow. They are, moreover, what their countenance indicates, of an unquiet temper, and are commonly restless and dissatisfied, especially if not bred on the farm on which they are kept. They are, therefore, chiefly kept as breeders; are generally in fair condition, even while milking; and no cows, except the Devon ogr Hereford, will thrive so fast after being dried; they fatten even faster than the ox. Nearly all the calves are reared, adds Mr. Youatt - the males for work, and the females for breeding or early fattening. By the best breeders, the bull is changed every two years. (On C'attle, p. 40.) The Hereford and Sussex cattle have so many points in common that in Loudon's Encyclopadia of Agriculture, both breeds ar illustrated by one figure. 
The Welch.-The cattle of Wales are principally of themiddle-horns, and stunted in their growth from the poverty of their pastures. Of these there are several varieties. The Pembrokeshire are chiefly black, with white horns; are shorter legged than most other Welch cattle; are larger than those of Montgomery, and have round and deep carcasses; have a lively look and good eyes; though short and rough, not thick; have not large bones, and possess, perhaps, as much as possible, the opposite qualities of being very fair milkers, with a propensity to fatten. The meat is equal to the Scotch. They will thrive, says Mr. Youatt, where others starve, and they rapidly outstrip most others when they have plenty of good pasture. The Pembroke cow has been called the poor man's cow. The Pembroke ox is a speedy and an honest worker, and when taken from hard work fattens speedily. Many are brought to London, and rarely disappoint the butcher.

The Glamorganshire breed were patronised by George III., and were held in great estimation. They were, however, allowed to degenerate during the period of the late war, and have not since, in spite of the exertions of Mr. David of Radyr, been entirely restored. 'The counties of Carmarthen, Card'igan, Brecon, and especially Radnor, also produce many excellent black cattle, which have been materially improved of late by the introduction of other breeds, especially by crossing with the Herefords. Of North Wales, the cattle are rather more approaching to the long-horns than those of the south. In the counties of Anglesea, Carnarvon, and Merioneth, the chief attention of the farmer is directed to the rearing of stock. In Denbigh, Flint, and Montgomery, the dairy is chiefly regarded. The cattle of Anglesea, says Mr. Youatt, are small and black, with moderate bone, deep chest, rather heavy shoulders, ennrmous dewlap, round barrel, high and spreading haunches, flat face, horns long, almost invariably turning upwards; the hair coarse; the hide mellow; hardy, easy to rear, and well disposed to fatten when transplanted to better pastures than those of their native island. Attempts have been made, with little success, to improve the breed by crossing them with others; but it is difficult to find any other sufficiently hardy to withstand the climate and the privations of Mona. Many yearlings are brought frum the island, and very few are kept in the island after they are three years old. They were formerly not castrated till they were a year old; this gave them a peculiar bull-like appearance. 'This operation, however, is now practised earlier. There is still with them, however, adds Mr. Youatt, a striking contrast with the mild intelligence of the Devon and the quiet submission of the Hereford. The Anglesea cows are not kept for the dairy to a greater extent than for home consumption. The cheese is neglizently made, and, in consequence, poor and worthless. The cattle of the other Welch counties, bred amongst the rocks of Carnarvon, and the hills of Merioneth, Montgomery, and Denbigh, have little distinguishing features from other Welch cattle. They are small, hardy, and rapidly fatten, when produce is excellent. (Ibid. p. 58.)

The Scotch.-Of this valuable and improving race of cattle there are several varieties, all of which are thus classed by Mr. Youatt, and are to be considered as belonging to the middlehorns. Of these the chief varieties are,

1. The West Highlanders, which, whether we regard those found in the Hebrides or in the county of Argyle, seem to retain most of the aboriginal character. They have remained unchanged, or improved only by selection, for many generations, or, indeed, from the earliest accounts that we possess of Scottish rattle.

2. The North Highlanders are a smaller, coarser, and in every way inferior race, and owe the greater part of what is valuakle about them to crosses from the western breed.

3. The northeastern cattle were derived from, and bear a strong resemblance to the West Highlander, but are of considerably larger size.

4. The Fife breed are almost as valuable for the dairy as for the grazier, and yield to few in activity and docility.

5. The Ayrshire breed are second to none as milkers; many of the varied mingled breeds of the Lowlands are valuable.

6. The Galloways, which, scarcely a century ago were middle-horned, and with difficulty distinguished from the West Highlanders, are now a polled breed, increased in size, with more striking resemblance to their kindred the Devons; with all their aptitude to fatten, and with a hardness of constitution which those of Devon never possessed.

The West Highlanders, or kyloes, as they are called (supposed to be from a corruption of a Gaelic word pronounced kael, signifying Highlands), are bred in great abundance in, and exported from, the Hebrides. The true bull of this breed is described by Mr. M'Neil of Islay as black; the head not large, the ears thin, the muzzle fine, and rather turned up; broad in the face; eyes prominent; countenance calm and placid; the horns should taper to a point, neither drooping too much nor rising too high, of a waxy colour, widely set at the root; the neck fine, particularly where it joins the head, and rising with a gentle curve from the shoulder; the breast wide, and projecting well before the legs; the shoulders broad at the top, and the chine so full as to leave but little hollow behind them; the girth behind the shoulder deep; the back straighi, wide, and flat; the ribs broad, the space between them and the ribs small; the belly not sinking low in the middle, yet, in the whole, not forming the round and barrel-like carcass which some have described; the thigh tapering to the hock-joint; the bones larger in proportion to the size than in the breeds of the southern districts; the tail set on a level with the back; the legs short and straight; the whole carcass covered with a long thick coat of hair, and plenty of hair also about the face and horns, and that hair not curly. They are hardy, easily fed; the proportion of their offal is not greater than in the most approved larger breeds; they lay their fat and ilesh equally on 


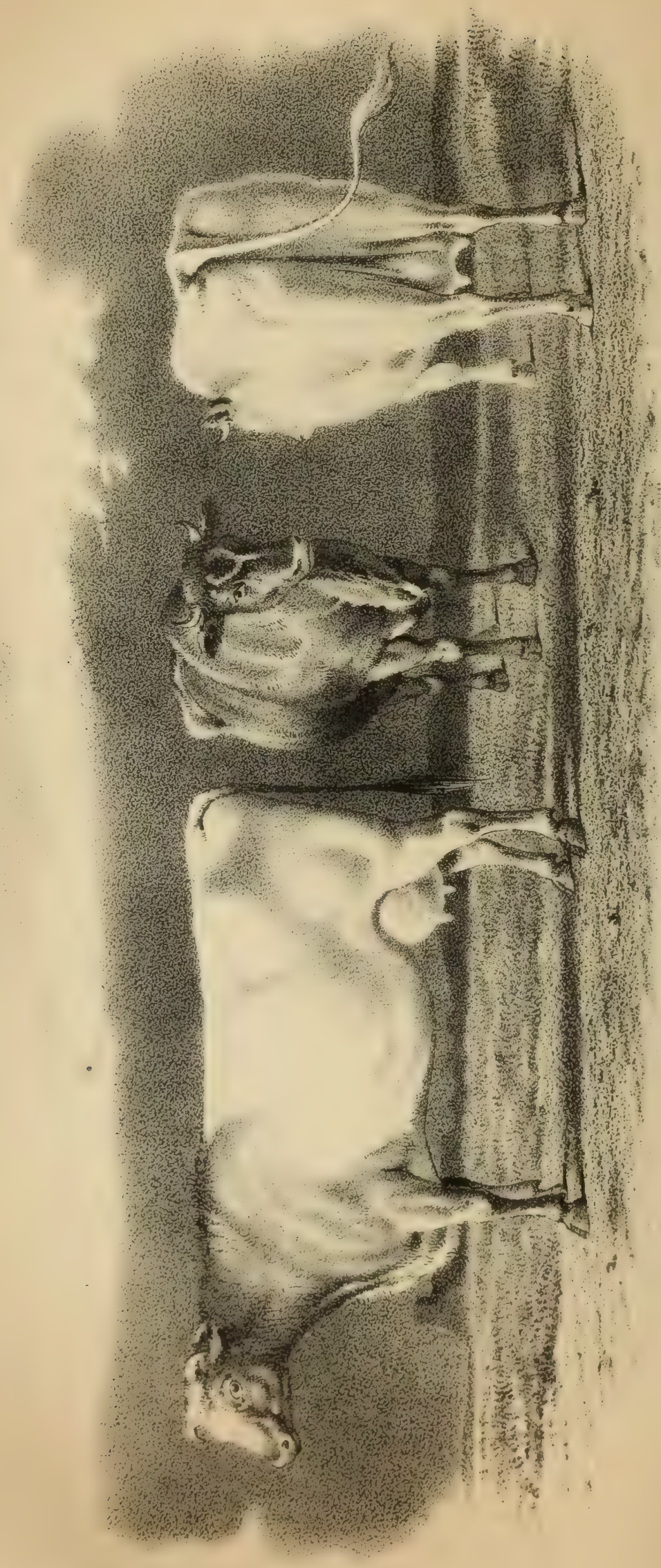

E 
the best parts, and when fat, the beef is fine in the grain, and so well mixed or manbled that it commands a superior price in every market. About 30,000 of these are annually sent from the Hebrides to the main land. (On C'altle, p.67.)

In the Hebricles, the dairy is only attended to so far as to serve the family with milk, butter, and cheese. The milk of the Western Highland cow is small in quantity, but excellent in quality; she does not yicld, however, more than one-third of that of the Ayrshire. 'The oxen of the Hebrides are never worked. (Itrid. p. 71.)

The Irgyleshire breed are larger than those of the Hebrides, and are bred according to what the soil and the food will best support. The Highlander, however (says the gentleman whom I have in this article quoted so often), "must be reared for the grazier alone; every attention to increase his weight, in order to make him capable of agricultural labour, every effort to qualify him for the dairy, will not only lessen his hardiness of constitution and propeusity to fatten, but will fail in rendering him valuable for the purpose at which the farmer aims. 'The character of the Highnder must still be, that he will pay better for $s$ quantity of food than any other breed, and will fatten where any other breed will scarcely live." (Ilid.p. 79.)

Of the North Highland cattle, those of the Shetland islands are the smallest; dwarfish, ill-shaped, and covered with hair; they sometimes are not more than 35 or $40 \mathrm{lbs}$. to the quarter. When they are taken to the north of Scotland, they thrive and fatten on very poor food with great rapidity; but when brought further to the south, the change is too great for them; they languish and sicken. The Shetland calf suffers privations from her birth; it is, in fact, killed often as soon as it is born. It is never allowed to suck its mother, but, if reared, is fed at first with milk, and afterwards with bland, a wretched kind of buttermilk; and when it grows up it has nothing to subsist upon but moss, heath, and sea-weed. The cows are housed at night, and, in the absence of straw, are littered with heath and the dust of peat. Their milk, which is exceedingly rich, is very small in quantity.

In the mortherly counties of Scotland, there is nothing very peculiar in the breed of their cattle. 'The introduction of sheep, and of better modes of cultivating the soil, have gone far to diminish the stocks of poor, ill-fed, and worse managed breeding herds of this once desolate extremity of the island. 'These improvements, however, were long opposed by the husbandmen and the tenders of cattle as bold innovations, which were, at all events, to be opposed. Mobs, therefore, collected; the sheep were driven away; fences destroyed; the new farmers intimidated: the laws alone supported these national improvements to a successful issue.

The county of Aberdeen breeds more cattle than any other in Scotland. Its stock has been estimated at 112,000 , and its annual sale of both fat and lean cattle is equal to more than 20,000. These vary in character with the soil and elevation: amongst the hills, they are chiefly of the Highland breed; in the plains, a better description has been produced, by breeding from these by bulls from Fifeshire. 'The horns of these, says Mr. Youatt, do not taper so finely, nor stand so much upwards, as in the West Highlanders; and they are also whiter; the hair is shorter and thinner; the ribs cannot be said to be flat, but the chest is deeper in proportion to the circumference, and the buttocks and thighs are likewise thinner. The colour is usually black, but sometimes brindled; they are heavier in carcass; they give a larger quantity of milk, but they do not attain maturity so early as the West Highlanders, nor is their flesh quite so beautifully marbled; yet, at a proper age, they fatten as readily as the others, not only on good pasture, but on that which is somewhat inferior. They are rarely used for husbandry work, or, at most, for only one year. 'They are sent to grass at four years old for six months, after which they will weigh from 5 to $6 \mathrm{cwt}$. "The breed," adds Mr. Youatt, "has progressively improved, and this by judicious selections from the native stock: it has increased in size, and become nearly double its weight, without losing its propensity to fatten, and without growing above its keep." There is also in this great agricultural county an excellent breed of poll cattle; they are not so handsome, yet larger than the horned cattle; the quality of their meat is also said not to be so good. The calves are reared in Aberdeenshire much in the ordinary way. They are commonly fed with milk warm from the cow, and they are even sometimes reared partly on oil-cakes.

In Fifeshire the breed of cattle are of a very superior description. "They are generally," says Dr. Thompson, "of a black colour; the horns small and white, generally pretty erect, or, at least, turned up at the points, and bending rather forward; the bone small in proportion to the carcass; the limbs clean but short, and the skin soft; wide between the extreme points of the hock-bones; the ribs narrow and wide set, having a greater curvature than in other kinds, which gives the body a thick round form; they fatten quickly, and fill up well at all the choice points; are hardy, fleet, and travel well; are docile, and excellent for work." Whatever may be the explanation of the fact, it is certain that, at the present day, the Fifeshire breed of cattle is peculiarly her own. That they were centuries since improved by a cross with the then small cattle of England, is pretty certain; but whether English cattle formed part of the dowry of Margaret, the daughter of Henry VII. of England, when she married James IV. of Scolland, or whether English cattle were sent as a present to Scotland by James II. of England, is almost mere matter of conjecture; but, be that as it may, "the Fifeshire farmers," says Mr. Youatt, in his valuable work on cattle, "are convinced that their cattle cannot be further improved as a whole by any foreign cross, and they confine themselves to a judicious selection from their own." "The pure Durhams have been established in some parts of Fife, but not al. ways without difficulty.

Ayrshire has a peculiarly fine breed of dasr 


\section{CATTLE.}

CATTLE.

cattle, which is thus described by Mr. Aiton, in his excellent treatise (p. 26) on the dairy breed of cows:-" The most approved shapes in the dairy breed are, small head, rather long, and narrow at the muzzle; eye small, but smart and lively; the horns small, clear, crooked, and their roots at considerable distance from each other; neck long and slender, tapering towards the head, with no loose skin below; shoulders thin; fore-1]uarters light; hind-quarters large; back straight, broad behind; the joints rather loose and open; carcass deep, and pelvis capacious and wide over the hips, with round fleshy buttocks; tail long and small; legs small and short, with firm joints; udder capacious, broad, and square, stretching forward, and neither fleshy, low hung, nor loose; the milk-veins are large and prominent; teats short, all pointing outwards, and at considerable distance from each other, skin thin and loose; hair soft and woolly; the head, bones, horns, and ali parts of least value, small; and the general figure compact and well proportioned. See Pl. 12, fig. 2. (Youatt, On Cattle, p. 127.)

"The qualities of a cow," adds Mr. Aiton in another place, "are of great importance. Tameness and docility of temper greatly enhance the value of a milch cow. Some degree of hardiness, a sound constitution, health, and a moderate degree of spirits, are qualities to be wished for in a dairy cow, and what those of Ayrshire generally possess. The most valuable qualities which a dairy cow can possess are that she yields much milk, and that of an oily, butyraceous and caseous nature; and that after she has yielded very large quantities of milk for several years, she shall be as valuable for beef as any other breed of cows known; her fat shall be much more mixed through the whole flesh, and she shall fatten faster than any other." And again, "the best Scotch dairy cows vield 1000 gallons of mille in one year; and in general, from $3 \frac{3}{4}$ to 4 gallons of their milk will yield $1 \frac{1}{2} \mathrm{lbs}$. of butter, and about $27 \frac{1}{2}$ gallons will produce $1 \frac{1}{2}$ stone imperial of full milk cheese."

Lanarkshire is noted for its calves, whose veal is highly esteemed in the markets of Glasgow and Edinburgh. These, according to Mr. Aiton (Survey of Ayrshire, p. 441), are fed on milk from a dish, not suckled. This is often given to them sparingly at first, to improve their appetite and relish for their food; but it is gradually increased till the calf has a full supply. Other farmers allow them as much as they please from the first. For the first week or two a calf consumes about half a good cow's milk; at a month old the whole of a cow's milk; and at two months old the greater part of that of two cows. Those which are reared for stock have commonly the first drawn milk; those which are fattening, the last drawn from two or three cows. When the calves are costive, they have a little bacon or mutton broth given them; if they purge, a little rennet in their milk cures the complaint. They are used to have, also, a lump of chalk in their cribs

The Galloway polled cattle are a peculiarly hino and valua 1 s breed. They are described A.y Mr. Youatt, or: the authority of the author 296 of the Survey of Galloway, as straight and broad. in the back, and nearly level from the head to the tail-round in the ribs, and also between the shoulders and the ribs, and the ribs and the loins-broad in the loins, without any large projecting hook-bones-long in the quarters and deep in the chest, but not broad in the ribs, and twist. There is much less space between the hook or hip-bones and the ribs than in most other breeds. They are short in the leg and moderately fine in the shank-bone. The happy medium seems to be preserved in the leg, securing hardihood and a disposition to fatten With the same cleanness and shortness of shank, there is no breed so large and muscular above the knee, while there is more room for the deep, broad, and capacious chest. They are clean, not fine and slender, but well proportioned in the neck and chaps; a thin and delicate neck would not correspond with the broad shoulders, deep chest, and close, compact form of the breed. The neck of the Galloway bull is thick even to a fault. The Galloway has a loose, mellow skin, of medium thickness, with long, soft, silky hair. The skin, which is thinner than the Ieicester, is not so fine as the improved Durham : it handles soft and kindly. Their colour is commonly black, but there are several varieties; the dark-coloured are preferred, from their being considered to indicate hardness of constitution. 30,000 of these are estimated to be sent yearly out of Galloway to the south. (Youatt, On Cattle, p. 158.) 'The Galloway breeders prefer allowing the calves to suck the cow; they consider they thrive materially better than those fed from the pail, and that fewer die of stomach complaints. Another valuable breed of polled cows is bred in Angus, which much resemble in appearance those of Galloway; they are, however, rather larger and longer in the leg, flatter sided, and with thinner shoulders.

In Norfolk and Suffolk a polled breed of cows prevails, which are almost all descended from the Galloway cattle, "whose general form," says Mr. Youatt (p. 172), "they retain, with some of, but not all their excellences; they have been enlarged, but not improved, by a better climate and soil. They are commonly of a red or black colour, with a peculiar golden circle around the eye. 'They are taller than the Galloways, but thinner in the chine, flatter in the ribs, and longer in the legs; rather better milkers; of greater weight when fattened; though not fattening so kindly, and the meat is not quite equal in quality."

The Suffolk dun cow; which is also of Galloway descent, is celebrated as a milker, and, there is little doubt, is not inferior to any other breed in the quantity of milk which she yields; this is from six to eight gallons per day. The butter produced, however, is not in proportion to the milk. It is calculated that a Suffolk cow produces annually about $1 \frac{1}{2} \mathrm{cwt}$. of butter.

The Suffolk duns derive the last part of their name from their usual pale yellow colour. Many, however, are red, or red and white. They are invariably without horns, and small in size, seldom weighing over 700 lbs. when fattened. 'The male and female are nearly of the same height, and selfom exceed $4 \frac{1}{4}$ to $4 \frac{1}{2}$ fret 
They are rather rough about the head, with large ears. Their bodies are long and legs short, hip-bones high, and generally deficient in the points of the finer breeds. Still many of the cows fatten well, and produce beef of superior quality. In proportion to their size, the Suffolk dun cows yield a great abundance of milk; and as a dairy stock, there are very few breeds that are preferable.

Irish Catlle.-Of the Irish cattle there are two breeds, the middle and the long-horns. The middle-horns are the original breed, and tenant the forests and most mountainous districts. "They are," says Mr. Youatt, "small, light, active, and wild; the head commonly small; the horns short but fine, rather upright, and frequently, after projecting forward, turning backward; somewhat deficient in hindquarters; high-boned, and wide over the hips, yet the bone not commonly heavy; the hair coarse and long, black or brindled, with white faces. Some are finer in the bone and in the neck, with a good eye and sharp muzzle, and great activity; are hardy, live upon very scanty fare, and fatten with great rapidity when removed to a better soil: they are good milkers. The Kerry cows are excellent in this respect. These last, however, are wild and remarkable leapers. They live, however, upon very little food, and have often been denominated the poor man's cow."

The other breed is of a larger size. It has much of the blood of the old Lancashire or Craven breed, or true long-horn. Their horns first turn outwards, then curve, and turn inwards. Of each of these kinds, an immense nurnber of both lean and fat stock are annually exported to England; in 1825 it amounted to $63,524$.

The long-horns. - The long-horns of England came originally from Craven in Yorkshire, and derived their name from a length of horn, which often extended to an unbecoming degree. Bakewell, Culley, and other great breeders improved upon, and have long since destroyed, the chief traces of the old, long-bodied, coarse, large boned breed. It is needless, therefore, to follow this breed through the various counties in which it once predominated, for it has long been rapidly disappearing, and has almost everywhere given place to better kinds.

The improved breed of Leicestershire, is said to have been formed by Webster of Cauley, near Coventry, in Warwickshire. Bakewell, of Dishley, in Leicestershire, afterwards got the lead as a breeder, by selecting from Cauley's stock; and the stocks of several other eminent breeders have been traced to the same source.

The Lancashire breed of long-horned cattle may be distinguished from other cattle by the thickness and firm texture of their hides, the length and closeness of their hair, the large size of their hoofs, and their coarse, leathery, thick necks. They are likewise deeper in their fore quarters, and lighter in their hind quarters than most other breeds; narrower in their shape, less in point of weight than the shorthorns, though better weighers in proportion to their size; and though they give considerably less milk, it is said to yield more cream in pro- portion to its quantity. They are more varied in colour than any other breeds; but, whatever the colour may be, they have in general a white strealk along their back, which the breeders term finched, and mostly a white spot on the inside of the hough. (Culley, p. 53.) "In a ge. neral view," says Loudon, "this race, notwithstanding the singular efforts that have been made towards its improvement, remains with little alteration; for, except in Leicestershire, none of the subvarieties (which differ a little in almost every one of those counties where the long-horns prevail) have undergone any radical change or any obvious improvement." (Loudon's Encyc. of Agr. p. 1015.)

The short-horns. - Of this noble breed of cattle, which seems to be annually increasing in fa. vour with the dairyman and the grazier, we are mainly indebted to the description of the late Rev. Henry Berry. Durham and Yorkshire have for ages been celebrated for a breed of these possessing extraordinary value as milkers, "in which quality," says Mr. Youat, "taken as a breed, they have never been equalled. The cattle so distinguished were always, as now, very different from the improved race. They were generally of large size, thin skinned, sleek haired, bad handlers, rather delicate in constitution, coarse in the offal, and strikingly defective in the substance of girth in the fore-quarters. As milkers they were most excellent, but when put to fatten, as the foregoing description will indicate, were found slow feeders, producing an inferior quality of meat, not marbled or mixed as to fat and lean; the latter sometimes of a very dark hue. Such, too, are the unimproved short-horns of the present day."

About the year 1750, in the valley of the Tees, commenced that spirit of improvement in the breeders of the old short-horns, which has ended in the improved modern breed. These efforts, begun by Sir William Quintin, and carried on by Mr. Milbank of Barmingham, were nearly completed by Mr. Charles Colling. The success of this gentleman was, from the first, considerable. He produced, by judicious selections and crossings, the celebrated bull Hubback, from whom are descended the best short-horns of our day. Of this breed was the celebrated Durham ox, which was long shown in a travelling van at country fairs, and which, when slaughtered in Apri\}, 1807 , at eleven years of age, weighed 187 stone; and the Spottiswoode ox, probably the largest ever exhibited. In June, 1802, he measured-height of shoulder, 6 feet 10 inches; girth behind the shoulder, 10 feet 2 inches; breadth across the hooks, 3 feet 1 inch; computed weight, 320 stones of $14 \mathrm{lbs}$. (Quar: Journ. of Agr. vol. vi. p. 271.)

Besides Mr. Colling, his brother Mr. Rciort Colling, Mr. Charge, and Mr. Mason were hardly second to him in skill and success as breeders of the short-horus.

With the pure improved short-horns, crossed with a red polled Galloway cow, was produced a variety of this breed, which was long namet "the alloy," but for which at Mr. C. Collings's sale, October 11, 1810, some most extraordinary prices were obtained: thus a cow called 


\section{CATTLE.}

\begin{tabular}{|c|c|c|c|}
\hline Lady, 14 years old, so & for & & $\begin{array}{c}\text { Guineas. } \\
206\end{array}$ \\
\hline Countess, her daughte & 9 years & & 4110 \\
\hline Laura, & 4 years & & 210 \\
\hline Mijor, her snn, & 3 years & & 200 \\
\hline Geurge, ditto, a calf & - & - & 130 \\
\hline
\end{tabular}

In short, at this sale, forty-eight lots produced 7115\%.17s., Comet, a six year old bull, selling for 1000 guineas. (See Colling, Robent and Chamles.)

The colours of the improved short-horns are red or white, or a mixture of both; "no pure improver short-horns," adds Mr. Youatt, "are found of any other colour but those above named." That the matured short-horns are an admirable grazier's breed of cattle is undoubted: they are not, however, to be disregarded as milkers; but they are inferior, from their fattening qualities, to many others as workers.

"In its points," says Mr. James Dickson (Quart. Journ. of Ag\%. vol. vi.p. 269), for quantity and well laid on beef, the short-horn ox is quite full in every valuable part; such as along the back, including the fore-ribs, the sirloin and rump, in the runners, flanks, buttocks, and twist, and in the neck and brisket as inferior parts. In regard to quality of beef, the fat bears a due and even preponderating proportion to the lean, the fibres of which are fine and well mixed, and even marbled with fat, and abundantly juicy. 'The fine, thin, clear bone of the legs and head, with the soft mellow louch of the skin, and the benign aspect of the eye, indicate, in a remarkable degree, the disposition to fatten; while the uniform colours of the skin, red or white, or both, commixed in various degrees, bare, cream-coloured skin on the nose and around the eyes, and fine, tapering, white, or light-coloured horns mark distinctly the purity of the blood; these points apply equally to the bull, the cow, and the heifer. 'The external appearance of the shorthorned breed," adds Mr. Dickson, "is irresistably attractive. The exquisitely symmetrical form of the body in every position, bedecked with a skin of the richest hues of red, and the richest white approaching to cream, or both colours, so arranged or commixed as to form a beautiful fleck or delicate roan, and possessed of the mellowest touch; supported on clean small limbs, showing, like those of the racehorse and the greyhound, the union of strength with fineness; and ornamented with a small, lengthy, tapering head, neatly set on a broad, firm, deep neck, and furnished with a small muzzle, wide nostrils, prominent, ' mildly beaming' eyes, thin, large biney ears set near the crown of the head and protected in front with semicircularly bent, white, or brownish coloured, short (hence the name), smooth pointed horns; all these parts combine to form a symmetrical harmony, which has never been surpassed in beauty and sweetness by any other species of the domesticated ox."

An excellent paper by Mr. Dickson on crossing the short-horns with other cattle, may be consulted with advantage by the breeder in the Edin. Quurt. Journ. of $A g r$. vol. vii. p. 495, and on crossing in general, Ibid.p. 247.

In the first plate a representation is given of short-horned cows; in Plate 12, fig. 1 , is a drawing of a short-horned bull, which may re-

\section{CATTLE.}

present the breeds variously termed, Dutch, Holderness, Teeswater, Yorkshire, Durham, Northumberland, \&c. The Teeswater breed, a variety of short-horns established on the banks of the Tees, at the head of the vale of York, is at present in the highest estimation, and is alleged to be the true Yorkshire shorthorned breed. Bulls and cows from this stock, purchased at most extraordinary prices, are spread over all the north of England and the border counties of Scotland. The bone, head, and neck of these cattle are fine; the hide is very thin; the chine full; the line broad; the carcass throughout large and well fashioned; and the flesh and fattening quality equal, or perhaps superior, to those of any other large breed. The short-horns give a greater quantity of milk than any other cattle; a cow usually yielded 24 quarts of milk per day, making 3 firkins of butter during the grass season. (Culley, p. 48.)

The Yorkshire cow.-With Mr. Youatt's account of the Yorkshire cow (and this article is, in fact, hardly any thing else but an abridgment of his excellent work "On Cattle" in the Library of Useful Knowledge) we shall conclude. The Yorkshire cow is that generally found in the great dairies in the vicinity of London, and in these the character of the Holderness and the Durham unite. "A milch cow good for the pail as long as she is wanted, and then quickly got into marketable condition, should have $a$ long and rather small head; a large-headed cow will seldom fatten or yield much milk. The eye should be bright, yet with a peculiar placidness and quietness of expression; the chaps thin, and the horns small. The neck may be thin towards the head; but it must soon begin to thicken, and especially when it approaches the shoulder. The dewlap should be small; the breast, if not so wide as in some that have an unusual disposition to fatten, yet should be very far from being narrow, and it should project before the legs; the chine to a certain degree fleshy, and even inclining to fulness; the girth behind the shoulder should be deeper than is usually found in the shorthorn; the ribs should be spread out wide, so as to give as globu.ar a form as possible to the carcass, and each should project farther than the preceding one, to the very loins. She should be well formed across the hips, and on the rump, and with greater length there than the milker generally possesses, or if a little too short not heavy. If she stands a little long on the legs, it musi not be toolong. The thighs somewhat thin, with a slight tendency to crookedness or being sickle-hammed behind; the tail thick at the upper part, but tapering below; and she should have a mellow hide, and but little coarse hair. Common consent has given to her large milk-veins. A large milk-tein certainly indicates a strongly developed vascular system, one favourable to secretion generally, and to that of the rnilk amongst the rest. The udder should rather incline to be large in proportion to the size of the animal, but not too large; its skin thin and free from lumps in every part of it; the teats of a moderate size. The quantity of mills given by some of these cows is very great; it is by no means uncum 


\section{CATTLE.}

CAT'TIE.

mon for them in the beginning of the summer most corner of the blade-bone of the stoulder, to yield thirty quarts a day. There are rare in a straight line to the hindmost point of the instances of the cow yielding thirty-six quarts; rump. (See engraving below.)

the average is about twenty-two to twenty-four quarts. 'The milk, however, is not so rich in its produce of butter as that of the long-horns, the Scotch, or the Devons." (For the Alderney cow, see Aldennex.)

The quantity of cattle annually sold in Smithfield is very great: it was (according to $\mathrm{M}^{*} \mathrm{Cul}$ loch's Dict. of Commerce) in-

$\begin{array}{rrrrr}\text { Year. } & & & \text { Catte. } & \text { Sheep. } \\ 17: 32 & - & - & 76,210 & 511,700 \\ 1742 & - & - & 79,601 & 503,260 \\ 1752 & - & - & 73,703 & 612,1100 \\ 1762 & - & - & 102,831 & 772,160 \\ 1772 & - & - & 89,503 & 609,540 \\ 1782 & - & - & 101,176 & 728,970 \\ 1792 & - & - & 107,348 & 761,859 \\ 1802 & - & - & 126,389 & 743,470 \\ 1812 & - & - & 133,854 & 95,, 630 \\ 1822 & - & - & 142,043 & 1.340,160 \\ 1832 & - & - & 166,224 & 1,364,160\end{array}$

Fatted calves-

$$
1823=-: \quad 21,255
$$

The quantity of cattle in various European countries has been estimated to be as follows:

\begin{tabular}{|c|c|c|c|c|}
\hline Great Britain & - & - & - & $\begin{array}{c}\text { Cattle. } \\
-\quad 5,100,000\end{array}$ \\
\hline Russia & - & - & - & - $19,000,000$ \\
\hline Neiherlands & - & - & - & $\begin{array}{l}-\quad 2,500,000 \\
\end{array}$ \\
\hline Denmark & - & - & - & $=\quad \mathbf{1}, 607,000$ \\
\hline Altstria & - & - & - & $-\quad 9,912,500$ \\
\hline France & - & - & - & $-\quad 6,681,900$ \\
\hline Spain - & - & - & - & $-2,500,000$ \\
\hline Porfugal & - & - & - & 650,000 \\
\hline Iraly - & - & - & - & $-\quad 3,500,000$ \\
\hline
\end{tabular}

United states of America in $1810 \quad 14,971,586$

Live and dead weight of cattle.-Salesmen commoniy calculate that the dead weight is one-half of what the animal weighs when alive; but the butcher knows that the produce is greater: it often approaches to three-fifths; and by an extensive stock bailiff of the late $\mathrm{Mr}$. Curwen, it was found that the dead weight amounted to fifty-five per cent. of the live. But the amount differs strangely, as may be seen by the following statement of Mr. Ferguson of Woodhill. (Brit. Husb. vol. ii. p. 392.)

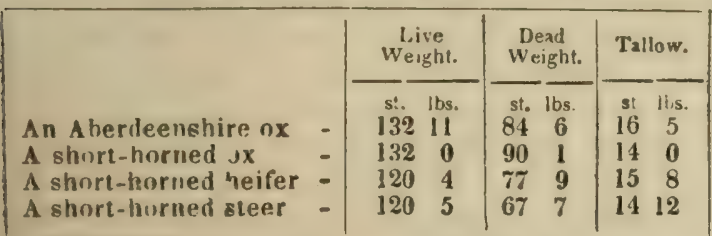

In ascesoning the weight by admeasurement, tha wirth is taken by passing a cord just bahind the sho:lder-blade and under the forelegs: thus $x_{\Delta-S}$ the circumference, and the length i, waer along the back from the fore-

Table for Admeasurement of Callle.

\begin{tabular}{|c|c|c|c|c|c|c|c|c|c|c|c|}
\hline \multirow{2}{*}{\multicolumn{2}{|c|}{$\frac{\text { Girth. }}{\text { fi. in }}$}} & \multicolumn{2}{|c|}{ Length. } & \multicolumn{2}{|c|}{ Weight. } & \multicolumn{2}{|c|}{ Girth. } & \multicolumn{2}{|c|}{ Lng'h. } & \multicolumn{2}{|c|}{ Weight } \\
\hline & & & in. & t. & tbs. & ft. & in. & & & at. & its. \\
\hline & & & 0 & 12 & 12 & 6 & 6 & 4 & 6 & 45 & 3 \\
\hline & & 3 & 3 & 13 & 13 & & & 4 & 9 & 47 & 10 \\
\hline & & 3 & 6 & 15 & 0 & & & 5 & 0 & 50 & 4 \\
\hline & & 3 & 9 & 16 & 1 & & & 5 & 3 & 52 & 11 \\
\hline & & & 0 & 17 & 2 & & & 5 & 6 & 5.5 & 4 \\
\hline \multirow{6}{*}{\multicolumn{2}{|c|}{46}} & 3 & 0 & 14 & 6 & & & 5 & 9 & 57 & 11 \\
\hline & & 3 & 3 & 15 & 9 & & & 6 & 0 & 60) & 4 \\
\hline & & 3 & 6 & 16 & 12 & & & 6 & 3 & 63 & 0 \\
\hline & & 3 & 9 & 18 & 1 & 6 & 9 & 4 & 6 & 48 & 11 \\
\hline & & 4 & 0 & 19 & 4 & & & 4 & 9 & 51 & 7 \\
\hline & & 4 & 3 & 20 & 6 & & & 5 & 0 & 51 & 3 \\
\hline \multirow[t]{7}{*}{4} & 9 & 3 & 3 & 17 & 6 & & & 5 & 3 & 56 & 13 \\
\hline & & 3 & 6 & 18 & 11 & & & 5 & 6 & 59 & 9 \\
\hline & & 3 & 9 & 20 & 2 & & & 5 & 9 & 62 & 6 \\
\hline & & 4 & 0 & 21 & 6 & & & 6 & 0 & 65 & 1 \\
\hline & & 4 & 3 & 22 & 11 & & & 6 & 3 & 67 & 11 \\
\hline & & 4 & 6 & 24 & 2 & 7 & 0 & 4 & 9 & 5.5 & 6 \\
\hline & & 4 & 9 & 25 & 7 & & & 5 & 0 & 53 & 4 \\
\hline 5 & 0 & 3 & 3 & 19 & 5 & & & 5 & 3 & $6 I$ & 3 \\
\hline & & 3 & 6 & 20 & 12 & . & & 5 & 6 & 61 & 2 \\
\hline & & 3 & 9 & 22 & 7 & & & 5 & 9 & 67 & 1 \\
\hline & & 4 & 0 & 23 & 12 & & & 6 & 0 & 69 & 13 \\
\hline & & 4 & 3 & 2.5 & 5 & & & 6 & 3 & 72 & 12 \\
\hline & & 4 & 6 & 26 & 13 & & & 6 & 6 & 75 & 11 \\
\hline & & 4 & 9 & 28 & 6 & 7 & 3 & 4 & 9 & 59 & 6 \\
\hline & & 5 & 0 & 30 & 0 & & & 5 & 0 & 62 & 8 \\
\hline 5 & 3 & 3 & 3 & 21 & 4 & & & 5 & 3 & 65 & 9 \\
\hline & & 3 & 6 & 22 & 13 & & & 5 & 6 & 68 & 11 \\
\hline & & 3 & 9 & 24 & 8 & & & 5 & 9 & 71 & 13 \\
\hline & & 4 & 0 & 26 & 3 & & & 6 & 0 & 75 & 1 \\
\hline & & 4 & 3 & 27 & 12 & & & 6 & 3 & 78 & 3 \\
\hline & & 4 & 6 & 29 & 7 & & & 6 & 6 & 81 & 4 \\
\hline & & 4 & 9 & 31 & 2 & 7 & 6 & 5 & 0 & 66 & 13 \\
\hline & & 5 & 0 & 32 & 11 & & & 5 & 3 & 70 & 4 \\
\hline 5 & 6 & 3 & 6 & 25 & 2 & & & 5 & 6 & 73 & 9 \\
\hline & & 3 & 9 & 27 & 0 & & & 5 & 9 & 77 & 0 \\
\hline & & 4 & 0 & 28 & 11 & & & 6 & 0 & 80 & 5 \\
\hline & & 4 & 3 & 30 & 8 & & & 6 & 3 & 63 & 9 \\
\hline & & 4 & 6 & 32 & 5 & & & 6 & 6 & 87 & 0 \\
\hline & & 4 & 9 & 34 & 2 & & & $€$ & 9 & 90 & 5 \\
\hline & & 5 & 0 & 36 & 0 & 7 & 9 & 5 & 0 & 71 & 7 \\
\hline & & 5 & 3 & 37 & 11 & & & 5 & 3 & 75 & 1 \\
\hline 5 & 9 & 3 & 9 & 29 & 7 & & & 5 & 6 & 78 & 9 \\
\hline & & 4 & 0 & 31 & 6 & & & 5 & 9 & $8 \Omega$ & 3 \\
\hline & & 4 & 3 & 33 & 6 & & & 6 & 0 & 85 & 11 \\
\hline & & 4 & 6 & 35 & 5 & & & 6 & 3 & 89 & 5 \\
\hline & & 4 & 9 & 37 & 5 & & & 6 & 6 & 92 & 13 \\
\hline & & 5 & 0 & 39 & 5 & & & 6 & 9 & 96 & 7 \\
\hline & & 5 & 3 & 41 & 4 & & & 7 & 0 & 100 & 0 \\
\hline & & 5 & 6 & 43 & 4 & 8 & 0 & 5 & 3 & 80 & 0 \\
\hline 6 & 0 & 4 & 3 & 36 & 6 & & & 5 & 6 & 83 & 11 \\
\hline & & 4 & 6 & 38 & 8 & & & 5 & 9 & 87 & 8 \\
\hline & & 4 & 9 & 40 & 10 & & & 6 & 0 & 91 & 6 \\
\hline & & 5 & 0 & 42 & 12 & & & 6 & 3 & 95 & 3 \\
\hline & & 5 & 3 & 45 & 0 & & & 6 & 6 & 99 & $\theta$ \\
\hline & & 5 & 9 & 47 & 2 & & & 6 & 9 & 102 & 12 \\
\hline & & 5 & 9 & 49 & 4 & & & 7 & 0 & 106 & 9 \\
\hline & & 6 & $\theta$ & 51 & 8 & 8 & 3 & 5 & 6 & 83 & 1 \\
\hline 6 & 3 & 4 & 6 & 41 & 11 & & & 5 & 9 & 93 & 3 \\
\hline & & 4 & 9 & 44 & 2 & & & 6 & 0 & 97 & 3 \\
\hline & & 5 & 0 & 46 & 7 & & & 6 & 3 & 101 & 3 \\
\hline & & 5 & 3 & 48 & 11 & & & 6 & 6 & 105 & 4 \\
\hline & & 5 & 6 & 51 & 2 & & & 6 & 9 & 109 & 5 \\
\hline & & 5 & 9 & 53 & 6 & & & 7 & 0 & 113 & 6 \\
\hline & & 6 & 0 & 55 & 11 & & & 7 & 3 & 117 & 6 \\
\hline & & 6 & 3 & 58 & 2 & & & & & & \\
\hline
\end{tabular}

(M'Derment's Farmer's Assistant.)

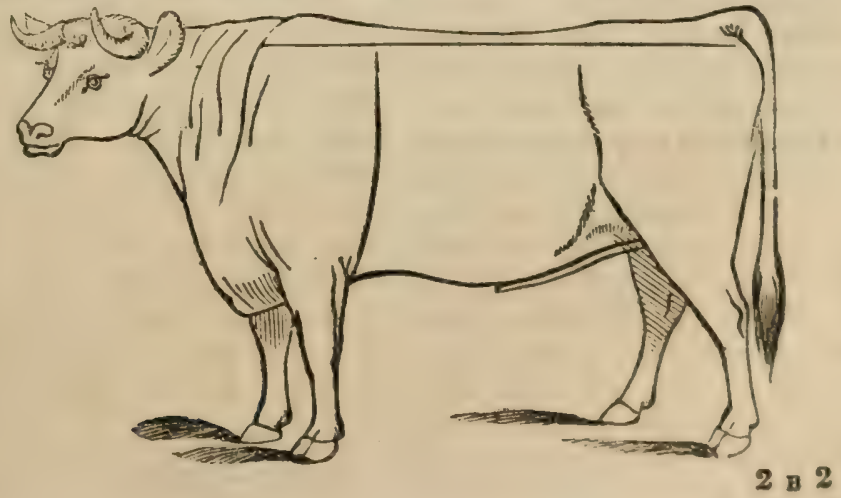


The breeds of cattle which stock the farms of the United States are all derived from Europe, and, with few exceptions, from Great Britain. The highest hreeds at the present day are comparatively of recent origin, since the great improvements commenced by Bakewell only date about the period of the American Revolution. The old importations made by the primitive settlers must consequently have been from comparatively inferior grades. In some sections of the Union, and more particularly in New England, the primitive stock is thought to have undergone considerable improvement, whilst in many parts of the Middle, and especially of the Southern States, a greater or less depreciation has ensued. The prevailing stock in the Eastern States is believed to be derived from the North Devons, most of the excellent marks and qualities of which they possess. Hence they are very highly esteemed, and have been frequently called the "American Devons." The most valuable working oxen are chiefly of this breed, which also contributes so largely to the best displays of beef found in the markets of Boston, New York, and Philadelphia. The prevailing colour of the New England cattle is a deep red. Sometimes, however, they are dark-brown, or brindle, or nearly black. Their horns are moderately long, smooth, and slender. The oxen are remarkable for their docility, strength, quickness, and powers of endurance. The cows are fair milkers, and both kinds are hardy and fatten readily. By means of this fine domestic stock, and the importations still so extensively made of selections from the short-horned, and other of the finest European breeds, the cattle, not only of New England, but of other sections, are rapidly improving, especially in the Middle and Western States.

The graziers of Kentuchy and other parts of the West have heretofore generally shown the greatest preference to the short-horned breed, which, with various crosses, is now perhaps the predominant stock of the country. Since Durhams have become so common, the extravagantly high prices they once brought are no longer maintained; and, indeed, the farmers now not only think of changing the breed, but have actually commenced doing so. They have been led to this chiefly for the reason, that the short-horned cattle, which take on fat so readily when well fed, and become so heavy, are unable to retain their fat and flesh on being driven some 1000 or 1200 miles to the Eastern markots, where they generally arrive in such a meager condition as to bring only the price of lean stock. The Western graziers, therefore, wish to adopt some breed which will be able to carry their beef along with them. The English Herefords have been sought after, and as much as $\$ 500$ paid for an imported cow. Captain Barclay, 2 gentleman owning a large estate in Scotland, called Ury, and who has recently made a tour through the United States, says that he thinks our Western furmers will find themselves mistaken in this selection from the British breeds, and that they would deruve more advantage by importing Angus or Aberdeenshire Doddies, which are kindred breeds of wel!-formed, moderate-sized, active animals; or, perhaps still better, the small and peculiarly symmetrical West High. land cow; and to cross them with a short-horn or Durham bull. The West Highlander, he says, possesses all the points of a good feeder; and being hardy, and active as a deer, would suffer little from being driven even 1000 miles. In its native glens it may feed to 20 or 25 stones, Amsterdam ; but the heifers, on being transplanted to a rich and sheltered pasture, attain to nearly double that weight. This he says he has demonstrated by introducing a herd of forty West Highland heifers on his farm at Ury, where they were crossed with short-horned bulls, and the experiment, on repeated trials, has been attended with great success; for while the mothers, by removal to better pasture, have greatly increased in size, the cross has produced strong and handsome animals, kindly feeders, rising to a great weight, and bringing high prices. It is a great desideratum for the graziers of Kentucky and other parts of the West, where pastures of the richest kind abound, could they find some active breed which would be able to perform the long journeys to the Eastern markets, and carry their beef with them.

A very general impression now exists in the United States in favour of breeding a cross from the best short-horned bulls with the finest native cows.

Mr. Colman, in his Reports upon the agricultural interests of Massachusetts, recently made to the legislature of that state, has collected a fund of valuable information in relation to American neat cattle, showing their distinguishing characteristics for dairy and other purposes, together with the improvements made and still making by the introduction of select cattle from Europe, and the results of feeding in various ways. Several books and periodicals published in the United States, and devoted to agriculture, are rich in details relating to American and European neat stock. But, instead of culling from these, we prefer drawing upon Mr. Colman's Report to the Legislature of Massachusetts, as we regard it a high source of authentic information, and calculated to be the more highly useful from the exactness of the details. We regret that our limits will not admit of some particular notice of nume. rous mammoth beasts which have been raised and fattened in Pennsylvania, New Jersey, and elsewhere. Particular accounts of these, with the modes of management and feeding, are duly recorded in more or less of the periodicals.

Stall-fed animals.-It appears that the stallfeeders in Massachusetts usually select cattle brought from Vermont, New Hampshire, and New York, choosing such as are small-boned, neat, and thrifty. Rather than keep these on hand a long time, they generally find it most advantageous to "turn them soon," and after thus disposing of their fat stock early in the season, many purchase an additional supply pretty far advanced for the market, and finish these so as to be ready to send them off in the spring. In the hilly districts, where Indian

* The Amsterdam stone is unly abdut 10 lbs. of Eng. lish troy weight. 
corn is not raised to any considerable extent, the cattle are generally fed upon hay and potatoes, whilst in the river valleys Indian meal is generally and most advantageously substituted for potatoes. When potatoes are chiefly depended upon in stall-feeding, a bushel of these well washed, are usually given in a day to each head, at two or more times, along with as much good hay as the animal can consume, but no water is allowed. Many farmers think that a yoke of oxen put up in good condition, may be well fatted or finished off for market with one hundred bushels of potatoes, in addition to the hay they will consume. Cattle fed upon potatoes will, it is said, in general prove as well, that is, have as much tallow, as those fed in any way, and the beef of such cattle is thought by many to have a peculiar juiciness or sweetness. In driving to market, however, the cattle fed upon potatoes will fall away more than those fed upon hay and corn; and when they come into market by no means appear as well. Several farmers are in the practice of boiling or steaming the potatoes which they give to their cattle, and profess to find a great advantage in it. The experiments which have come within my own knowledge have not yet satisfied me that the advantages are a compensation for the labour and expense incurred by such operation.

"The articles usually employed in fattening cattle are hay and Indian meal, or corn and rye meal mixed, or pease and oats, or oats and corn ground together. Besides this, many farmers are in the practice of giving their stall-fed cattle occasionally certain quantities of potatoes. An excellent farmer, of fifty years experience in the fatting of cattle, is of opinion that potatoes are good feed for fatting cattle in the fall and spring, when the weather is warm; but that they do no good in cold weather unless they are cooked. I rely much upon his judgment and experience. 'The value of potatoes is differently estimated by different individuals; some considering five bushels, others rating four bushels, as equivalent to one bushel of corn.

"In the feeding of cattle for market a great deal of practical skill is required, and constant observation of their condition, otherwise they may be surfeited and their appetite destroyed; or their digestive powers be overtasked and the feed fail of its object.

"A farmer in Charlemont, of large experience in the fatting of stock, considers the common English or flat turnip of little value for fattening stock. 'The cattle fed upon them appear healthy and in fine condition, but yield very little tallow. A pair of cattle fatted by him and much admired by the butchers, which weighed eighteen hundred pounds when dressed, had only thirty pounds tallow each.

"I presume the experiment has never been fairly tried, of the value of turnips for fattening stock. 'This is likely to have been only a solitary instance; besides this, we want to know in the case, how many turnips, were given; under what circumstances they were given; and with what other feed accompanied.

"The same farmer is of opinion, that oil-meal for fattening cattlc is of grea! ralue. Hc is quite content to pay tweaty to twenis-three dollars per ton, the current price for it in his town. A farmer in Conway concurs in this opinion; and believes that fror a beneficial change a farmer can well affurd to buy 0.l. meal with corn at bushel for bushel. The price here rises sometimes to thirty dollars per ton. 'The weight of oil-meai is abou. forty. five pounds to the bushel."

In England and Scotland, turnips are freely given to growing and fattening cattle, though, more sparingly to milch cows, in consequence of the flavour they impart to milk and butter.*

Mr. Colman furnishes the results of expe rience gained by many persons who have been long in the practice of stall-feeding. A few of these we shall notice.

"A. R. has twenty head of cattle in the stal: They are of good size and calculated to aver age over eleven hundred pounds each, whey dressed in Brighton.

"He has tried a variety and a mixture of feed, such as oats, broom-corn seed, \&c., but he pre fers Indian meal to every other feed. He dis approves of excessive feeding; and thinks it a great error to give too much. He deems fou. quarts with hay ordinarily enough; and te. quarts a day sufficient for any animal. He feeds twice a day with great regularity. Hi: present cattle have never received over eigh quarts per day each; and at first putting up : much less quantity. He deems it best to re duce their feed of provender a few days befort starting for market. He buys his cattle for feeding in the fall; and his present stoch averaged in the cost seventy-five dollar's pet pair.

"S. W. is of opinion that one bushel of corn one year old for feeding any kind of stock, is equal to one bushel and one peck of new corn, or corn before it becomes perfectly sound and dry.

"T. C. has in stall, 27 th February, five pairs of oxen, which were purchased in Brighton, in June last. When purchased, they were thin in flesh and were immediately put into good pasture. The cost was as follows:

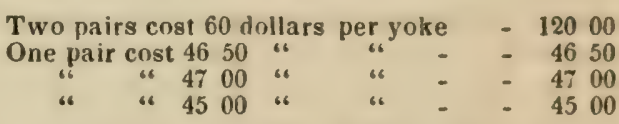

"These cattle were put into a good pasture until the 20th of November, when they were brought to the stall. From that time until the 20th December, they were fed with hay only. From that time until the first of January, they received six quarts of provender each, daily. From the first of January, they received each

* 'Turnips, though used extensively as an auxiliary in feeding cattle and other stock in Europe, and especially feeding cattle and other stock in lourope, and especiatly United States, unless perhaps if may be in some portions of New England. The general complaint against them in the Middle States, is that they do not anpear to posthey do notitios. Thence sess sufficient nourishing and fattening qualities. Hence the sugar beet, ruta baga, mangel-wirtzel, and carrot are greatly preferred, all of which ronts may be given with verv great advantage to stnck, as auxiliaries. Testimonials of their value when thus employed are Ther numernus and conclusive. For information relative to
the feeding of catte on turnios, see Stephens's "Book of the Farm." 
eight quarts daily. 'This provender consists of one-half oil-meal, one quarter oats and one juarter corn; the two last ground together and the whole intermixed when given to the sattle.

"The oil-meal in this case cost forty dollars per ton. It weighs about forty-five pounds to a bushel. If ground very fine, it will not weigh more than thirty-eight or forty pounds to the bushel. It is best, therefore, to buy it by weight. 'This farmer is of opinion that his oxen, if now killed, would return him one thousand pounds of beef each.

"Meal made from the seed of broom-corn," Mr. Colman says, "is occasionally used, mixed with other provender, but for neat cattle it is not approved by the best farmers. Flaxseed jelly, that is, half a pint or a pint of flaxseed formed into a jelly by boiling, as an allowance for a stall-fed animal per day, has been used for fattening cattle by some farmers with remarkable success. It does not supersede the use of meal, but is best mixed with it. It is believed that no article, according to cost, can be used with more advantage than this for this object; and that none is known, which is more nutritious. This jelly, which I have myself used with great advantage, is prepared as follows: 'to seven parts of water let one part of linseed be put for forty-eight hours; then boil it slowly for two hours, gently stirring the whole lest it should burn. Afterwards it ought to be cooled in rubs; and mixed with meal, bran, or cut chaff, in the proportion of one bushel of hay to the jelly produced by one quart of linseed well mashed together. This quantity given daily with other food will forward cattle rapidly, but it must be increased when they are intended to be completely fattened." "

The quantity of Indian corn meal required to fatten cattle, usually varies a little. One experienced feeder gives it as the result of his observation that a yoke of good cattle, to be well stall-fed, will take from twenty to twentyfive bushels of meal, besides the usual allowance of hay.

Some farmers have ground their corn for fattening cattle on the cob. In such cases it is suggested that the miller has it in his power to take advantage by drawing his measure of toll from the lowermost portion of the grist to which the corn usually settles. There can be little doubt that corn cobs will serve the purpose of coarse hay for distension, etc., since cattle are often quickly fattened upon nubbins or the smaller ears of corn. They will thus often be found a useful auxiliary.

The Massachusetts stall-feeders consulted by $\mathrm{Mr}$. Colman are almost universally agreed upon one point-namely, that a mixture of provender is best. While Indian meal is to be considered as the basis, certain proportions of rye, or oats, or pease and oats, are always deemed best $\omega$ be mixed with it. An excellent farmer, whose fat cattle do him much credit, is of opinion that the meal given should always be scaided. Oxen from four to six years old are generally selected for fattening, though some prefer young stock of from three to five yeari old. With regard to the particular breeds preferred, Mr. Colman says that the 296 small-boned, medium-sized animals, of good length, strongly marked with the Devon blood, are those which are chosen. In considering the capacities of cattle for fattening, a wide chest has been regarded as an unerring sign of a good and quick feeder. Bearing upon this point, Dr. Jenner, the great benefactor of mankind, made an observation, the truth of which appears to have been fully confirmed by further examination-namely, that no animal whose chest was narrow could easily be made fat. This observation applies not only to neat cattle, but to sheep, goats, and hares. It even holds good in the human species. The experienced farmer is seldom at a loss to distinguish the most thrifty cattle, in respect to which there are great differences among individuals of the same breed. To the assistance of the eye is added the sense of touch by the operation technically called handling, the mode of conducting which, according to the most approved English authorities, has been already detailed. In reference to the several breeds of cattle and their distinguishing qualities, Mr. Colman makes the following remarks as the result of his observations and inquiries :-

"The pastures in New England are short, and the winters long and severe, and therefore ill-adapted to a race of large size, of tender habits, and requiring extraordinary keeping and the most particular care to maintain their condition. The most celebrated breeds in England are the improved Durham short-horn, the Hereford, the Ayrshire, and the North Devon. Of these different races, highly improved animals of each sex, for the purposes of breeding. have been introduced into the country and inte the state; and each race has found strong advocates, who have preferred it to every other. For dairy purposes, as far as my own limited experience and observation go, I have no doubt that the Ayrshire, or a first cross with the improved Durham and the Devon, are to be preferred. For early maturity and size as beef animals, the improved Durham short-horn appears to me to take the lead. But they are tender, and require extraordinary keeping and care to maintain their good qualities. They seem better adapted to the rich prairies and feeding grounds of the Western States than to our scanty pastures. The Hereford, of which some remarkably beautiful animals have been imported into $\mathrm{Al}$. bany, have warm advocates both here and abroad, and come in strong competition with the improved Durhams. Those of the Herefords, which I have had the pleasure of seeing, seemed to me considerably larger than the Devons, but smaller than the Durhams. These were choice specimens, and were remarkably thrifty and beautiful animals, clean about the limbs, not so straight on the back and square behind as the Durhams, but exhibiting upon the whole admirable constitution and symme. try. Having had no farther persinal observa. tion or experience with this breed of animals, I will not venture to speak of them with any confidence. Of their particular qualifications for the dairy I know nothing. For nur purposes as working oxen and for stall-feeding, the North Devon cattle are most generally approved. 'This undoubtedly is the prevalent 
.

- 
Plate 12

$+4$

and wat

G. 100 , on

3.

How

ito

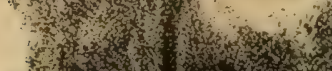

tit?

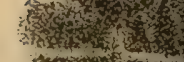

Heris

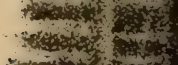

wongty
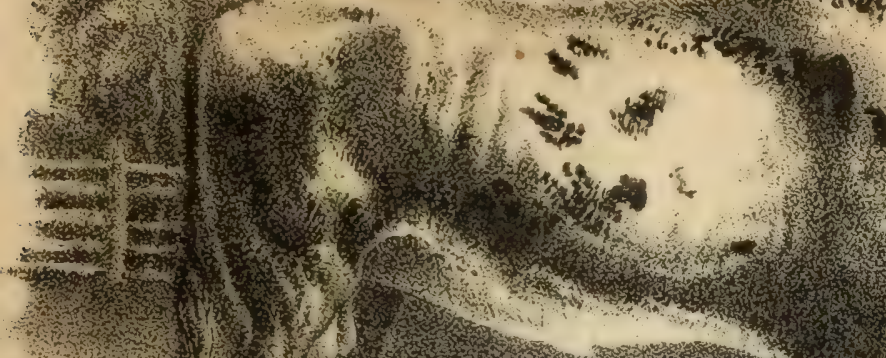

a. 1)

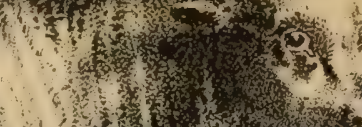

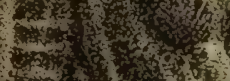

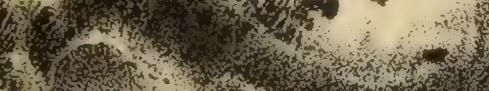

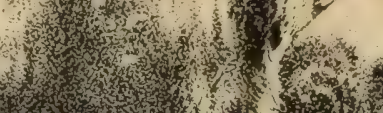
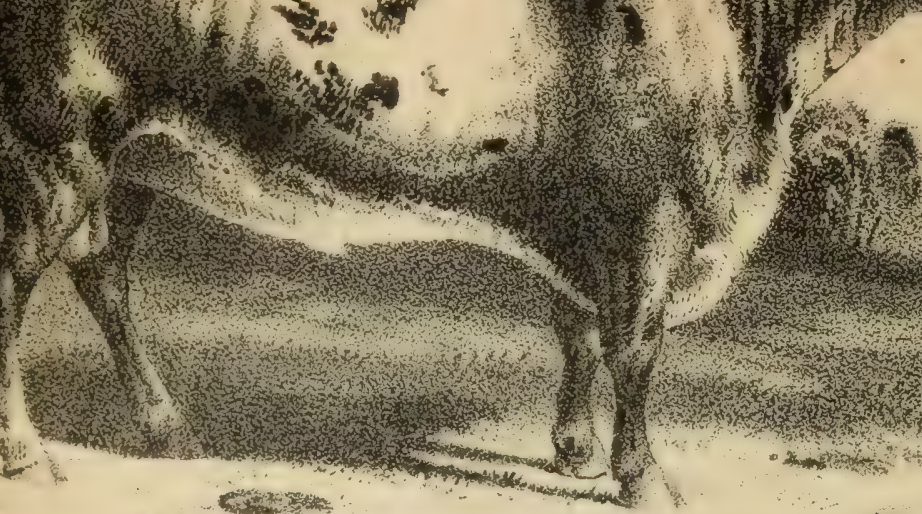

(.)
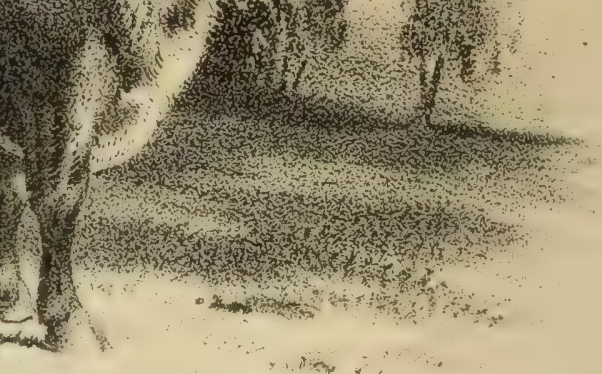

2
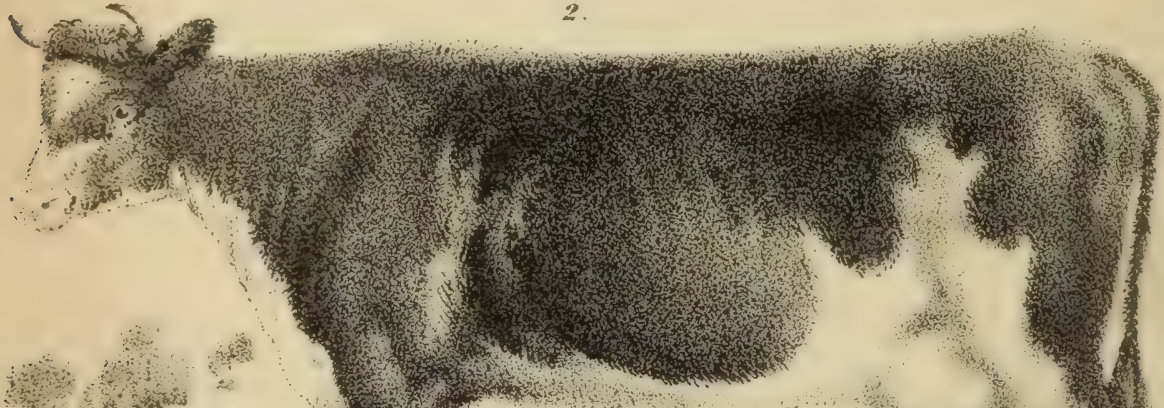

8
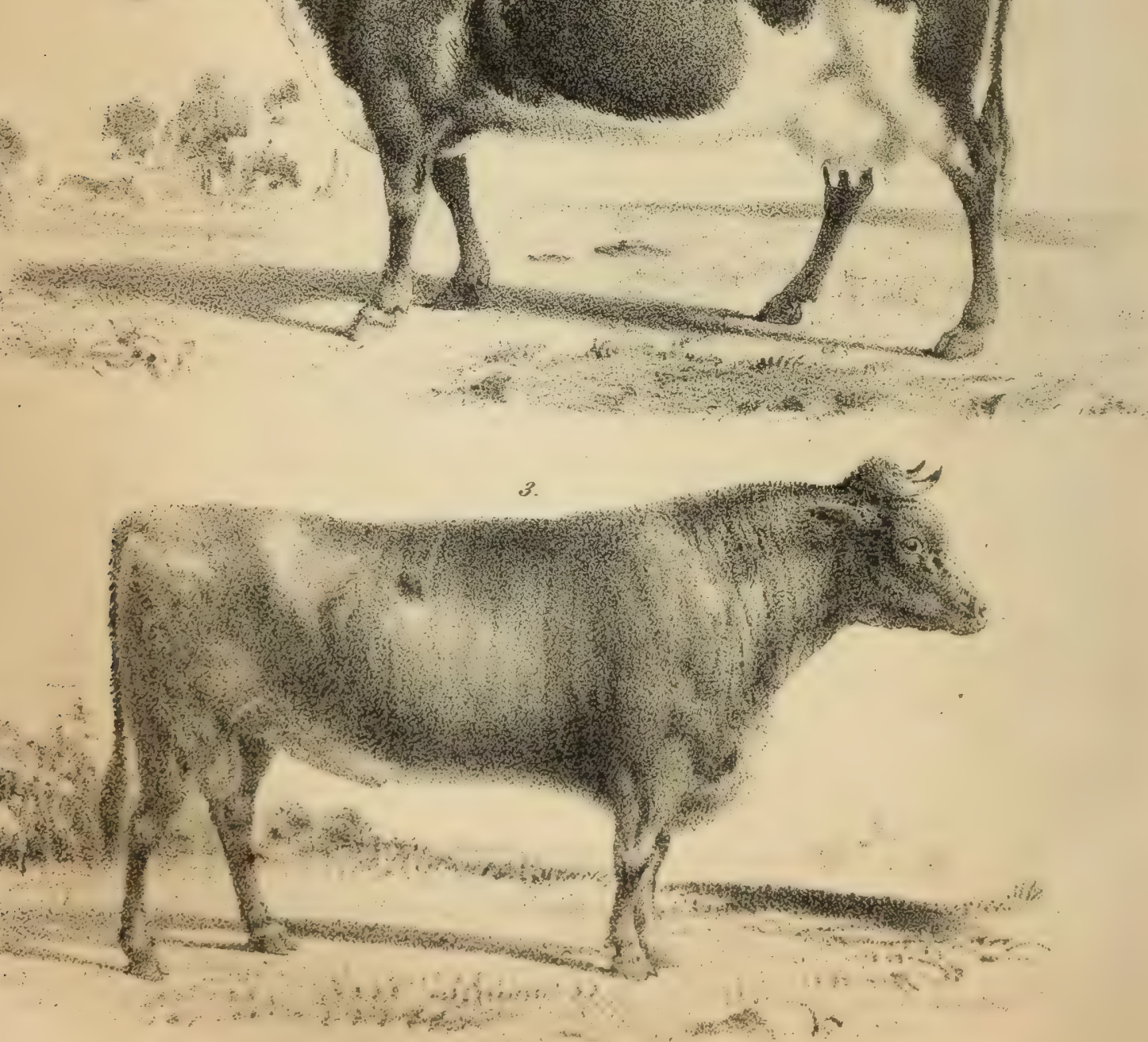

I. Shore Homed Bull.2. Irrshire Cow. 3. Devon Bull, 2 Years old. 
stock of the country, though diversified and contaminated by various mixtures. No pains have been taken, by systematic efforts, by judicious selection, and by perseverance in endeavours to combine the best qualities and to eradicate or remedy defects, in order to form, from what we call our native stock, a distinct and valuable breed. Indeed, where the improved blood has been introduced, it has been suffered, after a short time, to run out through neglect, or to become degenerate by poor keeping."

As regards the capacity for thrift in the different hreeds, Mr. Colman thinks that the perfection of any animal depends essentially upon his good keeping from his birth; and that severity or hard fare, or negligence while in a growing state, do an injury to the constitution, and so stint the growth, that no after keeping can ever repair it. The animal constitution always suffers essentially by reverses. It is said that a sheep is never fat but once. Perhaps this as. sertion is to be received with some qualification, but still it must be admitted as a dificult task to raise an animal from a low condition. "The farmers prejudice very greatly their own interest in suffering their milch cows to come out in the spring in low condition. During the time they are dry, they think it enough to give them the coarsest fodder, and that in limited quartities; this, too, at a time of pregnancy, when they require the kindest treatment and the most nourishing food. The calf itself under this treatment of the cow is small and feeble. He finds comparatively insufficient support from his exhausted dam; and the return which the cow makes in milk during the summer is much less than it would be, if she came into the spring in good health and flesh. It requires the whole summer to recover what she has lost. The animal constitution cannot be triffed with in this way.

"It is so with all live-stock, and especially with young animals at the period of their most rapid growth. 'They should not be prematurely forced; but, on the other hand, they should not be stinted or checked. It is a very important question, whether it is more profitable to fatten young animals than older ones. I have given the different opinions of different farmers on this subject. In England, it seems an almost universal opinion, that the sooner an animal can be made fit for the market the better, and their fatted animals, especially of the improved breeds, are slaughtered at two and three years old. They are often brought to market at even an earlier age than this; but it is con. sidered, and with reason, that the meat of such animals is not so good as when they have attained a full growth. It is natural to suppose that the animal can only be in perfection when he has ceased to grow, and if killed before that pericl, there would seem to be a loss of that enlargement of size and weight, separate from an increase of fatness, to which he might attain. While an animal is growing and well fed at the same time, there is evidently a double gain; and if he increases one pound a day by his extra feed, he may be supposed to increase another poind by his ordinary growth. After this period, however, it may be advisable to send him to market as soon as he can be put into condition. Farmers often make great mistakes in keeping their cattle too long. There is a reasonable calculation to be made in respect to the markets, which are generally higher in the spring than in the autumn; but the advance in price does not always meet the increased expense of keeping. It is import. ant, as a general rule, that the animal should go to market as soon as the gain which he makes ceases to pay the expense of his keeping.

"It has been made a question, whether heifers are not more profitable than steers. They are as thrifty, and, in general, pay as well for their keeping. It is the practice of some farmers, to allow them to come in with calves at two years old; if at that time they promise well as cows, a good market can almost always be found for them; but, if otherwise, after suckling the calf three months or more, they are turned out to be fatted for beef, and are either sold immediately at the close of the pasturing season, or otherwise, after being stallfed for a short time. 'Their meat, if well fed, is always highly esteemed. This proves, in general, a good operation. In England, heifers designed for the stall are very frequently spayed, by which their thrift is greatly assisted.

"This is often done in Kentucliy and some other of the Western States; but I have never known more than one instance of its being practised in New England. I do not feel authorized, therefore, to pronounce upon its advantages.

"It is sometimes asked, whether oxen are injured in their growth from bcing worlked. If their strength is prematurely and too severely taxed, or if they are subjected to severe usage, undoubtedly it must prove injurious; but, if otherwise, if reasonably worked and carefully and kindly attended, there is no dnubt that their health and growth are promoted by it. It is often matter of inquiry, whether fatting cattle should be kept in close stalls, or be sutfered to lie out-doors. The experience of all the farmers whom I have corrsulted, who have made any trial, is conclusive in this case, in favour of the superior thrift of animals kept constantly in the barn, or turned out only for watering and immediately put up again, over those which are kept in open sheds, or tied up for feeding only, and at other times allowed to lie in the yard. No exact experiments have been made in this country in relation to this subject; but experiments made abroad lead to the conclusion, that cattle thrive best in a high and equable temperature, so warm as to keep them constantly in a state of active perspiration, and that their thrift is much hindered by an exposure to severe alternations of heat and cold. It is certain, that in order to thrift, cattie cannot be made too comfortable; their mangers should be kept clean; their stalls be well littered; and the catlle protected from currents of air blowing through crevices or holes in the Honrs or the sides of the stables, which prove often much more uncomfortable than an open exposure."

As at present conducted in Massachusetts, and at the presen! prices of provender and beef, Mr. Colman thinks the business of fat 
tening cattle for market any thing but profitable, and that if extensively and exclusively carried on by individuals, the result must generally be embarrasment and ruin. "From the best observation which I have been able to make, I have," he says, "found very few instances in which a pair of cattle or a single ox kept for any length of time in the stall have ever made compensation for the produce which they or he consume, even at prices considerably below the current prices in the market. There are occasional and accidental exceptions, but they are very seldom to be met with." In the estimates presented to $\mathrm{Mr}$. Colman, Indian corn-meal is reckoned at from 60 to $75 \mathrm{cts}$. per bushel, potatoes $25 \mathrm{cts}$. per bushel, a mixture of peas and oats at $50 \mathrm{cts}$. per bushel, and hay at $\$ 10$ per ton.

"It has been supposed that farmers by going extensively into the cultivation of esculent roots, such as carrots, ruta-baga, parsnips, or mangel-wurtzel, could fatten cattle to much more advantage, or rather at much less expense than on hay or corn. This deserves great consideration. On this subject we want light, and that which springs from actual and intelligent experience. My belief is, that for the fatting of cattle, where the coarse fodder is well saved, few crops are more profitable to the farmer than a crop of Indian corn at the rate of seventy bushels to the acre. Next to corn, putatoes at the rate of four hundred bushels to the acre would be a profitable crop. In number of bushels to the acre, there is no doubt that more can be produced and at a less expense of cultivation and harvesting of common turnips, of ruta-baga, and of mangelwurtzel, than of potatoes. But it is believed that more nutritive matter can be obtained from one hundred bushels of potatoes than from two hundred of common turnips. Ruta. baga and mangel-wurtzel have undoubtedly a great superiority over the common white turnip, but these are much inferior to the best and most farinaceous potatoes. Hay is without question one of the best articles which can be given to fattening animals; but where an abundance of meal or of esculent vegetables is given, the nature of the long feed to be given them seems of much less importance. Rye, wheat, or oat straw, in such case, is found to be given with an almost equal advantage as the best hay. Many of the best beasts in England are fatted upon straw and turnips. In England, it is considered as doing well, if an acre of turnips will fatten an ox for market. An experienced farmer here is of opinion, that one hundred bushels of potatoes with a small amount of hay will fatten an ox. Another says, that he allows twenty-five bushels of corn to fatten an ox, and but little hay will be required.

"It is curious to compare the gain of fattening cattle with the actual cost of keeping. Two pounds live weight per day in an ox are considered a large gain. The largest gain mentioned in this report is a little more than three pounds perday. At seven dollars per hundred, this would be equal to twenty-seven cents. To make this, we suppose the animal to receive one peck of Indian meal, which, at $66 \frac{2}{3}$ cents 298 per bushel, would be $16 \frac{2}{3}$ cents, and $28 \mathrm{lbs}$. of hay, which, at 8 dollars per 2000 lbs., would be 11 cents and 2 mills, or both about 28 cents. Or suppose him to gain only 2 lbs. per day, which would be 14 cents; and his dainy al. lowance of meal be reduced to 4 quarts, and hay the same as before, the daily cost of keeping would be about 20 cents; in which case, if we place the manure as an offset for the attendance, interest, and commissions on sale, \&c., there will be a loss of about six cents per day. I believe the result is often much worse than this; and it is much to be regretted that farmers are not willing to look these facts in the face. I do not mean to deny that there are instances of success in this department of husbandry, instances in which the farmer is well paid for his trouble and attendance, and receives a full compensation for the feed supplied to them; but these instances are comparatively rare, and so much matter of contingency, that even the most skilful farmers cannot always rely upon their best judgment. The farmer always feels satisfied, if he can, as he terms it, double his money; that is, if he receives for his cattle in the market twice as much as they cost him when he first put them into the stall. This is sometimes done. It is seldom exceeded; and fatteners often fall short of it."

At Mr. Colman's request, a careful farmer made experiments for the purpose of ascertaining the actual quantity of hay ordinarily consumed by a fatting ox. In conducting these, the hay was first weighed, and then the weight of the leavings deducted. Five oxen consumed $150 \mathrm{lbs}$. hay per day. Two of these oxen had at the same time 20 quarts of provender-half Indian corn and half broom-seed meal; two of them 24 quarts of the some provender per day; and one of them eight quarts per day. Upon a second experiment with the same cattle, fed as just stated, the consumption of hay by each ox averaged 25 lbs. per day.

It is stated in the Complete Grazier, that an unworked ox for several days together consumed $33 \mathrm{lbs}$. of hay per day. In the New York Memoirs of Agriculture, it is stated that an ox will eat every twenty-four hours $14 \mathrm{lbs}$. of hay, half a bushel of potatoes, and 8 quarts of Indian meal. It hence appears that the capacities of cattle for the consumption of food vary according to circumstances of size, age, condition, \&c. Many farmers who engage in fattening cattle only expect to get paid in the operation for their grain, without taking into account the hay consumed. They, however, derive the great advantage of consuming their crops upon the ground, and reserving the manure to keep up the productiveness of the soil. The farmer who annually sells off the produce of his land in the form of grain, hay, \&c., soon finds the necessity of making a considerable outlay for manure, to compensate for certain and often rapid deterioration. It is freely ad. mitted that with respect to hay, straw, and all kinds of what is called "long feed," it is always better to consume the produce on the farm, even at a nominal loss of twenty-five per cent. than to carry it off any distance to market; that is to say, a farmer had best feed his hay 
at home, although it may net him only $\$ 6$ per ton in fattening his cattle, than carry it even a short distance to market and obtain $\$ 8$ for it. Such estimates would seem to indicate that the value of articles consumed in fattening stock ought not to be valued so high as the current market prices.

If the hay consumed on the farm nets the farmer $\$ 5$ per ton, and the average product is two tons, it will pay a remunerating profit, allowing the land to be valued at $\$ 75$ and even much higher, per acre.

Gain of stall-fed cattle.-Colman gives some interesting estimates showing the actual gain per day in stall-fed cattle, a matter generally left to conjecture.

"Example 1.-A pair of cattle owned by S. C. weighed

Oct. 16, $2305 \mathrm{lbs}$, and $2110 \mathrm{lbs}$, together - $\quad-4415 \mathrm{lbs}$

Jan. 17,2435 " 2185
The gain, therefore, in 3 months and 1 ojay, was 205 "

"The same cattle weighed on the following March 11 th,

One 2590 and nne $2345 \mathrm{lbs}$, together

The gain, then, in this 1 month and 22 days,

The whole gain in 4 mos. 23 days, being - -315 "

4935 Iths.

The gain during 146 days was at the rate of $3 \cdot 56$ lbs. per day.

"These cattle had, besides hay, a small allowance of meal, and ran in a good pasture through the summer. They were put up to be stall-fed early in the autumn, and were soon brought to receive together one bushel of meal per day, even measure; one-third pease and oats, two-thirds corn, with a liberal allowance of hay.

"Example 2.-A pair of oxen belonging to R. D. weighed

Nov. 8. $1995 \mathrm{lhs}$. and $1985 \mathrm{lbs}$, together 3980 lbs Mar. 12, ensuing, $2250 \mathrm{lbs}$. and $2255 \mathrm{lbs} .$, together 4505 เ6

"The whole gain in 124 days, was $525 \mathrm{lbs}$. or at the rate of $4.33 \mathrm{lbs}$. per day.

"Example 6.-One pair of cattle fed by R. D. weighed in the first part of Nov. 3765 lbs. Dec. 15, 4220 lbs. Jan. 15, 4410 lbs. The gain in one month was 190 lbs. March 7, weighed 4730 lbs. The gain from the cornmencement was $965 \mathrm{lbs}$; from Dec. 15 to March 7, was 510 lbs.

"The average gain of the above, from Dec. 15 to March 7, 81 days, being 510 lbs. is $6 \cdot 29$ lbs. per day. The gain from Dec. 15 to Jan. 15, 30 days, being $190 \mathrm{lbs}$. is $6.33 \mathrm{lbs}$. per day.

"These cattle were old, and at the time of being purchased appeared to have been hardly driven and poorly fed."

Loss of weight in driving.-. The loss of cattle in driving to market is generally estimated at from 50 to $100 \mathrm{lbs}$. dead weight, in a distance of some seventy-five or eighty miles. Cattle fatted upon potatoes lose more than others during the journey, which is ascribed to the difficulty of getting them to eat upon the road. The drover usually receives from the farmer a commission of two dollars a head for driving and selling the cattle, with no allowance for feeding. He is therefore but little interested in the fare or treatment they are to receive on the way.

The respectable and responsible officer $\mathrm{em}$ ployed to take an account of all the cattle and other stock brought to the Brighton market, note the average prices, and report weekly these and other interesting particulars, states that the ordinary allowance for shrinkage, in cattle driven to market, is from thirty to thirty. five per cent. Some which have come a long distance, or are very fat or hollow from want of food, will not shrink more than twenty-five per cent.; while others thin of flesh, or full of food, will shrink forty per cent. In sheep, the wethers usually shrink fifty per cent. and sometimes more. It depends very much upon the state of the animal at the time of weighing. Oxen fresh from the pasture at night have frequently been weighed and reweighed on the following morning at nine o'clock, and found to have shrunk 80 or $100 \mathrm{lbs}$. each.

Live and dead weight of cattle.-In England, the difference between the dead and live weight is calculated at eleven-twentieths; this, however, only includes the four quarters; the fifth quarter, as it is there termed, being the hide, loose tallow, and offal, goes to the butcher as his perquisite. In New England, five quarters are also made, the hide and tallow being weighed, and the amount of it and the meat returned to the owner. That is to say, the cattle brought to market by the farmer or drover, being sold, the purchaser turns them over to a slaughtering establishment to be killed and dressed, for which he pays what amounts in money and perquisites to about two dollars per head. The meat is then sold to the retailing butchers. 'The heart and liver are valued at 50 cents, excepting in the barrelling season; the tongue is considered worth 2 cents; the tripe 50 cents; the head, which ha on it a large piece of the neck, being of late years cut off at the second joint from the crown, furnishing some good meat for cooking, and when boiled given to swine with great advantage, and also the feet, from which oil and glue are obtained, valued at $40 \mathrm{cts}$., go among the offal, and of course are lost to the farmer or drover. Some cunning butchers are said to have a way by which, after cutting through the shoulders, in splitting down the chine they turn the edge of the axe outwards, thus leaving a large portion of the neck attached to the head, i perquisite of the slaughterer. With respect to the value of the hide at different seasons, a skilful farmer informed Mr. Colman that the hide of an ox, which, if the animal was killed in December, might weigh 100 lbs., would not weigh more than $\mathbf{8 5} \mathrm{lbs}$. if kept till. June, such is the loss from shedding the hair, an.i perhaps from the thinning of the hide itself.

The offal or perquisites of the slaughterer consist of the entrails, feet, head, a strip from the foreskin, and the blood. The tongue, cheeks, and heart of the bullock go to the butcher. The slaughtercr sells the reet and head to the tallow-chandler and soap-boiler, who extract the tallow and oil; the claws go to the comb-maker, the bones and pith of the horns to the bone-mill for manure or for the 


\section{CATTLE.}

purpose of making animal charcoal, and the blood to the sugar-refiners.

In New York only four quarters are made by the slaughterer, and the hide and tallow are not weighed or reckoned in the price: facts which are to be remembered in making comparisons of prices in the different markets.

The following are some examples of live and dead weights of New England cattle, killed at home and after having been driven from the Connecticut river to Brighton, the Boston beef market, a distance of 75 or 80 miles.

"Example 1.-One ox, live weicht in market $2393 \mathrm{lbs}$; quarters weighed $418 \mathrm{lbs}, 415 \mathrm{lbs}$, 324 lbs., 331 lhs.; hide, 150 lbs.; tallow, 173 lbs. $=1811$. Difference $582 \mathrm{lbs}$.

"Example 2.-Two oxen of A. S., killed at home, weighed as follows:

$$
\text { Live-One } 1979 \mathrm{lbs} . \quad-\quad-\quad \text { Killed-1400 lbs. }
$$

About 29.4 lbs. loss on a hundred of the live weight.

"Example 3.-An ox owned by A. S., conveyed to Brighton on a sled, weighed at home about 2630 lbs.; the precise number of pounds not recollected. On being slaughtered, his weight was as follows: quarters, $480 \mathrm{lbs}$., 479 lbs., 374 lbs., 383 lbs.; hide, 154 lbs.; tallow, 250 lbs. Total, 2120 lbs. Loss, 510 lbs.

"Example 4.-Ox belonging to R. D.; when he left Connecticut river weighed 2435 lbs. Weight at Brighton when dressed, 1588 lbs. Loss of weight, 867 lbs. This is a little more than ne-third, and is a remarkable result.

" Example 5.-An ox weighing on Connecticut river $2250 \mathrm{lbs}$, weighed in market $1472 \mathrm{lbs}$. I.oss, 778 lbs.

"Example 6.-An ox weighing as above 2255 lbs., weighed in market 1487 lbs. Loss $768 \mathrm{lbs}$.

"Example 7.-A fat bull of D. S., killed at home, weighed alive 1495 lbs.; dead $1051 \mathrm{lbs}$. Loss, 444 lbs.

"Example 8.-A fat heifer of E. W., killed at home, weighed alive 1120 lbs.; dead, 832 lbs. Loss, 288 lbs.

"Example 9.-An ox belonging to S. C. weighed on Connecticut river, alive, 2590 lbs.; at Brighton, dressed, as follows : quarters, 394 lbs., 350 lbs., 362 lbs., 358 lbs.; hide, 120 lbs.; tallow, 207 lbs. Total, 1791 lbs. Difference botween live and dead weights, $799 \mathrm{lbs}$.

"Example 10.-An ox belonging to S. C. weighed as above 2345 lbs.; at Brighton, dressed, as follows: quarters, 352 lbs., 310 lbs., 364 lbs., 308 lbs.; hide, 115 lbs.; tallow, 217 lbs. Total, 1666 lbs. Difference between live and dead weights. 679 lbs."

Pasturage.-The cost of pasturage is difficult to estimate, since the qualities of soil and facilities affurded differ so much in different sections of country, and even in the same neighbourhiod. In Conway, situated a little west of the Connecticut river, the pasturage is excellent; inat is to say, 30 acres will keep twelve cattle, consisting of cows and oxen, the year round. Oxen from four to six years of age are taken to be pastured at from 50 to 67 rents per week; farrow cows at 25 cents per seek; steers at two years old at 75 cents per 300 week each. Sheep are pastured at 3 cents each per week, and lambs at $1 \frac{1}{2}$ cents.

In Buckland, in the same county, cows are pastured at 25 cents per week, including salt. Pasturing of an average quality will feed eight cows upon 30 acres. A yoke of oxen require half as much again as two cows. In Hawly two acres of pasturage are considered sufticient for a cow.

In the fattening of cattle, universal experience, Mr. Colman remarks, shows the importance of a scrupulous punctuality as to the times of feeding. Under the influence of that mighty despot, habit, which reigns throughout the animal creation, these animals measure time with great exactness; and if at the customary hour the feed is not ready for them, they become restless, uneasy, and fretful, dispositions exceedingly unfriendly to all cases of thrift. During the time of feeding they should have little given to them at once, that their food may not become loathsome by being frequently tossed over and blown upon.

In regard to the native stock of New England, in which various bloods and breeds are intermingled, Mr. Colman remarks that "many of them are indeed miserable in appearance, in shape, in condition, and every other quality. This comss in general from neglect and indifference, because we kill or sell to the butcher our best calves, and commonly leave what we do attempt to raise 'to shift for themselves.' Yet at the same time without presumption, I think, New England may challenge the world to produce finer teams of oxen, by fifties and hundreds of pairs, than are to be found at our cattle-shows. Let any intelligent judge of stock go into Worcester county, Mass.; into New Haven and Hartford counties, in Connecticut; or especially to Saccarappa, in Maine, where ox teams are constantly employed in carting lumber to Portland, and if he will find any superior oxen for labour and condition than are to be found there, he would do a signal favour to the agricultural public in letting us know where we may look for them. I have seen none. I believe we should search the world over in vain to find any.

"Our native cows are of every variety, but there are several parts of the state where, though it cannot be said that any scientific or systematic improvement has been undertaken, yet by a long-continued selection from the best, whole families or breeds are to be found distinguished for their excellent properties as dairy stock. The list of native cows which I have given shows conclusively that we have those which, for the quantity of milk they give, are scarcely inferior to any, and for the amount of butter and cheese which they produce are surpassed by none. The numbers referred to prove that they are not rare.

"Whether any thing would be gained by substituting the improved short-horns for our present stock is, to say the least, questionable. The short-horns are great consumers. Though animals do not always consume in proportion to their size, yet this must be considered as a general rule. They require most particular attention and liberal feeding to bring them to 
maturity, though we admit that they arrive at maturity early. Many of the short-horned premium young animals which have been exhibited at our cattle-shows have had the benefit of two wet-nurses for six months. Most of our native calves are put off with two teats, and at eight or ten weeks old are turned adrift into the pasture to live or die as they please. Our own stock has never had fair play; and if treated in the same manner as the best shorthorned stock, they would not perhaps fall so far behind them as might be supposed. Our pastures are in general short, and our winters long. A smaller race of cattle, thercfore, and a more hardy stock would seem better adapted to our condition.

"The London milk establishments are mainly supplied with the short-horns, because, it is said, they give more milk, and, after becoming dry, take on flesh sooner than other races, and are therefore more easily disposed of to the butcher. The size of these animals would naturally indicate a larger yield of milk, and, at the same time, a greater consumption of food. But the yield of milk is put down at an average of nine quarts daily. 'These are presumed to be wine quarts, and deducting one-fifth, it itoes not much exceed the yield of some milk establishments among us. Besides, in the London dairies, cows are not suffered to become with calf.

"One of the most extraordinary short-horn cows known in England, it is said, produced 373 pounds of butter in 32 weelss : 17 pounds being the largest quantity made in any one week. This is quoted as quite remarkable: but this, as far as it goes, does not equal the Oakes, the Nourse, the Adams, or the Springfield cow. One of the best-informed and most ardent adrocates for the short-horns, the late Henry Berry, remarks:- 'That their milk does rot contain the same proportionate quantity of butter as that from the long-horns, the Scotch cattle, or the Devons, is probably true; but we have reason to believe that the difference has been much exaggerated, and is more than compensated by the additional quantity of millk.'

"The quantity of cheese made in a year from a cow in the celebrated cheese district of Wiltshire, England, is thus stated:- 'The quantity of cheese that is made from each cow in this district is greater than is common in any other cheese-making country, sometimes as much as $4 \frac{1}{2} \mathrm{cwt}$. or $5 \mathrm{cwt}$. per cou, seldom lower than $3 \mathrm{cwt}$. Perhaps $3 \frac{1}{2} \mathrm{cwt}$. is a fair average in a good cheese-making year on every cow that calves in proper time.' In the famous district of Cheshire, in England, the average amount of cheese to a cow is stated at $2 \frac{1}{2} \mathrm{cwt}$. The old breed of Irish cattle, much valued for the dairy, will produce from 84 to $112 \mathrm{lbs}$. of butter per year; a very good cow will yield $1 \frac{1}{2} \mathrm{cwt}$., that is, $168 \mathrm{lbs}$. net. Of the Ayrshire cows, kept in the highest condition for giving milk, it is stated that the year!y average in milk may be 650 gallons or 2600 quarts, (wine measure, I presume, is intended), and 90 gallons will make 24 lbs. of butter, or 15 quarts (wine measure) to a pound. In another case it is said 'that a well-fed cow of a good breed will produce on an average $180 \mathrm{lbs}$. of butter in the season, though the comm in calculation is $150 \mathrm{lbs}$. In the Epping district, where there is an indiscriminate mixture of lievon, suffolk, Leicester, Holderness, and Scotch, the calcula. tion in a well managed dairy amounts to 212 lbs. per year to a cow. In one case in Sussex, upon an actual trial, the cows produced only 136 lbs. per season.'

"As far, then, as we can depend on these accounts, our own native cattle for dairy stock will not suffer by comparison with the best English stock of any of those races most distinguished for their milking properties. Our own Cheshire cheese dairies certainly yiela the palm to none.

"The cross of the Durham short-horns with the Devon has produced in many cases an excellent stock. But, if of no other value to the country, their introduction will prove an immense benefit by showing our farmers what can be done in improving the size, form, and condition of their own stocks, by a most careful selection from the very best, by persevering attempts to amend defects and engraft good properties in the animal constitution, and by constant care and good keeping.

"It cannot be denied that a vast proportion of our cows are wretched in their form, health, and condition. There is no reason, on the other hand, to doubt that by breeding only from the best on both sides, and by a liberal mode of keeping, we may produce a dairy stock and a stock for labour as well adapted to our pastures, climate, and husbandry as can be found. Perhaps I should be authorized to add for beef also, that is, producing as many pounds accord ing to the expense of their keep. 'The average weight of bullocks slaughtered at Sinithfield, the great cattle market of England, is $656 \mathrm{lbs}$. At Brighton, in this county, the average weight of oxen is $875 \mathrm{lbs}$, and of steers $600 \mathrm{lbs}$. each. The last is thought by some persons to be overrated. The weight used at Brighton is ne? weight; $1 \mathrm{cwt}$. being now reckoned at $100 \mathrm{lbs}$. avoirdupois.

"The great cattle fair of the state, and indeed of New England, is held at the beautiful village of Brighton, about six miles from Boston, on the Monday of every week. Here capacious pens are erected for the reception of such livestock as may be brought in, and the drovers and butchers assemble from all directions. The business of selling and buying is principally got through with on Monday, though cattle and other stock, when prices are not satisfactory to the seller, are frequently kept over, for a week or fortnight, for a better market. With the exception of a small fair at Danvers, in Essex county, held occasionally in the fall, I know of no other cattle fair in New England. Cattle, sheep, and swine are brought here from the interior of the state, from Mairie, New Hampshire, Vermont,-from New Ycrk, and sometimes from Pennsylvania, Ohio, Indiana, and Kentucky.

"I ascertained some time since at the Bull's Head Market, in New York, that the expense of a drove of cattle, consisting of one hundred head, from the vicinity of I,exington, Kentucky, to that place, including the expenses of one night and a day in New York, was 1,300 dollars 
or 13 dollars per head. This was at a season when the drovers could avail themselves of pasturage. The price of corn is not recollected. They came in in good condition.

"Store hogs or shoats, driven moderately in the mild season and well fed on the road, will gain in flesh, it is said by some, almost sufficiently to pay the expenses of their drift."

The number of cattle of all descriptions brought to Brighton frequently exceeds 8,000 head on a market day. Many of these, and the proportion increases, instead of being slaughtered, are sold on the hoof. The mathematical rules and tables, so much in use in England for determining the live weight of animals, are seldom resorted to in the United States, although they are said to give very exact results. A diagram and table have been given in the preceding part of this article, to show the mode and facilitate the process of making estimates of live weight.

By the revised statutes of Massachusetts it is declared that "All beef cattle, except bulls, sold in market by weight, shall, when slaughtered, be prepared for weighing in the following manner:- the legs shall be taken off at the knee and gambrel joint, the skin shall be taken from all other parts of the animal, the head shall be taken off at the second joint of the neck, the entrails taken out, and all the fat of the same be taken off and weighed as rough tallow; and every other part of the animal, including the hide and rough tallow (the udder of cows excepted), shall be weighed.

"All beef shall be weighed upon the first week-day succeeding that on which it may be slaughtered," \&c.

Rearing Calves.-As so many different opinions are entertained upon the subject of rearing calves, some of the views derived from high sources of intelligence will be stated.

In Pennsylvania, heifers intended for milch cows are generally put to the bull at fifteen to eighteen months of age, in preference to leaving them run to a greater age. Mr. Isaac W. Roberts, of Montgomery county, has been very successful in raising and fattening cattle, chiefly of the Durham breed. It is his practice to take the calves of this fine breed, and, when two or three weeks old, put them with common nativebred cows. He weans at three or four months old, when the calf is able to thrive well on grass alone, and the native cow, going dry, is soon fit for the butcher, at a price that will nearly, if not quite, pay for her first cost and a fair allowance for pasturage. He thinks that calves thus raised and entering the winter in good condition, being properly housed and fed during cold and inclement weather, gain nearly a year on such as are prematurely weaned or fed on skimmed milk. He entirely disapproves of letting calves run three or four months with valuable cows intended for breeding, and especially where milching properties are to be retained.

With all those who desire to possess an improved and .elect stock, it is dcemed highly important that they should raise their own calves; and this is rendered the more important from the high prices usually to be obtained for calves of the best breeds. Mr. Colman 302 gives the following information upon this subject, derived from his observations in Massachusetts. "A farmer of my acquaintance in the interior raises all his calves from a large stock of cows. His cows are known to be of prime quality. His heifers are allowed to come in at two years old, and are then sold with their first calf generally for thirty-five dollars, which he deems a fair compensation for the expense of raising. His calves are raised mainly upon skim-milk and whey, until they can support themselves on hay and grass. His steers pay a proportional profit when sold at three to four years old.

"The English authorities say, that upon two cows calving at different times, seven calves may be fattened for the butcher in the course of the year. More than this may be done if the calves are to be reared for stock, and if sume little addition of meal or vegetables is added to their feed.

"Mr. Jaques remarks, on the subject of raising calves, that 'he generally lets them take a portion of milk from the cows for about three months, and prefers keeping them in the stall until they are about a year old, thinking that he gets better forms, rounder barrels, straighter backs, greater broadness on the loin and hips, by this management. Calves turned to grass at two and three months old become pot-bellied, their backs bent, acquire a narrowness in the loins, and seldom get over the defect entirely.'

"I believe that it is decidedly better to raise them in the stall or yard the first season, as their feed is much more uniform, and their growth not interrupted by sudden changes. They soon learn to eat hay; and carrots or potatoes cut fine for them will be found highly beneficial. In all cases the calf should be taken from the cow as soon after his birth as the cow's udder is brought into good condition and her milk fit for use, and then should be fed by hand. 'In my opinion,' says a highly intelligent farmer of Stockbridge, 'calves ras ed for other purposes than veal should be early weaned from the dam, and nursed at least one year upon food adapted to give firmness and expansion of muscle, rather than to fatten them.' The observation of another farmer, a plain man, but one of the most observing and practical farmers in the state, is deserving of attention. 'One of the most important points,' says he, 'in the feeding of the calf, is to feed him well when the grass first fails in the fall by frost. If suffered to fall off then, he dines not recover, and suffers more by scanty food than other animals." "

There are many able papers on subjects relating to cattle dispersed in the best agricultural periodicals, which the breeder may wish to refer to, such as "On Stall-feeding Cows in Summer," by Mr. Collett of Christiana in Norway (Com. Board of $A g r$. vol. vi. p. 60; "On Soiling," by Mr. Curwen (Ihid. p. 49); "On their 'Treatment in Winter," (Quart. Journ. of Agr. vol. ii. p. 228; "On Fattening Cattle on different Kinds of Food," by Mr. Brodie, (Ibid. vol. viii. p. 327); "On Feeding Cattle on Sugar," by Mr. Ellis, (Com. Pourd of Agr. vol. vii. p. 327); and "On Potatoes," by Sir C. Burrell (Ibid. p. 323); "On House and Yard-feeding 
Miich Cows for the Supply of Milk," by Mr. Harley, (Quart. Journ. Agr. vol. i. p. 170); see also "The Harleian Dairy System" by the same gentleman, and "On a celebrated Yardfed Cow," the property of Mr. Cramp of Lewes, (Com. Board of Agr. vol. vii. p. 53). It will, perhaps, surprise an English farmer to learn to what coarse unnatural kind of food use will accustom animals. The cows of Shetland live upon the coarsest moss and seaweed ; those of still more northerly regions on even animal food. In Lapland and Iceland, according to Mr. De Broke, the cattle are uniformly fed on fish. "The English farmer's surprise," says Mr. Broke, "will not be lessened when he learns that the animals not only devour this kind of food with the greatest eagerness, but thrive and do well upon it; it seems that fish heads and bones are boiled together with some hay into a kind of soup, and poured into the naangers of the poor beasts." (Quart. Journ. of .Agr. vol. x. p. 299.) There is a paper "On Live-Stock and Crossing," by Mr. Ferguson, (Ibid. vol. i. p. 33); "On the Comparative Advantages of Feeding Stock with Mangel-Wurzel, Turnips, and Potatoes," by Mr. Howden, (Trans. High. Soc. vol. iii. p. 268); and "On Raw and Prepared Food," by Messrs. Walker, Howden, Boswell, and Walker, (Ibid. vol. iv. p. 253); and again by Mr. Walker, (Ibid.vol. v. p. 52) ; and "On different Descriptions of Food," by Mr. Stephenson. (Ibid. vol. vi. p. 61.) On the disease called the "Muir-ill," by Mr. M·Tarlane, (Ibid. vol. iv. p. 388); on the disease called "The 'Tail-slip," by Mr. Dick, (Quarterly Journal of Agriculture, vol. iii. p. 308); "On Calculi," (Itid. p. 642); "On Diseases of the Udder," (Ibid. p. 871); "On the Navel-ill," by Mr. Sitwell, (Com. Foard of $A g r$. vol. vi. p. 401); "On acclimating Cattle, by Dr. Smith of Kentucky, (Itid. vol. ii. p. 93; On determining the Weight of Cattle by Admeasurement, (Quart. Journ. of Agr. vol. v. p. 612); and Mr. Ferguson "On the value of Live-Stock with relation to the Weight of Offal, (Ibid. vol. ii. p. 207); "On their External Conformation," by Mr. Sparrow, (Veterinarian for 1839 ; Farmer's Mag. vol. iii. p. 95, n. 5 ; Baron Malthus; M:Culloch's Dict. Com.; Youatt on Cattle; Quart. Journ. of Agro, Farmer's Mag. Trans. of Highland Soc.; Lowe's Illustrations of the Breeds of Domestic Animals.) OF.

CATTLE, REMEDIES FOR DISEASES

Abortion. See Aportion.

Blackwater is the concluding and commonly fatal stage of redwater. See Renwaten.

Cleansing drink.-1 oz. of bayberry powdered, $1 \mathrm{oz}$. of brimstone powdered, $1 \mathrm{oz}$. of cumminseed powdered, $1 \mathrm{oz}$. of diapente. Boil these together for ten minutes; give when cold in a gruel.

Colir,-The best remedy is 1 pint of linseed oil mixed with $\frac{1}{2} \mathrm{oz}$. of laudanum.

$A$ cordial is easily made by $1 \mathrm{oz}$. of caraway seeds, $1 \mathrm{oz}$. of aniseeds, $\frac{3}{4} \mathrm{ez}$. of ginger powdered, 2 oz. of fenugreek seeds. Boil these in a pint and a half of beer for ten minutes, and administer when cold.

Diarluca.-Give $\frac{1}{2} \mathrm{oz}$. of powdered catechu, and $10 \mathrm{grs}$ of powdered opium, in a little gruel Sec Dinimita.

Dysentery.-The same as for diarrhœa.

Fever.-Bleed; and then if the bowels are constipated, give $\frac{1}{2} \mathrm{lb}$. of Epsom salts in three pints of water daily, in gruel.

Hoove or Hoven.-Use the elastic tube; as a prevention, let them be well supplied with common salt, and restrained from rapid feering when first feeding upon rank grass or clover. See Hoove.

Mange - $-\frac{1}{2}$ lb. of black brimstone, $\frac{1}{1}$ pint of turpentine, 1 pint of train oil. Mix them together, and rub the mixture well in over the affected parts.

Milk fever, or Garget.-2 oz. of brimstone, $1 \mathrm{oz}$. of diapente, $1 \mathrm{oz}$. of cummin-seed powdered, 1 oz. of powdered nitre. Give this daily in a little gruel, and well rub the udder with a little goose-grease. See Ganget.

Murrain. $-\frac{1}{2} \mathrm{lb}$. of salts, $2 \mathrm{oz}$. of bruised coriander-seed, $1 \mathrm{oz}$. of gentian powder. Give these in a little water. See Murrain.

Poisons swallowed by oxen are commonly the yew, the water dropwort, and the common and the water hemlock. $1 \frac{1}{2}$ pint of linseed oil is the best remedy.

Purge, in poisoning-either $1 \mathrm{lb}$. of salts in a quart of water or gruel, or a pint to a pint and a half of linseed oil.

Redwater.-Bleed, says Youatt, first, and then give a dose of $1 \mathrm{lb}$. of Epsom salts, and $\frac{1}{2} \mathrm{lb}$. doses repeated every eight hours until the bowels are acted upon. In Hampshire they give $4 \mathrm{oz}$. bole armeniac and $2 \mathrm{oz}$. of spirits of turpentine in a pint of gruel.

Sprains.-Embrocation: 8 o of sweet oil, 4 oz. spirits of hartshorn, $\frac{1}{2} \mathrm{oz}$. ' ' of thyme.

Sting of the adder, or slowiorm -Apply immediately to the part strong spirits of hartshorn; for sting of bees apply chalk or whitening mixed with vinegar. See Biтек and BEEs.

Worms.-Bots: give $\frac{1}{2}$ lb. of Epsom salts with $2 \mathrm{oz}$. of coriander-seed bruised in a quart of water. See Bots.

Yellows, $-2 \mathrm{oz}$. of diapente, $2 \mathrm{oz}$. of cumminseed powdered, $2 \mathrm{oz}$. of fenugreek powdered. Boil these for ten minutes in a quart of water, and give daily in a little gruel. See Yelzows.

CATTLE SHEDS. The cow-house should be a capacious, well-lighted, and well-ventilated building, in which the cows ur oxen can be kept dry, clean, and moderately warm; a temperature of about $60^{\circ}$ is perhaps the best. It is a mistaken idea that cattle suffer materially by dry cold. It is the wet and the damp walls, yard, and driving rains, and fogs of winter, that are so injurious to them. In this respect the Dutch farmers are very par.icular. They have their cows regularly groomed, and the walks behind them sprirkled with sand. A clean and dry bed, a portion of a trough to give them water, and another portion for their oil cake, or mangel, or turnips, and a rack for their dry food, will all be necessary comforts. These, with regular feeding, a lump of rocksalt in the manger, and occasional variations if possible in the food, are the chief points to be attended to in the stall management of rato 
lle. (Brit. Hush. vol. i. p. 202; vol. ii. p. 399.) See Vevtilation.

CAUF. A chest with holes in the top to ireep fish alive in the water.

CAUKER, or CAJ,KERS. A term employed in farriery to signify bending or turning up of the heels of the shoes of horses, and intended to prevent the animal slipping. This method, though once general, is now commonly limited to the outside heel of the shoes of the hind feet.

CAULIFEROUS (From caulis, a stalk, and fero, to bear). A term applied to such plants as are furnished with a stalk which bear shoots, as the cauliflower, cabbage, \&c.

CAULIFLOWER (From Lat. caulis; Brassica oleracea botry! is). A species of brassica, of which there are two varieties; - the early, which is smallest and most fit for growth under lights, for the winter-standing crop; and the large, for the open ground plantations. Cauliflower is propagated by seed; the first sowing to take place at the close of January or early in February, in a slight hot-bed, or warm border, in either situation to have the protection of a frame. The plants are fit to be pricked out in March in similar situations, and for final removal into the open ground during April and May; and some to be placed under hand-glasses for more immediately succeeding the winter-standing crop. At the beginning of March and April another sowing is to be performed in a sheltered border, the seedlings of which may be pricked out in May, and planted finally in June for protection at the end of summer. Again, another sowing may be done in the last week of May; for pricking out, in June; and for final planting, the end of July; to produce during October and November, and in favourable seasons until Christmas. The seed of these sowings must be inserted broadcast, and covered half an inch thick with fine mould. The seedlings are of sufficient size for pricking out when they have four or five leaves, about an inch in breadth; they must be set three or four inches apart each way. Water must be given moderately, both in the seed-bed and at the time of removal, if the weather is at all dry. When finally set out, they must be planted in rows two inches and a half apart each way. The mould must be frequently Inosened by the hoe, and drawn up about their

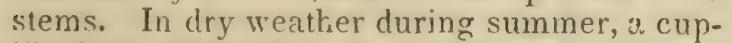
like hollow should be formed round each plant, and filled twice a week with water; but as soon as the flower makes its appearance, it must be applied every other day. As the head appears exposed, it is advantageous to break some of the leaves, and turn them over it as a shelter from the sun: this preserves then from becoming of a yellow hue, as well as retards their advancing to seed.

Winter-standing crop.-The seed for this crop must be sown in the third week of August, in a warm border or an o!d hot-bed, with the protection of a frame or hand-glass. That the cauliflower, though the most tender of the brassica tribe, is not so impatient of cold as some gardeners are led to imagine, is demonstrated by the fact, that the imperfect covering of mats will almost always preserve the plants 304 unınjured through the winter; and the practice of Mr. Bull, of Rossie Priory, Nurth Britain, proves that it is scarc $=3$ more so than the broccoli. He sows in the last wеeк ul August, transplants in the middle or end of Novermber, and often does not even afford the plants the protection of a south wall, and no description of covering. Plants thus raised are healthier, and produce finer heads than those which have additional shelter, though they are not so forward, neither are they subject to be blackshanked. (Mem. Caled. Hort. Soc. vol. iii. p. 192.)

The seed-bed, if not one that has grown cucumbers, \&c., must be well manured with dung from a cucumber bed, or, as is sometimes recommended, a basis five or six inches thick of dung in a perfectly decayed state must be formed, firmly trodden down, and covered with a simılar thickness of light rich mould: in this the seed is to be sown and buried a quarter of an inch deep, and, during the meridian of hot days, shaded with matting. Moderate waterings must be given, as may seem necessary. The plants appear in about a week, and the shading and watering must in like manner be afforded.

The plants are fit for pricking out at the close of September, when their leaves are rather more than an inch wide. They should be placed in a similar soil and situation to that from which they were removed. Towards the end of October, or first week in November, they must be removed, and planted in patches of from three to six together, these clusters being in rows three feet apart each way are to be sheltered with hand-glasses until the spring. At the end of February, if an open season, or not until March if otherwise, part of the plants may be removed from under the hand-glasses, two strong ones being left under each glass, and set out in the open ground; the soil and sheltered situation heing as nearly similar to that from which they are taken as possible. Some, also, may be planted out from the frames; but from either situation these removals must be concluded by the middle of April. Care must be taken to remove the plants with as much earth as possible retained to their roots, and they are to be planted at a similar distance as was recommended for the other open-ground crops.

Those continued under the glasses must have air admitted as freely as possible, and other precautions adopted that were recommended during their winter growth. Earth should be drawn carefully about their stems, without any being allowed to fall into their hearts. When they fili the glasses, these last are easily raised by a circular mound, four or five inches high, thrown up round them. In mild weather, hot sunny days, and during genial showers, the glasses may be taken completely off, but replaced at night. The plants being thus hardened by degrees, and when all danger of frost is past, about the end of April or early in May the glasses may be entirely removed. The leaves are to be broken dowr over the heads, as before directed. For the production of seed, some plants of the winterstanding crop which have fine and firm head must be selected, as these will produce 0 
best seed, though not in such quantity as those of a looser texture. For the necessary treatment, see Buoccou. The seed ripens in september, and the branches should be gathered as soon as this occurs, and not allowed to remain until the whole is fit for collecting. The seed remains, if carefully preserved, in a good state for use until it is three or four years old. (G. W. Johnson's Kitchen Gard.)

CAUSTIC. In farriery, a substance which, by its powerful operation, destroys the texture of the part to which it is applied. Corrosive sublimate is the best caustic; but that requires skilful hands, for it is a dangerous remedy except in the hands of the veterinarian. Mix one drachm of powdered verdigris with one ounce of basilicon ointment; apply this upon a piece of tow : or a drachm of blue stone (sulphat. of copper), dissolved in one ounce of water may be used; or lunar caustic in a quill may be rubbed on to the diseased part.

CAUTERY, or CAUTING-IRON (Old Fr. cautere). In farriery, a name given to a searingiron, which is made white hot, and used to destroy fungous flesh, \&c.

CAVESSON, or CAVEZON (Fr.). In horsemanship, a term applied to an apparatus resembling the musrol, which is used in the breaking of horses. From its formation, it binds and pinches the nose, and regulates the action of the animal to which it is applied.

CAZZONS. A provincial word used to signify the dried dung of cattle for fuel.

CEDARS. See Cypress.

CEDARS OF LEBANON (Abies cedrus). This sovereign of the forest appears to have been indigenous to Mount Lebanon: but at what period it was first introduced into England is not known. This noble tree is now so well naturalized in England, that the seerts not only ripen, but propagate themselves without care or trouble. One of the cedars at Chiswick measures 13 feet 4 inches in circumference, and is 80 feet high; but the largest now remaining on I.ebanon is $\mathbf{9}$ feet in diameter, or 27 in circumference. Cedar wood is known to be very durable; the ancients believed it to be imperishable. But according to Mr. Drummond Hay's observations at Tangier, the indestructible cedar wood is the timber of the Sandarac tree (Thuja articulata).

CEDAR, RED (Juniperus Virgiviana). This North American tree belonging to the junipers, is the most common species of its genus in the United States, and the only one which attains a size adapting it to the useful arts. Next to that found in Bermuda, it is the largest of the junipers hitherto discovered. It is found along the lands bordering the Atlantic, from Maine to the extreme South, and even passing round Cape Florida, shows itself beyond St. Bernard's Bay in the Gulf of Mexico. In retiring from the shore, it becomes gradually less common and less vigorous, and in Virginia and the more Southern States it is rare above tidewater. Farther inland, it is seen only in the form of a shrub in open, dry, sandy places. In the most favourable situations along the southern sea shore, it attains a height of 40 or 45 feet, with a diameter of 12 or 13 inches.

The leaves are evergreen, numerously sub- divided, and when bruised diffuse a resinous, aromatic odour. The seeds are small ovate berries, bluish when ripe, and coated with a whitish exudation. They arrive at pefection in the beginning of the fall, and are greedily devoured by cedar birds, robins, \&ce. If suwn immediately, the greater part of them will crome up the following spring; but they will not shoot before the second year if they are kept for several months.

The wood is odorous, compact, fine-grained and very light, though heavier and stronger than that of the white cedar and cypress. 'To these qualities it unites the still more precious character of durability, and is consequently highly esteemed for such purposes as require it in an eminent degree. But as it is procured with difficulty, and is every day becoming more scarce, it is reserved exclusively for the most important uses. The name of Red Cedar is only applicable to the perfect wood, which is of a bright tint; the sap is perfectly white. The nearer the red cedar grows to the sea and the farther southward, the better is its wood. 'The chief supply now comes from East Florida. (Michaux.) See Crpress, and Fir.

CELANDINE, COMMON (Chelidonium majus). Celandine is a wild plant with large leaves and bright yellow flowers, growing in shady places, waste and untilled lands, and thickets, \&c.. especially on a chalky soil, and flowering from April through the summer. It grows two feet high, and the stalks are round and green. The leaves are large, long, and deeply divided at the edges, and of a yellowish green, standing two at each joint. The flowers are small; several together upon long footstalks. Every part is brittle, and if you crush the stalk or leaves an orange-coloured acrid juice is expressed, which is medicinal.

There are two species of celandine', or horned poppy, found in the United States. The greater, or common celandine, ( $C$. majus), has an acrimonious juice of a saffron colour, which is a popular remedy for warty excrescences, as well as for ring-worms, tetter, the itch. \&c.

The sea celandine, (C. glaucum), or yellow horned poppy, flourishes in the sandy soil along the sea and bay shores where it is quite ornamental. Its juice is said to be poisonous.

CELERY (Apium graveolens). This is the wild original of cultivated celery. The name probably proceeded from apex, a tuft or crest, which its umbels form). This class of plants fourish best in a moist soil, friable, and raiher inclining to lightness; it must be rich, and that rather from prior application than the im. mediate addition of manure; celery and cele. riac, however, appear benefited even by its abundant application at the time of sowing and planting. The parsleys, likewise, prefer their soil to incline rather to dryness. For all it must be deep, and all equally refuse to thriv on a strong clayey soil. The situation they thrive the most in is one that is as open and as free from the influence of trees as possible. The common parsley is the one that bears best a confined or shady compartment.

There are six varieties of celery in general cultivation:-the gigantic, the dwarf-curled. the common upright, ved-stalked uprignt, giant in.

$$
2 \text { с } 2
$$

305 
ow upright, and the solid-stalked (red and white). The red is reared chiefly for soups, the white being much more delicate in flavour. It is propagated by seed. The first sowing should be performed either in a hotbed or on a warm, light border, towards the end of February; some gardeners even insert it as early as the middle of January. The border is by many gardeners considered the best situation, inasmuch as the plants are more hardy, and with proper care come forward with scarcely any difference as to time. This is to be repeated in March; but the principal sowings must take place in April and May, and the last one in June. As the produce of the early sowings will not continue long in a state fit for use, from their leaf-stalks becoming piped or hollow, they must be proportionably small; they must all be inserted broadcast, and the seed scattered thinly. The seed-beds of the early sowings should be light and dry, with the full enjoyment of the sun throughout the day, but for the three last in a moist situation; and it is advantageous for them to have a free exposure to the morning sun only, yet free from the drip of trees; so advantageous is it to have the plants of these sowings as luxuriant as possible in their first stage of growth, that to afford them as regular and unstinted a supply of nourishment as possible, the mould of the seed-bed is often formed artificially. Mr. Walker, gardener to J. Walker, Esq., of Longford, Scotland, recommends it to be formed of black loamy soil and old hotbed dung in ecual parts. (Mem. Caled. Hort. Soc. vol. ii. p. 295.) The plants from these several sowings will in general be ready for pricking out in four or six weeks from the time of insertion, and for final planting after a further continued growth of two months. A more determinate datum for judging the appropriate time for performing these operations is the size of the plants, they being fit for the first removal when three or four inches in height, and for the second when seven or eight. From the above enumerated sowings, monthly plantings may be successionally made from the commencement of June until September closes; but for the supply of a family, a sowing at the close of February for production during the same year, and another about the middle of May, to yield a produce in the winter and the following spring, will in general be amply sufficient.

They are usually planted out finally in trenches, from twelve to eighteen inches wide, and at least four foet apart. To cut the trench straight and with firm sides, the spade should be thrust down all along the line which marks the boundary on each side, previous to digging out the earth: the top spit of mould throughout the length must be turned alternately on either side, for this is required in the after cullivation for earthing up the plants. Some well putrefied dung, two or three inches thick, must be then spread along the bottom and dug in, care being taken that its surface is not more than four inches below the regular surface of the soil. Mr. Walkel here recommends the samr ausparing application of manure; he forms the soil in his trenches of three parts aung and one part fresh, strong soil. (Mem.
Caled. Hort. Soc. vol. ii. p. 296.) By this abun. dant application of manure his celery undoubtedly obtains a fine growth, being often $4 \frac{1}{2}$ feet long, and averaging 6 lbs. weigitt; but at the same time it is to be remarked, that many soils will grow it equally fine without such immoderate application.

Celery, as before mentioned, delights in a soil abounding in fertilizing matter; the mode adopted to effect this, as practised by Mr.Judd, gardener to C. Campbell, Esq, of Edmonton, is one which with equal advantage may be adopted for any crop requiring a very rich soil; he prepares his ground in the winter preceding the time of planting, or as long before as convenient, by manuring and trenching it two spades deep, performing this last operation twice, that the dung may be better incorporated with the soil, and then leaves it as rough as possible until the time arrives for forming the trenches, at the bottom of which he also turns in some manure. (Trans. Hort. Soc. Lond. voi. iii. p. 46.) As celery is very apt to decay in winter on account of excessive moisture, it would undoubtedly be a good practice, after preparing the ground as just detailed, to plant in rows five or six feet apart on the surface, taking the mould required for earthing them up from this allotted space.

Before planting, the long straggling leaves are to be cut away, and any side offsets re. moved; but if the plants are older or larger in growth than before mentioned, the tops of the leaves may be generally removed, which serves to check their running to seed, which they are otherwise apt to do. After this preparation, they may be planted, a single row in each trench, about eighteen inches apart. Mr. Judd says that he finds the plants much injured in their future growth if, during any of their removals, their roots become at all dry; therefore, when taking them either from the seedbed or for final planting, he lays them, as he draws them from the ground, in a garden pan containing a little water. (Ibid.p.45.) Planting is best performed in the evening, and water should be given plenteously at the time, as well as every other day subsequently until they are well established. Earthing them up must com. mence when they are about a foot high, and may be continued until the plants are fit for use, or are one foot and a half high and up. wards. In performing it one person must hold the bases of the plants together, whilst a second regularly follows and throws in the scil, utherwise the mould separating the leaves breaks them and induces decay, and ofttimes destroys them by injuring the heart. (Ibid. p. 47.)

The earthing is best performed gradually, a few inches being added once a week, and a dry day always selected to perform it in. In very severe weather the winter standing crops should be covered with straw or other litter, care being taken always to remove it in mild days. On the arrival of frost a quantity may be taken up and buried in sand under shelter. As celery will not continue in perfection except in winter more than three or four weeks after bleaching, it is advisable for family use only to make small plantations of the early crops at a time. To raise seed, some plants must be left where 


\section{CFLERY.}

grown; or in February or March some may be carefully taken up, and, after the outside leaves are cut off and all laterals removed, planted in a moist soil a foot apart. Those which are most solid and of a middling size are to be selected. When they branch for seed they must be each attached to a stake, to preserve them from being broken by the violence of winds. The flower appears in June, and when the seed is swelling in July, if dry weather occurs, they should be watered every other night. In August the seed will be ripe, and when perfectly dry, may be rubbed out and stored. A variety of celery with a roundish root (Apium rapace$u m$ ), is sometımes cultivated in gardens. ( $G$. W. Johnson's Kitch. Gard.; Brit. Husb. vol. ii. p. 575; Willich's Dom. Encyc.)

CEIERY, WILD, or SMALLAGE PARSLEY (Apium graveolens). This is a biennial, found in ditches and marshy ground, especially towards the sea; root tap-shaped, herb smooth and shining. Flowers numerous, small, greenish white. The seeds and whole plant in its native ditches are acrid and dangerous, with a peculiar strong taste and smell; but by culture it becomes the mild and grateful garden celery, for which and its name we are indebted to the Italians, and which has now supplanted our native Alexanders (Smyrnium olusatrum). (Smith's Eng. Flora, vol. ii. p. 75.)

CELL (Lat. cella). In botany, the hollow part of a capsule in which the seeds are lodged, and also the part of the anthers which contains the pollen.

CELLS. The small divisions in honeycombs, which have been observed to be always regular hexagons. They also denote the hollow places between the partitions in the pods, husks, and other seed-vessels of plants.

CEN'TAURY (Sabbatia angularis). An annual and biennial, of which there are seven or eight additional species found in the United states. Centaury is commonly found in barren fields, is intensely bitter, and deservedly a popular tonic.

CENTAURY, COMMON (Erythraa centaurium). From erythros, red, alluding to the pink colour of the flowers. The species of this genus are pretty, but not easy of cultivation; the herbaceous species require an open, loamy soil, and may be increased by divisions. The annuals and biennials require sowing in the open border in autumn, or they will not come up. (Paxton's Bot. Dict.) In England there are three native species of centaury, viz. the broad leaved tufted ( $E$. latifolia), the dwarf tufted ( $E$. littoralis), and the common centaury, to the last of which the following observations more especially apply. The two first-named varieties are found mostly in sandy ground near the sea shore. (Smith's Eng. Flora, vol. i. p. 320.) This

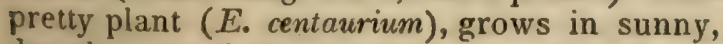
dry places, and in gravelly pastures; its roots are to be taken up in autumn, when out of flower. It is about eight or ten inches high. The leaves are radicle, or grow in a cluster from the root, and are about an inch long; the stalks divide towards the top into several branches, and the flowers, which are of a bright pir $k$, are long and slender. and stand in a cluster. The leaves growing upon the stalk
CHAFF-ENGINES.

are oblong, broad, and acute at the point. Com. mon centaury has all the medicinal properties which distinguish the family (the Gentianacea), to which it belongs. Its bitter is agreealle; and it might be advantageously used as a stomachic instead of gentian root. The dose of the plant in powder is from a scruple to a drachm.

CEN'TIPEDE (Lat. centum, a hundred, and pes, foot). The name of the myriapodous insects belonging to the genus Scolopendra of Linnæus. They are wingless; and the largest species possess, when full grown, more than fifty, and less than two hundred pairs of feet; they are sometimes called forty-legs. (Brande's Dict. of Science.)

CERATE (derived from cera, wax.) Cerates are ointments of rather stiff consistence; simple cercute is made by melting together sweet oil and beeswax, or hog's lard and beeswax, or all three together. The oil or lard employed should always be fresh, as nothing irritates or prevents the healing of wounds more than rancid applications.

CERES. The Roman Pagan goddess of corn and harvests; the Isis of the Egyptians. The festivals to her honour were denominated, at Rome, the Cerealia or Cerealion, hence the term Cerealian grass; and Sicily, long celebrated for its corn, was supposed to be her favourite retreat.

CEREAL, relating to corn or grain. Cereal plants are the various kinds of grain. Cereal grasses are all those raised to supply breadstuffs, such as wheat, rye, Indian corn, \&c.

CERINE. A substance which forms from seventy to eighty per cent. of beeswax. It may be obtained by digesting wax, for some time, in spirits of wine, at a boiling temperature, after which the cerine is decanted with the liquor, from which it is cleared by evaporation. It is white, analogous to wax, and melts at $134^{\circ}$ Fahrenheit.

CHACK. A term used in horsemanship when a horse beats upon the hand, and does not hold his head steady, but tosses up his nose, and shakes it all of a sudden, to avoid the subjection of the bridle. In order to fix and secure his head, it is only necessary to put under his nose-band a small flat ligature of iron, bent archwise, which serves as a martingale.

CHAFF (Sax. ceaf; Dutch, kaf). The husks of corn which are separated by thrashing and winnowing. It likewise implies hay, straw, \&c. cut small, for the purpose of being given to horses and other cattle.

CHAFF-ENGINES. That chaff has been employed as provender for live-stock from a very early period, we have abundant evidence. Cato (lih. 54) recommends it for oxen; and two centuries since, Hartlib recommended its use, mixed with cut oats and peas. The modo of preparing the chaff, however, from hay and straw by the knife, was a later improvement, and the first machines were rude and incomplete.

We are not aware (says Mr. J. A. Ransome of Ipswich, to whom I am indebted for this and other valuable articles on the implements of agriculture) of any attempt to improve upun the plan of pressing the hay in a trongh, and 


\section{CHAFF-ENGINES.}

by hand bringing it by small portions to the front edge, where it was severed by a long knife attached to the end of a lever, till in 1794-5 the Rev. J. Cooke of Holborn, London, and W. Naylor of Langstock, respectively obtained patents for machines for expediting the process.

In the year 1797 we find Robert Salmon, of Woburn, whose inventive talent and practical experience added many and various original ideas and improvements to the then limited linowledge of agricultaral mechanics, constructed a chaff-engine, which, although cumbrous in its appearance, was effective in its operation, and furnished the original idea, which was subsequently improved upon; first, by Rowntree, and afterwards by Thos. Passmore of Doncaster: the latter of whom, in 1804 , patented the machine known as the Doncaster engine, upon the plan of which, for many years, most of the engines in the midland and eastern counties were made; and even at the present time, few of the machines in general use are found more effective. A reward of thirty guineas was conferred on Salmon by the Society for the Encouragement of Arts, \&c. for this improved machine.

Passmore's machine was a simplification and improvement on Salmon's straw-cutter.

In 1800 and 1801, W. Lester of Paddington patented a straw-cutter, which, with some alterations, is much used at the present day, and is known as the "Lester engine." It is a very simple machine, having but one knife, placed on a fly-wheel; the fly-wheel turns on a cranked spindle, which eommunicates motion to a ratchet-wheel fixed at the end of one of the feeding-rollers by means of a small hook or catch, which is capable of being so adjusted as to lift one, two, three, or four teeth at each revolution, and by this is regulated the length of the straw projected in front of the face-plate, and which is severed by the knife. On the roller was fixed a revolving cloth or endless web, which passed over another roller at the hinder end of the box; a heavy block was used to compress the straw. In the more modern engines the rolling-cloth is entirely dispensed with, as the purpose for which it was intended is effected by the introduction of an upper feeding-roller, to which motion is communicated by a pair of cog-wheels, one of which is attached to the lower feeding-roller before described; the heavy block is substituted by a pressing-piece, which receives its motion from the cranked spindle, alternately presses down the straw previous to the cut, and rises afterwards to allow the straw free passage. The improved machine is made of different sizes, and the larger are frequently used with horse-power.

This is the best modern chaff-engine; it will adjust and vary the work to the following lengths of cut: $-\frac{1}{4}$ inch, $\frac{1}{2}$ inch, and $\frac{3}{4}$ inch.

Bushels nf fodder
per bour.

Another chaff-cutter is made on the same nrinciple, but a size smaller, which 308

CHAFT-ENGINES.

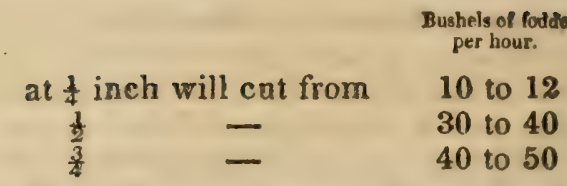

A still smaller engine can also be had, cut ting $\frac{1}{2}$ inch lengths only, suited to gentlemen's stables and small establishments, made entirely of metal, and adapted for hot climates. This will cut from 15 to 20 bushels of fodder per hoar.

Passing by several, which in the course of the next fifteen years were introluced, but which, however ingenious, were too complicated and cumbrous for general use, in 1818 we find a simple invention was patented by Thomas Heppenstall, of Doncaster. It consisted in the application of a worm to turn two wheels, which in their revolution meet each other. These wheels are attached to two feeding-rollers, which convey the straw forwards to the knives. Two of these knives are placed on a fly-wheel, which is fixed upon the same spindle as the worm. This is the simplest form of chaff-engine, and, with a slight alteration, substituting wheels with the cogs on the face instead of on the outer edge, is the common form for the small engines now in use.

Two patents have also, within the last year or two, been taken out for considerable improvements on this machine, one by Itord Ducie in connection with Messrs. Clyburn and Budding, two engineers residing at Uley.

The only remaining machine we have to bring before the notice of our readers, is one for which a patent was obtained a few months ago by Mr. Charles May, engineer of Ipswich, a partner in the house of Ransome. We saw this among the machines exhibited at the Royal Agricultural Society's meeting at Cambridge, where it appeared to perform its work admirably. It is intended to be used by horse-power, and is so contrived that $\operatorname{cog}$-wheels of differemt diameters may be placed on the spindle to which motion is first communicated; these, working in different movable wheels upon another spindle, will regulate the speed of the feeding-rollers, so as to vary the length of the chaff to be cut, from three-eighths of an inch to three inches. Its capabilities are estimated to cut $8 \mathrm{cwt}$. of straw per hour in half-inch lengths.

A chaff-cutter is indispensable on a large farm establishment. This implement, as has been shown, is either constructed with a gond deal of expensive machinery, or of very simple mechanism; it may be made up at the cost of only 11 . or $11.5 s$.

Patent straw-cutters in great variety are to be found in the United States. They are perhaps in most general use in the Eastern States, for which reason we extract the opinions of their respective merits held by an Eastern authority of high repute, Mr. T. G. Fessenden, editor of that valuable periodical, the New England Farmer. In his very instructive litile volume, "The Complete Farmer," Mr. Fessen. den makes the following remarks :-

"There is not only much saving and gain in cutting fodder when hay is low, but the animal is kept in better health, more particularly old 
horses, and such as may have been injured in their wind.

"It is a fact that horses will live and continue serviceable much longer when fed on cut fodder. The machine invented and manufactured by Willis, known as 'Willis's Improved Straw and Hay-Culler,' is the most durable and best operating machine that has come to our knowiedge; and, what is worthy of notice, they require but one person to work them, which is not the case with many other machines; in this respect there is a great saving in cutting feed, and likewise the fodder may be eut of any length required: the knives, being placed in front of the machine, can be at all times examined and put in good order. The feeding-rollers are so constructed, that while the machine is in the act of cutting, the rollers cease to feed, which renders the cutting operation very easy. When properly constructed, this machine works free and easy, and is not liable to get out of order. It will cut from thirty-five to forty bushels per hour. Price thirty-five dollars.

"Eastman's Straw-Cutter, with improved sidegearing and cylindrical knives. This machine is well calculated for large and extensive establishments. Price, fifty to sirty dollars.

"The Common Dutch Hand Cutting-Machine is one of those implements in common use, and known to every practical farmer; and is considered as good a machine for a small establishmeut as any in use. It will cut from ten to twenty bushels per hour.

"Safford's Improved and Common Siraw-Cutter with side-gearing. Well approved, and is in very general use.

"Green's Patent Straw-Cutter, one of the most approved machines now in use for cutting fodder: very simple in its construction, and not liable to get out of order; does the work with great ease and despatch."

"Green"s Patent Straw, Hay, and Stalk-Cutter," says another excellent authority, "is very simple in its construction, and being made and put together very strong, is not liable to get out of order. By the application of a mechanical principle not before applied to any implement for this purpose, the machine will cut easily two bushels per minute, requiring only the strength of a boy to work it. The knives require less sharpening than those of any other straw-cutter, owing to the peculiar manner in which they cut."

The Aibany Cultivator states, on the authority of an intelligent and worthy farmer, that two active men will, with this machine, by the application of manual power alone, cut five tons of hay per day! The machine called No. 2, which euts three-fourths of an inch long, is now sold for thirty-three dollars.

The saving effected by the use of straw-cutters often amounts to 50 per cent. The profits and advantages accruing from eutting provender, especially when this happens to be a high price, is strikingly demonstrated by the following statement.

Mr. Benjamin Hale's account of the savings made by the use of Straw-Cutters, employed to cut hay and straw as fodder for horses.

Mr. Hale is proprietor of a line of stages running between Newburyport and Boston He says,

The whole aunount of bay purchased from April 1 to OcL 1, 1816 (nix nonths), and used at the atage otable, was

At twenty-five dollars per ton (the lowest price at which bay was purchased in 1816, )

From Oct. 1, 1816, to April 1, 1817, whole amount of hay and straw prrchased for and consumed by the sawe number of horses, viz. $\begin{array}{lccccc} & T & \text { coot. } & \text { grs. } & \text { lbs. } & \text { Cost. } \\ \text { Straw } & 16 & 13 & 3 & 10 & 16022 \\ \text { Iay } & 13 & 14 & 1 & 00 & 35000\end{array}$ Iray $13 \quad 14 \quad 100 \frac{35000}{851023}$

Deduct on kayd April 1, 1817, by estimation, four tons more than there was Oct. 1, 1816, at cwenty-five dullars per ton, 100
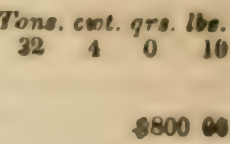

Saving by the use of the straw-cutter, four months out of the last six. unoubs, or the diffirence in expense in feeding with cut fodder and that which ig uncut

Whole amneint of bay used for the horses of the Saleu stage, i wentyfive in number, from A pril I to Oct. 1, 1816, viz.

At thirty dollars per ton (the lowest price in Salem),

Whole amount consumed by the same number of borses from Oct. 1, 1816, to April 1, 1817,

\begin{tabular}{|lrcccr} 
& $T$. & czot. & gris. las. & Cost. \\
Straw & 15 & 13 & 0 & 0 & $\$ 18780$ \\
Hay & 2 & 15 & 0 & 0 & 8100 \\
\hline
\end{tabular}

Saving in using chopped fodder five moniths,

Total saving in using the straw-cutter nine months, viz. at Newburyport four montres

At salem five months

\section{$\begin{array}{r}38977 \\ 39120 \\ \hline\end{array}$ \\ Total, $\overline{678998}$}

The members of the board of trustees of the Massachusetts Agricultural Society, to whom the above account was communicated by Mr. Hale, were informed by that gentleman that he used no more grain from Oct., 1816, to April, 1817. than was used from April, 1816, to Oct., 1816.

At a late exhibition of the Philadelphia Agricultural Society, a premium was awarded for a new chaff or straw-cutter, invented by $\mathrm{Mr}$. C. T. Botts, editor of the "Southern Planter," published at Richmond, Va. The improvement upon other machines for a similar purpose consists chiefly in shortening the knives, which are not wider than a common carpenter's plane-iron, and like them can be easily ground and set. It is a self-feeder, the operator having nothing else to do but turn the crank. The inventor remarks, that many straw-cutters at present in use are sufficiently effective whilst in order, but from the difficulty of bringing them within the power of common management, they have generally been abandoned for the imperfeet cutters made by the commol blacksmiths of the country. The inventor therefore applied himself to the construction of an implement which, if less rapid in execution, would be more durable, and within the control of the simplest capacity. These are the strongest testimonials in favour of the ex. cellence of Mr. Butts's straw-cutter, the cost of which varies from $\$ 25$ for the smallest ir $\$ 30$ for the largest size.

An extensive farmer residing near Pbila- 
delphia, who enjoys a high reputation for his agricultural management, and especially for his success in feeding cattle, has returned to the common old cutting-knife and box, so.long used by the German farmers in Pennsylvania, an improvement of which is certainly a very efficient implement. He says that he has expended much money for what were pronounced the best patent straw-cutters, and finds it to his advantage to lay them aside and return to the old and simple machine, which costs but five or six dollars. He had not seen the machine invented by Mr. Botts.

CHALDRON. An English measure, containing 36 bushels, or 12 sacks of 3 bushels each.

CHALK (Sax. cealc; Welsh, calk; Celtic, cal or kal). The carbonate of lime, or lime united with carbonic acid. See Lime. Carbonate of lime exists abundantly in various parts of the earth's surface in the state of chalk, limestone, and marble; and in smaller masses, as the arragonite, \&c., of which between one and two hundred varieties (all carbonate of lime) are known to mineralogists. For the purposes of agriculture they may be all classed under one head. Common chalk has a dull white colour, is soft, adhesive when applied to the tongue, stains the fingers, and thence is in common use for marking. In European agriculture chalk is perhaps the most extensively employed of the limestone species; it varies slightly in composition, containing usually some silica (flint), alumina (clay), and some red oxide of iron, and the remainder carbonate of lime, 100 parts of which contain,

Carbonic acid - - _ - $\quad-\quad \begin{gathered}\text { Parts } \\ 45\end{gathered}$

Lime - - - - - - - 55

100 parts of common limestone are composed, according to MM. Thenard and Biot, of

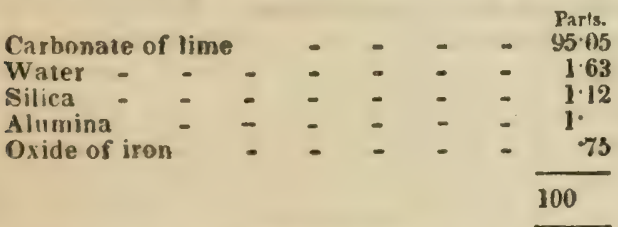

These carbonates, when burnt, form lime, for the heat drives off the carbonic acid. By exposure to the air the lime absorbs carbonic acid gas, and again becomes converted into carbonate of lime. A knowledge of these facts is of considerable value to the farmer even on the score of carriage, independent of the greater value of lime as a manure; for in some cases the object of the needless weight of water and carbonic acid in chalk is very material, as will be readily seen by the following analysis of the rhalk of Kent, which is the variety largely em. nloyed in the county of Essex, although it has .o be brought by sea nearly 70 miles, and then often carted several miles. I found by careful experiment 100 parts of chalk from Kent, in the state in which it was carted on the land in December, contained, besides some oxide of iron and silica.-

\begin{tabular}{|c|c|c|c|c|c|c|c|c|}
\hline t & & & & & & & & Parta \\
\hline Water & - & - & - & - & - & - & - & $24^{\circ}$ \\
\hline Carbonic & acid & & - & - & - & - & - & $34 \cdot 2$ \\
\hline Lime & - & - & - & - & - & - & - & $41 \cdot 8$ \\
\hline & & & & & & & & 100 \\
\hline
\end{tabular}

So that, when the farmer carts 41 tons of fresh lime, he conveys as much real manure to his soil as if he carried 100 tons of chalk. 'This must be assuredly a question of the highest importance to those farmers who have to carry the earth a considerable distance, especially if they can procure lime at a reasonable rate; which, in the large quantities required for agricultural purposes, must in most situations be the case.

Carbonate of lime is found in almost all vegetables; it is an essential food of plants. The cultivator will see, by the results of the experiments which I shall give under the head LIME, that the quantity of carbonate of lime contained in the cultivated grasses is very considerable, and still more so in trees; and that, as might be expected, the proportion increases with the quantity of this substance found in the soil. To the planter this fact offers an unanswerable reason in favour of the addition of chalk, marl, or limestone to all poor soils intended for plantations, in the manner long successfully practised on the black heathy sands of Norfolk by Mr. Withers of Holt, and which he has shown to be equally advantageous to trees, whether planted for ornamental or profitable purposes.

There is no fact more necessary to be un. derstood by the agriculturist, than that no land can be productive which does not contain a fair proportion of carbonate of lime. It is, perhaps, even in excess much less prejudicial to any cultivated soil than either silica or alumina. But, on the other hand, no soil can be productive if it contain more than nineteen parts in twenty of chalk. The earth of the fine sandy hop gardens near Tonbridge, in Kent, contain about five per cent. of chalk. The good turnip soils near Holkham, in Norfolk, are seven-eighths sand and the remaining eighth is composed of

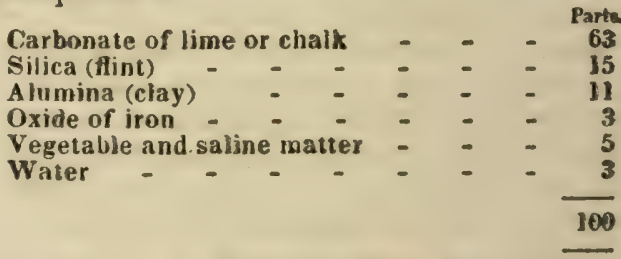

'The soil at Sheffeld Place, in Sussex, which is so admirably adapted for the growth of the oak, contains three per cent. of chalk. The fine wheat soils of West Drayton, in Middlesex, contain more than ten per cent. That of Bagshot Heath contains less than one per cent. The richest soils on the banks of the Parret, in Somersetshire, contain more than seventy per cent. Those of the valley of Evesham about six per cent. A specimen of a good soil from Tiviotdale, examined by Davy, was composed of five-sixths sand and the remainder of the following substances (Lectures, 202):-

\begin{tabular}{|c|c|c|c|c|c|c|c|}
\hline & & & & & & & Parts \\
\hline Clay & $-\quad-$ & - & - & - & - & - & -41 \\
\hline Silica & $(f \operatorname{lint})$ & - & - & - & - & - & -42 \\
\hline Chalk & - $\quad-$ & - & - & - & - & - & 4 \\
\hline Oxide & of iron & - & - & - & - & - & 5 \\
\hline Veget: & able an & & & & tatter & - & - \\
\hline
\end{tabular}

A soil yielding excellent pasture, from the banks of the Wiltshire Avon, near Salisbury, yielded the same chemist one-eleventh of jts 
weight of slliceous sand. The remainder was composed of

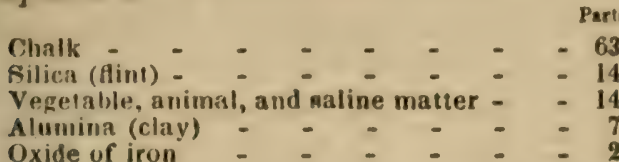

Many soils also contain a small proportion of carbonate of magnesia; but it very rarely amounts to a sufficient quantity to be worth estimating in the mode of analysis I shall presently give.

It is difficult to say in what form the carbonate of lime enters the system of plants, as it is an insoluble compound: unless we can suppose that it attracts an excess of carbonic acid from the air, becoming a bicarbonate, in which state it is soluble in water. But whatever may the cause of its being taken up by plants, its influence on soils is undoubted.

The mode of applying chalk as a manure. In the county of Essex, where chalking is practised to a very large extent, the chalk is brought in sailing barges from the Kentish shore of the Thames, at an expense of about two shillings per ton, and afterwards carted for some miles into the country. It is applied in quantities which vary from ten to thirty tons per acre, according to the description of the soil; the poor light soils requiring a larger addition of chalk than the richer lands. It is usually applied without any preparation; the larger lumps of chalk are not even broken, and the chalk being once ploughed in, the action of the frost, the plough, and the harrow, in time sufficiently pulverizes it. It is often mixed in smaller proportions with common farm-yard manure, ditch scrapings, pond mud, $\& c$., an! suffered to remain some time before it is carried into the field. An equally excellent plan is followed by some of the best Essex farmers, who spread quantities of chalk over head lands, banks, \&c., which require lowering, and then fallow those portions of land, ploughing them often, and letting the chalked earth remain as long as possible, incorporating before they carry and spread the mixed chalk and earth on to the field; by this means the effects of a few loads of chalk are diffused over a field. It is a plan admirably adapted for those situations where chalk is very expensive.

The good effects of chalk are more permanent than immediate; for, although a good dressing with chalk will remain in the soil for from ten to twenty years, yet, on some soils, one or even tuo years will elapse before the farmer perceives a decided improvement. 'There is hardly any manure that answers better for grass than chalk, especially on light, saridy soils. If, however, the soil already contains an abundance of chalk, its addition to that land cannot constitute a manure. The cultjvator can easily form a rough estimate of the quantity of chalk in a soil, by taking a quantity of it from three inches beneath the surface, well drying it in an oven, and adding to, say 400 grains, 800 grains of muriatic acid; the mixture, which weighs 1200 grains, will, if it contains chalk, effervesce; and the carbonic acid of the chalk being expelled, will, of course, lessen the weight of the mixture. When the effervescence has entirely ceased, weigh the mass; every $4 \frac{1}{2}$ grains deficient the experimenter may consider to indicate the presence of 10 grains of chalk in the soil. The agriculturist will then be able to judge, by comparing the quantity of chalk existing in the examined soils with that in other lands, the analyses of which I have given, whether his land requires the addition of chalk. In the United States chalk is nowhere found, and the lime applied to agricultural purposes, except it be in the form of gypsum or plaster of Paris, is obtained from burning limestone, marble. shells, either recent or fossil-and lastly from bones and calcareous deposits called marl. (C. W. Johnson's work On Fertilizers, p. 256 ; Brit. Farm. Mug. vol. iii. p. 129.)

CHAMPIGNONS (Agaricus orcudes). A species of mushroom, growing wild in Eng. land, having a much higher flavour than the common mushroom, but tough and leathery and consequently very indigestible. They are chiefly used for making catsup, or in the form of powder to flavour sauces, \&c., for all which purposes they are admirable.

CHAR. A species of lake trout found in Windermere; in length never exceeding fifteen or sixteen inches spotted like a trour, with very few bones. (Walton, p. 173.) It is also found in Loch Tay, in Scotland.

CHARBON. The little black spot or mark remaining after the large spot in the cavity of the corner tooth of a horse is gone.

CHARCOAL (From chark, to burn, and was formerly written charke coal). The remaining portion of wood after it has been heated to redness for some time, which dissipates all the hydrogen and oxygen of which, with carbon, it is composed. (See Carnor.) Charcoal. burning is a regular trade, followed in some of the woody districts by persons who do hardly any thing else.

For making gunpowder-charcoal, the lighte: woods, such as the willow, dogwood, and alder answer best; and in their carbonization care should be taken to let the vapours freely escape, especially towards the end of the operation, for when they are re-absorbed, they greatly impair the combustibility of the charcoal.

By the common process of the forests, about 18 per cent. of the weight of the wood is obtained; by the process of Foucauld about 24 per cent. are obtained, with 20 of crude pyroligneous acid of 10 degrees Baumé.

The charcoal of some woods contains silica, and is therefore useful for polishing metals. Being a bad conductor of heat, charcoal is employed sometimes in powder to encase small furnaces and steam-pipes. It is not affected by water; and hence the extremities of charred stakes driven into moist grounds are not liable to decomposition. In like manner casks when charred inside preserve water much better than common casks, because they fur. nish no soluble matter for fermentation or for food to animalcules.

Jowitz discovered that wood charcoal re. moves offensive smells from animai and vegetable substances, and counteracts thei- 


\section{CHARCOAL。}

putrefaction. He found the odour of succinic and benzoic acids, of bugs, of empyreumatic vils, of infusions of valerian, essence of wormwood, spirits distilled from bad grain, and sulphureous substances were all absorbable by freshly calcined charcoal properly applied. A very ingenious filter has been constructed for purifying water, by passing it through strata of charcoal of different fineness.

When charcoal is burned, one-third of the heat is discharged by radiation, and two-thirds by conduction.

The following table of the quantity of charcoal yielded by different woods was published by Mr. Mushet, as the result of experiments carefully made upon the small scale. He says, the woods before being charred were thoroughly dried, and pieces of each kind were selected as nearly alike in every respect as possible. One hundred parts of each sort were taken, and they produced as under :-

Jignum Vitæ afforded 26.0 of charcoal of a grayish coMahogany lour, resembling coke.

Laburnum

Chestnut

Oak

Inlly

Beech

Sycamore

Elm

Norway Pine -

Sallow or willow

Ash

Birch
Scotish Pine

25.4 tinged with

w, spongy velvet
hard. 23.2 glossy black, compact, firm. $22 \cdot 6$ black, close, very firm. 206 dull black, close, firm.

- 199 dull hlack, loose and bulky. - 19.9 dull black, spongy, tirm.

19.7 fine black, bulky, moderately firm.

- 19.5 fine black, moderately firm.

19.2 shining black, bulky, very soft.

- 18.4 velvet black, bulky, loose, and snft. 17.9 shining hiack, spongy, firm. 17.9 shining hlack, spongy, firm.
17.4 velvet black, bulky, firm.

16.4 tinged with brown, moderately firm.

Messrs. Allen and Pepys, from 100 parts of the following woods, obtained the quantities of charcoal as under :-

\begin{tabular}{|c|c|c|c|c|c|}
\hline Beech & & $15 \cdot 00$ & Oak & & \\
\hline tany & & 15.75 & Fir & - & \\
\hline Lignum Vita & - & $17 \cdot 25$ & Box & - & \\
\hline
\end{tabular}

It is observable that the quantities obtained by Messrs. Allen and Pepys are in general less than those given by Mr. Mushet, which may be owing to Mr. Mushet not having applied sufficient heat, or operated long enough, to dissipate the aqueous matter of the gaseous products.

To those persons who buy charcoal by weight, it is important to purchase it as soon after it is made as possible, as it quickly absorbs a considerable portion of water from the atmosphers. Different woods, however, differ iu this respect. Messrs. Allen and Pepys found, that by a week's exposure to the air, the charcoal of

\begin{tabular}{|c|c|c|c|c|c|}
\hline Lignun & m Vitæ & gained & - & - & $9 \cdot 6$ per cent. \\
\hline Fir & - & - & - & - & $13.0^{\circ}$ ditto. \\
\hline $\operatorname{Box}$ & - & - & - & - & -140 \\
\hline Beech & - & - & - & - & - 16.3 ditto. \\
\hline Dak & - & - & - & - & -16.5 \\
\hline Mahog & any - & - & - & - & -18.0 \\
\hline
\end{tabular}

The following is a tabular view of the voIumes of the different gases which were absorbed in the course of twenty-four hours, by une volume of charcoal, in the experiments of M. Theodore de Saussure, which were conductd in a wav likely to produce correct results.

\section{CHARCOAL.}

Each portion of charcoal was heated afresh to a red heat, and allowed to cool under mercury. When taken from the mercury, it was instantly plunged into the vessel of gas: Muriatic acid gas Sulphurous acid Sulphureted hydrogen

Nitrous oxyde

- 90 Bicarbureted hydrogen 3500 85 Carbonic oxyde - 9.42 65 Oxygen gas - - 925 - 7.50 Carbonic acid gas $\quad$ - 35. Hydrogen gas - - 1.75

(Ure's Dict. of Arts.)

In England charcoal is prepared in two different ways. In one, billets of wood are formed into a heap, which is covered with turf, and a few small openings only left for the admi;sion of the air requisite to maintain it in a state of low combustion after it is lighted. When the whole heap is on fire, the holes are stopped; and, after the mass has cooled, the residue is charcoal. In the other mode the wood is distilled in iron cylinders, in which case the products are pyroligneous acids, and empyreumatic oil; and what remains in the retort is charcoal. The quantity of the distilled products, as well as of the charcoal, depends on the kind of wood employed. 100 parts of dried oak yields, of

Pyroligneous acil Carbonate of potassa

Finpyreumatic oil -

Charcoal -

Parto
$-\quad 43$.
$-\quad 4.5$
$-\quad 9.06$
$-\quad 26.2$

The charcoal thus procured is lighter than common charcoal. Charcoal should be black, sonorous, brittle, and retain the texture of the wood. It has a powerful attraction for water, gases, and odorous and colouring principles. It is a powerful antiseptic, and well adapted for preserving animal substances from putrefaction. In fine powder it is much used as a tooth-powder, for which purpose, however, it is exceptionable, since, being insoluble, it gets between the teeth and gums and thus leads to their separation and much mischief.

Ivory, or bone black, is animal charcoal, prepared in the same manner as the second kind of vegetable charcoal. It has a remarkable property of abstracting colour from many vegetable solutions, on which account it is much used by sugar refiners.

"Plants," says Liebig, " thrive in powdered charcoal, and may be brought to blossom and bear fruit, if exposed to the influence of the rain and the atmosphere; the charcoal may be previously heated to redness. Charcoal is the most unchangeable substance known; it may be kept for centuries without change, and is therefore not subject to decomposition. The ouly substances which it can yield to plants are some salts which it contains, amongst which is silicate of potash. It is known, however, to possess the power of condensing gases within its pores, and particularly carbonic acid. And it is by virtue of this power that the roots of plants are supplied in charcoal exactly as in humus, with an atmosphere of carbonic acid an:- air, which is renewed as quickly as it is abstracte.?

"In charcoal powder, which hed been used for this purpose by Lukas for several years, Buchner found a brown substance soluble in alkalies. This substance was evidently due 
to the secretions from the roots of the plants which grew in it.

"A plant placed in a closed vessel in which the air, and therefore the carbunic acid, cannot be renewed, dies exactly as it would do in the vacuum of an air-pump, or in an atmosphere of nitrogen or carbonic acid, even though its roots be fixed in the richest mould.

"Plants do not, however, attain maturity, under ordinary circumstances, in charcoal powder, when they are moistened with pure distilled water instead of rain or river water. Rain water must, therefore, contain within it one of the essentials of vegetable life; and it will be shown, that this is the presence of a compound containing nitrogen, the exclusion of which entirely deprives humus and charcoal of their influence upon vegetation." (Liebig's Organic Chemisiry.)

"Dr. Webster, editor of the American edition of Liebig's Organic Chemistry, observes : - A few years since, I had an opportunity of observing a striking instance of the effect of carbonic acid upon vegetation in the volcanic island of St. Michael (Azores). 'The gas issued from a fissure in the base of a hill of trachyte and tuffa from which a level field of some acres extended. This field, at the time of my visit, was in part covered with Indian corn. The corn at the distance of ten or fifteen yards from the fissure, was nearly full grown, and of the usual height, but the height regularly diminished until within five or six feet of the hill, where it attained but a few Inches. This effect was owing to the great specific gravity of the carbonic acid, and its spreading upon the ground, but as the distance increased, and it became more and more mingled with atmospheric air, it had produced less and less effect."

CHARD. See Bret.

CHARLOCK (Sax. cenlice). Pl. 10 g. A troublesome weed, which abounds in most arable soils, and is very difficult to expel. In Eng. land it is frequently called chadlock, catlock, corlock, corn-loule, and white-rape. There are four diferent species of plants, says Sinclair, confounded under the name of charlock, viz. Sinapis arvensis, or common wild mustard; yellow blossom, in May; annual. S. nigra, black, or Durham mustard; blossom, pale yellow, in June; annual. Raphanus raphanistrum, wild radish; straw-yellow blossom, in June and July; annual. Brassica napus, wild navew (this last is the least common); yellow blossom, in May; biennial.

The seeds derived from the hard pods of the variety of the yellow-flowered charlock, called wild mustard, are collected in England and sold under the name of Durham Mustard. They furnish by expression an excellent oil, which it has been thought might be rendered profitable. In Germany 30 lbs. of pure lampoil has been obtained from 100 lbs. of seed.

Charlock has been introduced from Europe, and has become quite extensively naturalized in several parts of the United States. Being an annual plant it is very difficult to get rid of, and when once in possession of a spot will long bid defiance to all attempts made for its total extirpation. It infests clayey grounds, such as are particularly well adapted to the culture of wheat and other most valuable grains. Its seeds contain a preservative oil, which, with their great firmness enables them to remain sound under ground for an almust unlimited period. Those only which are brought by tillage within a certain distance of the surface, sprout and grow, whilst the deeper covered remain for the production of another crop when brought up by the plough sufficiently near the surface. The only practicable mode of eradicating this and other pests of annual growth, is to prevent the plants from coming to seed, by cutting down when in blossom. The greatest care should be taken to inspect seed. grain before sowing, and see that no seeds of charlock or other troublesome weeds are in the samples. The leaves, flowers, long, round and irregular seed-pods and odour of the roct are very similar to those of the common radish. Farm stock generally are fond of the plant, and especially sheep, which, when it is possible to turn upon the field sufficiently early, will keep it from growing up to seed.

In Ireland and the northern parts of Europe, as well as in some parts of America, young charlock is boiled for greens in the same manner as cabbage-sprouts, \&c. The flowers are much frequented by bees. (Wceds of Agriculture, p. 45; Smith's Florn, vol. iii. p. 321-6.)

CHARRING OF POSTS. The reducing that part of the surface of posts which is to be put into the ground to the state of charcoal. This method is highly useful where the parts are to be placed in wet situations, or to stand between wet and dry. 'This was a practice common to the ancients.

CHEAT AND CHESS. See Daryer.

CHEDDER CHEESE. A kind of cheese so named from its being made at Chedder, a village near the Mendip-hills in Somersetshire, famous for its pastures. The richness and fine flavour of Chedder cheese is supposed to be derived chiefly from a species of Agrostis upon which the cows feed.

CHEESE (Lat. caseus; Sax. cere). A wellknown kind of food, prepared from milk by coagulation, and separated from the serum or whey, by means of pressure, after which it is dried for use. See Butrar. Cheese has been made from a very ancient period; it is men. tioned by Job, and also by Homer. According to Strabo, our British ancestors did not understand how to make cheese, a deficiency with which their descendants cannot now well be charged.

Good cheese, says Dr. Thomson, melts at a moderate heat; but bad cheese, when heated, dries, curls, and exhibits all the phenomena of burning horn. From this it is evident that good cheese contains a quantity of the peculiar. oil of cream; hence its flavour and smell. Proust found in cheese a peculiar acid, which he called the caseic. (System of Chem.vol.iv. p. 499.)

The best season for making cheese is during those months when the cows can be fed on the pastures; that is, from the beginning of May till towards the end of September, or, in favour able seasons, the middle of October. In Eng land, on many of the large dairy tarms, in se

$$
2 \mathrm{D}
$$


veral disticts, cheese is frequently made throughout the year; but that made during the winter months is considerably inferior in qua. lity, and much longer in becoming fit for sale, or for use, than that which is made within the periods which have been just mentioned. In Gloucestershire, the season of making thin cheese is from April to November; but the principal one for making thick is during the months of May, June, and the beginning of July. If made late in the summer, the cheese does not acquire a sufficient degree of firmness to be marketable in the ensuing spring.

The milking in Cheshire, during the summer season is at six o'clock, both morning and evening; and in winter, at daylight in the morning, and immediately before dark in the evening. But in other districts, as Wilts, Suffolk, \&c., the people are frequently employed in milking by four o'clock in the morning in summer; and the business in a dairy of forty or fifty cows is nearly completed before the usual period at which it commences in Cheshire.

The colouring of cheese has been so long common in the cheese districts, that it is probable that cheese of the best quality would be in a great measure unsaleable if it did not possess the requisite colour. The degree of colour is regulated chiefly by the name under which it is intended the cheese should be sold, as Gloucester, Cheshire, \&c. The object of the introduction of this practice was no doubt to convey an idea of richness which the cheese did not really possess. This is the more evident, as it is universally allowed that the poorest cheese always requires the greatest quantity of dye to bring it to the proper degree of colour. The material which is employed for this purpose is the Spanish annotta. (See Anvotra.) The weight of a guinea and a half of it is considered in Cheshire sufficient for a cheese of 60 lbs.; and in Gloucestershire an ounce is the common allowance to $1 \mathrm{cwt}$.

In regard to the rennet, it may be observed, that milli may be coagulated, or curdled, by the application of any sort of acid; but the substance which is most commonly used is the maws or stomachs of young calves prepared for the purpose. These are most generally denominated rennels; but they are also often provincially called vells, and in Scotland yearnings. See Rennet.

In Cheshire, after the rennet is added to the milk, and as soon as the curd is firm enough to discharge its whey, the dairy woman plunges her hands to the bottom of the vessel, and, with a wooden dish, stirs the curd and whey; then lets go the dish, and by her hand agitates the whole, carefully breaking every part of the curd; and, at intervals, stirring it hard to the bottom with the dish, so that no curd remains unbroken larger than a hazel-nut. This is done to prevent what is called slip-curd, or lumps of curd, which, by retaining the whey, do not press uniformly with the other curd, but in a few days, if it happens to be situated lowards the rind of the cheese, turns livid and jelly-like, and soon becomes faulty and rotten. In a few minutes the curd subsides. The dairy-woman then takes her dish, and lades off the whey into a milk-lead to stand for cream, to be churned for-whey-butter. This is a prac. tice peculiar to the cheese counties. In Nor. folk the whey, even from new milk, passes from the cheese-vessels immediately to the hog. tub. Having laded off all the whey she can, she spreads a straining cloth, and strains the whey through it, returning the curd retained in the cloth in to the cheese-tub. When she has got all the whey she can by pressing the curd with her hand and the lading-dish, she takes a knife and cuts it into square pieces of about two or three inches. This lets out more of the whey, and makes the curd more handy to be taken up in order to be broken into the vats.

Having made choice of a vat or vats proportioned to the quantity of curd, so that the cheese when fully pressed shall exactly fill the vat, she spreads a cheese-cloth loosely over the mouth of the vat, into which she rebreaks the curd, carefully squeezing every part of it in her hands; and having filled the vat heaped up, and rounded above its top, she folds over it the cloth and places it in the press, on the construction and power of which much depends.

When the vat is properly placed in the press, the ordinary degree of pressure is applied, which is more or less, according to the sizes of the cheeses usually made. At all large dairies, there are two or three presses, all varying in respect to weight or pressure. There are various kinds of cheese-presses; one made entirely of iron by the Shotts Foundry Company is described in the Trans. High. Soc. vol. iv. p.52. As soon as the vat is placed in the press, and the weight applied, skewers are thrust in through the holes in the side of the vat; this is done repeatedly during the first day when the vat is in the press. From the time the vat is first placed in the press till it is again taken out does not, in ordinary cases, exceed two or three hours. When taken out, the cheese is put into a vessel with hot whey, with a view of hardening its coat or skin, where it stands for an hour or two: it is then removed, wiped dry, and after having remain. ed some time to cool, is covered with a clean cloth; and the vat being wiped dry, and the cheese replaced, it is again put into the press. In the evening, supposing the cheese to have been made in the morning, which is the usual time, it is again taken out of the vat; and another dry cloth being applied, it is turned and replaced; what was formerly the upper becoming now the under side. In this manner it is taken out, wrapped in clean cloths, and turned in the val twice a day for two days, when it is finally removed.

The salting is the next operation. The cheese, on being for the last time taken out of the vat, is carried to the salting-house, and placed in the vat in a tub filled to a consider. able depth with brise, in which it stands for several days, being regularly turned once at least every day. 'The vat is then removed from the brine-tub; and the cheese being taken out, is placed on the salting-bench, where it stands for eight or ten days, salt being carefully rubbed over the whole every day during the periol. When the cheese is of a large size, it is com- 
monly surrounded with a wooden hoop or fillet of cloth to prevent renting. After it is supposed to be sufficiently salted, it is washed in warm water or whey, and when well dried with a cloth, is placed on what is called the dryingbench, where it remains a like period before it is removed to the keeping-house or cheesechamber.

The last part of the business is the management in the cheese-room. In Gloucestershire the young cheeses are turned every day, or every two or three days, according to the state of the weather, or the fancy or judgment of the dairywoman. If the air be cold and dry, the windows and door are kept shut as much as may be; if close and moist, as much fresh air as possible is admitted. Having remained about ten days in the dairy (more or less, according to the space of time between the washings), the cheeses are cleaned; that is, washed and scraped.

The produce of a dairy of cows, where the milk is converted into cheese, is very variously stated by different writers. In some districts $2 \frac{1}{2} \mathrm{cwts}$. from each cow, whether a good or a bad milker, if at all in milk, is considered a good return. In others, the average runs as high as $3 \mathrm{cwt}$.; and in the county of Wilts in particular, from $3 \frac{1}{2}$ to $4 \mathrm{cwts}$. is the usual quantity. From accurate calculations made by Mr. Marshall, and these several times repeated, he found that in Gloucestershire about 15 gallons of milk were requisite for making little more than $11 \mathrm{lbs}$. of two-meal cheese, and that one gallon of new milk produced a pound of curd. It is the general opinion of dairy farmers that the produce from two and a half to three and a half acres is necessary to maintain a cow all the year round. Taking, therefore, the medium of the three averages of cheese above mentioned (amounting to $355 \mathrm{lbs}$. from each cow), the quantity of cheese by the acre is $118 \mathrm{lbs}$. Every calculation of this kind must, however, be extremely vague and uncertain. See Darry.

In the making of Parmesan cheese, we are informed by Mr. Price, in the Papers of the Bath and W. Engl. Society (vol. vii.), that the method is "to put, al ten o'clock in the morning, five brents and a half of milk, each brent about forty-eight quarts, into a large copper, which turns on a crane over a slow wood fire, made about two feet below the surface of the ground; the milk is stirred from time to time, and about eleven n'clock, when just lukewarm, or consiferably under a blood-heat, a ball of rennet,

hig as a large walnut, is squeezed through a cloth into the milk, which is kept stirred. By the help of the crane the copper is turned from nver the fire, and left till a few minutes past twelve; at which time the rennet has sufficiently operated. It is now stirred up, and left for a short time. Part of the whey is then taken out, and the copper again turned over a fire sufficiently brisk to give a strongish heat, but below that of boiling. A quarter of an ounce of saffron is now put into the milk to give it a little colour; and it is well stirred from time to time. The dairy-man frequently feels the curd. When the small, and, as it were, granulated parts, feel rather firm, which is in about an hour ard a half, the copper is taken from the fire, and the curd left to fall to the bottom. Part of the whey is taken out, and the curd brought up in a coarse cloth, hanging together in a tough state. It is then put into a hoop, and about a half hundred weight laid upon it for about an hour; after which the cloth is taken off, and the cheese placed on a shelf in the same hoop. At the end of two, or from that to three days, it is sprinkled all over with salt; the same is repeated every second day for about forty or forty-five days, after which no further attention is required. While salting, they generally place two cheeses one upon another; in which state they are said to take the salt better than singly. The country between Cremona and Lodi, says Mr. Evans, comprises the richest part of the Milanese. The irrigation, too, is brought to the highest degree of perfection; the grass is cut four times a year as fodder for the cows, from whose milk is made the well-known Parmesan cheese. The cows, which are kept in the stall nearly all the year round, are fed during summer on two of these crops of grass or clover, which are cut green; and in the winter on the other two, which are hayed. The milk of at least fifty cows is required for the manufacture of one Parmesan cheese. Hence, as one farm rarely affords pasture for such a number, it is usual for the farmers or metayers of a district to club together. (Quart. Journ. of $A g r$. vol. v. p. 622.)

Cream cheese is made in various places; but that which is generally known by the name of Stilton is made in Leicestershire, in the follow. ing manner, according to the Agricultural Report of that county:-The night's cream is put into the morning's new milk with the rennet; but when the curd is come it is not broken, as is done with other cheeses, but is taken out with a soildish altogether, and placed in a sieve to drain gradually; and, as it drains, it is pressed, till it becomes firm and dry; being then placed in a wooden hoop, and afterwards kept dry on boards, it is turned frequently, with cloth binders round it, which are tightened as occasion requires. Cream cheese of good quality is likewise made, in some districts, by adding the cream of one meal's milk to the milk which is immediately taken from the cow. This, after being made and pressed gently two or three times, and carefully turned for a day or two, is fit for use.

Since the late reduction of duties in England upon provisions introduced from abroad, cheese has been among the articles extensively shipped from the United States to that country, where the complaint against American cheese is, that it is generally insufficiently pressed, a fault which gives it, when cut, a porous or honeycomb appearance. Its flavour is also rendered unpleasant by the tno free use of rennet. The removal of these defects would very much enhance the value of American cheese both at home and abroad. Nevertheless, cheese of excellent qualities as to richness, flavour, and other requisites, is made in the northern portions of the Middle and Western States and throughou . New England. See Dainx. 
Pine apple Cheese.-E. Perkins, of Herkimer county, New York, a fine dairy district, gives the following description of the mode of making those cheeses moulded in the pine-apple form. These weigh from 7 to 8 lbs., and are chiefly made in the small dairy establishments. The cheese-making process, until fit for the press, is pretty much like that usually pursued in unaking common cheeses. Some add a little more salt. The pressing is performed in wooden blocks, griped together, and, after this process, the cheeses are suspended in nets, till so hardened as to stand on a trencher made for the purpose, where they remain till fit for market. This kind of cheese is chiefly made under contract. If the purchaser finds the pressers, nets, and trenchers, the price is from 7 to $7 \frac{1}{2}$ cents per $1 \mathrm{~b}$. When the maker finds every thing he gets about 8 or 9 cents per $1 b$. In the preparation of pine-apple cheese, more allowance is made for shrinkage than in the manufacture of common cheese. (Farmer's Instructor.)

All new cheeses require to be well dried to fit them for the market, and when taken out of the moulds must be laid upon a shelf and turned every day for some time. This operation was formerly done by hand, which proved very laborious. But contrivances have been invented by which the work can now be done very quickly and without the least exertion of strength. Some of these will be found mentioned under the head Dairx.

After the cheeses have passed through the different processes, and the drying is completed, they are to be deposited in the cheese or store-room. This should be dry and airy, and the hard and soft cheeses ought not to be kept in the same room. In some of the best dairy districts in the United States, it is thought best not to darken the cheese rooms, or attempt to keep out the flies, but in hot, sultry weather, the doors and windows are opened to admit the air freely. Cool dry air blowing directly upon the cheeses, is apt to crack them. These cracks are to be filled up with pepper, either black or cayenne. To mature cheese fast, the nom should be kept warm in the fall and spring.

We learn from the Transactions of the Highland Agricultural Society in Scotland, that the ilavour of an old cheese may be communicated to a new one of whatever species, by the insertion of some portions of the old into the new cheese. Small pieces are to be extracted with a sample-scoop from each cheese, and those taken from the old are to be inserted into the new, and those from the new put into the old. After this interchange, the new one, if kept well excluded from the air, will, in a few weeks, become thoroughly impregnated with the mould, and have a flavour hardly to be distinguished from the old one. The cheese selected must be dry, and the blue mould should be free from any portion of a more decaved appearance.

A great variety of cheeses are made in owitzerland, the most celebrated of which are the Schabzieger, (or sap-sago as we commonly call it.) and the Gruyere. Of the quantity of cheeses exported from Switzerland, we have no information that can be relied upon; but it is computed that $30,000 \mathrm{cwt}$. of Gruyère cheese alone, fit for exportation, is annually made; and that, from the middle of July to October, 300 horses, weekly, are employed in transporting Swiss cheese over Mount Grias. (For. Rev. and Cont. Misc.)

"The Schabzieger cheese is made by the mountaineers of the canton of Glarus alone; and, in its greatest perfection, in the valley of Kloen. It is readily distinguished by its marbled appearance and aromatic flavour, both produced by the bruised leaves of the melilot. The dairy is built near a stream of water; the ves. sels containing the milk are placed on gravel or stone in the dairy, and the water conducted into it in such a manner as to reach their brim. The milk is exposed to the temperature of about six degrees of Reaumur (forty-six degrees of Fahrenheit), for five or six days, and in that time the cream is completely formed. After this it is drained off, the caseous particles are separated, by the addition of some sour milk, and not by rennet. The curd thus obtained is pressed strongly in bags, on which stones are laid; when sufficiently pressed and dried, it is ground to powder in autumn, salted, and mixed with either the pressed flowers, powdered and sifted, or the seeds of the melilot trefoil (Melilotus officinalis, Pl. 10, $f$ ). The practice of mixing the flowers or the seeds of plants with cheese was common among the Romans, who used those of the thyme for that purpose. The entire separation of the cream or unctuous portion of the milk is indispensable in the manufacture of Schabzieger. The un prepared curd never sells for more than three halfpence a pound; whereas, prepared as Schabzieger, it sells for sixpence or seven-pence. (For. Rev, and Cont. Misc.)

"The Gruyere cheese of Suitzerland is so named after a valley, where the best of that kind is made. Its merit depends chiefly on the herbage of the mountain pastures, and partly on the custom of mixing the flowers of bruised seeds of Melilotus officinalis with the curd, before it is pressed. The mountain pastures are rented at so much per cow's feed from the 15 th of May to the 18th of October; and the cows are hired from the peasants, at so much, for the same period. On the precise day both land and cows return to their owners. It is estimated that 15,000 cows are so grazed, and $30,000 \mathrm{cwt}$. of cheese made fit for expurtation, besides what is reserved for home use.

"Ewe-milk cheese of Surizerland. One measure of ewe's milk is added to three measures of cow's milk; little rennet is used, and no acid. The best Swiss cheese of this kind is made by the Bergamese sheep-masters, on Mount Splugen." (For. Rev. and Cont. Misc.)

Sage Cheese, an humble imitation of the Swiss green cheese much relished in some parts of the United States. "To make this cheese, take the tops of young red sage, and having pressed the juice from them by beating in a mortar, do the same with the leaves of spinach, and then mix the two juices together. After putting the rennet to the milk, pour in some of this juice, regulating the quantity by the degree of 
CHEESE CLOTHS.

colour and taste it is intended to give the cheese. As the curd appears, break it gently, and in an equal manner, then emptying it into the cheese vat, let it be a little pressed, in order to make it eat mellow. Having stood for about seven hours, salt and turn it daily for four or five weeks, then it will be fit for the table. The spinach besides improving the flavour, and correcting the bitterness of the, sage, will give it a much more pleasing colour than can be obtained from sage alone."

Cream Cheese.-Excellent creain cheeses are sixplied to the Philadelphia market by the ueighbouring Pennsylvania farmers. They are round, generally from six to ten inches in diameter, and about one inch thick. The mode of preparing cream cheese is as follows. Expose cream to the air and it will be found to grow thick gradually, so that in three or four days the vessel containing it may be turned upside down without loss. In eight or ten days more, its surface will become coated over with a kind of mucus and a woolly moss or byssi. After this, it no longer retains the flavour of cream, but of a very fat cheese. 'This rich dainty differs from butter in containing both curd, and scrum or whey, together with the oily matter; whereas in butter the oil is obtained separate from the whey and curd or cheesy matter.

Another mode of making cream cheese is the following, given by the late Judge Cooper, whose endorsement makes it worthy of the highest credit. "Take of the top or surface cream that has been collected for three or four days in the cream-croak so as to be slightly acid, one pint: on each of two common plates lay a dry napkin four-doubled: put half a pint of cream on each napkin. Next day have ready another plate covered with a folded wet napkin, turn the two cheeses one on top of the other upon the wet napkin, cover them over with the ends of this wet napkin, and change it every day for a week till the cheese is ripe. It must not be done in a cellar or damp place, but in a room, otherwise it will mould."

In Lincolnshire, England, as well as in the neighbourhoods of Bath and York, rich and excellent cream cheeses are made. These, like all such kind of soft and rich cheeses, are used when but a few days old, to be eaten with radishes, salad, \&c.

For the mode of preparing the celebrated Stilton cream cheese see p. 315.

There are papers, by Mr. P. Miller, "On making cheese resembling that of Gloucester and Wiltshire" (Trans. High. Soc. vol. iii. p. 228 ) and "In Imitation of Double Gloucester," by Mr. Bell (Ibid. vol.i.p. 155); and "On communicating the Flavour of old to new Cheese by Inoculation," by Mr. Robinson (Ibid. p. 232). "On making Cheese from Potatoes in Thuringia." (Farmer's Mag. vol. viii. p. 14.)

CHEESE CLOTHS are large towels to put inside the chessel or vat, while the cheese is pressing. They are of home manufacture, and should be of strong and open texture : every time they are used for this purpose, they should be wrung out of boiling water, and dried in the sun, or before the fire.
CHEESE-PRESS.

CHEESE COI.OURING. Sec Arrotra.

CHEESE-FLY and MAGGO'T (Piophila cre sei). The small white larva found in ols and putrescent cheese, produce a small twcwinged fly, about two lines in length, which has a greenish-black, smooth, and shining body. It is fully described in the Quart. Jurn. of $A g r$. vol. xii. p. 125.

Dr. Harris describes the cheese-maggots found in Massachusetts as the young of a fly (Piophila casei) not more than three-twentieths of an inch long, of a shining black colour, with the middle and hinder legs mostly yellowish, and the wings tranapsrent like glass. See his Report, \&c.

CHEESE-KNIFE. A large sort of knife, or spatula, made use of in dairies for the purpose of cutting or breaking down the curt whilst in the cheese-tub.

CHEESE-LEP. The bag in which dairywomen keep the rennet for making cheese.

CHEESE-MITES. This is the Acarus siro, an almost microscopic apterous insect, furnished with eight legs, on the four first of which, between two claws, is a vesicle with a long neck, to which the insect can give every kind of inflexion. "When it sets its foot down, it inlarges and inflates; and when it lifis it up, it contracts it, so that the vesicle almost entirely disappears." (De Geer, quoted by Kirby, vol. xxxiv. p. 321.) It is not possible to say how this insect gets into cheeses. The brown powder, so valued by epicures, in which the mites live, is their excrement.

CHEESE-PRESS. A press employed in cheese dairies, to force the whey from the cur i when in the cheese vat.

Cheese presses are of different forms. The most simple and primitive press is merely a long beam, one end of which is placed in a hole of the wall, and frequently it is fixed to a bolt, or in the trunk of a tree. The sinker forms the fulcrum, a weight consisting of two or three undressed stones being placed on the other end of the lever. A second kind is formed by a large square stone, suspended by a screw between the side posts of a timber frame. The chessel is placed underneath it, and the stone is lowered upon the sinker by turning the screw to the left hand. The cineese vat is removed at pleasure by turning the screw to the right hand, which elevates the stone. To preserve the screw, a small block of timber is placed underneath the stone during the period that cheese-making is suspended.

Another kind of press consists of a timber frame formed of two perpendicular side posts and a cross top with a parallel beam, which is suspended from the top by two screws. The cheese vat is placed upon the beam, which is lifted up when the screws are turned to the right hand; and the sinker of the chessel or vat being pressed against the cross top, squeezes or stanes the cheese. When the chessel re. quires to be removed, the screws are turned to the left hand.

But more complicated presses, and therefore in many instances more convenient, can be adopted. The most complete, effective, and approved press consists of a frame of cast iron with a perpendicular piston, flat below to cover 2 D 2 317 
the sinker of the chessel. The piston is raised or depressed by a small pinion attached to a ratchet wheel and malleable iron lever, three ieet in length. The lever is grooved in several places on the upper side to hold the ring of the weight for increasing or diminishing the power, in proportion to its distance from the ratchet wheel. The weight of this press is about two stone, cost $1 l$. $4 s$. pressure 20 tons. (Martin Doyle's Pract. Husb.; Prof. Lowe's Elem. of $\mathcal{A g r}$.) See Dain $\mathbf{x}$.

CHEESE RENNET, or YELLOW BED. STRAW (Galium verum), is a perennial plant, common in waste places and the borders of fields, flowering in July and August. The stem, which is woody and much branched, rises eighteen inches, and sends off, in the same plane, narrow, deep green, deflexed .eaves, rough with minute points, each tipped with a hair. The flowers are golden yellow, in dense tufted panicles, and smell strongly of honey in the evening and before rain. The flowers of this weed were formerly used in Cheshire for curdling milk. (Paxton's Bot. Dict.; Smith's Eng. Flor. vol. i. p. 208.)

CHELIDONIUM. From cheledon, a swallow; it being said to flower at the arrival and wither at the departure of the swallows. See CenanIINE.

CHELONE (Chelone barbata. From chelone, a tortoise; to the back of which the helmet of, the flowers is fancifully compared). Known in Pennsylvania and other Middle States by the names of Shell-flower, and Snake-head. This plant is a native of North America, and a hardy perennial; blowing beautiful red flowers in July and August. It loves shade and mois. ture, and grows three feet high. The white chelone is hardy, and likes any soil. The downy chelone blows a flower which is yellow inside, and light purple outside. It is propagated by seed, and by separating the roots in autumn. It belongs to a hardy herbaceous genus, that ought to have a place in every collection: the species succeed well in a mixture of peat and loam. (Paxton's Bot. Dict.)

CHEMISTRY. The importance of this science to the agriculturist no intelligent modern farmer will doubt. Its triumphs in the cause of the cultivator have been far too many for him to hesitate in acknowledging the obligation. I have, in this work, under the heads Earths, Avalysis of Soils, Gases, Water, Salts, Organic Chemistrx, \&c., endeavoured, to the best of my power, to illustrate some of the many chemical facts on which the successful practice of agriculture depends; and to these I must refer the farmer. Most of the substances belonging to our globe, says Davy, (Chem. Philosophy, p. 1), are constantly undergoing alterations in sensible qualities, and one variety of matter becomes, as it were, transmuted into another. Such changes, whether natural or artificial, whether slowly or rapidly ferformed, are called chemical; thus, the gradual and almost imperceptible decay of the leaves and branches of a fallen tree exposed to the atmosphere, and the rapid combustion of wood in our fires, are both chemical operations. The object of chem.cal philosophy is to ascertain the causes of all phenomena of this kind, 318 and to discover the laws by which they are governed. The ends of this branch of know. ledge are the applications of natural substances to new uses, for increasing the comforts and enjoyments of man; and the demonstration of the order, harmony, and intelligent design of the system of the earth. The foundations of chemical philosophy are observation, experiment, and analogy. By observation, facts are distinctly and minutely impressed on the mind. By analogy, similar facts are collected. By experiment, new facts are discovered; and, in the progression of knowledge, observation, guided by analogy, leads to experiment; and analogy, confirmed by experiment, becomes scientific truth. To give an instance,-whoever will consider with attention the slender green vegetable filaments (Conferva rivularis) which in the summer exist in almost all streams, lakes, or pools, under the different circumstances of shade and sunshine, will discover globules of air upon the filaments exposed under water to the sun, but no air on the filaments that are shaded. He will find that the effect is owing to the presence of light. This is an observation; but it gives no informa. tion respecting the nature of the air. Let a wine-glass filled with water be inverted over the conferva thus acted upon by the light. The air-bubbles, as they rise, will collect in the upper part of the glass; and, when the glass is filled with air, it may be closed with the hand, placed in its usual position, and an inflamed taper introduced into it: the taper will burn with more brilliancy than in the atmosphere. This is an experiment. If the phenomena are reasoned upon, and the question is put, whether all vegetables of this kind, in fresh or in salt water, do not produce such air under like cir. cumstances, the inquirer is guided by analogy; and, when this is determined to be the case by new trials, a general scientific truth is established,-that all confervæ in the sunshine produce a species of air (oxygen gas) which supports flame in a superior degree: a fact which has been shown to be the case by various minute investigations.

By such researches the chemist ascertains the composition and uses of the various other gases, and also of the earths, metals, and salts, of which the materials of the earth we inhabit are composed; delightful inquiries, which will well repay the cultivator in more ways than one for the labour he may bestow upon them. 'They will speedily teach him that nothing in this world of ours is ever lost or destroyed; that the decaying materials of his most noisome manures speedily again make their appearance in new forms, and in salubrious and fragrant plants; that the expired breath of himself and his live-stock is the inhaled food of all vegetation; and that vegetables purify the very air which animals have vitiated. And again, the correct rotation of crops, the use of permanent or earthy additions to the soil, (which see), the fattening of live-stock, the origin of diseases, are a few only of the facts connected with the cultivation of the soil which the chemist's operations illustrate. "The nature of soils" (as it is remarked by Mr. G. W. Johnson), "of manures, of the food and functions of plants, 


\section{CIEMISTRY.}

would all be unknown but from the analyses which chemists have made." We know that every plant has a particular temperature in which it thrives best, a particular modification of food, a particular degree of moisture, a particular intensity of light ; and those particularities vary at different periods of their growth. It is certain that plants are subject, like all other organized bodies, to various influences. Acids are injurious to some, alkalies to others; the excess of some of their constituents, and the deficiency of others, insure disease to the plants to which such irregularities occur. Disease is accompanied by decay more or less extensive and rapid; and if these cannot be checked by salutary applications and treatment, death ultimately ensues. Now, if it was possible for any science or sciences to teach the cultivator of plants how to provide for them all the favourable contingencies, all the appropriate necessaries above alluded to, and to protect them from all those which are noxious to them, the art of cultivation would be far advanced to perfection. Such sciences are botany and chemistry. It is not asserted that they can, at present, do all that is desired of them,-all of which they are capable; but they can do much. As evidence of what can be effected by a combination of chemical and practical knowledge in the cultivation of the soil, we may quote the example of Lavoisier. He cultivated 240 acres in La Vendée, actuated by the beneficent desire of demonstrating to his countrymen the importance of sustaining the art of cultivation on scientific principles. In nine years his produce was doubled, and his crops afforded one-third more than those of ordinary cultivators. It is unnecessary to dwell upon the importance of such improvements. Science can never supersede the use of the dunghill, the plough, the spade, and the hoe; but it can be one of their best guides, -it can be a pilot even to the most experienced. (Baxter's Lib. of $A g r$.; Gard. Mag. vols. iii. and iv.; Davy's Chem. Phil.; Leibig's Organic Chemistry.)

So many important, facts bearing upon agricultural subjects have been discovered of late years through chemical experiments and researches, as to render it imperative upon every well-instructed farmer to make" himself acquainted with them. It has long been known to common observers, that certain crops will grow in some situations and not in others, and that after having flourished in a place for a considerable period, crops will decline in quality and quantity, and finally cease to compensate for the expenses of seed and tillage. That certain kinds of manure are most beneficial to some soils and plants, whilst another produces the best effects upon others. But the causes operating in the production of such effects have not been understood, and hence, great waste of means and labour have resulted in experiments often useless, for want of that chemical knowledge through which the precise defects of the soil could be detected and the deficiencies directly supplied.

Agricultural chemistry points out the respective elements entering into the formation of plants, and even those required at each stage of the : growth from germination to the perfec.
ChERRY TREE.

tion of the seed or fruit. It shows which of these elements are absorbed from the gases of the atmosphere, and what saline and other materials are furnished by the soil. 'The seed itself, like the egg, contains the first supply of nourishment for the roots of the infant germ of the plant. To assist its first growth before it rises above ground, the humus of the soil supplies carbonic acid, and the looser the soil the more of this essential food for the young plant can be retained. When it rises above the surface, and its stems and leaves are fully developed, its main, and, according to Liebig and others,-its entire dependence for nourishment, is upon the atmosphere. Chemistry points out the different gases which plants ab. sorb from the atmosphere or the soil in the progress of their growth. It also shows that plants have other constituents, such as potash, soda, lime, magnesia, \&c., without which, in due quantities, they cannot come to perfection. The proportions of these, though often very minute, are all important. The chemical processes described for analyzing soils, will show what elements for the growth of plants are present and what are wanting. Knowing this, the object of the skilful farmer will be to supply the deficiencies, in a way the most acceptable to plants. Some crops may be repeated on the same soil more frequently than others, because some consume more of the alkalies than others. One hundred parts of the stalks of wheat yield 15.5 parts of ashes. The same quantity of barley, 8.54 parts; and of oats, only 4.42 parts Thus, as the demands of each of these plant: for the alkaline elements of their growth is different, one may be raised on ground which has ceased to produce the others; and this is what is daily witnessed,-land, refusing to yield wheat, and yet affording good crops of barley and oats;-and when ceasing to yield compensating crops of wheat and barley, stil. affording excellent crops of oats, the proportion of alkali required by which is so comparatively small compared with the demands of the wheat-crop. How readily, then, may a good soil for oats be rendered productive in wheat by the simple addition of some alkaline dressing, all the other requisites of fertility having been before present. Chemistry teaches that the salts and other organic constituents removed from soils in the crops, is returned in the dung of animals fed upon such crops. It teaches the precise proportions of these, and explains the well-known facts, - that the excrements of some animals, such as man, are more fertilizing than those of others; that those of men living upon animal food are stronger than those of men confined to vegetable focid. All these matters may be found explained under the different heads of Animal Manures, Ammonia, Nitrogen, \&c. Men of science engaged in these useful subjects of investigation, are every day unfolding new and important facts, and what at one time was regarded as inscrutable mystery becomes so well under stood as to be comprehended by a child.

CHERRY TREE (Prunus C'erasus). It de rives its name from Cerasus, a city of Pontus, whence the tree was brought by Lucullus, about half a century before the Christian era. 
It soon after spread into most parts of Europe, and is supposed to have been carried to Britain about a century after it came to Rome. The cherry is pretty generally cultivated throughout the kingdom, as an agreeable suinmer fruit. 'The varieties are very numerous. The Horticultural Society's Catalogue embraces 246 ; but the following list is recommended by Mawe, as containing the best varieties for general cultivation, the whole being arranged in the order in which they ripen in England:- June: Early May, May Duke, Knight's Early Black, and Late Duke. July: Archduke, Black Tartarian, White Tartarian, Black Eagle, Kentish, Bigarreau, Holmon's Duke, Elton, Herefordshire Heart, Bleeding Heart, Carnation, and Waterloo. August: Harrison's Heart, Black Heart, Waterloo, Couronne, Lukeward, Black Geen, Small Black, Small Red Wild, White Swiss, Lundie Geen, Transparent Geen, Cluster, Yellow Spanish. September: Florence, Amber Heart, Flemish Heart, Red Heart, White Heart. October: Morello or Milan. For small gardens, either as wall trees, espaliers, or standards, the following varieties are recommended:-The May Duke, Morello, Archduke, Black Heart, White Heart, Bigarreau, Harrison's Heart, and Kentish Cherries. Miller considers the common Red or Kentish, the Duke, and the Lukeward as the best trees for an orchard; they are plentiful bearers. This tree prefers a light dry sandy loam, with a free exposure. The wood of the cherry tree is close, takes a fine polish, and is not liable to split. It is used in the manufacture of chairs, musical instruments \&c., and stained to imitate mahogany. The principal supplies of cherries for the London market are brought from the cherry orchards in Kent and Herts. The wild cherry tree is found frequently in the woods and hedges of England, and has round branches with a polished ash-coloured bark. The leaves, in all the varieties are simply folded flat while young, by which cherries differ from the Bullace tribe. (Phil. Hist. Fruits, p. 76; Willich's Domestic Encyclopodia; M'Culloch's Commercial Dictionary; Baxter's Library of Agriculture; Smith's Eng. Flora, vol. ii. p. 354; American Orchardist's Companion; Kenrick's New American Orchardist, \&c.)

CHERRY, WILD. Several kinds of wild cherry are found in the United States, and Michaux describes the following species.

Red Cherry Trce (Cerasus borealis). Red cherry. Small cherry; common only in the Northern States, (ineuding the highlands in the northern parts of Pennsylvania), in Canada, New Brunswick, Nuva Scotia. The tree attains a height of twenty-five or thirty feet, with a diameter of five or six inches. Flowers are collected in small white bunches, and the fruit, which is of a bright red colour, considerable size, and intensely acid taste, ripens in the month of July. The wood is fine grained and of a redish hue, but its inferior size limits its use in the mechanical arts. This species of cherry tree offers the same remarkable peculiarity with the canoe birch of reproducing itself, as it were, spontaneously in cleared grounds, and in such forests as have bcen 320 burnt, which is observable in spots where fire has been kindled by travellers. Of all the native species of North America, Michaux thinks the red cherry tree bears the greatest analogy to the cultivated cherry tree of Europe, and hence the most proper for receiving grafts, though it has been found difficult to make the grafts succeed.

Wild Cherry (Cerasus Virginiana). This is one of the largest productions of the American forests. Its wood is of an excellent quality and elegant appearance, and is usefully em. ployed in the arts. In Maine, where the winter is long and intense, it hardly exceeds thirty or forty feet in height, and eight to twelve inches in diameter; in the southern and maritime parts of the Carolinas and of Georgia, where the soil is arid and sandy, it is rarely seen, and even when found on the banks of rivers its growth is stinted. A milder climate and more fertile soil favour its growth, and it abounds in Virginia, Pennsylvania, and all the Atlantic States, and also in Western New York, and Illinois, uniting with the overcup white oak, black walnut, honey locust, red elm, and coffee tree of the forests covering the fertile regions of the West. On the banks of the Ohio Michaux measured trees twelve to sixteen feet in circumference, and from eighty to one hundred feet in height, with undivided trunks of uniform size to the height of twenty-five or thirty feet.

The flowers of the wild cherry are white and collected in spikes. The fruit is about the size of a pea and nearly black, at maturity, soon after which, notwithstanding its abundance and bitterness, it is devoured by birds. It is employed either alone or mixed with cultivated cherries,-generally the morillos or mazzards -in making a domestic cordial called cherry bounce, which consists of an infusion of the cherries in rum or brandy with a certain quantity of sugar. It is a faint imitation of the Kirschenvasser of the Germans, and Marasquin of the Venetians, both of which liqueurs or cordials are prepared by distillation, from wild cherries found in the north and south of Europe.

The wood of this tree is highly valuable, being compact, fine-grained and brilliant, and not liable to warp when perfectly seasoned When chosen near the ramification of the trunk it rivals mahogany in the beauty of its curls. The bark of the wild cherry tree infused in cold water and drank to the extent of half a pint or a pint a day is a popular and useful tonic.

Wild Orange Tree (Cerasus Caroliniano.). This beautiful species of cherry tree is found in the Bahama Islands, to which, with the islands on the coast of the Carolinas, Georgia, and Florida it appears to be nearly confined. The fruit is small, oval, and nearly black, the greenish pulp which covers the soft stone not being eatable. The wild orange, as it is there called, is one of the most beautiful productions of the Southern States on the sea-board, where it is a favourite ornamental and shade tree. The flowers are more frequented by bees than those of any other southern tree.

CHERRY 'IREE BORER. See Borras.

CHERRY-LAUREL (Cerasus lauro-cerasus). 


\section{CHERRY TREE WEEVIL}

This shrub is an exntic, although it is now naturalized to this climate, and was brought to Europe from 'Trebisonde, in 1576 . It is an evergreen, with smooth bark, and short-stalked, oblong, lanceolate, remotely serwated, coriaceous, shining leaves, with two or four glands at their base. The flower is white, with round spreading petals, and the fruit a small, black drupe or cherry. 'The leaves of the cherrylaurel have long been employed both in medicine and in confectionary, on account of the agreeable odour and flavour of the bitter almond which they possess. 'They lose their odour after they are dried, but retain their favour.

CHERRY TREE WEEVIL. See Puom TrEe WeEtil and Curculio.

CHERVIL, GARDEN (Charophyllum satioum). This herb grows in gardens, and sometimes wild in waste ground; perhaps the outcast of gardens. The flowers are white, and bitter-tasted; the seeds are smooth, furrowed, and large; altogether the plant resembles parsley, only the leaves are paler and more divided. 'The roots are given in decoction. Chervil is slightly diuretic; the cutters of simples distil a water from its leaves, which they consider excellent in colics. It is much nsed in France for.salads; and is mentioned as a potherb by Gerarde. 'The parsley-leaved chervil (Scandix cerifolium) and fern-leaved chervil (S. odorata), are still cultivated by the Dutch for soups, salads, \&c.; but in this country they are not often found in the kitchen garden. Seed may be said to be the only means of propagation, and the only sowing of this that can be depended upon must be performed in early autumn, immediately after it is ripe; for if kept until the following spring, it will seldom germinate; or if this first grade of vegetation takes place, the seedlings are generally weak, and die away during the hot weather.

'The seed may be sown in drills eight inches apart, or broadcast; in either mode being only just covered. 'The plants are to be thinned to eight inches asunder, and to remain where they are raised. The only after-cultivation required by them is the keeping them clear of weeds.

CHESSEL. The mould or vat in which the cheese is formed. It is made of thick staves, generally of white or $\Lambda$ merican oak, bound with two strong iron hoops to withstand the necessary pressure. The chessel is perforated with many small holes in the bottom and sides to let the whey drain out of the curd.

CHEST. The breast; or that part of an animal's body which contains the heart and the lungs.

CHEST-FOUNDER. In farriery, a disease incident to horses, which proceeds from intammation about the chest and ribs.

CHESTNU'1, or CHESNU'T (Fagus-castanea). The species cultivated in England are the common or sweet chestnut, of which there are two kinds, the Spanish (Cas. vesca) and the American (Cas. Americana); - and the horse chestnut, which belongs to a distinct genus. "The true chestnut tree flourishes on poor gravelly or sandy soils, and will thrive in any but moist or marshy situations. It has been much questioned whether the chestnut is indigrennus or exotic. It was at one time very common in England, and a great many chestnuts hape been planted within the last thirty years. It is long-lived, grows to an immense size, and is very ornamental. The wood is hard and com. pact; when young, it is tough and flexible; but when old it is brittle and often shaky. When divested of its sap wood, this timber will stand in situations exposed to wet and dry longer than oak; and for gate-posts it ranks ir. durability next after the acacia, the yew, and probably it lasts longer than the larch. The nuts form an article for our dessert. In some parts of the continent they are frequently used as a substitute for bread, and form a large proportion of the food of the inhabitants. In Eng. land, during the three years ending with 1831 , the entries of foreign chestnuts for home consumption averaged 20,948 bushels a year, and they pay a duty of $2 s$. per bushel.

The fruit is used either boiled, roasted, or in a raw state. Phillips informs us that in the south of France, in Italy, and Savoy, they are made into puddings, cakes, and bread. And "chestnuts stewed with cream make a much admired dish; they make excellent soup; and stewed and served with salt fish they are much admired." We are also further informed that there is now at Fortsworth, in Gloucestershire, a great chestnut tree, fifty-two feet round, which in 1150 was so remarkable that it was called The great chestmut of Fortsworth. And Marsham states that this tree is 1100 years old. Lastly, the timber of this tree is almost incorruptible, and more durable than oak. Its durability is commensurate with the long life of the tree. Corsica, it is said, exports annually of this fruit to the amount of 100,000 crowns. The American chestnut differs very little from that of Europe. 'The fruit is smaller, but equally good. Its growth is very rapid. The bark for tanning is superior to oak.

The chestnut is raised from the seeds, planted in autumn; the second year, they are transplanted, and fine varieties are extended by grafting. A sandy or gravelly loam, with a dry subsoil, best suits them.

The Spanish or Portuguese chestnut succeeds well in the United States, and produces fruit in about seven years from the seed. Its growth is more rapid than that of the native hind. The fruit is more than four times larger, and brings a much higher price in the market. It may be budded on the common chestnut, but is apt to overgrow the stock. The large Spenish chestnut deserves to be extensively propagated.

Michaux, in his North American Sylva, rol iii., gives the following directions for the culture of the chestnut :

"After the ground has been carefully loosened with the plough and harrow, lines are drawn six feet apart, in which holes abcz. a foot in depth and diameter are formed, at the distances of four feet. A chestnut is placed in each corner of the hole, and covered with aboul three inches of earth. As the soil has beell thoroughly subdued, the nuts will spring and strike root with facility. Early in the secon? 
year, three of the young plants are remored from each hole, and only the most thriving is left. 'J'he third or fourth year, when the branches begin to interfere with each other, every second tree is suppressed. To insure its success, the plantation should be begun in March or April, with nuts that have been kept in the cellar during the winter, in sand or vegetable mould, and that have already began to germinate."

Mr. Hopkins of Cayuga county, made some experiments in planting chestnuts. In his first attempt, he kept the nuts till the setting in of winter, or December, when he planted them four feet apart every way, and not one of them grew. The next year he procured a quantity of nuts as soon as gathered, planted them immediately, and covered them superficially with leaves and light earth, at the same distance as before. Most of them came up and grew well. There can be no doubt, where the ground is so situated as to be free from the attacks of squirrels, mice, \&c., that immediate planting after the nuts are gathered is the best mode, otherwise the plan of Michaux may be preferred. The best soil is a clay loam. (Tredgold's Princrp. of Carpentry; $M^{*} C$ Culloch's Com. Dict.; Willich's Dom. Ency.; Phillip's Hist. of Fruits, p. 84.)

CHESTNUT, HORSE (死sculus hippocas'athum). This ornamental tree, now so common throughout Europe, is a native of $\boldsymbol{A}$ sia. The first plant is said to have been brought into Europe by the celebrated botanist Clusius in a portmanteau. It is too well known to require description. The wood is soft and of little value. The fruit contains much nutritive matter, but it is combined with a nauseous bitter extractive, which renders it unfit for the food of man; but horses, kine, goats, and sheep are fond of it. 'The bark of the tree contains an astringent, bitter principle, which operates as a tonic. It has cured agues, and some authors affirm that it might be a substitute for the Peruvian bark; but trials and experience have not justified their opinion. Given in a decoction, made with an ounce of the bark to a pint of water, it may be advantageously taken, to strengthen the habit weakened by previous disease. See Buckeтr.

CHEVIOT SHEEP. See Sheep.

CHEWING-BALL. In farriery, the name of a medicine in the form of balls adapted to restore lost appetite in horses.

CHEWING THE CUD. The operation of leisurely re-chewing or masticating the food in ruminating animals, as the cow, sheep, \&c. : by this means the food is more effectually broken down, and mixed with the saliva. If a ruminant animal ceases to chew the cud, immediate illness may be expected, as the diges1ve organs cannot act without this natural process. See an excellent article "On Ruminaion, or Chewing the Cud," in the Quart. Journ. of $\boldsymbol{A g}_{\mathrm{g}}$., p. 344. Rumination, in certain graminiverous animals, has plainly for one object a renewed and repeated introduction of wxygen, for a more minute mechanical division of the food only shortens the time required for

whlution. (Lizbig's Animal Chemistry.)
CHICCORY, or SUCCORY (Cichorium inty- 1 markets. bus). An English perennial weed, the wild endive, common on the borders of corn-fields and poor gravelly soils; extensively cultivated in Belgium, Holland, and Germany. The cultivated variety was much broughi into notice by the late Arthar Young, as a forage plant He bronght the seed from France in 1783 , and grew it extensively on his own farm; and reports (Annals of Agr. xxxix.), "The quantity of seed required to sow one acre is $13 \mathrm{lbs}$. The root runs deep into the ground, and is white, fleshy, and yields a milky juice. On the Continent, the dried root is roasted and used instead of coffee, and it is now allowed by the excise to be mixed with coffee. The root contains a strong bitter, which may be extracted by infusion; it is also used in the brewing of beer to save hops." Mr. Gorrie (Quart. Journ. of Agr. N. S. vol. iv. p. 206) says, "No plant cultivated in this country will bring the cow-feeder nearly an equal return with the chiccory." It should be added, however, that the leaves give a bad taste to the milk of the cows which eat them. (Brit. Hush. vol. iii. art. "Flem. Husb." p. 42.) And Von Thäer, in his Principles of Agricullure (2d ed. vol. iv. p. 322), asserts that it is extremely difficult to eradicate from the land, and has been found to materially impoverish the soil.

Wild succory, or chiccory is becoming extensively naturalized in many parts of the United States. The species called Endive, (C. endiva), especially the variety called Crispa. with very narrow and ragged leaves, is much cultivated in the vicinity of Philadelphia as an early salad. There are no native species of chiccory in the United States. (Flor. Cest.)

When cullivated for soiling or feeding horses and cattle in the farm-yard, for which purpose it is admirably adapted, its rapid and luxuriant growth admits of its being cut three or four times a year.

When the roots are used as a substitute for coffee, they should be first cleaned, then put into an oven after the bread has been taken out, and allowed to remain until cool. Should once baking be not sufficient, the process is to be repeated, after which, mix with one-half of coffee.

The fresh root of chiccory, when sliced and pressed, yields a juice which is slightly tonic ; and has been used in chronic affections of the stomach, connected with torpid liver. See ENDIV E. (Sinclair's Hort. Gram. Wob. p. 412 ; M'Culloch's Com. Dict.; Willich's Dom. Encyc.; Brit. Husb. vol. ii. p. 303.)

CHICK, or CHICKEN. See Poultny.

CHICK PEA (Cicer arietinum). PI. 7, $t$. A plant too delicate for field culture in Enge land; but in the south of France it is grown for the same purpose as vetches in England. The seeds are used in Germany and some other parts of Europe as a substitute for coffee, and the plant is sometimes called the coffee-pea. It is called by the Spaniards, who cultivate it largely, Garbanza. It is likewise a great favourite with the French, who call it Poischiche. It grow's well in several of the Middle States, where it might doubtless be made a valuable crop, as it maintains a high price in European markets. 


\section{CHICK WEED.}

In every part of America and the West Indian islands setlled by Spaniards, they have always made the culture of the garbanza a primary object, and it is somewhat singular that it has not become better known and appreciated in the United States, in most parts of which it grows well. Trials made with it in the vicinity of Dover, Delaware, have proved very successful. The Spanish pea or garbanza, is perhaps the most delicious vegetable of its class ever placed upon the table, possessing, when served up in the manner of yreen peas, the flavour of these, mixed with that of green corn, or, as others think, something between the marrow fat pea and Lima bean. They do not yield so abundantly as the common pea, but both in a green and dry state are much superior in flavour and richness. A meal made of the dried garbanzas is much used in Paris and other parts of Europe for thickening soup which it renders extremely fine. In Provence and other parts of southern Europe, the chick pea is a great favourite when rnasted or parched, like ground or pea nuts, and hawked about the streets. In Paris, the dried garbanzas retail for about twenty-four cents per pound. They grow best in a rich sandy loam, and may be cultivated in rows, much after the manner of the common pea. Not being a trailing vine, they require no sticking, the plants growing only about eighteen or twenty inches high, and branching out so as very much to resemble a small locust tree or bunch of rue. The pods, are very short and round, containing only two, three, or four peas each, somewhat larger than cornmon pulse. Being very tender, they will not, perhaps, bear to be planted at the same time with common peas. In Spain, where the chick pea is very abundant and in general use, two kinds are distinguished by the names of garbanzos and garbanzas, the last being the largest, most delicate, and tender. Those raised in Spain are considered superior to such as are the product of the south of France. The pellicle which covers them seems to be almost entirely removed by the process of cooking. After being dried they require soaking in cold water during the night previous to the day they are used. They do not seem to be the prey of any insect, and will keep sound and sweet for years. It is the gram of India. (Paxton's Bot. Dict.; Low's Agr. p. 286.)

CHICKWEED. A low, creeping weed, of which there are several varieties. The common chickweed, or stitch-wort (Stellaria media), has an annual, small, tapering root; flowering from March to December. Small birds and poultry eat the seeds, and whole herb; whence its name. Swine are extremely fond of it; and it is eaten by cows and horses; but is not relished by sheep, and is refused by goats. The herb may be boiled for the table like spinach: it is reported to be nutritive. This foreigner is extensively naturalized in the United States. It is a hardy little plant, and when the winters are mild in the Middle States, may be found in flower in every month of the year. (Flor. Cestrica.) The field chickweed (Cerastium arvense) is a perennial, from four inches to a foot in length, found in fields and on banks and hillocks, on a gravelly or chalky soil. In this
CHINCAPIN.

order there are seven other species of mouseear chickweed, vizo, two kinds of bruad-leaved (C. vulgatum and $C$. lutifolium); the narrow. leaved $(C$. viscossum) ; the little monse-ear $(C$. semi-decandum); the four-cleft (C.telrandum); the alpine ( $C$. alpinum); and the water ( $C$. aquaticum). These call for no observation. The berry-bearing sort, which grows with smooth erect stalks, and the stamens longer than the petals, is the wild lychnis, or white behen, and is a very rambling weed, natural to most parts of England, frequently called spattling-poppy. Its roots are perennial, and strike so deep into the earth that they are not easily destroyed by the plough; for which reason, bunches of this plant are too common among corn, in land which has not been perfectly well tilled. Summer-fallowing, and carefully harrowing out the roots, which should then be burnt, is the best and most effectual remedy.

The common chickweed grows in almost every situation, in damp or even boggy woods, and on the driest gravel-walks in gardens. In its wild state, this plant frequently exceeds half a yard in height; and varies so much from the garden chickweed, that if a person were acquainted only with the latter, he would with difficulty recognise it in the woods. Its small white flowers, and pale green leaves spreading in all directions, sufficiently point it out to our notice. It may be considered as a natural barometer; for if the flowers are closed, it is a certain sign of rain, while, during dry weather, they are regularly open from nine o'clock in the morning till noon. The plant boiled in vinegar and salt is said to cleanse breakings-ut or eruptions of the hands and legs. (Smith's Eng. Flor. vol. ii. p. 301; Sinclair's Weeds, p. 52 ; Willich's Dom. Encyc.)

CHILIAN CLOVER. This plant, which is called Spanish clover, and in South America, Alfalfa, is identical with luzerne. Two communications upon the subject, by a person who had spent some time in Chili, noay be found in the 14th volume of the American Farmer, pages 108 and 153.

CHINCAPIN, or CHINQUEPIN (Castanen pumila). The limits of this American tree, which bears a very small kind of round and pointed chestnut, is bounded northward by the river Delaware, on which it is found to the distance of nearly 100 miles from Cape May. It is very common in Delaware and Maryland, still more so in the lower part of Virginia and other southern and Southwestern States both east and west of the Mississippi. It abounds most where the common chestnut is wanting. Though in its northern limits, this dwarf chestnut seldom rises higher than from six to ten feet; much further south it often grows to the height of thirty or forty feet, with a diame. ter of twelve or fifteen inches. The leaves, flower, and fruit-bur, resemble those of the common chestnut in miniature, being about half the size. The wood of the chincapin is finer-grained, more compact, heavier, and eveu more durable than that of the chestnut, and is admirably adapted for fence-posts, lasting in the ground more than forty years. But the tree rarely attains a size adapting it to such a useful purpose in agriculture. 


\section{CHINCH BUG。}

A species of the chincapin (Castanea alnifolia), remarkable for its dwarf growth, is found in the Carolinas and Floridas. Mr. Nuttall, who met with it in the vicinity of Charleston, \$. C., says it grows in small patches in sandy pine barrens, has creeping roots, and seldom exceeds a foot in height. The nut is larger than that of the other species of chincapins. (See Nuttall's Supplement to Michanx.)

CHINCH BUG. A name, which, from some resemblance to the bed-bug, especially in the disgusting smell, has been popalarly applied 10 an insect often of late years occasioning wide-spread destruction in the wheat, Indian corn, and other grain field's of the South and Southwestern States. Not being able to find any scientific description of this insect and its habits, we shall of course be compelled to cull the best information we can collect from the most intelligent correspondents of agricultural periodicals, \&c.

In the 7th volume of Ruffin's Farmer's Register, there are several communications relative to the chinch bug, some of which draw a most deplorable picture of its ravages in the old counties of Virginia, where they not only often destroy the corn, wheat, and other graincrops, but lay waste the pastures. They are described as small and black, with white wings; in their form, close and compact, and about the size of a bed-bug. They creep on the ground, seldom using their wings, and appear to be hardy. Whatever crop they get into, the $j^{\prime}$ generally stick about the plants near the ground, although they may sometimes be seen scattered all over stalks of Indian corn, the blades, and even down into the bud. When they attack wheat, oats, \&c., they cluster around the stalk in incredible numbers, and seem to suck out its substance, so that it soon withers and falls to the ground. When they take to the Indian corn, the stalk and leaves sometimes become perfectly black with them, for two feet from the ground, leaving not a spot of green to be seen, except about five or six inches of the ups of the blades, the bugs hanging to the lower portions like bees when swarming. "We are," says one of Dr. Ruffin's correspondents, "harvesting our wheat crop, in which they got rather too late to destroy it entirely, but on many farms have seriously injured it, many places in the fields being quite destroyed. On following after the scythes, you may see millions of the bugs, of all sizes and colours, red, black, and gray, running in the greatest consternation in every possible direcion, seeking shelter under the sheaves of wheat, and bunches of grass, which may happen to be near. But all those on the borders of the field, and indeed on every part of it, very oon quit the dry and hard stubble for the more tender and juicy corn or oats, whichsoever may be nearest at hand; and now commences heir havoc and dreadful devastation. We see ine healthy, dark-yreen, luxuriant oat, which a few days before looked so beautiful and rich, furn pale, wither and die, almost at their very touch. It would seem exaggeration and almost incredible 10 state how very prolific this derining insect is, their increase being so pro- digiously great a; to appear to be the work of magic.

"In one day and night they had been known to advance fifteen or twenty yards deep in a field, destroying as they proceed. Unless some kind dispensation of P'rovidence delivers us from this ruthless enemy to the farming interest, it is impossible to say to what extent their ravages will, and may extend, in the course of a year or two. To us farmers, who are dependent on the productions of the earth, for our every thing, it is truly awful. And if their increase in future is commensurate with the past, it must be but a short time before this section of country will be laid waste by this dreadful depredator, and its inhabitants reduced to want and misery. Every attempı hitherto made to arrest their progress, or destroy them, has proved abortive. Some have attempted to drive them from their corn by pouring boiling water over them; a remedy, for the corn, as bad as the disease. Others try to stop their ingress to the corn-fields by digging ditches around the fields; but with no avail, as they are furnished with wings in a short time after they are hatched, and of course can easily fly over the ditches. Would it not be advisable always to sow clover, or some other tender grass, with all small grain, to induce the bug to remain in the field after the grain is taken away long enough to enable the corn crop to get size and age, so as not to be seriously injured by them? I have observed that the older the plant, the much less liable it is to be either injured or attacked." (F armer's Register.)

Among the remedies proposed against this destructive insect, are the following:-Burning up the leaves and rubbish of any woods in the vicinity of grain fields, so as to kill the insects in their winter retreats; also the stalks of corn, \&c., where they are often found. It is said that they are natives of the forest, and that where these are occasionally burnt they never become troublesome. Digging ditches so as to intercept the progress of the bugs, filling the excavations with straw in which the insects generally halt a little while, during which time the straw is to be burnt so as to carry destruction to the enemy. This operation is to be repeated during the day. Burning them up, corn and all, has been attended with advantage in preventing further destruction, and also put an end to the further multiplication of the swarm.

CHINE. In horsemanship, the back-bone, or ridge of the back. In pork, that part of the back which contains the back-bone.

CHISLEY LAND. Soil between sandy and clayey, containing a large admixture of small pebbles or gravel.

CHIVES or CIVES (Allium schonoprasum). This plant is a perennial, flowering in May and June. It is easily propagated by offsets of the roots. The time for making plantations is January or February: however, March is the month to be preferred to either; but if previously neglected, it may be performed as late as June. It is also planted in the autumn. They are to be inserted by the dibble, eight or ten inches apart, and eight or ten offsets id 


\section{CHLORIDE OF LIME.}

each hole. The only cultivation required is to keep them free from weeds. By autumn they multiply into large-sized bunches; and if required may be taken up as soon as the leaves decay, and be stored, after the necessary precautions, as a substitute for the onion: the leaves, which are fit for use as long as they remain green, must, when required, be cut down close to the ground, when they will speedily be succeeded by others. (G. W.John son's Kitch Garden.)

CHLORINE. One of the elements found always in vegretable substances, among the inorfinic or mineral constituents derived from the so.l. It is a kind of gas of a greenish colour, with a peculiarly strong odour, and so much Luravier than cornmon air, that, like earbonic ascid yas, it may be poured from one vessel into another. A taper will burn in it, giving a feeble reddish light, which soon goes but. It exists in all fertile soils, not separate, but combined with soda, in the familiar form of common salt, every 10 lbs. of which contains about $6 \mathrm{lbs}$. of chlorine gas.

CHLORIDE OF SODIUM : Meriate of Sorla, or Common Salt. This mineral production, so nee sssary to the wants of mankind, is universally distributed over the globe, either in solution, as in sea water and mineral springs, or in beds and solid rocks, forming mourains, from which it is procured in masses by blasting and regular mining operations. Most animals have an instinctive taste for this salt, and all fertile soils contain it, so that to the growth and well-being of both animals and vegetables, salt is indispentiable. For its uses as a fertilizer, see Salt.

CHLORIDE OF SODA. A well known powprful disinfeetant or destroy er of offensive smells, discovered and brought into use by a French chamist, who prepared from it a solution sold extelisively under the name of Labarbaque's Disinfective Solution. It is employed by sprinkling in sick rooms, privies, \&c. Like the chloride of lime, it possesses the extraordinary property of preventing or arresting animal and verctable putrefaction, and of destroying those efflis via which are not only offensive to the smell but ingurious to the health of men and other animals. To preserve animal bodies from puirefaction, or correct their offensive odours, the solution of chloride of soda may be applied by sprinkling or covering them with wet cloths. The chloride of soda, in which chlorine gas is combined with the alkali soda, must not be confounded with chloride of sodium, in which the samo gas is united with the metallic base sodium, to form common salt.

CHLORIDE OF LIME. Commonly known as Blenching Salt, or Bleaching Powder, is a dry grayish-white powder, possessing a hot penetratine taste, and, when pure, soluble in water. It is used by putting a few tablespoonsful of the salt in a plate or shallow earthen vessel, and pouring on, from time to time, a little oil of vitriol or vinegar, which brings out the chlorine gas, that correets offensive smells and deleterious airs in houses, privies, stables, \&cc. It has been proposed as a fertilizer.

Davy reports that he steeped some radish seeds for twelve hours in a solution of chlorine, some in nitric acid, some in very dilute oil of vitriol, some in a weak solution of green vitriol, and some in common water. "The seeds in so-

\section{CHICOLATE.}

lations of chlorine and ox-sulphate of arus threw out the germ in two days, those in witric acid in three days, in sulphuric acid in five and those in water in five. But in every case of premature germination, though the plume was very vigorous for a short time, yet it be. came at the end of a fortnight weak and sickly, and at that periud less vigorous in its growth than the sprouts which had been naturally developed, so that there can be scarcely any useful application of these experiments. 'Too rapid growth and premature decay seem invariably connected in organized structures, and it is only by following the slow operations of natural causes that we are capable of making improvements." (Agr. Chem. p. 217.)

Chloride of lime is prepared in large quantities for the service of the bleachers in most of the manufacturing districts. It is composed, according to the analysis of Dr. Marcet, of

$$
\begin{aligned}
& \text { Parts. } \\
& \text { Linive - - - - }-\quad-6328 \\
& \frac{3677}{100}
\end{aligned}
$$

Dr. Ingenhouz, in a proper published by the Board of Agriculture in 1816, remarks, in alluding to some experiments he had tried al Hertford in company with the Baron Dimsdale with various salts, - "Be it sufficient to say here, that of ald the neutral salts we tried, the glauber salt did seem to be one of the best in promoting vegetation; and the steeping the seeds in water, impregnated with oxygenated marine salt (which is now employed in bleaching linen in an expeditious way), had a particularly beneficial effect in produeing vigorous and early plants. We were somewhat as tonished that those seeds, viz. of wheat, rye, barley, and oats, which had been steeped in the above mentioned oxygenated muriatic liquid, even during forty-eight hours, did thrive admirably well; whereas, the same seeds steeped during so long a time, in some of the other medicated liquids, were much hurt, or had lost their vegetative power. The same oxygenated liquid poured upon the ground had also a beneficial effect." "These experiments of Ingenhouz were made, it appears, in $\mathbf{1 7 9 5}$ See SALTs, their uses to vegetation. Leibig regards ehloride of lime as a fertilizing salt its virtues being similar to that of plaster of Paris, both of which, he says, fix the ammonia which is brought into the soil in rain water, which ammonia is indispensable for the nourishment of plants. A few table-spoonfuls of chloride of lime or bleaching salts, sprinkled occasionally in privies and other places where it may be required, corrects offensive odours. (Brit. Farm. Mag. vol. ii. p. 258; "On Fertio" lizers," p. 366.)

CHOCOLATE is an alimentary preparation of very ancient use in Mexien, from which country it was introduced into Europe by the Spaniards in the year 1520, and by them long kept a secret from the rest of the world. I.innæus was so fond of it, that he gave the specifie name, theotoroma, food of the gods, to the cacao tree which produced it. The cacao beans lie in a fruit somewhat like a cucumber. about five inches long and three and a half

$$
2 \mathrm{E} 325
$$




\section{CHOCOLATE.}

thick, which contains from 20 to 30 beans, arranged in five regular rows with partitions between, and which are surrounded with a rose-coloured spongy substance, like that of water-melons. There are fruits, however, so large as to contain from $\mathbf{4 0}$ to 50 beans. Those grown in the West India islands, Berbice and Demarara, are much smaller, and have only from 6 to 15; their developement being less perfect than in South America. After the maturation of the fruit, when their green colour has changed to a dark-yellow, they are plucked, opened, their beans cleared of the marrowy substance, and spread out to dry in the air. like almonds, they are covered with a thin skin or husk. In the West Indies they are immediately packed up for the market when they are dried; but in the Caraccas they are subjected to a species of slight fermentation, by putting them into tubs or chests, covering them with boards or stones, and turning them over every morning, to equalize the operation. They emit a good deal of moisture, lose the natural bitterness and acrimony of their taste by this process, as well as some of their weight. Instead of wooden tubs, pits or trenches dug in the ground are sometimes had recourse to for curing the beads; an operation called earthing (terver). They are lastly exposed to the sun, and dried. The latter kind are reckoned the best; being larger, rougher, of a darker brown colour, and, when roasted, throw off their husk readily, and split into several irregular fragments; they have an agreeable, mild, bitterish taste, without acrimony. The Guinea and West India sorts are smaller, flatter, smootherskinned, lighter-colnured, more sharp and bitter to the taste. They answer best for the extraction of the butter of cacao, but afford a less aromatic and agreeable chocolate. According to Lampadias, the kernels of the West India cacao beans contain, in 100 parts, besides water, 53.1 of fat or oil, $16 \cdot 7$ of an albuminous brown matter, which contains all the aroma of the bean, 10.91 of starch, $7 \frac{3}{4}$ of gum or mucilage, 0.9 of lignine, and 2.01 of a reddish dyestuff somewhat akin to the pigment of cochineal. The husks form twelve per cent. of the weight of the beans; they contain no fat, but, besides lignine, or woody fibre, which constitutes half their weight, they yield a light-brown mucilaginous extract by boiling in water. The fatty matter is of the consistence of tallow, white, of a mild, agreeable taste, called butter of cacao, and not apt to turn rancid by keeping. It melts only at $122^{\circ}$ Fahr., and should, therefore, make tolerable candles. It is soluble in hoiling alcohol, but precipitates in the cold. It is rbtained by exposing the beans to strong pressure in canvass bags, after they have been steamed or soakeu in bniling water for some time. From five to six ouncss of butter may be thus obtained from a pound of cacao. It has a reddish tinge wnen first expressed, but it becomes white by boiling with water.

"The beans, being freed from all spoiled and monldy portions, are to be gently roasted over a tire in an iron cylinder, with holes in its ends for allowing the vapors to escape; the upparatus being similar to a coffee-roaster. When the aroma begins to be well developed, 326 the roasting is known to be finished; and the beans must be turned out, cooled, and freed by fanning and sifting from their husks. The kernels are then to be converted into a paste, by trituration in a mortar heated to $130^{\circ} \mathrm{Fah}$. The chocolate paste has usually in France a little vanilla incorporated with it, and a considerable quantity of sugar, which varies from one-third of its weight to equal parts. For a pound and a half of cacao, one pod of vanilla is sufficient. Chocolate paste improves in its flavour by keeping, and should therefore be made in large quantities at a time. But the roasted beans soon lose their aroma, if exposed to the air.

"Chocolate is flavoured with cinnamon and cloves, in several countries, instead of the more expensive vanilla. In roasting the beans, the heat should be at first very slow, to give time to the humidity 10 escape; a quick fire hardens the surface, and injures the process. In putting the paste into the tin plate, or other moulds, it must be well shaken down, to insure its filling up all the cavities, and giving the sharp and polished impression so much admired by connoisseurs. Chocolate is. sometimes adulterated with starch; in which case it will form a pasty consistenced mass when treated with boiling water. The harder the slab upon which the beans are triturated, the better; and hence porphyry is far preferable to marble. The grinding rollers of the mill should be made of iron, and kept very clean." (Ure's Dict. of Arts, \&c.)

A substance called theobromin has been recently obtained from chocolate by a European chemist. It contains thirty-five per cent. of nitrogen, a larger proportion than that contained in cafféine.

CHOKE-DAMP, a common term applied to a kind of foul air, often met with in wells, pits, mines, \&c. It consists of carbonic acid gass, with or without a mixture of nitrogen. It is a source of great danger tu persons descending into wells and pits. See Canrovic acro Gass.

Cholic, or COliC. See Horses, Cattle, SheEp, Diseases of.

CHOPPER, HAY. See Chaff-engives. A new and very efficient straw-cutter ander the title of the "Canadian Straw and Hay-chopper," is figured and described in the Trans. High. Soc. vol. vi. p. 336. One person driving the machine can, it is said, cut with ease $5 \mathrm{cwt}$. of hay or straw in an hour.

C HOUGH, or RED LEGGED CROW (Fregilus graculus). The plumage of this British bird is uniformly black, glossed with blue; beak, legs, and toes, vermilion red; claws, black.

CHRONIC COUGH. In horses, this is a frequent consequence of chest diseases. In a few instances this seems to be connected with worms; and if the coat is unthrifty, the flanks tucked up, and there is mucas around the anus, it will be proper to put the connexion between the worms and the cough to the test; otherwise a sedative medicine may suffice to allay the irritation. (Clater's Far. p. 123.)

CHRYSAI.IS. Many worms or larvæe, after they have attained their full growth, leave off eating entirely and remain at rest in a deathlike sleep. This is called the pupa state, from 


\section{CHURN.}

a fancied resemblance to the manner in which the Roman children were trussed in bandages. The pupæ from caterpillars are most commonIy called chrysulids and aurelia. Grubs, after their transformation, are often called nymphs. Having passed through its change, the insect merges from its chrysalis, or pupa, perforates the shell and silken envelope, and makes its appearance in a winged form, which is its last or perfect state.

"In every species there may be distinguished two sides; the one of which is the back, and the other the belly of the animal. On the anterior part of the latter there may always be observed certain little elevations running in ridges : the other side, or the back, in most of the chrysalises, is smooth, and of a rounded figure: but some have ridges on the anterior part and sides of this part, usually terminating in a point and making an angular appearance. From this difference is drawn the first general distinction of these bodies, by which they are divided into two classes; the round and the angular. The first, French naturalists call feves; the chrysalis of the silk-worm being of this description, and so named. This division is extremely convenient to classification, the phalance or moths being almost universally procuced by the rounded chrysalises, and the papilios, day-flies, from the angular. Among the latter, are some whose colours are as worthy of observation as the forms of others. Many of them appear superbly clothed in gold. These species obtained the names of chrysulis and aurelia; derived, the one from a Greek, the other from a Latin word, signifying gold." (Domestic Ency.)

CHURN (cejnan; Goth. kerna; Dutch, kernen. Our old authors wrote it cherne, and kern is yet a local word, and generally used north of the Tweed). A vessel in which cream is coagulated by long and violent agitation. There are many different kinds of churns, but those most generally used are the upright or Dutch plunge churn and the barrel-churn. In large dairies churns are frequently turned by means of a horse; this is particularly the case in Flanders, where churns are used which will make forty or fifty pounds of butter at a time. In the large dairies of Cheshire they are now often driven by small high pressure steam-engines. On such farms as have thrashing-mills, churns might be very conveniently attached to and wrought by them. An improved butter-churn by Mr. C. Harley of Fenchurch-street, and another by Mr. W. Bowler, to which the Society for the Improvement of the Arts, \&c., awarded a prize of thirty guineas, are described in Willich's Domestic Encyc. Churns should admit the air; and hence it has been argued that the cornmon churn, which allows this most conveniently, is, after all, the best.

CIBOULE, or WELSH ONION. See ONION. CICADA. See Grasshopper and Locusts. CIDER, or CYDER (Fr. cidre; Ger. zider Ital. cidro; Russ. sidor; Span. sidra). A sharp and vinous heverage made by fermenting the juice of apples.

Cider, or the fermented juice of the apple, constitutes the principal vinous beverage of the c.izens of New England, of the Mid de: $\mathbf{S}$ at 's, and of the older states of the West. Gnod cider is deemed a pleasant, wholesome liquor, during the heats of summer; and Mr. Knight has asserted, and also eminent medical men, that strong, astringent ciders have been found to produce nearly the same effect in cases of putrid fever as Port wine.

The unfermented juice of the apple consists of water and a peculiar acid called the malir acid, combined with the saccharine principle Where a just proportion of the latter is wanting, the liquor will be poor and watery, without body, very difficult to preserve and manage. In the process of fermentation, the saccharine principle is in part converted to alcohol. Where the proportion of the saccharine principle is wanting, the deficiency must be supplied, either by the addition of a saccharine substance before fermentation, or by the addition of alcohol after fermentation; for every one must know that all good wine or cider contains it, elaborated by fermentation, either in the cask or in the reservoirs at the distillery. The best and the cheapest kind is the neutrai spirit-a highly rectified and tasteless spirit obtained from New England rum. Some, how ever, object to any addition of either sugar or alcohol to supply deficiencies, forgetful that these substances are the very elements of which all wine, cider, and vinous liquors are composed.

The strength of the cider depends on the specific gravity of the juice on expression: this may be easily ascertained by weighing, or by the hydrometer.

According to the experiments of Major Adlum, of Georgetown, District of Columbia, it appeared that when two pounds of sugar were dissolved in a gallon of rain water, the bulk occupied by 1000 grains of rain water weighed 1087 grains. From this it would appear that the juice produced by the best known apple contains about two pounds of sugar in a gallon. Mr. Marshall has asserted that a gentleman, Mr. Bellamy, of Herefordshire, England, has by skill "produced cider from an apple called Hagloe Crab, which, for richness, flavour, and price on the spot, exceeds, perhaps, every other liquor which nature or art has produced. He has been offered sixty guineas for a hogshead of 110 gallons of this liquor." Newark, in New Jersey, is reputed one of the most famous places in America for its cider. The cider apple most celebrated there is the Harrison apple, a native fruit; and cider made from this fruit, when fined and fit for bottling, frequently brings $\$ 10$ per barrel, according to Mr. Coxe. This and the Hughs' Virginia Crab are the two most celebrated cider apples of America. Old trees, growing in dry soils, produce, it is said, the best cider. A good cider apple is saccharine and astringent.

To make good cider, the first requisite is suitable fruit; it is equally necessary that the fruit should be not merely mellow, but thorough ly mature, rotten apples being excluded; and ripe, if possible, at the suitable period, or about the first of November, or from the first to the middle, after the excessive heat of the seaso". 
s past, and while sufficient warmth yet remains to enable the fermentation to progress slowly, as it ought.

The fruit should be gathered by hand, or shaken from the tree in dry weather, when it is at perfect maturity; and the ground should be covered with coarse cloths or Russia mats beneath, to prevent bruising, and consequent rottenness, before the grinding commences. Unripe fruit should be laid in large masses, protected from dews and rain, to sweat and hurry on its maturity, when the suitable time for making approaches. The earlier fruits should be laid in thin layers on stagings, to preserve them to the suitable period for making, protected alike from rain and dews, and where they may be benefited by currents of cool, dry air.

Each variety should be kept separate, that those ripening at the same period may be ground together.

In grinding, the most perfect machinery should be used to reduce the whole fruit, skin, and seeds to a fine pulp. This should, if possible, be performed in cool weather. The late Joseph Cooper, of New Jersey, has observed emphatically, that "the longer a cheese lies after being ground, before pressing, the better for the cider, provided it escapes fermentation until the pressing is completed;" and he further observes, " that a sour apple, after being bruised on one side, becomes rich and sweet after it has changed to a brown colour, while it yet retains its acid taste on the opposite side." When the pomace united to the juice is thus suffered for a time to remain, it undergoes a chemical change; the saccharine principle is developed; it will be found rich and sweet; sugar is in this case produced by the prolonged union of the bruised pulp and juice, which could never have been formed in that quantity had they been sooner separated.

Mr. Jonathan Rice, of Marlborough, who made the premium cider so much admired at Concord, Massachusetts, appears so sensible of the important effects of mature or fully ripe fruit, that, provided this is the case, he is willing even to forego the disadvantage of having a portion of them quite rotten. Let me observe, that this rottenness must be the effect, in part, of bruises by improper modes of gathering, or by improper mixtures of ripe and unripe fruit. He always chooses cool weather for the operation of grinding; and, instead of suffering the pomace to remain but iwenty-four or forty-eight hours at most before pressing, as others have directed, he suffers it to remain from a weck to ten days, provided the weather will atinit, sirring the mass daily till it is put to the press. See his communication in vol. vii. p. 123, N. E. Farmer.

The first fermentation in cider is termed the vinous; in this the sugar is decomposed, and leses its sweetness, and is converted into alcohol; if the fermentation goes on too rapidly, the cider is injured; a portion of alcohol passes off with the carbonic acid.

The design of frequent rackings is principally to restrain the fermentation; but it seems to be generally ac 'nnowledged that it weatens ihe liquor. It is not generally practised, al\$28

\section{though the finest cider is often produced by} this mode.

Various other modes are adopted with the view of restraining fermentation, one of which is the following. After a few gallons of cider are poured into the hogshead into which the cider is to be placed when racked off, a rag six inches long, previously dipped in melted brimstone, is attached by a wire to a very long, tapering bung; on the match being lighted the bung is loosely inserted; after this is consumed, the cask is rolled or tumbled till the liquor has imbibed the gas, and then filled with the liquid. This checks the fermentation. Yet the French writers assure us that the effect of much sulphuring must necessarily render such liquors unwholesome.

Black oxide of manganese has a similar effect; the crude oxide is rendered friable by being repeatedly heated red hot, and as often suddenly cooled by immersion in cold water. When finely pulverised, it is exposed for a while to the atmosphere, till it has imbibed again the oxygen which had been expelled by fire. An ounce of powder is deemed sufficient for a barrel. If the cider is desired to be very sweet, it must be added before fermentation, otherwise not till afterwards. Mr. Knight, from his long experience and observation in a country (Herefordshire, England) famous for its cider, has lately, in a letter to the Hon. John Lowell, stated that the acetous fermentation generally takes place during the progress of the vinous, and that the liquor from the com. mencement is imbibing oxygen at its surface. He highly recommends that new charcoal, in a finely pulverized state, be added to the liquor as it comes from the press, in the proportion of eight pounds to the hogshead, to be intimately incorporated; "this makes the liquor at first as black as ink, but it finally becomes remarkably fine."

Dr. Darwin has recommended that the liquor, as soon as the pulp has risen, should be placed in a cool situation, in casks of remarkable strength, and the liquor closely confined from the beginning. The experiment has been tried with good success; the fermentation goes on slowly, and an excellent cider is generally the result.

A handful of well-powdered clay to a barrel is said to check the fermentation. This is stated by Dr. Mease. And with the view of preventing the escape of the carbonic acid, and to prevent the liquid from imbibing oxygen from the atmosphere, a pint of olive oil has been recommended to each hogshead. The excellent cider exhibited by Mr. Rice was prepared by adding two gallons of New England rum to each barrel when first made. In February or March it was racked off in clear weather, and two quarts more of New England rum added to each barrel. Cider well fermented may be frozen down to any requisite degree of strength. In freezing, the watery parts are separated and freeze first, and the stronger parts are drawn off from the centre.-I finish by adding the following general rules; they will answer for all general purposes; they are the conclusions from what is previously stated: 1. Gather the fruit according to the foregning 
rules; let it be thoroughly ripe when ground, which should be about the iniddle of November. 2. Let the pomace remain from two to four days, according to the state of the weather, stirring it every day till it is put to the press. 3. If the liquor is deficient in the saccharine principle, the defect may be remedied in the beginning by the addition of saccharine substances or alcohol. 4. Let the liquor be immediately placed in a cool cellar, in remark. nbly strong, tight, sweet casks; after the pulp has all overflown, confine the liquor down by driving the bung hard and by sealing; a vent must be left, and the spile carefully drawn at times, but only when absolutely necessary to prevent the cask from bursting. The charcoal, as recommended by Mr. Knight, deserves trial.

Fresh and sweet pomace directly from the press, and boiled or steamed and mixed with a small portion of meal, is a valuable article of food, or for fattening horses, cattle, and swine.

Sour casks are purified by pouring in a small quantity of hot water, and adding unslacked lime; bung up the cask, and continue shaking it till the lime is slacked. Soda and chloride of lime are good for purifying. When casks are emptied to be laid by, let them be thoroughly rinsed with water and drained, then pour into each a pint of cheap alcohol, shake the cask and bung it tight, and it will remain sweet for years. Musty casks should be condemned to other uses. Cider should not be bottled till perfectly fine, otherwise it may burst the bottles. The bottles should be strong, and filled to the bottom of the neck. After standing a a hour, they should be corked with velvet corks. 'The lower end of the cork is held for an instant in hot water, and it is then instantly after driven down with a mallet. 'The bottles must be either sealed or laid on their sides in boxes, or in the bottom of a cellar, and covered with layers of sand.

Most of the above information relative to cidel-making is derived from the American $0 r$ chardist, by W. Kenrick, of Boston, Massachusetts, whose list of apple and other nursery trees comprehends almost every kind desirable for any purpose.

The reader will find very explicit instructions for the manufacture of cider in the Penny Cyclop. vol. vii. p. 161; in the Lib. of Useful Know.; Brit. Hush. vol. ii. p. 364; Low's Pract. Agr. p. 379; Croker, On the Art of Making and Managing Cyder; in the Quart. Journ. of $A g r$. vol. viii. p. 332 , by Mr. Towers ; and in Baxter's Agr. Lib. p. 135, by Andrew Crosse, Esq., of Somerset. The following instructions for making cider are by a Devonshire lady.

Gather the fruit when ripe; let it remain in a heap till the apples begin to get damp, then grind them in a mill (similar to a malt mill); take the pulp and put it into a large press like a cheese-press, only on a much larger scale place a layer of reed in the bottom of the vat and a layer of pulp alternately until the vat is full. The vat is square, and the ends of the reed must be allowed to turn over every layer of pulp, so as to keep it from being pressed out at the sides: the layers of pulp must be five or :ix inches thick. When you have 42 finished making your cheese, press it as hard as you can, and let it remain three or four hours; then cut down the corners of it, and lay them on the top with reed as before; then press it again, and allow it to remain for another three or four hours. Repeat this process as long as necessary, or until the cheese is quite dry. It takes seven bags of apples for one hogshead of cider, and the vat ought to be large enough to make from three to four hog.sheads at a time. 'The best sort of apple to make mild cider is the hard bitter-sweet. Any sort of sour apple will do to make the harsh cider. The liquor must be strained through a fine sieve into a large vessel, and allowed to ferment for three or four days, taking off the scum as it rises; then rack it, and put it into casks stopped down quite close. Before the cider is put into the cask, a match made of new linen and attached to a wire is lighted and put into the cask, and the bung is put in to keep the wire from falling into it. After a few minutes the match is removed, and the cider poured into the cask while yet full of the smoke.

A person would require three or four years' experience before he would be qualified to superintend the making of sweet or made cider. Much depends on the year, or rather on the ripening of the apples; it should be the second, not the first falling; and the "green bitter-sweet" and the "pocket apple" are the best for making it. After pounding, isinglass and brimstone are used to sweeten and fine it, and many other ingredients. ( $(., M . K$.)

The sweet cider, above described, is distinct from the other two kinds of cider (the harsh and mild). Cider, according to Brande, contains about $\mathbf{9} 8 \mathbf{8 7}$ parts per cent. of alcohol. It is a wholesome beverage for those who use much bodily exercise. (Willich's Dom. Ency. M'Culloch's Com. Dict.)

CINQUE-FOIL, COMMON CREEPING, or FIVE FINGERED GRASS (Potentilla reptans). This creeping plant is common about wrysides, and in mearlows and pastures in England, where it is a perennial, flowering in June. Its stalks are round, smooth, and red, lying upon the ground, and taking root at the joints. The leaves stand five in number on each foot-stalk, long and narrow in form, and indented at the edges. The flowers are large, of a bright yellow colour, standing upon long foot-stalks. The root is long and large, covered with a brown rind. Smith (Eng. Flora, vol. ii. p. 423) describes this and ten other species of cinque-foil, all belonging to the same genus. The root is the medicinal part, and once was an officinal plant; but is now discarded: dig it up in April, take off the outer bark or rind, and dry it. The powdered bark of the root is astringent.

There are a dozen or more species of cinque foil in the United States, among which is that usually called the barren strawberry (Poten. tilla Pennsylvanica). It is a small, perennial, creeping plant, very frequent on road-sides, fence-rows, and banks, having thick, branch ing, fibrous roots. The petals of the flowers are bright-yellow, the first fluwers often appearing when the stems are very short, bul others appear afterwards un runners, whicls $2 \leftleftarrows 2$ 


\section{CINQUE-FOIL}

runners resemble those of the strawberry. This common kind of cinque-foil in the Middle and Northern States is frequent in worn-out and neglected fields, and, where abundant, indicates thriftless farming. The Latin name of the genus is derived from polens, powerful; in reference to the supposed medical virtues of the cinque-foil family. Another species, commonly called five-fingers (Potentilla simplex), is also a very common, yellow flowered perennial, along the borders of woods, \&c.

CINQUE-FOIL, PURPLE MARSH (Comarium palustre). A perennial, found in spongy, muddy bogs and ditches. Root, creeping extensively, with many long fibres. Stems, round, reddish, a foot or more in height. Flowers, several, without scent, but handsome, an inch broad, all over of a dark purplish blood colour, as well as the fruit. They appear in June. (Smith's Eng. Flora, vol. ii. p. 433.)

CITRIC ACIDS. Acids contained in lemons and some other kinds of fruit. See Acids, Vegetares.

CLARY, or SAGE (Salvia). Smith (Eng. Flora, vol. i. p. 34) describes two kinds, the meadow clary (S. pratensis), and wild English clary ( $S$. verbenaca). The first is very uncommon, but sometimes met with in dry meadows and about hedges; grows three feet high, erect; not very aromatic; leaves, dark-green; flowers, large and handsome, of a fine purplish blue. The second species is more common on gravelly or chalky soils, a foot or eighteen inches high; leaves, grayish-green; flowers, small, violet-blue. Seeds, black, smooth; blows from June to October. This plant is of great virtue, and is kept in gardens on account of its excellent flavour. The whole herb is medicinal, and is equally good, freshly gathered, or dried. It is cordial and astringent in its quality.

CLASPERS. The threads or tendrils of creeping plants.

CLASS, an appellation used to denote the most general divisions of which any thing is susceptible. Thus in the I,innæan system of natural history, the animal kingdom is divided into six great classes, of mammulia, or animals which suckle their young; aves, or birds; pisces, or fishes; insecta, or insects; vermes, or worms.

In botany, the term class implies the primary division of plants into large groups, each of which is to be subdivided by a regular downward progression, into orders, genera, and species, with uccasional intermediate subdivisions, constituting varieties, \&c., all being subordinate to the division which stands immediately above them. Each class is divided into orders, each orcier inio genera, each genus into species, and each geins and species sometimes into subgenera or subspecies. The term family is sometimes used instead of genus, and objects are often arranged in families, which again are distingu: shed into varieties.

CLAY. A well known constituent of soils, adding to them compactness and tenacity. Under the head of Analysi.s, p. 91, is a table showing a classification of soils, from which it appears, that as a general rule, those exhibiting the highest per-centage of clay, are estcemed 330
CLIMATF.

the most valuable. Although what is e ommonly called clay, constitutes from 14 to 81 per cent. of soils, its basis, alumina, or pure clay, exists only in the proportion of from 72-100ths of 1 per cent. in light sandy soils, to 5.25 per cent. in heavier lands. Where it exists, as it often doce in sub-soils, in the proportion of 9 or 10 per cent. good draining-tiles and building bricks may be made of it. The clay from which the best building bricks in Baltimore are made, contains $19 \frac{1}{2}$ per cent. of alumina. (See BrIcks.)

Clays have various colours, owing to admixture with different substances. Yellow and red clays are silicates of alumina with small proportions of peroxide (or rust) of iron, united with lime, magnesia, sometimes potash, and very rarely soda.

Strange to say-in what are commonly called on the Eastern shore of Maryland, and elsewhere in the United States, "pipe clay or white oak soils," very little pure clay exists, seldom over 3.75 per cent., in the upper stratum, and sometimes only about 1 per cent. According to Dr. Higgins's analysis, 90 per cent. of this soil consists of sand so fine as to lose its grittiness, whilst the pure clay constitutes only about 2 or $2 \frac{1}{2}$ per cent. These white oak soils commonly rest on a bed of white or mottled clay, which should never be turned up in ploughing. They can generally be rendered very productive by perfect draining, with the addition of lime, ashes, or guano. Such land is very unprofitable, unless kept dry by numerous small ditches running into a main ditch. See Ashes, Mixture of Soils. For the modes of burning clay in kilns, or clod-burn. ing, see Paring and Burning.

CLICKLING. An unpleasant noise known also by the term "overreach," which arises from the toe of the hind foot of a horse knocking against the shoe of the fore foot. If the animal is young, the action of the horse may be materially improved; otherwise nothing can be done.

CLIMATE OF THE UNITED STATES. The temperature of the atmosphere constitutes the principal element of climate. If the temperatures of places depended solely upon the position of the earth in relation to the sun, then would every place receiving the rays at a similar angle be similarly heated, and places in the same latitude in every part of the globe would have similar climates, so far as heat was concerned. It would therefore be very easy to classify climates according to relative distances from the equator or proximity to the poles. But observations made in different parts of the world show that in similar latitudes climates differ greatly, as is exemplified on the two sides of the northern Atlantic, where the mean temperatures of places on or near the ocean are found to differ in some cases ten degrees of Fahrenheit, the climate of the Eurnpean coast being that much warmer, in its annual mean temperature, than the American in the same latitude. When, instead of mean temperatures, extremes of heat and cold are compared, the difference is still more striking.

Now, in explaining the rationale of this well known fact, we are compelled to refer to a grand natural phenomenon, which we shall designate the great atmospheric circulation. This commences in the tropical region where 


\section{CLIMATE.}

th: accumulated heat of the sun rarefies the air, which, ascending into the higher regions of the atmosphere, flows off towards the north and south. To compensate for the loss by this successive flowing off of the heated and rarefied portion, and maintain that equilibrium which the barometer informs us always subsists in the atmosphere throughout the globe, lower currents of heavier air sweep into the tropical regions from the northward and southward. These last have been denominated the polar currents, whilst the uppermost are designated as the tropical currents; and these, it is well known, do not flow directly north or south, but slantwise, a fact which is ascribed to the influence exerted by the motion of the globe upon its axis, and the different velocities existing at different parts of its surface. Owing, therefore, to the combined agencies of solar heat and diurnal rotation, the lower winds in the equatorial region have a slanting direction from the eastward, constituting the trade winds, which blow the year round between the tropics, except where changed into monsoons by the interposition of some influences by which a change is wrought in their direction during six months of the year. Whilst the winds within the tropics thus blow interminably from the eastward, those without the tropical limits have a prevailing direction from the west. Here then we find the solution of the problem, that in extra-tropical latitudes all countries situated to the eastward of seas or other great bodies of water have milder climates than those occupying the eastern portions of continents. Large bodies of water never become so cold in winter or so warm in summer as the earth. Hence, whenever the predominant winds sweep from the sea, they carry with them the temperature of the water to a greater or less distance inland, and thus obviate extremes. When, however, the prevailing winds pass over large tracts of country, they must necessarily bear with them the greater or less degrees of cold induced by congelation, and still more through radiation, whilst in summer they will convey the accumulated heat absorbed by the earth. This view enables us to understand why the proximity of the Gulf Stream, - that mighty lake of warm water, as Major Reynell calls it, not inferior in size to the Mediterranean,--does not shed upon the shores of the United States a larger portion of its high temperature, the greatest proportion of the warmth communicated by it to the atmosphere being actually wafted to the distant shores of Europe.

The celebrated Humboldt, who has devoted so much attention to the investigation of climate, and especially to the laws and agencies concerned in the distribution of heat over the surface of the globe, has formed a system of lines of equal temperature encircling the globe, and passing through places having the same mean temperature, either throughout the year or during particular seasons. Those passing through places having similar annual means are called isothermal lines. As, however, it is frequently found that where the annual temperatures agree there is a great difference in the means of particular seasons, other lines
Crima te.

have been drawn to show this, such as pass through places having equal summer temperatures being called isotheral, and those represen:ing equal winter means isocheimal lines.

These lines, which from their generally crooked forins are also called curves, demonstrate to the eye in a striking manner the well known fact, that the distribution of temperature on both sides of the equator is by no means in exact conformity to latitude or distance from the equinoctial line. Let us, for example, take Humboldt's isothermal line drawn through different points around the globe, having a mean annual temperature of $55^{\circ} .40 \mathrm{~F}$ ahr., and we shall find it in the eastern part of North America passing near Philadelphia, in latitude $39^{\circ} 56^{\prime}$; in the eastern part of Asia, near Pekin, in the same latitude with Philadelphia; whilst on the western side of Europe it runs near Bourdeaux, in latitude $45^{\circ} 46^{\prime}$; and on the western coast of North America, it is found at Cape Foulweather, a little south of the mouth of the Columbia river, latitude $44^{\circ} 40^{\prime}$. Between the western part of Europe and the eastern portion of North America, the following differences in the mean temperature are found in similar latitudes, the increase in latitude being attended by a very great increase in the difference of the means:

$\begin{array}{cccc}\text { Latitude. } & \begin{array}{c}\text { Mean temp. of E. } \\ \text { coast N. A m. }\end{array} & \begin{array}{c}\text { Mean temp. W. } \\ \text { coast of Linope. }\end{array} & \begin{array}{c}\text { Differences in } \\ \text { biean temp. }\end{array} \\ 30^{\circ} & 66^{\circ} .92 & 70^{\circ} .52 & 3^{\circ} .60 \\ 40^{\circ} & 54^{\circ} .50 & 63^{\circ} \cdot 14 & 8^{\circ} \cdot 64 \\ 50^{\circ} & 37^{\circ} .94 & 50^{\circ} \cdot 90 & 12^{\circ} .96 \\ 60^{\circ} & 23^{\circ} .72 & 40^{\circ} .60 & 16^{\circ} .88\end{array}$

Now all the great varieties in the lines of equal temperature are mainly dependent upon the operation of those extensive natural movements which we have styled the great atmospheric circulation.

The climate of the United States is distinguished by its extremes of heat and cold. It might be naturally expected that the greatest heat would be registered at the most southerly, and the severest cold at the most northern posts. But the exact instrumental observations now furnished prove this not to be the case, especially in the vicinity of the sea, where it would seem the proximity of water tends to moderate the heat of summer in the south, and the cold of winter in the north. It is in some of the western regions, remote from the ocean and inland seas, those, for example, in which forts Snelling, Gibson, and Council Bluffs, are situated, that the mercury rises highest and sinks the lowest. On the 15th of August, 1834, at Fort Gibson, two thermometers observed by Dr. Wright of the army, rose in the shade, carefully excluded from reflected or radiated heat, the one to $116^{\circ}$, and the other to $117^{\circ}$ Fahrenheit.

It is a law applicable to all parts of the world, wherever no inland lakes or seas exist to interpose a modifying influence,-that on leaving the coast and going into the interior, the difference between the mean temperature of summer and winter increases, the climates being more subject to extremes of heat and cold. To show that no exception to this law is furnished in the United States, we may ad. duce the instance of Fort Sullivan, Eastporh 


\section{CLIMATE.}

Me., on the ocean in latitude $44^{\circ} 44^{\prime}$, where the winter mean temperature is $17^{0.45}$ Fahrenheit above that of Fort Snelling in Iowa, the latitude being the same. The climate of Fort Snelling, Dr. Forry informs us, is the most excessive among all the military posts in the United States, resembling that of Moscow in Russia, as regards the extremes of the seasons, notwithstanding the latter is $11^{\circ}$ further north. But at Moscow the mean temperature both of winter and summer is lower,-that of winter being as $10^{\circ} .78$ to $15^{\circ} .95$, and that of summer as $97^{\circ} \cdot 10$ to $72^{\circ} .75$. That the influence of the lakes in modifying the climate in their vicinities is not less than that of the ocean, is demonstrated by a comparison of the summer and winter means of posts situated near them in about the same latitude. The difference between the mean temperature of summer and winter at Fort Preble, on the Atlantic, is $41^{\circ} .03$, and of Fort Niagara on Lake Ontario, $41^{\circ} \cdot 73$. At the excessive post, Fort Crawford, Wisconsin, a few minutes further south than the two places first mentioned, the difference amounts to $50^{\circ} 89$. Again, a comparison of the difference between the winter and summer means of some other posts situated in the same latitude shows the following results, by which the increase in extremes on going west is strikingly demonstrated. The difference between the mean temperature of summer and winter at Fort Wolcott, Newport, Rhode Island, is $36^{\circ} .55$; at West Point, New York, $40^{\circ} .75$; Fort Armstrong, Illinois, $49^{\circ} .05$; and at Council Bluffs, near the junction of the rivers Platte and Missouri, $51^{\circ} \cdot 35$. The highest, lowest, and annual range of the thermometer at three of the posts just mentioned is as follows :-

\begin{tabular}{lccr} 
Fort Wolcott, Newport, R. I. Highest. & \multicolumn{2}{c}{$\begin{array}{c}\text { Lowest. } \\
\text { Annual } \\
\text { range, }\end{array}$} \\
Fort Armstrong, Illinois & $-96^{\circ}$ & $2^{\circ}$ & $83^{\circ}$ \\
Council Blufis - & $-104^{\circ}$ & $10^{\circ}$ & $106^{\circ}$ \\
\hline
\end{tabular}

Although the mean temperature of winter on the sea-coast is $6^{\circ}$ higher, and of summer $8^{\circ} .71$ lower than in places situated on the same parallel in the interior, beyond the influence of the lakes, the means of spring are $4^{\circ} \cdot 13$, and of autumn $0^{\circ} .40$ higher in the interior situations. This is the result of a comparison made in the latitude of about $43^{\circ}$.

How strongly are all these views of the eastern climate of the United States contrasted with the equable temperature found in the Pacific region. At Fort Vancouver, for example, situated on the Columbia river, about seventy-five miles above its mouth, the difference between the winter and summer means is only $23^{\circ} \cdot 67$, although a degree farther north than Fort Snelling, five degrees more northerly than New York, and nearly on the same parallel with Montreal. During a year passed at Fort Vancouver, the lowest fall of the thermometer was to $17^{\circ}$. On nine days only was the temperature, below the freezing point in the month of January, so that ploughing is carried on whilst the vegetables of the preceding season are still standing in the gardens untouched by frost. And why does not New York, situated directly on the Atlantic Ocean, derive as much warmth from this magazine of heat as Fort Vancouver does from the more distant Pacific? Simply 332 because the predominant westerly winds sweep upon one place the chilling blasts of extensive districts of land, cooled to congelation, or covered with snow, whilst over the other they waft the genial warmth of the sea. For similar reasons the ameliorations of climate experienced in the vicinity of the interior akes must always be felt most to the eastward.

The classification of climates distinguished by Dr. Forry in the United States and territories, is founded upon a general division into Northern, Middle, and Southern regions; the first being characterized by the predominance of a low mean temperature, the Southern by a high temperature, and the Middle vibrating to both extremes. Each of these general divisions is subdivided into classes or systems sufficiently marked.

The Northern System has three classes, the first embracing the coast of New England, extending as far south as the harbour of $\mathrm{New}$ York; the second including the districts in the proximity of the northern lakes; the third, portions of country alike remote from the ocean and inland seas.

The Middle division has two classes, the first embracing the Atlantic coast from Delaware Bay to Savannah; the second, interior stations.

The Southern division has alsu two classes, the first including those parts in which the military posts on the Lower Mississippi are situated, and the second the peninsula of East Florida.

It is the Northern region which presents at the same time the greatest diversity of physical character and the most strongly marked variations in climate. East of the great. lakes, the several mountain ranges seldom exceed the height of 2500 feet above the level of the seathe table-lands, upon which the ridges rest, rising, perhaps, on an average, to half the height named. We have already adverted to the fact, that on the coast of New England the influence of the ocean is manifested in moderating extremes of temperature. Advancing into the interior, the extreme range of the thermometer increases, and the seasons are violently con. trasted, until getting within the influence of the lakes, when a climate like that of the sea-board is found. That the lakes have this capacity 10 modify the climate in their vicinity will be evident to any one who considers that they occupy not less than 94,000 square miles, having a depth varying from 20 to 500 feet. Beyond the modifying agency of these inland seas, temperatures still more excessive are exhibited, a comparative view of which, including exact estimates for the sea-coast and regions of and beyond the great lakes, has been already given.

When the climates on the sea-coast and interior country remote from the lakes are compared in relation to the proportion of fair and cloudy weather, rain and snow, the following results appear. During the year, the proportion of fair days on the sea-coast, compared with those of the interior, are as 202 to 240 : cloudy days, 108 to 77 ; rainy days, 45 to 31 ; snowy, 9 to 16 .

Comparing the climate of the lakes with that of the same region beyond their influence, the 
contrast is yet more striking, the prevailing weather of the former being cloudy, and the latter fair; thus, during the year, the proportion of days is,

$\begin{array}{lcccc} & \text { Fair. } & \text { Cioudy. } & \text { Rain. } & \text { Snow. } \\ \text { Iakes } & -117 & 139 & 63 & 45 \\ \text { Remote from lakes } & -216 & 73 & \mathbf{4 0} & 29\end{array}$

The relative proportion of rainy and cloudy days during the year is, therefore, in the former locality 247, and in the latter 148, giving the far west about 100 more sunshiny days out of the annual sum of 365 .

Thus much for the Northern division.

In considering the climate of the Middle division of the United States, Dr. Forry thinks himself justified by the results of the meteorological observations in his possession, in distinguishing two classes, designated as uniform and excessive climes, the first being slightly under the influence of the Atlantic Ocean, whilst the southwestern stations show the powerful influence of the Gulf of Mexico.

In proceeding south, the seasons, as a general rule, appear more uniform, the annual mean temperature increasing as a matter of course. Some of the eastern posts in this middle division present such great contrasts between their summer and winter temperatures, as almost to place them in the list of excessive climes. The modifying influence of the adjacent ocean and bays are, however, still apparent, since, farther westward on the same parallels, greater extremes are common.

"The region of Pennsylvania, as though it were the battle-ground on which Boreas and Auster struggle for mastery, experiences, inJeed, the extremes of heat and cold. But, proceeding south along the Atlantic Plain, climate soon undergoes a striking modification, of which the Potomac forms the line of demarcation. Here the domain of snow terminates. Beyond this point, the sledge is no more seen in the farmer's barnyard. 'The table-lands of Kentucky and Tennessee, on the other hand, carry, several degrees farther south, a mild and temperate clime. Although very few thermometrical observations have been made upon the table-land lying in the centre of the middle division, or upon the ridges which crest this long plateau, thus rendering it impracticable to determine fully the interesting question of their influence upon temperature; yet we are enabled to supply this deficiency, in some measure, by observations made upon the differences in vegetable geography. 'Thus, in Virginia, as the limits of the state extend quite across the Apalachian chains, four natural divisions are presented; viz., 1. The Atlantic Plain, or tidewater region, below the falls of the rivers; 2. The Middle region, between the falls and the Blue Ridge ; 3. The Great Valley, between the Blue Ridge and the Alleghany Mountains; and, 4. The 'Trans-Alleghany region, west of that chain. In each of these, the phenomena of vegetation are modified in accordance with the climatic features. On the $\mathbf{A}$ tlantic Plain, tobaccu is the principal staple; in the Great Valley, it is cultivated only in the southern portion; and beyond the Alleghany, its culture is unknown. In the first only is cotton cultirated, and in its southern part quite extensive. 1y. In North Carolina, the Allantic Plain extends sixty or seventy miles from the coast, whilst the Middle region, corresponding to that described in Virginia, gradually merges into the mountainnus regions farther west. As these table-lands are elevated from 1000 to 1200 feet above the sea, upon which rise many high crests, one of which (Black Mountain) is the highest summit of the Alleghany system, the diversity of climate on the same parallels causes a corresponding difference in the vegetable productions. Whilst the lowlands yield cotton, rice, and indigo, the western high country produces wheat, hemp, tobacco, and Indian corn. In South Carolina, three strongly-marked regions are also presented; but as the temperature increases, as a general law, in proportion as we approach the equator, cotton is cultivated throughout the state generally. Georgia, Alabama, and Mississippi, like the Carolinas, are divided into three well-defined belts, exhibiting similar diversities in vegetable geography. Cotton and rice, more especially the former, are the great agricultural staples; and on the Atlantic Plain of these three states, as well as its continuation into Florida and Louisiana (which last two will be more particularly adverted to in the southern division), sugar may be advantageously cultivated. In North Carolina and Virginia, the Atlantic Plain forms, as it were, a chaos of land and water, consisting of vast swamps, traversed by sluggish streams, expanding frequently into broad basins with argillaceous bottoms. Throughout its whole extent, as already remarked, it is characterized by similar features, besides being furrowed with deep ravines, in which the streams wind their devious way. The hot and sultry atmosphere of these lowlands, in which malarial diseases in every form are dominant, contrasts strongly with the mild and salubrious climate of the mountain regions.

"It may not be amiss, as illustrative of the comparative temperature of the Atlantic Plain and the adjacent mountain region, to present here a few thermometrical data, however limit. ed in extent, noted during the summers of 1839 and 1840, at Flat Rock, Buncombe county, North Carolina.

\begin{tabular}{|c|c|c|c|c|c|}
\hline \multirow{2}{*}{ Places of Observation. } & \multirow{2}{*}{ Latitude. } & \multicolumn{4}{|c|}{ Mean Teinperature. } \\
\hline & & July. & Aug. & Sept. & Oct. \\
\hline $\begin{array}{l}\text { Fort Monroe, coast of } \\
\text { Virginit - }\end{array}$ & $3^{\circ} 00^{\prime}$ & $80^{\circ}$ & $70^{\circ}$ & $72^{\circ}$ & $64^{\circ}$ \\
\hline Flat Rock, Buncombe, & & & & & \\
\hline N. C. - & $35^{\circ} 30^{\prime}$ & $69^{\circ}$ & $70^{\circ}$ & $62^{\circ}$ & $61^{\circ}$ \\
\hline Charleston, S. C. & $32^{\circ} 45^{\prime}$ & $81^{\circ}$ & $81^{\circ}$ & $77^{\circ}$ & $71^{\circ}$ \\
\hline
\end{tabular}

"Flat Rock is about 250 miles from the Atlantic, and is elevated perhaps 2500 feet above the level of the ocean, whilst the latitude given is also a mere approximation derived from. general knowledge. The observatious made at Charleston embrace the same vears as these at Flat Rock, but the data at Fort Monroe comprise the years 1828,1829 , and 1830 . It is thus seen that the difference of temperature at Flat Rock and the other two points, taking an average of the latter, is in July $11^{\circ}$, August $10^{\circ}$, September $13^{\circ}$, and October $6^{\circ}$. As regards the monthly range of the thermometer, ittl difference is presented." (Forry.) 
Along the Atlantic coast of the United States, the mean temperature of the year diminishes in a very unequal ratio. Between Charleston and Philadelphia, the difference of means is $10 \frac{1}{2}^{\circ} \mathrm{Fahr}$., or in the proportion of about $1 \frac{1}{3}{ }^{\circ}$ of temperature to $1^{\circ}$ of latitude. Between Philadelphia and Eastport, Maine, the difference in means is much greater, namely, $12^{\circ} .33$ Fahr. being in the increased proportion of nearly $2^{\circ} .5$ of mean temperature per degree of latitude. Again, between Charleston, S. C., and New York harbour, the difference of means is $12^{\circ} \cdot 78$, or $1^{\circ} .59$ per degree of latitude. Between New York harbour and Eastport, Maine, the difference is $11^{\circ}$, or about $2 \frac{3}{4}^{\circ} \mathrm{Fahr}$. per degree of latitude. The average proportion between Charleston, S. C., and Eastport, Maine, is equal to about $2^{\circ}$ of temperature for each degree of latitude.

In approaching south, the extremes of winter and summer grow less, and the seasons glide more imperceptibly into each other. At Fort Snelling, situated in the excessive climate of the west, in latitude $44^{\circ} \cdot 53$, the difference between the summer and winter means is, as has been before stated, no less than $56^{\circ} \cdot 60$; at Eastport, Maine, $39^{\circ} \cdot 15$, at West Point, N. Y., $40^{\circ} \cdot 75$, at Charleston, S. C., $30^{\circ} \cdot 34$, at St. Augustine, Florida, $20^{\circ}$, whilst at Key West, it is only $11^{\circ} .34$.

"There is," says Dr. Forry, "little difference between the thermometrical phenomena presented at Key West and the Havana. In the West India islands, the mean annual temperature near the sea is only about $80^{\circ}$. At Barbaloes, the mean temperature of the seasons is-winter, $76^{\circ}$, spring $79^{\circ}$, summer $81^{\circ}$, and autumn $80^{\circ}$. The temperature is remarkably uniform; for the mean annual range of the thermometer, even in the most excessive of the islands, is only $13^{\circ}$, and in some it is not more than $4^{\circ}$. Contrast this with Hancock Barracks, Maine, which gives an average annual range of $118^{\circ}$, Fort Snelling, Iowa, $119^{\circ}$, and Fort Howard, Wisconsin, $123^{\circ}$ !

"The peculiar character of the climate of East Florida, as distinguished from that of our morc northern latitudes, consists less in the mean annual temperature than in the manner of its distribution among the seasons. At Fort Snelling, for example, the mean temperature of winter is $15^{\circ} .95$, and of summer $72^{\circ} \cdot 75$, whilst at Fort Brooke, Tampa Bay, the former is $64^{\circ} \cdot 76$, and the latter $84^{\circ} \cdot 25$, and at Key West, $70^{\circ} .05$, and $81^{\circ} .39$. Thus though the winter at Fort Snelling is $54^{\circ} \cdot 10$ colder than at Key West, yet the mean temperature of summer at the latter is only $8^{\circ} \cdot 64$ higher. In like manner, although the mean annual temperature of Petite Coquille, Louisiana, is nearly $2^{\circ}$ lower, that of Augusta arsenal, Georgia, nearly $8^{\circ}$, and that of Fort Gibson, Arkansas, upwards of $10^{\circ}$ lower than that of Fort Brooke; yet at all, the mean summer temperature is higher. Between Fort Snelling on the one hand, and Fort Brooke and Key West on the other, the relative distribution of temperature stands thus:-Difference between the mean temperature of summer and winter at the former $56^{\circ} \cdot 60$, and at the two latter $16^{\circ} .49$ and $11^{\circ} .34$; difinr rnce between the mean temperature of the warmest and coldest month, $61^{\circ} .86 \mathrm{c}$ :mpared with $18^{\circ} .66$ and $14^{\circ} \cdot 66$; difference between the mean temperature of winter and spring, $30^{\circ} .83$ to $8^{\circ} .35$ and $5^{\circ} .99$; and the mean difference of successive months, $10^{\circ} .29$ to $3^{\circ} .09$ and $2^{\circ} \cdot 44$." $^{\circ}$

$\Lambda$ comparison in regard to equality and mildness of climate drawn between the seasons of Florida and those of the most favoured places on the European continent, those of Italy and southern France, results generally in favour of the Florida Peninsula. At Key West the annual range of the thermometer is but $37^{\circ}$. See table of monthly mean temperatures, under the head of Aтмоsphere.

CLIMATE, CHANGES OF. The question has been much debated, whether the temperature of the crust of the earth or of the incumbent atmosphere has undergone any perceptible changes since the earliest records, either from the efforts of man in clearing away forests, draining marshes, cultivating the ground, or other causes. La Place has demonstrated very satisfactorily, that since the days of Hipparchus, an astronomer of the Alexandrian school, who flourished about 2000 years ago, the earth cannot have become a single degree of heat warmer or colder, as otherwise the sidereal day must have become either lengthened or shortened, which is not the case.

As to the question of changes in atmospheric temperature affecting the seasons, M. Arago thinks that sufficient proofs exist to justify the conclusion that in Europe, at least, a sensible elevation of the annual mean temperature has resulted from the conquests of agriculture. The thermometer is comparatively a modern instrument, invented by Galileo in 1590, but still left so imperfect, that it was not till 1700 that Fahrenheit succeeded in improving and rendering it a correct and perfect instrument. It is evident that the want of exact instrumental observations prior to the commencement of agricultural improvements must render it extremely difficult to determine with any precision, what changes may have been effected through these in the mean temperatures of the year or particular seasons. Hence, notwithstanding the expression of his belief in the changes of atmospheric temperature, M. Arago looks to America for the necessary data by which the point must be definitely settled.

"Ancient France," he remarks, "contrasted with what France now is, presented an incomparably greater extent of forests; mountains almost entirely covered with wood, lakes and ponds, and morasses, without number ; rivers without any artificial embankment to prevent their overflow, and immense districts, which the hands of the husbandman had never touched. Accordingly, the clearing away of the vast forests, and the opening of extensive glades in those that remain; the nearly com. plete removal of all stagnant waters, and the cultivation of extensive plains, which thus are made to resemble the stepes of Asia and America-these are among the principal modifications to which the fair face of France has been subjected, in an interval of some hundreds of years. But there is another country which is undergoing these same modifications at the present day. They are there progressing 
under the observation of an enlightened population; they are advancing with astonishing rapidity; and they ought, in some degree, suddenly to produce the meteorological alterations which many ages have scarcely rendered apparent in our old continent. This country is North America. Let us see, then, how clearing the country affects the climate there. The results may evidently be applied to the ancient condition of our own countries, and we shall find that we may thus dispense with $a$ priori considerations which, in a subject so complicated, would probably have misled us."

There is great force in the following remarks of Dr. Forry, and the facts adduced in their support:-

"Dense forests and all growing vegetables doubtless tend considerably to diminish the temperature of summer, by affording evaporation from the surface of their leaves, and preventing the calorific rays from reaching the ground. It is a fact equally well known that snow lies longer in forests than on plains, because, in the former locality, it is less exposed to the action of the sun; and hence, the winters, in former years, may have been longer and more uniform. As the clearing away of the forest causes the waters to evaporate and the soil to become dry, some increase in the mear summer temperature, diametrically contrary to the opinion of Jefferson and others, necessarily follows. It is remarked by Umfreville that, at Hudson's Bay, the ground in open places thaws to the depth of four feet, and in the woods to the depth only of two. Moreover, it has been determined by thermometrical experiments that the temperature of the forest, at the depth of twelve inches below the surface of the earth, is, compared with an adjacent npen field, at least $10^{\circ}$ lower, during the summer months; whilst no difference is observable during the season of winter.

"It may, therefore, be assumed, that although cultivation of the soil may not be productive of a sensible change in the mean annual temperature, yet such a modification in the distribution of heat among the seasons may be induced as will greatly influence vegetation."

Bearing upon this point, Dr.Forry furnishes a table exhibiting a comparative view of the atmospheric temperatare at Philadelphia, at intervals of about a quarter of a century, (from 1771 to 1824 ,) which shows a successive decrease in the mean of winter, and an increase in the means of spring, summer, autumn, and whole year. Some allowance must be made in these estimates for the effects of increase in the size of the city, and the additional shelter in winter, and opportunity of accumulating heat in summer thus afforded. All towns are observed to grow warmer as they extend their limits. When, therefore, we find a decline in the mean temperature of winter, notwithstanding the extension of the city limits, we must infer that it can arise from no other cause than a general diminution in the winter temperature throughout the country.

Any changes in the climate of the United States as yet perceived, are very far from justifying the sanguine calculations indulged in a few years ago by a writer on the climate and vegetation of the fortieth degree of North latitude, who, in concluding his essay, says:

"But there will doubtless be an amelioration in this particular," (severity of cold,) "when Canaila and the United States shall become thickly peopled and generally cultivated. In this latitude, then, like the same parallels in Europe at present, snow and ice will become rare phenomena, and the orange, the olive, and other vegetables of the same class, now strangers to the soil, will become objects of the labour and solicitude of the agriculturist."

Had this writer extended his inquiries a little further, he might have found that the region of Oregon, lying west of the Rocky Mountains, though as yet in a primitive state of nature, has a climate even milder than that of highly cultivated Europe in similar latitudes. And again, China, situated precisely under the same conditions as the United States in regard to the sea, though long since subjected to the highest state of agricultural im. provement, possesses a winter climate as rigorous, and some assert even more so, than that of the United States in similar latitudes. See table of mean temperature under the head Атмosphere, page 126 .

CLIMATE, INFLUENCE OF, ON THE FRUITFULNESS OF PLANTS. The following observations upon a topic of naturai history of great interest to the agriculturist, are quoted from the same sensible and eloquent American writer, to whom reference has been made under the head of the Accumativa Principle of Puants.

"The cultivated plants yield the sreates: products near the northernmost limit in which they will grow.

"I have been forcibly impressed with this fact, from observing the productions of the various plants, which are cúltivated for food and clothing in the United States. The following instances will go far to establish the principle, viz.:-

"The cotton, which is a tropical plant, yields the best staple and surest product in the temperate latitudes. The southern parts of the United States have taken the cotton market from the East and West Indies, both as regards quantity and quality. This is partly owing to the prevalence of insects within the tropics, but principally to the forcing nature of a vertical sun. Such a degree of heat developes the plant too rapidly-runs it into wood and foliage, which become injuriously luxuriant; the consequence is, there are but few seed pods, and these covered with a thin harsh coat of wool. The cotton wooi, inke the fur of animals, is, perhaps, designed for protection; and will be thick and fine in proportion as the climate is warm or cool. Another reason is to be found in the providence of the Deity, wha rims to preserve races rather than individuals, and multiplies the seeds and eyes of plants, exactly as there is danger of their being destroyed by the severity of the climate, or other causes. When, therefore, the cares and labours of nsan counteract the destructive tendency of the climate and guaranty their preservation, they are, of course, more available and abundant.

"The lint plants, flax, hemp, \&c., are cultivated through a great extent of latitude, but 
their bark, in the southern climates, is harsh and brittle. A warm climate forces these plants so rapidly into maturity, that the lint does not acquire either consistency or tenacity. We must go far north in Europe, even to the Baltic, to find these plants in perfection, and their products very merchantable. Irelard is rather an exception as to latitude; but the influence of the sun is so effectually counteracted there by moisture and exposure to the sea air, that it is always cool: hence, the flax and potato arrive at such perfection in that region.

"It holds equally true in the farinaceous plants. Rice is a tropical plant; yet Carolina and Georgia grow the finest in the world; heavier grained, better filled, and more merchantable, than any imported into Europe from the Indies. The inhabitants of the East Indies derive their subsistence almost exclusively from rice; they must be supposed, therefore, to cultivate it with all skill and care, and the best contrivances for irrigation. Such is, however, the forcing nature of their climate, that the plant grows too rapidly, and dries away before the grain be properly filled. Indian corn, or maize, if not a tropical plant, was originally found near the tropics; and although it now occupies a wide range, it produces the heaviest crops near the northern limit of its range. In the West Indies it rises thirty feet in height; but with all that gigantic size, it produces only a few grains on the bottom of a spongy cob, and is counted on only as rough provender. In the southern part of the United States, it reaches a height of fifteen feet, and will produce thirty bushels to the acre; in the rich lands of Kentucky and the Middle States it produces fifty or sixty bushels to the acre; but in New York and New England, agricultural societies have actually awarded premiums for one hundred and fifty bushels to the acre, collected from stalks only seven feet high. The heats of a southern sun develope the juices of this plant too quickly. They run into culm and blade, to the neglect of the seed, and dry away before fructification becomes complete.

"Wheat is a more certain crop in New York, the northern part of Pennsylvania, and Ohio, and in the Baltic regions of Europe, than in the south either of Europe or America. In the north, snows accumulate, and not only protect it from the winter colds, but from the weevil, Hessian fly, and other insects that invade it; and in the spring it is not forced too rapidly into head, without time to mature fully, and concoct its farina.

"A cold climate also aids the manufacturing of flour, preserving it from acidity, and enables us to keep it long, either for a good market, or to meet scarcities and emergencies. Oats grow in almost every country; but it is in northern regions only, or very moist or elevated tracts, that they fill with farina suitable for human sustenance. Rye, barley, buckwheat, millet, and other culmiferous plants, might be adduced to illustrate the above principle; for all their habits require a more northern latitude than is necessary to their nere growth.

"The grasses are proverbially in perfection 336 only in northern and cool regions, although they will grow everywhere. It is in the north alone that we raise animals from meadows, and are enabled to keep them fat, and in good condition, from hay and grass alone, without grain. It is there the grasses acquire a succulence and consistency enough, not only to mature animals, but to make the richest butter and cheese, that contribute so much to the tables of the luxurious. The grasses which do, often, in the south, grow large enough, are without richness and nutriment; in hay, they have no substance; and when green, are too washy to fatten animals; the consequence is, most animals in those latitudes browse from necessity, and are poor, and without size or beauty. It is the same hot sun which forces them to a rapid fructification, before they have had time to concoct their juices. The sugarcane produces, perhaps, better where it never seeds, than in the tropics; for the juices will never ripen so as to granulate, until checked by frost or fructification. In the tropics, the cane grows twenty months before the juices ripen; and then the culm has contracted a woody, fibrous quality, to such a degree as to resist the pressure of the mills, and yields but little juice, and that to an increased effort. In Louisiana we succeed well with the sugar culture; because, while the crilm is succulent and tender, a white frost checks the growth, ripens the juices, and in fire months gives us a culm, tender, full of juice, easy to press, and yielding much grain of sugar. When Isouisiana, therefore, acquires all the necessary skill, she will most probably grow this article cheaper than the West Indies.

"Tobacco is a southern plant, but there it is always light and chaffy; and although often well-flavoured, it never gains that strong narcotic quality which is its only peculiar property, unless you grow it as far north as Virginia. In the south, the heat unfolds its bud or gem too soon, forces into full expansion the leaf, and drives it to seed before the narcotic quality can be properly elaborated. We may assert a general rule applicable to all annual plants, that neither the root, nor the leaf, acquires any further size or substance after fructification.

"The tuberose, bulbous, and other roots, cultivated for human and animal subsistence, are similarly affected by climate, and manifest habits in corroboration of the above principle. The Irish potato, although from or near the tropics, will not come to perfection but in northern or cool countries, or in moist, insular situations, as Ireland. It is in such climates alone, that its roots acquire a farinaceous consistence, and have size, flavour, and nutriment enough to support, in the eminent way in which they are susceptible, animal life. In the south, a forcing sun brings the potato to fructification before the roots have had time to attain their proper size, or ripen into the proper qualities for nourishment. In Ireland the plant grows slow, through a long and cool season, giving time for its juices to be elaborated and properly digested; hence that fine farina and flavour which characterizes them. The sweet potato produces larger. better fla- 
Thete 8
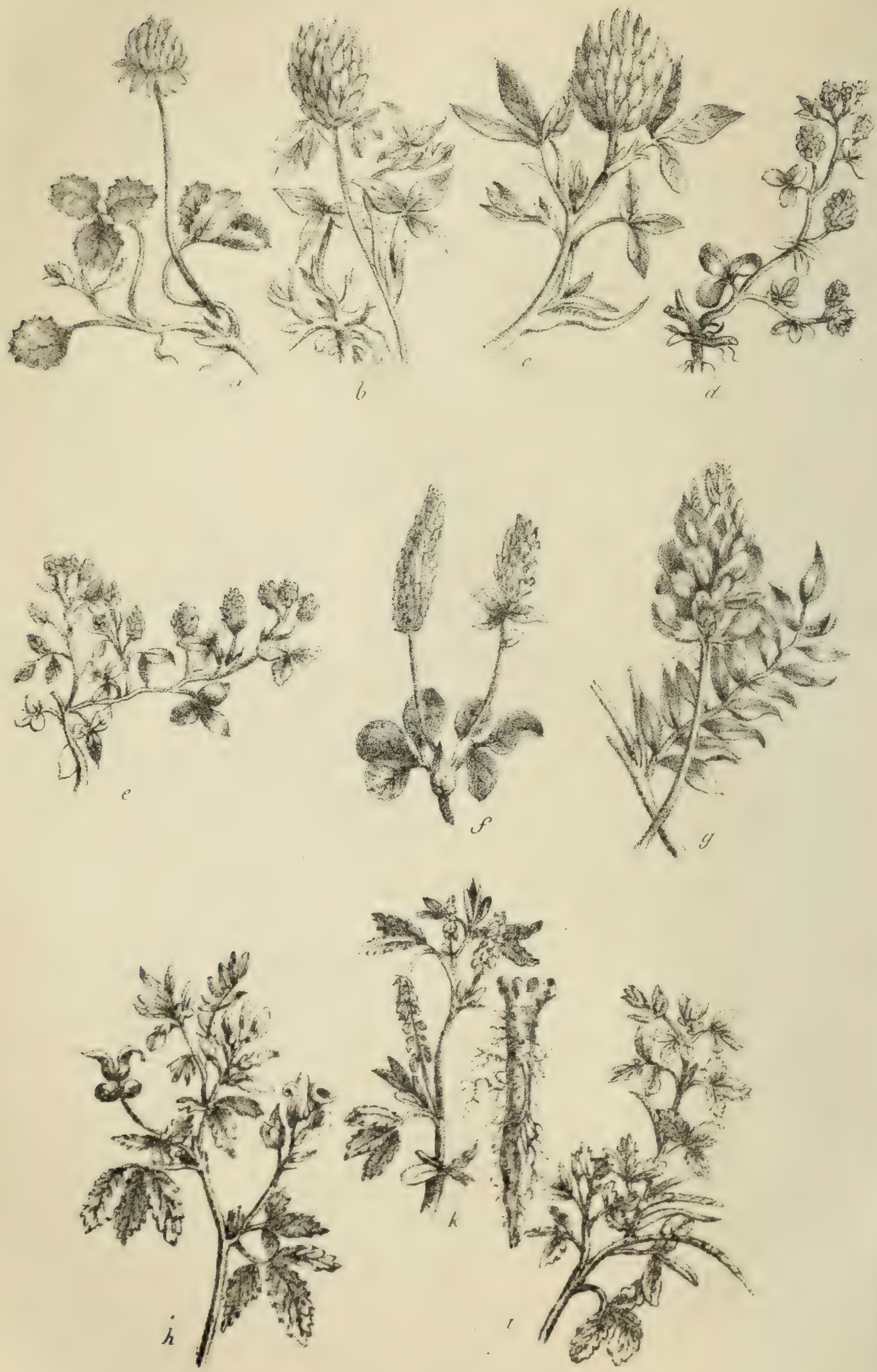
voured, and more numerous roots in Carolina, where it never flowers, than in the West Indies. In the latter place this plant runs wild, covers the whole face of the earth with its vines, and is so taken up in making foliage, that the root becomes neglected, and is small and woody.In order to have the onion in perfection, it must grow through two years, swelling all the time its bulbs. In the south, however, it seeds in one year, and before it has made much bulb. Beets, carrots, parsnips, turnips, radishes, and other roots, are equally affected by a hot sun, and scarcely worth cultivating far to the south. They all fructify before they have formed perfect roots, and make foliage at the expense of their bulbs; hence they will always be articles of commerce; the south will have to depend upon the north for them.

"The salad plants are in like manner affected by climate, and give further proofs of our assumption. Cabbages, lettuces, endive, cellery, spinage, plants whose leaves only are eat, to protect their germs from cold (through a lind of instinct), wrap them up in leaves, which iorm heads, and render many of their other parts tender and crisp for use. These leaves, thus protected, are not only tender, but more nutritious, because their growth has been slow and their juices well digested. In the south, a relaxing sun lays open the very buds of such plants, gives a toughness and thinness to the leaves, and they are too unsubstantial for animal support, because of such quick and rapid developement.

"The delicious and pulpy fruits are, in a still more striking way, illustrative of our principle. The peach, nectarine, plum, apple, cherry, currant, gooseberry, apricot, and many other such families, are not in perfection in the south. It is in Pennsylvania, Virginia, Maryland, Jersey, and in the north of Europe, that we enjoy them, although, originally, they came from places near the tropics. The peach of the Carolinas is full of larvæ, gum, and knots, and too stringy and forced to be juicy and flavoured. The apple of the south is too acerb to be either eaten or preserved. The plums, apricots, cherries, currants, gooseberries, \&c., will not even mature until we go far north. All the trees which bear these delicious fruits will grow luxuriantly in the south, make much foliage and wood, with but little pulp, and that unsavoury. The kernel in the one-seeded fruit seems to be the first object of nature in southern climes: that becomes strong, oily, and enlarged; and one of the peach family has so entirely neglected the pulp, that it has only a husky matter around the kernel, as the almond. The changeableness of the weather in the south, in the spring season, throws plants off their guard; the frosts attendant on those changes destroy the young fruit; and it is only one year in three that the crop hits at all. The desiccated or dried state of these fruits enables us to enjoy them through the year; but in the south their acidity carries them into fermentation or decomposition before they can be divested of their aqueous parts. The climate of the south is equally against converting them into cider, (14 any other fermented liquor, because the heat forces their compressed juice so rapidly into an active fermentation, that it cannot easily be checked until it passes into vinegar. For the same rtason distillation goes on badly in hot climates, and cannot be checked long enough at the proper point to give much alco. hol: and whether we aim to enjoy the delicious freshness of these fruits themselves, sip the nectarin of their juices, refresh ourselves with their fermented beverage, stimulate our hearts with their brandies and cordials, or feast through the winter upon the dried or preserved stores of their fruits, we are contincally balked by the severity of a southern climate, and for such enjoyment must look to the north.

"The melons are always affected by too great a degree of heat, even though their vines flourish so much in southern latitudes. The forcing sun hurries them on to maturity lefore they have attained much size, or acquire $f$ that rich saccharine and aromatic flavour for which they are so much esteemed. The cantelopemelon will rot, or have its sides baked by a hol sun, before it is fully formed; and the watermelon is always woody, dry, and devoid of its peculiar sweetness and richness in the south. Vines have been known to run one hundred feet, and bear no melon. It is in Philadelphia, and its neighbourhood, and in similar latitudes, that the markets are loaded with delicious melons of all sorts, whose flavour so much refresh and delight us. It is there, near their northern limit, that we cultivate them with such uniform success.

"The orange, strictly a tropical plant, is more juicy, large, and delicious, at St. Augus. tine (Florida), than at Havana ; and fruiterers, in order to recommend an orange, will say that it is from some place out of the tropics. In the West Indies, the pulp of the orange is spungy, badly filled with juice, and has too much of a forced flavour to be pleasant. The hot-house forcers of Europe, or at Rome, anciently at first produced bad fruit; too dry, too small, and without flavour; because they overacted. They have lately found out that fact, and now the productions of the hot-houses of London, Paris, \&c., astonish and delight us with the quantity and excellence of the fruit. They have found out that gradual and uniform heat is the desideratum; countervailing the cold, rather than imparting much heat. Fruit thus produced is pronounced better than any grown in the natural way, however perfect the climate.

"'The juices of the grape are best matured for wine near the northern limit of their growth. On the Rhine, in Hungary, the sides of the Alps, and in other elevated or northern situations, the wine is strongest, richest, and most esteemer. The French wines rank before the Spanish and Italian; and in no southern country oi Europe or Africa, except Madeira, where eltvation makes the difference, is the wine in much repute. The grapes of France are more delicious for the table than those of Spain or Madeira. In the southern part of the Lnitel States, the excess of heat and moisture blights the grape to such an extent that all attempis have failed in its cultivation. The grape-vine, however, whether wild or cultivated, grows
$2 \mathrm{~F}$ 
there very luxuriantly. The vinous fermentation can also be best conducted in a climate comparatively cool; and all the pressing, fermenting, and distillation of the juice of this delicate fruit can be safer and more profitably managed in a mild region.

"The olive, and other oleaginous plants, yield more fruit, of a richer flavour, and can be better pressed, and the oil preserved, in a mild climate. In France the tree is healthier, and the fruit and oil better than in Spain or Italy; and the Barbary States are known to import their oil from France and Italy.

"Many other plants might be named, whose habits would equally support our position. It is presumed, however, that enough have been cited to call the attention of philosophy to this curious subject, and enable us to give proper attention to it, in all the practical operations of agricultural pursuit. Much time and expense might be saved, and profits realized, if this were more generally understood.

"We have already observed, that the heat of the sun in southern climes forces plants to a false maturity, runs them on too rapidly to fructification, and renders dry and woody the culms, stalks, and leaves of the plants, where these parts are used. Hence the chaffiness of the leaf, the dryness of the culm, the lightness of the grain, and the unsavoury, spongy quality of the pulp of the plants in those latitudes. Hence the difficulty of fermenting their juices, distilling their essences, and preserving for use the fruit, juice, or blades of such plants. The prevalence of insects is another bar to the productiveness of southern plants: swarms of them invade and strip the leaves, bore the fruit, and lead to blight and decomposition; and just in proportion as the labours of man have rendered plants succulent, and their fruits and seeds sweet and pleasant, do these insects multiply on them, devour their crops, and defeat the objects of husbandry.

"The labour of man too is more conservalive in northern climates, because his arm is better nerved for exercise, his health and spirits more buoyant; and instead of saying, ' Go and work,' he says, 'Come and work;' treads with a cheerful heart upon his own soil, and assists in the cultivation, collection, and preservation of his own productions. It is in temperate climates that man can be most familiar with nature; it is there he has the best opportunities of observing the guarantees which nature has for the preservation of her animals and plants against the devastation of the elements; he sees an occasional apparent neg.ect of individuals, but a constant parental care of races. In every thing he sees the wisdom and benevolence of God."

CLIMATURE. A word sometimes employeu in much the same way as climate. It is a serm made use of by some agricultural writers.

CI,OG SHOES. The country name for wooden shoes.

'ClOTBUR. See Commox Burnock.

CLOTHING. In horsemanship, the practice of covering the animals with cloths, with the view of keeping them healthy, and giving fine coat.

GLOT'TED or CLOUTED CREAM. Under 338 the head of Burtrin, the process of making this preparation is described; but as the subject is one of particular interest to the American dairy, the following more detailed account is inserted, taken from the Library of Uscful Knowledge, $2 \mathrm{~d}$ vol. of British Husbandry. The dairy. maids of the western counties of England think that clouted cream furnishes one-fourth more cream from the same quantity of milk than can be obtained in any other way. The process is simply this. "The milk while warm from the cow is strained into either large shallow brass pans, well tinned, or earthen ones, holding from two to five gallons, in which should be a small quantity of cold water. 'This is thought to prevent the milk from burning, and to cause the cream to be more completely separated and thrown to the top.

"The morning meal of milk stands till about the middle of the day; the evening meal until the next morning. The pans are now steadily carried to, and placed over a clear, slow fire; if of charcoal, or over a stove, the cream is not so apt to get an earthy or smoky taste as when the milk is scalded over a turf or wood fire. The heat should be so managed as not to suffer the milk to boil, or, as they provincially term it, 'to heave;' as that would injure the cream. 'The criterion of its being sufficiently scalded is a very nice point; the earthen pan, having its bottom much smaller than the top allows this point to be more easily ascertained; because when the milk is sufficinntly scalded, the pan throws up the form of its bottom on the surface of the cream.

"The brass pan, if almost as big at the bottom as at the top, gives no criterion to judge by, but the appearance and texture of the surface of the cream, the wrinkles upon which become smaller and the texture somewhat leathery. In summer, it must be observed, the process of scalding ought to he quicker than in the winter, as in very hot weather, if the milk should be kept over too slow a fire, it would be apt to run or curdle.

"This process being finished, the pans are carefully returned to the dairy; and should it be the summer season, they are placed in the coolest situation; if on stone floors or slate benches, the better; but should it be the winter season, the heat should rather be retained, by putting a slight covering over the pans, as cooling too suddenly causes the cream to be thin, and consequently yield less butter: the mode of making which is this: The cream should, in hot weather, be made into butter the next day; but in winter it is thought better to let the cream remain one day longer on the milk. The cream, being collected from the pans, is put into wooden bowls, which should be first rinsed with scalding, then with cold water. It is now briskly stirred round one way, with a nicely cleaned hand, which must have also been washed in hot and then in cold water, for these alternate warm and cold ablutions of bowl and hand are not only for the sake of cleanliness, but to prevent the butier from sticking to either.

"The cream being thus agitated, quickly assumes the consistence of butter, the milky part now readily separates, and being poureo 
off, the butter is washed and pressed in several cold waters; a little salt is added to season it; and then it is well beaten on a wooden trencher until the milky and watery parts are separated, when it is finally formed into prints for the markets." (Surv. of Cornwall, p. 141.)

"If the quantity of cream be considerable, the cream will be an inch or more thick upon the surface, and it is then divided into squares and taken off. The remaining milk, however, r.ontains little besides the watery particles in its original composition." (Complete Grazier, sixth edition, p. 137.)

CLOUT. An iron plate put on the axletree of a cart or other carriage.

CLOVER. One of the most valuable species of the artificial grasses, of which there are several varieties, all too well known to need a particular description. 1. White clover, white irefoil, or Dutch clover (Trifolium repens), growing on almost all soils and situations. P $1.8, a$. 2. Perennial red clover ( $T$. pratense perenne) $b$; is found wild near Wainfleet, and in other rich natural English pastures. 3. Marl clover, cow grass (T.medium), $c$; when in flower it yielded Sinclair per acre, from a rich black loam, $20,418 \mathrm{lbs}$.; of nutritive matter, $717 \mathrm{lbs}$. 4 . Long-rooted clover ( $T$. macrohizum, $k$; a rich clayey loam yielded of this grass when flowering, 74,868 lbs.; of nutritive matter, 2,924 lbs. 5. Crimson clover (T. incarnatum), $f$. 6 . Egyptian clover (T. alexandrinum); see Quart. Journ.

Alsike clover, or hybrid trefoil, is a whiteflowered species, cultivated very extensively in Sweden, in the district of Alsike, from whence its common name. It possesses the strength and vigour of the red, with the permanency of the white clovers.

The creeping white clover is a perennial common to Europe and America, growing in the United States spontaneously in pastures, meadows, and upon woodlands, to the height of from 4 to 12 inches. The soil is so full of the seeds that the plant springs up wherever and whenever circumstances are favourable to its germination; and hence, when the season is good, it often furnishes a fine fall pasture after other grasses have almost disappeared. Though rarely cultivated in the United States, it is esteemed an excellent pasture at least in the Middle and Northern States, where it is sometimes sown with timothy and other grass for a regular hay crop. Mr. Eliott speaks unfavourably of it in the South. There is rather more difficulty in saving the seed of white clover than of the common red, and hence the seed of the former sells for at least double the price of the latter.

The yellow or shamrock clover (Trifolium procumbens), Plate $10, d$, is an annual, not very common in the United States, but found in the Middle States in dry, sandy soils, blooming its yellow flowers from May to August. The stem is from 3 to 8 inches long, sometimes trailing, at others nearly erect. It is a foreigner, and is gradually extending itself.

The common red clover is extensively cultivated in the United States, sometimes alone, sometimes with other grasses. With timothy It makes hay of a very superior kind, especially for neat cattle. The seed is usually sown with winter wheat or other grain crops, late in February or early in March, whilst the ground is still subject to freezing and thawing, and the seed can thus gain admission into the soil. Or it may be sown with the oat or other spring or summer crop, in which case, having the arlvantage of being harrowed in, it can generally be sown with even greater success than when put. with a crop of winter grain. Too little seed is generally applied, and the best quantity is from 10 to 12 or $14 \mathrm{lbs}$. per acre. 'The bushel weighs about 60 to 64 lbs., very nearly the same weight with guod wheat.

Clover is frequently turned under in the fall to enrich the ground preparatory to a crop of wheat, or in the ensuing spring for the benefit of the Indian corn. Some persons think the best time for turning down clover is in the rankest and most succulent stage of its growth, whilst others maintain that it is best to leave it to the period of its decline, when its extractive matter is most abundant. 'This last plan is undoubtedly the best in most if not all cases, and this opinion is founded upon the results of actual experiments. Being a biennial plant, clover of course leaves the field after the second year, unless allowed to seed itself. When timothy has been sown with it, this perennial grass then obtains exclusive possession of the field, where it is generally allowed to remain two or more years longer, affording the richest of all kinds of hay for horses, although for neat cattle the mixture of red clover and timothy is generally preferred.

Clover hay, when fed unmixed to horses, often produces a cough. This can always be removed by substituting timothy for a few weeks, after which the feed may consist of half clover and half timothy, with little or no danger of producing cough. Experience has shown that when the clover hay is fed from large troughs or mangers instead of racks above the head, horses escape the cough. Many of the most careful farmers in Pennsyl. vania have entirely excluded racks from their batus and stables, and substituted mangers or large troughs.

Clover, by which is understood the common red clover (trifolium pratense), is of immense importance in the improved system of American husbandry, taking the place of almost every other kind of ameliorating crop. Its tap roots penetrate and loosen the soil, whilst the leaves and stems produce abundance of nutritious food for the farm stock; and both roots and stems, when turned under by the plough, are extremely enriching to the soil. 'The first year's growth of clover is sometimes mown for hay and sometimes pastured, whilst the second crops are devoted to hay and furnishing seed. When the second crop is pastured in spring, the stock must not be turned on before the ground has become so firm that hoofs will not sink into the sod, nor until the growth is such as to enable the cattle to thrive. The pasturage may be continued from the middle of April or first of May for about six weelss, when the cattle are to be withdrawn, and the second crop allowed to go to seed for saving. Some farmers think that the closer the firs? growth of the second season is cut or cropped 
he better. By many, mowing the first crop is zonsidered preferable to grazing it, since the scythe takes off weeds which cattle would leave.

In the humid climate of England it is often lifficult to cure the clover properly after it is cut. But in the United States the greater dryness of the atmosphere renders it much more easy to save the crop, and consequently the practice of mixing it, layer upon layer, with dry wheat straw, dc., may generally be dispensed with. In saving clover, the object to be obtained is to cure the hay in the cheapest and best manner.

"The common practice of spreading clover hay from the swath," says Buel, "causes the leaves and blossoms to dry and crumble before the haulm or stems are sufficiently cured. Thus either the finer parts of the hay are lost, or the crop is housed with so much moisture as to cause it to heat, and often to spoil. Clover should only be spread when it has become wet with rain in the swath, and should be gathered again before the leaves dry and crumble. Both these evils may be avoided, and labour saved withal, by curing the grass wholly in swath and cock. After experiencing the serious disadvantages of the old method, I adopted the one I am about to recommend, and have pursued it satisfactorily ten or a dozen years. My practice has been to leave the clover to wilt in the swath, and, when partially dried, either to turn the swaths or to make grass-cocks the same day, so as to secure the dried portions from the dew. That which is not put into cocks the first day is thus secured the second day, or as soon as it has become partially dried. These grass-cocks are permitted to stand one, two, or three days, according as the weather is, and as the curing process has progressed, when they are opened at nine or ten o'clock on a fair day, the hay again turned over between eleven and three, and, soon after turning, gathered for the cart. Thus cured, the hay is perfectly bright and sweet, and hardly a blossom or leaf is wasted. Some care is required in making the cocks. The grass is collected with forks and placed on dry ground between the swaths, in as small a compass as convenient at the base, say two or three feet in diameter, and rising in a cone to the height of four or five feet.

"The advantages of this mode of curing clover are,

" 1 . The labour of spreading from the swath is saved.

" 2 . The labour of the hand-rake is abridged, or may be wholly dispensed with, if the horserake is used to glean the field when the hay is taken off, the forks sufficing to collect it tolerably clean in the cocking process.

"3. It prevents, in a great measure, injury from dew and rain; for these cocks, if rightly constructed (not by rolling), will sustain a rain of some days - that is, they have done this with me-without heating or becoming more than superôicially wet.

"4. Clover hay made in this way may almost invariably be housed in good condition; and if rain falls after the grass is mown, the quality of the hay is infinitely superior in 340 cocks to what it would be under the old iro. cess of curing." (Cullivator.)

Many prefer mowing the clover before it gets very ripe, as then so much of the seed would not be shaken off during the processes of curing, removing, \&c. As the hay of the seed-crop is seldom considered of much value except for litter and manare, it is frequently left long in the field to become thoroughly dry, so as to insure it against heating in the mow or stack, as this would be far more injurious to the seed than exposure to weather.

Besides mowing the seed crop in the usual manner for hay, several other methods have been devised. The one most commonly resorted to in Pennsylvania is the employment of a scythe and cradle to cut off the heads, which are canght by a kind of bag attached to the lower fingers, the rest being removed. Or the upper fingers being removed, the lower ones may be placed sufficiently close to catch the heads.

Among other contrivances which have been devised for gathering the heads in the field, one originally described by Mr. L'Homidieu, and since modified, is simple, cheap, and has been found very effectual. A description of the original machine, illustrated with a cut, may be found in the fifth volume of the Cultivator. It consists of an open box about four feet square at the bottom, and three feet high on the sides. To the fore part, which is open, fingers are fixed at the bottom, somewhat like those of a wheat cradle (or large points may be substituted resembling saw-teeth or a comb); these fingers or jagged points are about thirteen inches long, and so arranged as to catch and tear off between them the heads from the clover stems, which are thrown back in to the box as the horse advances. This box is fixed on an axletree provided with low wheels sixteen inches in diameter. Two shafts, each four feet four inches long, are attached to the axletree between the wheels and sides of the box. At the back part of the box, which is closed, there are two handles three feet long and twenty inches apart, resembling those of the wheelbarrow. The machine may be compared to a scraper, supposing this placed on low wheels, and to have high sides. 'The driver, by means of the handles, raises or lowers the fore part of the box, the notched bottom or fingers of which catch and tear off the clover heads. As often as the box gets filled with these it is emptied, and the horse moves on as before.

This machine has been advantageously modified, especially by Mr. James L. Bowman, of Brownsville, Pennsylvania, who, finding the wheels of the original contrivance too high, substituted ranners of three-inch scantling These runners, he says, ought to be about twc inches deeper behind than before, so as to ele. vate that part of the box, and give the teeth a depression towards the ground. The teetr ought to be left flat on the top, and the edges made sharp; underneath they should be bevelled dovetail fashion. Though wood will answes for these, it would be an improvement to have them made of iron, shaped like dirk blades Mr. Bowman also thinks the box should be 
made larger than that described, say six feet wide and five deep, as one of such a size can easily be drawn by a single horse, and would do more work. With the machine as modified by him, Mr. B. says the clover heads may be gathered cleaner and in half the time that would have been required to mow and save the hay. He sums up the advantages of employing the machine as follows:- "1st. The stalks are all left on the ground to benefit the land. 2d. The heads are immediately taken to the barn, ready for the hulling machine, without the delay and labour of separating the heads from the stalks by flails or tramping. 3d. A man with a horse can strip double the quantity in a day that he could cut. 4th. The seed is better, inasmuch as the heads are taken to the barn and secured from the weather, the dampress of which frequently causes them to sprout when exposed to the usual rotting process, as it is termed. For the use of this machine the clover ought to be permitted to get fully ripe, and if the spaces between the teeth become clogged, they can quickly be freed by a sharp spade or shovel, which the operator has with him in shovelling the heads to the back of the box."

In getting the seed from the heads, it has been common to employ the flail, and to clear it from the husk and chaff recourse has been had to a clover-mill, worked either by waier, steam, or horse-power. A clover-mill adapted to horse-power, with the advantage of being portable, has been patented by Rittenhouse \& Co., and is much used in the Northern and Eastern States, where the average product of seed per acre is four or five bushels. The cost of the mill is about $\$ 60$.

The old method of thrashing out clover seed by the flail or by the tramping of horses has been generally regarded as very tedious and disagreeable, so much so, indeed, as to have discouraged most farmers irom attempting to gather the seed at all. Those who were within the vicinity of clover-mills conveyed the seed in the hull to them to have it separated and eleaned. This was costly and troublesorne, and the refuse was lost to the farmer. Of latter time the introduction of thrashing machines has obviated all difficulty of this kind, and farmers can now thrash out their clover seed with nearly the same expedition that they thrash their grain. The dried clover stalks and heads are put through the machine in the same manner as wheat; a proper sifter separates the stems from the heads, when, by introducing an additional set of teeth into the machine to work closer, the heads or chaff are again put through the machine, by which process the seed is shelled from the hull with great expedition and very effectually, when it is cleaned by the fan in the usual manner. Many of the thrashing machines now in use have been constructed with the additional set of teeth for this purpose, and if they were all thus supplied, it would be a means of encouraging the cultivation of clover for seed on a much more extended scale, cheapen the article, and promote the sowing of it more extensively and thicker than is often done, by which fewer bald places would be seen in the fields, and the stalks would not be so gross and succulent, and the hay and pasture would be sweeter and better and in greater abundance than when it stands thin on the ground. (Sinclair's Hort. Grum.; Quart. Journ. of $A g r$. vol. xi. p. 249; "On turning the second crop of Clover;" Com. to Board of Agr. vol. iv. p. 197 ; Davy.)

ClÓVER, BOKARA. See Mellizoty AlaA. CLOVER BOX. A contrivance for sowing clover seed, of very simple construction, easily made and at trifling expense, was invented by the late Mr. Bordley, of Maryland. It is called the Clover box, and in some sections of the country it is in general use. It not only scatters the seed over the ground with entire certainty and equality, but makes a much less quantity answer than is usually required in the old process of sowing broadcast. It is stated that, "by the use of this box, one bushel has seeded fifteen acres, the clover well set, the plants in sufficient numbers, and the whole field evenly seeded.

"The box is eight or ten feet in length, about four inches in breadth, divided into partitions of six inches long. In the bottom of each partition is an opening of about three inches square, in which is inserted a piece of tin, parchment, or stiff paper, perforated with a number of holes of sufficient size for the cla ver seed to pass freely through.

"The seed is placed in each partition. To the box is affixed a strap, which is passed over the shoulders of the sower, and, carrying the box before him, he walks over the field, agitating the box by his hand if it requires more movement than it receives from his walk. In this manner the seed is equally distributed over all the ground.

"A very thin piece of board may be hooked at the bottom of the box; to prevent the seed dropping out before the sowing commences. The box may be made of light cedar, and not weigh more than six or eight pounds without the seed." See Am. Farmer, vol. ii. p. 60.

CLOVER, STONE (Trifoliumarvense), Welsh clover, Rabbit-foot. This is frequent in Pennsylvania and other Middle States, on sandy, barren fields. Though supposed to be a native of America, it is found on both sides of the Atlantic. It is a worthless plant, and indicatıve of eareless farming. (Flor. Cestric.)

CLUB GRASS (Corynephorus). An uninteresting species of grass, requiring only to be sown in common soil. The last articulation of the jointed beard is club-shaped, whence its name.

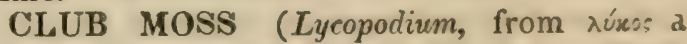
wolf, and roũs a foot, because of the resem. blance of the roots). This moss grows abundantly on mountainous heaths or stony moers; some of the species, which are numerous, reach to a foot high, in watery, healthy, mountainous situations. The seeds are often highly inflammable, like powdered sulphur. The iardy species of club moss require to be cultivated in peat soil, in a moist situation; some of them succeed in pots of water. They are readily increased by suckers.

The planed or flatted lycopodium grows m the United States, in woods and thickets. It is the well-known trailing variety so often cot $2 \times 2$ 
lected as an ornamental evergreen, 10 be hung in festoons around churches, ball-rooms, mirrors, picture-frames, \&c. (Flora Cestrica.)

CLUB RUSH. See Rush.

CLUMP (Ger. klump). A number of shrubs or trees growing together.

CLUSTER-GRAPE. The small black or currant grape. See Vive.

CLUSTER-SOWING. That method of sowing grain, in which a number of corns are placed together.

CLYSTER. See Gltster.

COAGULATION (Lat. coagulatio). A term signifying that chemical change which takes place when a fluid, or some part of it, is rendered more or less solid.

COAGUI,UM. A term applied to the curdled concretion formed by the mixture of two liquors. It sometimes also means rennet.

COB. A kind of wicker basket, made so as to be carried on the arm. Hence a seed-cob, or seed-lip, is a basket for sowing from. Cob was formerly the name for a spider, hence we have cobweb. Cob is also applied provincially in England to a round sort of stone, to a mud wall, and sometimes to a particular kind of horse. In the United States it is the common name given to that portion of the ear of Indian corn to which the grains are attached. When burned, corn-cobs yield a large proportion of potash.

COBBLE. A provincial term for a round sort of stone found in the fields. It also signifies a small kind of fishing-boat.

COBBLE-TREES. A sort of double swingletrees, whippins, or splinter-bars.

COCCIFEROUS PLANTS (from xsxusc, and fero to bear). Such plants or trees as afford nutrition to, and a habitation for, the insect called a coccus.

COCCUS. A genus of insects frequenting certain plants. Naturalists enumerate more than twenty species. Among these are the cochineal insect of the tropical parts of America, and the scarlet-grain of Poland (Coccus polonirus) which thrives only in cold climates. This last is sometimes called the Cochineal of the North, and is collected in great abundance ior the use of dyers, from the roots of the polygonum cocciferum. It is much inferior to the American cochineal.

Some interesting information relative to insects of the Coccus family may be found under ihe head of BARK-LICE.

COCCULUS INDICUS, or INDIAN BERRY, is the fruit of the Menispermum cocculus, a large tree, which grows upon the coasts of Malabar, Ceylon, \&c. The fruit is blackish, and of the size of a large pea. It owes its narcotic and poisonous qualities to the vegeto-alkaline chemical principle called picrotoxia, of which it contains about one-fiftieth part of its weight. It is sometimes thrown into waters to intoxicate or kill fishes; and it is said to have been employed to increase the inebriating qualities of ale or beer. Its use for this purpose is prohibited by act of Parliament, under a penalty of $200 l$. upon the brewer, and $500 l$. npon the zeller of the drug.

COCHINEAL. An America : insect greatly ralued on account of its use in lying crimson, searlet, \&c., and preparing carmine. When first discovered it was taken to Europe as a seed, but was proved by the observations of Lewenhoeck to be an insect, being the female of that species of shield-louse, or coccus, discovered in Mexico, so long ago as 1518. It is brought to us from Mexico, where the animal lives upon the cactus oprentia or nopal. Two sorts of cochineal are gathered-the wild, from the woods, called by the Spanish name grana silvestra; and the cultivated, or the grana fina, termed also mesteque, from the name of a Mexican province. The first is smaller, and covered with a cottony down, which increases its bulk with a matter useless in dyeing; it yields, therefore, in equal weight, much less colour, and is of inferior price to that of the fine cochineal. But these disadvantages are compensated in some measure to the growers by its being reared more easily and less expensively; partly by the effect of its down, which enables it better to resist rains and storms.

The wild cochineal, when it is bred upon the field nopal, loses in part the tenacity and quantity of its cotton, and acquires a size double of what it has on the wild opuntias. It may, therefore, be hoped that it will he improved by persevering care in the rearing of it, when it will approach more and more to fine cochineal.

The fine cochineal, when well dried and well preserved, should have a gray colour, bordering on purple. The gray is owing to the powder, which naturally covers it, and of which a little adheres; as also to a waxy fat. The purple shade arises from the colour extracted by the water in which they were killed. It is wrinkled with parallel furrows across its back, which are intersected in the middle by a longitudinal one; hence, when viewed by a magnifier, or even a sharp naked eye, especially after being swollen by soaking for a little in water, it is easily distinguished from the factitious, smonth, glistenirg, black grains, of no value, called East India cochineal, with which it is often shamefully adulterated by certain London merchants. The genuine cochineal has the shape of an egg, bisected through its long axis, or of a tortoise, being rounded like a shield upon the back, flat upon the belly, and without wings.

These female insects are gathered off the leaves of the nopal plant, after it has ripened its fruit, a few only being left for brood, and are killed, either by a momentary immersion in boiling water, by drying upon heated plates, or in ovens. The last become of an ash-gray colour, constituting the silver cochineal, or jaspeada; the second are blackish, calted negra. and are most esteemed, being probably driest; the first are reddish brown, and reckoned inferior to the other two. The dry cochineal being sifted, the dust, with the imperfect insects and fragments which pass through, are sold under the name of granillo.

Cochineal keeps for a long time in a dry place. Hellot says that he has tried some 130 years old, which produced the same effect as new cochineal.

Much adulteration is practised in England ppon cochirieal. In the republics of Mexico, 
Guatimala and other parts of Central America, where the temperature of the climate throughout ten months of the year seldom falls so low as $50^{\circ}$ Fahr., the circumstances are peculiarly fivourable to the culture of the cochineal insect. A large amount of the capital of the country is invested in the necessary plantations and fixtures.

The true cochineal insect has been found in South Carolina by the late Dr. Garden, and Mr. Raphael Peale of Philadelphia also identified it on the island of Little St. Simons, coast of Georgia. The Cartus opuntia grows abundantly on all the calcareous islands near the Southern coast. Still it is not very probable that cochineal will soon become an object of culture in the extreme Southern States, as it is an employment of a very tedious and fatiguing nature, exacting more attention than the management of the silkworm, which last bids fair to be a far more profitable resource.

COCK (Sax. coec; Fr. coq). A name applied to the male of chickens and other birds.

COCKCHAFFER (Melolontha vulgaris). One of the common names for a species of European tree beetle, whose food consists almost entirely of leaves. They come rather late in the vernal season, about May 20th, but occasionally appear at uncertain intervals in amazing swarms. White says, they abound only once in three years. They are also known by the provincial names of May-bug, dor, and dummador. Cockchaffers are sometimes used as baits in angling. The larva or grub of the common cockchaffer is one of the great ravagers of the English meadows and grass lands. It remains in the grub state for four years. "It undermines," says Kirby, "the richest meadows, and so loosens the turf, that it will roll up as if cut with a turfing spade. These grubs did so much injury seventy years ago to a poor farmer near Norwich, that the court of that city, out of compassion, allowed him $25 \mathrm{l}$, and the man and his servant gathered eighty bushels of the beetles. The damage done by them in 1785 was so great in France, that the government offered a reward for the best mode of eradicating them." The rooks are great friends to the farmer in destroying this grub, to procure which they follow the plough. (Kirby and Spence's Introd. to Entomology, vol. i. p. 180.)

COCK-FIGHTING. A very old and barbarous common pastime and amusement, which is happily growing into disuse in civilized England and America, and becoming superseded by more manly and noble sports.

COCKLE, CORN, or CORN CAMPION (Sax. coccel; Lat. Agrostemma githago). Pl. 10, a. A well-known troublesome annual weed, of rather an ornamental appearance, growing in grain-fields in summer, bearing purplish red Howers. It stands two feet and a half high, the stalk firm, hairy, slender, and round, with one large flower upon each top. The leaves stand two at a joint, long, narrow, and of a bright green colour. The flowers, which are of a violet-purple colour, stand in a cup composed of linear hairy sepals, which are longer than the corolla. 'The seeds, which are numerous, are black and rough, and nearly as big as small wheat kernels; they are filled with white flour, and very heavy. 'The miller's objection to these seeds is, that their black husks break so fine as to pass the boulters, and render the flour specky; also because the seed is bulky. and if there be much in the sample, it detracts considerably from the produce in flour. Being easily distinguished, this weed should be era. dicated from the field by the hand before flowering. (Smith's Eng. Flora, vol. ii.p. 325 ; Sinclair's Weeds, p. 9; Elements of Agricullure, 441 ; Willich's Dom. Encyc.)

COCK'S-FOOT GRASS (Dactylis glomerala) Pl. 5, b. Commonly called Orchard Grass in the Middle and Northern States. A species of grass, which, from the experiments of Sinclair appears to become by cultivation superior to rye grass and some others as a pasture grass, if kept closely cropped by cattle or the scythe; and also when made into hay. Oxen, horses, and sheep eat it readily. It flowers from June till August, and perfects its seed in July. The produce of herbage per acre, at the time of flowering, is $27,905 \mathrm{lbs}$, which affords of hay $11,859 \mathrm{lbs}$., and the proportion of nutritive matter is 1089 lbs. The produce is something less when the seed is ripe, and it loses about one-half its weight in drying. See $\mathrm{H}_{\Delta \mathbf{r}} \mathrm{Grass}_{\mathbf{a}}$. (Sinclair's Hort. Gram. p. 136; Smith's Eng. Flora, vol. i. p. 134.)

COCK-SPUR. A common name in Eng. land for the Virginian hawthorn; a species of medlar. See Hawrнorn.

COCOON. The fibrous web round a chry. salis.

COD. A term used sometimes for pod.

CODLIN. A well-known kind of baking apple. See Malus.

COFFEE. The seed of a tree of the family rubiacea. There are several species of the genus, but the only one cultivated is the Coffea Arabica, a native of Upper Ethiopia and Arabia Felix. It rises to the height of fifteen or twenty feet. Its trunk sends forth opposite branches in pairs above and at right angles toeach other; the leaves resemble those of the common laurel, although not so dry and thick. From the angle of the leaf-stalks small groups of white flowers issue, which are like those of the Spanish jasmine. These flowers fade very soon, and are replaced by a kind of fruit not unlike a cherry, which contains a yellow, glairy fluid, enveloping two small seeds or berries convex upon one side, flat and furrowed upon the other, in the direction of the long axis. These seeds are of a horny or cartilaginous nature; they are glued together, each being surrounded with a peculiar coriaceous membrane. They constitute the coffee of commerce.

It was not till towards the end of the fifteenth century that the coffee tree began to be cultivated in Arabia. Historians usually ascribe the discovery of the use of coffee as a beverage to the superior of a monastery there, who, desirous of preventing the monks from sleeping at their noctural services, made them drink the infusion of coffee upon the reports of shepherds who pretended that their flocks were more lively after browsing on the fruit of that plant The use of coffee was soon rapidly spread, tur 
It encountered much opposition on the part of the 'Turkish government, and became the occasion of public assemblies. Under the reign of Amurath III. the mufti procured a law to shut all the coffee-houses, and this act of suppression was renewed under the minority of Mahomet IV. It was not till 1554, under Solyman the Great, that the drinking of coffee was accredited in Constantinople; and a century elapsed before it was known in London and Paris. Solyman Aga introduced its use into the latter city in 1669, and in 1672 an Armenian established the first café at the fair of St. Germain.

The use of coffee became general among the English sooner than it did with the French. The first mention of coffee on the English statute books is in 1660 , when a duty of $4 d$. is laid upon every gallon of coffee bought or sold. Ray informs us that in 1688 London might rival Cairo in the number of coffee-houses.

When coffee became somewhat of a necessary of life, from the influence of habit among the people, all the European powers who had colonies between the topics, projected to form plantations of coffee trees in them. The Dutch were the first who transported the coffee plant from Moka to Batavia, and from Batavia to Amsterdam. In 1714, the magistrates of that city sent a root to Louis XIV., which he caused to be planted in the Jardin du Roi. This became the parent stock of all the French coffee plantations in Martinique.

The most extensive culture of coffee is still in Arabia Felix, and principally in the kingdom of Yemen, towards the cantons of Aden and Moka. Although these countries are very hot in the plains, they possess mountains where the air is mild. The coffee is generally grown alf way up on their slopes. When cultivated on the lower grounds, it is always surrounded by large trees, which shelter it from the torrid sun, and prevent its fruit from withering before their maturity. The harvest is gathered at three periods; the most considerable occurs in May, when the reapers begin by spreading cloths under the trees, then shaking the branches strongly, so as to make the fruit drop, which they collect, and expose upon mats to dry. They then pass over the dried berries a very heavy roller, to break the envelopes, which are afterwards winnowed away with a fan. The interior bean is again dried before Deing laid up in store.

In Demarara, Berbice, and some of the English West India islands, where much good coffee is now raised, a different mode of treating the pulpy fruit and curing the beans is adopted. See Ure's Dict. of the Arts, \&c.

The most highly esteemed coffee is that of Moka. It has a smaller and a rounder bean; a more agreeable taste and smell than any other. Its colour is yellow. Next to it in European reputation are the Martinique and Bourbon coffees: the former is larger than the Arabian, and more oblong; it is rounded at the onds; its colour is greenish, and it preserves almost always a silver gray pellicle, which comes off in the ruasting. The Bourbon coffee approaches nearest to the Moka, from which it origınally sprung. The Saint Dominge coffee has its two extremities pointed, and is much less esteemed than the preceding.

The coffee tree flourishes in hilly districts, where its root can be kept dry, while its leaves are reireshed with frequent showers. Rocky ground, with rich decomposed mould in the fissures, agrees best with it. Though it would grow, as we have said, to the height of fifteen or twenty feet, yet it is usually kept down by pruning to that of five feet, for increasing the production of the fruit, as well as for the con venience of cropping. It begins to yield fruit the third year, but is not in full bearing till the fifth, does not thrive beyond the twenty-fifth, and is useless in general at the thirtieth. In the coffee husbandry, the plants should be placed eight feet apart, as the trees throw out extensive horizontal branches, and in holes ten or twelve feet deep, to secure a constant supply of moisture.

Coffee has been analyzed by a great many chemists, with considerable diversity of results. The best analysis perhaps is that of Schrader. He found that the raw beans distilled with water in a retort communicated to it their flavour and rendered it turbid, whence they seem to contain some volatile oil. On reboiling the beans, filtering and evaporating the liquor to a syrup, adding a little alcohol till no more matter was precipitated, and then evaporating to dryness, he obtained 17.58 per cent. of a yellowish-brown transparent extract, which constitutes the characteristic part of coffee, though it is not in that state the pure proximate principle called cafeine. Its most remarkable reaction. is its producing, with both the protoxyde and the peroxyde salts of iron, a fine grass-green colour, while a dark-green precipitate falls, which redissolves when an acid is poured into the liquor. It produces on the solution of the salts of copper scarcely any effect, till an alkali be added, when a very beautiful green colour is produced, which may be employed in painting. Coffee beans contain also a resin, and a fatty substance somewhat like suet. According to Robiquet, ether extracts from coffee beans nearly ten per cent. of resin and fat, but he probably exaggerates the amount. The peculiar substance cafeine contained in the above extract is crystallizable. It is remarkable in regard to composition, that after urea and the uric acid, and theobromin from chocolate, it is among organic products the richest in azote. It was discovered and described in 1820 by Runge. It does not possess alkaline properties. Pfaff obtained only ninety grains of cafeine from six pounds of coffee beans. There is also an acid in raw coffee, to which the name of cafeic acid has been given. When distilled to dryness and decomposed. it has the smell of roasted coffee.

Coffee undergoes important changes in the process of roasting. When it is roasted to a yellowish-brown, it loses, according to Cadet, $12 \frac{1}{2}$ per cent. of its weight, and is in this state difficult to grind. When roasted to a chestnut brown, it loses 18 per cent., and when it becomes entirely black, though not at all carbo. nized, it has last 23 per cent.. Schrader has 
analyzed roasted coffee comparatively with raw coflee, and he found in the first $12 \frac{1}{2}$ per cent. of an extract of coffee, soluble in water and alcohol, which possesses nearly the properties of the extract of the raw coffee, although it has a deeper brown colour, and softens more readily in the air. He found also 10.4 of a blackish-brown gum; $5 \cdot 7$ of an oxygenated extract, or rather apotheme, soluble in alcohol, insoluble in water; 2 of a fatty substance and resin; 69 of burnt vegetable fibre, insoluble. On distilling roasted coffee with water, Schrader obtained a product which contained the aromatic principle of coffee; it reddened litmus paper, and exhaled a strong and agreeable odour of roasted coffee. If we roast coffee in a retort, the first portions of the aromatic principle of coffee condense into a yellow liquid in the receiver; and these may be added to the coffee roasted in the common way, from which this matter has been expelled and dissipated in the air.

of late years much ingenuity has been expended in contriving various forms of apparatus for making infusions of coffee for the table. I have tried most of them, and find, after all, none so good as a caffetière à la Belloy, the coffee biggin, with the perforated tinplate strainer, especially when the filtered liquor is kept simmering in a close vessel, set over a lamp or steam pan. The useful and agreeable matter in coffee is very soluble: it comes off with the first waters of infusion, and needs no lwiling.

To roast coffee richly, we should keep in view the proper objects of this process, which are to develope its aroma, and destroy its tough-

is, so that it may be readily ground to pow1:r. Too much heat destroys those principles which we should wish to preserve, and substitutes new ones which have nothing in common with the first, but add a disagreeable empyreumatic taste and smell. If, on the other hand, the rawness or greenness is not removed by an adequate heat, it masks the flavour of the bean, and injures the beverage made with it. When well roasted in the sheet-iron cylinders set to revolve over a fire, it should have a uniform chocolate colour, a point readily hit by experienced roasters, who now manage the business very well for the principal coffeedealers both of London and Paris, so far as my judgment can determine. The developement of the proper aroma is a criterion by which coffee-roasters frequently regulate their operations. When it loses more than 20 per cent. of its weight, coffee is sure to be injured. It should never be ground till immediately before infusion. (Ure's Dict. of Arts and Manuf.)

Coffee may be cultivated in the peninsula of Florida. A climate the temperature of which seldom falls below $55^{\circ}$, and where the soil is on gentle declivities, afford the most favourable circumstances. The trees may be set five or six feet asunder; they begin to yield good crops at three years of age, and the average produce of a tree is two and a half pounds.

The consumption of coffee is very great in Mohammedan countries, and especially in Tur- key, where their religion furbids the use of wine and spirituous liquors. In the United States, its consumption is already very greal and is rapidly increasing; being not less than 15,000 tons annually.

In Paris, the best coffee in the world is made by the following process. This is the celebrated liquor there called cafè au lait. The coffee is generally roasted in a rotary cylinder, over a small furnace of charcoal, and usually in the open air, until it becomes of a brown cinnamon colour; it is then turned into a wooden tray, and stirred till nearly cool. The pot in which coffee is usually made, is compound, and formed of two parts, of equal dimensions; the lower pot being made of the usual form; the spout being lrept covered and closed during the process, by a small cap, thimble formed. 'The upper pot is nicely fitted to the top of the lower pot, of which it forms a lid; it is pierced at the bottom with very fine holes, and thus forms a fine strainer; in the bottom of this pot, and on this strainer, the fresh and finely ground coffee is placed, and the top of this pot is closed by the insertion of a shallow tin cup, full of larger holes, which serves for a coarser strainer; and through this, either boiling water, or, most commonly, a strong infusion of boiling coffee, is poured, which has been formed by boiling the grounds of the former day, which had still retained a large portion of their criginal strength; thence the whole fluid slowly and gradually descends to the lower pot. Thus a very strong, clear, and black infusion is prepared, which, on being brought to the table, is reduced by the addition of at least an equal quantity or more of boiling milk; sugar being added to suit the taste. Nothing can be more fragrant and de. licious than coffee thus made. (Kenrick.)

In the Eastern countries of the old world and in Europe \& enerally, at present, coffee is alwavs taken in small cups as a cordial and restorative,-and not swilled in large vessıls as a heverage at meals, as is so frequently done in the United States, especially by the interior population. The French mode of preparing coffee for use having been given, we will sujjoin a description of the process pursued in Arabia, as related by Mr. Buckingham, who had ample opportunities of learning it from personal observation.

"It is found that the only certain mode of retaining the pure flavour of the corfee, is to roast, pound, and boil it, all in quick succession, the roasted berries soon losing their fla. vour if laid by for a day, and the pounded coffee becoming insipid, even in a few hours. The Arabs of the desert, who are from necessity economical in the use of this article, follow the same process, even if they require only two cups of the liquid, roasting a handiul of ber ries on an iron plate, pounding them in a pes le and mortar while warm, and the instant tho water boils, which it will generally do by the time the other preparations are completed, so that no time is lost, putting the pounded pow der into it, and suffering it to boil, stirring it at the same time for about a minute or two, when it is poured out to drink. As the beverage is 
taken without sugar or milk, the siightest difference in the flavour is perceptible; and long experience having shown this to be the best way of preserving it in perfection, it is perhaps worth mentioning in detail, particularly as the use of this article has become so general."

COFFEE TREE (Gymnocladus Canadensis). 'This native North American tree is found as high nor thward as Upper Canada beyond Montreal, and on the southern shores of Lakes Erie and Ontario. It is, however, much less abundant in these climes than in the states of Kentucky and Tennessee, and in the tract watered by the Ohio and Illinois rivers, between the 35 th and 40 th degrees of latitude.

By the French of Canada this tree is called Chicot; by those of the Illinois Gros Fevier, whilst the inhabitants of the Western States call it Coffee Tree.

The presence of this tree, is an evidence of the richest lands, on which it habitually grows in company with the black walnut, red elm, poplar, blue ash, honey locust, and hackberry. These trees it equals in height, but not in bulk; for a coffee tree fifty or sixty feet high does not generally exceed twelve or fifteen inches in diameter. "In summer," says Michaux, "this tree when fully grown has a fine appearance: its straight trunk is often destitute of branches for thirty feet, and supports a summit not very widely spread, but of a regular shape and of tufted foliage; such at least is its form in primitive forests, where it is confined by the trees which grow around it. In the winter when its leaves are fallen, the fewness of its branches and the size of the terminal ones, which are very large in comparison with those of other trees, give it a peculiar appearance, somewhat resembling a dead tree, which it retains in the spring long after other trees are clothed in foliage. This is probably the reason of its being called Chicot, stump tree, by the French Canadians. To this peculiar character is added another of the epidermis, which is extremely rough, and which detaches itself in small, hard, transverse strips, rolled backward at the ends, and projecting sufficiently to render the tree distinguishable at first sight. I have also remarked that the live bark is very bitter, so that a morsel no bigger than a grain of maize chewed for some time produces a violent irritation of the throat."

The foliage of the coffee tree bears some resemblance to that of the black walnut. The flowers are white, and the fruit consists of large bean-like crooked pods, of a reldish brown colour, and of a pulpy consistency within. They contain several large, gray seeds, which are extremely hard. The French in Upper Louisiana call them Gourganes.

"The name of the coffee tree was given by the early emigrants to Kentucky and Tennessee, who hoped to find in its seeds a substitute for coffee: but the small number of persons who made the experiment abandoned it, as soon as it became easy to obtain from the seaports the coffee of the West Indies.

"The wood of the coffee tree is very comaact and of a rosy hue. The fineness and closeness of its grain fit for cabinet-making, and its strength renders it proper for building. Like the locust, it has the valuable property of rapidly converting its sap into perfect wood, so that a trunk six inches in diameter has only six lines of sap, and may be employed almos: entire. These qualities recommend it for pro. pagation in the forests of the north and of the centre of Europe.

"The coffee tree was sent to France more than fifty years since. It thrives in the environs of Paris, where there are trees that exceed forty feet in height; but it does not yield fruit, and is multiplied only by shoots obtained by digging trenches round the old trees. The divided roots produce shoots three or four feet long, the first year. The young trees are sought, on account of their beautiful foliage, for the embellishment of parks and picturesque gardens."

A communication from Mr. M. D. Hardin, of Franklin county, Kentucky, published in the American Farmer (vol. 2), makes us acquainted with some interesting facts relative to the sensible properties of the fruit of the coffee tree, and its effects when eaten.

The subjoined preparation of the nut of the native coffee bean tree, or pea locust tree, "has," says Mr. Hardin, "been found to destroy flies more certainly than any preparation I ever saw. It is now used by many in this neighbourhood. I never heard of it until this season. There is no danger to children or any animal from the preparation. I have been familiar with the nut for more than thirty years; it grew in my father's yard, and is in abun. dance in my wood pastures. I have several times eaten the kernel of the nut raw, but never of many at a time-when roasted many are fond of them, and I have eaten a good many that way, I have never myself seen them used for coffee, but have heard of their being. so used as a matter of curiosity not of choice or economy. The cattle eat the pods including the nuts in the winter, as they do the wild honey locust pods; but the nut owing to its hard shell does not digest, but passes off whole. I have known children eat the green glutinous matter within the pod, as they would that of the wild honey locust, but it brings on sickness and puking. The nut itself is so well understood to be harmless and eatable, that the coffee-mill has been most usually made use of to prepare the nut for the flies.

"For destroying flies.-Take the nuts of the native pea locust or coffee-nut tree, crack them and take ont the kernel raw; reduce them to meal or powder (a coffee-mill or mortar are commonly used), put this into as much sweet milk as would make it into a paste. To this add some sugar to make the flies more readily eat it, put it into a plate or other vessel, and set it where you want to destroy the flies."

COFFIN-BONE. In farriery, that bone which lies encircled within a horse's hoof as in a coffin.

COINS, FOREIGN. The following tables will show the values and weights of various foreign coins in federal money of the United States: 
Table of various Foreign Coins, with their Value in Money of the United States. Also, the Value of Gold Coins per pennyweight.

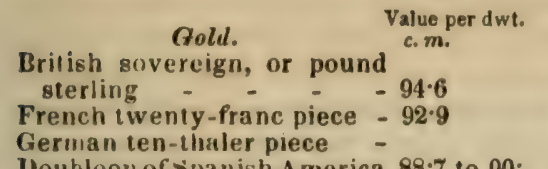

Value by tale. D. c. D. C. $4 \cdot 83$ to $4 \cdot 86$ 3.84 to 3.85 $7 \cdot 84$ to $7 \cdot 97$ Voubloon of spanish America 88.7 to $90^{\circ} \quad 15.39$ to $15 \cdot 62$

The value by tale depends upon the age, reign, section of country, and other qualifying circumstances, so that it cannot be precisely expressed in so small a compass.

Silver.
Val.bytale.
Dollar of Mexico and South A merica, about

By the Mint Iaws passed by Congress in 1837 , the eagle is to weigh 258 troy grains, the half and quarter in proportion; the dollar $412 \frac{1}{2}$ grains, the parts in proportion. The relative value, therefore, of silver to gold, is 15.9984 to 1 , or nearly 16 of silver for 1 of gold. In making this comparison, both the silver and gold are to be of the fineness of nine-tenths.

The coinage of silver in the United States, from 1826 to 1833 , was nineteen and a half millions; that from 1834 to 1841 was twenty millions.

COLCHICUM (Colchicum autumnale). Common meadow saffron. A bulb throwing up a reddish purple flower without leaves in September and October: grows three or four inches high: found in moist rich meadows, but not common. It may be propagated from offsets in July. Every part of the plant contains an alkaline principle named Colchicia, which is a most violent purgative as well as narcotic. This active matter is extracted by wine, spirits of wine, and vinegar. A tincture of the bulb or of the seeds of colchicum, in the dose of twenty to thirty drops twice a day, has been found very useful in gout and rheumatism. It has been too commonly taken without medical advice, and much mischief has resulted. In an overdose colchicum is a virulent poison. (Smith's Eng. Flora, vol. ii. p. 202.)

COLD (Sax. colo; Dan. kaald). See ĆAtaprh, and Diseases of Catrle, Horses, \&c.

COLE, or COLESEED (Celt. caal; Welsh, cawl; Lat. Brassica napus). A variety of the cabbage genus, much cultivated in the east of England; it is sown from the middle of July to the end of August, either for autumn sheepfeed, or for seed (which is very rich in oil) for the following summer. The ashes of the burnt straw of coleseed are excellent dressing for clover. (Brit. Husb. vol. ii. p. 312.) See Covza and RAPF.

COLEWORT. See Cabbagr.

COLIN, THE VIRGINIAN PARTRIDGE (Ortyx Virginiana). This bird has been introduced into England from the United States, and is a species of partridge. It lives on the borders of woods, among brushwood, or on the thick grassy plains. (Yarrell's Brit. Birds, vol. ii. p. 448.)

COLLAR (Span. collar; Lat. collare). That part of the harness of a horse or other animal that goes round his neck and rests on the shoulders. For horses, they are mostly made of canvass, \&c. stuffed with hair, tow, or straw, and covered with leather.

COLLEY, or COLLY. A kind of dog mich prized by the Scotish drovers. See Dow, SukpHERI's.

COLLEY SHEEP. A name for sheep that have black faces and legs. 'The wool of these sheep is generally very harsh, having hairs mixed with it.

COLLING, ROBERT and CHARLES. Two celebrated farmers of the county of Durham, who, by their skill, enterprise, and public spirit, not only secured for themselves the plaudits of after generations of farmers, but did honour to their country by the improvement which they effected in the Durham breed of short-horns, perhaps the most celebrated of all our modern breeds of cattle. It is not in my power to give any details with regard to their private history; their public efforts is all in which my readers will feel interested. The following account of the sale of their stock, and the enormous amount which it produced, will afford a much better view of their success as breeders than any eulogium of mine.

Charles Colling, of Ketton, near Darlington, made a very ample fortune. The prices he obtained for his stock could hardly indeed have failed to have produced such a result: thus at his sale of improved short-horns, Oct. 11, 1810, the following were some of the prices obtain ed :-

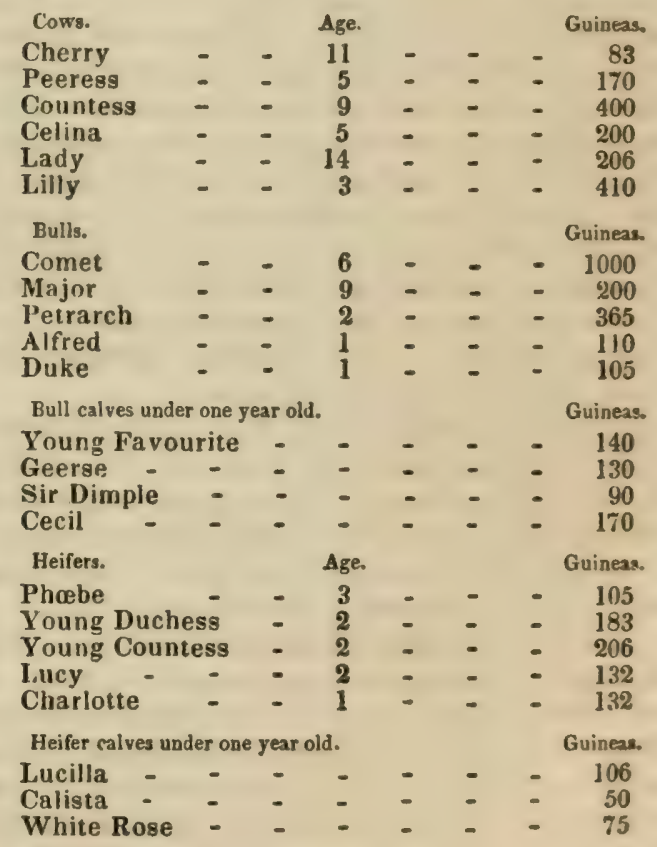

Altogether it appears that-

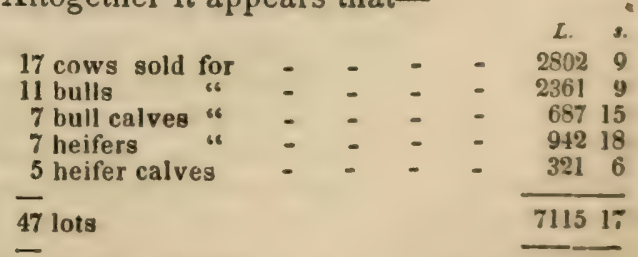

Robert Colling's stock was sold at Barmpton, near Darlington, September 29, 1818, when it produced for- 


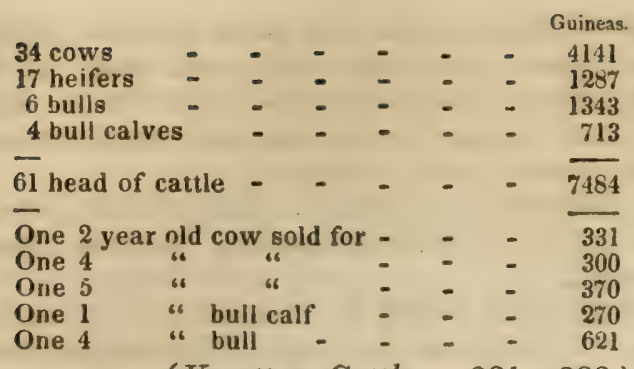

(Youatt on Cattle, p. 231-233.)

Charles Colling, after his retirement from business, resided at Croft, in the North Riding of Yorkshire, where he died January 16, 1836, aged 85. Robert Colling died in his 70th year, at Barmpton, near Darlington, March 7, 1820.

COLT (Sax. col $\tau$ ). A term applied to young horses. See Honses.

COLT-EVIL. In farriery, a distemper to which young horses are subject, consisting of a swelling in the sheath.

COL'TS-FOOT, COMMON. (Tussilago furfara). Pl. 10, $l$. This is an herb of peculiar growth, very common in England on chalky or marly soil, in moist situations. It is mostly found in fields that are over-cropped or exhausted, and often severely exercises the patience of the farmer. It may be eradicated by ploughing up the soil, carrying the plant away when rooted out, and laying the fields down to grass. The flowers rise in spring on stalks six or eight inches high, round, large, and yellow, like the dandelion; their stalks being thick, fleshy, scaly, and red coloured. Each stalk supports one flower. When the flowers have decayed, then the leaves appear on erect furrowed footstalks, broad and cordate, lobed and toothed, resembling the form of a horse's foot, whence the name. They are green above, and white and downy underneath. The leaves are used medicinally, and they dry well. A decoction of the leaves and roots, or a syrup of the juice, is useful in coughs, whence the generic name. The ancients inhaled the smoke for the relief of coughs.

There are two species of the colts-foot, butterbur, or Tussilago genus in the United States. See Nuttall's Genera. The plant known in Pennsylvania and some other Middle States by the name of colts-foot is not of the same genus, but an Asarum. See GINGER, WILn.

COLZA. Though comparatively but little cultivated in England, and hardly known in the United States, colza is an article of immense importance in French and Flemish husbandry. It belongs to the cabbage family, and is cultivated for its oily seed, which are crushed and pressed for their oil, similar to flax-seed. The oil is used to burn in lamps, and for a great variety of useful purposes. The cake left after pressing the seeds, like that of rape, is an article regularly in the markets of England, France, Germany, \&c., being purchased by farmers, who use it, either alone or mixed with other substances, as food for cattle, or io make into manure for various crops. In France, Germany, and the Netherlands, the rake is very often thrown into their urine-cis-

rns, where it soon becomes a very valuable ma348 terial for manure. The haulm, or stems, after the seeds are thrashed off, is frequently burned for the ashes, which are considered of treble the value of other ashes employed as manure.

Two species of colza are cultivated in France; the one a biennial, sown in summer or autumn, standing out all winter, and maturing its growth and seed the following summer. This is called winter colza, and is the Brassica campestris of botanists. The other species, or rather variety, is a spring crop, maturing its seeds the same year, and is the Brassica arvensis of naturalists. Neither of these must be confounded with rape, which the French term navette, and which is the Brassica napus, being the species most cultivated for similar purposes in England. Whether the winter colza will resist the intense cold of the winters in the more northern states may be doubtful; but should it not, the spring colza (B.arvensis) will doubtless succeed in any part of the United States not favourable to the winter species. As the plant may become of consequence to the American agriculturist, we subjoin, from Dombasle's Farmer's Calendar, a description of the French modes of managing the colza crops.

It is generally considered indispensable that the ground on which colza is sown should be rich, light, new, well manured, and prepared by much ivorking. "Nevertheless," says Dombasle, "many years' experience has taught me that, by pursuing a good system of culture, very satisfactory crops may be procured from light and gravelly soils. The plant is not afraid of a slightly clayey soil, which, in fact, is the one best adapted to it, provided this be very light in its texture. It is indispensable that the ground, of whatever nature its soil may be, shall be perfectly well drained during the winter, as frosts are fatal to colza in soils which retain water."

There are three methods of sowing colza :1. Broad-cast; 2. In rows or drills; 3 . In beds for transplantation. The last method can onl be pursued where labour-and especially $f$ male labour-is extremely cheap. The sowin in rows is done by the use of drills, the lines being placed about eighteen inches apart. This method admits of hand-hoeing, and even the use of the cultivator, to destroy weeds or loosen the soil. When sown broad-cast, about $14 \mathrm{lbs}$. of seed are required for one hectare (equal to about $2 \frac{1}{2}$ acres). Much less is required where sown by drills, when the seeds are dropped about an inch apart in the direction of the rows. The sowing broad-cast or in rows generally takes place from the middle of July to the middle of August. When the plants are picked from beds to be planted out, this is done in September or early in October, so that they may have time before winter to form good roots. They are placed in holes dibbled by means of a planter with points from 9 to 12 inches apart, and so formed that a man makes two rows at a time, whilst a second person puts the plants in the holes, pressing the earth well around them with his feet. Sometimes rows are run with the plough, and two or three women are employed after each plough, in distributing plants along the open furrow, which is covrred up by the plough in returning. 
When this is skilfully performed, the plantation may be effected with great regularity. In soils of moderate fertility, the plants need not be more than 9 inches apart in every direction. When the ground is very rich, they may stand about 12 inches apart; and when planted with the plough, every other furrow is left vacant, and the plants placed 9 or 10 inches apart.

In moderately fertile soils, the product of the colza is generally equal to, and sometimes a little greater than that of wheat. Thus, in soils which produce 20 bushels of wheat to the acre, 20 or 25 bushels of colza are obtained, and the product of rape has been nearly equal. But in more fertile soils the colza, when it has been well managed, far surpasses the product of wheat on the same soil, it being not unusual to obtain 28 or 30 bushels to the acre, on ground that will not yield more than 18 or 20 bushels of wheat. Sometimes, by very careful cultivation, and on ground of a very deep soil, especially when this is newly broken up, as much as 40 bushels of colza can be got from an acre, a larger product than could be expected from rape.

The chaff of colza and rape form very good ivul for woolly animals during winter. When given to horned cattle, it should be in the form of slop, made by mixing it in boiling water. Sheep eat the straw or stems very freely, when well kept and not too coarse.

When planted in rows, a hoeing or harrowing, by means of the cultivator, is generally given in the month of March. About the beginning of July, and sometimes even at the end of June, the navette, or rape, and winter colza arrive at maturity, the rape almost always 8 or 10 days the earliest. As the seeds of these plants shatter off very easily, it is necessary that, in harvesting, they should be cut before they become completely ripe. The most proper time is when the seed-pods begin to turn yellow and become transparent, and when the seeds are of a dark-brown, though still tender. Though the grains of all the pods may yet be green, the greatest number will ripen in the stack or mow. Sometimes, when the crop has become very ripe, to prevent the loss of the seed, it should only be cut in the evening or morning, whilst it is covered with dew, or during a bright moonlight. night. Twenty-four hours after reaping, or sometimes immediately after, if the plants are quite ripe, the colza is put into cocks, the sheaves being carried to an elevated part of the field, and placed in cocks, the height of which must be double that of the stock of colza. In laying them down, the first sheaves are placed on the outside, and the next towards the centre. The cock gradually diminishes in diameter, till raised to the height of five or six feet. When the cock is two or three feet high, the stalks or stems have an inclination on the outside downwards. This increases successively to the top, which is thus made to form a perfect cone. To keep out the rain, the top may be tied with a band of straw, willow twig, or branch of any other pliant wood. 'The cocks remain in this state until all the grains are matured. This generally requires from 8 to 12 days. If carefully put up, the cocks will be sufficiently protected against bad weather except in case of powerful and continuec rains, which would occasion still more damage to the crop in any other situation. The colza may also be put into large stacks, like those of wheat and other grain, very soon after it has been cut, and remain in this situation for a month or two. This is, in fact, the safest way of keeping the colza. But this method is more expensive than that of cocking, as it requires to be wagoned to the stack. The fermentation which always takes place in the cocks is very favourable to the grain, giving it a fine colour, and contributing qualities which are very desirable. The grain will only be injured, if it is heaped up whilst it is yet green or wet.

When the crop is small, it may be taken at once into a barn and thrashed off. In its trans. portation the seed is very apt to be shaken off, on which account it is necessary to carry them to the wagons in cloths, and the wagon itself should be lined with some coarse and cheap stuff.

Large crops of colza or rape are generally thrashed in the field by the feet of horses, the place being covered with strong hempen cloth, stretched upon a spot from which all stones, \&c., are carefully removed. If the colza has been put up in cocks, we carry the whole cock in a linen cloth eight feet square, which four men suspend to two long poles of light wood, eleven feet in length, attached to the two sides of the "nen. After spreading the cloth along the side : the cock, two other poles, of the same length as those described, are passed under the cock, which is thus raised up altogether and placed upon the cloth, to be carried to the thrashing-floor. When this is sufficiently filled with colza, spread evenly about two feet in thickness, and first beaten down by the feet of the workman who arranges it, three unshod horses are put upon the floor, or three two-yearold colts. These are trotted circularly around a man who occupies the centre, and who hoids them by a rein. After they have been round several times, the colza is turned with hayforks, and the horses brought on again. In this way the thrashing is done very quiclsly. If a very large crop, two thrashing-floors should be made, so that when one bed is preparing, another may be thrashing and emptying. After being thrashed, the seeds may be housed, either in the chaff or partially screened through riddles. When put into granaries, the colza should be spread in small beds, and turned frequently for some time, being subject to heating, by which much of their value is lost. It should only be compietely cleaned when perfectly dry, or when it is desirable to sell, as it keeps so much better when mixed with more or less chaff. It is scarcely necessary to ob. serve that colza may be thrashed by means of the common thrashing machines used for grain.

Spring Colza.-In clayey and new soils, the spring colza is generally more productive than the rape, yet it is always a very uncertain crop, like those of all oily grains which are sown in the spring. It is one of the must pro fitable plants that can be grown in the soils of newly-drained ponds and meadows. Some persons, however, have obtained abundani crops from ground adapted to the growth of 
wheat, but this has been in particularly favourable seasons.

The spring colza should not be sown as late as the rape, as its growth is much slower. "In one very favourable year," says Dombasle, "when I had sown colza on the $2 \mathrm{~d}$ of June, it did not arrive at maturity soon enough to admit of being harvested."

After the soil has been well prepared by two or three ploughings, the seed may be sown broad-cast, at the rate of 7 or 8 lbs. per acre on very light ground, covering it with the harrow. Some sow the colza in drills eighteen inches apart, and till between the rows with a horse-hoe. But, in general, cultivation, which is so beneficial to winter colza and rape, produces but a poor effect on a crop which occupies the soil so short a time.

COMFREY, COMMON (Symphytum officinale). This wild plant grows by the sides of ritches and in moist places to a height of three feet. The leaves are a deep green colour, pointed, long, and rough to the touch. The stalk is green, thick, and upright, and winged at the bases of the leaves. The flowers are sometimes white, and often reddish in colour. The root is thick, black externally, and white within. It is full of a slimy juice when crushed or broken. The root is the part used medicinally. It contains much mucilage, and may be used as a demulcent. Conserve of comfrey is the best way of preserving it through the year. The tuberous-rooted comfrey (S. tuberosum) is an herb of much humbler stature than the last-named root; knobbed and branched; externally whitish; flowers fewer, drooping, yellowish-white, tinged with green. (Smith's Eng. Flora, vol. i. p. 263.) The prickly comfrey (S. asperrimum) is a hardy perennial of gigantic growth, introduced from Caucasus as an ornamental plant, in 1811, by Messrs. Loddiges, of Hackney. (See Curtis's Bot. Mag. No. 929.) The attention of the agriculturist has recently been directed to the cultivation of comfrey as green food for cattie, by Mr. Grant, of Lewisham, who speaks highly of its merits. (Baxier's Agr. Lib.)

COMPOSITION FOR TREES. See CANKER.

COMPOST (Fr.; Lat. compositum). That sort of manure which is formed by the union or mixture of one or more different ingredients with dung, or other similar matter. An excellent essay, by Mr. James Dixon, on making compost heaps irom liquids and other substances, written on the evidence of many years' experience, was awarded a premium of $10 l$. in July, 1839, by the Royal Agr. Soc. of England, and is published in their Quart. Journ. vol. i. p. 135. See also Farm-tand Manure.

CONDITION (Fr. and Lat.). In horsemanship, a term supposed to imply a horse's being in a state of strength and power, so much above the purpose he is destined to, that he displays it in his figure and appearance: this, according to Taplin, signifies "fine in coat, firm in flesh, high in spirits, and fresh upon his legs."

CONIFEROUS PLANTS AND TREES. Such plants and trees as bear cones; as the fir, pine, cedar, \&c.

CONSERVATORY (Lat.). A glazed struc35,1 ure, in which exotic trees and shrubs are grown in a bed or floor of soil. It is distinguished from an orangery by its having a glazed roof, while that of the latter is opaque, and from a green-house by the plants being set in the fine soil, instead of in pots placed on shelves. The largest conservatory in the world at the present time (close of 1841), is that erected in Chatsworth, in Derbyshire, for palms and other tropical plants, which covers above an acre of ground, and is sixty feet high. (Brande's Dict. of Science and Art.)

CONTRACTION OF THE HOOF. In farriery, is a distorted state of the horny substance of the hoof in cattle, producing all the mischiefs of unnatural and irregular pressure on the soft parts contained in it, and consequently a degree of lameness which can only be cured by removing the cause. Contraction of the hoof rarely happens, however, except to those animals whose hoofs, for the convenience of labour, are shod.

CONVERTIBLE HUSBANDRY, or mixed husbandry, a term implying frequent change in the same field from tillage crops to grass, and from grass back to tillage crops; an alternation of wheat, rye, \&c., with root and grass crops.

COOP, or COUP (Icel. kuppa; Dut. kuype). A provincial name for a tumbrel or cart, enclosed with boards to carry dung, sand, grains, \&c. It is also a pen or enclosure where lambs, \&c., are shut up to be fed or fattened; and a kind of cage in which poultry are enclosed for the same purpose.

COPPICE, or COPSE (supposed from the Fr. couper; or Nor. copper, to cut off). Low woods cut at stated times for poles, fuel, \&c. A place overrun with brushwood. Its wood is called coppice-wood.

CORDGRASS (Spartina stricta. From spartine, a rope made of broom). A genus of perennial maritime grasses found in muddy salt marshes on the sea coast, of which this is the only native variety. They are very easy of culture, and increased by divisions and seeds. Roots, creeping, with strong fibres; whole plant, hard, tough, and rigid; stems ten to twenty inches high, several together; leaves, numerous, striated, of a dull green colour and smooth. (Eng. Flora, vol. i. p. 135; Paxton's Bot. Dict.)

Spartina juncea.-According to the experiments of Sinclair, this grass is very late in the production of foliage, and inferior in nutritive qualities to most other kinds of grass. It, however, yields well as a single crop, the produce from a rich, silicious, sandy soil, at the time of flowering, being $33,350 \mathrm{lbs}$., which afforded of nutritive matter $1433 \mathrm{lbs}$. It has been tried for the purpose of forming into flax ; and Sinclair tells us, the results were favourable, inasmuch as the clear fibre was equal in strength and softness to that of flax, but it was deficient in length. The only advantage that appears would result from this plant affording flax is, that it could be produced on a soil unfit for the growth of flax or the production of corn. It flowers the second week in August, and the seed is ripe by the middle of September. (Hort. Gram. Wob. p. 373.) Three or four species of 
Spartina are fornd in the United States, chiefly confined to the salt water districts along the sea coast.

CORD-WOOD. Small pieces of wood broken up for fuel. It also signifies top-wond, roots, \&c., cut up and set in cords; so denominated from its being formerly measured with a cord. A statute cord of wood should be eight feet long, four feet high, and four feet broad.

COREOPSIS, EAR-LEAVED, (Coreopsis auriculata). A hardy perennial, a native of North America. It grows three or four feet high, and its yellow flowers bloom in August. 'The $\mathrm{Co}$ reopsis delphinifolia is also a native of North America, growing about eighteen inches high, with yellow flowers. Blooms from July to October. Divide the roots, and plant it in open situations.

CORIANDER, (Coriandrum sativum. From repts, a bug; the fresh leaves, when bruised, emitting an odour very similar to that of this vermin). Coriander thrives best in a moderately rich but sandy loam: excessive moisture is equally inimical to it as the want of a regular supply. It must have an open and rather sheltered situation. It is propagated by seed, which, if it is required early, must be sown during February, in a warm border or moderate hotbed, in either situation with the protection of a frame. This may be repeated at the close of March. Afterwards small crops may be successionally inserted every month in an open bed or border until September, in which month, and October, if required for winter's supply, final crops must be sown under a frame, as in February. The summer sowings should always be of small extent, as the plants at that season are very apt to run.

The sowings are generally performed in drills eight inches apart, and half an inch deep; the plants to remain where sown. The only cultivation required is to thin them to four inches' distance and to have them kept clear of weeds throughout their growth. For the production of seed, some plants of the early spring sowings must be left ungathered from, at about eight inches apart each way; they will perfect their seed in early autumn, being in flower during June.

Kitchen Garden.)

(G. W. Johnson's

CORK OAK (Quercus suber). The tree producing the thick, light, and soft bark, out of which corks are made, is a species of oak found in the southern parts of Europe, in Spain, France, and Italy. Both public and private interest, says Michaux, requires the inhabitants of the southern coast of the United States, and especially of the neighbouring islands, to introduce and rear the cork oak, in places unfit for the culture of cotton. It should also, he thinks, be introduced into West Tennessee, and with the more reason as the vine is there cultivated successfully. It will grow wherever the live oak is found.

In size this oak seldom grows higher than forty feet, with a diameter of three feet. Its leaves are evergreen, but the greater part of them fall and are renewed in the spring. The acorns are large and oval, of a sweetish taste, and eagerly devoured by swine. The wood is hard, compact and heavy, but not so duiable as that of some other kinds of oak. The bark begins to be taken off at the age of twenty-five years, the first growth being of little value. It is not, however, till the tree is forty-five or fifty years old, that the bark possesses all the qualities requisite for good corks, and from that period it is collected every eight or ten years. The length of time which thus elapses between planting and reaping compensation renders it very improbable that the cork oak will ever be extensively introduced by individual enterprise, into those parts of the United States where it would thrive. Nothing short of $\mathrm{go}^{-}$ vernment patronage could effect the object recommended by Michaux. The consumption of corks is exceedingly great; in France alone it amounts annually to 125 or $150,000,000$.

CORN. A term which in Europe is applied alike to wheat, barley, and the other small grains, whilst in the United States it is used almost exclusively to designate Indian corn or maize.

CORN BINDWEED. See Brñwed.

CORN, BROOM-. The following account of the broom-corn, its culture and uses, is the substance of a communication made by $\mathrm{Mr}$. William Allen of Northampton, Massachusetts, to Mr. H. L. Ellsworth, Commissioner of Patents.

Of the genus sorghum (broom-grass) there are four or five species. Sorghum saccharatum is the broom-corn, abundantly cultivated in this country, both for the seed and for its large panicles, which are made into the brooms. The whole plant is saccharine. Attempts have been made in France to extract sugar from it, but with little success.

The other species are the following: Sorg. hum dora (or holcus dora), common Indian millet, a native of the East Indies, but cultivated in the south of Europe; S. bicolor, or twocoloured Indian millet; S. caffrorum, caffres Indian millet, and S. nigrnm, coal-black Indian millet.

Of the sorghum saccharatum (or holcus saccha. ratus), broom-corn there are several varieties raised in Hampshire county, Massachusetts, in the valley of the Connecticut river, princi pally in the broad meadows of Northampton, Hadley, and Hatfield. The pine tree kind is regarded as the poorest kind, or the lecst advan tageous for cultivation; yet, as it is the earliest (being three weeks earlier than the large kind), in a short season, when its seed will ripen, while the seeds of the other kind fail to ripen, this may prove the most profitable crop. The: North river crop is ordinarily the best crop; it is ten days earlier than the large kind, and yields about $720 \mathrm{lbs}$. of the brush per acrethe brush meaning the dried panicles, cleaner of the seed, with eight or twelve inches of the stalk. The New Jersey, or large kind, vields a thousand or eleven hundred pounds of brush per acre. The stallss and seed are large. In good seasons, this is the most profitable crop. But in the present season (1842), owing to an early frost (about September 23), much of the seed of this kind will fail to ripen. There is also the shirley, or black brush. Soil rich, alluvial lands are best adapted for the broom. 
corn, more especially if warmly situated, protected by hills, and well manured.

Method of planting. - The broom-corn is planted in rows, about $2 \frac{1}{2}$ or 3 feet apart, so that a horse may pass between them with a plough, or cultivator, or harrow. The hills in each row are from 18 inches to 2 feet apart, or farther, according to the quality of the soil. The quantity of seed to be planted is estimated very differently by different farmers-some say that half a peck is enough per acre, while others plant half a bushel, and some a bushel, in order to make it sure that the land shall be well stocked. The rule with some is to cast a teaspoonful, or 30 or 40 seeds, in a hill; the manure at the time of planting should be put into the hill, and old manure or compost is preferred, as being most free from worms.

Cultivation.-The broom-corn should be ploughed and hoed three times-the last time when about three feet high, though some hoe it when it is six feet high, and when they are concealed by it as they are toiling in the field. The number of stalks in a hill should be from seven to ten. If there are only five or six stalks, they will be larger and coarser; if there are about eight, the brush will be finer and more valuable. In the first hoeing, the supernumerary stalks should be pulled up.

Harvesting.-As the frost kills the seed, the broom-corn is harvested at the commencement of the first frost. The long stalks are bent down at 2 or $2 \frac{1}{2}$ feet from the ground; ard by laying those of two rows across each other obliquely, a kind of table is made by every two rows, with a passage between each table, for the convenience of harvesting. After drying for a few days, the brush is cut, leaving of the stalks from 6 to 12 inches. The longer it is cut, of course, the more it will weigh; and, if the purchaser does not object, the benefit will accrue to the farmer. However, the dry stalk weighs but little; if its weight is excessive, the purchaser sometimes requires a deduction from the weight. As it is cut, it is spread on the tables, still farther to dry. As it is carried into the barn, some bind it in sheaves; and this is a great convenience for the further operation of extracting the seed. Others throw the brush into the cart or wagon, unbound.

Scraping. - The process of extracting the seed is called "scraping the brush." Two iron horizontal scrapers are prepared-one movable, to be elevated a little, so that a handful of brush may be introduced between them. The upper scraper is then pressed down with one hand, and the brush drawn through with the other, the seed being scraped off. This is the old method. A newly invented scraper is superseding the old one. It is an upright instrument, of elastic wood or steel, inserted in a bench of a convenient height for the operator.

The form is as follows:

$a$ is a piece of wood or steel, immovable; $b$ and $c$ are pieces which are elastic, movable to the right and left at the top, but

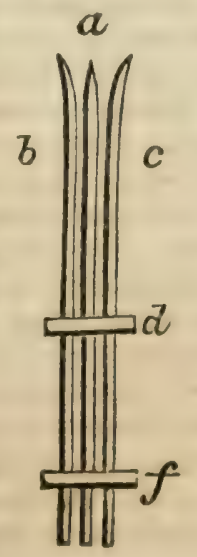
352 fastened to the central piece below. The de gree of elasticity may be regulated by wedges in the planks $d$ and $f$-wedges in the hole through which the pieces pass.

A quantity of brush is taken in the hand, and brought down upon the top of this instrument. As it is forced down, and drawn towards the body, it separates the elastic sticks from the central piece, but their elasticity presses sufficiently on the brush, so that the seed is scraped off.

The advantage of this scraper is, that both hands may be applied to the brush, instead of only one hand, as in the other kind, and the elastic power of nature is substituted for the pressure of one of the hands. The instrument also seems to double the scraping surface. The instrument was invented at Hartferd. I have been told it has not been patented.

The following plan may therefore be useful. The operator stands at the end $\mathbf{A}$.

A

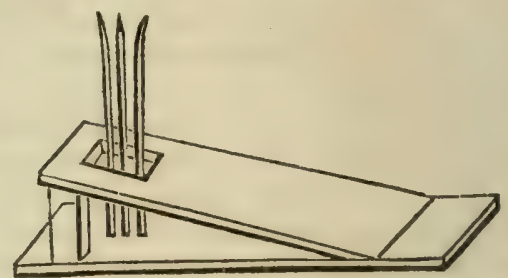

The lower plank may rest on the barn floor, or have short legs. The upper oblicue has a hole, through which the scraper passes, and down which the seed may fall. Each side of the instrument, a wedge may be inserted, to regulate its elasticity, or by some other contrivance this object may be secured. In scrap. ing, the panicles must first be laid evenly together, and the stalks taken in the hand. If this is not done in the field, and bundles not formed, then must it be done with considerable labour at the time of scraping in the barn.

Product.-A common crop is 700 to $800 \mathrm{lbs}$. per acre. There have been raised 1000 and $1100 \mathrm{lbs}$. per acre, with 80 to 100 bushels of seed. The large kind grows eleven feet high.

Value of the crop.-About the year 1836 or 1837, the brush sold for $12 \frac{1}{2}$ cents a pound; and one farmer in Northampton sold his crop standing, unharvested, at $\$ 100$ per acre. Since then, the price has been decreasing. This year it has been 4 and 5 cents. At 6 cents, the farmer, for $800 \mathrm{lbs}$, gets $\$ 48$ an acre, besides 60 or 70 bushels of seed, worth a third of a dollar a bushel-so that he receives $\$ 70$ or up. wards from an acre.

Good farmers regard the seed alone as equal to a crop of oats from the same land. Some land owners have rented their land for broom. corn, at $\$ 25$ per acre, they putting on five or six loads of manure.

One farmer, who, a few years ago, cultivated 50 acres in broom-corn, must have had an almost unequalled income for a New England farmer.

Quantity. - In Northampton, probably 200 acres are raised; in Hatfield, 300 ; in Hadley, 400 ; in other towns, Whateley, Deerfield, Greenfield, Easthampton, Southampton, SouthHadley, Springfield, and Longmeadow, perhaps 300 or 400 acres more; in all, in the valley of 


\section{CORN CALL.}

the Connecticut, 1200 or 1300 acres; the product, in brush and seed, worth $\$ 1,000,000$.

Manufacture of brooms.-Individuals tie up brooms with wire or twine. The expense is greater for materials and labour when wire is used.

The turned broom handles cost, as delivered, only one dollar a hundred-one cent each. 'The expense of other materials and labour in making a broom is 6 cents, or on the whole about 7 cents. In a good broom a pound and a half of brush is employed, which at the present price of 5 cents, would be $7 \frac{1}{2}$ cents, so that a broom made with wire costs now about $14 \frac{1}{2}$ cents. A manufacturer recently went to Buston, and could get an offer of only 12 cents, or $\$ 12$ per hundred, for his brooms; at which rate he could not afford to sell them and chose to retain them. Brooms are made with brush weighing $\frac{3}{4}$ of a pound, 1 pound, $1 \frac{1}{4}$ pound, and $1 \frac{1}{2}$ pound. 'The brush is whitened by the manufacturer. It is placed in a large tight box, and bleached by the fumes of sulphur; but this process is said to weaken the brush. Who would think of whitening broom brush, for beauty? Thus it is that fashion descends into the vale of life, and to the humblest of concerns. Why should not the housemaid wield a beautiful broom, with white brush and variously interlaced wire, and polished and variously coloured handle?

Miscellaneons. - $\Lambda$ few remarks will be added, some of which were omitted in their proper places. If the stalks are cut before the seed is ripe, they are better, stronger, more durable, than if cut after the seed is ripe. In this case, the farmer would lose the value of the seed. He of course will not submit to this loss, unless it is made up to him by the increased price of the brush.

The seed is used for feeding horses, cattle, and swine. It is ground and mixed with Indian meal, and is regarded as excellent foodit weighs forty pounds a bushel.

Mr. Shipman of Hadley is the greatest manufacturer of brooms in the valley of the Connecticut. If he employs, on an average, ten hands, and each hand makes 25 brooms per day, the number made in a year would be 78,000. It is said he has made 100,000.

The brush, when it is put in the barn, should be placed on a scaffold, so as to be exposed to a circulation of the air, that it may dry and not mould. For all the purposes of use, a broom made with twine is equal to one made with wire; and a man can make several more of them in a day.

Mr. Shipman uses 300 or $400 \mathrm{lbs}$. of large iwine, at 20 to 30 cents a pound, and $2,000 \mathrm{lbs}$. of small twine, at 31 cents. Perhaps he manufactures only $\frac{1}{8}$ part of the brooms manufactured in Hadley.

At the price of 20 cents, the price of brooms a few years ago, the broom manufacture of Hadley would thus amount to $\$ 160,000$.

It is probable that the extended cultivation of the broom-corn will reduce the profits on this product to the average profits of good farming.

CORN CALE. A provincial name for charock.

CORN-CROWFOOT (Ranunculus arvensis).
A weed very common among corn. Root fibrous. It has an upright stalk; the leaves are of a pale, shining green, and cut into long, narrow, acute segments. The lemon-coloured flowers are much smaller and paler than those of the crowfoot which is found in pasture. grounds, and the seed-vessels are very remarkable, being covered all over with prickles. It is very acrid and dangerous to cattle, though they are said to eat it greedily. M. Brugnon, who has given a particular account of its qualities, relates, that three ounces of the juice killed a dog in four minutes. (Smith's Eng. Flor. vol. iii. p. 53.) See Crowfoot.

CORN-CUTTING MACHINEs. Machines for cutting wheat and other grains by horse power, of which none have hitherto been produced in England whose merits have insured their adoption by the farmer. Of the several English patents obtained, that called Smith's Reaping Machine, is perhaps the most approved. For a minute description of this, with drawings, see Encyc. Britannica, vol. 2, part 1. Sin Mow. ing and Reaping Machine.

CORNEL TREE. See Dogwood.

CORNET. In farriery, a name sometimes given to the instrument used in venesection, called a fleam.

CORN, INDIAN. See Maizz.

CORN LAWS. The regulation of the supply, and consequently, the value of corn in different countries in Europe, has been an object of legislation from a very remote period; a public interference, varying, however, in degree, from that of protective taxation, to that which was intended to be prohibitory. Of the first kind are the modern English corn laws; of the last are the present local regulations of Paris, by which bread is sold always at the same price, both in bountiful seasons or in those of scarcity. It would occupy tco much space to follow these, generally necessary in. terferences with the sale of corn, which have occurred from the days of the Athenians (who depended upon Thrace for their daily bread), or from the popular broils about bread, which were long a source of disorder to Rome, even in its splendour. In England, there are traces of a corn law nearly six centuries since. By the statute Judicium Pillorie, 51 Hen. 3 (1266), it is directed that the municipal authorities of certain towns should inquire of the price of corn. By the 34 Ed. 3, c. 20 (1360), the exportation of corn was prohibited; but in 1436 , by the 15 H. 6, c. 2, it was allowed. In 1463, however, by the 3 Et. 4 , c. 2, the necessity (which was declared in the preamble) arose of preventing "the labourers and occupiers of land from being grievously endamaged by bringing corn out of other lands when corn of the growing of this realm is at a low price." It then declares that wheat shall not be impor:ed, unless wheat be sold at the place of import for $6 s .8 d$. per quarter. In 1532 , by the $25 \mathrm{H}$ 8, c. 2 , it was enacted that the exportation of corn should cease, and the price be regulated by the lords of the council, the preamble of the bill very sensibly remarking, that "dearth, scarcity, good and cheap and plenty or, \&c., victuals necessary for man's sustenance happeneth, riseth, and chanceth of so many and 
rvers occasions, that it is very hard and diffcult to put any certain prices to any such things." In 1534 ( 1 P. \& M. c. 5), corn was again allowed to be exported when the price of wheat did not exceed 6s. $8 d$. per quarter. This standard was increased to $10 \mathrm{~s}$. by the 5 Eliz. c. 5 (1562); and in 1571 (13 Eliz.c. 13), the exportation was directed to be regulated from average prices by the lords of the council. In 1807, the bounty upon the exportation of grain finally ceased.

According to the English Corn Law Act, existing in 1842 , corn inspectors are appointed in 287 towns, to transmit returns to the Board of Trade, who compute the average weekly price of each description of grain, and the aggregate average price for the previous six weeks, and transmit a certified copy to the collectors of customs at the different out-ports. The aggregate average regulates the duty on importation according to the following scale:-

\section{If imported from any Foreign Country.}

Wheat-Whenever the average price of wheat, made up and published in the manner required by law, shall be for every quarter

Inder 518 . the duty shall be for every quarter 100

$51 s$. and under 528 .

$\begin{array}{lll}52 s . & - & 558 . \\ 55 s . & - & 56 s . \\ 56 s . & - & 57 s . \\ 57 s . & - & 58 s . \\ 58 s . & - & 59 s . \\ 59 s . & - & 60 s . \\ 60 s . & - & 61 s . \\ 61 s . & - & 62 s . \\ 62 s . & - & 63 s . \\ 63 s . & - & 64 s . \\ 64 s . & - & 65 s . \\ 65 s . & - & 66 s . \\ 66 s . & - & 69 s . \\ 69 s . & - & 70 s . \\ 70 s . & - & 71 s . \\ 71 s . & - & 72 s . \\ 72 s . & - & 73 s . \\ 73 s .\end{array}$

73 s. and upwards

Burley - Whenever the average price of barley, made $u p$ and published in the manner required by law', shall be for every quarter

Vnder $26 s$. the duty shall be for every quarter 0 il 0

$26 s$, and under $27 s$.

30s. - 31s.

32s. - $\quad$ - $33 s$.

33. - $34 s$

34s. - $\quad$ - $35 \mathrm{~s}$.

36s. $\quad$ - $37 s$

37s. and upwards

Wats-Whenever the average price of oats, made up and published in the manner required by law, shall be for every quarter

Jnder $19 s$. the duty shall be for every quarter $\begin{array}{llll}x & 0 & 8 & 0\end{array}$

19s. and under $20 s$.

$\begin{array}{lll}0 & 7 & 0\end{array}$

23s. - $24 s$.

24s. - $25 s$.

25s. - $26 \mathrm{~s}$

27 , and upwards

$\begin{array}{lll}0 & 6 & 0 \\ 0 & 5 & 0\end{array}$

$\begin{array}{lll}0 & 5 & 0 \\ 0 & 4 & 0\end{array}$

$\begin{array}{lll}0 & 4 & 0 \\ 0 & 3 & 0\end{array}$

$\begin{array}{lll}0 & 2 & 0\end{array}$

ye, Pease, and Bcans. - Whenever the average price of rye, or of pease, or of beans, male up and published in the manner required by law, sball be for every quarier

Finder 30 s. the duty shall be for every quarter

E s. $d$. $30 \mathrm{~s}$, and under $33 \mathrm{~s}$.

\begin{tabular}{|c|c|c|}
\hline $33 s$. & - & $34 s$ \\
\hline $34 s$. & - & 35 \\
\hline $3.5 s$. & - & 36 \\
\hline $36 s$. & - & 37 \\
\hline 378. & - & 38 \\
\hline 38. & - & 39 \\
\hline $39 s$. & - & 40 \\
\hline $10 s$. & - & 41 \\
\hline 18. & - & 42 \\
\hline
\end{tabular}

Wheat Meal and Flour.-For every barrel, being $19616 \%$,
a duty equal in amount to the duty payable on $38 \frac{2}{2} \mathrm{gal}$. lons of wheat.

Oatmeul.-For every quantity of $181 \frac{1}{2}$ lbs., a duty equal in amount to the duty payable on a quarter of oats.

Maize or Indian Corn, Buckuheat, Bear or Bigg.-For every quarter, a duty equal in amount to the duty payable on a quarter of barley.

See Whеат.

An Accont showing the total Quantities of Wheat and Wheat Flour imported from Foreign Countries and from British Colonies.

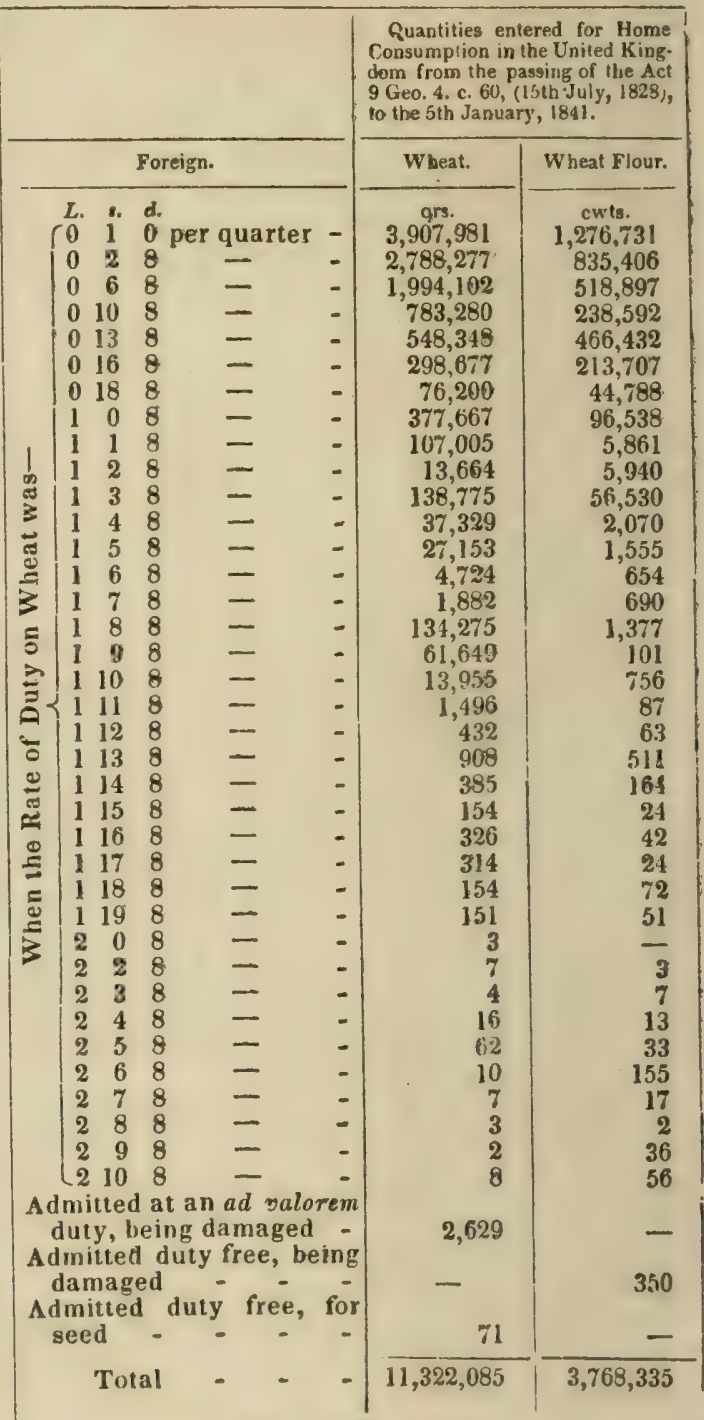

British Colonial.

\begin{tabular}{|c|c|c|c|c|}
\hline $\begin{array}{c}\text { When the rate } \\
\text { of duty on } \\
\text { wheat was }\end{array}$ & $\begin{cases}0 & 6 \\
5 & 0\end{cases}$ & & $\begin{array}{l}129,858 \\
393,407\end{array}$ & $\begin{array}{l}426, v(x) \\
596,996\end{array}$ \\
\hline Total & - & & 523,265 & $1,023,805$ \\
\hline
\end{tabular}

The average price of wheat in Great Britain in the year 1840 was - - - - perqr. 66 4 Average price of wheat at Rotterdam - $\quad 4911$ "6 at Odessa - $\quad-\quad-248$

Total number of quarters of $w$ heat and wheat flour imported and entered for home con- $2,401,360$ Total number of quarters of colonial wheat and wheat flour imported _ _ _ - 148,720 Total number of quarters of foreign wheat and wheat flunr imported - _ _ _ - 2,281,482 Total number of quarters of wheat and wheat flour imported

$2,433,202$

Grain, if the produce of, and imported from any British possessions in North America, or 


\section{CORN LAWS.}

elsewhere out of Europe, are charged the following rates of duty:-

Wheat.-Whenever the average price, made according to law, shall be

Under 55s. for every s. $d$. ${ }_{56}$ s. $d$. quarter, the duty $50 \quad 57 \mathrm{~s}$. and under 58.2 .20 \begin{tabular}{lll|lll} 
per qt. shall be & 5 & 0 & $57 s$. and under 58s, & 2 & 0 \\
5 s. and under 56.8. & 4 & 0 & 58 s. and upwards, & 1 & 0
\end{tabular}

Barley.-Whenever the average price of barley, made up accordiug to law, shall be

Under 28s, per quar- 8. d.

\begin{tabular}{lll|lll|} 
ter, the duty per qt. & & $29 . s$. and under $30 s$. & 1 & 6 \\
shall be & 2 & 6 & $30 . s$. and under $31 \mathrm{~s}$. & 1 & 0
\end{tabular}

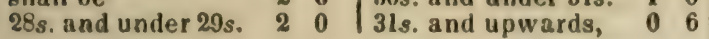

Oats.-Whenever the average price of oats, made up according to law, shall be

Under 22s. for every s. $d$. quarter, the duty $22 s$. and under 23s. 16 \begin{tabular}{lll|lll} 
per qt. shall be & 2 & 0 & $23 s$. and upwards, & 0 & 6
\end{tabular}

Rye, Peas, and Beens.-Whenever the average price of these articles shall be

Under 30 s. for every s, $d$. quarter, the duiy

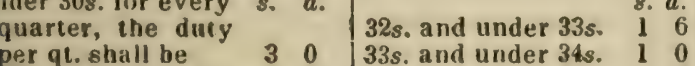
$\begin{array}{lllll}33 s, \text { and under 34s. } 1 & 0\end{array}$ 34 s. and upwards

Wheat-meal and Flour-For every barrel, being 196 lbs a dury equal to that payable on $38 \frac{1}{3}$ gallons of wheat. Oatmeal. $-181 \frac{1}{3}$ lbs. pays a duty equal to that charged on a quarter of oats.

Maize or Indian Corn, Buckwheat, Bear or Bigg, pay a duty equal per quarter to that charged per qr. on a quarter of barley.

Avernge Prices of Wheat from 1670.

The Mean of two half-yearly Prices (Winchester measure), from the Register kept in the Books of Eton College.

\begin{tabular}{|c|c|c|c|c|c|}
\hline Years. & 37 & d. & $\begin{array}{l}\text { Years. } \\
1704\end{array}$ & $4 i$ & \\
\hline $\begin{array}{l}1670 \\
1671\end{array}$ & $\begin{array}{l}37 \\
-\quad 37\end{array}$ & 4 & 1705 & $\begin{array}{l}-41 \\
-\quad 26\end{array}$ & \\
\hline 1672 & $-\quad 37$ & 0 & 1706 & - 23 & \\
\hline 1673 & $=41$ & 5 & 1707 & -25 & \\
\hline 1674 & -61 & 0 & 1708 & $-\quad 36$ & \\
\hline 1675 & - 52 & 1 & 1709 & - 69 & \\
\hline 1676 & - $\quad 33$ & 9 & 1710 & -69 & \\
\hline 1677 & $-\quad 37$ & 4 & 1711 & -48 & \\
\hline 1678 & $-\quad 52$ & 5 & 1712 & -41 & \\
\hline 1679 & 48 & 0 & 1713 & -45 & \\
\hline 1680 & -40 & 0 & 1714 & -44 & \\
\hline 1681 & -41 & 5 & 1715 & $-\quad 38$ & \\
\hline 1682 & $-\quad 39$ & 1 & 1716 & -42 & \\
\hline 1683 & $-\quad 35$ & 6 & 1717 & -40 & \\
\hline 1654 & $-\quad 39$ & 1 & 1718 & 34 & \\
\hline 1685 & -41 & 5 & 1719 & -30 & 0 \\
\hline 1686 & $-\quad 30$ & 2 & 1720 & $-\quad 32$ & \\
\hline 1687 & -31 & 8 & 1721 & - 33 & \\
\hline 1688 & -23 & 1 & 1722 & - 32 & \\
\hline 1689 & -26 & 8 & 1723 & 30 & \\
\hline 1690 & 30 & 9 & 1724 & 32 & 2 \\
\hline 1691 & - 29 & 11 & 1725 & -43 & \\
\hline 1692 & -41 & 9 & 1726 & 40 & \\
\hline 1693 & 60 & 1 & 1727 & 37 & \\
\hline 1694 & 56 & 10 & 1728 & -48 & \\
\hline 1695 & -47 & 1 & 1729 & $-\quad 42$ & \\
\hline 1696 & -56 & 0 & 1730 & - 32 & \\
\hline 1697 & -53 & 4 & 1731 & $-\quad 29$ & \\
\hline 1698 & -60 & 8 & 1732 & -23 & \\
\hline 1699 & -56 & 0 & 1733 & -25 & \\
\hline 1700 & - 35 & 6 & 1734 & - 33 & \\
\hline$\$ 701$ & -31 & 8 & 1735 & -38 & \\
\hline 1702 & -26 & 0 & 1736 & $-\quad 35$ & 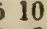 \\
\hline 170 & $-\quad 32$ & 0 & 1737 & - 33 & \\
\hline
\end{tabular}

Years.

1738 s. $d$.

$1739-339$

$1740-4810$

$1741=419$

$1742=285$

$1743-220$

$1744-220$

$1745-243$

$1746-348$

$1747-3011$

$1748-3210$

$1749-3210$

$1750-2810$

$1751-342$

$1752-408$

$1753-398$

$1754-30$

$1755-2911$

$1756-401$

$1757-534$

$1758-445$

$1759-353$

$1760-325$

$1761-269$

$1762-348$

$1763-361$

$1764-415$

$1765-480$

$1766-431$

$1767-574$

$1768-539$

$1769-40$

$1770-436$

(Parliamentary Paper, No. 100.-Session 1826.)

The average Prices as published by the Receiver of Corn Returns from 1771 to 1840.

Winchester

Measure.
Yeara.
$1771=47$
$1772=50$
$1773=51$
$1774=528$
$1775=48$
$1776=38$
$1777=45$
$1778=420$

Years.
$1779=33$
$1780=35$
$1781=4$
$1782=4710$
$1783=528$
$1784=4810$
$1785-4110$
$1786-3810$

Year. 1787 - $411^{4}$

$1788-450$

$1789-512$

$1790-532$

$17901-472$

$1792-419$

$1793-4710$
$1794-508$

\section{CORN MOTH.}

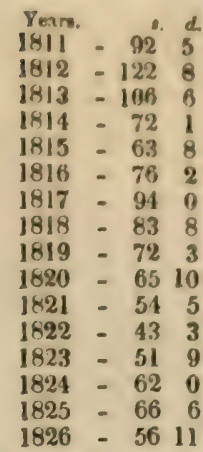

Imperlal

Measure.

$1827-568$

$1824-605$

1829 - 66

1月30 - 64

$1 \times 31-66$

$1 \times 32-588$

$1833=5211$

$1834-462$

$1835-39$

$1 \times 363-486$

$1937-5510$

$1834-64 \%$

$1839-70$

$1810-1033 \quad 1826-5611 \quad 1810-664$
(Thornton on the Corn Laros ; Parl. Papers; Statutes at large.)

By an act of Congress, approved in August, 1842 , the duties payable on grain, \&c., imported into the United States, are as follows:-

On wheat, 25 cents per bushel; barley, 20 cents; rye, 15 cents; oats, 10 cents; Indian corn or maize, 10 cents; wheat flour, 70 cents per 112 lbs.; Indian meal, 25 cents per 112 Ibs.; starch, 2 cents per lb.; pearl, or hulled barley, 2 cents per $1 \mathrm{~b}$. ; (potatoes, 10 cents per bushel.)

CORN MARYGOLD (Chrysanthemum sezm tum). In Scotland, this is called yellow gowons quills, gools; in Kent, England, yellow bottle; in Norfolk, budland; midland counties, golds, goulds, or gowls; north of England, gowluns, goldens, gules. Linnæus says there is a law in Denmark which obliges the farmers to extirpate this weed. He recommends the land to be manured in autumn, summer-fallowed, and harrowed in about five days after sowing. Martyn says it can only be eradicated by hand before the seeds ripen. It is abundant in grain and turnip fields, with its blue-green leaves, and broad, brilliant, yellow flowers. The stalks are round, stiff, and branched, growing two feet high. The leaves stand irregularly, and they are deeply indented at the sides, besides being long and very broad, smallest at their base, and growing broader as they advance to the end. The root is tapering and fibrous. (Smith's Eng. Flor. vol. iii. p. 450.) See Ox-Exe Daisr.

CORN MO'TH (Tinea granella). Among the insects most injurious in their attacks on grain, when laid up in magazines, is the larva of this small moth (the mottled woollen moth of $\mathrm{Ha}$ worth), the caterpillar of which is also called in England the white corn worm. The perfect moth measures, from the head to the tips of the wings, six or seven lines. The insect appears in that country as a moth in May, June, and July. It frequents granaries and other buildings where grain is stored, sits at rest in the day-time, and only flies about at night. It is in the summer months, from May to August, and sometimes in September, that the larvæ devour. the different sorts of grain; and they attack rye, oats, and barley, with the same zest as wheat From September to May the larva is sought for in vain in the corn-heaps; it has retired into the cracks and fissures of the floor and walls, and moreover has concealed itself in its cocoon. It does not reappear till April or May and then in a very different form; namely, as a moth, which flutters about the heaps of store corn, and deposits upon thern the invisible germ of future destruction. After a few day. 
have elapsed, small whitish worm maggots, or more properly speaking larvæ, proceed from the eggs, and immediately penetrate in to the grain, carefully closing up the opening with their white roundish excrement, which they glue together by a fine web.

"The European grain-moth (Tinea granella), in its perfected state, is," says Dr. Harris, "a winged irsect, between three and four-tenths of an inch long from the head to the tip of its wings, and expands six-tenths of an inch. It has a whitish tuft on its forehead; its long and narrow wings cover its back like a sloping roof, are a little turned up behind, and are edged with a wide fringe. Its fore-wings are glossy like satin, and are marbled with white or gray, light brown, and dark brown or blackish spots, and there is always one dark square spot near the middle of the outer edge. Its hind wings are blackish. Some of these winged moths appear in May, others in July and August, at which times they lay their eggs; for there are two broods of them in the course of the year. The young from the first laid eggs come to their growth and finish their transformations in six weeks or two months; the others live through the winter, and turn to winged moths in the following spring. The young moth-worms do not burrow into the grain, as has been asserted by some writers, who seem to have confounded them with the Angoumois grain-worms; but, as soon as they are hatched, they begin to gnaw the grain and cover themselves with the fragments, which they line with a silken web. As they increase in size they fasten logether several grains with their webs, so as to make a larger cavity, wherein they live. After a while, becoming uneasy, in their confined habitations, they come out, and wander over the grain, spinning their threads as they go, till they have found a suitable place wherein to make their cocoons. Thus, wheat, rye, barley, and oats, all of which they attack, will be found full of lamps of grains cemented together by these corn-worms, as they are sometimes called; and when they are very numerous, the whole surface of the grain in the bin will be covered with a thick crust of webs and of adhering grains. These destructive corn-worms are really soft and naked caterpillars, of a cylindrical shape, tapering a little at each end, and are provided with sixteen legs, the first three pairs of which are conical and jointed, and the others fieshy and wart-like. When fully grown, they measure four or five-tenths of an inch in length, and are of a light ochre or buff colour, with a reddish head. When about six weeks old they leave the grain, and get into cracks, or around the sides of corn-bins, and each one then makes itself a little oval pod or cocoon, about as large as a grain of wheat. The insects of the first brood, as before said, come out of their cocoons, in the winged form, in July and August, and lay their eggs for another brood: the others remain unchanged in their cocoons, :hrough the winter, and take the chrysalis form in March or April following. Three weeks afterwards, the shining brown chrysalis forces iself part way "ut of the cocoon, by the help 356 of some little sharp points on its tail, and b ursts open at the other end, so as to allow the moth therein confined to come forth.

"The foregoing account will probably enable the readers of this essay to determine whether these destructive insects are found in our own country. From various statements, deficien? however in exactness, that have appeared in some of our agricultural journals, I am led to think that this corn-moth,or an insect exactly like it in is habits, prevails in all parts of the coun. try, and that it has generally been mistaken for the grain-weevil, which it far surpasses in its levastations. Many years ago I remember to have seen oats and shelled corn (maize) affected in the way above described, and have observed seed-corn, hanging in the ears, to have been attacked by insects of this kind, the empty chrysalids of which remained sticking between the kernels; but, for some time past, no opportunity for further investigation his offered itself.

"There is another grain-moth, which, at various times, has been found to be more destructive in granaries, in some provinces of France, than the preceding kind. It is the Angoumois moth (Anacampsis? cerealelia). The winged moths of this group have only two visib!e feelers, and these are generally long, slender and curved over their heads. Their narrow wings most often overlap each other, and cover their backs horizontally when shut. The Angoumois grain moth probably belongs to the modern genus Anacampsis, a word derived from the Greek, and signifying recurved, in allusion to the direction of the feelers of the moths. In the year 1769, Colonel Landon Carter, of Sabine Hall, Virginia, communicated to the American Philosophical Society at Philadelphia, some interesting 'observations concerning the fly-weevil that destroys wheat.' These were printed in the first volume of the "Transactions" of the Society, and were followed by some remarks on the subject by 'the Committee of Husbandry.' It is highly probable that this fly-weevil is no other than the destructive Angoumois grain-moth; for Colonel Carter's account of it, though deficient in some particulars, agrees essentially with what has been published respecting the Furopean insect. $\mathrm{Mr}$. E. C. Herrick has recently sent to me, from New Haven, Connecticut, some wheat, that has been eaten by moths precisely in the same way as grain is attacked by the Angonmois grainmoth; and a gentleman to whom this motheaten wheat was shown, informed me that he had seen grain thus affected in Maine. Unfortunately the insects contained in this wheat were dead when received, having perished in the chrysalis state; had they lived to finish their transformations, 1 have good reason to think that they would have proved to be identical with the Angoumois moths. The following particulars respecting the latter are chiefly gathered from Réaumur's 'Mémoires,' and from a work by Duhamel du Monceau and Tillet, who were commissioned by the Academy of Sciences of Paris, in the year 1760, to inquire into the nature of the insect, on account of its ravages in Angoumois, a part of France wher 
it had long been known, and had multiplied to an alarning extent. The Angoumois moth, or Anacumpsis cerculella, in its perfected state, is a four-winged insect, about three-eighths of an inch long, when its wings are shut. It has a pair of tapering curved feelers, turned over its head. Its upper wings are narrow, of a light brown colour, without spots, and have the lustre of satin; they cover the body horizontally above, but droop a little at the sides. The lower wings and the rest of the body are ashcoloured. This moth lays its eggs, which vary in number from sixty to ninety, in clusters, on the ears of wheat, rye, and barley, most often while these plants are growing in the field, and the ears are young and tender; somelimes also on stored grain in the autumn. Hence it appears that they breed twice a year; the insects from the eggs laid in the early part of summer, coming to perfection and providing for another brood of moth-worms in the autumn. The little worm-like caterpillars, as soon as they are hatched, disperse, and each one selects a single grain, into which it burrows immediately at the most tender part, and remains concealed therein after the grain is harvested. It devours the mealy substance within the hull; and this destruction goes on so secretly, that it can only be detected by the softness of the grain or the loss of its weight. When fully grown this caterpillar is not more than onefifth of an inch long. It is of a white colour, with a brownish head; and it has six small jointed legs, and ten extremely small wart-like proplegs. Duhamel has represented it as having two little horns just behind the head, and two short bristles at the end of its tapering body. Having eaten out the heart of the grain, which is just enough for all its wants, it spins a silken web or curtain to divide the hollow, lengthwise, into two unequal parts, the smaller containing the rejected fragments of its food, and the larger cavity serving instead of a cocoon, wherein the insect undergoes its transformations. Before turning to a chrysalis it gnaws a small hole nearly or quite through the hull, and sometimes also through the chaffy covering of the grain, through which it can make its escape easily when it becornes a winged moth. The insects of the first, or summer brood, come to maturity in about three weeks, remain but a short time in the chrysalis state, and turn to winged moths in the autumn, and at this time may be found, in the evening, in great numbers, laying their eggs on the grain stored in barns and granaries. The moth-worms of the second brood remain in the grain through the winter, and do not change to winged insects till the following summer, when they come out, fly in to the fields in the night, and lay their eggs on the young ears of the growing grain. When damaged grain is sown, it comes up very thin; the infected kernels never sprout, but the insects lodged in them remain alive, finish their transformations in the field, and in due time come out of the ground in the winged form.

"It has been proved by experience that the ravages of the two kinds of grain-moths, whose history has been now given, can be effectually checked by drying the damaged gram in an oven or kiln; and that a heat of one hundred and sixty-seven degrees, by Fahrenheit's thermometer, continued during twelve hours, will kill the insects in all their forms. Indeed, the heat may be reduced to one hundred and four degrees, with the same effect, but the grain must then be exposed to it for the space of two days. The other means, that have been em. ployed for the preservation of grain from these destructive moths, it is unnecessary to describe; they are probably well known to most of our farmers and millers, and are rarely so effectual as the process above mentioned." (Harris's Treatise on Insects.)

From these considerations, the means which the agriculturist must employ to secure his grain from so dangerous an enemy, are clearly deducible. First of all, the lofts, before the corn is placed in them, must be carefully examined, and the cocoons, if any are discovered, got rid of. Sprinkling the floor with is mixture of strong white wine vinegar and salt, before laying up the corn, is strongly to be recommended. Sweeping the floor and walls thoroughly should not be neglected; and the dust should be removed immediately, in order that the larvæ may not find their way back into the corn-heaps. Common salt will also purify the infested grain. One of the surest remedies appears to be a free ventilation, by means of an artificial degree of cold, as the larvie can only live in a temperature of $55^{\circ}$ to $60^{\circ}$ of Fahr. Bats and spiders are the principal natural enemies of the corn-moth, and some small birds also feed on them. See Grain Wrevil. (Treatise on Insects, \& $c_{.}$, by J. and M. Loudon.)

CORN POPPY (Pepaver rhaus). Pl. 10, s. Indifferently called red-poppy, corn rose, coprose, head-wark, red-weed, red-mailkes, \&c. A troublesome weed in corn fields. Annual, flowering from June to July. Beautiful varieties of this species, with semi-double flowers, variegated with rose-colour and white, are easily cultivated for ornament, but liable to degenerate in luxuriance. (Smith's Eng. Flon, vol. iii. p. 11 ; Sinclair's Weeds, p. 46.) See Poppy, Fined.

CORN SALAD, or LAMB'S LETTUCE (Fedia olitoria, Smith; Valeriana locusta, Lin). A well-known annual weed in corn fields and light cultivated ground, which probably took its common English name from the circum. stance of the plants appearing in flower about the time that lambs are dropped. There is a second species ( $F$. dentata), oval fruited corn salad. The common variety is cultivated for winter and spring salads, and for this purpose has been long known. The first dish formerly brought to table was a red herring set in a corn. salad. The plant will flourish in any snil that is not particularly heavy. It is propagatei by seed, sown in February and the two following months, and once a month during the summer: but it is not so palatable during this season. Lastly, during August and early in September. the plants from which will be fit for use in early spring, or during the winter if mild. The seed may be sown in drills six inches apart, or broadcast, and raked in. Keep them free from 
weeds by frequent hoeings, previously thinned to four inches asunder. They should always be eaten quite young. In sunmer, the whole plant may be cut, as it soon advances to seed at this season; but in spring and winter the outer leaves only should be gathered. For the production of seed some of the spring-raised plants must be left ungathered. They flower in June, and perfect their seed during the two following months. (G.W.Johnson's Kitch.Gard.; Smith's Eng. Flor. vol. i. p. 44 ; Sinclair's Weeds, p. 54.)

CORN WEEVIL (Calandra granaria, Clairville; Curculio granaria, Linn.). This is another extremely injurious insect to grain. See Grain Weevil.

CORNS, IN HORSES' FEE'T. This disease is produced by some hard substance pressing on the sole at the quarters, as from shoes left on till the heels become buried in the hoof; the fibrous substance which lies between the sensible foot and the absolute horny hoof becomes inflamed by the pressure, and the inflamation produces a hardress of the spot, similar, if I may so express it, to a knot in a piece of soft timber. Palliate the evil as well as you can, by keeping the hoof constantly pared away between the corn and the ground, but do not wound in your vain endeavours to cut it out; avoid the hot irons, \&c.; let a bit of sponge be softly put in, merely to keep out gravel and keep the spot moist; and when the season arrives, turn the horse out without any shoes, into a soft marshy place, where his feet must be in a constant moist state for three months at least: by that time the hoof will be altogether renewed, the diseased part will have grown out, and if there is no new injury, there will be no new corns. (E. Maunsell. See also, Lib. Use. Know. 'Тне Horse, p. 305.

CORONET-BONE. The second of the consolidated phalanges of the horse's foot.

COSSAR'T, or COSSET (It. cassiccio, from casa, the house). A lamb left by the death of its dam before it is capable of providing for jtself; or a lamb taken from a ewe that brings more than one. 'The term is also applied to a colt, calf, \&c. and sometimes written cot-lamb.

COSTIVENESS. In farriery, a complaint to which horses are often subject, occasioned sometimes by violent or hard exercise, especially in hot weather; and at other times by standing long at hard meat without grass or other cleansing diet, and with very little exercise.

COTTAGES. These for labourers are commonly constructed merely with a regard to economy; the comfort and health of their future tenants being too often disregarded. Such cottages should never consist of less than two bedrooms, and a kitchen, and outhouse. They will be found to be considerably more healthy with wooden floors, raised above the level of the surrounding ground. They should be well furnished with windows, and the ceilings of the rooms of a fair height, eight or nine feet will not be too much to allow; they should have as good gardens as possible. The plans for their formation, and the materials of which vey ale composed, must vary with the locality. 358
Mr. Gillespie has given one for a cottage with a roof without wood, which he asserts could be built in Scotland for 30l. (Com. Roard of $\mathrm{Agr}$. vol. iv. p. 469.) There is also an essay by Mr. Smith, on cottages for the labouring classes, which may be consulted with advantage (Trans. High. Soc. vol. iv. p. 205), and on cottage windows (Quait. Journ. of Agr. p. 116), and also on cottage premiums, and on the cottages built on the estate of Lord Roseberry. (Trans. High. Soc. vol. vi. p. 527.)

By the erection of small, comfortable cottages on poor waste lands, and the allotment to each of a few acres of land, a field is opened for the rapid recovery by the spade of barren lands, and the profitable employment of the landowner's capital, too little understood. By merely deepening and mixing the soil, the cottager can bring into cultivation lands, which seem to defy all the powers of even the subsoil plough.

The following information relative to the best modes of building cheap cottages is from a report made to Congress by Henry L. Ellsworth, see pp. 55-57.

"After selecting a suitable spot of ground, as near the place of building as practicable, let a circle of ten feet or more be described. I tet the loam be removed, and the clay dug up one foot thick, or, if clay is not found on the spot, let it be carted in to that depth. Any ordinary clay will answer. Tread this clay over with cattle, and add some straw cut six or eight inches long. After the clay is well tempered with working it with the cattle, the material is daly prepared for the making of brick. A mould is then formed of plank, of the size of the bric's desired. In England, they are usuafly made eighteen inches long, one foot wide, and nine inches thick. I have found the more convenient size to be one foot long, seven inches wide, and five inches thick. The mould should have a bottom. The clay is then placed in the moulds in the same manner that brick moulds are ordinarily filled. A wire or piece of iron hoop will answer very well for striking of the top. One man will mould about as fast as another can carry away, two moulds being used by him. 'The bricks are placed upon the level ground, where they are suffered to dry iwo days, turning them up edgewise the second day, and then packed up in a pile, protected from the rain, and left to dry ten or twelve days, during which time the foundation of the building can be prepared. If a cellar is desired, this must be formed of stone or brick, one foot above the surface of the ground. For cheap buildings on the prairie, wood sills, twelve or fourteen inches wide, may be laid on piles or stones. This will form a good superstrueture. Where lime and small stones abound, grout made of those materials (lime and stones) will answer very well.

"In all cases, however, before commencing the walls for the first story, it is very desirable, as well in this case as in walls of brick, to lay a single rourse of slate; this will intercept the dampness so often rising in the walls of brick houses. The wall is laid by placing the brick lengthwise, thus making the wall one foot thick. 
Brdinary clay, such as is used for clay mortar, will suffice, though a weak mortar of sand and lime, when these articles are cheap, is recommended as affording a more adhesive material for the plaster. The wall may safely be carried up one story, or two or three stories; the division walls may be seven inches, just the width of the brick. The door and window frames being inserted as the wall proceeds, the building is soon raised. The roof may be shingles or thatch. In either case, it should project over the sides of the house, and also over the two ends, at least two feet, to guard the walls from vertical rains. The exterior wall is plastered with good lime mortar, and then with a second coat pebble-dushed. 'The inside is plastered without dashing. The floor may be laid with oak boards, slit, five or six inches wide, and laid down without jointing or planing, if they are rubbed over with a rough stone after the rooms are finished. Doors of a cheap and neat ap. pearance may be made by taking two single boards of the length or width of the doors; placing these vertically, they will fill the space. Put a wide batten on the bottom and a narrow one on the top, with strips on the side, and a strip in the middle. This door will be a batten door, but presenting two long panels on nne side and a smooth surface on the other. If a porch or verandah is wanted, it may be roofed with boards laid with light joints and covered with a thick paper dipped in tar, and then adding a good coat, after sprinkling it with sand from a sand-box or other dish with small holes.

"Houses built in this way are dry, warm in winter, and cool in summer, and furnish no retreat for vermin. Such houses can be made by common labourers, if a little carpenter's work is excepted, in a very short time, with a small outlay for materials, exclusive of floors, windows, doors, and roof.

"The question will naturally arise, will the wall stand against the rain and frost? I answer, they have stood well in Europe, and the Hon. Mr. Poinsett remarked to me that he had seen them in South America, after having been erected three hundred years. Whoever has noticed the rapid absorption of water by a brick that has been burned, will not wonder why brick walls are damp. The burning makes the brick porous, while the unburnt brick is less absorbent; but it is not proposed to present the unburnt brick to the weather. Whoever has erected a building with merchantable brick will at once perceive the large number of soft and yellow brick, partially burned, that it contains-brick that would soon yield to the mouldering influence of frost and storms. Such brick are, however, placed within, beyond the reach of rain, and always kept dry. A good cabin is made by a single rooin twenty feet square. A better one is eighteen feet wide and twenty-four feet long, cutting off eight feet on one end for two small rooms, eight by nine each.

"How easily could a settler erect such a cabin on the Western prairie, where clay is usually found about fifteen inches below the surface, and where stone and lime are often both very cheap. The article of brick for chimneys is found to be quite an item of expense in woodhouses. In these mud houses no brick are needed, except for the top of the coimneys, the oven, and casing of the fireplace-though this last might be well dispensed with. A cersen, to put around the chimneys, or to fill any other crack, is easily made by a mixture of one part of sand, two of ashes, and three of clay. This soon hardens, and will resist the weather. A little lard or oil may be added, to make the composition still harder.

"Such a cottage will be as cheap as a log cabin, less expensive than pine buildings, and durable for centuries. I have tried the experi. ment in this city by erecting a building eighteen by fifty-four feet, two stories high, adopting the different suggestions now made. Although many doubted the success of the undertaking, all now admit it has been very successful, and presents a convenient and comfortable building, that appears well to public view, and on:rs a residence combining as many advantages ..s a stone, brick, or wood house presents. I will add what Loudon says in his most excellent work, the Encyclopedia of Agriculture, pp. 74. and 75 :

"The great art in building an econom»al cottage is to employ the kind of materials and iabour which are cheapest in the given locality. In almost every part of the world the cheapest article of which the walls can be made will be found to be the earth on which the cottage stands, and to make good walls from the earth is the principal art of the rustic or primitive builder. Soils, with reference to building, may be divided into two classes : clays, loams, and all such soils as can neither be called gravels nor sands, and sands and gravels. The former, whether they are stiff or free, rich or poor, mixed with stones, or free from stones, may be formed into walls in one of these modes, viz., in the pisé manner, by lumps moulded in boxes, and by compressed blocks. Sandy and gravelly soils may be always made into excellent walls, by forming a frame of boards, leaving a space between the boards of the intended thickness of the wall, and filling this with gravel mixed with lime mortar, or, if this cannot be got, with mortar made of clay and straw.

"'In all cases, when walls, either of this class or the former, are built, the foundations should be of stone or brick, and they should be carried up at least a foot above the upper surface of the platform.

"We shall here commence by giving one of the simplest modes of construction, from a work of a very excellent and highly estimable individual, Mr. Denson, of Waterbeach, Cam. bridgeshire, the author of the Peasant's Voice, who built his own cottage in the manner de scribed below :

"Mode of building the mud walls of cottages in Cambridgeshire.-After a labourer has dug a sufficient quantity of clay for his purpose, he works it up with straw; he is then provided with a frame eighteen inches in length, six deep, and from nine to twelve inches in diameter. In this frame he forms his lumps, in the same manner that a brickmaker forms his bricks; they are then packed up to dry by the weather; that done, they are fit for the use, as a substitute for bricks. On laying the founda 
tion of a cottage, a few layers of brick are ne. cessary, to prevent the lumps from contracting a damp from the earth. The fireplace is lined and the oven is built with bricks. I have known cottagers, where they could get the grant of a piece of ground to build on for themselves, erect a cottage of this description at a cost from $£ 15$ to $£ 30$. I examined one that was nearly completed, of a superior order : it contained two good lower rooms and a chamber, and was neatly thatched with straw. It is a warm, firm, and comfortable building, far superior to the one I live in ; and my opinion is, that it will last for centuries. The lumps are laid with mortar, they are then plastered, and on the ontside once roughcast, which is done by throwing a mixture of water, lime, and small stones, against the walls, before the plaster is dry, which gives them a very handsome appearance. The cottage I examined, cost $£ 33$, and took nearly one thousand lumps to complete it. A labourer will make that number in two days. The roofs of cottages of this description are precisely the same as when built with bricks or with a wooden frame. Cow-house sheds, garden walls, and partition fence, are formed with the same materials; but in all cases the tops are covered with straw, which the thatchers perform in a very neat manner." (Denson's Peasant's Voice, p. 31.)

CO'TAGE-CHEESE. See Wheт Butrer.

COTTON-GRASS (Eriophorum: Ital. cotone; Fr. coton). A perennial native genus of grasses, comprising seven species, which have no particular merit to warrant their recommendation for the purpose of the agriculturist; their productive and nutritive powers being very inferior. Sinclair gives us the result of his experiments on two sorts, the common longleaved cotton-grass ( $E$. angustifolium), and the hare's-tail, or sheathed cotton-grass ( $E$. vaginatum.)

CO'TTON PLAN'T. See Gossxpium.

COTTON TREE (Populus argentea). See Poplar.

COTTON-WOOD (Populus Canadensis). See Portar.

COTTON, WILD (Asclepias Syriaca), popularly called silk-weed and swallow-wort. An American plant growing in low grounds and on road-sides, to the height of three or four feet. (Flora Cestrica.)

COTYLEDON. The seed leaf. See Botarx. COUCH, or CREEPING WHEAT GRASS (Triticum repens, Pl. 10, i.) Named from the French coucher, to lie down. Sometimes called dog-grass and knot-grass. Until of late years, when botanical science has afforded us better information, it was generally supposed that all couch or twitch was the roots of one species of grass. But many persons observed that some of these roots, on wet soils, were black and much smaller, and they had locally obunined the name of black twitch. This, on soils where it prevails, is much worse than the other, bec:ause it is wiry and small, and not so easily discharged from the soil; it is also more brittle, and by harrowing breaks short. This is the Agrostis repens. There are two other grasses which have strong creeping roots, and are inifferently called couch: these are the creep360 ing-rooted soft grass (Holcus mollis), and the smooth-stalked meadow grass (Poa pratensis). There is but one way of destroying couch, and that is by ploughing up the soil and pulverizing it. (Sinclair's Weeds, p. 27.) See Agrostis REPENs. Couch or quitch grass, or creeping triticum, is a troublesome perennial, fortunately but little known in the United States. Dr. Darlington has only been able to find it in one place, the Weston school farm, in Chester county, Pennsylvania. (See Flora Cestrica.)

COUGH (Goth. kueff, a catarrh; kof, suffocation; Dutch, kuch). in farriery, a convulsive motion of the lungs, being an effort of natur. to throw up some offending matter from the air tubes. This is best treated, in mild cases, by cold bran mashes with linseed. But coughs arise from so many different causes that it is impossible to prescribe any general remedy.

COULTER OF A PLOUGH. See Plough.

COUNTER. In horsemanship, the breast of a horse, or that part of his fore-hand which lies between the shoulders and under the neck.

COUPLES. A term applied to ewes and lambs. Couple is also a chain or tie that holds dogs together.

COUPLINGS, or CUPLINGS. Thongs of untanned leather, or other material, which are used to connect the handle or handstaff and swiple of a flail.

COVER, or COVERT (Fr. couvriv). A term applied to a place sheltered, not open or exposed. In sportsman's phrase, the cover is the chosen resort of the fox for kennelling; and such as lie high and dry are seldom without one or more, particularly if the underwood be thick and plenty. Artificial covers are often formed of broom and gorse, intermixed. (Elaine's Rural Sports, p. 452.)

COVEY (Fr. couvé, from the Lat. cubo). Provincially applied to a cover of furze, \&c., for game. It is also applied to an old bird with her young ones, but is generally used to designate a number of partridges or other game.

CoW (Sax. cu; Dutch, koe; Pers. gow). See Cattre.

COW-BANE, WATER, or WATER HEM. LOCK (Cicuta virosa). A perennial, fetid, poisonous aquatic herb, found in ditches, and about the margins of rivers, not very common. Root tuberous, hollow. Stems two or three feet high, hollow, leafy, branched, furrowed. Leaves bright green, tapering at each end, from one to two inches long. Umbels large, bearing purplish flowers; fruit roundish, smooth. This is a fatal plant to cattle, if they happen to meet with it before it rises out of the water, in which state only they will eat the young leaves. (Eng. Flor. vol. ii. p. 62).

COW-BANE, SPOTTED (Cicuta maculata). Water hemlock, a perennial root frequently found in low grounds and the margins of streams in Pennsylvania and other Middle States. The mature fruit of this plant is highly aromatic,- the odour something between that of aniseed and the kernels of the black walnut. The root is an active poison; and numerous lives have been lost, for want 
of sufficient botanical knowledge to distinguish the plant from the oxmorhiza or sweet cicely. The herb is also destructive to cattle, when eiten by them. There is one other species in the United States. (Flor. Cestric.)

COW-CLAGS. A provincial name for the clotted lumps of dirt that hang to the buttocks of cartle and other animals.

COW-HERD. A person whose office it is to attend upon the herds of cows in places where they run in common fields.

COW-HOUSE. See Cattre Shed.

COWISH. A new species of plant, called biscuit-root, found growing on dry land in the valley of the Columbia river. Its size is about that of a walnut, though sometimes larger. Its taste resembles that of the sweet potato, and it is prepared for food by the same process as the cammas, in which state it forms a tolerable substitute for bread.

COW-KEEPING. The business of keeping cows for the advantage of the milk, by disposing of it in large towns. The principal cowkeepers of the British metropolis have their establishments in the suburbs, where they are connected with pasture fields, in which their animals are turned out a portion of every day throughout the year, when practicable. The cows are fed in the house with grains, mangelwurzel, hay, tares, \&c., and as the animals get air and exercise, the milk may be considered wholesome. But there are other cow-keepers in the metropolis, who confine their cows in back houses, and even dark cellars, and while they feed them with rich food, give them no exercise; hence, the milk of such cows cannot be considered wholesome. (Harleian Dairy System; Frit. Husb.) See CatTre.

COW PARSNIP, or HOG WEED (Heracleum sphondylium). A biennial pasture weed, which in England is found in hedges, the borders of fields, and rather moist meadows, very common. Root tap-shaped, whitish, aromatic, sweetish, and rather mucilaginous. Stem four to six feet high, erect, branched, leafy, furrowed, and hollow. The leaves proceed from a large membrane or sheath. 'The flowers, which grow in large umbels, are either white or reddish; the fruit is abundant, and light brown. The whole plant is wholesome and nourishing food for cattle, and is gathered in Sussex for fattening hogs, hence its name of hog-weed. It is also frequently known by the name of wild parsnip, meadow parsnip, and madrep. (Sinclair's Weeds, p. 65 ; Eng. Flora, vol. ii. p. 102.)

The only ascertained species of this genus found in the Lnited States is the Heracieum lanatam, or woolly cow parsnip, a perennial root, the stem of which sometimes grows six or eight feet high. It is frequent in low grounds in Pennsylvania. See Flor. Cest.

COW PEA. A kind of pea much cultivated in the Southern States as a field crop, and substitute for clover. See Peas.

COW-POX. In farriery, is a disease affecting the teats of cows. This disease appears in the form of small bluish vesicles surrounded by inflammation, elevated at the edge and depress $r$ in the centre, and containing a limpid fluid. By the use of the virus of this disease, has origrinated the present excellent system of vaccination.

C OW SLIP, AMERICAN (J)olecuthern Meadia). A hardy perennial from South Arnerica, loving shade and moisture. It blows in April and May. Propagated by seed and offsets. Sow the seed in pots in autumn. Plant out the following autumn.

COWSIAP, 'THE COMMON, or PAIGIE (Primula veris). A native English perennial weed, growing in mealows and pastures, chiefly on a clay or chalky soil. It produces sweet-scented yellow flowers, which appear in April, and are used for making cowslip wine or balsamic tea. Its roots have a fine odjur, similar to that of anise, and give additional strength to ale or beer, when immersed in the cask. The leaves and flowers are excellent food for silk-worms, and are eaten eagerly by cattle. The leaves are also used as a potherb, and in salads.

The flowers, leaves, and roots are all medicinal portions of the cowslip, and are made into tea, wine, and conserve. It is anodyne in its quality, and the ancient writers upon herbs speak highly of its effects; but their opinions have lost their value by time. (Eng. Flora, vol. i. p. 271 ; Willich's Dom. Encyc.)

COWSLIP OF JERUSAI,EM, or LUNGWORT PULMONARIA (Pulmonaria ?ffeinalis). This plant is perennial and flowers in May. It grows eight or ten inches high, with long, broad, hairy leaves, of a deep green, spotted on the upper side with white spots. The stalks are slender and hairy, with small leaves upon them. 'The flowers are reddish in the bud but blue when blown, small, growing in clusters at the top of its stalk. The root is fibrous. The leaves have been used medicinally, from the idea that they resemble the lungs, and therefore must be useful in disease of those organs. They are inert, and consequently useless. Several species of lungwort are found indigenous to the United Siates.

COW-TIE. A provincial term applied to a short thick hair rope, with a wooden nut at one end and an eye in the other, being used for tying the hind legs of the corvs while milking.

COW-WHEAT (Melampyrum pratense). Pl. $7, q . \Lambda$ plant cultivated in Flanders for feeding stock.

There are some species of this plant found in the United States. One has been called by botanists American melampyrum. This is found in dry, hilly woodlands, and on mica-slate hills, where it flowers in June and July. A narrowleaved variety is abunuant in the pines of $\mathrm{New}$ Jersey. (Flora Cestrica.)

CRAB TREE, or WILD APPI.E TREE (Pyrus malus). 'There are in England several varieties among the wild crahi, some of which are of excellent flavour when baked with plenty of sugar, even surpassing cultivated apples. (Eng. Flora, vol. ii. p. 362.) Crab apples and sloes are the only fruits naturally belonging in the soil, and both are medicinal. 'The ex pressed juice of any of them, called verjuice. kept by good housewives in the country, being excellent as an astringent gargle in sore throats $2 \mathrm{H}$ 36 ] 
and in thrush and ulceration of the mouth and gums. It is sometimes mixed with beer-yeast, and applied outwardly, in inflammations, bad legs, burns, sprains, and scalds; but cold water and rest are better.

CRAB APPLE (Malus coronaria). This species of wild apple tree is found in North America, and at the time Michaux wrote his Sylva Americana, he says its nature had not been modified by cultivation. The wild apple tree of Europe, in a long series of years, has yielded a great number of species and varieties of fruit, which, in France alone, amount to nearly three hundred. Except the district of Maine, the state of Vermont, and the upper part of New Hampshire, the crab apple is found, on both sides of the mountains, throughout the United States: but it appears to be most multiplied in the Middle States, and especially in the back parts of Pennsylvania and of Virginia. It abounds, above all, in the Glades, which is the name given to a tract 15 or 18 miles wide, on the summit of the Alleghanies, along the road from Philadelphia to Pittsburgh.

The ordinary height of the crab apple tree is 15 or 18 feet, with a diameter of 5 or 6 inches; but it is sometimes found 25 or 30 feet high, and 12 or 15 inches in diameter. The two stocks which I found by measurement to be of this size, stood in a field which had long been under cultivation, and this circumstance may have contributed to their extraordinary growth. They were insulated trees that in appearance exactly resembled the common apple tree. I have universally remarked that the crab apple grows most favourably in cool and moist places, and on fertile soils.

The leaves of this tree are oval, smooth on the upper surface, and, when fully developed, very distinctly toothed: some of them are imperfectly three-lobed. While young, they have a bitter and slightly aromatic taste. which leads to the belief that, with the addition of sugar, they would make an agreeable tea. Like the common apple tree, this species blooms very early in the spring. Its flowers are white mingled with rose colour, and are collected in corymbs; they produce a beautiful effect, and diffuse a delicious odour, by which, in the glades where the tree is abundant, the air is perfurned to a great distance. The apples, which are suspended by short peduncles, are small, green, intensely acid, and very odoriferous. Some farmers make cider of them, which is said to be excellent: they make very fine sweet-meats also, by the addition of a large quantity of sugar.

No attempts have been made in the United States to improve the fruit of the crab apple tree, nor any experiments of uniting it, by grafting, with the species imported from Europe. These species succeed so perfectly, and furnish such excellent new varieties, that much time would be spent upon the crab apple, withcut bringing it to as high a state of improvement. Perhaps it might be cultivated with advantage for cider; but, aside from its utility in this way, it must be regarded only as a tree highly agreeable for the beauty of its flowers and for the sweetness of its perfume.
CRAB-GRASS (Eleusine Indica). Dog's-tail grass, Wire grass. 'The grass described under these several names in the Flora Cestrica, makes a fine carpeting in yards, lanes, and foot-paths, flowering in the Middle States in August. Cattle and hogs are very fond of it, and it is recommended as making excellent hay.

Another species of grass which in some places goes under the name of Crab-grass, is the Digitaria sanguinalis, or Finger-grass (see plate $7, f$ ). This is a very troublesome annual in gardens and cultivated grounds, being very difficult to keep in subjection in the latter part of summer. (Flor. Cestrica.)

CRACKS IN HEELS OF HORSES. In farriery, little clefts which are said to be sometimes constitutional, but more frequently owing to the want of cleanliness and proper attention.

CRADLE. A frame consisting of long fingers arranged above a scythe, for the purpose of receiving the grain when harvesting. 'The scythe and cradle is comparatively a modern invention, by the aid of which a hand can cut five or six times as much grain as could be harvested in the same time with a sickle.

CRANBERRY (Vaccinium oxyroccus). See WHORTLEBERRY.

The species of Cranberry most commonly found in the United States is the Oxyroccus macrocarpus. It is an indigenous, low trailing vine, growing wild in bogs and meadows, hearing a beautiful red berry of an exceedingly sour, though agreeable taste, much used in domestic economy for tarts and sweet-meats. The cranberry, says Mr. Kenrick, of Boston, is a plant of easy culture; and with but little expense, not a doubt exists that meadows which are now barren wastes, or yield nothing but coarse herbage, might be converted into pro fitable cranberry fields. According to Loudon, Sir Joseph Banks, who obtained this plant from America, raised, in 1831, on a square of 18 feet each way, $3 \frac{1}{2}$ Winchester bushels, which is at the rate of 460 bushels to the acre. Any meadow will answer. Captain Henry Hall, of Barnstable, has cultivated the cranberry 20 years. They grow well on sandy bogs after draining; if the bogs are covered with brush, it is removed, but it is not necessary to remove the rushes, as the strong roots of the cranberry soon overpower them. It would be well if, previous to planting, the land could be ploughed; but Capt. Hall usually spreads on beach sand, and, digs holes four feet asunder each way, the same distance as for corn; the holes are, however, deeper. Into these holes, sods of cranberry roots are planted, and in the space of three years the whole ground is covered. The planting is usually performed in autumn. Mr. F. A. Hayden, of Lincoln, Mass., is stated to have gathered from his farm, in 1830, 400 bushels of cranberries, which brought him, in Boston market, $\$ 400$.

An acre of cranberries in full bearing will produce over 200 bushels; and the fruit generally sells in the markets of $B \circ s t o n$ for $\$ 1.50$ per bushel, and much higher than in former years. Although a moist soil is best suited to the plant, yet, with a suitable mixture of bog 
earth, or mud, it will flourish, producing abundant crops, even in any dry soil. There is said to be a variety of cranberry in Russia of a. superior size.

Cranberries abound in vast quantities in the moist prairies in Michigan and some of the Western States. By means of a newly invented rake, very simple in its construction and not expensive, 40 bushels may be gathered by one man in a day; and a cargo of 1500 bushels has been sent to one of the Atlantic States, fiom the northern part of Indiana, in a flatboat, at one time. The price which this product often commands in the markets of the cities along the Atlantic varies from $\$ 150$ even up to $\$ 250$ or $\$ 350$ per bushel. They can be gathered at the west at an expense of not more than 50 cents per bushel. The duty on them in England is not more than 2 cents per gallon by direct trade.

The cranberry tree, or shrub, commonly called the Highbush Cranberry (Viburnum oxycoccum), is also indigenous to North America, and among other places in which it is found, are some of the western counties of $\mathrm{New}$ York. The blossoms are white, disposed in cymes, forming a flat surface from a common centre, and very beautiful. Its fruit is a berry about the size of the common cranberry, of a bright red colour, and very austere laste. They are valuable for pies, tarts, preserves, \&c. The tree is propagated by seeds, layers, and suckers. (Kenrick's Am. Orchardist.)

It may, with great ease, be transferred from its native forest to the yard or garden, flourishing in every kind of soil, whether wet, dry, sand, or clay. The shrub so much resembles the snow-ball as to be distinguished from it with difficulty. The fruit is but little if any inferior in flavour to that of the swamp cranberry, from which it differs in having a small pit or stone. For some purposes it is even preferable to the cornmon cranberry. It grows in clusters which will remain on the bush all winter.

In the valley of the Columbia river, a new species of bush-cranberry has been discovered, called Pambina.

CRANE'S BILL (Geranium). A genus of plants comprising a large number of species, of which, according to Smith (Eng. Flor.vol.ii. p. 221), only thirteen are indigenous. The blue meadow crane's bill ( $G$. pratense) is found in rich, rather moist pastures, and thickets, especially in the hilly parts of England. It is a perennial, flowering in June and July ; flowers, of a fine blue, often irregularly striped or blotched with white, sometimes entirely white. The species of crane's bill called Herb Robert (G. Robertianum, possesses most medicinal virtues, and is found under hedges and in uncultivated places, flowering all through the summer. The stalks, and indeed the whole plant, is often quite red, as are the flowers, and the fruit is long and slender, resembling a crane's bill, after which it is named. The leaves are large, divided into many parts, and stand in pairs at every joint of their long-footed stalks. It is a very powerful astringent, and may be given in any form, decocted fresh, or powdered whron dry. Several indigrnous species are found in the United States.

CRAP. A local name in some places for darnel, and in others for buckwhea:

CRAPULA. See Horr.

CREAM. A thick, unctuous, yellowish co. loured substance which collects on the surface of milk, when this is allowed to stand some time at rest. See Butrer.

CREAM GAUGE, or GLASS. A graduated glass tube to ascertain the produce of cream. In a tube containing ten inches' depth of milk, every tenth of an inch will of course indicate one per cent. of cream. It may be used for many purposes, such as to ascertain the state of the animal's health, regular and quiet feeding, \&c. (Quart. Journ. Agr. vol. ii. p. 245.)

CREAM-SLICE. A sort of wonden knife, twelve or fourteen inches in length.

CREOSOTE. A term derived from Greek words signifying "flesh preserver." It is the most important of the five new chemical products obtained from wood-tar, by Dr. Reichenbach. The other four, are Paraffine, Eupione, $P$ camar, and Pittacal, none of which have, as yct, been applied to any use in the arts. Creosote may be prepared either from tar or from crude pyroligneous acid. Its flesh-preserving quality is rendered of little use, from the difficulty of removing the rank flavour which it imparts.

CRESS. See American Cress.

CRESS, BITTER WINTER (Barbarea vulgaris). See Winter Cress.

CRESS, INDIAN, or MAJOR NASTURTIUM (Tropreolum majus, diminutive of tropan, a trophy; and $T$. minus). The major nasturtium being the most productive, as well of nowers and leaves as of fruit, is the one that is usually cultivated in the kitchen garden; the fruit being used in pickling, and the flowers and leaves in salads and for garnishing. They will flourish in almost any soil, but the one in which they are most productive, is a light fresh loam. In a strong rich soil, the plants are luxuriant, but they afford fewer berries, and those of inferior flavour. They like an open situation. Sow from the beginning of March to the middle of May; the earlier, however, the better. The seed may be inserted in a drill, two inches deep, along its bottom, in a single row, with a space of two or three inches between every two, or they may be dibbled in at a similar distance and depth. The minor is likewise often sown in patches. The major should be inserted beneath a vacant paling, wall, or hedge, to which its stems may be trained, or in an open compartment with sticks inserted on each side. The runners at first require a little attention to enable them to $c \operatorname{limb}$, but they soon are capable of doing so unassisted. The minor either may trail along the ground, or be supported with short sticks. If water is not afforded during dry weather, they will not shoot so vigorously or be so productive. They flower from June until the close of October. The fruit for pickling must be gathered when of full size, and whilst green and fleshy, during August. For the production of seed, some plants should be left ungathered, as the first produced are not only the finest in 
general, but are often the only ones that ripen. They should be gathered as they ripen, which they do from the close of August to the beginning of October. They must on no account be stored until perfectly dry and hard. The finest and soundest seed of the previous year's production should alone be sown; if it is older, the plants are seldom vigorous. (G.W. Johnson's Kitchen Garden).

CRESS, WALL, or ROCK CRESS (Arabis). A genus of plants of very different habit from the last, of which the species are numerous, and chiefly natives of the northern hemisphere. There are six species described by Smith ( $E$ ng. Flor. vol. iii. p. 209), but the wall cress ( $A v a-$ bis thaliana) is preferred. All the species have a pungent flavour. 'The plants are adapted for ornamenting rock work, and are propagated from seeds or cuttings. The wild sorts are found frequent on old walls, stony banks or rocks, dry sandy ground, and cottage roofs.

CRESS, WATER (Nasturtium). There are several native species of water cress, which may be included in the following summary. Creeping yellow cress, annual yellow cress, amphibious yellow cress, or great water radish, and common water cress. They are branching herbs, almost invariably smooth, throwing out numerous radicles, and either altogether aquatic or at least growing in wet ground. (Eng. Flor. vol. iii. p. $191-5)$. Water cress (N. officinaie) was seldom admitted as an object of cultivation, and then never to any extent, until Mr. Bradbury, of West Hyde, Herts, undertook its cultivation for the London market. Mr. Bradbury considers that there are three varieties,-the green-leaved, which is easiest cultivated; small brown-leaved, which is the hardiest; and the large brown-leaved, which is the best, having most leaf in proportion to the stalk, and is the only one that can well be cultivated in deep waters. (Trans. Hort. Soc. Lond. vol. iv. p. 538.) The plants thrive best in a moderately swift stream, about an inch and a half deep, over a gravelly or chalky bottom, and the nearer its source the better: when there is choice, such situations, therefore, should be exclusively planted. If mud is the natural bottom, it should be removed, and gravel substituted. The plants are to be set in rows, which is most conducive to their health and good flavour, inasmuch as that they are regularly exposed to the current of water, of which, if there is not a constant stream, they never thrive. In shallow water, as above mentioned, the rows may be made only eighteen inches apart, but in deeper currents from five to seven feet are sometimes necessary. The beds must be cleared and re-planted twice a year, for in the mud and weeds which quickly collect, the plants not only will not grow freely, but it is difficult to separate them in gathering; it is likewise rendered imperative by the heads becoming small from frequent cutting. The times for planting and renewal are in successional insertions during May and June, the plants from which will come into production in August; and again from September to Noveunber, those in the last month being ready in the spring. In renewing the plantations, the hed of the stream, commencing towards its head, being cleared of mud and rubbish, from the mass of plants taken out the youngest and best rooted must be selected. These are returned into the stream, and retained in their proper order, by a stone placed on each. After the plants have been cut about three times, they begin to stock, and then the oftener they are cut the better. In summer they must be cut very close. The situation being favourable, they will yield a supply once in a week. In winter the water should be kept four or five inches deep; this is easily effected, by leaving the plants with larger heads, which impedes the current. The shoots ought always to be cut off; breaking greatly injures the plants. (Trans. Hort. Lond. Soc. vol. iv. p. 537-42.)

CRIB. In England sometimes applied to a rack for hay or straw for cattle, and sometimes to a manger for corn or chaff; also to a small enclosure in a cow-house or shed for calves or sheep. In the United States it is commonly used to designate the building or apartment in which Indian corn is stored in the ear.

CRIB-BITING. A vice to which some horses are subject; consisting in their catching hold of the manger, and it is said sucking in the air. It generally proceeds from a deranged state of the stomach, but it is sometimes brought on by uneasiness occasioned by diseases of the teeth, or by roughness in the person who currycombs them. (Lrande.) There are several straps or muzzles in use to prevent crib-biting, one of the best being that invented by Mr. Stewart. (Blaine's Encyc. p. 318, 319.)

CRICK. In farriery, is when a horse cannot turn his neck any way, and when thus affected he cannot take his meat from the ground without great pain.

CRICKET. The common or hearth cricket (Gryllina). This insect in England frequents kitchens and bakers' ovens, on account of the warmth of those places. An easy method of destroying them is to place phials half full of beer or any other liquid near their holes, and they will crawl into them, and can then be easily taken. A hedgehog soon clear's a kitchen. There are, as yet, no house-crickets in the United States, where the species inhabiting gardens and fields enter dwellings only by accident. The American crickets belong to a group of insects (Achetada) which naturalists have placed in the same class as the grasshoppers and locusts. They are distinguished by having wing-covers horizontal, and furnished with a narrow, deflexed outer border; antennæ long and tapering; feet with not more than three joints, and two tapering downy bristles at the end of the body, between which, in most of the females, is a long spear-pointed piercer.

"There may be sometimes seen," says Dr. Harris, "in moist and soft ground, particularly around ponds, little ridges or hills of loose, fresh earth, smaller than those which are formed by moles. They cover little burrows, that usually terminate beneath a stone or clod of turf. These burrows are made and inhabited by mole-crickets, which are among the most extraordinary of the cricket kind. The common mole-cricket of this country is, when fully grown, about one inch and a quarter in length, of a light bay or fawn colour, and covered with 


\section{CRICKET.}

a very short and velvet-like down. The wingcovers are not hall the length of the abdomen, and the wings are also short, their tips, when folded, extending only about one-eighth of an inch beyond the wing-cavers. The fure-legs are admirably adapted for digging, being very short, broad, and strong; and the shanks, which are excessively broad, flat, and three-sided, have the lower side divided by deep notches into four finger-like projections, that give to this part very much the appearance and the power of the hand of a mole. From this similarity in structure, and from its burrowing habits, the insect receives its scientific name of Gryllotalpa, derived from Gryllus, the ancient name of the cricket, and Talpa, a mole; and our common species has the additional name of brevipennis, or short-winged, to distinguish it from the European species, which has much longer wings. Mole-crickets avoid the light of day, and are active chiefly during the night. They live on the tender roots of plants, and in Europe, where they infest moist gardens and meadows, they often do great injury by burrowing under the turf, and cutting off the roots of the grass, and by undermining and destroying, in this way, sometimes whole beds of cabbages, beans, and flowers. In the West Indies, extensive ravages have been committed in the plantations of the sugar-cane by another species, Gryllotalpa didactyla, which has only two finger-like projections on the shin. The molecricket of Europe lays from two to three hundred eggs, and the young do not come to maturity till the third year; circumstances both contributing greatly to increase the ravages of these insects. It is observed that, in proportion as cultivation is extended, destructive insects multiply, and their depredations become more serious. We may, therefore, in process of time, find mole-crickets in this country quite as much a pest as they are in Europe, although their depredations have hitherto been limited to so small an extent as not to have attracted much notice. Should it hereafter become necessary to employ means for checking them, poisoning might be tried, such as placing, in the vicinity of their burrows, grated carrots or potatoes mixed with arsenic. It is well known that swine will eat almost all kinds of insects, and that they are very sagacious in rooting them out of the ground. They might, therefore, be employed with advantage to destroy these and other noxious insects, if other means should fail.

"Crickets are, in great measure, nocturnal and solitary insects, concealing themselves by day, and coming from their retreats to seek their food and their mates by night. There are some species, however, which differ greatly from the others in their social habits. These are not unfrequently seen during the day-time in great numbers, in paths and by the road-side; but the other kinds rarely expose themselves to the light of day, and their music is heard only at night. With crickets, as with grasshoppers, locusts, and harvest-flies, the males only are musical; for the females are not provided with the instruments from which the sounds emitted by these different insects are produced. In the male cricket these make a part of the wing-covers, the horizontal and overlapping portion of which, near the thorax is convex, and marked with large, strong, and irregularly curved veins. When the cricket shrills (we cannot say sings, for he has un vocal organs), he raises the wing-covers a little, and shuffles them together lengthwise, so that the projecting veins of one are made to grate against those of the other. 'The English name cricket, and the French cri-cri, are evidently derived from the creaking sounds of these in sects. Mr. White, of Selborne, says that 'the shrilling of the field-cricket, though sharp and stridulous, yet marvellously delights some hearers, filling their minds with a train of summer ideas of every thing that is rural, verdurous, and joyous; sentiments in which few persons, if any, in America will participate; fur with us the creaking of crickets does not begin till summer is gone, and the continued and mono. tonous sounds, which they keep up luring the whole night, so long as autumn lasts, are both wearisome and sad. Where crickets abound, they do great injury to vegetation, eating the most tender parts of plants, and even devouring fruits and roots, whenever they can get them. Melons, squashes, and even potatoes are often eaten by them, and the quantity of grass that they destroy must be great, from the immense numbers of these insects which are sometimes seen in our meadows and fields. They may be poisoned in the same way as mole-crickets. Crickets are not entirely confined to a vegetable diet; they devour other insects whenever they meet with and can overpower them. They deposit their eggs, which are numerous, in the ground, making holes for their reception with their long, spear-pointed piercers. The eggs are laid in the autumn, and do not appear to be hatched till the ensuing summer. The old insects, for the most part, die on the approach of cold weather; but a few survive the winter, by sheltering themselves under stones, or in holes secure from the access of water.

"The scientific name of the genus that includes the cricket is Acheta, and our common species is the Acheta abbreviata, so named from the shortness of its wings, which do not extend beyond the wing-covers. It is about threequarters of an inch in length, of a black colour, with a brownish tinge at the base of the wing-covers, and a pale line on each side above the deflexed border. The pale line is most distinct in the female, and is oftentimes entirely wanting in the male.

"We have another species with very short or abortive wings; it is entirely of a black colour, and measures six-tenths of an inch in. length from the head to the end of the body. It may be called Acheta nigra, the black cricket.

"A third species, differing from these two in being entirely destitute of wings, and in having the wing-covers proportionally much shorter, and the last joint of the feelers (palpi) almost twice the length of the preceding joint, is furthermore distinguished from them by its greatiy inferior size, and its different colouring. It measures from three to above four-tenths of an inch in length, and varies in colour from dusky brown to rusty black, the wing-covers and hind. 
most thighs being always somewhat lighter. In the brownish-coloured varieties, three longitudinal black lines are distinctly visible on the top of the head, and a black line on each side of the thorax, which is continued along the sides of the wing-covers to their tips. 'This black line on the wing-covers is never wanting, even in the darkest varieties. The hindmost thighs have on the outside three rows of short oblique black lines, presenting somewhat of a twilled appearance. This is one of the social species, which, associated together in great swarms, and feeding in common, frequent our meadows and roadsides, and, so far from avoiding the light of day, seem to be quite as fond of it as others are of darkness. It may be called Acheta vitlata, the striped cricket.

"These kinds of crickets live upon the ground, and among the grass and low herbage; but there is another kind which inhabits the stems and branches of shrubs and trees, concealing itself during the daytime among the leaves or in the flowers of these plants. The males begin to be heard about the middle of August, and do not leave us until after the middle of September. Their shrilling is excessively loud, and is produced, like that of other crickets, by the rubbing of one wingcover against the other. These insects have been separated from the other crickets under the generical name of 2 icanthus, a word which means inhabiting flowers. They may be called climbing crickets, from their habit of mounting upon plants, and diwelling among the leaves and flowers. According to M. Salvi, the female makes several perforations in the tender stems of plants, and in each perforation thrusts two eggs quite to the pith. The eggs are hatched about midsummer, and the young immediately issue from their nests and conceal themselves among the thickest foliage of the plant. When arrived at maturity, the males begin their nocturnal serenade at the approach of twilight, and continue it, with little or no intermission, till the dawn of day. Should one of these little musicians get admission to the chamber, his incessant and loud shrilling will effectually banish sleep. Of three species which inhabit the United States, one only is found in Massachusetts. It is the OEcanthus niveus, or white climbing cricket. The male is ivory-white, with the upper side of the first joint of the antennæ, and the head between the eyes, of an ochre-yellow colour; there is a minute black dot on the under-sides of the first and second joints of the antennæ; and, in some individuals, the extremities of the feet and the undersides of the hindmost thighs are ochre-yellow. The body is about half an inch long, exclusive of the wing-covers. The female is usually rather longer, but the wing-covers are much narrower than those of the male, and there is a great diversity of colouring in this sex; the body being sometimes almost white, or pale greenish yellow, or dusky, and blackish beneath. There are three dusky stripes on the head and thorax, and the legs, antennx, and piercer are more or less dusky or blackish. The wing-covers and wings are yellowish white, sometines with a tinge of green, and $\mathbf{3} 66$ the wings are rather longer than the covers." (Harris on Destructive Insects.)

CROCUS. A well-known bulbous plant, of which there are many varieties, all handsome. Plant in clumps; move them once in three years, to separate the offsets; they like a good light soil. Plant them two inches deep in the ground. Smith (Eng. Flor. vol. i. p.46, and vol. iv. p. 262), describes four species of native English crocuses, viz., the saffron crocus, purple spring crocus, naked flowering crocus, and net-rooted crocus. See Saffron.

CRONES. A provincial word applied to the different descriptions of old ewes.

CROOK. A provincial term applied to a hook, as a yat-crook means a gate-hook.

CROOM. A provincial term applied to an implement with crooked or hooked prongs. There are muck-crooms, turnip-crooms, \&c. It is sometimes written Crome.

CROP. The produce or quantity of grain, roots, or grass, \&c. grown on a piece of land at one time; hence we have grain, root, and green crops. There is an able paper in the Quart. Journ. of $A g r$. vol. i. p. 55, by Mr. Henry Stephens, on the causes of destruction to crops, which may be consulted with advantage by the farmer. For course of crops, see Rotatrox or Chops.

CROPPING. An operation performed with a pair of shears, on the ears of horses, dogs, or other animals.

CROSS-FURROW. The grip or furrow which receives the superfluous rain-water from the outer furrows, and conveys it from the land into a ditch or other outlet. The operation of making these cross-furrows is sometimes performed by the spade, and at others by the plough.

CROTCH. A country term for a hook.

CROW, THE CARRION (Corvus corone). The carrion crow, like the raven which it so much resembles, is a denizen of nearly every part of the world. Crows are even found in New Holland and the Phillipine islands of the Pacific Ocean. They are comparatively rare in northern latitudes, where the raven most abounds. The crow is exceedingly mischievous in his depredations about farms and dwellings, where he sucks eggs, carries off chickens and other young broods. But the most serious mischief of which the crow is gurlty in the United States, is that of pillaging the fields of Indian corn. He commences at the planting time, by rooting out the grain as soon as the sprout shows above the ground, and in autumn, when the crop ripens, flccks, sometimes suffi cient to blacken the fields, do extensive damage.

"The crow," says Nuttall, "like many other birds, becomes injurious and formidable only in the gregarious season, at other, times they live so scattered, and are so shy and cautious, that they are but seldom seen. But their armies, like all other and terrific assemblies, have the power, in limited districts, of doing very sensible mischief to the agricultural interests of the community; and, in consequence, the poor crow, notwithstanding his obvious services in the destruction of vast hosts of insects and their larvæ, is proscribed as a felon in all 
civilized countries, and, with the wolves, panthers, and foxes, a price is put upon his head. In consequerice, various means of ensnaring the outlaw have been had recourse to. Of the gun he is extremely cautious, and suspects its appearance at the first glance, perceiving with ready sagacity the wily manner of the fowler. So fearful and suspicious are they of human artifices, that a mere line stretched round a field is often found sufficient to deter these wily birds from a visit to the corn-field. Against poison he is not so guarded, and sometimes corn steeped in hellebore is given him, which creates giddiness and death. According to Buffon, pieces of paper in the form of a hollow cone, smeared inside with bird-lime, and containing bits of raw meat, have been employed. In attempting to gain the bait, the dupe becomes instantly hoodwinked, and, as the safest course out of the way of danger, the crow flies directly upwards to a great height, but becoming fatigued with the exertion, he generally descends pretty near to the place from which he started, and is then easily taken.

"Another curious method, related by the same author, is that of pinning a live crow to the ground by the wings, stretched out on his back, and retained in this posture by two sharp, forked sticks. In this situation, his loud cries attract other crows, who come sweeping down to the prostrate prisoner, and are grappled in his claws. In this way each successive prisoner may be made the innocent means of capturing his companion. The reeds in which they roost, when dry enough, are sometimes set on fire also to procure their destruction; and, to add to the fatality produced by the flames, gunners are also stationed round to destroy those that attempt to escape by flight. In severe winters they suffer occasionally from famine and cold, and fall sometimes dead in the fields. According to Wilson, in one of these severe seasons, more than six hundred crows were shot on the carcass of a dead horse, which was placed at a proper shooting distance from a stable. The premiums obtained for these, and the price procured for the quills, produced to the farmer nearly the value of the horse when living, hesides affording feathers sufficient to fill a bed!

"The crow is easily raised and domesticated, and soon learns to distinguish the different members of the family with which he is associated. He screams at the approach of a stranger; learns to open the door by alighting on the latch; attends regularly at meal times; is very noisy and loquacious; imitates the sound of various words which he hears; is very thievish, given to hiding curiosities in holes and crevices, and is very fond of carrying off pieces of metal, corn, bread, and food of all kinds; he is also particularly attached to the society of his master, and recollects him sometimes after a long absence.

"It is commonly believed and asserted in some parts of this country, that the crows engage at times in general combat; but it has never been ascertained whether this hostility arises from civil discord, or the opposition of two different species, contesting for some exclusive privilege of subsisting-ground. It is well known that rooks often contend with each other, and drive away, by every persecuting means, individuals who arrive among them from any other rookery.

"The crow is much smaller than the raven, and is of a deep black with violet reflections. 'The bill and feet are also black. 'The iris hazel. (The European bird is twenty inches, or nearly, and has the feathers of the neck narrow and distinct.)"

Soaking seed-corn for 24 or 48 hours in a strong solution of glauber's salts, is said to effectually prevent crows, black-birds, and squirrels from pulling up the grain.

Wilson was the first ornithologist who discovered an American species differing from the common crow, and which he called the fish crow (corvus ossifragus). It is met with along the coast of the Southern States and as high up as New Jersey. It keeps apart from the common species, from which, however, it differs but slightly in appearance, being about 16 inches in length whilst the common crow measures about $18 \frac{1}{2}$ inches. Instead of assembling to roost among the reeds at night, it retires, toward evening, from the shores which afford it a subsistence, and perches in the neighbouring woods. Its notes, probably various, are at times hoarse and guttural, at others weaker and higher. They pass most part of their time near rivers, hovering over the stream to catch up dead and perhaps living fish, or other animal matters which float with. in their reach; at these they dive with considerable celerity, and seizing them in their claws, convey them to an adjoining tree, and devour the fruits of their predatory industry at leisure. They also snatch up water lizard: in the same manner, and feed upon small crabs, at times they are seen even contending with the gulls for their prey. It is amusing to see with what steady watchfulness they hover over the water in search of their precarious food, having, in fact, all the traits of the gull; but they subsist more on accidental supplies than by any re. gular system of fishing. On land they have sometimes all the familiarity of the magpie, hopping upon the backs of cattle, in whose company they, no doubt, occasionally meet with a supply of insects when other sources fail. They are also regular in their attendance on the fishermen in New Jersey, for the pur. pose of gleaning up the refuse of the fish. They are less shy and suspicious than the common crow, and, showing no inclination for plundering the corn-fields, are rather friends than enemies to the farmer. They appear near Philadelphia, from the middle of March to the beginning of June, during the season of the shad and herring fishery.

They breed in New Jersey in tall trees, haw. ing nests and eggs very similar to those of the? preceding species, and rear a brood of four. 5 five young, with whom they are seen in com pany in the month of July.

This species bears some resemblance to the rook in general appearance, and by the bare space near the bill, but it is smaller, longer tailed, and wholly different in its habits and mode of living.

The Hooded Cine (Corzus minix) resemblar 367 
the carrion crow in appearance; but is only a constant resident of the northern parts of England and the western islands of Scotland; it is more destructive to the farmers' lambs, \&c. than the carrion crow. Its colour is black. Length, twenty inches. (Yarrell's Brit. Birds, val. ii. p. 79-83.)

CROW-FOO'l', or Crane's Bill. The species usually known by this name in England, is the Ranunculus acris of botanists. This, with all its varieties, are poisonous. The common medicinal crow-foot is the medicinal plant, which, however, is only used externally, the application of the recent leaves or root producing a blister. The most poisonous variety is that called spear-wood. The plant known in the United States by the name of crow-foot, or spotted crane's-bill, is the spotted geranium (Geranium maculatum), a perennial tuberous root, found along fence-rows, in meadows, woodlands, \&c., flowering in May and June. The root is astringent and has been found useful in diarrhœa, hœmorrhages, \&c. See Flora Cestrica.

CROW NET. A net made of double thread or fine packthread, principally used for catching wildfowl in the winter season; but which may also be employed on newly sown cornfields for catching pigeons, crows, and other birds ; and, even in stubble-fields, if the stubble conceals the net from the birds.

CROWN IMPERIAL (Fritillaria imperialis). Native of Persia, with a large, scaly, bulbous, or orange-coloured, disagreeably smelling root. Blows pendent red flowers in April and May. 'There are three varieties, the red-flowered, the red striped-flowered with striped leaves, and the yellow-flowered; that blowing a yellow flower is the handsomest. Propagate by offsets every third year, taking up the bulbs in July for that purpose. It loves a sandy loam, and is averse to manure or wet. See Fertiltari.

CRUCIFORM-PLANTS (Cruciferc), a class comprehending such garden vegetables as the cabbage, cauliflower, broccoli, sea-kale, turnip, radish, mustard, and in fact almost every culinary article, except spinach. The class derives its name from the flowers having four petals or flower-leaves, disposed in the form of a cross, as exemplified in the wall-flower. It is remarked by botanists, that not a single species included in this group is poisonous. Jiven that great pest among weeds, charlock, or wild radish, which belongs to the cruciform class, affords when young most excellent and wholesome greens.

CRUPPER. A term applied to the rump of a horse; also to a roll of leather put under a horse's tail, and drawn up by a strap to the Juckle behind the saddle.

CRUSHERS FOR GRAIN, are evidently coming fast into use; the saving of food, by giving the grain in a broken state, being cerlainly very considerable. It is a practice at least as old as the days of Samuel Hartlib, who mentions it with approbation in his "Leyacie." Machines for cracking and crushing Indian corn by hand for feed, are quite common in the United States.

CUCKOO PINT. See Andm. 368
CUCKOO SPIT. Applied to a kind of frothy substance frequently found on plants, containing insects. See Frogroppens.

CUCUMBER (Cucumis sativus. From xurus or oixus. Varro says, "Cucumeres dicuntur a curvore, ut curvimere dicti"). The following are the chief varieties:-1. Early short green prickly; 2. early long green prickly ; 3. most long green prickly; 4. early green cluster; 5 . white Dutch prickly; 6. long smooth green Turkey; 7. large smooth green Foman; 8. Flanegan's; 9. Russian; 10. white Turkey; 11. Nepal; 12. fluted (from China); 13. the snake.

The early short prickly is about four inches long, and is often preferred for the first crop, as being a very plentiful bearer, quick in coming into production, and the hardiest of all the varieties. The early long prickly is about seven inches long; it is a hardy, abundantly bearing variety, but not quick in coming into production. It is generally grown for main crops. The longest prickly is about nine or ten inches in length; it is a hardy, good bearer. There is a white sub-variety. The early green cluster is a very early bearer. Its fruit is about six inches long. It is chiefly characterized by its fruit growing in clusters. The whole plant grows compact, and is well suited for handglass crops. The white Dutch prickly is about six inches long; it has an agreeable flavour, though differing from most of the others. It comes quickly into bearing.

The other varieties are slow in coming into production, and are chiefly remarkable for their great size. The Nepal often weighs twelve pounds, being occasionally eight inches in diameter and seventeen in length. It is a native of Calcutta. The snake cucumber is very small in diameter, but attains the length, it is said, of several feet.

A fresh loam, rather inclining to lightness than tenacity, as the top-spit of a pasture, is perhaps as fine a soil as can be employed for the cucumber. It will succeed in any open soil of the garden for the hand-glass and natural ground crops.

The out-door culture of cucumbers practised throughout the United States is so familiarly known as to require no particular description. In the neighbourhood of large cities the large demand for cucumbers causes these to be included among the articles of field-culture, and this is done to great profit by the Long Island and New Jersey truck farmers, for the supply of the New York and Philadelphia markets. It is a great object to get the produce into market as early as possible, as only a few days advantage makes a great difference in the value of this, in common with most other articles supplied by gardeners, fruiterers, and truclimen. Thomas G. Bergen, an intelligent and experlenced gardener on J Jong Island, communicated to the editor of the Cultivator the following account of his method of raising cucumbers, together with his estimate of the produce and profits of the crop.

"Cucumbers will grow on any good soil, but to have them early we require a rich sandy one, of a dark colour; yellow and light-colnurel ones being later. The field, if possible, re- 
yaires to be protected from the romtr ? northwest winds, and be situated near the pay or river, where there is aiways iess dang $r$ from late frosts. 'The south winds, with us, in May and June, retard vegetation more than al y other, in consequence of their being chilly atd cool, which qualities they receive from the ucean.

"Ground intended for cucumbers we prefer ploughing in August or the beginning of September of the preceding year, and sowing with rye; the pasture which this produces pays for the labour, and among its advantages are, the prevention of weeds going to seed and troubling us in the spring; the soil not blowing about in winter, especially on the knolls; neither is it so liable to blow when ploughed in the spring, in consequence of the roots of the plants, and the sustenance afforded to the crop by the decay of the rye. Previous to ploughing for the crop, there should be spread about seven twohorse loads of street or horse manure to the acre; but if the soil is poor, more will be necessary, and the ploughing should take place immediately after the spreading. The ground is then harrowed over two or three times until it is mellow, furrowed shallow, with a plough, inio hills four and a half feet asunder, manured with half a shovelful in a hill, which is flattened down with a hoe and covered about an inch thick with fine soil. Short hog manure, carted out of the pen the preceding fall, and cut over early in the spring once or twice, and made fine, is preferred for the hills; but this not being generally sufficiently abundant, we procure the manure of cows which have been fed on distillers' slops, mixed with that of horses, so as to make it sufficiently firm to handle with a fork, from New York in the fall, which we mix with the hog manure. The manure should be cool, for fermentation in the hills is injurious to the plants.

"The sooner the seed is planted after ploughing the better; the time of planting depends upon the forwardness of the season, and it is generally commenced when single apricot blossoms are open, but some seasons earlier. About a week is occupied in putting in the first seed, and nearly the same period in planting over the first and second times. The casualties to which the seeds and plants are subject induces us to continue putting in seed almost every day for this space of time, so as to make certain work. It sometimes happens, when the weather has been unfavourable, that every hill in some fields is planted over the third, and even single hills the fourth time. I prefer spreading the first seed in the south half of the hills, the first planting over in the northwest, and the second in the northeast quarters; if it becomes necessary to plant over the third time, I put the seed in the south half, where the first seed by that time is rotten. If this plan is properly followed, the different plantings will not interfere with each other. We generally put in from thirty to forty seeds each time, and cover them with fine soil from three-quarters to an inch deep. Sprouting the seed previous to planting does not succeed well early in the season, but does sometimes when the weather is favourable in the latter part. Cucumber seed is the tenderest of the vine kind, for if, after planting at the usual depth, wet weather should follow, it is almost certain to rot; if dry, it dries out; if, when favourable to their vegetating, and the planis have advanced so as to be breaking ground, a storm should occur, they generally perish; a northeaster of three or four days' continuance destroys the plants when young, and in some instances when more than a week old; if up too early, a late frost is apt to sweep them clean. Seed to vegetate requires to be near the surface of the wet soil, not buried deep into it; our ignorance of the weather which will follow after planting, causes most of our errors; when planted in a heavy soil, it is less liable to rot and dry out than in a sandy one, but the fruit is later. If it happens that there are more plants in a hill than we require, we find it an easy matter to eradicate them with the hoe and fingers, but it is not so easy to place them in the hills when deficient.

When the first rough leaves of the plants are about the size of a twenty-five cent piece, a cultivator is run through the rows both ways, and they receive the first hoeing; the plants are also thinned out, so as not to crowd each other. In hoeing, the soil between the plants should not be disturbed; large weeds (if any) must be pulled out; and fine soil drawn around the plants up to the seed leaves, so as to cover small weeds. The hill must be made flat and not concave. We are careful not to hoe while the plants are very young, for if a storm should occur shortly after the operation has been performed, the hills soak in too much water, which is injurious. Ten or twelve days after the first hceing, the plants (if good) are thinned to six or eight in a hill, leaving the largest ones, and if possible three or four inches apart. About eighteen days after the first hoeing, or about the time when single blossoms open, we run a one-horse plough twice through a row each way (if the ground is hard, three times), throwing the furrow from the hills, and then commence the second hoeing, which is performed in the same manner as the first, care being taken not to earth up higher than the seed leaves, and to scrape out the crust between the plants, if the ground is hard or covered with weeds; they are also, if the plants are fair, thinned down to five in a hill.

"When the vines extend so that single ones meet each other between the hills, to prevent injury they are carefully laid aside by hand, or with a short stick, and the cultivator for the last time is run once through a row each way. They then receive the third and last hoeing, the ground being loosened and drawn up around the hills with the hoe, and broken between the plants with the fingers. It is customary to, leave five plants in a hill, standing from four to five inches apart, but some reduee them to four; have tried no experiment to test whicn is the best.

"Cucumber vines will yield fruit about eight weeks, and the fields are picked over at least every second and sometimes everv lay. In picking, a light stick with a cross-prece framed to it so as to resemble the letter $\mathrm{F}$, is made use of to push the leaves aside and more reacily to discover the fruit. 
"We are acquainted with the system of rotation of crops, and it has been practised among our farmers for years, but cucumbers, as well as some other vegetables, do not seem to require it. I have a piece of about half an acre on which I have cultivated them for the last ten successive years, ploughing in the usual quantity of street manure every second year, and they have flourished as well as on the adjoining ground, which has been similarly manured, and on which the crops have been changed.

"The following is the quantity planted, produce, and amount of sales, for the last four years, viz.

$\begin{array}{lcrr}\text { Year. } & \text { Hills planted. } & \text { Cucumbers sold. } & \text { Am't received. } \\ 1835 & 6,000 & 104,965 & \$ 82384 \\ 1836 & 6,600 & 99,670 & 82096 \\ 1837 & 7,370 & 130,735 & 53200 \\ 1838 & 7,110 & 118,600 & 73487\end{array}$

$1838 \quad 7,110 \quad 118,600 \quad 73487 \frac{1}{2}$

"During each of these years large quantities of cullings, and, when unsaleable, good ones, were fed to the hogs and cattle, of which no account was kept." (Cultivator, v.)

CUCUMBER, INSECTS ATTACKING. In the United States the vine of the cucumber is preyed upon at all ages, but more especially when very young and tender, by various insects, which make it necessary to replant frequently, and very often entirely destroy the hopes of the gardener and truckman. Among the most destructive of these is the beetle generally known by the names of striped bug, cucumber bug, and striped Galeruca. It is of a tight yellow colour above, with a black head, and a broad black stripe on each wing-cover. Its length is rather more than one-fifth of an inch. It belongs to the cxtensive tribe of leafeating beetles, called by naturalists Chrysomelians, a word applied to designate golden beetles, many of which are of the most brilliant colours, with the finest metallic lustres.

Dr. Harris informs us that the striped cucumber bug in early spring devours the tender leaves of various plants, before the cucumber, squash, and melon vines are out of the ground. As soon, however, as the leaves of these come up and begin to expand, they are attacked by the bug; and, as several broods are produced in the course of the summer, it may be found at various times on these plants, till the latter are destroyed by frost. "Great numbers of these little beetles may be obtained in the autumn from the flowers of squash and pumpkin vines, the pollen and germs of which they are very fond of. They get into the blossoms as soon as the latter are opened, and are often caught there by the twisting and closing of the top of the flower, and when they want to make their escape, they are obliged to gnaw a hole through the side of their temporary prison. The females lay their eggs in the ground, and the larvæ probably feed on the roots of plants, but they have hitherto escaped my researches.

"Various means have been suggested and tried to prevent the ravages of these striped rucrumber beetles, which have become notorious throughout the country for their attacks upon the leaves of the cucumber and squash. Dr. B. S. Barton, of Philadelphia, recommended sprinkling the vines with a mixture of to. bacco and red pepper, which he stated to be attended with great benefit. Watering the vines with a solution of one ounce of Glauber's salts in a quart of water, or with tobacco water, an infusion of elder, of walnut leaves, or of hops, has been highly recommended. Mr. Gourgas, of Weston, has found no application so useful as ground plaster of Paris; and a writer in the 'American Farmer' extols the use of charcoal dust. Deane recommended sifting powdered soot upon the plants when they are wet with the morning dew, and others have advised sulphur and Scotch snuff to be applied in the same way. As these insects fly by night as well as by day, and are attracted by lights, lighted splinters of pine knots or of staves of tarbarrels, stuck into the ground during the night around the plants, have been found useful in destroying these beetles. The most effectual preservative both against these insects and the equally destructive black flea-beetles which infest the vines in the spring, consists in covering the young vines with millinet stretched over small wooden frames. Mr. Levi Bartlett, of Warner, N. H., has described a method for making these frames expeditiously and economically, and his directions may be found in the second volume of the New England Farmer, p. 305, and in Fessenden's New American Gardener, sixth edition, p. 91." (Harris.)

A correspondent of the Cultivator says that a thin layer of tow spread over cucumber and melon plants when they first appear will save them from the striped yellow bug. To this the editor appends the following observation:"Our remedy for the bug, and for the worm in the garden, is to put a coop with a hen and good brood of chickens there, and these intruders, and most others of the insect depredators, will soon become scarce." The thin layer of tow doubtless suggested the millinet frame protectors just referred to.

Mr. Bergen, whose mode of cultivating cucumbers has been given, makes the following observations in relation to the insect enemies of the plant:-

"The insects which trouble and destroy the plants are the black worm and striped bugs; the first is apt to be numerous in ground which was occupied the preceding year with red clover; they cut off the plants at or above the surface in the night, and are generally hunted out early in the morning, when their burrowing is fresh and they lie near the surface, until the ground is cleared of them: the striped bug or yellow fly eats the plants in the day time, and is sometimes very destructive on land where a crust is formed on the surface, which, being raised up by the young plants, affords them a harbour. The best remedy is, with the fingers to catch and destroy them in the morning when the dew is on them and they are chilled, which prevents their flying and escaping as freely as when the sun has warmed them. Sandy land, having no crust to shelter these pests, is generally exempt from their depredations."

The cucumber flea-beetle referred to, is a little, black, jumping insect, well known from the injury done by it in the spring, not only to the young plants of the cucumber, but to those of the cabbage, turnip, ruta baga, mustard, 
radish, cress, potato, and some others of tne cruciferous family. It is closely allied to the turnip-fly or more properly the turnip fleabeetle, which lays waste the turnip fields in Europe, devouring the seed-leaves of the plants as soon as they appear above ground, and continuing their ravages upon new crops throughout the summer. It is stated in Young's Annuls of Agriculture (vol. vii.), that the loss in Devonshire, England, in one season, from the destruction of the turnip crops by this little insect, was estimated at $£ 100,000$ sterling. These turnip flies belong to a family of beetles to which naturalists have applied the name haltica, derived from a word signifying to leap. In the American cucumber flea-beetle, the surface of the body is smooth, generally polished, and often prettily or brilliantly coloured. See Flea-Bertus.

"The flea-beetles," says Dr. Harris, "conceal themselves during the winter, in dry places, under stones, in tufts of withered grass, and in chinks of walls. They lay their eggs in the spring, upon the leaves of the plants upon which they feed. The larvæ, or young, of the smaller kinds burrow into the leaves, and eat the soft pulpy substance under the skin, forming therein little winding passages, in which they finally complete their transformations. Hence the plants suffer as much from the depredations of the larvæ, as from those of the beetles, a fact that has too often been overlooked. The larvæ of the larger kinds are said to live exposed upon the surface of the leaves which they devour, till they have come to their growth, and to go into the ground, where they are changed to pupx, and soon afterwards to beetles. The mining larvæ, the only kinds which are known to me from personal examination, are little slender grubs, tapering towards each end, and provided with six legs. They arrive at maturity, turn to pupæ, and then to beetles in a few weeks. Hence there is a constant succession of these insects, in their various states, throughout the summer. The history of the greater part of our halticas or flea-beetles is still unknown; I shall, therefore, only add, to the foregoing general remarks, descriptions of two or three common species, and suggest such remedies as seem to be useful in protecting plants from their ravages.

"The most destructive species in this vicinity (Boston) is that which attacks the cucumber plant as soon as the latter appears above the ground, eating the seed-leaves, and thereby destroying the plants immediately. Supposing this to be an undescribed insect, I formerly named it Halica cucumeris, the cucumber flea-beetle; but Mr. Say subsequently informed me that it was the pubescens of Illiger, so named because it is very slightly pubescent or downy. It is only one-sixteenth of an inch long, of a black colour, with clay-yellow antennæ and legs, except the hindınost thighs, which are brown. The upper side of the body is covered with punctures, which are arranged in rows on the wing-cases; and there is a deep transverse furrow across the hinder part of the thorax.

"The wavy-striped flea-beetle, Haltica striouta, may be seen in great abundance on the horse-radish, various kinds of cresses, and or the mustard, and turnip, early in May, and indeed at other times throughout the summer. It is very injurious to young plants, destroying their seed-leaves as soon as the latter expand. Should it multiply to any extent, it may, in time, become as great a pest as the European turnip flea-beetle, which it closely resembles in its appearance, and in all its habits. Though rather larger than the cucumber flea-beetle, and of a longer oval shape, it is considerably less than one-tenth of an inch in length. It is of a polished black colour, with a broad wavy buff-coloured stripe on each wing-cover, and the knees and feet are reddish-yellow. Specimens are sometimes found having two buffyellow spots on each wing-cover instead of the wavy stripes.

"In England, where the ravages of the turnip flea-beetle have attracted great attention, and have caused many and various experiments to be tried with a view of checking them, it is thought that 'the careful and systematic use of lime will obviate, in a great degree, the danger which has been experienced,' from this insect. From this and other statements in favour of the use of lime, there is good reason to hope that it will effectually protect plants from the various kinds of flea-beetles, if dusted over them, when wet with dew, in proper season. Watering plants with alkaline solutions, it is said, will kill the insects without injuring the plants. The solution may be made by dissolving one pound of hard soap in twelve gallons of the soap suds left after washing. This mixture should be applied twice a day with a water pot. Köllar very highly recommends watering or wetting the leaves of plants with an infusion or tea of wormwond, which prevents the flea-beetles from touching them. Perhaps a decoction of wainut leaves might be equally serviceable. Great numbers of the beetles may be caught by the skilful use of a deep bag-net of muslin, which should be swept over the plants infested by the heetles, after which the latter may be easily destroyed. This net cannot be used with safety to catch the insects on very young plants, on account of the risk of bruising or breaking their tender leaves." (Harris.)

Dr. Harris says, that several years agn he observed cucumber vines much infested by some minute jumping insects, rather less than one-tenth of an inch long, of a broad oval shape, and black colour, without wing-covers or wings, but furnished with short, thick hinder thighs. They injured the vines very much by eating holes into or puncturing the leaves and were expelled by dusting the plants with flower of sulphur. These cucumber-skippers were so soft and tender, and withal so agile, that it was difficult to catch without crushing them. Consequently he was unable to examine them thoroughly, and failed to preserve specimens of them.

Since the time referred to they have escaped the doctor's observation. He, however, thinks they were very different from the little flea beetles just described as belonging to the halricis family.

CUCUMBER TREE. There are three spe. 
cies of the magnolia, natives of the U, ited States, which go under this name, from the resemblance of their cones to the green fruit of the cucumber. One of these, the Magnolia acuminata, is a tree of considerable size, somesimes exceeding eighty feet in height and three or four feet in diameter. The trunk is perfectly straight, of a uniform size, and often destitute of branches for two-thirds of its length. The tree is one of the most splendid ornaments of the American forests. The leaves are six or seven inches long and three or four broad, upon old trees, and often twice the size upon saplings. Their form is oval, entire, and very sharp pointed, from which last characteristic the tree derives its specific name of acuminata. They fall off in autumn. The flowers are five or six inches in diameter, bluish, and sometimes white with a tint of yellow. They have a feeble odour, and being large and numerous, give a fine effect in the midst of the elegant foliage. It makes a superb ornamental tree in lawns, \&c.

The cones or fruit are about three inches long, and one inch in diameter, nearly cylindrical in shape, and often a little longer at the extremity than at the base. When greer, they very much resemble a young cucumber. They have cells, each of which contains one rosecoloured seed, which, before it escapes, remains suspended on the outside by a filament, like those of the great and small magnolias. Most of the inhabitants of the country bordering on the Alleghanies gather the cones about midsummer, when half ripe, and steep them in whisky; a glass or two of this liquor, which is extremely bitter, they habitually take in the morning, under the alleged excuse of preserving them against autumnal fevers.

The most northern point at which Michaux observed the cucumber tree, was on the Niagara river, in the latitude of $43^{\circ}$. It abounds along the whole mountainous tract of the Alleghanies, to their termination in Georgia, a distance of 900 miles. It is, however, rarely met with at a greater distance than 40 or 50 miles from the mountains, either eastward or westward. Michaux concludes that it is a stranger to all the Atlantic parts of the United States, to the distance of 100,150 , and 200 miles from the sea, the nature of the soil and extreme heat of the climate being utterly uncongenial to its growth. It may, however, be found in a highly flourishing condition at the seats of the Messieurs Dupont, on the banks of the Brandywine, and would doubtless grow anywhere in the vicinity of Philadetphia, especially on the banks of the Schuylkill, and perhaps still further north.

Another species of magnolia, which, in its general appearance and in the form of its fruit, very nearly resembles the preceding, has been confounded with it by the inhabitants of the regions in which it grows. Michaux calls it the heart-leaved cucumber tree (Magnolia cordata). He found it on the banks of the Savannah river in Upper Georgia, and also on the streams in the back parts of South Carolina, approaching within twelve miles of $\mathrm{Au}$ gusta. It grows to the height of forty or fifty feet, with a diameter of twelve or fiteen inches.
The bark is rough and deeply furrowed like that of the sweet gum and young white oak.

The flowers, which appear in April, are yellow, and nearly four inches in diameter. The succeeding cones are about three inches long and one inch thick, and with the seeds, resemble those of other magnolias. The beauty of its yellow flowers form an agreeable contrast with its luxuriant foliage, and, together with its capacity to resist intense cold, recommend it highly as an ornamental tree in northerly situations.

The long-leaved cucumber tree, (Magnolia auriculata) is also remarkable for the beauty of its foliage and for the size of its flowers, which possess an agreeable odour. Michaux states that it appears form his observations to be confined to that tract of the Alleghany Mountains which traverse the Southern States, at the distance of nearly 300 miles from the sea. Besides the popular name already given, it is also called Indian physic.

The growth of this is far below that of the first named tree, nor does it even attain the size of the heart-leaved species. Its limbs are widely spread and sparingly branched, which, when the tree is stripped of its leaves, give it a peculiar effect. The leaves are eight or nine inches long, and much larger on the youngest trees. They are broader at the top than towards the bottom, or base, which is divided in to rounded lobes, resembling the ears of some animals, whence the tree derives its specific name of auriculatc. The flowers are three or four inches in diameter, of a fine, white colour, of an agreeable odour, and situated at the extremity of the young shoots, which are of a purplish-red, dotted with white. 'The cones are oval, three or four inches long, and, like those of the umbrella tree, another species of magnolia, of a beautiful rose colour when ripe. Each cell contains one or two red seeds. The bark has an agreeable aromatic odour, and is infused in spirits as a popular remedy in rheumatic affections. Inasmuch as the virtues ascribed to this spirituous preparation are very doubtful, and the practice of using it fraughi with great danger, not only from misapplication at improper stages of disease, but from its tendency to form a vicious taste for ardent drinks, it had best be dispensed with, and other better and less mischievous remedies resorted to. The tree flourishes in Europe, where it is a popular ornamental tree. (Michaux.)

CUD. In cattle, the food in the first stomach, which is to be chewed over again and passed into the second to be digested. See Chewing The Cud.

CUDWEED, or EVERLASTING. A shrunby or herbaceous plant belonging to a genus (Gnaphalium) containing one hundred and twenty species, most of which are indigenous to the Cape of Good Hope. There are a few species in Europe, India, and in South as well as North America. 'The generic name is derived from a Greel word signifying soft down, or wool, with which the plants are clothed. The species known in the Middle States are the Purple Gnaphalium, a biennial growing in dry, open woodlands, \&c., to the height of six, twelve, or fifteen inches, producing dingy pur 
pissh flowers in July and August. The Miry, or Marsh Gnaphalium, or Marsh Cudweed, with an annual root, and stem four to six or eight inches high, bearing flowers in dense clusters, of a yellowish-tawny; growing in low grounds, dried-up pods, \&c. German Gnaphalium, or Common Cudweed, an annual root, producing a stem six to nine inches high: growing on dry hills, old fields, \&c., bearing flowers of a pale sawny, or straw-colour. Many-headed Gnaphalium, called Life Everlasting, with an annual root, and stem one to two feet high, growing in old fields and pastures, flowering in August and September, the blossoms being slender and of a yellowish colour. An infusion of this plant has enjoyed much reputation as a popular remedy for dysentery. Pearly Gnaphalium (G. margariticum), a very handsome species, with a perennial root, stem one to two feet high, and beautiful white flowers. Dioicons Gnaphilium, commonly called Mouse-ear Cudweed, with a perennial root, stem two or three to six inches high. The White Plantain, or Plantain-head Cudweed, is a variety of this last species. (See Flor. Cestric.)

CULIEY. The name of a distinguished family of farmers, to whom the agriculture of England is under very considerable obligations. Two brothers of the family, Matthew and George Culley, were seated originally on their paternal property of Denton, at Gainslord, near Darlington (now, 1841, in the possession of Mr. Matthew Culley), whence they migrated in June, 1767, to Fenton, in Glendale, county of Northumberland; and "on the 4th of August in that year, on my road to a fair at Kelso," says Mr. George Culley, in a letter to Arthur Young (Ann. of $A g r$. vol. xx. p. 162), "I first saw a field of drilled turnips." "They earried with them into Glendale," says Mr. John Grey (Journ. of Roy. Agr. Soc. vol. ii. p. 152), "superior knowledge and intelligence, which they at once brought to bear in their extensive undertakings with unremitting application and perseverance. That they were successful in their efforts is an undoubted fact. Thus on the farm of Wark, near Coldstream, which they entered in May, 1786, the crop was valued to them from the preceding tenant, and was estimated at 15 bushels per acre for oats, and 9 for wheat. But the crop on the same farm, after being in their occupation for fifteen years, was estimated at 84 bushels per acre for oats, 62 for wheat, and 72 for barley. (Ibid. p. 158.) The rent of this farm of 1200 acres in 1786 was $800 l$.; in 1812 it was $3200 l$. Mathew Culley died in 1805, in the $73 d$ year of his age, and George in 1814, aged 79, both in Glendale. The Culleys were the warm friends and correspondents of the celebrated Bakewell, of Dishley, from whose flock they introduced the breed of Leicester sheep, which is still a prevailing kind in Northumberland; and this breed is still preserved in a state of purity by the present owner of Denton, Mr. Matthew Culley, to whom I am indebted for several of the facts of this remoir. The attention which they paid to the improvement of their breed of live-stock was unremitting, and with a success which was equal to their labours They had the public mirit, too, not to conceal the improvements which they effected: they published one or two valuable works, and were not unfrequently corntributors to the agricultural periodicals of the day. 'Thus in the $A n n$. of $\mathcal{A} g r$. vol. xiv. p. 180 , there is a letter from Mr. George Culler in praise of the Dishley breed of sheep; and at p. 470 , on the wool, sheep, and corn of Nortnumberland; again on sheep, in vol. xvii.p. 347, and vol. xix.p.147; on turnips, vol. xx. p. 167.

In 1786, George Culley published a useful practical little book (Observations on Live Stork), which was reprinted in 1795 . Arthur Young describes its author (Ann. of $A g r$. vol. xxiii. p. 519 ), as "a man of the most extensive practice, and the deepest knowledge of his art." $\mathrm{He}$ also published, in conjunction with $\mathrm{Mr}$. Bailey, the agricultural reports of Northumberland, Cumberland, and Westmoreland, 1797 1805.

CUI.M. Among botanists, signifies straw or haulm; defined by Linnæus to be the proper stem of grasses, scitamineous plauts, and the like, which elevates the leaves, flower, and fruit. This sort of stem is tubular or hollow, and has frequently knots or joints, distributed at certain distances through its whole length.

CGLMIFEROUS PLAN'TS. Such as pro. duce culms, or have a smooth jointed stalk, and their seeds enveloped in chaffy husks, grass-like.

Culmiferous crops include wheat, barley, oats, rye, Indian corn, tobaceo, cotton, \&c., all of which have stems mostly jointed. They are all regarded as robbers and exhausters of the soil, some in a far greater degree than others. If cut green, or when in blossom, they are far less so than when allowed to mature their seeds.

CULTIVATOR. A name given to implements of the horse-hoc kind, invented for stirring the earth. The implements called cultivators are very extensively used in the United States, being found particularly serviceable in running between the rows of Indian corn, su. gar beets, and other root crops planted in drills or rows. They stir up and loosen the earth, and at the same time keep it free from weeds and grass. Their operation is somewhat between those of the plough and the harrow, and as they do not penetrate very deep, they leave below the manure and vegetable matter of the sod turned under by the plough, and at the same time do no injury to the roots of the plants under culture, unless these are ton far advanced in their growth. The cultivator should generally be run through a crop twice at a dressing, and if the soil be stiff or grassy, it may be passed oftener or renewed at short intervals. The implements most preferred in the United States bear a strong resemblance to the horse-. hoes of Europe. They are made with teeth of different forms, best adapted to the various purposes, of skimming the surface and destroying weeds, or for doing this and also breaking up and pulverizing the earth. The best kind of culcivators are those which are constructed so as to admit of being made wide or narrow, according to the width of the rows. They perform so much of the labour for which the noe and the plough were once resorted to, as to have greatly lessened the expenses of tillage in tie 
Indian corn crop, to say nothing of their great importance in the culture of root crops. Among implements of this kind in high repute in the United States, is Bement's Improved Cultivator and Horse-hoe, which not only admits of being widened and contracted at pleasure, but is so constructed as to be easily adapted to soils of different textures, being furnished with teeth or shares of various forms, suited to the nature of the soil to be operated on. An excellent cultivator, not protected by patent, is in general use among the Pennsylvania farmers near Philadelphia, where it can be procured at the agricultural implement stores for about $\$ 5$. See Grub ber and Scarimier.

CULTOR or COULTER. The strong sharpened bar of iron that is fixed in ploughs, for the purpose of cutting open the earth before the share. See Plovgr.

CUMIN SEED. The seed or fruit of the Cuminum cyminum, which is imported from Sicily and Malta. It has been occasionally grown in Englard, but as it does not produce its seeds until the second year, and requires a rich, and consequently high-rented soil, the double rent adds heavily to its culture. (Brit. Husb. vol. ii. p. 328.) Cumin is a plant of little beauty, and in a garden merely requires to be suwn in any open border to succeed.

CURCULIO (Curculionida). A name applied by naturalists to designate a family of beetles, distinguished from other insects of the same tribe by their shortness and thickness, and from each other by the length and direction of their snouts. The corn-weevil, so destructive to grain in the stack and garners, belongs to this family, together with the larvæ or maggots found so often in chestnuts, acorns, hickorynuts, and filberts; as well as unripe plums, apricots, peaches, and cherries.

The destruction of fruit occasioned annually by these species which bore into fruits and occasion them to fall from the tree before ripening, is so great as to make it a matter of great importance to acquire the most accurate knowledge in regard to the appearance and habits of these insects, as the only means by which their effects can be counteracted. Often in gardens and orchards, trees loaded with young plums lose the whole of their fruit from the depredations of grubs, which have been ascertained by naturalists to be the larva or young of a small beetle of the weevil tribe, called the Nenuphar, or plum-weevil, and still more commonly in the United States, the curculio. Dr. Harris states that he has found the beetles in Massachusetts as early as the 3'th of March, and as late as the 10th of June, and at various intermediate times, according to the advanced or retarded state of vegetation in the early part of the season. He has frequently caught them flying in the middle of the day.

"They are from three-twentieths to one-fifth of an inch long, exclusive of the curved snout, which is rather longer than the thorax, and is bent under the breast, between the forelegs, when at rest. Their colour is a dark brown, variegated with spots of white, ochre-yellow, and black. The thorax is uneven; the wingorover have several short ridges upon them, thore on the middle of the back forming two considerable humps, of a black colour, behind which there is a wide band of ochre-yellow and white. Each of the thighs has two little teeth on the under side. They begin to sting the plums as soon as the fruit is set, and, as some say, continue their operations till the first of August. After making a suitable puncture with their snouts, they lay one egg in each plum thus stung, and go over the fruit on the tree in this way till their store is exhausted; so that where these beetles abound, not a plum will escape being punctured. The irritation arising from these punctures, and from the gnawings of the grubs after they are hatched, causes the young fruit to become gummy, diseased, and finally to drop before it is ripe. Meanwhile the grub comes to its growth, and, immediately after the fruit falls, burrows into the ground. This may occur at various times between the middle of June and of August; and, in the space of a little more than three weeks afterwards, the insect completes its transformations, and comes out of the ground in the beetle form. 'The history of the insect thus far, is the result of Dr. Harris's own observations; the remainder rests on the testimony of other persons.

"In an account of the plum-weevil, by Dr. James Tilton of Wilmington, Delaware, published in Mease's 'Domestic Encyclopedia,' under the article Fruit, and since republished in the 'Georgical Papers for 1809,' of the Massachusetts Agricultural Society, and in other works, it is stated, that peaches, nectarines, apples, pears, quinces, and cherries, are also attacked by this insect, and that it remains in the earth in the form of a grub, during the winter, ready to be matured as a beetle, as the spring advances. These statements," says Dr. Harris, "I have not yet been able to confirm. It seems, however, to have been fully ascertained by Professor Peck, Mr. Say, and others, in whose accuracy full confidence may be placed, that this same weevil attacks all our common stone-fruits, such as plums, peaches, nectarines, apricots, and cherries; Dr. Burnett has recently assured me that he has seen this beetle puncturing apples; and it is not at all improbable that the transformations of some of the grubs may be retarded till the winter is passed, analogous cases being of frequent occurrence. Those that are sometimes found in apples must not be mistaken for the more common apple-worms, which are not the larræ of a weevil. The Rev. F. V. Melsheimer remarks in his Catalogue, that this insect lives under the bark of the peach tree. Professor Peck raised the same beetle from a grub found in the warty excrescence of a cherry tree, and from this circumstance named it Rhynchonus cerasi, the cherry-weevil. The plum, still more than the cherry tree, is subject to a disease of the small limbs, which shows itself in the form of large irregular warts, of a black colour, as if charred. Grubs, apparently the same as those that are found in plums, have often been detected in these warts, which are now generally supposed to be produced by the punctures of the beetles, and the residence of the grubs. Professor Peck says that "the seat of the disease is in the bark. The sap is diverted from 
its regular course, and is absorbed entirely by the bark, which is very much increased in thickness ; the cuticle bursts, the swelling becomes irregular, and is formed into black lumps, with a cracked, uneven, granulated surface. The wood, besides being deprived of its nutriment, is very much compressed, and the branch above the tumour perishes.' 'The grubs found by Professor Peck in the tumours of the cherry-tree, went into the ground on the sixth of July, and on the thirtieth of the same month, or twenty-four days from their leaving the bark, the perfect insects began to rise, and were soon ready to deposit their eggs in healthy branches. (See Professor Peck's account of Insects which affect $O$ ak and Cherry trees, with a plate; in the "Massachusetts' Agricultural Repository and Journal, vol. v. p. 312.) (Harris.)

In order to account for the occurrence of these insects both in the fruit and in the branches of the trees, Dr. Harris ventures the following explanation, although it rests only upon conjecture. The final transformation of the grubs, living in the fruit, appears to take place at various times during the latter part of summer and the beginning of autumn, when the weevil, finding no young fruit, is probably obliged to lay its eggs in the small branches. The larvæ or grubs from these eggs live in the branches during the winter, and are not perfected till near the last of the following June. Should the fall of the fruit occur late in the autumn, the developement of the beetles will be retarded till the next spring; and this I suppose to be the origin of the brood which stings the fruit. These suggestions seem to receive some confirmation from the known habits of the copper-coloured plum-weevils of Europe, which, "in default of plums, make use of the soft spring shoots of the plum and apricot trees." (Köllar's Trealise, p. 238.)

"It has been noticed, that trees situated in lanes and extensive yards, where numerous cattle are confined, generally escape the attacks of the curculio. This is supposed to be in part owing to the ground being trodden so hard as to render it difficult for the worm to enter the earth, and to the annoyance and fright to which this timid insect is subjected, by the cattle rubbing against the trees. The insects, according to Dr. Tilton, in such cases of fright, roll themselves into a little ball, and fall to the ground, where they become liable either to be trodden to death, or devoured by the farm-yard poultry as a delicious morsel. Poultry of all species have been recommended as very useful, from the multitudes of insects they devour, they being particularly fond of the beetle tribe.

"A case is mentioned by Dr. Tilton (see Dom. Encyc.), of Colonel T. Forest, of Germantown, who, having a fine plum tree near his pump, tied a rope from the tree to his pump handle, so that the tree was gently agitated every time there was nccasion to pump water. The consequence was, that the fruit on this tree was preserved in the greatest perfection.

" Hogs are stated to be extremely useful in orchards, by devouring at once the fallen fruit and the insect which it contains. And provided the hogs are sufficiently numerous to devour every fallen fruit, they will shortly exterminate the insects from the orchard in which they are permitted to roam.

"Paving the ground is said to be a most effect ual mode of preserving fruit from the attacks of the curculio. By preventing its descent into the earth, it finds no winter habitat,on. T'he ground should first be well manured, and the whole surface well paved with the common stones which so often encumber the fields. 'T'he trees, in this case, may be set very close. 'The excess of rain being carried off by the pavement, and their luxuriance being thus restrained, such trees must not only produce great crops, but from the effect of the sun on the naked pavement, the fruit must be of the finest quality.

"Another and ingenious mode of destroying the curculio has lately been devised by $\mathrm{Dr}$. Joel Burnet, of Southboro', Massachusetts, and in the single instance only, in which he has tried the experiment, it has proved completely successful. There stood in his garden a young plum tree of the prince's imperial gage, which was filled with blossoms every year, but bore no fruit. Early in spring, a hen. with an early brood of chickens, was placed in a coop beneath the tree. Thus were all the curculiones destroyed in the interval, soon after they arose from the earth, and before they had recovered strength sufficient to take to their wings or ascend the tree. This plum tree, in that year, bore, in consequence, a very large crop of fruit. He observed that the curculio often ascended by aid of its wings." (Kenrick's American Orchardist.)

'The wings of the curculio, plum, or cherryweevil are so small as to assist it in climbing, but not to enable it to fly to a distance. This explains the reason why trees standing so near each other as almost to interlace their branches will some escape, whilst others lose a:l their fruit.

Col. Forest's remedy may be partially applied by shaking the trees suddenly and briskly so as to produce a jar that will extend among the branches. This may be done morning and evening, and as much oftener as convenient, during the time when the weevils or beetles are engaged in stinging the fruit. Those which fall may be gathered in a sheet and thrown into the fire. All the fallen wormy plums should be immediately gathered and given to hogs, or, when this is not convenient, boiled or steamed, so as to kill the enclosed grubs. Diseased excrescences should be cut out and burned every year before the last of June. 'The moose-plum tree (Prunus Americana), Dr. Harris says, seems to escape the attacks of insects, since no warts are found upon it, even when growing in the immediate vicinity of diseased foreign trees. It would, therefore, he thinks, afford the best stocks for budding or engrafting upon. It can easily be raised from the stone, and grows rapidly, but does not attain a great size. This might secure the body of the tree, but it is evident that the branches, being of different wood. must be exposed to the attaclis of the weevil. See Mar Beetles, p. 173. (The 18th vol, of the "New England Farmer" contains a paper upon this insect, by Dr. Burnett, which may be read with advantage.) 
CURD. The c sagulum of milk, from which cheese is made. See Chess.

When milk sours, free acetic acid is formed, and by its action the coagulation of the caseous part of the milk takes place; rennet causes the same effect in milk which is not sour, which probably depends $n n$ the gastric fluid in the rennet. Curd is a white, insipid, inodorous substance, insoluble in water, but soluble in alkalies. By alcohol it is converted into a substance like spermaceti, which gives out a very fetid odour.

When dry curd procured from sour milk is well washed, and then mixed with its own bulk of alcohol, and the soluble matter filtered and separated from the insoluble, and thickened by gentle evaporation, it becomes viscid, and forms an excellent cement for glass and china.

CURING BEEF and PORK. See SALTING. A report of the committee for the premium offered for curing beef and pork, appears in the Trans. High. Soc. vol. v. p. 56.

CURRANT. The fruit of two species of Ribes, viz., $R$. mubrum, which furnishes the common red and white currants, and $R$. nigrum, which produces the black currant. There are five or six species of this indigenous plant. The rock currant ( $R$. petreum), the acid mountain currant ( $R$. spicatum), and the tasteless mountain currant ( $R$. alpinum), all grow wild in woods in the north of England; and the common red and black currants are also found wild in many parts of the country, but their fruit is insipid. The pale currant is a variety between the red and white.

The white, black, and red currant ripen their berries very early in July, in which month currant jelly should be made. All the currants may, by being matted, be preserved till the middle of winter, and on north walls and shaded situations sometimes hang, and are good till the end of November. They will thrive on almost any soil; but their fruit is more savoury when produced in a dry and open ground. They are very easily propagated by planting slips or cuttings at any time from September to March. After standing about two years, they will be fit to be removed to those places where they are intended to remain.

The currant, one of the most wholesome and grateful of fruits, has medicinal properties. Red currants are very conling in fevers. They quench thirst, and create appetite. When the fruit is not to be had fresh, red currant jelly, mixed in water, is equally refreshing. Black currants are useful in sorethroats. (Brande's Dict.; Phillip's Fruits; Willich's Dom. Encyc.; Eng. Flor, vol, i. p. 330.)

In addition to the varieties of gonseberries (Ribes uve crispa) and currants met with in gardens, seventeen or eighteen additional species are found in the United States. A black currant resembling those in gardens grows wild in Pennsylvania, whilst a red species on a trailing vine is found in the northern ccunties. See Goosenbrry.

ULRRANT-BUSH BORER. An insec: calerpillar belonging to the genus Egeria. See Daterpiliars.

CUSHAT. A local name for the ring-dove, 376 supposed to be derived from the Saxon cusceate, from cusc, chaste, in allusion to the conjugal fidelity of this bird.

CUSTOMS OF COUNTIES. With regard to the usual relation of landlord and tenant in England, these vary considerably. But in cases where there is a written agreement, no inquiry can be made as to the custom of the county (Liebenrood v. Vines, 1 Mer. 15); and when an express stipulation is made, the cus tom of the county is excluded entirely. (Ro berts v. Parker, 1 C. \& M. 808.) The follow ing epitome of usages in a few counties, chiefly abridged from the work of Kennedy and Grainger on the Tenancy of Land, must, of course, be regarded as having only a very general application.

Bedford.-The tenant commonly enters, in this county, at Michaelmas, some at Lady-day. Leases seven years. Rents paid half-yearly. Tenant generally restricted from breaking up pastures, or selling hay and straw, quitting at Michaelmas, is at liberty to plough and sow wheat, if at Lady-day; then may sow springgrain till day of quitting; but in either case has the option to do it himself or let his successor do it. When the outgoer sows, they are valued to the incomer so as to include all labour: has barn allowed him, but cannot carry away straw. Incomer takes all dung found on premises free of charge; but pays for grass-seeds, and that of the labour, and for fallow-ploughing, or spring-ploughing, which his predecessor, quitting at Lady-day, had not time to sow; but with respect to any fallow, either for wheat or turnips, when the outgoer takes the crop, there is no demand made upon the incoming tenant.

Berks.-Farms commonly lease for 7 or 14 years from Michaelmas, entering to plough fallows at Lady-day: from which time the incomer has part of the house allowed him, and room for one team; the outgoer retains the rest of the premises till May-day or Midsummer. The rents are commonly paid halfyearly, and in general there is no restraint upon the tenant's cultivation, except that he covenants to leave a stated number of acres for fallow. Usually he has power of selling hay and wheat straw, although in other portions of the county only to exchange it for dung. Wheat straw he must leave to his successor as well as the hay. Incomer has to pay for clover or other grass-seeds, the seed, and labour, and hay-crop, at a feeding-out price.

Carmarthen.-Farms were here formelly let upon leases for three lives; but terms of $\mathbf{1 4}$ years are now more common. The entry is made upon both house and land at Michaelmas. The tenant is under no restriction, cul. tivates as he pleases, and sells hay, straw, and dung.

Cheshire.-Farms let upon leases, but many only by the year, and this is a much more common practice than formerly. Tenant takes from Candlemas, but only gets possession of the house at May-day. The tenant is commonly restrained from having more than a given proportion of land, usually one-third, under plough. This portion, however, he may 


\section{CUSTOMS OF COUN'TIES.}

till in his own way; sometimes may dispose of his hay and straw, sometimes not. Outgoer ceases to work on the farm at Candlemas; but cuts the wheat crop at harvest; if the wheat was after a fallow he takes two-thirds of the crop, otherwise only one-half, and he houses his own portion. He is commonly not paid for grass-seeds, but where the custom varies, he cuts the clover or grass, and takes half the hay; the incomer taking the remainder, and paying the rent: he has no valuation to pay of any kind. The dung he does not pay for.

Cornwall.-Jeases generally from 14 to 21 years. The outgoing tenant leaves the dung for the incoming tenant.

A tenant is bound not to exceed two white crops without manure, using one hundred and one bushels of lime per acre for the first crop. When the land is sown with grass-seeds it must remain down for three years, and, except in water meadows, he can only cut his grass ance in the season, unless he dresses it with manure. He may sell hay, but the straw of wheat only; he is obliged also to feed a certain number of acres of grass, and whatever manure he makes must be left by the outgoing tenant free of charge.

Cumberlund.- Tenants enter at Isady-day into the farm, but not into the house till May-day. Leases commonly for three, seven, or nine years. The tenant commonly bound to plough the land in such proportions that a certain part may remain in grass for three years. Is prohibited from having two white crops in succession, and must leave as much land sown with grass-seeds as he found on the farm. Cannot sell hay or straw, and must apply not less than sixty bushels of lime per acre for his wheat or turnips after a fallow. The outgocr retains possession of the house and premises for cattle till May-day. Is paid for whatever crops he leaves which he himself paid for when he took the farm. Leaves all the straw and manure for the incomer's benefit.

Derby.-Tenants chiefly yearly tenants from Lady-day. The land almost entirely pasturage. The tenant is usually restricted from breaking these up without permission, even if he lays down arable land in lieu of it. $\mathrm{He}$ cannot sell either hay or straw. 'The outgoing tenant is not paid for either manure or straw ; he always sows the wheat, but is not paid for any fallows or ploughings which may have been done at his expense to promote the growth of it; he receives, however, two-thirds of the wheat if a fallow crop, or one-half if a brush crop, and for the seed crops he is allowed for seed and labour.

Devon.-In the west, entry at Michaelmas; in the east at Lady-day, with privilege of entry on the land at Midsummer to prepare for wheat. The tenant usually restrained from taking more than two white crops for a fallow, or sowing two wheat crops successively, without a fallow or green crop between them. Must use a certain quantity of lime per acre for his barley or wheat crop, and leave the same quantity of land for wheat at the expiration of his lease that he found on taking pos-

\section{CUSTOMS OF COUNTIES.}

session. He has the liberty of selling hay and wheat straw, and at the end of his lease the hay also. A Lady-day holder receives from his successor the value of the wheal upon the ground, and the young clovers or other grass seeds by valuation. A Micharel. mas tenant can only receive the value of the seeds; but in either case he freely leaves all the dung for his successor.

Essex.-The farmer in Essex commonly holds by leases of 7 or 14 years; entry at Michaelmas both of house and land. He usually covenants to farm on the four-shift system, dressing and fallowing after every third crop, and never to take two white crops in succession: on pasture land, however, he is commonly unrestrained. He may carry also hay or straw, but for every load of either he is bound to bring back a load of dung, and near London two loads are required for every load of straw, and one for every load of hay.

'The outgoing tenant sows the Michaelmas crop, and is paid by valuation for one year's improvement, which includes the labour, the seed, and the manure he has laid out upon the ground from the preceding Michaelmas. He is allowed for the seeds, for ploughing, harrowing, and rolling, which a summer fallow has undergone, for the manure laid on, and for the carting of it, and for all the unspread dung, or other manure on the farm. 'The outgoer has the use of the barns for his crop. The incomer claims the straw and chaff on condition of his thrashing the corn, and carrying it to market. The incomer has the Michaelmas crops, the hay, turnips, and young seeds valued to him, with all the seed, labour, and manure bestowed upon them.

Hertford.-Leases 7 or 14 years from I adyday. Mode of cultivation varies; somet:mes two crops and a fallow, in others, the four. course system. The tenant may sell hay and wheat straw, but no other straw. The outgoing tenant takes an offgoing crop of bolls spring and Michaelmas crops, and pays for the ground they stand upon till harvest. He must use, however, the last year's straw upon the premises, and he leaves all the dung for the incoming tenant.

Kent.-Much of the land of Kent, as in other counties, is held by the year, but a larger portion is rented under leases of 7 to 14 years: the tenant entering at Michaelmas.

The farmer is usually restrained from selling hay or straw; or, if he is allowed to dispose of them, it is on condition of his bringing on to the farm a certain quantity of dung. $\mathrm{He}$ is usually not much restricted in his mode of cultivation. He is commonly prevented from having more than two white crops to a fallow

The outgoing tenant thrashes his last crop and sells the straw to the incomer; and if he is obliged to feed the hay upon the premises, this is commonly valued also at a feeding out price. He is paid also for the labour bestowed upon the summer fallows, which he has the privilege of sowing up to the time of his quitting the farm; he is also paid for the seed and labour both for the turnips and the grasies: for the whole of the manure, and labour of carting and spreading the manure of the las 2 I 2 
year, and for half of the preceding. These, with the hop-poles, make the payments required of an incoming tenant rather heavy.

Leicester is chiefly farmed by yearly tenants, who enter at Lady-day, and occasionally at Michaelmas. They are not allowed to break up their pastures or sell either hay or straw. Sometimes they engage to lay an annual amount of lime on the land.

The outgoing tenant is paid for all clear fallows, for which he is allowed three ploughings; but if he has taken a green crop, he is allowed nothing. For his wheat crop-if it has been sown on a clear fallow, for instance-he is allowed for seed and labour, and for the ploughings, but otherwise only for seed and labour. $\mathrm{He}$ is allowed for his seed crop, labour, and seed; but nothing for a turnip fallow, either fed or pulled: if he leaves at Michaelmas, however, he is allowed for his turnips one year's rent. The incomer cannot enter to plough withou: permission till Lady-day.

Lincoln.-Farms commonly held by lease of from 7 to 14 years from Lady-day.

The tenant is usually restrained from selling either hay or straw, or from taking more than two white crops to a fallow. These restrictions, however, do not apply to the fen land.

The outgoing tenant has commonly the right of sowing spring-grain until Lady-day, and of taking an off-going crop, both of wheat and other corn, all of which, however, he must thrash on the premises. But a very common way is for the outgoer to be paid for all his crops, the value of seed and labour, and also for the manure. The crops are valued at harvest-time, and the price is set according to the average of three market-days, taken once a month, between harvest-time and the ensuing Lady-day.

Norfolk.-Farmers hold chiefly by leases of 7 or 14.years, some for 21, and they enter at Michaelmas. They generally covenant to farm on the four-course system, are often restrained from sowing above a certain number of tares and oats. This crop being considered to be much more impoverishing to the land than barley, he is not allowed to sell either hay or straw. The outgoing tenant either thrashes his harvest himself, or he agrees with his successor, who carries out the grain and keeps the straw and chaff; the incomer pays for the growing crops on the ground, but not for the labour; thus, if the turnip crop fails, he receives nothing for the labour.

'The incomer sows the wheat crop, but he cannot enter the farm before Michaelmas-day; to do this without leave, he has to pay for the hay on the farm; but he takes the dung free.

Nottingham is cultivated chiefly by yearly senants, who enter at Lady-day. They are commonly not allowed to sell either hay or straw, not to take more than three crops to a fallow, and never two white ones in succession. When the incomer enters at Michaelmas, the outgoer is prid by valuation, either upon wheat or turnips, for all the seed and labour he has bestowed upon that crop, and for all the f-oughing he has done before the time lie quits; for all artificial manure, such as bones, \&c., if for the first crop, then the full 378 tillage; if the secord, only half a tillage, and so on; but for dung in or on the land he is allowed nothing; but if he enters at Lady-day, then he is paid for both, for seed and for labour.

Salop.-Farms are generally held by yearly tenants, who enter at Lady-day; but on to the meadow land, in some places, at Candlernas, that he may water or manure. He is restrained from selling hay or straw, but not to any particular mode of cultivation. When he quits, he is allowed for any lime he may have brought on to the land within the last two years; the whole value for that of the last year, half the value for that of the preceding: he receives two-thirds of the value of the wheat crop, the value of the seed crops, but nothing for either fallows or dung. He cannot plough for fallows or spring crops without the authority of the incomer, who cannot enter himself to plough without leave before Lady-day.

Somerset.-Farmers have usually leases of 8 or 12 years from Lady-day, the outgoer retaining the wheat crop, thrashing it on the premises, and leaving the straw, chaff, and dung for the incomer; and for this purpose he commonly holds on till the Midsummer twelvemonth after he quits possession. A tenant cannot sell either hay or straw, or take more than two white crops and a green one without a fallow. $\mathrm{He}$ is restrained from breaking up pastures, and he very commonly consents to spend annually a certain sum in lime or some other kind of manure. The incoming tenant sows the spring corn, but he cannot enter before Lady-day without leave from the outgoer.

Stafford.-The farmers in this county usually hold from year to year. The tenant is commonly restrained from selling either hay or straw, and there are very few restrictions of any kind as to the mode of cultivation. The outgoing tenant is usually paid for all the dung he leaves upon the farm, and for all clear sum. mer fallows, but nothing for bastard fallows, even if the seeds or turnips are fed off. For all the wheat on a clean fallow, sown previously to his notice to quit, he receives two-thirds of the crop; if a brush crop, only one-half; but for all he sows after notice, only the value of the seed and labour. The incomer cannot enter to plough before Lady-day: he pays for both the dung and straw left on the farm.

Westmoreland.-Leases in this county ate commonly granted for $7,9,-11$, or 21 years from Lady-day. 'The house, and one field, however, is usually retained till May-tay: he has the privilege, however, of going upon the land at old Candlemas to plough for his fallow and spring crop.

'The tenant is commonly restricted from having more than two white crops before he sows the land with seed, and that between the two white crops he is to have either a green one or a fallow. He is to manure his meadow ground once in three years, and leave the farm in the same working plight as he found it. The nutgoer retains the house and one field till May-day, paying rent and taxes, however, for what he thus holds; with this exception, he is bound to fiee the land by the 6 th of April. In the south of this county, the outgoer receives for the wheat crop on the ground, two-thirds it 
fallowed for, and one-half after a bastard fallow. He pays for this, however, no rent after the 6th of April. He may plough for barley and take half the crop, but not for any other spring crop.

Yorkshire.-In this great county, the customs vary with the Riding. In the $\mathbf{W} . R$. the entry is Old Candlemas, or New Year's day. In the N. R. it is Isady-day: may go on to the land at Candlemas, and into the house at May-day. In the E. R. the entry is at Lady-day. In all three Ridings a yearly tenancy is the most common.

In the $\mathbf{N}$. R. the outgoing tenant sows his wheat, and has an offgoing crop, which he may either thrash himself, or sell to his successor or to a stranger; but he cannot carry away straw, but has barn and yard room to consume it on the premises until the following May-day twelvemonth.

The outgoer, however, cannot in the last year of his tenancy sow more than one-third of his arable land; but that third he may sow at whatever time and in whatever way he may think proper; for all the ground that he sows he pays a corn standage, that is, rent, till harvest time: if he sows more than his proportion, the incomer takes the crop, and the measurement is very nicely calculated. The incomer enters at Candlemas to plough for his spring crop and fallows: he takes the young seeds. In the upper part of the West Riding, the customs between the incomer and outgoer are the same as in the north; but below $\Lambda$ berford the customs are quite different, being, as the people say, "good ones to come out with, but bad ones to enter upon." For there the oulgoer sows the wheat crop, which the incomer is obliged to pay for, together with the grass-seeds, and tc pay for the tillage and half tillage of those crops and on the turnips, and for all the manure laid upon the lands, or about the premises; the incomer who enters at Canalemas has two and a half year's manure, and une and a half year's tillage to pay for. In the East Riding, the outgoer sows the wheat crop and the spring corn, until Lady-day, and takes what he sows as an offgoing crop along with the wheat, paying no rent after Lady-day: he must thrash them, however, on the premises, and leave the manure. An incomer has here only to pay for seeds. (Kennedy and Grainger on Tenancy of Land.) See Appraisement.

CUT. In farriery, a hurt or clean wound made with any sharp-cutting instrument. The way of treating such an accident is to bring the two incised surfaces together, and bind them up, if possible, with a little lint or tow, without any balsams or spirituous applications being used.

CUT-WORM. In almost every section of the United States, great complaints are annually made of green crops destroyed or injured, more or less, by what is popularly termed the cut-worm. The young Indian corn is an especial sufferer; but several other plants having tender stems, such as beans and cabbages, are liable to be cut off near the ground, or just beneath the surface, when beginning to grow. As all such mischief is ascribed to the cut-worm, it might be inferred that an insect thus spoken of in the singular number would be well known. And yet the opinions urion the sub:ject of its identity, or how many species there may exist, are various and conflicting. After a toilsome search through many of the $\Lambda$ merican agricultural publications, Dr. Harris says he became convinced that these insects and their history are not yet well known to some of the very persons who have suffered from their depredations. Various cut-worms, or more properly subterranean caterpillars, wire-worms, or Iuli, grub-worms or the young of May-beelles, and even spindle or bud-worms, or the young of a species of moth called corn Gorlyna, are often confounded together or mistaken for each other; sometimes their names are intercharged, and sometimes the same name is given to each and all of these different animals. Hence, the remedies that are successful in some instances are entirely useless in others. "The name of cut-worm," says Dr. Harris, "seems originally to have been given to certain caterpillars that live in the ground about the roots of plants, but come up in the night, and cut off and devour the tender stems and lower leaves of young cabbages, beans, corn, and other herbaceous plants. These subterranean caterpillars are finally transformed to moths belonging to a group which may be called agrotidians (Agrotidide), from a word signifying rustic, or pertaining to the fields. Some of these rustic moths fly by day, and may be found in the fields, especially in the autumn, sucking the honey of flowers; others are on the wing only at night, and during the day lie concealed in chinks of walls and other dark places. Their wings are nearly horizontal when closed, the upper pair completely covering the lower wings, and often overlappirg a little on their inner edges, thus favouring these insects in their attempts to obtain shelter and conceal. ment. The thorax is slightly convex, bul smooth or not crested. The antennæ of tho males are generally beset with two rows of short points, like fine teeth, on the under-side, nearly to the tips. The fore-legs are often quite spiny. Most of these moths come forth in July and August, and soon afterwards lay their eggs in the ground, in ploughed fields, gardens, and meadows. In Europe it is found that the eggs are hatched early in the autumn, at which time the little subterranean caterpil lars live chiefly on the roots and tender sprouts of herbaceous plants. On the approach of winter they descend deeper into the ground, and, curling themselves up, remain in a torpid state till the following spring, when they ascend towards the surface, and renew their devastations. The caterpillars of the $A$ grotidians are smooth, shining, naked, and dark-coloured, with longitudinal pale and blackish stripes, and a few black dots on each ring; some of them also have a shining, horny, black spot on the top of the first ring. They are of a cylindrical form, tapering a little at each end, rather thick in proportion to their length, and are provided with sixteen legs. They are changed to chrysalids in the ground, without previously making silken cocoons. The most destructive kinds in Europe are the caterpillar's of the corn rustic or winter dart-moth (Agrotis segetum) the 
wheat dart-moth (Agrotis tritici), the eagle-moth (.Agrulis uquilina), and the turf rustic or antlermoth (Charcas graminis). 'The first two attack both the roots and leaves of winter wheat; the second also destroys buckwheat; and it is stated that sixty bushels of mould, taken from a field where they prevailed, contained twentythree bushels of the caterpillars; those of the sagle-moth occasionally prove very destructive in vineyards; and the caterpillars of the antler-moth are notorious for their devastations in meadows, and particularly in mountain pastures.

"The habits of our cut-worms appear to be exactly the same as those of the European Agrotidians. It is chiefly during the months of June and July that they are found to be most destructive. Whole corn-fields are sometimes laid waste by them. Cabbage-plants, till they are grown to a considerable size, are very apt to be cut off and destroyed by them. Potatovines, beans, beets, and various other culinary plants suffer in the same way. The products of our flower-gardens are not spared; asters, balsams, pinks, and many other kinds of flowers are often shorn of their leaves and of their central buds, by these concealed spoilers. Several years ago I procured a considerable number of cut-worms in the months of June and July. Some of them were dug up among cabbage-plants, some from potato-hills, and others from the corn-fields and the flower-garden. Though varying in length from one inch and a quarter to two inches, they were fully grown, and buried themselves immediately in the earth with which they were supplied. They were all thick, greasy-looking caterpillars, of a dark ashen gray colour; but I neglected at first to examine them carefully in order to see if they were marked exactly alike. Some of the last found were observed to have one or two blackish stripes on each side of the body, and a pale stripe on the back, with four little black dots on each ring. The head was also blackish. They were soon changed to chrysalids, of a shining mahogany-brown colour; and between the 20th of July and the 15th of August they came out of the ground in the moth state. Much to my surprise, however, these cut-worms produced five different species of moths; and, when it was too late, I regretted that they had not been more carefully examined, and compared together before their transformation."

The largest of these moths expanded its wings more than two inches, and bore a close resemblance to one called in Europe the dark sword rustic (Agrotis suffusa). Dr. Harris named the American moth the lance rustic, (Agrotis telifera), and gives the following description of it.

"The fore-wings are light brown, shaded with aark brown along the outer thick edge, and in th 3 middle also in the female; these wings are divided into three nearly equal parts by two transverse bands, each composed of two wavy dark brown lines: in the middle space are situated the two orainary spots, together with a third oval spot, which touches the anterior band; these spots are encircled with dark brown, and the kidney-spot bears a dark brown 380 lance-shaped mark on its hinder part; the hindmost third of the wing is crossed by a broad pale band, and is ornamented by a nar. row wavy or festooned line, and several small blackish spots near the margin. The hindwings are pearly white, and semi-transparent, shaded behind, and veined with dusky brown. The thorax is brown or gray-brown, with the edge of the collar blackish. The abdomen is gray. The wings expand two inches or more." (Harris's Treatise on Insects.)

' 1 wo other species resemble the one just described, and are counterparts of European species. The fourth is the smallest of the five, expanding its wings an inch and a quarter. The fore-wings are dark ash-coloured, exhibiting very faint traces of the transverse wavy lines or bands more or less distinctly visible on the other species. The two ordinary spots are large and pale, and alternate, with a triangular and a square deep black spot. The hindwings are brownish-gray in the middle, and blackish behind. Dr. Harris calls this last the checkered rustic (Agrotis tesselata).

The fifth species answered very well to the description of the American cabbage cul-worm, described by Mr. J. P. Brace, in the first volume of Silliman's "American Journal of Science," and somewhat resembles Dr. Boisduval's figures of a European moth called Agrotis latens. The fore-wings are of a dark ashen colour, with a lustre like satin; they are crossed by four narrow, wavy whitish bands, edged on each side with black. There is a transverse row of white dots, followed by a row of black, arrow-shaped spots, between the third and fourth bands, and three white dots on the outer edge near the tip; the ordinary spots are edged with black and white. The hind-wings are light brownish-gray, almost of a dirty white in the middle. The head and thorax are chinchilli-gray, and the abdomen is coloured like the hind-wings. The wings expand from one inch and five-eighths to one inch and three-quarters. This kind of moth is very common between the 10th of July and the middle of August. Like all the foregoing species, it flies only at night. According to Mr. Brace, this moth lays its eggs in the beginning of autumn, at the roots of trees, and near the ground; the eggs are hatched early in May; the cut-worms continue their depredations about four weeks, then cast their skin and become pupre or chrysalids in the earth, a few inches below the surface of the grount; the pupa state lasts four weeks, and the moth comes out about the middle of July; it conceals itself in the crevices of buildings and beneath the bark of trees, and is never seen during the day; about sunset it leaves its hiding-place, is constantly on the wing, is very troublesome about the candles in houses, flies rapidly, and is not easily taken. From what is known respecting the history of the other kinds of Agrotis, and from the size that the cabbage cut-worms are found to have attained in May, I am led to infer that they must generally be hatched in the previous autumn, and that, after feeding a while on such food as they can find immediately under the surface of the soil, they descend deeper into the ground and 
remain curled up, in little cavities which each one makes for itself in the earth, till the following spring."

Such are the descriptions given by the naturalists of the cut-worms and their moths found in the Eastern States. We wish it was in our power to furnish as much accurate information upon the subject of the cut-worms found in the other portions of the United States, provided any essential differences exist. The deficiency, so far as a portion of the Middle States is interested, has been supplied in a great measure through the researches of Dr.F.E. Melsheimer, of York county, Pennsylvania, who, in a communication made to Dr. Harris, gives the following information.

"There are several species of Agrotis, the larvæ of which are injurious to culinary plants; but the chief culprit with us is the same as that which is destructive to young maize. The corn cut-worms make their appearance in great numbers at irregular periods, and confine themselves in their devastations to no particular vegetables, all that are succulent being relished by these indiscriminate devourers; but, if their choice is not limited, they prefer maize plants, when not more than a few inches above the earth, early-sown buckwheat, young pumpkin-plants, young beans, cabbage-plants, and many other field and garden vegetables." "When first disclosed from the eggs they subsist on the various grasses. They descend in the ground on the approach of severe frosts, and reappear in the spring about half-grown. They seek their food in the night or in cloudy weather, and retire before sunrise into the ground, or beneath stones or any substance which can shelter them from the rays of the sun; here they remain coiled up during the day, except while devouring the food which they generally drag into their places of concealment. Their transformation to pupæ occurs at different periods, sometimes earlier sometimes later, according to the forwardness of the season, but usually not much later than the middle of July." "The moths, as well as the larvæ, vary much in the depth of their colour, from a pale ash to a deep or obscure brown. The ordinary spots of the upper wings of the moth are always connected by a blackish line; where the colour is of the deepest shade these spots are scarcely visible, but when the colour is lighter they are very obvious." This moth, Dr. Harris informs us, is very abundant in the New England States, from the middle of June till the middle or end of August. The forewings are generally of a dark ash-colour, with only a very faint trace of the double transverse wavy bands that are found in most species of Agrotis. These expand one inch and threequarters. When shut they overlap and cover the back so flatly and closely as to allow the moth to creep into very narrow chinks and crevices. During the day they lie hidden under the bark of trees, in the chinks of fences, and even under the loose clapboards of buildings. When the blinds of houses are opened in the morning, a little swarm of these insects which, on the arrival of day, had crept behind them for concealment, is sometimes exposed, and suddenly roused from their beginning slumbers.
This kind of moth, Dr. Harris spys, has the form and general appearance of sorne species of the genus Porophila. IIe has niamed it the clandestine owlel-moth.

The fact of the identity established by naturalists between this moth as found in New England and Pennsylvania, affords strong reason to infer that the same species of cul. worms are to be met with over most, if not all, portions of the United States.

Having thus described these insects under their various forms of destructive larvæ or caterpillars, winged moths into which these are converted, and mentioned their times and seasons of coming, going, and changing, so far at least as naturalists have traced these out,- - we shall proceed to notice the remedies which have been tried and proposed to destroy them, or prevent their ravages.

Among the various means resorted to for the protection of Indian corn and other plants, is the soaking of the seed in copperas or other poisonous solution previons to planting or sowing. Rolling the seed in quick-lime, or unleached ashes, has also been recommended. Any one of these remedies may have some effect in protecting the seed against wire-worms (Iuli) which only attack the grain or its root, but cannot answer against cut-worms which do not eat the seed or root, but prey upon the sprouts and young stalks.* They may, however, as Dr. Harris observes, be of some benefit by stimulating the young plant and pro. moting its more rapid growth, by which it will be sooner placed beyond danger from the attacks of cut-worms. Fall-ploughing of swardlands, which are intended to be sown with wheat or planted with corn the follc wing year, will turn up and expose the insects to the inclemency of the winter, whereby many of them will be killed. Some will be destroyed at the time by birds. This remedy, however, may be objectionable in stiff clay soils, which would become very much packed or baked during the winter.

Among other remedies, one proposed by Mr. Park Shee of Delaware county, Pennsylvania, is said to be a simple and expeditious mode of destroying cut-worms. A pair of old wheels are to be fitted with projections like the cogs of a spur-wheel in a mill, which must be so formed as to make holes in the earth during the turning of the wheel, four inches deep. The smooth track which the wheels make on the soft ground, induces the worm in its nocturnal wanderings, to follow on till it tumbles into the pit. It cannot climb out, and is destroyed by the hot sun.

The only effectual remedy at present known, Dr. Harris thinks, consists in turning a suffcient force into the fields infested, to scratch. up and destroy the worms by hand. This may require several days, but will generally be successtul in securing the crop, when replanting is performed at the same time. Estimares of the cost of labour and time thus expended,

* In regard to wire-worms, care must be taken not confound the American insects with those bearing a similar name in England. See SPBING-BEsTLEs, undet the head of BEETLE, p. 174. 
show that the farmer is a great gainer by the cutlay.

Mr. Deane once prevented the depredations of cut-worms in his garden by manuring the soil with sea-mud. The plants generally escaped, although every one was cut off in a spot of ground contiguous. He acknowledges, however, that the most effectual remedy, even in field culture, is to go round every morning and open the earth at the foot of the plant, where, if present, the worm will be found at he root, within four inches of the surface. Mr. Preston of Stockport, Pennsylvania, protected his cabbage-plants by wrapping a hickory or walnut leaf around the stem between the root and leaves before planting. A piece of rag would answer equally well; but care must be taken to remove any such bandage when the plant has attained a size to resist the attacks of worms. Paper has been successfully used for this purpose by Mr. Fiske of Massashusetts.

Salt is known to be highly obnoxious to naked worms and caterpillars. Some farmers have found great protection from the depredations of these by mixing salt with the manure put upon the ground as mentioned by Mr. Colman in his "Third Report," where, however, no definite proportion is stated. Some Pennsylvania farmers place the greatest reliance in a mixture of equal parts of salt, ashes, and plaster of Paris, about a gill of which mixture is applied on each corn hill. The experiment has been tried on allernate rows which were exempt from the attacks of worms, whilst the rows to which no application was made suffered greatly. The plaster might probably be dispensed with.

Dr. Harris describes another naked caterpillar which is often found to be injurious to cabbages, cauliflowers, spinach, beets, and other garden vegetables with succulent leaves. It does not conceal itself in the ground, but lives exposed on the leaves of the plants which it devours. It is of a light yellow colour, with three, broad, longitudinal, yellow stripes, one on each side, and the third on the top of the back; and the head and feet are tawny. Dr. Melsheimer calls it the zebra-caterpillar, on account of its stripes. It comes to its full size in Massachusetts in September, and then measures about two inches in length. Early in October it leaves off eating, goes into the ground, changes to a shining brown chrysalis, and is transformed to a moth about the first of June. It is probable that there are two broods of this kind of caterpillar every summer, in some, if not all, parts of this country; for Dr. Melshcimer says that it appears in Pennsylvania in June, goes into the ground and is changed to a chrysalis towards the end of June or the beginning of July, and comes forth in the moth state near the end of August. The moth may be called Mamestra picta, the painted Mamestra, in allusion both to the beautiful tints of the caterpillar. and to the softly blended shades of dark and light brown with which the forewings of the moth are coloured. It is of a light brown colour, shaded with purple brown; the ordinary spots on the fore-wings, with a :hird oval snet behind the round one, are edged 382 with gray; and there is a transverse zigzag gray line, forming a distinct $W$ in the middle, near the outer hind margin. The hind-wings are white, and faintly edged with brown around the tip. It is evident that this insect cannot be included in either of the foregoing groups of the owlet-moths. It belongs to a distinct family, which may be called Mamestrada, or Mamestrians. The caterpillars in this group are generally distinguished by their bright co. lours; they live more or less exposed on the leaves of plants, and transform in the ground. The moths fly by night only; most of them have the thorax slightly crested; and they are easily known by the zigzag line, near the outer hind margin of the fore-wings, forming a $W$ or $M$ in the middle.

As the caterpillar of the painted Mamestra does not seek concealment, it may easily be found, and destroyed by hand." (Harris.) See Grues, Wire-Worms, Spindle or Bud Worms.

CUTTING. When a horse cuts or wounds one leg with the opposite foot. The best remedy is to put on the cutting foot a shoe of even thickness from heel to toe, not projecting in the slightest degree beyond the crusp, and the crusp itself to be rasped a little at the quarters. This shoe should only have one nail on the inside, and that almost close to the toe. (Lib. Useful Know., Тне Horse, pp. 252. 341.)

\section{CYDER. See Cidir.}

CYNOSURUS. The dog's tail grass, from xucov, a dog, and cupx, a tail. There are three commonly known varieties of this grass in England, and two in the United States. One of which was found by Mr. Nuttall in the plains of Missouri. Very little value is attached to this grass by the American farmer.

Cynosurus cristatus. Crested dog's tail grass. Pl.6, $f$. This is an excellent sheep grass. Sinclair found the produce per acre, from a brown loam with manure, at the time of flowering, to be 6125 lbs., containing nutritive matter 406 lbs. He says of it, "In all the most celebrated pastures, which I have examined, it constituted a very considerable portion of the produce."

Cynosurus crucaformis. Linear-spiked dog's tail grass, flourishes best on a rich deep loam; next best on a clayey loam; in which soil Sinclair obtained of this grass, when in flower, 6806 lbs. per acre, containing nutritive matter $365 \mathrm{lbs}$.

Cynosurus echinatus. Rough dog's tail grass. It is a scarce, and an inferior grass. When in bloom, it yielded Sinclair per acre from a sandy loam 5445 lbs., containing of nutritive matter 191 lbs. (Paxton's Eot. Dict.; Sinclair's Hort. Gram. Wob.)

CYPERUS (Cyprus-grass). This is a natural order, embracing some of the sedge tribe somewhat allied to grasses. The stems are either solid or filled with a spongy pith-like substance, generally without joints, or nodes, tapering, cylindric, or angular (often triangular), and the sheaths of the leaves which embrace the stem are not slit, but entire. The roots of some species of cyperusses possess an aromatic odour, especially those of the $C$. longus. A few others produce tubers said to 
be esculent. From the integuments of the $C$. papyrus of Egypt, the ancients first obtained a convenient substitute for skins to write upon, and the paper since invented still retains the name of paper, derived from Papyrus.

Although the genus Cyperus appears to be widely dispersed over the world, North America and the West Indies possess far the largest proportion. About twenty-five or thirty species are found in the United States. (Nuttall's Genera.)

CYPERUS-GRASS, MILLET (Scirpus sylvaticus). 'The wood clubrush. See Scinpus.

CYPERUS, SWEET, or ENGLISH GAIINGALE (Cyperus longus). This is a wild perennial plant, growing, but not common, in marshes and moist places, two or three feet high. Its stalk is green and lcafless, except two or three small leaves at the top from which the tufts of flowers rise. The root leaves are a foot long, narrow, grassy, and bright green. The flowers are brown. The root is long, moderately creeping, highly aromatic, and astringent. There is a smaller species, the brown cyperus (C. fuscus), which is an annual, and grows much smaller, not reaching to above six inches high; root of many simple fibres. (Smith's Eng. Flor. vol. i. p. 53.)

CYPRESS TREE (Cupressus sempervirens). A hardy shrub, native of the Levant; growing from fifteen to twenty feet high, which throws out yellow blossoms in May. Its wood is red, very hard, and sweet-scented. It likes a good soil. It is the symbol of sorrow all over Europe, in the East, and even in China. Its wood, from being sonorous, is used for harps, violins, and other musical instruments. Worms never attack it. (Phillip's Shrub. vol. ¿. p. 188; M'Culloch's Com. Dict.)

CY PRESSES. 'The researches of botanists, says Michaux, have made us acquainted with only seven species of cypresses, of which two are indigenous to the United States, namely, the Cypressus disticha, called, in the Southern and Middle States, Bald Cypress, Black Cypress, and White Cypress, the last popular names being applied in the Carolinas. The second species of American cedar is called by botanists, Cupressus thyoides, and popularly the White Cedar. Both are highly important trees, for the many useful purposes to which their wood is applied.

Michaux says of the black or bald cypress, that the banks of Indian river in the southern part of the state of Delaware may be assumed as its northern limit. In proceeding southward from this point it becomes constantly more abundant in swamps; but in Maryland and Virginia is confined to the vicinity of the sea, where the winter is milder. Beyond Norfolk, its limits correspond exactly with those of the Pine Barrens, and in the Carolinas and Georgia it occupies a great part of the swamps which border the rivers after they have passed from among the mountains and entered the low lands.

The Mississippi from its mouth to the river Arkansas, a distance of more than six hundred miles, following the windings, is bordered bv marshes, which, at the annual overflowing of this mighty stream, form a vast expanse of waters. In Louisiana, those parts of the marshes where the cypress grows almost alone are called Cypriéres, cypress swamps, and they sometimes occupy thousands of acres.

In the deep, miry soil of the swamps in the Southern States, the bald cypress attains its utmost developement, rising sometimes to the height of one hundred and twenty feet, with a circumference of twenty-five and even forty feet, at the conical base, which, at the surface of the earth, is always three or four times as large as the continued diameter of the trunk On this account, in felling them the negroes are obliged to raise themselves upon scaffolds five or six feet above the ground. The base is generally hollow for three-quarters of its bulk. The summit is not pyramidal like that of spruces, but is widely spread ar id even depressed or drooping upon old tree: The foliage is open, light, and of a fresh aln agreeable tint, the leaflets being small and fine. In autumn they change from a light green to a dull red, and are shed soon after. Boiled during three hours in water, they afford a fine, durable cinnamon colour. 'To bunches of very minute flowers, succeed cones about the size of the thumb, roundish and uneven on the surface, filled with irregular seeds containing cylindrical kernels. The seeds retain their productive virtue for two years.

The stocks which grow in places where for half the year they are surrounded with three or four feet of water, have the bark lighter coloured than trees not so much exposed to water. Hence they are called White Cypresses, whilst those less exposed to water, and having browner bark, and heavier, more resinous, and darker wood, are named Black Cypresses. When destined to be employed in the arts, both kinds should be felled in winter, and kept a sufficient length of time for the wood to become perfectly dry. The wood of the cypress is far more durable than that of the pine, and is especially useful for making shingles to cover buildings of all kinds. Cedar rails for post and railfences are also in great demand in every portiun of the Middle States where the oak and chestnut trees have become scarce. A large trade in cedar shingles is carried on between the southern parts of Norfolk, Wilmington, \& , with the West Indies.

It would be unavailing, says Michaux, to $r$. commend the preservation and multiplication of the cypress in the maritime districts of the Carolinas and Georgia, though for an extent of more than nine hundred miles they have neither stone nor slate for building; it becomes daily more profitable for the increasing popu lation to convert the marshes into rice-ground: which afford a sure subsistence to the inhabit ants and swell the mass of exported produce Instead of wood, the houses will be constructerl of brick, which is already beginning to bis done, and covered with slate imported from the Northern States or from Europe. It is highly probable that in less than two centuries, the cypress will disappear from the Southern States.

The White Cedar (Cypressus thyoia'es) is or.e 
of the most interesting trees in the United States for the varied utility of its wood. It grows only in wet grounds. In New Jersey, Maryland, and Virginia, it nearly fills the extensive marshes which lie adjacent to the salt meadows, and are exposed in high tides to be overflown by the sea. Farther south, it is mingled with the cypress, by which it is at length entirely supplanted. The white cedar is not to be mistaken for the white cypress, a variety of the bald cypress. In lower Jersey and Maryland, the swamps in which the white cedar grows, are only accessible during the dryest periods of summer, and whilst frozen in winter. The trees stand so thick in these swamps that the light can hardly penetrate the foliage. The white cedar grows seventy or eighty feet high, and rarely more than three feet in diameter, unless perhaps in the Great Dismai Swamp, near Norfolk, where it flourishes in company with the bald or black cypress. When the white cedars are close and compressed, the straight and perpendicular trunks are free from branches to the height of fifty or sixty feet. They are observed to choose the centre of the swamps, and the cypresses the outside.

The foliage is evergreen, each leaf consisting of a little branch numerously subdivided, and the flowers, which are scarcely visible, produce very small rough cones of a greenish tint, which changes to bluish towards the fall, when they open to release the fine seeds.

The wood is light, soft, fine-grained, and -asily worked. When perfectly seasoned and exposed some time to the light, it is of a rosy hue. It preserves its aromatic odour for a very long time, when kept dry, and resists the destructive tendencies of alternate moisture and dryness longer than any other wood, for which quality shingles made of it are preferred in Baltimore and Philadelphia to those of the bald cypress. In the first named city they are generally called juniper shingles. 'They will last on a roof for thirty or thirty-five years. The great domestic consumption and exportation has raised the price of cypress shingles from four and five dollars per thousand in 1808 , to thirty or forty dollars per thousand in 1842. Swamps producing white cedar, so useful for fence timber and other important purposes, constitute a valuable species of property. (Michaux.)

\section{D}

DACTYLIS. A genus of grasses which, with one exception, are of but little value for cultivation. See Cock's-Foot Grass.

DAIRY. The place where milk is kept, and butter and cheese prepared and preserved. The proper construction and management of a dairy are questions of considerable importance to the farmer. It should be situated, if possible, on a dry porous soil. The room should be made of brick or stone, with a floor of the same matcrials, for the sake of its being more readily and frequently washed with cold water not only on the score of cleanliness, but .hat the remperature of the place may in sum- mer be kept down to the most advantageous degree. And to this end, the dairy is com. monly placed on the northern side of the house, where it may be readily shaded from the sun by other more elevated buildings, or by trees. A temperature between $50^{\circ}$ and $60^{\circ}$ is the best, and the less occasion there is to reduce the temperature of the dairy by wash. ing the floor with cold water the better, since, amongst other disadvantages, the damp air thus produced is not so advantageous as a dry atmosphere for the retention of sweetness in milk and cream, and, therefore, the dairyhouse in England is generally covered with thatch, and can hardly be too well ventilated. It should be far removed from stagnant ponds and offensive drains; and furnished with wire gauze windows, by which insects are readily excluded without impairing the necessary ventilation. Adjoining to it should be placed a wash-house, furnished with a chimney, a large copper kettle to heat the water, or in cheese dairies the milk. This is commonly supported by a crane.

The wash-house should have an cater door, near to which the dairy utensils may be set on benches, to be dried by the sun and air. In Holland the dairy rooms are kept with the greatest order, neatness, and comfort; so much so, that the farmer's family often take their meals in them. On the ecoromy of the dairy the following excellent direction, abridged from those drawn up by the Agricultural Society of Aberdeenshire, may be studied by the farmer with advantage. They refer chiefly to salted butter:-

1. The milk-house or dairy should have no internal communication with any other building. It must be kept free from smolie, well aired, and clean, and no potatoes, fish, onions, cheese, or any thing likely to impart a strong or bad smell, should be kept therein; in short, nothing but the dairy utensils, which must also be kept sweet and clean. 2. The milk, when brought in from the cows, should be strained through a fine hair searce or drainer, and when cool put into sweet, well-seasoned oaken lkegs, keelers, or milk pans, the latter to be preferred. A tin skimmer with holes in it is the best for taking off the cream, which should always be churned while the cream is fresh. 3. The churn, whether plunge or barrel, should be made of the best well-seasoned white oak, and as cleanliness is of the first importance, great attention should be paid to the washing, drying, and airing of the churns immediately after use, otherwise they are sure to contract a sour and unwholesome smell, which must injure the quality of the butter. 4. The butter immediately after being churned should be thrown into fresh spring water, where it should remain one hour at least, that it may grow firm. 5. The butter should be immediately salted. 6. It is a very injurious practice to keep a making of butter uncured till the next churning, for the purpose of mixing the two together. It invariably injures the flavour of the whole, and renders it of too soft a quality ever afterwards to get firm. 7. The milk of new-calved cows should never be set for butter, until at least four days after calving, as a small quantity of 
biestmilk butter will injure a whole firkin. The practice of scalding cream in cold weather should also be avoided, as cream thus treated will never make good butter. 8. Great care should be taken not to steep the firkins, or other dairy vessels, in boggy or unwholesome water; only the purest spring or clear running water should be used. 9. Old butter should never be mixed with new.

Lime-tree yields perhaps the best wood for butter firkins; and the St. Ubes' Bay or marine sweet salt, free from bittern, is the best salt to use for dairy purposes: this should be kept in a dry, clean cask, in a place where smoke (which is apt to impart a bad flavour to it) cannot reach it. 'The management and construction of the dairy of necessity varies with the articles for which it is chiefly intended to be devoted, as Burter, Curase, Milk: see these heads.

In the United States one of the most celebrated dairy districts is that of Western Reserve, in Ohio, peopled generally by settlers from New England. It is computed that this fine grazing country sells, annually, cheese to the amount of a million and a half of dollars, besides large quantities of butter, and a great amount of beef and pork.

There is reason to believe that the exportation of butter and cheese from the United States to other countries will annually increase, and especially to England, where a great reduction of duties on these and other articles of the provision trade has recently taken place. From the objections made to American butter and cheese sent abroad, it seems highly desirable that more pains should be taken at home to improve their qualities, which can only be done by paying more at tention to their manufacture. There is no disguising the fact, says a late writer in the $\mathrm{Cul}$ tivator," that immense quantities of butter find their way to market in a condition which renders it unfit for any thing but grease. Hot weather, or the shortest voyage, renders it intolerably rancid. Now, butter made in Holland may be carried to any distance, and in any climate, without suffering material deterioration, and hence it is in such demand for exportation. Vast quantities annually find their way to Great Britain for domestic consumption and otherwise, and the high prices demonstrate the estimation in which it is held. There are no finer pastures in the world than in the United States, particularly those north of the Ohio, and if proper attention and skill were given to the products of the dairy, those products might be unrivalled. There is a considerable amount of excellent butter made in the country, but it is used for domestic conjumption, and the proportion of the first rate article bears but a slight comparison with the whole. There is less difference in the cheeses of this country and the European ones than there is in the butter, and consequently less difference in the prices. But in hoth butter and cheese, so far as the great mass of these products are concerned, there is room for a decided improvement, and we doubt not our dairy women would consult their own interest, as well as the credit of the country, in giving more care to the production of superior articles; but to the extract.

"At a public sale of American butter at Liver. pool, it brought, the best sorts, 848 s, seconds 72 to 74 s. per cwt., duty paid, while inferior sold only at 43 to 448 . in bond, of which the parcel chiefly consisted. The quantity arrived at the London market shows the same results, the principal part being sold for greasy purposes. The American makers of butter are very far behind the Irish, English, or Dutch; from the first operation to the last, all seems to be dune without system or care. The same materials would, if managed by experienced hands, bring in this market 25 or $30 \mathrm{~s}$. more money. 'There is evidently no proper attention paid to the making, salting, putting down, or packing. A correspondent of one of our commercial papers says, - 'The best American butter imported into England this year has sold not higher than $95 \mathrm{~s}$, while the best from the continent has brought 110 to $115 \mathrm{~s}$. per cwt.; this latter will keep for years." (London Contmerciul Journal for March, 1841.)

As a large portion of the United States is favoured with all the advantages requisite for dairy purposes, such as good pastures, excellent cows, fine spring-houses or facilities for making them, there is no apparent reason why good butter and cheese should not be produced in the greatest abundance. Among other instructions for improving the manufacture of butter, given in a recent volume of the Culturutor, the following merit particular attention:"Every thing connected with the making of butter should be perfectly sweet and clean. No smoke, dust, or disagreeable smells should ever exist in the milk-house or dairy. Every thing of this kind has its effect on the cream, and leaves its taint on the butter. The milk should be skimmed, and the cream churned at the proper time and the proper temperature. 'The buttermilk should be promptly separated; and in salting, none but salt of the finest, purest kind is admissible. Next to leaving milk $\mathrm{cr}$ whey in the butter to putrefy, the use of bad salt has the most influence in making this article worth. less. Many recommend washing butter in clear cold water to free it from the 1 nilk, and this mode is practised in some of the best butter districts of Europe or the United States. If the milk is thoroughly separated, however, the par. ticular method is of very little cunsequence and perhaps a machine for working the buttermilk out, such as has been figured in the Cultivator, or some similar contrivance, will be found as effectual as any thing. But butter, if made ever so perfectly, will rot keep well unless it is also packed well. Total exclusion from the air seems necessary, and when this is combined with a low temperature, buter can be lept for an indefinite period of time. It is the adventitious circumstances only that inire poor butter, for, as it is a pure animal oil, if freed from those things that have a tendercy to spoil it, it would keep as long and with as itlle trouble as tallow or lard. It is the clifficulty of freeing butter from the substances conrect. ed with it, that have a constant rerifeisey tw putrefaction, that renders the packiug ni britler 
of so much consequence to its preservation. Stone jars we have found superior to any thing else for packing butter. They are sweet, cool, impervious to air, and, from their shape, leave but a small surface to be exposed or covered with brine. The butter, whether packed in jars or firkins, must be beat solid, and the vessel, whatever it may be, should be filled at once. The difficulty attending firkins is, that all wood contains more or less acid, and this, decomposing the salt, imparts an unpleasant taste and flavour to the butter in the cask. This is partly remedied by filling the firkin with strong brine, and allowing them to stand a few days before using; but the cause is never entirely removed. Experiments made in Scotland proved that the wood of the linden or basswood contained the least acid, and this is supported by the fact that, in the Tyrolese salt-works, where water is brought to the point of saturation by percolating through bundles of twigs or fagots, those of the basswood are always preferred to any other. In this country firkins of heart-ash are preferred, and perhaps are as good as any that can be used. We have known a firkin of butter, properly headed, thrown into a well where the water was of the teinperature of about $50^{\circ}$ to $55^{\circ}$, and when taken out, after a submersion of a year, was as sweet as when put in. Perhaps, where circumstances admit, butter might be advantageously kept in this way in vats filled with running spring water of the proper temperature. Jars or firkins, when filled with butter, should have some pure strong brine poured on the top of the butter, and kept there for the purpose of excluding the air until the article is wanted for use. Instead of the brine some use salt, and others prefer a linen cloth saturated in brine for this purpose. But whatever is used, the top of the jar or firkin should be carefully covered with a board, or what is much better, a clean, flat stone. They should stand on flat stones, in a cool place in the cellar, and may be occasionally looked to, to see that the surface is properly secured, and the air excluded."

Some of the defects of American cheese bave been referred to under the head of Chesse. A very common one arises from its being too often sent to market in a very green state, frequently when but three weeks old. The best English cheeses, we are told, are not considered as ripe and marketable until two years old. "A great improvement," says Mr. Colman, "is thought by some to have been made in capping the cheeses, as it is termed; that is, as soon as they are taken from the press, covering them completely with cotton cloth, sewed over them tightly; or else drawn round the sides of the cheese and over the riges, leaving the centre partially exposed. Where the cheeses are covered entirely, the cloth itself is completely covered and saturated with the usual unguent of whey-butter and some simple and harmless colouring matter. "The effect is to preserve the cheese against the attacks of nies, and to render the daily turning of the cheeses not indispensably necessary, be-ides preventing their spreading and cracking. $f !$ is said by some persons that the cheese does 386 not cure jo perfectly in this way as when ex. posed, an.: that the sale is not so ready. Such contradic iory statements are made in this case, however, by those who have tried, and those who refuse to try it, that I cannot decide on its expediency. It impressed me favourabiy.

"I have much pleasure in saying that many of the Berkshire dairies are most exemplary in respect to neatness ; and in this matter present beautiful models of domestic management. There are exceptions, however, to this commendation. In some instances there is any thing but neatness. The sink and the pigstye, with all their offensive exhalations, on account of what is called convenience, which is only an apology in such cases for gross laziness, are in much too intimate proximity with the dairy-room; and there are cases-i shall not venture to say whether I saw them or only heard of them-where, if the pigs should perchance mistake their own apartment and go into the next door, they would never suspect their error, unless they were ordered out. Admonition, however, seems lost upon such persons. Slovenliness and sluttishness are incorrigible vices; and the fate of such persons seems, as it were, in despair of reformation, irrevocably pronounced.

"Wilbur's semi revolving slide cheese shelves is an admirable contrivance to save labour in the cheese-dairy. By it two men can easily turn twenty-four heavy cheeses in a minute, and are enabled to rub them without their being lifted from the shelves. The model consists of an upright frame, suspended by an axis passing through its horizontal centre; and into which slide eight pair of shelves, the distance of which may be graduated to the size of the cheeses. The cheeses are placed alternately above and below the axis. Slats are fixed upon the back of the frame to prevent the cheeses falling out when the frame revolves. The frame is made stationary by a pin, and when this is withdrawn, it is made to revolve half round upon its axis, which turns the cheeses. The shelves over them, and upon which the cheeses have lain the preceding day, may then be withdrawn, and left to dry till the next day, when they may be returned, the turning process repeated, and the other shelves cleaned and dried in turn. The improvement is a valu. able one in large dairies. Henry Wilbur, of Richfield, Otsego Co., N. Y., is the inventor.

"The saving in labour and risk of the cheese is great, and the expense of fitting up a new room on this plan would not greatly exceed that in common use, as the room may be much smaller. One rack with six shelves, six feet long, iwenty-four inches wide, set eleven inches apart, will hold eighteen cheeses weighing from 100 to 140 lbs. each, suspended by a wooden shaft two inches square, resting on two rails extending the whole length of the room, three and a half feet high, or if only a single rack, on two posts; each rack requires about four feet on the length of the rails to turn well,and its cost will not exceed six dollars, including the materials of which it is male. On this system the cheese dries much faster, as it is turned on the dry side of the shelf every day, 
and has a sound and dry rind. He has one set of extra shelves, which are slipped in close above the cheeses before turned, on which shelf the cheeses lay when turned over; the others are then liberated for another rack, and so on through the room. By the aid of these six extra shelves, the cheeses in turning need not fall but a trifle, if any."

The qualities of the butter generally produced by the New England dairies are even more defective than those of the cheese. These defects are chiefly owing to causes easily remedied,-by observing perfect ventilation and cleanliness in the milk-room and all its utensils, taking the cream from the milk whilst this is still fresh, and churning soon after the skimming. 'The working is a matter of primary importance, and is too often but half done. The operation should be continued till every trace of the buttermilk is removed, since, if any of this be left, the butter will quickly acquire a rancid or otherwise unpleasant flavour. The salting also is of much consequence. In general too much salt is added, and that not always of the very best kind for the purpose. Much salt destrnys the delicacy of fine butter. The additions of saltpetre and sugar, often made in New England dairies, is sanctioned by the practice in Scotland and other countries. See Butter. The noted richness and superior flavour of much of the Pennsylvania butter, found in the Philadelphia market, is chiefly to be ascribed to the fine sweet and clean spring-houses so common in that section of the United States, logether with good old pasture fields, and great attention to working. This last, when well done, renders very little salt necessary, and hence the fine and delicate flavour of the butter can be perceived. The processes followed in the dairy districts in England are well worth the attention of persons interested in this subiect. Some of these are referred to under the heads of Butren and Chense.

Mr. Colman, in his able Reports upon the Agriculture of Massachusetts, has furnished some highly interesting details in regard to dairy affairs in the Eastern States. Treating of the interests of Berkshire county, the dairy products of many farms in which is not surpassed by any accounts of other parts of our country, or of foreign countries, which he had been able to obtain, he observes: "The dairy business has always been a great business. For a time it gave way to the raising of fine wool, when the prices of that staple were high. Since the abatement of the demand for wool, with that caprice for which mankind always have been, and there is reason to think always will be remarkable, many farmers have sacrifices their flocks; and are now giving their exclusive attention to the dairy husbandry. These changes, in matters so important as the dairy or the sheep husbandry, involving as they do a considerable investment of capital, and many expensive fixtures, cannot be suddenly or frequently made without risk of serious loss and disadvantage."

Mr. Colman gives the following statements in relatinn to dairy products, expenses, net profits, \&c.

A farmer residing about twenty-five miles from the Hudson, who with a stuck of eighteen cows, turned his attention to making butter for the New York market, to which it was sent every week, sold in one year 2400 lbs. of butter, at 23 cts. per $1 b$. With the refuse milk he fed seventeen spring pigs until October, when their average weight was $177 \mathrm{lbs}$. each. Half of this pork, say $88 \mathrm{lbs}$. was to be credited to the cow. Reckoning the pork at $\$ 10$ per 100 lbs. (a much higher price, however, than it will now bear), the account wou'd stand thus:

Cow, Cr.

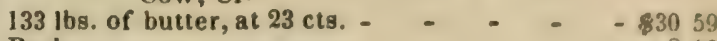
Pork - - - - - - -800 Cow, Dr. Cow, Dr.
Wintering - $-\quad-\quad-\quad-\$ 1200$
Pasturing - -500 Salt - - - - - - - - 25

Interest on $\$ 25$, at 10 per cent., risks included - - _ - _ 2501975 Annual profits of a cow - _ $\quad-\$ \overline{1864}$

This calculation is made without including any extra feed for the cow, and upon the supposition that the butter and milk used by the family pays for the attendance. The profit here allowed, Mr. Colman thinks, less than that actually derived. He mentions another dairy, in which nine cows yielded $1540 \mathrm{lbs}$. of butter per annum, and 300 lbs. of cheese; and a third, where twenty cows produced-of butter, $500 \mathrm{lbs}$; ; and of new milk cheese, $4000 \mathrm{lbs}$.

In the neighbourhood where these dairies are found, two acres of land are deemed sufficient for pasturing a cow or fattening a steer. Twenty head of cattle, made up of cows and three year old steers, were fattened upon thirty acres of land.

In the town or township of Otis, twenty cows gave $5000 \mathrm{lbs}$. of new-milk cheese, besides averaging $25 \mathrm{lbs}$. of butter each, for the family, which also used $600 \mathrm{lbs}$. of cheese. The credit and debtor account in this dairy may be reckoned thus :-

$$
\text { Cow, } \mathrm{Cr} \text {. }
$$

280 !hs. cheese, at 8 cts. per lb. - _ - $\quad$ - $\$ 2240$ $25 \mathrm{lbs}$. butter, at $20 \mathrm{cts}$ - . - - 500 Calf - - - - - - 400 Calf, 26 lbs. at 6 cts. - $\quad-\quad-\quad-\quad=\quad-\quad 400$ $\overline{3296}$

Wow, Dr.

Wintering - - - - - $\$ 1200$

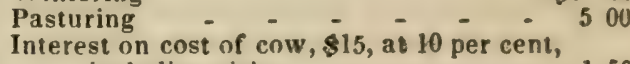
including risks

150

Labour and attendance - _ _ _ 2162066

Balance in favour of cow

$\$ 1224$

In Sandisfield, the average yield of a cow in ordinary seasons is rated at 250 lbs. of cheese, with common keeping. By extra keeping, the quantity is increased to 350 or $400 \mathrm{lbs}$. The quantity of butter in addition to the new milk cheese, is supposed to be 40 or $50 \mathrm{lbs}$. each cow. The amount of cheese made in this township, in 1837, was estimated by competent authority, at $300,000 \mathrm{lbs}$. The popula tion is 1493.

"Another farmer in the same neighbourhood, with a dairy of fifteen cows, states the average product of a cow, if she raises her calf, at 250 lbs.; if otherwise, $300 \mathrm{lbs}$; ; and $25 \mathrm{lbs}$. outter, also, from each cow. Four hogs may be kept in twenty cows. In this "ay, weighing $100 \mathrm{lbs}$. in 
the spring, they will weigh $300 \mathrm{lbs}$. in the fall. $140 \mathrm{lbs}$. of pork is to be credited to five cows.

"The cost of wintering a cow here, is rated at $\$ 10$; pasturage, $\$ 4$. A good dairy woman will take charge of thirty cows, with assistance in milking and in handling cheese. Her wages will be $\$ 150$ per week, with board.

"In Tyringham, the average yield of a cow is rechoned at-new milk cheese, $283 \mathrm{lbs}$. and butter at the same time, 57 lbs. A dairy of twenty-eight cows gave $7912 \mathrm{lbs}$. new milk cheese, and $1600 \mathrm{lbs}$. butter. A large amount of pork was fattened on this farm; but it is difficult to say what portion of it is to be credited to the dairy.

"In Sheffield, the average product of twentyeight cows was 394 lbs. new milk cheese, and $50 \mathrm{lbs}$, of butter each.

"The product of a cow is thus stated by this excellent manager :

$$
\text { Cow, Cr. }
$$

400 lbs. new milk cheese at $8 \mathrm{cts}$.

Calf, (killed at 3 days old)

50 lbs, butter, at $16 \frac{2}{3}$

Whey and butter-milk make 100 jbs. pork -

\section{Supra, Dr.}

\section{Winter keeping} One acre of land costing $\$ 50$ will pasture

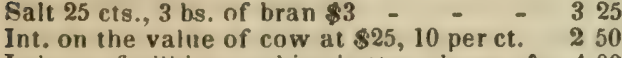

Labour of milking, making butter, cheese, \&c. 4002525

Balance in favour of cow -

- \$2408

"The quantity of land estimated for pasturage in this case seems small. It must be small for a general rule; another farmer in the same town assured me that he kept one yoke of oxen all the season, and one horse half the season, on two and a half acres of land, which he showed me. The land had been greatly benefitted by plaster.

"In New Marlboro", the yield of a cow is estimated at 300 lbs. new milk cheese; four hogs are kept to 20 cows; two tons of hay are deemed requisite for a cow; value of hay sold $\$ 10$; but if the farmer can realize $\$ 6$ per ton for it used on the place, he deems it better than to sell it. Eight to ten acres of land here, with the use of plaster, is deemed sufficient for the pasturage of four cows.

"In Great Barrington, nine cows produced 1900 lbs. new mille cheese, and 800 lbs. butter. In another case from eight cows were sold-of butter, 200 lbs., of new millk cheese, 1225 lbs. In another case 5 cows, through the season, and an additional cow half the season, from lst of June to 10th Nov., produced 651 lbs. butterand $200 \mathrm{lbs}$. new milk cheese. In this case the weekly returns were given. The same farmer says, that his cows will average one pound of butter per day through the season. He states his cow account thus:

\section{Cow, Cr.}

$200 \mathrm{lbs}$. Dutter at $20 \mathrm{cts}$

\section{Calf raised -}

Buttermilk, and skim milk for pork, equal to all the care

$$
\text { Supra, Dr. }
$$

Wintering, 2 tons of hay

Whek, 26 week

Profits of a cow 650

$200 \quad 2450$ 388
"In Alford, the actual yield of a cow was as follows: Butter, 240 lbs. sold. Cheese, 100 ibs. sold, besides using what milk and butter were required by two persons. She had her own skimmed milk, but no meal or grain. She consumed, as ascertained, two tons of hay, and her pasturage was 25 cents per week."

The following estimates apply to the township of Cheshire, which is devoted almost exclusively to the dairy husbantry, and celebrated for the excellence and abundance of its produce.

"A farmer with twenty-five cows, states their average yield at $300 \mathrm{lbs}$. cheese, and $20 \mathrm{lbs}$. butter to a cow. He says likewise that 1500 lbs. pork are to be credited to his cows.

"The average cost or value of his cows is $\$ 30$ each; wintering $\$ 14$; pasturing 26 weeks $\$ 625$; he raises some calves upon whey. It requires the whey of two or three cows to raise a calf. His hogs at 18 mos. average $350 \mathrm{lbs}$; they run in a pasture and have the refuse of the dairy until about six weeks before it is intended to kill them, when they are shut up and fed with corn and meal.

"The dairy of another farmer consists of 20 cows. The year before last they yielded 400 lbs. new milk cheese; the last year $400 \mathrm{lbs}$. each, besides an ample supply of butter for the family. He calculates upon the proportion of one hog to foar cows; with the above cows he made $1200 \mathrm{lbs}$. of pork, $600 \mathrm{lbs}$. of which he credits to the cows; he deems three acres necessary for the pasturage of a cow. His cows during the spring have an allowance of rye. meal and whey.

"In another case the produce of 23 cows was $12,000 \mathrm{lbs}$. new milk cheese and $500 \mathrm{lbs}$. butter.

"In another case 30 cows made 14,000 lbs. new milk cheese; and 500 lbs. butter. In this case some calves were raised; but most of them were killed at four daysold. Throughout the county of Berkshire this mode of dealing with the calves is termed 'deaconing' them. What is the particular propriety of this provincialism, I am unable to determine; and whether it had its origin in any superstition among the aborigines or the first settlers of the county, I shall leave to the antiquaries to ascertain. It is a peculiarity, and prevails no where else.

"The practice, with this farmer, is to give boiled corn in the ear to his cows; perhaps a dozen ears to a cow per day. When it is conveniently had, he gives a mess of rye-meal to each cow. at the rate of two quarts per day, for three weeks in the spring. He is anxious to let his cows go to the grass as soon as the ground is bare. He thinks cows are liable to suffer from excessive feeding in the barn.

The wintering of a cow requires $1 \$$ inns of hay $\$ 1400$ Pasturing, $20 \mathrm{cts}$. per week for 26 weeks - 520

"In 40 days of the best of the season on this farm, 30 cows produced 4000 lbs. butler. 'The land required for the pasturage of a cow is considered to be three acres.

"From thirty cows, an average of $425 \mathrm{lbs}$. of cheese has been produced to each cow, and ten lbs. of butter; or 300 the whole. 
"On one farm, where 18 cows were kept, 11,385 lbs. new milk cheese were made in a season, which gives the extraordinary average of $632 \frac{1}{2} \mathrm{lbs}$. to a cow. $200 \mathrm{lbs}$. of butter were made the same season from the same cows. One of these cows produced $1000 \mathrm{lbs}$. new milk cheese.

"During the first part of the season, for two months, two quarts of rye-meal were given to each cow. Half of this quantity of meal was given them for one month during the last of the season; and the greater part of the time they had their whey. $1000 \mathrm{lbs}$. pork were made on the farm; and half of this was credited to the cows.

"The same individual, when on another farm in South Adams, with 21 cows, made 626 lbs. new milk cheese to a cow, in a season. 1700 lbs. of pork were raised in connection with the dairy. Half the pork was considered as due to the cows.

"The process of making cheese began the 25th April, and ended the 1st December. As soon as the cows calved, the cows received 3 qts. of meal per day each-principally rye, with some Indian; and each had some whey, though not half what was yielded was given to them. Three or four of the cows received meal all the summer. He commenced feeding again with meal on the 25 th July, and continued to give them two quarts of meal until the 25th August. On the 25th August, he began feeding the cows with corn-stalks until 10th September. Then the cows had the after feed of the fields; and from the Ist October, these cows had half a load of pumpkins per day. In November, fed every cow fully with meal; two and three quarts per day until 1 st December. After that, the cows had nothing but hay until spring. From the same cows, at the same time, butter enough was made, and milk enough used, for a family of six persons. The cheese sold in New York for $\$ 10$ dollars per 100 lbs.

"These products are certainly remarhable, and show what may be done by attention, skill, and good treatment of the animals under our care. The pasturage in Cheshire is of an excellent description. The soil is generally of a rich gravelly loam resting upon limestone, and abounding in vegetable mould. It is likewise sensitive to the application of plaster, which is very commonly used."

The same excellent authority who has furnished the foregoing details, enables us to present the following views of farmers in those sections of Massachusetts most celebrated for dairy products in regard to dairy stock.

"The farmers are unanimous in their preference of the common native stock of the country, in which the Devon blood predominates, to any foreign stock with which they are acquainted. They are in general as decided in their preference of small, over large-sized cows. They are not, however, raisers of stock; and buy their cows wherever they can find them, according to their best judgment. The remarkable produce, if so it be considered, is to be attributed to extraordinary good management and keeping; and on this account, deserves the more attention, as showing what mav be done.
"The dairy stock in England which scems to have the preference over all others, is the Ayrshire. The origin of this stock is not well ascertained; but though it has some of the qualities of the improved Durham, is a race distinct from that. Great pains have been taken and great expenses incurred, in (rrler (") introduce this fine Ayrshire race of cows into our state, by the Massachusetts Agricultural Society, and by an intelligent and public-spirited friend to agricultural improvement in Waterstown. I regret that I ain not able to obtain such returns as would enable me to speak confidently of the merits or defects of this stock, so far as these cases go;-but I am safe in saying, that some slight disappointment has been experienced. It is probable from the celebrity which they had obtained abroad, too much was expected from them here. Extravagant statements have been made respecting their produce in Scotland. One of the advocates for this stock, and a man upon whose authority great reliance is placed, has undertaken to calculate precisely the number of quarts of milk given, and the number of pounds of cheese made from what is stated to be in money the average produce of an Ayrshire cow. This is certainly rather a loose way of reaching the result. Entire reliance cannot be placed upon it. This, another distinguished Scotch farmer and dairyman admits; and says that 'those statements are far too high and not well founded.'

"He refers to a farmer, on whose exactness he entirely relies; whom he pronounces a man of superior intelligence and accuracy; and who has devoted himself to dairy husbandry; and, further, whose stock were particularly select, and 'who had every inducement to keep them in the highest condition requisite for giving the largest product in milk.' The farmer referred to, states, that at the best of the season the average milk from each cow is 9 Scots pints ( $4 \frac{1}{2}$ gallons), and in a year, 1300 Scots pints or 650 gallons. A Scots pint is two quarts. Now, allowing these cows to be in milk 320 days, the average yield of a cow would be $8 \frac{1}{8}$ of a quart per day. But it we understand this to be wine measure, which is the usual standard of measurement in England, and compare it with our customary admeasurement of milk in Massachusetts, which is always beer measure, we must deduct one-fifth; and then the average product of an Ayrshire cow, compared with ours, is $6 \frac{1}{2}$ quarts per day for 320 days. Such a yield is often surpassed by cows of our native stock. I have before me the case of a cow of native stock among us, who, in 268 dars, ylelded 2923 beer quarts of milk; and of another, that produced 3975 beer quarts of milk in ten months. I can produce, within my own knowledge, a list of nearly fifty cows of native stock, almost as productive as these. I do not mean to undervalue the imported stock. Far from it. I deem the introduction of thi Ayrshire stock and the improved Durham short-horn, a great benefaction to the country. Their tendency to fatten, their early maturity, their beautiful proportions, highly commend them to our good will and our interests. As 2 K 2 
yet, we have not had, by any means, a sufficiently fair trial of their dairy properties so as to deternine fully, either for or against them; and it has been found here, in repeated instances, as it has proved abroad, that a cow, fiom a cross of an improved Durham, with the Devon, has given a valuable animal for the dairy. But among the great advantages which is to result from the introduction of this improved and beautiful stock, is this: to give our farmers a knowledge of what can be done by skill, intelligence, care, selection, and perseverance in the art of breeding animals for any purpose; in obviating defects of form, constitution, and habit; and in perpetuating and transmitting excellent and desirable properties. In the Ayrshire stock, and in the improved short-horns, the most shrewd and persevering efforts have been exerted, and the highest practical skill and philosophy have been taxed to carry this race to as great a degree of perfection as any thing of the kind can be; and the success has been decisive and wonderful. Excepting in one instance, to which I shall hereafter refer at large, perhaps there cannot be found in the whole of New England, a single instance of any enlightened, determined, and systematic attempt to form a race of animals of particular and desirable properties. It is most important that this should be attempted in different parts of our country, with what are called our native stock which have become, in various ways, so crossed and mixed up, that there is in truth no particular race among them. A large portion of them are as ungainly, unthrifty, and unproductive as can well be represented or imagined. Yet there are among them so many extraordinary animals, - extraordinary for their produce in milk, butter, and cheese,-that a few years of careful and intelligent selection from the materials already to our hand, and a strict observance of those philosophical principles of breeding which are well ascertained and understood, would undoubtedly give us a breed of animals, a stock or race of animals, greatly superior to that which now exists among us. This has been attempted in one instance by a highly intelligent breeder; and he is now able to show three generations of animals of as extraordinary character for the creamy or butyraceous quality of their milk as has erer been known. Two quarts of what is called the strippings, the last part drawn off of the milk of one of these cows, having repeatedly produced one pound of butter; and the cream, as it came from the pans, as I have seen myself, becoming by churning converted into butter of the finest description in less than one minute by the watch; and this process repeated at pleasure.

"Let us now compare the amount of cheese made by the English dairies, with some in this county of which I have given here an account.

"An Ayrshire cow, it is said by the English authoritirs, will yield 257 lbs. of butter per annum, or about 5 liss. per week, all the year round, besides raising the calf; or of new milk rheese, about $514 \mathrm{lbs}$. 'These returns are cerainly large; but they rest upon a calculation 390 $\therefore$ the quantity of milk which the cow is suprosed to yield, rather than upon any account cf an actual yield. None at least is given. This, therefore, is not so satisfactory as it would be, if it were a precisely ascertained result. One of the best authorities says, that in England, 'a well-fed cow of a good breed will produce, upon an average, $180 \mathrm{lbs}$. of butter in the season. The common calculation is indeed 150 lbs.; but this is made upon mixed stock, which affords no certain data. In the Epping district, where there is an indiscriminate mixture of Devon, Suffolk, Leicester, Holderness, and Scotch, the calculation, in a well-managed dairy amounts to $212 \mathrm{lbs}$; that is, $6 \mathrm{lbs}$. per week during 26 weeks, and $4 \mathrm{lbs}$. per week, during 14 weeks. The average product of cheese in the best dairies, where the whole milk and cream are used, cannot be estimated at more than $4 \mathrm{cwt}$. - that is, $448 \mathrm{lbs}$. On deep grazing soils, that carry a heavy stock, a well-managed cow is reclioned to make from $360 \mathrm{lbs}$. to $600 \mathrm{lbs}$. In Somersetshire, the average is $4 \frac{1}{2}$ cwt., or 540 lbs. ; in Essex not su high, and in the midland counties something more than $3 \mathrm{cwt}$.' It will be seen, in looking back upon the dairy returns in some parts of this country, that they are inferior to these, not frequently passing beyond 250 or $300 \mathrm{lbs}$. of new milk cheese. On the other hand, the re. turns of some of the dairies in Cheshire show an actual amount of annual produce of more than $500 \mathrm{lbs}$. to a cow, and in some cases 627 and 632 lbs. It may be said that this is owing to the fine pasturage which is to be found in Cheshire and its vicinity; to the particular care which is taken of the cows; and the system of high feeding adopted. But it shows conclusively that the cows are capable of being brought to this productive yield; and the feed and management are matters which can be adopted any where.

"A farmer in Sandisfield has a dairy of 24 cows; and they produce a cheese per day, weighing about 100 lbs. Supposing that it requires a gallon of milk to produce one pound of cheese, this would give 400 quarts of milk per day, or at the rate of $15 \frac{2}{3}$ of a qualt to a cow. These cows are all of native stock; most of them raised by himself. His average product of new milk cheese to a cow in a season, is between 500 and $600 \mathrm{lbs}$. Last year the actual yield was 598 lbs. to a cow. Of his 24 cows last year, two were heifers of two years old, just come in. Four years since he was the owner of a cow, whose milk in the best seasun amounted by actual weight to 70 lbs. per day. During the time of her greatest yield, she was fed with four pails of cheese whey, and some rye-meal. She was of native stock. This farmer has a heifer from her, which gives, as he supposes, $60 \mathrm{lbs}$. of milk per day. He gives an opinion, which from his successful experience certainly deserves attention; that heifers which 'come in' with their first calf at two years old, do better thas when their coming in is delayed until three years old. Their milking properíies are in this way improved. Probably he is right in this matter; but the general experience of the best farmers recommends that, if a beifer 
comes in at two years old, she should not be allowed to have another calf, under at least eighteen months from this time."

In regard to the improvements in neat cattle made and still making in New England, Mr. Colman furnishes the following results, obtained at 'Ten Hills Stock Farm, near Boston, under the enterprising efforts of Samuel Jaques, than whom, he thinks, no man, perhaps, in New England or the whole country, has more practical skill or better judgment in relation to this kind of live-stock, his experience having been long, and marked by critical observation. The following extract contains Mr. Jaques's own account of his enterprise and success, as communicated to Mr. Colman :

"It has," Mr. J. observes, "been my object to effect such an improvement in milch cows as should produce the greatest quantity of rich milk, affording the largest quantity of butter. There is a greater difference in pecuniary profit between a good or a poor cow than among any other domestic animals. In some yards there may be found those which will not pruduce more than three pounds per week, and others that would make nine, and all on the same keep. As we sometimes hear of cows which have produced seventeen pounds of butter per week, and even more, it occurred to me to inquire why a breed or race could not be formed with the same valuable properties. This I have attempted, and have carried it to the third generation; and I am confident of success. I have a cow whose milk has produced nine pounds of the best butter in three days, and this on grass feed only. This I call my Cream-Pot breed. I have bred my creampots with red or mahogany-coloured hair, yellow noses, with mahogany-coloured teats, yellow skin, silky and elastic to the touch. I have obtained the breed by the cross of a Durham short-horned bull on a selected native cow with certain extraordinary points and properties, anxious to retain as much of the form of the Durham as to insure capacious udders, and with the valuable property of affording rich milk. Though an admirer of the Durham short-horns, I have not found them producing so rich milk nor making so much yellow butter as I could wish. The Durham race are round and straight in the barrel, full in the twist, and inclining to be thick in the thigh. I have wished for some improvement in the form of the bag. But I would premise, that whatever I may say in respect to breeding animals, I only desire to express my own private notions, without a wish to dictate to any one from the experience I have had, which I am sensible is very limited. Generally, cows which I have examined, giving the largest amount of the richest milk, have had capacious bags, full behind, extending far up into the twist, and also well formed; hanging moderately deep when full in milk, and after the milk is drawn, quite the reverse; for I would avoid a fleshy bag. My cream-pot breed are full in the body, drop deep in the flank, are not quite so straight in the belly, nor as full in the twist, nor as thick in the thigh; but in other respects I wish them to approach the Durham as near as mav be. My cream pot breed excel particularly in afford. ing a great quantity of rich cream, and that cream capable of being formed into butter in a short time, and with little labour, leaving a small proportion of buttermilk. Their crearn produces more than eighty per cent. of pure butter; and it is not infrequent to form the cream into butter in one minute. It has been done in forty seconds.

"I have a heifer designated as Betty Cream Pot, one of the third generation, which pri. duced her first calf at two and a half years old. Mr. Brown, my foreman, made the fol. lowing experiment upon her milk, without my knowledge at the time. After milking, he took two quarts of her milk out of the pail, and, having strained it into a pan, al. lowed it to stand twenty-four hours. Having then skimmed the cream into a bowl, he churned it with a table-spoon, and in one mi. nute, by the clock, he formed the butter. It was then pressed and worked in the usual way, and amounted to half a pound of pure butter. After this, the following practice was pursued for eight or ten weeks in succession. At eacis of four successive milkings, two quarts of the strippings were strained into a pan, making eight quarts in the whole. All was mixed together in the same pan, and then churned. The average time of churning did not exceed ten minutes; in some instances the butter was formed in five minutes. After being properly worked over, it was weighed, and never fell short of two pounds. The remainder of her milk was for family use, and, when set for cream, produced the usual quantity. These experiments were made on grass feed only. She did not give a large mess; only about twelve quarts per day. I have forty cows and heifers, ten bulls and bull-calves of different grades of this cream-pot breed, all bred and raised by myself. I keep my bulls, selected as breeders, until I have prof of the quality of their ofispring. My old cream-pot bull is ten years old. My Don Cream-Pot, from which I am now breeding with some of my cows and heifers, is three years old."

"It will be seen," says Mr. Colman, "that Mr. Jaques speaks with all the enthusiasm of an amateur. I cannot endorse, certainly to their full extent, all his doctrines respecting the power of breeding, at pleasure, any animals of any desired shape or colour, and of forming them as a statuary would mould his plaster; but the approaches which a scientific and ex. perienced breeder can make to such a power as this are very considerable, as all the improved races of animals show, whether among neat cattle, horses, sheep, or swine.

"The dam of this stock was a noble-sized cow, raised in Groton, Mass.; but the owner there knew nothing particularly of her origin. She was sold to a gentleman by the name of Haskins, residing in Dorchester, about five miles from Boston; and her cream was of such extraordinary richness, that it would become separated into butter by the motion of the carriage in bringing it in to the city.

"Mr. Jaques is entitled to great credit for his care and judicious selection in continuing and improving the stock. I have repeatedly seer the cream from these curs, and its gellownesy 


\section{DAIRY.}

and consistency are remarkable; and in company with several gentlemen of the legislature, I saw a portion of it converted into butter with a spoon in one minute. The colour of Mr. Jaques's stock is a deep red, a favourite colour in New England. They are well formed, and thrifty upon common feed; and, if they continue to display the extraordinary properties by which they are now distinguished, they promise io prove themselves, for dairy purposes, the most valuable race of animals ever known among us, and as remarkable as any of which we have any information. They have now reached the third generation, and maintain their high character.

"From six cows taken promiscuously in a dairy of improved short-horn stock, in England, with a view to test the quality of the milk, it was found that they gave in the following proportion of butter to one quart of milk:
No. 1, 3 oz. $6 \mathrm{dwts.}$
$\begin{array}{lllll}2, & 1 & 6 & 6 & 6 \\ 3 & 1 & 6 & 12 & 4\end{array}$
No. 4,1 oz. 10 dwts.
5, 1 " 614 “ 14 “

"These measures, it will be perceived, are given in troy weight, of which it requires 175 lbs. to make 144 lbs. avoirdupois. It is not stated whether the quart was wine or beer measure, and it is therefore difficult to adjust the proportions. A variety of circumstances, likewise, would affect, in some degree, the result; as, whether the milk was taken at the beginning or the last part of the milking; and how long the cows had been in milk from the time of calving; and what was the kind of feed given them at the time of the experiment. Still, I have quoted the result, as, under any circumstances, showing by comparison the extraordinary product of the cream-pot breed."

Mr. Colman has added to his report of the dairy produce of the county of Cheshire, a table showing the number of cows kept on 45 farms in 1838, with their produce, the amount sold, and prices obtained. The whole number of cows was 913; the amount of new-milk cheese sold, 300,000 lbs.; skim-milk cheese, 11,050; cheese used, 7,500 lbs.; butter sold, $19,050 \mathrm{lbs}$. The average price for the newmilk cheese was $7 \frac{3}{4}$ cts.; of skim-milk cheese, 3 cts., and of butter, $17 \mathrm{cts}$. per pound.

In the dairy establishments about Boston, good hay, and corn-fodder are the general feed, with sometimes carrots, ruta-baga, and mangelwurtzel. The ruta-baga, and all the turnip family, are apt to impart a turnip taste to the mill, which is very generally disliked. $\mathrm{Mr}$. Colman was informed by a very careful milkman that no objection of this sort is found against ruta-baga, if they be given to the cows directly after, and not just before being milked. Before the next milking comes, the disagreeable odnur is entirely got rid of. The best milkmen prefer good clover hay for cows in milk to any other. "Potatoes and mangelwurtzel," says Mr. Colman, "increase the quantity without improving the quality of the milk. Carrots, parsnips, and sugar-beets improve the quality.-A milk farm, well situated and with a good custom, is a profitable husbandry where the milk brings 5 cents in sumsner and $6 \frac{1}{4}$ cents in winter. A good deal of wilk is sold by the farmers to the milkmen for 392

\section{DAIRY.}

3 cents per quart, of the profits of which management to the farmer $I$ have strong doubts. If we suppose that it requires 10 quarts of milk to make one pound of butter, this at 3 cents per quart would be 30 cents. Suppose the milk to be made into butter, there is a pound of butter worth 25 cents, and, if of superior quality, 33 ; there are the skim-milk and butter-milk remaining, worth certainly for young pigs $1 \frac{1}{2}$ cent per quart-say 9 quarts, 13 cents; and there is the manure made by the swine kept, which is of considerable value.

"The amount of milk furnished by a herd of cows through the year is very differently estimated by different persons. Rare individual cows may be occasionally met with, giving ten, and perhaps, in some remarkable case, even eleven quarts of milk per day through the year-that is, 365 times 11 quarts, or more than 4000 quarts per annum; but such cases are very few in number. In Curwen's dairy of 28 cows, kept and fed with great care for 220 days, the average was eight wine quarts per day, or a little more than six beer quarts. In the Harleian dairy, where a hundred cows were kept, it is said that twelve wine quarts were about the daily average; but the statement, in the form in which it is made, is very imperfect and doubtful. Twelve wine quarts would a little exceed nine beer quarts. Nothing could surpass the pains used in the selection of these cows, the care taken of them, and the abundance with which they were fed. If the statement were positive, I should regard it differently; but as it seems to be rather matter of conjecture than of proof, I place little dependence upon it. In a private letter to a respected friend from the celebrated Fellenberg, it is stated that, at that institution, the cows, which are considered amongst the best milch cows in the world, average through the year about six quarts per day. But here again we are left at a loss to know, whether the year includes only the season while they are in milk, or 365 days. These are foreign statements. I wish I had those from among ourselves, on which entire reliance can be placed. Men in these cases are so in the habit of dealing in conjecture instead of facts, that it is exceedingly difficult to arrive at the truth. I have been so often deceived in these matters that I place little confidence in any thing which is not matter of actual measurement and positive verification. 'The most intelligent and careful milkmen whom I have consulted are of opinion, that their cows average about six quarts per day for 365 days, and go dry in that time from two to three months. A very careful milkman, who may be entirely relied on, from 20 cows produced $11,131 \frac{1}{2}$ gallons of milk in a year. 'This was at the rate of $6 \frac{1}{8}$ quarts per day for 365 days, or $7 \frac{1}{2}$ quarts per day for 300 days. These cows were native stock, extremely well selected and well fed. Succes. sive tria!s on this same farm give about the same result.

"On a milk establishment in Medford, under excellent management for many years, with twenty cows in summer and more than thirty in winter, the average product for 365 days is from five to six quar:s to a cow per day. The 
cows are fed in winter upon clover hay, an allowance of a peck and a half each of succulent vegetables, and some Indian or oil-meal cake. The summer feed is not stated, but great advantage has been derived from green Indian corn fodder. Oil-meal cake is not considered of equal advantage with Indian. It is deemed too dear if more than $\$ 25$ per ton. Carrots are preferred to all other vegetables when the quality of the milk and the condition of the animal are regarded. Since the use of the most powerful hydrostatic presses in extracting the oil from the flax-seed, the cake is by no means so valuable as formerly, and the price should be proportional.

"In the case of a milk establishment in the vicinity of Salem, on an average of thirty-five cows in milk, the product in one year was 17,171 gallons of milk, beer measure; in another year, it was 17,530 gallons. In the first case it would be about $5 \frac{1}{3}$ quarts to a cow ; in the latter, $5 \frac{1}{2}$ to a cow per day through the year."

Several enterprising individuals have imported some of the very finest bulls and cows, of the Ayrshire breed, generally reputed the most celebrated dairy stock in England. In regard to the qualities of these and their progeny, Mr. Colman remarks that they are said to yield large quantities of milk and produce large amounts of butter and cheese; besides keeping themselves in good condition, and being easily made ready for the butcher. The cows are eminently beautiful. In size, however, and symmetry, they are decidedly inferior to the improved Durham short-horns; but there is good reason to think them a hardier race of animals.

Of the improved Durham short-horn race, we have, Mr. Colman remarks, had some of the best animals ever brought into the United States, and their blood has been considerably diffused throughout the country. In point of size according to their age, in respect to symmetry and perfection of form, these animals are, in my opinion, not surpassed, indeed not equalled by any others. "The Herefords," he says, "are extremely beautiful; in neatness and fineness of form perhaps superior to the improved short-horns. The Devons likewise, though considerably smaller in size, yield, in compactness of shape, in quickness of movement and muscular strength, and in softness of hair and beauty of colouring, to no other race known among us. They are the prevalent race of our country; and in an extraordinary instance, when I had the singular pleasure of seeing three hundred yoke of these cattle-that is, all more or less of this breed-in one team, in Connecticut, I could not resist the conclusion that a finer team, of the same number of cattle, could not be found in the whole country. Yet I am ready to admit that I have seen some few yokes of oxen of mixed blood, of the improved Durham, as fine in appearance, and in reputation as good animals for work, as any that I have met with and some individual animals of the improved Durham short-horns, both pure and half-blood, bulls, oxen, and cows, when all points have been considered, have surpassed any thing which I have seen. They have approached as nearly to what I imagine the perfection of form in this race of animals as is to be lonked for. With good keeping, they come early ts maturity, and attain a large weight. The butchers, however, whom I have consulted, give it as their opinion that they do not tallow sc weil, in proportion to their size, as our own smaller cattle. In my observation, no animal. degenerate sooner under neglect and poos keeping; and they require extraordinary feed and the most careful attendance to keep up their character and condition.

"So much sensibility exists in reference to this subject, the dairy properties of the improved short-horns, and so much of private interest and speculation is now mingling itself in the judgments which are formed or the opinions given in the case, that, if it is not difficult to speak with calmness and subriety, it may be unreasonable to expect to be heard with cardour and impartiality."

With this judicious remark, Mr. Colman proceeds to give well authenticated reports made of the milking exploits of the short-horns and their crosses, followed by the most celebrated performances of native cows, in yielding milk, butter, and cheese.

From the numerous examples recorded of superior dairy qualities exhibited in native cows, we cannot omit the following:-

"The Oakes cow, in Danvers, Mass., produced in 1813, $180 \mathrm{lbs}$. of butter; in 1814, $300 \mathrm{lbs}$; in 1815 , over $400 \mathrm{lbs}$; in $1816,484 \frac{1}{4} \mathrm{lbs}$. During this time, one quart of the milk was reserved daily for family use, and she suckled four calves for four weeks each, in the course of those years. She produced in one week $19 \frac{1}{4}$ lbs. butter; and an average of more than 16 lbs. of butter per week, for three months in succession. The largest amount of milk given by her in one day, was $44 \frac{1}{2}$ lbs. She was allowed 30 to 35 bushels of Indian meal per year, and all her own skimmed milk and most of the buttermilk. At one time, the owner gave her potatoes, which increased her milk, but not her butter. In the autumn, he gave her about six bushels of carrots.

"A cow owned by Thomas Hodges, in North Adams, produced last year $425 \mathrm{lbs}$. of butter; $400 \mathrm{lbs}$. of this amount were made in nine months. Her feed consisted of one quart of rye-meal, and half a peck of potatoes per day ; and very good pasturing.

"Cow of Ralph Haskins, Dorchester, Mass., 1827. Eighteen quarts per day-arerage 14 to 15 quarts. Before grass feed in April, the cream of two days made 23 lbs. butter, and was made from $2 \frac{1}{16}$ quarts of cream. Two or three minutes in churning. This was the mother of Mr. Jaques's famous C'ream-pot breed.

"Cow of H. G. Newcomb, Greenfield, Mass., 1830, from March 27th to May 25th, made 100 lbs. of butter, and reserved 160 ijuarts milk. In 14 days, made 293 . Ibs. Dutter.

"Cow of Shelburn, Vt., has yielded 26 quarts beer measure, in a day; and at two milkings in 24 hours, produced 3 lbs. 14 oz. of butter This cow was raised in Vermont. Some per sons, from her great product, call her English. 


\section{DAIRY.}

but the admixture of blood is very small if any ; and if any. it is not known, whether Durham, or Ayrshire, or what. There is nothing but her colour, which indicates any difference from our best formed native stock. She has some progeny by an Ayrshire bull, which are very promising.

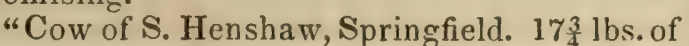
butter per week, and in one case, $21 \mathrm{lbs}$. of excellent butter. In $4 \frac{1}{2}$ days, that is 4 days and one milking, she produced $14 \mathrm{lbs} .3 \mathrm{oz}$. of butter, at the rate of $22 \frac{1}{4} \mathrm{lbs}$. per week.

Cow of O. Morris, Springfield. "The summer after she was seven years old, the quantity of butter made from her between the first day of April and the first of September, five months, was $206 \mathrm{lbs}$. During the time, we used milk and cream in the family freely. Some weeks we have made $14 \mathrm{lbs}$, exclusive of milk and cream used for family purposes. I have often weighed her milk in the month of June, and she has frequently yielded $31 \mathrm{lbs}$. at one milking at night. We have been particular to have her milked in the summer at five o'clock in the morning and at seven o'clock in the evening, and always by the same person. I think much of regularity in the times of milking; and that one person only should be permitted to milk the same cow the same season. My cow has always had a good milker, and her milk has been rapidly drawn. Her food in the winter is good hay, and in addition thereto from 2 to 4 quarts of rye-bran at noon. I feed and give her water three times each day. In the summer, besides the pasture, she has 4 quarts of rye-bran at night. From the experience I have had with this cow, I feel quite sure that many cows which have been considered as quite ordinary, might, by kind and regular treatment, good and regular feeding and proper care in milking, have ranked among the first-rate."

For their dairy products these examples of native New England cows are certainly admirable. They do not, however, equal those reported of many Durhams in our country, among which may be mentioned the Belina of Mr. John Hare Powell of Pennsylvania, an improved Durham, which yielded repeatedly 26 quarts of milk in 24 hours, and produced in three days $8 \mathrm{lbs} .13 \mathrm{oz}$. of butter; or at the rate of $20 \frac{1}{2}$ lbs. per week; the feed consisted of slop composed of Indian meal, with clover and orchard-grass. One quart of the cream produced $1 \mathrm{lb} .5 \frac{1}{4} \mathrm{oz}$. of butter. In one instance two minutes, and in another only three seconds were required to convert the cream into butter.

The celebrated B'ossom, also an improved Durham short-horn cow, owned by Mr. Canby, in Delaware, gave $253 \frac{1}{2}$ quarts per week, being an average of 36 quarts per day; from which were made $17 \frac{1}{2} \mathrm{lbs}$. of well-worked butter.

The famous Durham cow Dairy Muid, belonging to Mr. James Gowen of Germantown near Fhiladelphia, yielded $33 \frac{1}{2}$ quarts of milk per day.

Neither do any of these distinguished milch cows equal in dairy qualities the celebrated Cramp cow, owned in Lewes, England, which still bears the palm both abroad and at home. She was of the Sussex breed, and came of a

\section{DAIRY.}

celebrated stock. Her performances recordid were as follows:-

"From the first lay of May, 1805, the day slie calved, to the second day of April, 1806, a space of forty-eight weeks and one day, her milk produced $540 \mathrm{lbs}$. of butter. The largest amount made in any one week, was $15 \mathrm{lbs}$. From May to June, she gave 20 quarts per day. From 20th June, to 10th September, $18 \frac{1}{2}$ quarts. In forty-seven weeks, she prisduced 4,921 quarts of milk.

"In the next year, from 19th day of Aprii, 1806 , the day she calved, to the 27th February, 1807 , forty-five weeks, she produced $450 \mathrm{lbs}$. of butter. The largest amount per week was 12 lbs. The quantity of milk for the time was 4,137 quarts. During this year, she was sick and under a farrier's care three weeks after calying. She went dry seventeen days only.

"In the third year, from the 6th of April, 1807, the day she calved, up to the 4th April, 1808, fifty-one weeks and four days, she produced $675 \mathrm{lbs}$. of butter. The largest amount made in a week was $18 \mathrm{lbs}$. The quantity of mills given in that time was 5,782 quarts. In the fourth year, from the 22d April, 1808, the day she calved, to the 13th February, 1809, fortytwo weeks and three days, she produced 466 lbs. of butter. The quantity of mills given in the time was 4,219 quarts. In the fifth year, from April 3d, 1809, to May 8th, fifty-seven weeks, her produce in butter was 594 lbs. The amount of milk given in the time was 5,369 quarts. The largest quantity of butter in any week was 17 lbs. This is the most extraordi. nary cow of which we have any record. Though it has been presented to the public before, yet the account may not be accessible to all; and I deem it useful to state the mods. of her treatment.

"In the summer season, she was fed on clo. ver, lucerne, rye-grass and carrots, three or four times a day; and at noon, about four gallons of grains and two of bran, mixed together, always observing to give her no more feed than she eats up clean. In the winter season, she was fed with hay, grains, and bran, mixed as before stated, feeding her often, viz., five or six times a day, as was seen proper, and giving her food when milking; keeping the manger clean, where she is fed with grains; not to let it get sour; wash her udder at milking three times with cold water, winter and summer; never tied up; lies in or out the barn as she likes; particularly careful to milk her regularly and clean. Milch cows are often spoiled for want of patience at the latter end of milking them."

With regard to the merits of the Durham breed, about which such a variety of opinions have been entertained, Mr. Colman expresses himself as follows :-

"The beauty of the improved Durham shorthorns and their perfection of form are admirable. They come with good keeping early to maturity. They have a tendency to keep themselves in good condition; and, with extranrdinary feeding and care, they arrive at a large size, and some individuals, all points considered, have surpassed any thing within my knowledge. The Claremont ox, a half-blond Tinr. 
ham, whose pedigree is not known, which was sent from this country to England for exhibition three years since, was pronounced by competent judges the finest animal of the kind ever seen there. His live weight was reportud as not far from $3700 \mathrm{lbs}$. The Greenland $0 \mathrm{x}$ was nearly as heavy, and singularly beautíul. A native ox exhibited in Boston, in 1840, did not differ much from these in size, fulness, and weight; but compared with them in appearance, he was misshapen and deformed. The Durham cows, in general, especially the selected ones, which have been imported on account of these qualities, are large milkers; but their milk seems generally inferior as to richness or butyraceous properties. The milking properties of Mr. Whitney's stock, at New Haven, are very remarkable. The Durham cows are large animals, and should be expected to secrete largely of mills; but many of them, however, are inferior as milkers; and, upon as calm and impartial a view of the subject as I can take, from my own personal observation, I cannot pronounce them, as a race, distinguished and preferable to all others for their dairy qualities. I have come to this conclusion with very strong prejudices in their favour; and as I measure my words in this case, I wish to be judged only by what I say. Whenever a shorthorn cow proves an inferior milker, the enthusiastic advocates of the race are pleased to tell us that it is because she has no pedigree, and is not a herd-book animal; but admitting that her genealogy is somewhat mixed, it is singular that the virtues of the blood should not show themselves to a degree, and that the impurity or defect should always predominate. It is certain, however, that many mixed bloods have in every respect excelled many of the pure bloods."

Such are the respective merits of the shorthorned and common breeds for dairy purposes, according to the experience of one who has had extensive opportunities for observation, and who is to be regarded as a candid and impartial witness. We think, however, that the most just view of the subject is presented in the following extract from the Edinburgh Quarterly Journal of Agriculture, and we are pleased to find this opinion sustained by no less an authority than the late Judge Buel, who has endorsed the sensible views of the European writer, lyy imbodying them in his Farmer's Instructer.

"It has been frequently asserted that shorthorned cows are bad milkers; indeed, that no kind of cattle are so deficient in milk. Those who say so do not know the still greater deficiencies of the Herefords, a species of cattle quite unknown in Scotland. The highest bred stocks of the Messrs. Collins, Mr. Mason, and Mr. Robertson, yielded little milk. Indeed, Mr. Robertson's could not supply milk sufficient for their own calves, at least not in the quantity which it was desired by him they should receive. Cows were kept for the purpose of supplying the deficiency of milk of the highbred cows. But this deficiency of milk did not altogether proceed from the circumstance of the cows being of the short-horned breed; because those eminent breeders devoted their whole attention to the develupeinent of flesh, and noi at all to the derelopement of mills. Had the flesh been neglected as much as the milk, and the property of giving milk as much cheristed as the developement of flesh, their short-horned cows would have been deep milkers. As it is, the generality of short-horned cows are not bad milkers. Indeed, it is not to be doubted that where the general secreting powers of the animal system have been in creased, as it nas been in that of the short-horns, the power of secreting milk will be increased with the power of secreting flesh and fat; all that seems requisite is to encourage the power of that secretion which for the time is most wanted. I have no doubt that it is completely in the power of the breeders of short-horns to make them good milkers. It would be to desire an impossibility, to desire the full developement of flesh, fat, and milk at the same time; but there is no absurdity in desiring a large secretion of flesh and fat at one time, and a large secretion of milk at another, from the same cow. Accordingly, this is the very character which has been acquired by short-horned cows. They will yield from six to sixteen quarts a day throughout the season; and they are so constant milkers that they seldom remain dry above six weeks or two months before the time of calving.

"But the practice of the owners of public dairies in towns, were there no other proof, would prove the milking powers of short-horn cows. They prefer them as the greatest and most steady milkers; and it is now difficult to see cows of any breeds but short-horns or crosses with them in these dairies. In I,ondon, Edinburgh, and Liverpool, fine short-horn cows may be seen at the public dairies. They are bought by the milkmen whenever they come of age, that is, five or six years old. They give milk till they attain the age of eight or nine, and are then fed off fat for the butcher. These cows can be fed off fat. This property, and that of milking, prove clearly that short-horns possess both in a remarkable degree. They do not, it is true, possess both in an eminent degree at the same time; but they exhibit either property separately when it is desired. They thus give a return in flesh for part of their original high price, while they remunerate their owners in the mean time with an abundance of milk for their food."

Dairies in Holland.-Holland has k.xg been celebrated for its fine dairies, and the Highland Society of Scotland, considering that the Scotch dairies might derive some advantages from an acquaintance with the management of those of Holland, offered a premium for the best report upon that subject, founded upus personal observation. The premium was in 1833 awarded to John Mitchell, whose report, filled with interesting facts and details, is published in the Transactions of the Highland Society for that year. In the quotation formerly made from the London Cummercial Journal, the superior qualities and higher market value of Dutch butter were referred to. Some idea of the dairy produce of Holland may be gained by considering, that in addition to the home consumption of a populous country, and the 
vast quantilies sent to other parts of Europe, to the West and East Indies, and other parts of the world, England imported in 1830 no less than $116,233 \mathrm{cwt}$. of Dutch butter, and 167,913 cwt. of Dutch cheese.

The pastures in Holland, as is generally known, have been reclaimed from the ocean, the waters of which are kept off by artificial embankments. The lands, of course, lie very low and flat, and as the water in the numerous canals is always near the top, the soil must be moist. The ground is seldom broken up with the plough, but is kept in good condition by top dressings, consisting chiefly of the solid, and especially the liquid manures collected in the cow-houses, mixed with the scrapings of the small canals. The first year after such dressing the land is generally mown for hay.

The Hollanders make careful selections of their cows for the dairy, the price of good ones being usually from $\$ 40$ to $\$ 45$. "They are generally fattened and turned off to the butcher, at eight years old, and bulls at four or five. The cows are turned to pasture in March or A pril, and are at first covered with a very thick cloth of tow, covering the upper half of the body from the shoulders to the tail, to prevent diseases from cold. They are pastured about thirty weeks. Hay is their common food in winter, though rape-cake and brewer's grains are sometimes added. The byers or cowhouses are generally lofty, airy, paved with large square bricks, and kept perfectly clean. The ronf is about ten feet high. There are no racks or mangers, but the food placed in gutters, always clean, near their heads. Gutters in the rear serve to carry off the urine and dung, and these gutters are also kept clean.

"Process of manufacture.-The cows are always milked by the men, and the butter and cheese made by the women, generally of the family. Ninety cows are managed by nine men and two women. There is generally one man required to ten cows; while two women are considered enough for any dairy. The farmer reckons that he can make 100 guilders, about $\$ 40$, per annum, by each cow.

"Butter.-There are three distinct kinds of butter made in Holland; grass butter, made when the cows are at grass; whey butter, from the whey of sweet milk cheese; and hay butter, made in winter.

"Grass butter.-The cows being carefully milked to the last drop, the pitchers containing the milk are put into the koclbak. When the cream has been gathered and is soured, and if there is a sufficient quantity from the number of cows, they churn every twenty-four hours, the churn being half filled with the soured cream. A little boiled warm water is added in winter, to give the whole the proper degree of heat, and in very warm weather the milk is first cooled in the koelbak or cooler. In small dairies the milk is sometimes churned, when soured, without separating the cream. The butter, immediately after being taken out of the churn, is put into a shallow tub, called a vloot, and carefully washed with pure cold water. It is then worked with a slight sprinking of fine salt, whether for immediate use or 'he barrel. When the cows have been three weeks at grass, the butter is delicious, is made in fanciful shapes of lambs, stuck with the flowers of the polyanthus, pyramids, \&c., and sells as high as 44 stivers, 60 to 70 cents, the $17 \mathrm{oz}$. or Dutch pound. If intended for barrelling, the butter is worked up twice or thrice a day, with soft, fine salt, for three days, in a flat tub, there being about two pounds of this salt allowed for fourteen pounds of butter; the butter is then hard packed by thin layers into casks, which casks are previously carefully seasoned and cleaned. They are always of oak, well smoothed inside. Before being used, they are allowed to stand three or four days, filled with sour whey, and thereafter carefully washed out and dried. Each cow, after being some time at grass, yields about one Dutch

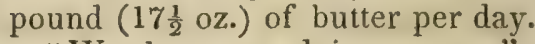

"We beg our dairy-women," says Judge Buel, "to mark two points in the preceding process. 1. No salt is used but what is incorporated with and dissolved in the butter, and which is necessary to give it flavour; and, 2. The butter intended for keeping is worked from six to ten times, to incorporate the salt, and to separate from it every particle of liquid, which, if left in it, would induce rancidity.

"Hay butter undergoes a like process.

"Whey butter.-The whey is allowed to stand three days or a week, after being separated from the curd, when the cream is skimmed off, or the whey itself put into the churn, and the butter is formed in about an hour. By this process, in winter, one pound of butter is obtained from each cow in a week, and in summer one pound and a half. The relative prices are generally, grass butter $8 \frac{1}{2}$ stivers, hay butter 7 , and whey butter 6 .

Cheese.-There are four kinds of staple cheese made in Holland; the Edam and Gouda, both made from unskimmed milk; and two kinds, Kanter cheese, made from milk once or twice skimmed.

"Edam cheese.-The process of manufacture of the Edam cheese is as follows:

"The milk being yearned as soon as taken from the cow, when coagulated, the hand or a wooden bowl is passed gently two or three times through the curds, which are then allowed to stand a few minutes. The bowl or finger is again passed through them, and they stand a few minutes. The whey is then taken off with the wooden bowl, and the curd is then put into a wooden form (of the proper size and shape of the cheese to be made). This form is cut out of the solid wood by a turner, and has one hole in the bottom. If the cheese is of the small size (about $4 \mathrm{lbs}$.), it remains in this form about ten or twelve days ; if the large sized, it remains about fourteen days. It is turned daily, the upper part during this time being kept sprinkled with about two ounces of purified salt of the large crystals. It is then removed into a second box or form of the same size, with four holes in the bottom, and put under a press of about $50 \mathrm{lbs}$. weight, where it remains from two to three hours if of the small size, and from four to six if of the large size. It is then taken out, and put on a dry, airy shelf in the cheese apartment, and daily turned over for about foizr 
weeks, when they are generally fit to be taken to market.

"Alkmaar, in North Holland, is the great market for Edam cheese. It is not uncommon to see 800 farmers at the market, and 470,000 cheeses for sale on one day. The price there averages about 30s. per cwt. (\$6 66). (Cultivator.)

"Gouda cheese. - This kind of cheese is also made from the milk immediately on its being taken from the cow. After gradually taking off the principal part of the whey, a little warm water is put upon the curd, which is left standing for a quarter of an hour. By increasing the heat and quantity of water, the cheese is made hard and more durable. All the whey and water is then taken off, and the curd is gradually packed hard into a form cut out by the turner, flatter and broader than the form for the Edam cheese. A wooden cover is placed over it, and the press, with a weight of about $8 \mathrm{lbs}$., put upon it. It is here frequently turned, and altogether remains under the press about twenty-four hours. The cheese is then carried to a cool cellar, put into a tub containing pickle, the liquid covering the lower half of it. The water for the pickle is boiled, and about three or four handfuls of salt melted in about thirty imperial pints of water. The cheese is not put in until the water is quite cold. After remaining twenty-four hours, or, at most, two days, in the pickle-tub, where it is turned every six hours, the cheese, after being rubbed over with salt, is placed upon a board slightly hollowed, having a small channel in the centre, to conduct the whey which runs off into a tub placed at one end. This board is called the zouttank, upon which several cheeses are placed at a time. About two or three ounces of the large crystallized salt is placed upon the upper side of the cheese, which is frequently turned, the side uppermost being always sprinkled with salt. It remains on the zouttank about eight or ten days, according to the warmness of the weather; the cheese is then washed with hot water, rubbed dry, and laid upon planks, and turned daily, until perfectly dry and hard.

"The cheese-house is generally shut during the day, but must be open in the evening and early in the morning.

"Grouda is the principal market for this kind of cheese, where it sells at about $35 \mathrm{~s}$. per cwt.

"Each cow at grass in Holland is calculated to give about three or four pounds sweet milli cheese per day.

"We omit the method of making the Kanter cheese, which is similar to our slim-milk cheese, and of the cheese utensils.

"The milk-houses are generally between the dwelling and cow-house, in a square apartment, in a corner of which is the cooler; it is airy, roomy, and paved with square bricks, the upper part serving for churning, making cheese, \&c.; and descending a few steps, into a sort of cellar, is the milk-room, having two or four windows, which are opened or shut according to circumstances.

"The cheese-houses are also generally cellars, kept clean and well ventilated.

" The Dutch are remarkably particular as to the quantity and quality of their salt, of which there are three kinds manufactured; and it is this, our reporter thinks, which is the principal cause of the sweet and delicious flavour of their butter, which, although well-flavoured, hardly tastes of salt, or, rather, of that acrid quality which is perceptible in the butter of Great Britain.

"Cleanliness governs in all the Dutch dairies. Every dwelling-house is a model and a pattern. They seem to vie with each other on this point. The cow-house is pure and clean, not a particle of filth being to be seen in it; the cows, says Mr. M., are as clean as if they were in a dining-room; the milk and cheese-houses, and, in short, every part of the house, are free from dust and dirt of any kind. The whole apartments, even the byre (stalls) and hay-house, are generally under one roof; and the cleanly system and the admirable arrangement give that comfort and pleasure which are too often wanted in other conntries." See Euel's Farmers' Instructer.

The Journal of the English Agricultural Socjety contains an article on the rural affairs of some parts of Holland, in which an excellent account is given of the Holstein mode of making the butter which is so very famous. The Holstein dairies are very extensive, varying from 100 to 400 cows, and provided with buildings and every necessary accommodation on a corresponding scale. Whenever practicable, the milk room or cellar is made to face the north, and sufficiently capacious to hold the proceeds of at least four milkings. The brick or tile floors have already been described. Numerous windows or air passages are prepared so as to secure the most perfect ventilation; they are furnished with glass sashes arıd shutters, and within have gauze curtains to exclude insects.

When, as is sometimes the case, both cheese and butter are made at the same dairy, the apartment for cheese is always kept separate from that devoted to butter-making, from the vicinity of which last every thing is carefully kept away which by any possibility could exercise a sinister influence on the very susceptible substances of milk and butter, which suffer to a degree those unaccustomed to observe it little suspect from an impure atmosphere. The dairy is managed by women, of whom there is the superintendent, or head dairy woman; and one dairy maid to every eighteen cows. There is besides the owner or overseer, and one or more men who attend to the feeding of the swine. There are others whose business is to attend to the cows, see that they are properly fed, and every thing in its proper place and keeping. The overseer sees that the cows are fully milked, as on this the quantity and excellence of the cream is greatly depending. It has been ascertained by carefully repeated experiments that the first drawn milk contains five, the second eight, and the fifth seventeen per cent. of cream.

The business of the head dairy woman is arduous, and demands a full acquaintance with the various processes. "She must not only thoroughly understand, but accurately ouserve the precise time when the milk should be $2 \mathrm{~L}$ 
creamed; the degree of acidity it must attain in the cream barrels; its temperature, whether requiring the addition of warm water or cold to the churn; as well as the all-important operations of kneading, beating, salting, and packing the butter." The milking commences at four in the morning (the milkers rising at three), in the field, and the milk is conveyed to the dairy by a one horse wagon, from hooks on which large vessels are suspended. To prevent the milk from flying over the brim of these vessels in moving the wagon, thin pieces of wood, of nearly the size of the vessel, float on the milk, and this practice is adopted when pails are carried by the hand.

The effect which vessels made of different materials has on the promoting or retarding the acidity of milk, has received much attention in Holland, and the vessels most generally preferred on all accounts are shallow wooden keclers, holding about eight quarts. In some few instances glass vessels are used, and some of the reports speak of them highly. It has been found that cream, to make first rate butter, must be removed from the milk before the latter gets at all sour, and that the cream will not fully rise under thirty-six hours; to prevent souring before that time, especially in sultry weather or during thunder storms, requires particular attention to temperature.

A cellar temperature of from 60 to 62 degrees gives the best and the most cream, the rising being completed in thirty-six hours; a greater degree of warmth hastens the process, but lessens the quantity of the butter; a lower temperature preserves the milk forty-eight or sixty hours, but imparts an unpleasant flavour to the cream and butter. The commencement of souring in milk is marked by a slight wrinkling of the cream, and a slightly acid taste. When this appears, whether the milk has stood a longer or a shorter time, skimming commences. As fast as it is collected, it is poured through a hair sieve kept for this purpose alone, into large barrels of 240 quarts each, in which it remains till the necessary sourness is attained, which in summer usually takes twenty-four hours, and in winter thirtysix or forty-eight hours. During this advance to acidity, the cream is frequently stirred, to prevent its coagulating or becoming cheesy, and when fit for churning, the skill of the dairy woman is required to determine the proper temperature to make good butter. In warm weather the churn is rinsed with the coldest water, and if necessary cold spring water is added to the cream, but if the cellar is properly made, this is rarely necessary. In cold weather the churn is washed in warm water, and is sometimes applied to the cream itself. The churning being completed, the butter is immediately carried to the butter cellar, where, in a large tray or trough made of beech or oak highly polished, and provided with a plug at the lower extremity to let off the milk, the butter is slightly worked and salted with the purest salt, moulded with a ladle into a mass at the upper end of the trough, and left for some hours to drain. In the evening it is thoroughly kneaded and beat, the dairymaid lifting a piece of :hroe or four pounds, and slapping it against the trough with great force to beat out the milky particles. After the whole mass has thus, piece by piece, been freed from the buttermilk. it is again spread out, and receives its full salting (in all about $1 \frac{1}{8}$ ounce of salt to a pound of butter), which is worked with the utmost care equally through the whole, and is then mould. ed into a compact mass. Butter in Holstein is seldom washed, though in some other parts of Holland it is practised with the greatest success. When enough is made to fill a cask, the several churnings are once more kneaded and beat thoroughly together, a very little fresh salt is added, and it is then packed in the barrel, which is made of red beech wood, water tight, and previously well washed with water and salt. The cask must be filled at a single packing, each layer pounded down, and care being taken that no interstice is left between the butter and the sides of the cask. 'This packing of a cask at a time gives the butter of large dairies the advantage over small ones, as it must be left longer exposed to air before the quantity requisite to fill the barrel is obtained.

"The qualities of first rate butter are considered to be, 1st, a fine yellow colour, neither pale nor orange tinted; $2 d$, a close, waxy texture, in which extremely minute and perfectly transparent beads of brine are perceptible; but if these drops be either large, or in the slightest degree tinged with colour, it indicates an imperfect working of the butter; while an entirely dry, tallowy appearance is equally disapproved; $3 d$, a fresh, fragrant perfume, and a sweet, kernelly taste; 4 th, good butter will, above all, be distinguished by keeping for a considerable time, without acquiring an old or rancid flavour.

"The quantity of food which can be afforded to the cows during winter is determined at the beginning of the season, when the harvest returns are known; and in plentiful years the calculation is, that each cow should be allowed three sacks of grain (generally oats, at 140 pounds the sack), 3,000 pounds of straw, including bedding or litter for the stable, and 1,800 pounds of hay of good quality; while for every 100 pounds of hay deducted she must receive 25 pounds of grain more, and vice versa."

During the winter the requisite colour is given to the butter by some colouring material; and the best for this purpose is found to be a mixture of annatto and turmeric, in the proportion of five ounces of the latter to one pound of the former.

The average quantity of milk from the $\mathrm{Hol}$ stein cows is about 2500 quarts per annum; much depending on the food and care; and it is calculated that every 100 pounds of milk will give $3 \frac{1}{4}$ pounds of butter, 6 pounds of fresh cheese, 14 pounds of buttermilk, and 763 pounds whey, where cheese is made. Fifteen quarts of milk are considered a fair average for a pound of butter, though sometimes a cow gives milk so rich that 12 quarts make a pound. "On the whole, it is considered a fair return from the Holstein dairies when the produce amounts to 100 pounds of butter and 150 pounds of cheese per annum to each cow." (Buel.)

The farmer will find a good article on the 
dairy in Professor Low's Brects of British Animals, - a beautifully illustrated work, which should be patronised by all the Farmer's Clubs, as well as by those agriculturists to whom its price is not an object. The following authorities may also be consulted with advantage: "On the Meadows and Dairies of Holland." (Trans. High. Soc. vol. i. p. 202); "Reports upon Dairy Management," (Ibid.) p. 341 ; vol. ii. p. 254 ; vol. iv. p. 406); Mr. Aiton "On the Making of Butter and Cheese in the Dairy District of Scotland," (Quart. Journ. of Agr. vol. v. p. 350, and Com. to Board of $A g r$. vol. iv. pp. 211-337); also the article "Dairy" in vol. viii. of the Penny Cyc. in Baxter's Lib. of .Agr. Know., and in vol. iii. of British Husbandry, Lib. of Use. Know.)

DAISY, COMMON, or DAY'S EYE (Bellis perennis). These large white gawky-looking flowers are so universal in English pastures and meadows, that description is almost needless. 'They flower all the year, principally dotting the meadows early in May; in March they begin to be common, and after Midsummer to be less numerous. The root is slender, and the plant flowers from March to September. Double as well as proliferous daisies are common in gardens, and the proliferous variety is now and then found wild. Domestic cattle scarcely touch this plant. Notwithstanding its beauty and its celebration by poets, the daisy is thought a blemish or intruder in neat grass-plats, and can be overcome by perpetual stubbing only. (Eng. Flor. vol. iii. p. 448.) The most common daisies in the United States are that called Flea-bane, and by botanists Erigeron strigiosus, and the Horse-ueed or Eutterweed (Erigeron Canadensis). This last has an annual root, the stem growing from six inches to five or six feet in height, very hairy and much branched above. The flowers are white, and disposed in rays. In the Middle States it is a common weed in fields and on roadsides, flowering in August and September.

The daisy called Flea-bane has a biennial root, as some botanists believe, and is common in pastures and upland meadows, flowering in Iune and August. The flower consists of white rays. It is a very common and worthless weed, especially in the first crop of upland meadows after a course of grain crops. (Flor. Cest.)

Another species of daisy called the Handsome Erigeron (E. pulchellus), is common on the borders of woods and thickets, where it flowers in the Middle States in May and June. Its root is perennial, and the whole plant is somewhat hoary. The rays composing the flowers, which are large, are of a pale bluish purple.

Silme ten or twelve additional species of erigeron have been found in the United States. (Flor. Cest.; Nuttall's Genera.)

DAISY, MOON, or MIDSUMMER DAISY (Chrysanthemum leucanthemum). The Ox-eye Daisy, or white-flowered chrysanthemum (Pl.10,w), is a vile weed introduced in to the United States from Europe. In many parts of the country it is spread wide and far, constituting a serious nuisance.

D.AM. The mother of any young domestic animal. Also a mole or bank to confine water. See Eм⿱亠䒑⿰кмехт.
DAMSON. A small, uscful, black plem, brought originally from Damascus, whence the name.

DANDELION, COMMON (Lenntodon tararncum). A corruption of the French name dent. de leon, or lion's tooth. An indigenous, perennial plant, growing in meadows and pastures, on roadsides, ditch banks, and indeed everywhere. Root tap-shaped, very milky, externally black, difficult of extirpation; leaves numerous, spreading, of a bright shining green, quite smooth, and they may be called liontoothed; flowers one and a half inches wide, of a uniform yellow colour, which blow from April to August, and have the remarkable property of expanding early in the morning in fine weather only, and closing in the evening. (Eng. Flora, vol. iii. p. 349.) It is a valuable medi. cine, is aperient, powerfully diuretic, and alterative in its qualities, and, if persevered in, is excellent in liver complaints; it must be taken in decoction, or in the form of extract. Its de. obstruent influence in torpid conditions of the liver is striking; but its use must be persisted in for a considerable length of time. It should now and then be omitted for a few days, as it is apt to derange the stomach.

By culture, and especially by blanching, this herb, though, like the garden lettuce and endive, originally full of bitter milk, becomes sufficiently mild to be eaten in a salad, nor is its bitterness of a disagreeable kind. In France the roots and leaves are eaten with bread and butter. The marsh dandelion ( $L$. palustris), is a distinct species, smaller in size than the fore. going, and naturally a bog plant, growing in low boggy meadows. Dandelion is relished by goats, and especially by hogss, who devour it eagerly; but sheep and cows dislike it, and horses totally refuse it. (Willirh's Dom. Encyr.)

DANDELION HAWKBIT (Apargia tarax-

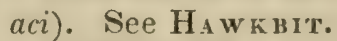

DANDRIFF. A species of scurf which is brushed out in grooming the horse, and consists of scales or portions of the cuticle, or scarf skin, detached in its gradual change or renewal.

DANE-WORT, or DWARF ELDER WALI. WORT (Samburus ebulus). The green leaves of this European plant have a narcotic smell, and are said to expel mice from granaries; nor will moles come where these leaves or those of the common elder are laid. Cattle will not eat the foliage. Its berries impart a violet colour, and their juice, mixed with vinegar, dyes raw linen. as well as morocco leather, of an azure blue. (Eng. Flora, vol. ii. p. 108; Willich's Encyr.) This perennial plant is frequently mistalien for the common elder. It grows four or five feet high, and dies away every autumn to the ground. The stalks are green and round, very like the shoots of common elder; but having no woody part about the plant, they rise areen from the ground. The leaves are longer than common elder leaves, and they are serrated round their edges. The flowers are small and white, succeeded by black berries, which the birds rarely suffer to ripen. It loves untilled ground, hedgeways, \&c., flowering in summer. and ripening its berries in autumu.

DANGEROIS ANIMAI.S. See NuIsaxc. 
DANNOCKS. A provincial name for hedging-gloves.

DAPPLE. A term sometimes used to signify marked with various colours.

DARGUE. A local word signifying the quantity of peat turf one man can cut and two men wheel in a day.

DARNEL (Bromus secalinus). Smooth rye brome-grass. (Bromus mollis, PI. 7, b.) Soft brome-grass. Both these grasses pass in England under the common name of darnel. Professor Martyn supposes the annual bearded rye-grass (Lolium tomulentum, PI. 7, c), to be the darnel of the Romans (Virg. Georg. i. 153). Mr. Holdich, of the Farmer's Journal (Essay on Weeds), observes that he never found this grass among corn crops. Sinclair (Hort. Gram. p. 32), says, "I have found the Eromus mollis and Alopecurus agrestis, with the Bromus secalinus to be the most prevalent weeds (of the annual grass kind) in corn fields ;" these, therefore, may be considered the darnel of the British farmer. In the Essay of Mr. Pitt, he treats of darnel as a plant which he had often seen in wheat crops, and perfectly well knew. Dr. Withering, in his Botany, a!so mentions this darnel (Lolium temulentum), as "common in corn-fields, mostly among barley and flax;" and that it is a very troublesome weed among wheat, in Norfolk and Suffolk. The doctor also describes another species of Lolium ( $L$. arvense), as being much like the other, only it is smooth, and calls it white darnel. (Pl. 7, d.) He observes that it is common in many parts and places, and "very injurious to a crop of wheat," for which he quotes Mr. Pitt's authority. Mr. Pitt, indeed, names his darnel white darnel, but immediately calls it $L$. temulentum. Both these are annuals, and flower in July and August. Now it seems never to have occurred to writers on this subject, that, when they were in any difficulty about agricultural weeds, they should have recourse to the characters of the seeds of the plants. It is quite impossible that any grass seed should be darnel, either ancient or modern, unless the seeds are heavy enough to resist the operation of dressing, and to remain in the wheat in part, in spite of all effurts to get rid of them. The ancients had wind and sieves, and they no doubt exerted themselves as much as possible to rid their wheat of such seeds as those of the $L$. temulentum, while such deleterious effects are ascribed to them if baked in bread, \&c. Whether these plants be common in corn fields in any part of England, or whether, if they be, their seeds are heavy enough to remain in samples of wheat and barley, must here be left undecided. I can only say that, in all my experience, and as far as I have ever seen or heard from practical authority, I know of no darnel in England but the Bromus secalinus, and, less generally, the Bromus mollis. (Eng. Flora, vol. i. p.151-3; Hort. Gram. Wob.; Sinclair's Weeds, p. 4.)

DARNEL (Lolium). There are in England three species of darnel enumerated by Smith (Eng. Flora, vol.j.p. 173). The perennial darnel (L. perenne), common in meadows, pastures, and waste ground, and well known to the farmer by the name of rye-grass or ray-grass. It vields an early crop of hay upon high or sandy 400
, and makes a fine turf, which, however is said not to be lasting except upon a rich soil. Much valuable information coricerning its cultivation and merits is collected by Professor Hooker in his continuation of the Flora Londinensis. The result seems to be, that the grass is best suited to the light land of Norfoll where it first obtained its reputation. See Rri Grass. 2. The bearded darnel (L. temulenium), the seeds of which are of very evil report for causing intcxication in men, beasts, and bircls, and bringing on fatal convulsions. Haller speaks of them as communicating these properties to beer. 3. Short-awned annual darnel (L. arvense), rather smaller and smoother than the preceding, of which it is probably but a variety. (Eng. Flora, vol. i. p. 172-5.)

It would appear that different countries attached the name of darnel to different plants. Thus, in England darnel is referred to under the head of Rye-Grass, or I.olium, and also described as a species of Bromus. In some parts of continental Europe it appears the seeds of darnel have the reputation of causing intoxication in men, beasts, and birds, the effects being sometimes so violent as to produce convulsions. In Scotland the name of Sleepies, is applied to darnel, from the seeds causing narcotic effects. In England and America these effects have never been known to arise from eating flour made from wheat containing cheat. It is evident that the enemy of the grain crops called darnel, chess, and cheat is not the same plant in all countries, probably for the reason that different species of grasses somewhat resembling each other in external characters may be more favoured by circumstances of soil and climate and exposure in some places than in others. Cheat or chess is evidently a more hardy plant in resisting the effects of frost than wheat or rye, which often die in situations exposed to cold or other unfavourable influences, leaving the darnel, which, from some resemblance in the plant before heading, is thus supposed to be degenerated wheat, barley, or rye. When, however, the soil is rich and the other circum. stances favourable to the growth of wheat and other winter grains, these spread first over the ground and keep down the cheat or chess, or brome and rye-grasses, at least until after harvest. Not only does the idea prevail that wheat and other cereal grains degenerate to darnel, but also to spelt, well known to be a peculiar and very inferior species of wheat, of hardy growth, and much cultivated in some parts of Europe, especially in mountiinous districts. Thus, we find that to believe the evidence of common observation, wheat degenerates into spelt in some countries, and in others into a species of bromus, fescue, or that species of rye-grass (the lolium temulentum) which is endowed with intoxicating qualities, all being designated as the wheat enemy, darnel. Nothing analogous to such metamorphosis can be found in nature, neither can it be fairly believed that such degeneration is possible, until some one makes a crucial experiment. It belongs to the credulous to afford the demonstration. For more particular information in regard to cheat or chess in the United 


\section{DARTARS.}

States, see Dr. Darlingrton's Flora Cestrica, under the head of Bromis secalinus, Rye bromus, Cheat or Chess.

DAR'TARS. In farriery, a sort of scab or ulceration taking place on the chin, to which lambs are subject.

DAUBING. A word meaning provincially plastering with clay.

DAUBY. A word applied to land when wet, signifying clammy or sticky.

DAVYING. A provincial word applied to the getting of marl out of the face of the cliffs on the sea-coasts, when it is drawn up by a wince.

DEADLY NIGHTSHADE. See BrLlaDONNA and NIGHTSHADE.

DEAD-NETTLE (Lamium). A genus of perennial or annual European herbs, of which twenty species are described. Among which, are the white dead-nettle ( $L$. album) and red dead-nettle ( $L$. purpureum) to which medicinal properties are ascribed. The herbage of the former is scarcely eaten by cattle, and has a slightly fetid scent. The flowers abound with honey. Low says (Frac. Agr. p. 446) it is sometimes common in corn-fields, and having a strong, creeping, perennial root, it should be sarefully extirpated.

DEAD-TOPS. A disease incident to young trees, which may be cured by cutting off-the withered parts close to the nearest sound twig or shoot, and claying them over, in the same manner as practised in grafting.

DEAF. A provincial word signifying blasted or barren, as a deaf ear of grain, a deaf-nut, \&c. or such as have no grain or kernel. In such cases it is probable that the pollen has been scattered, and never communicated the fertilizing principle to the seed, which resembles in this respect an addle egg.

DEAL (Sax. oelan, to divide; Ger. dielen, Dutch, deelen: Dan. daeler). 'The small thickness into which a piece of timber of any sort is cut up; but in England the term is now improperly restricted in its signification to the wood of the fir tree, cut up into thicknesses in the countries whence deals are imported.

DEATH-WA'TCH (Anobium tessellatum; Termes pulsatorium, Lin.). The popular name in England for a small insect that harbours chiefly in old wood. It is produced from a very minute white egg, hatched in March; in the perfect state these insects are about $\frac{5}{16}$ ths of an inch in length, and of a dark brown, spotted colour. They make a ticking noise, which is an expression of mutual affection between the male and female, but which has and is still superstitiously imagined by some to be an omen of death. See Penny Cyclo. vol. viii.

DEBRIS (Fr.debrée). In geology, any worn materials, such as fragments of rocks, ruins, or rubbish.

DECAY. All vegetable as well as animal substances undergo two processes of decomposition after death. One of these is named fermentation, the other decay, putrefaction, or eremacausis. The decay of woody fibre (the principal constituent of all plants) is accompanied by a phenomenon of a peculiar kind. This substance, in contact with air or oxygen

\section{DECIDUOLS.}

gas, converts the latter into an equal volume of carbonic acid, and its decay ceases upon the disappearance of the oxygen. If the car bonic acid is removed, and ixyeren replaced, its decay recommences, that is, it again con verts oxygen into carbonic acid. Worrly fibru consists of carbon and the elements of water and if we judge only from the products formed during its decomposition, and from those form ed by pure charcoal, burned at a high temperature, we might conclude that the causes were the same in both: the decay of woody fibre proceeds, therefore, as if no hydrogen or oxygen entered into its composition.

A very long time is required for the completion of this process of combustion, and the presence of water is necessary for its maintenance: alkalies promote it, but acids retard it; all antiseptic substances, such as sulphurous acid, the mercurial salts, empyreumatic oils, \&c., cause its complete cessation.

Woody fibre, in a state of decay, is the sub. stance called humus.

The property of woody fibre to convert surrounding oxygen gas into carbonic acid di. minishes in proportion as its decay advances, and at last a certain quantity of a brown coalylooking substance remains, in which this property is entirely wanting. This substance is called mould; it is the product of the complete decay of woody fibre. Mould constitutes the principal part of all the stratia of brown coal and peat.

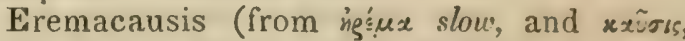
combustion) is the act of gradual combination of the combustible elements of a body with the oxygen of the air; a slow combustion or oxidation.

The conversion of wood into humus, the formation of acetic acid out of alcohol, nitrification, and numerous other processes, are of this nature. Vegetable juices of every kind, parts of animal and vegetable substances, moist sawdust, blood, \&c., cannot be exposed to the air, without suffering immediately a progressive change of colour and properties, during which oxygen is absorbcd. These changes do not take place when water is excluded, or when the substances are exposed to the temperature of $32^{\circ}$, and different bodies require different degrees of heat, in order to effect the absorption of oxygen, and, conse. quently, their eremacausis. The property of suffering this change is possessed in the hignest degree by substances which contain $\mathrm{ri}$ trogen. (Liebig, Org. Chem. Part 2d.)

In the Appendix to the Third Report of the Agriculture of Massachusetts, 1840, Dr. S. L. Dana adduces the following example, to sh: ${ }^{\text {w }}$ w that even with the presence of moisture, vegetable matter will not decay, if air is exc.uded. A piece of a white birch tree was taken from a depth of twenty-five feet below the surface, in Lowell. "It must have been inhumed there probably before the creation of man, yet this most perishable of all wood is nearly as sound as if cut from the forest last fall." See $N_{1}$

\section{TRIFICATION.}

DECIDUOUS (Lat. decido, I fall off). In zoology, a term applied to parts which have but a temporary existence, and are shed during 2. 2 401 
the lifetime of the animals, as certain kinds of but it snly congregates in low covert:s. The hair, horns, and teeth. In botany, it is applied to such trees and plants as shed their leaves in the autumn, in contradistinction to evergreens. 'Thus the oak, the elm, the beech, \&c., are called deciduous trees.

DECOMPOSITION (Lat. decompositus). The reduction or dissolution of any mixed body to the separate parts of which it is composed. It is of great importance to be assured, that, in every process of decomposition, whether by heat, air, or putrefaction, nothing is lost, nothing is ultimately destroyed; the components of the decomposed substance form new compounds. Decomposition is therefore not, in strict language, a destructive process; but merely a change of aftinities, and a transformation of old into new compounds.

DEER (Sax. oenp; Swed. diur; Lat. cervus). The general name of animals of the stag kind, of which there are several species. These may be primarily divided into two groups; of which one includes those with antlers more or less flattened, the others those with rounded antlers. The elk is the most characteristic species of the first group. The reindeer differs from the rest of the genus in the presence of antlers in both sexes, and in the great developement of the brow-antlers. The third species of deer, referable to the flat-horned group, is the English park, the fallow-deer (Cervus dama, Lin.). The period of gestation in the fallow-doe is eight months. We have in England two varieties of the fallow-deer, which are said to be of foreign origin; the beautiful spotted kind, and the deep brown sort. These have multiplied exceedingly in many parts of the kingdom, which is now become famous for venison of superior fatness and flavour to that of any other country in the world. The spotted deer of the Dama species must not be confounded with the spotted deer brought from India, which is a distinct species, namely the Cervus (Axis) maculatus, and never changes its spots, whereas the spotted fallow-deer becomes a uniform brown in winter. This species has been domesticated in England, and propagates freely in parks. It is smaller and more elegant in form than the fallow-deer, and furnishes as good venison. Of the species of deer of which the beam of the antler gives a rounded form in section, the red deer ( $C$. elaphus) and the roebuck ( $C$. capreolus) are indigenous species. The male red deer, in the language of "the noble urt of venerie," is called a "hart," and the female a "hind." She goes with young about a week longer than the fallow-doe; and brings forth in May a single fawn, rarely two. The young of both sexes are at first styled "calves." In the common stag, or red deer, the shedding of the horns takes place about the end of February, or during March. The fallow-deer sheds his horns from about the middle of Aprit. $h$, the first weeks of May. The roe-buck is the smallest species of European deer; the male is monogamous; and the female brings forth two fawns. They are not confined to the ocotish mountains, being still found in some of the rugged woods of Westmoreland and - 'umberland. The roe-buck in its native wilds tces not keep in herds in its perambulations; food $c$ ? the roe-buck in the Highlands of Scotland is the Rubus saxatilis, or roe-buck-berry; but in winter they browse on the tender twigs of the birch and the fir. The flesh of the roebuck is tender and delicate, when the animal has been hunted. The horns are used for handles of knives, and other instruments Three varieties of the genus Cervus are professed objects of the chase; the stag, the fallow-deer, and the roe-buck; each of which have long been followed with great ardour, according to the tastes of different spurtsmen, and their means of gratifying them: the roebuck is, however, becoming scarce.

The following notice of the several kinds of deer found in the United States, is chiefly condensed from Dr. Harlan's "Fauna Americana."

1. The Moose (Cervus alces), is by some called elk. It is the largest species of the deer kind, and is distinguished from all others by having broad and flattened horns, and a hairy tuft and protuberance under the throat. In size, these animals are sometimes larger than a common sized horse. The upper lip is square, very bread, deeply furrowed, and hangs over the mouth.

The length of the moose, measured from the tip of the nose to the base of the tail is 6 feet 10 inches: height of fore-part 5 feet 2 inches; behind 5 feet 4 inches: horns 3 feet 1 inch long; breadth between these at their summits, 3 feet 10 inches: those on the male sometimes weigh $60 \mathrm{lbs}$. 'They consist of a simple and flattened expansion furnished with numerous prongs on the external border. The tail is exceedingly short. The neck is short, and the female has no horns. Both sexes have a tuft of long hair, like a beard, beneath the throat, the male having a protuberance in the same place. The general colour is fawn-brown on the top of the head, the back, and rump; and a deeper brown beneath the lower jaw, neck, \&c. The under part of the tail is whitish. The young animal is of a reddish brown colour without spots.

Moose live in small troops, in swampy places. Their gait, which is commonly a trot, is much less active than that of other deer. They live upon the buds of trees, moss, and some kinds of plants. In eating from the ground they are compelled, from the shortness of their necks, either to kneel or separate their fore-legs. They rut about the end of August and all the month of September. The females bring forth from the middle of May to the middle of June, generally two and sometimes three and occasionally only one at a time. 'The old moose shed their horns annually, in January and February, and the young in April. They live 15 or 20 years. This species of deer is met with at present only in the more northern parts of the United States, and beyond the great lakes.

2. The Rein-deer (Cervus tarandus), has a total length of 5 feet 6 inches; the horns are 2 feet 10 inches long, and 2 feet 2 inches apart at their summits. Their size is about that of the common deer. the legs being thicker in proportion, and the hoofs shorter and thicker, the neck is very short. The colour varies according to the seasons and age of the animal. The 
adult is of a deep brown in the spring, passing, as the season advances, to a grayish-brown, and grayish-white, and during the warmest portion of the summer, is almost white.

The Rein-deer is the only animal of the deer genus which has been subjugated by man. The Laplanders have large troops of them. The greater part of the males are castrated and harnessed to sledges. The females furnish milk, the flesh food, the skins clothing, cordage, \&c.

In America, however, the Rein-deer has never been domesticated for use. The male adults and sterile females lose their horns in winter, and the new ones are not perfectly hard and matured till August. They carry their young 33 weeks, at the end of which time, generally in the month of May, they bring forth. They abound in the northern regions, but are not found in the United States south of the state of Maine.

3. The Elk (Cervus Canadensis) called also the Canadian or American stag, inhabits Canada, Missouri, and other western states. The head of this species very much resembles that of the common deer. Its height at the withers is 4 feet; length of its branched horns 3 feet to 3 feet 10 inches; length of the tail only 2 inches. A black spot or mark descends from the corner of the mouth on each side of the lower jaw. The prevailing colour of the body above the flanks is a clear bloody-red. The female has no horns, and its colours are less strong. The elks associate in families. The females bring forth in the month of July. A fine specimen preserved in the Philadelphia museum, 13 years old, measures from the tip of the nose to the base of the tail 7 feet 7 inches.

4. The Virginian Deer (Cervus Virginianus), is the common deer found throughout the United States wherever extensive forests remain. It is met with as high north as Canada, and passing southwards through the Isthmus, is even seen on the river Oronoco, in South America. Its total length is $\mathbf{5}$ feet $\mathbf{5}$ inches; the horns, measured following the curvatures, are 1 foot 10 inches long; these are provided with antlers or branches; the tail is 10 inches in length; the weight of the animal ranges from 90 to $120 \mathrm{lbs}$. Its form is light, and its motions quick and exceedingly graceful. The colour of the young animal is of a deep brown, with small white spots; the adults in summer are of a beautiful brown or fawn colour, whilst the belly, insides of the thighs, and lower part of the tail are white. They take their winter coat in October; their summer dress in March and April; their horns fall off in February; they carry their young nine months, and bring forth in July or August. Towards autumn the fawn loses its spots, and the hair becomes grayish, a state to which the hunters apply the phrase in the gray. The coat is shed in the latter part of May and beginning of June, and is then substituted by the reddish coat; in this state the animal is said to be in the red. Towards the last of August, the old bucks begin to change to the dark bluish colour; the doe commences this change a week or two later; in this state they are said to be in the blue; this coat gradually le agthens until it comes to the gray. The skin is said to be toughest in the red, thickest in the blue, and thinnest in the gray; the blue skin is most valuable. The horns are cast in January; they lose the velvet the last of September, and beginning of October.

This species displays great enmity towards the rattlesnake, which enemy they attack and destroy with singular dexterity and courage: when the deer discover one of these reptiles, they leap into the air to a great distance abruve it, and descend with their four feet brought together, forming a solid square, and light on the snake with their whole weight, when they immediately bound away; they return and repra: the same manœuvres until their enemy is completely destroyed.

In Pennsylvania, by act of Assembly, the killing of deer is restricted to the period between the Ist of August and the Ist of January, and similar enactments exist in other states. Deer are very timorous animals, and the hunter must be intimately acquainted with their habits and haunts. To approach them, even with the rifle, he exercises an instinct, which he has patiently cultivated, but little inferior to his dog. During or after a shower is chosen as the most favourable season for deer-stalking; both as a time when the deer will be more readily met with on the ridges, and that the noise made by the steps of the hunter may be drowned in the droppings from the trees. Their fondness for salt is also often employed for their destruction. A rotten log is salted, and when the hunter perceives that it is much frequented, he conceals himself within rifle-shot near it; or if it bears the marks of being recently visited, with a keen and tutored eye, he traces them to their lair In October, November, and December the venison is best, if the weather has been mild; but after the country has been covered for some time with snow, it generally acquires an unpleasant taste, from their browsing upon the laurels (rhododenrons and kalmias) of the swamps.

5. Great eared Deer (the Cervus macrotis of Say), and by others called the Black Tailed Deer, and Mule Deer, inhabits the most remote northwestern territories of the United States. (Fauna Amer.; also Long's Expedition to the Rocky Mountains, vol. 2.)

6. The sixth species of the American deer, having become extinct, is now only met with in a fossil state. Part of a skeleton having been sent by President Jefferson to the late Professor Wistar, the bones are described by the latter in the Transactions of the American Philosophical Society, vol. i., new series. It possessed many of the characters of the elk (Cervus Canadensis). The bones of this fossil elk have hitherto been discovered only in the morass near the falls of Ohio, called Big-bonelick, in company with the bones of the masto don, \&c. (Harlan's Fauna Americana.)

DEER-NECK, in horsemanship, signifies a thin ill-formed neck.

DENMARK. The agriculture of Denmark, especially of the duchies of Sleswic, Holstein. and Lauenherg, has been described by $\mathbf{M r}$. Carr. A large portion of this extensive district is alluvial soil, of a very fertile descrip. tion, composed of- 


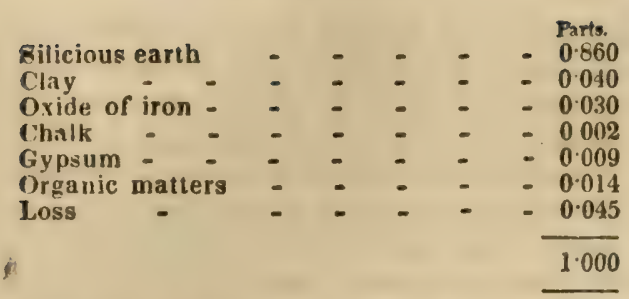

The size of the farms varies between 50 and $\$ 00$ acres, a portion of which is commonly left ior eight or ten years in pasture. The meadows in the marshes are not uncommonly let for two guineas per acre. The usual rotation of crops commonly followed is, after grass, oats, fallow, winter barley, rape for seed, wheat, oats, beans, oats. The Danes plough deep, with four heavy horses; crops usually heavy, often returning as much per English acre, according to Mr. Carr, as-

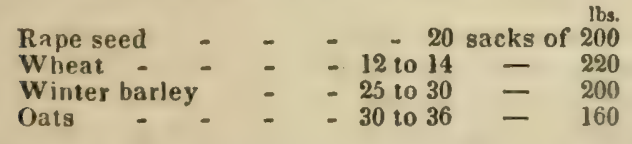

This, however, seems an enormous produce. Their horses, sheep, and cattle are large, but coarse. Jutland is the greatest breeding district, the cows commonly yield from thirty to forty quarts of milk per diem. Their implements of husbandry are poor. The wheel ploughs, with wooden mould-boards, are drawn by two horses. 'The harrows, with the exception of the brake, have generally wooden teeth. The rotation on arable lands, is fallow dunged, rape seed, wheat or rye, barley, oats. In reference to seeds, red clover is sown in the proportion of $8 \mathrm{lbs}$., timothy or rye-grass $6 \mathrm{lbs}$. per acre. Clover is made into hay; and then pastured for four years. There are three distinct breeds of cattle in these duchies. 1. The native cow, middle sized with not very long legs, fine head and horns, moderately thick neck, colour usually red or brown : these give most milk in proportion to their food. 2. The marsh cows, of a larger size, larger boned, colour red, requiring luxuriant pasturage, giving, when in full milk, twenty-four to thirty-two quarts per day, but their butter is smaller in quantity and of inferior quality to the others. 3. 'The Jutland cow, of fine bone, rather long body, colour gray or dun, more valued for its fattening than its milking qualities.

of Roy. Agr. Sor. vol. ii. p. 371.)

DENSHIRING or DEVONSHIRING. A term formerly ased for the operation of paring and burning.

DEVIL'S-BIT SCABIOUS (Scabiosa succisa). This perennial weed, delighting in moist pastures, woods, and hedgeways, grows a foot high, with slender stalks and dark purplishblue flowers, often milk white, resembling the garden scabious. It is also frequently seen in grain-fields. The stalks are round, firm, and upright, divided into several branches, and having two small leaves at each joint. The aves which grow from the root are four inches long, dark green, harsh, and somewhat hairy. The root is blackish, tapering, the end appearing bitten off. It was called "Devil'slint," from the idea among the superstitious of the olden time that the devil had endeavoured to seize upon a plant so useful in its properties to mankind, but could not effect his purpose. $\mathrm{He}$ only bit off a piece of the root in the struggle, and carried with it all the virtue of the plant. (Eng. Flor. vol. i. p. 194.)

The plant known by this name in the Middle States, is the Helonias dioica of Pursh, the Veratrum luteum of Muhlenburg, commonly called Blazing Star. It has a perennial root, and is frequent in woodlands and meadows, where it flowers in May and June. The root of this plant is bitter, and a tonic of some value. (Flor. Cestric.)

DEW (Sax. seap; Dutch daaw; Germ. thau, moisture). The deposition of water from the atmosphere during the night upon the ground, leaves of trees, and plants, blades of grass and other objects on or near the surface of the earth. The phenomena of dew have been considered by all writers on Meteorology, from Aristotle downwards; but they were first successfully investigated by the late Dr. Walls, who gave the true theory of the meteor in an admirable essay on the subject, first published in 1814. Dew does not fall from the atmosphere like rain, but forms in very different quantities on different substances; thus, on metals, it is sparingly deposited; on glass it forms abundantly, as it does also on straw, grass, cloth, paper, and other similar substances. Animal substances are among those which acquire dew in the greatest quantity. The temperature of grass covered with dew is always lower than that of the surroanding air. On calm and very clear nights (the period wher. dew is deposited most abundantly), Dr. Wells very frequently found the grass seven, eight, or nine degrees, and on one occasion, fourteen degrees, colder than the air about four feet above the ground. In England dew probably begins to appear upon grass, in places shaded from the sun, during clear and calm weather, soon after the heat of the atmosphere has declined; that is, three or four hours after midday.

Very erroneous notions in regard to the manner in which dew is formed or deposited, have existed until a very recent period. This im. portant agent in the promotion of vegetable life has been supposed by some to rise from the ground, whilst the phrase "falling dew," common in all languages, would seem to imply an almost universal betief that dew falls from the air, similar to the finest rain or mist. These general impressions have, however, been demonstrated to be incorrect, by the experiments of Dr. Wells; whose explanation of the causes operating in the production of dew is as simple as it is satisfactory. When substances not perfectly transparent, are exposed to the sun, they gain more or less heat; but when the sun goes down they part with their heat and become cold. The surrounding air, however, with its invisible vapour or moisture, being transparent, does not radiate or shoot off its heat, and hence remains comparatively warmer than bodies not transparent. Hence grass, leaves, wood, or stone, by growing cold in the absence of the sun, have moisture to settle on them precisely for the same reason that it iudeposited on the outside of a pitcher or glass containing very cold water 
The dew, therefore, is a deposit from that portion of vapour which enters into the composition of common air, and which is swept in contact with objects at or near the surface of the earth, like breath thrown upon the blade of a knife or other polished surface. When the sky is clear, as in starry and moonlight nights, then do grass, leaves, and other objects, throw off their heat most rapidly and become cooler than the air immediately above them, and the colder they get the more dew is condensed upon them. Different substances part with their heat more or less rapidly, and this explains the cause why different proportions of dew are observed on objects similarly exposed to the atmosphere. A gravel walk will have little or no dew upon it, whilst the grass on each side will be reeking wet: because the grass not only radiates its heat more rapidly than the walk, but does not derive warmth from below to compensate for the loss. Besides, the moisture falling upon the gravel walk is absorbed more rapidly than the dew deposited upon plants.

The temperature at which dew begins to form is called the dew-point, and may be ascertained very accurately. Thus, by laying a chermometer on the grass in the evening, as the herbage parts with the warmth collected throngh the day, and gets colder, the moment little globules or particles of dew are observed on the grass, the degree at which the mercury in the thermometer stands shows the dew-point or temperature at which the watery vapour condenses. It has been observed aiready, that grass possesses a faculty of radiating or parting with its heat very rapidly, on which account it quickly becomes considerably colder than the air immediately above. If, when a thermometer is placed upon the herbage, another is suspended in the air two or three feet above, this last will not fall so low by many degrees, the difference being sometimes as great as 10 or 15 degrees of Fahrenheit.

In making this experiment, the instrument suspended in the air must of course have its bulb covered from the sky by means of a piece of tin-foil, or otber non-radiating substance, to prevent its heat from passing off, in which case the instrument would itself radiate, and thus represent its own temperature and not that of the surrounding air. It may be often observed that in the morning, whilst the grass is reeking wet with dew, a polished substance, lying upon it, such as the blade of a knife, will have little or no moisture on its surface. This shows that polished surfaces part with heat and become cooled down to the dew-point very slowly. 'The most dew will of course always be found on substances which have the power of cooling most rapidly, and few objects do this so readily as grass and the leaves of plants and trees.

'The degree of cold necessary to be acquired by grass and other objects, before they can have dew deposited on them, can always be ascertained beforehand. 'Thus, take a thin tumbler of cut-glass, having polished sides; fill this about half full of pump or ice-water. Plunge into it the bulb of a thermometer, and the moment a film of dew or misty cloud is ceen to form on the polished or side surface, note the degree at which the thermometet stands, and this will be the dew-point. Should pump-water not be sufficiently cool to produce a cloudiness on the polished surface of the glass, some ice may be added; or common salt and nitre, sal ammoniac, or some other substance employed in the production of artificial cold. The temperature at which atmospheric vapour condenses to form dew is generally several degrees below the temperature of the atmosphere. But this is only the case during clear weather, since, when there is a fog, or a rain, the dew-point will be found to correspond with the temperature of the air; showing that any cause which contributes to bring down the atmospheric temperature to the dew-point, will directly promote the condensation of its vapour or moisture into mist, cloud, rain, snow, or hail. The many relations which the dew-point, or degree at which vapour condenses, holds with atmospheric phenomena, may be understond from this. And let it be borne in mind that the dew-point is almost continually rising or falling, like the temperature of the atmosphere, being usually, in clear weather, some four, six, eight, or ten degrees lower than common air, as indicated by the thermometer.

'The very simple means just described, by which the dew-point can be ascertained, approximately, with the aid of a tumbler and thermometer, is by no means the only mode practised for the purpose. On the contrary, it is the most primitive plan, and one requiring great skill and judgment to ensure tolerable accuracy. Mr. Daniells, a learned meteorologist, of London, several years since invented a contrivance called a Hygrometer, for determining the dew-point, which is rather complicated and too costly for general use. It will, we think, be entirely superseded by an instrument very recently invented by Prof. A. D. Bache, of Philadelphia, of which the following general description may furnish some idea.

One of the forms of this instrument consists of a square bar of high!y polished steel, about half an inch in depth and breadth, and ten inches long, one end of which fits into a case attached to a box of tinned iron or copper. 'This box is to contain cold water, ice, or a freezing mixture, according to the season or rather to the temnerature of deposition, or dew-point. The end of the bar which fits into the case has its temperature brought below the dew-point, while the other end is at the temperature of the air; one of the sections of the bar is, therefore, at the dew-point. Between this section and the box vapour is deposited on the side of the bar, and beyond it, in the highly burnished surface of the steel, appears in strong contrast, the line of junction being very well defined. To ascertain the temperature of the line where the deposit of dew commences, cylindrical holes are made perpendicularly downwards in the bar, at intervals of about half an inch apart, throughout the whole length, large enough to admit the bulb of a very small thermometer, and deep enough to carry the bulb entirely into the substance of the bar. If the line of deposition is opposite the middle of one of these holes, the thermometer then gires the dew-point; if between two of them, the 
temperature at each hole is taken, by the same thermometer, or by two thermometers, and the proportional part of the difference corresponding to the distance of the dew-point line from the lower thermometer is added to the temperature observed by it. Care should be taken in making this observation to let the temperature of the different parts of the bar become stationary before attempting to register them. In another form of the instrument, an iron or copper trough containing mercury is substituted for the bar; one side of the trough, which is best made square in its section, is of polished steel or gilded. The trough is attachea to a tin vessel, as in the other instrument. When the surface is cooled down so as to obtain the line of deposit on the face of the trough, the bulb of a small thermometer, which may be moved along in the mercury within, is brought opposite to the line. The temperature which it denotes is, of course, the dew-point. See AтмоSPHERE and HYGROMETER.

DEW-BERRY. The fruit of the blue bramble (Rubus casius), so termed from the resemblance of the glaucous bloom, or waxy secre. tion upon the black shining berries, to dew. (Eng. Flor. vol. ii. p. 409.) See Bramule.

DEWLAP (from lapping or licking the dew). A term applied to the membranous fleshy substance that hangs down from the throats of neat cattle.

DEY. An old English word for milk, now obsolete, but from whence we derive dairy.

DIARRHCA. See Diseases of Sheep, CatTLE, and HonsEs.

DIASTASE. When cold water is poured upon barley newly malted and crushed, is permitted to remain over it for a quarter of an hour, is then poured off, filtered, evaporated to a small bulk over boiling water, again filtered if necessary, and then mixed with much alcohol, a white tasteless powder falls to the bottom, to which the name of diastase has been given.

If unmalted barley be so treated, no diastasc is obtained. This substance, therefore, is formed during the yrocess of malting.

If wheat, or barley, or potatoes, which by steeping in water yield no diastase, be made to germinate or sprout, and be afterwards bruised and treated as above, diastase will be obtained. It is therefore produced during germination. (J.F. $W$. Johnston's Lectures.)

Diastase, like sulphuric acid, possesses the property of transforming starch entirely, first into gum, and then into grape-sugar. One part of diastase will convert into sugar 2000 parts of starch. Seeds which have germinated always contain much more diastase than is necessary for the conversion of their starch into sugar. This excess of diastase Liebig thinks can by no means be regarded as accidental. One of the functions for which diastase appears to be created in the living seed to subserve, is to contribute to the wants of the young plant. "The starch in the seed," says Iohnston, "is the food of the future germ, prepared and ready to minister to its wants whenever heat and moisture concur in awakening It to life. But starch is itself insoluble in water, and could not, therefore, accompany the 406 fluid sap when it begins to move and circulate. For this reason diastase is formed at the point where the germ first issues from the mass of food. 'There it transforms the starch, and ren. ders it soluble, so that the young vessels can take it ap and convey it to the point of growth. When the starch is exhausted, its functions cease. It is then itself transformed and carried into the general circulation. Or when, as in the potato, much more starch is present than is in many cases requisite, its function ceases long before the whcle of the starch disappears. Its presence is necessary only until the leaves and roots are fully formed, when the plant is enabled to provide for itself, and becomes independent of the starch of the seed. When this period arrives, therefore, the production of diastase is no longer perceived.

"This I have said is one of the purposes which appears to be served by diastase in the vegetable economy. That it is the only one we have no reason to believe. There may be others quite as interesting which we do not as yet understand. This.is rendered more probable by the fact that the diastase contained in one pound of malted barley is capable of converting into singar five pounds of starch. (Liebig.) It is the diastase in malt which dissolves the starch of the barley in the process of brewing, but as the diastase contained in malt is sufficient to dissolve so large a quantity of starch, it is obviously a waste of labour to malt the wholc of the barley employed. One of malt to three of barley would probably be sufficient in most cases to obtain a wort containing the whole of the starch in solution. Advantage is taken of this property in the manufacture of the white beer of Louvain, and of other places in Flanders, and in Germany, where the light colour is secured by adding a large quantity of flour to a decoction of a small quantity of barley. And though at the temperature at which the seed germinates, more of this substance may be necessary to transform the same weight of starch than is required in our hands, when aided by artificial heat,-yet as we never in the ordinary course of nature find any thing superfluous or going to waste, there is reason to believe that the diastase may be intended also to contribute directly to the nourishment and growth of the plant. As it contains nitrogen, it must be derived from the gluten or vegetable albumen of the seed; and as a young plant of wheat, when already many inches from the ground, contains no more nitrogen than was originally present in the seed itself (Poussingault), this diastase may only be the result of one of those transformations of which gluten is susceptible, and by which it is rendered soluble, and capable of aiding in the production of those parts of the substance of the growing plant into which nitrogen enters as a necessary constituent." (J. F.W. Johnston's Lectures.)

DIBBI.E (from dipfel, Dutch, a sharp point). An instrument or conical stick to make holes in the ground for setting grain, plants, \&c. "The subject of drilling by machinery," say the Messr... Ransome of Ipswich, "naturally suggests the consideration of whether the operation of dibbling may not be similarly accom. 


\section{DIBBLING.}

pli: hed. Many ingenious contrivances have from time to time been projected for this purpose, and several patents have also been obtained, but we are not aware of any that have been successfully and advantageously used.

DIBBLING is a mode of sowing grain, especially wheat, much practised in some parts of England. It is found to answer the best on the cluver leys of the 'ighter descriptions of land. It is performel by a man walking backwards with an iron aibble into each hand, with which he makes the holes, on the furrow slice, into which the seed is dropped by children, who place one or two seeds into each hole. $\mathrm{By}$ this mode there is a very considerable saving of seed, the quantity employed of wheat being usually from three to five pecks. The wheat plant obtains a more solid soil, and considerable additional employment is afforded to the labourer and his family. It is, however, a rather tedious process, and is not adapted to the stiffer descriptions of soil, for on these the dibble forms little cups, in which the rain is apt to lodge to the destruction of the seed grain. A good dibbler with three active attendants will plant about half an acre per day. The expense for labour is commonly about $7 s$. to $9 s$. per acre for wheat.

Dibbling was first pretty extensively introduced into the east of England about the commencement of the present century. It is spoken of as a novel practice in 1805, by $\mathrm{Mr}$. Curtis of Lynn (Com. Board of Agr. vol. iv. p. 158), and by Mr. Pung of Sudbury, and Mr. Jones of Wellington, in Somersetshire (Ibid. 159); they had previously to this time made some rude attempts to employ the dibble near Yarmouth, in Norfolk, for, in 1784, Mr. Oxley describes the farmers of that district dibbling six, seven, and eight pecks per acre, in two rows on each furrow, by three or four droppers to one dibbler, at an expense of half a guinea per acre. (Young's Annals of Agr. vol, iii. p. 220.)

In Norfolk, and the neighbouring counties, broad-casting is now almost unknown. Mr. J. Barton, of East Leigh, Hampshire, says, 1836 (Hints to Schoolmasters, p. 2), I brought a man from Norfolk, twelve months ago, for the purpose of instructing my labourers in dibbling, and he brought with him the implements, which are made in the following manner. The body of the dibble is a core of hard steel, round which is soft iron, so as always to wear itself sharp; at the upper end is a handle.

The instrument is three feet long, all iron excepting the handle; it weighs six pounds; a man walks with one in each hand backwards, and makes from 3000 to $\mathbf{3 0 5 0}$ holes in a day, giving a slight twist with the wrist at the moment of plunging the iron into the ground, which makes a hole that does not again fill up by the crumbling in of the earth. The ground should be even, then the rows are dibbled, the holes four inches apart, so that four of them can be covered at once by the foot; the rows are about four and a half inches apart; the holes are filled by a rake, or harrow with a few bushes woven into it. I pay nine shillings per acre of 160 rods for the work, out of which the dibbler pays the child-
DIGI'ARIA.

ren who drop the wheat; three grains should be dibbled in each hole, which will take about one bushel and a half per acre. The Norfolk farmers say the yield by dibbling exceeds that by broad-casting by four bushels per acre.

Dibbling costs in Hertfordshire only 6s, and in Norfolk and Suffolk from 78. 10 108. per acre, according to the distance of the lowles, but where they are thickest, and three or four grains placed in each hole, it does not use more than two bushels of seed per acre.

A writer in the Mark Lane Express says, drilling wheat is the most generally practised in the eastern part of the county of Suffulh, and dibbling wheat has been upon the decline for the last twenty years; I believe, because it is more trouble to attend to dibblers than to drilling; but I was in the habit of dibbling wheat when I took business for myself in 1807 , and I continue the practice to the present day, for the following reasons:-1st, It encourages the poor man and his family, by increasing his wages, and gives employment to his children which they would not have if wheat was drilled. 2dly, It shows the children, when young, that Providence has ordained them to get their bread by the sweat of their brow; and I grow upon the four-course shift 100 acres of wheat every year. For wheat I pay for dibbling 7 s. per acre, which is done by seven men that have the largest families: those men earn $5 l$. each in five weeks, generally, but if the weather be fine in less time. Another and $3 \mathrm{~d}$ reason why I prefer dibbling is, that the men and children tread the land with their feet, which makes the land firmer and better for the crop. 4thly, It is better to clean the land, because you can only hoe between the rows of the drilled wheat, when you can hoe all round the dibbled plant. 5thly, The seed goes farther into the ground from dibbling than drilling, the small end piercing deeper than it appears, while the drill appears deeper than it really is, the coulter of the drill raising mould vii each side, so that when harrowed the corn is not so deep as when dibbled. 6thly, There is always more under-corn, that is, small ears, from the drill than from the dibble, and dibbling takes less seed. Six pecks is about the quantity of seed it takes, unless it be very early in the season. I am a great advocate for dibbling, for the above reasons; I have tried both on the same field, and generally found the dibbled wheat the most productive; and it stands up better against the wind and rain :Thus dibbling saves half the 3 bushels usually broud-cast -
And the gain in the crop being - - -+-
-

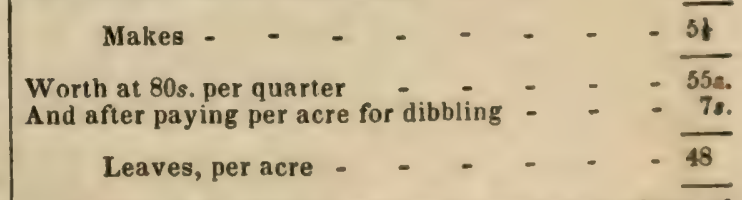

And even at $5 s$. gives a gain over broad-cast wheat of upwards of $20 \mathrm{~s}$.

DICK, DIKE, or DYKE. A provincial word applied to the mound or back of a ditch, and dick-hole is the excavation or ditch itself. In Scotland it means a stone wall. See Diтсн. DIGGING. See Spanf. Hrsasint. DIGITARIA SANGUINALIS. Pl. 7. f. Slen 
der spiked finger-grass, or cock's-font fingergrass. See Finger-grass and Crar Grass.

DILL (Anethum graveolens, from ürntev, on accourt of its running up straight). A plant kept in kitchen gardens in England. It flowers and seeds in August; the stalk is round, hollow, and upright, three feet high, and divided into many branches. The flowers are yellow and small, and stand in umbels on the top of its branches; the root is long. Its leaves and umbels are used in pickling, and the former in soups and sauces. It is a hardy plant, and if grown merely for domestic use may be cultivaled in any'open compartment: but if for seed, a sheltered situation, and a soil rather dry than damp, is to be allotted for it. It is propagated by seed, which is best sown immediately it is ripe, for if kept out of the ground until the spring, it is often incapable of germinating, or if plants are produced they usually decay without perfecting their seed; if neglected until the spring, it may be sown from the close of February until the commencement of May: the earlier, however, the better. Dill may be sown in drills a foot apart, or broadcast, very thin and raked in. The plants are to remain where sown, as they will not bear removing. When of three or four weeks' growth they must be thinned to about ten inches apart; for if not allowed room, they spindle, their leaves decay, no lateral branches are thrown out, and their seed is not good. To prevent these bad effects, in every stage of growth, they require to be kept clear of weeds. The leaves are fit for gathering as wanted, and the umbels about July and August. In September their seed ripens, when the umbels must be immediately cut and spread on a cloth to dry, as the seed is very apt to scatter. A volatile oil and a distilled water are procured from the seeds. Both are used as carminatives; the water is a good vehicle for powders prescribed for children. (G. $W$. Johnson's Kitch. Garden.) The kindred species called sweet fennel (Anethum faniculum) is by far the most esteemed. See FEnNeL.

Dill. A name sometimes given to the twoseeded tare, a species of large vetch.

DINDI,ES. A provincial word applied to the common and corn sow-thistles, as well as to the taller hawk-weed.

DINGLE (from the Sax. oen, or oin, a hollow). A small clough or valley between two steep hills.

DISEASES OF CATTLE. See SHEEP, Horses, and Catter.

DISHLEY BREED. This name, applied to certain well-known breeds of cattle, and especially sheep, is derived from the title of the paternal estate of the celebrated Robert Bakewell. The Dishley, is, therefore, synonymous with the Bakewell breed.

The name of this celebrated original improver of stock is too intimately associated with the history of a great agricultural interest, to be passed over without some particular notice.

Robert Bakewell was born about the year 1725, on his paternal estate at Dishley, in Leicestershire, and died there, October 1st, 1795. 'Though it does not appear that he contributed 408 any thing to literature, even on the subjects to which he devoted his life, yet his efforts, particularly to improve the breed of sheep, justly procured for him a widely extended reputation. The cross breed which he introduced is well known as the Dishley, or new Leicestershire breed. $\mathrm{He}$ is to be distinguished from a $\mathrm{Mr}$. Robert Bakewell, who, in 1808, published Observations on Wool, with notes, by Lord Somerville. (Penny Cyclop.; Gent. Mag. vol. lxv. p. 969.) Of his cattle, Arthur Young remarked, in 1783 (and Young was no flatterer), when speaking of another excellent farmer-" $\mathrm{His}$ cattle are of Bakewell's breed, which is giving them sufficient praise." (Ann. vol. ii. p. 156.) And in the same volume, p. 379, when noticing his breed of sheep, he says, "I have not a doubt that it is, without any exception, the first in the world." To attain this excellence Bakewell devoted himself, travelling in search of stock to breed from, not only over England, but into Ireland and Holland. In 1787 his fame enabled him to reap some reward for these labours; for in that year he let three rams for 1250l., and was offered 1050l. for twenty ewes. The principles which guided him in the breeding of stock are given, in $A n n$. of $A g r$., vol. vi. p. 466, by Arthur Young, who twice visited him at Dishley. He kept con. stantly in view, in all his exertions, these objects-the most meat from the least food-the least offal, and the size of the best joints. He thought, it seems, that the pale-coloured beasts yielded finer meat than the dark ones: he was one of the first who generally introduced the practice of feeling stock under examination: not but what it was a practice partially adopt ed, even in the days of old Holinshed. Young describes, vol. viii. p. 473, the Dishley sheep, and Bakewell's neat cattle at p. 486, which were, perhaps, the finest of his day; and then his great heavy black cart horses, speaking of them as "by far the finest I have seen of that breed." Bakewell did much, too, in the construction of water-meadows (Ibid. p. 490), and it is evident from his various observations reported by Young, that he was an enlightened and successful agriculturist, as well as breeder. The Dishley sheep have long been celebrated for their aptness to fatten, their quietude, and the smallness of their bones-they will long hand down the name of Bakewell as one of the farmer's best benefactors. Bakewell made no secret of his modes of improving stock, and rarely, if ever, entered into controversies with rival breeders. He wrote nothing himself, and the first scientific work on the subject was written by George Culley, in 1792, who formed himself on Bakewell's model. 'The examples of opulent and spirited proprietors have since continued to spread the inprovements commenced by Bakewell, and followed up by Culley, Collins, Kline, and others too numerous to mention.

DISTEMPER is frequently used in the same sense as disease, but is particularly applied to cattle. In racing stables it is the distinguish. ing names for epidemic catarrh or influenza in horses. Bleeding in the early stage is recommended, and it is important that the bowels should be evacuated, and sedative medicines 
given. (The Horse, p. 189.) In dogs distemper is one of the most fatal diseases; a little emetic powder ( 3 grains of tartar emetic and 1 grain of opium) is recommended to be given (Clater's Fur. p. 392), followed by a dose once a day of 4,5 , or 6 grains of 'Turpith's mineral.

J)I'CH (Sax. oic). A trench cut in the ground, usually round the fences of a field. 'I'renches of this kind are formed differently in various localities, but they should always be made so as to keep the water in them as pure as possible.

DIURE'TICS. In farriery, such remedies as nave the power of forcing urine, that is, of stimulating the kidneys to a moderate degree, so as to augment their secreting power. Nitre, iodide of potassium, turpentine, cubebs, and juniper are diuretics. See BALL.

DOCK (Rumex). A large genus of perennial plants, of which ten are natives of England. The bloody-veined dock ( $R$. sanguineus) has already been described under the head Buoonwort. 'The curled dock ( $R$. crispus), a very troublesome and unprofitable weed, abounds in waste grounds, pastures, and by ruad-sides; root tapering, yellowish stem, two or three feet high, somewhat zigzag; leaves smooth, of a lightish green ; clusters of numerous rather crowded tufts or whorls of drooping pale green flowers. The sharp dock ( $R$. acutus) is also not uncommon in low meadows and watery places. Root blackish and rather slender. 'The broad-leaved dock ( $R$. obtusifolius) is a rank and very troublesome weed, common everywhere, which can only be conquered by stidbbing up the root. Mowing is to little purpose; stems a yard high; root black; many headed; yellowish within. The other docks are the golden dock ( $R$. maritimus), the yellow marsh dock ( $R$. palustris), and the great water dock (R. Hydrolapathum). (Eng. Flor. vol. ii. p. 190.) All these docks are purgatives, and may be used instead of rhubarb. A decoction made with an ounce of the root of Rumex obtusifolius and a quart of water, reduced by boiling to a pint, then strained and sweetened, is a valuable remedy in that peculiar cutaneous affection called fish-skin disease (Ichthyosus).

Doск. A term signifying to trim the buttocks, \&c. of sheep.

DOCKING. In farriery, the art of cutting off the tails of horses; and for a description of which see The Horse (Lib. Use. Know., p. 327).

DODDED SHEEP. Such as are without horns.

DODDER (Cuscuta Europaa). Pl. 10, e. The name of a species of bird-weed, which is not very commonly met with. This curious plant is unlike all others in appearance, having no leaves. The thread-shaped, red, or purple stalks, twining about other plants, headed with small reddish flowers, are easily to be recognised; they grow upon heaths and commons, intersecting the furze and nettles, and twisting themselves round every thing they can meet with. The common people, who speak truly, but not in courtly terms, call it devil's-guts and hell-weed, because it does great damage among their tares and flax. The lesser dodder ( C. epithymum) is of a similar habit, but smaller than the preceding.
This is the curious creeping plant or vule which was formerly so frequent and injurious to flax-crops in the United States, often ettangling and spoiling whole lots of it; but since the culture of flax has so much diminisbed, dodder has become rare.

'The American Cuscuta, Dodder, or Iore-Vine, is also a singular parasite, which seizes upon any herbaceous plant which may be within its reach; but it is most commonly found in localities where the snap-weed, spearmint, and false-nettle occur. Its thread-lilie naked stems have some resemblance to brass, or copperwire, and twine constantly against the apparent course of the sun,-or west, south, eust. (Flor. Cestrica.)

DOE. In the technical language of the hunter, the female of the buck or fallow deer. The female of the red deer is called a hind.

DOG (Lat. Canis). An extensive genus of animals, consisting of more than thirty syecies. of which that most generally known is the domestic dog ( $C$.familiaris). The arrangement of M. Cuvier classes the dogs of the present day in to three groups, dogs properly so called, wolves, and jackals. It will be sufficient for our present purpose to speak of the dogs under three heads: 1. Farm dogs; 2. Hunting dogs; 5. Shooting dogs. The first includes the shepherd's dog, the mastiff, and the bull-dog. The second, the terrier, the hound, the harrier, the beagle, and the greyhound. The third class includes the pointer, the setter, and the spaniel. All these will be found noticed under their separate heads. That ingenious naturalist $\mathbf{M r}$. James Wilson has entered into the question of the origin of our domestic breed of dogs. (Quart. Journ. of $A g r$. vol. vii. p. 539-681.) Col. Hamilton Smith has also taken up the natural history of dogs. (Naturalist's Lib. vols. xxv. xxvi. See a notice in the Quart. Journ. of $A g r$. vol. ii. p. 511.) All zoologists agree that there is no trace of the dog to be found in its primitive state of nature, although wild dogs exisi in India and America. The great affinity to the wolf, and the period of gestation being the same, have led some to believe that the wolf is the original dog. The two animals will breed together; the young of both are born blind, and at the expiration of the same time, namely, 10 or 12 days, the puppies of both acquire the power of vision. But one fact renders this supposition at least doubtful,-none of the wild dogs, living in a state of nature, have ever returned to the true form of the wolf. The minute examination of this question, however, would be out of place in this publication. In all the varieties of the dog, the following circumstances in his economy are constant: he is born with his eyes closed, he opens them on the 10th or 12th day; his teeth commence changing in the fourth month; and his full growth is attained at the expiration of the second year. The period of gestation is 63 days, and from 6 to 12 pups are produced at a birth. The dog is old at 15 years, and seldom lives beyond 20 ; his vigilance and bark are universally known. The dog is liable to so many diseases, that to treat of them here would be impossible. Among the principal are the distemper, rabies, canker in the ear, the mange
$2 \mathrm{M}$ 
diseases of the eyes, fits, diarrhœa, \&c., all of which are treated of under their several heads.

In England, the shepherd's dog ( $C$. fam. domesticus, Lin.) offers the example of one of the purest races of this domesticated animal, and that which, in its straight ears, its hair and tail, approaches nearest to the original stock. The sagacity of this variety in the peculiar department in which his services are rendered to man is well known, and has been illustrated by a hundred interesting anecdotes. It is a curious fact, that the brain of the shepherd's dog is larger than that of any other of the race; but how far this is connected with his sagacity we shall not pretend to affirm. Notwithstanding the great variations in size met with in the pasture or shepherd's dog, in different countries of the glohe (for he is probably the most extensively diffused of the race), yet he everywhere preserves some personal characteristics, which mark his adherence to the original type in a greater degree than in any other breed over which man has so arbitrarily exercised his dominion. One of these characteristics is his quantity of covering, which is invariably great, particularly about the neck. The large drover's dog, which attends the beast-markets, is larger, and usually of a stronger build than the sheep-dog. The sagacious colly of Scotland is a dog deservedly prized, though much smaller than either the English sheep-dog or the drover's cattle-dog. The ears are never wholly pendent in any of the race; but in the British varieties, and many others also, they are half-erected, or half-pricked, as it is called. The prevailing colour is very generally gray, more or less dark; the tail is bushy, somewhat pendent, and recurved; visage more or less pointed.

DOG BRAMBLE (Ribes cynosbati). One of a valuable genus of plants, which contains the gooseberry and the currant: some of the species are well suited for ornamenting shrubberies. They will grow in any soil, propagated by cuttings planted in autumn, or early in spring.

DOG-BRIER and DOG-ROSE (Rosa canina). The wild brier bearing the hip or hep.

DOG-DAYS, or CANICULAR DAYS. The name given to certain days of the year, during which the heat is usually the greatest. They are reckoned about forty, and are set down in the almanacs as beginning on the $3 d \mathrm{July}$, and ending on the 11 th August. In the time of the ancient astronomers, the remarkable star Sirius, called also canicular, or the dog-star, rose heliacally, that is, just before the sun, about the beginning of July; and the sultry heat which usually prevails at that season, with all its disagreeable effects, among which the tendency of dogs to become rabid is not one of the least disagreeable, were ascribed to the malignant rage of this star. Owing to the precession of the equinoxes, the heliacal rising of Sirius now takes place later in the year, and in a cooler season; so that the dog-days have not now that relation to the particular position of the dog-star, from which they obtained their name.

DOG-FENNEL. One of the provincial names of the weed corn-camomile.
DOG-FLY (Cynomia, Lin.). A genus of insects common in woods and among bushes, that is particularly troublesome to dogs, fastening upon their head and ears. 'They sting very severely, and always raise a blister in the part they touch.

DOG POISON, FOOL'S PARSLEY (Ethusa cynapium). Pl. 10, $q$. An umbelliferous plant, frequently found in gardens. It is easily distinguished from the other umbellifera by the partial umbels, consisting of three narrow, long, linear leaflets, which hang down. The leaves have short sheathing footstalks, are doubly pinnate, with decurrent, pinnatifid leaflets. It has been eaten for parsley, and has proved fatal. 'The stem and leaves are poisonous, and contain a peculiar alkali, called cynapia.

DOG'S-BANE (Cynanchum monspeliacum). A perennial, native of Montpelier, which loves warmth and a good soil. Blows pale pink flowers in July and August. Cover the roots in frosts. Propagate by suckers.

A plant under the same popular nanse is deseribed by Dr. Darlington, as found in Chester county, Pennsylvania. (Flor. Cest.)

DOG'S CABBAGE (Thelygonum cynobrambe). A common garden soil suits this species; propagate by seeds.

DOG'S GRASS. See Couch.

DOG'S TAIL GRASS. See Cryosurus.

DOG'S TONGUE (Cynoglossum). See Hound'S-TONGUE.

DOG'S TOOTH GRASS, CREEPING ( $C y$ nodon dactylon). Pl. 7, $k$. This grass was identified by A. R. Lambert, Esq. (Trans. Linn. Soc. vol. vi.) as the celebrated hallowed doobgrass of the Hindoos. In the East Indies this grass grows luxuriantly, and is highly valued as food for horses, \&c.; in England, however, it scarcely begins to vegetate till the month of June, and experiments made by Sinclair and others show that its produce and nutritive powers here are not sufficiently great to hold out any hope that its valuable properties in the East Indies can be made available in the climate and soil of Britain. The doob-grass flowers in September, and the seed is ripe about the end of October, and sometimes in November. The plants, natives of the English coasts, flower about a month earlier than the above. It is found on the sandy shores of Cornwall abundantly, and was first noticed by Mr. Newton, in the time of Ray. (Hort. Gram. Wob. p. 290 ; Eng. Flor. vol. i. p. 94.)

DOG-WHEAT. See Couch.

DOGWOOD. A name applied to two different plants: in England to any of the shrubby species of Cornus; in the West Indies to the Piscidia erythrina. The former are of ittle interest, except as ornamental shrubs; the latter is a powerful narcotic, the real value of which in medicine has still to be determined.

There are two indigenous species of cornel or dogwood; the $C$. sanguinea, a bush of four or five feet high, with smooth branches of a dark red when full grown; fruit dark purple, very bitter, like every nther part of the plant; found common in hedges and thickets, especially on a chall or limestone soil: and the dwarf cornel (C. succica), growing in moist 
alpine pastures, on the herbaceous stem four to six inches high. (Eng. Flora, vol. i. p. 221.) The English names of this shrub, says Phillips (Syl. Flora, vol. i. p. 183), are scarcely less numerous than the tints of its leaves. It is often called female cornel, to distinguish it from Cornus mascula, and hound's berry tree, dogberry, \&c. (because, says Parkinson, the fruit is not even fit for the dogs), and hence the name of dogwood.

The Cornelian cherry (Cornus mascula) is a native of Austria, growing from fifteen to twenty feet high. See Connaliar Cherry.

The A.nerican dogwood (Cornus Florida) is a small North American tree, the botanical name of which is derived from the horny toughness of its close-grained and firm wood. It is a very common undergrowth in woods, composed of deciduous trees. Very early in the spring, before the trees by which they are overtopped put ont their leaves, the dogwood expands its beautiful white blossoms, and in such profusion as sometimes, at a distance, to resemble a snow-bank. The wood of this small tree is highly prized for a variety of useful purposes, among which is the making of cogs for mill-wheels. The bark is an excellent tonic, thought by some almost equal to Peruvian bark in its efficacy in curing intermittent fevers. A preparation caller cornine has been extracted from it, very much resembling quininc. The unfolding of the blossoms of the dogwood is the signal to the American farmers to plant Indian corn.

"Among the eight species of dogwood which have been observed in North America, this alone is entitled by its size to be classed with the forest trees. It is the most interesting, too, for the value of its wood, the properties of its bark, and the beauty of its flowers. In the United States at large, it is known by the name of dogwood, and in Connecticut it is also called box wood.

"The dogwood is first seen in Massachusetts between the $42^{\circ}$ and $43^{\circ}$ of latitude, and in proceeding southward, it is met with uninterruptedly throughout the Eastern and Western States, and the two Floridas, to the banks of the Mississippi. Over this vast extent of country it is one of the most common trees, and it abounds particularly in New Jersey, Pennsylvania, Maryland, and Virginia, wherever the soil is moist, gravelly, and somewhat uneven; farther south, in the Carolinas, Georgia, and the Floridas, it is found only on the borders of swamps, and never in the pine barrens, where the soil is too dry and sandy to sustain its vegetation. In the most fertile districts of Kentucky and West Tennessee it does not appear in the forests, except where the soil is gravelly and of a middling quality.

"The dogwood sometimes reaches thirty or thirty-five feet in height, and nine or ten inches in diameter; but it does not generally exceed the height of eighteen or twenty feet, and the diameter of four or five inches. The trunk is strong, and is covered with a blackish bark, chapped into many small portions. which are often in the shape of squares more or less exact. The branches are proportionally less numerous than on other trees, and are regu- larly disposed nearly in the form of crosses. The young twigs are observed to incline upwards in a semicircular direction.

"The leaves are opposite, about three inches in length, oval, of a dark green above, and whitish beneath: the upper surface is very distinctly sulcated. Towards the close of summer they are often marked with black spots, and at the approach of winter they change to a dull red.

"In New York and New Jersey the flowers are fully blown about the 10th or 15th of May, while the leaves are only beginning to unfold themselves. The flowers are small, yellowish, and collected in bunches, which are surrounded with a very large involucre composed of four white floral leaves, sometimes inclining to violet. This fine involucre constitutes all the beauty of the flowers, which are very numerous, and which, in their season, robe the tree in white, like a full blown apple tree, and render it one of the fairest ornaments of the American forests.

"The seeds, of a vivid, glossy red, and of an oval shape, are always united. They remain upon the trees till the first frosts, when, notwithstanding their bitterness, they are devoured by the Robin, Turdus migratorius, which, about this period, arrives from the northern regions.

"The wood is hard, compact, heavy, and fine-grained, and is susceptible of a brilliant polish. The sap is perfectly white, and the heart is of a chocolate colour. This tree is not large enough for works which require pieces of considerable volume : it is used for the handles of light tools, such as mallets, small vices, \&c. In the country, some farmers select it for harrow teeth, for the hames of horses' collars, and also for lining the runners of sledges; but to whatever purpose it is ap. plied, being liable to split, it should never be wrought till it is perfectly seasoned. The shoots, when three or four years old, are found proper for the light hoops of small, portable casks; but the consumption in this way is inconsiderable. In the Middle States, the cogs of mill-wheels are made of dogwood, and its divergent branches are taken for the yokes which are put upon the necks of swine, to prevent their breaking into cultivated enclosures. Such are the profitable uses of this tree; it affords also excellent fuel, but it is too small to be brought into the markets of the cities." (Michaux's North Amer. Sylva.)

DOLPHIN-FLY. The name in England of an insect of the aphis tribe, very destructive to beans. (See Bears.) It is sometimes called the collier. The destruction which this insect causes is not wonderful when we reflect on the astonishing fecundity of all the aphides family. The sexual intercourse of une original pair serves for all the generations which proceed from the female in the succeeding year; and Réaumur informs us, that, in five generations, one aphis may be the progenitor of $5,904,900,000$ descendants: in one year there may be twenty generations. At one season they are viviparous, at others oviparous. The dolphin-fly or collier is of a black colour: it begins its depredations at the top of the bean 
and continues multiplying downwards. The only method of preserving the crop is to top the plants, and to burn the tops.

DOOB-GRASS. See Dog's Tooth Grass.

DOSS (a corruption of toss). A provincial word signifying to strike with the horn or gore slightly, as cattle frequently do each other.

DOVE. A species of pigeon, of which the principal varieties are the ring-dove or wood pigeon, the stock-dove, the rock-dove, and the turtle-dove. See Pigros.

DOVE-COTE. A structure usually erected of wood for the accommodation and rearing of tame pigeons; the only essential difference between which and a common poultry house is, that the entrance for the birds must be raised to a considerable height from the ground, because pigeons fly higher in the atmosphere than most other birds.

The utmost cleanliness ought to prevail in pigeon houses, hence the holes should be carefully examined before the breeding season arrives. They should be frequently well washed out, and the dung and other impurities removed; but this should be done early in the day, when the birds are out, so that they may not be disturbed. Some old dove-cotes are circular buildings, of considerable size, with ranges of square holes formed in the anterior wall, in which the birds make their nests. From this feature in old dove-cotes, the term pigeon-holes in desks is arrived. These dovecotes are entered by a door below; and by means of a ladder the young pigeons are easily taken from the nests. Many dove-cotes of this hind exist in Scotland. (Brande's Dict. of Srienie, \&c.; Willich's Dom. Encyc.)

DOWNS (Sax. oun; Erse, dune, a hill). In European agricultural parlance, large, open, elevated, unenclosed tracts of land, generally reserved for grazing purposes.

DOWNY I.IME 'TREE (Tilia pubescens). A tree belonging to the southern United States. See Linner, and Lime Tree.

DOWNY OAT GRASS. See AVENA.

DRAG. An implement of the harrow kind used in breaking down and reducing land into a fine state. Also an iron catch to fix on the wheels of heavily laden carts or carriages when descending steep hills or declivities.

DRAGON-FLY. A common name for the Neuropterous insects belonging to the genus Agrion or Lobellula.

IRAINING. The very first care of the farmer, that on which the success of his future crops almost entirely depends, is the removal of unnecessary supplies of water-whether arising from the tenacity of the surface retaining too much water, or from springs exuding to the surface. For it is evident that as different crops require very varying quantities, so the cultivator must adapt the moisture of the so:- :o the crops he purposes to produce;the supply which is necessary, for instance, for the profitable growth of the rice plant would rlestroy the meadow grasses of England:--and again the damp soils, of which many of the richest mearlows of England are formed, would be much too moist for the cereal crops. The nature of the climate, the soil, and ihe subscil must all be taken into account.
The plants growing on sandy scills, of course, will bear a much larger proportion of water than those vegetating on clay soils:-and thus the very soil which, in the dry eastern side of England, grows excellent crops of corn, would. in the western counties, where twice the amount of rain falls, on an average, than in the east, be found materially to injure the plants. (See Water, its Uscs to Vegetritun.) Placed as the farmer is under such a rariety of circumstances, cultivating lands of all kinds, it is useless, in this article, to attempt to assis: him with more than general directions.

'The water carried off the soil by artificial drainage is either by boring, by opon or by under-ground drainage, or by both. Boring was first recommended by Elkington. It is chiefly adapted for low situations, surrounded by high lands, and merely consists in boring with an auger, or digging a well in the land intended to be drained, until a spring of water is pierced, whose head is lower than that of the surface of the field; and hence it follows that when the water is suffered to drain into the hole made by the auger, or the well, it of necessity drains from the land out of the bottom of the well, as fast as it flows into it at the top. This plan might be profitably employed to a much greater extent than at present. When combined with surface draining, it saves, by shortening the water channels, a considerable portion of the expense.

In open surface drains, the nature of the soil, its declinations, and its chemical composition can alone guide the farmer. In either case too much care can hardly be bestowed upon it; it is a question that the legislature has deemed to be of even national importance; for by the $3 \& 4$ Vict. c. 55, landowners possessing only limited interests in estates are empowered to raise money, by way of mortgage, on such property, to be employed for the purposes of improving them by drainage; and the government has promoted the use of drain tiles by exempting them from duty. I shall confine my observations, therefore, chiefly to the formation of under-drains. These common ly vary in depth from $2 \frac{1}{2}$ to 4 feet; and, in peat soils, on account of the very material settling which takes place, as they are brought into cultivation, from this to 6 or 7 feet. The first operation necessary upon a field intended to be drained, is the examination of the strata, or veins of earth of which it is composed; and this is commonly effected with the boring auger, or by digging small pits, or open drains, as by this means the oozings or weepings will speedily display themselves, and indicate pretty correctly the source whence the superabundant water proceeds. This being ascertained, the direction of the under-drains will be the more easily decided. If the soil is of such a description that the subsoil plough can be used with advantage, then the top of the stones, bricks, or tiles by which the drain is forried and preserved, should not be less than $2 \frac{1}{2}$ feet from the surface of the soil. In the formation of these drains the workman always com mences on the lowest extremity; by this means besides other advantages, the water, as he arrives at it, drains away from him, and shows 
him, by its escape, that he is preserving a proper fall. When the drain is cut to the requisite depth, he proceeds to fill it up with the materials through which the drainage waters are to flow, to within such a distance only as is out of the reach of the plough; and then the earth is shovelled back again over the drainage materials. The description of these materials, of necessity, varies with the nature of the country and its produce; in Essex, brushwood and straw are chiefly employed; in the northern parts of the island, stones, broken lime, or sandstone are used. Bricks and tiles are resorted to in districts where cheaper materials are not to be procured; and these are made in a variety of forms; and recently one or two valuable improvements have taken place in the construction of them by machinery; so that, by those of the Marquis of Tweeddale and Mr. Beart, draining tiles are now made at a very reduced price. Upon tilemaking, in general, there is a goud paper by Mr. Wiggins, Journ. Roy. Agr. Sor. vol. i. p. 315. The tiles of the Marquis of 'Tweeddale are described Trans. High. Soc. vol. vi. p. 50, and Journ. Roy. Agr. Soc. vol. ii. p. 148; and those of $\mathrm{Mr}$. Beart, with engravings of his machine, in the Journ. of the lioy. Eng. Agr. Soc. vol. ii. p. 93 ; by which it seems that in Huntingdonshire the cost of the tiles made by his apparatus is about $15 \mathrm{~s}$. per 1000 : this varies, of course with the price of coals, of which variation $\mathrm{Mr}$. Pusey has constructed the following table.

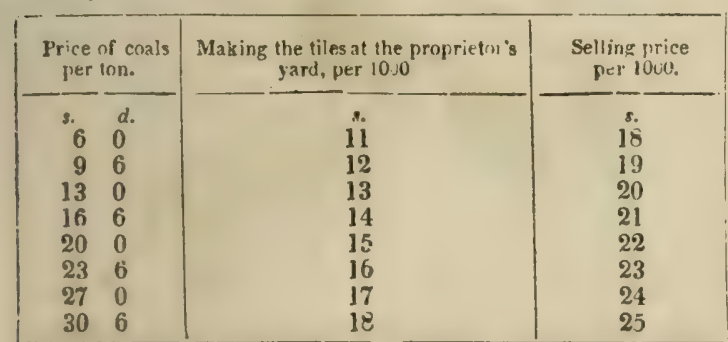

These are commoniy used with the flat or sole tiles, which cost, in Huntingdonshire, from 8s. to 10 s. per 1000. The clay best adapted for tiles is that which contains a small proportion of sand, or sand may be mixed

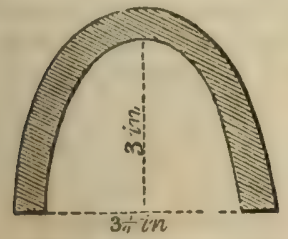
with the clay. 'The annexed cut gives the shape of the Tweeddale patent drain tile. It is commonly made 3 inches deep, $3 \frac{1}{2}$ wide, and about 12 in length.

The subject of under-draining is, cornparatively, so little understood in the United States, and its importance so great, that we are induced to subjoin the following additional information, chiefly condensed from that excellent work "The Book of the Farm, by H. Siephens," now publishing in Edinburgh.

The dimensions of tile-drains, depends entirely. on the way these are to be constructed. If the bottom be hard and no soles are to be placed under the tiles, the drain may be cut narrower; and if nothing else but tile and sole are to be put into them before the earth is returned, they may be shallower. In regard to the emp.oyment of soles where the drain has a clay bo:tom, Mr. Stephen: is strenuous in his as. sertions that they are always necessary. Wha* ever may be the nature of the earthy lottom to be occupied by the tiles, these should always have soles, or something equivalent, to protec: the earth from the destructive effects of water

Where soles are employed their widih must deler mine the width of the botlom of the drain. As yet no regular width has been agreed upon gene. rally, though it would be a matter of some importance to have this done. 'The brearth of soles made in the neighbourhood of Kilmarnock, at the tile-kilns belonging to the Duke of Portland in Ayrshire, as well as those made by Mr. Boyle, tile-maker in Ayr, is 7 inches; and this breadth is made to answer tiles varying from 4 to 3 inches in width, inside measure. For a 4-inch tile, a narrower width than 7 inches would not answer; as the tile is $\frac{3}{4}$ of an inch thick, only $\frac{3}{4}$ of an inch is left beyond each side of the tile when placed on the sole, which is as little space as it can stand on secure. ly. For the smaller sized tile of 3 inches, the width is ample; but still, it is no disadvantage to a tile to have plenty of room on a sole, as its position can easily be fixed by wedging in stones on each side against the walls of the drain, when stones are used above the tiles; or it leaves sufficient room for a lapping of turf over, and wedging of earth on each side of, the top of the tile. In the case of a 5-inchwide drain at bottom, the smallest size of tile, 23 inches wide inside, must be used, as only of an inch would be left on each side of that width of tile.

Soles are usually made flat, but Mr. Boyle makes them curved; not because they are better suited for the purpose, but merely because they are more easily dried in the sheds; but a curved sole is objectionable, as it is more difficult to form a smooth bed for it to lie upon, and it is more apt to break when it happens not to be firmly laid upon its bed than a flat sole.

As to tiles, their perfect form is thus well described by Mr. Boyle: "All tiles should be a fourth higher than wide; the top rather quickly turned, and the sides nearly perpendicular. Tiles which are made to spread out at the lower edge and flat on the top, are weak, and bad for conveying water. Some people prefer tiles with flanges instead of soles; but if placed, even in a drain with a considerably hard bottom, the mouldering of the subsoil by the currents of air and water causes them to sink and get deranged." Tiles should be smooth on the surface, heavy, firm, and ring like cast-iron when struck with the knuckle. They should be so strong when set, as to allow a man not only to stand, but to leap upon them without breaking. The introduction of machinery in the manufacture of drain-tiles, by compressing the clay, and working it thi): roughly in a pug-mill to prepare it for being compressed, has greatly tended to increase the strength of tiles. I have seen drain-tiles sc rough, spongy, crooked, and thin, as to be shivered to pieces by a night's frost when laid down beside the drain. The use of machinery has caused a great deal more clay to be put into them, and their greater substance has been the cause of improvement in the construction $\alpha$ ? 
kilns, in which they are now burned to a uniform texture, as well as some avoidance of breakage in the manufacture, by all which, of course, their cost is lessened. An under-burnt as well as an over-burnt tile is bad, the former being spongy and absorbing water, and ultimately falling down; and the latter is so brittle as to break when accidentally struck against any object.

The length of drain-tiles varies in different parts of the country. Mr. Boyle's are 13 inches; the Duke of Portland's, in Ayrshire, and Mr. Beart's Godmanchester, Hertfordshire, 12 inches; and those from the Marquis of 'Tweeddale's machine, 14 inches, when burnt. If the price is the same per 1000 , of course the 14-inch tile is cheaper than the 12-inch; but otherwise, the 12-inch is the handiest article in the manufacture, as being less apt to waste in handling, and twist when in the kiln; and their number is much more easily calculated in any given length of drain. The following table shows the number of tiles required for an imperial acre, of the different lengths made, and placed at the stated distances:

$\begin{array}{lllllll}\text { Drains at } & & 12 \mathrm{in.} & 13 \mathrm{in} . & 14 \mathrm{in} . & 15 \mathrm{in.} & \\ 12 \text { feet apart require } & 3630 & 3351 & 3111 & 2904 & \text { per acre. } \\ 15 & - & 2904 & 2681 & 2489 & 2323 & - \\ 18 & - & 2420 & 2234 & 2074 & 1936 & - \\ 21 & - & 2074 & 1914 & 1777 & 1659 & - \\ 24 & - & 1815 & 1675 & 1556 & 1452 & - \\ 27 & - & 1613 & 1480 & 1383 & 1291 & - \\ 30 & - & 1452 & 1340 & 1245 & 1162 & - \\ 33 & - & 1320 & 1218 & 1131 & 1056 & - \\ 36 & - & 1210 & 1117 & 1037 & 968 & -\end{array}$

The numbers of each length of tile required at intermediate distances can easily be calculated from these data.

A representation of what Mr. Stephens considers the best formed drain-tile, and the man. ner of setting this on the soles, is given in a cut, where $a$, and $b$, are two 12-inch tiles, of the most correct shape, placed upon the soletiles, $c$.

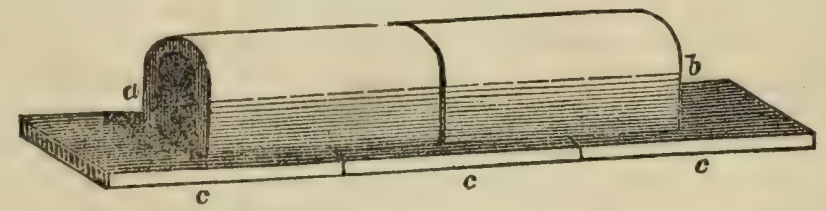

The length of the tiles and soles being equal, their joinings are made in the middle of the soles, and this course is to be continued throughout. It is the practice of some tiledrainers, Mr. Stephens observes, to put a $\frac{1}{2}$ inch sole under every joining of 2 tiles, leaving the intermediate space of the bottom without any sole, imagining that this will insure sufficient steadiness to tiles on what they call hard clay, whilst only half the number of soles are used. But this he pronounces a precarious practice.

In making the side-joinings of the tiles it has been usual to break a piece of the corner of 1 or 2 main-drain tiles, where side-drains are led into them. In breaking off the corners, there is a risk of breaking the entire tile. Another plan is to set 2 main-drain tiles so far asunder as the inside width of a common-drain-tile, and the opening on the other side of the tiles, if not occupied in the same manner by the tiles of ancther drain, is filled up with pieces of hroken tiles or stones, or any other hard substance. This is perhaps a better plan than running the risk of breaking a number of tiles, and, after all, failing in making the opening suitable for the reception of the adjoining Jrain tiles. Both plans, however, Mr. Stephens pronounces very objectionable, and never to be resorted to where tiles, formed for the purpose of receiving others in their sides can be procured. Main-drain tiles of this description are made with openings on purpose to receive the shouldered end of the smaller sized side-drain tiles. To answer a similar purpose in particular situations where such tiles cannot be conveniently joined, main and furrow or side-drain tiles are made of $\frac{1}{2}$ and $\frac{1}{4}$ lengths, which may be so arranged in regard to one another's position, as to conjoin the openings of both at the same place.

The junction of a common tile with a mainIrain one is represented in the following cut, in which $b$ represents the common tile, and $a_{4}$ the opening in the main-drain tile.

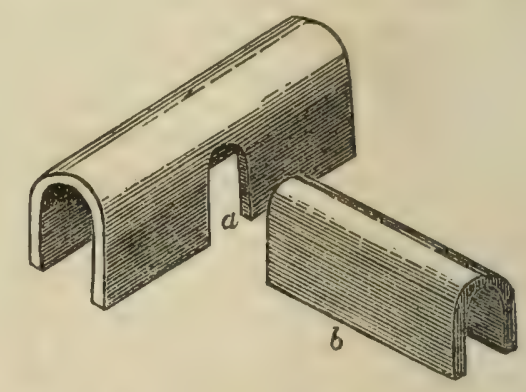

Mr. Stephens says there should be always a decided fall from the outlet, whether it be affected by natural or artificial means. The open ditch into which the main-drain issues should be scoured deep enough for the purpose, even for a considerable distance; and it will moreover be necessary to see every year that the outlet is kept open; and the ditch scoured as often as necessary for the purpose.

It is, says Mr. Stephens, a frequent charge of neglect against farmers, that they allow open ditches almost to fill up before they are again scoured out, and a not unfrequent excuse for the neglect is, that scouring of ditches to any extent incur considerable labour and expense. No doubt they do, and no wonder, since so much work has to be done, when it is done. Were the ditches scoured out when they actually required it, nay every year, if that is found necessary for the welfare of stock, fences, or drains, so little expense would be incurred at one time, as to remove every complaint against the labour as a burden; but much better, in every case where it can be done, to incur the expense at once of converting an open ditch into a covered drain, than grudge the expense of keeping it in a proper state.

Should the fall from the mouth of the main. 
drain to a river be too small, and there be risk, at times, of the overflowings of the river sending back-water into the drain, the drain should be carried down as far by the side of the river as will secure a suflicient fall for the outlet. Rather be at the expense of carrying the drain under a mill-course or rivulet than permit backwater toenter it.

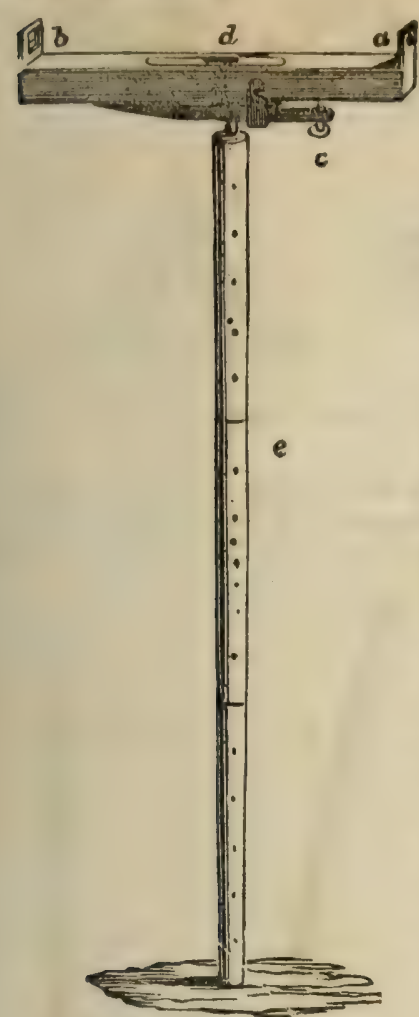

A spirit level (see cut) has been found a very convenient instrument for ascertaining such a point, and generally for taking levels in fields. It is furnished with eye-sights $a b$, and when in use is placed into a framing of brass, which operates as a spring to adjust it to the level position $d$, by the action of the large headed brass screw c. A stud is affixed to the framing, and pushed firmly into a gimblethole in the top of the short rod $e$, which is pushed or driven into the ground at the spot from whence the leve! is desired to be ascertained. It need scarcely be mentioned that the height of the eyesight from the ground is to be deducted from the height of observation, and which quantity is easily obtained by having the rod marked off in inches and feet; but it may be mentioned that this instrument should be used in all cases of draining on level ground, even where one is confident that he knows the fall of the ground, for the eye is a very deceitful monitor for informing you of the levelness of ground. Such a spirit level, well finished, costs in England, 15 shillings, (about $\$ 4$ ). Its whole length is 8 inches, depth $1 \frac{3}{4}$ inches, width or breadth, 1 inch. It is so light as to admit of being carried in the pocket, whilst its rod may be used as a staff or cane.

The cutting of the main-drain should be $e n-$ tirely finished before the tiles are laid in it; and immediately after it is finished, it should be measured with the drain-guage, to ascertain whether it contains the specified dimensions and fall. This drain-guage is an excellent substitute for the tape-line or foot-rule, which are both inconvenient for the purpose of measuring the dimensions of a drain. This simple instrument consists of a rod divided into feet and inches, with two arms fixed cross-wise, the length of which is to correspond with the required width of the drain. When this rod is put down to ascertain the depth, it is afterwards turned partially round, whilst its end rests on -he bottom of the drain, until the ends of its arms touch the earth on both sides. If the arms can. not come round square to the sides of the drain, the drain is narrower than intended; and if they cannot touch both sides, it is wider than necessary. When made larger than intended, a greater expense may be incurred in filling up with stones, \&c.

'The person intrusted with the laying of the soles and tiles into drains, should be one who has been long accustomed to that kind of work, or otherwise a good workman, possessing judg. ment and common sense. He should rernain constantly at the bottom of the drain and have a boy or other assistant to hand him the tiles and tools. After laying three soles in length, he must examine to see if they are straight in the face, and neither rise nor fall more than the fall in the drain. As a safe guide to him, where the fall is not decidedly cognisable by the senses, a mason's plumb-level will be found a convenient instrument. After three soles are thus placed, two tiles are set upon them, being so placed that their joinings shall meet on the intermediate spaces belween the joinings of the soles.

The tiles for small drains are usually made, according to Mr. Stephens, about 3 inches wide and 5 inches high, inside measurement, which may be considered a large tile in places where those of $2 \frac{3}{4}$ inches wide by $3 \frac{1}{2}$ inches high are used. The soles for small drains are made of different breadths, varying from 5 to 7 inches. They usually shrink about one-eighth in the kiln.

Several ingenious and efficient machines have been invented in Great Britain, which have greatly facilitated the manufacture of drain tiles and soles, and reduced their cost to the very moderate prices stated in the estimates presented. In the 12 th volume of the Prize Essays and Transactions of the Highland Agriculural Society, descriptions of some of these will be found, illustrated with drawings. That invented by the Marquis of 'Tweeddale, and for which a gold medal was awarded him, will make 12,000 tiles in a day of ten hours, it being understood that the clay is previously prepared and milled, as in the common way, when three or even four men can only produce 1500 tiles in the same time. The machine requires a power only equal to one horse, and the assistance of one man and two boys, one of these to feed in the clay and two to remove the tiles to the shelves.

The Essays, in the same volume, of Mr. Boyle and Mr. Taylor, upon the manufacture of draining tiles are well worth the attention of persons particularly interested in the subject, as they not only treat of the minutix of the operations, but are illustrated with very numerous figures of the implements, mode of placing the tiles in the furnace, \&c., \&c.

Much capital has been wasted in the erection of tile-works, by those who have not at first known the best modes of proceeding, and $\mathrm{em}$ ployed men to manage them who knew little about the processes. Like most other kinds of business, tile-making and baking require : regular apprenticeship, in orler to sircceed properly. As the machine of Mr. Beart har 
Deen highly approved of in Scotland, and seems so simple in its construction and mode of management, we think it perhaps better adapted to common purposes than the more formidable contrivance of the Marquis of Tweeddale. A description and cut of the instrument, by which 3000 tiles can be made in a day, with an explanation of the mode in which it is managed, will also be found in the 12 th volume of the work to which we have just referred.

Mr. Stephens thinks that the very best method of draining land, is by the union of stones and tiles in the same drain. The width of the bottom of the drain covered with the sole, may be 7 inches; width at the top 12 inches; total depth $2 \frac{1}{2}$ feet, consisting of the drain-tile and covering of stones, packed with the hand above and on each side, extending 12 inches above the sole, leaving 18 inches to be filled in with turf and earth. Such a drain, when properly constructed, is pronounced the ne plus ultra of the art. But it is seldom done, either for want of the necessary supply of stones of the proper size, or the additional expense incurred.

Judge Buel was among the first who employed tiles in draining in the United States, beirig, he says, led to it by necessity, having no stone. He has laid some 10,000 feet of tiles, at an expense of about $\$ 15$ per 1000 feet, and found them to answer an excellent purpose. Dr. J. J. Spencer, of Moorestown, New Jersey, has also drained a piece of low ground by means of tiles, and can now drive carts, plough and raise heavy crops of Indian corn, \&c., where before there was a useless, unsightly, and unhealthy morass.

In general, under-drains may be dug no broader than is just necessary to afford room to work in, the sides being left straight or perpendicular. The ditch should be commenced at the lowest end or outlet, and opened up to higher ground. Where stones are employed either as a conduit at the bottom, or to form the drain of themselves, they should be broken to so small a size, that moles or ground-mice cannot penetrate among them, as they are very much inclined to do, opening holes through which the surface water enters, mixed with clay and earth, by which the interstices of the drain will be ultimately choked up. Judge Buel recommends the stone to be broken so as not to exceed 4 inch pieces. The expense of doing this, he says, will not be more than 25 or $30 \mathrm{cts}$. the cubic yard.

The use of draining tiles is evidently on the increase, and every improvement which is made in them naturally extends their field of usefulness; they are by far the most permanent and effective of all the materials used

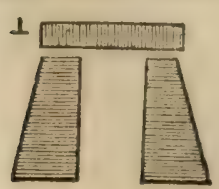

for draining land. Of draining bricks there are various shapes; the annexed figures represent a few of the most common, and the mode of placing them.

In fig. 1 and $1 a, 84$ bricks are required for every eight yards. In fig. 2,55 bricks are required for every eight yards. In fig. 3, 110 i,ricks are required for every eight yards. Figs.
4 and 5 have been found very useful in the drainage of peat-bogs or quicksands. They

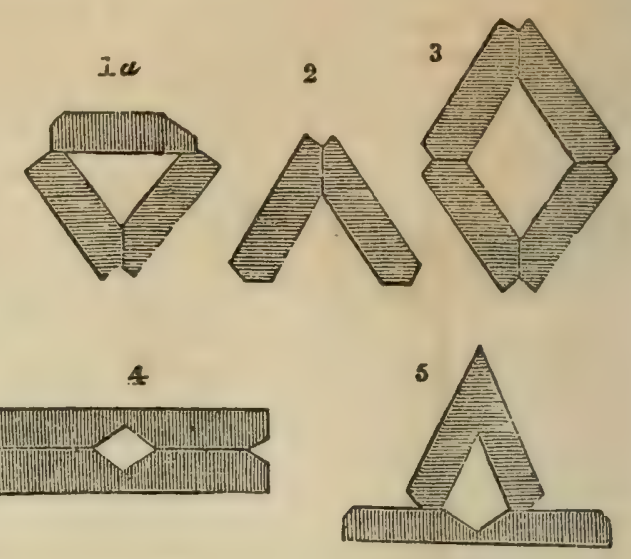

are all, however, for most purposes inferior to the draining tile.

In the formation of drains, a shovel tapering to a point, and scoops of a peculiar shape, are commonly used. These are represented
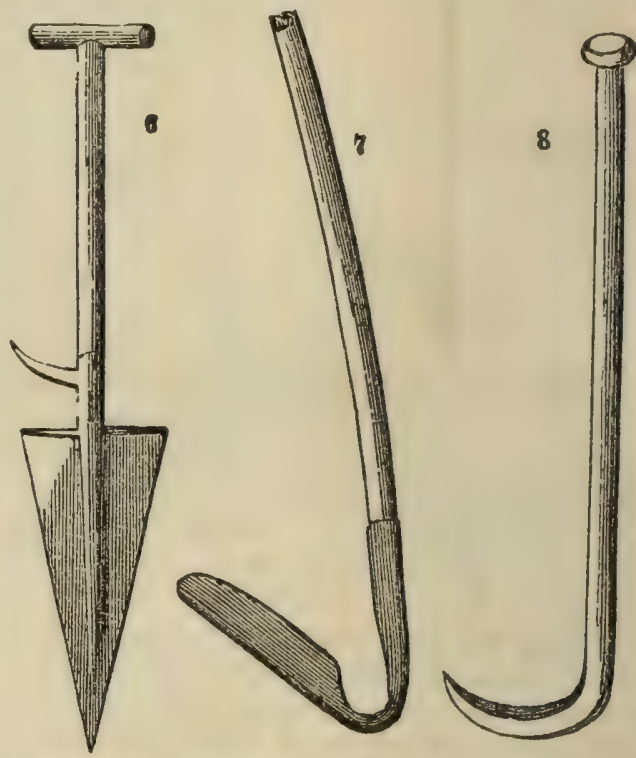

in the figures $6,7,8$. The old-fashioned way of forming a drain is depicted in figures 9 and
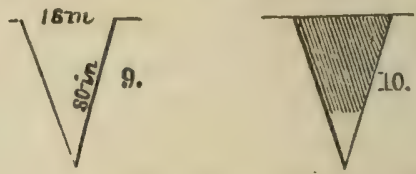

10 ; in these the bottom of the drain was filled up partially with brushwood, stones, lon ropes of twisted straw, others of ling or heath, which are much more tough and permanent. The expense of digging and filling in any of the above drains (exclusive of the brushwood or other materials) varies from $4 s .6 d_{0}$ to $5 s_{0} 6 d_{\text {. }}$ per score rods (120 yards local measure). The expense per acre will be, according to $\mathrm{Mr}$. S. Taylor (Brit. Farm. Mag. vol. ii. p. 359),

$£$ s. $d$.

If the drains are 8 yards distant 1139

\begin{tabular}{|c|c|c|c|c|c|c|}
\hline & & & & & & \\
\hline- & - & 7 & - & & 1 & 17 \\
\hline- & - & 6 & - & - & 2 & 0 \\
\hline - & - & $5 \frac{1}{8}$ & - & - & 2 & 5 \\
\hline & - & 5 & - & - & 2 & 8 \\
\hline & - & 4 & - & - & 2 & 17 \\
\hline
\end{tabular}




\section{DRAINING.}

In many situations, where a spring is io be reached, it is vary desirable to form a well by the side of the drain, according to the annexed outline. (Trans. High. Soc. vol. i. p. 223.) A very common modern mode of constructing
12

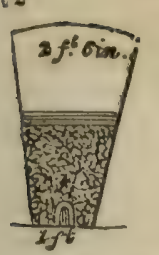
the Arain is according to the form in fig. 12. Ioose mould or gravel is placed at the top to the depth of 1 foot. Sod, straw, heath, or rushes 4 inches; and then land stones 1 foot 8 inches thick surround the draining tiles.

The drain tiles, bricks, or other materials, are covered with any porous material that the locality affords. Stones, gravel, scoria, refuse nit the foundries, ashes, peat, moss, sods, brushwood, straw, heath, ling, rushes, \&c. Instead of draining-tiles of the horseshoe form, pipes are now substituted in many parts of England, as much more economical, and equally effectual in conveying off the surplus water. At first, the pipes were made by bringing the edges not quite together, leaving an open seam at the under part for the admission of water. But it is now generally thought better to close the seam, and form a complete pipe, with a bore of sufficient diameter, say 1 or $1 \frac{1}{2}$ inches. Some of the machines for moulding these pipes will turn off eleven at one operation, all of uniform thickness of bore, and in length about 12 to 15 inches. A machine invented by Mr. Scragg, of Calvely, Cheshire, is equivalent to the easy manufacture of more than 20,000 pipes of an inch bore per day of 10 hours, and so on in proportion for other sizes. Whether tiles or pipes are employed, the opinion is very generally in favour of laying both at a greater depth than was formerly recommended, seldom, if ever, less than 4 feet. 'The substitution of small pipes for tiles, has lessened the cost of draining, from $\$ 25$, and sometimes $\$ 50$, to $\$ 10$ or $\$ 15$ per acre.

Square or triangular tubes, made of larchwood of the following shapes, so as to give a water way of 2 or $2 \frac{1}{2}$ inches, with sides fastened together with wooden pegs, and pierced with auger holes, have been recommended for their economy.
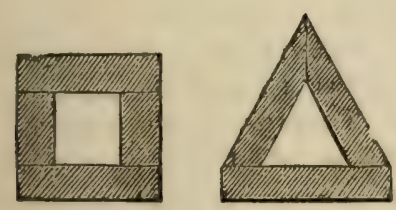

Mr. Wilson calculates the average expense with stones per rood to be $7 s_{0} 8 d$. (Quart. Journ. $A g r$. vol. i. p. 242.) Mr. Yule at per rood of 21 feet, 2 feet 9 inches deep with 3 inch tiles, at 1 s. $0 \frac{1}{2} d$.; with 4 inches, $4 \frac{1}{2}$ to 5 feet deep, 1s. $3 \frac{1}{2} d_{\text {. }}$; with 6 inch tiles, the same depth, $1 s$. $5 \frac{3}{4}$ d. (Ibid. p. 397.)

The expense of tile draining has been thus estimated by Mr. Carmichael (Trans. High. Soc. vol. vi. p. 98) at per imperial acre; tiles being 28. $6 d$. per 100, and soles $1 s .6 d$. per 100 .
Ds ak aleminoun Char.

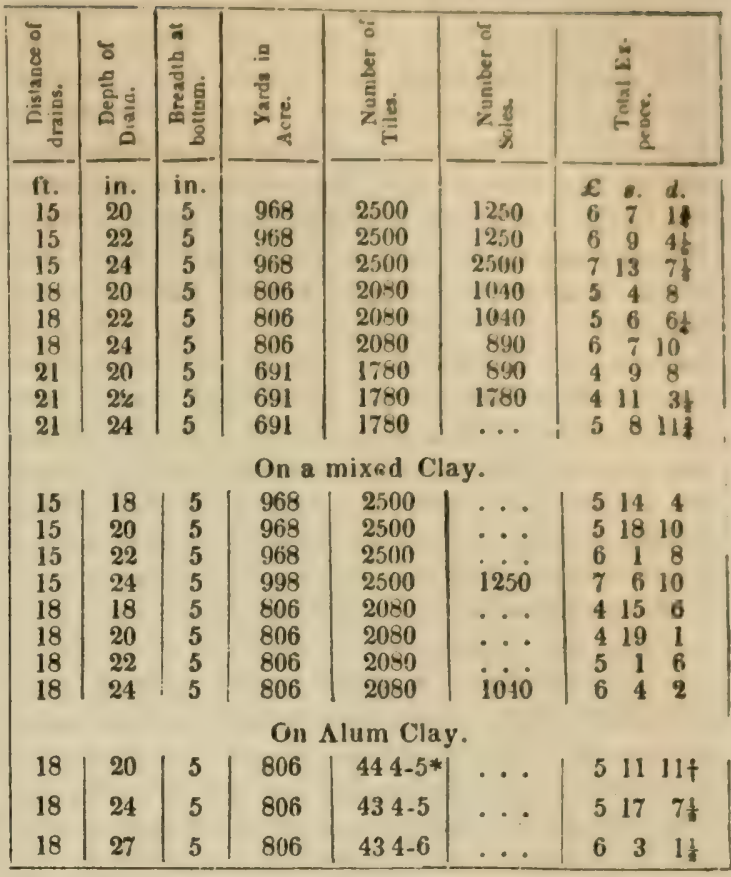

With regard to the cost of thorough draining in Scotland, Mr. Stephens gives the following details, drawn from actual experiments :-

Opening drains 33 inches deep and 7 inches wide at bottom, at $5 \frac{1}{2} d$. per rood or rod of 6 yards.

Preparing stones, 4 inches in diameter, at $4 d$. per rood. Carriage of stones, at $4 \frac{1}{2} d$. per rood.

Unloading carts and moving screen-barrow, $\frac{q}{q} d$. per rood. Filling in earth, $\frac{1}{4} d$. per rood.

Extra expense in the main drains about 10 s. per acre.

Another statement for drains of rather smaller size, viz.:-

23 inches deep, 7 inches wide at bottom, allows $4 d$. per rood of 6 yards for npening.

Preparing stone, at $2 \frac{\pi}{2} d$. per rood.

Carriage of stones, at 2 sd. per rood.

Unloading carts and moving screen-barrow, at $2 \frac{1}{2} d$. per rood.

Filling in earth, at $1 \frac{2}{4} d$. per rond

Extra expense in the main drains, 10s. per acre.

In computing the cost in Scotland of the la. bour in draining with stones, the hire of the horse is put down at $3 s .4 d$, the man's wages 1.s. $8 d$., and that of the driver $10 d$. per day. Taking into consideration the necessary num. ber of drains required, the first estimate makes the cost, supposing each imperial acre to contain 70 roods of drains of 6 yards each, $£ 4,12 s$. $6 \frac{1}{2} \pi$; the second estimate $£ 3,8 s .4 d$. per acre.

Mr. Stirling estimates the expense of draining per imperial acre (Trans. High. Soc, vol, vi. p. 111), to be,-

\begin{tabular}{|c|c|c|c|c|c|}
\hline $\begin{array}{l}\text { Distance } \\
\text { hetiveen } \\
\text { the Drains. }\end{array}$ & $\begin{array}{l}\text { Number of } \\
\text { chains } \\
\text { per Acre. }\end{array}$ & $\begin{array}{l}\text { With broken } \\
\text { Siones } \\
\text { screened. }\end{array}$ & $\begin{array}{l}\text { With b } \\
\text { Ston } \\
\text { riddl }\end{array}$ & $\begin{array}{l}\text { roken } \\
\text { es } \\
\text { ed. }\end{array}$ & $\begin{array}{l}\text { With Tiles } \\
\text { ard } \\
\text { Sche. }\end{array}$ \\
\hline feet. & & $£$ s. d. & f s. & $d$. & E s. d. \\
\hline 14 & $47 \cdot 14$ & 7184 & 82 & $5 \frac{1}{2}$ & $\begin{array}{lll}9 & 13 & 5 \text { 쪼 }\end{array}$ \\
\hline 16 & $41 \cdot 25$ & $6186 \frac{2}{9}$ & 72 & $1 \frac{1}{6}$ & $\begin{array}{lll}8 & 9 & 3 j\end{array}$ \\
\hline 18 & $36 \cdot 66$ & 631 & 66 & 3 & 7106 \\
\hline 20 & 33. & $\begin{array}{lll}5 & 10 & 10\end{array}$ & 513 & $8 \frac{1}{2}$ & $615 \quad 5 t$ \\
\hline
\end{tabular}

Brushwood and Straw Draining.-When irles. stones, and other materials best adapted to the construction of drains cannot be procured, brush. straw, or even sod, has been employed to $\mathbf{f l}$.

- Carts of stones.

+ Stone drains.

418 
the bottom of under-drains. When brushwood is used, the trench may be dug from eighteen to twenty-four inches wide, and three or four feet deep. Saplings from two to six inches thick at the butt may be cut into lengths of four or five feet, and, commencing at the upper end of the ditch, placed diagonally or slantwise, the butts down and towards the outlet. When this is done the trench is apparently full. The brush is then all brought within the edges of the ditch, well trodden down, and the earth thrown in. Bundles of fagots are sometimes employed to lay at the bottom of the trench, and at other times large straw ropes. When the ground is marshy, coarse hay or straw should be put upon the bottom of the trench before laying the brush, and also upon the top of the brush after this is stamped down.

Wedge Draining is another method sometimes resorted to. The general mode of performing this is to form a narrow trench with a long, narrow shovel. The spit being taken out as deep as the shovel can go, a scoop is employed to clear out the mud and loose earth at the bottom. Then another shovel corresponding with the first is used, and a second spit is taken out, and then a narrower shovel still to clear the whole out, thus forming a trench with a ledge. A piece of sod, with the grass-side below, is then forced down, and, resting upon the ledge, a space is thus left for the water below. Sometimes the ledge is dispensed with, and the sod is merely formed into a wedge, narrowed towards the grassy side, and this, when the little trench is cleared out, is pressed into it and covered with earth; and, as it does not reach the narrow bottom, a channel remains below through which the water percolates. It is evident that where such under-drains can be constructed the bottom must be hard. This and the brush and straw drains are formed at comparatively little expense, and for a while operate very efficiently in conveying off the superfluous water. Still, as the materials are more or less perishable, and, moreover, liable to become closed up, they are an indifferent substitute for stone, and yet more so for the proper draining tile.

On the heavy clay soils, the drainage is sometimes effected by a drain or mole plough, which on some soils answers very well at a moderate expense. In this the plough draws a long tubular orifice in the clay by a heavy sharppointed rod instead of a share, which on some adhesive soils remains open, provided the fall for the water is sufficient, for years. It is, however, liable to too many casualties for general introduction. It is commonly worked, either with a windlass or otherwise, by 18 or 20 horses drawing from strong whippletrees. (Brit. Husb. vol. i. p. 455.)

An excellent and improved imitation of the mole plough system is sometimes practised on heavy clay lands. A stout piece of rope or cable, four or five yards long, is laid at the botlom of the newly cut drain (one of the narrow wedge-formed drains); to the ends of this piece of rope is fastened a cross or $\mathrm{T}$-headed piece of wood, by means of which it is drawn along the bottom of the drain after the clay and other materials have been filled over it; an arch or 418 ppening is thus left. similar to that formed by the mole plough; the expense in this case is merely that of digging and filling up the drain. (Brit. Farm. Mag. vol. ii. p. 367.)

In spite, however, of open and under-ground drainage, and of all that these and the boring system can effect, there are yet many thousands of acres in the east of England that, without the aid of the pump and the steam-engine, would still be covered with water. These were recommended many years since for this pur. pose by Mr. Savory, of Downham. (Com. Eoard of Agr.vol.iv. p. 52.) The gigantic powers of these great engines will be readily seen from the report of Mr. Glynn (Brit. Farm. Mag. vol. iii. p. 289.) Deeping Fen, near Spalding, containing 25,000 acres, is effectually drained by two steam-engines of 60 and 80 horse power. Littleport Fen, near Ely, of about 28,000 acres, is drained by two engines of 30 and 80 horse power. By this last engine, on July 18 th, 1830 , in a trial of eight hours, by the combastion of only 87 bushels of coals, 51,230 tons of water were raised. Before the introduction of steamengines, windmills were employed to a considerable extent. They were maintained, it is true, at a less expense, but the certain powers of the steam-engine have induced its general adoption. The carriage drain is an open, ca. pacious drain, used very commonly in irrigation, and is usually made of wood, for the purpose of carrying the flood waters across ditches, hollow drains, \&c.

DRAINING-PLOUGHS. Such ploughs as are contrived for the purpose of cutting drains, in order to carry off the water from wet soils. See Ploughs.

DRANK, or DRAUK. A very common name in many parts of England for darnel; but is properly only the provincial name for the scaly brome-grass, cheat, or chess.

DRENCH. In farriery, a large drink or draught of any liquid remedy given to an animal, usually by means of a horn properly cut for the purpose. A very able paper on drenching horses, by Mr. John Stewart, veterinary surgeon, appears in the Quart. Journ. of Agr. vol. x. p. 626, which may be consulted with advantage. A drink is not so portable as a ball; it is more troublesome to give, and a portion of it is usually wasted. (The Horse, p. 392.) Mr. Stewart strenuously urges the following propositions: 1. That draughts, particularly when pungent or disagreeable, are dangerous. 2. That by no care can the danger be altogether avoided. 3. That no draught should be given unless the horse be in danger of dying without it. 4. That the safest way of administering draughts is to give them when the horse is lying. 5. That a draught is seldom or never absolutely necessary but in diseases which make the horse lie. 6. That a bottle is a better drenching instrument than a horn.

DRESSING. Any sort of manure applied to land for the purpose of its improvement. Topdressing is that sort of fertilizer which is spread over or applied upon the surface of the land, either when the crop is upon the ground or not.

DRILI. A small track or longitudinal opening in the form of a slight furrow, made in 


\section{DRILL-HUSBANDRY.}

tillage lands for the purpose of receiving any kind of seeds.

DRILL-HUSBANDRY. 'The practice of sowing or planting grain and other seeds or roots with a machine, in regular rows or drills, in place of scattering them by the hand, by which means they are dropped at more equal distances, and lodged at better depths, than can be done in the latter way. "Of our modern improvements," says Dr. Fothergill (Com. Board of Agr. vol. iv. p. 156), "the introduction of drillhusbandry has been generally allowed to be the most important." Horse-hoeing is intimately connected with it, and for the most part forms part of the same system.

DRILLING. The act of putting different kinds of crops into the ground in the drillmethod. Mr. Bramston gives the result of an experiment on the comparative advantages of narrow and wide drilling. (Journ. of Roy. Eng. Agr. Soc. vol. i. p. 294.)

DRILL-MACHINES. Implements for distributing seed and manure easily, and at regular distances. A rude kind of drill has been used in agriculture from a very remote period. The cultivators of China, Japan, Arabia, and the Carnatic, have drilled and dibbled in their seed from time immemorial. (The Chinese drill, or drill-plough, is noticed Quart. Journ. of Agr. vol. i. p. 675.) After the Hindons have thus deposited their seed, they use a kind of subsoil plough, which passes under and loosens the soil to the depth of about eight inches three drills' breadth at a time. (Com. Board of $A g r$. vi. 355). Gabriel Platte, in 1638-1653, describes a rude dibbling machine formed of iron pins, "made to play up and down like Virginal jacks;" and John Worlidge, in his Husbandry, published in 1669 , not only advocated the use of the seed drill, but of the manure drill. Evelyn, in the same year (Trans. Roy. Soc. vol. v. p. 1056), mentions with much commendation a drill-plough which had been invented in Germany, whence it had found its way into Spain, and had been noticed by the Earl of Sandwich, the English ambassador, who forwarded it to England as the inveation of a Don Leucatilla. Jethro Tull at a later period (1730-40), devoted all his energies to promote the introduction of this machine, more especially as it admitted the use of the horse-hoe. The united advantages of these excited in him the highest enthusiasm. But it was not until the drill had been gradually improved by the labour of succeeding mechanists, that this invaluable machine, principally through the exertions of Lord Leicester and others, became generally used in England. Thence it appears that the method of sowing corn and other seeds by machines in England is not (as is well remarked by Mr. J. A. Ransome, the eminent agricultural machinemaker of Ipswich, to whom I am indebted for almost the whole of this article), a modern idea, though the machines have been so much improved within the last century as to make them bear but little resemblance to those formerly in use.

Passin 5 by those of more ancient date, we come to the inventions of Jethro Tull, for the purpose of carrying out his system of drill- husbandry, about 1733. His first invention was a drill-plough to sow wheat and turnip seed in drills, three rows at a time. There were two boxes for the seed, and these, with the coulters, were placed one set behind the other, so that two sorts of seed might be sown at the same time. A harrow to cover in the seed was attached behind.

Jethro Tull also invented a turnip-drill somewhat similar to the other in general arrangement, but of lighter construction. The feeding spout was so arranged as 10 carry one half of the seed backwards after the earth had fallen into the channel; a harrow was pinned to the beam; and by this arrangement one half of the seed would spring up sooner than the other, and so part of it escape the turnip fly. When desirable to turn the machine, the harrow was to be lifted and the feeding would stop. The manner of delivering the seeds to the funnels in both the above drills was by notched barrels, and Tull was the first who used cavities in the surfaces of solid cylinders for the feeding. Nothing material in the history of the drill occurred afterwards till 1782, and but little progress appears to have been made to that period in drill-husbandry.

About this time Sir.John Anstruther, near Edimburgh, presented the model of an improved drill-plough of his own invention to the Bath and West of England Society, having had one in use for eight years previous without its getting out of order. It was a double drill-plough of simple construction, by which two furrows could be sown at a time, the horse walking between them, and by this means the injury usually done by the horse's feet to the fine ground was avoided. Within the next ten years twelve patents were taken out for drillmachines, two of which were for depositing manure with the seed; but the most approved appear to have been those invented by James Cooke, a clergyman of Heaton Norris, in Lancashire; and the general principles of these machines, from their simplicity, have been adopted in the construction of some of the most approved of the present day.

For a cut of Cooke's grain-drill, see Pl. 14. fig. 1.

The seed-box of Cooke's drili, is of a peculiar shape, the hinder part extending lower than the fore part. It is divided by partitions, and so supported by adjustable bearings as to preserve a regular delivery of the seed whilst the machine is passing over uneven ground. The feeding cylinder is made to revolve by a tooth-wheel, which is fixed on each end of the main axle, and gears with other toothed wheels on each end of the cylinder; the surface of the cylinder is furnished with a series of cups which revolve therewith, and are of various sizes, according to the different seeds. These deposit the seed regularly in funnels, the lower ends of which lead immediately behind the coulters, which are connected by a beam, so as to be kept in an even line, and are capable of being held out of working when desired by a hook and link in the centre. 'The seed, as it i: deposited, is covered in by a harrow fixed behind. The carriage wheels are larger in size 
than usual, by which means the machine is more easily drawn over uneven ground; and the labour of working is reduced.

"Of corn drills," says Joudon, "Cooke's improved drill and horse-hoe, though not the most fashionable, is one of the most useful implements of this kind on light dry soils, on even surfaces, and in dry climates. It has been much used in Norfolk and Suffolk, and many other parts of England. I he advantage of this machine are said to consist,-1. In the wheels being so large that the machine can travel on any road without trouble or danger of breaking; also from the farm to the field, \&c., without taking to pieces. 2 . In the coulter-beam $(a)$, with all the coulters moving with great ease, on the principle of the pentagraph, to the right or left, so as to counteract the irregularity of the horses' draught, by which means the drills may be made straight; and, where lands or ridges are made four and a half, or nine and a half feet wide, the horse may always go in the furrow, without setting a foot on the land, either in drilling or horse-hoeing. 3. In the seed supplying itself regularly, without any attention, from the upper to the lower boxes, as it is distributed. 4. In lifting the pin on the coulter-beam to a hook on the axis of the wheels, by which means the coulters are kept out of the ground, at the end of the land, without the least labour or fatigue to the person who attends the machine. 5. In going up or down steep hills, in the seed-box being elevated or depressed accordingly, so as to render the distribution of the seed regular; and the seed being covered by a lid, and thus screened from wind or rain. The same machine is easily transformed into a cultivator, horse-hoe, scarifier, or grubber, all which operations it performs exceedingly well; and by substituting a corn-rake, stubble-rake, or quitch-rake, for the beam of coulters, or hoes $(a)$, it will rake cornstubbles, or clean lands of root weeds. When corn is to be sown in rows, and the intervals hoed or stirred, we scarcely know a machine superior to this one; and from being long in a course of manufacture, few can be made so cheap. But these advantages, though considerable in the process of drilling, are nothing, when compared with those which arise from the use of the horse-hoe; with which from 8 to 10 acres of land may be hoed in one day, with one man, a boy, and one horse, at a trilling expense, in a style far superior to, and more effectual than, any hand-hoeing whatever; also at times and seasons when it is impossible for the hand-hoe to be used at all. Pl. 14, fig. 2.

"The Norfolk drill, or improved lever drill, is a corn drill on a larger scale than Cooke's, as it sow's a breadth of nine feet at once: it is chiefly used in the light soils of Norfolk and Suffolk as being more expeditious than Cooke's, but it also costs about double the sum.

"Morton's improved grain drill-machine is decidedly the simplest and best of corn drills. In this machine three hoppers are included in one box, the seed escaping out of all the three by the revolution of three seed cylinders upon one axle; and drills of different breadths are produced simply by the shifting of a nut, that fires a screw moving in a groove in the under420 rame, by which the distance between the two outside conductors and the central one (which is fixed) can be vitried from 9 to 10 or 11 inches; and that the two small wheels may always be at the same distances respectively as the conductors, there are two washers (hollow cylinders), an inch in breadth, on the axlearms of each, which may be transferred either to the outside or inside of the wheels, so as to make their distances from the outside conductors 9, 10, or 11 inches respectively also. The small wheels may be raised or depressed, so as to alter the depth at which the seed shall be deposited, by the action of a wedge, which retains the upright part of the axle in any one of a number of notches, which are made similarly in both, and which are caught by an iron plate on the upper side of the arms which carry the axles. This machine may be still farther improved by increasing the number of conductors to five instead of three; the latter number giving too light work to the horses." (Highland Soc. Trans. vol. vii.)

About the year 1790, Henry Baldwin of Mendham, near Harleston in Norfolk, a farmer, aided by an ingenious workman named Samuel Wells, then in his employment, improved upon the drill known as Cooke's drill, which by this time was in use in several parts of Norfoll. The improvement consisted-first, in making a sliding axletree, by which the carriage wheel could be extended at pleasure to the width of the "stetches" or lands, and by which means another box with cups and more coulters could be used. Thus a drill containing 14 coulters could be enlarged to one of 13 or 20 . Second. in making self-regulaling levers, to which the coulters were attached; this was done by hanging each coulter on a distinct lever, placed at right angles with the cross bar of the framing, upon which each lever was made to swing by an ordinary hinge joint, and had a movable weight at its opposite end, to press the coulter into the soil. By the levers being thus contrived to work independently of each other, they accommodated themselves to the irregularity of the surface of the land, and the impediments which they might meet, without disturbing the whole. The above were two very important improvements; and they are both in use in England, to this day.

Suffolk Corn and Manure Drill.-Following the improvements just referred to, are those by James Smyth of Peasenhall, and his brother Jonathan Smyth of Swefling, who have beer engaged in the manufacture upwards of $4 \theta$ years. A brief summary of which is as follows:-1. A mode of adjusting the coulters to distances apart from each other, from four and a half inches and apwards. 2. An improved manure-box and cups, for the delivery of manure with the grain. 3. A plan to drill in manure and grain, and sow small seeds at the same time. 4. The swing steerage, by which means the man attending the drill can move the coulters to the right or to the left hand, sn as to keep the straight and parallel lines for sowing the seeds. 5. Various improvements in gearing and driving the wheels, barrel, \&c. An engraving taken from one of Smyth's most perfect grain and manure drills is given in 
Plate 14, fig. 3, by the description we have given of Cooke's and of the subsequent improvements by Baldwin, Wells, and Smyth, the plan will be fully understood.

The Suffolk grain and manure drill may also be arranged for sowing turnips and manure at the same time. In such cases the corn-box has to be exchanged for a double one, in one part of which runs a spindle with brushes, where the turnip-seed is contained. There are small copper slides, with different numbers, from one to six holes pierced in them, through which the seed is delivered as required. The other part of the box contains the manure, which is thrown into the funnels, and these are so arranged that it drops into the earth just before the seed.

Morton's improved grain drill, is spoken of in the Highland Society's Transactions, (vol. vii.) as decidedly the simplest and best of grain drills. A description and cut of this machine which drills 3 rows, is given in Loud. Encyc. of $A g r .$, p. 409.

Hornsby's Patent Drop Drill is intended for dropping seed with manure at intervals, but the construction of it is very different from the Suffolk. In this, the manner of regulating the delivery is by having a coulter of a peculiar form inside, in which a circular box revolves on an axle which passes through one side thereof. This box is divided into compartments closed by small doors, which are kept shut by a spring to each; the compartments in the box are supplied through a series of funnels, the end of the lower one entering one side of the box below the centre.

On the machine being moved forwards, this box revolves by means of appropriate cogwheels; and as each spring arrives at the ground, the door to which it is attached opens, and the contents of that compartment are deposited, to be again replaced, when it arrives at the part of its rotation at the end of the funnel, and so on successively.

Grounsell's Patent Drop Drill.-This drill is for the purpose of depositing corn, grain, pulse, and manure at intervals, the distances of which may be regulated at pleasure. (Pl. 14, fig.4.)

To effect the purposes above mentioned, a circular iron ring is fixed about midway between the nave and rim of the drill carriagewheel. In this there is a number of holes to carry a series of studs, which may be varied according to circumstances; and as these studs eome in succession, when the wheel turns they open valves for the delivery of the seed and manure, which close again immediately the stud has passed. A further improvement is by the adoption of projecting arms or shovels, to draw the manure and grain to the funnels, instead of taking the same up in eups in the way adopted in other drills.

The Messrs. Ransome give the following sketch of the chief modern improvements made in the drill, which have greatly added to its usefulness, without having increased its cost.

The drills usually made by the best makers in England, are of several kinds; but their description may be briefly comprehended under three or four heads.

1. The C'ommon Lever Drill. This invaluable machine, which is the one in the most general use, is adapted for drilling grain, on either level grounds or ridges, and on all descriptions of soil. These are, as we have stated in our previous description, furnished with independent levers, by which the coulters are euch readily and separately made to avoid any rocks or irregularities of the ground, and a "press steelyard," to force the coulters, in case of need, into hard ground, with a varying degree of pressure, according to the texture of the soil.

These coulters can now be set so as to drill the corn at any width, from 4 inches to a greater distance; they also, if required, readily allow of the introduction of the horse-hoe; and from being placed, by another excellent improvement, in double rows, they admit, when at work, of large stones, \&c., passing between them, of a size that was not possible under the old plan of placing the coulters in one line. These are also, in the most complete drills, furnished with a "swing steerage," by which the drill-man keeps the rows at exact or even distances from those which have been previously drilled in the centre of the ridge, or out of the furrows, \&c. The "corn-barrel" of this drill is made to deliver from two pecks to 6 or 7 bushels or strikes per acre of any kind of grain; and they have an additional barrel for drilling turnips and mangel-wurzel, \&c. And again, these barrels, by a peculiarly simple, yet excellent "regulator," are kept on unequal, hilly ground, on the same level; so that the grain is evenly delivered, in whatever situation the drill may be placed.

A "seed engine" is also sometimes added to this drill, by which the grass-seeds and clover are sown at the same time as the grain, and each kind of seed, if required, separately; hy which plan any quantity per acre of the seeds may be much more evenly distributed, than by mixing them up together. For these seeds, being of different sizes and weights, are in the ordinary seed engines very apt to separate in the boxes; and thus the brushes 100 often deliver them in unequal proportions.

The weight of these drills necessarily varies with the number of coulters; they are usually from about 3 to $10 \mathrm{cwts}$, and are drawn, aceording to circumstances, by either one, $t w 0$, or threc horses; and have, if required, slip axletree. with which, by merely adding to the number of the coulters, \&c., the drill is adapted to any breadth of land.

2. The next description of drill to which I shall allude, is The Manure Drill. This drill is formed very readily, by merely adding to the common corn drill, an operation which any husbandman ean perform, "a manure box." It is a simple yet accurately working arparatus for delivering the manure, which, in the best drills, it does with great evenness, and in quantities varying as "the slip" is placed, from 6 to 8 bushels per acre. In the best drills, also, a very important improvement has been made within the last few years, which eonsists in the use of separate coulters for manure and seed. 'I'he manure is row deposited according to the mode preferred by the cultivator, nos only from 2 to 3 inches deeper in the ground than the seed, but from 10 to 12 inches in ad 


\section{DRILL-MACHINES.}

vance $\mathrm{c} f$ it, so as to give the soil time to cover the manure before the next coulters deposit the seed;-whereas, on the old plan of depositing the seed and the fertilizer together down one pipe, an evil was liable to arise when it was used with some of the more powerful artificial manures; the seed and the manure were too close together, and the manure was not always dropped in what is commonly its best position, under the seed.

3. The third variety of drill which 1 shall notice, is The Northumberland Frame Manure and Turnip Ridging Drill. This excellent drill is furnished with pressing rollers (one to each coulter), which form the land into ridges-and precede the coulters. These deliver in separate coulters, 1st, the manure; and 2dly, the seed; and the drill is provided with a second roller, which follows the coulters and closes the rows. This machine drills two rows at a timeweighs only about $1 \mathrm{cwt}$ - -and one man and a horse can easily drill from 8 to 10 acres per day.

Besides these three most commonly used drills, there are several others-such as the Two Coulter Seed and Manure Lever Drill; - this has a swing steerage, to which we have before alluded, and a slip axletree to vary the distances of the ridges-(for this valuable implement a prize was awarded to $\mathbf{M r}$. Garret at the Cambridge meeting). To this a set of hoes is occasionally attached, furnished with independent levers either for ridge-work or otherwise.

There are in England many other varieties of drills, but they involve no particularly useful principles, if we except the drop drills, the chief object of which is to save the quantity of manure. In these the seed or corn is mixed, and deposited with the manure.

Frnm this brief enumeration the farmer will see that the modern drill-makers have not neglected their duty, in the adoption of every improvement calculated to simplify and render more serviceable the common and the manure drill; and I am highly gratified to be able to add, that there is now every prospect of their skill and enterprise being rewarded by the cultivators of our country; for I find, from an eminent maker, that the demand for manure drills has within the last two years been greater than ever was remembered before.

The chief advantages of the use of the drill, are the regular deposition of the seed at a uniform regulated depth, from which arises a considerable saving of seed (at least one-third) -and the facility afforded in cleaning the land either by the hand $G r$ horse-hoe. The importance of these results is, happily for our country, rapidly becoming generally understood: and the result of experiments which I witnessed to a considerable extent, upon some of the poorest gravelly soils of Surrey, by Mr. Hewitt Davis and others, convince me that, by the use of this machine, combined with careful hoeing and weeding the crops, a saving even of half the usual quantity of seed now used by the drill may be effected. And again, $I$ cannot too often urge upon the farmer of the upland soils, tar away trom supplies of manure, the use of 'he manure drill, and those fertilizers expressly 422 prepared for its use; since by these one ton of manure is sufficient for three acres And let the farmer remember, that it is not only the first cost of all manures which makes them expensive, but the comparative labour saved in their application, which must also be taken into the account when the cultivator is estimating their value. And further, let him remember that the best and richest farm compost is likely to convey to his fields a multitude of weeds, the cost of whose removal too rarely forms a portion of such comparative estimates.

The patents which have been taken out in England, during the last half century, for drill ploughs and improvements in sowing machines form a long list.

The advantages derived from using drill machines for sowing wheat and the other small grains have been summed up by Mr. Binns, at a meeting of an English agricultural society, as follows :-

1. The seed is delivered with regularity:

2. It is deposited at proper depth.

3. The weeds, during the growth of plants, are destroyed with great facility.

4. The plants cultivated receive the undivided benefit of the soil and manure, and have not to maintain a constant struggle with weeds.

5. The land by the process of hoeing, is undergoing preparations for another crop.

6. The necessity of summer fallowing is avoided.

7. By admission of the sun and air between the rows, a stronger and healthier plant is produced, and of course a heavier crop.

8. By stirring the soil it is more susceptible of benefit from the atmosphere, imbibing more oxygen, and being both warmed and enricheo by the sun.

9. The roots shoot freely in pulverized soil.

10. By drilling, the farmer is enabled to have heavier crops of beans and wheat on light land.

11. Clover and grass-seeds answer incomparably better in the palverization produced by hoeing, independent of the clearness from weeds.

12. The drills give facility for depositing smaller portions of manure with greater effect. "These advantages," says the editor of the Cultivator, "are all self-evident to a good farmer; and it might have been adied, as a thirteenth advantage, that drilling economizes seed, though Mr. Binns rejects it, on the ground that, if the plants are thin, they throw oat sideshoots, which prodnce imperfect grain, and ripen unequally. In drill husbandry, Mr. Binns affirms, fifty-six bushels of wheat per acre have been raised on the light soils of Norfolk."

It is believed by some that the plan of sowing wheat by drill machines is a refinement in agriculture which cannot be profitably adoptei in the United States, where the price of grain is of late years much lower than in England. The introduction of the practice will perhaps be slow, but there cannot, we think, be a doubt of its final general adoption in all the best cul. tivated wheat-growing districts. The first expense of the machine is doubtless she princi 
pal obstacle to their general introduction, as to import a good one costs between $\$ 150$ and $\$ 200$.

An admirable drill for sowing wheat has been invented and patented by Moses Pennock and son Samuel, of Kennett Square, Chester county, Pennsylvania. (See Plate 14, fig. 5.) It has been used for several years in the southern parts of Pennsylvania and adjoining states, and the greatest satisfaction has been expressed for its performance.

Pennock's drill is capable of sowing 8 acres of wheat, or planting 15 acres of Indian corn, per day. The wheat is placed in boxes, connecting with sowing tubes which penetrate into the ground, scattering it in rows 9 inches apart, and covering about an average depth of $2 \frac{1}{2}$ inches. If one or more of the tubes comes in contact with a stone, root, or other obstacle beneath the surface, a small chain to which it is attached breaks a wooden peg, and thus saves the machine from any serious injwry, the detention being only a few seconds when pegs are kept on hand. The preparation of the ground is similar to that adopted in the broad-cast method. The machine is drawn with great ease by one horse, and requires but one attendant, in sowing wheat. For every bushel sown by hand in the ordinary way, the drill saves from 8 to 12 quarts. The machine is easily managed and not liable to get out of order. Besides covering the wheat much more effectually than can be done by the harrow, it raises ridges about 3 inches high on each side of the tubes. These ridges crumble down by the action of the frost and rains, and thus cover the young plants and prevent them from being thrown out during the freezing and thawing of the ground and killed, as so commonly occurs in the winters of the United States. Samuel Pennock, the junior inventor, has for several years been using the drill extensively in putting in crops. His usual charge, for the use of a machine, including the horse and his own services, is $\$ 4$ per day, or 50 cents per acre. When wheat sells for $\$ 1,25$ or $\$ 1,50$ per bushel, the seed saved will pay all the expense of drilling, (especially when the farmer owns the drill), the crop being placed in a far better condition than can be effected by the broad-cast method, as will be evident from a consideration of the various advantages enumerated, and these constitute the chief profit.

When the machine is used for planting Indian corn, (for which purpose it is singularly well adapted), some of the levers are thrown out of gear, leaving the remainder so arranged as to strike out two rows, $4 \frac{1}{2}$ feet apart, in which the corn is dropped at regular distances and covered with about $3 \frac{1}{2}$ inches of earth, or less if desired. It may be afterwards thinned, but must of course be always tilled in one direction. The ground is flushed and harrowed, after which rows 9 feet apart are run with a plough and one horse, in which rows the horse drawing the drill walks in going and returning. In this way about 15 acres of Indian corn may be planted in a day, and thus a considerable saving of labour is effected by the owner of a drill, siuce to plant the same number of acres by han.1, in the usual was. would require 5 hands equal to fifteen days work, with the addition of a second plough (1) run out furrows, and two droppers. Although Pennock's drill costs $\$ 100$, it seems evident that the saving of labour in planting the corn crop will more than pay the interest and wear and tear of the machine, leaving none of these charges to be placed against the wheat crop. Persons who have watched the progress of corn crops planted by the drill, and compared the results with those of crops planted by hand, say, that under ordinary circumstances, a gain of 5 bushels per acre may be fairly credited " the drilled corn. Some even go so far as to say that drilling has added one-fourth to the crop. The deep covering is regarded, where the soil is perfectly dry, and of a light texture, as a very great advartage. The corn will at first appear backward, but is soon observed to catch up and outstrip that which has been covered more superficially. It is also placed more out of the reach of birds, and escapes injury from the cut-worm, and heart-worm, or, as it is also called, bud-worm. 'The cut-worm usually commits its depredations by night; taking off the plants at, or very near, the surface of the ground, whilst by day it cuts a little below the surface. Now, when corn is deeply covered it admits of being topped, without being entirely killed, and suffers little further injury than retardation.

Pennock's drill, besides sowing beans, peas, and all kinds of round seeds, including rutabaga, is, like Cooke's English drill, capable of being adapted to the purposes of a horse-hoe, cultivator, extirpator, and harrow, by the adjustment of hoes, harrow-teeth, \&c. Besides the approbation bestowed on Pennock's drill by individual farmers, for some of whom they have sown as much as 100 acres a season, several public institutions have awarded premiums to the inventors, among which we may mention the Philadelphia Agricultural Society, Franklin Institute of Pennsylvania, and American Institute of New York.

It would be a desideratum in the United States to have drills like those used in England. adapted to sowing seeds and sprinkling with them at the same time some of the concentrated manures, such as bone-dust, poudrette, \&c. But this again, like every other addition, must increase the cost, already so great an obstacle.

As yet the drill system in the United States has been principally confined to sowing turnips and beets, and sometimes Indian corn. The results with many who have had good implements and known how to use them, has been a conviction of their utility and economy, especially where the root culture has been extensively carried on. One-rowed drills are almost the only kind to be met with in the warehouses where agricultural implements are kept for sale.

Drill-barrows are implements furnished with handles, similar to those of a wheel-barrow. and designed to be propelled by hand. Among these Willis's Latest Improved Seed-sover is said to be the best, as it puts the seed into the ground with regularity and in the best manne: 
It opens the furrow, drops the seed, covers and rolls them down. It will sow almost any kind of garden seeds, such as beets, rutabaga, mangel-wurtzel, carrots, turnips, parsnips, onions, \&c., and costs $\$ 14$.

Buckminster's Seed-planter is of simple construction, and has been found to answer well for planting corn, sugar-beet, \&c. It deposits the seed either in drill-rows or hills, as may be desired. When the ground is properly prepared, a man, with one horse, it is said, can jurrow out, drop, cover, and press down the seed on an acre of ground in one hour, or 10 acres in a day. The seed is covered by falling into the furrow of the soil, which is finely pulverized by a row of cultivator teeth. The machine will bury the seed 3 inches deep, if desired-one inch being the general rule for Indian corn, and only one-fourth of $2 \times$ inch for turnips. By simply turning a screw one way or the other the depth is regulated.

Iiement's Improved Turnip Drill, which is a modification of the English Northumberland Drill, enjoys a good reputation. It sows beets, peas, and, generally, all kinds of round or ovalshaped seeds.

Merchant's Drill Barrow, is said to perform well, and is recommended by its simplicity of construction and cheapness. By multiplying the wheels, or rather by uniting several machines, it may be adapted to horse power, and thus applied to field culture for sugar-beets, ruta-bagas, \&c., and, even, it is said, for wheat and other small grains.

DRILL-ROLLER. A roller so contrived as to form regular small incisions or drills in the ground at proper depths for the seed. It is merely a common cylinder roller, generally of iron, about seven feet long, around which are put cutting-wheels of cast iron, each of which generally weighs about a ton. The cutting wheels, being movable, may be fixed at any distance, by means of washers.

DROPSY. In farriery, a disease incident to horses, and sometimes called water-farcy. See Horses and Sheep, Diseases of.

DROPWOR'T, WATER (Enanthe). Smith (Eng. Flor. vol. ii. p. 68), describes five species in England. The common water-dropwort; the parsley water-dropwert; sulphur-wort water-dropwort; the fine-leaved water-dropwort; and the hemlock water-dropwort. They are aquatic herbs, perennials, and biennials; fetid, and often poisonous: found in ditches, ponds, and other watery places. The first three species are not reckoned poisonous; but the last (Enanthe crocata), is perhaps, in its fresh state, the most virulent of British plants. Brood mares, according to Sir Thomas Frankland, sometimes eat the root, and are poisoned by it. The root consists of many fleshy knobs, resembling parsnips externally, abounding with an orange-coloured, fetid, and very poisonous juice, such as exudes less plentifully from all parts of the herb when wounded. The stem is from two to five feet high, much branchad, somewhat forked, and hollow. The leaves are of a dark shining green, and doubly pinnate. The flowers are white, or tingec with purple, very numerous and crowded.

Two or three species of cowbane are enu124 merated in the United States, where the plan: is believed to be an active poison, particularly to horned cattle, when eaten by them; for which reason it should be eradicated from all pastures where it is discovered. (Darlington's Flor. Ces.)

DROSOMETER (from the Greek). An instrument constructed for measuring the quantity of dew that collects on the surface of a body exposed to the open air during the night. The first instrument for this purpose was proposed by Weidler. It consisted of a bent balance which marked in grains the preponderance which a piece of glass of certain dimensions, laid horizontally in one of the scales had acquired from the settling and adhesion of the globules of moisture. A simpler and more convenient drosometer would be formed on the principle of the rain guage; and in order to facilitate the descent of the dew down the sides of the funnel into the tube, a coat of deliqueate salt of tartar may be spread over the shallow surface. Dr. Wells, in making his celebrated experiments on dew, exposed a small quantity of wool to the open sky, and the difference in its weight when laid down and taken up showed the quantity of moisture it had imbibed in the interval. (Brande's Dict. of Science.)

DROUGHT. The effect of long-continued dry weather, or the want of rain: when applied to animals, it signifies thirst, or want of drink.

DRUDGE. An implement of the rake or harrow kind, peculiar to West Devonshire. Ir is a sort of long heavy wooden-toothed rake, the teeth being broad, and placed with the wide or flat side foremost. It is drawn by horses or oxen, and made use of, in paring and burning operations, to collect the broken parts or fragments of the sward which have been loosened by the operation of the plough and harrow.

DRY ROT. The name of a disease which attacks wood, rendering it pulverulent by destroying the cohesion of its parts. It frequently depends on fungous plants, which are nourished upon the sap in the wood, and by taking that away destroy the cohesive property of the woody particles. The fungi most destructive are the Merulius lacrymans, the Polyporus destructor, and several species of Sporotrichium. The production of these fungi is favoured by whatever causes the sap remaining in the wood to ferment; as, for example, defect of ventilation. In the old cathedrals and other public edifices, the dry rot never appeared, because care was taken to ventilate the beams. It oceurs among the timbers of ships, where it sometimes commits the most serious damage and in damp ill-ventilated houses. Mr. Batson, in the Trans. of Soc. for Encour. of Arts, recommended charring as a preventative. Some excellent advice is also given on this subject in a paper by Mr. Hart, "On the Cause of Dry Rot in the Lareh and other Trees" (Trans. High. Soc. vol. iv. p. 395). The process which has been patented by Mr. Kyan, namely. steeping the wood for a week or two in a strong solution of corrosive sublimate, which coagulates the albumen of the wood, and destroys the 
fungus, appears to be the best preventative at present known. Sir W. Burnet has recently invented another process for rendering wood, cordage, and all descriptions of woollen, free from the effects of dry rot, which has lately been tested and found very efficacious by government. I understand the active matter in Sir William Burnet's solution is sulphate of copper. (Willich's Dom. Ency.)

DUCK (Dutch Ducker, to dip; Lat. anas). There are many varieties of ducks described by naturalists, but only two are to be found in our farm-yards; namely, the common duck and the Muscovy duck. The common duck is a useful and economical bird, requiring little care. It is perfectly independent, if there is only a pond or mud hole to dabble in; for moisture is its element, and it cannot thrive without it. One drake is sufficient for eight or ten ducks. Duck hovels should be kept very clean and warm, with a row of boxes inside to induce the duck to lay her eggs in them; otherwise in the laying season she drops her egg in the water, or on the bare ground, or seeks by-places, where the eye of the vigilant housewife cannot penetrate. For this reason, it is better not to let them out very early in the morning during the laying months, which are March, April, and May. Their hovel should be well secured from the entrance of foxes, polecats, weasels, \&c., and it should be defended from wind and weather. Ducks "feed themselves" a great part of the year, as they are gross eaters; loving every sort of garbage, such as offal, earthworms, caterpillars, sweepings of barns, residue of breweries, slugs, toads, spiders, and insects. In this particular, they are admirable gardeners, effecting more in one night than two gardeners could perform in a week towards clearing a garden of slugs, snails, and caterpillars. The waters which ducks frequent should contain no leeches. If a pond has any leeches in it, put in a few tench, which will soon devour them. The herb henbane should also be carefully rooted up from the neighbourhood of ducks and poultry in general, from its poisonous qualities. A duck lays from 50 to 60 eggs between the months of March and May, which are as nourishing in their quality as hen's eggs. The duck is not naturally inclined to sit, but let her always sit upon her own eggs if possible. It is observed that they do not like sitting upon strange eggs, and that they even suffer pain by it. Let her nest be remote and quiet from alarms. While the duck is sitting, her food should be placed near her, and doled out sparingly. They sit closer if not fed too profusely. The food should be very moist. 'The young ducklings are hatched in a month, and then the mother should be put in a coop for some time, or she will carry her brood immediately to the water, and tire them; besides which, many perish with cold. They should be allowed to get strong first. Many housewives prefer setting duck eggs under hens and hen turkeys, in order to prevent this; but if the duck is secured, the end is answered. Let the ducklings have dishes of water near the coop to dabble in, and feed them when out of the ego-shell with

bread crumbled in mills, for a few days. Nettle. leaves boiled tender and chopped very small, made into a paste with barley meal, is also a warm, wholesome food. When the ducklings gain strength, give them plenty of raw potherbs well chopped, mixed with soaked bran, barley, mashed potatoes, mashed acorns, or fish, if near the coast. Ducklings intended for the table should not be allowed to swim about much; it keeps them lean. Early ducks are valuable. They should be confined to their hovel or to a coop during the process of fattening, and fed there for one month upon oats and water in clean troughs. It is of no use giving them musty oats: they will no more fatten upon musty oats than we can thrive upon musty bread. Do not try to fatten them either upon garbage. It gives the flesh a bad taste. Boiled rice is a nice delicate variety of food. The fine, white Aylesbury breed are the most profitable and the handsomest duck. They are also the earliest in laying and setting.

I will give a recipe for salting ducks, as they are done in Brittany: it is economical and excellent food. 'Two days after the well-fatted ducks are killed, cut them open at the inferior part, and draw away the thighs, wings, and flesh of the stomach and rump. Put the whole, with the neck and tip of the rump in a tub of salt, with a little nitre and a few bay leaves mixed in it, to give the flesh a fine red colour. Cover it up in the salt a fortnight; then cut the fowl in four quarters, lard it with cloves, and pui it into a pot or pots, with some spice.

Duck feathers are very profitable, and, mixed with those of the goose, make good pillows, \&c. The feathers should be plucked in May and September, while the duck is yet warm after death. Dry the feathers in bags in the oven after the bread has been withdrawn, and repeat the process several times. See Feathers.

UUCK, THE MUSCOVY (Anas Moschata), a native of South America, is a gaudy-looking large bird, often introduced into our farmyards, but not much approved; more for show than use. Their flesh is not so good to eat as that of the common duck, and the drake is very tyrannical in attacking the poultry, and causing an uproar in the peaceful homestead, besides spoiling a superior breed.

DUCK, THE WILD (Anas boschas, Linn.), is rather less in size than the tame duck, but differs little in plumage; it weighs usually about $2 \frac{1}{2}$ lbs., but has been known to reach $3 \frac{1}{2}$ In-shore shooting of wild ducks is considered to be legitimate sporting about the middle of August, when the flappers, or young ducks, have begun to take wing. The last Game $\mathrm{Act}$ in England has a clause to prevent wild-fow"? being killed from the last day of March to the 1st of October, and this applies equally to shooting and taking them in decoys. The wild ducks pair in the spring, build their nest among rushes near the water, and lay from 10 to 16 eggs. (Willich's Dom.Ency.) For descriptions of the numerous species of the wile duck found in the United States, see Nuttall', Ornitholngy of Water Birds.

$2 \times 2$ 
DUCK'S FOOT (Podophyllum; a bridged from anapodophyllum, a word signifying a duck's foot, as the leaves bear some resemblance to it). This plant requires a moist, shady situation, and to be grown in peat soil; increased by division at the root. (Paxton's Bot. Dict.)

DUCKWEED (Lemna). A genus of minute, herbaceous, floating plants, consisting of four species, all of which are natives of England, and grow abundantly in ponds, ditches, and stagnant waters. They are in flower from June to August. Duckweed is a small green herb, consisting of little roundish leaf-like disks. It is not, perhaps, generally known that duckweed, if allowed to spread itself over ponds and stews, in which fish are preserved, will ultimately destroy them, by its forming a compact mat upon the surface, thereby preventing the fish, when they rise to the surface of the water for air, from breathing. It should on this account be abstracted diligently with a rake, or some such implement, and kept under before it attains an ascendency, which it will do in a very short time if not seasonably withdrawn. The quantities of fish that perish under the influence of this weed are incalculable. Ducks feed upon the "lemna" with surprising avidity, and thence it derives its name (duck's meat or duckweed). Ducks, by dabbling and grovelling in foul pools, where it predominates, and its adhering to their feathers, are in the habit of introducing it into other waters, where it never appeared bcfore. (Eng. Flora, vol. i. p. 31 ; Willich's Dom. Ency.)

DUN (Sax. oun). A colour partaking of brown and black, frequent in horses.

DUNES (Ang.-Sax. low hills). Hills of movable sand, which are met with along the sea coast in various parts of Great Britain, Ireland, and the Continent. (Brande's Dict. of Science.)

DUNG and DUNGHILL. See FArM-хaнD Dung and Compost.

DURHAM CATTLE. See Cattle.

DUST BRAND. One of the local names for the smut in wheat.

DUTCH ASHES. See Asues.

DUTCH ELM (Ulmus suberosa). See Elm. DWARF BAY. See MEzEREON.

DWARF ROSE BAY. See Mountain LAURET.

DWARF BERRIES. See NightshaDr.

DWARF OAK. A shrub, sometimes employed for making live fences. It grows very fast, and becomes thick by cutting very rapidly.

DYKE (Sax. ole; Erse, dyk). A sort of wall or mound formed of earth or turfs. In Scotiand it is applied to any wall round a field. See Drtcr.

DYNAMOMETER (Gr. fovs $\mu$ s, power, and

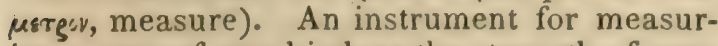
ing power of any kind, as the strength of men and animals, the force of machinery, \&c. Some interesting results relating to the average strength of men at different ages, and of different weights and sizes, have been produced by $M$. Quetelet of Brussels, from numerous experiments with Regnier's dynamometer, one of the most convenient that is made.

It consists of two flat plates of steel of a curved form, increasing in thickuess towards the ends, which unite into solid cylindrical loops; the curved sides of the plates being placed opposite to each other, and the whole forming an entire elliptic spring. On the application of this instrument as a link in the line of draught, the oval becomes lengthened in proportion to the degree of force acting on the loops in opposite directions, and the curved sides approach more nearly towards each other accordingly. The degree of approximation in the plates is shown on the scale, in divisions corresponding to half and whole hundred weights, by means of a cross rod secured to one plate acting on a crank attached to the opposite one, thus communicating its effect to the lever index, which, moving over the divisions of the scale, marks the varying degree of force exerted each moment by the draught to which the instrument is subjected.

Messrs. Cottam and Hallen, engineers and agricultural implement makers, of Winsley street, Oxford street, London, have recently patented an improved dynamometer, contrived with the intention of obviating the continual vibration of the indicator of the dynamometer formerly in use, which was caused (with reference to the plough) by the obstructions met with in the soil through which it was passing. These vibrations were so incessant, that the indicator could scarcely be discerned during the experiment. The improvement consists in the attachment of a small brass pump filled with oil, the piston of which has one or two small apertures. There being no outlet from the pump, it is evident that when any shock occurs, caused by a stone, root, \&c., the oil having to pass from one side of the piston to the other, the suddenness is greatly diminished by the resistance, producing a corresponding effect upon the pointer, which, as these shocks are rapid, vibrates nearer the actual draught of the machine; which is the object in view, and not the measurement of any impediment, but a mean result of the whole. Mr. Pusey, in his "Experimental Inquiry on Draught in Ploughing" (Journ. Roy. Eng. Agr. Soc. vol. i. p. 219 ), speaks very favourably of this draughtguage, and remarks (Ibid. p. 222): "Such is the goodness of Mr. Cottam's new draughtguage, that we scarcely ever, I believe, differed by more than a quarter of a hundred weight, and often agreed to an eighth, or one stone."

DYSENTERY (Fr. dysenterie). See SHEEP. Disfases of.

\section{E.}

EAR (Sax. eane; I،at. auris). The organ of hearing in animals. In a horse, the ears should be small, narrow, straight, and the substance of them thin and delicate. They should be placed on the very top of the head; and their points, when stiled or pricked up, should be nearer together than their roots. When a horse carries his ears pointed forwards, he is said to have a bold or brisk ear. In travelling, it is considered an advantage when the horse keeps them firm. The exterior ears of the horse are merely organs for collecting sound 
consequently, he has a complete power over the muscles attached to them, and can turn them in every direction. It is probable that the organ of hearing is the safeguard of the horse in his natural state. He is ill adapted for combat; his swiftness of foot and his acuteness of hearing are therefore requisites to him of the utmost importance.

EAR MARK. A mark on the ear by which shepherds know their sheep. Cattle, hogs, and other animals are sometimes marked in the same way, by notching, clipping, or slitting the ear.

EARNEST (Sax. eopnere; Fr. arrhes; Dan. ernitz penge). In commercial law, the sum advanced by the buyer of goods in order to bind the seller to the terms of the agreement. As to what amounts to sufficient earnest, Blackstone lays it down, that " if any part of the price is paid down, if it is but a penny, or any portion of the goods is delivered by way of earnest, it is binding." To constitute earnest, the thing must be given as a token of ratification of the contract, and it should be expressly stated so by the giver. (Chitty's Com. Law, vol. iii. p. 289; $M^{*}$ Culloch's Com. Dict.)

EARS of Corn (Sax. æhhen.). The spike or head containing the seeds of wheat, \&c.

In the United States the term ear as applied to grain, refers almost exclusively to that of Indian corn.

EARTH (Sax. eano.). This word was anciently employed to signify one of the four elements of which all matter was supposed to be formed; namely air, fire, water, and earth. In the present period, the word in common language has two meanings; it implies either the globe we tenant, or the soil on which plants vegetate. In this work it has reference to the latter. The soil, as well as the rocks, \&c., of which our planet is formed, is composed of a variety of substances, such as lime, silica, alumina, magnesia, \&c., to which chemists long since gave the name of earths; and although by the researches of Sir H. Davy and others, these earths have been shown to be, in reality, metallic oxides-that is, metals united with oxygen-yet the term earth is so well and so extensively known, that I should, even if this was intended to be a chemical dictionary, retain it. The following is the composition of the four earths most commonly met with by the farmer in his land, or in the crops which it supports:-

Lime: a compound of a peculiar metal called

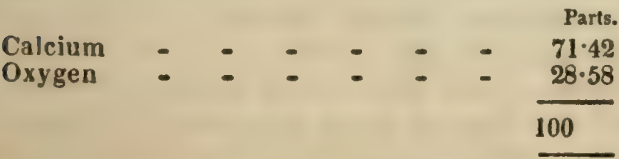

Alumina (clay): a compound of,

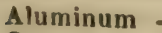

Oxygen

Magnesia: a compound of the metal

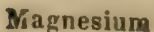

Oxygen
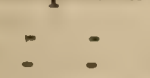

Silica, which is by modern chemists c.assed with the acids, is a compound of a metal called

\begin{tabular}{|c|c|c|c|c|c|c|c|}
\hline & - & - & - & - & - & - & $\begin{array}{c}\text { Parto. } \\
49 \leqslant \times 9\end{array}$ \\
\hline \multirow{2}{*}{ Oxygen } & - & - & - & - & - & - & 50112 \\
\hline & & & & & & & 100) \\
\hline
\end{tabular}

In this place, however, our business is with the earths only so far as their uses to vegeta. tion are concerned.

EARTHS, their Use to Vegelation. In the investigation of the use of the earths to vegetation, not only as regards their position as necessary portions of all cultivated soils, but as forming the essential constituents of most vegetable substances, several very important circumstances will present themselves to the notice of the cultivator. The order and the regularity with which these earths are found in plants is most remarkable; the harmony, too, with which the various chemical ingredients are arranged, the uniform manner in which they are absorbed by the roots of the plant and distributed in its juices, cannot escape our attention, nor fail to excite our gratitude for the benevolence and the wisdom displayed in the contrivance. Thus we shall find, as we proceed in our researches (to give only a single instance), that the earth silica (flint) abounds in the straw of the wheat plant, where its presence helps to impart the requisite degree of strength and hardness to the stem; but scarcely a chemical trace of this earth is discoverable in the flour of the seeds of the same plant, for there its presence in our food would be worse than useless.

Let not, however, the reader, when he is considering the discoveries of vegetable chemistry, feel surprised that more has not been accomplished by the chemical philosopher in that important branch of science. There are many reasons why the discoveries in this branch of chemistry have been gradual, and only by slow degrees: he may be assured that the difficulties which attend the chemist when he is investigating the properties of organic matter, are more than usually numerous; for the living plant, in many instances, seems endowed with powers that appear even to neutralize the effects of chemical attraction and repulsion: thus the earths and alkalie:, to give one instance only, are often found in juxtaposition with uncombined vegetable acids. 'The roots of most plants, also, are endowed with a remarkable capacity of absorption; not only do they absorb water, the gases of the atmosphere and those formed by putrefaction, but they take up earths, alkalies, and saline substances; and, besides doing this with a regularity which is almost unvaried, they exercise a power of absorbing certain saline bodies when dissolved with others in water, and of leaving the others in solution, which shows them to be endowed with properties of a very remarkable natule. Some curious experiments were long since made by M. Saussure on this interesting question. "When various salts were dissolved at once in the same solutions,' says Dr. Thomson, "and plants made to vege tate in them, it was found that different proportions of the salts were absorbed. The follow. 
ing table exhibits the results of these trials, supposing the original weight of each salt to have been 100. Each solution contained one hundredth part of its weight of each salt-

1. $\{$ Glauber sait - Common sait

2. $\left\{\begin{array}{l}\text { Glauher salt } \\ \text { Common salt }\end{array}\right.$ $\left\{\begin{array}{l}\text { Acetate of lime: } \\ \text {. }\end{array}\right.$

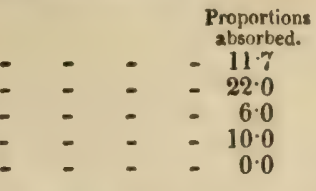

On examining the plants the salts absorbed were found in them unaltered." (Chemistry, vol. iv. p. 325.) In these experiments the cultivator will observe that the plants (which were Spotted Persicaria (Polygonum Persicaria) and the Bur-marigold (Bidens tripurtita), with their roots attached) absorbed the common salt with avidity, but that they rejected entirely the acetate of lime. 'The earths are, in all probability, always imbibed by the plant in a state of solution; we know, in fact, that both lime and silica are, to a certain extent, soluble in water, and alumina is also very probably absorbed as a component of some of the soluble salts which contain this earth.

The part which the earth fulfis in the support of plants early attracted the attention of philosophers. The earthy ashes produced by the combustion of vegetable substances must have very soon indicated to mankind the real truth of the case, that there were certain solid substances found in vegetables which they could only derive from the earth they tenanted. That the soil furnished its earthy matter to the plant was, therefore, the natural conclusion of some of the Greek philosophers; and although their observations in this way were commonly very loose, and always general, yet when they decided, which they did with all gravity, that earth, air, fire, and water composed every thing on the earth, the vegetable world was of course included in the list; they still, however, thought that the chief use of the earth to plants consisted in keeping them upright, and furnishing them with a sufficient supply of moisture.

When the ancient naturalists came to the conclusion that the whole earth was composed of four elements, they founded their decision upon certain rude observations; but they did not stop there, they proceeded to confuse themselves by various incomprehensible or delusive phrases, such as more modern observers have too often imitated. Fire they regarded as the active principle of the universe, the source of both animal and vegetable life, the cause of renovation and decay. Earth they considered as the principle of fixity, of hardness, and of solidity. These rude, though sagacious observations, the early chemists, and then the alchemists, strongly confirmed by the mode in which they analyzed vegetable substances. They had only one mode of effecting this, that of subjecting them in a retort to dry or destructive distillation. By this mode the results are almost always the same; first the water of the plant comes over; then a volume of carhuretted hydrogen and carbonic acid gases is driven off; and finally a quantity of earthy matters, mixed with various salts and potash remains at the bottom of the retort. We need hardly feel surprised, therefore, that after such 428 an analysis, the chemists of old readily agreed with the naturalists that earth, air, and water, alone formed the vegetable world.

Evelyn, in 1674, wrote a work upon earth, in which he lauded its powers with much enthusiasm. "What shall I say," he exclaims, "Quid Divinum? the original of all fecundity; nor can I say less, since there was nor sacrifice nor discourse withont it." And in another place he says (for Evelyn was exceedingly credulous), "Whatever then it be, which the earth contributes, or whether it contains universally a seminal virtue, so specified by the air, influences, and the genius of the climate, as to make that a cinnamon tree in Ceylon which is but a bay in England, is past my skill to determine; but it is to be observed with no little wonder, what M. Bernier in his history of the empire of the Mogul affirms to, as of a mountain there, which being on one side of it intolerably hot produces Indian plants, and on the other as intemperately cold, European and vulgar plants." There is much valuable matter, however, in The Terra of Evelyn, whose modesty enhanced his great merits. Thus, in conclusion, he told his Fellows of the Royal Society, to whom his valuable essay was addressed, that it was merely "a dull discourse of earth, mould, and soil."

Fitzherbert, the earliest English writer upon agriculture (1532), did not pay any attention to earths, beyond the usual necessary routine of the farm; he confined himself entirely to practical details : not a trace of any thing like scientific inquiry is to be found in his Boke of Husbandrye. John Worlidge, who published his System of Agriculiure in 1669, thought it necessary, as he professed to "unveil the mystery of agriculture," to give the cultivator an explanatory chapter on the food of plants, in what he called "a plain and familiar method," and this he did in the true jargon of the alchemists; for the age of "the transmuters" was not yet nver when Worlidge wrote. He gave, therefore, the husbandmen of those days a dissertation upon "the universal spirit, or spirit of mercury, the universal sulphur, and the universal salt;" but still, after all, he thought that the earth was the true food of plants, and that all the operations of the husbandman only tended to enable the roots of the plant to take up more earthy matter, and he devotes a chapter of his book to the "Soyls and Manures taken from the Earth." But his ideas, like those of the alchemists, were usually a mixture of common sense and absurdity, too closely united to be always readily distinguishable $b v$ the good sense of the cultivator.

Jethro Tull, who wrote between 1730 and 1740 , considered earth to be the sole food of plants. "Too much nitre," he tells us (p. 13, of his valuable Book on Husbandry), "cor. rodes a plant, too much water drowns it, too much air dries the routs of it, too much heat burns it; but too much earth a plant can never have, unless it be therein wholly buried: too much earth or too fine can never possibly be given to their roots, for they never receive so much of it as to surfeit the plant." And again, he tells us in another place, "That which nourishes and augments a plant is the true food 


\section{EARTHS.}

of it. Every plant is earth, and the growth and true increase of a plant is the addition of more earth." And in his chapter on the "Pasture of Plants," Tull told his readers with great gravity, that "this pasturage is the inner or internal superficies of the earth; or, which is the same thing, it is the superficies of the pores, cavities, or interstices of the divided parts of the earth, which are of two sorts, natural and artificial. The mouths or lacteals of roots take their pabulum, being fine particles of earth, from the superficies of the pores or cavities, wherein their roots are included."

Tull wrote with all the enthusiasm of genius, and carried his admiration of the powers of the earth to support vegetation much too far; he was deceived, in fact, by the effects of his finely pulverizing system of tillage, and did not sufficiently attend to the fact, that there are many other substances in the commonly cultivated soils of the farmer besides the earths, and that so far from their being always the chief constituents of the soil, they very often form the smallest portion of even a highly productive ficld.

That the four earths of which all cultivated soils are composed are all the necessary food or constituents of vegetables, has, long since Tull wrote, been decided by the accurate investigations of the chemist. Of these, lime, either as a carbonate, or an acetate, or a sulphate, is by far the most generally present in plants; indeed, in one form or another, it is rarely absent from them. The presence of slica (flint) is almost equally general. Magnesıa is less usually present, or, at least, it exists in smaller proportions; and the same remark arplies to alumina (clay).

The quantity of the earths which is present in varicus vegetables is, therefore, a primary question for the cultivator's guidance. This will be seen from the following tables:-

1000 parts of the nak contain of the earths

beech
Turkey wheat (Indian corn)
sunflower
vine branches
box
willow
elm
aspen
fern
wormwnod

Parts.

$1 \cdot 030$

0.453

0.003

$7 \cdot 110$

3. 7.20

$2 \cdot 850$

2674

$2 \cdot 515$

$1 \cdot 960$

$1 \cdot 146$

$3 \cdot 221$

$2 \cdot 444$

The proportions of the earths contained in the commonly cultivated crops of the farmer have been ascertained by M. Schræder: this able chemist ohtained from thirty-two ounces of the seeds of wheat (Triticum hybernum), of rye (Secale cereale), barley (Hordeum vulgare), oats (Avena sativa), and of rye-straw the following results :-

\begin{tabular}{|c|c|c|c|c|c|}
\hline & Wheat. & Rye. & Barley. & Oats. & $\begin{array}{c}\text { Rye } \\
\text { Straw. }\end{array}$ \\
\hline Silica - & $13 \cdot 2$ & $15 \cdot 6$ & $66 \cdot 7$ & 144.02 & $152 \cdot 0$ \\
\hline \multirow{2}{*}{$\begin{array}{l}\text { Carbonate of lime } \\
\text { of of magnesia }\end{array}$} & $12 \cdot 6$ & $13 \cdot 4$ & $24 \cdot 8$ & $33 \cdot 75$ & $46 \cdot 2$ \\
\hline & $13 \cdot 4$ & $14 \cdot 2$ & $25 \cdot 3$ & 33.09 & $28 \cdot 2$ \\
\hline \multirow{4}{*}{$\begin{array}{l}\text { Alumina } \\
\text { Oxide of manganese } \\
\text { Oxide of iron }\end{array}$} & 0.6 & 1.4 & 4.2 & $4 \cdot 05$ & $3 \cdot 2$ \\
\hline & $5 \cdot 0$ & $3 \cdot 2$ & 6.7 & 695 & $6 \cdot 8$ \\
\hline & $2 \cdot 5$ & 0.9 & 38 & $4 \cdot 05$ & $2 \cdot 4$ \\
\hline & $47 \cdot 3$ & $48 \cdot 7$ & 131.5 & $227 \cdot 8$ & 238.8 \\
\hline
\end{tabular}

(Gehlen, Journ. vol. iii. p. 525.)

The earth silica or flint abounds in almost every description of vegetable matter, espe. cially in the grasses and Equisetum (horse-tail). In the Dutch rush it is so plentiful that that plant is used by the turner to polish wood, bone, and even brass. It forms so considerable a portion of the ashes of wheat-straw, that when these are exposed to the action of the blowpipe, it unites with the potash found also in the straw, and forms an opaque glass. Davy found it most copiously in the epidermis or outer bark of the plants he examined.

100 parts of the epidermis of bonnet-cane contain of silica parts of the epidermis of bamboo-cane contain
of silica

parts of the epidermis of common reed contain

00 parts of the epidermis of stalks of wheat contain of silica

Parts. 900 $71 \cdot 4$ $48 \cdot 1$ $6 \cdot 5$

In the joints of the bamboo a concrete substance is found, which Fourcroy and Vauquelin examined, and ascertained that it consists of 70 parts of silica, and 30 parts of potassa. This substance, which is named tabasheer, can only be furnished by the soil. (Gehlen, vol. ii. p. 112.)

This earth, according to M. Saussure, constitutes 3 per cent. of the ashes of the leaves of oak gathered in May, 14.5 per cent. of those gathered in September, and 2 per cent. of the wood. In the ashes obtained by burning the wood of the poplar, it exists in the proportion of 3.3 per cent.; of the hazel, 0.25 per cent.; of the mulberry, 0.12 per cent.; of the hornbeam, 0.12 per cent.; 0.5 per cent. in peas $(P i$ sum sutivum); 61.5 in the straw of wheat; 0.25 in the seeds ; 57.0 per cent. in the chaff of barley; 35.5 in its seeds; and in the oat plant 60 per cent.

Lime is, if possible, still more generally present in all plants than silica. "The salsola soda," says Dr. Thomson, "is the only plant in which we know for certain it does not exist." (Syst. of Chem. vol. iv. p. 190.) It is, however, united with carbonic acid as carbonate of lime; oi it exists as the base of some other salt, such as in oxalate of lime, or in sulphate of lime (gypsum). It was found in the ashes remaining after the combustion of oak wood, at the rate of 32 per cent., by M. Saussure. In that of the poplar at the rate of 27 per cent. He discovered also 8 per cent. in those from the wood of the hazel; 56 in those of the mulberry wood; 26 in the hornbeam; 14 in the ripe plant of peas; 1 per cent. in the straw of the wheat, but not any in its seeds; 12 in the chaff of barley, but none in either its flour or its bran; neither did he find any in the oat plant; but then, in the ashes of the leaves of the fir (Pinus abies), raised on a limestone hill, he found 43.5 per cent.

Alumina, as I have elsewhere observed. is found in most vegetables, but in much smaller proportion than either silica or carbonate of lime, and the same remark applies to magnesia. M. Schræder found, as re have before seen, in $2 \mathrm{lbs}$. weight of tine seeds of wheat only $\frac{5}{10}$ ths of a grain of alumina, in rye $1 \frac{4}{10}$ grains, in barley $4 \frac{2}{1 n}$ grains, in oats $4 \frac{1}{2}$ grains. and in rye-straw $3_{T}^{2}$ grains. In 12 ounces o wormwood there are about 5 grains of alu 
mina. This earth, however, necessarily exists in all fertile soils as the food of plants; for although the proportions in which it is found are rather small, yet still there is no reason to believe that its presence is not essential to the healthy growth of the plant. M. Saussure found the ashes of the Pinus abies, growing on a granitic and on a calcareous soil, to contain nearly the same quantity of alumina ( 15 per cent. on the calcareous and 16 per cent. on the granitic), although these soils differed widely in the proportion of the alumina they contained; for 100 parts of each wood were composed of:

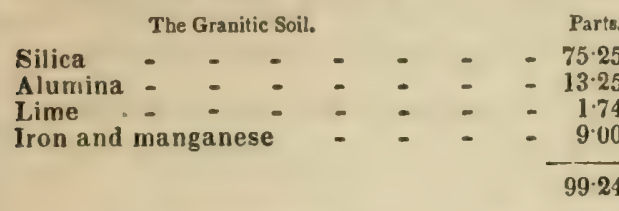

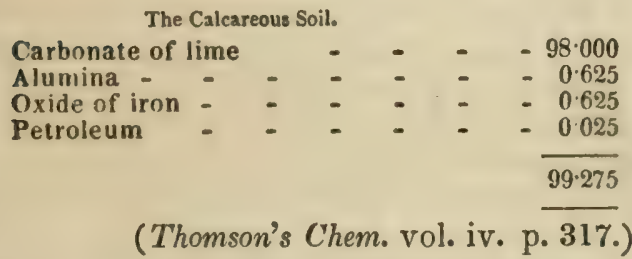

Such are the earths which constitute all cultivated soils, and such is the necessary proportion in which they form the constituent elements of some of the plants which they support. In the soils of the cultivator, however, they exist in an endless variety of proportions: thus, I found 68.5 per cent. of silica in the gravelly soils of Great Totham, in Essex, and 62 in those of Kintbury, in Berkshire. Davy discovered about 50 per cent. in the soil of the Endsleigh Pastures in Devonshire, 54 in that near Sheffeld Place in Sussex, 15 in the turnip soils of Holkham in Norfolk, 32 in the finely divided matters of the wheat soils of West Drayton, and about 97 per cent. in the soil of Bagshot Heath. Mr. George Sinclair found about 66 per cent. in the grass garden of $\mathrm{Wo}_{\mathrm{O}}$ burn Abbey.

Of alumina, or pure earth of clay, the proportions are equally varying. I ascertained the presence of 4.5 per cent. of this earth in a gravelly soil of Thurstable in Essex, and 8.5 in one at Kintbury in Berkshire. Mr. G. Sinclair found 14 per cent. in the soil of the grass garden at Woburn Abbey. Davy detected 8.5 per cent. in that at Endsleigh, 6.25 in one at Croft Church in Lincolnshire, 7 in that in Sheffield Place, 11 in that of Holkham, 29 in a field at West Drayton, and about 1 per cent. in the soil of Bagshot Heath.

Of carbonate of lime, the presence is just as varying in amount as that of the other carths. I found 18 per cent. in a soil at Totham, and 19 per cent. in a soil at Kintbury; Sinclair, 2 per cent. in the soil of the Woburn Abbey grass garden. Davy discovered 8 per cent. in that from Croft Church, 3 per cent. in that of Sheffield Place, 63 per cent. in the finely divided matters of the soil from Holkham, and about 1 per cent. only in the soil from l3agshot.

The farmer, however, must not conclude, that by merely mixing the pure earths, silica, lime, and alumina together in the most frrtule pro- portion, a soil can be formed on which plants will flourish, for such is a very erroneous conclusion. $\Lambda l l$ attempts which have been made to make plants flourish in the pure earths have failed utterly when they have been watered with pure water; yet a totally different result I have invariably experienced when I have employed an impure solution or liquid manure. My trials have been entirely supported by those of M. Giobert, who having formed of the four earths, silica, alumina, lime, and magnesia, a soil in the most fertile proportion, in vain essayed to make the plants flourish in it when watered with pure water only; but every diffculty was removed when he moistened it with the water from a dunghill, for they then grew most luxuriantly; and M. Lampadius still further demonstrated the necessity for, and the powers of such an addition to the soil; for he formed plots composed only of a single earthnamely, pure lime, pure alumina, or pure silica-and planted in each different vegeta. bles, watering them with the liquid drainings from a dunghill, and he found that plants on all of them flourished equally well. The soluble matters of a soil ever constitute, in fact, its most fertilizing portion ; and if by any artificial means the richest mould is deprived of these, as by repeated washings in cold or boiling water, the residuum or remaining solid matter is rendered nearly sterile. This fact, first accurately demonstrated by M. Saussure, I have since confirmed by a variety of experiments. Neither must the cultivator imagine that these carefully considered conclusions, the results of often-repeated laborious experiments, are erroneous, because transparent water, apparently pure, when viewed in water-glasses, or in irrigation, promotes the growth of bulbs, grass, \&c., since the very purest spring water, even rain water, contains foreign substances; and when only chemically pure water is employed to water plants, they cannot be made to flourish. I have fruitlessly varied the attempt in several ways. All the experiments of Dr. Thomson were equally unsuccessful, the plants vegetating only for a certain time, and never perfecting their seeds. Similar experiments were made by Hassenfratz, Saussure, and others, with the same unfavourable result. Duhamel found that an oak, which he had raised from an acorn in common water, made less and less progress every year. 'The florist is well aware that bulbous roots, such as those of hyacinths, tulips, \&c., which are made to grow in water, unless they are planted in the earth every other year, at first refuse to flower, and finally they cease even to vegetate. Moreover, it has been unanswerably shown by many very accurate experiments, at the repetition of which I have personally assisted, that the quantity of nourishment or solid matters absorbed by the roots of plants is always in proportion to the impurity of the water with which they are nourished; thus some common garden beans were made to vegetate under three different circumstances; the first were grown in distilled water, the second were placed in sand and watered with rain water, the third were sown in garden mould. The plants thus produced, when accurately analyzed, 
were found to yield the following proportion of ashes-

Parts.
1. Those fed by distilled water - $\quad-\quad 3.9$
2. Thuse fed by $\quad-\quad 7.5$

2. Thuse fed by rain-water
3. Those grown in the soil - $\quad-\quad-7 \cdot 5$

The mode in which the earths are absorbed by the roots of the plant is, it is almost certain, by means of their solution in water, for both carbonate of lime and silica are, in small proportions, soluble in water; they exist together in many springs; and they were both found in the water of the Clyde by Dr. Thomson, in that of the Thames by Dr. Bostock, and in the springs of Upsula, celebrated for their purity, by Bergman. Alumina, as far as we know, is not soluble in water, but then it exists in very small proportions in plants; and the soluble salts of which it is the base may serve to yield this earth to vegetables: the earth itself is soluble in ammonia.

The way in which soils are gradually formed by the action of the atmosphere upon the hard primitive rocks has been well explained by Davy, and is a natural process which cannot but be interesting to the farmer. I merely slightly alter his words in the following account of this important natural phenomenon. It is not difficult to comprehend the manner in which this change is effected, and rocks converted into soils, by referring to the instance of soft granite or porcelain granite. This substance is composed of three ingredients, quartz, feldspar, and mica. The quartz is almost pure silicious earth in a crystalline form. The feldspar and mica are very compound substances;* both contain silica, alumina, and oxide of iron: in the feldspar there is usually lime and potash; in the mica, lime and magnesia.

When a granitic rock of this kind has been long exposed to the action of the atmosphere, the lime and the potash contained in its constituent parts are acted upon by water or carbonic acid; and the iron, which is almost always in its least oxidized state, tends to combine with more oxygen; the consequence is, that the feldspar decomposes, and likewise the mica, but the first the most rapidly. The feldspar, which is, as it were, the cement of the stone, forms a fine clay; the mica, partially decomposed, mixes with it as sand, and the undecomposed quartz appears as gravel, or sand of different degrees of fineness. As soon as the smallest layer of earth is thus formed on the

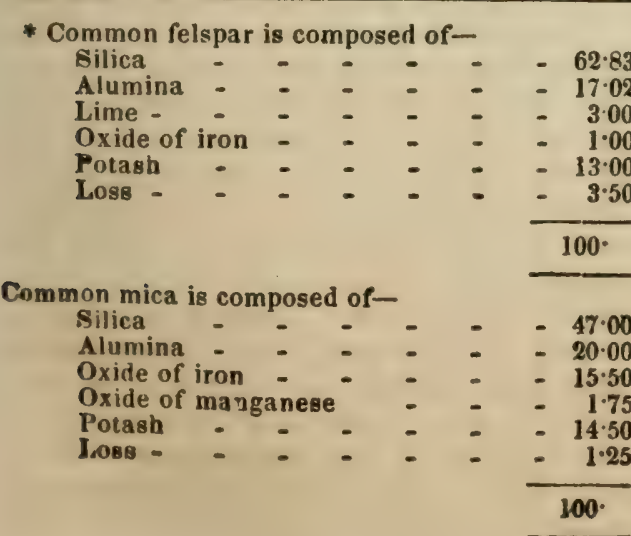

surface of a rock, the seeds of lichens, mosse:, and other imperfect vegetables, which are con. stantly floating in the atmosphere, and which have made it their resting-place, begin to vegetate; their death, decomposition, and decay afford a certain quantity of organic matter, which mixes with the earthy materials of the rock. In this improved soil, more perfect plants are capable of subsisting; these in their turn absorb nourishment from water and frem the atmosphere, and as these, too, decay, afford more new materials to those already provided; and the decomposition of the rock still continues. At length, by such slow and almost imperceptible processes, a soil is formed in which even forest trees can fix their roots, and which is fitted to reward the labours of the cultivator.

Where successive generations of vegetables have grown upon a soil, unless they have been carried off by man or consumed by animals, the vegetable matter increases to such an extent that the soil approaches to peat in its nature. Poor and hungry soils are commonly produced by the decomposition of the granite and sandstone rocks: such soils usually remain for ages with only a thin covering of vegetation. The soils produced by the same gradual means on the limestones, chalks, and basalts, are often clothed by nature with the perennial grasses and afford, when ploughed up, a rich bed of vegetation for every species of cultivated crop

The quantity of moisture which a soil, or the earths of which it is chiefly composed, contain influences to a very material extent its fertility This not only differs in different seasons, but this power varies very considerably indeed in soils, according to their chemical composition. This was experimentally decided by Professor Schubler, of the University of 'Tubingen, in his "Agronomy, or Principles of Agricultural Che. mistry," for a translation of which the English farmer is indebted to Mr. Hudson, the present excellent Secretary to the Royal Agricultural Society of England,-a translation of which I have largely availed myself in this paper. (Journ. of Roy.Ag. Soc. vol. i. p. 177.) M. Schubler found that a cubic foot of different soils, when thoroughly saturated with water and when completely dried, weighed as follows :-

\begin{tabular}{|c|c|c|c|c|c|c|}
\hline \multirow{2}{*}{\multicolumn{4}{|c|}{ Kind of Earth }} & \multirow{2}{*}{$\begin{array}{l}\text { Specific } \\
\text { Gravity }\end{array}$} & \multicolumn{2}{|c|}{$\begin{array}{l}\text { Weight of a cubie } \\
\text { foot, in lbs. }\end{array}$} \\
\hline & & & & & Dry. & Wel. \\
\hline Calcareous sand & 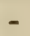 & - & - & $2 \cdot 722$ & $113 \cdot 6$ & $141 \cdot 3$ \\
\hline Silicious sand & - & - & - & $2 \cdot 653$ & $111 \cdot 3$ & 1361 \\
\hline Gypsum powder & - & - & - & $2: 331$ & $91 \cdot 9$ & 1276 \\
\hline Sandy clay - & - & - & - & $2 \cdot 601$ & $97 \cdot 8$ & $129 \cdot 7$ \\
\hline Loaniy clay - & - & - & - & $2 \cdot 581$ & $88 \cdot 5$ & $124 \cdot 1$ \\
\hline Stiff clay or brick & & & - & $2 \cdot 560$ & $80 \cdot 3$ & $119 \cdot 6$ \\
\hline Pure gray clay & - & - & - & 2553 & $\tau 5 \cdot 2$ & $115 \cdot 8$ \\
\hline Pipe clay - & - & - & - & $2 \cdot 440$ & $47 \cdot 9$ & $102 \cdot 1$ \\
\hline Fine carbonate of & $\operatorname{lin}$ & & & $2 \cdot 468$ & $53 \cdot 7$ & $103 \cdot 5$ \\
\hline Garden mould & - & - & - & $2 \cdot 332$ & 68.7 & $102 \cdot 7$ \\
\hline Arable soil - & - & - & - & $2 \cdot 41) 1$ & 84.5 & $119 \cdot 1$ \\
\hline Fine slaty marl & - & - & - & 2631 & 1120 & $140 \cdot 3$ \\
\hline
\end{tabular}

The result of these trials will be useful in the farmer in explaining to him the reason why, on account of their requiring more or lese moisture, certain crops flourish best on particular soils; and even in the carriage of the earths he will perceive that their weight in the wet or dry state is mucl greater than suma persons suppose. 
The next important inquiry instituted by the same excellent chemist, was the relative degree of tenacity with which different soils retain the moisture when exposed under similar circumstances to the action of the atmosphere; and he found that they parted with their moisture according to the following rate:-

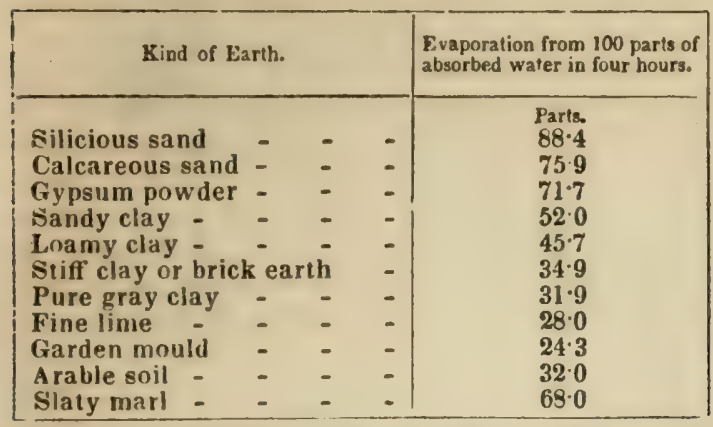

In these experiments the soils were spread out to dry very thinly over a plate of metal; but in the following comparative trials (to render the results in all respects more similar to those which the cultivator would experience), the soil was exposed to the atmosphere in masses of an inch in depth :-

\begin{tabular}{|c|c|c|c|}
\hline \multicolumn{3}{|c|}{ Kind of Earth. } & $\begin{array}{l}\text { Water evaporated in } \\
\text { four days. }\end{array}$ \\
\hline Calcareous sand & & & $\underset{146}{G r a i n s}$ \\
\hline Light garden mould & - & - & 143 \\
\hline Gypsum powder & - & - & 136 \\
\hline Very light turf soil & - & - & 132 \\
\hline Slaty marl - & - & - & 131 \\
\hline A rable soil - & - & - & 131 \\
\hline Fine magnesia - & - & - & 129 \\
\hline Black turf soil not so & light & - & 128 \\
\hline White fine clay - & - & - & 123 \\
\hline Gray fine clay - & - & - & 123 \\
\hline
\end{tabular}

The amount of the relative contraction of different soils, when they are deprived of their moisture, is another equally important question to the farmer to be ascertained. "Many of them." says M. Schubler, "become contracted into a narrower space in drying, and in consequence of this circumstance cracks and fissures frequently occur in land, and have an injurious effect on the vegetation, as the finer roots, which often ramily horizontally, and not unfrequently supply to the plants the greater part of their means of nourishment, are, by such contractions, either laid bare of soil or torn asunder. In order to subject soils to comparative experiments on this point, the following plan may be adopted. We either form of the earths, in their wet state, large cubic pieces of equal size, being at least ten-twelfths of an inch in height, breadth, and length, or we let such earths be fitted and driad one after another in an accurately worked cubic inch; after some time, when the weight of these cubes of earth ceases to change by further drying, we measure the dimensions of the cube by means of a rule on which the tenths of lines can be distinguished, and may thus calculate easily the volume of the earth, and consequently ascerlain the diminution in bulk which has been caused by the drying. The experiments which I made with the following earths exhibited on Ji:s point the subjoined differences:-

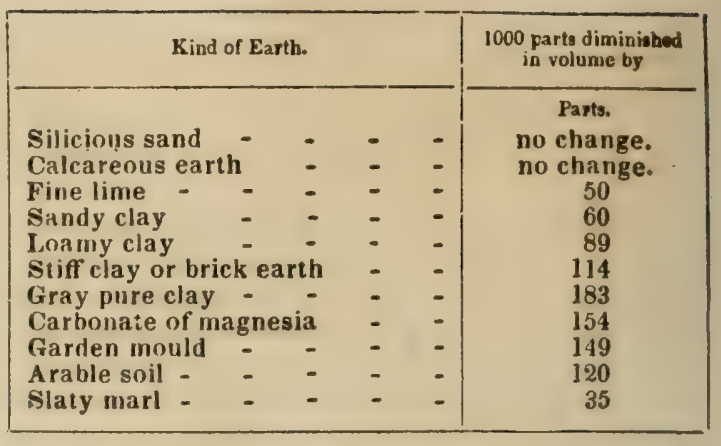

Such is the effect upon various soils of depriving them of their moisture. In these cus mical investigations the farmer will see how entirely they confirm his own observations. The heavy clay soils, he well knows, are the most contracted by exposure to the heats of summer; the sands the least affected of any.

A still more important property of soils, their attraction for the aqueous vapour of the atmosphere, is next to be considered-a property the importance of which to the cultivator, Sir H. Davy long since saw in its true light, and his observations cannot be too often quoted, since they well illustrate and enforce, amongst other things, the truth of the great Tullian system of agriculture: of the advantages of finely dividing the soil, of the subsoil plough, and of the horse-hoe husbandry. "The power of the soil to absorb water by cohesive attraction," said this "great chemist, "depends in a great measure on the state of division of its parts; the more divided they are, the greater is their absorbent power. The different constituent parts of soils likewise appear to act, even by cohesive attraction, with different degrees of energy: thus vegetable substances seem to be more absorbent than animal substances, animal substances more so than compounds of alumina and silica, and compounds of alumina and silicia more absorbent than carbonates of lime and magnesia; these differences may, however, possibly depend upon the differences in their state of division, and upon the surface exposed. The power of soils to absorb water from air is much connected with fertility; when this power is great, the plant is supplied with moisture in dry seasons; and the effect of evaporation in the day is counteracted by the absorption of aqueous vapour from the atmosphere by the exterior parts of the soil during the night. The stiff clays, approaching to pipe-clay in their nature, which take up the greatest quantity of water when it is poured upon them in a fluid form, are not the soils which absorb most moisture from the atmosphere in dry weather; they cake, and present only a small surface to the air, and the regetation on them is generally burnt up almost as readily as on sands. The soils that are most efficient in supplying the plant with water by atmospheric absorption are those in which there is a due mixture of sand, finely divided clay, and carbonate of lime, with some animal or vegetable matter; and which are so loose and light as to be freely permeable to the atmosphere. With respect to this quality, carbonate of lime and animal and vegetable matter are of great use 
in suils; they give absorbent power to the soil without giving it tenacity: sand, which also destroys tenacity, on the contrary, gives little absorbent power. I have compared the absorbent powers of many soils with respect to atmospheric moisture, and I have always found it greatest in the most fertile soils; so that it affords one method of judging of the productiveness of land. 1000 parts of a celebrated soil from Ormiston, in East Lothian, which contained more than half its weight of finely divided matter, of which eleven parts were carbonate of lime, and nine parts vegetable matter, when dried at $212^{\circ}$ gained in an hour, hy exposure to air saturated with moisture at a temperature of $62^{\circ}, 18$ parts ; 1000 parts of a very fertile soil from the banks of the river Parret, in Somersetshire, under the same circumstances, gained 16 grains ; 1000 parts of a soil from Mersea, in Essex, worth forty-five shillings an acre, gained 13 grains; 1000 grains of a fine sand from Essex, worth twenty-three shillings an acre, gained 11 grains; 1000 of a coarse sand, worth fifteen shillings an acre, gained only 8 grains; 1000 of the soil of $\mathbf{B a g}$ shot Heath gained only 3 grains."

In my own experiments upon the absorbent powers of various earths, I extended the examination to various organic and saline fertilizers. The result of these may be seen in the following table:-

1000 parts of horse dung dried in a temperature of 100 degrees, absorbed, by exposure for three hours to air saturated with moisture and of the femperature of 62 degrees

1000 parts of cow dung, under the same circum-

etances, absorbed

1000 parts pig dung

1000 - sheep dung

1000 - pigeon's dung

$\$ 000$ - of a rich alluvial soil, worth two guineas

per acre (reut), -

The following were dried at 212 degrees:1000 parts fresh tanner's bark

1000 - putrefied tanner's bark - - - - 145

1000 - refuse marine salt sold as manure - $49 \frac{1}{8}$

1000 - soot

1000 - burnt clay

1000 - coil ashes

1000 - lime

1000 - sediment from saltpans

1000 - crushed rock salt -

1000 - gypsum

1000 - chalk

(Johnson on Fertilizers, p. 41.)

Davy's experiments and my own are confirmed by those of M. Schubler, who varied his observations at intervals of three days; his results were as follows:-

\begin{tabular}{|c|c|c|c|c|c|c|}
\hline \multirow{2}{*}{ Kind of Earth. } & & & \multicolumn{4}{|c|}{$\begin{array}{l}1000 \text { grains on a surface, of } 50 \text { square } \\
\text { inches, absorbed in }\end{array}$} \\
\hline & & & 12 hours. & 24 hours. & 48 hours. & 72 hours. \\
\hline Silicious sand & - & - & ${ }_{0}^{g r a b}$ & $\mathrm{grs}_{0}$ & grs. & $\underset{3}{g r s .}$ \\
\hline Calcareous sand & - & - & 2 & 3 & 3 & 3 \\
\hline Gypsum powder & - & - & $\vec{l}$ & 1 & 1 & 1 \\
\hline Sandy clay - & - & - & 21 & 26 & 28 & 28 \\
\hline Loamy clay - & - & - & 25 & 30 & 31 & 35 \\
\hline Stiff clay - & - & - & 30 & 36 & 40 & 41 \\
\hline Cray pure clay & - & - & 37 & 42 & 48 & 49 \\
\hline Fine lime - & - & - & 26 & 31 & 35 & 35 \\
\hline Fine magnesia & - & - & 69 & 76 & 80 & 82 \\
\hline Garden mould & - & - & 35 & 45 & 50 & 52 \\
\hline Arable soil & - & - & 16 & 22 & $\mathbf{2 3}$ & 23 \\
\hline Slaty marl & - & - & 24 & 29 & 32 & 33 \\
\hline
\end{tabular}

Another property possessed by all cultivated soils, that of absorbing the gases of the atmo- sphere and of putrefaction, is a power equally worthy of the consideration of the farmer. It was long since shown, in some experimental researches of Mr. Hill, that when oxygen gas is supplied to the roots of plants, their growth and vigour are very considerably increased. Some years since, also, Alexander Von Ifum. boldt announced that the earths possess the property of absorbing this gas from the atmo sphere (Gilbert's An. of Phil. vol. i. p. 512); and although the fact was doubted at the time, yet later researches have shown that moist earth has the property assigned to it by Humboldt, and the amount absorbed by various earths has since been ascertained by, and will be seen in the following table of M. Schubler :-

\begin{tabular}{|c|c|c|c|c|c|}
\hline \multicolumn{4}{|c|}{ Kind of Earth. } & $\begin{array}{l}\text { Absorbed } \\
\text { in the } \\
\text { dry state. }\end{array}$ & $\begin{array}{l}\text { In the wel sate ab. } \\
\text { mibed in } 30 \text { days by: } \\
1000 \text { grains of eartit } \\
\text { from is cubic inctes } \\
\text { of atmospheric air, } \\
\text { containing } 21 \text { per } \\
\text { cent. of oxygen. }\end{array}$ \\
\hline Silicious sand & - & - & - & 0 & $\begin{array}{l}\text { grains. } \\
0 \cdot 10\end{array}$ \\
\hline Calcareous san & & - & - & 0 & 0.35 \\
\hline Gypsum powde & & - & - & 0 & 0.17 \\
\hline Sandy clay & - & - & - & 0 & 0.59 \\
\hline Lnamy clay & - & - & - & 0 & 0.70 \\
\hline Stiff clay or brie & ck & rth & - & 0 & 0.86 \\
\hline Gray pure clay & - & - & - & 0 & 0.97 \\
\hline Fine lime - & - & - & - & 0 & 0.69 \\
\hline Magnesia - & - & - & - & 0 & $1 \cdot 08$ \\
\hline Garden mould & - & - & - & 0 & $1 \cdot 10$ \\
\hline Arable soil & - & - & - & 0 & 1.03 \\
\hline Slaty marl & - & - & - & 0 & 0.70 \\
\hline
\end{tabular}

This attractive power of the earths and of the plants for the aqueous vapour and the oxygen gas of the atmosphere are, as I have on more than one occasion contended, two of the most important facts to be kept in mind by the farmer, with regard to the deepening and pulverization of his soils. The power of absorbing moisture is a power which all plants possess in a certain measure, but some in such a perfect degree as to depend entirely upon it for all the moisture they need. 'The aloe, the agave, and many of the native plants of the East, nearly support themselves in the same way; the lichens and some of the mosses of this country also do the same. The quantity of water consumed by plants, when in a state of healthy vegetation, is in fact so great that, if it was not for the gentle steady supply thus imperceptibly furnished to the soil by the at mosphere, vegetation would speedily cease, or only be supported by incessant rains. Thus Dr. Hales ascertained that a cabbage transmits into the atmosphere, by insensible vapour, about half its weight of water daily; and that a sunflower, three feet in height, transpired in the same period nearly two pounds' weight. (Veg. Stat. vol. i. pp. 5-15.) Dr. Woodward found that a sprig of mint, weighing 27 grains, in seventy-seven days emitted 2543 grains of water. A sprig of spearmint, weighing 21 grains, ernitted in the same time 2.558 grains, a sprig of common nightshade, weighing 49 grains, evolved 3708 grains, and a Lathyrus of 98 grains emitted 2501 grains. (Phil.Trans. $1699, \mathrm{p} .193$.$) "The power of soils to absorb$ moisture," says Davy, "owght to be much greater in warm or dry couneries than in cold or moist ones, and the quantity of clay or vegetable or animal matter greater. Soils, also, or: 20 433 
declivities ought to be more absorbert than it plains, or in the bottom of valleys. Their pro. ductiveness, likewise, is influenced by the nature of the subsoil, or the stratum on which they rest. When soils are immediately situated upon a bed of rock or stone, they are much sooner rendered dry by evaporation than where the subsoil is of clay or marl; and a prime cause of the great fertility of land in the moist climate of Ireland is the proximity of the rocky strata to the soil. A clayey subsoil will sometimes be of material advantage to a sandy soil; and, in this case, it will retain moisture in such a manner as to be capable of supplying that lost by the earth above, in consequence of evaporation or the consumption of plants." (Davy's Lectures, p. 186.)

It has been shown by the experiments of $M$. Saussure, with some sprigs of peppermint, that when supported by pure water only, and allowed to vegetate for some time in the light, they nearly doubled the portion of carbon which they originally contained. (Recherches sur la

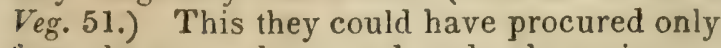
from the atmosphere; and, under these circumstances, there is now little doubt of the correctness of the conclusion of $\mathrm{M}$. Berthollet, that plants, by means of their roots and leaves, have the power of decomposing the water as well as the carbonic acid of the atmosphere, and furnishing, with these elements, new combinations. How essential a free access of the atmosphere is to the roots of plants was long since shown by M. Saussure, who found that oxygen gas is absorbed by the roots of plants as well as by their leaves, and that it is at the roots united with carbon, and transmitted to the leaves to be decomposed. Even the branches absorb oxygen; in its absence flowers will not even expand. (Thomson's Chem. vol. iv. p. 353.) It has been proved that their vegetation is greatly increased by nourishing them with water impregnated with oxygen gas; hence, too, the superiority of rain-water. Some remarkable experiments were made by Mr. Hill, demonstrative of the great benefits plants derive from oxygen gas being applied to their roots: hyacinths, melons, Indian corn, \&c., were the subjects of the experiments. The first were greatly improved in beauty, the second in flavour, the last in size, and all in vigour. This, too, is another use of increasing the moisture of the soil, by deep and complete ploughings, for M. Humboldt and M. Schubler have clearly shown that a dry soil is quite incapable of absorbing oxygen gas. Thus, it must be evident to the most listless observer, that the more deeply and finely a soil is pulverized, and its earths rendered permeable, the greater will be the absorption by them of both oxygen and watery vapour from the surrounding atmosphere.

It is perhaps needless to prove that the roots of commonly cultivated plants will penetrate, under favourable circumstances, much greater depths intc the soil in search of moisture than they can, from the resistance of the case-hardrned subsoil, commonly atain. Thus, the roots of the wheat plant, in loose deep soils have been found to descend to a depth of two or three feet, or even more: and it is evident 434 that if plants are priacipally sustaired in dry weather by the atmospheric aqueous vapour absorbed by the soil, that then that supply of water must be necessarily increased, by enabling the atmospheric vapour and gases, as well as the roots of plants, to attain to a greater depth; for the earth, \&c., of the interior cf a well pulverized soil, be it remembered, continues steadily to absorb this essential food of vegetables, even when the surface of the earth is drying in the sun.

By facilitating the admission of air to the soil another advantage is obtained, that of increasing its temperature. The earths are naturally bad conductors of heat, especially downwards : thus, it is a well-known fact, that at the siege of Gibraltar, the red hot balls employed by the garrison were readily carried from the furnaces to the batteries in wooden barrows, whose bottoms were merely covered with earth. Davy proved the superior rapidity with which a loose black soil was heated, compared with a chalky soil, by placing equal portions of each in the sunshine; the first was heated in an hour from $65^{\circ}$ to $88^{\circ}$, while the chalk was only heated $69^{\circ}$. 'This trial, however, must not be regarded as absolutely conclusive, since the surface of the black soils naturally increases more rapidly in temperature when exposed to the direct rays of the sun than those of a lighter colour. A free access of the air to the soil also adds to their fertility, by promoting the decomposition of the excretory matters of plants and other organic substances of the soil.

In the truth of these conclusions and laborious experimental researches of the chemist, does not the practical testimony of the ablest cultivators of all ages and in all countries concur? Thus, in enforcing the advantages of rendering the soil more completely permeable by the atmosphere, nearly two thousand years since, Cato asked the Italian farmers, "What is good tillage?" To plough. "What is the second?" To plough. 'The third is to manure. Cato, however, mistook the cause of the benefit, for he says, "He who stirs his olive ground oftenest and deepest will plough up the very slender roots; if he ploughs ill, the roots will become thicker, and the strength of the olive will go to the root." (Lib. 61.) Virgil, when giving an erroneous explanation of the advantages of paring and burning, says, "The heat opens more ways and hidden vents for the air, through which the dews penetrate to the embryo plant." (Georg. i. 90,91.)

And at this very period do not the best of England's agriculturists find the greatest advantage from stirring the ground between their rows of drilled turnips, which only operates so beneficially to the plants, by promoting the access of the air to their roots; and that, too, on soils where a weed is hardly to be seen? Is not one great object of fallowing to produce by pulverizing and deepening the soil the same result ? Did not Jethro 'Tull labour long, and sometimes too sanguinely, in illustrating the same position? And does he not support almost all the observations of the chemist, as to the attraction of the earth for the gasses and aqueous vapour of the atmosphere, when he says-"I have had the experience of a multi- 


\section{EARTHS.}

tude of instances, which confirms it so far that I am in no doubt that any soil (be it rich or poor) can ever be made too fine by tillage. For it is without dispute, that one cubical foot of this minute powder may have more internal superficies than a thousand cubical feet of the same or any other earth tilled in the common manner: and I believe no two arable earths in the world do exceed one another in their natural riches twenty times; that is, one cubical font of the richest is not able to produce an equal quantity of vegetables, cateris paribus, to twenty cubical feet of the poorest; therefore, it is not strange that the poorest, when by pulverizing it has obtained one hundred times the internal superficies of the rich untilled land, should exceed it in fertility; or, if a foot of the poorest was made to have twenty times the superficies of such rich land, the poorest might produce an equal quantity of vegetables with the rich. Besides, there is another extraordinary advantage when a soil has a larger internal superficies in a very little compass, for then the roots of the plants in it are better supplied with nourishment, being nearer to themon all sides within reach-than they can be where the soil is less fine, as in common tillage, and the roots in the one must extend much farther than in the other: to reach an equal quantity of nourishment they must range, perhaps, above twenty times more space, to collect the same quantity of food. But, in this fine soil, the weak and tender roots have free passage to the utmost of their extent, and have also an easy, due, and equal pressure everywhere, as in water." (Tull's New Husbandry, p. 43.) The farmer, too, is aware that when the inert substratum of most cultivated soils is first brought to the surface, it is entirely barren, and that yet, by mere exposure to the atmosphere, it becomes readily productive.

The comparative rapidity with which soils absorb heat by exposure to the rays of the sun is also a question of much importance. M. Schubler found that when the temperature of the upper surface of the earth was $77^{\circ}$ in the shade, earth, \&c., exposed to the sun in vessels four inches square and half an inch deep, from eleven till three o'clock, attained the subjoined temperature :-

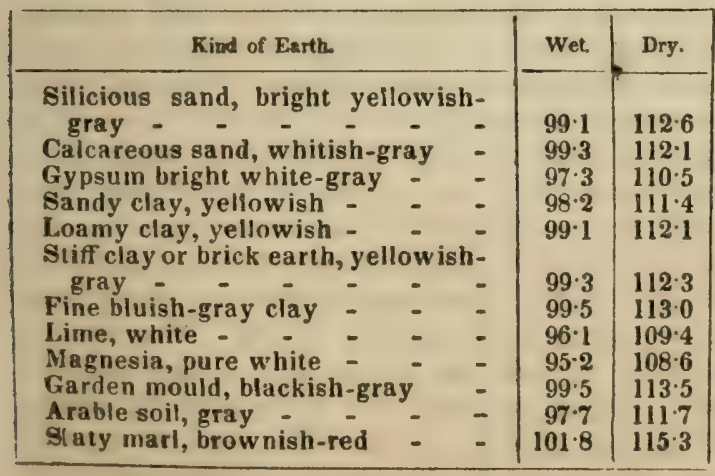

As different soils absorb heat with varying rapidity, so they retain it with more or less tenacity, as displayed in the following table by Prof ssor Schubler:-
EARTHS.

\begin{tabular}{|c|c|c|c|c|c|}
\hline \multirow{2}{*}{\multicolumn{4}{|c|}{ Kind of Earth. }} & \multicolumn{2}{|c|}{ 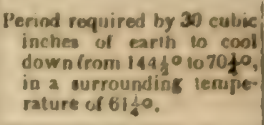 } \\
\hline & & & & Houra. & Minutea \\
\hline Calcareous san & - & - & - & 8 & 30 \\
\hline Silicious sand & - & - & - & 3 & 20 \\
\hline Gypsum powde & - & - & - & 2 & 34 \\
\hline Sandy clay & - & - & - & 2 & 41 \\
\hline Loamy clay & - & - & - & 2 & 30 \\
\hline Stiff clay or bri & ick earth & - & - & 2 & 24 \\
\hline Gray pure clay & - & - & - & 2 & 19 \\
\hline Fine lime - & - & - & - & 2 & 10 \\
\hline Fine magnesia & - & - & - & $\hat{1}$ & 20 \\
\hline Garden mould & - & - & - & 2 & 16 \\
\hline A rable soil & - & - & - & 2 & 27 \\
\hline Slaty marl & - & - & -1 & 3 & 26 \\
\hline
\end{tabular}

From these experiments, the farmer will perceive that the popular ideas, with regard to the quality of soils when they are denominated hot and cold, are nearly accurate. He will see that sandy soils absorb the heat of the sun faster than any others, but then their rate of cooling is equally great;-more rapid in their transitions from heat to cold than any others, the crops which they produce are commonly thin; and to these rapid transitions we may assign one reason for the poverty of the produce. The clays, on the contrary, which imbibe the sun's rays more slowly, retain their heat much longer.

There are several other properties of the earths with which it is highly desirable that the cultivator should be acquainted: thus, the resistance which soils offer to the plough or the spade, in their wet and dry state, is a question on several accounts highly interesting to the farmer. This property of the soil has alsn been examined by Professor Schubler, and the result of his experiments will be found in the following table :-

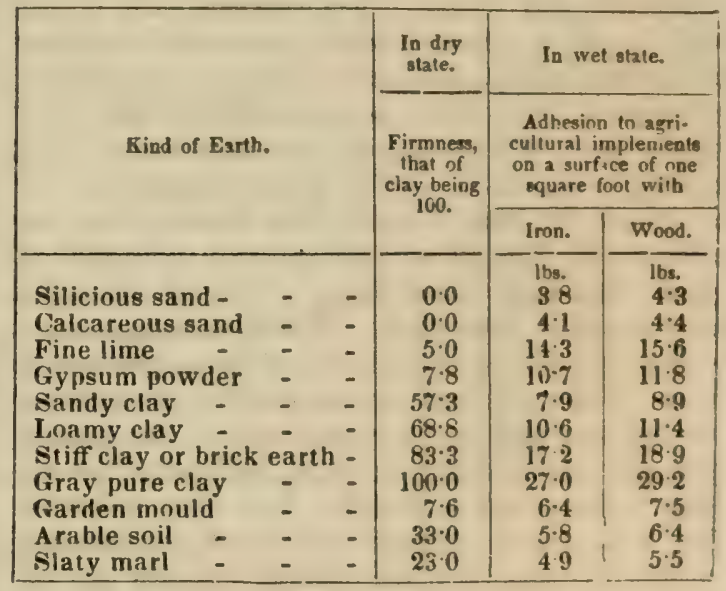

From these laborious researches of the chemical philosopher the intelligent farmer may derive many new and important conclusions with regard to the improved cultivation of the earth. They may serve to explain to him one great reason why fallowing and pulverizing the soil, either by machinery or by the mixture of chalk or sand with the heavier clay soils, promotes so decidedly, or so permanently, their fertility. And, again, the advocate for all old customs and obsolete modes of tillage may hence, among other things, learn why it is thas deep ploughing, either by the common or by 
the subsoil plough, produces such beneficial results; how the gases and aqueous vapour of the air are hence rendered more serviceable to the ronts of his crops; and how it is that this free passage of these elastic fluids, first caused by the action of the plough, is preserved and facilitated by that of the common or the horsehoe. Such researches, too, into the important properties with which the Creator has endowed the soil will be serviceable to the cultivator in even an indirect manner. 'These investigations will, assuredly, suggest to him the very reasonable conclusion, that there may be yet other chemical properties hidden in the land, which will serve to awaken the curiosity, and reward the labours of future scientific cultivators for many succeeding generations. (Brit. Farm. Mag. vol. v. p. 1.) See Mrxture or Sorls, Analysis of Solls, Absorpton, Chalk, HuMus, \&e.

EAR'TH-BOARD. That part of a plough which turns over the earth. It is generally termed the mould-board. See Plovgr.

EARTH-BUILDINGS. Buildings formed by rammed or compressed earth or clay. 'This kind of building is supposed to have been known at a very early period, and is still much in use in the southern parts of France. Not only the walls of the houses, but garden walls are formed in the same manner, and of the same materials in many parts of Normandy. In some instances, boards are placed between the layers of clay, and form a kind of framework, which increases the strength of the wall.

Clay cottages are not uncommon in some parts of England; but they are not constructed in the above-mentioned manner.

EARTH, EATING OF. Stall-fed cattle, and horses which have not the opportunity of plucking up the roots of grass, evince a great partiality for earth. It is seldom that a cow will pass a newly-raised mole-hill without muzzling into it, and devouring a considerable portion of it. This is particularly the case when there is any degree of indigestion, and it probably acts as a sort of gentle purgative. It is stated by Mr. Youatt (On Cattle) that the celebrated Kinton ox always had a basket of earth standing near him, of which he ate a considerable quantity. When decomposition commenced, and the acescent principle began to be developed, and the animal felt uneasiness on that account, he had recourse to the mould; and the acid uniting itself to the earth, the uneasy feeling was relieved. It is also probable that a purgative neutral salt was manufactured in the paunch, but this would depend on the nature of the earth. The absorbent or alkaline earth taken up with the roots of grass by sheep, also neutralizes the acids of the stomach. (Lib. of Use. Know. "Sheep," p. 3 ; “ Cattle," p. 104 -317.) It is usual to allow sucking calves to have access to chalk. In the stomachs of almost all young animals, man not excepted, there is a tendency to form superabundant acid, which, it not corrected, impairs digestion, and interferes with the assimilative function, that which converts the chyle into the animal tissue or substance of the body. The importance, therefore, of correcting this, by the administration of absorbed earths, is obvious.
It might become a matter of curious nqui:y, how far this desire of earth in cattle has affinity to that of the human stomach, which leads the Otomacs, a South American tribe, to eat clay. It is an unctuous clay, containing an oxide of iron ; and during some months, when provisions are scarce, an Otomac devonrs about three-quarters of a pound of clay daily, and he does not suffer nor become lean upon it. 'The negroes on the coast of Guinea, and the natives of Java, and of some of the other islands of the Indian Archipelago, are also earth-eaters; and in this and many European countries, pregnant women, and young girls in a state of disease connected with the uterine function, also evince a strong inclination to eat earth.

Among quadrupeds, earth-eating is not confined to the horse and ox tribes; for, when pressed for food, wolves in the north-east of Europe, reindeer and kids in Siberia, all eat clay. It is probable that the earth operates as a mechanical stimulus to the stomach, and abates. the sensation of hunger, which always attends certain diseased conditions of the stomach. But, whatever may be the cause, this instinctive longing for earth in horses, cows, and oxen should not be overlooked, and the animals should be supplied with it when they are stall-fed.

EARTH-NUT (Bunium flexuosum). The common earth-nut, kipper, or pig-nut, for it is known by all these names, is a perennial plant growing in sandy or gravelly meadows, pastures, orchards, and woods; flowering in May or June. The root is eatable, nearly globular, black, internally white, aromatic, sweet, and mucilaginous, with some acrimony. The stem is a foot high or more, striated, with long, narrow, acute leaves; the radicle leaves are twice or thrice pinnatifid. 'The flowers are in umbels; they are pure white. The roots are at present searched for only by hogs, who devour them with avidity; but as they are little inferior to chestnuts, they might form an agreeable addition to winter desserts, eaten either raw, boiled, or roasted. (Willich's Dom. Encyc.)

EARTH-WORMS (Lumbricus, Linn.). Wellknown molluscous animals, which are common in ali parts of the country, at little depths beneath the surface of the earth. White, in tris Nat. Hist. of Selborne, speaking of their effects on the soil in promoting vegetation, says, "The most insignificant insects and reptiles are of much more consequence, and have much more influence in the economy of nature, than the incurious are aware of; and are mighty in their effect from their minuteness, which renders them less an object of attention, and from their numbers and fecundity; earthworms, though in appearance a small and despicable link in the chain of nature, yet, if lost, would make a lamentable chasm. For, to say nothing of half the birds and some quadrupeds which are entirely supported by them, worms seem to be equal promoters of vegetation, which would proceed but lamely without them, by boring, perforating, and loosening the soil, and rendering it pervious to the rain and the fibres of plants, by drawing straws and stalks of leaves and twigs into it; and most of all, by throwing up such infinite numbers of 
lumps of earth, called worm-casts, which being their excrement, is a fine manure for grain and grass. Worms probably provide new snil for hills and slopes, where the rain washes the earth away, and they affect slopes probably to avoid being tlooded. Gardeners and farmers express their detestation of worms : the former, because they render their walks unsightly, and make them much work; and the latter, because, as they think, worms eat their green corn. But they would find that the earth without worms would soon become cold, hard-bound, and void of fermentation, and consequently sterile; and besides, in favour of worms it should be hinted that green corn, plants, and flowers are not so much injured by them as by many species of Coleoptera (scarabs) and Tipula (long-legs) in their larvæ or grub state, and by unnoticed myriads of small shell-less snails, called slugs, which silently and imperceptibly make amazing havoc in the field and garden. Worms work most in the spring, and are out every mild night in the winter: they are very prolific." (Quart. Journ. of Agr. vol. ii. p. 145.) Worms are readily destroyed by the application of common salt, sown broadcast at the rate of five or six bushels per acre; or on grass plats, by the application of lime-water, or rather milk of lime, which is readily made by stirring for ten minutes a pound of hot lime in four or five pailsful of water. But, for the reasons already given, they should not be destroyed. Earth-worms are viviparous, their eggs are hatched in the body, and the young are expelled alive. They generally come out of the earth during the night in June to copulate.

EARTHY MANURES. These are the most aniversal of all fertilizers. In England they are chiefly limited to three, viz. chalk and lime, clay or alumina, sand or silex. In the United States, where no chalk is found, its place is well supplied by lime and calcareous marls, which last, in New Jersey, Delaware, Maryland, and Virginia, are used to the greatest advantage by farmers. Then again the green sand or silicate of potash, found in the states mentioned, proves, in many situations, a powerful mineral fertilizer. With these may be classed the coal, or other ashes produced by the combustion of peat, turf, and other vegetable substances, the composition of which is usually similar to that of the soils on which the combustible matter is produced. Ashes from chalk soils usually abound in carbonate of lime and gypsum, which is produced in the chalk by the gradual decomposition of the iron pyrites which most chalk contains; while those from clay lands as generally abound with alumina and sand. Those which are brought from the seashore almost always contain a considerable quantity of soda, and some common salt. There are no researches more likely to amply repay the cultivator than the investigation of the composition of his soils. All the difference between a fertile soil and the poorest cultivated land consists in the presence of the indispensable constituents of a soi! in proportions that are more or less profitable. The addition of the desired substance, whether organic or inorganic, constitutes the fertilizing ingredient. Davy long since remarked that "Fertility seems to depend upon the state of division an? mixture of the earthy materials and the vege. table matter. In ascertaining the composition of fertile soils, with a view to their improve. ment, any particular ingredient which is the cause of their unproductiveness should be particularly attended to; if possible, they should be compared with fertile soils in the same neighbourhood, and in similar situations, as the difference of composition may, in many cases, indicate the most proper methods of improvement." (Agricultural Chemistry, r. 203.) 'Thus, either peat, or chalk, or clay is an excellent permanent addition to sandy soils. Chalk and sand improve the texture and productiveness of clays. To peat, the earths are all more or less permanent fertilizers; lime removes the excess of sulphate of iron (green vitriol); chalk is equally efficacious in what the farmer calls acid or sour soils. This class of marures differs from the organic and saline, in this highly important yet seldom sufficiently remembered quality, that as they are more frequently employed in larger quantities than either of the other two, so their beneficial influence on the soil far exceeds in duration all others.

EARWIG (Forficula auricularis, Linn.). A well-known insect, which is common in damp places, and often found in numbers under stones, and beneath the bark of trees. They do much damage in gardens, by preying upon the fruit. The English common name, and also the French pierce-oreille, relate to a habit absurdly attributed to these insects, of penetrating the ears. (Brande's Dict. of Art.)

It is a curious fact that the earwig sits upon her eggs like a hen; and when the young are hatched, they creep under the mother, like a brood of chickens under a hen. De Geer, who has observed the habits of this insect, says, the parent will sit over them for hours. She usually carries them about on her back, until they are able to provide for themselves. Une of the species of forficula, namely, $F$. minor, has wings, and flies in groups.

They are very injurious to flowers, eating holes in the blossoms, and otherwise disfiguring them, particularly the dahlia: and Mouffet says that "ox hoofs, hog"s hoofs, or old cats things are used as traps for them by the English women, who hate them exceedingly, because of clove-gilliflowers that they eat and spoyl." It is common with English gardeners to hang up, among the flowers and fruit-trees subject to their attacks, pieces of hollow reeds, lobster claws, and the like, which offer enticing places of retreat for these insecrs on the approach of daylight, and by means thereof great numbers of them are obtained in the morning. The little creeping animal, with numerous legs, commonly, but erroneously, called earwig in America, is not an insect; but of the true earwig we have several species, though they are by no means commin, and certainly never appear in such number: as to prove seriously injurious to vegetation. (Harris's Treat. of Insects.)

EDDER. A small straight shoot of ash, hazle, oak, or any other kind of fexible wood used for binding the tops of hedges. 
EFT, NEWT, or EVET (Salamandra). A small kind of lizard, that chiefly lives in the water. As the newt is an amphibious animal, it requires to ascend frequently to the surface of the water, to take fresh air into its lungs.

EGGS (Fr. cufs; Germ. ei; Lat. ova). The vva of birds and oviparous animals. The shell of the egg is lined throughout with a thin but tough membrane, called pellicula ovi; which, dividing at or near the obtuse end, forms a small bag-the air follicule. This membrane weighs about 2.35 grains in an egg of 1000 grains in weight. It contains what is called the albumen or white, and the vitellus or yellow. The white consists of two distinct parts, one of which is a delicate membrane forming a series of cells, which enclose the other, or fluid part. It has the well-known property of being coagulated by heat. It consists of 12 parts of albumen, $2 \cdot 7$ of mucus, $0 \cdot 3$ of salts, and 85 of water, in a hundred parts. The yolk consists of oil, suspended in water by means of albumen, and held in a membranous sac-the yolk-bag, each end of which is twisted, to form what is called the chalazce, intended to preserve the yolk in such a position that the cicatricula, or rudimental embryo, shall always be uppermost. The yolk consists of 28.75 of yellow oil and crystallizable fat, with iraces of sulphur; 17.47 of albumen, containing phosphorus, and 53.8 of water. The relative weights of these parts, in an egg weighing 1000 grains, are, 106.9 shell and membrane, $604 \cdot 2$ albumen, and 288.9 yolk. The egg loses 2 or 3 per cent. of its weight when boiled in water. The white is more easily digested than the yolk; and both are more digestible in the soft than in the hard state. 'The changes which the hen's egg undergoes during incubation have been described by Sir E. Home (Phil. Trans. 1822, p. 339), and illnstrated by a beautiful series of plates, after drawings by Bauer. The same volume also contains a valuable paper, by Dr. Prout, on this subject, but chiefly treating of the chemical changes of the egg during that process. The egg does not receive its outer coat, or pellicule, until it arrives at that part of the oviduct which is called the uterus; and not its shell until it has passed through one half of the uterus. Eggs are sometimes expelled withont shells, and are called oon-ggs. The specific gravity of newlaid eggs at first rather exceeds that of water, varying from 1.08 to 1.09 ; but they soon become lighter, and swim on water, in consequence of evaporation through the pores of the shell. The mean weight of a hen's egg is about 875 grains.

Hen's eggs are decidedly wholesome; and, when new laid, are an agreeable and nourishing food. Vast quantities of eggs are brought from the country to London, and other great towns. It is stated in the Quart. Journ. of Agr. vol. jii. p. 1077, that, about 15 years ago, the number of eggs exported from Berwick-uponTweed to $\mathbf{I}$ iondon amounted to $30,000 l$. worth a year.

The trade in eggs is of great value and importance. It appears from official statements, that the eggs imported into England from France amounted to $60,000,000$ a year; and 138 presuming them to cost, on an average, $4 d$. per dozen, it follows that the English pay the French above $83,000 l$. a year for eggs; and supposing that the freight, importer's and retailer's profit, duty (10d. per 120$)$, \&c. raise their price to the consumer to $10 d$. per dozen, their total cost will be $213,000 l$. The number of eggs imported into England from various parts of the Continent, for the year ending January 5, 1839, was $83,745,723$; and the gross amount of duty received for the same was 29,111l. The Netherlands and the Channel islands furnish a large quantity of the eggs consumed in England. (M'Culloch's Com. Dict.) See Fow $\mathbf{~ s . ~}$

A new method of preserving eggs, by packing them in salt with the small end down wards, and by which they have been kept perfectly good for eight or nine months, will, it is believed, enable the inhabitants of portions of our country where these abound to make them profitable. Thousands of bushels may be sent off to the Atlantic marliets. Great quantities are used in France; and as the duty on them in England is so low, (not 2 cents per dozen,) they might bear exportation. They have been gathered and sold at the West as low as 90 cents per bushel; which, as a bushel contains 45 dozen, is but 2 cents per dozen. (Ellsworth's Report, 1843.)

EGG-PLANT (Solanum melongena). This is a tender annual, a native of Africa. It loves a light rich soil, and blows violet flowers in June and July, which are succeeded by fruit, shaped and coloured like an egg. The plant is propagated by seed. In French and Italian cookery it is used in soups, and for the same purposes as the love-apple.

Two varieties of this annual plant are commonly met with in the United States; one of these bears a very large purple oval-shaped fruit, which is highly relished as a delicious and rich tasted vegetable. It is cooked by frying transverse sections or slices, and in other forms and ways. In size and shape the fruit resembles an ostrich egg, though it frequently attains a size many times larger, even to that of a small water-melon. The second variety is white, and the shape bears a striking resemblance to the eggs of the domestic fowl. To raise them in the Middle and Northern States, the seed must be sown in a hot-bed in March, and transplanted into the open air as: soon as there is no danger from frost, placing them about two feet apart. A pretty high degree of heat, blended with a good supply of moistare, are required to make the seeds germinate and bring forward the young plants.

The insane egg-plant (Solanum insanium). Mad-apple, or purple egg-plant, called by the French Aubergine rouge, is occasionally cultivated in the United States as a culinary vegetable. The whole plant is coated with a downy nap. The flowers are purplish and pubescent, and the berries very large, ovoid-oblong, mostly of a dark purple colour when mature, and sometimes pale-green. (Flora Cestrica.)

EGI.ANTINE (Rosa rubiginosa; Fr.eglantin). The old English name of the sweetbrier rose. The odour which is so agreeable, is exhaled from reddish, viscid glands, which cover the 


\section{FLATERS.}

under suriace of the leaflets. This odour enabtes it to be readily recognised from all our other wild roses, except the small-flowered sweetbrier (Rosa micrantha), which some believe to be only a variety of $R$. rubiginosa. The term eglantine is improperly applied by Milton to the honeysuckle.

ELATERS. See Berthe, Sphing-berte.

ELBOWS. A term applied to the shoulderpoints of cattle.

ELDER (Sambucus nigra). It appears (says Phillips) that we have taken the word elder from holder, the Dutch name of this tree. The common elder tree is a native of England, and is found also in most parts of Europe, as it will grow on any soil, and in situations where few other trees would thrive. The stem is much and oppositely branched; the branches being covered with a smooth, gray bark, and having a large spongy pith; the leaves consist of two pair of leaflets, with an odd one. 'The flowers are in cymes; the berries globular, deep purple. It may be observed, that our uncertain summer is established by the time the elder is in full flower, and entirely passed when its berries are ripe. An infusion of the leaves proves fatal to the various insects which thrive on blighted or delicate plants, nor do many of this tribe, in the caterpillar state, feed upon them. Cattle scarcely touch them, and the mole is driven away by their scent; but sheep eat the leaves greedily, and it is said to be a cure for the rot. The Rev. Mr. Farquharson, in an able paper in the Trans. High. Soc. vol. iv. p. 336, advocates the cultivation of the elder for hedges, from its rapidity of growth, hardihood, and cheapness. The only objection appears to be, that it does not thicken and close up its branches, so as to form an impervious fence, like the white thorn. M. Wehrle of Viemna has found, by a series of experiments, that the berries of the elder tree produce a much greater quantity of spirit than the best wheat. The spirit is obtained by pressing the berries, the juice of which is treated in the same way as the must of the grape, and afterwards distilled. If the results obtained by $\mathbf{M}$. Wehrle are confirmed, it will be an additional motive for cultivating a plant which possesses many other useful qualities. (Quart. Journ. $A g r$. vol. iii. p. 183.) An odorous water is prepared by distilling the flowers; it is used as a perfume. The inspissated juice of the berries is laxative and diuretic; and, mixed with water, forms a cooling beverage in fevers. The inner bark is purgative and emetic.

A correspondent of the Now England Farmer says that the expressed juice of elder leaves will kill skippers in cheese, bacon, \&c.; and strong decoctions of the leaves or roots are fatal to insects, which depredate on plants in garciens and fields. Dr. Willich observes, that the leaves of the elder are eaten by sheep, to which they are of great service when diseased vith the rot; for if placed in a situation where they can easily reach the bark and young shoots, they will speedily cure themselves. Dr. Elliott observes in his Essay on Field Husbandry, that elder bushes are stubborn and hard to subdue, yet I know by experience, that mowing them five times a year will kill them. (N. E.

\section{ELEC'TRICITY.}

Farmer.) Sume persons have found a very effectual plan for destroying elders by taking a pole or staff and beating them down whilst in full blossom.

The species of elder most cominon in the United States, is called by botanists, Sambucus Canadensis. It is often a great nuisance alnng fence rows and hedges, where its straight stems attain a height of 5,8 , or 10 feet, being filled with a large pith. The flowers bloom in July and August, the peduncles spreading out so as to display the blossoms somewhat like an umbrella. The berries are very abundant, small, juicy, and dark purple, or nearly black when fully ripe. The long roots are very tenacious: of life, and very much disposed to spread from lateral joints. The inner bark is a popular ingredient in making ointments for sores. An infusion of the bruised leaves is often used (o) expel insects from young cucumber and other vines. The ripe berries, according to $\mathrm{M} . \mathrm{Coz}$ zens, afford a delicate re-agent, or chemical test, for detecting acids and alkalies. There is one other species in the United States, callerl Sambucus pubens, which is found on the mountains in the north-eastern part of Pennsylvania. In this the flowers do not spread out like those of the common elder of the $M$ ddle States. but are crowded together so as ir form dense ovoid heads or panicles. The $t$ irries are a scarlet red.

ELDER, BOX. In some parts of the United States, the name of box elder is popularly applied to the ash-leaved maple (Acer negundo). See Maple.

ELDER, THE WATER (Vibarnum opulus). Commonly called Snow-ball. See Gúctor Rose. ELECAMPANE (Inula Helenium). Called by the French Aunée. This is a plant with a perennial root and annual stem, which has been naturalized in the United States, where, in the old settled parts, it is frequent about houses, road-sides, \&c., flowering in July and August. The stem or stalk is downy, and grows to the height of 3 to 6 feet, branching near the top. The leaves are long and large, with much down on the under surface. The flowers are large, and of a golden yellow. The roots, which constitute the medicinal part of the plant, should be dug up in autumn and in the second year of their growth, as when older they are apt to be stringy and woody. The dried root has a very peculiar and agreeable aromatic odour, slightly camphorous. 'The taste at first is glutinous and somewhat similar to that of rancid soap; upon chewing, it becomes warm, aromatic, and bitter. A peculiar principle, resembling starch, has been discovered in elecampane, by that distinguished German chemist, Rose, of Berlin, who named it aluntin; but the term inulin is most generally adopted. It has been found in the routs of several other plants. In its medical properties elecampane is tonic and gently stimulant, \&c. By the ancients it was much employed, especially in complaints peculiar to females. In the United States, its use is mostly confined to diseases of the lungs. It has also been extolled for its virtues when applied externally for the cure of itch, tetter, and other diseases of the skin.

ELEC'TRICITY. The application of this 
science to the cultivation of the earth has titherto not been very practically useful. Its sperations-the very nature of electricity - are is yet much too little understood for the culti. vator to derive instruction from its study. "Electrieal changes," said Davy (Elements of Agr.Chem. p. 41), "are constantly taking place in nature on the surface of the earth, and in the atmosphere: but as yet the effects of this power in vegetation have not been correctly estimated. It has been shown, by experiments made by means of the voltaic battery (the instrument in which electricity is evolved by the mutual action of zinc, copper, and water), that compound bodies in general are capable of being decomposed by electrical powers ; and it is probable, that the various electrical phenomena occurring in our system must influence both the germination of seeds and the growth of plants. I found that corn sprouted much more rapidly in water positively electrified by the voltaic instrument, than in water negatively electrified; and experiments made upon the atmosphere show that clouds are usually negative; and as when a cloud is in one state of electricity, the surface of the earth beneath is brought into the opposite state, it is probable that, in common cases, the surface of the earth is positive. Different opinions are entertained amongst scientific men respecting the nature of electricity: by some, the phenomena are conceived to depend upon a single subtile fluid, in excess in the bodies said to be positively electrified, in deficiency in the bodies said to he negatively electrified; a second class suppose the effects to be produced by two different lluids, called by them vitreous and resinous; and a third set regard them as affections, or motions of matter, and merely an exhibition of attractive powers, similar to those which produce chemical combination and decomposition, but usually exerting their action on masses."

E LE VA T I ON, ATMOSPHERIC. The height of land above the sea or common level, exerts a very great influence upon the growth of plants. One of the main causes operating under such circumstances to diminish the size of plants, Professor Dobereiner believes to be the diminution of atmospheric pressure. Experiments have been made in order to prove this by placing seeds of barley in vessels, containing soil, water, and air, under different degrees of atmospheric pressure; and the result has been, that, where the pressure was greatest, the vigour of the plants was also greatest. See Altitune.

ELM (Ulmus). A genus of forest trees, common in Great Britain, of which there are several varieties. The characters of the genus are flowers, bisexual; calyx, bell-shaped, four to five toothed, coloured persistent; stamens, three to six; stigmas, two, fruit, sub-globular, with a bread membranous margin. Sir James A. Smith (Eng. Flor. vol. ii. p. 19), describes five species of native elm:-viz. 1. The rommon small-leaved elm (U.campestris), which is found chiefly in the southern parts of England. The wood is hard and tough, particularly durable in wet situations, and is greatly preferred in Norfolk (where it is the most common speries) to any other, and sells for nearly double 410 the price, serving more especially for the naves of wheels. In other parts of England, and particularly about London, the wond of the common elm is used for coffins. 2. The crmmon cork-barked elm (U. suberosa), which is taller and more spreading than the foregoing. The bark when a year old is coverec with very fine dense cork in deep fissures; whence the name. It is far inferior to the former in value. There are various cultivated varieties raised from seed. 3. The Dutch cork-barked elm ( $I$. major); a doubtful native. The branches. spread widely in a drooping manner, and the bark is rugged, much more corky than even the foregoing. Miller says this elm was brought from Holland in King William's reign, and being recommended for its quick growth, was a fashionable tree for hedges in gardens, but afterwards fell into disuse. He adds, that "the wood is good for nothing, so its use is almost banished in this country." 4. The broad-learcd Scotch elm, or wych hazel (U. montana). It is sometimes called the Hertfordshire elm, being very frequent and luxuriant in that county. The large hop-like fruit is abundant, and very conspicuous in May or June; and the seeds appear to be usually perfected. This is one of the most general species of elm throughout Europe. It is a large spreading tree, of quicker growth than the common small-leaved elm, and the wood is consequently far inferior in hardness and compactness, and more liable to split. The branches are in some individuals quite pendulous, like the weeping willow. The bark is smooth, and downy in a young state. 5. The smooth-leaved, or wych elm (U. glabra). A tall, elegant tree, with spreading, rather drooping, smooth, blackish branches, and smaller leaves than any of the preceding, except the first.

The elm (says Brande) is valued for the rapidity of its growth, its hardness, and its capability of thriving in poor soil unfit for tillage. Tredgold (Princip. of Carp.), however, says the elm is of slow growth. The elms of England are scarcely less remarked for their age, bulk, and beauty than the British oaks. The colour of the heart-wood of elm is generally darker than that of oak, and of a redder brown. The sap wood is of a yellowish or brownish white, with pores inclined to red. It has a peculiar odour, is in general porous and cross-grainedsometimes coarse-grained, and has no large septa. It twists and warps much in drying, and also shrinks considerably both in length and breadth. It is difficult to work, but not liable to split, and bears the driving of bolts and nails better than any other timber. What is known in Europe as the twisted elm (Orme tortillard $)^{\text {) }}$, is not a distinct species but only a variety of the European elm. The twisted form of the fibres is secured by culture, the young stalks being properly grafted and planted separately from the parent tree. In Scotland, chairs and other articles of household furniture are frequently made of elm wood; but in England, where the wood is inferior, besides the purposes already specified, it is chiefly in demaad for the manufacture of casks, mill-wheels, pumps, water-pipes, axletrees, \&c. It is appropriated to these purposes because of 
its great durability in water, which also occasions its extensive use as piles and planking for wet foundations. A second-rate charcoal is made from this wood; and rails and gates of eim, thin sawed, Evelyn tells us in his Sylva, are not so apt to rive as oak. Elm is said to bear transplanting better than any other large tree. I* is propagated by seed, layers, o: suckers, and by grafting and budding. Suckers, however, generally disfigure those trees raised from layers or suckers. As the value of this timber consists more in the length and bulk of the shaft than in the irregular growth of its branches, it is the business of the planter to train them up tall and straight, and not to suffer them to branch till within a few feet of the top. 'The leaves of the elm are eagerly eaten by cattle, sheep, and hogs. 'The inner' bark of the elm is nearly as valuable a medicinal agent as the much-vaunted sarsaparilla. The decoction of it forms an excellent vehicle for minute doses of corrosive sublimate in some obstinate skin diseases; and in combination with vinegar or muriatic acid, it is a useful gargle in inflamed throats.

Several species of the Ulmus family are found in the United State.. Among these the white or weeping elm (Ulmus Americana), is met with over a very extensive tract of the continent. Michaux says that his father notice - it as high north as latitude $48^{\circ} 20^{\prime}$, near the entrance of the river Mistassin into Lake St. John, and that he had himself observed it from Nova Scotia to the extremity of Georgia, a distance of at least 1200 miles. It abounds in all the Western states. The district of country in which it seems to flourish best is comprised between the $42 \mathrm{~d}$ and $46 \mathrm{th}$ degrees of latitude, in Western New York, the Eastern States, and adjoining British provinces. It delights in low and humid soils, and is frequently met with on the borders of swamps and fertile bottoms, associated with the white maple and buttonwood. On the banks of rivers its base is frequently overflowed by freshets, and its diameter often increases to four feet. But it is where the primitive forests, in which it has been once insulated, have been cleared away, that the American elm when left appears in its greatest majesty, towering to the height of 80 or 100 feet, with a trunk 4 or 5 feet in diameter, regularly shaped, naked, and insensibly diminishing to the height of 60 or 70 feet, where it divides into two or three primary limbs. These limbs do not part so suddenly as those of most other trees, but approach and cross each other, interlacing and bending their flexible branches so as to form regular arches of the Gothic character, floating lightly in the air. Michaux mentions a singularity in this tree he had found in no other, namely, that two small limbs, 4 or $\mathbf{5}$ feet long, grow in a reversed position near the first fork, and descend along the trunk.

The American white elm differs essentially from the red elm and the European elm in its flowers and seeds. The flowers appear before the leaves, and are very small and of a purple colour. The seeds are contained in a flat, oval, fringed capsule, being mature from the $:$ th of May to the 1st of June.
The buttonwond astonishes the eye by the size of its trunk and the amplitude of its head: but the white elm has a more majestic appearance, owing to its greater height, and the disposition of its principal limbs. When growing alone, the limbs generally branch off at 8 , 10 , or 12 feet from the ground.

"The trunk of this elm is covered with a white, tender bark, very deeply furrowed. 'The wood, like that of the common European elm, is of a dark brown, and, cut transversely or obliquely to the longitudinal fibres, it exhibits the same numerous and fine undulations; but it splits more easily, ard has less compactness, hardness, and strength. 'This opinion was given me by several English wheel-wrights established in the United States, and I have since proved its correctness by a comparison of the two spe. cies. 'The white elm is used, however, at New York and farther north, for the naves of coachwheels, because it is difficult to procure the black gum, which at Philadelphia is preferred for this purpose. It is not admitted into the construction of houses or of vessels, except occasionally in the district of Maine for keels, for which it is adapted only by its size. Jrs bark is said to be easily detached during eight months of the year; soaked in water and suppled by pounding, it is used in the Northern States for the bottoms of common chairs.

"Such are the few and unimportant uses of the white elm in the United States; it is far inferior to the European elm, which is a tree of very extensive utility, and it deserves attention in the old world only as the most magnificent vegetable of the temperate zone." (Michaur.)

'The Red or Tawny elm (Ulmus mera), called also the slippery clm.- Except the maritime districts of the Carolinas and Georgia, this species of elm is found in all parts of the Inited States and of Canada. It bears the names of red elm, slippery elm, and moose elm, of which the first is the most common; the French of Canada and Upper I,ouisiana call it Orme grus. "The red elm, though not rare, is less common than the oaks, the maples, the sweet gum, and the sassafras; it is also less multiplied than the white elm, and the two species are rarely found together, as the red elm requires a substantial soil, free from moisture, and even delights in elevated and open situations, such as the steep banks of rivers, particularly of the Hudson and the Susquehanna. In Ohio, Kentucky, and Tennessee it is more multiplied than east of the mountains, and with the hickories, the wild cherry tree, the red mulberry, the sweet locust, the coffee tree, and some other species, it constitutes the growth upon the richest lands of an uneven surface.

"This tree is 50 or 60 feet high, and 15 or 20 inches in diameter. In the winter it is distinguished from the white elm by its buds, which are larger and rounder, and which, a fortnight before their developement, are covered with it russet down.

"The flowers are aggregated at tise extremity of the young shoots. The scales which surround the bunches of flowers are downy like the buds. The flowers and seeds differ from those of the preceding species; the calyx is downy and sessile, and the stamina are shor 
and of a pale rose colour; the seeds are larger, destitute of fringe, round, and very similar to those of the European elm; they are ripe towards the end of May. The leaves are ovalacuminate, doubly denticulated, and larger, thicker, and rougher than those of the white elm.

"The bark upon the trunk is brown; the heart is coarser-grained and less compact than that of the white elm, and of a dull red tinge. I have remarked that the wood, even in branches of one or two inches in diameter, consists principally of perfect wood. This species is stronger, more durable when exposed to the weather, and of a better quality than the white elm; hence in the Western States it is employed with greater advantage in the construction of houses, and sometimes of boats on the banks of the Ohio. It is the best wood of the United States for blocks, and its scarceness in the Atlantic States is the only cause of its limited consumption in the ports. It makes excellent rails, which are of long duration, and are formed with little labour, as the trunk divides itself easily and regularly; this is provably the reason that it is never employed for the naves of wheels.

"The red elm bears a strong likeness to a species or a variety in Europe known by the name of Dutch elm. The leaves and the bark of the branches, macerated in water, yield, like those of the Dutch elm, a thick and abundant mucilage, which is used for a refreshing drink in colds, and fur emollient plasters in place of the marsh-mallow root, which does not grow in the United States.

"Though the red elm is superior to the white elm, it is not equal to our European species, and its culture cannot be generally recommended.

"Observation. In the district of Maine and on the banks of Lake Champlain I have found another elm, which I judged to be a distinct species. Its leaves were oval-acuminate, rough, and deeply toothed, but I have not seen its flowers or its seeds. 'T'he length of its young shoots announced a vigorous vegetation. It is confounded in use with the white elm, to which it is perhaps superior; it is found in the nurseries of France, and probably it came originally from Canada." (Michaux.)

The red elm of the United States bears so strong a resemblance to the Dutch elm, both in foliage and fruit, that it is not always easy to tell them apart. The species of elm known in the South by the Indian name of Wahoo, is the Ulmus, alata of Michaux. It is a stranger to the Northern and Middle States, and to the mountainous regions of the Alleghanies; being found almost exclusively in the lower part of Virgınia, in the maritime districts of the Southern States, in West Tennessee, and in some parts of Kentucky. It prefers the banks of rivers and great swamps, and attains a middle size, commonly not rising higher than 30 feet, with a diameter of 9 or 10 inches. 'The branches of the wahoo are furnished throughout their whole length, on two opposite sides, with a fungous appendage or ridge, two or three lines wide, from which the specific name, alata, winged, is derived. 'The wood is fine-grained, more compact, heavier and stronger than that of the American white elm. The heart is of a dull red, approaching to chocolate-colour, and always bears a large proportion to the sap. In those parts of the country where it grows, it is employed for coach-wheels, and is even preferred for this purpose to the black gum, as being more hard and tough.

Another American species of elm has been discovered by Mr. Nuttall, who calls it the Opaque-leaved elm. He found it in Arkansas, on the plains of the Red river, 1100 miles above its mouth, where it forms a majestic forest tree. It is distinguished for the smaliness and thickness of its oblique and usually blunt leaves, which, with their short stalks, are only about an inch in length by half an inch in breadth, and very numerous. The taste of the plant is astringent, and it is not mucilaginous.

Mr. Nuttall considers this remarkable tree to be nearly allied to the Chinese elm (Ulmus Chinensis). Of the uses and quality of its wood he does not speak. The density of shade produced by it, so crowded with rigid leaves, and the peculiarity of its appearance, he says, entitle it to a place in the nurseries of the curious, as he thinks it quite hardy enough for all temperate climates. To this species, he remarks, Virgil's epithet,

\section{"Fæcundæ frondibus ulmi,"}

might be more justly applied than to any other. (Nuttall's Sup. to Michaux.)

An American species called Thomas's elm (Ulmus raceniosa), which has hitherto been con. founded with other elms, is, according to Professor Torrey, abundant in the western part of the State of New York, and probably of the Western States generally. Mr. Thomas, its discoverer, found it in Cayuga county, New York, and the adjacent country. G. B. Emerson, Esq., says that specimens have also been obtained from Vermont, collected by Dr. Robbins, so that it is probably both a northern and western species.

The lowermost stout branches, according to Mr. Thomas; produce corky excrescences like the Wahoo elm. For a further description, see Eaton's North Amer. Botany; Silliman's Journal, vol. xix. p. 170, with a plate; Nuttall's Supplement, p. 37.

ELYMUS. The lyme grass. A genus of large, rigid, or coarse grasses, mostly perennial, growing frequently on the sea-coast. Smith (Eng. Flora, vol. i. p. 177), describes three native species:-1. Upright sea lyme grass (E. arenarius). 2. Pendulous sea lyme grass ( $E$. geniculatus). 3. Wood lyme grass (E. Europous). 'The last is found in woods, thickets, and hedges, on a chalky soil; herbage of a grassy green; stem erect, two feet high, and striated. As Sinclair has treated copiously of the proportional value of the different native and foreign species of Elymus, I shall follow his classification.

Elymus arenarius (Germ. Sand-haargras, Pl. $7,0)$. Upright sea lyme grass, starr, or bent, named from its upright, close spike. Its stalk is not winged, and the leaves are spinous, pointed. The calyx is lanceolate, the length of the spikelets. 'The nutritive matter affurded 


\section{ELYMUS.}

by this lyme grass is remarkable for the large quantity of saccharine matter which it contains, amounting to more than one-third of its weight; this grass may, therefore, be considered as the sugar-cane of Britain. The saccharine matter must render the hay made from this grass very nutritious, particularly when cut into chaff, and mixed with corn or common hay. Its natural soil (if soil it can be called) is the sands of the sea-coast. This grass, when combined with the Arundo arenaria, seems admirably adapted by nature for the purpose of forming a barrier to the encroachment of the sea. The culms are very deficient, both on its natural soil and when cultivated. A greater proportion of saccharine matter is afforded by the culms of this grass than by the leaves. It flowers about the third week in July.

Elymus geniculatus. Knee-jointed or pendulous lyme grass. 'The stem is winged, and the spikes bent directly downwards. At the time of flowering, the produce from a sandy loam is $20,418 \mathrm{lbs}$. per acre. The foliage is tough and coarse, and the quantity of nutritive matter it affords is not considerable. The Elymus arenarius is nearly allied to this species in its general habit; but differs specifically in the spikelets being pubescent, more compact, and the spike perfectly upright. The leaves are broader, the culms taller and stronger, and the root is more powerfully creeping. This species is greatly superior to the above in produce and nutritive properties, but neither appear to have merits sufficient to recommend it for cultivation; for even though both were early in the produce of fine foliage, and grew rapidly after being cut, their strong creeping ronts, which exhaust the soil very much, would preclude their introduction on the farm. This species flowers in the second week in July, and the seed is perfected in about three weeks.

Elymus hystrix. Rough lyme grass. At the time of flowering, the produce from a rich, silicious, sandy loam was 27,225 lbs., of which half the weight is lost in drying. The nutritive matter afforded by the produce of an acre is only $1063 \mathrm{lbs}$. The harsh, broad, thin, lightgreen leaves of this species, and of those of the E. striatus and $E$. sibiricus, indicate that they are naturally inhabitants of woods, or wet, shady places. Grasses of this description are generally (indeed in every instance that has come under my observation) deficient in nutritive matter, and contain an excess of bitter extractive. Cattle appear to dislike these grasses. Oxen eat the Philadelphian lyme grass when it is offered to them, but they refuse the striated, Siberian, and rough lyme grasses. From the above details, there is no authority for recommending the rough lyme grass to the notice of the agriculturist. It flowers in the second week in July, and ripens the seed in about a month.

Elymus Philadelphicus. Philadelphian lyme grass. At the time of flowering, the green produce per acre from a clayey loam and retentive subsoil is $30,628 \mathrm{lbs}$., dry produce 15,314 lbs., nutritive matter, $2033 \mathrm{lbs}$.; so that it is a very productive grass, and contains a considerable quantity of nutritive matter. With respect to foliage, it is rather early in the spring.
ELYMLS.

From the large size it attains, the proluce is rank and proportionably coarse, and is unfit for pasture. It appears that for soiling, or hay to be used in the form of chafr, this and some other of the gigantic grasses would be profit. able plants on soils unfit for the production of the superior pasture grasses, or of corn. A comparison of the quantity of nutritive matter contained in hay of the best quality with that made from this grass, will show nearly their comparative value. One pound of hay composed of the best natural grasses contains of nutritive matter $57 \mathrm{drs}$.; one pound of hay of the E. Philadelphicus $34 \mathrm{drs}$. With regard to nutritive powers, therefore, five tons of the hay of this grass are scarcely equal to three tons of that of the superior grasses. But the soil that will produce this grass and others of the same class at the rate of six tons per acre, would not produce one-fifth the quantity of the superior grasses; consequently the adoption of the tall fescue and Philadelphian lyme grasses on soils of this description for the uses now described, might be found a profitable measure. This grass flowers in the first and second weeks of July, and successively till the end of summer. The seed ripens in about three weeks after the time of flowering.

Elymus Sibericus. Siberian lyme grass. At the time of flowering, the produce per acre from a rich sandy soil is $16,335 \mathrm{lbs}$., dry produce 5,717 lbs., nutritive matter $574 \mathrm{lbs}$. The produce of this grass is very coarse, and the weight of the crop, therefore, though considerable, is comparatively of no value. It is a native of Siberia, and withstands the effects of the severest continued frost, but not sudden changes from frost to fine weather. It requires to be sown every year, and treated as an annual. It comes into flower the second season, about the second or third week in June, and continues to emit flowering culms till autumn. A light, rich, silicious soil appears to be best adapted to its growth.

Elymus striatus. Striated lyme grass. At the time of flowering, the green produce per acre of this grass from a clayey loam is $20,418 \mathrm{lbs}$., dry produce $8,933 \mathrm{lbs}$, nutritive matter 1276 lbs. From these details, therefore, this species is inferior in nutritive powers to the Philadelphian lyme grass in the proportion of 17 to 16 It is also much later in the production of foliage in the spring, and does not come into flower till after that species has nearly perfected its seed. It cannot, therefore, be recommended for the purposes of the agriculturist Flowers about the latter end of July, and ripens the seed in August. (Hort.Gram.Wob. p. 365371.)

About eight American species of the lyme grass have been enumerated by botanists, found along streams or on the sea-shore, where, as in Europe, they often prove extremely useful in resisting the encroachment of the water.

The Virginian lyme grass is sometimes called wild rye, although its spikes, like those of the Canadian lyme grass, more resemble at a little distance the heads of barley. It is a perennial, found along the banks of the Brandywine and in other parts of the Middle States, where i attains a height of three or four feet. 
The Canadian lyme grass is also a perennial, growing to a similar height with the species just mentioned, found in similar localities, and resembling it in most other respects, except in having its flowerets and their receptacle clothed with stiffish hairs. The variety glaucifolius of Torrey is generally a taller plant, with longer spikes, the awns long and somewhat curved, and the whole plant covered with a greenish-white or silvery appearance. It is found on the Schuylkill, near Black Rock.

The villous or hairy lyme grass is a species also found on the banks of the Brandywine.

The species called Porcupine lyme grass (E. hystrix), is remarkable for its expanded, bristly spike, somewhat resembling an apothecary's bottle-washer. It is a perennial, frequently found in the southern parts of Pennsylvania and other Middle States, in rich, moist, and rocky woodlands, where it flowers in July and ripens its seed in August. (See Flor. Cestric.)

EMBANKMENT. A large mound or bank of earth, thrown up for the purpose of protecting or reclaiming lands from being injured or inundated by the water of the sea, rivers, or lakes. Mr. P. Howard narrates in the Com. to the Board of Agr. vol. vi. p. 148, the methods in use for embankments abroad.

In Yorkshire, Lincolnshire, Cambridgeshire, and other places in England, many hundred thousands of acres have been taken in by embanking. In Holland, the whole country has in a great measure been gained in this way. Ncar Chester, the River Dee Company have also reclaimed some thousands of acres from the sea, which are now divided into several beautiful farms. Mr. A. W. Maddocks, of Carnarvon, enclosed 1080 acres from the sea, by an embankment of two miles in extent. (Ibid. vol. vi. p. 159.) Lord Boringdon also reclaimed a large tract of land from the sea by embanking. (Ibid.p. 252.) Mr. D. Sheriff, of Inverness-shire, likewise describes (Ibid. vol. vii. p. 59), the plan he pursued in taking in from the sea 100 acres of valuable carse land. In the Lib. of Useful Know., "Brit. Husb." vol. i. p. 447-449, will be found some excellent observatiuns on the embankment of rivers, and the cost of an operation of the kind. In the Quart. Journ. of $A g r$. vol. viii. p. 37\%, will also be found some interesting details on the same subject.

There are many other parts of the United Kungdom in which capital might be advantageously employed for the same purpose. It is a question of even national importance, and, as in the proposed embankment of the Wash, may be carried in some districts to a much greater extent than is commonly supposed. It is an improvement which must be so much varied, according to the situation in which the farmer is placed, that it would be impossible, in this work, to go into engineering details; for, as Mr. Blackie remarks (Trans. of High. Sor. vol. ii. p. 745, ) "It would be an Herculean task to attempt to lay down rules, or give directions for raising the requisite structures in every situation. So many local impediments occur, so many unlooked-for obstacles must be surmounted, and there are always so many circumstances to be attended to and provided for, that much must ever de. pend on the ingenuity and ability of the director." See also Rev. G. Hamilton, Mr. Sidney, and Mr.Macleod. (Ibid.p.97-103); Johnstone on Draining and Embanking, and Stephens on Irrigation.

EMBROCATION (Gr. $\left.\varepsilon \vee R_{y} \varepsilon^{\prime} \chi \omega\right)$. In farriery, it is a liquid application, usually prepared of volatile and spirituous ingredients, chiefly used by friction to relieve pains, numbness, \&c.

EMOLIENTS (Lat. emolliens). In farriery, such remedies as relax and diminish the hardness and rigidity of the parts to which they are applied.

ENCHANTER'S NIGHTSHADE (Circcea). of this perennial herbaceous genus of plants there are two indigenous species, the common enchanter's nightshade (C.lutetiana), and the mountain enchanter's nightshade (C. alpina). The former grows in moist, shady places, hedgebottoms, church-yards, orchards, \&c.: the root is tenaciously creeping; the stem 18 or 20 inches high ; round and branching: the leaves, of a darkish dull green, waved, with short teeth, one rib, and many veins; the flowers are in clusters, many, small, and scentless, white or reddish, with a brownish-green calyx; the fruit is a bur, cloihed with hooked bristles. Two species of this plant are known in the United States. The one commonly found in moist, rich wood-lands in Pennsylvania and other Middle States, varies somewhat, Dr. Darlington says, from the circxa of Europe. (Flor. Cest. and Eng. Flor. vol. i. p. 15.)

ENDIVE (Cichorium endivia). This plant is too well known to require description. 'There are three varieties. The green-curled is the only one cultivated for the main crops. When the larger seedlings have been transplanted, the smaller ones which remain may be cleared of weeds, and have a gentle watering; by which treatment, in 12 or 14 days they will have attained a sufficient size to afford a second successional crop; and by a repetition of this management, in general, a third. The plants are generally fit for transplanting when of a month's growth in the seed bed; but a more certain criterion is, that when 5 or 6 inches high, they are of the most favourable size. They must be set in rows 12 or 15 inches apart each way; the Batavian requires the greatest space. Some gardeners recommend them to be set in trenches or drills, 3 or 4 inches deep; this mode is not detrimental in summer and dry weather; but in winter, when every precaution is to be adopted for the prevention of decay, it is always injurious. About three months elapse between the time of sowing and the fitness of the plants for blanching. This operation, if conducted properly, will be completed in from ten to fourteen days in sum. mer or in three or four weeks in winter. In hot weather, the blanching is completed in half the time that is required if the season is cold. To blanch the plants, it is the most common practice to tie the leaves together; to place tiles or pieces of board upon them; or to cover them with garden pots; whilst some recommend the leaves to be tied together, and then to be covered up to their tips with mould, making it rise to an apex, so as to throw off 


\section{ENGRAFTING.}

excessive rains. All these methods succeed in dry seasons, but in wet ones the plants treated according to any of these plans are very apt to decay. 'The one which succeeds best in all seasons, is to fold the leaves round the heart as much as possible in their natural position, and being tied together with a shred of bass mat, covered up entirely with coal ashes in the form of a cone, the surface being rendered firm and smooth with the trowel. Sand will do; but ashes are equally unretentive of moisture, whilst they are much superior in absorbing heat, which is so beneficial in the hastening of the process. If the simple mode of drawing the leaves together is adopted to effect this etiolation, they must be tied very close; and in a week after the first tying, a second ligature must be passed round the middle of the plant, to prevent the heart-leaves bursting out. A dry afternoon, when the plants are entirely free from moisture, should be selected, whichever mode is adopted for this concluding operation. For the production of seed, the finest and soundest plants should be selected of the last plantation, and which must agree with the characteristics of the respective varieties. For a small family, three or four plants of each variety will produce sufficient. These should be taken in March, and planted beneath a south fence, about a foot from it, and 18 inches apart. As the flower-stems advance, they should be fastened to stakes; or if they are placed beneath palings, the supporting string can be nailed to them. They must be kept clear of weeds. In July the seed will begin to ripen; and here it must be observed, that each lateral branch is to be gathered as the seed upon it ripens; for if none are gathered until the whole plant is changing colour, the first ripened and best seed will have scattered and be lost, so wide is the difference of time between the several branches of the same plant ripening their seed. Each branch must be laid, as it is cut, upon a cloth in the sun, and when perfectly dry, the seed beaten out, cleansed, and stored. Endive seed will vegetate after being kept five or six years.

\section{ENGRAFTING. See Graftivg.}

ENTOMOLOGY. A term signifying the knowledge of insects. The importance of such knowledge to those interested in agriculture or rural affairs, must be obvious to every one who refiects upon the advantages derived from the useful labours of some insects, and the devastations committed by others. The first step in proof of the utility of this science, might be to show that insects do a great deal of harm. Besides wire-worms and other insects which eat the seed in the ground, and weevils which destroy the contents of the granaries, flies torment the domestic animal whilst alive and blow their flesh when dead. Caterpillars eat cabbages, and moths riddle holes in cloth. Clover-seed is destroyed by a small weevil (Apion flavi-femoratum); Dutch clover by the Apion flavipes; peas in the pod by the small beetle (Bruchus granarius). The turnipfly is properly a beetle-a little jumping beetle (Haltica nemorum).

The problem of course is, how to destrcy this legion of enemies. Now to do this with the greatest effect, we must watch then thastrigh: all their changes. There may probably be many persons ignorant that most insects pass through four stages of existence (of which the silkworm affords a familiar instance):-1. The egg; 2. The caterpillar; 3. The chrysalis; and, 4. 'The butterfly or imago. It is in the second stage that insects generally do the most mischief. In the egg and the chrysalis they do none; and in the imago, some do and some do not. Though we are all familiar with the insect in the shape in which its ravages compel our attention, we are frequently unconscious of its identity under other shapes. We look on the cockchaffer, without suspecting that its issue is the grub which eats the roots of the grass. But however desirable a knowledge of entomology may be, no single individual could acquire it all for himself. He would need the eyes of Argus, the patience of Job, and the years of Methuselah. The diligence and sagacity of men who have passed their lives in this study have at length accumulated a body of facts of the highest value; being printed, they have become the property of everybody who will take the trouble to read them; and thus a school-boy may learn in a few months facts which the labours of his whole life might have been vainly exerted in seeking.

Messrs. Kirby and Spence in Europe, and Dr. Harris in America, are the great authorities upon this subject, and from their books most of the facts stated in this encyclopædia have been taken. They themselves suggest a similar application to practice of the truths of their favourite science. "With respect to noxious caterpillars in general," say they, "farmers and gardeners are not us dally aware that the best mode of preventing their attacks is to destroy the female fly before she has laid her eggs; to do which, the moth proceeding from each must be first ascertained; but if their research were carried still farther, so as to enable them to distinguish the pupa, and discover its haunts (and it would not be diffcult to detect that of the greatest pest of our gardens, the cabbage butterfly), the work might be still more effectually accomplisher.."

The process of destroying noxious insects by attacking them in their early stages is not new. P. Musgrave collected the chrysalids in the spring, so as to become acquainted with them, and then employed people to catch and kill the moths and butterflies. If you catch 200 in a day, you destroy 10,000 eggs, which would give 120,000 in a fortnight. Might not boys and girls be well employed in doing this? They have all the organ of destructiveness.

In short, it is abundantly evident, that if we knew them in all their changes, and know where they are concealed in autumn, winter, and spring, we might exterminate those multitudes which are now as the sands which are upon the sea-shore. And if not all the know ledge required be yet in our possession, a greal deal is, and might be easily imparted to the young farmer, if we could catch him in his chrysalis state; and what little is still wanting would soon be accumulated when we had se! so many keen and interested eyes to obser" 
a fly could scarcely move but they would be watching him. (Farmer's Register.)

EPIDEMIC (Gr. ṡi and dŕuss; Fr. epidémique). In farriery, a term applied to such fevers, or other distempers of cattle, as attack great numbers at certain seasons, or any time, if many suffer in the same manner. The term is frequently confounded with infectious, which is perfectly distinct, and implies a disease communicated, not from the atmosphere, but from one individual to another. Horses are liable to epidemic fevers, and to several distempers of that kind, such as the epidemical catarrh or influenza, strangles, staggers, \&c.

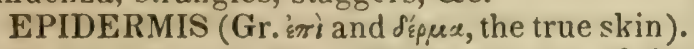
In botany, the exterior cellular coating of the bark, leaf, or stem of plants and trees. It is composed of cells compacted together into a stratum, varying in thickness in different species, and is often readily separable by gentle violence. It is believed to be intended by nature as a protection of the subjacent parts from the drying effects of the atmosphere. (Brande's Dict. of Science.)

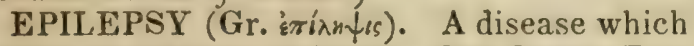
occurs in various animals. See Sheer, DisEASES OF.

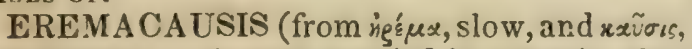
combustion). A term applied in organic chemistry to denote one of the changes which vegetable and other organic matters undergo after death.

The conversion of wood into humus, the formation of acetic acid out of alcohol, nitrification, and numerous other processes, are of this nature. Vegetable juices of every kind, parts of animal and vegetable substances, moist sawdust, blood, \&c., cannot be exposed to the air, without suffering immediately a progressive change of colour and properties, during which oxygen is absorbed. 'These changes do not take place when water is excluded, or when the substances are exposed to the temperature of $32^{\circ}$; and different bodies require different degrees of heat, in order to effect the absorption of oxygen, and, consequently, their eremacausis. The property of suffering this change is possessed in the highest degree by substances which contain nitrogen.

The decay of woody fibre (the principal constituent in all plants) is accompanied by a phenomenon of a peculiar kind. This substance, in contact with air or oxygen gas, converts the latter into an equal volume of carbonic acid, and its decay ceases upon the disappearance of the oxygen. If the carbonic acid is removed, and oxygen replaced, its decay recommences, that is, it again converts oxygen into carbonic acid. Woody fibre consists of carbon and the elements of water; and if we judge only from the products formed during its decomposition, and from those formed by pure charcoal, burned at a high temperature, we might conclude that the causes were the same in both: the decay of woody fibre proceeds, therefore, as if no hydrogen or oxygen entered into its composition.

In the Appendix to the Third Report of the Agriculture of Massachusetts, 1840, Dr. S. I. Dana adduces the following example, to show that pven a moist plant will not decay, if air is ex446 cluded. A piece of a white birch tres was taken from a depth of twenty-five feet lelow the surface, in Lowell. "It must have been inhumed there probably before the creation of man, yet this most perishable of all wood is nearly as sound as if cut from the forest last fall."

A very long time is required for the comple. tion of this process of combustion, and the pre. sence of water is necessary for its maintenance: alkalies promote it, but acids retard it; all antiseptic substances, such as sulphurous acid, the mercurial salts, empyreumatic oils, \&c., cause its complete cessation.

Woody fibre, in a state of decay, is the substance called humus.

The property of woody fibre to convert surrounding oxygen gas into carbonic acid diminishes in proportion as its decay advances, and at last a certain quantity of a brown coalylooking substance remains, in which this property is entirely wanting. This substance is called mould; it is the product of the complete decay of woody fibre. Mould constitutes the principal part of all the strata of brown coal and peat. (Liebig's Organic Chemistry.)

The eremacausis or putrefaction of substances containing nitrogen, is the process technically called nitrification.

ERGOT (Spermodia clavus). A parasitic fungus, which most frequently appears upon the ears of rye, but sometimes upon other plants of the gramineous order. It most commonly appears in hot, damp summers. It is known to be present by the change which the affected grains assume; but these seldom exceed five or six in an ear. The grain lengthens to more than double its natural size, becomes angled, of a deep purplish-brown colour, and curved at its apex, where the ergot is seated. 'The surface, when viewed through a magnifying glass, appears studded with transparent, shining, white, angular dots; and when sliced and viewed in water under the microscope, it is seen to consist of white, flocculent threads, bearing globular sporules. The ergotted crrains have a heavy, unpleasant odour, and an acrid, nauseous taste, leaving a slight sensation of heat in the palate. Ergotted rye is poisonous both to man and other animals. When, in bad seasons, it has prevailed, and has been ground into flour with the rye, and baked in bread, it has caused many fatal depopulating epidemics in the north of Europe. On quadrupeds its use is followed by emaciation, palsy of the hindlegs, and extreme debility; mules in South America lose their hoofs and hair when fed on ergotted maize; and hens who have ergotted rye mixed with their food, lay eggs without shells, owing to its excitement of the oviduct. It is employed as a medicine in difficult parturition, but it ought not to be administered without the greatest caution and discretion. (Edin. Med. and Surg. Journ. vol. liii.) See Mrrovw.

ERICA VULGARIS. The common heath, ling, or heather. See Hiатн.

ERIOPHORUM. The genus of cotton grasses, which see.

ERYNGO (Eryngium). A genus of planis consisting of eleven species, two of which are perennials, natires of England, viz., 1. The sea 


\section{ESCULENT.}

holly, or sea eryngo (E. maritimum), which grows on the sandy sea-shore, where it strikes its long creeping roots eighteen or twenty feet deep into the soil; the radical leaves are more or less sheathing, stiff, spinous, three-lobed; it blows a bright blue flower in July or August. Stem a foot high; root whitish, of a pungent aromatic flavour, with a mixture of mucilage; herb smooth, glaucous, with an elegant blue tint. The roots, reckoned stimulating and restorative, are either sold candied or administered in decoctions variously prepared.

2. The field eryngo ( $E$. campesire) grows on waste ground chiefly near the sea, and is not so common as the last. It is more bushy and slender, and of a paler glaucous green than the foregoing; radical leaves larger; flowers white or purplish. The leaves of both are somewhat sweet, and of a pungent flavour.

Mr. Nuttall notices five species of the eryngo or sea-holly, as found in the United States: 1. E. Virginianum; 2. E. virgatum; 3. E. fetidum; 4. E. aquaticum. His general description of the foregoing is,-Stem rather low; leaves sword-shaped, distinctly margined with setose spines; setæ frequently in pairs, \&c.; flowers greenish-white. 5. E. gracile, without spines. This last was found in Florida by Dr. Baldwyn. Many other species are submarine; some exist in inland depressions, and a considerable number grow in arid wastes. (Nuttall's Genera.)

ESCULEN'T (Lat. esculentus). A term applied to edible roots and plants, as carrots, turnips, cabbages, \&c.

ESPALIERS (Fr. espalier), in horticulture, are trees trained by lattice-work or other supports on the borders of beds, or as hedges to enclose plots of ground. They may serve to defend in a great measure many tender plants from the inclemencies of wind and weather. The trees chiefly planted for espaliers are apples, pears, and plums. The principal objects aimed at, however, in espaliers, are to expose the foliage ard fruit of the plants or trees more perfectly to the light and sun, to prevent the branches from being blown about by the winds, and to economize space by confining them within definite limits. (Loudon's Sub. Gard. p. 232.)

ESPARCET. A local name for Sainfoin, which see.

ESTA'TE (Fr.estat), in common parlance, is applied to the landed property held by individuals; and a man is said to be of good or of small estate, according to the magnitude of his landed property. Estates vary exceedingly in size and value, in most parts of England. The largest estate in the kingdom may be worth $100,000 l$., or upwards, a year; and there are estates of most inferior degrees of magnitude, down to the annual value of $40 \mathrm{~s}$. In some ccunties the property is more, and in others it is less subdivided.

EUDIOMETER. The name of any apparatus or contrivance by which the purity of the air can be tested. It implies a measure of purity, and is chiefly employed to determine the proportion of oxygen which the air may contain.

EVAPORATION is the process by which substances in the fluid or other form are con. -erterl intr vapour and steam. Ice, camphor, carbonate of ammonia, and many noliee so. lids evaporate readily in the open air. The evaporation of water is, however, the most in. teresting consideration in its relations to arri. culture, as will be more particularly shown when treating of the evaporating qualities of soils, \&c.

Water, when expanded into vapour, is himhly elastic, and spreads itself by a force of $i t s$ own. The amount of vapour existing at any time in a given place is determined by the degree of heat present. According, therefore, to the temperature of the water from which the vapour emanates, will be the elastic force and density of the vapour, provided the process be carried on in an open vessel.

The pressure of the air and of other vapours upon the surface of water in an open vessel, does not prevent evaporation of the liquid; it merely retards its progress. Experience shows that the space filled with an elastic fluid, as air or other gaseous body, is capable of receiving as much aqueous vapour as if it were vacuous, only the repletion of that space with the vapour proceeds more slowly in the former predicament than in the latter, but in both cases it arrives eventually at the same pitch. Dr.Dalton has very ingeniously proved, that the particles of aeriform bodies present no permanent obstacle to the introduction of a gaseous atmosphere of another kind among them, but merely obstruct its diffusion momentarily, as if by a species of friction. Hence, exhalation at atmospheric temperatures is promoted by the mechanical diffusion of the vapours through the air with ventilating fans or chimney draughts; though, under brisk ebullition, the force of the steam readily overcomes that mechanical obstruction.

The atmosphere has seldom as much watery vapour as it is capable of holding, and therefore the process of evaporation is almost al ways going on wherever there is a source of moisture present. Under certain circumstances, however, evaporation is checked and even suspended. Suppose the temperature of the water to be midway between freezing and boiling, viz., $122^{\circ}$ Fahrenheit; also, that the air in contact with it be of the same temperature, but filled with moisture, so that its interstitial spaces are full of vapour of corresponding elasticity with that given off by the water; it is certain that, under such circumstances, no fresh formation of vapour could take place. The air would then be said to be saturated, as it is at times when clothes hung out at common temperatures remain without drying, and the grass, leaves, and grain remain soaked in moisture. But the moment a portion of vapour escapes, or is drawn off by condensation into. dew, cloud, rain, \&c., an equivalent portion of vapour will immediately be enabled to rise. and the process of exhalation or evaporation recommences. The water exhaled at low temperatures, that is to say, below the boiling point, is commonly called vapour. When the tem perature of fresh water in an open vessel, at or near the common level of the sea or tide-water. rises to $212^{\circ}$ Fahrenheit, the water begins 11, boil and evaporate with exceeding rapidity, producing what is commonliv romed stcam 
In such case the evaporation takes place, not only from the surface, but from every point in the interior of the vessel. This indicates that the evaporating force of the water gained from the increase of heat has become greater than the pressure of the atmosphere, which is sufficient to sustain a column of mercury thirty inches high in the barometer. If the pressure of the atmosphere be removed by the air-pump, the turbulent evaporation or boiling of water will take place at a much lower temperature than $212^{\circ}$, even down to the freezing point. But under the common pressure of the atmosphere, and below the temperature at which water boils, evaporation goes on quietly and slowly. In deep mines, which descend below the level of the sea, water requires a greater heat than $212^{\circ}$ to make it boil. But on high mountains, or districts rising far above the level of the sea, the pressure of the air is lessened, and boiling takes place, as in the airpump, at lower degrees.

The vapours exhaled from a liquid at any temperature contain more heat than the fluid from which they sprung; and they cease to form whenever the supply of heat into the liquid is stopped. Nevertheless, a thermomerer held in the steam proceeding from hot water rises no higher than when placed in the water itself. The additional heat, therefore, contained by the vapour, is in a latent or concealed state, and does not become sensible to the thermometer until the vapour condenses. Any quantity of water requires, for its conversion into vapour or steam, five and a half times as much heat as is sufficient to heat it from the freezing point of $32^{\circ}$ to the boiling point of $212^{\circ}$. The quantity of heat absorbed by one volume of water in its conversion into steam, is about $1000^{\circ}$ Fahrenheit; it would be adequate to heat 1000 volumes of water one degree of this same scale; or to raise one volume of boiling water, confined in a non-conducting vessel, to $1180^{\circ}$. Were the vessel, charged with water so heated, spened, it would be instantaneously emptied by vaporization, since the whole caloric equivalent to its constitution as steam is present. When, upon the other hand, steam is cordensed l,y contact with cold substances, so much heat is set free as is capable of heating five and a half times its weight of water, from $32^{\circ}$ to $212^{\circ}$ Fahrenheit. If the supply of heat to a copper be uniform, five hours and a half will be required to drive off its water in steam, provided one hour was taken in heating the water from the freezing to the boiling point, under the atmospherical pressure.

It thus appears that evaporation is a cooling process, because the water is obliged to take up an additional supply of heat to expand and keep it in a state of invisible vapour. It is equally plain, that when vapour is condensed into mist, cloud, dew, rain, snow, and ice, it must give out that extra supply of heat required to convert it into vapour. Hence, in suinmer and mild weather, evaporation is a cooling process, whilst in winter the condensation of vapour and congelation of water must tend to prevent more excessive cold, by throwing out latent heat into the atmosphere. The 1000 !egrees of heat absorbed by watery vapour on 448 its expansion into vapour, must of necessity be set free on its condensation and conversion into water.

EVERLASTING-PEA, BROAD-LEAVED (Lathyms latifolius). A perennial plant of the vetch kind, which grows naturally in some places; is easily cultivated, and annually yields a great burden of excellent provender, and might be cultivated to advantage as a green food for cattle, on any of the more strong sorts of soil. See Vетсн and Vетснцivg.

EVERLASTING, PEARI, (Gmaphalium margaritaceum). One of the narnes of the American cudweed. See Cunwern.

EVERY-YEAR'S-LAND. Such lands as have been cropped with a brown and white crop, or pulse and grain in alternation, for a length of time, without any intervening fallow. There are extensive common fields in Gloucestershire and other parts of England, which have been conducted under this management for perhaps centuries past.

EXOTICS (Gr. \& dening, a name given to plants which are not natives, but have been introduced from some other country.

EX'TRAC'TS (Fr. Extraits; Ger. Extracten). The olter apothecaries used this term to designate the product of the evaporation of any vegetable juice, infusion, or decoction; whether the latter two were made with water, alcohol, or ether; whence arose the distinction of aqueous, alcoholic, and ethereous extracts.

Fourcroy made many researches upon these preparations, and supposed that they had all a common basis, which be called the extractive principle. But Chevreul and other chemists have since proved that this pretended principle is a heterogeneous and very variable compound. By the term extract, therefore, is now meant merely the whole of the soluble matters obtained from vegetables, reduced by careful evaporation to either a pasty or solid consistence. The watery extracts, which are those most commonly made, are as various as the vegetables which yield them; some containing chiefly sugar or gum in great abundance, and are therefore innocent or inert; while others contain very energetic impregnations. The conduct of the evaporating heat is the capital point in the preparation of extracts. 'They should be always prepared, if possible, from the juice of the fresh plant, by subjecting its leaves or other succulent part, to the action of a powerful screw or hydraulic press; and the evaporation should be effected by the warmth of a watei-bath, heated not beyond $100^{\circ}$ or $120^{\circ}$ Fahr. Steam heat may perhaps be applied advantageously in some cases, where it is not likely to decompose any of the principles of the plant. But by far the best process for making extracts is in vacuo, upon the principles involved in the process of evaporation.

For exceedingly delicate purposes, the concentration may be performed in the cold, by placing saucers filled with the expressed juice over a basin containing sulphuric acid, putting a glass receiver over them and exhausting its air.

EXUVIF: (Lat.). The cast-off parts or co- 


\section{EYE.}

vering of animals, and also the shells and other marine productions met with in the bowels of the earth, having been deposited there for a vast aength of time. 'The lobster casts his shell, the toad and snake shed their skin periodically, leeches and fishes seem to cast off exuvial lavers of mucus only; but in most reptiles the cpidermis is periodically moulted, either entire or in large coherent masses. The periodically moulted feathers of birds, and hairs of various species of mammalia, may also be rezarded as exuviæ. Substances of these kinds, where they can be procured in sufficient quantities, are highly valuable as manures, and capable of extensive application, especially on ail the clay soils.

EYE (Sax. ear; Ice. eiza). In the management of fruit-trees, implies the germ, small bud, or shoot inserted into a tree.

EYF-BRIGH'T (Euphrasia officinalis). An elegant plant, indigenous to England, very common in mountainous pastures and dry heaths, varying in height from one to six inches. It flowers from July to September; its stalk is square and hard; the leaves of a bright green, nat, broad, and indented at the edges. The flowers are small and white, streaked and spotted with dark colours. On the mountains of Scotland there is a more slender variety, with smaller but more richly tinted blossoms; on the Alps a dwarf, large-flowered, more purpled variety is common. It must be gathered about September, when it has done flowering. The distilled water is spoken of by the old herbalists as a fine eye-water to strengthen and improve the sight. This reputation gave it the name of eye-bright, but, like many other ancient opinions respecting the virtues of plants, the value of the reputation is worn out. The eye-bright will not grow in gardens; it loves to hide itself in grass or heath, and will not thrive unless it be surrounded by plants that are taller than itself. It is eaten by cattle and sheep, but refused by hogs. (Eng. Flora, vol. iii. p. 122.)

'Two herbs are known in the United States by this popular name. One is the Hypericumleaved Euphorbia (Euphorbia hypericifolia), a milky annual plant common in pastures and on road-sides. The juice applied to the eye causes severe smarting. The severe salivation to which grazing horses are subject is said to be caused by their eating this species of Euphorbia.

The other plant also sometimes called eyebright, is the Indian tobacco, or Lobelia inflata, a biennial found abundantly in pastures, or roadsides, \&c., flowering in July and August, and ripening its seeds in August and October. This plant is possessed of highly acrimonious properties, and is an active emetic, cathartic, and narcotic. 'These properties render it capable of doing much harm or good according to the judgment and discrimination with which it is employed in different diseases and the proper stages. Without such attention, and in the hands of ignorant professed quacks and rash pretenders, the indiscriminate use of this potent herb has been fraught with serious injury to the constitution, and not unfrequently with death more or less speedy.
FAIR.

EYE OF THE IORSE. The eye of the horse appears to be naturally more disponed to disease than that of any other animal. It diseases of the eye, although few in number. are frequent in their appearance, obstinate. and generally baffie all the skill of the veterinarian. The following are the principal: common inflammation, specific ophthalmia or moon blindness, cataract, and gullo, serena or amaurosis. For the last there is no cure.-Monn blindness, as it is termed, is brought on in a great measure by close confinement in dark, heated, and un wholesome stables. No specific remedies can be given for these diseases. (The Horse, p. 113 ; Lib. Use. Know.) See Bunnugsa and Cataract.

\section{F.}

FACTOR (Lat. factor; Fr. facteur). In mercantile law, an agent who is intrusted with the property of others, which he is commissioned to dispose of. In Scotland the word factor is used synonymously with steward in England, signifying one who has the overlooking or management of an estate or a farm for another person.

FAGOT (Welsh fagnd; Fr. fagot). A bundle of small cut wood tied together closely for fuel or other purposes. They are made up from the cuttings or thinnings of coppices or hedges; and, in many districts, are sold to the bakers.

FAIR (Old Fr. fiere; Lat. ferice or forum). A public place where merchants, traders, and other persons assemble from remote parts on some fixed day in the year to buy and sell commodities, and to partake of the diversions usually to be met with on such occasions. See MaRKET. Fairs and markets are very closely allied. A fair, as the term is now generally understood, is only a greater species of market recurring at more distant intervals. Both are appropriated to the sale of one or more kinds of goods, the hiring of servants or labourers, \&c.; but fairs are in most cases attended by a greater concourse of people, for whose amusement various exhibitions are got up.

Fairs originated in England in monkish days, when proud bishops and mitred abbuts were not unwilling to increase their revenues by the tolls which they were empowered by royal charter to levy on the crowds who commonly attended the festivals of their patron saints. Spreading rumours with an intent to increase the price at fairs or markets is in England an offence at common law. (Rex v. Waddington, 1 East, 143.)

Various statutes have been passed to regum late fairs.-By the 2 \& 3 P. and M. c. 7 , the owner or keeper of every fair must appoint a certain open place for the sale of horses, and must, under a penalty of 40 shillings, appoint some one to attend to take toll, from $10 \mathrm{~A} . \mathrm{M}$. till sunset ; must keep a book, and enter therein the marks, price, colour, \&c... Hler's and buyer's name and residence, or forfeit $\$ 0$ shillings.-By the 31 Eliz. c. 12, if the parties are strangers to the book-keeper, they must procure a person to vouch for them; his fce fo:

$$
2 \text { P } 2 \quad 419
$$


entering in the book, where there is no toll is
one penny, for giving a certificate two-pence.

A list of the fairs and markets of the United Kingdom will be found in several almanacs, particularly that entitled The Farmer's Almanac, by Johnson and Shaw. (M'Culloch's Com. Dict. \&.c.)

FAIRY RINGS. Whoever has passed over our down lands in search of the vegetable Ireasures of creation, or in pursuit of the rational employments of a country life, cannot fail to have noticed, says the Rev. G. Smith, the circles of verdant grass, and correspondent circles of fungi, most abundant upon turfy hills, and known under the name of fairy rings. The various superstitions and poetical fancies connected with these phenomena need not be detailed. These circles have been accounted for by various theories, of which no one, however, is alone sufficient to embrace all the facts. The recent discovery of the habitual rejection by the roots of any substance injurious to the growth of vegetables, has made it evident in what manner a race of plants may occupy one spot, until they can no longer exist on it, in consequence of the excretions their roots have deposited, rendering the land altogether destructive to them; while, on the other hand, the change thus effected in the soil may render it more nutritious and desirable for some other race of plants, than before any such change had taken place. This theory, based upon a series of familiar facts, explains the necessity for a rotation of crops. The fungi, it is ascertained, soon render the land on which they grow unfit to support themselves; but they enrich the soil for other plants, especially for the grasses, which grow up in rank luxuriance in the space left bare by the extinction of the fungi. The circumstance of the plants taking a circular form, may perhaps arise from a single fungus first throwing its seed all around it, and as a single crop of fungi is sufficient to exhaust the soil, the grass springs up in the space it has occupied, and the second year's crop of fungi appears in a small ring round the original centre. The rings go on extending in circumference year after year, until something occurs in the soil or its products to check their progress, or the species wears out or becomes dormant for a season. A similar mode of growth takes place in some of the crustaceous lichens. The rings have been observed to be frequent on hill-sides, and then almost always with the lower part of the circle open. They sometimes contain a small circle within the larger one, but not always in the centre. Within such circle the herbage is very luxuriant and rank, consisting of the Anthoxanthum odoratum, and the common daisy; without the circle there is not any very apparent change in the vegetation; but on the circumference, Thymus serpyllum, T. monotropa, Carex recurva, and Hieracium pilosella, have all been observed. ('The Wild Garland, by s. Warirg.)

FALLOW. Such land as has been repeatedly ploughed over, and exposed to the infuence of the atmosphere, for the purpose , f rendering it friable, clearing it from weeds; seaving it to rest after the tillage before it is again sown.
Fallows have different names given to them, and are of different kinds, according to the purposes for which they are intended, and the manner in which they are made. Thas, a naked fallow is that in which the ground is ploughed and harrowed at suitable intervals for several successive times, accurding to the kind of crop that is ultimately to be grown, but without being sown till it has remained in fallow for some length of time. A green fallow is that where the land has been rendered mel. low and clear from weeds by means of some kind of green crop, such as turnips, peas, tares, potatoes, \&c. In this mode of fallowing, no time is lost by the land being left idle, or in an unproductive state. Fallows are also some. times distinguished by the season of the year in which the business is chiefly or wholly performed, hence we have summer and winter fallows; and likewise from their being in some cases only done in a partial manner, we have bustard fallows. Fallows are also named after particular crops, as wheat, turnip, and potato fallows.

"The chemical theory of fallowing," observes Sir H. Davy (Elem. of $A g r$. Chem. p. 23), " is very simple; fallowing affords no new source of riches to the soil, it merely tends to produce an accumulation of decumposing matter, which, in the common course of crops, would be employed as it is formed; and it is scarcely possible to imagine a single instance of a cultivated soil, which can be supposed te remain fallow for a year with advantage to the farmer; the only case where this practice is beneficial seems to be in the destruction of weeds, and for cleansing foul soils." It has been indeed recently contended by Iiebig in his Organic Chemistry, that during a fallow, a quantity of ammonia is collected from the atmosphere, potash disengaged from its combinations, and other chemical effects produced, which it is hardly necessary to examine at much length. He says (Organic Chem.p. 156), "The fallow time is that period of culture, during which land is exposed to a progressive disintegration by means of the influence of the atmosphere, for the purpose of rendering a certain quantity of alkalies capable of being appropriated by plants. Now it is evident, that the careful tilling of fallow land must increase and accelerate this disintegration. For the purpose of agriculture, it is quite indifferrent whether the land is covered with weeds, or with a plant which does not abstract the potash enclosed in it. Now many planis of the family of the Leguminosa are remarkable on account of the small quantity of allalies or salts in general which they contain; the Vicia faba, for example, contains no free alkalies, and not one per cent. of the phosphates of lime and magnesia. The bean of the Phaseolus vulgaris contains only traces of salts. The stem of the Medicago sativa contains only 0.83 per cent., that of the Ervam lens only 0.57 per cent. of phosphate of lime, with albumen. Buckwheat dried in the sun yields only $0 \cdot 681$ per cent. of ashes, of which 0.09 parts are soluble salts. These plants belong to those which are termed fallow crops, and the cause why they do not exercise any injurious in- 
Quence on corn which is cultivated immediately after them is, that they do not extract the alkalies of the soil, and only a very small quantity of phosphates."

FAN, FANNER. See Winnowing Machine.

FAR (Sax. feon). In horsemanship, a term used to denote a horse's right side; thus the far foot, far shoulder, \&c. is the right foot, right shoulder, \&c.

FARCY. In farriery, a disease of the absorbents affecting the skin and its blood-vessels, by which, when inveterate, their coats inflame and are so thickened that they become like so many cords. Farcy is intimately connected with glanders, and they will frequently run into each other. The treatment varies with the form it assumes. In the button, or bud farcy, in which indolent boils appear, a mild dose of physic should be first administered. The buds should then be carefully examined, and, if any of them have broken, the budding iron, of a dull red heat, should be applied to them, and the buds all opened as soon as they appear to contain matter, and afterwards washed with a lotion composed of a drachm of corrosive sublimate, dissolved in an ounce of rectified spirit. Daily exercise and green food are also essential to the animal's recovery.

FARCY, WATER. See Dropsx.

FARDING-BAG. The first stomach of a cow, or any other ruminant animal. It is a mere receptacie for receiving and retaining the green food, until the animal has time to repose and chew the cud.

FARINA (Lat. far, corn, of which it is made). Meal or flour obtained by grinding and sifting wheat and other seeds, or by pulverizing and preparing edible roots, \&c.; hence the term farinaceous food.

FARM. A portion of ground cultivated for the purpose of profit. There are different kinds of farms. Where the principal part of the land is under the plough, they are termed arable farms; but where the fattening of cattle or other live-stock is more immediately the object, they are distinguished by the title of grazing farms; where the chief intention is the obtaining different animal products, such as milk, butter, and cheese, they are denominated dairy farms; and where the two systems of arable and grass management can be combined, they are called convertible farms. As manure must be had in order to render farms of any kind productive, the last may probably, in general, be considered as the most advantageous. Besides these, in districts where hay is the principal produce, there are hay or grass farms, and there are also what are denominated breeding or cattle farms.

The old writers on husbandry, who lived in warm countries, where the heat and moisture of the air had sensible and frequently very dangerous effects on the health of the inhabitants, were very particular in their directions for the choice of farms or estates, and of the spots whereon houses should be built, so as to avoid the inconveniences arising from the climate, or from the quality or situation of the ground. The Romans had generally pleasure as well as profit in view, when they bought and stocked a farm; and therefore they laid it down as a rule, that no degree of fertility should tempt a man to purchase in an unhealthy country, nor the pleasantest situations in a barren one. "Buy not too hastily," said Caw, "but view again and again the purchase you intend to make; for, if it be a good one, the oftener you see it the better it will please you. Examine how the neighbouring inhabitaro's fare. I.et the country it lies in be a good one; the ways to and from it good; and the air temperate. Let your land, if you can choose your situation, be at the foot of a hill, facing the south, in a heaithy $r$ lace where a sufficiency of labourers, of cattle, and of water may be had. Iset it be near a flourishing town, the sea, or a navigable river; or bordering upon a good and well-frequented road. Let the build. ings upon your ground be strong and substantial. Do not rashly condemn the methods of others. It is best to purchase from a good husbandman and a good improver."

Besides the healthfulness of the situation, three other things should be particularly attended to in the choice of a farm or estate; these are, the air, the water, and the soil. The air should be pure and temperate, the water wholesome and easily come at, and the soil fertile; and the farm should be at a reasonable distance from good markets, both for the sale of the produce and the purchase of manure. See Farm Bulldings.

The ancients were particularly attentive to the quality of their water, and to the ease of coming at it. 'They advised bringing into the farm-houses the water of such springs as never dried up; or, if there was no such spring within the farm, to bring running water as near to it as possible; or to dig for well-water, not of a bitter or brackish taste. If neither of these was to be found, they directed large cisterns to be provided for men, and ponds for collecting and retaining rain-water for cattle. They esteemed that running water to be best for drinking which had its source in a hill; spring or well-water from a rising ground was deemed the next best; well-water in the bottom of a valley was held to be suspicious; and marshy or fenny water, which creeps slowly on, was by them rightly regarded as the worst of all.

The nature of the soil of a farm may be ascertained either by analysis (see Arıtrsis), by observation of the weeds which flourish upon it (see Botany and Wents), and of the trees growing in the hedge rows (see Pravt. Tross). In England the elm and the oak are commonly tenants of good soils; the birch, the holly, and the ash indicate those which are poor. And again, the productiveness of a soil may be estimated from the degree of its attraction for the insensible moisture of the atmosphere; by the substratum on which it rests (see Grolog $\mathbf{\text { ) }}$; and by its inclination. There are many other circumstances, also, which the farmer in search of a farm should regard, most of which he will find treated of in this work under the heads Appraiseyraxt, Agrakment, Customs of Counties, Capital required, Rax, LEAsF, \&c. Let him also closely examine the state of the buildings, the mode in which the farm has been cultivated, and the 
course of cropping which the out-gong tenant has followed. This last inquiry is one very material point to be carefully and accurately ascertained.

The number of farms in the United Kingdom is estimated to be about 2,000,000, and the property annually derived from agriculture at 215,817,624l.

There are in-

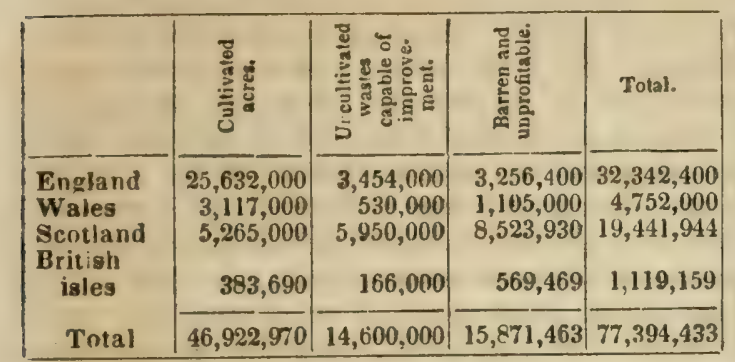

In England and $W$ ales it is calculated that there are

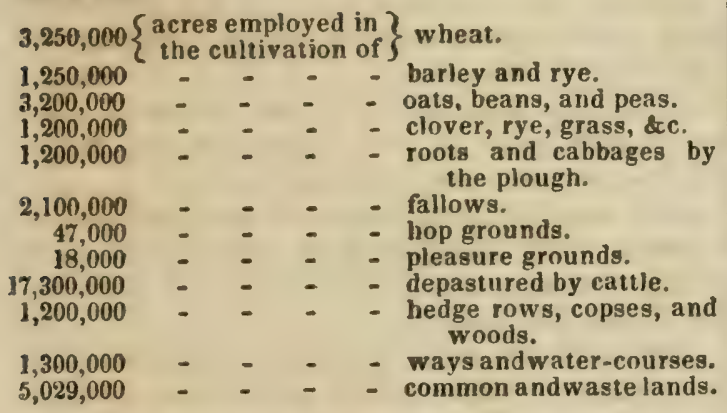

FARM ACCOUNTS. The necessity and utility of correct and detailed particulars of all matters concerning the farm, have already been spoken of under the head Book-K EEPING. Let any farmer make the experiment, and he will find it both interesting and useful, to know from year to year the actual products of his farm. Let every thing, therefore, which can be measured and weighed, be so tested; and let that which cannot be brought to an exact standard he estimated, as if he himself were about to sell or to purchase it. Let him likewise, as near as possible, measure the ground which he plants, the quantity of seed which he uses, and the manure which he applies. The labour of doing this is nothing compared with the satisfaction of having done it, and the benefits which must arrive from it. Conjecture, in these cases, is perfectly wild and uncertain-varying often, with different individuals, almost 100 per cent. Exactness enables a man to form conclusions which may most essentially, and in innumerable ways, avail to his advantage. It is that alone which can give any value to his expe:ience; it is that which will make his experience the sure basis of improvement; it will put it in his power to give safe counsel to his friends; and it is the only ground on which he can securely place zonfidence in himself.

FARM BUILDINGS. In the construction of farm buildings, the first thing to be regarded is the convenience of their situation; and to this end must be considered the best shelter, feeding and watering of live-stock; the carriage of the crop, and of manure, and the preservation of the produce. To combine all these advan452 tages together is rarely attainable; the olject with the practical farmer is to obtain as many of them as possible. The improved economical construction of farm buildings some years since engaged the attention of the Highland Society in Scotland, and from their report (Trans. vol. ii. p. 365), the reader who wishes for working plans will derive abundant information. The committee say, very justly, "one of the most common errors in these designs is the crowding the buildings together, under the idea of giving them greater compactness, and the not sufficiently extending the shelter sheds for the feeding of cattle. This is a fault so universal that it is only on the larger class of breeding and feeding farms in the border counties of England and Scotland that experience has taught builders fully to avoid it. In giving designs of the outhouses of a farm, little more can be done than to give general useful examples. Although a certain similarity must exist in the form and arrangement of the parts of all such buildings, yet these must be modi. fied according to the circumstances of the farm itself, the nature of the soil, the situation with regard to markets, and the particular kind of management to be pursued. No one rule that can be given is of general application, and the judgment of the architect must be shown, in adapting the size, form, and arrangements of the buildings to the nature of the farm, and the wants of the occupier. While every suitable accommodation should be afforded to the tenant, it is the province of the architect to take care that the heavy cost of such buildings be not unnecessarily enhanced, either by erecting buildings that are useless, or by giving unnecessary dimensions to such as are requisite. It may be particularly remarked that the giving unnecessary breadth to the buildings adds materially to the expense, by increasing the dimensions of the timbers, and adding to the size of the roofs. At the same time care must be taken that in the cow-houses and stables the animals shall not be cramped from the want of necessary room. In general, it may be said that the most convenient arrangement of the outhouses of a farm is in the form of a rectangle, the side to the south being open, and the farm-house being placed at some convenient distance in front of it. And again, the most approved mode of keeping and feeding the larger and finer kinds of cattle is in small sheds with open yards attached, each capable of holding two animals. It is recommended that the water-course from the stables, cowhouses, and yards should be carried off by causewayed open channels to a pond or tank near to the buildings. This mode of conveying away and receiving the urine is conceived to be better in ordinary cases than sewers below ground, which, even when executed in the best manner, will be subject to be cholsed up from want of necessary attention to cleaning; and such sewers become nurseries for rats, notwithsianding every precaution that can be taken. Should the situation of the buildings incline to the north, conduits can be made through the north range below the floors, as proper places, for discharging the liquids.

"For watering cattle, if a stream cannot be 
obtained, there are few situations where water cannot be got by sinking a well; the best way is to raise it into a cistern, which may be placed in any of the shelter yards, and from this be conveyed by pipes to the different yards, furnished with proper cisterns and ball-cocks. The passages and entrances to the buildings should be wide; the gates hung on wooden posts or hewn stone pillars.

FARMER (Sax. feopmen, Fr. fermier). A person whose business or employment is the cultivation of land, the breeding, rearing, and feeding of different sorts of live-stock, and the management of the various products which are afforded by them; hence those engaged in this way may be further distinguished into arable, grazing, dairy, hay, and other kinds of farmers, according to the modes in which their farms are cultivated or employed.

The farmers of Great Britain, who are generally men of superior intelligence to those of Flanders or other parts of Europe, may be arranged into the following classes: 1 . The great proprietors and country gentlemen. 2. Yeomen and farmers, properly so called. 3. Possessors of small farms. 4. Cottagers, including different descriptions of people, who cultivate small farms, and a few acres adjoining to cowns and villages.

FARM-HOUSE. The dwelling occupied by a farmer. The principal objects to be attended to in erecting a farm-house are, convenience and a salubrious situation. Besides the general salubrity of the spot where dwellings are tu be erected, the air, water, and soil also require to be particularly attended to: the first should be pure and temperate; the second wholesome and easily obtained. The most healthy and convenient site on the farm ought to be selected for building the house; easy access and central situation being taken into consideration. An abundant supply of water for domestic purposes, and for live-stock, is indispensable. The water, however, should not be stagnant. Ponds in the immediate vicinity of a house are not essentially injurious, unless they beeome dry in summer, or towards ausumn; for at the period between the drying up and the complete dryness of ponds, or stagnant pools, the decomposition of animal and vegetable matter which is then proceeding evolves miasmata that generate disease. A dry gravelly soil, through which the rain can freely percolate, is to be preferred. The degree of dampness of a locality may be always pretty correctly estimated by observing the quantity of moss and lichens upon the trees; and the weeds being those that grow in marshy situacions.

FARMING. The business or management of a farm, comprehending the whole circumstanees and conduet of it.

It is a practice that demands constant care and attention, as well as much activity and judgment, to conduct it in a proper and advantageous manner. It requires an intimate and practical knowledge of all the arts of cultivarion and management, as well as of the nature and value of every kind of live-stock; and ctill further, a perfect acquaintance with the arious modes of buying and selling, and the constant state of different markets and fairs. In addition to all these, there are severisl uther minutiæ of much consequence to the success of the farmer, which will be treated of under their respective heads.

Farming, once regarded as a profession easy to be understood and successfully followed only by the empiric, has long since been viewed in a different, in a wiser manner. It has been justly said that no pursuit requires more talent, perseverance, and more careful observation, than the cultivation of the earth; that so far from its being an empirical business, it is, in fact, one that several other sciences illustrate and assist-one, whose professors cannot too often examine the practice of other cultivators; and hence, since it has been found that the labours of the chemist, the botanist, the mechanist, and the geologist, are all arailable in the service of the farmer, it has followed as a natural consequence, that the farmers of our age have become a more scientific, more educated, and a far more enlighteried class than those of any previous generations.

FARMS, OLD AND NEW. Whether it is more profitable in the United States, to lay out money in the purchase and improvement of exhausted farms, or in the clearing and improvement of new land, is a question which requires more mature consideration than has been generally given to it Calculations embracing the several expenses required in the two operations would seem to show, that the intelligent farmer, versed in the various processes of producing manure and taking advantage of green fallow crops, will lay out his means most profitably in restoring worn-out land to fertility; provided he does not commit the common error of endeavouring to improve more land than his resources will enable him to do justice by.

On the other hand, the man of more limited means, who eannot buy an old farm or get one on a sufficiently long lease, may, by going west, purchase land at $\$ 1.25$ per acre, or 200 acres for $\$ 250$, which will be already in the highest state of fertility, but seriously eneumbered with heavy timber or other natural besetment. This he clears and brings under cultisation little by little, working, perhaps, a certain portion of his time for others, in order to obtain subsistence previous to the coming in of his crops. Every acre cleared may cost him some 15 or 20 dollars, which, however, adds the same amount to the value of the farm, whilst every bushel of grain and every addition to his stock is so much gained. It may be several years before the pioneer will accumulate much property. Still, however, the prospect of an ultimate independence thus held out to the poor and industrious settler, is a good one.

He who has the advantage of sufficient means to enable him to purchase exhausted lands at from 5 to 10,20 , and even 30 or 40 dollars per acre, may, by a judicious application of lime, mall, plaster, and other mineral fertilizers, aided by green fallow crops ploughed under to form a mould, soon resuscitate a farm and render it again highly productive and valuable. The following facts will demonstrate the practicability of what is here asserted. More 


\section{FARMS, OLD AND NEW.}

instances could be produced, but this, being on unquestionable authority, is ample for present illustration.

Mr. George W. Cummins, of Smyrna, Delaware, purchased a farin near that place, containing about 200 acres. 'The land had been under cultivation for half a century or more, and its soil so completely exhausted as not to be capable of compensating for the labour and seed expended upon crops. It had, nevertheless, been rented, up to the time of purchase, and one of the conditions was the payment, annually, of two-fifths of the Indian corn crop. From a thirty acre field, the rent paid the last year was only about 30 bushels! Clover refiused to grow upon this land, and wheat would not yield much more than the seed sown. The soil was a sandy loam. The first step taken by $\mathrm{Mr}$. Cummins for the restoration of this land to fertility, was, to sow one bushel of ground plaster per acre, flush it up in the spring, and spread upon it 70 bushels of slaked lime per acre. Oats were then sown at the rate of 2 or 3 bushels to the acre, and in July, when nearly fit for harvest, the straw being partly yellow and partly green, they were ploughed under, an ox-chain having been rigged in front of the coulter, so as to turn them down before the plough. Previous to this ploughing, $1 \frac{1}{4}$ bushel more of ground plaster of Paris was sprinkled upon the ground. A second crop of oats sprung up in a thick mat from those ploughed under, and about the first of October, these were turned down by the plough like the first growth. Wheat was now sown, about $1 \frac{1}{2}$ bushel to the acre, and harrowed in, followed by clover early in the spring. The crop of wheat averaged about 8 bushels to the acre, and this, it will be observed, without a shovelfull of stable or other kind of animal manure. The clover had a bushel of ground plaster sprinkled upon it in the spring, and yielded the second season of its growth, about a ton per acre at the first mowing. Thus, land from which the vegetable mould had been entirely exhausted was, in a comparatively short time, and without the assistance of barn-yard or any other kind of animal manure, brought into a condition to yield compensating crops of wheat, corn, and vigorous clover. By the assistance of the ordinary quantity of barn-yard manure, the produce of wheat would average about 25 bushels, and of Indian corn $\mathbf{4 0}$ or $\mathbf{5 0}$ bushels per acre. The ground was very light and easy to work, and Mr. Cummins estimated the actual expenses incurred per acre in this improving course, as follows:-

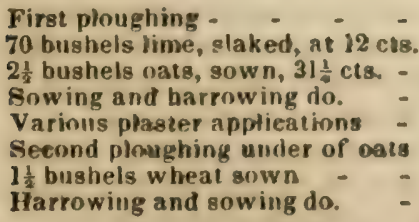

Total expewses per acre -

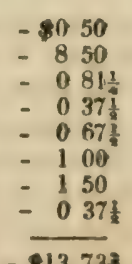

$-\$ 13734$
Thas the whole expenses incurred preparatory to the wheat and clover crops, amounted to $\$ 13^{2} 73^{3}$; and as the wheat raised was about 8 bushels, and sold for $\$ 1.50$, and the clover mown about 1 ton per acre, worth about 8 or 454
FARM-YARD MANURE.

10 dollars the ton, the expenses were abundantly repaid by the first crops, and the land left in good heart for future profitable tillage.

When farms are situated near towns, animal manures can generally be obtained at fair prices, and hence the usual productiveness exhibited by lots and fields in the proximity of towns. But with large farms situated at too great distances from such places to admit of the transportation of stable manure or street dirt at fair prices, the farmers are left to the fertilizing substances at hand, or to the pur. chase of concentrated manure that will bear the cost of transportation, such as lime, ashes, soot, plaster, crushed bones, poudrette prepared from night soil, \&c., the salts of nitre, soda, ammonia, etc. Those who live near enough to marl-beds to admit of the hauling of such heavy substances at a fair cost, are indeed fortunate. Then there are the manures or composts prepared from peat or bog-weed, by the addition of ashes, the salts of potash, soda, \&c., the me rits of all which can now be readily ascertained from results of actual experiments, reported in numerous recent publications, upon agricultural matters, and especially in that highly valuable little treatise by Dr. Dana, "The Muck Manual."

FARM YARD. The area or court in which the farm buildings are situated, and which generally adjoins the farm-house. It is the place where cattle are foddered, dung prepared, and several other necessiry operations belonging to the farm performed.

FARM-YARD MANURE. Of all fertilizers the most universal and most valuable to the cultivator, and yet the most generally mismanaged, is farm-yard manure, which has been often well described as the farmer's sheet anchor. From this fertilizer, man must have derived some benefits, even before he was compelled, by the increase of population, to cultivate and manure his land. It is the earlies mentioned of all manures; althoagh, at first, the only notice we meet with of dung and dunghills, describes them as employed in $\mathrm{Pa}$ lestine for fuel ; and, to this day, in the barren deserts of the East, that of the camel, after being dried in the sun, is the only combustible article the natives possess. (Ezeki.,iv. 12, 15 ; Niebuhr's Voyage, i. 121.). This nanure is noticed by the earliest agricultural writers. M. P. Cato tells us, in his fourth chapter, to "study to have a large dunghill; keep your crmpost carefully; when you carry it out, scattes it and pulverize it: carry it out in the autumn. Lay dung round the roots of your olives in autumn." And in his 29th chapter, "Divide your masure; carry half of it to the field where you sow your provender: and if there are olive trees, put some dung to their roots." And in c. 37, he advises the use of pigeons' dung for gardens, meadows, and corn land, as well as amurca, which is the dregs of oil; and recommends the farmer to preserve carefully the dung of all descriptions of animals. These directions were given 150 years $\mathbf{B .} \mathbf{c}$; after a lapse of nearly 2000 years, the direction to the farmer must still be the sanae; little can be added to the advice of Cato, when he said, "Study to have a large dunghill." Virgil is still mare 
particular; in his description of fertilizers, he mentions with common manure, ashes (Georg. 1. i. v. 80). Punice-stone and shells (1. ii. v. $346-350$, and $350-358$ ). Varro (c. 38,1 . i.) mentions many kinds of animal manure, and is particularly minute in his enumeration of the dung of birds, and includes even that of blackbirds and thrushes kept in aviaries. Columella (1. ii. c. 5) advises the cultivator not to carry out to the field more dung than the labourers can cover with the soil the same dav, as the exposure to the sun does it considerable injury; and he enumerates (1. ii. c. 15), as well-known fertilizers, night-soil the excrements of birds and sheep, urine (especially for apple-trees and vines), dregs of oil, the excrements of cattle, of the ass, the goat, of pigs; ashes, chopped stalks of the lupine leaves, of trees, brambles, \&c., and mud from sewers or ditches.

Of the early inhabitants of Britain, Pliny tells us (b. xvii.c. 6, 7, 8), that they highly vaiued the use of marl for particular soils, but on other lands they never employed it. We are told that they grew corn, and lived in houses thatched with straw, which would necessarily require an attention to fertilizers. They had also, according to Strabo (Geography, p. 306), gardens, which could not have been cultivated, neither could their apple orchards have flourished, without manure. The Roman invasion taught the original inhavitants better modes of using fertilizing materials; but their Saxon successors, in all probability, knew less of agriculture than the natives. War and fighting was their profession; they held the husbandman in much contempt. The confusion attendant upon British, Saxon, and Danish inroads, still farther retarded, in England, the progress of agriculture, which never prospers in a poor disturbed country. The very laws made in those days for its encouragement show to what a low ebb the art of cultivating the land was then reduced. Thus it was provided, that if any one taid dung upon a field, the law allowed him, if the owner of it consented, to use it for one year; and if the quantity of manure conveyed was in considerable quantities, so as to render it necessary to employ a cart, he was then entitled to use the land for three years; and if any person, with the consent of the owner of the soil, folded his cattle on it for the space of a year, he was then entitled to cultivate it for four years for his own benefit. (Leges Wallia, p. 298.) All these laws were evidently for the purpose of encouraging the better manuring of the land; but the necessity of such an inducement betrays the poverty of the farmers of those days, and the insufficiency of their live-stock. In the middle ages little was done for agriculture. The monks, after the introducion of Christianity, were the most learned an ? skilful in the best modes of applying manures. They early excelled in their gardens. The population of England in those days, however, was too limited to require the cultivation of inferior soils.

In 1570, Conrad Heresbach, a learned German, published his four books of husbandry, which were translated by Googe: he there mentions the several descriptions of inanure employed in his days. His bouk is a strange mixture of good sense and superstition. He speaks of the dung of poultry and pigeons with much approbation; but reprobates the use of that of geese and ducks. Human freces, he says, when mixed with rubbish, is good; bue. by itself, is too hot. Urine he commends highly for apple trees and vines. Of the dung of animals, he mentions that of the ass as first in order for fertilizing effects; then that of sheep, goats, oxen, horses; lastly, swine, "very hurtful to corne, but used in some places for gardens." Green manure was used in his days. "Where they have no store of cattle, they used to mend their ground with straw, fern, and the stalks of lupines, and the branches, laid together in some ditch. Hereunto you may cast ashes, the filth of sinks and privies, \&.c." And again he says, "The weeds growing about willow trees and fern, \&c., you may gather and lay under your sheep." He speaks of the practice of placing turfs and heath clods in heaps, with dung; much in the same way as Lord Meadowbank has advised with peat. $\mathrm{He}$ also advises the placing of the same turf-parings in sheep-folds. "This is also to be noted," says our author, "that the doung that hath lyen a yeere is best for corne, for it both is of sufficient strength and breedeth less weedes; but, upon meadowe and pasture you must laye the newest, because it brings most grasse, in Februarie, the moone increasing, for that is the best time to cause increase of grasse." When, however, the manure is applied for corn lands, "looke that the winde be westerly, and the moone in the wane."

The manure commonly furnished by the farm-yard is compounded of a mixture of ani$\mathrm{mal}$ and vegetable substances of the putrefying straw of various descriptions of grain, mixed with the excrements and urine of cattle, horses, and swine. The mixture forms no new substance, neither does the putrefaction which ensues add to the bulk of the dung; on the contrary, it causes a considerable loss of weight. Neither is the manure produced equal to the amount of food the stoch consume. "If," says Dr. Sprengel "we weigh the dry food given the cattle to eat, and also dry and weigh the resulting excrements, we shall find the weight of the latter considerably less than that of the former. Block, who has lately made a great number of experiments on this circum. stance, found that $100 \mathrm{lbs}$. of rye-straw yjelded only $43 \mathrm{lbs}$. of dried excrement (liquid and solid), while $100 \mathrm{lbs}$. of hay gave $44 \mathrm{lbs}$. Food which contains many watery parts furnished. as may be naturally supposed, a still smaller proportion. Thus, for instance, $100 \mathrm{lbs}$. of pa tatoes gave only $14 \mathrm{lbs}$; $100 \mathrm{lbs}$ of mangelwurzel, $6 \mathrm{lbs}$.; and $100 \mathrm{lbs}$. of green clover, $9 \frac{1}{3}$ lbs. of excrement." (Transl. by Mr. Hudsom Jour. Roy. Agr. Soc. vol. vi. p. 460.)

It will assist us very materially in our examinations of various modes of preparing and applying manure, if we first examine its cherical composition; and for that purpose I will give the analysis of straw and the fæces and urine of animals.

1000 parts of diy wheat straw being burnt, 


\section{FARM-YARD MANURE.}

fielded M. Saussure 48 parts of ashes; he same quantity of the dry straw of barley yie. led 42 parts of ashes. The portion dissipated by the fire would be principally carbon (charcoal), carburetted hydrogen gas, and water: 100 parts of these ashes are composed of -

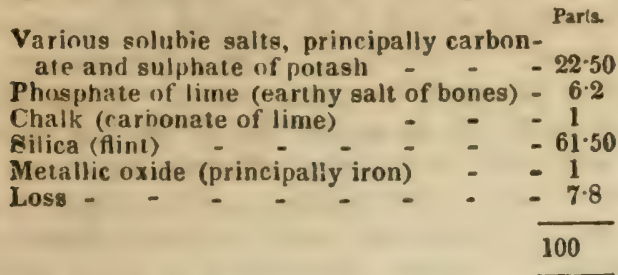

The straw of barley contains the same ingredients, only in rather different proportions.

The fresh urine of the cow has been analyzed by Mr. Brande; he found in 100 parts the following ingredients :-

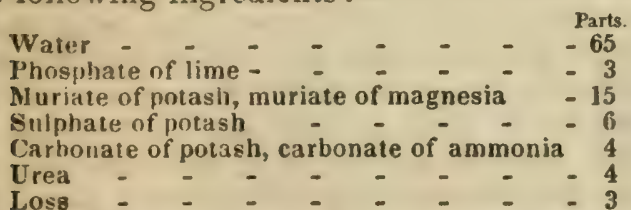

The urine of cattle, after it had been putrefying for a month, was analyzed by Dr. Sprengel, and found to contain the following ingredi :nts :-

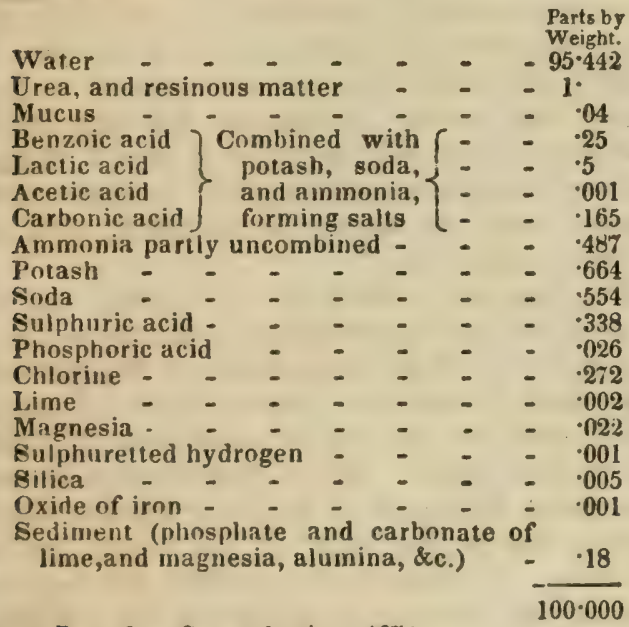

(Jour. Roy. Agr. Soc. vol. vi. p. 467.)

According to Block, $100 \mathrm{lbs}$. of chopped rye straw, given as fodder to horses, yield $42 \mathrm{lbs}$. 100 lbs. of hay, 45 lbs.; 100 lbs. of oats, 51 lbs.; 100 lbs. of rye, 53 lbs. of dried excrements (fluid and solid). The solid excrements of horses fed on hay, oats, and straw, contain, according to the analysis of M. Zierl, in 1000 parts-

Water
Picromel and salts - - - - -
Bitinus and extractive matter -
Green matter, albumen, mucus, \&c. -
Vegetable fibre, and remains of food

These, when burnt, yielded to the same chemist 60 parts by weight of ashes, which were composed of-

Carbonate, sulphate, and mitriate of soda
Carbonate and phosphate of lime
silica

3000 parts of the urine of the horse contain, according to the analysis of MM. Foure roy and Vanquelin (Thomson's Chem. vol. iv. p. 348).

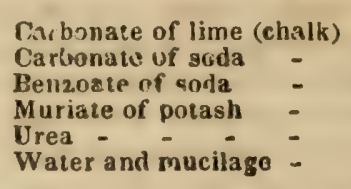

The feces of catt $t$ fea principa!ly on turnips have been analyzed by M. Einhof. 100 parts evaporated to dryness yielded $28 \frac{1}{3}$ parts of solid matter; the $71 \frac{7}{8}$ parts lost in drying would consist principally of water and some ammoniacal salts. In haif a pound, or 3840 grains, he found 45 grains of sand; and by diffusing it through water he obtained about 600 grains of a yellow fibrous matter, resembling that of plants, mixed with a very considerable quantity of slimy matter. By evaporating the fæces to dryness, and then burning them, he obtained an ash which contained, besides the sand, the following substances:-

\begin{tabular}{|c|c|c|c|c|}
\hline Limé & - & - & - & -12 \\
\hline Pbosphate & of lime & - & - & -12.5 \\
\hline Magnesia & $-\quad-$ & - & - & -2 \\
\hline Iron - & - & - & - & 5 \\
\hline Alumina, & with som & manganese & - & $\begin{array}{l}-14 \\
-\quad 10\end{array}$ \\
\hline Silica & & $-\quad-$ & - & -52 \\
\hline Muriate an & d sulpha & e of potash & - & $1 \cdot 2$ \\
\hline
\end{tabular}

The ingredients of which the urine and fæces of cattle are composed, will, of course, differ slightly in different animals of the same kind, and according to the different food upon which they are fed; but this difference will not in any case be found very material.

The excrements of the sheep have been examined by Block; according to him, every 100 lbs. of rye-straw given as fodder to sheep yield $40 \mathrm{lbs}$. of excrements (fluid and solid); from $100 \mathrm{lbs}$. of hay, $42 \mathrm{lbs}$; from $100 \mathrm{lbs}$. of potatoes, $13 \mathrm{lbs}$; from $100 \mathrm{lbs}$. of green clover, $8 \frac{1}{2}$ lbs.; and from $100 \mathrm{lbs}$. of oats, $49 \mathrm{lbs}$. of dry excrement. The solid excrements of sheep fed on hay were examined by Zierl : 1000 parts by weight, being burnt, yielded 96 parts of ashes, which were found to consist of-

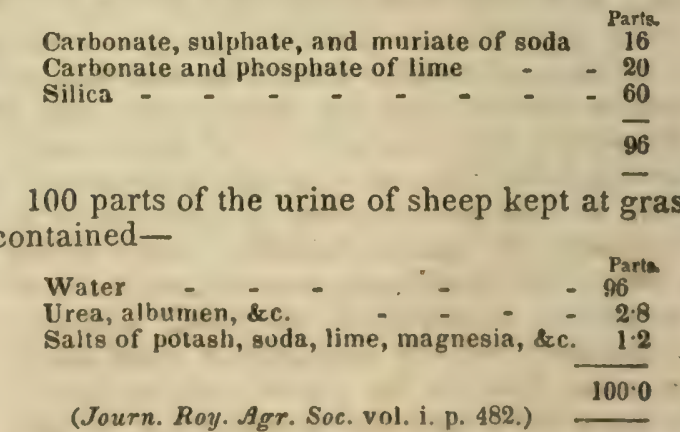

The urine of the pig has been examined by Dr. Sprengel (ibid. p. 492); he found in 100 parts of that of the animal fed on corn offal-

$$
\begin{aligned}
& \text { Water - - - _ - _ - } \begin{array}{c}
\text { Park. } \\
92.6
\end{array} \\
& \text { Urea, inucus, albumen, \&c. - - - } 5.64 \\
& \text { Common salt, muriate of potash, gypsum, } \\
& \text { chalk, and glauber salt _ - } \quad \text { 1.76 } \\
& 100 \cdot 00
\end{aligned}
$$

Such are the principal constituents of the manure from a farm-yard; but of these, most 
of the soluble salts are usually washed away by the rain, or are suffered to drain away into ditches, whilst a considerable quantity of the salts of ammonia and some of the carbon are commonly lost by being either over-heated, or by being allowed to remain too long in a putrefying state.

Farm-yard manure has a very considerable attraction for the moisture of the atmosphere: some experiments to ascertain its extent are given under the head MavunE.

There have been many arguments and much difference of opinion among cultivators, with regard to the advantages of employing dung in a fresh or in a putrid state; and, as is too of ten the case, both parties have run into extremes, the one side contending for the propriety of employing it quite fresh from the farm-yard, the other contending that it cannot well be too rotten. The mode employed by Lord Leicester is the medium between these equally erroneous extremes. He found that the employment of the fresh dung certainly made the dung go much farther; but then a multitude of the seeds of various weeds were carried on to the land along with the manure. He has, therefore, since used his compost when only in a half putrefied state (called short dung by farmers); and hence the seeds are destroyed by the effects of the putrefaction, and the dung still extends much farther than if suffered to remain until quite putrefied.

Putrefaction cannot go on without the presence of moisture. Where water is entirely absent there can be no putrefaction; and hence many farmers have adopted the practice of pumping the drainage of their farm-yards over their dung-heaps; others invariably place them in low damp situations. This liquid portion cannot be too highly valued by the cultivator. The soil where a dunghill has lain in a field is always distinguished by a rank luxuriance in the succeeding crop, even if the earth beneath, to the depth of six inches, is removed and spread with the dunghill.

The controversy, too, which once so keenly existed, as to the state of fermentation in which dung should be used on the land, has now pretty well subsided. There is no doubt but that it cannot be applied more advantageously than in as fresh a state as possible, consistent with the attainment of a tolerably clean husbandry, and the destruction of the seeds of weeds, grubs, \&c., which are always more or less present in farm-yard dung. These are the only evils to be apprehended from the desirable employment of this manure in the freshest state; for otherwise the loss of its most valuable constituents commences as soon as ever fermentation begins. This was long since demonstrated by Davy, whose experiments I have often seen repeated and varied. He says, "I filled a large retort, capable of containing three pints of water, with some hot fermenting manure, consisting principally of the litter and dung of cattle; I adapted a small receiver to the retort, and connected the whole with a mercurial pneumatic apparatus, so as $t()$ collect the condensible and elastic fluids which might arise from the dung. The receiver soon became lined with dew, and

drops began, in a few hours, to trickle down the sides of it. Elastic fluid likewise was generated; in three days thirty-five cubical inches had been formed, which, when analyzed, were found to contain twenty-one cubical inches of carbonic acid; the remainder was hydrocarbonate, mixed with some azote, probably no more than existed in the common air in the receiver. The fluid matter collected in the receiver at the same time arnounted to nearly half an ounce. It harl a saline taste, and a disagreeable smell, and contained some acetate and carbonate of ammonia. Finding such products given off from fermenting litter, I introduced the beak of another retort, filled with similar dung very hot at the time, in the soil amongst the roots of some grass in the border of a garden; in less than a week a very distinct effect was produced on the grass: upon the spot exposed to the influence of the matter disengaged in fermentation it grew with much more luxuriance than the grass in any other part of the garden." (Lectures, p. 204.)

Nothing, indeed, appears at first sight so simple as the manufacture and collection of farm-yard dung; and yet there are endless sources of error into which the cultivator is sure to fall, if he is not ever vigilant in their management. The late Mr. Francis Blakie, in his valuable tract upon the management of farm-yard manure, dwells upon several of these; he particularly condemns the practice "of keeping the dung arising from different descriptions of animals in separate heaps or departments, and applying them to the land without intermixture. It is customary," he adds, "to keep the fattening neat caltle in yards by themselves; and the manure thus produced is of good quality, because the excrement of such cattle is richer than that of lean ones. Fattening cattle are fed with oilcake, corn, Swedish turnips, or some other rich food; and the refuse and waste of such food thrown about the yard increases the value of the manure: it also attracts the pigs to the yard. These rout the straw and dung about, in search of grains of corn, bits of Swedish turnips, and other food: by which means the manure in the yard becomes more intimately mixed, and is proportionally increased in value. The feed. ing-troughs and cribs in the yard should, for obvious reasons, be shifted frequently."

"The horse dung," continues Blakie, "is usually thrown ont at the stable doors, and there accumulates in large heaps. It is some. times spread a little about, but more generally not at all, unless where necessary for the convenience of ingress and egress, or perhaps to allow the water to drain away from the stable door. Horse dung, lying in such heaps, very soon ferments, and heats to an excess; the centre of the heap is charred or burned to a dry white substance, provincially termed fircfanged. Dung in this state loses from 50 to 75 per cent. of its value. The diligent and attentive farmer will guard against such profligate waste of property, by never allowing the dung to accumulate in any considerable quantity at the stable doors. The dung from the feeding hog-sties should also be carted and spread about the store cattle-yard, in the same manner $2 Q$

$45 \%$ 


\section{FARM-YARD MANURE.}

as the hurse dung. (Blakie on Farm-yard Dung, p. 6.) There is no doubt of the superior fertilizing effects of horse-dung. In an experiment with beans, in which six acres were manured with horse-dung, and nine with that from a cow-yard, the six yielded more beans than the nine. (Agr. Rep. of Essex, vol. ii. p. 280.) The same observation was made in Lincolnshire. (Sinclair's $A g r . p .214$. .) 'The heat produced by the fermentation of the dung of different animals has been made the subject of repeated experiment. When the temperature of the air was $40^{\circ}$, that of

Common farm-yard dung was - - $\quad-70^{\circ}$

A mixture of lime, dung, and earth - $\quad-\quad 55^{\circ}$

(Farmer's Magazine, vol. x. iv. p. 160.)

The cultivator will readily allow the advantages of the plan thus recommended by $\mathrm{Mr}_{8}$ Blakie; and the student must see from the following experiments, that the dung of different animals vary very much in their fertilizing powers.

'The subjoined table contains the results of the experiments made with three different manures on the growth of potatoes, by Mr. Oliver, of Mid-Lothian; the cow and horse-dung were recently made; the potatoes were of the description called Pinkeyes, and forty loads of about eighteen cwt. per acre were employed of each manure. (Ency. Metrop. vol. vi. p. 61.)

\begin{tabular}{|c|c|c|c|c|c|c|c|c|c|c|c|}
\hline \multirow{3}{*}{$\begin{array}{c}\begin{array}{c}\text { Distance } \\
\text { between } \\
\text { Rows. }\end{array} \\
12\{\end{array}$} & \multirow{2}{*}{$\begin{array}{c}\text { Kind of } \\
\begin{array}{c}\text { Manures } \\
\text { used. }\end{array} \\
\text { Cow }\end{array}$} & \multirow{2}{*}{$\begin{array}{c}\begin{array}{c}\text { Produce } \\
\text { per acre. }\end{array} \\
\text { B. F. P I. }\end{array}$} & \multirow{2}{*}{ 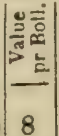 } & \multicolumn{3}{|c|}{$\begin{array}{c}\text { Value } \\
\text { per Acre. }\end{array}$} & \multicolumn{3}{|c|}{$\begin{array}{l}\text { Cost of } \\
\text { pro. } \\
\text { duction. }\end{array}$} & \multicolumn{2}{|c|}{$\begin{array}{l}\text { Price of } \\
\text { Manure } \\
\text { pr Cart. }\end{array}$} \\
\hline & & & & $\bar{L}$ & & & 25 & 8 & & & \\
\hline & Horse & 47000 & 8 & 18 & 17 & & 23 & 8 & & 3 & \\
\hline & is & 42000 & 8 & 10 & 16 & & 24 & 8 & & 3 & \\
\hline & $\mathrm{Co}$ & 60000 & 8 & 24 & & & 24 & 8 & & 4 & 0 \\
\hline & H & 51280 & 8 & 23 & 0 & & 22 & 8 & & 3 & 0 \\
\hline & & 45000 & 8 & 18 & 0 & & 23 & 8 & & 3 & 6 \\
\hline & C & 60100 & 8 & 24 & 2 & & 22 & 0 & & 3 & 0 \\
\hline & H & 61030 & 8 & 24 & 9 & 6 & 24 & 0 & & 4 & 0 \\
\hline & & $\begin{array}{llll}39 & 0 & 0 & 0\end{array}$ & 8 & 15 & 12 & & 23 & 0 & & 3 & 6 \\
\hline & $\mathrm{C}$ & 66220 & 8 & 26 & 1 & & 23 & 13 & & 4 & 0 \\
\hline 30 & & 66220 & 8 & 2 & 13 & 6 & 21 & & & & \\
\hline & & $\begin{array}{llll}46 & 3 & 2 & 0\end{array}$ & 8 & 18 & 15 & & 22 & & & & \\
\hline & & 63030 & 8 & 25 & 5 & 6 & 23 & It & & 4 & 0 \\
\hline & & 67221 & 8 & 27 & 0 & $7 \frac{1}{\frac{1}{2}}$ & 21 & I & & 3 & 0 \\
\hline & & $\begin{array}{lll}47 & 0 & 0\end{array}$ & 8 & 18 & & & 22 & 10 & & 3 & 6 \\
\hline
\end{tabular}

Malcolm (see Brit. Husb. vol. i. p. 260) has given an estimate of the number of cubic yards or tons of farm-yard compost necessary for various soils per acre, which is as follows :-

\begin{tabular}{|cl|l|l|l|l|}
\hline \multicolumn{2}{|c|}{ On strong Land. } & Loams. & Gravels. & Chalks. & Sands. \\
\hline For Wheat & 30 & 20 to 25 & 25 & 20 & 20 \\
Barley & 25 & 20 & 22 & 16 & 18 \\
Turnifis & 30 & 20 & 25 & 20 & 20 \\
Clover & 15 to 20 & 15 & 20 & 16 & 16 \\
Saiufoin & -15 & - & - & 20 & - \\
Pasture & 15 to 20 & 15 & 16 & 16 & 16 \\
\hline
\end{tabular}

Some experiments of $\mathrm{Mr}$. Wright, made upon plots of ground of equal size, indicate the number of stems of barley produced by various fertilizers: each plot was dibbled with 60 corns of barley. (Agr. Mag. vol. i. p. 328.)

1. No manure

2. Manured with 5 tons of cow-dung per acre $\overline{ }$
$=$
$\overline{\mathbf{4 5 8}}$
No. of Iiems

167

226

233

244

233

211

18.5

303
282

\section{FARM-YARD MANURE.}

With regard to the form of dung-yards, thers is some little difference of opinion. "Some theorists," says Blakie, "recommend the yards to be made so concave, as almost to amount to a $w e l l$-shape, giving, as a reason in support of their opinion, that the virtues of dung can only be preserved by being saturated in urine, or some other moisture. Others, again, assert that dung-yards should be formed convex, and assign as their reason, that farm-yard dung should be kept dry. Practical experience points out that a medium between those two extremes is the best; and a yard a little hollowed is the most common shape.

I will here introduce the description recommended by Mr. Blakie, of the best mode of forming dung-heaps or pies in turnip-fields, so as to prevent, as much as possible, the waste of gaseous matters, during the fermentation of the manure. "When," said this intelligent agriculturist, "it is found necessary to empty the dung-yards early in the season, I recommend that preparation should be made, in the usual way, for the reception of the dung-heaps in the intended turnip-fields, by collecting large heaps of clay marl, or such other materials. The bottoms for the heaps should not, however, be laid above six or eight inches thick of the earthy material, and a good quantity of it should be placed in rows on each side of the bottoms marked out; the dung should then be drawn out of the yards, and placed upon the bottoms, but not in the usual way of throwing it up lonsely, to cause fermentation; on the contrary, by drawing the carts with their loads upon the heaps, for the purpose of compressing the dung, and thereby retarding fermentation. One or two men should remain constantly at the heaps, while the teams are at work, on purpose to spread and level the dung regularly, so as to render the ascent easy for the succeeding teams, as they come with their loads. If the dung has not been previously mixed in the yards, it should be so in drawing to the heaps, by taking up a few loads from one yard, and then a few from another, alternately; and even from the same yard, the loads of dung should be taken from different parts alternately; for the dung is not of equal quality, nor made with the same regularity, in all parts of the yard.

"The coal-ashes, road-scrapings, and all other collections of manure about the farmhouse, should also be carried to these dungheaps; and when the heaps are raised as high as convenient for the horses to draw up, several loads should be shot up at the ends of the heaps, for the purpose of making them up to the square of the centre. The whole heaps should then be completely covered with the marl and clay, or soil previously collected in rows by the sides of the heaps, so as effectually to enclose the dung-heaps in crusts, and they are thenceforth denominated pies. In these, the dung will be preserved in a very perfect state, with little or no fermentation, and without loss by exhalation or evaporation. 'The pies, within ten days or a fortnight of the time the compost is wanted for the turnip ground, should be turned carefully over, and the crust, top, bottom, and sides intimately mixed up with the dung. When the turning is completed, with the natu- 
ral soil around the heaps, again coat the heaps all over; the pies will then undergo a gentle fermentation; the earth, intermixed with and covering the dung, will absorb the juices and gaseous matters produced, and the compost coine out in a fine state of preparation for using on the turnip lands. When the dung is taken out of the yards late in the spring, or oniy a short time before it is required for the turnip ground, the preparation should be somewhat different, because of the compost heaps having less time to incorporate. Thus the dung should not be carted upon the heaps to compress them, and prevent fermentation, as in winter. On the contrary, the dung should be thrown up lightly with the fork upon the bottoms, and the side-heaps of earth mixed intimately along with the dung. Turf turned up for a year preceding on wastes by the sides of roads makes excellent pie-meat."

The temperature of the dung-heap is a pretty sure criterion of the state of its fermentation. If a thermometer, plunged into it, does not rise above $100^{\circ}$, there is little danger of too much gaseous matter being lost. If the temperature is higher, means should be taken to check the fermentation; and the same overheating may be regarded as going on, if, when a piece of paper moistened with muriatic acid is held over a dunghill, dense fumes appear, for then ammonia is disengaging. (Davy, p. 307.) With skilful management, and under ordinary circumstances, one ton of dry straw is found to produce three tons of manure; so that, as the common weight of straw per acre is about one ton and a half, the straw grown upon that extent of land should yield about four tons and a half of compost. The quantity of manure produced by stock necessarily varies with the quantity and quality of the food upon which the animals are fed. In an experiment made at the Cavalry Depôt, at Maidstone, a horse consumed in a week-

\begin{tabular}{|c|c|c|c|c|c|c|}
\hline Dats & - & - & - & - & - & - \\
\hline Hay & - & - & - & - & - & - \\
\hline Straw & - & - & - & - & - & - \\
\hline
\end{tabular}

He drank, within this time, 27 gallons of water. The weight of the dung and litter produced was $327 \frac{1}{2}$ lbs.

In another experiment, on a large-sized Yorkshire milch cow, she consumed in 24 hours-

\begin{tabular}{|c|c|c|c|c|}
\hline Brewers' grains & - & - & - & - \\
\hline Raw potatoes & - & - & - & - \\
\hline Meadow hay & & - & - & - \\
\hline
\end{tabular}

And during this period she drank two pailfuls of water. The urine was allowed to escape. She had no litter of any kind. The weight of the solid dung she produced was $45 \mathrm{lbs}$. When fed, on another day, with

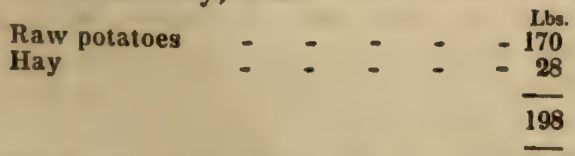

she produced, under the same circumstances, 73 lbs. of solid manure. (British Husbandry, vol. i. p. 255.) Taking, therefore, the average produce to be equal to $60 \mathrm{lbs}$. per day, it follows that a cow will make about 9 tons of solid dung in the course of the year.

The quality of farm-yard compost naturally varies with the food of the animals by which it is made: that from the cattle of the strawyard is decidedly the poorest; that from those fed on oil-cake, corn, or Swedes, the richest. Of stable-dung, that from corn-fed horses is most powerful-from those subsisting on straw and hay, the poorest; the difference between the fertilizing effects of the richest and the in. ferior farm-yard dung is much greater than is commonly believed-in many instances the disparity exceeds one-half; thus, that produced by cattle fed upon oil-cake is fully equal in value to double the quantity fed upon turnips. My friend, Mr. Hewitt Davis, of Spring Park, near Croydon, an excellent scientific practical farmer, had occasion to notice this in an experiment which commenced in 1834. In that year, on half of a field of turnips fed of with sheep, he gave them oil-cake; on the other half they fed only on the turnips. The succeeding crops were all distinguished by their superiority on the half of the field where the sheep had oil-cake; and in 1838, when the field had again a crop of turnips, the half of the field, on which four years previously the sheep were fed with oil-cake, had by far a better crop of turnips than that which had been manured in common with the rest of the field and fed off in the ordinary manner. And as the food consumed so materially influences the quality of the manure, it follows, as a natural consequence, that that made in summer by the clover, grass, and tare-fed stock is much superior to that produced during the winter months by the store-fed cattle of the straw-yard, which is usually still further impoverished by the rains andsnows. Hence, too, the superior richness of the manure of fatting swine to those of pigs in a lean state, and the far superior strength of night soil to any manure produced from meiely vegetable food. Chemical ixaminations are hardly necessary to prove these facts. Every farmer who has had stall-fed cattle will testify to their truth-every cultivator will readily acknowledge the superiority of " townmade," that is, corn-produced stable-dung, to that from horses fed only on hay and straw. and that night-soil is far superior in "strength" to either. The relative quantities employed by the cultivator betray the same fact; for on the soils where he applies 20 loads of good farm. yard compost per acre, he spreads not half that quantity of night-soil. Mr. Dixon, whose observations I have quoted at some length in this paper, deems "six tons of night-soil in compost with peat amply sufficient for an acre." Mr. H. Davis is of the same opinion. It is not, as the farmer is well aware, the mere straw of the farm-yard manure which influences its fer tilizing quality, but the excrements with which that straw is mixed. Thus other substances, when thoroughly saturated with the stercordccous matters of cattle, are found to be just as fertilizing as straw: sawdust, peat, tanners' bark, or turf, are as serviceable in this respect as the best straw. Arthur Young found this to be the case when turf was employed mixed with 


\section{FARM-YARD MANURE.}

urıne. (Annals of Agric. vol. ix. p. 652,-Ibid. vol. iii. p. 67-69.) Lord Meadowbank, Mi. Dixon, and others have successfully employed peat in a similar way (English Agric. Soc. Journ. vol. i. p. 138), and the latter agriculturist often makes his excellent compost heaps of merely peat and urine. The liquid or soluble portion of farm-yard manure constitutes, in fact, its richest portion. Of the powerful effect produced by the urine of cattle, and other liquid fertilizers, I shall have hereafter occasion to speak, when treating on liquid manure.

It is usual for the farmer, although not so common a practice as is desirable, to increase the bulk, if not the quality, of his dung-heaps, by adding to them various other substances; thus, as to enlarging them, by adding to that of the farm-yard, peat-moss, the late Lord Meadowbank made many experiments with success; and his directions are of a very simple and easily followed description. "Let the peatmoss," he says, "be thrown out of the pit for some weeks or months, in order to lose its redundant moisture. By this means it is rendered the lighter to carry, and less compact and heavy when made up with fresh dung for fermentation; and, accordingly, less dung is required for this purpose than if the preparation is made with peat taken recently from the pit; the peat taken from near the surface or at a considerable depth answers equally well. Take the peat-moss to a dry spot convenient for constructing a dunghill, to serve the field to be manured; lay the cart-loads of it in two rows, and of the dung in a row between them. The dung thus lies nearly on an area of the future compost dunghill, and the rows of peat should be near enough each other that workmen, in making up the compost, may be able to throw them together by the spade. In making up, let the workmen begin at one end, and at the extremity of the row of dung (which should not extend quite so far at that end as the rows of peat on each side of it do), let them lay a bottom of peat six inches deep and fifteen feet wide, if the ground admits of it; then throw forward and lay on about ten inches of dung above the bottom of peat, then add from the side rows about six inches of peat, then four or five of dung, and then six more of peat; then another thin layer of dung, and then cover it over with peat at the end where it was begun, and at the two sides. The compost should not be raised above four feet or four feet and a half high, otherwise it is apt to press too heavily on the under parts, and check the fermentation; when a beginning is thus made, the workmen will proceed working backwards, and adding to the column of compost, as they are furnished with the three rows of materials directed to be laid down for them. They must take care not to tread on the compost, or render it too compact; and, of consequence, in proportion as the peat is wet, it should be made up in lumps, and not inuch broken. In mild weather, 7 cart-loads if common farm dung, tolerably fresh made, is sufficient for 21 cart-loads of peat-moss; but, in cold weather, a larger proportion of dung is desirable. 'To every 28 cart-loads of the compost when made up, it is of use to throw on above it a cart-load of ashes, either made from 460 coal, peat, or wood; or, if these cannot be had, half the quantity of slaked lime may be used, the more finely powdered the better: but these additions are nowise essential to the general success of the compost. The dung to be used should either have been recently made or kept fresh by compression, as by the treading of cattle or swine, or by carts passing over it; and if there is little or no litter in it, a smaller quantity will serve, provided any spongy vegetable matter is added at making up the compost, as fresh weeds, the rubbish of a stackyard, potato-shaves, sawings of timber, \&c.; and as some sorts of dung, even when fresh, are much more advanced in decomposition than others, it is material to attend to this; for a much less proportion of such dung as is less advanced will serve for the compost, provided care is taken to keep the mass sufficiently open, either by a mixture of the above-mentioned substances, or, if these are wanting, by adding the peat piecemeal; that is, first making it up in the usual proportion of three to one of dung, and then adding, after a time, an equal quantity more or less of moss. The dung of this quality of greatest quantity is shamble dung, with which, under the above precautions, six times the quantity of peat, or more, may be prepared. The same holds as to pigeons' dung and other fowl dung, and, to a certain extent, also, as to that which is collected from towns, and made by animals that feed on grains, refuse of distilleries, \&c.

"The compost, after it is made up, gets into a general heat sooner or later, according to the weather and the condition of the dung: in summer, in ten days or sooner; in winter, not perhaps for many weeks, if the cold is severe. It always, however, has been found to come on at last; and in summer it sometimes rises so high as to be mischievous, by consuming the materials (Fire-Fanging). In that season a stick should be kept in it in different parts, to pull out and feel now and then; for, if it approaches to blood heat, it should either be watered or turned over, and, on such an occasion, advantage may be taken to mix it with a little fresh moss. The heat subsides after a time, and with great variety, according to the weather, the dung, and the perfection of the making up of the compost, which then should be allowed to remain untouched till within three weeks of using, when it should be turned over upside down, and outside in, and all lumps broken; then it comes into a second heat, but soon cools, and should be taken out for use. In this state the whole, except bits of the old decayed wood, appears a black, free mass, and spreads like garden mould. Use it weight for weight as farm-yard dung, and it will be found in a course of cropping fully equal to stand the comparison." After a long-continued observation and successful use of peat, Mr. H. Davis is of opinion that peat, in common with most organic manures, has a strong tendency to rise to the surface of all cultivated soils, thus following a rule directly opposite to those of earthy fertilizers, which certainly descend into the land. (Young's Annals, vol. xli. p. 547.)

Compost, if made up before January, has hitherto been in good order for the spring- 


\section{FARM-YARD MANURE.}

crops; but this may not happen in a long frost. In summer, it is ready in eight or ten weeks; and, if there is an anxiety to have it sooner prepared, the addition of ashes, or of a little lime rubbish of old buildings, or of lime slackened with foul water, applied to the dung used in making up, will quicken the process considerably. "Peat prepared with lime alone has not been found to answer as good manure; in one instance, viz. on a bit of fallow sown with wheat, it was manifestly pernicious." (Edinburgh Encyc. vol. i. p. 279.) The opinion of Lord Meadowbank in favour of the use of peat or sawdust as a mixture with farm-yard compost, has been recently confirmed by $\mathrm{Mr}$. Dixon, of Hathershaw, in Lancashire, who, in his Prize Essay, thus describes the result of his long experience (Journ. of the English Agric. Society, vol. i. p. 135):-

"My farm is a strong, retentive soil, on a substratum of ferruginous clay. My object was to improve its texture at the least cost. For this purpose we carted great quantities of fine sawdust and peat-earth, or bog; we had so far to go for the latter, that two horses would fetch little more than three tons in one day; one horse would fetch three cart-loads of sawdust in the same time. Having brought great quantities of both peat and sawdust into my farm-yard, I laid out, for the bottom of a compost heap, a space of considerable dimensions, and about three feet in depth; three-fourths of this bottom was peat, the rest sawdust; on this we conveyed, daily, the dung from the cattlesheds; the urine, also, is conducted through channels to wells for its reception (one on each side of the compost heap); common water is entirely prevented from mixing with it. Every second day the urine so collected is thrown over the whole mass with a scoop, and at the same time we regulate the accumulated dung. This being continued for a week, another layer, nine inches or a foot thick, of peat and sawdust (and frequently peat without sawdust) is wheeled on the accumulated heap. These matters are continuously added to each other during winter; and, in addition, once in every week, never less than $25 \mathrm{cwt}$., more frequently $50 \mathrm{cwt}$, of night-soil and urine: the latter are always laid next above the peat or bng earth, as we think it accelerates their decomposition. It 1s, perhaps, proper here to state, that the peat is dug and exposed to the alternations of the weather for several months before it is brought to the heap for admixture: by this it loses much of its moisture. Some years' experience has convinced me of the impropriety of using recently dug peat: used in the manner I recommend, it is superior and more convenient on every account; very much lighter to cart to the farm-yard, or any other situation where It is wanted; and so convinced am I of its utility in composts for every description of soil, except that of its own character, that wherever it can be laid down on a farm at less than 4 shillings per ton, I should recommend every agriculturist and horticulturist that can command it, even at the cost here stated, to give it a fair trial. So attractive and retentive of moisture is peat, that, if liberally applied to an arid, sandy soil, that soil does not burn in a dry

\section{FARM-YARD MANURE.}

season, and it so much improves the texture and increases the produce of an obdurate clay soil, if in other respects rightly cultivated, that actual experience alone can fairly determine its value.

"For the conveyance of night-suil and urine, we have the largest and strongest casks, such as oils are imported in; the top of which is provided with a funnel to put the matters through, and the casks are fixed on wheels like those of a common dung-cart. For the convenience of emptying this carriage, the compost heaps are always lower at one end; the high est is where we discharge the contents, in order that they may, in some degree, spread themselves over the whole accumulation. The situation on which the wheels of these carriages stand while being discharged, is raised considerably; this we find convenient, as the compost heap may be sloped six or seven feet high; low compost heaps, in my opinion, should be avoided. The plan here recommended I have carried on for some time. I find no difficulty in manuring my farm over once in two years; by this repetition I keep up the fertility of my land, and it never requires more than a moderate application of manure.

"I am fully aware that there are many localities where neither peat nor night-soil can be readily obtained; but it is worth a farmer's while to go even more than 20 miles for the latter substance, provided he can have it without deterioration: the original cost is often trifling. On a farm where turnips or mangel are cultivated to some extent, the system here recommended will be almost incalculably advantageous. A single horse is sufficient for one carriage; mine hold upwards of a ton each; six tons of this manure in compost with peat, or, if that is not convenient, any other matters, such as ditch scourings, or high headlands which have been properly prepared and laid dry in a heap for some time, would be amply sufficient for an acre of turnips or mangel. This manure is by far the most invigorating of any I have ever yet tried; bones in any state will bear no comparison to it for any crop; but it must be remembered that I write on the supposition that it has not been reduced in strength before it is brought.

"Convenience frequently suggests that compost heaps should be raised on different parts of a farm; but, unless in particular instances, it is well to have them in the yard. In the farm-yard, all the urine from the cattle-stalls may be employed with the greatest econony ; and, be it remarked, that the urine from animals, in given weights, is more powerful than their solid excrements. How impor'ant, then, must it not be to the farmer to male the most extensive and the most careful use of this. liquid! It is sometimes carted on the land: but that practice will not bear a comparison with making it into composts in the manner here recommended. Great waste is often made in putrescent manures after they are carted on the land; instead of being immediately covered or incorporated with the soil, we not unfrequently see them exposed for days together in the hot rays of a scorching sun, or to the inju. rious influences of a dry wind. I have beror" 
stated that compost heaps should, on many considerations, be raised in the farm-yard; still, circumstances are frequently such that it is more proper to make them at some distance in the fields. If a headland becomes too high by frequent ploughings or working of the land, in that case it should be ploughed at the time when clover or mixed grass-seeds are sown with a white crop; for instance, barley or oats, and clover for the year following: a headland might then be ploughed, and a number of cartloads of some manure heaped from one end to the other. Immediately after this it should be trenched with the spade (or what is sometimes called digging), and ridged high, in order that an action may take place between the soil and the manure; by this means the mass would soon be in a condition for turning over, and any ditch scourings, or other matters which had not in the first instance been used, might now be added to the mixture. The heap should then be allowed to remain closed for a few weeks, then turned over again; at this turning, in all probability, the mass would be much reduced; and if so, raise the ridge of compost well on both sides; but, instead of its top being pointed, make a trench or cavity on the top from one end of the heap to the other. This cavity should be made tolerably retentive of moisture, which may be effected by treading with the feet; carriages of night-soil, or urine from the cattle-stalls, may then be emptied into the trench, and the bulk of the heap would desermine how many were required. This being done, a little earth should be thrown into the trench, and the heap allowed to remain in that state until the middle or latter end of autumn; it will then be ready for another turning; but at this time care must be taken to have the heap well made up at the sides, and pointed at the top; in this situation rain will be thrown off, and the compost preserved dry until winter presents some favourable opportunity for laying it on the young clover, wheat, or any other crop which may require it.

"In the year 1826," adds Mr. Dixon, "my attention was first directed to raising compost heaps from urine. This I now do frequently, without the help of any dung from the cattlestalls. The same occasion called my mind to another matter, well worthy every farmer's attention. I allude to the great superiority of the manure raised in summer soiling, to that produced in the stalls during winter."

"The strength and consequent value of all cattle-dung," says Mr. Burke, in a note upon this paper, "will of course depend upon the nature of their food; if soiled, during the summer, upon clovers, tares, sainfoin, \&c., there can be no doubt that the manure will have a proportionately greater effect upon the land, than if the beasts be kept in the straw-yard; and if stall-fed, either in winter or in summer, for the purpose of fatting, it will be still better. Thus, it was found, on comparing the effects of duny voided by animals fed chiefly on oilcake with that of store-stock, 12 loads of the iormer exceeded in superiority of product 24 of the latter." (See The Complete Grazier, 6th edit. p. 103.)

verily believe the difference is 50 per cent., 462 unless stock are fed, in a great measure, during winter, with artificial food. In an arrange. ment for making compost heaps from urine, I would recommend a receptacle to be made at the back of the cattle-stalls, just outside the building: this should hold about 20 cart-loads of mould, or any other matters to be employed; if its situation were a little lower than the cattle-sheds, all the urine would pass into it, and remain there until the mass is completely saturated, which will be sufficient; when the earthy matters are covered over, the compost may then be thrown out, and the proceeding again renewed. In order to show part of the benefits of this practice, I beg here to observe, that the most foul or weedy mould may be used; the action of the urine, if not reduced by water, is so powerful, that wire-worms, the black slug, many other destroying insects, and all vegetables, weeds, \&c., when in contact with the urine for a time, are killed. The situation for raising this compost should be protected from the weather by a covering, similar to a cart-shed; indeed, the deteriorating influences of rain, sun, and arid winds, on all putrescent manures or compost, are so serious, that, in my humble judgment, it would be worth while to have places under cover where these are usually laid down.

The urine of the cow far exceeds in quantity that of the dung, being as 18 or $19 \mathrm{lbs}$. of the former to $8 \mathrm{lbs}$. of the latter, and likewise in fertilizing power. Professor Johnson found that to produce the saine effect, it required of cow-dung 125 parts, but of the urine only 91 parts; of the dung of the horse, 73 parts were required, but of its urine only 16 , so that the amount of the urine of live stock is not only much larger than that of the more solid excrements, but it is possessed of much greater fertilizing powers.

The farmer cannot be too careful to prevent the loss of the most fertilizing principles of his manures, which so often ensues from washing away in rain water, or the flying off of the ammonia during its fermentation. To prevent the loss of this ammonia, stables and dung heaps should be sprinkled frequently with powdered gypsum, or charcoal, or a mixture of both.

A gallon of the dark-coloured drainings from a heap of cow-dung, says Professor J. F. W. Johnston, when evaporated to dryness, left about 480 grains, or $1 \mathrm{oz}$. of dry solid matter. This being analyzed gave: ammonia, $9 \cdot 6$ grs.; organic matter, $200.8 \mathrm{grs}$.; inorganic, (ash) $268.8 \mathrm{grs}$. The inorganic portion contained alkaline salts $207 \cdot 8$ grs. ; phosphates of lime and magnesia $25 \cdot 1$ grs. ; carbonate of lime (or chalk) 18.2 grs.; carbonate of magnesia and loss $4.3 \mathrm{grs}$.; silica and a little. alumina 13.4 grs.; total 268.8 grains. This demonstrates most clearly, the great waste incurred where manure heaps are much exposed to rain.

Peat, which has been so successfully employed as a manure or compost, is composed principally of the inert, long accumulating vegetable remains of either wood, moss, or heath; it abounds also with earthy and saline matters; those of Berkshire and Wiltshire contain from one-fourth to one-third of their weight of gypsum: their earthy matters are always analogous to the stratum of earth on which it reposes; where that is chalk, the peat abounds with 


\section{FARM-YARD MANURE.}

calcareous earth and gypsum, and but little alumina or silica. "Different specimens of peat, that I have burnt," says Davy, "from the granitic and schistose soils of different parts of these islands, have always given ashes principally silicious and aluminous; and a specimen of peat from the county of Antrim gave ashes which afforded very nearly the same constituents as ine great basaltic stratum of the county." (Chemistry, p. 192.) In those instances, where the farmer finds such excellent results from dressing young clover with a mixture of peat and compost, as noticed by Mr. Dixon, with the Lancashire peat, it may be reasonably concluded to contain gypsum; (Journ. Eng. Agr. Soc. vol. i. p. 138); and, if it requires the addition of a portion of lime, before it is found to promote very decidedly the growth of clover, it then is very likely to be saturated with sulphate of iron.

The too general neglect of peat as a mixture with farm-yard dung is not owing to its being a very modern discovery, for it was publicly recommended in England nearly half a century since. "In Sweden, as in other countries," says the Baron de Schulz, when writing to Sir John Sinclair in 1796, "farmers have endeavoured to increase the quantity of manure by mixtures of all kinds of vegetables and soils, and by collecting urine in cow-houses well adapted for that purpose; they likewise, in some parts of the country, lay below their catthe soil from the shores of the lakes, leaves, moss, saw-dust, chopped alder, and pitch fir, brushwood, reeds, and straw. They often now place their dunghills on a slope instead of the former hollow, and by means of pumps, water them with urine and dung-water. Many farmers, however, still prefer the fresh dung to that which is fermented, and which they suppose has lost in the process a great part of its vegetating power." (Com. Board of Agr. b. i. p. 326.)

On the sea-shore, it is usual for the farmers to mix sea-weed with their dung; in Essex they mix it with chalk; in Suffolk, with a peculiar red shelly sand or marl; and in the west of England, with the calcareous sand of the sea-shore; a practice which is thus described by Edward Bennet:-

"The quantity of sand which a barge usually contains is about 90 horse teams of $2 \frac{1}{2} \mathrm{cwt}$. each; the price varies according to the distance it is carried up the rivers Notter and Tamar, from 18s. to 25s., and 3s. drinking money, or three gallons of cider. It is dragged for in Plymouth sound in three to six fathom water. In summer the barges frequently run on the sand bank in Whitsand Bay at two hours before low water; when the tide leaves them, they load, waiting for the flood to bring them off. For arable land, the sand is thought to be best mixed with old earth, or manure collected in roads; but for pasture it is best mixed with stable muck; the proportion is two teams of muck to one of sand; a barge load thus mixed is thought to be good manure for an acre." (Annals of Agr. vol. xii. p. 35.)

Farm-yard dung is usually employed in all experiments upon manures, as the basis upon which comparative results are most usually obtained; and it is not ofien that any substance
FARM-YARD MANURE.

can be found to exceed it in fertilizing effects. It was compared with salt, lime, and oil-cake, by Mr. George Sinclair, most of whose elabo rate experiments are given under the head SALT. In my own experiments with potatoes in a light gravelly soil, I found that when the soil simply produced 120 bushels per acre, that manured with 20 tons of stable dung it yielded 219 bushels; and with 20 bushels of salt only $192 \frac{1}{2}$ bushels. (My Essay on Sialt, p. 84). In those of my brother, Mr. George Johnson, where 20 tons per acre of stable dung produced 23 tons of carrots, 20 bushels of sal: applied to a similar space produced 18 tons (Ibid.p. 146); and, with the same proportions, when the salted soil produced $4 \frac{1}{2}$ tons of red beet-root, the spit manure yielded $6 \frac{1}{2}$ tons. (Ilid. p. 149.) In those of the Rev. E. Cartwright upon potatoes, when the soil simply produced 157 bushels per acre, the same quantity of land when dressed with

\begin{tabular}{|c|c|c|c|c|c|}
\hline 363 & ish & fresh dung, & ielde & 192 & ushe \\
\hline 30 & - & gont & - & 192 & $\longrightarrow$ \\
\hline 60 & - & wond ashes & - & 187 & - \\
\hline 60 & - & malt dust & - & 184 & - \\
\hline 363 & 一 & decayed leaves & - & 175 & - \\
\hline 363 & - & peat & - & 159 & - \\
\hline 363 & - & saw-dust & - & 155 & - \\
\hline
\end{tabular}

Some valuable experiments on farm-yard dung, compared in various proportions with other manures, applied to potatoes and oats, were made by Arthur Young, of which the following was the result :-

"In the last week in March, 1787," he says, "the white champion potato was planted in beds, each containing a square perch of a good sandy loam, on a wet clay marle bottom, the sets being planted one foot apart.

\begin{tabular}{|c|c|c|c|}
\hline & & $\begin{array}{l}\text { Quantity per Acre } \\
\text { of Mauure. }\end{array}$ & $\begin{array}{l}\text { Produce in Bushe's } \\
\text { per Acre. }\end{array}$ \\
\hline Soil simple - & - & - & 180 \\
\hline Farm-yard dung & - & 16 cubic yards & 240 \\
\hline - & & $21-$ & 200 \\
\hline 一 & & 32 & 250 \\
\hline - & & - & 400 \\
\hline 一 & & - & 360 \\
\hline - & & - & 400 \\
\hline Soot - - & - & 160 bushels & 360 \\
\hline Wood ashes - & - & $160-$ & 240 \\
\hline
\end{tabular}

"At the same time, and on the same ground, 12 square perches were planted with the same potatoes, and manured as described in the following table, which also gives their respective products.

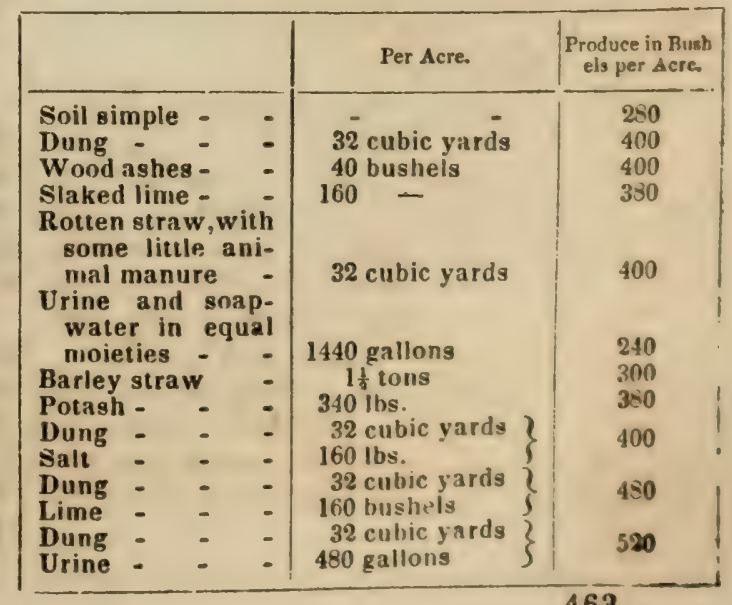


"The great product," adds Young, "which attends the addition of urine to dung, affords a very important lesson; which is, to manage dunghills in such a manner as to save, if pos. sible, every drop; this is a point too much neglected, and, indeed, by most common farmers very little attended to." (Annals of Agr. vol. ix. p. 652.)

A rood of a poor blue pebbly gravel, which yielded turnips in 1770 , in June, 1771, was marked in spaces for manures, each of two square perches, by Arthur Young, and sown with oats.

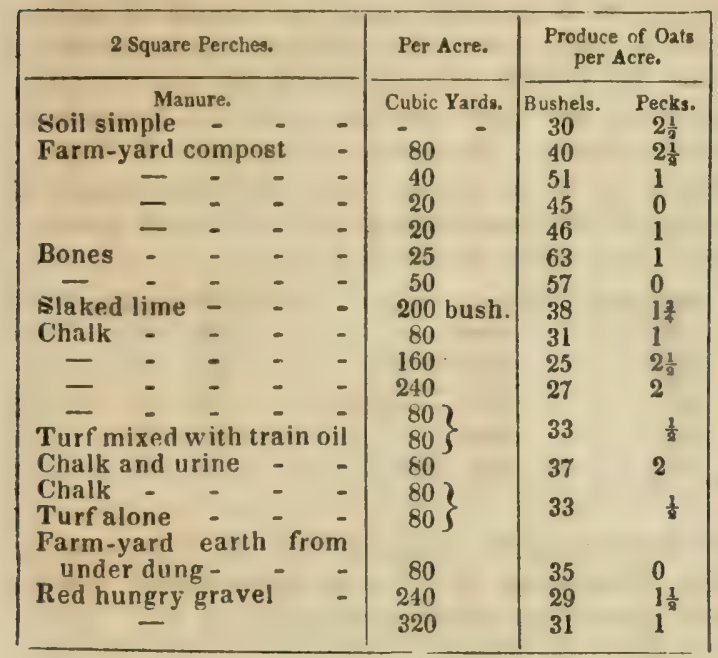

"I observe," adds Young, " that dung in general much exceeds all the manures but bones, the superiority of which is very remarkable. (His following remarks show how little was then known of bones as manure.) It is a manure not uncommon in this neighbourhood; all are brought from London, where are people who make it their business to collect them and break them in small pieces for those who boil them for the grease : this operation, one would suppose, would leave them of not much value, but the contrary is the fact. When I found, by this and other trials, that their effect was so very great, I bought all I could get; the price 10s. $6 d_{\text {. a }}$ wagon-load, at London 96 bushels, which by the time they were on the farm (for I generally went on purpose for them) amounted from $25 s$. to $30 \mathrm{~s}$. a load. Five-and-twenty cart loads in this trial being superior to 50 , was owing to the latter quantity being too great a dressing. For this miserable soil, which with a summer fallow yielded but 30 bushels, to produce 63 by a moderate manuring of bones, shows their amazing effect.

"The advantage of using fresh long dung," adds Arthur Young, "appears very strong; nor can any thing be clearer than the benefit of retaining the drainings of the dunghill. The lime without mixture appears to more advantage than it has generally done with me; but even here, in the profitable view, it has done nothing." (Ann. of $A g r$. vol. iii. p. 67-77.)

The turf composts have nothing decisive in their effect. The urine appears to have the superiority. $\Lambda$ portion of the same soil was planted wit? potatoes: the following table gives the result:

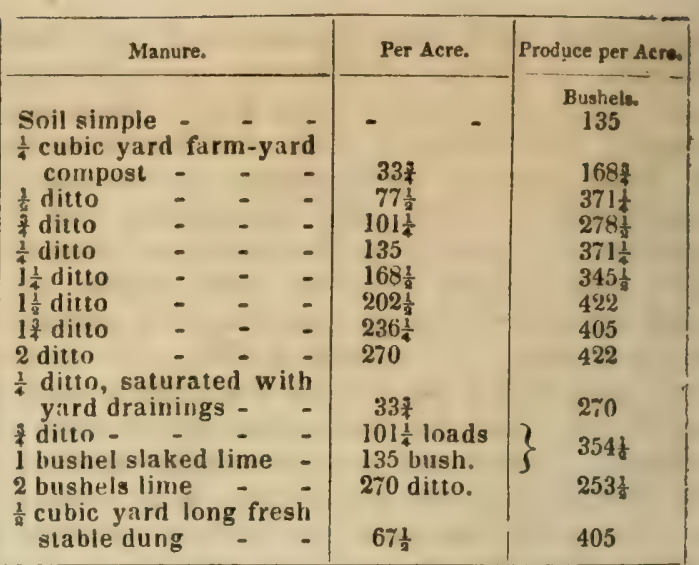

As manures are often applied in cubic yards, it might be well for the farmer to know the respective weight of various measures of manures. (Farmer's Mag. vol. xiv. p. 102).

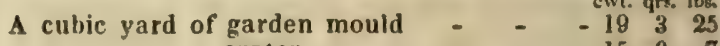
cwt. qrs, $1 \mathrm{bs}$ - water -
compost of dung, with weeds
and lime, which had been
once turned over in 9 mos. 140
new dung

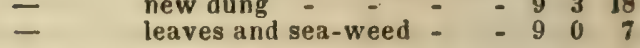

There have been many excellent suggestions for the improvement of farm-yard manure. The late Mr. Blakie published an excellent essay, of which I have largely availed myself. Mr. Kirk, of Preston Mains (Quart. Journ. of Agr. vol. viii. p. 483), has suggested that the straw produced by different soils should be kept separate, and, when made into manure, applied to different soils. Mr. Pearson has very properly (Quart. Journ. of Agr. vol. ix. p. 299), condemned the careless way in which farm-yard manure is often flooded with the rain water from buildings, \&c. Mr. Baker is an advocate for using farm-yard manure in its freshest state. (Quart. Journ. of Agr. vol. vii. p. 584, and ix. p. 597.) Mr. W. Sim has reported several comparative experiments at Drummond, in Ross-shire, with barley. The soil a good deep loam on a gravelly subsoil; the previous crop, peas. (Journ. Royal Agr. Soc. vol. i. p. 419.)

\begin{tabular}{|c|c|c|c|c|}
\hline $\begin{array}{l}\text { Kind of } \\
\text { Manure. }\end{array}$ & $\begin{array}{c}\text { Quantity per } \\
\text { Scuech Acre, } \\
\text { equal to I I-4 } \\
\text { English. }\end{array}$ & $\begin{array}{l}\text { Produce o } \\
\text { Grain per } \\
\text { Acre. }\end{array}$ & $\begin{array}{l}\text { Weight } \\
\text { per } \\
\text { Bush. }\end{array}$ & $\begin{array}{l}\text { Straw per } \\
\text { Acre, in } \\
\text { stones of } \\
16 \text { lbs, }\end{array}$ \\
\hline & & grs, uls. ps & lbs. & st. lbo. \\
\hline manure - & 18 double $1 \mathrm{ds}$. & 811 & 53 & 2268 \\
\hline Rape dust - & $10 \mathrm{cwt}$. & $\begin{array}{lll}7 & 3 & 0\end{array}$ & $51 \frac{1}{8}$ & 2528 \\
\hline Bone dust - & 10 bushels & 752 & 53 & 21114 \\
\hline $\begin{array}{c}\text { Nitrate of } \\
\text { soda }\end{array}$ & 140 & 75 & $52 \frac{1}{2}$ & 2130 \\
\hline Saltpetre - & $140 \mathrm{lbs}$. & 6.2 & $52 \frac{1}{4}$ & 1560 \\
\hline
\end{tabular}

A treatise recently published at Lowell, Massachusetts, by Dr. S. L. Dana, under the title of "Muck Manuai," contains much highly interesting matter relative to the preparation and qualities of farm-yard and other kinds of manures.

FARRIER (Fr. ferrier; Lat. ferrarius). A person who forges horses' shoes. As the errors committed by ignorance in this art were the cause of many diseases in the feet of horses, it naturally followed that farriers were resorted to for the cure of them. Hence the whole of the diseases of these animals came by degrees 


\section{ARRIERY.}

to be treated by farriers, who are, however, now superseded in England by a more enlightened class of veterinary practitioners.

FARRIERY. The art of preventing, curing, or alleviating the disorders to which horses and cattle are subject. The practice of this useful profession in England was, until within the last half century, almost entirely confined to a class of men who were utterly ignorant of the anatomy and physiology of the horse, \&c., and the general principles of the art of healing. Their prescriptions were as absurd as the reasons they assigned for administering their boluses and drenches. But the establishment of a veterinary college, and a better educated class of persons having taken up the profession, has created a new era in veterinary science.

FARROW. A sow is said to farrow when she brings forth pigs; and the pigs brought forth are called a litter or farrow.

FAR'THING-BOUND. A provincial term for a stoppage or obstruction in the intestines of the cow.

FAR'THING-DALE. The fourth part of an acre of land, now generally called a rood. It is sometimes witten farding-dale.

FAT (Teut. vet; Ice. feits; Sax. $\approx$ ). An anctuous, solid substance, or, more properly, a concrete oil, deposited in little membranous cells in various parts of animal bodies. It is generally white or yellowish, with little taste or smell, and varies in consistency according to the relative quantities of stearine and oleine which it contains. Goats' fat, besides these principles, contains also hircine, to which it owes its peculiar smell. Different kinds of fat liquefy at different temperatures. Lard is softer than tallow, melts at $97^{\circ}$; but the fat extracted from meat by boiling requires a heat of $127^{\circ}$. The ultimate elements of animal fat are the same as those of vegetable oils. According to the analysis of Chevreul, 100 parts of human fat are composed of 79.0 carbon, 11.4 hydrogen, and 9.6 oxygen. Hog's lard and mutton suet are very similarly constituted. Fat is insoluble in water, alcohol, and ether. The strong acids dissolve, and gradually decompose it. With the alkalies it combines and forms soap; hard with soda, and soft with potassa. Fat serves to defend the muscles and bones against cold, to temper the acids of aliments, and to invigorate and support the whole frame.

FAT HEN. A provincial name for the wild spinach (Chenopodium album), commonly called in the United States Lamb's-quarter, and sometimes Goose-foot.

FATHOM (Sax. jaerem). A measure of length containing six feet or two yards; chiefly used for measuring the length of cordage and the depth of water and mines.

FEATHER-GRASS (Stipa pennata). This is a doubtful native; it is found sometimes on dry, mountainous rocks. It is a perennial, flowering in June. The root is fibrous; stems a foot high, covered with dense tufts of long, narrow, acute, dark green, roughish leaves; sheaths striated and very long; stipules oblong, obtuse; flowers in panicles, simple, erect, six to seven flowers; awns nearly a foot long. At the time of flowering, the produce per acre from a heath soil was $9528 \mathrm{lbs}$, dry produce 3454 lbs., nutritive matter 409 lbs. This pro duce was taken from a heath soil that had been planted with the grass, for the wild seed does not vegetate; but it may be propagated to any extent by parting the roots. Its agricultural merits appear to be so inconsiderable as to rank it among the inferior grasses. 'T'he beautiful feather-like awns which terminate the larger valves of the blossom, and adhere to the seed, serving as a sail to waft it from rock so rock, have procured it a place in the flowergardens of the curious, and serve to distinguish it from all other grasses. The feathered awns are sometimes worn by ladies instead of feathers, which they resemble. The seed is ripe about the middle of September.

Nuttall describes several American species of feather-grass, which abound in some of the warmer portions of the United States and Territories. One species, the Juncea, grows very commonly on the grassy plains of the Missouri, as well as the Stipa Virginica, both being very troublesome when in seed, adhering by the sharp stipe to every thing which comes in their way. Not a single species is useful in agriculture. In Barbary and Upper Louisiana they appear in many places the prevailing herbage, communicating to the desert plains the colouring of harvest, called payjonal by the American Spaniards. (Nuttall's Genera.)

FEATHERS (Sax. fooen; Germ. federn). A general name applied to the exterior covering or plumage of birds, and by which they are enahled to fly. Feathers vary in form, size, and function in different parts of the bird, and have accordingly received distunct names in ornithological science. The quill part consists of coagulated albumen. Great quantities of goose and other feathers are annually imported into England from the north of Europe, which, however, are insufficient for the demand; hence poulterers dispose of vast numbers of the feathers of other domestic poultry, all of which are much inferior to those of geese. The feathers, after they are plucked, are generally dried in an oven. Notwithstanding every apparent caution, the feathers will frequently be found to be tainted, either from carelessness in plucking, or by neglecting to attend to them afterwards. In this case, the only method to render them sweet is to boil them a few moments in stout calico or canvass bags in a copper, and afterwards dry them in the open air. In about a fortnight, if the weather be fine, they will become perfectly sweet and ready for use

FEBRIFUGE (Fr.) In farriery, such medicines as are beneficial in cases of fever. See Fever.

FEED (Sax. feoan). The quantity of cats. or grain given to a horse or other animaı at one time. It also signifies to fatten animals, as cattle or sheep.

FELL. The skin or hide of an animal.

FELLING TIMBER. The act of cutting down trees for the purposes of timber. This term is only used in respect to full-grown trees, and is never applied to young trees nor to bushes, underwood, or hedges. Much has been written respecting the proper season for felling trees; some arguing in favour of mis 4 fis 
winter, and others in favuur of midsummer. The question principally turns upon the quantity, and the value of the soft or outer wood in the trunk of the tree to be felled, known by foresters and carpenters as the sap-wood. As this sap, or outer wood is the only portion of the trunk in which the sap or juices of the tree now, it is evident that if no value be set upon it, the tree may be cut down at any season; because the truly valuable part of the trunk, the mature timber, is impermeable to the sap in its ascent through the soft wood, and is therefore in the same state at every season of the year. On the other hand, where much value is attached to the soft or outer wood, where this outer wood is to be made as valuable as possible, or where, as in the case of comparatively young trees, the greater part of the trunk consists of sap-wood, felling ought to take place when there is least sap in the course of ascending. This season is without doubt mid-winter, which, all other circumstances being equal, is unquestionably the best season for felling timber; the next best being midsummer, when the sap is chiefly confined io the young shoots, the circumference of the soft wood and the bark. The worst time for felling timber is the spring, just before the developement of the buds, when the tree is fullest of sap, and receiving constantly fresh supplies from the root; and in autumn, immediately before the fall of the leaf, when there is a superabundance of sap, from its being as it were thrown out of employment by the falling of the leaf. In general, all the soft woods, such as the elm, lime, poplars, willows, \&c., should be felled during winter: hard woods, like the oak, beech, ash, \&c., when the trunks are of large size, and valued chiefly for their heart wood, may be felled at any time. When the bark, however, is to be taken into consideration, as in the oak, the tree should be felled in spring, as then the bark contains four times the quantity of astringent matter to that felled in winter. See Timber and Woons. (Brande's Dist. of Science.)

FELLMONGER'S POAKE AND CLIP. PINGS. Poake is the waste arising from the preparation of skins, and is compounded of various proportions of lime, oil, and hair. It is commonly used as a manure, in the state of compost with earthy substances, and sometimes, when it is thought expedient to increase the powers of farm manure, also with stable dung. The clippings are the parings and scrapings of the skins. When ploughed in upon a summer fallow for wheat, these clippings have been found highly serviceable to deep loamy land, and to strong soils which are not too wet, for they not only produce a full clean grain, with a bright straw, but the bulk of the crop is also greatly increased. Care should, however, be taken to cover them well with the soil, for if left near the surface, the putrid effluvia, which they soon emit, attract the crows ir. swarms, and great quantities are thus ost out of the ground. From thirty to furty bushels per acre is the usual quantity applied; the price varies in different places from $4 d$. to $9 d$. per bushe'. heaped loose. (Brit. Husb. vol. i. p. 423, 424.)
FELLY. $\Lambda$ provincial word meaning .o break up a fallow. It also signifies a part of a wheel.

FELON, or FETLOW. In farriery, a term for a sort of inflammation in animals similar to that of whitlow in the human subject.

FELT. A kind of stuff formed of fur wool alone, or of a mixture of these articles with camel's hair, which are blended into a compact texture used principally in the manufacture of hats. Hare and rabbit's fur, wool and beaver, are the chief materials used; they are mixed in proper proportions and lossed about by the strokes of a vibrating string or bow, till they become duly matted together. Felt strongly compressed is now used as cloth. It has one advantage over woven cloth, it does not become threadbare by use.

FEN. The name of a distemper to which hops are subject. It consists of a quick growing mould, or moss, which spreads itself with much rapidity, and occasions great injury.

FENCE. In rural economy, is any kind of erection made for the purpose of enclosing ground; as a hedge, wall, ditch, bank, paling, \&c., or any continuous line of obstacle interposed between one portion of the surface of land and another, for the purpose of separation or exclusion. The kind of obstacle or material differs according to the animals which are to be separated, excluded, or confined, and the nature of the soil and situation. In the early state of husbandry, fences were little known or wanted, except in particular places, as near houses or yards. The introduction of fences into agriculture was about as great an improvement in the progress of that art, as that of the principle of the division of labour into the art of manufacture. The subject of fences is one of high interest to the farmer, an immense amount of whose capital is annually expended chiefly for the purpose of preventing the depredations of stock belonging to other persons. Many valuable observations on this topic will be found in various American agricultural periodicals.

FEN LANDS, or FENS. Boggy or marshy lands, the subsoil of which is constantly in a state of saturation with water, and the surface liable to be overflown by rivers or streams during spring or autumn. The soil of these lands is generally black, light, and rich to the depth of two or three feet; and as the surface water readily filtrates through this soil to the subsoil, fen lands generally produce, when properly drained and cultivated, bulky crops of grass and corn. As they have very seldom any natural outlet for their drainage, this is usually performed by machinery; and when this is the case fen lands are more productive. (See Draining and Wanping.) The principal fens in England are those of Lincolnshire. Cambridgeshire, and the adjoining counties, a very full account of which will be found in M'Culloch's Geogr. Dict., art. "Bedford Isevel." (See also Erit. Husb. vol. i. p. 466-469. "On the Course of Cropping in the Fens," vol. ii. p. 107.) Fens generally abound with saline plants, which are very nourishing to cattle. See Innigation.

FENNEL, COMMON (Meum foniculum, Smith). This is a well-know' n hiennial planh 
cultivated in our kitchen gardens as a garnish. It is likewise used as a domestic medicine. The taste and aromatic qualities of the garden fennel are well known. The sweet and warm seeds are a common carminative for infants.

FENNEL, SWEET (Frniculum dulce). This species of fennel is an annual plant, a native of Italy and Portugal, where it is cultivated as a pot-herb, as well as for the seeds and the oils which these afford. It is a smaller plant than the common fennel. The stem is somewhat compressed at the base. The fruit is much longer than that of the common fennel, being nearly five lines long, less compressed, somewhat curved and paler, with a greenish tinge. The turions are also sweeter and less aromatic, and the fruit (seed) has a more agreeable odour and flavour.

The fruit is imported, and affords the oil of fennel and the fennel water of the druggists. Both are useful in flatulent colic ; and the latter is a pleasant vehicle for administering other medicines to children.

FENUGREEK (Trigonella, Fænumgracum). Fenugreek is a species of trefoil sometimes cultivated in fields for its seed; but it yields a very uncertain crop, owing to the variable nature of the weather in England. The stem is a foot high, erect, with round branched stalks, trifoliate leaves, toothed; the flowers small and white; the fruit a sessile, straight, erect, some curved, acuminate, flat pod ; containing a number of yellowish seeds having a strong, disagreeable smell, and an unctuous, farinaceous, and somewhat bitter taste. These seeds are very emollient, and useful in cataplasms and fomentations.

FENUGREEK, RUSSIAN (Trigonella ruthenica). A hardy perennial native of Siberia, blowing yellow papilionaceous blossoms in July and August. It loves a strong loamy soil, and an open situation. It is propagated either by parting the roots in spring, or from seed.

FERMENT (Lat. feroeo, I boil). Any substance employed to raise or produce fermentation when mixed with or applied to another. Ferments are therefore either such substances as are naturally present in the vegetable juice, as in the grape and apple: or are added, as in the manufacture of beer and bread, where yeast and leaven constitute the ferment. Fermentation is met with in fermenting liquors of different kinds, as wine and beer, and the froth or head thrown up by them, and its principles are contained in the newly expressed saccharine juices of various summer fruits.

Ferments are of an albuminous and glutinous character; and the presence of nitrogen seems essential in their composition.

FERMEN'TATION. When certain vegetable substances are dissolved in water and subjected to a temperature of $65^{\circ}$ to $85^{\circ}$, they undergo a series of changes which terminate in the production of alcohol or spirit; these changes constitute the phenomena of vinous fermentation. Sugar and some ferment are essential to the process, and during the formation of the alcohol the sugar disappears, and carbonic acid is more or less abundantly evolved. The simplest case of fermentation is that of must, or of the expressed juice of the grape, which, when exposed either in close or open vessels to a temperature of about $70^{\circ}$, soon begins to give off carbonic acid, and to become turbid and frothy; after a time a scum collects upon the surface, and a sediment is deposited; the liquor which had grown warm gradually cools and clears, loses its sweet taste, and is converted into wine. The chief component parts of must are water, sugar, inucilage, gluten, and tartar (bitartrate of potassa). During the fermentation carbonic acid escapes, the sugar disappears, and with it the greater part of the mucilage: the gluten chiefly forms the scum and a portion of the sediment; and the tartar originally in solution is thrown down in the form of a coloured deposit. Sugar and water alone will not ferment; the ingredient requisite to the commencement of the change is the gluten, which absorbs in the first instance a little oxygen from the air, becomes insoluble, and induces the subsequent changes. The reason why grapes never ferment till the juice is expressed, seems to depend upon the exclusion of air by the husk or membranes. In beer the alcohol is derived from the sugar in the malt. When wine is exposed to air and a due temperature, a second fermentation ensues, which is called the acetous fermentution, and which terminates in the production of vinegar. During this process oxygen is absorbed, and more or less carbonic acid is evolved; but the apparent cause of the formation of vinegar is the abstraction of hydrogen from the alcohol, so as to leave the remaining elements in such proportions as to constitute acetic acid. Thus alcohol is theoretically constituted of charcoal, water and hydrogen, and acetic acid of water and charcoal only; the oxygen of the air, therefore, converts the hydrogen of the alcohol into water, and so effects the change into vinegar. See Accoнor and Brewing. (Brande's Dict. of Science, \&c.)

To illustrate these facts let us suppose that the following substances are put together to undergo fermentation:-300 parts sugar, 600 parts water, 60 yeast; - the produets will be 771.5 parts of weak spirit, of which 171.5 is alcohol of spec. grav. $0.822 ; 94.6$ carbonic acid, which flies off and carries with it 41.9 of water, 12 nauseous residue, and 40 residual yeast.

Or it may be illustrated in reference to the formation of the alcohol and the carbonic acid, which are the only real products of vinous fermentation, by the changes which take place in the chemical components of the sugar. If we take 162 parts of sugar, and 18 of water, regarding any yeast employed as merely the means of commencing the fermentation, the product should be 92 of alcohol and 88 of car: bonic acid-

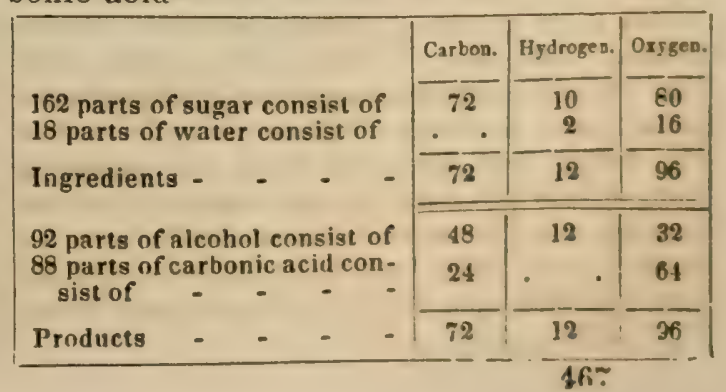


Thus we see that the 72 parts of carbon of the sugar is divided between the alcohol and the carbonic acid; that the whole of the hydrogen both of the sugar and the water enter into the composition of the alcohol, and only 32 parts of the ogygen of the sugar, and none of that of the water. Fermentation, therefore, effects merely a change in the distribution of the components of the bodies subjected to its action; the yeast or ferment being the agent which effects these changes without itself entering into the products resulting from theia. The yeast, if added, remains as residual matter, but where no yeast is required, that substance is one of the products of the process.

But this is only that species of fermentation which is denominated vinous. If the fermentation proceeds beyond the point which has been described, such changes, as already stated, take place; and vinegar or acetic acid is generated, and the process is then termed acetous fermentation. A third kind of fermentation also follows in most vegetable matters, namely, the putrefactive, in which there is a large production of gases, and vegetable mould or humus. In general parlance, however, the term fermentation implies either the vinous or the acetous fermentation.

FERMENTED LIQUORS are those liquors obtained by the process described in the preceding article. See also Befr, Cider, Wine, Arconot, \&c. All liquors which have undergone the vinous fermentation are considered as great antidotes to putrefaction; for it has been remarked that since the custom of brewing and distilling liquors has prevailed in Europe, many of those cutaneous and putrid diseases with which our forefathers were afflicted have been less frequent and severe than they formorly were. The total abstinence from fermented liquors by the Turks is further assigned as one of the chicf causes why they are more liable to the plague and other contagious diseases, than those nations among whom beer or wine is the common beverage. (Willich's Dom. Encyc.) 'This opinion, however, is purely hypothetical.

FERN. An acotyledonous or flowerless class of weeds, of which there are many species in Great Britain. They grow chiefly in mountainous tracts of natural pasture. Fern is extremely difficult to eradicate, as the roots in deep soils have been found at the depth of seven or eight feet. But however troublesome this plant may prove to the industrious husbandman, it is not altogether useless. It forms a good litter for cattle, and may be used as thatch; for though inferior to many other materials, it will last ten or twelve years. It forms a good manure for potatoes, when dug into the soil; and serves for fuel, where it is plentiful, for brewing, baking, heating ovens, burning lime, \&c. The ashes, which the plant, affords in great abundance, yield potash ; anc the poor in some districts mix the ashes with water and form lye balls for scouring linen, which are a useful and cheap substitute for soap. In Norway, the dried leaves are iniused in hot water, and thus afford a wholesome and relishing food for all domestic cattle, 468 which eat them eagerly, and manage to thrive and grow fat upon them.

In a botanical point of view, it would be im. possible and useless to describe all the species of ferns in this work; we shall therefore notice particularly those only which are applicable to other uses than thatching, or the production of alkali from their ashes, or constituting manure, as they may all be employed for these purposes.

1. Male Shield Fern (Aspidium filix-mas) is a perennial, growing in woods, dry ditehes, and on shady banks. Its roots are tafted, large, scaly; its fronds or herbage are several from one root, three feet high, doubly pinnate, erect; the midribs scaly, and the leaflets obtuse, serrated, partly confluent; the masses of seminal capsules near the midrib, and not occupying more than the half of each leaftet; and the capsular cover orbicular.

The root is nauseous, and was at one time much used as a remedy for tape worm; it indeed was the principal ingredient in the celebrated remedy of Madame Nouffer, who received 18,000 francs from Louis XVI. for her secret: but since the introduction of the oil of turpentine, as a remedy for tape worm, fern root has ceased to be employed.

2. Maidenhair (Adiantum capillus veneris) is a perennial found on moist rocks and old walls near the sea. It is an elegant fern; the roots are blackish, shaggy, creeping; the fronds from 6 to 12 inches high, doubly compound; the leaflets alternate on capillary staliss, wedgeshaped, lobed, deep green, smooth, and each segment terminated in a roundish, flat scale, with the cover transversely oblong.

'This fern as well as another species of the same genus, $A$. pedatum, is employed for making the well-known syrup called capillaire, which is, when diluted with water, a pleasant beverage in fever.

3. Fir Club Moss (Lycopodium selugo). A perennial, common on the Derbyshire and Yorkshire hills, and in the Highlands of Scotland. The root is fibrous; the stem 5 to in inches high, once or twice forked, and level at the top. The leaves uniform, crowded in eight rows, lanceolate, obtuse, entire, slightly spreading; capsules on the uppermost shoots, kidneyshaped. See Cuu Moss.

The Highlanders use this ferm instead of alum to fix colours in dyeing. The root is a powerful emetic and purgative; but its action is attended with giddiness and convulsions, consequently it is dangerous.

4. Greater Rough Horsetail (Equisetum hyemale). A perennial, found in boggy woods. The root is black and variously branched; the stem 2 to 3 feet high, erect, naked, rough, branching at the top, embraced by tight whitish sheaths, black at the top and bottom; and the teeth deciduous. The fruit is in a terminal catkin, and abounds with whitish powdery seeds.

This fern is well known for its use as a polisher, owing to the flinty particles (silex) deposited in the furrows of the cuticle. It is usually imported from Holland, and is there

fore called Dutch rushes. (Willich's Dom. En cyc., Low's Prac. Agr.) 
FERN SWEET (Complonia asplenifolia) is commonly found in Pennsylvania and other Middle States, where it is most abundant on dry slaty hills; but rare elsewhere. The bruised leaves emit a strong resinous, aromatic odour; and the plant is reputed medicinal. The infusion is a popular remedy in dysentery. This is the only known species of the genus Comptonia. (Flor. Cestrica.)

FERRE'T (Mustela furo, Linn.). A useful animal, which came originally from Africa, whence it was introduced into Spain, and subsequently into England. It has red, fiery eyes; the colour of its whole body is of a pale yellow; and its length from the nose to the end of the tail is about 19 inches. The female is rather smaller in size, and produces, twice annually, from five to eight or nine young ones, after a gestation of six weeks. Ferrets are principally employed for the purpose of hunting rabbits, to which they are mortal enemies, and of destroying vermin in corn stacks and outbuildings. These animals are always kept confined in a box or cask, and fed upon bread, milk, \&c.

FERRUGINOUS SOILS. Soils which contain a large proportion of iron.

\section{FESCUE GRASSES. See Festuca.}

FESTUCA. A very extensive genus of grasses, of which the meadow fescue (Festuca pratensis) and the hard or smooth fescue (Festuca duriuscula, ve! glabra) are those of the greatest use in permanent pasture. Combined with cock's-foot or orchard grass, and some other of the natural grasses, these two species of festuca will be found well adapted for the alternate husbandry, and secure the most productive and nutritive pasture in alternation with grain crops. Sir J. E. Smith, in his Eng. Bot., observes, "that in this genus it is hard to say what may, or what may not, be a species;" and with his usual force and clearness he reduces the $F$.glauca, $F$. glabra, $F$. cambrica, $F$.duriuscula, and $F$. rubra of Hudson, Lightfoot, Withering, Winch, and StillingMeet, \&c. into one species. All these grasses vary much from change of soil and situation; the flowers are particularly apt to vary in number as well as in the length of their awns. There is one character, however (says Sinclair), which I have never found to change under any variety of culture, which is the creeping root; and this is also an agricultural distinction which is never to be lost sight of, as it always produces a specific effect upon the soil, very distinct indeed from that of the fibrous-rooted kinds. It will be sufficient, therefore, for the purposes of the agriculturist, to consider these grasses as two distinct species, the fibrous-rooted and the creeping-rooted, noting at the same time their varieties from other parts of the plant. Following the experiments instituted by Sinclair, in his valuable work on the grasses, I shall proceed to notice, seriatim, the different species of festuca, and point out their relative properties.

Festuca alopecuris.-Foxtail-like fescue grass. Root annual. Although sometimes classed as a Bromus, this grass is evidently a Festuca. From the amount of produce and nutritive powers afforded by this annual fescue, it will be found much inferior to the soft brome-grass (Bromus mollis), many flowered brome-grass B. multiflorus), and other of the annual indigenous grasses, and it does not therefore appear suitable for agricultural purposes.

Festuca bromoides.-Barren fescue grass. A pale, smooth, slender, insignificant grass of short duration, at least after it has flowered.

Festucu calamaria.-Reed fescue grass. 'This species, which is too large and coarse to possess any agricultural merits, is found in moun tainous woods in Scotland, Ire!and, and the north-west part of England. 'There is a smaller variety, with much narrower leaves sometimes met with in Scotland.

Festuca Cambrica.-Welsh fescue. This constant variety of F. rubra (see Smith's Engl. Flora, vol. i. p. 142) is readily distinguished from the $F$. ovina, and the varieties of $F$. rubra and $F$. duriuscula, by the pale green colour of the panicle and culms. Experiments tend to prove that this grass is greatly inferior to the $F$. duriuscula in the quantity and nutrient qualities of its produce.

Festuca dumetorum.-Pubescent wood-fescue grass. Root perennial, slightly creeping. 'This grass, which appears to belong to the inferior kinds, is a native of woods, where the soil is dry and sandy.

Festuca duriuscula.-Hard fescue. Pl.6, fig.g. Panicle unilateral, oblong, much spreading when in flower; florets longer than their awns; stem round, upper leaves flat, root fibrous, perennial; scarcely creeping, though sometimes throwing out short lateral shoots. Stem $1 \frac{1}{2}$ or 2 feet high, erect, leafy, striated, smooth. 'The hard fescue early attains to maturity; the culms are succulent and nutritious; it grows quickly after being cropped, and springs pretty early. From the above details, although very deficient in the weight of produce, it appears to be one of the chief of the fine or dwarf-growing grasses. This grass is most prevalent on light rich soils; but it is also continually found in the richest natural pastures where the soil is retentive of moisture, and is never absent from irrigated meadows that have been properly formed. It attains to the greatest perfection when combined with the $F$. praiensis and Poa trivialis. From its property of withstanding drought in rich natural pastures better than many other grasses, added to the merits abovementioned, this grass is entitled to a place in the composition of the best pastures, but not in any very large proportion on account of its inferior productive powers.

When cultivated on a poor silicious soil, or on a thin heath soil, the culms become very fine and slender, and promise to be valuable for the manufacture of straw hats. This grass flowers about the middle of June, and the seed is ripe late in July.

Festuca elatior, var. fertilis. Fertile-seeded tall fescue grass. This is a coarse but nutritious grass, forming sometimes a consider. able proportion of the crop of marsh lana hay. Root somewhat creeping, with downy fibres penetrating deeply into the mud or clay. Stem about 4 feet high, reedy, striated, smoth, and leafy. Panicle a foot or more in length, repeatedly compound, spreading widely. This 
grass differs from the common variety of tall fescut in having the panicle somewhat drooping; spikelets six-flowered, more ovate and flat; the larger husks of the calyx often uncovered, and the awn is fixed on the apex more in the manner of a bromus than of a fescue. Leaves smoother, and of a less dark-green colour. For damp soils, that cannot conveniently be thoroughly drained, this would be a most valuable plant, either to be cut for soiling, or made into hay, and reduced to chaff as it might be wanted. This grass (which is nearly allied to the common $\boldsymbol{F}$. elatior next to be described) perfects an abundance of seed (though not entirely free from diseased portions), and is therefore not liable to the objection which takes so much from the value of that variety. It is equally early in the produce of foliage, and the nutritive properties are about the same. It flowers early in July, and the seed is ripe in the first week in August.

A species is described under the name of floating fescue (Festuca fluitans) in Loudon's Ency. of $A g r$. and there said to be found in rich swamps, especially in Cambridgeshire, England, where it is thought to give the peculiar flavour to Cheddar and Cottenham cheese. It is also found in the ditches and ponds in most parts of England. Pl. 5, $l$.

Festuca elatior, var. sterilis.-Pl. 5, e. Barrenseeded tall fescue. This species greatly resembles the $F$. pratensis, but is larger in every respect, and flowers eight or ten days later. This is a grass admirably adapted for tenacious clay soils, and might be cultivated with advantage by the farmer combined with some of the other highly productive grasses, in such moist spots of the soil as are peculiarly suited to the growth of this species, although less fitted for the growth of proper pasture grasses. It is nutritive and very productive, and one of the first grasses in the production of foliage early in spring. The produce, like that of all grasses which yield a great weight of crop, may be considered coarse when compared with the $F$.pratensis and Alopecuris pratensis; but this objection may be overcome by reducing the hay to chaff, and mixing it with cloverhay. The nutritive matter contains but little bitter extractive or saline matter, while the cluver contains an excess. In England it flowers in the second week in July; the seed is universally affected with the disease termed clavus, and consequently unfertile; it can only, therefore, be propagated by parting and planting the roots.

Festuca gigantea.-Tall fescue grass. This species is confined to woods in its natural state; but it continues in the soil, and appears to thrive equally well when cultivated in open situations. It is a coarse grass, and but little nutritive, although greatly superior to the spiked and wood fescue grasses.

Fesiuca glabra, var.-Smooth fescue. Pl. 6, $h$. Panicle branched, upright, compact; spikelets spear-shaped, 4-6-flowered, smooth, awned; root fibrous; perennial. This grass is nearly allied to the $F$. duriuscula and $F$. rubra. According to Sir J. Smith, it is a variety of the last-named. From the trials made with this grass, it seems to be inferior both in produce and nutritive matter to the $\boldsymbol{F}$. duriuscula, but is superior in regard to early produce, and the herbage is uncommonly fine and succulent. 'These merits, however, appear hardly suffcient to compensate for the deficiency of produce. If it be compared with some of the early grasses, Anthoxantum adoratum, for instance, it will be found superior in nutritive matter in the proportion of about one-third. While this grass cannot be recommended in preference to the $F$. duriuscula, yet, among the fine-leaved fescues, it will be found the best substitute for that species when wanting.

Festuca glauca.-Glaucus fescue grass. This is a native of alpine situations, but thrives better when culnivated on lower ground than most other species having the same origin. Although its merits do not appear sufficiently great to entitle it to a prominent place among the superior grasses for light soils, yet its hardy and nutritive nature, and property of forming a thick turf, prevent it from being altogether rejected as of no value. It flowers in the second week of June, and the seed is ripe about the first week of July.

Festuca loliacea. Darnel-like fescue grass. Pl. 5, $f$. Spike two-ranked, drooping; florets cylindrical, awnless, pointed with fine slight ribs at the rop. Root fibrous, perennial. At a casual glance this grass bears a near resemblance to the Lolium perenne (rye-grass), and affects the same kind of soil; but, on a more minute inspection, the caly $\boldsymbol{x}$ or outer husk so conspicuous in the spikelets of the rye-grass, in this grass will be found almost wanting. Another mark of difference is, that in the ryegrass the spikelets are arranged so as to stand facing the spike-stall; ; while in the darnel-like fescue they stand with their back towards it. 'This grass possesses all the valuable properties of rye-grass, and few of its defects. Its produce is larger; it springs earlier and improves by age, which is not the case with common rye-grass. It would, doubtless, be the best substitute for that species in alternate cropping: but, unfortunately, it does not perfect a suffciency of seed, the flowers generally proving abortive, which renders its propagation inconvenient and expensive. In rich meadows this grass is very common, particularly where the land is periodically overflown.

Festuca myurus. Wall-fescue, Capon's tailgrass. Panicle dronping, elongater, rather close; florets tapering, shorter than their awns, rough a: the top; leaves awl-shaped; stem leafy to the very summit. It is, perhaps, the "trembling rye-grass" of poets. Root annual. "The flowers have only one stamen, which distinguishes it from all other species of fescue. This grass has great affinity to the barren fescue ( $\boldsymbol{F}$. bromoides), but the whole plant is larger and stouter, the stem clothed with leaves to the top, and the panicle four times as long. The inner valve of the blossom is fringed rowards the top; the awns are longer than those of the $F$. bromoides. This grass is found on walls, and dry, barren, sandy places. As soon as the seeds are the, they fall out of the husks, and vegetate quickly after, without any covering of earth. The plants are of the finest green colour, and retain their verdure luring the winter. 
This circumstance seems to have led to the supposition that it was a biennial grass. The seeds being numerous, the young plants form a most beautiful dark green turf, surpassing, in this respect, every other grass. But this property declines with the spring, when the growth of other grasses becomes general; and before the time of flowering it is invariably attacked with the rust, which renders its produce of small value, even were it afforded in a quantity sufficient to induce its cultivation. It flowers in the first week of July, and the seed is ripe about the last day of that month. Birds appear to be very fond of the seed.

Fcstura ovina. Sheep's fescue-grass. (Pl. 6,k.) Panicle small, erect, unilateral, rather close; florets four or five, nearly cylindrical, pointed or awned, smooth at the base and at the edges of the inner valve; stem from 6 to 12 inches high, erect, slender, rather rigid, smooth, leafy below, square in the upper part; leaves very numerous, composing dense tufts, folded, bristle-shaped; stipuløe very short and obtuse; root fibrous, perennial. The awns appear to be an uncertain character in this grass, as it is frequently awnless, and there are varieties of it having awns. All the varieties, however, may be distinguished at first sight from the $F$. duriuscula, glauca, rubra, \&c., to which it is nearest allied, by the compact though simple appearance of the panicle, which more distinctly faces one way.

Linnæus affirms that sheep have no relish for hills and heaths that are destitute of this grass. Emelin, in his Flora Siberica, also informs us that the Tartars select places for pasturage during the summer where this grass is in the greatest plenty, because it affords a most wholesome food for all sorts of cattle, but chiefly sheep. Dr. Anderson, in his Agricultural Essays, affirms that it is capable of affording an immense quantity of hay. Mr. Curtis, however, in his Practical Observations on British Grasses, very justly combats this opinion, and asserts that it is more fitted for forming grass-plats; but even for this purpose it will only succeed on soils which are nearly as dry and light as that on which it is spontaneously produced. From trials which have been made, the sheep's fescue does not appear to possess the nutritive powers usually ascribed to it. It has, however, the advantage of a fine and succulent foliage, and may, on that account, be better adapted to the masticating organs of sheep than the larger grasses, whose nutritive powers are greater. Hence it may be of some value as a pasture for sheep in situations where it grows naturally. In England it flowers in the third week of June, and ripens the seed about the last day of July.

Festuca ovina hordeiformis. Long-awned sheep's fescue-grass. (Pl. 6, i.) Panicle comract; branches subdivided, upright. Spikelets crowded, 6-10-flowered. Root-leaves threadshaped, stem-leaves very long. Root fibrous, perennial. This grass is much superior to the F. ovina, of which it is considered a variety. It flowers earlier than any of the other fescues, and appears to possess sufficient merit to entitle it to a place in the composition of the best pastures, particularly as a substitute for the $F$. dus:usculu, on soils of a drier or sandy nature. Its nutritive qualities are nearly the same as those of the $\boldsymbol{F}$. duriuscula, but it is superior to that species, and to most others, in the produce of early herbage in the spring; and the herbage is very fine, tender, and succulent. The culms are well adapted for the manufacture of the finest straw plait, being very distant in the joints, and of an equal thickness through out. In England this grass flowers in the last week of May, and the seed is ripe in June.

Festuca pinnata. Spiked heath fescue-grass. This grass grows chiefly in dry, hilly wood. lands, particularly where the soil is calcareous. It cannot as yet be considered in any other light than a noxious weed; for, though the weight of the produce is considerable, it is neither early, nor nutritive, nor relished by cattle. This, and the $\boldsymbol{F}$. sylvatica, which is also an inhabitant of woods where the soil is silicious, may be considered the least useful of the British grasses. It flowers about the third week of July, and ripens the seed late in August.

Festuca pratensis. (Pl.5,d,d.) The meadow or fertile fescue-grass. Panicle nearly upright, branched, spreading, turned to one side; spilelets linear, compressed; florets numerous, cylindrical, obscurely ribbed; nectary fourcleft; root fibrous, perennial.

Dr. Withering makes this grass a variety of the $F$. elatior; but it is more justly made a distinct species by Sir J. E. Smith. It differs from the $F$. elatior in being only half as high, the leaves only half as broad, and the panicle shorter, and containing only half the number of flowers. The panicle is but once branched, droops but slightly, and leans to one side when in flower, and the flowers grow all one way. In the elatior the panicle branches both ways, it droops much at first, and the flowers grow more loosely; the spikelets are rounder, ovate, and pointed, while in the pratensis they are somewhat linear, flat, and obtuse.

The $F$. pratensis is eaten by horses, cattle, and sheep, which are all very partial to it. In point of early produce in the spring, this grass stands next to the meadow fox-tail (Alopecurus pratensis), and is superior in this respect to the cock's-foot.

The meadow fescue constitutes a very considerable portion of the herbage of all rich natural pastures and irrigated meadows; it makes excellent hay, and though a large plant, yet the herbage is succulent and tender, and much relished by cattle, as it does not form rank tufts like the larger grasses. Although essential for permanent pasture, yet this grass is not by itself very well adapted for the alternate husbandry, but should be combined with cock's-foot, rye-grass, and rough-stalked meatdow-grass. The $F$. pratensis is not so abundant in the deep alluvial soils of Lincoln as in the clay districts. In the vale of Aylesbury it constitutes a considerable portion of the mist valuable and fattening pastures of that rich grazing district. Mr. Taunton's experience of this grass, grown on a stiff, clayey soil, proved that a copious crop of seed-stalks may be ob tained the second year from sowing. In Ergland it flowers in June, and ripens the seed late in July or early in the following month. 


\section{FESTUCA.}

Festuca rubra. Creeping or purple fescuegrass. There are two varieties of this species; one with narrow bristle-shaped root-leaves, and the other with broader leaves. It has much affinity to the $\boldsymbol{F}$. duriusrula, from which it is however distinguished by the leaves, which are broader and longer, and the branches of the panicle are also songer.

The creeping fescue has no sufficient merit over those species it resembles in habit to compensate for the impoverishing effects of its roots to the soil.

Festuca sylvatica. Slender wood fescue-grass, or the wood brome-grass of some botanists. The general appearance of this grass promises but little to reward the labours of the experimentalist.

Festuca uniglumis. Single-husked fescuegrass, found on the sandy sea-coast, chiefly of Sussex; it possesses no agricultural merits, and Sinclair does not even notice it.

Festuca vivipara. Viviparous fescue-grass. The roots, leaves, and general habit nearly agree with the $F$. ovina, of which most botanists have esteemed this a variety. This grass forms a curious exception to the general law of nature in the propagation of plants by their seed. It has every part of a flower, except the two most essential ones, for its propagation, namely stamens and pistils. Yet from this imperfect flower it produces perfect plants. The rudiment of the future plant originates in the upper floret of each spikelet, and in its first stage appears like a minute globule of water, scarcely visible to the naked eye; but after the spike is developed, it gradually assumes an oblong figure, becomes pointed, and at last puts forth a single leaf, after the manner of perfect seed of grasses; other leaves succeed to this, till the weight of these (now a perfect plant of grass, except the root) forces it to fall from the spike to the ground, or bends down the spike, where it soon strikes root. This grass continues viviparous on all soils. Many other grasses are viviparous, as Alopecurus pratensis, Cynosurus cristatus, Poc alpina, Phleum pratense, Anthoxanthum odoratum, \&c.; but in these the seed is first perfected, and merely vegetates in the husk from accidental circumstances, such as grow. ing in shaded places, and from long continuance of moist warm weather.

This grass, which is natural to alpine situations, can only be propagated by parting the roots, or by planting the young plants formed in the ear. But from the trials that have been made of it, it appears to have no excellence that can recommend it to the notice of the agriculturist.

The species found in the United States, are, 1. $\boldsymbol{F}$. tenella, little, or slender fescue, frequent on dry sterile banks, and the borders of woods, a slender, wirv little plant of little or no value to the farriser, and generally confined to poor soils. 2. F. elatior, or Fall fescue, a perennial, found frequently in swampy meadows and low grounds, flowering like the former in June and July. A ccording to Dr. Darlington, this species, which he supposes to come from Europe, is a larger plant than the slender fescue, to which it is nearly allied, but not so valuable. 3. Mcadow fescue, a much more valıable grass, 472 according to Dr. Darlington, than the $F$, elatior, to which it is so closely allied that it may be doubted whether it is more than a variety. It is a naturalized foreigner that has found its way into all the best meadows and pastures of the Middle and many other States of the Union. 4. Nodding fescue (F.nutans) found in moist woodlands. It is not a grass of much value, being rather solitary in its habits, and chiefly confined to woodlands. Eight or nine additional species of fescue have been deseribed in the United States. (See Darlington's Flor. Cestrica; Nuttall's Genera.)

FETLOCK. In horsemanship, the part of the leg where the tuft of hair grows behind the pastern joint of horses : those of low size have scarcely any tuft. In working horses, which have them large with much hair, care should be taken to keep them clean, in order to prevent the grease. The fetlock-joint is a very complicated one, and from the stress which is laid on it, and its being the principal seat of motion below the knee, it is particularly subject to injury. An affection of this part should be well fomented and immediately blistered. (The Horse, p. 252; Clater's Far. p. 258.)

FETTER. A term applied to the chain used for confining the legs of animals.

FEVERFEW (Pyrethrum; from pyr, fire, the roots being hot to the taste). Of this interesting European genus of plants, the Matricaria of Linnæus, three species only are indigenous to England.

1. The common feverfew (P. parthenium), a biennial which grows in waste grounds, hedges, and walls, flowering in June or July. Root tapering, small, and white; stem erect, branched, leafy, round, many flowered, about two feet high; leaves stalked, of a hoary green, pinnatifid. Flowers numerous, like daisies, white or yellowish, in a corymbose panicle, sometimes compound, on long naked stalks, erect, about half an inch broad. The whole plant has a strong disagreeable smell, a bitter taste, and yields a volatile oil by distillation. It was formeriy reckoned tonic, stimulating, and anti-hysterical, and the oil is still regarded as such. It contains much tannic acid; and in Germany it has been usefully employed in tanning and currying leather.

2. The corn feveriew, or scentless May weed $(P$. inodorum $)$, is very common in cultivated fields, and by waysides, on gravelly soils. Root tapering, rather large, annual, flowering in August or September. Herb nearly destitute of the peculiar agreeable or disagreeable odours of its tribe. Stem branched, spreading, leafy, angular, smooth. Leaves sessile, pinnate. Flowers as in the last. The seeds crowned with a membrane, the best diagnostic character of the species.

3. The sea feverfew ( $P$. maritinum), a perennial, flowering in July or August, is found on the sea coast in sandy or stony ground. The thick, woody, long-enduring root runs deep in to the ground, producing a number of hollow stems, spreading circularly on the ground, often tinged with purple. Leaves crowded, sessile, doubly pinnate, of a dark shining green* 
cruwn of the seeds lobed; stem diffuse. Flowers not quite so broad as those of $P$. inodorum. The whole herb is slightly aromatic.

The common wild chamomile (Matricaria chamomilla, PI. 10, w, w), was formerly classed as a feverfew. The greenhouse kinds of feverfew grow in any rich light soil, and young cuttings root readily when planted under a glass. Any common soil suits the hardy kinds, which are increased by divisions or seeds. It possesses the properties of the real chamomile in a marked degree, and might be substituted for it as a medicinal agent. (Eng. Flor. vol. iii. p. 451.)

FIAR. A word of Gothic origin, applied, in the northern parts of Great Britain, to certain averaged returns of the prices of grain for the current year in the different counties, which are fixed by the sheriffs respectively, with the assistance of juries, in the month of February. When the jury has been called, evidence of the prices of the different grains raised in the county must be laid before them: and the averages struck by the jury and sanctioned by the judge are termed fiars of the year in which they are struck, and regulate the prices of all grain stipulated to be sold at the fiar prices. These fiars also regulate (where no price has been otherwise agreed upon) the contract price upon delivery for grain grown in the county. Having the prices of grain, \&c., ascertained in each county has greatly facilitated the introduction into Scotland of the practice of letting land for corn rents, convertible at the prices of the day. In England, where there are no such authentic local returns, there is great difficulty in converting corn rents into money rents, as reference can only be made to the prices of some particular market, which would be too limited a criterion, or to the kingdom at large, which, on the other hand, would be too extensive. (Bell's Law Dict.)

FIELD (Sax. Jelo; Germ. feld; Dutch. veld). A portion of land enclosed by a fence, or rendered distinct by some line of separation, and set apart either for tillage or pasture. In former times, and until within the last two centuries, almost all the land cultivated with the plough throughout Europe was unenclosed; and the term "field" was then applied, in Britain at least, to the lands under culture by the plough. Subsequently, when farmers enclosed and subdivided a portion of the lands near the farm-yard, these portions were called fields, and the more distant portion which remained open was called open field, or common field, while grass lands unenclosed were called commons. In the present improved state of agriculture, every farm is divided into fields, either simply by lines of demarcation, which are sufficient when no animals are to be grazed on the farm, or by lines of separtion which will act as fences, such as walls, hedges, ditches, \&c., where cattle are to be grazed. Each field on a farm is always known by a particular distinguishing name. Without some regular fixed division of arable lands, it would be next to impossible to conduct a rotation or succession of crops. It is interesting to observe that, as agriculture in a rude state had no fences, so this is also beginning to be the case in agriculture in its most refined form; because it is found much more advantagenus, both for the production of butcher's meat and manure, to consume the grass and herbage grown on farm-lands in farm-yards, with the single exception of that portion which is eaten by sheep; and these are now often merely con. fined to successive portions of grass and other green crop lands by light netting or hurdles, scarcely visible at a short distance. (See Fonnis. By thus getting rid, to a more considerable extent, of fences of every description, from a tenth to a fifth will be added to the contents of the greater number of corn-farms; and a very considerable first cost and annual ex. pense will be saved in planting hedges or building walls, and in keeping them in repair afterwards. (Erande's Dict. of Science, \&c.)

FIELDVOLE (Arvicola agrestis). A name of the short-tailed field mouse or meadow mouse; a species which subsists exclusively on vegetable productions; and being, like the rest of the rat tribe, extremely prolific, multiplies occasionally to such a degree, even in England, as to become the most injurious of wild quadrupeds. "After having followed the labours of the reaper, and taken their share of the harvest," the fieldvoles, says Mr. Bell, "attack the newly-sown fields, burrowing beneath the surface, and robbing the husbandman of his next year's crop, and at length, retreating to the woods and plantations, commit such devastations on the young trees as would scarcely be credible, were not the evidence too certain to be doubted. In the years 1813 and 1814 , these ravages were so great in the New Forest and the Forest of Dean, as tc create considerable alarm, lest the whole of the young trees in those extensive wood. should be destroyed by them." A timely anc assiduous attention to restraining the increase of this pernicious species, by the aid of terriers ferrets, and traps, is imperative on those whc have the charge of young plantations; but when the numbers of the fieldvole have sur passed the usual bounds, then it is recom. mended to dig holes about a foot in depth, and the same in diameter, taking care to make them much wider at the bottom than at the top, so that the animal once in canrot easily get out again. In holes of this kind, Mr. Jesse states that at least thirty thousand fieldroles were caught in the course of three or fous months in Dean Forest plantations; that num ber having been counted out and paid for by the proper officers of the forest. (Brande's Dict. of Science.)

FIG (Ficus). The genus to which the common fig tree belongs is of considerable extent; and its species are among the most noble objects belonging to the vegetable lingdom. In tropical countries the trees which vield caou:chouc (India rubber) of the finest quality belong to this species, particularly $F$. elastica. The celebrated ban-yan tree ( $F$. religwsa) of India is a kind of fig tree. It is remarkable that the common fig tree ( $F$.carica), although it produces so agreeable a fruit, is in some measure poisonous, particularly the milky juice which exudes from the leaves and the 2 r 2

473 
branches when wounded, and which is acrid to the taste. The fruit of the fig tree is of a different nature from the orange, apple, and other tleshy seed vessels; being a hollow receptacle, containing a multitude of minute flowers; the ripe fruit of which is the seed, as it is wrongly called, that is imbedded in the pulp. 'The fig is a rative of Asia and Barbary, and also inhabits the south of Europe; according to the Hortus Kewensis, it was first planted in this country in 1548. The varieties in fig countries are almost as numerous as those of the grape. 'Those held most in esteem in England are the brown chestnut-coloured Ischia, the black Genoa fig, the small white early fig, the large white Genoa fig, the black Ischia, brown and black small Italian figs, the Malta fig, the Murrey or brown Naples fig, the green Ischia, the Madonna, the Brunswick or Hanover fig, the common blue or purple fig, the long brown Naples fig, the small brown Ischia fig, the yellow Ischia fig, and the Gentile fig. According to Forsyth, the figs nroper for a small garden are the large white Genoa, the early white, the Murrey fig, the small brown Ischia, and the black Ischia. Figs may be propagated from seed, cuttings, layers, suckers, roots, and by ingrafting; the most generally approved method is by lavers or cuttings, which come into bearing the first or second year. Standard fig trees require protection during winter, and should be covered with matting, reed, pease-haulm, straw, or any other light covering.

The only orchards of standard fig trees in England are at Tarring and Sompton, near Worthing: the produce is great, and the fig: of a very superior quality. The fig has been analyzed by Bley, and found to contain the following substances, 62.5 of sugar, 0.9 fatty matter, 0.4 extractive with chloride of calcium, $5 \cdot 2$ gum with phosphoric acid, 150.0 woody fibre and seeds (achenia). Figs are nutritive and laxative. The oldest cataplasm on record was composed of figs. In the illness of Hezekiah, Isaiah said, "Take a lump of figs; and they took and laid it on the boil, and he recovered." (2 Kings, chap. xx.; Loudon's Ency. of Gard. Brande's Dict. of Science.) The cultivation of the fig has been 100 much neglected in the United States. In the Middle and more Northern States they require protection in winter. With a good soil and plenty of water in the summer the yield of this wholesome fruit is great.

FIGWORT (Srrophularia). There are, in England, four kinds of indigenous figwort, all perennial; the spccies found in the United States is called S. Marylandica, Maryland S. or Carpenter's Square: it is perennial, frequent in fence rows, woodlands, \&c. The root bruised in to the form of a poultice, is a popular application to boils and other inflammatory gatherings. One or two varieties of this plant are also met with. (Flor. Cestrica.)

FILBERT, or FILBERD (Corylus avellana, so named from Abella or Avella, a town of Campania, where the best were cultivated. Pliny, b. xv.c. 22). In England the best known varieties of the filbert are the white, the red, and the frizzled. The white is the kind most commonly grown. In the neighbourhood of
Kent many hundred acres are plantel with fil. berts, for which the county is celebrated, and whence the London market is principally supplied. When quite ripe, filberts will keep for several years in a dry room; and if the air is excluded, or the nuts placed in an air-tight jar, they will keep good and retain their flavour for an indefinite period.

In a late number of that excellent Journal, the Boston Magazine of Horticullure, \&c., there is a paper by Mr. Downing, of Newburgh, $\mathbf{N}$. $Y$., on the cultivation of this nut. From the great quantities annually imported, there can be little doubt a ready market would be found for the product of a filbert garden or orchard and the ease and certainty with which they may be grown, should recommend them to favour.

Mr. Downing recommends a soil naturally dry rather than moist, but a dry gravelly loam or sandy loam is preferable. They will suc ceed, however, in any good soil. The kinds preferred by Mr. Downing for cultivation in this country, are the Cosford, Frizzled, and Northampton prolific. There are other varieties, but these have been well tested, and will abundantly repay the grower. The cultivation of such nuts is a great object in some parts of England, and the average crop is considered about 800 lbs. per acre, though at times, when the soil and season is favourable, more than three times that quantity have been gathered.

There are two species of the filbert found in the United States. One of these (the Corylus Americana) is very commonly found in the Middle States, growing wild along the borders of thickets, fence rows, \&c., flowering in March and April. It grows to the height of 4 to 6 feet, and the nuts, which it bears very abundantly, are pleasantly flavoured, though considerably smaller than the European hazelnuts.

FILLER, or THILLER. A term provincially applied to the horse which is fastened immediately to the cart, and which supports the shafts. It is most commonly written thiller.

FILLY. A young mare, or female of the horse kind.

FILMY-FERN, TUNBRIDGE (Hymen ophyl. lum Tunbridgense; from hymen, a membrane, and phyllon, a leaf; aliuding to the leaves). The genus to which this species belongs ranks among the most elegant of the ferns; it is a native of wet mossy rocks or trunks of trees, most plentiful in tropical countries. This species is the only one of European growth, and flourishes amongst moss in watery shady places, in the rocky or mountainous parts of Great Britain, and grows in rnost parts of Europe from Norway to Italy.

FIN. A term applied to the sharp or cutting plate, fixed upon a sock or coulter of a plough. It is also a provincial name for tho troublesome weed called Rest-harrow.

FINCHED, or FINCHBACKED. A term signifying streaked with white in cattle.

FINGER GRASS, COCK'S-FOO'T (Digitaria sanguinalis, from digilus, a finger; the head is divided so as fancifully to resemble fingers). Pl. 7, $f$. This must not be confounded with the Dactylis glomerata, cock's-foot or orchard grass. 
It is an uninteresting native wild grass, found in sandy cultivated fields, in England, but not common; like all other plants it is variable in its places of growth. Leaves broad, pointed, striated, wavy at the edges, besprinkled, like their long swelling sheaths, with little warts, many of which bear bristly hairs. Flowers in pairs, dark purplish, erect.

FINGERS AND TOES. The common name for a disease in turnips. See Anbunr.

FIORIN GRASS. A name under which a variety of the longer leaved creeping bent (Agrostis vulgaris, or stolonifera, var. latifolia) was introduced about 27 years ago by Dr. Richardson, of Clonfeale, in the county of Tyrone, Ireland. (Pl. 5, n.) That gentleman laboured with great zeal, by his writings and practice on a large scale, to prove the superiority of this grass over every other for meadow purposes. One of his modes of propagating fiorin was to plant the stoles of the grass, which are as vivacious as those of couch grass, on fallow ground, and thus create a meadow; but his favourite and most expeditious system was to encourage its spontaneous growth on alluvial and flat peaty ground. Unquestionably Dr. Richardson did exhibit extraordinary crops of fiorin on the level surface of denuded and cut-out bog land of little value, and for several years mowed enormous crops. Fiorin, being one of the indigenous grasses of Ireland, especially on peaty soil, is seen abundantly on the black shallow bogs which have been drained in any degree, and particularly on the margins of pools and ditches. Cows relish it much if it be not soured by stagnant water, and yield milk abundantly when fed upon it. However, though it has produced from six to ten tons per acre when top dressed and preserved from the poaching of cattle, the attempt to keep any land under the occupation of this grass for meadows, to the exclusion of all others, has been totally abandoned. Two great objections to fiorin are, the difficulties of mowing it, as it lies flat and entangled, and of saving it at the very late season when it is ripe, for the scythe. Some writers very erroneously describe the Agrostis alba as fiorin; and add, "it sometimes passes under the name of black couch grass." I am surprised that any person of experience should mistake fiorin for black couch grass (though the Woburn reports make a similar remark), to which it scarcely bears any resemblance, and from which in some respects it is essentially different. Fiorin is a soft silky-like grass, with a very narrow or linear leap, and, although rough on both sides, yet not creeping, throwing out roots .with its joints under the surface: it is very easily pulled out, and has not those knotted and vivacious roots which characterize black couch. The varieties may sometimes be mistaken for one another, but the different species have always some broad distinguishing marks of difference. As it is of great importance to the farmer to be able to distinguish fiorin from the other species of bent grass, which are unprofitable and pernicious weeds, I will here point out a few distinguishing characteristics. In fiorin the body of the seed is covered with the husks of the blossom, which do not open : it is
cylNdrical, but tapers to a point at each end. The seed of the clayey couch grass ( $($. alba) is very slender and smooth, one half the size only of the fiorin, and more slender than the A. vulgaris. The seed of the $\mathcal{A}$. canina is furnished with a jointed awn of a brown colour, which readily distinguishes it from the other species. There is an awnless variety of the $A$. canina which is distinguished by being shorter and more plump than the fiorin of the clay couch bent. The seed of the $\mathcal{A}$. fusicularis is not one-third of the size of that of the fiorin, more rounded at the bottom, and of a light straw colour. The $\mathcal{A}$. palustris has seed about one-fifth shorter than that of the fiorin, of a lighter brown colour, and more plump and rounded. The variety of fiorin called arestata has an awn which distinguishes it at once from the seed of the more valuable variety. The distinguishing characters of the different species of agrostis are well set forth in the late Mr. G. Sinclair's valuable work on grasses; but it would rather tend to perplex than inform were I to attempt any further notice, which must necessarily be a mere abridgment. See Agrostis. (Hort. Gram.Wob.)

FIRE-BLAST. A term of very doubtfal meaning, like the word blight, but generally implying an accident to which hops are very liable: it usually occurs in the month of July, and sometimes scorches up whole plantations from one end of the ground to the other, when a hot gleam of sunshine has come immediately after a shower of rain; while at others it only affects them partially, or in a particular portion of the plant. When the lower leaves of hops are shrivelled up and unhealthy, they are said to be fire-blasted. This is stated to arise from the want of sufficient nourishment in the root, the whole supply of the sap juice being required to complete the growth of the hops on the top of the pole, but little can return to the lower leaves: this is particularly observable when the hops are ripening, on those hills which have too long a pole put to them. (Brit. Husb. vol. ii. p. 354; The Hop Farmer, p. 89.)

In the United States, the term fire-blast is generally used to designate that destruction so often witnessed in the branches of the apple, and especially the pear tree. For the discovery of the cause and remedy for this blast or blight, agricultural and horticultural societies have offered the highest premiums, which as yet have never been awarded.

FIRES. Sax. Fyn. In England, the legislature has wisely afforded very considerable facilities to the insurance of farming stock. "The Farmer's Insurance Institution" insures it at $1 \mathrm{s.} 9$. per cent., without the average clause; thus easily repaired are the ravages of the incendiary, of accidental fires, and lightning.

Causes of Fire. Mr. J. Murray has recently published a letter in a Liverpool paper on the frequency, causes, and prevention of fire, which contains many facts well worthy of attentive consideration. Among other observations, he says:

"There is far too little attention paid to the locomotive engine on our railroads. The ignited coals that fall below are often blown to considerable distances, carried into the adjoin. 
ing fields, and may, in contact with farming stock, prove a serious evil; and I have witnessed brushwood and tufts of grass consumed by this means. A green taper, coloured as it is by means of oxide of copper, when blown out, acts on an aphlogistic principle, and may continue to the end of the coil in an ignited though flameless state, and, in contact with combustible materials, may prove seriously destructive. It has set a mahogany table on fire-providentially discovered in time. Damp rags, en masse, may spontaneously take fire, and have consumed the premises. Linseed and other oils, but especially that of linseed, have been the fruitful sources of conflagration in cotton factories and the warehouses of the merchants. Nets dipped in oil, and cast over the rafters in an outer shed, set them on fire; and a bale of cotton wool burst into a flame from linseed oil being poured upon it. Even animal matters, such as woollen, under such circumstances, come within the precincts of danger, I find that strong red fuming nitrous acid will set fire to straw; and an accident of this kind once occurred to myself. The vapour of sulphuric ether, instead of being volatile, and ascending, as is generally supposed, falls to the ground like water; and accidents in the laboratory and shop of the druggist, from ignorance of this fact, are by no means unfrequent. I am personally acquainted with three distinct cases, wherein the premises were set on fire originating in this source. Specks or bull's eyes in window glass may, on the principle of burning lens, ignite inflammable substances brought within the limits of their focus; hence the curtains used in some factories may be easily ignited: thus, too, a water-bottle left in a window may in sunshine be the means of setting premises on fire, especially in a house shut up during the absence of the family; and I have seen a silk curtain consumed to tinder by the concentrated rays of the sun, in passing through the show-bottle in the druggist's window. Spirits of turpentine will inflame if poured out in the hot sunbeam; and I am informed by the distillers of tar and turpentine that the head of the still cannot be safely removed for 30 hours after the fire has been extinguished, as an explosion might be otherwise anticipated. Lucifers, or Congreve matches, are one of the fruitful sources of fires. Those that are called Dutch, containing phosphorus, and having a very fotid phosphoric smell, are exceedingly dangerous: they may ignite spontaneously at the temperature of summer heat; and it may now suffice to say that a recent conflagration has been traced to this cause. The cigar and the pipe are pre-eminent sources of modern conflagration; and I have no doubt that of the seat of the Marquis of Londonderry, and the late one of York Minster, are entirely attributable to the pipe or cigar used by the workmen engaged in repairs. It is $\boldsymbol{r}_{\text {at }}$ generally known that tobacco contains nitre, and that, like "touch-wnod," it may continue ignited for houre Fires occurring from this cause are, 1 apprehenu, too notorious to need specific detail. It is clear that the end of a cigar dropped among wood shavings might be fanned into a flame by a current of air; and tossed from the top of the coach into an adjoining field, and carried by the breeze into a farmer's stackyard, hay-ricks and wheat stacks may even burst into a flame. I believe many a cigar smoker is an unintentional incendiary."

Fires in farm yards, also, may originate from quicl lime left in a cart under a shed, and moistrse getting to it. Heat sufficient to cause combristion is developed. The spontaneous coml istion of haystacks from the dampness of the hay, is a danger to which the negligent farmer is often exposed. In our present state of chemical knowledge it is idle to attempt to follow this phenomenon through its course, or explain the reasons for the heat produced in fermentation. As water must be present in fermentation, it is probable that it is decomposed, and it is commonly said that the flame produced is the result of intense chemical action; but, as Dr. Thomson remarks (System of Chem. vol. iv. p. 364), "All the phenomena of fermentation lay for many years concealed in complete darkness, and no chemist was bold enough to hazard an attempt even to explain thern. They were employed, however, and without hesitation too, in the explanation of other phenomena; as if giving to one process the narne of another of which we are equally ignorant, could, in reality, add any thing to our knowledge."

FIRE-WEED (Hieracium-leaved Senecio). An American plant with an annual root, growing in moist grounds, and remarkable for its prevalence in recent clearings, especially in and around spots where brushwood has been burned, from whence it derives its popular name. The stem grows 2,4 or 5 feet high, stout, succulent and tender when young, more or less hairy, sometimes nearly smooth. Flowers whitish. (Flor. Cestrica.) See Azkal.

FIRING. In farriery, an operation perform ed on different parts of the horse, but which is growing into disuse. It is principally resorted to in bad cases of sprains. In firing about the sinews and nervous parts, great care should be taken not to go too deep, for if the fire once touches the sinew the horse will go lanne for life. Firing is sometimes resorted to in cattle, in order to remove bony tumours about the region of the eye, which incommode or obstruct the vision. In general, this operation is performed in a manner calculated to excite great pain to the horse. When the iron is white hot, and is rapidly applied, the life of the part is instantly extinguished, and all sensation being destroyed, no pain, except when the iron is ap. proaching the part, is experienced; but much pain follows the application of an imperfectly heated iron.

FIRKIN. A measure of capacity in England, being the fourth part of a barrel, or containing 9 ale gallons, or $7 \frac{1}{2}$ imperial gallons that is, 2538 cubic inches.

FIR, SCOTCH. See Prnes.

FIR TREE (Lat. Abies; Sax. Funh; Welsh, fyrr; fir-wood). "The fir, the pine, and the larch," says Mr. Baxter, "constitute a perfectly natural genus or family, and, next to the oak, are the most valuable of our timber trees; but, independently of their value in this respect, their beautiful foliage and magnificent appear 
ance have at all times rendered them objects of admiration and attention. They constitute the greater part of the natural order C'oniferce. The term fir is often indiscriminately applied both to the fir and the pine, or Abies and Pinus, and hence we frequently hear the Scotch pine umproperly called the Scotch fir, by those who are unacquainted with botanical nomenclature. The most obvious and ready character of distinction between the different genera Abies and Pinus is to be found in the natural arrangement of the leaves. 'The firs (Abies), have the leaves solitary, or issuing from one scale or sheath on the bark of the branches, over which they are scattered." The catkins of male flowers are also solitary, not racemose; the scales of the cone are imbricated, and thin at the apex, and are all turned to one side. They are further distinguished from the pine by their more pyramidal form. 'The spruces have also the leaves growing singly round the branches, and all spreading equally.

The larches have the leaves growing in clusters, which are deciduous.

The cedars and pines have from two to five leaves issuing from one sheath at their base, growing also in little bundles or tufts, but they are evergreen. Of these four natural tribes, into which the firs resolve themselves, the silver fir may be taken as the representative of the first, the Norway spruce of the second, the Larch of the third, and the Cedar of Lebanon of the fourth. As all the others are noticed under their separate heads, we have only to confine our attention in this place to the firs. One property is common to all the species of this genus, that of affording resinous matter, either from the wood, bark, or cones.

'The silver fir ( $A$. picea, or pectinata) is grown in England for ornament generally. The name of silver fir is derived from the colour of its leaves on the under side, which are shorter, broader, and set much thicker on the spray than those of other firs and pines, and have a beautiful silvery appearance when the under side is viewed, or when the wind turns the branches from the eye; whilst the upper surface is of the brightest and handsomest green of all the species of fir. It is a fine majestic tree, and the most beautiful, but at the same time the most delicate, of the fir tribe usually cultivated in Britain. This tree is very rapid in its growth, and soon attains to a great size; but the timber is not so valuable as that of the pine and the spruce fir. It yields, however, Burgundy pitch (whence its name of picea) and Strasburgh turpentine; and it is much used on the Continent both for carpentry and ship-building. The silver fir likes a deep soft soil, and a sheltered situation. From its extreme tendency to lose its leader it does not appear to be well suited for exposed grounds. Some of the finest trees in Englnnd are in the vale of Mitcham, between Dorking and Guildford, where the soil is nothing more than a deep soft sand lying on chalk. The well-known disease of the larch, commonly called American blight (see this head), or plant lice, proves fatal to the silver fir. Col. Miller says he has cured the disease with a wash of lime-water; but recommends. in advanced stages of the disease, free and early pruning. This doctrine may startle many wood growers; but the Colonel, in proof of the soundness of his opinion. adds, that he has adopted it successfully for many years. No large branch should, however, be removed when the tree is near maturity. The Swedes and Norwegians prune their trees freely, and hence the reason why they produce such a large quantity of sound tim. ber, and are so free from knots. A weak solution of spirits of turpentine and tobacen liquor appears to be a useful wash for the disease.

2. The balm of Gilead fir ( $A$. balsumea). This is also a delicate ornamental tree, but :t rarely attains to any considerable size. This species and the silver fir are often confounded, but may be distinguished thus: "the leaves of the silver fir are arranged nearly on opposite sides of the branch, comb-like. The under sides of the leaves have a white line running lengthwise on each side of the mid-rib, which gives them a silvery hue. The leaves of the balm of Gilead fir are shorter, blunter, and stand nearly upright in double rows, on the upper side of the branches; while in the silver fir they are flattened and irregularly singlerowed." The balm of Gilead fir is so called because the clear transparent turpentine which is obtained from the wounds of this tree is very similar to the true balm of Gilead of the shops, which is the production of the Balsama. dendron Gileadense. It commonly passes under the name of Canadian balsam. The wood of this tree is of a pale yellow colour, and but slightly resinous; its principal use is to split up into staves for fish barrels, for which the wood of some of the other species is much preferable.

3. The Norway or spruce fir ( $\mathcal{A}$. excelsa), when standing singly, with its regular pyramidal figure, and its long drooping branches reaching to the ground, forms a beautiful object; but it does not thrive well generally in exposed situations. It grows best in moist anu springy places, and likes a deep soil. The spruce is readily known by its leaves of one uniform dull green colour, spread equally round the branches, and by its long pendant cones. All these firs may be raised from seed, which can be separated from the cones by a moderate heat before a fire, care being taken not to destroy the vegetative power. Or the separation may be facilitated by steeping the cones a few hours in warm water. The seed ripens in December, and the cones should be preserved till April, which is the proper period for sowing. The seeds must be only covered ábout half an inch deep. The soil be tole. rably rich. The seedlings must be transplanted the second year; for if left longer it will be completely spoiled. For the Scotch pine or fir I must refer the reader to the head Prsis (Pinus); and other information on the subject of firs will also be found under the head Larch. It may, however, be well to enumerate the principal other firs: anything like a description in this place would be needless.

1. Fins. The Siberian silver fir ( $A$. Siberica). The great Californian fir ( $A$. grondis) The large-bracted fir (A. nobilis). The double balsam fir (A. Frazeri). Webb's fir (A. Welibiana) 
The hemlock spruce fir (A. Canadensis). The deciduous silver fir ( $A$. Brunoniana). The sacred Mexican fir (A. religiosa). The hairy fir (A. hirtella). The Indian silver fir (A. Smithiana).

2. Spruces. The oriental fir ( $A$. orientalis). The white spruce fir $(\mathcal{A}$. alba). The black or red, spruce fir ( $A$. nigra). The Douglas fir (A. Douglassii). The Menzies fir (A. Menziesii).

3. Larches. The common larch fir (A. larix). The red larch fir ( $A$. microcarpa). The black larch fir (A. pendula).

4. Cenars. The cedar of Lebanon fir ( $A$. cedrus). The sacred Indian fir ( $A$. deodara). See Cedar of Lebanon.

Michaux enumerates 14 species of pines and spruces including firs, as found in different portions of the United States and Canada. His methodical arrangement of these is as follows :-

Two-leaved Pines with smosth Concs.

Red (Norway) pine, or Pinus rubra. Common in Canada and the Northern Sections of the United States, but not seen in Pennsylvania south of Wilkesbarre. It is called in the state of Maine Scrub-pine. This species is found farther northward than any other pine, being seen in the environs of Hudson's Bay. Yellow pine (Pinus mitis). This species abounds in the Middle States. In the south it is called Spruce pine, and Short-leaved pine.

\section{Two-leaved Pines with thorny Cones.}

Jersey pine (Pinus Inops). This species is not confined to the southern portion of New Jersey, but is seen in Maryland, Virginia, and others of the Southern and Western States. Table mountain pine ( $P$. pungens). Found only on the Table mountain in North Carolina.

Three-leaved Pines with smooth Cones or very small Thorns.

Long-leaved pine (Pinus australis). This tree so extremely valuable for its timber, tar, and other resinous products, is known in the countries where it grows, and the places to which it is expoited, by different names. In the Southern States, where it abounds, it is called Yellow pine, Pitch pine, and Brown pine. In England and the West Indies, Georgia pitch pine. $P$ itch pine $(P$. rigida), is found throughout the United States except the region west of the Alleghanies. It abounds on those mountains as they traverse Pennsylvania and Virginia. Loblolly Pine (P.Treda). This is common in lower Virginia and more Southern States.

\section{Five-leaved Pines.}

White pine ( $P$. strobus). One of the most interesting of American pines. It is diffused over a great extent of country in the Northern and Eastern States, being the loftiest and most majestic production of the American forest. Its wood is most valuable for building and nther purposes.

\section{Spruces.}

These have very short leaves disposed singly round the branches. The American species are, black or double spruce (Abies nigra), common in the Northern States and British provinces; also in the northeastern parts of Pennsylvania, and Black Mountain of South Carolina, and sometimes in the White Cedar Swamps in New Jersey near Philadelphia and New York. In the northern sea-ports the spars of ships are mostly of black spruce. It is largely exported to Europe. White, or single sprure ( $A$. $a l b a)$. Common in the same northern regions of the States. Pond pine ( $P$. serotina), common to the maritime parts of the Southern States.

\section{Spruces with lateral Leaves.}

Hemlock spruce (Abies Canadensis), natural to the coldest regions of the United States and British Provinces. It is always larger and taller than the black spruce. American silver fir (Abies balsamifera), or Balm of Gilead; common in the state of Maine and the British Provinces.

FISH (Lat. Pisces; Germ. Fische; Du. Vischer; Dan. and Swed. Fisk). A term used in natural history to denote every variety of animal inhabiting seas, lakes, rivers, ponds, \&c. that cannot exist for any considerable time out of the water. 'The most natural and popular division of this subject is into fresh and saltwater fish.

According to Linnæus, there are about 6,000 species of fish with which naturalists are acquainted, but those yet unknown are supposed to be still numerous, and many species will probably remain forever undiscovered. The anatomy and physiology of fish offer a wide field of study for the inquiring mind. Their extraordinary fecundity is truly astonishing. Fish in general are less nourishing than other animal food, but are not difficult of digestion, when in a fresh state, to a healthy stomach. To a dyspeptic stomach, however, fish is apt to prove irritating. Except in London and a few sea-port towns, the consumption of fish in England is not great. See Brending Ponds.

FISH, as a MaNore. The fish which are usually employed as manures in England are sprats, pilchards, herrings, sticklebacks, and whale blubber. 'These are very rich fertili: zers; the fleshy or muscular portions abounding in oil. The scales are composed of coagu lated albumen and phosphate of lime; their bones are full of oil, and the solid portion is composed of phosphate of lime and carbonate of lime, in different proportions.

Sprats.-In the English counties of Essex. Kent, and Suffolk, the use of this manure is very general, although the practice is not of very long standing. The quantity applied per acre varies from 25 to 45 bushels, the pour gravelly soils requiring more than the loamy lands. They are spread by hand, from seed baskets, and on winter fallows intended for oats, on which, especially if the summer is not too dry, it produces most luxuriant crops, of a peculiar dark-green colour, yielding 10 or 11 quarters per acre, and that on land of a very second-rate description. The effect of the application, however, remains only for one crop. They produce an equally good result if mixed with earth, and suffered to remain and dissolve, for some time, in the heap, before they are carted on the land. In this way they answer exceedingly well for turnips. They 
are usually obtainable at the rate of from $6 d$. to $8 d$. per bushel.

The extent to which this manure is used may be judged by that of the Stow-boat fishery, which is solely devoted to catching these fish. Upon this fishery the committee of the House of Commons of the session of 1833 reported: - "This fishery, which prevails principally upon the Kentish, Norfolk, and Essex coasts, have been proved to yourcommittee to occasion very extensive injury to the span and brood of fish. 'The nets used in it are of a very fine description, so small as not to let a pen pass through, and they enclose not only sprats, but the span and young brood of all other kinds of fish; and as these nets are frequently drawn along the ground, and in shallow waters, during the breeding season, and in the winter months before the young fish are gone into deep waters, an immense destruction of the spawn and breed of fish is the inevitable consequence; whilst, from the almost unlimited demand for this species of manure for land, and there being a ready sale for all that can be procured, this branch of fishing has sreatly increased; and there are at present from 400 to 500 boats engaged in Stow-boating on the Kentish coast unly, which remain upon the fishing grounds frequently for a week together, not for the purpose of catching sprats or any other fish to be sold as food in the market, but until they have obtained full cargoes of dead fish for the purpose of manuring the land."

The Farmers of Essex and Suffolk purchase these fish by thousands of bushels at a time, and carry them in wagons 10 or 15 miles into the inland districts.

Pilchards are extensively employed in Cornwall and Devonshire, both in the fresh and in the salted state. The pilchard is a small fish not larger than a herring; it visits part of the coast of Cornwall and Devon in large shoals, during the months of August and September, and again in November or December. The refuse fish, which are those principally used by the cultivator, are usually mixed with earth, sea-sand, sea-weed, or some other substance, to prevent them from causing too rank a growth. The effects of these pilchards, according to Sir H. Davy, are apparent for several years. The pilchard is a very oily fish, and may be had in almost inexhaustible quantities. Between 8000 and 9000 persons, at sea and on shore, are employed in this fishery, and about 30,000 hogsheads are annually exported either to the West Indies or the Mediterranean.

The herring.-The employment of this valueable fish for the purpose of manuring the ground is limited to those districts near the sea to which the shoals of herrings are regularly visiters; and even there, their use is confined to those seasons in which there is an annual glut, as occasionally happens on the coasts of Scotland and the eastern side of England. They are a very oily fish, and produce the same rank luxuriance of growth as sprats or pilchards. Arthur Young has given us an account of an experiment, in which some wheat, manured with these fish, grew so luxuriantly, that it was entirely laid before the eriod of harvest. Very numerous or accurate comparative experiments with this fish can hardly be expected, for its use must necessarily be confined to peculiar districts; and when obtained, it is generally ploughed in with crinsiderable expedition, or dug into earth heaps, which is a mode found to answer extremely well. And it has been found, in the case of spoiled red herrings, that their application is extremely advantageous to the hop plantations. (Essay on Salt, p. 101.)

Sticklebacks. - The use of the stickleback is principally confined to the neighbourhood of the Fens of Lincolnshire and Cambridge, in which it breeds with great rapidity, and in shallow waters they are caught at certain seasons entirely as an article for manure. They are used in much the same proportions, either by themselves or mixed with earth, \&c., as sprats, and are not more durable in their good effects.

The Fat or Blubber of the Whale.-Whale blubber was employed by the late Lord Somerville, at his farm at Fairmile, in Surrey, as a manure, and produced the richest crops. It was mixed with the sandy earth, and suffered to dissolve in the heap. It cost at the wharf in London 20 shillings, and, with the expenses of carriage, about $2 l$. per ton. It answered equally well upon arable and pasture lands, producing most luxuriant crops; and its good effects were visible for two or three years. Its general high price, however, rarely admits of its employment by the farmer

Whale blubber is composed principally of train oil and other animal matters; but the oil is by far the largest portion of the blubber, and to the presence of this fish oil, which does not appear to differ materially in composition from whatever fish it is obtained, must be at tributed the chief fertilizing value of all fish Train oil has been analyzed by Dr. Thomson He found in 100 parts (Chemistry, vol. iv. p 433), -

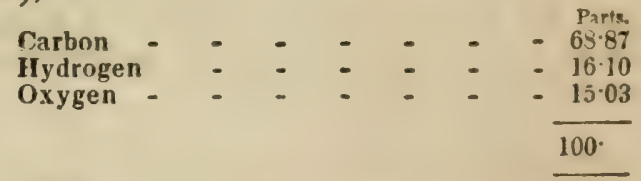

Spermaceti oil, according to Dr. Ure, con tains, in 100 parts, -

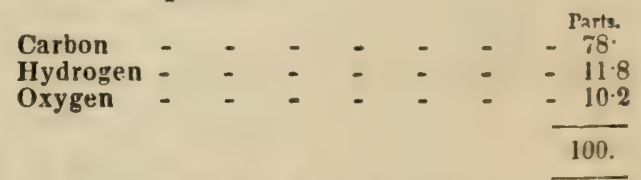

Fish oils, therefore, are composed of exactly the same materials that constitute almost al vegetable substances, differing only in the pro portions; for sugar, starch, gluten, gum, \&c $\& c .$, are all composed of these three substances -carbon, hydrogen, and oxygen; blubber, therefore, may be regarded as the most condensed manure that it is pessible to apply to at soil: it contains little, if any, water, and every portion of it is food for plants. The same re mark will apply to the dregs of train oil, \&c. which are sometimes applied, mixed with earth, to the same purpose; but it is seldom that these substances can be procured, in any quantity, at a sufficiently reasonable rale. 
It is evident, from the experience of all who have tried blubber, that it is best used when previously mixed with from 10 to 20 times its weight of earth, and turned over once or twice during three or four months. In its uncombined state it is evidently too powerful. When mixed with mould, it speedily undergoes a strong fermentation, and the mass becomes of the most friable and fertilizing description. 'Jrain oil has also been employ'ed with the most decided success; it has been used united with screened earth, and produced the most luxuriant of crops. In an experiment made by Mr. Mason, of Chilton, which is described by Lord Spencer, in a communication furnished to the Doncaster Agricultural Society, 40 gallons of unrefined train oil, which cost $8 \frac{1}{2} d$. per gallon, were mixed with 120 bushels of screened earth about a month before it was applied to one acre of a tenacious soil, sown with turnips; and on an adjoining acre of similar land were applied 40 busheis of bones, broken small, and mixed with 80 bushels of burnt earth; the crop produced was as follows:-

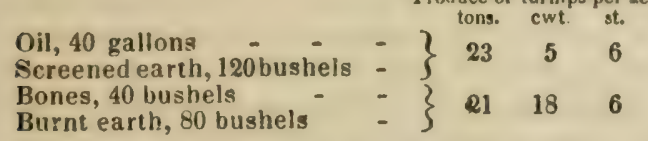

And in The Mark Lane Express of February 8, 1841 , M.r. W. Sharp, of Scarthing Moor, in Nottinghamshire, thus describes his experiments with fish oil, mixed with bone dust:- "I will give you my experiment with oil. 'The soil is a poor gravel,- the farm in the parish of Edwinstow, and enclosed off the old Forest, near to Thorseby Park.

"My attention was drawn to the use of oil in consequence of the serious expense (3l. to $4 l$. per acre) I was obliged to go to in bones and rape dust, for I never use yard manure for turnips, as the soil is so poor, I cannot get wheat without manure; I therefore save it all for my wheat. My first trial was in 1839, on 2 acres, in a 9 -acre field, and nearly in the middle of it. I give you the cost of one acre,-

5. strikes of half inch bones, the dust in (2s. $7 \frac{1}{2} d$. per strike), per acre

3 gallons of train-0il, at $2 \vec{s} .6 d$. per gallon

10 strikes of coal ashes -

\& s. d.

$\begin{array}{lll}0 & 13 & 11\end{array}$ $\begin{array}{lll}0 & 7 & 6\end{array}$

$\begin{array}{lll}0 & 0 & 0\end{array}$

$\frac{0}{1} 0 \frac{0}{7 \frac{1}{1}}$

Remainder of the field as below, -

16 strikes of bones, as above, at $2 s .7 \frac{1}{2} d$. per

5 hundred of rape-dust, at $6 s . \overline{9}$. per hundred

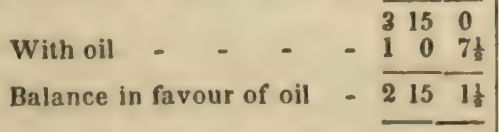

"The oil turnips were as good as the remainder of the field; and all as fine as I could wish, for the land. The barley as good,-and the clover is now excellent. My next trial in 1840 , on 9 acres, -

11 strikes of half inch bones, dust in, at $23.6 \mathrm{~d}$. per strike, per acre - - - - 3 gallons of train-oil, at 20.62. per gallon - 076

1150
" 11 acres, dressed as below, is a trial against oil,-

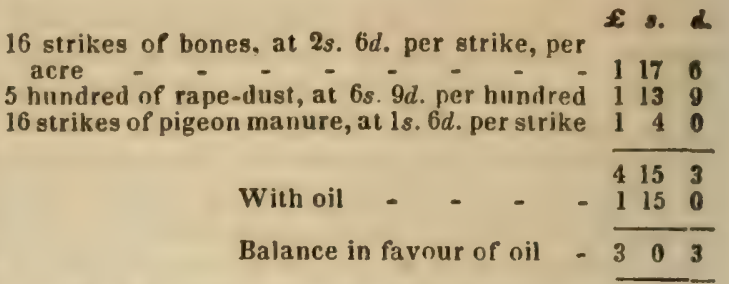

"I think the 9 acres with oil rather the best field, and the turnips are decidedly better. The rape-dust I sow broadcast on the surface; it is then drawn in its proper place by ridging; I then drill my bohes on the ridges 22 inches apart,- the turnips were white tops. I do not like the ashes mixed with the oil; it makes it dirty and bad to drill; the 11 strikes of bones carefully mixed will absorb the oil, so as to drill excellent. I let them lie about two days after mixing. I know your readers will say, how is barley grown after so light a dressing? I answer-with my feeding sheep I use oilcake, and with my store sheep malt-coombs, and the straw in the yard is all consumedwith oil-cake I take my seeds up for wheat.

"Some farmers may possibly doubt the correctness of my assertion, that all the principal vegetable substances are composed of precisely the same ingredients as oil and other purely animal matters; and as it is of the first importance that the cultivator should clearly understand the reason why the decomposition of animal matters furnishes such admirable food for vegetation, I must beg of him to compare the analysis of the oils which I have already stated, with that of the following common vege. table substances, as ascertained by the most careful analysis. I will merely give that of three substances:-sugar, 100 parts of which are composed, according to M. Berzelius, of-

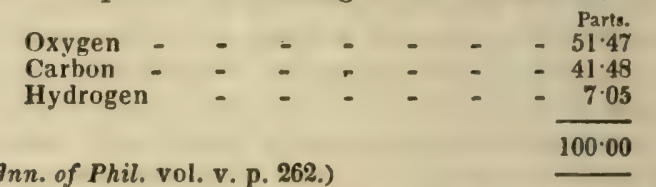

\section{In 100 parts of starch from wheat flour are} found-

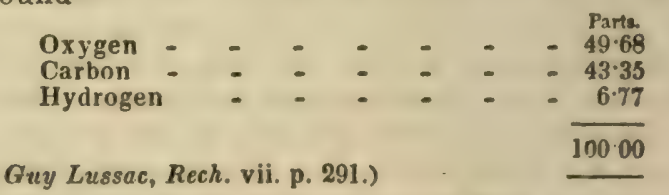

The wood of oak is composed of-

$$
\text { (Ibid. vol. li. p. 294.) }
$$$$
\text { Oxygen - - - _. - - - } 41.78
$$$$
\text { Carbon - - - - - }-59.53
$$$$
\begin{aligned}
& \text { Carbon } \\
& \text { Hydrogen }
\end{aligned}-\quad-\quad-\quad-\quad-\quad-5253
$$

"All oily and other animal substances, therefore, as they decompose in the soil, are slowly converted into those gaseous substances which are the food or breath of vegetable life, such as carbonic acid gas (fixed air) or carburetted hydrogen (the gas employed for illumination), and which are absorbed either by the roots or the leaves of the plant as they are formed. There is little or no waste in these, for when the decomposition of the oils and fibrous mat. 
ters of fish is finished, there is very little or no earthy or solid matter remaining useless in the soil. In this, again, the experience of the farmer substantiates the chemist's doctrines, for he uniformly tells us, in answer to our inquiries, that the fish only last for one crop."

In the east of England, the farmers of those soils conveniently situated for water carriage, employ to a very considerable extent, as manure, several kinds of fish besides sprats, such as fivefingers, cockles, muscles, \&c., and this use is only limited by the supply, or whai is commonly a more important impediment, the difficulty of transporting them any distance while sufficiently fresh. When once the fish begin to putrefy, their fertilizing properties rapidly diminish; the oil from the fermenting sprats I have seen dripping from the wagons as they travelled along: thus they speedily lose in weight, and become intolerably obnoxious to the district through which they pass; several convictions have, indeed, taken place among my neighbours in Essex, for carrying putrefying fish through towns and populous villages.

This is hardly a matter of astonishment, since the farmer, who has to convey a freight of several hundred bushel of sprats, perhaps ten or twelve miles, has often much too little time allowed him for that purpose. The fish, perhaps, arrive stale. It is a load detained by contrary winds, or prevented by circumstances from reaching another destination? the farmer has to be informed of their arrival; he cannot despatch his teams as speedily as the nature of the case requires, the fish become offensive, and his ardour for the improvement of his land is checked by a magistrate's summons and a conviction for a nuisance. These are the reasons which retard the use of these kinds of fish as a manure, but cannot entirely prevent their being employed. Their use is still, in spite of all impediments, annually increasing, especially in the neighbourhood of those places to which the fishing smacks find a ready access.

By the general formation of railroads, the culivator, even of the inland soils of England, will have all these valuable sources of improvement offered for his service-fertilizers of even national interest, since they are drawn from an inexhaustible source, afford employment to a branch of industry invaluable in a maritime point of view, as a nursery for seamen, and have, moreover, this great and paramount advantage, that they add to the permanent riches of the land, and are not, as is the case with other fertilizers, drawn from one district of the state to enrich another. There need be no fear of the supply not keeping pace with the demand, for the ocean is inexhaustibly tenanted with fish. As fresh agricultural marliets arise and are furnished by the railways, fresh sources of supply will be discovered, other coasts explored, and increased fisheries cstablished. (Johnson on Fertilizers, p. 113.)

On Long Island and those parts of the New England States bordering upon the sound, or the sea, fish are very extensively and profitably used as manure. In the Chesapeake and tributaries, where herring fisheries abound, these fish are also often appropriated to the same purpose.
FISTIILA (Lat.). A long sinuus uleer,often communicating with a larger cavity, and hav. ing a small external opening.

All animals are liable to fistulas, but the horse more particularly so; they attack the withers and the poll. They are produced by blows, by bruises from the saddle, and what. ever causes inflammation; also by the pre. sence of extraneous substances.

In curing this disease, it is requisite, in the first instance, to ascertain the direction the fistula pursues, and whether it materially interferes with any of the larger blood-vessels, so as to render a full incision into the parts a matter of too much hazard to be attempted. When secure from any danger of this nature, the most effectual practice is, to lay the fistnla, or fistulas, when more than one, so thorough!y open as to have a complete view of their internal surfaces. It is not, however, necessary in the simple sinus, where the matter is in a healthy state, and requires only a sufficient passage; but in cases where the discharge, by having been long detained, indurates and corrodes the contiguous parts; as the means fully adequate to remove the former avail little in the radical cure of the latter, a more severe practice of course becomes necessary.

When the fistular cavities have been fully laid open by the knife, they should be dressed with powerful caustic compositions, until the unsound parts slough away, and the wound presents a healthy appearance. Cleanliness, with more mild applications, should now be had recourse to, taking care that the wound be not closed before the cavities are properly and uniformly healed.

FIVE-FINGER. See Cinaue-fort.

FIX'TURES. In Law, a term generally applied to all articles of a personal nature affixed to land. This annexation must be by the article being let into, or united with the land, or with some substance previously connected therewith. Thus a barn built on a frame not let into the earth, is not a fixture; a brewer's stills set in brickwork resting on a foundation, are fixtures, and the application of the same principle gives in every case the true rule to judge whether a thing be a fixture or not. What ever is thus fixed becomes by law parcel of the freehold or realty. It is, therefore, on general principles, not removable; but there are exceptions to this rule established by custom. (Brande's Dict. of Science.)

The English common law with regard to fixtures or any thing affixed to the freehold, is by no means so clear and defined as is desira. ble; and what is granted in favour of trade, to the removal of fixtures erected for the purpose of manufacture, does not extend to the erections made by tenants for agricultural purposes. The agreement made between the farmer and his landlord should therefore always contain a covenant by which this power should be clearly defined. The celebrated judgment of Lord Ellenborough in Elues v. Mawe, 3 East, 38, con tains such an epitome of the law of fixtures. that I shall insert at length the opening portios: of it:-

"This was an action upon the case in the nature of waste by a landlord, the reversiones

$$
2 \mathrm{~S}
$$


in fee against his late tenant, who had held under a term for twenty-one years a farm, consisting of a messuage and lands, outhouses and barns, \&c., and who at the case reserved, stated that during the term, and about fifteen years before its expiration, he erected at his own expense $a$ beasthouse, carpenter's shop, a fuel house, a cart-house, a pump-house, and a fold-yard. The buildings were of brick and mortar, and tiled, and the foundations of them were about a foot and a half deep in the ground. The carpenter's shop was closed in, and the other buildings were open to the front, and supported by brick pillars. The fold-yard wall was of brick and mortar, and its foundation was in the ground. The tenant previous to the expiration of his lease, pulled down the erections, dug up the foundations, and carried away the materials, leaving the premises in the same state as when he entered upon them. The case further stated these erections were necessary and convenient for the operation of the farm ; and the question for the opinion of the court was whether the tenant had a right to take away those erections? Upon a full consideration, we are all of opinion that he had not a right to take away those erections."

Without any special agreement, a tenant cannot remove a border of box planted by himself; neither can ordinary tenants remove fruit trees, though planted by themselves, but nurserymen may. If the freehold is sold without any stipulation about the fixtures, they pass with the land. Neither can the fixlures be taken in execution by the sheriff. Ranges and ovens are fixtures. But a pump erected by a tenant, and so fixed as to be removable without injury to the freehold, may be taken away by him at the expiration of his term, as being an article of domestic use or convenience. $\Lambda$ conservatory on a brick foundation, affixed to and communicating with rooms in a dwellinghouse by windows and doors cannot be removed by the tenant, even if he erected them.

FLAG, THE WATER; or FLEUR-DE-LIS. See Iris.

FLAG, THE SWeET. See Aromatic Reed (Calamus aromaticus).

FLAG. A term sometimes applied to the turf, or surface of the ground, which is pared off for burning. It also signifies a large flat paving stone, and the furrow-slice of ley lands, when under the plough. See PArivg and BuRnina.

FLAIL (Lat. flagellum). A wooden implement for thrashing corn by hand. It anciently was truly a whip, and sometimes had two or more lashes: the modern flail consists of the handle or handstaff, which the labourer holds in his hand, and uses as a lever, to raise up and bring down the swiple, or part which strikes the corn, and beats out the grain and chaff from the straw. The swiple is joined to the hand-staff by the caplins or couplings, which are thongs of untanned leather, and sometimes the skins of eels or of other fish. These thongs are passed through holes in the ends of the handle and swiple, and made fast by being sewed together. 'The whip-flail was in use among the Romans, though the prevailing mode of separating corn from straw among the nations of 182 antiquity was by treading it out with cattle in the open air. (See Agriculture.) In the colder parts of Europe, this could never have been generally the case, for obvious reasons; and hence the flail was the universal thrashing implement till the introduction of the thrashing machine, which is now taking the place of the flail in all countries where capitalists engage in farming. See Thrashivg Machive.

FLANDERS, the Agriculture of. The mode of tillage adopted by the cultivators of Flanders has long and beneficially engaged the attention of the British farmer; who, what ever may be his superiority to the Fleming in most respects, yet in some particular instances has learnt, and in others (such as in the careful husbanding and preparation of manure, the succession of crops, the deepening of the soil, \&c., ) may still profitably imitate the practices of the small industrious cultivators of Flanders. The best report of the modern agriculture of the Flemish farmers is that drawn up for the Society for the Diffusion of Useful Knowledge, by the Rev. W. Rham, from which, and from his paper in the Journ. of Roy. $A g r$. Soc. of Eng. vol. ii. the chief facts of this article are obtained. The climate of Flanders pretty closely resembles that of Kent and Essex in England : it is, however, rather warmer in summer, and the snow lies longer in winter. The soil is various; there are extensive districts of sand which are brought into cultivation by dressing them with mud. In proportion to the quantity of the mud, which is a very fine clay, a portion of decayed shells and organic matter, the soil is more or less fertile; and when the mud enters into it in considerable proportion, it forms a rich compact loam. In many places there are alternate narrow strata of sand and loam, which, being mixed together, form a very productive soil. A small portion of carbonate of lime produced from the decomposition of sea shells, is found in the mud when it is analyzed; but there is no chalk, nor marl, in any portion of this coast.

The industry of the tenants of these sands is proverbial. The poor sandy heaths which have been converted into productive farms, evince their indefatigable industry and perseverance. The sand in the Campine can be compared to nothing but the sands on the seashore, which they probably were originally. It is highly interesting to follow step by step, the progress of improvement. Here you see a cottage and rude cow-shed, erected on a spot of the most unpromising aspect. The loose white sand, blown into irregular mounds, is merely kept together by the roots of the heath; a small spot only is levelled, and surrounder by a ditch. Part of this is covered with youn: broom; another part is covered with potatoes; and perhaps a small patch of diminutive clover may show itself; but there is a heap of dung and compost forming. 'The urine of the cow is collected in a small tank, or, perhaps, in a cask sunk in the earth; and this is the nucleus from which, in a few years, a little farm will spread around.

Of their use of liquid manure, I shall hereafter, under that head, have occasion to speak. Their implements of husbandry are much inferior 


\section{FLANDERS.}

to the English. They employ, however, the spade to a much greater extent than is done in England; thus it is a common practice with them to deepen the trenches between the lands with the spade, and spread the earth over the surface of the ground; by this means the land is gradually completely trenched, and the immediate good effect by keeping the soil of the field dry is very considerable.

Their rotation of crops on sandy soils is commonly, 1. Flax and carrots; 2. Rye and turnips ; 3. Rye and turnips; 4. Potatoes, peas, and carrots; 5. Oats and rye; 6. Clover; $\%$. Rye, or barley and turnips; 8. Turnips, oats, and potatoes; 9. Flax and carrots; 10. Rye and turnips.

In a stiff loam near Alost, the following rotation is adopted: 1. Potatoes, with 20 tons of dung per acre; 2 . Wheat, with $3 \frac{1}{2}$ tons and 50 barrels of urine: 3 . Flax, with 12 tons of dung, 50 barrels of urine, and $5 \mathrm{cwt}$. of rape-cake ; 4 . Clover, with 20 bushels of wood-ashes ; 5 . Rye, with 8 tons of dung, and 50 barrels of urine. 6. Oats, with 50 barrels of urine; 7 . Buckwheat without manure.

They grow large quantities of hemp and tobacco; and are large exporters of seeds of all kinds. With such exhausting crops, therefore, an attention to the careful saving of all kinds of manure is absolutely essential to the preservation of the fertility of the soil ; and no cultivators are more particular in this respect than those of Flanders.

They keep large quantities of cattle. "A beast for every three acres of land is a common proportion; and in very small occupations, where much spade husbandry is used, the proportion is still greater. These are maintained on turnips, potatoes, carrots, \&c., which are chopped together in a tub, with beans, rye, or buckwheat meal, and mixed with boiling water (which they call brassin), about two pails full are given each cow.

"The horses of Flanders have been long noted for their bulk. Flanders mares were at one time in request for the heavy town carriages of the nobility and men of fortune in England and on the continent. Since the improvement in the roads, and in the paving of streets, activity has been preferred to strength, and the English carriage horses now partake more of the breed of hunters, and are more nearly allied to full blood. The Flanders horses are probably the same at this time as they were a century ago; but compared with the present breeds of coach and cart-horses in England they are inferior. They are in general large in the carcass, and pretty clean in the leg; patient and enduring, if not too much hurried. They are steady in the collar, and good at a dead pull, in consequence of their weight; but they are very heavy in the forehand, inclined to get fat, and deficient in activity. They fall off in the rump, and the hips stand out too much from the ribs. The worst point in most of them is the setting on of the tail, which is low, and pointing downwards. These are the general characters of the real Flemish horse. A more useful kind of horse, although not so sleek, is found in the provinces of Brabant and Namur, where they draw heavy loads
FLANDERS.

of stones and coal over bad roads. The feet of the Flemish horses are generally flat, denoting the moist pastures in which they are fed when young, or the dung of the stables in which they have stood: for many of them hare never been turned out loose, and have been reared and fed in the stable as the cuws are. This will account for the want of vigour and muscle, as well as for the propensity to get fat. The food of the farmer's horses is not calcu. lated to produce hard flesh: green clover in summer, and roots with cut straw in winter, are the chief provender."

Of the spade-husbandry of $\boldsymbol{F}$ landers, the following description is given by the author whom I have already quoted so freely:-

"The husbandry of the whole of the northeastern part of East Flanders, where the soil is a good sandy loam, may be considered as a mixed cultivation, partly by the plough, and partly by the spade. Without the spade, it would be impossible to give that finish to the land, after it is sown, which makes it appear so like a garden, and which is the chief cause of the more certain vegetation of the seed. There is great saving of seed by this practice, as may be seen by comparing the quantity usually sown in Flanders with that which is required in other countries, where the spade is more sparingly used. In large farms in England, the spade is only used to dig out waterfurrows, and to turn heaps of earth, which are made into composts with different kinds of manure. But in Flanders, where the land is usually laid in stitches of about six or seven feet wide, the intervals are always dug out with the spade, and the earth spread evenly (sified, as they call it) over the seed which has been harrowed in. The earth may not be of a fertile nature below the immediate surface; sometimes it is only a poor sand, or a hard till; but this is no reason why it should not be dug out. If it is very light and poor, a good soaking with urine, a few days before it is dug sout, will impart sufficient fertility to it. If it is very stiff, the clods must be broken as small as possible in the digging, as is done when stiff ground is trenched in gardens; and what is left unbroken on the surface, and not pulverized by passing the traineau (a kind of heavy broad wooden sledge, made of beams of wood and boards) over it, will inevitably be reduced to a powder by the frost in winter. Thus the land is not only perfectly drained, but the seed, being covered by an inch or more of earth, is placed out of the reach of birds, without danger of being buried too deep. The snil from the bottom of the trench contains few seeds of weeds, and the root-weeds are necessarily cleaned out in the spreading. This earth, spread over the surface of the land, keeps it clean, by burying the smaller seeds, which the harrows may have brought to the surface, and preventing their vegetating. It is for this reason that the roller, or the traineau, is made to press the surface, or that, in very light soils, men and women tread it regularly with their feet, as gardeners do after they have sown their beds. The trench, which is thus dug, is a foot wide, or, more properly, one-sixth part of the width of the stitch, or bed; and the depth is from a foot to 18 
inches, according to the soil. Thus, a layer of earth, about two inches deep, at least, is thrown over the seed, which has been sown on a surface made even by the small harrows, or the bush-harrow. These two inches gradually incorporate with the soil below; and thus, at every such operation, the soil is deepened so nuch.

The trenches are so arranged, that every year a fresh portion of the ground is dug out, and in six years the whole land will have been dug to the depth of at least one foot. In the next course, the trench is dug a few inches deeper, which brings up a little of the subsoil; and, after four or five such courses of trenching, the whole soil comes to be of a uniform quality to the depth of 18 or 20 inches; a most important circumstance to the growth of flax, potaloes, and carrots, all of which are very profitable crops to the farmer, and the last two indispensable to the maintenance of the labourers and the cattle. In the Waes country, they proceed differently, for they have a soil which, by repeated trenchings, has long been uniform in quality to the required depth. There they regularly trench one-sixth part of the land every year, and plant it with potatoes, or sow carrots in it.

"From this outline of Flemish husbandry," concludes Mr. Rham, "the general principles which pervade the whole system are easily discovered. The garden has evidently been the model for the operations of the farm. The spade has originally been the chief instrument of cultivation; and when a greater extent of farms necessarily introduced the plough, the favourite spade was not entirely laid aside. A Flemish farm of 40 or 50 acres must still be looked upon as an enlarged garden; and if a comparison is instituted with the cultivation of land in England, we can only compare the Flemish husbandry, as far as tillage is concerned, with those large unenclosed gardens which are found in the neighbourhood of London, where the common vegetables are raised which supply the markets; where green crops are cut early for horses and cows kept in London; and where the soil is continually enriched by the manure which is brought every time a cart returns from having carried out the produce. In these grounds, the system is similar to the Flemish-deep digging, or trenching, abundant manuring, and a rapid succession of crops." (Flemish Husb.; Journ. of Roy. Agr. Soc. of Eng. vol. ii. p. 43.)

FLAX (Lat. Linum, from the Celtic word llin, a thread; whence the Greek linon, the Ital. and Span. lino, and Fr. lin). An extensive genus of plants, of which more than 70 species are enumerated by botanists. It belongs to the natural order Linacee. The plants are distinguished by the tenacity of their fibres, the mucilage of their seeds, and, generally, by the beauty of their flowers.

Four species only are indigenous to England, of which the common flax ( $L$. usitatissimum) to be next noticed, is the most important and useful. As ornamental plants, they are well worth cultivating in every collection. The greenhouse and irame kinds grow best in a mixture of loam and peats; the hardy shrubby kinds do well in any light soil. The hardy he: ba. ceous species are well suited for ornamenting flower-borders; but the dwarf kinds do best on rock-work, or in pots, that they may be protected by a frame in frosty or very wet weather; they may be increased by divisions of the root, by cuttings, or by seeds. The annual and biennial species should be sown in the open ground in April.-1. Common flax ( $L$. usitatissimum) is an annual, rising one to two feet high, with a smooth, slender, upright stem, branched near the top, narrow lanceolate leaves, rather glaucous, blowing in July a corymbose panicle of pale purplish-blue flowers. The testa or skin of the seed abounds with mucilage; the cotyledons with oil, easily procured by pressure. The mucilage extracted by hot water is demulcent, the oil a mild laxative. The use of linseed oil in the arts is very extensive. 2. Perennial blue flax (L. perenne). 3. Narrow-leaved pale flax (L. angustifolium). 4. Purging flax (L. catharticum). The first and fourth species are mentioned further in detail in articles which follow. The others require little notice; they are found growing in sandy or chalky soils, and are perennial, flowering in June or July.

FLAX, BASTARD TOAD. See Bastakn TOAD-FLAX.

FLAX, COMMON (Sax. yax or flex, Ger. flachs; Dutch, vlasch). The fibre of the Linum usitatissimum, which, after undergoing the process of washing, beating, and other operations, is spun into thread, and woven into linen tex. tures, lace, \&c. The seed is also crushed for oil; and the refuse husk, after the oil is expressed, is made into oilcake for cattle. The fibres of the bark of this important plant have been applied to the manufacture of thread and cloth in this and other countries from the remotest periods. "Flax," says Professor Low, " being a native plant, is sufficiently hardy to endure the climate of this and other northern countries. It has, indeed, a wide range of temperature, being cultivated, and for the like purposes, from Egypt almost to the pular circle." The wild flax grows in corn-fields, and gravelly or sandy pastures; but, when cultivated, it thrives most luxuriantly in deep rich mould, but particularly in untilled alluvial soils.

Its roots sink very deep when it has room; and it is generally said that the roots of good flax should strike into the soil to a depth equal to half the length, at least, of the stem above ground. A porous subsoil, or one that is well drained, is therefore essential. In Flanders, flax may be considered as a staple commodity, and a great portion of the population of tha country is employed in preparing large quantities for exportation; the cultivation and preparing of it, is, therefore, most perfectly understood, and the Dutch flax is always well dressed, and of the finest quality. The premiums given by the legislature of England to force the cultivation of flax have had very little effect, $1 t$ being one of the most exhausting crops when allowed to ripen its seed; and its culture being found to be much less profitable than corn. The native growth of flax being quite insuffcient to the demand for home consumption, \& $\mathrm{c}_{\mathrm{m}}$ England has long been in the habit of import 


\section{FLAX, COMMON.}

ing a large proportion of her supplies. The principal countries from whence these are obtained are Russia, the Netherlands, Prussia, and France, with small quantities from America, Italy, New South Wales, \&c. The duty in England is at present $1 d$. per cwt.

In Ireland, flax usually follows potatoes. In Scotland, land that has been several years in pasture, and from which one crop of grain has been taken, is preferred. In Flanders, the crops which immediately precede flax, in light soils, are barley or rye, with turnips after them the same year. All these crops are more highly manured than usual, and before the flax-seed is sown, peat ashes, at the rate of 30 bushels per acre, are spread and harrowed in, and a few days afterwards 10 hogsheads of strong liquid manure is poured regularly over the land, and left for a week or 10 days to soak thoroughly into the soil. The seed is then sown very abundantly; cloudy or showery weather is the time chosen; the quantity varies, but the general proportion is $160 \mathrm{lbs}$. to the acre. It is lightly covered in by a bushharrow, drawn over the land, for if the seed were buried more than half an inch deep it would prevent its vegetating. The choice of seed requires great care and circumspection: good fresh seed should be of a bright colour, with a sweet taste, and it will feel smooth, slippery, and plump, and, on being broken, should appear of a greenish yellow colour, and should sink in water. Genuine seed will suerage $18 \mathrm{lbs}$ per peck, but good Riga seed is somewhat lighter. Hand weeding should be attended to when the stems are from two to three inches above the surface, for when the flax is higher, it is liable to be injured by the weeders. The proper time for pulling flax, when not intended for seed, is when about twothirds of the stalk is observed to turn yellow, and to lose the leaves. If intended for seed, the flax sbould not be pulled until the capsules have acquired a brown colour, and the points have become firm, and so sharp as to fix themselves in the hand when pressed, and when nearly all the leaves and foliage have withered and fallen from the stem.

When flax is raised both for the seed and stalk, it is submitted to an operation called rippling, which consists in separating the seed from the stalk, by passing the flax through a kind of comb, before it is steeped in water. The iron teeth of these combs are placed so close together that the heads cannot pass through, and are consequently pulled off. Another practice is to beat out the seed in the field with a piece of wood, or a heavier stick than that of the common flail, and then to sift the seed into a large sheet. In preparing flax for the manufacturer, the first operation it undergoes is that of steeping it in water, to loosen the bark and separate it from the stalk; for this purpose it is tied into small bundles, and then placed in a pond or reservoir of soft water. The sheaves are slightly covered with straw, fern, rushes, or coarse herbage (kept down by stones or heavy bodies), to prevent the flax from being discoloured by the sun. In the course of seven or eight days the rind will be suriciently loosened, and the flax must be
FLAX, PURGING.

taken out of the water and spread out to dry. Phillips says there is an act of parliament in force, which forbids the steeping of flax in rivers, or any waters where cattle are accustomed to drink, as it is found to communicate a poison destructive to the cattle which drink of it, and to the fish which live in such waters. The odour it exhales is most disagreeable, and has often been productive of fever. Another but far more tedious process, resorted to for separating the bark from the stalk, is called dew retting, and consists in spreading the flax upon grass lands, and exposing it to the constant action of rain and dew. Hot water and soft soap are said to decorticate the stalk in a few hours. Grassing or bleaching the flax on old grass ground is the next operation, and is intended to rectify any defect in the steeping. The last process is that of bruising and scutching, previous to which it should be morerately dried. The woody part of the stem was formerly beaten or bruised with a hand mallet; but this operation is now more effectually performed by machinery. Flax-mills, with suitable wheels and rollers, now greatly facilitate the processes of bruising and scutching. Mr. James Durno (then British consul at Munich) gives an interesting account in the sixth volume of the Com. to Board of $A g r$. p. 75, of "the mode of cultivating flax and hemp in Russia, Prussia, and Poland;" and Mr. Robert Somerville, of Haddington, has also a very excellent paper in the same volume ( $p .84$ ), urging very strenuously the necessity for a more general home cultivation of those essential articles, hemp and flax, and suggesting improvements in the processes of dressing, \&c., many of which have since been carried out (Brit. Husb. vol. iii. p. 42; Quart. Journ. Agr. vol. iv. p. 159 ; $M^{\circ}$ Culloch's Com. Diet.)

In the United States flax, which was once considered a erop so indispensable among the crops of our farmers, is now but little cultivated; its linty product being superseded by the cotton of the South. It is a crop which involves a good deal of troublesome labour, and, without being profitable, is generally believed to be injurious to the soil; an opinion as old as the time of Virgil,-who says "Urit enim Lini campum seges, urit avenæ."-Georg. 1, 71. The seeds, besides yielding a most valuable oil, afford one of the best mucilaginous drinks for coughs, and dysenteric affections. Two or three other species are enumerated in the United States. (Flor. Cestrica.)

FLAX, PURGING. Mill mountain. Dwarf wild flax (Linum catharticum). This is a pretty herb, seldom more than eight or ten inches high, growing in the English parks, warrens, and dry hilly pastures. The stalk is slender and delicate, round, firm, and divided into small branches. The leaves are small, obtuse, bright green, and standing two at each joint. The tremulous fowers are sinall and white, pendulous before expansion, and not unlike chickweed. 'The root is small and tapering. This plant is bitter and cathartic. Dr. Withering found two drams or more in a dose, of the dried herb, useful in obstinate rhenmatism. It is purgative in doses of three scruples. The. country people boil it in their aie or becr fir

$$
2 \div 2 \quad 185
$$




\section{FLAX-SEED.}

the cure of rheumatism; but it is not so useful as a dose of colchicum.

FLAX-SEED. See Lrysen.

FLAX, WILD (L. Virginianum). A plant growing one to two feet high, often with three or four slender and angular stems from the same root, bearing pale yellow flowers, is often found in the old fields and open woodlands of the Middle States. Authors generally describe the rout of the American wild flax as annual, but Muhlenburg, Bigelow, and Darlington think it perennial. (Flor. Cestrica.)

FLEA (Pulex). The flea tribe (Pulicida) was placed among the bugs (or Hemiptera) by Fabricius. These very annoying insects are destitute of wings, have a mouth fitted for suction, and are provided with several lancet-like pieces for making punctures. They undergo a complete transformation; their larva are worm-like and without feet; and their pupæ have the legs free. The flea may almost be considered as a wingless kind of fly. Its proboscis seems to be intermediate in its formation between that of flies and bugs; its antennæ are concealed in holes in the sides of its head, like those of certain water-bugs, which they somewhat resemble in shape; whilst the transformations of the flea are not very much unlike those of the flies, whose maggots cast off their skins on becoming pupæ. (Harris.)

Want of cleanliness contributes greatly to the multiplication of fleas, and hence the propriety of the frequent removal of straw and rubbish from about houses and yards, and recourse to sweeping of floors, especially when carpeted. Various devices are adopted for the purpose of expelling fleas. Frequent sprinkling of a room with a simple decoction of wormwond, or sassafras, will soon extirpate the whole breed of these troublesome vermin; and the best remedy to expel them from bed-clothes, is a bag filled with dry moss, the odour of which is to them extremely offensive. Others cover the floors of the rooms where fleas abound with the leaves of the alder tree, while the dew is on the foliage, to which these insects fondly adhere, and thus may be easily destroyed Fumigation with the leaves of pennyroyal, or the fresh gathered foliage of that plant, sewed up in a bag, and laid in the bed, are also remedies pointed cut for the expulsion of fleas. Sprinkle with camphurated whisky or other ardent spirits.

Dogs and cats may be effectually secured from the persecutions of these vermin, by occasionally anointing their skin with sweet oil. The fleas and lice of poultry are destroyed by a decoction of sassafras wood. (Domestic Encyc.)

FLEABANE (Erigeron, from er, spring; and geron, an old man; the plants become old in the beginning of the season). This extensive genus comprehends many exceedingly handsome species, varying from a few inches to two feet or more high, and producing a great and copious display of blossom; they will grow in almost any soil, and are increased with facility from either seeds or divisions. The fleabare has lost its reputation both for banishing fleas and insects by its smell, and answering other superstitious incantations, for 86 which it was celebrated in former times. There are four indigenous species. The Canada fleabane ( $E$. Canadensis), and blue fleabane ( $E$. acris), which are diuretic. The alpine fleabane (E. alpinus), and pale-rayed mountain fleabane ( $E$. uniflorus.) The first is annual, the second biennial, the third and fourth perennial.

Several species are found in the United States, among which are the $E$. Canadensis, called Horseweed, and Butter-weed, an annual common in fields and road-sides in the Middle States, where it flowers in August and seeds in September and October. E. strigosus, called Fleabane and Daisy, a very common and worthless weed in the Middle States, where it frequents the pastures, flowering in June and July, and maturing its seed in September. It is particularly injurious to the first crop of upland meadows, after a coarse of grain crops. E. Philadelphicus. E. Pulchellus, or Handsome Erigeron. E. Heterophyllus or various-leaved Erigeron, together with some eight or ten additional species. See Daisy. (Flor. Cestrica.)

FLEABANE, COMMON (Inula dysenterica). This plant is very abundant in clear ditches and in watery places about road-sides. It is a perennial, with a creeping root; herb more or less woolly or cottony, glutinous, with a peculiar acid aromatic scent, somewhat like the flavour of peaches. The stem is 12 or 18 inches high, branched and leafy, corymbose at the summit, with many bright yellow flowers. Linnæus records, on the authority of General Keith, that the use of this plant cured the Russian army of dysentery;-hence the specific name. Its medical properties, however, are simply diuretic. The small fleabane (I. pulicaria), is an annual, and is said to barish insects by its smell. It grows on moist sandy spots, especially where water has stagnated during winter. There is another species, the samphire-leaved fleabane, which grows on the seacoast, in a muddy soil. (Eng. Flor, vol. iii. p. 440-443.)

FLEABANE, GREAT. Ploughman's Spikenard. See SpiknNann.

FLEA-BEETLE (Haltica). Several of these have been described among the insects destructive to the cucumber. Some others known in the United States and described by Dr. Harris, will be referred to under different heads. See Turnip Flx, Vine Bfitlen \&c.

FLEAM. In farriery, an instrument used for letting blood in horses-or other animals.

FLEA-WOR'T (Plantago). A genus, the greater number of the species of which are mere weeds, of the easiest culture and propagation. See Plantaiv.

FLECKED. A provincial term used to sig. nify pied, as cattle.

FLEECE. The woolly covering shorn from off the body of the sheep. Mr. James Dickson of Edinburgh contributed a very able prize essay to the Highland Society (Trans. vol. vi p. 205), "on the treatment of sheep, with a view to the improvement of the fleece." The earliest and rudest method of obtaining the fleece was to drive the flocks hastily through a narrow passage, when by their pressure against each other the greater part of the fleece 
was lonsened, or completely detached. To this succeeded another more inhuman mode. The sheep was caught, and the fleece pulled from its back. This harbarous practice prevailed to a very recent date in the Orkney Islands. In England the average value of the fleece in 1315 was $6 l_{\text {. }}$ ( 7 s. $6 d$. of the present money), being nearly half as much as the value of the carcass. (The Sheep, Lib. of Use. Know. p. 3.3, 205.) See Hair, Shemp-Shaning, and Wool.

FLEMISH HUSBANDRY. See FlaNders, Agriculture of.

FLESH. Muscular flesh, which is too well known to need any particular description, is composed of a number of white or red fibres, compounded of still smaller fibres. It is united in ordinary cases with a variety of substances, such as blood, fat, ligament, sinew, and nerves. It has been analysed by $M$. Berzelius who found in it-

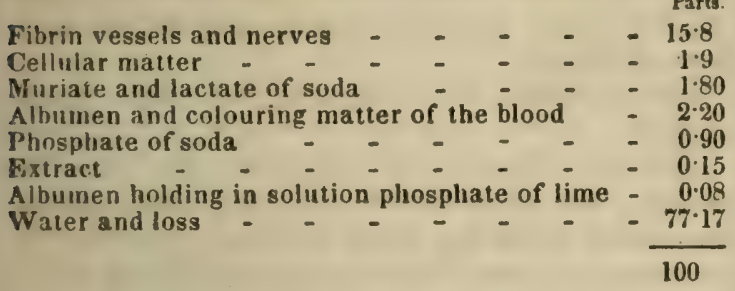

The chief nutriment afforded by animal food is derived from muscle or flesh. That of adult animals is more nutritive than that of young animals; hence beef and mutton are better adapted to support the frame than veal or lamb. The latter yield most gelatin; but the popular idea of the nutritive property of animal jellies is erroneous.

FLIES. "A host of flies," says Harris, "forming nearly one-third of the whole number of species in the order Diptera, will be found to have a short and soft proboscis, ending with large fleshy lips, enclosing only two bristles, and capable of being drawn up within the cavity of the mouth. Their antennæ are generally short, hang down over the face, and end with a large oval joint, bearing a little bristle. Their larvæ, or young, are fleshy, whitish maggots, which never cast their skins, but when the pupa-state comes on, shorten, take the oblong oval form of an egg, and become brown, dry, and hard on the outside. This immense tribe includes the various kinds of flesh-flies, blow-flies, house-flies, dung-flies, flower-flies, fruit-flies, two-winged gall-flies, cheese-flies, and many others, for which we have no common names, but all composing the tribe of Muscans, or Muscala. Some of these flies do not strictly conform to the foregoing characters of the tribe, in all respects; but the exceptions are few in number, and the most remarkable of them will be noticed in the following pages.

"Many flies of this tribe are parasitic in their larvæ state, their young living and undergoing their transformations within the bodies of other insects, particularly in caterpillars, which they thereby destroy. These flies belong chiefly to the family of Tuchinada, a name applied to them on account of the swiftness of their fight. In form they somewhat resemble house-flies; like them they have very large winglets, and their wings spreat apar' when they are at rest. They are easily distiuguished, however, by the stiff hairs wherewith they are more or less covered, and by the bristles on their antennx, which are not usual's feathered. A large fly of this kind, the Tuchuv vivida of my 'Catalogue,' is often seen on fences, and on plants, and sometimes in houses, towards the end of June and during the month of July. Its large, oval hind-body is of a clear light-red colour, with two or three black spots in a row, on the top of it, and a thick row of black bristles across each ring. The face is grayish white, like satin, and the eyes are copper-coloured. The thorax is gray, with brownish lines upon it. 'The antennæ, proboscis, and legs are light red. Its body is short and thick, and is about half an inch long, and its wings expand rather more than nine-tenths of an inch."

Viviparous Flesh-flies. - "Most insects are hatched from eggs which are laid by the mother on the substances that are to serve for the food of her young. Some flesh-flies produce their young alive, or already hatched, and drop them on the dead and putrefying animal matter, which they are obliged to consume and remove in the shortest possible time. An exception from the usual course among insects appears therefore to have been made in favour of these viviparous flesh-flies, to enable their young promptly to perform their appointed tasks. These insects produce an immense number of young, as many as 20,000 having been observed by Réaumur in a single fly. Our largest viviparous American flesh-fly is the Sarcophaga Georgina of Wiedemann. It appears towards the end of June, and continues till the middle of August, or perhaps later. Its face is silvery white, and there is an oblong square black spot between the eyes, which are copper-coloured. The thorax is light gray, with seven black stripes upon it. The hind-body is nearly conical, has the lustre of satin, and is checkered with square spots of black and white, shifting or interchanging their colours according to the light wherein they are seen. The legs are black, and the hindmost pair are very hairy in the males. The female is about half an inch long; and the male is rather smaller. In the Sarco. phagans, or flesh-eaters, as the name implies, the bristles on the antennæ are feathered."

Stable-fly.-_"The flies that abound in American stables in August and September, and sometimes enter houses on the approach of rain, might be mistaken for house-flies, were it not for the severity of their bites, which are often felt through our clothing, and are generally followed by blood. Upon examination they will be found to differ essentially from house-flies in their proboscis, which is very long and slender, and. projects horizontally beyond the head. The bristles on their antennæ are feathered above. Cattle suffer sorely from the piercing bites o: these flies, and horses are sometimes so much tormented and enraged by them as to become entirely ungovernable in harness. The name of this kind of fly is Stomorys calcitrans; the first word signifying sharp-mouthed, and the second kicking, given to the fly from the effect it produces on horses. It lays its eggs in 
dung, where its young are hatched, and pass through their transformations. The larvæ and pupæ do not differ much in appearance from those of common house-flies."

Meat-flies.- "It is found all summer ahout slaughter-houses, butchers' stalls, and pantries, which it frequents for the purpose of laying its eggs on meat. The eggs are commonly called fly-blows; they hatch in two or three hours after they are laid, and the maggots produced from them come to their growth in three or four days, after which they creep away into some dark crevice, or burrow in the ground, if they can get at it, turn to egg-shaped pupæ, and come out as flies, in a few days more; or they remain unchanged through the winter, if they have been hatched late in the summer. A smaller fly, of a brilliant blue-green colour, with black legs, also lays its eggs on meat, but more often on dead animals in the fields. It seerns hardly to differ from the Musca (Lucilia) Casar of Europe. The house-fly of this couniry has been supposed to be the same as the European Musca domestica; but I cannot satisfy myself on this point for the want of specimens from Europe. It is possible that our sharpbiting stable-flies, the meat-flies, and the housefly, may really be distinct species from those which are found in Europe."

House-fly.-The American house-fly is the Musca harpyia, or harpy-fly of Dr. Harris's Catalogue. It begins to appear in houses in July, becomes exceedingly abundant in September, and does not disappear till killed by cold weather. It is probable that, like the domestic fly of Europe, it lays its eggs in dung, in which its larvæ live, and pass through their changes of form. The Americans are accused of carelessness in regard to fiies, and apparently with some reason. But, if these filthy, dung-bred creatures swarm in some houses, covering every article of food by day, and absolutely blackening the walls by night, in others comparatively few are found; for the tidy house-keeper takes care not to leave food of any kind standing about, uncovered, to entice them in, and makes a business of driving out the intruders at least once a day. If a plateful of strong green tea, well sweetened, be placed in an outer apartment accessible to flies, they will taste of it, and be killed thereby, as surely as by the most approved fly-poison. In the first volume of The Transactions of the Entomological Society of London, Mr. Spence gives an account of a mode of excluding flies from apartments, which has been tried with complete success in England. It consists of netting, made of fine worsted or thread, in large meshes, or of threads alone, half of an inch or more apart, stretched across the windows. It appears that the flies will not attempt to pass through the meshes, or between the threads, into a room which is lighted only on one side; but if there are windows on another side of the room, they will then fly through; such windows should therefore be darkened with shutters or thick curtains. (Harris.)

FLINT. Common flints are nearly pure slica, which is composed of a metal (silicium) and oxygen gas; it is tasteless, insoluble in water, or fuoric acid, an: ${ }^{3}$ issolvable only by means of potash. Flints usually occur in irregular nodules in chalk. T'hey abound considerably in some sorts of soils. Sand is commonly chiefly composed of flint. A specimen of flint analyzed by M. Klaproth contained

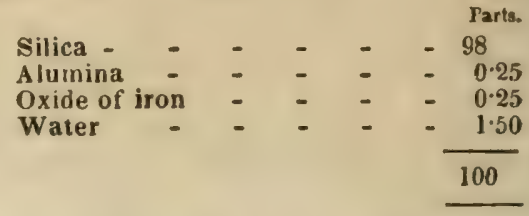

Flint, when exposed to intense heat, becomes opaque, and forms a kind of porcelain. This was well illustrated in the fire in the 'Tower of London, in 1841. 'The flints of the muskets were all thus changed. See Eartus.

FLOAT. A raft of timber bound together to be conveyed by water. It also signities locally to turn water upon meadow land for improving it; and likewise to pare off the surface or sward.

\section{FLOATING OF MEADOWS. See IrRI-} GATION.

FLOUR (Span. flor; It. fiore; Fr. fleur de farnie). The meal of wheat corn or other grain, separated from the husk or bran, and finally ground and sifted. There are in England three qualities of flour, denominated first, seconds, and thirds, of which the first is the purest. (See BnEAD.) The proportion of flour which a bushel of grain affords greatly varies. A bushel of Essex wheat, Winchester measure, weighs upon an average about 60 lbs., which, when ground, will yield (exclusive of the loss incurred by the grinding and drying) $45 \frac{1}{2} \mathrm{lbs}$. of the flour called seconds, which alone is used for baking throughout the greater part of England, and affords the most wholesome, though not the whitest bread. Besides the seconds, such a bushel of wheat yields 13 lbs. of pollard and bran; the total loss in grinding seldom exceeds one pound and a half.

The corn of the different species of grain produces, when ripe, nearly the following quantities of meal or household flour and bread per bushel: viz.

Wheat if weighing $60 \mathrm{lbs}$, of flour $48 \mathrm{lbs}$. of bread 64 lhs

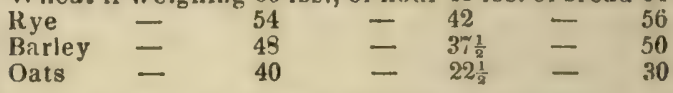

The flour of wheat which is cut before it is quite ripe is whiter than that which is allowed to come to maturity, and bears a higher price in the marliets. The grain which is inten led for the miller should, therefore, be reaped before it has reached its utmost growth; but that which is meant for seed should be allowed to stand until the last moment at which it can be cut with safety. The corn is ground into meal of various degrees of fineness, and a bushel of $60 \mathrm{lbs}$.generally yields, when dressed, about the following quantities, viz.

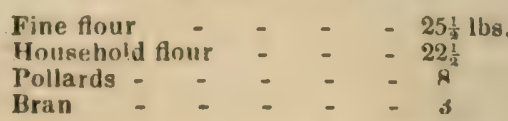

A bushel of wheat, therefore, averages 48 lbs. of both kinds of flour of the sort called "seconds," and a sack of marketable flour should by law weigh $280 \mathrm{lbs}$. These products must, 
however, vary according to the quality of the grain; some will produce more or less bran, Rs the husk may be more or less thick; and the bakers admit they can make two or three more quartern loaves than the usual quantity from one sack of flour, when it is the genuine produce of good wheat. Thus it was found upon a comparative trial between English and Scotch wheat, of apparently equal quality, that there was a difference in favour of the former of no less than $13 \mathrm{lbs}$. of bread upon $21 \mathrm{cwts}$. of flour. (Willich's Dom. Ency.; Bril. Husb. vol. ii. pp. 137, 155.)

FLOWER DE LUCE, or LIS. FLAG. See InIs.

FLOWERING ASH (Scopoli). All the species of the genus scopoli are ornamental and useful; they are easily cultivated, and may be raised from seeds, like the common ash, or they may be increased by budding or grafting on the common ash.

FLOWERING RUSH, COMMON (Butomus umbellalus). This beautiful aquatic plant is in England a native of ponds, ditches, and the margins of rivers on a gravelly soil. It flowers in July and August. 'The leaves are narrow, acute, nearly a yard long. The stalk is still taller, round, and very smooth, and bears a large bracteated umbel of handsome rose-coloured flowers, each about an inch broad, without scent. 'This rush may be increased with little difficulty. The leaves of this plant are said to cause the mouths of cattle to bleed that crop it; hence the name, from bous, ox, and temno, to cut. It was some years since much celebrated in Russia as a remedy for hydrophobia; but like all specifics, its fame was destroyed by excess of praise. It has no influence in curing that disease.

FLOWERS. The most beautiful parts of plants and trees, which contain the organs of fructification. (See Botany.) From their frequent utility as medicinal drugs, as well as their external beauty, the cultivation of flowers in our gardens becomes an object of some importance. Flowers are many of them excellent indicators of the approaching weather by expansion or closing, and other motions. It is an established fact, that flowers as well as fruits grow larger in the shade, and ripen and decay soonest when exposed to the sun. The immediate cause of the various colours presented by some flowers, such as poppies, has not hitherto been distinctly ascertained. Colouring matter is contained in almost every flower and root of vegetables, and may be extracted by a very simple process. Flowers which are to be used or preserved for medicinal purposes should, with a few exceptions, be gathered in full bloom, and dried as speedily as possible. The rose, Rosa Gallica, is gathered before it is fully blown. In drying flowers, the calyces, claws, \&c. should be previously taken off: when the flowers are very small, the calyx is left, or even the whole flowering spike, as in the greatest portion of the labiate flowers. In some instances, as in the baulistines, or pomegranate flower, the active matter resides chiefly in the calyx. Compound flowers with pappous seeds, as colt's-foot, ought to be dried very high, and before they are en- tirely open, otherwise the slight moisture that remains would develope the pappus, and form a kind of cottony nap, which would be very hurtful in infusions, by leaving irritating par. ticles in the throat. Flowers of little or no smell may be dried in a heat of 75 to $100^{\circ}$ Fahr. The succulent petals of the liliaceous plants, whose odour is very fugacious, cannot well be dried, as their mucilaginous substance rots and grows black. Several sorts of flower. ing tops, as those of lesser centaury, wormwood, melilot, water germander, \&c., are tied in small parcels and hung up, or else exposed to the sun, wrapped in paper cornets, that they may not be discoloured. After some time, blue flowers, as those of violets, bugloss, or borage, grow yellow, and even become entirely disco. loured, especially if they are kept in glass vessels that admit the light: if, however, they are dipped for a moment in boiling water, and slightly pressed before they are put into the drying stove, the blue colour is rendered permanent. (Gray's Sup. to Pharmacop.) It is probable that varieties in the colours of single flowers raised from seeds may be generally obtained by sowing those which already possess different shades contiguous to others of the same species; or by bending the flowers of one colour, and shaking the antherdust over those of another. The origin of double flowers is believed to result from the luxuriant growth of the plant, in consequence of excessive nourishment, moisture, and warmth; they arise from the increase of some parts of the flower, and the consequent exclusion of others: thus the stamens are often converted into retals. Botanists very properly term such multiplied flowers vegetable monsters, because they possess no stamens or pistils, and therefore cannot produce seeds. There subsists (says Dr. Darwin) a curious analogy between these vegetable monsters and those of the animal world; for a duplicature of limbs frequently attend the latter, as chickens and turkeys with four legs and four wings, and calves with two heads, \&c. The science of floriculture, or the culture, propagation, and general management of plants, divides itself into five sections, viz. 1. Stove plants; 2. Greenhouse plants; 3 . Hardy trees and shrubs 4. Hardy herbaceous plants; 5. Annuals and biennials.

FLUKE WORM (Distoma hepaticum; Fasciola hepatica, Linn.). A small flat entozoon or worm, about an inch long, which infests the ducts of the liver and gall-bladder of different animals, especially sheep. In those that have died of the rot, it is generally found fixed by two points, one at one extremity, and the other about the middle of the abdomen of the worm it bears some resemblance to the seed of the common gourd, and thence is often called the gourd-uorm. See SHFEp, Disfases of.

FI,Y IN SHEEP. See Sireep, Diseases or.

FLY IN TURNIPS (Altica nemorum). A species of flea-beetle, which in England attacks the turnip crop in the cotyledon, or seed leaf, as soon as it appears: it is sometimes called the black jack, and sometimes the flea, or black fly. All the species are among the smallest insects; several are scarcely a line 


\section{FLY IN TURNIPS.}

long: the length of the largest is hardly two lines, and one in breadth. The greatest number are shining green, with a brown or yellowish hue. Early in spring they are seen sitting on walls in great numbers; in winter they live under leaves, stems of plants, and in chinks in walls: during summer they are the most dangerous enemies of various vegetables, particularly the cabbage tribe. They also attack different sorts of the root genus Brassica, such as the turnip, \&c., as well as the radish, the common cress, and the water cress. Besides these sorts of vegetables, they also prey upon flax, tobacco, hops, seedling clover, and sainfoin, but more especially the summer and winter turnips, which are left for seed, and often entirely spoil the future harvest during the flowering season, when the weather is warm and dry. The turnip beetle belongs to the order Coleoptera, from its wings with which it flies being folded beneath two horny cases. It is included in the family СнnysoMELIDE, or golden beetles, for certain scientific reasons, in conformity with its structure, and is one of about 100 species forming the genus Altica, sometimes written Haltica.

The striped turnip beetle is named in the English catalogues Altica nemorum. The former word, derived from the Greek, alludes to the leaping powers of the genus, and the latter signifying that this species inhabits woods and groves, which were more especially its haunts before turnip cultivation became general. See Cucumber Insects.

The remedies recommended are numerous, among which, hoeing and rolling may harass and kill many of the beetles; and as this process promotes the more rapid growth of the plants, it must be attended with no slight advantages. From the dislike the fly has to repeated wet, frequent watering the turnips would evidently be very beneficial, particularly with brine (not strong enough to injure the plants) or liquid manure, which would stimulate the growth most effectually; and many of the beetles would necessarily be forcibly brushed off, and get set fast in the earth, and die. Sulphuric solutions sprinkled by machinery would also have a powerful effect. Nitrate of soda has been tried in a few instances on crops of Swedish turnips with very beneficial results. A net (called after its inventor the Paul net) dragged over the field has been usefully employed; and a board newly painted with white paint, or tarred, drawn over the turnips, will catch multitudes of the beetles; for, on being disturbel, they leap against it, and cannot release themselves.

The rapid growth of the plant appears to be the best security against the ravages of the ansect; and to insure this, plenty of seed should be sown, all of the same year's growth. Deep ploughing will be found advantageous when the chrysalides are in the soil. Drilling is far superior to broadcast sowing, and in Scotland is believed to keep away the beetles. Early sowing is attended with disadvantages; for the same warmth and sunshine that make the seed vegetate will also bring the hungry swarms of beetles from their winter quarters.

In England, where the ravages of the flea490 beetle have attracted so much attention, it is thought that the careful and systematic use of lime will obviate, in a great degree, the danger which has been experienced from this insecx. As soon as the plants appear above ground they are to be dusted with quicklime, and this is to be repeated as often as rain or wind beats it of and the fly reappears. Watering plants with alkaline solutions, it is said, will kill the insects without injuring the plants. To make the solution, $1 \mathrm{lb}$. of hard soap may be dissolved in 12 gallons of soap-suds left after washing clothes. This may be sprinkled twice a day by means of a watering pot. The solution of whale oil soap as recommended for the destruction of Aphides or plant-lice, would doubtless answer an excellent purpose in destroying the turnip fly.

The turnip saw-fly (Athalia spinarum), is a less common depredator, butt in England is occasionally found in company with the former. A very minute account of it is given by $\mathrm{Mr}$. Duncan. (Quart. Journ. of Agr. vol. vii. p. 558.) It receives its name from the use and appearance of the instrument with which it deposits its eggs. 'This is placed at the extremity of the abdomen of the female, on the under side, and is so constructed that it combines the properties of a saw and auger. (Kollar on Insects injurious to Farmers, Miss Loudon's Transl.; Doncaster Report; Mr. Curtis on Insects affecting the Turnip Crop; Pract. Husbandry; Himris on Destructive Insects.)

FLY IN WHEAT (Tipula tritici, Kirby; Cecidomyia tritici, Latr.). See Pl. 2 , $i$. In England when the wheat is in blossom, it is sometimes attacked by this small beautiful fly, with an orange-coloured body and white wings, which lays its eggs in the middle of the blossom, by means of a long retractile ovipositor. When the eggs are hatched, the larvæ, which are very small, from 10 to 14 being sometimes found in one grain, prevent the fructification of the grains, probably by eating the pollen, and thus frequently destroy some part of the harvest. Mr. Shirreff (Quart. Journ. of Agr. vol. iii. p. 501) says the fly generally appears when the wheat plant comes into ear. In 1829 and 1830, flies were first seen by him on the 21 st of June, and, in 1831 , on the 10th of the same month. The larvæ, after a period, fall to the ground, and burrow in the earth, where they remain till the following summer. Ac cording to Mr. Gorrie (Mag. Nut. Histo, Septo, $1829, \mathrm{p} .324)$, all the larvæ have quited the ears of wheat and descended to the earth by the 1st of August; going into the ground to about the depth of half an inch, where it is probable that they pass the winter in the pupa state.

The extraordinary smallness of this insect, both in its larva and perfect state, with the circumstance that the destruction of the wheat takes place when it is in blossom, and that not all the ears on one and the same field are at. tacked, allows of but little that can be effected by human aid against this enemy of grain. The safest and almost only certain means of diminishing such an evil for the succeeding year, consists in not sowing wheat again on 'he same field, nor in its neighbourhood; for, in all pro. bability, the pupx lie in the earth, and will 
inly become flies next year at the season when the corn is in blossom. Fortunately, nature has in this case provided another still smaller parasitic insect, allied to the family of Ichneumons, to keep the midge also within its proper bounds. Mr. Kirby, who first made us acquainted with the natural history of this insect, calls the parasite Ichneumon Tipula. It is a species of the genus Platygaster of Latreille, belonging to the family Proctotrupida.

$\mathrm{Mr}$. Gorrie states that, from the experiments which he made in the season 1831, the variety of wheat cultivated under the name of Cone wheat (Triticum turgidum, Pl. 2, d), is not liable to the attacks of the fly. (Quart. Journ. of $A g r$. vol. iii.p.639.) Mr. Shirreff (Ibid.p. 305), also considers the Polish wheat (T. Polonicum, Pl. 2, c), to be in a measure secure from its attacks.

The ravages committed by the wheat-fly in scotland are sometimes very extensive. It is stated by Mr. Shirreff, that throughout the whole of East Lothian, during the years 1827, 1828, 1829 , and 1830 , the fly injured the wheat crop to the amount of 30 per cent. Should the fly abound in this proportion throughout the kingdom in successive years, the loss to the community would be incalculable. Mr. Gorrie seems to think that the wheat-fly maggot might be so buried as not to be able to work their way up through the superincumbent soil; if, in ploughing in the wheat stubble, a scarifier or skimmer were fixed upon the beam before the coulter, so constructed as to lay about an inch of the surface in the bottom of the furrow. There is another kind of fly or midge (Tipula rerealis, Sauter), which is particularly injurious to spelt (a kind of dwarf wheat) and barley. (Kollar on Insects injurious to Agriculture. Quart. Journ. of $A g r$. vol. ii. p. 3 ; Westwood on Wheat Flies, in Gard. Mag. vol. xiii. p. 289.)

An insect resembling the European wheatfly in its habits, and known, in its maggot form, by the name of "the grain-worm," has been observed for several years in the northern and eastern parts of the United States and in Canada. (See Pl. 2, $i$, where the maggot and fly are represented as highly magnified.) "It seems," says Dr. Harris, "to have been mistaken by some for the grain-weevil, the Angoumois grain-moth, and the Hessian $\mathrm{fly}$, and its history has been so confounded with that of another insect, also called the grain-worm in some parts of the country, that it is difficult to ascertain the amount of injury done by either of them alone. The wheat-fly is said to have been first seen in America about the year 1828, in the northern part of Vermont, and on the borders of Lower Canada. From these places its ravages have gradually extended in various directions from year to year. $\mathbf{A}$ considerable part of Upper Canada, of New York, New Hampshire, and of Massachusetts has been visited by it; and, in 1834, it appeared in Maine, which it has traversed, in an easterly course, at the rate of 20 or 30 miles a year. The country over which it has spread has continued to suffer more or less from its alarming depredations, the loss by which has been found to vary from about one-tenth part to nearly the whole of the annual crop of wheat; nor has the insect entirely disappeared in any place till it has been starved out by a change of agriculture, or by the substitution of late-sown spring wheat for the other varieties of grain. Many communications on this destructive insect have appeared in the Cenespe fiarmer and in the Cultivator, sume of them written by the late Judge Buel, by whom, as well as by the editors of the Yanke Farmer, rewards were offered for the discovery of the means to prevent its ravages. Premiums have also been proposed for the same end by the Kenneber County Agricultural Society, in Maine, which were followed by the publication in the Maine Farmer of three "Essays on the Grain-Worm," presented to that Society. These essays were reprinted in the 17th volume of the New England Farmer, wherein, as well as in some other volumes of the same work, several other articles on this insect may be found.

"The American wheat-insect, in its winged form, has not yet fallen under my notice. It is stated by Judge Buel, Mrs. Gage, and others, to agree exactly with the description of the European wheat-fly (Cecidomyia tritici), being a very small, orange-coloured gnat, with long, slender legs, and two transparent wings, which reflect the tints of the rainbow. Immense swarms of these orange-coloured gnats infest fields of grain towards the last of June. While the sun shines they conceal themselves among the leaves and weeds near the ground. They take wing during the morning and evening twilight, and also in cloudy weather, when they lay their eggs in the opening flowers of the grain. New swarms continue to come forth in succession, till the end of July; but $\mathrm{Mr}$. Buel says that the principal deposit of eggs is made in the first half of July, when late sown winter-wheat and early sown spring-wheat are in the blossom or milk. The flies are not con. fined to wheat alone, but deposit in barley, rye, and oats, when these plants are in flower at the time of their appearance. The eggs hatch in about eight days after they are laid, when the little yellow maggots or grain-worms may be found within the chafiy scales of the grain. Being hatched at various times during a period of four or five weeks, they do not all arrive at maturity together. Mrs. Gage informs me that they appear to come to their growth in 12 or 14 days. Specimens of these maggots which she has sent to me were found to agree, in every respect, with the descriptions and figures of those of the European wheat-fly. 'They'do not exceed one-eighth of an inch in length, and are not provided with feet. From 2 to 15 ol 20 have been found within the husk of a single grain, and sometimes in every husk in the ear. After a shower of rain they have been seen in such countless numbers on the beards of the wheat, as to give a yellow colour to the whole field. These insects prey on the grain in the milky state, and their ravages cease when the grain becomes hard. They do not burrow within the kernels, but live on the poilen and on the soft matter of the grain, which they probably extract from the base of the germs. It appears, from various statements, that very early and very late wheat escape with comparatively little injury; the amount of which, in other cases, depends upon the condition of the 
grain at the time when the maggots are hatched. When the maggots begin their depredations soon after the blossoming of the grain, they do the greatest injury, for the kernels never fill out at all. Pinched or partly filled kernels are the consequence of their attacks when the grain is more advanced. The hulls of the im. poverished kernels will always be found split open on the convex side, so as to expose the embryo. This is caused by the drying and shrinking of the hull, after a portion of the contents thereof has been sucked out by the maggots. Towards the end of July and in the beginning of August the full-grown maggots leave off eating, and becofne sluggish and torpid, preparatory to moulting their skins. This process, which has been alluded to by Judge Buel and some other writers, has been carefully observed by Mrs. Gage, who has sent to me the maggots before and after moulting, together with some of their cast skins. Within two or three days after moulting, the maggots either drop of their own accord, or are shaken out of the ears by the wind, and fall to the ground. They do not let themselves down by threads, for they are not able to spin. Nearly all of them disappear before the middle of August, and they are very rarely found in the grain at the time of harvest.

"Several cases of the efficacy of fumigation in preventing the depredations of these insects are recorded in our agricultural papers. For this purpose brimstone has been used, in the proportion of one pound to every bushel of seed sown. Strips of woollen cloth, dipped in melted brimstone, and fastened to sticks in different parts of the field, and particularly on the windward side, are set on fire, for several evenings in succession, at the time when the grain is in blossom; the smoke and fumes thus penetrate the standing grain, and prove very offensive or destructive to the flies, which are laying their eggs. A thick smoke from heaps of burning weeds, sprinkled with brimstone, around the sides of the field, has also been recommended. Lime or ashes, strown over the grain when in blossom, has, in some cases, appeared to protect the crop; and the Rev. Henry Colman, the Commissioner for the Agricultural Survey of Massachusetts, says that this preventive, if not infallible, may be relied on with strong confidence. For every acre of grain, from one peck to a bushel of newiy slaked lime or of good wood ashes will be required; and this should be scattered over the plants when they are wet with dew or rain. Two or three applications of it have sometimes been found necessary. Whether it be possible to destroy the maggots after they have left the grain, and have betaken themselves to their winter quarters, just below the surface of the ground, remains to be proved. Some persons have advised burning the stubble, and ploughing up the ground, soon after the grain is harvested, in order to kill the maggots, or to bury them so deeply that they could not make their escape after they were transformed to fies. Perhaps thoroughly liming the soil before it is ploughed may contribute to the destruction of the insects. It is stated that our crops may be saved from injury by sowing carly in the autumn or late in the spring. By the first, it is supposed that the grain will be. come hard before many of the flies make their appearance; and by the latter, the plants do not come into blossom until the flies have disappeared. In those parts of New England where these insects have done the greatest injury, the cultivation of fall-sown or winter grain has been given up; and this, for some years to come, will be found the safest course. The proper time for sowing in the spring will vary with the latitude and elevation of the place, and the forwardness of the season. From numerous observations made in this part of the country, it appears that grain sown after the 15th or 20th of May generally escapes the ravages of these destructive insects. Late sowing has almost entirely banished the wheatflies from those parts of Vermont where they first appeared; and there is good reason to expect that these depredators will be completely starved out and exterminated, when the means above recommended have been generally adopted and persevered in for several years in suc. cession.

"Mrs. Gage has discovered another pernicious insect in the ears of growing wheat. It seems to agree with the accounts of the Thrips cereulium, which sometimes infests wheat in Europe to a great extent. This insect belongs to the order Hemiptera. In its larva state it is smaller than the wheat maggot, is orangecoloured, and is provided with six legs, two antennæ, and a short beak, and is very nimble in its motions. It is supposed to suck out the juices of the seed, thus causing the latter to shrink, and become what the English farmers call pungled. This little pest may probably be destroyed by giving the grain a thorough coating of slaked lime.

"Our agricultural papers contain some accounts of an insect or insects much larger than the maggots of the wheat-fly, growing to the length of three-eighths of an inch or more, and devouring the grain in the ear, and after it is harvested. The insects to which I allude have received the names of wheat-worms, gray worms, and brown weevils; and, although these different names may possibly refer to two or more distinct species, I am inclined to think that all of them are intended for only one kind of insect. Sometimes this has also been called the grain-worm; whereby it becomes somewhat difficult to separate the accounts of its history and depredations from those of the Cecidomyia, or wheat-insect, described in the foregoing pages. It may, however, very safely be asserted that the wheat-worm of the western part of New York and of the northern part of Pennsylvania is entirely distinct from the maggots of our wheat-fly, and that it does not belong to the same order of insects. From the description of it, published in the sixth volume of the Cultivator, by Mr. Willis Gaylord, this depredator appears to be a caterpillar, or span-worm, being provided with twelve feet, six of which are situated near each extremity of its body. Like other span-worms, or Geometers, it has the power of spinning and sus. pending itself by a thread. Mr. Gaylord says that it is of a yellowish-brown or butternus colour ; that it not only feeds on the kernel in 


\section{FLY IN WHEAT.}

the milky state, but also devours the germinating end of the ripened grain, without, however, burying itself within the hull; and that it is found in great numbers, in the chaff, when the grain is thrashed. He says, moreover, that it has been known for years in the western part uf New York; and that it is not so much the new appearance of this insect, as its increase, which has caused the present alarm respecting it. The transformations and the appearance of this insect in its perfected state have not yet been described. Mr. Nathaniel Sill, of Warren, Pennsylvania, has given a somewhat different description of it. On thrashing his winter-wheat, immediately after harvest, he found among the screenings a vast army of this new enemy. He says that it was a caterpillar, about three-eighths of an inch in length, when fully grown, and apparently of a straw-colour; but, when seen through a magnifier, was found to be striped lengthwise with orange and cream colour. Its head was dark brown. It was provided with legs, could suspend itself by a thread, and resembled a caterpillar in all its motions. This insect ought not to be confounded with the smaller worms found by Mr. Sill in the upper joints of the stems of the wheat, and within the kernels, until their identity has been proved by further observations. It appears highly probable that Mr. Gaylord's and Mr. Sill's wheat-caterpillars are the same, notwithstanding the difference in their colour. Insects, of the same size as these caterpillars, and of a brownish colour, have been found in various parts of Maine, where they have done much injury to the grain. Unlike the maggots of the wheat-fly, with which they have been confounded, they remain depredating upon the ears of the grain until after the time of harvest. Immense numbers of them have been seen upon barn-floors, where the grain has been thrashed, but they soon crawl away, and conceal themselves in crevices, where they probably undergo their transformations. These wheat-worms, or wheat-caterpillars, as they ought to be called, if the foregoing accounts really refer to the same kind of insect, are supposed by some persons to be identical with the clover-worms, which have been found in clover, in various parts of the country, and have often been seen spinning down from lofts and mows where clover has been stowed away."

Fries Destructive to Banzer. Several communications respecting a disease of barley-straw, produced by the punctures of insects, were published in Fessenden's New England Farmer, in 1829 and 1830 (vol. 8th). In one of these, from the Hon. J. Merrill, of Newburyport, it is stated that the barley in that vicinity yields not much more than the seed sown. Most of the stalks were found to have a number of small worms within them, near to the second joint, and had become hardened in the part attacked. During several years previous to this date the crops of barley in various parts of Essex and Middlesex counties, had been more or less injured in the same way, so as in some places to induce farmers to abandon the culture. It was supposed that the insects had been imported from Bremen, or
FI.Y IN WHEAT.

some other port in the north of Eurape The maggots were found to be transfurmed into small flies, which were though the same as Hessian flies. In the summer of 1831, myriads of these flies were found alive in straw beds in Gloucester, the straw having been taken from the fields the year before. Complaints were made that the insects in these straw beds stung those that slept upon them. But Dr. Harris thinks that the stings mus: have come, not from the grain-fly itself, but from parasites, vast numbers of which, closely resembling the Eurytoma Destructor, have been found to come out of the diseased straw.

When the barley is about 8 or 10 inches high, the effects of the disease in it begin to be visible by a sudden check in the growth of the plants, and the yellow colour of their lower leaves. If the butts of the straw are now examined, they will be found to be irregularly swollen, and discoloured, between the second and third joints, and, instead of being hollow, are rendered solid, hard, and brittle, so that the stem above the diseased part is impoverished, and seldom produces any grain. Suckers, however, shoot out below, and afterwards yield a partial crop, seldom exceeding one-half the usual quantity of grain. "It is evident," says Mr. Gourgas, "that the soundness of the grain, raised in a blighted field, is not affected thereby in the slightest degree; the seed (eggs) to perpetuate the disease from year to year is lodged in the straw, which, when hatched, are the worms" before mentioned. Dr. Andrew Nichols, of Danvers states, that these worms are about one-tenth of an inch in length, and of a yellow or straw colour; and that in the month of November, they appeared to have passed to the chrysalis state. They live through the winter unchanged in the straw, many of them in the stubble in the field, while others are carried away when the grain is harvested. When the barley is thrashed, numerous small pieces of diseased straw, too hard to be broken by the flail, will be found among the grain. Some of these may be separated by the winnowing machine, but many others are too large and heavy to be winnowed out, and remain with the grain, from which they can only be removed by the slow process of picking them out by hand.

Dr. Harris, who examined portions of the diseased barley-straw, states that he found each piece to contain several small, whitish maggots, each maggot imbedded in the thickened and solid substance of the stem, a little longitudinal hollow, of the shape of its own body; and its presence was known by an oblong swelling upon the surface. In some pieces of straw the swellings were so numerous as greatly to disfigure the stem, the circulation in which must have been very much checked if not destroyed. Early in the following spring, these maggots entered the pupæ or chrysalis state, and on the 15th of June the perfected insects began to make their escape through minute perforations in the straw, which they gnawed for this purpose. Seven of these little holes were counted in a piece of straw only half an inch in length. The insects continued to release themselves from their confinemens till the 5 th of July, after which no more were 
seen. Much to his surprise they proved to be minute, four-winged Ichneumon-flies, which are parasitical, or prey, in the larva state, on the bodies of other insects. He had hoped to have obtained the true culprits, the cause of the disease, supposing that the latter were allied to the Hessian fly; but these little insects, while in the larva state, had destroyed them all, and, having finished their appointed task, and undergone their transformations, now made their escape from the straw in the winged form. The scientific name, given to this newly discovered parasite, was Eurytoma Hordei, so called from Hordeum, the Latin name for barley. It is very much like the parasite (Eurytoma destructor) of the Hessian Ay, described by Mr. Say, but is rather larger, of a jet black colour, except the legs, which are blackish, with pale yellow joints. The head and thorax are somewhat rough, and slightly hairy; the hind-body is smooth and polished. 'The female is thirteen-hundredths of an inch long; the male is rather smaller. It often moves by little leaps, but the hindmost thighs are not thickened. This minute insect is to be reckoned among our friends, being appointed, by an all-wise and provident Creator, to check the increase of the destructive $\mathrm{fly}$ that attacks our barley. Though disappointed in my attempts to obtain the latter, in its perfected state, I hail with pleasure the appearance of its mortal enemy. "Although," says Dr. Harris, "the barley-fly has not yet been seen by me, there does not exist the smallest doubt in my mind that it is a two-winged gnat, like the Hessian fly and wheat-fly. Any one, who will compare the history of the latter two with what is known of the barley insect, will arrive at the same conclusion. Both the Hessian fly and the barley insect attack the culms or straw of grain, which they injure to a great extent; and both have a similar four-winged parasite appropriated to them. It is probable that the barley-fly is a species of Cecidomyia, distinct from the Hessian and the wheat-flies."

We have reason to believe, that the maggots of the barley-fly remain in the straw during the winter, and that they take the winged form in the spring, in season to lay their eggs on the young barley. It is therefore important to prevent them from completing their transformations. 'This may be done by burning the stubble, which contains many of the insects, in the autumn; by destroying in the same way, all the siraw and refuse which is unfit for fodder; and by keeping the grain in close vessels over one year, whereby the insects, which are disclosed from the small heavy pieces of straw remaining unwinnowed from the grain, will perish without an opportunity to escape.

FLY, HESSIAN. One of the most formidable enemies of the wheat crop in the United States, is the far-famed Hessian fly, a small gnat or midge, which naturalists have placed in the family of gall-gnats (Cecidomyiado). The insects of this family are very numerous, and :most of them in the maggot state live in galls, or unnatural enlargements of the stems, leaves, and buds ot plants, caused by the punctures of the winged insects in laying their eggs. I"he following account of the Hessian fly, the dread of farmers wherever wheat is cultivated in North America, is chiefly taken from Harris's Report on Destructive Insects, and Herrick's valuable paper upon this insect, published in Silliman's American Journal of Srience, vol. 42. The brief history of the habits and transformations of the Hessian fly will be found to agree essentially with the excellent observations on this insect, written in 1797 , by Dr. Isaac Chapman, and published in the Memoirs of the Philadelphia Society for Promoting Agriculiure.

"The head and thorax of this fly are black. The hind-body is tawny, and covered with fine grayish hairs. The wings are blackish, but are more or less tinged with yellow at the base, where also they are very narrow: they are fringed with short hairs, and are rounded at the end. The body measures about onetenth of an inch in length, and the wings expand one-quarter of an inch, or more. Two broods or generations are brought to maturity in the course of a year, and the flies appear in the spring and autumn, but rather earlier in the Southern and Middle States than in New England. The transformations of some in each brood appear to be retarded beyond the usual time, as is found to be the case with many other insects; so that the life of these individuals, from the egg to the winged state, extends to a year or more in length, whereby the continuation of the species in after years is made more sure. It has frequently been asserted that the flies lay their eggs on the grain in the ear; but whether this be true or not, it is certain that they do lay their eggs on the young plants, and long before the grain is ripe; for many persons have witnessed and testified to this fact. In the New England States, winter wheat, as it is called, is usually sown about the 1st of September. Towards the end of this month, and in October, when the grain has sprouted, and begins to show a leaf or two, the flies appear in the fields, and, having paired, begin to lay their eggs, in which business they are occupied for several weeks. The following interesting account of the manner in which this is done, was written by Mr. Edward 'Tilghman, of Queen Ann county, Maryland, and was published in the eighth volume of the Cultivator, in May, 1841. "By the second week of October, the first sown wheat being well up, and having generally put forth its second and third blades, I resorted to my field in a fine warm forenoon, to endeavour to satisfy myself, by ocular demonstration, whether the fly did deposit the egg on the blades of the growing plant. Selecting a favourable spot to make my observation, I placed myself in a reclining position in a furrow, and had been on the watch but a minute or two, before I discovered a number of small black flies alighting and sitting on the wheat plants around me, and presently one settled on the ridged surface of a blade of a plant completely within my reach and distinct observation. She immediately began depositing her eggs in the longitudinal cavity between the little ridges of the blade. I could distinctly see the eggs ejected from a kind of tube or sting. After she had deposited eight or ten eggs, I easily caught 
her upon the blade, and wrapped her up in a piece of paper. I then proceeded to take up the planı with as much as I conveniently could of the circumjacent earth, and wrapped it all securely in a piece of paper. After that I continued my observations on the fies, caught several sinilarly occupied, and could see the eggs uniformly placed in the longitudinal cavities of the blades of the wheat; their appearance being that of minute reddish specks. My own mind being thus completely and fully satisfied as to the mode in which the egg was deposited, I propeeded directly to my dwelling, and put the plant with the eggs upon it in a large glass tumbler, adding a little water to the earth, and secured the vessel by covering it with paper, so that no insect could get access to the interior. The paper was sufficiently perforated with pin-holes for the admission of air. The tumbler with its contents was daily watched by myself to discover the hatching of thereggs. About the middle of the fifteenth day from the deposit of the eggs, I was so fortunate as to discover a very small maggot or worm, of a reddish cast, making its way with considerable activity down the blade, and saw it till it disappeared between the blade and stem of the plant. This I have no doubt, was the produce of one of the eggs, and would, I presume, have hatched much sooner, had the plant remained in the field. It was my intention to have carried on the experiment, by endeavouring to hatch out the insect from the flax-seed state into the perfect fly again; but being called from home, the plant was suffered to perish. The fly that I caught on the blade of the wheat, as above stated, I enclosed in a letter to Mr. John S. Skinner, the editor of the American Farmer, of Baltimore, who pronounced it to be a genuine Hessian fly, and identical in appearance with others recently received from Virginia.

"Dr. Chapman agrees with the writer, in saying that the Hessian fly lays her eggs in the small creases of the young leaves of the wheat. Mr. Havens, in an article on this insect, which will again be referred to, states, that the fly lays her eggs on the leaves. In the fortieth number of The Connecticut Farmer's Gazette, Mr. Herrick says, 'I have repeatedly, both in autumn and spring, seen the Hessian fly in the act of depositing eggs on wheat, and have always found that she selects for this purpose the leaves of the young plant. The eggs are laid in various numbers on the upper surface of the strap-shaped portion (or blade) of the leaf.' His remarks in Professor Silliman's Journal are to the same effect. Other authorities on this point might be mentioned; but the foregoing are sufficient, in my opinion, to establish the fact, that the Hessian fly lays her eggs on the leaves of wheat soon after the plants are up. 'The number on a single leaf,' says Mr. Herrick, 'is often twenty or thirty, and sometimes much greater. In these cases many of the larvæ must perish. 'The egg is atout a fiftieth of an inch long, and four-thousandth of an inch in diameter, cylindrical, translucent, and of a pale red colour.' Mr. Tilghman $v$ as correct in supposing that the eggs would hatch in less than fifteen days, under favourable circumstances; for, if the weather be warm, they commonly hatch in four days after they are laid. The maggots, when they first come out of the shells, are of a pale red colour. Forthwith they crawl down the leaf, and work their way between it and the main stalk, passing downwards till thry corne to a joint, just above which they remain, a little below the surface of the ground, with the head towards the root of the plant. Having thus fixed themselves upon the stalk, they become stationary, and never move from the place till their transformations are completed. They do not eat the stalk, neither do they penetrate within it, as some persons have supposed, but they lie lengthwise upon its surface, covered by the lower part of the leaves, and are nourished wholly by the sap, which they appear to take by suction. 'They soon lose their reddish colour, turn pale, and will be found to be clouded with whitish spots; and through their transparent skins a greenish stripe may be seen in the middle of their bodies. As they increase in size, and grow plump and firm, they become imbedded in the side of the stem, by the pressure of their bodies upon the growing plant. One maggot thus placed seldom destroys a plant; but when two or three are fixed in this manner around the stem, they weaken and imporerish the plant, and cause it to fall down, or to wither and die. They usually come to their full size in five or six weeks, and then measure about three-twentieths of an inch in length. Their skin now gradually hardens, becomes brownish, and soon changes to a bright chestnut colour. This change usually happens about the first of December, when the insect may be said to enter on the pupa state, for after this time it talies no more nourishment. Mr. Herrick informs me, that the brown and leathery skin, within which the maggot has changed to a pupa or chrysalis. is long, egg-shaped, smooth, and marked with eleven transverse lines, and measures one. eighth of an inch in length. In this form it has been commonly likened to a flax-seed. It appears, then, from the remarks of Dr. Chapman, Mr. Herrick, and other careful observers, that the maggots of the Hessian fly do not cast off their skins in order to become pupæ, wherein they differ from the larva of most other gnats, and agree with those of common flies; neither do they spin cocoons, as some of the Cecidomyians are supposed to do. Mr. Herrick, in one of his letters, observes, that 'the pupa gradually cleaves from the dried skin of the larva, and, in the course of two or three weeks, is wholly detached' from it. Still enclosed within this skin, which thus becomes a kind of cocoon or shell for the pupa, it remains throughout the winter, safely lodged in its bed on the side of the stem, near the root of the plant, and protected from the cold by the dead leaves. Towards the end of April and in the forepart of May, or as soon as the weather becomes warm enough in the spring, the insects are transformed into flies. They make their escape from their winter-quarters by breaking through one end of their shells and the remains of the leaves around them.

"Very soon after the llies come torth in th: 
spring, they are prepared to lay their eggs on the leaves of the wheat sown in the autumn before, and also on the spring-sown wheat, that begins, at this time, to appear above the surface of the ground. They continue to come forth and lay their eggs for the space of three weeks, after which they entirely disappear from the fields. The maggots hatched from these eggs pass along the stems of the wheat, nearly to the roots, become stationary, and turn to pupæ in June and July. In this state they are found at the time of harvest, and when the grain is gathered, they remain in the stubble in the fields. To this, however, as Mr. Haven remarks, there are some exceptions; for a few of the insects do not pass so far down the side of the stems as to be out of the way of the sickle when the grain is reaped, and consequently will be gathered and carried away with the straw. Most of them are transformed to flies in the autumn, but others remain unchanged in the stubble or straw till the next spring. Hereby, says Mr. Havens, "it appears evident, that they may be removed from their natural situation in the field, and be kept alive long enough to be carried across the Atlantic; from which circumstance it is possible that they might have been imported' in straw from a foreign country. In the winged state, these flies, or more properly gnats, are very active, and, though very small and seemingly feeble, are able to fly to a considerable distance in search of fields of young grain. Their principal migrations take place in August and September in the Middle States, where they undergo their final transformations earlier than in New England. There, too, they sometimes take wing in immense swarms, and, being probably aided by the wind, are not stopped in their course either by mountains or rivers. On their first appearance in Pennsylvania, they were seen to pass the Delaware like a cloud. Being attracted by light, they have been known, during the wheat harvest, to enter houses in the evening in such numbers as seriously to arnoy the inhabitants.

"The old discussion, concerning the place where the Hessian fly lays her eggs, has lately been revived, in consequence of a communication made by Miss Margaretta $\mathrm{H}$. Morris, of Germantown, Pennsylvania, to 'The American Philosophical Society, of Philadelphia. The following remarks upon it are extracted from a report made to the same society, and published in their Proceedings for November and December, 1840. 'Miss Morris believes she has established that the ovum (egg) of this destructive insect is deposited in the seed of the wheat, and not in the stalk or culm. She has watched the progress of the animal since June, 1836, and has satisfied herself that she has frequently seen the larva within the seed. She has also detected the larva, at various stages of its progress, from the seed to between the body of the stalk and the sheath of the leaves. According to ner observations, the recently hatched larva penetrates to the centre of the straw, where it may be found of a pale greenish-white, semi-transparent appearance, in form somewhat resembling a silk-worm. From one to six of these have been found at various heights from the seed to the third joint" Miss Morris's communication has not yet been published in full; but, from the foregoing report, we are led to infer that the egg, being sown with the grain, is hatched in the ground, and that the maggot afterwards mounts from the seed through the middle of the stem, and having reached a proper height, escapes from the hollow of the straw to the outside, where it takes the pupa or flax-seed state. The fact that the Hessian fly does ordinarily lay her eggs on the young leaves of wheat, barley, and rye, both in the spring and in, the autumn, is too well authenticated to admit of any doubt. If, therefore, the observaticns of Miss Morris are found to be equally correct, they will serve to show, still more than the foregoing history, how variable and extraordinary is the economy of this insect, and how great are the resources wherewith it is provided for the continuation of its kind." (Harris.)

Dr. B. H. Coates of Philadelphia, whose attention has been recently drawn to the Hessian and other flies destructive to wheat crops, states that a number of examinations made in the vicinity of Philadelphia during the summer of 1841 , showed the presence of a pale yellow larva in the hollow of the straw of wheat, which he considered as proved to be the same with that which is ultimately converted into the Cecidomyia Destructor of Say, and the Hessian fly of our cultivators. In many instances, "communicated to him by Miss Morris," referable, perhaps, to a peculiarity in the season, the animal went through all its stages before escaping from the cavity; "thus affording," says Dr. Coates, "irrefragable evidences of the identity of the species." In no case known to Dr. C. had any thing resembling a caterpillar or maggot, or any thing apparently capable of locomotion, been found under the sheath of the leaf: the body observed was always immovable and fixed in a depression of the straw. (Proceedings of the Am. Phil. Soc.)

"Various means have been recommended for preventing or lessening the ravages of the Hessian fly; but they have hitherto failed, either because they have not been adapted to the end in view, or because they have not been universally adopted; and it appears doubtful whether any of them will ever entirely exterminate the insect. It is stated in the before-mentioned report to "the Philosophical Society,' that Miss Morris advises obtaining 'fresh seed from localities in which the fly has not made its appearance,' and that 'by this means the crop of the following year will be uninjured; but in order to avoid the introduction of straggling insects of the kind from adjacent fields, it is requisite that a whole neighbourhood should persevere in this precaution for two or more years in succession." (Harris.)

It seems to be generally admitted that the variety of wheat called Mediterranean, introduced a few years since into the United States, where it is now extensively cultivated, resists the attacks of the Hessian fly. Hence it may be sown very early in the fall, long before if would be safe to sow the common varieties, by which another great advantage is gained, in its escaping the rust and mildew so apt in 
affect crops which are backward in the time of ripening.

FOAL (Su. Goth. fole; Sax. rola). The young of the horse kind; the male being termed a colt foal, and the female a filly. 'The foal and its mother should always be well fed, and two feeds of corn, at least, be added to the green food which they get, when turned out after their work at night. The growing colt should continue to have liberal nourishment; bruised oats and bran should form a considerable part of his daily provender. In five or six months, according to the growth of the foal, it may be weaned. It should then be housed for three weeks or a month, or turned into some distant rick-yard. The process of breaking in should commence from the very period of weaning; and the foal should be daily handled, partially dressed, accustomed to the halter, led about, and even tied up; for on this much of the tractability, good temper, and value of the horse will depend. After the second winter, the work of breaking in may commence in good earnest.

Management of Foals after Weaning.-The principal object with most breeders is to have their stock large and powerful at an early age. It is really wonderful what may be done towards effecting this by means of good food judiciously supplied, proper shelter, and liberty of range in favourable weather. It is natural to suppose, when a foal is first taken from its dam, that it will, in some degree, fall away in condition and lose flesh; the nutritive properties of its "mother's milk" cannot be taken from it without affecting its yet tender constitution. To guard against this, every attention must be directed to the quality as well as quantity of food which is presented to it; that which contains most nourishment must be provided, and although the bulk of hay which a foal consumes is very trifling, it should be of the best quality. For foals, when they are first weaned, linseed gruel should be their constant beverage, and, indeed, it cannot be too highly recommended for all horses. A liberal allowance of oats is likewise necessary; foals, if in health, will eat at least two quarterns per day; and, as they increase in age, this allowance may be augmented. The seeds which are left from the linseed-gruel, should be given with the corn. I have frequently recommended the practice of bruising the oats, and must certainly repeat it, even in opposition to the arguments of some persons who are averse to it. Bran mashes may be given at least once a week, and in some instances more frequently. Carrots will likewise be found a very proper food for young stock, and should be given once or twice a day. 'Too long a continuance of the same food cloys the appetite. Boiled barley is found to be very nutritious food, and most horses are very fond of it. As an alterative, it may be given with great advantage, if foals do not consume their corn with their usual appetite. It requires to be well boiled for two or three hours in a small quantity of water, frequently replenishing it that the grain may not burn, and constantly stirring it that every grain may undergo an equal process; it may be considered suthiciently boiled when all the corns have burst, and, when given, should have a little bran or finely-cut hay mixell with it. About ten days or a fortnight after they are weaned, each foal should have a gentle dose of physic -one drachm to a drachm and a half of aloes, with a drachm of Castile soap, and the same quantity of ginger, will generally be found sufficient.

FOALING. A term applied to the act of parturition, or bringing forth young in the mare. Good feeding and moderate exercise are found to be the best preventives against slinking, which is most prevalent when half the time of pregnancy has elapsed. See A nonTroN. If a mare has been regularly exercised, and apparently in health while she was in foal, little danger will attend the act of parturi. tion. If there be false presentations of the fotus, or difficulty in producing it, it will be better to have recourse to a well-informed veterinary practitioner, rather than injure the mother by the violent and injurious attempts which are often made to relieve the animal. As soon as the mare has foaled, she should be turned into some well sheltered pasture, with a hovel or shed to run into when she pleases; and as, supposing she has foaled in April, the grass is scanty, she should have a couple of feeds of corn daily. The mare may be put to moderate work a month after foaling.

FODDER (Germ. futter; Sax. foovon; from Foezan, to eat; Irish, foder, straw ; Icel. fodr). In agriculture, the ordinary food given to caitle, which consists of the stems and leaves of plants, such as clover, hay, chopped straw, dried blades and tops of Indian corn, \&c.; the culmiferous stems of the grasses, the haulm of legumes, potatoes, \&c. Grain, beans, turnips, and other articles which present nourishment in a more concentrated form, are not included under the term fodder, but are rather known as solid food. See Foop.

FOG (Dan. fog). In meteorology, a dense vapour near the surface of the land or water. Fogs in general are the consequence of the nocturnal cooling of the atmosphere. The air, by its rapid cooling, becomes surcbarged with moisture; a part of which being condensed in the form of a cloud, gives rise to the ordinary fog. During the day the heat of the sun generally disperses the fog, because the quantity of moisture which the air is capable of holding becomes considerable in proportion as its temperature is increased. In calm weather the surfaces of rivers, lakes, \&c., are frequently covered with fog. The reason is this. During the night the air is colder than the water; the strata of air in contact with the water are consequently heated, and become saturated with moisture. The mixture of the vapour with the air, together with its elevation of temperature, renders the air specifically lighter. It rises in consequence, and mixing with the cold air in the superior strata, is cooled, an 3 has its moisture condensed. The cloud or fug resulting from this precipitation can only rise to a smail height, because the uniformity of temperature is soon restored. Hence it is easy to see how winds, or a great agitation of the water, prevent the formation of fogs over the surface of water. In the equinoctial regions, fogs some 2 × 2 
times continue during a considerable part of the year. In the Polar seas thick fogs often prevail, even during the warmest months; and they are so dense that objects frequently cannot be distinguished at the distance of a few yards. (Brande's Dict. of Science.)

FOGGAGE (Low Lat. fogagium). Coarse or rank grass not eaten down in the summer or autumn. The practice of fogging grasslands for the winter support of stock has been found highly useful.

FOGGE. A common word in the north, that properly signifies the grass which immediately springs after the hay-crop has been taken, but it is sometimes used for the long grass remaining in the pastures till winter. (See AftenGrass.) It is also used for moss, in some parts of Srotland: thus a fog-house means a house built or lined with moss.

FUGGING. A peculiar practice in the management of grass-lands, confined chiefly to the district of South Wales. It consists in keeping the whole growth of grass in upland meadows free from either scythe or stock, and eating it in the following winter. Arthur Young states, that many years ago, he knew a Suffolk clergyman, who was in the regular habit of this singular practice, and spoke of it as a most profitable one. He has, he says, tried it thrice, and with success; and he finds that it thickens the herbage greatly, and yields far more valuable winter and spring food than any person would expect, who never tried it. But it should be practised only on dry or tolerably dry land.

FOLD (Sax. realoe). A temporary pen or enclosure for keeping cattle or other agricultural animals together, either for the purpose of confinement during the night, or jointly for protection and feeding. Sometimes, also, sheep are folded for the purpose of manuring. Sheepfolds are of two kinds; either houses or sheds set apart for that purpose adjoining to the farmyard, or movable folds formed by hurdles, \&c. On the Continent, sheep are principally folded in sheds, \&c., the floors of which are strewed with straw, sand, or elean dry earth, by which an additional quantity of manure is obtained. The temporary fence or barrier of which movable folds are constructed, is most commonly wooden hurdles; but sometimes, when the fold is only to contain ewes and lambs, netting strctched between posts is inade use of, there being a strong rope fixed to the lower parts of the post, close to the ground, to which the under edge of the netting is attached, while its upper edge is fastened to a rope stretched along the tups of the same post. Netting is by far the cheapest and neatest substance for barriers for folds. (See Hunbles.) Mr. Children has recently advocated a system of shed-feeding (Jour. Rny. $\Omega$ gr. Soc. vol. i. p. 40); and there is little doubt that sheep, in common with all live stock, suffer more from the effects of wet and culd, when feeding in exposed situations, than is commonly supposed.

FOLDING. 'The practice of confining sheep ind other animals upon land, by means of hurAles, \&c., for the purpose of feeding on and nanuring it. The practice of folding sheep on raked fallows, with a view to manuring them, is still common in several parts of Englard; but the more improved sheep farmers consider that it deteriorates the wool and impedes the fattening of the sheep, by keeping them for the greater part of every night wholly without food. Others, however, assert that folding is not injurious to sheep, if they are kept in a good pasture during the day, and not folded too early in the evening, or kept in the fold too long in the morning. In some large arable land farms in Hampshire and other counties, folding is still considered necessary, and large flocks of breeding ewes are kept specially for that purpose. Sheep are occasionally penned or folded on young wheat, but more commonly on turnips, a certain portion being enclosed, sufficient for them to eat off in one or two days.

FOLD-YARD. The yard where cattle of different sorts are confined and fed during the winter season. Yards of this nature should be properly fitted up with convenient sheds and racks for the animals to eat their fodder from, and have suitable divisions for containing different denominations of cattle, or other live stock. See FARM-YARD.

FOOD (Sax. roo). All substances susceptible of digestion and assimilation may come under the denomination of food. Animals require, for their support and developement, atoms or elements highly organized. The food of all animals, under all circumstances, consists of portious of organized matter. Vegetables, on the contrary, require for their support elements derived from the complete destruction of organized substances, whether animal or vegetable, through the processes of putrefaction and decay. The proximate principles of organic bodies, on which their nutritive powers depend, are comparatively few. Although the articles employed in different countries for the support of animal life are almost infiniteiy various, their sustaining powers may be referred to certain substances capable of being separated and identified by chemical analyses and tests. Amongst the proximate elements of vegetable food, gluten and its modifications, starch, gum, sugar, and lignin or woody fibre, are by far the most important; and amongst those of animal food, fibrin, albumen, gelatin, and their modifications, together with fats and oils, which are common to both kingdoms of nature. To illustrate the actual simplicity of our food, as compared with its apparent multifariousness and complexity, it may suffice to state that wheat, and almost all the esculent grains, consist principally of starch and gluten that the same ingredients are found in many fruits and roots; that sugar, gum, or a relation of gurn, which is called vegetable jelly, together with minute traces of aromatic principles which give flavour, and more or less abundance of water and of vegetable acids, are the chief component parts of apples, peaches, currants, \&c., and all pulpous and juicy fruits; a very few also contain oil. Then, as regards animal food, the muscular fibres of various animals closely resemble each other in composition and nutritive power: in some cases texture merely, and in others minute additions of foreign matters, confer upon them their relative digestibilities and their different aspects and flavours. 
Albumen or fibrin and gelatin, small proportions of saline bodies, and a large quantity of water, are found in them all.

It often happens that the truly nutritious part of food is so combined with or protected by indigestible matters as to escape the solvent powers of the stomach, unless previously prepared and modified by various chemical and mechanical agents. Indurated woody fibre, for instance, or lignin, as chemists call it, will often resist the joint action of the stomach and bowels, and pass through the alimentary canal with scarcely any alteration. The husks of many seeds and fruits are composed almost exclusively of this material. This is the case with the kernels of the apple, pear, \&c.; the seeds of the currant, gooseberry, melon, and so on; the skin or husk of peas, beans, \&c., and of wheat, barley, and oats; so that unless the woody part is either broken down by the teeth or previously removed, the food which it envelupes is protected in some degree from the solvent action of the secretions of the stomach. This is a wise and curious provision in nature, for birds in this way become the carriers of seeds, which pass through them not only undigested, but even retaining their vegetative powers; and in this way uninhabited and sterile portions of the globe may gradually become clothed with verdure, and shrubs, and trees; hence the advantage derived from bruising the corn given to live-stock. Bones are highly nutritive, but, unless broken into very small fragments by the masticatory powers of the animals which eat them, they too would elude digestion.
There is another important point in the history of food, which is, its ultimate cornposition. Four elements only are principally concerned in the production of the food of animals; these are carbon, hydrogen, oxygen, and nitrugen. Among vegetable substances, gluten (including vegetable albumen) is the only one which abounds in nitrogen; gum, sugar, starch, and the rest, are constituted of carbon, hydrogen, and oxygen only. There are two very singular points in reference to the chemical history of food: the one is, that no animal can subsist for any length of time upon food which is destitute of nitrogen; and the other, that a certain mixture of different food is absolutely essential. Habit, as is well known, will do much in accustoming the stomach to particular descriptions of food: many persons live exclusively, or almost so, on vegetables, others on animal matters, and particular kinds of diet are forced on the inhabitants of many regions of the globe; but as far as we are concerned, a due mixture of vegetable and animal matter is not only most palatable, but most conducive to health. Nothing is fit for food which has not already undergone organization; and water, though an essential part of the food of all animals, is obviously not in itself nutritious, though it performs the extremely important function of dissolving nutritive matter, so as to render it conveyable by the lacteals and other absorbents into the blood.

The subjoined table will serve to show the comparative value of the principal cereal and other grasses, legume:i, roots, \&c. (Davy, Elem. Ag. Chem.150.)

I. Table of the Quantities of Soluble or Nutritive Matters afforded by 1000 Parts of different Vegetable Substances examined in their green state.

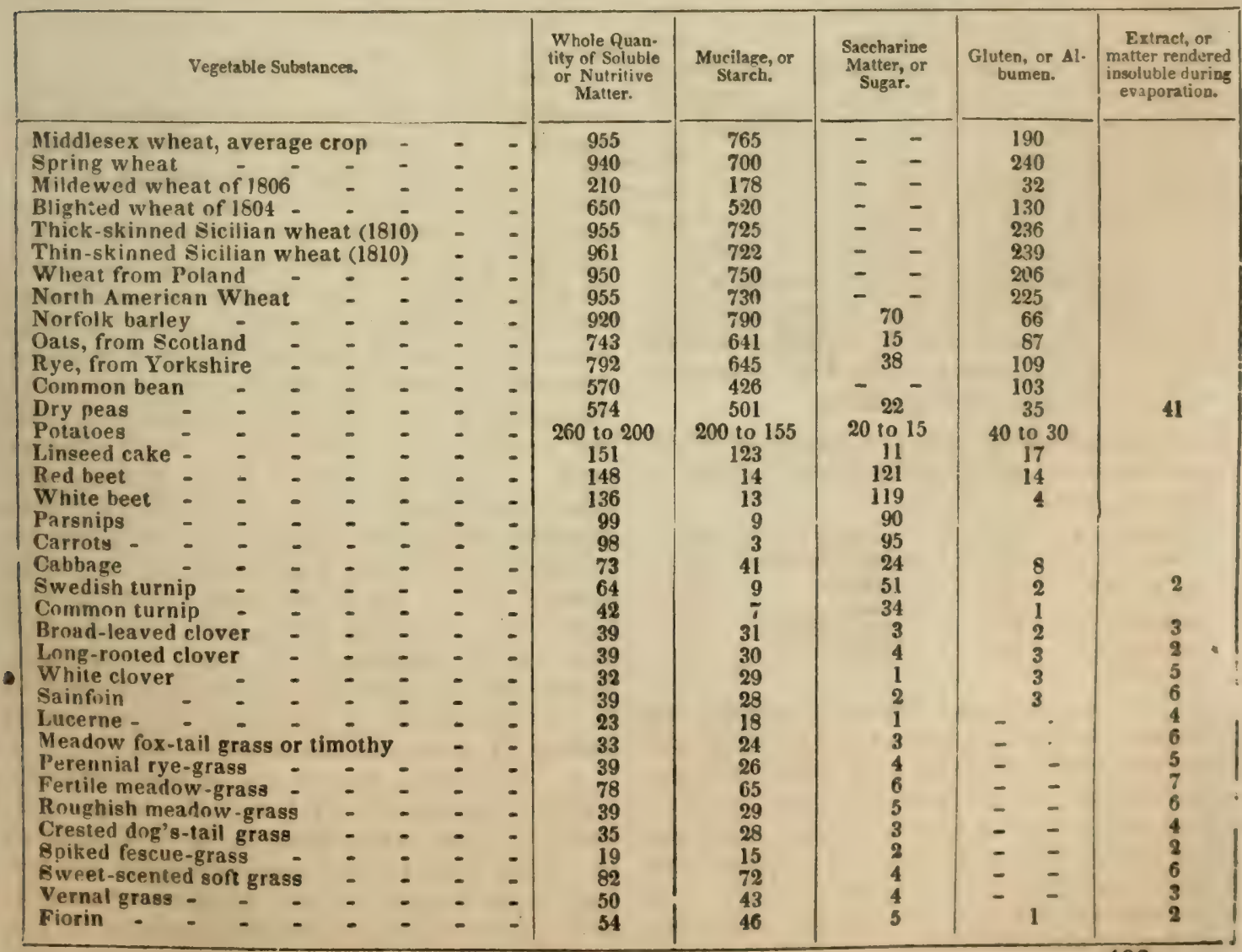


The following table represents the relative proportion of solid digestible matter contained in 1000 parts of the different articles of food which are enumerated. Upon an average, the nutritive matter in a pound of meat is not more than four ounces. This, however, applies only to raw meat; for, when dressed, a considerable portion of its constituent water is dissipated.

\section{Table showing the average Quantity of Nutritive} Matter in 1000 parts of several varieties of Animal Food.

\begin{tabular}{|c|c|c|c|}
\hline Bones & 510 & Veal & 250 \\
\hline Mutton - & -290 & Pork & 240 \\
\hline Beef & -260 & Blood & 215 \\
\hline Chicken & -270 & Cond and sole & -210 \\
\hline Brain & -200 & White of egg & 140 \\
\hline Haddork & 180 & Milk & - \\
\hline
\end{tabular}

A very interesting report on the nutritive properties of food was recently presented to the French Minister of the Interior, by MM. Iercy and Vauquelin, two members of the Institute. The result of their experiments is as follows :-

In bread, every $100 \mathrm{lbs}$. weight is found to contain $80 \mathrm{lbs}$. of nutritious matter. Butchers? meat, averaging the variuus sorts, contain only 35 lbs. in 100. French beans (in the grain), 92 lbs. in 100 ; broad beans, 89 ; peas, 93 ; lentilles, 94 in 100. Greens and turnips, which are the most aqueous of all vegetables used for domestic purposes, furnish only $8 \mathrm{lbs}$. of solid nutritious substance in 100. Carrots, 14 lbs.; and what is very remarkable, as being in opposition to the hitherto acknowledged theory, $100 \mathrm{lbs}$. of potatoes only yield $25 \mathrm{lbs}$. of substance valuable as nutritious. $1 \mathrm{lb}$. of good pread is equal to $2 \frac{1}{2} \mathrm{lbs}$. or $3 \mathrm{lbs}$. of the best potatoes; and $75 \mathrm{lbs}$. of bread and 30 of meat are equal to $300 \mathrm{lbs}$. of potatoes; or, to go more into detail, $\frac{3}{4}$ of a $\mathrm{lb}$. of bread and $5 \mathrm{oz}$. of meat are equal to $3 \mathrm{lbs}$. of potatoes. $1 \mathrm{lb}$. of potatoes is equal to $4 \mathrm{lbs}$. of cabbage and $3 \mathrm{lbs}$. of turnips; but $1 \mathrm{lb}$. of rice, broad beans, or French beans (in grain), is equal to $3 \mathrm{lbs}$. of potatoes.

In the esculent roots, such as carrots, \&c. but especially turnips, sugar is the leading nutritive matter; and the common fruits contain sugar, gum, albuminous matter, and acids, together with a highly attenuated form of woody fibre or lignin, which in that state is probably digestible. The comparative nutritive properties of the most common fruits will be seen by a reference to the annexed table.

III. Table showing the average Quantity of Nutritive Matter in 1000 Parts of several varieties of Vegetable Food.

\begin{tabular}{|c|c|c|c|}
\hline Morels - & - 896 & Peaches - & -200 \\
\hline Almonds & -650 & Gooseberries & -190 \\
\hline Tanuarinds & -340 & Apples - & -170 \\
\hline Plums - & $-\quad 290$ & Pears & -160 \\
\hline Grapes - & - 270 & Btrawberries & -100 \\
\hline Apricots & -260 & Melon & 30 \\
\hline Cherries & -250 & & \\
\hline
\end{tabular}

On fattening Animals. - There is a very great difference in the quantity of food which animals require, and in the time which they can pass without it. In general, those animals which are the most active require most, and those which are most indolent require least food. The cause of this is pretty obvious; the bodies of animals do not remain stationary, they are constantly wasting, and the waste is 500 proportioned to the activity of the animal; hence the body must receive, from time to time, new supplies in place of what has been carried off. The use of food answers this purpose. Almost all the inferior animals have narticular substances on which they feed exclusively. Some are herbivorous, some are granivorous, and others, again, are carnivorous.

From various experiments we have the fol. lowing result:-

A horse will consume as much food, besides

\begin{tabular}{|c|c|c|c|c|c|c|c|c|}
\hline corn, as & - & - & - & - & - & - & 8 & hee \\
\hline A cow - & - & - & - & - & - & - & 12 & - \\
\hline A fattening & $x$ & - & - & - & • & - & 10 & $一$ \\
\hline A three year & old heifer & - & - & 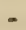 & 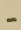 & - & 8 & - \\
\hline A two year & Id heifer & - & - & - & - & - & 6 & 一 \\
\hline I one yeur 0 & Id heifer & - & - & - & - & - & 4 & 一 \\
\hline calf & - & - & - & - & - & - & 2 & - \\
\hline
\end{tabular}

There are some rules which may be advantageously adopted in feeding animals, which, however obvious they may be, are too often neglected. 1. Food should be so prepared that its nutritive properties may be all made available to the use of the animal; and not only so, but appropriated with the least possible expenditure of muscular energy. 'The ox that is obliged to wander over an acre to get the food he should find in two or three square rods-the horse that is two or three hours eating the coarse food he should swallow in fifteen minutes if the grain were ground or the hay cur as it should be-the sheep that spends hours in making its way into a turnip, when, if it were sliced, it would eat it in as many minutes-the pig that eats raw potatoes or whole corn, when either cooked could be eaten in one quarter of the time, may indeed fatten, but much less rapidly than if their food were given them in a proper manner. All food should be given in such a state to fattening animals, that as little time as possible, on the part of the animal, shall be required in eating.

2. From the time the fattening process commences, until the animal is slaughtered, he should never be without food. Health and appetite are best promoted by change of diet rather than by limiting the quantity. The ani$\mathrm{mal}$ that is stuffed and starved by turns may have streaked meat, but it will be made too slowly for the pleasure or the profit of the good farmer.

3. The food should be given regularly. This is one of the most essential points in feeding animals. If given irregularly, the animal will consume his food, but he soon acquires a restless disposition, is disturbed at every appearance of his feeder, and is never in that quiet state so necessary to take on fat. It is sarprising how readily any animal acquires habits of regularity in feeding, and how soon the influ. ence of this is felt in the improvement of his condition. When at the regular hour the pig has had his pudding, or the sheep his turnips, they compose themselves to rest, their digestion is not unseasonably disturbed, or their quie? broken by unwonted invitation to eat.

4. The animal should not be needlessiy in. truded upon during the hours of eating. All animals fatten much faster in the dark than in the light, a fact only to be accounted for by their greater quiet. Some of those creatures that are the most irritable and impatient of restraint while feeding, such as turkeys and 
geese, are found to take on fat rapidly when confined in dark rooms, and only fed at stated hours by hand. 'There is no surer proof that a pig is doing well than to see him eat his meal quickly and then retire to his bed till the hour of feeding returns. Animals, while fattening, should never be alarmed, never rapidly driven, never be fed at unseasonable hours, and, above all things, never be allowed to want for food.

The following table will show the ultimate composition of those proximate principles which have been already adverted to as constituting the nutritive parts of food.

IV. Table showing the ultimate elementary composition of 1000 parts of the following proximate principles of Animal and Vegetable Food.

\begin{tabular}{|c|c|c|c|c|c|c|}
\hline \multirow[b]{2}{*}{ Albume } & \multirow[b]{2}{*}{ - } & \multirow[b]{2}{*}{ - } & \multirow{2}{*}{ Carbon. } & \multirow{2}{*}{$\frac{\text { Hydrogen. }}{76}$} & \multirow{2}{*}{$\frac{\text { Oxygen. }}{258}$} & \multirow{2}{*}{ Nitrogen. } \\
\hline & & & & & & \\
\hline fielatin & - & - & 483 & 80 & 276 & 161 \\
\hline Frt - & - & - & 780 & 122 & 98 & \\
\hline Curd of & & - & 609 & 73 & 116 & 203 \\
\hline Sigar o & illk & - & 454 & 61 & 485 & \\
\hline Gluten & - & - & 557 & 78 & 220 & 145 \\
\hline stareh & - & - & 438 & 62 & 500 & \\
\hline Gum - & - & - & 419 & 68 & 513 & \\
\hline Nugar - & - & - & 444 & 62 & 494 & \\
\hline liguin & - & - & 500 & 56 & 444 & \\
\hline
\end{tabular}

See also the heads Cattre, Fodner, Shenp, Swine, Horses, \&c. See Ventilation and Food, Agricultikal Products.

FOOD OF PLANTS. See EArths, G Silts, Water, and Manures, their uses to Veretatioy. Plants absorb their nutriment from the air and from the soil; they become the food of the gramniverous tribes, and from these man derives the great bulk of his animal susienance.

FOOL'S PARSLEY. Common Lesser Hemlock (Ethusa cynapium). Pl. 10, q. A numbelliferous plant, common in gardens, waste grounds, and cultivated fields, and so called from its resembling parsley enough in appearance to deceive ignorant persons. It is an annual weed, with a tapering whitish root; stem round, often purpish, a foot high; flowers pearl white; the herbage of a dark livid green, and fetid. The plant is poisonous, acting like hemlock upon the human system, and is easily known by the involucels having each three linear leaflets, which are placed next the circumference of the umbel. It is eaten by cattle and sheep, but is pernicious to the latter.

FOOL'S STONES (Orchis morio). See TWAYBLADF.

FOOT (Sax. yor. Germ. fuss; Dutch fute). A linear measure, which, since the term is employed in almost all languages, has doubtless been derived from the length of the human foot. Though the denomination is the same, the measure itself varies considerably in different European countries. In all of them, however, it is divided, like the English foot, into 12 equal parts, or inches. See WEIGHTs and Messures.

Foot is also the lower part of the limbs of an animal, which afford support, and enable it to move with ease and convenience from place to place. An excellent article on the anatomy and diseases of the foot of the horse, by Mr. Dick, will be found in the second volume of the Quart. Journ. of Agr. p. 214. The best and most natural form of the fuot of the horse is that where the bottom approaches is a crreic: it is most complicated in its structure, and liable to a variety of diseases. Sce the heads Canken, Corns, Cracks, Shozing, and DisEASES OF THE HOHSE.

FOO'T-RO'T. See SHeEp, Diseaseg of

FOOT-TRENCHES. A term signifying small superficial drains, about a foot wide.

FORCING. In horticulture, the art of accelerating the growth of plants so as to obtain fruit, vegetables, or flowers at sfasons when they are not produced naturally in the open air. The practice appears to be as old as the time of the Romans. In England forcing seems to have been practised from a very early period. At the present time forcing is carried on in Britain, and in analogous climates throughout Europe and North America, chiefly under glass roofs. Structures for forcing are known, as frames, pits, and houses, all of which have glass roofs: but there are also structures for forcing without glass roofs, such as cellars and sheds for growing mushruoms in the winter season; and also sea-kale, rhubarb, blanched succory, and such other stalks or leaves of plants as are eaten in a blanched state, and consequently do not require much light.

FORCING PITS. Instead of forming hotbeds with open sides, pits of brick-work and other materials are very generally constructed for containing the fermenting mass of dung necessary for forcing.

Mr. Flanagan, gardener to Sir T. Hare, of Stow Hall, Norfolk, and Mr. West, who holds the same situation under the Marquis of Northampton, at Castle Ashby, have each proposed plans of pits, of which that of the first horticulturist is the least expensive; that of the latter more economical in other respects, not only as preventing the waste of heat, but the best mode of applying it. It may be laid down as a fundamental principle that, in applying heat, it should always be brought to the bottom of the body to be heated.

Mr. Flanagan only allows the heat of fermenting dung to be employed, the steam being prevented entering the frame. One advantage arising from this he states to be, that freshmade dung may be employed, and, consequently, the loss sustained by any preparation is prevented. If, however, it be a fact that the steam of dung is rather beneficial than otherwise, fresh fermenting dung can be used, without any detriment that I am aware of, in other pits of which we have plans. Mr. F. describes his pit as follows:-It is 4 feet deep within; the lowest 10 inches of solid brick-work sunk in the earth; the remainder is a flue, 3 inches wide in the clear, carried entirely round the pit; the inner wall of which, forming the sides of the pit, is 4-inch work, well bedded in mortar, and pointed, to prevent the steam penetrating; the outer wall of the flue is also 4-inch, but open-work, to admit the steam and that of dung-coatings into the flue, the top of which is rendered tight by a covering of tiles, \&c. The frame rests on the external wall of the flue The cavity of the p t, which is hent fry br means of drains. is \& feet 2 inches long, 2 imei 
8 inches wide, and 4 feet deep. It is filled vith broken bricks, to within 18 inches of the top; then a foot of short cold dung, 6 inches of very rotten dung, trod down so as to admit half an inch depth of coal ashes, for preventing the intrusion of any worms that may be in the dung, complete the structure. (G.W. Johnson's Kitchen Garden.)

FOREHAND. In horsemanship, that part of the animal which is before the rider.

FOREST (Germ. forst; Fr. forêt; Ital. foresta). Strictly an extensive surface covered naturally by trees and undergrowth, as opposed to a plantation which has been made by art, but indiscriminately used for any very extensive tract covered with trees. The utility of timber plantations to a commercial nation is very great, as, by the quantity of timber they afford, a considerable expense may be saved which must otherwise be incurred by the importation of materials for ship-building. (See Puantation.) In former times the greater part of every country in the temperate parts of Europe was undoubtedly covered with forests and these, by harbouring and nourishing wild animals of every description, particularly wild swine, afforded a principal part of the food of man. With civilization, however, they gradually disappear before the increase of pasture or arable land. In every country a large portion of the forests belonged to the government, and formed a main source of its revenue. This is still the case in France and Germany, and, till lately, it was also the case to a certain extent in Britain. Hence extensive tracts in England still bear the name of forest, though they are now in a state of cultivation, and in a great measure without trees.

The royal forests of Britain occupy about 125,000 acres of land. There are 32,768 acres of forest land enclosed and planted, principally with oak, and with other trees where the soil is not adapted to oak. There are 6211 acres of other freehold land belonging to the crown, which are also appropriated to the growth of timber, making in all 38,979 acres, the whole of which have been enclosed and planted within the last twenty years.

For an account of the existing forests of England, see "Statistics of the British Empire." (Brit. Husb. vol. iii. article "Plantations," pp. 83, 85; Brande's Dict. of Science.)

FOSSE. A large ditch or moat; also a waterfall.

FOWI. Cock and hen (Phasiunus gallus). Fowls were originally natives of Persia and India. They are most valuable to the farmer as yielding profit in eggs, broods, and feathers. The varieties of the common fowl in England dre very numerous, and are distinguished from one another by their size, colour, and fecundity. Fowls should be kept very clean and dry in the hen-house, and particular care must be taken to furnish them with clean, sweet water; foul water produces that fatal disurder among chickens cal!ed roup, or gapes, which is known by the chick gasping for breath, and dying in a few hours. No remedy has yet been discovered for this disorder; therefore care and cleanliness should prevent

it. Foul water, and a scarcity of water, are 502 also causes of the pip in hens, and originate all their diseases. Poultry of all sorts should have clean, sweet houses to retire into during the night, and in seasons of wet. Warmth is necessary to the comfort and well-doing of poultry. If hens are kept with care, and have clean, quiet places to deposit themselves in, they will lay regularly, and repay all trouble. One cock is sufficient for ten hens. He should be chosen with care. $\mathbf{A}$ good cock should be well-sized, carrying his head high; he should have a quick, animated look, a strong shrill voice, the comb of a fine red, broad breast, strong wings, legs thick, and his bill thick and short. (Main's Domestic Poultry, p. 230.) The vigour of the cock lasts three years; he must then be superseded, and a fine spirited youth. ful successor installed in his room. A cock is at full age at three months old. Three sorts of hen are useful. The common hen, whose proper signs should be in having a large head blueish feet, sharp eyes, and pendant comb. The tufted hen, for eating, as she does not lay much, therefore fattens well; and the large white Dorking breed, which always fetches a higher price in the market. The Dorking fowls are distinguished by having five claws on each foot. Equal to the Dorking in estimation (says Professor Low) are the Poland fowls. Their colour is black, their heads flat, and surmounted with a crown of feathers. They are a very useful variety; prolific of eggs, but less inclined to sit than those of any other breed. All others are kept more for show than for use. The bantam is a little Indian breed, very delicate to eat, but, from the smallness of its size, not of any economical importance.

The Chitagong, or Malay fowl, is the largest breed that has yet been brought to England, but the flesh is regarded as inferior to that of the Dorking and Poland. Fowls should not be allowed to wander much: they lay better and more regularly when confined to their own yard. Their food should be given with great regularity at sun-rise and sun-set, and they should be fed under cover during rain or high winds. During harvest their portion of food is always diminished. All sorts of pot-herbs, boiled, in the washings of dishes, mixed with bran, and then drained, is excellent; the paste warmed up as required, while sweet. Well boiled mealy potatoes, buckwheat, barley, whole or ground, refuse of fruit, bread, offal from the kitchen, \&c., is taken greedily. Let all their food be fresh of its kind.

The laying time in England begins about February. A hen gives notice of her intention by being busy and restless, and talking to herself for some time, and her comb becomes very red. Her cackling soon gives notice that the deed is done. Let her have a dark, quiet box to lay in. The moulting season begins in autumn, when the hen ceases to lay for some time: the whole feathered tribe are then drooping and dull, till the new feathers have replaced the old ones. A hen is old at four years of age: for three years she is valuable, and in her fourth year she must make way for younger birds. A hen sits three weeks; her disposition to sit is soon discovered, by her placing her- 
self upon any eggs she can find, and remaining thereon instear of roosting. She should be placed upon fresh eggrs, unless allowed to sit as nature directs upon her own natural number, which rarely exceeds eighteen; but if one egg alone is allowed to remain in the nest she will continue to lay many more before she wishes to sit. If the brood is hatched irregularly, the firstlings should be kept in tlannel near a fire all day, till the others come forth, but they should be returned to the mother at night. The lien and her brood should be kept warm, and be cooped out of doors only in dry, fine weather. They should be fed for some days on bread crumbs, with some finely chopped leeks, and be carefully supplied with clear, clean water daily. Boiled barley, and boiled rice, \&c. succeeds, till in about three weeks they are sufficiently strong to be turned into the poultry-yard. When the young chickens get their head feathers, they are out of danger of all infantine disorders. Nothing is so requisite for all poultry as warmth, cleanliness, and good water. Fowls fattened for the table should be put into coops for a fortnight or three weeks, and fed upon good barley-meal, moistened with milk or water, and lard. Give it four or five times per day, sufficiently moist to require no drink with the food.

Eggs are preserved any length of time, by greasing them well over with butter or lard, when warm from the nest. It keeps out the air. Fresh laid eggs are easily known by holding them up to the light of a candle. If the inside appears transparent and fluid, and the yolk in the centre, it is a fresh egg. If it looks turbid, it is a stale one. If, also, an egg held up against a candle shows a small vacancy at the top of it within, it will produce a male bird: if the little vacancy is observed at the side of the egg, it will prove a female. (Main's Dom. Poultry, p. 253.) See Fras. Every poultry-yard should have a bed of ashes deposited in a corner: the fowls delight in a dunghill and an ash-hole; the former produces seeds and insects, and the latter calcareous matter, and destroys their vermin by its sharpness, as they revel in its rough particles. See Capos.

There is a communication in the Farmer's Cabinet, (vol. ii. p. 95,) upon keeping hens, and the profits from eggs, from a poulterer in Eaton, Massachusetts, which contains much useful information. On the 1st of January, says the writer, I had ten hens and one cock. In the spring three of the hens were suffered to set, which left seven to experiment with. The three which set raised 24 chickens, which were sold for $12 \frac{1}{2}$ cents each, when about the size of quails. The sooner, he observes, you sell chickens the better, since they do not bring prices corresponding with their increase in size. The seven hens which did not set, laid 100 dnzen of eggs. During half the time in winter the fowls were fed upon boiled potatoes and bran or meal mixed together with warm water, and as the place where they were kept was well sheltered, none were lost by the dough freezing in their craws or crops. For the remainder of the time oats were given them, which the writer considers better for fowls than Indian corn, having tried both. The oats were first allowed (o suak in warm water for three or four hours, till well swelled, after which they were given to the fowls. Treated in this way he considers one bushel of oats will go as far as a bushel and a half of corn. Hens, \&c. should never be allowed to roost in stables or kept near cattle, as they communi. cate their vermin to these, which worries and prevents them from growing fat

FOWL, GUINEA, or Pintano (Numida meleagris). These birds are very wild and restless in their nature, owing to their native habits. They are shy, and love to make their nests in dark, obscure places, far from home; for which reason their eggs are generally placed under a common hen to be hatched and fostered. They give no notice of laying or setting. A brood of Guinea fowls is an excellent guard. They love roosting in the trees; and at night, if any footstep disturb them, their loud cries are sure to give notice to the farmer that a trespass is committing. The Guinea fowl is delicate eating, and is in fine season about Lent. The young chickens must be treated in the same manner and with the same food as young turkeys, and they must be kept warm and dry. In fatting, they should be shut up in a house for a fortnight, and fed four or five times a day with sweet harley-meal, moistened with milk and good lard. They pine if confined any length of time. The great drawbacks to the rearing of Guinea fowls are the vigilance required to watch for their nest. and the harsh screaming of their cry.

FOWL, PEA (Phasianus Io). Native of India, tender in infancy, but soon inured to our climate, as they become older. From their native wild habits, they love to lay their eggs in woods or coppices far from home. As the hen covers her eggs over with dead leaves after laying them, and generally deposits them under a bush, without the ceremony of making a nest, she must be closely watched, and each day her fresh egg should be withdrawn, and an egg cut in chalk substituted, and covered over again with the leaves. The eggs should be placed under a common hen for safety, both on account of the fox, and because the pea-hen would lead the young ones to ramble as soon as they had escaped from the shell. The best food for pea-chicks is barley-meal made into a paste, and mixed with sweet curd, and finely chopped, hard-boiled eggs. They are also exceedingly fond of the large horse ant and its eggs, which in England are found in woods, deposited in little hillocks of small leaves and twigs. All the tribes of wild birds, such as pea-fowl, turkeys, pheasants, \&c. love ants: it is their natural food. Two or three handfuls of their eggs twice a day, makes a good variety with their usual food. Keep the young petfowls well housed while under the mother's care: when they grow up, they prefer roosting in trees or on buildings If a pea-hen is allowed to brood her own whickens, she should be kept under a coop for three weeks at least. to prevent her rambling. Pea-fowl will feed well on any kind of corn. They are exreedingly destructive in a garlen. Our ancest $r$. considered them very delicate eating. 
FOWL'S DUNG. See Guano and Pigeuv's Dung.

FOX.EVIL. A disease in which the hair falls off.

FOXGLOVE, COMMON (Digitalis purpurea). A very handsome biennial plant, blowing purplish-crimson, or occasionally white flowers, from June to September. In England it is found wild in pastures and about he lges or banks, on a gravelly, sandy, or chalky soil. In gardens it is easily propagated by seed.

The lesser yellow foxglove (D. parviftora) is a native of Italy, and perennial: grows three feet high, blooming yellow flowers in June and July. It may be propagated from seed.

The large yellow foxglove ( $D$, ambigua), with larger flowers, is also a perennial, growing three feet high.

The medicinal qualities of the foxglove are diuretie, powerfully emetic, and narcotic; and, under proper management it is a most useful medicine. The leaves are inert in the first year of the growth of the plant. They are sometimes used externally as cataplasms for resolving scrofulous tumours. As every part of the foxglove is poisonous, children ought to be warned against chewing it. No person not qualified to practise medicine should venture to prescribe foxglove.

FOX-TAIL GRASS (Setaria glauca). common American grass, with a bristly head, found in cultivated grounds, old stubble-fields, orchards, \&c., flowering in July. Its root is annual, and the stem grows 2 or 3 feet high. When mature it has a tawny, or orange colour.

Another species of fox-tail is popularly called green fox-tail, or butter-grass (Setaria viridis). Its general resemblance to the species firstnamed, render it liable to be passed by as a green variety of that plant.

A species of Setaria (S. verticillata), commonly found about gardens and cultivated lots in the Middle States, has teeth on the bristles, which cause the spikes to adhere to objects with which they come in contact.

Another species called German Setaria, millet or Bengal grass, is occasionally found in fallow fields. Dr. Muhlenburg supposed this annual plant might be a variety of the green fox-tail, to which Dr. Darlington thinks it certainly allied. Some years ago, the Bengal grass was introduced into the Middle States as an object of culture, and, for a time, excited much interest among farmers. It was soon found, however, not to be as valuable as the usual summer crop, of which it occupied the place, and its cultivation is now pretty much abandoned. The seed is sown in the early part of May.

Several other species of this genus are found in the United States, of which one called the Italian Seturia is met with along the river Delaware, distinguished by its very large spikes. The others are southern plants. None of them, except the German setaria, possess any value to the agriculturist. (Flor. Cestric.) See Alopecurus.

FRANCE, THE AGRICULTURE OF.llthough the two kingdoms of Britain and 504
France, are such near neighbours, and enjoy a soil so similar, yet the agriculture of each differs very materially. The chief features in the farming system of France which strike an Englishman are the almost total absence of hedges, and the smallness of the farms or plots; the minute divisions of landed property having been long encouraged by the laws of France in every possible way. 'The end has been attained; considerable comfort has been diffused amidst the mass of the people, but with injurious results to agriculture. For in a country where the farms generally do not comprise more than from 15 to 20 acres, all the common evils of a land of small holdings are naturally felt. 'The capital required for them being limited, the competition to obtain them is naturally considerable; the charge for the labour to cultivate them is also great; the livestock kept on them inferior; the rotation of crops bad, and agricultural improvements of all kinds but slowly adopted. The government of France, it is true, in the absence of large landed proprietors, and opulent, enterprising, and scientific farmers, does all it can, by expensive state agricultural institutions, to supply their place; but these are not attended with the general advantages which are derived in other countries from the exertions of private individuals. Of these small farms, Mr. Denison has given the following graphic description (Jour. Roy. Agr. Soc. vol. i. p. 263):-" In comparison with the English system of enclosures, France may be called one vast open field; you may travel from Calais to Paris, from Paris to the German frontier, to the Alps, to the Pyrenees, and scarcely see a hedge or a partition fence of any sort. This vast open field (unlike the open districts of England, where the operations of farming are generally conducted on the largest scale) is cut up into the smallest conceivable plots of every variety of produce. As far as the eye can reach, over vast plains bounded by sloping hills, you see the surface varied by every description of crop; none, perhaps, above an acre or two in size, the larger portion not more than the fourth or the eighth of an acre. Here a vineyard 100 yards by 20 ; there a strip of wheat, lucerne, barley, oats, potatoes, clover, and vetches. Few roads intersect this extensive garden, which, from the nature of the cultivation, must be traversed every day in all directions by the proprietors and cultivators of the various lots. The residences of these proprietors are almost invariably, congregated into villages or towns, and lie, therefore, for the most part, wide of their respective allotments." The advocates of such a general system of cultivation will hence see that this mode of tillage is attended with sundry insuperable disadvantages. 'The public agricultural establishments maintained entirely by the French government are-1. Sheep farms; 2. Model farms; 3. Veterinary schools; 4. Haras, or studs. And it assists, by its patronage and with funds-1. Public lectures; 2. Agricultural societies; 3. Local associations; 4. Departmental model farms.

There are three public sheep farms; viz., at Rambouillet, Perpignan, and I،a Hayevalıx. 
FRANCE, AGRICULTURE OF.

At these, sheep are bred, and experiments in crossing tried. The chief breeds are the merino, the naz, a race with small frames and fine wool, and the English long-woolled sheep.

of the model farms, Grignon, founded in 1829, and containing 1100 acres of land of different qualities, is the chief. It consists of arable, pasture, meadow, water meadow, and wood. Pupils are taken here, who pay in the house from $30 l$. to $60 l$. per annum, or, if they only altend the courses of instruction, from $8 l$. to 20l: : the shortest course occupies two years; and after attending this period, and passing a public examination, the pupil may receive a diploma, taking rank as a sort of master of arts of Grignon.

The chief veterinary schools are at Alfort, near Paris, Toulouse, and Lyons. 'The three chief haras, or breeding studs, are at Dupin in Normandy (English blood horses), at Rozières (a mixed breed called the "race ducale"), and at Poinpadour (Arab and Persian). These contain together about 1300 horses. Of thorough-bred stock, in 1840 , they had 167 stallions, 98 mares, and 121 colts and fillies; for the use of the departments 870 stallions are kept at different stations. These are allowed the following amount of forage at three different stations :-

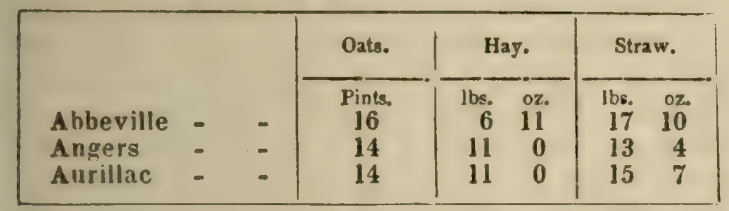

These various public objects cost the govern ment 119,452l.; viz., sheep farms, 20,303l. veterinary schools, 11,263l.; haras, or studs $70,526 l$; other items of expense, $32,000 l$; department of government, $3,360 l$.

Sir Charles Lemon has given the result of the returns of the agricultural survey of 21 out of the 84 departments of France, comprehending the whole of the north-eastern portion of the kingdom, or the whole or the greater part of the old provinces of Flanders, Artois, Picardie, Isle de France, Champagne, Lorraine, and Alsace, equal to a surface of $31,720,000$ acres, or about the area of all England. (Jour. of Roy. Agr. Soc. vol. i. p. 415.)

The following table shows the number of English acres tilled with each sort of grain, the produce, and the seed sown, in the $21 \mathrm{de}$ partments before alluded to:-

\begin{tabular}{|c|c|c|c|c|}
\hline & & Acres. & $\begin{array}{l}\text { Produce in } \\
\text { Bushely. }\end{array}$ & $\begin{array}{l}\text { Amount of } \\
\text { Seed soivn. }\end{array}$ \\
\hline Wheat & - & $3,913,789$ & $59,075,391$ & $9,458,471$ \\
\hline Barley & - & $1,115,916$ & $17,532,875$ & $2,731,799$ \\
\hline Oatต & - & $3,129,359$ & $54,179,336$ & $8,298,751$ \\
\hline \multicolumn{5}{|c|}{$\begin{array}{l}\text { Meteil (mixture } \\
\text { of wheat and }\end{array}$} \\
\hline rye) & - & 630,321 & $9,526,777$ & $1,494,236$ \\
\hline Rye. & - & $1,124,909$ & $13,332,935$ & $2,675,389$ \\
\hline Potaloes & - & 645,233 & $93,649,112$ & $10,748,567$ \\
\hline
\end{tabular}

Total grown

Seed

$19,205,914$ quarters

The average produce per acre of the 21 departments, is as follows:-
FRANCE, AGIRICULTURE OF.

\begin{tabular}{|c|c|c|c|c|c|c|}
\hline & & & $\begin{array}{c}\text { A verage } \\
\text { Prosuce pr. } \\
\text { Acre in } \\
\text { Bushels. }\end{array}$ & 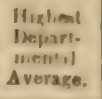 & $\begin{array}{l}\text { I. nweat } \\
\text { IJejart: } \\
\text { ment i } \\
\text { Average. }\end{array}$ & soed. \\
\hline Wheat & - & - & 15 & 23 & 10.3 & $2 \cdot 6$ \\
\hline Barley & - & - & 17 & 35 & 8 & $2 \cdot 6$ \\
\hline Oats & - & - & $18 \frac{1}{6}$ & $44 !$ & 11 & $2 \cdot 8$ \\
\hline Meteil & - & - & $13 \frac{1}{2}$ & 221 & 8 & $2 \cdot 3$ \\
\hline Rye & - & - & 13 & $20 \div$ & 8 & $2 \cdot 6$ \\
\hline Potatoe & & - & 127 & 257 & 67 & \\
\hline
\end{tabular}

In these departments were contained-

$\begin{array}{llllll}\text { Cattle - } & - & - & - & - & -2,629,924 \\ \text { Sheep - } & - & - & - & - & -6,764,107 \\ \text { Pigs and goats } & - & - & - & - & -1,399,599 \\ \text { Horses - } & - & - & - & - & - \\ \text { Mules and asseg - } & - & - & - & -971919\end{array}$

The food of the small French Farmers, especially in Normandy, is very poor. "Many (says a writer in the Quart. Jour. of Agr. vol. xii. p. 2), like the common labourers, live upon a few apples or pears, and a bit of bread, without the formality of sitting down to a table, and are content with a drink of their own home-made miserable cider." The breed of sheep is very inferior. Although many of the sheep are kept in flocks, yet there is little or no free range for them; they are usually kept in small lots of three or four, or half-a-dozen, and generally tied together by the legs. The average price of mutton is $3 \frac{1}{2} d$. per pound. Of the cattle, the Alderney blood seems to predominate. Bullocks are worked to a considerable extent, both in the plough and in the wagon. "Some centuries ago, Normandy was the source whence our Henries, and Edwards, and the flower of European chivalry, obtained their chargers; which were then a breed of large, powerful, active horses, able to bear the weight of an armed knight, with suffcient speed for the purposes of war. That breed has long since degenerated into an active and hardy horse, but totally devoid of those qualifications as to size and general appearance which we should think essential in a charger even for a common soldier; they seldom attain 15 hands in height, and are very short-necked; they are rather large in the head, have good forelegs, but are frequently imperfect in the hind ones, being too long from the hock to the hoof, and they are often diseased in those limbs from curb or spavine, and deficient in width and muscle in the thigh. They have generally, however, good shoulders, back, and loins, many of them possessing very useful and short actions in the trot; and considered generally as a breed, they are able to go faster, and do more work than their aprearance at first indicates: they are commonly worked at two years of age." With regard to the rotation of crops, there is little worthy of observation. In Normandy, a very commor rotation is a three-shift of wheat, barley, clover whea! : in others, a four-shift of putatoes, barley, clover, wheat. Their agricultural implements are few and defective. Dombasle's plough, modelled from that of Smali's English plough, is the favourite plough in France; it has cunmonly, however, wheels added. The spade is employed to a considerable extent in the field culture of this great country, and the greatest portion of the cuuntry partakes of the nature of garden husbandry 'Tlu' cinsumptirn of $2 i^{T} \quad 505$ 


\section{FRANCE, AGRICULTURE OF.}

vegetables of all kinds is much greater in France than in England; and the same remark applies to bread, the price of which, in Paris, is regulated by the public authorities.

The care which is talien in France, by the government, to husband every particle of organic manure, is well worthy of the consideration of the public authorities in England, for nowhere is there a greater waste of the richest fertilizing matters than from the large cities and towns of England; a great and public loss, to which Dr. Granoitte, in his report to the Thames Improvement Company, thus alludes: "In no part of France, Wurtemberg, Bavaria, Bohemia, Prussia, Saxony, the Confederated States of Germany, Holland, and Belgium, is there a city in which, as in London, the general mass of filth, of every description, created by a vast population, is first allowed to enter the river which may happen to traverse that city, and is then returned, diluted with the water of that river, to the houses of the inhabitants, to be used either for domestic or culinary purposes : although, by avoiding the latter disgusting alternative, foreign cities are less free from unpleasant smells than London is. In this respect it may be truly said, that foreigners smell the filth of their cities, but do not swallow it; whereas the Londoner swallows it, but seldom smells it.

"In no large city of that part of Europe which I have recently visited, possessing a river, is any portion of the contents of closets and cesspools suffered to find its way, or to be emptied into it ; except at Amsterdam, Antwerp, Brussels, Stuttgard, and Leipzig; and even there, only in a partial manner. In Paris the Seine is contaminated by one large drain only, conveying the urine from the large reservoirs of night-soil at Montfaucon, and by two smaller ones proceeding from cesspools. To convey generally, or to empty, even partially, any such matter into the river, is a practice against which the laws have provided by heavy fines and incarceration; and such is the present feeling of all the governments on that subject, even in the great cities I have just enumerated as exceptions, that the authorities are seriously engaged in devising means for preventing, in future, every possible infraction of those laws; not because it is desirable to preserve pure the water of such rivers (since no domestic use is made of it), but on account of the loss of a material, deemed most valuable, which such infractions must necessarily entail.

"In Paris extensive improvements in regard to drainage are now in progress, at the conclusion of which, that capital will have subterraneous drains and sewers in as complete a state as those of London, and something better. More than two-fifths of that city are now so drained. When this great undertaking was in agitation, it was suggested that all the latrines, public as well as private, should, as in London, communicate, by proper drains with the great sewers, which are intended to be emptied into the Seine. As the project of supplying pure water, direct to the houses, is simultaneously to be carried into effect, and as the water for that purpose is to be derived from other 506 sources than the river, there could have been no objection on that score, to the adoption of so general and so complete a draina. But when scientific men, agriculturists, and political economists were consulted, it was agreed that, by adopting the London system, the city would lose a revenue of nearly 800,000 franes, and agriculture the means of producing four times as much. The government, therefore, came to the resolution of not suffering any portion of the contents of the latrines to enter the common sewers; but, alive to the great importance of saving them, enacted a police regulation, strictly enjoining that every house should have its cesspool (whether new or old, and within a given time) made water-tight, in order that none of those contents should be wasted. In consequence of this regulation, all cesspools must be emptied once in four years."

FRANKLINIA (Gordonia pubescens). This species of Gordonia, appears to be restricted by nature, within very narrow bounds, having hitherto, says Michaux, been found only on the banks of the Altamaha, in the state of Georgia. It was discovered there in $\mathbf{1 7 7 0}$, by John Bar. tram, who gave it its specific name. In height i: rarely exceeds 30 feet, with a diameter of $\mathfrak{c}$ or 8 inches. It blooms in Carolina about the beginning of July, and a month later near Philadelphia. The flowers are more than an inch in diameter, white, and of an agreeable odour. They have a slight resemblance to those of the dogwood (Cornus Florida). Jike those of the Loblolly bay (Gordonia lasyanthus), they open in succession during two or three months, and begin to appear when the tree is only 3 or 4 feet high. The fruit is in the form of round, ligneous capsules, which, when ripe, open at the summit in four seams to release the small angular seeds.

Although the Franklinia is found 2 or 3 degrees farther south than the Loblolly bay, it appears to be far less sensible to cold, and stands the climate well near Philadelphia, and will perhaps resist the winters higher north. (Michaux.)

FRENCH BEANS. See Brans.

FRENCH CLOVER. See Lucerne.

FREE-MARTIN. A name given by breeders to a twin cow calf born with a bull calf, which generally proves an hermaphrodite, and therefore barren; but in some cases, there not being this admixture of the organs of different sexes, or those of the female prevailing, she is capable of breeding. (Youatt on Cutlle, p. 539.)

FRINGE-TREE (Chionanthus Virginica), a beautiful, small, Arnerican tree, abounding in the Southern States, and as high up as the vicinity of Dover, in the state of Delaware. It has been even met with on the banks of the Brandywine. The specific name is derived from its snow-white flowers, which are pendulous and fringe-like. There is another variety in the United States (the maritima of Pursh), which Lindley considers a distinct species. (Flor. Cestrica.)

FROG OF A HORSE. In farriery, is a tri. angular portion of horn projecting from the sole almost on a level with the crust, and defending a soft and elastuc substance called the 
sensible frog. The sensible frog occupies the whole of the back part of the foot, above the horny frog and between the cartilages. See Shoning.

FROG-HOPPERS. The familiar name applied to singular insects (Cerropidida), which pass their whole lives on plants, upon the stems of which the eggs are deposited in autumn. "The following summer they are hatched, and the young immediately perforate the bark with their beaks, and begin to imbibe the sap. They take in such quantities of this, that it oozes out of their bodies continually, in the form of little bubbles, which soon completely cover up the insects. They thus remain encirely buried and concealed in large masses of foam, until they have completed their final transformation, on which account the names of cuckoo-spittle, frog-spittle, and frog-hoppers have been applied to them. We have," says Dr. Harris, "several species of these frog-hoppers in Massachusetts, and the spittle, with which they are sheltered from the sun and air, may be seen in great abundance, during the summer, on the stems of our alders and willows. In the perfect state they are not thus protected, but are found on the plants, in the latter part of summer, fully grown and preparing to lay their egos. In this state they possess the power of leaping in a still more remarkable degree than the tree-hoppers; and, for this purpose, the tips of their hind shanks are surrounded with little spines, and the first two joints of their feet have a similar coronet of spines at their extremities. 'Their thorax narrows a little behind, and projects somewhat between the bases of the wing-covers; their bodies are rather short, and their wing-covers are almost horizontal and quite broad across the middle, which, with the shortness of their legs, gives them a squat appearance."

FROGS (Rana, Linn.). A genus of amphibious reptiles, consisting of 17 species, but two only require to be here noticed:-

1. The Common Frog (R.temporaria), which is too well known to need description. Some of its properties are very singular, particularly its powers of leaping and swimming. Its body is naked, and without any tail ; the fore limbs are very lightly made, while the hind legs and thighs are remarkably long, and furnished with strong muscles. As soon as the spawn is vivified, the future frog becomes a tadpole, in which state it is wholly a water animal, breath111r by bronchia or gills, like fish; but as soon as it is changed into a frog, and attains its proper shape, it acquires lungs, by which it breathes, and then immediately migrates to the shore.

2. The Gibbous, Green, or Edible frog ( $R$. esculenta), which differs from the former species only in having a high protuberance in the middle of the back, which forms an acute angle. Its colours likewise are more vivid, and its marks more distinct, the ground colour being a pale or yellowish green, marked with rows of black spots from the head to the rump. The flesh of the hind thighs is used as a restorative food. The flesh of the Surinam frog (R. paradoxa) is also used as food. Frogs are recommended by Walton as bait for pike, but frogs retaliate by feerling on the spawn and young fry of fish in ponds and rivers.

Of the utility of frogs, in destroying insects injurious to gardens and farms, the filluw wng view presented in a French periodical, is highly favourable to those much despised animal?

"Gardeners wage the same war against fro" as with moles and all other insects mi-chievous to their crops. But they are wrong in including frogs in the general proscription, since thry not only do them no injury, but render them, on the contrary, important services; for they are carnivorous as well as herbivorous, and greatly prefer insects to vegetable food. They are particularly fond of snails, and swallow them even with their shells on, when they are not too large. If you open a frog, you will find his stomach full of insects hurtful to agriculture, and especially snails. The shells they digest, or rather dissolve in their stomachs, in the same way that dogs do bones, and turkeys the shells of nuts." (American Famer.)

FROND. A combination of stem and leaf in one organ, as in ferns, Marchantia, and such like plants.

FROST. In meteorology is the cause of the congelation of water or the vapours of the atmosphere. Water begins to freeze when the temperature of the air is such that Fahrenheit's thermometer stands at $32^{\circ}$. At this temperature ice begins to appear, unless some circumstance, for example, the agitation of the water, prevents its formation. As the cold increases the frost becomes more intense, and liquids which resist the degree of cold required to congeal water at length pass into the solid state. When water remains at complete rest it may be cooled down to $28^{\circ}$ Fahrenheit without freezing; but the moment it is agitated, the thermometer rises to $32^{\circ}$ and the water freezes. In this case the insensible heat of the water is retained when the fluid is at rest. No experiments have hitherto ascertained to what depth frost will extend, either in earth or water, but its effects will of course vary according to the degree of coldness in the air, the longer or shorter duration of the fro' $t$, the texture of the earth, the nature of the fluids with which the ground is impregnated, \&c. In England the frost rarely extends in the ground below 18 inches from the surface. Frost is peculiarly destructive to vegetation. During severe frost almost all vegetables fall nito a state of decay, and even a moderate degree of frost is sufficient to destroy many of the more tender kinds. The injury which vegetables sustain from frost is greatest when it is preceled by a thaw or copious rains; for the plants are then turgid with moisture, which, expanding in bulk as it passes into the solid state, produces the rupture of the vegetable fibres. Therefore it is that a sharp, north wind, or any thing which dries the sap or juices of vegetables previous to frost, tends to their preservation. The great power of frost on vegetables is well known. Trees are sometimes destroyed by it as if by fire, and split with a noise resembling the $\mathrm{e} x$ plosion of artillery, since the juices of the tree expand with great force, as they are converted into ice. In winter, however, trees generally have neither leaves nor flowers, and their buds 
are so hard as to withstand the effects of congelation; but hard frosts late in spring are often very injurious, as the buds are then appearing. Fruits are in like manner destroyed by frost. Their watery portion being changed into crystals of ice, occupying a greater space than the fluid from which they were produced, burst the small vessels in which they are formed; hence the fruit is deprived of its flavour, and when thawed putrefies.

The hoar-frost or white frost, which appears in the mornings chiefly in autumn and spring, is merely frozen dew. It is generally the consequence of a sudden clearing up of the weather after rain, when a considerable degree of cold is produced by the rapid evaporation. In northerly climates, it usually happens that after a fall of rain the wind shifts into a northern quarter, and the atmosphere suddenly clears up. When this takes place during the night, or early in the morning, a strong radiation of heat from the earth commences, the cooling effect of 'which is increased by the copious evaporation from the wet surfaces of the plants and the grass. The influence of evaporation on the phenomenon is obvious from this, that the moisture which appears in the form of dew before sunrise, is often changed into rime, or hoarfrost, on the appearance of that luminary. The reason is, that as the atmosphere begins to be warmed by the sun's rays, the evaporation is accelerated, and consequently the cold at the wet surface of the ground augmented; hence, we see one reason why frosty nights are so much more prejudicial to the tender shoots of plants when they are succeeded by very bright mornings. Hence, also, hoar-frost is found on grass or plants, when the thermometer placed a few feet above the ground, indicates a temperature three or four degrees above the freezing point.

In late autumnal frost, the effect of evaporation by the heat of the sun is often exemplified on the stems of potatoes. If a hoar-frost be immediately succeeded by the influence of the sun, the dew liquefies, and by the process of evaporation the stalks lose their vitality; for although plants, as well as animals, have an inherent power of resisting cold, yet it is in the former only to a very limited degree. If the hoar-frost be brushed off (and this can easily be done by two men moving along the beds or drills with a rope between them, very early. in the morning, before the evaporation takes place), the stalks will sustain no injury. The destructive power of evaporation appears to be proportioned to the degree of humidity in the body on which it acis.

The following is recommended as a simple and easy method of securing fruit trees from the effects of frost:-

If a thick rope be intermixed among the branches of a fruit tree in blossom, the end of which is directed downwards so as to terminate in a pail of water, should a slight frost take place during the night, it will not in the smallest degree affect the tree, while the surface of the pail which receives the rope will be covered with thin ice: though the water placed in another pail by the side of it, by way of experimint. may not, from the slightness of the frost, have any ice on it at all. In this case the rope aids the evaporation of the water, and thereby cools it down to the freezing point. Frost is merely the effect of cold, which, itself is a negative quality; namely, the absence of heat. As evaporation carries off heat and re. duces temperature, whatever aids this is favourable to freezing. (Quart. Journ. of $A g r$. vol viii. p. 421.) Early hoar-frost may, it is said, be rendered harmless in its effects by pouring fresh spring water on the trees and vines thus covered before the sun rises. Various other projects have been proposed at different times to avert the disastrous effects of the morning frosts on vegetation in spring; but, unfortu. nately, it is only on a very limited scale that any means can be adopted for the purpose. Whatever prevents the formation of dew will protect plants; hence a covering of net or thin gauze will often preserve the blossoms of wallfruit. But the most effectual means is to check the radiation, by screening the plant from the chilling aspect of the clear sky. See DEw. Every farmer knows that frost in winter is serviceable to the soil, by breaking down and pulverizing land, and that a failure of crops frequently takes place after a winter of extreme mildness. The principle is this :-in the process of congelation, the water, as it freezes, expands, and, therefore, necessarily separates the particles of earth in which it is held: frost thus operates better than any instrument of human construction, for its action reaches to the minutest particles, and thus renders them friable. In dry earth it has little or no effect in this way, but is beneficial in destroying grubs and insects. On sand it makes no impression. On ploughed clay-land frost has the mosi beneficial effect. 'Therefore, where the soil is close, stiff, or of an obstinate clayey nature, it should be turned up in ridges in the autumn or at the beginning of winter, which tends greatly to separate its particles, and render it more fine and mellow.

Hard winters seldom injure winter grain in any respect, especially where the land has been thoroughly drained, and is covered much with snow. By leaving the earth in a loose and finely divicled state, frost adapts it better for the extension of the roots as the warmth of spring approaches, and thereby enables them to produce strong plants. (Brande's Dict. of Science.)

FRUI'T (Fr. fruit; It. frutta; Span. fruta; Lat. fructum). In botany, comprehends many kinds of what are commonly called seeds; as those of corn, buckwheat, caraway, parsley, $\& c .$, as well as the succulent inflorescence of the pine-apple, which is a mass of ovaria and envelopes in a consolidated condition. But in horticulture the term fruit is restricted to the pulpy and juicy seeds of trees and shrubs, \&c., as the apple, the peach, the currant, \&c.

The fruits of vegetables are equally various with the seeds. They almost all contain an acid; and this acid is usually either the tartaric, the oxalic, the citric, or the malic, or a mixture of two or more of them. Hardly any other, except, perhaps, the acetic, has hitherto been found in fruits. 'They usually contain likewise a portion of saccharine gummy matter, sometimes starch; and the flrehy fruits 


\section{PRUIT-MAGGOTS.}

contain also a fibrous matter, not yet accurately examined. The colouring matters of fruits, especially the red, dissolve freely both in water and alcohol, but very speedily decay when exposed dry to the action of the sun and weather. Hence they cannot be used as dyes.

The diseases of fruit-trees are various, and for these the reader is referred to the different heads of Blight, Canker, Mildew, \&c. As the culture and propagation of the different fruits are also treated of in separate articles, it will suffice in this place to enumerate a few of the principal works which may be consulted with advantage for fuller details than the limits of this work will enable me to give; among these are Phillips's Hist. of Fruits; Rogers's Fruit Cult.; Hoare on the Vine; Abercrombie's Fruit Gard.; Lindley's Guide to the Orchard and Kitchen Gard.; Loudon's Encyc. of Gard. \&e. Bliss's Fruit Grower's Instructor.

Several American works have been published of great value, upon the culture of fruittrees, \&c.: among these are included Coxe on Fruit-trees; Thatcher's American Orchardist; Hovey's Magaz. of Horlicullure, \&c.; Kenrick's Am. Orchardist; Fessenden's Am. Farmer and Gardener; Hoffey's Orchardist's Companion, the last a splendid original work with plates.

FRUI'T MAGGO'TS. The little white maggots often found in our ripe whortleberries, raspberries, cherries, and other fruits, are the young of small two-winged flies, some of which family deposit their eggs in the stems, buds, and leaves of plants, thereby producing large tumors or galls wherein their young reside. The larvæ of those laying their eggs in fruit, live upon the pulp. The family of insects has received the name of Ortalidians, from a word signifying to shake or flap the wings, these being kept in motion all the time. Some of them are in the habit of suddenly raising their wings perpendicularly above their backs, and running along a few steps with them spread like the tail of a peacock. Their powers of light are feeble, and they are rarely found sporting on flowers in the sunshine, but generally prefer shady and damp places. The wings of the ortalidians are often beautifully variegated, striped or spotted, with shades of brown or black. (Harris.)

FRUIT-MOTH, or CODLING-MOTH. The insect, the eggs of which produce the wellknown apple-worm, which has been brought from Europe to America, and naturalized wherever the apple tree has been introduced. This mischievous creature has sometimes been mistaken for the plum-weevil (see Curculio), but it may, says Dr. Harris, be easily distinguished from it by its shape, habits, and transformations. The plum-weevil is, however, sometimes found in apples; but the apple-worm has never yet been found in plums, so far as Dr. Harris has been able to learn. The apple-worm is nol a grub, but a irue caterpillar, the product of a moth, and not of a beetle, as grubs are. An anonymous writer in the Entomological Magazine of London, has well remarked of this moth (Carpocapsa pomoneilla), that "it is the most beautiful of the tribe to which it belongs; yet, from its habits not being known, it is seldom seen in the moth state; and the apple-grower knows mo moire than the man in the moon to what cause he is indebted for his basketfuls of worm-eater windfalls in the stillest weather."

A good account of the apple-worm and its transformations, by Joseph Tufts, Esq. of Charleston, Massachusetts, was published in

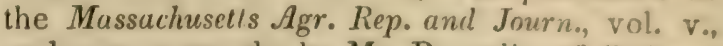
and some remarks by Mr. Burrelle, of Quincy, Massachusetts, may be found in the Now England Furmer, vol, xviii. At various times between the middle of June and first of July, the apple-worm moths may be found in Ncw England. "They are sometimes seen in houses in the evening, trying to get through the windows into the open air, having been brought in with fruit while they were in the caterpillar state. Their fore-wings, when seen at a distance, have somewhat the appearance of brown watered silk; when closely examined they will be found to be crossed by numerous gray and brown lines, scalloped like the plumage of a bird ; and near the hind angle there is a large, oval, dark brown spot, the edges of which are of a bright copper colour. The head and thorax are brown, mingled with gray; and the hind-wings and abdomen are light yellowish brown, with the lustre of satin. Its ivings expand three-quarters of an inch. This insect is readily distinguished from other moths by the large, oval, brown spot, edged with copper colour, on the hinder margin of each of the fore-wings. During the latter part of June and the month of July, these fruit-moths fly about apple trees every evening, and lay their egg; on the young fruit. They do not puncture the apples, but they drop their eggs, one by one, in the eye or hollow at the blossom end of the fruit, where the skin is most tender. They seem also to seek for early fruit rather than for the late kinds, which we find are not so apt to be wormy as the thin-skinned summer apples. The eggs begin to hatch in a few days after they are laid, and the little appleworms or caterpillars produced from them immediately burrow into the apples, making their way gradually from the eye towards the core. Commonly only one worm will be found in the same apple; and it is so small at first, that its presence can only be detected by the brownish powder it throws out in eating its way through the eye. The body of the young insect is of a whitish colour; its head is heart-shaped and black; the top of the first ring or collar and of the last ring is also black; and there are eight little blackish dots or warts, arranged in pairs, on each of the other rings. As it grows older its body becomes flesh-coloured; its head, the collar, and the top of the last ring. turn brown, and the dots are no longer to be seen. In the course of three weeks, or a little more, it comes to its full size, and meanwhile has burrowed to the core and through the apple in various directions. To get rid of the refuse fragments of its fool, it gnaws a round hole through the side of the apple, and thrusts them out of the opening. 'Through this hole also the insect makes its escape after the apple falls to the ground; and the falling of the fruit is well known to be hastened by the iniary it has 
received within, which generally causes it to ripen before its time.

"Soon after the half-grown apples drop, and sometimes while they are still hanging, the worms leare them and creep into chinks in the bark of the trees or into other sheltered places, which they hollow out with their teeth to suit their shape. Here each one spins for itself a cocoon or silken case, as thin, delicate, and white as tissue paper. Some of the appleworms, probably the earliest, are said by Köllar to change to chrysalids immediately after their cocoons are made, and in a few days more turn to moths, come out, and lay their eggs for a second generation of the worms; and hence much fruit will be found to be worm-eaten in the autumn. Most of the insects, however, remain in their cocoons through the winter, and are not changed to moths till the following summer. The chrysalis is of a bright mahogany-brown colour, and has, as usual, across each of the rings of its hind-body, two rows of prickles, by the help of which it forces its way through the cocoon before the moth comes forth.

"As the apple-worms instinctively leave the fruit soon after it falls from the trees, it will be proper to gather up all wind-fallen apples daily, and make such immediate use of them as wil! be sure to kill the insects, before they have time to escape. Mr. Burrelle says that if any old cloth is wound around or hung in the crotches of the trees, the apple-worms will conceal themselves therein; and by this means thousands of them may be obtained and destroyed, from the time when they first begin to leave the apples, until the fruit is gathered. By carefully scraping off the loose and rugged bark of the trees, in the spring, many chrysalids will be destroyed; and it has been said that the moths, when they are about laying their eggs, may be smothered or driven away, by the smoke of weeds burned under the trees. The worms, often found in summer pears, appear to be the same as those that affect apples, and are to be kept in check by the same means." (Harris.)

FRUIT-WEEVII. See Curculio; PlumWEETIL.

FUEL (Norm. Fr. fuayle). Any combustible substance which is used for the production of heat constitutes a species of fuel; but the term is more properly limited to coal, coke, charcoal, wood, and a few other substances.

In England, coal, from its abundance and cheapness, is the commonly employed fuel; but where wood is abundant, or where its value is little more than that of felling it, it is used either in its original state, or in the form of charcoal. It is essential to good and profitable fuel that it should be free from moisture; for unless it be dry, much of the heat which it gencrates is consumed in converting its moisture into vapour; hence the superior value of old, dense, and dry wood, to that which is porous and damp. A pound of dry wood will, for instance, heat 35 pounds of water from $32^{\circ}$ co $212^{\circ}$, and a pound of the same wood in a moist or fresh state will not heat more than 25 vounds from the same to the same tempera7re; the value, therefore, of different woods for fuel is nearly inversely as their moisture, and this may be roughly ascertained by finding how much a given weight of their shavings loses by drying them at $212^{\circ}$.

The following table exhibits at one view the power of various species of wood in producing heat.

The number indicates the quantity of timber in pounds, required to raise the temperature of a cubic foot of water from $52^{\circ}$ to $212^{\circ}$.

\begin{tabular}{|c|c|c|c|c|c|c|c|c|}
\hline \multicolumn{2}{|c|}{ Oak chips } & - & - & - & - & - & - & $-4 \cdot 20$ \\
\hline $\mathbf{E} / \mathbf{m}$ & - & - & . & - & . & . & - & -3.52 \\
\hline Fir & - & - & & - & - & . & - & -3.52 \\
\hline Ash & - & - & 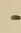 & 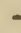 & - & . & - & $-3 \cdot 50$ \\
\hline \multicolumn{2}{|c|}{ Hornbeam } & - & 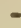 & 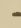 & . & - & - & $-3 \cdot 37$ \\
\hline \multirow{2}{*}{\multicolumn{2}{|c|}{ Cherry tree }} & - & 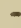 & . & . & & - & - \\
\hline & & - & 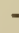 & 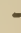 & 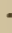 & & - & $-3 \cdot 16$ \\
\hline \multicolumn{2}{|c|}{ Lime tree } & - & $=$ & - & & & - & - \\
\hline \multicolumn{2}{|c|}{ Poplar - } & - & . & 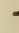 & 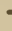 & . & - & - \\
\hline Mapl & & - & - & 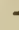 & 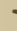 & 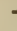 & - & 00 \\
\hline \multicolumn{3}{|c|}{ Service tree } & - & - & & & - & -3.00 \\
\hline
\end{tabular}

The value of turf and peat, as fuel, is liable to much variation, and depends partly upon their density, and partly upon their freedom from earthy impurities. A pound of turf will heat about 26 pounds of water from $32^{\circ}$ to $212^{\circ}$, and a pound of dense peat about 30 lbs.: 1 compressing and drying peat its value as a fuel is greatly increased. Dr. M·Culloch has divided peat into five classes:-mountain peat marsh peat, lake peat, forest peat, and marin peat; the names implying the locality of their production. Of these the mountain peat, from its loose, spongy texture, is the least productive of heat, although it soonest inflames. The reader is referred to an excellent essay "on economizing Fuel and Lighting," \&c. by the Rev. P. Bell, in the Trans. of High. Soc. vol. iv. p. 149. See Charcoar and Peat. (Brande's Dict. of Science; Willich's Dom. Encyc.)

FULLER'S THISTLE (Dipsacus fullonum). A name sometimes applied to a plant used by the makers of cloth. See Teasez.

FULLER'S EARTH. A native saponaceous mineral of the aluminous kind, found in many parts, but the best comes from the south of England and Saxony. It is much used by fullers in cleaning and scouring their cloth, from its property of absorbing grease. It is of a very soft, unctuous nature, falls to pieces in water, and appears to be capable of promoting the growth of plants in a high degree; consequently may be used with advantage as manure, on some of the lighter sorts of land. Its constituents, according to Klaproth, are as follows :-

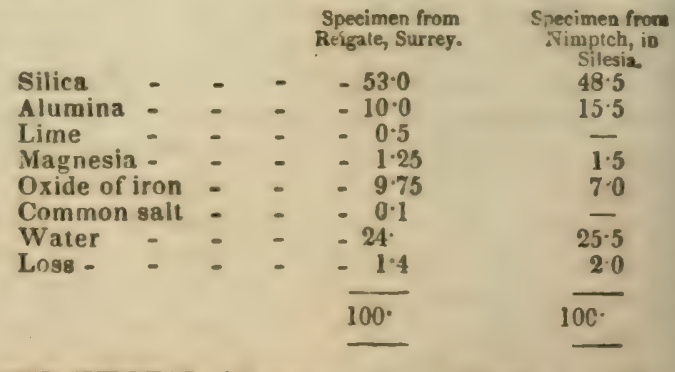

FUMITORY (Fumaria, from fumus, smoke, alluding to the disagreeable smell of the plant, Our English word fumitory is derived from the French name of the genus Fumeterie). There are six indigenous species of fumitory, amon: which are:- 
Common sumitory ( $F$.officinalis), an annual, very common in cultivated ground and about hedges; root tapering, herb glaucous, stem much branched, leaves mostly alternate, twice or thrice pinnate. Flowers in clusters, rosecoloured or pale red. 'The leaves are succulent, saline, and bitter. The plant is eaten by cows and sheep; goats dislike it, except the young shoots, and horses totally refuse it.

Ramping fumitory ( $F$. capreolata). This species is much like the common fumitory, but larger in every part; the leaves less glaucous; their tendrils twisting round other plants, by which the branching stem climbs to the height of 3 or 4 feet. The flowers are on the whole paler, and the plant also less common.

This species and the white climbing fumitory are the only ones worthy of extensive culture. They do best sown under a hedge, to which they will attach themselves and make a beautiful appearance. The common fumitory is the only species found in the United States, where it has been naturalized to some extent, being not unfrequently cultivated in gardens. (Eng. Flor. vol. iii. p. 252-257; Paxton's Bot. Dict.)

FUNDI, or FUNDUNGI. An African grain produced by a plant of Lilliputian growth, which is described by Mr. Clarke, in the proceedings of the London Linnæan Society. This grain is represented as about the size of mignonette-seed, and is cultivated in the village of Kissy and in the neighbourhood of Waterloo by industrious individuals of the Soosoo, Foulah, Bassa, and Joloff nations, by whom it is called "hungry rice." The ground is cleared for its reception by burning down the copse-wood and hoeing between the roots and stumps. It is sown in the months of May and June, the ground being slightly opened and again lightly drawn together over the seed with a hoe. In August, when it shoots up, it is carefully weeded. It ripens in September, growing to the height of about 18 inches, and its stems, which are very slender, are then bent to the earth by the mere weight of the grain. They are reaped with hooked knives. The patch of land is then either suffered to lie fallow, or planted with yams or cassada in rotation. Manure is said to be unnecessary or even injurious, the plant delighting in light soils, and being raised even in rocky situations, which are most frequent in and about Kissy. When cut down it is tied up in small sheaves and placed in a dry situation within the hut, for if allowed to remain on the ground or to become wet the grains become agglutinated to their coverings. The grain is trodden out with the feet, and is then parched or dried in the sun to allow of the more easy removal of the chaff in the process of pounding, which is performed in wooden mortars. It is afterwards winnowed with a kind of cane fanner on mats.

In preparing this delicious grain for food, Mr. Clarke states that it is first thrown into boiling water, in which it is assiduously stirred for a few minutes. The water is then poured off, and the natives add to it palm oil, butter, or mills; but the Europeans and negroes connected with the colony stew it with fowl, fish, mutton, adding a small piece of salt pork for the sake of flavour, and the dish thus prepared is stated to resemble kous-kous. The grain is also made into a pudding with the usual condiments, and eaten either hot or cold with milk; the Scotch residents sometimes dress it as milk-porridge. Mr. Clarke is of opinion that if the fundi grain were raised for exportation to Europe, it might prove a valuable aldition to the list of light farinaceous articles of foord in use among the delicate or convalescent.

Specimens of the grass have been examined by Mr. Kippist, Librarian to the Linnæan So. ciety. It is a slender grass with digitate spikes, which has much of the habit of Digitn ria, but which, on account of the absence of the small outer glume existing in that genus, must be referred to Paspalum. Mr. Kippist regards it as an undescribed species, and distinguishes it by the name of Paspalum exile (Proceedings of Lin. Soc.)

FUNGI (Lat.). A large natural tribe of plants of a very low organization, consisting chiefly of cellular tissue, sometimes intermixed with flocculent matter, and very rarely furnished with spiral vessels. They form, as it were, a link between the animal and vegetable kingdoms. They inhabit dead and decaying organic bodies, and are also a common pest to living plants, upon which they are parasites, and prey in the same manner as vermin and intestinal worms upon animals. A vast number of species are described by writers upon fungi, and they are often of great importance to man, either for their use or their mischievous qualities. The common mushroom (Agaricus campestris), the truffle (Tuber cibarium), and morel (Morclella esculenta), (see these heads) are delicacies well known at table. Not less than thirty-three species of fungi are eaten in Rus. sia. Ergot, one of the tribe, is valuable in obstetric practice as a uterine stimulant; very many of the species are dangerous poisons. Blight, mildew, rust, \&c. (see these articles), are diseases caused by the ravages of microscopic fungi; and, finally the destructive effects of dry-rot are owing to the attacks of $M_{e-}$ rulius lachrymans, and many other species. The best general work on Fungi is Fries's Systema Micologicum. Numerous species are figured in the works of Greville, Bulliard, Sowerby, Corda, and Nees von Esenbeck. (See Fairy Rings.) Dr. Christison gives the following general directions for distinguishing the esculent from the poisonous varieties. "It appears that most fungi which have a warty cap, more especially fragments of membrane adhering to their upper surface, are poisonous. Heavy fungi, which have an unpleasant odour. especially if they emerge from a vulva or bag. are also generally hurtful. Those which grow in woods and shady places are rarely esculent, but most are unwholesome; and if they are moist on the surface they should be arolded. All those which grow in tufts or clusters from the trunks or stumps of trees ought likewise to be shunned. A sure test of a poisonous fungus is an astringent styptic taste, and perhaps also a disagreeable, but certainly a pungent odour Those, the substance of which becomes liue soon after being cut, are invariably poisnnoms 
Agarics, of an orange or rose-red colour, and boleti, which are coriaceous or corky in texture, or which have a membranous collar round the stem, are also unsafe. These rules for knowing deleterious fungi seem to rest on fact and experience; but they will not enable the collector to recognise every poisonous species." The general rules laid down for distinguishing wholesome fungi are not so well founded, but the most simple and easy mode of testing the quality of field fungi is to introduce a silver spoon or piece of coin of that metal, or an onion, into the vessel in which mushrooms are seething: if on taking either of them out, they assume a bluish black, or dark discoloured appearance, there are certainly some dangerous fungi among them; if, on the other hand, the metal or onion, on being withdraw'n from the liquor, wears its natural appearance, the fungi may be considered wholesome and innoxious. The symptoms indicating poisoning by fungi are nausea, vomiting, purging, and colic, in general accompanied with great depression of the pulse, cold extremities, clammy sweats, stupor, delirium, convulsions, sometimes paralysis. In such cases immediate means should be taken to clear the stomach, and a medical practitioner sent for, as the subsequent treatment must vary according to the symptoms in each individual instance. (Christison on Poisons; Erande's Dict. of Science.)

FUNGUS. In farriery, a spongy excrescence which arises in wounds and ulcers, commonly known by the name of proud flesh. It may be destroyed and removed by caustic applications, such as nitrate of silver, or sulphate of copper, blue vitriol, and the use of tight bandages.

FURLONG (Sax. funlanz). An English measure of length containing forty poles, the eighth part of a mile.

FURMENTY, or FRUMENTY (from frumentum, corn). A kind of country pottage prepared of wheat, which is first wetted, and beaten to deprive it of its husks, and afterwards boiled. When boiled up with milk, sugar, and a little spice, it forms a wholesome and agreeable food. This 'preparation was well known to the Roman farmers. Cato, the earliest of the agricultural writers whose works have escaped to us, gives (lib. Ixxxvi.) the modern mode of making it under the name of wheat frumenty.

FURRIER'S REFUSE, or CIIPPINGS; are sometimes applied as a fertilizer to light chalks and gravelly scils, either ploughed in or laid upon the surface, in the proportion of twenty-four to thirty bushels to the acre. They are usually sold by the quarter, which commonly contains as much as two five-bushel sacks will hold when closely pressed. The price is said to be about $14 s$. to $16 s$. per quarter. (Brit. Husb. vol. i. p. 426.)

FLRROW (Sax. funh; Dan. fur; Lat. forus). In agriculture, a term not very properly defined, as it has three or four distinct significations; viz. 1. The soil turned up by the plough; 2. The trench left by this operation; 3 . The interval between two ridges; and 4 . The cross drain which receives the rain water 512 collected by these intervals. Dr. Johnson adds a fifth; but he obviously mistakes furrow for drill. According to Mr. Marshall there are three ideas which lay claim to the word furrow. 1. The trench made by the plough, which may be called a plough furrow; 2. The collateral drains, or an inter-furrow; and 3. The transverse drains, or the cross-furrow. See Plovghing and Furnow, Water.

FURROW-SLICE. The narrow slice or slip of earth turned up by the plough. By the Scotch writers on husbandry, it is mostly termed fur-slice.

FURROW, WATER- That kind of deep, open furrow which is made by the plough in tillage-lands, for the purpose of drawing off and draining them, in order to favour the healthy growth of the crops. Furrows of this kind should always be drawn in such directions as will the most readily take off the water, and be kept open during the winter months, especially on the wheat-grounds. The making of these furrow-drains should be performed immediately after the ploughing and sowing have been finished; and this is particularly necessary on all the more stiff and retentive kinds of soil.

FURZE, COMMON; GORSE, or WHIN (Ulex Europaus). Pl. 9, c. This hardy evergreen shrub is indigenous to most parts of Great Britain, and grows abundantly on sandy or gravelly heaths and commons; and when viewed in the light of a weed it is one of the most determined growers, and most difficult to get rid of that the agriculturist can meet with. The stem of the furze varies from 2 to 5 feet high; but in Cornwall and Durham it sometimes grows to the height of 8 or 9 feet. It bears innumerable dense, roughish, green, furrowed or ribbed branches, spinous at the ends, and beset with large, compound, striated, permanent thorns. The leaves are few, scattered, small, awl-shaped, deciduous. Flowers large, solitary or in pairs, of a bright golden yellow, with a very peculiar oppressive scent. One of our poets has well described the beautiful appearance of this shrub in blossom-

"And what more noble than the vernal furze, With golden baskets hung? Approach it not. For every blossom has a tronp of swords Drawn to defend it."

The legumes are downy, bursting elastically in dry, hot weather, with a crackling noise, and scattering their seeds extensively. The wood of furze is very hard. Furze is chiefly used for fences, as food for cattle, and for fuel. Its preference for sterile soil has caused it to be extensively employed for fences in such land, and as a cover for game, and shelter for young plantations. With common care furze fences last for a very long period, but they require peculiar management to prevent the roots becoming exposed. Sowing in three tiers on a bank is perhaps the best mode, as it allows of one tier to be kept low by the shears or bill, the second of higher growth, and the last to attain its natural stature.

There are generally two objections advanced against the adoption of whin-fences. The first is, that the wall or mound required for raising the whin is of such dimensions as to occasion a great waste of ground; and the second is. 
that the whins have a great tendency to spread over and injure the adjoining grounds. But with a slight, well trimmed wall-fence of furze these objections may easily be obviated.

The formation and management of whinfences have bsen treated of by a number of agricultural and botanical writers, as Lord Kames, Dr. Anderson, Marshall, Billington in his work On Planting, Dickson in his Modern Husb., and others; there is also an essay on this subject in the Trans. of the IIigh. Soc, vol. v. p. 466, by Mr. W. Bell, and it is noticed in a number of the County Reports.

Furze has long been known as a plant highly nutritious as food for horses, sheep, and cattle, and has only been neglected from the supposed difficulty of converting it into a state fit to be comfortably eaten by domestic animals; the process of culting, gathering, and bruising the young shoots, when taken from the old stunted bushes, being both laborious and expensive. 'These difficulties are, however, comparatively easily overcome when gorse is allowed the privilege of a cultivated spot, and the most worthless part of the farm is good enough for it to vegetate upon.

Respecting the merits of furze as a fodder, a good deal has been written, as by Duhamel in France, Evelyn in England, and Dr. Anderson in Scotland; and it is now extensively cultivated for this purpose by Mr. Attwood of Birmingham, who has devoted an hundred acres to French furze; ( $U$. provincialis, which is nearIy allied to the common furze). These are regularly mown with a scythe for a corresponding number of milch cows, and bruised in a mill: mixed with chopped straw or hay, this constitutes the entire food of his cows. Bruised furze is alsr) an excellent substitute for hay for horses, and it is even asserted that they prefer it to corn; but they should at the same time have oats and beans to counteract the relaxing properties of the gorse. Dr. Anderson says that when properly bruised, cattle are very fond of $i t$, and increase in fatness as fast as on turnips. Cows yield as much milk as when fed on grass, without any bad taste, and the butter made on such food is very superior. The smail holder bruises the furze for his solitary cow or pair of horses, in a trough, with a wooden pounder, furnished at the lower end with a sharp piece of iron. The farmer on a large scale should have a mill worked by horses or by water-power. In 1802 and 1803, the Dulie of Richmond fed his deer, sheep, and horses extensively on whins. In the Peninsular war the forage consumed by the horses of the British army was principally furze. Mr. F. Tytler, in an account of experiments which he made on feeding horses, between the years 1812 and 1815 (Trans. High. Soc. vol. v.), states, that one of the chief kinds of food he used was furze. But the principal use of furze is for the purpose of fuel. In many parts of Great Britain it forms the main dependence for the supply of fagots for the poor man's hearth and the baker's oven. The common furze generally attains its full size in 4 years, and it ought not to be cut more frequently. An acre of land sown with the French furze will yield between 4 and 5000 fagots, which are chiefly consumed in the heating of ovens. The fresh and dried nowers of this plant afford in dyeing a fine yellow colour. The medicinal qualities of furze are attenuant, diuretic, de. termining to the skin, and occasioning nausea.

Furze may be propagated by seed sown from February to May. Young plants or even slips planted in Spring or October will grow readily. It should be cut the year after sowing, beginning in September or October: it will grow again until Christmas, and be fit for use till March. Besides the common furze there are two other species:

1. The dwarf whin or furze (U.nanus) which is less common than the preceding, and only grows to half the size. It blossoms chiefly in autumn, has the leaves or spines shorter and closer, and the branches decumbent, the flowering ones more cylindrical and elongated; and the flowers are paler. These points of structure distinguish this species from the others at first sight. Its value is estimated in comparison to that of the common, as two to one inferior.

2. The French or Provence furze (U. pro vincialis), is a native of the South of Europe. It closely resembles the common furze. In Devonshire the common furze, and in some other parts the dwarf furze, are frequently called French furze. (Phillips's Syl. Flor, vol. i. p. 247 ; Brit. Husb. vol. iii., On Planting, p. 100 ; Eng. Flora, vol. iii. p. 265; Quart. Journ. of Agr. vol. ii. p. 731, vol. viii. p. 591; Willish's Dom. Encyc.)

\section{G.}

GAD-FLY, or BREEZE (Estrus equi et bovis, Lin.). Insects with spotted wings and a yellow breast, which have a long proboscis, with a sharp dart. These flies are particularly troublesome to cattle by their sting or dart. The horse-bot (Estrus equi) deposits its eggs on such parts of the horse as the animal can reach with his tongue. They are thus licked up, and introduced into the stomach; are there hatched and form bots. Another mole tormenting fly of the same genus is the fundament-bot (CE. hamorrhoidalis), which lays its eggs on the lips of the horse, causing so much irritation to the animal, as to induce him to gallop and seek refuge in the water. In Sweden, the grooms are accustomed to clean the mouths and throats of the horses daily with a peculiar kind of brush, which prevents the larrx of this in. sect getting into the stomach of the animal. The ox-warble ( $\alpha_{i}$, bovis) deposits its eggs on the back of oxen, causing great th rture to the animal, and much agitation to the herd, if many are attacked at once. The vipositor. of the insect pierces the skin on tho bac $n$ of the ox, and there drops the eggs. At the sei son when the gad-fly infests them, the narness should be so managed as to allow the animals to be easily let loose. The ovipositor of the GE. bovis is furnished with teeth, and acts like an augur or gimlet; and when this comes in contact with a nerve of sensation, the oxen seem to be driven almost to a state of madness: the tail is stretched out, and they gallop about the pasture, lowing and seeking for 
water, into which they instinctively enter. Hence Virgil, describing this, says:-

\section{"The universal herds in terror fly;}

Their lowings shake the woods and shake the sky."

Humboldt mentions a species of Estrus which is found in the low regions of the torrid zone, and has been named $O$ Estrus hominis, from its attacking man, and depositing its eggs in his skin, causing there painful tumours. (LaGéog. des Plantes, p. 186.)

Of the large Gad-fies, or Horse-fies found in America, one if the most common is of a black culour, having its back covered with a whitish dust or bloom, like a plum. The eyes are very large, and almost meet on the top of the head; they are of a shining purple-black or bronzed blach colour, with a narrow, deep black band across the middle, and a broad band of the same hue on the lower part. The body of this fly is seven-eighths of an inch or more in length, and the wings expand nearly two inches. The Tubanus cinclus, of Fabricius, or orange-helted horse-fly, is not so common, and is rather smaller. It is also black, except the first three rings of the hind-body, which are urange-coloured. The most common of our smaller horse-flies is the Tabanus lineola, so named by Fabricius, because it has a whitish line along the top of the hind-body. Besides these tlies, we have several more kinds of $T a$ banus, some of which do not appear to have been described. These blood-thirsty insects begin to appear towards the end of June, and continue through the summer, sorely tormenting both horses and cattle with their sharp bites. Their proboscis, though not usually very long, is armed with six stiff, and exceedingly sharp needles, wherewith they easily pierce through the toughest hide. It is stated that they will not touch a horse whose back has been well washed with a strong decoction of walnut leaves: The eyes of these flies are very beautiful, and vary in their colours and markings in the different species.

The golden-eyed forest fiies are also distinruished for the brilliancy of their spotted eyes, and for their clouded or banded wings. They are much smaller than the horse-flies, but resemble them in their habits. Some of them are entirely black (C'hrysops ferrugatus, Fabricius), others are striped with black and yellow (Chrysops vittalus, Wiedemann). They frequent woods and thickets, in July and August. (Harris.)

GALLIC ACID. An acid obtained from galls and several other vegetable astringents, thiefly from the bark. The following table will serve to show the proportions of this acid in different plants :-

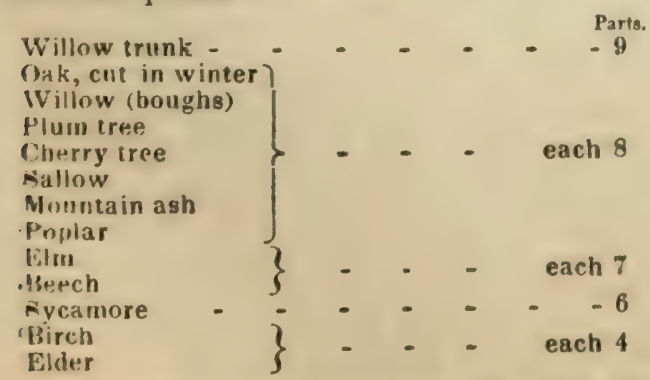

isut although the above-named barks yield 514 the zuantities of gallic acid mentioned, yet it is incertain whether they actually contain any ready formed. Gallic acid is procured by exposing the decoctions of galls, or of any astringent bark, to the air, until it becomes mouldy, and the tannic acid attracts the oxygen of the air, and is converted into the gallic acid. In this state the acid forms in crystals, mixed with crystals of another acid, the ellagic, which are easily separated from it, being insoluble in water.

Pure gallic acid has a weak, sour, astringent taste. It is soluble in $\mathbf{1 0 0}$ parts of cold water, and forms an ink with solution of green vitriol (sulphate of iron). It is distinguished from tannic acid, which is ready formed in astrin. gent barks, by not precipitating solution of glue. It is a powerful astringent, and may be administered in doses of two or three grains in internal bleedings.

GALLINACEOUS FOWLS. One of the two divisions of domestic poultry reared in Europe, comprehending, among others, the common cock and hen, the turkey, the guineafowl, the peacock, and the pigeon.

GALL FLIES. See Fruit Maggots.

GALL NUTS (Fr. gallis; It. galle). Excrescences produced by the Cynips, or Diplolepsis galle tinctoria, a small insect which deposits its eggs in the tender shoots of the Quercus infectoria, a species of oak abundant in Asia Minor, \&c. When the maggot is hatched, it feeds on the morbid excrescence formed by the irritation of the deposited ovum on the surrounding parts, and ultimately, when perfected as the fly, it eats its way out of the nidus thus formed. Good gali nuts are of a bluish-green hue, heavy, and break with a flinty fracture. When they are white, light, with a hole in one side, they are useless. Gall nuts are employed in lyeing, and in medicine.

GALLON. An English measure of capacity, containing 4 quarts. By act of parliament the imperial gallon is to contain $10 \mathrm{lbs}$. avoirdupois of distilled water weighed at the temperature of $62^{\circ}$ of Fahrenheit, and the barometer standing at 30 inches. This is equivalent to 277.274 cubic inches. The old English gallon, wine measure, contained 231 cubic inches, and held $8 \mathrm{lbs}$. avoirdupois of pure water; ale and beer measure, 282 cubic inches, and held $10 \mathrm{lbs}$. $3 \frac{1}{4} \mathrm{oz}$. avoirdupois of water; and the gallon for corn, meal, \&c., 272 cubic inches, containing $9 \mathrm{lbs} .13 \mathrm{oz}$. of pure water. Hence the English imperial gallon is about $\frac{1}{5}$ larger than the old wine gallon, and about $\frac{1}{6} n$ less than the old ale gallon. See Werghts and MEASURES.

GALLOP. In horsemanship, a well-known pace to which horses are trained, and of which many kinds are enumerated, but two only are worthy of regard, namely the hand gallop and the full gallop. And these distinctions are founded on the different degrees of velocity in which the animal is impelled, rather than on any peculiarity in the pace itself. In the gallop, the horse leads with one fore-leg somewhat advanced, but not so much beyond the other, as happens in the canter; and, when he is urged to his utmost speed, his legs are almost equally placed. The fleetest horses 
when gailoping, carry their bodies perfectly in a horizontal posture, and the fewer curves or successive arches are described, the more rapid of course is their progress.

In galloping, the fore-legs are thrown forward nearly simultaneously, and the hind-legs brought up quickly and nearly together; it is, in fact, a succession of leaps, by far the greatest interval of time elapsing while the legs are extended after the leap is taken. The canter is to the gallop very much what the walk is to the trot, though probably a more artificial pace. The exertion is much less, the spring less distant, and the feet come to the ground in more regular succession. (The Horse, p. 413.)

GALIOWAY. The usual name for a poney or saddle-horse, between 13 or 14 hands in height. The original galloways are a pure breed of small, elegant horses from the south of Scotland, said to be of Spanish extraction. See Hors:

\section{GALLOWAYS. See Catrte.}

GALIOWS OF A PLOUGH. A part of the plough-head, so named by farmers, from its resemblance to the common gallows. It consists of three pieces of timber, of which one is placed transversely over the heads of the other two. See Plougr.

GALLS. In farriery, a term signifying an abrasion or rubbing off of the skin by the harness, saddle, \&c. The little tumours resulting from the pressure of the saddle are called warbles, and when they ulcerate they frequently become sit-fas's. For saddle galls there is no belter application than strong salt and water, mixed with a fourth part of tincture of myrrh. The saddle and the collar, when they are found to rub or gall, should be padded or chambered. A mixture of white-lead moistened with milk is stated (Quart. Journ. of Agr. vol. ix. p. 299), to be an excellent liniment for galled backs in the early stages of the wound. It is a common $\Delta$ merican remedy. "For the information of other travellers, we may mention," says Mr. Keating, "that, after having tried many applications to the backs of horses when galled, we have found none that have succeeded so well as white-lead moistened with milk. When milk is not to be procured, oil may be substituted. Whenever the application was made in the early stage of the wound, we have found it to be very effectual; and it is likewise a convenient one, as two ounces of white-lead sufficed for the whole of our party for more than a month." (Expedition to St. Peter's River, p. 190.)

GALLS. In agriculture, a term signifying vacant or bare places in a crop.

GAMA GRASS (Tripsacum dactyloides), Finger-like Tripsacum, called also Sessame grass alud Rough-seeded gama grass. (See Pl. 7, n.) This stout and very remarkable grass has a perennial root. The culm rises to the height of 4,5 , or 6 feet, is somewhat compressed, channelled on one side, smooth, solid with pith, furnished with nodes or knots, smooth, slightly raised, with a dark-brown contracted ring. The leaves are large, often measuring 3 feet, and an inch to an inch and a half wide, smooth beneath, roughish on the upper surface, serrulate or finely jagged on the edges. Flower a dark purple; seed ovoid and smooth.
"A few years ago," says Dr. Darlington, in his Flora Cestrica, "this grass was much extolled by some writers in the West, as an article of fodder for stock. The leaves and young plant may probably answer very well where better cannot be had; but any one who will examine the coarse culms of the mature plant may soon satisfy himself that it can never \&?persede the good hay of this region (the Middle States), nor be as valuable in any respect as common Indian corn fodder." It is the or!y species of the genus Tripsacum which is incigenous in the United States, the T. monustachyon of some authors being only a variety. It has been found in Chester County, Pennsylvania.

From some communications in American poriodicals, the gama grass appears to be particularly well adapted to Southern culture. It is exceedingly productive, being said to admit of at least six cuttings in a season, and to furnish a large quantity of palatable and nutricious food for cattle and horses. It is a hardy perennial plant, and its duration, according to a Spanish proverb, coeval with the "age of a man and a mule." (Silk Culturisl.) The modes of culture are by planting the seeds and transplanting the roots. Mr. Beekman, of Kinderhook, N. Y., gives the following directions: "Sow in drills 18 inches apart, and cover about 2 inches deep. In a month it will come up like oats, and when about 8 inches high and two suckers appear, one on each side, then transplant about 3 by 2 feet. The second year in Georgia the first cutting may be made in May, and once every month to lst October, say six cuttings. The blades will be 3 feet or upwards - each forming a large bunch, which may be annually divided into from 40 to 50 plants."

The variety of gama grass so much vaunted in the Southern and Western States is said to be a hermaphrodite plant from the island of Jamaica, where it is extensively cultivated as a forage grass.

GARDENING. There is not in the arts and sciences one link of their circle so suitable for the occupation of man in a state of innocence, as that which embraces the cultivation of plants; and it is an instance of the beneficent providence of the Deity, that he assigned a garden as the dwelling of our first-crealed parents. It is no consequence of the fall of Adam that plants require cultivation: he was placed in Paradise to till and to keep it. Then the weed had not sprung up to render the tillage toilsome; fruit trees which God had "planted" were the cnief objects of care, and it was an employment without much labour, combining the preservation of health with amusement, pure without insipidity, constant without sameness. From that period gardens have never ceased to engage the attention of nan; and even now that their labours are manisuld, they still afford the "purest of human pleasures."

To be an efficient cultivator of plants, a knowledge of botany is requisite. Whilst that science remained the chaos of unarranged facts, and ill-classified individuals, which it was until the master-mind of Linnæus rednced its confusion and discord to harmony in 1737 , it required for its acquisition the devotion of a life. Such acquisition the new system of classt. 


\section{GARDENING。}

fication rendered comparatively easy in a few months. That gardeners availed themselves of the advantage needs no further instance than Philip Miller, in whom the perfect botanist and horticulturist were combined, and who was a correspondent of the chief men of science then living.

For the working with full effect of the spirit of the immortal Swede, our own Ray had prepared the arena. Indefatigable, enthusiastic in his pursuits, of clear and comprehensive mind, he gave an impetus to botany and its correlative arts, more effectual to their advancement than they had received during ages of years preceding. For 50 years he most successfully laboured to clear the path of this science and to increase her stores. Nor does he enjoy his fame only among his countrymen; it is afforded to him by all Europe. Haller says, he was the improver and elevator of botany into a science, and dates from his life a new era in its history. In little more than 20 years, Ray recorded an increase in the English Flora of 550 species. His Catalogus Plantarum Anglia, in 1670, contains 1050 species: his Synopsis, in 1696, describes more than 1600 species. A phalanx of botanists were then contemporaries which previous ages never equalled, nor succeeding ones surpassed. Ray, 'Tournefort, Plumier, Plukenet, Commelin, Rivinus, Bobart, Petivir, Sherard, Boccone, Linnæus, may be said to have lived in the same age.

I will not pass unnoticed, as being of this period, Abraham Cowley, the well-known poet, physician, and author of The Four Books of Plants. Although he deserves little praise as a botanist or as a gardener, he merits notice as assisting in their advancement, by winning to them and encouraging the attention of the literary. Of the influence which botanists possess over the forwarding the interests of horticulture, I shall quote but one more instance. Sir Arthur Rawdon was so gratified with the magnificent collection of West Indian plants possessed by Sir Hans Sloane, that he despatched a skilful gardener, James Harlow, to Jamaica, who brought thence a vessel nearly freighted with vegetating and dried plants, the first of which Sir Arthur Rawdon cultivated in his own garden at Moira in Ireland, or distributed amongst his friends, and some of the continental gardens. His taste for exotic plants was probably much encouraged by his intimacy with $\mathrm{Dr}$. William Sherard, who, being one of the most munificent patrons and cultivators of exotic botany during that "golden age" of the science, appeared, as Hasselquist observed, "the regent of the botanic garden" at his house at Sedekio, near Smyrna, where he was British consul: for here he cultivated a very rich garden, and collected the most extensive herbarium that was ever formed by the exertions of an individual. It contained 12,000 species. His younger brother, Dr. James Sherard, also cultivated at Eltham, in Kent, one of the richest gardens England ever possessed. (Pultney's Sketches of Bot. vol. ii. p. 150.)

But it was not on'y in the collecting and arranging of plants that butany was adding fresh stores and zest to gardening. Previous to this

eriod little was known of the structure of 510
GARDENING.

plants, and the uses of their several parts Grew, Malpighi, I,innæus, Hales, Bonnet, Du Hamel, Hedwig, Spallanzani, \&c., cleared away, in a great measure, the ignorance which enveloped vegetable physiology. Previous to their days the male bearing plants of diœcious plants, as spinach, and the male flowers of cucumbers, \&c., were recommended to be removed as useless; they taught the importance of checking the return of the sap; the mode of raising varieties: in short, all the phenomena of vegetable life, which throw so much light upon the practice of the gardener, were first noted and explained by the labours of these philosophers. Another class of philosophers who contributed a gigantic aid to the advance of horticulture, were those chemists who especially devoted themselves to the vegetable world. Such men were Ingenhouz, Van Helmont, Priestley, Sennebier, Schraeder, Saussure, \&c. To them we are indebted for the most luminous researches into the food of plants, the influence of air, of heat, of light, and of soils. Previous to their researches the immense importance of the leaves of plants was unknown. Cultivators were unaware that by removing one of them they were proportionably removing the means of breathing and of nourishment from the parent plant; and mankind in general were ignorant that it is by the gas which plants throw off that the aninal creation is alone enabled to breathe.

The scientific institutions of previous years, which had merely existed, were now in a state of vigorous exertion. The Botanic Garden at Chelsea was especially distinguished under its curator Philip Miller. This garden, as previously stated, was founded in 1673 , though the inscription over the gateway is dated 1686 , until which year it was not effectually arranged. It was strengthened and rendered permanent by Sir Hans Sloane, in 1721. He, having purchased the manor, gave the site, which is a freehold of four acres, to the company, on condition that they should pay $5 l$. per annum for it, and that the demonstrator of the company, in their name, should deliver annually 50 new species of plants to the Royal Society, until the number amounted to 2,000 . This presentation of plants commenced in 1722 , and continued until 1773 , at which time they had presented 2550 species.

If old botanical institutions improved, so also new ones were formed. The Kew Gardens were commenced in 1760 , by the Princess Dowager of Wales, mother of George III. The exotic department was established chiefly through the influence of the Marquis of Bute, a great patron of gardening. It was placed under the care of Mr. W. Aiton, and it has since become one of the most celebrated botanical institutions in the world.

The Cambridge Botanical Garden was also founded in 1763, by Dr. Walker, vice-master of Trinity College. He gave the site, comprising nearly five acres, in trust to the chancellor, masters, and scholars of the university, for the purpose of establishing the garden. Thomas Martyn, the titular professor of botany, was appointed reader on plants, and Charles, son of the celebrated Philip Miller (who had 
aided Dr. Walker in selecting the ground), was made first curator. (Loudun's Lncyco of Gard. pp. 86, 1071 , edit. 5.)

Previous to this period, the number of exotics caltivated in England probably did not exceed 1000 species; during this century above $\mathbf{5 0 0 0}$ new ones were introduced. Some tolerably correct idea may be formed of the improvement arising tc norticulture, from this spirit of research after plants, by a knowledge that in the first edition of Miller's Dictionary, in 1724, but 12 evergreens are mentioned. The Christmas flower and aconite were rare, and only to be purchased at Mr. Fairchild's nursery at Hoxton. Only seven species of geranium were then known. In the preface to the eighth edition of the Dictionary, in 1768, the number of plants cultivated in England are stated to be more than double those which were known in 1731. The publication of the seventh edition of that work, in 1759, was of the greatest benefit to horticulture. In it was adopted the classical system of Linnæus. It gave a final blow to the invidious line of dislinction which had existed between the gardener and the botanist, and completed the erection of the art of the former into a science, which it had been long customary to esteem as little more than a superior pursuit for a rustic. From being merely practised by servants, it became more extensively the study and the delight of many of the most scientific and noble individuals of England. Miller improved the cultivation of the vine and the fig, and was otherwise distinguished for his improvement of the practice, as he had been of the science, of gardening. Having thus decisively gained the attention of men of science, the rapid progress of horticulture from this era is no longer astonishing. The botanist applied his researches to the increase of the inhabitants of the garden, and the better explanation of their habits. The vegetable physiologist adapted his discoveries to practical purposes, by pointing out the organs and functions which are of primary importance; and the chemist, by his analysis, discovered their constituents, and was consequently enabled to point out improvements which practice could only have stumbled on by chance, and perhaps during a lapse of ages.

The general introduction of forcing houses likewise gave to our science a new feature. Green-houses, we have seen, were in use in the 17 th century; but no regular structures, roofed with glass, and artificially heated, existed until the early part of the succeeding one. Though a pine-apple had been presented by his gardener to Charles II., it is certain that they were only successfully cultivated here about 1723, by Mr. Henry Talende, gardener to Sir Matthew Decker at Richmond; Mr. Loudon gives the date as 1719. Mr. Bradley says, that Mr. Talende having at length succeeded in ripening them, and rendered their culture " easy and intelligible," he hopes bananas may flourish for the future in many of our English gardens. (Irradley's Gren. Treatise on Husb. and Gard.) That forcing was rare, and but of late introduction, is further proved by Mr. Lawrence, who, in 1718, cbserves, that he had heard that the Duke of Rutland, at Belvoir Castle in Lincolnshire, hastened his grapes by having fires burning from Lady-day to Michaelmas behind his sloped walls, a report to which he evidently does not give implicit credence, but which "it is easy to conceive." (Lawrence's Fruil Gard. Cul. p. 22.) That such, however, was the fach is confirmed by Switzer, who further adds, in 1724, that they were covered with glass. The walls were erected, he says, at the suggestior. of Mr. Facio, whom we have before mentioned The walls failing in their anticipated effect were covered with glass, and thus led to the first erection of a regular forcing structure of which we have any account. (Switzer's Practical Fruit Garden, p. 318.) Lady Wortley Montagu, in 1/16, mentions having partaken of pine-apples at the table of the elector of Hanover; and speaks of them as being a thing she had never seen before, which, as her ladyship moved in the highest English circles, she must, had they been introduced to table here.

Mr. Fowler, gardener to Sir N. Gould at Stoke Newington, was the first to raise cucumbers in autumn, for fruiting about Christmas. He presented the king, George I., with a brace of full-grown ones on new year's day, 1721 . (Bradley's General Treatise on Husb. and Gard. vol. ii. p. 61.)

Even as late as the commencement of the century we are tracing, every garden vegetable, in a greater or less degree, was obtained from Holland. The purveyors of the royal family sent thither for fruits and pot-herbs; and the seedsmen obtained from thence all their seeds. But in 1727, Switzer boasts of the improvements made in his art. Cucumbers, that 25 years before were never seen at table until the close of May, were then always ready in the first days of March, or earlier if tried for. Melons were improved both in quality and earliness. "The first, owing to the correspondence that our nobility and gentry have abroad, now equalling, if not excelling, the French and Dutch in their curious collections of seed; but the second is owing to the industry and skill of our kitchen gardeners." Melons were now cut at the end of April, which before were rare in the middle of June. The season of the cauliflower being in perfection was prolonged from three or four, to six or seven months. Kidney-beans were now forced. The season of peas and beans was extended to a period from April until December, which previously only lasted two or three months, \&c. (Preface to Switzer's Pract. Fruit Gard.)

The early part of this century witnessed the labours of Professor Bradley, who was one of the first to treat of gardening and agriculture as sciences. Although deficient in discoveries, his works are not destitute of informanon derived from contemporary gardeners and other writers. He wrote luminously on the buds of trees, on bulbs, and especially on the mode of obtaining variegated plants and double flowers. He must be looked upon as a benefactor of horticulture, for hi: at least made himself acquainted with the discoveries of others, and, recoraing them in his widely-circulated works. 


\section{GARDENING.}

ne spread such increased knowledge, and diffused over the whole such philosophic views, as the science of the age afforded.

Some of our most celebrated nurserymen flourished during this century. Fairchild, Gordon, Lee, and Gray introduced many plants during its first half. Hibbert of Chalfont, and Thornton of Clapham, deserve particular meniion for their encouragement of exotic botany The garden and hothouse of the latter were among the best stocked about London.

We have seen under what favourable auspices and with what great improvements gardening was on the advance at the close of the $18 \mathrm{th}$ century; but the present century was ushered in with even greater promise of success, for the light of science was still more powerfully concentrated upon its practice, and began to be felt and appreciated. This especially applies to the labours of the chemist and physiologist. Such combination of horticultural art and science was especially promoted by the institution of the Horticultural Societies of London and Edinburgh. The first of these societies began to be formed in 1804 , the latter in 1809. Nothing can more conspicuously aisplay the high estimation in which gardening is held, nothing can afford a greater guarantee for its improvement, than the lists of the fellows of the above societies. In them are enrolled the names of the most talented, the most noble, and the most wealthy individuals of the United Kingdom.

The increase of the inhabitants of our pleasure grounds within the last few years places the taste and patronage which are bestowed on gardening in a very cnnspicuous point of view. Of stove plants we now cultivate about 1800 species and varieties. Of green-house plants, nearly 3000. Of hardy trees and shrubs, nearly 4000. Of hardy perennial flowers, nearly 3000. Of biennial and annual flowers together, about 800 . To particularize the different genera of these would exceed the limits I have prescribed to this article. I have not include the varieties of florist's flowers in the above general list. They are more than proportionably numerous. Of hyacinths we have about 300 varieties, whereas in 1629 Parkinson mentions but 50. The passion for this flower, however, has much abated; for Miller, in the early part of the last century, says the Dutch gardeners had 2000 sorts. Of tulips, we have nearly 700 varieties. The cultivation of this flower has also declined of late years. It was at its height both in England and in Holland towards the middle of the 17th century. In Holland nearly $600 \%$ was agreed to be given or a single root. Of the ranunculus we have nearly 500 varieties. Of the anemone, about 200. Of dahlias, between 200 and 300 ; narcissi, 200 ; auriculas, more than 400 ; pinks, 300 ; carnatious, about 350 . Of roses, incloded in the list we have given of hardy trees and shrubs, there are more than 1450 . An. other instance of the progress made in increasing the number of our cultivated plants is furnıshed by the genus Erica. But five kinds of heath were described by Mille: as know ' $n$ England abou' 60 years since we now cul. vate nearly 250 .

518
Mr Loudon makes the number of plants cultivated by gardeners at present amount to 13,140 . Of these 1400 are natives of Great Britain; 47 were exotics introduced previous to and during the reign of Henry VIII.; 7 dur. ing that of Edward VI.; 533 during that of Elizabeth. In that of James I., 20. Charles I., 331. During the usurpation, 95. Charles II., 152. James II., 44. William and Mary, 298. Anne, 230. George I., 182. George II., 1770. George III., 6756. During the first 16 years of this century, on an average, 156 plants were annually introduced. The ardour of research is not the least abated now.

The style in which grounds in England are now usually laid out may be characterized in one sentence. Convenience is endeavoured to be rendered as attractive as possible, by combining it with the beautiful and appropriate. The convenience of the in mates of the mansion is studied by having the kitchen and fruit gardens near the house, fully extensive enough to supply all their wants, and kept in the appropriate beauty of order and neatness; without any extravagant attempt at ornament by the mingling of useless trees, or planting its cabbages, \&c., in waving lines. In the flower garden which immediately adjoins the house, dry walks-shady ones for summer, and sheltered, sun-gladdened ones for the more intemperate seasons-are conveniently constructed. Their accompanying borders and parterres, are in forms, such as are most graceful, whilst their inhabitants, distinguished for their fragrance, are distributed in grateful abundance; and those noted for their elegant shapes and beautiful tints are grouped and blended as the taste of the painter and the harmony of colours dictate. The lawn from these glides insensibly into the more distant ground occupied by the shrubberies and the park. Here the genius of the place dictates the arrangement of the levels and of the masses of trees and water. Com. mon sense is followed in planting such trees only as are suited to the soil. A knowledge of the tints of their foliage guides the landscape gardener in associating them, and aids the laws of perspective in lengthening his distant sweeps. If gentle undulations mark the surface, he leads water among their subdued diversities, and blends his trees in softened groups, so as to form light glades to harmonize with the other parts. If high and broken ground has to be adorned, the designer mingles waterfalls with broader masses of darker foliaged trees, and acquires the beauty peculiar to the abrupt and the grand, as in the former he aimed at that which is secured by softer features.

He is no philosopher who neglects a certain present good for fear that in some future period it may be abused; but in the encouragemen of gardening, whilst an immediate good is obtained, there is no fear of its perversion in after days. Its diffusion among the poorer classes is an earnest or means of more important benefits, even than the present increase of their comfort. The labourer who possesses and delights in the garden appended to his cottage is generally a mong the most decent of his class; he is seldom a frequenter of the ale- 
house; and there are few among them so senseless as not rearlily to engage in its cultivation when convinced of the comforts and gain derivable from it. Gardening is a pursuit adapted alike to the gay and the recluse, the man of pleasure and the lover of science. 'To both it offers employment such as may suit their taste; all that can please by fragrance, by flavour, or by beauty; all that science may illustrate; employment for the chemist, the botanist, the physiologist, and the meteorologist. There is no taste so perverse as that from it the galden can win no attention, or to which it can afford no pleasure. He who greatly benefited or promoted the happiness of mankind in the days of paganism was invoked after death and worshipped as a deity: in these days we should be as grateful as they were without being as extravagant in its demonstration; and if so, we should indeed highly estimate those who have been the improvers of our horticulture; for, as Socrates says, "it is the source of health, strength, plenty, riches, and honest pleasures." "It is the purest of human pleasures," says Lord Verulam. It is amid its scenes and pursuits that "life flows pure, the heart more calmly beats." (G. W. Johnson's History of Gardening.)

GARGET. In farriery, a disease in the udders of cows, arising from inflammation. of the lymphatic glands. It is also a distemper incident to hogs; and which is known by their hanging down their heads, and carrying them on one side, moist eyes, staggering, and loss of appetite.

In order to remove the disease in cows, where the inflammation is great, the cow should be bled, a dose of physic administered, the udder well fomented, and the milk drawn gently but completely off, at least twice a day. (Yonatt on Catlle, p. 553.) When the disease happens to hogs, they may also be bled, and should have warm, stimulating cordial drinks.

GARLIC (Allizm, from the Celt.; all, hot or burning). Under this name Sir J. Smith, (Eng. Flor. vol. ii. p. 133) enumerates seven native species; viz.:-

1. The great rounded-headed garlic, ( $A$. ampeloprasum ). A rare plant, found occasionally in open hilly places. The stem is two or three feet high, and the herbage somewhat similar to that of the leek; the white globose bulbs or cloves increase rapidly in a garden, by lateral offisets, till they compose a mass as big as a man's head, resembling a bunch of grapes. The scent of the whole plant is strong, and of the most disagreeable kind.

2. The sand garlic ( $A$. arenarium), found in mountainous woods and fields in the north, on a sandy soil; stem two or three feet high, bulbs small, ovate, with many purplish offsets.

3. The mountain garlic ( $A$. carinatum) which is nearly related to the next following species, though differing in the flatter form of its leaves.

4. The streaiked field or wild garlic ( $A$. oleraceum) found in pastures, meadows, corn fields, and their borders-producing whitish green blossoms in July. The whole plant has an unpleasant scen* of garlic, and is a very troublesome weea, difficult of extirpaticn, though not of common occurrence. It is eaten by cattle, sheep, and hogs, and the tender leaves, boiled in soups, or fried with other herbs, form a wholesome article of food.

5. The crow garlic (A. vineule) which grows in dry pastures, corn fields, and waste ground among ruins, especially on a chalky or gravelly soil. 'The stem is slender, about two feet high, bulb small, ovate, white, flowers small, pale rose-coloured.

'This species of garlic has generally been considered perennial, but Dr. Darlington regards the common garlic of our American fields as biennial, propagated every year by new lateral bulbs, the old ones, after once sending up a stem and flowering, dying away. This species is a foreigner which has been extensively naturalized in the United States, constituting in many places a great nuisance, not only by imparting a disgusting flavour to milk, butter, cheese, \&c., but seriously injuring flour, and rendering its manufacture difficult. Farmers are however able to subdue it by a judicious rotation of crops. The oat and other spring crops, are highly instrumental in the destruction of garlic.

The species called meadow garlic (Allium Canadense), is found in the Middle States, being frequent on the banks of the Brandywine, in which last mentioned locality the three-berried or three-seeded garlic, is also met with. The bulbs of this last are of an oblong oval shape, pointed, and rather large. The leaves are 5 to 8 inches long, and $1 \frac{1}{2}$ to 3 inches wide, tapering to the base. This species, says Dr. Darlington, differs remarkably from all other alliums found in the United States, and has much resemblance to the $A$. ursinum, of $\mathbf{E u}$ rope. The large leaves die, and disappear, early in the season-before the flowers are developed. The bulbs emit a fetid, disagreeable odour, whilst drying. Three or four additional species of garlic are found in the United States. (Flor. C'estrica.)

6. The broad-leaved garlic or ramsons ( $A$ ursinum), which grows in moist woods, hedges, and meadows, and produces large white flowers, that blow in the rnonth of May and June. Every part of the plant, when trodden upon, or otherwise bruised, exhales the strong odour of its genus. This species is eaten by cows; but if they feed on it ever so sparingly, it communicates its nauseous flavour to the milk and butter to such a degree as to render those articles offensive during the spring. It should therefore be carefully eradicated as an intolerable nuisance from all pastures. It affords an excellent remedy for driving away rats and moles, and it is said the plant will not suffer any other vegetable to thrive near it.

7. Chive garlic ( $A$ schonoprasum), which is rare, but sometimes found in meadows and pastures, and was formerly in great request as an ingredient in salads, but has been bitterly neglected.

The cultivated varieties are-Common gat lic (.A. sativum), which is a hardy plant, and though generally known in the United States by the name of English garlic, it is a native of Sicily, capable of growing in almost any soil. 
It is generally propagated by the clures obtained by parting the roct, but may be raised from the bulbs produced on the stems. The planting may be performed any time in February, March, and early in April, but the middle of the second is the usual time of insertion. A single clove to be placed in each one of holes made 6 inches apart and $1 \frac{1}{2}$ deep, in straight lines, 6 inches distant from each other, care being taken to set the root end downwards; to do this with the greatest facility, it is the best practice to thrust the finger and thumb, holding a clove between them, to the requisite depth, without any previous hole being made.

The only cultivation required is to keep them clean of weeds, and in June the leaves to be tied in knots, to prevent their running to seed, which would greatly diminish the size of the bulbs. A few roots may be taken up as required in June and July, but the whole must not be lifted until the leaves wither, which occurs at the close of July, or in the course of August. It is usual to leave a part of the stalk attached, by which they are tied into bundles, being previously well dried by exposure to the sun and air, for keeping during the winter.

Rochambole, or, as it is sometimes called Spanish garlic ( $A_{\text {. scorodoprasum), has its bulbs }}$ or cloves growing in a cluster, forming a kind of compound root. The stem bears many bulbs at its summit, which, as well as those of the root, are often preferred in cooking to garlic, heing of much milder flavour. It is best propagated by the root bulbs; those of the stem being slower in production. The plantation may be made either, in February. March, or early part of April, as well as throughout the autumn. They may be inserted either in drills or by the dibble, in rows 6 inches apart each way, and usually 2 inches within the ground, though this, as well as the preceding variety, would thrive better if grown on the surface. A very small bed is sufficient for the supply of the largest family. See Sralot and LEFK.

Besides the above, there are large numbers of different foreign species, most of which are pretty: they increase abundantly from offsets. The onion, leek, garlic, shalot, chives, \&c., all agree in their stimulant, diuretic, and expectorant effects, differing in degree of activity. See Orios.

GARNER. A term used provincially to signify a granary, or repository for corn; also a binn or a mill. See Granary.

Gas, ammoniacal. See Saline Sunstancus; their uses to vegetation.

GASES, their uses to vegetution. It is not, I think, necessary, in drawing the cultivator's attention to the uses of that great $y$ ortion of the food of plants which they imbibe in the state of gas, or of aqueous vapour, to enlarge upon the importance of the question, since that is a truth which, as illustrating the value of certain modes of cultivation, I hope to render intelligible in the following paper, as I examine in succession the advantages of the gases and vapour of the atmosphere, as well as those snitted during putrefaction, to the commonly 520 cultivated crops of the farmer. And even if the accomplished farmer shall dissent from some or all of my conclusions, he will yet readily admit that all such observations, with regard to the habits and food of plants, and their ready absorption by the soil, cannot be too generally understood and acted upon by the cultivators of the soil.

That the atmospheric air exerts an extensive and very important influence upon vegetation, is a fact which has been well known from the earliest days of agriculture. Too many circumstances combine to render this truth apparent to the very meanest cultivator for it long to escape observation. The superior luxuriance of the borders of all growing crops, from those of the field to the outer circle of timber in a wood, naturally pointed out that something was gained by these, of which the inner sheltered portions were partially deprived. And that this something was the air of the atmosphere, appears to have been the conclusion of the early Italian cultivators who, on all occasions, were attentive to let their crops enjoy as much of the breeze as possible; an object which they endeavoured to attain, not only by an attentive consideration of the natural and acquired habits of the plants in transplanting them, but also by increasing the access of air to their roots by deep and regular periodical stirrings of the soil around them. Thus Cato, the earliest of their agricultural writers, whose works remain to us, when instructing the Roman farmers as to the best mode of cultivating the vine and the olive, advised them, if they wished their vines and olive-trees to grow luxuriantly, to stir the trenches around them once a month, until they were three years old; and he adds, "bestow the same care upon other trees:" (lib. xliii.j And Virgil, when commending the very doubtful plan of paring and burning lands, alludes to the same well-known advantage of a free and copious supply of air to the roots of plants, when he says, "the heat opens more ways and hidden rents for the air, through which the dews penetrate to the embryo plants." (Georg. i. 90,91.) They, in fact, considered, in common with the Greek philosophers, that air was one of the four elements of which all sub. stances were composed; but then, as in those days, the air of the atmosphere was considered to be a simple body, we need not search in the works of the early agricultural writers for any evidence of very definite ideas of the mode of its action. That the air they breathed was highly serviceable to plants of all kinds was the extent of their information; they had no knowledge of the existence of three distinct gases in the atmosphere. That was a discovery reserved for modern ages - for the days of Priestley, and the dawn of pneumatic chemistry in England. When, therefore, the early cultivators made the observation, that the free supply of air to the leaves and roots of plants materially promoted their growth, they did what too many modern agriculturists have since done, merely noticed the effect, without making any very accurate inquiries as to the cause of the benefit; they were too often content, in fact, with merely substituting words as 
$u$ explanation of facts. It is probable that he early Greek and Italian phlosophers were farther led to this know!edge of the advantages of air to vegetation, from noticing the power which some eastern plants possess, such as the Flos ceris and others, of entirely supporting thernselves upon the nourishment they derive rom the atmosphere, even when suspended by a string from the ceiling of a room,-many Darasitical plants subsist upon hardly any hing else; thus, sorne of the mosses of this country cling to life, and even grow well, in situations where hardly any thing except air and moisture can nourish them: some of the aloe tribe do the same.

Carbonic acid gas.-When, however, Mter ages had acquired the knowledge that it was oniy a portion of the air that maintained vegetable and animal life, or supported combustion, new views opened upon the chemical philosopher. It became then a question of onsiderable interest to ascertain which por: $10 n$ of the atmosphere it was that the plant absorbed; and it was speedily ascertained by Dr. Priestley and other chemists, that the portion of the atmosphere which the leaves of all plants absorb in the light is the carbonic acid gas or fixed air-a gas composed of $27 \cdot 27$ parts carbon, and $72 \cdot 73$ parts oxygen,-and that this sarbonic acid gas is always contained in the utmosphere, in the proportion of about one part il 500. The question thus became one of some interest to ascertain, whether a larger volume If carbonic acid gas would promote, in a still greater degree, the growth of plants, such as in $\pi n$ impure, confined portion of air spoiled by the lireathing of animals, or exhausted of its oxygen gas or vital air by combustion, since both these varieties of air contain a very considerably increased proportion of carbonic acid gas. Many very accurate experiments speedily demonstrated that such foul air materially increased the luxuriance of vegetables confined in them, and that plants possessed also the power of restoring to such exhausted air the portion of oxygen which either fire or the breathing of animals had removed: thus, a confined portion of air, in which a mouse had died in ten minutes for want of air, having had a sprig of mint introduced into it for some hours, was then found to be so replenished with vital air, that a second mouse being placed in it lived as long as the former mouse; and, by similar treatments, a lighted taper being merely substituted for the mouse, the same effect was produced-the exhausted air was again replenished with oxygen gas.

These facts naturally opened new views. It then became an interesting object to ascertain the proportion of the carbonic acid gas in the atmospheric air, which possessed the maximum advantage to vegetation; and it was found that, in pure carbonic acid gas, plants would not vegetate at all, or in air containing 75 per cent. of it, but that, when the proportion present in common air was reduced to 50 per cent., then the plants confined in it slowly vegetated, and that they grew more freely when the proportion was 25 per cent.; still better when it was $12 \frac{1}{2}$ per cent.; and that when it was reduced to only 9 per cent., then they flourished 66 much better than in common atmospheric air. It was remarked, however, that the increased presence of carbonic acid gas was only beneficial to plants when they were vegetating in the light, but that, when this was excluded, the carbonic acid gas was rather prejudicial to their growth than otherwise; that, in fact, all plants, though they absorb it in the light, yet in the dark emit this gas. It was ascertained, however, that the presence of it in their atmosphere was absolutely essential to all piants vegetating in the light; that they grew when it was present, and that all vegetation was stopped by its withdrawal.

These results naturally led to the additional inquiry, Whether the presence of carbonic acid gas in water produced the same results on plants, since it was well known that, when plants were immersed in water and exposed to the sun's rays, they emitted bubbles of oxygen gas, by decomposing the carbonic acid gas, and setting its oxygen free. Various kinds of water were tried, containing different proportions of carbonic acid gas; and the beneficial result upon vegetation was found to be exactly proportionate to the quantity of carbonic acid gas which they contained. In pump-water, they yielded the most oxygen; from river water a smaller quantity; but from boiled water little or none. Now, by boiling, all the gases are driven out of water, and this is the reason why such water is flat and insipid. And yet it was found that when the boiled water was again impregnated with carbonic acid gas, those plants confined in it emitted as much oxygen gas as they did before jt was boiled; and, finally, that when the plants had exhausted the water of carbonic acid gas, then they ceased to emit oxygen.

The quantity of carbonic acid gas which is emitted by plants varıes in different species. Thus, M. Saussure found that the purple loose. strife (Lythrum salicaria) absorbed in 12 hours 7 or 8 times its bulk; while the Cactus opuntia, in common with other fleshy-leaved plants, did not absorb above one-fifth of that amount. In these experiments, however, the atmosphere in which the plants were confined contained $7 \frac{1}{2}$ per cent. of this gas; so that when they are vegetating in the open atmosphere, in which the proportion of this gas does not exceed one part in 1000, the quantity absorbed is considerably less.

This absorption of the carbonic acid gas, the cultivator should clearly understand, influences in a great degree the composition of the plant. All those vegetable, carbonaceous, nutritious substances which are found in plants, such as gum and sugar, are increased in quantity by its copious supply; for when this gas is no longer secreted by the plant, its health becomes languid, and its compositon more watery. Thus a Byssus vegetating in the dark (when carbonic acid gas is emitted by plants), was analyzed by M. Chaptal, and found to contain only 1-89th of its weight of carbonaceous matter; but when, after it had been a.lowed to vegetate for 30 days in the light, it was again examined, it was found to contain 1.24 th of its weight of carbonaceous matter. Similar results were obtained by $\mathbf{M}$ Sennebier, who found that when plants were $2 \times 2$ 
made to vegetate in the dark, they contained much less oil than those vegetating in the light,-their resinous matter being then as 2 to $5 \frac{1}{2}$ compared with those vegetating in the light. They had even less earthy matters by one half; but then they had exactly double the quantity of water that the light-growing plants possessed.

Such, then, are the results of the free access of the carbonic acid gas of the atmosphere to the leaves of plants,-it promotes their growth, increases their vigour, and enriches their secretions. The application of the same gas to their roots, although it has not been examined with the same care as its action upon their leaves, is yet evidently attended with the highest advantage. Thus, this gas is one of the constant products of putrefaction, wherever this is going on; as over stagnant drains, dung-heaps, and other putrefying matters: there vegetation is sure to be rankly luxuriant, and that, too, in situations where the roots of the plants are far removed from immediate contact with the decomposing organic matters. 'This may be easily shown by the repetition of a very simple experiment, which was first made by Davy. This great chemist filled a glass retort, capable of containing three pints, with the not, fermenting dung and litter of cattle, and examined the elastic fluids which were generated. In 35 cubic inches which were thus produced in 3 days, he found 21 of carbonic acid gas, the remainder being chiefiy nitrogen; and after thus ascertaining the composition of these gases, he introduced the beak of another retort, filled in a similar manner, in the soil under the roots of some grass growing in the border of a garden. In less than a week, a very remarkable effect was produced on the grass exposed to the action of these gaseous matters of putrefaction; their colour became deeper, and their growth was much more luxuriant than the grass in any other part of the garden. And hence, too, is derived one of the chief advantages of applying organic matters to the soil, and that in as immediate contact with the crop as possible, just as is effected when manures are added to the soil by the drill; for the roots or leaves of the plants are, by the adoption of this plan, immediately in contact with the evolved carbonic acid, and other gases of putrefaction; they are thus readily absorbed as they are generated, and nothing is lost by escaping into the atmosphere. The gas, in fact, is instantly yet gradually transmuted from the putrefying products of the farm-yard into the flour of the wheat or the nutritive matters of the grasses. And there is yet another chemicai reason why the manuredrill or any other machine should be adopted by the farmer to bring, as closely as possible, every plant into immediate contact with the decomposing manure he applies to his soil; and that is, the superior readiness with which, in all cases of decomposition, the disengaged substance enters into new combinations at the very instant of $\mathrm{its}$ disengagement than it does after it has been completely formed. Thus, to give an instance, during the putrefactive ferinentation of vegetable substance, a quan:ity of nitrogen is disengaged; and if this takes 522 place under certain favourable circumstances - such as the presence of calcareous matters, potash, and a dry, warm temperature at the moment it is formed-the nitrogen combines with oxygen, forms nitric acid, which unites with the potash, and thus nitrate of potash, or saltpetre, is formed; but if the nitrogen is once fairly disengaged, almost every endeavour of the chemist nas failed in making it unite with oxygen so as to form the acid of saltpetre.

In every way, therefore, in which the question of applying manures in immediate contact with the roots of plants can be viewed, the more advisable does the adoption of the practice appear.

The important services of the carbonic acid gas of the atmosphere to vegetation have been illustrated in various ways by more than one able chemist. That given by Professor J. F. Johnston, in his able Lectures on Agricultural Chemistry, p. 218, is perhaps the most recent and the most practical. He observes, "If we were to examine the soil of a field on which we are about to raise a crop of corn, and should find it to contain a certain per centage, say 10 per cent. of vegetable matter (or 5 per cent. of carbon), and after the crop is raised and reaped should, on a second examination, find it to contain exactly the same weight of carbon as before, we could not resist the conviction that, with the exception of what was originally in the seed, the plant, during its growth, had drawn from the air all the carbon il contained. The soil having lost none, the air must hav. yielded the whole supply. Such was the prir ciple on which Boussingault's experiments were conducted. He determined the per centage of carbon in the soil before the experiment was begun; the weight added in the form of manure; the quantity contained in the series of crops raised during an entire rotation or course of cropping, until, in the mode of culture adopted, it was usual to add manure again; and, lastly, the proportion of carbon remaining in the soil. By this method he obtained the following results, in pounds per English acre: -From a course of, 1. Potatoes or red beet, with manure; 2. Wheat; 3. Clover; 4. Wheat; 5. Oats. Carbon in the manure, \&c., $2513 \mathrm{lbs}$; carbon in the crops, 7544 lbs.; difference, or carbon derived from the air, 5031 lbs."

The result of this course indicates that the land, remaining in equal condition at the end of the four years as it was at the beginning, the crops collected during these years contained three times the quantity of carbon present in the marure, and therefore the plants, during their growth, must, on the whole, have derived two-thirds of their carbon from the air.

Oxygen.-Oxygen gas, or vital air, which constitutes 21 per cent. of the bulk of the air we breathe, is absolutely essential to the growth of plants. If this is withdrawn from the atmo. sphere, they will no longer vegetate,-their leaves can no longer perfurm their functions. But this use of oxygen by the leaves of vegetables is confined to the night; it is only in the dark that they absorb it. During this absorptinn the leaves of some plants, such as the Cactus opuntia, and the houseleek (Sempervivum tectorum), do not emit any inrtis, n of carbonic 
acid gas; but the common oak (Quercus robur), the yellow stone crop (Sedum reflexum), and the great majority of plants, emit a considerahle portion, not equal, however, in amount to the oxygen gas which has been imbibed; and this absorbed oxygen enters, there is little doubt, into immediate combination with other substances, and forms vegetable matters in other shapes. A variety of experiments have, in fact, been made to ascertain this. Thus, the leaves of plants which have but recently absorbed a portion of oxygen gas have been exposed in the exhausted receiver of an air-pump. Other leaves have been submitted to the greatest heat they could bear without undergoing combustion, but in neither case was any oxygen gas extricated from them. And it has been noted that those plants which absorb the greatest proportion of oxygen during the night are precisely those which evolve the most considerable quantity of carbonic acid gas during the day.

Plants of different kinds vary very much in the quantity of oxygen which they absorb. Fleshy-leaved plants, which emit little or no carbonic acid gas, absorb very little oxygen; and these plants, it may be remarked (says Dr. Thomson), can vegetate in elevated situations, where the air is very rarefied. Next in order come the evergreen trees, which, although they absorb more oxygen than the tleshy-leaved plants, yet require much less than those which lose their leaves during winter. Those plants which flourish in marshy ground likewise absorb but little oxygen. M. Saussure iried a great number of experiments on this subject, with a variety of plants of different kinds. The following are some of his results: in erery case the weight of the leaves is supposed to be equal to $1 \cdot 00$, and the bulk of oxygen is expressed in the table. (Recherches, p. 99.)
Leaves of Evergreens.

Prunus lauro-cerasus

Vinca minor (lesser periwinkle)

Pinlls abies (the fir) - _ _ - Sept. 3.00

June $2 \cdot 60$

Leaves of Trees which lose them in Winter.

Quercus robur (the nak) - _ - May 5.50

Amygdalus Persica - - - - - $\quad$ - Sept. 436

- June $6^{\circ} 60$

- June 5.40

Rosa centifolia -

$-$

Populus alba (the abele) - $\quad$ - May 6.20
Ieaves of Herbaceous Plants.

Solanum tuberosum (the potato) - Sept. 2.50

Brassica oleracea (the cabbage) $\}$ - Sept. 2.40 - $\quad$ - young leaves

Vicia faba (vetch), before flowering in flower -

Brassica ripa (the turnip), in flower Avena sativa (the oat)

Pisum sativun (the pea) -

Ruta graveolens

- Sept. 2.00

3. 70

$3 \cdot 70$
$2 \cdot 00$

160

1.25

- June $2 \cdot 70$

- May 5.00

- May 3.72

- Aug. 200

Leaves of Aquatic Plants. Alisma plantago

Polygonum persicaria

Lythrum salicaria

Carex acuia

- Aug. 0.70

- Sept. 2.00

- May 2.30

- May 2.25

- Sept. 1.50

Leares of the Fleshy Plants

Cactus opuntia -

Aug. 1.00

Agave Americana

- Aug. 100

- July 1.00

- July 0.63

$$
\text { - } \quad \text { - old leaves }
$$

Triticum astivum
Saussure continued his researches upon the uses of oxygen gas to vegetation. He found that it was essential to many of its functions, that it was absorbed not only by the leaves, but by the roots of plants, - that it then combined with carbon, and the carbonic acid gits thus formed was thence transmitted to the Jeaves to be decomposed: the very stems and branches of plants absorb it, and its presence is essential to the expansion of flowers; in its absence, seeds will not germinate, and hence the reason why they will not vegetate when placed beyond a certain depth in the soil. The quantity of oxygen gas consumed during their germination, by equal weights of different seeds, varies considerably. Wheat and barley consume less oxygen than pease, and pease less than common broad and kidney-beans-the latter consuming $-\frac{1}{1} 0^{\text {th }}$ part of their weight, while wheat and barley, during their germination, only absorb from $\frac{1}{000}$ th to $\frac{1}{0} \overline{0}$ th their weight of oxygen gas. Recent experiments have shown also, that the more water is impregnated with oxygen gas, the more excellent are " 2.3 effects when employed for the purpose os vatering plants; and hence one of the causes o the superiority of rain-water, every 100 cubic inches of which contain 3.5 of oxygen gas. Some recent experiments were made by Mr. Hill, which clearly demonstrated these facts. Hyacinths, melons, Indian corn, and other plants, were watered for some time with water im. pregnated with oxygen gas; the first grew with additional beauty and luxuriance, the melons were improved in flavour, the Indian corn increased in bulk, so as " to equal in size most of those imported from North America," and all of them grew more vigorously.

The uses, therefore, of oxygen gas to plants are many and important, and accord with the conclusions which naturally suggest themselves from the results of the analysis of vegetable substances, from whence oxygen is never absent; it must be, therefore, one of the necessary supporters of vegetable life.

Nitrogen.-This is the last atmospheric gas which exerts its influence upon vegetation, and enters in small proportions into the composition of plants. Entering in the large proportion of 79 per cent. into the composition of the atmosphere, it is yet supposed to exert but a slight influence upon vegetation. It is found in much smaller proportions in plants than eitlser oxygen gas or carbonic acid gas, although recent researches have shown that it is much more commonly present in vegetable substances than was once supposed; and as I have elsewhere observed (Johnson on Fertilizers. p. 338), that it exerts a more sensible intuence upon their growth than is commonly believed, is very certain, and that the proportion of it present in them varies with the different states of their growth, has been clearly shown by the experiments of Mr. Robert Rigo, who found in 100 parts of

The finur of wheat unripe

The same nearly ripe

Leaves of wheat unripe

- - nearly ripe

Stem of wheat unripe -

- - nearly ripe

Chaff of wheat unripe -
Parts of nitrozes $-2 \cdot 9$

$-2 \cdot 3$

-2.3
-3.3

- 21

$-3 \cdot 5$

$-1.3$ 
Chaff of wheat nearly ripe Common grass, not growing freely - growing freely Turnip, when attacked by the fly Cabbage, not attacked by insects partly eaten by insects

The insects themselves

Red clover stems

Leaf of do. -

Flower of do.

Potato itselp

- stem

- apple

- corolla

It is also well worthy of the farmer's attention, that Mr. Rigg found that when barley was made to vegretate in the shade, the increase in the quantity of its nitrogen was nearly 50 per cent., but when vegetating exposed to the direct rays of the sun, the increase was only 30 per cent.; and he also made the observation, that the more rapidly the plants vegetate, the more nitrogen they are found to contain. It is also well known to the cultivator, that plants growing in the shade have usually a deep green colour, vegetating with much luxuriance, and that certain animal manures applied to plants produce similar results in a remarkable degree, such as gelatin, oils, urine, blood, fish, ammonia, \&c. Now these fertilizers all contain nitrogen, and which gas must be evolved in some shape or other during their decomposition in the soil;-gelatin, containing $\mathbf{1 6} \cdot 998$ per cent., albumen, $15 \cdot 705$, the fibrin of blood 19.934, urea 46.66 per cent.; and although nitrogen usually exists in plants in very sinall proportions, yet I am entirely disposed to agree with Mr. Rigg in his conclusion, that more attention should be paid than has hitherto been done, in the examination of vegetable substances, "to those products, which, though so minute in quantity as to be with difficulty detected in our balances, have nevertheless been wisely assigned to discharge the most important functions." (Phil. Truns. 1838, p. 406.)

Such, then, are the essential and highly important uses of the three gases of the atmosphere, nitrogen, oxygen, and carbonic acid, to all vegetation; an attentive consiaeration of which will explain to the farmer the cause of many of the phenomena he daily witnesses, and suggest to him an unanswerable argument for the adoption of those modes of cultivating his land, the results of careful and scientific investigations, which such chemical researches suggest and render intelligible.

Thus, the absolute necessity for all crops receiving a regular supply of carbonic acid gas, will explain to him why his crops always yield an inferior produce when they are surrounded by thick plantations of timber trees; and why the portion of all kinds of plantations growing on the side of the field the most exposed to the winds is almost always of the most luxuriant growth; it will explain to him the reason why many skilful farmers drill their corn so that the most prevalent winds may, with the more facility, circulate along the rows, instead of across them; and why all farmers find that their crops prosper better in moderately windy weather than in calms; since in all these instances, and in many other well

nown popular observations of the same kind, the copious supply of the carbonic acid and oxygen gases of the atmosphere is naturally impeded by thick plantations of other vegetable substances, and promoted by the winds.

The consumption of oxygen gas by the roots of plants, and their increase of growth and vigour when their usually impeded supply is increased, is equally fraught with instruction to the cultivator; for it serves to explain the reason why stirring the soil around the roots of trees, according to the fashion of the early vine and olive cultivaters of Italy, or merely disturbing the rows of cabbages and turnips, as practised by. the best English farmers, is attended with decided advantage, since it suffers the air to have more free access to their roots. It renders apparent, too, one of the chief reasons why nere subsoil-ploughing adds so materially to the luxuriant produce of even the poorest cultivated lands, since, as the soil is deepened and pulverized, the atmosphere more freely and more copiously penetrates to the roots of the vegetation it supports. The same facts explain the advantages of deepploughing, of sub-turf ploughing, and of trenching; why the indolent farmer in vain tries to render productive his shallow-ploughed lands ; and why, when the industrious cottager encloses his garden from the barren waste, too poor to sufficiently manure it, he yet renders it productive of excellent crops, by merely trenching it to the depth of 18 or 20 inches.

And it is vain for the cultivator to urge that this benefit is not to be mainly attributed to the freer circulation in the soil of the gases and watery vapour of the atmosphere, but that it is owing to the mixture of the surface-soil with the substratum. For such a conclusion is not only opposed by the fact, that many soils do not differ in composition from the substratum on which they rest, and yet are materially benefitted by trenching or subsoiling, but is contradicted by many agricultural facts with which every cultivator is familiar; and if any other answer were requisite, that would be amply supplied by the recent experiments of Sir Ed. ward Stracey, with his new subturf plough. which merely passes under the turf at a depth of ten inches, and disturbs and loosens very effectually the soil; but when the plough has passed under, every thing resumes its former position, although every portion has been tho. roughly agitated, and rendered more permeable to the atmosphere. The soil is neither cisplaced nor mixed, and yet this mere loosening is productive of the highest advantage, the produce of grass is extensively and permanently improved. Sir Edward Stracey, after describing the increased produce of the grass as being very remarkable,tells us that there are no marks left by which it can be known that the land has been so ploughed, except from the lines of the coulter, at the distance of about fourteen inches from one another. In about three months from the time of ploughing, these lines are totally obliterated, and yet the quantity of aftermath, and the thickness of the bottom, have been the subject of admiration of all his neighbours. (Jour. Eng. Agri. Soc., vol. i. p 253.) 
And then, with regard to the carbonic acid and the carburetted and sulphuretted hydrogen gases evolved during the putrefaction of animal and vegetable manures, the discoveries of the chemist are equally instructive and confirmatory of the observations of the intelligent farmer. The one finds that these gases, so grateful to the farmer's crops, are the most copiously emitted in the early stages of putrefaction; that these gradually decrease in volume as the fermentation proceeds; and finally, when the mass is reduced to the state of vegetable mould, cease altogether. Now, the farmer is well aware that the manure of the farm-yard, in common with all organic decomposing fertilizers, is by far the most advantageously applied, and produces the most permanent good effect when it is used in the freshest state that is at all compatible with the destruction of the seeds of weeds, with which such collections usually abound. He is aware, that in all situations where the gases of putrefaction are emitted, such as near to stables, marsh-ditches, covered drains, \&c., that there vegetation of all kinds indicates by its rank luxuriance that some unusual supply of nutriment is afforded; the gardener in his best arranged hot-beds notices that the gases which ascend from his piles of litter through the earth (which earth is not in immediate contact with the dung) produce the same effects long after all the warmth of putrefaction has subsided. The growth of some of his plants is in this way stimulated, he says, in an extraordinary manner. These facts and observations are entirely confirmed by those of the chemist. He notices that all the gases of putrefaction are precisely those which are the most nourishing to the growth of plants; that air which has been spoiled by the presence of the gases evolved in putrefaction, or by the breathing of animals, is exactly that which is the most grateful to vegetation; and that where these gases are applied to the roots of plants in the most skilful manner, so as to insure a regular, steady supply, that then the plant is enabled to vegetate in a most vigorous and unusual manner. Thus, when green manures, such as sea-weed, buckwheat, leaves of trees, fern, \&c., the most slowly decomposing of all vegctable manures, are applied to the roots of plants, the effects, according to chemical experiments, are excellent; and, as I have elsewhere observed, the farmer assures us that they are so. He tells us that all green manures cannot be employed in too fresh a state; that the best corn is grown where the richest turf 'as preceded it; and that where the roots, stalks, and other remains of a good crop of red clover have been ploughed in, that there an excellent crop of wheat may be expected; and that when buckwheat is ploughed into the soil, this is most advantageously done when the crop is coming into flower. The chemist again explains this without any difficulty. Davy and other chemists have shown that when the flower is beginning to appear, then the plant contains the largest quantity of easily soluble and decomposable matters; and that when these green plants are in this state buried in the soil, their fermentation is checked and gralual, so that their soluble or elastic matters are readily absorbed by the succeeding crop. and every portion of it becomes subservient to the demands of other plants. No cultivator, perhaps, ever examined this question more accurately, or tried his experiments with more neatness, than the late excellent President of the London Horticultural Society, the lamenced Knight of Downton; and these were the more valuable, from being instituted to ascertain the state of decomposition in which decaying vegetable substances could be employed most advantageously to afford food to living plants. This he clearly proved, however erroneous were his explanations of his own observations and discoveries. One of his experiments with a seedling plum tree was very remarkable. $\mathrm{He}$ placed it in a garden-pot, having previously filled the bottom of it with a mixture of the living leaves and roots of various grasses, covered over with a stratum of mould. 'The plant appeared above the surface of the ground in April, and, during its growth in the summer, was three times removed to larger pots in the greenhouse, in every case the bottom of them being filled as at first with living grasses, covered over with a layer of mould; and by the end of October its roots occupied a space of about one-third of a square foot, it having then attained the extraordinary height of nine feet seven inches. This experiment was varied by Mr. Knight in several ways: he drilled turnipseed over rows manured with green fern leaves, and compared the produce with other rows of turnips by their side, manured with rich vege. table mould; and in all cases those which grew over the gradually fermenting green iern not only grew more rapidly than those treated in any other manner, but they were distinguished from all others in the same field by their deep green colour. Now, when the gases of putrefaction are mixed with the roots of all growing crops, this is exactly the effect produced. The most foul, stinking water, eve when transparent, is ever the most grateful to plants; that from stagnant ditches, which has always a peculiar taste from the carburetted hydrogen it contains, is excellent. Every gardener prefers that from ponds, however clear; the purer water from wells, he tells you, is very inferior, it is too cold; but then he confesses that even warming it does not render it equal to that from stagnant places in its effects upon his plants; so that, in whichever way the experiment is made, there is no doubt of the value of these gases to the cultivator's crops, and he will rea. dily therefore agree with Knight in the conclusion, that any given quantity of vegetable matter can generally be employed in its recent and organized state with much more advantage than where it has been decomposed, "and no inconsiderable portion of its component parts have been dissipated and lost during the progress of the putrefactive fermentation." (Trans Hort. Soc. vol. i. p. 248.)

Aqueous Atmospheric Vapour.-The last sub stance ever present in the atmosphere in con siderable proportions, and which bears a very important relation to the prosperity of the farmer's crop, is the aqueous vapour, without whose unvaried presence no commonly cultivated plant could flourish, and few exis: at all 
Providence, therefore, has ordained that this should be ever ready to meet the demands of vegetable life, and that its quantity should vary with the temperature, increase with the warmth when its pressure is most needed by the plant, and diminish in proportion as the air becomes cooler. Thus, at a temperature of $50^{\circ}$, supposing it to have a free communication with water, the atmosphere contains about 1-75th of its weight of vapour; but when its temperature is increased to $100^{\circ}$, then its proportion of water is increased to 1-21st of its weight: and this beautiful arrangement is the more important, as Davy well observed, in the economy of nature, because, in very intense heats, and when the soil is dry, the life of plants is mainly, if not entirely, preserved by this absorbent power of their leaves and the earth in which they grow ; and, happily, this watery vapour is most abundant in the atmosphere when it is most needed for the purposes of life: when other sources of its supply are cut off, this is most copious. 'The amount, however, of the atmospheric vapour varies with the kind of wind. Those which have passed over warm seas contain more than those which have traversed extensive dry countries; that which crosses the hot, dry sands of Asia and northern Africa is so dry that it scorches, as it were, all the adjoining countries. It is the cause of the siroce of Malta being so noxious, and why the English farmer finds that an easterly wind, in England the driest of all winds, is the least propitious to vegetation. He well knows, on the other hand, that the westerly or south-western breezes, the most watery of all winds in Britain, which come to his fields surcharged with all the vapours of the Atlantic, are precisely those which bring with them luxuriance to his crops, and clothe his woods with verdure.

'The cultivator will derive many advantages from a carefi. investigation of the support yielded by the vapour of the atmosphere to his plants. He will perceive that its unvaried presence affords an additional reason why the air should be allowed to circulate freely through the well-pulverized and loosened soil, to the roots of all growing crops; and let him, above all, avoid the very common erroneous conclusion, that the atmosphere is ever $d r y$, that it no longer contains watery vapour; for the real fact is, he will find the very opposite to the common vulgar conclusion. The chemist's laborious investigations have clearly demonstrated, that though the watery vapour varies in amount, yet it is never absent from the atmosphere, but that it happily always the more abounds where the cultivator's crops need its assistance most; it is then the most able to furnish the roots of his grain crops with all the moisture they require; and if it is unable to penetrate to them, the fault is not in the wise economy of nature, but in the carelessness of the cultivator, who is either too inattentive to see the advantages which he might thus freely derive, or too indolent to loosen the case-hardened soil, which prevents the entrance of the requisite supply of moisture. One of the causes (1) the ungroductiveness of cold, clayey, adhe-ive soils. as Davy well remarked, is, that the seed is coated with matter impermeable to arr. The farmer can convince himself of these facts by the simplest ot all experiments. Iset him merely use his rake or his hoe on a portion of a bed of wheat, of turnips, or lettuces, or any other kind of crop, and let him, in the driest weather, merely keep this portion of soil loose by this gentle stirring, and he will find that, instead of prejudicing his crop by letting out the moisiure, as is often ignorantly supposed, something is evidently let into the soil; for the portion thus tilled will be soon visibly increased in luxuriance by the mere manual labour thus bestowed; and in this experiment, which I have often tried, I am supposing that both the portions of the ground are equally free from weeds; that in every other respect the treatment of both the tilled and undisturbed portions of the experimental plot is exactly the same. To a very great extent, some of the best of the English farmers have long found out these facts, and have acted upon the discovery. The horse-hoe of the east and south of England, in the driest days of summer, may be seen at work in the large sandy turnip-fields of Norfolk and Suffolk, with unvaried regularity, not for the mere destruction of weeds, for these are not the abounding tenants of such skilful farmers' lands, but for the chief and highly beneficial purpose of increasing the circulation of the gases and vapour of the air. "The longer I keep stirring the soil between my turnip drills," said Lord Leicester to me, some years since, " in dry weather, the better the turnips grow."

The same uniform presence of aqueous vapour which marks the atmosphere in all times and seasons, in a still more remarkable degree distinguishes its constituent gases, for these never vary in amount in any times, or seasons, or countries. The atmospheric air has been analyzed, when obtained from the lowest valleys, and the tops of the highest mountains, in crowded cities, and in the open country, but its composition was always found to be the same, viz., nearly 21 per cent. of oxygen, and 79 of nitrogen, and from 1 part in 500 to 1 part in 800 of carbonic acid gas.

Such, then, are the principal matters contained in the atmosphere, or added to it by putrefaction, which influence the progress of vegetation. That there are other matters occasionally present in the air, which are in all probability grateful to vegetation, is very certain; our very senses tell us that there are clouds of smoke, which is a mixture of carburetted and sulphuretted hydrogen, soot, and vapour, hourly hovering over all large towns and cities, and which huge mass the winds disperse over the country. Of these the soot, and finely divided earthy matters with which it is combined, are very speedily deposited; it is one reason why the lands near to populous places are very commonly rich and fertile. Ammonia has been detected in rain-water. That other substances also exist in the air in minute, yet active proportions, is very ccrtain, though they are too subtle to allow the chemist to detect them: thus, to such finely divided matters the physician attributes the progress of contagion-the chemical nhilosopher the aroma of flowers, and of many other sub- 
stances. Certain diseases follow the course of particalar winds; and the stones or firebal's, and similar substances, which have in all ages been scen to fall from the atmosphere, completely baffle the scientific conjectures of the meteorologisi. With such speculations, however, the cultivator need not disturb himself: resting contented with the knowledge he possesses of the invaluable and essential powers of the known gases and vapour of the atmosphere to assist and sustain the growth of his crops, and adopting in consequence those improved modes of cultivation which that knowledge suggests, he will patiently await the time when the future discoveries of science shall still farther enlarge his sphere of usefuiness, by enabling him to draw forth those latent powers of production which, there is every reason to believe, yet remain hidden in the soil. (Quart. Journ. of $A g r$. vol. ii. p. 32.)

Some curious experiments upon the gases hurtful to vegetation were made by M. Macaire. Some plants of euphorbium, mercury, groundsel, cabbage, and sowthistle, with their roots, were placed in the morning in a large vase into which chloride of lime had been introduced. The roots were then separately soaked, and the quantity of chlorine disengaged was by no means sufficient to destroy the vegetable issue. At night the plants had not suffered, and the smell of the chlorine was unchanged. The same plants placed in the same vase without any addition of chlorine, were found quite faded the next morning, with the exception of the cabbage. The odour of the chlorine had entirely ceased, and had been succeeded by a disagreeable acid smell. The experiment being several times repeated, by rendering the extrication of chlorine more considerable, produced the same result, and the plants supported an atmosphere strongly impregnated with chlorine by day, while a much weaker dose always destroyed them during the night. Similar results were obtained when the vapour of nitric acid was employed, nitrous acid gas, sulphuretted hydrogen, and muriatic acid gas; and, as a general conclusion, M. Macaire was of opinion. from these trials, "that many of the gases are hurtful to vegetation; but that they act on them only during the absence of light." (Quart. Journ. of $A g r$. vol. v. p. 301.)

GAS-WURKS, the Refuse Matters of, as Fertilizers. It is only within these few years that the attention of the farmer has been attracted to the various matters produced by the gasworks now so common in all parts of England. This attention, however, is confined at present to only particular localities: while in one district it is zealously used, and bought up with avidity, in others it appears to be totally neglected. In the vale of Kennet the farmers clear away from the gas-works all the refuse matters they can obtain, even at advanced prices. Those of the valley of the Itchin, in Hampshire, find it, in small proportions, an excellent dressing for grass.

The refuse matters which are produced during the distillation of pit-coal in the gasworlis, consist of three substances; the arnmoniacal liquor, the hydro-sulphuret of lime, formed by passing the gas through lime to de- prive it of its sulphuretted hydrogen, and the coal-tar; these substances are worthy of the cultivator's attention, for they are all fertilizers of considerable value. Let us examine them in the order in which I have enumerated them.

1. The ammoniacal liguor obtained from gasworks is an impure solution of the carbonate and acetate of ammonia; and these salts, there is little doubt, not only act as stimulants to piants, but both the acids and the ammonia, when decomposed, furnish direct food to, or constitute parts of, vegetables. Carbonate of ammonia has been detected in the stinking goose-foot (Chenopodium olidum), by MM. Chevalier and Lassaigne, and it probably exists in other plants which are distinguished for their powerful disagreeable odour. If the plants do not contain ammonia, or its salts, it is the ammonia either in the soil or the air which affords them the nitrogen which enters into their composition. (Annals of Phil. vol. xii. p. 231.) Hydrochlorate of ammonia has been found in wood by M. Chevreul. (Ann. de Chim. 68, p. 284.)

There are many testimonials in favour of the use, as fertilizers, of the salts of ammonia, either in their pure state, or as found in an impure combination with soot, or in the liquor of gas-works. "Soot," said Davy, "owes part of its efficacy to the ammoniacal salt it contains. The liquor produced by the distillation of cual contains carbonate and acetate of ammonia, and is said to be a very good manure. In 1808 , I observed that the growth of wheat in a field at Roehampton was greatly assisted by a very weak solution of acetate of ammonia." (Lectures, p. 342.) The experiments of $\mathrm{Mr}$. Robertson with soot clearly show the fertilizing effects of the soluble portion of it, which is principally the salts of ammonia. He mixed together, in order to form a liquid manure, six quarts of soot in a hogshead of water. "Asparagus, peas, and a variety of other vegetables," says this intelligent horticulturist, "I have manured with this mixture with as much effect as if I had used solid dung; but to plants in pots, particularly pines, I have found it admirably adapted; when watered with it they assume a dark, healthy green, and grow strong and luxuriant," (Gard. Mag. vol. ii. p. 18.) Care must be taken in using this, and all other liquid fertilizers, not to make the solution too strong; it is an error into which all cultivators are apt to fall in their early experiments. Davy was not an exception; from making his liquids too concentrated, he obtained results which widely differed from his later experlments. (Lectures, p. 170.) There is no doubt but that the salts of ammonia, and all the compound manures which contain them, have a considerable forcing or stimulating effect upon vegetation. In the experiments of Dr. Belcher, upon the common garden cress, by watering them with a solution of phosphate of ammonia, the plants were 15 days forwarder than cther plants growing under similar circumstances, but watered with plain water; and he also describes the experiment of a Mr. Gregory, who, by watering one-half of a grass field with urine (which abounds with the salt of ammnnia) 527 
nearly doubsed his crop of hay. (Com. to Board of $A g r$. vol. iv. p. 416.)

"It is probable," says Mr. Handley, "that the ammoniacal liquor which abounds in gasworks, and which, when formerty allowed to run waste into the 'Thames, was said to destroy the fish and prejudice the quality of the river water for human consumption, and which is still thrown away throughout the country, except at a few works where they manufacture sal ammoniac, will, ere long, be extensively used as a manure, either through the intervention of the water-cart, or for the process of saturating and decomposing soil or vegetable matter. A very satisfactory illustration, on a small scale, has recently been submitted by Mr. Pain. He put into a vessel some leaves of trees, saw-dust, chopped straw, and bran, to which he applied ammonia, and closed it up. In about three weeks the whole was reduced to a slimy mass: he then stirred it, and added a little more ammonia; and when submitted to the English Agricultural Society, it was reduced to a black mass of vegetable mould, strongly impregnated with volatile salts, and in comminuted particles similar to surface peat mould. When applied in its liquid form to grass, like salt, it apparently destroys the plant; but the spot is distinguished by increased verdure the succeeding year." (Eng. Agr. Soc. Journ. vol. i. p. 46.)

Mr. Paynter, of Boskenna, in Cornwall, has given the result of an experiment made with the water in which street gas had been cleansed, on a piece of barley land. A quarter of an acre was taken in the middle of a field of rather close soil, in a granite district. The land was of average quality ; the gas-water was distributed over the quarter acre by a contrivance resembling that of a common watering cart, and at the rate of 400 gallons to the acre; about a week before seed time, the rest of the field was manured in the usual way. The difference both in colour and vigour of the barley plant was so strikingly in favour of the part manured by the gas-water, that persons passing within view of the field almost invariably came to inquire about the cause. The yield also was superior, as well as the after-pasture, the field having been laid down with the barley." (Ibid. p. 45.)

The refuse Lime of Gas-Works.-This powder is produced by passing the gas through dry lime, in which operation the earth combines with a quantity of sulphuretted hydrogen, from which the coal gas needs purifying, and is partly converted into hydro-sulphuret of lime: in the state that the powder is usually vended by the gas manufacturers, it contains a considerable portion of uncombined lime. The hydro-sulphuret of lime has a bitter and acid taste; it is soluble in water, and has the peculiarly disagreeable smell of sulphuretted hydrogen. When mixed with or spread upon the soil, it gradually decomposes, a portion of hydrogen separates from it, and it is converted into sulphuret of lime, which, by absorbing oxygen from the atmosphere, finally becomes sulphate of lime. There is no reason, therefore, to doubt the fertilizing properties of this manure; but it is too powerful in its effects 528 upon vegetation, to be used in the large pro. portions in which it has been sometimes em. ployed; and it should not, for these reasions, be added to the soil immediately in contact with the seed. It is generally to be obtained at a very moderate rate, and by its gradual conversion to sulphate of lime (gypsum), it must be a very excellent addition to those soils which are described by the farmer as having become "tired of clover."

"In many parts of the country," says Mr. Handley, "where gas-works are established, the refuse has become an object of interest to the agriculturist, as containing many of the essentials of the most effective manures. The refuse lime which was formerly an inconvenience to the manufacturers, and was carted away as valueless rubbish, is now contracted for by the neighbouring farmers (in an instance within my own knowledge at $7 s_{0} 6 d$. per chaldron), and applied either in compost, or in a direct form, to the land, where, in addition to the usual operation of lime, it is said to furnish a protection against many of the noxious grubs and insects." (Ibid.)

Gas Tar.-This substance being produced in smaller quantities, and employed very com. monly as a paint, has not been used as a manure to any extent; but wherever it can be obtained (as I am aware it ever can in some places, almost for the expense of carriage), it is an article every way worthy of the farmer's notice. It is composed entirely of substances which enter into the composition of all plants, is gradually decomposed in the soil, is powerful in its efiects, and still more so from its con. taining a considerable portion of the carbonate and acetate of ammonia; hence it is best applied mixed with earth, so as to be easily and evenly spread over the ground. These facts will explain some of the phenomena witnessed in the recent experiments of Mr. Bowley with gas refuse, at Sidington, Gloucestershire. He says (Farm. Mag. vol. ix. p. 197), "I have long used the refuse of the gas-house as a manure; my usual practice is to form out my compost-heap with long dung about three feet deep, pour the coal tar regularly over it, then put another layer of dung or turf, throw up the lime on the top, allow $j$ to remain in this state two or three months before it is turned. The lime should not be under the tar in the first instance, as the tar will find its way through the dung, and unite with the lime into a hard cement, in which state, even if, with considerable labour, it is broken into sniall particles, I believe it to be of little service on the land.

"After pursuing the above system for some time, I resolved to try some experiments with each in its unsophisticated state. I accordingly commenced with the tar, which I had poured out of a watering-pot, in a small stream, regularly over about haif an acre in a field of ryegrass; this was done in February, 1838. Soon afterwards, the seeds presented the rather sin. gular appearance of having been burnt in stripes with a hot iron, for the tar had completely destroyed all it touched, and I was told I had poisoned the land, and it would never recover itself; however, in June, I noticed that the 
grass tretween the streams of tar looked more luxuriant, and the sheep fed on it in preference to the other parts of the field. In the autumn the whole was ploughed, and sown with wheat, which looked much more flourishing on the half-acre dressed with tar than anywhere else; the difference was so conspicuous from the first, that the most casual observer could not pass without remarking it; and at the present time (August, 1839), there is a heavy crop on it ready for the sickle, while the rest of the field is light, and will not be ripe for a week or ten days. I put some tar in the same way on a piece of land, a month before it was ploughed for spring vetches; the vetches were sown two weeks after the plough, and many of them were destroyed; but the crop of wheat which succeeded was benefited equally with the one in the other experiment. I have tried the lime with great advantage, putting from 12 to 15 cart-loads to the acre, but I find it is better to remain a time before it is ploughed in. All these experiments were tried on a cold, sandy clay, worth about 10s. per acre." In these experiments, the quantity applied per acre was too large, and the manure in a state much too powerful. It was only where it had become diffused through the soil by time, that its fertilizing powers were apparent.

Coal tar is much improved in effect, when ernployed as a coating for palings, by mixing it with a small portion, say one-fortieth of its weight, of grease; this is easily united by heating the tar.

GATES. Good gates are no less essential to the respectable appearance of a farm than they are necessary for the convenience of an occupier. There are few outgoings that cost so much and are so little thought of, as the repairing and renewing gates upon enclosed farms. The most common defects are,

1st. Not sufficient height, so that horses and large cattle, when pushing against the gate, break it, however strong it is, as the back thereof comes in contact with that part of the chest of a horse where the collar goes, and without inconvenience he leans his weight against the opposing bar, which, if a few inches higher presses against his neck and windpipe, and he makes no impression upon it.

$2 d$. They are generally hinge-bound, so that in attempting to lift up the head, which is often required to be done, the ledges and braces are either pulled from the back head or broken therein; the person lifting the head having a nine-feet leverage, which enables him to do this mischief.

$3 \mathrm{~d}$. The places of contact between the brace and the uprights and the ledges are broad, and it being impossible to keep those places of contact dry, the parts become prematurely decayed.

The two great objects to be combined in a gate are strength and lightness. In the Cultivator and some other American agricultural periodicals, many useful observations, with drawings of gates, may be found.

Much has been written on the subject in England: see Quar. Journ. Agr. vol. i. p. 727; and the Trans. of the High. Sor. vol. ii. p. 260, where a self-acting gate, suited for the en- ances to parks or the approaches to marsion houses, is figured and described. There is also a useful essay "On the Construction of Gates for the common purposes of a Farm, the causes of their Decay, and the manner of improving them," in the Commun. to Board of $\mathrm{Agr}$. vol. vii. p. 144: see also Loudon's Enryc. of Agricullure.

Among the excellent observations upon the subject of farm gates, to be met with in the agricultural periodicals of the United States, we would particularly refer to a paper in the Cultivator, (vol. ii. p. 132,) headed Parker's Farm Gate, giving the most minute directions for constructing, accompanied with drawings of the gate and its several parts. See alse Cultivator, vol. vii. p. 124, for the plan and drawing of a cheap gate, which never sags; and more especially the same valuable periodical, vol. viii. p. 53, for Mr. Bennet's Communication on Ornamental Gates, accompanied with descriptions and drawings.

GATHERING. Provincially, rolling cornswaths into cocks or bundles. Also a popular name for Abscess, which see.

GAVELKIND. An ancient custom or tenure annexed to all land in the county of Kent (not especially exempted), and some other parts of England, and which extensively prevails in Ireland, by which the land of the father is equally divided at his death among all his sons, or the land of the brother among all his brethren if he have no issue of his own. Tenure in gavelkind is considered by Blackstone to have been in the nature of free socage. In most places the gavelkind tenant had the power of devising by will before the statute of wills. The same custom seems to have been prevalent in $\mathrm{W}$ ales, where all gavelkind lands were made descendible to the heir at common law by the stat. 34 \& 35 H. 8, c. 36 . In Kent the lands have for the most part been disgavelled, or deprived of their customary descendible quality by particular statutes; but lands in Kent are presumed to be gavelkind uniess the contrary be shown. Mr. Ross, in his Survey of Londonderry, gives an interesting account of this custom and its pernicious effects. This notion of the equal and unalienable right of all the children to the inheritance of their father's property, whether land or goods, which is so general in Ireland, is one great obstacle to improvement. However just and reasonable the opinion may be in theory, it is ruinous in practice. In spite of every argument (says Mr. Ross) the smaller Irish landholders continue to divide their farms among their children, and these divide on until division is no longer practicable; and, in the course of two or three generations the most thriving family must necessarily go to ruin.

GEERS. A country phrase for the harness of draught or team horses.

GELA'TIN. In chemistry the name given to an abundant proximate principle in animals. It is confined to the solid parts of the body, such as tendons, ligaments, cartilages, and bones, and exists nearly pure in the skin; but it is not contained in any healthy animal fluid. Its leading character is the formation of a tremulous jelly, when its solution in boiling $2 \mathrm{Y}$ 
water cools; and it may be repeatedly liquefied and again gelatinized by the alternate applicatron of heat and cold. Isinglass, glue, and size are various forms of gelatin, the first being this substance in a very pure state, obtained by washing and drying the swimming bladder of the sturgeon (Acipenser huso) and some other fish. Its most distinctive chemical character is the formation of a dense white precipitate when its solution in warm water is poured into an infusion of galls, or that of any other astringent vegetable; the substance formed in such cases is a tannate of gelatin, by the union of the tanic acid with the gelatin. Gelatin is semi-transparent and colourless when pure. Its consistency and hardness vary considerably. The best kinds are very hard, brittle, and break with a glassy fracture. Its taste is insipid, and it has no odour. A solution of one part of gelatin in 5000 of water is rendered slightly turbid by the addition of a strong infusion of galls. Gelatin, as an article of food, is not so nutritious as is generally supposed.

The ultimate components of gelatin are-

\begin{tabular}{|c|c|c|c|c|c|c|}
\hline Carbon & - & - & - & - & - & - \\
\hline Hydrogen & - & - & - & - & - & - \\
\hline Nitrogen & - & - & - & - & - & - \\
\hline Oxygen & - & - & - & - & - & - \\
\hline
\end{tabular}

00 lbs. of bones yield about 25 or $27 \mathrm{lbs}$. or gelatin. It is used for making carpenter's glue, as the fat in the bones gives it a bad taste, and renders it unfit for soup. See Glu s. (Brande's Dict. of Science.)

GELDING. In farriery, a castrated animal and also the act of castrating. In performing this operation, attention should be paid to the age, and also the season of the year. The most proper seasons are either the early spring months, or those of the autumn.

GENTIAN (Gentiana). This, in England, is an extremely beautiful genus of plants; the roots of which form one of the principal bitters of European growth. The stems and roots of most of the species, especially the autumnal gentian (G. amarella), the field gen$\operatorname{tian}$ (G. campestris), and some of the foreign species are tonic, stomachic, and febrifuge. That which is principally used in medicine is the root of the great yellow gentian (G. lutea), which is imported from Germany. 'The generic name was given to them after Gentius, King of Illyria, who is reported to have first experienced the virtues of the plant. The species of gentian, indigenous to England, according to Sir J. E. Smith, are six in number.

1. The Marsh Gentian or Calathian violet (G. pneumonanthe). A perennial herb, found on moist, turfy heaths, blooming in August and September.

2. The Dwarf Gentian (G. acaulis). A peIrnnial, but very doubtful native, found on unountains. The stems generally very short, rising from the centre of tufts of leaves, single1!cwered. 'The flower, which blow's in June or July, is large, often two inches long, exquisitely heautiful, of a rich blue in the limb, waier the tube, which is dotted internally with black. Root fleshy and brant hing. 530
3. The Spring Gentian (G.verna). $\Lambda$ peren. nial, growing in barren, mountainous situations, but rare, flowering in April.

4. Small Alpine Gentian (G. nivalis). An annual found on the loftiest mountains of Scotland.

5. The Autumnal Gentian (G. amarella). An annual plant, growing frequent in limestone and chalky pastures, flowering in August and September.

6. The Field Gentian (G. campestris). An annual, flowering in September or October, growing on elevated pastures, or upon green hills towards the sea-coast, where the soil is chalky or gravelly. The roots are very bitter and tonic. It is sometimes known as yellow centaury and blue gentian.

Most of the herbaceous kinds of gentian grow well in a rich, light soil, but some require to be grown in peat; indeed, all will grow much stronger in it. Several of the species should be grown in pots, placed among alpine plants, and protected in winter. Some of them may be increased by divisions. The annual and biennial kinds may be sown in a dry, sandy situation in the open border; but they must be sown as soon as the seeds are ripe, because, if left till spring before they are sown, they will not, very probably, come up till the second year.

The species of gentian best known in the United States, are:-1. The one called Soapwort (G. saponaria), a handsome plant, frequently found in Pennsylvania and other Middle States, along the margins of swampy rivulets and in low grounds. It flowers in September, and ripens its seed in November. The root, as in all the genus, is bitter and tonic. 2. Yellowish-white Gentian (G. ochroleuca), found in fields and woodlands in the Middle and Southern States, but not so common as the former kind. 3. Haired, or Fringed Gentian (G. crinita), frequent in hilly, open woodlands and old fields in Pennsylvania, where it is one of the most beautiful autumnal flowering plants in the months of September and Oc. tober. Its flowers are often destroyed by frost. Though generally described as a biennial, Pro. fessor Eaton considers it a perennial. Dr. Darlington thinks it an annual.

Seven or eight additional species of gentian are enumerated in the United States. (Flora Cestrica.)

GEOLOGY ( $\mathrm{z}^{n}$, the earth; $\lambda$ ogos, a discourse). The use of this science to the cultivator is considerable. The farmer is, in fact, obliged to vary his modes of tillage with the different strata which he tenants, and hence he is often following in practice the very rules, and observing the laws which the science of geology would prescribe, without being aware of the scientific reasons by which his labours are guided. It is a science he will find closely connected with the best modes of cultivating the soil, the drainage of land, the mixture of earths, and other agricultural improvements. From geological observations, the farmer learns the process by which the soils he cultivates were originally formed, their connexion with the substratum, and the readiest mode of improving their constituents; thus, as it is 


\section{GEOLOGY.}

well observed by Mr. Morton, in his valuable little work on Soils, p.3. "If we can show an identity of the materials which form the soil with those of the subsoil upon which it rests, we shall obtain a key to a more correct and satisfactory classification of soils than at present exists; their nature and properties, the kind of crops which they are best calcalated to produce, and the materials necessary for their permanent improvement will also be more evident." That such scientific observances of the order of nature cannot but be attended with benefit, is a remark which we cannot too often make to the farmer: it was an observation which Davy long since made, (Lectures, $p$. 204); he told the farmers of his day, that "the best natural soils are those of which the materials have heen derived from different strata which have been minutely divided by air and water, and are intimately blended together; and in improving soils artificially, the farmer cannot do better than imitate the processes of nature;-the materials necesary for the purpose are seldom far distant-coarse sand is often found immediately on chalk, and beds of sand and gravel are common below clay. The labour of improving the texture or constitution of the soil is repaid by a great permanent ad. vantage-less manure is required, and its fertility insured, and capital laid out in this way secures forever the productiveness, and consequently the value, of the land " and again, Dr. Paris, when addressing the Penwith Agricultural Society, remarked, "The composition and arrangement of the different rocks of which a country consists, is always an object of important interest to the liberal and well-informed farmer, for it will generally be found more or less connected with its agricultural economy, and is frequently capable of explaining peculiarities and anomalies which are otherwise quite unintelligible. At the same time a knowledge of them will suggest the best method of improving a soil by exhibiting the nature of its texture and constitution, and the various causes of its sterility." That geological surveys of even particular estates have been attended with considerable benefit, we have the valuable testimony, amongst many others, of Sir J. V. Johnstone, who says (Journ. of Eng. Agric. Soc. vol. i. p. 273), "The geological survey and map of my estate has not only explained the reason of the discrepancy between the soil and productiveness of neighbouring fields-a matter of great interest, and tending to develope the true conditions of vegetable life-but the following positive practical results have been also derived from it:-1st, The knowledge of applying lime to advantage over the property; 2d, Laying down fields to advantage to grass, and where and how to plant wheat; $3 \mathrm{~d}$, What trees to plant upon each stratum; and as, he very correctly adds, "Certain soils are so obviously connected with their bases, that we need scarcely ask how geology and agriculture are mixed together " and to use Dr. Smith's own words, "The strata succeed each other in a certain order, and being delineated, a knowledge of the strata becomes the natural and safe foundation of improvement; and if agricultural chemistry be ever

\section{GEOI.OGY.}

successful iy applied to the practical purposes of agriculture, it must be by proceeding with the chemical analysis of soils along the range of each stratum." (Furmer's Almanac.)

And it is quite true, as Mr. Macgillivray remarks (Quarlerly Journal of Agricullure, vol. iii. p. 209), that "an experienced agriculturist may judge correclly of the general capabilities of a district from a superficial inspection, and may perceive its adaptation to the cultivation of certain plants, or to the rearing of certain species of animals, in consequence of a single glance of his eye; but how much more precise will be the estimate of him who examines the slopes of the declivities; the depth and quality of the soil; the nature of the subsoil; the distribution of rills, pools, and springs; the kind and disposition of the mineral strata; the existence of limestone beds; the elevation above the level of the sea; the exposure to particular winds; the prevalent atmospheric currents; the frequency of rains and frosts; and all the other physical phenomena which influence a country. Even the nature of the rock itself, independently of other circumstances, discloses the capabilities of the soil, in a degree which could scarcely be imagined by one totally unacquainted with the influence which it possesses."

$\Lambda \mathrm{s}$ my observations on geology in this work will be chiefly confined to its connexion with practical agriculture, I shall not detain the farmer with any of the valuable geological researches which extend far beneath the earth's surface. Indeed, as Professor Brande remarks in his Outline of Geology, p. 32, when speaking of geology, "Its first and leading object is to become practically acquainted with the present state of the earth's external structure, for, excepting of its crust or rind, we know nothing; and all that has been suggested either by theory or experiment, relating to its internal composilion, its density, and the constitution of the entire mass, is mere surmise and guess-workdeductions hastily drawn from superficial observation or unwarranted inferences from imperfect researches." To the student who wishes to make himself practically master of the science, I commend the lectures of Professor Brande, as well as the Outlines of the Geology of England and Wales, by Conybeare and Phillips. To the practical, intelligent farmer, the work On Soils, by Mr. John Morton, will also be very valuable. To this excellent little book I gratefully acknowledge my obligations in this and many other articles.

The best popular description, perhaps, of the position in which the various strata of the earth are placed, is that long since given by Mitchell. "This very ingenious writer," says Brande (Outlines, p. 13), "describes the general appearance of the strata, points out their analogies and differences, adverts to their in clination and disturbance in mountainous districts, and to their horizontality in flat countries; and having explained with much minute and practical perspicuity the arrangement of the strata in England, he exemplifies its uni. versal application to the general structure of the globe, and ingeniously represents it in the following manner:- Let a number of leaves 
of paper,' he says, 'of several different colours, be pasted one on another, then binding them up together into a ridge in the middle, conceive them to be reduced again to a level surface by a plane so passing through them as to cut off all the part that had been raised; let the middle now be again raised a little, and this would be a good general representation of most, if not all, large tracts of mountainous countries, together with the parts adjacent throughout the whole world. From this formation of the earth, it will follow that we ought to meet with the same kinds of earths, stones, and minerals, appearing on the surface in long narrow slips, and lying parallel to the greatest rise of any large ridge of mountains, and so, in fact, we find them." (Phil. Trans. 1760.)

And this system of layers or strata not only marks the arrangement of the great masses of which our earth is composed, but it is that of the very rocks themselves. It is to us attended with many advantages, such as the formation of springs, - the constitution of soils, - which last is that alluded to by Dr. Paris, On the Soils of Cornwall. "The phenomenon of stratification, which is so well characterized in clay slate, I have often regarded as a wise provision of nature to facilitate its decomposition, and to admit the descent of the roots of trees: and this idea is further strengthened when we discover that this structure is almost entirely confined to secondary rocks, whose situation and nature render them capable of cultivation: they are all, for instance, resolved into gently undulating hills, and by farther decomposition they form rich and fertile soils. Primitive formations, on the contrary, which possess no such structure, disintegrate into rugged piles, whose declivities are too steep to admit the accumulations of soil, and cannot, therefore, ever constitute the habitable parts of the globe; and, as far as our geological knowledge will allow us to generalize, it would appear that primitive rocks are accumulated towards the poles, whereas the great mass of secondary formations is found to occupy the middle and southern latitudes, principally between the 20 th and 55th degrees, which constitute a portion of the globe eminently calculated for the abode of man, and the animals which are subservient to his wants and comforts."

The farmer must not imagine, as he pursues his researches in this very interesting science, that he will find a great variety of earthy substances in the different, often-varying strata of the earth ; "for," as Mr. Brande says very truly, "siliceous, calcareous, and argillaceous substances, either pure, or nearly so, or in a state of mixture, or loosely and indefinitely blended, rather than in strict chemical combination, constitute a very large relative proportion of those rocky masses, or scattered or comminuted substances, which form, or have formed, the most exterior constituents of our planet, and of these, considered in the abstract, the chemical and mineraiogical history is soon told." Of that brief history, however, it will be well for the farmer to have a general know.elge. Davy, who saw very clearly the imprortance of the science to practical agricul532 ure, described them with a view to assist the farmer in his tillage operations.

The formation of a soil from the different strata by natural causes is also well described by the same great chemist. "It is easy," he says, "to form an idea of the manner in which rocks are converted into soils by referring to the instance of soft granite or porcelain granite. This substance consists of three ingredients, quartz, feldspar, and mica. The quartz is almost pure siliceous earth, in a crystalline form. The feldspar and mica are compound substances: both contain silica, alumina, and oxide of iron; in the feldspar there is usually lime and potassa; in the mica, lime and magnesia.

"When a granitic rock of this kind has been long exposed to the influence of air and water, the lime and the potassa contained in its constituent parts are acted upon by water or carbonic acid; and the oxide of iron, which is almost always in its least oxidized state, tends to combine with more oxygen; the consequence is, the feldspar decomposes, and likewise the mica, but the first the more rapidly. The feldspar, which is, as it were, the cement of the stone, forms a fine clay. The mica partially decomposes, mixes with it as sand, and the undecomposed quartz appear as gravel or sand of different degrees of fineness.

"As soon as the smallest layer of earth is formed on the surface of a rock, the seed of lichens, mosses, and other imperfect vegetables which are constantly floating in the atmosphere, and which have made it their resting-place, begin to vegetate. Their death, decomposition, and decay, afford a certain quantity of organizable matter, which mixes with the earthy materials of the rock; in this improved soil more perfect plants are capable of subsisting; these, in their turn, absorb nourishment from water and the atmosphere, and, after perishing, afford new materials to those already provided. The decomposition of the rock still continues, and, at length, by such slow and gradual processes, a soil is formed in which even forest trees can fix their roots, and which is fitted to reward the labour of the cultivator." (Ibid.p. 189.)

That the geological formation of the soil influences to a considerable degree its relations to a fertilizing supply of moisture, was thus noticed by Dr. Paris when addressing a Cornish Agricultural Society:- "There is a popular adage well known to all the nembers of this society, that 'the land of Cornwall will bear a shower every week-day, and two upon a Sunday, - the fact is, that the shallowness of the soil, and the nature of its rocky substratum, render a constant supply of moisture indispensable; and here we cannot avoid admiring the beautiful contrivance of nature in connecting the wants and necessities of the different parts of the creation with the power and means of supplying them; thus, in rocky cuuntries like Cornwall, where the soil is necessarily greedy of moisture, the very cause which creates this want is of itself capable of supplying it; for the rocks elevated above the surface solicit a tribute from every passing shower, while in alluvial and champaign 
countries, where the soil is deep and rich, and consequently requires less moisture, the clouds float undisturbed over the plains, and the country frequently enjoys that long and uninterrupted series of dry weather which is so congenial to it. As a general rule it may be stated, that to obtain the greatest fertility the proportion of siliceous sand in a soil ought to increase in proportion to the quantity of rain that falls, or rather perhaps to the frequency of its recurrence; for one of the effects of silex is to diminish in the soil its power of absorbing moisture; we accordingly find that in the rainy climate of 'Turin the most prolific soil has from 77 to 80 per cent. of siliceous earth, and from 9 to 14 of calcareous, whereas, in the neighbourhood of Paris, where there is much less rain, the silex bears only the proportion of from 26 to 50 per cent. in the most fertile parts; and I have found some of the most productive corn lands in the parish of St. Burian to contain as much as 70 per cent. of that earth." See Earths, their Use to Vegetation.

It will, perhaps, considerably assist the cultivator in his examination of the different geological formations to which he may have to direct his attention, if we examine the chemical composition of a few of the stones and other substances of which rocks are chiefly formed.

Common clay is merely a mixture of alumina with silica, in endless proportions. The alumina is in the form of a very impalpable powder; but the silica, says Dr. Thomson, is almost always in small grains, large enough to be distinguished by the eye. Clay, therefore, exhibits the characters of alumina, and not of silica, even when this last ingredient predominates. Besides alumina and silica, clay often contains carbonate of lime (challs), carbonate of magnesia, carbonate of baryta, oxide of iron, sce. (Chem. vol. iii. p. 341.)

Loam may be regarded as a very impure potter's clay united with iron, ochre, and mica.

Common Mica.-This stone is composed, according to the analysis of M. Klaproth, of-

\begin{tabular}{|c|c|c|c|c|c|c|c|}
\hline Silica - & - & - & - & - & - & - & $\begin{array}{l}\text { Parta } \\
-47^{\circ}\end{array}$ \\
\hline Alumina & - & - & - & - & - & - & -20 \\
\hline Oxide of & ron & - & - & - & 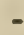 & . & -15.5 \\
\hline Oxide of $\mathrm{n}$ & nanga & anese & - & - & - & . & -1.75 \\
\hline Potash & - & - & - & - & - & - & $-14 \cdot 5$ \\
\hline Loss - & - & - & - & - & - & - & -125 \\
\hline
\end{tabular}

Common feldspar, according to M. Vauquelin, is composed of-

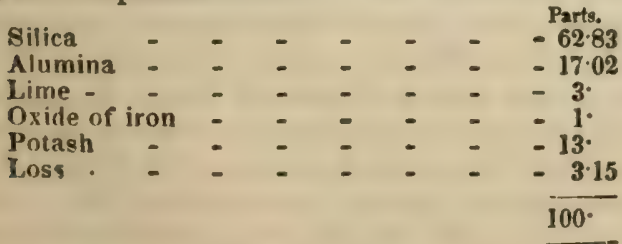

The decomposing feldspar of Cornwall is composed, according to Mr. Wedgwood, of-

Alumina

Silex - - - - - - $\begin{gathered}\text { Parts } \\ -60\end{gathered}$

Moisture and loss - $\quad-\quad-\quad-\quad-\quad-\quad-20$
Brande found in a specimen of pale fleshcoloured feldspar from the Alps-

Silex - -
Alumina -
Potash -
Lime -
Oxide of iron
Loss -

Parta.
-68 .
-68

$-20^{\circ}$

- 8.30

- 2.

- 0.50

$-1.20$

$100^{\circ}$

Common hornblende was found by M. Kla:roth to contain-

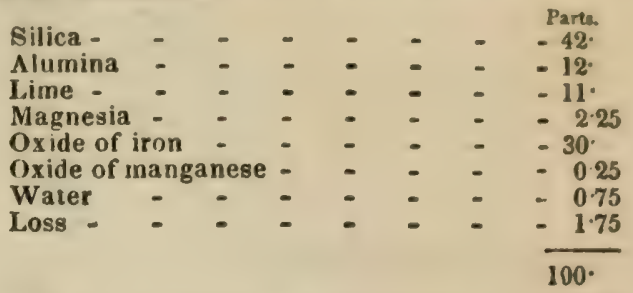

Common serpentine contains, according to M. Vauquelin-

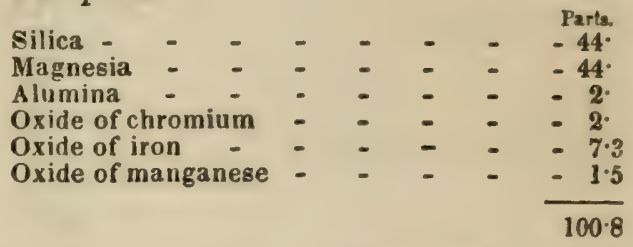

Another specimen, examined by Dr. John, was found to contain-

\begin{tabular}{|c|c|c|c|c|c|c|}
\hline Silica - & - & - & - & - & - & \\
\hline Magnesia & - & - & - & - & - & - \\
\hline Alumina & - & - & - & - & - & - \\
\hline Lime - & - & - & - & - & - & - \\
\hline Iron - & & & - & - & - & - \\
\hline Oxide of $\mathrm{m}$ & nang: & anese & - & - & - & - \\
\hline Water & - & - & - & - & - & - \\
\hline
\end{tabular}

Chalk contains-

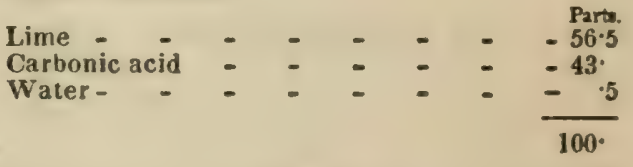

Common compact limestone contains-

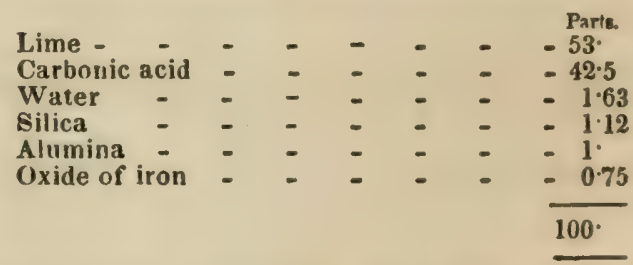

Magnesian limestone, from Sunderland, contains, according to Dr. Thomson (System of Chem. vol. iii. p. 396)-

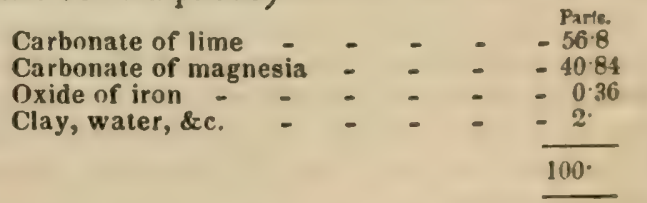

Quartz, according to the analysis of $\mathrm{M}$ Bucholz, is composed of -

Silica

Alumina

Water

Loss .

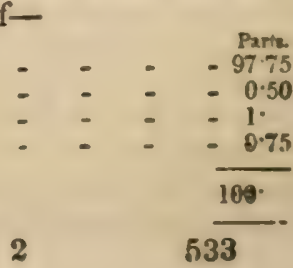


Porcelain earth was analyzed by Mr. Rose sJameson's Min. vol. i. p. 298): he found in it-

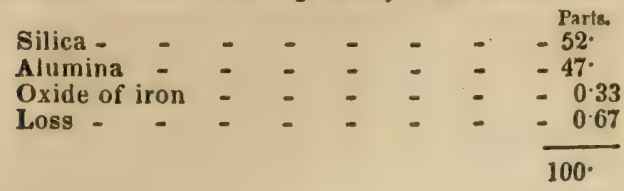

Potter's clay, according to M. Vauquelin, contains-

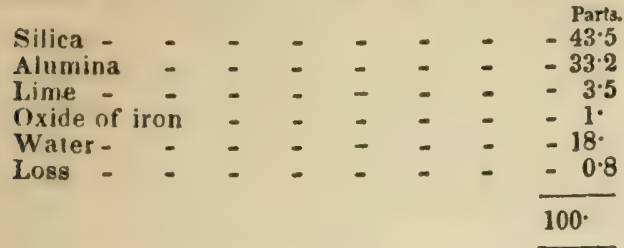

Clay slate is composed of -

\begin{tabular}{|c|c|c|c|c|c|c|}
\hline Silica - & - & - & - & - & - & $\begin{array}{l}-48.6 \\
\end{array}$ \\
\hline Alumina & - & - & - & - & - & $-23 \cdot 5$ \\
\hline Magnesia & - & - & - & - & - & -1.6 \\
\hline Peruxide o & iron & - & - & - & - & $-11 \cdot 3$ \\
\hline Oxive of ma & nganese & - & - & - & - & -0.5 \\
\hline Potash & - & - & - & - & - & $-4 \cdot 7$ \\
\hline Carbon & - & - & - & - & - & - 0.3 \\
\hline Sulphur & - & - & - & - & - & - 0.1 \\
\hline Water and & volatile $\mathrm{m}$ & oatter & & - & - & $-7 \cdot 6$ \\
\hline \multirow[t]{2}{*}{ Loss } & - & - & - & - & - & -18 \\
\hline & & & & & & $100^{\circ}$ \\
\hline
\end{tabular}

Basalt is composed, according to Mr. Kennedy (Edin. Trans. vol. v. p. 89), of-

\begin{tabular}{|c|c|c|c|c|c|c|c|}
\hline Silica & - & - & - & - & - & - & - \\
\hline Alumina & & - & - & - & - & - & - \\
\hline Lime & - & - & - & - & 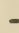 & - & - \\
\hline Soda & - & - & - & - & - & - & - \\
\hline Oxide of & jron & & - & - & - & - & - \\
\hline Muriatic & acid & & - & - & - & - & - \\
\hline Water & - & - & - & - & 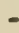 & - & - \\
\hline Loss & - & - & - & - & - & - & - \\
\hline
\end{tabular}

Chlorite earth is composed of-

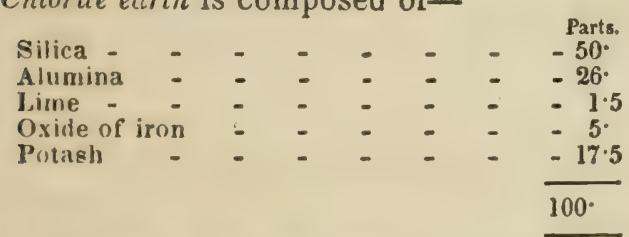

Gypsum, of which there are several varieties, is composed of-

\begin{tabular}{|c|c|c|c|c|c|c|}
\hline & of lime & - & - & - & - & $\begin{array}{r}79.32 \\
-79\end{array}$ \\
\hline \multirow[t]{2}{*}{ Water } & $-\quad-$ & - & - & - & - & $-20 \cdot 68$ \\
\hline & & & & & & $100^{\circ}$ \\
\hline
\end{tabular}

The cultivator, therefore, must take it as an axiom in his geological observations, that the carthy composition of the surface soil almost a!ways partakes of the nature of the rock or subsoil on which it immediately rests, and from which, in fact, it has been generally thus formed, in the progress of time, by various external agencies.

Alluvial soils, perhaps, are the most extensive exceptions to this remark, for they are former commonly of the materials of different strata, brought from various distances by the Iood waters, and mingled together, often in -ery confused, yet most ommonly in very fertile proportions. (See Aluuvium.) Of this tescription of soil there are in England many 531 valuable tracts, such as that extending from Lynn, through Lincolnshire to the Humber, and thence to Bridlington. Both sides of the valley of the Thames, about Sandwich in Kent, Romsey Marsh, between Bristol and Bridgewater, and Liverpool and Lancaster, and on the banks of the rivers Forth and Tay in Scotland. "This kind of soil," says Mr. Morton, "is always fertile, free in its nature, and easily cultivated; is fitted for the production of every variety of crop, which it brings to the highest perfection, and produces in the greatest abundance. 'This formation is perfectly dry. About one-half of all the alluvial accumulations may be in tillage, and the remaining half in meadow and pasture land." (On Soils, p. 10.)

Diluvium is the geological name for those masses of soil, composed of sand, gravel, \&c., which are found in many places, covering some of the older formations. It is of various composition: when it is found resting on the tertiary and chalk formations, it is usually composed of red clay and rounded flints. In Dorsetshire the diluvium is commonly composed of a mixture of sand and gravelly flints. "Most of this soil," says Mr. Morton, "is in arable culture, and produces turnips, barley, oats, wheat, clover; and, when under proper management, it becomes a useful soil. The tenacious clay gravel is expensive in the cultivation, as it is most difficult to work, except between wet and dry. The greatest improvement which has been made in this soil is by the application of chalk." The larger portion of Suffolk and Norfolk is composed of a diluvium sand, resting on chalk or marl. This district is very level: it extends from Sudbury to Bungay and Cromer, from Southwold to Shelford, and from Swaff ham to Yarmouth. Resting as it does on a calcareous substratum, the excellent cultivators of this district have gradually and permanently improved the soil by bringing the chalk or marl to the surface, and spreading it over the land at the rate of about 100 cubic yards per acre; in this way mere rabbit warrens of blowing sands have been improved so as to yield excellent crops of corn, and rentals have been in this way raised from a few pence to $20 \mathrm{~s}$. per acre.

Peat Soils.-These abound in many portions of the United Kingdom. Their best mode of improvement is, usually, by mixing them with the earths. See Prat Sorls.

The Chalk Formation.-This formation, very common in England, but which does not exist in the limits of the United States, is divided by geologists into two divisions, the upper and the lower chalk: the upper abounds in flints, which are absent from the lower formation. Chalk is chiefly carbonate of lime, with some small portions of alumina, iron, and silica. "The water which comes from below the lower chalk," says Mr. Morton, "is pure and limpid. and delicious to drink. It contains carbonate of lime, and is of the best quality for watering meadows; hence the best water meadows are in the chalk valleys." The soil of the chalk formation is composed of chalk and flint in various proportions. These soils are materially improved by a mixture with those of the green sandstone formation, and by enclosing 
Wi to much smaller fields than those into which they are at present generally divided.

Green Sund Formation.-This formation is found under the chalk. It is formed of a variety of beds: the upper beds near the chalk have a green or grayish colour, the lower beds, which are commonly much thicker, vary in colour, from yellow to brown and red. It is composed of silicious sand, mixed with mica and chlorite. "The means of permanently improving this soil," says Mr. Morton, "after it is drained and enclosed (if for pasture), are so immediately within the reach of the farmer, that he can at little comparative expense improve its texture, and permanently increase its productiveness, by chalk or chalk marl, on the one hand, and the oak or clunch clay, on the other; but even without the application of these substances, deep or double ploughing or trenching has the effect of deepening the soil, and increasing its capability. When mixed with the chalk marl above it, it has the power of receiving and transmitting moisture more freely, and is neither so easily injured by wet weather, nor by excessive droughts, as other soils are." (On Soils, p. 43.)

Gault has commonly a bluish or gray aspect, and its geological position is in the centre of the green sand formation: the two greatest deposits of it, in England, are in the Vale of White Horse, in Berlshire, and in the counties of Cambridge and Huntingdon. It is found at South Marston, in Wiltshire, at Wantage, Thame, through Berfordshire to Caxton and St. Ives.

Before the year 1807, although mineralogy had received some attention in the United States, little or nothing had been done towards ascertaining its geological features. At that time William Maclure commenced the task, and single-handed, made a progress which reflects the highest credit upon his memory, for he developed the leading characteristics of the rock formations, in doing which, he crossed the Alleghany mountains in fifty places. The state geological surveys which have been carried on for several years past, and are still prosecuted, seem to be enterprises peculiarly American, having preceded those regularly undertaken in any other country. The annual reports of these surveys have dwelt much upon economical geolngy, and placed an immense mass of minute and accurate information before the public, which cannot fail to be profitable to agriculture and other useful objects. North Carolina has the honour of having first directed a survey of her territory, a duty percormed by Prof. Olmsted, whose reports were made in 1824, 1825; since then, South Carolina has been geologically explored by Prof. Vanuxum. These two Southern States were succeeded by Massachusetts, the last report of which, by Prof. Hitchcock, was made in 1837. Tennessee has been explored by Prof. Troost; Maryland by Prof. Ducatel; New Jersey and Pennsylvania by Prof. H. D. Rogers; Delaware by Prof. J. C. Booth; New York by Profs. Vanuxum, Mather, Emmons, and Mr. James Hall; Virginia by Prof. William B. Rogers; Maine, Rhode Island, and New Hampshire, by Dr. Charles T.Jackson; Connecticut by Dr. J. G. Percival and Prof. C. U. Shepard - Ohio by Prof. Mather, assisted by
Dr. S. P. Hildreth, and Profs. Iocke, Briggs, and Fostor; Michigan by Mr. D. Houghton; Indianna by Dr. D. D. Owen; and Georgia by Mr. J. R. Cotting. It thus appears that within the last 16 or 17 years, surveys have been commenced, and most of them completed, in 19 states and two territories of the Union, embracing an area of nearly 700,000 square miles, and that for some years past not less than 25 principal geologists, and 40 assistant geolo gists, have been almost constantly engaged under the patronage of the state governments, in the examination of the various parts of the Union. The British provinces of New Brunswick and Nova Scotia have also been geologically examined by Dr. Gessner, whilst the exploration of Canada has been commenced under the superintendance of Mr. Logan. Much of the materiel thus amassed cannot fail to be of high interest in an agricultural point of view, as pointing the situation and exact value of soils, and the invaluable beds of mineral fertilizers, in the form of lime, marl, green sand or silicate of potash, \&c., \&c.

From such facts as these the farmer will readily perceive that the science of geology is not without its material and extensive value to the tiller of the earth. It enables him at least to cultivate his soils on solid data, to avoid the adoption of idle and fruitless modes of cultivation, to pursue that which the situation of the strata he tenants determines to be the best. It is no reason for the neglect of its assistance that other sciences can perhaps do more for the farmer; and even the objection, though very common, amounts, in fact, to an admission that geology is a science capable of rendering services to agriculture. (Brande's Lect. on Geology; Morton on Soils; Davy's Elem. Ag. Chem.; Paris on the Soils of Cornwall; J. F. Johnston's Lec. Chem. and Geol.; Prof. H. D. Roger's Geological Surveys of Pennsylvanio, and New Jersey; Prof. C. J. Booth's Survey of Delaware; Professor Jackson's Survey of Massachusetts; Geulogical Survey of New York; Dr. Ruffin's Survey of North Carolina, \&c., \&c.)

GEOMETERS. A species of caterpillar. See Span-worms.

GEORGIA BARK (Pinckneya pubens). "This tree," says Michaux, the younger, "still more interesting by the properties of its bark, than by the elegance of its flowers and of its foliage, is indigenous to the most southern parts of the United States: probably it grows also in the two Floridas and in Lower Louisiana. My father found it for the first time in 1791 on the banks of the St. Mary. He carried seeds anit young plants to Charleston, and planted them in a garden which he possessed near that city. Though intrusted to an ungrateful soil, they succeeded so well, that in 1807 I found several of them 25 feet high, and 7 or 8 inches in diameter; which proves that the vegetation of this tree does not require a very warm climate, nor a very substantial soil.

"With a great affinity to the cinchona which yields the Peruvian bark, my father discerned in the Georgia bark sufficient differences, to distinguish it as a new genus. In testimony of his gratitude and respect, he consecrated it to Charles Cotesworth Pinckney, an enlightenred 
patron of the arts and sciences, from whom my father and myself, during our residence in South Carolina, received multiplied proofs of benevolence and esteem.

"The Georgia bark is a low tree, dividing itself into numerous branches, and rarely exceeding the height of 25 feet, and the diameter of 5 or 6 inches at the base. A cool and shady exposure appears the most favourable to its growth. Its leaves are opposite, 4 or 5 inches long, of a light green colour, and downy underneath, as are also the shoots to which they are attached. The flowers, which are white with longitudinal rose-coloured stripes, are pretty large, and are collected in beautiful panicles at the extremity of the branches. Each flower is accompanied by a thoral leaf, bordered with rose-colour near the upper edge. The capsules are round, compressed in the middle, and stored with a great number of small winged seeds.

"The wood of the Georgia bark is soft, and unfit for use in the arts; but its inner bark is extremely bitter, and appears to partake of the febrifuge virtues of the cinchona, for the inhabitants of the southern parts of Georgia employ it successfully in the intermitting fevers which, during the latter part of summer and autumn, prevail in the Southern States. 4 handful of the bark is boiled in a quart of water till the liquid is reduced one-half, and the infusion is administered to the sick. From the properties of its bark the pinckneya has taken the name of Georgia bark. The tree which produces it so nearly resembles the Peruvian vegetable, that some botanists have included them in the same genus."

GEORGIA PITCH PINE, or long-leaved pine. See Fir.

GERANIUM. From a Greek word signifying a crane, the beaked fruit bearing some resemblance to a crane's bill. The varieties of this genus of beautiful plants cultivated are very numerous, but all are tender. The common scarlet geranium is the hardiest shrub, and the handsomest. It looks beautiful planted in lawns and gardens, and grows extremely bushy and handsome in a fine light soil. Cuttings strike so readily, that the old shrub may die every fall, and be renewed every summer from the frame. The best plants come from seeds sown in July: the seedlings must be kept warm, but not forced. The scarlet geranium thrives well through the winter, if placed in the house, free from damp and stagnantair. It is very ornamental during summer and autumn.

Sweet's Geraniaceo, and other works on the subject, may be consulted with advantage by those desirous of further information as to the best varieties of geranium, \&c.

The species of geranium family most frequently found growing wild in the United States are, 1st. The maculatum, or spotted geranium, known by the common names, crow-foot and spotted crane's bill. It is perennial, and frequents fence-rows, woodlands, and meadows, flowering in May and June in Pennsylvania. The root is astringent, and has been found serviceable in the treatment of dysentery, diarrhac, and hemorrhage. 2. Carolinian Gentian, not so common as the former. Three or four addi- tional species are enumerated in the United States. (Darlington's Flor. Cestrica.)

GERMANDER (Teucrium). Of this genus of perennia! plants there are three wild species common to England. 1. The wood germander, or wood sage ( $T$. scorodonia), which is found growing very profusely in heathy, bushy places and woods, on a sandy soil, and flowers in the month of July. 'The root is creeping; the stem reaches to two feet high, is leafy, hairy, acutely quadrangular. The leaves are deep green, wrinkled, hairy, copiously serrated; the flowers are pale yellow, in clusters, terminal, and axillary; corolla pale yellow, middle lobe concave and hairy. The whole plant is glutinous, and has a bitter taste, with an agreeable aromatic scent, much resembling that of hops, for which it is said to be no bad substitute in making beer. It is used in the island of Jersey in brewing.

2. The water germander ( $T$. scordium) is less common, and grows in low, wet meadows and damp marshy situations, and produces purplish flowers in July and August. The herb is downy; the leaves are very bitter, and somewhat pungent, with a strong garlic-like odour. The root is creeping; the stem recurnbent, branching, with obtuse, horny, scarcely serrated sessile leaves, an inch long. Flowers two, from axilla of each leaf. Corolla pale Aull purple; middle lobe flattish, with two spots. It is eaten by sheep and goats, but re fused by horses, hogs, and cows, though the latter will eat it when impelled by hunger; but it spoils the flavour of their milk.

3. The common wall germander ( $T$. chamadrys) is found on the borders of cornfields that are remote from houses, or old ruined buildings and stony banks : it produces crimson or reddish purple flowers, which blow in the month of June or July. Root creeping; stems erect, bushy, leafy, hairy; angles rounded; leaves dark green, tapering, fringed, entire at the base. Flowers have the central lobe rounded, a little concave; the lateral lobes and the tube hairy. The whole herb is very bitter, with a weak aromatic flavour, and was formerly used to remove obstructed secretions, to promote expectoration, perspiration, \&c. (Eng. Flor.vol. iii. p. 69.) In the United States there is a species of germander called, in the Middle States, Wood Sage (T. Canadensis). The root is perennial, and it frequents fence rows and low shaded grounds. One other species of this plant has been found on the Rocky Mountains. (Flor. Cestrica.)

GERMANY. The agriculture of a district so extensive as that of Germany, naturally varies with the nature of the climate and the degree of knowledge possessed by the inhabitants of the numerous and extensive provinces of which the empire is composed. In the Mecklenburgs, or that portion of Germany bounded by the Baltic on the north, according to Mr.J.S. Carr, "from north to south there is a ridge of elevated sandy land (the same which may be traced from the Bannat in Hungary to Jutland in Denmark) varying from 10 to 20 miles in breadth, affording miserable crops of corn and worse pasture; but the soil improves on both sides towards the Elbe and 
the Baltic, where fine districts of rich loams and clays are managed with considerable plodding industry." The farms in northern Germany vary in size from 50 to 60 acres, cultivated by peasants, to 300 and even 2000 in the hands of the farmers and proprietors. The number of cows kept by the farmers are often 300 and 400 , and they are sensibly alive to the advantages of sheltering stock in winter. Their sheep-houses are commonly large enough to hold 5000 head. 'They usually harvest all their corn in barns. Their agricultural implements are defective: for instance, they use generally, instead of a plough, an instrument called a haken, which is exactly similar to one used by the Roman farmers. Their harrows have commonly wooden teeth, and are worked with five horses, in a very bungling manner. They often break up their pastures with this clumsy instrument in summer, expose it to the frosts of the following winter, spread over it their dung, and in the following July sow broadcast rape seed. This they dress with $100 \mathrm{lbs}$. of gypsum dust per acre, in the following spring, and in July the seed is ripe, which is then trodden out by horses on large canvass sheets in the field. "The oil of this seed, when putrefied, is without smell, gives a brilliant, clear-burning flame, and is universally used all over Germany, in the saloon and the cottage." If this crop escapes the manifold contingencies of slugs, caterpillars, turnip fly, and beetles, it is a very remunerative one, worth from $10 l$. to $20 l$. per acre. The improved rotations now commonly followed in Germany are, 1. Fallow, well dunged. 2. Rape. 3. Wheat. 4. Barley. 5. Peas (with light dunging). 6. Rye. 7. Oats, sown down with rye or Timothy grass, and red clover, "which, as well as the peas, is gypsumed with great effect before the dew has left the plant of a May morning." The clover, after being twice mown, is left 2 years longer for pasture. Marl, at the rate of 164 cubic feet per acre, is much used, and is the beginning, in many places, of all improvements. The haken is worked by oxen. The merino breed of sheep is now extensively cultivated in the Mecklenburghs and in Saxony. There is little else to be noticed in their live-stock. The farm servants are commonly lodged and fed in the house, and are paid from $5 l$. to $6 l$. per annum. The married labourers have a free house and firing, the keep of a cow, and about one rood of garden, and twice as much potato land. The average rent of wheat and barley lands is about 18 s. per acre. Manures of all kinds are preserved with much care; and they show a wisdom in the collection of night-soil and that of the sewerage of their towns, which it would be well to imitate in England. These manures are exteusively used for their vineyards in several parts of Germany. The following account of them is taken from a paper by Dr. Granville:

"In most of the cities of the second order, and the smaller capitals, night-soil is a source of profit, first to the householder, next to a middleman, and thirdly to the farmer, who is the last purchaser, and employs it. In all the towns of the Grand Duchy of Baden, of the kingdom of Würtembure, of Bavaria (excepl Munich and Würtzburg), of the province of Salzburg, of Bohemia (except Prague), of Baxony (except Dresden), in some of the minor cities of Prussia, in all the confederated prin. cipalities, in all the cities on both banks of the Rhine, particularly Strasburg, Mayence, $\mathbf{C}_{()-}$ blentz, Bonn, Cologne, Dusseldorf, Nimeguen, \&c., the householder disposes of the contents of his cesspool for a certain sum of money, besides getting the operation of emptying it performed gratuitously. By comparing the returns of the different prices paid in those cities for the commodity in question, one year with another, and equalizing them by an average price, founded on positive data, which I possess, the inhabitants appear to be benefited to the amount of 4 francs a head yearly, and the middle-man to at least 40 per cent. more on the sum he pays to the original seller. I will cite Strasburg as an example, since most of the other cities of the same extent (on the Rhine, and in many parts of Germany), and a few cities even larger, presented the strongest analogy to the case I have selected. At Strasburg a company of middlemen engage to empty the cesspools, of which every house has at least two (built air and water tight), once a year for nothing, and pays, moreover, 6 francs per charette, containing 96 baquets, of the capacity of 4 gallons each. This quantity the company sells afterwards to the farmers for ten francs. (The capacity of the charetle being to that of a ton, as 28,772 ounces are to 35,840 , it follows that the price of a ton at Strasburg would be 10 s.) Now, as there are 14,000 houses in Strasburg, 10,000 of which have cesspools. affording the soil in question (which is always semi-liquid), supposing the latter to be emptied only once a year, and to furnish each 3 charettes only, at six francs, we have $10,000 \times 6 \times 3$ $=180,000$ francs, which the company pays yearly to the inhabitants of a town having a population of 70,000 souls. But as the company resells to the farmer the said soil for manuring purposes, at ten franes per charette, it follows that this article of traffic produces yearly at Strasburg 300,000 francs, or just about $4 \frac{1}{4}$ francs for each inhabitant. The average sum, therefore, for each inhabitant of a city, where the mixed contents of cesspools are sold for their benefit, which I have assumed may be adopted with safety, as founded on fact. (Journ. Roy. Agr. Soc. vol. i. p. 124 371 ; Rep. Thames Improv. 17.)

GERMEN (Lat. a bud). In botany, the organ commonly called the ovarium.

GERMINATION (Lat. germen). The process by which a plant is produced from a seed. It is, in truth, the springing into life of a new individual. The phenomena of germination are best observed in dicotyiedonous seeds; such, for instance, as the beati, pea, lupin, \&c. These seeds consist of two lobes or cotyledons, enveloped in a common membrane; when this is removed a small projecting body is seen, which is that part of the germ which subsequently becomes the root, and is termed the $r a$. dicle: the other portion of the germ is seen on carefully separating the colyledons, and is termsed the plumula; it afterwards forms the stens 
and leaves. When the ripe seed is removed from the parent plant it gradually dries, and may be kept often for an indefinite period, without undergoing any change; but if placed under circumstances favourable to its germination, it soon begins to grow: these requisite circumstances are a due temperature, moisture, and the presence of air. The most favourable temperature is between $60^{\circ}$ and $80^{\circ}$; at the freezing point none of the most perfect seeds vegetate, and at temperatures above $100^{\circ}$ the young germ is usually injured. No seed will grow without moisture: water is at first absorbed by the pores of the external covering, and decomposed; the seed gradually swells, its membranes burst, and the germ expands. The root is at first most rapidly developed, the materials for its growth being derived from the cotyledons; and when it shoots out its fibres or rootlets, these absorb nourishment from the soil, and the plumula is developed, rising upwards in a contrary direction to the root, and expanding into stem and leaves. For this growth the presence of air is requisite; if it be carefully excluded, though there be heat and moisture, yet the seed will not vegetate. Hence it is that seeds buried very deep in the earth or in a stiff clay, remain inert; but on admission of air, by turning up the soil, begin to vegetate. From experiments which have been made upon the germination of seeds in confined atmospheres, it appears that the oxygen set free by the decomposition of water, combines with a portion of the carbon of the seed, and carries it off in the form of carbonic acid, and that the consequence of this is the conversion of part of the albumen and starch of the cotyledons into gum and sugar; so that most seeds, as we see in the conversion of barley into malt, become sweet during germination. Light is injurious to the growth of the seed. It is, therefore, obvious that the different requisites for germination are attained by placing a seed under the surface of the soil, where, warmed by the sun's rays, and moistened by the humidity of the atmosphere, it is excluded from light, but the air has access to it.

Oxygen is an essential agent in the process of germination, and without it seed will not germinate, a fact which has been demonstrated by placing seeds in vacuo, and in nitrogen, hydrogen, and carbonic acid. But, as in animal life, too much oxygen is hurtful: it abstracts the carbon too rapidly, overstimulates, and causes feebleness of growth to the infant plant.

When the young plant is perfected, the cotyledons, if not converted into leaves, rot away, and the process of rutrition is carried on by the root and leaves: the principal nourishment is taken up from the soil by the root, and chiefly by its small and extreme fibres; so that when these are injured or torn, as by careless transplantation, the plant or tree generally dies. The matters absorbed, consisting of water holding small portions of saline substances, and of organic matter in solution, become the sap of the plant: and this is propelled upwards in the vessels of tne stem, or of the nuter layer if the wood, into the leaves; here it is exposed $n$ the agency of air and of light; moisture, 538 and occasionally carbonic acid, is transpired. But the leaves also at times absorb moisture, and during the influence of light they decompose the carbonic acid, and retaining the carbon, evolve oxygen; the sap thus becomes modified in its composition, and the charac. teristic proximate principles of the vegetable are formed. These return in appropriate vessels from the leaves chiefly to the inner bark, where we accordingly find the accumulation of the peculiar product of the plant; they also enable it annually to form a new layer of wood. Hence it is that the transverse section of the wood exhibits as many distinct zones as the tree is years old. We are ignorant of the causes of this ascent of the sap; but that it does follow the cause which has been stated is proved by the operation which gardeners call ringing, and which they sometimes resort to, to make a barren branch bear flowers and fruit. It consists in cutting out and removing a circular ring of bark, so as to prevent the return of the sap by the descending vessels, which at first ooze copiously, but afterwards the wound heals, and the juices are accumulated in all parts above the extirpated ring, producing tumefaction in the limb, and often inducing a crop of flowers and fruit, or causing those to appear earlier than on the uncut branches.

If a tree be wounded so as to cut into the central portions of the wood, or the outer layer of new wood, the flow of ascending sap is then seen to take place upon the lower section, where the vessels are that carry it up to the leaves; and the flow of descending proper juice is principally confined to the upper section of the inner bark, from which, after a time, new barls is produced, and the parts are again united. To return to the process of germination, every part of the seed is not essential, nor the whole of the parts. Kidney beans will germinate with only one cotyledon: and oaks, also, germinate in the same state; gourds have been robbed of the radicle and also the plumule, as they shoot forth, and yet germination has proceeded; but the plants produced in all these cases were small, delicate, and never come to perfection.

GESTATION. The gestatory term in quadrupeds is much regulated by their bulk. In the elephant it is about 20 months, in the camel between 11 and 12 , in the mare and ass the same. According to the observations of $\mathbf{M}$. Teissier of Paris, in 582 mares, which copulated but once, the shortest period was 287 days, and the longest 419 ; making the extraordinary difference of 32 days, and of 89 days beyond the usual term of 11 months. The cow usually brings forth in about nine months, and the sheep in five. Swine usually farrow between the 120th and 140th day, being liable to variations, influenced apparently by their size and their particular breeds. In the bitch, on the contrary, be she as diminutive as a kitten, or as large as the boarhound, pupping occurs on or abont the $63 d$ day. 'The cat produces either on the 55th or 56th day. The true causes which abridge or prolong more or less the period of gestation in the females of quad. rupeds, and of the incubation of birds, are yet unknown to us. Many persons are also 
unacquainted with the proper age for repro- be interes ing to find in the following table the duction, the duration of the power of repro- results of observations made on this subject duction, and other conditions even of the do- by the best ancient and modern naturalists mesticated animals. It cannot, therefore, but (Oeconomische neukundige Verhandl.)

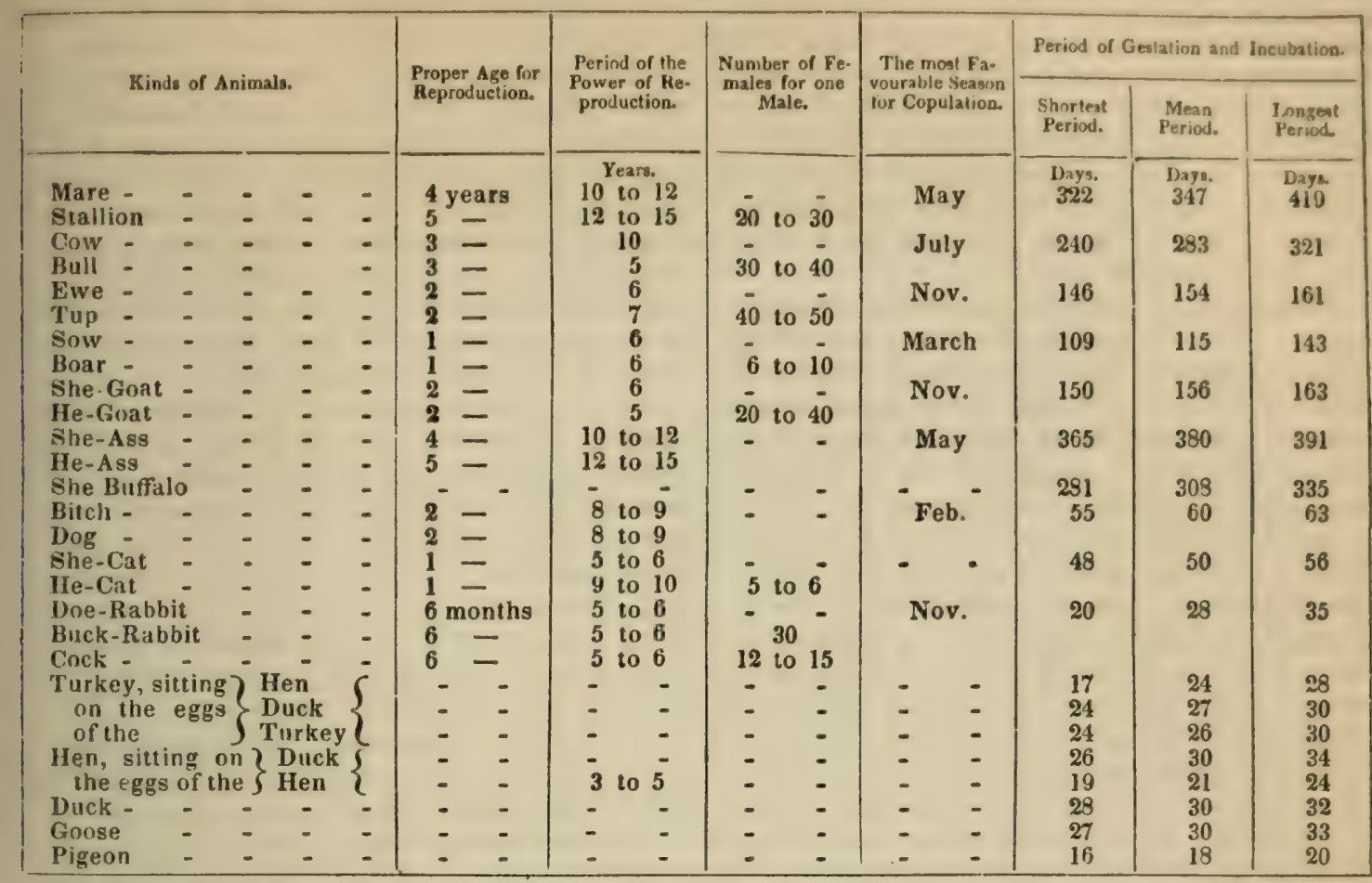

Some of these results do not altogether co- riod; though, with a bull-calf, the cow has incide with the results of observations in Eng- been generally observed to go about 41 weeks land, where, for example, July, the season of and a few days less with a female. Any calf copulation for the cow, is considered too late. produced at an earlier period than 260 days That period would produce late calves in the must be considered decidedly premature, and following year. November is stated to be the any period of gestation exceeding 300 days best season for the ewe; for the black-faced must also be considered irregular; but in this ewe it is, but for the Leicester, and, in many latter case, the health of the produce is not situations, for the Cheviot ewe, it is a month too affected. I will conclude this article with the late. The duration of the power of reproduc- remarks of Mr. C. Hilliard, of Northampton, tion accords with our experience as respects who states that the period of gestation of a the mare and stallion; but 13 years of age for cow is 284 days, or, as it is said, 9 calendar the cow, and 8 for the bull, is too young a months and 9 days; the ewe 20 weeks; the period for old age in them, fine animals of both sexes, of a valuable breed, having been kept in a useful state to a much greater age. I have seen a short-horn bull in use at 13 years, and a cow of the same breed bearing calves at 18 ; but if the ages of 8 and 13 respectively refer to the usual time bulls and cows are kept for use, the statement is not far from the truth.

From some carefully collected and very extensive notes made by Lord Spencer on the periods of gestation of $764 \mathrm{cows}$, it resulted that the shortest period of gestation when a live calf was produced was 220 days, and the longest 313 days, but he was not able to rear any calf produced at an earlier period than $\mathbf{2 4 2}$ days. From the result of his experiments it appears that 314 cows calved before the 284th day, and 310 calved after the 285 th; so that the probable period of gestation ought to be considered 284 or 285 days. The experiments of $\mathbf{M}$. Teissier on the gestation of cows, are recorded to have given the following results :-

21 calved between the 240 th and 270 th day, the mean time being $259 \frac{1}{8}$

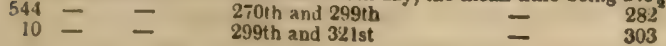
In most cases, therefore, between nine and
ten months may be assumed as the usual pe- from May to July. The root is creeping, sow 16 weeks; the mare 11 months. The well-bred cattle of the present time appear to me to bring forth twins more frequently than the cattle did 50 years ago. The males of all animals, hares excepted, are larger than the females. Castrated male cattle become larger beasts than entire males. (Elaine's Ency. pp. 205, 281 ; Quart. Journ. of Agr. vol. x p. 287.)

GILL. A small valley, connectel with a stream and some woodiness. Also a rivulet, or small brook. It is likewise a provincial name in some districts for a pair of timber wheels.

GILTS. A provincial term applied to young female pigs, whether open or spayed.

GINGER, WILD (Asarum, Asarabacca, Indian ginger). This genus of herbaceous plants are small and unobtrusive. Botanists enumerate three species as found in the United States. That called Canada snake root ( $A$. Canadense), very closely resembles the European asarabacca, and is met with in old woods from Canada to the Carolinas. It has only two round, flat, and kidney-shaped leaves with naked stalks, which, on plucking the plant are found connected below, with an obscure flower in their fork, buried under the decayed leaves. It flowers 


\section{GINSENG.}

GLASSWORT, JOINTED.

fleshy, somewhat jointed, and has an agreeable aromatic taste, intermediate between that of ginger and the Virginia snake root. Hence its popular names. As a warm stimulant and diaphoretic it is much praised, being given in the form of tea or powder; and as a substitute for ginger, in common domestic use, I know of no indigenous article, says Dr. Bigelow, which promises so fairly as this. It does not possess the very active emetic, cathartic, and sternutatory powers of the European asarum. The other American species are the $\mathcal{A}$. Virginicum, and $A$. arifolium.

GINSENG (Panax quinquefolium, five-leaved panax). This American plant, which has great commercial importance, has a perennial root, which sends up annually a smooth, round stem, about a foot in height, dividing at the summit into three leafstalks, each of which supports a compound leaf, consisting of five, or more rarely of three or seven petiolate, oblong, obovate, acuminate, serrate leaflets. The flowers are small, greenish, and arranged in a simple umbel, supported by a peduncle, which rises from the top of the stem in the centre of the petioles. The fruit consists of kidney-shaped, scarlet berries, crowned with the styles and calyx, and containing two, and sometimes three seeds. 'T'he root is fleshy, somewhat spindle-shaped, from 1 to 3 inches long, about as thick as the little finger, and terminated by several slender fibres. Frequently there are two portions, sometimes three or more, connected at their upper extremity, and bearing a supposed though very remote resemblance to the human figure, from which circumstance it is said that the Chinese name ginseng originated. When dried, the root is yellowish white, and wrinkled externally, and within consists of a hard, hornlike substance, surrounded by a whitish, softer, cortical portion. It has a feeble odour, and a sweet, slightly aromatic taste, somewhat analogous to that of liquorice root. It has not been accurately analyzed, but is said to be rich in gum and starch.

The plant grows in the hilly regions of the Northern, Middle, and Western States, and prefers the shelter of thick, shady woods. It is a native also of Chinese Tartary. The root is the part employed. This is collected in considerable quantities in Ohio and Western Virginia, and brought to Philadelphia and other cities on the sea-board for the purpose of exportation to China, where it is highly valued. While supplied exclusively from their own native sources, which furnished the root only in small quantities, the Chinese entertained the most extravagant notions of its virtues, considering it as a remedy for all diseases, and as possessing almost miraculous powers in preserving health, invigorating the system, and prolonging life. It is said to have been worth its weight in gold at Pekin; and the first shipments made from North America t) Canton, after the discovery of the root in this country, were attended with enormous profits. But the subseauent abundance cí supply has greally cimmished $\iota s$ value, and though it still iccasionally forms a part of the investments sor Canton, it has become an object of less :mportance than formerly. 540
The following statement shows the value of the ginseng exported from the United States for seven years ending the 30th September, 1841 : viz. 1834, $\$ 70,202 ; 1835, \$ 94,970 ; 1836$, $\$ 211,405 ; 1837, \$ 109,368 ; 1838, \$ 36,622 ; 1839$, $\$ 118,904,1840, \$ 22,728 ; 1841, \$ 437,245$.

Medical Properties and Uses.-The extraordi. nary medical virtues formerly ascribed to ginseng, had no other existence than in the imaginations of the Chinese. It is little more than a demulcent; and in this country is not employed as a medicine. Some persons, however, are in the habit of chewing it, having acquired a relish for its taste; and it is chiefly to supply the wants of these that it is kept in the shops. (U.S. Dispensatory.)

There is another species of ginseng indigenous to the lower part of Pennsylvania and other sections of the United States, called the dwarf ginseng, or three-leaved panax ( $P$. trifolium). This has also a perennial root, a globose tuber about half an inch in diameter, rather deep in the ground. The stem grows 4 to 6 inches high, slender, minutely grooved, smooth, mostly of a tawny purple colour, divided at the summit into three petioles of half an inch to an inch long. Leaflets, generally three, but not unfrequently five, unequal, half an inch to two inches long, and $\frac{1}{4}$ to $\frac{2}{3}$ of an inch wide, lance-oblong shape, rather acute. The flower is white and has five petals. The plant frequents shaded grounds, along rivulets, where it blooms in April. (Flora Cestrica.)

Professor Hooker describes a third species of ginseng ( $P$. horridum), which is large, shrubby and prickly. This grows west of the Rocky Mountains.

GI PSE - W ORT, or WATER HORE. HOUND (Lycopus Europaus). An herbaceous perennial plant, growing on the banks of clear ditches, pools, and rivers, on a sandy or gravelly soil, flowering in July or August. The root is creeping, stem two feet high, leaves numerous, oblong, acute, deeply serrated, often deeply pinnatifid. Flowers white, with purple dots. See Bugle WEED.

GLANDERS. A disease in horses, attended with a copious discharge of mucus from the nose. It is needless to endeavour to describe the various attempts which have been made to cure this almost invariably fatal disorder. But the farmer must avoid a common error of confounding ulceration of the membrane of the nose with glanders, for the symptoms are very similar. Blue vitriol (sulphate of copper) in thin gruel (one drachm doses) has been given in recent cases with occasional success. The nostrils may be washed with a solution of chloride of lime. The farmer will do well, as soon as he finds a horse attacked with this disease, to place him by himself, give him green food, and thoroughly whitewash the stable from which he is taken, for it is a most contagious disease.

GLASSWORT, JOINTED (Salicornia; from sal, salt, and cornu, a horn). Of this genus of plants there are, in England, four indigenous species, which are found very common in salt marshes and muddy sea-shores that are fre. quently overflowed by the tide.

1. The common jointed glass wort, sea-grass 
or marsh samphire (S. herbacea), is an annual plant, with a small fibrous root, a bushy, green stem a foot high, with opposite branches; woody centre very tough. Flowers on numerous short-jointed spikes. The whole plant has a saline taste, abounding in salt juices, and is therefore devoured with avidity by all kinds of cattle; and it is a very wholesome food, especially for sheep. It is often pickled, as a substitute for the very different strongly aromatic rock samphire (Crilhmum maritimum), to which it is for this purpose very little inferior.

Several other species of glass-wort are enumerated, three of which Mr. Nuttall gives as American, which, like the European, affords soda when burned, and are preserved in vinegar as a pickle.

Soda is yielded in large quantities by the ashes of the different species of Salicornia; and is in great request for manufacturing soap and glass: the best is imported from Spain, under the name of Barilla (see SonA). These plants will grow in any common soil, and are readily increased by divisions. Being natives of the sea-shore, the plants will thrive better if a little salt be nccasionally sprinkled on the surface of the soil. (Willich's Dom. Ency.)

GLOW-WORM (Lampyris noctiluca). This insect is remarkable for the light it emits during the night. This luminous appearance depends upon a phosphorescent fluid found at the lower extremity of the insect; which, by unfolding or contracting itself, it can withdraw at pleasure ; a power of consequence to the insect, as it is thus secured from the attacks of nocturnal birds. The light arises from a sac, which is diaphanous, and contains a secreted thuid consisting of albumen and phosphorus. Glow-worms are sometimes called St. John's worms, from appearing first as a common occurrence about the Feast of St. John the Baptist. 'The glow-worm is the perfect female of a winged beetle; the males fly about chiefly in autumn, and frequent the grassy plantations of juniper trees.

GLUE (Lat. gluten). is prepared from the chippings of hides, hoofs, \&c. The refuse matter of the glue-makers, according to $\mathrm{Mr}$. Miles, is an excellent manure for turnips.

GLUTEN (Lat.). The viscid elastic substance which remains when wheat flour is wrapt in a coarse cloth, and washed under a stream of water, so as to carry off the starch and soluble matters. Gluten, when pure, is inodorous, insipid, tenacious, adhesive, and elastic. It is insoluble in water, but soluble in hot alcohol. It is also soluble in a dilute solution of potash. When kept moist and warm, it ferments. Gluten exists in grains, and occasionally in other parts of vegetables; but it is a characteristic ingredient in wheat, giving wheat flour its particular toughness and tenacity, which particularly fits it for the manufacture of bread, and for viscid pastes, such as macaroni and vermicelli. There is generally more gluten in the wheat of warm climates than of cold; hence the excellence of that grown in the south of Europe for the manufactures just mentioned. Gluten seems also to constitute the essential part of yeast. Its uses as a varnish, a ground for paint, \&c., pointed out by Cadel, likewise deserve altention. Gluten was discovered in 1742 by Beccaria, an Italian philosopher, to whom we are indebted for the first analysis of wheat flour. The number of plants containing gluten is very considerable. Proust found it in acorns, chestnuts, rice, barley, rye, peas and beans, and in apples and quinces. He found it also in the leaves of the cabbage, cress, hemlock, borage, saffron, \&c., and in the sedums; in the berries of the elder, the grape, \&c.; in the petals of the rose, \&c. Gluten has been shown to resemble albumen so closely that they can hardly be considered as distinct principles. Gluten contains nitrogen, and has, consequently, been called the vegeto-animal principle, on this account. It yields ammonia, when subjected to destructive distillation; and the vegetables which contain it give out a peculiarly disagreeable odour during their putrefaction. M. Magendie, after feeding animals upon different kinds of food, states that gelatine, fibrin, albumen, when taken singly, do not possess the power of nourishing animals for any length of time; they always die. The reverse is the case, however, with gluten, upon which animals thrive well and long.

GNATS (Culex, Linn.). A genus of insects comprising several species, which are well known by the severe punctures they inflict The gnat most common in Europe is the $C$. pipiens, so named from the sourd which it emits in its flight. The sting consists of 5 pieces and a sheath; some of the pieces are simple lancets; others are barbed, and act both as piercers and as siphons, to extract the blood from the wounds which they make. Gnats deposit their eggs, to the number of 200 by each female, on stagnant waters, where they are hatched into small grubs in the course of 2 or 3 days. On the sides are 4 small fins, by the aid of which the insect swims about, and swiftly dives to the bottom. The larva retains its form a fortnight or 3 weeks, when it is converted into the chrysalis, in which state it continues 3 or 4 days, floating on the surface of the water, till it assumes the form of the gnat. The most efficacious remedies for their sting are olive oil, unsalted butter, or fresh hog's lard, timely rubbed in. Gnats have occasionally appeared in such numbers as to form a cloud, almost darkening the air, as was the case in August, 1766, near Oxford. Spencer describes a similar flight of them in Ireland-

"As when a swarme of gnats at eventide, Out of the fennes of Allan doe arise,

Their murmuring small trumpets sownden wide, Whiles in the air their clustering army flies, That as a cloud doth seem to dim the skies." Faery Queene.

The mosquito of tropical climates is a species of the same genus as the gnat; and the latter is not less troublesome in some of our marshy districts than the mosquito in the West Indies. In the marsh land of Norfolk, the bet ter classes are forced to have gauze curtains to keep them off during the night.

The species of gnat best known in America is a small, black fly, which swarms during the month of June, and is especially annoying to travellers, and the first inhabitants of new set- 
tlements. Every bite made by these fierce little insects draws blood, and is generally followed by considerable irritation, and even inflammation. "These little tormentors," says Dr. Harris, "are of a black colour; their wings are transparent; and their legs are short, with a broad, whitish ring around them. The length of their body rarely exceeds one-tenth of an inch. They begin to appear in May, and continue about 6 weeks, after which they are no more seen. They are followed, however, by swarms of midges, or sand-flies (Simulium nocivum), called no-see-'em, by the Indians of Maine, on account of their minuteness. So small are they, that they would hardly be perceived, were it not for their wings, which are of a whitish colour, motiled with black. Towards evening these winged atoms come forth, and creep under the clothes of the inhabitants, and by their bites produce an intolerable irritation, and a momentary smarting compared to that caused by sparks of fire. They do not draw blood, and no swelling follows their attacks. They are the most troublesome during the months of July and August." (See MosqurTo.)

GOATS (Capra). There are three species of this genus enumerated by naturalists. 1. The wiid goat (C. agagrus); 2. The ibex (C. ibex); 3. The Caucasian ibex (C.Caucasia): of these, the first is believed to be the original of the many varieties of the domestic goat.

The goat appears (says Prof. Low) to form the connecting link between the sheep on the one hand, and the antelope tribes on the other. Being the natural inhabitant of mountainous regions, it is, therefore, in wild, rocky countries that the goat is chiefly reared. Goats are stronger, more nimble, and less timid than sheep, and are more easily supported than any other animals, for there are few herbs which they do not relish : they will browse on heaths, shrubs, and plants, which are rejected by other animals; and it is well known they can eat with safety herbs (such as the hemlock, henbare, \&c.) which would prove destructive to sheep and other animals. Goats are more hardy, and rot liable to so many diseases as sheep. The goat is not well adapted to a country of enclosures, because it feeds upon the twigs of hedges, and escapes over the barriers intended to confine it. But where there are no young trees to be injured, they may browse at large on the mountain brakes without expense; and in winter, when housed, they are easily supported on whins or furze, cabbage leaves, potato-peelings, and such worthless food.

Goats emit at all times a strong and disagreeable odour, named hircine, which, however, is not without its use, for if one of these animals be kept in a stable, it is affirmed that it will be an effectual preventative of the staggers, a nervous disorder which is often very fatal to horses. In Great Britain the cultivation of the goat is limited and partial. It is chiefly confined to the mountainous parts of Wales, the Highlands of Scotland, and to the little farms of the poorer peasants of Ireland, whose scanty possessions will not support a cow. The great objection there to the rearing of the goat, is the want of demand for its flesh, which 542 is hard, and almost indigestible. Even the kid, whose flesh is known to be very delicate and nourishing, is held in no estimation : hence all the other properties of the goat are insufficient to render it an object of profitable production. But the goat, although it never can be so valuable there as in the dry and rocky countries of the south of Europe, does not deserve that entire neglect with which it is treated. It arrives early at maturity, and is very prolific, bearing two and sometimes three kids at a birth. The period of gestation is five months. The female bears for six or seven years; the male should not be kept longer than five. In Portugal and some other countries the goat is used as a beast of draught for light burdens. The hair of the goat may be shorn, as it is of some value, making good linsey; that of the Welch hegoat is in great request for making white wigs. Ropes are sometimes made from goats' hair, and are said to last much longer, when used in the water, than those made of hemp. Candles are manufactured from their fat, which, in whiteness and quality, are stated to be superior to those of wax; their horns afford excel. lent handles for knives and forks; and the skin, especially that of the kid, is in demand for gloves and other purposes. Goats' milk is sweet, nutritive, and medicinal, and less apt to curdle on the stomach than that of the cow : it forms an excellent substitute for that of asses. When yielding milk the goat will give, for several months, at the average of two quarts per day. Mr. Pringle of Kent, in his Essay "on Cottage Management" (Gard.Mag. vol.5), informs us that two milch goats are equivalent to one small Shetland cow. Cheese prepared from goats' milk is much esteemed in mountainous countries after it has been kept a proper age. (Low's Pract. Agr. and Breeds of Dom.

\section{Animals: Willich's Dom. Encyc.)}

GOAT'S-BEARD (Tragopogon). Of this common pasture-weed there are two species 1. The yellow goat's-beard (T. pratensis), a hiennial, growing in grassy pastures and merdows, on a loamy or clayey damp soil. 'The root is tapering, flowering in June; the whole herb very smooth, abounding with milky juice, rather bitter, but not acrid. Stems several, round, leafy, often purplish, $1 \frac{1}{2}$ to 2 feet high. Leaves long and taper poirted, often flaccid, or curling at the extremity. Flowers large, 2 inches wide, bright yellow, opening very early in the morning, and closing before noon, except in very cloudy weather. The roots and young shoots have been eaten as pot-herbs.

2. The purple goat's-beard (T. porrifolius), also biennial, grows in most meadows, near great rivers; herb smooth, 3 or 4 feet high, glaucous. The dull purple flowers, like the preceding species, close at midday; thence it is called in the country Go-tu-bed-at-noon.(Smilh's Eng. Flor. vol. iii. p. 337.)

GOAT-WEED (Capraria biflora). An uninteresting species of plants, of easy culture. The leaves of this genus are liked by goats; hence the common and generic names.

GOGGLES. See Suere, Diseastis of.

GOLD and SILVER FISH. These beautiful creatures were first introduced into Eng. land from China about the close of the !7th 
century. The first are of an orange colour, with very shining scales, and finely variegated with black and dark brown. The silver fish are of the colour of silver tissue, with scarlet fins, with which colour they are curiously marked in several parts of the body. These fish are usually kept in ponds, basins, and small reservoirs of water, to which they are a very great ornament. It is also a very common practice to keep them in large globular glass vessels, frequently changing the water, and feeding them with bread and gentles. The gold fish is now abundant in the river Schuylkill, near Philadelphia, into which they first made their way in consequence of the overflowing of a fish-pond in Pratt's garden, where considerable numbers were kept.

GOLDEN CLUB, called also Never-Wet, and Floating Arum (Orontium aquaticum). A plant not unfrequent in pools along the fresh water streams of the United States. It has a perennial root, leaves enlarging, finally to 8 , 10 , or 12 inches long, and 3 to 5 inches wide, a little succulent, very smooth, of a deep green and velvety appearance on the upper surface, paler and somewhat glaucous beneath. Flowers yellow.

\section{GOLDEN OAT GRASS. See Avena.}

GOLDEN-ROD (Solidago, from solidare, to unite, on account of the supposed vulnerary qualities of the plants). This is an extensive genus of coarse flowering plants suitable for the back of flower borders. Any common soil suits them, and they are readily increased by division of the roots. The common goldenrod, or wound-wort (S. virgaurea) is a native of Britain, growing in woods, hedges, heaths, and copses; and on mountains at every degree of elevation. It is perennial, and flowers from July to September. It is a very variable plant in magnitude, number, and size of flowers, and serrature of the leaves: nor do these varieties altogether depend on situation, except that in alpine specimens the flowers are larger and fewer. The root is woody, with long, stout, simple fibres; the stem usually from one to three feet high, never quite straight, purple below, most downy in the upper part, where it terminates in a leafy cluster, either simple or compound, of bright yellow flowers. When bruised, the whole herb smells like wild carrot. Its qualities are diuretic, astringent, and perhaps tonic; and it has been recommended as a vulnerary both externally and internally, but it is now never used in medicine. It may, with greater advantage, be employed as a dyeing drug, for both the leaves and flowers impart a beautiful yellow colour, which, according to Bechstein, is even superior to that obtained from woad. The Canada golden-rod (S. Canadensis) is frequently used for this purpose. (Eng. Flora, vol. iii. p. 438.)

Solidago is exclusively a North American genus of plants, with the exception of 5 or 6 species in Europe, and $\mathbf{2}$ found near Canton, in China. About 50 species of golden-rod have been enumerated by botanists in the United States, some of which are, however, regarded as mere varieties. (Nuttall's Genera._Flor. Cest.)

GOLDEN-SAXIFRAGE (Chrysosplenium, frnm chrysos, gold, and splen, the spleen, in refence to the deep yellow colour of the flow ers, and the supposed medicinal virtues of the plant). This is a curious and rather pretty genus. It requires a moist situation, and may be increased by dividing the roots. The native species in England are found in the great. est perfection upon the shady banks of small rivulets. They are two in number, both perennials, flowering in May. The alternate-leaved golden-saxifrage (Ch.alternifolium) has the root fibrous and creeping; stems angular, decum. bent, branched at the top only; leaves alternate, reniform, rough on both sides the notches, but the under disk pale and polished; radical leaves on long stalks, those of the summit crowded and sessile; flowers in a corymb, deep yellow. The opposite-leaved golden. saxifrage ( $C h$. oppositifolium) resembles the preceding, but is paler; the leaves smaller and the flowers of a pale lemon yellow. (See $S_{\mathbf{A} x I}$ FRAGE.

GOLD OF PLEASURE (Camelina sativa, wild flax). This is rather a dwarf plant, growing from 1 to 2 feet high, which is found in cultivated fields, chiefly among flax, with whese seeds it is often introduced from abroad; but it does not long propagate itself with us spontaneously. It is an annual, blowing small, pale-yellow flowers in June. It is cultivated in some parts of Europe for the sake of the oil, which is obtained from the seeds. The species of the genus to which it belongs have but little beauty, and require to be sown in the open border. See Wild Frax.

GOOSE. A well-known large, web-footed bird, belonging to the order natatores, or swimmers. These are remarkable for their powers of swimming and diving; they are commonly called water-fowl, and, as an order, have frequently been designated palmipedes, in reference to their webbed feet. From the geographical position, extent, and varied character of the British islands, the species of this order are very numerous, comprehending nearly onethird of the whole number of our British birds. The first family of this order, the anatida, is also extensive; including the geese, swans, ducks, and mergansers. The first three portions were formerly considered as belonging to but one genus, anas; and hence the family name, anatida. Modern systematic authors have found it more convenient, as well as desirable, to divide them into smaller groups, which are known to be distinct in their character and habits. Many of the species are of great interest and value. The present article will, however, be restricted to some account of tame geese.

Two varieties of the domestic goose are indigenous to Great Britain, the gray and white goose, and the pure white, which is of a larger size. The first is our most plentiful breed: the second are bad breeders, seldom producing more than three goslings at a brood, and that only every alternate year. There is, also, the Chinese breed, which is naturalized among us, valuable for their early breeding, and quis: fattening. The Chinese goose lays about the end of November, if the weather is noi sevele, and produces her goslings in January. There goslings, if lept dry and warm, are fit for the 
table in April and May. This goose 1s, however smaller, less delicate eating, and more noisy than the common gray goose. The common goose begins to lay towards Candlemas, and after laying from 9 to 11 eggs, she sits 30 days, and then brings out her little flock. If, however, she show a wish to sit when she has only laid two or three eggs, she must be driven from the nest, or be shut up for a day or two. She will then take to lay again. One gander and five geese are the regular stock to begin with: they will produce 50 goslings in a season. Geese are grazing birds: they love a common, but horses do not like their company in a field, as they object to feed after them. The herb called goose-grass they are immoderately fond of, and it is plentiful always under hedges during the gosling season. Water is important to geese, but they succeed in situations where there is no pond: a large, shallow pan filled with water, sufficiently capacious to admit of their washing in it, has often answered the purpose; but a pool is most desirable. The goose-hovel should be low, well thatched, and not facing into the farm-yard, otherwise pigs will get through the gooseaperture. It should have a door, also, for the poultry-woman to enter. The nests should be composed of straw, lined with hay, and the birds should be fed near their home, to allure them to it. If some of the goslings are hatched before the others, they should be removed from the mother, kept warm in flannel before the fire, and returned to her when the whole brood are hatched. Thin barley meal and water is excellent food for goslings, with chopped goose-grass; they soon learn to eat oats, and feed themselves. Mow down hemlock, if any grows near the poultry-yard: it is pernicious in its effects upon poultry. Fatten geese in small parties, as they love society. They should be cooped a month, fed plentifully with sweet oats and clean pure water in a narrow wooden trough. An experiment has lately been tried of feeding geese with turnips, cut up very fine, and put into a trough with water. The effect was, that six geese, weighing only nine pounds each when shut up, actually weighed 20 pounds each, after about three weeks' feeding with this food alone. Halfgrown or green geese are delicate eating in June and July; but they need not be cooped, they must only be well fed. Goose feathers are valuable, and their dung is employed as a manure by agriculturists.

GOOSEBERRY (Ribes grossularia). The gooseberry is indigenous to Great Britain, some other European countries of cool temperature, and also to the mountains of North America. The varieties of this fruit are too numerous to notice. By some botanists they are referred to two species, Ribes grossularia, the rough gooseberry, and $R$. uva-crispa, the smooth gooseberry; but others consider the latter as being merely a variety of the former, which is more correct, as it has been proved iny successive reproductions that the rough will sometimes become smooth and the smooth rough. The gocseberry ripens in the extreme northern parts of Britain, if near the level of the sea; and at an altitude of about 900 feet, 544 in the centre of the island, it acquires greal perfection of flavour. In the southern coun. ties, if the season be warm, it cannot bear full exposure to the vertical rays of the sun: in such circumstances evaporation takes place from the surface faster than the subjacent tissues can supply the loss, the superficial cells get emptied, and the fruit dies.

In England the gooseberry is esteemed one of their most valuable fruits. In spring it fur. nishes the earliest as well as the best fruit for tarts and sauces: and can be preserved green as well as ripe for winter use. When ripe it makes an excellent jam, a delicious sweetmeat, a luscious wine, and is a favourite dessert.

The following selection is recommended for small English gardens: Reds-Old rough red, Melling's crown bob, Farmer's roaring lion, Knight's Marquis of Stafford, Champagne and Capper's top sawyer: one of the best of the red gooseberries is the Scotch ironmonger: it is hairy, and thin-skinned. Yellows.-Hardzastle's gunner, Hills's golden gourd, Prophet's rockwood, Hamlet's kilton, Dixon's golden yellow, Gordon's viper. Greens.-Edward's jolly tar, Massey's heart of oak, Nixon's green myrtle, early green hairy, Parkinson's laurel, Wainwright's ocean. Whites.-Coleworth's white lion, Moore's white bear, Crompton's Sheba queen, Saunders's Cheshire lass, Wellington's glory, Woodward's whitesmith. Smooth skins become tough in cooking, and should not be selected for that purpose.

The gooseberry can be raised from cuttings, from suckers, or from seeds: the former is generally resorted to as being the most expeditious; and seed is only sown to raise new varieties. Cuttings may be planted in the fall, or as early in the spring as the weather will permit.

The gooseberry is, comparatively, but little cultivated in the United States, though there is no doubt that in several districts of the Middle and Eastern States it could be brought to as great perfection as in England. It is a native of the soil: and loves to climb the sides of our mountain ridges, and if planted in places that somewhat resemble its native habitats, it would no doubt repay our care. It ought to have an airy situation, a rich soil, and a dry subsoil is essential, or it becomes infected with mildew. If it has no natural shade, during a few hours in the middle of the day, it must be shaded from the extreme heat of the sun. The berries acquire their finest flavour when brought to maturity gradually, under a low temperature. In pruning, instead of the lateral young shoots being cut close in, immediately above the first bud at their base, as recommended in colder climates, two buds should be left, to produce leaves to shade the fruit in summer. The vigorous-growing varieties ought to be prefer. red for planting.

Gooseberrx Catenpilian. For the destruction of these insects fumigations of various kinds; dusting with quick lime, and other methods have been resorted to, but they do not always answer the purpose. Wetting them by means of a proper syringe, with fresh lime-water, whilst the sun is shining strongly, is said to be a very effectual remedy. The 
roots of the plant are not made wet by this operation which promotes the growth of the bushes and helps their bearing properties. Tobacco liquor is also often found a good application for the destruction of caterpillars, and also the solution of whale oil soap, as recommended for the destraction of bark-lire and aphidians. This last remedy is also said to be completely effectual in removing the mould, rust, or mildew to which the gooseberry-bush is so very subject, an affection which would seem to be capable of propagation with the plants. Mr. S. R. Gummere, of Burlington, New Jersey, an intelligent botanist, and successful horticulturist, states that the russet mould to which the gooseberry-bush is subject, may be prevented by carefully removing the buds from that portion of the cutting which, in planting, is inserted into the ground.

Seventeen or eighteen species of gooseberry, says Dr. Darlington, are enumerated as natives of the United States. Of these the Missouri currant (libes aureum) is much cultivated, and greatly admired for the beauty and spring fragrance of its flowers.

GOOSEFOOT (Chenopodium). An extensive genus of plants, of which 13 species are enumerated by Sir J. E. Smith, as natives of Britain, viz. 1. Mercury goosefoot (C. bonus Henricus), growing in waste ground and by road sides frequent, and occasionally in pastures. The root is branchy and fleshy; the herb dark green, nearly smooth; stem a foot high, terminating in a compound crowded cluster, or spike, of numerous green flowers; their stalks sometimes unctuous and mealy. This, our only perennial chenopodium, may be eaten, when young, like spinach, and is cultivated for the table in some parts of Lincolnshire. It is insipid and mucilaginous, rather mawkish, and soon becomes tough and fibrous. Neither goats nor sheep relish this plant, which is also refused by cattle and hogs. 2. 'The upright goosefoot (C. urbicum), and 3., The red goosefoct, also occur commonly on waste ground; the former sometimes on dunghills, and the latter in low, muddy situations. In exposed situations the whole herb of $C$. rubrum assumes a red colour. This species and its allies are said to be poisonous to swine; 4. The many spiked goosefoot ( $C$. botryoides); 5. The nettle-leaved goosefoot, 6 . The mapleleaved goosefoot, call for no observation. The whole plant of the two last species is fetid; 7. White goosefoot, or common wild orache (C. album), is found in cultivated as well as waste ground everywhere. 'The herb is mealy, with a silvery unctuous pubescence, which, by age, becomes dry and chaffy. The young plant is reported to be eatable when boiled, and is known by the name of fat-hen in some parts of Norfolk. It is eaten by cattle, sheep, and hogs, which last devour it with avidity; 8. 'The fig-leaved goosefoot ( $C$. ficifolium), flourishes most on dunghills, especially about London; 9. The oak-leaved goosefoot ( $C$. glaucum), varies in height from 2 inches to 2 feet, and grows for the most part on a sandy soil; 10. Standing gonsefoot ( $C$. olidum), This species is found very commonly among sand or rubbish near the sea. 'The whole herb is of a dull grayish-green, covered with a greasy mealiness, which, when touched, exhales a strong, permanent, nauseous odour, like stale salt fish. It is, nevertheless, eaten by cattle, horses, goats, and sheep, but refused by swine; 11. The round-leaved, or all-seed goosefoot, or upright blite ( $C$. polyspermum); 12. The sharp entire-leaved goosefoot ( $C$. acutifolium), are two other species, which are less crommon. The former is a curious plant, whose numerous black shining seeds might perhaps be advantageously employed in fattening poultry; 13. The sea goosefoot, small glasswort, or sea blite ( $C$. maritimum): this species abounds on the sea-shore, and grows also in sandy as well as muddy places, flowering in July and August. Stem thick and juicy, leaves smooth, about an inch long, salt to the taste, of a light bright green. Dr. Withering mentions this as an excellent pot-herb. In Siberia and Astracan the inhabitants obtain from this plant their potash, which probably partakes more of the nature of soda. The alkaline salt contained in this herb renders it serviceable in making glass, though it is inferior to some kinds of salsola found in the south of Europe.

Ten or twelve species of goosefoot have been found in America, six of which Dr. Darlington has detected in Pennsylvania. Most, if not all, are supposed to be foreigners. They are a homely family, generally regarded as weeds. Those best known are the $C$. album or lamb's quarter, used sometimes as spring greens; and the $C$. anthelminticum, or wormseed, a plant having a strong, disagreeable odour, and yielding the well-known worm-seed oil, a valuable and powerful vermifuge.

GOOSE-GRASS (Galium trifidum). Threecleft galium; also known by the common name of ladies bed-straw. This native Ame. rican plant is met with in moist, low grounds and thickets, where its small, white flowers appear in July. Its root is perennial, the stem rising 1, 2, or 3 feet long, and much branched. Professor Hooker thinks this may be distinct from the G.trifidum of Europe, which, he says, is a more slender plant than ours. (Flor. Cesirica.) See Hariff.

GOOSE-GRASS, DYER'S. See MADDER, WILD.

GOSSYPIUM. The generic name of cotton. This plant, which administers so greatly to the wants of man, and to the wealth of countries producing it abundantly, has been known and employed by the Asiatics and Egyptians in the fabrication of clothing, from the earliest dates of antiquity that have reached us. By the Greeks and Romans, however, it does not appear to have been in use. Pliny informs us that in Upper Egypt, on the borders of Arabia, grew a shrub called gossipion or zylon, the fruit-pod of which enclosed a sort of soft wool, of which the garments of the Egyptian priests were manufactured. Goz, which, in the Arabic, implies a silky substance, is doubtless the ront of the word designating the genus of the plant.

There are several species of the cotton plant cultivated in different parts of the world, which may be resolved into the following: 1. Thr common Green-seed Cotion of the United States. the Gossypium herbaccum of botanists, - fig. 1 . This has a smooth stem, leaves with five lobes $2 \mathrm{z} 2$ 
which are round, mucronate, and serrate. It grows from two to five or six feet high, bearing yellow flowers on the end of its numerous branches, which flowers are succeeded by roundish capsules or bolls, full of seed and cotton. 2. The Tree Cotton (G. arboreum) has a high perennial stalk, with branches six or eight feet long, five-lobed, palmate leaves, and yellow flowers, succeeded by oval pods. 3. Vine-leaved Cotton (G. vitifolium), fig. 3, with lower leaves five-lobed and palmated, the upper leaves threelobed. 4. Hairy Cotton (G. hirsutum), with the uppermost leaves undivided and heart-shaped, the lower three five-lobed, the stems and branches hairy, the flowers yellow, succeeded by oval nods. 5. Spotted-barked Cotton (G. religiosum), fig. 4, with the upper leaves three-lobed and lower five-lobed, and branches spotted with black. 6. Barbadoes Cotton (G. Barbadense), fig. 2, branching 4 or 5 feet high, with yellow flowers and oval pods, the upper leaves three-lobed and lower five-lobed, with smoothish stems.
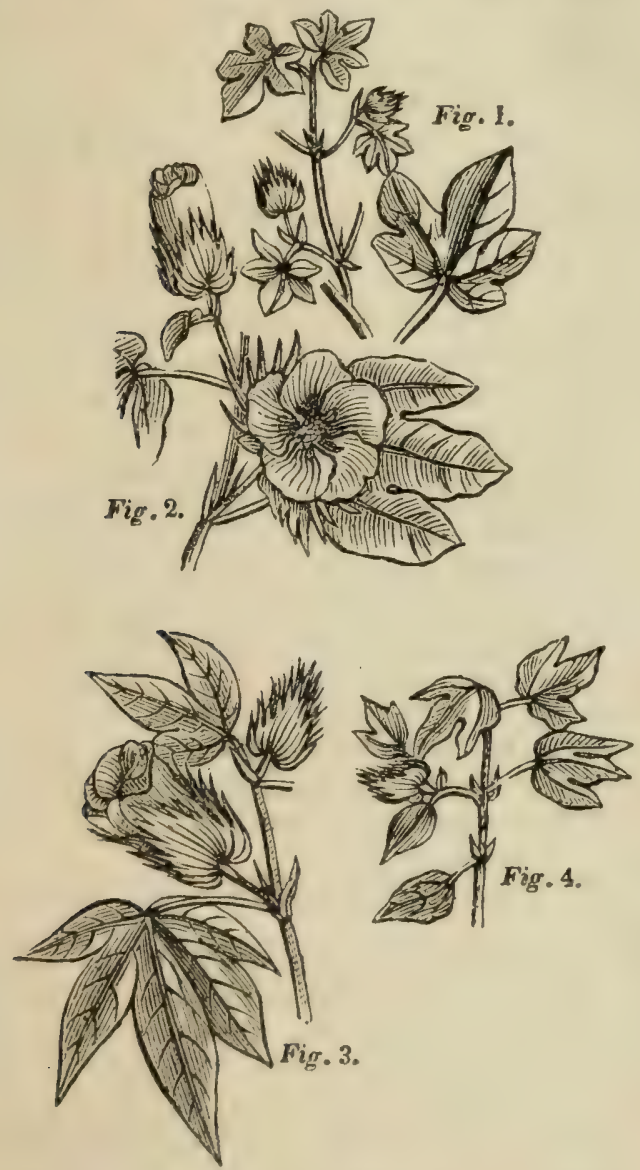

The cotton blossom, though described as yellow, is very often only slightly so, and that while just blowing, appearing almost white when in full bloom. When wilting, the blossoms appear reddish; and the whole process of efflorescence continues but two or three days, when they fall off.

In those portions of southern Europe where cotton is produced, Naples, Sicily, Malta, and mpecially the Levant, the Green-seed or cominn corlon is the only one cultivated for the wants of commerce. The hairy cotton is somerimes raised in the West Indies, although the lizarbadoes is the species most commonly cul:svated. I: … Eart Indies and in China, the 546 common and tree cotton are cultivated, together with some other species or varieties, especially that which produces the nankeen-coloured down. This last has been successfully introduced into the United States, where it is now raised in sufficient quantity to manufacture the yellow cotton cloth called nankin, which was. till lately, all imported from China.

The seeds of the common cotton are eaten in the Levant, where they are esteemed wholesome and nourishing. All the species afford a valuable oil from the seeds, which, besides being eaten, is used for burning, and many other purposes connected with the useful arts.

Nicot first made known the tobacco plant, and Sir Walter Raleigh has the credit of introducing the potato into Europe. Two monks, in the reign of Justinian, brought the eggs of the silk-worm from China to Europe, concealed in the hollow of a bamboo. But of the indivividual who first introduced the seeds of the cotton plant into America, history is silent. He was, perhaps, one of that class of whick examples are daily met with, who take pleasure in seeking out objects either curious or useful, and dispensing their acquisitions to others. The cotton is a pretty plant, bearing a beautiful flower, and was therefore, perhaps, first dedicated to the parterre of the American garden, where it appears to have long remained, devoted to ornament, and of little further use. Authentic information shows that in 1736, and probably earlier, it was an object of horticulture in Talbot county, on the eastern shore of $\mathrm{Ma}$ ryland; and although it may have been raised in squares and patches in neighbouring provinces, no particular attention was bestowed upon it as a profitable crop, till some time after the date mentioned. In 1754 a small quantity of cotton was exported to Europe from South Carolina, the warmer climate of which and the neighbouring provinces, was found more favourable to the crop than the peninsula between the Chesapeake and Delaware Bays, where its culture was first attempted. (Am. Farmer, vol. ii.) It was not, however, until the Revolution caused the supplies of foreign materials for clothing to be cut off, that necessity drove the American planters to raise cotton extensively for home use; and so general did this culture soon become, when urged by this necessity, that the cotton region was made to extend as high north as the lower counties of the state of Delaware. At the close of the Revolution, great financial distress prevailed throughout the States, which had achieved their freedom at the expense of immense pecuniary sacrifices. Many were the plans suggested by individuals and public bodies, called upon to consider the ways and means adapted to relieve the embar. rassments of the times. The subject came up before the celebrated Convention of Annapolis, in 1786. The late President Madison, a member of that body from Virgunia, who had given much attention to the subjed". of the cotton criture, here expressed it as $r$ is decided opinion, that, from the results of the garden culture in Talbot county, and numerows other similar proofs furnished in Virginia, thera was no reason to doubt that the United s'ates would one day become " a great colton-producing 
country." The agitation of the subject was commenced in the public prints of Philadelphia, and the promising capacities of soil and climate were discussed in essays and discourses read in and about the year 1787, before the societies which were led to the consideration of this and other matters calculated to advance the interests of the country. The most early and decided proof of the practicability of raising cotton crops to advantage in the United States, was first received in a letter from Mr. Leake of Georgia, addressed to General Thomas Proctor of Philadelphia. When it is estimated that the cotton brought to Philadelphia about the year 1787, and some time after, sold for home consumption at two shillings sterling, or four-ninths of a dollar, the inducements to raise it may be readily imagined. Congress being at length convinced that the States could produce sufficient cotton for domestic use, in the first reformed tariff bill laid a duty of three cents per pound on that brought from other countries. American cotton began to be an important article of export in 1798 and 1799. It was, however, soon discovered that more could be raised than could be picked or cleared from seed by hand, the only mode of accomplishing this object then known, and the one which had been practised by the Egyptians and Eastern people for thousands of years. Eli Whitney, a native of Massachusetts who emigrated to the south, invented a mill to gin, pick, or separate cotton from the seed, and this with such facility as to perform in one day the labour of three thousand pair of hands. To work or attend this mill, impelled by water-power, requires only three persons. Thus, by the aid of machinery, the capacity to prepare cotton for market was made equal and even superior to the immense productive capacities of the climate and soil of the Southern States. These two facts, (says a writer in the American Farmer, vol. ii.), First, the capability of the southern country to produce cotton, and, Secondly, the invention of the water sau-gin, have effected the greatest and most enriching change in the agriculture of the United States, ever experienced by any people, ancient or modern. And to this view must be added the results of inventions, principally in Fingland, but many in America, of those Jabour-saving machines and processes to pick, rove, spin, double, twist, wind, weave, dye, print, bleach, dress, \&c., all within a comparatively few years.

Such are the considerations which are calculated to inspire correct views of the importance and extension of the cotton crop of the United States, the immense exportable produce of which has so much favoured every branch of domestic industry in other parts of the country; for those States situated too far northward to admit of the advantageous culture of cotton, by which the attention of the southern planter is almost exclusively engrossed, supply him with bread-stuffs, meat, horses, mules, and most other important appliances of life. The necessities of the Revolution, and subsequent financial embarrassments of the country, led to the developement of the cotton culture in the United States; whilst the last war, by cufting off the customary supplies of British and other foreign fabrics, taught the Americans to manufacture for themselves, and thus opened to the producing States a horne market for their exuberant cotton crops.

The progressive developement of the cotton culture in the United States is shown in the following statement of the crops for different periods; viz.-

\begin{tabular}{|c|c|c|c|c|c|}
\hline In 1800 , & boult & & - & - & - $35,(100,000 \mathrm{fbs}$ \\
\hline 1810 & - & - & - & - & $85,000,000$ \\
\hline 1820 & - & - & - & - & - $160,000,000$ \\
\hline 1830, & - & - & - & - & $-350,0000,000$ \\
\hline 1840 , & - & - & - & - & - $790,479,257$ \\
\hline
\end{tabular}

It is estimated that good lands yield, on an average, from 250 to $300 \mathrm{lbs}$. of clean cotton per acre, and inferior lands from 125 to $150 \mathrm{lbs}$; and that the capital invested in the cotton culture in the Union is about $\$ 800,000,000$. 'The annual value of the crop is about $\$ 80,000,000$, and of the exports $\$ 63,000,000$.

The cotton exports of the year 1840 were as follows :-

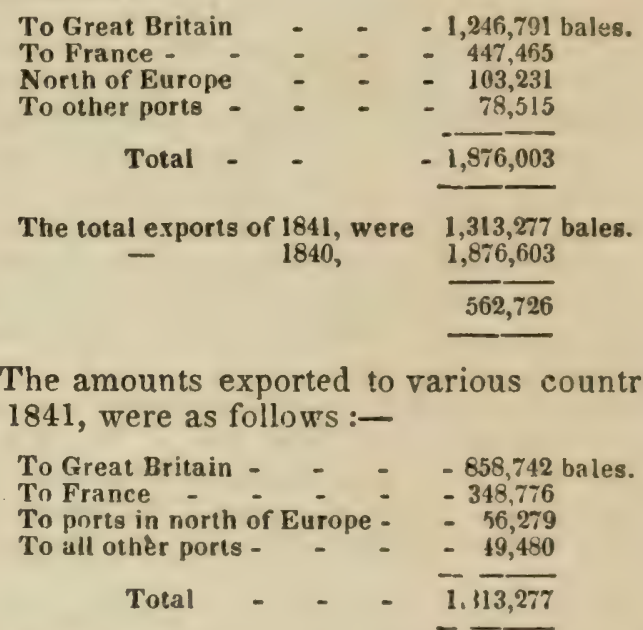

We subjoin, also, the ports from which the article has been sent, with the portion from each.

In 1841, from New Orleans and Mississippi - $\quad$ - 656,816 bales.

From Alabaina $\quad-\quad-\quad-\quad-216,239$

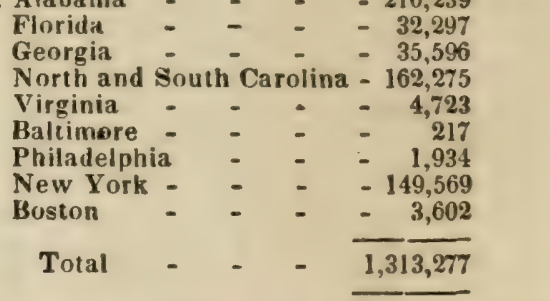

We annex an account of the home consump. tion.

Quantity consumed by, and stock remaining in the havds of United States manufacturers, Sept. 30 , 1841 - - - - $-297,258$ Dules. Do. Sept. 30,1840 - $\quad-\quad 295,193$

Do. do. 1839 - $\quad$ - 276,018

The cotton produced and gathered in the United States is stated, in the returns accompanying the census taken in 1840 , at $790,479,257$ lbs., which product exceeds two-thirds of the annual cotton crop of the whole world, this being estimated at $1,000,000,000 \mathrm{lbs}$. Of the whole amount raised in the United States, South Carolina furnishes about 1-13th. Every year, however, opens new lands in the Wes! to 'bi 
cotton culture, where congeniality of soil and climate to this commodity increases the product per acre, far beyond the average in the old cotton States. This consequently reduces the value far below those prices which formerly poured so much wealth into the Southern States. These newly cleared lands yield, on an average, $2500 \mathrm{lbs}$. of cotton per hand, whilst the lands in the Carolinas yield but $1200 \mathrm{lbs}$. per hand. As the expenses on a labourer are about the same in either place, this home competition must be almost ruinous to the old cotton States, to say nothing of that which is threatened abroad in India, South America, and Egypt. In a recent speech in Congress, Mr. Dixon H. Lewis declared that cotton, divested of government embarrassments, might be raised in Alabama for three cents a pound. (Southern Review for April, 1843.)

There were formerly three species of cotton :ommonly cultivated in the United States: 1. The Green Seed (G. herbaceum), popularly and :ommercially called Upland Cotton; 2. The Black Sced, producing a fine, soft, long, and strong cotton, of a good staple. This, from its flourishing in the lower country, and especially the islands on the coast of South Carolina and Georgia, has been called the Sea Island cotton. It is regarded as a variety of the Arboreum or Tree Cotton, and on new alluvial soils, in warm situations, is found to live 4 or 5 years, and attain a height of 18 feet, assuming the character of trees rather than shrubs. But when the cotton grows so large, it yields no adequate returu to the cultivator. The seed of Sea Island cotton was originally obtained from the $\mathbf{B a}$ hama Islands about the year 1785, being the kind known in the West Indies as the Anguilla cotton.

Of late years, in addition to the Nankin or yellow cotton, two species or varieties of upland cotton have been introduced, which, in some places, have almost superseded the common green seed kind; these are the Mexican and Petit-Gulf, both of which agree in most of their botanical characteristics with the Hirsute or hairy cotton, especially in the rough stem and petiole. The Petit-Gulf kind is exceedingly productive, and differs from the Mexican chiefly in this characteristic, and in maturing earlier, a great desideratum with the planter, since it allows him a longer time to gather the crop. Some think the Petit-Gulf a mere variety of the Mexican, improved by its transportation io the banks of the Mississippi, where the soil and climate are peculiarly favourable to its developement. The planters of the upland sections have to purchase their Petit-Gulf seed from the neighbourhood of Rodney, where it now costs only 25 cents per bushel. The 4 th year after removal from this locality, it has so degenerated as to be no more productive than the common green-seed kind, or better in quality.

It has been remarked, that in most if not all the species or varieties of cotton cultivated in the United States, especially the herbaceous and hairy kinds, the close, short fur immediately enveloping the seed, somewhat analayous to the fur on an animal, has a tendency (1) increase in quantity mis, though it tends the separation of the more fficult, has no other disadvantage.

'The introduction of the plough, of the horse. hoe, cultivator, and other contrivances for saving labour and improving the culture, have been of great service to the cotton as well as to the corn-planter. By the practice of drilling in rows set wide apart, the same fields may be cultivated frequently without such rapid exhaustion as would attend a different course. The land is thus tilled sometimes three successive years without rest, the drills being run at first $4 \frac{1}{2}$ feet apart, the position of the drillrows being changed every year, so that the cotton does not occupy the same place two successive years. At the end of the $3 d$ year the 3 drill-rows will be $1 \frac{1}{2}$ feet distant from each other, and thus the growing crop is annually furnished with fresh soil.

The following account of the cotton culture, as conducted in the Southern States, is abridged from a highly interesting essay upon the subject by Mr. Thomas Spaulding, of Sapelo Island, Georgia:

"It was soon noticed by cotton growers," says Mr. Spaulding, "that soil and situation had more than common influence, as well upon the quality as upon the quantity of cotton produced upon any given portion of land. Certain soils and situations retained in the cotton its original appearance, an intenseness of yellow in its blossom, a fruit full and sound, a seed quite black, and free from fur or down; while upon other soils and upon other sitnations the plant, the flower, and fruit was putting on other appearances. The plants, as if anxious to adjust themselves to a new temperature, took on a more coarse configuration of limbs and stem, a thicker branch, a rougher, larger, and more scalloped leaf, a more cone-like pod, a seed covered either in whole or at its points with the close down or fur that has already been described. At first the most careful cultivators were anxious by selection to keep the seed as much as possible resembling the seed first introduced; that is, black and free from down, and the more so as it was most easily separated from the cotton by the machines employed, and was considered most productive; but in process of time the varieties that stole up among the original stock was found to produce a finer and more uniform and longer wool. The current of selection has now, therefore, directed itself another way, and these hybrids, for I believe them to be so, although the germs of these changes may have lingered for ages in the original seed without developing themselves, have taken on three distinct appearances in seed; neither in blossom or plant differing to the eye from each other, although greatly differing from the parent stock, as being coarser and rougher in their form and leaf, with blossoms of a lighter yellow; having bolls larger and more conelike in their shape. The finer cottons of the sea islands are obtained from these three va. rieties of seed; one with little or no down upon it, but with a long beak or point, to a seed longer than the original; a seed with down upon the two ends, but still with the pointed beak; and, thirdly, a long seed with a sharp 
beak, but completely covered with a soft, close, fine fui or down inseparably connected with the shell of the seed. These new varieties which produce the cotton now most in request, are later in perfecting their fruit, and have, consequently, increased the uncertainty of the most uncertain and doubtful crop to which perhaps human care was ever directed.

"There is a long string of islands extending from Georgetown, in South Carolina, to St. Mary's, in Georgia, that is, from $32^{\circ} 30^{\prime}$ to $30^{\circ}$ north, a distance of about 200 miles. These islands were covered with live oak and other evergreens of a southern climate. They had been the abode of the red men of the West, but rather when the natives were fishermen than hunters; and the vast accumulation of oyster, and clam, and other shells, mingled with the remains of the bones and pottery of their old inhabitants, fill every stranger with astonishment at the multitudes which their remains would bespeak, or the long time that must have been required to introduce such accumulated masses. These decaying shells seem to have intermingled with the original sandy soils of these islands, and digesting the vegetable matter that fell from trees and other sources, formed with them a light and fertile loam. These islands at an earlier period of colonial story, had been employed in growing indigo. It was upon two of these islands, surrounded by the salt waters of the sea, and separated from the continent by several miles of grassy, but salt meadows, that the cultivation of the sea island cotton commenced.

"If Frederick the Great never forgot him that introduced a better description of rye into Prussia, and if Swift is right in saying he merits a great name who will make two blades of grass grow where one had grown before, why should we deny to the dead what may be their due? The first cultivators of the sea island cotton in Genrgia were Josiah Tattnall and Nicholas Turribull, on Skideway island, near Savannah; James Spaulding and Alexander Bisset, upon St. Simon's island, at the mouth of the Altamaha; and Richard Leake upon Jekyl island, adjacent to St. Simon's. For many years after the introduction of the Anguilla cotton, it was confined to the warm highland of these islands, bathed by the saline atmosphere, and surrounded by the salt water of the sea. Gradually, however, the cotton culture was extencled into lower grounds, and beyond the limits of the islands to the adjacent shores of the continent, into soils containing a mixture of clay, and lastly into coarse clays deposited by the great rivers where they met the tides of the sea. In all'these soils the cotton plant gt: ws well. In all these soils nine cottons are preduced. 'The only essential property that is required is a saline atmosphere; with it any soil in Georgia or Carolina may produce fine cotton; without it no soil will produce fine cotton.

"It is within this district of country, from Georgetown, in South Carolina, to St. Mary's, in Georgia, and extending not more than 15 miles from the sea, to which the sea island cotton is still confined. Whenever it has been carried either south, or north, or west beyond these limits, a certain decline in quality has followed its removal. Many changes have taken place in the manner of cultivating the sea island cotton since the first introduction. When first introduced, the seed was deposited either in hills raised a little above the cornmon surface, at five feet distant each way, or in holes at the same distance apart, and the intermediate spaces were dug up, pulverized, and kept free of grass or weeds by the hand hoe or by ploughing. But it was soon found that this distant planting, with a few seeds only, left a great portion of the field unoccupied by planis, and, consequently, unproductive; for, as it has already been said, the cotton plant is one of the tenderest productions of vegetable life. The growers of cotton found it, therefore, necessary to increase the quantity of seed, to insure a sufficient number of plants, and to bring them nearer together. Fortunately for the cotton culture, Tull's book upon husbandry had been more read in the Southern Colonies than in England; and his ridge husbandry was adopted for sea island cotton, and is particularly adapted to it, I may say necessary to its successful culture.

"The present process (and it has been the same for 25 years past) is to make up the field into ridges occupying 5 feet of space each, and extending in straight lines across the entire field. If the land is at all low, or subject in any degree to water, these ridges are intersected at 105 feet from each other by ditches which receive the water that may collect in the hollow spaces upon which the cotton plant is growing. These hollow spaces represent the water furrow in wheat cultivation, and serve the same purpose, that is, in directing the redundant water that falls, into the drains that take it off the fields.

"A field is well prepared to receive the cotton seed when drains intersect it at regular distances of 105 feet; when the surface of the land is thrown up into ridges of 5 feet, rising abuut 10 inches above the intervals, the crown of the ridge flat, broad, and regular. A trench is then made along the middle of the ridge from 2 to 4 inches, dependent upon the time of planting, which extends from the lst of March to the 1st of May. Upon this subject, as upon all others in which men are concerned, wisdom is found between the extremes, and experienced growers of cotton generally prefer planting from the 1 st to the 15 th of April. Whis cotton is planted early in March, before the sun has warmed the soil to any great depth, it is necessary to deposit the seed in drills not more than two inches deep, or there will not be warmth enough to vegetate the sced. Later in the season, when the power of the sun has increased, it is necessary, in seeking for that" moisture which is as requisite for regetation as heat itself, to sink deeper into the soil, and the drills which are then made to receive the cotton seed are required to be 4 inches deep. From the many accidents to which this feeble plant is subject in its first growth, experience has taught the Georgia cultivator that it is necessary to place many more seeds in the gruund than can grow there; and it is usual, therr. fore, to sow at jeast 1 bus.eel of setton seed h, 
the Englislı acre. The persons employed ir. planting the cotton are generally divided into gangs of three. One of these opens the drill along the top of the ridge; the most intelligent of them carefully drops the seed into the trench, while the third follows in his, or more often in her steps, and with a hand-hoe returns the soil while yet moist into the trench from whence it was taken. For myself, I prefer performing this operation with the foot; it is less troublesome to the labourer than carrying and using the hoe. It keeps the mind intent upon one operation rather than two. Walking along erect, the feet are alternately employed to return the soil into the trench upon the cotton seed; and the whole weight of the person brought to bear upon the foot that has just performed the operation, presses the yielding and crumbling soil into close contact with the seed. 'This pressure of the foot after sowing, is like the roller in English husbandry, and is as beneficial to cotton as the roller is known to be to wheat or other grain. But after all this care you are never sure that from your first sowing a sufficient number of plants will stand. One night's frost, which sometimes comes as late as April, will destroy the whole field, and drive you back upon your labours; one day of a strong, dry, northeast wind will tear, blight, and destroy your whole field; and upon the best and richest soils, when both these evils are passed over, there is another ensuing, equally destructive. The cock-chaffer or cut-worm is to be apprehended during all the month of April, and as the cotton comes through the ground, and remains for several days, like the pea or other pulse, with but two radical leaves, every one of the plants that are cut by the worm, either above or below the ground, are destroyed; so that it is not unfrequent that whole fields have to be replanted in the month of May, about which lime the worms pass into their winged state. At the close of the month of May, when apprehension from these accidents have passed away, a new labor begins. The numerous plants which crowd the ground begin to injure each other, and must be removed. Prudent persons divide their removal into three operations, gradually adjusting the number to the increased growth of the plants, which are at length left in the drills, at from 6 inches to 24 inches apart from each other, depending upon the fertility of the soil and the expected growth of the plant, which rises in altitude, from 3 feet to 8 feet high. And here it may be well to observe, that the cotton plant is a leguminous plant (a green plan:), a plant that sends its roots down into the ground, and draws much of its nourishment, by its broad leaves, from the atmosphere. This increased distance in the drill, therefore, is rather to a!low space for the plant to extend itself at its inclination, than from a desire to add nourishment to its roots, for at last the whole field should be shaded from the sun when the plants are fully grown, and the number should be adapted to that end.

"But at every one of these thinnings, as they ire called, or drawing of the plants, the field is cieared with the hand-hoe from all weeds and 550 grass, and new soil brought up around the remaining plants to support them, now bending to every wind, from their tall but feeble structure. This course of thinning, when it is necessary, and the weeding, and grassing, and drawing up, which is always necessary, continues until about the 20th of July, by which time the operation has been repeated from 3 to 6 several times, dependent upon the soil and season. About the 20th of July we may expect our summer rains should commence. These rains are not tropical, but they approach to tropical in their violence. Up to that time no climate can be more temperate than the climate of the sea-coasts of Georgia and Carolina. Volney, from report, supposed it the best in the United States, and the writer of this paper believes it is so. The atmosphere is elastic, the winds that blow every day from the sea are cool and refreshing; they bring health and healing upon their wings; they drive the vapours which have been gathered upon the waters, or that have arisen from the marshes which margin the shores, over the woods of the interior. But the time has now come when evil spirits should prevail. These vapours have been collecting dark and ponderous clouds upon our western hills; the equilibrium of our atmosphere is destroyed. Whether it is that the adjacent seas have become heated by the mass of warm water which the gulf stream brings along the coast, or that the same general cause which operates with such great power within the tropics, operates in part here, I know not; but from the 20th of July to the 1st of August, the winds change from southeast to southwest, and bring clouds charged with lightning and rain, in such masses as to deluge our fields. From the time this change takes place all labour in the cotton field should cease; for the plants with broad, succulent leaves, and tall and slender stem, heavy naturally in its growth, and feeble in its structure, can illy bear up against beating rains and strong winds, and requires all the support that the original ridge in which it was planted, and the repeated dressings up which have been directed, can give it. And hence arises the necessity of the ridge husbandry of the sea island cotton in Georgia and Carolina, and the importance of the repeated gathering or dressing up of the soil to the plants, which has been described. The month of August is a month of doubt and anxiety with the cotton grower. Too much rain makes the plant cast off its fruit, its blossoms, and even its leaves. The full moon in the month of August, too, is the time when the caterpillar is expected. This worm proceeds from a small brown butterfiy. greatly resembling the candle moth. This moth or hutterfly deposits its eggs upon the leaf of the cotton plant always a night or two before the full or change of the moon. They hatch in a few hours after they are deposited, then so small as scarcely to be visible to the naked eye. Like the silk worm, they appear to linger in their first stages, doing no great injury during their first 9 or 10 days. But a few days before they have completed their growth, they become voracious in the extreme, and like the visitations of the locusts in the Fast, destroy 
whole fields in a few days. We have seen 400 acres of cotton that looked promising and well to-day, and that 4 days afterwards had not a green leaf, and scarcely a small pod remaining upon it. These destructive visitations, judging from the past, may be expected once in about 7 years. When cotton fields have escaped injury from rains, from wind, or worrns, they offer as beautiful a spectacle to the observer as the cultivation of any plant can present. One wide and waving field of green leaves, covered from the 1st day of July to the lst day of September with blossoms of 3 colours, and with a multitude of pods of every growth. The blossom, on the first day of its coming out, is of a fine, yellow colour, and it sustains that colour during the day. It changes under the influence of the night air to a crimson or red hue; and again, on the third day, it becomes of a rich chocolate brown, and falling to the ground leaves a pod already of half an inch in diameter. 'The time which intervenes from the biossoming to the perfection of the fruit, greatly varies, depending upon the season. We have marked hundreds of blossoms which ripened and perfected their cotton in 21 days from the day of blossoming; and again we have frequently seen them require six weeks to arrive at the same end, which is, however, a bad omen as to ultimate results.

"The cotton pods begin to open about the Ist of August. From this time to the 1st of December the whole attention of the cultivator is directed to the picking in of the cotton as the pods daily open. During this autumnal season in Georgia and Carolina, upon the seacoast, the winds are violent and the rains heavy; so that the operation is tedious, although not laborious; and during this time the persons employed may be expected to gather from the field 25 pounds per day, when the weather admits of gathering or picking cotton as it is called. When every thing is favour. able, the persons employed should bring in 50 pounds daily of cotton in the seed; but as the gathering is continued so long as they bring in 10 pounds, 25 pounds may be considered the full average of labour so directed. There are few subjects upon which there is more contrariety of opinion than upon the real amount of product given by the soil in any cultivation; agriculturist as I am, loving my profession as I do, seeking information to enlighten my labours as I have done, I know no book upon which I can lay my hand which would give me correctly the real mean result of labour or of land employed upon any one object throughout a whole extended district. The Abbe Raynal kindly tells us how many coffee plants and how many cotton plants grew upon the French part of the island of St. Domingo; and yet there was not one planter in St. Domingo who could really have told how many cotton plants or how may coffee plants grew upon any one arpent of his own field. Taking, however, the best means my long experience would give, I should say that a labourer cultivates, in sea island cotton, 4 English acres, and that these 4 acres yield, as the result of his labour, 500 weight of clean cotton, or cotton separated from the seed, which consists of 400 weight of white cotton and 100 weight of coloured or stained cotton: and that these 500 pounds of clean cotton have, for the last 15 years, averaged tn the grower 20 cents per pound for his white cotton, and 10 cents per pound for his stained cotton, yielding in American money, consequently, $\$ 90$ to the labourer - a small remunera. tion, certainly, to the cultivator, and not calcu. lated to excite jealousy or hostility in any other persons engaged in any other pursuit.

"Preparing sea islund cotton for market.The process of preparing the colton for market commences as soon as it is generally gathered in from the field, and is tedious and troublesome in a high degree. The cotton, when gathered from the plant, is put into a bag, containing about half a bushel, which hangs upon the person engaged in the operation, suspended from the neck or waist as they may prefer, and when it is desired by them they deposit the contents of the bag in a large light basket, which contains the amount of each nne's gathering in the day. At the approach of night, the cotton gathered in the day is brought home and weighed and deposited in a common house, from whence the next morning, if the weather is good, it is carried out and spread upon drying floors made of 2 -inch American pine. These floors are of course proportioned to the quantity of cotton expected to be placed upon them at any one time, but may be estimated at 20 by 40 feet of floor to every 100 acres of cotton cultivated, and in that ratio of quantities upon these floors. If it has been gathered from the fields in good weather, the cotton is allowed to remain but one day to take off the dew of the morning or the damp of the night air; but if gathered in wet weather, it may require two or even three days' exposure upon the drying floors, which are raised upon posts three feet from the ground, as well to preserve the wood of which they are made, as to admit a more free circulation of air. It is, however, known that strong, cold winds or very bright suns, if continued too long, have an injurious effect upon the fibre of the cotton; and this extreme exposure to either wind or rain is, therefore, carefully avoided, and the cotton left no longer upon the drying floors than is necessary to preserve it from heating in the house. Before it is put up f.nally in the house, it is usual, and quite proper to pass it through what is called a 'Whipper,' to shake off any sand or broken leaves, or any other extraneous matter that may have attached itself to the cotton either in the field or in the gathering. The cotton having been gathered, dried upon the floors, and whipped, is ready for the next operation, or ginning.

"The whipper, which is a very necessary instrument in the well-preparing of cotton, is made of wood, is a long barrel composed of slats or reeds (or it would be better made of wire) 6 or 8 feet in length, and 2 fect in diameter, with one end closed and the other open, and is supported at the two ends by feet of different lengths, so that the barrel, in its horizontal position, declines about 1 foot at the lower end; a hopper containing about a hushel rests upon the upper side of the barrel, at the upper enclosed end of il. This hopper lets the 
cotton that is to be cleaned fall into the barrel, through which runs in its whole length a shaft, which is turned by the hard by a crank attached to the shaft at one end. This shaft is intersected by rods which reach to within an inch of the barrel. 'The cotton, as it falls from the hopper, is whirled round by these rods until it escapes at the lower end of the barrel, by which time any sand or dirt, or leaves, or other matter attached to the cotton, has escaped through the spaces intentionally left between the slats or reeds, which constitute the external rim of this barrel or whipper. This whipping was formerly performed as well upon the cotton in the seed, as after it was separated from the seed; but the second operation of the whipper has lately been discontinued under a belief that it produced a stringy appearance in the cotton wool.

"The whipping of cotton at its first gathering, and while attached to the seed, is really beneficial, and should never be omitted. When these operations are completed, the harvest may be considered as closed, and the preparation of the cotton for market really begins. Many machines have been designed, and many forms of the same machine adopted, for separating the seed from the sea island cotton, but all of them at last resolve themselves into two wooden rollers turning by opposite movements upon each other. The rollers are from half an inch to an inch in diameter, and revolve from 100 times to 500 times in a minute. The whole resolving itself into this simple rule, that the smaller the rollers, and the slower they revolve, the cleaner will be the cotton separated from the seed, because, if the rollers are an inch in diameter, and, above all, if they revolve with a high velocity, they will take in soft seeds, small seeds, and false seeds, or motes as they are called, and in crushing them in their passage through the rollers, will stain and injure the cotton in its appearance.

"Much moriey has been spent upon costly machines, propelled by horses, by water, or by wind, first in the Bahama Islands, and for many years in Georgia, and Carolina, but at last most of the growers of sea island cotton have returned to their first and most simple machine, to wit, two wooden rollers, kept together by a wooden frame and a square shaft, upon which is fixed a wooden or iron fly wheel from 2 to 3 feet in dimeter. The iron cranks which turn the rollers are connected by strips of wood, with a treadle worked by the foot; this treadle runs under the machine, and is connected at the farther end of the floor of the house by sockets, within which it revolves; the man stands, therefore, in the front of the rollers, with a board between him and the rollers, upon which he holds a large handful of seed of cotton, which he presents from time to time to the $\checkmark$ illers that are kept in motion by the pressure wi the foot upon the treadle; this labour, from habit, becomes easy, as the feet are often changed in the operation. The task expected from the labourer with the machine (which costs, when new and complete; 10 American tollars) is from 25 to 30 pounds per day. Women, from their careful attention in keep. no the rollers, while they revolve upon each other, well supplied with seed cotton, were unquestionably the best ginners, as they are called from the term gin, applied to the machine; but in process of time it began to be believed that the continued motion of the feet produced a relaxed system in women, which was likely to lead in the end to abortion or miscarriage: men have, consequently, been substituted for this work, one which being within doors, and exercising both hands and feet without vely much labour, is preferred by them to any other in the winter. What is a little surprising, this simple machine, the foot gin, which we received from the West Indies, is mentioned, if I mistake not, in the remains of 'Nearchus's' voyage down the Indus in Alexander's expedition, as gleaned and translated by Dr. Vincent or Major Rennell, in his map of Hindostan. as there employed for separating the seed from the wool, which the Greeks, for the first time, saw growing upon trees and shrubs. Could Asia Minor, could Greece and Egypt have been acquainted with the cotton plant up to that time? The inquiry is a little curious, nor is it uninteresting, but can better far be made by one who lives surrounded by much of the wreck of past knowledge, by many of the memorials of past time, than by him who is living in solitude, under the shadow of his oaks, on the shores of the Altamaha. To prepare the cotton for this ginning, or separation from the seed, when taken from the house where it was put from the field, it is carefully looked over and separated, or sorted, as it is called, the yellow cotton, the motes, any hard cotten, that may have passed through the whipper, is separated from the white; this is a work of care and attention, and the future appearance of the cotton much depends upon the manner in which the work is done. Women are employed in this operation, seated upon benches with tables before them; the seed cotton is spread in small parcels, taken out of one basket, examined and turned over to another, into which the person puts the entire of her day's labour. The quantity required to be thus examined and cleaned in the day by each one is from 60 to 100 pounds, according to the care bestowed upon the cotton by the grower; after this sorting it is exposed lightly and shortly to the sun, that it may take off any dampness the cotton may have acquired in the house; it is then passed from this drying immediately to the gin, or machine that separates the seed from the wool; after going through the gin, and being separated from the seed, it is again turned over to the women, who are generally in a large room, well lighted with glass windows. They sit with small tables before them, made either with open slats, reeds, or wire, when any crushed seeds, and cotton burnt or blackened by the former machine, or motes that have escaped the former searches, are removed; and to have this work well done, 30 pounds is all that is required per day from each woman. After this third operation it is considered ready to be bagged for market.

"The bags in which sea island cotton is shipped are almost exclusively Scotch, are made of hemp, 42 inches wide in the web, and should w:aigh $1 \frac{1}{2}$ pounds to the yard; these 
bags each required from $4 \frac{1}{4}$ to $4 \frac{1}{2}$ yards, and then are made to receive 300 pounds of cotton. Two men are generally employed at a time in packing, and usually pack two bags in a day, in the manner following. The room into which the cotton has finally passed, after being prepared for the bag, is reserved expressly for that purpose, and is kept as clean in floor and walls as possible; adjoining to it is a small apartment under the same cover, with a round hole made in the floor just large enough to contain the bag when full of cotton; the open end of the empty bag is strongly sewed with twine, round a strong hoop, which, extending beyond the hole, suspends the bag vertically from it; one of the men then gets into the bag, and with a heavy wooden or iron pestle he presses the cotton gradually with his feet, and finally beats it down with the pestle until the requisite quantity is pressed down into the bag. The bags were formerly made wet before they began to fill them, under the belief that it kept the cotton down in the bag, when pressed there, better than when dry, but this is an idle and often an injurious practice, and should be always avoided. We will now look back and collect the quantities of labour that is or should be applied to every bale of 300 pounds of sea island cotton in preparing it for market. It requires 1000 pounds of seed cotton to produce 300 pounds of clean white cotton wool; 15 persons will be required to sort and prepare this 1000 pounds for the gin or machine; taking all weather 25 pounds is the mean quantity received from each gin per day; this gives 12 days' labour to each bag for ginning, and 10 women mote these 300 pounds of cotton in the day, makiner for sorting 15 , for ginning 12 , for moting 10, for packing 1 , in all 38 . But besides these 38 that must be good and steady persons, there are usually two inferior persons, young or old, to place the cotton which is apout to be ginned upon the drying floor, or to remove and pass it about in any change of weather, thus requiring to every bag of sea island cotton well put up the labour of 40 persons 1 day. The bag costs for bagging, for twine, and trouble in making, not less than \$1 25 of American money; this, with 75 cents for freight, is to be subtracted from the value of cotton, as there is never any return made for the bag by the purchaser.

"The quantity of sea island cotton has not materially increased within these last 10 years, nor is it likely that it will increase. The particular soils and climate that have heretofore produced it, and to which it probably owes its quality, are confined to the limits first stated, that is, from Georgetown, in South Carolina, to St. Mary's, in Georgia. By looking at a map of the United States, it will be seen that the jong string of islands that bound our southern shore, and separate the Atlantic Ocean from the continent, end at these points; but what is more, the tides that probably assisted to cast up these islands, have changed their climate. The tides along the shores of North Carolina and Virginia, are much less than in Georgia, and they rise still less in Florida and the Gulf of Mexico, that bounds the new acquired provinces of the American Union to the southwest.

"Whether it is that the cultivation of the sea island cotton has afforded fewer induce. ments than other subjects of cultivation, certain it is that the number of those engaged in it, even within these limited districts, have not greatly increased, and it is the successors of the first cultivators that are still engaged upon this object. 'They are generally an educated people, and a stationary one, less anxious after change than their countrymen are supposed to be; and although severely smitten in war by $\mathrm{Eng}$. land, and, in peace, by the National Tariff, they have still clung, with some degree of fondness, to the places whereat they were born, and to the seas in which they were bred.

"Short Staple Cotton.-The short staple cottons, of every part of the United States, are derived from the first and second varieties of cotton which were found in the United States, from Virginia to Georgia, at the close of the American revolutionary war, cultivated in small quantities by the poorer classes of the white population of the country, to be mixed, in their domestic manufactories, with their own wool. The cotton for this purpose was separated from the seed by the old and the young with their fingers, sitting around their evening fire, and was spun by the hand wheel, to serve as a warp, to be filled with the wool of their own sheep.

"As soon as the attention of the Southern States was called to the profitable cultivation of cotton, by a few persons along the shores of Georgia and Carolina, the cultivation began to be extended into the interior. The small quantity of cotton that had been grown for domestic uses, was exchanged for larger quantities, to be prepared for sale. But the great difficulty to be overcome in the progress to extension, was to find out any instrument by which the cotton wool could be separated from the seed.

"By this time various machines had been introduced for ginning the sea island cotton, but all of them ended at last in two rollers revolving upon each other, either longer or shorter, and moving with, some more, some less, velocity. Those rollers were but badly adapted to the hairy cotton, or second variety. which soon began to obtain the preference in the interior of Georgia and South Carolina, over the first or smooth-leaved variety, and merited to obtain that preference, as giving when separated from its downy seed, a finer and stronger, although shorier fibre, and as perfecting its fruit sooner, but which it was almost impossible to separate with the rollers, because the down or fur upon the seed retained the seed hanging upon the roller, and denied admission to the rollers of the fresh cotton in the seed that was offered. Many plans were suggested, many substitutes for the rollers de. signed. All succeeded in part, but still they went on slow. Something was desired to do much in a short time; something that was strong enough to travel about without being broken to pieces, and light enough to move with its moving master. At last such a thing 
was found in Miller and Whitney's gin, prohably not the best machine that could have been designed, but so operative to its end, so efficient to its purpose, that it took possession of the whole ground. From thence forward no other machine was sought for, and Miller and Whitney's gin is employed to separate the cotton seed from Virginia to Louisiana, save where the roller gin is used, and its use is now altogether confined to the sea island cotton, whose superior value is supposed to warrant the great increase of labour necessary in that mode of ginning. Miller and Whitney's gin was designed by Mr. Whitney, and executed at the plantation of Mr. Miller, 16 miles above Savannah, about the year 1795 , and it seems to be derived from two machines already used upon cotton, a kind of cylindrical whipper, and the circular cards, before that time introduced in manufacturing cotton, a wooden shaft. or roller enclosed within a wooden box. This roller or shaft has at every inch of its length a steel blade or saw about a foot in diameter; above these saws is a box containing the cotton in the seed. The box has the bottom of metal slits, through which the saws pass about an inch, and pulling off the cotton, but sometimes cutting the fibres as it passes. This revolving of the saws carries the cotton in the box gradually round, until the seeds contained in the box are freed of the wool attached to them, when it is emptied of the seed and refilled with fresh cotton: it too often leaves some of the fibre behind it, which diminishes the quantity as well as injures the quality, so much so that the estimated difference of the products in these two modes of ginning are, with rollers, 300 pounds to the 1000 , and 250 pounds to the 1000 with Miller and Whitney's gin. This gin having at last given a cheap and expeditious mode of taking the wool from the hairy American cotton (for a gin that cost 10 pounds sterling will clean a bale a day with a single horse acting upon the gin, with a band wheel which any man can make for himself), the cultivation of this description of cotton diverged in all directions around Georgia as the common centre; it went north into the two Carolinas; it went west into the hill country of all the Southern States; it was found capable of adjusting itself to the soil and climate of the interior country, which the Anguilla cotton had not been adapted to; still the fibre of the hairy or short staple cotton is better near the sea than in the interior. Above all, it is found to be most productive in alluvial soils that are a little touched with salt, as are some of the districts of Louisiana, where the rivers rising in the Rocky Mountains draw some of their waters through the salt and arid plains which separate the waters of the Arkansas from the waters of Red River, where these two varieties of cotton, and a cotton that is possibly a hybrid hetween them, have arrived at the greatest periection. It was there that soils which are deeply tinged with red, and heavily seasoned with salt, which all the tributary streams of Red River, flowing in from the north, bring with them, give forth the most abundant crops of the best quality of these descriptions of cotin. Directing myself by the information 554 received from one or two friends who have property there, I should say, with reasonable diligence and attention to the object, 1000 pounds of seed cotton, or about 250 pounds of cotton wool may be expected to the English acre, while the average products of the hill lands, from the Mississippi to North Carolina, should not be taken at more than 500 pounds of seed cotton, or half the quantity; nor do I believe there is any material difference upon the great scale of products through this wide extent of country, judging for myself from personal observation, for I have passed through all these districts, yet scarcely a year passes without the newspapers announcing some new-discovered land of promise within these wide limits, themselves misled by some single or partial result, or stimulated on by land speculators, a curse of no common character to a new country. But in whatever cause originating, the evil is the same. These rumours fall among a people already heated with a desire of change-a people quite sensible to present evils, but not reflective enough to hold in remembrance that every wave of the hand without necessity, and every momentary evolvement of time without usefulness, is a waste of power and waste of time irreclaim. able to humanity. The system of agriculture through all those districts is essentially the same. You find the Virginian upon Red River; you find the North Carolina man, the South Carolina man, and the man from Georgia, alongside of him; any improvements, any increased quantity of product, by any new course of cultivation, spreads like the fire of the American prairie, a spark has carried it, and enkindled it, far in advance of the mass of flame that rolls after it. Any substantial improvement, therefore, that is made in Virginia or Georgia, from this extension of mind, from this intermingling of men, is as likely to be reflected back upon the intermediate country from Red River as to reach it from its first source. The system of cultivation is, therefore, the same; the moment the cultivation of cotton spread into the interior country, from the shores of Georgia and South Carolina, the hand-hoe was exchanged for the plough. The latter instrument had been employed at all times and in all cultures in the hill country of the Southern States; in no agricultural country were oxen or horses cheaper, in no agricultural country were soils freer for the ploughshare, but it was not adapted to the seacoast, because the land is so little above the waters that ebb and flow, that many drains, inconvenient to the ploughman, are required to carry off the surface waters. The trees, too, of necessity, send their roots along the surface, rather than vertically in quest of moisture, and many of them, like the live oak, are scarcely destructible by time. They, too, obstruct his course; but, above all, the plant under cultvation sends its roots around in quest rather of nourishment than down in quest of moisture, and must not be too readily dealt with. These various causes have, finally, after long experience, fixed the hoe husbandry upon the seacoast, and carried the plough husbandry into the hills. The short staple cotton is, therefore 
as exclusively cultivated by the plough, as the sea island cotton is exclusively cultivated by the hoe. 'The manner of treating the plant is really the same; the hoe dressing the land more neatly and garden-like, the plough breaking up the land more radically, and extending far more widely its operation for the quantity of force employed. The consequence has been, that while 4 English acres is the quantity cultivated upon the sea-coast of Georgia and Carolina with the hand-hoe, 8 acres is about the quantity cultivated of short staple cotton, in the interior, with the plough. It is the ridge husbandry in both instances that is now pursued; more neatly executed, in the first instance, by the hoe, and more roughly by the plough in the second, but still the same. The month of April is the best time of planting either variety. The distance between the ridges is most generally 5 feet, the plants left in the drills varying from 6 to 24 inches, dependent, as before stated, upon the expected growth of the plants. Two other circumstances contributed to aid the cultivation of short staple, extrinsic of soil or real products. The winds of autumn are far more violent upon the sea-coast of Georgia and Carolina, than in the interior country, and the capsules that contain the sea island cotton expand more than those that contain the short staple, so that the first has to be gathered much more frequently from the fields than the last, or it falls to the ground and is lost. The consequence is, the general gathering to the labourer per day is more than twice the quantity of short staple than of sea island, for it is allowed to hang upon the plants until they are white with the open cotton, so that there is only 2, and at best 3 , gatherings of the one, to 10 or 12 scanty gleanings of the other. This one circumstance, more than any other, gives to the grower of short staple cotton the power of something more than duplicating the quantity of cotton wool produced by the same quantity of labour expended.

"Cottons of various kinds grow well, and perfect their fruit, from the southern borders of Virginia to the southwestern streams of the Mississippi, a space of 1200 miles, and from the sea for 200 miles into the interior; through this wide space of country, in every soil, whether of clay, or loam, or even sand, the cotton plant will grow, and produce its seed and wool, its accompaniment, provided the waters are kept well drained from the surface of the land. The quantity of products will of course depend upon the soils, whatever they may be, containing these ingredients, which constitute fertility in all countries, which neither experiment or the philosophy of chemistry has yet been able fully to discover or define. The mean quantity given of 100 pounds of sea island cotton wool to the English acre, and of 125 pounds of short staple cotton to the same quantity of land, we believe not materially wrong, but the quantity of labour to bring forth these results are very different. The sea island cotton is cultivated neatly by the hoe, the short staple more roughly by the plough; still it is, or should be, the ridge husbandry in both instances. The plants are left to stand in drills upon the ridge, at distances from each other, graduated as before stated, to the expected growth of the plants from 6 inches to 2 feet from each other, and bearing, without injury, to stand much nearer than at first sight may be imagined, for the cotton plant does not oc. cupy much space with its roots, sending thein down in to the ground, and not over the surface, like white or grain crops, and drawing like all large-leaved green crops, much of its nourishment from the atmosphere. It is not an exhauster of soil, shading and protecting it from the sun, and soon, by its decay or by its com. bustion, returning almost as much as it has taken away; but from the density of its shade, and the size and swell of its roots, it soon makes the soil too loose to sustain the plant, and the continued culture of the same soil, brings on a disease in the plant greatly resembling the blight in wheat, and leaving a propensity in the seeds of cotton to extend the evil, like the propensity in blighted wheat to extend and multiply; nor have I ever doubted that in both instances the evil had originated in insect depredations, for although Sir Joseph Banks discovered a fungous attaching itself to blighted wheat, I still believe that the microscope discovered in that minute parasitic plant the effects of injury previously received from something that lived and moved and had animal being. Fire, therefore, I have always believed, and have always acied upon that belief, is the best security against this increasing and extending evil; all the weeds and grass that are on the land should be burnt upor the surface of the land, leaving no vegetable matter to conceal and protect the germ, and by fermentation to give heat and life to it; it is the neglect of this course which I think has been the cause that this evil, under various names, rot, and rust, and blight, has spread so widely as it has done within a few years.

"There is no plant that requires the interchangeable husbandry more than the cotton plant, and there is no country where that husbandry is more essential than in the Southern States. The cotton requires continued cleaning during the droughts of spring and the heats of midsummer; these cleanings, together with the shade and rapid growth of the plant, break up the soil, and leave it to be carried away by the first violent autumnal rains. The best remedy is to give to the fields of cotton intermediate crops of grain; as good a series as can well be adopted is cotton, rye, and wheat (where the soil is fit for it), pasture, and again cotton. A more extended rotation might bis adopted, but as all root crops should be avoid. ed in series with cotton, this simple tri-annual course, with manure applied during the grain. year, to as great extent as may be convenient, will keep the field without material decay When cotton was first introduced, the growers were misled as to the necessity of this change, by observing that the cotton plant, upon new lands, grew large, and gave little fruit, and that it improved for the second and third year in productiveness, they unfortunately pushed the culture too far, until possibly to this cause many of the diseases that have afflicied it in its growth may be attributed. 
"In a preceding part of this article, the probable mean results for these last 15 years, in growing sea island cotton, has been taken at $\$ 90$, or about $20 l$. sterling to the labourer; and taking, as we have already done in this letter, the medium crop of short staple at 125 pounds to the English acre, and 8 acres of this cotton, as cultivated by the plough, it will give 1000 pounds of short staple cotton wool to each labourer employed upon it, which for the last 7 years may have given to the grower a mean return of 10 cents to the pound, or 100 dollars for the year's work. There are exceptions, unquestionably, to these estimates; a few men have received much higher prices for their sea island cotton, and a few men have raised much larger quantities of both descriptions of cotton :o the acre than are given, but exceptions can never serve as a guide, in conclusions, as to either the wealth or productiveness of a whole country."

Mr. Croom, of Middle Florida, thinks Mr. Spaulding has made the limits within which the sea island cotton may be cultivated too narrow. He states that "it has been raised in Middle Florida since its first settlement about the year 1822 ; and the crops made here have been annually sold in the Charleston market, at prices a little exceeding, generally, those of the 'Mains and Santees,' though not quite equalling good 'sea islands.' Moreover, it is produced from the coast to the distance of 30 miles inland, but, at the same time, it is not denied that the presence of sea air is beneficial to this crop. If I have not been misinformed, this cotton is also produced by the planters on the St. John's, in East Florida, and was formerly produced in the Bahamas, until the ravages of the caterpillar compelled its abandonment. I think it may be doubted whether $\mathrm{Mr}$. Spaulding is correct in the opinion that this cotton becomes less fine when carried south of the St. Mary's. It is probably a native of a tropical climate, and, therefore, most probably would not be less fine when produced in the West Indies. I have heard that some of this cotton produced at Cape Sable has commanded 50 cents per pound in the Charleston market, without unusual care in its growth and preparation.

"In limiting the range of the short staple cottons to 200 miles of the sea-coast, Mr. Spaulding appears to have overlooked North Alabama and West Tennessee. In receding from the sea-coast, however, two causes are constantly operating against the growth of cotton; a higher latitude and a greater elevation, both tending to produce a colder climate. To these causes may probably be added a third, the loss of sea air. Other things being equal, the cotton planter, therefore, should prefer the neighbourhond of the sea-coast."

To Mr. Spaulding's highly interesting acrount of the cotton culture we shall add some further details of a miscellaneous character. The quantity of seed sown is usually from 1 to 2 bushels per acre. This is scattered in the rows drawn upon the cotton beds, and very lightly covered. It sprouts and comes up in a very few days. If injured from too early planting, it seldom recovers from the 5.56 effects, and matures late. When worms or lice attack the young plants, it is advisable to stop thinning the plants, and replant as quickly as possible. The crop is a precarious one. In favourable seasons more cotton is sometimes raised than can be picked, whilst in others there is such a falling off in the product as to leave many hands unemployed, or but partially so. Much wet weather occurring in the spring may lead to serious injury of the young plants, and in the latter part of the season the same kind of weather may cause the bowls to shed or fall off too soon, and thus spoil the cotton. The kind called Petit-Gulf, now so highly prized by planters in Mississippi and some other states, is not only of finer quality, but more productive and easily gathered, a hand picking $20 \mathrm{lbs}$. per day more than of the ordinary upland kind. But it sheds its bowls much sooner, and does not admit of picking more than half the usual time of the common green seed species, which last is often gathered during 4 months of the year. Hence the planters in some places put in only a part of the crop of Petit-Gulf, reserving another portion of the common kind for later gathering.

The distance between the rows is usually regulated by the strength of the soil and capacity for producing vigorous plants. It has been recommended as a good rule to place the rows on land capable of producing from 10 to 15 bushels of Indian corn per acre, about 4 feet apart; from 15 to 25 bushels per acre, 5 feet; from 30 to 50 bushels, 6 feet; 50 to 70 bushels, 7 and 8 feet. It is important to be in readiness to plant as quickly as possible after frosts have ceased, one week in the first part of the season being considered worth a fortnight in the latter part. As soon as the fourth leaf makes its ap pearance, the thinning by hand commences. when the plants, if to be cultivated in drills. are allowed to stand two and two, from 9 inches apart in light land, to $2 \frac{1}{2}$ and even 3 feet where the ground is strong. When the earth is dry, it may be ploughed, and the dirt drawn up to the cotton so as to cover and smother the young grass. When wet, the grass and earth are drawn away from the cotton very gently, after which the ground is ploughed and drawn up again as soon as sufficiently dry to permit. This plan of ploughing and hoeing is followed up until the cotton becomes so large as to be injured by the passage of the plough, after which the earth is chopped over with the hoe until the crop is made, of which a judgment may be formed by its beginning to open freely at the bottom. Ten hands are considered enough to cultivate 100 acres of cotton with ease; but if a good crop, it would require at least 20 hands to pick it out.

The advantages derived from substituting the plough to the hoe, so generally used in the low lands of the old cotton states, are strikingiy exhibited in the following communication from a Georgia planter to the editor of the Farmer's Register. We shall only give extracts from the article, which may be found in the 6th vol.p 269.

"An emigrant from your own state, and the vicinity of your city, formerly engaged in the culture of the long-staple cotton on the main 
lands, conversant with the modes of culture prevalent there, and now engaged in growing the short cotton upon the plans adopted throughout the whole western country, my experience has enabled me to detect some of the errors formerly practised by myself, and my neighbours in Carolina. My attention has been called to this subject by the perusal of an article in one of your late numbers, signed 'An Observer,' giving an account of the crop of $\mathbf{E}$. Frost, Esq., in St. Andrew's parish. Mr. Frost, it appears, planted, according to the low-country system, four acres of cotton to the hand, and each hand made 4,000 pounds seed cotton. This the writer considers an extraordinary production-and, for that region of country, so it is. It may safely be predicted that it will not soon be equalled by Mr. Frost, or any of his neighbours. With hands till lately accustomed to the same manner of working, I planted last year 10 acres of cotton and 10 of corn to the hand. I never had a cleaner crop, and though the season was excessively wet, my negroes never performed their tasks with greater ease. The cotton crop, seriously injured by the worm, yielded $800 \mathrm{lbs}$. to the acre, and $8,000 \mathrm{lbs}$. to the hand. Mr. Frost's land exceeded mine in productiveness, yet my crop doubled his. His is considered so extraordinary, that it is held up as an argument against emigration-mine was an ordinary crop, nearly doubled by many of my neighbours. But the question to be solved is, how is the difference in the results obtained?

"It is unquestionably true that the soil and climate of the west is better adapted to the growth of cotton,-that here a plant of the same size, and on a soil of equal strength, will send forth and retain a greater number of pods, than upon the sea-board. It is equally true that the grass will grow as rapidly and as plentifully in the one place as in the other. The difference in the soil and climate has not, however, as much influence as is generally imagined by residents on the sea-board. Would they adopt the same management, pursue the same modes of culture, which, somewhat modified, they unquestionably can, there can be no doubt that, though they could not obtain the success of the western planter, yet they would make some approximation toward it."

With regard to the management by which so large a product was obtained, the judicious use of the plough was considered as the chief agent. By it the beds were prepared for planting, the trenches or drills made, and the seed covered. By it the most part of the grass was destroyed, and the plant furnished with the earth requisite for its support and sustenance. $B_{y}$ it the use of the hoe was in a great measure superseded. "It may," says the writer, "interest some of your readers who groan under the pressure of their crops of 8 acres of corn and cotton to the hand, and whose fears are alarmed lest the grass should overrun them, to learn how, by the use of the plough, 20 acres to the hand can be planted, and the same crop secured. I will, therefore, give you in detail the arrangement of the crop on our plantation last year. There were, besiles the regular crop, 75 acres of oats, pota- toes, and slips, enough for the use of the plantas tion, and about 15 acres of wheat. The planta. tion worked 30 hands -15 at the plough, the rest with the hoe. In March, 300 acres were planted with corn, on land previously well ploughed and checked. In the first week of A pril, 300 acres of cotton were planted. The land was prepared by throwing together with a turning-plough, in the alleys of old cottonfields, four furrows. Thus bedded, the drills were opened with a small scutter, or bulltongue plough, in which the seed was sown; they were covered by a board fastened on the plough-stock, in the place of the mould. The drilling, planting, and covering occupied four days and a half. 'There was an excellent stand, and no replanting necessary. The ploughs and hoes then went into the corn-field. "These were well ploughed and hoed by the time the cotton was out of the ground and required work. The cotton was four times ploughed, and as often hoed, and when laid by in July, a hat would have held all the grass that could have been found. The corn was twice more ploughed, and once hoed. The grass was constantly kept down by the ploughs. The daily task of a hoer was 100 rows of cotton 100 yards long. The first and second hoeings, when the cotton had to be chopped out and reduced to a stand, proved good, though not severe tasks; the other hoeings were light, and the workers were often out of the field by 12 o'clock. 'The crop was well worked, and with ease, by low-country hands, who would think it the worst calamity that could befall them to be compelled to return to the place of their nativity. The mules and horses were in as good, if not better, con. dition than when the ploughing commenced."

Picking.-The bowls of cotton mature and open about the last of August and beginning of September, when the picking commences. This is performed by hands, male and female, who are provided with osnaburg bags hung over the neck and shoulders, into which the cotton is placed as fast as picked. These, when filled, are emptied into large osnaburg sheets, placed in convenient spots. These sheets are carried home in the afternoon. The pickers are cautioned to guard as much as possible against a small leaf, which, when dry, often intermixes with the cotton, and never can be got rid of, thus injuring the sale. The general average in what is called a good opening is from 45 to $50 \mathrm{lbs}$. per day to each hand. The freshly picked cotton is first dried upon scaffolds made about 4 feet wide, so as to admit of reaching far enough to turn it over with ease whilst drying. A cotton-house is at hand to receive the cotton in case of rain. After being perfectly dried, the short-staple or upland cotton is ginned and prepared for market.

There are several kinds of gins used for cleaning the cotton of its abundant seeds, such as the Barrel gin, Eves's gin, and Whitney's gin. The last is that depended upon for ginning the green seed, upland, or short-staple cotton; the long-staple or sea island has still to be prepared for market by hand, involving tedious and expensive operations. Whitney's saw gin, for separatign the seed from upland or shortstaple cotton, is a mill worked by nxen or 
water. "The teeth in the circular iron plates serrated, about three-fourths of an inch apart, fixed to a cylinder, draw the cotton wool from the seeds, through the openings of iron straps, out of the bin and hopper in which the cotton is placed. These openings are too narrow to suffer the seed to pass. 'The cotton is brushed off the saws by counter-moving brushes on another cylinder. By an ox gin, 6 to 900 lbs. are cleansed in a day. After ginning, the cotton is picked of all remaining broken seeds and trash, and packed in bags of 250 to 300 lbs."

Varieties of Cotton.-Besides the Mexican and Petit-Gulf, some other kinds have recently obtained great celebrity in the United States. One is called by some the twin, by others the Aldridge cutton, the first name being derived from the peculiar manner in which the branches shoot out from the stalk, the second from its supposed first introducer. There seems to be some doubt as to the origin of this cotton. The advantages claimed for it are, 1st, its being better able to stand the effects of drought; $2 d$, not casting the squares however severe this may be; $3 \mathrm{~d}$, admitting of very close planting in consequence of the great shortness of its branches; 4 th, the rapidity of growth and productiveness superior to what is observed in common kinds. The advantages of maturing early, and thus allowing a longer time for picking, is, as before observed, a great desideratum to the planter. The superior merits of this new variety of cotton caused great competition for its seed, which at one time sold for $\$ 5$ per quart, and even 50 cents the single seed.

A communication in the 7th volume of the Furmer's Register (p. 252), makes the following statement in relation to this variety, which, from a resemblance in its stalk to a member of the Hibiscus family, has been called Okra cotton.

"A Mr. Terry, of Autauga county, Alabama, some years ago bought some Petit-Gulf seed. A single stalk was observed in a field without limbs, and having great numbers of bolls adhering immediately to the stalk, or in clusters on very short limbs. The cotton had all been picked out except a single lock with nine seeds. From these seeds this variety has been propagated. The seed sold, in 1837, at 50 cents a piece. Last fall I bought at $\$ 160$ a bushel. The cotton examined by me exhibited a distinct variety. It had rarely any limbs longer than one joint, sometimes two; the bolls were two, three, and as much as seven in a cluster. I had one limb about 4 inches long, with 7 good bolls opened on it. The stems of all of the bolls shooting from one place, at the top of the short limb. The cotton was exceedingly fine, being, I think, 2 to 4 cents a pound better; being in colour and staple the finest and softest short-staple I have ever seen. It opens earlier. The field I examined was planted the 20th A pril. A very intelligent gentleman, living in the neighbourhood, told me he planted similar land on the 1st of April, and that the new cotton was open two weeks earlier than his. It grows in good land quite tall, say 6 or 8 feet; and in this, I fear, will be the greatest objection to it, *s it may fall when heavily fruited towards the (uj) . but perharis this may be avoided by top558 ping. Its advantage to an Alabama planter, if it succeeds in rich prairie lands, will be its early opening, by which the worm will be avoided, a terrible enemy, which has eaten up full one-third of my crops for five years. The appearance of the stalk is more like okra than any other-the leaf being a cotton leaf."

Another writer in the same periodical, speaking of the two new kinds of cotton, says, "There are two distinct varieties of twin or okra cotton. The one called okra was discovered in Alabama, in first year's Petit-Gulf seed. It grows up generally in one tall stalk, sometimes as high as 8 or 9 feet, with very short limbs, which are seldom more than 6 or 8 inches long, and having its bolls in clusters of 2 to 7 or more. I have seen 10 blossoms or forms in one bunch. Sometimes 1,2 , or 3 long limbs put out near the ground, turn upwards, and grow parallel to the main stem, bearing fruit as it does."

"The other new variety of cotton is said to have been discovered in Chester District. It is now somewhat like the Alabama okra, without being the same. It is about a halfway plant between the okra and Petit-Gulf. I have never seen it taller than 4 or 5 feet. Its limbs are longer than the okra, and not as long as those of the Petit-Gulf. Both kinds have twin bolls, but the bolls and blossoms are more numerous in the okra. Two bolls on the same stem are frequent in both; but it is only on the okra that I have seen 3 blossoms within the same calyx, or 4,5 , or more bolls in one cluster. There is also a clearly defined difference in the Chester twin, a darker, green, and more naked seed. No person who has once seen the two plants groving, or the two kinds of seed, will ever mistake the one for the other.

"I am not prepared to say that the Chester kind is not a good cotton. I know too little of it. The staple is good; I have seen some stalks in gardens very well filled with bolls.

"To the Alabama okra there is one objection, which I think can be easily obviated. It grows too tall, and is liable to fall down. The remedy is to top it at $4 \frac{1}{2}$ or 4 feet. The stalk grows stronger, the bolls fill up larger, and the product is increased by it. As it will bear great crowding on the land, the yield will be greater than from Petit-Gulf. It is, in fact, an improved Petit-Gulf seed."

Okra cotton is also called by some Alvarado cotton. With regard to its productiveness some idea may be gained from the following advertisement in the Columbia papers, offering for sale the seed of this cotton.

"Dr. J. H. Taylor, from little more than $\frac{1}{4}$ of the stand he ought to have had, gathered upwards of $1,200 \mathrm{lbs}$. per acre. The following is an extract of a letter from Dr. Taylor: 'You must observe I had not more than $\frac{1}{4}$ of a stand, and planted, too, at 5 feet instead of 3 , and yet I will make about 1,200 lbs. per acre. I believe it capable, on the same land, of yielding 5,000 lbs., planted at 5 feet in double rows. If I live another year, I will try 100 acres in that way. Mr. F. M. Gilmer, of Montgomery, Alabama, from as bad a stand, gathered 1,400 lbs. to the acre. Mr. C. T. Billingslea, of Bibb county 
Alabama, from $\frac{1}{4}$ of an acre gathered 1,060 lbs., and expected 200 lbs. more. Mr. Aldridge, who first cultivated the cotton, it is said raised 3,000 lbs. per acre this year, and refused $\$ 30,000$ for his crop of 30 acres. Dr. J. H. Taylor, from $22,000 \mathrm{lbs}$. of seed cotton, ginned 13 bales of $600 \mathrm{lbs}$. average, or $35 \mathrm{lbs}$. of clean to 100 of seed cotton. Jesse P. Taylor, well known here, weighed $425 \mathrm{lbs}$. of Petit-Gulf and the same of okra in the seed, and ginned each; the result was $124 \mathrm{lbs}$. of ginned Petil-Gulf, or 29 lbs. to the 100, and of okra $156 \mathrm{lbs}$., or $36 \frac{9}{3}$ to each $100 \mathrm{lbs}$. of seed cotton. The staple is decidedly finer."

The price of the seed here offered for sale is $\$ 100$ per bushel, $\$ 20$ per gallon, and $\$ 5$ per quart; which are stated to be the Alabama prices.

Defects in Cotton as prepared for the Manufacturer.-The cotton manufacturers in England having met with certain defects in the sea-island or long-staple cotton, which they thought might be remedied by proper attention in the primary manipulation, have recently addressed a communication on the subject to Messrs. Browns and Welsman, extensive cotton importers in Liverpool, to be forwarded by them to the planters in the United States. From this we extract portions which indicate the defects complained of, as well as the qualities most desired by the manufacturer, to all which it may he the interest of the producers to give attention. especially since the competition which has sprung up in other parts of the world. The Manchester manufacturers say,

"We have often, in conversation with you, expressed our regret that the growers of fine sea islands, in so many instances, injured their cotton by stringing and matting it in the getting up; and in hope of drawing their attention to the subject through the medium of your house, we beg to trouble you with the following observations.

"Fine cotton yarn is esteemed in proportion as the thread is uniform in substance, free from lumps, and strong. The latter has been decidedly improved by the introduction of the select seed cotton; but the levelness of the thread has been impaired rather than otherwise, and this arises from the multitude of small white specks, or nitters, with which the staple of the finer and softer kinds of seaislands, and the select cotton seed particularly abounds.

"In examining these nitters through a microscope, we find them in general composed of kinds of fibres, presenting an appearance much resembling the misletoe plant in this ccuntry, and for some time we feared they were excrescences peculiar to the fine fibre, and inseparable from it; but the two recent samples of beautifully fine select seed cotton, sent us by you, are so free from this defect, that we have now a strong impression they are chiefly produced by an overhandling in the getting up; at least we can multiply such nitters here, by mismanagement in the cleaning process; and we have no doubt the same effect is produced in America. We would, therefore, strongly urge the planter's attention to this point; for in all cotton goods, such as gruze, muslins, and laces, it takes immensely from their value and beauty, and limits the use of the finer yarns, which are chiefly used for these articles. As an instance of this, we may state, that one of our customers informs us he frequently pays from 9 d. to 18 . per yard, upon his finest muslins, for picking out the nitters one by one with a needle, after the goods are woven-an expense which is equal to from $10 \mathrm{~s}$. to $30 \mathrm{~s}$. upon each pound weight of muslin. Our experience has proved that the softer and more silky the staple, the more easily it is nittered; and, as the spinners possess no means by which nitters can be removed from the cotton when once formed, the only means of remedying the evil is to prevent their formation.

"To this point, therefore, the attention of the grower should be strongly directed. All unnecessary handling, whipping, tossing, or shaking of the cotton ought to be avoided. It should be as well cleaned as possible, but yet free from stringiness, and the fibres be left in the loose and disentangled state they appear when just separated from the seed. If this were attended to, it would materially improve the appearance of fine yarn, and remove the never-ceasing complaints of the fine muslin manufacturers, and, we are persuaded, tend to increase the consumption of fine cotton goods."

The committee to whom this letter was referred reported:- "That the matter to which their notice had been directed is one of deep importance to the grower of that valuable staple production. If, in consequence of his neglect or want of skill, a pound of mus. lin, which would otherwise command its full price, is depreciated from 10 to 30 shillings, duty and interest obviously impel him to the providing of a remedy at once prompt and efficient.

"Through the politeness of Messrs. Browns and Welsman, three samples of cotton, being specimens forwarded from Manchester, were received from Messrs. Gourdin, Matthiessen \& Co. These samples are endorsed as follows:-'No. 1, illy got up and nittered:' 'No. 2 , illy got up and partially open;' ' $\mathrm{N}$ o. 3, well got up.' In examining the 'nitters' in No. 1, through a microscope that magnified one thousand times, they were discovered to be, in general, of a globular form, and to consist of filaments of cotton, with interstices of various diameters, readily reducible in size by pulling the long threads attached to the mass. This, however, could not always be done, as the knot of fibres constituting the nitter was in many in. stances too strongly formed. The committee next proceeded to the examination of samples of seed cotton. In about a pound, personally gathered by one of them, from fully maturer pods, produced from healthy plants, no niters were observed. In the same quantity picked from diseased stalks, which bore defective fruit, several were seen. These were subjected to the test of the microscope, and precisely the appearance that characterized those taken from the ginned cotton in No: 1 was exhibited. Kepeated inspections since have produced no marked variation in the general results. The committee, therefore, with confidence ieduce the inference, that preparation, except perhape 
in the isolated instance hereafter to be noticed, is not the cause of the nitter. In confirmation of the opinion, putting aside the conclusive facts adduced, the different processes through which the cotton passes, whilst in the hands of the planter, need only to be briefly adverted to. After the stained is separated from the white, the latter is thrown, in small parcels, into a whipper, in order to extract the dirt and to throw off the short and weak fibres, which, if allowed to remain, would detract very materially from the value of the crop. This machine, constructed of wood, with round wooden teeth, is turned by the hand. Unless the door of the whipper be closed, which is never done, the egress of the cotton is quickly effected. After this operation the cotton is ginned, and then taken to the moting-house, where, on a frame of wood-work, it is gently shaken and partially opened by the hand. When clean, it is received by the packer, who, with a wooden instrument, compresses it into a bag, weighing, when finished, from 300 to $400 \mathrm{lbs}$. In these various but necessary modes of treatment, in not one of which any violence is used, the committee feel persuaded that the staple sustains no injury whatever. It is well known that every description of cotton, except the finest qualities of sea island, before it is converted into fabrics, is subjected to numerous operations, all of which are performed by machinery. From the willow, which, by its revolving spikes, tears open the matted masses, succeeded by the scutching machine, in which the cotton is beaten by metallic blades, revolving on an axis at the speed of from 4000 to 7000 revolutions in a minute, other machines with iron fingers, teeth, and wheels, follow, so that it may almost be said that, without the aid of human hands, the vegetable wool ' is opened, cleaned, spread, carded, drawn, roved, spun, wound, warped, dressed, and woven.'

"Now, although it is represented that the superior qualities of black-seed cotton are not thus wrongly treated, yet, as they are 'opened and cleaned by being placed upon cords stretched on a wooden frame, and then beaten by women with smooth switches,' the committee are at no loss to perceive how the complaints of the manufacturers by their own act may be increased. This last mode of cleansing the raw material was very generally pursued by the planter a few years ago. Were he now to resume that ready method of preparing his crop for market, he is satisfied that, whilst his time and labour would be saved, the fabrication of fine goods would be likely to incur an additional expense of no ordinary magnitude. By using switches, it is nearly certain that the weak fibres are broken into minute parts, and, with the naturally short and rotien, intermix and become entangled. Although, therefore, the imperfection of the staple, which is the special subject of this report, is undeniably common to the cotton plant under peculiar circumstances, the committee incline to the opinion that that imperfection can be created by artificial means, and, from experiments instiluted by them, is engendered by the different prucesses through which the cotton goes in its mnversion into cloth, as already particularly 560 sescribed. That the nitter, however, is occaly formed through the want of foresight on the part of the planter, when his crop, from adverse seasons or other causes, is defective in texture, is highly probable. The filaments of unripe cotton are transparent, cylindrical tubes. When ripe, even before the capsule bursts, the tubes coliapse in the middle, forming semi-tubes on each side, which give to the fibre, says Mr. Baines, in his able treatise on the cotton manufacture of Great Britain, when viewed in certain lights, the appearance of a flat riband, with a hem or border at each edge.

"The twisted and cork-screw form of the filament of cotton distinguishes it from all other vegetable fibres, and is characteristic of the fully ripe and mature pod. This form and character the fibres retain ever after, and, in that respect, undergo no change through the operations of spinning, weaving, bleaching, printing, and dyeing, nor in all the subsequent domestic operations of washing, \&c. \&c., till the stuff is worn to rags, and then even the violent process of reducing those rags to pulp for the purpose of making paper effects no change in the structure of these fibres. From the difference between the elementary fibres of cotton and flax, the latter being transparent tubes, cylindrical, and articulated or jointed like a cane, it has been incontestably proved that the mummy cloth of Egypt was linen.

"Unripe cotton is finer than that which has attained its full age, but is deficient in the other essential attributes of a perfect staple, strength and length. Some of the filaments, indeed, are not the eighth of an inch long, and until several days after the opening of the capsule are found doubled or curled, full of watery and oleaginous particles; the cotton is wet to the touch, and is of a brown hue. In this state, unless dried in the sun, it becomes more or less mouldy; the superfluous oil from the seed, which ought to have escaped, is diffused through the mass; the colour soon changes; heat is generated; and the staple, originally strong, is quickly perceived to be materially affected. Hence it is not surprising that in immature cotton, distinguished, as it is known to be, for its delicacy of texture, variableness in length, and want of pliability, when subjected to the mildest mode of treatment to free it from extraneous matter, the threads should cross and mix with each other, thus forming artificial nitters. Within a few years, the action of the sun, with a view to the dessication of the wool, has been sedulously avoided by perhaps a majority of our planters. 'The daily gatherings are spread in houses, or under scaffolds erected for the purpose, and thus the dry. ing process, if a few exposures in that way is worthy of this appellation, is conducted. That the practice is radically wrong, for the reasons already assigned, the committee firmly believe. Damp cotton, also, can neither be ginned nor cleaned but with difficulty; this of itself is a serious objection, to which may be added the indubitable fact that, from its too unctuous properties, the floating dust of the atmosphere tends to its discoloration.

"From these observations it will appear that nitters are either natural or artificial, and that 
both are primarily to be traced to a defective staple, arising from diseased plants; that the artificial nitter may be generated even by the common method of preparation, unless the cotton be judiciously dried; and that the means to which the manufacturer is obliged to resort are evidently calculated to bring about the same results.

"Of these samples, Nos. 1 and 2 , which are 'illy got up,' are lumpy and stringy, of a deep sellow tinge, and weak and uneven in fibre. The cottons from which these are taken, it is likely, were never dried; it is still more probable that they were the produce of a scanty harvest. No. 3 is of natural colour, open, and in texture strong and long. It is necessary here to remark, that the stringy appearance of cotton is not always, or even mainly, the fault of the planter. It arises principally from the same cause to which the nitter is referable: the imperfectness of the staple, or the immaturity of the fruit. This was especially true the last year.

"To two considerations, pertinent to the matter under review, it may be proper to advert. In every field, no matter under what sinister circumstances the crop has grown, there are small sections in which the plants come to perfection and bear healthy fruit. From these the cotton that is picked is marked perhaps by every characteristic of the best staple, yet, almost from necessity, it is thrown into the general bulk. Again, in harvest season the labourer cannot stop to examine, if he had the ability to know, the variant qualities of the cotton he is engaged in gathering, but promiscuously the bad, the fair, and the good are blended. This is unavoidable. Subsequently the stained is separated from the white, but the weik and strong continue together; a part only of the most deficient of the former being afterwards detached by the whipper.

"On the immediate topic of inquiry, the committee ask leave to conclude with the following suggestions:-

"1. The necessity of drying cotton in the sun for 3 or 4 hours, as its dampness may seem to indicate.

"2. Select sced for planting, not with a view to superiority of staple, but the production of sound cotton. For that purpose, choose from healthy stalks those pods that are fully blown.

"3. 'The first pickings should be set apart, and not mixed with the general crop. The fibre is weak and short. The same course ougnt to be pursued with cottons gathered after a storm or much rain.

"4. Cotton ought to be thoroughly cleansed before it is carried to the gin. If it be well done the after-labour will be trifling, and the fault of over-handling avoided. 'Too much pressure on the roller gives to the cotton a matted appearance; if the pressure is unequal, it will be stringy.

"Before closing this report, the committee would offer a few reflections, not irrelevant, they trust, to the occasion. For many years the sea island crop has scarcely repaid the toil and perseverance incurred in its production. From highly unpropitious seasons, the ravages of worms, and the cultivation of a plant pecu- liarly delicate and unfruitful, it may in verity be said that it is annually a subject of congratulation with the planter if his necessary expenditures do not exceed his profits. Except 1826, when the exportation was about $6,000,000$ Ibs., from 1833 to 1835 inclusive the production was less by from 1 to 7,000,000 than at any former period since 1821.

Number of pounds of sea island cotton exported in

$\begin{array}{rrrrrr}1821 & - & 11,344,066 & 1829 & - & 12,833,307 \\ 1822 & - & 11,250,634 & 1830 & - & 8,147,165 \\ 1823 & - & 12,136,688 & 1831 & - & 8,311,762 \\ 1824 & - & 9,525,722 & 1832 & - & 8,743,373 \\ 1825 & - & 9,655,278 & 1833 & & \\ 1826 & - & 5,972,852 & 1834 & - & 8,085,935 \\ 1827 & - & 15,140,798 & 1835 & - & 7,755,736\end{array}$

$1828=$

"From these facts, added to the wonderful machinery which enables a workman now to perform the work required of 2 or 300 men 60 years ago, the increase of population in those countries where the finest goods are used, and the decrease in the rates of duties in Great Britain, it was reasonable to infer that an augmentation of price, in some measure proportional to the diminished production, would have taken place. From 1821 to 1829 inclusive, when the average export was $11,016,418$ lbs., the average price in Liverpool was $19 d$. From 1830 to 1835 (excluding 1833, the export of which year is unknown to the committee), when the average export was reduced to $8,208,194 \mathrm{lbs}$., the average price was as low as $17 \frac{1}{4} d$.

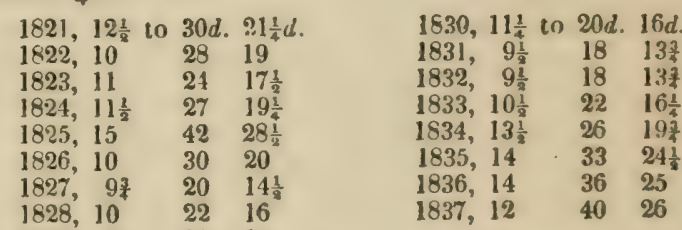

$1829,9 \quad 21 \quad 15$

2s. 11 . percwt. In 1821 the duty was 6 per cent. ad val.

"The table from which the above (to 1833 ) is taken, was published in 1833, by Messrs. George Holt \& Co., of Isiverpool. It exhibits the extreme prices of cotton and wool in that place from 1806 to 1835 inclusive. The statement of prices from 1834 to 1836 inclusive, is extracted from a Liverpool circular, published in January last. The difference between the extreme prices has been assumed as the medium price. What the average price really was cannot with certainty be stated.

"The long staple is generally used for the twist or warp, and the short staple for the weft. In this way, the black seed is made to participate in the changes which, no matter from wha: cause, mark the market value of the green seed. This, perhaps, is the strongest reason why a more decided inequality in price between the fine and superfine qualities of long staple cotton ought to exist, to which may be added the variety* of uses to which the former, alone or mixed, is applicable. From these conside? rations it is apparent that, in relation to those two descriptions of vegetable wool, the one is really worth from two to three-fold more than the other, instead of from 30 to 50 per cent, which continues to be paid.

"One pound of cotton usually makes 8 yards of coarse muslin, and is then increased in value from the raw cotton eight-fold. But, if spun 1 . 
the finest yarn, it is worth 5 guineas, and in marks Mr. Baines, in ordinary states of the 1780 , if woven into muslin and tamboured, was worth 15l. It may now be converted into a piece of lace worth 100 guineas-Report of the Secretary of the Treasury, 1836.

"The finest quality of sea island cotton, remarket, is worth three times as much as the common quality of the same class. The varieties in quality in most of the other denominations is from 20 to 25 per cent., and in none of them 1 more than 50 per cent.

The following Table, taken from the Liverpool Price Current, under date of December 9, 1842, is subjoined, as showing the comparative prices of cotton from different countries, and the sections of the globe where the staple is cultivated.

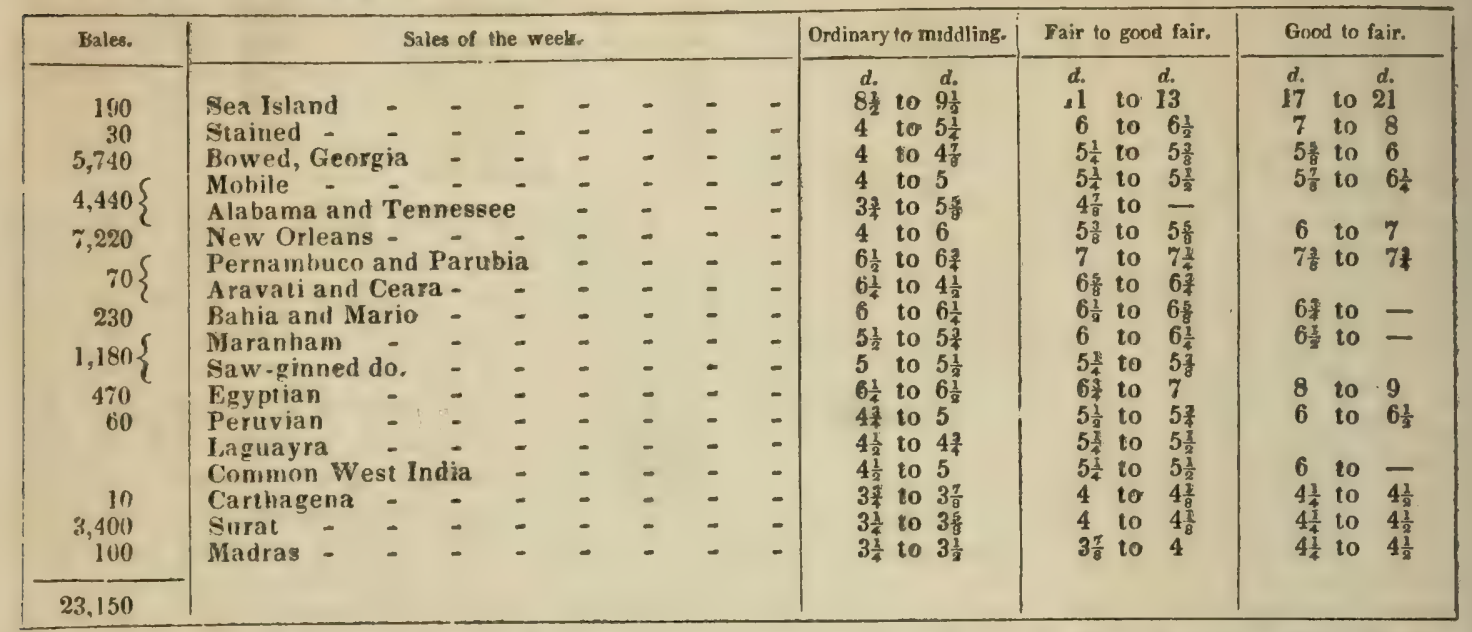

Discases and Accidents to which Cotton is subject.-The cotton crop is not only rendered very uncertain from the effects of the weather, but frequently suffers the most serious injury from the depredations of insects. The most fatal enemy of the cotton crop in Georgia, Alabama, Mississippi, Louisiana, and Texas, is a disease called the rot, which has been thus described by Mr. Troup, in the Ist volume of the American Farmer. "The first indication is seen in a small circular spot on the outside of the bowl, exhibiting a darker green than the circumjacent parts, as if a globule of water had dropped upon it and been absorbed. Many of these are frequently seen at the same time on the same bowl. They spread themselves sometimes faster, sometimes slower, as if influenced either by the state of the atmosphere, or condition of the plant; changing colour as they progress, until they assume a dark brown approaching to black, and until tne whole exterior is affected in like manner, or until it receives from some cause a sudden check, and then this appearance is only partial. In the first case, the disease has penetrated to the centre of the fruit, the fermentation is complete and universal, and is seen in a frothy white liquid, thrown out on the surface. Putrefaction follows, and the destruction of the seed and immature wool being finished, nothing is left but the rind or exterior coating of the bowl, which, extsausted of its juices, hardens and turns hack, and thus terminates the process. In the wher case (that of suddenly checked disease), the interior of the bowl, in some instances, remains unhurt; in others, is only partially ininred, and in this last case, the pods remaining unhunt, mature and expand. 'This, however, rarely happens, as the disease is wonderfully capricious, going and coming unaccountably; attacking at one time with more, at another with less violence: so that the fruit which escanes entire destruction on the first altack, 502 may fall a victim to the second. Nor is this capriciousness justly attributable to changes in the atmosphere; its origin even does not seem to have any connection with weather. The year 181\%, when rot first appeared, was one of remarkable wet. The year 1818, one of remarkable drought. The rot in 1818 was both more general and more destructive than that of 1817. In 1819, which has been as the planters say, a seasonable year, there is more rot discoverable than at the same time of any preceding year, and there is every probability that it will be both more general and more destructive. In the same season too, according to my observation, it is in no degree influenced by it-for instance, this year it showed itself in my neighbourhood in the most alarming manner for the first time, when the corn and cotton had begun to suffer from a dry spell of two or three weeks. I have known it to stop for a considerable time in very wet weather, and to recommence its progress after the rains had ceased. It is earlier in its appearance this year than before, and I believe earlier the last year than the preceding. This disease attacking at different times with different degrees of violence, I will not hazard the assertion that its cause is uniformly distinguished by the same appearances. The first indication in very many cases is a dark brown or black spot on the bowl; in others, the whole exterior of the bowl seems to have passed at the same time from the green to the dark brown, and is saturated with moisture, and whilst it is evidently suffering the process of fermentation, will open and deliver the wool uninjured. It is the same disease, exhibiting different features as it rages with greater or less degree of acrimony. It attacks the bowl in every stage from the first formation to that stage of its perfection which immediately precedes developement.

"It has visited all varieties of soil and treated all alike. I do not mean that every plantation, 
or that every district of country, shared, in equal degree, the evils of this visitation. Some have escaped with more or less injury; but I am inclined to think that these who have escaped with least, will have their turn. The mode of cultivation makes no difference. There are two modes, the close and the thick-set. The last has become fashionable of late; but I have seen the isolated plant and the one environed by the branches and overshadowed by the top of its neighbours, equally afflicted.

"I think you will conclude from the foregoing statement that rain or sunshine, hill or dale soil, whatever the predominant earth, cultivation whatever the mode, stop not its march. We recur, therefore, to the existing controversy, Is insect or constitutional disorder of the plant the cause of rot? If insect, would they not be seen in great numbers and where their ravages are greatest? I have examined fields most injured by rot, and could never make any discovery of them; besides, the year of drought is the year of insect-the rot made its appearance in a year of wet-since that, it seems not to have been affected by either wet or drought."

There are some who think that the rot in cotton is neither a constitutional disease of the plant nor the result of destructive insects attacking the pod, but that the true cause is a fungus production or parasite, similar to that which produces the mildew, rust, and blight in wheat. As yet no remedy for this evil has been found deserving confidence, unless it be the substitution of the Petit-Gulf variety, which is confidently asserted to answer the purpose, by a correspondent of the Farmer's Register, who had given a two years' trial with perfect success. (Vol.ii.p.548.) He believes the rot -which, he says, is most prevalent in rainy seasons, and in humid states of the atmosphere-is the result of insect depredation, and thinks the new kind of cotton not agreeable to the insect.

The upland cotton is sometimes very much injured by a disease called the rust, and also suffers from the depredations of a greenish caterpillar which eats into the bowl and causes great destruction. The Mexican cotton was introduced mainly with the hope of its resisting the ravages of the caterpillar. The cotton whilst young is also apt to be infested with plant lice (Aphidians). The remedies adopted against these are of the most opposite kinds, namely, allowing the grass to grow for the nurpose of inviting the insects from the cotton, or working and cleaning the ground with extra attention.

The cotton planters of Upper Mississippi do not suffer much from the rot, the caterpillar, or the rust, the greatest enemies of their crops being the louse, snails and slugs, and a disease of the stem of the plant cominonly known by the homely name of sore-shin. This comes on when the plants are small and only have the third leaf, and is supposed to be the effect of wet weather and heavy, packing rains. In Louisiana the planters complain of their losses from the rot, rust, boll-worm, army-worm, and rains. Such are some of the difficulties, in addition to those commonly met with from atmo spheric agencies, against which the cotton crop in the United States has to contend, and by which it is rendered exceedingly precarious.

A rich oil has recently been expressed from cotton seed, and a residuum or cake obtained, which promise to give an additional value to this already profitable crop. A patent machine has been invented by Mr. R. Burn, which entirely removes the cotton usually closely adhering to the seeds, thus putting them in the most favourable state for expression, and the production of the cake. Chemical analysis made of this care, shows it little if any inferior, in the amount of its feeding and fertilizing qualities, to linseed or rape cake; the proportion of oil being 9.08 per cent.; sugar 10.70 ; albuminous compounds (nitrogen $=3 \cdot 95$ ) $24 \cdot 69$; the ash amounts to 5.64 per cent., and contains of silica 1.32 ; phosphates $2 \cdot 19$; excess of phosphoric acid $0 \cdot 15$. The oil-cake from cotton seed would thus appear to be a very important substance to the farmer, whilst the oil must become a new source of profit to the planter. In the East Indies, where the poor and badly cultivated cotton yields only $2 \mathrm{lbs}$. of seed to $1 \mathrm{lb}$. of cotton, the seed sells for feeding cattle, at $4 s$. the kulsee, $(=666$ lbs.) The quantity of seed obtained from good American cotton, is $1 \frac{2}{3}$ to $2 \frac{1}{2}$, for each pound of cotton. See OrL-CAKE, and RAPE.

GOURD (Lagenaria vulgaris, calabash). The gourd family flourish well in the United States in the open air, and the several varieties make up a large amount of the produce of the gardens and farms. The large bottle gourds are extremely useful among the country people, by whom they are used as dippers. Some of them are so large as to hold nearly a gallon. They are light, and with good usage may last for months and even for several years. If, after a few gourds have set, the ends are pinched off the vines, the gourds will grow larger and bet ter. Some kinds of gourds are cultivated for their beauty. The fruit of the bi-coloured variety is small and very pretty, deep green on one side and yellow on the other. There are several other varieties, distinguished by the shape and appearance of the fruit. It is believed, says Dr. Darlington, that there are no native species of gourd in the United States, though the plant is said to have been cultivated by the aborigines, from time immemorial. (Flora Cestrica.)

GRAFTING. The operation of affixing a portion of one plant upon another, so is to produce a vital union between them, ras been practised from the most remote antiquity. In general, all the species of one genus or tribe may be grafted on another reciprocally; but in choosing the stock or stem the nearer the affinity of this to the species from whence the scion comes, the better. The grafted plant consists of a stock or stem rooted in the ground, and the scion or graft, consisting of the detached portion of another plant, to be affixed to it. This operation affords the means of multiplying and perpetuating all our best varieties of fruit trees, and many kinds of trees and shrubs not so conveniently propagated by other means. Varieties of fruits are originally procured by selection from plants raised from seed, but they can only be perpetuated by some mode which continues the individual; and though this may be done by cuttings and layers, yet by far the most elicilita 
node is by grafting, as it produces stronger plants in a shorter time than any other methods. Grafting is performed in a great many difforent ways; but the most eligible for ordinary purposes is what is commonly called splice-grafting, whip-grafting, or tongue-grafting. In executing this mode, both the scion and the stock are pared down in a slanting direction; afterwards applied together, and made fast with strands of bass matting, in the same manner as two pieces of rod are spliced together to form a whiphandle. To insure success, it is essentially necessary that the alhurnum, or inner bark of the scion, should coincide accurately with the inner bark of the stock; because the vital union is effected by the sap of the stock rising up through the soft wood of the scion. After the scion is tied to the stock, the graft is said to be made; and it only remains to cover the part tied with a mass of tempered clay, or any convenient composition that will exclude the air. Some of the other modes practised are termed cleft, or slitgrafting, crown-grafting, cheek-grafting, sidegrafting, and grafting by approach, or inarching.

The season for performing the operation is, for all deciduous trees and shrubs, the spring, immediately before the movement of the sap. The spring is also the most favourable period for evergreens: but the sap in this class of plants being more in motion during winter than that of deciduous plants, grafting, if thought necessary, might be performed at that season.

Grafting Timber Trees.-The oak, ash, hornheam, and hazel, may be grafted, but there is a little difficulty in grafting some of the hardwood trees. On the oak may be worked its striped-leaved variety of pedunculata, and the varieties of sessiliflora. The lucombe, and other oaks of that kind, require to have the Turkey oak for a stock; and the evergreen, or Ilex oaks, must have their own species. The common ash will take with the ornus, and any of the hardy varieties of true ashes, such as the Chinese and entire-leaved. The hornbeam may be used as a stock for Carpinus orientalis, and the cut-leaved sort; but the scions must be from irro years old wood. The purple-leaved hazel may be grafted on the hazel stocks.

Crafting by approach, or inarching, is a mode of grafting, in which, to make sure of success, the scion is not separated from the parent plant till it has br.come united with the stock. Inarching is chiefly practised with oranges, myrtles, jasmines, walnuts, firs, \&c., which do not flour:sh by the common mode of graftहु.

Grafting herbaccous plants differs in nothing trom grafting such as are of a woody nature, excepting that this operation is performed when both stuck and scion are in a state of vigorous growtn. The only useful purpose to which ihis mode has been hitherto applied is, that of grafting the finer kinds of dahlias on tubers of the more common and vigorous-growing sorts. In the Paris gardens, the tomato is sometimes grafted on the potato, the cauliflower on the horocole, and one gourd on znother, as matter of curnisity.
Grafting the herbaceous shoots of woody plints is scarcely known among English gardeners: but it has been extensively employed by French nurserymen, and even in some of the royal forests of France. The scions are formed of the points of growing shoots; and the stocks are also the points of growing shoots, cut or broken over an inch or two below the point, where the shoot is as brittle as asparagus. The operation is performed in the clef manner; that is, by cutting the lower end of the scion in the form of a wedge, and inserting it in a cleft or slit made down the middle of the stock. The finer kinds of azaleas, pines, and firs, are propagated in this way in the French nurseries; and thousands of Pinus larix have been so grafted on Pinus sylvestris in the forest of Fontainebleau. At Hopetoun House, near Edinburgh, this mode of grafting has been successfully practised with Abies Smithiana, the stock being the common sprace fir. (Brande's Dict. of Science.)

GRAIN (French graine; Ital. gran; Norv. grion, corn). The general name of all kinds of corn. See Wheat, Maize, OAts, Banlex, Corn-Laws, \&c. It means, in another sense, the seed of any fruit, the direction of the fibres of wood, \&c.; the form of the surface, with regard to roughness or smoothness; or a minute particle. In this article $\mathbf{I}$ have only to insert those facts with regard to grain that could not be well included under other heads. It has been calculated that the total consumption of wheat and other grain in the United Kingdom is, in a year-of wheat $12,000,000$ quarters, and of other grain 40,000,000 quar. ters, equal to $52,000,000$ quarters, or per day 154,762 quarters. (Quart. Journ. of $A g r$. vol. iii. p. 1063). Of this about $25,000,000$ bushels of barley are consumed in malt by the brew. eries and distilleries.

Dr. Colquhoun has calculated that the annual consumption of grain in England by each person is as follows:-

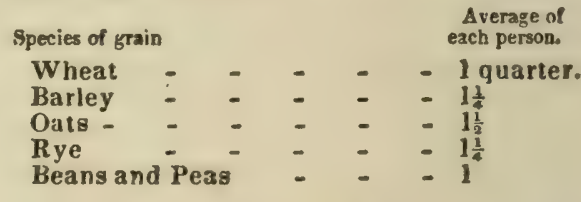

The second Fiar Prices of Grain per imperial Quarter for the County of Haddington from 1647 (at Intervals of Ten Years) to 1829.

\begin{tabular}{|c|c|c|c|c|c|c|c|c|c|}
\hline \multirow{3}{*}{$\begin{array}{c}\text { Year. } \\
1647\end{array}$} & \multicolumn{3}{|c|}{ Wheat. } & \multicolumn{3}{|c|}{ Earley. } & \multicolumn{3}{|c|}{ Dats. } \\
\hline & $\boldsymbol{L}$ & 8. & d. & $L$. & 8 & d. & $\boldsymbol{L}$. & s. & d \\
\hline & 1 & 13 & $4 \frac{1}{8}$ & 0 & 16 & $0 \frac{1}{4}$ & 0 & 13 & $0 !$ \\
\hline 1650 & 2 & 4 & $8 \frac{3}{4}$ & 1 & 13 & $0 \frac{3}{4}$ & 1 & 4 & ? \\
\hline 1660 & 1 & 10 & $0 \frac{1}{4}$ & 0 & 15 & $2 \frac{1}{2}$ & 0 & 12 & ? \\
\hline 1670 & 0 & 18 & $10 \frac{i}{4}$ & 0 & 11 & $5 \frac{\pi}{4}$ & 0 & 9 & 14 \\
\hline 1680 & 1 & 0 & $0 \frac{i}{2}$ & 0 & 11 & $5 \frac{1}{4}$ & 0 & 8 & 1 \\
\hline 1690 & 1 & 8 & $8 \frac{1}{2}$ & 0 & 18 & 117 & 0 & 12 & 吗 \\
\hline 1700 & 1 & 10 & $0 \frac{1}{2}$ & 0 & 19 & $9 \frac{1}{2}$ & 0 & 12 & $2 \frac{1}{4}$ \\
\hline 1710 & 1 & 5 & $8 \frac{1}{2}$ & 0 & 17 & 2 & 0 & 12 & 11 \\
\hline 1720 & 1 & 2 & $8 \frac{1}{4}$ & 0 & 15 & $2 \frac{1}{8}$ & 0 & 10 & 9 \\
\hline 1730 & 1 & 4 & $4 \frac{1}{8}$ & 0 & 11 & $5 \frac{1}{2}$ & 0 & 10 & $6 \frac{1}{4}$ \\
\hline 1740 & 2 & 0 & 07 & 1 & 2 & $10 \frac{3}{4}$ & 0 & 18 & $3 \frac{2}{2}$ \\
\hline 1750 & 1 & 5 & $10 \frac{1}{\frac{1}{2}}$ & 0 & 13 & 2 & 0 & 11 & $10 \frac{8}{2}$ \\
\hline 1760 & 1 & 4 & 0 每 & 0 & 11 & $2 \frac{1}{2}$ & 0 & 9 & 10 \\
\hline 1770 & 1 & 12 & $0 \frac{1}{2}$ & 0 & 18 & $9 \frac{1}{4}$ & 0 & 15 & 67 \\
\hline 1780 & 1 & 18 & $0 \frac{3}{4}$ & 0 & 19 & $1 \frac{1}{4}$ & 0 & 15 & $9 \frac{1}{2}$ \\
\hline 1790 & 2 & 5 & $6 \frac{1}{9}$ & 1 & 3 & 7 & 0 & 19 & $6 \frac{9}{2}$ \\
\hline 1800 & 6 & 6 & $4 \frac{1}{5}$ & 3 & 4 & 6 & 2 & 8 & 114 \\
\hline 1810 & 4 & 1 & $1 \frac{1}{8}$ & 2 & 1 & 37 & 1 & 8 & 10 \\
\hline 1820 & 3 & 1 & $5 \frac{1}{2}$ & 1 & 8 & 10 & 1 & 3 & 6 \\
\hline
\end{tabular}


Average Price of Grain per Quarter in England and Wales, for Twenty Yeurs, ending 1840.

\begin{tabular}{|c|c|c|c|c|c|c|c|c|c|c|}
\hline \multirow{3}{*}{$\begin{array}{l}\text { Year. } \\
1 \delta 21\end{array}$} & \multicolumn{2}{|c|}{ Wheat. } & \multicolumn{2}{|c|}{ Barley. } & \multicolumn{2}{|c|}{ Oas. } & \multicolumn{2}{|c|}{ Beans. } & \multicolumn{2}{|c|}{ Peas. } \\
\hline & . & d. & & d. & & & o. & $d$. & 8. & $d$. \\
\hline & 56 & 2 & 26 & 0 & 19 & 6 & 30 & 11 & 32 & 9 \\
\hline 1822 & 44 & 7 & 21 & 11 & 18 & 2 & 24 & 6 & 26 & 5 \\
\hline 1823 & 53 & 5 & 31 & 7 & 22 & 11 & 33 & 1 & 35 & 0 \\
\hline 1824 & 64 & 0 & 36 & 5 & 24 & 10 & 40 & 10 & 40 & 8 \\
\hline 1825 & 68 & 7 & 40 & 1 & 25 & 8 & 42 & 10 & 45 & 5 \\
\hline 1826 & 58 & 9 & 34 & 5 & 26 & 9 & 44 & 3 & 47 & 8 \\
\hline 1827 & 56 & 9 & 56 & 6 & 27 & 4 & 47 & 7 & 47 & 7 \\
\hline 1828 & 60 & 5 & 32 & 10 & 22 & 6 & 38 & 4 & 40 & 6 \\
\hline 1829 & 66 & 3 & 32 & 6 & 22 & 9 & 36 & 8 & 36 & 8 \\
\hline 1830 & 64 & 3 & 32 & 7 & 24 & 5 & 36 & 1 & 39 & 2 \\
\hline 1831 & 66 & 4 & 38 & 0 & 25 & 4 & 39 & 10 & 41 & 11 \\
\hline 1832 & 58 & 8 & 33 & 1 & 20 & 5 & 36 & 5 & 37 & 0 \\
\hline J833 & 52 & 11 & 27 & 6 & 18 & 5 & 35 & 1 & 37 & 0 \\
\hline 1834 & 46 & 2 & 29 & 0 & 20 & 11 & 36 & 7 & 33 & 0 \\
\hline 1835 & 39 & 4 & 29 & 11 & 22 & 0 & 30 & 0 & 30 & 3 \\
\hline 1836 & 48 & 9 & 33 & 2 & 23 & 1 & 38 & 4 & 37 & 3 \\
\hline 1837 & 55 & 10 & 30 & 4 & 23 & 1 & 38 & 7 & 37 & 9 \\
\hline 1838 & 61 & 4 & 31 & 5 & 22 & 5 & 37 & 4 & 36 & 8 \\
\hline 1839 & 70 & D & 39 & 1 & 26 & 6 & 41 & 3 & 41 & 1 \\
\hline 1840 & 66 & 6 & 36 & 3 & 25 & 9 & 43 & 6 & 42 & 5 \\
\hline
\end{tabular}

GRAINS. The amount of the different grains produced in the United States, collectively, and also for each of the states, has been given under the head of Agriculoruar Provucrs. Tabular statements under the various heads will show the prices of grain in the United States for a series of years. See W HEAT, Corn, Onts, \&c.

GRAINS, BREWERS', are very extensively used in the feeding of live-stock. They consist chiefly of the husk, and other insoluble matters of the corn employed in the operation of brewing. When speaking of the large dairies of the metropolis, Mr. Youatt remarks, "The principal food of the cows in all these is grains; and as the brewing seasons are chiefly in autumn and spring, a stock of grain is generally laid in at those seasons for the rest of the year. The grains are laid up in pits lined with brick-work, set in cement, from ten to tifenty feet deep, and of any convenient size. They are firmly trodden down, and covered with a layer of moist earth, eight or nine inches thick, to keep out the rain and frost in winter, and the heat in summer. A cow consumes about a bushel of these grains daily, the cost of which is from fourpence to fivepence, exclusive of carriage and preservation. The grains are, if possible, thrown into the pit while warm and in a state of fermentation, and they soon turn sour; but they are not liked the worse by cattle on that account: and the air being perfectly excluded, the fermentation cannot run on to putrefaction. 'The dairymen say that the slow and slight degree of fermentation which goes on tends to the greater developement of the saccharine and nutritive principle, and they will have as large a stock on hand as they can afford, and not open the pits till they are compelled. It is not uncommon for two years to pass before a pit of grains is touched: and it is said that some have lain nine years, and been perfectly good at the expiration of that period. The grains from a large ale brewery are the most nourishing; those from the porter brewers, not so good; and those from the little ale brewers hardly worth having. It is found by the distillers that rough clover chaff, mixed with grains and wash, will fatten to any extent."
(On Cattle, pp. 255-264.) Grains fresh from the mash. tub, either alone or mixed with oats or chaft, or both, may be occasionally given to hrirses of slow work: they would, however, afford very insufficient nourishment for horses of quicker or harder work. Grains, in common with most vegetable substances, are an excellent dressing for grass lands, an application which is thus described in a recent communication to the editor of the Mark Lane Express, by Mr. W. H Buckland of Glamorganshire.

"Having observed the remarkable luxuriance of the grass on a small portion of land upon which some brewers' grains had been scattered, was induced to manure several meadows with grains mixed with stable-dung, and a few acres with grains only. The crop of hay is an extraordinary one off the land manured with grains and stable-dung together, but from the land manured with grains alone, the crop is prodigious. On one part of a steep declivity, where the ordinary produce has been about 10 or $12 \mathrm{cwt}$ of hay to the acre, and the quality very coarse, a good sprinkling of grains was strewed, leaving the other part of the same ground untouched. Where the grains were spread, there is more than two tons of hay to the acre, and the grass is of the finest quality where no grains were applied, the crop is as usual, both as to quantity and quality.

"In addition to the abundance of the crop is the advantage of its earliness. On the 29th of May I mowed a field manured with grains. The grass was over-ripe, and might have been cut a week sooner. The neighbouring fields, not so manured, were full three weeks later. This is a matter of no little importance in this part of the country, where the weather is generally dry about the end of May and beginning of June, when there is no grass fit to cut; and almost invariably wet about the end of June and beginning of July, when all the farmers are busy hay-making."

GRAIN, STANDARD WEIGHTS OF. In England the standard and common weights of the most important grains, are as follows :-

$\begin{array}{llc} & \text { Common Weight. } & \text { Standard Weight } \\ \text { Of Wheat - from } 58 \text { to } 64 \text { lbs. } & 60 \mathrm{lbs} . \\ \text { Rye - } & -49-56 & 56 \\ \text { Barley - } & -48-56 & 48 \\ \text { Oats - - }-30-42 & 32 \\ \text { Indian corn - } 54-62 & 56\end{array}$

The same standard weights are established in New York, and to a greater or less extent in other states. It is observed that the weights of the different kinds of grain increase in proceeding from the Southern towards the Northern and Eastern States.

The grain of each species produces when ripe, nearly the following quantities of meal, or household flour, and bread, per bushel, namely-

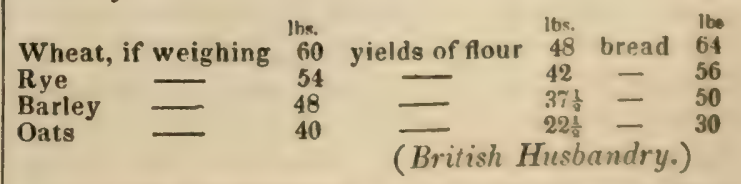

GRAIN-WEEVII,S and MOTHS. In Eu rope, stored grain is often subject to seric . $s$ jury from the depredations of two little irsests. and attacked in the same way, and apparent. 
by the same kind of insects in the United states.

"The European grain-moth, (Tinea granella), in its perfected state, is," says Dr. Harris, "a winged insect, between three and four-tenths of an inch long from the head to the tip of its wings, and expands six-tenths of an inch. It has a whitish tuft on its forehead; its long and narrow wings cover its back like a sloping roof, are a little turned up behind, and are edged with a wide fringe. Its fore-wings are glossy like satin, and are marbled with white or gray, light brown, and dark brown, or blackish spots, and there is always one dark, square spot near the middle of the outer edge. Its hind-wings are blackish. Some of these winged rnoths appear in May, others in July and A ugust, at which times they lay their eggs; for there are two broods of them in the course of the year. The young from the first laid eggs come to their growth and finish their transformations in six weeks or two months; the others live through the winter, and turn to winged moths in the following spring. The young moth-worms do not burrow into the grain, as has been asserted by some writers, who seem to have confounded them with the Angoumois grain-worms; but, as soon as they are hatched, they begin to gnaw the grain and cover themselves with the fragments, which they line with a silken web. As they increase in size they fasten together several grains with their webs, so as to make a larger cavity, wherein they live. After a while, becoming uneasy in their confined habitations, they come out and wander over the grain, spinning their threads as they go, till they have found a suitable place wherein to make their cocoons. Thus, wheat, rye, barley and oats, all of which they attack, will be found full of lumps of grain cemented together by these corn-worms, as they are sometimes called; and when they are very numerous, the whole surface of the grain in the bin will be covered with a thick crust of webs and of adhering grains. These destructive cornworms are really soft and naked caterpillars, of a cylinảrical shape, tapering a little at each end, and are provided with sixteen legs, the first three pair of which are conical and jointed, and the others fleshy and wart-like. When fully grown, they measure four or fivetenths of an inch in length, and are of a light ochre or buff colour, with a reddish head. When about six weeks old they leave the grain and get into cracks, or around the sides of corn-bins, and each one then makes itself a little oval pod, or cocoon, about as large as a grain of wheat. The insects of the first brood, as before said, come out of their cocoons, in the winged form, in July and August, and lay their eggs for another brood: the others remain unchanged in their cocoons through the winter, and take the chrysalis form in March or April. following. Three weeks afterwards, the shining brown chrysalis forces itself part way out of the cocoon, by the help of sume little sharp points on its tail, and bursts open at the other end, so as to allow ine moth therein confined to rome forth.

"The foregoing account, drawn from Euro;ear authorities, will probably enable readers 566 to determine whether these destructive in sects are found in the United States. From various statements, deficient, however, in exactness, that have appeared in some of our agricultural journals, I am led to think tha this corn-moth, or an insect exactly like $i$ in its habits, prevails in all parts of the country, and that it has generally been mis taken for the grain-weevil, which it far sur passes in its devastations. Many years ago) remember to have seen oats and shelled cor (maize) affected in the way above described, and have observed seed-corn, hanging in the ears, to have been attacked by insects of this kind, the empty chrysalids of which remained sticking between the kernels; but, for some time past, no opportunity for further investiga. tion has offered itself." See Con $\mathrm{N}$-Мотн.

The most pernicious of what naturalists call snout-beetles (Rhynchophorians), are the insects properly called grain-weevils. These insects, says Harris, must not be confounded with the still mure destructive larvæ of the corn-moth (Tinea granella), which also attac'is stored grain, nor with the orange-coloured maggots of the wheat-fly (Cecidomyia Tritici), which are found in the heads of growing wheat.

Although the grain-weevils are not actually injurious to vegetation, yet as the name pro perly belonging to them has often been misap plied in the United States, thereby creating no little confusion, some remarks upon then may tend to prevent future mistakes.

"The true grain-weevil or wheat-weevil of Europe, the Calandra (Sitophilus) granaria, or Curculio granarius of Linnæus, in its perfected state is a slender beetle of a pitchy red colour, about one-eighth of an inch long, with a slender snout slightly bent downwards, a coarsely punc. tured and very long thorax, constituting almosi one-half the length of the whole bgdy, and wingcovers that are furrowed, and do not entirely cover the tip of the abdomen. This little insect, both in the beetle and grub state, devours stored wheat and other grains, and often commits much havoc in granaries and brew-houses. Its powers of multiplication are very great, for it is stated that a single pair of these destroyers may produce above six thousand descendants in one year. The female deposits her eggs upon the wheat after it is housed, and the young grubs hatched therefrom immediately burrow into the wheat, each individual occupying alone a single grain, the substance of which it devours, so as often to leave nothing but the hull; and this destruction goes on within, while no external appearance leads to its discovery, and the loss of weight is the only evidence of the mischief that has been done to the grain. In due time the grubs undergo their transformations, and come out of the hulls, in the beetle state, to lay their eggs for another brood. These insects are effectually destroyed by kiln-drying the wheat; and grain, that is kept cool, well ventilated, and is frequently moved, is said to be exempt from attack.

"Another grain-weevil, hardly differing from the foregoing except in its colour, which is black, is found in New York. It is the Calan dra (Silophilus) remotepunstata of Schünherr 
Whether wheat and other grain suffers to any extent in this country, from either of these weevils, I have not been able to ascertain, as the accoun!s given of the ravages of the insects supposed to he weevils are rarely accompanied by any description of them in their different states.

"Rice is attacked by an insect closely resembling the wheat-weevil, from which, however, it is distinguished, by having two large red spots on each wing cover; it is also somewhat smaller, measuring only about one-tenth of an inch in length, exclusive of the snout. This beetle, the Culandra (Sitophilus) Oryza, or riceweevil, is not entirely confined to rice, but depredates upon maize or Indian corn also. I have seen strored Southern corn swarming with them; and, should they multiply and extend in this section of the country, they will become a source of serious injury to one of the most valuable $r$, f our staple productions. It is said that this weevil lays its exgs on the rice in the fields, as soon as the grain begins to swell. If this indeed be true, we have very little to fear from it here, cur Indian corn being so well protected by the husks that it would probably escape from any injury, if attacked. On the contrary, if the insect multiply in stored grain, then our utmost care will be necessary to prevent them from infesting our own garners. The parent beetle bores a hole into the grain, and drops therein a single egg, going from one grain to another till all her eggs are laid. She then dies, leaving, however, the rice well seeded for a future harvest of weevil-grubs. In due time the eggs are hatched, the grubs live securely and unseen in the centre of the rice, devouring a considerable portion of the substance, and when fully grown they gnaw a little hole through the end of the grain, artfully stopping it up again with particles of rice-flour, and then are changed to pupæ. This usually occurs during the winter; and in the following spring the insects are transformed to beetles, and come out of the grain. By winnowing and sifting the rice in the spring, the beetles can be separated, and should then be gathered immediately and destroyed." (Harris.) See Corn-Motr.

GRANARY. A place where corn is stored. These have of necessity been constructed in all ages of the world, and of different materials, according to the facilities afforded for their construction by the neighbourhood in which they are placed; in England they are commonly, for farming purposes, made of wood or brick. In Sicily the public granaries are in some places hollowed out of the solid rock. According to a modern authority (Brit. $H u s b$. vol. i. p. 94), "The best situation for a granary is over the thrashing-floor. It may be easily secured from vermin; and requiring only six feet in height, it will not interfere materially with the bays of the barn, especially if they be loaded through the gables. A trap-door in the floor, with a rope and pulley, raises and lowers the load in the most easy manner, besides securing it more effectually from depredators; and strong wired windows at each end ventilate it sufficiently. The most general mode, however, of forming granaries, is to erect them of timber, and place them upon pil. lars of stone or wood." It has been suggested that corn kept in granaries would be effectually protected from the ravages of the weevil, by mixing with it a small quantity of cosnmon salt. See Conv-Moти, WerviL, and Conx.

GRAPE-VINE. See VIN\&.

GRAPE-VINE CATERPIILAR. Every person, says Dr. Harris, who has paid any attention to the cultivation of the grape-vine ir this country, must have observed upon it, be sides the large sphynx caterpillars that devour its leaves, a small blue caterpillar transversely banded with deep orange across the middle of each ring, the bands being dotted with black. with the head and feet also orange, the top of the eleventh ring somewhat bulging, and the forepart of the body hunched up when the creature is at rest. These caterpillars begin to appear about the middle of July, and others are hatched afterwards, as late, perhaps, as the middle of August. When not eating, they generally rest upon the under-sides of the leaves, and, though many may be found on one vine, they do not associate with each other. They live on the common creeper as well as on the grape-vine. They eat all parts of the leaves, even to the midrib and stalks. When fully grown, and at rest, they measure an inch and a quarter, but stretch out, in creeping, to the length of an inch and a half or more. Towards the end of August they begin to disappear, and no more will be found on the vines after September. They creep down the vines in the night, and go into the ground, burying themselves three or four inches deep, and turn to chrysalids without making cocoons. The chrysalis is dark-brown, and rough, with elevated points. The moths begin to come out of the ground as soon as the 25th of June, and others continue to appear till the 20th of July. Though of small size, they are very beautiful, and far surpass all others of the family in delicacy of colouring and design. The name of this moth is Eudryas grata, the first word signifying beautiful wood nymph, and the second agreeable or pleasing. The antennz are rather long, almost thread-like, tapering to the end, and not feathered in either sex. The forewings are pure white, with a broad. stripe along the front edge, extending from the shoulder a little beyond the middle of the edge, and a broad band around the outer hind margin, of a deep purple-brown colour; the band is edged internally with olive-green, and marked towards the edge with a slender wavy white line; near the middle of the wing, and touching the brown stripe, are two brown spots, one of them round and the other kidney-shaped; and on the middle of the inner margin there is a large triangular olive-coloured spot; the under-side of the same wing is yellow, and near the middle there are a round and a kidney-shaped black" spot. The hind-wings are yellow above and beneath; on the upper-side with a broad purple-brown hind border on which there is a wavy white line, and on the under-side with only a central black dot. The head is black Along the middle of the thuiax there is a trnad crest-like stripe of black and pearl-coloured ylittering scales. The shoulder-covers ar white. The upper side of the abdomen is y cl 
low, with a row of black spots on the ton, and another on each side; the under-side of the body, and the large muff-like tufts on th: forelegs, are white; and the other legs are black. This moth rests with its wings closed like a steep roof over its back, and its fore-legs stretched forward like a Ceruva. It expands from one inch and a half to one inch and three quarters.

Eudryas unio, of Hubner, the pearl Eudryas, as its name implies, is a somewhat smaller moth, closely resembling the preceding, from which it differs in having the stripe and band on its fore-wings of a brighter purple-brown colour, the round and kidney-shaped spots contiguous to the former also brown, the olivecoloured edging of the band wavy, with a powdered blue spot between it and the triangular olive-coloured spot on the inner margin, and a distinct brown spot on the inner hind angle of the posterior wings; all the wings beneath are broadly bordered behind with light brown, and the spots upon them are also light brown. It expands from one inch and three-eighths to one inch and a half. This species has been taken in Massachusetts, but it is rare, and the caterpillar is unknown to me. (Harris.)

GRASS (Goth. gras; Icel. graes, from gro, to germinate, to sprout). The common herbage of the field on which cattle feed.

The grasses, it has been often and well said, "are nature's care." There is, perhaps, no class of the vegetable world so little understood as this. "Grass," says Professor Martyn, "vulgarly forms one single idea, and a husbandman, when he is looking over his enclosure, does not dream that there are upwards of 300 species of grass, of which 30 or 40 may be at present under his eye. They have scarcely had a name besides the general one till within these 20 years; and the few particular names which have been given them are far from having obtained general use, so that we may fairly assert that the knowledge of this most common and useful tribe of plants is yet in its infancy." (Letters on Botany, xiii.) It is certain, however, that since Professor Martyn wrote, much has been done to add to our knowledge of the grasses. These grow in all parts of the world promiscuously, and without cultivation, affording both directly and indirectly the means of subsistence to man. Europeans live chiefly upon wheat, rye, and barley, to which list their American descendants have added maize or Indian corn. "The cultivation of the earth," says Professor Johnson, "preceded the improvement of the intellect, and was the herald of civilization. It is remarkable that we have no direct criterion of the origin of many of those grasses met with every where in cultivation, as none of them are, to any extent, found wild. Some travellers have thought that barley was indigenous to Tartary, rye to Creta, and wheat to Asia, but these might have heen diffu sed from some cultivated some years previously. Corn is not only the support of man, but the grasses are the subsistence of the animals which form his lutriment. The nutritive quality of grasses is rrincipally owing to the sugar which they conrain, and of which some English grasses con568 tain large quantities, but the sugar cane is the only grass that is exclusively cultivated for obtaining this article for commerce. The grasses are applied to a vast variety of important mechanical purposes; they are found in every part of the world, from the Poles to the Equator; on the land, as well as floating on the water, and are the universal food of animals."

The botanist has shown that there are more than 130 distinct native species and varieties of grass in Great Britain, all possessing distinct properties, and varying in their degrees of value to the farmer, from the most worthless, to those on which his successful farming chiefly depends. 'The researches, ton, commenced by the late Duke of Bedford, and carried on during a series of years in the grass garden at Woburn, have added very materially to our stock of knowledge concerning these plants ; for, instituted with a public object, and under the careful and skilful management of one of my earliest correspondents, the late $\mathrm{Mr}$. George Sinclair, the results were given by him to the public in the Hortus Gramineus Wobur nensis, a valuable and elaborate work, to which I am chiefly indebted for the matter of this and other articles upon the grasses. The manrer in which these celelorated experiments of the Duke of Bedford were conducted, is thus described:

"Spots of ground, each containing 4 square feet, in the garden at Woburn Abbey, were enclosed by boards in such a manner that there was no lateral communication between the earth included by the boards, and that of the garden. The soil was removed in these enclosures, and new soils supplied; or mixtures of soils were made in them, to furnish as far as possible to the different grasses those soils which seem most favourable to their growth, a few varieties being adopted for the purpose of ascertaining the effect of different soils on the same plant. The grasses were either planted or sown, and their produce cut and collected, and dried at the proper seasons, in summer and autumn, by Sinclair, his Grace's gardener. For the purpose of determining, as far as possible the nutritive powers of the different species, equal weights of the dry grasses or vegetable substances were acted upon by hot water till all their soluble parts were dissolved; the solution was then evaporated to dryness by a gentle heat in a proper stove, and the matter ob. tained carefully weighed. This part of the process was likewise conducted with much address and intelligence by Sinclair, by whom the various details and calculations were furnished. The dry extracts supposed to contain the nutritive matter of the grasses, were sent to me for chemical examination. 'The compo. sition of some of them is stated minutely; but it will be found, from the general conclusions, that the mode of determining the nutritive power of the grasses, by the quantity of matter they contain soluble in water, is sufficiently accurate for all the purposes of agricultural investigation." (Agr. Chem. app.)

In regard to the description of soils - 1st. By loam, is meant any of the earths cumbined with decayed animal or vegetable matter. $2 d$. Clayey loam, when the greatest proportion is 
clay. 3d. Sandy loam, when the greatest proportion is sand. 4th. Brown loam, when the greatest proportion consists of decayed vegetable matter. 5th. Rich black loam, when sand, clay, animal, and vegetable matters are combined in unequal proportions, the clay, greatly divided, being in the least proportion, and the sand and vegetable matter in the greatest. The terms light sandy soil, light brown loam, \&c., are varieties of the above, as expressed.

The systematical arrangement of grasses is a difficult and unsatisfactory task, and has occupied the attention of many botanists. The most recent work upon the subject is Kunth's Agrostographia, published at Berlin in 1836 .

In choosing the mixture of grass seeds most valuable for the farmer's soil, many considerations must be taken into calculation; not only the nature of the soil, and the supply of water to which its habits are best adapted, but also the objects which the farmer has in view. Thus, the meadow foxtail (Alopecurus pratensis), although an early, nutritive, and productive grass, requires more than two years to arrive at perfection; it is, therefore, better adapted for permanent pasture than for the alternative husbandry. And then, again, the meadow cat's-tail or timothy (Phleum pratense), although remarkable for producing the most nutritious culms of all the grasses, and that, too, in a considerable bulk, yields aftermath of very little value. Valuable, therefore, as it is for hay, it is of little consideration for feeding purposes if sown by itself; it must, therefore, be combined with other grasses. So the cock's-foot or orchard grass (Dactylis glomerata), which soon arrives at perfection, and yields early and late a profusion of leaves, which are highly nutritive, has culms or stalks of little value; it is a grass, therefore, most profitable for feeding purposes. "Under these different relations, therefore," says Mr. G. Sinclair, "a grass should be considered, before it is absolutely rejected, or indiscriminately recommended."

The knowledge of the relative nutritive matters contained in different grasses, will also not only be a highly important object of research, as connected with their feeding properties, but as throwing considerable light on the powers of the different grasses to exhaust or impoverish the soil, a question which I shall examine more at length under the head "Rotation of Crops." A more intimate and extensive knowledge, with regard to the composition of plants, may be derived from even an examination of their external appearance than many persons would deem possible. The following are some of the general results of the observations of Sinclair:

1. Grasses which have culms with swollen joints, leaves thick and succulent, and flowers with downy husks, contain greater proportions of sugar and mucilage than those of a less succulent nature.

2. When this structure is of a light glaucous colour, the sugar is generally in excess.

3. Grasses which have clums with small joints; flowers pointed, collected into a spike or spike-like panicle; leaves thin, flat, rough, and of a light green colour, contain a greater proportion of extractive matter than others.

4. Grasses which have culms furnished with numerous joints; leaves smoc th and succulent; flowers in a spike or close panicle; florets blunt and large, contain most gluten and mucilage.

5. When this structure is of a glaucous colour, and the florets woolly, sugar is in the next proportion to mucilage.

6. Grasses which have their flowers in a panicle, florets pointed or awned, points of the culm smooth and succulent, contain most mu. cilage and extractive.

7. Grasses with flowers in a panicle; florets thinly scattered, pointed, or furnished with long awns; culms lofty, with leaves flat and rough, contain a greater proportion of saline matter and bitter extractive.

8. Grasses with strong, creeping roots, culms few, leaves flat and rough, flower in a spike. contain a greater proportion of bitter extract with mucilage. (Hort. Gram. Wob. p. 42.)

In the first part of April 1920 grains of the leaves of the following grasses, \&c. afford, according to Mr. G. Sinclair, the following proportions of nutritive matter:

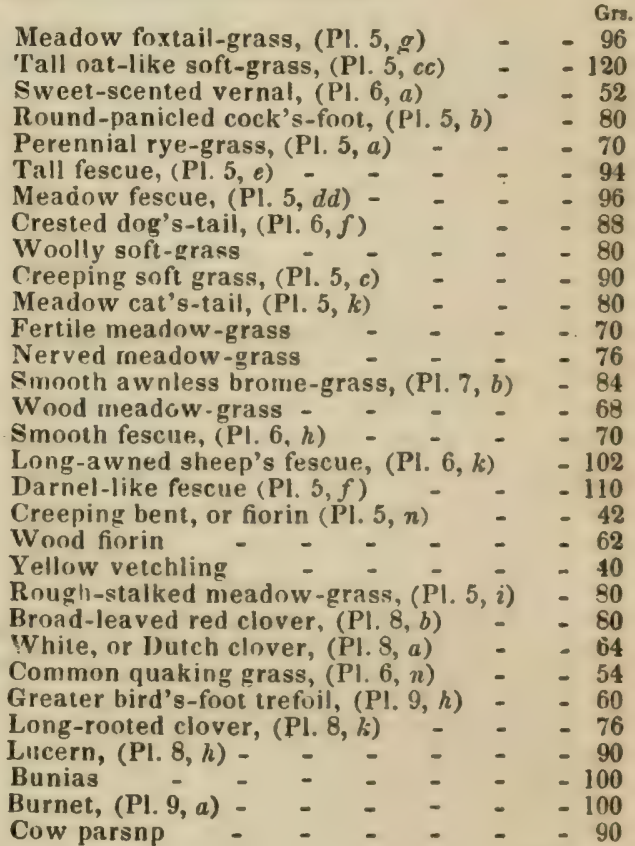

(Ibid. p. 239.)

It may not be uninteresting to the cultivator to learn of what these nutritive matters con. sist; the following is the result of Mr. Sinclair's examinations :

\begin{tabular}{|c|c|c|c|c|}
\hline $\begin{array}{l}100 \text { grains of the Nutri- } \\
\text { tive Matter of the }\end{array}$ & $\begin{array}{c}\text { Mucilage, } \\
\text { or } \\
\text { Starch. }\end{array}$ & $\begin{array}{l}\text { Sacch. } \\
\text { Matter, or } \\
\text { Sugar. }\end{array}$ & Gluten. & $\begin{array}{l}\text { Bitter Ex- } \\
\text { tractive } \\
\text { and } \\
\text { Saline } \\
\text { Matters. }\end{array}$ \\
\hline Meadow foxtail & & & - & 28 \\
\hline $\begin{array}{l}\text { Consists of } \\
\text { Meadow fescue }\end{array}$ & $\begin{array}{l}64 \\
59\end{array}$ & $\begin{array}{r}8 \\
20\end{array}$ & - & 20 \\
\hline Rye-grass - & 65 & 7 & - & 28 \\
\hline Meadow cat's- & & & & \\
\hline tail - - & 74 & 10 & - & 16 \\
\hline Cock's-foot & 59 & 1 & - & 30 \\
\hline Meadow-rat - & 80 & ${ }_{4} \mathrm{C}$ & - & 10 \\
\hline White clover (in & & & & \\
\hline flower) - - & 77 & 2 & 7 & 14 \\
\hline Red clover (do.) & 79 & 8 & 5 & 8 \\
\hline Tares - - & 68 & 25 & - & \\
\hline $\begin{array}{c}\text { Fiorin (Agrostis } \\
\text { stolonifera }\end{array}$ & 55 & 5 & - & 40 \\
\hline
\end{tabular}




\begin{tabular}{|l|c|c|c|}
$\begin{array}{l}\text { 9000 grains of the Green } \\
\text { Herlage of }\end{array}$ & $\begin{array}{c}\text { Wondy, or } \\
\text { Indigestible } \\
\text { Fibre. }\end{array}$ & Water. & $\begin{array}{c}\text { Nutritive } \\
\text { Matter. }\end{array}$ \\
\hline $\begin{array}{l}\text { Tares consist of - } \\
\text { White clover }\end{array}$ & $55 \%$ & 2250 & 193 \\
Cock's-font grass - & 470 & 2430 & 100 \\
Meadow-fescue - & 1135 & 1740 & 1250 \\
\hline
\end{tabular}

(Sinslair's Hort. Gram. Wob. p. 240, 241.)

The chemical composition of the grasses varies materialiy in the progress of their growth, a fact well worthy of the farmer's serious attention in inore ways than one. "I found," says Davy, " in all the trials I made, the largest quantity of truly nutritive matter when the seed was ripe, and least bitter extract and saline matter; most extract and saline matter in the autumnal crop, and most saccharine matter in proportion to the other ingredients in the crop cut at the time of flowering. I shall give one instance :

" 100 parts of the soluble matter obtained from the round panicled cock's-foot grass (Dactylis glomerata), cut in flower, afforded, of

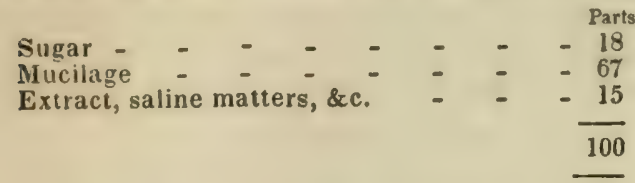

"100 parts of the soluble matter from the seed :rop, afforded, of

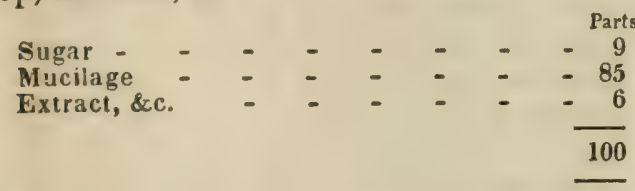

" 100 parts of soluble matter from the aftermath crop gave, of

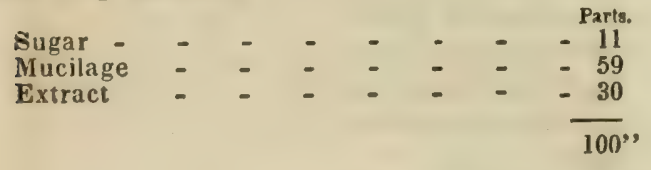

(Elm. of Agr. Chem. 477.)

The seeds of the Grasses.-The ripening of the seeds of the essential grasses (says Sinclair), takes place at three different periods of the season, or, if they are classed according to the time about which each species ripens its seed, they will form three divisions or groups; the first, consisting of the earliest species, pefect their seed about the end of June-such $d s$ the sweet-scented vernal-grass and the alarrowleaved meadow-grass: the second cunsisting of the sheep's-fescue grass, and others, about the end of July; and the third, such as the fiorin grass, and others, about the first or second week in September, as may be seen from the following

Table of the average periods at which different species of Grasses ripen their seed, drawn up by the late $M r$. G. Sincluir, from the details of ten years' practical observation and experiment. (Allowance must be made for difference of climate between England and America.)

Annual meadow-grass (Poa annua, P..6, c, from A pril 10 to frosts.

Sweet-scented vernal grass (Anthvanthum odoratum), P1, 6, a

Soft annual brome-grass (Bromus mollis), Pl. $7, b$
Silver-hair, hair-grass (Aire caryophylla) Shea Sheathed cotton-grass (Eriophorum vaginatum) $18-20$ arrow-leaved cotton-grass (E. angustifolium) $20-30$ ne-flowered melic-grass (Melica uniflora) - 18-2 Spring nillet-grass (.Milium vernale) - - 18-25 Alpine meadow-grass (Poa alpina) PI. $6, l-18-24$ Narrow-leaved ineadow-grass ( $P$. angustifoiii) Pl. $6, \theta$

Blue meadow-grass (Sesleria carulea)

Meadow foxtail-grass (Alopecurus pratensis) Pl. 5, $g-$ - - - - - - - - -
Sweet-scented soft-grass (abortive generally) (Holcus odoratus repens)

Barley-like fescue (Festuca ovina hordeiformis)

PI. $6, i$ _ _ _ _ _ _ June 20 to July 20 July

Small-flowered oat-grass (Avena parviflora) - 4 to 10

Long-flowered (Bromus longiflorus) - - 4-13

Glaucous fescue (Festuca glauca) - - - $\quad$ - $4-24$

Hungarian (Festuca pannonica) - - $\quad 4-17$

Hard wheat-grass (Triticum nardus) - $\quad 4-17$

Smonth meadow-grass (Poa pratensis) Pl. 5, $h \quad 10-17$

Woolly soft-grass (Holcus lanatus) - - 12-24

Creeping soft-grass (Holcus mollis) PI. 5,c - $14-26$

Field or meadow brome-grass (Bromis arvensis) Pl. 7, a

Jointed fox-tail (Alupecurus geniculatas)-

Bulbous meadow-grass (Poabulbosus) - -

Yellow oal-grass (Avena pubescens) Pl. 6, b -

Blue meadow-grass (Poa corulea) - _ -

Nodding panicled bent-grass (Bromus tectorum) Crested dog's-tail (Cynosurus cristatus) Pl. $6, f$

Horn of plenty (Cornucopia cucullatum) - -

Round-headed cock's - foot grass (Dactylis glomerata) Pl. 5 , b

Glaucons cock's-foot grass (D. glaucescens) -

Striped cock's-foot grass (D. variegata)

Striped American variety (D. Americana var.) Wood fescue (Festuca dumetorum) - $-{ }_{-}$

Perennial rye-grass (Lolium perenne) PI. 5, a

Russell-grass (Lolizm Russellianum) _ _

Reflexed meadow-grass (Poadistans) - $\quad 16$

Rigid meadow-grass ( $P$. rigida) - - -

Rough-stalked meadow-grass ( $P$. Trivialis)
PI, 5, $i$ -

Smooth-leaved fescue-grass (Festucu glabra var.) Pl. 6, $h$ - _ _ _ _ -

Creeping fescue-grass (Festuca rubra) - -

Cominon quaking grass (Briza media) Pl. $6, n$

Melilot clover (Trifolium Melilotus officinalis) -

Upright brome-grass (Bromus erectus) - - 20

Bush vetch (Vicia sepium) - - -
Sheep's fescue-grass (Festuca ovina) PI. 6, $k$ -

Early hair-grass (Airupracox)

Water hair-grass $(A$ equ

Crested hair-grass (A cristata)

Gigantic brome-grass (Bromus giganteus) -

Slender oat-grass (Avena fragilis) - - - 24

Eustern oat-grass $(A$. orientalis $) \quad-\quad-\quad 25$

Meadow nat-grass (A. pratensis) - _ - 24

Two-rowed brome-grass (Bromus distachyos) 30

Wall brome-grass (B. diandrus) - - - 21

Tongue-formed brome-grass (B. ligusticus) - 30

Iarge-panicled brome-grass (Bromus maximus) 21

Flat-spiked brome-grass (B. unioloides) - - 21

Wood millet-grass (Milium effusum) - - 21

Brome-like fescue-grass (Festuca bromoides) - 2

Hard fescue-grass ( $\boldsymbol{F}$. duriuscula) PI. 6, g - 30

Crested brome-grass (Bromus cristatus) - - 30

Slender fescue-grass (Festuca gracilis) - $\quad$ - 30

Slender sheep's-fescue ( $\boldsymbol{F}$. ovinu tenuis) - $\quad 30$

Meadow fescue-grass (F. pratensis) PI. $5, d d$

Slender-leaved fescue $(\boldsymbol{F}$. tenuifolia $) \quad-\quad-30$

Viviparous fescue ( $F$. vivipara) - _ - 30

Sand canary-grass (Phalaris .urenaria) - $\quad 30$

Ciliated melic-grass (Melice ciliata) - $\quad-27-31$

Nerved meadow-grass (Poa nervala) - $\quad 30$

Rye-grass-like fosiul: (F'es/ura loliacea), Pl. $5, f 21$

Lesser meadow cat's-tail (Phleum pratense minus)

Linear-spiked (Cynosurus crucaformis) - Meadow cat's-tail (Phleum pratense) Pl. $5, k=2$ Wond meadow-grass (Poa nemoralis) _ - 30

Bulbous-jointed cat's-tail grass (Phleum nodosum

Fertile meadow-grass (Poa fertilis)

Larger bird's-foot irefoil (Lotus major)

Smaller bird's-fout trefoil (L. minor)

Capon's-tail fescue (Festucu Myurus)

Sea-green meadow-grass (Pucesia)

Way-bennet, wall-barley (Horleam inurinum)

Thouin's vetch (Ficis Thouinii)

$\begin{array}{llll} & \\ \text { Welsh fescue-grass (Festucn Cumbricu) PI. } 7, \bar{c} & 20-30\end{array}$

$-26$

$-25$

$-30$

$-30$

$-3$

$-25$

$-20$

$-20$

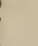

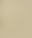


Crested hair-yriss (Aira cristatu)

\section{Giant lyme-grass (}

Decumbert ureadow - grass (Pou decumbens)

Szpelt wheat-grass (Triticum spella)

Slender wheat-grass ('T'ilicum tenue)

Bearded wheal-grass (T'rilicum caninum)

Awuless wheat-grass (Triticum caninum var.)

Common-bell-grass (Agrostis vulgaris) -

Upright mil-grass (Nardus stricta).

Small spurious tare (Ernum Ervilia)

Broad-leaved oat-grass (Avena planiculmis)

Hairy tare (Firvum hirsutum)

Four-steded tare (Ervum tetraspermum)

Glaucous meadow-grass (Poa glauca)

Procumbent meadow-grass (Poa procumbens)

Long-rooted clover (T'rifolium macrorhizum) PI

$8, k$

Wund bent-grass (Aorostis sylvaticus)

Tall fertile fescue-grass (Festuca elatior fertilis)

Many-flowering brome-grass (Bromus multiflo-

rus)

Philadelphian lyme-grass (Elymus Philadelphi-

eus )

Sordid vetch (Vicia sordida) - _ - -

Slender-leaved vetch (Vicia tenuifolia) -

Beardless tall vat-grass (Holcus avenaceus muticus)

Red brome-crass (Bromus rubens)

Baubin's melic-grass (Melica Bunhini)

Foxtail-like fescue (Festuca alopecuroides)

Hedgehog lyme-grass (Elymus hystrix).

Barren brome-grass (Bromus sterilis)

Jointed lyme-grass (Elymus geniculatus)

Golden oat (Avena flavescens)

Fine-panicled (Arundo Calamagrostis)

Meadow barley-grass (Hordeum pratense) 1 H. $5, d$

Narrow-leaved brome (Bromus ungustifolius)

Slender rye-grass (Lolium tenue) - - -

Spear-panicled brome-grass (Bromus lanceola-

tus) - - - - - _ - - 24

Sainfoin (Onobrychis sutiva) Pl. 8, g - - 24

Winged brome-grass (Bromus pinnatus) - $\quad$ Aug. to Sept

Brown bent-grass (A grostis canina) - $29-30$

Bundled-leaved bent ( $\boldsymbol{A}$. vulraris fascicularis) 20

Conch grass (T'riticum rcpens) - -

Wood vetch (Viciu sylvatica) - _ - $\quad$ - 30

Tufted vetch (Vicia cracca)

Foxtail nat-urass (Avena alopecuroides)

Awnless brown bent (Avrostis cunina var. $m u$ tica

Couch bent-grass (Agrostis alb

Fiorin grass $(\mathcal{A}$. stolonifera) $\mathrm{Pl} .5, n$

And many others

Common reed-arass (Arundo phragmites

American cock's-font (Dactylis cynosuroides)

Stiff wheat-grass (7'riticum rigidum)

And five or six others. (Sinclair's Hor 35.)

Of these grasses those regarded in England as the chief and most useful species and varieties are comprehended in the following list:-
Agrostis canina.
Ayrostis stolonifera.
Alopecurus pratensis.
Anthoxanthum odoratum.
Avena flavescens.
Avena pratensis.
Briza media.
Bromus arvensis.
Cow-grass, or perennial red clover.
Cynosurus cristatus
Dactylis glomerata.
Festuca cambrica.
Festuca duriuscula.
Festuca fluitans.
Festuca glabra.
Festuca heterophylla.
Festuca hordeiformis.
Festuca ovina.
Festuca pratensis.
Festuca rubra.
Festuca sylvatica.
Festuca tenuifolia.
Holcus avenaceus.
Holcus lanatus.
Hordeum pratensis
Lolium perenne.
Phleum pratensis.
Poa annua.
Poa cærulea.
Poa fertilis.
Poa nemoralis.
Poa nervata.
Poa pratensis.
Poa trivialis.
Red suckling.
Rib-grass.
Trefoil.
White or Dutch clover.
Yarrow.

From some experiments, given in the Trans.

High. Soc. vol. ii. p. 250, by Messrs. Lawson \&

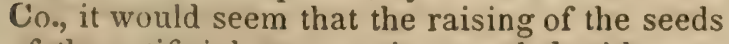
of the artificial grasses is attended with consiclerabie profit.

The late Mr. Blakie suggested a very excellent plax for saving the seeds of down grasses, or of those grasses which are peculiarly adapt. ed for elevated dry soils (Farm. Journ. March 17, 1823), viz. to fence off a sufficient portion of these pastures, choosing such prolums as have the best kind of grasses, ard to now these enclosures for seed in succession, at three, four, or more different periods of the season. "By these neans," said Mr. G. Sinclair, "the seeds of the early, midsummer, and late vegetating grasses will be obtained, and which could not, it is evident, be obtained by one mowing in one season. This is," he adds, "a highly valuable mode of obtaining the seeds of those grasses adapted for downs; which, to cultivate separately for the seed, would be a fruitless undertaking. Fence the selected turf well, and early in the season, and prepare for mowing by picking the stones or rubbish from the surface, and by rolling. As the seeds ripen, employ a careful bird-watcher. Mow in dry, favourable weather. If the swaths are heavy, they should be turned with great caution, so as not to shake out the ripe seeds. As soon as the mowing is dry, the seed should be immediately thrashed out on a close woven cloth in the field, and on a dry day; and when a certain portion of the later grasses ripen their seed, another mowing should be effected, and so on, until all the grasses in the enclosure have perfected their seed." (Hort.Gram.Wob.p. 39, 40.) "As every different soil," continues Sinclair, in another portion of his invaluable work, "produces grasses peculiar to itself, and as no other kinds can be established or cultivated upon it without first changing its nature to resemble that which produced the kind of grasses we wish to introduce; it becomes a point of the first importance in making experiments on different species of this numerous family of plants, and in stating results, to determine with sufficient accuracy the nature of the soil or different soils employed. The basis of every improvement in the cultivation of grasses is to sow the seeds of those species only which are adapted to the soil, or to change the nature of unsuitable soils to that which is fitted for the growth of grasses most desirable to be cultivated; and, unless this important point is in the first place attended to, disappointment rather than success may be expected to follow the labours of the farmer."

1. Of the grasses of rich natural pastures.Every farmer is aware that peculiar grasses are the productive tenants of his rich natural pastures, and that if these are ploughed up, and a course of grain crops taken fiom the soil, a considerable period elapses before the turf with which it was formerly covered can be restored. George Sinclair carefully noted this fact, and examined, not altogether unsuccessfully, its cause. He observed that "the different grasses and other plants which compose the produce of the richest natural pastures are in number 26 , and that from the spring to the end of autumu there is not a month that does not constitute the particular season of luxuriance of one or more of these grasies, hence proceeds the constant supply of rich, succulent herbaye throughout the whole of the season, a circum stance which but seldom or never happens is artificial pastures, where the herbage consists 
of two or three plants only. The plants which usually tenant the best natural pastures are the meadow fox-tail, round cock's-foot, meadow fescue, meadow cat's-tail, sweet-scented vernal grass, tall oat-like soft-grass, creeping vetch, rye-grass, field brome-grass, annual meadow or Suffolk grass, meadow oat-grass: these yield the principal grass in the spring, and a chief portion of that of the summer. Then, again, we find the yellow oat-grass, meadow barley, crested dog's-tail, hard fescue, rough-stalked meadow-grass, smooth-stalked meadow-grass, woolly soft.grass, perennial red clover, white or Dutch clover, yellow vetch or meadow lathyrus, and the smooth fescue, which yield the principal portion of the summer and autumn produce. Lastly, we find the yarrow, creeping bent or fiorin, marsh bent-grass, and creeping wheat-grass or couch, vegetating most vigorously in the autumn. Besides these," continues Sinclair, "in the richest natural pastures are invariably found the butter-cups (Ranunculus acris), rib-grass or ribwort plantain (Plantago lanceolata), and sorrel dock (Rumex acetosa)." Of these, however, except in cases of necessity, live-stock will only eat the rib-grass.

To examine the nature of the change produced on rich pasture land by a course of grain crops, $\mathrm{Mr}$. Sinclair made the following valuable experiments:-

"A space of 2 square yards of rich ancient pasture land was dug to the depth of 8 inches; 400 grains of this soil, freed from moisture and the green vegetable fibres, contained-

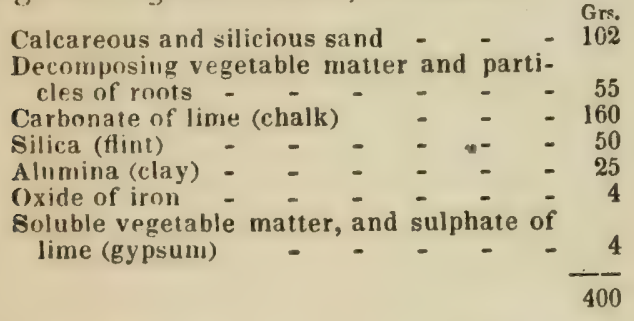

"This soil was then cropped for 5 seasons alternately with 1 , oats; 2 , potatoes; 3 , wheat; 4 , carrots; 5 , wheat. It was then examined, to ascertain what change it had undergone by bearing these crops. It appeared to consist of

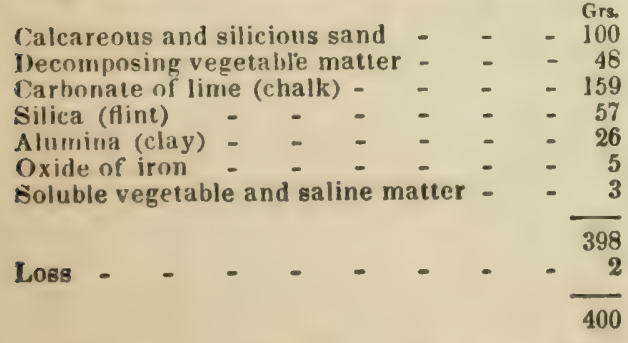

"Thus, the earthy portion of the soil had undergone but little change, but it had sustained a very considerable diminution of its decomposing vegetable and animal matters, particularly when it is considered that the turf also was incorporated with the soil. Manure was now for the first time applied, and, with the wheal stubble, dug in to the depth of 6 inches. 'The surface was then made fine with a rake, and scwn with a mixture of the following grass seeds, at the rate of 5 bushels to the acre:-Meadow fescue, meadow fox-lail, round 572 cock's-foot, tall oat-like soft-grass, creeping vetch, rye-grass, meadow cat's-tail, crested dog's-tail, yellow oat, meadow oat, hard fescue, smooth-stalked meadow-grass, fertile meadowgrass, nerved meadow-grass, cow clover (Trifolium medium), Dutch or white clover, and fiorin, marsh-bent. 'These were sown on the 28 th of August, 1813. They all vegetated be. fore the first week of October except the creeping vetch (Vicia sepium), which did not germinate till the autumn of 1814. Before the frost set in they had a top-dressing with a compost of rotten dung, lime, and vegetable mould, laid on in a fine and dry state, and rolled, and again rolled in February. The plants sprang earlies than those of the old pasture (a circumstance common to young plants in general). In the first week of July the produce was cut and weighed: it amounted to one-eighth more than the produce of the ground in its original state. The aftermath, however, of the seedling grasses weighed one-fifth less than that of the natural pasture. But in 1815, upon cutting and weighing the grass in the first weeks of June and August, and again in the middle of September, the total weight of these three crops exceeded that of the old turf exactly in the proportion of 9 to 8." (Hort. Gram. Wob. p. 131.)

2. The grasses which are the natural tenants of dry sandy and elevated soils.-These, according to Sinclair, are the sheep's fescue, viviparous fescue, purple fescue, pubescent fescue, glaucous fescue, wall fescue, wall barley, fine bent, brown bent, lobed bent, rock bent, snowy bent, purple bent, tufted-leaved bent, waved hairgrass, feather-grass, slender foxtail, hairy oatgrass, blue melic grass, upright mat-grass, blood-coloured panic-grass, green panic-grass, barren brome-grass, crested brome-grass, upright annual brome-grass, nodding brome-grass, Alpine meadow-grass, Alpine foxtail-grass, blue moor-grass, crested hair-grass, panicled cat's-tail grass, reflexed meadow-grass, flatstalked meadow-grass, meadow-barley, bird'sfoot clover, larger bird's-foot clover, trefoil or nonsuch, sainfoin, soft brome-grass, creeping soft-grass, and white or Dutch clover. (Ibid. p. 256.)

"When these sandy upland soils are improved by the application of clay or marl, they are then capable of supporting a very superior description of grasses to these, and the following varieties," says Sinclair, "should be sown, for experience will prove that, under such circumstances, they are the best for that purpose." (Ibid.p. 337.)

\begin{tabular}{|c|c|c|c|c|c|c|}
\hline Barley-like sheep & 's-fescue & - & - & & & ecks. \\
\hline Cock's - foot grass & - & - & & - & 3 & - \\
\hline Crested dog's-tail & grass & - & & & 1 & - \\
\hline Yellow oat-grass & $\therefore$ & - & & & 2 & - \\
\hline Rye-grass & - & - & & & 1 & - \\
\hline Flat-stalked mead & low-grass & - & 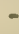 & & 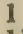 & - \\
\hline Various-leaved fe & scue - & - & & & 1. & - \\
\hline Iard fescue - & - & - & & & 2 & - \\
\hline Lesser bird's-foot & trefoil & - & - & 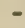 & & h \\
\hline White clover & - & - & - & 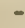 & 5 & - \\
\hline
\end{tabular}

3. The grasses of bogs, or other very moist soils.These are commonly of the most worthless description to the cultivator: they are chiefly the marsh bent, awnless brown bent, awned creeping-bent, smaller-leaved creeping-bent, creeping-rooted bent, white bent, flote fescue, tall fescue, turfy hair-grass, knee-jointed fox- 
tail-grass, water hair-grass, water meadowgrass, long-leaved cotton-grass, and sheathed cotton-grass. (Hort. Wob. p. 340.)

4. The grasses of water meadous.- "All the superior perennial grasses," observes Sinclair, "thrive under irrigation when the meadow is properly formed; the following species of grass I have invariably found to constitute the produce of the best water meadows:-Meadow foxtail, round-panicled cock's-foot, field bromegrass, meadow fescue: these occupied the crowns and sides of the ridges. The furrows were stocked with the creeping bent, marsh bent, hard fescue, lesser variety of meadow cat's-tail, woolly soft grass, rough-stalked meadow-grass, meadow fescue. A small admixture of other species were thinly scattered over every part of the ridge; these were meadow barley, yellow or golden oat, crested dog's-tail, rye-grass, sweet-scented vernal-grass, tufted vetch, with a larger proportion of the tall oat-like soft-grass. The soil of the water meadows which produced the above grasses was either a deep active peat incumbent on a silicious sand, or a sandy loam, on a chalky or gravelly subsoil. In some irrigated meadows, where the ridges were formed nearly flat, and the soil consisted of a sandy loam on a retentive clayey subsoil, the following grasses constituted the chief produce :Crested dog's-tail, creeping-rooted soft-grass, rye-grass, meadow barley, tall oat-like softgrass, sweet-scented vernal, and soft bromegrass." (Ibid. p. 383.)

The grasses best adapted for the alternate husbandry also attracted the attention of George Sinclair; but he saw the difficulty of laying down any systematic rules which should be adapted for all soils and situations, and the demands for animal food: he hardly, therefore, made any very practical general observations. He gives us, however, among other valuable statements, the following little table of the relative value of three of the crops he had examined on similar soil :

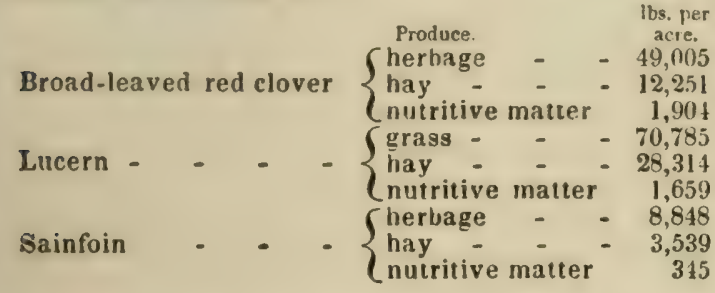

5. The grasses best adapted for pasture during the uinter.-In the fourth volume of the Trans. of the High Soc. p. 31, is an essay on this subject by the late Mr. George Sinclair. 'The following are the grasses he recommends as being productive of the most considerable quantity of winter's grass; and the proportion of seeds which he advises to be sown to produce such a pasture -

Cock's-font (Dactylis glomerata) Meadow fescue (Festuca protensis) 4 pecks.

Tall ferile meadow-grass (Festura elatior var.

fertilis), only in very heavy suils constantly depastured with cattle.

Meadow cat's-tail, or true timothy grass (Phle-
Mead um pratense major)

Broad-leaved bent, or fiorin ) Agrostis stolo-

Tall oot-like soft grass (Holcus avenaceus)
Woolly soft-grass (Tolcus lanafus), only in cases of considerable elevation and poverty of soil.

Pacey's perennial rye-grass (Lolium perenne)

Burnet (Poterium Sunguisorba)

Cow-grass, or perennial red clover (Trifolium

pracense perenne)

White clover (T'rifolium repens)
3 peeke

$6 \mathrm{lbm}$. 8 -
The quantity of the grass seeds employed per acre, for permanent ordinary pasture necessarily varies with the nature of the soil. A practical. English farmer gives the following as an excellent mixture. (Mark Lane Exp. April 5, 1841.)

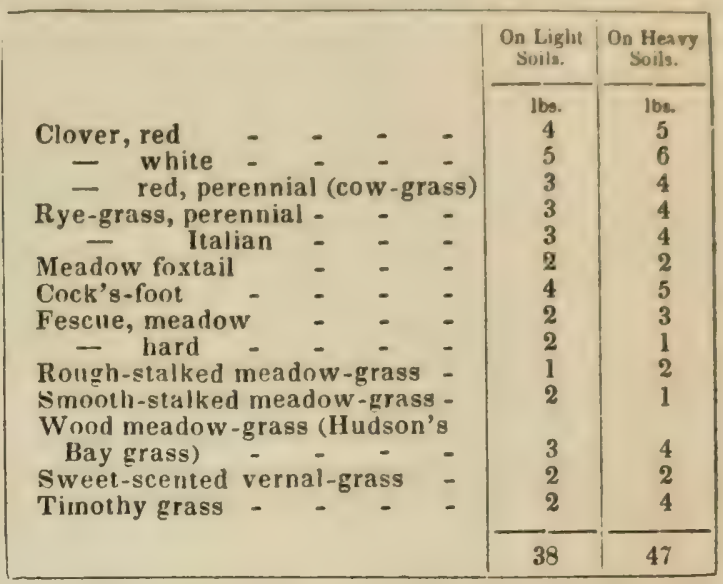

6. Transplantation or inocularion of turf. - This plan, which is one in certail, situations, offering considerable advantages, is described in the Brit. Husb. vol.ii. p. 523, and by G. Sinclair, Hort. Gram. Wob.p. 415. The mode of returning tillage land to permanent pasture, called transplanting, was originally invented by Mr. Whitworth, of Acre House, I,incolnshire, and it was first practised to any extent by Mr. Ichn Bloomfield, of Warham, Norfolk. In laying down land to permanent pasture by this mode, it is essential that the soil should be free from the seeds and roots of weeds, and made perfectly clean by a summer fallow. The autuinn is the best time for transplanting turf, and that as soon as the autumn rains have sufficiently moistened the turf to fit it for paring off clean : the roots of the grasses thus get established before the commencement of warm weather in the spring. It is also essential that the turf should be selected or taken from the very best pasture, for otherwise weeds and inferior grasses will be propagated. If the field from which the turf is to be taken to make the new pasture, is intended to be broken up for a course of tillage crops, then the whole of the turf may be taken off and employed in forming the new pasture to the required extent. But should the field be required to remain in permanent pasture, a portion only of the turf must be taken from the field, and a suffciency of the sward, or grass-plant, left standing for that purpose. In the first of these cases, Mr. Blakie directs a paring-plough to be used; but if that cannot be convenier.y obtained, a common plough, with the cuulter and share made very sharp, wil: answer the purpose : a wheel plough is preierable, adds Sinclair, to a swing plough for paring turfs, because it goes steadier, and cuts the turf more regularly. The turf should be cut about 2 t 
inches thick, and 7,8 , or 9 inches wide, according to the nature of the turf-gage of the plough, and the width of the wing of the share: it is sometimes cross cut into short lengths, previous to the operation of paring; but this can only be effected when the turf is moist and free from stones. The cross cutting is done by a scarifier, with cimeter tines, the convex edges made very sharp, and faced to the work, and the implement heavily weighted, so as to press the tines a proper depth into the turf: : but it is best in large flags. "The turf is then carried in broad-wheeled carts to the field, at the rate of 50 cart-loads to an acre, placed in heaps, and then chopped into small pieces of about 3 inches square; the ground is then levelled with a scarifier, and the turf spread with shovels over the field; the pieces of turf are then placed or planted by women and children, and pressed into the soil by the foot ur a wooden rammer. One acre of turf divided into pieces will plant 9 acres-each piece of turf standing $\mathbf{9}$ inches apart. The expense per acre of this mode of converting arable land into pasture is as follows: say

Extent of grass land clean paired of

Extent of arable land transplanted with the above

\section{Expense.}

To ploughing or pairing 1 a. 2 r. 18 p., at 10 s. per acre

To carriage of 600 loads of tuft, fifty days' work for one horse, at $3 s$, per day

To boys driving carts -

To scarifying 11 acres or 15 poles of ground when covered with tuft cut in pieces, at $2 s .6 d$. per acre

To labourers, at 30 s. per acre

$$
\text { Or } 2 l .9 s, 2 \frac{3}{7} d \text {. per acre. }
$$

A plan of improving old worn-out pasture lands (by dibbling peas and vetches, with a mixture of 18 pounds of Dutch clover, and 2 bushels per acre of Bay grass) is described by Mr. Salter, Com. to Toard of Agr. vol. vi. p. 357. On the advantages of deep ploughing, fallowing, and liming land intended to be again laid down to permanent pasture, with an experiment on 17 acres at Jedburgh, there is a paper by Mr. Bell, Quart. Journ. of Agr. vol. i. p. 570, and another by Mr. Sinclair (ibid.p. 65). To this gentleman's excellent work (Hort. Gram. Wob.), I would especially commend my readers, as it abounds with information on the grasses. There is also a paper on the economical improvement of grass lands in Scotland (Quar\%.Journ. of $A g r$. vol. vii. p. 547); and in all improvements of this kind, the use of the sub-turf plough should not be forgotten by the farmer. See InRIGATION.

In addition to the original article in the English edition, we deem the subject of grasses so important, and the knowledge of the subject so limited in the United States, that we subjoin the following information derived from the best British authorities.

English writers have divided hay grasses, according to their duration, into two classesthe temportry and permanent.

The tall hay grasses of temporary duration, regarded as most valuable, are-

The Annual or Perennial Rye-Grass (Lolium i74

annua or perenne), see Plate of Tall Hay Grasses, Pl. 5, $a$; Cock's-foot or Orchard Grass (Dactylis glomerata), $b$; and Woolly Soft-Grass (Holcus lanatus), $c$.

Where a crop of hay is desired within thr, year, it is necessary to resort to such grasses as are annuals in the strict sense of the word. and none (says Loudon) can be better for this purpose than the common oat (Avena sativa). cut and made into hay when it comes inte flower. Next in order may be mentioned the other cereal grasses, and the annual varieties of Bromus; the latter, however, are very coarse grasses, though prolific in culm.

The biennial rye-grass, a variety of the pe rennial Lolium, is almost universally sown in England, either with or without clover, among grain crops, with a view to one crop of hay in the succeeding season. It attains a greater height, and produces a longer, broader spike of flowers than the perennial rye-grass, and the produce in hay is considered greater than that of any other annual grass, equally palatable to cattle. It prefers a rich, loamy soil, but will grow on any surface whatever, except undecayed rock or bog. The perennial rye-grass, which will be more fully described hereafter, differs from the biennial variety in being of somewhat smaller growth, and in continuing in the ground for several years; according to the circumstances of soil and culture.

The Cock's-foot Grass, or, as it is generally called, in the United States, Orchard-Grass, from its thriving well in moist shady places, and especially orchards (Pl. 5, b), is an imperfect perennial, and grows naturally on dry, sandy soils. This grass may be recognised by its coarse appearance, both of the leaf and spike, and also by its whitish green hue. It grows freely in most situations, is very hardy and productive, but rough, harsh, and coarse, and much improved by cultivation in open grounds. Hence its name of rough cock's-foot.

This grass is rather early in its growth, and in many excellent old pastures it constitutes one of the plants always found in the turf. It vegetates much during the winter in England, and when sown at the rate of 2 bushels an acre with red clover, it has speedily formed a very good sward. As a single plant to sow with clover for hay, it is altogether unsuitable. On good lands it shoots up strong, coarse stalks, too tall and few in number, and unfit for fodder; and the hassocky tufted roots do not yield at that season a quantity of leaves to be cut for hay. But on inferior soils that are used for pasturage for two or three, or more years, in remote or high situations, it forms one of the most valuable of grasses, shoots early, and affords, from its tufted growth, an early bite for sheep, and produces an abundance of sound, healthy seed, which is easily gathered. The general complaint of running up to coarse stalks may be remedied by early and close grazing, and when sown on poor lands along with other perennials, it will produce the earliest feed, and the most abundant herbage during the season. It is much relished by all kinds of live-stock, and especially sheep, the quantity of which that can in England be kept upon it summer and winter is quite surprising, 
the land meanwhile becoming richer in $+v^{\circ} n$ or three years from the sheep manure. After midsummer, however, sheep prefer the rye-grass. Sinclair, it is stated, considers "no grass so well suited for all purposes as cock's-foot." (Code of Agricullure.)

It is observed, by high authority, "that if one species only is thought preferable to another in the alternate husbandry, that species is the cock's-foot, from its more numerous merits. But a certain supply of the most nutricious herbage throughout the season will be in vain looked for from any one species of grass, and can only be found where nature has provided it in a combination of many." (Hort. Grum. Wob., 2d ed. p. 414.)

The Woolly Soft Grass (Pl. 5, c), is an imperfect perennial, and rather a late flowering grass, of a short, unsubstantial appearance, and found chiefly in poor, dry soils. It is, however, a very common grass on all soils, from the richest to the poorest. It affords abundance of seed, light, and easily dispersed by the wind. According to Sinclair, of Woburn, it appears to be generally disliked by all sorts of cattle. It answers, however, for sheep pasture. Being left almost untouched by catlle, it appears the most productive part of the herbage, which leads to a false conception of its produce. The hay made from it is generally disliked by cattle. The Woburn experiinents lead to the conclusion that the Holcus mollis, or couch grass, is a better plant for hay than the species here noticed, but that is a more durable perennial, and therefore belongs (o) another class of grasses.

Tall Har Grasses of permanent duration."No permanent grass," says Loudon, "has been found equal to the rye-grass for the purposes of convertible husbandry, but others have been selected, which are considered superior for hay meadows. The principal of these are the fescue, fox-tail, and meadowgrass." (Encyc. of $A g r$ )

Of the various species of fescue grass, there are three held in the highest estimation in England as meadow hay-grasses, viz.:

The Meadow or Fertile Fescue Grass (Festuca prutensis, Pl. 5, dd). This is found in rich meadows and pastures, and is highly grateful to all kinds of stock. In England it is more in demand for laying down meadows than any other species, except the rye-grass. The loss sustained by leaving the crop of this grass till the seed be ripe is very great, since by the $\mathrm{W}_{0}$ burn experiments it appears that the value of this grass, at the time the seed is ripe, is, to that at the time of flowering, as 6 to 18 . It may be observed, that there is a great difference between straws or leaves that have been dried after they were cut in a succulent state, and those which are dried by nature while growing. The former retain all their nutritive powers, but the latter, if completely dry, very litile, if any.

The Tall or Infertile Fescue Grass (Festuca elalior, $\mathrm{Pl} .5, e)$. This, in appearance, differs but little from the meadow fescue, except in being larger in every respect. The produce, however, is nearly three times greater; the nutrilive properties being also greater, in the pro- portion of 6 to 8. This grass takes its name in England from its seeds being infertile when cultivated, it being produced by parting the roots and planting them out.

'The Spiked Fescue Gruss, or Darnel Fescue Grass (Festuca loliacea, Pl. 5, $f$ ), resembles. the rye-grass in appearance, and the tall fescue in the infertility of its seeds. "It is," says Iorudon, "considered superior to rye-grass either for hay or permanent pasture, and improves in proportion to its age, which is the reverse of what takes place with the rye-grass."

The Meadow Fox-tail Grass (Alopecurus pratensis, Pl. 5, g), is found in most English meadows, and where the soil is neither very moist nor very dry, but in good heart, is very produc. tive. It also does well on water meadows. Sheep and horses seem to relish it better than oxen. In the Woburn experiments, the result gave nearly three-fourths of produce greater from a clayey loam than from a sandy soil, the grass from the latter being comparatively of less value in the proportion of 4 to 6 .

Of the Meadow Grasses, there are two species most esteemed in England and Scotland as hay plants, the smooth-stalked and roughish, which compose the greater part of some of the most celebrated meadows, especially those near Edinburgh.

The Great or Smooth-stalked Meadow Grassthe Spear-grass of America (Poa pratensis, PI. $5, h)$, is distinguished by its height, smouth stem, and creeping roots. According to Sole, it is the best of all the grasses. Its foliage begins to shoot and put on a fine verdure early in the spring, but not so soon as some other grasses. Every animal that eats grass is fond of it; while it makes the best hay, and affords the richest pasture. It abounds in some of the best meadows in Great Britain, and has the valuable property of abiding in the same land, while most other grasses are continually changing. According to some, it delights in rather a dry than a moist soil and situation, on which account it keeps its verdure better in dry seasons, but it thrives most luxuriantly in rich meadows. A loss of more than one-fourth of the value of the whole crop is sustained if it is not cut till the seed be ripe, the straws being then dry, and the root-leaves in a decaying and sickly state. Those of the lattermath, on the contrary, are luxuriant and healthy. This species sends forth flower-stalks but once in a season, and those being the most valuable part of the plant for the purpose of hay, it will, from this circumstance, and the superior value of the grass of the lattermath, compared to that of the seed-crop, appear well adapted for permanent pasture. It was of this grass that the American prize bonnet, in imitation of Leghorn, was manufactured by Miss Woodhouse.

The roughish meadow-grass (Poa trivialis, Pl. $5, i)$, delights in moist, rich, and sheltered situations, where it grows 2 feet high, and is very productive. By the Woburn experiments it appears that the proportional value in which the grass of the seed crop exceeds that at the time of flowering is as 8 to 11 . The proportional value by which the grass of the lattermath ex. ceeds that of the flowering crop is as 8 to 12. and that of the seed crop as 11 to 12 . Herr. เ)? 
inen, is a satisfactory proof of the superior vaJue of the crop at the time the seed is ripe, and of the consequent loss sustained by taking it when in flower; the produce of each crop being nearly equal. The deficiency of hay in the flowering crop in proportion to that of the seed crop is very striking. Its superior produce, the highly nutritive powers which the grass seems to possess, and the season in which it arrives at perfection, are merits which distinguish it as one of the most valuable of those grasses which affect moist, rich soils, and sheltered situations. But on dry, exposed situations, it is altogether inconsiderable; it yearly diminishes, and ultimately dies off, not unfrequently in the space of four or five years. (Loudon's Encyclop. of Agriculture.)

The above constitute six of the best British grasses for either dry or watered meadows. The seeds of the two sorts of meadow-grass are apt to stick together, and when sown with clover and other kinds of seeds, require to be carefully mixed before sowing. The tall and spiked fescue grasses, having a number of barren flowers, are not prolific in seeds, and are therefore seldom to be got at the seedstores, though they may occasionally be had there gathered from plants in a wild state.

As hay grasses, adapted for particular soils and situations, the cat's-tail or timothy, floating fescue, and fiorin grass have been recommended hy British agriculturists, though not with perfect unanimity.

The Cat's-tail or Timothy grass (Phleum pratense, Pl. 5, $k$ ), is said to be a native of England, although, from its still partial use there, and its universal culture in all the grazing districts of the United States, its valuable properties were here first properly appreciated, as a hay grass taking precedence of all others. It is said to have acquired its name of timothy from its first introducer into Maryland, Timothy Hanson. It is a favourite grass in Sweden, and is destined to becnme so in England, although some of the highest British authorities upon rural matters, Withering, Swaine, Curtis, and others, have disapproved of its culture, as having no properties in which it is not greatly surpassed by the meadow foxtail. Probably some mistakes have been made by the authorities who have treated upon the subject, who have thus referred to different grasses. This is rendered more probable from the fact that the English Flora enumerates six species of cat's-tail, but one of which seems to have any particular claims to the attention of the farmer. 'The Woburn experiments present timothy as one of the most valuable grasses for hay. In England, according to Donaldson, it has very undeservedly sunk in estimation, as being harsh, late, and yielding little aftermath, and from possessing no quality in which it is suppnsed not to be excelled by the foxtail grass. This last observation must have pro:eedea from a very limited experience, for in general purposes, and in a variety of soils and of climate, i: far exceeds the foxtail, and also in yielding readily an abundance of sound, healthy seed, while many of the seeds of the fixcall are abortive, and the plant is very shy of growth, and confined to the best cultivation. 576
At the time of flowering, timothy grass produced on one acre 40,837 lbs., when ripe it yielded the same weight, but the quantity of nutritive matter was more than doubled; the lattermath yielded $9528 \mathrm{lbs}$, and the same quantity of nutritive matter as at the time of flowering: 1920 grains of leaves gave 80 grains of nutritive matter, and 100 grains of nutritive matter gave 74 of mucilage or starch, 10 of saccharine matter or sugar, and 16 of bitter extractive or saline matter. The ripe crop exceeds the flowering in value as 14 to 5 , which circumstance gives great value to the plant for the purpose of hay. If these statements of comparative produce and value be admitted as an authority, it will be seen that cat's-tail exceeds the foxtail grass in every respect except in the produce of the lattermath: an advantage that is much over-balanced by the greater produce and the ready growth of the timothy grass. It thrives much on peaty lands, and in humid climates, and on all damp soils, and on those that possess a degree of loamy softness in their composition; and is unfit for hot sands, gravels, and chalks, and for hard, sterile clays. With that exception, experience on a great variety of soils and for a long period of time places this grass next to ray grass for general utility. It grows readily and abundantly, yields much seed and of good quality. On very good lands, it has a tendency to produce height of stems in place of number, and the leaves are soon blanched and yellowed with rain in making into hay; but the other grasses have a simı. lar tendency, and they are all inferior to ray grass in producing a crop of the greatest num. ber of stems of an equal height. The time of flowering is little if any later than the cock'sfoot, fescue, or ray-grass, and for one crop of hay, or for two and three years' pasture, and for permanent purposes, the meadow cat's-tail must form a very considerable part of the mixture. The comparative merits of this grass will, from the above particulars, appear to be very great; to which may be added, the abundance of fine foliage that it produces early in the spring. In this respect it is only inferior to the narrow-leaved meadow-grass ( $P$ oa angustifolia), and Poa fertilis. The value of the straws at the time the seed is ripe exceeds that of the grass at the time of flowering in the proportion of 28 to 10 , a circumstance which raises it above many others; for, from this property, its valuable early foliage may be pastured to an advanced period of the season without injury to the crop of hay, a treatment which, in grasses that send forth their flowering straws early in the season, would cause a loss of nearly one half in the value of the crop; and this property of the straws makes the plant peculiarly desirable for hay. Timothy is doubtless a very exhausting crop, and some persons think it entirely too costiy a provender for horses in common use, and only to be given to racers, \&c. Coch's-foot and rye-grass afford a much cheaper hay, and are not such great exhausters of the soil. It seems certain that for horses no kind of hay is equal to timothy. Mixed with clover it also makes an admirable hay, fit for both horses and cattle. (See PI. 5, of Tall Hay grasses, a.) 


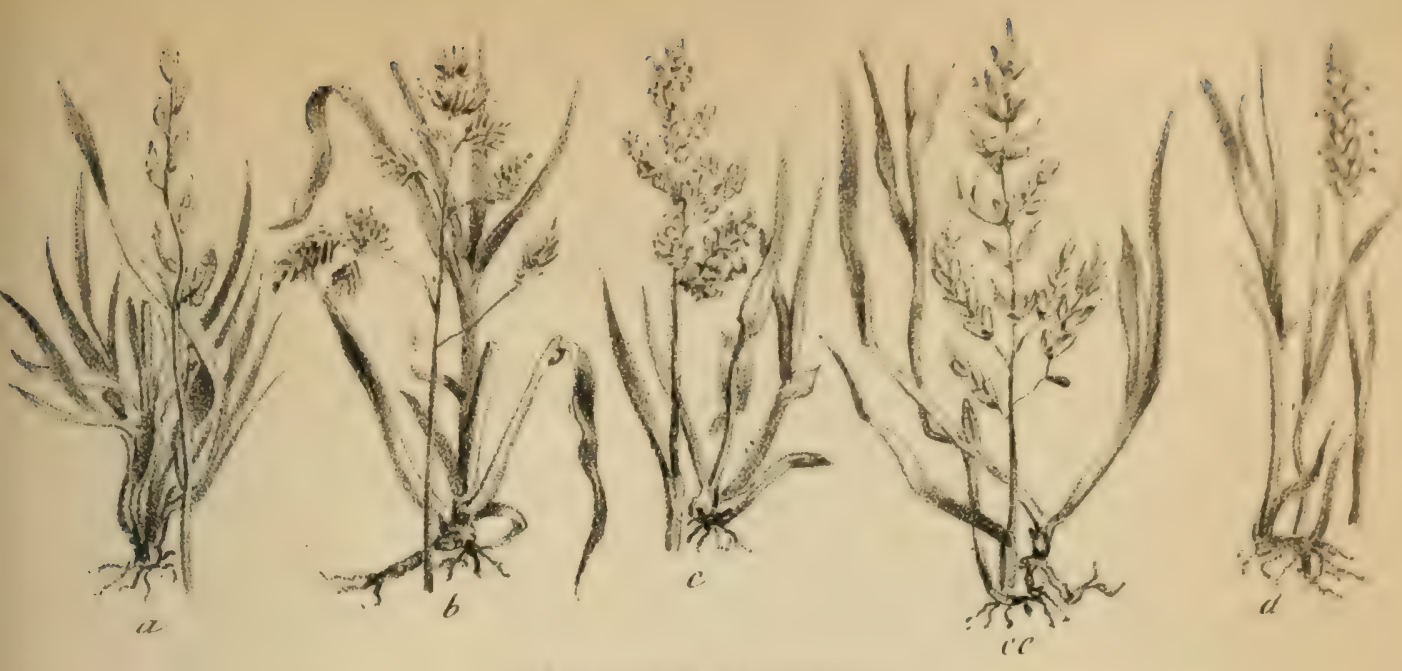

TALL HAY GRASSFS.

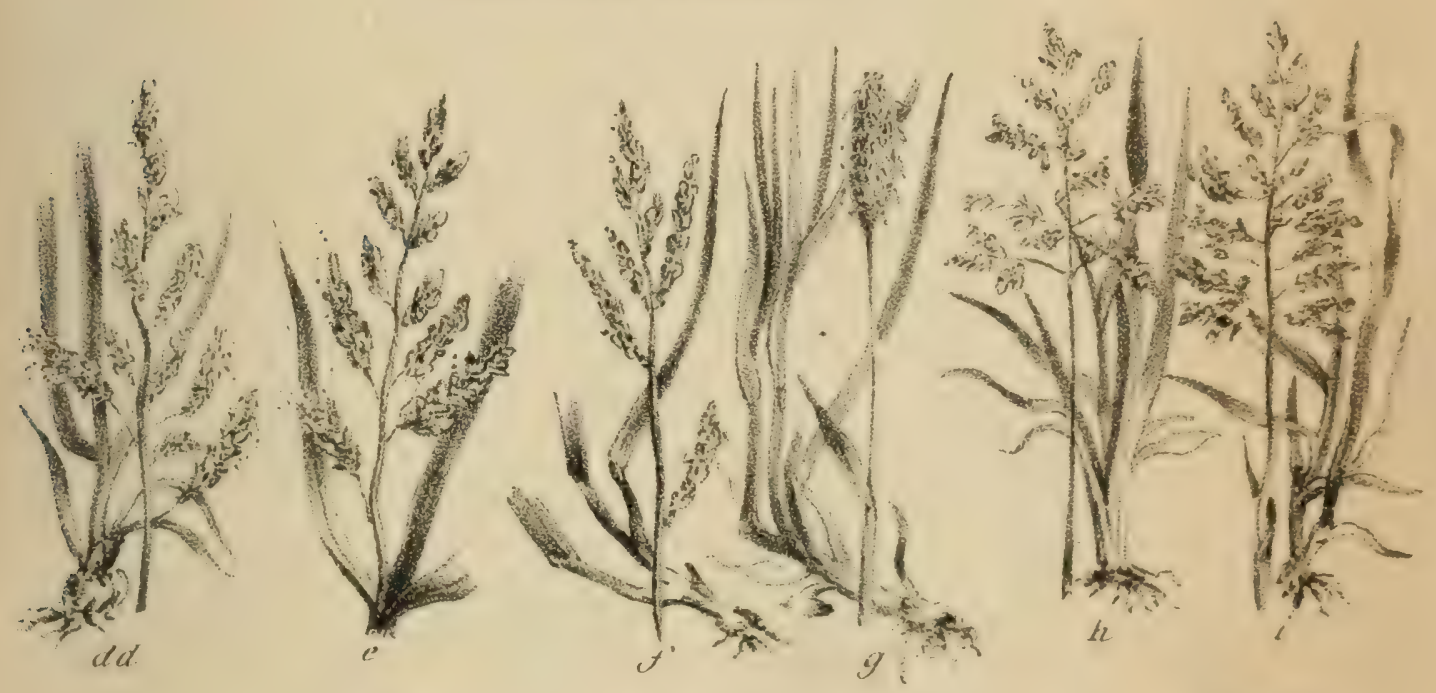

TAI.L HAY GRASSFS OF PERMANENT DURATTON

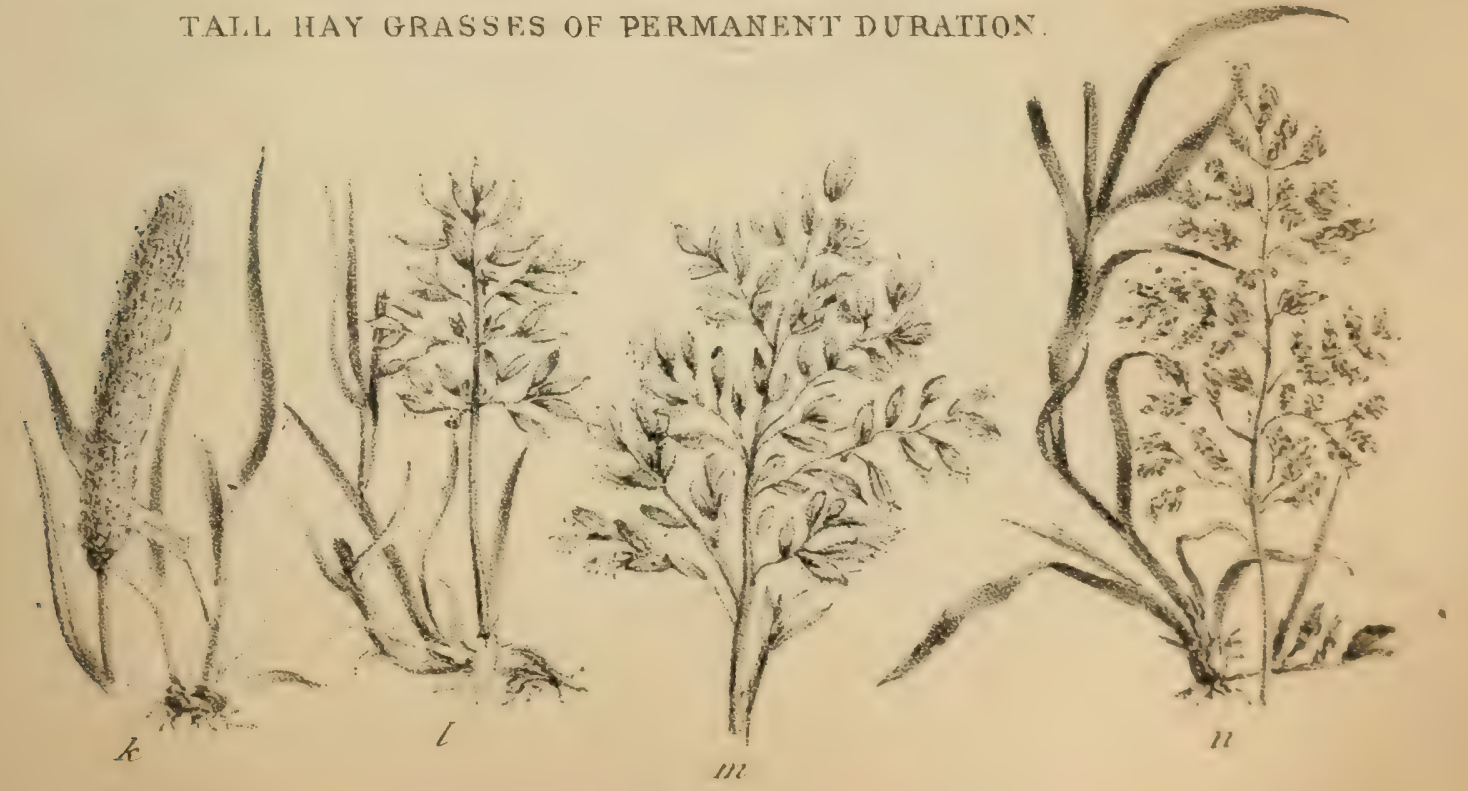

HAY GRASSES ADAPTED TO.PARTICULAR SOILS \& SITUATIONS 



$$
\text { Plenli }
$$

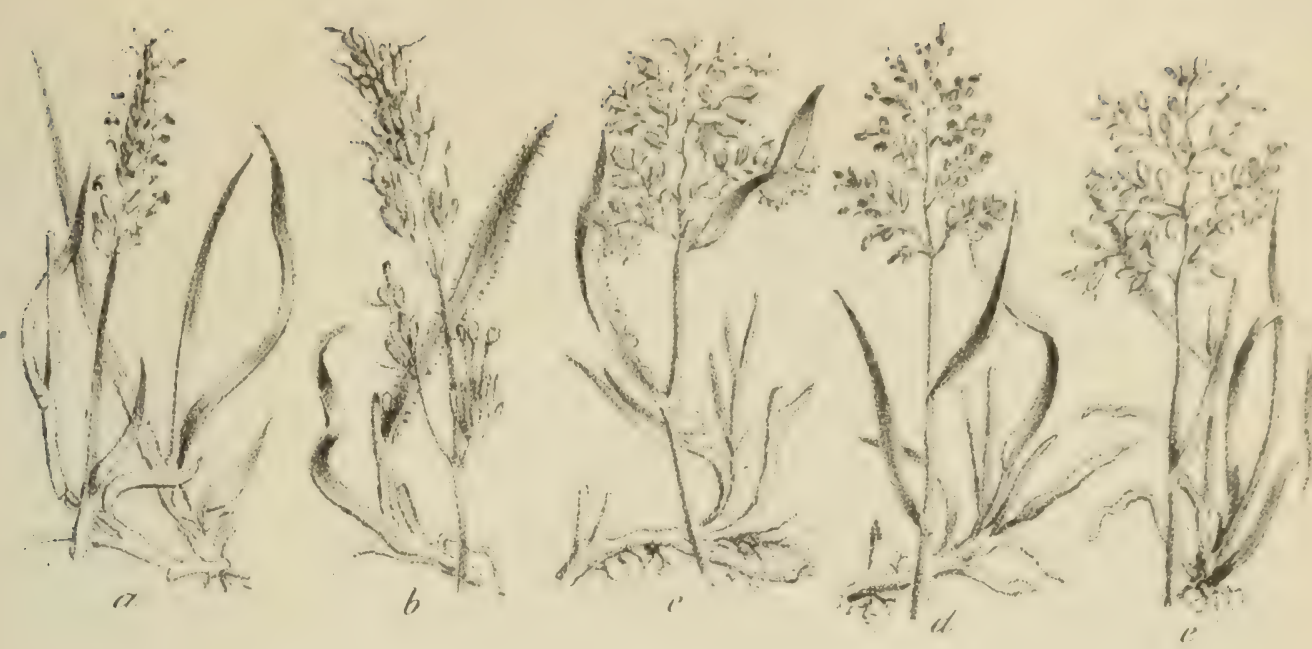

EARLY PASTURE: GRASSliS.

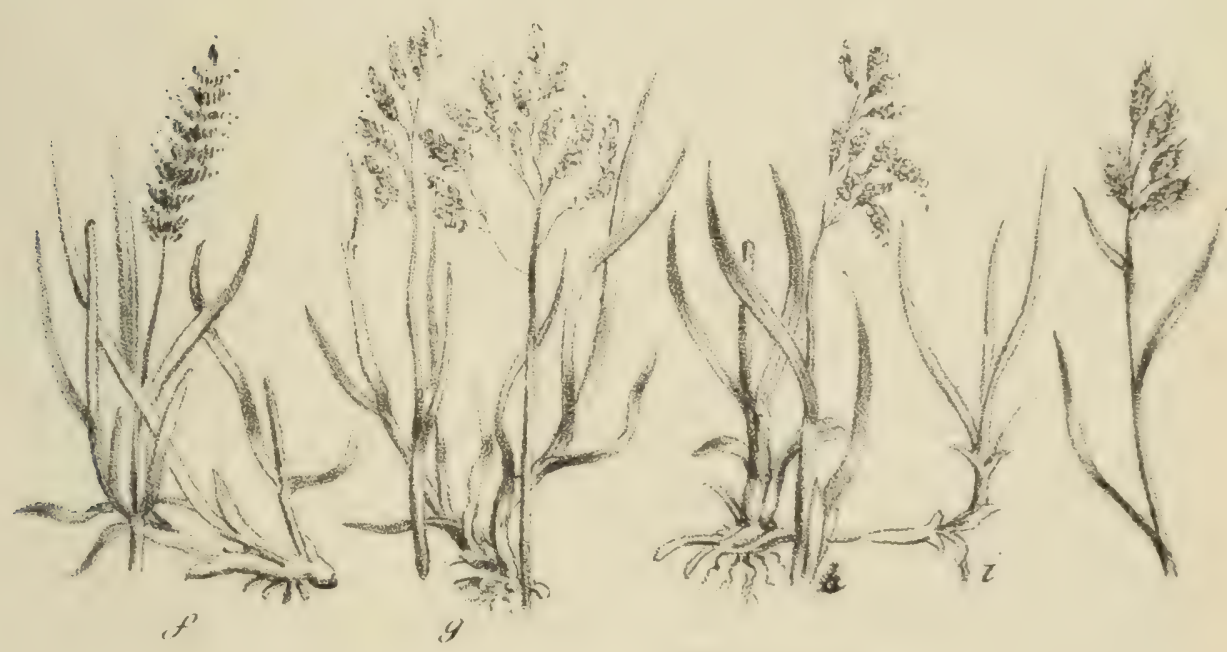

PASTURF GRASSFS ADAPTED TO

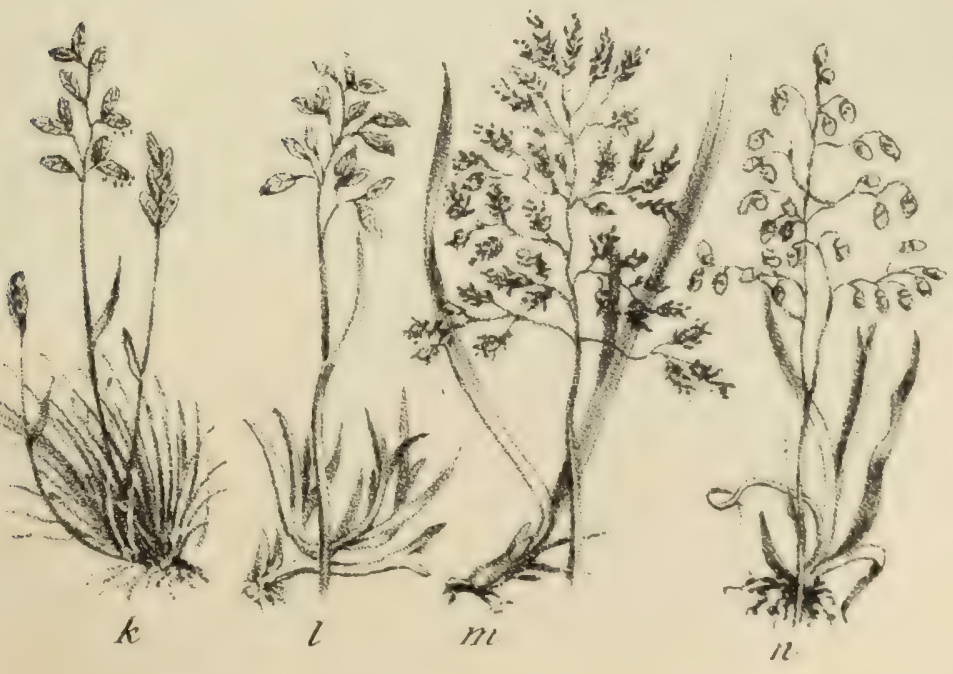

PARTICIILAR SOTLS AND STTLITIONS 



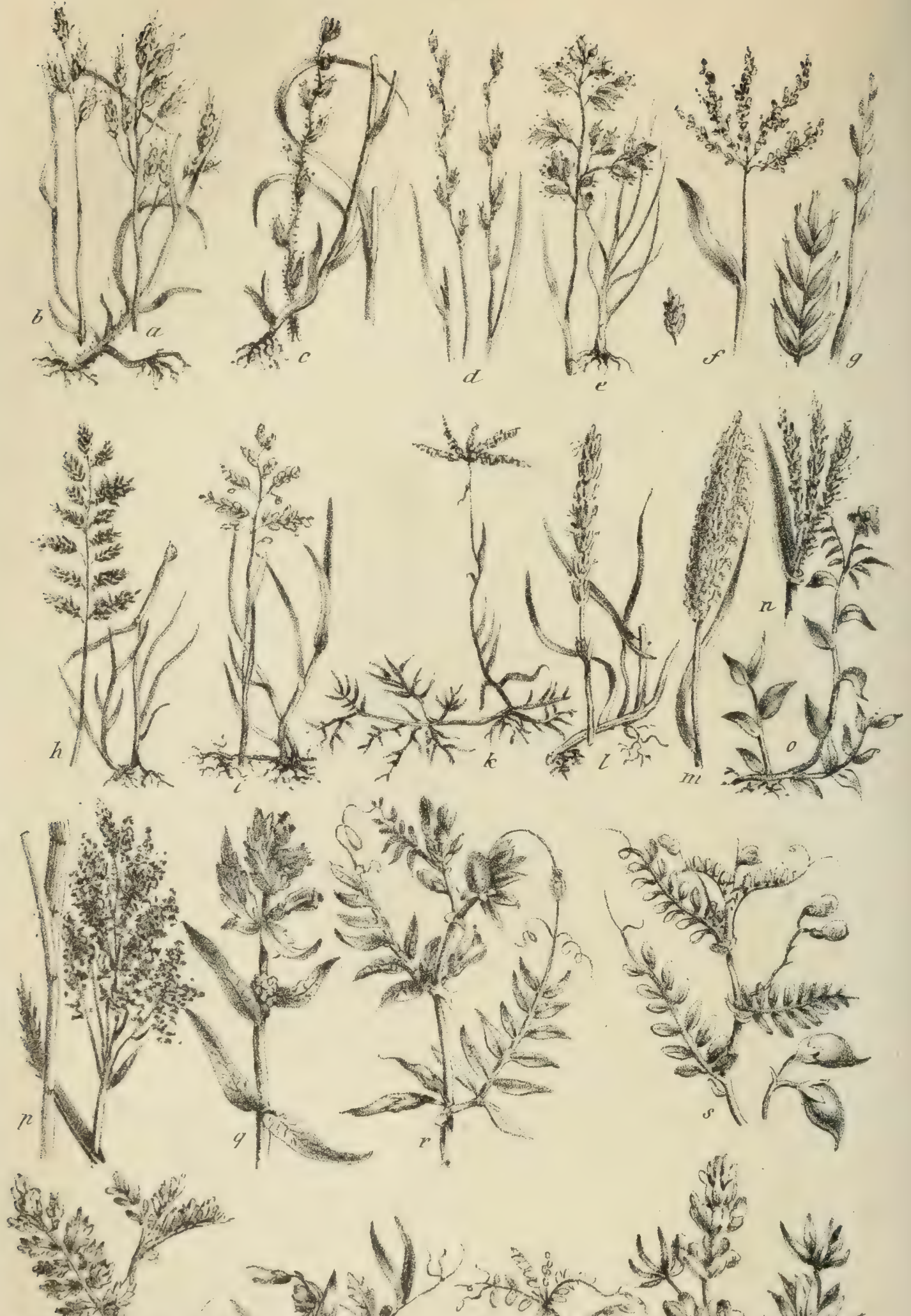

$$
\text { - }
$$

tit Hig
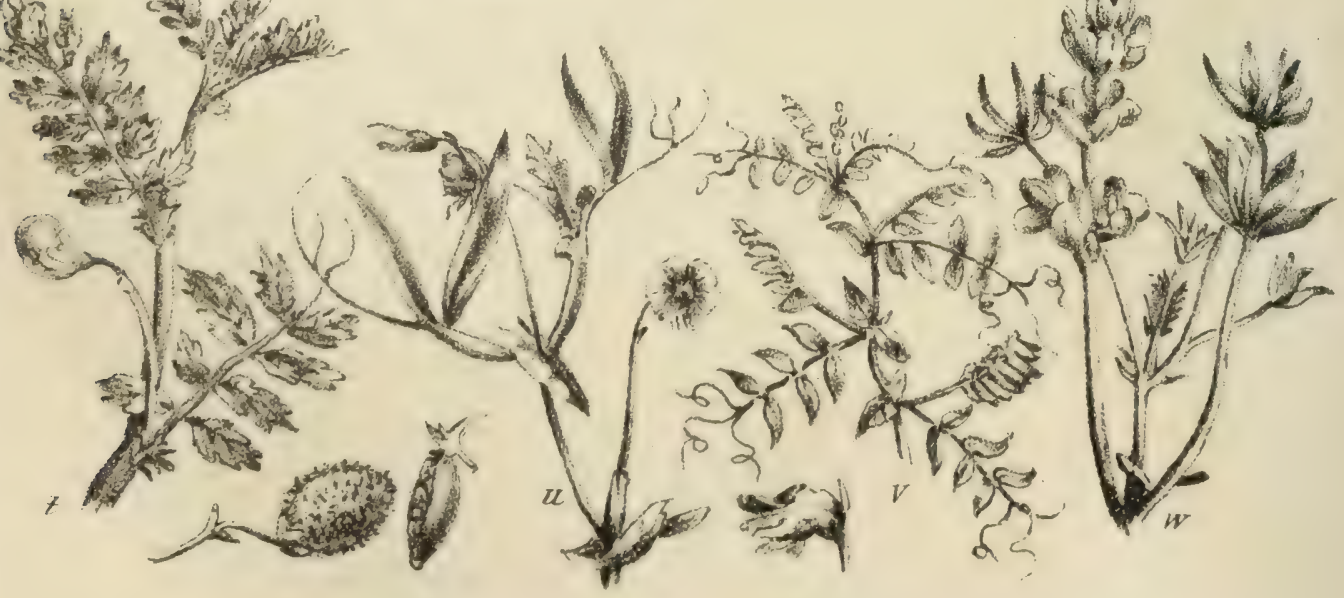
The common Ray or Rye-grass (Lolium perenne), is said to be the first of the grasses cultivated in England, and even in Europe. According to Donaldson, the latest English writer upon grasses, it is still regarded as not far removed from being first in point of general utility. One of the species of Lolium, the temulentum, or bearded annual darnel, is sometimes mistaken for what is known in the United States by the names of Cheat or Chess, so often found among wheat and barley crops. See Dannez. The varieties of the Lolium perenne are very numerous, and several improvements have been effected in England on the original plant, known under the names of Pacey's, Stickney's, and Russell's Ray-grasses, Pacey's and Russell's being considered the best. For more than a century and a half this grass has continued in high repute in England, both for the purpose of a single crop and for pastures, and now constitutes a part of all kinds of the imnroved mixtures. The modern objection to ray-grass is the shooting up to stems and culms, and the want of foliage, together with a deficiency of aftermath. "But," says Do. naldson, "the first only happens in upland situations and on poor soils, where any other plant would have the same tendency; for on good soils ray-grass grows large, leafy, and succulent, and in many cases it affords as good lattermath as most others, and forms, when sown with clover, a very useful sward for several years. No plant is liable to greater variation from soil and situation, and hence may have arisen the many discordant opinions of its value; and from being sown singly with clovers it has been more exposed to observation than any other grasses which are usually sown in mixtures, and seldom tried singly for one crop or for a longer duration. It has accordingly been much subjected to fancies and conjectures, which are about equally divided for and against the use of it, the former being yet the most numerous. Coarseness is inferred from the benty stalks standing uncropped; these might be kept under by early and close grazing, and other grasses are equally objectionable on that point; and it produces stems during the whole season, while some grasses produce only one, and it is not yet. known if the leaves or stalks of plants contain most nutriment. So far as our knowledge extends, after all the investigations and best experience upon the subject, ray-grass forms the plant of all others the best suited for general purposes. For a crop of hay along with clovers, no other grass will afford an equal quantity and quality of produce on all the different variety of soils on which they are sown. It yields very readily, and with much less comparative trouble, an abundance of sound, healthy seed, and of certain growth; it rises early in the spring, and is much relished by all kinds of stock; the hay is gond and fetches a high price, and it is used with much advantage when sown in autumn along with other plants as spring feed for sheep." (Donaldson, on Manures, Grasses, \&c.)

After all the experiments that have been made on the other grasses, none, says Loudon, have been found to equal the perennial ryegrass for a course of mowing and pasturing for two, three, or seven years. It is sown in Italy, and especially in Lombardy, and also in France and Germany, along with clover, for the same purposes as in England; and, as Von Thaer has remarked, though some have tried other species, both in these countries and in England, they have in the end returned to the rye-grass. When intended as a pasture grass, if stocked hard, and when for hay, if mown early, the objections to it are removed. (C'ode of Agriculture.)

The Floating Fescue-grass (Festuca fluitans, Pl. $5, l$ ) is found in England in ditches, ponds, and swamps, and in most parts of the country, especially in Cambridgeshire, where it is said to give the peculiar flavour to Cottenham and Cheddar cheese.

It is greedily devoured by all kinds of stock, not excepting hogs and ducks, and geese eagerly devour the seeds, which are small, but very sweet and nourishing. They are col. lected in many parts of Germany and Poland under the name of manna-seeds (schwaden), and are esteemed a delicacy in soups and gruels. When ground to meal, they make bread very little inferior to that from wheat. Fish feed upon the seeds, and trout are said to thrive greatly in streams where this grass grows abundantly. Curtis justly remarks, that the flote fescue will not flourish except in land that is constantly under water, or converted into a bog or swamp. (Loudon's Ency. of Agr.)

The Water Meadow-grass (Poa aquatica, P1. 5, $m$ ), is one of the largest of English grasses. It is found chiefly in marshes, but will grow on strong clays, and yield, as the Woburn ex. periments prove, a prodigious produce. In the fens of Cambridgeshire, Lincolnshire, \&c., immense tracts, that used to be overflowed and to produce useless aquatic plants, and which, though drained by mills, still retain much moisture, are covered with this grass, which not only affords rich pasturage in summer, but forms the chief part of the winter fodder. It has a powerfully creeping root, and bears frequent mowing well, sometimes being cut three times in one season. It grows not on!y in very moist ground, but in the water itself, and with cat-tail, bur-weed, \&c., soon fills up ditches, and occasions them to require frequent cleansing. In this respect it is a formidable plant, even in slow rivers. In the Isle of Ely they cleanse these by an instrument called a bear, which is an iron roller, with a number of pieces of iron, like small spades, fixed to it. This is drawn up and down the river by horses walking along the banks, and tears up the plants by the roots, which float and are carries down the stream.

The forin grass (Agrostis stolonifera, P.. $5, n$, is in England a very common grass, boik in wet and dry, rich and poor situations. Few plants, however, appear to be more under the influence of local circumstances than this grass. On dry soils it is worthless, but on rict. and moist soils, if we may attach confidence to the accounts given of its produce in Ireland, it is the most valuable of all herbage plants. (See Agrostrs.) Though fiorin will, in England and Ireland, ripen its seeds on a dry soil, and these seeds being very small, a few pounds $3 \mathrm{C}$ 577 
would suffice for an acre, yet it is generally propagated by stolones, or root-shoots. The ground being previously prepared by ploughing, harrowing, and laying into ridges, the shoots are deposited, touching each other at the ends, in drill rows an inch or two deep and about 6 or 9 inches apart. In 6 months, if the planting be performed early in spring, the whole surface will be covered with thick verdure, affording, by autumn, a heavy crop.

With regard to the last described grasses, Mr. Loudon gives it as his opinion, that neither fiorin, timothy, or floating fescue, is ever likely to be cultivated in Britain, though, he observes, the two latter may succeed well on the bogs and moist, rich soils of Ireland, where, to second the influence of the soil, there is a moist warm climate. In regard to the merits of timothy, the reports of several high authorities, one of which (Donaldson) we have just quoted, seem to lead to a very different conclusion. The observation may be strictly applicable to fiorin and floating fescue, both in England and America, although there may be some localities in the United States into which one or other of these may be advantageously introduced.

Pasture Ghasses.-In regard to grasses for pasturage, the following selection is given by Loudon, as best adapted to three main purposes ; namely :-

For early pasture on all soils, the sweet vernal grass (Anthoxanthum odoratum), the sweetscented soft-grass (Holcus odoratus), the downy oat-grass (Avena pubescens), and the annual meadow-grass (Poa annua).

For late pasture on all soils, the different species of Agrostis and Phleum.

For pasture on pon or secondary soils, the crested dog's-tail (Cynosurus cristatus), hard and sheep's fescue ( $F$. duriuscula and ovina), Poa compressa, cristata, and angustifolia.

The grasses which, according to Loudon, afford most nutritive matter, in early spring, are the foxtail grass and the vernal grass.

The sweet-scented vernal grass (see Pl. 6, a), is common in almost all English pastures, and is that which gives the fragrance to natural or meadow hay. It is chiefly valuable as an early grass; for, though it is eaten by stock, it does not appear to be much relished by them. It is said to thrive best in lands that are deep and moist, and even in peat bogs. Donaldson places it in the lower order of the better grasses. See Axrhoxanthum Odoratum.

The douny oat-grass (see Pl. 6, $b$ ), according to the Woburn experiments, possesses several good qualities which recommend it to particu3ar notice, as being hardy, early, and more productive than many others which affect similar soils and situations.

'The anrual meadow-grass (Poa annua, Pl. 6, c), is the most common of all grasses, being the frrst herbage with which nature covers the earth. The root is annual, and it is almost the nn'ty grass that will grow in towns, or near works where the smoke of coal abounds. Though an annual grass, it is found in most uneadows and pastures perpetually flowering, and affording an early sweet herbage, relished fiv au stock, ar. of as grea* :mportance to birds $5 \% \%$ a wheat is to man. It hardly requires to be sc $w n$, as it springs up everywhere of itself. However, it may not be amiss to sow a few pounds of it per acre, whenever perpetual pasture (not hay) is the object.

The fine bent (Agrostis vulgaris, see Pl. 6, d), is one of the most common grasses, and one of the earliest. See Agrostis Vurgaris.

The narrow-leaved meadow-grass (Poa angustifolia, see Pl. 6, $\ell$ ), though it flowers late, is remarkable for the early growth of its leaves, which, according to the Woburn experiments, attain to the length of more than 12 inches before the middle of April, and are soft and succulent; in May, however, when the flowerstalks make their appearance, it is subject to the disease termed rust, which affects the whole plant, in consequence of which the produce of the crop is deficient at the time the seeds are ripe. (See Poa Avgustifolra.). This grass is evidently most valuable for permanent pasture, for which, in consequence of its superior, rapid, and early growth, and the disease beginning at the straws, nature seems to have designed it. The grasses which approach nearest to this in respect to early produce of leaves, are, the fertile meadow-grass, rough cock's-foot, timothy, meadow foxtail, avena elatior, and bromus littoreus, all grasses of a coarser kind.

Late Pasture Grasses.-Of these the principal are timothy, and the various kinds of bent or agrostis. The grasses which are propagated by stolones, like fiorin, and others of the same species, supply pasture throughout the year, the concrete sap laid up in the joints of their roots, rendering them good food even in winter.

Of Pasture grasses for inferior soils, one of the most durable is the dog's-tail grass (Cynosurus cristatus, see Pl. 6, f), in England, a very common grass on dry, clayey or firm surfaces. In the United States it is either little known, or slightly estimated. The foliage is small and rather late in the spring. The wiry stems are refused by cattle, and become very unsightly, and from the smallness of produce, and the dense tufts formed at the roots, it is unfit for alternate husbandry. But for pastures, and for all permanent purposes, if the land be of a dry and hard nature, and inferior in quality, and if sheep are to be fed upon it, this grass must form, according to Donaldson, a principal part of the mixture of seeds sown for that purpose. It is not at all adapted to low swampy situations, but on poor, dry clays, and gravelly soils, it often covers the ground and affords a bite where every other grass had nearly failed.

The hard fescue grass (Festuca duriuscula, see Pl. 6, g), is one of the best of the dwarf sorts of grasses, grateful to all kinds of cattle. It is, in England, present in most good meadows and pastures, and with the sheep's-fescue is the best for lawns.

The smooth fescue ( $F$. glabra, see PI. $6 h$ ), and long-awned sheep's-fescue (F.hordeiformis, Pl. 6, i), greatly resemble the hard fescue, and may be considered equally desirable as pasture and lawn grasses.

The sheep's fescue ( $F$.ovina, Pl. $6, k$ ), is one of the principal pasture grasses for inferion 
soils and upland situations, peculiarly adapted for hilly sheep pastures. It is a low dwarf grass, relished by all kinds of cattle.

The Alpine meadow-grass (Poa alpina, see Pl. 6, l), turfy hair-grass (Aira crespitosa, Pl. $6, m$ ), common quaking-grass (Briza media, $\mathrm{Pl}$. $6, n)$, are all dwarf mountain grasses, well adapted for hilly parks or lawns.

GRASSHOPPER (Gryllida). The destruclive insects, popularly known in the United States by the name of grasshoppers, but which, in our version of the Bible, and in other works in the English language, are called locusts, have, from a perind of very high antiquity, attracted the attention of mankind by their extensive and lamentable ravages. It should be remarked, observes Dr. Harris, that in America the name of locust is very improperly given to the cicalla of the ancients, or the harvest-fly of English writers. The name of locust will here be restricted to certain kinds of grasshoppers; while the popularly named locust, which, according to common belief, appears only once in 17 years, must drop this name and take the more correct one of cicada or harvest-fly. 'The very frequent misapplication of names, by persons unacquainted with natural history, is one of the greatest obstacles to the progress of science, and shows how necessary it is that things should be called by their right names, if the observations communicated respecting them are to be of any service. Every intelligent farmer is capable of becoming a good observer, and of making valuable discoveries in natural history ; but if he be ignorant of the - proper names of the objects examined, or if he give to them names, which previously have been applied by other persons to entirely different objects, he will fail to make the result of his observations intelligible and useful to the community.

The insects which Dr. Harris calls locusts, together with other grasshoppers, earwigs, crickets, spectres or walking-sticks, and walkingleaves, soothsayers, cockroaches, \&c., belong to an order called Orthoptera, literally straightwings; for their wings, when not in use, are folded lengthwise in narrow plaits like a fan, and are laid straight along the top or sides of the back. They are also covered by a pair of thicker wing-like members, which, in the locusts and grasshoppers, are long and narrow, and lie lengthwise on the sides of the body, sloping outwards on each side like the roof of a house; in the cockroaches, these upper wings or wing-covers are broader, almost oval, and lie horizontally on the top of the back, overlapping on their inner edges; and in the crickets, the wing-covers, when closed, are placed like those of cockroaches, but have a narrow outer border, which is folded perpendicularly downwards so as to cover the sides of the body also.

"The young grasshopper comes from the egg a wingless insect, and consequently unable to move from place to place, in any other way than by the use of its legs; as it grows larger it is soon obliged to cast off its skin, and, after one or two moultings, its body not only increases in size, but becomes proportionally longer than before, while little stump-like wings begin to make their appearance on the top of the back. After this, the grasshopper con. tinues to eat voraciously, grows larger and larger, and hops about without any and from its short and motionless wings, repeatedly casts off its outgrown skin, appearing each time with still longer wings, and more perfectly formed limbs, iill at length it ceases to grow, and, shedding its skin for the last time, it comes forth a perfectly formed and matured grasshopper, with the power of spreading its ample wings, and of using them in flight." (Harris.) See Locusts.

GRA'TEN. A term provincially applied to arable lands in a commonable state. But it is used in Cornwall to imply the mowing of grass the first year after the land has been manured with sea-sand; and this operation they call "mowing in gratten."

GRAUWACKE. A German miner's term, implying gray rock; adopted in geology to designate some of the lowest secondary strata, which form the chief part of the transition rocks of several geologists. See Geologr.

GRAVEL. A term applied to a well-known material, consisting of small stones, which vary in size from that of a pea to that of a walnut, or something larger. It is often intermixed with other substances, such as sand, clay, loam, flints, iron ores, \&c., from each of which it derives a distinctive appellation. See GeoLogr.

The best kinds of manure for this sort of land are mari, or any stiff clay, cow-dung, chalk, mud, and composts formed of rolten straw from the dung-hill.

"Gravels," says Professor Low, in his remarks on soils (El. of $\mathcal{A} g r$. p. 8), "like sands, have all the gradations of quality from fertility to barrenness. The loose soils of this nature, in which the undecomposed material is great, and the intervening soil silicious, are held to be the worst of their kind. These are, in some places, termed hungry gravels, not only to denote their poverty, but their tendency to devour, as it were, manure, without any corresponding nourishment to themselves.

"The rich gravels will produce all the cultivated kinds of grain. Their lonse texture renders them less suited than the clays to the growth of wheat and beans; but they are admirably adapted to the growth of barley and oats. They are quick in their powers of producing vegetation; and from this quality, they are, in some places, termed sharp or quick soils.

"Gravels, like sands, are suited to the culture of the different kinds of plants raised for the sake of their roots and tubers; and they are in so peculiar a degree suited to the growth of turnips, that in some parts they receive the distinguishing appeliation of turnip soils."

Gravel, if mixed with stiff loam, makes excellent and durable gravel walks for gardens, \&c. The kind generally preferred for this purpose, is the red gravel. Previous to laying it down, a solid substratum of lime, rubbish, large flints, or broken earthen pots, or any other hard substance, should be formed to the depth 
of 16 or 18 inches, in order to keep the path dry, and prevent weeds from shooting through to the surface. The permanent or earthy manures, adapted to the gravels, are marl, clay, and chalk. See Mixture of Sorls.

GRAVES, or GREAVES. The waste and refuse of tallow-chandlers after the candles have been made, which is sometimes used as a manure. It corisists of the sediment of melted tallow, and is composed of the membranous, vascular, nervous, and muscular matters blended with the fat, and which, not being fusible, are easily separated from it by straining; the graves are made up into hard cakes, and are chiefly used as a coarse food for large house-dogs.

GRAZIER. A person engaged in the art or business of pasturing or feeding and fattening different kinds of live-stock on grass-land. In order to be capable of managing this business to the greatest advantage, he should have a perfect knowledge of the nature and value of all kinds of live-stock, as well as of the land on which they are to be fed, and of properly suiting them to each other. Upon these being well understood and attended to, his success must depend. According to Mr. Hillyard, a practical grazier, and the well-known president of the Northampton Farming and Grazing Society, "the knowledge requisite to carry on grazing to the most advantage is not easily obtained. A man should know how beasts ought to be formed; should have a quick eye for selecting those with a frame that is likely to produce weight; and a hand that should feel the known indication of the probability of soon becoming fat."

The business of grazing is more general in some of the counties of England than in others; it is for the most part carried on in Somersetshire, Lincolnshire, Leicestershire, and the midland counties. It is a system of husbandry that can only be profitably practised in districts where the extent of pasture is considerable, or the value of the produce of grass-land small in comparison with that of animals.

It is well observed, by an author of the last century, that the stocking of land with proper cattle is one of the nicest parts of the science of farming. Where nature is left to herself, she always produces animals suitable to her vegetation, from the smallest sheep on the Welsh mountains to the largest sort in the Lincolnshire marshes; from the little hardy bullock in the northern Highlands to the noble $o x$ in the rich pastures of Somersetshire. But good husbandry admits of our increasing the value of the one in proportion to that of the other. Land improver. enables us to keep a better sort of stock. The true wisdom of the occupier is best shown in preserving a due equilibrium between this improvement of his land and stock. They go hand in hand, and if he neglect the one he cannot avail himself of the other. It should, therefore, be first considered what kind of cattle or other stock will answer the purpose best, on the particular description of land upon which they are to be grazed.

In stocking the ground, as the proportion of cattle must depeut apon the nature of the soil, 580 it will perhaps be generally found that locs habit, as being usually the result of experience, is the surest guide. In the opinion, however, of the most intelligent graziers, in stocking enclosures, the cattle should be divided in the following manner:-Dupposing our fields, each containing a nearly equal quantity of land, one of them should be kept entirely free from stock until the grass is got up to its full growth, when the prime or fatting cattle should be put into it, that they may get the best of the food; the second best should then follow; and after them either the working or store stock, with lean sheep to eat the pastures close down; thus making the whole of the stock feed over the four enclosures in this succession:-

No. 1. Clear of stock, and reserved for the fattening beasts.

No. 2. For the fattening beasts until sent to No. 1.

No. 3. For the second best cattle, until forwarded successively to Nos. 2 and 1.

No. 4. For stores and sheep to follow the other cattle; then to be shut up until the grass is again ready, as at No. 1 , for the fattening beasts.

By this expedient the fattening cattle will cull the choicest parts of the grass, and will advance rapidly toward a state of maturity, for they should always have a full bite of short and sweet grass; and with such cattle, the greatest care should be taken not to overstock the enclosures. It is also advisable to divide the fattening enclosure by hurdles, so as it confine the beasts within one half of it at a. time, and to allow them the other half at the other, so that they may continually have fresh pasture.

Shade and pure water are essentially necessary; and where there are no trees, rubbingposts should be set up to prevent the cattle from making that use of the gates and fences. In marsh land, which is chiefly divided by dykes, this, indeed, should never be neglected, as it is materially conducive to their comfort. (Comp. Grazier, 6th edit. p. 74; Brit.Husb. vol. i. p. 482, vol. ii.p. 368; Hillyard's Farm. and Graz. p. 117.)

GREASE. In farriery, a disease incident to horses or other cattle, consisting of a swelling and inflammation of the legs.

It is sometimes confined to the neighbourhood of the fetlocks; at other times spreading considerably further up the legs, and secreting an oily matter, to which the disease is probably indebted for its name.

It is brought on by sudden changes from a cold to a hot temperature; such as removing horses from grass into hot stables; from hastily substituting a generous after an impoverishing diet; from the negligence of grooms in leaving the heels wet and full of sand and from constitutional debility.

The farmer's horse is not so subject to grease as many others, because he is not usually exposed so much to sudden and extreme changes of temperature, and the heels particularly are not thus exposed. In many instances he lives almost entirely out of doors, or, if he is stabled, the stables of the small farmers are not always air-tight. The wind finds its way through many 
a cranny, instead of entering at the door alone, and blowing upon the heels. On the first appearance of grease, the heels should be well washed with soap and water, and an ointment of sugar of lead and lard applied. In the more advanced stage, when cracks begin to appear, if they are but slight, a lotion of blue vitriol (sulphate of copper), alum, and water will suffice to dry and close them up; but if they are deep, with an ichorous discharge, and the lameness considerable, it will be necessary to poultice the heel with linseed meal, or carrots boiled soft and mashed. When the inflammation and pain have subsided, the cracks may be dressed with an ointment composed of-resin, 1 part, lard, 3 parts, melted together, and 1 part of calamine afterwards added. (The Horse, p. 277.)

GREASE, for wheels and machinery. M. D'Arcet, the celebrated French chemist and Master of the Mint, recommends the following as the best grease for wheels and machinery; viz., 80 parts of grease and 20 parts of plumbago (black lead), reduced to very fine powder, and most intimately and completely mixed together. A very small quantity suffices. (Journ. des Con. Usuelles et Prat. vol. ii. p. 237.)

GREEN CROPS. Crops, in England, which are consumed on the farm in their unripe state. (See Cabrages, Tares, Turnips, Cannots, Rotation of Crops, \&c.) One of the many great improvements in modern farming, has been the general introduction of green crops, a practice which $I$ think will yet be materially extended; and to this end, for the heavy land farmers, the use of the white or Belgian carrot promises to be very serviceable. Green crops are either fed off, soiled, or ploughed in for manure. (See Gries Manunes.) When fed off, the fertilizing effects of the sheep pastured upon them are very materially promoted by the addition to their food of oil-cake or of corn, and, as a condiment, common salt. See Crover.

GREEN FALLOW. Such land as is rendered clean by means of green crops, without having recourse to naked fallowing. It is a great improvement in modern farming. See Fallowing.

GREEN FOOD. Such food as is made use of in its green, succulent state, in the feeding and support of different sorts of live-stock. This kind of food has lately been much more extensively employed than formerly; but its advantages are not, probably, yet so fully understood by farmers in general as they ought. A few trials will, however, show their importance and great utility, when properly made. Sce SoILIng.

GREEN GRASS (Poa viridis, Poa annua). A native of the United States, and especially of the Middle and Northern States, where it grows in all meadows and rich soils. $-P l$. 6 . e.

Dr. Muhlenburg says it is not described by Linnæus, though nearly allied to his poa angus. tifolia. It may be easily known by the following description: "Culm (or haulm) erect and round (columnar), panicle diffuse, spicules five-flowered and hairy at their base." Cattle are very fond of this grass, if cut when the biossom opens. It produces less than the Avena elatior, or tall ineadow-oats, but horses prefer it. It continues green until even after frost, and when all other herbage is destroyed; and, if manured, will cuntinue forever. The fine grazing-farm of Mr. William West, of Upper Darby, Delaware county, Pa., consists entirely of this grass. Mr. West finds it necessary to sow clover thinly on the green grass sud every three or four years, to correct a slight tendency which green grass has to bind the soil. When the green grass appears upon meadows made by banking out rivers, care must be taken to secure a supply of water; otherwise, according to Mr. J. Cooper, the ends of the seeds will become affected with a black spear, about one-fourth or one-half an inch in length, similar to the smut on rye, and cause a loss of the hoofs of cattle that eat the grass. (Deane's N. E. Farmer.)

GREEN-HOUSE. In gardening, a house with a roof and one or more sides of glass, for the purpose of containing plants in pots which are too tender to endure the open air the greater part of the year. The green-house, being a structure of luxury, ought to be for the most part situated near the house, in order to be enjoyed by the family in inclement weather; and, if possible, it should be connected with the flower-garden, as being of the same character, with reference to use. Its length and breadth may be varied at pleasure, but its height should never be less than that of the loftiest apartment of the house to which it belongs. The best aspect is to the south or south-east; but any aspect may be chosen, provided the roof is en. tirely of glass, and abundant heat is supplied by art. Of late years, green-house roofs have been made of either cast iron or of zinc, and sometimes in the form of a dome. Both metals are preferable to wood. In green-houses facing to the north, however, the more tender plants will not thrive so well in winter: more artificial heat will be required at that season; and the plants should be chiefly evergreens, and other plants that come into flower in the summer season, and grow or flower but little during winter. In most green-houses the plants are kept in pots or boxes, and set on stages or shelves, in order that they may be near the roof, so as to receive the direct influence of the rays of light, immediately on their passing through the glass. An orangery differs from a green-house in having an opaque roof, and in being chiefly devoted to plants which produce their shoots and flowers in the summer season in the open air; and they are set in the orangery merely to preserve them through the winter. Such a structure might with more propriety be termed a conservalory; but custom in the pre sent day has applied this term to structures having glass roofs, in which the plants are not kept in pots, but planted in the free soil, and in which a part of them are encouraged to grow and flower in the winter months. There are some interesting papers on the subject of green-house plants by Mr. Towers, author of the Domestic Gardener's Manual, in the Quart. Journ. of $A g r$. vol. v. p. 65, rol. vi. p. 48. (Brande's Dict. of Science and Art.) See CosSERVATORY and OHAYGERY.

GREEN MANURES. Th, use of green manures early attracted the attention of the cultivator. Xenophon recommended greer 
plants to be ploughed into the soil, and even that crops should be raised for that, purpose; for these, he says, "enrich the soil as much as dung." And the lupin is named as an excellent manure by very early agricultural writers. The white lupin is even now grown in Italy for the purpose of being ploughed into the soil, an operation generally performed in October.

The white lupin, which is extensively employed for this purpose in 'Tuscany, is the leguminous annual plant, well known in our gardens, growing in sandy and loamy soil to the height of two or three feet, with a stem of equal strength with the bean, and having somewhat similar blossoms and pods; but the produce is so bitter, that it is unfit for the nourishment of either man or beast. It arrives to a considerable size in the month of October, when it is ploughed into the soil. It abounds with gluten, to which, in fact, its fertilizing effects have been chiefiy attributed.

Green manures, although in some measure rendered subservient to the enriching of the soil, as soon as man began to till the earth, and dig in the weeds of his land and the remnants of former crops, have never been systematically employed by the farmer. He has ever been more desirous of employing, as food for his stock, the vegetable produce of his land, than to bury it in the earth to promote the future productiveness of the soil. Yet, whenever green succulent substances, such as weeds, river collections, sea-weed, \&c., have been used, the result has always been most satisfactory. The putrefaction of the vegetables, and the gases in that case emitted, appear to be on all occasions highly invigorating and nourishing to the succeeding crop. During this operation, the presence of water is essentially necessary, and is most probably decomposed. The gases produced vary in different plants: those which contain gluten emit ammonia; onions, and a few others, evolve phosphorus; hydrogen, carbonic acid gas, and carburetted hydrogen gas, with various vegetable matters, are almost always abundantly formed. All these gases, when mixed with the soil, are very nourishing to the plants growing upon it. The observations of the farmer assure us that they are so. He tells us that all green manures cannot be employed in too fresh a state; that the best corn is grown where the richest turf has preceded it; and that where there is a good produce of red clover, there will assuredly follow an excellent crop of wheat: he finds also, that when he ploughs in his crop of buckwheat to enrich his land, that this is most advantageously done when the plant is coming into flower. The chemical explanation of these practical observations is not difficult. "All green succulent plants," says Davy, "contain saccharine or mucilaginous matter, with woody fibre, and readily ferment; they cannot, therefore, if intended for manure, be used too soon after their death. When green crops are to be employed for enriching a soil, they should be ploughed in, if it be possible, when in flower, or at the time the flower is beginning to appear; or it is at this period that they contain the .urgest quantity of easily soluble substances, and that their leaves are most active in forming 582 nutritive matter. Green crops, pond weeds. the parings of hedges or ditches, or any kind of fresh vegetable matter, require no preparation to fit them for manure. The decomposition slowly proceeds beneath the soil, the soluble matters are gradually dissolved, and the slight fermentation that goes on, checked by the want of a free communication of air, tends to render the woody fibre soluble without occasioning the rapid dissipation of elastic matter. When cld pastures are broken up and made arable, not only has the soil been enriched by the death and slow decay of the plants which have left soluble matters in the soil, but the roots and leaves of the grasses living at the time, and occupying so large a part of the surface, afford saccharine, mucilaginous, and extractive matters, which become immediately the food of the crop, and the gradual decomposition affords a supply for successive years." (Agr. Chem. p. 280.) Nothing will aid the practical farmer so much in understanding the value of green manure, as a knowledge of the constituent elements of plants. Woody fibre, starch, sugar, gum, are compounds of carbon, hydrogen, and oxygen; the fixed and the volatile oils, wax and resin, are constituted of carbon, with the elements of water, and an excess of hydrogen; vegetable albumen and gluten contain nitrogen as an element; and it is never altogether absent in plants, either in their solid or fluid contents. Now, reflecting upon these facts, it follows that the developement of a plant requires the presence of substances containing carbon and nitrogen, and capable of yielding these elements to the growing organism ; secondly, of water and its elements ; and, lastly, of iron, lime, and other inorganic matters essential to vegetable life. (Liebig's Organic Chem.) It is always refreshing to find the sagacious conclusions of the philosopher supported by the practical farmer's observations. "In October, 1819," said the late Dr. Browne, of Gorlstone, in Suffolk, in a letter which he sent to me, " a violent gale of wind drove to this part of the coast an unprecedented quantity of seaweeds. These were eagerly scrambled for; and, from my greater vicinity to the beach, I collected twenty-seven cart-loads, each as much as four horses could draw; and although other persons deposited their collections in their farm-yards, to rot among their other manure, yet I spread mine, fresh and wet, upon little more than an acre of bean stubble, instantly ploughed it in, and dibbled wheat upon it. On the 6th of October I then salted the adjoining land with three bushels per acre, manured it with fifteen loads of farm-yard dung per acre, and dibbled it with wheat on the 15th of November. The result was, that the sea-weeded portion gave three times the produce of any equal part of the field." (C. W. Johnson's Essay on Salt, p. 48.)

No one more perseveringly advocated the employment of green manures than the late Mr. Knight. In his paper on the question, he supported his views by some ingenious experiments, and used every argument that could fairly be employed in their favour. "Writers upon agriculture," he observed, "both in ancien! and modern times, have dwelt much upon 
the advantages of collecting large quartities of regetable matter to form manures; whilst scarcely any thing has been written upon the state of decomposition in which decaying vegetable substances can be employed most advantageously to afford food to living plants. Both the farmer and gardener, till lately, thought that such manures ought not to be deposited in the soil until putrefaction had nearly destroyed all organic texture, and this opinion is, perhaps, still entertained by the majority of gardeners; it is, however, wholly unfounded. Carnivorous animals, it is well known, receive most nutriment from the flesh of other animals when they obtain it most nearly in the state in which it exists as part of a living body; and the experiments I shall proceed to state, afford evidence of considerable weight that many vegetable substances are best calculated to reassume an organic living state when they are least changed and decomposed by putrefaction." The allusion to carnivorous animals is misplaced; as green food must be soluble, and in a decomposing state, before it can be taken up by plants; but this does not weaken the argument in favour of its utility. "I had," continues Mr. Knight, " been engaged in the year 1810 in some experiments, from which I hoped to obtain new varieties of the plum, but only one of the blossoms upon which I had operated escaped the severity of the frost in the spring. The seed which this afforded having been preserved in mould during the winter, was in March placed in a small garden pot, which was nearly filled with the living leaves and roots of grasses mixed with a small quantity of earth, and this was sufficiently covered with a layer of mould which contained the roots only of grasses, to prevent, in a great measure, the growth of the plants which were buried. The pot, which contained about one-sixteenth of a square foot of mould and living vegetable matter, was placed under glass, but without artificial heat, and the plant appeared above the soil in the end of April. It was, three times during the summer, removed into a larger pot, and each time supplied with the same matter to feed upon, and in the end of October its roots occupied about the space of one-third of a square foot. Its height above the surface of the mould being then 9 feet 7 inches. In the beginning of June a small piece of ground was planted with potatoes of an early variety, and in some rows green fern, and in others nettles, were employed instead of other manure; and, subsequently, as the early potatoes were taken up for use, their tops were buried in rows in the same manner, and potatoes of the preceding year were placed upon them, and buried in the usual way. The days being then long, the ground warm, and the decomposing green leaves and stems affording an abundant moisture, the plants acquired their full growth in an unusually short time, and afforded an abundant produce, and the remaining part of the summer proved more than sufficient to mature potatoes of any early variety. The market gardener may probably employ the tops of his early potatoes and other green vegetable substances in this way with much advantage.
"In the preceding experiments the plum stone was placed to vegetate in the turf of the alluvial soil of a meadow, and the potatoes grew in ground in which, though not rich, was not poor, and therefore some objections may be made to the conclusions I am disposed w draw in favour of recent vegetable substancer as manures. The following experiment is, I think, decisive. I received from a neighbour. ing farmer a field, naturally barren, and sn much exhausted by ill management, that the two preceding crops had not returned a quan. tity of corn equal to that which had been sown upon it. An adjoining plantation afforded me a large quantity of fern, which I proposed tis employ as a manure for a crop of turnips: this was cut between the 10 th and 20 th of June, but as the small cotyledons of the turnip seed afford little to feed the young plant, and as the soil, owing to its extreme poverty, could not afford much nutriment, I thought it necessary to place the fern a few days in a heap to ferment sufficiently to destroy life in it, and to produce an exudation of its juices, and it was then committed in rows to the soil, and the turnip-seed deposited with a drilling machine over it.

"Some adjoining rows were manured with the black vegetable mould obtained from the site of an old wood pile, mixed with the slen. der branches of trees in every stage of decom. position; the quantity placed in each row appearing to me to exceed more than four times the amount the vegetable mould, if equally decomposed, would have yielded. The crop succeeded in both cases, but the plants upon the green fern grew with more rapidity than the others, and even than those which had been manured with the produce of my fold and stable-yard, and were distinguishable in the autumn from the plants in every other part of the field by the deeper shade of their foliage. I had made, in preceding years, many similar experiments with small trees (particularly those of the mulberry when bearing fruit in pots) with similar results; but I think it unnecessary to trespass on the time of the society by stating these experiments, and conceiving those I have stated to be sufticient to show that any given quantity of vegetable matter can generally be employed in its recent and organized state with much more advantage than when it has been decomposed, and no inconsiderable part of its component parts have been dissipated and lost during the progress of the putrefactive fermentation." (Trans. Hort. Soc. vol. i. p. 248.)

In an article upon this subject, M. Knoles, of Secheim, writes thus: "My vineyard has been manured for eight years on the branches cut from the vines, without receiving any other manure, and yet more beautiful and richly-laden vines could scarcely be pointed out. The branches are pruned from the vine in August, whilst still fresh and moist, and are traced into the soil after being cut into small pieces. At the end of four weeks not the smallest trace of them can be found."

When green vegetable substances are bu ried in the soil, they first lose their green colour, speedily wither, and then putrefactiru 
soon commences. It is requisite, however, for this purpose, that moisture should be present, and that the temperature of the soil should not be less than about $45^{\circ}$. If the atmosphere has access to the vegetable matter, the putrefaction proceeds with more rapidity, but its presence is not essential. Putrefaction cannot, however, proceed if water is absent, and hence it has been concluded that water is decomposed during the process. The smell which proceeds from the gases emitted varies according to the vegetable substance which is putrefying. Thus, as I have before remarked, those which contain gluten emit ammonia; others, such as the onion, evolve phosphuretted hydrogen. Almost all emit carbonic acid gas and hydrogen gas, which, combined with various vegetable matters, are commonly produced in very copious volumes. When wood decomposes, a portion of oxygen is absorbed from the atmosphere, carbonic acid gas is emitted, and the whole mass is gradually reduced to a dark vegetable mould. This black substance is an excellent fertilizer; plants grow in it with great luxuriance. The soils of some of the famed newlyenclosed American lands owe all their fertility to the abundance of this vegetable mould which they contain. These are the American soils from which we are told 20 successive good crops of wheat have been obtained. There are some lands in the Hundreds of Essex. in Kent, and other places, whose luxuriant, unfailing produce is hardly credible; alternate crops of wheat and beans have been obtained from them from time immemorial. (Johnson on Fertilizers, p. 168.) Vegetable mould, as obtained from the trunlss of oak trees, has been examined by MM. Saussure and Einhoff; by distilling it they obtained from 200 grains (Rec. sur la Veg. p. 162)-

Carburetted hydrogen -
Carbonic acid gas -

By the effects of cultivation, exposure to the action of the atmosphere, and the roots of plants, this mould becomes gradually exhausted in the soil, and the land is of course sensibly impoverished. On this mould the alkalies nperate very powerfully, almost entirely dissolving it, and hence one great use of soda and potash as fertilizers.

It is also a continued source of carbonic acid, which it emits slowly; hence it might be asserted, that in a good fertile soil there is an utmosphere of carbonic acid, which is the most nutritive food of the young plants raised in it; lor when a plant is fully matured, and is fitted 10 obtain most of its nourishment from the air, the carbonic acid of the soil is no longer required. It is on that account that vegetable mould is so fertile; not by being itself assimilated into the substance of the plant, but by furnishing a slow but lasting supply of carbonic acid.

With regard to the best time to turn under c!rver, buckwheat, and other green crops, for ine purpose of enriching the ground, we have seen in the preceding observations that Davy and others have decided in favour of the period of full vigour, or when the plants may be in blossom. It seems, however, that the results of many well-conducted experiments and repeated observations lead to a different conclusion. namely, that it is best to allow the green crop to decay more or less before ploughing it in. In the course of his agricultural survey of Massachusetts, Mr. Colman found the opinion of some most successful farmers to be in favour of allow. ing the crop to mature and perish, before it was subjected to the plough as a manure for the soil. As the opinion of such men was at variance with the commonly received one, Mr. Cole man addressed a letter to the well-known chemist, Dr. Dana, requesting his views on the matter, as a question for chemical investigation. Dr. Dana's reply is contained in the report of the commissioner.

The essential element of fertility in a soil, he says, has been called humus, geine, vegetable extract, mould, as well as several other names, all meaning a brownish-black, powdery mass, the result of putrefactive decay, and the remains of decomposed organic matter. This substance combines with the alkaline, earthy, or metallic bases of the plant or the soil, and constitutes the means of growth or nutrition in the new vegetable. Without it, there seems to be no power in the earths of producing vegetation; and if in too great excess, as it sometimes appears to be in very pure manures, it is destruc. tive or unpropitious to all growth. In the question now at issue, the inquiry, of course, was, which furnishes to the soil the greatest quantity of geine or humus, the green or the dried plant. Dr. Dana decides in favour of the latter.

Fermentation appears to be the great agent in the decomposition of organic matter; and Dr. Dana's survey of the several kinds, such as vinous, acetous, and destructive fermentation, seems to have a direct bearing on the formation of the elements of fertility. The juices only that contain sugar or starch, convertible first into gum and then into sugar, by the action of azolized vegetable principles, especially gluten, are capable of the vinous fermentation. The conditions necessary to this fermentation are moisture, air, and a temperature not below $50^{\circ}$, nor above $86^{\circ}$.

"If," says Dr. D., "we plough in green plants, we put them in a temperature favourable to the commencement of vinous fermentation; we bury them full of sap, the requisite moisture for vinous fermentation. The sugar and starch of the plant, fermented by its gluten and albumen, are converted into gases and alcohol; the former are lost in air, and the last washes away or is changed to vinegar. All that remains for the farmer is the altered gluten and albumen, which soon putrefy and form geine. All the starch and sugar of the plant are thus lost."

In his remarks on destructive fermentation, Dr. Dana has the following observations:

"Doubtless, all green plants ploughed in undergo, to a greater or less extent, destructive fermentation, which succeeds the vinous and acid fermentations, perhaps caused by the ra- 
pidity of these processes. Hence, in addition to the sugar, gum, and starch of the plant, we lose a large portion of its other substances, by turning it in green. 'The products of this rapid fermentation have been but little studied. Happy the farmer who never witnesses the process! He should never induce it, and may generally prevent its extension when once begun. It is a dead loss to him; but in all the other cases of putrefaction, the products are valuable."

Will not the remark made above by Dr. D., that the alcohol formed during the vinous fermentation washes away or is converted into vinegar, account for the fact of what some far. mers complain of, as souring the soil in turning in heavy crops of green clover? We have heard some very successful farmers and wheatgrowers assert that their experience in turning in the clover crop before it had reached maturity, or while abounding in sap, had been so unfavourable, that they had relinquished the practice, and chose either to feed it off with sheep, or let it decay on the ground.

Still, no one can doubt but that excellent effects are produced by turning in green crops, particularly such as buckwheat, of which three or four can be ploughed in in a year; thus evidently giving more geine than where the ripened product is turned under. The danger of the practice appears to arise from ploughing in the green crop in that condition, and under such circumstances, that the vinous fermentation and acetous one are so rapid as to convert the valuable products into vinegar, and thus seriously injure the land; or when the destructive fermentation converts the plant into substances unfit for the food or nutrition of vegetables. (Cultivator.)

During the growth of plants, substances containing a large proportion of carbon are excreted or thrown out by the roots, and absorbed by the soil. 'These substances were either in excess, or unfitted for the nutrition of the growing plants. 'They constituted, therefore, excrementitious matters, through which the soil received again, with usury, the carbon which it had first yielded to the young plants as food, in the form of carbonic acid.

"The soluble matter thus acquired," says Liebig, "by the soil is still capable of decay and putrefaction, and by undergoing these processes furnishes renewed sources of nutrition to another generation of plants; it becomes humus. The cultivated soil is thus placed in a situation exactly analogous to that of forests and meadows; for the leaves of trees which fall in the forest in autumn, and the old roots of grass in the meadow, are likewise converted into humus by the same influence: a soil receives more carbon in this form than its decaying humus had lost as carbonic acid.

"Plants do not exhaust the carbon of a soil in the normal or regular condition of this growth; on the contrary, they add to its quantity. But if it is true that plants give back more carbon to a soil than they take from it, it is evident that their growth must depend upon the receptinn of nourishment from the atmosphere in the form of carbonic acid.

"Humus does not nourish plants by being taken up and assimilated in its unaltered state, but by presenting a slow and lasting source of carbonic acid, which is absorbed by the roots, and is the principal nutriment of young plants at a time when, being destitute of leaves, they are unable to extract food from the atinosphere."

The supply of humus usually effected by turning under clover, rye, buckwheat, \&ce., is accomplished, as Liebig informs us, with much greater certainty when the fields are planted with sainfoin or lucern, a plan now universally adopted in Bingen and its vicinity, the Palatinate, and other parts of Germany, where the fields, thus treated, receive manure only once every nine years. In the first year after the land has been manured, turnips are sown upon it; in the next following years barley, with sainfoin or lucern; in the 7 th year, potatoes; in the $8 \mathrm{th}$, wheat; in the 9 th, barley; on the 10 th year it is again manured, and the same rotation ensues. Sainfoin and lucern are remarkable for the ramification of their roots and the strong developement of their leaves, as well as for requiring but a comparatively small quantity of inorganic matter.

"An immediate consequence of the production of the green principle of the leaves, and of their remaining component parts, as well as those of the stem, is," says Liebig, "the equally abundant excretion of organic matters into the soil from the roots.

"The favourable influence which this exercises on the land, by furnishing it with matter capable of being converted into humus, lasts for several years, but barren spots gradually appear after the lapse of some tinse. Now it is evident that, after from 6 to 7 years, the ground must become so impregnated with excrements that every fibre of the root will be surrounded with them. As they remain for some time in a soluble condition, the plants must absorb part of them and suffer injurious effects in consequence, because they are not capable of assimilation. When such a field is observed for several years, it is seen that the barren spots are again covered with vegetation (the same plants being always supposed to be grown), while new spots become bare and apparently unfruitful, and so on alternately. The causes which produce this alternate barrenness and fertility in the different parts of the land are evident. The excrements upon the barren spots receiving no new addition, and being subjected to the influence of air and moisture, they pass into putrefaction, and their injurious influence ceases. The plants now find those substances which formerly prevented their growth removed, and in their place meet with humus, that is, vegetable matter in the act of decay.

"We can scarcely suppose a better means. of producing humus than by the growth of plants, the leaves of which are food for animals; for they prepare the soil for plants of every other kind, but particularly for those to which, as to rape and Hax, the presence of humus is the most essential coudition of growth.

"The reasons why this interchange of crop is so advantageous - the principles which regulate this part of agriculture, are, therefore, the 
artifi-ial pracuction of humus, and the cultivation of difierent kinds of plants upon the same tield in such an order of succession, that each shall extract only certain components of the soil, while it leaves behind or restores those which a second or third species of plant may require for its growth and perfect developement.

"Now, although the quantity of humus in a soil may be increased to a certain degree by an artificial cultivation, still, in spite of this, there cannot be the smallest doubt that a soil must gradually lose those of its constituents which are removed in the seeds, roots, and leaves of the plants raised upon it. The fertility of a soil cannot remain unimpaired, unless we replace it in all those substances of which it has been thus deprived. (Org. Chem.)

GREEN SAND. This mineral fertilizer, which, in some portions of the United States, has been of such immense service as a manure, and especially in restoring worn-out soils to productiveness, is found in great abundance in certain portions of the Atlantic States. The stratum in which it abounds as the principal ingredient cornmences in Monmouth county, New Jersey, at the base of the Highlands of Nevesink, and along the shore of the Atlantic from a little north of Long Branch to Shark Inlet. Ranging southwestward, it passes in a wide belt through Monmouth, and gradually contracting, runs parallel with the Delaware river, at a distance of a few miles, to Salem. It is prolonged across the state of Delaware, in a narrow strip, to the edge of Maryland, where it disappears under the overlapping tertiary formations. The mineral shows itself again on the Potomac and through the tide-water region of Virginia, but in a different stratum, in which it forms a less proportion than in the so-called "green marl" of New Jersey and Delaware.

The green sand or "marl" of New Jersey, is the second stratum in the ascending order of the five which compose the upper secondary or cretaceous group of that state. Strictly speaking, says Professor H. D. Rogers, it comprises several subordinate beds, all belonging, however, to two principal varieties. In the first of these, the green, granular mineral is the predominant and characteristic ingredient. The second consists, on the other hand, of a darkblue clay, mingled with more or less silicious sand. This latter material constitutes the usual floor upon which the true green sand deposit rests. In New Jersey, between Long Branch and Deal, the marl stratum has been penetrated thirty feet. The upper two feet consist of a green clay, seemingly derived from the disintegration of the green grains, intermixed with a large proportion of yellowish-white clay. The main marl-bed, having a thickness of about twenty-six feet, contains several subordinate layers; but all contain a large share of the green grains. Beneath the whole there is a grayish-yellow clay, in which the grains abound, they are remarkably large, and are associated with numerous casts of shells.

"When," says Professor Rogers, "we behold a luxuriant harvest, gathered from fields in which the original soil is a kind least of all congenial to vegetation; when we find that all 586 this fertility, contrasting so strikingly with the barrenness around it, proceeds from a few granules of a substance sparsely distributed through the enormous and counteracting excess of sea-beach sand, more arid than the sosl to which it is applied, are we not led to look with admiration on the potent properties of this curiousiy constituted mineral ? The developements of geology are full of instances like this, showing in how many unlooked-for ways the mineral world may be made subservient to the good of mankind.

" This striking proof of the fertilizing power of the marl ought to encourage those districts not directly within the tract, where some of the strata possess the green granules in a sensible proportion. It expands most materially the limits of the territory where marling may be attempted, and points us to many beds as fertilizing, which otherwise would be deemed wholly inefficacious.

"There can be no doubt that the agriculture of our seaboard states is destined to derive essential benefit from the remarkably wide distribution of this green granular mineral under various geological relationships, besides those in which it presents itself in New Jersey.

"Thus the tertiary shell-marls of Delaware, Maryland, and Virginia, and, I might add, of other states still farther south, contain not unfrequently as high a per centage of the green sand as does the sea-beach sand upon the coast of Monmouth county, New Jersey; and I may mention that my brother, Professor William B. Rogers, of the University of Virginia, charged with the geological survey of that state, has already done important service to the agriculture of some districts, by discovering and cailing attention to the existence of the green sand in the tertiary strata of Virginia."

"Composition of the green sand.-The predominant and often the sole ingredient in this bed, is a peculiar mineral, occurring always in the form of small, dark granules, about the size of grains of gunpowder. 'Their form is roundish, and they are often composed of two or three smaller ones united together; a distinctive feature, by which they may at once be recognised from other dark kinds of sand. Though they contain on the average nearly fifty per cent. of silica, they are not gritty, but may be readily bruised between the teeth, or upon the nail; and some varieties, when moistened, admit of being kneaded into a half-plastic mass, like impure clay. The prevailing colour of the grains is a deep green, though sometimes the tint is as light as that of verditer. It is often of a dull greenish-blue, and not unfrequently of a dark chocolate colour.

"Along the castern side of the marl tract in Monmouth, Burlington, and Gloucester, the stratum comprises very generally two varieties of the green sand, distinct as to colour, and holding generally the same relative position to each other. The uppermost layer, where it appears (for it is not always present), is of a light and glowing green, having very nearly the hue of the green paint called vo:diter; while the lower one is the common dark variety, of a dull bluish-green, or sometimes of a dull blue colour from adhering clay. 
"In some instances, particularly where the material constitutes the soil, the granules possess a brownish colour, the consequence evidently of the protoxide of iron which they contain having undergone upon the surface a change to the condition of the peroxide. 'The dull colour so usual to the surfaces of these grains, when contrasted with the brighter green within the mass, would appear manifestly to proceed from the same cause. Some shade of green may be pronounced to be the colour essential to this mineral, as all the deviations from this tint are attributable either to oxidafion or to a thin coating of clay, which frequently encrusts each grain, and from which the deposit is rarely altogether free. When a mass of the green sand or 'marl' is washed, especially with water to which a small quantity of an acid has been added, we invariably find the granules assuming a bright green surface. This colour is also produced in all cases when we mash or bruise a grain, no matter what may be its colour externally. By crushing the grains upon a sheet of white paper, we have an easy and unerring test in the colour of the streak, by which to recognise this material from all other varieties of sand.

"Though the green granular mineral here described constitutes the essential and distinclive ingredient in the green sand stratum, it rarely exists unassociated with several extraneous substances, particularly clay and white silicions sand. These constitute sometimes as large a proportion as fifty per cent. of the bed, causing much variety in its external aspect, and influencing materially its properties as an agricultural agent; the sand, which is generally white or semi-transparent quartz, existing usually in relatively small amount, the clayey matter being ordinarily the most abundant. 'This latter is of several tints, but is commonly of a light gray or lead colour. It is also occasionally chocolate coloured, brown, and even nearly white. Coating frequently the surfaces of the green grains, it conceals their true colour, imparting its own hue to the entire mass. As it is somewhat adherent when moist, it gives to the stratum where it is abundant the character of a partially plastic clay. Besides the white sand and this clayey material, we often find a minute quantity of finely divided mica mingled with the green sand." (Report of Geological Survey of New Jersey.)

Professor Rogers gives several analyses of specimens of green sand obtained from pits in various parts of the region where this mineral abounds near the surface of the ground. In some of the beds the green sand is mixed with proportions of clay and common quartzose sand, while in others, although ten per cent. of clay may be present, no common sand is perceptible. Besides the clay and common sand usually present with the green sand in the general inass, there occur occasionally several other substances, "which, though comparatively minute in quantity, are," observes Professor Rogers, "possessed of active properties. Some of these materials are probably deleterious, while others are undoubtedly beneficial in their action upon vegetation. The substances referred to are carbonate of lime, sulphate of iron (copperas), sulphate of alumina, sulphate of lime, and sulphate of magnesia; also phosphate of iron.

"They appear to be derived, mainly, at lcast, from constituents in the clay, and only very partially, if at all, from elements in the green sand itself.

"The carbonate of lime, in most instarces, we can trace to fossil shells and other organic remains, imbedded in the stratum. The sul. phate of iron obviously proceeds from the action of the atmosphere and moisture on the sulphuret of iron, so abundant in the clay; and the sulphate of alumina from the union of a portion of the sulphuric acid thus developed with the argillaceous earth of the clay; while the sulphates of lime and magnesia may result, either from the combination of the same acid with some of the lime and magnesia, sometimes present in a minute share in the green mineral, or, more probably, from its reaction on the carbonates of lime and magnesia, existing, like the sulphuret of iron, in an insulated state The phosphate of iron is no doubt derived from phosphoric acid, traceable to the animal remains, acting on oxide of iron.

"Several of these substances develope themselves upon the mass of the marl after it has been dug and exposed to the atmosphere, in the form of a white efflorescence, encrusting alike the clayey matter and the granules of green sand with a delicate crystallization, resembling a light frost. Collected and carefully examined and analyzed, this efflorescence will be found almost invariably to consist, when it is of a pure white, of either the sulphate of magnesia or sulphate of lime (gypsum), the latter predo. minating; and sometimes these two occur united. In some instances, we recognise it to contain the sulphate of magnesia (Epsom salts) in sufficient quantity to be distinguishable by its taste. A yellowish tint and an astringent flavour are apparent when it consists chiefly of the sulphates of alumina and iron. The carbonate of lime more generally shows itself, not in the shape of an efflorescence on the surface, like the others, but dispersed in minute granules throughout the body of the marl. Many of these calcareous granules are grains of dolomite, analogous in composition to the magnesian variety of the limestone, which overlies the green sand; whence, probably, the true source of the sulphate of magnesia above referred to. When the traces of shells are very numerous in the bed, and their conversion into the sulphate of lime has happened on the large scale, the gypsum forms a conspicuous part of a soft, white, clayey matter, derived from the shells and interspersed among the green grains. 'The mixed mass of carbonate and sulphate of lime is then usually in a yellowish-white, chalky condition. Sometimes we may detect the gypsum in the marl in the shape of small regular crystals of transparenı selenite, at times so minute as only to be de tected by the magnifier.

"Various fossil shells, and other marine ul ganic remains, amounting to considerably moro than one hundred species, are scattele? through the green sand. These collections of fussius would seem to be most abundant in those paris 
of the stratum which consist largely of the green sand.

"The water, percolating through the overlying sands, and also through the pervious green sand itself, has effected, and is daily effecting, important changes in the condition of the shells and other fossils; sometimes replacing their carbonate of lime with oxide of iron, sometimes removing it altogether, and leaving a mere mould, forming either an inner or an outer cast, and sometimes obliterating nearly every trace of their former presence.

"The total thickness of the green sand formation, estimating it from the bottom of the lowermost layers abounding in the green granular mineral to the overlying yellow ferruginous sands, or the limestone bed, when this is present, may be stated approximately at about one hundred feet. The only place in the whole district where it is practicable to ascertain, with any approach to accuracy, either the depth of the formation, or the relative situation and number of the separate beds which it comprises, is along the shore of Sandy Hook bay, in the cliffs of the Nevesink highlands. This, the only coast section of the strata, is still an imperfect one ; large masses of the upper beds, fallen from above, covering the lower deposits near the water-side.

"Owing to the large amount of water which it usually contains, the green sand is rarely penetrated in the numerous diggings which are made in it for the marl, to a greater depth than about twenty feet, the pits becoming at that limit too wet to be prosecuted deeper.

"In one or two instances, wells have been sunk through the stratum, and the depth of the green sand ascertained to be about thirty feet, as already mentioned.

"Sperific Gravily.-The specific gravity of the green granular mineral, carefully freed from all extraneous adhering matter, is, according to several experiments cautiously made, about $2 \cdot 65$. Three different specimens, taken from remote localities, gave for the two lowest each $2 \cdot 63$; for the highest, $\mathbf{2} \cdot 70$.

"The hardness of this mineral varies materially, being dependent somewhat upon the time elapsed after it has been dug: it is softest when moist and recently uncovered. Freshly extracted, its hardness often does not exceed that of talc; but when long uncovered and dry, it nearly equals that of gypsum.

"It would appear by experiment to be entirely insoluble in water, both cold and boiling; but it dissolves with tolerable facility in any of the stronger acids, though different specimens vary materially in this respect."

The experience of farmers, continued through nearly half a century, had amply tested the utĩity of green sand as an active fertilizer when spread upon the ground. Various were ine views maintained in regard to its active principles, and much speculation was, as usual, indulged upon the subject. The demonstration, made first by Mr. Henry Seybert, of Philadelphia, that the green sand of New Jersey contained a considerable amount of potash, seemer tc afford a very satisfactory clue by which its mysterious effects might be traced nt.
Chemical composition of Green Sand. From a number of analysis of specimens of this mineral, selected with the greatest care by Professor Rogers, and ascertained to be entirely free from extraneous matter, it would seem that it is not quite uniform in its composition, but exhibits slight variations in the proportions of its principal constituents. The following results will serve to display the prevailing chemical nature of green sand, and the moderate variation of the several ingredients:

\section{Green Sand of Squankum.}

Description.-Colour, a dark olive-green; granules of a medium size; it composes 58.36 per cent. of the marl of the upper part of the bed, and 72.36 per cent. of the lower.

Composition.-In 100 parts :

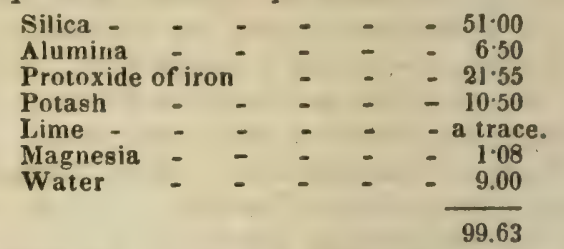

Greensand of Freehold, Monmouth County.

Description.-Colour of the granules, rich green; size, small; composes 70 per cent. of the upper part of the bed, and $\mathbf{5 0}$ per cent. of the lower.

Composition.-In 100 parts :

Silica -
Alumina
Protoxide of iron

Green Sand of the Marl of Poke Hill, near Plattsburg, Burlington County.

Description.-Colour of the granules, a rich dark olive-green; their size, rather above the medium; composes 98 per cent. of the marl.

Composition.-In 100 parts :

\begin{tabular}{|c|c|c|c|c|c|c|}
\hline Silica - & - & - & - & - & - & 50.75 \\
\hline Alumina & - & - & - & - & - & $6 \cdot 50$ \\
\hline Protoxide & f iron & & - & - & - & $22 \cdot 1$ \\
\hline Pntash. & - & - & - & - & - & $12 \cdot 9$ \\
\hline Water & - & - & - & - & $=$ & $7 \cdot 50$ \\
\hline
\end{tabular}

Comparing the details of the several analyses furnished by Professor Rogers, we perceive that the green sand, even when of the greatest purity, is not absolutely constant, either in the nature of the ingredients which enter into its composition, or in their relative proportions. The per centage of the silica varies from 47.5 to 51.5 ; that of the alumina from 6 to 9.35 ; that of the protoxide of iron from 20.86 to $24 \cdot 74$; that of the potash from 9.96 to 12.96 ; and that of the water from 5.5 to 9.5 . We find, moreover, that, in some instances, besides these elements, lime enters into the constitution of the green sand, in other cases magnesia; while, occasionally, both occur. The amount of these earths is, however, always inconsiderable.

It appears that the mean proportion of the silica is approximately 49.5 per cent.; that of the alumina $\mathbf{7 \cdot 3}$; of the protoxide of iron $\mathbf{2 2 . 8}$; of the potash 11.5 ; and of the water 7.9 per 
cent.; while the lime, when present, seldom exceeds one-half per cent, and the magnesia is rarely more than a mere trace.

A comparison of the green sand of $\mathrm{New}$ Jersey with that of France, shows no essential difference in their chemical nature.

Green Sand of Havre, in France. Composition.-In 100 parts :

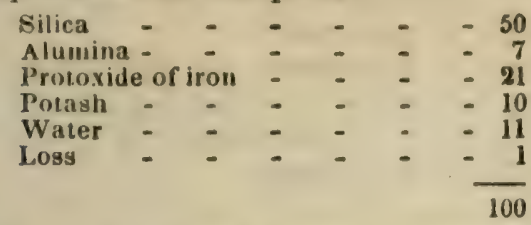

The late lamented chemist, Dr. Edward Turner, of London, also examined, with great care, the chemical constitution of the green sand of Kent, in England.

His experiments gave, in the 100 parts;

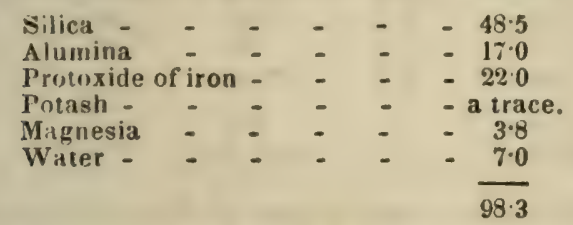

The absence of potash in the green granules of the English green sand, and the large proportion of magnesia, are facts not a little remarkable.

Economical relations of the Green Sand formation.-Abundant evidence might be adduced to prove that the true fertilizing principle in marl is not lime, but potash. The analyses which have been made give us, in several cases, no lime at all; and where a small proportion of lime is present in the green granular mineral, it is in a combined state, chemically united with the other ingredients, and not traceable to the organic remains which are in many of ihese instances not present in the stratum. Besides, the quantity of shelly matter, even where the shells are plentiful, is so disproportionately small, and the matter of the shells often so firm and unsusceptible of that easy disintegration necessary to form a calcareous marl adapted to act speedily upon the crop, that the striking effects witnessed from the marl can in nowise be attributed to the trivial amount of lime which the shells may occasionally furnish to the land. Nevertheless, as some feebly beneficial effects may possibly arise from this source, it may be of service to the agriculturist in choosing between different fossiliferous marls, to attend to the nature of the particular fossils, and the state of more or less decomposition or change in which they are to be found.

Selection of Green Sand.-For judging of the quality of a marl by observation, says Professor Rogers, "some familiarity with the multiform aspects which it assumes is indispensable. The leading rulc, however, is to bear in mind that the fertilizing efficacy of the compound resides in the minute, round, greenish grains which compose most, or sometimes all of it; and that it seems, moreover, to be dependent upon the proportion in these green grains of those powerful alkaline stimulants to vegetation, potash and lime, but especially potash. The first thing, then, is to approximate to the relative quantity of the green grains in the whole mass, and this may be effected with a greater or less degree of ac. curacy in several ways. The simplest and readiest method is to employ a small pockel magnifying glass, and to become familiar with the dark green grains, so as to distinguish them at once from other dark varieties of sand which sometimes occur associated with them. A little practice will very soon enable one to use the glass expertly, and to arrive at a pretty true estimate of the probable percentage of the green granules. But as these granules cannot sometimes be distinguished from the grains of ordinary white flinty sand, or from other kinds, in consequence of the particles being all alike coated with a thin film of the dark cementing clay, it will be useful to adopt some method of bringing out, under the magnifier, their different characteristics of colour and form. Let the mass be washed in a large glass tumbler, and repeatedly agitated with the water, until as much of the clay as possible has been detached from the grains. After pouring off the turbid water by repeated rinsings, and permitting it to settle until clear, we may estimate the. comparative quantity of clay in different marls by the relative amount of sediment which subsides. If we wish to be more accurate, we can weigh out a given quantity of the marl, then pursue the above plan, and decant the clear water from the clay, and after thoroughly drying the clay, weigh it to ascertain its amount. Having got away most of the clay, we should spread out the granular matter upon a sheet of paper and dry it, when there will be no further difficulty in distinguishing, by their colour and lustre, the foreign impurities from the grains of true marl, and also of estimating the relative abundance of each. When the mari to be examined contains much clay, I would recommend the experiments to be made upon a regularly weighed quantity, weighing both the clayey and the granular portions. A delicate apothecary's balance will commonly be found accurate enough. Another more expeditious, though less accurate method, is merely to dry the marl, spread it extremely thin upon a sheet of white paper, and then hold it near a window, or in the light, to examine it carefully by the magnifier. The flinty sand, though stained with clay, may then be clearly discerned in consequence of its transparency; whereas, when we inspect a solid lump, all the particles upon the surface are nearly alike dark.

"A useful suggestion is, to place a portion of the marl upon a hot shovel, or on the top of a stove, when all the granules will change from their ordinary green tint to a light red or brick colour, while the other materials of the mass sustain little alteration. This will often render obvious to the naked eye the proportion of the green grains.

"When there is a yellowish or whitish in crustation upon the marl after the moist sur face has remained for some time exposed ic the weather, it is indicative of the existence of a portion of either copperas or sulphate of alu mina, the burtful nature of which has already been explained.

"An astringent inky taste will rery often de 
tect the presence of these noxious substances at times when no such efflorescence shows it self. If the quantity be too small to betray them distinctly to the palate, and we are still in doubt as to their presence, other more rigorous tests are within our reach; and as these astringent matters are so unquestionably pernicious in their action, it is of importance to have the means of determining in what proportion they abound in different marls. 'This can be effected with precision only by a systematic chemical analysis, but their existence can be made to appear by the following simple tests. Put a small portion of the marl in a flask or other thin glass vessel; pour upon it some pure water, and heat it moderately; after causing the water to dissolve in this way as much as possible, remove the heat, and let it settle; then decant the clear fluid into some glass vessel, such as a wine-glass. If there is any copperas present, it will be evident upon adding to the fluid a little lime water, which will produce a milky turbidness that after a little while will become stained of a yellowishbrown colour. The milkiness is owing to the formation of gypsurn, and the brown colour to oxide of iron from the copperas. Or, in lieu of this, add a solution of oak bark, and, if copperas be present, we shall have a dark inky colour at once produced.

"A good marl will, upon being squeezed in the hand, fall asunder again, rather than bake into a tough doughy mass; and upon being left in heaps to dry, will assume a light grayish-green colour, and be extremely crumbly. It seems to be a very general characteristic of the better class of marls, that they throw out a white efflorescence or crust upon those grains which are most exposed to the air; hence the very light colour externally which some heaps of marl possess. This crust I have already shown to consist usually of the sulphate of lime (gypsum), sulphate of magnesia, and carbonate of lime. A drop or two of strong vinegar, or any strong acid, will produce an effervescence or frothing, if it be the carbonate of lime; and should nothing of this kind take place, we may set it down to be gypsum. Of course, from the minuteness of the quantity of the white coating, much care and accuracy of observation are demanded in doing this, in order to avoid erroneous conclusions.

"Marls deemed equally good with the kind showing the efflorescence, very frequently occur, exhibiting none of the white incrustation.

"It does not seem that any general rule can be given for distinguishing the fertilizing properties of a marl by its mere colour, as it must appear from what has been said, that the peculiar shade of colour is frequently owing to the colour of the intermingled clay. When the mass, however, is comparatively free from clay or common sand, and consists of little else than the green sand, observations go to show that the rather dark green variety is more potent in its effects than the very light green which sometimes overlies it.

"The prestnce or absence of shells I look t'pon to be' a poir of but little moment, for I 590 find that several of the most active marls in the region show no traces of fossils. The whole amount of carbonate of lime in the shape of fossils, and in that of the occasional white incrustation upon the grains, can in very few instances amount to 1 per cent.; while, as analysis shows, the lime chemically combined with the other ingredients in the green grains, is sometimes 1 per cent., and the potash nearly 12 per cent."

Professor Hitchcock, in his Elementary Geology, has given the following tabular view of the analysis of specimens of green sand from different countries :

\begin{tabular}{|c|c|c|c|c|}
\hline & $\begin{array}{c}\text { French } \\
\text { green sand, } \\
\text { by M. Ber- } \\
\text { thier. }\end{array}$ & $\begin{array}{l}\text { English sand, by } \\
\text { Prof. Turner. }\end{array}$ & $\begin{array}{l}\text { Massachu- } \\
\text { selts sand, } \\
\text { by Jr. L.S. } \\
\text { Dana. }\end{array}$ & $\begin{array}{l}\text { New Jerse } \\
\text { sand, by } \\
\text { Professor H } \\
\text { D. Kogers. }\end{array}$ \\
\hline Silica & 50.0 & $48 \cdot 5$ & $56 \cdot 700$ & $49 \cdot 27$ \\
\hline iron & $21 \cdot 0$ & $22 \cdot 0$ & $20 \cdot 100$ & $24 \cdot 67$ \\
\hline Alumina & $7 \cdot 0$ & $17 \cdot 0$ & 13.520 & $7 \cdot 71$ \\
\hline Water & 11.0 & $7 \cdot 0$ & $7 \cdot 000$ & $5 \cdot 91$ \\
\hline Potassa & 10.9 & traces. & - & $9 \cdot 99$ \\
\hline Lime & - & & $1 \cdot 624$ & $5 \cdot 08$ \\
\hline Magnesia & - & $3 \cdot 8$ & $1 \cdot 176$ & \\
\hline Manganese & 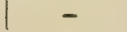 & traces, loss. & 0.080 & \\
\hline
\end{tabular}

Application and effects of Green Sand.-The resemblance in composition of green sand to glass, each being composed mainly of silex and potash, is striking. The investigations of Liebig demonstrated the indispensable importance to the growth of many plants, and especially to wheat, of silex and potash in that state of commixture called by chemists silicate of potash. He even went so far as to declare an opinion that one of the best of manures that could be applied to the wheat crop would be a solution of glass. In making this admirable induction, he was, apparently, una ware of the fact that a natural kind of glass, or silicate of potash, under the form of green sand, had been long spread over the American fields with the most striling advantages to the growth of wheat and other crops.

The effects of green sand applied as a manure, are strongly set forth in the following extracts from Professor H. D. Rogers's Report of his Geological Survey of New Jersey :

"Mr. Woolley manured a piece of land in the proportion of 200 loads of good stable manure to the acre, applying upon an adjacent tract of the same soil his marl in the ratio of about $\mathbf{2 0}$ loads per acre. The crops, which were timothy and clover, were much heavier upon the section which had received the marl; and there was this additional fact greatly in favour of the fossil manure over the putrescent one, that the soil was also entirely free from weeds, while the stable manure had rendered its own crop very foul.

"This green sand stratum at Poplar Swamp seems to be almost entirely free from any sulphate of iron or other astringent material, and as a consequence the crops seem not to be scorched by an extra dose, however lavishly applied.

"There can be no doubt that 20 loads of marl per acre must be regarded as an unnecessarily bountiful dressing; but computing the relative cost of the two manures, when employed in the ratio above stated, we find a 
considerable disparity in favour of the green sand. Placing the home value of farm-yard manure at 100 cents for each two-horse load, and that of the marl at 25 cents per load, we have the expense of manuring one acre $\$ 200$; of marling the same $\$ 5$.

"'This being an experiment, an extravagantly large dressing of manure was employed, but not exceeding the usual average application more than the 20 loads of marl surpassed what was necessary.

"Experience has already shown that land once amply marled retains its fertility with little diminution for at least 10 or 12 years, if care be had not to crop it too severely; while with all practicable precaution the stable manure must be renewed at least three times in that interval to maintain in the soil a corresponding degree of vigour.

"At the Squankum pits, which are very extensive, the marl is sold at the rate of $37 \frac{1}{2}$ cents the load, the purchasers having to dig it. It is transported by wagons to a distance, in some directions, of 20 miles, and retailed, when hauled that far, at the rate of 10 , or even $12 \frac{1}{2}$ cents per bushel, being very profitably spread upon the soil in the small proportion of 25 or even 20 bushels to the acre."

This is certainly a strong proof of the high estimation in which green sand is held as a manure by the prudent and thrifty farmers of New Jersey.

Professor Booth, in the report of his geological survey of the state of Delaware, has given much highly interesting information in regard to green sand. In all essential particulars, the marl-beds found in Newcastle county resemble those of New Jersey described by Professor Rogers.

"Practically speaking," says Prof. Booth, "there are two pritucipal kinds of green sand, that containing lime as an essential ingredient, and that consisting chiefly of green particles. The former contains variable quantities of carbonate of lime, the highest limit yet observed being twenty-five per cent. The average composition of the latter, in its natural state and selected, may be thus expressed:

\begin{tabular}{|c|c|c|c|c|c|}
\hline Silica & - & - & & $\begin{array}{c}\text { Unselected } \\
58\end{array}$ & $\begin{array}{l}\text { Selected. } \\
50\end{array}$ \\
\hline Potassa & - & . & & 7 & 10 \\
\hline Protoxid & le of iron & - & - & 22 & $22 \frac{1}{8}$ \\
\hline lumina & - & - & & 5 & $\tau$ \\
\hline Water & - & - & - & 8 & $10 \frac{2}{8}$ \\
\hline
\end{tabular}

The first is either cretaceous, containing finely divided carbonate of lime not formed by comminuted shells, and occurring on the canal; or decomposed calcareous, on the western limit of the state, from which the calcareous matter has been wholly or partially removed, although abounding in casts of shells; or shelly green sand, on the southern line of St. George's hundred, in which there is no fine calcareous matter but that of comminuted shells. The second contains mere traces of lime, and consists of green sand particles, with variable quantities of clay and common sand, and is either bluishgreen, and of the finest quality, as found on Drawyer's and Silver Run; or yellowish-green, containing white silicious sand, as on Draw- yer's and the Appoquinimink; or black-a) loured, decomposed externally, rarely interma. ly, and containing both white sand and argillaceous matter, from Silver Run to Scritt's Run. or dark-coloured, and containing pyrites, as from the south-west corner of St. Gerrge's hundred, and along the ridge to the Deep-rut; or, lastly, the blue micaceous sand of the Deepcut, rarely containing particles of green sand, although abounding with casts and impressions of shells characteristic of the green sand for. mation. We have seen that the yellow sand is the principal member of the series, both over and underlying the green sand; that it is characterized by its uniformity of grain and colour, and, rising to the surface, constitutes the chief and most valuable soil of the region. We farther observe that the green sand stratum is undulating, and varies in its depth, the average thickness being 21 feet, from which we may form a rough estimate of the amount contained in the whole district. It is 7 miles long, and nearly $6 \frac{1}{3}$ broad, and therefore embraces about 44 square miles. Deducting from this one-quarter for the place where it fines out, and for streams, ravines, \&c., we have 33 square miles underlaid by green sand. There are then $102,220,800$ square yards, which mul. tiplied by 7 yards, the average thickness, gives $715,545,600$ cubic yards of green sand in Delaware. Supposing, then, that the 1-100th part of it is accessible, we have more than $7,000,000$ cubic yards which may be niade available. In a majority of cases, the flowing of water into the pits presents a source of inconvenience that may be remedied without great difficulty, and with a trifling expense, compared with the value of the material."

Upon the subject of the fertilizing properties of green sand, Professor Booth makes the following highly interesting observations:

"When it is decomposed by the ordinary processes of the laboratory, only a small quantity of silica and all the other constituents being dissolved, we may regard the oxide of iron, potassa, and alumina as performing the principal functions, assisted by the presence of water. The useful action of potash or of ashes in the soil has been long acknowledged, and hence, as soon as it was known that the green sand contained potassa, its utility was immediately referred to that alkali; latterly, however, the opinion has gained ground that the protoxide of iron plays an important part by acting with the organic matter in the soil, in a inanner resembling the saponification of oil by potash.

"'The addition of much unleached ashes to a soil determines the formation of salts of potassa, which, being very soluble, are taken up in excess by growing plants, and produce such luxuriant vegetation as to cause it, technically speaking, to burn up. The same operation would probably occur with protoxide of iron, were its salts not soon converted into more insoluble humate and crenate of the peroxide.

"It might be objected by many that green sand being decomposed with difficulty by the powerful acids of the laboratory, there is little probability that it can be resolved into its con. stituents by the feeble action of humic or at 
mospheric agents. Independently, however, of the proof of its decomposition by its inducing increased fertility, and of the mode by which nature, operating with feeble agents during a lengthened period of time, produces great results, it may be shown that it is more readily decomposed than is generally admitted. William M. Uhler, in conjunction with the author of this memoir, has lately been engaged in making a series of experiments on this subject, which, although incomplete, nevertheless afford sufficient grounds for drawing a few conclusions. Dilute acetic acid decomposed green sand after the lapse of a week or more; oxalic acid produced the same result in a few days, and in the course of two weeks nearly all the green sand had disappeared, and the yellow oxalate of iron precipitated. But the most surprising effects were produced by the action of carbonic acid, one of the feeblest known to the chemist, the use of which for this purpose was first proposed by $\mathrm{Mr}$. Charles $\mathrm{R}_{0}$ berts, of Philadelphia. By a well-charged solution of this acid a large portion of the sand was decomposed in a few days, and a weak solution induced the same effects in the course of a few weeks. Although few experiments were made to determine quantitatively the relative amounts of the constituents taken up by the acids, yet the qualitative tests were sufficient to show that all the ingredients were separated from each other, and that the green sand might be analyzed even by the feeble operation of carbonic acid.

"As the present state of our knowledge of these subjects is limited when compared with that advanced stage which we firmly believe chemistry will produce in process of time, it would be presumption to make unhesitating assertions relative to the modus operandi of organic and inorganic manures; we may, nevertheless, and indeed we ought to draw such inferences as are consistent with our present knowledge of facts. The potassa of the green sand appears to act on organic matter in the soil by catalysis forming soluble salts of potassa; the protoxide of iron acts in a similar manner, but is itself changed to a less soluble compound; and the alumina probably has a similar action, proportional to its feeble atfinity. 'To the question that, since potassa acts in this manner, why does not a large quantity of green sand produce excessive luxuriance? it may be answered, that it does where the quantity is very large, but that its action is modified and extenuated by the difficulty with which the marl is decomposed, and by the presence of other bases besides potassa. When green sand is decomposed by nature or in the laboratory, a small quantity of silica is taken up, and even this substance, by forming a salt with crenic acid, may assist in increasing fertility, as i* is an essential constituent of plants.

"There are two points touching the theory if the operation of green sand, which remain to be noticed, the first of which is, that when its decomposition has commenced, it advances in an increasing ratio; and the second, that the constituents of green sand in their nascent state, that is, at the moment of their disengagevaent from the rompound, act with much 592 greater energy. Thus it would appear, then, that all the constituents of the marl exercise an influence in promoting vegetation; and this action must take place in proportion to their respective affinities, potassa being the most powerful, followed by lime, magnesia, protoxide of iron, alumina, and silica; that the first four assist in the generation of organic acids, with which they and a small portion of alumina and silica combine to form salts of different degrees, but generally of difficult solubility, which nourish and invigorate nascent vegetation; that by the presence of a large portion of bases which will form salts of difficult solubility, a more prolonged and healthy action is insured.

"The above remarks relative to the mode of operation of marl, apply equally to the seve. ral varieties, as far as relates to the content of green grains, but the calcareous species owe their action partly to lime, in proportion as its carbonate exists in the marl. When phosphate of iron occurs in quantity, some notice must be taken of its probable influence, for in regard to it, we can only reason from theory, since it has never been applied directly to land, with the view of ascertaining its effects on vegetation. It appears from the analyses of Berthier, that both phosphate of lime and of iron exist in appreciable quantity in the ashes of plants for, in the composition of oak ashes, he divides the 7 per cent. of phosphoric acid between lime and iron in such a manner as to form nearly 14 per cent. of phosphate of lime, and $\frac{1}{5}$ per cent. of phosphate of iron; and in other cases he gives the amount of the salt of iron as high as 9 per cent.; and we believe from experience that the utility of bone manure is largely due to its phosphate of lime; and hence we may infer that the marl alluded to may be serviceable, or even very valuable, from its phosphate of iron; and that if it were mingled with a little lime, where it is wanting in the marl, the atmospheric and humic agents, if the expression be allowed, will cause such a transmutation of the constituents as to bring both phosphates to exert their influence in advanciing the growth of plants. It would appear unnecessary to add lime, when there is already a small quantity in the marl, were it not that there is still another substance mentioned as occurring chiefly in the marl of the dividing ridge and deep cut. This substance is the sulphuret of iron, the presence of which is shown by the large amount of white efflorescence with which it becomes coated after exposure to the air, precisely similar to those pits where it is observed in pieces of considerable size. After the marl has been exposed to the air for a short time, a whitish efflorescence forms on its surface, which has a strong styptic taste, and is the sulphate of iron, formed from the sulphuret; but the snow-white efflorescence is chiefly sulphate of lime, or plaster. Now, the latter marl contains lime, and the former does not; and hence this operation of nature in the formation of plaster from sulphuret of iron points out to us the manner of attaining the same result, viz., by mixing with marl which exhibits an efflorescence after exposure to the air, a quantity of lime sufficient 
w) convert all the sulphuret of iron into sulphate of lime; for if this be not done, the sulphate of iron, or copperas, will be formed, which is known to be prejudicial to vegetation. The quantity required for this purpose will vary with the amount of sulphuret of iron: where the efflorescence is light, one oushel of lime to 100 of marl will be amply sufficient; and where it is abundant. it may be necessary to use two, three, or four to the 100 of marl. If the green sand contain already a portion of lime, a smaller quantity will be required. The best method of applying it will be to remove the marl from the pit to any convenient adjoining spot, to form a stratum not more than two feet thick, and, after it has been exposed to the air for two weeks or a month, to cover it over with slaked lime. After exposure to one or i wo rains, it may then be most thoroughly mixed by passing a plough through it, or digging it down with the spade.

"In what manner and in what quantity should the green sand be applied? All varieties of the marl are more or less compact, when freshly extracted from the pit, and if applied in such a state, would be unequally distributed over the soil; and hence the first precaution is to suffer it to be exposed to the air for a few days, according to its compactness or tenacity, in order that it may crumble to powder, if possible: for the finer the pulverization, as shown of lime, the greater will be the immediate benefit. 'There is another advantage attending this delay, that we may then observe the efflorescence, and obviate its ill effects by lime. Indeed, in a majority of cases, the addition of lime in small quantity will prove serviceable, since it is generally wanting in the pure green varieties, and yet it is an important requisite in the fixed constituents of vegetables. The most economical method of applying the marl as above proposed, will be to cart it from the pits immediately into the fields to which it is to be applied, to throw it into heaps at convenient distances for spreading, and then to put a small quantity of lime on each heap, which should remain exposea to the air for a longer lime. In regard to the quantity to be applied, a variety of opinions exist; and hence from 50 to 1000 bushels per acre have been tried, with and without success. A little attention to the theory of its operation will enable us to sproximat to the true proportion. Its strong - ises appear to act on the organic matter in the soil, and to combine with it; hence it would be useless to apply a large quantity to a poor and light soil, for which 60 to 100 bushels would suffice; but a clayey soil would be rendered looser by it; and as there is usually more organic matter present in such a case, from 100 to 200 may be cmployed with advantage. Where the land is already of good quality, from 200 to 500 may be used, according to its richness and tenacity. Many persons believe that because one kind of marl is inferior to another, a much larger quantity will be required; but the truth is, that the differences, although important, are less so than is generally believed, and should not lead to the employment of quantities greater than have just heen enumerated. Notwithstanding the effects of marl will be shown to be striking on ordina. ry, and even on very poor land, yet it is essens tial that the soil should contain a fair proportion of organic matter, in order to reap the highest benefit from it. Hence the failure of some experiments made with the green sand; for. although it stands superior to lime in requiring the presence or addition of less organic manure, still the views offered to explain its mode of action show the necessity of some or. ganic materials on which to operate, and this conclusion is strengthened by experience.

"The difficulty of overcoming prejudice is clearly exemplified in the progressive employ. ment of green sand in Delaware. One of the first experiments made with it in St. George's hundred may probably be dated as far back as the year 1826, when a small quantity was drawn out from the site of the canal. One spot of ground where this was applied was observed in 1837 on the farm of James Wilson, eleven years after its application; and although that soil had received no other assistance, a luxuriant growth of corn clearly pointed out the limit to which it had been spread."

The cost of the green sand marl at the pits, where these beds lie near the surface, is comparatively trifling, so that it can be raised and hauled to the distance of a mile or two for three cents per bushel, and yicld a small profit. Its weight is very great, owing principally to the large proportion of iron contained. Reference to its specific gravity $(2 \cdot 63-2 \cdot 70)$, as determined by Professor Rogers, shows it to be nearly three times heavier than the same bulk of a measure of water, a bushel weighing from 110 to 120 lbs. This, of course, causes its transportation to be expensive, except where facilities for water carriage are at hand. For fields worn out by long culture, the green sand is generally found of immediate and permanent advantage. Under such circumstances every successive crop having removed from the soil a portion of the potash which existed in abundance in the first years of its culture, the absence of this essential agent of fertility has been supplied by the green sand. Where ashes have been formerly applied freely, it is needless to expect much apparent benefit, and the same may be said where the soil is already duly supplied with potash from the decomposition of feldspar, or mica, all of which contain proportions of potash which they contribute to the soil. Hence the source of frequent failures in deriving advantage from the application of green sand.

GREYHOUND. This is one of the principal coursing agents, being a dog remarkable for his swiftness, strength, and sagacity, in pursu. ing game.

There are several varieties, such as the I: 0 . lian, the Oriental, and the Highland greyhound, the last of which is now become exceedingly scarce. A good greyhound ought to have a long and rather large body, a neat pointed head, sparkling eyes, a long mouth, with sharp teeth, small ears, formed of a thin cartilage; a broad and strong chest; his fore legs straight and short, his hind legs long and limber; broais shoulders, round ribs, muscular buttocks, but not fat, and a long tail, strong and full of si 3 D 2 
news. (Treatise on Greyhounds.) As it is out of our province, in a work of this nature, to treat at large of coursing and its agents, we must refer the sportsman who wishes for detailed information on the points of a good greyhound, and on breeding, feeding, \&c., to that excellent manual of reference for all matters relating to the chase, Blaine's Encyclopeedia of Rural Sports, a very learned and carefully arranged work, digested and compiled by a master hand.

GRIP. A small gutter, or ditch, cut across a field, to drain it. When cut for draining, it is mostly called a water or draining furrow.

A good method of draining meadow or swardland, by grips, is that of cutting out the pieces in a somewhat wedge-like form, taking off the bottom part, and then replacing them, by which means, a hollow is left below, for permitting the water to How off.

Grip is also provincially used to signify the hollow or cavity behind the cattle, in cowhouses or cattle-sheds, into which the dung and urine is discharged. These cavities should always be sunk about 8,10 , or 12 inches below the surface on which the cattle stand.

GRIPES, or COIIC. We have found that, in the absence of a veterinary surgeon in this dangerous complaint, the following is the best remedy for a horse: $-1 \frac{1}{2}$ pint of linseed oil, $1 \frac{1}{2}$ ounce of laudanum, given in a little warm gruel. Some persons assist the operation of the above with a glyster composed of $\frac{1}{2} \mathrm{lb}$. of epsom salts, $\frac{1}{2} \mathrm{lb}$. of treacle, dissolved in three quarts of warm water. See CatTLE, and Sheep, Disfases of.

GRIT. Hard sandstone, employed for millstones and grindstones, pavement, \&c.

GRITS. See Groats.

GROATS. In agriculture, are the small grains formed from oats after having the husks or shells taken off the grain. When crushed, they are called Embden groats. Gruel made from groats is a mild, little nutritive, easily digested food, well adapted for cases of fever and inflammation. An ounce of groats should make a quart of gruel; the mixture should be constantly stirred during the boiling; and when cold, the clear liquor poured off from the sediment. Sugar or lemon juice may be added if circumstances admit of such additions.

GROMWELL; GRAY MILLE'T (Lithospersmum, from lithos a stone, and sperma a seed. The little nuts or seeds being extremely hard, and having a surface as smooth as a polished pebble). Of this herbaceous perennial plant there are four indigenous species in England.

1. The common gromwell ( $L$. officinale), gro* inill, gray-mill, or gray millet, for it has various local names, which grows in dry, gravelly, or challiy soils, and frequently amongst rubbish and ruins, blowing pale buff flowers, in May and June. The root is tapering, strong, and whitish. The whole herb rough with minute, close, callous bristles. The stem is annual, nearly two feet high, branched and leafy. 'The leaves are sessile, alternate, grayish-green, ovate nr lanceolate. 'The seeds are gray, with a kind of porcelain polish, and a stony hardness; whence they have been falsely reported to $\mathrm{c}(n)$ siin calcareous earths, effervescing with acids.
These seeds afford excellent flour, which might in times of scarcity be converted into bread.

2. Corn gromwell. See Bagtand Alkanet.

3. Creeping or purple gromwell ( $L$. purpuro coruleum). A rare plant, found occasionally in thickets on a chalky soil.

4. Sea gromwell ( $L$. maritimum), growing in many parts of the coasts of Scotland and the north of England on the sea-shore among sand or loose stones. The whole herb is remarkable for its beautiful glaucous hue. (Eng. Flor. vol. i. p. 254.)

The field lithospermum, or stoneweed, a worthless plant, is the only species described by Dr. Darlington, as found in Pennsylvania. There are five or six additional species in the United States. (Flora Cestrica.)

GROOM (Flem. grom, a boy). A name now usually applied to servants who are employed about horses. The chief requisites in a groom are, a mild disposition, and a fondness for the animals of which he has the care. Great attention is also necessary to the feeding, dressing, littering, and keeping horses clean. These different operations should be daily executed with regularity and exactness. The stable, as well as the various articles that belong to it, should also always be kept clean and in per. fect order.

GROUND CHERRY (Physealis viscosa), clammy viscosa. The specific name of this American plant is derived from the Greek word Physa, a bladder or bag, in allusion to its in. flated calyx, or seed-pod. It is found in fields, fence-rows, \&c., where, in the Middle States, it flowers in July. The root is annual, the stem growing 12 to 18 inches high, with spreading branches. Leaves 2 to 4 inches long, and 2 to 3 inches wide, roundish ovate or obtuse. Flower greenish-yellow, with purplish-brown spots at the base. The berry succeeding the flower is roundish, viscid, enclosed in the inflated calyx, and of a greenish-yellow colour, and when fully mature, orange. The flower stems are very hairy. The ripe berries of one of the more hairy varieties of the ground cherry (P.Pennsylvanica), are orange-coloured, more succulent than some others, and rather palatable. (Flora Cestrica.) GROUND IVY. See Alehoof.

GROUND-NIT (Apiss tuberosa. From apios a pear, in allusion to its pear-shaped tubers) sometimes called wild bean. An American plant, growing in the Middle States, having a perennial root, producing oval tubers half an inch or more in diameter at the base of the stem. The stem is from 4 to 8 feet long, slender, striate, slightly hairy, sparingly branched, and climbing. The flower blooms in August, is of a dingy purple with tinges of green, rather handsome and pleasantly fragrant. The tubers on the roots are esculent and nutricious, and the plant has been considered an object worthy of culture. It is the only species of the genus. (Flora Cestrica.)

Another plant producing a ground nut is the Arachis hypogea. This is an annnal plant, with long, trailing stalks. A native of Mexico, but now cultivated in the West Indies for its nuts, which are oblong, and grow beneath the surface. These are used by the negroes as food. But in France they are now cultivated for the 
abundance of the oil they produce. This is said to be equally as valuable, for the table and other purposes, as the oil of olives, and superior to that for burning. A bushel of the nuts produces by cold expression a gallon of oil; but more may be produced by heat, but of a quality inferior. (Am. Orchardist.)

GROUNDSEL, or RAGWORT (Senecio). An extensive genus of plants, many of the species of which are very ornamental. Of this genus Sir John Smith includes ten species as indigenous to England, four only of which, however, come properly under the head groundsel. The remainder are referred to under the name of RaG worT, by which name they are generally known.

Common groundsel, or Simson (S. vulgaris), grows almost every where in cultivated or waste grounds, in rubbish, dry banks, the tops of walls, \&c.; it llowers almost all the year. It is too well known to need description. Cage birds (particularly goldfinches and linnets) are fed with the young buds, seeds, and leaves, which are cooling, and have a saltish herbaceous flavour. Cows do not relish this plant; it is, however, eaten by goats and swine, bu refused by horses and sheep. A weak infusion of groundsel is in England a common purge; a strong infusion or juice is used as an emetic, and sometimes given to horses to free them from bots. All the groundsels are annual.

Fifteen or sixteen species of senecio are found in the United States, of which Dr. Darlington met with four in Pennsylvania. 'These are:-1. The golden; 2. The obovate, which in New York is called squaw-weed, and denounced as poisonous to sheep. 3. Balsamitalike, common groundsel. 4. Fireweed, or hieracium-leaved. This plant is remarkable for its prevalence in newly cleared grounds, especially around spots where brushwood has been burned; whence it derives its name of fire-weed.

GRUB. The common name for worms or maggots, hatched from the eggs of beetles. Under the name of gentles, grubs are a principal bait to the angler for many kinds of fish. The grub produces the beetle, and is by some called the rook-worm, because rooks are particularly fond of it. I.and newly brought into cultivation is generally most subject to the grub. The best way of destroying it is by good and frequent ploughings, and the applications of lime in pretty large proportions in its caustic or most active state, or common salt. Irrigation is also very beneficial, as tending to destroy grubs. See Bretres and Insects.

GRUBBER, or CULTIVATOR. See HARROW and SCARIFIER.

GUANO. The name of a manure recently imported for the first time into England, which has long been extensively employed by the cultivators of Peru to fertilize their sterile sandy places-lands, on which occasionally there is a total absence of rain for many months. This manure is the excrements of sea-birds, and, like that produced by all animals feeding on animal food, is of a very powerful description. It exists, according to M. HumDoldt, in the greatest abundance in some of the small rocky islands of the Pacific Ocean, as at Chinche, Ilo, Iza, and Arica. Even when
Humbolde wrote, some 20 years since, 50 vessels were annually loaded with the guano at Chinche alone, each trader carrying from 1500 to 2000 cubic feet. The guano is found on the surface of these islands, in strata of several feet in thickness, and is, in fact, the putrefying excrements of innumerable sea-fowl that re main on them during the breeding season. It is used by the farmers of Peru chiefly as a manure for the maize or Indian corn, and it is said sometimes in the small proportion of about $1 \mathrm{cwt}$. per acre. "The date of the discovery of the guano and of its introduction as a manure," says Mr. Winterfeldt, " is unknown, although no doubt exists of its great antiquity. In many parts of America, where the soil is volcanic or sandy, no produce would be obtained without the guano. It has been calculated that from 12,000 to $14,000 \mathrm{cwts}$. are annually sold in the port of Mollendo for the use of the country round the city of Arequipa. In the province of Taracapa and in the valleys of Tambo and Victor the consumption should be something more, as wheat, all hinds of fruit, trees and plants, with the single exception of the sugarcane, are manured with the guano; which is not the case with the district of Arequipa, where maize and the potato alone require it. In the district of Arequipa $3 \mathrm{cwts}$. of guano is spread over an extent of 5000 square yards (about an English acre); but in Taracapa and the valleys of Tambo and Victor $5 \mathrm{cwts}$. are required. The land thus manured in Arequipa produces $\mathbf{4 5}$ for 1 of potatoes, and 35 for I of maize, where wheat manured with horse dung produces only 18."

There are, it seems, three varieties of guano, which bear on the coast of Peru different prices. "The white guano is considered the most valuable, as being fresher and purer. It is found on nearly all the islands along the coast. The red and dark gray are worth $2 s .3 d$. the cwt.; a higher price is given for the white on account of its greater scarcity; it is sold at the port of Mollendo at $3 s .6 d$. per cwt., and at times, as during the war, it has obtained as high a price as $12 s$.

It appears, in the state in which it has been lately introduced into England, to be a fine brown or fawn-coloured powder, emitting a strong marine smell: it blackens when heated, and gives off strong ammoniacal fumes. When nitric acid is mixed with it, uric or lithic acid is produced. It has been analyzed by various chemists. In 1806, an analysis of a very elaborate description was published by MM. Fourcroy and Vauquelin; they found in it a fourth of its weight of uric acid, partly saturated with ammonia and partly with potash. Some phosphate of lime and ammonia, and sniall quantities of sulphate and muriate of potash, a little fatty matter, and a portion of sand. It has been more recently analyzed by $\mathrm{Mr}$. Hennell of Apothecaries' Hall, who found in guano-

\section{Bone earth}

Sulphates and muriates

Uric or lithic acid

Carbonate of ammonia

Matters volatile at $212^{\circ}$ consisting chlefly of

and carbonate of ammonia Other organir matters 
It has also been analyzed by Mr. Brett of Liverpool, who found in 100 parts-

Earthy insoluble salts, chiefly phosphate of lime

Soluble salis, fixed alkaline, sulphate, and muriate

rganic matter

The organic matter consists of -

Jithic acid

Amunonia

Dther organic matter and moisture

Parts. $2 \cdot 5$ $68 \cdot 3$ $16 \cdot 1$
$8 \cdot 7$

The composition of guano varies, however, considerably. According to the analyses of MM. Voelckel and Klaproth, the varieties which they examined contained-

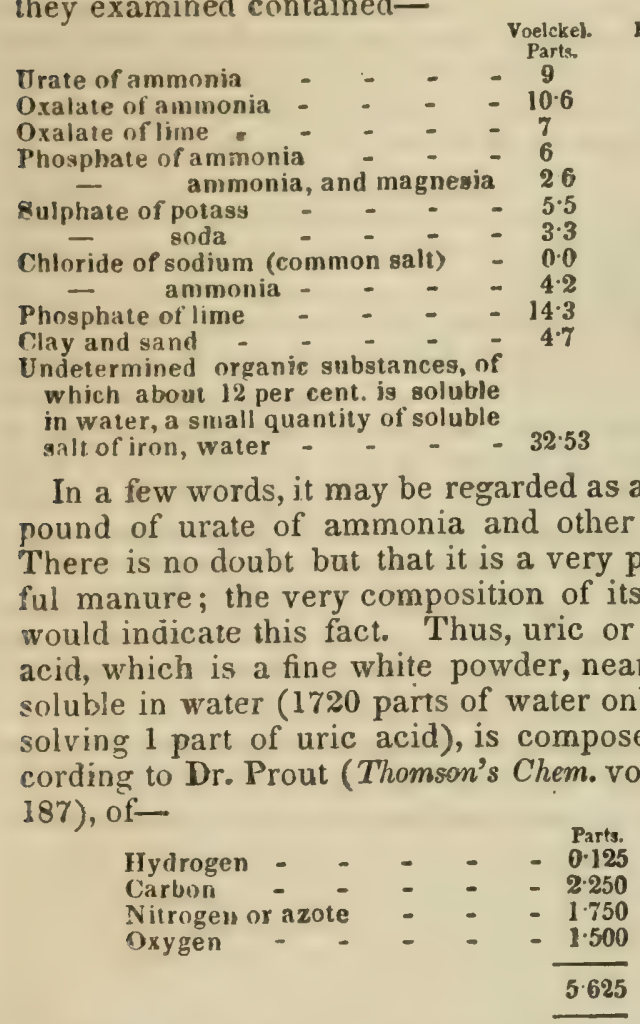

Urate of ammonia and urate of potash are fine white powders, also very insoluble in water : of the phosphate oi lime, of the guano, the earthy salt, and most valuable portions of bones, it is unnecessary to comment; I have, in my work "On the Fertilizers, p. 136," endeavoured to show how essentiaiiy valuable this salt is to all the farmer's commonly cultivated crops. The use of the dung of birds is not a modern improvement, for that of poultry tas been adopted as a manure from a very eany period. M. P. Cato, the earliest of the ggricultural writers, in his work, (lib. Ixxxvi.) conmmends the use of pigeons' dung for meak, ws, corn-lands, or gardens. And John Worudge, in 1669, was warm in the praise of the dung of fowls. "Pigeons" or hens' dung," he says (Myst. of $A g r .71)$, "is incomparable: one oad is worth ten loads of other dung, and is heref re usually sown on wheat or barley that ieth far off and is not easy to be helped." And he says, in another place, "A flock of wild geese had pitched upon a parcel of green wheat, and had eaten it up clean, and sat there-

* Fo* these 1 am indebted to Mr. M'Donald, of St. Milired Court, London, a considerable importer of the B') no on, and dunged it several nights; that the owner despaired of having any crop that year; but the contrary happened, for he had a far richer stock of wheat there than any of his neighbours had."

In some experiments made by Mr. Skirving of Walton, near Liverpool, in 1841, the guano was tried at the rate of two or three cwts. per acre, as a manure for Swedish turnips and Italian rye-grass, with very considerable success; it appeared to be equally, or rather more, efficacious than 20 cubic yards per acre of farm-yard manure.

The most elaborate set of experiments upon the guano with which I am acquainted were made, in 1810 , for potatoes and mangel-wurzel, at the island of St. Helena, by the late General Beatson; and they are the more valuable from being comparative. The soil on which these experiments were made was rather stiff, being composed of blackish mould, intermixed with friable fat clay. The following table gives the results of every experiment: 35 loads of horsedung litter per acre were ased, 35 of hogs' dung litter, and 35 bushels per acre of the guano.

1. With potato seed the size of walnuts. planted whole-

\section{Six inches deep.}

Guano -
Horse dung

2. Large potatoes cut in pieces.

Six inches deep.

\begin{tabular}{|c|c|c|c|c|}
\hline Guano - & - & - & & - \\
\hline Horse dung & - & - & - & - \\
\hline Pigs' dung & - & - & - & - \\
\hline Sojl simple & - & & - & - \\
\hline
\end{tabular}

Three inches deep.

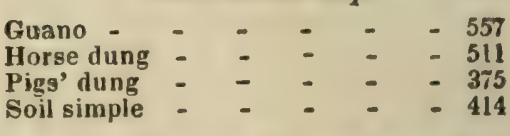

3. From middle eye of potato seed scooped out.

Six inches deep.

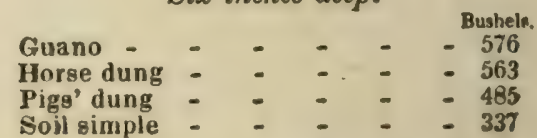

Three inches deep.

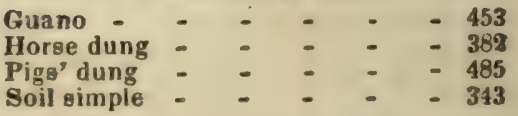

4. With small potatoes planted whole.

Six inches deep.

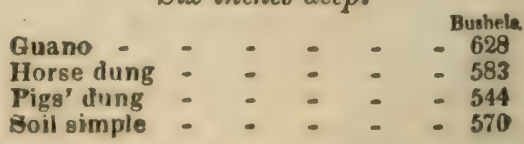

Three inches deep.

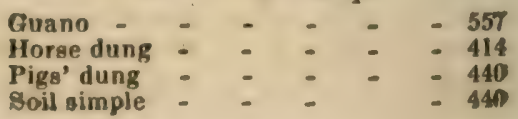


The total comparative produce in $\mathrm{lbs}$. of potatoes from these manures was therefore-

Guano, or sea-fowl dung, at 35 bushels per acre - 639 Horse dung, 35 cart Inads per acre - - - 626 Itogs' dung, 35 cart loads per acre _ _ _ - 534 Soil simple - - - - - - - - 446

With mangel-wurzel the produce per acre on a similar soil was as follows:Leaver. Ronts.
tons.
tons. Snil simple tons. Hngs's dung and ashes, 360 bushels per acre 38

191

Guano, 35 bushels perqucre - - - $\quad-153 \frac{1}{4} 77 \frac{3}{4}$

The guano, or sea-fowl dung, adds General Beatson, which is found in considerable quantities upon Egg Island, was first recommended to my notice by Sir Joseph Banks, President of the Royal Society. "It furnishes," says he, "the loading of an immense number of vessels that are constantly employed in bringing it from small islands to the main land on the western coast of South America, where it is sold and distributed for the purpose of manure, for which it answers in a degree infinitely superior to any other article we have tlic knowledge of. A handful is considered as sufficient for several square yards of land, the produce of which is exuberant in consequence of the force of this application."

The accuracy of this valuable communication has been most amply confirmed by my experiments in the culture of potatoes, as well as upon grass lands. Thirty-five bushels of the guano, or 3 cart-loads per acre appear to me equivalent in effect to 70 loads of good rotsen dung. I should imagine that abundance of this most valuable manure might be had from many of the rocks and islands on the coast of Scotland. The effect of the guano upon grass lands is comparatively greater than in the potato experiment. From what cause this proceeds it may be difficult to explain ; but as Dr. Priestley found, by experiment, that vegetables throve best when they were made to grow in air made putrid by the decomposition of animal and regetable substances, it may be inferred that the very strong effluvia which issue from the sea-fowl dung or guano, logether with its being readily washed among the roots of vegetables by the first falls of rain, are circumstances that may possibly render its effects as a top-dressing greatly superior to those it produces when it is mixed with the soil. On the 29th of July, 1808, I marked out a space on the lawn in front of Plantation House, which measured 1 rod in breadth and 12 rods in length; this was divided into 12 equal parts, or square rods, and numbered progressively from 1 to 12 . The guano was reduced to a powder and sifted, and upon No. 1 a quart of this powder was evenly strewed $\mathrm{t}$ - the hand; this is at the rate of $5 \mathrm{~W}$ inchester bushels per acre, because 160 square rods, or an acre, would have required that number of quarts, or exactly 5 bushels. In the same manner No. 2 had 2 quarts, No. 3, 3 quarts. and so on to No. 12, which had 12 quarts, or at the rate of 60 bushels per acre. From the 29 th of July there were daily drizzling rains until the 5th of August, when the effect of this invaluable manure began to appear. On the following day the whole extent of the 12 rods became highly verdant, and exhibited such a contrast to the unmanured parl of the lawn, that it had the appearance of having been newly turfed with a finer kind of sod. 'The effect gradually increased, and in the first week of October, that is, in a little more than two months, the higher numbers, from 6 to 12 , having from 30 to 60 bushels per acre, excited the surprise of every person who saw them, being covered with the most exuberant grass that can be imagined, and having more the resemblance of a crop of young wheat very thickly sown, than of any grass I ever beheld. This is more remarkable, as at that time the copious rains which fell in August and the spring season had made no visible effect on the adjoin. ing part of the lawn. It was from a frequent and careful inspection of the above experiments that I have estimated 35 bushels of guano per acre to be equivalent in effect upon grass lands to seventy loads of well-rotted dung. I have been informed that guano is sold at Lima, and at other towns on the coast of Peru, for a dollar a bag of 50 pounds weight, and that it is much in use there for manuring fruit trees and gardens. It is certainly one of the most powerful of manures, and therefore it is necessary to be cautious in using it. I have observed, when too much is laid on grass, that it burns and destroys it. I would, therefore, recommend to those who may try it on fruit trees, to begin with not more than threequarters of a pin: to each tree, and to trench it about a foot deep all round the roots. If the first application be found insufficient, a second or third may be given at intervals of two or three months; or a better mode, perhaps, of determining the quantity of guano proper for each fruit tree, would be to select about a dozen trees of the same kind and size, and to vary the quantities by an easy progression, from three-quarters of a pint to one or two quarts, or more, to each tree. (Com. Board of $A g r$, vol. vii. p. 225-240.

The price at present of guano in England is about $\$ 45$ to $\$ 50$ per ton. When Peruvian guano brings $\$ 47$ per ton in England or the United States, the Peruvian government receives about $\$ 12$ export duty, and the remaining $\$ 35$ goes to pay for freight, commissions, \&c.

The importation of guano into England was commenced by Mr. Myers of Liverpool, who, in 1840 , received 20 casks from Peru. In the year 1849, about 150,000 tons arrived in the different ports, more than one-half of which was Peruvian. Estimated at an average price of about $\$ 40$ per ton, this would make the value of all kinds of guano imported into England in 18.19 , about $\$ 6,000,000$.

It is a matter worthy the attention of chemists to consider whether a mixture similar to the guano, and of equal efficacy, cannot be formed by art-not only at a cost so reasonable as at once to make the farmer independent of the importer, but also in such atundance as at the same time to place a highly valuable concentrated manure within the reach of all.

From the many mixtures proposed as substitutes for guano, some of which have proved bighly successful, we extract the following, furnished by Prof. J. F.W. Johnston, containing the various in- 
gredients found in guano in nearly the average proportions; and Mr. Johnston believes it is likłly to be at least as efficacious as the natural grano, for all the crops to which the latter has hitherto been applied.

$3151 \mathrm{bs}$. (7 bushels) of jone dust, at $2 \mathrm{~s}, 9 d$. per f s. $d$. bushel.

$100 \mathrm{lbs}$. of sulphate of ammonia, containing 35

lbs. of anmonia, at $20 \mathrm{~s}$. a $\mathrm{cwt}$.

5 lbs. peirl ash

100 lbs. of common salt

11 lbs. of dry sulphate of soda

531 lbs. of artificial guano cost

The quantity here indicated may be intimately ruixed with $100 \mathrm{lbs}$. of chalk, or deadlime, and will be fully equal in efficacy, 1 believe, to $4 \mathrm{cwt}$. of guano, now selling at $£ 5$.

In the preceding observations and experimental trials, Peruvian guano is alone referred to. This is unquestionably much the best guano known, but its high price, and the monopoly of its trade, by a company of English merchants who purchased of the Peruvian government the exclusive right of taking it away, has induced a search for this fertilizer in other places, from which thousands of shiploads are now received into England and the United States. That supplied by a small island called Ichaboe, situated on the west coast of Africa, though very different in appearance from Peruvian, comes nearest to it in its excellent qualities. But this is nearly exhausted, and the other African guanos, from Saldanha and Algoa Bays, sold in England from $\$ 15$ to $\$ 20$ per ton, are very inferior, and chiefly composed of bard lumps difficult to manage. Large quantities of guano are brought from Chili and Patagonia; but the deposits being considerably farther south are subjected to rains, by which some of the most fertilizing constituents of the bird-excrements are washed away. The urate and other soluble salts of ammonia are the most important of these, and their retention in the Peruvian guano, from its never being washed by rains, greatly contributes to its superiority; cold water dissolves about 3-5ths of this guano, which if exposed io rains would thus lose more than half its best ingredients.

As guano is now used to a considerable extent in the United States, and undoubtedly destined to become one of very great consumption, it is important that some legal inspection should be established to protect the agricultural interests from frauds and impositions to which they must otherwise be exposed, not only from the introduction of inferior kinds of guano, but from adulterations, imitations, and misrepresentations of dealers. Most of those in the English market have been analyzed by Professor J. F. W. Johrston, who found in these, per cent.,

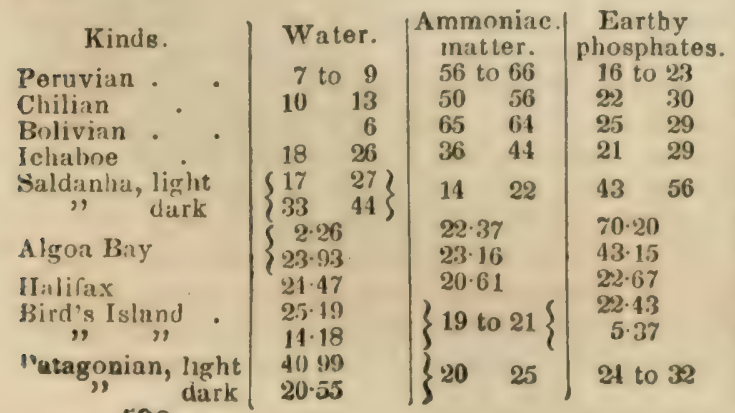

A few general rules may be here given for the application of guano. 1. When used, as it commonly is, in a dry state, it should be in fine powder, in order to secure which, sifting must be resorted to. 2. When employed in a liquid form, dissolve in the proportion of $1 \mathrm{lb}$. in 4 gallons of water, and sprinkle from time to time by means of a watering-pot, over young tobacco beds, or other plants, grass or grain. fields, sought to be benefited. 3. For most field crops it is best applied broadcast, scattered as evenly as possible, either just before the plough, or on the rough ground before the harrow; the great object is to have it speedily; but not too deeply covered. 4. Previous to sowing it may be useful to mix 1 bushel of ground plaster of Paris, or the same quantity of powdered charcoal, or both, with 100 lbs. of guano. 5. When applied in the fall or spring as a top-dressing to growing grain or grass, it is well to follow with the harrow and roller. 6. When applied by the drill, or in the hill to corn, \&c., it should be previously well mixed with 5 or 10 parts its bulk of light vegetable mould, or soil, and then well sprinkled. It must not come in immediate contact with the seed, or lie in a dense layer immediately beneath it. Half an ounce of guano to the hill, supposing the hills 3 by 4 feet apart, will give 150 lbs. to the acre. 7. As a general rule, $10 \mathrm{lbs}$. of Peruvian guano is more than equivalent to an ordinary load or cubic yard of barn-yard manure, and on light land, $300 \mathrm{lbs}$. guano spread broadcast, will produce better crops than 40 or 50 loads of rich manure, and last quite as long. It is seldom if ever profitable to spread ahove $400 \mathrm{lbs}$. to the acre. In dry seasons, the fullest effects of guano are not to be expected, any more than from barn-yard or other manures, to which the same observation will apply. See PHosPHATES.

GUINEA-CORN (Holcus sorghum, Linn.), an exotic vegetable, growing on the coast of Africa; its stalks are large, compact, generally attaining the height of 7 or 8 feet, and producing abundance of grain. It may be easily raised in sheltered situations, especially in exhausted hot-beds and other loose soils, where its seeds should be sown early in the spring, as the large flowery tops appear in June. In Tuscany, Syria, and Palestine, the flour made of this grain is mixed with other meal, and converted into bread; which, however, is generally brown, tough, and heavy. Hence the former is better calculated for milk porridge, that is equally wholesome and nutritive. The juice exuding from the stalks of the Guinea-corn is so agreeably luscious, that. it affords excellent sugar, by a process similar to that adopted with the sugar-cane; the seeds furnish nourishing food to poultry and pigeons, as well as for horses and hogs. (Dom. Encyc.)

GUINEA FOWL. See Fowls.

GUINEA GRASS. A valuable species of herbage, thus denominated, as it was first discovered on the coast of Guinea, whence it was brought to Jamaica. In point of real utility, this plant ranks, in Jamaica, next the sugarcane; for the breeding farms throughout the island were originally established, and are still supported, chiefly by means of the Guinea grass, which bestows verdure and fertility on lands that would otherwise not deserve to be 
raltivated. Alout ten years since, it was also introduced into the East Indies, where it is now successfully cultivated, and grows to the height ol seven frect: it admits of being frequently cut, and makes excellent hay. Cattle eat it, both in a fiesh and dry state, with great avidity: hence the culture of this valuable herbage has been strongly recommended to the farmers of Cornwall and Devonshire.

The following remarks on the culture of this wrass are by the late $H$. Lawrence, of South Carolina.

- In the last spring, I procured from Jamaica three half-pints of Guinea-grass seed, which I planted in the drills of one-fourth part of an ucre of very indifferent land; the seed sprung up and soon covered the ground with grass four feet high and upwards. Being desirous of saving as much seed as possible, I cut one bundle of grass for horses: they ate it all with great avidity.

"In August I took one of the grass roots and divided it into 28 parts, which were immediately replanted: every part took root, and the whole are now growing very finely and seeding. I am of opinion this grass will make the best pasture we can wish for. From former experience I have reason to believe the Guinea grass is perennial. It is easily managed, requires but onr good hoeing, after which it will take care of itself.

"I am informed a gentleman near Kingston, in Jamaica, makes upwards of $1000 l$. sterling per annum by Guinea grass hay." (Domestic Euryclopardic.)

GUINEA PIG (Covia cobaya). This curious little animal is not a native of Guinea, but of Brazil, whence it has been imported into Europe. It is about seven inches in length, and its white body is variegated with irregular black aud orange-coloured spots. In their wild state these animals multiply prodigiously, and would become innumerable, if they were capable of sustaining cold and moisture. The female breeds at two months old, and brings forth 10 , 12 , or 14 young ones, several times in the course of the year, after a gestation of three weeks. Guinea pigs feed on all kinds of herbs, but are particularly fond of parsley, as also of apples and other fruits.

GULLION. A provincial name for gripes in horses. See Gripes.

GUM, BLACK. See BLACK GUM.

GUTTA PERCHA. A peculiar gummy sub. stance, consisting of the dried juice exuding from trees growing abundantly in Singapore, Borneo, and other parts of the East Indies. The remarkable properties of this singular substance were first made known to us by Dr. Montgomerie, in 1845 , since which it has come rapidly into use for numberless purposes in the various mechanic arts, those especially in which leather, wood, iron, brass, and tin were used. When immersed in water heated to $150 \mathrm{deg}$. Fahrenheit it becomes plastic, and is capable of being moulded to any required form, which it retains upon cooling. It is a perfect repellant of water, acids, and fixed oils, and is therefore well adapted for machine belts in damp localities. It is also found to possess, at ordinary temperatures, a permanent elasticity of about 5 per cent., and noes not oxidize like metals, or mould like leather; for water pipes, both for suction under great pressure, and for aqueduet purposis, is is found superior to any other substance. It is imporous, and conveys sound better than woms or metal, hence it is superior for speaking fulwes. It is a non-eonductor of electricity, and is useful for insulating telegraph wires under water or the ground. It never contracts or expands under any degree of cold or heat from zero 10100 deg. Fah.., and is unaffected by dryness or moisture. A 2220 deg. of Fah., it is the most adhesive substance known, remains perfectly adhesive at all lower temperatures, as well as under water. It resis? abrasion in an eminent degree, and is decidedly more durable than the best of sole leather. It is a good absorbent of heat when exposed to is direct rays, and a poor conductor. Ice and milk can, it is said, be kept in gutta percha vessels longer than in any other substance. It has great strength, and cannot be broken by the. most violent blow-is insoluble in alcohol, ether, or camphene at any ordinary temperatures; but is readily cut by heated camphene, or dissolved by coal naphtha and chloroform, and held in solution at a temperature of summer heat. The trees producing it are the largest in the Eastern forests, growing from 60 to 70 feet high, and 2 or 3 feet in diameter. Their fruit yields an oil which the natives use with their food, but the wood is of little value.

GYPSUM. See Praster of Paris.

\section{H.}

HACK, or HACKNEY, In horsemanship, a general term for a road horse, which does not always convey any sense of inferiority, or refer to horses let out for hire. It is, however, often used in that sense.

HACKBERRY. A species of nettle tree, a native of the United States, where the banks of the Delaware, above Philadelphia, may be considered its north-eastern limit. East of the mountains it is abundant only on the Potomac and Susquehanna, especially near Columbia and Harrisburg. In the western country it is abundantly multiplied in all the river valleys where the soil is fertile. On the Ohio it is called Hoopash, and in Kentucky, Hackberry. On rich soil this tree grows straight and undivided to a great height; its bark is grayish, and unbroken. The wood is weak, and subject to speedy decay when exposed to the weather. Its elasticity, however, adapts it for making baskets and chair bottoms. It splits readily, and makes handsome fence rails.

The hackberry is certainly one of the most beautiful trees of its genus, and one of the most remarkable for height and for majesty of form. In rich soils, the luxuriance of its vegetation is shown by sprouts 6,8 , and 10 feet in length, garnished on each side with large, substantial leaves. In France it is principally. esteemed for the rapidity of its growth. ( $A m$. Sylva.)

HACKLE. A board set with sharp iron spikes for combing or pulling out hemp and flax. Also the name of an artificial fly used by anglers.

HACKMATACK, or American larch (Larix Americann). The European and American larches, says Michaux, are more strictly confined than any other resinous trees to the northern 
zone of the two continents, and they are the first to disappear in approaching a milder sky. The American species is most abundant in the States of Vermont, New Hampshire, and Maine; but though the soil is well adapted to its growth and the winter is long and severe, it does not form the hundredth part of the resinous growth, which consists principally of the black spruce, the hemlock spruce, and the red cedar. According to my father's observations in his journey to Hudson's Bay, it is only beyond the St. Lawrence, particularly near lake St. Jown and the great and the little lake Mistassin, that it begins to abound and to form masses of woods, some of which are several miles in extent. I have been informed that it is profusely multiplied in Newfoundland, in nearly the same latitude. New Jersey, Pennsylvania, and the coldest and gloomiest exposures in the mountainous tracts of Virginia, are the limits of its appearance towards the south: hut it is rare in these states, and in I. ower Jersey, in the vicinity of New York, it is seen only in the swamps of white cedar, with which it is scantily mingled. The numerous descendants of the Dutch in New Jersey call it tamarack.

I have remarked that in the States of Vermont and Maine the larch grows only in low and moist places, and never on uplands, as about Hudson's Bay and in Newfoundland; hence we may conclude that the climate of the northern extremity of the United States is too mild for its constitution.

The American larin, like that of Europe, is a magnificent vegetable, with a straight, slender trunk 80 or 100 feet in height, and 2 or 3 feet in diameter. Its numerous branches, except near the summit, are horizontal or declining. The bark is smooth and polished on the trunk and longer limbs, and rugged on the smaller branches. The leaves are flexible, shorter than those of the European species, and collected in bunches: they are shed in the fall and renewed in the spring. The flowers, like those of the pines, are separate upon the same tree: the male aments, which appear before the leaves, are small, oblong, and scaly, with two yellow anthers under each scale; the female flowers are also disposed in aments, and are composed of floral leaves covering two ovaries, which in process of time become small erect scaly cones 3 or 4 lines long. At the base of each scale lie two minute winged seeds. On some stocks the cones are violetcoloured in the spring instead of green; but this is an accidental variation, for the trees are in no other respect peculiar.

The wood of the American larch is superior (1) any species of pine or spruce, and unites all the properties which distinguish the Eu. ropean species, being exceedingly strong anc singularly durable. In Canada it is considered as among the most valuable timber, and has nc fault except its weight. In the State of Maine it is more esteemed than any other re. sinous wood for the knees of vessels, and is always used for this purpose when proper pieces can be procured. 'Turpentine is never extracted from it in America, as is done from IIs native species in Europe.
The larch is justly appreciated in the United States, but it is little employed, because it is rare and may be replaced by several resinous trees which are cheaper and more abundant.

Sir A. B. Lambert, in his splendid work upon the pines, describes two species of the American larch, the first of which is evidently the tree we have been considering; the second he denominates Larix microcarpa, and characterizes it by smaller fruit and drooping branches. My father doubtless considered it as a variety, and has omitted to mention it: as I have never visited the northern parts of America, I cannot decide the question.

'The cones of the European larch are twice as large as those of the American species, but the two trees are so analogous that a separate description is unnecessary. (Am. Sylva.)

HAIR (Germ. haare). The characteristic covering of the mammiferous class of animals. It consists of slender, more or less elongated, horny filaments, secreted by a matrix, consisting of a conical gland or bulb, and a capsule, which is situated in the meshwork of the corium or true skin. The hairs pass out through canals in the corium, which are lined by a thin layer of cuticle adherent to the base of the hair: the straightness or curl of the hair depends on the form of the canal through which it passes. The hair is formed in an elongated sheath or sack, to the bottom of which the bulb or soft part of the hair is fixed. The structure of hairs differs: thus, in the bristle of the hog there is an internal cellular part, and an external or cortical fibrous part; and this is also the structure of the hair of the roe deer. The hair of the bat is knotted, and that of the mouse is mottled with black and white. Hair is usu. ally distinguished into various kinds, according to its size and apgearance. The strongest and stiffest of all is called bristle: of this kind is the hair on the backs of hogs. When remark ably fine, soft, and pliable, it is called wool, and the finest of all is known by the name of down. Spines, bristles, fur, and wool (see those heads) are therefore all modifications of hair, having the same chemical composition, mode of formation, and general structure.

In the spine of the porcupine, the bulb secretes a fluted pith, and the capsule invests it with a horny sheath, the transparency of which allows the ridges of the central part to be seen. In the spine-like whiskers of the walrus, as well as the bristles of the hog, the twofold structure of the hair is very conspicuous; but in the finer kind of hair, as of the human head and beard, the central pith can only be demonstrated in fine transverse sections, viewed with a microscope. Some kinds of hair, as of the human head, the mane and tail of the horse, are perennial, and grow continuously by a persisting activity of the formative capsule and pulp: other kinds, as the ordinary hair of the horse, cow, and deer, are annual, and the coat is shed at particular seasons. In the deer the horns are shed contemporaneously with the decidunus hair.

Many quadrupeds, especially those of cold climates, have two kinds of hair: a long and coarse kind, forming their visible external covering; and a shorter, finen and more 



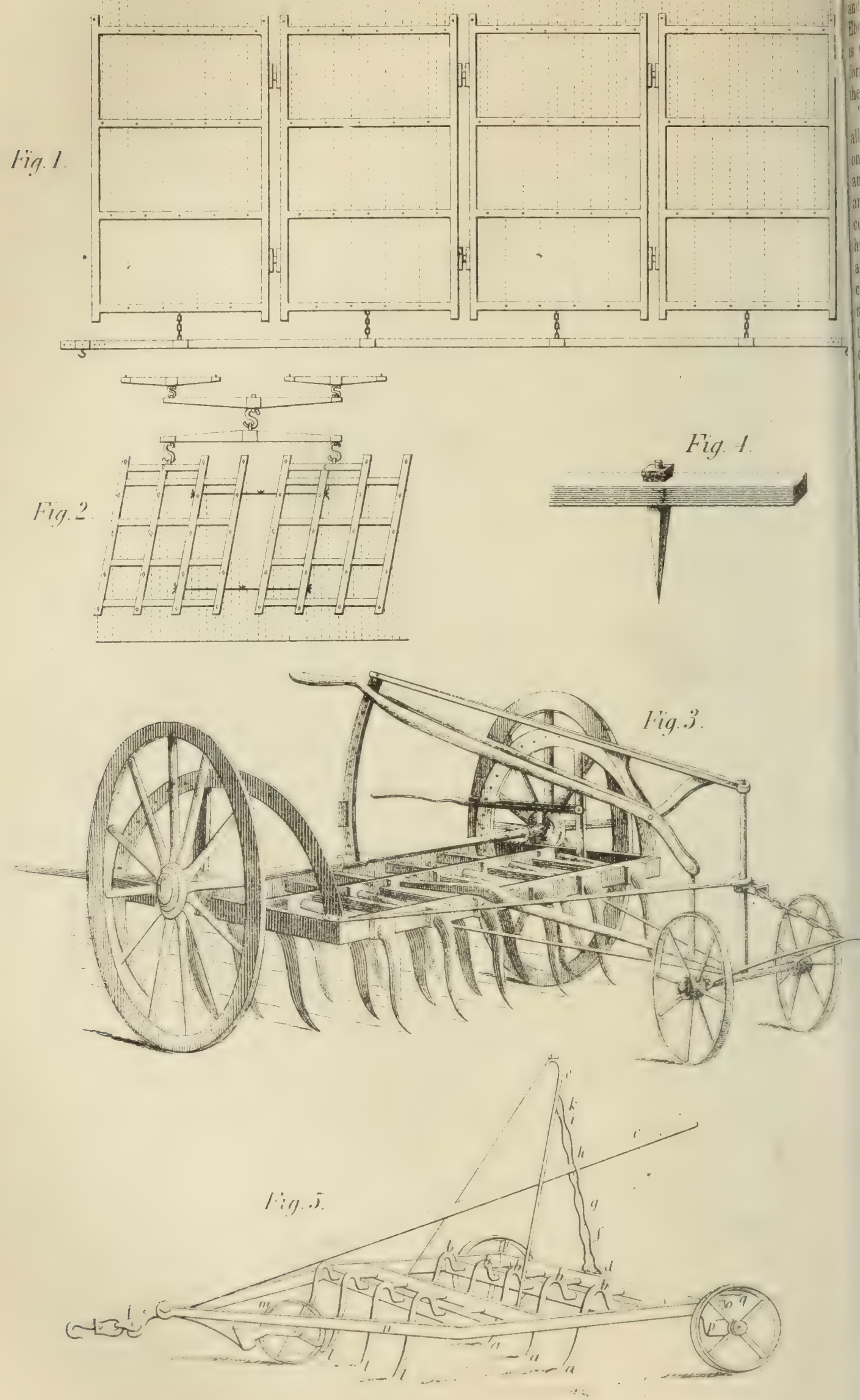

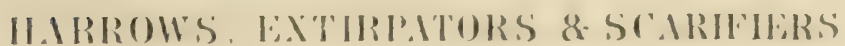


abundant kind, which lies close to the skin, and called "fur." With respect to structure, Eberle has proved that the sheath of the hair is vascular, and the substance of the hair is formed by the secretion of horny matter on the surface of the vascular pulp.

The organization of the hair is such as to allow of its undergoing certain changes when once formed, according to the state of health and general condition of the rest of the frame, and even to be affected by loss of colour in consequence of violent mental emotions in the human subject. Some of the lower animals, as the Alpine hare, are subject to periodical changes of colour of their fur, by which it is made to harmonize with the prevailing hue of the ground which they habitually traverse. The chemical properties of hair were first pointed out by Mr. Hatchett, in his paper in the Phil. Trans. for 1800 . It chiefly consists of an indurated albumen, and when boiled with water, it yields a portion of gelatin. Soft flexible hair, which easily loses its curl, is that which is most gelatinous. Vauquelin discovered two kinds of oil in hair: the one colourless, in all hair; the other coloured, and imparting the peculiar tint to hair. Black hair also contains ron and sulphur. The following is his analysis:-1. An animal matter, constituting the greatest part. 2. A white solid oil, small in quantity. 3. A grayish-green oil, more abundant. 4. Iron; state unknown. 5. Oxide of manganese. 6. Phosphate of lime. 7. Carbonate of lime, very scanty. 8. Silica. 9. Sulphur. Leuwenhoeck (Phil. Trans.) and Hooke (Micrographia, p. 156) have published heir microscopical observations on hair.

Human hair makes a very considerable article in commerce, for wigs, \&c. The hair of horses is extensively used in the manufacure of chairs, sofas, saddles, \&c.; while the nair or wool of beavers, hares, and rabbits, \&c., $\therefore$ much employed in the manufacture of hats, sc. The refuse hair of different animals, paricularly the short hair from hides, and that of logs, when it can be procured in sufficient quantity, will be found useful as a fertilizer; a act that might readily be imagined when it is known that its chemical properties closely aporoximate to those of horn.

\section{HAIR GRASS. See Aira.}

HALESIA. The name of two beautiful speies of shrub, or small trees, natives of North Carolina and other Southern States. They are nown by the familiar names of silver-bell and now-drop tree, and are highly ornamental, roducing very early, whilst the tree is comletely leafless, a profusion of snow-white tanging blossoms, having a pleasant odour and rery much frequented by humming-birds, bees, and other insects. The flowers are disposed $n$ bunches all along the branches, each bud roducing from 4 to 8 or 9 . The flowering continues during two or three weeks, and the lossoms are succeeded by pretty large winged uiceless drupes, hanging likewise in bunches. The tree is propagated by cuttings or suckers rom the roots, and appear to stand the severe winters of more Northerly States, very well. A Halesia, with several distinct trunks from the original root, is now flourishing at the seat of
J. Cowperthwait, Esq., near Bristol, Pennsylvania. It is quite an old tree, and has attained the height of 35 or 40 feet. There are two species of halesia, one called flower-winged (H. tetraptera), and the other the two-winged (H. diplera). The leaves of the latter are six times the size of the former, and the fruit has two large wings and two minute ones.

HAM (Dutch, hammen; Fr. jambon). In commerce denotes the thigh of a hog or bear salted and dried, so as to preserve it in a state possessing a pungent and agreeable flavour. York, Hants, Wilts, and Cumberland in Eng. land, and Dumfries and Galloway in Scotland, are the counties most famous for producing fine hams. Those of Ireland are comparatively coarse, and without flavour. See Bacov. The hams of Portugal, Westphalia, and Virginia are exquisitely flavoured, and are in high estimation. 'The method of curing hams in the most celebrated districts, is to rub them very hard with bay or other salt; then leave them on a stone bench, in order that the brine may discharge itself. In a few days the rubbing process is repeated; about half an ounce of saltpetre (nitrate of potassa) being added to each ham. When they have continued about a week longer on the bench, or in the saltingtub, among the brine, they are commonly hung up to dry in the sides of large open chimneys; some have them exposed to the smoke of wood, peats, coals, or other sorts of fuel, while others carefully avoid having them smoked. And when not sold sooner, they are continued in these situations till the approach of warm weather, when they are packed up in casks with straw, or the seeds of oatmeal, and consigned for sale. Hams lose about 20 per cent. of their weight in drying.

Hams may be cured in order to resemble, in taste, those of Westphalia, by the following process:-Cover a young ham of pork with dry salt; let it be for 24 hours to draw off the blood; then wipe it perfectly dry, and take one pound of brown sugar, a quarter of a pound of saltpetre, half a pint of bay salt, and three pints of salt; incorporate these ingredients in an iron pan over the fire, and stir them continually till they acquire a moderate degree of heat. In this pickle the ham must be suffered to remain for three weeks, frequently turning it, when it should be suspended in a chimney for drying by means of smoke from no other but a wood fire. The smoke from oak saw-dust or shavings is the best for imparting a fine flavour. This smoke contains imperfectly formed pyroligneous acid, which is the agent that com. municates the flavour to the Westphalia hams. In Dumfriesshire the pickle for hams is sometimes made with one-half ale, which renders the hams shorter, and adds greatly to the richness of their flavour. The imports of bacon and hams into England, have been kept low by the heavy duty of $28 \mathrm{~s}$. exacted on each $\mathrm{cw}$. But the duty having been recently greatly reduced, a large amount of hams cured in America will be sent to the English market. In 1842 , the duty on foreign hams imported into England was reduced to $14 s$. the $\mathrm{cwt}$, or just half of what it had been for many years. On those imported from British colonies the duty $3 \mathbf{E}$ 601 
is ouly 3s. 5d. per cwt. Although dried hams pay a duty of $14 s$, those shipped in pickle pass the English Custom House at the pork duty of 8s. per cwt. As a set off, however, against the $6 s$. saved in duty, it must be observed that pork cured in pickle is of inferior quality to that cured in dry salt, and will not bring an equal price. It is also shipped in that form at an increased cost of packages and freight, and pays a duty on a greater weight than when dried. See Swrine.

HA.MES. The iron or wooden harness by which draught-horses are attached to the carts, \&c.

HAND. The measure of the fist when clenched; it is equal to four inches. The height of horses is computed in this way. A horse $\mathbf{1 5}$ hands high stands five feet at the shoulders.

HARE (Lepus timidus). The hare is naturally a timid animal, and extremely swift in motion when pursued by dogs. Hares are dispersed over almost every climate, and consequently the varieties are extremely numerous; and the sizes, forms, and habits, adapted to the physical wants of the family, greatly multiplies their diversities. Although hunted in all countries, being prolific in the extreme, their species does not apparently diminish in number. They begin to breed in the first year, and the female generally produces four or five leverets, after a gestation of about 31 or 32 days; and she is supposed to breed four or five times in the year. Unlike dogs, the eyes of these animals are open at their birth; and after being suckled for about three weeks, they are abandoned to their fate. Hares in a state of nature are believed to live from 9 to 12 years. The hare is known to have been a favourite object of the chace more than 2000 years ago.

Two or three species of the hare genus are natives of the United States. The common American rabbit, found all over the country, is the Lepus Americanus and Lepus Hudsonius of naturalists. It is smaller than the English hare, and even less than the European rabbit. In dry places it often burrows in the earth, and is very prolific, bringing forth 3 or 4 times a year from 5 to 10 at a time. It carries its young about 6 weeks. In the domestic state the male rabbit will often destroy the young.

A second American species is the Varying Hure, the Lepus Irirgianianus or Lepus variabilis of naturalists. This inhabits the Southern and Middle States, and most probably as far north as New England. Its colour is grayishbrown in summer, and white in winter; the orbits of the eyes are at all times surrounded by a reddish fawn-colour; tail very short. The largest of this species are about 18 inches, :-tal iength, and weigh from 7 to $8 \mathrm{lbs}$. These animals never burrow, but frequent meadows, \&c., near the base of mountains, and when pursued retreat into hollow trees. They bring forth several times a year, 3 or 4 at a birth, after a gestation of about 30 days.

In the extreme northerly parts of the contiaent. Captains Parry, Sabine, and other travellers, describe another American species under the rame of Lcpus glarialis, which is somewhat larger than the varying rabbit, being 602
2 feet 4 inches from the end of the nose to the arms, the average weight being $8 \mathrm{lbs}$. The ear: are longer in proportion than those of the com mon hare, and especially those of the varying rabbit. The fur is exceedingly thick and woolly, of the purest white in the spring and autumn, excepting a tuft of long black hair at the tip of the ears, which is readish-brown at the base. The whiskers are also black at the base for one-half their length. In the summer the back and sides become a little grayish, the fur beneath still remaining white. The lepus glacialis, or hare of the icy regions, inhabits the Arctic circle, Greenland (where it remains entirely white even in summer). The food consists chiefly of tender herbs gathered from ravines. (Fauna Americana.)

HARIFF, Goose-Grass, Cliders, Cleavers, or Catchweed (Galium aparine). Pl. 10, h. This is an annual plant, with a fibrous root, growing in hedges almost everywhere. It is found wild even in Nepal. The flowers are small, pale, and buff-coloured, few together, on lateral leafy stalks, and blowing from May to August. The root is fibrous. The stem branched, brittle, supporting itself upon other plants; often three or four feet long; the four angles beset with hooked prickles, which are also abundant on the edges and keels of the leaves, by all which the herb sticks to the hands and clothes of those who touch it, as well as to the coats of animals, as do likewise the seeds. The fruit is a double globe, beset with minute, short hooks. The expressed juice of the herb is reckoned anti-scorbutic; but this is doubtful, as well as some imaginary virtues in cancer which have been attributed to it. The roasted seeds are said to be no bad substitute for coffee, to which they are botanically related.

Three-flowered goose-grass is one of the names of the rough-fruited common bed straw. (G. tricorne).

HARRIERS. A breed of dogs kept principally for hunting the hare. There are three prominent varieties of the harrier,-the old southern hound, the modern harrier, and the beagle. Subordinate divisions occur, and a cross breed is used in hunting the otter. The modern harrier is little more than a dwarf foxhound. The size and form of the harrier, like those of the fox-hound, should be adapted to the nature of the country hunted over. Some sportsmen have a penchant for packs of undersized harriers; and a gentleman of the name of Harding used to hunt the open grounds about Dorchester with about 17 couple, which were not more than $16^{\circ}$ or 17 inches high. (Blaine's Rural Sports, p. 404.)

HARROW. For the chief portion of the following article, I am inclebted to the Messrs. Ransome, the celebrated agricultural implement makers of Ipswich; than whom no persons can be better acquainted with the construction and uses of different machines and implements for agricuitural purposes. This instrument succeeds to the plough in the natural order of description, and in the uses to which it is applicable. Its purpose is to pulverize the ground which has been moved by the plough, to disengage from it the weeds and roots which it may contain, ir to cover the 
seeds of the cultivated plants, when sown. The form of the plough has been very different in different ages and countries, and there is little resemblance between the rude machines of the ancients and some of those which are now employed; but the harrow seems to have been nearly of the same form from the earliest times to which we are able to trace it on sculptures, medals, and other remains of antiquity. It is a much more simple machine than the plough, and may even be held to be imperfect in any form in which it can be made; yet it is an instrument of great utility in tillage, and no other has yet been devised to supersede its use, or to equal it, for many of the purposes to which it is applicable. (Quart. Journ. of $A g r$. vol. i. p. 503.)

There were various stages in the gradual introduction of the modern harrow. The first implement used by men, for the purpose of covering seed, is generally the branch of a tree; to these soon succeed more desirable substances, such as beams of wood; and then, again, two or more beams are fastened together: spikes, or teeth, are a much later improvement. Even now, in India (and there the natives but rarely alter their modes of culture or their implements), an instrument is nsed which is intended to produce the combined fffects of the roller and the harrow. 'This, aciording to Mr. G. W. Johnson, "is nothing more in form than an English ladder made of bamboo, about 18 feet long, drawn by four bullocks and guided by two men, who, to increase its power, stand upon it, as they direct and urge on the cattle: again and again has it to pass over the same surface, and thus it causes a great waste of time and labour."

Important as is the operation of harrowing, and second only to that of ploughing, it has often appeared to us that these implements have scarcely obtained the attention which is their due. We here speak less with reference to the improvements which have been carried into effect, than to the selection which appears generally to have been made. The operation is in many neighbourhoods so performed as to exhibit a prominent defect, either in the management of the farm, or in the construction of the implement: perhaps the blame may be fairly shared. It is admitted by all acquainted with the subject, that harrowing, especially on heavy soils, is the most laborious operation on the farm,--not so much, perhaps, on account of the quantum of power requisite for the draught (though this is sometimes considerable), as for the speed with which the operation is, or ought to be, accompanied; and yet it is frequently left to the charge of mere boys, and sometimes performed by the worst horses on the farm. If we examine a field, one-half of which has been harrowed by weak, inefficient horses, and whose pace was consequently sluggish, the other half by an adequate strength and swiftness of animal power, we shall find the former will be rough and unfinished; the latter comparatively firm and level, and completed in what would be called a husbandrylike manner. Scarcely any thing in farming is more unsirhtly than the wavy, serpentine traces of inefficient harrowing. 'The generality of harrows appear to us tou heary and clumsy to admit of that despatch without which the work cannot be well done; and though it is eviden that different soils demand different imple. ments, of proportionate weiglat and power, yet, for the most part, harrows liave been rather over than under-weighted, particularly when empluyed after a drill, or to bury seeds of any kind. Harrowing has been so long regarded as an operation which must be attended with considerable horse-labour, that our attention has been turned to the inquiry, whether this labour might not be greatly reduced by lightening the harrows. Many, we think, would be surprised at the amount of reduction of which seed-harrows, at least, are capable, and where land is clear, to see how effective a gang of very light small-toothed harrows may be made. Having noticed the perfect manner in which seed-corn is covered by a common rake with wooden teeth, in some parts of Norfolk, a friend of ours constructed a gang of harrows on the following plan, and he states that they proved the most popular and useful implement of the kind on the farm. Pl. 15, fig. 1.

The frames are of ash, and as light as possible, the teeth (of iron) being but three inches long, exclusive of the part which enters the wood-work. They screw into the balks in the manner shown in Pl. 15, fig. 4.

It will be observed that the above four harrows are amply sufficient to cover a twelvefurrow stetch or ridge of 108 inches, but three will be wide enough for a three-furrow stetch of 90 inches, exclusive of a small portion of the furrows. If for some purposes the teeth be found too thick, every other tooth may be taken out; but for general purposes this will hardly be necessary. The two horses require, on this plan, to be kept quite level; for if one is suffered to go in advance of the other, a diagonal line is produced, by which the teeth will be made to follow each other, instead of cutting fresh ground. We are aware that, by the usual construction of harrows, a diagonal line of draught is required, in order to throw the teeth into a proper working position; but we are strongly inclined to the opinion, that the due execution of the implement ought to depend on its construction, and not on any particular mode of working it. Besides, the system of keeping one horse in advance of his partner is bad in principle; it is an unequal division of labour, the fore-horse being compelled to do more than his share of the work, which, under any circumstances, is always heavy enough. We have stated that the above set of harrows are of wood. Their extraordinary lightness renders this necessary; but, for general purposes, we prefer those made of iron, the weight of which can be increased to any reasonable degree without adding much to their substance. This is important in working tenacious clays, which, by adhering to the clumsy wooden balks, considerably increase the labour, and at the same time impede the proper execution.

In an experiment made between a pair of wooden harrows and a pair of iron ones, constructed on the same plan, having the same number, and precisely the same disposition of the teeth and balks, although the iron wer* 
found to be $20 \mathrm{lbs}$. lighter than the wooden ones, yet they worked decidedly better and steadier than the latter; in fact they cut into the land, while the wooden ones rode, or rather danced, on the surface.

We will now take up the consideration of the length and position of harrow-teeth. The common plan is to set them springing a little forward, and gradually increasing in length from the fore to the hind row. We think there is no advantage in this, but the contrary; for, if the action of harrows so constructed be carefully examined, it will be found the reverse of what it ought to be,-the hind part will be thrown up, and the fore-teeth, short as they are, will have to do all the work. In some experiments made with harrows, the fallacy of the idea, that an inequality in the length of the teeth was essential to the proper working of harrows, was made evident. For this purpose, a harrow was constructed on the old-fashioned plan of unequal and springing teeth in front; the whole of the teeth pointing backwards instead of forwards. Nothing could work better: there were no chucks and snatches, but all went on smoothly and steadily. We do not, from this circumstance, recommend harrows to be so constructed, but we have no doubt that each harrow should have all its teeth of equal length, and should stand perpendicularly from the balk.

Armstrong's Harrows.-These instruments differ from others in the form of their balks or framing, which are of iron, and of a zigzag shape, so arranged that the tooth or tine shall be fixed at each angle, in such manner that the lines formed by them shall be equidistant over the breadth of the land they are intended so cover. 'They can be adapted either for heavy or light work.

We now proceed to give a brief description of some other implements intended for the same operation, but of a more elaborate character.

Biddell's Extirpating Harrow.-This is a new implement, somewhat on the principle of Biddell's scarifier, and invented by Arthur Biddell of Playford. It is intended for breaking up land when it is too hard for the heaviest harrows, and for bringing winter fallows into a state of fine tillage. In working summer lands, by the shape of its teeth, it is calculated to bring to the surface all grass and rubbish; it will also be found generally useful for accomplishing fine tillage. The tines may be either used with points or with steel hoes; and with the latter the skimming, or, as it is frequently called, the "broad-share" process, may be quickly accomplished. The weight is not found to be a disadvantage, but the contrary; and, being borne on high wheels, it does not require $\therefore$ much horse-labour as might be supposed. It is at present but in limited operation, though highly valued by those who have made use of it. Fig. 3, Pl. 15, is a sketch of this harrow obtained from one in use.

The Perwickshire harrow is, says a writer in the Quart. Journ. of $\mathcal{A g r}$, the most perfect im. plement of the kind in general use. It consists "two parts joined together by iron rods, hav.2g hasps and hooks. Pl. 15, fig. 2. Each part 60* consists of four bars of wood, technically term ed bulls, and connected together by an equal number of cross bars of smaller dimensions mortised through them. 'The former of these bars may be $2 \frac{1}{2}$ inches in width by 3 inches in depth, and the latter 2 inches in width by 1 inch in depth. The longer bars are inclined at a certain angle to the smaller, so as to form the figure of a rhomboid, and they have inserted into them the teeth at equal distances from each other. This inclination of the longer bars is made to be such, that perpendiculars from each of the teeth, falling upon a line drawn at right angles to the line of the harrow's motion, shall divide the space between each bar into equal parts; so that the various teeth, when the instrument is moved forward, shall equally indent the surface of the ground over which they pass. (Quart. Journ. Agr.)

HARVEST (Germ. herbst.) In agriculture, the period at which any crop is reaped. The term is more commonly applied to the crops of corn or hay.

HARVEST FLIES, Cicadians. See Loc USTS.

HARVEST-HOME. A sort of feast given by the farmer, after harvest, to the labourers and others that have assisted in cutting and securing the crops. The term is sometimes also applied to the song made use of on the occasion.

HARVESTING. The operation of pulling, cutting, rooting up, or gathering field crops, and drying or otherwise preparing them for being stored up for winter use. The first harvest which occurs' in Britain and similar climates is that of the forage grasses, or other plants made into hay; the next is the harvest of cereal grasses, or of corn crops; and the third, the potato harvest, or harvest of root crops, such as potatoes, carrots, turnips, mangel-wurzel, \&c.

There is also the harvest of occasional crops, such as that of rape-seed, turnip-seed, dyer'swoad, hemp, flax, and various other articles. The commencement of harvest is necessarily regulated by the state of the weather, and varies in different seasons, even when the weather is favourable, from the middle of July to the end of August; while, in some years, and in exposed situations, it is still later. It is, therefore, an object of importance to the farmer to ascertain the exact time when it may be begun, for he must employ extra hands to perform the work; and as it only lasts during a comparatively short period, they receive high wages, and are maintained at a heavy cost. It is also attended with the most anxious solicitude, for it is a business which cannot be for a moment neglected; and the man who wishes to get it rightly managed, must superintend it, without intermission, from the dawn of the day until its final close. He should previously get rid of all other work, and make every preparation for the due performance of this; the barns should be thorcughly swept out, both roof, walls, and floors; the stack-frames repaired, and every tool should be in complete condition. The straw-bands should be in readiness for tying the sheaves, as well as the ropes for securing the stacks; and artangements should 
be made in the house for the regular supply of whatever is to be furnished to the labourers, so that every unnecessary delay may be avoided. The strictest order should also be maintained; but the work will never be well performed unless it be conducted with perfect good temper. Fortunately, the crops do not usually ripen at the same precise period; that of rye being the earliest, and wheat about a fortnight later; some of the early species of rats and barley come in between the rye and wheat; but barley more generally comes afterwards, followed by some of the later kinds of oats. Grain, if not reaped until the straw is wholly yellow, will be more than ripe, as the ear generally, except in late seasons, ripens before the entire of the straw ; and it is observable that the first reaped usually affords the heaviest and fairest sample.

The indications of ripeness in wheat are few and simple. When the straw exhibits a bright golden colour from the bottom of the stem nearly to the ear, or when the ear begins to bend gently, the grain may be cut. But-as the whole crop will not be equally ripe at the same time-if, on walking through the field and selecting the greenest heads, the kernels can be separated from the chaff when rubbed through the hands, it is a sure sign that the grain is then out of its milky state, and may be reaped with safety; for although the straw may be green to some distance downwards from the ear, yet if it be quite yellow from the bottom upwards, the grain then wants no further nourishment from the earth, and, if properly harvested, it will not shrink. These tokens will be found to sufficiently indicate the ripeness of wheat, barley, and oats; but that of rye arises from the straw losing some of its golden hue, and becoming paler.

'The usual practice in England is to cut down all grain before it is quite ripe, and to leave it in shocks, or, in the case of barley, on the ledge, until the grain is perfectly matured and hardened; and the same practice prevails in Scotland. Experience, however, has occasioned a remarkable distinction in the mode of harvesting barley in the two portions of Great Britain just mentioned. In England, barley is usually cut with the scythe, treated like hay in the saving, and put loose into the rick or mow. In Scotland, it is cut, as in Ireland, generally with the reaping-hook, and, when sufficiently dry, bound up and stacked. The cause of this different treatment is the difference of climate. See Barlex, Realing, WHEAT, \&c.

HARVEST-MOON. That lunation about harvest-time when the moon at full rises nearly at the same hour for several nights.

HASEL, HAZEI, or STOCK NUT (Corylus avellana). This small, bushy tree is common everywhere in our hedges and copses, and also grows wild in most parts of Europe. The leaves are two inches wide, doubly serrated, light green, downy, especially beneath. The catkins are barren, clustered, or panicled, grayish, long, and pendulous, opening in the early spring before the leaves appear, and, indeed, formed during the preceding autumn. The ovare scaly buds, containing the fertile fowers, become conspicuous at the same time by their tufts of crimson stigmas. The nuts, two or three from each bud, are sessile, roundish-ovate, half covered by the jagged unter calyx of their respective flowers, greatly en. larged, and permar.ent. 'The wood of the hazel. tree is used in England for making hoops for casks, hurdles, crates, springles to fasten down thatch, fishing-rods, \&c. It is alsn repurted to make excellent charcoal for drawing, of the preparation of which, and of the whole history of this plant, Dr. Hooker gives a full account, annexed to an admirable figure. It was formerly much used for making gunpowder. (Eng. Flor. vol. iv. p. 157.) See Fruв вт.

In the country where yeast is scarce, they twist the slender branches of hazel together, and steep them in ale yeast during its fermentation; they are then hung up to dry, and at the next brewing are put into the wort instead of yeast. The chips of this wood are used to fine wines. (Phillips's Fruits.)

HATCHING. See Incuratror.

HAULM. A name given to the stalks of beans and pease. When well harvested, these form a very hearty species of fodder. 'The stalk of the beans is indeed tough and some. what woody, and is therefore commonly thrown out as farm-yard litter; but the coving chaff is very good manger-meat; and even the stalk, if bruised and cut, and then steamed, would be found useful in a farm-stable.

Pea haulm is very generally given as rackmeat to cart-horses instead of hay, for which purpose it is well adapted, being succulent and nutritious, and nearly as much relished as hay; although it may not go quite so far, yet there is great saving in its use. But both these and all other kinds of straw haulm should be given as fresh as possible from the flail, for they grow brittle, and lose a portion of whatever sap they possess, by exposure to the air; if long kept they grow musty, and in that state neither are wholesome nor will be eaten by horses. Pea haulm should be given cautiously, as it is flatulent, and apt to occasion colic; it is also said to be productive of bots ; but that, if true, is not so peculiar a property as to prevent its use. Sheep are extremely fond of haulm; so much so, indeed, that it is by no means uncommon for farmers who keep large flocks to grow pease chiefly with a view to it as winter food in pinching seasons; the seed being in that case generally sown broad. cast, both to preserve the succulence of the haulm, and to save the trouble of the drill culture. (Brit. Husb. vol. i. p. 133; vol. ii. pp. 219, 463.) See Pease and Brass.

HAVER. A name given to oats (particularly to wild oats) in some parts of Britain; hence haver meal is meal made from oats by grinding and sifting through a proper sieve for the purpose. In sc me parts of Scotian 1 thick oat cake is used, and called a haver ral bannock.

HAW, BI,ACK; SLOE. Plum-leaved V. burnum. A shrub frequent in Pennsylvania along fence-rows and in thickets, flowering in May, ripening its sweetish and esculent fruit in October. See Hawтнок.

HAWKBIT (Apargia). A genus of herba 
seous plants of easy culture. The indigenous species found in Britain are four.

The autumnal hawkbit (A. autumnalis) is a very common and troublesome weed in all meadows and pastures. It varies very much in luxuriance, and is often found thriving in extremely poor land newly turned up. The root is abrupt, with very long, simple, lateral fibres. Leaves several, almost entirely radical, lanceolate, deeply and unequally toothed or pinnatifid. The stalks are several, ascending or spreading, branched, from 6 to 18 inches high. Each stalk is hollow internally, containing a lnose, white, cottony tuft. The flowers are bright yellow, not large, often reddish underneath. As these are all perennial weeds and encumber the ground, they should be rooted up in spring. (Eng. Flor. vol. iii. p. 350.)

HAWKWEED (Hieracium, from hierax, a hawk, being supposed to sharpen the sight of hirds of prey). A very numerous perennial genus, generally inhabiting mountainous or woody situations. They are, for the most part, pretty tlowering plants, with yellow blossoms, hut a great number are mere weeds. The herbage, in general, is milky, and more or less bitter; but these qualities are, in some instances, hardly perceptible. The dwarf herbaceous kinds are remarkably adapted for rock work, or the front of flower borders, the taller kinds at the back; they may be increased by seeds, or divisions. The annual species need only be sown in the open border.

Sir J. E. Smith describes no less than eightcen distinct indigenous species, which it would carry me too far into detail to particularize.

'ren or twelve species of hieracium have been found by botanists in the United States, and 14 in the British provinces. One called the veined hieracium, or hawkweed (H.venosum), is a frequent plant in clearings and woodlands in New Jersey, Pennsylvania, and other Middle States, where it flowers in May and June. It has a perennial root, and stem 1 to 2 feet high. A few years since, this plant was announced as a certain antidote against the poison of the rattlesnake. But its specific virtues neea to be further tested before they can be regarded as fully proven. A great many specifics and antidotes are vaunted by credulous, or designing persons, for the poison of reptiles as well as the bite of a mad dog, and persons who have taken them and escaped any serious mischief, have led others to believe in the virtues of the remedies when the patients would have recovered without. In this way the most inert and inefficient prescriptions often get the credit of what properly belongs to the agency of common homely appliances, or the wonderful restorative powers with which a kind Providence has endowed both man and beast.

HAWTHORN, WHITETHORN, Or MAY (Mespilus oxyacantha). A common small tree, or shrub, but beautiful in its appearance, and iragrant in odour. The hawthorn grows almost everywhere in thickets, copses, hedges, and hign open fields. The wood is very hard, with a smooth, blacinish bark, and, like the white'veam hawthorn ( $P_{y}$ sus aria), is converted in axle trees and handles of tools. The 606 have lateral, sharp, awl-shapei thorns. The leaves are alternate, deciduous, on longish, slender stalks; smooth, deep-green, veiny, an inch or two long, tapering at the base, or wedge-shaped, and more or less deeply three. lobed, with crescent-shaped stipules. The flowers are corymbose, terminal, white, occasionally pink or almost scarlet. 'The fruit (called haws) is mealy, insipid, dark red, occasionally yellow, furrowed externally, and very hard. Birds are fed with the fruit all the winter long; but the haws may be more usefully employed in fattening hogs. In Kamschatka they are eaten by the peasants, and fermented into wine. The common hawthorn blows in May, and can be propagated from seed, which must be kept in sand through the winter, and sown in spring. The young plants will be fit to place out in two years. There are several varieties of this species, among others the celebrated Glastonbury thorn, which blossoms sometimes as early as Christmas. The double blossomed hawthorn is one of the greatest ornaments of our pleasure-grounds, whether it be kept as a shrub, or trained as a tree.

The yellow-berried hawthorn, which was originally brought from Virginia, has a double recommendation to the shrubbery, for its buds are of a fine yellow in the spring, and its fruit, which is of the colour of pure gold, hang on the branches nearly the whole of the winter, giving great variety to the plantation. Evergreens should never be planted without a few of these shrubs being intermixed to enliven them in the winter months. The hawthorn is peculiarly adapted for small lawns or paddocks, where larger trees cannot be admitted. When standing singly, the hawthorn often reaches to the height of 25 or 30 feet, with a trunk from 4 to 8 feet in circumference.

In husbandry, these shrubs are called quicksets; and when kept well cut, they form hedges, scarcely less impregnable than those composed of holly. The clipping of hedges and trimming of trees is certainly advantageous to the farmer, although it adds nothing to the beauty of rural scenery. Hawthorn hedges appear to have come into use, in England, about the time of Charles II.; as Evelyn observes in his Sylva, "I have been told of a gentleman who has considerably improved his revenue, by sowing haws only and raising nurseries of quicksets, which he sells by the hundred, far and near. This is a commendable industry, and any neg. lected corner of ground will fit this plantation." See 'Tноге.

HAY (Germ. heu, Du. hovi). Any kind of grass cut and dried as fodder for cattle. Hay constitutes the chief dependence of the farmer and others as winter food for their horses and cattle. The sale of hay within the bills of mortality, and 30 miles round the cities of London and Westminster, is regulated by the act $36 \mathrm{Geo} .3, \mathrm{c} .88$. It enacts, that all hay shall be sold by the load of 36 trusses, each truss weighing $56 \mathrm{lbs}$., except new hay, which is to weigh $60 \mathrm{lbs}$. till the 4 th of September, and afterwards $56 \mathrm{lbs}$. only; so that till the 4 th of September, a load of hay weighs exactly a ton, but thereafter only $18 \mathrm{cwt}$. There are three public markets in the metropolis for the 
sa'e of hay and straw, Whitechapel, Smithfield. ead the Haymarket.

When horses are fed on hay, it is a matter of dispute whether the light and apparently acrid grass of uplands, or that of more fertile natural meadow ground, or the rich produce of the artificial grasses, is to be preferred. This must, however, depend on the quantity of corn with which they are supplied. When that is abundantly furnished, there can be no doubt that the former will be found better for their general health, and especially for their wind; but as farm-horses are usually limited in their consumption of grain, and the slowness of their movements renders the clearness of their wind a matter of comparatively little moment, the other kinds will be found the best adapted to support their strength. In gentlemen's stables no other than meadow hay is generally admitted; and it is in all respects the best. But farmers find more profitable uses for it in the feeding of fatting-stock and cows; and clover, either alone or with rye-grass, sainfoin, or tare hay, though coarser, answers every necessary purpose for farm-horses, more especially when cut into chaff, and used along with straw. Sainfoin is commonly esteemed the first, and clover the next, in quality; but tare hay, if well made, is very hearty food. Old hay, as having longer undergone that slow process of fermentation by which the sugar that it contains is developed, is far more nutritive and wholesome than new hay. Mow burnt hay is more injurious to horses than to any other of the domestic animals, and is a fruitful source of disease.

It is an excellent plan, especially when hay nas been exposed to continued wet weather, to add to it a portion of common salt. It not only induces live-stock to consume it with avidity, but it prevents mouldiness or mow burning; it is usual to put about half a bushel of salt to every load of hay: it may be spread by hand, or through a sieve. Mr. Woods, of Ingatestone, in Essex, has employed it for thirty years; his plain, unvarnished statement need not be supported by any other. He says, "I use about a quarter of a peck at each laying, thinly spread, which I find is about four bushels to a stack of twenty loads. I am fully satisfied that double the quantity would be much better. In a particularly wet season, a few years since, I used twelve bushels to a stack of forty loads, the whole of which was consumed by my own horses, and I never had them in better condition. I am so fully convinced of the benefit of salt to hay, that while it is allowed duty free, I shall use it in all seasons." (Johnson on Salt, p. 100.) The avidity with which animals consume salted hay is not so generally known as it ought to be; I will give, therefore, a fact related to me a short time since by Mr. Law, of Reading. Mr. Green, of Wargrave, in Berkshire, had, in the season of 1824 , a parcel of sour rushy hay from a meadow on the banks of the Thames, which both he and his men despaired of rendering of the least value; it was, therefore, stacked by itself, and well salted: the quantity supplied was large, but Mr. Jaw did not know the exact proportion. When the period arrived that his sheep wanted a supply of hay, Mr. Green directed his shwpherd te ase the salted inferior hay first; and, to his surprise, the sheep consumed it with the greatest avidity. The stack being finished, the shepherd was directed to supply them now with the best hay he could find of other stacks of fine meadow hay. He came, however, the next morning to his master, and made the following remark: "We, sir, must have made a great mistake, and forgotten which stack we salted, for our sheep will not eat the hay which we think the best."

As the hay grasses do not thrive in the Southern U. States, the principal supply of this provender is sent pressed in bales or packages from the Eastern, Middle, and Western States. In those states where hay constitutes a principal product of the farms, New York stands first and Pennsylvania second. In his observations, relative to the hay crop of $1842, \mathrm{Mr}$. Ellsworth observes, "Ohio, Indiana, Illinois, Michigan, and Missouri, though devoting comparatively little attention to its production, yet seem to be making some advance in the same; and accordingly there has been some increase the past year, though doubtless not a very material one. Some damage was experienced from the invasion of the army worm, but not enough to lessen the crop to any great amount. Though reliance is still placed on the prairie hay, yet there is a gradual improvement with respect to the introduction and cultivation of the tame grasses. The low price of grain in New Orleans will no doubt lessen the demand for pressed hay, which has heretofore been a considerable article of export from the states bordering on the Ohio river and its branches. The whole number of tons of hay raised in the United States in 1842, is estimated to have been $14,053,355$."

HAYMAKING. The operation of cutting down, drying, and preparing grasses and other forage plants for being stacked for winter use. The plants are mown down at the time when they are supposed to contain, diffused through. out the whole plant, a maximum of nutritious juices; viz., when they are in full flower. Too often this period is exceeded, and the nutritive property of the plant suffers; for it is a wellknown fact that the saccharine juices of a plant disappear in the progress of the ripening of the seed. Dry weather, and, if possible, that in which sunshine prevails, is chosen for this operation; and the mown material is spread out, and turned over two or three times in the course of the same day in which it is cut. In the evening it is put into small heaps. In the morning of the second day these heips are spread out, and turned over two or three times; and in the evening they are formed into heaps, somewhat larger than they were the day vefore. If the weather has been remarkably warm and dry, these heaps, in the course of the third day: are carted away and made into a stack; but if the weather has been indifferent, the process of opening out the heaps and exposing them to the sun is repeated on the third diay, and stack-making is not commenced till the fourth. The grand object in making hay is to preserve the colour and natural juices of the herbage. which is best done by continually turning is, 
so as never to expose the same surface for any length of time to the direct influence of the sun. In stacking hay, the object is to preserve the green colour, and at the same time induce a slight degree of fermentation, which has the effect of rendering the fibres of the plants, which compose the hay, more tender, and changing a part of the parenchymous matter into sugar, on the same principle as is effected by malting barley. This sweet taste renders the hay more pelatable to horses. The best general directions for haymaking will be found in the following extract from Middleton's Agricullural Survey of Middlesex, although the various kinds of hay, and different soils and situations with which the farmer is connected, are so very numerous, that such directions can, of necessity, have only a very general application.

Mr. Middleton observes, when speaking, be it remembered, of haymaking in Middlesex, "In order that the subject may be more clearly understond, I shall relate the particular operations of each day, during the whole process, from the moment in which the mower first applies his scythe, to that in which the hay is secured, either in the barn or in the stack.

"First Day.-All the grass mown before nine o'clock in the morning is tedded (or spread), and great care taken to shake and strew it evenly over all the ground. Soon afterwards it is turned, with the same degree of care and attention; and if, from the number of hands, they are able to turn the whole again, they do so, or at least as much of it as they can, till twelve or one o'clock, at which time they dine. The first thing to be done after dinner is, to rake it into what are called single windrows; that is, they all rake in such a manner, as that each person makes a row, which rows are three or four feet apart; and the last operation of this day is to put it into grass-cocks.

"Second Day.-The business of this day commences with tedding all the grass that was mown the first day after nine o'clock, and all that was mown this day before nine o'clock. Next, the grass-cocks are to be well shaken out into staddles (or separate plats) of five or six yards diameter. If the crop should be so thin and light as to leave the spaces between these staddles rather large, such spaces must be immediately raked clean, and the rakings mixed with the other hay, in order to its all drying of a uniform colour. The next business is to turn the staddles, and, after that, to turn the grass that was tedded in the first part of the morning, once or twice, in the manner described for the first day. This should all be done before twelve or one o'clock, so that the whole may sie to dry while the workpeople are at dinner. After dinner, the first thing to be done is, to rake the staddles into double windrows; in doing which, every two persons rake the, hay in opposite directions, or towards each other, and by that means form a row between them of double the size of a single windrow. Fach of these double windrows are about six or eight feet distant from each other. Next, to rake the grass into single windrows; then the touble windrows are put into bastard-cocks; arci. iastly, the single windrows are put into 608 grass-cocks.
second day.

"Third Day.-The grass mown and not spread on the second day, and also that mown in the early part of this day, is first to be tedded in the morning; and then the grass-cocks are to be spread into staddles, as before, and the bastard-cocks into staddles of less extent. These lesser staddles, though last spread, are first turned, then those which were in grass-cocks; and, next, the grass is turned nnce or twice before twelve or one o'clock, when the people go to dinner as usual. If the weather has proved sunny and fine, the hay which was last night in bastard-coclss will this afternoon be in proper state to be carried. It seldom happens, in dry weather, but that it may be carried on the third day. But if the weather should, on the contrary, have been cool and cloudy, no part of it, probably, will be fit to carry. In that case, the first thing set about after dinner is, to rake that which was in grass-cocks last night into double windrows; then the grass which was this morning spread from the swarths into single windrows. After this, the hay which was last night in bastard-cocks is made up into full-sized cocks, and care taken to rake the hay up clean, and also to put the rakings upon the top of each cock. Next, the double windrows are put into bastard-cocks, and the single windrows into grass-cocks, as on the preceding days.

"Fourth Day.-On this day the great cocks, just mentioned, are usually carried before dinner. The other operations of the day are such, and in the same order, as before described, and are continued daily until the hay-harvest is completed.

"In the course of hay-making, the grass should, as much as possible, be protected, both night and day, against rain and dew, by cocking. Care should also be taken to proportion the number of hay-makers to that of the mowers, so that there may not be more grass in hand, at one time, than can be managed according to the foregoing process. This proportion is about 20 hay-makers (of which number 12 may be women) to four mowers: the latter are sometimes taken half a day, to assist the former. But in hot, windy, or very dry weather, a greater proportion of hay-makers will be required than when the weather is cloudy and cool.

"It is particularly necessary to guard against spreading more hay than the number of hands can get into cock the same day, or before rain. In showery and uncertain weather, the grass may sometimes be suffered to lie three, four, or even five days in swath. "But, before it has lain long enough to become yellow (which, if suffered to lie long, would be the case), particular care should be taken to turn the swaths with the heads of the rakes. In this state it will cure so much in about two days, as only to require being tedded a few hours, when the weather is fine, previous to its being put together and carried. In this manner, hay may be made and stacked at a small expense, and of a goed colour; but the tops and bottoms of the grass are insufficiently separated by it."

HAY-RAKE, or HAY-SWEEP. An implement contrived for the purpose of collecting 
and conveying hay to the stack in an easy and expeditious manner after it has been put into rows. See Rak $\mathbf{k s}$.

HAY-KNIFE. A sharp instrument employed for culting hay out of the stack.

HAY.RICK. Mr. Chambers (Com. to Board of $A g r$ vol. vii. p. 374) describes an improved hay-rick which admils very freely the cool air to check the fermentation. A channel or gutter, a foot wide and deep, is cut through ground marked out for the rick, and two across, which is 13 yards by 9. Two chimneys are introduced, like the common hay funnels, only these go full home to the earth, which being drawn up as the rick is forming, and the channels previously covered with fagots, except where the chimneys are placed, leave them open at all points; and let the wind blow from what quarter it may, the current is uninter. rupted.

\section{HAZEL. See HASEL.}

HEAD-LAND. A term applied to the lands or ridges in fields, on which the plough turns in cultivating them. As much soil is continually accumulating on them, by means of the frequent ploughing of the field, it is a common plan to form them into composts with lime or other manures.

HEA'T. In horsemanship, a term used on the turf, to denote a certain distance which a horse runs on the course. A race may consist of one or more heats, and "the best of three heats" are common at most races; but there is never more than one heat for a race at Newmarket. See Trмpenatuñ.

HEATH. In a general sense the term heath is applied to waste land in which the prevailing plants consist of one or more of the common species of heath.

HEATH, HEATHER, or LING (Calluna and Erica). A very large and varied genus of plants, of which the following species are indigenous to Great Britain :-

1. Common heath (Calluna vulgaris, Sal. The Erica communis of Linnæus). This plant covers many hundreds of acres in the Highlands of Scotland, in Ireland, and in similar climates on the continent. It attains in many places the height of three or four feet; and is much used for thatching houses, making besoms, and for a variety of other purposes. The tender tops form a substitute for mattrasses in Highland cottages; and they are also eaten green and in a dried state by horses, cattle, and sheep, in countries where the grasses and clover do not begin to grow till late in the spring. The tender tops also furnish food for grouse.

2. Cross-leaved heath (Erica tetralix). In chis shrub the roots are creeping, stems erect, from four to six or eight inches high. Leaves crowded, spreading four in a whorl, revolute, downy, glaucous beneath. Flowers remarkable for their delicate wax-like hue of every shade of rose-colour, solnetimes snow-white, on hairy cuttony stalks collected into a dense, round, terminal cluster, all elegantly pendulous to one side. It is wonderful that this most elegant and not uncommon plant is scarcely delincated at all by the old authors, nor by any of them correctly.

3. Fine-leaved heath ( $E$. cinerea), found 77 plentifully on dry turfy heaths everywhere. It grows on a stem a foot high, or more, with $n u$. merous upright, round, hoary, flowery, and leafy branches. The flowers are crimsun, everlasting, with a tinge of blue or gray, ncca. sionally pure white.

4. Cornish heath (E.vagans), growing ahun. dantly in Cornwall: stem woody, two feet high, copiously and determinately branched, with a smooth, pale, deciduous bark; leaves ever. green, smooth.

Mr. J. Hall (Com. Bourd of Agr. vol. vi. p. 381) speaks favourably of the advantages to be derived from heath in the feeding of stoct, and also asserts that an infusion of the finer parts of heath, when cut young and in bloom, is preferable to tea.

HEATH GRASS (Triodia decumbens). The genus to which this species belongs consists of hard, rigid, perennial grasses, with leafy stems. Inflorescence variously panicled. The decumbent heath grass grows frequent in spongy bogs, and on barren, sandy, mountain. ous ground. The root is very slightly creeping, with strong fibres. The whole plant is harsh and rigid, lying close to the ground, except when in flower. The stem is from 4 to 12 inches long, jointed, bent, leafy, and very smooth. The leaves are linear, striated, rather glaucous, smooth, except towards the points, where the rib and edges are very rough. (Smith's Eng. Flor. vol. i. p. 131.)

HEATH, SEA (Frarkenia). Of this maritime decumbent genus of plants there are two species, natives of these islands.

1. The smooth sea-heath ( $F$.lavis) is a perennial, flowering in July, found common on muddy salt-marshes, chiefly on the eastern shores of England. It has a woody root; the stems are quite prostrate, forked, slightly downy, with leafy, partly ascending branches. The leaves are somewhat glaucous, about a quarter of an inch long, revolute, fringed at the base, convex, and smooth above. The flowers spring from the forks of the stem, partly ter. minal, sessile, solitary, and flesh-coloured.

2. Powdery sea-heath ( $F$.pulverulenta). This is a very rare species, much resembling the last, but annual, and flowering in July. The root and stems the same as the former: the leaves, which are smooth and green above, are hoary, as if powdery, beneath; opposite or four together, single ribbed, and revolute. The flowers are pale red. (Smith's Eng. Flor, vol. 1 . p. 186.)

HEATHY I.AND. Ground which is covered with heath. In many districts of the kingdom of Great Britain, there are immens. tracts of this kind of land, that, in their present state, are of little value, except for the support of a few sheep; but which, by proper cultiva. tion, might afford useful crops. They, how. ever, differ much in the nature of the soilo. The best mode of reclaiming these lands is by draining, deep trenching, or ploughing, anc spreading upon them any calcareous matter such as lime, chalk, or marl. And it is verv desirable, in many instances, to provide tnem shelter by plantations of timber trees. See

Plantations.

HEDGE. A living wall formed of woots 
plants, sown or planted in a line, and cut or clipped in such a manner as to form a compact mass of any degree of width or height that may be required, either for the purpose of shelter, separation, or defence. The fences most generally used in agriculture are made of the whitethorn, because it has spiny branches, and forms a strong defence against cattle. Fences for the purposes of shelter and separation are chiefly used in gardening, and for the most part are formed of evergreen shrubs, such as the holly, yew, box, \&c.; or sub-evergreens, such as the privet; of flowering shrubs, such as the Cydonia japonica; or of deciduous shrubs or trees, with persistent leaves, such as the hornbeam and beech.

In the management of hedges of every description, an important point is to keep them thick, and impervious to wind or animals, near the ground; for which purpose the section of the hedge requires to be made broader at the base than at the top, in order that the exterior leaves in every part of the hedge may enjoy in an equal degree the influence of light, air, and perpendicular rains. Mr. Stephens (Quart. Journ. of $A g r$. vol. i. p. 574) gives some very detailed instructions "On the Planting and Management of Thorn Hedges ;" but as these extend over upwards of 50 pages, we can only recommend the farmer, who needs information as to the formation of quickset hedges, to consult the above article; Mr. Blakie's little work On Hedges; and some essays on raising and managing hedges in the Trans. High. Soc, vol. iv. p. 353, to 378, by Messrs. Montgomery, Grigor, and Manson. In the same volume, p. 336 , there is an essay on the cultivation of the common elder (Sambucus nigra) for hedges. Sir John Sincair also recommends the tala plant as a substitute for thorn in hedges. (Quart. Journ. of $A g r$. vol. ii. p. 408.) It is a small prickly shrub, growing wild in various parts of South America, and which has been extensively used for fences by the Scotch farmers who have settled near Buenos Ayres. An "Old Hedger," in the Quart. Journ. of Agr. vol. v. p. 505, also gives the result of his experience and practice in hedge-making. The late Francis Blakie of Holkham saw the importance of the farmer paying more attention than is customary with him to the plantation of fences, and the management of hedgerow timber; and in his excellent little work on this subject, he told him (and his experience was of perhaps the most difficult of all soils upon which to rear good hedgerows), "There may be some difference in opinion as to the best method of planting and rearing quickset (whitethorn) hedges, but I think there can be none in respect to the propriety of thoroughly cleaning and preparing the ground in the first instance; and all experienced men will agree, that it is not advisable to plant a new hedge upon the same spot where an old one had been recently crubbed up, unless under unavoidable circumstances, such as boundary fences, \&c.; in that rase the ground should be well loosened, fallowed for a year or two, and have fresh earth sor compost added. The better the ground is mrepared, the sonner will the hedge arrive at maturity, and the longer will be its duration. 610
The practice in this country (Norfolk), even on our lightest soils, is to put the quicksets (here called layers) horizontally into the side of the bank, raised from a four or five feet wide ditch, of a proportionate depth; and I have never seen whitethorn hedges raised quicker or better than in this country, and all upon that prin. ciple. I must, however, acknowledge, that although the Norfolk farmers very generally excel in raising hedges, they but too frequently err in the future management of them; youth is succeeded by infirmities; there is no prime of life."

There is another error which frequently occars where quicksets are planted on the sides of banks; that is, in not varying the height of the line of quick in the bank according to the nature of the sides. On the management of hedgerow timber, the directions of Blakie are equally excellent. He says, "It is not necessary for me to particularize all the varieties of forest trees usually planted in hedgerows. It is sufficient, in exemplification, to say, beech, ash, and firs are not only ruinous to fences, but are also otherwise injurious to farmers; while oaks, narrow-leaved elm, and black Italian poplars do comparatively little injury; and as to the age of plants, it surely must be obvious that a thrifty transplanted nursery tree of three years' growth is more likely to suc. ceed, when properly planted in a hedgerow, than a puny yearling drawn out of a seed-bed, with its root like a piece of whipcord; or a tender sapling, of six or seven years' growth, drawn out of a thick wood, whence it had not been previously transplanted.

"In planting, the usual practice is to lay the roots of the forest-tree plants horizontally into the bank along with the whitethorns, and to cut their heads or tops off close to the ground, in the same manner as the thorns; a moment's reflection will show the absurdity of this practice. A surface-rooted plant, like the whitethorn, will thrive if laid into the bank horizontally, or nearly so; but a deep-rooted plant, such as the oak, is not likely to thrive if treated in that manner. The roots of oaks strike deep into the ground; consequently, the plants should be set perpendicularly, and their heads or tops should on no account be cut off at the time of planting. But suppose that an oak plant, when laid into the bank horizontally along with the quicksets, does grow, and even prospers for a time, which it may do when the extremities of the roots are bent downwards by the pressure of the earth in the bank above, and the plant in consequence finds nourishment and support from the earth below; the top of the plant will then grow up among the row of thorns, and be protected by them until the hedge is cut (which, in process of time, it must be): the oak plant will then be left ex posed, and as the stem will have bent upwards. at a sharp angle from the face of the bank, the top of the tree (when agitated by the wind) will act as a powerful leverage, and have tbe effect of twisting and breaking the crooked roots of the plant in the bank.

"These remarks are, in some degree applicable to all forest trees planted in hedgrrows, but more particularly to deep-rooted nnes. 
The method which I recommend for planting forest trees generally in hedgerows, but more particularly oaks, is as follows: Let the quicksets be laid in, and the bank finished in the usual way; then select good transplanted trees of 2 or 3 years' growth, fresh drawn from the nursery. The broken roots and tips of the long fibres may be cut off; then push the spade down perpendicularly into the bank between the roots of the quicksets; press the spade from side to side, so as to make a cleft opening, into which put the root of the plant as deep as it had before stood in the nursery; tread the earth firm to the root, and face the bank up, as before: leave the tops of foresttree plants uncut at the time of planting, unless when they are bushy-headed, and without leaders or top-shoots; in that case a few of the larger side shoots may be cut in, that is, the extremities of the branches shortened. It is a most pernicious practice to cut the tops of young forest trees at the time of planting, and should only be adopted in particular cases. "The time most proper for planting hedgerow trees and quicksets is autumn, or early in spring; and the work should never be delayed till late in spring, if it can be avoided. But when (from necessity) trees are planted late in spring, and the ground dry at the time, the roots of the plants should not only be kept moist before planting, but they should also be dipped into some earthy sludge at the time they are planted.

"Training of hedgerow trees is seldom or never thought of; and I will now add, when pruning is practised, it is generally performed in a very injudicious manner. Young hedgerow trees seldom require much attention in training until the hedge is cut the first time; the trees should then be examined; if they appear crnoked, stunted, and unthrifty, they should be cut off close to the face of the bank in the same manner as the thorn plants are. The oak stubs may be expected to throw up several strong shoots from each plant in the following season; and in a year or two afterwards, the best young shoot on such stub should be selected to remain, and all the others be slipped, or cut off close to the stub; the reserved shoot, or (as they may be called) regenerated plants, may then be expected to become timber trees.

"When an unthrifty young tree is to be cut off, as here recommended, particular attention should be paid to the method of cutting. The stroke from the workman's bill-hook or hatchet should always be upwards, or from the stub, and never downwards, or to the stub; whenever the latter practice is followed, the stub is left shattered, the wet penetrates through the clefts into the stool, or crown of the roots, canker is produced, and the tree rots. No good timber can be expected to grow from diseased roots.

"There may be said to be four different sorts or methods of pruning now in practice; these I designate under the styles or titles of-first, natural pruning; second, close pruning; third, snag pruning; and fourth, cutting in, or foreshortening. The three latter more immediately apply to hedgerow trees; but I will review the four, and in this review I wish fir trees to be understood as excepted.
"The best of all pruning is what I call nutural. This is effected in woods and plantings where trees stand thick: there the topy of the trees unite; they draw one another up; light and air is excluded from the lower branches, and those, consequently, dwindle away; the stems of the trees grow up straight and tall; and they gather proportionate strength, from the top branches extending, when the planting is thinned out gradually (as all plantations of trees ought to be). This remark is also applicable to hedgerow trees, in their infant state, when they are drawn up and nourished by the thorn bushes. But when trees stand singly, they throw out strong side branches, and their boles or stems seldom rise to much height, or attain to much cubic measure, unless the side branches are either cropped by cattle (which is a species of pruning), or are cut off by the hand of man. Hence arises the diversity of opinion with respect to the most proper method of obtaining the desired object, by the assistance of art, when nature ceases to operate in the matter wished for. "Close pruning answers to a certain extent. The operation is performed by cutting the side branches off close to the bole of the tree, when it is expected that the bark and the timber will heal over the wound and become united. If this operation is completed when the branches are young, or mere saplings, the tree in a vigorous growing state, and a few only of the branches cut off in one season, the object will be obtained, without injuring the growth of the tree. But the system, from having been misunderstood, has been misapplied, and carried to an alarming extent, doing incalculable injury, not only to individuals, but to the country at large. Immense numbers of large boughs have been amputated from the truriks of trees, in the vain hope of the timber growing over the wounds, and uniting with the stumps of the boughs left in the body of the tree; the bark and sap-wood does indeed sometimes grow over such wounds, but the stumps of the branches enclosed go to decay, become a canker in the bole of the tree, and the result is calamitous. It is the ready extension of the bark over the wounds in trees which has been the means of misleading so many people; because, as they see that the bark unites, they take it for granted that the woody fibres does so also; and so, in fact, the growing part of the tree will do, but the stump of the amputated arm becomes a dead substance, and cannot unite with a living one. On the whole, it is a dangerous practice to cut large boughs close to the stems of trees, particularly old and unthrifty trees. Young thriving trees will succeed, if close pruned, to a certain extent; but old, stunted, or full-grown trees, never.

"Snag pruning is a very pernicious practice, it is performed by cutting the boughs off several inches from the bole or stem of the tree. In old trees, those stumps act as conductors for wet into the body of the tree; in young trees the bark of the stubs throw out young shoots, which flourish for a time, but the heart-wood of those stumps decays, and has a similar effer. to the stumps of boughs in old trees, wh ch an not throw out young shoots. 
Freshortening, or cutling in, is an approved method of pruning, and is admirably adapted to training hedgerow trees, to benefit the landlord without doing much injury to the tenant. This operation is performed by shortening the over-luxuriant side branches, but not to cut them to a stump, as in snag pruning; on the contrary, the top only of the branch should be cut off, and the amputation effected immediately above where an axillary (side shoot) springs from the branch on which the operation is to be performed: this may be at the distance of two, four, or any other number of feet from the stem of the tree; and suppose the axillary branch which is left (when the top of the branch is cut off) is also over-luxuriant, or looks unsightly, it should also be shortened at its sub-axillary branch, in the same manner as before described.

"The branches of trees pruned in this manner are always kept within due bounds; they do not extend over the adjoining land to the injury of the occupier, at least not until the stem of the tree rises to a height (out of the reach of pruning) when the top branches can do comparatively little injury to the land. By adopting this system of pruning, the bad effects of close and snag pruning will be avoided, the country will be ornamented, and the community at large, as well as individuals, benefited." (Blakie, On Hedges and Hedgerow Timber.) See Frnces and Hawthor.

A great deal of valuable information upon the subject of hedges in the United States will be found in almost every agricultural periodical, in many of which the merits of the Virginia thorn, Newcastle cock-spur, English blackthorn, Buck-thorn, Osage orange, \&c. \&c., and their adaptations to particular parts of the country, are discussed. It has been objected against hedges, that they are not only very expensive to raise and keep in good order, but by shading and exhausting the ground, destroy on each side the product of a land or ridge. To other objections must be added the difficulty of getting horses near them, and the consequent retarding of the plough and has row, with not unfrequent accidents from dangerous wounds inflicted by the thorns. The loss of ground from hedge-rows is most sensibly felt, where the enclosures are small, averaging about 12 per cent., when the lots are between 2 and 3 acres, and in fields of 10 acres amounting to 4 per cent. Hedges undoubtedly add great beauty to country scenery, but, according to many utilitarians, are more sightly and poetical than profitable to the farmer.

HEDGE MUSTARD (Sisymbrium.) A genus composed for the most part of worthless annual and biennial plants, flourishing in the open ground in any soil. 'The indigenous species are three, all annuals.

1. The common hedge mustard (S. offirinale), growing in waste ground, by road-sides, and on banks; very common in England; flowering in June and July. According to Haller, hedge muslard springs up wherever houses have been ournt. The herb is of a dull green, minutely aairy or downy; the stem solitary, two feet high, erect, with numerous horizontal branches, leafv, round, clothed with fine deflexed bristles. Treaves hyrate, their lobes runcinate, unequally ii) 2 tonthed; the upper ones narrowest. The flowers are pale yellow, small, in little corym. bose heads, soon becoming very long, straight, close clusters of erect, tapering pods, finely downy, rather more than half an inch long, on very short stalks. Seeds not numerous, about six in each cell. This species was once used as a stimulating expectorant, but it is now de. servedly out of favour.

2. The broad hedge mustard, or Londnn rocket (S. irio), grows chiefly about Lond. I, and in habit is somewhat like the precedil, species; bat the herbage is of a lighter grees: and entirely smooth. The leaves are pinnatifid, runcinate, acute, the upper lanceolate, with hastate base; the seed-pod is two inches long, rugged when ripe; the seeds are very abundant. It is sometimes used as a heating potherb.

3. Fine-leaved hedge mustard or flixweed (S. sophia). In this species the root is small and tapering, and the whole plant of a slender, delicate structure; stem branched, bushy, erect; flowers small, greenish-yellow. Pods an inch long, numerous, erect, bearded. (Smith's Eng. Flor. vol. iii. p. 196.)

This is one of the plants which defeats the opinion that popular names are never imposed without good reason. The plant was formerly supposed to be a cure for fractured limbs, hence its name, Sophia chirurgorum; an opinion only demonstrative of the contemptible state of surgery at the period when the name originated. Its medicinal powers as an antidysenteric rest on equally mistaken observations.

The S. officinalis is a naturalized foreigner in the United States. The indigenous species of this weed found in the States are, 1. The $\$$ Canadensis, or Hoary sisymbrium. 2. Arubis-like sisymbrium. 3. Thalian sisymbrium, commonly called Wall cress, Mouse-ear cress, extensively naturalized in the United States, in which 3 or 4 additional species of the plant are erramerated. (See Flor. Cestric.)

HEDGE-KNIFE. Of this implement, for trimming hedges, there are two sizes, to be used either with one or both hands. The smaller one is a common and well-known implement. The larger-sized knife should have the blade 20 inches long by $2 \frac{1}{2}$ broad, and the handle 3 feet. It is slightly curved at the point. HEDGE PARSLEY (Torilis). Of this useless weed there are in England three common species: the upright hedge parsley ( $T$, anthriscus), the spreading hedge parsley ( $T$. infesta), and the knotted hedge parsley ( $T$. nodosa). They are annual plants, growing by waysides and the borders of fields; varying in height from 6 inches to 3 feet. The flowers are small, white or flesh-coloured, blowing in June; the umbels lateral and terminal; the rays from 7 to 10 , rough, little spreading. Fruit small, purplish at the summit, furnished with incurved bristles. (Smith's Eng. Flor. vol. ii. p. 42.)

HELIOTROPE (Heliotropum; from helios, the sun, and trope, twining. The flowers are said to turn towards the sun). Some of the plants of this genus are highly valued for the fragrant perfume of their flowers, and are therefore to be met with in most gardens. They succeed freely in any rich, light soil; and cuttings of 
the shrubby kinds, tatien off when joung, readily strike in the same kind of soil. (Puxton's Bot. Dict.)

HEMLOCK (Conium maculatum). A herbaceous biennial plant distinguished for its poisonous qualities, very common in hedges, orchards, and waste ground, especially near towns and villages. The root is tape-shaped, whitish, and fleshy; from 6 to 12 inches long, not unlike a young parsnip.

HEMLOCK, THE WATER. See Cow-
GANE.
BANE.

HEMLOCK, SPRUCE (Abies Canadensis).
Dee Fins.

HEMP (Dan. hamp. Cannabis sativa). A very valuable plant of the nettle tribe, Urticarca, which came, it is believed, originally from India, but has long since been naturalized in various parts of Europe. The cl.ief cultivation is now, for the most part, confined to the Russian empire, where it is grown by the peasants in small plots. It there forms an article of export of very considerable commercial importance. Of $530,820 \mathrm{cwts}$. of undressed hemp, imported into England in 1831, 506,803 came from Russia, 9472 from the East Indies, 7405 from Italy, 2262 from the Philippine islands, 2248 from the United States. (M'Culloch.) As Great Britain is principally dependent on other countries for a supply of hemp, it follows as a natural consequence, that, in periods of war, its price is very considerably increased. The hemp plant is grown in some parts of Lincolnshire, Suffolk, and Norfolk, and in Ireland (where it reaches a height of 6 or 7 feet); but it is not nearly so much cultivated in the British islands as formerly, and it is believed by some of the best of the English farmers to be a crop that cannot be profitably grown in England, although the quality of the best British hemp is much superior to that of Russia. In Oriental countries it sometims attains a height of 16 to 18 feet. The hemp plant requires for its growth a fair, highly manured soil, but it is not particular as to the quality. Old deep meadow lands, all rich alluvial, and even peaty soils, are adapted to its growth. Its leaves are strongly narcotic, and in the eastern climates are used like opium, and smoked like tobacco. From its seeds (which are greedily devoured by birds) is extracted an oil, generally employed by painters. The Russians and Poles, even of the higher classes, bruise or roast the seeds, mix them with salt, and eat them on bread. The hemp plant is fine and graceful; its tough and elastic fibres are adapted, above those of every other plant, for the making of cordage, canvass, netting, and various eloths, used in domestic economy, such as towels, and coarse table-cloths. Besides the strong cloth and other articles made from it, hemp is of considerable utility for other purposes. The refuse, called " hemp sheaves," affords an excellent fuel; and the fine oil, obtained from the seed, is peculiarly adapted for burning in chambers, as it is perfectly limpid, and possesses no smell. Another valuable property of hemp is, that it effectually expels vermin from plantations of cabbages; if it be si'wn on the borders of fields, \&c., planted with that vegetatsle, no caterpillar will infest it. (Willich's Dom. Ency.) It possesses th: anomalous property of growing, without degenerating, for a series of years, on the sarne ground, provided the land is well manured. It is what is called a smothering-crop, for $1 t s$ copious foliage kills every thing that is attempted to be sown with it. It may be grown in the following rotation, as suggested by Professor Low :-1. Fallow ; 2. Wheat ; 3. Grasses ; 4. Hemp; 5. Oats. The land intended for hemp should be brought, by repeated ploughings, into a fine tilth. The seed may be sown in April and May, irom two to three bushels per acre, either broadcast, and hoeing out the plants to a distance of 16 or 17 inches, or by the drill, at a distance of 30 inches. In the autumn, the plants are pulled, the male plants first, and the female plants six or seven weeks afterwards, when they have ripened their seed. Thus there are two harvests of the hemp crop. The male plants are readily known by their faded flowers, and yellowish colour. They are then tied in small bundles and carried to the pool, where they are to be steeped. Hemp, like flax, poisons the water in which it is steeped. The same process is followed when the female plants are pulled; only these, before they are steeped, have their seeds beaten out.

The process of steeping commonly lasts four or five days, and is continued until the outside coat of the hemp readily separates. It is then carefully and evenly spread on some grass turf, where it remains for three or four weeks, being turned over about twice every week, by which the decomposition of the woody part of the stem is materially accelerated. It is next carried to the barn, where it is bruised by the break, a machine constructed for the purpose; it is then bound up into bundles, and carried to market. (Low's Prac. Agr.p. 348.) There is a paper on a species of African hemp by Mr. A. Hunter (Trans. High. Soc. vol. iii. p. 87); others on the cultivation of hemp in America, by Mr. W. Tonge (Ann. of $A g r$ vol. xxiii. p. 1 ) ; in Italy (ibid.vol. xvi. p. 439, and vol. ii. p. 216), and in Catalonia. (Ibid. vol. viii. p. 243.) It seems that 100 parts of Indian hempseed yield 20 to 25 per cent. of oil. (Com. Agr. Asiat. Soc. 1838, p.69.) See Flax.

Hemp being an article of extensive utility, various plants have been tried as substitutes; among which are the Canada golden-rod (Solidago Canadensis), a perennial plant that might easily be cultivated in Britain; its stalks are numerous, straight, and grow above five feet in height; they afford very strong fibres, if treated in the same manner as hemp. The sun-flower (Helianthus) also affords single filaments or fibres, which are said to be as thick, and in all respects as strong, as small pack-thread. "The fibrous stalk of the common nettle (Lrtice dioica) has been advantageously manufactured into eloth. Others of the nettle tribe, such as the Chinese, or white-leaved nettle (U. nivea). and the Siberian, or hemp-leaved nettle ( $U$. cannabina), yield tough and durable fibres; ani the Syrian swallow-wort (Asclepicts Syriaca) ds 
aut ther of the textile plants; but no conclusively satisfactory experiments of their culture appear to have been made.

"Various common plants," says Professor Tow (El. of Prac. Agr. p. 351), "yield fibres of sufficient toughness to be made into thread; as the Esparto-rush (Stipa tenacissima), which is used in Spain for obtaining coarse thread; the common broom (Cytisus scoparia); the Spanish broom (Spartium junceum); different species of aloe, and several plants of the lily tribe. The warmer regions of the world abound in plants possessing a fibrous structure of the bark, which renders them capable of being employed in making ropes, thread, and cloth."

In Mexico and South America, the famous centennial American aloe (Agave Americana), which there grows spontaneously, is extensively used in the manufacture of cordage of various kinds. There is no doubt that this plant would do well if introduced into the Florida Peninsula, as it even bears the winters at Charleston, South Carolina, and Augusta, Georgia. "If," says a correspondent of the Farmers Register, (vol. ii.p.6, "any additional material for cordage is requisite or desirable in this country, we have one in a native plant, probably not inferior, for that purpose, to the Agave Americana. I allude to the $Y$ ucca filamentosa, which grows spontaneously in light sandy soils, (and often on the very poorest) from Virginia to Florida, and is commonly known under the name of bear grass, and sometimes under that of silk grass. 'The fibres of this plant are remarkable for their strength, and I have seen ropes made of it equal in strength and appearance to any other. To obtain the fibres, the leaves are ' rotted' in water, or by burying them in the earth. Mr. Elliot, in his Sketch of the Botany of South Carolina and Georgia, says of this plant, that it appears to possess the strongest fibres of any vegetable whatever; and, if it can be raised with facility, may form a valuable article in domestic economy. The root is also a substitute for soap in washing woollens.

" Of the facility of its production, I entertain no doubt. No plant is more hardy, or bears transplanting better. Its roots are extensive, having numerous eyes, or buds, and each one of these will produce a plant. There are millicns of acres in the Southern States unfit for the ordinary purposes of agriculture, which would produce this plant very well."

In the Western United States, and especially in the upper part of Kentucky, hemp is extensively cultivated, and constitutes a staple crop. A very interesting communication was made a few years since to the "Western $\Lambda$ griculturist," upon the mode of conducting the various processes connected with the hemp culture in Kentucky, by the distinguished statesman and agriculturist, Mr. Clay. The correctness of his views and recommendations are fully confirmed by those who have put them to the test of experience; and as the subject is one of great agricultural importance, we shall extract nearly the whole of Mr. Clay's essay.

Though raised in other parts of the state of Kentucky, hemp is most extensively cultivated in the Elhhorn region around and near Lex. ington.
The soil of that region, says Mr. Clay, is a rich, deep, vegetable loam, free from sand and with but little grit. It lies on a bed of clay, interspersed with small fragments of iron ore, and this clay in its turn reposes on a mass of limestone lying many feet in depth in horizontal strata. The surface of the country is generally undulating. The rich land (and there is but little that is not rich), in this whole region, is well adapted to the growth of hemp, where it has not been too much exhausted by injudicious tillage. The lands which produce it best, are those which are fresh, or which have lain some time in grass or clover. Manuring is not yet much practised. Clover is used in lieu of it. Lands which remain in clover four or five years without being too constantly and closely grazed, recover their virgin ferti ity. The character of the soil in the other parts does not vary materially from that in the Elkhorn district.

The preparation of the ground, for sowing the seed, is by the plough and horses, until the clods are sufficiently pulverized or dissolved, and the surface of the field is rendered even and smooth. It should be as carefully prepared as if it were for flax. 'This most important point, too often neglected, cannot be attended to too much. Scarcely any other crop better rewards diligence and careful husbandry. Fall or winter ploughing is practised with advantage-il is indispensable in old meadows, or old pasture-grounds intended for producing hemp.

Plants for seed are ordinarily reared, in a place distinct from that in which they are cultivated for the lint. In this respect, the usage is different from that which is understood to prevail in Europe. The seeds which are intended to reproduce seeds for the crop of the next year, are sowed in drills about four feet apart. When they are grown sufficiently to distinguish between the male and female stalks, the former are pulled and thrown away, and the latter are thinned, leaving the stalks separated seven or eight inches from each other. This operation is usually performed in the blooming season, when the sexual character of the plants is easily discernible; the male alone blossoming, and, when agitated, throwing off farina, a yellow dust or flour which falls and colours the ground, or any object that comes in contact with it. A few of the male plants had better be left, scattered through the drill, until the farina is completely discharged. for an obvious reason. Between the drills a plough is run sufficiently often to keep the ground free from weeds and grass; and between the stalks in each drill the hoe is employed for the same object. The seed plants are generally cut after the first smart frost, between the 25th September and the middle of October, and carried to a barn or stackyard, where the seeds are easily detached by the common thrail. They should be gathered after a slight, but before a severe frost; and, as they fall out very easily, it is advisable to haul the plants on a sled, and, if convenient, when they are wet. If transported on a cart or wagon, a sheet should be spread to catch the seed as they shatter out. After the seeds are separated, the stalks which bore them being too large, coarse, and harsh, 
to produce lint, are usually thrown away; they may be profitably employed in making charcoal for the use of powder-mills. In Europe, where the male and female plants are promiscuonsly grown together in the same field, both for seeds and for lint, the male stalks are first gathered, and the female suffered to remain growing until the seeds are ripe, when they are also gathered, the seeds secured and lint obtained, after the rotting, from both descriptions.

After the seeds are thrashed out, it is advisable to spread them on a floor to cure properly and prevent their rotting, before they are finally put away for use the next spring. Seeds are not generally used, unless they were secured the fall previous to their being sown, as it is believed they will not vegetate, if older; but it has been ascertained that, when they are properly cured and kept dry, they will come up after the first year. It is important to prevent them from heating, which destroys the vegetating property, and for that purpose they should be thinly spread on a sheltered floor.

The seeds-whether to reproduce seeds only, or the lint-are sowed about the same time. Opinions vary as to the best period. It depends a good deal upon the season. The plant is very tender when it first shoots up, and is affected by frost. Some have sowed as early as the 1st of April; but it is generally agreed, that all the month of May, and about the 10th of it especially, is the most favourable time. An experienced and successful hemp-grower, in the neighbourhood of Lexington, being asked the best time to sow hemp, answered immediately before a rain.-And undoubtedly it is very fortunate to have a moderate rain directly after sowing.

["Would it not be well to soak the seed in water a few hours previous to sowing? We have found this to answer nearly as good a purpose as rain after sowing, with all seeds with which we have tried it. The vegetation of mangle-wurzel is wonderfully accelerated by it."-Ed. Am. Farmer.]

When the object is to make a crop of hemp, the seeds are sown broadcast. The usual quantity is a bushel and a half to the acre; but here again the farmers differ, some using two bushels or even two and a half. Much depends on the strength and fertility of the soil, and the care with which it has been prepared, as well as the season. To these causes may be ascribed the diversity of opinion and practice. The ground can only sustain and nourish a certain quantity of plants; and if that limit be passed, the surplus will be smothered in the growth. When the seeds are sown, they are ploughed or harrowed in ; ploughing is best in old ground, as it avoids the injurious effect of a beating rain, and the consequent baking of the earth. It would be also beneficial, subsequently to roll the ground with a heavy roller.

After the seeds are sown, the labours of the cultivator are suspended, until the plants are ripe, and in a state to be gathered-every thing in the intermediate time being left to the operations of nature. If the season be favourable until the plants are sufficiently high to shade the ground (which they will do in a few weeks, at six or eight inches height,) there is a strong probability of a good crop. When they attain that height, but few articles sustain the effrct of bad seasons better than hemp.

It is generally ripe and ready to be gathered about the middle of August, varying according to the time of sowing. Some sow at different periods, in order that the crop may not all ripen at the same time, and that a press of labour, in rearing it, may be thus avoided. 'The maturity of the plant is determined, by the evaporation of the farina, already noticed, and the leaves of the plant exhibiting a yellowish hue: it is then generally supposed to be ripe, but it is safest to wait a few days longer. Very little attentive observation will enable any one to judge when it is fully ripe. In that respect it is a very accommodating crop: for if gathered a little too soon, the lint is not materially injured, and it will wait the leisure of the farmer some 10 days or a fortnight after it is entirely ripe.

Two modes of gathering the plants are practised; one by pulling them up by the roots, an easy operation with an able-bodied man, and the other by cutting them about two inches (the nearer the better) above the surface of the ground. Each mode has its partisans, and I have pursued both. From a quarter to a third of an acre, is the common task of an average labourer, whether the one or the other mode is practised. The objections to pulling are, that the plants with their roots remaining connected with them, are not afterwards so easily handled in the several operations which they must undergo; that all parts of the plant do not rot equally and alike, when exposed to the dew and rain; and, finally, that before you put them to the brake, when the root should be separated from the stalk, the root drags off with it some of the lint The objection to cutting is, that you lose two or three inches of the best part of the plant nearest the root. Pulling, being the most an. cient method, is most generally practised. I prefer upon the whole, cutting-and I believe the number who prefer it is yearly increasing. When pulled, it is done with the hand, which is better for the protection of an old leather glove. The labourer catches 20 or 30 plants together, with both hands, and, by a sudden jerk, draws them without much difficulty. The operation of cutting is performed with a knife, often made out of an old scythe, resemliling a sickle, though not so long, but broader. This knife is applied much in the same way as the sickle, except that the labourer stoops more.

Whether pulled or cut, the plants are carefully laid on the ground, the evener the better, to cure-which they do in two or three days, in dry weather. A light rain falling on them whilst lying down is thought by some to be beneficial, inasmuch as the leaves, of which they should be deprived, may be then easier shaken off or detached. When cured, the plants are set up in the field in which thev were produced, in shocks of convenient size, the roots or butt-ends resting on the ground, and the tops united above by a band made of the plants themselves. Previous to putting them up in shocks, most cultivators tie the 
plants in small hand-bundles of such a size as that each can be conveniently held in one nand. Before the shocks are formed, the Jeaves of the plants should be rapidly knocked off with a rough paddle or hooked stick. Some suffer the plants to remain in these shocks until the plants are spread down to be rotted. Others, again, collect the shocks together as soon as they can command leisure (and it is clearly best), and form them into stacks. A few farmers permit these stacks to remain over a whole year, before the plants are exposed to be rotted. I have frequently done it with advantage, and have at this time two crops in stalks. By remaining that period in stalks, the plants go through a sweat, or some other process that improves very much the appearance, and, I believe, the quality of the lint, and this improvement fully compensates the loss of time in bringing it to market. The lint has a soft texture and a lively hue, resembling water-rotted hemp; and I once sold a box of it in the Baltimore market at the price of Russia hemp. In every other respect, the plants are treated as if they were not kept over a year.

The method of dew-rotting is that which is generally practised in Kentucky. The lint so spread is not so good for many purposes, and especially for rigging and ships, as when the plants have been rotted by immersion in water, or, as it is generally termed, water-rotted. The greater value, and consequently higher price, of the article, prepared in the latter way, has induced more and more of our farmers every year to adopt it; and, if that prejudice were subdued, which every American production unfortunately encounters, when it is first introduced and comes in competition with a rival European commodity, I think it probable that, in a few years, we should be able to dispense altogether with foreign hemp. The obstacles, which prevent the general practice of water-rotting, are, the want of water at the best season for the operation, which is the month of September; a repugnance to the change of an old habit; and a persuasion which has some foundation, that handling the plants, after their submersion in water during that month is injurious to health. The first and last of these obstacles would be removed by water-rotting early in the winter, or in the spring. The only difference in the operation, performed at those seasons and in the month of September, would be, that the plants would have to remain longer in soak before they were sufficiently rotted.

The plants are usually spread down to be dew-rotted, from the middle of October to the middle of December. A farmer who has a large crop on hand, puts them down at different times for his convenience in handling and dressing them. Autumnal rotting is more apt to give the lint a dark and unsightly colour than winter-rotting. The best ground to expose the plarits upon is meadow or grass-land, but ther are not unfrequently spread over the same field $\mathrm{cn}$ which they grew. The length of time they ought to remain exposed, depends mon the degree of moisture and the tempera"ure of the weather that prevail. In a very wet and warm spell five or six weeks mav be long enough. Whether they have been suffciently rotted or not is determined by experiment. A handful is taken and broken by the hand or applied to the brake, when it can be easily ascertained, by the facility with which the lint san be detached from the stalk, if it be properly rotted. If the plants remain on the ground too long, the fibres lose some of their strength, though a few days longer than necessary, in cold weather, will not do any injury. If they are taken up too soon, that is before the lint can be easily separated from the woody part of the stalk, it is harsh, and the process of breaking is difficult and troublesome. Snowrotting, that is when the plants, being spread out, remain long enough to rot (which how. ever requires a greater length of time), bleaches the lint, improves the quality, and makes it nearly as valuable as if it had been waterrotted.

After the operation of rotting is performed, the plants are again collected together, put in shocks or stacks, or which is still better, put under a shed or some covering. When it is designed to break and dress them immediately, they are frequently set up against some neighbouring fence. The best period for breaking and dressing is in the month of February and March, and the best sort of weather, frosty nights and clear thawing days. The brake cannot be used advantageously in wet or moist weather. It is almost invariably used in this state out of doors and without any cover, and to assist its operation, the labourer often makes a large fire near it, which serves the donble parpose of drying the plants and warming himself. It could not be used in damp weather in a house without a kiln or some other means of drying the stalks.

The brake in general ase is the same handbrake which was originally introduced, and has been always employed here, resembling, though longer than the common flax-brake. It is so well known as to render a particular description of it, perhaps, unnecessary. It is a rough contrivance, set upon four legs, about two and a half feet high. The brake consists of two jaws with slits in each, the lower jaw fixed and immovable, and the upper one movable, so that it may be lifted up by means of a handle inserted into a head or block at the front end of it. The lower jaw has three slats or teeth made of tough white oak, and the upper two, arranged approaching to about two inches in front, and in such manner that the slats of the upper jaw play between those of the lower. These slats are about six or seven feet in length, six inches in depth, and about two inches in thickness in their lower edges: they are placed edgeways, rounded a little on their upper edges, which are sharper than those below. The labourer takes his stand by the side of the brake, and grasping in his left hand as many of the stalks as he can conveniently hold, wirh his right hand he seizes the handle in the head of the upper jaw, which he lifts, and throwing the handful of stalks be. tween the jaws, repeatedly strikes them by lifting and throwing down the upper jaw. These successive strolies break the woo if 



\section{Plateg.}
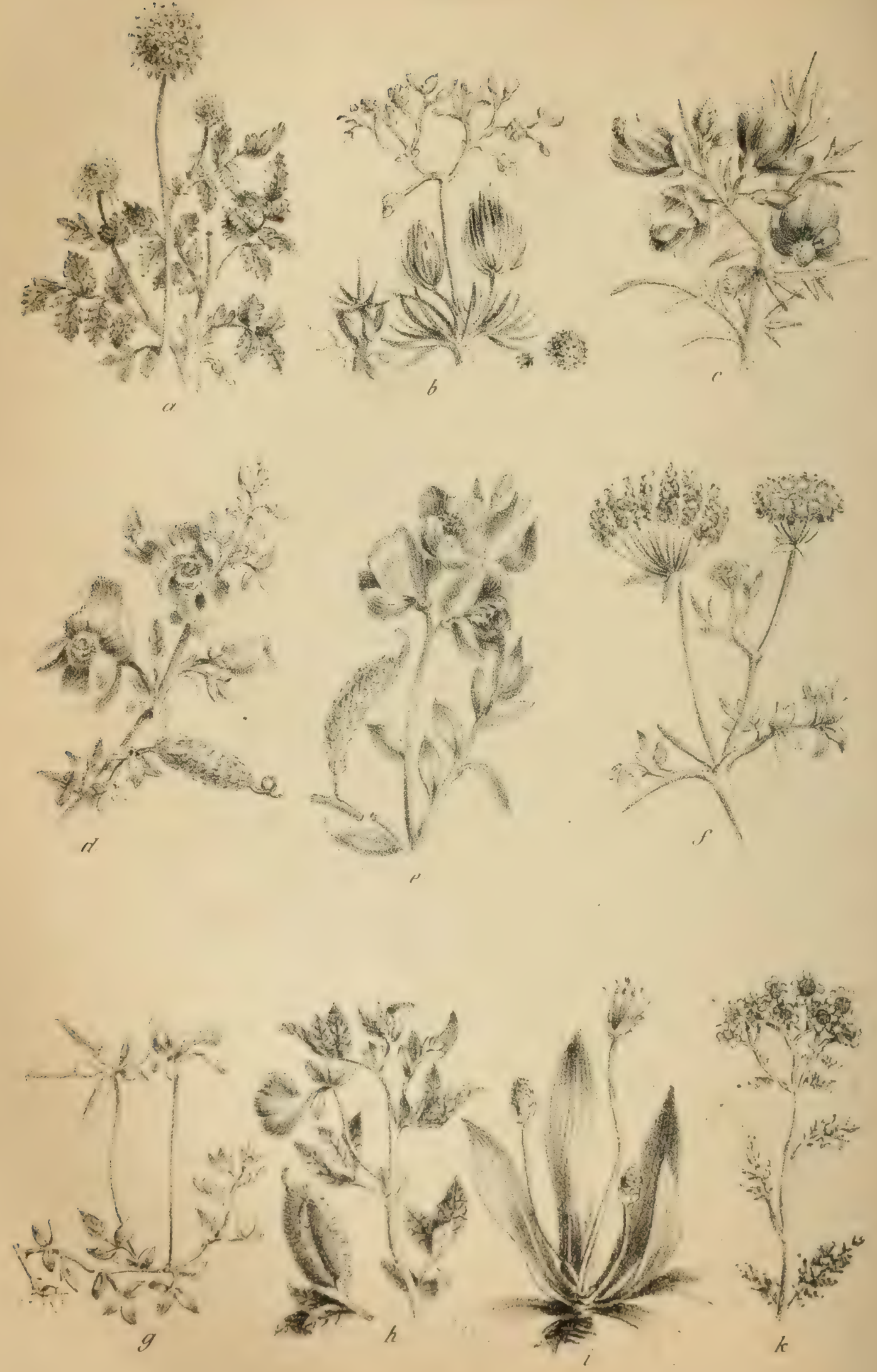
reedy part of the stalks into small pieces or shoes, which fall off during the process. He assists their disengagement by striking the handful against a stake, or with a small wooden paddle, until the lint or bark is entirely clean, and completely separated from the woody particles.

After the above operation is performed, the hemp may be scutched to soften it, and to strengthen the threads. That process, however, is not thought to be profitable, and is not therefore generally performed by the grower, but is left to the manufacturer, as well as that of beating and heckling it. Scutching is done by the labourer taking in his left hand a handful of lint: and grasping it firmly, then laying the middle of it upon a semi-circular notch of a perpendicular board of the scutching-frame, and striking with the edge of the scutch that part of the lint which hangs down on the board. After giving it repeated strokes, he shakes the handful of lint, replaces it on a notch, and continues to strike and turn all parts of it, until it is sufficiently cleansed, and the fibres appear to be even and straight.

The usual daily task of an able-bodied hand at the brake is 80 pounds' weight, but there is a great difference not only in the state of the weather, and the condition of the stalks, produced by the greater or less degree in which they have been rotted, but in the dexterity with which the brake is employed. Some hands have been known to brake from 150 to 200 pounds per day. 'The labourer ties up in one common bundle the work of one day, and in this state it is taken to market and sold. From what has been mentioned, it may be inferred, as the fact is, that the hemp of some growers is in a much better condition than that of others. When it has been carelessly handled or not sufficiently cleansed, a deduction is made from the price by the purchaser. It is chiefly bought in our villages, and manufactured into cottonbagging, bales, and other kinds of untarred cordage. The price is not uniform. The extremes have been as low as three, and as high as eight dollars, for the long hundredthe customary mode of selling it. The most general price during a term of many years, has been from four to five dollars. At five dollars it compensates well the labour of the grower, and is considered more profitable than any thing else the farmer has cultivated.

The most heavy labour in the culture of hemp, is pulling or cutting it, when ripe, and braking it when rotted. This labour can easily be performed by men. Various attempts have been made to improve the process of braking, which is the severest work in the preparation of hemp. A newly invented machine was erected for that purpose on my farm six or eight years ago, to dress hemp by dispensing with rotting altogether, similar in structure to one which was exhibited about the sanie time at Columbus, during the sitting of the Ohio legislature. It was worked by horse power, and detached the lint tolerably well, producing a very fine looking article, equalling in appearance Russia hemp. A ton of it was sold to the navy department, which was manufactured into rigging for the ship of the line, the North Carolina, prior to her making a voyage of three years in the Mediterranean. Upon her return, the cordage was examined and analyzed; and although its excerior looked very well, it was found, on opening it, to be decayed and affected somewhat like the dry-rot in wood. I considered the experiment decisive; and it is now believed that the process of water or dew-rotting is absolutely necessary, either before or after the hemp has been to the brake. There is a sappy or glutinous property of which it should be divested, and that is the only process that has been hitherto generally and successfully employed to divest it.

An ingenious and enterprising gentleman in the neighbcurhocid of Lexington, has been, ever since the erection of the above-mentioned machine, trying various experiments, by altering and improving it, to produce one more perfect, which might be beneficially employed on rotted hemp, to diminish the labours of the brake. He mentioned the other day that all of them had failed; that he had returned to the old hand-brake, and that he was convinced that it answered the purpose better than any substitute with which he was acquainted. I observe Mr. H. L. Barnum has recently advertised a machine, which he has constructed for braking and dressing hemp and flax, which can be procured at the establishment of $\mathrm{Mr}$. Smith, in Cincinnati. I most cordially wish him success; but the number of failures which I have witnessed, during a period of 30 years, in the attempts to supersede manual labour by the substitution of that of machines, induces me to fear that it will be long before this desideratum is attained.

The quantity of net hemp produced to the acre, is from 600 to 1000 weight, varying according to the fertility and preparation of the soil and the state of the season. It is said that the quantity which any field will produce, may be anticipated by the average height of the plants throughout the field. Thus-if the plants will average eight feet in height, the acre will yield 800 weight of hemp, each foot in height corresponding to a hundredweight of the lint.

Hemp exhausts the soil slowly, if at all. An old and successful cultivator told me that he had taken 13 or 14 successive crops from the same field, and that the last was the best That was probably, however, owing to a concurrence of favourable circumstances. Nothing cleanses and prepares the earth better for other crops (especially for small grain or grasses) than hemp. It eradicates all weeds, and when it is taken off, leaves the field not only clean, but smooth and even.

The rich lands of Ohio, Indiana, and Illinois, are, I have no doubt, generally well adapted to the cultivation of this valuable plant; and those states enjoy some advantages for the cultivation of it, which this does not possess. 'Their streams do not dry up as much as ours, and they consequenlly emplny better than we can, the agency of water, in the preparation of it. Their projected canals, when completed, will admit of its being carried to the Atlantic capitals at less expense in the transportation than we can send it. (Amrrican $\boldsymbol{F}$ armer, vol. xiv.) 


\section{HEMP AGRIMONY.}

Mr. Ellsworth, in bis report upon improvements in agriculture, \&c., made in the United States, in 1842, observes in relation to the hemp culture, that attention is still directed, and it would seem with somewhat more success, to the discovery of a process of water-rotting hemp; and it is hoped that the difficulties on this subject may yet be removed. It is stated that, in consequence of the promise last winter of sending out a government agent to purchase water-rotted hemp for the navy, the farmers of Kentuchy and Missouri have water-rotted 700 tons or more. This, at the prices paid by the government for Russian hemp, is worth $\$ 200,000$. Many specimens, it is further stated, have been examined, and pronounced equal to Russia hemp. Were a suitable reward to be offered, to stimulate the ingenious, it can hardly be doubted that, by a variety of experiments, some process of preparing it for the use of the navy, as well as the Russia hemp, might be found out.

An important discovery, respecting the application of waste hemp to the purpose of paper-making, has recently been announced; and if, when it is sufficiently tested, it proves all that it promises, it will afford an additional inducement to the culture of hemp. A process is said to have been found out, by which hemp can be made white as snow, and that it can be used in manufacturing the finest and whitest paper; and a belief is entertained that hemp waste, which can be furnished at two cents per pound, will ere long be sought for by paper-makers, to supply the place of linen rags.

Hemp is beginning to be raised somewhat more in the Northern and Eastern States. This is true especially of the northern part of the state of New York. At present, however, it is confined to the seed crop, owing to the high price of the seed. It is affirmed to be a mistake to suppose that it must be confined to alluvial lands, as has been shown by the farmers of Saratoga and Washington counties, in the state of New York. We import hemp or hempen articles, some years, to the extent of $\$ 9,000,000$ or $\$ 10,000,000$ in value. It is worth from $\$ 200$ and upwards per ton. When planted in drills, at a suitable distance, as it should be, and properly cultivated, hemp generally produces from 20 to 40 bushels of seed to the acre; and instances are not rare of its yielding from 50 to 60 . The seed is generally worth from 3 to 6 dollars per bushel. When sown for the lint, it should be sown broadcast, from 2 to 3 bushels of seed to the acre, depending on the quality of the land; and it usually produces from 700 to 1000 weight of clean hemp to the acre. Much valuable information respecting the culture and importance of this crop may be found in the files of the Kentucky Furmer for the last few years.

HEMP AGRIMONY (Eupatorium cannabinum). A rough perennial herb, growing in England in watery, boggy places, especially about the banks of rivers, with a tufted, somewhat creeping root, with many long fibres. Stems several, 2 or 3 feet high, branched, diwry, often brown or purplish, filled with 618
HENBIT.

pith. Leaves on short stalks, deep green, downy, but rather rough to the touch. The flowers form dense, pale, purplish corymkr: tufts, at the top of the stem and upfs: branches. The whole herb is slightly aromatic. Some species of agrimony are used in gargles, and as tea. See Agrimory. (Smith's Eng. Flor. vol. iii. p. 400.)

HEMP, INDIAN (Apocynum cannabinum). An American plant with a perennial root, found in the borders of woodlands and other situations in the Middle States, flowering in August. The stems grow from 2 to 4 feet high, smooth, purple, slightly glaucous, with rather erect branches. The leaves are from 2 to 4 or 5 inches long, half an inch to an inch and a half wide, elliptic in general form, and more or less downy beneath. The greenishwhite flowers are numerous, and sometimes tinged with red. There seems to be several varieties referrable to this species, the bai': of which affords a strong fibre similar to that of hemp. One or two additional species of apocynum have been met with in the United States. (Flora Cestrica.)

HEMP-NETTLE (Galeopsis). A genus of annual weeds common in corn fields, flowering in July, August, and September. Dr. Smith describes four native species in England.

1. Red hemp-nettle (G. ladanum).

2. Downy hemp-nettle (G. villosa).

3. Common hemp-nettle (G. tetruhit).

4. Large-flowered hemp-nettle. Bee nettle (G.versicolor). (Smith's Eng. Flor, vol. iii. p.92). HENBANE (Hyoscyamus niger). Black henbane. This annual herb abounds about villages, road-sides, and among rubbish, and in England flowers in July. Neither horses, cattle, swine, nor sheep, will touch this plant, and it is not relished by goats. The whole plant is fatal to poultry, whence its common name; it intoxicates hogs; but cows, horses, dogs, and goats are able to bear a tolerable proportion before they are affected. The leaves are active only in the second year of the plant: if scattered about buildings, "they are said to drive away mice and rats. If more than a small portion of the leaves should have been accidentally swallowed, brisk emetics ought instantly to be taken; and after discharging the contents of the stomach, it will be necessary to administer some mild drinks, such as large portions of vinegar, or lemon juice diluted with water, as the stomach is able to support them.

Henbane owes its medicinal properties to an alkali, hyoscyamia, which can be obtained in a separate state. It is crystallizable. Besides this alkali, the plant yields by destructive distillation an empyreumatic oil, which is a powerful narcotic poison. Notwithstanding these virulent properties, henbane has been professionally administered with considerable success in many obstinate diseases. The expressed juice of the leaves, evaporated to the consistency of extract, has long been used as a narcotic, an anti-spasmodic, and a sopo. rific.

HENBIT, THE GREAT, or Hrantit Dean Netrle. See Dean Netrle. In England 
henbit is also one of the common names of the fetid black horehound (Ballota nigra).

In Pennsylvania and other Middle States, where the dead nettle is extensively naturalized, it is a troublesome weed in gardens, where it may often be seen in flower as early as February and March. (Flora Cestrica.)

\section{HENBIT, SMALL. See SPEEDWLL.}

HEPATICA, or LIVERWORT (Anemone hepatica). Miller mentions five sorts : the single blue (nobilis), the double blue (plena), the single white (alba), the single red (vulgaris), and the double red (rubra). In England these beautiful and early perennials produce their flowers in February and March, before any leaf appears. The double sorts remain longer in flower than the single ones. The single flowers produce seed every year; the seed should be sown in pots or boxes of light earth in August, to receive only the morning sun till October, when the plants must be placed in as sunny a spot as possible through the winter. The seedlings may be transplanted the following August into the borders, and left there undisturbed. Hepaticas do not bear transplanting well; and the roots should only be parted once in three or four years. The hepatica loves an eastern aspect, and a loamy soil. They are three years before they flower handsomely. See IIIVER WORT.

HERBACEOUS (Lat. herba). In describing the texture of bodies, denotes their being green and cellular, as the tissue of membranous leaves. It is also applied to such perennial plants as lose their stems annually, while their roots remain permanent in the ground.

HERBAL (Lat. herbarium). A collection of dried plants, such as the old botanists termed a hortus siccus or dry garden. It is also applied to books which contain a methodical arrangement of the classes, genera, species, and varieties of plants, together with an account of their properties. Dry herbals are formed by glueing to sheets of paper, twigs and other parts of plants pressed flat, and dried in bibulous paper or otherwise. If well prepared, they are as useful to the botanist as living plants; but it is necessary to have some practical skill to be able to employ them advantageously. The best method of making a hortus siccus or herbal, is to place the plant to be dried between paper of a soft and spongy, unglazed texture, under a slight pressure. On the following day the plant should be spread, in as natural a form as possible, between folds of fresh, dry, blotting paper; and a pressure greater than before employed. In a week it will be sufficiently dry for pasting on a half sheet of white paper ; to which the name of the plant, its habitat, and the natural order, with the date, may be appended. The largest public herbaria are those of the museum at Paris, the imperial collection at Vienna, the royal of Berlin, and that of the British museum, London, formerly Sir Joseph Banks's. Nothing certain is known of the extent of these collections, but they probably contain in some cases as many as 60,000 species. The herbarium is not an attractive part of public museums; but a very important one for numerous purcoses of science, both practical and speculative. (Brande's Dict. of Science.)

HERBIVEROUS ANIMAIS, FOOD GF

$M$. Dumas, in a paper recently read before the French Academy, states, that he has as. certained the quantity of fat in animals in a healthy state does not depend on some peculiar process in the digestion, but upon the quantity of fatty matter contained in the food eaten. He states, that on analysis of hay and Indian corn or maize, he found the former yield 2 per cent. of fatty matter and the latter 9 per cent. Herbiverous animals, he says, always make less fat than the amount of fat contained in their food; but the milch cow furnishes a larger quantity than any other animal, and the quantity of butter that she sup. plies, would, if weighed, be found equivalent to that contained in her food.

HERD (Sax. hýno). A number of beasts congregated together. It is particularly applied to black cattle. Herd or herdsman also anciently signified a keeper of cattle, and in the north of England it is still used.

HERD'S GRASS, or Foul Meadow Grass. This grass is a spontaneous growth, says Buel, of the wet lands of the United States. The white top and red top are different varieties of herd's grass.

HERRING (Clupea harengus). This wellknown fish is found in great abundance from the highest northern latitudes down to the northern coast of France. Large shoals of them frequent the coasts of the British Islands, and give employment to a considerable number of boats and men, forming a principal article of commerce. A very elaborate treatise on the natural history and the different modes of fishing and curing the herring, by Mr. John Mitchell, was published in the Edin. Quart. Journ. of $A g r$. , vol. x. p. 1.

The scales and other refuse of the herring fishery of the Suffolk coast are used with great success as a manure by the farmers in the ineighbourhood of Lowestoff. There is no doubt that this fish is a powerful manure. The cake produced in Sweden by the herring oil-makers is considered by the farmers of that cold country to be the most powerful of fertilizers. And I have in another place given the result of an experiment with some spoiled dried herrings on a Kentish hop plantation. (Johnson on Salt, p. 101 ; Trans. High. Soc. vol. v. p. 404.) See Fish, as a Manure.

Most of the varieties of herring found in Europe have been recognised on the Atlantic coast of the United States. The manhaden, caught in such numbers on the shores of Long Island Sound, and there used so extensively and profitably as manure, belongs to the herring family (Chepea manhaden).

HESSIAN FLY. See Fry ry WHEAT.

HICKORY. A common name throughout the United States, applied to several species of the walnut genus, which, in the variety of trees composing the vast original forests east of the Mississippi, ranks after the nak in the number of its species. The botanical section which includes the hickories, according to Michaux' arrangement, contains eight species; namely Pacanenut Hickory, Bittermut Hicknr Water Bil 
'ernut Hickory, Mockernut Hickory, Shellbark Hickory, Thick Shellbark Hickory, Pignut Hickory, and Nutmeg Hickory. The three first-named species bear the nearest relation with the black walnut and butternut, their buds not being covered with scales.

The various species of hickory differ very greatly from the black walnut and butternut in the properties of their wood. The general form and foliage of hickories, also, bear a striking resemblance, though they differ in the number and size of their leaflets. The fruit often varies greatly in appearance. All the species of hickory, together with the black walnut and butternut, comprise an indigenous genus, no species of which is met with in Europe, or any other part of the old world.

1. Pacanenut Hickory (Juglans olivaformis of Michaux; Carya angustifolia and Juglans angustifolia of other naturalists). This species, which, says Michaux, is found in Upper Louisiana and Illinois, is called by the French Pacanier, and its fruit Pacanes. On the borders of the rivers Missouri, Illinois, St. Francis, and Arkansas, it is most abundantly multiplied. It is also common on the Wabash, and on the Ohio is found for 200 miles from its junction with the Mississippi. Higher than this it becomes more rare, and is not seen beyond Louisville. This tree is partial to cold, wet grounds. On the right bank of the Ohio, opposite the river $\mathrm{Cum}$ berland, there is a swamp of 800 acres, which is said to be entirely covered with it.

The Pacanenut is a beautiful tree, with a straight and well-shaped trunk, attaining in the forests the height of 60 or 70 feet. Its wood is coarse-grained, and, like that of other hickories, heavy and compact, possessing great strength and durability, though in this last respect not equal to some other species. The nuts, which are usually abundant, are contained in a husk from one to two lines thick, and have four slightly prominent angles, corresponding to their internal divisions. They vary in length from an inch to an inch and a half, are pointed at the extremities, of a cylindrical form, and of a yellowish colour, marked, at the period of perfect maturity, with blackish or purple lines. The shell is smooth and thin, though too hard to be broken by the fingers; the kernel is full, and, not being divided by ligneous partitions, is easily extracted. These nuts, which are of a very agreeable taste, form an object of petty commerce between Upper and Lower Louisiand. From New Orleans they are exported to the West Indies and to the ports of the United States. They are not only better than any other species of North American walnuts, but they appear to be even more delicately flavoured than those of Europe. And, besides, varieties of the pacanenut are found whose fruit is far superior to that of the European walnut unimproved by culture. This tree therefore merits the attention of both Americans and Europeans, that by assiduous cultivation it may be brought to the highest degree of perfection. These advantages, it is true, are balanced in part by the slowness of its growth; there are rees in France which have been planted more than thirty years, and which do not yield fruit. 620
If the practice should be successfully adopt. ed of grafting the pacanenut on the black walnut, or on the common walnut, its vegetation would be incomparably more rapid, and no motive would discourage its propagation in Europe.

2. Bitternut Hiclory (Juglans amara). This tree is also called in I Lancaster county and some other parts of Pennsylvania and the Middle States by the names of While Hickory and Swamp Hickory, the latter name being derived from its frequently flourishing on the rich alluvium found in swamps and on the banks of rivers subject to overflowing. Farther south it is confounded with the Pignut hickory. Its vegetation is more liardy than that of other hickories.

The Bitternut hickory, Michaux informs us, is nowhere found much beyond the boundaries of Vermont in the latitude of $45^{\circ}$. "The fruit is ripe about the beginning of October; it is so plentiful that several bushels are sometimes gathered from a single tree. The husk is thin, fleshy, and surmounted on its upper half by four appendages in the form of wings. It never becomes ligneous like those of the other hickories, but softens and decays. The form of the nut in this species is more constant and more regular than in the others. It is broader than it is long, being 6 or 7 lines one way and 10 lines the other. The shell is white, smooth, and thin enough to be broken by the fingers. The kernel is remarkable for the deep inequalities produced on every side by its foldings. It is so harsh and bitter that squirrels and other wild animals will not feed on it while any other nut is to be found.

"In some parts of Pennsylvania, where this tree is multiplied, an oil is extracted from the nuts, which is used for the lamp and for other inferior purposes. But from these experiments, in which individuals have succeeded, it is not to be concluded that a sufficient product of this sort can be obtained to form a branch of in dustry.

3. Water Bitternut Hickory (Juglans aquaticu). "No specific name," says Michaux, "has hither. to been given to this species, which is confined to the Southern States; it is confounded with the Pignut hickory, though differing from it is many respects. The name which I propose appears sufficiently appropriate, for I have always found this tree in swamps; and in the ditches which surround the rice fields, where it is accompanied by the red-flowering maple, Tupelo, cypress, and Carolina poplar. The Water Bitternut hickory grows to the height of 40 or 50 feet, and in its general appearance resembles the other hickories. Its leaves are 8 or 9 inches long, and of a beautiful green. They are composed of 4 or 5 pair of sessile leaflets, surmounted by a petiolated odd one. The leaflets are serrate, 4 or 5 inches long, 8 or 9 lines broad, and very similar to the leaves of the peach tree.

"The husk is thin, and the nuts are small, angular, a little depressed at the sides, somewhat rough, of a reddish colcur, and very ten. der. The kernel is formed in folds like that of the Bitternut hickory: as may be supposed, 


\section{HICKORY.}

\section{HICKOIRY.}

it is not eatable. The wood of this species, though partaking of the common properties of the hickories, is in every respect inferior to the others, from the nature of the grounds on which it grows.

4. Mockernut Hickory (Juglans tomentosa of Michaux, Carya tomentosa of other naturalists), Common hickory. "In the parts of New Jersey which lie on the river Hudson, and in the city of New York and its vicinity, ihis species," says Michaux, "is known by the name of the Mockernut hickory, and less commonly of White-heart hickory; at Philadelphia and Baltimore, and in Virginia, that of Common hickory is the only one in use. The French of Illinois call it Noyer dur, or Hard walnut. The first of these denominations, which is descriptive of the fruit, I have for that reason adopted.

"This species is not, as the name which it bears in that country would indicate, more multiplied in Pennsylvania, and further south, than the other hickories. I have not seen it north of Portsmouth in New Hampshire, though 100 miles south, in the neighbourhood of Boston and Providence, it is common. It is most abundant in the forests that still remain on the coast of the Middle States, and in those which cover the upper parts of the Carolinas and of Georgia; but in the last mentioned states it becomes more rare in approaching the sea, as the sterility of the soil, in general dry and sandy, is unpropitious to its growth. I have noticed, however, that this is the only hickory which springs in the pine barrens; the sprouts are burnt every year, and never rise higher than 3 or 4 feet. I have made the same observations in traversing the $\mathrm{Big}$ barrens of Kentucky and 'Tennessee, where the Mockernut hickory and Black Jack oak alone are seen. They survive the conflagrations which almost every spring envelope the prairies, but their vegetation is checked by the fire, and they do not exceed the height of 8 or 10 feet.

"Like most of the walnuts, the Mockernut hickory flourishes in rich soils, and chiefly on the gentle acclivities which surround the swamps, where it grows, mingled with the sweet gum, poplar, sugar maple, bitternut hickory, and black walnut. In these situations it reaches its greatest size, which is commonly about 60 feet in height, and 18 or 20 inches in diameter. I remember to have seen larger Mockernut hickories near Lexington, in Kentucky, but this extraordinary growth in several species of trees is rarely seen on this side of the Alleghanies, and is attributable to the extreme fertility of the soil in the Western country. Of all the hickories, however, the Mockernut succeeds best on lands of a middling quality; for it forms a part of the waste and impoverished forests which cover the meager, sandy soil of Lower Virginia; though under these disadvantages it exhibits but a mean and stunted appearance.

"The buds of this species are large, short, of a grayish white, and very hard; in the winter, after the falling of the leaf, they afford the only characteristic by which the tree can be distinguished, when it exceeds 8 or 10 feet in height.
"The fruit is ripe about the 15th of Nivenber. It is odorous, sessile, or rarely pedunca. lated, and commonly united in pairs. In form and size it exhibits remarkable var.eties: on some trees it is round, with depressed seams; on others oblong, with angular or prominent seams; it is sometimes 2 inches long and 12 or 15 lines in diameter, and sometimes of less than half this size. The shell is very thick, somewhat channelled, and extremely hard. The kernel is sweet, but minute, and difficule to extract, on account of the strong partitions which divide it: hence, probabiy, is derived the name of Mockernut, and hence, also, this fruit is rarely seen in the markets.

"Of all the hickories this species is of the slowest growth: a fact which I have proved by planting nuts of the several species, and by comparing the length of their annual shoots. I have also been led to believe that it is the most liable to be attacked by worms, and especially by the Callidium flexuosum, whose larva eats within the body of the tree. These considerations appear sufficiently weighty to $\mathrm{in}$ duce cultivators, in forming large plantations, to prefer some other species which are described in the sequel."

5. Small-fruited Hickory (Carya microcarpa of Nuttall and Darlington, Juglans compressa of Muhlenburg, and $J$. alba odorata and Balsam Hickory of Marshall.) This species is allied to the Carya tomentosa or Common hickory. Nuttall informs us that he first observed it on the banks of the Schuylkill, in the vicinity of Philadelphia, and Dr. Darlington remarks that it is frequent in moist woodlands in Chester county, Penn. The nut is of nearly the same form as that of the Common hickory, has a thin shell, pleasant taste, but is quite small, seldom exceeding the size of a nutmeg. These peculiar nuts grow in Massachusetts. The species is remarkable for the smoothness of its leaflets, which in this respect, says Nuttall, resemble those of the Carya glabra or Pignut, but they are larger and less deeply serrated.

6. Shellbark Hickory (Juglans squamosa of Michaux, and Carya alba of Darlington and other botanists). 'The singular disposition of the bark in this species has given rise to the descriptive names of Shellbark, Shagbark, and Scalybark hickory, the first of which is in most general use in the Middle and Southern States. Many descendants of the Dutch settlers, says Michaux, call it Kisky Thomas nut. It is not found further north than Portsmouth, New Hampshire, where its stature is stunted by the rigours of the climate. "It abounds on the shores of Lake Erie, about Geneva in Gene. see, along the Mohawk river, in the neighbourhood of Goshen in New Jersey, and on the banks of the Susquehanna and Schuyllill rivers in Pennsylvania. In Ma? -land, in the lower parts of Virginia, and in the other Southern States it is less common. In South Carolina I have not noticed it nearer Charleston than the parish of Goose-Creek, akout 24 miles distant It is met with in the Western States, but not as frequently as the following species, the Thick Shellbark hickory, to which it bears a striking analogy, and with which it is confounded by the inhabitants. East of the $\mathbf{A l !}$. 
ghanies the Shellbark hickory grows almost exclusively about swamps and wet grounds, which are exposed to be inundated for several weeks together: in these situations it is found in company with the swamp white oak, redflowering maple, sweet gum, buttonwood, and tupelo. Of all the hickories this species grows to the greatest height with proportionally the smallest diameter, for it is sometimes seen 80 or 90 feet high and less than 2 feet thick. 'The trunk is destitute of branches, regularly shaped, and of an almost uniform size for three quarters of its length, thus forming a very fine tree. The greatest peculiarity in its appearance, and that by which it is most easily distinguished, is the surface of the trunk. The exterior bark is divided into a great number of long, narrow plates, which bend outwards at the ends, and adhere only in the middle. Bristling in this manner with projecting points, the Shellbark hickory attracts the attention of the most careless observer. This remarkable exfoliation of the epidermis takes place only in trees which exceed 10 inches in diameter, though it is much earlier indicated by seams. This characteristic, by which the tree may be recognised in winter when stript of its leaves, does not exist during the 7 or 8 first years of its growth; and during this period it may easily be confounded with the Mockernut hickory and Pignut hickory, if recourse is not had to the buds.

"The fruit of the Shellbark hickory is ripe about the beginning of October. Some years it is so abundant that several bushels may be gathered from a single tree. It varies in size according to the soil and the exposure in which it is produced, but $5 \frac{1}{2}$ inches may be assumed as the average of its circumference. The shape is uniformly round, with four depressed seams, in which the husk opens at the season of perfect maturity, dividing itself completely into equal sections. The entire separation of the husk, and its thickness disproportioned to the size of the nut, form a character peculiar to the Shellbark hickories. The nuts of this species are small, white, compressed at the sides, and marked by four distinct angles, which correspond to the divisions of the husk.

"The Shellbark nut contains a fuller and sweeter kernel than any American walnut except the Pacanenut. These nuts are in such request, that they form a small article of commerce, registered on the list of exports of the products of the United States. This exportation, which does not exceed 4 or 500 bushels annually, takes place from New York and from the small ports of Connecticut, to the Southern States, to the West India islands, and even to Liverponl, where the fruit is known by the name of Hickory nuts. In the market of New York they are sold at two dollars a bushel. They are gathered in the forests, and from insulated trees which in some places have been spared in clearing the lands: a precaution which I have particularly noticed to have been used near Goshen, in New Jersey, and on seveal estates about 30 miles beyond Albany.

"The Indians who inhabit the shores of Lake Erie and Jake Michigan lay up a store of these rats for the winter, a nart of which they pound 622 wooden mortars, and boiling the paste in water, collect the oily matter which swims upon the surface to season their aliments.

"I cannot forbear mentioning a fine variety of Shellbark nuts, produced upon a farm at Seacocus, near Snake-hill, in New Jersey. They are nearly twice as large as any that I have seen elsewhere, and have a white shell, with rounded prominences instead of angles. A century of cultivation, perhaps, would not advance the species generally to an equal degree of perfection, and probably this variety might still be improved by grafting."

7. Thick Shellbark Hickory (Juglans laciniosa). "This species," says Michaux, "bears a striking analogy to the preceding, and is frequently confounded with it by the inhabitants of the western country: some of them distinguish it by the name of Thick Shellbark hickory, which should be preserved as its appropriare denomination. East of the Alleghanies this tree is rare, and is found only in a few places; it grows on the Schuylkill river 30 or 40 miles from its junction with the Delaware, and in the vicinity of Springfield, 15 or 20 miles from Philadelphia, where its fruit is called Springfield nut. It is also found in Gloucester county, in Virginia, under the name of Gloucester walnut. These different denominations confirm my observation, that this species is little multiplied on the eastern side of the Alleghany mountains; a fact of which I became assured in travelling through the country. It abounds, on the other hand, in the bottoms which skirt the Ohio and the rivers which empty into it, where it unites with the honey locust, black maple, hackberry, black walnut, wild cherry, white and red elm, box elder, white maple, and buttonwood, to form the thick and gloomy forests which cover these valleys. Like the Shellbark hickory, it grows to the height of 80 feet, and its ample head is supported by a straight trunk, in diameter proportioned to its elevation. The bark exhibits the same singular arrangement with that of the Shellbark hickory; it is divided into strips from 1 to 3 feet long, which are warped outwards at the end, and attached only in the middle. They fall, and are succeeded by others similarly dise posed. It is only observable that in this species the plates are narrower, more numerous, and of a lighter colour.

"The Thick Shellbark hickory, as has been said, is nearly related to the Shellbark hickory, and its wood, which is of the same colour and texture, unites the peculiar qualities of that species with such as are common to the hiciories. Its fruit, though larger, is inferior in taste, and this consideration should induce proprietors in the western country, in clearing their new lands, to spare the true Shellbark hicknry in preference, when both species are found upon the same soil."

8. Pignut Hickory (Juglans porcina of Michaux, Carya porcina of other naturalists), also called Broom hickory. "This species is generally known in the United States by the name of Pignut and Hognut hickory, sometimes alsu by that of Broom hickory. 'The first of these names is most commonly in use; the others are known only in some districts of Pennsyl- 
vania, and particularly in the county of Lancaster. Portsmouth in New Hampshire may be considered as limiting towards the north the climate of this tree. A little farther south it is abundant, and in the Atlantic parts of the Middle States it helps, with the Mockernut hickory, white oak, swamp white oak, sweet gum, and dogwood, to form the mass of the forests. In the Southern States, especially near the coast, it is less commoll in the woods, being found only on the borders of swamps and in places which are wet without being absolutely marshy or exposed to be long inundated. This tree is met with in the western country, but less frequently, I believe, than the Thick Shellbark and Mockernut hickories. I have observed that the last mentioned species grows wherever the Pignut is found, but that the Pig. nut does not al ways accompany the Mockernut, which is satisfied with a less substantial soil. This remark I have made more particularly in the lower parts of Virginia, of the two Carolinas, and of Georgia. It appears, then, that, with the exception of the States of Vermont and New Hampshire, of the District of Maine, of the Genesee country, and of the cold and mountainous tracts along the whole range of the Alleghany mountains, this tree is more or less abundant in the forests throughout the United States.

"The Pignut hickory is one of the largest trees in the United States. It grows to the height of 70 or 80 feet, with a diameter of 3 or 4 feet.

"The nut is small, smooth, and very hard on account of the thickness of the shell. Its kernel is sweet, but meager and difficult to extract, from the firmness of the partitions. These nuts are never carried to market, but serve for food to swine, racoons, and the numerous species of squirrels which people the forests.

"In the Pignut hickory the form and size of the nuts vary more than in the other species. Some are oval, and when covered with their husks, resemble young figs; others are broader than they are long, and others are perfectly round. Among these various forms some nuts are as large as the thumb, and others not bigger than the little finger."

9. Nulmeg Hickory (Juglans myristicaformis). This tree, so named by Michaux from the resemblance of its fruit to the nutmeg, is found in the Southern and Southwestern States. The nuts are very small, smooth, and of a brown colour, marked with lines of white. The husk is thin. and somewhat rough on the surface. The shell is so thick as to constitute two-thirds of the volume of the nut. The kernal is therefore very minute, and the fruit even inferior to that of the Pignut.

Properties and Uses of Hickory Wond.-The wood of all the species of hickory bears a striking resemblance, both as to fibre and the uniform reddish colour of the heart. It possesses great weight, strength, and unusual pliability and toughness. When exposed to heat and moisture it is subject to rapid decay, and is peculiarly liable to injury from worms.

"Throughout the Middle States it is selected :or the axletrees of carriages, for the handles of : res ar d other carpenter's tuols, and for large crews, particularly those of bookbinder's presses. 'The cogs of mill-wheels are made of hickory heart thoroughly seasoned; but it is proper only for such wheels as are not ex. posed to moisture; and for this reason some other wood is by many mill-wrights preferred The rods which form the back of Windsor chairs, coach-whip-handles, musket-stocks, rakt-teeth, flails for thrashing grain, the bows of yokes, or the elliptical pieces which pass under the necks of cattle: all these are objects customarily made of hickrory. At Baltimore it is used for the hoops of sieves, and is more esteemed than the white oak, which is equally elastic, but more apt to peel off in small shreds into the substance sifted. In the country near Augusta in Georgia, I have remarked that the common chairs are of hickory wood. In New Jersey it is employed for shoeing sledges, that is, for covering the runners or parts which slide upon the snow; but to be proper for this use it must have been cut long enough to have become perfectly dry.

"Of the numerous trees of North America east of the Alleghany mountains, none except the hickory is perfectly adapted to the making of hoops for casks and boxes. For this pur. pose vast quantities of it are consumed at home, and exported to the West India islands. The hoops are made of young hickories from 6 to 12 feet high, without choice as to the species. The largest hoop-poles sold at Philadelphia and New York in February, 1808, at $\$ 3$ a hundred. Each pole is split into two parts, and the hoop is crossed and confined by notches instead of being bound at the end with twigs like those made of chestnut. From the solidity of the wood, this method appears sufficiently secure.

"When it is considered how large a part of the productions of the United States is packed for exportation in barrels, an estimate may be formed of the necessary consumption of hoops. In consequence of it, young trees proper for this object have become scarce in all parts of the country which have been long settled. The evil is greater, as they do not sprout a second time from the same root, and as their growth is slow. The cooper cannot lay up a store of them for future use, for unless employed within a year, and often within six months after being cut, they are attacked by two species of insect, one of whach eats within the wood and commits the gleatest ravages.

"The defects which unfit the hickory for use in the building of houses, equally exclude it from the construction of vessels. At New York and Philadelphia the Shellbark and Pignut hickories have been taken for keels, and are found to last as long as those of other wood, owing to their being always in the water. Of the two species, the Pignut would be preferable, as being less liable to split, but it is rarely found of as large dimensions as the other.

"In sloops and schooners the rings by whiclı the sails are hoisted and confined to the mast are always of hickory. I have also been assured that for attaching the cordage it makes excellent pegs, which are stronger than those of oak; but they should be set loosely in th. 
holes, as otherwise, for want of speedily sea. soning, they soon decay. For handspikes the hickory is particularly esteemed on account of its strength; it is accordingly employed in most American vessels, and is exported for the same purpose to England, where it sells from 50 to 100 per cent. higher than ash, which is brought also from the north of the United States. The hickories are cut without distinction for this use, but the Pignut, I believe, is the best.

"All the hickories are very heavy, and in a given volume contain a great quantity of combustible matter. They produce an ardent heat, and leave a heavy, compact, and long-lived coal. In this respect no wood of the same latitude in Europe or America can be compared to them; such, at least, is the opinion of all Europeans who have resided in the United States.

"It has been seen by what precedes, that though hickory wood has essential defects, they are compensated by good properties which render it valuable in the arts."

In concluding this article, Michaux recommends particularly for propagation in European forests the Shellbark hickory and the Pignut hickory, whose wood unites in the highest degree the valuable properties of the group. He thinks, also, that the Pacanenut merits attention from promoters of useful culture, not so much for its woall as for its fruit, which is excellent, and more delscate than that of the European walnut. It might probably be doubied in size, if the practice was successfully adopted of grafting this species upon the black walnut, or upon the common European walnut.

HICKORY CATERPILLAR. Whilst the wood of the hickory is preyed upon by borers, the foliage suffers in the latter part of summer from troops of caterpillars covered with short spreading tufts of white hairs, with a row of eight black tufts on the back, and two long, slender, black pencils on the fourth and tenth rings. When fully grown, they are nearly one and a half inch long. They leave the trees in September, make cocoons, which are thin, oval, and hairy. The moths, which come out of the cocoons in the month of June, are of a very light ochre-yellow colour, the wings being sprinkled with brown dots. In England, the moths that come from caterpillars having long pencils and tufts on their backs, are called tussock-moths; and Dr. Harris says we may name the one under consideration the hickory tussock-moth (Lophocampa carya). They expand their wings from $1 \frac{7}{3}$ to $2 \frac{1}{4}$ inches or more. The caterpillars found on the black walnut, butternur, the ash, and even the oak, closely resemble the hickory caterpillar in shape, but not in colour. They belong to a different species.

HICKORY TREE BORER. 'The hickory tree is much exposed to the ravages of the iarvæ of wood-eating insects or borers, which not only attacks the trees of the forests, but those of orchards, especially after they have passed their prime. The transformations of the insects take place in the trunks and limbs of the trees. "The larvæ," says Dr. Harris, "that are known to me have a close resemslance to each other; a general idea of them 624 can be formed from a description of that which attacks the Pignut hickory. It is of a yellowish-white colour, very long, narrow, and depressed in form, but abruptly widened near the anterior extremity. The head is brownish, small, and sunk in the fore-part of the first segment; the upper jaws are provided with three teeth, and are of a black colour; and the antennæ are very short. These grubs are found under the bark and in the solid wood of trees, and sometimes in great numbers. They frequently rest with the body bent sidewise, so that the head and tail approach each other. This posture those found under bark usually assume. They appear to pass several years in the larva state. The pupa bears a near resemblance to the perfect insect, but is entirely white, until near the time of its last transformation. Its situation is immediately under the bark, the head being directed outwards, so that when the pupa-coat is cast off, the beetle has merely a thin covering of bark to perforate, before making its escape from the tree. The form of this perforation is oval, as is also a transverse section of the burrow, that shape being best adapted to the form, motions, and egress of the insect.

"Some of these beetles are known to eat leaves and flowers, and of this nature is probably the food of all of them. The injury they may thus commit is not very apparent, and cannot bear any comparison with the extensive ravages of their larvæ. The solid trunks and limbs of sound and vigorous trees are often bored through in various directions by these insects, which, during a long-continued life, derive their only nourishment from the woody fragments they devour. Pines and firs seem particularly subject to their attacks, but other forest trees do not escape, and even fruit trees are frequently injured by these borers."

A borer belonging to another family of beetles is also found in the hickory, namely, the larvæ of the beetle called by naturalists Stenocorus cinctus, or banded stenocorus, the generic name signifying narrow or straitened. I,ong galleries, running in the direction of the fibres, are made by this grub in the hard wood of the hickory. The beetle is of a hazel colour, with a tint of gray, arising from the short hairs with which it is covered. There is an oblique ochreyellow band across each wing-cover. (Harris.)

HIDE-BOUND. In farriery, applied to a certain disease of cows and horses, in which the skin adheres to their sides. Want of proper care, spare diet, and bad food, such as rank long grass in swampy situations, and musty hay or oats, aie the most probable causes of this affection. Hide-bound is rarely a primary disease; it is a symptom of unhealthiness, and often of disease, of the digestive organs. It is sometimes an accompaniment of chronic cough, grease, farcy, and founder. A few mashes, and a mild dose of physic, often have a very beneficial effect. If the horse cannot be spared for physic, the following alterative, which is in common use, may be given every night for some time in a mash, or in the form of a ball: levigated antimony, 2 drachms; nitre, 3 drach ms; sulphur, 4 drachms. For the cow, eight ounces of sulphur, with half an ounce of ginger, anı 
a few mashes should be given. (Lib. of Use. Know.; The Horse, p. 371; Callle, p. 571.)

HIDE OF LAND (Sax. Hyde lands) was considered, in ancient Britain, to be such a quantity of land as one plough and its team could plough in a year. It was hence called a ploughland. It was about 100, 120, or 150 acres. Bede calls it a fumiliare, and says it is as much as will maintain a family. Crompton, in Jurisdiction, f. 222, says that a hide of land contained 100 acres, and that 8 hides made a knight's fee. But, according to Sir Eidward Coke, a knight's fee, a hide or ploughland, a yardland, or an ox-gang of land, did not contain any certain quantity of acres (On Lit.f.69), but was determined by the value of $20 \%$ per annum. And a ploughland may contain a messuage, wood, meadow, and pasture; and every ploughland of ancient time was of the yearly value of five nobles; and this was the living of a ploughman or yeoman. The distribution of England into hides of land is very ancient, for they are mentioned in the laws of King Ina.

HIDES (Sax. hýoe; Germ. haute; Dutch, huiden). Generally speaking, this term is apapplied to the skins of most beasts; but in commerce it is limited to the strong and thick skin of the horse, $o x$, and other large animals. Hides are raw or green; that is, in the state in which they are taken off the carcass, or dressed with salt, alum, and saltpetre, to prevent them from putrefying; or they are cured or tanned. 'The hides of South America are in the highest repute, and vast quantities of them are annually imported into Great Britain. Large quantities are also received from various parts of the continent, and from Morocen, the Cape of Good Hope, \&c. About $200,000 \mathrm{cwt}$. of untanned hides are annually imported, and about 120,000 cwt. of other hides, exclusive of Russia hides, which form a large proportion of the imports. The rate of duty charged on hides is-untanned, dry, per cwt., 4s. 8d.; wet, $2 s .4 d$. ditto; pieces of hide, or hides tawed, curried, or dressed, $9 d$. per lb.; cut or trimmed, $1 s$. $2 d$. per lb. Those imported from British colonies are only liable to half this rate of duty.

HIGHWAYS received their name from the Roman method of elevating the road upon causeways, or by raised earth. In the English common law, highways are roads common to all the Queen's subjects, which the parish are liable to repair. All ways, either for foot passengers, or carriages and horses, are properly highways. If a road is dedicated to the public for 25 years, it becomes a highway, which the parish are bound to repair, although they have not acquiesced in the dedication of the road. And if a road has been freely used by the public for 4 or 5 years, a jurv is warranted in presulving that the owners of the soil consented to its being thus used. Bridges in highways become public by whomsoever built, but not raised causeways furnished with culverts over meadows, if niore than 300 feet from the bridge; and a bridge only used by the public in periods of floods, is merely a public bridge during that period. By the common law, the obligation to repair the road lies upon the parish; the bridges are to be repaired by the county, and not only the bridge, but since the 22 Henry VIII. c. 5, s. 9, the road or approaches for 300 feet "from any of the ends of it." Sur. veyors of the highways are now anrually elected by the parishioners on or within 14 days of the 25th of March (5 and 6 W. IV., c. 50, s. 6 ); and the surveyor may be, by sect. 6 of this act, re-elected, who must serve, under a penalty of $20 \mathrm{~L}$ : he is entitled, however, 10 a salary; by s. 20 , he is liable to a penalty of $5 \%$ for neglect of duty. The surveyor, by $\mathbf{s}, 25$, is authorized to use adjoining grounds as a tem. porary highway whilst the old road is repairing and widening; and, by s. 27 , he is emporved to make a rate on the inhabitants, which must, however, be allowed by the justices. By s. 47 , any person taking road scrapings or other materials from the sides of roads, is liable to a penalty of $10 l$. The surveyor is em. powered to dig for road materials within his own, or any other parish, and to gather stones free from charge, on any land within his parish, but he must pay for any damage done to the land during their removal; and after obtaining license from the justices in special sessions, he may enter upon and dig for road materials, making, however, satisfaction to the owners; and he must fill up the holes he makes, or have them filled up and sloped down. No tree shall be allowed to be planted within $\mathbf{1 5}$ feet of the centre of the highway: and with the authority of a justice of the peace (after duly summoning the owner to show cause), the surveyor may order hedges and trees, which shade or otherwise injure highways, to be cut and plashed. Cartways must be 20 feet, horseways 8 , and footways 3 fee: wide.

A surveyor of highways is not personally liable to the labourers; they must look to the commissioners, or their treasurer. A way warden may charge law expenses incurred in the discharge of his duty.

Repairing Roads.-The advantages of keeping ruads in repair, if only regarded by the farmer as lessening the draught of his horses, may be estimated from the following table of the average force required to draw a light four-wheeled cart, weighing, with its load, 1000 pounds:

Description of Road.

Turnpike road-hard dry

Turnpike road-dirty Hari, compact loam Ordinary bye-road Turnpike road, newly gravelled Loose sandy road

Force of tracture reqnired to move the carriage. $30 \frac{1}{8}$ Ibs. 39 -53
$-\quad 53$ - 106 - 143 204

The annual expense of repairing the roads throughout England, according to a report of a committee of the House of Commons in 1814, amounted to $1,500,000 l$., which Mr. Penfold in his Treatise on Road-making, divides into

Materials, tradesmen, and officers -

$£ 500,000$ Manual labour

250,1300 Cartage

750,000

The chief points to be attended to in road making are-1, the foundation; 2 , the drainage 3 , the choice of the materials; 4 , the preparation of them; and 5 , the size of them. In re pairing-1, the scraping; 2 , the removal of shading trees, \&c.; 3 , the watering. A careli 
attention to which points will well repay the parish for the care bestowed upon them. There is a paper, by Mr. Whyte, upon a machine for scraping and cleansing highways (Trans. High. Soc., vol. iv. p. 349), and on roads, and the excessive weights carried on them in narrow-wheeled wagons, by $\mathrm{Mr}$. Whetly (Com. to Board of Agr., vol. vi. p. 182); and there is a work on road-making by Sir $\mathbf{C}$. M.Adam, which every road-surveyor should possess. Sir Henry Parnell has also published a valuable treatise on road-making. Of the materials best adapted to road-making, Mr. Penfold remarks, "The trappean and basaltic rocks are those best suited for the construction of roads. No material has ever been used superior to the tough basalts, which are brought as ballast in ships from China and Bombay, and which have been partially used in the macadamised streets of London. Limestones, in many respects, afford an excellent material. 'The more unyielding the material, the smaller is the size to which it ought to be broken. J.imestones have in general a peculiar quality of making smooth roads, even if not broken to a small size. Pit gravel, especially that belonging to the new red sandstone formation, is in general not to be depended upon, as containing stones of different sorts, and consequently of different degrees of strength. It is one of the greatest mistakes in road-making to lay on thick coats of materials. If there be substance enough already in the road, and which, indeed, should always be carefully kept up, it will never be right to put on more than a stone's thickness at a time."

HIPPOPATHOLOGY. The science of veterinary medicine which comprehends the diseases of the horse. Among the writers on this subject, within the last century, may be enumerated Gibson, Clater, Blaine, Lowson, White, Rydge, Coleman, Dick, Sewell, Percivall, White, Rydge, Stewart, Youatt, and many others; and although a few of their works may now be obsulete, the greater portion, particularly the valuable work of Mr. Youat contain a vast fund of practical and useful information.

HOAR FROST. To the authorities quoted in the article Fros'r, I would add that of the Rev. J. Farquharson. He draws from his observations the conclusions that these frosts nccur when the thermometer is at ten feet from the ground, of varying degrees of temperature, sometimes is high as $41^{\circ}$; $2 \mathrm{dly}$, that they take place at the time of a high daily mean temperature only during a calm; $3 \mathrm{dly}$, that the air is always, or nearly all of it, unclouded; 4 thly, that they most frequently take place when the mercury of the barometer is high and rising, and when the hygrometer for the season indicates comparative drynes.5. 5thly. In general, low and Hat lands in the bottoms of valleys, nut grounds that are in land-locked hollows, suffer from these frosts, while all sloping lands an'd open uplands escape injury. This he accounts for by supposing that on sloping grounds there are always currents of air which mix the upper and warmer strata of air with !hat which rests immediately on the ground, and avhich it would seem, from some experistents of Dr. Wells, is ne unfrequently much .626 colder thar that only four feet from the sur. face. He found, on the 19th of August, 1813 (Trans. High. Soc. ix. 250) :-

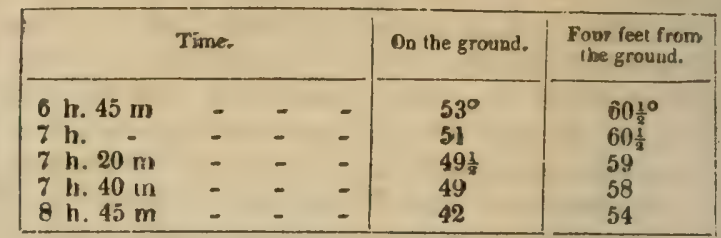

The slightest protection, even that of a bush, thin sprinkling of straw or litter, is sufficient to prevent the deposition of frost, because it is only necessary to prevent radiation.

HOEING BY HAND. The hand hoe is an instrument too well known to need any description. The operation of hoeing is beneficial, not only as being destructive of weeds, but as loosening the surface of the soil, and rendering it more permeable to the gases and aqueous vapour of the atmosphere. Hoeing, therefore, not only protects the farmer's crops from being weakened by weeds, but it renders the soil itself more fertile, as more capable of supplying the plants with their food. Jethro Tull was the first who warmly and ably inculcated the advantages of hoeing cultivated soils. He correctly enough told the farmers of his time, that as fine hoed ground is not so long soaked by rain, so the dews never suffer it to become perfectly dry. This appears by the plants which flourish in this, whilst those in the hard ground are starved. In the driest weather good hoeing procures moisture to the roots of plants, though the ignorant and incurious fancy it lets in the drought.

HOGS. See SwrNE.

HOGWEED (Heracleum sphondylium). The weed known by this name in Pennsylvania and other Middle States, is also called Rag-weed and Bitter-weed, the Ambrosia Elutior or Taller Ambrosia of botanical writers. This apparently very worthless weed is common in pastures and cultivated fields, always following the wheat crop immediately after harvest, as though a parasite of this species of grain. If the land be good, the plant seems to give place, the following season, to the crop of clover or timothy. "I have," says Dr. Darlington "been puzzled to determine this species satisfactorily. It is evidently, I think, the Ambrosia Elatior of Bigelow, and some others, and as clearly the A. artemisifolia of Barton, \&c.; whilst, at the :iame time, it agrees pretty well with Elliott's A. paniculata. Are they, all distinct species? Five or six additional species are enumerated in the United States." (Flor. Cestrica.)

This plart comes into flower about the middle of May; its nutritive powers appear to be considerable when compared to those of lucern and some other plants. Sinclair found that 64 drs. of the herbage afforded of nutritive matter 90 grs., lucern an equal proportion, the same weight of burnet and of Bunias orientulis 100 grs. each, of the broad-leaved cultivated clover $\mathbf{8 0}$ grains. See Cow-Parsur. (Hort. Gram. Wob.p. 411.)

HOLCUS. The soft-grass. A genus of grasses of which Smith, in his Eng. Flor. (vol i. p. 107), describes three species, but whic! 
Sinclair, in his Hortus Gramineus, has extended to 5 species and varieties, including the northern holy-grass (Hierochloe borealis), which Smith very properly refers to another class.

Holcus avenaceus (Pl. 5, cc). Tall oat-like soft-grass. In this species the calyx is smooth, the barren floret lowest, with a sharply bent prominent awn; fertile one bent, slightly elevated, scarcely awned; leaves rather harsh; roots knobbed, or with tuberous joints and downy fibres. In dry or fluctuating soils the roots become largely bulbous, and then constitute a troublesome weed. In the works of Linnaus, Curtis, and Host, this grass is found under the name of Avena elatior; it has since ieen thought to agree better with holcus in structure; but it appears to belong to neither of these justly, serving rather to form the connecting link between the avena, holci, and aira. This grass grows common in pastures, hedges, thickets, and by road sides. The stem rises to 3 feet high, is smooth, simple, and jointed; the joints sometimes downy; the leaves are deepgreen, rough-edged, and rather harsh to the louch, with long striated sheaths, and abrupt stipules. 'The flowering panicle is erect, lateral. 'The seeds are nearly cylindrical, and coated with the hardened corolla. This grass sends forth flowering culms during the whole of the season. The entire plant is subject to rust after the period of flowering; hence the crop should be cut as soon as the grass is in flower. This grass is eaten by all sorts of cattle, and is always present in the composition of the best natural pastures; but it does not constitute a large proportion of the herbage. It perishes rapidly after being cropped; and though later in flowering (end of June) than many other species, produces an early and plentiful supply of herbage in the spring. These properties would entitle it to rank high as a grass adapted for the alternate husbandry, but with respect to its nutritive properties, it contains too large a proportion of bitter extractive and saline matters to warrant its cultivation without a considerable admixture of different grasses; and the same objection extends to its culture for permanent pasture.

Holcus avenaceus, var. muticus. Awnless, tall, oat-like soft-grass. In this variety, which is smaller in every respect than the preceding, the leaves are very short, the roots slightly l. erous, the panicle much contracted, the flowers without awns; glumes pencilled at the apex with purple. It flowers a week later than the awned variety; in all other respects it is the same. It seldom perfects any good seed, and appears to be much inferior in point of produce. Hares give a decided preference to the awnless variety.

Holcus lanatus. Woolly or meadow softgrass. The root in this species is fibrous; the stem simple, $1 \frac{1}{2}$ to 2 feet high, smooth above, hairy below, with hairy sheaths, and short blunt stipules. The panicle is thrice compound, erect, and spreading. The calyx of the flower is wonlly, lower floret perfect, awnless; upper with an arched awn; leaves downy on both sides. This is a very troublesome grass, which is difficult to get rid of; it grows abun- dant in meadows and pastures on all soils, from the richest to the poorest. Cattle prefer almost any other grass to this; hence it is seen in pastures, with full-grown perfect leaves, while the grasses that surround it are cropped to the roots. Sir Humphry Davy has shown that its nutritive matter consists entirely of mucilage and sugar; while the same property in the grasses most relished by cattle has either a sub-acid or saline taste. This grass might probably be rendered more palatable to cattle by being sprinkled over with salt.

Hard stocking, and never suffering it to run to seed, will at least prevent this grass from spreading; but ploughing up the pasture, and taking not less than a five years' course of crops and then returning the land to other grasses, will be found the best means of getting rid of it. It flowers and ripens the seed in July.

Holcus mollis. Creeping soft-grass. PI. 5, c. Couch-grass. The specific character of this species is, root creeping, calyx partly naked. lower floret perfect, awnless, upper with a sharply bent prominent awn; leaves slightly downy. The distinctions between this grass and the woolly or mcadcm scft-grass H.lana. tus, are the creeping root, and the whule plant being more slender and less downy. The leaves are also narrower and more soft than those of the H.lanatus, and grow more distinct from each other: on the contrary, those of the H. lanatus are in dense tufts. The panicle is more loose and smoother, with conspicuous awns, which, in drying, bend at a right angle, and extend beyond the calyx. The panicle of the $H$. lanatus is generally of a reddish purple colour tinged with green, or, when growing under the shade of trees, of a whitish-green colour. The panicle of the $H$. mollis is always of the latter colour. This grass would rank as one of the superior grasses if it did not usually tenant a light barren sandy soil; but it produces little herbage in the spring, and the aftermath is next to nothing. Pigs are very fond of the roots, which contain a very considerable quantity of nutritive matter, having the flavour of newmade meal. The herbage is apparently more disliked by cattle than that of the $H$. lanatus: it is extremely soft, dry, and tasteless. The roots, when once in possession of the soil, can hardly again be expelled without great labour and expense. It is the true couch grass of light sandy soils, for its roots frequently attain in a few months to 4 or 5 feet in length. The best mode of banishing this impoverishing and troublesome weed from light arable lands that are infested with it, is to collect the roots with the fork after the plough; and when thus in some measure lessened to apply yearly dressings of clay, perhaps 50 loads per acre, till the texture of the soil is changed to a sandy loam; this grass will then be easily overcome, and the fertility of the soil permanently increased.

\section{See Covcr.}

Holcus odoratus (repens) Sweet-scented soltgrass or northern noly-grass. See HoLr. Gnass.

I have placed together in a tabular form the comparative yield of produce of these grasses. (Sinclair's Hort. Gram. Wob.) 


\begin{tabular}{|c|c|c|c|}
\hline \multirow{3}{*}{$\begin{array}{l}\text { Holcus avenaeeus, soil } \\
\text { clayey loam in fower } \\
\text { Holcus avenaceus, seed }\end{array}$} & \multicolumn{3}{|c|}{ Produce per Acre in Pounds. } \\
\hline & Green. & Dry. & Nut. Mat. \\
\hline & 17,015 & 6,380 & 664 \\
\hline $\begin{array}{c}\text { Holcus avenaceus, geed } \\
\text { ripe - }\end{array}$ & 16,335 & 5,717 & 255 \\
\hline Holcus avenaceus, latter- & & & \\
\hline $\begin{array}{l}\text { math - } \\
\text { H. uvenaceus, var. mu- } \\
\text { ticus, soil rich clayey }\end{array}$ & 13,612 & 4997 & 265 \\
\hline $\begin{array}{l}\text { loam, in flower - } \\
\text { latter-math }\end{array}$ & $\begin{array}{r}12,251 \\
3,453\end{array}$ & 4,287 & $\begin{array}{r}669 \\
53\end{array}$ \\
\hline $\begin{array}{l}\text { H. lanatus, clayey loam, } \\
\text { in flower - - } \\
H \text {. mollis, sandy loam, in }\end{array}$ & 19,057 & 6,193 & 1191 \\
\hline flower - - & 34,031 & 13,612 & 2392 \\
\hline H. odoratus (repens), in & 21,099 & 8,439 & 1153 \\
\hline flower - $\quad-$ seed & 9,528 & 2,441 & 632 \\
\hline ripe - & 27,225 & 9,528 & 2233 \\
\hline
\end{tabular}

HOLLY (Ilex aquifolium). A handsome evergreen tree, of slow growth, with a smooth, gray bark, which, abounding in mucilage, makes bird-lime by maceration in water. The wood is hard, close-grained, and covered with the above smooth gray bark. The leaves are alternate, stalked, rigid, shining, waxy, with spinous divaricated lobes; the upper ones on old trees entire, with only a terminal prickle. The flowers are copious, white, tinged externally with purple, the earlier ones least perfect. The berries are scarlet, casually yellow. The holly grows in hedges and bushy places upon dry hills. Numerous variegated varieties are kept in gardens, and one whose leaves are prickly on the disk. Darwin suggested the idea, that the points on the lower leaves of the holly was a provision of nature to prevent them from being eaten by cattle; hence, when the tree grows beyond the reach of the cattle, the leaves lose the pines, that species of armature being no longer necessary. The tree bears clipping well; but it is not so fashionable for cut hedges as formerly. The branches, laden with berries, are stuck about rustic kitchens and churches at Christmas, and remain till Candlemas Day. In Norfolk and some other English counties the misseltoe accompanies them, and sometimes branches of the spindletree or prickwrood.

The common holly of the United States is the Ilex opaca of naturalists, a handsome evergreen which, though in some of the Middle States a mere shrub, in others assumes the dignity of a tree. In Kent county, Delaware, the holly frequently attains a height of 30 to $\mathbf{4 0}$ feet. Seven or eight additional species are found in the United States, chiefly in the south.

HOLM (Sax. and Danish). An island or fenny place surrounded by water.

HOLM OAK, or HOLLY OAK. See OAK.

HOLT (Sax. a wood; Germ. holz). The termination of many names of places in England, derive $\mathrm{l}$ from their ancient situation in a wood.

HOI,Y-GRASS, NORTHERN (Hierochloe borealis). The sweet-scented soft-grass, Holcus vdoralus (repens) of some botanists. The powerful creeping ronts of this grass, its tender nature, and tne great deficiency of foliage in the spring are demerits which discourage the ;3a of recommending it further to the notice 628 of the agriculturist. It comes into flower about the end of April, and perfects hardly any seed; but few grasses propagate more quickly by the roots. This grass is said to be used at high festivals, for strewing the churches in Prussia, as Acorus calamus has time out of mind been employed in the cathedral an streets of Norwich on the mayor's day.

HOMESTEAD, or FARM STEADING. A collection of farm buildings and offices arranged in a convenient form.

HONEY (German, honig). A well-known vegetable substance collected by bees. "Its flavour," says Dr. A. T. Thomson, "varies according to the nature of the flowers from which it is collected. Thus, the honeys of Minorca, Narbonne, and England are known by their flavours. It is separated from the comb by dripping, and by expression; the first method affords the purest sort, the second separates a less pure honey, and a still inferior kind is obtained by heating the comb before it is pressed. When obtained from young hives which have not swarmed, it is denominated virgin honey. It is sometimes adulterated with flour and starch, which may be detected by mixing it with tepid water; the honey dissolves, while the flour or starch remains nearly unaltered." Honey is easily soluble in water, and, like sugar, readily undergoes the vinous fermentation; in this way, in fact, mead is made, an intoxicating beverage, once much more extensively prepared than now.

Honey constitutes a very important product of some countries, among which we may name Poland, where the management of bees is an extensive branch of forest culture. Poland honey is commercially divided into three classes; the finest, called lipiec, is gathered by the bees from the lime tree alone, and is considered on the Continent most valuable, not only for the superiority of its flavour, but also for the estimation in owhich it is held as an arcanum in pulmonary complaints, containing very little wax, and being, consequently, less heating in its nature; it is as white as milk, and is only to be met with in the lime forests in the neighbourhood of the town of Kowno, in Lithuania. It is the June and July work alone that constitutes this delightful product, and which is carefully taken from the hives, in which is left for the store of the bees the honey collected by them before and after the flowering of the linden, a tree quite different from all the rest of the genus Tilia, and called Kamienna lipsa, or Stone Lime.

The leszny, the next class of honey, which is inferior in a great degree to the lipiec, being only for the common mead, is that of the pine forests.

The third class of honey is the stepowey prasznymird, or the honey from meadows or places where there is an abundance of perennial plants, and hardly any wood. The province of Ukraine produces the very best, and also the very best wax. In that province the peasants pay particular attention to this branch of economy, as it is the only resource they have to enable them to defray the taxes leviod by Russia; and they consider the produce if bees equal to ready money. 
$+$

$$
+
$$




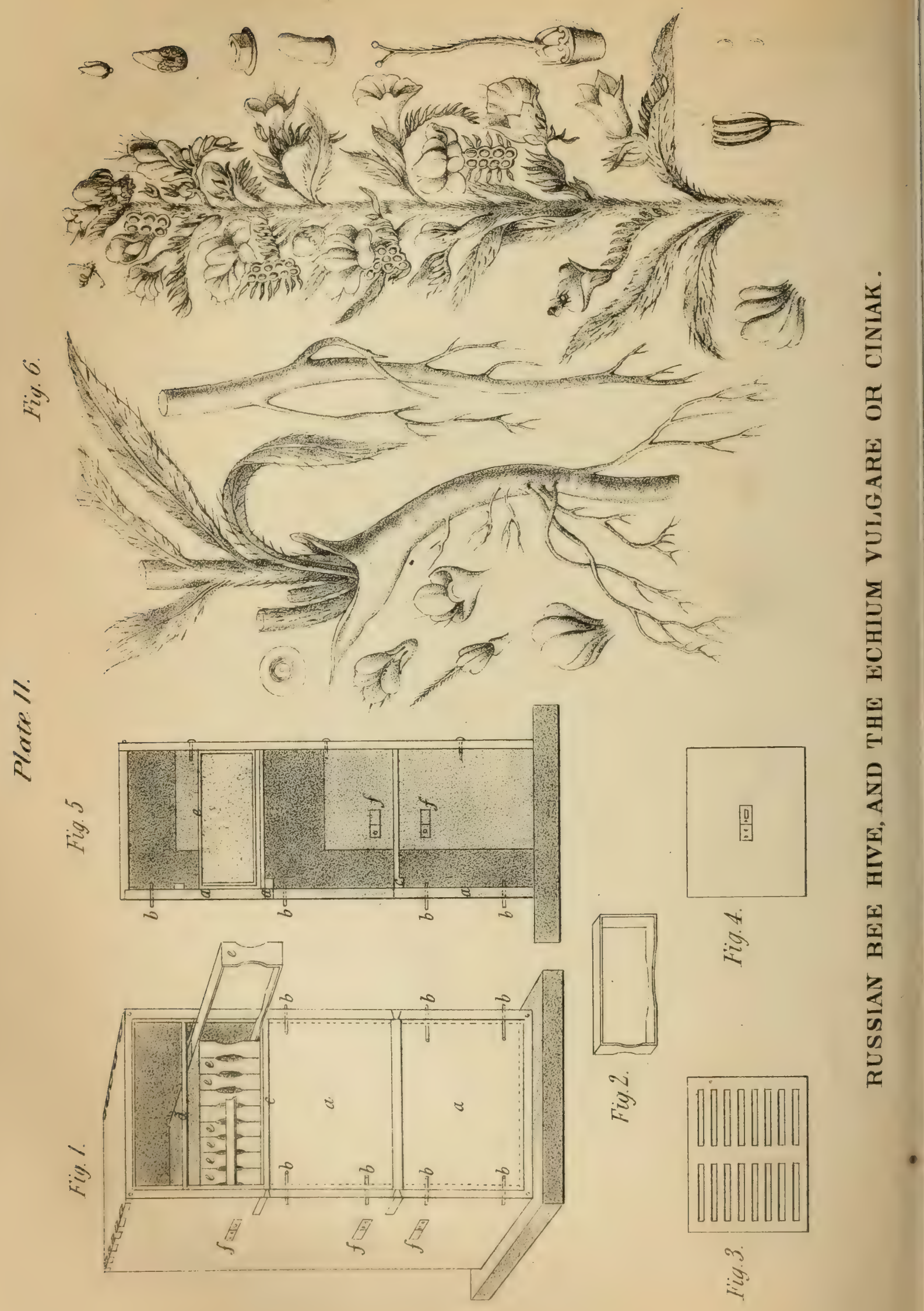


In the United States, the capacity to produce honey seems only limited by the ravages of that great pest, the bee-moth. Over this, however, it is to be hoped ingenuity will finally triumph, if it has not done so already. Sce BEES and BEE-MOTH.

\section{Russian Strtem of managing Bees and constructing Hives.}

In Russia and other northern parts of Europe, honey and wax constitute great sources of private wealth and general trade. A large amount of this honey is obtained from trees in the wild forests, which, when not hollowed by nature, are scooped out by man for the accommodation of swarms, nails being driven into the body, to prevent the bears from climbing up and getting at the honey. This primitive plan may be called the Forest system, to distinguish it from another, consisting of large assemblages of hives, entitling it to the appellation of the Camp system. These bee-camps are often removed from place to place, according to the abundance or scarcity of flowers. A new system of managing bees has been lately introduced into Russia, which has acquired immense celebrity, not only in that country, but in other parts of continental Europe, to the northern portion of which it may perhaps be more specially adapted. It is, however, at present receiving great encouragement in France, where the most active efforts are making to promote its extension. Although we believe that the most essential objects obtained by the Russian mode are gained through some of the almost innumerable contrivances worked out by American ingenuity, still we think it proper to make the citizens of the United States acquainted with what is deemed of so much individual and national importance abroad.

The Russian system owes its origin and establishment to M. Prokopòvitsh, an individual who has devoted more than half his life to the subject. His reputation as an apiarian is at present so high as to have enabled him to establish an extensive school for teaching the art of managing bees. His school and dwellinghouses are situated in the midst of a vast garlen, in which are found no less than twenty-eight hundred hives. The number of his pupils is never under eighty, which come from all parts of Russia, and remain two years. His terms are very moderate.

In studying the nature and characteristics of the queen, he made the discovery that she always keeps upon the honeycomb, and never creeps upon any part of the hive. This observation he has turned to advantage, so as to make the bees assort and dispose their honey in whatever manner he desires it to be deposited.

By discovering a plant pre-eminently rich in honey, he has rendered another service to his country, not less important than that just referred to. This is the Echium Vulgari, called in Russia Ciniak. It has long been known to abound in the materials of honey, but had always been left in a wild state until this intelligent Russian took it into regular cullivation for the use of his bees. In doing shis, says a French writer, he has rendered a service to Europe similar to that conferred by Parmentier, who placed the potato among the number of plants indispensable to the purposes of domestic economy. Many of the Russian provinces possess only a very few plants rich in honey; or, rather, owing to the rigours of the climate, the plants furnish honey during a very short period. The Echium is therefore the more valuable from the fact that it is so little sensible to the effects of both heat and cold, neither of which cause it to part with its mellifluous qualities. Even after the setting in of white frosts, which ordinarily commence about the end of September or first of October, it still continues to flower.

It is proper to observe that the plant which has thus acquired such great celebrity bears the same name with a common and very beautiful English wild plant, belonging to the $\mathrm{Bo}$ rage family, and that, in his Flora Cestrica, Dr. Darlington describes the common Echium as a foreign weed, extremely troublesome in some portions of the United States, though as yet rare in Chester county, Pennsylvania. A species called Violet Echium is cultivated in some flower-gardens in the United States, but no American species has yet been pointed out by botanists. The French call the common Echium Viperine, and Herbe aux Viperes; the Germans, Wilde Ochsenzunge, and Der Natterkopf. The popular names in the United States are Blue Weed, Blue Devils, and Viper's Bugloss. It is highly probable that the plant so much prized in Russia is a variety of Borage differing considerably from the weed denounced by Dr. Darlington. His caution, however, ought by no means to be forgotten by persons who introduce the Echium for the benefit of their bees, as it is a biennial, furnished with a very thick and hard tap-root, which must be very difficult to get out of ground when it has once gained possession. It should therefore be sown and kept in places where it may be restrained within bounds. It may be popularly described as a plant with long and rather narrow leaves, coming to a point, which leaves, with the stalks, are covered with a profusion of hairs. It puts out numerous spikes bearing one or two bellshaped flowers, of a purple-blue colour, having five petals, which are pubescent or hairy. It produces small, rough, and brownish ovalshaped nuts, which are angular on the inner side. (See Fig. 6, on the Plate representing the Russian Bee-hive, etc.)

\section{Description of the Russan Bee-hive.}

Fig. 1 represents the hive in perspective, supported upon a floor of brick or stone, carried beyond the sides of the hive, so as to secure a solid foundation. The usual size of this hive is three feet six inches in height, fourteen, twenty, and even as much as twentytwo inches in width, and from twelve to sixteen inches in depth. The box or case is made of five boards, either nailed, or, what is better, dovetailed together. The pieces represented at $a, a, a$, are three doors of equal size, which are fixed into mortices or grooves and fastened by the pegs $b, b$. $c, c$, are two movable pieces. an inch wide, unon which the morable donrs 3 \& 2 $6: 9$ 
rest. $d$, sinall slats fastened into the sides of the hive by mortices. These serve to prevent the doors from touching the honeycomb. Each range of frames has one of these slats.

$e, e, e$, are small frames in which the bees work and deposit their honeycombs. These frames are notched or scooped out circularly upon the lower side, as well as upon both edges of the front end, as represented in fig. 2 . The opening left by the hollow in the lowermost side serves for the bees to enter from beneath, whilst the hollows on the two sides of the front end of the frame admits the movements of the bees to be observed. These frames are thin; their thickness, however, is not arbitrary, but must be made to correspond to the size and form which the bees give to their combs. When placed side by side the frames must not touch, but a small space is to be left between to allow a little play, and prevent them from wedging together and becoming tight in warm weather, when the wood swells.

$f, f, f$, are three places of entrance for the bees, furnished with slides. These are so arranged that the middle one comes exactly in the middle of its compartment; the upper one is an inch higher than the upper slat; whilst the lower opening is an inch lower than the lowermost slat.

$h$ (fig. 3 ) is a grating to be used in autumn, when it may be desired to separate the empty parts from those filled with comb. This grating, or adapter, remains in contact with the bees. g (fig. 4) represents a small board, which is to be placed on top of the grating.

Fig. 5 is a transverse section, in which may be seen the places of entrance, $f$, the depth of the frames, $a$, and at $c$, one of the combs.

The various kinds of hives, constructed in sections or compartments, may be divided into two classes, namely, - those in which the divisions are made either horizontally or vertically. The first are founded upon the well-known necessity for allowing space for the new combs; the second from the advantage derived from separating the swarms artificially. To carry out these plans, very complicated contrivances have generally been employed, whilst the Russian hive effects every necessary object to be gained from section or division hives.

The leading principle of the Russian hive, which, it will be seen, is quite plain in construction, and economical as to first cost,consists in its capacity to be reversed or turned "pside doun, a very simple operation, which, however, leads to the most important results in the management of bees.

Reversing the hive not only allows of the perfect renewal of the wax, but furnishes an opportunity of inspecting every thing passing within, by means of the movable doors, and at the same time, of conducting all the operations at pleasure, thus uniting all the advanlages of the two systems of horizontal and vertical section hives, such as the separation of swarms, \&c.

By means of the operation of reversing, the see-manager who introduces a swarm into the Russian hive, will, during three years, be able to withdraw each year one of the three divisions alternately, or one-third of the whole mass of honey deposited; at the end of the period mentioned, he will have thus produced a perfect renewal of the wax; that is to say, at this time he will be obliged to reverse or turn up the hive, the former bottom of which now becomes the top.

The mode in which M. Prokopovitsh manages to make his bees assort their honey themselves, is effected by means of a very simple contrivance. Many others have devised modes very similar to those adopted by the Russian apiarian, but it is asserted that their objects had not the same end, since they only sought to obtain the virgin honey. No one has before believed it practicable to pro cure honey of a uniform quality and which at the same time is virgin honey. The idea therefore originally belongs to M. Prokopovitsh, who, whilst pursuing his apiarian studies, had it suggested to him by a plan adopted by Huber for the mere purpose of being able to watch the habits of bees.

The process of working the Russian hive is as follows: In autumn, after having taken the upper portion of the crop, when the amount of honey admits this to be done, the part of the hive thus left empty is separated from the rest of the comb, by introducing the grating $h$, and placing upon it the board $g$. In this state the hive is conveyed to some suitable place to pass the winter. The following summer, at the ar rival of the season when the plant from which honey is to be collected is in flower, the boarc? is removed, and the frames $e$ placed upon the grating. These frames, which are made of very thin stuff, have a length equal to the depth of the hive. Their height is about half that of their length, and their width or thickness ought not to exceed an inch and a half.

Two sides of the frame, have, as already described, two notches or hollows which reduce their width. One of these is the long side which comes in contact with the grating, affording passage to the bees, whilst the other is the end near the door which admits the movements of the bees to be inspected. Before these frames are arranged in their places, a little dry wax is to be stuck along the middle of the upper side of the frame, (the side which is not scooped out). This is for the purpose of directing the bees where they must place their combs.

By the arrangement described, the bees finding above them a vacant space, commence their work in it, and finding in the flowers in bloom sufficient material, fill the cases with honey, and this they do with the more rapidity from the circumstance of the queen's being separated by a space not yet occupied by the combs, and her inability to reach these to lay her eggs in them. The cases in which the honey is deposited are sealed up immediatcly, the comb is observed to have reached the lower part of the box, and before the queen has had an opportunity of depositing in it any eggs. The honey thus obtained is of remarkable purity, and may be taken to market in the same frames in which it was originally made. These may even be packed up torether in cases, and transported in wagons to great distances, without doing the least injury to the honey. 


\section{HONEY DEW.}

HONEY DEW. See ApHrmans.

HONEY LOCUST, or Sweet Locust (Gleditsia triacan(hos). The sweet locust belongs peculiarly to the country west of the Alleghany Mountains, and it is scarcely found in any part of th: Aclantic States, except in Limestone Valley and its hranches, which lie between the first and second ranges of the Alleghanies, beginning near Harrisburg in Pennsylvania, in the latitude of $40^{\circ} 42^{\prime}$, and extending from north-east to south-west into the state of Virginia. The soil in this valley is generally very substantial. In the fertile bottoms which are watered by the rivers emptying into the Mississippi, in the Illinois country, and, still more, in the southern part of Kentucky and Tennessee, the sweet locust is abundant. It commonly grows with the black walnut, shell-bark hickory, red elm, blue ash, locust, box elder, and coffee tree, and forms a part of the forests that cover the most fertile soils. In different parts of the United States, this species is called indifierently sweet locust and honey locust; the French of Illinois call it févier.

In situations the most favourable to its growth, such as are observed on the banks of the Ohio, between Gallipolis and Limestone. the sweet locust attains a very ample size. Michaux measured several stocks which were three or four feet in diameter, and which appeared to equal in height the loftiest trees of these immemorial forests. Some of them had the trunk undivided for forty feet.

The sweet locust is easily known by its bark, which, at intervals of a few inches, detaches itself laterally in plates three or four inches wide and two or three lines thick, and by the form of its trunk, which appears to be twisted, and which presents three or four crevices of inconsiderable depth, opening irregularly from the bottom towards the top. The large thorns which cover the branches, and frequently the trunk of young trees, afford another very distinct characteristic. These thorns are sometimes several inches long, ligneous, of a reddish colour, and armed, at some distance from the base, with two secondary thorns, about half the size of the first.

The leaves of the sweet locust are pinnated, and composed of small, oval, serrate, sessile leaflets. This foliage is elegant, and of an agreeable tint; but it is thin, and scarcely obstructs the passage of the sunbeams. It is shed annually at the approach of winter.

The flowers are small, not very conspicuous, and disposed in bunches. 'The fruit is in the form of flat, cronked, pendulous pods, from twelve to eighteen inches long, and of a reddishbrown colour. 'The pods contain brown, smooth, hard seeds, enveloped in a pulpy substance, which, for a month after their maturity, is very sweet, and which then becumes extremely sour. Beer is sometimes made by fermenting this pulp while fresh; but the practice is not general, as the apple tree and peach tree, particularly the last, have become common in the western country, and afford a much superior beverage.

The perfect wood or heart of the sweet locust nearly resembles that of the locust, but its grain is coarser and its pores more open: in there
HONEYSUCKLE.

respects it is mure strikingly characterized than even the wood of the red oak. When perfectly seasoned, it is extremely hard. It is little esteemed in Kentucky, where it is more employed, and consequently can be beller ap. preciated, than elsewhere. It is used neither by the carpenter nor the wheelwright: it is sometimes taken by the farmers for rails us fence their fields, but only when they are unable to procure better wood. It is found by experience to be far inferior to the wild cherry and black walnut for cabinet-making. The only destination for which it appears to be peculiarly adapted, is the forming of hedges, which would be rendered impenetrable by its long thorns.

The sweet locust has been cultivated for many years in Europe. It flourishes, blooms and yields seed in the climates of London and Paris; but its vegetation is less active than in the south of France. (Michaux.)

HONEYSUCKLE (Lonicera, named after Adam Lonicera, a German botanist, who died in 1586). This is a genus of very ornamental shrubs, closely allied to the genus Cuprifolium. The species grow in any common soil, and are readily increased by cuttings taken off in autumn and planted in a sheltered situation. (Puxton's Bot. Dict.)

In the English Flora, by Dr. Smith, three indigenous species are described.

There are five hardy sorts of honeysuckle mentioned by Miller; namely, the Virginian trumpet honeysuckle (L. sempervirens), the German honeysuckle, the Italian honeysuckle, the English honeysuckle or woodbine (L. periclymenum), and the evergreen honeysuckle. He names also three other sorts, which are too tender to raise without artificial heat.

There are two varieties of the trumpet honeysuckle; one is a native of Virginia, and the other is from Carolina. The Virginia trumpet honeysuckle is hardier, its leaves are of a darker green, and its flowers are a deeper red than the Carolina. These plants are weak and trailing; they should therefore be placed against walls and trellis-work.

The German or Dutch honeysuckle is a hardy shrub, which can be formed into a good round head: the flowers are reddish outside and yellowish within, blooming in June, July, and August. Miller mentions two varieties of this honeysuckle, the "long blowing" and the "late red."

The Italian honeysuckle has two varieties, the "early white," which is fragrant, but of short duration, blooming in May; and the "yellow," which bears yellowish flowers, and is succeeded by red berries.

The American or evergreen honeysuckle is the most valuable, for it flowers from June til the frost nips its blooms. It has strong branches bearing evergreen leaves and fragrant flowers, which are bright-red outside and yellow within.

All the sorts are propagated by layers or by cuttings. The plants produced from cuttings are the best rooted, and should be done in september. Each cutting should have four joints and only one joint should be left above ground. The honeysuckle loves almost any soll, pro. vided it be not too dry. See Ruonodernaon. 
HONEYSUCKLE, FRENCH (Hedysarum). Almost all the species of this genus are very handsome flowering plants, producing racemes of very beautiful pea flowers, particularly adapted for borders ol rock-work. Miller mentions nimeteen sorts. 'The greater number are perennials. The most general species in English gardens is the $H$. coronarium, which blooms bright-red flowers, and a variety of it, which blooms white flowers, both flowering in June and July. They are propagated by sowing seed in the spring in light garden mould, and transplanting the young plants into their destined places in autumn. The herbaceous kinds are increased by dividing the roots.

HOOF. 'The horny part which covers the feet of many valuable quadrupeds. It is either cloven, as in cattle, or entire, as in the horse. In the horse it is that portion of the foot which is composed of the crust or wall, the bars, the sole, and the horny frog. There is no frog in the foot of cattle, nor are there the provisions for the expansion and elasticity of the foot which we admire in the horse. There is a laminated connection between the hoof of the ox, and the sensible parts beneath, as in the horse; but the horny plates of the hoof, and the fleshy ones of the substance which covers the coffinbone, are not so wide and deep, and therefore the attachment between the hoof and foot is not so strong. The hoofs of cattle are used for making starch and Prussian blue, as they will not make glue or soap like the heels. (Cattle, p. 568 ; The Horse, p. 281.)

HOOP-ASH. See Hackarrit.

HOOVE. See Cattre, Diseases of.

HOP (Humulus lupulus). This is a wellknown climber, supposed to be indigenous to England, plants of it being found in hedgerows and waste places. The ancients were not unacquainted with the hop. It is mentioned by the Arabian physician Mesue, who lived about 845 ; and it was used for beer in Flanders in 1500. The female flowers, indeed, have been long used in many parts of Europe for the purpose of imparting a flavour to beer. It was not, however, cultivated in England for this purpose until about the year 1525 ; and as the Reformation was then in progress, the introduction of the hop is perpetuated by the following doggerel :

Hops, heresy, pickerel, and beer

Were brought into England in one year.

In 1528 the parliament was requested to prohibit its use, as an unwholesome weed that would spoil the taste of beer. It is mentioned for the first time in 1552 in the statute-book, in the 5 Edward VI. c. 5 (repealed 5 Eliz. c. 2 ); an act directing that land formerly in tillage should again be so cultivated, but excepting, amongst other ground, "land set with saffron or hops ;" and down to the year 1693 hops were imported from Flanders in considerable quantities. In 1578 Reynold Scott published a curious little sork on the cultivation of the hop, which is now rare: it was entitled, "A Perfite Platforme of a Hoppe Garden," in which the directions for the cultivation of the hop are given with considerable care.

The chief counties in which the hop is now rultivated in England, are those of Kent, 632
I Sussex, Surrey, Worcester, and Essex; but the hop-gardens of these counties are only situated in particular portions.

'The hop plant delights in a rich loam, or calcareous sand; and when these are situated on a calcareous bed, the plants will continue to flourish for many years; but otherwise ten or twelve years is about the limit of their continuance in perfection. Under favourable circumstances, as on the Kentish ragstone, the roots of the hop plant extend in some instances to a depth of eight or ten feet. The hop plant is usually raised from cuttings in the spring. "In the early part of the spring," says Mr. Lance, "the old root begins to bud or shoot from the old stump of the last year's bine, which will have two or more buds; the crown of the root is then cleared, and these old stumps are cut off, or most part of them, the hole covered up, and the crown of the root throws up additional shoots to be tied up the poles. The plant is therefore said to have an annual stem, but a perennial root. The cuttings, or old stumps, are bedded for a season, to make ruots the best way they can from the edge of the cutting: the plant being exceedingly tenacious of life, every portion of the crown cutting that has a bud will grow and throw out roots from the extremity of the woody cutting; they will make a circle of roots when healthy, and throw up bine from the eyes or buds at the surface of the ground, and other roots will issue from under the eyes. The shoots of the former year that may have become covered with earth will make plants as layers, throwing out many fibrous roots before they are cut off from the stump or crown. This is often the most successful method of obtaining plants, although it may in some measure weaken the old root; but the layer gets the plants a year more forward, as the roots are already formed when the plant is taken from the old stock; but if all the supernumerary shoots are cut off after the principal ones are well up the pole, then there can be no suckling plants formed. There are several varieties of the hop," adds Mr. Lance, "named according to the colour of the bine, the hanging of the fruit, or local circumstances. The grape-hop takes its name from the hanging of the strobiles; the cluster being close together, like a bunch of grapes. 'Those named from the bine are the green, the white, the red. Others are named from places, as the Canterbury grape, the Farnham bell, the Mayfield grape; and some few are named from the persons who have raised them from seed, as Williams's white bine, at Farnham, being first raised by a gentleman of that name at Badshot Place, about the year 1780. This is the variety now principally cultivated at Farnham, and may be said to be one of the causes which make that place so famed for hops, they being purchased with avidity by the brewers of the west of England."

The qualities of the hop regarded by the lealers are the colowr, scent, seed, and glutinous touch. The colour, which should te a light green, is attained either by a very careful and early picking, or by exposing the hops when they are drying to the action of fumes of sulphur. By exposure to the air, however, the

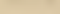


natural brown colour of the hops thus treated returns; and hence the Farnham hops are often preferred by the brewers of pale ale, because the colour is not apt to alter.

About 60 to 100 bushels of the picked hops are required for a $\mathrm{cwt}$. of dried hops in the bag; but this varies with circumstances. When there is an abundance of plump, well-formed seed, from 40 to 70 bushels will form a cwt. A bag of hops will weigh about $2 \frac{1}{2} \mathrm{cwts}$., and a Kent pucket about $1 \frac{1}{4} \mathrm{cwt}$. The produce of an acre of hops will sometimes amount to 24 cwt., but the average is about $10 \mathrm{cwt}$. 'The hop plant is subject to many diseases, to the attacks of caterpillars and other insects, to mildew, and to a variety of atmospherical influences, which renders it ever the sport of the weather, and occasions the proverbial uncertainty of the crop.

In the culture of the hop, a deep soil is preferable, and many powerful fertilizers may be had recourse to. There is, perhaps, no plant which delights more in those of an oily nature than the hop. The Kentish growers of the valley of the Medway successfully employ large quantities of sprats, for which they readily give $10 \mathrm{~d}$. per bushel. They use from 40 to 60 , or more, bushels per acre. Other planters employ woollen rags, chopped into small pieces, from 1 to 2 tons per acre. They last for 2 years. These cost about $5 l .5 s$. per ton. Salt, also, is an excellent addition, in conjunction with these, at the rate of from 10 to 15 bushels per acre.

The plants are usually placed on hills, at the distance of 5 or 6 feet, and this is usually done early in the spring, about the end of March. The first year's poles may be about 6 feet in length, but twelve feet poles are afterwards needed. Two or three of these are commonly placed on a hill: they are generally set in the ground in the end of April. About 500 fresh poles are annually required per acre, to keep up the stock of poles, and supply the place of those broken or otherwise destroyed.

The ground in hop gardens can hardly be too much stirred over. The drying of the hops is effected soon after they are picked. For the despatch of drying, a thickness of from 1 to 2 feet of hops are placed on the kiln floor, and a fire of culm or Welch coal, coke, charcoal, or other material that gives out no smoke, is made in an open fireplace, with only a perforated hood over it; or, if the kiln fireplace is enclosed, and the smoke-flue is made to pass round the building, any firing may be used: but the neatest and cleanest method is by passing hot water through pipes, close beneath the drying-floor. About 100 to 200 bushels are commonly dried at once in the ordinary-sized hop-kilns. Considerable quantities of sulphur are sometimes added to the fire, sometimes as much as a cwt. to a ton of hops. About 98 to $\mathbf{1 1 2}$ degrees of heat is that commonly employed in the drying, and the cost of the process is about 14s. per cwt.

In bagring the hops, great care is requisite to tread them as close as possible; for the more completely the air is excluded, the better the hops will keep.

The dried hop has been analyzed, and found to contain lupuline, a titter principle, opism, a 81) fatty astringent matter, gum, chlorophylle, and lig. nin. In the grains of the lupuline a volatile oil is deposited. 'The salts of iron, gelatin, chloride of barium, and oxalate of ammonia, cause precipitates in the decuction of the hop. As a medicinal agent, hops display tonic and narcotic properties. A pillow of hops is supposed to be a good soporific, and was obtained for George III. when a lunatic. The extract has been found to allay pain; but, after all, it is better as an adjunct to beer than as a. medicine.

In England, the expense of $1 \mathrm{cwt}$. of hops, if purchased on the poles (says Mr. Lance,) may be thus stated:-

\begin{tabular}{|c|c|c|c|c|c|c|c|c|c|c|}
\hline The duty & & - & - & - & - & - & - & - & & 18 \\
\hline Picking & - & - & - & - & - & - & - & - & 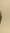 & 10 \\
\hline Bags & - & - & - & - & - & - & - & - & 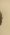 & 1 \\
\hline Drying & - & - & - & - & - & - & - & - & 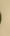 & 5 \\
\hline Bagging & - & - & - & - & - & - & - & - & 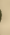 & 0 \\
\hline Cartage & - & - & - & - & - & - & - & - & 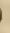 & 2 \\
\hline Sale & - & - & - & - & - & - & - & - & & 1 \\
\hline
\end{tabular}

The following are the expenses and produce of 4 acres of hop ground in Mid-Kent, in 1836 :-

Rent and taxes on 4 acres, at 40 s.

L. $\quad$ s. $d$

Culture labour, at $50 \mathrm{~s}$. - - - - - - -100 Repair of poles - - - - - - - 40 Dunging, at $40 \mathrm{~s}$. - - - - -800

Picking 4,332 bushels, at 7 for 18. - - $\quad-2315$

Drying, labour ouly - - _ - $\quad$ - 3120

39 pockets, making, marking, sifting, and treading, at $1 s$. $2 d$.

Pocket cloth -

$-400$

Charcoal - $-[-\ldots$

Sulphur and lime - $-\quad \ldots \quad-0176$

Rent of kiln - - - - _ - -400

Interest on first years' expenditure - $\quad 400$

juty on $64 \mathrm{cw}$ ts., at $18 \mathrm{~s} .8 \mathrm{~d}$. -

Tithe - $-\ldots+\ldots 00$

147106

The produce, $64 \mathrm{cwt}$, at $6 l .10 \mathrm{~s}, 416 l$.

The average produce of hops from 1807 to 1836 , as shown in a table from the work of $\mathrm{Mr}$. Lance on the hop, is $5 \frac{1}{2} \mathrm{cwt}$. per acre, the highest product in one year having averaged for the crop $12 \frac{20}{100} \mathrm{cwt}$. in 1808, and the lowest only $\frac{97}{100}$ in 1825 .

Number of Acres of Hops in cultivation.

\begin{tabular}{|c|c|c|c|c|c|c|c|}
\hline \multirow{2}{*}{ Year. } & \multirow{2}{*}{$\begin{array}{c}\text { No. of } \\
\text { Acres esti- } \\
\text { mated in } \\
\text { England. } \\
50,148\end{array}$} & \multirow{2}{*}{$\begin{array}{l}\text { Non of } \\
\text { Acres } \\
\text { in the } \\
\text { Clays. }\end{array}$} & \multicolumn{2}{|c|}{$\begin{array}{l}\text { Average } \\
\text { price of } \\
\text { the } \\
\text { country. }\end{array}$} & \multicolumn{2}{|c|}{$\begin{array}{l}\text { Average } \\
\text { price of } \\
\text { the Clays. }\end{array}$} & \multirow{2}{*}{$\begin{array}{c}\begin{array}{c}\text { Presumed ac- } \\
\text { lual value, in } \\
\text { cluding the } \\
\text { duty. }\end{array} \\
L .5 .110\end{array}$} \\
\hline & & & $L$. & 8. & $\begin{array}{l}L \\
4\end{array}$ & & \\
\hline 1821 & 45,662 & 691 & 4 & 4 & 4 & 6 & $1,000,000$ \\
\hline 1822 & 43,554 & 672 & 3 & 12 & 5 & 5 & $1,221,985$ \\
\hline 1823 & 41,458 & 671 & 10 & 0 & 12 & 0 & 446,038 \\
\hline 1824 & 43,449 & $6 \% 0$ & 7 & 0 & 9 & 0 & $1,847,960$ \\
\hline 1825 & 46,718 & 709 & 23 & 0 & 23 & 0 & 805.871 \\
\hline 1826 & 50,471 & 715 & 4 & 4 & 6 & 0 & $2,010,590$ \\
\hline 1827 & 49,485 & 715 & 4 & 12 & 6 & 0 & $1,360,835$ \\
\hline 1828 & 48,365 & 711 & 5 & 5 & $\tau$ & 0 & 1.813 .680 \\
\hline 1829 & 46.135 & 702 & 9 & 0 & 11 & 11 & 656,125 \\
\hline 1830 & 46,726 & 704 & J0 & 10 & 11 & 10 & $1,509,560$ \\
\hline 1831 & 47,129 & $\tau 12$ & 5 & 15 & 8 & () & $1,767,324$ \\
\hline 1832 & 47,101 & 714 & 9 & 0 & 10 & 0 & 2.114 .545 \\
\hline 1833 & 49,187 & 720 & 6 & 0 & 8 & 0 & $1,841,610$ \\
\hline 1834 & 51,273 & 726 & 5 & 10 & 6 & 10 & 1.974 .010 \\
\hline 1835 & 53,816 & 734 & 5 & 0 & 6 & i & $2,416,640$ \\
\hline 1836 & 55,422 & 757 & 8 & 10 & 8 & 10 & 3.155 .832 \\
\hline 1837 & 56,323 & 759 & 4 & 10 & 4 & 15 & $1.647,396$ \\
\hline 1838 & 56,101 & 749 & 5 & 0 & 6 & 0 & $1.753,120$ \\
\hline 1839 & 52,365 & & 3 & 3 & 3 & 12 & $1,241,252$ \\
\hline
\end{tabular}

The number of acres devoted to the cultira. tion of the hop has long veen steatily on liv 


\section{HORDEIN.}

increase since 1693 ; when they were first successfully cultivated in Kent; in 1807, it was found that the hop-grounds throughout England amounted to 38,218 acres: these had increased to 46,293 acres in 1817 , to 49,485 in 1827 , and to 56,323 acres in 1837 ; they had decreased however in 1839 to $\mathbf{5 2 , 3 6 5}$.

Hops are extensively and advantageously cultivated in some parts of the United States. Gurdon Avery, in the village of Waterloo, Oneida county, N. Y., raised in 1842, on 12 acres of land, $29,937 \mathrm{lbs}$. of hops.

The hop is also well known as a garden plant. It blows its flowers from June till August, and is propagated by seed and by dividing the roots. It likes a deep loamy soil, and is valuable as an ornamental climber over tem. porary arbours, trellis, \&c. in summer, as its leaves are very large, and make a fine shade. The "white bind" and the "gray bind" are the best sorts for this purpose; they succeed each other.

The young shoots of the hop are eaten as a lepurative; the flowers, besides their bitter narcotic qualities, are diuretic and sedative.

HORDEIN. A modification of starch, which, according to Proust, constitutes about 55 per cent. of barley-meal.

HORDEUM. The barley-grasses. Besides the species of cultivated barley enumerated in the article under that head, there are three indigenous species which grow wild in Engand.

Hordcum murinum. Wall-barley, mouse-barley, or way-bennet grass.

This is an annual grass, with a fibrous root, supporting a number of culms 12 to 18 inches :iigh, procumbent at the base, afterwards erect, with three or four joints. Spikes-brittle, two "1hree inches long, flowers placed in two rows. This is one of the most inferior grasses with respect to nutritive powers; and the long awns, with which it is armed must make it langerous to the mouths of horses, when it cnters into the composition of their hay. Forlunately it is uncommon in pastures, being chiefly confined to roadsides and other beaten or barren places. I never could observe this grass eaten by cattle of any description, not : ven by the half-starved animals which feed by roadsicles, where, in England, this is often the most prevalent grass. Dr. Withering, however, says, it is eaten by sheep and horses, and that it feeds the brown moth (Phalcena g:anclla), and the barley-fly (Musca frit.) The nutritive matter afforded by this grass consists chicfly of mucilage and extractive matter insoluble after the evaporation of a decoction of it. ' $t$ flowers in England abnut the first week of July, and the seed is ripe towards the end of the same month.

Hordcum pratense. Meadow barley-grass. Pl. 5, d. This species has some affinity to the wall barley-grass in appearance, but differs from it in being strictly perennial; and in having the culms more slender, much taller, and erec: and the sheaths roundish; the spike (about two inches long) is also slender in com. var!son with that of the $H$. murinum, and of a purple or greenish hue, while that of the wall barley-grass is of a dirty yellow. The husks 634 of the calyx are bristle-shaped, rough, but not ciliate, and the awns much shorter.

This is a very hardy grass, which is tolerably early in the spring produce of foliage, and its nutritive powers are considerable. Though said to be partial to dry chalky soils, I have always found this grass most prevalent on good rich meadow ground; it thrives under irrigation, and there are but few pastures in which it is not to be found. The Rev. G. Swayne observes, that in moist meadows it produces a considerable quantity of hay, but is not to be recommended as one of the best grasses for the farmer. It is liable to the same objection as the last, viz., the long sharp awns with which the spikelets are armed, rendering it dangerous to the mouths of cattle by sticking in small fragments to their gums and producing inflammation. In England it flowers in July, and the seed is ripe in August.

Hordeum maritimum. Sea-barley, or squirreltail grass. This species is annual in its habit, and grows in pastures and sandy ground near the sea. It most resembles $H$. murinum in general habit, but is on the whole rather smaller, and more glaucous. The awns are all rougher, with minute bristly teeth. The plant is not of common occurrence, although it abounds in the isle of Thanet. (Eng. Flor. vol. i. p. 179; Hort. Gram. Wob.)

HOREHOUND, WATER. One of the names of the common gipsy-wort (Lycopus Europaus); which see.

The plant called by this name in the United States, is the $L$. sinuatus, which frequents the low grounds of Pennsylvania and other Middle States. (Flora Cestrica.)

HOREHOUND, WHITE (Marrubium vulgare, from marrob, a Hebrew word, signifying a bitter juice; in allusion to the extreme bitterness of the plant). This species grows in rubbish by roadsides, in dry waste grounds, and on commons, flowering from July to September. The stem is bushy, branching from the bottom, bluntly quadrangular, clothed with fine woolly pubescence. The shape and size of the leaves varies; the flowers are white, in dense convex whorls. The whole herb has a white or hoary aspect, and a very bitter, not unpleasantly aromatic, flavour. Its extract is a popular remedy for coughs and asthmatic complaints; hence also the celebrity of horehound-tea among the common people. Bees collect honey froin the flowers; but the herb is not eaten by any of the domestic animals.

Any common soil will suit these plants, and they are readily increased by divisions of the roots, or by seeds. (Eng.Flor. vol. iii. p. 103 ; Paxton's T.ot. Dict.)

HORN. A hard substance, growing on the heads of various animals, which partakes of the chemical nature of the cartilaginous part of bone; it consists chiefly of albumen, with some gelatin and a trace of phosphate of lime.

The horn of the ox is composed of an elongation of the frontal bone, covered by a hard coating, originally of a gelatinous nature. Its base is a process or continuation of the frontal bone, and it is, like that bone, hollow and divided into numerous compartments or cells, all of them communicating with each other, 


\section{HORNBEAM.}

and lined by a continuation of the membrane of the nose. The bone of the horn is exceedingly vascular, and hence, when broken, the hæmorrhage is so great that there could scarcely be more bleeding from the amputation of a limb. The rings on the horns of cattle have been considered as forming a criterion by which to determine the age of the ox. At three years old the first distinct one is usually observed; at four years old, two are seen; and afterwards one is added each succeeding year. Thence was deduced the rule, that if two were added to the number of rings the age of the animal would be given. These rings, however, are perfectly distinct in the cow only; in the ox they do not appear until he is five years old, and they are often confused: in the bull they are either not seen until five, or they cannot be traced at all. As a criterion of age, this process of nature is far too irregular for any certain dependence to be placed upon it, and the rings are easily effaced by a rasp. The length of the horn-whether classed as long horns, short horns, or middle horns-now forms the distinguishing character of the different breeds of cattle. The oxen of the northern part of central Africa, although smaller than the majority of the English cattle, have horns that are nearly four feet in length, and will contain more than ten quarts. The Burmese oxen, which are much larger, have singular horns of a half spiral form, very soft, the pair together scarcely weighing 4 pounds; yet Captain Clapperton tells us, they are 3 feet 7 inches in length, 2 feet in circumference at the base, and 1 foot 6 inches midway towards the tip. Some of the true Arnee buffaloes at Bengal, and the Abyssinian cattle, have also enormous horns. The horns of cattle are applied to a variety of purposes; for making combs, knife-handles, the tops of whips, substitutes for glass in lanterns, glue, and the refuse chippings are used as manure.

The Iceland sheep sometimes carry five or six horns. (Youatt on Cattle, p. 278-283.)

HORNBEAM (Carpinus betulus, from the Celtic car, wood, and pinda, head, the wood being fit for the yohes of cattle). A rigid tree of humble growth, patient of cropping, and well suited for hedges or covered walks in gardens of the old style, some of which may still be seen attached to several old English mansions. In England fashion has entirely swept away the hornbeam, which composed the labyrinth, the maze, the alleys, the verdant galleries, arcades, porticoes, and arches of our forefathers, and which formed the leafy walls that divided their stately gardens into stars, goose-foot avenues, and devices as numerous as geometrical figures are various. When standing by itself and allowed to take its natural form, the hornbeam makes a much more handsome tree than most people are aware of, growing from 12 to 30 feet high. It is found in woods and hedges, on a meager, damp, tenacious soil, and makes a principal part of the ancient forests on the north and east sides of London, as Finchley, Epping, \&c. The wood is, as Gerarde says, of a horny toughness and hardness: the bark smooth and whitish or light gray. Leaves resembling those of an elm, but smooth, doubly
HORNED-POPPY.

serrated, pointed about two inches long, piaited when young, having numerous, parallel trankverse hairy ribs.

Young trees are raised from seeds or layers without difficulty. It is known by different local names, such as the hard beam tree, the horse, or horn beech tree, \&c. 'The leaves of the hornbeam afford a grateful food to cattle, but no grasses will grow under their shade. The wood burns like a candle, is much employed by turners, and is very useful for various implements of husbandry, being wrought into cogs for the wheels of mills, presses, \&c. which are far superior to those made of yew.

There are two trees in the United States which go under the common appellation of hornbeam, namely, the water beech (Carpinus Americana of Michaux, Betulus Virginica of Marsh,) and the hop hornbeam, more generally known by the name of ironwood (the Ostrya Virginica of Darlington, and Carpinus ostrya of Michaux and others).

The water beech is the only known species of the Carpinus genus in the United States. It is found along the margins of rivulets in the Middle States, where it attains the height of only 10 or 20 feet, with 2 to 5 inches in diameter, irregularly and obtusely ridged, and sulcate, often branching from the root. It bears a broad ovoid nut, somewhat flattened, smoothish, and dark brown.

The ironwood, or hop hornbeam grows from 20 to 40 feet high, and 4 to 10 inches in dia. meter, with a brown, roughish, slightly fissured bark, and slender branches. It bears a nut seated in the bottom of a sac, 3 or 4 lines in length, somewhat compressed, smooth, shining, of a pale olive colour, with a leaden tinge. 'This tree is of very slow growth, and its wood, as its name implies, is very hard, which adapts it to the various useful purposes enumerated in the description of the English hornbeam.

HORN BUG. A kind of beetle. The largest of these beetles, in the New England States, was first described by Linnæus under the name of Lucanus capreolus, signifying the young roebuck; but here it is called the horn bug. Its colour is a deep mahogany brown; the surface is smooth and polished; the upper jaws of the male are long, curved like a sickle, and furnished internally beyond the middle with a little tooth; those of the female are much shorter, and also toothed; the head of the male is broad and smooth, that of the other sex nar. rower and rough with punctures. The body of this beetle measures from one inch to one inch and a quarter, exclusive of the jaws. The time of its appearance is in July and the beginning of August. The grubs live in the trunks and roots of various hinds of trees, but particularly in those of old apple trees, willows, and oaks.

Several other and smaller kinds of stagbeetles are found in New England, but their habits are much the same as those of the more common horn bug. (Harris.)

HORNED-POPPY (Glaucium, from glaukos, alluding to the hoary gray colour of the plants) A genus of very pretty annuals, or biennials, some of which are particularly handsome in the flower borders of the garden, where they 
fower and ripen seed in abundance, which bas only to be sown in the open border. The following are the English species.

i. Yellow horned-poppy (G. luteum). This is a biennial, growing wild on the sandy seacoast, producing golden-yellow flowers in July and August.

2. Scarlet horned-poppy (G. phceniceum). This is a very rare, or, as Smith observes, perhaps doubtful native. It is annual in habit, the root is tapering, the herb rather less glaucous, and more upright than the preceding. The flower-stalks and calyx are hairy. The petals are smaller and narrower than those of the last described species, and of a rich scarlet, with an oblong black spot at the base. The pod is clothed with numerous rigid, silky bristles.

Violet horned-poppy (G.violaceum). This is an annual met with sometimes, but not frequently, in grainfields. The root is slender, stem erect, a foot high, round, even, and quite smooth; leaves dark green, twice or thrice pinnatifid; flowers of a brilliant violet blue, very splendid, but extremely fugacious, somewhat larger than the last; pods 2 or 3 inches long, cylindrical, more or less clothed with bristly prickles. (Eng. Flor. vol. iii. p. 5; Paxton's Bot. Dict.)

HORNET (Vespa crabro). A well-known fierce insect, which is about one inch in length, and builds its nest in hollow trees. The sting of the hornet is severe, and occasions a considerable tumour, accompanied with intense pain; for the mitigation of which, there is no better remedy than sweet oil, or honey water immediately applied to the place. Hornets are very dangerous enemies to bees, which they attack and consume entirely, except the wings and feet: they are also very destructive to fruit.

The American hornet is the Vespa maculata of naturalists. Instead of building their nests in hollow trees, the American hornets are natural paper-makers, and manufacture watertight nests of paper, which they construct around the branches of trees or shrubs where they appear as large globes, sometimes a foot or more in diameter. The material of these nests consists of the fibres of wood, prepared by the insects, and wrought into a substance very similar to common brown paper made of rags. Like others of the wasp family the American hornet is a depredator upon fruit, and comes about houses in search of flies.

HORNWORT (Ceratophyllum, from keras, a horn, and phyllon, a leaf: the petals are cut so as to appear like a stag's horn). These are uninteresting water plants, thriving in any pond, and easily raised from seeds. The common hornwort ( $C$. demersum) is abundant in ditches and fish-ponds; the herb floating entirely under water, dark green, copiously branched, 2 or 3 feet long, densely clothed with whorled spreading forked leaves, eight in each whorl, and axillary, suiltary, sessile, pale green flowers. The truit armed with two spreading 'atera!. spines. There is another indigenous species the unarmed hornwort ( $C$. submersum), which is a more rare plant, and the fruit is destitute of soines.
There are two species of this plant founc in the United States. One of them (Ceratophyllum demersum) is described by Darlington as found in the waters of the Schuylkill, Brandywine and tributaries; the other (C. submersum) is described by Messrs. Nuttall and Eaton.

HORSE, THE. The genus Equus, according to modern naturalists, consists of six different animals,-viz. the Equus caballus, or horse; $E$.hemionus, the dziggithai; $E$. usinus, the ass; E. quagga, the quagga; E. zebra, or mountain zebra; and E. burchelli, the zebra of the plains. It is only of the first that I shall have to treat in this article.

Horse, the. This noble animal, there is little doubt, is a native of the warm countries of the East, where he is found wild in a state of considerable perfection. It is there that we find the barb and the Arab, noble races of horses that have long mainly contributed to improve the present English race-horse, until he has arrived at his present state of unequalled perfection. The use of the horse, both as a beast of burden, and for the purposes of war, early attracted the attention of mankind. Thus the Canaanites are recorded as having gone out to fight against Israel with many horses and chariots. (Joshua ii. 4.) And 1650 years B. c., when Joseph proceeded with his father's body into Canaan from Egypt, there accompanied him both chariots and horsemen. (Gen. xix.) They were fed in those days on barley ( 1 Kings, iv. 28): and 150 years afterwards, the chariots of Egypt are described as being exceedingly numerous. The horse was early employed on the course. 1450 years . c. the Olympic Games were established in Greece, at which horses were used in the chariot and other races.

Preserved from the flood waters in the ark, the first breed of horses must have proceeded from the neighbourhood of Mount Ararat; but whether the original stock were first located in Asia or in Africa is an inquiry which we have no means of deciding. Equally ineffe "u: ' are all the attempts which have been made to decide as to which variety of the horse constitutes the original breed; while some contend for the barb, others prefer the wild horses of Tartary. It is certain, however, that so late as the seventh century there were but few '.orses in Arabia; even now the breed is much more limited in number, according to Burckhard, than is commonly supposed. He remarked, in a letter to Professor Sewel, "It is a mistaken idea that Arabia is very rich in horses; the breed in that country is limited to the extent of its fertile pasturing districts; and it is in these parts only that the breed prospers; while the Bedouins, who are in possession of poor ground, seldom possess any horses. We therefore see that the tribes richest in horses are those who dwell in comparatively the fertile plain of Mesopotamia, on the borders of the Euphrates and in the Syrian deserts. It is there that the horses can feed for several spring months upon the green grass and herbs of the valleys and plains, produced by the rains, which seem to be in absolute requisite for its reaching to its full vigour and growth." The care with which the Arabs tend their horses is prover 


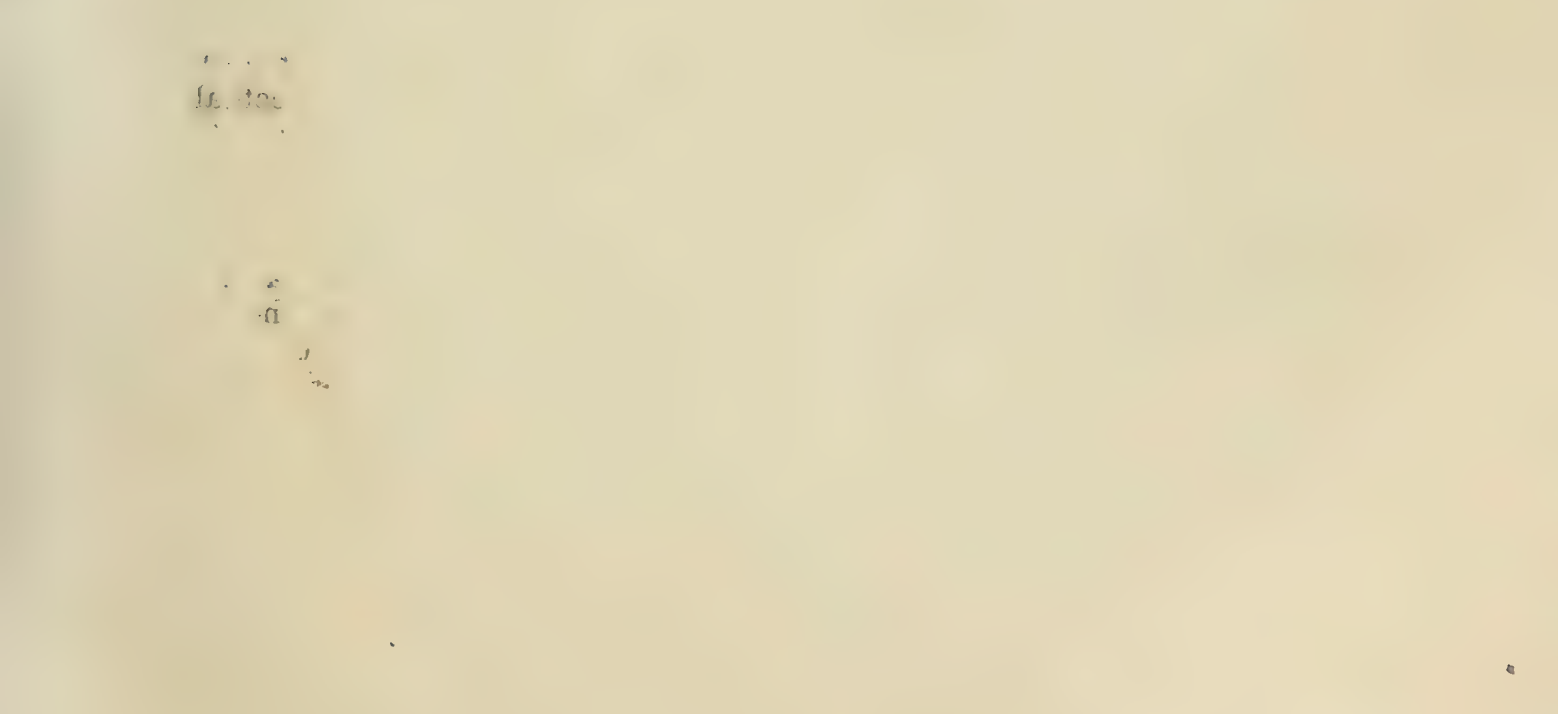

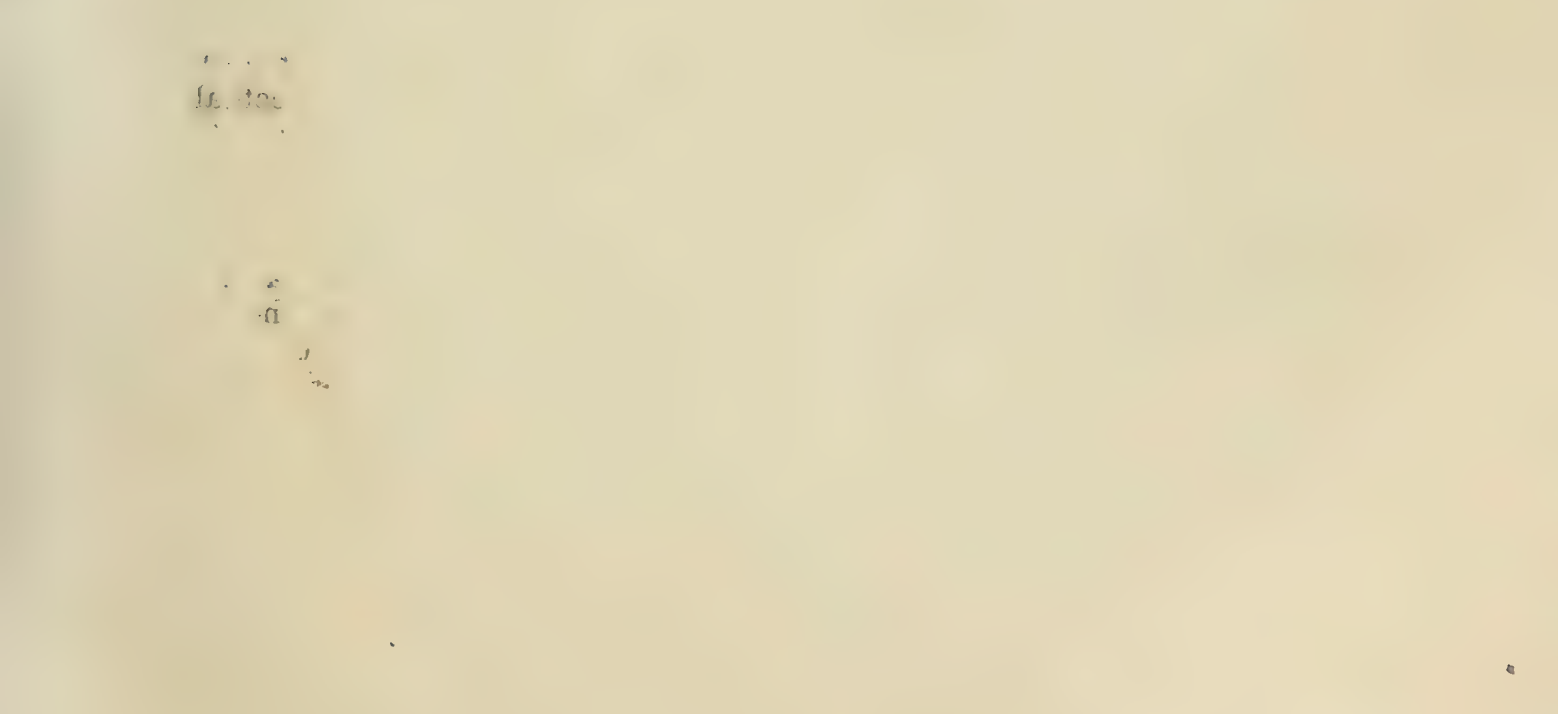

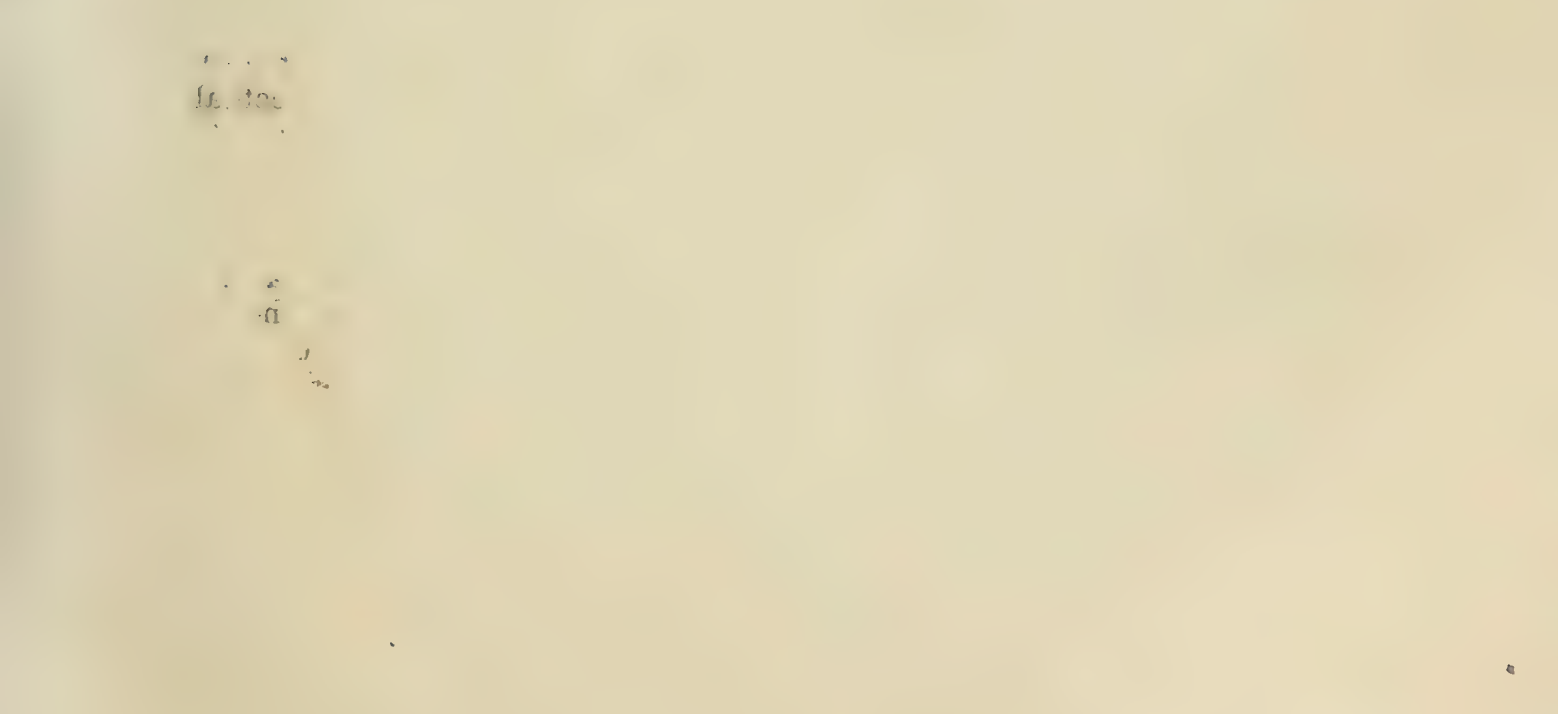

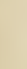



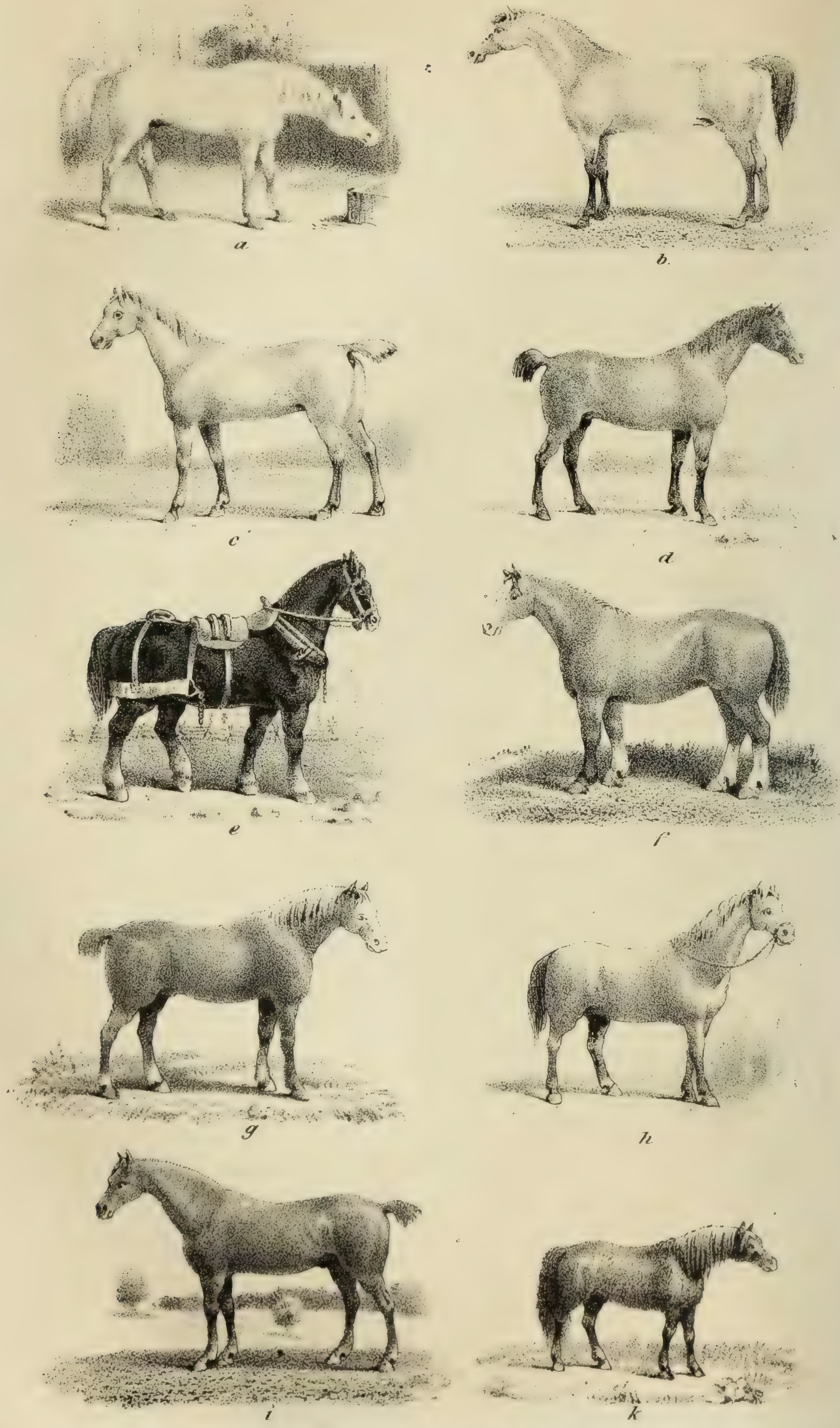

British Horses. 
bial. "The Bedouins," adds Burckhardt, "when a horse is born, never let it drop down to the ground, but receive and keep it for several hours upon their arms, washing it, stretching and strengthening its limbs, and hugging it like a baby." (Quart. Journ. of $A g r$. vol. vii. p. 577.) None were found either on the continent or on the islands of the New World. And yet the large droves of wild horses which have descended from the two or three mares and stallions left by the early Spanish voyagers, and which now abound in the plains of South America, prove very clearly that the climate and the soil of the New World are not adverse to the propagation of the wild horse.

"The horse," says Professor Low (Illustrations of the Breeds of the Domestic Animals, part ix.), "is seen to be affected in his character and form, by the agencies of food and climate, and it may be by other causes unknown to us. He sustains the temperature of the most burning regions; but there is a degree of cold at which he cannot exist, and as he approaches to this limit, his temperament and external conformation are affected. In Iceland, at the arctic circle, he has become a dwarf; in Lapland, at latitude $65^{\circ}$, he has given place to the reindeer; and in Kamtschatka, at latitude $52^{\circ}$, he has given place to the dog. The nature and abundance of his food, too, greatly affect his character and form. A country of heaths and innutritious herbs will not produce a horse so large and strong as one of plentiful herbage. The horse of the mountains will be smaller than that of the plains; the horse of the sandy desert than of the watered valley."

Leaving, however, these interesting, but for this work too extensive, researches, I propose to direct my attention to the English breed of horses, and more especially to those which come particularly within the farmer's province.

From a very early period there appears to have existed in England a powerful, active, useful, and numerous breed of horses. Cæesar, perhaps with the natural inclination of a conqueror to elevate the prowess of his defeated enemies, gives a very lively account of the horses used by the early Britons in their war chariots; which, armed with iron scythes affixed to their axletrees, were driven furiously and destructively amid the ranks of their enemies. And if it be true, that when Cassibellaunus had disbanded the chief portion of his army, he yet retained 4000 war chariots to harass the foraging parties of the Roman army; the supply of good horses able to work these heavy war chariots with sufficient speed over the open country, and bad roads of that period, must have been pretty considerable.

Of such imperfect materials is constituted all the accounts in our possession, of the native breed of English horses. That they were valuable, is proved, amongst other things, by the fact, that the Roman generals carried many of them to Italy. The improvement of the breed was an object of the early Saxon princes of England. Athelstan imported several German running horses, and he even (930) prohibited the exportation of those bred in England, a decree, which of itself proves that they were then in demand abroad. It is supposed tha? oxen were, in his days, solely used for the plough; there is no early record of the horse being used for such a purpose. The first notice of a horse being employed in agriculture, is in tapestry of Bayeux (woven in 1066), where one is depicted drawing a harrow.

With William of Normandy came many Spanish horses. His army was furnished with a powerful cavalry, to whom he might wel! attribute his hard-earned victory of Hastings.

In 1121, we have the first notice of an Arabian horse being in Great Britain; for in that year, I find that Alexander I. of Scotland presented one to the church of St. Andrews. King John procured from Flanders 100 stallions, and is to be gratefully remembered for other efforts to improve the English breed of horses. Edward II. and Edward III. also imported horses from Lembardy, France, and Spain. Henry VIII. did all he could to encourage the breed. Race-courses were now established at Chester and at Stamford. But it was not till the time of James I. that the modern system of racing, under certain rules and regulations, commenced, and a peculiar breed of race-horses began to be formed; for previous to that time fast horses of all breeds ran in the same race.

'This noble breed of race-horses, which now excels in beauty, speed, and endurance that of all oiher nations, has been gradually formed by the introduction of the best blond of Spain, of Barbary, of Turkey, and of Arabia. It woula be a grateful task to follow the English racehorse through his entire history, to trace his progress by gradual yet steady degrees towards perfection, his generous properties, his contests, and his triumphs over the best horses of Arabia, of Persia, and of the New World; outfooting the fleetest, and in endurance excelling all that the proud nobles of Russia could produce of the best and most celebrated Cossack horses of the banks of the Don. But in a work devoted to agriculture, my attention must be more directed to those valuable breeds of horses generally employed by the farmer.

The Arabian horse is represented in Pl. 13, $a$; the English racer, $b$, reduced, from Professor Low's splendid work on British animals. The English improved hackney, $d$.

The Cart Horse.-Of this description there are several varieties, the principal of which are the Cleveland, the Clydesdale, the Northamptonshire, the Suffolk punch, and the heavy black or dray horse.

The Clydesdale is a valuable breed of carthorses, bred chiefly in the valley of the Clyde (hence their name). They are strong and hardy, have a small head, are longer nected than the Suffolk, with deeper legs, and lighter carcasses. $\mathrm{Pl} .13, h$.

The Suffolk Punch is a very valuatie breed of horses, especially for farms composed of soils of a moderate degree of tenacity. They originated by crossing the Suffolk cart mare with the Norman stallion. Pl. 13, g.

"The true Suffolk," says the author of the Lib. of Useful Knou. ("The Horse," p. 38), "like the Cleveland, is now nearly extinct. It stood from 15 to 16 hands high, of a sorrel colour 
was large-headed, low-shouldered, and thick to the breeding of superior cart horses by the on the top, deep, and round-chested, longbacked, high in the croup, large and strong in the quarters, fall in the flanks, round in the legs, and short in the pasterns. It was the very horse to throw his whole weight into the collar, with sufficient activity to do it effectually, and hardihood to stand a long day's work. The present breed possesses many of the peculiarities and good qualities of its ancestors. It is more or less inclined to a sorrel-brown : it is a taller horse, higher, and finer in the shoulders, and is a cross with the Yorkshire half or threefourths bred. The excellence, and a rare one, of the oid Suffolk (the new breed has not quite lost it) consisted in nimbleness of action and the honesty and continuance with which he would exert himself at a dead pull even until he dropped."

The heavy black horse is chiefly bred in Lincolnshire, and the midland counties. Pl. 13, e. These are commonly sold by the breeders at two years old to the farmers of Surrey, and other metropolitan counties, who work them till they are four years old, and then sell them to the London merchants for brewers' drays, and other heavy carriages. "This kind of horse," says the same excellent authority I have just quoted, "should have a broad chest, and thick and upright shoulders (the more upright the collar stands on him the better), a low forehead, deep and round barrel, loins broad and high, ample quarters, thick fore-arms and thighs, short legs, round hoofs, broad at the heels, and soles not too flat. The great fault of the large dray horse is his slowness. This is so much in the breed, that even the disciplined ploughman who would be better pleased to get through an additional rood in the day, cannot permanently quicken him. The largest of this heavy breed of black horses are used as dray horses. The next in size are employed as wagon horses; and a smaller variety, and with more blood, constitutes a considerable part of nur cavalry; and is likewise devoted to undertakers' work." (Lib. of Useful Know. p. 46.)

"The dray horse," says Mr. Wilson, "probably restits from a fine carriage horse, possessed of a certain portion of blood, and a very strong well-formed mare of the country breed. The gigantic proportions and immense powers of these horses are only equalled by their intelligence and docility. It may safeiy be said that this breed of horses is not to be paralleled on the face of the earth." (Quart. Journ. of $A g r$. vol. ii. p. 34.)

Besides these valuable kinds of English draught horses, there are a variety of mongrel breeds employed by the farmers, especially in the neightourhood of London, and other large towns, which it is needless to name, and difficult to describe. Aged or lamed cab horses, he refuse of the London hackney coaches, \&c. may all be seen drawing the small farmers' teams in the neighbourhood of London. An Eng!ish draught mare is represented at $\mathrm{Pl}$. 13 , $f$. reduced, from Stephens's Book of the Farm. farmer. The soil and the food which the dis. trict produces, has commonly more influence upon the size of the animal than the choice of the mare or the stallion; and although by the exertions of the Highland, and other Agricultural Societies, the breed is now considerably improved, yet still much more remains to be effected in this way The Ayrshire Agricultural Association, at a late meeting, determined upon the purchase of a Flemish stallion, for the purpose of improving the breed in Scotland, the Society being convinced that there is a much better breed of draught horses in Flanders than in any part of Great Britain.

"The most important circumstance," says a well-known author, "which influences the profits of the farmer, is the cost of his team and the wages of his labourers. These vary in different situations. In some parts of the country the horses are pampered and kept so fat that they can scarcely do a day's work as they ought. In others they are overworked and badly fed. Either extreme must be a loss to the farmer. In the first case the horses cannot do their work, and consume an unnecessary quantity of provender, and, in the other, they are soon worn out; and the loss in horses that become useless, or die, is greater than the saving in their food, or the extra work done by them. A horse properly fed will work 8 or 10 hours every day in the week, resting only on Sundays. By a judicious division of the work of the horses, they are never over-worked, and an average value of a day's work is easily ascertained. This, in a well-regulated farm, will be found much less than the common valuations give it."

The labour of a horse is commonly reckoned equal to that of 5 men; he works, however, only 8 hours, while a man works 10 . It has often been asserted that the powers of endurance of a man are considerably greater than that of a horse; and in a hurdle race at Ipswich, in 1841, between a capital hunter carrying 10 stones, and Townshend, a celebrated rurner, over 6 miles of ground, and 100 hurdle leaps, the horse was easily beaten. In a second trial, however, the horse came off the winner. 'The power of a horse in pulling seldom exceeds $144 \mathrm{lbs}$; ; but he will carry from $500 \mathrm{lbs}$. to $1000 \mathrm{lbs}$. The power of a horse in pulling, if equal to $144 \mathrm{jbs}$. at a rate of 2 miles an hour, would be reduced to $64 \mathrm{lbs}$. at 4 miles an hour, and to $36 \mathrm{lbs}$. at 6 miles. In wheel carriages, on level roads, a horse will draw easily about 15 times the power exerted. A horse, in a single-horse cart, seems capable of drawing his load to the greatest advantage, and of late several improved single-horse carts have been suggested. (See CArrs; and Jour. of Roy. Agr. Soc. vol. ii. p. 73.) The singlehorse carts, both of London and Liverpool, convey enormous weights over the paved streets; and at Paris a single horse draws 2 tons. The carriers between Edinburgh and Glasgow, in carts weighing $7 \mathrm{cwt}$., convey a ton of goods 22 miles a day with one horse. The carriers of Normandy, with 4 horses, in Tun little attention is generally paid, in fact, 2 -wheeled carts, weighing $11 \mathrm{cwt}$, convey from 638 
14 to 22 miles per day 4 tons of goods. See Tracrion.

The Hunter. Pl. 13, c. It has been said that the hunter should be rarely under 15 or 16 hands high; below this he cannot well stand over his work, and above this he is apt to be long-legged and awkward at his work. With the increased speed of the hounds, and by the enclosures increasing the powers of the country to retain the scent, the speed of the modern hunters is much greater than that of the olden time, when with slow hounds, and strong, active horses, the country gentlemen had their "meets" at break of day, and continued the chase for hours. Hence it is now pretty generally agreed that the modern hunter should be at least three-quarters bred. Many prefer the thorough-bred horse, especially if he can be procured with sufficient bone. The properties which a good hunter should possess, are thus described in the Library of Useful Knowledge (The Horse, p. 51): "He should be light in hand; for this purpose his head must be small, his neck thin, and especially thin beneath his crest, firm and arched, and his jaws wide. The head will then be well set on; it will form that angle with the neck which gives a light and pleasant mouth. Somewhat of a ewe-neck, however it may lessen the beauty of the race-horse, does not interfere with his speed, because more weight may be thrown forward, and consequently the whole bulk of the animal more easily impelled; at the same time the head is more readily and perfectly extended, the windpipe is brought almost to a straight line from the lungs to the muzzle, and the breathing is freer. Should the courser, in consequence of this form of the neck, bear more heavily on the hand the race is soon over, but the hunter may be our companion and our servant through a long day, and it is of essential consequence that he shall not too much annoy and tire us by the weight of his head and neck. The forehead should be loftier than that of the racer. A turf horse may be forgiven if his hind quarters rise an inch or two above his fore ones. His principal power is wanted for behind, and the very lowness of the forehead may throw more weight in front, and cause the whole machine to be more easily and speedily moved. A lofty forehead, however, is indispensable in the hunter, the shoulder as extensive as in the racer, as oblique, and somewhat thicker; the saddle will then be in its proper place, and will continue so, however long may be the run. 'The barrel should be rounder, to give greater room for the heart and lungs to play, and send more and purer blood to the larger frame of this horse; and especially more room to play when the run may continue unchecked for a time that begins to be distressing. A broad chest is an excellence in the hunter. In the violent and long-continued action of the chase, the respiration is exceedingly quickened, and abundantly more blood is hurried through the lungs in a given time, than when the animal is at rest. There must be sufficient room for this, or the animal will be blown, and possibly destroyed. The majority of horses that perish in the fieid are narrow-chested. The arm should be as muscular as that of the courser, or even more so, for both strength and endurance are wanter. The leg should be deeper than that of the race. horse (broader as you stand at the side of the horse), and especially beneath the knee. In proportion to the distance of the tendon from the cannon or shankbone, and more particularly just below the knee, is the mechanical advantage with which it acts. A racer may be lied beneath the knee without perfectly destroying his power, but a hunter with this defect will rarely have stoutness. The log should be shorter than that of a race-horse, for higher action is required of him, that the legs may be cleanly and safely lifted over many an obstacle, and particularly that they may be well doubled up in the leap. The pastern should be shorter, and less slanting, yet retaining considerable obliquity. The long pastern is useful by the yjelding resistance which its obliquity affords to break the concussion with which the race-horse, from his immense stride and speed, must come to the ground; and the oblique direction of the different bones beautifully contributes to effect the same purpose. With this elasticity, however, a considerable degree of weakness is necessarily connected, and the race-horse occasionally breaks down in the middle of his course. The hunter, from his different action, takes not this length of stride, and therefore wants not all this elastic mechanism; he more needs strength to support his own heavier carcass, the greater weight of his rider, and to endure the fatigue of a long day. Some obliquity, however, he requires, otherwise the concussion even of his shorter gallop, and more particularly of his frequently tremendous leaps, would inevitably lame him. The foot of the hunter is a most material point, for it is battered over many a flinty road and stony field, and if not particularly good, will soon be disabled and ruined. The position of the feet requires some attention in the hunter; they should, if possible, stand upright. If they turn a little outward, there is no serious objection, but if they turn inward, his action can hardly be safe, particularly when he is fatigued or over-weighted. The body should be short and compact compared with that of the race-horse, that he may not, in his gallop, take too extended a stride. This would be a serious disadvantage in a long day, and with a heavy rider, from the stress on the pasterns; and more serious efforts required when going over clayey, poachey ground in the winter months. The compact, short-strided horse will almost skim on the surface, while the feet of the longer-reached animal will sink deep, and he will wear himself out by efforts to disengage himself. The loins should be broad, the quarters long, the thighs muscular", the hocks well bent, and under the horse." (Ibil. p. 53.)

Galloways. A horse between 13 and 14 hands high is called a galloway. The name originated from a beautiful race of little horses once bred in Scotland, on the banks of the Solway Frith. The pure galloway was distinguished for its speed and stomtness, and war 


\section{HORSE.}

remarkably sure-footed. Horses of this kind dre very serviceable and useful; are capable of performing a great deal of light active work, and are rarely so high-priced as the larger horse.

Ponies. Of these there are an endless variety, both in fine shape and value. The Welch pony is perhaps the most beautiful of the class. He has a neat small head and barrel that is at once round and deep, good feet, short, strong joints, flat legs, with high withers. Some of the most beautiful ponies of England are of this breed.

The New Foresters are commonly very illmade, coarse, ragged, large-hipped, ugly animals, but active, enduring, hardy, and easily maintained upon very coarse food. The same remarks will pretty generally apply to those of Exmoor and Dartmoor in Devonshire.

of the Scotch breeds, the Highland is the largest, and the most useful; those of the Shetland Isles, called in the north shelties, (Pl. $13, k$ ) range between $7 \frac{1}{2}$ and $9 \frac{1}{2}$ hands in height, are often small-headed, beautiful, goodtempered, and docile. They have commonly short necks, low and thick shoulders, short backs, possess greai strength, and will fatten upon the coarsest food.

The Irish Horse.-In the rich grazing districts of Roscommon and Meath, many large thoroughbred horses are reared, that were formerly distinguished for their large, coarse, ragged, rawboned appearance, but the breed has been very materially improved by the introduction of superior stallions and other means, so that now many of the Irish horses claim an equality with the best of those of England. The Irish horse is commonly beautiful, fiery, yet goodtempered, easily excited, of great endurance, and perhaps the best leaper in the world. 'The Irish Hunter is represented in Pl. 13, $i$, from Lowe's work on British animals.

Feeding Horses.-The best method of feeding horses, especially those belonging to the farm, is a ouestion highly interesting to the farmer. Many are the substances employed for this purpose, such as oats, oatmeal, barley, bran, beans, peas, potatoes, turnips, carrots, parsnips, hay, sainfoin, clover, rye-grass, straw, grains, and sometimes oil-cake : bruised gorse or furze is excellent. The oats are best given when bruised, the potatoes should be steamed and mixed with chaff and salt; hay and straw are economically cut into chaff. In many of the stabies about London, hay is never put into the rack. Thus in the stables of Hanbury and Truman, each horse is allowed per day $18 \mathrm{lbs}$. of cut hay and straw (one-eighth of the latter), $14 \mathrm{lbs}$. of bruised oats, and $1 \mathrm{lb}$. of bruised beans; half a pound of salt per week is also given; in summer the beans are withdrawn, and the oats increased. In France the daily rations allowed to the heavy cavalry horses are, oats $10 \mathrm{lbs}$., hay $10 \mathrm{lbs}$, straw $10 \mathrm{lbs}$. ("On the Norman Horse," Quart. Journ. of Agr.)

Dr. Sully, of Wivelscombe, some years since, ave the following statement of the different articles of food which his horses received to keep them in excellent condition. He, too, had no racks in his stables. (Ibid. vol. ii. p. 826.)
HORSE.

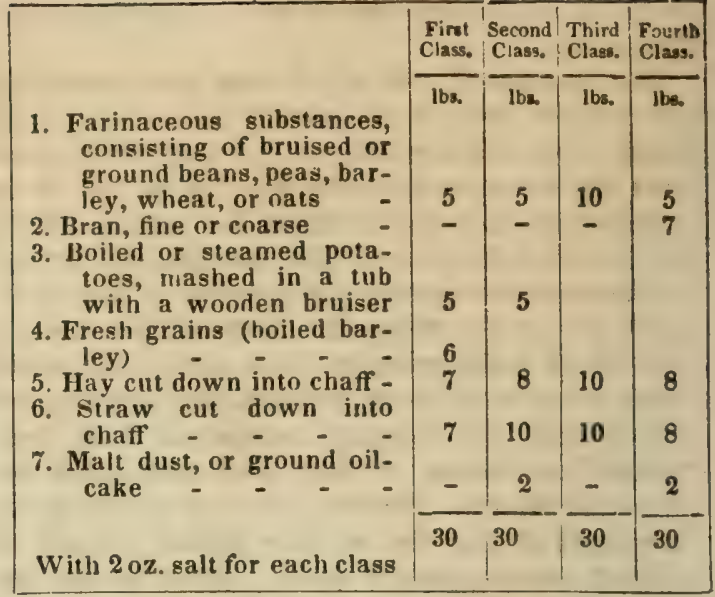

The advantage of cooking the food for horses has been advocated by Mr. Dick, Ibid. vol. iii. p. 1024 ; and in many cases is a practice highly to be commended. An apparatus for steaming food for horses with an engine is given, Ibid. vol. vi. p. 33 ; and Mr. Fisher details the mode of feeding them with potatoes, Com. Board of Agr. vol. iv. p. 335. A machine for bruising grain for horses is described in Quart. Jounn. of $A g r$. vol. v. p. 100.

The number of horses of all kinds in Eng. land is estimated by $\mathrm{Mr}$. M'Culloch, to be from $1,400,000$ to $1,500,000$, which, at an average value of from $12 l$. to $15 \mathrm{l}$, makes their total value from $18,000,000 l$. to $22,500,000 l$. In 183 s the riding-horse duty was paid for 182,878 horses. (Com. Dict.)

It appears from the statement accompanying the census of the United States in 1840, that the number of horses and mules in the Union was 4,333,669.

The Wild Horse.-The horse is still found wild in Africa, in Tartary, and in America, in the Southern continent, of which last country they are said to be sometimes found in droves of 10,000 . It is here that they seem to act both in self-defence, and for the attack of their enemies, with a subordination and union of purpose that is not a little curious. It seems that they have some bold and strong horse for their chief, who is their courageous leader in the onset, the first to direct their retreat. They close, at some intelligible signal, upon their enemies, and trample them to death. These, amongst the natives of America, are neither very numerous nor dangerous. The leopard, tiger, and lion of the New World are very in ferior animals to their narnesakes of the olden continents. Man is their greatest enemy; they are hunted and captured by the Guachos with their lassos, or even killed for their skins and flesh, in considerable numbers. 'These wild American horses are not particularly fast, but they can endure great fatigue, and, when once tamed, are exceedingly docile. Other wild herses are found in various parts of the world, but nowhere in a state of nature does he equal the size, the form, the speed, or the strength of the domesticated horse.

For an interesting account of the wild horses of South America, see the Farmer's Register. vol. ii.

Good keep and gond management, indeed, strangely improve the appearance of even the 
maturally poorest breeds. The ponies of Shetland, or the still more diminutive steeds of China, when bred on rich English pastures, rapidly increase in size. The horses of Arabia do the same.

In the extensive territory of the United States, several breats of horses are found, the characteristics of which are widely different.

'The Canadian. 'This is one of the principal races found in the Northern States, and is generally considered of French or Norman ilescent, many of the characteristics of which are retained.

The Morgan horse. Perhaps the very finest breed of horses in the United States, when general usefulness is taken into consideration, is what is commonly known in the Northern and Eastern States, as the Morgan horse. This breed is distinguished by its activity, united with strength and hardiness. Its size is moderate, and though not often possessing the fleetness which recommends it to the sportsman, it has enough speed to entitle it to the appellation of a fast traveller. Their usual height is from 14 to 15 hands, colour bay, make round and rather heary, with lean heads, broad and deep chests, the fore-limbs set wide apart, legs clean and sinewy, short, strong backs, with that projection of the ribs from the back-bone which is a sure indication of great developement of lungs, and consequently of great wind and bottom. For saddle, draught, and other useful purposes, the Morgan horses bred in Vermont, and in all the Eastern States, including the Northern and Western part of New York, are so much prized as to command much higher prices in the principal cities of the Atlantic States than horses from other parts of the Union.

This fine race is generally believed to have originated in the northern part of Vermont about the year 1804, from a mixture of the French horse from Canada, with New England mares. 'The breed is sometimes known by the name of the Goss horse. Some of the celebrated American trotters are of the Morgan breed.

Conestnga horse. This horse, which is found chiefly in Pennsylvania and some of the adjacent states, is more remarkable for endurance than symmetry. In height it sometimes reaches 17 hands, the legs being long and the carcass light. The Conestoga breed make good carriage and heavy-draught horses.

Iirginia and Kentucky horse. This breed, which predominates in the states named, and, in a greater or less extent, in all the Southern, Middle, and Western States, derives its origin from English blood horses imported at various times. It has been most diligently and purely preserved in the South. The celebrated Shark, the best horse of his day, was the sire of the best Virginia horses, whilst T'ally-ho, a son of Highflyer, peopled the Jerseys. (Farmer's Regisier, vol. ii.)

In the Southwestern States, wild horses abound, which are doubtless sprung from ihe same Spanish stock as the wild horses of the Pampas and other parts of the Southern continent, all of which are of the celebrated Andalusia breed, derived from the Moorish Barb.
The prairie horses are often captured, and, when domesticated, are found to be capable of great endurance. They are not, however, recommended by the symmetry or elegance of appearance, for which their type is so greatly distinguished, being generally rather small and scrubby.

'The following interesting observations rela. tive to some of the American breeds, were lately addressed by the editor of the Now York Spirit of the Tiones to the editor of the Cultivator.

Fifteen years ago, thousands of dollars would have been wagered, that no horse in the world could trot a mile within three minutes; as many would be laid down now, that it could be done in two minutes twenty-eight seconds. Ten years ago, to drive a horse 70 miles between sun and sun, would have been deemed a great performance; but since strains of the blood of old Messenger have been introduced into our road stock, at the North, hundreds of horses can be found that can travel from 80 to 90 miles without distress. In our paper of this day is a report of the performance of a horse in Boston that, without being trained, was driven 103 miles between sunrise and sunset, over a hilly road, before a carriage, which, with the rider, weighed 470 lbs.

The acknowledged superiority of northern carriage and draught stock is owing almost entirely to the fact, that thorough-bred horses have found their way north and east from Long Island and New Jersey, where great numbers are annually disposed of that are unsuited to the course. The use of thorough and half-bred horses, for domestic purposes, is becoming so common in England, that in a few years, no other will be used for the road. The half-bred horse is not only much handsomer, but his speed and powers of endurance are infinitely greater. His head and neck are light and graceful, his limbs fine, his coat glossy and soft as satin, while his action is spirited, and his courage and stamina sufficient to carry him through a long journey without his falling off in condition, or to undergo an extraordinary trial of speed and game without distress. The ordinary coclitail is, in most instances, a mere brute, that in travelling, sinks daily in strength, losing his appetite, and, of course, his flesh and action, so that at the termination of a ten days' journey, he is nearly knocked up; he can travel but about 40 miles per day, and requires the whole day to perform this distance. An eminent southern turfman, well known the country over, recovers his horses on a journey; they are all from the North, and have a dash of biood in their veins; after driving them hard about his plantation in the spring, until they begin to look thin and rough, he starts on his annual journey, and by the time he reaches the Vir. ginia Springs, his horses are literally as tine as silk, with fine coats, great spirit, and ia good condition for fast work. In travelling, he starts early, and drives at the rate of 8 or 9 miles the hour until 10 o'clock, when his horses are taken out, rubhed dry, watered, and fed. In the cool of the day, they are again harnessed, as fresh as if they had not travelled a mile. In this way he accomplishes a long journey, travelling be tween 50 and 60 miles a day, without fatigus

3 н 2

641 
to himself or injury to his horses. The slowgoing, no-giving sort of style in which horses are jogged along at a snail's pace all day under a hot sun, knocks them up in a short time; they would neither tire nor lose flesh in double the time, if driven sharply a few hours in the morning and evening, allowing them to rest in the middle of the day. It is the all-day work sinat knocks up horses, not the pace.

Our friends of the Cultivator may not be aware of the vast amount invested in thoroughbred horses at this moment in the United States, or of the prices some of fashionable blood command. We can point them to two 5 year old horses for which $\$ 20,000$ each has been refused; to brood mares that will command $\$ 5000$ each at auction; to a colt six months old, for which $\$ 4000$ has been refused. Among the popular stallions we have advertised this season, three stand at $\$ 150$ each, fourteen at $\$ 100$, twelve at $\$ 75$, eleven at $\$ 60$, and twenty-three at $\$ 50$. Probably not less than 6000 thorough-bred mares, and as many more that are full or three-quarters bred, will be stinted this season to horses that are standing at from $\$ 35$ to $\$ 150$. As not above 2000 out of the whole number foaled next season, will probably come upon the turf, it is clearly to be seen that a vast number of terribly high bred cattle must be used for ordinary purposes. Of these, the colts of good form, that have plenty of bone and substance, will of course oust the common tackies and cider-suckers that infest country taverns, whilst the others will be used for the saddle and the road. The result will be, that in a few years, the stock now in use will be supplanted by horses of superior action, wind, and courage, whose greater beauty will not be more apparent than their better style of going, and their unequalled powers of endurance. (New York Spirit of the Times.)

In the observations which follow these remarks, the editor of the Cultivator states that he hails with pleasure any improvement which promises a better race of horses than those which, too generally in our country, are a mere caricature of the noble beast. Our duty and our inclination, however, prompt us to pay more attention to those breeds and varieties adapted to agriculture and the road, than to those calculated for the turf alone. That for both these purposes horses of a better kind may be introduced by crosses of the fine-limbed, hardy-constitutioned, and beautiful thoroughbred, with those possessing the bone and substance necessary to give the weight and firmness required in the draught horse, whether the labour is to'be performed on the road or the farm, we do not doubt. For the farm, the thoroughbred horse would be comparatively worthless; he lacks weight and substance to give value and power for draft; for road work, the same sbjections will apply, though not perhaps to the same,extent. 'The best English road horse is a cross of the thorough-bred and the Cleveland, and a cross of the same horse with the thick, heavy Suffolk, has given a most valuable farm horse. It is not to be expected that the proper desrees of blood, activity, power of endurance, weiuht and docility, so essential to the horse wif the farmer, or for the road, can be oblained at once: but from what we almost daily witness, of the good effects that have resulted already from the comparatively little attention the improvement of horses for labour has received, we can have no doubt that a field is here open for effectually benefiting the community at large more extensive than can be found almost anywhere tlse. (Cultivator, for Aug. 1840, Vol. 7.)

A public benefit has been conferred upon the country by Mr. Edward Harris, of Moorese town, New Jersey, in the importation of a fine pair of Norman horses, male and female. The following particulars relative to the stud were communicated by Mr. Harris to the Farmer's Cabinet for April, 1842, and furnish much information that must be esteemed valuable:

"Diligence is of a handsome dapple-gray colour, measures 15 hands, and is one of the most perfect animals of the distinguished breed of Normandy horses called Percheron. He was chosen as a full-sized specimen of the breed, possessing all the quick action of the smaller horses, in order that his immediate progeny from our light mares might approach nearer the true type of the race. It must be observed, however, that it is more in breadth and size of bone and muscle that he exceeds the staridard, than in his height, which is very little above the average. An inspection of the horse will convince any one that this race is the origin of the Canadian pony, about whose valuable properties little need be said, as they are well known and highly prized in this section of the country, and still more to the Nurth, where they have, undoubtedly, given that stamina and character to the horses of Vermont, New Hampshire, and the northern section of New York, which makes them so highly valued all over the Union as road horses; while it is a remarkable fact, that in those states where the attention of breeders has been exclusively devoted to the English race-horse, the carriage and the stage-horse is almost universally sup. plied from the North. It remains, therefore, for breeders to determine whether it is not better to resort to the full-sized Percheron to cross upon our light and already too highly-bred mares, than to use the degenerated Canadian (degenerate in size only, through the rigour of the climate, for it must be admitted that the little animal retains all the spirit and nerve of his ancestors, and lacks strength only in proportion to his size). My own opinion is, that a due portion of the French blood mixed with the English will produce a stock of horses invaluable, as combining all the properties that are required for quick draught on the road or the farm. I need not assure you, who are acquainted with the success of Diligence as a stud-horse in this place, that such too is the opinion of the farmers of New Jersey.

"I have frequently been questioned as to $\mathrm{mv}$ reasons for selecting this horse for farmers' use in preference to the English draught-horse. My reply has always been, that the draughthorse of England, whenever rrought to this country, must prove a failure; he wants the go-ahead principle; he cannot move out of a walk, which is saying quite enough for him, without dwelling upon his defects of form, which can only be concealed by loads of fat. 
and not even then, from the eye of the hurseman. The true Percheron, or Norman Diligence horse, on the contrary, combines more strength with activity than any horse I have ever sat behind. All travellers, on entering France, are struck with the properties of these horses, as displayed in drawing the ponderous machine called a Diligence, by which they are conveyed through the kingdom at the rate fully equal to the average of stage travelling in this country. English horsemen confess that their road-horses could not hold out the same pace before the same load.

"The origin of this race, according to French authorities, dates from the occupation of the Netherlands by the Spaniards, who introduced the Andalusian horse, which soon became the favourite stud-horse all over the continent. The Spanish horse is known to spring from the Barb or Arabian, introduced by the Moors on their conquest of that country. All who are conversant with the history of the horse, know that the Andalusian has always been celebrated for his beauty, and for his great spirit, combined with extraordinary powers of endurance. The French horse, upon which he was crossed, was the old Norman draught-horse, which still exists in the country in all its purity, and is perhaps the best of all horses for slow draught.

"The average height of these horses is 16 hands, and they may be described as follows: Head short, wide, and hollow between the eyes; jaws heavy; ears small, and pointed well forwards; neck very short and thick; mane heavy; shoulder well inclined backwards; back extremely short; rump steep; quarters very broad; chest deep and wide; legs very short, particularly from the knee and hock to the fetlock, and thence to the coronet, which is covered with long hair, hiding half the hoof; much hair on the legs; tendons large, and muscles excessively developed."

An English writer in the British Quarterly Journal of Agriculture, thus speaks of the Norman horse. After giving an account of its origin, which he agrees in tracing to the Spanish horse, he observes, "The horses of Normandy are a capital race for hard work and scanty fare. I have never seen such horses at the collar, under the diligence, the post-carriage, the cumbrous and heavy voiture or cabriolet for one or two horses, or the farm cart. They are enduring and energetic beyond description; with their necks cut to the bone, they flinch not; they put forth all their efforts at the voice of the brutal driver, or at the dreaded sound of his never-ceasing whip; they keep their condition when other horses would die of neglect and hard treatment. A better cross for some of our horses cannot be imagined than those of Normandy."

Whilst lately in Europe, Professor Gibson, of Philadelphia, a passionate admirer of the horse, and well versed in the finest blood of the United States, made close observations of the horses in different parts of England and Ircland. The following passage from his "Rambles" furnishes a condensed view of the res:ults of his observations:

- The Irish horses have long been consider- ed the finest in the kingdom, and certainly I saw none to be compared to them in any part of Europe. In general they are very compact, strong, active, and spirited, but hightempered, and difficult to manage. 'They bear a close resemblance to our Vermont horse in style, action, and shape, and might readily pass for the same breed, with the exception of being larger. In England they bring high prices, and it is not uncommon to meel with English dealers at the Irish fairs buying them up, in great numbers, for their own markets. 'The English horse, indeed, within the last 20) years, has degenerated so much, in some respects, as not to serve the many useful purposes to which he was accustomed at that period, owing to breeders having run too much upon blood. On this account it is now hardly possible to meet with any of the old stock of hunters so large and powerful, and with so much bone and sinew; so that even in Yorkshire I saw but a single specimen, a fine black, in possession of $\mathrm{Mr}$. Whittaker, of Otley, 30 years of age, but which felt under me like a colt, after a ride of 20 miles. Even the carriage horses, indeed, throughout every part of England, are conspicuous for their long, low necks, slab sides, and spindle shanks, and very inferior, as a race, to our own stock, for the same purposes. In London, it is true, large showy animals are to be seen in the carriages of noblemen and other persons of fortune; but they are procured at immense prices, often 400 or 500 pounds each, and even then are deficient in action, and too often have broken knees, to which indeed most of the English horses are so liable, as seldom to be led or ridden out by the groom without having their knees protected by leather or woollen covers or caps. The Irish horse, on the contrary, is not apparently so high bred as the English, and therefore a better animal for draught, saddle, and most other purposes. Yet no blood horses in England have proved superior to the Irish racer in speed, bottom, and other requisites; and I believe it is admitted on all hands that there is now no horse in the British empire to be compared to Irish 'Harkaway,' bred and owned by a linen-bleacher of Belfast. A great many inquiries were made of $\mathrm{me}$, also, respecting 'Skylark, an Irish horse im. ported into this country a few years back, and represented, by all that spoke of him, as a most extraordinary animal, and one that never should have been allowed to leave the king. dom. Both animals I had an opportunity of seeing-the one in England, and the other in Richmond, Virginia, soon after his arriva.and finer specimens of the kind I cannot ima gine to exist in any country. Through every part of Ireland I travelled, I could not help being struck with the form and activity of all classes of horses; and in Dublin, especially, scarcely passed a day without noticing ladies and gentlemen splendidly mounted, the finest teams in mail and other coaches, and carriage horses of beautiful style and proportion; all which, however, command there as many pounds sterling as American horses-excepting, per haps, first-rate trotters-dollars in this coun try; and it is only surprising some of onr 
spirited Yankee dealers do not furnish the English market with such luxuries."

HORSE, AGE OF. See Ages of Amimals.

HORSE-CHESTNUT. If, says a writer in the American Farmer (vol. xiv.), the value of this nut was more generally understood, it would not be suffered to rot and perish without being turned to any account, as at present. The horse-chestnut contains a saponaceous juice, very useful, not only in bleaching, but in washing linens and other stuffs. The nuts must be peeled and ground, and the meal of 20 of them is sufficient for 10 quarts of water; and either linens or woollens may be washed with the infusion, without any other soap, as it effectually takes out spots of all kinds. The clothes should, however, be afterwards rinsed in spring water. The same meal, steeped in hot water and mixed with an equal quantity of bran, makes a nutritious food for pigs and poultry. See Chestrut, Horsz.

HORSE DEALERS. Persons whose business it is to buy and sell horses. Each person carrying on the business of a horse dealer is required to keep a book, in which he shall enter an account of the number of horses kept by him for sale and for use, specifying the duties to which the same are respectively liable. This book is to be open at all reasonable times to the imspection of the officers; and a true copy of the same is to be delivered quarterly to the assessor of the parish in which he resides. Penalty for non-compliance, 50l. (43 Geo. 3, c. 161.) Horse dealers are assessed if they carry on their business in the metropolis 25l., and if elsewhere, 12l. 10s. per annum. From the papers published by the Board of Trade, it appears that the number of persons of this class assessed in 1831, was 74 in the metropolis, and 963 in other parts of the kingdom.

HORSE, DISEASES OF. See each disorder.

HORSE-FLY or FOREST-FLY (Hippobosca equina, Linn.). In England this fly lives chiefly on horses, but sometimes also attacks horned cattle and other mammalia. The male is scarcely so large as the house-fly; the female is larger. The insect generally attaches itself to the abdomen of the animal, which is least covered with hair, particularly between the hind legs. 'This fly has a singular movement: it runs very quickly, but sideways like a crab: it is covered with a hard crust; and adheres so firmly by its claws as to render it difficult to take it off. As it torments the animals very much, means of driving it away must be thought of. Picking off by hand is too troublesome. By the following remedy it may be got rid of in 24 hours' time: take of mineral earth eight ounces; lard one pound, and make them into a salve. Some of this salve is to be rubbed on here and there upon the hair, and worked in with a wisp of straw. After 24 hours the salve is to be washed off with warm water, in which brown soap has been dissolved. Care must be taken for sorne days that the horse does not catch cold. (Kollar on Insects, Miss Loudon's I'rans.) See Gan-Fur.

HORSE.HOE, THE. For this valuable imflement of agriculture, the farmer is indebted to the justly celebrated Jethro Tull. Previous to his time, we search in vain in the works of agricultural authors for the slightest allusion to such an instrument. The production of the horse-hoe, indeed, seems to have been almost a natural consequence of the adoption of the drill system, for which also the cultivator is mainly indebted to Tull. He gave in his Huso bandry, more than a century since, an engraving of a horse-hoe of his own invention, which resembles a common, rudely-shaped swing plough, with the mould board omitted, and the shares having a cutting edge turned up on its landside. A variety of improvements were gradually made in the construction of this implement: I proceed to notice those which are now considered to be the best.

The advantages which these possess over the hand-hoe are very fairly stated by the late Mr. Francis Blakie: he remarks, "In many cases the hand-hoe may be used to advantage, and should then be so used. But generally speaking, the hand is not so efficient as the horse-hoe. Expedition is a most material point in all processes of husbandry, carried on in a variable and uncertain climate, and it fre. quently happens, that hoeing, in any way, can only be executed to advantage, in a very few days in spring : hence the horse-hoe has a most decided advantage over the hand-hoe, for a man will only hoe about half an acre a day with the latter, while, with the former, a man and a boy, with one horse, will hoe eight or ten acres a day, and that in a more effectual man ner." (On Farm-yard Manure, p. 39.)

Among the most approved implements of the kind in England, are the following:-

Clarke's Universal Ridge Horse-hoe.-This is a very ingenious contrivance for carrying ont the several operations of ridge culture. It is adapted for the uses of a do'ble tom, a mould ing plough, a broad share ur cleaning plough, and a horse-hoe. It is only as fitted for the latter purpose that we have now to describe it: its other forms will be given under the head Plovgh.

To the frame of the plough is attached a pointed share, which serves as a hoe for the centre of the furrow: a movable frame is attached to the beam, which is readily adjusted to any given width: to this is attached, when it is intended to hoe plants upon the ridge, the stalks of two curved hoes; when used upon flat work, the flat hoe should be substituted for the curved or inverted hoe. This forms a very perfect and simple horse-hoe.

Blakie's Inverted Horso-hoe.-This excellent hoe, which was the first that successfully hoed between several rows of turnips at once, and which led the way to the recent improvements of Mr. Garrett, was intended to be attached to a drill-carriage, or any light axletree, by the draft-irons fixed to the handles. Blakie de. scribed it pretty accurately when he said, "it is adapted for cleaning between rows of plants. growing at narrow intervals, within which is may be worked with perfect safety when in their infant state; indeed the idea first struck me on observing a large proportion of the plants buried by the operation of the hor: formerly in use." 
Gurrett's Horse-hoe.-This horse-hoe, invented by the manufacturers, Garrett and Son, of Leiston, Suffolk, is suited to all methods of drill cultivation, whether broad, stetch, or ridge ploughing; and is adapted to hoeing corn of all kinds as well as roots. The peculiar advantages of this implement are that the width of the hoes may be increased or diminished to suit all lands, or methods of planting; the axletree being movable at both ends, either wheel may be expanded or contracted, so as always to be kept between the rows of plants.

The shafts are readily altered, and put to any part of the frame, so that the horses may either walk in the furrow, or in any direction, to avoid injury to the crop.

Each hoe, or each pair of hoes, works on a lever independent of the others; so that no part of the surface to be cut, however uneven, can escape; and in order to accommodate this implement to the consolidated earth of the wheat crop, and also the more loosened top of spring corn, roots, \&c., the hoes are pressed in by different weights being hung upon the ends of each lever, and adjusted by keys or chains, to prevent their going beyond the proper depth.

And what has hitherto been an objection to the general use of the horse-hoe is avoided in this, by adopting a mode of readily shifting the hoes, by a plan similar to that of the steerage, so that the hoes may be guided to the greatest nicety. This implement is so constructed that the hoes may be set to a varying width, from seven inches to any wider space; the inverted hoes are preferred when the distance between the rows is sufficient to admit two of them; or any other form that may be considered best for the purpose.

Lord Ducie's Expanding Horse-hoe.-The parallel expanding horse-hoe is used for hoeing drill crops, and is eonstructed principally of wroltght iron: it has five tines, and can be regulated to any width, from 12 to 27 inches, with the greatest facility, so that the tine shall always present its edge to what it has to cut: this is effected by the support of each tine moving parallel with the beam : it is worked on the principle of the parallel rule; the machine has one wheel in front, with a tiller for the horse to yoke to: the depth it enters into the ground is regulated by raising or lowering the wheel; there is a pair of handles for the man who attends the machine to steady it by.

Grant's Horse-hoe, and Moulding Plough. By substituting mould-boards in the place of the wrought iron frame and hoes, this horse-hoe becomes a moulding plough.

White's Double-action Turnip Hoe.-This implement is constructed so that it may be used with only one horse and a man, and is intended to hoe either broadeast, drilled, or ridged turnips. It hocs two rows lengthways and crossways at one time when necessary. It can be set to suit the drills at any distance, from 15 to 30 inches, and to leave the distance of each turnip 9, 12, or 15 inches apart. It may be used also as a scarifier by removing the cross-cut hoes, and replacing them with spear-footed tines. (See Cultivator.)

HORSE MINT (Mentha sylvestris). A species of wild mint, growing freely in waste ground, especially in watery places. It is a perennial, blowing dense crowded whrorls of small, pale purple flowers in August and firn. tember in England. The whole herb is of a hoary or grayish green, clothed with fine soli downy hairs, and exhaling a strong peculiat scent. The stems are 2 or 3 feet high, rathed bluntly quadrangular; the leaves nearly ses sile, $1 \frac{1}{2}$ to $2 \frac{1}{2}$ inches long, spreading, strongly and sharply serrated, acute; their upper surface hoary; under, shaggy, with dense soft white hairs. It affords oil by distillation with water. The infusion of it allays sickness.

The plant commonly called Horse Mint, in the United States, is the monarda fistulosa of botanists-sometimes called Wild Bergamot. It has a perennial root, and stem 2 or 3 feet high, branched, mostly hairy, especially at the joints and towards the summits. The violetpurplish or often greenish-white or flesh-co. loured flowers are pubescent or downy. This, says Dr. Darlington, is a variable plant; and Mr. Bentham has reduced several species of preceding authors into this one. Five or six additional species of Monarda are enumerated in the United States. (Flora Cestrica.)

HORSE POWER, in steam-engines, is esti. mated by $\mathrm{Mr}$. Watt at 32,000 pounds avoirdupois lifted one foot high per minute for one horse. M. D'Aubuisson, from an examination of the work done by horses in the whims or gigs (machines à molettes) for raising ore from the mines at Freyberg, the horses being of average size and strength, has concluded that the usual effect of a horse yoked during eight hours, by two relays of four hours each, in a manege or mill course, may be estimated at 40 kilogrammes raised 1 mètre per second, which is nearly 16,440 pounds raised one foot per minute; being very nearly one-half of $\mathrm{Mr}$. Watt's liberal estimate for the work of his steam-engines.

HORSE-RADISH (Cochleario armoraciafrom cochlear, a spoon, the form of the leaves being rather hollow, resemble an old-fashioned spoon). The horse-radish delights in a deep, mouldy, rich soil, kept as much as possible in a moderate but reguial degree (If moistness; hence the banks of a ditch, or other place which has a constant supply of water, is a most eligible situation for the buds, so that they do not lie so low as to have it in excess. If the soil is poor, the roots never attain any corsiderable size; and the same effect is produced if grown in a shady place, or beneath the drip of trees. Should the ground require to be artificially enriched, Mr. J. Knight recommends leaf mould, or other thoroughly decayed vegetable substance, to be dug in to the depth at which the sets are intended to be planted. If cow or horse-dung is from necessity employed, it should be in a highly putrescent state. Horse-radish flowers in Jume, but in England seldom perfects its seed; consequently it is propagated by sets, which are provided by cutting the main root and offsets into lengths of two inches. The tops or crowns of the roots form the best; those taken from the centre never becoming so soon f: for use, or of so fine a growth. Each set should have at least two eyes, for without one they refice $\omega$ 
regetate at all. Mr. J. Knight recommends, for the obtaining a supply of the crowns, any inferior piece of ground to be planted with sets, 6 inches apart and 6 deep; these will furnish from 1 to 5 tops each, and they may be collected for several successive years with little more trouble than keeping them clear of weeds.

Horse-radish may be planted from the close of January until the same period in March, but the best times are in October and February; the first for dry soils, the latter season for moist ones.

The sets must be inserted in rows 18 inches apart each way. The ground should be trenched between 2 and 3 feet deep, the cuttings being placed along the bottom of the trench, and the mould turned from the next one over them, or inserted to a similar depth by a long, bluntpointed dibble. When the planting is completed, the surface should be raked level, and liept clear of weeds, until the plants are of such size as to render it unnecessary. It is of great benefit if the mould lies as light as possible over the sets; therefore, treading on the beds should be carefully avoided. They speedily take root, and send up long straight shoots, which make their appearance in May or June. The only cultivation required is to keep them free of weeds, and as the leaves decay in autumn, to have them carefully removed; the ground being also hoed and raked over at the same season, which may be repeated in the following spring before they begin to vegetate. In the succeeding autumn they merely require to be hoed as before, and may be taken up as wanted. By having three beds devoted to this root, one will always be lying fallow and improving, of which period likewise advantage should be taken to apply any requisite manure. If the plants, when of advanced growth, throw out suckers, these should be carefully removed during the summer as they appear. In September or October of the second year, the roots may be taken up, and in November a sufficient quantity should be raised to preserve in sand for winter supply. To take them up, a trench is dug along the outside row, down to the bottom of the upright roots, which by some persons, when the bed is continued in one place, are cut off level to the original stool, and the earth from the next row is then turned over them to the requisite depth, and so in rotation to the end of the plantation. $\mathbf{B}_{y}$ this mode a bed will continue in perfection for $\mathbf{5}$ ur $\mathbf{6}$ years, after which a fresh plantation is usually necessary. But the best practice is to take the crop up entirely, and to form a plantation annually, for it not only causes the roots to be finer, but also affords the opportunity of changing the site. If this mode is followed, care must be taken to raise every lateral root, for the smallest of them will vegetate if left in the ground. See Scunvr-Grass.

HURSE'TAIL (Equiselum, from equus, a horse, and seta, hair, in allusion to the fine hairlike branches). Although the plants of this genus are looked upon as mere weeds, they have a very interesting aspect when seen growing in their natural situations; they are f and in boggy places, and multiplied by di646 visions. Several of the species, like grasses, secrete a quantity of flinty earth (silica) mostly lodged in their articulations. There are seven indigenous species.

1. Branched wood horsetail (E. sylvaticum), growing in shady moist woods, by trickling rills, but not very frequent. This is a very elegant species, 12 or 18 inches high, stems erect, beset with many whorls of slender, compound, angular, smooth, spreading branches.

2. Great water horsetail (E. fluviatile). Horses eat this plant with avidity, and in some parts of Sweden it is collected for the purpose of serving them as winter food; flourishing in watery places, about the banks of rivers and lakes. This is by far the largest English species, differing from the foregoing in the fructification, which is a large cylindrical catkin, having four or five pale teeth on a separate short stem, differing from the branched or whorled frond, as is likewise the case with the following one, E. arvense : all the others hitherto observed in Britain have terminal catkins at the top of the fronds. The terminal stems of the great water horsetail are quite erect; at least a yard high, often much more, furnished from top to bottom with whorls of numerous long slender branches. The catkins are brown, with scales, which separate and show the white scales when they are ripe.

3. Corn horsetail (E. arvense). This, in England, is a very common species growing in wet meadows and moist grain fields. It is a most troublesome weed in pastures, and is seldom touched by cows, unless pressed by hunger, when it occasions an incurable diarrhcea ; it is eaten with impunity by horses, but is noxious to sheep. The fronds are reckoned unwholesome to such animals as feed upon them in autumn, especially swine. This rough grass is employed for cleansing and polishing tin vessels. In this species the root is much branched, creeping extensively, producing in the spring several simple, upright, flowering stems quite destitute of branches; a span high, cylindrical, smooth, juicy, of a pale brown, bearing three or four brown-ribbed sheaths, and at the top a solitary catkin.

4. Marsh horsetail, or paddock pipe ( $E$. palustre). This species grows most frequent in spongy watery bogs, and other marshy places, flowering in June and July. The stem is rather slender, deeply furrowed, beset throughout with whorls of slender, angular, minutely rough branches.

It is not so strong as the preceding species, but is equally prejudicial to cows. It is also very troublesome in drains, within which it vegetates, and forms both stems and roots several yards in length: thus the course of the water is interrupted, and the drains are totally obstructed.

5. The smooth naked horsetail (E. limosum) grows also in marshy watery places, and has stems stouter than the last, about two feet high, very smooth to the touch, though finely striated.

6. Greater rough horsetail. Shave-grass pewterwort ( $E$. hyemale). This species is found in boggy wonds, but not very common. The root is black, variously branched; stems 
of a deep glaucous green, from one to two feet high, cylindrical, uniformly and rather copiously furrowed, the furrows minutely toothed and of a strong hardness. This species is wholesome to horses, and is eaten by them; but it is hurtful to cows and disagreeable to sheep. That eminent chemist, Sir H. Davy, first detected a quantity of pure silex in the furrowed cuticle of this plant, which accounts for its power, as a file, in polishing wood, ivory, or cven brass. This purpose it has long served in England, under the name of Dutch rushes, being usually imported from Holland, and is chiefly employed by turners and cabinetmakers to polish their work, as well as by dairy-maids for cleaning pails and other wooden utensils. So wheat-straw, whose cuticle contains the same earth in an impalpable state, like others of the natural family of grasses, is used, when burnt, to give the last polish to marble.

Mr. Nuttall observes that this species is very ahundant on the banks of the Missouri below the Platte, and called "Rushes." It is, he says, found to be injurious to horses which feed upon it for any considerable length of time.

7. Variegated rough horsetail (E.variegatum) is found in wet, sandy ground in Scotland and Ireland. The whole plant is smaller and much more slender than the last. The fibres of the root of this curious little species are remarkably woolly, like those of grasses that grow in loose sand. The sheaths which crown the joints are lax, with lanceolate teeth. The catkin is ovate, acute, blacker than $E$. hyemale, with a more slender stem. (Eng. Flor.iv. 335 -341; Willich's Dom. Encyc.)

HORTICULTURE (Lat. hortus, a garden, and colo, I cultivate). The culture of the kitchen garden and orchard. The chief difference between horticulture and agriculture is, that in the former art the culture is performed by manual labour in a comparatively limited space, called a garden; while in the latter it is performed jointly by human and animal labour in fields, or in an extensive tract of ground called a tarm.

HORTUS SICCUS. A collection of dried plants preserved in books or papers. See Hera ax.

HOT-BEDS. In gardening, are made either with fresh horse-dung, or tanner's bark, and covered with glasses to protect them from the severity of the wind and weather. It is very important in making hot-beds not to raise the temperature too high, as the plants become scorched. See Kitchen Garden, and Forcisg Pits.

HOT-HOUSE. A general term for the glass structures used in gardening and including Stoves, Greenhouses, Orangeries and Con. SERVATORIES. See these heads.

HO'T WALLS. In gardening, walls for the growth of fruit trees, which are built with flues or other contrivances for being heated in severe weather, so as to facilitate the ripening of the wood or the maturity of the fruit. The advantages of hot walls are well illustrated by their influence in ripening peaches, nectarines, and similar fruits in England, Scotland, and many parts of the north of Europe, where such without this aid.

HOUND. An appellation given to dogs of the chase. See Dow and Ginzuruon.

HOUNDS'-I'ONGUE (Cynoglossum). A genus of herbaceous plants, of which only two species grow wild in Great Britain. The cultivated foreign species are pretty border plants, succeeding in any common soil, and readily multiplied by division.

1. Common hound's-tongue ( $C$. offrinale) is found abundant in waste ground and by roadsides. The root is fleshy and tapering. The whole herb of a dull green, downy, and very soft, exhaling when touched a pungent and nauseous scent. When bruised it is affirmed to drive away mice. The stem grows to two feet high, branched, leafy, furrowed, and hairy bearing terminal panicled clusters of dull crimson flowers. This plant is eaten by goats, but refused by sheep, horses, hogs, and cows. It has a bitter taste, and is esteemed powerfully narcotic and dangerous for internal use. The roots are astringent and sedative; and are used externally and internally in decoction in cases of scrofula.

2. Green-leaved hound's-tongue (C. sylvaticum). This is a more rare plant, growing by road-sides and hedges in shady situations, and is distinguished from the common species in its bright shining green colour, and want of downy softness, besides having scarcely any scent. The flowers, which blow in June, are at their first opening reddish, subsequently of a dull blue. (Smith's Eng. Flor. vol. i. p. 259; Paxton's Bot. Dict.)

Four species of this plant are enumerated in the United States. The common hound's-tongue is a foreigner, now frequent in the Middle States, and extending itself throughout the country. It is a biennial, and may be readily known by its disagreeable odour, somewhat resembling that of young mice. It formerly enjoyed some reputation for medicinal properties.

The wild comfrey ( $\vec{C}$. Virginicum) has a perennial root, and is common in rich woodlands. The root is mucilaginous, and frequently employed, in domestic practice, for complaints of the chest, internally, and externally in poultices for bruises, sprains, \&c.

HOUSELEEK (Sempervivum, from semper vivo, to live forever; the tenacity of life in the houseleek is well known). There are seven species of houseleek mentioned by Miller (but these are only a few of this extensive genus). They all thrive best on dry rocky situations. These interesting plants are worthy a place in every collection. The mountain houseleek is a very hardy perennial, bearing a purple flower in June and July. The houseleek (S. arboreum), which is a native of the Levant, is hardy and handsome, bearing a golden-yellow flower in autumn and even in winter. Cuttings taken off and laid to dry for two or three days, will root very freely The juice of the common houseleek (S.tectorum), applied either by itself or mixed with cream, gives immediate relief in burns or other external inflammations. (Pax. ton's Rot. Dirt.)

HOVEN. See Cattle, and Shesp, Dis EASES OF. 
HUMMELLER, BARLEY. An instrument for separating the awns of the barley plant from the seed. There are various modes of taking off the awns: a common one is by treading it by a horse walking over it; another, by rolling it with a grated roller, an instrument something similar to a garden roller, the cylinder being formed of thin, flat, wrought iron bars, placeu about two inches apart, and the edges to the surface: this, rolled over the barley, takes off the awns or ailes. We have also seen a grated presser or chopper, about a foot square, barred across with thin plates, which is lifted np and down by the workman, and thus cirop's off the awns. But the best machine we have seen is one upon a wood stand, with a hopper into which the barley is thrown, from whence it falls into a box in which a spindle is placed in an inclined position, having, when at a few inches apart, short knives placed spiral$\mathrm{ly}$, so as to form a sort of screw, which, when put in motion, has a tendency to draw the barley from the upper end of the box to the lower: during the operation the awns of the barley are effectually knocked off. 'This mode of dressing barley constitutes one of the principal improvements in Salter's patent winnowing machine, which will be described hereafter; but the hummeller is made in the form described for barley only, by several makers. See Winnowixg Machise.

HUMUS. A modern term given by some chemists to the very finely divided organic matters which all cultivated soils contain, and which is generally regarded as the chief element of fertility, the source from which plants are directly nourished. Woody and vegetable fibre in a state of decay constitutes the substance called humus. Liebig lays it down as established, that man and other animals derive the means of their growth and support from the vegetable kingdom, whereas plants find new nutritive material only in inorganic substances. According to this doctrine, humus, being the product of organic matter, does not contribute direct nourishment. to plants, but only constitutes a medium and agent through which their nutriment is derived. "The opinion," he observes, "that the substance called humus is extracted from the soil by the roots of plants, and that the carbon entering into its composition serves in some form or other to nourish their tissues, is so general and so firmly established, that hitherto any new argument in its favour has been considered unnecessary; the obvinus difference in the growth of plants, according to the known abundance or scarcity of humus in the soil, seemed to afford incontestable proof of its correctness.

"Yet this position, when submitted to a strict examination, is found to be untenable; and it becomes evident from most conclusive proofs that humus, in the form in which it exists in the soil, does not yield the smallest nourishment to plants.

"The adherence to the above incorrect opinion has hitherto rendered it impossible for the true thenry of the nutritive process in vegetahlc. ro pecome known, and has thus deprived as of our best guide to a rational practice in agriculture. Any great improvement in that 648 most important of all arts is inconceivable without a deeper and more perfect acquaintance with the substances which nourish plants, and with the sources whence they are derived; and no other cause can be discovered to account for the fluctuating and uncertain state of our knowledge on this subject up to the present time, than that modern physiology has not kept pace with the rapid progress of chemistry."

The chemical process through which humus is usually obtained, is by making an alkaline solution or decoction of mould, peat, soot, woody fibre, \&c., and adding to such decoction acids. The ffocculent matter precipitated is called humic acid, a substance but slightly so. luble in water, requiring no less than 2500 times its weight for this purpose. The compounds which it forms with alkalies, lime, and magnesia, have the same degree of solubility. (Sprengel.)

"Vegetable physiologists agree in the suppo. sition that by the aid of water humus is rendered capable of being absorbed by the roots of plants. But, according to the observation of chemists, humic acid is soluble only when newly precipitated, and becomes completely insoluble when dried in the air, or when exposed in the moist state to the freezing temperature. (Sprengel.)

"Both the cold of winter and the heat of summer, therefore, are destructive of the solubility of humic acid, and at the same time of its capability of being assimilated by plants so that, if it is absorbed by plants, it must be in some altered form.

"According to Dr. Jackson, the substances contained in humic extract form soluble salts with lime. The acids form soluble salts with the same substance, and the salts are decomposed in the process of vegetation.

"The correctness of these observations is easily demonstrated by treating a portion of good mould with cold water. The fluid remains colourless, and is found to have dissolved less than 100,000 th part of its weight of organic matters, and to contain merely the salts which are present in rain-water.

"Decayed oak wood, likewise, of which hu. mic acid is the principal constituent, was found by Berzelius to yield to cold water only slight traces of soluble materials; and I have myself verified this observation on the decayed wood of beech and fir.

"These facts, which show that humic acid in its unaltered condition cannot serve for the nourishment of plants, have not escaped the notice of physiologists; and hence they have assumed that the lime or tlie different alkalies found in the ashes of vegetables render soluble the humic acid, and fit it for the process of assimilation.

"Alkalies and alkaline earths do exist in the different kinds of soil in sufficient quantity to form such soluble compounds with the humic acid.

"Other considerations, of a higher nature, confute the common view respecting the nutritive office of humic acid, in a manner so clear and conclusive, that it is difficult to conceive how it could have been so generally adopted.

"Fertile land produces carbon in the form 
If wood, hay, grain, and other kinds of growth, the masses of which differ in a remarkable degree." (Liebig.)

In relation to the fact observed of carbon and humus often becoming every year more abundant, in spite of cropping, Mr. Ruffin, an author so advantageously known to the American farmer, says there is great difficulty in admitting that land receives no manure, cren when none is conveyed to it by man. In the case of cultivated lands, from which crops are taken off, the quantity, it is true, is small, compared with that of a forest, where much is left to fall and rot. Mr. Rutfin maintains, that so much carbon is derived from the atmosphere, through the leaves of growing plants, that more than half the whole products may be taken away, and the other half may supply as much humus and carbon, or, perhaps, even cause an increase of both. The severely cropped lands of the United States, Mr. Ruffin considers as affording many examples of the draught upon the land being carried beyond the amount supplied, and a proportional reduction in the quantity of humus. See Green Manures.

"The humic acid of chemists," observes Liebig, " is a product of the decomposition of humus by alkalies: it does not exist in the humus of vegetable physiologists." He says in another place, "Transformations of existing compounds are constantly taking place during the whole life of a plant, in consequence of which, and as the result of these transformations, there are produced gaseous matters which are excreted by the leaves and blossoms, solid excrements deposited in the bark, and fluid soluble substances, which are eliminated by the roots. Such secretions are most abundant immediately before the formation and during the continuance of the blossoms: they diminish after the developement of the fruit. Substances containing a large proportion of carbon are excreted by the roots and absorbed by the soil. The soluble matter thus acquired by the soil is still capable of decay and putrefaction; and by underguing these processes furnishes renewed sources of nutrition to another generation of plants, and it becomes humus. The leaves of trees which fall in the forest in autumn, and the old roots of grass in the meadow, are likewise converted in to humus by the same influence: a soil receives more carbon in this form than its decaying humus had lost as carbonic acid. Humus does not nourish plants by being taken up and assimilated in its unaltered state, but by presenting a slow and lasting source of carbonic acid, which is absorbed by the roots, and is the principal nutriment of young plants at a time when, being destitute of leaves, they are unable to extract food from the atmosphere." (Liebig's Organic Chemistry.)

Some recent experiments of Saussure go to prove that plants do assimilate humus as direct nourishment, contrary to the views of Liebig, who, as we have seen, regards it only as a medium by which nourishment is absorbed and subsequently given out.

HUNDRED. An ancient division of a county, which originated either from its being occupied by 100 families, or because every such district found the king 100 able-bodied men for 82 his wars. They were first constiuted by difred the Great. He is supposed to have derived the idea from northern Germany; but there centa, or centena, is a jurisdiction over 100 towns.

HUNDRED-WEIfiH'T A weight of 112 lbs avoirdupois, generally written c:wl.

HUNGER-RO'T. 'The name of a diserse in sheep which speaks for itself. It is ucuasioned by poor living, especially during the winter, and is best cured by better keep.

HURDLE (from the Sax. hynoel, to keep, or the Germ. hurden). 'I'he hurdles of the ancients (crates) were somewhat similar to those of the moderns; they were a kind of wicker-work, and used for various purposes. When employed for drying figs or grapes, they were called ficnria: they were also used for screening fruit from the weather. (Colum. xii. 15.) Hurdles, Virgil informs us (Georg. i. 94), were employed as harrows to level the ground which had been turned up by the rastrum, or heavy rake. They are also employed to feed silk-worms upon. In modern husbandry, hurdle implies a light frame of wood or iron, somewhat in the form of the common gate, constructed for the purpose of forming a movable fence for the confining of sheep and other animals. They are generally made of some light split timber, or of nazelrods wattled together. 'These are principally employed where sheep are folded on arable lands, or where they are fed with turnips in the field, to keep them on a certain space of ground, or to confine them to a certain portion of their food at a time, in which way they are extremely useful; as the sheep, by being so closely confined, contribute greatly to the improvement of the land, in the first case; and they improve by having a given nantity of food allowed them at once, with less loss than they would do if allowed to range at large over the field.

A dozen and a half hurdles will fold thirty sheep, and twelve dozen, one thousand. On the South Downs the allowance is three sheep to a hurdle: this of course varies with the description of sheep. A shepherd and his dog, without any other assistance than having the hurdles carted to the field, will, with the requisite number of hurdles, feed off one hundred acres of turnips. "The number of hurdles required (Quart. Journ. of Agr. vol. iii. p. 647), is one row the whole length of the ridges of an enclosed field, and as many more as will reach twice across two eight-step lands or ridges, or four four-step lands. This number is sufficient for a whole quadrangular field, whatever number of acres it may contain. The daily portions are given, more or less, accorking to the number of the flock. Two of these portions are first set off, or "pitched," the sheep being let in on the first or corner piece. Next day they are turned into the second piece, and the crosshurdles that enclosed them in the first are carried forwards and set to form the third piece. These removes are continued daily till the bottom of the field is reached: both the cross-rows are then to spare, and are carried and set to begin a new long row, close to the off-side of a furrow, and the daily folding carricd back over two or four lands, as at first. It is always proper to begin at the top of the field, if there $h$. any difference in the level, in order that the 3 I 
a ck may have the driest lair to retire to in wet weather. In the setting of hurdles, an iron crowbar, or fold pitcher, is employed, by which much time and loss by breakage of the hurdles is effected." New hurdles, in the south of England, are about 16s. per dozen. They are made at $4 d$. by professed hurdle-makers, who find their own tools: they make about a dozen per day. A larger kind of hurdles, called park hurdles, cost $2 s$. each, and iron hurdles about $4 s .6 d$. to $6 s_{\text {. }}$; and these are, in the long run, for permanent divisions, more economical than wooden ones. A new kind of iron hurdle for feeding sheep in gardens and pleasure-grounds is described, with a wond engraving, by $\mathbf{M r}$. Baist (Ibid. vol. ii. p. 113), and the complete process of wooden hurdle-making is given, Ibid. vol. iii. p. 647. There is also another kind of hurdle, made with twisted hazel-rods, very common in the south of England, whose first cost is less than the other kinds, but they do not last so long, and sooner get out of repair.

The farmer who uses the ash hurdles would find the advantage, on the score of durability, of charring (or partially burning) that portion of them which goes into the ground. Net hurdles are also sometimes economically used; but they are rather more troublesome than wooden or iron hurdles, and require to be kept carefully in a dry place, when not in use. There is a very elaborate paper on hurdling off, and more especially upon all kinds of fencing, for the temporary or permanent enclosure of land, by Mr. Somerville (Com. Eoard of Agr. vol. ii. p. 1); he advocates the more general hurdling off of grass lands in the spring of the year.

There are two modes of folding, which should be practised according to circumstances: the first is where the sheep fed during the day on waste or common land, are penned at night, for the sake of their manure, on the enclosed arable pastures of the farm. This is a highly profitable mode. It is calculated that the dressing thus given by 300 sheep is sufficient, in a week, for one acre of land, and is worth three pounds. Hence the enhanced value of farms having ready access to downs, or possessing a right of common. The second mode of folding is the feeding off of green crops by sheep enclosed in daily divisions, by hurdles, by which means the land has the full benefit, equally distributed, yielded by the consumption of the green crop; of course the value of the folding will mainly depend, both in quality and quantity, upon the food consumed: hence, too, the superior fertilizing effect lerived from sheep having oil-cake or corn added to their green food. The plan of feeding sheer on one field during the day, and folding them : $n$ another during the night, is a bad practice long since condemned by Arthur Young, who describes it as "merely robbing Peter to pay Pau"," since it is, in fact, only the removal from ore field to another of the richest organic matters, the sheep being also injured by the drift or iabour of removal, and by the fasting (so contrary to their natural habits) during the night.

The folding of sheep on green crops is one if the great modern agricultural improvements. 6.50
It insures the equal distribution of the manure, prevents waste of food, keeps the sheep quiet, gives them fresh ground daily, and enables the farmer to plough close after the sheep, and thereby prevents the loss by evaporation of the finest portion of the manure. See Folds and Folning.

HURDS, or HARDS. A provincial name for the refuse of hemp or flax.

HURTLEBERRY, and HURTS. Provincial names of the whortleberry.

HUSKS. The dry envelopes, or outward integument of either fruits or flowers.

HUSBANDRY. A comparatively primitive term, including both agriculture and gardening, or all those country occupations which the father of a family is expected to perform in the country. The term is very commonly used as synonymous with agriculture. The Berwickshire husbandry, the alternate husbandry, and the convertible husbandry, are terms employed in agriculture for certain systems of cropping, in which the land is alternately kept under grass and tillage. See Agriculture, and RoTation of Crops.

HYBERNATION (Lat. hybernus, wintry). The act by, or the state in, which certain animals exist during the season of the year when excess of cold, or lack of food, prevents their going abroad, and performing their customary functions. The bat and the hedgehog, lizards, snakes, frogs, toads, \&c., are among the animals and reptiles which hybernate. Some quadrupeds, as the dormouse and squirrel, which subsist on articles of diet better adapted to be laid up in store than insects, carry a winter provision to their hybernating nests; and their torpidity is more nearly allied to a profound, but ordinary sleep.

HYBRIDS (Gr.). The produce of a female plant or animal which has been impregnated by a male of a different variety of species.

The most common hybrids are those which result from the connection of different varieties of the same species, as the produce of the wild boar and domestic sow; the endless modifications which result from analogous inter-breed. ing from varieties of the rose, the African geranium, and other ornamental plants, are familiar examples of the principle among vegetables. The most common and useful of hybrids is the mule. Although some rare exceptions to the rule are on record, it seems to be a principle of nature that all hybrids should be sterile.

HYDRANGEA (Hydrangea arborescens). A hardy perennial, native of North America, which flowers in July and.August. It loves a moist soil, and should be kept free from weeds. Its roots may be parted in October. If a severe winter attacks the plant, it will only die down to the ground.

Besides the common species, botanists enumerate 2 or 3 others found in the southern and Southwestern States.

H. hortensis, or the changeable hydrangea, blooms from June to October. It is a native of China. Cut the stems down every autumn, and cover the root through the winter, to guard it from frost. Hydrangeas are propagated by cuttings. 
HYDROGEN. A chemical element, which derives its name from two Greek words that signify "a generator of water," because it is one of the constituents of that nuid, which is always formed when hydrogen gas is burned in combination with atmospheric air, or with oxygen gas. It is known to us, in its simplest form, only in the state of gas, and is speedily fatal to animal life when it is breathed unmixed with atmospheric air. It is, however, a component of animal matters, and it forms a very essential part in the economy of vegetable substances, in which it is always found. Thus sugar contains 6.90 per cent. of hydrogen; gum, 6.93 ; bee's wax, $12 \cdot 672$; wood of the oak, 5.69 ; wheat starch, 6.77 ; acetic acid (the acid of vinegar), $6 \cdot 35$ per cent. It is regarded as an element, because it has resisted every attempt to decompose it. It is the lightest of all ponderable matter, 100 cubic inches weighing only $2 \cdot 15$ grains. No known degree of cold has been able to condense it to a liquid. It cannot support combustion, but is combustible in conjunction with atmospheric air. It constitutes one-ninth of the weight of water,a substance essential to vegetation, and which plants are supposed to have the power of decomposing. Under such circumstances, Liebig asserts that 8.04 parts of hydrogen unite with 100 parts of carbonic acid to form wuody fibre, whilst the oxygen is separated in the gaseous state. (Organic Chem. p. 63.) Most vegetable structures contain hydrogen in the form of water, but the hydrogen essential to this constitution cannot exist in the form of water. That hydrogen gas exerts a considerable influence upon the leaves of plants, was first noticed by Dr. Priestley. Sennebier found that plants which lose their green colour in the dark, preserve it under those circumstances, if a small portion of hydrogen gas is present in the atmosphere in which they are placed; and Dr. Ingenhous noticed that its presence, when they are growing in the light, renders their colour of a deeper green (Am. de Chem. vol.iii.p. 57); and, again, M. Humboldt has noticed that the Pou annur, Trifolium arvense, and other plants growing in the galleries of coal mines, preserve their green colour, although vegetating in the dark, and that, in such situations, the atmosphere contains a proportion of hydrogen gas.

When applied to the roots of plants in moderate proportion, the influence of hydrogen gas is evidently beneficial in all those situations where this gas is evolved, as in drains, stagnant waters, dung-hills; and the vegetation growing over such places is uncommonly rank and luxuriant. The gas observed to arise by the agitation of the mud of stagnant pools is the same gas employed for the purposes of illumination, or carburetted hydrogen gas, a peculiar gas composed of carbon 0.416 ; hydrogen 0.0694 . In the process of putrefaction, a quantity of water exactly corresponding to that of the hydrogen, is formed by the extracion of oxygen from the air; while all the oxygen of the organic matter is returned to the atmosphere in the form of carbonic acid. Now the process of vegetable assimilation consists in the extraction of hydrogen from water, and carbon from the carbonic acid; hence the ad- vantage of decomposing vegetable matter to living plants. A small portion of carburetted hydrogen gas in the atmosphere, or in the soil of plants, certainly therefore promotes their vegetation; but like pure hydrocen gas, when it constitutes their entire atmosphere, it de. stroys them. (Thomson's Chem. vol. iv. p. 347.)

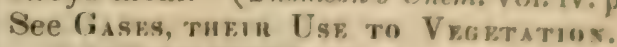

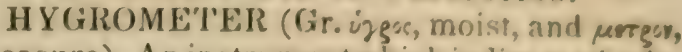
measure). An instrument which indicates the de. gree of moisture or vapour present in the atmo. sphere, or its relative degrees of dampness and dryness. Hygrometers are of several forms, and a rude hygrometer is easily made by means of a long hair, or strip of leather, or cat-gut, suspended from a peg, kept in its upright position by a slight weight: these, by their very sensible contractions and expansion according to the humidity of the air, indicate, by an attached scale, its variations. Hygrometers of this kind, however, are defective, from the irregularity of their action, and the impossibility of comparing them with each other, their alteration by time, and other circumstances. These disadvantages gave rise to the construction, by Professor Daniel, of that now commonly used in England, and called by his name. This instrument is, however, somewhat complex and costly, requiring considerable skill in its use. It will doubtless be superseded by other contrivances for ascertaining the precise quantity of moisture in air, one of which, invented by Prof. A.D.Bache, of Philadelphia, has been already described under the head of $D_{E} w$.

The dew-point is the temperature immediately below that of the vapour contained in the surrounding atmosphere: the difference, however, between the dew-point and that of the vapour is so slight, that for all ordinary purposes they may be considered the same.

The temperature of the invisible vapour of the atmosphere being thus ascertained (for it differs materially from the temperature of the air in which it is contained), it is easy to calculate the force it exerts as thus existing in the state of steam, and the weight of a given bulk of it. Tables have been formed showing the proportion of watery vapour in each cubic foot of atmospheric air corresponding to every degree of the dew-point.

HYSSOP, COMMON (Hyssopus ofirinalis, probably from the Hebrew). There are three varieties, distinguished by the colour of the flowers, the white, red, and blue; the last of which is most coinmonly cultirated. It is a perennial, native of Siberia. The root is knobbed, woody, fibrous; the stem about $t w c$ feet high, quadrangular, erect, branching.

A dry soil is the one most appropriate for hyssop. If it is grown on a rich or wet one, it becomes luxuriant; but, from a deficiency of woody matter, is generally destroyed by the frost, as well as rendered less aromatic and powerful in its medicinal qualities. It is propagated by seed and slips of the branches and young shoots, as well as by ofisets. The seed may be sown from the close of February until the end of May. Rooted offsets may be planted in March, April, August, and September; cuttings of the branches in April and May, anc slips of young shoots in June or July. 
The seeds may be inserted broadcast, or preferably in drills, six inches apart, in either case not being buried deeper than half an inch. It is the usual practice, when the seedlings have attained the growth of six weeks, to prick them out 12 inches apart; but it is by much the best practice to raise them where they are to remain.

The slips and offsets are best planted at first in a shady or north border; they are generally firmly rooted in two months.

In September or October they are all fit for removal to their final stations. After every removal, whether of planting, pricking, \&c., they must be watered plentifully and regularly until established. Hyssop possesses some excitant and tonic powers, but is now rarely employed in medicine.

\section{I.}

ICE (Sax. 1r; Dutch, eyse). Water in a state of congelation. Ice is about one-eighth part lighter than fresh water; hence it swims in that element; and, owing to this property, the icebergs and ice-islands are floated down to southern latitudes from the arctic circle. Water, which freezes at $32^{\circ}$ of Fahrenheit, suddenly expands, and consequently, when it is interposed in crevices and clefts of rocks, it separates these, and often precipitates immense masses from the tops of mountains into the adjoining valleys. This is a principle which should be kept in remembrance by the farmer in making mounds or walls of earth, for if the smallest clefts be left, the walls may be broken down and crumbled to pieces even by moderate frosts.

ICE-HOUSE. A house or vault for the preservation of ice in summer, should not be regarded as merely administering to purposes of luxury, since ice contributes so much to the convenience, comfort, and even health, as to make it almost an indispensable article of domestic economy. The effects of the excessive heat which commonly prevails in the summers of the United States, are greatly obviated by the use of ice, which not only serves for the preservation of fresh meats, butter, \&c.; but in addition to these advantages and its grateful employment for assuaging common thirst, it is a powerful agent in tranquillizing the irritability of the stomach in bilious fevers and dysenteries, and relieving the pain and burning heat often attendant upon inflammations and fevers. Thus, by soothing the stomach, and removing excessive heat, iced drinks and applications restore the deranged functions of the nervous and muscular systems of the sick, whilst they refresh and invigorate persons in health so as to render them capable of enduring exercise and exertion even under circumstances calculated to produce great oppression and irconvenience.

An interesting writer, has left the following testimony in favour of ice, as a restorative and remedy in fevers, which has been abundantly corroborated by subsequent experience. "I never," says he, "was in better spirits than here in this hot country (Sicily). I believe the ruantities of ice we eat, in ices, contribute to

for I find, in a very violent heat there is no 652 such cordial to the spirits as ice, or a draught of iced water. Its cold braces the stomach, and gives a new tone to the fibres. I knew an English lady, at Nice, soon cured of a threatening consumption, by a free indulgence in the use of ices. It is the common practice here, Sicily, to give quantities of ice-water to drink in inflammatory fevers." (Brydone.)

"The custom in Sicily and Italy," says another author, "of taking ice, is considered as a powerful remedy in many diseases. The physicians of these countries do not give many medicines; but frequently prescribe a severe regimen; and prevent the baneful effects of various diseases, by suffering the sick, for several days, to take nothing but water cooled by ice, sweet oranges, and iced fruits." (Siolberg.)

One of the greatest advantages afforded by ice houses, is that of enabling families to preserve their butter, meat, fish, poultry, game, \&c., in states of the weather which would, otherwise, quickly induce them to spoil. In no part of the world are ice-houses more essential to comfort, convenience, and health, than in the United States, and in all the northern and Middle States the winters are sufficiently cold to furnish ice of sufficient thickness to lay by for preservation. The cities of the Southern States are now regularly supplied with thick blocks of ice from New England, which not only afford a regular article of export to the West Indies, but also to Calcutta!

Considering the small expense and trouble at which ice houses or vaults may be constructed, and the many advantages to be derived from them, it is surprising that any respectable country establishment should be without one.

It is considered that the simplest, and most scientific form for an ice-house, is a double cone, that is to say, two cones joined base to base, the one sunk into the earth with its point downwards, into which the ice is rammed, the other being a conical roof, generally of wood-work, covered with thatch and pointed at top. The entrance should be placed always on the north side, and provided with two doors some distance apart, and the spot screened from the sun by trees, shrubbery, a hill, cliff, or other barrier. The lower part may be dug about 16 feet in diameter, terminating below like the point of a sugar-loaf. Its ordinary depth, for a moderate family, may be about 24 feet. The larger the dimensions, the longer will it preserve the ice, provided it be filled. In digging, the workmen should slope the ground progressively towards the axis of the cone, to prevent the earth falling in. This conical slope should be faced with brick or stone work about one foot thick, and jointed with Roman cement, so as to be air and water tight. A well is to be excavated at the bottom two feet wide and four deep, covered at top with an iron grating for supporting the ice and letting the water drain away.

The upper cone may likewise be built of brick-work, and covered with thatch; such a roof would prove the most durable. Whatever kind of roof be preferred, there must be left in it an oblong passage into the interior. This porch should face the north, and be at least 8 
teet long by $2 \frac{1}{2}$ feet wide; and perfectly closed by a well-fitted door at each end. All round the bottom of this conical cover, a gutter should be placed to carry of the rain to a distance from the ice-house, and prevent the circumjacent ground from getting soaked with moisture.

The ice-house should have no window to admit light; but be, so to speak, hermetically sealed in every point, except at its cess-pool, which may terminate in a water-trap to prevent circulation of air.

A clear day should be selected for charging the ice-house; but before beginning to fill, a quantity of long dry straw should be laid on the bottom crosswise; and as the ice is progressively introduced, straw is to be spread against the conical sides, to prevent the ice from coming into contact with the brick or stone work. The more firmly compacted the ice is, the better does it keep. No layers of straw should be stratified among the ice, for they would make its body porous. Some persons recommend to pour in a little water with the successive layers of ice, in order to fill up its small crevices, and convert the whole into one mass. This may answer well when the jee is put up very cold, as the water may then be directly frozen into a solid mass.

Over the top-layer a thick bed of straw should be spread, which is to be covered with boards surmounted with heavy stones, to close up the interstices in the straw. The inner and outer doors should never be opened at once; but the c ne should always be shut before the other is opened.

Dry snow well rammed keeps equally well with hard ice, if care be taken to leave no cavities in the mass, and to secure its compactness by sprinkling a little water upon the successive charges.

'To facilitate the extraction of the ice, a ladder is set up against its sloping wall at one side of the door, and left there during the season. (Uic's Dict.)

The time preferred for filling an ice-house, should, when practicable, be during the prevalence of extreme cold, or as soon after as possible, since the colder the ice when packed away, and the thicker the blocks, the longer it will last. Ice and snow can often be laid by, even in the Middle States, many degrees below $32^{\circ}$ or the common freezing point of water. The larger the quantity of ice accumulated ir one place, the slower will be the rate at which it will melt.

One of the principal objects to be kept in view in the construction of an ice-house, is to have it so that the water will pass off directly, as fast as the ice thaws. If the situation is sandy, or if you come to a layer of sand or gravel about the proper depth, no further care will be necessary; but if you find a stiff clay, rock, or earth of any kind impervious to water, you must contrive an outlet or abandon the place. This outlet may be constructed in several ways. If on the side of a hill, dig a drain and make it air-tight by means of a water-trap or inverted syphon; or the water may be drained into a well and pumped out; or you may sink a well in the bottom until you come to sand or gravel, and fill it up with stone. The cellar walls may be laid with stone, brick, or even lined with wood, as is most convericent or economical. A space of 8 or 10 inches is renerally left between the wall and surrounding earth, which is filled in with tan, charcoal, straw, corn-stalks, or any other non-conductor of heat, the first-named article being generally preferred. A house 9 feet square in the clear, and 9 feet deep, will hold about 25 cart-load's of ice, which will be enough for a large family.

A cheap ice-house may be made thus :-Dig a cellar, say 10 feet square, and 10 feet deep. Then cut small timber from the woods the proper length, and build up in the cellar after the plan of building log-cabins, leaving a space between the logs and earth to be filled in with straw, tan, or other suitable material. Raise the wooden walls 2 or 3 feet above the surrounding ground, and heap up a bank so as to turn off the rain-water. A thatched roof is generally recommended, as the best to keep out heat, but some object to such covering as affording harbour to rats and other vermin.

The importance of keeping ice well surrounded vith a non-conductor, and having the water absorbed as fast as melting takes place, is shown in the following extract from the Kentucky Farmer:-

"We take at sunrise from the ice-house, as much as will be probably wanted through the day, and cover it up in some saw-dust placed in a barrel in the dairy-house. At night, the size of any given piece is scarcely perceptibly diminished. It is a perfect charm."

In some parts of the United States where thick ice is rare, some persons pack away large quantities of snow, which, if the mass be large, and the snow dry or previously well drained, will often keep through the summer. In most seasons ice may be collected in suffcient quantities to fill ice-houses in every latitude of the Midule States. If no pond or stream of water of sufficient size be at hand, advantage may be taken of any little rill, which, by the erection of a small dam, may be made to overflow a considerable space. If the water be not more than 6 or 8 inches deep it will answer every purpose.

In stowing away ice the pieces should be as square as possible, and as large as they can be got or handled. They should be placed closely together like stone in a wall, and the crevices well filled with smaller fragments. 'The plan sometimes recommended of pounding cr crushing the large pieces is reprehensible.

ICHNEUMON FLIES. Insects belonging to the natural order Hymenoptera, which includes bees, wasps, ants, saw-flies, \&c. The injury caused by this whole order is so small, and the benefits derived from many of them so great, that instead of being enumerated among destructive insects, they may be pronouniced the benefactors of the human race.

With regard to the ichneumon flies, they perform an important and very singular pars in the economy of nature, by working the dc. struction of caterpillars, plant-lice, and other destructive insects. 'This they effect by piercing their bodies with a kind of sting or juercer called ovi-positor, and thus laying their egg: in a living nest. Each ichneumon fly serm: 3, 2 
to single out the larva or pupa of some particular kind of caterpillar or other insect, to which it therefore stands in the relation of parasite. The eggs hatch in due time, and the larva of the ichneumon commences feeding upon its victim, the vitals of which are soon destroyed, after which the parasite or ichneumon comes forth in due time to another state of existence.

Some of the ichneumon fies are extremely small, and confine their attacks to the eggs of other insects, which they puncture, and the little creatures produced from the latter find a sufficient quantity of food to supply all their wants within the larger eggs they occupy. The ruby-tails and cuckoo-bees lay their eggs in the provisional nests of other insects, whose young are robbed of their food by the earlier hatched intruders, and are consequently starved to death. The obligations which the farmer and society at large owe to certain parasite insects is forcibly illustrated in the case of the Hessian fly, the devastations of which are often prevented through the destruction, during a single season, of nearly a whole race by its parasite.

Professor Peck has described a minute ichneumon fly, stated by Mr. Westwood to be a species of Encyrtus, that stings the eggs of the slug-fly, and deposits in each one a single egg of her own. From this in due time a little maggot is hatched, which lives in the shell of the slugfly's egg, devours the contents, and afterwards is changed to a chrysalis, and then to a fly like its parent. Professor Peck found that great numbers of the eggs of the slug-fly, especially of the second hatch, were rendered abortive by this atom of existence.

In treating of the pigeon tremex (Tremex columba), which in its larva state is a destructive tree-borer, Dr. Harris observes that it is often destroyed by two kinds of ichneumon-flies, (Pimpla atrata and lunator of Fabricius), which may be frequently seen thrusting their slender borers, measuring from three to four inches in length, into the trunks of trees inhabited by the grubs of the tremex and by other wood-eating insects; and, like the female tremex, they sometimes become fastened to the trees, and die without being able to draw their borers out again.

The ichneumon flies are little busy-bodies, ever on the alert, and with untiring scrutiny continually prying into every place to find the lurking caterpillar, grub, or maggot, wherein to thrust their eggs. (Harris.)

A specimen of this extensive family is represented in $\mathrm{Pl} .15$, fig. 12, in the Trogus fulvus, which commits great havoc among caterpillars and grubs. See Aphidians, \&c.

IGNIS FA'TUUS (Lat. vain or foolish fire; a translation of the French feu follet.) A kind of luminous meteor, which flits about in the air a little above the surface of the earth, and appears chiefly in marshy places, or near stagnant waters, or in churchyards, during the nights of summer. There are, we are told, mar. $y$ instances of traiellers having been decoyed by these lights into marshy places, where they have perished; and hence the names Juckwith-a-lantern, Will-uith-a-wisp; the common peoile ascribing the appearance to the agency of . il spirits, who take this mode of alluring men 6.54 to their destruction. The cause of the pheno menon does not seem to be perfectly understood; it is, however, generally supposed to be produced by the combustion of sorne highly inflammable gas, such as phosphorated hydrogen, which takes fire spontaneously on rising and mingling with atmospheric air.

Milton, in his Paradise Lost, b. ix. 1. 634, thus alludes to it:-

A wandering fire,

Cof unctuous vapour, which the night

Condenses, and the cold environs round,

Kindled through agitation to a flame,

Which oft, they say, some evil spirit attends,

Hovering and blazing with delusive light,

Misleads the antazed night wanderer from his way

To bogs and mires, and oft through pond or pool,

There swallowed up and lost, from succour far.

IGNITION (Lat. ignis, fire). The act of setting fire to, or of taking fire, as opposed to combustion, or burning, which is a consequence of ignition. The term "spontaneous ignition" is applied to cases in which substances take fire without previous application of heat. This is illustrated in the burning of hay-stacks, when the hay has been put up too green; the scorching of corn-stacks from the same cause, and the taking fire of ships laden with fermentable products.

IMBRICATED. In botany, a term used in speaking of the arrangement of bodies, to denote that their parts lie partly over each other in regular order, like the tiles upon the roof of a house, as the scales upon the cup of some acorns; also applied in speaking of the æstivation of petals or leaves, to denote that they overlap each other at the margin without any involution. (Brande's Dict. of Science.)

IMPLEMENTS, AGRICULTURAL. Almost all the operations of agriculture may be performed by the plough, the harrow, the scythe, and the flail; and these, or similar tools for performing the same work, are the sole implements in the primitive agriculture of all coun. tries. With the progress of improvement, however, many other implements have been introduced, the more remarkable of which are the drill-plough, the horse-hoe, the winnowing machine, the thrashing machine, and the reaping machine. The object of all these implements and machines is to abridge human labour, and to perform the different operations to which they are applied with a greater degree of rapidity, and in a more perfect manner than before. In the present work the different implements are treated of in their alphabetical order. Of the progress made in the construction of agricultural instruments in England, the jud ges of implements at the Liverpool meeting of the English Agricultural Society, in their report very justly remark, when speaking of "the good effects which have already resulted from the public exhibition of implements at the Society's meetings, in stimulating the talent of the mechanic and the zeal of the husbandman. At Oxford the show-yard may be said to have presented an epitome of the state of agricultural mechanism existing in 1839 , the era of the formation of the Royal Agricultural Society of England. No spectator of that show can have failed to be struck with surprise and admiration at the Liverpool exhibition. At Oxford there were sume examples of good machinery 
and workmanship, but many more of rude, cumbrous, and ill-executed implements. At Liverpool many machines were exhibited, not only of surpassing still in contrivance and execution, but also having for their object the effecting of processes in tillage-husbandry of the most refined nature and acknowledged importance, but hitherto considered of very difficult practical attainment. Some of these may already be considered as forming part of the necessary apparatus of every well-managed farm, and to be essential to its economy and profit. This vast stride in the mechanics of agriculture, made within so short a period, has doubtless arisen from the congregating together of agriculturists and mechanicians from all parts of the empire: and a still higher perfection in machinery may be confidentiy anticipated from the opportunity offered, under the auspices of the Society, of periodically contrasting and estimating the merits of varied implements used for similar purposes in different localities and soils. It is apparent that the manufacture of even the commoner instruments has already, to a great extent, passed out of the hands of the village ploughwright and hedge-carpenter, and been transferred to malsers possessed of greater intelligence, skill, ard capital. The improved style of finish, the greater lightness and elegance of construction, and the generally superior adaptation of the means to the end, in every class of implements, were sufficient manifestations of the beneficial results arising from the encouragement given by the Society to these objects. Neither were examples wanting in the higher classes of maclines to show that the fourth important object $\mathrm{fc}_{\mathrm{f}}$ which the Society was incorporated is, to some extent, fulfilled-viz. "to encourage men of science in their attention to the improvement of agricultural implements.'"

The great variety of soils and fluctuations of climate in the extensive territory of the United States, call for multiplied expedients to till the various plants, and provide shelter from heat as well as cold. The wants and exigencies known in various parts of the country must therefore contribute to make the United States a fruitful field of inventions. Accordingly, by consulting the records of the Patent Office at $W$ ashington, we find that since the year 1793, when the first patent law was instituted, and up to the year 1836 inclusive, the number of patents taken out for inventions is 6000 , of which 124 are for improvements in the plough,-119 for threshing-machines, -80 for churns, - 125 for washing-machines, \&c.

The remarks of the Messrs. Ransome, of Ipswich, upon the preservation of agricultural implements in general, are such as every farmer should be guided by. They suggest to farmers generally, that a little instruction given io the workmen in the use of the machines, and care in preserving them, would add to their effriency and durability. Attention to washing implements and machines before laying them by, a little oil on such as have rerolving wearing parts, and a coat of paint iccasionally to each, will cost but little, and make the lifference between having a machine ready for use, $0^{*}$ covered with rust and want- ing repair just as the season for its nee com mences. These sugerestions are sn obvious, that one would think no apolicy neredful for making them, as experience proves that a large proportion of the repairs required arises from want of attention to these apparently trifling matters. And to this end the artvice of Mr. Crosskill, of Beverley, maly he acted upon with considerable advantage: he says, "Select the most likely labourer on the farm, put the implements under his care, make it a strict rule with all the men that each imple. ment done with for the season shall be brought to one particular place, say near the pond or pump; the man having charge of the implements must then wash and clean them well before putting then into the shed."

IMPOSTHUME. In farriery a sort of swelling, or collection of matter or pus in any part of the body of an animal. See A iscrss.

IN-AND-IN-BREEDING. The practice of breeding from close relations. See Breedrsa, Cattue, Sheep, \&c.

INCH. A measure of length, the tweifth part of a foot.

INCISORS or INCISORES (Lat. incido, I cut). 'The teeth implanted in the inter-maxillary bones of the upper jaw, and in the corresponding place in the lower jaw, and which are generally shaped for the purpose of cutting or coarsely dividing the food. The ruminating animals, including the bull and cow, sheep, goats, the deer tribe, and the camel have no incisors in the upper jaw; but some of them have canine teeth, which project from the mouth. See Age of Animals.

INCI,OSURE (Lat. includo, I shut up). See Evclosure.

INCUBATION (Lat. incumbo, I brood over). Hatching or the laying down of an animal upon her own or another's eggs, communicating to them heat, and maintaining them at her own temperature, a condition essential to their developement. In many animals the developement of the fœtus takes place after the exclusion of the egg, and whilst it is maintained in contact with the external surface of the parent's body, as in the crab and lobster tribes beneath the caudal plates; or agglutinated to the surface of the abdomen, as in certain species of pipe-fish (syngnathus), or concealed in cutaneous marsupial cavities, as in other species of syngnathus, and the hippocampus; but in these and other instances from the cold-blooded animals, the eggs are retained by special contrivances in contact with the parent, without occasioning any restraint upon her postures on movements.

That a due degree of warmth is the essential object of incubation in birds is proved by the ancient and well-known practice of substituting artificial heat, by which fertile eggs are hatched in the same period, and the excluded chick is as fully and strongly developed as when produced by natural incubation.

Artificial incubation has been practised from a remote period by the Egyptians and Chinese: the former, indeed, have carried this process to such a high degree of perfection, as in many instances to have entirely superseded the us. of the hen in hatching.

6.ร. 
It is effected either by means of an oven, stove, or steam, and it has been calculated that the ovens of Egypt every year communicate life to about $93,000,000$ chickens. This porcess has received considerable attention from the French philosophers; but perhaps the best exemplification of its results, that has been witnessed in Europe, was given by the proprietor of the Eccaleobion, which was lately exhibited in Pall Mall, London.

The mean temperature of incubation is $100^{\circ}$ Fahr.; it may vary from $95^{\circ}$ to $105^{\circ}$, and towards the close of the process may be suspended for one or two hours, or for a longer period, according to the degree of extraneous heat which the eggs may derive from their situation, without fatal consequences to the embryo. The power of communicating the requisite degree of warmth to their eggs arises out of the unusual developement of, and determination of blond to, a peculiar plexus of vessels, distributed over the skin of the abdomen, and which, in most birds, is connected with a derivation of blood from the internal organs of generation after the subsidence of the funcional activity of the ovarium and oviduct to the external integuments. The vascular, hot, and sensitive condition of the skin of the abdomen is the exciting cause of that uncontrollable propensity to incubate, which the Greeks denominated "storage," and which, with its associated phenomena of patience, abstinence, ind self-denial, forms so remarkable a feature in the economy of birds. The eggs of the bird present several peculiarities in relation to the circumstances under which the foctus is to be developed; their oval form permits a greater proportion of their surface to be in contact with the heat-communicating skin of the parent, than if they had been a spherical body; while the shell, by virtue of its hard, calcareous texture, and its arched disposition about the soft contents, sufficiently defends them from the superincumbent pressure. As warmth is the only essential influence which the egg delives from the parent, the shell is porous and permeable to air, and the germ is surrounded by an adequate store of nutritious matter. See EGG.

The period of incubation is generally directly as the size of the bird, but the degree of developement which the chick attains prior to exclusion varies. As a general rule, it is inferior in birds of flight, as the Accipitrine and Passerine orders, than in the terrestrial, wading, and swimming birds; and the warmth and complexity of the nest bears relation to this difference of developement. If the thrush had been forewarned that her young would be excluded from the egg naked and helpless, she could not have prepared beforehand a warmer and more comfortable abode than her instinct had led her to construct for their accommodafion; and if with such a nest we contrast the rude mass of straw in which the hen deposits and incubates her eggs, it might be imagined that she knew beforehand that her chickens would come into the world well clothed and strong enough at once to run about and pick up their own food. In this case, therefore, the nest relates only in incubation; in the other, :o incubation and subsequent rearing of the young; and according to the degrees of developement attained during incubation, and the associated condition of the nest and habits of the parent, birds have been divided into two great groups, the Aves altrices and Aves pracoces. See Gestation.

INDIA, THE AGRICULTURE OF. The British farmer will, I am afraid, not derive many useful hints from the most careful study of the agriculture of the eastern portions of Asia. In Hindostan, for instance, too many causes have contributed to retard the march of agricultural improvement. The innate dislike of the natives to innovations of all kinds, the nature of their region, their indolence, and the political oppressions under which they have long been labouring, are amongst the many causes of the degraded state of Indian agriculture. I am indebted to my brother, Mr. George Johnson, of the Supreme Court of Calcutta, for most of the following sketches of Indian modes of cultivation. He says, in describing the residences of the Indian ryots or farmers, "When I speak of an Indian farm, the image must not rise to the mind of the European reader of a substantial dwelling-house, surrounded by commodious outbuildings, and conveniently placed amongst its compactly enclosed fields; such an agricultural establishment bespeaks a far advance in the art of cultivation, the employment of large capitals, and remunerating prices to the cultivator. Now, none of these contingencies occur in Hindos. tan; but, on the contrary, the operations of agriculture are rudely executed; the cultivators are poor, the profits are small, the results correspondent. The dwellings of the ryot: throughout India are in no degree superior te the other mean huts with which they are associated in the village. No barn is attached to the residence of the poorer cultivators, for the pittance of grain annually raised is immediately beaten out-the major part sold at once to the merchant, and the small residue for seed and sustenance is stored in baskets or jars, and these are usually placed in the room where the family dwells. The outbuildings rarely extend beyond an enclosure in which to secure the cattle at night. By far the greatest num ber of farms do not exceed a size requiring a single yoke of oxen, for the occupier is the only ploughman."

The various imposts to which these little farmers are exposed, sound strange to English agriculturists; they are enumerated by Dr. Buchanan. (Ind.Rech. vol. ii. p. 200.) The ryot's heap of grain is usually about 3000 seers : of this is first set apart-

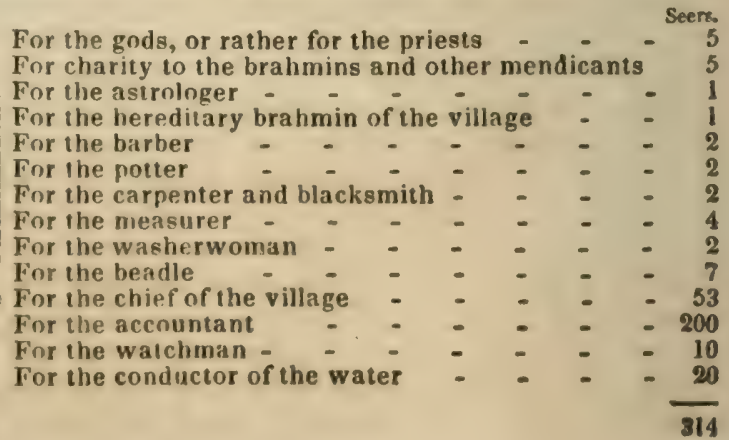


This leaves a residue of 2686 seers; of this government takes 10 per cent, and, after all the drains have been satisfied, the grower is left in possession of a residue of two thousand seers of rice. (Eucilanan's Mysore, vol. i. p. 265.)

Irrigation is practised in India, and in almost all the hot countries of Asia, to an extent of which the English farmer has little conception; for, as Mr. George Johnson remarks, "In every district of Hindostan, as in all other tropical climates, irrigation is the most effectual mode of promoting fertility. In places favoured by nature, whole plains are occasionally flooded merely by the construction of a dam across the outlet of some mountain stream, or it is confined nearer to its source, so as to form a reservoir, from which the water may be obtained at the most desirable seasons. In less favourable situations, the water frequently has to be raised to a considerable height, in order to attain an elevation level with, or stightly above the cultivated land. This is very generally effected by a scoop of matting suspended between two ropes, the ends of which are held by two men who bale it from the reservoir into a hole some feet above it, and from thence it is similarly baled by others, from hole to hole, until the desired height is attained. Sometimes the scoop is suspended between poles erected in the form of a gallows; at others, as in the Jiut wells, from which the water is raised by cattle or by hand in some districts. The extensive canals formed in the neighbourhood of Delhi and in the Punjab are no longer employed. The machinery, so general in China, is nowhere used in India for raising water. In 1798 , Dr. Tennant relates, that the practice of the natives then was, and is still followed, after ploughing the fields in the usual manner, but before sowing, to divide them into regular small squares, like a chessboard; each square is surrounded with a shelving border about four inches high, capable of preverting the escape of water. Between these siuare enclosures, small dykes are formed for conveying a rivulet over the whole field; when the water has stood a sufficient time in one square, it is let off into the surrounding dyke, and conveyed to another, and so on in succession through the whole field. The fertility induced amply recompenses the labour, and the neatness imparted to the country by this husbandry is very striking." (Ind. Rech. ii. 167.) In some places the water has to be raised from deep wells, several of which are in the most elevated parts of each field. The work of drawing the water is performed by two bullocks, not travelling round in a mill, but pacing in a line direct from the well's mouth. The various little trenches already mentioned, all radiate from these wells. About Patna the irrigation water is raised from the wells by means of a bamboo lever, with its fulcrum on a frame about 10 feet high, a weight at the opposite end being employed to assist the workmen in counterpoising the leather bag of water; this plan is only resorted to when the wells are shallow, and the water near the surface of the earth, and then not bags but buckets are used, snmetines of leather, but more frequently of iron. Four bullocks and three labourers are engaged nune days in irrigating one acre of land thoroushly. 'The importance of this branch of agriculture is evidenced by the great number of wells, which even these most indolent people sink in districts deficient in streams. Near Madras, at Saymbrumbacum, a reservoir inore than 7 miles long and 3 broad, for the purposes of irrigation, has been formed by merely raisiug a bank across a natural ravine. In the 'Tamul language a reservoir of this kind is called an Eray. 'This supplies 32 villages containing 5000 persons employed in agriculture (should the rains fail) for 18 months. Sluices lined with bricks pass under the banks to supply the fields; the inner opening of the sluice is covered by a flat stone, in which is cut a circular hole, through which the water is allowed to pass as required, by means of a plug fixed to a bamboo, and secured from escape by means of stone pillars and cross-bars. When bullocks are employed to raise water from wells, a leathern bucket is used which holds 45 gallons; this two bullocks will raise every minute and a half from a well 44 feet deep, and they work eight hours per day.

To the insoluble matter of the water employed in irrigation, must be attributed a considerable portion of its value. These vary at different seasons. That of the Ganges, which is extensively employed in irrigation, was examined by Mr. Everett. He found in it of insoluble matters-

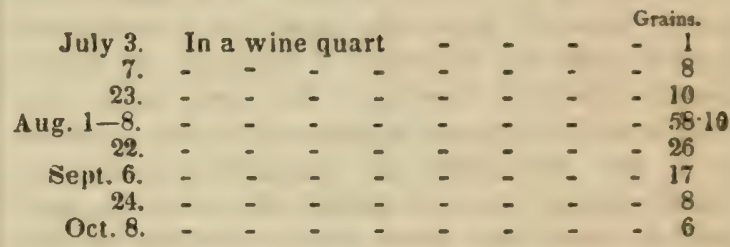

This insoluble or mechanically-suspended matter was analysed by Mr. Piddington: he found in 200 parts from the banks of the Ganges, at Mohulpore-

Vegetable matter

Saline matters, chiefly muriate of potass Carbonate of lime Phosphate of lime Oxide of iron

Silex

Alumina

Water

Loss

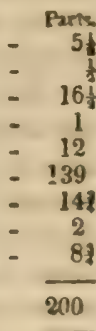

As these rich, purely divided matters, are depositing on the lower grounds within reach of the flood waters, it follows as a natural consequence that "the higher soils are generally and rapidly impoverishing, and this to a degree of which few, who have not made the subject one of attention, are aware."

The rapid effects produced by a copious artificial watering of grass lands under the burn. ing sun of India, may be judged by the follow. ing report made in 1841 , by Sir Edward Burnes to Jord Aucliland, upon the artificial grasses of Cabool.

"There are three kinds of grasses cultivated in Cabool- rishku,' or lucern, 'shuttul,' a kind of trefoil, and 'si barga,' or clover. The firs 
and the last continue to yield crops for some years, but the 'trefoil' (shuftul) is an annual. The lucern (rishku) is sown in spring, generally about the vernal equinox; for each jureeb, or about half an English acre, 2 seers of Cabool, or about 28 lbs. English, are required as seed. In $\mathbf{4 0}$ days it comes to perfection, and is cut down, and will yield 4 full-grown crops ere winter sets in, but by early cutting 6 or 8 crops may be drawn; the last may sometimes be inferior from premature cold. One jureeb ur half an English acre yields on an average ten camel loads of grass at each cutting, as a camel carries about $500 \mathrm{lbs}$.; this is a produce of $5000 \mathrm{lbs}$. the jureeb, or $10,000 \mathrm{lbs}$. the English acre, and for four fine crops $40,000 \mathrm{lbs}$. English. The third crop is considered the best, and from it the seed is preserved: of :his the half acre sown with the two seers of Cabool will yield 40 sears, or about $560 \mathrm{lbs}$. This plant requires the best black soil, much manure, and is watered 5 times each crop-in fact whenever it droops. It is sometimes sown along with barley, but in that case the grain, by exhausting the soil, injures the crop. The seed is never exported, but the grass is so plentiful, though all the cattle are fed on it, as much to exceed the consumption; it is, therefore, dried, and that produced at any distance from a market is generally stored in this manner, and sold during winter. A camel load of it, or about 500 lbs. English, whether green or dry, sells for one Cabool rupee, a coinage of which $115 \frac{1}{4}$ are equal to 100 Company's rupees. Lucern generally lasts for 6 years, but it will yield for 10 years if manure be abundantly scattered over it. The seed is at present sold for a rupee, a stone of $14 \mathrm{lbs}$.; but as it is not cultivated for exportation, this is much dearer than it might otherwise be had, and its price has been almost doubled by the arrival of the British troops. The trefoil or ' shuftul' in cultivation, in the time of sowing, reaping, and soil, resembles lucern, and the calculations of produce for the one will suffice for the other, only it is an annual plant. The seed, too, is dearer by one half than that of lucern.

"'The clover or 'si barga' (i.e. three leaves), assimilates likewise to the lucern, and it lasts as long. I may, however, observe, that the clinase of Cabool is much later than that of iEnglamd, and, excepting the seed sown in autumn, wothing is put in the ground here with advantage before the 1st of April."

Of arrection of crops, or of fallows, the ryots of Bengal have but little idea: their richest low-lying grounds are devoted to the growth of rice, and on the uplands they generally crop the soil till it is exhausted, and then abandon it to the weeds, which soon occupy it in profusion: they have, besides, a wretched method of sowing various seeds together, in a manner that eannot be sufficiently reprehended. It is only in some parts of India that any thing like rolation of crops is observed. In the highlands of Behar, the following rotation is usually allopted:-1. Year-fallow and wheat; 2. Maize (muckai), followed by big or bear, a kind of carley; 3. Murwa, sama, and cowaree, being snecies of millet, followed by cotton.

There is nothing, remarkable in the domestic 658 animals of Bengal : the oxen are inferior, and their sheep are described as "small, lank, and thin:" the colour of three-fourths of each flock is black or dark-gray. The quality of the fleece is worse, if possible, than its colour; it is harsh, thin, and hairy, in a very remarkable degree: no part of clothing or domestic furniture, so far as Dr. Tennant had observed, is manufactured of wool, except a coarse kind of blanketing which some of the boatmen (dandies) and people in the upper districts use during the cold season, as a wrapper at night.

The same system of irrigation which prevails in Arabia, in Persia, and in Mindostan, is carried on to a very considerable extent in the empire of China, where the soil is cultivated perhaps more carefully, and with a greater minuteness of detail, or garden system of husbandry, than in any other country. I do not allude in this work to their cultivation of crops such as the tea plant, or those from which the English cultivator is as little likely to derive useful hints. They are remarkable for the care with which they deepen, even by the spade, their cultivated lands, and their husbanding of manures of all kinds is admirable; every thing that is produced in their cities endued with fertilizing properties, is collected and preserved with the utmost care. The night-soil, for instance, is made into a kind of bricks with calcareous matter, and carried into the most distant provinces, for the use of the farners. "There is, perhaps," says the author of Eritish Husbandry (vol. i. p. 273), "no pari of the world in which the preparation and the practical application of vegetable and animal manure is so well understood as in China; but, owing to its overflowing population, almost the whole of the labour is performed by man, by which the number of working animals is so much reduced, that night-soil forms the principal dependence of the farmer. It is extensively employed in a dried state, and is sold as an article of commerce throughout the empire, in the form of cakes, mixed up with one-third of their weight of marl." "To the same end the poor are employed in collecting in the public roads and streets all the horse and other dung, which is also made into cakes with marl, and these are afterwards dried in the sun.

The system of tillage formed by the Chinese, however antiquated, is not of a general description, calculated to instruct the English cultivator; and the Chinese husbandmen are entirely uninformed as to any scientific principles, by the observance of which the cultivation of the earth is improved. The same remark, in fact, extends to most oriental farmers: they merely follow a regular routine of operations, because it is that which their forefathers adopted: followed without consideration, it is transmitted unimproved. See InRgation, and Nigrt-solu. (Memoir on the Agriculture of India, by (G. W. Johnson.)

INDIAN CORN. See MAIzE.

INDIAN CRESS. See Cress, Intan.

INDIAN MIILLET (Sorghum vulgare). Sorghi is the Indian name, according to Bauhin. The French call it grand millet, the Italians saggena or sorgo, and the Spaniards alcundia. It is much cultivated in Arabia and mosi 


\section{INDIAN RUBBER.}

parts of Asia Minor, and has been introduced into Italy, Spain, Switzerland, and some parts of Germany; also into China, Cochin-China, and the West Indies, where it grows commonly five or six feet high or more, and, being esteemed a hearty food for labourers, is called Negro Guinea corn. Its long awns or bristles defend it from the birds. In England, the autumns are seldom dry and warm enough to ripen the seeds well in the field. In Arabia it is called dora or durra. The flour is very white, and they make good bread of it, or rather cakes, about two inches in thickness. The bread which they make of it in some parts of Italy is dark and coarse. In Tuscany it is used chiefly for feeding poultry and pigeons; sometimes for kine, swine, and horses. Brooms are made of the spikes, which are also sent to England for the same purpose. The Indian millet, as well as the common sort (panicum) is cultivated in some parts of North America, and has been tried in England, but it is only in the warmest autumns that it ripens its seeds. (Loudon's Evtryclopadia of Plunts.) See Guinea Conv.

INDIAN RUBBER, Gum Elastic, or Caoutshouc, is a well-known tough and yielding substance, obtained in South America and Java from the sap of a tree called the Siphonia cahuca. To procure the sap,incisions are made through the bark in many places, and the milky juice which exudes is spread over clay moulds, and dried in the sun, or by a fire, the smoke from which last blackens it.

'The juice itself has been of late years imported. It is of a pale-yellow colour, and has the consistence of cream. It becomes covered, in the bottles containing it, with a pellicle of concrete caoutchouc. Its specific gravity is 1.012. When it is dried, it loses 55 per cent. of its weight: the residuary 45 is elastic gum. When the juice is heated, it immediately coagulates, in virtue of its albumen, and the elastic gum rises to the surface. It mixes with water in any proportion; and, when thus diluted, it coagulates with heat and alcohol as before.

The specific gravity of caoutchouc is 0.925 , and it is not permanently increased by any degree of pressure. By cold or long quiescence, it becomes hard and stiff. By long boiling in water it softens, swells, and becomes more readily soluhle in its peculiar menstrua; but when exposed to the air, it speedily resumes its pristine consistence and volume. It is quite insoluble in alcohol; but in ether, deprived of alcohol by washing with water, it readily dissolves, and affords a colourless solution. When the ether is evaporated, the caoutchouc becomes again solid, but is somewhat clammy for a while. When treated with hot naphtha, distilled from native petroleum, or from coal-tar, it swells to $\mathbf{3 0}$ times its former bulk; and if then triturated with a pestle, and pressed through a sieve, it affords a homogeneous varnish, which being applied by a flat edge of metal or wond to cloth, prepares it for forming the patent water-proof cloth of Mackintosh. " $\Gamma$ wo surfaces of cloth, to which several coats of the above varnish have been applied, are, when partially dried, brought evenly in contact, and then passed between rollers, in order to
INDIAN RUBBER.

condense and smooth them together. Thi double cloth is afterwards suspended in a stove-room to dry, and to discharge the disa. greeable odour of the naphtha.

Caoutchouc dissolves in the fixed oils, such as linseed oil, but the varnish has not the property of becoming concrete upon exposure to air.

It is more or less soluble in the oils of la. vender and sassafras.

It melts at $248^{\circ}$ Fahrenheit, and stands afterwards a much higher heat without undergoing any further change. When the melted carulchouc is exposed to the air, it becomes hard on the surface in the course of a year. When kindled, it burns with a bright flame and a great deal of smoke.

Neither chlorine, sulphurous acid gas, muriatic acid gas, ammonia, nor fluosilicic acid gas affects it, whence it forms very valuable nexible tubes for pneumatic chemistry. Cold sulphuric acid does not readily decompose it, nor does nitric acid, unless it be somewhat strong. The strongest caustic potash ley does not dissolve it, even at a boiling heat.

Mr. William Henry Barnard, in the course of some experiments upon the impregnation of ropes with caoutchouc, at the factory of Messrs. Enderby, at Greenwich, discovered that when this substance was exposed to a heat of about $600^{\circ} \mathrm{Fahrenheit,} \mathrm{it} \mathrm{resolved} \mathrm{itself} \mathrm{into}$ a vapour, which, by proper refrigeratory methods, was condensable into a liquid possessing very remarkable properties, to which the name caoutchoucine has been given. For this invention "of a solvent not hitherto used in the arts," Mr. Barnard obtained a patent, in August, 1833. His process for preparing it is described in his specitication as follows:

"I take a mass of the said caoutchouc, or Indian rubber, as imported, and having cut it into small lumps, containing about two cubic inches each (which I prefer), I throw these lumps into a cast-iron still. I then apply heat to the still in the usual manner, which heat is increased until the thermometer ranges at 600 degrees of Fahrenheit, or thereabouts. And as the thermometer ranges progressively upwards to 600 degrees of Fahrenheit, a darkcoloured oil or liquid is distilled over, which I claim as my said invention, such liquid being a solvent of caoutchouc, and other resinous and oleaginous substances. When the thermometer reaches 600 degrees, or thereabouts, nothing is left in the still but dirt and charcoal.

"I afterwards subject the dark-coloured liquid thus distilled to the ordinary process of rectification, and thereby obtain nuids varying in specific gravity, of which the lightest hitherto has not been under 670 , taking distilled water at 1000 , which fluids I also claim as my said invention.

"At each rectification the colour of the liquid becomes more bright and transparent, until, at the specific gravity of 680 , or thereabouts, it is colourless and highly volatile.

"In the process of rectification (for the pur pose of obtaining a larger product of the oil colourless) I put about one-third of water into the still. In each and every state the liquid is a solvent of caoutchouc, and several resinous and oleaginous substances, and also of othee 
substances (such as copal), in combination with very strong alcohol."

The discovery of the chemical solvent which forms the subject of the patent above described, has excited considerable interest in the philosophic world, not only from its probable usefulness as a new article of commerce, but also from two very extraordinary characteristics which it is found to possess, viz., that, in a liquid state, it has less specific gravity than any other liquid known to chemists, being considerably lighter than sulphuric ether, and, in i state of vapour, is heavier than the most ponderous of the gases.

Its elementary constituents are,

Carbon - $-6.812-\quad-8$ proportions.
Hydrogen - $-1.000-7$ ditto.

This new material (when mixed with alcohol) is a solvent of all the resins, and particularly of copal, which it dissolves, without artificial heat, at the ordinary temperature of the atmosphere; a property possessed by no other solvent known; and hence it is peculiarly useful for making varnishes in general. It also inixes readily with oils, and will be found to be a valuable and cheap menstruum for liquefying oil-paints; and, without in the slightest degree affecting the most delicate colours, will, from its ready evaporation, cause the paint to dry almost instantly.

Cocoa-nut oil, at the common temperature of the atmosphere, always assumes a concrete form; but a portion of this caoutchoucine mixed with it will cause the oil to become fluid, and to retain sufficient fluidity to burn in a common lamp with extraordinary brilliancy.

Caoutchoucine is extremely volatile; and yet its vapour is so exceedingly heavy that it may be poured, without the liquor, from one vessel into another, like water. (Ure's Dict.)

INUIAN TOBACCO. See EY⿸-BRIGнт.

INDIAN TURNIP (Arum triphyllum), Wakerobin, \&c. An American plant, distinguished by its head of beautiful red berries growing upon a single stem, and its perennial bulbous root, resembling a small rough turnip, possessing such an extremely acrid juice as, when hitten or chewed, causes violent inflammation in the mouth and salivary glands, inducing copious salivation. This acrid quality of the root is, however, dissipated by boiling or drying. The dried root, grated and boiled in milk, is a popular remedy for coughs and pulmonary consumption.

'The English wake-robin, or cuckoo-pint, is the Arum maculatum, which in many of its sensible qualities resembles the American Indian turnip.

INDIGENOUS PLAN'TS. Such plants as are natives of or are common to a country.

INDIGO (Indigofera, from indigo, a blue dyestuff, a corruption of Indicum, India, and fero, to bear; most of the species produce the wellknown dye called indigo, the finest of all vegetable blues). This is an extensive genus of rather elegant plants, the shrubby kinds of which are well worthy of cultivation. The stove and green-house shrubby kinds thrive best in a mixture of sandy loam and peat, and may be increased without difficulty by cuttings rit the young wood, planted in sand, under a glass, in heat. 'The annual and biennial kinds 660 must be raised from seeds sown in a hotbed in spring; and when the plants have grown a sufficient height, they may be planted singly into pots, and treated as other tender annuals and biennials. The genus belongs to the natural order Loguminosa: hence the flowers resem. ble the pea tribe. The vexillum is round, emarginate; the keel furnished with a subulate spur on both sides; stamens diadelphous; style filiform; legume continuous, one or more seeded, two-valved. The Indigofera corulea yields the finest indigo; the $I$. argentia, an inferior kind, which comes from Egypt; the I. tinctoria, besides yielding indigo, is also medicinally employed; and the powdered leaf of $I$. anil is used in some diseases of the liver. (Paxton.)

Indigo, when cultivated, thrives best in a free, rich soil, and a warm situation, frequently refreshed with moisture. The usual course pursued for its culture is as follows:-

Having first chosen a proper piece of ground, and cleared it, hoe it into little trenches, not above two inches or two inches and a half in depth, nor more than fourteen or fifteen inches asunder. In the bottom of these, at any season of the year, strew the seeds pretty thick, and immediately cover them. As the plants shoot, they should be frequently weeded, and kept constantly clean, until they spread sufficiently to cover the ground. Those who cultivate great quantities, only strew the seeds pretty thick in little shallow pits, hoed up irregulariy, but generally within four, five, or six inches of one another, and covered as before. Plants raised in this manner are observed to answer as well as the others, or rather better; but they require more care in the weeding. They grow to full perfection in two or three months, and are observed to answer best when cut in full blossom. The plants are cut with reapinghooks, a few inches above the root, tied in loads, carried to the works, and laid by strata in the steeper. Seventeen negroes are sufficient to manage twenty acres of indigo; and one acre of rich land, well planted, will, with good seasons and proper management, yield five hundred pounds of indigo in twelve months; for the plant ratoons (stools, stoles, or tillers, $i$. e. it sends out stolones, or new growths), and gives four or five crops a year, but must be replanted afterwards. (Browne.)

The process by which the blue colouring matter is extracted from the plant in Mexico, the East Indies, \&c., is as follows :-

The leaves are gathered at maturity, and immersed in vessels filled with water till fermentation takes place. The water then becomes opaque and green, exhaling an odour like that of volatile alkali, and evolving bubbles of carbonic acid gas. When the fermentation has been continued long enough, the liquid is decanted and put into other vessels, where it is agitated till blue flakes begin to appear. Water is now poured in, and flakes are precipitated in the form of a blue powdery sediment, which is obtained by decantation, and which, after being made up into small lumps and dried in the shade, is the indigo of the shops. It is insoluble in water, though slightly soluble in alcohol; but its true solvent is sulphuric acid, with which it forms a fine blue dye, known by 


\section{INDURATED.}

the name of liquid blue. It affords by distillation carbonic acid gas, water, ammonia, some oily and acid matter, and much charcoal; whence its constituent principles are most probably carbon, hydrogen, oxygen, and nitrogen. Indigo may be procured also from several other plants besides Indigofera tincloria, and particularly from Isatis tincloria, or woad, a plant indigenous to Britain, and thought to be the plant with the juice of which the ancient Britons stained their naked bodies, to make them look terrible to their enemies. If this plant is digested in alcohol, and the solution evaporated, white crystalline grains, somewhat resembling starch, will be left behind; which grains are indigo, becoming gradually blue by the action of the atmosphere. The blue colour of indigo, therefore, is owing to its combination with oxygen.

Indigo is not cultivated to so great an extent in the United States as formerly, the imported article being obtained so readily. The following process of manufacturing indigo in small quantities for family use is extracted from the Southern Agriculturist:-Cut the indigo when the under leaves begin to dry, and while the dew is on them in the morning; put them in a barrel, and fill this with rain water, and place weights on to keep it under water; when bubbles begin to form on the top, and the water begins to look of a reddish colour, it is soaked enough, and must be taken out, taking care to wring and squeeze the leaves well, so as to obtain all the strength of the plant; it must then be churned (which may be done by means of a tolerably open basket, with a handle to raise it up and down) until the liquor is quite in a foam. To ascertain whether it is done enough, take out a spoonful in a plate, and put a small quantity of very strong lye to it. If it curdles, the indigo is churned enough, and you must proceed to break the liquor in the barrel in the same way, by putting in lye, (which must be as strong as possible,) by small quantities, and continuing to churn until it is all sufficiently curdled; care must be taken not to put in too much lye, as that will spoil it. When it curdles freely with the lye, it must be sprinkled well over the top with oil, which immediately causes the foam to subside, after which it must stand till the indigo settles to the bottom of the barrel. This may be discovered by the appearance of the water, which must be let off gradually by boring holes first near the top and afterwards lower, as it continues to settle; when the water is all let off and nothing remains but the mud, take that and put it in a bag, (flannel is the best) and hang it up to drip, afterwards spreading it to dry on large dishes. Take care that none of the foam, which is the strength of the weed, escapes; but if it rises too high sprinkle oil on it.

Seven or eight species of indigo are found in the United States, most of which are in the south. The wild indigo (Dyer's Bcotisia), common in Pennsylvania and other Middle States, yields a considerable proportion of blue colouring matter of an inferior kind. (Flora Cestrira.)

INDURATED (Lat. induro). A term imply. ing that a substance naturally soft is hardened.

\section{INFLAMMATION.}

It is a term frequently used in botanical works to signify the above-mentioned changr.

INER'T VEGE'ABI.E MATTER The inert vegetable matters of the soil are those which decompose very slowly, and conserpuently afford very little nourishment to the growing plant. Of this kind are woody fibre, tanner's bark, peat, \&c., all of which, if not previously rendered more easily soluble by being mixed with farm-yard dung, or other easily fermenta. ble substances, afford food to vegetation by very slow degrees.

INFIRMARY (Lat. infirmus, weak). An hospital for the reception of the sick. The Veterinary College in London have an infirmary for sick and diseased horses, to which the horses of their subscribers have access and medical treatment, free from charge.

INFLAMMATION. In farriery, is a disease or affection consisting in an increased heat and action in any part of an animal, arising from various causes, external or internal, local or universal. In animals, the chief causes are wounds, bruises, and sudden or excessive cold, and the application of heat afterwards.

The horse is subject to inflammation of the lungs, stomach, bowels, kidney, and of the eye and foot. Of inflammation of the bowels I have already spoken (see Bowexs). Of inflammation of the stomach in the horse, except from poisonous herbs or drugs, we know little. It very rarely occurs, and then can with difficulty be distinguished from inflammation of the bowels; and in both diseases the assistance of a skilful veterinary surgeon is required.

Among the causes of inflammation of the kidney are, improper food, such as mow-burnt hay, musty oats, \&c. Bleeding, in this case, must be promptly resorted to, and carried to its full extent. An active purge should next be administered; and a counter-inflammation excited as near as possible to the seat of disease.

Inflammation of the lungs is one of the causes of roaring: it is generally brought on by the respiration of heated and empoisoned air, in neglected and filthy stables; by sudden changes from heat to cold, or cold to heat, from grass to the stable, or stable to grass, and so on. Bleeding, blistering, and relaxing medicines should be resorted to under the advice of a professional man; for the cure of this malady can scarcely be safely undertaken without proper advice.

Cooling applications, such as Goulard's extract, one drachm or half an ounce of the tincture of opium to a pint of water, with mash diet and gentle physic, will usually get rid of common inflammation of the eye, or the inflammation will subside itself; but should three or four days pass and the inflammation not be abated, we may begin to suspect that it is specific and fatal inflammation, or true ophthalmia, for which there is no cure. See ErE.

Inflammation of the foot is brought on ". over-exertion. If a horse that has been riddels or driven hard be suffered to stand in the cold, or if his feet be washed and not speedily dried, he is very likely to have "fever in the feet." Bleeding at the foot, and poultices of linseed meal to cover the whole of the foot and pastern, with sedative and cooling medicines, should tie 
resorted to. And to promote evaporation it is advisable tu remuve the shoe, pare the sole as thin as possible, and have the crust, and particularly the quarters, well rasped. See Grease.

For inflammation in sheep, see Shrep.

In inflammatory fever in cattle, profuse bleed$\mathrm{ing}$, followed by immediate purging $\left(1 \frac{1}{2} \mathrm{lbs}\right.$. of Epsom salts dissolved in water or gruel), must be had recourse to. (Youatt on Cattle, p. 359.)

INFLORESCENCE (Lat. inflorescere, to flourish). The general arrangement of the flowers upon a stem or branch. It consists of the following principal kinds: viz., the spike, the raceme, the panicle, the capitulum, the cyme, and the umbel.

The spike is a long rachis of flowers sessile, or without foot-stalks. The term raceme is commonly applied to flowers when they are arranged round a filiform or thread-like simple axis, each particular flower being stalked. The panicle is a loose disposition of inflorescence, in which the primary axis developes secondary axes, which themselves produce tertiary, as in oats; or, in other words, it is a raceme bearing branches of flowers in place of simple ones. Capitulum implies the arrangement in small heads. The cyme is a mode of inflorescence resembling a flattened panicle, as that of the elder.

Of the particular arrangement of the umbel, the carrot is a familiar example; the peduncles and pedicles spring from a common centre, and rise till they form a nearly flat tuft. The difference between an umbel and a corymb is, that whilst in the latter the flowers form a flat head, the pedicles do not, as in the former, spring from a common centre. (Paxton's Bot. Dict.; Brande's Dict. of Science.)

INFLUENZA. An epidemic catarrh, attended by febrile and other symptoms, which often run very high, and assume a variety of aspects, dependant upon the seasons and other causes. The possibility of the existence of a peculiar state of the atmosphere, although we have no means of detecting it, is undoubtedly the true cause of influenzas. Miasms, or vapours of a noxious kind, may exist, though in very minute quantity, also as exciting causes of influenza, an idea suggested by Dr. Prout. It may possibly be of volcanic origin; and such a substance as seleniuretted hydrogen, which, even in extremely minute quantity, is highly deleterious, might perhaps account for some of the phenomena of influenza; but we must acknowledge that nothing certain is known respecting the cause of this disease. See Distemper, Epidemic, and Murrain.

INOCULATION. An operation in the management of fruit trees, which is sometimes called budding. It is a kind of grafting practised in the summer months on various trees and plants, and often succeeds better than the common method of grafting. (See Buding and Graftiva.) It is also a term used to signify the process of transplanting grasses. See Grassris.

INSECTS (Lat. insecta). A very extensive and, w the cultivators of the earth, important olass of animais. Insects are distinguished from Worms by always having feet in their pariect or wingerl state, as the beetle, butterfly, moth \&cc. Worms crawl on their bellies, and have no feet, as the earth-worm, snail, slug. \&c. Insects, above all other animals, are by far the most destructive to vegetation.

On the subject of the science of entomology in this work, we propose only to touch upon those which are the most injurious or important to the farmer; and many of these, such as the bee, ant, fly in turnips, wireworm, \&c., will be found under their respective heads; indeed the mere list of known insects is so numerous, that the catalogue alone would be too extensive for a work of this description. "The great characteristic of this vast assemblage of animals," says Mr. Swainson "is the total absence of internal bones; hence, their hardest parts are always external, and the muscles are usually attached to the under side of the substance which forms the covering of the animal. The body is always divided into rings or transverse joints, from which circumstance naturalists have agreed to call them annulose, or ringed animals." This name is peculiarly applicable, since it expresses a marked distinction from such as have an internal skeleton, analogous to that of man, and which are called Vertebrata, from possessing a spine. The Annulosa contain Insecta (insects proper); Arachnida (spiders); Crustacea (crabs); and Annelida (worms); excluding the soft Vermes of Linnæus, which include the shell-fishes, or Mollusca. So diversified, indeed, are the different groups of this immense assemblage, or sub-kingdom of the animal world, that it is im possible to assign to them any other character, as a whole, than that just mentioned.

From the works of Mr. Swainson, of Kirby and Spence, the papers of Mr. Duncan, in the Quart. Journ. of $A g r$., the work of V. Köllar, On Insects injurious to Gardeners, Foresters, and Farmers, and especially from that of Dr. Harris, the chief facts are obtained. In the words of M. Köllar, "To enable the readers, for whom this work is intended, to find more easily the insect particularly interesting to each, it has been considered proper not to treat of families and species in any systematic arrangement, but according to the branch of culture to which they are particularly injurious." And, in pursuance of this object, I shall only briefly allude to some of the chief of the insect depredators, for "to enumerate," says Davy, "all the destroying animals and tyrants of the vegetable kingdom, would be to give a catalogue of the greater number of the classes in zoology; almost every species of plant is the peculiar resting-place or dominion of some insect tribe; and from the locust, and caterpillar, to the minute aphis, a wonderful variety of inferior insects are nourished, and live by their ravages upon the vegetable world."

Of the considerable extent to which the various insect tribes commit their depredations, no farmer will for a moment doubt, and yet he forms his judgment only upon the ravages of the larger insects. Of the smaller tribes-the minute trespassers-the animalculs-those only discernable through the microscope, he forms no estimate. Yet of those that he does see, the catalogue is fearfully alarming. "There 1s," says Mr Duncan, "scarcely one 
of our most useful plants which is not assailed in some way or other; and the forms of insects, and their modes of living, are so infinitely diversified as to enable them to continue their depredations in all the different states of these plants. 'The various sinds of grain, for example, have a host of enemies in the subterraneous larvæ of beetles which consume the roots; various kinds of caterpillars feed on the blade; some particular species attack the ear; and even when laid up in apparent security, a small beetle is often found to scoop out the interior of each grain, and convert it into an abode for itself. (See Cons WeEviL.) In England, if the seed of the turnip escape the attack of a minute weevil, another enemy awaits the unfolding of the cotyledon leaves, and a third buries itself in the bulb and rootlets, which become diseased and covered with unseemly excrescences (see Aveurr), while the mature foliage is often consumed by caterpillars.

"But even when there is no remarkable augmentation of their numbers, there is reason to believe that the injury occasioned to vegetation by insects is at all times greater than is generally supposed. Their operations are often carried on under cover, either beneath the surface of the soil, within the substance of the plant, or in other situations where they escape observation. Many kinds again feed only during the night, and conceal themselves during the day in holes and crevices. In consequence of this latent and insidious mode of attack, there is no doubt that we are often led to ascribe the unhealthiness and decay of plants to badness of soil, unfavourable weather, and other causes, when in reality they are produced entirely by insects." (Quart. Jou"n. Agr. vol. viii. p. 97.) "The only course," adds Mr. Duncan, "which is likely to lead to the discuvery of proper remedies, is to investigate carefully the habits and natural history of insects in connection with the structure and general physiology of the plants which they attack. In prosecuting this object, the attention should be directed to ascertain the time when, and the manner in which, the eggs are deposited, as well as their composition, and that of the enclosing membrane, with a view to determine in what way the vital principle might be most easily destroyed. The habits of the larva call for particular attention, as it is generally in this state that the mischief is committed; the period of their appearance, their times of feeding, plants on which they feed, and (if attached to more than one) the kind they seem to prefer, the part of the plant attacked, duration of the larvæ state, should be carefully noted; an acquaintance with the places to which the larvæ usually retreat when about to change to pupæ, and with the structure, duration, \&c. of the latter, might probably suggest some easy means of destroying many in that dormant state. A knowledge of the economy of the perfect insect is of course of the uimost importance; if we could become acquainted with the retreats in which they pass the winter, or find means to destroy the few that generally survive, when they first appear in the spring, and before they have de- posited their eggs, the injuries which are sus. tained by their means might be altogether provented." (Ibid.p. 99.)

Let not, however, the farmer, when he is thus warmly engaging in the destruction of the an. noying insects of the field, omit to consider whether many of these are not, in some shape or other, productive of benefit-whether they do not serve to keep within reasonable limits other insects, or perhaps perform some nther wise purpose in the works of the creation. This has been proved to be the fact in the case of the common earth-worm, whose casts so often annoy the gardener and the farmer. (See Еантн-Wonм.) For these not only assist in the continual admixture of different strata of earths, but, by boring the soil, they promote in it the circulation of the atmospheric gases, and even the drainage from it of its superfluous moisture. And as White, of Selborne, remarks in his Natural History, "The most insignificant insects and reptiles are of much more conse. quence, and have much more influence in the economy of nature, than the incurious are aware of. From their minuteness, which renders them less an object of attention, from their numbers and fecundity, earth-worms, though in appearance a small and despicable link in the chain of nature, yet, if lost, would make a lamentable chasm."

Insects have been divided by entomologists into two great divisions-the winged and the wingless.

Winged insects are divided into the following orders :-

1. Coleoptera. Of this order are the weevils, the rose-bug, ground and dung beetles, \&c.

2. Orthoptera. Of this order are the cockroach, field cricket, grasshopper, \&c.

3. Hemiptera. Of which are the field, tree, and bed-bugs, fetid bugs, \&c.

4. Neuroptera. In which are comprehended the dragon fly, lace fly, ephemera, \&c.

5. Hymenoptera. In this order are bees, wasps, ants, saw-flies, gall-flies, \&c.

6. Lepidoptera. Of which order are the butterflies, moths, \&c.

7. Rhipiptera. Of which are certain minute insect parasites living on bees, wasps, \&c.

8. Diptera. Of this order are gnats, house flies, musketoes, $\mathrm{ox}$ and horse flies, \&c.

The insects without wings (Aptera) are divided into the following orders:

9. Myriayoda. Of this are the centipede, Iulus, \&c.

10. Thysanura. Including small, soft, leaping insects, generally covered with a silvery down. and found in damp places, under logs, \&c.

11. Parasita. The lice tribe, \&c.

12. Suctoria. The flea.

I. The Transformation of Insects.-Insects commonly change their form several times in the most apparently magic manner. A few, the Aphis, for instance, are viviparous, but they are generally produced from eggs, that is, the eggs are produced in the body of the mother. "The female," says Küllar, "lays her eggs (which are often stuck on and covered with a kind of glue to protect them from the weather) shortly after pairing, instinctuvely in the place best adapted for their developemen: 
and which offers the proper food to the forthcoming brood.

Most insects issue from their eggs as larvæ; those of the butterflies are provided with feet, and are called caterpillars; those of beetles, grubs; and when they have no feet, they are called maggots. In this state, as their bodies increase, the insects often cast their skin, and sometimes change their colour. Many winged insects, such as the grasshoppers, dragon flies, $\& c .$, very much resemble in the:r larva state the perfect insect; they only want the wings, which are not developed till after the last change of the skin. 'The larva state is the period of feeding; and insects are then usually the destructive enemies of other productions of nature, and objects of persecution to farmers, gardeners, and foresters.

The nympha or pupa state succeeds that of the larva. Insects do not now require nourishment (with the exception of grasshoppers and a few others), and repose in a death-like slumber. To be safe from their enemies and the weather, the larvæ of many insects, particularly butterflies, prepare for themselves a covering of a silky or a cottony texture. Many form themselves a house of earth, moss, leaves, grass, or foliage. Many even go into the earth, or decayed wood, or conceal themselves under the bark of trees, and other places of security.

After a certain fixed period the perfect insect appears from the pupa. It is usually iurnished, in this state, with other organs for the performance of its appointed functions, as for the propagation of is species, \&c. The male insect seeks the female, and the female the place best suited for laying her eggs; hence most insects are furnished with wings. Food is now a serondary consideration; consequently, in many, the feeding organs are less perfectly developed than in the larva state, or very much modified, and suited for finer food, as, for example, in butterflies, which, instead of the leaves of plants, only consume the honey out of their flowers.

II. The food of inserts is indeed procured from an extensive pasture. "From the majestic vak," observes M. V. Köllar, "to the invisible fungus or the insignificant wall-moss, the whole race of plants is a stupendous meal to which the insects sit down as guests. Even those plants which are highly poisonous and nauseating to other animals are not refused by them. But this is not yet all. The larger plant-censuming animals usually limit their attacks to leaves, seed, and stalks: not so insects, to the various families of which every nart of a plant yields suitable provender. Some which live under the earth, attack roots; others choose the stem and branches; a third div: ,ion live on the leaves; a fourth prefers the flowers; while a fifth selects the fruit or seed. Jiven here a still further selection takes place. Of those which feed on the roots, stems, and branches, some species only eat the rind like the bee-hawk moth; others the inner bark : ind the alburnum, like the bark beetle; a third division penetrates into the heart of the solid w'sod, like the family of the long-horned beelles. (See Bonens.) Of those which prefer the filliage, some take nothing but the juice out of the sap vessels, as the aphides: others devour the substance of the leaves without touching the epidermis, as the mining caterpillars; others only the upper or under surface of the leaves (leaf rollers), white a fourth division (as the larvæ of the Lepidoptera) devour the entire leaf.

Of those feeding on flowers, some eat the petals (the rose-bug, \&c.), others the farina (bees, \&c.); a still greater number consume the honey from the nectaries (wasps, flies, \&c.); other insects injure the plant by puncturing it, and laying their egg in the wound, and with it an acrid matter, which causes a peculiar excrescence in which their young are hatched and live, until they are able to eat their way out, to perform the functions of the parents, such as the gall-fly, \&c. The deathwatch or ticking beetle (Anobium) feeds on dry wood, long used, as portions of our dwelling houses.

Those insects which tenant and feed upon animal matters, have an equally varied taste: of these are the different kinds of bird and sheep lice, \&c., gnats, midges, breeze flies, bugs, fleas, \&c. Some of the carnivorous beetles devour their prey entire; others only suck out their juices; others live upon the food they obtain in water, and devour swarms of the infusoria. Many live on carrion and the excrements of the larger animals, such as the dungbeetle, and carcass-beetle; others live in the stomachs of animals; many moths live entirely upon hair, leather, wool, and feathers.

The food of insects varies strangely with their transformations: the caterpillar requires very different food from the butterfly; the maggot from the beetle and fly. The larva of the Sirex gigas feeds on wood, the perfect insect on flies. Those of some melolonthians live on roots and tubers, the beetle on leaves. The quantity of food consumed by different insects varies very much: many consume more than their own weight in a day. The maggot of the flesh-fly, according to Redi, becomes 200 times heavier in the course of 24 hours. Caterpillars digest every day about one-third to onefourth of their weight; hence the ravages they commit in a few days. Of others, however, such as the day-flies (Ephemerida) and the breezeflies, and even amongst the Lepidoptera which spin cocoons, many appear to abstain from nourishment. Some eat only during the day, others in the evening; and others, such as the caterpillars of the night moths, during the night. Most of them provide their own food; but a few which live in communities, such as the wasps, bees, ants, \&c., are fed by the perfect insect. Many provide a store of food, but the greater number die unprovided with a store: others feed their larvæ." See BeEtre, and Boners.

III. Destruction of Insects, \&c. by Artificial Means.-Various have been the recipes suggested for the destruction of the insects which destroy the cultivator's crops. Ants, it is said, may be easily destroyed by toasting the fleshy side of the skin of a piece of bacon till it is crisp, and laying it at the root or stem of any fruit tree that is infested by these insects r acing something over the bacon to 


\section{Ples/r lif}
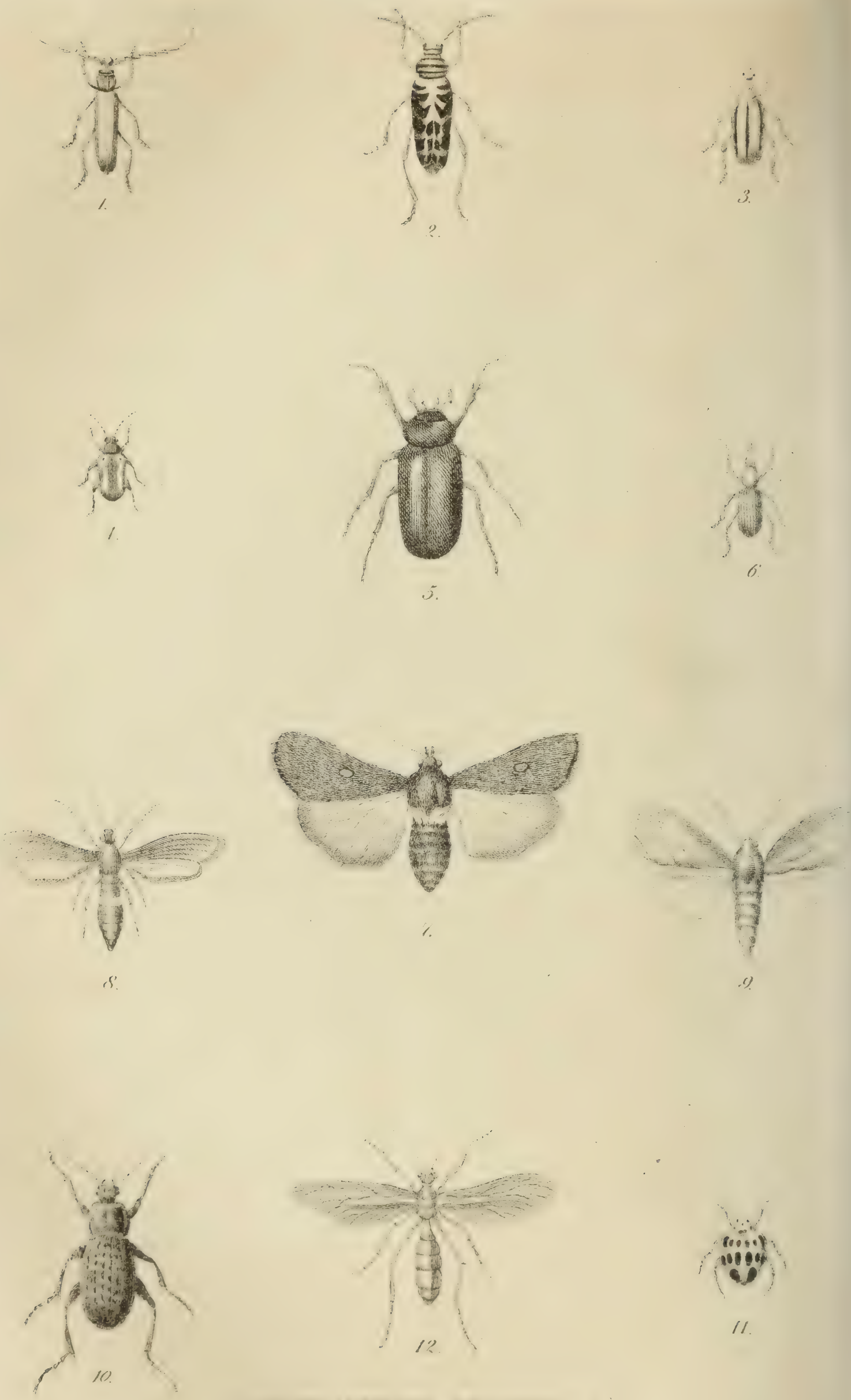

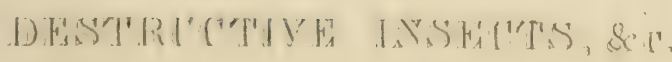


keep it dry - the ants will go under it; after a time lift it up quickly, and dip it into a pail of water. While treating of insects, I may incidentally allude to worms and slugs, or naked snails. For the destruction of slugs, warm in an oven, or before the fire, a quantity of cabbage leaves, until they are soft, then rub them with unsalted butter, or any kind of fresh dripping, and lay them in the places infested by slugs. In a few hours the leaves will be found covered with snails and slugs. Woodlice are destroyed in the same way. For field operations, perhaps, the best means of destroying slugs and worms is common salt, an agent too little known for this purpose, yet its powers are undoubted.

No person has employed common salt for the purpose of destroying worms to a greater extent than Jacob Busk, Esq., of Ponsbourn Park, in Hertfordshire. His valuable experiments have extended over some hundreds of acres of wheat. 'To use his own words,- "In every situation, and at every time, the effect appeared equally beneficial." The quantity per acre,- "about four or five bushels sown out of a common seed-shuttle." The period,"In the evening." The effect,-"In the morning each throw may be distinguished by the quantity of slime and the number of dead slugs lying on the ground. In some fields it has certainly been the means of preventing the destruction of the whole crop." Six bushels of salt per acre was applied by hand, in April, 1828 , to a field of oats attacked by the slugs and worms, and the crop was completely saved by this application, although an adjoining field, not salter, was entirely destroyed by this sort of vermin.

Salt, too, is a complete preventive of the ravages of the weevil in grain. It has been successfully employed in the proportion of a pint of salt to a barrel of wheat. I learn from an American merchant, that wheat placed in old salt barrels is never attacked by these destructive insects. Six or eight pounds of salt sprinkled over 100 sheaves in stacking, produces exactly the same effect.

The Eriosoma lanigera upon apple trees, and several other insects (See American Buight), may be killed by clay and water, made as thin as whitewash, and mixing with every 6 gallons of it 2 lbs. of cream of tartar, $1 \mathrm{lb}$. of soft soap, and half a peck of quicklime. "When you think," says Mr. Loudon, "that the weather is likely to continue dry for some time, take a bucketful of this mixture, and with a large brush wash over the bark of the trees, wherever you think it has been infected with the bug. A man will dress a number of trees over in a few days with a whitewash brush and this liquid; it is only necessary to be careful to do it in dry weather, so that the rain may not wash over the mixture for some time. The clay and water alone are sometimes effectual. Flies and wasps.-A mixture of pepper, sugar, and water will speedily attract and destroy them. (Gard. Mag. No. 37; Quart. Journ. Agr. vol. iii. p. 1071.)

Moss and Insects.-Mr. Thomas recommends that the trees infected should be sprinkled with a fine powder in March, and again in Oc- tober, on a foggy day when the trees are damp but not dripping, and I have no doubt of its efficacy. It is composed as follows: slack five bushels of lime, hor from the kiln, with cornmon salt and water (say one lb. of salt to each gallon of water). When the lime has fallen to a fine powder, ard by small quantities at a time a bushel of soot, stirring it until cum. pletely incorporated. Mr. 'Thornas has fuund that one man can dust over with the powder fifty trees in a day, and that the moss in the turf under fruit trees thus treated is also completeiy destroyed by the application. (Trans. Soc. Arls.) Worms in grass r.lats may be readily destroyed by copiously watering the turf with lime-water (half a pound of the hottest quick-lime well stirred in each gallon of water), or by sprinkling common salt ( 20 bushels per acre) over it, or by strewing it on gravel walks in rather large proportions. Lime is recommended for the destruction of the worm which sometimes injures young larch plantations; coal-tar and tar water to preserve hop poles and other wood from the ravages of insects. The caterpillars on cabbages may be readily destroyed by sprinkling them with finely powdered lime; and when some years since a black caterpillar attacked very generally and extensively the turnips, in some instances they were very successfully destroyed by turning into the fields considerable numbers of common duchs. Heavy rolling, especially during the night, is in many cases destructive of slugs; and it is certain that, by occasional material variations in the rotation of crops (see Rotatios of Crops), the number of predatory insects may be very considerably reduced in cultivated soils by depriving the larvæ of their particular and essential food.

Mr. Knight recommends the use of carbonate of ammonia for the destruction of the insects upon the pine and other plants. Mr. Baldwin, in effect, does the same, when he commends the use of the steam from hot fermenting horse dung. Mr. Robertson found soot (which contains ammonia), when diffused in water, to be an excellent application. When speas.ing of the use of fermenting horse dung in ate destruction of insects, Mr. Knight remarked, "I conclude the destructive agent in this case is ammoniacal gas, which Sir Humphry Davy informed me he had found to be instantly fatal to every species of insect; and, if so this might be obtained at a small expense by pouring a solution of crude muriate of ammonia upon quicklime; the stable or cow-house would afford an equaliy efficient, though less delicate fluid. The ammoniacal gas might, I conceive, be impelled by means of a pair of bellows amongst the leaves of the infected plants, in sufficient quantity to destroy animal whhour injuring vegetable life." Ammonia scems peculiarly distasteful to insects. Carborale of ammonia is often successfully placed in meat. safes to prevent the attacks of flies.

IV. The natural Encmies of Insects.-Among:" the enemies by which insects are kept in check, may be numbered long-continued rains, late frosts, inundations, storms; and, amony the animals, bats, mice, moles, squirrels, foxes, \&c. Birds devour them by myriads; the grees

$$
3 \text { к } 2
$$


finch tears open (says Reaumur) the strong nest of the yellow-tailed moth, and eats the infant caterpillars. The woodpeckers and treecreepers commit great ravages amongst the beetles and caterpillars. Crows, which in some sections destroy the corn, commit great ravages upon cutworms and destructive insects. In one of the English counties where the rook (a bird allied to the crow) had increased so as to do some damage to the crops, a destructive war was waged against them, so that they were isarly exterminated. But under these circumstances various species of the insect tribe increased so rapidly, that it became necessary to import the rooks again from the adjoining counties. In fact, it remains to be proved whether any omnivorous bird is more prejudicial than useful. Insects in their various states exist throughout the warm season, whilst the crops are exposed to the birds for a comparatively short period. Every protection should be given to birds, and boxes should be fitted up for martins, wrens, and bluebirds. To these may be added the frog, the toad, \&c. Many insects, such as the ground beetles, devour the pupæ of others. Then, again, there is the numerous order of the Ichneumonida, which lay their eggs in the bodies of other insects and destroy them. The eggs are hatched within the body of the living insect, and the young parasites, in the most literal sense, fatten on the entrails of their prey. At last the wounded caterpillar sinks, the enemies escape through the skin and become pupæ; or the caterpillar, notwithstanding its internal parasites, enters the pupa state; but, instead of a butterfly, one or more Ichneumonidce appear. The beautiful little red insect familiarly known as the lady-bird or lady-bug, is of vast service by the havoc which it makes among the plant and bark-lice. Many a friendly ichneumon fly or lady-bird has been killed by those whose want of knowledge led them to consider these insects destructive to vegetation. To these wonderful animals we often owe the preservation of our orchards, woods, and grains. Many other modes, besides those I have enumerated, have been suggested, by which the number of the cultivator's predatory insects may be reduced, most of which I shall notice under their respective heads. I am quite of the opinion, however, of the authors of the work I have so extensively quoted, "that the most essential and necessary means to be opposed to the serious injuries caused by insects, consists in the universal disseinination of the knowledge of the natural history of hurtful insects amongst farmers, gardeners, foresters, and all those, in fact, who are in any manner connected with agriculture."

V. Of the Insects which live and propagate on domsstic animals.-The chief are lice, which corrmonly originate from want of cleanliness, poor, unwholesome food, or from the weakening effects of other diseases. Old horses are more subject to them than young ones; they are common in sheep, and in swine; for which the best remedies will be found under their respective heads. (For the bots in horses, see Box; for those in sheep, see Shenp Boт; for the ox-warble, see WАкиц..) The forest fly, $6 f 6$ or horse Ay, lives chiefly on horses. It flies in short flights quickly, and moves about with considerable agility. The female lays but one egg at a time, from which the fly is hatched. They abound in the New Forest. See Horsa Fxx.

The well-known sheep tick has no wings; the fore part of its body is very small, but the abdomen is large. Its colour reddish. with white lines on the side of the abdomen. The farmer will find the following an excellent receipt for a sheep-dipping wash, by which they are readily destroyed:- $\frac{1}{2} \mathrm{a} \mathrm{lb}$. of powdered white arsenic, $4 \frac{1}{2} \mathrm{lbs}$. of soft soap. Boi. these for a quarter of an hour, or until the arsenic is dissolved, in five gallons of water. Add this to the water sufficient to dip fifty sheep. The quantity of arsenic usually recommended is too large. See Ticrs.

VI. Insects which injure Bees.-There are several insects which injure bees, such as a parasite bee-louse, which is about the size of a flea, has no eyes, but the rudiments of four feelers. They tenant chiefly populous hives: sometimes two or three are found on a bee. These parasites disturb and annoy even the queen bee. "A bee," says M. Köllar, " infested with a beelouse, endeavours, but to no purpose, to get rid of such an unwished-for guest, till at last she creeps under a number of other bees, and rubs off the louse from her back, when it immediately betakes itself to the back of another bee. That the presence of this parasite causes pain to the bee, is apparent from the restlessness with which she runs out at the hole and back again. The queen is also disturbed in her employment of egg-laying, when she is infested by them, so that the hive suffers in another way by impoverishment. It may even happen that when many of these parasites infest a queen, she must eventually perish. In winter the infected bees usually fall to the floor, and perish with cold and hunger." Spiders also destroy bees, but only in their nets. Then there is the caterpillar of the honeycomb-moth, whose ravages are very considerable, when once they find their way into a hive. They devour only the wax. Three hundred have been found in a hive, and there are two generations of these caterpillars in a year. Ants also are very fond of honey, and find their way into hives. Wasps very frequently do the same. Bees even rob each other's hives.

VII. The Insects which injure Grain.-These are numerous: the chief of them are the larva which feed on the green leaves and roots of grain. On these the blackbirds, crows, and other useful birds feed very copiously. The barley-midge (Tipula cerealis) attacks the barley and spelt plants.

VIII. Insects which injure Meadows.-This is also a very numerous class. "Most of the insects that choose the various sorts of corn for their food," says M. Köllar, "do not reject the other sorts of grasses, in the meadows. The herbage of the meadows has also often peculiar enemies, which are very difficult to find out and destroy. In most cases the meadows suffer from the roots of the grass plants being injured, which is chiefly occasioned by the larvæ of various species of cockchaffers, living 
in the earth. When bare spots are seen on meadows, we may be pretty sure that the larvæ of some species of melolontha are there carrying on their work of destruction. 'The sub-turf plough disturbs the operations of these vermin; the crows devour them.

IX. Insects injurious to cultivated VegelablesAre also numerous, and highly injurious to the gardener's crops. The flea-beetles (Hultica) are great pests to the gardener: they attack and devour, during the summer months, various members of the cabbage tribe, such as the cabbage, cauliflower, and colewort, the turnip, the radish, common and water cress: they also prey upon flax, hops, sainfoin, \&c. (See FLY Is 'Tuusips.) The mole cricket (Gryllotalpa) is often peculiarly injurious to the German cultivators. It does not confine its ravages to the garden crops, but injures very materially those of the meadow and corn-fields. It measures, when full-grown, about two inches in length. The plant-lice (Aphis) chiefly haunt the cabbage, peas, and beans. They are devoured in great numbers by several of the ladybirds (Coccinella) and fly tribes.

X. Insects which injure Green-house Plants.of these I need only mention the orange scale insect (Cocius hesperidum); the pine-apple scale insect (Coccus bromelia); the mealy bug (Coccus Adonidum); the oleander scale insect (Aspidio(us Nerii), abounding on oleanders, acacias, aloes, palms, \&c.; the rose scale ( $A$. rose), found in old rose stems and twigs; the cactus scale ( $A$. echinocarti), on the cacti; the sweetbay scale ( $A$. lauri), on the sweet bay; the rosemoth (Tinea (Ornix) rhodophagclla); and the plant-mite or red spider (Acarius telarius).

X1. Insects which attack Fruit Trees.-The number of insects which live either partially or entirely upon fruit trees, is very considerable. I can hardly do more in this work than give the names of the most formidable of these little depredators.

XII. Insects injurious to Forest Trees.-These are divided by M. Köllar into two classes:1. Those which attack deciduous trees; and, 2. Those which are injurious to the evergreens.

XIII. Insects which attack the Fir and Pine Tribe-These often injure very seriously the leaves, bark, and young shoots of some of the Pinus tribe.

Such, then, is a very brief glance at that immense and important class of animals which are included in the science of entomology. It must be considered, to use the words of $\mathrm{Mr}$. Swainson, only as suggestions and stimulants to further inquiry. The review, however, cannot but fill us with astonishment; for, although we see only a very limited portion of the insect world, yet that view, limited as it is, is fraught with instruction to the cultivator. It will lead him, perhaps, to a clearer understanding of the often-repeated truth, that nothing is created in vain. It may suggest to him also the means, in some cases, of arresting their ravages, when, by their excessive numbers, they become a nuisance; and it may perhaps be instrumental in saving from destruction many a useful bird, when the sportsman is made aware of the number of predatory insects which they so unceasingly destroy. The astonishing number, habits,
Ind iustincts of the insect tribe, too, are equally instructive, and can only be explained in one way. These phenomena did not escare the notice of the great Paley. Thus he observes, "Moths and butterflies deposit their eggs in the precise substance (that of a cabbage, for instance) from which not the butterfly herself, but the caterpillar which is to issue from her eggs, draws its appropriate food. The butterfly cannot taste the cabbage; cabbage is no food for her; yet in the cabbage, not by chance, but studiously and electively, she lays her eggs." And when referring to this imfucis:z mass of animal life, he says, in another place, "To this great variety in organized life the Deity has given, or perhaps there arises out of it, a cor. responding variety of animal appelites. For the final cause of this we have not far to seek. Did all animals covet the same element, retreat, or food, it is evident how much fewer could be supplied and accommodated than what at present live conveniently together, and find a plen. tiful subsistence. What one nature rejects, another delights in. Food which is nauseous to one tribe of animals, becomes, by that very property which makes it nauseous, an alluring dainty to another tribe. Carrion is a treat to dogs, ravens, vultures, fish. The exhalations of corrupted substances attract flies by crowds. Maggots revel in putrefaction." Neither can the astonishing changes of some of the insect tribe be regarded by a rational being without very considerable interest. "The wonderful metamorphosis undergone by the order Lepidoptera," says Swainson, "would be almost incredible, were it not familiarized to us from early childhood, that a crawling worm, ravenous of grass food, should voluntarily seek a retreat in the earth, or spin its own shroud; that such a change should come over it, so complete, as that not a lineament of its first form was retained; that in this state, after remaining a misshapen lump, tc all appearance inanimate, it should suddenly burst forth, full of life and joy, and, with many coloured wings, ascend into mid-air, and derive its only sustenance from the nectar of flowers;-all this, we say, is one of those miracles of nature, which, were it told of an insect that had never yet been seen, the world would not helieve."

Description of the Plate of Noxious Insects.Throughout this work we have made great use of the valuable treatise of Dr. Harris on destructive insects; but, as it is unaccompanied by plates, the reader who is unacquainted with the subject may be occasionally in doubt as to the aspect of those described. On this account we have devoted Plate $\mathbf{1 6}$ to the illustration of a few of the principal forms, both of destructive insects and those which prey upon them. The species figured are,

1. Elaphidion putator, oak pruner. See Horers, p. 205.

2. Clytus flexuosus, locust tree borer. See

Borers, p. 206.

3. Criociris trilineata. Potato-vine bug.

4. Haltica striolata, cucumber Hea (magas

fied), p. 371 .

5. Phyllophaga quercina, p. 172, 173.

-6. Hylobines pales, which is very destrucuve to the pine forests of the south. The plum 
weevil and grain weevil, as well as this species, belong to the Curculio family.

7. Agrotis clandestina, cut-worm.

8. Egeria exitiosa, peach tree borer, female.

9. Gallerea cereana, bee-moth, n. 168 .

10. Caravus Goryi, which may be taken as a representative of a large family which feeds upon other insects, caterpillars, etc.

11. Coccinella borealis, which in its larva and perfect state, feeds upon the aphides so destructive to roses and other plants.

12. Trogus fulvus. The members of the extensive family (Ichnemonide) to which this species belongs, commit great havoc among caterpillars and grubs.

INS'TEP. In farriery, a name given to that part of a horse's hind-leg which reaches from the ham to the pastern joint.

INSURANCE. One means of security against fire. The farmer being constantly surrounded by much combustible matter, should never, when possible, omit rendering himself safe by insuring his stock of every kind in some public office, instituted for this purpose.

In England, the legislature has wisely afforded very considerable facilities to the insurance of farming stock, which, by an act of Parliament, is exempted from duty. "The Farmer's Insurance Institution" of London insures it at 2s. 9 d. per cent., without the average clause; thus sasily reprired are the ravages of the incenliary, of accidental fires, and lightning.

INTFGUMENT. The outer covering or -kin of an animal: it is also used in the same sense as a synonyme for Testa, for the husk or exterior covering of seeds.

INVENTORY (Fr. inventaire; Lat. inventarium). A detailed account taken of any thing upon a farm. Inventories of the various kinds of farming stock should be taken annually, at the close of the year. See Book-Kenping and Appraisement.

INVOLUCRE, or INVOLUCRUM. In botany, the bractes (or small leaves placed near the calyx, or the peduncle or pedicil) which surround the flowers or the umbels. Involucels are the partial involucres of umbelliferous plants. (Paxton's Bot. Dict.)

IRIS (from iris, the rainbow; alluding to the variety and beauty of the colours of the flower). This extensive genus has long been, as it still continues to be, a great favourite in the flower garden. "The sword-leaved sorts (says Sweet) do best in a light loamy soil, and increase freely by suckers from the roots or by seeds. 'The tuberous-rooted ones are more difficult to culivate, and thrive best in a mixture of loam, peat, and sand, as does also the tribe to which I. persica belongs, as $I$. alata, I. caucasica, I. reticulata, \&c. The common bulbous species do well in any garden soil, the more sandy the better." I. iuberosa is aromatic as well as emetic and purgative, and $I$. versiculor and $I$. verna are used in the United States as cathartics. (Paxton's Bot. Dict.) Two species of iris only are indigenous to England,

1. The yellow water iris, or flower-de-luce (I. pseud-acorus), which grows wild in ditches, nomls, and rivers, and forms a handsome orna668 ment for the banks of ponds and streams, blowing from three to six large, bright yellow flowers in July. The root is horizontal, depressed, brown, very astringent; the stem 3 or 4 feet high; leaves erect, ribbed, grass-green. The disks of the larger segments of the flowers are pencilled with dark purple.

2. Stinking iris, or Gladwyn. Roast-beef plant (I. fatidissima). This species grows in groves, thickets, and under hedges, but it is rather rare. Dr. Withering, however, observed it to be very common in England in all the southwest counties. It is a perennial, growing to about 2 feet high; the leaves are dull green, exhaling, when rubbed, a scent compared to that of roast beef, to which it is no compliment. The flowers, which appear in May, are dull, pale purple, pencilled with dark veins. Seeds orange-coloured, polished. (Eng. Flor. vol. i. p. 48.)

Miller only mentions 19 species of cultivated irises, but there are now nearly 100 known species and varieties. Two or three only are much admired as ornamental flowers. The I. xiphium is a bulb from Spain, blowing blue, white, yellow, and violet flowers in June. The Persian iris blows a fragrant flower in March and April; plant the bulb in October, in a pot filled with equal quantities of fine mould and sand, and house it during frost. The dwarf iris is ornamental in clusters in a garden; it grows only three inches high, and blows in April. Part its roots in autumn. The Siberian iris blows in June, and likes a moist situation; it bears flowers whose falling petals are blue, and the upright ones dark purple; its stem is tall, and its leaves are narrow. I. susiana, or fleur-de-lis. 'The plant is tuberous rooted, loves a good soil, and should be removed every three years. It flowers handsomely in June, bearing varieties of pale blue, deep blue, and striped or bluish-white flowers. Its odour is feeble, but it is fetid. These are the most favourite kinds in gardens. The $I$. florentina, which is occasionally seen in our gardens, yields the orris root, which is the dried and peeled rhizomes of the plants. Orris root is prized chiefly on account of its odour, which resembles that of the violet. It is added on this account to tooth powders and hair powder. A hazardous custom prevails of giving the entire root to infants to gnaw during teething, from which fatal results have followed.

The wild flag, Colour-changing flax (Iris Virginiana), is common on the margins of ponds and in miry places in the Middle States. Dr. Bigelow remarks that the root of this is a violent emetic. Seven or eight other species of iris are enumerated in the United States. (Flor. Cestrica.)

IRON-WOOD (Carpinus ostrya). See HoR:BEAM.

IRRIGATION (Lat. irrigio, to water). In agriculture, the watering of the earth, to increase its productiveness. The term, however, is confined to that species of flooding which consists of spreading a sheet of water over a field or meadow, in such a manner that it can be easily withdrawn.

Irrigation, or the artificial watering of the 
earth, chiefly to produce increased crops of grass, has been in use from a very early period. In Oriental countries, in fact, the heat of the climate is such, that in many situations the now productive soil would be absolutely sterile, were it not that the cultivator enriched his ground with a copious supply of water. The simile employed by Isaiah (i. 30 ), to indicate barrenness and desolation, is "a garden that hath no water." And that, in patriarchal times, they laboured hard to supply their grounds with water by means of various hydraulic machines, some of which resembled the water-wheels of the fen districts of England, and were worked by the feet of men, something after the style of the modern treadmill, is certain. Moses alluded to this practice when he reminded the Israelites of their sowing their corn in Egypt, and watering it with their feet (Deut. xi. 10; 2 Kings, xix. 24), and in the sandy soils of Arabia the same system is still continued. (Niebuhr, vol. i. p. 121.) According to Dr. Shaw, the following is the modern mode of raising and using the water of the Nile for the purpose of irrigation in Egypt. "Such vegetable productions as require more moisture than what is occasioned by the annual inundation of the Nile, are refreshed by water that is drawn at certain times out of the river, and lodged in large cisterns made for that purpose. The screw of Archimedes seems to have been the instrument formerly made use of for that purpose, though at present the inhabitants either supply themselves with various kinds of leathern buckets, or else with a sakiah, as they call the Persian wheel, which is the most useful and generally employed machine. Engines and contrivances of both these kinds are placed all along the banks of the Nile, from the sea to the cataracts, their situations being higher, and consequently the difficulty of raising the water being greater, as we advance up the river. When their pulse, saffron, melon, sugar-canes, \&c. (all of which are commonly planted in rills), require to be refreshed, they take out a plug from the bottom of the cistern, and then the water gushing out, is conducted from one rill to another by the gardener, who is always ready as occasion requires to stop and divert the current. In Egypt at the present day, according to I)r. Clarke, the water is sometimes raised for the purposes of irrigation by means of a wicker basket lined with leather, which is held by cords between two men, who, by this laborious means, swing it over the banks of the Nile into the canal which conveys it to the lands intended to be irrigated. A machine similar to the Persian wheel is still employed in China by the cultivators for the purposes of irrigation. This use of machinery for the purposes of watering might, in fact, in many situations, be advantageously employed in England to a much greater extent than is commonly believed. It is well known how many thoulsand acres of valuable land are profitably drained by means of the steam-engine. At this very period a public company is proposing to enclose and drain an arm of the sea in Lincolnshire, by the assistance of its gigantic aid. Yet how rarely, if ever, is that power employed to irrigate the thirsty lands of England; lands of all others the most profitable, the best adaph ed for the formation of water meadows. The tracts to which I allude are those on a slope, as on the side of a hill; but these are rarely found in situations where a sufficiently copious supply of water can be constantly obtained for the purposes of irrigation. Yet the quantity thus required is not so large as to be beyond the power of the steam-engine to supply; thus, to sufficiently saturate a square yard of a calcareous sand soil with water to the depth of one foot, as in irrigation, requires about 30 gallons of water, equal to about 145,000 gal. lons per imperial acre. Now, that the steamengine could readily and profitably supply this quantity of water may be concluded from several facts; thus, the two engines, one of 80 , the other of 60 horses' power, which keep Deeping Fen, near Spalding, completely drained, when working, in 1835, only 96 days, of 12 hours each, raised more than $14,000,000$ tons of water several feet. The district drained by them contains about 25,000 acres (Brit. Farm. Mag. N. S. vol. iii. p. 300), which would otherwise be a complete swamp. And it has been proved that, by a common condensing steam-engine, one bushel of coals will raise more than $50,000,000 \mathrm{lbs}$. of water one foot. In many situations, therefore, where, for the purposes of irrigation, good river water can be copiously obtained, and fuel is at a moderate price, I am confident that great results are yet to be oltained by the aid of mechanical power. For, by the steam-engine, the soils of all others the best adapted for irrigation, may be successfully brought in to cultivation; for instance, the poor sands and gravels on the sloping banks of many of the English and Scotich rivers, many of whose waters, from being charged with organic matter, the carbonate and sulphate of lime, and various earthy substances, are excellent for the use of water meadows. The early employment of irrigation by the Egyptians and Chinese was most likely the result of the good effects which were observed to be produced by the overflowings of the Nile and the Chinese rivers; for, in the "Celestial Empire," irrigation has, it seems, been employed, according to their veracious historians, for a period long before that assigned to the flood. In Italy, especially on the banks of the Po, the cultivators of the earth have certainly employed this process for a period previous to the days of Virgil (Georg. lib. i. v. 106-9), -

Deinde satis fluvium inducit, rivosque sequentes-

and it is still carried on with a zeal and care worthy of the art they practise. M. P. Cato, the earliest of the Roman writers upon agriculture ( 150 years before Christ), in his ninth chapter, told the Italian farmers to "malte water meadows, if you have water, and if you have no water, have dry meadows." The directions of Columella seem to have all the freshness of a modern age about them. II was the first who noticed the inferior nutrition afforded by the hay from water neadows. "Land," says he, "that is naturally rich, and is in good heart, does not need to have water set over 1 : and it is better hav 


\section{IRRIGATION.}

which nature, of its own accord, produces in a juicy soil, than what water draws from a soil that is overflowed. This, however, is a necessary practice when the poverty of the soil requires it; and a meadow may be formed either upon a stiff or free soil, though poor when water may be set over it; neither a low field with hollows, nor a field broken with steep rising ground, are proper; the first, because it contains too long the water collected in the hollows; the last, because it makes the water run too quickly over it. A field, however, that has a moderate descent may be made a meadow, whether it be rich, or so situated as to be watered; but the best situation is where the surface is smooth, and the descent so gentle as to prevent either showers, or the rivers that overflow it, remaining too long; and, on the other hand, to allow the water that comes over it quietly to glide off; therefore, if in any part of the field intended for a meadow, a pool of - water should stand, it must be let off by drains, for the loss is equal either from too much water or too little grass." (Col. lib. ii. c. 16.) Pliny tells us that "meadows ought to be watered immediately after the spring equinox, and the waters restrained whenever the grass shoots up into stalk." (Nat. Hist. lib. xviii. c. 27.) When, after the fall of the Roman Empire, agriculture, in common with all other sciences, rapidly declined, a very remarkable exception to this melancholy result of slavery and despotism was presented in the case of irrigation, which was carried on and extended through the long period of the dark ages with equal zeal and success. This was more especially the case in Lombardy, where it was certainly prosecuted on a very bold and profitable scale long before 1037. The princes of Lombardy patronised and followed the example of the various religious establishments which then monopolized all the wealth and learning of the land, in extending the employment of water in all possible directions. The monks of Chiazevalle, in particular, were so celebrated for their knowledge of this branch of agriculture, and of hydraulics in general, that the emperor Frederick the First, in the 13th century, very gladly sought their advice and assistance. This system has ever been zealously and carefully extended and improved in every possible way. The waters of the chief rivers of the north of Italy, such as the Po, the Adige, the Tagliamento, and of all the minor streams, are employed in irrigation. There is no other country, which possesses an extent of rich water meadows equal to that of the Lombards. The entire country from Venice to Turin may be said to be formed into one great water meadow : yet the irrigating system is not confined to grass lands; the water is conveyed into the hollows between the ridges in corn lands, into the low lands where rice is cultivated, and around the roots of vines. From Italy the practice extended into the south of France, into Spain, and then into Britain. In the States of Lombardy, the water of all the rivers belongs to the state; in those of Venice, the government extends its claims to that of the smallest springs, and even to collections of rain water, se highly for the use of the cul67: tivator, is water of every kind valued in the north of Italy. It is necessary, therefore, in Lombardy, to purchase from the state the water taken from the river; this may be taken, by means of a canal, through any person's grounds, the government merely requiring the payment of the value of the land to the proprietor, and restraining him from carrying his channel through a garden, or within a cer. tain distance of a mansion. The water is sold by the government at a certain rate, which is regulated by the size of the sluice, and the time the run of water is used; this is either by the hour, half-hour, or quarter, or by so many days at certain periods of the year; the right to these runs of water is regularly sold like other property. Arthur Young gives an account of the sale of an hour's run of water through a sluice near Turin, which produced, in 1778 , 1500 livres. The rent of the irrigated lands in the north of Italy is, upon an average, more than one-third greater than the same description of land not watered. (Com. Board of $A g r$. vol. vii. p. 189.)

In Bengal, wells are dug in the highest part of their fields, and from this, by means of bullocks and a rope over a pulley, water is raised in buckets, and conveyed in little channels to every part of the field. No attempts at cultivation are here made without the assistance of water, obtained by some mode or other. (See India, Agriculture of.) The art of irrigation was not confined to the Old World. The Mexicans practised it long before the days of Columbus; they collected the mountain torrents, and conducted their waters to their lands in proper channels, with much care and address. It was only towards the termination of the 17th century that water meadows were constructed in Britain upon any thing like a regular system. Of these, those in Wiltshire, which are amongst the most celebrated in England, especially those in the Wyley Bourn, were made between 1700 and 1705 . Those of Hampshire and Berkshire were constructed about the same period, but they were at first formed very inferior to the modern noble wa. ter-meadow lands of those countries. Great improvements were made towards the conclusion of the 18th century, through the publications of G. Boswell on Meadow Watering in 1780, and of the Rev. T. Wright, of Auld, in Northamptonshire, whose writings appeared at intervals from 1789 to 1810 . It is noticeable that the water employed for these celebrated southern meads is perhaps the most clear and swift flowing of all the English rivers; issuing from the chalk formation, it is equally copious and transparent. Some of the chief advantages, therefore, of irrigation may evidently be derived from almost any description of water; for it is proved by the good effects produced by the brilliant chalk-waters of the south of England, and the still greater fertilizing effect of those surcharged with organic matter, as in the Craigintinny meadows, near Edinburgh, that there is no water too bright, or too full of impurities, to be useless for the purposes of irrigation.

I propose, in this paper, to investigate the chemical properties of river water, and of the 
effects produced by it in irrigation, adding a few remarks upon the practice of the best and most skilful cultivators of the water meadows of the south of England.

1. With regard to the composition of river water, there have been several chemical examinations; that of the Thames was analysed by Dr. Bostock, who found, in 10,000 parts, after most of its mechanically-suspended matters had subsided, about $1 \frac{3}{4}$ parts of foreign substances, viz. :

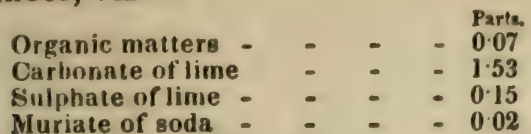

In an equal quantity of the waters of the Clyde, Dr. Thompson found $1 \frac{1}{6}$ part of solid substances, namely :

\begin{tabular}{llll} 
Common salt - & - & - & Parts. \\
Muriate of magnesia & - & - & -369 \\
Sulphate of soda & - & - & -305 \\
Carbonate of lime & - & - & 0.114 \\
Silica - & - & - & -394 \\
\hline
\end{tabular}

The water of the Itchen, in Hampshire, is one of the most celebrated of all the southern streams, for the use of the irrigator. I found, in 10,000 parts of water, about $2 \frac{1}{2}$ parts of solid matter, viz. :

\begin{tabular}{|c|c|c|c|}
\hline Organic matter & & & Parte. \\
\hline Carbonate of lime & - & - & $\begin{array}{l}-1.89 \\
-\quad 1.2\end{array}$ \\
\hline Sulphate of lime & - & - & -0.72 \\
\hline Muriate of soda & - & - & -0.01 \\
\hline
\end{tabular}

From an examination of the substances found in these streams (and they afford a pretty correct view of the contents of most others), the farmer will see that they all yield ingredients which are the food or natural constituents of the grasses. Thus, sulphate and carbonate of lime are found in most of them, and there is no river-water which does not contain, in some proportion or other, organic matter. To ascertain, therefore, whether pure water was alone able to effect all the magic effects of irrigation, it was necessary to $\mathrm{em}$ ploy other water than that of rivers, lakes, or even springs. Pure water, as obtained by distillation, therefore, has been tried as a supporter of vegetation, but it was found totally inadequate to the support of plants; they merely vegetated for a time, but they could not, by any means, be made to perfect their seeds. In this conclusion the experiments of Dr. Thomson, and of MM. Saussure and Hassenfratz, entirely agree. Pure water, therefore, notwithstanding the dreams of the Greek philosophers, and the celebrated deceptive experiments of $\mathrm{V}$ an Helmont with his willow tree, is not able to support the growth of the grasses. Van Helmont's tree, when he planted it in an earthen pot, weighed 5 pounds; the earth, previously dried in an oven, weighed 200 pounds; - after 5 years it weighed 164 lbs., although it had been watered during that time with only rain and distilled water, and the earth had lost only two ounces of weight. Hence, said Van Helmont and his disciples, water is the sole food of plants. Bergman, in 1773, first pointed out the source of error. He showed, from the experiments of Margraff, that the rain-water contained a sufficient quantity of earth to account for the increased weight in the willow, every pint of rain-water cuntainirz one grain of earth. Then, again, the earthen vessel (which was sunk in the earth) would, in this experiment, transmit its moisture im. pregnated with all kinds of soluble substances. And yet it has been shown that impure water, such as that from a sewer, or from a dunghill, is alone sufficient to sustain vegetation. "This was clearly evidenced in the experiments of M. Lampadius; for he found that plants placed in a pure earth, such as silica or alumina, although they would not grow when watered with pure water only, yet, when watered with the liquid drainage of a dunghill, they flourished very luxuriantly, and this fact has been also proved in another way. It has been shown, by chemical analysis, that the quantity of solid or earthy matters absorbed by plants is in exact proportion to the impurity of the water with which they are nourished. Thus, equal quantities of some plants of beans, fed by distilled water, yielded-

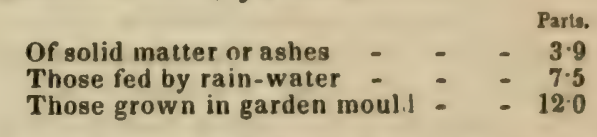

These facts strongly confirm the conclusions of some of the most sagacious cultivators, that the chief advantages of irrigation are attributable to the foreign substances with which the water is charged; although, as I have elsewhere observed, almost every farmer has a mode of accounting for the highly fertilizing effects of irrigation; one thinks it cools the land, another, that it keeps the grass warm in winter. And this was Davy's opinion. He thought that a winter flooding protected the grass from the injurious effects of frost. He says, "Water is of greater specific gravity at $42^{\circ}$ than at $32^{\circ}$, the freezing point; and hence, in a meadow irrigated in winter, the water immediately in contact with the grass is rarely below $40^{\circ}$, a degree of temperature not at all prejudicial to the living organs of plants. In 1804, in the month of March, I examined the temperature in a water-meadow near Hungerford in Berkshire, by a very delicate thermometer. The temperature of the air at 7 in the morning was $43^{\circ}$. In general, those waters which breed the best fish are the best fitted for watering meadows; but most of the benefits of irrigation may be derived from any kind of water."

Such were the opinions of Davy as to the fertilizing properties of water. It is to be regretted that the opportunities for agricultura' observations of this great chemical philosophe: were so few, for his valuable remarks were always cautiously made. He appears, however, as I have remarked elsewhere, never to have steadily investigated the chemical com. position of river-water, with regard to its uses in irrigation, and, in consequence, knew little of the value of some of its impurities to vegetation. Thus, if the river-water contains gypsum (sulphate of lime), which it certainly does -if the water is hard, it must, under ordinary circumstances, on this account alone be highly fertilizing to meadows, since all grasses contain this salt in very sensible proportions; $f(r$, calculating that one part of sulphate of lime is contained in every two thousand parts of river. 
water, and that every square yard of dry meadow soil absorbs only eight gallons of water (and this is a very moderate allowance, for many soils will absorb three or four times that quantity), then it will be found that, by every flooding, more than one hundred weight and a half of gypsum per acre is diffused through the soil in the water, a quantity equal to that generally adopted hy those who spread gypsum on their clover crops, lucern, and sainfoin, as a manure, either in the state of powder, or as it exists in ashes. And if we apply the same calculation to the organic substances ever more or less contained in flood-waters, and allow only twenty parts of animal and vegetable remains to be present in a thousand parts of river-water, then we shall find, taking the same data, that every soaking with such water will add to the meadow nearly two tons per acre of animal and vegetable matters, which, allowing, in the case of water-meadows, five floodings per annum, is equal to a yearly appliition of ten tons of organic matter.

The quantity of foreign substances present in river-water, although commonly less, yet very often exceeds what I have thus calculated to exist in it. I have found it impossible, however, to give, from analysis, the amount which, under ordinary circumstances, is present in river-waters, with any tolerable accuracy, since the proportion not only varies at different seasons of the year, but a considerable proportion of the merely mechanically suspended matters subside, when the specimen water is suffered to rest. In my conclusions with regard to the theory of irrigation, I have found many excellent practical farmers concur. 'Thus, Mr. Simmons, of St. Croix, near Winchester, considers that the great benefit of winter flooding for meadows is derived, in the first place, from the deposits made by the muddy waters on the grass; and, secondly, from the winter covering with water preventing the ill effects to the grass of sudden transitions in the temperature of the atmosphere. This gentleman is perfectly aware of the value of the addition of the city drainage of Winchester to the fertilizing qualities of the Itchen river-water, and of its superiority for irrigation after it has flowed past the city, having water-meadows both above and below the town; and he finds that, if the water has been once used for irrigation, that then its fertilizing properties are so materially reduced, that it is of little value for again passing over the meadows; and so convinced is he of this fact by long experience, that, having in this way long enjoyed the exclusive and valuable use of a branch of the waters of the Itchen for some grass land, a neighbour higher up the stream followed his example, constructing some watermeadows, and using the water before it arrived at those of my informant, who, in consequence, found the water so deterinrated in quality (though not sensibly diminished in quantity), that he had once thought of disputing the right with his more upland neighbour. The experience of other irrigators tends to the same cunclusion. In the best-managed water-meadows of Hainpshire, the farmer does not procure annually more than three crops of grass; yet in situations where a richer water is em672 ployed, as near Edinburgh, four or five are rea. dily obtained. It is evident, therefore, that the chemical properties of water have a much greater influence in irrigation than is commonly believed. The quality of the water, therefore, employed for the purposes of irrigation, is of the first importance to be well understood by the farmer; and although many more modern discussions have taken place upon the subject, yet the definition which the great Lord Bacon gave, in his Natural History, of the advantages of "Meadow Watering," has never been excelled,- "that it acts not only by supplying useful moisture to the grass, but likewise by carrying nourishment dissolved in the water." 'This nourishment is, generally speaking, composed almost entirely of the animal and vegetable matters mechanically suspended or chemically dissolved in the water;-the fouler the water, the more fertilizing are its effects. The objection which has been sometimes urged to this explanation, by instancing the prejudicial effects of some very thick muddy waters (as those of the Humber) on meadow lands, is very erroneous; for, in those cases, the mud deposited on the grass did not consist of animal or vegetable matters, but of fine carthy particles, such as clay or chalk, sub. stances of which the alluvial soil, on which the same flood waters had for ages occasionally deposited their earths, was in fact entirely composed, and to which, in consequence, any further supply was almost useless, the earthy slime merely covering the grass with mud, without adding a single fertilizing ingredient not already abounding in the soil. If, however, the soil is naturally deficient in any of the earthy ingredients contained in the water, then even such flood waters are ever found most fertilizing.

"The agency of water in the process of ve. getation," says Mr. Stephens, "has not till of late been distinctly perceived. Dr. Hales has shown that, in the summer months, a sunflower, weighing three pounds avoirdupois, and regu. larly watered every day, passed through it or perspired 22 ounces each day, that is, half its weight. Dr. Woodward found that, in the space of 77 days, a plant of common spearmint in creased 17 grains in weight, and yet had no other food than pure rain water; but then he found that it increased more in weight when it lived in spring water, and still more when its food was Thames water." (Practical Irrigator, p. 2.) And when speaking of the fact, that some irrigators think clear spring water equal to any, he adds (p. 24), "I would recommend to those who are of the same opinion, to inspect the irrigated meadows which are watered by the washings of the city of Edinburgh, where, I trust, they will find the superiority of muddy water to that of clear spring water most strikingly manifested."

Edinburgh has many advantages over the most of her sister cities; the large supply of excellent spring water is one of the greatest blessings to her numerous inhabitants, both in respect to household purposes and keeping the streets clean, as well as irrigating the extensive meadows siruated below the town, by the rich stuff which it carries along in a state of semi- 


\section{IRRIGATION.}

IRRIGATION.

solution, where the art of man, with the common sewer water, has made sand hillocks produce riches far superior to any thing of the kind in the kingdom, or in any other country.

By this water, about two hundred acres of grass land, for the most part laid into catchwork mearlow, are irrigated; whereof 130 belong to W. H. Miller, Esq., of Craigintinny, and the remainder to the Earls of Haddington and Moray, and other proprietors. The meadows belonging to these noblemen, and part of the Craigintinny meadows, are what is called the old meadows, containing about 50 acres, have been irrigated for nearly a century. They are by far the most valuable, on account of the long and continual accumulation of the rich sediment left by the water; indeed the water is so very rich, that the tenants of the meadows lying nearest the town have found it advisable to carry the common sewer water through deep ponds, into which the water deposits part of the superfluous manure before it runs over the ground. Although the formation of these meadows is irregular, and the management very imperfect, the effects of the water are astonishing; they produce crops of grass not to be equalled, being cut from four to six times a year, and the grass given green to milch cows.

The grass is let every year, by public sale, in small patches of a quarter of an acre and upwards, and generally brings from $24 l$. to $30 l$. per acre per annum. In 1826, part of the Earl of Moray's meadow fetched $57 l$. per acre per annum.

About 40 acres of the Craigintinny lands were formed into catch-work water meadow before the year 1800, which comprises what is called Fillieside Bank old meadows, and is generally let at from $20 l$. to $30 l$. per acre per annum. In the spring of 1821,30 acres of waste land, called the Freegate Whins, and 10 acres of poor sandy soil, were levelled and formed into irrigated meadow, at an expense of 1000 . The pasture of the Freegate Whins was let, previously to this improvement, for $40 l$. per annum, and the 10 acres for 60l. They now bring from $15 \%$. to $20 l$. per acre per annum, but may be much improved by judiciously laying out $200 l$. more in better levelling that part next the sea, and carrying a larger supply of water to it, which might be easily done without prejudice to the other meadows.

This, perhaps, is one of the most beneficial agricultural improvements ever undertaken; for the whole of the Freegate Whins is composed of nothing but sand, deposited from time to time by the action of the waves of the sea. Never was $1000 l$. more happily spent in agriculture; it not only required a common sewer in bring about this great change, but a resolution in the proprietor to launch out his capital on an experiment upon a soil of such a nature.

Since the making of the Freegate Whins into water meadows, Mr. Miller has levelled and formed 40 acres more of his arable land into irrigated meadow, worth, before the formation, $9 \%$ per acre per annum. It will only require a few years before these meadows will be as productive as the former; for it is evi- dent that the longer water is suffered to run over the surface of grass land, the greater quantity of fertilizing substance will be coller:ted; therefore, as the water is so very superior in quality to all other water, a speedy return for the capital laid out may be experted. The expense of keeping these meadows in repair is from 10 s. to 158. per acre per annum, which is more than double the expense of keeping water meadows in repair in general.

It by no means, however, follows, as a necessary result of any contemplated improvement in irrigation, that the water should previouly undergo a chemical examination. There are many other modes by which the farmer can form a pretty correct conclusion as to the fertilizing properties of the water he proposes to employ.

"I'he surest proofs," says Mr. Exeter, "of the good quality of water (and the observations of this gentleman will be readily confirmed by the irrigators of the southern counties) as a manure, are the verdure if the margin of its streams, and the growin of strong cresses in the stream itself; and wherever these appearances are found, though the water be perfectly transparent, the occupier of the soil through which it flows may depend, in general, on having a treasure, if he is attentive to it; but that this is not invariably the case, and that there are instances where a good water will not improve the herbage of certain soils, is proved by the following account (and there are several other cases with which I am acquainted) of the meadows of Mr. Orchard, of Stokes Abbey, Devon. These two meadows are situated on the side of a hill, their aspect nearly souththe superstratum a fine rich loam, from 8 to 10 inches deep, on a substratum of strong yellow clay. No difference whatever can be seen by the naked eye, in either the upper mould or the substratum, or in the herbage growing or: the surface of them; except that, in the lower part of one, a few rushes appear, in consequence of some small springs which rise near them, but the water from them is not sufficient to render any part of the land poachy. At the head of the two meadows is a large pond, formed by the collecting of some small runs of spring water rising near $\mathrm{jt}$, and which is also improved by the wash of a small farm-yari adjoining, which, of course, must add to its efficacy as a manure. When this water is thrown over one of the meadows, it produces the richest herbage in abundance, and this field is regularly mowed for hay; on the other meadow, though repeatedly tried, it produces no good whatever." (Ann. of $\mathcal{A g r}$. vol. xxx. p. 206.)

This result is attributable to the superior tenacious, retentive quality of the substratum of the lower field, or of some chemical difference in the composition of the soil; and although almost any description of soil is adapted to the formation of water meadows, those of a heavy clay description are generally the most unsuitable, those of a light or peaty kind are better, and those with a sandy or very absorbent gravel substratum still more so. Ther are some of the most celebrated water mea dows on the bants of the Kennet of this do $3 \mathrm{I}$ fira 
scription, and many of the best on the banks of the Wiltshire Avon have a mass of broken, perous flints for a subsoil. Those near Edinburgh, irrigated by the city drainage, rest upon the sands thrown up by the sea.

It is evident, therefore, that it is as important an object in the construction of these meadows to secure a ready and rapid exit for the flood-waters, as to procure, in the first instance, a copious and fertilizing supply.

The farmer is generally well aware of the injurious effects to his meadows of suffering the water to remain too long on them. He watches, therefore, with much care, for the first indications of fermentation having commenced, which is evinced by the rising of a moss or scum to the surface of the water-puirefaction is now beginning in the turf, and he knows very well that if the water is not speediIy removed, that his grass will be either materially injured, or entirely destroyed; he hast"ns, therefore, to open his water-courses. 'There are some soils in the vicinity of Standen, in Berkshire, however, of so porous a quality, that they need not any drains to empty the water-courses; and, in fact, in many instances, the farmer does not even require them : after a few hours all the water is absorbed by the ;oil ; and yet these lands, with hardly 6 inches of mould above the gravel, are amongst the richest of water-meadows; the roots of the grasses penetrate readily into the gravel, and ihe earliest and sweetest grasses are produced in them.

Almost any description of grass will flourish under proper management in water-meadows. 'Those whose soils consist of peat resting on sand, or on sandy loam, with a substratum of chalk or gravel, generally produce the meadow foxtail (Alopecurus pratensis), the brome-grass (Bromus arvensis), and the meadow-fescue (Festuca pratensis), on the tops and sides of the ridges. The furrows and sides of the drains are usually tenanted by the creeping-bent, the hard-fescue, the rough-stalked meadow-grass, and the woolly soft-grass. In those watermeadows whose soil consists of a sandy loam on a clay subsoil, the chief grasses are commonly the creeping-rooted soft-grass, the crested dog's-tail, the meadow barley, and the sweet-scented vernal-grass. But some grasses change their appearance in a very remarkable degree, when exposed under favourable circumstances to the influence of the floodwaters. This fact is strikıngly exemplified in the case of two small meadows situated at Orcheston, six miles from Amesbury, in Wiltshire, denominated, from their great produce, "the long grass meads." These, says Davis, "contain together only two acres and a half, and the crop they produce is so immense, that the tithe hay of them was once sold for 5 guineas." Much discussion took place amongst the Wiltshire farmers as to the nature of the reop of these meads, before it was at last hown that the greatest part of their herbage cunsisted of nothing else than the black-couch, " couchy-bent, the Agrostis stolonifern, one of the worst of the grasses or weeds which haunt .e ponr ill-cultivated arable soils.

It 1 ; a very general, as well as correct con674 clusion of the English farmers, that the gras and hay of water-meadows is not so nutritious as that of the permanent pasture lands. The difference, however, is not so great as is com. monly supposed. The late Mr. George Sinclair determined this experimentally, and he is no mean authority with regard to all that relates to the grasses.

He obtained from the rye-grass (Lolium perenne), at the time of flowering, taken from a water-meadow that had been fed off with sheep till the end of April, of nutritive matter 72 grains; and from the same weight of this grass, taken from a rich old pasture, which had been shut up for hay about the same time, 92 grains. From the same grass from the meadow, that had not been depastured in the spring, 100 grains. And from the same grass from the pasture which had not been fed off, 120 grains. All the grasses, in fact, where their growth is forced by the application of either liquid or solid manures, are found contain nutritive matter in diminished quantities: this, too, was determined by Sinclair. From 4 ounces of a very rankly luxurians patch of rye-grass, on which a large portion of cow-dung had been deposited, he obtained of nutritive matter 72 grains. From the same quantity of the same grass growing on the soil which surrounded this luxuriant patch, he obtained 122 grains.

And, in a second trial, the same species of grass, on a soil entirely destitute of manure, afforded of nutritive matter, 95 grains. On the same soil, excessively manured, the grass afforded only 50 grains. In these experiments the plants were of the same age, and were examined at the same stage of their growth. (Hortus Gram. 384.)

With regard to the construction and man. agement of water-meadows, there are many practical works of the highest authority to which the farmer has ready access; and, in the following observations, therefore, I shall merely very briefly paraphrase the accounts given by Mr. Davis and others, of the practice of irrigation in the southern counties. In this, however, even since the time that Davis wrote, there has been a great and steady improvement. The land is better levelled, the slopes more evenly preserved, the water-way, aqueducts, and hatches, better constructed, and in many of the more recent improvements, in the valley of the Itchen, in Hampshire, the sliding-water doors are regulated by a cogged wheel turned with a movable winch, so as to render them safe from alteration during the absence of the meadow-keeper.

The management of the Wiltshire and Hampshire water-meadows, as well as it can be briefly described, is as follows :-In the autumn the after-grass is eaten off quite bare, when the manager of the mead (provincially the drowner) begins to clean out the main drain, and the main carriage, and to "right up the works," that is, to make good all the carriages and drains which the cattle have trod. den in, so as to have one tier or pitch of work ready for drowning. This is immediately put under water, whilst the drowner is preparing the next pitch. 


\section{IRRIGATION.}

In the flowing meadows this work ought to be done, if possible, early enough in the autumn to have the whole meadow ready to catch the first floods after Michaelmas; the water, being the first washing of the arable lands on the sides of the chalk hills, as well as the dirt from roads, is then thick and good; and this remark, as to the superior richness of the flood waters, is one that is commonly made in Berkshire and other parts of England. The length of the autumnal watering cannot be precisely stated, as much depends upon situations and circumstances; but if water can be commanded in abundance, the custom is to give meadows a "thorough good soaking at first," perhaps for a fortnight or three weeks, with an intermission of two or three days during that period, and continue for the space of two fortnights, allowing an interval of a week between them. The works are then made as dry as possible, to encourage the growth of the grass. This first soaking is to make the land sink and pitch close together, a circumstance of great consequence, not only to the quantity, but to the quality of the grass, and particularly to encourage the shooting of new roots, which the grass is continually forming, to support the furced growth above.

While the grass grows freely, a fresh watering is not wanted; but as soon as it flags, the water must be repeated for a few days at a time, always keeping this fundamental rule in view, "to make the meadows as dry as possible after every watering, and to take off the water the moment any scum appears upon the land, which shows that it has already had water enough."

Some meadows that require the water for thrce weeks in October, and the two following months, will nat, perhaps, bear it one week in February or March, and sometimes scarcely two days in April and May.

In the catch-meadows, which are watered by springs, the great object is to keep the works very dry between the intervals of watering; and as such situations are seldom affected by floods, and generally have too little water, it is necessary to make the most of the water, by catching and rousing it as often as possible; and as the upper works of every pitch will be liable to get more water than those lower down, a longer time should be given to the latter, so as to make them as equal as possible. Davis's .Agriculture of Wiltshire, p. 125-127.)

In Berkshire they first flood their watermeadows about Michaelmas; these are situated principally on the banks of the Kennet. The first flooding they deem the richest in quality: this they keep on the land for about four days, and they then dry them for about a iortnight, and after that the water is let on for three or four days more; those meadows which are the most readily dried are the most productive. There are none more so, in fact, than those which have a porous, gravelly, or broken flint bottoms, from which the flood-water readily escapes, almost without drains. They begin to feed their meadows with sheep about the 6th of April, and continue feeding till ahout the 21 st of May, when the meadows are agan flooded for a crop of hay; the land is

\section{IRRIGATION.}

then flooded and dried alternately for threo days until hay-time.

The number of acres of land in Wiltshire, under this kind of management, has been com. puted, and with a tolerable degree of accuracy, to be between 15,000 and 20,000. Some considerable additions, however, have been made to the water-meadows of the district since this calculation was made. (Davis's Wilts, p. 122.) About the same number of acres are formed into water-meadows in Berkshire, and a still larger number in Hampshire. No one has at. tended more carefully to his water-meadows than Lord Western, on some of those situated on the London clay-formation in the Blackwater valley, in Essex, a soil of all others, perhaps, from its tenacity, the least adapted to their successful formation, and his testimony is very important:- "There is an old adage," says his lordship, "that water is the best servant in agriculture, and the worst master. Water has in itself intrinsic value; distilled through chalk, lime, or marl, it acquires a portion of their qualities, though preserving the most perfect transparency, and, coming down in torrents and floods, it carries along the finer particles of earth and manure from the mountains, or higher grounds, into the valleys; hence, of course, it is that the valleys derive their fertility, and the value of the meadow has been originally created by an accumulation of wealth from the hills."

"In descending the Jura mountains, which divide France from Switzerland, the very first pasture you find on the descent evinces the value placed on the mountain floods by the inhabitants of those districts; and, accordingly, every stream is sedulously directed and conducted over the pastures in a most skilful manner. The very washing of the roads in hasty rains is also attended to and applied to the same purposes." This system of catching the uncertain flood-waters is known amongst farmers by the name of catch-work, and though highly valuable, yet they deem it infinitely less important to them than irrigation, which is watering (generally five or six times a year) from a certain and ever-accessible head of water, as a river, \&c. And yet Lord Western's testimony is decisive in favour of even one catch-flooding; for he observes, when speaking of the expense of constructing the requisite little channels to disperse the flood-waters over the grass, "In many cases it will be trifling, in some cases considerable; but when the farmer reflects that one winter's flooding will do more in many, I may say in most cases, than thirty loads an acre of the best rotten dung manure that can be laid upon his grass lands, he can hardly shrink from some considerable expenditure." If, then, the effects even of a catchflooding with water are so great, how infinitely superior are the advantages capable of being derived from a regular constant supply of the enriching foul waters, like those issuing from the drains of a large city, which is even now most successfully employed near Edinburgh, but worse than wasted in the case of London! Whatever may be the value, in an agricultural point of view, of the solid contents of the London sewers, yet to me the alisolutely liquid. 


\section{IRRITABILITY.}

portion, for the purposes of irrigation, appear at !east equally important.

Liebig informs us that, "in the vicinity of Liegen (a town in Nassau), from three to five perfect crops are obtained from one meadow, and this is effected by covering the fields with river water, which is conducted over the meadow, in spring, by numerous small canals. This is found to be of such advantage, that supposing a meadow not so treated to yield $1000 \mathrm{lbs}$. of hay, then from one thus watered 4500 pounds are produced. In respect to the cultivation of meadows, the country around Liegen is considered to be the best in all Germany."

There is no agricultural question, therefore, of more consequence, in a national point of view, than that of the improvement of the soil by the practice of irrigation; for, in its prosecution, all the rich, organic, and other matters diffused through the rivers, which would otherwise be carried into the sea, are saved to agriculture. This is not, therefore, a question like that attending most other modes of fertilizing the soil, merely transposing manure from one field or district to another; but it is the absolute recovery, as it were, from the ocean, of a mass of finely divided, enriching substances, constantly draining from the land. It is the effectual diversion of a stream which is ever steadily impoverishing all cultivated soils, and which unnoticed, and in too many instances deemed worthless, gliding into the ocean, is almost the only drawback to the steadily increasing fertility of our country.

There are papers on irrigation by $\mathrm{Mr}$. J. Purdy, of Castle Acre, in Norfolk, Com. Board of $A g r$. vol. vii. p. 112; by Mr. D. Shank, of Wigtonshire, ibid.p. 170; by Mr. Beck, of Norfolk, itid. p. 108; on the irrigation of Lombardy and Piedmont, by Don R. S. Coutinho, ibid. p. 189; in Aberdeenshire, ibid. vol. iv. p. 263; in Denbighshire, ibid. p. 266; by Mr. Eyres, of Norfolk, ibid. vol. vi.p. 328; by Professor Rennie, Quart. Journ. of $\mathcal{A g} r$. vol. v. p. 24; on the foul water irrigation of Edinburgh, ibid. vol. $x$. p. 256. (Quart. Journ. of $A g r$. vol. x. p. 558 ; Stephens's Practical Irrigator; Brown's Rural Affairs, p. 263; Sinclair's Hortus Gram. p. 382; Davis's Wiltshire; Driver's Hampshire.)

IRRITABILITY OF PIANTS. See Botami, Temperature, and Acchmitation of Plants.

ISNARDIA (named in memory of Anthony Isnard, member of the Academy of Sciences). These plants are mere weeds, or creeping aquatic herbs, growing in marshy situations.

The marsh isnardia (I. palustris) is the only indigenous species.

It is an annual, growing in ponds and watery places, blowing axillary, solitary, sessile, small, green, and inconspicuous flowers in July. The herb is floating, smooth, with numerous long filamentous roots. The stems are several, about a span long, simple, or slightly branched, leafy, bluntly quadrangular. 'The leaves are opposite, stalked, ovate, acute, entire, scarcely an inch in length, bright green, somewhat succulent, the mid-rib often red or "urplish. (Eng. Flor, vol. iv. p. 264.)

The 1. Palustris is common to America as 576 well as to Europe, and is found from Canada to the West Indies. In Pennsylvania another species is met with-the Alternate-leaved Isnardia (I. alternifolia), commonly called Bas. tard Loose-strife. The roots of both species are perennial.

Besides these, there are about a dozen additional species, as the genus is now constituted, in the United States. (Flor. Cestrica.)

ITALIAN RYE-GRASS, See RTE-Grass.

ITCH. In farriery, a cutaneous disease. See Mange.

IVY (Hedera helix). The name appears to be derived from hedra, a Celtic word signifying a cord; and the English name ivy is derived from ivo, a word in the same language signify ing green.) A hardy evergreen climber, com mon everywhere in Europe, which is excel lent as a screen planted against trellis-work The common ivy is very often employed for covering naked buildings or trees, which latter it invariably kills. The stem is branched, either trailing on the ground and bearing 5-lobed white-veined leaves, but no flowers; or climbing, flattened and attached by dense tufted fibres, which serve for support, not nourishment; the flowering branches are loosely spreading, round, bearing ovate, undivided leaves. Umbels aggregate, green, many-flowered, their stalks covered with starry pubescence, and ac. companied at the base by several small bracteas. The berry is the size of a currant, smooth, black, internally whitish and mealy, with seldom more than five seeds. The whole plant is somewhat aromatic; and a very fragrant resin exudes from the old stems when bruised.

IVY, AMERICAN, Virginia Creeper ( $A m$ pelopsis hederacea). Ivy-like ampelopsis. The stem of this climbing plant sometimes grows 30 or 40 feet long, branching diffusely, climb. ing fences, trees, and walls, and clinging to them by adhesive expansions at the points of the tendrils. The leaves are digitate in clusters of fives, on long stems. The plant is common in the United States in woodlands, fencerows, thickets, \&c. Sir J. E. Smith (in Rees Cyclop.) contends that this is a true vitis; but Dr. Darlington thinks, that although nearly allied to, it may be very properly separated from our grape vines. $T$ wo or three other species of ampelopsis are enumerated in the United States.

IVY, GROUND. See Alehoor.

IVY, IRISH (Canatiensis), is a fast-growing climber, with large lobed leaves, which soon covers walls and houses. It is propagated by layers, or slips taken off and planted where they are to grow.

\section{J.}

JACOB'S LADDER, BLUE or GREEK VALERiax (Polemonium coruleum). This plant is a common ornament of flower borders in rustic gardens, of no particular qualities, notwithstanding its name of valerian, derived perhaps from the leaves, which resemble those of some of the Valeriana. The root is fibrous, not creeping, herb nearly smooth, perennial, $1 \frac{1}{2}$ or 
- feet high; stems angular, leafy, hollow, often reddish, unbranched, panicled at the top; leaves alternate, of many eliptic-lanceolate, entire leaflets, with an odd one of nearly equal size. The flowers, which appear in June, are rather drooping, numerous, blue, occasionally white. All the species are of the easiest culture and propagation.

\section{JERUSALEM ARTICHOKE. See Anti-} CHOK F。

JOHN'S WORT, or ST. JOHN'S WORT (Hypericum). The generic name is said to be derived from uper, and eicon, an image. The superior part of the flower represents a figure. The common name is derived from their coming into flower about St. John the Baptist's day. The most part of the species of this extensive genus are showy plants. The greenhouse and frame shrubby kinds do well in loam and peat, and young cuttings root freely in sand under a glass. The hardy shrubs are well fitted for the front of shrubberies, being dwarf and showy. They may be increased by divisions or seeds, as well as the herbaceous kinds, which thrive well in any common soil. The seeds of the annual species have only to be sown in the open ground in spring. Some of the species indigenous to Britain are as follows:-

1. Large-flowered St. John's Wort (H. calycinum). A shrub, growing wild in bushy places in the west of Ireland and Scotland. The root of this species is creeping, the stems shrubby, erect, 12 or 18 inches high, with simple, leafy, square branches, smooth like every other part. The flowers, which appear from July to September, are 2 or 3 inches wide, of a bright golden yellow, with innumerable reddish tremulous anthers. This plant is a great ornament to shrubberies and parks, and excellent as a shelter for game, bearing any cold of our climate.

2. Tutsan, or Park Leaves (H. androsamum). This shrub is found in moist, shady lanes, thickets, and woods in Britain and Ireland, but not very general. It is rather taller and more branched than the preceding. The flowers, which appear in July and August, are an inch wide, yellow, with three sets of stamens, and as many styles. The leaves and other parts have an aromatic scent when rubbed.

3. Square St. John's Wort, or St. Peter's Wort (H. quadrangulum). This species is perennial, and common in moist meadows and thickets, and about the banks of rivers. The root is somewhat woody, creeping; the herb smooth, light green; stems several, from one to two feet high, erect, leafy, acutely quadrangular; leaves elliptical or ovate, obtuse, manyribbed, veiny, full of minute, colourless, pellucid dots, and bordered with a more or less perfect row of dark-coloured ones yielding a blood-red liquor. The uppermost branches form a leafy dense panicle of numerous lemoncoloured flowers, about half the size of the last-described species.

4. Common perforated St. John's Wort ( $H$. perforatum). This perennial species is met with abundantly in thickets, woods, hedges, and on dry banks. The root is woody, tufted, and somewhat creeping; the stem reaches to the height of 18 inches, and is round and bushy in consequence of the much greater length of its axillary leafy branches. The whole herb is moreover of a darker green, with a more powerful scent when rubbed, staining the fingers with a dark purple, from the greater abundance of coloured essential oil lodged in the herbage and even in the petals: the leaves are very numerous, smaller than the last, elliptical or ovate, obtuse, various in width; the flowers are numerous, in dense, forked, terminal panicles, bright yellow, dotted and streaked with black or dark purple. This species is eaten by goats, cows, and sheep, but is refused by horses and hogs. As this plant was found to bleed at the slightest touch, it was supposed to have a vulnerary quality, and became the "balm of the warrior's wound," giving a bloodred colour to every composition, whether of a spirituous or oily nature, into which it entered. It contains resin, and the leaves give a good red dye to wool and oil.

5. Imperforate St. John's Wort ( $H$. dubium). This species inhabits rather mountainous groves and thickets. The young radical shoots are bright red; the stem quadrangular in the upper part, but not winged or bordered; the petals and caly $x$ are dotted and blotched with dark purple.

6. Trailing St. John's Wort (H. humifusum). This is a pretty little procumbent smooth species, with the lemon-like scent of $\boldsymbol{H}$. dubium and perforatum, which tenants sandy or gravelly, heathy, and rather boggy pastures. The root is fibrous, stem compressed, prostrate; flowers few, somewhat cymose; leaves elliptical, smooth.

7. Mountain St. John's Wort ( $H$. montanum). Though not an ostentatious plant, this species well deserves John Bauhin's epithet of "most elegant." The glutinous dark fringes of its caly $x$ and bracteas resemble the glands of a moss-rose; the stems are erect, round, smooth, about two feet high; the leaves ovate, naked, clasping the stem.

8. Bearded St. John's Wort (H. barbatum), which grows for the most part in bushy places in Scotland, on an herbaceous stem a foot or more in height, flowering in September and October: 9. Hairy St. John's Wort (H. hirsw tum), flourishing in thickets and hedges, chienly on a dry, chalky soil, stem two feet high: 10 . Small upright St. John's Wort (H. pulchrum), met with very frequently in woods and bushy, heathy places, on a clay soil; stem 12 to 18 inches high: 11. Marsh St. John's Wort ( $H$. elodes), stems procumbent, creeping. There are other species, which call for no detailed description.

The whole genus, says Mr. Nuttall, in his account of the American species, appears :0. possess active medicinal properties in common with vismia, which affords indeed much more abundantly a yellow and resinous gum, acting as a cathartic in doses of 7 or 8 grains. The Vismia guttifera of Surinam produces a sind of gamboge. 25 or 26 American species of hypericum are enumerated by botanists. 'The following are mentioned by Dr. Yarlington as found in Chester county, Pennsylvania. 
1. Hypericum Virginicum, or Virginia hypericum, having a perennial root, stem 18 inches to 2 feet high, whole plant of a purplish hue, flowering in July and August, the blossoms being of a dull orange colour. It is found in wet, low ground, though rare.

2. H. punclatum, or dotted hypericum, frequent in open woodlands and fields, flowers of a pale yellow colour, with numerous oblong black dots, appearing in July and August.

3. H. perforatum, or perforated hypericum, oommonly called St. John's Wort. This plant has a perennial root and stem growing from 1 to 3 feet high. It is frequent in elds and pastures where it puts forth its rich clusters of yellow, or orange-yellow flowers, from June to October. 'This, says Dr. Darlington, is an introduced and pernicious weed. The plant has a resinous odour; and is believed to produce troublesome sores on horses and horned cattle, especially those which have white feet and noses, the skin of such being more tender, or irritable. The dew which collects on the plant appears to become acrid; as I have seen the backs of white cows covered with sores, wherever the bushy ends of their tails had been applied, after dragging through the St. John's Wort. A tincture of the flowers and leaves has been used, it is said, with good effect in some complaints of the stomach and bowels.

4. H. quinquenervum, or five-nerved hypericum. This is frequent in low grounds, along streams. Its root is supposed to be annual, and its slender stems grow 6 to 12 inches high; the flowers have very small petals of a yellow colour.

5. H. Canadense, or Canadian hypericum. This so much resembles the last mentioned species as to be regarded by some botanists as identical.

6. H. sarothra, broom-like hypericum, commonly called ground pine, netweed, and orange grass. This is frequent in sandy fields and along road-sides, where it puts forth yellow flowers in July and August. Its root is annual, the stem is slender and grows 4 to 8 inches high. (Flora Cestrica.)

JONQUIL. A species of daffodil, of which there are several sorts. The great jonquil and the odorous jonquil blow about the middle of March. The lesser or proper jonquil somewhat later. When they blow well and early they forebode a fine season.

JUDAS TREE (Cercis). This is a beautiful genus of ornamental trees, flowering early in spring, and looking very pretty planted singly on a lawn, or trained to a wall or trellis; they grow to the height of 20 feet, prefer an open loamy soil, and may be plentifully increased from seeds.

The species found in the United States is the Cercis Canadensis of botanists, commonly called red bud. In the Middle States, it is a small tree 15,20 , or 30 feet high, greatly admired for the clusters of small flowers, which in April clothe the limbs in purple before the leaves appear. The flowers are acid to the taste. It is the only species of cercis in the United States.

JUNE BERRY (Mespilus arborea of Michaux).

With the exception of the maritime parts of ô79 the Carolinas and Georgia, this tree, as Michaux informs us, is spread over the whole extent of the United States and Canada. But it is most multiplied upon the Alleghany moun. tains, and upon the elevated banks of the rivers which flow from them. In the northern section of the Union it is called wild pear tree, whilst in the Middle and other States it goes by the various names of wild service berry, June berry, snowy medlar, and shad-flower. The last name is derived from its blooming about the time the shad ascend the rivers (beginning of April), when it is quite a showy little tree. The flowers, which are white and pretty large, are arranged in pannicles at the extremities of the branches. As it blossoms early, so does it mature its fruit amongst the earliest trees of the forest. The largest tree, however, rarely yields more than half a pound. Long culture has been found to improve the fruit, both in size and quality. The berries are roundish, 3 or 4 lines in diameter, smooth, dark-red, and even purple when mature, pleasant flavoured, and not unwholesome. In Pennsylvania and the neighbouring states, it is generally found in moist and shady situations, especially along brooks and rivulets. In the western country, however, it grows in the midst of the forest among the oaks, walnuts, \&c., and here reaches its greatest height, which does not exceed 35 or 40 feet, with a diameter of 10 or 12 inches.

JUNIPER (Juniperus, derived from the Celtic juniperus, rough or rude, in allusion to the stiff habit of the shrubs). This genus is too well known to need to be particularized here. All the species will grow in sandy loam, and some in any common garden soil. They are mostly raised from seed, though cuttings will strike when planted in a sheltered situation, under a hand-glass. The stimulating and diuretic powers of the savin (J.sabina) are well known. The fruit of $J$. communis are proverbial for the flavour they give to gin. (Paxton's Bot. Dict.) The species are all evergreen aromatic shrubs, with narrow leaves, either spreading and sharppointed, or closely imbricated, minute, and obtuse. The fruit is globular or oval, black or brown, with a glaucous efflorescence.

$J$. sabina is a native of the south of Europe, but it is cultivated as an evergreen in our gardens. The plant is a pyramidal shrub, with small, closely-adhering, glandular leaves, which exhale, when rubbed, a strong, heavy odour, and have a bitter, nauseous taste. By distillation they yield a large quantity of volatile oil, which has the odour and taste of the recent plant. Savin is a powerful acrid poison, irritating and vesicating the skin when it is applied to it. When swallowed in large doses, it causes vomiting, purging, and inflammation of the stomach and bowels.

The common juniper ( $J_{0}$ communis) grows wild on hills and heathy downs, especially where the soil is chalky. Dr. Sibthorpe found it on Olympus and Athos, in Greece. It is, like all the species, a bushy shrub, with evergreen, linear pointed, glaucous leaves, dark green on the under disk. The flowers are axillary, small, sessile, male and female organs in separate flowers. The fruit, although called 
a berry, is a galbalus or succulent cone. It requires two seasons to arrive at maturity. The dwarf alpine juniper ( $J$. nana) is a variety of the communis. It grows upon lofty mouncains, and is, as its name implies, more humble in its growth. 'These are the only indigenous species. The tops and the fruit are used in medicine as powerful diuretics. The former have a bitter, turpentine flavour and colour; the fruit is sweetish, with an agreeable, somewhat balsamic odour, depending upon a volatile oil, and a peculiar saccharine matter analogous to the sugar of the grape. The volatile oil is contained in cells in the shells of the seeds; hence, in making infusion of juniper, the seeds should be bruised. The infusion is made with an ounce of the bruised fruit and a pint of boiling distilled water. It is a useful beverage in some kinds of dropsies. The red cedar ( $J$. Virginiana), is a hardy, handsome evergreen, native of North America, with dark foliage, producing a small blue berry-like fruit in May. It frequently attains to the height of a very lofty tree. See CEDar, RED.

JURY (from the Isatin jurare, to swear). A body of men sworn to decide a certain fact or facts according to the evidence produced before them.

'This noble institution, like many others as dearly cherished by all lovers of freedom, com. menced among the northern nations of Europe at a very early period. The early notices of this mode of trial remaining to us do not speak of its institution: and, in truth, it most probably originated in some rude form or other as soon as men began to dwell together in fixed habitations.

That trial by jury was employed by our Saxon ancestors from time immemorial is very certain, and over-industrious historians have wasted much time in fruitless endeavours to assign the honour of the first discoverer to the real author. Thus Stiernhook (De Jure Sueonum, l. i. c. 4), ascribes the glory to Regner, king of Denmark and Norway, who was the contemporary of our Egbert. Archbishop Nicholson carries the date of the invention back to Woden, the great captain, legislator, and god of the Northernmen.

Sir Edward Coke appears to have fancied that there is something in the very number twelve, in which the laws of God and man seem to delight; and he instances the twelve judges, twelve counsellors of state, twelve to wager the laws, twelve apostles, tribes, stones, \&c. (Coke on Littleton, s. 234 b.)

Trial by jury is mentioned as early as the reign of King Ethelred, but not as a novel institution. (Wilkins' Laws of the Anglo-Saxons, 117.) And in Magna Charta it is mentioned more than once, and particularly ordained, That no freeman shall be dispossessed of his lands or goods, unless by the judgment of his peers; and amid all the long continued strug. gles of Englishmen for the liberty of the subject (from the days of $\mathbf{K i n g} \mathbf{J}$ ohn down to the time of Fox and his declaration of the office of juries in libel cases), the preservation of the freedom of juries has ever been a darling object with English patriots.

\section{K.}

KALE, SEA (Crambe marilıma), is found wild on the seashore on the southwestern cuast of Great Britain, where the common people have from time immemorial been in the practice of watching when the shoots and leaf-stalks bergir to push up the sand and gravel, in March and April, when they cut them off under ground, a done with asparagus, and boil them as greens. About the middle of the last century it was first introduced into gardens, and is now a! most as universal as asparagus.

A light, moderately rich soil, on a dry substratum, suits it best; though in any dry soi? it will succeed. A bed may be composed for it of one-half drift sand, one-third rich loam, and one-third small gravel, road stuff, or coal ashes; if the loam is poor, a little well-rotted dung or decayed leaves being added. The soil must especially be deep, so that the roots can penetrate without being immersed in water, which invariably causes their decay. Mr. T. Barton, of Bothwell Castle, has even found it succeed well on a pretty strong loam that had a loose bottom. The depth should not be less than $2 \frac{1}{2}$ feet; and if not naturally deep, it should be worked to it by trenching. If at all tenacious, this opportunity may be taken to mix with it drift or sea sand, so as to reduce it to a mouldy texture. If the soil be wet it must be drained, so that water never shall stand within three feet of the surface. If poor, well-putrified dung must be added; but decayed leaves are preferable (Trans. Hort. Soc. Lond. vol. i. p. 17), and sea-weed still more so. These precautions must all be particularly attended to, for upon the due richness and dryness of the soil not only depend the luxuriance and delicate fiavour of the plants, but their very existence. Common salt, as might be anticipated, is found to be a very beneficial application, either applied dry, or by occasional waterings with a solution containing 4 or 5 ounces in the gallon, round every stool during the summer. As regards the situation, it cannot be too open or free from trees. Sea kale is propagated both from seed and slips of the root; the first is by far the best mode, for although it may be obtained from slips with greater certainty, yet the plants arising from seed are the strongest and longest lived; whilst the failure of seed, which is sometimes complained of, mostly arises from its being old, buried too deep, or some other extraneous cause. The seed may be inserted in drills from October, or as early in the spring as the ground can be brought into good condition. It is by much the best mode to leave the plants where raised, and with that intent, to guard against failure, inserting the seed in patches of 6 or 12 seeds, each 6 inches * apart, and the patches 2 feet asunder. If, however, they are intended for transplanting, the seed may be sown in drills 12 inches asunder; in either case it must not be buried more than 2 inches below the surface; and it is a good practice, previous to inserting it, to bruise the outer coat of the seed, without injuring its vege toting power, as by this treatment the ger 


\section{KALE, SEA.}

mination is accelerated. The plants will in general make their appearance in 4 or 5 months, never sooner than 6 weeks; but, on the other hand, the seed will sometimes remain 12 months before it vegetates.

The best time for increasing it by slips is in March and April. Rooted offsets may be detached from established plants; or their roots, which have attained the thickness of the third finger, be cut into lengths, each having at least two eyes. To plant the offsets requires no particular direction: the cuttings must be inserted in an upright position 2 or 3 inches beneath the surface. It is best to plant two together, to obviate the danger of failure, at 2 feet apart, so remain.

Whatever mode of propagation is adopted, the bed should be laid out 3 feet wide, and a 2 feet alley between every 2 , in preference to the plan sometimes recommended of planting 3 rows in beds 7 feet wide, for in such the soil must be consolidated by the feet during the necessary grades of cultivation.

If the months of June and July prove dry, the beds should be plentifully watered. The seedlings require no other attention during the first summer than to be kept free from weeds, and, if they come up too numerous, to be thinned to 5 or 6 in each patch. When their leaves have decayed, and been cleared away about November, they must be earthed over an inch or two with dry mould from the alleys, and over this about 6 inches depth of long litter be spread, and thus left to stand the winter. In the following spring the litter is to be raked off, and a little of the most rotten dug into the alleys. When the plants have perfectly made their appearance, they must be thinned, leaving the strongest plant, or, as Mr. Maher recommends, the three strongest, at each patch; those removed being transplanted at similar distances if required; but it must be remarked that those transplanted never attain so fine a growth, or are so long-lived. In this second winter the earthing must be increased to 5 or 6 inches deep over the crowns, and the covering of litter performed as before. In the third spring, the litter being removed, and some dug into the alleys as before, about an inch depth of drift sand or coal ashes must be spread regularly over the surface. The sprouts may now be bleached and cut for use; for if this is commenced earlier, the stools are rendered much less productive, and much shorter lived. In November, or as soon as the leaves are decayed, the beds being cleared of them, the coating of sand or ashes removed, and gently stirred with the asparagus fork, they must be covered with a mixture of three parts earth from the alleys, and one part of thoruughly decayed leaves, to the depth of 3 or 4 inches. The major part of this is to be removed in the folJowing spring, the beds forked, and the covering of sand renewed; this routine of cultivation continuing during the existence of the beds.

The above course is the one also pursued if the plants are raised from offsets or cuttings, as it is much the best practice not to commencr cutting until they are two years old. 680

\section{KALE, SEA.}

Blanching, as before observed, may commence the second spring after sowing. The most simple mode is that originally adopted, namely, to cover over each stool sand or ashies to the depth of about a foot; the shoots in their passage through it, being excluded from the light, are effectually bleached. But pots aro by much to be preferred to these coverings. Common flower-pots of large dimensions may be employed, care being taken to stop the hole at the bottom with a piece of tile and clay, so as to exclude every ray of light.

Previous to covering the stools with the pots, \&c., the manure laid on in the winter must be removed; and the operation should commence at the close of February, or at least a month before the shoots usually appear, as the shelter of the pots assists materially in bringing them forward. In 4 or 6 weeks after they are covered the plants should be examined, and as soon as they appear 3 or 4 inches high, they may be cut; for if none are taken until they attain a fuller growth, the crop comes in too much at once. In order to prolong the season of production, Mr. Barton recommends plants to be raised annually, so that every year a cutting may be had from a yearling crop, which comes in much later, and consequently succeeds in production the old established roots. The shoots should be cut whilst young and crisp, not exceeding 5 or 6 inches in height: the section to be made just within the ground, but not so as to injure the crown of the root. Slipping off the stalks is said to be preferable to cutting. The plants may be gathered from until the flower begins to form, when all covering must be removed. If, when arrived at the state in which broccoli is usually cut, the stalks and immature flowers are employed as that vegetable, they will be found an excellent substitute; and this greatly enhances the value of the plant, as broccoli does not stand the winter frosts in the Northern States, and can only be had when carefully protected; but this pla is sufficiently hardy to bear the frost without injury. It flowers about June, and produces abundance of seed on every stem, which ripens about the close of July or early in August.

To force sea kale, Mr. T. Baldwin, of Ragley, recommends that, on each side of a 3 foot bed, a trench is to be dug 2 feet deep, the side of it next the bed being perpendicular, but the outer side sloping, so as to make it 18 inches wide at the bottom, but $2 \frac{1}{2}$ feet at the top. These trenches being filled with fermenting dung, which of course may be renewed if ever found necessary, and frames put over the plants, the light is to be completely excluded by boards, matting, \&c. Unlike the generality of vegetables, the shoots of forced sea kale are always more crisp and delicate than those produced naturally.

"To have this rare vegetable in perfection," says Bridgeman, "it should be cooked as soon as gathered. Let it be first soaked in water, seasoned with salt, for half an hour; then wash it in fresh water, and put it into the cooking utensil; keep it boiling briskly, skim clean, and let off steam. When the stalks are tender, which may be expected in from 15 to 
25 minutes, according to size and age, take it up, dish it, and serve it up with melted butter, gravy, and such condiments as may be most agreeable to the palate." (Gardener's Assislanl.)

KALE, 'THE WOBURN PERENNIAL. See Cа инан, Bor ecore, \&c.

KAI.I. A sea weed, from the ashes of which the alkali, called soda, is procured. See KELP, SAltwort, and Grasswort.

KALMIA. American laurel. A North Ame. rican genus of hardy shrubs, remarkable for the beauty of their flowers. The leaves are considered poisonous to cattle, and are particularly fatal to sheep. The honey gathered from the flowers is also charged with possessing deleterious qualities. The plants do best when grown in a peat soil, though they will grow in a very sandy loam; they may be increased by layers or seeds.

Mr. Nuttall describes five species of kalmia found in the United States:-1. $K$. latifolia, laurel, or calico bush, common from Canada to Georgia. The stem grows 3 or 4 to 10 or 12 feet high, with irregular, crooked, straggling branches. It frequents shaded banks and rocky hills, and blooms its beautiful flowers in May and June. The wood of this splendid flowering shrub is very hard, and is often used to make handles for small mechanical implements. A decoction of the leaves is sometimes used as a remedy for cutaneous diseases. (Flora Cestrica.)

2. K. angustifolia, or narrow-leaved laurel, cummonly called sheep laurel, and dwarf laurel. The stem of this species grows about two feet high, being slender and somewhat branching. This pretty little species of laurel is thought to be particularly poisonous to sheep and other stock, when eaten by them. 3. K. glauca. 4. $K$. cuneata, found in swamps betwixt Camden and Statesville, South Carolina. 5. K. hirsuta, found constantly on the drier margins of open swamps, abundant around Savannah, Georgia.

KA'TY-DID. See Platy Phyllum.

KELP, SEA-WEED, BARILLA, \&c. I class these manures together, when treating of kelp, since it is to the presence of various salts of soda that sea-weed principally owes its fertilizing qualities, for when they are washed out, the residuum is nearly inert. Sea-weed has been analyzed by M. Gaultier de Claubry. In the Furus saccharinus and in the Fucus digitatus (which is much used in Scotland as a manure) he found the following substances (Thomson's Chem. vol. iv. p. 298):-

$\begin{array}{ll}\text { Saccharine matter. } & \text { Muriate of magnesia. } \\ \text { Mucilage. } & \text { Carbonate of potash. } \\ \text { Vegetable albumen. } & \text { Carbouate of soda. } \\ \text { Oxalate of potash. } & \text { Hydriodate of potash. } \\ \text { Malate of potash. } & \text { Silica. } \\ \text { Sulphate of potash. } & \text { Phosphate of lime. } \\ \text { Sulphate of soda. } & \text { Phosphate of magnesia. } \\ \text { Sulphate of magnesia. } & \text { Oxide of iron. } \\ \text { Muriate of soda. } & \text { Oxalate of lime. } \\ \text { Muriate of potash. } & \end{array}$

Muriate of potash.

By burning these weeds the kelp and barilla of commerce is formed; the first of which has been often advantageously employed in Ireland and on the coast of Scotland as a manure. The Sufiolk and the Kentish farmers, however, as well as some of the Scotch, employ the seaweed in its freshest state, either ploughing it into the ground, or spreading it on the top of their heaps of cumpost. The first plan, how. ever, I have ever seen productive of the best effects; and in that conclusion I am supported by the experience of many excellent farmers.

The salt turf of the sea-shore has been long used in many parts of England as an excellent manure, especially for potatnes; and, according to Dr. Holland (Survey of Cheshire, p. 143), even the salt mud of the Mersey is extensively used for the same crop, at the rate of twenty tons per acre. "The ground thus manured not only gives a large produce of potatoes, but is in a state of excellent preparation for a succeeding crop of either wheat or barley. The adoption of this practice has increased very greatly the value of land about Weston."

There can be no doubt of the advantage of using the sea-weed, or sea-turf, in the freshest possible state, after it has been covered with the salt water, as by a spring tide; for if the salt water has been suffered to drain away from the weeds, and a partial decumposition has taken place, their value as a manure must be materially diminished. The Cornish farm. ers, when they fetch the calcareous sand from the sea-beach, are careful to obtain it as much wetted with the salt water as possible: and there are in the juices and other components of marine plants a variety of ingredients which must produce the most luxuriant effects upon vegetation growing at a distance from the sea : and their constituents are peculiarly noxious to the vermin with which all cultivated soils abound. If this conclusion be correct, then the mode adopted by the Isle of Thanet and Suffolk farmers, of collecting the sea-weed into heaps, and suffering it to putrefy, is dc. cidedly wrong; for, by being thus decomposea, half its fertilizing virtues are lost to the soil. The common excuse for rendering dung putrid before it is spread, viz. that it is a necessary practice to kill the seeds of weeds, has no application here, for those of marine weeds will not grow on arable upland soils.

The use of sea-weed as a manure, in the isies of Jersey and Guernsey, has been very extensive from time immemorial. Thus, in a work upon Jersey, by the Rev. Philip Falle, published in 1694, he observes, that "Nature having denied us the benefit of chalk, lime, and marle, has supplied us with what fully answers the end of them in husbandry-it is a sea-weed, but a weed more valuable to us than the choicest plant that grows in our gardens. We call it vraic (varec), in ancient records veriscum, and sometimes wrecum, and it grows on the rocks about the island. It is gathered only at certain times appointed by the magistrate and signified to the people by a public crier on a market day. There are two seasons for cutting it, the one in summer, the nther about the vernal equinox. The summer vraic, being first well dried by the sun on the sea-shore, serves for fuel, and makes a hot, glowing fire; but the ashes are a great improvement to the soil, and are equal almost to a like quantity of lime. The winter vraic being spread thin on the green turf, and afterwards buried in the furrows by the plough, it is incredible how with its fat unctuous substance it ameliorates the ground, imbibing itself into it, sciftening the 
clod, and keeping the root of the corn moist during the most parching heats of summer. In stormy weather, the sea does often tear up from the rocks vast quantities of this weed, and casts it on the shore, where it is carefully gathered up by the glad husbandman."

The plants chiefly valued for making French varec are $F$ ucus vesiculosus, $F$. nodosus, $F$. serratas, Laminaria digitata and bulbosa, Himanthalia lorea, and Chorda filum. 'Twenty-four tons of the sea-weeds make one ton of kelp. The Jersey and Guernsey Agricultural Society confirmed this account of the excellent effects of the ashes from sea-weed, in $179 \pi$, in their report to the English Board of Agriculture, when they observed-

"It is judged, that a chabot (half a bushel), strewed over a perch of ground in winter or the beginning of spring, will be a sufficient manure. Our labourers are unanimously of opinion, that it gives a full ear to the corn, and prevents it being laid-those who have any varech to sell may at all times get a chabot of wheat for a quarter or six bushels of varech." (Com. to Board of $A g r$. vol. i. p. 216.)

The fertilizing effects of sea-weed are not confined to the better description of soils; the poorest kind of heath lands are benefited by the application of this manure;-thus, Mr. John Sherriff, of Haddington, has described the effects of sea-weed, or sea-tang, as it is called in Scotland, on common heath or moor land, in the following terms: "Sea-weed, which is a capital manure for any land, may often be procured at little or no expense. Crops almost incredible of turnips, barley, clover, and rye, have, to the writer's certain knowledge, been obtained on an extensive tract of the most miserable benty wastes and poor rabbit warrens, by the powers of this manure; soils which, twelve years since, were not worth three shillings per acre. The bent was torn up by the sommon swing plough, burnt, and the ashes spread; the soil was then manured with the sea-tang, as much as could be ploughed in. Turnips were immediately drilled, and rolled to prevent blowing; this crop was succeeded by rye or barley, and that by red clover and rye-grass. On the clover stubble, and sometimes after the turnip crop, plenty of tang was again laid, the ley ploughed down, and sown with oats, barley, or rye, and frequently with turnips, which in this way have succeeded admirably on the ley with one ploughing." (Com. to Board of Agr. vol. iv. p. 122.) It is certain, from the experiments of the late Mr. Knight, that green manures of all kinds are an admirable manure; and it seems well established that the more the juice of the vegetables so cmployed is impregnated with saline matters, the more fertilizing are their effects: thus, in Bavaria, borage is very commonly cultivated for this purpose, and the reason assigned for the preference shown to this plant is, that it contains soda and other salts. (Gardener's Mag. vol. i. p. 203.)

I have no doubt that in many situations the sea-weed may be successfully cultivated on the sea-coast, expressly for manure; and it seems that for this purpose hardly any thing is recuired except placing stones on the shore, to 682 which the fuci can attach themselves, and in two years the crop may be cut. According to Mr. Jamieson (Miner of Scottish Isles, vol. 2, p. 251), various kinds of stones have been employed in Scotland, as basalt, sandstone, and jimestone, which last is the best adapted for the purpose, and after that the basalt.

There are also in many parts of the coa: $t$ of Britain extensive tracts of land which it would be difficult to enclose, and yet these places are either already covered with a coarse turf, or might be so with a little management, and this turf, when cut and carted on to the light upland soils, is found almost invariably to be an admirable fertilizer;-for instance, when spread over land during the winter, and then turned into the soil, for potatoes, the crop is sure to be excellent. No description of fertilizer, perhaps, can be named, which freshens, as the farmers say, an over-cropped soil so much as a dressing of from 20 to 25 loads per acre of the turf from the sea-shore, soaked with sea-water; and no plant delights in fresh soi so much as the potatoe. It is, therefore, more than probable, that the exertions of the com. monly cultivated corn crops are peculiar noxious to this plant; and it is certain that the potatoe, by the deposit which it leaves in the soil, renders it distasteful to the crop by which it is succeeded. 'Thus the wheat plant rarely looks well on soils where the potato has immediately preceded it. Saline fertilizers, in these cases, are sure to be serviceable, for they unite with, and neutralize the effects, as well as promote the decomposition, of the excretory matters which all plants deposit in the soil.

The chief fertilizing qualities possessed by barilla are attributable to the presence of soda. This alkali is found in all marine vegetables, and in most of those which grow on the seashore. It has been used in several experiments as a manure since the price of soda has been so much reduced; but these have not been conducted with sufficient accuracy to enable us to judge of its value as a fertilizer. What little has been done, promises well. 'Thus, it has been found, when a pound of soda is dissolved in 14 gallons of water, that this solution forms an excellent liquid manure for many culinary vegetables; for instance, the vegetable-marrow plant, when thus treated, has been found to flourish better in common garden mould than other plants growing on a dunghill And, as I have remarked in another place, nature is here again our instructor: the fertile plains of Syria, and some of the most profusely luxuriant fields of the orientalist, abound in carbonate of soda. This alkali not only enters into the composition of many regetables, but it promotes the growth of all, by preserving the moisture of the soil, and by accelerating the decomposition of the numernus organic substances found in all cultivated lands. The sewer water of towns and cities, which has been found so very rich and fertilizing as a dressing for grass lands, abounds with soda: for that is contained in the soap suds and other refuse washings which such drainage matters always convey. Soda has been found in very sensible proportions in the urine of the horse, by $\mathbf{M}$. Fourcroy; and in that of the ass, by Mr. 
Brande; and a small portion of this alkali is usually presented in the waste ashes of soapmakers, which many cultivators consider highly valuable as a manure.

As the use of kelp has been of late much greater than formerly as a manure, it will be useful for the cultivator to learn the proportion of alkali contained in the kinds usually met with in commerce, as determined by Mr. Jamieson (Min. of Scottish Isles, vol. ii. p. 248) :-

\begin{tabular}{l} 
Barilla from Alicant, good - \\
Teneriffe, bad - \\
Kelp from Norway, indifferent \\
Shetland, indifferent \\
Lewis, indifferent - \\
W. Highlands, much damaged \\
Arran - \\
Isla, good - \\
Mull, good - \\
Morven, good - \\
Skye, good - \\
leith shores - - \\
\hline
\end{tabular}

\begin{tabular}{|ccc} 
lbs. & oz. & $16 s$. \\
23 & 8 in 100 \\
8 & 7 & \\
2 & 11 \\
2 & 6 \\
2 & 6 \\
0 & $5 \frac{1}{6}$ \\
3 & 8 \\
4 & 0 \\
4 & 8 \\
4 & 8 \\
5 & 0 \\
4 & 0
\end{tabular}

But, besides the allrali referred to, kelp contains iodide of potassium, bromide of potassium, and sulphuret of potassium; all of which probably exert considerable influence on vegetation. It is well known that seeds sown in pure sand, and watered with a solution of iodine, germinate very rapidly.

The residuum, when all the soda and common salt are extracted from the barilla, is principally earthy matters, which are of a very inert nature, and need not be regarded by the cultivator as possessing any peculiar fertilizing properties different from marl, which they much resemble in composition.

100 parts of these insoluble matters of kelp are composed of-

Sulphureted hydrogen and carbonic acid
Carbon -
Sulphuric acid -
Silica -

From the quantity of kelp produced on the shores of Scotland, and its reduced price since the peace, which again allowed the unrestricted import of Spanish barilla, and more especially since the discovery of a cheap mode of extracting soda from common salt, the application of kelp as a manure has engaged the serious attention of the farmers of that part of the island, and a committee was some time since appointed by the Highland Society of Scotland to report apon its pretensions; in much of that report, from which the following extracts are made, I cordially agree:-

"Your committee are unwilling to offer any theoretical opinion as to the way in which kelp may operate as a manure. From the quantity of alkali which it contains, it may naturally be expected to operate by rendering the animal and vegetable matter soluble, and a fit food for plants; but, from the series of facts to be noticed, kelp would seem to possess other qualities as a manure. Although it may be beneficially applied as a dressing by itself, yet the committee are at present inclined to think that, with a view to raising of green crops, it would be better to mix it in compost with other substances. The selection of these must depend upon what the farmer can furnish; but the committee think that good earth or moss will form a good compost, and if to this mixture can be added a little vegetable or animal ma. nure, a beneficial result can be relied on. In this way, a few tons of kelp would enable a farmer to extend his farm dung over at least four times the quantity of land."

The relative value of kelp as a manure may be estimated from the following experiments, made in the neighbourhood of Edinburgh:A field upon the estate of Inverleith, possessed by Mr. Hutchinson, was selected, which had been in wheat in the year 1828, hence it was in some measure in an exhausted state: upon one ridge of this field there was sown at the rate of $12 \mathrm{cwt}$. of kelp per acre; on a second, at the rate of $10 \mathrm{cwt}$. per acre; and on a third at the rate of $4 \mathrm{cwt}$. per acre. Two other ridges were manured with the best cow and horse dung, at the rate of 20 tons per acre; and the whole was sown with wheat late in the spring of 1829. The two ridges which had got the greatest quantity of kelp were equal to that which had the dung, and the ridge which had got the smallest quantity was decidedly superior to the others. Similar experiments were made upon the same field, by sowing barley after the previous crop of wheat; the result was, that the barley manured with the kelp was, according to the estimate of the tenant and his stewart, a much heavier crop than after an application of horse and cow dung, and that the ridge with the smallest quantity of kelp appeared the heaviest crop.

A portion of the lands of Bangholm were manured with kelp of inferior quality, at the rate of one ton per acre, and the land sown with yellow turnip; the crop, upon examination, is considered to be fully equal to that part of the field which has been manured with dung. (Baxter's Lib. of Agr. Knowl. p. 406.)

Mr. Kerr, of Henfield, has given the result of his experiments on kelp, from which he is of opinion that " $5 \mathrm{cwt}$. of kelp per Scotch acre will produce a manifest improvement on any crop." (Trans. High. Soc. j. p. 320.) Care must, however, be taken not to apply tno copious a dressing of kelp. Mr. Mackinnon, of Corry, draws the following conclusion from his experiments; he used the ashes of sea-weed burnt in a heap: "of the ashes thus manufactured, 20 bushels were allowed to the acre, and distributed in the drills. When the turnips sprouted, they had an unhealthy green or rather yellowish appearance, but after some time several patches in the field seemed to be growing luxuriantly, while others seemed to retain their sickly hue. Upon a careful investigation, it was discovered that wherever the ground was deepest, and the ashes of the sea-weed had been most mixed up with the soil, the turnips were best; and, on the other hand, that where the ashes, not being mixed up with the soil, came in contact with the seed, the turnips did not at all thrive. In clearing the ground the weeds were collected into heaps, and burn upon the spot; and it was observed that on 
the side of tnese heaps the turnips were very nearly as good as those on an adjoining piece of ground manured solely with dung." (Ibid. voi. iv. p. 246.) There is a good paper on the manufacture of kelp in Quart. Journ. of $A g r$. vol. ii. p. 927; and on mixing kelp with composts, peat, turf, \&c., ibid. vol. iii. p. 556.

Every farmer has it in his power, even in the most inland situations, to procure soda for the use of his farm, by means of a mixture of two parts of lime and one part of common salt, and suffering the mixture to remain incorporated in a shady place, or covered with sods, in a dry state, for two or three months; a plan which I suggested some years since (Johnson on Salt, p. 32, 3 d edit.), and which has been recently successfully adopted by Mr. Bennet, in Wiltshire. By this process a gradual decomposition takes place, chloride of calcium and soda are formed, the whole mass speedily becoming encrusted with this alkali. There is another advantage to be derived from the adoption of this process, besides the formation of the soda, viz. that the chloride of calcium is one of the most deliquescing or moisture-absorbing substances with which we are acquainted; and, in consequence, wherever it exists in a soil, the warmth of the sun has, in summer, much less influence upon it than it would otherwise have.

Mr. G. Irwin, of Taunton, bears testimony to the value of common soap-suds. "The portion of the garden invigorated by the soap-suds, only annually exhibits a luxuriance almost equal to anything this fertile neighbourhood can produce." 'The Rev. J. Falconer, when commenting upon this experiment, says, "This mixture of an oil and an alkali has been more generally known than adopted, as a remedy against the insects which infest wall fruit trees. It will dislodge and destroy the insects which have already formed their nests and bred amongst the leaves. When used in the early part of the year, it seems to prevent the insects from settling upon them. Mr. Speechly, the author of a treatise upon the Cultivation of the Vine, published in 1796, used this mixture with great success, although, from not having employed a garden engine, he applied the soap-suds awkwardly and wastefully. $\mathrm{He}$ directs it to be poured from a ladder, out of a watering-pot, over both trees and wall, beginning at the top of the wall, and bringing it on in courses from the top to the bottom."

Mr. Martin, of Warbleton, has recently used soda for turnips, half a cwt. per acre, previously to the last ploughing, thinking, as he observed, that it would destroy such insects as lie in the ground in an embryo state, or prevent their arriving at maturity so as to injure his crop. In respect to the use of soda on corn lands, he said he used it rather extensively last season, and that he had tried several experiments with it, both upon grass and arable land. That in a field of wheat, a very thin, poor, gravelly soil, he sowed one warp without any manure at all; on another warp adjoining, he ised one cwt. per acre; and on a third warp ne put $1 \frac{1}{2} \mathrm{cwt}$. per acre. The produce of eight rods on each warp was as follows: this was in iand of a very bad description:-
8 rods without manure, 7 gallons, or $17 \frac{1}{8}$ bushels.
8 rods with I cwt. soda per acre, $10 \frac{1}{2}$
gallons, or 26 bushels, 2 galls.
8 rods with $1 \frac{1}{8}$ cwt. soda per acre,
$15 \frac{1}{2}$ gallons, or -

KENNEL (Fr. chenil, from chien, a dog). The hole of a fox or other wild beast. In rural economy, a habitation for dogs, especially those of the hound kind: it should be situated a good distance from the house. Large kennels require to be kept clean, well aired, and strewed with fresh straw to prevent the mange or other infectious distempers. Those readers who wish to acquire information on the management of the kennel will do well to consult Blaine's Encyclopadia of Rural Sports.

KERN-BABY (a corruption of corn-baby) was an image formerly dressed up with corn, carried before the reapers to their harvesthome.

KERNEL (Sax. cýnnel, a gland). In general this word signifies the substance within a shell; but it has different meanings, sometimes implying anything included in a husk or integument, as the seed of pulpy fruits, the grain of oats, \&c. In horticulture the hardy fruits are generally arranged under the heads of kernel fruits, or pomes, including the apple, pear, quince, medlar, and service; stone fruits, as the peach, nectarine, almond, apricot, plum, and cherry; berries, as the mulberry, barberry, elderberry, gooseberry, currant, raspberry, cranberry, and strawberry; and nuts, as the walnut, chestnut, and filbert.

KIDNEY-BEAN, the kind of bean most cultivated in the United States, whereas the variety mostly cultivated in Europe is the horsebean. See Beans.

KIDNEY-VETCH (Anthyllis; derived from $u v \theta=s$, a flower, and $\dot{z}: v \lambda c s$, down, in reference to the flowers being usually covered with a soft or silky pubescence). The species are, for the most part, elegant and free-flowering, plants proper for ornamenting rock-work. The hardy perennial and annual kinds thrive well in a warm situation and light soil. The greenhouse and frame kinds succeed best in sandy loam and peat; and increase plentifully from seeds, and sometimes from cuttings. (Paxton's Bot. Dict.)

The common kidney-vetch, or ladies' finger (A.vulneraria), is the only species indigenous to the British Islands. It is found growing wild in chalky or limestone countries; where the soil is dry and rather barren, and the herbage affords good pasturage for sheep. The root of this species is woody, the stems annual, round, hairy, leafy, mostly simple, ascending, about a foot high. The radical leaves are simple, elliptical, on long stalks, soon disappearing; the rest alternate, pinnate, with a terminal elliptical leaflet, and several pairs of opposite, small, lanceolate ones; all entire, smooth, and a little glaucous above, hairy, or rather silky, underneath and at the margin. The flowers, which are numerous, in a pair of crowded terminal hea's, accompanied by figured bracteas, are usually yellow, rarely of a fine red. In Germany, according to Haller, the flowers are most frequently wite. This plant formerly had the reputation of possessing some vulne 
rary properties, whence the specific name. (Smith's Eng. Flor. vol. iii. p. 269.)

KILN (Sax. cylu). A kind of furnace or stove for admitting heat, in order to dry substances of variuus kinds, as corn, malt, hops, \&c. It also signifies a fabric or building constructed for the purpose of burning limestone, challs, and other calcareous stones, into lime. Kilns are of various kinds, and formed in different ways, according to the purposes for which they are designed. See Hops, Malt, Lime, Cra

KILN ASHES. The ashes made in kilns where wond, straw, furze, \&c. are burnt. These ashes are useful as manure for almost any kind of soil. They are found to succeed best when spread just before rain. See Ashrs.

KIT. In some places a name given to a milking-pail or vessel in the form of a churn, with two ears and a cover, used to convey milk in.

KITCHEN GARDEN. A piece of ground laid out for the cultivation of fruit, herbs, pulses, and other culinary vegetables.

The kitchen garden is the most important object of the horticulturist's care, inasmuch as its productions, next to those of agriculture, rend most to the support of mankind.

It often affords the chief support of the cotager, and ought to be the constant attendant of his dwelling. Of more exalted mansions it is always an accompaniment, but it is much to be regretted that a more plentiful use of its products is not adopted in preference to grosser aliment.

The kitchen garden also has for its inmates many plants chiefly valuable as rendering other kinds of food more palatable, or as possessing sanative qualities. 'These last formerly far exceeded in number the edible plants. The subsequent more general employment of mineral medicines has reversed this state of our kitchen garden. The culture of aromatic herbs is also much less attended to since the introduction of spices. In selecting the site, and in erecting the enclosures, as well as in the afterpreparation of the soil, the ingenuity and science of the horticulturist are essentially requisite. He will be called upon to rectify the defects, and to improve the advantages which nature affords; for it is very seldom that the natural situation of a mansion, or the plan of its grounds, allows him to construct it in the most appropriate spot.

The garden is best situated at a moderate elevation; the summit of a hill, or the bottom of a valley, is equally to be avoided. It is a fact, not very difficult of explanation, that lowlying ones are the most liable to suffer from blights and severe frosts; those much above the level of the sea are obviously most exposed to inclement winds. To determine the appropriate size of a kitchen garden is impossible. It ought to be proportionate to the number of the family, their partiality for vegetables, and the fertility of the soil. It may serve as some criterion to state, that the management of a kitchen garden occupying the space of an acre affords ample employment for a gardener, who will also require an assistant at the busiest periods of the year. In general, a family of four persons, exclusive of servats, requires a full rood of open kitchen garden. It ought not to be larger than car be conveniently cultivated; and it is too large if its proprietor is induced to bring into it the culture of the field, for that neatness and fertility which is essential to the garden can be obtain ed by the use of the spade only.

A wall of brick or stone is the best fence; one of paling may be placed next in order. It ought to be set close, and kept in gond repair, and not lower than 6 feet, that poultry may be effectually excluded. The form of the walks or divisions must depend upon local circumstances, but to some extent the following recommendations of Bridgeman (Gurdener's Assistant, p. 7), may be carried out: "Form a border round the whole garden, from 5 to 10 feet wide, according to the size of the piece of land; next to this border, a walk may be made from 3 to 6 feet wide; the centre of the garden may be divided into squares, on the sides of which a border may be laid out 3 or 4 feet wide, in which the various kinds of herbs may be raised, and also gooseberries, currants, raspberries, strawberries, \&c. The centre beds may be planted with all the various kinds of vegetables. 'The outside borders facing the east, south, and west, will be useful for raising the earliest fruits and vegetables; and the north border, being shady and cool, will serve for raising and pricking out such young plants, herbs, and cuttings, as require tc be screened from the intense heat of the sun." 'The walks ought to be drained in some cases, and in all well gravelled. The edging or border may be of brick, which for a kitchen garden is preferable to all others, as it affords no shelter for slugs and vermin, is durable, and requires little labour to keep it in repair.

The order in which successive crops are grown on the same compartment has very considerable influence in prolonging the continuance of the soil in fertility. Some vegetables, as onions and carrots, are extremely impoverishing to the soil, whilst lettuces are but in a small degree prejudicial. It is, therefore, obvious, that a succession of exhausting crops should never be grown on the same bed, however plentiful manur: may be, not merely because abundance is no excuse for a want of economy, but that fresh applied dung is not so immediately beneficial as those remains of organized matters, which, by long continuance in the soil, have become impalpably divided and diffused through its texture, and of which each succeeding crop consumes a portion. Those plants in general are the least exhausting which have the larges" surface of leaves, and vice versâ, because the first are not only possessed of a larger prof srtion of aqueous, than solid matter than the latter, but also are enabled to obtain a greater cuantity of their food from the atmosphere. It may be objected to many crops included by this rule, and especially to turnips, that they require a soil of extreme fertility; but this is only an apparent anomaly, for, although the turnip, fo- example, requires a rich soil, it is only becalise it requires a regular supply of moisture: neithep will a tenacious soil therefore be benticial. 
on the cortrary, a superfluity or deficiency, according to the season, being then afforded, decay or immaturity is induced.

There are many other contingencies which should regulate the rotation of crops. The roots of different plants strike in different directions, and to different depths; and, as their constituents vary, absorb different matters. Deep-rooted plants, therefore, should be succeeded by such as spread but a little below the surface; perennials always by annuals; crops left for seed, or those that are of a dry, solid texture, by such as are succulent and juicy; but, above all, the same species of plant should never be grown in successive crops upon the same ground. This is not even palliated by the excuse that manure is abundant, for, as Sir H. Davy observes, "though the general composition of plants is very analogous, yet the specific difference in the products of many of them prove that they must derive different materials from the soil; and though the vegetables having the smallest systems of leaves will proportionably most exhaust a soil of common nutritive matter, yet particular vegetahles, when their produce is carried off, will require peculiar principles to be supplied to the land which produces them." (Lect. on Agr. Chem. p. 358.) It is known to every cultivator of soil, that land soon becomes tired of the same crop; in many instances, peculiar diseases are induced by the repetition. The most beneficial plan of rotation appears to be that where an exhausting and non-exhausting crop alternately succeed each other, for example,

$\begin{array}{ll}\text { Onions. } & \text { Turnips. } \\ \text { Lettuce. } & \text { Peas. } \\ \text { Carrots. } & \text { Potatoes. } \\ \text { Manure. } & \text { Manure. }\end{array}$

Mr. Kelly, of Airthrey Castle, Scotland, says, that on poor ground the rotation he finds best is, 1 st, celery; $2 \mathrm{~d}$ season, caulifowers, and red beet; $3 \mathrm{~d}$, onions; 4 th, German greens or peas. By digging deep, and manuring abundantly for celery, the ground is brought into such fine tilth, that the whole rotation is often gone through without any further addition, and without failing in any of the crops.

$A$ Holbed will be found useful for forwarding several kinds of vegetables early in spring. In it tomatoes, egg-plants, peppers, early bush squashes, and cucumber plants may be raised, and planted out as soon as the danger of frost is. over. The best material for a hotbed is fermenting stable manure, which may be mixed with a portion of cow manure or leaves, and turned over two or three times, at intervals of !j or 6 days, before using. If dry, give it a little water at each turning. The frame may be made of strong boards or two-inch plank, about 1 foot high at front, and $1 \frac{1}{2}$ foot at back. The width from back to front may be about 6 feet, and the length of any number of sashes that may be required. The sashes may be glazed with small glass from 5 to 10 inches. The smaller sizes will answer every purpose, are cheaper, and not so liable to break. IIaving fixed upon the size of the frame, and a sneltered sicuation in which to make the bed, olace a stake at each corner of it, allowing a raw inches larger each way than the frame. 686
The manure must be well shaken up and thoroughly mixed, and, in building, the bed regularly beaten down with the fork or lightly trodden, and if at all dry, well sprinkled with water. If wanted for early forcing, the bed should be at least $4 \frac{1}{2}$ feet high; if for starting vegetables 2 feet will be sufficient. The frame and sashes may then be put on, and in three or four days 8 or 10 inches of good light earth may be put in, and the seed sown. Squashes and cucumbers will do best in pots. A pot of 4 to 5 inches in diameter will be large enough for three plants. 'Tomatoes, egg-plants, and peppers may be sown over the bed, and afterwards thinned to regular distances. Early cabbages, cauliflowers, celery, and lettuce may be raised in the same way, and afterwards planted where wanted. But should the management of the hotbed be attended with 100 much trouble or expense,

The Frame can be used with much advantage, as in it plants can be raised and kept safe from frosts long before they would bear exposure in the open air. The frame may be set on the ground on the south side of the fence, and if the earth is rich and light, or made so, the seeds may be sown broadcast over a space allotted to each kind, and afterwards thinned out to proper distances. Lima beans may be started in this way, and transplanted before they attain to any great size. The frame is also useful for preserving cabbage, cauliflower, and lettuce plants during winter, for planting in the spring; as well as cabbages, lettuce, and celery for family use. A few leaves or litter put among the vegetables will aid materially in excluding the frost, and a shutter and mat must be put over the sashes in severe weather.

Our object in this article is to give a condensed view of the common operations in the kitchen garden, as adapted to the United States, with a list of such varieties of the different species of vegetables as have been cultivated in this country, and can be had from the principal seedsmen in Boston, New York, and Philadelphia.* Several articles are omitted, which obtain a place in some gardens, but these are either thought not to deserve a place, or to belong more properly to field culture. Fuller information on any particular subject can always be found under the proper head in the alphabetical arrangement.

Asparagus (Asparagus officinalis). Sow early in the spring; having previously soaked the seed in warm water for 24 hours, then drill it thinly, in rows sufficiently wide apart to admit the hoe; when two years old, transplant into permanent beds, which should be so situate as to cast off an excess of moisture, and having the soil prepared to the depth of two feet with plenty of manure under. A convenient width for the beds is four feet. The plants should be placed 12 inches apart in each direction; planted at least 4 inches beneath the surface; well manured at the time, and annually thereafter. If planted in rows, they should be $2 \frac{1}{2}$ feet apart. Common salt scattered over the bed in the winter operates favourably in im-

* In compiling this article, we would here acknow!edge our obligations to the excellent catalogue of $D$. Landreth \& Co. of Philadelphia. 
proving the growth of asparagus. Meat pickle or brine is still better.

Beans, Engusu (Viria faba). Plant very early in the spring, in rows. Broad Windsor and Mazagan are the best varieties.

Bush Beans (Phascolus vulgaris). The Early Six weeks, China red-eye, and Red speckled Valentine, are among the earlier; the Valentine, Mohawk, and Marrow are very superior varieties. They may be planted for the first and succession crops from the middle of spring till the close of summer; the usual mode of culture is in rows, two or three in a clump, at intervals of 10 or 12 inches.

Pole or Climbing Beans (P. mulliflorus). The best varieties are the Lima, Carolina, White Dutch, Red and White Cranberry, and London Horticultural. The Limas are tender, and should not be planted till the close of spring. They may be forwarded by sprouting them in a hotbed, and transplanting them into hills 4 feet distant from each other. Poles 8 or 10 feet long should be put in to the ground before planting, and (if of seed) 6 or 8 planted round each pole, as the seed is apt to rot in cold or damp weather. 'Thin them afterwards, leaving three or four good plants in each hill. The London Horticultural is an excellent variety, and may be used for the Lima in those districts where the Lima frequently fails to ripen. See Beans.

BEET (Eeta vulgaris). The Turnip-rooted and Long Blood-red are generally esteemed the best for tahle use. The turnip-rooted is somewhat earlier than the long, and is equally good for wintel use. Sow in drills from early in the spring till the commencement of summer. The plants should stand 6 or 8 inches apart in the drills, but the seed should be put in thick, to secure a full crop. A good plan is to drop several seeds together at proper distances, and when up remove all but the strongest.

Swiss Chard (Eeta cicla), is much grown in Germany and Switzerland, and used as chard or asparagus. The laminæ or thin parts of the leaves, are eaten as spinage or put in soups; and the stalk or midrib is boiled, and eaten with melted butter or gravy like asparagus. The culture is the same as for the blood beet, but the leaves are much larger, and a greater space should be left between the plants on that account. See BEE'r.

CABbage (Brassica olcracea var. capitala). The earliest variety is the Early York; next the Early Sugarloaf, and Landreth's large York; Farly Battersea is late in the summer. The flat Dutch and Drumhead are for winter use, and red Dutch for pickling. Early and summer varieties are usually sown in seedbeds early in autumn, protected therein or in cold frames, during winter, and transplanted early in the spring. Where the climate is mild, and the lan light and dry, they are planted in the autumn, in which case they head earlier than those put out in spring.

Should a supply of plants not have been obtained in autumn, sow in a hotbed very early in spring, or somewhat later, on a warm border in the open air. But let it be borne in mind that in no case can fine cabbage (especially he earlier kinds) be had, unless on heavily manured and well-tillel land-heavy or strong loamy soil is best adapted tis this crup.

For winter sorts, sow in a seelbed in the middle or latter end of spring, and transplant early in summer. To have these kinds to head early in autumn, sow at the same time as the early sorts. To preserve from the cabbage-fly, sow in boxes elevated two or three feet atove the surface, and as soon as the plants are established, place them on the ground, lest the plants burn up. 'To keep them during winter, bury the stalk and part of the head with earth, over which, if the cold be severe, sprinkle straw, or put in a cold frame.

Savoys and Brussels Sprouts (B. oleracea var. bullata), are good for winter use, and become very tender after being touched by frost. Cultivate as winter cabbage.

Borecole, Kale, \&c. (B. oleracea var. acephala), may be treated as winter cabbages. They are said by Bridgeman to be delicious when rendered tender by smart frosts; and to be valuable plants to cultivate, particularly in the Southern States, as they will there be in the greatest perfection in the winter months; they will also, if planted in a gravelly soil, and in a sheltered, warm situation, bear the winter of the Western States; and may be kept in great perfection in the Eastern States, if taken up before the frost sets in with much severity, and placed in trenches up to their lower leaves, and then covered with straw or other light covering. See CA B BAGE.

Broccoli and Cauliflower (B. oleracea var.botrytis). Purple Cape broccoli is decidedly the best of many varieties. Sow in seedbeds in the mid. dle of spring, and transplant and manage generally as winter cabbage. Early Asiatic cauliflower is sown in seedbeds in the beginning of autumn, kept in a cold frame during winter, and transplanted to very rich ground as soon as the frost ceases. Hand glasses or boxes put over them at night, when they are first put out. are useful. The late variety matures in autumn, and is sown at the same time, and managed like Cape broccoli. It is, however, not so sure to succeed as the brocccli, nor is it a better vegetable when obtained. See Broccorr.

Carrór. (Daucus carota val. hortensis). 'The Early Horn is best for table use. 'The Long Orange is more productive. The Altringham produces great crops, and is suitable to raise for horses and cattle. Sow the seeds in the middle of spring, in a rich, sandy loam, well pulverized, in rows a foot apart, cover about half an inch deep, and thin the plants to 4 inches distance. Gather the crop soon after the first hard frost, and keep them in a cave or warm cellar. See Cannot.

Cerenr (Apium graveolens). Sow the seed early in spring, in rich, mellow ground, and in a situation where the plants can be protected from the parching heat of the sun. It can either be sown broadcast or in drills, if in drills. they may be half an inch deep and 6 incher apart, that a small hoe may be worlied between them. Plant out in July, in a piece of rich ground, in an open exposure, in trenches 8 or 10 inches wide, and allow the space of 4 feet between them. Dig each trench a spade deep, laying the earth equally on each side, an.t 


\section{KITCHEN GARDEN.}

put 4 inches of good rotten dung into the bottom; tread it firmly, and cover with an inch of soil from the sides, then plant a single row in the middle of each trench, leaving 7 or 8 inches between the plants. Give a plentiful watering, and shade with a board till they strike root. It may be grown also in beds, 4 feet wide, with alleys 4 feet between, prepared as above. Plant 4 rows in each bed, at from 6 to 8 inches apart, and water and shade as before. To blanch, earth up gradually in dry weather, as the plants progress in growth, repeating the earthing every 2 weeks, at which time care should be taken to gather up all the leaves neatly, and not to bury the heart of the plants. The earthing up may begin in September. See Cererr.

Cons, Innian (Zea Mays). There are several varieties used at table, but none are better than the common Sweet Corn.

Cucurbar (Cucumis sativus). The Early Frame and Early Green Cluster are good varieties. The Long Green is chiefly used for pickling. As soon as the ground becomes warm in spring, plant in hills 6 feet asunder each way, putting a dozen seeds in a hill, and covering half an inch deep. Jueave finally but three of the strongest plants. The ground must be rich and well manured. For very early use, sow in small pots in a hotbed; turn them into the open ground in May, taking care to protect them from the sun and late frosts. For pickling, plant in the end of June. See Cucumare.

Egg-Plast (Solanum melongena). Sow in hotbed, or other protected place, very early in the spring, and late in the spring transplant into very rich ground, keeping the plants about two feet asunder. 'The seed requires much warmth to cause it to vegetate. See EquPrant.

Evdive (Chichorium endiva). Sow at close of spring to middle of summer in shallow Irills; when up an inch or two, thin out to stand a foot apart. In dry weather tie up to blanch as needed. See Chiconx and Eviriv.

LEEK (Allium porrum). Sow in seed-bed middle of spring; when the plants are 4 or 5 inches high transplant into rows, setting them loosely and deeply into the soil, and leaving space to admit the hoe between them. See LEEK.

Letruce (Lactuca sativa). The Early Cabbage, brown Dutch, Royal Cabbage, Curled India and Tennisball are good, and stand the climate. Of the Cos varieties, which are very crisp and tender, but soon shoot to seed, the Egyptian Green $\mathrm{Cos}$ can be recommended. Sow in seedbed from commencement to middle of autumn, protect the plants by a cold frame or with litter as they stand on the ground; early in the spring transplant them into rich ground. For a later supply, sow in drills from time to time during spring and summer; when up a few inches, thin out, leaving plants at proper distances. See LetTuc F.

Melon (Cucumis melo). The Citron, Persian, Nutmeg, and Murray's Pine-apple are good varieties of the canteleup or musk-melon. Plant $i$ hills of rich, light soil, at the distance of 6 feet asunder, in the latter end of spring, putting f or 8 seeds intu each hill, 2 inches distant 688 from one another, and half an inch deep. Thin out to 3 in each hill; draw the earth from time to time about the hills as high as the seed leaves. Pinch off the top at the first or second joint, as this will strengthen the plants, and cause them to fruit early. Grow no pumpkins or squashes near them.

Melon, Water (Cururbita citrullus). The Spanish and Mountain Sprout are gond varieties. The Citron is cultivated for preserves. Cultivate as for canteleups, but let the hills be 7 or 8 feet distant.

Oкка (Hibiscus esculentus). Plant in good, rich ground late in spring, as it is a very tender vegetable. Make drills an inch deep, and 3 or 4 feet asunder, into which drop 2 or 3 seeds together, at intervals of about 8 inches, and cover them nearly an inch deep. Thin them out to 8 or 10 inches as the plants advance, and earth up 2 or 3 times.

Onion. See that head.

Parscex (Apium petroselinum). Sow in rows early in the spring. By soaking the seed in warm water some hours immediately before sowing, it will vegetate more speedily. It some. times lies in the ground 2 or 3 weeks before vegetating.

Parsnip (Pastinaca sativa). Sow early in spring, in good soil, deeply dug, making drills 18 inches apart. When the plants are 2 or 3 inches high, thin out to 6 or 8 inches apart.

Pea (Pisum sativum). Isandreth's Extra Early, and Bishop and Russell's Early Dwarfs are the earliest varieties, and good of their kind. Dwarf Blue Imperial, and Dwarf Scimetar are much esteemed. Knight's Dwarf and Tall Marrowfats are late kinds, but superior to all others for flavour and productiveness. Tall and Dwarf Sugar or string peas are sweet, and productive; they are boiled without shelling, and served up as kidney beans. The dwarfs require sticks from 2 to 3 feet long, the others from 4 to 6 , and a greater width between the drills.

Pepper (Capsicum). Grossum or bellshaped, Large sweet, and Squash or tomato-shaped, are used for pickling; the last variety is the best. The Sweet has a delicate taste, and is used as a salad. Sow in hotbed in March, and transplant; or in the open ground, late in spring, in drills 2 feet apart. When the plants are an inch or two high, thin them out to about 15 inches apart in the rows, and hoe them repeatedly.

Potato. See that head.

RADish (Raphanus sativus). Short-top Scarlet, Salmon, Red and White turnip-rooted, may be sown in the spring, as early as the ground can be worked. Yellow turnip-rooted and Summer White are best for summer use. White and Black Spanish for winter. Sow these at close of summer, or early in autumn, and when ripe store them in a cellar. For a succession in spring and summer, sow every two weeks. The ground should be light, rich, and well worked.

Rиоинвв (Rheum). Tobolisk, Maminoth, and Giant, are the best varieties, and may be raised by dividing the roots early in spring, and planting them in rich, deep soil, in rows 4 feet asunder and 3 feet distant in the ruws. 
To raise fiom seed, sow late in autumn or early in spring. Young seedling plants require to be protected the first winter by soil. 'To force very early, cover with boxes or barrels surrounded and covered with horse manure. Gather before the leaves are fully expanded.

SAlsify, or Vegetable Oyster (Tragopogon porrifolius). Cultivate as directed for carrot. Sra-Kalk. See Kale, Sea.

Spinach (Spinucia oleracea). Round Savoyleaved, and Prickly seeded. May be grown either broadcast or in drills. For spring and early summer use, sow as early as the ground can be tilled, and afterwards at short intervals. For the autumn supply, sow at close of summer. For winter and early spring use, sow middle of autumn. The latter sowing will need a sprinkling of straw or long manure on the arrival of cold weather. Spinach is one of those vegetables for which the ground cannot be too rich; the stronger it is the more succulent will be the leaves, and of course the more delicate and tender.

Seuash (Cucurbila melopepa). Early Bush, Early Crook-neck, Early Orange, Valparaiso, Winter and Canada Crook-necks. The three first are early varieties. The bush occupies but little room, and is best adapted for small gardens. Cultivate as directed for cucumber. The three last are winter varieties, and require more room.

Tomato (Solanum lycopersicum). Sow in hotbed in March or April, or in a warm border early in spring, and transplant, after settled w arm weather, in row's 4 feet apart and about 3 feet distant in the row. They may be supported with brushwood, or trained to a trellis or fence.

Turen (Brassica rapa). Early White Dutch, Early Stone, Early Red-topped, are best for early garden culture. For winter use the Rutabaga, Yellow Stone, Yellow Aberdeen, and Dale's Hybrid, are excellent.

'There is also a variety of aromatic and medicinal herbs cultivated in the kitchen garden, which are useful for many purposes. Of these, the Bene Plant, Sweet Basil, Carraway, Coriander, Sweet Marjoram, and Summer Savory are annuals, the seeds of which may be sown in the middle of spring, and thinned out to convenient distances.

Balm, Chamomile, Horehound, Hyssop, Fennel, Lavender, Mint, Pennyroyal, Rosemary, Rue, Sage, and Thyme, are perennials, and may be propagated by offsets or parting of the roots, and from seed sown in drills, and afterwards iransplanted.

These are the most useful productions of the ritchen garden. The varieties named are believed to be the best, and such as are most certain, in the United States, to repay their culture. Those who desire to go extensively into the cultivation of vegetables, can consult the works of M'Mahon, Bridgeman, and Fessenden, for more minute details of the modes of culture and more extensive lists of varieties.

Much success in cultivating vegetables will depend on the rotation of crops. The same irinds should not be grown on the ground successively. The ground must also be kept rich, by the application of manure, well work87 d, and above all kept clear of weeds. I ought always to be remembered that what will nourish a crop of weeds will proluce a cropl of useful vegetables; and no operation will tend more to produce luxuriant vegetation, and prevent the ill effects of drought, than the fre. quent use of the hoe.

For the compilation of the preceding article we are indebted to Mr. William Simion, gar. dener to General Patterson, Philadelphia.

KNAPFIA, EARLY (Knapria ugrostidea). It was named by Sir J. Smith in compliment to Mr. M. Knapp, a writer on British grasses. Of this, one of the least of the British grasses, only one species is known; although common on the coasts of France, it is very rare in England, but is found in maritime pastures, some. times in Wales. It is an annual; root of many long, slender fibres; stems 1 to 3 inches high, erect, simple, slender, smooth, triangular, naked, except at the very bottom, where they are invested with the membranous sheaths of a few short, obtuse, channelled leaves. Stipules membranous, bluntish, cloven, but not deeply divided. Spikes solitary, simple, erect, of from 6 to 10 flowers, mostly sessile, alternate, erect; two or three of the lowermost only more or less stalked; their common stalks zigzag, slender, smooth, angular, but not excavated, as in the truly spiked grasses. Flowers, like the top of the stem, purplish. ( $E n g$. Flor. vol. i. p. 84.)

KNAPWEED (Centaurea). This is a large herbaceous genus of plants, which Jussieu, after Tournefort, has divided into several, by the structure or termination of the calyx scales. Linnæus has kept it entire, and Decandolle has not disturbed it. Smith (Eng. Flora), also, makes one family of them. The following are the indigenous species known under the common name of knapweed. I have treated of other species under the heads BuU Bortue and Stan Thiste.

1. Brown radiant knapweed ( $C$. Jacea). This grows in meadows where the soil is tenacious and moist. It is a perennial, flowering in August and September. The root is rather woody, with many long fibres. Stem solid, erect; a foot high, branched, angular, furrowed and roughish, leafy. Leaves, light green, rough, with short hairs; radical ones largest, stalked, toothed or pinnatifid; the rest scattered, sessile, oblong, or linear lanceolate, entire, or toothed near the base. Flowers large, numerous, radiant, light crimson, solitary at the tumid end of each branch, accompanied by a few leaves close to the calyx, which is brown; the calyx scales are membranous, torn. Linnæus says, the herb steeped in water, with alum, before the flowers expand, dyes silk of a fine yellow.

2. Black knapweed (C. nigra). This grows in pastures, and by road-sides, very common, flowering from June to August. In habit it is like the last, but the stem is taller, more bushy, more deeply furrowed, and rather less rough. The lower leaves are somewhat lyrate, with angular lobes; upper ones orate; their colour always darker than that of C. Jarea. The flowers are also of a deeper crimson, ccinmonly without any radiant or abortive flurets The flowers are uccasionally white.

3 x 2 
3. Greater knapweed (C. serbiosa). Tris is also a very common species, growing in the borders and ridges of corn-fields, and by waysides. The root is somewhat woody; stem about two feet high, erect, branched, angular, furrowed, leafy, smooth to the touch. Leaves dark green, slightly hairy on both sides, pinnatifid. The flowers, which blow in July and August, are terminal, stalked, solitary, large, and of a handsome crimson colour, rarely white; their radiant florets are large, each with five deep, long, and narrow segments. Ualyx-scales ovate, green, somewhat downy, fringed with fine parallel teeth. The seeds are crowned with many reddish bristles; and after they are blown away, the calyx becomes reflex, and displays the silvery shining hue of its inside. (Eng. Flor. vol. iii. p. 463.)

KNAWEL (Scleranthus, from orangos, hard, and avtos, a flower; in allusion to the dry, juiceless caly $\mathrm{x}$ ). These are dry, rigid herbs, which can only be considered as useless weeds.

The genus is European. There are 3 species, one of which, called S. annuns, is so abundantly naturalized in sandy, arable fields, as to appear native to some of the United States. (Nuttall).

1. The annual knawel, or German knotgrass (S. annuus), which grows commonly in dry, sandy soils and corn-fields, flowering in July. The root is small and tapering. 'The stems numerous, widely spreading, and partly decumbent; round, leafy, a little downy, branched, and many-flowered at the upper part. Leaves linear, acute, pale green, combined at the base by a membranous fringed border. Flowers small, green, nearly sessile, partly axillary, partly collected into dense forked tufts. Calyx of the fruit spreading, with taper, acute segments. The Swedes and Germans introduce occasionally the steam arising from a decoction of the knawel into their mouths, with a view to cure the toothache. Its leaves are astringent. Goats and sheep eat this plant, but cows totally refuse it.

2. Perennial knawel (S. perennis). This species is less common; it flowers from $\mathrm{Au}$ gust to Octnber, while the annual knawel blows in July. The root is woody, branched, with many decumbent or prostrate stems, 3 or 4 inches long. 'The whole herb is of a glaucous, glistening appearance, turning red with age, especially the stems. The leaves are more tapering, crowded, and curved, than in the foregoing. Segments of the calyx more obtuse, concave, and finally converging. In several parts of Europe the roots of this species are attacked by the insect called Coccus polonicus (Limn. Syst. vol. i. p. 741), which yields a fine crimson dye: it is said likewise to live on S. annures and on some Potentilla. A good account of its economy is given in the Upsal Transcictions for 1742 , t. i. p. 51.

KNEE GRASS. A name sometimes given -o the rough panic grass.

KNIGH'T, THOMAS ANDREW, President ot the Horticu':ural Society of London, F.R.S., *co, a äisting ushẹd vegetable physiologist and norticulturist, was born at Wormsley Grange, th Herefordshire, August 12, 1759. "My faaher," says Mr. Knight, in a la.e coinmunica696 tron to me, "was a man of much learning and acquirements. Having great powers of mind, and living in an extremely quiet and sequestered spot, he was supposed by his ignorant neighbours, in their language, to know everything." He died at an advanced age, when Mr. Knight was an infant, and as evidence of the respect his knowledge obtained him, when. ever in childhood his son sought for informa. tion upon any unusual subject, he was told that his father would have answered him, but that nobody now could. Being born in the midst of orchards, "I was early led," he continues, "to ask whence the varieties of fruit 1 saw came, and how they were produced; I could obtain no satisfactory answer, and was thence first induced to commence experiments, in which, through a long life of scarcely interrupted health, I have persevered, and probably shall persevere as long as I possess the power." Mr. K. was distinguished for his skill in producing hybrid plants, by impregnating the blossoms. We owe to him a debt of gratitude for many fine fruits.

He died May 11, 1838, in the 80th year of his age. The death of Knight was lamented by all men of science, for, as it was soon after well remarked by the Duke of Sussex, when addressing the Fellows of the Royal Society, "It would be difficult to find any other contempo. rary author, in this or other countries, who had made such important additions to the knowledge of horticulture and the economy of vegetation. (Selection from his Papers, p. 69.) To this interesting work a memoir of its author is prefixed.

Mr. Knight was author of the following works, besides numerous papers in the Philosophical and Horticultural Transactions:

1. A Treatise on the Culture of the Apple and Pear, and on the Manufacture of Cyder and Perry. London. 1797. 12mo. The 3d edition in 1808. 2. Some doubt. relative to the Efficacy of Mr. Forsyth's Plaister, in renovating trees. Londion. 1802. 4to. 3. Report of a Committee of the Horticultural Society of London. London. 1805. 4to. 4. Pomona Herefordiensis, or a Descriptive Account of the old Cyder and Perry Fruitg of Herefordshire. London. 1809. 4to. 5. A Letter on the Origin of Blight, and on raising Late Crops of Peas. This is appended to Sir.J. Banks's Essay on the Mildew. London. 1806. 8vo. 2d Edition. (G. W. Johnson's Hist. Eng.Gard.)

KNOLL (Sax. cnolle). A little round elevation; the top of a hill or mountain.

KNOT-GRASS. The common oat-like softgrass (Holcus avenaceus), from its bulbous roots is often called by farmers knot-grass; but in a botanical sense the following are the true knotgrasses.

This grass is preyed upon in Europe by a species of leaf-beetle (Chrysomela polygoni), and likewise in the United States by an insect scarcely to be distinguished from the European beetle. By these the knot-grass is completely stripped of its leaves two or three times in the course of a summer. This little beetle, says Harris, is about three-twentieths of an inch long. Its head, wing-covers, and body beneath are dark blue; its thorax and legs are dull orange-red; the upper side of its abdomen is also orange-coloured; and the antennæ and feet are blackish. The females have a very odd appearance before they have laid their eggs, their abdomen being enormously swelled 
out like a large orange-colcured ball, which makes it very difficult for them to move about. I have found these insects on the knot-grass in every month from April to September inclusive. The larva eat the leaves of the same plant. (Harvis.)

KNO'T-GRASS, COMMON (Polygonum aviculare; from $\pi 0 \lambda$. , many, and govu, a knee; referring to the numerous joints of the stem). This common annual grass is in England found almost everywhere, in waste as well as cultivated ground, streets, paths, and barren sandy places. The root is fibrous, long, very tough, and somewhat woody, branched below, simple at the crown. Stems several, spreading in every direction, generally prostrate, much branched, round, striated, leafy at the numerous knots or joints. Leaves alternate, stalked, hardly an inch long, elliptic or lanceolate, entire, obtuse, single ribbed, smooth except at the margin; tapering at the base, very variable in width; their substance rather coriaceous; their colour grayish or glaucous, stipules membranous, acute, often red, with a few remote, brownish ribs. 'The flowers which appear from April to October are axillary, 2 or 3 together on simple stalks, small, seeds acutely triangular, of a shining black, the food of many small birds. It is common in the United States.

KNOT-GRASS, VALENTIA. A name by which the powdery sea-heath (Frankenia pulverulenta), is known in some districts.

KNOT-GRASS, WHORLED (Illecebrum verticillatum). This is an interesting dwarf perennial plant, which is not uncommon in marshy, boggy ground in Cornwall and Devonshire, flowering in July. The different species are pretty, may be grown in any soil, and increase from seed without difficulty. The root is creeping; herb smooth, branched, procumbent. Leaves small, ovate, acute, or sometimes spatulate, scarcely stalked, rather fleshy. Stipules intra-foliaceous, small, white, jagged. The flowers are small, white, or reddish, whorled, without bractes. (Eng. Flor. vol. i. p. 335.)

KNOT-WEed. See Persicaria.

KOHL-RABI. Bulb-stalked cabbage (Brassica oleracea, var. caula-rapa). This curious variety of cabbage is a native of Germany, where it is much cultivated, and whence it was first introduced into England by Sir Thomas Tyrwhitt. The stem is swollen like a tuber, and, when divested of the leaves, may readily be mistaken for one. The produce is nearly the same as that of Swedish turnips, and the soil that suits the one is equally good for the other. It may either be sown in drills, or raised in beds, and transplanted like cabbages; in this case the beds require to be made and sown the preceding autumn. Two pounds of the seed will produce a sufficiency of plants for one acre of ground. Hares are so fond of it, that, on farms where these animals abound, the culture of this plant is found io be impracticable. 3840 grains of the tubes of kohl-rabi afford 105 grains of nutritive matter (Sinclair's Hort. Gram. p. 411). See CAnNAE, p. 247.

\section{I.}

I.ABELI.UM (Lat.). In botany, the front segment of an orchidaceous or vither flower: also the lower petal or lip.

LABOUR (Fr. labeur; Lat. labor). In a general sense, labour implies the exertion of human strength in the performance of any kind of work.

Without entering into an abstruse treatise on the science of political economy, it may not be out of place to examine shorily the subjech for labour is the only source of wealth to the farmer; and having done this, I shall next inquire into the means by which labour may be rendered most efficient. Nature spontaneously furnishes the matter of which all commodities are made; but until labour has been applied to appropriate that matter, or to adapt it to our use, it is wholly destitute of value, and is noh nor ever has been, considered as forming wealth. Were we placed on the banks of a river, or in an orchard, we should infallibly perish of thirst or hunger, unless by an effort of industry we raised the water to our lips, or plucked the fruit from its parent tree. But this illustration is an extreme case; and it is more to our purpose to remark, that the mere appropriation of matter is seldom sufficient. In the vast majority of cases, labour is required not only to appropriate matter, but to convey it from place to place, and to give it that peculiar shape without which it may be totally useless, and incapable of administering either to our necessities or our comforts. The coal used in our fires is buried deep in the bowels of the earth, and is absolutely worthless, until by the labour of the miner it has been extracted from the mine, and brought into a situation where it may be made use of. The stones and mortar used in btilding our houses, and the rugged and shapeless materials that have been fashioned in to the various articles of convenience and ornament with which they are furnished, were in their original state destitute alike of value and utility. And of the innumerable variety of animal, vegetable, and mineral products which form the materials of our food and clothes, none were originally serviceable, while many were extremely noxious to man. The labour that has subdued their bad qualities, that has given them utility, and fitted them to satisfy our wants, and to minister to our comforts and enjoyments, is plainly therefore the only source of wealth. "Labour," to use the words of Adam Smith, "was the first price, the original purchase-money, that was paid for all things. It was not by gold or by silver, but by labour, that all the wealth of the world was purchased." (Weaith of Nations, p. 14.) Those who observe the progress and trace the history of the human race in different countries and states of society, will find that their comfort and happiness have in all cases been principally dependent on their ability to appropriate the raw products of nature, and to adapt them to their use. The savage whose labour is con fined, like that of the Australian, to the gather ing of wild fruits, or of shell-fish on the ses 
coast, is placed at the very bottom of the scale of civilization, and is in point of comfort decidedly inferior to many of the lower animals. The first step in the progress of socicty is made when man learns to hunt wild animals, to feed himself with their flesh, and clothe himself with their skins. But labour, when confined to the chase, is extremely barren and unproductive. Tribes of hunters, like beasts of prey, whom they closely resemble in their habits and modes of subsistence, are but thinly scattered over the countries which they occupy; and, notwithstanding the fewness of their numbers, any unusual deficiency in the supply of ganie never fails to reduce them to the extremity of want. 'The second step in the progress of society is made when the tribes of hunters and fishers devote themselves, like the ancient Scythians and modern Tartars, to the domestication of wild animals and the rearing of flocks. The subsistence of herdsmen is much less precarious than that of hunters; but they are almost entirely destitute of the various comforts and elegancies that give to civilized life its chief value. The third and most decisive step in the progress of civilization, in the great art of producing the necessaries and conveniences of life, is made when the wan. dering tribes of hunters and shepherds renounce their migratory habits and become agriculturists and manufacturers. It is then that man begins fully to avail himself of his productive powers. He then becomes laborious, and by a necessary consequence his wants are then, for the first time, fully supplied, and he acquires an extensive command over the articles necessary for his comfort as well as his subsistence. The importance of labour in the production of wealth was very clearly perceived by Locke. In his Essay on Civil Government, published in 1689, he has entered into a lengthened, discriminating, and able analysis, to show that it is from labour that the products of the earth derive almost all their value. "Let any one consider," says he, "what the difference is between an acre of land planted with tobacco or sugar, sown with wheat or barley, and an acre of the same land lying in common, without any husbandry upon it, and he will find that the improvement of labour makes the far greater part of the value. I think it will be but a very modest computation to say, that of the products of the earth useful to the life of man, nine-tenths are the effects of latour; nay, if we rightly estimate things as they come to our use, and cast up the several expenses about them, what in them is purely owing to nature, and what to labour, we shall find that in most of them ninely-nine hundredths are wholly to be put on the account of labour.

"There cannot be a clearer demonstration of any thing than several nations of the Americans are of this, who are rich in land and poor in all the comforts of life; whom nature having furnished as liberally as any other peonle with the materials of plenty, $i . e$. a fruitiul soll apt to produce in abundance what might serve tor food, raiment, and delight, yet for want of improving it by labour have not one nundredth part of the conveniences which might be enjs yed.

692
"To make this a little clearer, let us $t$ at trace some of the ordinary provisions of life through their several progresses before they come to our use, and see how much they receive of their value from human industry. Bread, wine, and cloth are things of daily use and great abundance; yet, notwithstanding, acorns, water, and leaves or skins must be our bread, drink, and clothing, did not labour furnish us with these more useful commodities; for whatever bread is more worth than acorns, wine than water, and cloth or silk than leaves, skins, or moss, that is solely owing to labour and industry; the one of these being the food and raiment which unassisted nature furnishes us with; the other provisions which our in. dustry and pains prepare for us; which how much they exceed the other in value, when any one hath computed, he will then see how much labour makes the far greatest part of the value of things we enjoy in this world. And the ground which produces the material is scarcely to be reckoned in as any, or, at most, but a very small part of it; so little that even amongst us, land that is wholly left to nature, that hath no improvement of pasturage, tillage or planting, is called as indeed it is, waste; and we shall find the benefit of it amount to little more than nothing.

"An acre of land that bears here twenty bushels of wheat, and another in America, which, with the same husbandry, would do the like, are, without doubt, of the same natural intrinsic value (utility). But yet the benefit mankind receives from the one in a year is worth five pounds, and from the other possibly not worth a penny, if all the profit an Indian received from it were to be valued and sold here; at least, I may truly say, not one thousandth. It is labour, then, which puts the greatest part of value upon land, without which it would scarcely be worth any thing. It is to that we owe the greatest part of all its useful products; for all that the straw, bran, bread, of that acre of wheat, is more worth than the product of an acre of good land which lies waste, is all the effect of labour.

"For it is not barely the ploughman's pains, the reaper's and thrasher's toil, and the baker's sweat is to be accounted into the bread we eat; the labour of those who sell the oxen, who digged and wrought the iron and stones, who felled and framed the timber employed about the plough, mill, oven, or any other utensils, which are a vast number, requisite to this corn; from its being seed to be sown to its being made bread, must all be charged on the account of labour, and received as an effect of that; nature and the earth furnished only the almost worthless materials as in themselves. It would be a strange catalogue of things that industry provided and made use of about every loaf of bread before it came to our use, if we could trace them; iron, wood, leather, bark, timber, stone, bricks, coals, lime, cloth, dyeing drugs, pitch, tar, masts, ropes, and all the materials made use of in the ships that brought away the commodities made use of by any of the workmen to any part of the work; all which it would be almost impossible, at least too long. to reckon up." 
Labour is the sole source of exchangeable value, and, consequently, of wealth. It is the talisman that has raised man from the condition of the savage; that has changed the desert and the forest into cultivated fields; that has covered the earth with cities, and the ocean with ships; that has given us abundance, comfort, and elegance, instead of want, misery, and barbarism. Labour, according as it is applied to the raising of raw produce, to the fashioning of that raw produce, when raised into articles of utility, convenience, or ornament, or to the conveyance of raw and wrought produce from one country or place to another, is said to be agricultural, manufacturing, or commercial. An acquaintance with the particular process, and most advantageous methods of applying labour in each of these grand departments of industry, forms the peculiar and appropriate study of agriculturists, manufacturers, and merchants.

In thus endeavouring to exhibit the importance of labour, and the advantages which its successful prosecution confers on man, it must not be supposed that reference is made to the labour of the hand only. This species, indeed, comes most under our observation; it is that, too, without which we could not exist, and which principally determines the value of commodities. It is questionable, however, whether it be really more productive than the labour of the mind. The hand is not more necessary to execute than the head to contrive. All the means by which labour may be facilitated and wealth increased resolve themselves, 1 st, into the better division and combination of employment among individuals and nations; and $2 \mathrm{~d}$, into the more extensive or more judicious application of capital or stock in industrious undertakings.

The division of employments can only be imperfectly established in rude societies and thinly-peopled countries; but in every state of society -in the rudest as well as the most improved-we may trace its operation and effects. Even in the simplest business this co-operation and subdivision is required; neither hunting nor fishing, any more than agriculture or manufacture, can be advantageously carried on by solitary individuals. As society advances, this division of labour extends itself on all sides; one man becomes a tanner or dresser of skins, another a weaver, a third a smith, and so on. The wealth and comforts of all classes are, in consequence, prodigiously augmented. In countries where the division of labour is carried on to a considerable extent, agriculturists are not obliged to spend their time in clumsy attempts to manufacture their own produce, and manufacturers cease to interest themselves about the raising of corn, and the fattening of cattle. The facility of exchanging is the vivifying principle of industry; it stimulates agriculturists to adopt the best system of cultivation, and to raise the largest erops, because it enables them to exchange whatever portion of the produce of the land exceeds their own wants for other commodities contributing to their comforts and enjoyments, and it stimulates manufacturers and merchants to increase and improve the quantity, variety, and quality of their goods, this they may thereby obtain greater supplies of raw produce. A spirit of industry is thus universally diffused; and that apathy and languor which characterize a rude state of society enturely disappear.

Besides that sort of division of labour which enables each individual in a united society to confine himself to a particular employment, there is another and most important branch of the division of labour, which not only enables particular individuals, but the inhabitants of entire districts, and even nations, to addict themselves in preference to certain branches of industry. It is on this territorial division of labour, as it has been appropriately termed, that the commerce carried on between different districts of the same country, and between different countries, is founded. The variations in the situation, soil, climate, mineral products, \&c. of the different districts of an extensive country, render them more suitable for some than for other species of industry. A district where coal is abundant, which has an easy access to the ocean, and a considerable command of internal navigation, is the natural seat of manufactures. Wheat and other species of grain are the proper products of rich arable soils; and cattle, after being reared in mountainous districts, are most advantageously fattened in meadows and low grounds. Nothing can be more obvious than that the inhabitants of these different districts will be able, by confining themselves to those employments, for the prosecution of which they have some peculiar capability, to produce a much greater quantity of useful and desirable articles than they could do were they to engage indiscriminately in every possible employment.

Providence, by giving different soils, climates and natural productions to different countries, has evidently provided for their mutual intercourse and civilization. By permitting the people of each to employ their capital and labour in those departments in which their geographical situation, the physical capacities of the soil, their national character and habits fit them to excel, foreign commerce, or the territorial division of labour, has a wonderful influence in multiplying the products of arts and industry.

Having been led thus far into this fertile subject, I will conclude with some apposite and excellent observations by Dr. Paley:"Every man has his work. The kind of work varies, and that is all the difference there is. A great deal of labour exists besides that of the hands; many species of industry besides bodily operation, equaliy necessary, requiring equal assiduity, more attention, more anxiety. It is not true, therefore, that men of elevated stations are exempted from work; it is only true that there is assigned to them work of a different kind: whether more easy or mure pleasant may be questioned; but certainly no? less wanted, nor less essential to the cominot good." (Brande's Dirt. of Lit. and Art.)

LABOURER. One who is employed in: coarse and toilsome work. But, in agricu! ture, the term is applied to a person who per forms the manual or most laborious part " 
the busines 3 of a farm. The price of labouz has at all times varied; and, as the pooret classes feel, with additional rigour, every evil. arising from the pressure of the times, different expedients have been devised, with a view to alleviate their burdens, supply their wants, and render them more comfortable. From these investigations, it appears that, in the Iniddle of the 14th century, the usual price of labour was $2 d$. per day, and wheat was sold at from $3 s .4 d$. to 4 s. per quarter. In the middle of the 15th century the pay of a labourer per day was $3 d$., and wheat cost from 58 . to $5 s$. $6 d$. per quarter. In the earlier part of the 16th century the price of labour rose to $3 \frac{1}{2} d$, and that of a quarter of wheat to 7s.6d. A bout the middle of the 17 th century the pay of a labourer upon an average was (in Essex) $13 d$., and corn had risen to 40 s. per quarter. Towards the latter end of the 18th century the daily pay of a labourer was from $14 d$. to $18 d$. in the country, and from 2s. to $2 s .6 d$. in the metropolis, while the price of wheat was 48 s. per quarter. The payment of daily wages, however, serves but imperfectly to ascertain the real price of labour, as a considerable portion of work is performed by the piece, so that a labourer in general earns from $3 d$. to $6 d$. per day more than by the cornmon pay. The curious and philanthropic reader, who feels an interest in this popular inquiry, will be fully gratified by a perusal of Mr. Davies's Case of Labourers in Husbandry Stated and Considered, \&c. 4to, 1795, p. 200 ; and Sir F. M. Eden's State of the Poor, \&c., 3 vols. 4 to, 1797. Mrs. Davies Gilbert, of Eastbourne, a lady whose active interest for the prosperity of agriculture, and the improvement of the condition of the labouring poor, may fairly (as has been justly observed) be set as an example for many country gentlemen to follow, urges most strenuously, in many publications (but particularly in the Quart. Journ. of $A g r$. vol. xii. p. 252), the advantages to be derived from manual labour, in preference to horse labour. In England, many benevolent persons of distinguished rank have also recently taken up the cause of the labourer, and formed themselves into a society, very appropriately named "the Labourer's Friend Society." They advocate strongly, and endeavour to promote more generally the system of home colonies for the cultivation of waste land. See Allotment and Spade Husbandrt, Farm Senvavts, Wonkmis, \&c.

Farm labourers, being the most valuable class of men that a populous country possesses, should have every comfort provided for them that is compatible with their situation, and conformable to the general interest of the community. Their wages ought to be everywhere and at all times sufficient for the mairitenance of themselves and families while in health, with a surplus to provide against the day of sickness, without their being under the debasing necessity of making application to their nerghbours for relief. Persons so essentially useful to society should not merely support existence, but have the comforts of wholesome habitations, with sufficient spaces 1) ground to furnish them and their families 594 with changes of proper vegetable food without much expense.

LACTARY. A milk-house, dairy, or place where milk is kept. The term has been made to designate the whole establishment of a dairy. See Darry.

LACTIC ACID. This substance, in the opinion of Berzelius and some other chemists, exists in milk, and in larger proportion when it has become sour; but others imagine that it is the product of its decomposition. It was first recognised as a peculiar acid by Scheele, but he did not obtain it perfectly pure. It was afterwards observed by Berzelius in many animal fluids; and by Braconnet to exist with acetic acid in fermented rice-meal, wheatpaste, the juice of the beet-root, and other vegetable substances: he named it nancéic acid. It is formed, also, during the putrefactive process in some animal bodies. Lactic acid is a colourless, inodorous, syrupy liquid, and very sour. It may be so concentrated as to have a specific gravity of $1 \cdot 215$ : it attracts moisture from the atmosphere, and dissolves in water and alcohol in all proportions. At $480^{\circ} \mathrm{Fah}$ renheit, it is decomposed. When added to boiling milk, it is capable of immediately coagulating about 700 times its weight; but, when cold, it produces comparative little effect upon it: it also coagulates albumen. It has the property of dissolving fresh precipitated phosphate of lime; a property which is of great advantage in the animal economy, and might even be rendered useful in manures. The constituents of the lactic acid are, 6 parts of carbon, 5 of hydrogen, and 5 of oxygen. (Penny Cyclopedia, vol. xiii. p. 268.)

LAC'TOMETER (Lat. lac, milk, and metrum, a measure). A term applied to a glass tube for ascertaining the proportion which the cream bears to the milk of any particular cow, or the produce of a whole dairy. Lactometers of different kinds have been invented; the best is called "the four or five glass lactometer."

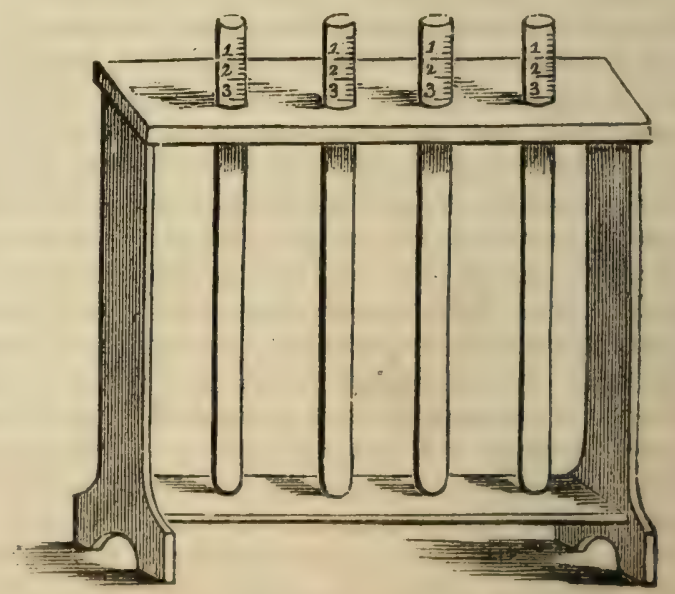

The principle of the instrument is, that if new milk is poured into glass tubes and allowed to remain, the division between the cream, which floats upon the surface of the milk, will be so evident that its depth may be easily measured; and should the milk from any cow produce more cream than that of another, the difference will be seen by the divisions or 
marks on the glass tubes. The lactometer consists of 4 or 5 glass tubes, about half an inch diameter, and 11 inches long, fitted into an upright mahogany frame; each tube having a fine line drawn round it 10 inches from the bottom; 3 inches from the line downwards, it is graduated into inches and tenths of inches. At milking time each tube is to be filled up to the line with new milk. After standing 12 hours, the quantity of cream which floats upon the surface is shown by the scale of inches and tenths; each division will therefore represent one per cent. of the whole.

If the milk given by a cow at one meal is 1 gallon, or $\mathbf{8}$ pints, and the thickness or depth of the cream which floats upon it measures 14 divisions, multiply the number of pints, 8 , by the depth of the cream, 14 ; the result will be that the produce of the cream of that meal is 112 , or 1 pint $\frac{13}{1 \frac{1}{\partial}}$. Care must be taken to fill these tubes as soon as the pail is taken from under the cow, for if any delay takes place, some of the cream will have ascended towards the top. The milk should be taken from the middle of the pail, which is to be done by dipping a cream-pot below the froth. (Journ. Roy. Inst. vol. iv. p. 157; Rees's Cyclo. vol. xx.)

LADIES' FINGER. A name given to the common kidney-vetch (Anthyllis vulneraria), which, from its soft and downy nature, was supposed to possess vulnerary properties in stanching the blood of slight wounds. See KIn NET-VETCH.

LADIES' MANTLE (Alchemilla). 'The species of this genus of plants are all astringent in their root, and somewhat mucilaginous. $A$. vulgaris is slightly tonic. Many of them are ornamental, and well adapted for planting in gardens near the front of borders, or for adorning rockwork. They succeed well in any common soil, if not over wet, and may be increased from seeds or divisions. The species indigenous to Britain are-

1. Cummon ladies' mantle ( $A$. vulgaris). A perennial, growing in dry, rather mountainous pastures. The root is woody, with long fibres : stems from 4 to 8 inches high, more or less procumbent, alternately branched, round, hairy, leafy, terminating in numerous little corymbose clusters of green flowers, or smooth, almost capillary stalks. The radical leaves are numerous, on long footstalks, large, roundish, kidney-shaped, bluntly-lobed, plaited, serrated, of a fine green above; soft and hairy beneath. The stem-leaves are of the same form, but a great deal smaller; alternate, on short stalks, with a pair of large notched stipules to each. Horses, sheep, and goats, eat this vegetable; but it is not relished by cattle, and hogs totally refuse it.

2. Alpine ladies' mantle ( $A$. alpina). A perennial plant growing on alpine rocks, especially in a micaceous soil. It is rather smaller in habit than the last species, and essentially different, not only in the silvery pubescence of the stalks, flowers, and backs of the leaves, but in the latter, being separated to the base into 5 or 6 obovate lobes, closely serrated towards the extremity. Nothing can be more beautiful than the silvery splendour of their under sicies, especially in exposed and barren spots, when the leaves are agitated by the wind. No figure can do them justice. The upper surface is smooth and naked, of a fine green. This species is found on the mountains of New Hampshire.

3. Field ladies' mantle, or parsley piert ( $A$. arvensis). This annual species will generally be found in England growing in sandy or gravelly fields, especially when fallow, as well as on heathy banks. The root is small and fibrous; stems numerous, about a finger's length, spreading or prostrate, round, leafy. hardly subdivided. Leaves flat, three-lobed. variously cut on short stalks. The whole plant is more or less hairy, and in flavour and scent approaches its natural ally, burnet. (Smith's Eng. Flor. vol. i. p. 223.)

LADIES' SLIPPER (Cypripedium, from Cypris, one of Venus's names, and podion, a slipper; hence the name Venus's or ladies' slipper). The species of this genus are remarkably handsome when in flower, and on that account deserve a place in every collection. They are all of the easiest culture. The hardy species succeed well in peat soil, either kept in a frame, or planted out in a shady border. The species, natives of America, require to be protected from severe frost and rain. The only indigenous species is the common ladies' slipper ( $C$. calceolus), which is very rare, growing only in mountainous woods and thickets in the north of England. It is perennial, blowing large yellow, solitary, terminal flowers, without scent, in June. The stems are solid, 12 or 18 inches high, downy, bearing 3 or 4 large alternate, ovate, rather pointed leaves, clasping or sheathing at their base.(Eng. Flor. iv. 51; Paxton's Bot. Dict.; see Darlington's Flor. Cest. 513.)

LADIES' SMOCK (Cardamine). An interesting genus of the simplest culture and propagation, natives of various countries, generally preferring watery situations. The native species are five in number:-

i. Daisy-leaved ladies' smock (C.bellidifolia). This perennial species grows in moist, grassy, lofty, alpine pastures. The root is rather woody, divided at the crown. Herb 2 or 3 inches high, unbranched, erect, bright green, smooth leaves, sometimes a little wavy or angular, the uppermost nearly sessile. Flowers few, corymbose, white, appearing in August. Style short, conical.

2. Impatient ladies' smock (C. impatiens). This annual species grows in shady, rather moist, rocky situations in the north of England; it is rarely met with in Scotland. The root is small and tapering; the herbage pale green; stem $1 \frac{1}{2}$ to 2 feet high; leaves pinuate: leaflets lanceolate, mostly cut; stipules fringed. The flowers, which are numerous, and small, and white, appear in May and June. Pods erect. very slender, composing long clusters, and discharging their seeds with a crackling noise and great force on the slightest touch or concussion, by means of the revolute valves. The plant is disagreeably bitterish and pungent.

3. Hairy ladies' smock (C. hirsuta). Also annual in habit. This species is found verp frequent in waste or cultivated ground, espe cially in moist, shady places; flowering fro 


\section{LADIES' TRACES.}

LADY BIRDS.

March to June. The root consists of many white fibres. The herb is variable in size and luxuriance, deep green, more or less hairy, rarely quite smooth; stem from 3 to 12 inches or more in height; leaves pinnate, without stipules; leaflets stalked, rounc̈ish, oblong, notched.

4. Meadow ladies' smock (C.pratensis). See Cuckoo Flower.

5. Bitter ladies' smock (C.amara). This is not a common species, but is found occasionally in watery places, by the sides of rivers and brooks. It is perennial, and before it flowers greatly resembles water-cress, but the taste is bitter and nauseous. The root is toothed, somewhat creeping; stems 1 to 2 feet high, more or less hairy, creeping at the base, with several radicles, and sometimes a few slender scions. Leaves pinnate, without stipules; leaflets of the lowermost roundish; of the rest, toothed or angular. Style obliquely elongated. Flowers, which appear in April or May, always white or cream-coloured, with violet anthers. (Smiih's Eng. Flor. vol. iii. pp. 186-91.)

LADIES' TRACES (Neottia, a bird's nest, in allusion to the interwoven fibres of the ronts). This is a pretty genus of orchidaceous plants. The hardy species will succeed well in chalky soil, or a mixture of loam, peat, and sand; they are all increased by divisions. (Puxton's Bot. Dict.)

There are in Britain only two indigenous species:-

1. Sweet ladies' traces (N. spiralis), which grows in open pastures, on a chalky or gravelly soil, or in meadows in various parts of England, flowering in August and September. The leaves are awned, all radical, on broad stalks, spreading, ovate, acute, ribbed, rather glaucous. Stalk a finger's length or more, viscid, and downy upwards, clothed with several sheathing, upright, pointed bractes. Spike spiral, of many crowded small white and highly fragrant flowers, in a single row, each with an ovate, tumid, pointed, downy, close bracte.

2. Proliferous ladies' traces ( $N$. gemmipara). 'This species grows in marshes on the west coast of Ireland, and flowers in July. The root consists of two thick, fleshy, downy, annual, perpendicular knobs, each abcut 3 inches long, and one-fifth of an inch in diameter near its origin, tapering downwards to a blunt point. After flowering the root decays. Leaves 5 or 6 , upright, broadly lanceolate, acute, three-ribbed, 3 inches in length. Foot-stalks broad, sheathing, near an inch long. Stalk erect, 2 inches high, sheathed more than half way up by the foot-stalks of the innermost leaves, and bearing in the upper part 2 or 3 lanceolate, smooth, upright bractes. Spike an inch long, ovate, dense, erect, of about 18 white flowers in 3 rows, twisted round in a very remarikable way, and each accompanied by a smooth, lanceolate brar.e, as tall as itself. The outside of the Howers and capsule are downy; every other part of the herb is smooth. Buds destined to flowe: the following year are formed among the leaves, at the bottom of the flower-stalk. In :he spring, each bud puts forth a pair of oblong 696 knobs and becomes a separate plant. (Smith's Eng. Flor. vol. iv. p. 35.)

\section{LADIES' 'TRACES. Ladies' hair or quak-} ing-grass. See Briza Menia.

LADDER. A framework of steps between two upright pieces. Ladders of various length are essential requisites on a farm, whether for use in repairs to buildings, for reaching stacks, or in cases of fire.

"Garden ladders are of three kinds: the comınon wall tree ladder, which differs from those used in other arts in having two pieces of 10 or 12 inches in length, projecting at right angles from the upper end, the use of which is th avoid injuring the trees, by keeping the top of the ladder at a small distance from the walt. and thus admit of the operation of nailing. The orchard ladder consists of a frame on low wheels, as a basis for several ladders which fit into each other, and are capable of being hoisted up by machinery, so as a person near the extremity of the ladder may have access to any part of a tree with convenience, either to prune it or gather the fruit.

The three-styled, forked, and double ladders are also well adapted for the ordinary purposes of gathering fruit or pruning. The rule-joint ladder is used for working on curvilinear roofs either of glass, or domes of lead, stone, \&c., which require panes renewed or trees nailed. Such ladders are particularly useful for repairing the roofs of hothouses and greenhouses. The stepladder, instead of round rods on which to place the feet, has steps or boards, an improvement essentially necessary where much work is to be done, because less fatiguing to the feet. Such ladders have a back or fulcrum, by which they stand independently of any other object, and which is removable at leisure by drawing out an iron bolt." (Loudon's Enc. of Gard.p. 290.)

LADY BIRDS, or LADY BUGGS. Familiar names applied to small hemispherical beetles, scientifically denominated coccine?'a. These little beetles are generally yellow or red, with black spots, or black, with white, red, or yellow spots; there are many kinds of them, and they are very common and plentiful insects, and are generally diffused among plants. They live, both in the perfect and young state, upon plant-lice, and hence their services are very considerable. Their young are small flattened grubs of a bluish or blue-black colour, spotted usually with red or yellow, and furnished with six legs near the forepart of the body. They are hatch. ed from little yellow eggs, laid in clusters among the plant-lice, so that they find themselves at once within reach of their prey, which, from their superior strength, they are enabled to seize and slaughter in great numbers. There are some of these lady-birds, of a very small size, and blackish colour, sparingly clothed with short hairs, and sometimes with a yellow spot at the end of the wing-covers, whose young are clothed with short tufts or flakes of the most delicate white down. These insects belong to the genus Scymnus, which means a lion's whelp, and they well merit such a name, for their young, in proportion to their size, are as sanguinary and ferocious as the most savage beast of prey. I have often seen one of these 
little tufted animals preying upon the plant-lice, catching and devouring, with the greatest ease, lice nearly as large as its own body, one after another, in rapid succession, without apparently satiating its hunger or diminishing its activity. (Harris.) See ApHrs.

I.AIR. Provincially, land in a state of grass or sward. (See LAx.) Also employed in some countries, to signify soil and dung. Lair is used sometimes to express the couch or resting-place of a boar or wild beast, or of cows in dairies.

I.AMA, or LLAMA. See Alpaca.

LAMB'S LE'T'TUCE. See Cohn Sarad.

LAMB'S QUAR'IERS. A name given to wild or mountain spinach. (Chenopodium allum.) See Goos zғoот.

LAMB SKINS (Germ. Lammsfelle). The value of lamb skins varies according to the fineness, brilliancy, and colour of the wool. Black lamb skins are more generally esteemed than those of any other colour. English lamb sliins are seldom to be met with perfectly black; but since the introduction of merino sheep into England, many of the white fleeces have, in point of quality, arrived at a pitch of perfection which justly entitles them to be ranked with some of the best fleeces in Spain. The importation of lamb skins is immense, having amounted on an average in 1831, and 1832 , to $2,365,635$. Eight-tenths of the whole quantity are supplied by Italy. They are mostly used in the glove manufacture. (M'Culloch's Com. Dict.) See Woow.

LAMENESS. In farriery, an affection in the feet or limbs in horses and other animals, hy which motion is rendered less perfect. In the horse, it is brought on from various causessprains, over-exertion, diseases of the foot, \&c. The muscles of the shoulder are occasionally sprained, and in this case the animal cannot lift his foot without great difficulty, indeed he will be observed to drag his toe along the ground. In this case few local measures can be adopted. The horse should be bled from the vein on the inside of the arm, fomentations applied, and a dose of physic given. In this, as in most other cases of lameness, quiet and rest are essential to the restoration of the animal. (The Horse, p. 229.)

LAMMAS DAY. In the English calendar, the 1st of August. Dr. Johnson supposes this term to be a corruption of lattermath, which signifies a second mowing of grass. Others derive it from a custom which once prevailed in some parts of England, of bringing a lamb alive on this day into the church at high mass. Others again derive it from a Saxon term signifying loaf mass, so named as a feast of thanksgiving for the first-fruits of the corn. (Erande's Dict. of Lit. \&c.)

LAMP BLACK. A colouring substance which is in very general use for several purposes. The finest lamp black is produced by collecting the smoke frum a lamp with a long wick, which supplies more oil than can be perfectly consumed, or by suffering the flame to play acraınst a metalline cover, which impedes the combustion, not only by carrying off part of the heat, but by obstructing the current of air Lamp black is prepared, however, in a much cheaper way for the demands of trate The dregs which remain after the purificatiot. of pitch, or else small pieces of fir word, are burned in furnaces of a peculiar construction. the smoke of which is made to pass through a long, horizuntal flue, terminating in a close boarded chamber. 'The roof of this chamber is made of coarse cloth, through which tho current of air escapes, while the soot remains. (Ure's Dict.)

LANCEOLATE. In botany a term used (o) describe leaves which are oblong and gradu. ally tapering towards each extremity, or shaped like a spear or lance.

LANCEWOOD (Guatteria, in honour of J. B. Guatteri, an Italian botanist, and once pro. fessor at Parma). 'This is a splendid genus of evergreen shrubs, succeeding in a mixture of loam, peat, and sand. They are natives of warm climates and require stove culture. Young plants are readily obtained by cuttings raised in sand under a glass in heat. (Pux. ton's Bot. Dict.)

LAND (Germ.), in the widest acceptation of the word, is used to denote the solid matter of which the globe is composed; in contradistinction to the liquid matter or water (see GroLOG $\mathbf{X}$ ): but in its most restricted signification it is confined to arable ground. The latter is the legal meaning of the term; and in this sense it is used in all original writs, and in all court and formal pleadings.

LAND-DITCHING, or hollow draining as it is sometimes termed, is chiefly practised in England in the counties of Essex and Hertford. It consists in digging both main and side drains, similar to those generally adopted in draining land: the former are usually made from 22 to 24 inches, the latter from 20 to 22 inches in depth. The soil is previously ploughed, and the length to which the main drains may be protracted without a vent, depends upon the situation of the land. When the land has a regular declivity, the most proper method will be to carry off as much water as possible, by means of side drains; but if the ground be irregular, it will be requisite to form additional main drains, so that every advantage may be derived from the valleys, into which the latter must often be conducted to a considerable extent.

The length of the side drains varies according to the elevation of the soil; in general they need not be more than one rod apart from each other; though in very loose or porous grounds, they may be dug at a distance of one rod and a half. When the trenches are cut to a sufficient depth, they are filled up and covered in the usual manner with straw and bushes. The expense of this method of draining is cumputed in England to be nearly 3/. per acre.

Land-ditching not only carries off the water from wet or marshy soils, but also meliorates stiff loamy clays, which being thus better enabled to resist the long continuance of moisture on their surface during the winter, promote ve. getation very early in the spring, and the grass is rendered of a superior quality. The weeds, \&c. change their colour, and are totally divest ed of their rankness; the corn also increases both in quantity and weight. Another important advantage arising from this practice is, that $3 \mathrm{~N}$ 


\section{LANDLORD.}

t will admit of the soil being ploughed at an earlier jeriod of the spring and later in autumn : while $1 t$ may be tilled with greater facility, and kept clean from weeds at a very small expense.

LANDLORD. One who owns lands or houses, and has tenants under him. See TEnant, Customs of Counties, Lease, AgreeMENT, \&C.

LANDMARK, signifies in a general sense any thing by which the boundary of a property is defined. In ancient times the correct division of lands was an object of great importance; and various means were adopted to give distinctness and permanency to the boundaries of every man's property. Stones and hillocks were the most usual landmarks. The importance of this subject among the Israelites particularly, may be judged of from the denunciation of Moses, "Cursed be he that removeth his neighbour's landmark."

LANDSCAPE GARDENING. The art of laying out grounds so as to produce the effect of a natural landscape. Its principles are the same as those upon which the landscape painter proceeds in composing a picture; and though it is an art of which, like many others, everybody thinks he is a judge, it requires to be properly practised, and the possession of powers of a much higher order than fall to the lot of most men. Mr. Brown, commonly called Capability Brown, was the first who practised the art in England, so as to render himself worthy of the name of artist. To lay down the principles of this art here would be quite impossible; but this general observation contains the sum of them; let selected and beautiful nature be constantly your model, and success must follow. Loudon's Enc. of Gardening, and Downing's Landscupe Gardening, recently published in New York, may be consulted with advantage by these desirous of practising the art.

LANDSLIP. A portion of land that has slid down in consequence of disturbance by an earthquake, or from being undermined by the action of water or other means.

LAND SPRINGS. Land springs are sources of water which only come into action after heavy rains; while constant springs which derive their supplies from a more abundant source, flow throughout the year. All springs owe their origin to rains. In the case of land springs, the water when it sinks through the surface, is speediiy interrupted by a retentive stratum, and there accumulating soon bursts out into a spring, which ceases to flow a short period after the cause which gave it birth has ceased to operate; but the water which supplies constant springs sinks deeper into the earth, and accumulates in rocky or gravelly strata, which become saturated with the fluid.

I.AND STEWARD. A person who has the care of a landed estate, and whose duties vary in different countries, according to the mode in which lañded property is managed. In England, where the landlord very commonly undertakes to keep the buildings and fences of his tenants in repair, the duties of the land steward are constant and multifarious; while in Scotland, where the buildings and fences are kept in repair by the tenant, the duties of the stew. ard are limited to receiving the rents, and see598 ing that the covenants of the leases are duiy fulfilled. In many parts of the Continent, and particularly in Italy, where the landlord is a partner with his tenant, and shares the produce with him, the duties of the land steward or fattore, as he is there called, are much more one. rous than in Britain. See BaIliff.

LAND TAX. In England, a branch of the public revenue, which was first raised in its present form in 1692. The rate at which this tax is charged is $4 s$. in the pound on the annual value. The amount which it yielded to the exchequer in 1837 was $1,192,635$. (Penny Cyclo, vol. xiii. p. 300.)

LARCH TREE (Lat. larix; It. and Span. larice). The larch is one of the most valuable exotics which has been introduced in to Britain. In the north of Scotland it has been grown to a great extent, cultivated with particular attention; and found to be one of the most profitable of all trees to the planter, provided the land be well drained, but it will not succeed in swampy situations. It grows with great rapjdity, is subject to very few accidents, transplants with but little risk, and produces timber of great excellence and value, not only for domestic but for naval purposes.

In bridges, dock-gates, mill work, and especially in mill axles (where oak only used formerly to be employed), larch has been substituted with the best effect. The small larch is useful for agricultural implements, gates, upright palings, rails, and hurdles. Boats built of larch have been found sound when the ribs made of oak 40 years old were decayed. A fine frigate of 36 guns, named the Atholl, was launched at Woolwich in 1820 , built entirely of larch, the growth of the Atholl plantations. It is also very useful for staves for casks.

1. The common larch fir or white larch (Abies larix). The leaves of all the species are clustered, and deciduous. The cones vary: in the common larch they are ovate, oblong, blunt; and the flowers are pink. In mountainous districts in Scotland the Duke of Atholl planted this species in immense quantities, having had nearly 9000 acres in cultivation with the larch alone. We are told by Dr. Anderson that his grace planted 200,000 every year; and in the winter of 1819 and the following spring no less than $1,102,367$ were planted on 556 acres, at 2000 per Scotch acre. The late Earl of Fife also planted 181,813 in Morayshire. Goodwood, the property of the Duke of Richmond, was probably the first place at which the larch was planted as a forest tree, and even there it was only in smal! numbers. A few year's after, viz. in 1738, it was introduced into Scotland by a Mr. Menzies. A bout 1740, James, Duke of Atholl, commenced planting larches around Dunkeld House and Atholl House, the two residences of his grace; and great attention having been paid to these nurseries by his grace's successors, the plantations have amazingly increased. A very detailed account of the plantations on the Atholl estates, and experiments on the wood, will be found in the $3 \mathrm{~d}$ vol. of the Prize Essirys of the Highland Sociely, p. 165, drawn up from papers and documents communicated by his grace's trustees. In a communication to the 


\section{LARCH TREE.}

Board of Agriculture in February, 1812 (vol. vii. p. 273), the Duke of Atholl, speaking of the advantages to be derived from a more general culture of the larch, says, "The lower range of the Grampian Hills, which extend to Dunkeld, are in altitude from 1000 to 1200 feet above the level of the sea; they are in general barren, and are composed of mountain schist, slate, and iron-stone. Up to the highest tops of these, larch grow luxuriantly, where the Scotch fir, formerly considered the hardiest tree of the north, cannot rear its head. In considerable tracts, where fragments of shivered rocks are strewed so thick that vegetation scarcely meets the eye, the larch puts out as strong and vigorous shoots as are to be found in the valleys below, or in the most sheltered situation." And it further appears from a report of that nobleman to the Horticultural Society (Trans. vol. iv. p. 416), that in situations 1500 to 1600 feet above the level of the sea, he has felled trees 80 years old that have each yielded six loads of the finest timber. The growth of larch is not, however, confined to Scotland; but much land has been planted in the northern counties of England. 'The Society in London for the Encouragement of Arts and Manufactures, so long ago as 1783 , offered premiums for the planting of larch. A gold medal was offered to those who should plant within any one year 5000 larches from two to four years old at a distance of 5 feet asunder; and a silver medal to any one who should plant 3000 larches at the same distance. This premium only contemplated making plantations solely of the larch. 'The first claimant for the premium was the Bishop of Llandaff, who had by that time planted 48,500 larches on 18 acres of the high grounds near Ambleside in Westmoreland, at a distance of 4 feet from one another. Immense numbers continued to be planted annually up to the year 1805 , from which year to 1816 , no candidates appeared to claim the premium, in consequence of the severe blight which affected the larch trees in England for some years; and which preventing the formation of the cones, deprived the growers of larch plants of the usual supply of seed.

There is no account given of the height at which these larches were planted. Had they been placed at a considerable elevation above the level of the sea, they would have probably escaped the contagion of the blight. In the account of the Dunkeld larch plantations, the late Duke of Atholl conceived that he had introduced three great improvements in the planting of the larch, when it was to be raised for useful timber. These improvements were the planting it at a high elevation on the mountain side, in a region in which no other kind of timber tree would grow to perfection in this country; the inserting the tree in the soil at an early age, not exceeding two years old in the seed-bed; and the notching the small plants in to the ground by a peculiar instrument at wide intervals, not nearer than $5 \frac{1}{2}$ feet to each other; for, if planted close, they exhaust the soil, and prevent its being nourished by the annual deposition of spines, on account of the closeness of the trees.

\section{LARCH TREE.}

In 1820 the gold medal was a warded to the Duke of Devonshire fur planting 1,981,065 forest trees, 980,128 of which were larch. Besides these instances of the planting the larch rlone, there are many others in England in which they were planted along with other trees; but as they would probably be so planted mere. ly as nurses to the hard timber, such planta. tions cannot be considered as interesting experiments, in regard to the value of the larch as timber. From the foregoing details, how. ever, we find that, mainly under the auspices of the Society for the encouragement of Arts and Manufactures, $1,407,036$ larches were planted in England in 37 years. It is singular that so much elevated barren land in the counties of Hants, Sussex, and Kent should be suffered to remain unplanted with this and other timber, which would find a ready sale in the neighbouring government yards.

Plantations that are formed exclusively of larch destroy the heath and all other vegetables; but after a few years a fine grass springs up which is so valuable for grazing, that it has been let from 10 s. to $5 l$. per acre for this purpose, which, previously to its being planted, would not bring as many pence.

Three varieties of the common larch are mentioned by botanical writers; one remarkable for the young cones being pale green instead of crimson, and erect, not drooping. A second has a weeping habit, with pendulous branches, but is distinct in botanic characters from the black larch (Laryx pendulu) of North America; both these varieties are natives of the Tyrol. The third sort is of a slow, stunted growth, and an inelegant appearance, leafing early, and very subject to injury from spring frosts. The bark is cinereous, not yellowish brown. It was raised by the Duke of Atholl from seed, procured at Archangel in 1806. Both in its appearance as a tree, and its value as timber, this Russian larch is much inferior to the common larch. From the boiled inner barir, mixed with rye flour, and afterwards buried a few hours in the snow, the hardy Siberian hunters prepare a sort of leaven, with which they supply the place of common ieaven when the latter is destroyed, as it frequently is by the intense cold to which hunters are subject in the pursuit of game. The bark of the larch is nearly as valuable to the tanner as oak bark; this valuable property was first discovered by Mr. T. White in 1812. (Com.to Board of $A g r$.vol.vii. p. 278.) The larch also produces the substance called Venice turpentine, which is of considerable use in medicine, and flows in abundance when the lower part of the trunk of old trees is wounded or tapped between th: months of March and September. When fo rests of larch in Russia take fire, which sometimes happens, a gum issues from the medullary part of the trunks, during the combustion, which is called Orenburgh gum. A saccharine matter, also, resembling munna, and called manna of Briançon, exudes from the larth in June; and another sort of manna is exuded from its leaves in the form of a white, flocculent substance, which finally becomes concreted into small lumps. From the inner rind or bark of the larch the Russians manufacture 
fine white gloves, not inferior to those made of the most delicate chamois, while they are stronger, cooler, and more pleasant for wearing in the summer.

The larch is propagated by seed, which is generally ripe in September and December, when the cones may be collected and carefully dried, and put away till April, which is considered the best time for sowing. The most proper season for felling the larch is July.

2. The red larch fir (A. microcarpa). In this species the cones are oblong, small, thin; scales erect, close pressed, the upper ones much smaller than the lower. It is a graceful tree, with much of the habit of the common larch, from which, however, its very small cones, of a bright purple, readily distinguish it. It is a native of North America. This is by no means so well adapted to the planter's purposes as the common larch. According to the Duke of Atholl, trees when 50 years old do not contain one-third as many cubic feet as the common larch. The wood is so heavy that it will scarcely swim in water.

3. The black larch fir ( $A$. pendula). Cones oblong, with numerous spreading scales, which gradually diminish from the base to the apex of the cones. Branches weak and drooping. The leading shoot will often begin to droop at the height of 15 or 20 feet from the ground, and after gradually acquiring a horizontal direction, will bend towards the earth, so as to form a natural arch of great beauty. This species is also a native of North America, where it is found growing on a rich clay soil, mixed with sand, in cold, mountainous districts. When cultivated in Britain it is an elegant tree, having a good deal of resemblance to the common larch, but being of a brighter green colour,and much more graceful. The wood is less valuable than the common larch.

There is a report (Trans. High. Soc. vol. v. p. 391), by Mr. Lawson on larches raised by him from seed imported from the Tyrol, which being the native country of the larch, is supposed to mature the most perfect seed.

The larch is affected with many diseases in Britain. Some of these have been supposed to arise from a constitutional weakness engendered in the tree from the seed not having heen perfectly ripened. 'The reader's attention may be drawn to several valuable treatises on the diseases of the larch, distributed through the volumes of the Trans. of the High. Soc. of Scotland, \&c. In the Quart. Journ. of $A g \%$. there are also some able papers, "On the probable Cause of the Diseases of the Larch in Great Britain," by the late M. Decandolle (vol. v. p. 403); "On the Diseases of the Larch in the South of Scotland," bv Mr. Webster (Ibid.p. 535); "On the Rot in Larch," by Mr. Gorrie (Ibid. p. 537); and some remarks on the foregoing papers (Ibid. p. 574); "On the Canker in Isarch," by Mr. Drummond, vol. ii. p. 221. (Penny Cyclo. vol. i.; Quarl. Journ. of Agr. vol. iii. p. 794 ; Brit. Husb. vol. iii.) See CANker, F1Rs, and Pinly.

LARCH, AMERICAN. see Hackмatack.

LARD. The melted fat of the hog, which is much used for domestic purposes and in cookcry, for cintments, pomatums, and other pur700 poses. Pure lard has little or no taste, and no odour; its melting point is about $97^{\circ}$ Fahrenheit. When long exposed to the air it attracts oxygen, and becomes rancid; whilst a portion of carbonic acid is evolved. Lard is a com. pound of a solid, firm fat, stearine, and a semifluid substance termed elaine, in the proportion of 38 of the former to 62 of the latter.

Most fats and oils, whether of animal or vegetable origin, are composed of these two ingredients, upon the relative proportion of which their consistence respectively depends. They may be obtained separate by the action of boiling alcohol, which on cooling deposits the stearine, and yields the elaine upon evaporation. Another method is to compress fat, or oil congealed by cold, within the folds of bibulous paper. The elaine is absorbed by the paper, and may be separated by compression under water; the stearine remains.

Elaine resembles oil in appearance, is colourless when pure, congeals at $20^{\circ}$ Fahrenheit, may be evaporated unchanged in vacuo, has little odour and a sweetish taste, is insoluble in water, but soluble in boiling alcohol, and consists of carbon, oxygen, and hydrogen.

Stearine is white, concrete, fusible at $111^{\circ}$ Fahrenheit, volatilizable unchanged in vacuo, partly volatilized and partly decomposed when heated in a retort, insipid, inodorous, slightly soluble in alcohol, insoluble in water, and composed, like the former principle, of carbon, hydrogen, and oxygen.

Exposed to the air, lard absorbs oxygen and becomes rancid. It should therefore be kept in well-closed vessels, or procured fresh when wanted for use. In the rancid state it is irritating to the skin, and sometimes exercises an injurious reaction on substances mixed with it. Lard should never be used when it becomes rancid. See FAt and Aners.

I.ARD OIL. In the United States, where swine are raised so abundantly, oil is now very extensively separated from lard. Its close connection with the question of disposing of the agricuitural products of the Union, and especially of the Western States, forms a reason for giving it an extended consideration. Several large factories for the manufacture of this oil have been some time in operation in Cincinnati, and thousands of gallons are daily prepared for home consumption and exportation. It is also carried on at Cleveland, Ohio; Chicago, Illinois; Burlington, Iowa; Hanns bal, Missouri; and other places both in the Western and the Atlantic States.

It is considered much superior to olive or sperm oil for machinery and for the manufac. ture of woollens, \&c. It can be furnished also at half the price, and therefore it will doubtless supersede that article of import. As it contains less stearine than other oils, it is found much better for combing wool, for which pur. pose a single factory wished to contract for 10,000 gallons from one establishment. It is also undergoing trial in England; and, if it succeeds, of which there can scarcely be a doubt, large orders for it may be expected, or at least the American lard itseif, which pays a less duty, will find a ready market.

Repeated experiments have shown that for 
the purpose of combustion, no oil is superior. It is important, in trying it with this view, to obtain a good article, manufactured from good lard, and not from the dark-burned, which creates smoke and clogs the flame. For want of sufficient care in this respect, some have no doubt met with disappointment in their attempts to substitute this oil for sperm oil in their lamps.

The following are given as the relative constituents of lard oil and sperm oil, in 100 parts of either:-

$\begin{array}{llll} & \text { Carbon. } & \text { Hydrozen. } & \text { Oxyzen. } \\ \text { Lard oil } & 79.03 & 11.422 & 9.518 \\ \text { Sperm oil } & 79.05 & 11.6 & 8.9\end{array}$

It will thus be seen that the difference in carbon is only 3.00 ; about the same in hydrogen; while in oxygen it is about $4 \cdot 10$ in favour of the lard oil. 'The large quantity of carbon proves that it may be relied on as a material for giving light, as it is well known that whenever carbon predominates in an animal oil, the article is capable of a high degree of luminous power. Experiments have been made which have shown results in favour of lard oil. A bout 60 lbs. in 100 of good lard, in tallow only 28 is oil; and the processes of manufacture resorted to show that it may be made a profitable business. Large orders have already been executed at the West for this oil, to be used in the Eastern States. The heat of lard oil for the blow-pipe has been found to be much greater than that of sperm. Jard itself melts at $82^{\circ}$ to $97^{\circ}$ of Fahrenheit; its specific gravity at $60^{\circ}$ is 0.939 . Lard crystallizes in small globules; sperm in flakes or scales. It is soluble in boiling alcohol. The proportion is 80 gallons of lard to 1 of alcohol. The application of stearine for candles promises greatly to reduce the price of that article, so that candles equal to spermaceti may eventually be reduced to $12 \frac{1}{2}$ cents per pound.

As the capillary attraction of the lard oil is not so great as that of sperm, it is recommended that the form of the lamp should be such as to bring the bulk of the oil as near to the point of combustion as possible.

It is also recommended that the tube should be filed thinner at the top where the wick is inserted, to prevent the escape of heat. Various lamps have been constructed for burning lard as well as lard oil, which have been found to answer very well. The burning of this oil has been introduced with entire success into the light-houses on Lake Erie. An objection has been made against lard oil, that it is not capable of being preserved in a liquid state in cold weather; but by a process similar to that by which the winter sperm is prepared, lard oil can be made which will not chill at $30^{\circ}$ of Fahrenheit.

The importance of this application of lard can scarcely yet be realized. Vast quantities of the oil can be manufactured at the West. Indeed, there is hardly any assignable limit to the power of production of the article, so that, while the demand continues, the business may be conducted profitably. The immense herds of swine which can be suffered to range over the lands adapted to them, and gather their food from mast as well as the surplus of corn, wheal, potatoes, \&c., on which they may be ustained, admit of the manufacture being carried on to almost any extent.

The proportion of lard to the whole hog is about 60 per cent., after taking out the hams and shoulders, or taking out the hams only: the estimate for hogs of the best breeds, and si fed as to produce the greatest quantity of fat, is 70 per cent. As the object is not in this case to make pork for food, the objectirn against those species of nuts, and other modes of feeding which render the animal more gross and oily, is obviated; and it has been proposed to feed out oil-cake to swine, to increase the proportion of oil.

By a new process of steaming, a very sim. ple method described by Mr. Stafford, it ap. pears that the whole of the lard or oily matter in the hog, or of tallow in cattle, may be obtained; while the danger of burning (common in other modes) is avoided, the consumption of fuel lessened, and the degree of pressure required not so great as otherwise. It will be recollected that, while conducting the manu. facture of lard, the other parts of the animal, as the hams and shoulders, may be tirned to profit. Besides these, also, the hide's may be tanned by a cheap process: and the bones, which are worth half a cent per pound, may be calcined and made into animal carbon, for which they are said to be worth, in this calcined state, $2 \frac{1}{2}$ cents per pound. (Ellsworth's Report.)

LARKSPUR (Delphinium, from delphin, a dolphin, in reference to the supposed resemblance in the nectary of the plant to the imaginary figures of the dolphin). All the species of larkspur are showy, and valuable as border flowers, especially $D$. ajacis and $D$. consolida, both of which are universally grown among the border annuals. The herbaceous and perennial kinds are increased by divisions or seeds, and the annual and biennial kinds merely require sowing in the open border, where they will flower and seed freely. The field larkspur ( D. consolida), grows wild in sandy or chalky corn-fields in England, and is regarded as a simple astringent. In gardens this species is called the branching larkspur, and attains the height of 3 or 4 feet, hlowing vivid blue flowers.

D. Grandiflorum is a hardy ind beautiful perennial, blowing dark blue flowers in July and August. It loves a dry soil, and open situation.

The bee larkspur is a beautiful perennial, blowing bright blue flowers in $\mathrm{J}^{\prime}{ }^{\prime} \mathrm{y}$ and $\mathrm{Au}$ gust. Sheep and goats eat the wila larkspur, horses do not relish it, while cows and swine totally refuse it. Bees are remarliably attached to its flowers, which are likewise gathered by the country people of Germany, cut small and mixed with tobacco, to improve its flavour.

LARVA (Lat. a mask). A term applied tı that state, in which an insect exists, immedi. ately after its exclusion from the egg, and which precedes the pupa state. The animals commonly called grubs, maggo!s, and caterpillars, are larvæ. Grub appears to be a seneral term analogous to larva; the term maggot is most generally applied to the larva state of dipterous insects ; and caterpillar, in the mos! common acceptation of the term, is used in ir $3 \times 2$ 
signate the larva state of lepidopterous insects. These terms, however, are used in a very vague manner. (Penny Cyclo. vol. xiii. p. 338.)

LAST. An uncertain quantity, varying in different countries, and with respect to various articles. The following quantities of different commodities generally make a last:-12 dozen of hides or skins; 12 barrels of meal ; $10 \frac{1}{2} \mathrm{qrs}$. of cole seed; 10 qrs. of corn or rape seed (in some parts of England 21 qrs. of corn go to a lasts); 12 sacks of wool, 1700 lbs. of feathers or flax. (M'Culloch's Com. Dict.)

LATHYRUS (from la, augmentative, and thouros, any thing exciting, in allusion to the medicinal qualities of the seeds). This genus belongs to the natural order Legumineæ. It consists for the most part of very handsome plants when in flower, well adapted for arbours or shrubberies, where they must be supplied with branches to support them, as they climb by means of tendrils terminating the footstalk, and sometimes without tendrils. Any common soil suits them; they are increased by seeds, and some of the perennial kinds by dividing the roots.

'The yellow vetchling ( $L$. aphaca) is an annual, flowering in June. The plant is glaucous, without any true leaves or leaflets, except near the root. The flowers are solitary on long stalks, small, drooping, lemon-coloured. The pod is an inch in length, nearly cylindrical, smooth, and containing six seeds, which produce intense headache if eaten in any quantity, while the roots of $L$. tuberosus are said to be wholesome food. (Paxton's Bot. Dict.) See VETCHLING.

Crimson vetch (L.nissolia) is also an annual, fowering in May. It is destitute of tendrils, it has a grass-like form, and bears beautiful crimson flowers, variegated with purple and white. The pod is long and the seeds numerous.

There are five other species of lathyrus:

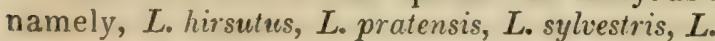
palustris, and L. latifolius, which is the only one of importance as a garden flower.

Broad-leaved, everlasting pea (L. latifolius) is a perennial, flowering in July and August. The herb is glaucous, the stem winged, the leaffets broadly elliptical, bluntish, three or five ribbed, and the tendrils in five branches. The stipules are ovate in their upper part, and broader than the stem. The flowers are large, handsome, of a fine rose colour, and in tufts of five or ten. The legume is long, compressed, and narrow. It is one of the most showy of the herbaceous species of the pea tribe; and well adapted as an ornanient to cottages.

Several American species of lathyrus are enumerated by Nuttall, among which are, $L$. myrtifolius found near Philadelphia. L. venosus, with about five pair of leaflets. This grows on the declivities of shady hills, and is comnon in the Alleghany mountains. L. polymorphus, with naked quadrangular stems, and four or five pair of leaflets. This is found on the grassy alluvial plains of the Missouri from its confluence to its sources. The flowers are, as large as those of the Pisum maritimum, and - f a tine purple, variable however in size. (Nuttall's Genera.) See Evenrastino Pra.

$-02$
LAUREL (from the Celtic word blaur the $b$ is dropped, signifying green, in allusion to the foliage of the plants). This is a very handsome and interesting genus of plants: among the most interesting and valuable of the hardy kinds, is the bay tree ( $\boldsymbol{L}$. nobilis), which is in. jured by severe frost. (See $\mathbf{B}_{\mathbf{A}} \mathbf{X} \mathrm{T}_{\mathrm{R} \mathrm{E}_{0} \text { ) } L} \boldsymbol{L}$ benzoin, $L$. sassafras, and several others are deciduous, and in some situations attain a great size. They may be increased by layers or cuttings of the roots. The bark of $L$. benzoin or spice wood is stimulant and tonic, and in North America it is used in intermittent fevers. In the $L$. fotens, an acrid red or violet juice is particularly abundant. All the species are more or less aromatic and stomachic.

The Portugal laurel (Prunus lusitanica), is a beautiful evergreen, which grows frum 10 to 15 feet high, blowing handsome spikes of white flowers in June and July. It forms a round head, and is very ornamental upon lawns.

The Alexandrian laurel (Ruscus racemosus) is a dwarf evergreen shrub, growing about two feet high, and blowing a yellow flower, suc. ceeded by beautiful red berries. See Kamia, Cherry Iauret, and Spurge Ladrex.

LAURESTINE, Lauristinus, or Wild Bay (Viburnum tinus, said to be derived from vieo, to tie; because of the pliability of sorne of the branches). All the species of viburnum are very elegant, rather early-flowering shrubs. The hardy kinds are well fitted for planting in ornamental shrubberies. They are increased by layers or by cuttings planted under a glass in a shady situation. The berries are vio. lently purging, but become eatable after fermentation, and are made into a sort of cake by theNorth American Indians. See Guelder RosE.

LAURUS (Sassafras, spicewood, \&c.). This extensive genus of shrubs and small trees, which afford the cinnamon, the cassia, and the camphor of commerce, is for the most part confined to the tropical and temperate latitudes. One species ( $L$. nobilis) is found in Europe; five in Japan; India affords three of the most important species, long celebrated as spices; in the Canary islands there are two, the tropical regions of America afford no less than 21, amongst the most remarkable of which is $L$. caustica of Chili, being poisonous, and the $L$. Persea, called avocado, and alligator-pear, producing a large and very grateful fruit formed like a pear.

In the Southern States two species are found, one called $L$. catesbai, and the other $L$. Carolinensis, or Red Bay. This last, which flowers in July, Mr. Nuttall says he has met witl as far north as Sussex county, in the state of Delaware. The whole plant is aromatic. See Sassafmass, Ren Bax, Camphor Tree, Spicfwoon, \&c.

I.AVA. The substances which flow in a melted state from a volcano. They vary considerably in texture and composition.

LA VENDER (Lavandula, from lavo, to wash, in allusion to the use formerly made of its distilled water in baths, on account of its fragrance). The hardy kinàs are the only plants of this genus worth cultivating.

Common garden lavender ( $L$. vera) is well 
known and much esteemed for the fragrance of its flowers, and the volatile oil which they yield by distillation with water. It is cultivated in great abundance for the London market, at Mitcham in Surrey. A very poor and light gravelly soil is best suited to this plant, being in such more fragrant, longer lived, and more capable of enduring severe weather than in a rich soil. In rich or moist soils it grows luxu. riantly, but is in general destroyed during the winter. The situation cannot be too open. It is propagated by slips and cuttings of the current year's shoots, which may be planted in May and June, as well as by cuttings of those which are a year old; these are to be planted in March, April, and early in May. Both slips and cuttings must be from five to seven inches in length, these, after being stripped to half their length of the lower leaves, are to be planted to that depth either in a shady border, or in any compartment, to have the shade of a mat during mid-day until they have taken root, in rows six inches apart each way. Water mast be given in moderate quantity every evening until fully established.

Having attained sufficient strength, they may be moved to their final stations in September or October, which is the season to be preferred if the soil is not light and dry on which they have been raised; or they may be left until the succeeding spring. If it is grown in considerable quantity for medicinal purposes, which is the only claim it has to a place in the herbary, it must be planted in rows two feet apart each way, otherwise, only detatched plants are inserted along the borders. The only after-culture required is the occasional employment of the hoe, the decayed spikes and branches being removed in autumn, and the surface gently stirred with the spade in the spring.

The flowers are ready for gathering either to dry or for distillation, in July or the end of June. The flowers are used as excitants and carminatives in medicine, in the form of tinctures. The nil is an agreeable perfume, and one or two drops rubbed up with sugar and mixed in water forms a useful draught in nervous headache and hysteria.

LAVENDER, SEA. See Thrift.

LAWN. A space of ground covered with grass, kept short by mowing, and generally situated in front of a house or mansion, or within the view from such. Lawns, when once established, require only to be kept neat by the ordinary routine of rolling, mowing, and sweeping, except keeping the surface perfectly even, by making up small hollows with screened mould early in spring. When lawns become worn out, a top dressing of any finely divided manure will refresh them; malt dust applied in October is excellent for this purpose; and at the same time an additional quantity of grass seed may be sown.

I.AY. A term applied to land in the state of grass or sward. This kind of ground is frequently distinguished into such as has been long in the state of sward, and such as is newly laid down to grass, or into old and new lays. The proper method of managing the latter is of great importance to the farmer, and which Young thought should be by keeping them per. fectly free from stock for the following atutumn and winter after their being laid down, when, in the spring, they will affird a growth of young grass highly valuable for sheep, with which they should only be well stoched, and kept down then, and during the following summer. Nothing, in his opinion, being more pernicious than mowing a new lay, as clirected by certain authors. 'They may, he thinks, have succeed. ed in spite of such bad management, tut never by it.

LAYERING. In gardening, an operation by which the propagation of plants is effected by laying down or bending the shoot, so that a portion of it may be covered with earth. $\Lambda$ shoot so operated on is called a luyer, and the point which furnishes the layers bears the name of stock. Some plants are so much disposed to emit roots that if their branches happen to come in contact with the earth they immediately begin to strike. Plants so situated a: to render it impossible to bend their branches to the ground, may nevertheless be layered by having their shoots introduced into a pot or box of soil elevated to them, and supported in a convenient position. 'ThL' is a common practice among the Chinese who cause branches of trees to root in this manner by partially ringing them, and covering their parts so ringed with a ball of clay, which is kept moist. (Penny Cyclo.)

LEADWORT (Plumbago; from plumbum, lead). A genus of pretty free-flowering plants, growing in any common soil, and increased readily by cuttings. The root of $P$. europaen, it is said, when chewed, will cure the toothache.

LEAF (Sax.). The well-known fine membraneous part of a tree or plant, which is put forth and unfolded in the spring, and which in some trees falls off in the autumn. "The leaf," says a writer in the Penny Cyclopcedia, "is an expansion of the bark of a plant, from whose axil a leaf-bud is developed: but this opinion is hypothetical. The leaf is usually thin, and traversed with one or more veins, composed of woody and vascular tissue; sometimes it is fleshy, and occasionally cylindrical, or nearly so." The functions of the leaf being at once that of respiration, digestion, and nutrition, its surface is covered with stomata, or breathing pores, which communicate with minute hollow chambers in its interior. It is in the leaf that all the peculiar secretions of a plant are prepared out of the under sap which the roots obtain from the soil, and which, carried up to the leaves, is exposed to the air, and undergoes the action of the vital chemistry which converts it into the proper juice. It is then returned $t$ the stem, and forms the different secretions of the plant, as resin, starch, sugar, gum, \&c. A leaf is either united to the stem by means of a petiole, or stalk, or it is sessile-that is to say, seated on the branch without an intermediate stalk; the veins pass through the petiole bcfore they can expand into the broad or green part forming the blade of the leaf. Some leaves are furnished with an appendage, which in grasses is a thin membranous boly arising from the base of the lamina, and in palms is a coarse net, formed, it is said, of tissue belong. ing to the veins of the leaves. When leaves 
have but one blade, they are simple. as in the apple; but when there is more than one blade, each seatcd on a ramification of the petiole, a leaf is called compound. Of these, and of the external form of the leaf, there are endless modifications. Between 200 and 300 are enumerated by Bischoff.

The distinction of leaves made by those who have written on botany are the following: a simpie leaf is that which is not divided to the middle. A compound leaf is divided into several parts, each resembling a simple leaf, as in liquorice, \&c. A digitate leaf is a leaf divided into several parts, all of which meet together at the base, as in hemp, black hellebore, \&c. A trifoliate leat is a compound leaf, consisting of three leaflets, as the trefoil, \&c. A quinquefoliate leaf is a leaf consisting of five leaflets, as in Hedera quinquefolia. A pinnated leaf is a compound leaf divided into several parts, each of which is called a leaflet, placed along a middle axis, either alternately or by pairs. When the axis is terminated by an odd leaflet, it is said to be unequally pinnated; and equally pinnated when it is not terminated by an odd leaflet, as in the cassia; when the leaflets are all nearly of the same form and bigness, it is called an uniform pinnated leaf, as in the liquorice; when they are not so, it is said to be difform, as in the agrimony. A winged leaf is a pinnated leaf, with an intervening membrane. A ramose leaf is that which is still farther divided than the pinnated leaf, as in the osmund royal, female fern, \&c. An entire leaf or lobe is that which has no division on its edges, as in the apple-tree, \&c. A sinuated leaf is that which is cut about the edges into several long segments, as in coinmon mallows. A serrated leaf is that which is cut about the edges into several acute segments, resembling the teeth of a saw, as in the nettle, \&c. A crenate leaf is that which is cut on the edges into several obtuse segments, as in betony, \&c. A laciniated or jagged leaf is that which is cut on the edges into several pretty deep portions in an irregular manner, as in the horned poppy, \&c.

All the experiments which have been made, in order to show how serviceable the leaves of trees and plants are to their well-being, have proved that when the plants have been divested of their leaves, or their leaves have been eaten or cut during their growth, they have been remarkably weakened or destroyed. If the leaves of plants be the means by which their juices are prepared for their support, as has heen just stated, it should teach us not to pull or cut off the leaves of trees or plants on any accouni, while they retain their verdure, and are in health, as they may be greatly injured thereby. Hence, probably, the error of the common. practice of feeding down wheat in the winter and spring with sheep, as, by so doing. the stalks may in many cases be rendered weak, and the ears shorter, the grains of corn not being so. plump and well nourished as when it is not fed down upon the ground. It is well known, too, that in grass which is often inowed, the blarles are rendered finer in pronortinn to the frequency of mowing; so that, fir uon this may be a desirable thing in lawns, \&c., where regard is had to the produce, it should certainly be avoided.

The leaves of trees or plants, where they can be collected in large quantities, as in parks and woods, may be highly useful in augmenting the manure heaps of the farm.

Mr. Young, in his Calendar, recommends that, in wooded countries, all the leaves that can be had at little expense, should be raked up in October, and carted to the yards and standing folds, for littering and making them into dung: he did it, he said, at $3 d$. per onehorse cart load. They do not rot easily, but that is, he thinks, no objection to them; they are a sponge to be saturated with urine, and if not touched previously to carting on to the land, will convey to the field much of what might otherwise be lost; and they are extremely useful in aiding the main object of bedding the yards in the autumn and winter season.See Botary.

LEAF-BUDS. Rudiments of young branches, made up of scales imbricated over each other, the outermost being the hardest and thickest, and surrounding a minute axis, which is in direct communication with the woods and cellular tissue of the stem. When stimulated by light and heat they extend into branches; or if artificially removed from the plant that bears them, they are capable of multiplying the individual from which they have been taken. In this case, however, the individual is not a pro. geny as from seed, but merely an extension of the parent.

LEAFLET. A part of a compound leaf, or a small leaf formed on the petiole of a leaf branching out.

LEAGUE. A measure of length, principally used in reckoning distances at cea. The sea league is 3 nautical or geographical miles, or the 1-20th of a degree, and consequently about 3.45 English miles. The common landleague is a well-known itinerary measure on the continent of Europe, chiefly in France. The French, however, have two distinct leagues; the legal posting league, containing 2000 toises, and equal to $2 \cdot 4.2$ English miles, and a league of 25 to the degree, or equal to about $2 \cdot 76$ English miles.

The word is said to have been derived from the Celtic leach, stone; the distances having been marked by stones in the Roman provinces. See MrL.

LEOPARD'S BANE (Doronicum). An ornamental genus, and from the plants flowering early in spring, they are well deserving of cultivation; they grow in any garden soil, and may be increased with facility by diviciing at the root.

The great leopard's bane (D. pardalianchis), is a perennial, native of Great Britain, growing in mountainous pastures or meadows. The root is creeping, and consists of several knobs connected by !ong fibres; woody at the crown. The stem is 2 or 3 feet high, hollow, round, leafy, and hairy; branched, and glutinous at the upper part. The leaves are rather soft and downy, heart-shaped, more or less regularly toothed, or wiry. The flowers, which appear in May, are solitary at the ends of the branches; 2 inches wide, of a uniform bright yellow; the 
earliest overtopped by sicceeding ones. The roots are aromatic, and used by sportsmen in Alpine countries against giddiness.

LEASE (from locutio, letting, or dimissio; from the French luisser, i. e. dimittere, to depart with). "A lease," says Woodfall, in his Law of Landlord and T'enant, "is a contract for the possession and profits of lands and tenements on the one side, and a recompense of rent or other income on the other; or it is a conveyance of lands and tenements to a person for life, or years, or at will, in consideration of a return of rent or other recompense. The party letting the land is called the lessor or landlord, and the party to whom the lease is made the lessee or tenant. The connection between landlord and tenant has gradually improved from that of master and slave intu a state of almost total independence and mutual interes in the soil.

"The beneficial effects, both to the landlord and tenant, of leases of a sufficient duration to encourage men of capital and skill to properly cultivate the land need hardly be pointed out. And it will be very desirable to have as few restraining covenants introduced into these as possible. They merely retard and annoy the good farmer, and rarely improve the practice of the unskilful.

"In the northern part of England, custom and expediency have very generally fixed the duration of the lease at about 20 years. Experience will evince that the time is not always more than enough to allow the possessor of the land to conduct and mature a profitable system of management, and to pay to the owner an adequate rent. All the great operations of the husbandman have a prospective result as regards the profit to be derived. The capital expended in such cases is only to be drawn back by periodical returns after the lapse of time. In the provirling of extraneous manures, in the adoption of rotations of crops, which, to be effectual to the purposes intended, must be extended through many seasons, in the draining of the land, and the like, time is necessary, both to effect the operations, and to recover with a future profit the capital employed. When, indeed, land is of very rich quality, and at onre productive, without other outlay than the mrdinary expenses of tillage, or when it has the means of fertilization near to it, and abundant, as in the vicinity of cities, the duration of the term may be comparatively short. Rut in other and dissimilar cases, this cannot be without a sacrifice of present income; ard a landlord will scarcely fail to experience that if there be not a sufficient period of secure possession accorded to the occupier, the necessary expenditure on the culivation of the ground will not be hazarded; iut more than this, a person of good capital will, like every trader, regard as a benefit the power of carrying on his business undisturbed, and will set a pecuniary value on security and independence." (Quart. Journ. of $\mathcal{A g r}$. vol. i. p. 795.) With regard to a lease in general, and its covenants, see a good paper (Ibid. vol. ii. p. 134). In speaking of rents, the author remarks, "As to the kind of rent to be paid, constant experience proves that the best and most satisfactory is a fixed rent in money.
To rents payable in grain, or in money regy lated by the prices of grain, there is this ob vious objection, that the tenant will generally be required to pay the highest rent when he is least able to do so, that is, when prices rise from a deficiency in the produce of the crop." And when speaking of the lease and its prp. cautionary covenants, he observes, "the great est error consists in vain precautions and al. tempts to provide against every possible contingency whicil, from the nature of the transaction, and the unforeseen events to which it may give rise, it is impossible to do. All that can be done is to make as precise as possible the conditions which experience shows to be necessary. The terms of the contract shoulc be few and simple, and easily understood and complied with. Not only are hurtful covenants to be avoided, but such as are unnecessary, since to increase the number of them tou much serves but to perplex the lessee, and give birth to future quarrels, and since all experience on the subject shows that the interests of either party may be sufficiently guarded without multiplying too much conditions, penalties, and restrictions."

LEASH. A term applied to game, \&c., by sportsmen, and which implies three; as three hares, partridges, \&c. It also signifies a line to hold a dog by.

LEATHER (Germ. leder; Dan. lüder). The prepared skins of animals. The principal object of the art of converting skin into leather is to render it strong and tough, durable, an.t often water-proof, and to prevent its destruction by putrefaction. The skins are first cleansed of hair and cuticle, then impregnated either with vegetable tan and extract, as in the pro. duction of what is called tanned leather. In this process the tannic acid, which is the active principle of the astringent vegetables employed, combines with the gelatin of the skins, and forms an insoluble tannate of gelatin. It is this formation which renders the skins impermeable to water, and checks the tendency to decomposition which they, in common with all animal matter, possess. Instead of tan, some leather is prepared with alum and other salts, as for tawed leather. These processes are sometimes combined; and tanned leather often undergoes the further operation of currying, or impregnation with oil. As instances of these different results, - thick sole-leather is tanned; white kid for gloves is tawed; the upper-leather for boots and shoes is tanned and curried; and fine Turkey leather is tawed and afterwards slightly tanned. Morocco leather, as it is called, is chiefly prepared from sheep-skins. Shammoy leather is generally sheep or due-skin, prepared by dressing, lining, \&c., and dyed, it necessary, and then finished in oil. Russia leather acquires its peculiar odour from birch tan. There is an excellent abstract of the manufacture of different kinds of leather in 're's Dictionary of Arts, \&c., which those who wish to pursue the subject further may consult. 'The: leather manufacture of Great Britain is of very great importance, being inferior, in point of value and extent, only to those af cotton, woot. and iron.

LEATHER-WOOD (Dirca galustris). This 
is a low shrub, and native of the United States, growing in moist, shady places, seldom rising more than four feet high, spreading into a head, with many small and very flexible branches. The flowers are produced at the extreme ends of the former years' shoots; they are of an herbaceous colour, and make a tolerable appearance. The flowers, which appear the latier end of March, before any perfect leaves, are of a yellow colour. The bark is ancommonly tough, yet the enclosed wood is very brittle. It was highly valued by the native Indians, and used in the place of cords. This plant, according to the information of Mr. W. Bartram, occupies an extensive range of territory, from Canada to Georgia. (Willich's Dom. Ency.)

LEAVEN (Lat. levare, to raise). A piece of sour dough, used to ferment and render light dough or paste. It is a very imperfect substitute for yeast; and as it communicates to the bread an astringent taste, which few persons relish, it ought to be used only where yeast cannot be procured. As, however, the latter ferment cannot always be obtained, especially luring winter, I shall state the most simple methods of preparing, as well as of preserving it, under the article YEAsT.

By the law of Moses, leaven was strictly forbidden during the passover; and the Jews, who were taught to regard it from the vigil of the feast as unclean, with religious scrupulo.ity purified their houses from the contaminat:ng influence. See BraAd.

LEEK (Allium porrum). The leek is a hardy biennial; for, although it attains perfection in size and for culinary purposes the first year, it does not run to seed until the second, the perfecting of which it aiso often survives. The whole plant is eaten, being employed in soups, \&c., and is by some persons boiled and eaten with meat. There are four varieties : the Musselburgh, and the large London leek, which are by far the best; the Scotch or flag, which is larger and hardier; and the Flanders. It is rajsed solely from seed, which must be sown first in the end of February, a small crop for transplanting in June and July, as well as in part to remain where sown; again for the main crop in the course of March or early in April ; and, lostly, towards the close of April or beginning of May, for late transplanting. These sowings are in general performed broadcast, and raked in; though some gardeners employ drills, the plants to remain after thinning: the leek, however, is so much benefited by transplanting as obviously to point out the error of this practice. When the plants are three or four inches in height, in eight or ten weeks alter sowing, they must be weeded, hoed, and thinned, where growing too close, to two or three inches apart; water also being given, in dry weather, will, with the above treatment, strengthen and forward them for transplanting in another month, or when six or eight inches high: They must be taken away regularly from the seed-hed, the ground being well waiered previously, if not soft and easily yielding. When thinned out, they may be left to remain in tne seed-bed six inches asunder, as they do not grow so large as the transplanted ines, which must be set by the dibble in rows ten 706 inches apart, and eight in the lines, being inserted nearly down to the leaves, that the neck, by being covered with the earth, may be blanched. Water in abundance must be given at the time of planting, and the long weak leaves shortened, but the roots left as unin. jared as possible. The bed should te hoed over occasionally, as well to kill the weeds as to loosen the soil. By this treatment, and by cutting off the tops of the leaves about once a month, as new ones are produced, the neck swells to a mach larger size. The several sowings above directed will yield a supply from August until the following May, when they advance to seed. A portion should be always taken up and laid in sand previous to the ground being locked up by continued frost, but they will not keep many days in this situation. To obtain seed, some of the finest roots of the previous year's growth, which have been left where raised, may be transplanted thence in February or the early part of March, eigh: inches asunder, in a row beneath a warm fence; and when seed-stems arise, they must be attached to stakes for support, or to the fencing: the closer and sooner they are drawn to this latter, the better will it enable the seed to ripen; for in cold summers, particularly in open exposures, it never comes to maturity, and by the first sharp autumnal frost it is entirely destroyed. Good varieties never flower before May or June, and ripen their seed in September. The heads should be cut when changed to a brown. ish colour, with a foot in length of the stalk left attached, for the convenience of tying in bundles, three or four together, to dry: when they are perfectly dry, they may be hung up and kept in the head until wanted, or immediately thrashed out and stored. As the husk is very tough, it is usual, when small quantities have to be operated upon, to rub them against a tile, which breaks it more easily than any other mode that can be adopted. (G.W. Johnson's Kitchen Garden.)

LEES. The dregs or feculencies of liquors, which, after being separated by fermentation, fall to the bottom of the vessels. All the various kinds of lees, such as those of wine, beer, ale, oil, \&c., may be made use of as manures when they can be had in sufficient quantities.

LEGS. The extremities that form the support of animals. Of the four legs of a horse, the two before have several parts, each of which has a peculiar name: thus, by the name of fore-leg, we commonly understand that part of the fore-quarters that extend; from the hough to the pastern-joint, and which is fiequently called the shank. The part that corresponds with it in the hinder quarters is called the instep. In the language of the manege, a horse is said to want the fifth leg when he is tired, and, bearing upon the bridle, lies heavy upon the rider's hand.

LEGUMINOUS PLAN'TS (from legumen, pulse) are those which bear legumes or pods, such as beans, peas, tares, \&c. The Leguminosa are a very extensive natural order of plants, found in all parts of the world, forming large trees and huge twiners in the tropics; herbaceous plants or small bushes, rarely trees in colder countries. 'The order contains a very 
great variety of useful and beautiful species, sume of which, like clover, lucern, sainfoin, and vetches, are cullivated for cattle; others, as beans, peas, lentils, and various other kinds of pulse, form part of the food of man. Indigo, logwood, and many more, are well-known dyeing plants: several acacias produce gum; certain Astragali yield tragacanth; the tamarind and others bear pods whose interior is filled with an agreeable pulp; Cassia aculifolia and other species of cassia yield senna; Glycyrrtiza, the liquorice-root; Ceratoria, the wild locust fruits of Scripture: finally, many are valuable tonics, and some are dangerous narcotics, among which the common laburnum is to be named.

Leguminous crops, according to the strict agricultural acceptation, include beans, peas, and other pulse. But the class is made to embrace a much more extensive range of plants, namely, all such as are considered as ameliorating or enriching crops, such as clover, potatoes, turnips, carrots, beets, cabbages, \&c. 'These latter are far less exhausting than the culmiferous or grain plants, as few of them mature their seeds, and all, on account of their broad leaves, draw more or less nourishment from the atmosphere. They also ameliorate the condition of the soil, by dividing and loosening it with their tap and bulbous roots. As they generally receive manure and drill culture, they are peculiarly adapted to enrich and prepare the soil for the culmiferous crops.

I.EICESTER SHEEP. See SнегP.

LEN'TICULAR. A botanical term, signifying lens or pea-shaped.

LENTIL (Evvun Lens, from erw, tilled land in Celtic; some of the species are a pest in cultivated ground, being useless and too prolific weeds). Pl. 7, s. An exotic plant of the vetch or tare kind, cultivated in some parts of England as fodder for cattle. The lentil is an annual, growing to the height of about eighteen inches, with stalks and leaves like those of tares, but smaller, and producing pale purple flowers, which are succeeded by small flat pods, containing two or three round, hard, smooth, and flat seeds. There are two sorts of lentil, the white and the yellow; but the latter affords the greater quantity of fodder. The seeds of this plant are generally sown in March or April, in the proportion of one and a half to two bushels per acre. Lentils also furnish good dry fodder for cattle, and particularly for cutting into chaff as trough-meal for sheep and horses.

LET'TUCE (Lactuca, from lac, milk, on account of the milky juice which exudes from the plants when broken). There are in England three indigenous species of lettuce, all biennials.

1. Strong-scented lettuce ( $L$. virosa), which grows about hedges, old walls, and the borders of fields on a chalky soil, not uncommon. The whole herb abounds with an acrid, fetid, milky juice, having the smell of opium, but only slightly narcotic, and little likely to produce the consequences attending the use of that drug. This juice springs out suddenly in large drops, on the slightest touch, from the calyx and tender leaves, when the plant is in flower, but not at other times; evincing a considerable degree

of irritability in the plant. The root 15 tapshaped. Stem solitary, two or three feet high, round, smooth, sparingly leafy, scarcely branched, panicled at the top, a little prickly below. Leaves horizontal, nearly smooth, finely toothed, radical ones numerous, obovate, undivided, depressed. Flowers numerous, panicled, lightyellow.

2. Prickly lettuce ( $L$. scariola). This species is found in waste ground, and dry, stony borders of fields. The whole herb is glaucous, milky, bitter, but less fetid than the preceding. Stem two or three feet high, leafy, panicled. Leaves numerous, vertical, not horizontal, va. riously pinnatifid and toothed; thin midrib furnished with a close row of prominent prickles, their base clasping the stem. Flowers small, pale lemon-coloured.

3. Least lettuce (L. saligna). This species grows in chalky waste ground, or about salt marshes. The whole plant is very slender. Stem about two feet high, wavy, pale-brown or whitish, somewhat branched, leafy throughout. Leaves glaucous, smooth except the midrib beneath, linear, hastate or pinnatifid, entire, sessile. Flowers in small alternate tufts composing long clusters, very small, pale-yellow, open in sunshine only, and soon fading. (Smilh's Eng. Flor. vol. iii. p. 344.)

Of the well-known cultivated lettuce ( $L$. sativa) there are many varieties, which are divided into families, the cos and the cabbage. The first are more grown in summer than winter; the second at all seasons, but more usually in winter, on account of their superior hardihood. The cos varieties are characterized by being of an upright growth, and, with the exception of the Brighton, require to have their leaves drawn together for blanching; the cabbage, as growing close to the ground, produces a blanched heart, in the manner of a cabbage, without any assistance. The cilicias are of a nature intermediate between the two. When young, the cabbage varieties are in general sweeter than those of the cos at the same age; but at full growth this is reversed: hence the latter are preferred for salads, and the former for soups.

The cabbage varieties succeed better in a hotbed than the cos.

The following varieties are recommended for cultivation in England; but as some of them have been found not to succeed well in this country, those enumerated in the article Kiтchen Garnex had better be depended on for the main crop.

CABBAGE VARIETIES.

Drumheaded.

Brown Dutch.

Tennisball.

IIardy green, or Capuchin.

Prussian.

Prince's.

Common white.

Large white.

Imperial.

Grand admirable.

Large Roman.

Lettuces thrive best in a light, rich soih, with a dry substratum. In a poor or tenacious one they never attain any considerable size, but run to seed prematurely. Like most other crops. that soil is to be preferred which is rich ratter
COB VARIBTIES.

\section{Brighton}

Black-seeded green.

Early Egyptian.

Green.

White or Versailles.

Silver.

Spotted or leopard.

Green and brown Cilicis Lop. 
from prior cultivation than the immediate application of manure. It is of advantage to trench it; and if manure is necessarily applied at the time of insertion, it should be in a state of forward decay. For the first and last crops of the year, a warm, sheltered situation is required; but for the midsummer ones, a border that is sheltered during the meridian, but far from being confined or under the shadow of trees, is to be preferred. Lettuce is propagated by seed: that for the first crop should be sown in a frame, on a warm border, or slender hotbed, at the end of January or early in February; at the close of this last month a larger quantity may be sown in any open situation, and repeated once every three weeks in small proportions until the end of July, for summer and autumn use; to be continued, at similar intervals, until the close of September, for winter and early spring. They may be sown either broadcast or in rows, moderately thin, each variety separate, lightly covered, and care being taken that the bed is trampled upon as little as possible. It is usual, when the plants are about a month old, or two inches in height, to thin them to three or four inches apart, those removed being pricked out at similar distances. Those from the sowings in January and February, in a similar situation to that in which they were raised; and thence until August in any open situation. Those of the August sowing must be divided into two portions; the largest being selected and planted in an open compartment for late autumn use, and the smaller on a warm border for winter and early spring.

When planted out finally, they must be set in rows a foot apart each way, which is abundant for the largest variety, and not more than necessary for the smaller. At the time of every removal, whether of picking out or planting, water must be given moderately, and until the plants are rooted. It may be remarked, that transplanted lettuces never attain so fine a growth as those left where sown, nor become so soon fit for use; those which are planted out at once to remain, being better in these respects than those which are pricked out previous to final planting. The difference in their time of becoming fit for use, however, is of advantage, as by these means a more perfect succession is obtained. Those which are planted to withstand the winter are best planted on the summit or south side of ridges, as this is a great protection from excessive wet, from which they always suffer. In every stage of growth they must be kept free from weeds, well watered, and the earth around them frequently stirred for the extirpation of slugs and snails, which are particularly injurious, and are very preva. lent in moist seasons.

' $N$ hen the cos varieties have attained an advanced growth, they require their leaves to be drawh together with a shred of matting, to render the interior blanched, care being taken that it is not performed so tight as to bruise them. Utder every favourable circumstance for a vigo ous growth, the plants, especially of the cos varieties, and during dry seasons, will yet run up to seed before the heart is perfectly blanched: to retard this, it is an effectual practice, at the ume of tying them up, to cut out the centre of 708 each with a sharp knife. The plants raised from the September sowing may be divided as directed for those of August; but, in addition, some of the cos varieties may be planted on a warm border, to have the shelter of frames and hand-glasses.

To produce seed, some of the finest and most perfect plants of each variety that have survived the winter, or from the forwardest sowing of the year, should be selected. The seed from any that have run up prematurely cannot be depended upon. All other plants must be removed from their neighbourhood, themselves being left at least a foot apart; neither is it allowable for two varieties to flower near each other, as only mongrel varieties will be obtained. Each stem is advantageously attached to a stake, as a support in tempestuous weather. It is to be observed, that the branches must be gathered as the seed ripens upon them, and not left until the whole is ready, as some will ripen two or three weeks before others, and consequently the first and best seed will be shed and lost. It must be well dried before it is beaten out and stored. Lettuce seed is considered to be best the second year; but when three years old it refuses to vegetate.

The juice of the lettuce inspissated is termed lactucarium. It possesses slight narcotic properties, and is useful in coughs.

LETTUCE, LAMB'S. See Corr SALAD.

LEVELLING. In husbandry, implies rendering the ground even, and removing of impediments to the common operations of tillage. This is generally done by the plough, but sometimes machines are employed for the purpose.

LEVER. In mechanics, an inflexible rod or bar, movable upon a fulcrum or prop, and having forces applied to two or more points. The lever is one of the mechanical powers; and being the simplest of them all, was the first that was attempted to be explained.

Examples of the application of the lever are of constant occurrence in the mechanical arts. The crowbar, the handspike, nippers, pincers, \&c., are levers of the first kind. The second kind includes the chipping knife, the common door, nutcrackers, the wheelbarrow, \&c. To levers of the third kind belong the sheep-shears, the treddle of the turning-lathe, tongs, \&c. The bones of animals are generally levers. The socket of the bone is the fulcrum; a strong muscle, attached to it near the socket, is the power; and the weight of the limb, with whatever resistance is opposed to its motion, is the weight. A very moderate contraction of the muscle thus gives considerable motion to the limb. (Gregory's Mech. vol. ii.)

LEVERET. A young hare, in the first year of tts age.

LEY, LEA, or LAY. Land in the state of sward or grassy surface.

LIBER (Lat. bark). In botany, the interior lining of the bark of exogenous plants. It consists of woody tissue in great quantity, and very thick-sided, intermixed with cellular tissue. It appears to be formed annually, at the same time as the concentric zones of wood, and is intended by nature to convey downwards the secretions elaborated in the bark and leaves 
The liber is the principal seat of lactiferous vessels.

LIBRARIES, FARMERS'. Collections of books on agricultural and horticultural subjects are now becoming very general throughout the country, through the instrumentality of farmers' clubs. They cannot fail of being eminently useful to the cause of agriculture, by fiffusing among the cultivators of the soil the latest discoveries and improvements in liusbandry, as well as the different opinions and theories entertained on matters having reference to agriculture and its collateral sciences of chemistry, botany, natural history, geology, meteorology, and vegetable physiology, \&c.

LICE ON ANIMALS. There is not an animal that does not, under suitable circumstances, nourish in its hair, wool, feathers, or its skin, some kind of louse; and sometimes more than one kind of these parasites lodge and prey on the same animal. In ordinary cases, they do not produce much mischief, but when they increase so much as to produce the disease called mange (Pityriasis), they become truly formidable. The cause of animals being troubled with lice, may usually be traced to a want of cleanliness. When the dust and sweat accumulated on the hair, and in contact with the skin of the ox or horse, are allowed to remain undisturbed by the comb or brush; when the stables are kept filthy, unventilated, and unwholesome; when animals, reduced in autumn by want of pasture, or by living in unhealthy ones, are suffered to take their chance for the winter without extra care or attention; or when a beast loaded with pediculi is turned in to the yards or the stables of those exempt from these parasites, it may be expected that they will multiply and infest animals. When we see horses rubbing their tails, biting their manes, and showing other signs of urieasiness and irritation; when cattle are observed to be rubbing their heads against posts or fences, and the hair coming off from the head and neck; or when sheep tear out tufts of wool with their teeth, and bite these places till blood appears, we may expect that lice are present. On most animals, these parasites have some favourite place of resort; on horses, the mane and tail; on horned cattle, around the nose, base of the horns, and the neck; on sheep, they run over every part; and on swine, they do not seem to be confined to any particular location.

Pure air, room for exercise, plenty of food, and above all, cleanliness, are the first things to be attended to in the cure of this evil. Currying, brushing, and washing should be resorted to, as, except in bad cases, this treatment will be usually sufficient to free the animal from these insects, without recourse to other remedies. Where these fail, it will be necessary to have recourse to such external or internal applications as shall operate directly on the vermin.

One of the most common remedies is the mercurial ointment, commonly called unguentum; but this, though effectual, cannot be used without some danger, as numerous instances have occurred in which valuable animals have been destroyed by its too free use. Care should be taken to prevent the animal from biting itself where the ointment is applic $\lambda$, until it has had time to take effect. A decoction of tobacco leaves, in a strong lye, forms a very good wash; but this, too, owing tis the narcotic poison of the tobacco, has caused death. Various vegetable remedies have been resorted to, among which are the seeds of the larkspur (Delphinium staphysagria); and the leaves and flowers of the ledum palustre, or marsh, or Labrador tea. The roots of the black hellebure, or a decoction made from them, have been used with success; and it is said that the water in which the skins or parings of potatoes have been boiled will effectually destroy lice by a few washings. The internal use of sulphur is an excellent remedy, and if given to animals occasionally, is one of the best preventives.

It is more difficult to apply remedies for lice to sheep than to any other animals. The English shepherds make use of a salve compounded of white arsenic and corrosive sublimate, carefully parting the wool, and applying the ointment in small quantities directly to the skin, and rubbing it down with the finger. 'Tessier prefers tobacco smoke to this ointment, as attended with less danger in its use. The sheep is held in such a manner that tobacco smoke is forced from a bellows among the wool to the skin in all directions. After this fumigation, the sheep must be placed in the open air, that the vapor may have room to pass off without being inhaled by them. Perhaps the best remedy for lice in animals, where they have not become so numerous as to produce the disease Pityriasis, is to rub any oil, such as whale oil or melted lard, on such places as they most frequent, or on parts of the animal where they will be most likely to come in contact with it. All the pediculi breathe through what are termed spiracles or openings in their bodies, and the least particle of oil spread over their bodies, by causing suffocation, at once effects their destruction. This is also a perfectly harmless remedy. But prevention in this case is better than cure; and neatness, cleanliness, and good keeping, by insuring comfort and health, leaves no opportunity for the attacks of vermin. (Cultivator.)

LICE ON PLANTS. See Aphidrays, Axerucan Blight, and Insects.

LICHENS. Plants of a very low organization, which grow on the bark of trees or rocks, when they form a kind of incrustation, or upon the ground, when they consist of irregular lobes, parallel with the earth's surface. Occasionally, in all situations, they are found in a branched state; but their subdivisions are generally irregular, and without order. Their fructification consists of hard nuclei, called shields, which break through the upper surface of the thallus, or main substance of the lichen, are of a peculiar odour and texture, and contain the reproductive particles. Lichens abound in the cold and temperate parts of the world. The greater part are of no known use; bus some, as the reindeer-moss (Cenomyse rangiferina), the Iceland moss (Cetraria Islandica), and various species of Gyrophora, are capable of sustaining life, either in animals or man. The Iceland moss, when deprived of its bitterness by soaking in an alkali and then boiling, br. 30 709 
comes, indeed, a diet recommended to invalids. Others are used as tonic medicines, as Variolxria faginea and Parmelia parietina. 'Their principal use is, however, that of furnishing the dyer with brilliant colours; orchall, cudbear, and perolle, with many more, are thus employed. (Brande's Dict. of Science.) See Moss.

LICKS. A term applied in the United States to places where salt springs escape from the earth and impregnate the soil, and sometimes give rise to an efforescence of common salt. To such spots the deer, buffalo, and almost all graminivorous animals resort, for the purpose of licking the surface. See SALT.

LID. In botany, the calyx which falls off from the flower in a single piece.

LIFE EVERLASTING. See Cunwran.

LIGHT, ITS INFLUENCE ON VEGETATION. That light has a considerable influence upon the growth of plants, is an observation that must have been very early made by mankind. The inferior green colour of plants growing in the shade, as in woods, or when covered with earth, or inverted vessels, would clearly indicate to the most careless observer, that light at least influenced the colour of vegetation: every gardener, in truth, takes advantage of this fact, when he is blanching his culinary vegetables. But it was not till after the days of Priestley, that the other chemical effects which light produces upon a growing plant were so much better understood.

It is probable that this influence commences at a very early period in the life of the plant, with even the germination of the seed. Ingenhouz, says Dr. Thomson, found that seed always germinate faster in the dark than in the light. (Exper. surla Veg. 11.) And these experiments were repeated by Sennebier with equal success. (Mém. Physico-Chem. vol. iii. p. 41.) But the Abbé Bertholin, who distinguished himself so much by his labours to demonstrate the effect of electricity on vegetation, objected to the conclusions of these philosophers, and affirmed that the difference in the germination of seeds in the shade and in the light, was owing, not to the light itself, but to the difference in the moisture in the two situations, the moisture evaporating much faster from the seeds in the light than from those in the shade; and he affirmed that when precautions were taken to keep the seeds equally moist, then those in the sun germinated sooner than those in the shade. (Jour. de Physique, 1789.) But when Sennebier repeated his former experiments, and employed every possible precaution to insure equality of moistare in both situations, he constantly found the seeds in the shade germinated sooner than those in the light. We may conclude, therefore, that light is injurious to germination; and hence one reason for covering seeds with the soil in which they are grown. But from the more recent experiments of Saussure, there is reason to believe that light is only injurious 10 vegetation in consequence of the heat it produces; for where the direet rays of the sun were intercepted, though light was admitted, the germination of the seeds was not sensibly relarded. (Rech. Chem. sur la Veg. p. 23; Thom. v's Chem. vol. iv. p. 307.)

An't with regard to the after-g 'wth of plants, 710 light exercises a very considerable influence. It is now clearly ascertained that plants vegetating in the light, abscrb carbonic acid gas from the atmosphere, and emit oxygen gas; but when vegetating in the dark different effects are produced, for then carbonic acir gas is emitted, and oxygen gas absorbed. (See Gases.) This latter process is thus explained by Liebig:- "It is true that the decomposition of carbonic acid is arrested by the absence of light; but then, namely, at night, a true chemical process commences, in consequence of the action of the oxygen in the air upon the organic substance, composing the leaves, blossoms, and fruit. This process is not at all connected with the life of the vegetable organism, because it goes on in a dead plant exactly as in a living one. The substances composing the leaves of different plants being known, it is a matter of the greatest ease and certainty to calculate which of them during life should absorb most oxygen by chemical action where the influence of light is withdrawn. The leaves and green parts of all plants containing volatile oils, or volatile constituents in general, which change into resin by the absorption of oxygen, should absorb more than other parts which are free from such substances. Those leaves, also, which contain either the constituents of nutgalls, or compounds in which nitrogen is present, ought to absorb more oxygen than those which do not contain such matters. The correctness of these inferences has been distinctly proved by the observations of De Saussure; for whilst the tasteless leaves of the Agave Americana absorb only 0.3 of their va lume of oxygen in the dark during 24 hours, the leaves of the Pinus abies which contain volatile and resinous oils absorb 10 times, those of the Qucrcus robur containing tannic acid 14 times, and the balmy leaves of the Populus alba 21 times that quantity. This chemical action is shown very plainly also in the leaves of the Cotyledon calycinum, the Cacalia ficoides, an' others; for they are sour like sorrel in the morning, tasteless at noon, and bitter in the evening. The formation of acids is effected during the night by a true process of oxydation; these are deprived of their acid properties during the day and evening, and are changed, by separation of a part of their oxygen, into compounds containing oxygen and hydrogen, either in the same proportions as in water or even with an excess of hydrogen, which is the composition of all tasteless and bitter substances. When the green leaves of the poplar, the beech, the oak, or the holly, are dried under the airpump, with exclusion of light, then moistened with water, and placed under a glass globe filled with oxygen, they are found to absorb that gas in proportion as they change in colour. The chemical nature of this process is thus completely established. The diminution of the gas which occurs can only be owing to the union of a large proportion of oxygen with those substances which are already in the state of oxides, or to the oxydation of the hydrogen in those vegetable compounds which contain it in excess. The fallen brown or yellow leaves of the oak contain no longer tannin, and those of the poplat no balsamic constituents. (Org. Chem. p. 28.) 
The action of light upon the growing plant is in every point of view full of interest to the cultivator: "If all the branches of a tree, exclusive of one," said Mr. T. M. Knight (and he was one of the ablest of modern vegetable physiologists), "be much shaded by contiguous trees, or other objects, the branch which is exposed to the light attracts to itself a large portion of the ascending sap, which it employs in the formation of leaves and vigorous annual shoots, whilst the shaded branches become languid and unhealthy. The motion of the ascending current of sap appears, therefore, to be regulated by the ability to employ it in the trunk and branches of the tree; and this current passes up through the alburnum, from which substance the buds and leaves spring. But the sap which gives existence to, and feeds the root, descends through the bark, and if the operation of light give ability to the exposed branch to attract and employ the ascending or alburncus current of sap, it appears not inmprobable that the operation of proper food and moisture in the soil, upon the bark of the root, may give ability to that organ 10 attract and employ the descending or cortical current of sap." (Selection of Papers, p. 160.) "M. Decandolle, I believe, first observed that the succulent shoots of trees and herbaceous plants, which do not depend upon thers for support, are bent towards the point from which they receive light, by the contraction of the cellular substance of their bark upon that side, and I believe his opinion to be perfectly well founded. The operation of light upon the tendrils and stems of the Ampelopsis and ivy appears to produce diametrically opposite effects, and to occasion an extension of the cellular bark wherever that is exposed to its in fluence; and this circumstance affords, I think, a satisfactory explanation why these plants appear to seek and approach contiguous opaque objects, just as they would do if they were conscious of their own feebleness, and of power in the objects to which they approach, to afford them support and protection. The tendril of the vine is internally similar to that of the ampelopsis, though its external form and mode of attaching itself, by twining round any slender body, are very different. Some young plants of this species which had been raised in pots in the preceding year, and had been headed down to a single bud, were placed in a forcing house, and the shoots from these were bound to slender bars of wood, and trained perpendicularly upwards. Their tendrils, like those of the ampelopsis, when first emitted, pointed upwards, but they gradually formed an increasing angle with the stems, and ultimately pointed perpendicularly downwards, no object having presented itself to which they sould attach themselves. Other plants of the vine, under similar circumstances, were trained horizontally, when their tendrils gradually descended beneath their stems, with which they ultimat ly stoon very nearly at right angles. A third set of plants were trained almost perpendicularly downwards, but with an inclination of a few degrees towards the north, and the tendrils of these permanently retained very nearly their first position relatively to their
Stems; whence it appears that these organs like the tendrils of the ampelopsis and the claws of the ivy, are to a great extent under the control of light. A few other plants of the same species were trained in each of the preceding methods, but proper objects were placed in different situations near them, with which their tendrils might come into contact, and I was by these means afforded an opportunity of ob. serving with accuracy the difference between the motions of these and those of the ampelopsis under similar circumstances. The latter al. most immediately receded from light, by what. ever means that were made to operate upon them; and they did not subsequently show any disposition to approach the points from which they once receded. The tendrils of the vine, on the contrary, varied their positions in every period of the day, and afterwards returned again during the night to the situations they had occupied in the preceding morning, and they did not so immediately or so regularly bend towards the shade of contiguous objects. But as the tendrils of this plant, like those of the ampelopsis, spring alternately from each side of the stem, and as one point only in three is without a tendril, and as each tendril separates into two divisions, they do not often fail to come into contact within their reach, and the effects of contact upon the tendrils are almost immediately visible. It is made to bend towards the body it touches, and, if that body be slender, to attach itself firmly by twining round it, in obedience to certain causes. The tendril of the vine, in its internal organization, is apparently similar to the young succulent shoot and leaf-stalk of the same plant; and it is abundantly provided with vessels or passages for the sap; and I have proved that it is alike capable of feeding a succulen shoot, or a leaf when grafted upon it. It appears, therefore, I conceive, not improbable that a considerable quantity of the moving fluid of the plant passes through its tendrils, and that there is a close connection between its vascular structure and its motions." (Ibid. p. 166.

"The stems of the potato," he adds in another place, "as of uther plants, rise perpendicularly under the influence of their unerring guide, gravitation, so long as they continue to be concealed beneath the soil; but as soon as they rise above it they are, to a considerable extent, under the control of another agent, light. Each inclines in whatever direction it receives the greatest quantity of it, and consequently each avoids and appears to shun the shade of every contiguous plant; gravitation labouring to give a perpendicular, the other a horizontal direction to the leaves, and the comparative power of one agent increasing, as that of the other decreases." (Ibid. p. 300-306.)

The opinions of Liebig, as to the chemical changes produced in plants, by the action of light, and its withdrawal, seem confirmed, in some degree, by those of Davy. "In the changes that take place in the composition of the organized parts," said that excellent philosopher, "it is probable that saccharine compounds are principally formed during the ab. sence of light; gum, woody fibre, oils, a a:? 
resins, during its presence; and the evolution of carbonic acid gas, or its formation during the night, may be necessary to give greater solubility to certain compounds in the plant. (Agric. Chem. p. 223.) And after giving a variety of experiments to elucidate the action of vegetation on the atmosphere (see Gases, their Usfis to Vegetation), he adds, "These facts confirm the popular opinion, and when the leaves of vegetables perform their healthy functions, they tend to purify the atmosphere in the common variations of weather, and changes from light to darkness. It may occur, however, as an ohjection to these views, that if the leaves of plants purify the atmosphere towards the end of autumn, and through the winter and early spring, the air in our climates must become impure, the oxygen in it diminish, and the carbonic acid gas increase, which is not the case; but there is a very satisfactory answer to this objection. The different parts of the atmosphere are constantly mixed together by winds which, when they are strong, move at the rate of from 60 to 100 miles in an lour. In our winter, the southwest gales convey air which has been purified by the vast forests and Savannas of South America, and which, passing over the ocean, arrives in an uncontaminated state. The storms and tempests which often occur at the beginning and towards the middle of our winter, and which generally blow from the same quarter of the globe, have a salutary influence. By constant agitation and motion, the equilibrium of the constituent parts of the atmosphere is preserved; it is fitted for the purposes of life: and those events which superstition formerly referred to the wrath of heaven, or the agency of evil spirits, and in which they saw only disorder and confusion, are demonstrated by science to be ministrations of Divine intelligence, and connected with the order and harmony of our system." (Ibid. p. 230.)

LIGHTNING. An electric phenomenon, produced by the passage of electricity between one cloud and another, or between a cloud and the earth. The identity of lightning with electricity, though it had been previously suspected, was first directly demonstrated by the celebrated Dr. Franklin, in the year 1749, by the experiment of drawing sparks by the electric kite. Since that time the science of electricity has been greatly advanced; nevertheless, the cause of some of the appearances connected with lightning is not well explained even at the present day.

There are three phenomena in particular for which theory fails satisfactorily to account. The first is the form of the flash, which is almost always zigzag, or in broken lines, making a greater or smaller angle with each other. The second is the frequent repetition of the flashes from the same cloud, which often follow one another in quick succession, contrary to what takes place in the case of electric conductors, which generally recover their natural state, or discharge the whole of their electricity at a sirgle stroke The third is the length of the flash, which sometimes appears to embrace a large extent of the sky. This phenomenon can be best observed from the tops of mountains, $\div 12$ reaching above the clouds from which the light. ning proceeds; and observers in such cases agree in stating that they have seen flashes certainly extending several miles in length.

The zigzag form of the flashes is common to lightning and the electric spark: the same explanation should consequently apply to both; but this the theory has not yet been able to give.

'The theory of the electric fluid, and the wellascertained differences in the conducting power of different substances, suggested the idea of protecting buildings from the destructive effects of lightning by metallic rods. Such rods are usually made of iron about half an inch in diameter. The lower portion should descend into the ground some 3 or 4 feet, and in all cases penetrate to the moist earth. It should be made rather larger than the rest of the rod, and have a slant from the foundation, or outwardly. Some recommend that the lower end should be pointed in the same manner as the upper extremity. The top of the rod should have one or more sharp points. As iron is so liable to rust, by which the points become blunted, it is usual to have these either gilt or tipped with platinum, so as to be preserved from oxidation. The tops of the rods may be raised some 4,6 , or 8 feet above the chimneys or highest points of the buildings they are intended to protect. If the buildings be large, there shoul be more points than one elevated at the different parts. Indeed, some persons who have devoted attention to the subject, say that there should always be several projecting points raised to receive the lightning from different directions. Lightning rods cost but little, as the platinum points can be bought for $\$ 1,25$, and the conductors may be easily made by any blacksmith. They should have as few joints as possible, and be inspected from time to time to see whether any separation exists, and whether the joint remains in its place. Where, from rust or other causes, any interruption to the course of the electric fluid occurs, a lightning rod, instead of furnishing protection, is an additional source of danger.

LIGHTS, NORTHERN, or AURORA BOREALIS. A luminous meteor, generally appearing in the northern part of the sky, and presenting a light. somewhat resembling the dawn or break of day. The appearances which it exhibits, and the forms it assumes, are so proverbially unsteady, that it is not possible to comprehend them under any general description. In the Shetland Isles, and other countries in high latitudes, the northern lighis are the constant attendants of clear and frosty evenings in winter. They are most frequent in autumn. A very interesting account of this meteor, and of the works treating on this subject, vill be found under the head "Aurora Borealis," in Frande's Dict. of Science, \&c.

LIGNEOUS (I,at. lignum, wood). In entomology, a part so called when it is composed of a hard, inelastic substance like wood.

LIGNIN (Lat. lignum). The woody fibre. This most important proximate principle of vegetables exhibits itself in a variety of forms, constituting the different textures of hard and soft wood, and various fibruus products, such as hemp, flax, cotton, \&c. When by fine me. 
chanical division it is reduced to a pulpy state, it is formed into paper. When by different reagents all the soluble matters are extracted from wood, the insoluble residue is lignin; its ultimate components are carbon, oxygen, and hydrogen, the two latter elements being in the same relative proportions as in water; so that woody fibre may be considered as a compound of carbon and water, and, according to Dr. Prout's experiments, almost exactly in equal weights. Lignin is very unperishable, but under certain circumstances it is attacked by dry rot, arising out of the growth of a parasitic fungus, which causes its rapid decay. Damp timber, in situations where air has not free access, is particularly subject to its attacks; and when once it has made its appearance, the well-seasoned timber in its neighbourhood becomes liable to the same disease. The dry rot may be prevented by impregnating the timber with certain saline solutions, and of these, solution of corrosive sublimate has been found most effectual; this (the bi-chloride of mercury) combines chemically with the albumen of the wood, and the compound is very inde. structible. (See Dar Ror.) Lignin has also a strong attraction for alumina, and hence linen, cotton, paper, and other forms of this fibre, may be aluminized by steeping them in hydrated alumina diffused through water, or more effectively by soaking them in certain aluminous solutions, drying them, and afterwards washing out the excess of the salt. It is in this way that cotton goods are impregnated with alumina for the purpose of dyeing and calico printing. Other metallic oxides exhibit similar attractive powers, especially the oxide of iron. The analogy that exists between the composition of sugar, gum, starch, and even vinegar and lignin, suggests the possibility of the conversion of those substances, by an cxchange of their proximate elements, into each other; and it has accordingly been found that by carefully roasting pure and fine sawdust, it is rendered partially soluble in water, and that a part of it is converted into a nutritious substance, probably intermediate between sugar and starch, and which, when mixed with a little flour, yields a palatable bread, not very unlike that made by some of the inhabitants of the northern parts of Europe of the bark of trees. Mixed with sulphuric acid, lignin passes into gum, and from this sugar may be obtained, by boiling it for some hours in a very dilute silphuric acid; this sugar, when purified, much resembles grape or honey sugar. By this process, rags may be converted into nearly their own weight of this peculiar saccharine matter.

The production of vinegar by the destructive distillation of wood, was originally suggested about the middle of the 17th century, by Glauber, a celebrated German chemist of that time; it has lately become a very important branch of manufacture in England. Upon the whole, there are very few natural products equally important with lignin in their applications to the useful and ornamental arts. See PrnoIIG NEOUS AcID.

ILILAC (Syringa, from syrinx, a pipe. The branches are long and straight, and are filled with medulla; hence the old name of the lilac, pipe-tree. The English name of the gersus is from lilac or lilag, the Persian word for the flower). The species of lilac are well known elegant shrubs.

The common lilac (Syringa vulgraris) is a shrub originally from Constantinople, growing to the height of 18 or 20 feet. The elegant lilac-coloured bunches of flowers are very sweet and graceful to the eye. There is also the white lilac, still more delicate-looking, and equally sweet-scented. The most beautiful variety of the common purple lilac is that known by the title of the Scotch lilac.

The Chinese lilac ( $S$. chinensis) is a native of China, and less in size than the common lilac; it was first brought to this country in 1795. Blooms violet-coloured flowers in May. The Persian lilac (S. persica) is a native of Persia, and seldom exceeds five or six feet in height, blowing light purplish pink flowers in May. The lilacs love a good garden soil, and may be propagated by layers, shoots, and suckers from the roots.

LILY (Lilium, derived from the Celtic word $l i$, signifying whiteness; on account of the beautiful white flowers of the original species). This is a fine ornamental and well-known genus of exotic plants, almost all of which are remarkable for the delicacy and beauty of their flowers. Most of the species succeed in a rich, light soil, but the American species should be grown in peat. (Paxton's Bot. Dict.) Miller, in his Dictionary, mentions 13 species, with their varieties: but there are now more than $\mathbf{3 4}$ known species, besides innumerable varieties: the finest for garden ornament are as follows:-

The superb martagon (L. superbum). A beautiful plant, blowing many bright orange flowers spotted with violet. It loves bog soil.

Purple martagon, which grows 3 or 4 feet high, blooming reddish or white flowers spotted with purple. It blows in July. It is sometimes called Turk's cap. It is a native of Germany.

Scarlet martagon ( $L$. chalcedonicum). Native of the Levant, blowing a bright scarlet flower in June and July. It likes a good soil.

Turk's turban (L. pomponium), blows a pretty pendulous red flower in June, in the shape of a turban. In Kamschatka the bulb of this species is cultivated the same as the potato is in this country.

Orange or fire lily ( $L$. bulbiferum). Large flower, of a deep orange colour, llowering in June and July. The Russians and Tungusians also eat the roots of this species, either boiled in milk or roasted. A German author informs us that these mealy roots might, in times of scarcity, be made into wholesome bread. The roots are cathartic, and the leaves cooling.

Tiger lily ( $L$. tigrinum). A beautiful showy bulb, blowing an orange flower in June: is loves a sandy soil and open situation.

Philadelphian lily (L. Philadelphicum). Na tive of North America, blowing a deep orange spotted or scarlet flower in July. This very elegant plant may be known from the other 3 o 2
719 


\section{LILY OF THE VALLEY.}

species by the claws of the petals. The colour of the flower is orange-red. Protect it in winter by spreading coal ashes over it.

The American or Canadian lily ( $L$. Canadense), has flowers of a yellowish orange. It is a fine plant, growing 2 or 3 feet high, and found in abundance on the marshy shores of the Delaware below Philadelphia. It is perennial, and flowers in July.

The Superb American lily ( $L$. superbum), is a magnificent plant, which, says Dr. Wm. P. C. Barton, may be ranked among the finest vegetable productions of the United States. It frequently attains the height of 6 or 7 feet, supporting a profusion of elegant deep scarlet flowers. It is found on the marshy shores of the Delaware, and in the bogs of New Jersey and other states. A perennial, flowering in July and August.

'The common white lily ( $L$. candidum), is too well known to need description. It is hardy, and produces a beautiful flower, the fragrant odour of which is so powerful as to induce fainting if numbers of them be kept over night in a close apartment. The bulb roasted is emollient and suppurative. All descriptions of lilies are propagated freely by offsets from the bulbs, which should be taken up when the stem decays, and parted and replanted early in October, 5 to 6 inches deep, in a light, dry soil. The bulbs of martagons must never be transplanted till after the stem is decayed, as they will not bear being disturbed. Many varieties of lilies are produced from seed, which is treated in the same way as tulip seed.

LILY-OF-THE-VALLEY (Convallaria majalis, from the Latin convallis, a valley). This very elegant sweet-scented indigenous perennial is not reckoned among the lily tribe. It grows in woods, heaths, and at the foot of hills, flourishing and shedding its fragrance in May and June. The roots are thread-shaped, creeping, much entangled. Leaves two, radical, eliptical, 3 or 4 inches long, acute, entire, many-ribbed, smooth-stalked. Flower-stalk solitary, simple, radical, naked, semi-cylindrical, bearing a simple curved cluster of several pendulous, cup-shaped, white flowers, with rather distant segments. Berry as large as a black currant, scarlet. There are varieties with double or with purple flowers, sometimes seen in gardens; but not easy of cultivation, and far less elegant than the wild kind, which is among the most favcurite of our native flowers.

This vegetable is eaten by sheep and goats, but refused by cows, horses, and swine. The flowers when dried have a narcotic scent, and if reduced to powder excite sneezing; hence they are sometimes used as a sternutatory. A beautiful green colour may be prepared from the leaves, with the addition of lime. The lilyof-the-valley will grow in any moist, shady situation, and even under the drip of trees, where few other plants would succeed. It is multiplied by dividing the roots in autumn. See Solomor's Siat.

LILY, THE DAY (Hemerocallis, from inpéses, a day, and xánsos, beauty; alluding to the beauty and duration of the flowers). This is an ornamental genus of exotic flowering plants of the 714 simplest culture, thriving well in any light loamy soil, and readily increased by divisions. The most common species are the yellow daylily (H. flava), a native of Siberia, blowing yellow flowers in June, and the fulvous or coppercoloured day-lily ( $H$. fulva), a native of the Levant, blowing fulvous flowers in July and August.

LILY, THE WHITE WATER. Candoch, or water-socks. (Nymphaa, from nymphe, a water-nymph; alluding to the habitation of the plants.) These are beautiful plants, well worthy of cultivating in every collection. The stove species should be grown in tubs of water, placed in a warm part of the house, with some rich loamy soil at the bottom. The hardy kinds inay be grown in ponds, canals, \&c. They are all increased either by seeds, dividing the roots, or separating the tubers. (Paxton.)

The great white water-lily $\left(N_{0} a l b a\right)$ is a beautiful perennial, native of Great Britain, perhaps the most magnificent of all its native flowers, growing in clear ponds and slow rivers. The root is tuberous, horizontal, sending down numerous long, stout radicles which are fibrous at the extremity; leaves floating, a span wide, oval, heart-shaped, with nearly parallel or close lobes at the base, entire, smooth. Every part of the herb is slightly vascular, perspiring rapidly, and, though so succulent, drying very soon. Flowers four or five inches wide, white, with yellow stamens and pistil; the upper surface of the calyx leaves white, often tinged with pale red, generally destitute of scent. The stems are superior to oak-galls for dyeing green. The roots are astringent, and a weak infusion is said to be useful in lepra. The roots are used in Ireland and Jura for dyeing a brown colour. The Egyptians eat the roots boiled, and convert the seeds into bread. The Swedes also have used this root in prevailing dearth, as a substitute for corn; though it requires to be previously divested of its bitter taste by frequent washings. According to Gleditsch, the roots of this species and of the yellow lily are equally useful in tanning and currying. This plant is eaten by hogs, but disliked by goats, and totally rejected by cows and horses.

The white water-lily looks very handsome in sheets of water, or ponds in ornamented grounds, blowing its large flowers in June and July. They have a faint, sweet scent, and expand in sunshine, in the middle of the day only, closing towards evening, when they recline on the surface of the water, or sink beneath it The same circumstance is recorded of the Egyptian $N$. lotus, from the most remote antiquity. 'The stimulus of light, which indeed acts evidently on many othei blossoms and leaves, expands and raises with peculiar force these splendid white flowers, that the pollen may reach the stigma uninjured; and when that stimulus ceases to act, they close again, drooping by their own weight to a certain depth. When the flower-seeds ripen in August, the plant sinks again to the bottom. In transplanting the water-lily, the pond must be entered, the stem of the plant felt for, and the ronts dug up with a large ball of its mud left round them place it in an old fish-basket, and remove it speedily, to sink it in the place intended for its 
LILY, THE YELLOW WATER.

removal. As the basket rots, the plant becomes fixed in its new situation. Propagate by throwing the ripe seed-vessels into large ditches of standing. water, when the young plants appear the following spring.

The Great American Water-Lily, one of the most splendid productions of floral nature, is comparatively a rare plant. It is found in a pond about a mile below the city of Philadelphia, and not far from Gloucester Point, a place much resorted to by naturalists and amateur florists during the season of flowering (August). Some have asserted a belief that the seeds were introduced from Europe; but the fact that a plant precisely similar is found in other parts of the country, and even in ponds along rivers west of the Mississippi (the Kanses and Osage, for example), proves the Cyamus or Nelumbium a native of North America as well as of India, where it is called the Sacred Bean, and consecrated to religious purposes. "There is not," says Professor W. P. C. Barton, "any plant in North America comparable to this for grandeur, simplicity, and beauty. Truly may it be styled, as I have elsewhere called it, the Queen of American Flowers. I regret to say that it is not as abundant in our vicinity as it was five years ago. This may be an accidental or temporary decrease, owing to a disturbance of the site where it grows. The leaves are perfectly round, and centrally peltate. They are from a foot to eighteen inches in diameter, of a rich velvety green above, and very pale inderneath. They are supported by petioles from two to three and a half feet in length." The flowers are pale-yellow, globose, and about three or four inches in diameter, supported above the surface of the water by petioles or a scape, a yard in length, frequently muricate towards the upper part. From this circumstance, together with an accurate examination of a fine Chinese painting of the India species, which differed in nothing from the American plant, except in the rose-coloured flower, Dr. Barton considers the two species as identical.

The seeds are a kind of nut, very similar to the chinquepin, of a very pleasant flavour, and eagerly sought after by boys. The Indians in the Far-West resort to them as food.

of the genus Nymphrea, the Fragrant WaterLily is a species native to the United States, a very beautiful aquatic plant, with white flowers, which exhale a delicious fragrance. The leaves and flowers both float on the surface of the water. It is a perennial.

LILY, THE YELLOW WATER (Nuphar, from naufar or nyloufar, the Arabic name of Nympha(i). This, like the last described, is a genus of very beautiful plants, admirably adapted for growing in ponds, cisterns, or lakes; and they are increased by dividing the roots, or by seeds, which have only to be thrown into the water where they are intended to grow. (Paxton.)

In England, the only indigenous species are, 1. The common yellow water-lily, or water-can ( $N$. lutea), which is met with very frequent in the wild state in rivers and pools. The whole plant is rather smaller than the white waterlily. Footstalles two-edged, flattened on the upper surface; leaves entirely smooth, and
I.IME:

even rounded at the end, and generally at the lobes, which meet and lap over each other. The flowers, which appear in July, are about two inches wide, cupped, all over of a golden yellow, with the scent of brandy or ratafia, whence they are called brandy-boules in Norfolk. They perhaps communicate this flavour by infusion to the cooling liquors or sherbets, so much used in the Levant. The sced-vessel, a coated berry, when ripe, bursts irregularly, not dissolving away into a mass of pulp, like the Nymphae. The roots, like those of the white water-lily, are astringent, and contain a quantity of fecula. If moistened with milk, they are said by Linnæus to destroy crickets and cockroaches. Hogs will eat this aquatic plant, but all the other species of live-stock reject it.

'This aquatic plant is what is so familiarly known in the United States by the name of splatter-dock, a perennial, blooming its yellow globular flowers in July and August, filling ditches, and extending for miles along the shallow banks of rivers, below high water-mark.

2. The least yellow water-lily ( $N$. pumila). This is much smaller than the preceding, and flourishes principally in the highland lakes of Scotland. The marsh-trefoil is often called the dwarf water-lily.

Of the genus Nuphar, another species ( $\mathrm{Kal}$. miana) found in the United States is the Small Water-Lily, with leaves floating like those of the common splatter-dock, but only about onethird the size; yellow flowers, also floating, and about half an inch in diameter.

LIMB. The border of a flower; also the branch of a tree.

LIME (Germ. leim, glue). This very useful earth is the oxide of a metal called calcium. In England it is obtained by exposing chalk and other kinds of limestone, or carbonates of lime, to a red-heat,-an operation generally conducted in kilns constructed for the purpose: the carbonic acid is thus expelled, and lime, more or less pure, according to the original quality of the limestone, remains. In this state it is usually called quick-lime. The purest quicklime is obtained from the calcination of white marble. When sprinkled with water it becomes very hot, and crumbles down into a dry powder, called slaked lime, or hydrate of lime, owing to the water becoming consolidated and an essential part of the lime. When exposed for some weeks to the air, it also falls into powder, in consequence of the absorption of moisture; but a portion of carbonic acid is also absorbed, and the lime partially converted into limestone. The uses of lime are very numerous. Its most important application is in the manufacture of mortar and other cements used in building. It is also very extensively used as a manure to fertilize land.

LIME as a manure. There is some reason to infer that lime has been used as a manure from a very remote period. M. P. Cato, in the oldest agricultural treatise which has escaped to us, describes, in his sixteenth and thirty-eighth chapters, with much minuteness, the best means of preparing it. And although, in the early writers on rural affairs, we find but few notices of its use as a fertilizer, yet we may reasonably 
conclude that its empluyment was nearly as extensive and as early as that of chalk or marl, which were in very primitive times largely and skilfülly used for a similar purpose. Pliny attests the use of it by the Roman cultivators as a dressing for the soil in which fruit trees were planted.

Of all the earthy manures found in England, lime is certainly the most powerful and rapid in its effects on the soil; and if its use is not so extensive on the clays and peaty lands of inany districts of the island as is desirable, this Hoes not arise from the limited powers of this earth, but rather from a variety of other causes, such as its expense, the impurity of the lime employed, and an ignorance of its most economical mode of application.

The common varieties of lime used by the English farmers, are procured by calcining either chalk or limestone. Such lime is therefore rarely, if ever, chemically pure, for it aimost always contains a portion of silica (flint); alumina (clay), and some red oxide of iron. These, however, are not often present in sufficient quantities to influence the fertilizing powers of the lime to any material extent, as will be readily seen by the analysis of the limestones and the chalk usually employed by the limeburners. Common limestone is composed of

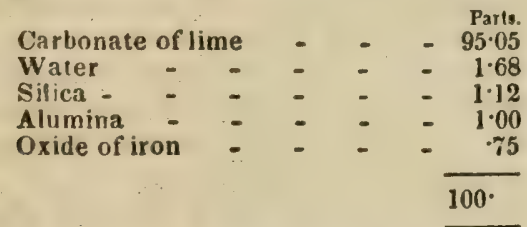

The slate-spar limestone contains-

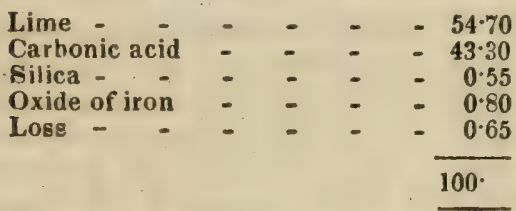

Common chalk is composed of-

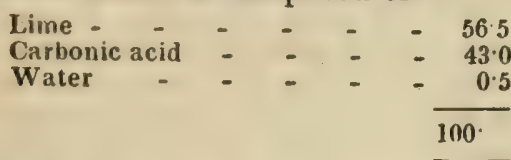

united with various small proportions of the ather earths. There is also a very considerable proportion of lime made in the north of England from the magnesian limestone (called by the Yorkshire farmers "hot lime"), all of which differ considerably in composition; that from Sunderland contains, in 100 parts,

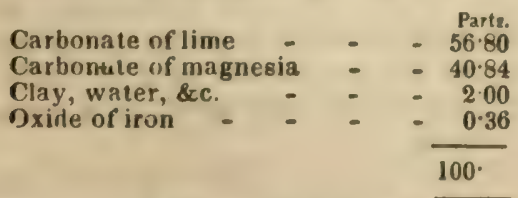

This "not lime," which is well known by the farmers in the neighbourhood of Doncaster, and other parts of the north of England, can unly be applied in limited quantities, for the calcined magnesia of the limestone remains for a considerable period in its pure caustic form, without absorbing carbonic acid gas 716 from the atmosphere, and in this state its effect is very pernicious to many kinds of plants. It is only when pure, however, that magnesia is prejudicial to vegetation: by exposure to the atmosphere, it gradually and slowly absorbs carbonic acid gas, becomes carbonate of magnesia, and in this state forms a part of many cultivated plants. Some of the most fertile soils of Britain, in fact, contain it in this form, in considerable quantities.

Limestone occurs of various colours and shades, as well as of different degrees of hardness. In weight the compact varieties are very much alike, being generally a little more than $2 \frac{1}{2}$ times $(2 \cdot 7)$ heavier than water. Limestone may be distinguished from other varieties of rock, by dropping on it some strong acid, such as the acetic acid (vinegar), sulphuric (oil of vitriol), or muriatic (spirit of salt), upon the addition of either of which bubbles of gas are observed to escape when lime is present, but not otherwise.

The action of the fire upon the chalk and the limestones merely deprives them of their water and carbonic acid gas, or fixed air. The farmer must not fall into the very common error of supposing that any thing is added by the fire to the lime; on the contrary, it loses very materially in weight, by being deprived of its carbonic acid gas, burnt or quick-lime losing about 44 per cent. of its original weight, a loss, however, which it gradually recovers by exposure to the atmosphere, which always contains this elastic vapour.

One of the most remarkable properties of quick-lime, is its tendency to combine with water. If quick-lime be moistened with a certain quantity of water, it soon becomes heathed, throws off a portion of the water in the form of steam, and falls to a very fine, white powder, which is a hydrate of lime, al. ways containing 24 per cent. water; if, how. ever, more water be added, the same hydrate is formed, but the excess of water agglutinates the powder into lumps or masses which will eventually become hard, and resemble stone. Still more water immediately applied to quicklime, dissolves it, and forms lime-water. If quich-lime be exposed to the air, it also falls to a coarser powder by absorbing 12 per cent. of water and 24 per cent. of carbonic acid from the air, constituting a mingled carbonate and hydrate of lime. The same change occurs gradually with that which has been slacked by water and is exposed to the air, the carbonic acid of the atmosphere replacing the water of the hydrate. The carbonate of lime, such as exists in chalk, limestone, \&c., is scarcely soluble in pure water, but if the latter contain carbonic acid, as rain water usually does when in contact with the soil, the limestone enters into solution. (Booth's Geology of Delaware.)

The lime which I have used, observes Mr. C. W. Johnson, has been principally made from chalk, at an expense of about five pence or six pence per bushel. That which I made from the magnesia limestone was from the neighbourhood of Sunderland. This requires less fuel to convert it into lime than the common limestone. For the ordinary kinds, about one bushel of coals is required for five or six 
bushels of the limestone; and from my own experiments, I am inclined to agree in opinion with many of the farmers of the midland counties, that the lime procured from limestone is rather more powerful in its effects on clay soils than that made from chalk.

In either case the shape of the kiln, and the steady gradual application of the heat, are very material circumstances to be regarded by those who burn their own lime. The limestone and chalk should be placed in the kiln (which I think is best of an egg shape), in moderatelysized pieces, free from the powdered chalk or stone; and care must be taken to have the earth thoroughly burnt, of which perhaps the best indications are its lightness, and the alteration of the colour of the flame issuing from the top of the kiln, which, when the lime is sufficiently made, loses its red tinge. The price of the fuel, and readiness of access to the limestone or chalk, of necessity governs the price of the lime: in some districts of the north it is made by the farmers for not more than one penny to three halfpence per bushel.

The chemical uses of lime to vegetation may be conveniently divided into two heads; first, its direct action upon vegetation; and secondly, its chemical operation on the matters contained in all cultivateable soils.

In its direct action, as a food or constituent nf plants, its uses are highly important; for hardly a single plant has yet been analyzed, in which the presence of lime has not been detected, in combination with an acid. It must be regarded indeed as an essential ingredient in almost all vegetable substances, as a direct food of plants.

It is found in the commonly cultivated crops of the farmer, however, in very varying proportions: thus the ashes of the oat-plant contain more than five per cent. of lime; in two pounds' weight of the seeds of wheat are commonly found about 12 grains of carbonate of lime; in the same quantity of rye, about 13.4 grains; in barley 24.8 grains; 33.75 grains in the oat, and 46.2 in the same weight of ryestraw. It abounds also with magnesia in the wood of trees: the ashes of that of the oak contain about 32 per cent. of the earthy carbonates; those from the poplar 27 per cent.; from the hazel 8 ; of the mulberry 56 ; and from the hornbeam 26 per cent. The proportion however of lime found in plants varies with the composition of the soil on which they are produced. Thus the ashes of the leaves of the fir (Pinus abies), growing upon a limestone hill, were found to contain 43.5 per cent. of the carbonates of lime and magnesia, but the ashes from the leaves of another fir growing upon a granite soil yielded only 29 per cent. of the same earthy salts. There are very few soils fit for cultivation from which this earth is entirely absent, and its addition is commonly found by the farmer to promote the fertility of most barren lands-the most sterile heaths, for these are the very lands whose soils contain hardly a trace of lime; in that of Bagshot, for instance, it exists in a very minute proportion. The altraction of lime for the aqueous particles of the atmosphere is considerable. In my own experiments 1000 parts of lime previous. ly dried in a teinperature of $212^{\circ}$ gained by ex posure for three hours to air saturated with moisture, at a temperature of $60^{\circ}, 11$ parts. Professor Schubler found that the same weight gained in 12 hours 26 parts, in 24 hours 31 parts, in 48 hours 35 parts, when it appeared to have become saturated with moisture, for in 72 hours it had not again increased in weight. Lime therefore is not without its uses even in this respect to vegetation. Lime and chalk differ in their action, and in their value as fertilizers in several respects; thus lime dissolyes and renders soluble the organic matters of the soil, which chalk does not; its action, to $Q_{2}$ as a direct food of plants, is more rapid, from the superior readiness with which it mingles with the soil. And again, its carriage is considerably lighter, for in the process of lime-burning almost all the water and carbonic acid gas of the chalk are driven off. These amounted in some specimens of Kentish chalk, which I examined, to more than 58 per cent.; so that when the farmer carries 42 tons of recently. well-burnt lime, he conveys as much real earth on to his land as is sometimes contained in 100 tons of chalk.

The chemical action of the lime on the soil is also very considerable; mixing with the heavy adhesive clays, it renders them more friable, less liable to be injuriously acted upon by the sun, and much more readily perineable by the gases and vapour of the atmosphere. It renders them, the cultivator tells you, "more easily workable." And, again, the action of lime upon the organic substances always more or less contained in the farmers' soils is very considerable; and this benefit is not merely confined to the vegetable remains in the land, but it extends with equal energy to the dead and the living animal matters, with which, in a countless variety of forms, the soil is tenanted. There are few substances, in fact, more destructive to grub-worms, animalculæ, \&c., than lime; and where these are destroyed by the action of the lime, the soil is, as a natural consequence, enriched by their remains. On soils which abound in sulphate of iron, which is commonly the case with those containing an excess of peat, the action of lime is not only highly beneficial in decomposing or rendering soluble the mass of inert vegetable remains, but the lime decomposes the sulphate of iron, and, uniting with its sulphuric acid, forms the well-known fertilizer, the sulphate of lime or gypsum of commerce.

When quick-lime is applied to the soil, it gradually becomes converted, by exposure to the atmosphere, into carbonate of lime (chalk); its action as a solvent ceases, and its presence is now only useful as a direct food or constituent of the farmer's crops. This, however, affords an opportunity for the beneficial repetition of the dressing with lime, so far as its solvent powers are available. But then, as might, for the above reasons, have been anticipated, the farmer finds that the after-limings never do so much good as the first; and as hy each successive application the lime reduces still more and more the quantity of organic matters in the soil, so it follows as a natural consequence that after each succeeding dress. 
ing, the benefit produced becomes less and less, and finally the cultivator informs us that "the land is tired of lime." This result has been experienced to a very considerable extent in the north of England, where the cheapness of fuel and the abundance of the common limestone has, in too many instances, tempted the farmer to add to his land lime in excessive quantities. For such over-limed soils, the only remedy is the addition of organic matters. In such cases, peat will, in moderate quantities, be occasionally found an excellent dressing.

The quantity of lime used per acre of necessity varies with the soil, and the expense with which it is procured. The heavy clay and peat soils require the largest proportions; the light lands need a much smaller quantity to produce the maximum benefit. I have used it at the rate of 25 bushels per acre, mixed with earth, on light soils, and never more than 100 bushels per acre on clays. This is the proportion commonly used on the heavy soils of the midland counties, and the deep clays of the weald of Kent. In Scotland they apply sometimes as much as 360 bushels per acre, and in Ireland still larger quantities have been successfully employed; and on some of the peat mosses of the north of England, more than 1000 bushels have been used with good effect. The employment of such large proportions, however, can rarely be justified, even when the lime is obtainable at a very low rate.

I have used lime, and have been present at other liming operations for many years. I have chiefly employed it either as a top-dressing, or which, for light soils, I much prefer, mixed with ditch scrapings, old banks or pond mud, at the rate of one bushel of lime to a cubic yard of earth. And then, after thoroughly mixing them together, and allowing the mass to remain for a month or six weeks, I have always succeeded in forming a most enriching compost, which, on even the gravelly soils of Jssex, applied at the rate of 20 to 25 cubic yards per acre, both for wheat, clover, and potatoes (to which crop, in general, lime is prejudicial), has produced the most powerful effects, certainly increasing by one-third the produce of the natural soil. It is only in the state of mixture with earth, or peat, or salt, that I have found lime profitably useful for light, gravelly soils. Yet $\mathbf{I}$ have varied the application in a variety of ways and proportions, but still, for the gravels or sands, the result was never entirely satisfactory. But I have witnessed, as a dressing for the black hungry gravels of Spring Park, near Croydon, lime and peat mixed together, at the rate of 1 part of lime and 3 parts of peat, with the most complete success. The peat is reduced to a finelydivided state, and rendered partially soluble by the action of the lime, and is a most powerful tho-dressing for young clovers. This is explainable (amongst other reasons) by the fact that the peat employed being saturated with a suiution of sulphate of iron, the lime converted It into sulphate of lime, which is a constituent or direct food of clover. Equally successful, nn light soils, have been my trials of lime, when mixed with common salt; a parts of lime, inixed with 1 part of salt in a dry state, and 718 suffered to remain for three months previous to its being used in a dry place. By applying this mixture at the rate of from 40 to 50 bushels per acre, crops of turnips have heen grown under my directions fully equal to any produced by 20 cubic yards per acre of farm-yard compost: and in 1840, the produce of ground thus dressed fully equalled that of some adjoining lands of the same field, which had been manured with the ordinary compost. And an excellent neighbouring farmer, Mr. Foster, of Great Totham, in July, 1840, made an experiment with turnips, entirely confirming those I had elsewhere instituted. He applied a mixture per acre of 30 bushels of lime with 15 bushels of salt, to 10 acres of a field containing 12 acres. The land previously had a crop of rye, which was fed off with sheep; and on the 2 acres to which the salt and lime were not applied, the sheep had oil cake given to them, and, moreover, the land was sub-soiled to a depth of 18 to 20 inches. The field previously had a good summer fallow. The lime and salt was spread broadcast after the last ploughing, and harrowed in before the seed. The turnips were of the variety called green rounds. The land slopes to the south, and its soil is a light, mouldy turnip soil. In examining them in company with Mr. Foster, in the last week in August, he expressed himself abundantly satisfied with the result. The crop of turnips was equally good all over the field; if there was a shade of difference, it was in favour of the sub-soiled and cake-fed land; but the advantage, if any, was exceedingly inconsiderable.

In the use of this mixture, I have found the moisture of the atmosphere highly advantageous in increasing the operation of the lime and salt; an observation, too, which is not confined to the dry, gravelly soils on which my experiments were carried on. Thus, in 1839 , on an exhausted, rather heavy turnip loam, 80 bushels per acre of a mixture of salt 1 part, and lime 2 parts, made three months previously, were spread in July, and sown with the white round turnips. The turnip plants came-up equally well all over the field; but on the portions where the salt and lime were omitted, they speedily perished; but in every part dressed with the lime and salt, the crop was excellent.

In the dry season of 1840 , however, another portion of the same field being treated in a similar manner, the effect produced by the lime and salt was not nearly so decisive; the plants were weak, the crop inferior.

I have found the lime and salt equally beneficial as a dressing for wheat and barley; but a description of those experiments will more properly be found under the head $S_{A L T}$ and LIME; for when the application is made to the land, the lime and salt have, in fact, entered into new combinations; the compound applied is no longer a dressing with lime and salt, but with a mixture chiefly composed of chloride of calcium and carbonate of soda, with a portion of undecomposed lime and common salt. I have several times mixed lime, in cases where I suspected the presence of grub and the seeds of weeds, with farm-yard compost, 
but never successfully. Convinced of the ill eflects of the lime being thus mixed, I have long since abandoned the practice. There is, in fact, no beneficial object to be attained by this mode. The natural well-regulated fermentation of the dung effects all that the lime can do, and in a better manner; for the lime dissolves, and, to a considerable extent, decomposes the finer and richer portions of the compost; and it certainly renders the straw and other coarser portions of the manure drier and more difficult to dissolve in the soil. The practice, therefore, seems worse than useless.

In the application of lime to heavy clay land, I have always found that it was best, used either in its simple uncombined state, or after an ultimate mixture of sandy or light calcareous earths, or peat, or salt. But by no means of applying it (and I have varied my experiments in a variety of ways with considerable industry) on the land, could I ever produce superior effects than by applying the lime in its uncombined state, as well burnt and finely divided as possible ; and this I have generally done as a top-dressing (merely harrowing it in with the seed), from considering that by the soluble property of lime ( $1 \mathrm{lb}$. of lime dissolving in $480 \mathrm{lbs}$. of water), the rain always conveys it deeper into the soil.

And yet, from an experiment recently made at $\mathrm{my}$ suggestion by my next neighbour, $\mathrm{Mr}$. Foster, a very excellent farmer of Great Totham, in Essex, I am inclined to believe that the lime will produce effects nearly equally important when it is ploughed into the soil. This trial was made in December, 1839 , on a field of 5 acres, whose soil is a cold, stiff, deep, hungry loam, that had previously borne a very poor crop of turnips, which were fed off with sheep. This field has a declination lowards the southwest, and has always produced crops of a very inferior description. In the middle of December, after spreading 80 bushels per acre of lime (made from chalk) from the cart's tail, by the shovel, it was immcdiately ploughed in and drilled with the common red wheat. 'The effect was excellent, every one of the neighbours agreeing that the land never produced such a crop before. And that this was owing to the lime, was evident rrom the inferior produce on the spots where the lime had not been spread.

The exact quantity, however, per acre, Mr. Foster is unable to state, owing to his being prevented in the hurry of harvest from keeping it separate: he estimates it, however, at about $4 \frac{1}{2}$ quarters per acre, and he is clearly of opinion that this large produce (for his land) arose not so much from the thickness of the crop, as from the largeness of the ears.

In the boggy, unreclaimed lands of Spring Park, the effect produced by the direct use of lime, at the rate of 200 bushels per acre, is exreltent. 'The cost is there 4 pence per bushel, and it is that made from chalk. But on the light, hungry, black gravels of that farm, as well in fact as upon the clays of that district (and the same remarks apply in general to almost all light soils and situations), the lime is never productive of such powerful effects as when irixed with the earthy matters from ditches, ponds, old banks, or headlands. But here let me earnestly impress upon the farmer the necessity and the great advantage of paying much more than common attention to the mixing of the lime with the earth.

The lime should not only be of the best and recently burnt description, but should be mixed as thoroughly and as finely as possible with the earth. By this means the heat generated in the mass by the slaking of the lime is considerable, and is productive of several ad. vantages: it kills more completely insects of all kinds-seeds of weeds, and the more stubborn roots of weeds. And the mixed earths are rendered considerably more friable, and capable of a much more even and economical distribution on the farmer's crops, than by the ordinary careless way of mixing them. On peat soils, and on those abounding in the tough inert remains of the heath plants, lime is best applied in its purest state, unmixed with any other substances to weaken its effect. Its action on such soils is not difficult of explanation. It dissolves and renders soluble the organic matters of the soil, and it decom poses the sulphate of iron (or green vitriol) which it often contains. In such lands, too. we rarely find any lime: it furnishes, therefore, to them a portion of an earth whose pre. sence is absolutely essential to the profitable growth of all the most valuable vegetables. How excellent such an addition is to these soils, even when applied only at the rate of 4 bushels per acre, has been proved by some extensive experiments of the Scotch planter, the growth of whose young woods has been very mate. rially and rapidly promoted by merely placing a handful of lime under each plant. Now we have already seen how copiously this earth is found in the ashes, not only of the fir, but in those of all other timber trees. So unvaried, indeed, is the presence of the salts of lime in vegetables, that they have been supposed to produce a similar supporting effect to that the same salts of lime yield in the bones of animals. And it is certainly worthy of remark that the phosphate and carbonate of lime, of which the bones of all animals are chiefly composed, are precisely the salts of lime the most universally present in vegetables.

Lime must, therefore, be classed amongst those manures which commonly serve to promote the permanent fertility of the land, for unless it is washed by the moisture of the atmosphere, or the flood waters, it can only be removed from the soil by becoming the food for the cultivator's crops. In poor, peaty soils, no other manure can be compared to it, either for powerful effect, or for rapidity of action; and its usefulness is nearly as great on the stiffest clay land. Whenever, therefore, the permanent improvement of such soils shall be consi tered with that general and that patient attention which the importance of the object demands, at that period the fertilizing powers of lime will be still more generally appreciated, anu its services be far more extended than at present.

The quantity of lime applied per acre of necessity varies with the description of the soil; that which contains most organic malter wil! 
of necessity, bear a larger proportion than that which is more free from vegetable or animal remains. The quantity usually applied is much too large, and the dressing too often repeated without proper consideration; and it is not until the land becomes absolutely overcharged with lime, that the farmer begins to have a suspicion that his land is tired of it. In Ireland it is sometimes applied to old pasture leys intended for potatoes, at the rate of 400 bushels per acre; and on some of the moors in Derbyshire, 1500 bushels per acre have been found not too large a quantity. In Scotland. the quantity usually applied for light land is about 160 -bushels per acre; for stiff clay soils from 240 to 360 bushels. On the stiff clays of the Weald of Kent, the quantity usually employed is about 100 bushels per acre, and that is often repeated every 5 years, on the fallow before wheat.

Lime may be as readily produced by burning limestone with peat as with coals; the heat produced is amply sufficient, and the heat mose easily managed.

According to the views of Professor Daubny and M. Prideaux, lime operates beneficially on some soils, by promoting the disengagement of potash and other substances, where these exist in the mineral materials, thus converting dormant earthy or saline constituents into agents active in the promotion of vegetable growth. The soil of a field exhausted by longcontinued cropping, was found to yield double the quantity of potash, after being dressed with lime. The action, therefore, of lime upon the earthy matters of many soils, is exceedingly beneficial. The frequent application of lime, however, tends to exhaust such soils, by the rapid reduction of the proportion of their potash, which is not only furnished more copiously as a constituent to the growing crops, but by dissolution in the water becomes drained from the land.

Although beneficial, from these chemical effects exerted over the soil in setting free and rendering active some of its most fertilizing agents, it is generally admitted that the greatest benefit derived from the use of lime, is from its action upon the vegetable and animal matters with which it is brought into contact, when introduced into the soil. In numerous trials made by Professor J. F. W. Johnston, lime appeared to produce very slight benefits upon lands, in which organic (animal and vegetable) matter was deficient.

An ordinary liming will rarely amount to 1 per cent. "of the entire weight of the soil. It requires about 400 bushels, or 12 or 15 tons of burned lime, per acre, to add 1 per cent. of lime to a soll 12 inches deep, or 2 per cent. when the depth is only 6 inches. The good effects of lime are most decided, when used as a top dress. ing and kept near the surface. A much smaller quantity will answer, when applied immediately upon being slaked with water, as in this state lime is quite soluble, but very slowly so, after it has been exposed to the atmosphere and become like chalk. See CHaLk. When after slaking it has become too wet, so as to be cemented into lumps, these decompose so slowly, that they may be almost regarded as a dead inss.

The amount of lime taken from the soil by 720 crops, is far greater than is generally understooo. Prof. J. F. W. Johnston states the weight of lime thus carried off in 25 bushels of wheat at 9 lbs.; 50 bushels of oats 9 lbs.; 38 of barley at $15 \mathrm{lbs} . ; 2$ tons of rye-grass $33 \mathrm{lbs} . ; 2$ tons red clover $126 \mathrm{lbs}$; 25 tons of turnips $140 \mathrm{lbs}$; 9 tons of potatoes $270 \mathrm{lbs}$. This includes the lime in all its forms, and especially the all important phosphate in the grain. To this great source of exhaustion of the soil, must be added the lime which combines with several acid matters, forming compounds more or less soluble in water, in which state it is drained from the land, or sunk into the earth beyond the reach of plants.

Although light soils are most readily exhausted of lime, they possess the great advantage over heavy clays, of allowing the carbonic acid in rain water more ready access to the roots of plants, and atmospheric air more ready entrance to all decomposing manures, such as bones, fish, rape-cake, \&c. This may afford an explanation of the cause why lime, as well as other fertilizers, frequently fail to show prominent benefits on certain lands. In order to act most favourably, they need the presence of carbonic acid and atmospheric air.

There is perhaps no other country so richly endowed with this earth as England, for, to say nothing of its great strata of chalk, how endless are the masses and varieties of limestones. Let us not therefore neglect, but extend, by every means in our power, the use of the treasures we possess; for by so doing we may not only increase the fertility of lands already (like the more tenacious clays for instance) in some degree productive of food, but we can bring into cultivation, by the judicious employment of this powerful earth, the most sterile peats, the trembling bogs, the most worthless heaths: the inferior plants, such as the acid sorrel, are banished by its influence, and the soil which once only held the stagnant water impregnated with unwholesome vegetable and mineral matters, is now made to produce the most useful of the cultivator's crops; and the improvement, too, is of even national importance, for such lands not only furnish additional employment to the labourer, but they now purify an atmosphere which their exhalations in an unimproved state once corrupted.

"Much has been written and said relative to the preservative and destructive effects of lime on organic manures, from which we learn that it operates both ways, according to its chemical state. If employed as quick-lime, and placed in contact with organic matter, its alkaline properties would lead us to infer a decomposing influence, which is confirmed by experience; but the effect is of short duration, and is succeeded by the reverse operation, that of preserving such matter from farther decomposition. The truth is, if we could insure a continuance of its caustic state, we might be equally sure of its constant decomposing power, but by this action it generates carbonic acid from the organic matter uniting with it and forming a neutral carbonate, which either acts like other salts in preventing decomposition by its presence or catalytic influence, or 
being formed and hardened in the interior of the organized material, protects it from farther decay. For this reason it may be used to prevent excessive fermentation in the dung-hill; and to the same properties we may in part ascribe its utility in the soi!, viz., that of permitting the slow and gradual decay of organic matter in quantities suited to the demands of vegetation. It has been supposed that the chief value of lime as a manure lay in its caustic or destructive effects, but that this position is untenable is proved by the successful application of marls, and even powdered lime. stone, which are robbed of their caustic qualities. Sir H. Davy and others who have written on the subject of agriculture, refer the utility of lime to its causticity, and state that 'chalk, marl, or carbonate of lime will only improve the texture of the soil or its relation to absorption; it acts merely as one of the earthy ingredients.' This view is unquestionably incorrect, for it has been known to produce astonishing effects on peaty soils, when applied in the form of carbonate and not caustic lime, and powdered limestone as well as marl have been successfully used on ordinary soils. Besides, if the formation of soluble matter from insoluble organic materials' be the chief effect of lime, this effect should take place immediately, while the lime is in its canstic state; but it appears that it soon becomes carbonated in the soil, or by exposure to the air, and yet its useful effects are more perceptible a considerable time after its application, and may be perceived for many years. Whence it appears that its action on organic matters in the soil is continued (probably not increased) in the soil after carbonation.

"Much of the vagueness in descriptions relative to the use of lime has arisen from an imperfect knowledge of the organic constituents of soils, which have lately been partially developed. Authors have divided the organic matter into soluble and insoluble, by the former of which we understand the humic, crenic, and apocrenic acids, and by the latter, humin, humus-coal, and vegetable fibre; and they state that lime is injurious where there is much soluble matter in the soil, as it forms insoluble combinations. The truth is, the humate of lime is partially soluble, the crenate somewhat so, and the bi-crenate very soluble. Now, by admitting these acids as active ingredients in soils, we are at no loss to account for the utility of carbonate of lime, for the weak affinity of the carbonic acid is overcome by their superior attraction, and more soluble salts are formed which may then be received into the rootlets of plants. There can be no doubt, however, that caustic lime is of greater benefit where a soil contains humin and vegetable fibre, as it promotes their incipient decomposition. The utility of lime, therefore, is threefold: first, that of decomposing organic matter, and rendering it a suitable nourishment for plants ; secondly, that of combining with orgasic matter and rendering it capable of being received into the vessels of vegetable organization for promoting vegetation; and, lastly, that of lengthening the time of decomposition of organic matter, which, therefore, fields nu- trition in proportion to the demands of a plant in the progress of its growth.

"It has been supposed by many to be neces sary that lime should be caustic, as it is only then soluble, but it should not be forgotten that the carbonate is also soluble in water containing carbonic acid; and farther, it is not necessary that either the carbonate or quick-lime alone should be dissolved in order to explain its infuence in vegetation, for moisture, the medium of chemical action, is always present in the soil, and assists in its soluble combination with the organic acids. There is, how. ever, another action of lime with reference to the soil itself, which is of importance, viz., that it renders clayey lands looser, and sandy soils more tenacious. The latter of these contrary effects is of a chemical character, and there is little doubt that lime acts like mortar by $\mathrm{cnm}$ bining the particles of sand together. The former is partly mechanical, the mingling of less cohesive earthy matter with the clay, and partly chemical, in which the lime dissolved by rains is washed into the crevices and cracks of the clay, where, becoming carbonated, it prevents their farther adhesion. To effect these results most powerfully, it is evident that the lime should be employed in a caustic or water-slaked state. According to these views, therefore, it is a matter of less moment on what kind of land lime should be spread, as it tends to ameliorate its condition or texture, and is the medium of conveyance of nutrition to vegetable life.

"Nearly all the limestone employed in Dela. ware for spreading on the soil is magnesian, and it is therefore worth investigating how far the magnesia may be injurious. One of the first limestones employed for this purpose in Pennsylvania, from which lime derived much of its reputation as a manure in this section of country, and which has not lost its character to the present time, is nearly of the same composition with Jeanes' stone; a very fair proof that such a content of magnesia is not injurious under certain circumstances. Sir $\mathbf{H}$. Davy's view of the subject appears to be correct, that magnesia in a caustic state is injurious, but that when carbonated it is beneficial. It was stated that it remains caustic for a long time exposed to the air, and particularly when mingled with lime; therefore, in employing a magnesian limestone, if there is little vegetable matter in the soil it will be apt to injure the crops; but this effect may be obviated by mingling it with fermenting manure, which will rapidly carbonate it. There is anoher view of the subject which has never been broached, viz., the influence of the organic acids in the soil. If much humic acid be present, it will form humate of magnesia, soluble in 160 parts of water, while humate of lime requires 2000 , so that it will be taken up in greater quantity than lime. But by referring to the quantity required by plants as shown by an analysis of their ashes, we find that nak requires about $5 \frac{1}{2}$ times as much lime as masnesia, and that ashes of straw yicld near'y 12 per cent. of carbonate and phosphate of lime. and no magnesia, from which it would seem that the latter is injuriouss 20 plants from its $3 \mathrm{P}$ 221 
excess where humic acid is abundant. But if the soil contain much humin, and other insoluble organic matter, its action in a caustic state would be beneficial like that of lime. We have, therefore, in Delaware abundant means of rendering magnesian lime useful, by emplaying it in conjunction with peaty matter, the black soil of marshes, creeks, \&c." (Booth's Geology of Delaware.)

All the grain crops, as well as those of grass, are greatly benefited by judicious applications of lime in some of its various forms. Oats lake up a larger proportion than almost any other grain, and hence are observed to be specially benefited by lime. Rye and Indian corn are also greatly benefited by lime, and with regard to wheat, the following strong testimony is from Dr. Jackson, the able American chernist and geologist. "I find," he says, "by chemical examination of several soils, that a very minute quantity of carbonate of lime, viz. from one to two per cent., is amply sufficient to render them capable of bearing heavy crops of good wheat. I am also satisfied that a soil is incapable of producing wheat of good quality if it does not contain carbonate of lime, for this substance is an essential ingredient of this grain."

It has been computed that every person who consumes $1 \mathrm{lb}$. of wheat bread daily, will, in the course of one year, take into his system $3 \mathrm{lbs}$. $6 \mathrm{oz} .3$ drs. and $44 \mathrm{grs}$. of phosphate of lime. "This circumstance is supposed to explain the reason why this kind of bread is so superior to that made of other grain, as phosphate of lime forms a principal element of human bodies. It is found in milk, where nature seems to indicate that it is contained for the nourishment of the young animal, from the remarkable fact that, when they are able to take other food, the milk loses its proportion of this substance. Although phosphate of lime is contained in considerable quantities in the adult secretions, it is not known in those of the young, being all taken up for the purposes of nutriment. The shells of eggs are formed of this substance, and Dr. Paris has ascertained the singular fact that, if the legs of a hen be broken, she will lay her eggs without shells until these are repaired, for which the lime is required. Hens will also lay their eggs withcut shells if there is a deficiency of lime in the yard in which they roam. It is a remarkable circumstance, that although the grain contains the phosphate, the straw contains the carbonate of lime. Carbon is, next to water, the principal support of vegetation." (Cultivator.)

Lime-Kilns and Burning.-A lime-kiln is a furnace or rough structure erected for the purpose of converting limestone into the lime of commerce, by keeping it for some time in a whitc heat.

The forms of lime-kilns vary; but the best is that of the frustrum of a cone, which perinits the ignited mass in the upper part to settle down freely as the lower portion is drawn out. In some places the kilns are sunk in the earth, in the form of inverted cones, and lined with brick. It is calculated that such kilns will hurn 150 bushels of lime in 24 hours. When rhalk is used, and it is dry, 5 bushels may be hurnt with one bushel of coals; but the damp722 riess $t$. the chalk lessens considerably the nower of the fuel. Peat is sometimes used in. stead of coals, and some burners prefer it to coal. Whatever the fuel may be, that is the best which prevents the lime from running together in masses. The best test of the lime being sufficiently calcined is its slaking, and falling into complete powder when water is poured on it.

Some excellent practical remarks upon lime burning, by Sir G. C. Stewart Monteath, were published some time since. He observes:"Having been engaged in burning lime for the supply of an extensive district of country for agricultural improvements, and being distant from coal 16 miles, it was desirable to find out the best constructed kiln for burning lime with the smallest quantity of coal, and having been aware, from experiment, that the kilns generally employed in Great Britain for burning lime are of a construction too narrow at bottom and too wide at top, many kilns of this construction being not more than 3 or 4 feet wide at bottom, and 18 feet wide at the height of 21 feet, were found to waste the fuel during the process of calcining the lime, or, in other words, did not produce more than two measures of burnt lime shells for one measure of coal; but it is to be understood that, in whatever construction of kiln lime is burnt, the fuel required to burn limestone must vary according to the softness, or hardness, or density of the stone, and the quality or strength of the coal used. The same measure of coal in Scotland called chews, when employed, will burn a greater quantity of lime in a given time than the same quantity or weight of small coal, the chews or small pieces of coal admitting the air to circulate more freely through the kiln. Though this fact should be well known to lime burners, yet they frequently employ small coal in burning lime, from its being procured at a less price, though really at a greater expense, as it requires a much larger quantity to produce the same effect, and a longer time to admit of equal quantities of lime being drawn out of the same kiln in a given time.

"For a sale of lime for agricultural purposes in a limited district, I have found kilns of small dimensions to be most profitable; the construction of a kiln I have employed for many years was of an oval shape, 5 feet wide at bottom, widening gradually to 6 feet at the height of 18 feet, and continuing at that width to 28 feet high from the bottom. A kiln of this construc tion has been found to burn lime in much less time, and with a smaller proportion of fuel, than kilns of larger dimensions narrow at bottom and wide at top, as heat is well known to ascend more rapidly in a perpendicular than in a sloping direction, from which arises the superiority of a narrow kiln, with sides nearly perpendicular, compared with one with sides that slope rapidly.

"These narrow kilns will admit of being drawn out of them every day, if fully employed, more than two-thirds, or nearly three-fourths, of what they contain, of well-burnt lime; and aftord fully three of lime shells for one measure of coal, when large circular kilns will not give out more than one-half of thesr contents every 
day, and require nearly one of coal for every two measures of lime burnt. In a country sale of lime, the quantity sold every day is liable to great fluctuations : two or three cart-loads will sometimes only be required fiom an establishment which, the day before, supplied forty; and as lime is known to be a commodity, when exposed to the action of air, which becomes more bulky and heavy, and in that state does not admit of being carried to a distance without additional labour, it has been an object of importance with me to find out a construction of a kiln which will allow of lime being kept for several days without slaking, and at the same time to prevent the fire escaping at the top of the kiln, if the kiln stands 24 hours without being employed, especially during the autumn and winter, when the air is cold and the nights long. I now employ kilns of an egg shape, and also oval; the oval-shaped kilns are divided by arches across the kiln, descending 4 feet from the top; the object of the arches across the kiln is to prevent the sides of the kiln falling in or contracting, and also to enable you to form circular openings for feeding in the stone and coal at the mouth of the kiln; upon this plan, a kiln of any length might be constructed with numerous round mouths. In the model of the kiln sent to the Highland Society, Booker's conical cover may be seen revolving upon an iron ring placed upon the circular mouth, and having placed a lid to the cover, I am enabled to prevent the escape of heat at the top, and by cast-iron doors at the bottom the air is prevented passing through the kiln; so that, by these precautions, the lime burner can regulate the heat, and prevent its escape for several days, when the fire would be extinguished at this season in the course of 24 hours. This is an object of great importance, as it enables the lime to be burnt as well, and with as small a quantity of fuel in the winter as the summer season, and to supply the farmer with as well burned lime, and at any time of the year, which cannot be done in the common construction of hilns, open both at top and bottom, for the reasons I have before stated. From the great expense attending the driving of fuel from a distance of 25 miles from my own coal-pits, I bave adopted the practice of coking the coal, which is a saving of eight-twentieths of the weight; and I find that an equal measure of coal and coke furnish the same quantity of heat in burning lime, which is somewhat paradoxical, but not the less true. The coal is found to have little effect upon the stone till it is deprived of its bitumen, or is coked in the kiln; for, during the time the smoke is emitted from the top of a lime kiln, little or no heat is evolved. A kiln in which coke is the fuel employed, will yield near a third more lime shells in a given time than when coal is the fuel; so that coke may be used occasionally when a greater quantity of lime is required in a certain time than usual, as it is well known to lime burners that the process of burning is done most economically when the kiln is in full action, so as almost constantly to have a column of fire from the bottom to the top of the kiln, with as short intervals as possible in working the kiln.

"In working a kiln with narrow circular muuths, the stone and coal should be carefully measured, so that the workmen can propurtion the fuel employed to the quantity of stones, and it is obvious that the quantity of coal to be used must depend upon its relative quality and the hardness of the stone to be burnt. If this measure was adapted to kilns of any construction, the lime snells would be found better burnt.

"Circular kilns are constructed with similar eyes or openings at the bottom, and not more than 8 feet wide at 18 feet from the base, and contracted to 4 or 5 feet wide at top. In lighting the kiln at the commencement of burning, some care should be taken not to allow the fire to remain below the upper grate. There are two iron grates at the bottom of the kiln: the upper grate consists of iron bars 8 or 10 inches distant from each other across the kiln, between which the pieces of burnt lime fall down upon a lower grate with iron bars one inch from each other, which allows the lime ashes to fall through them into an ash pit; these lime ashes are found very useful as a topdressing for grass ground, and are a clear gain to the proprietor of lime-kilns for public sale. As a burner of lime for agriculture in an extensive district of country to the extent of 150,000 imperial bushels annually, the value of the lime ashes which fall through the lower grate amounts to more than $150 \%$ annually; the lower grate is 3 feet above the ground, and the upper grate is the same distance from the lower one. The kilns I employ at Closeburn are upwards of 30 feet high, and nearly perpendicular, which is the cause of the great heat in this construction of kiln, and which is found to burn lime more equally than circular kilns of large dimensions. (Trans. High. Soc. vol. ii. p. 127.)

The limestone quarries of Scotland are described by Mr. Carmichael (Ilid. vol.v. p. 57): he observes, when speaking of the uses of this valuable earth, "how sterile must have been the soil, how cheerless the dwellings, and how scanty the resources of Britain before lime came into general use." And on the method of calcining limestone in some of the limestone quarries in Scotland there is a paper. (Ibid. p. 441.)

Limestone Gravel.-There are some traces of this manure in the Isle of Anglesea; but in general, it is seen in quantities only in Ireland, where it is very common. It is in appearance only common gravel, of a blue colour, mixed with stones as large as a man's fist, and also with loam or clay: it has a strong effervescence with acids, and, when used, is attended with the usual effects of marl or lime. $\Gamma_{L}:$ bogs, it exceeds every other manure, as its weight assists in the improvemont of that loose and spongy soil. Upon strong clays, the use of it is unrivalled, for it has all the effect of a dressing of lime, and gives friability yet more than chalk does. It destroys moss infallibly. Upon wharever soil it is used, it is found very durable, lasting, in many instances, in great heart, from twenty to forty years. In limestone counties, all blue gravels should be examined; for it $\Perp$ an invaluable treasure, wherever found.

LIME or LYME GRASS. See Errmo. 


\section{LIME PLANT.}

LIME PLANT. A name applied in the Northern and Eastern States to the indigenous plant called in the Middle States May Apple (Podophyllum peltatum).

LIMESTONE. A generic term for those varieties of carbonate of lime which are neither crystallized nor earthy; the former being calrareous spar, the latter chalk; when burned, they yield quick-lime. See Grorogr, Сhацк, Lime.

LIME TREES (Tilia). These are for the most part ornamental, lofty-growing trees, well suited for avenues and parks. They thrive in any soil, and are increased by layers or seeds; if by layers, the tree must be cut down close io the ground, and from its roots a great number of shoots are produced in the following vear: these will be strong enough to lay down the succeeding autumn. Trees raised from seed are far preferable to those raised from layers. The Russian bass-mats are made from the inner bark of the lime tree, while the wood, from its being light and white, is much ased by the carver and musical instrument maker.

The charcoal is used in the manufacture of gunpowder, and is considered as scarcely inferior for that purpose to the charcoal produced from the alder and willow. If we possess no evidence sufficiently conclusive to prove that the lime tree in any of its forms is truly indigenous in Britain, we have at least enough to show that it has long been naturalized, and that its introduction must have taken place at a very distant period; for, upon referring to the earlier works, such as Turner, Gerard, \&c., we find it (in the form of $T$. $E$. microphylla) spoken of as a well-known, and in their estiimation, apparently, as a native tree. By many botanists (says Mr. Selby), several species of lime are enumerated as inhabitants of Europe; and Sir J. E. Smith makes three distinct species of those cultivated and grown in Britain; viz., $T$. Europcea, $T$. grandifolia, and $T$. parvifolia, the two latter answering to the $T$. platyphylla and T. mirroplyylla of other authors. We are, however, continues Mr. Selby, inclined to adopt the riews and follow the opinion of the author of the Arboretum Britannicum, and to consider these not as specifically distinct from $T$. Europaa, in is usual form, but as marked varieties, or, as Mr. Isoudon designates them, races, originally produced from the seed of one, and which have been kept distinct, and perpetuated by means of layers, grafing, and other artificial modes of propagation; a view we think strongly corroborated by the fact that the seeds of the different linds, or supposed species, do not always produce plants exactly similar to the trees from which they are gathered, but run into varieties, ihe seed of $T . E$. ylatyphylla often producing plants similar in every respect to those of $T$. Huropaa (the common lime), and so with the other kinds.

The lime tree appears to have been held in repute in ancient as well as in modern times; for we learn from Theophrastus that it was 'nnown to the Greelis; and Pliny speaks of it as a tree held in high esteem by the Romans, not only for the ornament and shade it afforded, but for the qualities of its wood, and the various purposes to which it was adapted. Nearly two wundred years have elapsed since it was plant- ed along the streets of continental as well as English towns, where their width would admit of it, as affording a pleasant shade and protection during the summer heats, and it was extensively used in that style of gardening called architectural, as it bore cutting with the knife or shears with patience and comparative impunity. Examples of this style still exist in some parts of England, and are frequent upon the Continent, in France and Holland, where pyramids, arches, and colonnades are formed of this tree, and sometimes these produce an imposing effect. As an ornamental tree in picturesque gardening, the lime is well worth cultivating, as it ranks in the first class in point of magnitude, frequently attaining a height of eighty or ninety feet, and a trunk corresponding in circumference to such an altitude. The lime holds an important place in the Materia Medica of France and other continental countries; but its medicinal powers are very feeble. Loudon, in his Encyclopædia of Plants, enumerates eight species or varieties of the linden or lime tree (Tiliacea). 1. Tilia vubra, the red or common linden. 2. T. intermedia, or intermediate. 3. T. parvifolia, or small-leaved. 4. Platyphylla, or broad-leaved. All these are found indigenous in the woods of Britain. 5. T. Americana, American lime or linden. (See BAss-woon.) 6. T. pubescens, downy and thin-leaved lime tree. 7 . $T$. heterophylla, or various-leaved lime tree. The three last-named species are indigenous to North America. 8. T. alba vel argentia, the white or silver linden, which is stated to be a native of Hungary.

Michaux has described the three American species of lime tree, one of which has been already referred to under its common name of Bass-wood. The American white lime is doubtless a distinct species from the Tilia alba of Hungary.

"I have not," says Michaux, "met with the white lime tree east of the river Delaware, bat it is abundant in Pennsylvania, Maryland, Delaware, and the Western States. It does not grow, like the preceding species, in elevated places, nor amidst other trees in the forests, and is rarely seen except on the banks of rivers. I have particularly observed it on those of the Susquehanna, the Ohio, and the streams which empty into them.

"The height of the white lime tree rarely exceeds forty feet, and its diameter twelve or eighteen inches. Its young branches are covered with a smooth, silver-gray bark, by which it is recognised in the winter. The leaves are very large, denticulated, obliquely heart-shaped and pointed, of a dark-green on the upper surface, and white beneath, with small reddish tufts on the angles of the principal nerves. This whitish tint is most striking on solitary trees exposed to the sun.

"The flowers come out in June, and, as well as the floral leaf, are larger than those of any other lime tree with which I am acquainted. The petals are larger and whiter, and are impregnated with an agreeable odour. The seeds are round, or rather oval, and downy.

"The wood of this tree is white and tender, and $I$ believe it is never employed in the arts.

"This and the follr ${ }^{\prime}$ 'ng species have re 
ceived no popular specific names, but arc both called lime tree and bass-wood: that of white lime, which I have given to this species on account of the colour of its foliage, is peculiarly appropriate.

"The Downy Lime Tree belongs to the southern parts of the United States. It grows on the borders of rivers and large marshes, where the soil is cool and fertile, but not exposed to inundation. It is little multiplied, and consequently is not taken notice of by the inhabitants; for this reason, and because it is the only species of its kind in the maritime parts of the Carolinas and of Georgia, it has received no specific denomination, and is called simply lime tree; to which I have added the epithet downy, derived from a character of its foliage not observed in the preceding species.

"This tree is forty or fifty feet in height, with a proportional diameter. In its general appearance it resembles the American lime tree, which grows farther north, more than the white lime tree, which belongs to the Middle and Western States. Its leaves differ widely in size, according to the exposure in which they have grown: in dry and open places they are only two inches in diameter, and are twice as large in cool and shaded situations. Thev are rounded, pointed at the summit, very obliquely truncated at the base, edged with fewer and more remote teeth than those of the other lime trees, and very downy beneath. The flowers, also, are more numerous, and form larger bunches, and the seeds are round and downy.

"The wood is very similar to that of the other species, and I do not know that it is ever employed."

In some parts of Europe, the honey gathered hy bees from a species or variety of the linden is in great request for its superior qualities, and real or supposed healing virtues. It would be highly desirable to have a tree introduced into the United States which offers such a great resource to the bee culturists. See Honer.

Insect enemies.-The European species of lime or linden, which has been extensively introduced into the United States as an ornamental tree, has suficred greatly of late years from the attacks of several destructive insects. Some of these are in the form of long, dark-coloured worms or caterpillars, with strong webs, which eat off the foliage; others bore into the wood of the body and branches, chiefly in the crotches, and so destroy the strength of the $\operatorname{limb}$, or the body itself, that one or both yield readily to the wind, or gradually decay and die. There are also the leaf-beetles, the most elegant of the family of Chrysomelians, which inhabit the leaves, not only of the linden, but of the elm, the broods being found in April, May, and June, and even a second brood in September and October. The trees are often seriously injured by these fies or beetles and their larvæ. After a very minute description of this beautiful leaf-beetle, with its dark-green body, silvery-white wingcovers, ornamented with green spots, and rosecoloured wings, Dr. Harris remarks that he thinks the grubs go into the ground to turn to pupæ. When they become so numerous as seriously to injure the lime and elm trees, Dr.
Harris recommends the employment of decoc. tions of tobaceo or of walnut leaves, thrown on the trees by means of a garden or fire engine; a method which has been tried with goud eflect for the destruction of the larva of Gialeruca cul. mariensis, which appear occasionally in swarms, and entirely strip the leaves from the elm trees in midsummer. Dr.Harris descritues a spectes of lime-looper which proceeds from an umbermoth greatly resembling that known in Eurupe, and called by naturalists Hybernia defoliaria. The American insect, however, differs so much in the larva state from the European, as to entitle it to be classed as a distinct species; and accordingly Dr. Harris has called it Hyberniu tiliaria, the lime tree winter-moth, from Tilia, the scientific name of its favourite tree. The fore-wings of the male moth are rusty buff or nankin-yellow, sprinkled with very fine brownish dots, and banded with two transverse, wavy, brown lines, the band nearest the shoulders being often indistinct. In the space between the bands, and near to the thick edge of the wing, there is generally a brown dot. The hind-wings are much paler than the others, and have a small brownish dot in the middle. The colour of the body is the same as that of the fore-wings; and the legs are ringed with buff and brown. 'The wings expand one inch and three-quarters. 'The body of the female is grayish or yellowish-white; it is sprinkled on the sides with black dots, and there are two square black spots on the top of each ring, except the last, which has only one spot. The front of the head is black; and the antennx and the legs are ringed with black and white. The tail is tipped with a tapering, jointed egg-tube, that can be drawn in and out, like the joints of a telescope. Exclusive of this tube, the female measures about half an inch in length. The eggs are beautiful objects when seen under a microscope. They are of an oval shape and pale-yellow colour, and are covered with little raised lines, like net-work, or like the cells of a honey-comb.

As these span-worms appear at the same time as canker-worms, resemble them in their habits, and often live on the same trees, they can be kept in check by such means as are found useful when employed against cankerworms. See Span-worm.

IINDEN TREE. See LIME TREE.

LINF:N (Germ. lienwand). A species of cloth woven with the fibres of the flax plant. The linen manufacture has been prosecuted in England for a very long period; but though it: progress has been considerable, particularly of late years, it has not been so great as might have been anticipated. It is only within the last fifty years that any machinery has been used in the production of linen cloth: the firs: mills for the spinning of fiax having been cor. strueted at Darlington, about forty-eight yeass ago. The principal seat of the manufacture is, in England, Iseeds and its immediate vicinity, and in Lancashire, Dorset, Durham, and Salop; in Scotland, Dundee, which, indeed. may be regarded as the chief seat of the British manufacture; and in Ireland. the province of Ulster. The entire value of the linen manufacture of Great Britain and Ireland is esti 3 × 2 725 
mated at $8,000,000 l$., and the total number of persons employed in it, about 185,000.

LING (C'alluna vulgaris). A species of heath. To avoid the inconvenience of giving a new generic appellation to the hundreds of plants familiar to everybody as Erice or heaths, Mr. Salesbury has judiciously called our common ling Calluna, from rexג.uva; which is doubly suitable, whether with Mr. Salisbury and Dr. Hull we take it to express a cleansing property, brooms being made of ling, or whether we adopt the more common sense of the word, to ornament or adorn, which is very applicable to the flowers. This shrub grows almost everywhere, on dry moors, heaths, and open, barren wastes, as well as in woods where the soil is sandy or turfy. The stems are bushy, repeatedly and irregularly branched. Leaves deep green, minute, sessile, acute, keeled, somewhat arrow-shaped, closely imbricated on the young branches, making a quadrangular figure, like a close-beaten chain; they are generally smooth, but in one variety are densely hoary all over. The flowers are stalked, drooping, in longish unilateral clusters, soon overtopped by leafy shoots. The inner calyx, which is the most conspicuous part of the flower, is of a shining permanent rose colour. The flowers appear in June and July. Grouse and other birds, as well as some quadrupeds, eat the seeds and young shoots. There is a white-flowered variety, and a very beautiful double red one, cultivated in gardens, whose flowers, from a copious multiplication of the corolla, resemble little roses. See Heatr.

LINIMENT (Lat. lino, I anoint). In farriery, a semi-fluid ointment, or a soapy application to rub upon painful joints. The term is also applied to spirituous and other stimulating applications for external use. Liniments are intended either to lubricate or to stimulate; but in either case they can only be regarded as topical applications, their influence not extending beyond the part to which they are applied. In some instances they are anodyne; and contain solutions of opium in oil.

LINSEED or FIAXSEED (Lat. lini semen; Germ. Leinsaat). The seed of the flax plant. See Flax. This seed is small, oval, oblong, flattened laterally, acute at the extremities, glossy, brown; but internally white. It is inodorous, and tastes mucilaginous and oily. The husk or testa yields much mucilage to water, and the kernel a large proportion of oil to pressure. Besides upwards of 11 per cent. of oil, linseed contains wax, an acrid soft resin, extractive, a yellow colouring matter, starch, gum, tannic acid, albumen, gluten, emulsive, and some salts. When the seeds are burnt, the ashes contain oxide of copper. The infusion of linseed in boiling water yields a demulcent mucilage, which is much used as a domestic medicine in coughs, and in cases of acrimony in the urinary discharge. The linseed should not be boiled in the water, as that extracts the oil as well as the mucilage, and remders the decoction nauseating.

Jinseed is much used in the economy of the farm, for feeding calle and other purposes. A lushel of linseed averages in weight abnut 51 onsuds; this weight, when crushed, produces 726 about a quarter of its weight of linseed oil, and the remainder is cake. The great bulk of this seed is obtained from the Baltic and the Black Sea, and recently considerable quantities have been received from Egypt and Hindostan: of this last, the general character is, that although the seed is good, the impurities with which it is mixed are very considerable, such as the seeds of rape, \&c.; for which reason the oil obtained from it does not possess the drying oualities of that expressed from the unmixed linseed, and the dealers in consequence will not give so much for it. 'This arises not from any intentional adulteration, but from the bad farming and want of cleanliness of the orientalists.

Linseed oil contains a very considerable quantity of mucilage, which it almost entirely deposits by time; and hence, old linseed oil is more valued by the painter, but for the grazier, perhaps, its nutritive powers decrease by time. It is said by some persons, that it is to the presence of this mucilage that we must attribute the fattening quality of linseed oil when mixed with other substances, for linseed oil by itself is almost as powerful a purgative as castor oil, for which purpose indeed it is very commonly employed by the farmer; but on the other hand, we must remember, that in small doses, even castor oil is very fattening. Linseed is in fact commonly given to some birds, parrots for instance, for this purpose. Its purgative properties are very inferior to those of castor oil.

LINSEED CAKE. Linseed cake is a wellknown and valuable article for the food of live stock, almost equally good for cattle, sheep, and horses. It is the residuum, or refuse, left after the oil is expressed from linseed. 1000 parts of it, according to Davy, contain about 151 parts of nutritive matter. Its price has induced many attempts to economize its application. It has been often given as recommended by $\mathbf{M r}$. Hillyard, mixed with other substances, whose value he thus estimates:-

"The weekly cost of feeding each beast, including the expense of getting up, carting, and cutting the turnips and hay, and attendance, will be-

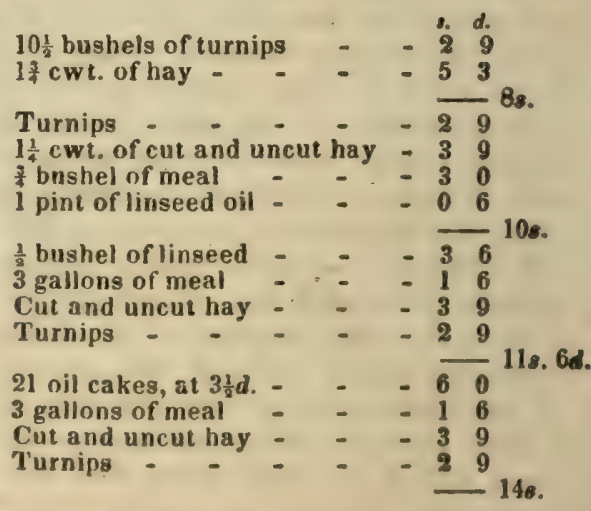

"No food," says Mr. Hillyard, "can be given to stall-feeding beasts that will fatten them so soon or so well as linseed oil-cake. It certain$1 y$ is expensive feed, but not so expensive as it appears to be, taking into consideration that it fattens quicker. Beasts that have been fed with it, do not, after a long drift to market, lose their firmness of handling, as those do, fed 
without either cake or linseed, and whose dung is not of equal value. Some winters I have fed with linseed instead of cake, and found it answer very well, although it added to the trouble of feeding. My mode of preparing it has been to break it in a little hand-mill, and steep it in cold water in seven tubs of a size sufficient for one day's feed; in this way it will have been steeped seven days before it is mixed with cut hay and barley, or (which is better) bean meal. If steeped in hot water, two days will do; if steeped longer than three, it is apt to get a little sour, which, in my opinion, is not quite so well for the beasts. Builing it is troublesome, but it thus becomes more of a jelly, and mixes better with the cut hay and meal, and it prevents the numerous seeds of weeds, found in foreign linseed, from vegetating. One stone of linseed, in a mixture of other food, will do as much towards feeding as two stone of cake, which is merely the husk of the seed after the oil has been pressed out. Linseed, without being mixed with meal, is of too relaxing a nature.

"Finding at Christmas, 1838, that I could not get English oil-cake at home at less than about $12 l .10 \mathrm{~s}$. per ton, I determined to feed the 35 beasts then in my stalls, in the following way, and I never had beasts that became better meat; but as the process of preparing the food is very troublesome, I should not recommend this way of feeding without the owner of the beasts will daily see that all is done right:-

Three feeds daily, of half a bushel of cut hay, which is $5 \mathrm{lbs}$. each, and $4 \mathrm{lbs}$. uncut at night; 1 cwt. and not quite a quarter - - - -

Boiled linseed, 2 lbs. daily, 56s. per quarter; weight, 50 lbs. per bushel

Boiled potatoes, 2 lbs, daily, $1 \frac{1}{2}$ gallons

Molasses (which is feeding, but may be left out ivhen the heasts have taken to the linseed, as it is only given to make the mixture palatable), about a $\frac{2}{4}$ b. dail

Turnips, or mangel wurzel

Barley and bean meal, mixed, $3 \frac{1}{3}$ gallons

"If this mixed food could be pressed together to form a cake, it would be a feeding one, and the cost $11 d$. per stone. As a proof that this mixture is both palatable and nutritive to beasts, they will not eat, excepting in the night, where they have none of it, any of the sweetest hay that can be put before them." (Prac. Farm, p. 89.)

Many farmers use ground linseed mixed with bran and chaff for their stock, deeming it a more economical plan than the employment of linseed cake. Others use the linseed unground. The saving by this mode, however, is doubtful, for it is by no means certain that the oil possesses any very material fattening properties; and if it does not, then the cake is decidedly the cheapest. For at the present prices (1841), $51 \mathrm{lbs}$. of linseed are worth $7 \mathrm{~s}$. $6 d$, while 51 lbs. of cake, at $11 \%$. per ton, are only worth about $5 s$.; and admitting that the oil does contain some fattening properties, yet it must be remembered that the value of the oil obtained from a bushel of linseed is worth, for other purposes, about $4 s$. But, on the other hand, I am aware that a very intelligent farmer near Rumford. Mr S Poole, who, in 1840, fed his bullocks with a mixture of linseed oil and cut chaff, and also other bullocks with linseed! cake and hay, considered the oil to be the cheapest of the two, and in all respects equally fattening, but then it is certain that this mode requires more attention in the mixture of the oil and chaff than the other plan. He commenced with about a quarter of a pint per day. and gradually increased it to a pint.

The reported results of experiments in feed ing cattle with linseed do not always agree. In a standard work we find the following passage: "Two Scots were fed on English linseed cakes: two Devons on unboiled linseed; two others on boiled linseed; and another pair of Devons on foreign; all of them having as much hay and chaff as they could eat. It was a losing concern in every case. The value of the manure was not equal to the difference of the cost and the selling prices; and, strange as it may appear, the greatest loss was sustained, when the beasts were fed on oil-cake; the next when foreign cake was used; the next when boiled linseed was used; and the least of all when the simple unboiled linseed was given.

LINSEED JELLY is easily made by adding to 6 quarts of water 1 quart of linseed, boiling it for 10 minutes. This, mixed with other substances, is sometimes given to live-stock as food, and, mixed with milk, is very nutritive for calves.

LINSEED OIL is an excellent purgative for sheep, from 2 to 3 ounces; for horses, in doses of from 16 to 24 ounces; for cattle, from 16 to 20 ounces. The quality of linseed oil may be determined in the following inanner: Fill a phial with it, and hold it up to the light; if bad it will appear opaque, turbid, and thick. its taste is acid and bitter upon the tongue, and li smells rancid: and strong oil, from fine full-gruwn ripe seed, when viewed in a phial, will appear limpid, pale, and brilliant; it is mellow, and sweet to the taste, has very little smell, is specifically lighter than impure oil, and when clarified dries quickly and finely. (Quart. Journ. of Agr. vol. v. p. 467.)

LIP. In botany, the lower petal of any irregular flower.

LIQUID MANURE. Liquid manure is not a mode of fertilizing the land altogether of modern origin, for a fermented mixture of water and night-soil has, from a very early period, been employed by the Chinese farmers; those of Italy certainly practised irrigation in the days of Virgil (Georgics, b. i. v. 106-109), and Cato adds that they employed a mixture of grape-stones and water to fertilize their olive trees (b. xxxvii.). Columella praises very highly the use of putrid stale urine for vines and apple trees (b. ii. c. 15), commending also the lees of oil for the same purpose. More modern agricultural writers have united in praising various liquid preparations; thus Evelyn (whose ingredients most of the authoro recommend), in his Treatise on Earth, p. 123. 160 , gives several recipes, some of which have: served as the basis for recent modes of preparing liquid manure, such as the dung of cattle, urine, salt and lime, and nitre. Of these artificial mixtures, salt 1 part, and lime 2 parts. mixed together and allowed to remain in a heap for 2 or 3 months (Mr. Bennelt turns 


\section{LIQUTD MANLRE.}

over 3 or 4 times in this period), is fully equal, if not supericr, to any inus recommended, most of which I have tried. When mixed with water and spread over land intented for wheat, at the rate of from 25 to 35 bushels of the salt and lime to 10 or 15 tons of water per acre (and it answers very nearly as well when carried on the land dry), excellent results are produced. The wheat which I have thas grown on clover leys has been superior in height, and strength of straw, to any have seen produced under different modes of treatment, and the seed very bright and heavy.

All substances, whether crganic, earthy, or saline, which are employed to fertilize the soil, or become the food of plants, can only be rendered thus serviceable to vegetation when they are presented to the roots of plants in solution, or in a fluid state; and although this may appear at first rather a sweeping position, yet such is the real fact, the compost of the farmyard, the crushed bones of the turnip cultivator, the oil and bones of fish, the gypsum of the grazier, the earths, lime, magnesia, and even silica, and ail the saline manures, are dissolved by some process or other before they can be absurbed by vegetables. Every attempt which has been hitherto made to make plants imbibe the most minutely divided powders which chemistry can produce, has been entirely fruitless. Davy ineffectually tried the finest impalpable powder of charcoal, and with much perseverance I have fruitlessly employed the earths, saline substances, and organic matters, for the same purpose.

This absolute necessity for every substance which is the food of plants being of a soluble nature did not escape the sagacity of the early Greek and Egyptian philosophers; it is true they carried their conclusions with regard to subjects of natural philosophy too far, as in this instance, when they asserted that water is the only food of plants; yet they must have patiently noticed many facts in vegetable economy, unaided as they were by the light of modern vegetable chemisiry, before they could have arrived at a conclusion so nearly approaching the truth. The idea was probably of Egyptian origin, for the cultivators of that country could not fail to notice the magic fertilizing powers of the waters of the Nile, whose annual overflow is perhaps the most extensive natural irrigation taken advantage of by the cultivators of the earth.

'The same wild dream of water being the sole food of vegetables was again revived, so lately as 1610 , by M. Van Helmont, a celebrated Dutch chemist, who made some very plausible, deceptive experiments on a willow tree, which he watered only with rain water; researches, however, whose inaccuracy (owing principally to rain water, as usually collected, not being quite pure) was shown in 1691 by Mr. Woodward. Although, therefore, it is now well ascertained that water is not the only food of jilants, yet it certainly contributes universally and largely to their support; and, as it has been well observed by Davy, no manure can be taken up by the roots of plants unless water is present; and water, or its elements, exists in all the products of vegetation. (Lecture 15.) 728
It mast not, however, be concluded that these carefully considered conclusions, from the results of often-repeated laborious experiments, are erroneous, because transparent water, apparently pure, as in water-glasses, or in irrigation, promotes the growth of bulbs, grass, \&c., since the very purest spring water, even rain water, contains foreign substances, as I have elearly ascertained by experiment; and when only ehemically pure water is employed to water plants, they cannot be made to flourish. I have fruitlessly varied the attempt in several ways. All the experiments of Dr. Thomson were equally unsuccessful, the plants vegetating only for a certain time, and never perfecting their seeds. Similar experiments were made by Hassenfratz and Saussure, and others, with the same unfavourable result. Duhamel found that an oak which he had raised from an acorn in common water, made less and less progress every year. The florist is well a ware that bulbous roots, such as hyacinths, tulips, $\& c .$, which are made to grow in water, unless they are planted in the earth every other year, at first refuse to flower, and finally even to vegetate. Moreover, it has been unanswerably shown by many very accurate experiments (Rech. sur la V'́g.p. 51), at the varied repetition of which I have personally assisted, that the quantity of nourishment or solid matters absoribed by the roots of plants is always in proportion to the impurity of the water with which they are nourished; thus some bears were made to vegetate under three different circumstances; the first were grown in distilled water; the second were placed in sand and watered with rain water; the third were sown in garden mould. The plants thus produced, when accurately analysed, were found to yield the following proportions of ashes :-
1. Those fed by distilled water
2. Those fed by rain water
3. Those grown in soil
$3 \cdot 9$
$-\cdot 5$
$12 \cdot 0$

And again, all attempts to make plants flourish in the pure earths have failed utterly when they have been watered with pure water; yes a totally different result I have invariably experienced when I have employed an impure solution or liquid manure. My trials have been entirely supported by those of M. Giobert, who, having formed of the four earths, silica, alumina, lime, and magnesia, a soil in the most fertile proportion, in vain essayed to make the plants flourish in it when watered with pure water only; but every difficulty was removed when he moistened it with the water from a dunghill, for they then grew most luxuriantly; ard $M$. Lampadius still further demonstrated the powers of such a foul liquid manure, for he formed plots composed of only a single earlh, pure lime, pure alumina, pure silica, and planted in each different vegetables, watering them with the liquid drainings from a dunghill, and he found that they all flourish. ed equally well. The soluble matters of a soil ever constitute, in fact, its most fertilizing portion; and if by any artificial means the richest mould is deprived of these, as by repeated washings in cold or boiling water, the residuum, or remaining solid matier, is rendered nearly sterile: this fact, frrst accurately demon. 


\section{LIQUID MANURE.}

strated by M. Saussure (Rech. 150), I have since confirmed, by a variety of experiments of $\mathrm{my}$ own.

The soluble matters or liquid manures consumed by plants are sometimes imbibed by their roots unaltered; in other cases they are decomposed during their absorption. The earths, gypsum, and other salts, are instances of the first class; oil, and other purely animal matters, of the last. Davy found that some plants of mint, which he forced to vegetate in sugar and water, apparently absorbed the sugar unaltered, for they yielded a considerably larger proportion of a sweetish vegetable extract than those of the same weight which he had grown in common water; and it is an ascertained fact, that the roots of plants will absorb or reject the various earthy substances of a soil, or even when placed in a saline solution, in a very remarkable manner: thus, when equal parts of gum and sugar were dissolved together in water, and some perfect plants of Polygonum Persicaria placed with their roots in the solution, it was found that they absorbed 36 parts of the sugar, but only 26 of the gum; and when in precisely the same proportions and manner Glauber salt, common salt, and acetate of lime were used, then it was found that the roots of the Persicaria separated these salts from the solution with much ease, absorbing 6 parts of the Glauber salt, 10 parts of the common salt, but not a trace of the acetate of lime. (Thomson, vol. iv. p. 321.)

'These facts will not be uninteresting to the irrigators or occupiers of the English watermeadows, since they may, in some degree, serve to account for the beneficial action of water on such lands-a question not nearly so well understood as it ought to be, and on which widely differing opinions are commonly held by practical farmers. It is a theme intimately connected with the subject of this article, for irrigation is, in truth, a mode of applying the weakest of liquid manures, on a very bold scale, to grass-lands. See In rigation.

The employment of artificially-prepared liquid manure (though little known at present in England) is very extensive on the Continent: the Swiss farmers call it gulle; in France it is denominated lizier : and by the Germans, mist-wasser. They prepare it throughout many of the German states, and in the Netherlands, by sweeping the excrements of their stall-fed caltle in to under-ground reservoirs, mixing it with four or five times its bulk of water, according to the richness of the dung: five reservoirs are generally employed, of such a size that they each take a week to fill; and thus each has four weeks allowed to ferment before the mass, which in this time becomes of an uniform consistence, is removed, by means of a portable pump, in water carts, or large open vessels. A similar plan is adopted in the north of Italy, and from time out of mind has been practised by the Chinese. In that empire, however, the cultivators chiefly employ night soil, which is made into cakes for this purpose with lime or clay, in all their large cities, to prepare their liquid manure.

It is from long experience an admitted fact among the German farmers, that there are no manures so powerful in their operation as those which are liquids, such as human urine or bullocks' blood; so that no English farmer need fear deception as to their asserted value. This very fact was submitted some years since to the consideration of Professor Ifemb. stadt, of Berlin, by the Saxon and Prussian atl. thorities, who were anxious to apply the contents of the city drains towards fertilizing the barren lands in the neighbourhood of Dresden and Berlin. This talented agriculturist undertook, in consequence, a series of valuable experiments, which, varied in every possible way, were carried on for a considerable period; the result of them, so highly advantageous to the prosperity of Germany, Hembstadt then published. They were repeated with unvaried success by Professor Schübler, and the results may be stated in the following order:-

If the soil, without any manure, yield a produce of three times the quantity of seed originally sown, then the same quantity of land wil! produce-

5 times the quantity of seed sown, wher. dressed with old herbage, grass, leaves, \&c.

7 times, when dressed with cow dung.

9 times, with pigeons' dung.

10 times, with horse dung.

12 times, with human urine.

12 times, with sheep's dung.

14 times, with human manure or bullocks' blond.

Thus it will be seen that, of seven usually employed fertilizers, the liquid manures, urine and blood, were found to be decidedly the most powerful.

Both with regard to the quantity of liquid manure applied per acre, and the mode of spreading it, much must depend upon the circumstances under which the cultivator is placed, and the richness of the liquid he employs. If the impurities dissolved, or mechanically suspended in the water, are equal to $]$ part in 10, then 20 to 30 tons per acre of the liquid manure I have found amply sufficient, under ordinary circumstances, to produce the most excellent results; if the fluid mass is purer, then more must be applied. For gardens, and small plots of ground in general, the liquid may be readily and evenly distributed. over the beds by means of a watering-pot or garden-engine; for fields it must be carried in water-carts, and distributed either by being let into a transverse trough, pierced with holes ir. the manner of those employed for street waterings, or the Flemish plan may be adopted (especially when the manure is of ton considerable thickness to flow readily through holes). of taking it into the fields in the water-carts: open at the top (furnished with slight movable covers), and then distributing it out of the cart very evenly by means of a scoop: and I have invariably perceived the advantage of plough. ing the liquid into the soil as soon afler it was spread on the land as possible. The cultivato will find great advantage if he uses the garden engine, watering-pot, or cart, from straining the liquid manure before he pumps it out of the reservoir, either through straw, coarse sand, or a basket; the pieces of straw, and other coarsely-divided matters thus separated by the strainer, he will discuver add very 


\section{LIQUID MANURE.}

slightly to the fertilizing powers of the liquid, and yet they all materially hinder the even distribution of the manure.

The expense, per acre, of such an application of liquid manure, I thus estimate, supposing the cow-herd to be employed:-

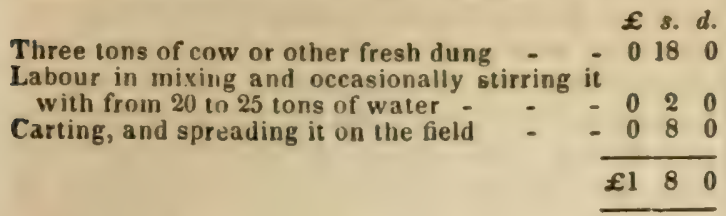

If it shall occur to the farmer that the quan:ity of solid manure thus added to the soil will not, in reality, much exceed two tons per acre, and that this is, in appearance, a very small allowance, I would remind him that the quantity thus conveyed consists of the soluble or richest portion of the manure, and is, in fact, the extract without any of the straw, or other inert residuum usually carried on to the soil; besides, it is a very erroneous, though common conclusion, that to produce fertility a manure must be used in large quantities. I have observed in this paper that a flooding with river water, so productive of heavy crops of grass in the water meadows, does not carry on to the land more than 2 tons per acre of animal and vegetable substances; and in the successful experiments of the late Lord Somerville,. at Fairmile, with whale blubber, not more than a ton and a half per acre were applied. The Essex farmers find three-quarters of a ton of sprats amply sufficient; and $2 \mathrm{cwt}$. per acre of gypsum is the ordinary successful allowance for grass land. The exact evenness, therefore, with which a manure is spread over the land is a highly important consideration as regards the economy of manures. There is no commonly cultivated plant which more delights in liquid manure than the potato. It naturally luxuriates near to wet ditches: on plots which have received the drainage of a dunghill it grows with the greatest rapidity. I have invariably found that, to any liquid mixture intended as a manure for potatoes, the addition of 5 or 6 bushels of salt per acre is productive of great good, both as regards the quantity and quality of the potatoes.

On clover leys intended for wheat, the liquid should be turned into the soil as early as possible after it is spread; and if this operation is performed in moist, cloudy weather, a very material advantage will be perceptible in the succeeding crop. The warmth of the sun is certainly prejudicial to the thinly-spread liquid manure, composed of finely-divided animal and vegetable substances.

Of the tanks for receiving or preparing the liquid manure, I may remark that $\mathbf{I}$ have always fuund them best made of flints or bricks set in good mortar or Parker's cement; they may be bedded in clay, but I would not recommend the use of ciay for the brickwork, since worms are sure eventually to penetrate through it; and I advise the shape to be something like a decanter, larger at the top than at the bottom, in the manner introduced at Eastbourne and in Cornwall, chiefly by the advice of Mr. Davies Cilbert.
Mr. Milburn has given the annexed estimate for cutting, walling, plastering, and covering a tank of the following dimensions:-Length within, 13 feet 6 inches; width, 6 feet 6 inches; depth, 6 feet, equal to $19 \frac{1}{2}$ cubic yards.

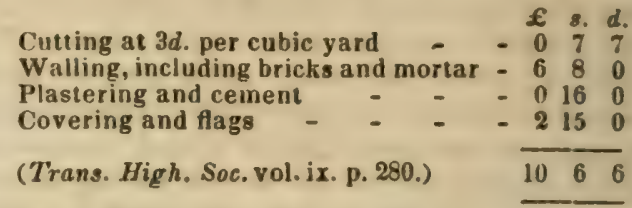

This would be a tank sufficiently capacious for a farm of 150 to 200 acres.

To the presence of a large proportion of urine, the richest of liquid fertilizers, must be chiefly attributed the luxuriant effects produced by the liquid manure, as prepared on the Con. tinent, and from the use of the sewerage matters of large towns, as so strikingly proved in the case of the Craigintinny water-meadows, near Edinburgh, where the drainage is employed in the state in which it issues from the sewers, and from its use several crops of the most luxuriant grass are annually obtained. "All urine," said a late distinguished chemical philosopher, "contains the essential elements of vegetables in a state of solution." By a careful analysis, human urine in its fresh state was found, by Berzelius, to contain the following substances:-

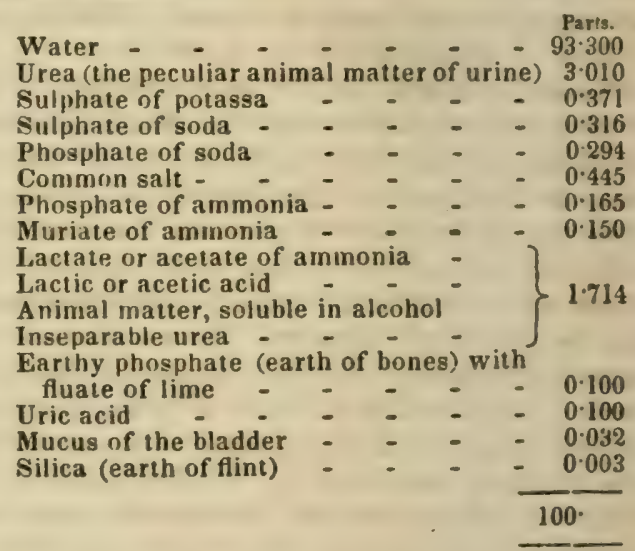

Thus it will be seen that there is hardly a single ingredient found in urine which is not either a direct food for vegetation, or furnishes by its decomposition a supply in another form; for in it are thus detected the ammoniacal salts of the dunghill, the phosphate of lime of bones, as well as of many cultivated vegetables, and abundance of easily decomposed animal matters.

The urine of the horse is nearly as rich in animo-vegetable matters; its composition, ac cording to the experiments of Fourcroy and Vauquelin, are as follows:-

\begin{tabular}{|c|c|c|c|c|c|}
\hline Water and mucus & - & - & - & - & $\begin{array}{r}\text { Parts } \\
-\quad 94.0\end{array}$ \\
\hline Urea - - - & - & - & - & - & 07 \\
\hline Carbonate of lime ( & chalk) & & - & - & $1 \cdot 1$ \\
\hline Carbonate of soda & - & - & - & - & 0.9 \\
\hline Benzole of soda & - & - & - & - & $2 \cdot 4$ \\
\hline \multirow[t]{2}{*}{ Muriate of potassa } & - & - & - & - & 0.9 \\
\hline & & & & & $100^{\circ}$ \\
\hline
\end{tabular}

The following are the constituents in that of the cow, as found by Professur Brande :- 


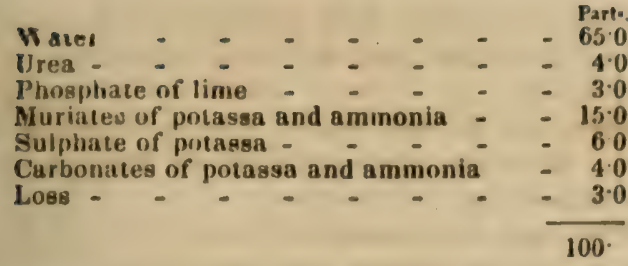

It would appear, from some experiments of 1)r. Belcher, that the ammoniacal salts of urine have a forcing or stimulating power, which considerably hastens the vegetation of plants. His experiments were made with the common garden eress; and, in his trials, some plants nourished with a solution of phosphate of ammonia were 15 days more advanced than plants growing under similar circumstances, but watered with plain water. In some experiments of Mr. Gregory, who watered half a grass field at Leyton with urine, the portion thus treated yielded nearly double the quantity of hay produced by the other unmanured portion; and the use of the urine of the cow, so extensively employed for grass lands, and in the garden and orchard, by Mr. Harley, in the neighbourhood of Glasgow, was attended with results equally satisfactory, producing, when diluted with water or soap-suds, very superior crops of grass on land of a very inferior description. I shall conclude with a few observations on the loss which the cultivated lands of England incessantly sustain from the neglect of the liquid manure of the sewers of her cities and large lowns, - a question to which I have before alluded in this paper, and which is not nearly so well understood as is desirable. Thus, by carefully conducted experiments, and very accurate gaugings, it has been found that the chief London sewers convey daily into the Thaines about 115,000 tons of mixed drainage, consisting, on an average computation, of 1 part of solid and 25 parts absolutely fluid matters; but if we only allow 1 part in 30 of this immense mass to be composed of solid substances, then we have the large quantity of more than 3800 tons of solid manure daily poured into the river from London alone, consisting principally of excrements, soot, and the débris of the London streets, which is chiefly carbonate of lime: thus, allowing 20 tons of this manure as a dressing for an acre of ground, there is evidently a quantity of solid manure annually poured into the river equal to fertilizing more than 50,000 acres of the poorest cultivated land! The quantity of fond thus lost to the country by this heedless waste of manure is enormous; for, only allowing one crop of wheat to be raised on these 50,000 acres, that would be equal to the maintenance (calculating upon an average produce of three quarters of wheat per acre) of 150,000 persons. London, too, is only one huge instance of this thoughtless waste of the agricultural riches of the soil of England; from every other English city, every town, every hamlet, is hourly passing into the sea a proportionate waste of liquid manure: and I have oniy spoken of the solid or mechanically suspendea matiers of the sewerage; the absolutely fluid portion is still rich in urine, ammoniacal salts, soda, \&c., when all the mechanically suspended matters have been separated from the other portions. According to very careful experiments, this fluid part often contains 16 per cent. of animal matlers, salts, \&c., intimately or chemically cumbined with the water.

No farmer, after such an analysis of the sewerage of a large cily, can feel surprised at the important results from the use of that sewer water, as long practised in the vicinity of Edinburgh. After learning the composition of such a foul mass-its endless mixture of organic matters-its soot-its carbonate of lime-and, above all, its urine, the forcing nature of the ammoniacal salts which that fluid contains, added to the presence of the other matters which are the food of plants, and the constant supply of such irrigation water in all seasons - he will readily give credence to the talented editor of the Quarterly Journal of Agricullure, when he asserts that, by such treatrnent of the Edinburgh meadows with the sewerage irrigation, they have been increased in value several pounds per acre yearly.

I have often employed, with decided effech, in my own garden, for vines, peach, and standard apple trees, liquid manure, prepared either by mixing one part by weight of cow dung with four parts of water, or the collected drain. age of the stable and cow-house. Of these the vine is by far the most benefited by the application; but to whatever fruit-tree the gardener has occasion to apply manure, there is no form so manageable and so grateful to the plant as the liquid. It has been found advantageous to plants cultivated in stoves to apply even a liquid manure, composed of six quarts of soot to a hogshead of water; and although this is a very unchemical mixture, yet it has been found by Mr. Robertson to be peculiarly grateful and nourishing to pines, causing them to assume an unusually deep healthy green; and for stoved mulberry, vine, peach, and other plants, the late Mr. Knight, of Downton, employed a liquid manure, composed of one part of the dung of domestic poultry, and 4 to 10 parts of water, with the most excellent result-the trees maintaining, at the end of two years, "the most healthy and luxuriant appearance imaginable." (Trans. Hort. Soc. vol. ii. p. 127.)

In whatever way we view the question of liquid manure, an abundant field of research presents itself on every side: it is evidently an investigation likely to amply repay the cultivator for the labour he may be induced to bestow upon it. By such manures, nourishment for vegetation is more equally diffused through the soil, and becomes more speedily serviceable to the crop, than by any other mode of cultivation. I have endeavoured, also, in this article, to convince the farmer of what I have long remarked in my own practice-that a much smaller quantity of manure, if uniformly mixed with land, is sufficient for all the pur. poses of fertilization than is commonly believed. Such investigations must be of the highest interest to the farmer and to the public in general, for they relate to the increased pro duce of the land of England; and not only does a fortunate experiment carry with it its own reward, but even an unsuccessful one is not without its advantages,-it serves, at least, as 


\section{LIVE-STOCK.}

a beacon to other cultivators, and affords that satisfaction which ever accompanies the acquirement of knowledge. (Journ. Roy. Ag. Soc. vol. i. p. 147.)

LIQUORICE (Glycyrrhiza, from glnkus, sweet, and rhiza, a root; the sweetness of the root of liquorice is well known). A deep, light, sandy loam suits all the species of this genus, and they are readily increased by slips from the roots with eyes, and planting them in spring.

Common liquorice ( $G$. glabra) is a native of the south of Europe; but it is also cultivated in England for medicinal use. It is a leguminous plant, with unequally pinnated leaves, composed of ovate, retuse leaflets; the flowers are in racemose spikes, shorter than the leaves. The legumes are smooth, and six-seeded. The root, when fit for use, is long, about the thickness of the finger, grayish without, and yellow within. The sweet, subacrid, mucilaginous juice contained in the root is much esteemed as a pectoral demulcent. Liquorice requires three years to perfect its growth, when the roots are taken up about the end of November with the spade; they are then washed, the fibres trimmed off, and the smaller roots which are termed "offal," are separated from the larger. The small roots are dried and ground into powder; but the larger, which form the principal article of profit, are packed up and sold to the druggists. A fair crop will yield from 18 to $20 \mathrm{cwt}$, at an average price of about $45 \mathrm{~s}$. per cwt.; but the expense of digging up and preparing it for market is not short of $10 l$. per acre; which, great as it nay appear, is by no means extravagant, if $v$ e consider the depth to which the roots run, and the care which is necessary to avoid breaking or leaving any of them in the ground. (Paxton's Bot. Dict.; Brit. Husb. vol. ii. p. 330.)

LIQUORICE, WILD. A species of the genus Galium (Circazans) found in the United States, frequent in rich woodlands, \&c. Its root is perennial, and the stems grow 12 to 18 inches high, often branched near the base. The flowers are purplish-white, and appear in June and July. The leaves have a sweet taste, resembling liquorice. See MrLk-VE'rcr.

LIT'TER. The straw, fern, or other dry substances which are placed under horses and cattle in the stables, cow-houses, farm-yards, \&c., for the purpose of keeping the animals clean and warm, and providing a supply of manure. In this last view, all sorts of dry materials should be carefully collected and stacked up for winter use.

LIVERWORT (Anemone hepatica, Hepatica Americana, or Three-lobed Liverwort) is very cornmon in the open woodlands of the United States, where it flowers in Pennsylvania in May, and matures its seed in May and June. This plant has acquired much notoriety, of late years, as a remedy in pulmonary consumption; but its virtues have doubtless been greatly exagge. rated. Dr. Darlington thinks it the only species in the United States. (Flora Cestricu.) See HEPATICA.

LIVE-STOCK. See Honsfs, Cattle, Sheep, \&c. In Great Britain, the live-stock forms the chief wealth of a tarm. The term implies catle; but poultry. too, is strictly live-stock; and in some countries, fish, game, bees, \&c., are of that importance that they are considered to be live-stock. In several districts of England, rabbits are so, and that to a very essential extent. In some parts of southern Europe, even the silk-worm is live-stock.

Through the combined exertions of many distinguished writers, and the practical know. ledge of modern breeders, a very material alteration for the better in the breeds of live-stock has taken place, and is still progressing; and there is little reason to doubt but that still greater improvements are yet to be effected. To such researches too much attention can hardly be paid; for on the well or ill stocking of the land will mainly depend the cultivator's success. To this end, however, much must rest on the circumstances in which he is placed. See Agricucture in the United States.

LIVE OAK (Quercus virens). See $\mathrm{O}_{\mathbf{A K}}$.

LOAD. A term used in the United States rather vaguely, and meaning different amounts or measures in different places. The general meaning of a load of manure, according to Buel, is what can be drawn by two horses, or two oxen, to the field where it is to be applied. At Boston and other large towns in the Eastern, as well as other States, the term load is applied commonly to express as much as can be drawn by four and even six cattle upon a hard road, or about 96 cubic feet. A load of earth, clay, or marl, is generally estimated at a cubic yard, or 27 cubic feet.

LOAM. By this term is generally understood dark-coloured, rich mould, principally composed of dissimilar particles of earth and decomposed vegetable matter, moderately cohesive, and therefore neither retentive of moisture, like clay, nor too ready to part with it, like sandy soil. According as the different ingredients predominate, loamy soils are of different qualities-friable and mellow, middling, or heavy loams. (Pract. Husb. p. 234.) Loam is supposed to consist chiefly of woody fibre in a state of decay, which, as it progresses, acquires a black-brown colour, and is then mould or loam. It is a continued source of carbonic acid, as almost every particle of it is enveloped by an atmosphere of that gas, which is absorbed by the roots of plants, and replaced by atmo. spheric air, to be again converted into carbonic acid. Upon this transformation the influence of loam on vegetation is readily understood: it does not itself nourish plants, but it presents to them "a slow and lasting source of carbonic acid, which is absorbed by the roots." (Liebig, Organic Chemistry in its Application to Agriculture, p. 48-61.) See Humus.

LOBEIIA (Lobelia, in honour of Matthew I.obel, author of various botanical works. He was a native of Lisle; became physician and botanist to James $I$., and died in London in 1616). This is an extremely interesting genus of plants, on account of the beauty of the blossoms, and the medicinal properties of some of the species. The green-house, and stove, shrubby, and herbaceous kinds, grow well in a mixture of peat and sand; the shrubby kinds are readily increased by cuttings in the same kind of soil, and the herbaceous species by dividing and by seeds. The hardy herbaceous 
kinds do well in a light, rich earth, or peat soil; but in winter most of them require the protection of a frame. The green-house annuals and biernials must be sown in pots, and treated as other green-house annuals and biennials. The seeds of the hardy kinds have only to be sown in the open border. L. longiflora is one of the most venomous of plants. Barton says the Spanish Americans call it Rebenta cavallos, because it proves fatal to horses that eat it, swelling them till they burst. Taken internally, it acts as a violent cathartic, the effects of which no remedy can assuage, and which terminate in death. Another American species, namely, L. inflata, commonly called Indian Tobacco, is a powerful antispasmodic and emetic, and is much employed to allay the paroxysm of spasmodic asthma. 'There are two indigenous species: 1. The water lobelia ( $L$. Dartmanna), which grows in the lakes of Wales, Scotland, Ireland, and the north of England. 'The root consists of many long, simple, whitish fibres. Herb smooth, immersed in water like the Hottonia. Leaves numerous, two inches long, linear, entire, with two longitudinal cells. The stem is nearly naked, terminating in a simple cluster of light-blue, drooping, alternate flowers, raised several inches above the water, which appear in July and August.

2. Acrid lobelia (L. urens). This grows wild on bushy heaths in Devonshire. The root is fibrous; stem a foot or more in height, nearly upright; lower leaves ovate, slightly toothed; upper lanceolate, serrated; the flowers are in erect clusters, terminal, of a purplish-blue colour, appearing in August and September. The whole herb is milky, fetid, and very acrid.

I.OBLOI.LY BAY (Gordonia lasyanthus). This American tree is comprehended within the same limits with the long-leaved pine, being confined to the maritime parts of the Southern States, to the two Floridas, and to Lower Louisiana. It is very abundant in the branch swamps, and exists in greater proportion than the red bay, swamp bay, and black gum, with which it is usually associated. In the pine barrens, tracts of 50 or 100 acres are met with at intervals, which, being lower than the adjacent ground, are kept constantly moist by the waters collected in them after the great rains. These spots are entirely covered with the loblolly bay, and are called bay swamps. Although the layer of vegetable mould is only 3 or 4 inches thick, and reposes upon a bed of barren sand, the vegetation of these trees is surprisingly luxuriant.

The loblolly bay grows to the height of 50 or 60 feet, with a diameter of 18 or 20 inches. For 25 to 30 feet its trunk is perfectly straight. The small divergency of its branches near the irunk gives it a regularly pyramidal form; but as they ascend they spread more loosely, like those of other trees of the forest.

The leaves are evergreen, from 3 to 6 inches long, alternate, oval-acuminate, slightly toothed, and smooth and shining on the upper surface. The flowers are more than an inch broad, white and sweet-scented; they begin to appear about the middle of July, and bloom in succession during 2 or 3 months. This tree possesses the agreeable singularity of bearing fowers when it is only 3 or 4 feet high

The fruit is an oval capsule, divided into 5 compartments, each of which cuntains small, black, winged seeds. These seeds appear to germinate successfully only in places covered with sphagnum, a species of moss which copiously imbibes water, and in which are found thousands of the young plants, which are plucked up with ease.

The bark of the loblolly bay is very smooth while the tree is less than 6 inches in diameter; on old trees it is thick and deeply furrowed. In trunks which exceed 15 inches in diameter, four-fifths of the wood is heart. The wood is of a rosy hue, and of a fine, silky texture: it appears to be very proper for the inside of furniture, though the cypress is generally preferred. It is extremely light: when seasoned it is very brittle, and it rapidly decays' unless it is kept perfectly dry: hence it is entirely neg. lected in use, and is not employed even for fuel.

The value of the loblolly bark in tanning compensates in some measure for the useless ness of its wood: it is employed for this pup pose throughout the maritime parts of the Southern States and of the Floridas. For, although this branch of industry is by no means as extensively practised in this part of the country as in the Northern States, and though these regions afford many species of oak, yet the species whose bark is proper for tanning are not sufficiently multiplied to supply the consumption. As much of the bark of the Spanish oak as can be obtained, of which the price is one-half greater, is mixed with that of the loblolly bay. This tree has the advantage of maintaining very long the circulation of its sap, so that the bark may be taken off during three or four months.

The luxuriance of its vegetation, the beauty of its flowers, and the richness of its evergreen foliage place the loblolly bay among the magnolias; and, with the other species, it contributes to the ornament of the forests in the southern parts of the United States. It is less sensible to cold than the big laurel. (Michaux.)

LOBLOLLY PINE (Pinus tada). See Firs.

LOCKED-JAW. See Tetanus.

LOCKING OF WHEELS. The means of fastening them so as to prevent their running too swiftly upon the horses, when coming down steep hills. This is effected in various ways; as by chains, sledges, friction-bars, \&c. See WHFEL, and WAGON.

LOCULAR. A term in botany. A fruit is called unilocular if it contains but one cell, bilocular if it contains two cells, and so on. In many instances, one or more of the cells are abortive, and become obliterated as the fruit ripens.

LOCUST. A name given by the English to. the large grasshoppers, but which, in the United States, and indeed almost universally, is applied to the group of insects which naturalists have termed Cicadians, and which are also called harvest-flies.

These insects are readily distinguished by their broad heads, the large and very convex eyes on each side, and the three eyelets on then 
crown: by the transparent and veined wingcovers and wings; and by the elevation on the nack part of the thorax in the form of the letter $\mathbf{X}$. 'The males have a peculiar organization, which enables them to emit an excessively loud buzzing kind of sound, which, in some species, may be heard at the distance of a mile; and the females are furnished with a curiously contrived piercer, for perforating the limbs of trees, in which they place their eggs. The musical instruments of the male consist of a pair of kettle-drums, one on each side of the body, and these, in the seventeen-year Cicada (or locust, as it is generally but improperly called in America), are plainly to be seen just behind the wings. These drums are formed of convex pieces of parchment, covered with numerous fine plaits, and, in the species above named, are lodged in cavities on the sides of the body behind the thorax. They are not played upon with sticks, but by muscles or cords fastened to the inside of the drums. When these muscles contract and relax, which they do with great rapidity, the drum-heads are alternately tightened and loosened, recovering their natural convexity by their own elasticity. The effect of this rapid alternate tension and relaxation is the production of a rattling sound, like that caused by a succession of quick pressures upon a slightly convex and elastic piece of tin plate. Certain cavities within the body of the insect, which may be seen on raising two large valves beneath the belly, and which are separated from each other by thin partitions having the transparency and brilliancy of mica, or of thin and highly polished glass, tend to increase the vibrations of the sounds, and add greatly to their intensity. In most of our species of $\mathrm{C} i$ cada, the drums are not visible on the outside of the body, but are covered by convex triangular pieces on each side of the first ring behind the thorax, which must be cut away in order to expose them. On raising the large valves of the belly, however, there is seen, close to each side of the body, a little opening, like a pocket, in which the drum is lodged, and from which the sound issues when the insect opens the valves. The hinder extremity of the body of the female is conical, and the under-side has a longitudinal channel for the reception of the piercer, which is furthermore protected by four short grooved pieces fixed in the sides of the channel. The piercer itself consists of three parts in close contact with each other; namely, two outer ones grooved on the inside and enlarged at the tips, which externally are beset with small teeth like a saw, and a central, spear-pointed borer, which plays between the other two. Thus this instrument has the power and does the work both of an awl and of a double-edged saw, or rather of two key-hole saws cutting opposite to each other. No species of Cicada possesses the power of leaping. The legs are rather short, and the anterior thighs are armed beneath with two stout spines.

The duration of life in winged insects is :omparatively very short, seldom exceeding two or three weeks in extent, and in many is limited to the same number of days or hours. 'To increase and multiply is their principal business in this period of their existence, if not the only one; and the natural term of their life ends when this is accomplished. In their previous states, however, they often pass a much longer time, the length of which depends, in great measure, upon the nature and abundance of their food. Thus maggots, which subsist upon decaying animal or vegetable matter, come more quickly to their growth than caterpillars and other insects which devour living plants: the former are appointed to remove an offensive nuisance, and to do their work quickly; the latter have a longer time assigned to them, corresponding in some degree to the progress or continuance of vegetation. The facilities afforded for obtaining food influence the dura tion of life; hence those grubs that live in the solid trunks of perennial trees, which they are obliged to perforate in order to obtain nourishment, are longer lived than those that devour the tender parts of leaves and fruits, which, though they last only for a season, require no laborious efforts to be prepared for food. The harvest-flies continue only a few weeks after their final transformation, and their only nourishment consists of vegetable juices, which they obtain by piercing the bark and leaves of plants with their beaks; and during this period they lay their eggs, and then perish. They are, however, amply compensated for the shortness of their life in the winged state by the length of their previous existence, during which they are wingless and grub-like in form, and live under ground, where they obtain their food only by much labour in perforating the soil among the roots of plants, the juices of which they imbibe by suction. To meet the difficulties of their situation and the precarious supply of their food, for which they have to grope in the dark in their subterranean retreats, a remarkable longevity is assigned to them; and one species has obtained the name of Cicada septendecim, on account of its life being protracted to the period of seventeen years.

Tiss insect has been observed in the southeastern parts of Massachusetts, but does not seem to have extended to other parts of the state. The earliest account that we have of it is contained in Morton's Memorial, wherein it is stated that "there was a numerous company of flies, which were like for bigness unto wasps or bumblebees," which appeared in Plymouth in the spring of 1633 . "They came out of little holes in the ground, and did eat up the green things, and made such a constant yelling noise as made the woods ring of them, and ready to deafen the hearers." Judge Davis, in the Appendix to his edition of Secretary Morton's Memorial, states that these insects ap. peared in Plymouth, Sandwich, and Falmouth in the year 1804; but, if the exact period of seventeen years was observed, they should have returned in 1803. Circumstances may occasionally accelerate or retard their progress to maturity, but the usual interval is certainly seventeen years, according to the observations and testimony of many persons of undoubted veracity. Their occurrence in large swarms at long intervals, like that of the migratory locusts of the East, probably suggested the name of locusts, which has commonly been applied to them in this country. It appears 
tnd these insects come forth at different places in different years.

Dog-duy IIarvest-fy. - Another species of harvest-fly, though it does not make its appearance in such formidable numbers as the seventeenyears locust, is much more frequently met with. Dr. Harris calls it the dog-day harvest-fly (Cicuda canicularis), from its invariably coming about the beginning of dog-days. "During many years in succession," says Dr. Harris, "with only one or two exceptions, I have heard this insect on the 25th day of July, for the first time in the season, drumming in the trees, on some part of the day between the hours of ten in the morning and two in the afternoon."

Dr. Harris describes about twenty other species of the locust family found in Massachusetts, and concludes the subject in the following words :

"After so much space has been devoted to an account of the ravages of grasshoppers and locusts, and to the descriptions of the insects themselves, perhaps it may be expected that the means of checking and destroying them should be fully explained. The naturalist, however, seldom has it in his power to put in practice the various remedies which his knowledge or experience may suggest. His proper province consists in examining the living objects about him with regard to their structure, their scientific arrangement, and their economy or history. In doing this, he opens to others the way to a successful course of experiments, the trial of which he is generally obliged to leave to those who are more favourably situated for their performance.

In the south of France the people make a business, at certain seasons of the year, of collecting locusts and their eggs, the latter being turned out of the ground in little masses, cemented and covered with a sort of gum, in which they are enveloped by the insects. Rewards are offered and paid for their collection, half a franc being given for a kilogramme (about 2 lbs. $3 \frac{1}{4}$ oz. avoirdupois) of the insects, and a quarter of a franc for the same weight of their eggs. At this rate 20,000 francs were paid in Marseilles, and 25,000 in Arles, in the year 1613; in 1824, 5,542; and in 1825, 6,200 irancs were paid in Marseilles. It is stated that an active boy can collect from 6 to 7 kilogrammes (or from $13 \mathrm{lbs} .3 \mathrm{oz} \cdot 13 \cdot 22 \mathrm{dr}$. to $15 \mathrm{lbs} .7 \mathrm{oz} .2 .09 \mathrm{dr}$.) of eggs in one day. The locusts are taken by means of a piece of stout cloth, carried by four persons, two of whom draw it rapidly along, so that the edge may sweep over the surface of the soil, and the two others hold up the cloth behind at an angle of 45 degrees. This contrivance seems to operate somewhat like a horse-rake, in gathering the insects into winrows or heaps, from which they are speedily transferred to large sacks. A somewhat similar plan has been successfully tried in this country, as appears by an account extracted from the Portsmouth Journal, and puti:shed in the New England Farmer, vol. v. p. b. It is there stated that, in July, 1826, Mr. Amold Thompson, of Epsom, New Hampshire, canght in nne evening, between the hours of 8 and 12 , in his own and his neighbour's grain- fields, 5 bushels and 3 pecks of grasshoppers, or, more properly, locusts. 'His mude of catching them was by attaching two sheets together, and fastening them to a pole, which was used as the front part of the drag. The pole extended beyond the width of the sheets, so as to admit persons at both sides to draw it forward. At the sides of the drag, braces extended from the pole to raise the back part considerably from the ground, so that the grasshoppers could not escape. After running the drag about a dozen rods with rapidity, the braces were taken out, and the sheets doubled over; the grasshoppers were then swept from each end towards the centre of the sheet, where was left an opening to the mouth of a bag which held about half a bushel; when deposited and tied up, the drag was again opened and ready to proceed. When this bag was filled so as to become burdensome (their weight is about the same as that of the same measure of corn), the bag was opened into a larger one, and the grasshoppers received into a new deposit. 'The drag can be used unly in the evening, when the grasshoppers are perched on the top of the grain. His manner of destroying them was by dipping the large bags into a kettle of boiling water. When boiled, they had a reddish appearance, and made a fine feast for the farmer's hogs.' When these insects are very prevalent on utr salt marshes, it will be advisable to mow the grass early, so as to secure a crop before it has suf. fered much loss. 'The time for doing this will be determined by data furnished in the foregoing pages, where it will be seen that the most destructive species come to maturity during the latter part of July. If, then, the marshes are mowed about the first of July, the locusts, being at that time sinall and not provided with wings, will be unable to migrate, and will consequently perish on the ground for the want of food, while a tolerable crop of hay will be secured, and the marshes will suffer less from the insects during the following summer. This, like all other preventive measures, must be generally adopted, in order to prove effectual; for it will avail a farmer but little to take preventive measures on his own land, if his neighbours, who are equally exposed and interested, neglect to do the same. Among the natural means which seem to be appointed to keep these insects in check, violent winds and storms may be mentioned, which sometimes sweep them off in great swarms, and cast them into the sea. Vast numbers are drowned by the high tides that frequently inundate our marshe?. They are subject to be attacked by certain thread-like brown or blackish worms (Filaria), resembling in appearance those called horsi:hair eels (Gordius). I have taken three or four of these animals out of the body of a single locust. They are also much infested by licte red mites, belonging apparently to the senus Ocypete: these so much weaken the insects by sucking the juices from their bodies, as to hasten their death. Ten or a dozen of these mites will frequently be found pertinaciously adhering to the body of a locust, beneath its wing-covers and wings. A kind of sand-wasp preys upon grasshoppers, and provisions her nest with them. Many birds devour them, par. 
ricularly our domestic fowls, which eat great numbers of grasshoppers, locusts, and even crickets. Young turkeys, if allowed to go at large during the summer, derive nearly the whole of their subsistence from these insects." (Harris's Treatise on Insects.)

In England, Locust is the common name of a species of insects forming a group or subgenus of the gryllus of Linnæus. They have coloured elytra, and large wings, disposed, when at rest, in straight, fan-like folds, as in other orthoptera, and frequently exhibiting bright blue, green, or red colours. The thorax is capacious, to afford room for the puwerful muscles of the wings, and is marked in many species with one or more crests, or wart-like prominences. The locusts fly by starts, but frequently rise to a considerable height. Certain species, called "migratory locusts," unite in incalculable numbers, and emigrate, resembling, in their passage through the air, a dense cloud: wherever they alight, all signs of vegetation quickly disappear, and cultivated grounds are left a desert. One species (Acridium migratorium, Latr.), occasionally commits devastations in the south of Europe and Poland; and stragglers have sometimes reached England, a circumstance which happened in 1748: but they soon perished. To our ideas of the association of insects, the swarms of locusts which have occasionally appeared in oriental countries seem almost incredible. Major Moor states that a flight which ravaged the Mahratta country, and which he saw at Poonah, extended in a dense column 500 miles, and hid the sun like an eclipse. On that occasion, the natives fried and ate them. The devastation which they make is forcibly described by the prophet Joel: "The land is as the garden of Eden before them, and behind them a desolate wilderness."

LOCUST-BORER. See BorFrs.

LOCUST, HONEY or SWEET. See HoNer Locust.

LOCUST TREE (Hymencea, from Hymen, the god of marriage; in reference to the two leaflets). The species of locust tree are highly ornamental; they delight to grow in loam and peat, and cuttings will root in sand under a glass in heat. The young plants should be planted out in the autumn of the second year, cutting them down within three inches of the ground. They must be preserved from the attacks of hares and rabbits, which are very destructive to them. See Acacia.

LOCUS'T TREE CATERPIILARS. These are produced from the eggs of a butterfly beinnging to a tribe which, from their habit of flying but a short distance at a time with a jerking motion, have acquired the name of skippers (Hesperiadx or Hesperians). They frequent grassy places, low bushes, and thickets. When they alight, they usually keep the hind-wings spread out horizontally, and the fore-wings partially closed, but not entirely so, as in other butterflies.

The Tityrus skipper (Eudamus tityrus), and its offspring, are thus described by Dr. Harris. " Wings brown; first pair with a transverse, semi-transparent band across the middle, and a few spots towards the tip, of a honey-yellow rclour; hind-wings with a short rounded tail \%36 on the hind arrgles, and a broad silvery band across the middle of the under-side. Expands from 2 to $2 \frac{1}{2}$ inches.

"This large and beautiful insect makes its appearance, from the middle of June till after the beginning of July, upon sweet-scented flowers, which it visits during the middle of the day. Its flight is vigorous and rapid, and its strength is so great that it cannot be cap. tured without danger of its being greatly de. faced in its struggles to escape. The females lay their eggs, singly, on the leaves of the common locust tree (Robinic pseudacacia), and on those of the viscid locust (Robinia viscosa), which is much cultivated here as an ornamental tree. The caterpillars are hatched in July, and when quite small conceal themselves under a fold of the edge of a leaf, which is bent over their bodies and secured by means of silken threads. When they become larger, they attach two or more leaves together, so as to form a kind of cocoon or leafy case to shelter them from the weather, and to screen them from the prying eyes of birds. The full-grown caterpillar which attains to the length of about two inches, is of a pale green colour, transversely streaked with darker green, with a red neck, at very large head roughened with minute tubercles, slightly indented or furrowed above, and of a dull red colour, with a large yellow spot on each side of the mouth. Although there may be, and often are, many of these caterpillars on the same tree and branch, yet they all live separately within their own cases. One end of the leafy case is left open, and from this the insect comes forth to feed. 'They eat only, or mostly, in the night, and keep themselves closely concealed by day. These caterpillars are very cleanly in their habits, and make no dirt in their habitations, but throw it out with a sudden jerk, so that it shall fall at a considerable distance. They frequently transform to chrysalids within the same leaves which have served them for a habitation, but more often quit the trees and construct in some secure place a cocoon of leaves or fragments of stubble, the interior of which is lined with a loose web of silk. They remain in their cocoons without further change throughout the winter, and are transformed to butterflies in the following summer. The viscid locust tree is sometimes almost completely stripped of its leaves by these insects, or presents only here and there the brown and withered remains of foliage, which has served as a temporary shelter to the caterpillars. For the modes adopted to destroy these, see CатвнPILLARS.

LOLIUM. See Rre-Grass.

LONDON PRIDE. See SAXIFRAGE.

LONDON ROCKET. See Hedar-Mustant.

LONG-HORNED CATTLE. A breed of neat cattle now nearly extinct, chiefly distin. guished by the length of the horn, the thickness and firm texture of the hide, the length and closeness of the hair, the large size of the hoof, and the coarse, leathery thickness of the neck. See Cattre.

LOOPERS. See Span-wonms

LoOSENESS. See Diarrhara, and Dregases of Cattre axd Shemp. 
LOOSESTRIFE (Iysimachia, from lusis, dissolution, and marhe, strife). A very pretty genus of plants, with mostly yellow flowers. All the species are of the easiest culture, and may be propagated by divisions, except $L$. dubia and $L$. Linum-stellatum, which inust be increased by seeds.

Great yellow loosestrife ( $L_{*}$ vulguris), grows in watery, shady places, particularly the reedy margins of rivers. The root is creeping; stems 3 or 4 feet high.

Wood loosestrife, or yellow pimpernel ( $L$. nemorum). 'This species, which is one of the elegant though not uncommon English plants, inhabits woods and shady, rather watery places. The stems are creeping at the base, decumbent, often pendant from banks and rocks.

Creeping loosestrife. Money-wort or herb twopence ( $L$. nummularia). This is a handsome free-flowrering plant, which, from its trailing habit, is well fitted for decorating rockwork. It grows wild in wet meadows, boggy pastures, and the borders of rivulets. The herbage is smooth, of a pale green; stems quite prostrate, creeping, a foot or two in length; leaves somewhat heart-shaped; flowers solitary, pale lemon-coloured, rather larger than the last species; stamens glandular. It flowers froun June to August, and affords a wholesome food for cattle, especially sheep. On account of its sub-acid and mildly astringent properties, it is considered as one of the most efficacicus vulnerary herbs. Bechstein asserts that the leaves and flowers of this plant, steeped in nil, furnish an excellent remedy for destroying the worms and insects infesting the floors of granaries.

LOPPED MILK. Provincially, milk that has stood till it has become sour and curdled.

L.OPPING. The operation of cutting off the lateral or other branches of trees. See Pnuning and Puavtations.

LO'TUS. See Birns'-Foot Trefort.

LOUSINESS. In farriery, an affection of the skin, arising, in cattle or other animals, from the irritation of lice or other animalculæ, which may be distinguished by the naked eye. Most animals, and even insects, are subject to this annoyance. Lousiness in live-stock is produced by neglect and low keep. The best remedy is more attention to cleanliness, with better food. The lice may be killed by a dressing applied with a brush to the chief affected parts, composed of four ounces of black sulphur, mixed with a pint of train oil, or a small portion of weak mercurial ointment.

LOUSE-WORT. See RATTLE.

LOVAGE (Ligusticum, so named because some of the species grow in Liguria). A genus of hardy, herbaceous, and biennial, aromatic plants, which, as flowers, are not worth cultivating. They will grow in any soil, and are increased by seeds.

The Scottish lovage or sea parsley ( $L$. Scoticumt), grows on rocks, cliffs, and the sea-coasts of Scotland and the north of England, on a stem a foot high; root tap-shaped, warm and pungent; leaves stalked, twice ternate; footstalks bordered with a purplish compressed membrane at the base; umbels smooth, not very large, bearing white flowers, with a red- dish tinge: these appear in July. This herb „2 eaten by the natives of Scotland and its isles, either crude as a salad, or hoiled as greens. The flavour is highly acrid, and, though aromatic, stomachic, and perhaps not un wholesome, yet very nauseous to those who are unaccustumed to such food. It is relished by horses, sheep, and goats, but refused by cows. The stem yields English opoponax. The roots are reputed to be carminative, and an infusion of the leaves affords a good physic for calves.

Cornish lovage ( $L$. cormubiense). This is a less common species, found sometimes in bushy fields in Corn wall. 'The root is spindleshaped, contracted at the crown, descending to a great depth; when wounded, discharging a yellow, resinous juice. The stem is two or three feet high, solitary, erect, branched, striated, purple at the base. Leaves deep green; the radicles once, twice, or thrice pinnate, rough-edged, cut; stem-leaves ternate, lanceolate, entire. Ribs of the seeds bluntish.

LOVE-APPLE. See Tomato.

LOVE-GRASS (Eragrostis, from cros, love, and agrostis, grass; in allusion to the beautiful dancing spikelets, whence also the English name). It is a pretty species of foreign grass, growing in gardens about a foot high in any common soil.

LOVE-LIES-BLEEDING. The common name of a species of amaranth (A. caudatus).

LOY. A very long, narrow spade, peculiar to the province of Cunnaught and some parts of Munster, and only suited to stony land, where a wider edge could not so easily penetrate. (M. Doyle's Pract. Husb.)

LUCAMA. A species of fruit growing in Chili, in size and flavour resembling a peach. (Ed. Encyc.)

LUCERN, or PURPLE MEDICK GRASS (Medicago sativa, Pl. 8, $h$ ). An artificial grass, called by the French grand trefle, which affords perhaps a larger produce of fodder than any other species of artificial grass. Although found growing wild in hedges, pastures, and the borders of fields in dry, calcareous soils, yet it can scarcely be considered a native of England. The stems are erect or somewhat reclining, about two feet high. Leaflets oblong, inclining to wedge-shaped; more or less acute, sharply serrated towards the end, clothed with close, silky hairs on both sides. The flowers are in clusters, many, bluish purple, with a small bristle-like bracte under each partial stalk. The legumes are spiral, with rarely more than two or three turns; they are silky when young.

This valuable grass is best cultivated on a good, dry, warm, barley soil; it is not adapted for heavy or wet soils. Being a deep-rooted plant, it requires a soil in which its roots can penetrate to a considerable depth. It should be sown on land perfectly clean, in the months of March or April, with (or best without) a crop of grain. It is only adapted to the southern parts of England, since extreme cold destroys it. It is best sown alone in drills, at a distance of 12 to 15 inches; the quantity of seed is from 10 to 16 lbs. per acre. Any va cancies in the drills may in the autumn or following spring be made gond by transplanting $3 \times 2$

737 
By careful weeding and hoeing, and frequent top-dressings (for which purpose gypsum, calcareous matters, ashes, \&c., are excellent), the profitable duration of this crop may be extended eight or ten years, giving during that period, on an average, three or four cuttings per annum: the first of which, in favourable seasons, will be as early as the middle of April. It should always be cut before the appearance of the blossom. It may be made into hay, although much better adapted for soiling. An acre will, upon an average, produce fodder for two horses, from the first cutting to October. It is admirably adapted for milch cows, and is, indeed, relished by all live-stock.

"Lucern," as observed by Mr. Loudon ( $E$ ncyclo. of Gard.) "is highly extolled by Roman writers; it is also of great antiquity in Spain, Italy, and the south of France; is much grown in Persia and Peru, and mown in both countries all the year round. It is mentioned by Hartlip, Blythe, and other early writers, and was tried by Lisle; but it ęxcited little attention till after the publication of Harte's Essays in $1757($ ? 1764). Mr. Towers, speaking of lucern, calls it 'the plant of plants.' 'I have grown lucern (he adds) during four or five years, and previously I had witnessed its great success and extensive culture in the Isle of 'Thanet."

In cutting for a cow, it will always be advisable to take the plant when it is tender and juicy; and such it will be when about a foot high. I have thus cut my plot over six times after the first year; but they who leave the plants to grow two feet high, will find the stems rigid, fibrous, and less juicy; and that what they gain in bulk will be lost in time and quality. Lucern is known to produce much milk, perhaps more than any other of the artificial grasses (Leguminose); but some complain that it communicates an austere or bitter flavour. I doubt the fact, but would always recommend that it be not given quite fresh to a cow, particularly at an early period after calving.

If the required quantity be cut over night, it will be fit for the stall by ten o'clock of the following morning, and again the afternoon meal should be exposed to the sun for 2 or 3 hours before it is used. "As to the trouble in managing an established crop, it is really nothing. Though I allow it is good to hoe twice during the summer, as the plot is cut piece by piece, yet one general fork-digging at that period of early spring when the plants exhibit the first symptom of growth, so as to remove every weed, and loosen the surface of the soil, will be amply sufficient to secure the safety and full developement of the herb. Upon the whole, lucern is a plant of the utmost value; for if the seed be good, the ground rich and in neart, and rendered deep in the first instance by a thorough trenching, the young plants start into lively growth, attain strength in the shortest possible time, and yield a bulk of luxuriant herbage that cannot be surpassed. If the plant require four years to attain its maximum of power, it is still a giant even from its infancy, advancing from strength to strength. A well jinepared field, if kept clean by the forking, will remain productive for more than ten years; 798 but as a change of crop always promotes abundance, it would be advisable to prepare a suc. cessional plot every six years." (Quart. Journ. of $A g r$. vol. ix. p. 96.)

About 80 pounds weight per day of 24 hours is sufficient for the largest cow, and half this, with corn, for a horse. No stock should at any time be permitted to graze upon it.

There are several varieties of lucern, with violet, yellow, and variegated flowers, which are supposed to be only a variation of the same plant, arising accidentally from the seed. However, neither the yellow nor the variegated is ever so strong as the purple flowered, and cannot, of course, be so profitable to the cultivator. Lucern may be estimated as the choicest of all fodder, because it lasts many years; will bear cutting down four, five, or six times a year; enriches the land on which it grows; will fatten cattle, and often proves a remedy for the diseased.

Those who wish to acquire more minute information relative to the management of lucern, may consult the Rev. Walter Harte's learned Essays on Husbandry; Rocque's Practical Treatise on Cullivating Lucern Grass; and British Husbandry, vol. ii. p. $30 \%$.

Lucern is sometimes called French clover, and has been introduced into the United States as a new plant under the name of Brazilian clover, called in South America Alfalfa, the Spanish name for lucern. It is a kind of grass which in some situations has been cultivated with great success in the United States. It is not; strictly speaking, a clover, though in some respects similar. It is a perennial, and in favourable soils the ronts are said to live and flourish a great many years. Its advantages consist in affording a greater amount of foliage for any kind of stock than any other plant, with the same labour and expense. "Several years since, while residing in the State of Maine, we made several experiments with lucern, which, although some of them termirated unfavourably, satisfied us that the most favourable soil for it is a deep, sandy loam; and as the alluvial soils on this river are generally of this character, we last spring resolved on giving it a fair trial here. We procured from Boston a small quantity of seed, which was sown on the river 'bottom' the last week in May. As the soil had been badly managed for several years previous, we had feared that the great growth of weeds would check and smother the lucerne, and to guard against this, and get a chance to extirpate the weeds, we sowed the seed in drills. This was done very expeditiously and exactly with one of Ruggles, Nourse, and Mason's seed sowers.

"In the latter part of the month of July, the lucern had reached the height of 18 inches on an average, and had considerably blossomed. We cut it and fed it green, partly to hogs and partly to milch cows, - both ate it voraciously. In just four weeks from the time it was cut, it had again grown to nearly the same height as before, and was cut a second time,- - and on the first of November it was cut a third time,-the crop being heavier than either of the preceding. A piece of common red clover (very flourishing) immediately adjoining, the soil 
LUG.

precisely similar, did not yield nearly half as much, in proportion, as the lucern.

"We have no doubt that it may be cut five times another year, and will yield at the rate of a ton and a half of hay to the acre at each cutting." (Zanesville Gazelle.)

Upon analysis, the steris, \&c.., of lucern are found to contain gypsum, and this furnishes a satisfactory explanation of the fact, that plaster of Paris applied to the crop generally causes it to grow luxuriantly. Live-stock prefer plastered lucern to any other herbage.

I.UG. A long measure of land, the same with a pole or perch, $16 \frac{1}{2}$ feet. In Gloucestershire it however signifies a land measure of 6 yards, or a rod, pole, or perch of 6 yards. It is a measure by which ditching and other similar operations are performed there. This term is likewise applied to the stick by which the work is measured. It is sometimes called $\log$.

LUNGWORT (Pulmonaria; it derives both its common and generic names from its supposed medical properties in diseases of the lungs). The species of this genus are very pretty flowering plants, well adapted for ornamenting the front of shrubberies. They thrive in any common soil, and are readily increased by divisions.

I.UPINE (Lupinus, from lupus, a wolf; in allusion to its exhausting or devouring the soil). The species of this genus are among the most beautiful of border flowers. They will flourish in almost any soil, but a rich loam suits them best. They perfect their seeds very freely, from which young plants are easily obtained. In agriculture, the lupine is cultivated principally for being turned in as a manure. (See Grenv Mavones.) This plant requires but little trouble or labour in its cultivation, as it will thrive in any soil except the bad chalks, and such as are very wet. It will even grow well on poor, hungry, worn-out land, especially if it be dry and sandy. When sown in February or March, after a single very shallow ploughing, and slightly harrowed in, it will blossom two or three times between May and A ugust, and prove an excellent enricher of the ground when ploughed in just after its second blooming. The best time for mowing this sort of crop is after a shower of rain, as the seeds drop easily out of their pods when they are gathered too dry. They must, however, be laid up very dry, or worms suon breed in them. They are inferior to many other plants for the above use.

I.UPINE, WILD. Mr.Nuttall has enumerated seven species of the lupine genus found in different parts of the United States and territories. Dr. Darlington has described common wild lupine, an ornamental plant, found in the woodlands and hills of the Middle States. The root is perennial and creeping; stem 9 to 18 inches high, herbaceous, erect, or decumbent, somewhat branching, striated, angular, and pubescent. Flower purplish-blue, with violet shades. Legume or pod about an inch and a half long and onethird of an inch wide, somewhat flatrened, hairy, and of a dark tawny colour. Seed ohovoid, slightly compressed, smooth, speckled or variegated with whitish and dark brown.

\section{MADDER.}

I.URCHER. A sort of hunling dog, much like a mongrel greyhound, with pricked ears, a shaggy coat, and generally of a yellowishwhite colour. It is a very swift runner, so that, if it gets between the burrows and the rabbits, it seldom misses taking them; and this is its common practice in hunting.

LURID. In bolany, signifies a colour between a purple, yellow, and gray.

I.YME-GRASS. See ELrmus.

LYCHNIS (from lychnos, a lamp; on accouns of the brilliancy of the flowers of most of the species). This is an extremely beautiful genus of plants, well meriting extensive cultivation for the brilliancy of their flowers. A red va. riety is often cultivated in a double state, and called bachelor's buttons; a name, however, which is more frequently given to a species of ranunculus.

LYNCHET. A country term applied to the stripes or grassy partitions in arable fields in England, but mostly to such as are in the state of commonage.

LYNCH-PIN, or LINCH-PIN. The small pin, in carts or other carriages, that is put through the ends of the axle-trees, to confine the wheels on them.

LYRATE. In botany, leaves are called lyrate which are shaped in the form of a lyre

\section{M.}

MACERATION. The act of softening any substance by steeping it in cold water or other liquid.

MACHINE (Gr.). In a general sense this word signifies any thing which serves to in. crease or regulate the effect of a given force. Machines are either simple or compound. The simple machines are usually reckoned six in number; namely, the lever, the wheel and axle, the pulley, the wedge, the screw, and the funicular or rope machine. Compound machines are formed by combining two or more simple machines.

In husbandry, the term is applied to various implements, such as the Drilu, Thrashivg, and Winnowing Machines, the Steam Evgine, \&c. See these respective terms.

MADDER ( $R$ ubia, from ruber, red, in allusion to the colour of the roots). This is a genus of interesting plants; any common garden soil suits them, and they are easily increased by seeds or divisions of the roots. The root of $R$. tinctorum is one of the most valuable dyes with which we are acquainted, and is a very important article of commerce. The plant is herbaceous, several stems rising from the same root; tetragonal, with hooked prickles at the angles. The leaves are four or six in a whorl, lancenlate, with the midrib on the under disk, and the margins aculeated. The flowers are small. yellow, supported on axillary trichotomous peduncles.

The dried root of the madder is long, cylindrical, the thickness of a goose quill, branched and covered with a reddish cuticle, which, as well as the bark, is easily separated; the odour is feeble, and the taste bitter and astringent. It is imported entire from Smyrna and the Levanh but in coarse powder frnm Holland and France. 
The cultivation of madder has been attempted in England, and it is still carried on to a limited extent in some districts, but without any very great success or beneficial results, owing to the low price at which it can be procured from the Dutch growers and from Turkey.

Dyers' madder is an agricultural product which has been very successfully and profitably cultivated in the United States. The root of the plant is composed of many long, thick, succulent fibres, almost as large as a man's bittle finger; these are joined at the top in a head, like the root of asparagus, and strike very deep into the ground, being sometimes more than three feet in length. From the upper part or head of the root come out many sideroots, which extend just under the surface of the ground to a great distance, whereby it propagates very fast; for these send up a great number of shoots, which, if carefully taken off in the spring, soon after they are above ground, become so many plants. The root is perennial, although the stalk dies down every winter.

The soils most suited to the cultivation of madder are deep, fertile, sandy loams, not rerentive of moisture, and having a considerable portion of vegetable matter in their composition. It may also be grown on the more light descriptions of soil, of sufficient depth, and in a proper state of fertility. The preparation of the soil may either consist in trench ploughings, lengthwise and across, with pronged stirrings, so as to bring it to a nine tilth; or, what will often be found preferable, by one trenching, two feet deep, by manual labour. The sets or plants are best obtained from the runners, or surfaceroots of the old plants. These being taken up, are to be cut into lengths of from six to twelve inches, according to the scarcity or abundance of runners. Sets of one inch will grow if they have an eye or bud, and some fibres; but their progress will be injuriously slow for want of maternal nourishment. Sets may also be procured by sowing the seeds in fine, light earth, a year before they are wanted, and then transplanting them; or sets of an inch may be planted one year in a garden, and then removed to the field plantation. The season of planting is commonly May or June, and the manner is generally in rows nine or ten inches asunder, and five or six inches apart in the rows. Some plant promiscuously in beds with intervals between, out of which earth is thrown in the lazy. hed manner of growing potatoes; but this is unnecessary, as it is not the surface, but the lescending roots which are used by the dyer. The operation of planting is generally perform"d by the dibber, but some ley-plant them by the aid of the plough. By this mode the ground is ploughed over with a shallow furrow, and in the course of the operation the sets are deposited in each furrow, leaning on and pressed against the furrow-slice. This, however, is a bad mode, as there is no opportunity of firming the plants at the roots, and as some of the sets are apt to be buried, and others not sufficiently covered. The after-culture consists in hoeing and weeding with stirring by pronged hoes, either of the horse or hand kind. Some earth up, but this is unnecessary, and even injurious, as tearing the surface-roots. The madder crop 740 is taken at the eld of the third autumn after planting, and generally in the month of October. By far the best mode is that of trenching over the ground, which not only clears it effectually, but fits it at once for another crop. Where madder, however, has been grown on land prepared by the plough, that implement may be used in removing it. Previously to trenching, the haulm may be cleared off with an old scythe, and carted to the farmery to be used as litter to spread in the straw-yards. Drying the roots is the next process, and, in very fine seasons, may sometimes be effected on the soil, by simply spreading the plants as they are taken up; but in most seasons they require to be dried on a kiln, like that used for malt or hops. They are dried till they become brittle, and then packed up in bags for sale to the dyer. The produce from the root of this plant is different according to the difference of the soil, but mostly from ten to fifteen or twenty cwt., where they are suitable to its cultivation. In judging of the quality of madder-roots, the best is that which, on being broken in two, has a brightish-red or purplish appearance, without any yellow cast being exhibited. The use of madder-roots is chiefly in dyeing and calicoprinting. The haulm which accumulates on the surface of the field, in the course of three years, may be carted to the farm-yard, and fermented along with horse-dung. It has the singular property of dyeing the horns of the animals who eat it of a red colour. Madder-seed in abundance may be collected from the plants in the September of the second and third years, but it is never so propagated. Madder is sometimes blighted, but in general it has few diseases. (Loudon's Ency. Agr.)

In the Netherlands, where every agricultural process is conducted with such skill and success, madder sometimes forms a crop. It is always put upon land of the best quality, and with plenty of manare. At the end of April or May, accordingly as the young plants are large enough to be transplanted, the land must be ploughed in beds of two feet and two feet and a half wide; the beds are then to be harrowed and raked, and the young suckers of the roots or plants are to be put down in rows, at intervals of a foot or a foot and a half, and six or eight inches distant in the row. During the entire summer the land should be frequently stirred, and kept free from weeds. In the month of November, when the leaves are faded, the plants are covered with two inches of earth by a plough, having the point of the coulter a little raised or rounded, so as not to injure the young plants. In the following spring, when the young shoots are four or five inches long, they are gathered or torn off, and planted in new beds, in the same manner as has been pointed out above; and then, in the month of September or October, after the faded leaves have been removed, the old roots are taken up. The madder thus taken up should be deposited under cover, to protect it from the rain; and, after ten or twelve days, placed in an oven moderately heated. When dried sufficiently, it is gently beaten with a flail, to get rid of any clay that may adhere to the plants; and, by means of a small windmill, is ground and sifted, 
to separate it from any remaining earth or dirt. It is then replaced in the oven for a short time, and when taken out is spread upon a haircloth to cool; after which it is ground and cleaned once more. It is then carried to a bruising-mill, and reduced to a fine powder, after which it is packed in casks or barrels for market.

Several interesting communications upon she subject of the culture of madder in the Northern and Eastern States, may be found in the agricultural periodicals. (See American Farmer, New England Farmer, Cultivator, \&c.)

Mr. Russel Bronson, of Birmingham, Huron county, Ohio, a successful cultivator of madder, has published a communication upon this subject, which contains the following information:

A location facing the south or south-east is to be preferred. A sandy loam not over stiff and heavy, or light and sandy, or a good brown, deep, rich upland loam, free from foul grass, weeds, stones, or stumps of trees. Where a crop of potatoes, peas, corn, or wheat has been cultivated the past season, plough deep twice, once in September and once in October, and if rather stiff let it lie after the plough until spring. When the spring opens, and the ground has become dry and warm (say in Tennessee, Ist of April, Ohio, 15th, and New York, 25th to Ist of May-I speak of the spring of 1836), plough again deep, the deeper the better, then harrow well and strike it into ridges with a one-horse plough, 3 feet wide and 4 feet vacant, or making a ridgè once in 7 feet, raising it, if on rather moist ground, 8 or 10 inches, and dry land 6 or eight from the natural level; then with a light harrow, level and shape ihe ridges like a well-formed bed of beets, \&c.

We will suppose you intend to plant one acre of ground, and that you have purchased 8 bushels of tap roots in the fall and buried them like potatoes on your premises-count the ridges on your acre, and take out of the ground 1 bushel of roots and plant it on one-eighth of your ridges; you will then be able to ascertain how to proportion your roots for the remainder. The following is the manner of planting, cultivating, \&c., when the quantities of ground do not exceed 3 or 4 acres. One person on each side of the ridge to make the holes (plant 4 inches below the surface of the bed, or thereabouts, when covered) one on each side to drop the roots, and 1 on each side to cover, pressing the hill in the manner of planting corn; or, 3 persons may be placed on one side, as the case may be, whether you have 1 or more acres to plant. Let the owner be the dropper of roots, and his most thorough assistants behind him. Make the holes from 12 to 18 inches apart, and about 6 inches from the edge of the ridge. As the plants are supposed to have been purchased in the fall, the roots may have thrown out sprouts, and possibly have leaved. In this case, in dropping and covering, you will leave the most prominent sprout or sprouts a little out of he ground, as where a plant has leafed, it might not to be smothered.

When the plant gets up 3 or 4 inches, weed with the hoe, and plough with 1 horse, between the ridges or beds, but not on them; this will take place 2 or 3 weeks after planting. When up 12 or 15 inches, mrny of the tops will fall; assist them with 10 foot poles erossing the bed, covering them with a shovel or garden rake, throwing the soil from between the ridges. After loosening with the one-horse plough, you will with a shovel scatter the earth between the stalks rather than throw it into heaps; of course we wish to keep the stalks separate, as they are to form new and important roots in the centre of the beds. About the 20th of June, you may plough between the beds, and scatter more earth on the fresh tops (all but the ends), and when you get through, you may plant potatoes between the beds if you please. I do not recommend it, if you have plenty of land, although I raised 1070 bushels of pink eyes on 8 acres the first year, and 60 bushels of corn. If your land is perfectly clear of weeds, you are through with your labour on the madder crop for this year, except in latitudes where there is not inuch snow, and considerable frost ; in this case cover in October 2 inches or thereabout. Second year, same operations in weeding, but no crop between; cover once in June. Third year, weed only. Fourth year, weed in the spring, if a weedy piece of ground.

Begin to plough out the roots in Tennessee, [3 years old] 1st September. Ohio, [4 years] same time. New York, 15th or 20th, after cutting off the tops with a sharp hoe. In ploughing out the roots use a heavy span of horses, and a large plough. We ought to choose a soil neither too wet nor too dry, too stiff or light. Shake the dirt from the roots, and rinse ot wash, as the soil may be stiff or light; dry in a common hop kiln; grind them in a mill similar to Wilson's Patent Coffee Mill; this mill weighs from 1 to 2 pounds. The madder mill may be from 60 to 80 pounds weight Grind coarse, and fan in a fanning mill; then grind again for market. The profit of this crop is immense; the exhaustion of soil trifling, and glutting the market out of the question.

Madder is used in whole, or part, for the following colours on wool, both in England, France, and America, viz. blue, black, red, buff, olive-brown, olive, navy blue, and many others; finally it produces one of the most beautiful, durable, and healthy colours that is at this time dyed; as for calico printers, it enters greatly into their dyes. (Am. Farmer's Instructor.)

As the tops of the plants spread very much, some advise placing them in hills somewhat like Indian corn, 4 and even 6 feet apart each way, and 2 plants in each hill.

Rules have been laid down by Miller, On the Culture and Manufacture of Madder, for managing the land, separating and planting the shoots, gathering and drying the roots, and for pounding, casking, and preparing them for sale, according to the most approved English practice. The reader who wishes to attempt the cultivation of madder, will also find some use. ful hints in the Penny Cyclopredia, vol. xiv. p 260, and Brit. Husbandry, vol. ii. p. 332 ; Beckmann's Hist. of Invent. vol. iii.; and The Complete Farmer, vol. ii. The haulm of madder. though sometimes employed in the feeding of eattle, is not very generally used for that purpose, for it tinges red the milk, the urine, the sweat, and even the bones of the animals fed 


\section{MADDER, THE FIELD.}

npon it. The average annual imports into lingland are about $180,000 \mathrm{cwt}$. of madder-root and ground madder. The duty chargeable on consumption is $2 s$. per cwt. on the prepared madder, and $6 d$. per $\mathrm{cwt}$. on the roots. Madder was formerly used as a medicine in jaundice: but it possesses no properties which entitle it to be regarded as a remedy in any disease.

MADDER, THE FIELD. See Sherardia.

MADDER, WILD (Rubia peregrina.) This is an indigenous species which is found growing in thickets and on stony or sandy ground in the west of Britain. The root is creeping, fleshy, and tender, of a tawny red, useful in dyeing, but it is very inferior to the cultivated madder. The stem is branched, spreading, square, perennial, partly shrubby, its angles rough with hooked prickles, as are the edges and midrib of the broad, shining, dark, evergreen, elliptical leaves, which are four or more in a whorl. The flowers, which appear from July to August, are yellowish green, five-cleft, in forked terminal panicles. The berries are juicy, in pairs, black and shining.

The plant known in the United States by the name of wild madder, is the Galium tinctorium of botanists, or Dyers' Goose-grass. It is a perennial, found in moist woodlands and low grounds, flowering in July and August. The stems rise 12 to 18 inches high, generally erect, and branched. The flowers are white. Pursh says, the North American Indians use this plant for dyeing their porcupine quills, leather, feathers, and other ornaments, of a beautiful red colour.

MADI. A plant, said to be a new genus, growing in Chili. Its seeds furnish an oil which has been preferred to any of the French olive oils. (Ed. Encyc.)

MAGGOT. See FLy iv Shezp.

MAGNEsIA (Fr. Magnésie; It. Magnesia). One of the primitive earths having a metallic basis. It is an oxide of magnesium. It is sometimes found native, nearly in a state of purity; but is generally prepared by calcining the common carbonate of magnesia. It is inodorous and insipid, in the form of a very light, white, soft powder, having a specific gravity - of 2.3. It turns to green the more delicate vegetable blues, and requires for its solution 2000 parts of water at $60^{\circ}$. It is found combined with carbonic and other acids in plants.

It is a useful purgative in an acid state of the stomach; and taken daily, with short intervals intervening, it is a useful preventive of red gravel or lithic acid deposits in the kidneys.

As all kinds of grain are found to contain a certain proportion of phosphate of magnesia, the presence of this substance cannot be supposed to be mereiy accidental. Hence the inference that magnesia must be serviceable as a fertilizer. It enters largely into the composition of limestone, of which it constitutes sometimes almost one half. The magnesian lime has been long applied with the greatest advantage in Pennsylvania and elsewhere. In other places the admixture of magnesia with lime has been considered as producing sterility rather than benefit. See Ea rтн, Liмs.

When magnesian lime has been applied to ground in undue quantity, so as to have pro. suced uniavourable effects upon vegetation, it 742 has been found that after two years its hurtful influence has become exhausted. Great quan. tities of it are annually taken from Sunderland to Scotland by the Fifeshire farmers, and applied by them as a manure, with the greatest benefits, even in preference to other kinds of lime. The same preference is shown by many Pennsylvania farmers, for magnesian lime. Experience has shown that it has been unfairly denounced by Sir H. Davy and Mr. Tennent, as a sterilizer.

MAGNOLIA (named by Plumier after Pierre Magnol, prefect of the botanic garden at Montpelier, and author of several works on plants; he died in 1715). This is a genus of very elegant and showy plants when in flower, and well worthy of extensive cultivation. The hardy kinds, being remarkably handsome shrubs, should be planted in conspicuous situations where they will flower profusely when they attain a good size. M. glauca, and some others, grow best in a peat soil in a moist situation. They are generally increased by layers put down in spring or autumn, or by seeds; when the layers are first taken off, they should be potted in a mixture of loam and peat, and placed in a close frame till they have taken fresh root. None of the leaves should be taken off or shortened, nor any shoots be cut off, as they will not succeed so well; for the more branches and leaves are on the sooner they will strike fresh root. The Chinese kinds are often inarched or budded on $M$. obovata, one of the readiest growing kinds, which takes readily. The seeds of the North American species are received annually from that country. They should be sown as soon as possible after their arrival, in pots of light rich earth, covering them haif an inch deep; these may be placed either in a hotbed or a warm sheltered situation, or they may be sown in the open ground, and when the plants are of sufficient size, they should be planted out singly into pots, and sheltered till they have taken fresh root; they should also be protected from the frost by : frame for two or three successive winters, giving them the benefit of the open air in mild weather.

The Genus Magnolia contains about fifteen species, almost exactly divided between China and the United States. There is also one species in tropical America. The trees are distinguished by a bark more or less camphorated and aromatic; the leaves are alternate, entire, and large, partly ovate, and in some species auriculate at the base. The flowers are large, fragrant, white, yellowish, or brown; the seeds searlet or fulvous.

The following summary of the American species is from Nuttall's Genera of North Ameriean Plants.

1. M. grandiflora. The most magnificent tree of the southern states, the trunk often presenting a living column of 80 or 90 feet elevation, almost unobstructed by branches, and terminated by a spreading top of the deepest perennial verdure. 2. Glauca. 3 Macrophylla. This small pyramidal tree produces the largest leaves and flowers of any other North American plant. The limits of this interesting species appear to be extremely local. I first 
observed it in Tennessee near the hanks of Cumberland river, but of very small size. In the Southern States it is not at present known to the most assiduous collectors in any other spot than a single narrow tract of about 2 miles in length, 12 miles southeast of Lincolnton (Isincoln county, North Carolina). These limits I have carefully examined and found them invariable. 4. Tripetala (Umbrella-tree). 5. Acuminata (Cucumber-tree). Flowers yellowish green. 6. Cordata. Flowers yellow; appearing twice in the year in the garden of Mr. Landreth of Philadelphia. Leaves subcordate-oval, never truly cordate. 7. Auriculata. Leaves rhomboid-lanceolate, auriculate at the base. Considerably allied to M. Macrophylla. f. Pyramidata. Nothing more than a variety of the preceding, having leaves a little broader and shorter. See Cucuman Trke.

MAIDEN HAIR (Adiantum, derived from adiantos, dry. Pliny says, it is in vain to plunge the adiantum in water, for it always remains dry). These are elegant species of rerns with beautiful leaves. 'They succeed well in a mixture of loam and peat; but they appear to thrive best if planted in loose rockwork where there is a good drainage, and may be increased by divisions or by seeds. $A$. $C a$ pillus veneris is the only indigenous species. It is often supposed that the French syrup called cavillaire is made from this plant; but it is from the Adiantum pedatum, a plant growing in the south of France. Our adiantum, however, would make as useful a syrup. It is a refreshing beverage, mixed with water, in fevers. See Fins.

MAIZE, MAIZ, or INDIAN CORN (Zea mays, from $z a o$, tolive, in reference to the nutritive properties of the plants belonging to the genus). A gigantic herbaceous annual plant, belonging to the family of grasses cultivated for their grains (Graminea). Although, in Europe, the word corn is synonymous with wheat, rye, and breadstuffs generally, in the United States the term, used alone, applies exclusively to maize.

In one of the counties of Pennsylvania, a man having been indicted for stealing so many bushels of "corn," exception was taken by his counsel, that this was not a perfect description of Indian corn; the exception, however, was overruled by the court, who thius decided that "corn" was the established name for Indian corn.

Maize is the erop, of all others, best adapted to the climate of the Lnited States, where it is cultivated, on every variety of soil, from one extremity of the Union to the other. It constitutes the main stay of the cereal farmer, most depended upon to furnish food and provender for man and beast. The crop raised in the United States in 1839 , has been estimated at nearly $400,000,000$ of bushels. That of 1842 was much greater. Supposing it to have been $500,000,000$, this at an average price of only 40 cents per bushel, would make the total value of the crop no less than $200,000,000$ of dollars, which is considerably more than double the value of the wheat crop estimated at $\$ 1$ per bushel. The article on A miculture will show the states and districts where the largest proportion of this grain is produced.
The amount raised annually, increases in rapid progression.

Although America is doubtless the native country of a plant so important to her interests: still this has been a disputed point. Fuchs very early maintained that it came from the East; and Mathioli affirmed that it was from America. Regmir and Gregory have presented fresh arguments in favour of its Eastern origin. Among them is the name by which it has long been known in Europe: Blé de Tur. quie; and varieties, it is said, have been brought from the Isle of France, or from China. Moreas de Jonnes, on the contrary, has recently main. tained, in a memoir read before the Acarlemy of Science, that its origin was in America. The name Blé de Turquie no more proves it to be of Turkish origin, than the name of the Italian Poplar or Irish potato, proves that the tree and the plant grew wild in Italy and Ireland. It can only signify that it spread from Turkey into the neighbouring countries. Its general cultivation in Southern Europe, and the production of some new varieties, proves nothing with regard to the country of the species. In favour of its American origin, is the fact that it was found in a state of cultivation in every place where the first navigators landed. In Mexico, according to Hernandez; and in Brazil, according to Zeri; and that in the various countries it had proper names, such as Maize, Flaolli, \&c.: whilst, in the Old World, its names were either all of American origin, or from the neighbouring region, whence it was derived. Immediately after the discovery of America, it was spread rapidly in the Old World, and soon became common, a fact not reconcilable with the idea of its former existence there. To these proofs, Aug. de Saint-Hilaire has added another. He has received from M. de Larranhaga, of Monte Video, a new variety of maize, distinguished by the name of Tunicata; because instead of having the grains naked, they are entirely covered by the glumes. This variety is from Paraguay, where it is cultivated by the Guaycurus Indians, a people in the lowest scale of civilization; and where, according to the direct testimony of one of them, it grows in the humid forests as a native production.

The early authors who have written about America, with few if any exceptions, mention maize as an indigenous grain. Thus Acoste, in his Natural History of the West Indies, calls it "Indian wheat, to make bread of," and says "that it was the only grain found, in the West Indies by the Europeans:-that it grows upon a long reed with large grains, and sometimes two ears on a reed, on one of which 700 grains have been told:-that they sow it grain by grain and not scattering, as is done with. wheat; and it requires a hot and moist soil. There are two sorts of it" (says our author), "one large and substantial, the other small and dry, which they call ' moroche.' The leaves of it and also the reed are very good food for cattle, green; and dry, it serves as well as straw. The grain is better for beasts than barley, but they must drink before they eat it; for if thew drink after it, it swells and gives them pair The Indian eat it hot, boiled, and call . 
mote', and sometimes toasted. There is a surt of it large and round, which the Spaniards eat toasted; they also grind it and make cakes, which they eat hot; and these, in some places, they call 'arepas.' They also make bread, to keep, and sweet cakes of jt."

As Acoste died in 1600, at Salamanca, in his 60 th year, this must be regarded as very early testimony upon the subject. He surely would not have been so very particular in his description of this grain had it been previously known. in Europe. Indeed entire ears of Indian corn have been found enveloped in Peruvian and Mexican mummies, preserved long before the discovery of America.

It is probable that some inferior species of the genus to which maize belongs, have been found in Guinea, Turkey, and other portions of the Old World; but that the kinds now so highly valued and generally cultivated were of American origin, there can be no doubt, both from the strongest negative and positive evidence. Maize is now extensively cultivated in Asia and Africa. In Europe, it is only in the extreme southern parts, France, Spain, and Italy, that the crop can be raised so as to be profitable.

Varielies of Indian Corn. The varieties of corn cultivated in the United States are very numerous. A list embracing many of these has been furnished by P. A. Brown, Esq., in an interesting Essay on Indian corn. (See Farmer's Cabinet, vol, ii.) The following varieties, distinguished by peculiar characteristics of the grain, cob, \&c.. are included in $\mathrm{Mr}$. Brown's enumeration. It is an interesting fact, that the rows of grains on a cob, however numerous or limited, always present even numbers.

Yellow Corn. No. 1. The yellow gourdseed, so called from the resemblance of its long, narrow grains to the seed of the gourd. This has 24, and occasionaliy even more rows. Mr. Brown makes 7 varieties of this according to the number of rows regulated by admixture with other kinds of corn. No. 8. The genuine King Philip corn, so called from the celebrated chief of the Wampanoags. It has 8 rows, the lowest number found on any kind of Indian corn. It is a hardy plant, the seed of which was originally obtained from the Northern Indians. No.9. The Sioux or yellow-flint corn with 12 rows, derived from the Sioux tribe of Indians which formerly resided in Canada. No. 10. The Sioux variety grown in Pennsylvania. No. 11. The Sioux and gourdseed mixed-16 rows.

White Indian Corn, a division in which $\mathbf{M r}$. Brown includes the white flint, white flour-corn, and white sugar, or sweet corn. He has omitted the white gourdseed, which is by far the most common corn raised in the South, where it is sometimes found with from 24 to 36 rows of grains upon the ear. No. 12. Genuine white-flint, 12 row corn raised in Virginia. No. 13. White-flint, -10 rows. No. 14. Early white flint, and white flour corn,-12 rows. No. 15. Peruvian corn, -8 rows. No. 16. Pennsyivaria, 8 rows,-called in Maryland, Smith's sarly white. No. 17. New Jersey-8 rows. No. 18. New Y rik. 10 rows. and Mandan In744 dian corn. No. 19. Mandan corn, and white sugar corn. No. 20. Early sugar corn, with shrunken grains and 12 rows.

Hametite, or Blond-red Indian Corn. 21. Com. mon sized hæmetite, with 12 rows and red cob. 22. The red cob with white grains. 23. Red cob with yellow grains. 24. Red cob with brown grains. 25. Red cob, with white gourdseed. 26. Red cob with gourdseed and yellow flint. 27. White cob with red grain. 28. Speckled red and yellow grains on a white cob. 29. The same on a red cob. 30. The dwarf hæmatite, commonly called Guinea corm. 31. Blue corn, with 10 rows. 32. Texas corn, each grain of which grows enveloped in a distinct covering or tunic, the whole ear being also enveloped in a husk. 33. Mexican corn, found in the envelope of a mummy. 34. Corn raised in England by William Cobbett. 35. The celebrated Dutton flint corn.

The remarks of the late John Jorain, in his Practice of Husbandry, convey so much information relative to the kinds of corn chiefly cultivated in the United States, the various merits of each kind, and the modes of culture, that we cannot refrain from giving a condensation of them.

'There are five original corns in use for field? planting, in the Middle and Southern States, to wit: the big white and yellow, the little white and yellow, and the white Virginia gourdseed. The cobs of the two first mentioned are thick and long, the grains are much wider than deep, and where the rows of grains meet and unite with each other, their sides fall off almost to nothing. This gives the outside ends of the grain a circular form; and communicates to the ear an appearance somewhat like a fluted column. This formation greatly diminishes the size of the ends and sides of the grains; and is the cause of the hard flinty corns being less productive, in proportion to the length and thickness of their cobs, than the gourdseed corn. As the little white and yellow are formed much in the same way, and the cobs considerably smaller, they are still less productive than the big white and yellow, but ripen earlier.

The grain of those four flinty kinds are very firm, and without indenture in their outside ends. The two smaller kinds seem to be still more hard and solid than the larger; and the colour of the little yellow deeper than that of the big.

The ears of the Virginia gourdseed are not very long, neither is the cob so thick as that of the big white and yellow. But the formation of the grain makes. the ear very thick. They frequently produce from thirty to thirtytwo, and sometimes thirty-six rows of very long narrow grains, of a soft open texture. These grains are almost flat, at their outside ends, are also compactly united from the cob to the surface of the ear, withcut any of that fluted appearance between the rows of grain, which causes the flinty corns to be much less productive in proportion to the size of the ears.

'The gourdseed corn ripens later than any other, but is by far the most productive. It is invariably white, unless it has been mixed with the yellow flinty corns. 'Then it is called the yellow gourdseed, and too many farmers 
consider it and most other mixtures original corns. I have often heard of original yellow gourdseed corn, but after taking much trouble to investigate the fact, could never find any thing more than a mixture.

So prevalent are mixtures, says Mr. Lorain, that I have never examined a field of corn, (where great care had not been taken to select the seed,) which did not exhibit evident traces of all the corns in general use for field planting, with many others that are not used for this purpose.

None can be longer or more readily traced than the gourdseed. If the smallest perfectly natural indenture appear in the grain of the hardest corns, those grains, with their descendants, may be grown, until a perfectly white gourdseed is obtained, be their colour what it may.

In the northerly divisions of the United States, they frequently plant the small Canadian corns.

These are solid and very early, but have been generally thought too small to be very productive, and are seldom planted in fields, where the larger corns ripen.

These corns and others which are still much smaller and earlier, are grown by many for early boiling or roasting while green.

The Canadian corn plant is considerably smaller than the corns in general use for field planting. It is also productive in ears. Therefore, the intervals, as well as the clusters in the row, might be closer together. If the soil were as well manured for this kind of corn as is done for the larger corns (when the farmer is well informed and able to do it), very valuable crops might be obtained from it: particularly if it were only slightly mixed with the gourdseed corn.

There are also red, blue, and purple corns, but none of these are used for field planting; still, having been introduced, they too often appear in our fields, either in their native colours or in variegated or enamelled grains. The leaves of the plant are also sometimes variegated from the same cause. It is said that a good purple dye is formed by using the purple corns for this purpose; and the stalks and leaves of this plant are purple, or a shade between that colour and green. I have also seen corn with red stalks and leaves, but mixed with more or less green.

As novelty and other causes have introduced such a great variety into our fields, they will continue to appear in them until farmers generally give more attention to the economy of maize, and see the necessity of growing out inferior kinds, so far as it may be practicable. Although they may be divided almost ad infinitum, they cannot be entirely eradicated. They may, however, be readily reduced and kept under, so as not to do any material injury to the crops, provided the cultivator very carefully and annually selects his seed. It may be from the latent remains of these mixed varieties, that nature, from combining causes, sometimes produces plants and animals more perfect than the class from which they sprang.

This variety, as it regards corn, proceeds from the farina fecundans, a light minute sub- stance of a mouldy colour, seen on the clothes of those working among the plants, when it is disengaged from the tassels. I'tris is wafted far by high winds, and is the cause of distant and unthought-of mixtures. However, in general, it is lightly and plentifully diffused through the field, and lodges in sufficient quantities on the silky fibres which project from the ears. A single fibre proceeds from each grain. This has been so constructed as to convey the principle of life contained in the farina fecundans to the grain from which the fibre springs, even to the further end of the cob. This is done with so much certainty that we rarely see abortive grains, when the plants have been rendered healthy and vigorous by a sufficiency of nutriment and good cultivation. The change produced by this mysterious cause is generally gradual. We first see scattering, whitish looking grains on the ears of the yellow corn growing among the white, and the reverse on the ears of the latter, when grown near to the yellow corns.

The foregoing facts bave induced me to make experiments. The result seems to determine, that if nature be judiciously directed by art, such mixtures as are best suited for the purpose of farmers, in every climate in this country where corn is grown, may be introduced. Also, that an annual selection of the seed, with care and time, will render them subject to very little injurious change; provided the desirable properties of any of the various corns be properly blended together. They do not mix minutely, like wine and water. On the contrary, like mixed breeds of animals, a large portion of the valuable properties of any one of them, or of the whole five original corns commonly used for field planting, may be communicated to one plant; while the inferior properties of one, or the whole, may be nearly grown out.

When this object is oblained, and we become acquainted with the proper arrangement of the plants in our fields, so as to promote the utmost product, the crops of maize will by far exceed any estimate which would at this time be considered probable by those who have not carefully examined the economy of this plant.

It should, however, never be forgotten, that a sufficiency of nutriment and good cultivation are quite as necessary to increase and perpetuate the size of grain as plentiful and nutritious food, and proper care and management, are to accomplish the same in animals.

My ears of maize are now at least one-third larger, on an average, than were the ears procured three years ago from Huntingdon for seed. The same may be also said of some white, flinty corn, procured by my neighbour, Mr. H. Philips, from near Erie, for seed.

The quantity of the gourdseed corn mixed with the flinty yellow corns, may be determined. so as to answer the farmer's purpose. When the proportion of the former greatly predominates, the grains are pale, very long and narrow, and the outside ends of them are so flat that but little of the indenture is seen. As the portion of gourdseed decreases in the mixture, the grains shorten, become wider, and their outside ends grow thicker. 'The indentures $3 \mathbf{R}$

74.5 
also, beconie larger and rounder, until the harder corns get the ascendancy. After this, the outside ends of the grains become thicker and more circular. They also grow wider, and the fluted appearance between the rows increases. The indentures also decrease in size until they disappear, and the yellow, flinty variety is formed. But, as I believe, not so fully but that the latent remains of mixture will forever subject it to more or less change.

It is more difficult to determine the quantity of big and little yellow corns, which may happen to be mixed with the gourdseed; and at the same time with each other. However, by attention, a tolerably correct opinion of this may be formed. The grain of the big yellow is much wider, and nothing like so deep as that of the gourdseed; and although the grain of the little yellow is not so wide and deep as that of the big, still it is wider than the gourdseed; and $j$ ts colour is deeper than that of the big yellow, and its cobs are much slimmer, as well as shorter.

When a mixture with the big yellow and gourdseed is desirable, care should be taken, in growing out the little yellow, to preserve as much as possible of the deep yellow tinge and solidity communicated to the grain by this variety, and also of its property to ripen early.

The soft, open texture of the gourdseed renders it unfit for exportation, unless it be kilndried. This has given rise to an unfounded prejudice among the shippers of this grain, in favour of the yellow corns, although they are not more solid than the white, flinty varieties. However, while this prejudice continues, it is best for those who depend on selling it for shipping, to mix the gourdseed with the yellow flints, and for those who consume the produce on their own farms, or can readily sell the white corns, to form mixtures with them and the gourdseed. It is thought that the white corns are the most productive, and ripen earlier than the yellow; but of this I know nothing certain, having generally grown the yellow. There can, however, be no question but that the white furnishes much handsomer meal for culinary purposes. It is also free from that strong taste so readily distinguished by those who have been accustomed to use the white; but as most of the Pennsylvania farmers, and cultivators still further north, have been used to eat the yellow, and habit causes most kinds of food to become agreeable, they seem generally to prefer the strong taste of this variety to the much milder and pleasanter taste of the white. However, in the countries where neither is grown, and to which it is often exported, there can be but little doubt that the white would find a readier market, and that the demand for this very nutritious grain would greatly increase, if none but the white were exported: especially, if laws were passed prohibiting the exportation ot maize until it had been kiln-dried.

I believe there is no grain that will keep longer or safer than corn, if it be kept on the cob in open dry cribs, and the climate also be dry, unless the weevil be introduced by not carefully cleaning the cribs of every vestige of the grain and vegetable matters introduced with it.
Flinty corns, after they have been well dried in such cribs, may be shipped in tight, dry vessels, with tolerabte safety, to the West Indies: but longer voyages subject this grain to greater injuries, although it may arrive in port in tolerable safety; a little damp communicates a musty taste to maize, and if this does not happen, it is often spoiled by lying in bulk after it arrives, and will be considered much less valuable on this account.

Either the big yellow or white should be mixed with the gourdseed, for planting in every climate where this mixture will certainly ripen. Their cobs being very long, and the grain so much wider and deeper than those of the little yellow or white, the mixture with them will be much more productive. It is also thought, that the length of the ear communicated by the big yellow or white will fully compensate for the shortening the grains of the gourdseed: therefore, if the mixture be properly formed, its pro duct may even exceed that of the original gourdseed corn; I have measured the product from ears of this mixture, which, when shelled, yielded a full pint of corn, after they had lain twelve months in a very dry place, although the mixture had not been well improved.

The little yellow and white, being earlier than the big, they should form mixtures with the gourdseed corn for being grown in climates more unfavourable for maize. But whoever may form either of those mixtures, will find, that he must grow out either the big or little flinty corns, with many others, as they are more or less mixed.

The speediest and best way to form either of those mixtures, is to select one ear that may possess most of the desirable properties united in it, and to plant the seed where the farina fecundans from the general crop cannot readily obtain access. If it happen to the cultivators, as it has done with me, he will certainly find from the growth of this seed many ears in his patch, very much like the ear that grew the seed, and many very unlike it; however, it may be that he will find some ears approaching nearer to the variety which he wishes to form than the original ear; if so, he will of course select the best, and go on in the same way, until he has full enough for planting his general crop. After this, he should aim at an increased improvement, by carefully selecting his seed annually for the ensuing crop. (Practical Husbandry.)

Of these numerous varieties some are best adapted to the Southern States-the white and yellow gourdseeds: others to the Midrile States - the gourdseed and flint varieties, pure or mixed; whilst the heavy flinty grained kinds are almost exclusively cultivated in the Northern and Eastern States-to which they are specially adapted by their disposition to grow and mature with great rapidity, and thus accomodate themselves to the shortness of northern summers. Like all early maturing corn, they are dwarfish, though very productive. The effect of the longer and warmer summers in more southerly situations is to favour greatly the growth of the stalk, which frequently attains 10 or 12 feet in height; but such luxuriance, however splendid in appearance, is by no means 
attenuled by a corresponding increase in the product of grain. The time taken by different varieties in growing and maturing, differs exceedingly. In the Southern and Middle States the crop occupies the ground from 5 to 7 months, whilst in the Northern and Eastern States the ears come to maturity in 3 or 4 months, and some is even found so precocious as to ripen in 6 weeks. An interesting and plausible explanation of these facts is given in the article on Crimate, and its Influence on the Fruitrulase of Plants.

Since Mr. Lorain wrote his excellent book, several demonstrations have been furnished of the practicability of improving corn. One of the most interesting is that made by 'Thomas $\mathbf{N}$. Baden, Esq., of Prince George's county, Maryland, who, by carefully selecting the best seed in his field for a long series of years, having special reference to those stalks which produced the most ears, ultimately obtained a variety which yields $4,5,6$, and even as high as 8 and 10 ears to the single stalk. The particulars of the plan pursued are as follows:

When the corn was husked, he made a re-selection, taking only that which appeared sound and fully ripe, having a regard to the deepest and best colour, as well as the size of the cob. In the spring, before shelling the corn, he examined it again, and selected that which was the best in all respects. In shelling the corn, he omitted the irregular kernels at both the large and small ends. He has carefully followed this mode of selecting seed corn for twenty-two or twenty-three years, and still continues to do so. When he first commenced, it was with a common kind of corn, for there was none other in that part of the country. At first he was troubled to find stalks with even two good ears on them, perhaps one good ear and one small one, or one good ear and a 'nubbin.' It was several years before he could discover much benefit resulting from his efforts; however, at length the quality and quantity began to improve, and the improvement was then very rapid. At present he does not pretend to lay up any seed without it comes from stalks which bear 4,5 , or 6 ears. He has seen stalks bearing 8 ears. One of his neighbours informed him that he had a single stalk with ten perfect ears on $i t$. In addition to the number of ears, and of course the great increase in quantity unshelled, it may be mentioned that it yields much more than common corn when shelled. A barrel (10 bushels of ears) of his improved kind of corn measured a little more than six bushels. The common kind of corn will measure about 5 bushels only. He believes that he raises double, or nearly so, to what he could with any other corn. He generally plants the corn about the first of May, and places the hills five feet apart each way, leaving two stalks in a hill.

Some of Mr. Baden's seed-corn was sent to Illinois, with instructions how to manage it, and the product was one hundred and twenty bushels on an acre; there was no corn in Illinois like it, and it produced more fodder than any other kind. (Farm. Cab. vol. ii.)

The Baden corn is a white gourdseed, the stalks of which grow to an extraordinary height, so that the ears are uften 6 or 8 feet above the ground, and the summits twice that elevation. 'The grain is of excellent quality, but the ears are short and considerably under the average size of the common varieties of corn. When removed but little farther north, as for example to the vicinity of Philadelphia, it seldom matures perfectly. It does not answer well for high-land culture, but flourishes and produces abundance of grain and fodder in the rich flat lands of the Southern and Southwestern States. It verifies the observation that high-growing corn is the least disposed to ripen the ears, and consequently most liable to injury from autumnal frosts.

Varieties cultivated for particular purposes.Among the varieties of corn cultivated for special purposes, we may mention the white flint, used for making the beautiful hominy sold in the Philadelphia market; the flour corn, with a round, thick grain, filled with a snowy white powder resembling starch, much used in New Jersey for grinding up with buckwheat, in the proportion of about one-fourth or one-fifth of the corn, giving the buckwheat-meal a lighter colour and otherwise improving it. The early Jersey truck corn, a middle-sized ear, with white and rather flinty grains, the earlicst corn raised for the market, but not so sweet as the Early sweet or Sugar corn, which, when dry, has shrivelled grains; there are two varieties of this, the white and red cob kinds. The small flinty-grained corn usually raised for parching or popping is considered a distinct species of maize, under the name of Zea Caragua, or Valparaiso corn, to which a sort of religious reputation has been attached, from the circumstance of its splitting open when parched or roasted so as to present some resemblance to a cross. Its appearance under this form is peculiarly beautiful, and bears a strong resemblance to the flowers of a cruciferous plant. The flavour is pleasant, and it makes a very pretty dessert-dish.

Preparation of the Land for planting.-In the Middle States corn is planted in all conditions of the land, but in Virginia and Maryland, it generally follows the wheat crop, upon which all the farm-yard manure has been spread. In the upper portion of Delaware and in Pennsylvania, the crop is generally put upon a grass sward or clover lay. Where the snil is a stiff clay, much labour is bestowed in ploughing deep, then rolling and reducing to the finest tilth by means of harrows. As a general rule, after a sward has been turned, care is taken not to harrow so deep as to reach and drag up the sods, which are suffered to lie and decom pose, thus furnishing nutriment to the corn, and keeping the ground loose and favourable to the spreading of the roots. Many farmer: spread lime upon the land intended for corn, in the autumn or winter, previously to plough ing. Others put the lime dressing on the ploughed ground. Although the first may be considered a good plan, still there can be little doubt that lime operates most effectually when left upon the surface so as to be exposed to the atmosphere, and especially to the full action of rain water with its dissolving agent carbonic acid gas. But the hest plan of all is to 
spread the lime on the grass the year preceding the tillage in corn, as then the vegetation is greatly benefitted, and the lime has full time to dissolve in considerable proportion and impregnate the soil. Where the land is light or sandy, shallow ploughing is frequently practised and much less labour is required to prepare the ground for the crop. In all cases, however, where there is a retentive clay below the soil, no doubi can exist of the propriety of stirring the earth as deeply as practicable, first by the common plough, and next by the subsoil plough, which loosens the earth or clay below the furrow run by the common plough, without turning it up. This effectual and deep breaking up of the earth allows the water to penetrate quickly into the soil charged with all its fertilizing gases and salts, which would otherwise be rapidly dispersed if exposed to the open atmosphere.

Season for Ploughing.-With regard to the best time for ploughing, this must depend much upon the character of the soil. Late fall or winter ploughing has been thought useful in turning up and exposing to perish, the grubs and other insects which have retreated below the surface for winter quarters; but in Pennsylvania this practice is now generally abandoned in favour of spring ploughing.

The roller, when used, must be drawn in the direction of the furrows, and never crosswise. Then follows the drag-harrow, in the same direction, being the last instrument which, on flushed ground, is employed preparatory to planting. The spikes of this implement should never be set so deep as to reach and drag up the sod, an observation which will apply to all other implements called in requisition during the working of the crop. The harrowing should be continued until the surface of the inverted sward is completely broken up and pulverized.

In the Middle States, it is a very general custom to prepare the ground for corn by a method called listing or double furrowing. This consists of ploughing so as at first to turn two furrow-slices together, leaving a middle space which is subsequently ploughed out by turning an additional furrow on each side. This places the ground in narrow lands or ridges, consisting of four furrow-slices with deep, intervening trenches. The width from the middle of one land to the other is generally about 4 feet. In signing out for planting, a plough is run across these narrow lands, so as to strike out rows generally 4 feet apart. The plough which performs this cross-ploughing, is immediately followed by a boy who drops 4, 5 , or 7 grains of corn directly opposite the middle of each of the ridges, and the operation of planting is completed by a man who covers the seed with a hoe.

Farmers generally agree that corn should be pianted as early in the spring as the weather will permit, and some of the best are not even afraid of having the young shoots nipped off by frost. The usual time of planting in the Floridas is early in March, whilst in Massa. chusetts it cannot be done before the middle of May,-facts which show the great range of climate in the United States.
Mr. Lorain, one of the best authorities upon this and most other agricultural subjects upon which he has treated, says,-When corn is planted very early, it is commonly severely affected by frost; so much so, that many of the plants are cut off by the ground. This is unquestionably an injury to which no judicious farmer would expose the plant, if the advantages obtained by very early planting could be had by planting later. Still if the roots remain unhurt, they are of consequence established, and very soon repair the injury done above the soil, after the frost ceases to act on the plants. Of course they take the lead, and will maintain their superiority over later planted corn. The ears also fill and ripen much better in northerly climates from this practice.

The shooting and filling of them take place when the heat of the sun is much greater; and when less cloudy, cold, dripping weather prevails, and the crop is nothing like so liable to be injured by frost. The grounds are also suoner ready for crops sown in the fall. This mode of management will often enable the cultivator to grow the large and more productive corns, in climates where they have been abandoned, from observing that they did not ripen when planted at the usual time.

When I introduced the large yellow gourd. seed corn, from seed procured from Hunting don county, every farmer here ridiculed the idea of attempting to grow corn of this description. They considered the soil and climate hostile to the growth even of the smaller corns, and but little was planted. As they waited until the earth was warmed before they planted, the crops were frequently either destroyed, or greatiy injured by frost. (Pract. Husb.)

In Pennsylvania, corn generally forms the first crop of the regular rotation, the sod being ploughed without manure, except the occasional addition of a light dressing of plaster of Paris (about one bushel per acre) or a full coat of lime ( 50 to 100 bushels per acre). The plan of listing and ploughing out, so common in the Southern and Middle States is not followed by Pennsylvania farmers, who flush up the ground so as to present a uniform surface.

Planting.-After rolling, and then harrowing well, the rows are struck out very shallow, and the corn is planted in hills $3,4,4 \frac{1}{2}$, or 5 feet apart, or dropped in rows from 3 to 5 feet asunder, so as to leave the stalks, when thinned out, about 1 or 2 feet apart. In this last case the tillage has of course to be conducted in the direction of the rows, and never cross-wise, as is practised when the grain is in hills at regular distances. The distance of the corn hills or plants apart must be regulated by the kind of corn to be planted, and the nature of the soil. When the growth is high, and the soil rich, the rows should be farther apart than where the growth is low, as is the case with the Northern varieties, which may be planted 3 reet apart.

Whenever manure can be spared for the corn crop, it will always make a good return. for maize cannot well be too highly manured. If the supply be sufficient, it may be spread broadcast upon the land previous to ploughing. or, what is better, spread upon ground that has 
been flushed up in the autumn or winter, and then lightly ploughed in. In the Northern and Eastern States where the summers are short, a liberal quantity of manure is generally required to assist in forcing the crop to early maturity. When not enough is at band to afford a good dressing broadcast, it is advisable to apply a portion of short manure to each hill just before planting. Ashes are an excellent manure for Indian corn, and may be dropped upon the hills in the proportion of a gill to a pint. It is common to make a mixture of these with lime and plaster. But there is no doubt that the main benefit of the mixture proceeds from the live ashes. Almost every kind of artificial manure may be advantageously applied to corn, either in the hill or broadcast; and there is none perhaps which acts so promptly upon the young plants as the Poudrette manufactured in New York and other cities, the basis of which fertilizer is night-soil. A gill of this to the hill furnishes a fair dressing, and pushes the young corn forward with such rapidity as to place it very soon beyond dauger from the grub, cutworm, and other insect depredators, by which the plants, especially those on light and exhausted soils, suffer such destruction during their feeble and tardy growth. As conducing to the same end, soaking the seed for $24 \mathrm{dr} 36$ hours in solutions of saltpetre, urine, the drainings of the stables and cattle-yards, \&c. \&c., have a very good tendency. To protect it from the depredations of insects, birds, and vermin, it is often coated with liquid tar, and subsequently rolled in ashes, plaster, lime, or saltpetre, which last is considered one of the most convenient, cheapest, and best of steeps. Strong solutions of copperas, blue vitriol, and even corrosive sublimate and arsenic, are sometimes used for the same purpose-which last, however, is only soluble in water by the addition of potash, or some other alkali. "The enemies to be combatted," says Buel, "are the wire-worm, brown grub, birds, and squiriels. Of these, the first and two last prey upon the kernels, and against these tar offers a complete protection. I soak my seed 12 to 20 hours in hot water, in which is dissolved a few ounces of crude saltpetre, and then add (say to 8 quarts of seed) half a pint of tar, previously warmed and diluted, with a quart of warm water. The mass is well stirred, the corn taken out, and as much plaster added as will adhere to the grain. This impregnates and partially coats the seed with the tar. "The experience of years will warrant me in confidently recommending this as a protection for the seed."

Number of grains to the hill, and depth of planting.-Where there is reason to apprehend much mischief to the young plants from blackbirds, crows, vermin, and insects, it is always best to drop from 4 to 7 grains to each hill, so that some 2 or 3 may have a chance to escape. An old quaint couplet lays down a pretty good (though not sufficiently liberal) rule upon this subject, when it recornmends 5 grains-

"One fur the blackbird, and one for the crow,

One for the cut-worm, and two left to grow.",

The deficiency is always attempted to be made up by replanting other grain, but the product of this replant is too often feeble, and so late in maturing, as to be frequently injured $b$, the frost in autumn. A much better plan is to re. plant with the surplus of other hills. But this requires a damp and very favourable condition. of the weather. As to the proper depth of cover. ing for the seed, much difference of opinion exists; some advocating shallow covering, that is to say, from an inch to 2 or $2 \frac{1}{2}$ inches, whilst others recommend from 3 to 6,8 , and even 10 inches. All covering which exceeds 4 or 5 inches must, under ordinary circumstances, be considered extravagant and detrimental. 'T'hose in favour of deep covering say that although the corn does not come up so soon, or appear so forward, it makes a much better growth later in the season; sends its roots lower, and of course is less affected by dry wealher, whilst the stalks stand much better against the violence of storms, by which they are often prostrated. They also urge as additional re. commendations, that the crows and blackbirds are unable to pull up the young shoots, so as to get at the grain from which it springs, whilst the cut-worm may sever the sprout in the common situation just beneath the surface, learing enough still below to push up and continue the growih. See Diricz.

It cannot be doubted, that where the mould is of a light texture, moderately deep covering answers best as a general rule. To cover deep where the soil is a heavy clay loam, would either cause the grain to rot, prevent it from rising, or dispose it to come up twisted, unless opportunely assisted by rain, to soften the packed covering.

Tillage.-The corn once planted, its tender blade pushes through the ground, usually in about a week or ten days, and even sooner when the grain has been previously soaked. Although the field is generally left at rest until the plants have, all fairly risen above ground before the tillage of the crop commences, some begin with the harrows even before the corn is up. The first objects to be effected are, to keep the ground stirred and free from grass and weeds. Where danger is apprehended from worms, by which it is so frequently attacked, many maintain that the tillage should not commence very soon, so that some other vegetation being allowed to start up, the young corn will thus be in a measure spared; where as, if the ground is perfectly clean, the worms, having nothing else to feed upon, will, of course, destroy all the young corn. Instances may occasionally occur where this practice may prove advantageous, but as a general rule, the young corn cannot be kept too clean, or the ground about it too loose.

The modes of tillage vary exceedingly, not only with the variations in soil and climate, but with the views of different persons in the same locality. On stiff, clay soils, there is no doubt that harrowing just before the proper time for the corn to come up, favours this pro cess, by loosening the tenacious soil, especially where a timely rain does not occur to soften the earth. After the corn appears, the harrow should be kept going until the ground is ren. dered perfectly loose, hands following with hoes or short rakes to clear the corn which may be covered. Then comes the plougi. 
which, in the Southern and lower portion of the Middle States, is often used to turn a furrow from the young corn. This operation is termed bar-plnughing, because the bar of the plough is run next to the plants. A few days after this, the process is reversed, and the nould-board being turned next the corn, the .oose earth is thrown back again. Many think that this second ploughing, called moulding, ought not to be left longer than a few hours before the earth should be turned back again. In some places ploughs are still used for this last purpose with wooden mould-boards, as these serve best to push the loose earth before them, crumbling and spreading it about the plants more advantageously than ploughs furnished with smooth and polished iron mouldboards. Some use narrow, deep-cutting ploughs, which do this work with comparatively little labour to the horse, and render the soil near the corn much more permeable by the roots, and at the same time, quickly accessible to the rain and atmospheric influences. Whatever tends to favour the extension of the roots downwards, serves to place the crop beyond the vicissitudes of the season.

There is, perhaps, no plant which withstands the effects of drought so well as Indian corn, whilst young; but when its top blades begin to be heavy, its demands for moisture increase so as to cause it to suffer greatly from very dry weather. Heat and moisture are the great promoters of its luxuriant growth.

Mr. Lorain's comments upon the custom of bar-ploughing, as practised by a distinguished Maryland farmer and agricultural writer, are very judicious. Mr. Boardly, he says, ploughed from each side of the rows of the plants five inches deep, while the plants were young; he then let them rest 10 or 12 days on the narrow ridges formed by this practice; this was done, that the lateral roots should take their direction under the artificial surface of the ground formed by the ploughshare. If the corn-plant, when scarcely three inches high, be pulled up by the roots from an open free soil, the lateral roots will be found about 12 inches long, beside what remains in the ground; consequently these roots are cut off on each side of the rows, even by the first cultivation, while the plant is yet very young; they are also cut off by every succeeding cultivation. If the furrows made along each side of the rows, by the first cultivation, were kept continually open, and the lateral roots of the plants compelled by this means to cross the bottom of them, a little within the ground, this would not cause the ronts to grow under the artificial surface of the ground formed by the ploughshare. Nature immediately after they passed the open furrow, would direct them up into the soil above, to take their natural range through it: especially in that part of it where the most genial heat and nutriment obtained. This is clearly seen when the lateral roots of trees cross ditches, or even deep gullies, at the bottom of them. a little within the ground. They immediatery mount upward after they have crossed the bottom of the ditch, and take their natural gri'wth at the same distance from the surface 750 of the soil as would have happened if they had met with no obstacles in getting into it.

The roots of the corn-plant which proceed downward from the stalk, also those that take their course along the rows, are not injured; neither are all those which grow the deepest within the soil in the intervals cut off. Therefore as the corn-plant is very hardy, it is supported by these roots, until nature repairs the damage done by this truly inconsiderate and barbarian practice. It is of consequence by no means wonderful, that Mr. Bordley, who was in many respects a judicious farmer, should by his general good management so far counteract the evils arising from this savage practice, as to grow, under all the disadvan. tages resulting from it, crops that were more than equal to the general crops of his neighbours. Reason, however, as well as practice, determines that crops obtained in this way must fall very far short of those that may be obtained from a rational system of manage. ment. It is also obvious, that his mode of cultivation is well calculated to cause an extensive, useless waste of the animal and vegetable matter contained in the soil. Likewise of the farm-yard manure, if that be applied for the growth of the crop. (Lorain's Pract. Husb.)

The farmers in some of the finest districts in Pennsylvania have of late years made much less use of the plough in cultivating their corn than formerly. They now generally content themselves with moulding, or throwing a single furrow on each side of the young plants, leaving a space between the rows of from 3 to $3 \frac{1}{2}$ feet untouched. The space left, is afterwards worked by means of shovel-ploughs, and cultivators, which completely destroy the grass, and loosen the ground. This mode of culture is more quickly and economically performed than the old plan of ploughing the whole space between the rows, and leaving the surface comparatively level. If the land be sufficiently loose and deeply stirred, there is little use in hilling it. It is sometimes said corn requires hilling to support it. Nature disproves this argument, by the stiff, bracing roots thrown out by this plant, at the time they are wanted, and for this very purpose. On wet lands, planting on ridges and hilling may be advisable, but such lands should never be chosen for corn. If wet, drain thoroughly in the first place. Allow no weeds to grow in your corn, says Buel, and do not fear to stir the surface in dry wea. ther. Fvery weed absorbs nutriment enough to make a good ear of corn, and if any remain after the plough cannot be used, pull them up, or cut them with the hoe.

Thinning and Surcouring.-As quickly as possible after it is ascertained that the plants are in a thrifty condition, and no longer in danger of being destroyed by the cut-worm and other enemies, they are thinned out, so as to leave only two or three in a hill. Or, should they stand in rows or drills, the plants are left about one or two feet apart. The operation of succouring takes place some time after thinning, and consists in tearing off the side-shoots which often sprout from the bottom of the main stalk. It is beginning to be thought that this practice 
is much more hurtful than advantageous, injuring the growth and developement of the corn, and lessening the produce of both fodder and grain. The truth of these opinions seem to have been confirmed by actual experiments. (See Cultivator, vol. viii. p. 90.)

Many farmers deem the use of the plough altogether unnecessary and even injurious, and conduct the tillage of the corn crop throughout first with the drag-harrow, and successively with the cultivator, horse-hoe, and hand-hoe. These are kept going very constantly until wheat harvest, after which further culture is suspended, and the corn crop, in common phraseology, is said to be laid by. The plants have now attained from 2 to 4 or 5 feet in height, and thrown out their side-shoots. These should be left to extend themselves uninterruptedly in all directions, which they will do with great rapidity provided the season be favourable and the soil loose and in good tilth. Should they be cut or torn asunder by late and too deep working, the crop must suffer serious injury.

The progressive growth and developement of Indian corn are well described by Mr. Lorain.

The roots and stem of maize, he says, spring from the heart of the grain; the former grows from one to two or more inches long before the latter appears, and progresses so very rapidly, that if pulled up from a loose soil, they will measure about 12 inches long when the stem is only about 3 inches high, although their finer fihres must be left in the ground by this rude operation.

'The stem protrudes itself through the soil in the form of a bodkin, and is composed of leaves rolled very compactly together; the first two leaves expand soon after the plant penetrates the soil, and other rolled leaves continue to unfold in succession from the crown of the plant, until the tassel appears wrapped up in its own leaves: these also gradually spread themselves, until the plant is fully formed.

The leaves increase in width and length from the ground up to where the most perfect ear is formed; after this they decrease in length and width, more rapidly than they increased below, and this decrease is regularly maintained even to the uppermost leaf, which forms itself a little below the tassel.

One leaf grows from every joint in the stalk, but in such a way as to alternate sides; the first formed leaf, and after this every leaf in regular succession, clasps the stalk closely, intil it approaches near to the under side of the leaf above; after this it grows out from the stalk, and a beautiful fan-like appearance is at length produced, which is not equalled by any other annual plant cultivated for the value of its fruit; especially when the large luxuriant ears display at their points elegant tufts of silky fibres, which vary in colour when mixtures form the seed.

The height of this plant differs much. The sinallest variety that has been noticed by me did not seem to exceed 3 feet in height. The largest plants which $I$ have seen measured lut 13 feet. I have, however, heard of some which allained the height of 17 feet. These must have been grown on a very rich, an wel. as a very deep and open, free soil.

The lateral roots of maize soon spread through the whole soil. 'The finger-roots, as they are sometimes called, dip much deeper. I have seen them traced two feet below the surface of the soil by a grubbing hoe, in the hands of a rugged workman. How much further their finer fibres might have gone was not ascertained by me, but this convinced me that the roots of maize were capable of drawing very much moisture and some nutriment from a much greater depth than most of the plants cultivated by us. Also, that these manures and smaller roots were better calculated to effect this very interesting purpose than they would have been if nature had formed the whole of them into one single taproot, which extended no deeper. This is one cause, among many others, why maize is capable of contending so powerfully with poverty, and notwithstanding severe and continued drought, better than most other cultivated plants. This should convince us that a plant capable of drawing such important supplies from beyond the range of plants in general, will not prove peculiarly exhausting if it be treated fairly, by having as much manure or as good a soil appropriated for it as is commonly used for those plants which farmers in general have not learned to grow on poor soils without manure.

The prop roots of maize appear about, or a little before, the tassels may be seen. They proceed from the joint at or near the surface of the soil. They are numerous. and form a circle round the plant. That portion of them which grows outside of the ground is hard and woody, similar to the substance which forms the outside of the stalk; but so soon as they penetrate the soil they become softer, and spread through it in search of nutriment; this is just at the time the plant requires most of it. The tassel and the top of the plants have after this to attain their full size, and the farina fecundans, which impregnates the grain, is to be formed. The ears now begin to shoot, and they are also to be filled and perfected.

The prop roots are exactly calculated to support the weight of the tassels and ears during high winds, and when the grounds are softened by rain. But farmers too generally thwart this simple but wise arrangement of nature, by hilling or ridging up the plants. These in. considerate operations not only cut and rend the roots, but also compel the plants to grow new sets of prop roots from the joints above. These seldom get sufficiently established in time to support the weight and height of the tassels and ears; and many of the plants are of consequence blown down, or fall by their own weight, when the grounds have been previously much softened by rain.

Maize, from its woody texture and commanding size, might (without straining the point very far), be called an annual bread tree, producing the best of all corns, and at the same time crops which in magnitude far exceed that of any other grain. Also tops, husks, and leaves which can be readily gathered, and furnish abundant fodder for catile, equal to tine 
nest hay; and independent of this, the stalks supply much valuable litter for the cattle yard.

'That part of the leaf which surrounds the stalk, and adheres so closely that it does not permit a particle of moisture to escape, is very interesting. The peculiar insertion of the leaf, together with the formation of that part of the stalk covered by it, forms a cavity for the reception of the rich moisture, which is gathered into it from the atmosphere by the leaves, and for which they are most admirably formed.

The shoots which form the ear commence at the joint in contact with the ground. If the soil be rich or highly manured, they issue from every joint up to where the uppermost ear is formed at the footstalk of the tassel. 'This last or highest up ear is almost invariably the largest, and ripens soonest. It seldom occurs that more than two ears are perfected on one stalk, unless the clusters of plants are very distant from each other, and but few plants stand in each cluster If the plants stand thick on the ground, but one ear is cummonly perfected by each of them. The abortive ear shoots are called suckers. These are commonly removed, so far as the farmer considers conducive to the welfare of his crop. This should be done so soon as they are large enough to be pulled off effectually. No part of them should be left adhering to the stalk, or they will grow again from the stub left behind.

If this operation be not early commenced and frequently repeated, they become so numerous and large in fields highly manured, especially if the plants stand thin on the ground, that they are greally injured; not only from the loss of nutriment, but also from the many and large wounds inflicted by the removal of them.

After careful experiment in the removal of stuckers, I now pull none above the joint in contact with the ground; and would not remove these if they did not take root in the soil, and by this means become powerful exhausters. Although it commonly happens that several ear shoots above this point prove abortive, no sucker can be removed without injuring the leaf which binds it to the stalk; and so much that it is commonly rendert altogether incapable of conducting moisture. If it be not so extensively injured, the receptacle formed by it is so much deranged by this operation, that it cannot retain the slight portion which may happen to be conducted by the leaf into it.

I am still further encouraged to let so many of these abortive ears stand, as I have observed that so soon as nature has determined the number of ears which existing circumstances may enable her to fill, all her efforts are directed to them, and the abortive ones immediately dwindle, and finally wither; and, for aught we know to the contrary, nature may cause them to part with the rich matters they had preriously gathered, and apply this nutriment to assist in maturing her favourites.

I trust it will appear from what has been advanced, that in place of abusing this invaluable plant as an exhanster of the soil, we should eonsider it the pride and boast of American 752 husbandry, as mathematical demonstration cannot well afford stronger proof than has been produced that maize gathers a large portion of the nutriment necessary to perfect its fruit from the atmosphere.

Still, it should be remembered that sufficient nutriment, provided in the soil, is absolutely necessary to enable it to do this very extensively. Therefore, "let not what God has joined together, by man be put asunder," by vain philosophical theories and sophistical reasonings. Such as, that the chief use of the soil is merely to support the plants in their proper place, or that cultivation will supersede the necessity of keeping the soil well stored with animal and vegetable matter.

The middle path is certainly the path of rea. son and experience, and should be carefully and diligently pursued by the practical farmer, leaving those ideal speculations for the amusement of the learned.

There is no corn crop grown by us which is so certain as maize. Its diseases are few, and most, if not all of them, proceed from an incon. siderate cultivation. I do not recollect ever to have seen them so extensive in any field as to do any very material injury to the crop.

It withstands drought and contends with poverty better than most other plants cultivat. ed by us, either for the value of their grain or roots. It may be advantageously grown in any soil fit for cultivation, not excepting blowing sands or retentive clay.

Still, this crop fails occasionally, especially in the higher latitudes, or situations rendered cold from local causes. It cannot withstand grass or weeds, and is too generally planted by far too late. The seed is also covered too deep, as well as oppressed with clods, stones, or any other rubbish near at hand, which prevents the plant from coming up. Too little seed is planted to secure a sufficiency of plants after birds and quadrupeds have taken that portion which even proper vigilance cannot prevent. (Practical Husbandry.)

Saving the Fodder, \& $\&$. - The tops of the Indian corn, when cut off for fodder, should be removed previous to stripping the blades from the stalks below the ear, which last operation should be delayed till near the time of maturity, indicated by some dryness of the leaves and hardness of the grain. The ears are gathered by hand, and the husks, when perfectly dry, stript off, and, together with the stalks, laid by for winter fodder, while the ears are conveyed to the granary. The green stems and leaves abound in nutritious matter for cattle, and in some places it is cultivated solely for this purpose, especially afier early crops of other vegetables; when planted for this object, it should be sowed very thickly. Corn, when well dried, will keep good for several years, and preserve its capability of germination. It is eaten in various manners in different countries, and forms a wholesome and substantial aliment. Domestic animals of every kind are also extremely fond of it. According to Count Rumford, it is, next to wheat, the most nutritious grain. It is considered as too stimulating for the common food of cattle, and is found to be more stimulating than any other kind of 
bread used by us. The fattening and invigorating qualities of Indian corn make it the best of all kinds of food for persons exposed to hard labour or fatiguing duty. In the United States, however, the preference so generally bestowed by the labouring classes upon Indian corn, is by no means confined to them, but shared alike by rich and poor, for the sweetness of the bread, and its wholesome and superior invigorating virtues. Mixed with rye meal, it forms the common brown bread of New England; mixed with water alone, it makes a very palatable species of extemporaneous bread. When pounded in a mortar, or ground very coarse and boiled, it forms the "hominy" and "grits" which are such great favourites at the south; and the fine meal, boiled thick in water, is the "mush" of Pennsylvania, and the "hasty-pudding" of the Eastern States. In the form of hulled corn, or samp, the whole grains furnish a very palatable, although rather indigestible luxury. Of the husks a beautiful kind of writing-paper has been manufactured in Italy; and when soaked in hot water, they make excellent mattrasses. A grayish paper may be made form all parts of the plant.

Enemies and Diseases.-The bird, insect, and other depredators have been already referred to under the head of Brads, Cur-wonm, WraEwonm, Praxt-lice, \&c. Among the diseases, the chief one is a dark or blue-black spungy growth, which sometimes takes the place of the blighted ear of corn. The mass sometimes grows till 5 or 6 inches in diameter, and is to be considered a luxuriant or rank species of fungus. As the species of parasitic plants to which this belongs are so readily destroyed by applications of common salt, there is reason to believe that soaking the seeds well in saltwater previous to planting, or scattering salt over the ground, will prevent this disease.

In all the fields of maize, says Mr. Lorain, which have been examined by me, some plants entirely barren have been seen without any apparent cause.

The fungus appears to be principally occasioned by wounds inflicted during cultivation. 'The plants commonly bleed from these wounds, and a fungus is formed. This, when in contact with the ear, is certain destruction to it, unless the fungus be soon seen and removed. When it is formed on other parts of the plant, it frequently corrodes them so much that they are incapable of perfecting their fruit. The only remedy known to me is speedy removal, and repeating the operation if the fungus should reappear: which generally occurs. But even this tedious remedy is too often found insufficient. It is, therefore, far better not to create this disease, by mangling the plants, either by the savage practice of harrowing over them, or by covering them with clods, stones, or sods, as is too often done by the inconsiderate mode of hilling or ridging them up. Although many of the plants wounded by these injudicious practices survive and appear to flourish, even when the fungus is not removed, still, numbers of them become too debilitated to perfect their fruit.

A reddish kind of rust sometimes appears on the leaves, but seldom does much apparent injury to the ears, unless it becomes extensive.
However, the same rust somolimes fixes upon the stalks and causes them to decay.

When this is near the ear, or the decay is extensive, the plant produces little or no grain; but I have never seen very extensive injury done by this disease. The cause of it is un. known to me. It may, however, proceed from the bruises and wounds inflicted by an incon. siderate cultivation; especially as the tassel. wrapped in its own leaves, may be seen furmed in the plant when it is quite young. Too many farmers think the health and vigour of the plants are greatly promoted by harrowing over them, and mangling their tops while they are young. Also, by cutting and rending the rosts of them, provided this be not done after the tassels and ear shoots appear; than which nothing can appear more preposterous. (Prur. tical Husbandry.)

It sometimes happens, as the effect of storms. that the pollen is blown or beaten off the tassel before all the silk has protruded from the ear. The consequence of this is a failure in the developement of grains in the extremity or other portion where the silk was deficient. It has been urged, among the reasons for letting the suckers grow, that being later in tasseling and less exposed to high winds, they assist to promote the process of fecundation after the tassels of the main stallss have shed their pol. len. As an evidence of this, it has been stated that the earliest ears are always best covered with grain, while those which push late often exhibit a quarter or a half of naked cob,-the consequence of imperfect impregnation.

Harvesting the Crop.-This is effected very differently in different portions of the Union.

1. In Pennsylvania, and the Northern and Eastern States, the corn is usually cut off at the surface of the ground, as soon as the grain has become glazed, or hard upon the outside, and whilst the blades are still green, put immediately into shoclis, and thus left some time standing in the field. The corn after becoming sufficiently dry is husked and cribbed, and the stalks with all the attached fodder and husks are carted home and stacked for provender.

2. In the Southern and Southerly portions of the Middle States, the corn is commonly husked in the field, the stalks having previously had the blades stripped below the ears, and the tops lopped off above the ears. When, therefore, the ear has been separated, the naked stalk is left standing with the husk, which is soon afterwards eaten off by cattle.

There are some other modes of gathering corn and securing the fodder, but those described are by far the most general. In some parts of the fertile Western States, where the crops are extremely luxuriant, with the absence of facilities to get the grain to market, it is common to husk out and secure enough of the corn for family use and then turn the hogs and cattle into the field to consume the remainder.

By the first of these methods the crop may be secured before the autumnal rains, with all its valuable fodder, and the ground cleared in time for a winter crop of wheat or rye. The juices retained by the stalk are sufficient $w$ nourish the corn to inaturity. By the second mode there is always a loss in the grain pr... 
thet, which is never so well filled after the blades and tops have been removed in a green state. 'This has been proven by actual experiments, for the particulars of which see Buel's Farmer's Instructor; also Farmer's Register, vol. ii. p. 91 ; and Colman's Fourth Report, p. 16.

All, or nearly all the accounts we have published of great products of Indian corn, agree, says the editor of the Cultivator, in two particulars, viz.: in not using the plough in the after criture, and in not earthing, or but slightly, the hills. These results go to demonstrate, that the entire roots are essential to the vigor of the crop; and that roots to enable them to perform their function as nature designed, must be near the surface. If the roots are severed with the plough, in dressing the crop, the plants are deprived of a portion of their nourishment; and if they are buried deep by hilling, the plant is partially exhausted in throwing out a new set near the surface, where alone they can perform all their offices. There is another material advantage in this mode of cultivating the corn crop-it saves a vast deal of manual labor.

There is another question of interest to farmers, which relates to the mode of harvesting the crop, that is, whether it is best to top the stalks, cut the whole at the ground when the grain is glazed, or cut the whole when the grain has fully ripened. Experiments made by Mr. Clark, of Northampton, one of the best practical farmers of Massachusetts, and of other gentlemen, show that the grain cuffers a diminution of six or eight bushels to the acre, by topping the stalks; and there seems to be no counterbalancing benefit to the fodder, unless at the expense of carrying the stalks to the borders of the field, that they may be secured before the crop is gathered, and before they become blanched and half-ruined. And it is no protection against early autumnal frosts, but rather exposes unripened grain to be more injured. Hence so far as regards these two modes, all who have made a comparison seem to concur in the opinion, that stripping the corn of its tops and leaves is a bad practice.

The blades and tops of corn, if well cured, furnish an excellent fodder for neat cattle and horses, all kinds of stock being very fond of them. They serve greatly to increase the amount of manure, collected in the cattle-yard. In Pennsylvania, in the Southern parts of which the crops of corn are very luxuriant, the fodder is generally considered worth at least $\$ 4$ per acre as provender. A distinguished farmer in Whitemarsh, Montgomery county, (1)btained, in 1842 , from a 30 acre field, sufficient corn-fodder to winter $\mathbf{3 0}$ large steers intended for spring beef. The stalks had been cut down with blades, \&c., attached. Corn is accasionally sown broad-cast for the purpose of being mown down as green provender for milch cows, \&cc., for which it answers an admirable purpose. It has been also cured as hay, and on some highly fertile or rich spots has yielded 6 tons of hay or fodder.

Preserving Corn.-Corn is usually preserved $\therefore y$ storing away the ears cleared from the zuisks, in small or narrow granaries called 7.54 cribs, the sides and ends of which are constructed of logs or laths, so as to leave interstices of about an inch, or rather more, permntting a free circulation of air. If the cribs be wider than 8 or 10 feet, the middle part is very apt to have the corn injured, especially when put away before becoming thoroughly dry. In the Southern States, corn in the crib is often seriously injured by the weevil when attempts are made to keep it over the summer. But in the Middle and Northern States, it may be preserved for many years on the cob. In the Louisiana Register it is stated that sprinkling the corn whilst housing, with a solution of common salt and water (in the proportion of about one pint of salt to a gallon of water), will entirely prevent the insect from breeding. The ears of corn are there frequently stored up in the husks, which are rendered much more grateful to stock by the addition of salt.

There is perhaps no plant-certainly none of such vigorous growth,-which will so long continue highly productive when raised year after year upon the same soil. In a communication to the Farmer's Register, by Mr. Shultice, of Mathews county, Va.; he says that there are in the county named, small tracts of land which have been in corn, year after year, as far back as the recollection of the oldest inhabitants extends. The same fields planted in corn successively for more than half a century, at present yield fair crops. Such land, when new (judging by the product of contiguous recently cleared land), yielded from 3 to 5 barrels per acre. At present the product is from 2 to 3 barrels, with the occasional application of a very meagre dressing of manure. With a fair supply of manure, the land can be readily made to yield as much and even more than it did when first brought under cultivation. As, in the tillage of this crop, all vegetation is carefully destroyed, the materials constituting the soil or mould must have decomposed very slowly indeed. Where there is much sand in the soil, exhaustion takes place very quickly; but Indian corn can be cultivated on land, long after it has ceased to afford compensating crops of any other grain.

Expenses of Culture.-These are very differently estimated in different parts of the United States, being influenced by a variety of local circumstances. The following estimate and accompanying statement is from Jonathan $R_{0}$ berts, Esq., a very eminent agriculturist residing in Montgomery county, Pennsylvania:

"An estimate of the expense of cultivating an acre of maize 15 miles northwest of Philadelphia. Soil, a calcareous loam.

Ploughing sward

Harrowing to proper fineness

Harrowing to proper fineness - - - - -200

3 loads (2-horse wagon) manure to dress the hills

IIorse-hoeing, at least three times

Moulding and horse-hoeing

Harvesting -

Saving fodder

Rent of land

Wear of gears and -

A mount of expengh -

A mount of crop 60 bushels, at $60 \mathrm{cts}$. per bushel Fodder

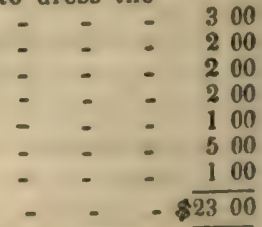

$\overline{3600}$

$\frac{400}{\$ 400}$

I.eaving a balance in favor of the corn-crop of $\overline{1700}$ 
"This estimate," says Mr. R., "is predicated on practical husbandry, with a fair season. It is not found economical, in a regular course of cropping, to manure corn land beyond hill dressing. The decomposing sward will be found equal to its production. The renovating process of manure should be applied in putting in the winter crops with the cultivated grasses. Lime should not be immediately applied before sowing the winter crops. Its application ought to follow the maize in the fall, or at the latest in the following spring. By such a course of culture ground may be kept improving in fertility. It is not the part of practical farming to increase the crop of corn by an expensive manuring; it must be taken as one of a series of ploughed and green crops. On a good soil, and with a good season, corn may run to 70 and 80 bushels an acre. Good management will be directed to produce a series of good crops, with an improvement of soil."

With great deference to an agriculturist of such matured experience, we cannot help expressing an opinion that some of the items in the statement are rated too high, and that it would perhaps be more correct to bring down the expenses at least as low as those in the following estimate furnished by Judge Buel. This last, it must be remembered, does not include manure, so much more of which is usually required at the North, as greatly to increase the expense of the crop.

Estimated expense of cultivating an acre of Indian corn in the State of New York:

One ploughing (suppose a clover lay)

Harrowing and planting

Hoeing, 4 days, and borse-team

2 hoeings, 4 days, and horse-team

Harvesting, 2 days

Cutting and harvesting stalks

Rent

In the New England States the expenses of culture are stated to exceed these calculations considerably. Mr. Colman, in his Fourth Agricultural Report to the Legislature of Massachusetts, gives the following estimates for different townships.

"In Northfield, the estimate was made as follows:

Ploughing

Dragging

5 cords of manure in the hill $-\quad: \quad-1200$

retting out and putting in the hill - $-\quad 400$

Seed corn I peck planted $3 \frac{1}{8}$ feet each way - $37 \frac{1}{3}$

Planting - - - - - - - - 134

lst hoeing with man and horse - $--_{-}^{-}-{ }_{-} 34$

$2 d$ hoeing, $\$ 117$; 3 hoeing, $\$ 117=-\quad 234$

ratheriug and husking $-\quad-\quad-550$

Fodder equal to 1 ton of hay $-\quad+\quad-\quad 1000$ 10 bushels of corn, at $\$ 1$

$\$ 5000$

Balance in favour of corn . _ _ . $\$ 1710 \frac{1}{8}$

"Another farmer in Northfield gives the following estimate of the expense of an acre of corn:
Pinughing, 9250 ; harrowing, 12 50; holeln $50 \mathrm{ctm}$.

6 bushels leeched asher.

1 bushel plaster or gypmen, 65

Seed, 10 quarte, 8100 ; putting on ashes and

plaster, and planting, 120
Harrowing, 30 ; weeding, 8150

Cultivating $t$ wice in a row, $30 ; 2 d$ hoeing, 8110

Cultivating, 15 ; last hoeing, $\$ 120$. - 1 as

Gathering and husking, 500 ; gathering stalks

150 - _ - - 630

$\frac{650}{1950}$

Corn fodder equal to 1 ton of hay -

Crop 50 bushels corn, at $\$ 100$ per bushel - $\quad-5000$

$\longdiv { 8 0 0 0 }$

Balance in favour of crop - _ _ _ -

"It will be seen," says Mr. C., "that in the above case nothing has been charged for manure, excepting ashes and plaster. The corn was raised after a stubble clover-crop ploughed in, or a green sward inverted. His corn usu. ally averages 70 bushels per acre.

"The estimate of the expense of a corn crop in Deerfield is thus given by a very careful and successful cultivator:

Ploughing, $\$ 234$; harrowing, 50 ; holeing, $\$ 100$, 4 cords of manure, $\$ 800$; spreading manure, Seed, 25; planting, - $10 \overline{0}^{-}$; weeding, $\$ 200$;

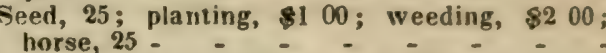
horse, 25 - 58 ; 3 $-350$ Cutting up and gathering butts, $\$ 100$ - $\quad 100$

Interest on land - _ _ _ _ _ - 600

Dr. the above crop - $+\ldots+\overline{\$ 3167}$

Proceeds of crop:

Fodder equal to $\frac{\text { t }}{4}$ ton of hay, $\$ 900-\quad-\quad 900$

50 bushels corn - - - - - 5000

$\$ \$ \$ 500$

Balance in favour of corn - _ _ _ _ $\$ 2733$

"In Shelburn, the estimate of the cost of cultivating an acre of corn is given by a farmer, whose skilful and successful cultivation needs no commendation.

Ploughing, 350 ; 20 loads manure (7 cords), $\$ 1500$ - - - - - $-\overline{4}$ ging or harrowing, $\$ 100$
Seed, I peck, 38 ; manure for the hills ( 8 loads), Seed, I peck, 38; manure for the hills (8 loads), Weeding and hoeing, 333 ; 2 d hoeing, 33 3 hoeing, $\$ 233 \quad-\quad-\quad-799$

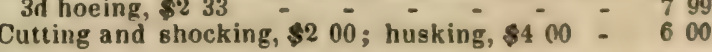
$\overline{8487}$

Prnceeds of above crop :

Fodder equal to $1 \frac{1}{4}$ inn of hay - _ _ $\quad 1250$ 70 bushels corn, at $100 \ldots .+2000$

Balance in favour of corn - . _ _ . $\overline{83423}$

Several other estimates of the expense of cultivating an acre of Indian corn, varying from 14 to 25 dollars, are given by Mr. C. The above statements are from farmers of the highest respectability for intelligence and ex. actness, and may be relied upon. 


\section{MAIZE.}

Mr. Colman says, "that on the hilly portions of Massachusetts but little corn is raised, but that it makes a large product on the alluvial lands of the Deerfield and Connecticut. The largest amount I have known raised in one year, by one individual, has been 1400 bushels; but many farmers produce from 300 to 1000 bushels. The judgment of some of the most intelligent farmers in Deerfield places the average yield at 35 bushels to the acre, which seems to be underrated. I have," he says, "known upwards of 90 bushels grown on an acre in Deerfield meadows; an average yield of more than 70 bushels on several acres in Northfield; and other abundant crops, which show at least what might be obtained by good cultivation; and likewise how much more profitable is good than inferior cultivation."

It is evident that over that portion of the Middle and Southern States lying east of the Mountains, and where the lands have been so greatly impoverished by long and scourging culture, commencing with that greatest of exhausters, tobacco, the expenses per acre incurred in the raising of corn must be very much lower than either of the estimates furnished for Pennsylvania and the Northern and Eastern States. Large tracts of the light alluvial districts forming the tide-water sections of Virginia and Maryland, do not yield an average per acre exceeding from 10 to 20 bushels; and still corn continues to be cultivated, even when the price is below 50 cents per bushel. Such crops would be ruinous to the farmer, were he not able to cultivate his acres of light unmanured soil at less than 5 or 10 dollars each. In the rich prairies of the West it is stated that crops of corn, averaging 50 bushels to the acre, can be raised at an expense of only 3 or 4 dollars per acre.

Qualities of Corn.-Abundant experience has shown that the fattening qualities of Indian corn are exceedingly great; so that all who can obtain this grain prefer it to every thing else for fattening stock, all kinds of which eat it with avidity and advantage. It is rich in oil of a very pleasant and useful kind. That which is best known is obtained in the process of distillation for making whisky and alcohol-a great perversion of the use of so precious a grain. The temperance reform is correcting this evil, and another mode of manufacturing the oil is now in great vogue, namely, by passing the grain through the secreting organs of swine, and thus obtaining it in the modified forms of lard and lard-oil. As these commodities are both in great request at home, and more especially in Europe, a new and rich resource is thus opened to the corn planters of the United States, those especially who cultivate fertile Western lands too far from grain-markets, to be able to dispose of their crops in that form.

The chemical analysis of Indian corn has been lately effected by Dr. Dana, of Massachusetts, and published in the New England Farmer. For the purposes of comparing its nutritive and fattening qualities with those of some other articles extensively used for feeding stock, Dr. Dana has added the analyses of ruta-bagas and potatoes. The great difference of what
Dr. Dana calls the fat forming principles in favour of corn, will excite but little surprise in those who have witnessed the effects of the several substances on animals, and will go far to establish the position assumed by Payen and Boussingalt, that plants are valuable for giving fat to animals only in proportion to the vegetable oils ready formed such plants contain.

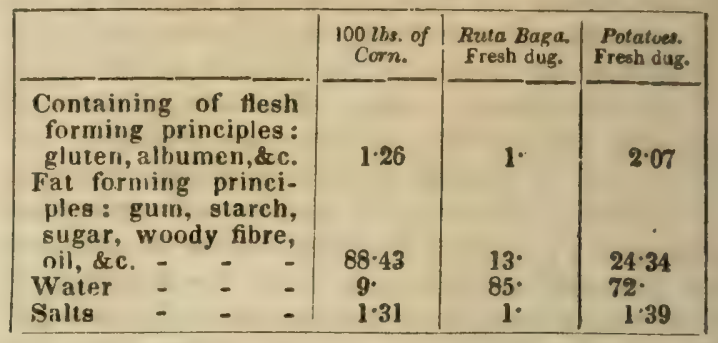

Table showing the average prices of Indian corn in Philadelphia market for each quarler of the year, and also the annual averages for the following years, viz.:

\begin{tabular}{|c|c|c|c|c|c|}
\hline & lat Quar. & 2d Quar. & 3d Quar. & 4th Quar. & $\begin{array}{l}\text { Average for } \\
\text { the year. }\end{array}$ \\
\hline 1827 & $56 \mathrm{cts}$ & $48 \frac{2}{3}$ cts. & 49 cts. & $48 \frac{2}{3} \mathrm{cts}$ & $51 \mathrm{cts}$. \\
\hline 1828 & $43 \frac{1}{5}$ & $39 \frac{2}{3}$ & $39 \frac{2}{3}$ & $49 \frac{3}{3}$ & 43 \\
\hline 1829 & $46 \frac{1}{5}$ & $47^{3}$ & $47^{3}$ & $46 \frac{1}{3}$ & 49 \\
\hline 1830 & $36 \frac{1}{3}$ & 39 & 48 & $55 \frac{1}{3}$ & 45 \\
\hline 1831 & $61^{3}$ & $67 \frac{2}{3}$ & 66 & $57^{2}$ & 63 \\
\hline 1832 & $46 \frac{2}{3}$ & $53 \frac{2}{3}$ & 67 & $71 \frac{2}{3}$ & 60 \\
\hline 1833 & $49 \frac{2}{3}$ & $67 \frac{1}{3}$ & $64 \frac{2}{3}$ & $61 \frac{2}{3}$ & 64 \\
\hline 1834 & $49 \frac{2}{3}$ & $57 \frac{1}{3}$ & $67^{3}$ & $60 \frac{1}{3}$ & 59 \\
\hline 1835 & $61 \frac{1}{3}$ & $79 \frac{1}{3}$ & 89 & $86 \frac{2}{3}$ & 78 \\
\hline 1836 & $78 \frac{8}{3}$ & $82 \frac{1}{2}$ & 91 & $90^{3}$ & 85 \\
\hline 1837 & $96 \frac{2}{3}$ & $91 \frac{i}{3}$ & 101 & $85 \frac{1}{2}$ & 94 \\
\hline 1838 & $72 \frac{1}{3}$ & $74^{\circ}$ & $85 \frac{1}{8}$ & $80 \frac{1}{3}$ & 78 \\
\hline 1839 & $86^{\circ}$ & 89 & $78^{\circ}$ & $62 \frac{2}{3}$ & 79 \\
\hline 1840 & $53 \frac{1}{3}$ & $50 \frac{1}{8}$ & 55 & $53 \frac{1}{3}$ & 52 \\
\hline 1841 & $42 \frac{2}{3}$ & 52 & $69 \frac{1}{3}$ & $60 \frac{2}{3}$ & 61 \\
\hline \multirow[t]{2}{*}{1842} & $52 \frac{3}{3}$ & $55 \frac{2}{3}$ & $52 \frac{2}{3}$ & $45^{3}$ & 51 \\
\hline & & Ave & ge for 1 & years & - $63 \mathrm{cts}$. \\
\hline
\end{tabular}

The above average prices are for Southern flat yellow corn, commonly called gourdseed, which generally sells for about 3 cents less per bushel than the Pennsylvania round or flint corn, which last is heaviest by 3 or 4 lbs. to the bushel. The amount of white flat corn sent to the Philadelphia market is inconsiderable, being only occasionally in demand for shipment to Southern ports, where the white corn is preferred for bread, whilst in the North the preference is always given to yellow corn meal. White flat corn usually sells about 3 cents lower per bushel than the flat yellow.

Measuring Corn, Shelled or on the Ear.-The following rule for this purpose is given by William Murray, Esq. of South Carolina. It is not to be regarded as strictly accurate, but an approximation.

Having previously levelled the corn in the house, so that it will be of equal depth throughout, ascertain the length, breadth, and depth of the bulk; multiply these dimensions together, and their products by 4 , then cut off onc figure from the right of this last product. This will give so many bushels and a decimal of a bushel of shelled corn. If it be required to find the quantity of ear corn, substitute $\mathbf{8}$ for 4 , and cut off one figure as before.

Example.-In a bulk of corn in the ear, measuring 12 feet long, 11 feet broad, and 6 feet deep, there will be 316 bushels and $\frac{8}{10}$ of a 756 
bushel of shelled corn, or 633 bushels and io of ear corn-as:

\begin{tabular}{rr}
12 & 12 \\
11 & 11 \\
\hline 132 & 132 \\
6 & 6 \\
\hline 792 & 792 \\
4 & 8 \\
\hline 316,8 & 633,6 \\
\hline
\end{tabular}

The decimal 4 is used when the object is to find the quantity in shelled corn, because that decimal is half of the decimal 8 , and it requires two bushels of ear corn to make one of shelled corn. In using these rules a half bushel should be added for every hundred, that amount of error resulting from the substitution of the decimals. (Southern Agriculturist.)

Distances of Planting.-The following table furnished by Judge Buel, exhibits the difference in product of planting and serves to explain. in part, the manner in which large crops of this grain have been obtained. It is assumed in the estimate, that each stalk produces one ear of corn, and that the ears average one gill of shelled grain. This, says the judge, is eslimating the product low; for while I am penning this (October), I find that my largest ears give two gills, and 100 fair ears half a bushel of shelled corn. The calculation is also predicated upon the supposition that there is no deficiency in the number of stalks, a contingency pretty sure on my method of planting.

1. An acre in hills, 4 feet apart each way, will prodice

2. The same, 3 by 3 feet

3. The sime, 3 by $2 \frac{1}{2}$ feet

4. The same, in drills at 3 feet, plants

6 stalks, 1 inch apart in the drills -

5. The same in do., 2 rows in a drill, 6 inches apart, and the plants 9

inches, and 3 feet 9 inches from

centre of drills, thus - - -

6. The same in do., 3 rows in a drill, as above, 3 feet from centre of drills $-43,560 \quad 1 \% 0 \quad 5$

'The fifth mode I have tried. The ground was highly manured, the crop twice cleaned, and the entire acre gathered and weighed accurately the same day. The product in ears was 103 baskets, each $84 \mathrm{lbs}$. nett, and $65 \mathrm{lbs}$. over. The last basket was shelled and measured, which showed a product on the acre of 118 bushels 10 quarts. I gathered at the rate of more than 100 bushels the acre from four rods planted in the third method last summer, the result ascertained in the most accurate manner. Corn shrinks about 20 per cent. after it is cribbed. The sixth mode is the one by which the Messrs. Pratt, of Madison county, obtained the prodigious crop of 170 bushels per acre, the largest crop on record. These gentlemen, I am told, are of opinion that the product of an acre may be increased to 200 bushels.

I am told the Messrs. Pratt, above alluded to, used seven bushels of seed to the acre, the plants being subsequently reduced to the requisite number. (Buel's Farmers' Instructer.) See also Pranter's TABLE.

According to the mode usually adopted in Pennsylvania, and other States in which the high-growing varieties of corn are planted, the cornhills will average a disfance of 4 by 3 feet, which gives 3,600 hills to the acre, and allowing 2 stalks to each hill, this makes 7,200 stalks per acre. In more northern situations where they are compelled to rely upon the quick-maturing varieties, the lowness of the stalks admit of closer planting, the hills averaging about 3 by $2 \frac{1}{2}$ feet apart, with 4 stalks per hill, by which means an acre is made to contain 5,808 hills, and no less than 23,232 stalks-every stalk, in a good season and with proper tillage, yielding a good ear.

Sugar from Maize.-Every one familiar with Indian corn in its growth, must have observed the very great sweetness of the juice exuding from the green stalks, when broken or cut. This, together with the great resemblance between the true sugar-cane and maize, afforded ample ground for believing that sugar could be procured from its juice. But whether this can be manufactured with profit, still remains to be fully demonstrated. Partial experiments have afforded favourable results, among which the following may be mentioned. 'The juice of maize contains as much, if not a larger proportion of sugar than that of the sugar-cane. This sugar is precisely similar in its crystallizing and other properties to that of the cane.

The attention of scientific investigators has for some years been directed to this subject, and it has been regarded as an important discovery that the removal of the shoots forming the rudiments of the ears, before these have had time to fill, has caused the stalks to retain all their saccharine matter at an advanced stage of their growth. Very recently this has been contested. At a recent meeting of the French Academy, the distinguished philosopher, M. Biot, read the report of a committee, which paper contained the following statements: Of the corn stalks experimented upon, the ears had been removed from one portion, and left to grow on others. The juice obtained from the stalks which had been castrated, yielded 12 per cent. of sugar; that expressed from the stalks on which the ears had been permitted to grow, 13 per cent. It would hence appear that the results of former experiments showing great apparent advantages from castration, were fallacious, the operation being rather injurious than otherwise. The rapidity with which maize attains its growth, admits of its being removed from the soil sufficiently early to give place to a winter crop. This, in France, is reckoned among the great advantages it has over the sugar-beet, for which it is proposed as a substitute. In those countries where the climate is not sufficiently warm to bring the grain of Indian corn to perfect maturity, such as England and Northern France, it is probable that the plant might be brought sufficiently forward to admit of the manufacture of sugar. Mr. Webb, of Wilmington, Delaware, has made some interesting experiments upon this subject, which are highly worthy of attention. (See Farmer's Cabinet, 1842, and Ellsworth's Report, 1843.) The results afford reasons for believing that the manufacture of sugar from maize may be auvantageously carried on in the United States, 
especially in the Western States, where such luxuriant crops of maize can be raised at little expense.

MALE FERN. See FER.

MALIC ACID. This vegetable acid exists in the juices of many fruits and plants, alone, or associated with the citric, tartaric, and oxalic acids; and occasionally combined with potash or lime. Unripe apples, pears, sloes, barberries, the berries of the mountain-ash, elderberries, currants, gooseberries, strawberries, raspberries, bilberries, brambleberries, whortleberries, cherries, ananas, afford malic acid; the house-leek and purslane contain the malate of lime.

The acid may be obtained most conveniently from the juice of the berries of the mountainash, or barberries. 'This must be clarified, by mixing with white of egg, and heating the mixture to ebullition; then filtering, digesting the clear liquor with carbonate of lead, till it becomes neutral; and evaporating the saline solution till crystals of malate of lead be obtained. These are to be washed with cold water, and purified by re-crystallization. On dissolving the white salt in water, and passing a stream of sulphureted hydrogen through the solution, the lead will be all separated in the form of a sulphuret, and the liquor, after filtration and evaporation, will yield yellow granular crystals, or cauliflower concretions, of malic acid, which may be blanched by re-dissolution and digestion with bone-black, and re-crystallization.

Malic acid has no smell, but a very sour taste, deliquesces by absorption of moisture from the air, is soluble in alcohol, fuses at $150^{\circ} \mathrm{Fahr}$., is decomposed at a heat of $348^{\circ}$, and affords by distillation a peculiar acid, the pyromalic. It consists in 100 parts, of 41.47 carbon; 3.51 hydrogen; and 55.02 oxygen; having nearly the same composition as citric acid. A crude malic acid might be economically extracted from the fruit of the mountainash (sorbus accenparia), applicable to many purposes; but it has not hitherto been manufactured upon the great scale. (Ure's Dict.)

MALLOW (Malva, altered from the Greek malache, soft, which comes from malacho, to soften, in allusion to the emollient qualities of the species). This is an extensive genus of plants, some of the species of which are very urnamental. Among the most interesting of the hardy herbaceous species, are $M$. moschata, M. munroana, and M. purpurata. They should be planted in the flower-border, and increased by divisions of the roots, or by seeds. The annual species should be sown in the open ground; but few of these are worth cultivating.

In England, the indigenous species are three in number. 1. Common mallow (M. sylvestris), a perennial weed which is very common about hedgerows, roadsides, and in cultivated as well as waste ground. The root is tapering, branching, whitish; stem upright, much branched, widely spreading, $1 \frac{1}{2}$ to 3 feet high, in a barren soil recumbent; leaves deep-green, soft, ant downy, with seven acute lobes; foot-stalks and flower-stalks hairy; the flowers, which anpear from May to August, are uumerous, of 758 a shining: purple, veiny, on simple aggregate stalks. The leaves are mucilaginous and emollient, like the marsh-mallow; and were formerly often used in food to prevent costiveness. The fruit is a depressed disk, and is called by the country people "cheeses."

2. Dwarf mallow (M. rotundifolia). This species is also very common in waste ground, and by footpaths near towns and villages. It is annual in habit; has a tapering root. The whole plant is smaller than the last, and is quite prostrate, with numerous stems scarcely branched. Leaves roundish, heart-shaped, with five, often seven, shallow lobes. Flowers pale lilac-coloured, several together on axillary hairy stalks; the stalks when in fruit are bent downwards.

3. Musk mallow (M. moschata). This is a less common perennial species, found in the grassy borders of fields, \&c., on a gravelly soil. The root is tough and woody; the herbage is bright green, more or less rough, with spreading, simple, not starry hairs, unaccompanied with any short, dense, woolly pubescence, and exhaling a musky odour, especially in hot weather, or when drawn tightly through the hand. Stems about two feet high, leafy, round, but little branched. Radical leaves kidney-shaped, cut, soon withering away; the rest in five deep, pinnatifid, jagged segments. The flowers, which appear in July and August, are on long, axillary, simple stalks, rose-coloured, large and handsome; calyx hairy, its outer leaves linear-lanceolate.

Five North American species of the genus Malva are described by Nuttall. One of these, the $M$. coccinea, is very beautiful, with scarlet flowers disposed in dense racemes, and is found from the confluence of the river Platte and Missouri, often extending over the plains in such quantities as to communicate a brilliant redness to thousands of acres. Dr. Darlington describes two species as found in Chester county, Pennsylvania, one of which is the woodland or wild malva (M. sylvestris), sometimes called high mallows. It is a naturalized foreigner, met with in fields and waste places, whither it has escaped from gardens. The other species is the round-leaved malva ( $M$. rotundifolia), commonly called low mallows, and running mallows. 'This is common in yards, gardens, and grass-lots. It is also a foreigner, and so extensively naturalized as to be somewhat troublesome. It is a popular ingredient in domestic practice for poultices, drinks, \&c. "The $M$. crispa and $M$. moschata are frequent in our gardens, and the latter has in a few instances strayed beyond the garden limits, but can scarcely be considered as naturalized. Several species have been recently found in the distant territories of this Republic, and in British America; but it is doubtful whether any genuine malva is indigenous in the old thirieen states." (Flor. Cesirica.)

MALLOW, THE MARSH. See MarsmMallow.

MALLOW, THE TREE. See Tree-MaYe Low.

MALT (Fr. mal; Ital. malto; Lat. maltum). The term malt is applied to designate grain which, being steeped in water, is made to ger- 
minate to a certain extent, after which the process is checked by the application of heat. This evolves the saccharine principle of the grain, which is the essence of malt. Rice, and almost every species of grain, has been used in malting; but in Europe, and especially in England, malt is prepared almost wholly from barley. It is the principal ingredient in the manufacture of beer and of ardent spirits.

The process of malting is performed by steeping any quantity of good barley in cold water for a period which (as regulated by law) must not be less than forty hours; but beyond that period the steeping may be continued as long as it is thought proper. The proportion of water imbibed depends partly upon the barley, and partly upon the length of time that it is steeped; but the result of a good many trials proves that the medium increase of weight from steeping may be reckoned at $47 \mathrm{lbs}$. in every 100. 'The average increase of bulk is about one-fifth. After the grain has remained a sufficient time in steep, the water is drained off, and the barley thrown out of the cistern upon the malt floor, where it is formed into a heap, called the couch, about 16 inches deep. In this situation it is allowed to remain about 26 hours. It is then turned by means of wooden shovels, and diminished a little in depth. This turning is repeated twice a day or oftener, and the grain is spread thinner and thinner, till at last its depth does not exceed a few inches. The temperature which it is wished to preserve by these frequent turnings varies from $55^{\circ}$ to $62^{\circ}$, according to the different modes of malting pursued. Soon after the rudiments of the future stem, called acrospire by the maltsters, has appeared, the process of germination is stopped by drying the malt upon a kiln. The temperature at first does not exceed $90^{\circ}$, but it is raised very slowly up to $140^{\circ}$, or higher according to circumstances.

Barley, by being converted into malt, generally increases 2 or 3 per cent. in bulk, and loses at an average about 20 per cent. in weight, of which 12 are ascribed to kiln drying, and consist of water which the barley would have lost had it been exposed to the same temperature; so that the real loss does not exceed 8 per cent.

The following is Dr. Thomson's analysis of barley, and the pale malt made from it.

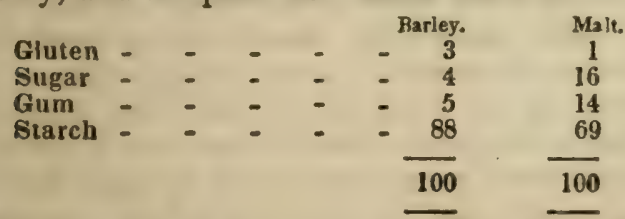

The gluten in this case is a most important component, as by its transformation, when the malt is converted into wort, ferment is gene. rated; whilst the saccharine matter, which is increased fourfold, is the origin of the alcohol cf the beer. Oxyc $n$ is appropriated by the gluten at the same time that the transformation of the sugar is going on; and thus carbonic acid and yeast are disengaged simultaneously.

In brewing ale, porter, and table beer, three different kinds of malt are employed: 1 , pale or amber malt. which yields the saccharine or fermentable extract; 2 , brown or blown malt which is not fermentable, but is used to impar Mavour; 3 , roasted, black, or, as it is some. times called, pateat malt, which is employen instead of burnt sugar, merely as a colouring matter for porter.

The manufacture of malt has been carries on in England to a great extent from a very early period; but it is singular that notwith. standing the products obtained from it have aiways formed the principal beverage of the great bulk of the people, instead of increasing with the progressive wealth of the population of the country, it remained nearly stationary for more than a century, and it is only within the last 8 or 10 years that there has been anv increase in the manufacture. This extraordi. nary result is most probably to be attributed to the introduction and universal use of tea, coffee, \&c., and to the heavy duties that were formerly levied on beer and malt. The present duty on malt from barley is $2 s$. $7 d$. per bushel, and from bere or bigg, 2s. The quantity of malt charged with duty in the United Kingdom during the three years ending 1838 , was $41,814,811$ bushels; and the revenue derived from it averaged in the same period 5,282,975/.

The following is the quantity of malt consumed by the brewers of London and its vicinity from the 10 th of October, 1830 , to the 10 th of October, 1840.

\begin{tabular}{|c|c|c|c|c|c|}
\hline 1831 & - & $\begin{array}{c}\text { Rrs. } \\
622,549\end{array}$ & 1836 & - & $\begin{array}{c}\text { Qru. } \\
754,313\end{array}$ \\
\hline $183^{\circ}$ & - & 601,477 & 1837 & - & 714,488 \\
\hline & - & 578,588 & 1838 & - & 742597 \\
\hline & - & 662,713 & 1839 & - & 750,176 \\
\hline & 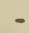 & 702,533 & 1840 & - & 776,219 \\
\hline
\end{tabular}

The 6 Geo. 4 , c. 107 , s. 52 , enacts that "malt may not be imported into the United Kingrom for home use under pain of forfeiture; but it may be warehoused for exportation." The importation of malt is, however, now allowed under very high duties, fluctuating with the price of home produce; but under no state of the market can any addition be thus made to the quantity of malt in this country, becaus barley which has undergone a voyage of muca length is unsuited to the process of malting. See Barlet, Beer, and Brewing.

MALT-DUST. The dust or substance that separates from the malt in the act of drying, or during its preparation. It is sometimes called malt-combs, and has been found useful as a manure or a top-dressing when sown over the cereal grasses in the early spring season.

'The proper quantity of this dust is, if topdressed, for wheat, 36 to 40 bushels; if drilled with the crop, for barley and turnips, 30 to 34 bushels. It is also eminently calculated for grass lands; and if applied in the latter proportion, it will produce a very considerable increase of the best feed. The common price. at most malt-kilns is from $5 s$. to $6 s$. per quarter. Malt-dust is also in some places employed in the feeding of milch cows and pigs.

MALUS (Lat, malum, an apple). The wild crab (Pyrus malus, see Cran-TRE ) is the only apple indigenous to England, and it is on this stock that most of our valuable apples have been grafted and raised by the ingenuity of the gardeners, who have, by sowing the seeds and studying the soil, so improved and multi 
ed the varieties of this most excellent fruit, that it has now become of great national importance, affording an agreeable and wholesome diet, in a thousand shapes, to all classes. leonard Mascal was the first who introduced the common or cultivated apjle into England, about the year 1525. 'The varieties of the apple are now so numerous that the Horticultural Society's catalogue includes more than 1400. The apple, like most other hardy trees, may be propagated by seeds, cuttings, suckers, layers, or engrafting; by seeds for obtaining new varieties, and by the other modes for extending the number of such as are in esteem.

In every garden and private orchard, apples for ten different purposes are desirable:

1. For summer culinary use, the codlings, while not fully grown or imperfectly ripe, are fit for using in June, July, and August.

2. For summer eating or table use, the jenneting. pomroy, \&c., which ripen in the end of June or in July. Margaret, summer pearmain, \&c., (July). Kentish fill-basket, Hawthorn dean, \&c. (August).

3. For autumn baking, the codlings and Burknott's red-streaks, Eve apple, court pender, nonsuch, \&c., which ripen in September. Piles's russet, Carlisle codling, catsheads, embroidered, \&c. (October). Wormsley pippin, golden Harvey, queening, golden russet (November)

4. For autumn table use, the Kirton and Dalmahoy pippins, Loan's pearmain, Colville, Kent, Godulphin, \&c., which ripen in September; urange and ribstone pippins, gray rennet, fameuse, violet, \&c. (October). Franklin's golden, and Borsdorf pippins, Dredge's russet, margil, \&c. (November).

5. For winter culinary use, the Nimier's dumpling, Burknott, John apple, Mansfield tart, \&c., which are fit to use in December. Halldoor, royal pearmain, Dutch queening, Aclam's russet (January). Brindgwood pippin, cockagee, tankerton, box-apple (February).

6. For winter table use, the golden and Kentish pippins, golden and Caradian rennets, brandy, \&c., which are fit to eat in December. The Norfolk storing, Hubbard's Sykehouse, white court pender, \&c. (January). Dredge's Queen Charlotte, Feams, Skenn's kernel, and Dalmahoy pippins, royal pearmain, \&c. (February).

7. For spring culinary use, the quince, white Colville, Lord Camden's rennet, winter pearmain, which keep till the end of March. Spencer pippin, 'Trevoider rennet, Macdonald's Scotch nonpareil, Spaniard, \&c. (A pril). Norfolk paradise, Loan's pearmain, English rennet, \&c. (May).

8. For spring table use, the hollow-eyed, Cornwall rennet, Hughes's new golden pippin \&c., which will keep till the end of March. Cockle and Whitmore pippins, golden anı Piles's russet, Wheeler's extreme, \&c. (April) Stune and Spencer pippins, Royal George, Ward, \&c. (May).

9. For summer culinary use, till the apple seasun returns, the Lord Cheney's green, Baxter's pearmain, stoup codling, \&c., which will keep till the end of June. Norfolk beaufin, Norfolk storing, French crab (July).
10. Fo: summer table use, till the apple sea. son returns, the Dredge's fame, oaken peg, carnation, \&c., which keep till the end of June. Nonpareil, Yorkshire greening, Norfc.lk Colman, which keep till the end of July.

Although the apple flourishes in every part of the United States, if we except the extreme southern portions, the fall and witter varieties commonly come to the greatest perfection in the Northern States and northern portions of the Middle States, where this fruit constitutes a very profitable resource to the farmer, beth for the home markets and exportation to the Southern States, the West Indies, and Europe, and even to Asia. Good judges assert that the apples of England and France are not to be compared, for excellence of flavour, to those produced in the United States.

The following directions for the culture and subsequent managernent of apple trees, is from the valuable manual published in 1842 by William Kenrick, nurseryman, near Boston.

The seeds or pomace of the apple should be sown in autumn in a rich soil. When the young plants appear in spring, they should be carefully thinned to the distance of 2 inches asunder, and kept free from weeds by carefully hoeing during the remainder of the season, or till of sufficient size to be removed.

At 1 or 2 years of age they are taken up, their tap-roots shortened, that they may throw out lateral roots; they are transferred to the nursery, set in rows about 4 feet asunder, and at 1 foot distance from each other in the row, in a rich and loamy soil. In the summer following they are inoculated, or they are engrafted or inoculated the year following.

Size and age for transplanting to the orchard.An apple tree, when finally transplanted to the orchard, ought to be at least 6 or 7 feet high, with branches in proportion, and full 2 years from the bud or graft, and thrifty. Apple trees under this size belong properly only to the nursery.

Distance.-The distance asunder to which apple trees should be finally set, when trans. planted to the orchard, depends upon the nature of the soil, and the cultivation to be subsequently given. If the soil is by nature extremely fertile, 40 feet distance may be allowed, and even 45 and 50 feet in some very extraordinary situations; for before the trees become old, they will completely shade the ground. If, however, the soil is not very extraordinary by nature, or so rendered by art, this distance would be tou great; for the trees would become old, and their growth would be finished, before the ground could be covered by their shadow: 30 feet only may therefore be allowed in land usually denominated of good quality, and but 20 to 25 feet in land of ordinary quality. But where economy of time, of land, and of all things else is consulted, but one-half this distance will answer for a series of years.

The quincunx mode is recommended for close arrangement, and short-lived trees may be set in the intervals.

The size to which an apple tree may attain, and the ground which should be allotted to it, depend also, in some measure, on the particular variety of apple; some sorts being well 
known to attain to a much greater size than that of others.

The period of growth, or the duration of the apple tree is comparatively limited; this is sufficiently evident from the perishable nature of its timber. Those species of trees only will continue living and growing for centuries, whose timber may we preserved incorruptibie during the lapse of a long succession of nges.

Soil and situation.-A rich soil, rather moist than dry, is that adapted to the apple tree; but what is usually termed a deep pan soil is to be preferred.

On such a soil, whether on the plains, or in the valley, or on the sides and summits of our great hills, which alınost always consist of good land, and even in situations the most exposed, the apple tree will flourish.

One of the most productive apple-orchards in the immediate vicinity of Boston is situated on the north and north-west sides of a hill, the most exposed to cold winds. The soil of great hills is generally of far superior quality to that of the plains; and it is a very mistaken opinion, which seems adopted by some, that the soil of all hills must of necessity be dry and deficient in moisture. It is the plains and the knolls that are but too generally thus deficient, not the great hills, which almost always abound in springs.

Land half-covered with rocks, and incapable of being cultivated with the plough, is in some respects admirably suited to the apple tree; for, in such situations, they are not liable to suffer from drought; they receive nearly a double portion of moisture from the rains that fall, and a greater degree of heat by the reflected rays of the sun.

They may even flourish on sandy plains, if, where the tree is to be placed, an excavation is formed 6 or 8 feet in diameter, and 3 or 4 feet in depth, and half-filled either with useless small stones, intermixed with rich loam, mud from the low grounds, clay, or gravelly clay, or mixtures of any of these substances with a portion of manure, and the remainder of the excavation filled to the surface with rich loam.

Management of the Land.-If the ground intended for the orchard cannot conveniently be kept wholly in a state of cultivation during the first years, a portion, at least, ought to be.

A strip of land to each row, of 8 or 10 feet in width, well manured, may be kept cultivated, and the vegetables which may here be raised will amply repay the expense and labour bestowed during the first 4 or 5 years. After this, if the trees have grown well, as they probably must have done, cultivation at a distance in the intervals becomes even more important than within the limited distance of a very few feet from the trunk of the tree; for, on examination, it will be found that the small fibres or spongelets, by which alone the tree derives all the nourishment it receives from the earth, are now remote from the trunk of the tree; they are now to be found seeking pasture beyond the limits of its shade, and it becomes neces. sary that the whole ground should be kept in a high state of cultivation for the 4 or 5 following years. After this period it may occasion- ally be laid to grass, which, however, should be broken up at frequent intervals, the land being always kept in goud heart.

Pruning.- If the branches of a young tree, issuing at and above the requisite height, be made, by pruning, to diverge from the trunk in every direction above the horizontal, and the interior of these be carefully kept from any interference with each other for a few years, little prunmg will ever afterwards be necessary.

Heavy pruning is seldom necessary or advisable; but when, as in the case of grafting, or of heading down for a new growth, it becomes unavoidable, it should always be performed in that interval between the time the frost is coming out of the ground in spring, and the opening of the leaf.

For that moderate pruning, which alone is generally needful, June and July, and during the longest days of summer, is the very best time: for wounds of all kinds heal admirably at this period, the wood remaining sound and bright; and even a tree debarked at this season recovers a new bark immediately.

Trees ought not to be pruned in February and March, at the time the frost is coming out of the ground. This is the season when most trees, and particularly the vine and sugarmaple, bleed most copiously and injuriously. It causes inveterate canker; the wounds turn black, and the bark, for perhaps several feet below, becomes equally black, and perfectly dead, in consequence of the bleeding.

The lower side limbs of young trees in the nursery should be gradually shortened, but not suddenly close pruned; they are essential for a time to strengthen the trunk, and to the upright and perfect formation of the tree.

These directions are particularly applicable to the apple tree. I would only add, that when these directions have been followed, - when large and profitable crops are desired,-our cultivators generally avoid robbing their trees unnecessarily of a particle of bearing wood.

Those limbs which interfere with other limbs by galling, the suckers, and dead wond, are alone removed; for they consider that the warmth of the atmosphere is of itself sufficien: in our climate to ripen the fruit, without attempting to admit the sun to every part of the tree.

These directions are to be more especially observed in regard to old trees in their declining years: their trunks being too old for the reproduction and sustenance of a crop of new and fruitful wood, nothing should be taken away but the dead branches and suckers. We have seen old trees, whose branches were annually loaded with fruit, despoiled at once by the hand of man of half their bearing wood, under the mistaken idea that the destruction of the one half of the tree would confer a bencfit on the remainder, and render it still more productive. We noticed, however, that the effect thus produced was directly the reverse, as their total destruction usually followed, as a consequence, not long after.

Insects.-See Borens, Catripillars, Curcullo, \&c. (Kenrick's New American Orchardist.) 


\section{MALUS.}

The same publication may be referred to for a descriptive list of apples in cultivation in the United States, together with select foreign varieties. From more than 200 kinds, our limits will only admit an enumeration of a list recommended by the experienced author, as a moderate selection of the kinds best known and most valued at the present day. The numbers refer to the entire catalogue.

\section{Sumper Apples.}

3. Benoni, a medium-sized, red, and good early apple.-July.

4. Early Sweet Bough. Size from medium to large, form oblong, skin yellow, juicy, and flavour excellent.-Early in August.

8. Maiden's Blush, or Hawthornden of the English. A large and beautiful fruit, shape flattened, colour yellowish-white, with a red blush on the sunny side. An excellent apple for marhet, and also for drying.-August to September. A popular fruit in the Philadelphia market.

9. Porter. Size medium, oblong, light-yellow, with pale blush next the sun, very beautiful; flavour lively and pleasant; productive and profitable; a popular fruit in the Boston marbet. Origin, Sherburne, Massachusetts.

10. Pumpkin Sweeting of New England. Large, round, flattened, and colour yellow-russet; the Havour sweet and excellent.-August to October.

11. Red Astracan. An eminently beautiful and very early apple, of medium size, nearly globular, of a rich crimson colour, covered with a fine bloom. Crisp, juicy, and agreeable. The tree a great bearer, originally from Russia.

18. Williams Apple. A beautiful fruit, of medium size and oblong form; colour deep-red; flavour lively and very pleasant.-First of August. A native of Roxbury, Massachusetts.

\section{Autumn Apples.}

22. Lrabant Belle Fleur. Very large and handsome; of great solidity; shape rather conical; slightly ribbed; yellow with reddish stripes; juicy and of very pleasant flavour. A fine fruit.-November.

28. Emperor Alexander. The fruit of this Russian variety is very large, cordate, narrow at the crown; the eye is in a broad, deep cavity; colour greenish-yellow, slightly streaked with red in the shade, and beautifully marked and streaked with bright red and orange next the sun. Flesh yellowish-white, crisp, tender, juicy, rich, and of aromatic flavour. Excellent for dessert._October. Keeps till Christmas.

30. Fameusc. Pomme de Neige. A middlesized fruit; shape globular, flattened; skin light green, tinged with light-red and dark-red streaks; deep red next the sun. Flesh white as snow and very tender; juice sweet, with a musky perfume.-October. A most beautiful dessert fruit. Origin Canada.

33. Gravenslein, said to be the best apple in Germany. Shape large, round, and angular at the crown; the eye sunk in a broad, deep, knotty cavity; colour clear straw yellow, with broken stripes of red next the sun. Flesh pale yellow, crisp, high flavoured and delicious. Good for dessert and cider. Ripens in autumn and keeps till winter.
35. Kenrick, a large round fruit, pale green, with bright red next th": sun. Flesh tender and occasionally stained with red. A native of Newton, Massachusetts.

38. Lyscom. Sometimes called Osgood's Favourite; a large fruit, striped with red; of excellent quality. Origin Worcester, Massachusetts. Ripens in October.

39. Monmouth Pippin. A superior, 'arge, anc' handsome fall fruit. Productive and saleable, from Monmouth, New Jersey.

41. Orange Pippin, called also Marigold Pippin, and Isle of Wight Orange; in size, form, and colour, much resembling a middle-sized orange. Flavour pleasant and gond for dessert. Excellent for cider. In Monmouth county, New Jersey, considered one of the most saleable, profitable, and productive of all fall apples.

42. Orange Sweeting, or Golden Sweet; rather large, flattened at the base and summit; colour yellow or orange; flesh sweet and excellent. In high estimation at Providence, Rhode Island, where it is brought from Connecticut.-September. Keeps till December.

44. Red Calville; ; medium size, and very beautiful; form conical; colour fine red, and on the sunny side, deep crimson; flesh stained with red; of a vinous sweet taste, and perfume of violets. Ripens in September, and keeps till winter.

49. Spice Sweet. Fruit large, very sweet and excellent. Native of Taunton, Massachusetts. Sometimes called Spurr Apple.September.

53. York Russeting; remarkably large, conical-shaped, and swollen towards the base; colour russet-yellow; juicy, subacid, and good. Valuable for market, cooking, \&c.-October to December.

\section{Winter Apples.}

55. Esopus Spitzenberg, large, very beautiful, and excellent; shape oblong; colour deep scarlet, deepening to dark crimson next the sun; flesh juicy and high-flavoured. A very celebrated fruit, ripening in December, and keep. ing till March. The Flushing Spitzenberg differs from this in being round or flat.

56. Baldwin. This capital variety is a native of Massachusetts, a large, beautiful, and famous fruit. Shape round, of a pale colour in the shade, and fine scarlet crimson on the sunny side; sometimes entirely red. Flesh white, juicy and sugary, and of an agreeable acid flavour. The most popular winter apple in the Boston market. Ripens in November, and keeps till February and March.

59. Bellflower, or Yellow Bellfower. A large and beautiful fruit, of an oblong or conical form, colour bright yellow, with an occasional blush next the sun. Rich and finely flavour. ed; excellent for dessert and cooking, and a prime favourite in the Philadelphia market. Ripens in October and November, and will keep nearly all winter. The seeds are so loose as to rattle in the middle when shaken.

62. Blue Pearmain. A large, beauti:ul apple, of a dark-red colour, covered with a thick bloom.-October. Keeps till January.

63. Chandler, a superior variety from Con- 
necticut, where it is deemed one of the best of winter fruits. Isarge, flat, with dull red stripes next the sun. Eye large and in a deep cavity. Flavour equal to the Baldwin. Keeps till March.

67. Danvers' Winter Sweet, or Epses Sweet. Large and beautiful. Colour bright yellow, with a faint blush next the sun. Fine for dessert and baking. Native of Danvers, and a popular market iruit.

74. Golden Ball. Size rather above medium; ribbed at the sides; colour golden yellow. A very popular apple in Maine.

81. Lady Apple, or Pomme D'Api. Very small and beautiful. Skin bright and yellow, with a red blush on the sunny side.-November. Keeps till March.

85. Minisler. Large, oblong, and tapering towards the eye, like the Bellflower; with large ribs, or calville-formed; striped, with bright red on a ground of pale greenish-yellow. Flesh yellow and high flavoured. Esteemed by Manning one of the first fruits New England has ever produced.-November to January. Origin, Rowley, Massachusetts.

86. Late Pound Sweet. Very large; form flattened. Colour pale yellow. Origin Vermont.

87. Mela Carla, or Malcarle, Charles Apple, Pomme Ferivale. One of the most famous of iruits; size rather large; form globular, but slightly ovate. Eye and slender stem both inserted into deep cavities. Skin beautiful waxen, a little marhled with faint green near the eye. Splendid crimson colour on the sunny side. Flesh white, delicate sweet, with rose perfume. -September. Keeps till spring. In Italy this is considered the best of all apples in the world. It is there cultivated extensively for exportaiion. Near Boston, this apple proves good but llot excellent

88. Monstrous Pippin, or New York Gloria Mundi; a fruit of uncommon size. Colour yellow with numerous spots of white; eye very dcep. Excellent for cooking. Origin, Long Island.

90. Murphy. A large and splendid fruit, resembling in appearance the Blue Pearmain, but more oblong and rather smaller. Colour pale red, streaked or blotched with darker red, and covered with bloom. Keeps till February. Urigin, Salem, Massachusetts.

94. Pownal Spitzenberg. Origin, Vermont. Resembles the Esopus Spitzenberg, and highIy esteemed.

97. Ransdell's Red Pumpkin Sweet; a beautiful fruit; over medium size : round or oblong; colour a dark and beautiful red, covered with a dense blue bloom. The tree a prodigious bearer, native of Connecticut. Fruit saleable and profitable: keeps till January.

98. Rhode Island Greening; Jersey or Burlington Greening; a very large apple, flattened at both ends; colour yellowish green at maturity, covered with dark clouds or blotches; ripens in September, and keeps till March. A highly esteemed and profitable fruit. Tree bears abundantly every other year, and, in the New England States, is preferred for its productiveness to the Green Newtown Pippin.
99. Ribsion Pippin, also called Formosa Pippin, and Glory of York; in England esteemed very highly; medium size, and glubular form: colour pale yellow, mottled with red next the sun. Keeps till February.

100. Red Seck-No-Farther. A large round fruit, contracted towards the summit; colour fine deep red; flavour sweet and excellent. Keeps till March. A Rhode Island fruit.

101. Roxbury Russeting. A fine old native of Massachusetts; fruit large and of a slightly flattened form; colour, brownish yellow russet, with an occasional blush next the sun; skin rough. Keeps well till June and July. Raised in great quantities near Boston, for exporta tion, \&c.

102. Scolloped Gillyflower. Said by good judges to far excel the Black Gillyflower, and much resembling the Cornish variety.

103. Swaar. This and the Jonathan apple are esteemed equal, at least, if not superior to, the Newtown Pippins and Spitzenbercs. Size, medium; shape, round; skin, greenish yellow, with a blush next the sun, and thickly dotted with brown specks, intermixed with some scarlet. Keeps till April.

104. White Spitzenberg. A beautiful, fair, and fine flavoured fruit, about the size of the Esopus Spitzenberg. Keeps all winter, and sells well in the Albany market.

105. Wine Apple, or Hay's $\Lambda$ pple ; also called Large Winter Red, and Fine Winter. Fruit very large and beautiful; colour, bright red on the sunny side, with sometimes a few stripes and blotches of yellow on the shady side. Flesh rich and excellent. Keeps till February and March. Tree very productive, and fruit very saleable in the Philadelphia market.

106. Winter Suceting; called also Seaver Sweeting, and Grafton Sweeting. Fruit large, round and conical; colour, pale yellow, with a blush on the sunny side. Flesh yellow, sweet and fine-flavoured. Keeps till March.

107. Winter While Culville, or Bonnet Carré. Fruit large and of a bright yellow colour, with a bright red blush on the sunny side; form rather flat and ribbed; flesh white, tender, and pleasant. Keeps till March.

108. Ycllow Newtown Pippin. A large flat fruit, of a bright yellow colour, and faint blush next the sun. Keeps all winter, and flourishes better in the New England states than the Green Variety.

Celebrated Cider Apples cultivated in тhe UNited States.

109. Harrison, or Long Stem. A native of Essex, New Jersey. The celebrated Newark cider is made from this apple; one tree in Es. sex county, New Jersey, produced 100 bushels in one year, and 10 bushels make a barrel of cider, which will yield 14 quarts of brandy. The fruit is below the medinm size, rather long, and deeply indented at the ends; stem very long; colour yellow, covered with black spots. Fruit ripens 1st of November. Flesh yellow, firm, tough, and dry.

110. Taliafero. A Virginia fruit, about the size of a grape-shot, or from 1 to 2 unches in diameter; colour white, streaked with red. 
111. Virginia Crab, or Hewes's Virginia Crab. $A$ very small round cider apple, of a small, red colour, with streaks of pale yellow.

\section{Varieties for Preservive or Ornamental PURPOSES.}

112. Red Siberian Crab. Tree a profuse bearer, and very beautiful when the fruit is at maturity, resembling at a little distance a plum or cherry tree; fruit in clusters of a bright scarlet colour, with long stems. Much used for preserving.

113. Yellow Siberian Crab. The tree, foliage, and fruit equally beautiful with the preceding kind, which it even excels in productiveness. The little apples grow in clusters, with long stems; colour golden yellow.

114. Chinese Double Flowering. Tree small, bearing very double flowers in clusters, resembling small roses; very superb when in full bloom. Fruit very small, but tolerable for eating.

\section{Sodthen Apples.}

The following are stated to be some of the most esteemed varieties of native apples of Virginia. Part are described from the authority of Mr. Coxe, and the remainder on the authority of a Virginian.

115. Beverley's Red. The fruit is very large, the skin smooth, of a crimson colour; flesh very white, of a pleasant flavour. A winter fruit.

116. Cart House, or Gilpin. The tree is a great bearer. The fruit hangs long on the tree in autumn. A small fruit, rather oblong; the skin smooth, of a deep crimson colour, with occasional yellow stripes; the flesh yellow, tender, and of good flavour. A native of Virginia; highly esteemed for its excellence as a table fruit in spring; also a good cider fruit. Coxe.

117. Curtis. The skin is smooth, of a red colour; flesh juicy and pleasant. Ripe middle to end of August.

118. Gloucester White. The tree is of vigorous growth, and beautiful form, and very productive; the fruit of medium size, its form varying from flat to oblong; of a fine yellow colour, clouded with spots of black; the flesh yellow, breaking, juicy, rich, and delicious. It ripens early in October; and, according to $\mathrm{Mr}$. Coxe, is not only a most excellent dessert fruit, but makes exquisite cider. Much cultivated atd of high reputation in the lower counties of Virginia.

119. James River, or Limber Twig. Branches drooping or pendent; the fruit is of a greenish colour, with a blush next the sun; the flesh very juicy, and pleasant at maturity. Winter. Ic keeps a long time.

120. Lippincot. A fruit of Maryland. Very handsome, and striped; excellent; one of the best of all early apples. July and August. $R$. Sinclair.

121. Prynr's Red. The fruit is very large: colour brownish red; its flesh at maturity ju.cy, and very fine. A winter fruit.

122. Rawle's Janet, or Rockrimmon. The form is globular, flattened; the colour red and green; flesh very fragrant, more juicy, and of superior 764 flavour to the Newtown Pippin, and keeps equally as well.

123. Royal Pearmain. Fruit fine, of a large size, flattened; skin rough, of a fine russet colour, but red next the sun, and faintly streaked with russet; flesh a rich yellow, firm, but at maturity, tender, sweet, and of very sprightly flavour. A good table apple; excellent for cider; and highly esteemed by the planters of Virginia, near Richmond, from whence Mr. Coxe procured it. The tree bears uniformly and abundantly. It ripens in October, and will keep till February or March.

124. Striped June Apple. The fruit is as fra. grant as a pine-apple melon. It ripens the last of June and beginning of July.

125. Virginia Greening. The fruit is of medium size; colour green, striped with red; flavour very superior. A winter fruit.

\section{Gathering and Presenving the Fruit.}

Various theories have been offered for preserving apples in a sound state for winter use, or for distant voyages. Some have proposed gathering the fruit before it is ripe, and drying it on floors before it is put up; this has been tried; the apples lose their sprightly flavour, and keep no better than by some less troublesome modes. Dr. Noah Webster has recom. mended that they should be put down between layers of sand which has been dried by the heat of summer. This is without doubt an excellent mode, as it excludes the air, and absorbs the moisture, and must be useful when apples are to be shipped to a warm climate.

Chopped straw has also been highly recommended to be placed between the layers of fruit; but I have noticed that the straw, from the perspiration it imbibes, becomes musty, and may probably do more hurt than good. When apples are to be exported, it has been recommended that each be separately wrapped in coarse paper, in the manner oranges and lemons are usually put up. This is, without doubt, an excellent mode. And Mr. Loudon has recommended that apples destined for $\mathbf{E u}$ rope should be packed between layers of grain Packing in oats is said to succeed very well.

Great quantities of fine winter fruit are raised in the vicinity of Boston, and put up for winter use, for the markets and for exportation. The following is the mode almost universally adopted by the most experienced; and by this mode apples, under very favourable circumstances, are frequently preserved in a sound state, or not 1 in $\mathbf{5 0}$ defective, for a period of 7 or 8 months. The fruit is suffered to hang on the tree to as late a period as possible in October, or till hard frosts have loosened the stalk, and they are in imminent danger of being blown down by high winds; such as have already fallen are carefully gathered and inspected, and the best are put up for eariy winter use. They are carefully gathered from the tree by hand, and as carefully laid in baskets. New, tight, well-seasoned flour-barrels, from the bakers', are usually preferred: the baskets, being filled, are cautiously lowered into the barrels and reversed. The barrels, being quite filled, are gently shaken, and the head is gently pressed down to its place, and 
secured. It is olsserved that this pressure never causes them to rot next the head, and is necessary, as they are never allowed to rattle in removing. No soft straw or shavings are admitted at the ends; it causes mustiness and decay. They are next carefully placed in wagons, and removed on the bulge, and laid in courses in a cool, airy situation, on the north side of buildings, near the cellar, protected by a covering on the top, of boards, so placed as to defend them from the sun and rain, while the air is not excluded at the sides. A chill does not injure them; it is no disservice; but when extreme cold weather comes on, and they are in imminent danger of being frozen, whether by night or day, they are carefully rolled into a cuol, airy, dry cellar, with openings on the north side, that the cold air may have free access; they are laid in tiers, and the cellar is in due time closed and rendered secure from frost. The barrels are never tumbled or placed on the head. Apples keep best when grown in dry seasons, and on dry soils. If fruit is gathered late, and according to the above directions, repacking is unnecessary; it is even ruinous, and should on no account be practised till the barrel is opened for use. It has been fully tried.

When apples are to be exported, $\mathbf{M r}$. Cobbett has recommended that 'they should, if possible, be carried on deck; otherwise between decks.' Between decks is the place, and in the most dry, cool, and airy part.(Kenrick.)

\section{Insects injorrous to Trees and Fruit.}

Among the insects that have been brought to America with other productions of Europe, may be mentioned the Apple-tuorm, as it is commonly called, which has become naturalized wherever the apple tree has been introduced. This mischievous creature has been sometimes mistaken for the plum-weevil, from which, however, it may be easily distinguished by its shape, habits, and transformations. Although the plum-weevil prefers stone-fruit, it is somelimes met with in apples. On the other hand, Dr. Harris says he has never known the appleworm to be found in plums. It is, he observes, not a grub, but a caterpillar, belonging to the Tortrix tribe, and in due time is changed to a moth, commonly called the Codlingmoth, or fruitmoth of the apple. An anonymous writer, in the Entomological Magazine of London, has well remarked that this moth "is the most beautiful of the beautiful tribe to which it belongs; yet, from its habits not being known, it is seldom seen in the moth state; and the apple-grower knows no more than the man in the moon to what cause he is indebted for his basketfuls of worm-eaten windfalls in the stillest weather."

Some interesting facts collected by Dr. Harris, serving to establish the difference between the plum-weevil and apple-worm (codling caterpillar), will be found under the head of PLomWrevit.

The apple-worm has been long known in Europe, and its history has been written by some of the ablest naturalists. Accounts of it have also been furnished in the New England Farmer and other good American periodicals.
The apple-worm moths may be found in the early part of summer, about the time of the first ripening of the fruit. They are sometimes seen in houses in the evening, trying to get through the windows into the open air, having been brought in with fruit while they were in the caterpillar state. Their fore-wings, when seen at a distance, have somewhat the appearance of brown watered silk; when closely examined, they will be found to be crossed by numerous gray and brown lines, scalloped like. the plumage of a bird; and near the hind angle there is a large, oval, dark-brown spot, the edges of which are of a bright copper colour. The head and thorax are brown, mingled with gray, and the hind-wings and abdomen are light yellowish-brown, with the lustre of satin. Its wings expand three-quarters of an inch. This insect is readily distinguished from other moths by the large, oval, brown spot, edged with copper colour, on the hinder margin of each of the fore-wings. During the latter part of June and the month of July, these fruit-moths fly about apple trees every evening, and lay their eggs on the young fruit. They do not puncture the apples, but they drop their eggs, one by one, in the eye or hollow at the blossomend of the fruit, where the skin is most tender. They seem also to seek for early fruit rather than for the late kinds, which we find are not so apt to be wormy as the thin-skinned summer apples. The eggs begin to hatch in a few days after they are laid, and the little apple-worms or caterpillars produced from them immediately burrow into the apples, making their way gradually from the eye towards the core. Com. monly only one worm will be found in the same apple; and it is so small at first, that its presence can only be detected by the brownish powder it throws out in eating its way through the eye. The body of the young insect is of a whitish colour; its head is heart-shaped and black; the top of the first ring or collar and of the last ring is also black; and there are eight little blackish dots or warts, arranged in pairs, on each of the other rings. As it grows older, its body becomes flesh-coloured; its head, the collar, and the top of the last ring, turn brown, and the dots are no longer to be seen. In the course of three weeks, or a little more, it comes to its full size, and mean while has burrowed to the core and through the apple in various directions. To get rid of the refuse fragments of its food, it gnaws a round hole through the side of the apple, and thrusts them out of the opening. Through this hole also the insect makes its escape after the apple falls to the ground; and the falling of the fruit is well known to be hastened by the injury it has received within, which generally causes it to ripen before its time.

Soon after the half-grown apples drop, and sometimes while they are still hanging, the worms leave them and creep into chinks in the bark of the trees, or into other sheltered places, which they hollow out with their teeth to suit their shape. Here each one spins for itself a cocoon or silken case, as thin, delicate, and white as tissue-paper. Some of the apple worms, probably the earliest, are said by $\mathbf{K u}$ l lar to change to chrysalids immediately arter 
their cocoons are made, and in a few days more turr to moths, come out, and lay their eggs for a second generation of the worms; and hence much fruit will be found to be worm-eaten in the autumn. Most of the insects, however, remain in their cocoons through the winter, and are not changed to moths till the following summer. The chrysalis is of a brigh:" mahogany-brown colour, and has, as usual, across each of the rings of its hind-body, two rows of prickles, by the help of which it forces its way through the cocoon before the moth comes forth.

As the apple-worms instinctively leave the fruit soon after it falls from the trees, it will be proper to gather up all wind-fallen apples daily, and make such immediate use of them as will be sure to kill the insects, before they have time to escape. Mr. Burrelle says that if any old cloth is wound around or hung in the crotches of the trees, the apple-worms will conceal themselves therein; and by this means thousands of them may be obtained and destroyed, from the time when they first begin to leave the apples until the fruit is gathered. By carefully scraping off the loose and rugged bark of the trees, in the spring, many chrysalids will be destroyed; and it has been said that the moths, when they are about laying their eggs, may, be smothered or driven away by the smoke of weeds burned under the trees. The worms often found in summer pears appear to be the same as those that affect apples, and are to be kept in check by the same means. (Harris.) See Cidra and Orcharn.

MANDRAKE (Mandragora; the name is derived from mandra, an ox-stall, something relating to cattle, and agauros, cruel; on account of its poisonous effects on cattle, when accidentally gathered with their fodder in the countries where the plants abound). These plants, which are natives of the south of Europe, thrive well in a light soil, in a shaded situation. They can only be increased by seeds. The roots are very apt to rot during winter. The root has an uncouth form, which is supposed to resemble the human shape; on which account it was imagined to be capable of preventing barrenness. It is, however, an acro-narcotic poison, and when taken proves fatal by the extreme purging which it causes. The common people still believe in its properties; but the root of a species of Bryony ('Tamus communis) is usually sold for it in the herb shops.

MANGE. A cutaneous disease, which attacks several domestic animals, especially the $\mathrm{dog}$, and which is attended with an eruption and loss of hair.

In the horse it is known to exist by the animal's constantly rubbing or biting himself, co as to remove the hair, and sometimes produce ulceration; the hair of the mane and tail frequently falls off, and small scabs may generally be observed about the roots of those which remain. This disease is seldom met with, except in common stables where scarcely any attention is paid to the horses, and where their food is of the worst quality; horses highly kept, if not properly attended to, are also subiect to this disease, which is very contagions.
The causes of mange are, sudden changes of temperature, hot stables, bad diet, joined to want of cleanliness. The perspirable matter being never properly removed by friction, and being frequently mixed with dust, \&c., completely plugs up the external exhalents, whereby they become obstructed, and a diseased action takes place. It may also be caused by infectious matter coming in contact with the skin; as when a sound horse rubs himself against the stall in which a mangy horse has been kept. 'The principal symptoms are, the horse growing very thin, without any apparent cause, attended with a staring of his coat. This is soon followed by eruptions, which discharge a thick yellowish matter, forming a kind of scurf, which peels off, and is succeeded by fresh eruptions, and the hair falls off. This, though partial at first, soon spreads all over the body, is attended with an itching, and causes the horse to rub against every thing he comes near. In this disease great attention to cleanliness is necessary.

In the horse the following will be found the best remedy. Bleed to the extent of two or three quarts, according to the constitution of the animal, and after first preparing the horse by bran mashes, give the following dose of physic :-

Barbadoes aloes - $\quad-\quad-\quad 6$ drachıns
Powdered ginger - $\quad-\quad=22-$
Castile soap - $\quad-\quad 22-$
Oil of carraways - $\quad-\quad 20$ drops.

Honey or treacle sufficient to form a ball. After which give the following alterative balls: 2 ozs. each of powdered black antimony, powdered nitre, flour of sulphur, Castile soap, and aniseed powder, $1 \mathrm{oz}$. of rosin, added to a sufficient quantity of honey to make eight balls, one to be given every night.

The following ointment may be applied externally:-

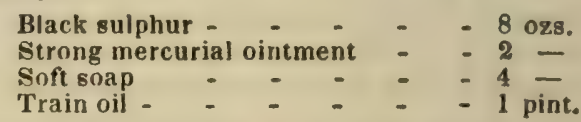

These ingredients to be well mixed, and one third part carefully rubbed in daily. If the above ointment should be found ineffectual, 4 ozs. of spirit of tar may be added.

Dogs and swine are frequently subject to mange. For the common scabby variety in the dog, the following ointment is recommended :-

Powdered sulphur -
Muriate of ammonia, powdered -4 ozs.
Venice turpentine - - - $-\frac{1}{1}-$
Lard, or other fatty matter - $-6=$
Well mixed.

MANGEL WURZEL. Field Bect, or Root of Scarcity. (Germ. Mangold Wurzel.) The root of the Beta hybrida, or B. albissima, Linn. This is a kind of red beet, which, according to Von Thaer, is a mongrel between the red and white beet. It has been long cultivated in France, Germany, and Switzerland, partly as food for cattle, and partly to be used in distillation, and in the extraction of sugar. Its culture in Great Britain is more recent; but its value is now becoming very generally appreciated, and the cultivation likely to become more extensive. So far back as the year 1811 , 
General Beatson, then Governor of St. Helena, writing to the English Board of $\mathbf{A g r i c u l t u r e}$, and describing the extraordinary produce of some plants, the leaves of which had been repeatedly cut to serve as a substitute for spinach, says:-It certainly possesses advantages over every other plant hitherto introduced in field culture. Its produce is immense; and I have found it to grow, with considerable luxuriance, upon land where no other vegetation was ever seen. It has also the singular property of being unmolested by the dolphin-fly, which is here extremely destructive to cab. bages, turnips, and radishes. I have very often observed, where alternate plants of cabbage and mangel wurzel were growing in the same rows, and touching each other, that whilst the former were absolutely annihilated by the destructive insect, not one was to be seen on the mangel wurzel leaves."

Lord Spencer reports the result of a trial on the comparative feeding properties of mangel wurzel and Swedish turnips. "Believing," says his lordship, "that mangold wurzel contained more saccharine matter than Swedish turnips, and ought, consequently, to be the more nourishing root of the two, I determined to try, practically, whether an ox fed upon mangold wurzel increased in weight more than one fed upon Swedish turnips, in proportion to the quantity of each consumed. In order to have rendered my experiment perfectly accurate, I ought to have ascertained the weight of hay consumed by each beast during the progress of the trial; but I did not do this, although I am pretty confident that the quantity consumed by each was nearly the same. I selected two steers, tolerably, and at least equally, well bred. No. 1, calved March 29th, 1823, and No. 2, calved May 6 th of the same year; and on the 24th of December, 1825, I put No. 1 to Swedish turnips, and No. 2 to mangold wurzel. I ascertained their weight by measurement, and both of them measured the same, viz. $4 \mathrm{ft} .10$ in. in length by $6 \mathrm{ft} .5 \mathrm{in}$. in girth, making them to weigh $668 \mathrm{lbs}$. each. On the $23 \mathrm{~d}$ of January, No. 1 had consumed 1624 lbs. of Swedish turnips, and measured $4 \mathrm{ft} .10 \mathrm{in}$. in length by $6 \mathrm{ft} .7$ in. in girth, making him to weigh $703 \mathrm{lbs}$., and to have increased in weight $35 \mathrm{lbs}$., or at the rate of $48 \frac{1}{4}$ lbs. for every ton of Swedish turnips consumed. No. 2 had consumed 1848 lbs. of mangold wurzel, and measured $4 \mathrm{ft} .10$ in. in length by $6 \mathrm{ft}$. $8 \mathrm{in}$. in girth, making him to weigh $721 \mathrm{lbs}$, and to have increased in weight $53 \mathrm{lbs}$, or at the rate of $65 \frac{1}{2} \mathrm{lbs}$. for every ton of mangold wurzel consumed.

"This difference, however, might have arisen from No. 2 having a greater propensity to feed than No. 1. I therefore now put No. I to mangold wurzel, and No. 2 to Swedish turnips. On the 20th of February, No.1 had consumed $1884 \mathrm{lbs}$. of mangold wurzel, and measured 4 ft. 11 in. in length by $6 \mathrm{ft}$. $8 \mathrm{in}$. in girth, making him to weigh 734 lbs., and to have increased in weight this month $31 \mathrm{lbs}$, or at the rate of $36 \frac{3}{3}$ lbs. for every ton of mangold wurzel consimed. No. 2 had consumed $1880 \mathrm{lbs}$. of Swedish turnips, and measured $4 \mathrm{ft} .11 \mathrm{in}$. in length hy $6 \mathrm{ft} .8 \mathrm{in}$. in girth, making him to weigh also
$734 \mathrm{lbs}$, and to have increased in wrieht during this month $13 \mathrm{lbs}$, or at the rate of 15 \& lis. for every ton of Swedish turnips consumpit. I then put both to mangold wurzelpand diviled the food equally between them. On the 19th of March, they had each consumed 1792 lbs. of mangold wurzel; No. 1 measureil $5 \mathrm{f}$. in length by $6 \mathrm{ft} .10 \mathrm{in}$. in girth, making him io weigh $784 \mathrm{lbs}$, and to have increased in weight 50 lbs.; No. 2 measured $5 \mathrm{ft}$. in length by $6 \mathrm{ft}$. $9 \mathrm{in.}$ in girth, making him to weigh $765 \mathrm{lbs}$., and to have increased in weight 361 ibs.

"It would appear, therefore, as if the propensity to feed of No. I was greater than that of No. 2 in the proportion of 50 to 31 ; but, notwithstanding this, in the first month, when No. 1 was upon Swedish turnips, and No. 2 upon mangold wurzel, No. 2 beat No. 1 in the proportion above stated of $65 \frac{1}{2}$ to $48 \frac{1}{4}$. It appears as if there could be no great inaccuracy in estimating the relative weight of the animals, as, soon after the experiment was concluded, $\bar{I}$ sold No. 1 to a butcher in the country for 24l. 3s., and No. 2, at Smithfield, for $24 l$.

"It will be for practical men to decide upon the value of this trial; what appears to me to be the most conclusive part of it is, that No. 2, who had during the first month, when he was feeding upon mangold wurzel, increased in girth $\mathbf{3}$ inches, in the next month, when his food was changed to Swedish turnips, did not increase in girth at all; and when, in the third month, he was feeding again upon mangold wurzel, he again began to increase in girth: because it is very well known, that, if an animal is changed from more to less nutritious food, the probable consequence will be that his growth will be stopped. The result appeared to me so decisive that I have not tried the ex. periment with the same accuracy since; but I did try, the following year, the feeding a cow alternately on Swedish turnips and mangold wurzel, and though 1 have not by me the de. tails of the trial, I remember that the result confirmed the experiment of the previous year."

Mr. Miles of Kingsweston, in the same volume of the Journal, p. 298, commenting on the communication of Lord Spencer, describes so fully and explicitly the best mode of culture, \&c. of this root, that I cannot do better than adopt his paper entire.

"Notwithstanding the favourable results of Lord Spencer's experiment with mangold wurzel, the consideration will naturally suggest itself to the mind of the farmer, previously to his adopting the cultivation of this root, whether, although the mangold wurzel may bring on his cattle faster and better than the Swedish turnip, it is not more difficult of culture, more tender in its habits, and less productive in bulk per acre than the Swedish turnip; and I think, therefore, it may not be unprofitable to lay before the readers of the journal, first, the chemical analysis of the highest or lowest order of turnip and of mangold wurzel as given by Sir H. Davy, and of the sugar beet and orangeglobe mangold wurzel as lately obtained on the same plan by the celebrated Bristol chemist Mr. Herepath; and then to point out the system 
adopted ly myself in the west of England in the cultivation of mangold wurzel, which has been at:3nded with complete success.

\begin{tabular}{|c|c|c|c|c|c|}
\hline \multirow{2}{*}{$\begin{array}{l}\text { Roote. } \\
\text { Species. }\end{array}$} & \multicolumn{5}{|c|}{ Quantity of Nutritive Matter in 1000 parts. } \\
\hline & $\begin{array}{l}\text { Muci- } \\
\text { lage or } \\
\text { Starch. }\end{array}$ & $\begin{array}{c}\text { Saccha- } \\
\text { rine } \\
\text { nalter } \\
\text { or } \\
\text { Sugar. }\end{array}$ & $\begin{array}{l}\text { Glufen } \\
\text { or Al. } \\
\text { bumien. }\end{array}$ & Extract. & $\begin{array}{l}\text { Total } \\
\text { soluble } \\
\text { or nutri- } \\
\text { five } \\
\text { matter. }\end{array}$ \\
\hline Swedish turnip & 9 & 51 & 2 & 2 & 64 \\
\hline White turnip - & 7 & 34 & 1 & - & 42 \\
\hline Mangold wurzel & 13 & 119 & 4 & - & 136 \\
\hline Orange-globe - & 257 & $106 \frac{3}{4}$ & $1 \cdot 20$ & less than 1 & $135 \frac{1}{3}$ \\
\hline Sugar-beet - & $17 \frac{7}{4}$ & $126 \frac{3}{4}$ & $1 \frac{1}{6}$ & 1 & 1467 \\
\hline
\end{tabular}

"By this table, it is apparent that equal quantities of Swedish turnip, orange-globe, and mangold wurzel contain very different proportions of nutritive matter, the latter more than doubling the former in quantity; and should the mangold wurzel be of equally easy culture with the Swedish turnip, it seems almost unaccountable that it should not yet have come in to more general cultivation. I have grown the common red sort for six, the sugar beet for four, and the orange-globe for three years; these kinds have regularly come into course with Swedes upon light land; the product has always been equal, in most cases far heavier. The Swedish turnip has enemies innumerable; I have never observed the mangold wurzel attacked either by fly, slug, or wireworm. Equally a cleansing crop with the Swede, it stores better, and lasts good for a longer period. In the summer of this year I was using sugar beet with stall-fed cattle, which cut perfectly good and crisp in August. The mode of culture I adopt, up to depositing the seed in the ground, is the same as that adopted in Northumberland for ridging the Swede; great care, however, must be taken that the seed of the mangold wurzel is not buried too deep, or it will not vegetate. Dibbling, as you never can insure an equal depth, does not answer; nor does the seed drill well, if properly prepared by steeping, which I should recommend, for at least 24 nours before planting. To insure, therefore, a proper depth, I have been in the habit of nsing an iron wheel, round the outer circumference of which, 18 inches apart, iron points project, broad at the base and tapering towards the point, about $2 \frac{1}{2}$ inches long; this is wheeled upon the top of the ridge, the man walking in the furrow, and thus holes are formed which can never run into the excess of great depth, and into which the seeds are deposited by women and boys following the wheel, and generally covering the seed by drawing the foot as they advance at rignt angles with the ridge over the holes; the roller follows, and thus the sowing terminates. One man with the wheel will keep six persons well employed in depositing the seed after him. This system was recommended me by my friend Mr. Webb Hall, and since I have adopted it my crop has never failed.

"The after-culture and the storing is similar to that of the Swede; great care, however, should be taken in never permitting two plants tc grow in the same spot, which will be the case freciuently, should only one capsule even be deposited in each hole, as every capsule 76 , contains many seeds. Should the tops remain uncut, the plant will stand a considerable de. gree of frost; it should, however, be stored early in November; the best and cheapest method is to build it up against some high wall contiguous to your beast sheds, not more than 7 or 8 feet deep, carried up square to a certain height, and then tapering in a roof to the top of the wall; protect the sides with thatched hurdles, leaving an interval between the roots and the hurdles, which fill up with dry stub. ble; cover the roof with about a foot of the samey and then thatch it, so as to conduct all moisture well over the hurdles placed as a protection to the sides. In pulling the plants care should be taken that as little injury be inflicted upon them as possible; cleansing with a knife should on no account be permit ted, and it is safer to leave some of the leaf on than by cutting it too close to impair the crown of the root. The drier the season is for storing the better, although $I$ have never found the roots decayed in the heap by the earth, which in wet weather has been brought from the field, adhering to them. As to the productiveness of the different sorts, in one year I have grown a larger quantity of sugar beet per acre, in another of mangold wurzel; both these, however, I consider exhaust the land in a greater degree than the Swede; but I have formed a very high opinion of the orange-globe, though not so large a producer generally as the two other sorts; it appears always to throw at least two-thirds of its weight above ground, neither is its tap-root larger nor its fibrous roots greater than those of the Swede turnip. Care should be taken in giving cattle every species of this root, as if taken in excess it is apt to scour ; indeed, from the avidity with which cattle eat the sugar beet, and from its viscous properties when quite fresh from the ground, it should be stored so as to come into consumption the last of the roots.

"In feeding store cattle I should commence with Swede turnip, proceed with the orangeglobe, then with mangold wurzel, and finish off with the sugar beet; thus not only frequently varying the food, but using them in the order corresponding exactly with the nutritive matter contained in each description of plant. I have found, indeed, equally with Lord Spencer, that it will not do to return from any sort of mangold wurzel to Swede turnips, as even beasts in the straw-yard have for two or three days refused such a change. I may add that the earlier in April your mangold wurzel is sown the better, the deeper the tilth the greater probability of a heavy crop, but that althe ugh both the mangold wurzel and sugar beet require a deeper and stronger land than the Swede turnip, yet that the orange-globe will flourish wherever the latter will succeed."

Mangel wurzel may be grown on stiffer soils than those adapted for the turnip, and it is better food for milch cows, as it does not, like turnips, give to the milk a taint. It cannot bear the cold, however, so well as the Swedish turnip, and hence is more cultivated in the southern portions of England than in Scotland. Mr. W. Lester (Quar. Journ. of Agr. vol. iii. $p, 365$ ) describes a method of making ale from this root. 
MANGER. A trough or crib in the stable, $n$ which corn or cut provender for the horse is laced. The usual methord is to have them the whole breadth of the stall; but this is unnecesary, as, if 18 or 20 inches in length, and 14 or 6 in breadth, they will be sufticient for every iseful purpose. In the fixing of them, they hould be so contrived as to admit of being emoved for the purpose of being cleaned. rhis could, however, never be done in the old nethod of fixing them, but by a little contriance may be easily effected. It is, in many ases, a convenient plan to have them in the corners or angles at the heads of the stalls. see Starte and Stalt.

MANHADEN (Clupea manhaden). A species of herring frequenting the waters of the New England States and Long Island, where it goes ander the various names of Bony Fish, Moss or Marsbanker, Hardhead, and Paukaugen. The usual ength of the manhaden is from 10 to 14 inches. from July in the last of August, the shores of he sea swaria with shoals of this fish, which, eing very oily, is but little resorted to for food, hough the better adapted for manure, to which urpose it is most extensively applied, and with uch beneficial effects that lands formerly worn ut so as hardly to compensate for their tillage, How yield abundant crops of wheat, grass, \&c. $t$ is taken in large numbers upon the coast of Massachusetts, where it is used for mackarelait, manure, and is also becoming an article of commerce. For the former purpose it is worth from $\$ 2$ to $\$ 4$ per barrel, in proportion o the demand. At Lynn, in 1836, 1500 barrels were used for bait for other fishes, and as many nore were thrown upon the land. At Provinceown they are used only for markarel-bait. At Sandwich, where they are very abundant, the nhabitants strew them upon their lands by the art-load; and thus, for miles, immense quanities enrich the soil. It is computed that a ingle manhaden of ordinary size is equal in ichness to a shovelful of barn-yard manure. $t$ is getting likewise to be thought worthy of reservation as an article of food. In 1832, 300 bbls. were inspected; in 1833, 480; 1834, $008 ; 1835,1443 ; 1836,1488$.

Mr.John Wells, of Long Island, in a commuication to the editor of the Cultivator, gives the ollowing information in relation to the mode of applying this fish as a manure, and the good ffects derived from the practice.

"I have," he says, "used fish manure 40 ears successively, and my land is much beter than when I first commenced fishing. I nake use of from 50,000 to 150,000 of fish, nown here by the name of mossbankers, per annum; and could I get a million, I should nave none to spare. There is no manure that use equal to fish for a crop of wheat, and all -inds of roots; but they do not have that effect after repeating that they have at first. But this $s$ the case with all kinds of manure. Thence he necessity of mixing manures. 10,000 mossbankers per acre are sufficient for a crop of wheat, without any other manure. My practice is, to put on 12 or 15 large wagon-loads of liter, and 5,000 fish per acre; and then I calcuate for a good crop of wheat, and after the wheat a good burden of grass for 3 or 4 yoals.
The same quantity of manure makes a goud crop of Indian corn. The manure fishery is the making of the east end of cur island. I think I may say that the production of our land is 3 times as much as it was befure we com. menced fishing. But it must not all be attributed to fish. We exert every means in make. and collect manure, for without it wre cannot raise our bread. For a farmer (1) break up a piece of land, and lay it down poorer than it was at first, is like borrowing money to pay his interest. It is astonishing to me that therr. are some few farmers yet, who will let their manure lie and ferment in the yard, when they must know that they lose half its virtue; for there is no time that it brings forth vegetation so well as when in a state of fermentation under the soil. I might say that our soil is a sandy loam."

The best history of the manhaden, which is a favourite food of the whale, is by Latrobe, published in Transactions of the Am. Phil. Society, vol. v.

MANNA (Fr. manne; It. manna). The con. crete juice of the Fraxinus ornus, a species of ash growing in the south of Europe. The juice exudes spontaneously in warm, dry weather, and concretes into whitish tears; but the greater part of the manna of commerce is obtained by making incisions in the tree, and gathering the juice in basliets, where it forms irregular masses of a reddish or brownish colour, often full of impurities. Manna consists of two parts; one a saccharine, crystallizable principle, named mannil, closely resembling sugar; the other an acrid, uncrystallizable principle, which is the purgative agent in the manna. This substance is now seldom used, except as a purgative for infants.

MANIOC. The Indian name of the starchy, nutritious matter obtained from the shrub Jatropa manihot, from which cassava and lapioca are made in the West Indies. See 'TAPIoca.

MANURES. The word manure, according to Todd, is derived from the French manouvrer. Lemon gives the derivation as follows: " $\mathrm{Ma}$ nure, "omnia a manu operando." Skinner,"All improvements in agriculture brought in by the hand." Webster, Eng. Dict., says, "Manure, Fr. mancuvrer, but in a different sense; Norm. mainoverer, to manure; main, Lat. mnnus, hand, and ouvrer, to work, Lat. operor." A manure may be defined to be any fertilizing compound or simple ingredient added to a soil, of which it is naturally deficient; and as ali cu.iv' ed lands should contain the earths, silica, car onate of lims, alumina, decomposing organic matter, and certain saline substances. it is evident that in cases where any one of these is contained in the land in insufficient quantities for the supply of cultivated regetables, that then the addition of that substance, either in its simple or in a compound form, constitutes the great art of manuring.

Fertilizers theretore naturally divide themselves into 3 classes: 1. The earthy, which are by far the most permanent portions of a soil. and are usually applied in the largest propur. tions; 2. The organic (vegetable and animai). which are the least permanent, and are used in $3 \mathrm{~T}$ 769 


\section{MANURES.}

much smaller quantities than the earthy; and, 3. The saline, which are the most sparingly applied of all fertilizers, are the most readily absorbed by plants, and whose period of duration in the soil is longer than the organic, but less than the earthy. A manure is either useful to vegetation, by affording, in its simple or decomposed siate, direct food or constituents, or else it is a fertilizer, by adding to the soil additional power to absorb and retain atmospheric gases and moisture. We shall see, hereafter, that most manures which are commonly applied to the land assist the growth of plants in both ways. Looking at the question abstractedly, it must be evident, that as animals receive almost the whole of their nutriment cither directly or indirectly from the vegetable kingdom, their excrement, or their decomposed bodies, returning these to the soil, must form the best manure.

With regard to inorganic substances, clay of the earthy manures, and some of the saline fertilizers, act principally by their absorption and retention of moisture. Gypsum, it is true, enters into the composition of some of the crasses, and, in minute proportions, other salts do the same; but, if we except phosphate of lime (the earthy salt of bones), none of the salts can be considered to be a very general direct food of plants. Davy very clearly explains the desirable objects in the fertilization of soils: he says, "The plants growing in a soil incapable of supplying them with sufficient manure or dead organized matter, are generally very low, having brown or dark-green leaves, and their woody fibre abounds in earth. Those vegetating in peaty soils, or in lands ton copiously supplied with animal or vegetable mater, rapidly expand, produce large bright-green leaves, abound in sap, and generally blossom prematurely. Excess of poverty or riches is almosi equally fatal to the hopes of the farmer; and the true constitution of the soil, for the best crop, is that in which the earthy materials, the moisture, and manure are properly associated, and in which the decumposable vegetable or animal matter does not exceed one-fourth of the weight of the earthy constituents." (Elenients of Ag. Chem. p. 264.)

of the organic manures, those which the most readily putrefy are the most rapid in their effects: but then they are the most speedily exhausted: thus oil and fish, the most rapid of fertilizers, are exhausted by the few first crops; while hones, which decay more slowly, will last souse time longer. The effect of chopped woollen rags is excellent for iwo years in tha rich clay hop-gardens of Kent, and for three or four in the light, chalky, arable soils of the valley of the Kennett Farm-yard dung, when applied in different states of freshness, illusrates the same position. M. Hassenfratz manured two pieces of the same kind of soil, the ine with a mixlure of dung and straw highly puirefied, the oiher with the same mixture newly made, and the straw almost fresh; he onserved, that during the first year the plants which grew - r the land manured with the putrefied dung protuced a much better crop than the other ful the second year, the ground which had heon manured with the unputrefied dung pro770 duced the best crop: the same result appeared the third year; after which both seemed to be equally exhausted. "Another experiment ct the same chemist," adds Dr. Thomson, "renders this truth still more evident. He allowed wood-shavings to remain in a moist place for about 10 months, till they began to putrefy, and then spread them over a piece of ground as a manure. The first 2 years this piece of ground produced nothing more than others which had not been manured at all ; the third year it was better; the fourth year it was still better; the fifth year it reached its maximum of fertility; after which it declined constantly till the ninth, when it was quite exhausted."

It is of the highest importance to the cultivator that he obtains a correct knowledge of the mode in which those manures operate which are found to be advantageous to the growth of his crops. He must discard from his mind all those false conclusions which are sometimes drawn with regard to an imaginary power as. signed to plants of generating vegetable substances, for they can effect no such miraculous results. It is true that they can combine the gases or elements of vegetable matters together, and form gluten, starch, gum, sugar, woody fibre, \&c.; they can absorb and arrange with these the earths and saline bodies; but the oxygen, the carbon, the nitrogen, and the hydrogen, of which the first-named are composed, and which plants usually obtain from either the atmosphere or by the decomposition of organic matter, they can no more create than they can form the lime or the silica, which are as commonly present in most vegetables as sugar, gum, or woody fibre. Davy proved this when he made a plant of the oat grow in pure carbonate of lime, and watered it with pure distilled water. It grew but languidly, and although it had a free supply of the atmospheric air, yet the access of all dust was carefully prevented. Upon analyzing the plant, it was found to have much increased in carbonate of lime, but its silica or flint was rather diminished, a grain of oat being found to yield more: this Davy attributed to the loss of its husk during vegetation. (Lectures, p. 312.) Whatever earthy or saline matters, therefore, are found in vegetables, must have been either derived from the natural soil or furnished by the manures added to it-whether it be carbonate of lime (chalk), or silica (earthy matter of flint), alumina (clay), sulphate of lime (gypsum), or phosphate of lime (earthy salt of bone). It should also be a received axiom with the farmer, that there is no part of any decomposing animal or vegetable manure but what is, either in its gaseous or solid state, the natural food of plants: thus the gases emitted by the putrefaction of a dunghill are so much lost to the vegetable matters of the soil, and such an injury is never submitted to by the intelligent cultivator, but from an unavoidable necessity. Hence the value of green manures; for in these cases every portion of the decaying and fermenting fertilizer is gradually absorbed by the roots and leaves of the succeeding crop.

When the cultivator is in doubt with regard to the possible advantages of any manure, whether earthy, saline, vegetable, or animal, 
he need only ask himself this question: Does this manure contain any constituents found in my crops, and is the land I cultivate deficient in any of them? An inattention to this consideration has been the cause of much disap. pointment and many mistaken conclusions: for instance, on many soils the application of gypsum to artificial grasses, and even to turnips, is very useful; on others it produces no effect. Strange opinions were in consequence long entertained with regard to this manure, until it was found that the soils on which it was valueless naturally contained it in abundance, and that those soils in which it did so much good were nearly or entirely deficient in this essential ingredient of clover, lucern, \&c.; for it was now evident, that to add gypsum to a soil which already contained it in sufficient quantities, was as needless as to add sand to a sandy, or clay to a clayey soil.

There is little doubt but that plants derive all their constituents from the soil or the air, in either the gaseous or liquid state; that in the light they absorb carbonic acid gas and emit oxygen is well known; by this means, therefore, they readily obtain the necessary supply of carbon. The hydrogen of vegetable substances is most probably furnished by the decomposition of either water or the carburetted hydrogen emitted during the putrefaction of animal and vegetable substances. This latter seems peculiarly grateful to plants in those situations where it is copiously emitted, as near to stagnant pools, over drains, \&c., where vegetation is always rank; and when present in the atmosphere, as in coal-mines, the green colour of plants growing in it is preserved even when they are deprived of light. The earthy or saline matters of vegetables, such as silica, carbonate, phosphate, and sulphate of lime, \&c., are all in minute proportions soluble in water; they are found more or less in all cultivated soils, and when they are deficient, their addition, as I have before observed, constitutes the great art of manuring : but there are such endless varieties of soils, that there is hardly a manure that will suit every description-each soil must be separately examined-practice is the only substitute for chemical investigations.

Thus, wood-ashes of the beech or bonepowder form excellent manures for soils deficient in the phosphates; lime, where chalk is altogether absent, and so on; and whilst we attend to the nature of the soil, we must also ever recollect, as one of the most important principles of agriculture, that whatever is completely removed from a soil by crops, must be in some way or other restored by artificial means.

That various earthy, animal, and vegetable substances, when applied to the roots of plants, accelerate their growth, has been known from a very early period; but in what manner these fertilizers serve as the food of vegetables has not been certainly determined. That they must all be in a fluid state, is supposed to be absolutely necessary: thus all the attempts of Sir Humphry Davy to make plants absorb the fine impalpable powder of charcoal obtained by washing gunpowder entirely failed.
The soluble matters consumed by plants are probably, in general, absorbed by their roots unaltered, although, in other cases, decomposed during their absorption. In the experiments of Davy, he caused the roots of some plants of mint to be analyzed, which had grown buth in pure water and in sugar and water. 120 grains of the roots of the mint which had grown in common water yielded $3 \frac{1}{2}$ grains of deep olive extract, of a sweetish and astringent taste; 120 grains of the roots which had grown in sugar and water afforded 5 grains of pale greenish, sweetish extract, not so astringent as the other. (Lectures, p. 270.) These experiments, therefore, are evidently in favour of the opinion that plants absorb many of the con. stituents of manures in an unaltered state, and the experiments of the late Mr. G. Sinclair with saline substances are still more decisive. See $\mathbf{S}_{\text {ALTS. }}$

The roots are the chief organs for absorbing the food of plants; and of the roots it is nearly established that the extremities, or spongioles, are the only parts which have the power of absorption; and hence one reason why they increase in length as the soil at their extremities is exhausted of nourishment. It is from this cause that liquid manure is so valuable a fertilizer; for in the dissolution of the excrements of animals in water, as practised so ad. vantageously in foreign countries, and long ably recommended by Mr. Knight, the late president of the Horticultural Society, for the adoption of the English farmers, the dung is merely rendered more easily soluble by the plant, and better diffused in the land. No new compound is formed by the mixture; the action of the dung, mixed with four or five times its weight of water, is apparently much less energetic; and yet this plan is decidedly advantageous, successfully produces the most luxuriant crops, is an old practice on the Continent, is gaining ground in England, and the more it is known the oftener it will be adopted. Yet hitherto in England much too little general attention has been paid to liquid manures; by many farmers the drainage of the farm-yard and the house is generally disregarded, and allowed to escape in the best way it can, into the nearest ditch or river, being supposed to contain nothing that is the food of plants; and this, too, by the very same persons who are particularly careful in the preservation, as food for their hogs, of every portion of a miserable. dish of cabbage-water. See Lreuid M. NURE.

There are certain properties in which all fertilizers, to a certain extent, agree :-thus they all contain one or more vegetable constituents, and they have all a strong attraction for atmospheric moisture (the insensible vapour always contained in the atmosphere). This property is of very considerable advan. tage to vegetation. The comparative powers, in this respect, of various manures may be judged of from the results of my experiments, which will be found in the following table. In these the animal matters were employed without any admixture of straw. (Essay on Salt, p 8-19.) 
1000 parts of horse-dung, dried in a temperature of $100^{\circ}$, absorbed by exposure for three hours to air saturated wils moisture of the tempera1000 parts of cow-dung, under the same circumgtances, absorbed

1000 parts of pig-dung

1000 narts of sheep-ding

1000 parts of pigenne' dung

1000 parts of a rich alluvial soil, worth 2 guineas per acre.

The following were dried at $212^{\circ}$.

1000 parts of fresh tanners' bark

1000 parts of putrefied tanners' bark -

1000 parts of refuse marine salt, sold as manure 1000 paris of sont

1000 parts of burnt clay

1000 parts of coal ashes

1000 parts of lime

1000 parts of sediment from salt parts

1000 parts of crushed rock-8alt -

1000 parts of gypsum

1000 parts of chalk

There is reason to conclude that some manures act as stimulants to plants, and excite them to a more vigorous growth: it is probable that the saline matters of farm-yard compost operate in this way, and that saltpetre and other saline fertilizers do the same. I have often had occasion to notice the increased luxuriance and productiveness of fruit trees, such as cherries and pears, by the application of common salt. (Essay on Salt, p. 4.) Priestley made similar observations. "It seems pretty plain," to give the words of Dr. Thomson, "that the vessels of plants are made to contract by various stimuli: the experiments of Coulomb and Saussure render this probable; and an observation of Dr. Smith Barton makes it next to certain. He found that plants growing in water vegetated with much greater vigour, provided a little camphor was thrown into the water. (Chemistry, vol. iv. p. 338.)

Of the organic manures, the richest abound in azote, or nitrogen; and, in fact, there are, as Dr. Liebig observes (Organic Chem. p. 70), "numerous facts showing that the formation in plants of substances containing nitrogen, such as gluten, takes place in proportion to the quantity of this element, which is conveyed to their roots in the stale of ammonia, derived from the putrefaction of animal matter. Ammonia, which is composed of 14.15 of nitrogen and 1 of hydrogen, is capable of undergoing such a multitude of transformations, when in contact with other bodies, that in this respect it is not inferior to water, which possesses the same property in an eminent degree." "The employment of animal manure," he adds ( $p$. $86)$, "in the cultivation of grain, and the vegetables which serve for fodder to cattle, is the most couvincing proof that the nitrogen of vegetables is derived from ammonia. The quantity of gluten in wheat, rye, and barley is very different: these kinds of grain also, even when ripe, contain this compound of nitrogen in very different proportions. Proust found French wheat to contain 12.5 per cent. of gluten: Vogel found that the Bavarian contained 24 per cent.: Davy obtained 19 per cent. from winter, and 24 per cent. from sum. mer wheat, from Sicilian wheat 21 , and from Barbary wheat 19 per cent. The meal of Alsace wheat, according to Boussingault, contains 17.8 per cent. of gluten; that of wheat growing in the Jardin des Plantes 26.7; and that of winter wheat 3.38 per cent. Such greal differences must be owing to some cause, and this we find in the different methods of cultivation. An increase of animal manure gives rise not only to an increase in the number of seeds, but also to a most remarkable difference in the proportion of the gluten which they contain." And he adds (p. 175), when speaking of the action of manures, "according to the common view, the action of solid animal excrements depends on the decaying organic matters, which replace the humus, and in the presence of certain compounds of nitrogen, which are supposed to be assimilated by plants, and employed in the production of gluten and other azotized substances. But this view requires further confirmation with respect to the solid excrements of animals; for they contain so small a portion of nitrogen, that they cannot possibly, by means of it, exercise any influence upon vegetation."

The following table of manures, constructed from the experiments of MM. Payen and Boussingault, showing the number of loads required in both the moist (or ordinary) and dried (or prepared) states to equal 100 loads of farmyard dung, so far as the quantity of the nitrogen they contain is concerned, will be interesting, I think, to the farmer. (Gard. Chron.)

Pea straw

Vetch straw

Wheat straw

Do.

Do., lower joints

Do., upper joints, with the heads after thrashing

Rye straw
Do., of 1841

Oat straw

Barley straw

Wheat chaff

Jerusalem artichoke straw

Broom

Green beet leaves

Potato leaves -

Heath leaves.

Sea wrack

Do.

Do.

Do., fresh from the sea

Malt dust

Buried clover roots

Flax cake

Rape cake

Fish cake

Grease cake

Beet-root prip

Do.

Potato pulp

Starch water

Do.

Starch refuse -

Do.

Dunghill drainings -

Sawdust of acacia

Do.

Do. firwood

Do.

Do. oak

Solid cow-dung

Cow urine

Mixed cow-dung

Solid horse-dung

Horse urine

Mixed hore-dung

Do. pig-dung

Do. sheep-dung

Do. goat-dung

Pigeon-dung

iquid Flemish manure

Do. 


Belloni's poudretle
Oyster shells -

It is a very common error to suppose that manures of a vegetable or animal nature im. part any sensible warmth to a soil ; the analogy sometimes attempted to be drawn between the action of a fermenting dung-heap and some 15 or 20 loads of fermented dung, or hall a ton of chopped woollen rags, spread thinly over an acre of ground, is too absurd to be admitted. Yet, although the dung does not sensibly increase the warmth of the land, the temperature of the earth, and the free access of the gases of the atmosphere have a very material influence upon the duration of the manure in the soil. Thus, in the heavy clay and deep alluvial soils it remains much longer than in the sandy, chalky, or gravelly. In the first its good effects may be traced for three or four years; in the last it is usually consumed in one, two, or at the utınost three years. To the last description of land, therefore, the judicious cultivator usually applies his compost in a half-putrefied state, in order that it may remain longer in the soil: this is now the practice of some of the most enlightened agriculturists.

Too little attention is paid, in general, to the mixture of manures by the farmer. This remark not only applies to those of the farmyard,-little care being usually taken to spread evenly those of the horse, the cow, and the pig, although it is notorious to the best cultivators, what was stated by the late Mr. Blakie, in his Essay on the Management of Farm-yard Manure, that this chief of fertilizers is very considerably improve $d$ by an even mixture,--but the remark applies to almost all other manures. Thus, old heaps of weeds, pond-mud, scourings of ditches, and all the earths in which there is any organic matter, are best applied to the soil after being mingled with lime or common salt. Peat, sawdust, wond-chips, and tanners' bark, nearly inert substances in themselves, become excellent manure when mixed with stable-dung. Sprats, and all other fish, are successfully and economically added to three or four times their bulk of mould; and even bone-dust is successfully applied with a third of its weight of the dung of the sheep, and may be then drilled as advantageously with the turnip-seed as the bones in their simple state. Then, again, mixing together some kinds of manures produces, by heir c'emical action, a third or fourth, which is more valuable than either. Thus, when salt and lime are united together, in the proportion of one part of the former to two parts of the latter, a chemical action takes place; the mas 3 swells, and the salt is gradually decom: posed; and in the course of three months, if the heap is suffered to remain undisturbed, boih the sali and the lime nearly disappear, and two new substances are formed by the combinations into which their constiluents have entered, viz. soda and chloride of lime; both excellent ma. nures. In other cases, the mere mixture of two well-known fertilizers, without any chemical action between the two, produces much greater effects than that of both when used separately. Thus, a compound of salt and soot possesses the most extraordinary fertilizing effects. The late Mr. G. Sinclair, in his Prize Essay on Salt, describes it "as remarkable," when applied to carrots; a fact which I have often witnessed myself. (My Essay on Salt for Agriculture, p. 145.) The Rev. Edmund Cartwright was the first to notice the same result with potatoes (Com. to Board of $A g r$. rol. iv. p. 376); and the same benefit is evident when the mixture is used as a top-dressing for wheat; in which observation my experience is confirmed by that of others. (My Essay on Salt, p. 41.) There are a few instances, however, in which substances used as manures are best employed in their simple state. Thus, seaweed, which many of the farmers on the seacoast throw on their dung-heaps, is much better employed by itself, turned in to the earth in the freshest and greenest condition: and to all green manures, and to those which contain salts of ammonia, such as urine, or the liquor from gas-works, the same remarks are applicable. See Mixtune of Soils.

The proportion in which fertilizers are applied is generally unnecessarily large, even of organic manures; and although this bad practice has been regularly diminishing as agricul. ture has become better understood, yet much remains to be done, in prgventing that wasteful expenditure of dung which is continually taking place.

It is more than probable, that the use of the improved manure-drills, by the even distribution of the fertilizer, and bringing it more closely into contact with the crop, will effect much towards this very desirable saving; for it must be evident to the most careless, that in the manner in which compost is commonly spread over a field,-suffered to be dissipate? by long exposure in heaps to the sun and wind. and afterwards spread over spaces in which there are not any plants to absorb, during its fermentation, the disengaging gases, a very considerable portion of it is lost to the farmer's crops. See Mavures applicable bi the Daicl.

It is almost needless to remark upon the importance of such investigations as thesp both to the cultivator and to the land-owner, or of the caution necessary in drawing conclusions from experiments in which vegetation is concerned. "Life," said Davy, "gives a peculiar character to all its productions: the power of attraction: and repulsion, combination and decomposicion are subservient to $i t ; a$ few elements, hr tho 
diversity of their arrangements, are made to form the most different substances, and similar substances are produced from compounds which, when superficially examined, appear entirely different." And, as he well remarks in another place, when speaking of the subject of this article-"The doctrine of the proper application of manures offers an illustration of an important part of the economy of nature, and of the happy order in which it is arranged. The fermentation and putrefaction of organized substances, in the free atmosphere, are noxious processes; beneath the surface of the ground they are salutary operations. In this case the food of plants is prepared where it can be used, and that which would offend the senses and injure the health, if exposed, is converted by gradual processes into forms of beauty and of usefulness." (Agr. Chem. pp. 54-309.) All researches like these carry with them their own reward; for not only does a successful experiment do so, but even an unsuccessful one is not unattended with advantages: it at least serves as a beacon to other cultivators, and is sure to afford to the farmer that pleasure and increased power which ever accompanies the acquisition of knowledge. (Johnson on the Fertilizers, p. 32.) See Gases, Eanths, Salts, Water, Fahy-Yard Mandre, Bones, Chalk, Iime, Liquin Manure, \&c.

Weight of a Cubic Yard of various Manures.

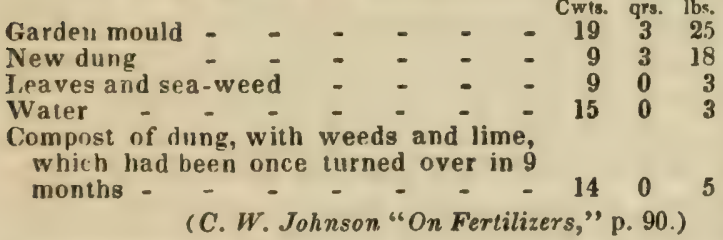

MANCREs, on rendering them more portable and applicable by the Drill.-The application of $\mathrm{ma}$ nures in a more concentrated form than that in which they naturally present themselves for the cultivator's service, was an effort reserved for modern agriculturists; an improvement chiefly induced by the increase of population, which almost compelled the farmer to force into cultivation the poor inland soils of England and the Continent: lands which could only be enriched by fertilizers brought from other districts, and from places where men congregated together in large masses. This necessity was, some years since, first felt and acted upon by many of the large continental cities, such as Paris, Berlin, Frankfort, and some of the other chief German towns. The contents of the cesspools were, in consequence, collected; their fertilizing matters were mixed with drying, disirfecting substances, and when thus reduced to powder, or into cakes, sold at a considerable profit. The enlightened constituted authorities of these places felt that they were, by so doing, conferring great and important benefits not only on their fellowcitizens, but upon the dislant cultivator. They rid not confine their attention to the farmers in their own direct vicinity; because they well knew that those, in common with the immediate agricultural neighbours of all large cities, have a ready acress to an abundance of organic alanures, since the cultivators so favourably situated carry their produce with facility into such populous places, and return with their carriages loaded with manure. And yet, when the German and French authorities thus husbanded,-thus rendered more portable, the manure of their large towns, they made no discovery; they merely practised what the Chinese had preceded them in from time immemorial, and what, in Flanders, is an old and long-cherished custom. The only improvement which the citizens of Paris and Frankfort have made is, that they form with their nightsoil an enriching powder; while those of China and of Belgium still make theirs into cakes, with a portion of either clay or marl; so that the powder of Paris can be either applied with the drill or dibble, but the Chinese and Flem. ings are obliged to dissolve theirs in water, before it can be used as a liquid manure with advantage. In England, however, notwithstanding the example of our neighbours, little or nothing has yet been done to render the commonest manures, such, for instance, as night-soil, more portable. The nightmen and scavengers are still compelled to hurry away their collections only at stated hours and in the dead of the night; are fined for any neglect, and harassed in all possible ways, rather than that this, the most powerful of all the animal fertilizers, should be preserved for the use of the farmer in any way that might endanger the olfactory nerves of the citizens. But an endangerment upon sensitive noses is not essential ; the night-soil might be preserved without any offence to the most sensitive. But this manure has been hitherto little known or employed in this country; its powers have been misrepresented; all sorts of prejudices have been created against it. I propose here briefly to show, first, the composition and fertilizing powers of various manures; and, secondly, to examine the modes which have been recently adopted to render them inodorous and more easily portable, so as to bring them within the reach of even the farmer who has to contend with the poorest, the most upland soils of Britain, far away from its great towns. And, although I confine my attention in this essay chiefly to one fertilizer, yet there are other manures, now well known to, and extensively employed by the cultivator, whose powerful action, when judiciously used in very small proportions, well illustrates the truth of what J have so often ventured to urge upon the farmer's attention, viz., that a much smaller quan tity of manure, composed of any description of organic decomposing matters, is sufficient, when applied in a skilful manner, to produce more luxuriant effects than is commonly believed. The very great importance of applying fertilizers in immediate juxtaposition with the young plant, even in very small proportions, as by the drill; is only now beginning to be considered with even patient attention; and yet there are many circumstances with which the farmer is well acquainted, which ought to convince the most inattentive that such is the fact. The small quantity of oil-cake drilled with the seed; the few bushels of bones suc. cessfully applied in the same way per acre: the woollen rags of the Berkshire farmers (half 
a ton per acre only); the $2 \mathrm{cwt}$ of gypsum applied to sainfoin and clover; the $1 \mathrm{cwt}$. of saltpetre, or of nitrate of soda, used on the same extent of land, all indicate the truth of the case, that it is not absolutely necessary to apply fertilizers of any kind in such great masses as are commonly deemed essential by the cultivator. I was told not long since by an excellent farmer of Middlesex, Mr. George Sherbourn, that he had succeeded in producing the finest crops of turnips by merely mixing about 30 bushels of coal-ashes per acre with 3 gallons of train-oil, and drilling these oiled ashes with the seed. It is a folly, therefore, to contend that the careless way in which organic manures of all kinds are usually employed is the most economical, and susceptible of no improvement. Such complacent feelings have ever been the bane of agricultural improvement; for it is then certain to follow as a natural result, that the system which the cultivator deems perfect will, in his hands, remain as he found it. Having no hope for better things, better modes will by him never be discovered.

Some recent experiments on a very broad scale, in the forest of Darnaway in Scotland, have shown that the application of a quan tity of lime under each seedling tree, even so small an amount as 4 bushels per acre, has been productive of the most excellent effects, imparting to the plantation a degree of luxuriance hardly credible. The same advantage, therefore, which is derivable from the application of a very small quantity of organic manure, in immediate contact with the growing plant, is evidently also derivable from a much smaller quantity of earthy manures than the farmer commonly supposes.

There are several advantages derivable from placing the seed in direct contact with the manure, to which the farmer very rarely attends. For instance, the germinating seed in the immediate neighbourhood of the fertilizer is by this means well nourished at the very period of its growth when it most needs assistance to enable it to develope its fibres, and to extend its roots. The young plant, so situated, is not exhausted in its extension ; it avoids the usual fate of those crops which tenant poor soils, whose roots are obliged to penetrate some distance in search of the requisite degree of nourishment. On the contrary, the strength of the plant is thrown into the stem and the leaves, and the crop flourishes luxuriantly ; for the leaves and roots of the invigorated and healthy plant are enabled to absorb the gases and aqueous vapour of the atmosphere, by which the plant is nourished in the most complete manner. The very mechanical effect, too, of placing the decomposing organic manure in direct contact with the roots of vegetables, facilitating the free access to them of the atmospheric gases and vapour, would be alone a sufficient reason for the adoption of the manure drill system, even if we say nothing of the other certain advantages of the plan, such as, in the case of decomposing fertilizers, the presentation of the gases of putrefaction to the roots of the plant, at the moment of their extrication, and the economical and forcing effects of this rode of distributing the manur. The farmer, in fact, tells us that the plan is probably a good one, but then his explanation of the derived benefit is very erroneous. He informs us, that thus to push forward the growth of the young crop is very likely to be good husbandry, especially on light so.ls. since, by this means, where the ground is w'e! covered with the crop, "the moisture is kept in, and the sun is kcpt out." If the culcivator would but remember, that the quantity of moisture transpired by a given surface of a growing crop is considerably greater than that emitted by the most naked fallow, he would no longer be content with such an explanation as this.

Dr. Hales ascertained that a cabbage transmits into the atmosphere by insensible vapour, about half its weight of vapour daily; and that a sunflower, three feet in height, transpired, in the same period, nearly two pounds weight. Dr. Woodward found that a sprig of mint. weighing 27 grains, in 77 days emitted 2543 grains of water; a sprig of spearmint, weighing 27 grains, emitted, in the same time, 2558 grains; a sprig of common nightshade, weighing 49 grains, evolved 3708 grains; and a lathyrus, of 98 grains, emitted 2501.

If I were asked to produce any evidence of the extreme difficulty with which agricultural improvements, even of the most undoubted value, are introduced, I should at once instance the manure-drill, the progress of which has been slow-for it has shared the fate of very many other scientific efforts: it has been zealously opposed by the ignorant, neglected by the indolent, and ridiculed by the bigoted farmer, as an innovation upon the gond old system of the days of the patriarchs of agriculture, when the earth brought forth its fruits in abundance, and the very seeds were not sown by man. But even here this solitary argument of the adherent to old customs fails; for the Chinese (the most expert of farmers) and the cultivators of Japan and of Arabia have drilled and dibbled in their seed from time immemorial. The natives of the Carnatic do the same; and after they have othus deposited their seed, the Hindoos use a kind of subsoil-plough, which passes under, and loosens, to the depth of about eight inches, the soil under, about three drills' breadth at a time. And so prejudiced are the natives of those empires, too, in favour of the customs of their ancestors-so rarely do they introduce new modes of cultivation, that it has been very reasonably concluded that the drill system, so far from being entitled to the appellation of "the new husbandry," ought rather to be classed with those branches of the sciences which degenerated, or were lost in the dark ages.

Sir George Staunton, in his Account of Lord Macartney's Embassy to China, says (vol. ii. p. 375)- NNear Sanchoo, wheat was perceived growing for the first time in China. It was, though on a dry sandy soil, where no rain had fallen for the three preceding months, looking remarkably well. It was very neatly sown in drills, or dibbled, according to the method used of late in some parts of England. A gentleman of the embassy calculated that the saving. the seed alune in China by this drill husbandr. 


\section{MANURES.}

which would be lost by that of broadcast, would be sufficient to maintain all the European subjects of Great Britain."

In a communication to the Board of Agriculture; dated at Junacondah, December 31, 1795, Captain Halcolt says,- "The drill-plough, I find, is in general use here, and has been so time immemorial, in the culture of all grain (except horse grain), and also of tobacco, cotton, rice, and the castor-oil plant."

The first drill introduced into Europe seems to have been the invention of a German, who made it known to the Spanish court in 1647. (Harte's Essuys on Husbandry.) The Roman farmers endeavoured to attain the advantages of row-culture by ploughing in the seeds.

It is useless to search in the works of Jethro Tull for any recommendation of the drill as a means of applying manure; for all Tull's arguments and experiments are directed to proving that the application of manure of any kind is utterly needless. And yet he had the discernment, when thus suffering his enthusiasm to carry him much too far, to make the observation, that "almost the only use of all manure is the same as of tillage, viz., the pulveration it makes by fermentation, as tillage doth by attrition or contusion; and with these differences, that dung, which is the most common manure, is apt to increase weeds, as much as tillage (of which hoeing is chief) destroys them." (New Husbandry, p. 166, 1st edit. 1731.) The advantage, thus glanced at hy 'Tull, of the manure keeping the ground light and porous, is much greater than the cultivator commonly suspects, and this benefit is mainly owing to the free access which is thus secured of the watery vapour and gases of the atmosphere to the roots of the plants. Now, for the vapour of the atmosphere, all well-pulverized fertile earth has a strong attraction: the richer and the better divided the soil, the more copiously does it absorb vapour; but the power of the richest cultivated soils in this respect is very much inferior to that of even the most ordinary manure. In my own experiments, I have never found, in a given space, say three hours, that 1000 parts of the richest soil, previously dried, absorbed more than from 14 to 20 parts of moisture; but in the same time, under similar circumstances, 1000 parts of horse-dung absorbed 145 parts; cow-dung, 130 ; pig-dung, 120 ; sheep-dung, 81 ; pigeons' dung, 50. ( $M Y y$ Work "On Fertilizers," p. 41.) It is evident, therefore, that for the mere purpose of withstanding long-continued dry weather, those plants whose roots have immediate access to organic manures will be much better enabled to absorb the necessary supplies of atmospheric moisture than those merely vegetating in the unmanured soil,

The merit of the introduction of the drill to soneral notice in England, is, however, to be ascribed, in a great measure, to Jethro Tull. Yet Jethro Tull certainly thought himself the inventor; for he tells us so very clearly, in the preface to the first edition of his Horse-hoe Husbandry, published in 1731, and even whence he derived the hint for his drill; he says, "When I was young, my diversion was music; I harl also the curiosity to acquaint myself 776 thoroughly with the fabric of every part of $\mathrm{my}$ organ; but as little thinking that I should ever take from thence the first rudiments of a drill, as that I should ever have occasion for such a machine, or practise agriculture; for 'twas accident, not choice, that made me a farmer." But he was certainly not the originator of the idea of thus applying the seed; for, nearly a century before his time, John Worlidge ineffectually, in 1669 , laboured hard to draw the English farmers' attention not only to the drill, but to the manure-drill also. And little can be now added to what, 175 years since, honest John Worlidge urged in its favour, when he said, after describing the seed-drill,- " By the use of this instrument, also, you may cover your grain or pulse with any rich compost you shall prepare for that purpose, either with pigeons' dung, dry or granulated, or any other saline or lixivial substance, made dispersable, which may drop after the corn, and prove an excellent improvement; for we find, experimentally, that pigeons' dung, sow'n by the hand on wheat or barley, mightily advantageth it in the common way of husbandry: much more, then, might we expect this way, where the dung, or such like substance, is all in the same furrow with the corn; whereas, in the other vulgar way, a great part thereof comes not near it. It may either be done by having another hopper on the same frame behind that for the corn, wherein the compost may be put and made to drop successively after the corn; or it may be sown by another instrument to follow the former, which is the better way, and may both disperse the soil and cover the manure and seed."

Worlidge was well supported by Evelyn, who, in a communication to the Royal Society, dated in February, 1669, urged the advantages of a drill-plough, which, first invented in Ger. many, had thence been introduced at Madrid under the auspices of the Spanish monarch, and had been forwarded from Spain by the Earl of Sandwich, as the inverition of a Don Leucatilla. It is there described as " the Spanish sembrador, or new engine for ploughing, and equal sowing all sorts of grain, and harrowing at once." Leucatilla saw very clearly the errors of the broadcast system: he observed,-_" Even at this day (1669) all sorts of seeds are sown by handfuls, heedlessly and by chance, whence we see corn sowed in some places too thick, in others too thin."

It was between the years 1720 and 1740 that Jethro Tull laboured thus hard, and with a success little equal to his merits, to introduce the drill system: the honour, however, was re served for the present.Lord Leicester, in the early part of the present century, of inducing its general employment, for which the soils of the greatest portion of Norfolk are so very well adapted. It then naturally followed, that various manures were found easily applicable at the same time with the seed. Powdered oil. cake was one of the first substances that was used as a manure, and the discovery of the value of crushed bones as a fertilizer for tur nips, opened another wide field for the useful application of this invaluable machine. The manure-drill, in fact, thence received an im- 
netus which it will probably never lose, for with its use is now almost inseparably connected the cultivation of some of the most extensive districts of the poor light lands in the north of England; such as on the Wolds of Lincolnshire, and the sands of Nottinghamshire. See Bowrs.

The most recent improvement in the manuredrill is that of Mr. Grounsel of Louth, for which the English Agricultural Society awarded him, in 1839, their silver medal. It is an attempt, and an excellent one too, to imitate the dibbling system, so as not only to save seed, but the manure also. And although, in all researches of this nature, it is especially necessary to proceed with great care, and to regard single experiments with caution, yet what has been yet experienced of its powers is certainly of a nature to induce farther and more extended trials; since it is evident that this drill can apply, and evenly too, as small a quantity of crushed bones or ashes as six bushels per acre. In reply to some inquiries of mine, the inventor says,-"My drill will deposit from 6 to 100 bushels per acre of any kind of compost that may be prepared for drilling, from 10 inches to any greater distance apart in the rows, with turnips or grain, and either in a wet or dry condition; but I recommend, from experience, ashes to be applied in a wet state, especially in a dry turnip-seed season, for then the seeds vegetate much sooner. Another equally excellent drop, and common drill, is that made by Mr. Hornsby of Grantham." See Dricl.

Admitting the truth of these experiments, that one-half the quantity of organic manures usually spread on the land is sufficient, when applied by the drill, in immediate contact with the seed, what a field is thus opened for the manuring of much larger breadths of land than has hitherto been deemed possible. The complaints of the deficiency of manures, which are now so prevalent with farmers, need then no longer be heard. Their crops will be properly nourished, and the manure applied with them will be not only bestowed in the most scientific manner, but it will lead to other improvements; it will enable the farmer to mix his manures, according to the nature of his soil and his crop, with much more facility than at present: he will then study, not merely the economy to be regarded in its distribution, but also its quality, or chemical composition, and to what soils the manure is best adapted.

There is one class of fertilizers, however, whose application by the drill requires great caution; I allude to the saline manures, for they are often much too powerful in their operation to be safely applicable in their pure state or in large proportions. Commun salt has, in this way, carried great destruction by being drilled in with the seed, and I have wit. nessed equally disastrous effects from applying the lime of the gas-works (sulphuret of lime) in the same way. Yet when the seed-wheat is wetted with a nearly saturated solution of salt, and then rolled in lime, or the salt and lime are not used until they have been mixed together for three months, and then sown on the land broadcast,- - or when the gas-lime is previously mixed with four or five times its bulk of siftel mould or ashes, then I have seen the most excellent effects produced by its being drilled with the turnip-seed: the same remarks apply to the chloride of lime of the calico-bleachers. Other salts, whose action is less eneruetic, or which are applied in very small proportions, are perhaps best applied by the drill; for in. stance, saltpetre, which is rarely applied in larger proportion than $1 \frac{1}{4} \mathrm{cwt}$. per acre, may very likely be still further reduced in quantity. especially if mixed with other substances, such as three or four times its bulk of mould. Mr. Beadel of Witham, in Essex, a very excellent farmer, has found, that where saltpetre was applied to his turnips broadcast as a top-dressing, it did not succeed, but it did so very decidedly when it was drilled with the seed.

In those situations where night-soil, or sprats, or bones cannot be obtained at a sufficiently reasonable rate, very great effects may be produced by the careful collection of the excrements of domestic animals, and mixing them with merely a sufficient quantity of dry ashes, mould, saw-dust, or, what is best of all, recently prepared finely powdered charcoal, to render them sufficiently friable to pass the drill: this is very easily accomplished, by making the preparation under cover some months before it is used, and, if necessary, by causing it to be spread in the sun. By the adoption of these means, a very recent mixture will be found available by the farmer; the excrements of the horse, cow, and especially the sheep (still more so if fed with oil-cake), will be found excellent for this purpose. And in very small proportions the Peruvian farmers, according to Humboldt, employ the guano, or excrements of seafowi (which abound in phosphate of lime, or earthy salt of bones), which is brought in sailing vessels, from the rocky islands of the Pacific, expressly for the use of the cultivators of that republic. See Guavo.

And that bones might be very profitably mixed with other fertilizers, so as to materially reduce the expense of the manure, is indicated by more than one successful experiment. To give another instance, which has recently been communicated to me, in the trials made by Daniel Dixon, Esq. of West Clandon, in Surrey. "On a poor chalk soil," observed an excellent and scientific friend of mine, "he has used a compost for a manure-drill for turnips with great advantage. He puts 8 bushels of ground bones with 24 bushels of any ashes he can get together in a dry place, and from time to time (as often as possible) he empties the liquid sewerage of the house upon it. In two or three months it is fit for use, working well out of the drill. 'The above is the quantity for an acre. The effect of drilling this mixture with the seed was very remarliable, and as bone-manure was drilled by the side of it, the contrast was at once visible; the difference was more than double. In fact, the bones by themselves seemed comparatively use'ess. The soil on which the mixture has been ap plied is poor, chalky, and flinty, abutting upon the sheep-walks and Guildford race-course. Whenever the mixture is ton wet for the drill, it is spread to dry for a day or two." (Letter, 
of Heury Dixon, Esq. to the Author, November, 1839, and March, 1840.)

"A friend of ours, a farmer in Northumberiand," says the excellent editor of the Quarterly Journal of .Agricuiture, "the late Mr. George Brown, Hetten Steads, mixed any quantity of coal-ashes, kept dry, and finely riddled, with a quarter of bone-dust per acre, and raised as good a crop of turnips (of course drilled) of all hinds, on a clayey soil, resting on a retentive bottom (but drained), as he could with two quarters of bone-dust." Mr. Turner of Tring, in Hertfordshire, drilled with his crushed bones an equal quantity per acre of sheep dung, collected for the express purpose, at an expense of $2 \frac{1}{2} d$. per bushel paid to the collectors: this he prepared in the winter, by laying the bonedust in alternate layers with sheep-dung, and suffering them to remain fermenting some months until the turnip sowing. By this plan, by the fermentation of the mass, the two manures are thoroughly incorporated; and he considers that 35 bushels of the mixture are fully equal in effect to 25 bushels of the bones. So that, allowing $3 . s_{.} 6 d$. per acre for the expense of collecting the sheep-dung, there will be a clear saving of $12 \mathrm{~s} .6 \mathrm{~d}$. per acre in bones, valuing these at $2 s$. per bushel. The mixed bones and sheep-dung are invariably drilled in with the turnip-seed.

The application of rape-cake powder by the drill has never been so common as it ought to be, for it is not only a very powerful, but a very easily manageable fertilizer; it has, moreover, the advantage of being moderate in price, and easily attainable at all seasons of the year. There is no doubt of the advantage of feeding stock with this food, the manure they produce when thus fed being exceedingly rich. Many farmers, however, owing to the want of cattle, or an unwillingness to lay out the requisite money in a long course of stall-feeding, are deterred from using oil-cake to the extent they would otherwise do. 'The use of the oil-cake powder conveys to the land all the enriching ingredients of this fertilizer at once, and to the exact extent the farmer requires; there is neither the waste, the risk, or the trouble of stall-feeding to be dreaded. 'The oil remaining in the cake certainly constitutes its most enriching portion; the oil abounding in sprats is an instance familiar to the farmer, and when this oil is imperfectly crushed out, the cake produced (as is well known to the Swedish cultivator in the case of herring-cake) is found to be exceedingly enriching. A very small quantity of oil left by the crushers in the cake will produce very great results; even three gallons of train-oil, as I have mentioned in another place, has been found amply sufficient per acre, when mixed with earth or ashes, to produce a capital crop of turnips. It has been found (and this is another illustration of the value of the manure-drill), that when rapecake is drilled with the turnip-seed, $3 \frac{1}{2} \mathrm{cwt}$. per acre is sufficient, but if it is applied broadcast, then double the quantity is required. My friend Mr. Daris, of Spring Park, in Surrey, is well aware of the pawers of oil-cake as a manure; he has found it even an advantageous plan to driil common coal, wood, or turf-ashes, at the rate of 40 bushels per acre, with his turnip seed; and this he has successfully practised for some years, so much is he in favour of bringing the seed and the manure into imme. diate contact.

In proceeding to examine, as an instance of one of the least likely substances successfully applied by the drill, the properties of night-soil, and the modes which have been adopted to reduce its weight, without impairing its effect, many reflections will suggest themselves to the farmer. He will notice that such a process, by producing it in the state of powder, renders it capable of being readily drilled with the seed; and that the same remarks apply in a great measure to the excrements of the farmyard, to whale-blubber, and to fish. 'The Essex farmers find, that when sprats are mixed with earth, finely divided, the mass, when these very oily fish are quite dissolved in the mould, forms a very powerful fertilizer, which is excellent as a drill-manure for turnips. They tell you, that the sprats lose none of their enriching powers, even when thus kept mixed with earth for some months.

Even earthy manures may be advantageously reduced in weight by exposure to the air, or by the application of artificial heat. Chalk, I have found by experiment, loses from 15 to 25 per cent. of its weight by being thus deprived of its water; and a cubic foot of calcareous sand, when thoroughly wet, contains, according to M. Schubler, more than 31 lbs. of water; the same measure of sandy clay, 38 lhs.; loamy clay, 41 lbs.; stiff clay or brick-earth, 45 lbs.; pure gray clay, 48 lbs.; garden-mould, 48 lbs.; and fine slaty marl, 35 lbs. By exposing the earths to an intense hear, their weight is still further reduced by the loss of their carbonic acid gas or fixed air; hence 100 parts of chalk, for instance, when thus treated, lose very commonly 24 parts of water and 34 parts of carbonic acid; so that $42 \mathrm{lbs}$. of lime, when well burnt, contain as much real earth as 180 parts of chalk. All these facts are such as the cultivator should be thoroughly acquainted with; for, in many cases, the earth which the farmer removes might be previously very advantageously dried, by exposure in spits to the action of the atmosphere. Even the difference of labour to the men and horses, between carting them after continued dry weather and in wet periods, is much more material than the cultivator commonly believes.

My attention, however, will, in this place, be principally confined to fertilizers of ar organic nature, and more especially to night-soil Night-soil has not, in any form, been employed by the farmers of England to the same extent as on the Continent, although it is certainly by far the most powerful of the organic manures, and the most easily rendered applicable by the drill of any of the class. To this neglect many causes have contributed. Its disagreeable odour, certain vexatious fiscal regulations with regard to its removal, to which I have before alluded, and the erroneous modes of applying it, either in excessive quantities, or mixed with other composts in such proportions that its powers could not be distinguished in the mass; its semifluid nature requiring for its removal 
carriages of a peculiar construction; the extent and completeness of the sewerage of our large cities, and several other minor obstacles, have rendered its use not nearly so extensive as, even in a national point of view, is desirable. (See Nigur-soir.) And yet the necessity for increasing the supplies of manures, in order to promote the fertility of the soil, will be self-evident to every one who remembers, not only the increasing population of the country, but the immense drains upon its organic fertilizing matters which are hourly pouring their contents into the sea. Thus, as I have elsewhere remarked, by carefully-conducted experiment it has been clearly ascertained that the principal London drains convey daily into the Thames 115,000 tons of mixed manure, consisting, on an average composition, of one part solid or mechanically suspended matter, and 25 parts absolutely fluid; but if we allow only 1 part in 30 of this immense mass to be composed of solid substances, than we have the large quantity of more than 3800 tons of solid manure daily wasted in the river from London alone. What might not the farmers of England effect if this mass of fertilizing matter was preserved, at a reasonable rate, for their use? 15 tons of this solid manure-nay, 10 tons, would render fertile an acre of the poorest cultivated, or even common or heath land. But allow, for the sake of argument, that 20 tons were required, even then 3800 would give a daily allowance of manure sufficient for 180 acres of the poorest land in England; and if we give 300 days on which this manure was collected, that would afford an annual supply for fifty-four thousand of such acres, which land would not again need manuring for 4 years; and in this calculation nothing is allowed for the fluid portion of the drainage. It is the reckless waste of the drainage of our large cities and towns, which has alone prevented the cultivated lands of England from becoming increasingly fertile, because yearly more abounding in organic decomposing matters. For such is the enormous yearly import of foreign products into this country, that it must tend to rapidly increase the natural fertility of the soil of England, since all their ingredients ought and do, in some measure, eventually find their way as a manure upon the land; thus, in 1834, were imported into the United Kingdom, according to a parliamentary report, now before me, of -

\begin{tabular}{|c|c|c|c|c|c|c|c|}
\hline Barilla & - & - & - & - & $\begin{array}{c}\text { Cwrts. } \\
215,750\end{array}$ & $\frac{q r 3}{1}$ & $\begin{array}{l}\text { lhs. } \\
22\end{array}$ \\
\hline Bark for & $\tan n$ & ers & - & & 854.869 & 3 & 16 \\
\hline Butler & - & - & - & - & 136,674 & 0 & 23 \\
\hline Cheese & - & - & - & & 134,085 & 3 & 5 \\
\hline Coffee, al & bout & - & - & & 250,000 & 0 & 0 \\
\hline Currants & - & - & - & & 141,540 & 3 & 1 \\
\hline Figs & - & - & - & & 15,416 & 3 & 14 \\
\hline Raisins & - & - & - & & 158,290 & 2 & 1 \\
\hline Molasses & - & - & - & 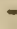 & 717,666 & 2 & 4 \\
\hline Rice & - & - & - & & 218,867 & 1 & 20 \\
\hline Seeds, cl & over & - & - & & 53,263 & 1 & 30 \\
\hline Sugar & - & - & - & $=$ & $4,732,749$ & 3 & 22 \\
\hline Tea, abn & & - & $=$ & 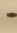 & 250,000 & 0 & 0 \\
\hline ool anc & $d \mathrm{co}$ & on & bout & 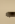 & $3,000,000$ & 0 & 0 \\
\hline
\end{tabular}

So that, including corn, oil-cake, timber, \&c., \&c., at least $1,000,000$ tons of vegetable matters alone are yearly imported from foreign countries into the United Kingdom, and added to the riches of the soil: thus our merchants are annually fertilizing, while the Commissioners of Sewers are in an equal ratio impoverishing the island. But against this great fertilizing import, we have at present to set off the large and ever-flowing drainage of the cities ard towns of the United Kingdom; not only Ionndon, but Liverpool, Manchester, and a hubdred others, are incessantly pouring the riches of the land into the sea; and to such an extent is this done at Bristol, that the Court of King's Bench was obliged, not long since, to interfere to protect the inhabitants from the nuisance created by the non-removal of the city drain. age from the bed of the Avon.

On the Continent, the use of various manure powders made from night-soil is equally extensive and successful. An elaborate report upon these was made a short time since to the Directors of the 'Thames Improvement Company, by Dr. Granville, who had been commissioned to make the requisite inquiries and surveys; and from this we learn that the con. sumption of night-soil in Flanders is very large; but that the farmers, instead of employ. ing it in the dry or powdered state, rather pre. fer to mix it with water, and thus form a rich liquid manure. Of late years, the French farmers have adopted the same views with regard to night-soil; but the practice of their farmers, in this respect, is somewhat different. They prefer, for the sake of easy and conve. nient transport, to dry the stercoral substances to powder, which, bearing the name of poudrette, is sent into the country from the neighbour hood of the capital, and is sold at a high price The success of the establishment for the manu facture of poudrette, first formed near Paris about 40 years since, by a person named Bri. det, has heen such that in almost every part of the kingdom similar manufactories have been erected, and nothing now is wasted. The Pari sians haye at present several such large works. M. Bridet obtained a patent for his process of manufacturing the poudre vegetatif. He proved, by experiments, that the poudrette is many times more valuable than the best sort of ordi. nary manure. It was found, after repeated trials, that $240 \mathrm{lbs}$ of the poudrette would ma. nure an acre of ground with greater effect than 8 cart-loads of the best stable manure.

Under the name of "Alkalino-vegetative Powder," another preparation of night-soil was ushered into notice in France, and generally adopted, under the auspices of an agricultural lady, Madame Vivert Duboul, to whom, in con. sequence, the Royal Society of Agriculture, in 1814, awarded their gold medal. This lady obtained a patent of 15 years for her process, which consisted in promoting fermentation in the most liquid portion of the excrementitious substances, and treating them with slaked lime afterwards, so as to form a powder, which has been found to be very superior to the first named poudrette upon cold, light, or moist soils. Its action is very powerful, and it extends its influence over the soil for several years without requiring, during that period, a repetition of the manuring process. This is not the case with the poudrette of Bridet, the influence of which over any soil is only annual. "M. Hermstadt gave, in the Monthly Journal of the Economic Society of Potsdcm, for August, i830 
as the result of his experiments instituted with the view of ascertaining the comparative fertilizing powers of farm-yard manure and poudrette, that poudrette is a complete substitute for common dung, whether with respect to price or quality."

In 1818 a company was formed near Paris (Messrs. Donat \& Co.), for the manufacture of another kind of manure from night-soil. The name of "urate" (from the principal ingredient used) was given to it; and the Royal Society of Agriculture deemed it an object of sufficient importance to deserve being submitted to the examination of a joint committee of chemists and agriculturists, in which were included the names of Vanquelin, Dubois, \&c. The report made by these distinguished men is full of interest to the agriculturist. Urine is the active ingredient, and plaster of Paris (gypsum), so common in the neighbourhood of that capital, the other constituent. This mixture is reported by the joint committee to be so powerful in its effects upon the dullest soil, that they recommend that it should only be employed by skilful and discriminating farmers. For this discovery the inventor received a gold medal from the government. A powerful manure of the same name is now extensively prepared by the "London Manure Company," of $40 \mathrm{New}$ Bridge street. It abounds with the salts of ammonia, phosphate of lime, and the animal matters of urine. It appears, also, from the fine, dry state of powder in which the "urate" is delivered, that it is admirably alapted for application by the drill with the seed. The quantity applied per acre is about $5 \mathrm{cwt}$; and, as it is almost entirely composed of organic matters, phosphate of lime (earthy salt of bones), sulphate of lime (gypsum), and various salts of ammonia, it is evidently a most powerful fertilizer, as well adapted for turnips as for the grass and grain crops. I have had an opportunity of inspecting the manufactory of this company, and from the care displayed in its preparation, the "urate" will, I think, be rapidly and extensively employed by the farmer.

In some recent reports of trials with this manure upon turnips, I observe that Mr. Anderson, of Oakley, Bedfordshire, describes it as proving "itself quite equal, if not superior, to the farm-yard manure. The land I used it on was a sharp gravel, and was much out of condition previous to the present crop. The 6 tons were drilled with Swedish turnip-seed, 18 inches apart, on 18 acres."

Mr. Manning, of Elstow, says, "I drilled a ton of urate upon 3 acres, in rows 17 inches apart, upon a very hot, gravelly soil; each side abutting on this was manured in the usual way, with good farm-yard manure, about 14 loads per acre. The turnips on the urate were itt to hoe 7 days before the manured part; from their first appearance, a stranger could point oui he spot where it commenced and euded; the difference is still evident, and in its favour. Both the manured and urate pieces were sown the same day, about the 14 th of June. I certainly consider it a good artificial dressing, and its fertilizing properties great."

In 1820, anuther patent was granted to a $\mathbf{M}$. 780
Loques, by the French government, for a ma nure called "stercorat," consisting of a mix. ture of both the solid and liquid parts of the excrementitious matters, and some earthy substance. It is said to be particularly efficacious, and sells at a very high price.

M. Parmentier, a celebrated French agricul. tural writer, some years since expressed his surprise at the tardiness of his countrymen in adopting the practice of their Flemish neighbours, and in continuing so long to pay money for getting rid of that which other nations first, and the French themselves afterwards, found to be so productive of wealth. He quotes the case of an individual who in former times had amassed great wealth by the sale of a manuring powder, which he manufactured from the very soil he was annually paid by government to remove out of the extensive military barracks of Lisle.

There existed at one time much public prejudice against this mode of rendering the land more productive, on the wild supposition that the obnoxious principles of such a manure would form part of the plants raised by means of it; but the most accurate experiments have proved, that not the least vestige of such animal substances is to be detected either in the ascending sap, or in the more solid parts of the plants so cultivated. A great extent of the rich plains of Normandy are fertilized every year by the manure powder manufactured at present out of the cess-pools of Paris.

The poudrette sells for eight francs the sestier on the premises, and the whole is fetched away at that price as soon as ready, and principally distributed within 12 leagues of Paris. Now, as there are $7 \frac{1}{2}$ sestiers in a ton, it is evident that the value of the latter is 60 francs, or $2 l$. $10 s . ;$ and vet the comparative agricultural value of this compost is not so great as that of the "Flemish manure." Messrs. Payen and Com pany, the patentees of the "engrais animalizé," or disinfected night-soil, sell their "poudrette" at $2 \frac{1}{2}$ francs per ton under the market price of that of Montfaucon, and they have rarely any left on the premises.

The engrais animalizé, or disinfected nightsoil, has recently been introduced into England by M. Poittevin, and a manufactory of it established in Whitechapel, near London. It is there produced by mixing the night-soil of the metropolis with a considerable quantity of recently prepared charcoal powder, and drying the mass in a very gentle heat. As thus prepared, its appearance somewhat resembles that of the friable, rich, vegetable mould of an old hot-bed; it is of very dark colour, and totally devoid of smell. Its introduction into England has been too recent for any very extensive trials to have been yet made with it; my own are only now carrying on; these, however, promise well. In some comparative experiments made last year with bones, they were found to answer very completely. These results have been confirmed by several communications with which I have been recently favoured, stating that, to use the words of Col Challoner, "this manure, in its effects upon the turnip crop, was fully equal to bones." 
stoke, who had applied it by the drill with the seed, at the rate of 14 bushels per acre to a portion of a field of turnips; and, on another portion, drilled three sacks per acre of crushed bones, mixed with turf-ashes; and, on a third portion, with ordinary stable manure, says, in February last, "It is impossible to distinguish any difference between the three, some persons fancying one part, and some another, to be superior. In their early growth, the night-soil had a decided advantage. The seed came up as thick as rows of mustard-seed in a hot-bed, and the turnips were hoed out within a month." Mr. Beach adds a suggestion, which I thiuk highly worthy of the attention of the turnip cultivators:- "I am so well satisfied with it for curnips, that I shall use a large quantity of the night-soil powder this season. I shall also mix 10 or 12 bushels with a quarter of crushed bones, which I am inclined to think will answer well." I have recently been shown a letter from Mr. Robert M.Crea, of Grange House, near Londonderry, in which he speaks of this manure in the highest terms, as a dressing for turnips; those thus treated having carried off last year the first prize offered by the Londonderry Farming Society.

A preparation of night-soil has been lately imported into Scotland and the north of England from Copenhagen, under the name of Owen's animalized carbon, which has answered, when applied by the manure drill, very well for turnips. Mr. James Waldie, in his recent prize communication to the Ayrshire Agricultural Society, describes it as a useful, auxiliary manure, and as likely, in a great measure, to supersede the use of bones, now that the latter have risen to the enormous rate of at least $3 s$. per bushel. He says, "One ton" of carbon, the cost of which is $3 l$, is sufficient for an acre of land; and from experiments which I have made this year, conjoined with what I have observed of two successive crops on a farm in this neighbourhood, where comparative trials were made with different mamures, on a very extensive scale, it may be inferred, that one ton of carbon is equal to 25 bushels of crushed bones." These experiments are supported by the observations of $\mathrm{Mr}$. M. Milburn, of Thorpefield, near Thirsk, when describing, in his report to the Yorkshire Agricultural Society, the various fertilizers advantageously employed on light lands in the cultivation of turnips; for, he observes, "Animalized carbon has been used advantageously; 16 bushels per acre, when drilled, is the quantity generally employed. Pigeons' dung is most valuable; rape-dust has been used successfully; malt-dust is useful as a top-dressing." 'There is a chemical "seed manure" prepared by Messrs. Hodgson and Simpson, near Wakefield, which is applied, mixed with water, as a liquid manure, or steep to the seed-corn, and seems, from a communication with which they favoured me in March, 1840, to be a kind of secrel preparation, composed principally of saccharine matter, ammonia, common salt, and nitre. This seed manure is applied according to the following directions, -instructions which might be advantageously followed in the use of other fertilizers: "Dissolve 28 lbs. of this manure in a pail, by adding water in small quantities, stirring it at the same time, unts! the mixture is of the consistence of thicts cream; it is then to be poured over the quantity of seed intended to be sown on an acre of land, and the whole repeatedly turned over, so that it appears one uniform mixture; it is then to be spread out thin on the floor to dry for 10 or 12 hours, and mixed with a sufficient quantity of soot, or any kind of dry ashes, to render it sufficiently friable to be sown by the hand or by the drill." The quantity thus directed to be applied per acre, is certainly very small, and yet, according to the testimonials which I have seen, the effect it produces is considerable. Mr. Milburn, of Thorpefield, in one of these, tells us: "A new principle in the application of manure has been developed in the use of the chemical seed manure, which, by applying a chemical composition to the seed itself, not only secures immediate effect in the precise situation required, but highly economizes the quantity necessary. I have great pleasure in detailing a very successful experiment with it on a barley crop. The field had grown a corn crop the preceding year-part of the field was dressed with a coating of fermented farm-yard dung-the remaining part with the chemical seed manure, at the rate of 28 lbs. per acre. The result was, that the barley sown with the chemical manure exhibited a decided superiority over the rest of the field, in colour, healthiness, and general appearance, and maintained that superiority to the time of cutting, so much so, that it lodged considerably more than the rest of the field.'

Various modes besides those to which I have alluded, have, at different times, been suggested, by which night-soil might be rendered more concentrated and more portable. Simply drying it has been attempted with some success; but though by this means about 70 per cent. of water is driven off, yet, at the same time, a considerable portion of ammoniacal and other gaseous matters are vaporized: thus the manure is impoverished, while the stench of the operation is intolerable. Then, again, it has been mixed with lime, in the way recommended by Davy; but judging by my own experiments, and those of my neighbours, I am fully persuaded that this is not the most economical way of using night-soil. The lime certainly dissolves, and partially decomposes it, but the fertilizing effect of a given weight of night-soil mixed with lime is clearly not so great as when a similar weight of it is used either by itself, or mixed with some merely drying odour-absorbing substance. There are several preparation of this kind made in large quantities in London, such as those of Mr. Clarke, and of Mr. Lance, the author of the Golden Farmer, all of which, I believe, are excellent manures; but I have not had an opportunity of examining any of their manufactures except those of the London Manure Company, and of the Messrs. Poittevin. The preparation of these gentle. men is the same as that so successfully carried into effect by $\mathbf{M}$. Payen at Paris : it combines, and successfully too, the great object of driving off the water of urine and night-soil by a gentle heat, after all its gaseous matters have been 
absorbed, by mixing with it a portion of newly prepared carbon, in the finest possible state of division, than which no known substance has such great powers of absorption of all gaseous matters like those which abound in and impart the disagreeable odour to night-soil. 'These purifying powers of charcoal have been long snown: the medical man applies it in putrescent cases, the housewife rubs it powdered over her tainted meat, and the sailor chars the inside of his water-casks for a similar purpose. The presence of the carbon in the manure thus prepared is valuable in two ways; gradually it combines with the oxygen of the atmosphere, forming in the state of carbonic acid gas the food of plants; and, at the same time, all the gaseous matters of putrefaction with which it is saturated are thus preserved, stored up, as it were, for the service of the roots of the cultivator's crops; nothing is lost, the emission of the gases from the slowly dissolving charcoal being so gradual as to be almost, if not entirely, imperceptible to the senses.

Such, then, are the principal facts already ascertained with regard to the fertilizing uses of night-soil and other decomposing manures, in their ordinary form, and when reduced by various processes to such a state of dryness, so as to be easily applied in the state of powder to the soil by the drill. In thus investigating the advantages of rendering manures more concentrated, I have been induced chiefly to confine my attention to one only of the organic manures, night-soil, because, from its nature, cheapness, and powerful effects, it affords, perhaps, greater facilities for accomplishing this important object than any other excrement, and is, besides, more commonly wasted than any other fertilizer. I hardly deem it necessary to make any remarks upon the importance of all researches which tend to the better understanding of the powers and best mode of employing manures, for with such investigations is inseparably connected the gradual and steady increase of the productiveness of our country. Such improvements, too, are full of interest, not only to the cultivator, but to every one to whom the vegetable kingdom is an object of importance. And, as I have elsewhere had occasion to remark, it is hardly possible, in reflecting upon the essential use of organic fertilizers in the production of our food, to avoid being impressed with the wisdom and beneficence of the Creator, in thus making decomposing noxious organic substances the nutriment of vegetation, rendering the very animal substances which the grass once formed, its food when dead. This interchange of their elements, so essential to each, is equally incessant and remarkable, the death and decomposition of the one ever imparting fresh food and life to the rither. Thus the same gases which are at one moment constituting the noxious products of putrefaction, are in the next existing in the exquisite aroma of the flower. These facts are, indeed, too apparent to escape our observation; and the marvellous rapidity and advantage to as of these magic vegetable combinations cannot but excite both our curiosity and our gratisude. (Quart. Journ. of Agr. vol. x. p. 142.)

Manures, Histry of. See the heads Ashes, 782
Farm-yard Manore, Bones, Chalk, Lime, Green $S_{\text {AND, }}$ \&c. The application of manures became one of the sustaining arts of life as soon as man was ordained to earn his bread by the sweat of his brow. From that time to the present, the art of manuring the soil has been steadily improving; and there is no doubt but that it will go on advancing, as long as mankind continue to increase.

The first manure used by man, as soon as he began to dwell in fixed habitations and till the land around him, would, of course, be that of his domesticated animals; but he is naturally averse to labour, and consequently this operation would be postponed until the rich alluvial soils, which would be certainly the first selected, were exhausted by over-cropping, and by the increase of population the poorer descriptions forced into cultivation; the occupier of the land would naturally avoid, if possible, the trouble of spreading the dung of his farm-yards over his fields. Instances of this kind have not been wanting in recent periods in the newly settled rich prairies of America, in which many cases have occurred where, in consequence of the enormous accumulation of dung around the farmer's sheds, he has been induced to remove his buildings to a new spot, rather than undertake the greater labour of removing the masses of fermenting manure which so deeply encumbered his old farm-yard. The first rude mode in which this was conveyed to the land, was naturally by hand-baskets, or by sledges or barrows; the use of beasts of burden was necessarily a later agricultural im. provement; and, at first, there is no doubt but that manure was carried on their backs to the fields, as is even now practised in the mountainous districts of the Continent, and in some parts of the north of England, and in Devonshire. Dung-carts were a much later improvement; and the preparation of compost heaps, and exciting and regulating their fermentation by the use of the fork, has been a much more modern discovery than is usually believed.

Irrigation, which is a mode of applying the weakest of liquid manure, by the use of the waters of rivers, is of a very ancient date. It has been used from a very early period in Italy and the East; in fact, in many warm, sandy countries, as in China, a copious supply of water is an essential requisite for the success. ful cultivation of the earth. Water-meadows were first constructed in England, on a tolerably regular system, about the termination of the 17th century. Some of the most excellent of those in Wiltshire, such as those in the Wyley Bourne, were made between the rears 1700 and 1705 ; and about half a century afterwards, the celehrated Craigintinny meadows were formed near Edinburgh, by which the town drainage is rendered available in the produc. tion of the most luxuriant crops of grass. These meadows were considerably enlarged towards the end of the 18th century, and again in 1821. These might be very advantageously imitated in the neighbourhood of other large towns.

Amongst the Egyptians and Israelites, whose climates were hot, a plentiful supply of mois ture was necessary for a healthful vegetation; 
and the simile of desolation, employed by Isaiah (chap. i. 30), is, "a garilen that hath no water." In Egypt they irrigated their lands, and the water thus supplied was by an hydraulic machine, worked by men, in the same manner as the modern tread-wheel. To this practice Moses alludes, when he reminds the Israelites of their sowing their seed in Egypt, and watering it with their feet; a practice still pursued in Arabia. (Deut. xi. 10; Niebuhr's Voyage en Arabis, i. p. 121.)

Of their knowledge of manures we know little. Wood was so scarce that they consumed the dung of their animals for fuel. (Parkhurst, p. 764.) Perhaps it was this deficiency of carbonaceous matters for their lands, that makes an attention to fallowing so strictly enjoined. (Levit. xix. 23 ; xxv. 3 . Hosea x. 12.)

Agriculture was too important and beneficial an art not to demand, and the Greeks and Romans were nations too polished and discerning not to afford to it, a very plentiful series of presiding deities. They attributed to Ceres, as the Egyptians did to Isis, the invention of the art of tilling the soil. Superstition is a prolific weakness; and consequently, by degrees, every operation of agriculture, and every period of the growth of crops, obtained its presiding iutelary deity. The goddess Terra was the guardian of the soil; Sterculius presided over manures, \&c.

Xenophon recommends green crops to be ploughed in, and leguminous plants to be raised for the purpose; "for such," he says, "enrich the soil as much as dung." He also recommends earth that has been long under water to be put upon land to enrich it. Theophrasius, who flourished in the 4th century B. c., is st:.. more particular upon the subject of manures. He states his conviction that a proper mixture of soils, as clay with sand, and the contrary, would produce crops as luxuriant as could be effected by the agency of manures. He describes the properties that render dungs beneficial to vegetation, and dwells upon composts. (Hist. Plant. ii. c. 8.) He also recommends the stubble at reaping-time to be left long, if the straw is abundant; "and this, if burned, will enrich the soil very much, or it may be cut and mixed with dung."

From the outline which we can draw from ancient authorities of the agriculture of the Romans, we shall be surprised to find how little they differed from the methods we now employ. We are superior to them in our implements, and consequently in the facility of performing the operations of tillage; but of the fundamental practices of the art they were as fully aware as ourselves. No modern writer could lay down more correct and comprehensive axioms than Cato did, in the following words; and whoever strictly obeys them will never be ranked among the ignorant of the art. "What is good tillage?" says this oldest of the Roman teachers of agriculture. "To plough. What is the second? To plough. The third is to manure." (Cato, 61.) In his 4 th chapter he thus expresses his conviction of the utility nf manure: "Study to have a large dunghill, keep your compost carefully; when you carry it out, scatter it and pulverize it ; carry it out in the autumn. Iay dung round the rocis of yor.t olives in autumn." And in his 29th chapter: "Divide your manure; carry half of it to the field when you sow your provender, and if threr? are olive trees, put some dung to their rursts." In his 37 th chapter he advises the use of pigeons' dung for gardens, meadows, and corn lands, as well as umerca, or dregs of oil: and recommends the farmer to preserve carrofully tlie dung of all descriptions of animals. This was advice given 150 years before the Christian era; and now, after the lapse of 2000 years, the direction must be still the same. We learn from Columella (i. 6) and Pliny (xvii. 9; xxiv. 19) that they collected their manure and stored it in covered pits, so as to check the escape of the drainage; and sowed pulverized pigerons' dung, and the like, over their crops, and mixed it with the surface-soil by means of the sarcle or hoe. (Colum. i. 16; Cato, 36.) They were aware of the benefit of mixing together earths of opposite qualities, and sowing lupines, and ploughing them in while green. (Varro, i. 23.)

Virgil is very particular in describing fertilizers. With common manure he mentions ashes (Georg. lib. i. 80), pumice-stone, and shells. (Lib. ii. v. 346, 50, and in v. 250, 8.) He advises the seeds of corn to be mixed with saltpetre and the dregs of olive oil, to make the grain swell. (Lib. i. 195.) Irrigation was employed in his days. (Lib. i. 106, 9.) The Italian farmers also fed down over-luxuriant crops (lib. i. 3), and burned the stubble. (Lib. i. v. 84,8 .)

Varro (lib. i. c. 38) mentions many kinds of animal manure, and is particularly minute in his enumeration of the dung of birds, and includes even that of blackbirds and thrushes kept in aviaries.

Columella (lib. ii. c. 5) advises the cultivator not to carry out to the field more dung than the labourers can cover with the soil the same day, as the exposure to the sun does it considerable injury; and he enumerates (lib. ii. c. 15), as well-known fertilizers, night-soil, the excrements of birds and sheep, urine (especially for apple-trees and vines), dregs of oil, the excrements of cattle, the ass, the goat, of pigs; ashes, chopped stalks of the lupine (or hop), leaves of trees, brambles, \&cc., and mud from sewers or ditches. Pliny also mentions that lime was employed as a fertilizer in Gaul, and marl in the same country and Britain; but we can only surmise thence, that they were also probably employed by the Romans. (Pliny, xvii. 5.)

Liquid manure is not a mode of fertilizing the land altogether of modern origin. For a fermented mixture of water and night-soil has from a very early period been employed by the Chinese farmers. Those of Italy certainly prac. tised irrigation in the days of Virgil (Georgic. lib.i.v. 106,9); and Cato adds, they employed a mixture of grape-stones and water to fertilize their olive trees. (Lib. xxxvii.) Columella praises very highly the use of stale, putrid urine for vines and apple-trees (lib. ii. c. xv.); commending also the lees of oil for the same purpose. More modern agricultural authors have united in praising various liquid prepara. tions; thus Evelyn (whose ingredients most of 
these authors recommend), in his Treatise on Earth (p. 123-160), gives several recipes, some of which have served as the bases for recent modes of preparing liquid manure; such as the dung of cattle, urine, salt, and lime, nitre.

The employment of crushed bones as a manure is but a very modern improvement; it is not one of the fertilizers even mentioned by the early agricultural writers; and to this neglect of bones several causes contributed. The necessary machinery for crushing them was, in the early ages of agricultaral efforts, totally unknown; and bones when unbroken dissolve in the soil much too slowly to be of any apparent value as a fertilizer. The use of bones is an improvement, for which agriculture is entirely indebted to the enterprize of the English farmers. The refuse matters produced by the ivory and bone turners and cutlers of Sheffield, which speedily accumulated in very considerable heaps around their manufactories, first drew the Yorkshire farmers' attention to bone manure. The cultivators of the poor soils in the neighbourhood of that town, towards the conclusion of the last century, began to carry away these refuse matters with some readiness, and the turners were at first too glad to be relieved from this bone-rubbish, to think of charging them any thing for the valuable manure they had been the first to employ. As, however, the Yorkshire farmers soon began to scramble for these bone-turnings, the manufacturers of Sheffield speedily made a small charge for them, which has since gradually increased in amount. It required, however, some time to bring about this great and successful improvement. Mr.'T. Ellin, late master cutler of Sheffield, well remembers, some fifty years since, the bone refuse carted into Sheffield Moor, and buried in pits as worthless rubbish; these old deposits, often found in digging foundations, are now carried off with much alacrity to the bone-crushing mills. The farmers at first gave sixpence a bushel for these parings and turnings; of these about 600 tons are annually sold in Sheffield. By the sole use of this fertilizer, great breadths of very poor land have been successfully brought into cultivation, and maintained in a state of the greatest fertility in the north and east of England and Scotland. Their effects upon the wolds of Lincolnshire has been magical. The first person, perhaps, who successfully used the roughly broken bones from the dog kennel as a manure was General St. Leger, in 1775. (Evelyn's Sylua, by Dr. Hunter.)

Manuring with fish was necessarily an improvement of an advanced state of agriculture; we have no mention of them as thus used in the early agricultural authors; the immense shoals of sticklebacks, and other small fresh-water fish, which once tenanted the fen counties of England, first gave the farmers of Lincolnshire an opportunity of using this rich oily manure; they were towards the latter end of the eighteenth century sold by the fen fisherrnen at about sixpence a bushel; and Arthur Young tells us, that at one village on the borlers of Cambridgeshire, 2000l. have been taken ior these fish in one season. It is not often that 784 a glut of herrings, pilchards, or other valuable fish, enables the farmer to obtain them at a rate sufficiently reasonable for his land, a purpose for which they have often, however, been em. ployed with the most luxuriant effect on the coasts of Scotland and Cornwall. Sprats, and the fish called five-fingers, are used to a great extent by the Essex farmers; the demand for these has of late years been fully equal to the supply, although from the evidence given before a Committee of the House of Commons in 1833, it seems that during the season more than 400 boats are employed in catching these fish, for the purpose of selling them as manure.

Manuring with calcareous sand was practised very early in the middle ages by the English farmers. This they obtained not only from inland pits, but from the sea-shore, especially in Norfolk and Cornwall. The privilege of freely taking it from the sea-shore, the West of England farmers enjoyed under a grant from Richard Duke of Cornwall, confirmed by another of 45th of Henry III., A. D. 1261. This is expressed in the preamble of the act of the 6th James II. c. 18, A. D. 1609, which says, "Whereas, the sea-sand by long trial and experience hath been found to be very profitable for the bettering of land, and especially for the increase of corn and tillage within the counties of Cornwall and Devon, where the most part of the inhabitants have not commonly used any other worth for the bettering of their arable grounds and pastures." This act, which empowers the farmers to take this sand free from any toll, was, after being several times renewed, made perpetual by the 16 th Charles I., c. 4 . This wise encouragement of the use of manures by the legislature of England has not been confined to the sea-land of Padstow harbour: thus, uncrushed bones passing through a turnpike to be crushed for manure are exempt from toll ; and carts loaded with common manure are equally free; or even when going empty to fetch it; but this exception does not extend to lime. And in authorizing the construction of railways, parliament has carefully provided, that the tolls levied upon the manures conveyed hy them shall be much smaller than those demandable for any other description of goods: thus, in the Birmingham and Gloucester Railway Act, the authorized toll is, for manure of all kinds, ouly one penny per ton per mile; while coals, \&c. are to pay threehalfpence, sugar twopence, cottons and other manufactured goods, threepence per mile. The same proportionate rate of tolls are authorized to be taken on several other railways, such as the Birmingham and Derby, the Midland Counties; and on the Eastern the difference in favour of the farmer is still greater; for while limestone, sand, and clay are to pay a penny, and all other manures three-halfpence, coals are to pay twopence, sugar, \&c. fourpence, and manufactured goods sixpence per mile.

Saltpetre is, perhaps, the most ancient of all the saline manures, and its introduction is not, as is commonly believed, a modern improve. ment. It is commended by Virgil as a steep with olive oil, to make the seed-grain swell To this knowledge of the fertilizing porvers of 
saltpetre the early cultivators of the carth were probably assisted from noticing that those soils which naturally produce saltpetre are ever found to be of the most fertile description, and that all those rich eastern fields which are so celebrated in Palestine for their fertility, abound in this salt. Three centuries since, according to Googe, it was employed by the German farmers. "Some saie coleworts prospereth best in salt grounde, and therefore they use to cast upon the grounde saltpetre or ashes." In 1676, Evelyn, in his Discourse on Earth, tells us, "rains and dews, cold and dry winters, with store of snow, which I reckon equal to the richest manures, impregnated as they are with celestial nitre;" which, although an error, yet displays his opinion of the fertilizing power of .ritre. "I firmly believe," he adds, "that were saltpetre, I mean fictitious nitre, to be obtained in plenty, we should need but little other composts to meliorate our grounds." Evelyn recommends saltpetre to be used in solution, three pounds of this salt to fifteen gallons of water mixed with earth. And in this way Sir Kenelm Digby made some barley grow very luxuriantly by watering it with a very weak solution.

It would be, perhaps, difficult to name any other substance in the catalogue of modern fertilizers whose powers have been so often disputed as common salt. For this controversy many reasons may be assigned. It has been generally employed with little scientific accuracy, has been tried in a manner far too caretess for any reliance to be placed upon the majority of the reports which have been furnished to us, and for many years a prohibitory duty rendered it inaccessible to the farmer; an impost which has not very long been removed, and which yet was the occasion of a great variety of blundering trials, miscalled experiments. The duty on salt was indeed one of long continuance. It originated, as a war-tax, in the ninth year of the reign of William the Third, and was not removed until after an ardunus debate at the end of that of George the Third. 'The price of salt, thus raised to more than 20 s. a bushel, was in consequence too expensive a fertilizer to be employed by the English farmers. During that long period $\mathrm{t}$ was known only in their traditions. Through these they were told that it was formerly used to kill worms and to destroy weeds, that it cleansed fallows, increased the produce of light arable soils, and sweetened grass. These reported advantages were rendered more probale by certain facts that had been forced as : : ere upon their attention. Every gardener $\checkmark$ as aware that the brine of the pickling tubs, when poured over his heaps of weeds, not only killed those weeds and their attendant seeds and grubs, but that these heaps were then converted into so many parcels of the most fertilizing manure, whose good effects, especially upon potatoes and carrots, were very decided. It was well known, too, that a single grain of salt, placed upon an earth-worm, speedily destroyed it; that if brine was poured upon a lawn, from that spot all the earth-worms were immediately ejecled; and that if it was sprinkled over a portion of the grass, on this salted portion all the deer, or sheep, or horses of the park era. stantly repaired, in preference to any other part of the field. Salt evidently therefore de. stroyed weeds and worms, and renilered grass more palatable to live-stock; and upon consulting the old agricultural writers, it was found that the notices of salt as a manure were many and important, and that salt had been employed in various agricultural operations from a very early period. 'Thus, it is referred to by St. Luke, chap. xiv. 34; Virgil reprobates a salt soil; Cato recommends it for cattle, hay, straw, \&c.; as does Virgil (Lib.iii. v. 394). The early German farmers knew of its value for sheep; and for the same purpose, in Spain, it has been employed from the earliest ages. In 1750, Conrad Herebasch commends it as a certain prevention of the "murrain or rotte." In 1653, Sir Hugh Platt speaks of salt as a fertilizer, in his usual visionary manner, and details the result of a very successful experiment on a "patch of ground" at Clapham, from which some late writers upon the uses of salt have led their readers into great blunders, by stating this experiment to have been performed upon an acre of land.

The use of salt by the cultivator, since the repeal of the duties in 1823 , has been considerable, however, in many districts of England, in spite of these blundering instructions, ill-contrived experiments, and ignorant conclusions. If to this be added the natural difficulty of obtaining correct results in any experiments in which vegetable life is concerned, we need no longer be surprised that many contradictory statements have been made with regard not only to salt, but to all other fertilizers.

A mixture of salt and lime was recommended as a manure by the celebrated German chemist, Glauber, in his "Hints for the Prosperity of Agriculture," more than two centuries since. $\mathrm{He}$ at some length described the mode of preparing it, and characterized the compound of soda and chloride of calcium produced as "most fit for dunging lands, and to be used instead of the common beasts' dung." (Pros. perity of Germany, vol. i. p. 417.) Christopher Packe, who, in 1688, published a huge folio translation of Glauber's works, enforces the value of this fertilizing compound with much earnestness in his preface, describing it "as the cheapest of all mixtures for the enriching of poor and barren land." The want of scientific knowledge amongst farmers, and the hin. drance to the use of salt through the duties which were so long imposed upon it, naturally prevented any extensive use of this fertilizer; yet there have been many accidental or occa. sional notices of its value. Thus, for a grea: many years, it has been the practice of the farmers of Essex, and other English maritime. counties, to steep their seed-wheat in sea-water. strengthened with salt, until it is of a sufficient gravity to float an egg, and then roll the brined seed in lime. This they consider not only prevents smut in the corn, but promotes the genem ral health and vigour of the plant. The Essec farmers have a tradition that this plan was cis. covered by the accident of a farmer's labawer dropping a sack of seedwheat from the boat in which he was crossing the nuuth of the River 3. ए ? 78 . 
Crouch. It was long, however, the superstitious belief of the district, that the salt-water wetting must be the result of accident to produce a good effect. 'The Cornish farmers have for centuries used the saline calcareous sand of the coasts of Devon, which contains 64 per cent. of lime, fetching it for some miles from the shore, in preference, says Dr. Paris, to the unsalted sand, which they can procure at their own doors. The very mixture of salt and lime was successfully employed in Ayrshire many years since. And George Sinclair, in 1818, very nearly demonstrated at Woburn the value of this application. He unfortunately, however, applied the salt and the lime separately, yet still with considerable benefit. ( $C$. W. Johnsou's Essay on Salt, p. 40.) The use of salt and lime was noticed in the year 1800, by Mr. Hollingshead, of Chorley, in Lancashire, who observes, "Lime prepared for manure should be slacked with salt springs or salt-water; lime so slacked will have a double effect." In 1304, in the experiments of the late Rev. Edinund Cartwright, upon potatoes, of $25 \mathrm{ma}-$ nures, or mixtures of manures, salt and lime were found superior, in their product of potatoes, to 19 others. And in 1816, Mr. James Manley, of Anderton, in Cheshire, when giving his evidence before a committee of the House of Commons, on the salt duties, mentioned that in getting marl (which is a mixture of carbonate of lime, alumina, and silica), he had found that, by mixing it with brine instead of water, the portion of the field on which the brined marl was used yielded 5 bushels of wheat per acre more than that portion on which the watered marl was employed.

The use of ashes as manure may be traced to a very early age. The Roman farmers were well acquainted with paring and burning. Cato recornmends the burning of the twigs and branches of trees, and spreading them on the land. Paliadius says, that soils thus treated would not require any other manure for 5 years. They also burnt their stubbles-a praciice common amongst the Jews in Palestine. 'The ancient Britons, according to Pliny, were used to burn their wheat-straw and stubble, and spread the ashes over the soil; and Conrad Herebasch, a German counsellor, in his Treatise on Husbandry, published in 1575 , which was translated by Googe, tells us (p. 20), "In Lombardie they like so well the use of ashes, as they esteem it far above doung, thinking doung not meete to be used for the unwholesomness thereof."

Gypsum, or sulphate of lime, when employed as it exists in an impure state in ashes, which owe all their virtues to the gypsum they contain, was used by the early Italian farmers. Virgil ('́corg. i. 1. 80) gives the following injunction:

Effotus cinerum immundum jactare per agros."

-Nor hesitate to scatter the dirty ashes over the exhausted soils." And he also recominends, in addition to ashes, two other remedies for sterility of soil, viz. sterroratio (or maliuring), and glebarum cum stipulis incensio (the turning up and burning the stubble). Rohert $\Lambda$ inslie, steward to the celcbrated John, Earl of Stair, at Culhorn, in Wigtownshire, had 786 very nearly discovered the agricultural advar. tages of gypsum in 1728; for in that year the earl sent from London several hogsheads of peat-ashes, which abound in sulphate of lime, with directions for their use, describing them to Ainslie as being much employed in the south of England as an admirable top-dressing for grass, and even tillage lands. These ashes were used, according to his lordship's directions, with great success, on both barley and grass lands. Ainslie, convinced of their fertilizing properties, immediately began to burn turf, moss, and peat, for the use of the farm under his care, in considerable quantities; he, moreover, submitted these ashes to what he very ludicrously calls an analysis, and gravely tells us, that "with a great proportion of earthy substances, they contained many particles of lime or shelly matter." This was most probably the gypsum.

The use of the mineral gypsum as a manure was discovered in 1768, according to Kirwan, by M. Meyer, a German clergyman of great talents; but as in those days the chemical composition of gypsum was totally unknown, he naturally confounded it with other calcareous earths which it resembled in appearance. His merit consisted in discovering the use of a certain mineral substance existing in his own neighbourhood, which was long afterwards shown to be sulphate of lime, but of which fact Meyer was entirely ignorant. Even as early as 1792 gypsum was tried very successfully by Mr. H. Smith, of Highstead, near Sittingbourne, who first notıced, what has since been confirmed by numerous observations, that clover manured with gypsum is always preferred by horses and cattle to all other clover.

Sir Joseph Banks recommended this sub. stance as a fertilizer to Lord Leicester, and, at his suggestion, it was tried at Holkham many years since; but, owing to mismanagement in its application, it did not then appear to answer the intended purpose. Some years afterwards, owing to the warm recommendation of Mr. Grisenthwaite, it was again employed pretly extensively by the same nobleman, and with great success; and so satisfied was this great friend of agriculture with the result, that he presented Mr.Grisenthwaite with a piece of plate for his exertions in its introduction. In a letter with which I was favoured from the Rev. R. Collyer, dated Holkham, October 17 th, 1837, that gentleman tells me, "Lord Leicester wishes me to say, in regard to gypsum, that its effects, when applied to clover and sainfoin, have been invariably such as to induce him to speak from his own experience in favourable terms of that fertilizer." It has since been gradually creeping into use in the east and south of England. Mills have been erected for grinding it, and considerable quantities have been brought from the northern counties; but still not one-thousandth part of the quantity is employed in agriculture that would be used if its correct mode of application were more generally known; since, from the small quantity used per acre, and the low price of the article, it constitutes one of the cheapest of the artificial manures. 


\section{MANURES.}

From this sketch of the history of the chief manures, and of the steady improvement in the mode of applying them, we may safely conclude that, as regards the cultivation of even the most barren soils, the drifting lands of Norfolk, the heath-lands of the north of England and Scotland, and even the shingle of its sea-coast, much will yet be effected by improved modes of applying manures. Let such improvements proceed; let science go hand in hand with practice; let the naturalist discover new cultivatable vegetables, or new varieties of those already known; let the chemist yield his magic aid to demonstrate the best mode of promoting their growth, and increasing the fertility of the soil; and then I fearlessly assert that many more than the present inhabitants of Britain may be amply supported by the produce of the land of our birth. "Nature," said Davy, "amidst all her changes, is continually directing her resources towards the production and multiplication of life; and in the wise and grand economy of the whole system, even the agents that appear injurious to the hopes and destructive to the comforts of man are, in fact, ultimately connected with a more exalted state of his powers and his condition. His industry is awakened, his activity kept alive, even by the defects of climates and seasons. By the accidents which interfere with his efforts he is made to exert his talents to look farther into futurity, and to consider the vegetable kingdom, not as a secure and unalterable inheritance, spontaneously providing for his wants, but as a doubtful and insecure possession, to be preserved only by labour, and extended and perfected by ingenuity." (Lectures, p. 267.)

Manure, Law with regard to.-In most English farm-leases there are covenants introduced with regard to manure, which are often worse than useless; encumbering the efforts of the skilful cultivator, and rarely improving the practice of the ignorant, lazy, and unprincipled. Thus, by some leases the farmer is allowed, on certain conditions, to sell his straw and hay, and bring on to the farm in its stead a given weight of manure (commonly 2 tons of stabledung for a load of straw, and $\mathbf{3}$ tons for a load of hay); in others he is restrained from selling either; in others, from liming or chalking his land. In most leases he covenants to spread the manure on the farm, and to leave it, in the concluding year of his term, properly laid up in heaps, if it is not already employed on the land.

The mere relation of landlord and tenant is a sufficient consideration for the tenant's promise to manage a farm in a husbandlike manner, and not to carry away any straw, dung, compost, \&c.; but to promise to spend $60 l$. worth of manure every year, is not in law an obligation arising out of the bare relation of landlord and tenant. A tenant from year to vear, under a notice to quit, cannot remove manure, except according to the custom of the country, and, if necessary, he may be restrained by an irjunction. The custom of the country 's usually followed with regard to the management and sale of manure; but in case there is a written agreement, no inquiry can be made as to the custom of the country; and when an

\section{MANURE8.}

express stipulation is made, the custom of the country is excluded entirely. In this case Lord Lyndhurst said, "The offgoing tersant was bound by the custom of the country to leave the manure on the premises, and was entilled to be paid for it by the landlord, or the succeeding tenant; but in this case they did not rely on the custom. The lease contained a covenant that the tenant, on quitting the farm, should not sell or take away the manure which should be in the fold, but should leave it to be expended on the land by the landlurd or his succeeding tenant. It is to be left for their use, and there is no provision as to any payment in respect of it. We are of opinion, therefore, that the plainviff is not entitled to be paid for the manure." But where an agreemeat is silent as to the question of manures, then the custom of the country is valid in law. If the outgoing tenant has covenanted with his landlord to sell the manure to the incoming tenant at a valuation, and to leave it on the farm, the outgoing tenant has a right of onstand on the farm; and if the incoming tenant remove the manure before such valuation, he is answerable to the outgoing tenant in an action of trespass. A tenant may sell or assign over manure to an assignee, although he thereby subjects himself to an action of covenant. And it is a reasonable custom for the landlord to pay the outgoing tenant the expense of manuring. If a tenant, during his tenancy, removes a dunghill, and at the same time digs into and removes virgin soil that is beneath it, his landlord may maintain either trespass de bonas asportatis, or trover, for the removal of the virgin soil. But if a tenant covenants to sufficiently muck and manure the land, with two sufficient sets of muck, within the last six years of his tenancy, the last mucking to be within the last three years, this covenant is satisfied by the tenant laying on two sets of muck within the last three years of his term, if he shall think fit to do so.

In valuing manure to an incoming tenant much depends upon the custom of the country, which is usually followed in these cases. Land which has been rendered perfectly clean by a year's fallowing, is denominated a full tillage, and by tillages the valuation is commonly made.

In estimating the value of manure in arable land, it is done by allowing a full tillage after a fallow or crop of turnips fed off; after a white crop, half a tillage; but after two white crops no allowance is made.

For bones one tillage more is valued than for dung, on arable soils; two-thirds of the value of the bones, and labour of procuring and spreading them, being allowed after one white crop, and one-third of the value after two white crops. Soot, rape-cake, oil, sprats, $\& c .$, which are quickly exhausted in the soil, are allowed for as one full tillage before a crop grown, or after turnips, \&c., eaten off; but if the turnips, \&c. have been carried off, then only one-third of the cost of procuring, carrying, and spreading is allowed.

For earthy manures more is allowed in a valuation than for those of a perishable na. ture. Thus, on pasture land, lime, cha!k, or 
marl are commonly valued for six years after they have been spread on the land. This includes prime cost, carriage, and labour in spreading in full, when laid on not more than a year; two-thirds of the value if spread within two years; one-half in three years; one-fourth in four years; and one-sixth in five years: but when lime is used on arable lands, it is commonly valued in the same way as farm-yard manure.

When compost is in the heap, it is usually valued in cubic yards, the value of which necessarily varies; it may be estimated, however, commonly as of the same value as half a bushel of wheat. (Woodfall, by Harrison, p. 529 ; Bayldon on lients; Grainger and Kennedy on Tillage.)

The custom of the incoming tenant paying for the dung varies in different counties. In the following counties he wholly pays for all dung on the farm: viz. Essex, Kent, Northumberland, Nottingham (artificial manure), Rutland, Stafford, Suffolk, Surrey, Sussex, Westmoreland, and the West Riding of York. In the other English counties the dung is usually left free of charge to the incoming tenant. This, in Scotland, is called holding in steel-bow. See Customs of Counties.

MANURES, ARTIFICIAL. A great many fertilizing compounds are now prepared in large manufacturing establishments specially devoted to the purpose, and these are extensively used upon the various field crops to which they have been found best adapted. The basis of many of these is night-soil, such as poudrette, \&c. The virtues of others depend upon various salts of potash and soda. The following list of the leading articles of this kind now prepared and extensively used by the English farmers, with the prices at which they are vended, cannot but be interesting to the American agriculturist. It forms an ordinary advertisement in a London newspaper:

Agricultural Salt, perton, $30 \mathrm{~s}$. to $32 \mathrm{~s}$

- - fine, per ton, $36 s$

Alexander's Crinirist, per bushel, is, $10 d$

Bleaching Powi.r, per cwt. 30 s.

Bone-dust and haif-inch Bone, per quarter, 18 s.

Brimstone, per ton, $11 l$.

Clarke's desiccated Compost, per bhd., 3l. 12s. $6 d$.

Daniell's Bristol Manure, according to quantity, per bushel, $10 d$.

Guano (foreign), per cwt., 10s. to 128.6d.

- Potter's English, according to quantity, per cwt. 138. to 148 .

Gypoum, according to quantity, per ton, 30 s. to $42 s$.

Hunt's New Fertilizer, per bushel, 18.8d.

Muriate of Ammonia, per cwt., 24s. to $26 \mathrm{~s}$ Lime, per cwt., $12 s$.

Nitrade of Soda, according to quantity, duty paid, per cwt. $178.6 d$. io $18 s .5 \mathrm{l}$

Petre Salt, perton, $3 l .10 \mathrm{~s}$. In $5 l$.

Phosphate of Ammon:a, per 1b., 1s. 9d. to 2s. 3d.

Phosphate of Soda.

Poittevin's disinfected Manure, per quarter, 138.6d. concentrated Manure, per quarter, 30 s.

Rape-dust, according to quantity, per ton, $7 l$. 108 .

Rock Sait, per ton, $4 l$, in quantity, $3 l$.

Saltpetre, percw t., 25s. $6 d$.

Silicate of Potash (pure), per cwt., $65 s$

Soda Ash, per cwt., 148.

Sulphate of Ammonia, per cwt., 18 s. - of Iron, per ton, of Soda, per ton, $7 l$

Sulphur, per cwt 168

Fulphuric Acid, nccording to strength, per $1 \mathrm{~b} ., 1$ t d. to 2 sd.

Trimner's Composition for Clnver, per cwt., 88 .

Potash, per cwt., 32

fur Wheat, with Silicate of
Trimmer's Compost for Turnips, per cwt., 8s.

Urate, per $\operatorname{tnn}, 5 l$.

Watson's Compost, per cwt., 10s., in quantity, 9l. pe ton.

MAPLE (Acer, from the Celtic ac, a point, the wood having formerly been much sought after for manufacturing into heads of pikes and lances). The maples are for the most part beautiful trees, of considerable size, generally employed in forming avenues or the back of shrubberies. The soil they delight most to grow in is open sandy loam, in which also cuttings will strike freely in the open air; or they may be increased by layers put down in the autumn: but all the best plants are obtained from seed, which should be sown soon after gathering. There are a great many species of maple; but two only, with some varieties, are common to Britain.

1. The greater maple or sycamore ( $A$. pseudoplatanus), which grows in hedges and about houses, common, but not truly wild. It is a large, handsome tree, of quick growth, with a smooth ash-coloured bark, and round spreading branches. The wood is white and soft, useful for many purposes, such as making musical instruments, cheese and cider presses, tables, mangles, and some parts of machinery but is chiefly employed by coopers. The sap is said to yield some portion of sugar, and to be made into wine in the Highlands of Scotland. The sycamore is propagated entirely by seed. The principal cultivated varieties are, the yellow variegated sycamore, or Costur. phine plane (Ac. p. flavo-variegata, I,oudon), the white variegated leaved sycamore $(A . p$. variegata, Loudon), and the purple-leaved variety.

2 . The common or field maple ( $A$. campestre) This is a common tree in hedges and thickets, but is rather rare in Scotland and the north of England. It is of much more humble growth than the preceding, with more spreading branches; the bark corky and full of fissures; that of the branches smooth. The wood is compact, of a fine grain, sometimes beautifully veined, celebrated among the ancient Romans for tables, though now superseded by mahogany, and even by our native oak.

The Norway maple ( $A$. platanöides) has latterly been classed among British forest trees. It is a tree of the first rank, thrives well in England, and attains a height equal to that of the sycamore within a like period of years it is a decided acquisition to park and wood land scenery, and its wood promises to be of more value, and adapted for a greater variety of purposes, than that of the sycamore, being white, close-grained, firm, susceptible of a fine polish, and frequently exhibiting the beautiful appearance in the direction and disposition of the fibre, for which the bird's-eye maple of America is so highly prized and sought after. 'The foliage, though not so heavy and massive as that of the sycamore, is umbrageous; the leaves, which in shape bear a striking resem. blance to those of the Platanus occidentalis, are large, with slender petioles, and, when fully expanded, of a fine, shining light-green; in ar. early or half-expanded state, they are of a delicate yellowish-green, and in autumn, before they fall, become of a rich, warm yellow. 
There are many species of maple found in the North American forests, which are generally lofty and beautiful trees. They are capable of enduring the most intense cold, and therefore form in the north of the new continent, as they do of the old, extensive forests, which, with those of the beech, appear to succeed the spruce, the larch, the pine, and to precede the chestnut and oak. Michaux gives 7 species of maple to Europe, and 7 to America, exclusive of the dwarf red maple of the Northeastern States, and the species found in the Northwestern territories.

The wood of the maples differs so widely in quality in different species, that it becomes difficult to characterize it by general observations. It may be remarked that it speedily decomposes and decays when exposed to the weather, that it is liable to be injured by worms, and that hence it is unfit for building. It possesses properties, however, which compensate in part for these defects, and which render it useful in the arts and domestic economy.

Two of the American maples not only flower but mature their seed during the spring months. These are:-the white maple (Acer eriocarpum) and the red-flowering maple ( $A$. rubrum). In the other kinds, the fructification is autumnal, namely:-the sugar maple ( $A$. saccharinum), black sugar maple ( $\mathcal{A}$. nigrum), moose wood, or striped maple ( $A$. striatum), box elder, or ash-leaved maple ( $\mathcal{A}$. negundo), mountain maple (A. montanum).

Some of the inhabitants of the Western States make sugar by boiling down the sap of the white maple, which, however, like that of the red maple, yields only half the proportion of sugar obtained from the juice of the sugar maple. The sap is in motion even earlier in the white than in the sugar maple, beginning Io ascend about the middle of January.

The red-fowering maple is the earliest tree whose bloom announces the return of spring, the beautiful purple blossoms unfolding more than a fortnight before the leaves. It never attains its full size except in swamps where the bottom is composed of fertile soil, and it affords the wood chiefly used in the manufacture of Windsor chairs.

The moose wood maple of the Eastern States was so called by the first settlers, from observing that the moose fed upon its twigs during the latter part of winter and beginning of spring. Although it fills the forests in Nova Scutia and Maine, it becomes rare on approaching the Hudson, to the west and south of which river it is confined to the mountainous tracts of the Alleghanies, on the cold and most shaded sides of which mountains it extends to their termination in Georgia. Where it mostly abounds, its principal advantage to the inhabitants consists in furnishing them, at the close of winter, when their forage is exhausted, a resource for sustaining their cattle, till the advancing season has renewed the herbage. As soon as the buds begin to swell, the famished horses and neat cattle are turned loose in to the woods, to browse on the young shoots, which they consume with avidity. Poor as this resource may appear, it is not wholly inadequate, since the twigs ar: tender, and full of sweet juice. This species of maple is much ardmired in European parks and gardens, particularly on account of its variegated trunk. When grafted on the Sycamore, as is commonly the case, the striped maple grows io nearly fuur times its ordinary size.

The box elder, or ash-leaved maple, is common in the states west of the Alleghanies, and rare to the eastward of these mountains. It is the species which ventures least to the north, not being seen on the Delaware higher than the neighbourhood of Philadelphia. It is chiefly found in low bottoms where the soil is deep, fertile, and constantly wet. Even in such situations it seldom attains more than 50 feet in height, and 20 inches in diameter.

The mountain maple abounds in Canada, Nova Scotia, and along the whole range of the Alleghany mountains, preferring the northern sides, and the moist, coolest, and most shady situations, on the abrupt and rocky banks of torrents and rivers. It seldom is more than 6 or 8 feet high, and is most frequently in the form of a shrub, with a single, straight stock. Like the moose wood, this maple is frequently grafted on the sycamore ( $A$. pseudo-platanus), by which means it is increased to nearly twice its natural size. This surprising developement proves how great are the advantages which may be derived from this process and from continued cultivation, in improving inferior vegetables.

But by far the most interesting tree of this family to the American is the sugar maple, which in the north begins to appear a little north of lake St. John, in Canada, near the $48^{\circ}$ of latitude, which in the intensity of its winter cold corresponds to the $68^{\circ}$ in Europe. It is nowhere more abundant than between the $46^{\circ}$ and $43^{\circ}$, which comprise Canada, New Brunswick, Nova Scotia, the states of Maine, New Hampshire, and Vermont, where it enters largely into the composition of the wide-extending forests. Farther south, it is common only in Genesee, in the state of New York, and in the northern highlands of Pennsylvania. Dr. Rush estimated that in the northern parts of these two states, there are $10,000,000$ of acres which produce these trees in the propor. tion of 30 to an acre. In some places large masses of woods are formed of them almost exclusively. In Virginia and other Southern States, the tree is comparatively rare, and only to be found in mountainous situations. In those sections of country where the sugar maple most abounds, they distinguish the kinds of soil into what are called black, or soft wood lands, comprising the pines and spruces covering the low grounds and valleys, and the hard wood lands, consisting of leaf-shedding trees, such as the sugar maple, the white and red beech, the birch, and the ash. These last occupy the level grounds. Above the $46^{\circ}$ of latitude, the maple and other trees of the hard wood class begin to be rare, and the pines and other resinous trees take their place. Below $43^{\circ}$, the spruce and other soft wood trees aro less common, and lose their preponderance 1 . the forests, where they become mingled with the numerous species of oaks and walnut.

Black sugar maple. In the Western States 
and in the parts of Pennsylvania which lie between the mountains and the Ohio, this species of maple is called the black sugar tree, probably on account of the colour of its leaves being darker than those of the genuine sugar maple. In the Genesee country of New York, both species are indiscriminately called rock maple and sugar maple. The two species have also been confounded by botanists. In the Northern States, the black sugar maple is inferior in size and also more rare than the true sugar maple. A few degrees farther south, it forms a large part of the forests of Genesee, where it is one of the most common and most lofty trees. The wood is much like that of the other species, but coarser grained and less brilliant when polished. It is comparatively but little used, because, wherever it abounds, other trees are found, such as oak, the walnut, cherry, and mulberry, more esteemed for building and cabinet work. It is, however, preferred for the frames of Windsor chairs, and, after hickory, considered the best of fuel. It forms one of the finest shade trees, assuming, when standing alone, a regular and beautiful form. (Michaux.)

The sugar maple covers a greater extent of the American soil than any other species of this genus, flourishing most in mountainous places, where the soil, though fertile, is cold and humid. Under sach favourable circumstances it is often found 70 or 80 feet high, and proportionably large in diameter. It is one of the most heautiful native trees, and distinguishable by the external whiteness of its bark. The grain of the wood is fine and close, and when polished it has a silky lustre. It is very heavy and strong, but wants the property of durability for which the chestnut and the oak are so highly esteemed. Exposed to moisture it soon decrys. The different forms of this wood furnish the most admired undulated or curled maple, and the highly esteemed and still more beautiful spotted variety called bird's eye maple.

The wood of the sugar maple makes good fuel, for which purpose it is extensively used in Boston and other northern cities. The ashes afford a large proportion of the alkaline principles, and, it is asserted, furnish four-fifths of the potash exported in such abundance from Boston and New York to Europe. 'The extraction of sugar from the maple is a valuable resource in a country where, all classes of society daily make use of tea and coffee. The process by which it is obtained is very simple, and everywhere nearly the same. Though not essentially defective, it might be rendered still more perfect and profitable than is commonly the case.

The work of sugar-making commonly begins in the month of February, or early in March, whilst the cold still continues intense and snow covers the ground. Thus the sap begins to move nearly two months before the general revival of vegetation.

In a central situation, lying convenient to the trees from which the sap is drawn, a shed is constructed, called a sugar-camp, which is desmed to shelter the boilers and the persons who and them, from the weather. An auger three79. fourths of an inch in diameter, small troughs to receive the sap, tubes of elder or sumac, 8 or 10 inches long, corresponding in size to the auger, and laid open for a part of their length, buckets for emptying the troughs and conveying the sap to the camp, boilers of 15 or is gallons' capacity, moulds to receive the syrup when reduced to a proper consistency for being formed into cakes, and, lastly, axes to cut and split the fuel, are the principal utensils employed in the operation. The trees are perforated in an obliquely ascending direction, 18 or 20 inches from the ground, with two holes 4 or 5 inches apart. Care should be taken that the augers do not enter more than half an inch within the wood, as experience has shown the most abundant flow of sap to take place at this depth. It is also recommended to insert the tubes on the south side of the tree; but this useful hint is not always attended to.

A trough is placed on the ground at the foot of each tree, and the sap is every day collected and temporarily poured into casks, from which it is drawn out to fill the boilers. The evaporation is kept up by a brisk fire, and the scum is carefully taken off during this part of the process. Fresh sap is added from time to time, and the heat is maintained till the liquid is reduced to a syrup, after which it is left to cool, and then strained through a blanket or other woollen stuff, to separate the remaining impurities.

Some persons recommend leaving the syrup twelve hours before boiling it for the last time; others proceed with it immediately. In either case the boilers are only half-filled, and by an active, steady heat, the liquor is rapidly reduced to the proper consistency for being poured into the moulds. The evaporation is known to have proceeded far enough, when, upon rubbing a drop of the syrup between the fingers, it is perceived to be granular. If it is in danger of boiling over, a bit of lard or of butter is thrown into it, which instantly calms the ebullition. The molasses being drained off frum the moulds, the sugar is no longer deliquescent, like the raw sugar of the West Indies.

Maple sugar manufactured in this way, is lighter coloured, in proportion to the care with which it is made and the judgment with which the evaporation is conducted. It is superior to the brown sugar of the colonies, at least, to such as is generally used in the United States; its taste is as pleasant, and it is as good for culinary purposes. When refined, it equals in beauty the finest sugar consumed in Lurope. It is made use of, however, only in the districts where it is made, and there, only in the country: from prejudice or taste, imported sugar is used in all the small towns, and in the inns.

The sap continues to flow for six weeks; after which, it becomes less abundant, less rich in saccharine matter, and sometimes even incapable of crystallization. In this case, it is consumed in the state of molasses, which is superior to that of the islands. After three or four days' exposure to the sun, maple sap is converted into vinegar, by the acetous fermentation. The amount of sugar manufactured in a year varies from different causes. A cold 
and dry winter renders the trees more productive than a changeable and humid season. It is observerl, that when a frosty night is followed by a dry and brilliant day, the sap flows abundantly; and 2 or 3 gallons are sometimes yielded by a single tree, in 24 hours. Three persons are found sufficient to tend 250 trees, which give 1000 pounds of sugar, or 4 pounds from each tree. But this product is not uniform, for many farmers on the Ohio do not commonly obtain more than 2 pounds from a tree. Trees which grow in low and moist places afford a greater quantity of sap than those which occupy rising grounds, but it is less rich in the saccharine principle. That of insulated trees, left standing in the middle of fields or by the side of fences, is the best. It is also remarked, that in districts which have been cleared of other trees, and even of the less vigorous sugar maples, the product of the remainder is, proportionally, most considerable. "Having introduced," says a writer, "twenty tubes into a sugar maple, I drew from it the same day, 23 gallons and 3 quarts of sap, which gave $7 \frac{1}{4}$ pounds of sugar; 33 pounds have been made this season from the same tree; which supposes 100 gallons of sap. It appears here, that only a little more than 3 gallons was required for a pound, though 4 are commonly allowed.

It has been advanced, and doubtless correctly, that the Northern parts of New York and Pennsylvania contain maples enough to supply the whole consumption of the United States. But the annual produce by no means answers to this patriotic calculation. The trees grow upon excellent lands, which by the influx of emigrants from the older settlements, and by the surprising increase of the population already established, are rapidly clearing; so that in less perhaps than half a century, the maples will be confined to exposures too steep for cultivation, and will afford no resource, except to the proprietor on whose domain they grow. At this period also, the wood will probably produce a greater and more ready profit than the sugar. Wild and domestic animals are inordinately fond of maple juice, and break through their enclosures to sate themselves with it.

MARC. The matter which remains after the pressure of fruit; or any substance which yields oil; or, in fact, any fluid matter for the separation of which the action of the press is required. What remains in the press is the marc.

MARCESCEN'T. In botany, a term applied to leaves, \&c., which are permanent, and when withered do not fall off.

MARCHES. The name given to the borders or frontiers of any district, but more especially applied to the boundaries between England and Wales, and England and Scotland.

MARE. The female of the horse. See Horse.

MARE'S-TAIL (Hippuris vulgaris). A curious indigenous aquatic, growing in marshy situations, and in ditches, pools, and the borders of slow streams.

MARGARIC ACID. An acid obtained from animal fat Its derives its name from its resemblance to pearl. Its appearance and pro- perties very much resemble those of stedric acid, another product of animal fat, the chiref difference being in the greater fusibility of the margaric, which melts at $140^{\circ} \mathrm{F}$ ah. See Acıdw, A vimat.

MARIGOLD (Calendula, named from calenda, the first day of the month; there being flowers almost any month in the year). $\Lambda$ genus of showy plants, among which is the old and well-known common marigold ( $C$. offirinalis). 'This species was formerly used in soups and broths, but is now little regarded.

There are several varieties of the common marigold, among which are-

1. Single. 2. Common double. 3. Largest very double. 4. Double lemon-coloured. 5. Great Childing. 6. Small Childing.

MARIGOLD, CORN. See Cons Marieold. MARIGOLD, AFRICAN. See Africas Marigoln.

MARIGOLD, THE MARSH. Sce Marsu MaRigOLD.

MARINE ACID. See Muratic Acro.

MARINF. SALT. Common sea-salt, or muriate of soda.

MARJORAM (Origanum, from oros, a moun. tain, and ganos, joy; the delight of the mountain, in allusiun to the habitation of the plants). A genus of well-known, pungent, and gratefully aromatic herbs. The plants are all of easy cultivation; the shrubby kinds are increased by cuttings or slips; the herbacenus species by dividing at the roots. There are as many as 8 species, besides numerous varieties. The species generally cultivated are the common or pot marjorum (O.vulgare), and sweet or summer marjoram (O. majorana), and bastard or winter marjoram ( $O$. heracleoticum.)

A light, dry, and moderately fertile soil is required for their healthy growth; and if it is one that has not been cropped for a considerable time, it is the more favourable for them. If the soil is wet or rich, they are deficient in their essential qualities, and the perennials are unable to withstand severe weather. The situation cannot be too open. The sweet marjoram is propagated solely by seeds; the 2 perennials by seed, as well as by parting their roots, offsets, and slips of their branches. Sowing may be performed of all the species, from the conclusion of February, if open weather, to the commencement of June; but the early part of April is the usual time for performing it. Portions of the rooted plants, slips, \&c.., may be planted from February until May, and during September and October.

The sowing is performed either in drills, 6 inches apart, or broadcast; in either case the seed being buried not more than half an inch deep.

The tops and leaves of all the species are gathered when green, in summer and autumn, for use in soups, \&c.; and a store of the branches are cut and dried in July or August, just before the flowers open, for winter's supply.

MARK. A term applied to a horse, which is said to mark when he shows his age by a black spot, like the eye of a common bean, which appears at about $5 \frac{1}{2}$ years old in the cavities of the corner teeth, and is gone when 
he is 8 years old. When he ceases to mark, it is said he has rased. See Agr of Animals.

The term is also applied to a common mode of marking hogs, \&c., in those parts of the United States where they are allowed to run at large, and where the owner fixes a mark upon his property by cropping more or less of the ears, slitting these into swallow-forks and every other shape of mutilation.

MARKET. In English law the liberty or ianchise, whereby a town is enabled to set up ind open shops, \&c., at a certain place within iis limits for buying and selling, and better provision of such victuals as the subject wanteth. The establishment of a market, with the grant of the tolls thereunto belonging, is one of the king's prerogatives, and can only be eflected by virtue of the king's grant, or supported on long and immemorial usage and prescription, which presuppose such grant. The general rule of law is, that all sales and contracts of any thing vendible in fairs or markets overt (i. e. open), shall not only be good between the parties, but valid against all claim by others having any right or property in the subject. See Farns.

MARL. Marl implies, properly speaking, a natural mixture of chalk, shells, or carbonate of lime, in some of its forms, with clay or sand, or both. Its application to land, as a fertilizer, is of very ancient date, as it was much used by our English forefathers as a manure; and no one can read the account given by Pliny of the agricultural operations of the early Britons, without being struck with the minute discrimination, the evident result of long, attentive practice, which was displayed by them in the application of marl to particular soils; and from a very early period the Cornish farmers have been used to employ extensively the sea sand of Padstow harbour (which contains 64 per cent. of carbonate of lime), for the same purpose, carrying it from the sea-shore either in carts, or even on horses' backs, some miles up the country.

Marl was certainly used by the early Italian cultivators as a valuable addition to the soil of their fields. It is thus spoken of by Columella:- "If, nevertheless, you are provided with no kind of dung, it will be of great advantage to it to do what I remember Marcus Columella, my uncle, a most learned and diligent liusbandman, was frequently wont to do, viz., to throw chalk or marl upon such places as abound in gravel, and to lay gravel upon such as are chalky, and too dense and stiff; and thus he not only raised great plenty of excellent corn, but made most beautiful vineyards; for this most skilful husbandman denied that dung ought to be applied to vines, because it would spoil the taste of the wine; and thought that stuff gathered together out of thickets, and from among briers and thorns, or, in a word, any other sort of earth fetched from any other place, and carried to them, was much better for making a plentiful vintage."

The mixture of soils, we find from Theophratus, was a practice common in his days: hey found, it seems, the advantag a of uniting he light with the heavy, the fat with the lean, and, in fact, any that were of a contrary nature. This mixture, he tells us, not only supplies what shallew soils need in depth, but adds to the power of both; so that a worn-out soil, thus treated, begins again to bear crops with renewed energy: thus barren clays, when thus fertilized, again become fruitful; in truth, this mode of cultivation he deemed a complete substitute for manure. The inhabitants of Megara, besides practising this system, were used every 5 th or 6 th year to trench their land, digging as deep as they imagined the rain to penetrate, and bringing the under soil to the top; for it was an axiom with the Megarian cultivators, that the lighter portions of earth proper for the nourishment of plants are always washed downwards as far as the influence of the surface water extends; so that we see from this that the advantages of deep ploughing, or subsoiling, is not a very modern discovery. (Col. lib. xi. c. 16 ; Theop. 1. ii. c. 25.)

The right of sinking marl-pits is mentioned in the Charta Foresta, A. D. 1285; and in the Statum Wallice, 12 Edward I., marl-pits are mentioned as being dug close to common roads. "It is one of the duties of the sheriff and coroner," says Daines Barrington, "to inquire de fossatis et marleris levatis juxta iter publicum," which shows that this kind of manure was very commonly used. When a marl-pit was sunk in ground that did not belong to the king, but which happened to be in the purlieus or neighbourhood of a forest, prosecutions were instituted in the forest, which imposed heavy fines for the offence, as the pit occasioned both inconvenience and danger to the hunter.

Marl is found in many parts of England; and any earthy substance in which the proportion of calcareous matter is apparent, mixed with sand or clay, is styled, in popular lan. guage, a marl. Of this there are 3 principal varieties : 1. Clay marl ; 2. Sand marl; 3. Slate or stony marl; 4. Shell marl. Of these the last is commonly the richest in calcareous matter. In some shell marl examined by Sir George Mackenzie, he found-

\begin{tabular}{|c|c|c|c|c|c|c|}
\hline \multirow{2}{*}{\multicolumn{7}{|c|}{ Lime - - }} \\
\hline & & & & & & \\
\hline Silex & (a) & - & - & . & & 14 \\
\hline \multicolumn{4}{|c|}{ Argil - - } & . & & 14 \\
\hline \multirow{2}{*}{\multicolumn{7}{|c|}{$\begin{array}{l}\text { Oxide of iron - } \\
\text { Inflammable matter }\end{array}$}} \\
\hline & & & & & & \\
\hline \multirow[t]{2}{*}{ Loss } & - & - & - & - & & $4 \cdot 70$ \\
\hline & & & & & & 100 \\
\hline
\end{tabular}

Clay marl usually contains from 68 to 80 per cent. of clay, and from 32 to 20 per cent. of calcareous matter. Silicious sand often contains 75 per cent. of sand (Kirwin on Manures, p. 13). Thus, M. Thaer found in that of Oldenburgh-

\begin{tabular}{|c|c|c|c|c|c|}
\hline Fine sand & - & - & - & - & - \\
\hline Clay & - & - & - & - & - \\
\hline Mould & - & - & - & - & - \\
\hline Carbonate & of lime & - & - & - & - \\
\hline Gypsum - & - & - & - & - & - \\
\hline
\end{tabular}

The quantity of marl applied per acre neces sarily varies with the kind of soil and the qua lity of the marl: it is usual to employ it 
very considerable quantities, and it is often some years before it is sufficiently incorporated with the soil to produce an evident improvement; but then that advantage is almost always, sooner or later, not only decided, but permanent.

The clay marls render light sandy soils more tenacious; the sandy marls materially improve the friability of the heavy clays. In Cheshire, they often apply 128 cubic yards of clay marl per acre to light sandy soils, and abeut half that quantity to their heavy lands. I) many parts of Scotland it is spread on grass lat ts, and suffered to remain for two or three winters exposed to the frost, before it is ploughed in, in about the same proportions per acre.

"The beginning of all improvements in Germany," says Mr. S. S. Carr, in his Prize Essay, "is, to give a dressing of marl (containing, on an average, 60 per cent. of carbonate of lime), at the rate of 164 cubic feet per acre: by this means land, not worth cultivation previously, yields excellent crops for 8 or 10 years; and if the straw produced during that time is carefully converted into manure, the productiveness dues not materially decrease. Should that, however, be the case, the deposits of ponds, and even plots of peat-moss, which not unfrequently occur, are carried upon the fallows in winter, where these substances, when broken down by the frost, prove a valuable alternative to the texture of the soil, especially where the pulse, rape, and clover crops are gypsimed."

On the heathy sands of Norfolk much improvement might be effected by the application of marl. Mr. Kiddle, of Marsham, in that county, made many experiments with marl; he preferred, from long experience, the variety denominated "clayey marl," which he thought the best for sandy lands, even if brought from a considerable distance. "A few years since," said General Vavasour, "I purchased, with other lands, a field of 10 acres; it had been part of a common enclosed about 15 years before, and was tithe-free, the soil sandy, mixed with moory earth. I ploughed and sowed it in divisions with various crops, most of which failed. Having discovered a stratum of rich clay marl, within 400 yards of the field, I carted on 75 cubic yards per acre, at $10 d$. per yard, or 3l. per acre." The result was, that the value of the land increased from $6 s$. to $1 l$. 1 s. per acre.

In Europe, the term marl is applied to various mixtures of calcareous matter with clay, sand, \&c., and the common test is to effervesce on the addition of vinegar, or other acid. But, in the United States, those at least on the Atlantic coast, where this fertilizer is met with in great abundance, two kinds of marl are extensively used, one of which has been already described under the head of Gresn SAND. 'I'his is often so free from lime, as scarcely to retain a trace, and, consequently, the addition to it of vinegar, or other acid, would not produce that effervescence necessary to constitute it a marl in accordance with the common test. What, in the states of New Jersey, Delaware, Maryland, and Virginia, is usually called green sand marl, instead of containing lime, abounds in potash. See GRvir SANi.

The calcareous marl found in the states named, generally contains more or less of the green sand; and this combination of lime and potash forms a natural fertilizing mixture, the value of which is scarcely yet appreciated as it deserves to be. Its great weight makes it an expensive application to land, wherever much hauling is required, and consequently it yields to burned lime under such circumstances. The admirable treatise upon the subject of "Calcareous Manures," by E. Ruffin, of Virginia, has been extensively circulated throughout the United States, and may be referred to as containing the most useful body of information upon the subject of marl ever brought together, embracing every detail in relation to lifting, transporting, application, and effects, that can be desired by the farmer or genera? reader. See Mixture of Soils, Inimf, Chalk, Earths, \&c. MARRAM. One of the common names of the sea mat-weed or sea-reed (Arundo arenaria). See ReEn.

MARSH (Sax. menrc, a fen). A flat surface, the soil of which is so far saturated with water throughout the year as to be unfit for culture by the spade or plough; but not so much as to prevent it from producing coarse grasses, and other kinds of herbage. Marshes are generally situated in bottoms, where they are kept moist by the water which descends from the surrounding lands; or along the banks of rivers or lakes, where their humidity arises from their being nearly on the same level with the adjoining water. Where a marsh is situated so as to be occasionally overflowed by the sea, or by a river, up which the tide flows, it is called a salt marsh; and the herbage produced by such lands is found highly conducive to the health of animals which pasture on them for a certain portion of the year, from the alterative effect of its saline properties.

Salt marshes abound along the shores of the bays and inlets of the Atlantic coast of the United States. The natural grasses which grow so luxuriantly are extensively mown, and furnish an inferior, and generally a coarse description of hay, which, however, is much relished by cattle in consequence of its saltness. It furnishes excellent litter, and thus contributes greatly to swell the manure-heap. On the Delaware bay it sells for about $\$ 2$ to $\$ 4$ per ton.

Salt marshes are often reclaimed by em. bankments, which keep off the tide-water. The best mode of managing land thus reclaimed, is well worth knowing; and the following directions from Mr. T. F. Lambson, of Salem, New Jersey, contain valuable information, the result of much experience and expense:- "1st. The marsh should be secured from the tide by a permanent bank. 2d. A sluice or sluices of sufficient capacity must be laid to discharge the rain-water and back-waters which pro ceed from adjacent uplands, so that at no time the water-courses and ditches will be filled to overflowing. 'The sluices should be laid deep enough to draw the water through them from the lowest part of the marsh : great care should be taken to have the doors made tight, so as 11

$3 \mathrm{X} \quad 793$ 
exclude all the tide-water possible. The watercourses and drains should intersect each other at right angles, and no lot of marsh should contain more than 10 acres. If any rain-water should lay upon the middle of these lots, it will be necessary to cut small drains, to let it pass off freely; these might be covered where the materials are at hand. The mud and earth which come out of water-courses and ditches should be removed in to the lowest part of the marsh; by a neglect of this, the rain-water will be confined too long upon the surface, and the most luxuriant growth of timothy or clover may in a short time be converted into a nursery of rushes.

"The best time to sow down in grass, is when the tide is first shut off, and when the mud is soft; a growth of coarse grass will spring up sufficient to protect the fine grass in its tender state; this crop should be mown off, and not suffered to lodge upon the marsh. 'Timothy and herds-grass require about 1 bushel to sow 4 acres. 'The former will flourish where the water can be kept $2 \frac{1}{2}$ or 3 feet from the surface; where it approaches nearer than this in the ditches, the latter will succeed best: in order to avoid having it sown in rows, it should he sown a second time across the first sowing. It is not advisable to mow longer than $\mathbf{3}$ years in succession; to mow and pasture alternately is the better plan. If the high marsh becomes bound and unproductive, ploughing will be necessary; and after raising 2 or 3 crops of rye, Indian corn, or broom corn, without the application of any manure, the soil will be quite renovated, and when sown down in grass will be much more productive. When the earthy deposit is several feet in depth, it will not soon become exhausted; when it is not desirable to plough, lime may be used with success. Low marsh, or turf, or, as we term it here, "horse-dung" mud, should not be ploughed; when it becomes unproductive, a covering of clay or loam, to the depth of $\mathbf{2}$ or 3 inches, will be found the cheapest application." See Bog, Wastre Layn, Peat Sorls, Grass Layos, Irrigation, and Meanow.

MARSH-LANDERS. A term provincially applied in England to neat cattle of the shorthorned breed, or such as are bred on lands of the marsh kind.

MARSH-MALLOW (Althea, derived from altheo, to cure; from the medicinal qualities of some of the species). 'This is a genus of tall, free-flowering plants: the biennial and annual kinds should be sown in the open border in spring, and transplanted when sufficiently sirong. The herbaceous kinds may be increased by dividing the roots or by seeds. $A$. rosea, the parent of the many beautiful varieties of holly-hock, yields a blue colouring matter equal to indigo. (Paxton's Bot. Dic.)

The common marsh-mallow (A. officinalis) is in. England an indigenous perennial, growing abundantly in marshes, especially towards the sea. 'The root is perennial, tap-shaped, rather wosdy. The herbage of a hoary green, peculiarly soft and downy, with a fine starry pubescence. Stems several, about a yard high, imple, round, leafy, tough, and pliant. Leaves 794 ovate or heart-shaped at the base, various in breadth, soft and pliable, slightly five-lobed. Flowers (which blow from July to September) in very short, dense, axillary panicles, rarely solitary, of a delicate uniform blush-colour, not inelegant. Bees are very fond of its mellife rous flowers. The whole plant, especially the root, yields in decoction a plentiful, tasteless, colourless mucilage, besides a fatty oil, uncrystallizable sugar, starch, and phosphate of lime. It is emollient, and salutary in cases of internal irritation. A syrup made with the root, as well as the decoction, is an officinal preparation of the Pharmacopœias. It is used in the coughs of children. See Mallow.

MARSH-MARIGOLD (Callha, a synonyme of kalathos, a goblet; in allusion to the likeness of the form of the carolla to a golden cup). The species of this genus are showy, and $\mathrm{dn}$ best in a moist situation, but will grow and flower in a common border. They may be increased by seeds or divisions. 'The British indigenous species are two in number, viz.:-

1. The common marsh-marigold (C.palustris), which grows in marshy meadows, and about the margins of ponds, rivers, and brooks, almost everywhere. It is perennial in habit, blowing in March and April. The root is thick and somewhat tuberous, with many simple fibres. Stem 12 or 18 inches high, round, hollow, leafy, branched, furrowed. Leaves variously heart-shaped, rounded. Flowers from 3 to 5, large, bright yellow, on alternate solitary stalks. The flower-buds pickled serve for capers, which they resemble, except in having numerous germens. A double variety is frequent in gardens.

2. Creeping marsh-marigold (C. radicans). This species is found by the sides of lakes and rivulets in Scotland, and is scarcely half the size of the common C.palustris. A double variety of this is cultivated near London.

MARSH-MUD. This substance, which forms such an excellent manure, is not so well appreciated or so generally employed in the United States as it deserves to be. An intelligent correspondent of the Farmers' Register (for July, 1834) states, that he deems it more valuable than barn-yard manure, and that it never failed in any application he had made of it. He even prefers it to marl, because its effects are more quickly manifested, and, when readily accessible, much more improvement can be effected for the same money than by applying marl. He, however, confesses that the permanent advantages of marling are much greater, and thinks that marl and marsh-mud will both be improved by combination. This result may certainly be expected in most cases, but must depend much upon the prevailing constituents of the mud. The alluvial deposits found in marshes, must of course contain more or less of the ingredients of the soils of the neighbour. ing uplands. When these contain lime, mag. nesia, silex, iron, \&c., so will the marsh-mud. This is clearly shown in the following tabular statements, giving the results of Dr. Dana's chemical examinations of a few specimens of marsh-mud taken from the rocky coast of New England. 
and lips, in consequence of which it is broken into small pieces, mixed with the saliva, and thus adapted for deglutition as well as more easy digestion; although it is, perhaps, not more essential for the latter purpose than water. Leuchs and Schwan, two German physiologists, have, however, proved that saliva has the properly of changing starch into sugar; and it is a well-known fact that the process of digestion in the stomach converts starch into gum, and gradually into sugar. Mastication, in the animal economy, is so essential to the prosperity of the 'individual, that old horses, \&c., whose teeth are impaired, always require to have their food broken, chopped, or crushed for them. See Rumination.

MAT-GRASS, or HEATH MAT-WEED (Nardus stricta). An insignificant species of grass growing on barren, sandy, moist heaths and moors, in many parts of Britain. The root consists of numerous very strong, downy fibres. Stems and leaves furrowed, roughish with minute bristles, rigid, four or five inches high, remaining bleached through the winter. Spikes solitary, purplish, bristle-shaped, straight, of many slender flowers. Schrank celebrates this deep-rooted grass as a safe support to the hands of the Alpine botanist, in precipitous situations, though it renders his path very slippery. The hard and wiry foliage of the mat-grass is eaten by horses and goats, but disliked by cattle and sheep. This species is often a troublesome weed on arable lands and pastures, where it affords but coarse food to caltle. As it, however, forms large and thick tufts, which resist the action of the scythe, it may be usefully transplanted to loose, sandy lands, where its spreading, horizontal roots will tend to consolidate the soil, and increase the stratum of vegetable mould, for the reception of more useful plants.

MATH. An old term for crop; hence lattermath is the last mown crop of grass.

MATRIX. The womb, or place where any thing is generated or formed. In mineralogy, it implies the earth or stone in which the mineral is imbedded.

MATWEED, THE SEA. One of the names of the sea-reed (Arundo arenaria). See REED.

MAUDLIN-WORT. See Ox-Ey E Disy.

MAUL. A provincial word, variously applied to a beetle, a mallet, and the mallow, in different localities.

MAW-SKIN. A word used in some places to signify the stomach of the calf prepared for cheese-making. See Rrinet.

MAY-APPLE. An American plant, so called from its flowers being very abundant in the month of May. Its botanical name is Podophyllum peltatum, and it has also the common names of Wild Mandrake, and Hog Apple; the last name must be regarded as inappropriate, since hogs seldom, if ever, eat them. The plant grows very abundantly in all moist and shaded places in woods, almost from one end of the Union to the other. It has usually a simple stem, terminating in a single broad leaf, 4 to 6 inches in diameter, and deeply divided into 5 or 7 lubes. The root of the plant is biennial, and is frequently used as a medicine, being ancive both as an emetic and cathartic, when 7.96 taken in powder, in small quantities. The fruit consists of a single large, long, and flattish apple, yellow when mature, and varying in size from 1 to 3 or 4 inches long by 1 or 2 broad. The soft pulp contained within the rind has a very peculiar musky taste, which is relished by many persons. The fruit is by no means unwholesome, and has been introduced with the dessert, in which case the pulp may be squeezed into a wine-glass, and, with the addition of a little old Madeira and sugar, is said to be equal to the luscious golden granadilla of the tropics, a fruit which it greatly resembles in appearance. (Am.Farm. vol.14.)

MAY-DAY. The first day of May.

MAY TREE. See HAWTHORN.

MAY-WEED, THE SCENTLESS. See Corn Fevenfew.

MAY-WEED, 'THE STINKING, or MATHER. Called in Pennsylvania, Stinking Chamomile, Dog's Fennel, \&c. (Pl. 10,v.) It is frequent in the farm-yards, lanes, \&c., in the Middle States, and is a disagreeable foreign weed, now extensively naturalized. It is readily distinguished from the preceding by its fetid odor,-as well as by its botanical characters,on which it has been generically separated from Anthemis, by Cassini, Lessing, \&c. There are no native species in the United States.

MEAD (Dutch, meede). An agreeable vinous liquor made from honey. The use of this substance as one of the ingredients in drink is of very ancient date. When fermented, honeywater obtains the name of mead, which is, in fact, honey-wine: indeed the Germans call it by that name (Honig-wein). Mead is said to have been the principal beverage of the Britons before the use of malt liquor among them; and long after the introduction of the latter beverage, mead was a favourite drink. Under the name of metheglin, it was frequently alluded to by old writers. Mead formed the ancient, and for centuries the favourite beverage of the northern nations. It is frequently mentioned in Ossian. Dryden has a couplet :-

" $T$ " allay the strength and hardness of the wine, Let with old Bacchus new Metheglin join."

Queen Elizabeth was so fond of mead, as to have had it made every year for her. Her receipt for it has been preserved, and is given by Dr. Bevan, in his interesting little volume on the Honey Bee:-Take of sweet-briar leaves and thyme each one bushel, rosemary half a bushel, bay leaves one peck. Seethe these ingredients in a furnace full of water (containing probably not less than 120 gallons). boil for half an hour: pour the whole into a vat, and when cooled to a proper temperature (about $75^{\circ}$ Fahr.), strain. Add to every six gallons of the strained liquor a gallon of fine honey, and work the mixture together for half an hour. Repeat the stirring occasionally for two days; then boil the liquor afresh, skim it till it becomes clear, and return it to the vat to cool: when reduced to a proper temperature, pour it into a vessel from which fresh ale or beer has just been emptied; work it for three days and turn. When fit to be stopped down, tie up a bag of beaten cloves and mace (about half an ounce of each), and suspend it in the liquor from the bung-hole. When it has stood 
for half a year, it will be fil for use. Such was the receipt.

In Wales, in ancient times, mead was held in very high repute; as appears from an ancient law, which has been given by Dr. Bevan, that"There are three things in court which must be communicated to the king before they are made known to any other person: 1st, every sentence of the judge; 2 d, every new song; $3 d$, every cask of mead." The mead-maker was the eleventh person in dignity at court, and took precedence of the physician. Besides the preparation of mead, our forefathers were accustomed to flavour their usual grape wines with honey and other ingredients. There were two kinds of spiced wines in use in England in the thirteenth century, called Hippocras and Clary. The first consisted either of white or red wine, and the latter of claret, both mingled with honey and spices. Dr. Henderson, in his History of Wines, speaks of a receipt still existing, which gives directions how "to make ypocrasse for lords with gynger, synamon, and graynes, sugour, and turesoll ; and for comyn pepull, gynger, canell, longe peper, and claryffyed honey:" Mead formed the nectar of the Scandinavian nations, and was celebrated by their bards: it was the drink which they expected to quaff in heaven out of the skulls of their enemies; and was, as might be expected, liberally patronized on earth. The Scandinavian mead is flavoured with primrose blossoms. (Penny Magazine.)

MEADOW. A field under grass cultivation, generally situated on the banks of a river or lake; but so far above the surface of the water as to be considerably drier than marsh land, and, consequently, producing grass and herbage of a superior quality. The soil of meadow lands is generally alluvial, and more or less mixed with sand; and it is kept in a state of fertility by the depositions made on its surface, in consequence of being occasionally cuerflowed by the adjoining waters. The produce of meadows is generally made into hay, which, though not equal in quality to that produced on drier grass lands, is yet superior to what is obtained from marshes. See Gnass, Hay, Irrigation, and Marsh.

In England some meadows of great extent, belonging to a community or district in which every inhabitant has a right to send his cattle to graze under certain regulations, are never mown. When the number of those who have a right of common pasture is not very great, they frequently agree among themselves to abstain from depasturing the meadows in spring, and, dividing them into portions, each makes hay of his share; after which the cattle are admitted in common for the remainder of the season. Thus a common meadow is conrerted into a Lammas meadow, that is, a meadow which becomes a common meadow after the 1st of August, this being the time when it is supposed that all the hay has been made and secured.

Low alluvial land, or that which can be :rrigated at pleasure, is usually left for the scythe, either from its productiveness from the rich deposits which are periodically laid upon it, or from its being too wet for cattle to graze on it in winter without poaching the surface. In a proper rotation system, upland is also occasionally devoted to the production of grass for the scythe. In upland situations meadows are either alternately mown and pastured, or broken up for nats or wheat, after they have yielded a crop of hay, and been grazed during the preceding year. The practice of leaving young leys in pasture one year after the first mowing, and then ploughing them up, is very general in England and Ireland. Grass land kept constantly for meadow, ought never to be depastured except in dry weather, as the breaking of the surface by the feet of the cattle, not only injures the grasses of the sward, but, by causing the stagnation of the water in holes, promotes the growth of rushes and other coarse aquatic plants, besides killing the finer grasses, and rendering the surface uneven for the scythe. A dressing of sand, even of the worst kind, and the use of calcareous manures, or salt, will be found excellent for coarse, rushy meadows, by tending to render the texture of the grasses finer; but as the rankness and inferiority of the herbage proceeds from a superabundance of 'water, draining will be found the most certain remedy, and effectual means of improvement. The meadows which are to be mown should be shut up early in spring, and those which are sc.ft and wet should have nothing larger than a sheep admitted into them from November till after hay-making time the next year.

Of late years the practice of soiling has been extensively adopted. By this means all the advantages of mowing for hay are obtain. ed, besides an abundant supply of rich manure, which can be applied to the land in a liquid and diluted state, when its effect is powerful and certain. So much more fodder is produced from the land by the system of soiling, that arable fields are converted into artificial and temporary meadows, in which the different spe. cies of grasses are sown, in order to be cut green or made into hay; and when, from the nature of the soil, the herbage degenerates, the field is ploughed up again, greatly improved by this change of cultivation.

When a natural meadow has been neglected, and the grass is of an inferior quality, and mixed with rank weeds and moss, it requires much care to restore it to its original fertility. In most cases (says a writer in the Penny Cyclopredia), the shortest method and the best is to plough it up, clean and manure it during a course of tillage, without taking very exhausting crops from it, and then to lay it down again, in a clean and enriched state, by suwing the best sort of grass-seeds; or, which is preferable, by inoculating or planting in it small tufts of grass from some rich meadow, which will soon increase, and produce a new and improved sward. But when the soil is a very stiff clay, with only a small depth of good mould over it, there is some danger in breaking the old sward, for it will take a long time and much manure to reproduce a proper covering of sward. In this case it is a preferable practice to scarify the meadow, by means of instruments which do not go deep, but only tear up the surface. If this is done in early spring, when the ground is moist, and the whole surface is 
3rought to resemble a fallow field, good grassseed may be immediately sown. If rich manure, mixed with lime or chalk, is then evenly spread over the land, and the whole well harrowed and rolled, the old and young grass will spring up together, and show a wonderful improvement in a very few months. Great Britain and Ireland are reputed to possess the most verdant pastures and the finest natural grasses in the vegetable creation.

In extent of meadow and pasture-land, as well as in flocks, Great Britain and Ireland (says a French statistical account) are the most favoured countries in Europe. They contain 5572 square leagues (more than twothirds of their territory), in meadow and pastureland. Germany comes next, having one-quarter of its surface in this description of land. Prussia, Holland, and Belgium have a fifth; Austria and Switzerland a sixth. France does not reckon in this respect more than a seventh part, namely, 4000 square leagues. Italy, Naples, Sicily, and Portugal have only a tenth.

MEADOW FOXTaIL. See Alopecurus and Grass.

MEADOW-GRASS. See Pos, Сочсн, HoLcus, and Grasses.

MEADOW OAT-GRASS. See Avena.

MEADOW-SAFFRON (Colchicum). An ornamental genus of bulbs, growing best in a light loamy soil, and increased by offsets, or from seeds. One species only is indigenous. See Cozchicum.

MEADOW-SWEET, or QUEEN OF THE MEADOWS (Spircea ulmaria). In England an indigenous perennial plant, growing in moist meadows, and about the banks of rivers and ditches; flowering in June and July. The root is fibrous, without knobs; the stems are herbaceous, 3 or 4 feet high, leafy, branched, furrowed, angular, smooth. Leaves interruptedly pinnate; downy beneath; the terminal leaflets largest, and lobed. Flowers extremely numerous, cream-coloured, with a sweet but oppressive, haw thorn-like scent, in dense, compound, cymose panicles, with many styles. 'T'he taste of the herbage, like the scent of the flowers, is aromatic, not unlike the flavour of orangeflower water. The distilled water is said to be used by wine merchants to improve the flavour of made wines. Hogs devour the roots with avidity; goats and sheep also relish the herb; but horses and cattle refuse it.

MEAL (Dutch, meel). The edible part of wheat, oats, rye, barley, and pulse of different kinds, ground into a species of coarse flour. See Frovr.

MEasures. See Weights and Measures.

MEA'T (Sax. mære, food). A general appellation for the flesh of animals when prepared for human food. See Beff, Bacon, Cattre, Mutton, Ponk, Sherp, Swine, \&c.

"In whatever manner meat is cooked," observes Mr. Donovan, "there is a considerable diminution of substance, the loss consisting chiefly of water, juices, soluble matter, and fat. In an economical point of view, a comparison of the loss incurred in the two most usually umployed processes, roasting and boiling, is interesting, yet it has not occupied the attention of the public so much as the importance of the 798 subject seems to demand. Professor Wallace, of Edinburgh, has given us the results of some experiments made to determine the loss which meat undergoes in cooking. It is to be regretted that it is not more in detail, and that the weight of the bone in each joint was not ascertained; but still it is of great value. The results, reduced to 100 pounds of meat, are as follows :-

100 lbs, of beef lost in boiling $100 \mathrm{lbs}$. of beef lost in roasting $100 \mathrm{lbs}$. of beef lost in roasting - $\quad-\quad-\quad-32$ $100 \mathrm{lbs}$. of legs of mutton, averaging about $9 \frac{1}{2} \mathrm{lbs}$. each, lost in boiling - - - - each, lost in roasting - - - $100 \mathrm{lbs}$ of loins of mutton, averaging $8 \mathrm{lbs} .12 \mathrm{oz}$. each, lost in roasting - - $100 \mathrm{lbs}$. of necks of mutton, averaging $10 \mathrm{lbs}$. each,
lost in roasting Thus, the loss in boiling beef or mutton was less than in roasting. And it appears that meat loses by the cooking about one-fifth to one-third. A few years since, I undertook the superintendence of some experiments of the same tendency, with the view of inserting the results in this volume. These trials were made on several parts of the different animals, with as much attention to accuracy as the nature of the subject permitted. They were made on different qualities of the same kind of meat, at various seasons, both in England and Ireland. Such experiments are exceedingly troublesome, and occasion no small inconvenience; it is, therefore, the less surprising that the subject has been so little investigated; and the following results, in the absence of any others so particularly detailed, will, perhaps, prove interesting. Allowance must be made for the nature of such processes, as the difficulty of fixing an average price of meat, fish, and poultry, owing to variations occasioned by the supply and the season, the want of uniformity in the prices of the city, and by the exorbitant demands of some vendors of these articles. The degree of fatness was in all cases brought to a standard by cutting off all excess, and leaving the meat in a proper state for housekeepers' use. The meat was in all cases cooked as nearly as possible to the same degree, and the weights were determined with exactness; avoirdupois weight throughout is intended. The bones were entirely stripped of their meat previously to their being weighed. The only cost taken into account is that of meat, leaving out fuel, \&c.

"Experiment 1.-A piece of beef, roasted. It consisted of four of the largest ribs, and was not remarkably fat: its weight was $11 \frac{1}{18}$ lbs. During the process of roasting it lost $2 \mathrm{lbs}$ $6 \mathrm{oz}$., of which $10 \mathrm{oz}$. were fat, and $28 \mathrm{oz}$. were water dissipated by evaporation. When the meat was dissected off with the utmost care, the bones weighed $16 \mathrm{oz}$. Hence, the weight of meat, properly roasted and fit for the table, was but $7 \mathrm{lbs} .11 \mathrm{oz}$., out of $11 \frac{1}{\mathrm{i}} \mathrm{lbs}$. originally submitted to experiment. This beef would cost in London $8 \frac{1}{2} d$. per lb. The roasted beef cost, therefore, $12 ! d$. per pound. In another trial, a piece of beef of the same description, the tops of the ribs having been rejected with their meal, was submitted to the same mode of trial: the weight of bone in $10 \mathrm{l}$ lbs. was $16 \mathrm{oz}$, and 
the fat $11 \mathrm{oz}$, which agrees with the former estimate."

Other parts of mutton, submitted to similar tests, gave the following results.

"Experiment 17.-A leg of mutton, weighing $9 \neq \mathrm{lbs}$, when boiled gave $1 \mathrm{lb}$. of bone, shank inciuded; it lost in the boiling $1 \mathrm{lb} .2 \mathrm{oz}$.: the meat weighed 7 lbs. $2 \mathrm{oz}$. If the butcher's price was $8 d$. per 1 b., the meat cost about $101 d$. per lb.

"Experiment 18.-A similar"leg, weighing 9 lbs. $6 \mathrm{oz}$, afforded $15 \mathrm{oz}$. of bone, and lost $12 \mathrm{oz}$. in the boiling: the meat weighed $7 \mathrm{lbs} .11 \mathrm{oz}$. At $8 d$. per lb. butcher's price, the boiled meat would cost $9 \frac{3}{4} d$. per $1 \mathrm{~b}$.

"Experiment 19.-A leg of small Scotch mutton, weighing 6 lbs., afforded $10 \frac{1}{2} \mathrm{oz}$. of bone, lost $5 \frac{1}{2} \mathrm{oz}$. in the boiling, and the meat weighed 5 lbs.: cost $9 \frac{1}{2} d$. per lb., if butcher's price be $8 d$."

The following are miscellaneous :-

"Experiment 28. - A fore-quarter of lamb, weighing 9 lbs., afforded, when roasted, $20 \mathrm{oz}$. of bone, and lost $1 \frac{3}{4} \mathrm{lb}$. in the roasting: the meat weighed $6 \mathrm{lbs}$. If the butcher's price be $8 \frac{1}{2} d$. per lb., the roasted lamb costs $12 \frac{2}{3} d$. per $1 b$.

"Experiment 31.-A hand of salt pork weighing 4 lbs. $5 \mathrm{oz}$, lost in boiling $11 \mathrm{oz}$. The bone weighed $9 \mathrm{nz}$ : : the meat was $8 \mathrm{lbs} .1 \mathrm{oz}$. If the first cost of the pork was $7 \frac{1}{2} d$. per lb., the meat, when duly boiled, cost $10 \frac{1}{4} d$. per $1 \mathrm{~b}$.

"Experiment 34.-A knuckle of veal weighing 6 lbs., when duly boiled, lost half a pound. Its bones, perfectly cleared of meat, weighed 2 lbs. $6 \mathrm{oz}$; the meat weighed $3 \mathrm{lbs} .2 \mathrm{oz}$. Hence, if the butcher's price was $5 \frac{1}{2} d$., the boiled meat :ost $10 \frac{1}{2} d$. per lb.

"Experiment 35.-A goose properly trussed, weighed $4 \frac{1}{2}$ lbs.: in this state it was roasted, and, when sufficiently done, was found to have lost $18 \mathrm{oz}$. The skeleton weighed $12 \mathrm{oz}$ : : the meat weighed 3 lbs. This goose would cost, in London, $4 s, 6 d$. Hence the roasted meat amounted to $1 s, 8 \frac{1}{2} d$. per $\mathrm{lb}$.

"Experiment 41.-A turkey, with its liver and gizzard, weighing 4 lbs. $14 \mathrm{oz}$., was boiled: it lost $12 \mathrm{oz}$. 'The skeleton weighed $13 \frac{1}{2} \mathrm{oz}$; the meat, $3 \mathrm{lhs} .4 \frac{1}{2} \mathrm{oz}$. If this turkey cost $3 s .6 d$., the boiled meat amounted to $1 s$. 1d. per lb.

"Experiment 43.-A young duck, weighing $20 \mathrm{oz}$., lost $5 \frac{3}{4} \mathrm{oz}$. in roasting. Its bones weighed $2_{T^{1}}^{1}$ oz.: the meat was $12 \frac{1}{4} \mathrm{oz}$. It cost $2 s$. 6d.: hence the flesh amounted to $3 s_{\text {. }} 3 \frac{1}{2} d$. per $1 \mathrm{~b}$.

"Experiment 46.-A fowl, with its liver and gizzard, weighing $1 \frac{1}{2} \mathrm{lb}$, was roasted. It lost $3 \mathrm{oz}$.: the skeleton weighed $4 \frac{1}{2} \mathrm{oz}$., and the flesh $16 \frac{1}{2} \mathrm{oz}$. If such a fowl cost $2 s .6 \mathrm{~d}$., its meat, when roasted, would cost $2 s .4 \frac{3}{4} d$. per $1 b$.

"Experiment 47.-A chicken, weighing $1 \mathrm{lb}$. $4 \frac{1}{2} \mathrm{oz}$., when roasted lost $3 \frac{1}{2} \mathrm{oz}$. The bones weighed $3 \mathrm{oz}$, the flesh, $13 \frac{1}{2} \mathrm{oz}$. If the chicken cost $2 s$. $4 d$, the meat, roasted, was worth $2 s$. Sd. per lb.

"Expcriment 56.-A fine mackerel, when trimmed, and ready for boiling, weighed $23 \frac{1}{4}$ oz. (including the weight of the roe, $2 \frac{1}{2} \mathrm{oz}$.) It const $10 \%$. It lost $1 \frac{3}{4} \mathrm{oz}$. in the boiling. The skeleton, carefully collected, along with gills, fins, and tail, weighed $4 \frac{1}{4} \mathrm{oz}$. Hence, the cost of the eatable parts of the boiled fish was $9 \frac{1}{3} d$. per lb."

It will now be necessary to collect the results of all these experiments into a kind of conspectus, for the sake of inore easy comparison: and it is to be understond, that, in the following estimates, when the butcher's price is mentioned, it of course comprises meat and bone in the usual manner. But, when the ultimate cost of the cooked meat is specifiod, il refers to the price cost of the meat only, the bone bring considered valueless: and it is suppored that the fatness of the meat was such as good rneat is expected to have, without any redunlancy being left on it. From an average of tive ex. periments, it appears that, when the butcher's price of ribs of beef is $8 \frac{1}{2} d$. per lb., the cost of the meat, when duly roasted and fit for the table, is $11 \frac{1}{2} d$. per $1 \mathrm{~b}$., and that the average loss of weight arising from the liquefaction of the fat, and the evaporation of water from the juices, is 18 per cent. From an average of six experiments, it appears that, when the butcher's price of sirloins of beef is $8 \frac{1}{2} d$. per $1 \mathrm{~b}$., the cost of the meat, when duly roasted and fit for the table, is 1 s. $1 \frac{1}{6} d$. per $1 \mathrm{~b}$., and that the average weight lost during the roasting is $20 \frac{1}{3}$ per cent. From an average of other experiments, it ap. pears that when the butcher's price of salted brislrets of beef is $6 d$. per lb., the cost of the meat, when duly boiled and fit for the table, is $8 \frac{1}{2} d$. per lb., and the loss incurred in boiling, arising from the extraction of fat and juices, is 18 per cent. From an average of two experiments, it appears that when the butcher's price of salted flanks of beef is $6 d$. per lb., the cost of the meat, when duly boiled, is $7 \frac{3}{4} d$. per lb., and the loss in boiling is $13 !$ per cent. From another experiment, it appears that, when the butcher's price of salted tail ends of beef is $7 d$. per $1 \mathrm{~b}$., the cost of the meat, when duly boiled, is $8 \frac{1}{2} d$. per lb., and the loss in boiling is $13 \frac{7}{1}$ per cent. From an average of experiments $1 \%$, 18,19 , and 2 others, it appears that, when the butcher's price of legs of mutton is $8 d$. per lb., the cost of the meat, when duly boiled and fit for the table, is $10 d$. per $1 \mathrm{~b}$., and that the average weight lost during the boiling is 10 per cent. From an average of two experiments it appears that, when the butcher's price of legs of mutton is $8 d$. per $1 \mathrm{~b}$., the cost of the meat, when duly roasted, is $1 \mathrm{~s}$. per $\mathrm{lb}$., and the loss incurred by roasting is $27 \frac{7}{10}$ per cent. From an average of two experiments, it appears that, when the butcher's price of shoulders of mutton is $7 d$. per $1 \mathrm{~b}$., the cost of the meat, duly roasted, is $11 \%$. per $1 \mathrm{~b}$, and the loss incurred by roasting is 28 per cent. From an average of experiments it appears that, when the butcher's price of the fore-quarter of lamb is $8 \frac{1}{2} d$. per lb., the cost of the meat, duly roasied, is $1 s .1 \frac{1}{4} d$. per $1 \mathrm{~b}$., and the loss by roasting is $22 \frac{1}{4}$ per cent. From experiment 30 , it appears that, if the first cost of hams be $10 d$. per lb., the meat, duly boiled, skinned, and browned, will amount to 1 s. $1 \frac{1}{3} d$. per 1 b., and the luss by boiling is $12 \frac{1}{2}$ per cent. From experiments 31 and 32 , it appears that, when the hand and leg of salt pork average $8 \%$. per $1 \mathrm{~h}$., the boiled meat amounts to $10 \frac{2}{3} \pi$. per $1 \mathrm{~b}$., and the loss in boiling is $13 \frac{1}{3}$ per cent. From an experiment it appears that, if the first cost of bacnn is $8 \%$. per lb., the meat, when duly boile I, slinned, and browned, amounts to 10 id per tho, the los* 
in boiling alone being $6 \frac{1}{4}$ per cent. From experiment 34 , it appears that, when the butcher's price of knuckle of veal is $5 \frac{1}{2} d$. per $\mathrm{lb}$., the meat, duly boiled, costs $10 \frac{1}{2} d$. per lb., the loss in boiling being $8 \frac{1}{3}$ per cent. From an average of experiments $35,36,37$, it appears that, at the prices of geese quoted, which average $12 \frac{1}{2} d$. per lb. for the raw flesh, the cost of the roasted flesh is $1 s .7 d$. per lb., and the loss per cent $19 \frac{1}{2}$. From an average of three experiments, it appears that, at the prices of turkeys quoted, which average $10 d$. per $1 b$, the cost of the roasted flesh is $1 s .2 \frac{1}{2} d$. per lb., and the loss per cent is $20 \frac{1}{2}$. From an average of experiments 41 and 42 , it appears that, when turkeys are sold at the last-mentioned price, the cost of the boiled flesh is 1 s. $1 \frac{1}{9} d$. per $1 b$, and the loss per cent is 16. It appears also, that the roasted flesh of turkeys sometimes amounts to $4 s .2 d$. per Ib. From experiments 43,44 , and 45 , it appears that, at the prices of ducks quoted, which average $1 s$. $1 \frac{1}{2} d$. per $l b$. in the raw state, the cost of the roasted flesh is $2 s .8 \%$. per 1 b., and the loss per cent. is $27 !$. From experiments 46,47 , and 48 , it appears that, at the prices of chickens quoted, which average $1 s .6 \frac{1}{2} l_{0}$ per $1 \mathrm{~b}$. in the raw state, the roasted flesh amounts to $2 s .7 d$. per lb., and the loss per cent. is $14 \frac{3}{8}$. From an average of six experiments, it appears that, at the prices of chickens last quoted, the average cost of the boiled flesh is $2 s$. $8 d$. per $1 b$. and the average loss is $13 \frac{1}{2}$ per cent. From an experiment it appears, that, when turbot in the raw state is sold at $9 \frac{1}{3} d$. per lb., the boiled fish costs $11 \frac{1}{2} d$. per lb.; the loss in boiling is $5 \frac{5}{9}$ per eent. From experiment 56, it appears that, when mackerel sells in the raw state at $6 \frac{3}{4} d$. per $1 \mathrm{~b}$, the boiled fish costs $9 \frac{1}{2} d$. per. lb., the loss in boiling being $7 \frac{1}{2}$ per cent. From an experiment, it appears that the roasted flesh of a woodcock sometimes costs $16 s$. per lb., and sometimes 2s. But the flesh of the quail is still more expensive. This bird, when fattened, is sold at the enormous price of $3 s$. ; and, when allowance is made for the loss in cooking

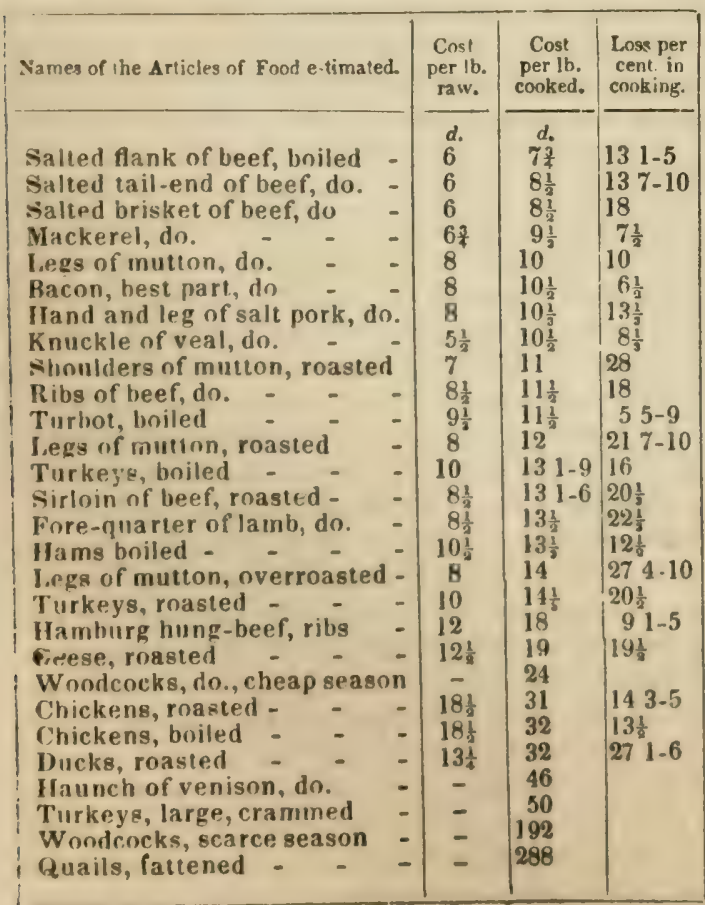

and the bones, the meat may be estimated as $2 \mathrm{oz}$, which brings the cost of the cooked flesh to $1 l .4 s$. per lb.! Those to whom such morsels are necessary are not to be envied. A haunch of venison, weighing $26 \mathrm{lbs}$., will cost $3 \frac{1}{2}$ guineas. The meat of this, when roasted and detached from the bone, will amount to about $3 s .10 d$. per $1 \mathrm{~b}$.; and if the animal was more than usually fat, to $4 s$. The foregoing table gives the results in a still more abstract form; but the prices apply to London only. The articles are arranged in the order of their costliness in the London market.

It appears from the experiments, that

The loss per cent. on roasting beef, viz. sirloins and ribs together, is

Do. on roasting mutton, viz. legs and shoulders together, is

is $-24 \frac{4}{5}$

Do. on roasting lamb, viz. the fore-quarter, is - 22,

Do. on roasting turkeys, is - - - - 20 -

Do. on roasting ducks, is - _ - _ - $27 \frac{1}{6}$

Do. on roasting chickens, is - - - - $14 \frac{3}{5}$

Thus, the loss on roasting varies from $14 \frac{3}{5}$ to nearly double that rate. The average loss on roasting butchers' meat is 22 per cent., and on roasting domestic poultry is $20 \frac{1}{2}$.

The loss per cent. on boiling mutton, viz. legs, is - 10 Do. on boiling hams, is - - - - - 12

Do. on boiling salt beef, is - - - - 15

Do. on boiling salt pork, is - - - - 131

Do. on borling bacon, is - - - : - $-6 \frac{1}{3}$

Do. nn boiling knuckles of veal, is : - $\quad-\quad 83$

Do. on boiling chickens, is - - _ - 13난

Thus, the loss on boiling varies from $6 \frac{1}{4}$ to 16. The average loss on boiling butchers' meat, pork, hams, and bacon, is 12 , and on boiling domestic poultry is $14 \frac{3}{4}$. These estimates of butchers' meat do not agree with those of Professor Wallace. I shall select for contrast all those cases that can be compared.

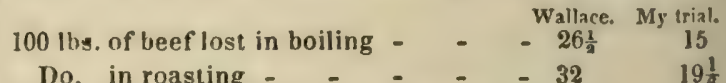

$100 \mathrm{lbs}$. of legs of mutton lost in boiling - $21 \frac{1}{3} \quad 10$ 100 ibs. of shoulders of mutton lost in roasting

The average loss in boiling and roasting together is, according to Professor Wallace, 28 per cent.; according to my trials, it is but 18 . I know not how to reconcile these results otherwise than by supposing a difference in the meat, or its fatness, or in the duration of the heat. I used meat of sufficient, but not unprofitable fatness, such as is preferred in families; the meat was in all cases a little rare at its centre, and the results were determined with the utmost care. In great public institutions, where economy is studied, and every thing is regulated by weight and measure, tables of this kind do not afford a guide that is to be implicitly relied on. It is obvious that another element must be taken into the calcu. lation, to insure true results; the ratio in which each article of food satisfies the appetite, which varies with almost every individual.

Butchers' meat, taking one kind with another, averages 35 per cent. of real nutritive matter; at least, such was the estimate presented by MM. Vauquelin and Percy to the French minister of the interior. Adopting this determination, we are prepared to appreciate the 
quantity of real nutritive matter received into the stomach, when a meal of plain meat and vegetables has been eaten : it is not practicable to come to any conclusion when made dishes are used. It is a subject of interest, and particularly so to the inhabitants of the British Isles, who are said by foreigners to make use of more animal food than is necessary or wholesome.

In order, then, to equalize the animal and vegetable matter, and to increase the total quantity, the ratio should be $8 \frac{1}{2} \mathrm{oz}$. of boiled mutton, $10 \mathrm{oz}$. of potato, and the same of turnip; the total amount of food swallowed will be $28 \frac{1}{2} \mathrm{oz}$., but the quantity of real nutriment will be but $6 \mathrm{oz}$, half being animal and half vegetable matter. 'This is certainly a sufficient meal for most persons who have but little laborious occupation; for, if a pint of liquid be drunk at the same time, the load on the stomach will weigh $3 \mathrm{lb}$; and this will be increased to $4 \frac{1}{4} \mathrm{lb}$. if a pint of wine be swallowed. Now, the difference between $8 \frac{1}{2} \mathrm{oz}$. of boiled meat and $10 \mathrm{oz}$. appears very trivial; but, if the greater of the two quantities be persevered in regularly every day for the term of a man's adult life of half a century, it may excite a little surprise in the person who practises it, to learn that he will have consumed a flock of sheep, consisting of about fifty-three head, in excess above what he ought to have made use of. In a life of sixty-five years, allowing $8 \frac{1}{2} \mathrm{oz}$. per day for fifty years, two-thirds of that quantity for ten years, and $3 \mathrm{oz}$. a day for three years of childhood, the total animal food amounts to 350 sheep. If to this be added the excess above mentioned, the number of sheep, the cooked meat of which is devoured by one man during a life of sixty-five years, is about 400 ; along with 5 tons of potatoes, about the same of turnips or other vegetables, 9 tons' weight of common drink, and 6 tons' weight of wine, at 1 pint per day for three years only: thus, for dinner alone, above 30 tons, weight of solids and liquids must have passed through the stomach. Inordinate work will wear out any machinery before its time, especially if the work performed be of a peculiar wearing character. Whether it is advisable to add the fifty-three unnecessary sheep to one's dinner, is a question which every reader will answer to himself as he thinks proper. The food of old Parr, who died at 153 years of age, consisted of cheese, coarse bread, milk, and small beer. Would it have made no difference in the duration of his life if he had swallowed 1050 sheep! for about this number would have been his share at the usual rate, along with his twenty tons of wine. It may assist in drawing a conclusion, to recollect that when he was brought to London, and lived in splendour, "fed high, and drank plentifully of the best wines," he soon died: and his death was generally attributed to that cause, for he had vigour of body "to have lived a good while longer," as the reporter says. (Lardner's Ency.)

1. Selection of Cattle and Beef.--In the selection of cattle to be sent alive to market, they should invariably possess fine symmetry and small bone, carrying the greatest weight of beef on the most valuable points, such as rumps, loins, and crops ; the back well covered, the buttocks and flanks well filled up, and the whole carcass exhibiting a fulness of flesh, ex. cepting the necks and coarser parts. They should handle hard and firm, in order to stand well the voyage, and handle and look well in the market. Firm handlers, whether heifers or oxen, always cut well up. A good coat of hair, too, is of great use in a sea-voyage on deck, and also in enabling cattle to stand the vicissitudes of weather in the markets, and it enables them to be turned out in safety, in case they should not be disposed of on the first market-day. Thin-coated cattle always look tender, and are, in fact, so under any circumstances. Cattle only possessing these requisite properties should be sent to Smithfield market, and any others will assuredly incur loss to the shipper. An ox or heifer of these properties, weighing 80 stones per Smithficld stone of $8 \mathrm{lbs}$., will actually realize more money than a coarse ox or heifer weighing 100 sinnes. Heavy cattle, however, do not take readily in Smithfield, except for a month about Christmas, unless they are remarkably handsome; nor do very light cattle, under 40 stones, for two or three months in summer, unless they are really neatly shaped, and thick on the backs and best points. The most saleable weights are from 50 stones to 55 stones. Of the Scotish breeds, the Galloway and West Highlanders fetch generally the top price; fine Angus and Aberdeenshires, of fine points and thick backs, take well; and handsome, wellbred short horns also take re.tdily, but do not realize so much money as Galıvways or West Highlanders. Fine crosses are also very saleable.

The meat intended to be sent to the carcass market in London should be taken from such cattle as we have described. It is not large quantities of lean and fat that are wanted there, but both well mixed. $\mathrm{O}_{\mathrm{x}}$ and heifer beef of equal quality command the sarne prices. Rumps, loins, crops, and other fine parts fitted for roasting and steaks, are mort in demand than the boiling pieces, and realize comparatively higher prices, and therefore they alone should be sent. Coarse beef always fetches low prices in London, and therefore should be purchased (to use a sporting phrase) at a low figure in the country to return any profit, for the best buyers look more to quality than quantity; and as this quality of beef is rather cheaper in London than in Scotland, ship. pers should be cautious in sending any such thither.

2. Selection of Sheep and Mutton.-Ripe, compact sheep, of light weights, carrying a large proportion of lean on the back, loins, and shoulder, with o. full round leg and handsome carcass, are admirably suited for Smithfield. Such, from $14 \mathrm{lb}$. to $20 \mathrm{lb}$. per quarter, will take readily; but they are most valuable from $16 \mathrm{lb}$. to $18 \mathrm{lb}$. The nearer the form and quality approach those of South Downs, the more likely are they to command the top prices; for the Downs have long been unrivalled favourites in Smithfield. True bred Cheviots and the black-faced Linton breed approach nearly ic the qualities of the South Downs, and c(ous 
mand as high a price. Half-breeds from Leicester rams and Cheviot and black-faced ewes, which resemble the true breeds in form and quality, form saleable sheep in London. The old black-faced breed are too thin in the leg and back, and are in London termed "goaty." There are by far too many of this kind sent from Scotland, and they are generally, besides, only half-meated, or half-fat, and of course only fetch middling prices. They, however, gene. rally please the consumer for flavour. Pure bred Leicesters are too fat, unless they are sent young, and do not exceed $20 \mathrm{lb}$. per quarter; when above that weight they fetch inferior prices. A fine South Down or Scotch sheep, of $18 \mathrm{lb}$. per quarter, will fetch $7 d$. per lb. by the carcass, whereas a heavy Leicester, Gloucester, Lincoln, or Kent, of $24 \mathrm{lb}$. a quarter and upwards, will realize no more than $6 d$.

The carcasses of mutton to be sent to London should, of course, be those of sheep such as are here recommended to be sent alive. Large quantities of fat are not so desirable as a proportionable mixture of fat with the lean. In using the loins and other parts of very fat inutton for chops, much of it has to be pared away, and sold for the price of raw fat, perhaps $4 d$. a pound; whereas well-mixed chops

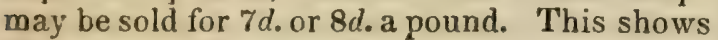
the nature of the mistake committed in sending fat, heavy mutton to London. The great point is, to select ripe mutton and sheep; for the la ter will stand the voyage better than half-fat, and will not lose half the quantity of flesh in three days as the latter. No overgrown animals, having masses of fat on one place and not on another, would therefore command the top price: but those having plump carcasses, well mixed with fat and lean, firmly and equally laid on, with fine symmetry and valuable points, will always command the top price, both at Smithfield and the carcass markets.

3. Selection of Lambs.-Lambs are a favourite stock to send to London, and they are always sent alive. Leicester lambs are admirably adapted for the London market. They are handsome, compact, thick on all the points, and although they might become too fat when grown to sheep, they cannot be too fat as lambs. Their flesh is white, a property much admired in London, and every joint of them looks well in the table. The lambs of the cross between the Leicester and the Cheviot and black-faced ewes are next best for fat and lean, and cut well into joints, although they have not the handsome figures of the pure Leicester. True Cheviot and black-faced lambs, unless very fat, do not take so well in Smithfield, not being so compact, taking longer time to come to malurity, not cutting up so thick, and presenting small joints on the table; but they make very delicate and high-flavoured chops. No lambs should be sent to Smithfield until they are at least three months old, and have obtained the weight of $9 \mathrm{lb}$. or $10 \mathrm{lb}$. a quarter; and if they are not fat enough, and have not attained that weight at that age, they should be kept on. Shippers may calculate on a loss of $1 \mathrm{lb}$. a zuarter on the voyage: unless, therefore, lamhs trom $9 \mathrm{lb}$. to $10 \mathrm{lb}$. a quarter, they would be .802 too small after that loss, and they then becom. unsaleable except at low prices. Ewe lambs are preferred, being more delicate than wethers, which are next in value, for ram lambs are very ansaleable. All wether lambs, therefore, intended for Smithfield, should be castrated when a few days old, and their tails cut short, leaving not more than three inches. The docking gives them a very compact form, and it causes the flesh to grow up towards the back, long tails giving a contrary tendency.

4. Selection of Pigs and Pork.-Much caution is requisite on the part of the shipper of pigs for London. A very mistaken notion prevails among many shippers, and the notion has been contracted in ignorance of the nature of the London market, that pigs must be fat to suit the English taste. The fact is quite the reverse, for the larger the pig is fattened, the less money per pound it fetches. Pigs are worth the most money when their weight ranges from $35 \mathrm{lb}$. to $40 \mathrm{lb}$; and from this weight up to $60 \mathrm{lb}$. or $70 \mathrm{lb}$, they are termed dairy-fed porkers. If at the former weight, they are of good symmetry, fine quality, delicate and white in the flesh, and not more than 1 inch or $1 \frac{1}{4}$ inch thick of fat on the back, they will fetch the top price of the day. Pigs of the average weight of $60 \mathrm{lb}$. will give about $7 d$. per $1 \mathrm{lb}$.; from $70 \mathrm{lb}$. to $100 \mathrm{lb}$., averaging $85 \mathrm{lb}$., and 2 inches thick of fat, $6 d$. per lb. ; from $100 \mathrm{lb}$. to $150 \mathrm{lb}$., averaging $130 \mathrm{lb}$., and about $2 \frac{1}{2}$ inches of fat, $5 d$. to $5 \frac{1}{4} d$. per lb.; from $150 \mathrm{lb}$. to $200 \mathrm{lb}$, averaging about $170 \mathrm{lb}$., and about 3 inches of fat, $4 d_{0}$ to $4 \frac{1}{2} d_{0}$ per lb.; and all above the last weight and thickness of fat, only about $3 \frac{1}{2} d$. per $1 b$. Besides the largesized, a very small fat pig is not relished in London. Indeed, we need not be surprised ai this preference, when we consider that only the small lean and fat porkers are used for roasting, chops, and pickled pork, and the large fat pigs are chopped down for sausages. No pigs, therefore, should be sent to London exceeding $100 \mathrm{lb}$., exclusive of head and feet, but which are only moderately fat and of fine quality; all other qualities should be cured as flitch, bacon, and hams. Pigs, if possible, should be sent alive to London. Occasionally they arrive in pretty good order in carcass; but in carcass, in thick weather, the flesh becomes very soft, and the skin dry; and in dry weather the skin becomes quite hard and brown coloured. Of equal qualities, the live pig will draw from a halfpenny to a penny a pound more than in carcass. Feeders of pigs should be careful on what they feed their pigs, especially fish. The retail butchers are such nice judges of pork, that on buying a carcass at Newgate or Leadenhall market, and cutting a slice, they can detect the least peculiarity in taste, which, if they do, they will return it again, and cause the carcass to be resold for what it will bring, rather than send any such pork to their customers.

Cutting up Meut.-The mode of cutting up meat is more diversified even than the slaughtering, almost every town having its own. But as London is the great emporium of the export meat trade of Scotland, the method of cutting up meat in the metropolis should constitute the particular study of the shippers of meat. 'I'n 
acquire this necessary information, the shippers should have a few of the most expert butchers in London to slaughter and cut up the carcasses of the various sorts of animals. They should never consider themselves above acquiring such information, when their own interest will be benefited by its adoption. Whether the London method of cutting up meat is really the best of any, and we think it ${ }_{\mathrm{s}} \mathrm{s}$, it must be admitted that the London butchers must have the most extensive and varied experience; and any one has only to witness the operation performed by expert London butchers to be satisfied that they display great skill in their art, and execute their work with the utmost precision. Indeed, the precision with which they divide the different qualities of meat from the same carcass shows their thorough knowledge of the qualities of meat; and the variety of prices which different parts of the same carcass fetch, shows with what accuracy they can gratify the tastes of the various grades of their customers.

In practising this precision, they not only make the best use of the carcass, but realize the highest value for it, and at the same time gratify the taste of the greatest number of cus-

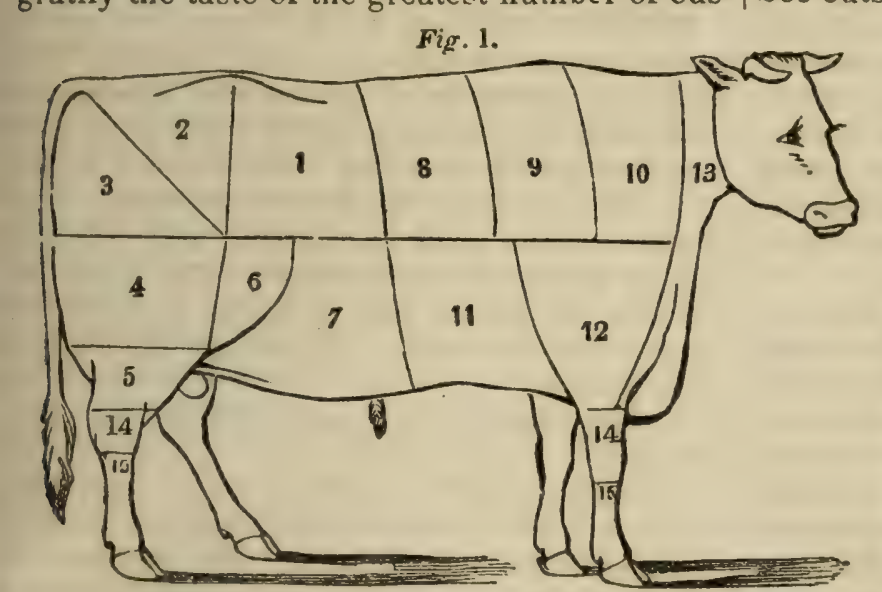

Hind-Quarter.

1. Loin.

2. Rump.

3. Itch or adze-bone

4. Buttock.

5. Inck

6. Thick flank.

7. Thin flank.

8. Fore-rib.

Fig. 2.

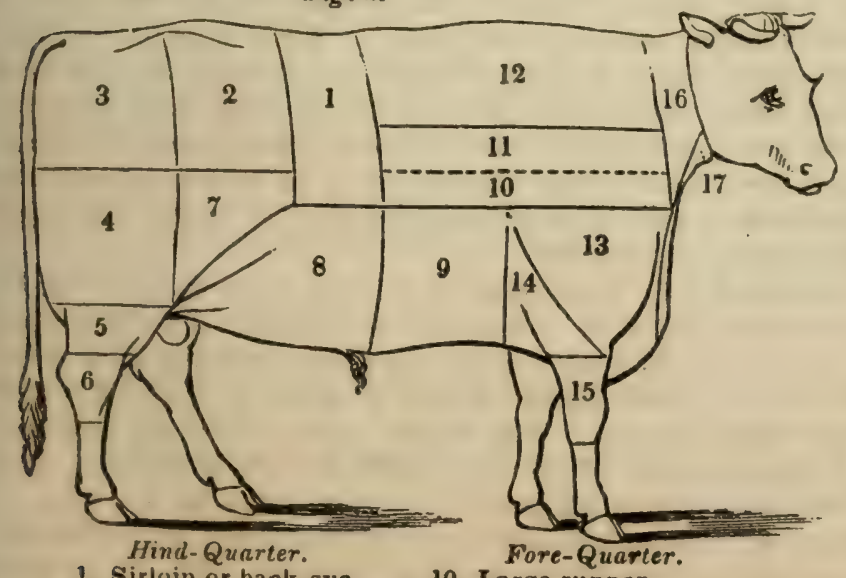

1. Sirloin or back-sye.

2. Hnck-bone.

3. 11. Small runner.

3. Butinck. Rump. 12. Snare-rib, or fore-sye.

4. Large round. Kamp. 13. Brisket.

$\begin{array}{ll}\text { 5. Smail round. 14. Shoulder lyer. } & \text { 15. Nap or shin. }\end{array}$

7. Thick flank

8. Thin flank.

9. Nine holes.
9. Middle-rib.

10. Chuck-rib.

11. Brisket.

12. Leg of mutton piece.

13. Clod and sticking and neck. 14. Shin.

15. Leg.

15. Nap or shin.

16. Neck.

17. Sticking piece. tomers. In the carcass of any animal, an ox. for instance, there are different qualities of meat, and these qualities are situated in differen. parts of the carcass. All the best parts are in London used for roasting and s:eaks, and the inferior for boiling, either in pieces, or making stock for soups, or minced meat, in the various forms of pies, sausages, \&c.

The carcass of an ox is cut up into the fol lowing pieces, as may be seen on referring to the numbers on the annexed cut, fig. 1 .

The relative value of these different cuts of an ox may be stated at their current value, viz., when the rumps, loins, and fore-ribs of a fine ox fetch $8 d$. a pound, the thick flank, buttock, and middle rib will fetch $6 r$. ; the itch or adzebone, thin flank, chuck rib, brisket, and leg of mutton piece, $5 d_{0}$; the clod and sticking, and neck, $3 d$. ; and the legs and shins, $2 d$. a pound. Such is the difference in value of the different cuts of an ox in the meat markets in London.

As an object of comparison, we shall also give a figure of an ox cut up in the Edinburgh method, as in fig. 2, and the great difference between both methods may be seen at a glance. See cuts.

It is therefore obvious that, of the two methods of cutting up beef, the London affords much more of roasting and steak, that is, the more valuable pieces, out of the same carcass; and, of course, more money would thereby be realized from it.

Much of what we have said on the management requisite in sending beef to the London market will apply equally to sending mutton, veal, or lamb to the same market. The best pieces only should be sent to London, and the remainder kept for the home market: and were this recommendati $n$ attended to, the expense of expu tation would be diminished on what was sent; for the best pieces would rack well together in a comparatively small space, whereas whole carcasses of mutton, by the roundness of the rib, occupy much unnecessary room, for which freight must be paid.

Mutton is also cut up differently in London and Scotlanả, as may be seen on referring to the figures at the top of next page, of which the first represents the Iondon method.

In the fore-quarter, No. I is the shoulder, 2 and 2 the neck, after the shoulder has been taken off, and 3 the breast; and in the hind-quarter, 4 is the loin, which, when cut double, that is, partly from both sides of the carcass, is called a chine or saddle, and 5 is the leg. A leg of mutton in London is cut short; a haunch is cut long, taking in the hook-bone, similar to a haunch of venison. The flap of the loin is left attached to that part of the fore quarter called the breast. The Scotch mode of cutting up mutton is represented by fig. 2 , in which, in the hind quarter, No. 1 is the gigot, and 2 the 
MEAT.

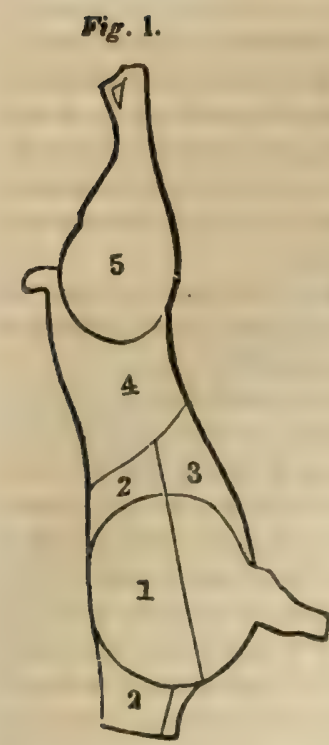

Fig. 2.

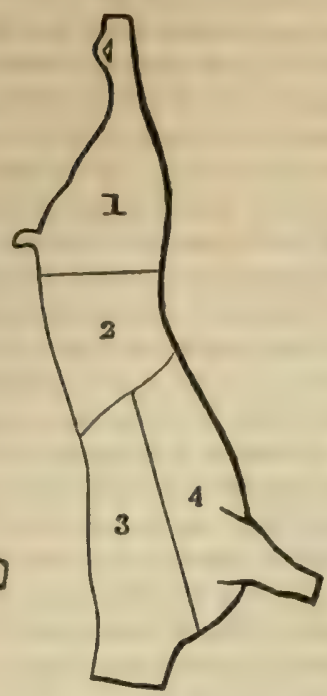

loin; and in the fore, 3 the back ribs, and 4 the breast and shoulders. The gigot is cut about half-way between the leg and haunch of the London method; and the fore-quarter is cut right through the shoulders in two places, called back-ribs and breast. Shoulders of mutton are never cut off in Scotland before being cooked, except by keepers of eatinghouses; but the London plan of cutting mutton is decidedly the best, the shoulder forming an excellent roast, and the best end of the neckpiece being admirably suited for chops.

The different joints of mutton vary almost as much in price in London as pieces of beef. The leg is sometimes sold as high as 10\%. a pound, whilst the breast of the same sheep will only fetch $4 d_{\text {o or }} 5 d_{0}$; and if, in the wholesale market, the whole carcass is sold at $6 d$. a pound, the hind-quarter will be worth $7 d_{\text {o }}$ and the fore only $5 \pi$. From these facts it is obvious, that it is the interest of the shipper only to send hind-quarters of mutton to London, for which $7 d$. a pound may be easily obtained, and a ready market for them in the west-end butchers, who seldom deal in fore-quarters. The fore-quarters could be sold at home; hence realizing as much for them as they could fetch in London, besides saving, on them the freight, commission, and wharfage. They form excellent joints for tradesmen's families, and are, in fact, generally preferred by them to the hind-quarters, which are considered dry eating, and certainly do not make so good broth as the fore-quarter. Besides the saving of room in packing the hindquarters, they would run no risk of being stained when sent by themselves, as the staining generally arises from blood oozing out of the veins in the fore-quarter.

Lamb is cut up in London in much the same manner as mutton, excepting that the neck and breast, when the shoulder is taken off, is roasted whole, and the piece is called ribs of lamb. In Scotland lamb is cut up exactly as mutton.

Veal is cut up in London in a different way from any other meat. The linife is drawn between the buttock and itch-bone, and through the pope's eye, raking a sloping direction inrough the coarse end of the buttock, leaving a flap Tise prece thus cut out is called a fillet 804 of veal. It is like a round of beef with a par? of the thin flank left to be skewered around it The round bone is taken out, and stuffing put into its place. When the itch-bone and hookbone are cut from the loin, the piece is called a chump of veal. The hind-quarter of veal thus consists of fillet, chump, loin, and leg. The fore-quarter is cut in the same manner as mutton, having shoulder, breast, and neck. In Scotland, veal is cut very much like mutton.

The London mode of cutting up pork is the same as the Scotch mode of cutting up mutton, so fig. 2 will illustrate the mode; in which, in the hind-quarter, No. 1 is the leg, and 2 is the loin; in the fore, 3 , back-rib, chine, or hand; and 4, breast and shoulders, spring or belly. The spring is used for pickling, and the hand for roasting, and for chops, or sausages. In Scotland, the hind-quarter consists of leg and loin, and the fore of back-ribs and breast. For pickling or roasting, pork is cut in the hindquarter like that of English mutton, and in the fore like that of Scotch. In both countries, the ham is cut out alike. (Donovan's Dom. Econ.; Quart. Jour. of Agr. vol. iii.p. 241-281.) See CATtre and Salting.

MEDICK (Medicago). An extensive genus of herbaceous, mostly procumbent, plants. The perennial herbaceous species are sometimes cultivated for ornament; they will grow in any common garden soil, and are increased by dividing the roots of the plants in spring. The shrubby kinds grow in a similar soil, and are readily increased by cuttings. The seeds of the annual species require to be sown in the open border in spring. There are six indigenous species.

1. Purple medick, or lucern (MI. sativa). See LuCER.

2. Yellow sickle medick, or button-jags ( $M$. falcala). This perennial species grows on dry, gravelly banks and old walls. The root is long and woody. In habit it very closely resembles lucern, but the numerous stems are procumbent, spreading every way, hairy. The flowers, which blow in June and July, are generally pale-yellow, but occasionally violet, and more frequently green, evidently from a combination of these two colours. The legumes are black, downy, sickle-shaped, not twisted in a screw, as in lucern. This species is, perhaps, as good fodder as lucern, though less succulent, and, from its position, less accessible to the scythe. It withstands severe winters better than lucern, and is eaten eagerly by cattle and horses, though its stalks are hard and woody.

3. Black trefoil medick, or nonsuch (M. lupulina). This annual species is, in England, very common in meadow pastures and cultivated fields, where it flowers from May till August. The black medick has the habit of some of the procumbent yellow trefolls, and has such general resemblance to the proper trefoils or clovers, that it is often mistaken fnr some of the smaller species. The form and colour of the seed-pods afford a ready distinction. The root is tapering, and somewhat fibrous. Flowers small, yellow, from 30 to 40 and upwards in each spike, which is at first roundish, afterwards ovate. Legumes kidnev- 
whaped, rugged and veiny, single-seeded, turning black when ripe. Sir J.E. Smith speaks of this as "one of the most valuable of artificial grasses, affording excellent fodder for sheep;" but this good opinion is hardly borne out by experience, for, though Arthur Young makes favourable mention of it, Sinclair, in his more recent experiments on the grasses, observes that it is only fit for light soils, and these must be deep, as the root penetrates to a considerable depth. It does not appear to be fit for separate cultivation, nor even to be employed in any large proportion in a mixture of atherseeds; and the root being annual, its use is, therefore, confined to the alternate husbandry.

4. Spotted medick (M. maculata). This is another annual species, growing on a gravelly soil in the southern parts of England. The root is fibrous, beset with little fleshy knobs. Stems prostrate, various in length. Leaflets inversely heart-shaped, spotted. Stipules dilated, sharply toothed. Flowers yellow, rather small, two or three together. Legumes spiral, depressed, fringed with long spreading bristles; when ripe, brown, not black. This has been mentioned, but not much recommended as a fodder for cattle.

5. Flat-toothed medick ( $M$. muricata). This is a doubtful native, growing on the sea-coast. It is an annual, and flowers in June and July.

6. Little bur medick (M. minima). This is a litile prostrate annual species, growing in sandy fields, but rare, clothed in every part with fine, soft, rather silky hairs.

MEDLAR (Mespilus). A genus of largegrowing fruit trees, which are very ornamental, and therefore worth a place in every shrubbery. Any common soil suits them, and they are readily increased by budding or grafting on the common hawthorn, or they may be increased by seeds, which do not vegetate till the second year.

The common medlar ( $M$. Germanica) is indigenous, growing wild in hedres. The branches of this tree are spreading, and thorny in a wild state; but the thorns disappear by culture, and are not to be seen in gardens. Leaves deciduous, lanceolate, 4 or 5 inches long, a little downy. Flowers solitary, nearly sessile, terminal, large, with white undulated petals, inodorous. Styles 5. Fruit depressed, concave at the top, somewhat hairy; austere, not eatable till it is mellowed by keeping. Cultivation has produced many varieties, differing in size and flavour. The Dutch medlar is the finest as to size, and the Nottingham the most delicate in flavour.

The wood, being hard and tough, resembling that of the pear tree, is useful for various domestic vessels, as well as for the smaller implements of husbandry.

MEDULLA, or MEDULLIN (Lat.) Marrow. In botany that tissue which constitutes the pith of certain plants, as the pith of the sunflower. Medullary rays are the vertical plates of cellular tissue, which radiate from the centre of the stem of exogenous plants, through the wood to the bark. They cause that appearance in timber which carpenters call silver grain, or flower of the wood. The medullary sheath is a thin layer of vessels, which surround the pulp of exogenous plants, and thence extend into the leaves and parts of fructification.

MELIC-GRASS (Melica, from mel, honey; the Italian name of the great millet). A genus of perennial harsh grasses, with slender, oblong panicles of elegant, often drooping, flowers, greatly varied in the different species. 'There are, in England, three indigenous species. 1. Wood melic-grass (M. uniflora). 2. Mountain melic-grass ( $M$. nutans), found in the mountains of England and Scotland. 3. Purple melic-grass (M. crulea).

For the purpose of pasture or hay, these grasses are comparatively of no value. The country people make of the tough straws a neat kind of besoms, which they sell to the neighbouring inhabitants as a cheap, and no despicable substitute, for hair brooms: they are even made into baskets where better materials are rare. Mr. George Sinclair made some experiments on an exotic species, the fringed or ciliated melic-grass ( $M$. ciliatn), which grows wild in Germany on hilly grounds, downs, and by the margins of woods; but the result of his observations only went to prove that it was one of the inferior grasses with respect to produce, nutritive qualities, and reproductive powers.

MELILOT, COMMON, Melilot Trefoil, King's clover, Hart's clover. Pl. 10,b. (Trifolium officinale.) This plant is very nearly allied to the long-rooted clover: the tapering root, however, appears to be strictly annual. The lower leaves are oblong, wedge-shaped; the upper ones elliptical: they are more serrate, and smaller in every respect than those of the long-rooted clover. The flowers are smaller and more drooping. The legume contains often more than two seeds, which is seldom or never the case in the long-rooted clover.

In England the common melilot grows wild in thickets, hedges, and the borders of fields, sometimes among corn. Stem 2 or 3 feet high, erect. Clusters unilateral, 2 inches or more in length, on long axillary footstalks. Flowers numerous, all drooping towards one side, of a full yellow, veiny. Stipules awl-shaped. Legumes prominent, acute, transversely wrinkled, hairy.

All the species of live-stock are said to eat this clover. The whole plant in drying acquires a scent like wew hay, but far stronger. The seeds, when u.ised with bread-corn, give it a nauseous flavour: This plant, or a variety of it, is used in lilaking the Swiss cheese called schabzieger. It is ground in a mill, and mixed with the curd into a kind of paste, which is put into conical moulds, and there dried. See SchanzIEger.

From the experience of Sinclair and others, this plant appears to be very much inferior tc the long-rooted clover. and cannot be put to any use for which that species is not equally good or superior: it grows chiefly in clayey soils. In very exposed situations it attains only to a small size; while in such as arc sheltered it sometimes reaches to the height of six feet. It ripens an abundance of seed, and flowers in the third or last week of June. Melilot is out of use in medicine, though it served too long to give a green colour and an

$$
3 \mathrm{Y} \quad 805
$$


odious scent to a sort of blister plaster, called by its name, of no use whatever.

MELILOTUS (Lat. mel, honey, and lotus, a leguminous plant). The plants are similar to the lotus, and are the favourite haunt of bees. These are, for the most part, honey-scented plants, with upright stems, and long erect racemes of small yellow or white flowers, resembling those of clover, of which they were formerly considered distinct species. In some parts of Europe two or three varieties are cultivated as annual fodder plants.

The Melilotus leucantha major is the celebrated Bohkara Tree Clover, a plant which Mr. Robert Arthur, of Edinburgh, says, "claims a place in every flower-garden, for its beauty. It is an herbaceous plant of very striking appearance, 10 or 12 feet in height, covered with spikes of white pea-blossoms, which also shed a sweet perfume. Hence it is sometimes called Sweet Flowering Clover.

"I esteem its value in agriculture of greater importance. The objections to its cultivation are, that cattle give a preference to other green food, and that the stem contains too much woody fibre. The plant, however, is new to Britain, and we know that man and animals frequently require successive trials of new food before taste is acquired for it. As a proof of this, I understand that some cattle are getting very fond of this clover; and we know that the tissue of plants in general is changed more and more into woody fibre as they progress towards maturity. Nature increases the woody fibre of this clover for support as it elongates its gigantic stem. If, however, it is cut for cattle, when about 2 feet in height, it will be found nearly as succulent as the common red clover.

"I exhibited plants of it at the Highland Society's show, last September, 9 feet in height, being the second crop of it that season, from poor sandy land. I know no plant whatever that will produce so much weight of vegetable matter in equal time and space; and were it only for the production of vegetable manure, it is a boon to the agricultural world. In my experiments with it last summer, as a manure, for new varieties of Alsike (?) Clover, I found it the very best and cheapest manure.

"In the economical formation of manure, it might be liberally supplied, with other food, throughout the summer, to young cattle and pigs, in an open straw-yard profusely bedded over with layers of turf, peat-earth, whins, broom, brushwood, ferns, straw, weeds, \&c., and thus save much outlay on the purchase of foreign manures.

"The Bokhara Clover may be sown at any tume throughout the growing season; but the most profitable time to sow it is immediately. after a crop of early potatoes, or even after grass, barley, wheat, \&c. The land being well manured, ploughed over, and harrowed smooth, it may be sown in shallow drills 18 inches apart; being cut once in autumn, it will produce a much earlier spring crop than tares, Italian rye-grass, \&c. It should always be cut very close to the ground, as the shoots produced from beneath the surface are the inost mxuriant, and it will thus stand a severe win806 ter much better than when its vitality is ex. posed on long stubble. Treated in this way with me, it stood two successive winters, and acquired all the characteristics of a perennial root. I have no dnubt of its continuing perennial and more vigisrous with the age of the plants, if only cut close in autumn, and topdressed with rich compost."

Mr. James Gowen, who resides at Moun Airy, near Philadelphia, has been much in the practice of keeping up a considerable stock of uncommonly fine cattle, and soiling them in summer upon lucern, rye, and red clover. He has raised patches of the melilotus, and from his observation says, "there is no grass or plant I have yet seen that affords to me such promise as the Sweet-scented or Bokhara Clover." (Cultivator, Nov. 1842.)

MELON, THE COMMON, or MUSK (Cucumis melo). An herbaceous, succulent, climbing, or trailing annual, cultivated for its fruit in hot eastern countries from time immemorial. The varieties of the melon are numerous; yet few of them comparatively are worthy of cultivation in England. The larger varieties especially are deficient in flavour and richness. Mr. Knight says, that whoever is acquainted with the green-fleshed, and Salonica, or whitefleshed, will cultivate no other.

The cantaleups are varieties characterized by their rinds being universally covered with reticulations. With the exception of the green, or oblong-ribbed, these bear round fruit, more or less approaching a flattened spheroid. Their common name is derived from that of one of the country-seats of the pope, where they are much cultivated.

MELON CULTURE. The warm summers of the Southern and most of the Middle States, are highly favourable to the culture of melons of every description, which in some places constitute a very profitable crop. The following communication relative to the culture of the musk melon or cantaleup, addressed to the Editor of the Cultivator, by 'T. G. Bergen, a person well versed in the business, will show how this is managed on Long Island, for the New York market:

The kind which we at present cultivate, says Mr. Bergen, and with which the New York market is principally supplied, is known among us by the name of Skillman melons, They average about 6 inches in diameter, are nearly round, have a rough skin, and their flesh is of a green colour. This is the sixth variety which has been in vogue during my recollection, and the finest of them all. The seed from which all these varieties originated, I believe to have been imported from the coasts of the Mediterranean. They soon degenerate unless care is taken in the selection of the seed. We prefer for melons a rich sandy soil, and on this they flourish better than on any other, and are not so liable to speck in rainy weather. When planted on a red clover sod I have seldom failed having a good crop; but when this is not to be had, we prefer preparing the ground by sowing with rye in August or September of the preceding year, as described in $\mathrm{my}$ former communication on the cultivation of cucumbers: the ground is also pre 
pared in a similar manner in the spring, except that the hills are furrowed 5 feet apart, and the same kind and quantity of manure made use of.

We generally commence planting about a week later than we do cucumbers, but occasionally at the same time, dropping from 20 to 30 seeds into a hill, and covering them about an inch deep with fine soil. Eight or 10 days after putting in the first seed we commence planting over, which we seldom perform the second time, unless by examination we find the first seed about to fail. The seed of melons is not so liable to rot as that of cucumbers, but long storms are very apt to destroy the young plants, and they will even produce great injury when the plants have vined from off the hills. In 1837, a succession of wet weather caused the ends of the principal part of the melonvines in our vicinity to die as late as the 8 th of July; but mine fortunately did not suffer as much as those of my neighbours. We cultivate the plants in the same manner as cucumbers, except that in hoeing it is generally necessary to remove a small portion of the soil from between them, in consequence of their being too short to admit of the young weeds being covered without injury to the plants. We gradually thin them down to 4 in a hill, standing from 5 to 6 inches apart. The plants are liable to the depredations of the same species of insects which prey upon cucumbers, and they are destroyed in the same manner.

Melon vines are in bearing from 5 to 6 weeks; whenever a drought occurs, this period is much less, for that of 1838 finished mine in 4 weeks. They often bear a second crop, which answers for pickling, hut I have known this crop to come to perfection.

When the fruit is ripe, it requires to be gathered every day, otherwise there would be large quantities lost in consequence of becoming too ripe and soft. When ripe, they have a yellowish colour; but such as are cracked around the stem and come off easily from the vines, we always gather, for they will be fit for eating by the next day, when sold in the markets.

To insure good crops, melons should not be planted two years in succession on the same ground; they require a rotation. Marshall, an English writer, recommends the carrying of cucumber and melon seeds a week or two in the breeches pockets previous to planting, to dry away some of the more watery particles: were we believers of this doctrine, it would be a difficult matter, and require large pockets or a regiment of small ones to carry it into practice, since some of us, to secure our crops, plant from 3 to 4 bushels of seed in a season.

The following is the number of hills planted, produce (large quantities of unsaleable ones fed to the hogs excepted), and amount of sales for the preceding 4 years : viz.

\begin{tabular}{|c|c|c|c|c|}
\hline $\begin{array}{l}\text { Year. } \\
1835\end{array}$ & 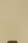 & $\begin{array}{l}\text { Hills planted. } \\
6.664\end{array}$ & Bushels sold. & Amount receirod \\
\hline 1536 & - & 7,850 & 561 & 59057 \\
\hline 1837 & - & 8,011 & 990 & 91356 \\
\hline 1838 & - & 7,590 & 823 & 71396 \\
\hline
\end{tabular}

MEI,ON PUMPKIN, or SQUASH (CururPitu nelopepo). See Seuash.
MELON, WATER (Cucumis citrullus), A plant well known in the United States for its delicious and refreshing fruit. To acquire the greatest perfection it demands a warm and sandy soil, and this it finds in New Jersey, and more Southern States, where the water-miclon is extensively cultivated. There are several varieties, such as the long and striped Caris lina, the more round and dark-skinned Spanish, \&c. In some parts of southern Russia, a kind of beer is brewed from their very abundant and cheap water-melons, with the adilition of hops: they also prepare a conserve or marmolade from this fruit, which is a good substitute for syrup or molasses.

MENDING. A country term used to signify the improving the quality or texture of land by the application of manure.

MERCURY (Mercurialis). These are regarded as mere weeds, possessing narcotic. fetid, and dangerous qualities.

MERINO SHEEP. See SuE

MESLIN. A term applied in New England to the crop of peas and oats when sown to. gether

MESLIN-CORN. A term applied to wheat and rye produced in a state of moisture.

METFOROLOGY. The science of meteors, or the science which explains the various phenomena which have their origin in the atmosphere. Under the term meteorology, it is now usual to include not merely the observation of the accidental phenomena to which the name of meteor is applied, but every terrestrial as well as atmospherical phenomenon, whether accidental or permanent, depending on the action of heat, light, electricity, and magnetism. In this extended signification, meteorology comprehends climatology, and the greater part of physical geography; and its object is to determine the diversified and incessantly changing influences of the four great agents of nature now named, on land, in the sea, and in the atmosphere. It is the object of meteorology to investigate and discover the modes of operation, and the causes instrumental, as well as final, of the multitude of interesting phenomena which exercise an influence on the animal and vegetable kingdoms. To this science belongs the examination of the force of radiation from the sun, or the temperature directly produced by his beams; the inquiry into the constitution, mechanical as well as chemical, of that intimate intermixture of gaseous bodies which is the subject of what are called atmospheric changes; the scrutiny of the laws governing the variations of climate; that also of those which regulate the diminution of heat in the atmosphere, in proportion to the altitude; the developement of the principles determining the quantity and state of the aqueous portion of the atmosphere; and the acquirement of knowledge, in short, on every subject of science presented by the atmosphere itself, or by its modes of relation to the aqueous and mineral kingdoms, and the general laws of its intuence on organized matter. This branch of natural history also comprehends the examination of two great series of phenomena, not strictiy comprised by the foregoing enumeration; iv which, on the one side, its boundaries ar 
nnited with those of physical geography, and on the other side with those of astronomy. The temperature of the interior of the earth itself, and that of the ocean, as well at the surface as at every accessible depth-subjects of the greatest interest, with respect not only to the present state of the earth, but also to its former physical condition-are so intimately connected with the temperature and other affections of the atmosphere, that the study of them becomes, in fact, a department of meteorology. And the various kinds of luminous and igneous meteors which appear within the atmosphere, though some of them originate, in a!l probability, in distant regions of the solar system,-such as the zodiacal light, the polar lights, or aurora borealis and australis; the meteors called shooting stars, and the stupendous masses of matter in combustion called fireballs, which cast down upon earth immense blocks of red-hot iron, or showers of heated stones,-constitute another wide field of mete. orological inquiry. This interesting branch of science must ever command the especial consideration of the shepherd, the farmer, and the cultivator of the soil in general.

METEORS. A name given to any phenomena of a transitory nature originating in the atmosphere. Meteors are of various kinds: some are produced simply by a disturbance of the equilibrium of the atmospheric fluid, and are called aërial meteors; such are WINDs, Whincwinns, \&c. A second class arise from the deposition of the aqueous particles which the atmosphere holds in solution, and which are precipitated in consequence of a diminution of pressure or temperature, sometimes in a fluid and sometimes in a concrete form. These are called aqueous meteors, as DEw, Fogs, HaIl, Rain, Snow, Vapour, \&c. A third class of meteors or atmospheric phenomena are caused by the action of the aqueous particles dispersed in the atmosphere, or the rays of light. 'These are called luminous meteors, and comprise fata morgana, halo, mirage, parhelia, the rainbow, \&c. A fourth class are the igneous meieors, comprehending those which present the phenomena distinctive of combustion. See Aenolite, Nonthent Ijghts, Lighteing, Shooting Stars, \&c.

METHEGLIN (Germ. meth, mead). A beverage made of honey and water, fermented by the addition of yeast. See MEAD.

MEZEREON, or SPURGE OLIVE (Daphne mezereum). This is a pretty shrub, indigenous to England, where it grows wild in woods, but is not common. The stem is bushy, 4 or 5 feet high, with upright, alternate, smooth, tough, and pliant branches; leafy while young. The flowers are pale garnet-coloured, highly, and to many persons too powerfully fragrant, seated in little tufts on the smaller branches. The scarlet berries, which are the favourite food of some species of finch (Loxia) are poisonous to many animals. There are varieties with pink and white flowers; and the berries also vary to a yellow or orange hue. The bark of the root is employed in medicine. It is excitant and sudorific. The active principle is a fixed acrid aloe resin. See Spurax LUETEL.
MICA. A well-known mineral, with a pearly, metallic lustre, consisting of extremely thin,e.astic plates or layers somewhat resembling glass. The largest sheets are brought from Siberia, and used instead of glass, especially to enclose fire where it is desirable to see the flame, as in stoves, \&c. Mica enters into the composition of granite. Its specific gravity is 2.65 . When analyzed it is shown to contain potash, mag. nesia, silica, oxide of iron, with other ingre. dients of well-known fertilizing properties. (See Grologr.) Hence, where any of these are deficient in soils, the application of mica must be advantageous.

MICE (Mus). A very destructive sort of vermin to many of the cultivator's growing and housed crops, and which should, therefore, be destroyed as soon as possible. Cats, dogs, owls, snakes, and hedge-hogs are the natural enemies of rats and mice, and should, therefore, be encouraged about the farm.

To destroy Rats and Mice in Corn Slacks. - The following method was adopted by the late $\mathrm{Mr}$. John Gibson, of Millbeck Hall, Keswick, and is still continued by his son, Mr. Joseph Gibson, of the same place, with never-failing success. It is accomplished by simply driving in a few hedge-stakes, at about 4 feet distance, round the stack intended to be housed, and having a woollen or linen web, of about 6-4ths or 7-4ths wide, upon the stakes, so as to be perfectly close at the bottom, of which particular care must be taken, in order that none of the vermin may creep under the folds. It is certain that none will attempt to climb over the top, and it matters not whether there are fifty or a hundred within the enclosed area, they will be quite safe. An active lad and a dog may easily destroy any number, and he must be a clumsy fellow if he lose one in a hundred. A few neighbours, by subscribing about $2 s .6 d$. each, might get an article at $10 d$. a yard that would serve them all for about 20 years. If the above simple method were generally adopted for a short time, those destructive enemies to the stack-yard would soon be considerably reduced. A correspondent of the Mark Lane Express suggests the following plan for the destruction of these obnoxious vermin. Feed with flour and a few sweet almonds bruised and mixed together with a small quantity of treacle, to form a paste (add a few drops of oil of aniseed), for 5 or 6 nights, until they talre it freely, never laying more of the mixture than they will eat up clean; then add a teaspoonful of earbonate of barytes to about a pound of the paste. I prefer the barytes to arsenic, it being free from the sour taste of the arsenic, which the rats will never take a second time. By using the above composition, I have kept my premises clear, without employing a rat-catcher, at the expense of a few shillings a year.

MID-RIB. In botany, the middle vein of a leaf, which passes from the petiole to the apex.

MIGNONETTE (Reseda, to calm or ap pease; the Latins considered its application useful in external bruises). The sweet mignonette $(R$. odorata) is an old and universal fa. vourite, on account of the very pleasant odour emitted by the flowers. Though usually an. nual, by care in a green-house and constantly 
pruning, the cultivated mignonette may be rendered perennial, and even shrubby.

MILDEW, or RUS'I. Of all the many diseases which attack our cultivated plants, not one is so destructive as the mildew. It is the "plague" of our wheat crops; and as that fatal distemper is always lurking in some district of climes warmer than our own, so the mildew is always in our fields, waiting for circumstances favourable to its outspread, and ready to destroy the expected harvest of the husbandman. So constantly present is this destructive disorder, that in the fairest fields of wheat grown in the richest corn districts of England, and in the most genial years, I never saw a single acre entirely uninfected. Every year the farmer is more or less injured by this disease, for the produce of each acre of wheat is unquestionably reduced annually several bushels. Yet those who suffer most by the loss, the farmers themselves, are almost universally ignorant of the fact; and their attention is rarely arrested by it till a year occurs in which their crop of wheat is nearly annihilated.

Its prevailing injurious nature was well known in an age as distant as that of the Hebrews; and it had not spared the Greeks and Romans. Even the poets, as Horace in his Odes, speak of it as the "sterile Rubigo" (Carmin. lib. 3, ode 23); and warning voices have not been since wanting to speak loudly of its ravages. Mr. Marshall says, "a certain preventive of the mildew would be a discovery worth millions to this country;" and many others have coincided in this estimate of its injuries.

This disease is known to be the effect produced by a minute fungus belonging to a genus closely allied to that which causes the smut. The roots of this fungus penetrate the vessels of the plant, and are nourished by the sap intended for perfecting its seed; consequently, if the fungi are so numerous in each stem as to make it a marked "mildew year," the grain is either partially or totally shrivelled, owing to the roots of these parasites intercepting the sap in its upward passage.

The ignorance relative to this disease is not a consequence of its novelty, since it has been known and dreaded in the earliest ages to which our knowledge extends. Thus, when Grod held out as a warning to the Israelites the affictions he would bring on them if disobedient, he enumerated the pestilence and the sword to destroy their persons, "with blasting and with mildew," to lay waste their fields (Deut. xxviii. 22; 1 Kings viii. 37; 2 Chron. vi. 28); and when the same Almighty Being had punished that rebellious people, he reminded them by his prophet; "I have smitten you with blasting and mildew; when your gardens and your vineyards, and your fig trees, and your oliv : trees increased, the palmer-worm destrcyed them." (Amos iv. 9.) "I smote you wit' blasting, and with mildew, and with hail, in al. the labours of your hands." (Haggai ii. 17.) The Hebrews called it yarcoon, implying a yellow pallidness arising from moisture. To the Greeks it was known as erusibe, guribn; and Theophrastus, who wrote his History of Plants about 320 years before the Christian era, observes (lib. viii. c. 10) that it occurs more 102 frequently to corn than to pulse; that in the climate of Greece barley was more subject in it than wheat, and particularly a varicty then known as achillum barley. Experience had taught them, that the crops on high lying lands were seldom attacked by this disease; but that the hollows surrounded by hills, where winds could not get at the crops they bore, were most frequently infected. It is chiefly gencrated, concludes Theophrastus, during the full morn.

By the Romans, the mildew was denominated "rubigo." Pliny informs us, in his History of Plants (lib. vii. c. 28 and 29), that it was the prevailing opinion that this disease arises from certain dews settling upon the corn, and obtaining a caustic or burning quality from the in. tense heat of the sun. 'This naturalist himself thought, on the contrary, that the disease arises from cold, considering that infection first occurs during the sun, and always about the new or full moon. Pliny, and the still later writers of the Geoponica (for this work is composed of fragments of Rornan writers living after the removal of the seat of empire to Constantinople, though written in the Greek language), considered that the best remedies were stinking pungent smokes; hence they recommended fish, horns, goat's dung, \&c., to be burned on such side of the field as would enable the wind to diffuse the smoke over and throughout the crop. They evidently had the same prejudice as is now entertained by our own farmers, that the mists which frequently prevai! during midday in the hottest periods of summer are the cause of the mildew; for they direct those fumigations to be performed at such time as it is seen in the atmosphere. They also thought that if branches of the laurel were fixed among their corn, the mildew would pass from the crops to those branches. (Geopon. lib. v. c. 33 ; Plinii Hist. Plant. lib. rvii. c. 17, \&c.) One of their practices recomınended is much more rational, namely, to bruise the leaves or roots of the colocynth, to macerate these in water, and, before the sun has risen, to sprinkle the infected crop with the liquor thus obtained. It is possible that the juice of the colocynth, which is a violent purgative to the human system, may be destructive to the fungus constituting the disease. It approaches to that which, in modern times, has been found the only effectual curative treatment; and the direction that the application should be performed in the morning evinces that it was a direction suggested and confirmed by experience. $\mathrm{C}_{0}$ lumella (lib. ii.c. 12) says, that hoeing cort during wet weather is apt to induce mildew.

Some modern writers have considered that the rubigo of the Romans is the disease known to us as the smut; but, independent of the name, which evidently referred to the red or rusty hue of the disease, and which is not a characteristic of the last-named disorder, we have the direct testimony of Virgil (Gecm L 150 ), that the rubigo was a disease of the straw; his words are, "Mox et frumentis labor addi" tus ; ut mala culmos esset rubigo, \&c."

Horace (Carminm, lib. iii. ode xxiii.) and Ovid (Fast. iv. 907) speak of the same rege. table epidemic. The Greels and Romans were as conscious as the Hebrews of the destruction

$$
3 \times 2
$$


it would inflict on their crops. They consi.lered it as the instrument of vengeance directed by a particular deity, to whom they applied the same appellation as to the disease itself. (Schneider's Scriptorum Rei Rustica, vol.i. pt. ii. p. 246.) To propitiate this presiding deity, a festival entitled Rubigalia, was instituted by Numa in the eleventh year of his reign, that is, 704 years before the birth of Christ. It was celebrated annually on the 25th of April, in the neighbourhood of a grove, at the fifth milestone, on the Claudian Way, and comprised sacrifices, races, and obscenities. Reddishcoloured bitches (rufa canes) were sacrificed, because the lesser dog-star was then in the heavens, and was considered unpropitious to corn. (Plinii Hist. Plant. lib. xviii.c. 29 ; Varii Flacci Facti, p. 63.)

Ovid, who enters fully into the religious performances of the festival, says, that the limbs of a sheep and the entrails of a dog were offered as a sacrifice on the occasion; and that the priest informed him that he knew of no reason for the latter animal being sacrificed, but that its name coincided with that of the constellation which at that season was apparent in the sky. The prayer addressed by the priest to the presiding deity marks so strongly their knowledge of the extent and inducements of the disease, that I shall give a nearly literal translation of a part :-

"O, blighting Rubigo, spare the corn-plants.

And let the ear wave gently o'er the surface of the earth:

Suffer the crops which have been nourished by the propitious

Stars of heaven, to grow until they becomo fit for the sickle.

Thine is no small power; the crops thou hast marked

The dispirited cultivator reckons as lost.

Neither winds, nor showers, so much injure the corn

Neither when bitten by the frost does it acquire a hue so pallid,

As if the sun fervently heats the moist stalks;

Then, O ! dread goddess, is the opportunity for thy wrath; -

Be merciful, I pray, and withhold your rusting hands from the crops;

Nor harm the cultivated land : it is sufficient to be able to do harm.'

The misty weather, mistaken by the Roman cultivators as actually a cloud of mildew, is only one of many numerous instances which might be quoted where causes of the disease have been considered to be the disease itself. T'o enumerate these would form a long catalogue of mistakes; yet these I should not hesitate to detail, because the refutation would incidentally introduce much useful informacion, but that they will for the most part be noticed among the circumstances which promote the vccurrence and aid the progress of this epidemic.

The first person, I believe, who correctly pointed out the nature of mildew, was Felice Fontana, who, in the year 1767 , published at Lucca a very particular description of the fungus occasioning it, in a work entitled "Osservazione sopra la Ruggine del Grano." Since then il has engaged the attention of many botanists, and the results of their researches have been to establish it as a distinct species of fungus, ihough they differ as to the genus to which Ley attach it. It is the Puccinia graminis of 810
Persoon (Disp.t. 3, f. 3); and it is the Uredo fru. menti of Sowerby.

In Plate 2 there is a representation of this fungi, in which

$l$, is a portion of wheat-straw affected with rust, magnified, to show the parasitic plant or fungus, giving rise to the disease called rust, blight, and mildew.

$m$, Another portion of a diseased stem in a green state, and before the fungus is quite ripe. $n$, The small portion marked 1 (i), still more strongly magnified.

$o, p, q, r, s, t, u$, Very highly magnified representations of the fungus parasite in different stages of growth and maturity.

$o$, Shows it in the young state; $p$, full-grown; $q$, two plants bursting and shedding their seeds when under water in the microscope; $r$, two plants bursting in a dry place; $s$, apparently abortive; $t$, seeds in a dry state; $u$, a small part of the bottom of a pore, with some of the parasitic fungi growing upon it.

Rust grows on the leaves and stems of wheat, \&c., appears in dense diffuse tufts, often confluent, forming long, parallel lines on the culms; at first brownish-yellow, but changing to black. Sporidia elongated, clavate, very slightly constricted at the septum; upper cell the shortest; stipes filiform. It must not be confounded with another parasitical fungus, which is common upon the wheat-leaves and culms, but which is not so injurious, namely, the Uredo rubigo, of Decandolle (Flora Franca, vol.vi.p. 83). Characterized by spots yellow; heaps oval, scattered, generally epiguous; epidermis at length bursting longitudinally; sporidia sub-globose, redbrown, easily dispersed. If the straw of wheat be examined with the assistance of a magnifying glass, its striped surface will be seen to arise from longitudinal partitions of the outer bark or epidermis. The depressed partitions are furnished throughout their length with 1 or 2 rows of pores or orifices, which seem capable of emitting or imbibing moisture as the wants of the plant may require. Similar pores, though varying in form and arrangement, pervade the leaves and chaff, or glumes; and it is in these pores that the seeds of the parasitical Purcinice obtain admission, and, vegetating in the cavities to which they lead, doubtless thrust their minute roots into the cellular texture beneath the bark, and intercept for their own nourishment that sap which should proceed to the grain for its developement and completion. The corn necessarily becomes shrivelled, proportionally as the fungi are more or less numerous on the plant: and as it is the nutriment that would have perfected the interior of the grain, which is chiefly extracted by the fungi, for the exterior form is nearly completed before the mildew occurs, the proportion of flour to bran is always much reduced. Sir J. Banks observed, in 1804, which was a "mildew year," that some of the wheat would not yield from a sack so much as a stone of flour.

Sir Humphry, then Mr. Davy, placed the loss caused by this fungus beyond a doubt, by chemical analysis. He found that 1000 parts of 


\begin{tabular}{|c|c|c|c|}
\hline -skinnned Sicilian & $\{$ Gluten, 239$\}$ & $\begin{array}{l}\text { Flour. } \\
961\end{array}$ & $\begin{array}{c}8 \mathrm{man} \\
39\end{array}$ \\
\hline $\begin{array}{l}\text { Middiesex wheat, ave- } \\
\text { rage crop - }\end{array}$ & $\left\{\begin{array}{l}\text { Gluten, } 190 \\
\text { Starch, } 765\end{array}\right\}$ & 955 & 45 \\
\hline Spring wheat, - & $\left\{\begin{array}{l}\text { Gluten, } 240 \\
\text { Siarch, } 700\end{array}\right\}$ & 940 & 60 \\
\hline Mildewed wheat of 1804 & $\left\{\begin{array}{l}\text { Gluten, } 130 \\
\text { Starch, } 520\end{array}\right\}$ & 650 & 350 \\
\hline Mildewed wheat of 1806 & $\left\{\begin{array}{c}\text { Gluten, } 32 \\
\text { Starch, } 178\end{array}\right\}$ & 210 & 790 \\
\hline
\end{tabular}

Showing, in one instance, a loss of 31 per cent. of flour in the mildewed when compared with the average English wheat, and in the other of nearly 74 per cent. (Elem. of $A g r$. Chem. p. 150.) Mr. W. Jones of Wilmington, Somerset, found that wheat, partially mildewed, produced onefifth less of flour than that not affected.

I have almost always been able to detect the Puccinia upon the lower part of the culms, generally on the shoot-blade (folia vaganans), early in June; but it is not till the following month that the season determines whether the ravages of this fungus will be more than ordinarily extensive. Throughout July the English farmer should scrupulously, and almost daily, examine his wheat crop, especially that which appears strongest and most luxuriant; and if he detects any considerable number of tufts of the fungus upon the stems, must lose no time in using those curative measures which will be detailed in the close of this article. If July is hot and dry, it may be concluded, without much fear of disappointment, that there will be but little injury incurred by the mildew. The reason of this is very apparent; for in such a season no fungus will vegetate vigorously. This order of plants invariably delights and flourishes in a moist atmosphere, and in a subdued light, accompanied by gentle warmth. A muggy season is the most expressive term to describe that wherein the mildew vegetates most rapidly. In such seasons likewise, it unfortunately happens that the wheat plants remain longest succulent, their pores expanded, and their fibres relaxed; circumstances peculiarly favourable to the admission of the seeds of the fungus, to their vegetation, and to the penetration of their roots. That it is in such seasons the Puccinia vegetates most rapidly and extensively, is supported by the observations of others; for, although they consider such a season as the actual cause of the mildew, their testimony is equally valuable, though from it they have drawn erroneous conclusions. Thus, M. Duhamel says, that the mildew is caused by mild, hazy, or gloomy weather, while the corn is at the height of its vegetation; that is, about the time of its blooming. When a hot sun has succeeded such weather, he observed the wheat crops mildewed in a few days. He always observed wet springs very productive of this disease; but it rarely occurs in clear, dry, hot years. One or two writers have given most incomprehensible theories of the cause of mildew.

Mr. R. Somerville concluded that the mildew originates from the attacks of insects introduced with the manure; but he evidently intended by his descriptions the minute acarus (a species of louse), which is almost always to be found upon decaying vegetable matter; and in the cases of mildews, this insect is the follower, not the introducer, of the disease.
The Abbe Rozier, in his "Dictionary"," observes that it is "caused by the drops of fog or dew, dissipated by a hot sun ;" an opinion which is the echo of Ovid's verses forming part of the Flamen's prayer for the preservation of the Roman crops from this disease-

"Quantum, si culmos Titan incalfacit udow:

Tunc focus est irae Diva tremenda tua."

And such a season, as I have before observed, has a damp atmosphere, which, above all other states of the air, is favourable to the vegetation of this Puccinia. 'There is no doubt, also, that in such seasons vegetables are more than ordinarily weak and prone to disease, in which condition they are likely to become the prey of parasitic plants. "The application of cold water to the plant," says Mr. Knight, "on which the sun is shining strongly, is very injurious to its health, and therefice likely to give increased activity to any disease to which the plant is subject." This observation follows the detail of an experiment, in which he found that sprinkling wheat plants growing on ground very dry, with cold water, in the afternoon of a warm, bright day, caused them to be extensively mildewed. "A considerable absorption, therefore, probably took place; and to this absorption," says he, "and the effects of a sudden change of temperature, as secondary causes, I am disposed to attribute the appearance of the disease; but whether the seerls of the mildew were carried into the pores of the plants by the water, or existed there before, is a question which I shall not attempt to solve." (Banks, On the Blight in Corn, p. 30.) There is no difficulty in accounting whence the seeds of the fungi came: for Mr. Knight records, in the previous page, that other wheat plants close by were extensively mildewed.

The observations of Mr. Marshall, which were the results of long experience in many counties in England, coincide with the preceding opinions. "In a dry, warm summer," he remarks, "which is well known to be favoura. ble to the health, vigour, and productiveness of the wheat crop, the seeds of the fungi are harmless, so long as the fine weather continues. On the contrary, in a cold, wet season, which gives languor and weakness to the wheat plants, few crops escape entirely. A succession of cold rains, while the grain is forming, is very inducive." Mr. Marshall previously concludes that "The fungi are an effect, not the cause of the disease;" an error which is at once refuted by the fact, that if all the fungi are removed from a plant, it is speedily cured.

of other circumstances favourable or unfavourable to the occurrence or exasperation of mildew, little need be said, because they have comparatively little influence upon its nccurrence. All soils and situations are liable to its incursions; for it is, in the fullest sense of the term, epidemic. The soil on which it appears the most rarely is a tenacious clay; and that on which, when it does occur, its ravages are the most extensive and destructive, is the light, calcareous, and rich. "As far as my observations extend," says Mr. Egremont, "the soils wherein clay predominates have yielded crops the least affected by the mildew. The soils most liable to have their crops injure.! 
particularly that of wheat, are the following, and in the order stated:-Peat or moor, calcareous, calcareous loams, sand, sandy loams, and another kind not found in any great breadth, but in patches, chiefly but not exclusively in clayey soils. The practical farmer calls it gray earth." (Egremont's Obs. on the Mildew, p. 93.)

The slightly superior power of clayey soils to protect the crop growing upon them from being the most severely affected by the mildew, probably arises from the temperature of such soils being less liable than lighter ones to sudden vicissitudes of temperature. Dr. Hales found, in the month of August, when the temperature of the air and of the surface of the soil were $88^{\circ}$, that the temperature of the soil 16 inches below the surface was $70^{\circ}$. In October, when the air and surface were at $35^{\circ}$, the temperature at 16 inches beneath was $48^{\circ}$, and at 24 inches $50^{\circ}$. This statement led me to make a few experiments upon the comparative rapidity of cooling, or, in other words, the power of conducting heat of various soils; and I invariably found, that the mercury in a thermumeter, whose bulb was buried equally deep in a silicious, as those of others were in a calcareous and in an aluminous soil, rose most rapidly, and that in the last-named most slowly. Their rapidity of cooling followed the same order. Some experiments substantiating the same fact will be found in Sir H. Davy's $A g$ ricullural Chemistry, p. 179. Every gardener knows the injury his plants sustain from sudden vicissitudes of temperature. "Whatever has a tendency to check a quick and great loss of heat in the substances which surround such vegetables, particularly their roots, will be best calculated to save them from that injury, and from vegetable death; consequently, those earths which are the worst conductors of heat, or, in other words, are the longest in heating or cooling, will be most favourable in resisting any sudden alteration, and the vegetables growing on them will be the least injured when so assailed." (Egremont's Observations on the Mildew, p. 30.)

Situation appears to have rather more tutelary power than the soil, since I have invariably found the wheat growing in fields lying in closely enclosed valleys more frequently and more seriously injured by mildew than those upon elevated exposures. "A Lincolnshire Farmer," Mr. Lambreth and other writers in the forty-fourth vol. of the Annals of Agriculture, agree in this observation, and it is no more than might be anticipated from our knowledge of the habits of the fungus tribe; such situations being always more damp, and subject to a moist, foggy atmosphere.

AIl varieties of wheat are liable to the disease, but the white is always the earliest affected, and the bezrded or rivet the last. This may arise from the latter variety having a firmer epidermis, arising from its containing a little more silex, and thence having its pores less easily acted upun by atmospheric changes, and consequently less liable to the entrance of the seeds of this fungus. Moreover, the hardnes $s$ the epidermis checks their rapid outspre

$$
812
$$

when vegetating. Mr. Sirs considered sithess sown wheat not liable to this disease if w mildew, and that is the general opizion in South Holland. Other authorities des.y that spring-wheat is exempted from it; and to this opinion I incline, in the absence of any thing like decisive knowledge on the point.

Early sowing is advisable, because the wheat plants, by this means, have a chance of passing the time of blooming before they are extensively attacked; and the more advanced the growth of the seed, the more it is out of the power of this parasite to check its perfection. Another reason suggested by Mr. W. Jones, of Wilmington, Somerset, is, that when sown late the plants are green and sappy in July, and even at the commencement of August, the season in which the cold and frosts occur that are so inducive of the disease; and this green state necessarily renders them more than ordinarily liable to suffer by such a reduction of temperature. On this account it is that in superluxuriant crops, and plants growing upon dunghills, the former are liable to, the later almost always are infected by, mildew. Yet the time for sowing is no unfailing preventive, for in "mildew years" all crops are attacked; and instances have occurred where, in fields sown in September, October, and November, the first and the last have been most injured.

The berberry has been anathematized as a source of this vegetable pest; but I have never yet met with any facts which establish the charge. It is true that Rolesbury, in Norfolk, is locally known as "mildew Rolesbury," and that the berberry abounds in the neighbourhood of that village; but I know many lowlying arable districts, proverbially liable to the mildew, having no berberries in their vicinity. It is true that a band of mildew has been traced across a field of wheat from a berberry bush growing in one of its hedge-rows; but then I have seen a similar track of the disease commencing from an oak. It is also true that $\mathrm{Mr}$. Knight, the late excellent president of the London Horticultural society, found wheat, sprinkled with water, in which berberry branches had been washed, speedily became infected with the mildew; but he also ascertained that wheat sprinkled with clear water, became similarly diseased. I have tried many experiments, with a view to ascertain the truth or error of this supposition, but have not succeeded. However, I am convinced that the parasite which affects the berberry is not the Puccinia graminis: the sporidia are dissimilar, and the colour totally unlike; but it may be, and certainly much resembles, the Uredo rubigo. It is no objection to say that the identity is unlikely, because the plants attacked are so widely distant; for, as already noticed, these parasites will vegetate on very various and even dead vegetable matters. The parasite which infects the leaves of the berberry is the Acidium berberidis: it is a beautiful minute gastro mycus, and there is no resemblance between it and the rust of wheat, except in colour. It is a vulgar error to suppose that an Ecidium on the berberry could produce a Puccinia on

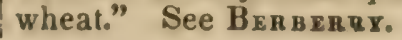


The age of the seeds, the thickness of sowtng it, and previous or subsequent cultivation, appear to have no preservative influence; therefore, it now only remains to consider whence the seeds of the fungi come to the crop, which will lead to a consideration of the modes of prevention; and, lastly, whether there is any practicable cure. There seems to me little doubt that the fungus is communicated from the soil to the crop. It is certainly not conveyed thither with the seed-corn, for no washing, no cleansing, nor pickling of this has ever been observed to have any effect. In "mildew years," all fields of any infected districts are affected; and when it is only partial, one end, or a breadth across the middle of a field, of which the seed has all been treated alike, will be grievously injured, whilst the other parts suffer little more than ordinarily; for I have previously noticed, every year, and in all fields, the mildew is partially present. There is little difficulty in accounting for this. Every Puccinia sheds some hundreds of seeds, more minute and lighter even than those of the puff-ball; and as every wheat crop annually produces some, these are wafted over neighbouring closes by every wind during their seeding-time, which is chiefly in the months between May and October. In the soil upon which those seeds alight, they attach themselves to the stubble or other matters, and vegetate, reproducing seeds, or remaining without germination until the following spring. This fungus has also the characteristic of spreading by stooling, or throwing out offsets. This may be seen if its progress is watched upon any culm which it affects. I once placed in a paper box some pieces of straw that were more completely mildewed than any I had before observed; this was left during the whole winter in a closet, which at this season is unusually damp. Upon opening the box in the spring following, I found the Puccinia had grown, and spread in various rectilinear forms, upon one of its sides, and upon the bottom, a fact which I remember to have seen confirmed in one of the volumes of the Quarterly Journal of Science. The fungus, then, though its natural habitat is the culm of the wheat, will vegetate upon other vegetable bodies; and this satisfactorily explains the mode in which it may, after being preserved through the winter, be conveyed to the succeeding year's crop,to say nothing of those seeds which may be attached to the straw of the preceding year, and be conveyed to the next year's crop by various modes.

These facts demonstrate that prevention is impossible ; for however careful a farmer may be to avoid every source whence the seeds of the Puccinia may arrive, yet every summer wind may waft them to his crops from other, even far-distant lands. To prevent the communication to the wheat from the soil by the stooling, or spreading power of the fungus, it will be well to sprinkle the surface with salt, immediately after sowing, at the rate of 5 or 6 bushels to the acre; and in the spring, early in May, to apply, in a similar manner, about the same quantity of caustic fresh-slacked lime, applications of which are not only destructive of the Pucrinia, but also of slugs, and promote the general health of the crop.

For testimonies to the power of common salt to prevent, in some instances, the occurrence of mildew, I would refer the reader in my brother's Essay on the Uses of Salt, p. 5060 , where will be found the concurrent instimony of Sir John Sinclair, Mr. Sickler, Rev. R. Hoblyn, Mr. S. Robinson, Mr. Wnod, and Dr. Paris. Mr. Prevost, quoted by Sir John Sinclair, states that the sulphate of copper, if dissolved in water at the rate of $3 \frac{1}{4}(1 \mathrm{z} .10$ the gallon, forms a solution which will prevent the attack of mildew upon the wheat plants arising from seed which has been steeped in it. I am afraid it has no such power.

Salt, if not a complete preventive, is an effectual cure of the mildew. Mr. Chatterton, a Lincolnshire farmer, says, in the 44 th vol. of the Annals of Agric., that "on the sea-side the wheat is little damaged by the mildew, yet within 3 miles inland the crops are as much affected as those still further from the sea." This fact can be supported by the experience of most farmers whose fields skirt our native shores; and unquestionably it is owing, not only to the soil containing a greater proportion of common salt than is found in more inland soils, but because the sea-haze, which rises almost nightly in the summer season, bathes, as it were, the crops in the immediate vicinity of the coast; and this haze holds in solution a portion of salt.

The following well-attested communication from the late Rev. Edmund Cartwright, of $\mathrm{Hol}$ lenden House, near Tunbridge, is conclusive on this subject, and gives full directions to the farmer how to apply, and at what expense, a practical remedy.

"It gives me great pleasure to have it in $\mathrm{my}$ power to furnish you with some information respecting the application of salt, which, perhaps, you are not aware of. I, and a neighbour of mine, have applied it as a remedy for the mildew in wheat, with the most unequivocal success. I first made the discovery 2 years ago; my experiments at that time were upon a very limited scale; they have this year extended only over an acre and a half, but under circumstances that leave not a shadow of doubt of salt being an absolute specific for mildew, in the most aggravated stages of the disorder; of this I will state to you a convincing proof. In the year $1818 \mathrm{I}$ found a few ears of wheat, which I conceived to be a new and improved variety; from these ears I raised as much wheat as last year planted a land 4 feet wide and 100 yards in length : the produce I had promised to Mr. Coke; and, to augment that produce, I had the ground, previous: 5 to plant ing, highly manured; and as soon as the wheat came up I gave it a good dressing with soot. and this dressing was repeated once or twice, in consequence of this superabundant dressing, the wheat, as might indeed have been expect. ed, was as rank as the wheat you may observe growing accidentally upon a dunghill, which never fails to rot upon the ground, withuilt bringing a single grain to maturity. The mil 
Hew made its appearance on thi, particular part of my field, while the straw was quite green, and the grain in a milky state; notwithstanding the danger that might be apprehended to the wheat itself, from its being thus succulent, I ventured to give it a dressing with salt and water; as a heavy shower of rain fell a few hours afterwards, the dressing was repeated the next morning. The proportion of salt to the water, 1 pound in a gallon, laid on with a plasterer's brush, the operator bearing a pail of the mixture in one hand, and the brush in the other, making his casts as when sowing corn, or else with a common watering-pot, which, being swung with great force, throws the water very rapidly; 2 men will get over about 4 acres a day-the one to spread, the other to supply the mixture. The result was, that the mildew was completely subdued, and the wheat went forward to maturity ; and although the sample was not so bold as it might have been, it was sound and marketable. In other parts of the field where the mildew showed itself, not under the aggravated circumstances described above, but as it usually appears, the wheat was not in the least injured by it after the salt and water was applied; it was, indeed, as fine a sample as could be grown. Both mine and my neighbour's wheat was examined by many practical farmers, who are so decidedly convinced of the efficacy of my remedy, that they intend never to be without a reserve of salt ready to meet the enemy the moment he appears. The effect of the salt upon the mildew, to those who do not consider the manner of its operation, is truly astonishing; I believe it to be instant death to the fungus; this, however, is certain, in less than 48 hours the straw nearly recovers its original colour and brightness. The certainty and celerity of its operation I account for thus: the mildew, it is now well ascertained, is a parasitical plant of the fungus tribe, the principal constituent of which tribe is water; when salt, therefore, is applied to them, the aqueous particles are immediately absorbed, and their vitality destroyed. The action of salt upon mushrooms, as in making mushroom catsup, confirms this theory." (Johnson's Essay on Salt, 3 d ed. p. 52-54.)

I can afford decided testimony to the efficacy of the cure recommended by Mr. Cartwright; but I would add these precautions. The safest quantity of salt per gallon is $8 \mathrm{oz}$., and then the application may be rendered more effectual by frequent repetition, without any danger of injury to the plants. If the application is not made during a clouded day, it is best to defer it until the evening. Some have recommended it rope, held at its extremities by two men, to be drawn up and down each ridge of the infected crop to remove the fungus; and there is no doubt that this treatment is partially effectual, for the parasite is removed whenever it comes in contact with the rope, but the points of contact necessarily are limited.

Professor Henslow endeavours to prove (by strengthening with additional evidence his previously expressed opinions) the specific intentity of the fungi producing rust and mil'ew. See Rust, Ergot, Dry Rot, \&c.
Mr. John Baker of Leeds, in commenting upon my brother's essay, is of opinion that the berberry has a considerable influence in the communication of the mildew to wheat, and gives several instances which seem to support his view of the case. But the distinction between the parasite of the berberry has alrearly been mentioned, and it is scarcely necessary to repeat that the one cannot produce the other.

MILE (Lat. Mille pasuum, a thousand paces). The following table, given on the authority of Kelly's Cambist, shows the length of the modern mile, and also the league, of various countries, and their relation to the English statute mile.

Modern Roman mile
English statute mile
Tuscan mile -
Ancient Scotish mile
Irish mile -
French posting league
Spanish judicial league
Portugal league
Gernan short mile -
Flanders league -
Spanish common league
Prussian mile -
Oanish mile -
Dantzic mile -
Hungarian mile -
Swiss mile -
German long mile -
Hanoverianmile -
Swedish mile -

\begin{tabular}{|c|c|c|}
\hline & Yards. & Stat. mile \\
\hline & 1760 & 1.000 \\
\hline & 1808 & 1.027 \\
\hline & 1984 & i. 127 \\
\hline & 2240 & 1.273 \\
\hline & 4263 & 2.422 \\
\hline & 4635 & $2 \cdot 634$ \\
\hline & 6760 & $3 \cdot 841$ \\
\hline & 6859 & 3.897 \\
\hline & 6864 & 3.900 \\
\hline & 7416 & $4 \cdot 214$ \\
\hline & 8237 & $4 \cdot 680$ \\
\hline & 8244 & $4 \cdot 684$ \\
\hline & 8475 & $4 \cdot 815$ \\
\hline & 9113 & $5 \cdot 178$ \\
\hline & 9153 & 5.201 \\
\hline & 0,126 & $5 \cdot 753$ \\
\hline & 1,559 & $6 \cdot 568$ \\
\hline & 1,700 & 6.648 \\
\hline
\end{tabular}

According to the same authority, the Arabian mile is 2148 yards, the Persian parasang 6086 yards, the Russian werst 1167 yards, and the Turkish berri 1826 yards. The English geographical mile is 1-60th of a degree of latitude, or about 2025 yards; the geographical league of England and France is 3 such miles, or 6075 yards; and the German geographical mile is equal to 4 English geographical miles, or 8100 yards.

MILFOIL, THE WOOLLY YELLOW. See YARROW.

MILIARY. In botany, a term signifying granulated; resembling many seeds.

MILK (Germ. Milch). A well-known fluid, secreted by animals for the nourishment of their young. See Lactometer, Butter, Chefese, Dairy, Cattle, \&c.

Cow's milk is that principally used by Eu. ropeans; that of the goat, and even of the sheep, is used in some parts of Britain; that of the mare is a favourite beverage in Tartary when it is fermented. If milk be left at rest, the fatty globules separate, rise to the surface, and form cream; if it be, long agitated, they attract oxygen, coalesce, and form butter.

Milk owes its whiteness and opacity to an emulsion composed of the caseous matter and butter, with sugar of milk, extractive matters, salts, and free lactic acid; the latter of which causes fresh milk to redden litmus paper. Milk, in general, contains from 10 to 12 per cent. of solid matter, on being evaporated to dryness by a steam heat. The mean specific gravity of cows' milk is 1.030 , but it is less if the milk be rich in cream. The specific gravity of the skimmed milk is 1.035 ; and oi the cream is 1.0244 . 100 parts of cream milk contain :- 
Casenus matter, containing some butter Eugar uf inilk

Alcoholic extract, lactic acid, aud lactates Salts; muriate and phosphate of potash, and plinsphute of lime.

Water

Cream consista of-Butter separated by churn-

ing - - - - - of the milk of the butter Buttermilk

\section{600 \\ 99,995 \\ $4 \cdot 5$

When milk contained in wire-corked bottles is heated to the boiling point in a water-bath, the oxygen of the included small portion of air under the cork seems to be carbonated, and the milk will afterwards keep fresh, it is said, for a year or two; as green gooseberries and peas do by the same treatment.

The number of cows kept in London and its environs for the supply of milk is estimated by $\mathrm{Mr}$. Macculloch to amount to 9000 , and their annual produce of milk to be equal to 78,800,000 quarts. For this purpose the Yorkshire cow is preferred to all others. The daily average of milk yielded by one of this breed is estimated, according to Mr. Youatt, at 22 or 24. quarts.

The quantity and quality of the milk produced by a cow is materially influenced by the food and distance from calving. Some interesting experiments to determine this were made by MM. Boussingault and Le Bel. They observe, "In the observations, of which the following table presents the abstract, it will be seen that the quantity of milk given by the cows progressively diminished. This diminution cannot be attributed to the regimen to which the cows were subjected, since, in gain putting them on the fond on which they had previously fed, the same quantity of milk was not obtained as at first; the diminution continued. The distance from the period at which the cow has calved seems to be the principal cause of the decrease of the milk. This cause is so strongly marked, that it may even prevent the influence that the nature of the food exercises over it from being seen....... Indeed, this result permits us to state, that the nature of the food consumed does not exert so very sensible an influence on the quantity and chemical composition of milk (we do not say on its quality), if the cows receive equal nutrition from the different kinds of food. It is very evident, that if the weight of the feeds were not calculated according to that of the equivalents, great variations would be observed in the products of milk; but then those varia. tions would be principally caused by the aug. mentation or diminution of the nutritive matter. We know, for example, that cows which, dur. ing winter, are reduced to simple feeding on chopped straw, cease almost entirely to produce milk, and with difficulty recover their ordinary rate of production; in cognisance of such a fact, we are led to ascribe the return and abundance of milk exclusively to the properties of the green food in spring, whilst that effect is in a great part produced by a real increase in the feeds.

"In establishments where a regular rotation is followed, healthy and abundant nourishmen. to cattle in winter is in a manner assured, the difference, if any exist, betwixt the feeding in winter and summer, being in all cases much less considerable. These are the results of experiments made during a year on eight cows constantly fed together on a great variety of food."

First Series of Experiments.-Codntr r Cow.

\begin{tabular}{|c|c|c|c|c|c|c|c|c|c|c|c|c|c|}
\hline \multirow{2}{*}{$\begin{array}{l}\text { Number of } \\
\text { days since } \\
\text { calving. }\end{array}$} & \multirow{2}{*}{$\begin{array}{l}\text { Mils given } \\
\text { in } 24 \text { hours. }\end{array}$} & \multirow{2}{*}{$\begin{array}{l}\text { Solid mat. } \\
\text { ters in } 100 \\
\text { lbs. of milk. }\end{array}$} & \multirow{2}{*}{\multicolumn{6}{|c|}{$\begin{array}{l}\text { Food given equivalent to } 15 \text { kilogrammes, } \\
\text { or about } 30 \mathrm{lbs} \text {. of Hay. }\end{array}$}} & \multicolumn{5}{|c|}{ Composition of Milk. } \\
\hline & & & & & & & & & Cheese. & Butter. & $\begin{array}{l}\text { Sugar of } \\
\text { Milk. }\end{array}$ & Salts. & Water. \\
\hline 1 & $\begin{aligned} \text { Litres. } \\
5 \cdot 0\end{aligned}$ & $21 \cdot 6$ & Potatoes, & hay & - & & & - & $15 \cdot 1$ & $2 \cdot 6$ & $3 \cdot 6$ & 0.3 & $78 \cdot 4$ \\
\hline 13 & $7 \cdot 5$ & - & Ditto & - & - & - & - & - & & & & & \\
\hline 24 & 106 & $11 \cdot 2$ & Hay, gre & en clov & ver & - & - & - & $3 \cdot 0$ & $3 \cdot 5$ & 4.5 & 02 & 88.8 \\
\hline 35 & $12 \cdot 0$ & $13 \cdot 1$ & Green clo & ver & - & - & - & - & $3 \cdot 1$ & $5 \cdot 6$ & $4 \cdot 2$ & $0 \cdot 3$ & $88 \cdot 9$ \\
\hline 200 & 5.6 & $12 \cdot 3$ & Hay - & - & - & - & - & - & 3.0 & 4.5 & $4 \cdot 7$ & 0.1 & $87 \cdot 7$ \\
\hline 207 & 6.0 & $12 \cdot 4$ & Turnins & - & - & - & - & - & 3.0 & $4 \cdot 2$ & $5 \cdot 0$ & 02 & $87 \cdot 6$ \\
\hline 215 & $5 \cdot 6$ & 12.9 & Red beet & - & - & - & - & - & $3 \cdot 4$ & 40 & $5 \cdot 3$ & 0.2 & $87 \cdot 1$ \\
\hline 229 & 5.0 & 13.5 & Potatoes & - & - & - & - & - & $3 \cdot 4$ & $4 \cdot 0$ & $5 \cdot 9$ & 0.2 & 86.5 \\
\hline 240 & $3 \cdot 6$ & - & Hay - & - & - & - & - & - & & & & & \\
\hline 270 & $3 \cdot 4$ & - & Potatoes & - & - & - & - & - & & & & & \\
\hline 290 & $3 \cdot 5$ & 12.5 & Jerusaleı & n artis & choke & es & - & - & $3 \cdot 3$ & $3 \cdot 5$ & $5 \cdot 5$ & 0.2 & $87 \cdot 5$ \\
\hline 302 & $2 \cdot 8$ & $13 \cdot 2$ & Hay and & oil-ca & & - & - & - & 3.4 & 3.6 & 6.0 & 0.2 & 86.8 \\
\hline
\end{tabular}

Second Series of Experiments.-Swiss Cow.

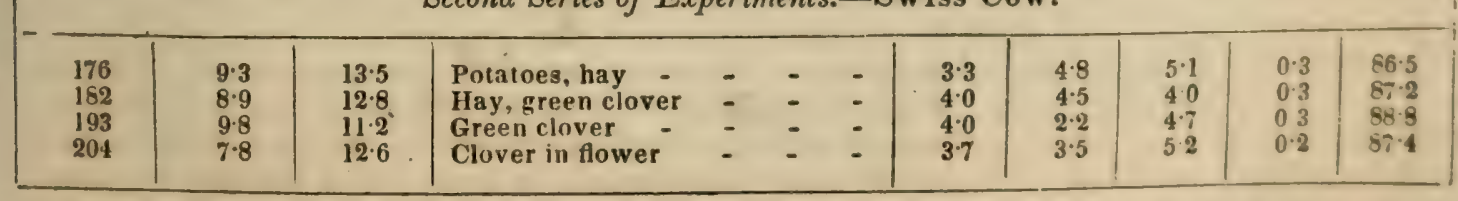

'There is a paper on the adulteration of milk, In Stephens's "Book of the Farm," we find the by $M$. Barruel (Quar. Jour. of $A g r$. vol. ii. p. 304), following interesting details relative to the subin which he states that the substances used ject of milk, milch-cows, and their treatment to adulterate milk in London and Paris are in Scotland, and more especially in the city of usually flour, sugar-candy, potash, and some- Edinburgh. 
though for very different purposes. On carse and pastoral farms they are merely useful in supplying milk to the farmer and his servants. On dairy farms, they afford butter and cheese for sale. On some farms near large towns, they chiefly supply milk for sale. And on farms of mixed husbandry, they are kept for the purpose of breeding young stock.

On carse and pastoral farms, cows receive only a few turnips in winter, when they are dry, and are kept on from year to year; but where the farmer supplies milk to his work people, as a part of wages, they are disposed of in the yeld state, and others in milk, or at the calving, bought in to supply their place, and these receive a large allowance of turnips, with perhaps a little hay. On these farms, little regard is paid to the breed of the cow, the fact of being a good milker being the only criterion of excellence.

On true dairy farms, the winter season is not a favourable one for making butter and cheese for sale ; for, do what you like to neutralize the effect of the usual rooted green crops on these products, and especially butter, they remain unpalatable to the taste. The cows are therefore in calf during this season, and receive the treatment described above until the period of calving in spring.

In and near large towns, the dairy-man must always have milk to supply his customers, and it is his interest to render the milk as palatable as possible. For the purpose of maintaining the supply, he buys cows at all seasons, just calved or about to calve. He disposes of the calves, without attempting to fatten them; and to render the milk he sells palatable, he cooks all the food partaken of by the cows. When the cows run dry, they are fattened for the butcher, and not allowed to breed again.

The cows in the public dairies in Edinburgh are supported in winter on a variety of substances, namely, turnips, brewers' and distillers' grains, called draff, dreg, malt-comins, barley, oats, hay-seeds, chaff, cut hay. One or more of these substances, with turnips, are cooked together, and the usual process in doing this, and administering the cooked food, is as follows:-Turnips, deprived of tops and tails, and washed clean, are put into the bottom of a boiler, and covered near to its top with a quantity of malt comins, cut hay, hay-seeds, chaff, or barley, or more than one of these, as the articles can be procured. Water is then poured in to the boiler sufficient to boil them, and a lid placed upon it. After being thoroughly boiled and simmered, the mess is put into tubs, when a little pounded rock-salt is strewed over it, and chopped into a mash with a spade. As much dreg is then poured upon the hot mash as to make it lukewarm, and of such a consistence as a cow may drink up. From 1 to $1 \frac{1}{2}$ stable-pailfuls of this mixture,-from 40 to 60 pints imperial,-according to the known appetite of the cow, is then poured into the trough belonging to each. The trough is afterwards removed and cleaned, and the manger is ready for the reception of fodder-hay or straw. This uness is given 3 times a day, after the cows have been milked, for dairy-men understand that animals should not be disturbed while eating 816 their food. The times of milking are $6 \mathbf{A}$. $\mathbf{M}$. 12 noon, and 7 P. M. The sweet milk and cream obtained by these means, and received direct from the dairy, are pretty good. The former sells in Edinburgh at $\mathbf{1} d$., and the latter at $1 \mathrm{~s}$. the imperial pint. Dr. Cleland states the price of sweet milk in Glasgow at $1 \frac{1}{2} d$. the im. perial pint.

It will be observed that none of the articles usually given to cows are so expersive as oilcake, cabbages, kohl-rabi, or cole-seed. These products were employed by the late Mr. Curwen in his experiments to ascertain the cost of raising milk for supplying the poor, and the results show they left him very little profit. (Curwen's Agricullural Hints, p. 47-52.)

Cattle are fed on other substances than turnips, either with themselves or in conjunction with turnips. Oil-cake and potatoes are the most common substances used for this purpose. Linseed oil and linseed have been recommend. ed, and many are fed at distilleries on draff and $d r e g$, as the refuse of distillation are termed; and these are also sold to the farmers for the purpose of feeding. Oats, barley-meal, and bean-meal, have also been pressed into the service of feeding cattle.

The potatoes used in feeding cattle are either the common kinds known in human food, or others raised on purpose, such as the yam and ox-noble; and they are given either alternately with turnips, or together. In feeding cattle with potatoes of any kind, and in any way, there is considerable risk of flatulency and choking. 'To prevent the latter, the potatoes should be smashed with a hammer, or with an instrument like a pavier's rammer, and though juice should come out in the operation, no loss is incurred, as it is considered of no service in feeding. To prevent flatulence from potatoes is no easy matter; but a friend of mine used a plan which completely answered the purpose, which was, mixing cut straw with the broken potatoes. The straw obliging the cattle to chew every mouthful before being swallowed, may prevent such a large quantity of gas being generated in the paunch as bruised potatoes alone would do, and it is this gas which occasions that distressing complaint called hoven. A farm-steward, who had considerable experience in feeding cattle on potatoes on a led-farm, always placed as many potatoes, whole, before cattle as they could consume, and they never swelled on eating them, because, as he conjectured, and perhaps rightly, they do not eat them so greedily when in their power to take them at will, as when doled out in small quantities. This fact confirms the propriety of mixing cut straw amongst potatoes that are given in small quantities, in order to satisfying the appetite, and filling the paunch with unfermentable matter. The only precaution required in giving a full supply of potatoes, is to give only a few and frequently at first, and gradually to increase the quantity.

Oil-cake has been long and much employed in England for the feeding of cattle, and it is making its way in that respect into scotland. It consists of the compressed husks of linseed. after the oil has been expressed from it, and is formed into thin oblong cakes. The cakes ar 


\section{MILK-PARSLEY.}

a slow, interrupted, gossiping manner, and leaving part of the milk in the udder, will ruin the best cow in the world." If the cow has sore teats, foment them before milking with warm water, and after milking, dress them with the following salve: Melt together $1 \mathrm{oz}$. of yellow wax, and $3 \mathrm{oz}$. of lard, and as these begin to get cool, rub in a $\frac{1}{4}$ of an oz. of sugar of lead, and a drachm of finely pounded aloes. (Youatt on Cattle, p. 552.)

MILK-PARSLEY (Selinum, from selinor, the Greek name for parsley; applied to this genus on account of the resemblance in the leaves). This is a hardy genus of plants of no interest. The only species indigenous to England is the marsh milk-parsley (S. palustre), which is perennial, or, as some have it, biennial, growing in wet and boggy meadows, with flowers white, numerous, uniform. The root serves the Russians for ginger; and the whole herb abounds with a white, bitter, fetid juice, of the consistence of cream, which soon dries to a brownish acrid resin.

MILK SICKNESS. This name, together with "'Trembles," has been applied to a peculiar and most malignant disease occurring in some localities of the Western United States, and affecting certain kinds of farm-stock, and persons who make use of the meat or dairy products of infected cattle. Bishop Hennipin, a French missionary, who ascended the western waters early in the last century, mentions the existence of this singular disease affecting animals. Although the cause and precise nature of so frightful a malady are still enveloped in great obscurity, and the treatment is far from being so generally successful as could be desired, it may be interesting to be acquainted with some facts connected with its existence. Dr. George B. Graff, a highly intelligent physician of Edgar county, Illinois, has a communication upon the subject in the American Journal of the Medical Sciences (April, 1841), from which we draw the following details:-

The milk sickness is a disease peculiar to the United States, occurring seldom, if ever, to the eastward of the Alleghany mountains. It is in a greater or less degree met with in all the Western States, as far south as Mississippi, and extends north to the boundary. The states of Indiana and Illinois are most subject to its occurrence, whilst its existence in the bordering states is comparatively rare. Among the early settlers it committed dreadful ravages, and in the formation of our Western settlements, its prevalence often served as a cause to disband a community, and compel the inhabitants to seek a location which enjoyed immunity from its occurrence. Many of the otherwise most desirable portions of that couniry remained long exempted from settlement, and even now the inhabitants of these localities have, as a condition of their residence, entirely tu abstain from the use of milk, its preparations, and the flesh of their cattle.

Its occurrence or prevalence is confined to no season or description of weather, existing in a like degree in the heat of summer or cold of winter, and with like virulence and fremency during a dry or wet season. An = Inion is entertained by some, that it is more 818 frequently met with in the spring and fall months, whilst others have expressed a belief of $\mathrm{jts}$ more common occurrence during the heat of summer. However this may be, we know of no season during which it does not occur.

The animals in which it has been observed are the beef-cattle, horses, sheep, and goats, which seem to acquire it with their food or drink.

We will first speak of the symptoms manifested in cattle affected with it, as it is only through them that we have yet found the disease communicated to man. They may be affected to such a degree as that their flesh and milk will produce the disease, and yet they themselves manifest no unhealthy symptoms whatever. This latent condition of the disease may be discovered by subjecting the suspected animal to a violent degree of exercise, when, according to the intensity of the existing cause, it will be seized with tremors, spasms, convulsions, or even death. This is a precaution practised by butchers in these countries always before slaughtering an animal in anywise sus pected of the poisonous contamination. An ordinary degree of exertion will not develope these phenomena unless it produce the symptoms usually preceding a fatal termination. When, for instance, a cow is sufficiently deeply affected, nothing peculiar is observed until im. mediately preceding the outbreak of the fata. symptoms. She is then observed to walk about, without any apparent object in view; all food is refused, and there is evidence of impaired vision. The eye is first of a fiery appearance, increasing to a deepened red colour, until the animal is observed to stagger and fall, when, if she rises, the trembling of the whole muscular system will prevent the maintenance of the standing position. The animal usually dies after repeated convulsions, never lingering beyond a few hours. Often it falls suddenly as if it received a blow from a heavy body on the head, and death is produced in a few minutes.

From the tremulous motion imparted to the muscles, the affection has received the commor name of the "Trembles" in cattle. A case which was characterized by the great violence of its symptoms, I had an opportunity to examine very shortly after death. The brain I found suffused with a large quantity of fluid blood, which, from the amount contained within the cranium, must have made great pressure on every part.

In man the symptoms differ from these, and are varied. The length of time found to elapse from the reception of the cause to the appearance of the disease, is dependent on a multiplicity of circumstances, as the age, sex, cr condition of the patient, and violence of the poison. It may be developed early as the third, or deferred until the tenth day. As a premon!tory symptom, a peculiar and indescribable fetor from the lungs is the most prominent; and so universally have I found it present and to precede the disease, that in almost every instance where I have been brought in proximity to a person predisposed or attacked, have I been able to foretell its approach, and pro 
nounce on the character of the disease. This fetor can no more be mistaken by a person accustomed to it, than that which is so universally attendant on variola; and it may in fact be safely stated to be pathognomonic of the forming and early stage of milk sickness. This halitus from the lungs, which I have never found entirely wanting even some days previous to an attack, increases in intensity until the disease is fully developed, when it gradually disappears with the specific symptoms, and at the termination of 4 or 5 days cannot be detected. A person labouring under the peculiar effluvia from the air passages, in many cases complains of no illness, and appears entirely unconscious of his situation, unless advised of it by his friends or attendants. His appetite may be, and usually is, destroyed; and after the lapse of a few days he is taken down with pain and excessive irritability of the stomach, obstinate constipation of the bowels, a cessation of all biliary secretion, general febrile action, sometimes an intense burning sensation in the epigastric region, with early and obstinate coldness of the extremities. Often the symptoms are observed to differ widely from these. Besides the peculiar smell emitted, there is a premonition of the attack; for some days previous to its developement, the patient experiences a restlessness and uneasiness which he cannot describe, with a dread of some impending calamity, confusion of ideas, and other indications of irritation of the brain and nervous system. Vomiting announces the onset of an attack. This continues at short intervals for many days, the matters thrown off the stomach consisting of the fluids swallowed, mixed with a glairy mucus, and not unfrequently tinged with blood. Some days frequently elapse before pain in the stomach is complained of, but during the time the suffering is intolerable, consisting of a sensation of deep distress, which, though referred to the pracordia, or abdomen, the sufferer cannot locate in any particular spot. Pain in the limbs is complained of, and is severally referred to each of the extremities, but is more constantly located in the spine, particularly at the nape of the neck. The pulse, during the forming stage, possesses greater force and volume, with slightly increased action. The bowels will remain obstinately constipated, the powers of nature being incompetent to relieve the condition, so that unless it be done by appropriate remedies, at the end of 6 or 8 days an offensive discharge takes place, quickly followed by dissolution, the symptoms being those which would indicate disorganization of the structure of the intestines. The tongue, during the initiatory stage, is slightly furred, but otherwise not much changed in appearance. This coat disappears soon after the occurrence of vomiting, and becomes clean, of a pale-red or pink colour, greatly resembling a piece of raw veal. Next to the fetor mentioned, the change of volume occurring in the tongue may be viewed as the great characteristic of this disease. It rapidly attains an inordinate size, completely filling the mouth, and so flabby and soft in its texture as to retain perfectly the impressions left by the teeth, when extruded.
Often a number of efforts are necessary before it can be forced out, and then it has a tremulous motion. This condition of the ungue changes with the stage of the disease. When the vomiting has been suspended, and free evacuations from the bowels obtained, it is re. duced in volume, the surface is for a time smooth and glazed, soon after becomes dark, cracks open in transverse fissures, is hardened, with an obstinately dry and rough surface. Of all the primary symptoms, vomiting is the last to disappear; it ceases very gradually to annoy the patient, and its continued absence is the most certain indication of a state of convalescence. In no disease is there a greater difference or diversity of symptoms than are usually found in different cases to constitute what may be properly termed the secondary stage of milk sickness.

In some cases the patient is affected with drowsiness, low muttering delirium, nervous tremors, and the whole train of symptoms associated in low typhus fever. When recovery takes place after severe attacks, the convalesence is very slow, and years may elapse before a perfect restoration to health. Indeed, it has been a question with many, whether those once severely attacked ever regain a perfect integrity of constitution. In cases which terminate fatally (of which description is a large majority), a length of time of from 1 to 4 weeks is required, proportionate to the intensity of the primary effects, the propriety of the treatment, and the natural powers of the resistance of the constitution, as they often seem to die from a wearing out, or gradual destruction of cerebral and nervous energy. Those cases which occur during the summer months, are most decidedly inflammatory, whilst in the winter there is always observed a disposition to assume a low form. The autumnal cases, in their secondary fever, are liable to assume a remittent aspect, and $I$ have seen them eventuate in a wellmarked intermittent. When recovery has taken place, the patient retains not the slightest recollection of any thing which occurred during the progress of the disease, and this forgetfulness often extends as far back as some days previous to the active developement of the disease.

Cause.-The cause of this disease in animals is as yet shrouded in mystery and uncertainty. No satisfactory account of its nature has ever yet been given, and it has in turn been sup. posed to be of vegetable, mineral, and eveli aërial origin. The limits of its prevalence is not often over a large continuous tract of country, but rather circumscribed, and sur rounded by localities never known to produce it. No example is known in which the property of producing the disease has been acquired by any locality which did not previously possess it. The boundaries which were at the first discovery of the country found to separate the infected from healthy districts, remain unchanged. The locality which serves to produce the disease, most commonly extends as a vein of variable breadth, traversing the cuuntry for a considerable distance. It can be traced in one instance for nearly a hundred miles. running parallel to the course of the Wabash river, in the state of Indiana. 
Again-it will be found to occupy an isolated spot, comprised in an area of 100 acres, whilst, for a considerable distance around, it is not produced. Thus, having the locality perfectly circumscribed, much labour has been expended in order to discover some production peculiar to the locality. The search has been uniformly unsuccessful in the attainment of its object. The general appearance of these infected districts is somewhat peculiar. I have always observed that the situation of the ground is elevated abnve that of the surrounding country, occupying what is denominated a ridge, and that the quality of the soil is in general of an inferior description. The growth of timber is not observed to be so luxuriant as in situations otherwise similar, but is scrubby, and stunted in its perfect developement, in many instances simulating what in the west is denominated "Barrens." Throughout the entire district in which these localities are interspersed, there is observed an absence of the occurrence of stones scattered over the surface, whilst in the infected tracts they are almost universally present. 'They are of a small size and darkened aspect externally, breaking with a regular and shining fracture, and, upon analysis, imperfectly made, were found to contain a considerable portion of iron, with slight traces of copper. Another more decided and peculiar appearance, which serves to distinguish them from other spots, is the breaking forth of numerous feeble springs, furnishing but a trifling supply of water, but not varying in quantity with the change of seasons. In its appearance, it presents the general evidences of a sulphurous and ferruginous contamination.

Experiments made upon the water collected from these springs, or more properly called nozes from the soil, with the greatest care by the employment of the most delicate chemical re-agents, failed to indicate the presence of any mineral except iron, sulphur, traces of magnesia, and a quantity of copper barely capable of being demonstrated. A belief being entertained by many that the disease is occasioned hy arsenic, or some of its salts, I with much care and patience subjected not only the water, but likewise the earth, from these districts to a most rigid examination, and by no test was I furnished with the slightest evidence of its presence.

An intelligent medical friend expressed to me his belief that it was produced by the inhalation of some noxious gases generated during the night; in proof, he stated that he had observed cattle, which were regularly housed each evening, escaped its attacks, and that when suffered to remain at large, they were frequently seized with the disease. It is difficult to form this belief of the nature of the cause, as we can hardly conceive the particular action of ar.y combination of circumstances, eapable of giving rise to such an emanation unly at night, ceasing to act during the day. The most popular belief is in favour of a vegerable origin. The advocates of this method of production having failed to designate the plant which they supposed occasions it, have endea:oured to sustain their views by supposing that he poison exists in some shrub or tree, 820 which is eaten by the cattle, but confess their inability to designate any such peculiar growth confined to these localities. If certain fields which are known to affect cattle fed upon them, be suffered to grow in grass, and the hay produced be given to them for their continual food, no disease results, which is a strong circumstance, unless it be urged that the active poisonous principle is destroyed by the desiccation. Again, it has frequently appeared with its greatest virulence when the ground has been for weeks previously covered with snow.

Butter and cheese, manufactured from the milk drawn from an infected cow, are supposed to be the most concentrated forms of this poison. They possess no distinguishing appearance, odour, or taste, from the healthy article. A very minute quantity of either will suffice to develope the disease in man. The cream, ordinarily sufficient to be added to the coffee drunk at a single meal, is said to have induced an attack. The butter or cheese eaten at one repast, has frequently been known to prove effective. The property is not contained in any of the elements of the milk exclusively, but distributed throughout the whole of them, being possessed by the buttermilk as well as by the whey. Beef, in the quantity of a very few ounces, will produce the disease, and, it is generally believed, in a more violent and fatal form than when it is produced by milk, or any of its preparations.

In the course of my observations I had an opportunity to experiment with a cow suffering in but a slight degree from the cause. She was affected with tremors when unusually exercised, exhibited a red and suffused eye, with frequent twitches of portions of the mascular system. She was kept confined without an opportunity to exercise, and was fed upon ordinary food. At the end of 8 days, the milk drawn from her possessed as violent poisonous properties as at the time of her incarceration. Her confinement was continued for a week longer, at the end of which period, the milk taken from her was found in an entirely healthy condition, and the eyes were restored to their natural appearance. In this instance it will be seen that the property of imparting the poison to the milk was lost in the space of between 8 and 15 days. We, of course, cannot fix on the precise period, but we wonld infer that the property is suddenly destroyed rather than gradually dissipated.

My trials with the poisoned flesh were, for the most part, made upon dogs, which I confined, and often watched the effect of the poison when administered at regular intervals. In the space of 48 hours from the commencement of the administration of either the butter, cheese, or flesh, from poisoned animals, I have observed unequivocal appearances of their peculiar action. In a few hours a thirst greater than natural is created; the appetite remains unimpaired until the expiration of the fourth or fifth day, or just before the appearance of fatal symptoms, when the animal will refuse drinks, and the most inviting descriptions of fond.

Vomiting does not, as in man, always precede death, but the bowels are constipated throughout, except that, in a single instanc 
observed copious alvine discharges largely mixed with blood. One ounce of butter or cheese, or 4 ounces of beef, either raw or boiled, administered 3 times a-day, will certainly prove fatal within $\mathbf{6}$ days, and often earlier. In these cases all exertions and exercise must be prevented, or death will occur much sooner, even as early as the third day. When an an mal has been subjected to its influence for only a short time, and is induced to fatigue itself, or is driven a distance at full speed, he suddenly stops and falls, and the severity and duration of the convulsion or spasm is in proportion to the intensity of the action of the poison. Often he will appear to entirely recover from the first attack, but to be repeated upon the renewal of the exercise to a sufficient degree.

There is, however, one animal which, from some peculiarity of organization, is rendered proof against the pernicious effects of this otherwise powerful agent. I allude to the hog. Most industriously did I feed a troublesome sow running at large, administering, daily, 5 or 6 pounds of infected beef. This was persevered in for more than a fortnight, and under the treatment she fattened, when I was compelled to desist from the great quantity necessary to supply her voracious appetite, without enjoying the satisfaction to perceive one muscular twitch as an evidence that it produced the slightest effect. When I last saw her she enjoyed excellent apparent health, and was the mother of a numerous offspring.

From all the experiments I have made, and the reasoning used, I can arrive at no conclusion, so far as relates to the nature of the ultimate cause in man, to whom it can only be communicated through the medium of an animal, and that capability of production can be acquired only by the animals of circumscribed localities. An intelligent medical friend, alike distinguished as a statesman, Dr. John W. Davis, of Indiana, in a late letter to me, expresses a belief that milk is never a cause of the disease. He merely states his belief of the fact, without the evidences or observations which have led him to the denial of a proposition heretofore viewed as settled beyond dispute. My own experience enables me to say that I have seen a peculiar affection, which I feel assured could have been no other than the milk sickness, in a city remote from any of its local causes, attacking every individual who partook of a certain cheese which had been purchased from a wagon arriving from an infected district. In this instance the well-marked symptoms, confined to those only who partook of this cheese, appearing nearly at the same time, with no occurrence of new causes after the removal of this cause, all together afford strong evidence of the nature of the origin.

There is a murderous practice now carried on in certain districts, in which the inhabitants will not themselves consume the butter and cheese manufactured; but, with little solicitude for the lives or health of others, they send it in large quantities, to be sold in the cities of the West, particularly Louisville, Kentucky, and St. Louis, Missouri. Of the truth of this I am well apprized by actual observation, and I am as certain that it has often caused death in those cities, when the medical altendants viewed is as some anomalous form of disease, not suspecting the means by which poison had beren conveyed among them. Physicians of the latter city having been questioned particularly on this subject, have mentioned to me a singular and often fatal disease which appeared in cer. tain families, the cases occurring simultaneously, and all traces of it disappearing sucldenly, and which I cannot doubt were the result of poisoned butter or cheese. This recklessness of human life it should be our endeavour to prevent, and the heartless wretches who practise it should be brought to suffer a punishment commensurate with the enormity of their crime. From the wide extent of the country in which it is carried on, we will readily perceive the difficulties to be encountered in the effort to put a stop to the practice. This being the case, our next proper aim should be to investigate the nature of the cause, and established a more proper plan of treatment by which it may be robbed of its terrors, and the present large proportionate mortality diminished.

Nature and Treatment of the Disease.-Much diversity of opinion exists among medical men in regard to the essential nature and most proper mode of treating this fatal disease, from which hundreds of persons throughout the West and Southwest annually perish.

Owing to the want of success which has so uniformly attended the practice of their physicians, many of the inhabitants depend entirely on their domestic remedies. It is in that country emphatically one of the opprobria nicdicorum.

"The primary operation of the poison," says Dr. Graff, "seems to be on the brain and nervous system, and this is indicated by the cerebral irritation which so often precedes, and always accompanies an attack, as well as by autopsic appearances. Without an exception, in the animals poisoned, I always found the brain and meninges phlogosed with a greater or less degree of inflammatory action."

Dr. Graff relates the following cirçumstance: connected with the occurrence of the disease, which will tend to show its mode of developement and characteristics. The entire family of a Mr. Frazier, moving westward, purchased a quantity of fresh beef in Indiana, of which every member of the company partook heartily, daily, until the evening of the fourth day, when they arrived in the Doctor's neighbourhood. On this evening they all retired apparently in their usual health, but during the night he was summoned to attend a female with an attack of milk sickness. Upon a careful examination he discovered the peculiar smell present with every member of the family, and, on inquiry. ascertained about the beef, and the locality in which it was purchased, "which," he says, "at once satisfied him that they were doomed. Be fore the next morning every member of that company of 6 was attacked in a violent $m$ ant ner, and only one of the number recovered."

The Legislatures of several Western State.s have offered rewards for the discovery of the origin of the milk sickness, in order to lead tw its prevention an 1 cure. 'The reward offere!
3 z 2
821 
in Kentucky is $\$ 1000$. A creeping vine has been of late years generally believed to be the occasion of the disease, but this has not been so well established as to enable the person who made the supposed discovery to claim the rewards.

MILK-VETCH (Astragalus). This is an extensive genus of herbaceous and shrubby plants; many of the species are very handsome, and well suited for the flower-garden. There are 4 species indigenous to England.

MILKWOR'T (Polygala, from poly, much, and gala, milk; reputed effects of the plant on cattle that feed upon it.) All the species of this genus are very showy. The annual kinds require sowing in the open ground, preferring a peat soil. Some of the species possess useful medicinal qualities. Decandolle enumerates above 160 species in this genus, but only one is British.

A considerable number of the species are natives of the United States, among which the best known is the $P$. senega, or Seneca snakeroot.

MILLET (Panicum, from panicula, a panicle, or panis, bread). A useful genus of grasses, one species of which, called Bengal grass, was some years ago introduced into Pennsylvania as an object of culture, and excited much interest for a time among farmers. It was found, however, not to be so valuable as the usual summer crop of which it occupied the place, and it is now pretty much abandoned. 'The seed is sown in the early part of May. (Flora Cestrica.)

Of the millet there are three distinct genera: the Polish millet (Digitaria), cultivated in $\mathrm{Po-}$ land; the common millet (Panicum), or panic grass, cultivated in Germany, and sometimes in England; and the great or Indian millet (Holcus), cultivated in India, Italy, and America.

Of the common millet there are 3 species: Setaria Germanica, a native of the south of Europe; the $P$. miliaceum $(\mathrm{Pl} .3, l$ ), a native of the East Indies; and the Setaria Italica $(m)$, also of Indian origin.

The German Millet (Fr. Moha de Hongrie; S. Germanica, Pl. 3, $k$ ) rises with a jointed reed-like stalk, about 3 feet high, and about the size of the common reed, with a leaf at each joint, $1 \frac{1}{2}$ foot long, and about an inch broad at the base where broadest, ending in an acute point, rough to the touch, embracing the stalk at the base, and turning downwards about half the length. The stalks are terminated by compact spikes, about the thickness of a man's finger at the bottom, growing taper towards the top, 8 or 9 inches long, and closely set with small round1sh grain. It is annual, and perishes soon after the seeds are ripe. There are three varieties of it, the yellow, white, and purple grained. It was formerly cultivated for bread in some of the nurthern countries.

The Common or Cultivated Millet (Fr. Millet commun; Panicum miliaceum), rises with a reedlike channelled stalk, from 3 to 4 feet high; at every joint there is one reed-like leaf, joined on the inp of the sheath, which embraces and covers that joint of the stalk below the leaf, and is cluthed with soft hairs; the lea? has 822 none, but has several small longitudinal furrows running parallel to the midrib. The stalk is terminated by a large loose panicle hanging on one side. Of this species there are two va. rieties, the brown and the yellow; the latter of which was formerly in cultivation, and is now sometimes sown for feeding poultry, and as a substitute for rice.

The Italian Millet (Panis d'Italie: Fr. Millet a grappe; Setaria Italica, $\mathrm{Pl} .3, m$ ), rises with a reedlike stalk, nearly 4 feet high, and much thicker than that of the preceding; the leaves are also broader. The spikes are a foot long, and twice the thickness of those of the common millet, but not so compact, being composed of several roundish clustered spikes; the grain is also larger. There are two or three varieties of this, differing only in the colour of the grain. It is frequently cultivated in Italy (whence its trivial name), and other warm countries. It is a native of both Indies, and of Cochin China.

The Polish Millet, or manna grass of the Germans (Digitaria sanguinalis, formerly $\mathrm{Pa}$ nicum sanguinalis, $\mathrm{Pl} .3, n)$, is a low, decumbent, annual plant, seldom rising above 9 inches or a foot high, with hairy leaves and slender panicles. It tillers much, and forms a close tuft, spreading and rooting at the joints. It is a native of England, but not common. It grows in abundance in Poland, and is sometimes cultivated, the seeds being used like those of the other millets as a substitute for rice or sago.

The Great or Indian Millet (Lat. Holcus sorghum, Sorghum vulgare, Pl. 3, o; Fr. Sorghn, gros nillet d'Italie; Ger.Sorgsamen; It. Sagina; Span. Mcloa) has a stem which rises 5 or 6 feet high, is strong, reedy: and like those of the maize, but smaller. The leaves are long and broad, having a deep furrow through the centre, where the midrib is depressed in the upper surface, and is very prominent below. The leaves are $2 \frac{1}{2}$ feet long, and 2 inches broad in the middle, embracing the stalks with their base. The flowers come out in large panicles at the top of the stalks, resembling, at first appearance, the male spikes of the Turkey wheat (maize); these are succeeded by. large, roundish seeds, which are wrapped round with the chaff. This grain is a native of India, where it is much used to feed poultry, and is frequently sent to Europe for the same purpose. It is much cultivated in Arabia, and most parts of Asia Minor; and has been introduced into Italy, Spain, Switzerland, and some parts of Germany, also into China, Cochin China, and the West Indies, where it grows commonly 5 or $\mathbf{6}$ feet high, or more, and, being esteemed a hearty food for labourers, is called negro Guinea corn. Its long awns or bristles defend it from the birds. In England, the autumns are seldom dry and warm enough to ripen the seed well in the field. In Arabia it is called dora or durra; the flour is very white, and they make good bread of it, or rather cakes, about 2 inches in thick. ness. The bread which they make of it in some parts of Italy is dark and coarse. In Tuscany it is used chiefly for feeding poultry and pigeons; sometimes for swine, kine, and horses. Cresalpinus says, that cattle fed on the green herb are apt to swell and die, but thrive on 't when dried. They maks brushes 
and brooms of its stalks in Italy, which Ray observed in the shops of Venice, and which are sent to Fingland, Of this species there are two distinct varieties; one distinguished by black, and the other by red, husked seeds, besides subvarieties.

The only sorts of millet which are cultivated with suceess in England are the German, cultivated, and the Polish sorts. According to Professor Thaer, the cultivated is to be preferred, as having the largest grain.

The soil for the millet should be warm, sandy, rich, and well pulverized to a good depth. In England the seed is sown in May, very thin, and not deeply covered. In the course of its growth, no plant, Professor 'Thaer observes, is more improved by stirring the soil, after which it grows astonishingly fast, and smothers all weeds.

In harvesting the millet, great care is requisite not to shed the seed; and as it ripens rather unequally, it would be an advantage to cut off the spikes as they ripen. No grain is easier to thrash, or to free from its husk by the mill. It is used instead of rice, and in Germany bears about the same price. It produces a great bulk of straw, which is much esteemed as fodder. (Loudon's Ency. of Agricullure.)

The great Indian millet will grow in England to the height of 5 or 6 feet; but will not ripen its seeds, or even flower, if the season is not dry and warm. It would doubtless succeed in the United States.

MILLET-GR ASS, Milica (Fr. millet; Lat. milinm, from mille, a thousand, in allusion to the immense number of seeds produced by it). These are hardy, annual, and perennial grasses; but in England the climate is seldom warm enough to ripen the seed, or to allow of their being cultivated to advantage. The hardened corolla, forming a coat to the seed, affords a mark of distinction between this genus and Agrostis, no less obvious than important, as those most deeply versed in grasses will most readily allow.

There are two English species:-

1. Spreading millet-grass (M.effusum). Growing very common in moist, shady places. The root is perennial and fibrous, with several creeping shoots. Stems erect, slender, generally 3 and 4 feet high, with about 4 joints, leafy, smooth. Leaves bright-green, flat, very smooth, thin and weak. Flowers solitary, slightly drooping, ovate, in a loose spreading panicle, without awns; panicles from 4 inches to a foot in length. Mr. Curtis observes, that this is distinguished from the panic grasses, to which it has the greatest affinity, by having a calyx of two valves only. The produce of this grass is very light in proportion to its bulk, and it is but little nutritive. Birds are remarkably fond of the seeds: so much as to render it likely that, for the sake of the seed only, it could be cultivated to advantage on the farm. But in covers where game are preserved there cannot be a better grass encouraged: it will save the corn fields. About the beginning of August is the best season for sowing the seed. The surface of the ground near the roots of the bushes should be lightly stirred, and the seeds scattered o ler it and raked in; a few of the decaying leaves that cover the ground should afterwards be thrown over. It flowers in the second week or latter end of June, and the seed is ripe in the middle of July and begin ning of August.

2. Panic millet-grass ( $M$. lanigerum). Thi, annual species is less common, and grows principally in fields where water has stag. nated, especially towards the sea. The stem is branched from the bottom and smonth. Flowers in a dense, spiked, erect panicle, palegreen, bristly; corolla awned.

MILLS (Lat. mola). The term mill seems to have signified originally an engine for grinding corn, but it is now used in a general sense to denote a great variety of machines, whose action depends chiefly on circular motion. The particular purpose is usually indicated by a prefix: thus, bark-mill, cotton-mill, flour-mill, oil-mill, saw-mill, spinning-mill, \&c.

The machinery by which it is necessary to accomplish the ultimate objects of the mil] must obviously vary almost indefinitely. Many voluminous works on this subject have beer, published, as well as separate accounts of particular structures.

The Kibbling-mill is well worthy of notice. It is composed of a small iron cylinder, usually about 8 or 9 inches wide, and 6 inches in diameter, tapering slightly to one end, and fluted on the inside. Within this a barrel of the same form, but a size less, and fluted on the outside, revolves by the turning of a spindle on which it is fixed. The meal is rendered finer or coarser in proportion as the working barrel is set nearer to or farther from the small end. This mill is made entirely of iron and steel, and is usually attached to a post. It is provided with a hopper, and is worked by a crank fixed at one end of the spindle, while a fly-wheel revolves at the other. It is used for beans, peas, and other pulse, for malt and various kinds of grain, and is a very useful and ingenious contrivance, but requires care in its adjustment and general management.

Bean-mill. A mill for grinding beans, constructed by Seaman and Bryant of Melton, in Suffolk, is as simple and effective an implement of the kind as any we have seen. It is placed on a wooden stand, with crank, flywheel, and hopper; and consists of a coarsely fluted barrel, working against a front cutting plate; the latter being set at the proper distance from the barrel by means of a screw. It is used chiefly for beans and peas, but may be employed for grinding malt, by exchanging the barrel and cutting-plate for a pair of rollers.

The Norfolk Crusher is similar in appearance to the foregoing, and is worked by two rollers of equal dimensions, each being flanged at one end, and reversed so as to prevent the grain from falling off at the side. The rollers are perfectly smooth, and consequently, as its name implies, it crushes the grain instead of cutting it.

The Suffolk Crusher is siru ly a variety of the above, and differs from it in having its hind roller finely grooved, and of half the dimen sions of the front one; this has no flange, but works within the langes of the front rolles 
which are attached at botin ends. To rende these mills effective for crushing oats, the rollers should be left rough as they come from the lathe, to draw in the kernels, as the latter are apt to start back at the moment of entering between the rollers, if they are polished. A grooved or fluted roller has not been found adequate to the perfect bruising or cutting of oats, and a mill that shall effect this object may be considered a desideratum in agricultural mechanics.

MILLSTONE GRIT. A geological term applied to a group of strata which occur between the mountain limestone and the superincumbent coal formations; it is a coarse-grained quartzose sandstone.

MINT (Mentha). The poets celebrate Minthe, a daughter of Cocytus, as being transformed into mint by Proserpine in a fit of jealousy. (Ovid.Metam.10, v. 729.) This is an extensive and well-known genus of useful herbs, with the culture and propagation of which every one is familiar. In England there are more than a dozen native species, besides numerous cultivated varieties. The roots are perennial, creeping widely. All the herbage is more or less hairy, but variable in that respect; rarely woolly or finely downy; full of pellucid dots, lodging a copious essential oil, which is pungenily aromatic, cordial, and stimulant, and is thence used in medicine as an excitant and stomachic for promoting digestion. The following are the indigenous species. Horse-mint (M. sylvestris), round-leaved mint (M. rotundifolia), spear ur green mint (M. viridis), black or peppermint (M. piperita), bergamot mint (M. citrata), hairy mint (M. hirsula), fragrant sharpleaved mint (M. acutifolia), tall red mint ( $M$. mubra), bushy red mint (M. gentilis), narrowedleaved mint ( $M$. gracilis), corn-mint ( $M$. arvensis), rugged field-mint (M. agrostis), and pennyroyal (M. pulegium). See CAT-Min'r, HorseMint, Peppermint, Pennt-Rotal, SpearMint, \&c.

MISSELTOE (Viscum; from vescus, birdlime, on account of the sticky nature of the berries). The misseltoe is a well-known parasite, readily propagated by sticking the berries on thorn or apple trees, after a little of the outer bark has been cut off, and tying a shade or net over them, to protect them from the birds. Sheep eagerly devour this plant, which is frequently cut off the trees for them during the severe winters; nay, it is even said to preserve them from the rot. Its branches are much sought after at Christmas to hang up in houses, along with other evergreens. It was one of those plants held sacred to the Druids.

MIST. See Fog.

MITE. See Chesse-Mite.

MIXEN. A compost heap.

MIXTURE OF SOILS, in agriculture, is the addition of one soil to another, to improve its fertility.

There is perhaps no agricultural improvement more important in both its immediate and permanent effects than the careful, judicious mixture of soils, and there is no question more 'ikely to repay the cultivator for the care he oeslows upcn it.

This mode of improving the land was one 824 which very early engaged the attention of the farmer. Nature herself, in fact, pointed out to him the means of producing the richest of soils by earthy mixtures in very intelligible language. 'The solid matters brought down from the distant hills by the flood-waters, and deposited in the valleys where the waters rested, evidently formed, by the mixture of different strata, and by their union only, the 1 ich alluvial soils of the old and the new worlds; for that the mere mechanical separation of the earth into a fine state of division is not the sole cause of the increased fertility, is apparent to every farmer.

It is useless, he well knows, to expect the débris of the hills to produce fertilizing effects on soil of a similar composition. It is the dis. similarity of the earths which insures a maximum fertile mixture: thus, in the soil of the rich marshes of the banks of the Thames are found the clay of the London basin, the sands of Middlesex, and the chalks of Oxfordshire and Kent; and in a similar manner are formed all rich alluvial lands. This good effect of earthy deposits naturally pointed out to the Italian farmers the use of earthy additions to the soil. Columella expressly notices the use of sand, gravel, marl, and chalk (book ii. c. 16, p. 93); and the people of Megara, according to Theophrastus, had made similar observations upon the importance of mixing together different strata of earth (lib. iii. c. 25); for every fifth or sixth year they trenched the gravel to a depth equal to that they imagined the rain had penetrated. The early inhabitants of Britain employed marl, as the people of Gaul did lime, for spreading over their lands. And that this was done to a very considerable extent, is shown by several facts. Thus, marl-pits are mentioned as early as 1285, in the charter of the forest, and again in the statute of Wales in the 12 Edward 1. And so early as the days of Richard, Duke of Cornwall, the Cornish farm. ers had a grant by which they were empowered to take the calcareous sand of Padstow harbour, and spread it over their clayey lands. The successful mixture of the farmers' soils, there. fore, is not a modern improvement; it has evidently been practised with success in all climates, in different ages, and on every description of cultivatable land.

I have witnessed, however, even in soils to all appearance similar in composition, some very extraordinary results from their mere mixture. Thus, in the gravelly soils of Spring Park, near Croydon, the ground is often excavated to a depth of many feet through strata of barren gravel and red sand, for the purpose of obtaining the white or silver sand which exists beneath them. When this fine sand is removed, the gravel and red sand is thrown back into the pit, the ground merely levelled, and then either let to cottagers for gardens or planted with forest trees; in either case the effect is remarkable: all kinds of either fir or deciduous trees will now vegetate with remarkable luxuriance; and in the cottage-garden thus formed, several species of vegetables. such as beans and potatoes, will produce very excellent crops in the very soils in which they would have perished previous to their mixture. 


\section{MIXTURE OF SOILS.}

These instances are remarkable, and well worthy of the careful consideration of the farmer; fol the poverty of both the sand and the gravel, which is thus so successfully mingled together, is very great. 'The appearance of the soil here gave no indications of any good being derived from the union of the two. The black gravel and the red sand were equally sterile; yet their mere mixture yielded a productive soil.

'The permanent advantages of mixing soils, too, is not confined to merely those entirely of an earthy composition; earths which contain inert organic matter, such as peat or moss earth, are highly valuable additions to some soils. 'Thus, peat earth was successfully added to the sandy soils of Merionethshire by Sir Robert Vaughan. The Cheshire farmers add a mixture of moss and calcareous earth to their "tight-bound earth," the effect of which they describe as having "a loosening operation;" that is, it renders the soil of their strong clays less tenacious, and consequently promotes the ready access of the moisture and gases of the atmosphere to the roots of the farmers' crops: their vigour is promoted, their food better supplied. There are certain natural indications with regard to the admixture of soils which are self-evident to every cultivator; and there are others which are well understood in particular districts. The Norfolk farmers consider that marl is not far from the surface when the weed coltsfoot (Tussilago forfara) abounds : and that all lands will be much benefited by marling which produce the weeds corn-marigold, or briddle (Chrysanthemum segetum), and smartweed, or pale-flowered persicaria (Polygonum Pennsylvanicum).

In the transfer of the earths the farmer will find it a profitable practice, especially when the distance is great, to have them previously dug in pits, and dried in the sun. In this way the weight of either chalk, marl, or clay is much more considerably reduced than the cultivator would suppose. I have found that when moist chalk is dried in this way it loses from 20 to 24 per cent. of water. Strong adhesive clay, under similar circumstances, loses from 32 to 41 per cent., and marl from 18 to 26 per cent. of its weight; so that, supposing he carts 100 cubic yards of each of these fertilizers, by merely having them previously dried, he saves in weight of carriage

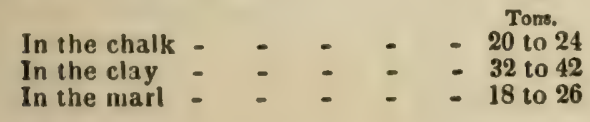

As there are only these earths present to any extent in all cultivated soils, and as the proport: $n$ which they bear to each other makes the cnief difference between fertile and barren lands, I shall confine my attention in this paper to the application of 1 . Chalk, 2. Clay, 3. Sand, to land which is naturally deficient ir: them; and in entering upon the investigation, I shall suppose that the farmer is aware that it is merely the excess of one of these earths which renders a soil unproductive, and that the application of the deficient earths operates so advantaseously by tending to render the comfosition more similar to those of richer soils,

\section{MIX'TURE OF SOILS.}

in which the earths are mixed in a more fertile proportion. It is of the first importance, how. ever, that the farmer should be aware of this fact; let him, to this end, contrast the analysis of a barren soil like that of Bagshot Heath. which is composed of

Coarse silicious sand
Fine sand -

Iron, clay, and chalk

$\begin{array}{r}\text { Bara } \\ -\quad 380 \\ -\quad 9 \\ \hline 400\end{array}$

with that of the soil of a Lincolnshire pasture. which contains, in the same weight,

\begin{tabular}{|c|c|c|c|c|c|c|}
\hline & - & $\begin{array}{l}\text { Yartio } \\
160\end{array}$ \\
\hline Soluble matters & - & - & \multicolumn{2}{|c|}{ Fine calcarenus sand and silicious sand } & - & 8 \\
\hline Organic matters & - & - & - & - & - & 40 \\
\hline Chalk & - & - & - & - & - & 32 \\
\hline Oxide of iron & - & . & - & - & - & 8 \\
\hline Alumina (pure clay) & - & - & - & - & - & 25 \\
\hline Silex (earth of flint) & - & - & - & - & - & 65 \\
\hline \multirow[t]{2}{*}{ Water, and loss } & - & - & - & - & - & 64 \\
\hline & & & & & & 400 \\
\hline
\end{tabular}

The soil of Bagshot, he will observe, contain nearly twice as much silicious matters, and only one-fifth the proportion of chalk and alumina, that is present in the pasture from Croft in Lincolnshire.

Chalk and marl are both used for the sake of the corbonate of lime they contain, and they may, therefore, be treated of under one head. The proportion in which I have witnessed these applied per acre naturally varied with the expense of the carriage of the material. On the light gravelly soils of the coast of Essex, I have used, in common with my neighbours, about 20 to 25 tons of the chalk of Kent per acre, a: a cost of about $6 s$. per ton; bat of marl the quantity applied in the same district is from 50 to 100 tons per acre, which may be commonly procured for the expense of carriage and spreading; and this addition to the soil is a very permanent improvement. Chalking, the Essex farmers say, lasts for 20 years, and marling for a man's life.

Upon analyzing a productive soil, worth $30 \mathrm{~s}$ per acre, which had been thus chalked about five years previously, it was found to contain

Stones and gravel, principally silicious - $\quad 2^{\mathrm{Pa}}$

Vegetable fibres

Soluble matters, principally vegetable extract -3

Carbonates of lime and magnesia - _ - 18

Oxide of iron - - - $_{-}-{ }_{-}-{ }_{-} 4$

Animal and vegetable matters - - - - -1
Alumina

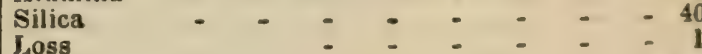

A portion of the same field (which was an enclosure from a poor common), not chalked, being examined, was found to yield nearly the same proportion of ingredients, but the chalk was almost entirely absent. Now, belore the addition of the chalk, the land was too poor to yield any thing except the fern and the furze.

In Dorsetshire, near Weymouth, and on the Coomb Hills, which separate Berks from Hamp shire, where chalk is in many places readily obtained by sinking a well, and drawing it up 


\section{MIXTURE OF SOILS.}

by a windlass to the surface, the quantity ap. plied per acre is much more considerable. I have seen from 50 to 100 , or even 150 tons per acre, spread on the gravel and clay lands with decided success.

The cultivator sometimes deludes himself with the conclusion that applying sand, or marl, or clay, to a poor soil, merely serves to freshen $i$ for a time, and that the effects of such applications are only apparent for a limited period. Some comparative experiments, however, which were made 16 years since on some poor, hungry, inert heath-land in Norfolk, have up to this time served to demonstrate the error of such a conclusion. In these experiments the ground was marled with 20 cubic yards only per acre, and the same of compost; it was then planted with a proper mixture of forest trees, and by the side of it a portion of the heath, in a state of nature, was also planted with the same mixture of deciduous and fir trees. Sixteen years have annually served to demonstrate, by the luxuriance of the marled wood, the permanent effect produced by this mixture of soils. The growth of the trees has been there rapid and permanent; but on the adjoining soil, the trees have been stunted in their growth, miserable in appearance, and profitless to their owner. Time has made no alteration; while the marled soil has yielded an annual and luxuriant crop, the land left in its original state has demonstrated by its produce that something was wanting, some earthy ingredient only needed to render it no longer barren, and the adjoining marled land has further shown of what that addition was composed.

The expense per acre of this marling, and ntherwise preparing the soil, was

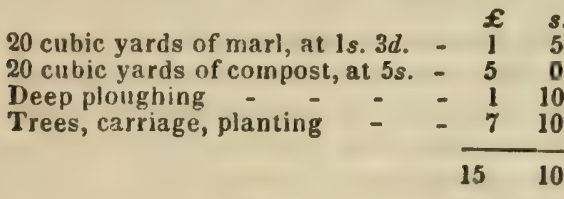

In this instance the marl had to be carried about a quarter of a mile.

It is difficult to account for the want of that general attention to the use of earthy admixtures which so many successful experiments with them would lead us to anticipate. Mr. Rodwell, of Livermere, in Suffolk, successfully clayed and marled 820 acres of sandy heath not many years since, using about 140,000 tumbril loads, which, at $8 \frac{1}{2} d$. per cubic yard, cost him 4958l. He found, from experience, that clay was to be preferred to marl on all his sandy soils. The result was highly satisfactory: $350 l$. per annum was added to the value of the estate.

This excellent farmer practised also the system of hand-barrowing the clay. "The men make good earnings at 10d. a cubic yard, wheeling it 30 rods; and down to $7 d$. a yard at shorter distances:" and on the whole, deemed this "the cheapest method of all others, especially on heavier soils." But he did by far the greatest part by tumbrils, the expense of which, by contract carting, and Jabour, was $8 d$. per cubic yard. He found also, contrary to the commonly recoived opinion, that deep ploughing 826 was the best for his marled and clayed lands "I have found," he said, "that the clay and marl works the better, the more soil it has to incorporate with."

One cause of the failures which have somrtimes taken place in the attempted improve ment of soils by their admixture, arises from the want of a thorough union of the heavy clays, added to the light sandy soils. The earths were in these cases never incorporated by the aid of the harrow, on such frosty mornings as are best adapted to the mixture, and, in consequence, the more ponderous lumps of clay or marl were allowed to gradually $\operatorname{sink}$, as the farmers say, into the sand; and in some such soils as these, the stratum of clay and marl which was applied 10 years since may now be found in one unbroken seam, at a depth of 12 or 14 inches in the soil. Such erroneous modes of applying the earths are much to be lamented: they decide no controverted question,- they prejudice the unreflecting cultivator,-they add nothing to the common stock of agricultural knowledge.

This error was noted by the late General Vavasour: he told the farmers very correctly, that under a poor sand, a stratum of clay, marl, or other substance peculiarly adapted to give fertility to the soil will generally be found that nature seems to have designed that no land should be unproductive, and if any be unfruitful, the cause is in the ignorance or indolence of man. If clay marl, he thought, could be had at a convenient distance, 75 cubic yards per acre was a good covering; if of a shelly or soapy marl, 20 or 25 yards will be sufficient. The marl, after being spread, should be repeatedly rolled and harrowed, to divide and pul. verize it the better.

The application of sand to the farmers' heavy clay soils is a practice which, in several districts of England, is attended with very decided success. Thus, in that part of Suffolk which is bounded on two sides by the rivers Orwell and Stour, there is found a fine red sand abounding with shells, both in their perfect and broken state, which, when applied to the clay soils at the rate of 20 to 30 tons per acre, is productive of very excellent permanent good effects.

In the valley of the Kennett, in Berkshire, in similar proportions I have witnessed the use of the gravelly débris of the Bath Road used upon the peaty soils of that district with excellent effect, and with equal success on some stiff clay meadow-land; the result of dressing it with about 30 tons per. acre with the same road-sand is equally decided. The land is not only prevented from cracking in the summer months, but the produce of grass is very materially increased.

The employment of sea-sand is a very an. cient custom in the west of England; it is one, in fact, to which no one can assion the period of its commencement: many thousand tons per annum are carried away by the farmers who cultivate the lands in the neighbourhood of Padstow Harbour, even on horses' backs, and they think it well worth their while to carry this sand some miles into the interior of the country. In a similar manner the farmers of 


\section{MIXTURE OF SOILS.}

Devon dredge for the sand at the mouth of the Tamar, and when they have filled their barges, carry it up the river. They deem the finegrained sand the most immediate in its effects, but both are very durable, and decided im. provements to the soil. The coarse sand, they say, lasts for many years.

The composition of the sands of Padstow Harbour, and of the estuary of the Tamar, are very similar; they contain from 60 to 70 per cent. of carbonate of lime, and are both preferred by the farmers, when they can be obtained, mixed with the sea-water.

Another, but the least commonly practised mode of improving the staple of a soil by earthy additions, is claying; a system of fertilizing, the good effects of which are much less immediately apparent than chalking, and hence one of the chief causes of its disuse. It requires some little time to elapse, and some stirring of the soil, before the clay is so well mixed with a sandy soil as to produce that general increased attraction and retentive power for the atmospheric moisture which ever constitutes the chief good result of claying poor soils. Clay must be, moreover, applied in rather larger proportions to the soil than chalk; for not only is its application rarely required as a direct food for plants, for the mere alumina which it contains, since this earth enters into the composition of plants in very small proportions, but there is also another reason for a more liberal addition of clay being required, which is the impure state in which the alumina exists in what are commonly called clay soils. For instance, chalk usually contains, when perfectly dry, about 98 per cent. of carbonate of lime. Mr. Kirwan found in a specimen of chalk 2 per cent of alumina, or

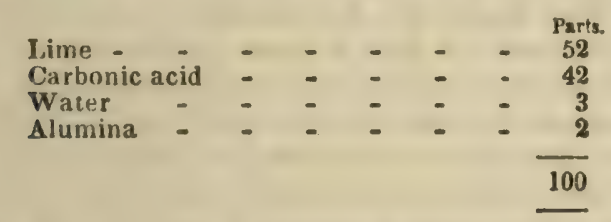

But the heaviest clay soils seldom contain more than 20 per cent. of alumina; in the stiff clays of Sussex and the Weald of Kent are found only about 28 per cent. of this earth: even the adhesive clays employed by the potter yield only about 33 per cent. of alumina, porcelain earth only 47 per cent.

The following is the analysis of a heavy Sussex clay soil :-

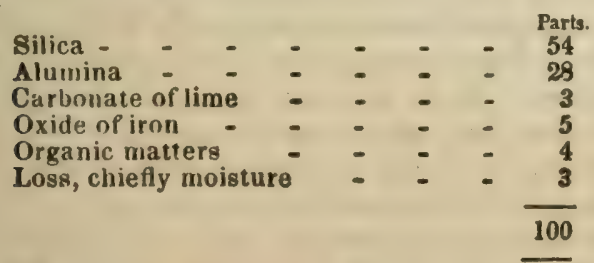

The farmer, therefore, who applies 50 tons per acre of such a clay to a sandy field, only adds about 14 tons of alumina to the soil; but if he applies 50 tons of chalk, he adds 49 tons of carbonate of lime.

Hence, is the reason why, in all efforts to alter the earthy constituents of a soil, a much smaller quantity of chalk produces more de-
MIXTURE OF SOII.8.

cided effects than the addition of a much larger proportion of the must tenacious clay. Chalk, too, when merely spread on the surface of the soil, and exposed to the action of frost, speedily crumbles to powder, and becomes intimately combined with the other eartis of the soils. The clay, however, is too adhesive to be thus readily, and without some little labour, so inti. mately mixed with the soil: its effects, however excellent, are much more slowly apparent; but patience and judicious managemens of clay will do wonders, even on the most un. likely soils; and I could not, perhaps, state any more complete cases of the recuvery of an absolutely barren soil by means of clay and chalk, and that, too, at a reasonably profitable rate, than those successful experiments which have recently been made on the shingle of the sea-coast near Eastbourn, in Sussex, consisting entirely of silicious pebbles, varying in size from that of hazel-nuts to hen's eggs, and that extending to a depth of many feet.

In this case the clay was drawn in hand-carts by three men, rather better than a quarter of a mile. The cart contained about $880 \mathrm{lb}$. of clay, or about 13 cubic feet. Eight of these cartloads, or about $3 \frac{1}{1}$ tons, were spread on each square rod of $16 \frac{1}{2}$ feet, which, when first spread loosely and in lumps, made the soil 5 or 6 inches deep, and when it had become settled and solid, about 4 inches; cach cart took back a load of shingle to fill up the hole made by the excavation of the clay. The work was laborious, but the men readily earned about $1 \mathrm{s.} 6 \mathrm{~d}$. per day, and were contented. They did their work by contract, receiving $3 \mathrm{~s}$. per square rod for the shingle they thus covered, or $24 l$. per acre; and for this sum they carried 250 tons of clay. The clay is of the ordinary red description, so common in Sussi $x$, and though not particularly adhesive, is yet sufficiently so to form a plate, on which in wet weather the rvater stands, although this superstructure of clay is resting on a mass of coarse shingle stones, 15 feet in depth. This experiment was made on a small field of about 3 acres in 1839, and promises as well as a similar effort made with the same clay in 1832 .

In this instance an acre and a quarter of shingle was covered with the same clay to a similar depth. But the clay being only divided in this case from the shingle by the Eastbourn and Hastings Road, the expense was less; the men digging, carrying, and spreading the clay, for $2 s$. per rod, or $16 \mathrm{l}$. per acre. This land was let in 1834, for a term of 14 years, at 40 s. per acre. The tenant has succeeded in making it produce excellent crops; has added to it a considerable quantity of muck and ditch scrapings; has paid his rent regularly, and is contented with his bargain: it produced, in 1838, an excellent crop of rye, which was cut green for horses; this was followed by a good crop of potatoes, and in 1839 , the tares which it produced were a very heavy crop. It is rate? to the poor at $21 s$. $8 d$. per acre.

It would be hardly possible, I think, to pro. duce a more complete case of the absolute for. mation of a soil, by means of claying, than these valuable experiments; the soil (if utterly barren boulder stones or large shingle thrown 


\section{MIXTURE OF SOILS}

ap by the sea can be called soil) not affording a single substance of any kind which could, to any extent, be profitably mixed with the clay. The attempt, therefore, was one of much more difficulty than any case which usually presents itself to the notice of the cultivator. It was not a mere claying a poor sand or chalk, or peat, either of which would assist in forming a mould, but the entire soil had to be formed; and this, it will be seen, was accomplished successfully and profitably, and by manual labour only.

Some valuable observations and experiments upon claying a light sand are contained in the prize essay of Mr. Linton. The description of land he improved "was a light barren sand; the substratum a white sand, from 1 to 4 feet deep; the surface of the same texture, but darker in its colour, through the decomposition of vegetable matter upon it. Beneath the bed of sand lay a yellowish kind of clay, about 1 foot thick; under it a rich marl, about 18 feet deep. The land generally being very wet, my first object was to underdrain it thoroughly with tiles; unless this is first done, where necessary, marling is a waste of capital. I cut my drains about 24 inches deep, and 9 yards apart." As to the choice of clay, Mr. Linton tested it with vinegar and water: the description he used "effervesced nearly as tartaric acid and carbonate of soda do when mixed together in water; this was my test, that it contained a quantity of carbonate of lime, which rendered it fit for my purpose, and worthy of the name of marl. I consider, that on the proper testing and selection of the clay or marl chiefly depends the success of marling operations. All clay will do good, there is no doubt, but on the quality used must rest the amount of benefit obtained." In these experiments "the land was made completely level by the plough-harrows, and in some places the spade, after which it was ready for the marl being laid on, which was done at all times of the year;" he prefers, however, doing this when the land is in seeds. The quantity laid on "varied from 100 to 200 cubic yards per" acre, the average 150 yards. Where the land was very light and barren (which was mostly the case on elevated parts), a larger quantity was laid on; but where it was a better soil, a much less quantity answered the same purpose, my object being to lay on just as much as would grow wheat after seeds; to do more than this would have been an injury to the land, for eating turnips upon it with sheep, and for the barley crop; when sufficiently clayed to grow wheat after seeds, a point requiring close attention, I always found it effectually done for any other crop.

"The vay in which il was done. It was necessary, in the first place, to fix upon the most fasourable situation for the pit, keeping three objects in view. 1. The most convenient place for carting to the plot of ground intended to be marled. 2. The best situation for a pond to unswer for a permanent watering-place, cutting, if possible, across a fence, so as to water 2 fields, one from each mouth of the pit. 3 . Where the clay could be got with the least difficulty. After the place was fixed upon, the work was carried 828 on by 5 diggers, a driver, 4 horses or beasts, and $\mathbf{2}$ carts (which are of the Scotch kind, with short bodies, and broad wheels); the pit was dug with a gradual descent, so that 3 horses could draw out about a ton, which was shot out where wanted, the last returning by the time the other was loaded: thus, 3 horses were always ready for the loaded cart: the clay was spread by the diggers, at broken times after being exposed to the action of the air; rain, after either frosty or droughiy weather, woulc cause it to fall to pieces, sufficiently for harrowing and ploughing in. The expense I paid for digging, filling the carts, and spreading, was from $4 d$. to $5 d$. per cubic yard (full 1 ton), varying according to the quantity of stones imbedded in the clay; the total expense per acre was as follows:-

Dizging and spreading 150 yards, at $4 \frac{1}{s} d$. per

4 hord 4 days, at $2 s .6 d$. each, $10 s$. per day

Driver 4 days, at $2 s .6 d$. per day

Other expenses (wear and tear)

Total expenses in marling 1 acre

Mr. Linton marled 80 acres in this way; but by employing a windlass to draw the carts out of the pit, he reduced the expenses per acre $7 s$. As regards the improvement of the land by marling, the value of the produce in 4 years before marling was

In four years after draining :-

When marled upon seeds

When marled upon fallow

Balance in favour of marling upon seeds $2 \longdiv { 1 6 }$

"The land," Mr. Linton adds, "is never so productive the first 2 years (or until the clay has got well pulverized and mixed with the sand) as it is afterwards, and it will not grow a good crop or a fine sample of barley for 5 or 6 years after the clay is laid on. I have therefore sown oats instead. If people (he concludes) would improve the land they have, particularly light land, by draining, marling, \&c., they would realize a far greater return for the outlay than by purchasing more." (Journ. Roy. Agr. Soc. vol. ii. p. 67.)

From these facts the cultivator, I think, will arrive at the conclusion, that the judicious admixture of soils, and other applications of manual labour, for the purpose of increasing their productiveness, can hardly fail, sooner or later, to amply repay him for the labour he thus employs. It is an improvement, let him remember, that, when once accomplished, lasts forever, since the very character of the soil is changed; his organic manures, such as farmyard compost, oil-cake, and even bones, are gradually dissolved or decomposed, and disappear from the land, are absorbed by his crops, or evolved in the gases of putrefaction; but no such results arise from either deepening the soil or the addition of the earths, they, when once united to the soil, remain there to increase the crops, to lessen the toils, and to add to the profits of succeeding cultivators, even in dis. tant periods. And to effect these important, 
these national results, let him, ton, remember, that no neighbouring lands are impoverished, no organic matters are drawn from one field to enrich another; the dead, the deep-buried earth is merely brought to the surface, and that which is utterly profitless in the mass diffuses riches and gladness when spread over the farmer's fields.

MOLASSES (Port. Melasso). The saccharine principle in the dregs or refuse drainings from the casks, \&c., of sugar, and the uncrystallizable part of the juice of the cane separated from the sugar during the process of granulation. It consists of sugar prevented from crystallizing by acids, saline, and other matters. All cattle are fond of sweets, and thrive well upon substances which yield a large proportion of saccharine juice, of which no better proof can be afforded than the condition of the cattle and swine of the West India Islands, which are fed mainly on the tops and refuse of the cane after the juice has been expressed for sugar. Mr. E. Waters (Com. to Board of $A g r$. vol. vi. p. 30 ) gives the result of a very satisfactory experiment as to the advantage of feeding live-stock with molasses. There can be no doubt that when this substance can be had cheap, its use must prove very beneficial in improving the condition of cattle.

MOI.E. A species of the genus Talpa, common in England and other parts of Europe. 'This quadruped exhibits in perfection that modification of structure by which the mammiferous animal is adapted to a subterranean life. Its head is long, conical, and tapering to the snout, which is strengthened by a bone, and by strong gristles worked by powerful muscles. The body is almost cylindrical, thickest behind the head, and gradually diminishes to the tail. There is no outward indication of a neck, that part being enlarged to the size of the chest by the massive muscles which act upon the head and fore-legs. These, which are the principal instruments by which the mole excavates its long and intricate burrows, are the shortest, broadest, and strongest, in proportion to the size of the animal, which are to be met with in the mammiferous class. The food of the mole consists of worms, insects, and the roots of plants; its voracity is great, and it soon perishes if food be scarce or wanting. The sense of sight is very feeble, the eyes being minute and rudimental; but the other faculties of smell and hearing, as being more serviceable in its dark retreat, are extremely acute. The female prepares a nest of moss, dry herbage, roots, and leaves, in a chamber commonly formed by excavating and enlarging the point of intersection of 3 or 4 passages. The young are brought forth to the number of 4 or 5 in A pril, and sometimes later.

The farmer views the operations of the mole as destructive to his crops, by exposing and destroying their roots, or by overthrowing the plants in the construction of the mole-hills; his burrows, moreover, become the haunts and hiding-places of the field-mouse and other destructive animals. The mole is also accused of piercing the sides of dams and canals, and letting out the water, and of carrying off quan. tities of young corn to form its nes: Hence every means are devised to capture and cestroy it, and in Europe men gain a livelihood exclu. sively by this occupation. Some naturalists, however, plead that the injury which It perpe trates is slight, and that it is more than coun. terbalanced by the benefit which it produces by turning up and lightening the soil, top-dressing pasture-land, and especially by its immense destruction of earth-worms, slugs, grubs, wireworms, and many other noxious animals and insects which inhabit the superficial layer of the ground, and occasion great injury to the roots of grass, corn, and many other plants. The soundest practical conclusion lies probably in the mean of these opinions; and the enlightened agriculturist, while he takes prompt measures to prevent the undue increase of the mole, would do well to reflect on the disadvantages which might follow its total extermination. The Ettrick Shepherd (James Hogg), from a course of 30 years' hard-earned experience and observation, speaks of the pernicious effects of destroying the moles on sheep pasture. He alleges, that besides the inferior pasturage which the soil affords when moles have been exterminated, the pining and the foot-rot, two baneful diseases, come in their place to annihilate the stock.

There can be no question that moles do much injury to gardens, by destroying the neatness of the beds, rooting up onions, tulips, and other tubers; but in the wide-spread surface of the field it is a question whether he does not do more good by his teeth than injury by his snout.

The animal so well known in the United States under the name of mole, belongs to an entirely different genus of quadrupeds from the common mole of Europe. The late Dr. God. man has designated the American, the shrew mole, and given, in his Rambles of a Naturalist, a most interesting account of its habits, \&c. It is the scalops aquaticus of naturalists. Whether the true mole has ever been found in the United States, appears doubtful. Moles live in pairs, and frequent soils of loose textures most abounding in earth-worms and insects. They exhibit great dexterity in skinning the worms, which they always do before they eat them, stripping the skin from end to end, and squeezing out all the contents of the body.

In the United States where professional molecatchers are not yet to be met with, other means of destroying the pest are resorted to. Dogs are sometimes found very expert in digging out moles. Mole-traps are also used, and for a good design of one see Ellsworth's Report. It is found that if fine shreds of fresh lean beef are placed in their furrows, the moles will eat them, if found soon after deposit; and if poison, arsenic or strychnine, is placed on these shreds, they are frequently killed. The trap most recommended is one constructed on the principle of that, a figure of which is given in the Cultivator. Wherever the mole shows itself in numbers, it is a pest of no small magnitude. For accurate descriptions, with drawings, $u$ ! the various animals known in the Unitel 
States under the names of moles, or mice, the reader is referred to the 1st volume of the $\mathrm{Na}$ tural History of the State of New York.

MOLE-CRICKET (Gryllotalpa vulgaris. Acheta gryllotalpa). This destructive insect is known in different localities in England, under the several names of churr-worm, jarr-worm, eve-churr, and earth-crab. The mole-cricket measures 2 inches in length, and 4 lines in breadth. Its colour is dark-brown. The most remarkable feature in the insect is the size and strength of its fore-arms. The power which is requisite to move them is great. The cavity of the main trunk is divided lengthways by a double gristly partition, surmounted by a bony frame, with an inferior condyle, with which the inner part of the base of the clavicle of the arm is hinged; and by this mechanism the arms are moved. The mole-cricket burrows under ground, and devours the roots of plants. The female hollows out a place for herself in the earth, about half a foot from the surface, in the month of June, and lays her eggs in a heap, which often contains from 200 to 300 . They are shining yellowish-brown, and of the size and shape of a grain of millet. The young, which are hatched in July or August, greatly resemble black ants, and feed, like the old ones, on the tender roots of grass, corn, and various culinary vegetables. They betray their presence under the earth by the withered yellow patches in the meadows, and by the withering decay of culinary vegetables in the gardens. In October or November they bury themselves deeper in the earth, as a protection from cold, and come again to the surface in the warm days in March. Their presence is discovered by their throwing up the earth like moles. The best method of destroying them is to dig up the young brood; but boiling water or oil of any kind poured over their holes will be found effectual. (Kollar on Insects, p. 144.) For a description of the American mole-cricket see Cricket.

MOLE-PLOUGH. See Draining and Plovghs.

MOLE-TREE (Euphorbia lathyrus). Commonly called Caper Spurge, and by the French Epurge: a plant with a biennial ront; stem 2 to 3 feet high; found in the United States in gardens and lots. It is a naturalized foreigner, and was originally introduced under a notion that it afforded a protection against the incursions of moles. The same common impression once existed in regard to the Palma Christi; but little faith seems now to be attached to either plant as protectives against moles.

MONADELPHOUS. In botany, having the flaments cohering into a tube, or one bundle.

MONANDROUS. A botanical term applied to plants having only one stamen, or male nrgan.

MONILIFORM. In botany, formed like a necirlace; that is to say, articulated with alternate swellings and contractions resembling a string of beads.

MONK'S HOOD. See WoLF's-Baye.

MONOCOTYLEDONOUS. In botany, hav$\eta g$ only one seed-leaf or cotyledon.

YOON, INFLUENCE OF. The following 830 observations upon this subject are taken from a lecture delivered before the Franklin Institute of Pennsylvania, by G. Emerson, M. D., of Philadelphia.

There is, perhaps, no opinion relative to the phenomena of the natural world, more universally maintained, than that the moon exerts a decided influence over the states of the weather. This long-cherished notion has doubtless derived increased strength, since it was shown that the ocean tides depend upon a phy. sical connection subsisting between our planet and her satellite.

I, however, think it capable of conclusive demonstration, that the moon exerts no influence in the production of wet or dry weather.

I assume it as incontrovertibly proven, by the experiments of Mr. Dalton, that the watery vapour from which rain and all the precipitations are formed, owes its elevation and suspension, in an invisible form, entirely to heat, deprived of a due proportion of which, by any refrigerating cause, it is condensed, and falls from the atmosphere in one or other of the forms of aqueous precipitation. The conditions of wet or dry weather are, consequently, to be res garded as regulated solely by temperature.

Now, the nicest experiments have failed to show that the presence and light of the moon are attended by the slightest change of temperature. The lunar rays have been concentrated by powerful lenses and the largest reflectors, and thrown upon that most delicate test of heat, the differential thermometer, without any indication of their effect in raising the temperature. Unless, therefore, it can be proved that the moon exerts some perceptible influence upon the temperature of our atmosphere, we shall be warranted in believing that she has no power in determining the conditions of the weather, whether this shall be wet or dry.

I am fully aware of the multitudes of observations which have from time to time been made upon this question, and that most of those reported appear to favour a belief contrary to the position here taken.

It cannot be denied that the power of the moon, so conspicuously manifested in the production of the ocean tides, may also be felt by the atmosphere. The aerial ocean must, weight for weight, be as subservient to the law of attraction subsisting between the earth and her satellite, as any other terrestrial matter; and I have no doubt of the correctness of the results of observations made in Italy and France, by Polina, Flaugergues, and others, which go to prove that the mean height of the barometer is affected by the different positions of the moon in relation to the earth, the greatest mean elevations corresponding with the quarters. But, in thus admitting the existence of lunar influence upon the terrestrial atmosphere, we should not deceive ourselves in regard to the nature of this influence. We must not admit that every cause which operates in producing the rise or depression of the mercurial column, is capable of influencing the hygrometric conditions of the air, $c, r$, in other words, exercising an influence in the production of wet ur dry weather. The attraction subsisting between 
the earth and moon, causes an accumulation of the liquid and movable materials spread over the terrestrial surface, on that part addressed, towards the moon; hence, the rise observel in the sea, and in the mercurial column. But all this is owing to the agency of gravity, or attraction, which, we contend, has nothing to do with the production of wet or dry weather; the elevation and deposition of aqueous vapour being, as we have said before, subject to the agency of temperature alone.

As to the calculations, the results of which seem so irresistibly in favour of lunar influence upon the weather, we think it easy to show that that they must be founded upon deceptive data, and will not bear a close examination. The estimates of Toaldo, a celebrated Italian philosopher, embrace a series of laborious observations, collected during many years, and compute the number of changes of weather to the different phases of the moon, as follows :

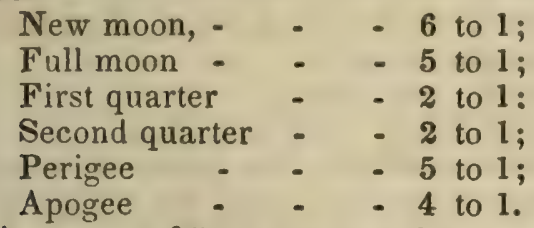

That is to say, of 7 new moons, 6 were attended with a change of weather, and at one of them there was no change; of 6 full moons, 5 were attended with a change; and, at the quarters, the changes were twice as frequent as the continuance of the previous weather.

Now, such a computation, coming from so high an authority, might almost be deemed conclusive upon the subject. When, however, we come to inquire more closely into the circumstances involved in the calculation, we find ample grounds for suspecting its accuracy. In the first place, the term "change of weather" is used by Toaldo in an ambiguous and arbitrary sense, so that we are left ignorant of the specific change he refers to. But, worse than this, he does not restrict himself to the day when the change takes place, but includes any changes within 2 or 3 days preceding or following a phase. It is easy to conceive how a person, especially one prepossessed in favour of a prevailing opinion, might have been led, with such a privilege as to limit, to take or reject a change, to throw it into one quarter or another, as he might choose to dispose of it, for the purpose of endowing the moon with a power to which he thought her entitled.

The results of a series of observations made by Pilgram, make it appear that the new moon has less to do with the changes of the weather than the other phases; a conclusion diametrically opposed to that of Toaldo, just referred to. As the estimate of Pilgram is founcled on observations extending through a series of no less than $\mathbf{5 2}$ years, it might be regarded, in point of authority, as at least equal to that of the Italian philosopher. How are these clashing results of observations, professing to be made with the utmost attention, to be reconciled with truth? Do they not leave us bo infer that the data employed have been either entive, unskil:ully grouped, or that some incidental or accidental circumstances here interfered with the estimates, and led to erroneous conclusions?

The belief in the moon's influence over the natural operations going forward upon our earth, has by no means been confined to the weather; and it would be a tedious task to enumerate all the agencies she has been allow. ed to possess over organic and vegetable life both animate and inanimate. "Many of the opinions vulgarly entertained upon this head," says M. Arago, "are founded on well-established facts, the error lying, not in the observations, but in the theory which makes the moon the cause of phenomena, of which she is only the silent and unconcerned spectator." The distinguished philosopher from whom we have just quoted, has cited a number of highly interesting cases, which show in the clearest manner how the effects that have been ascribed to the moon's influence, can be readily traced to natural agencies operating around us, and with which modern philosophy has rendered us familiar. Such, for example, as the pernicious influence upon vegetation, attributed by gardeners and agriculturists to the April moon; the effect of the moon's rays in hastening the putrefaction of animal substances, \&c.; all of which effects are doubtless connected with the presence of moonlight, merely, however, as an incidental circumstance, for they would take place equally well in a clear atmosphere, even should there be no such body as the moon in existence.

Let us take, for example, the case of the April moon, denominated by the French gardeners "la lune rousse." The change in this case takes place in April, and the full either about the end of this month, or some time in May; at which particular season, in our climate, the mean temperature of the air is but little above the freezing point. Under these circumstances the radiation from the earth, during a clear night, will often reduce its temperature to, or even below, the freezing point; whilst a thermometer suspended in the air, a few feet from the ground, will remain several degrees above $32^{\circ}$. Thus, the tender plants in the soil may become actually frost-bitten, whilst the atmosphere has been apparently too warm to admit of such an occurrence. If, on the contrary, the night be cloudy, the plants will suffer no injury; not, as the gardeners allege, because there is no moonlight to hurt them, but because the radiation and cooling of the earth will not take place. Thus, moonlight or starlight, the injury to vegetation will be precisely the same, and the effect might as well be ascribed to the stars as to the moon.

And, again, it has been noticed by Pliny and Plutarch, and is generally believed in most countries at the present day, that the moon's light sheds a copious humidity on substances exposed to its rays, and hastens the putrefaction of animal substances. 'That a copious humidity is often shed during a moonlight night, is not to be disputed neither can it be doubted that meats will spoil sooner, if exposed to her rays, than if protected from them. The nature and source of this humidity can be no mysteries now that the rationale of the 
ormation of dew is so happily explained; and it is sufficient to say, that the moisture deposited upon the meat causes it to spoil much sooner than if kept covered, when it would remain dry. Meats are constantly preserved by simple drying; and even the mummies in the dry caverns of Egypt have lasted thousands of years, mainly from their depositories being perfectly free from moisture. The preserving agency of embalming is, perhaps, a secondary consideration, when compared with the subsequent state of dryness in which the bodies are kept.

As to the notion of lunar influence on disease, which still counts numerous partisans, I regard it as upon precisely the same footing as the exploded doctrine of the agency of the stars, so long and stoutly maintained.

Upon the whole, therefore, I look upon it as clearly demonstrable, upon established philosophical principles,

Ist, That wet and dry weather are matters regulated solely by changes of temperature, over which the moon has no control:

$2 d$, That the mutual influence exerted between the earth and moon, as shown in the ocean and atmospheric tides, depends upon the play of another and entirely distinct principle, namely, gravitation or attraction :

$3 d$, That most, if not all, the effects upon animal and vegetable substances, popularly ascribed to the action of the moon, are to be traced to natural agencies, entirely independent of this satellite.

MOON-TREFOIL. A name for one of the species of medick (Medicago arborea).

MOONWORT (Botrychium, from botrys, a bunch; in reference to the form of the fructification, which is much like a bunch of grapes). The species of this genus of ferns are curious and interesting plants; one only is indigenous, the common moonwort (B. lunaria), which is a perennial growing in mountainous pastures or meadows. The root consists of several simple, cylindrical, clustered or whorled fibres. The herb is very smooth, a little succulent, of a pale opaque green, erect, not a span high. Leaf solitary, pinnate; leafsets fan-shaped, notched.

MOOR. An uncultivated surface of country, without trees, and with few grasses or other herbage fit for pasture; and usually containing scattered plants of heath, with a dark peaty soil. Moor lands are generally the least fitted for culture of any description of surface, not rocky or mountainous. Moors are covered with a very thin layer of soft, black, sterile soil ; and the subsoil is generally gravel or retentive ferruginous clay. By the destruction of the heath or othe: bad herbage, and by sowing down with grass-seeds, they may be improved. In many cases, also, trees will grow on drained moors; in which case the soil ultimately becomes ameliorated by the shade they afford, and the fall and decay of their leaves. see Heath, Morass, Peat Solls, and Waste LANIS.

MOORBAND PAN. This is a name given in Scotland to an indurated combination of rlay, small stones, and iron in a particular - tate, situated either immediately, or at some x32 distance below the path of the plough, and which is nearly impervious to water. All in. durated incrustations, however, formed under the sole of the plough, says a writer in a valu. able agricultural journal, are not moorband pan. In good alluvial loam of greater depth than the plough-furrow, and rendered adhesive by pressure, an incrustation or firming of the subsoil-that is, the bottom upon which the plough moves, is frequently formed by the sole of the plough rubbing constantly on the soil at the same depth. This incrustated earth can retain water, but its effects on soils and plants are innocuous compared to those of moorband pan. Nevertheless, its disruption by deep ploughing is of benefit to the soil, and we have experienced it in very fine deep mould. From an analysis by Mr. John Gray, of Dilston, of two portions of moorband pan obtained from My!nfield Plain, 120 parts of one were found to contain 34 of oxide of iron, 74 of silex, and 6 of alumina or clay and loss; the other contained 43 parts of oxide of iron, 64 of silex, and 8 of alumina and loss.

MOOSE. See DEen.

MOOSE-ELM. See ELM, RED.

MOOSE-WOOD. The name of a species of maple (Acrer striatum), so called in the northern section of the United States, but in the Middle States known by the common name of striped maple.

MOOR-GRASS (Sesleria, named in honour of M. Sesler, a physician and botanist of the 18th century). These are uninteresting grasses in an agricultural point of view.

MORASS. Moor lands saturated with water to such an extent as not to bear the tread of cattle. A morass is to a moor what a marsh is to a meadow. It is evident that the drainage of morasses and moors, by lessening the evaporation of water from their surfaces, must tend to improve the local climate. See Prat and Prantations.

MORDANT. Any substance used to fix dyes or colouring matters upon different stuffs.

MOREL (Germ. moschel). The Moschella esculenta is one of the few edible fungi which may be used as food with safety. It occasionally occurs in woods and orchards, whence it finds its way to the markets; but it is of comparatively rare occurrence. It has a hollow stalk an inch or two high, and a yellowish or grayish indented head 2 or 3 inches deep. See Fungi, and Mushrooms.

MOR'TAR. A well-known cement employed for building purposes, which is thus described by Dr. Thomson: "It is composed of quicklime and sand, reduced to a paste with water. When dry it becomes as hard as stone, anc as durable; and adhering very strongly to the surface of the stones which it is employel to cement, the whole wall in fact becomes no thing else than one single stone. But this effect is produced very imperfectly unless the mortar be very well prepared. The lime ought to be pure, completely free from carbonic acid, and in the state of a very fine powder; the sand should be free from clay, and partly in the state of fine sand, and partly in that of gravel; the water should be pure, and if previously 
saiurated with lime, so much the better." The best proportions, according to the experiments of Dr. Higgins, are 3 parts of fine sand, 4 parts of coarse sand, 1 part of quicklime, recently slacked, and as little water as possible. The stony consistence which mortar acquires is owing partly to the absorption of carbonic acid, but principally to the combination of part of the water with the lime. This last circumstance is the reason that, if to common mortar one-fourth part of lime, reduced to powder without being slacked, be added, the mortar, when dry, acquires much greater solidity than it otherwise would do. 'This was first proposed by Loriot; and afterwards Morveau found the following proportions to answer best:-

Fine sand - - -
Cement of well-baked bricks
Slacked lime -
Unslacked lime -
Unslacked lime

Parts.

The same advantages may be obtained by using as little water as possible in slaking the lime. Higgins found that the addition of burnt bones, in the proportion of not more than onefifth of the lime employed, improved mortar by giving it tenacity, and rendering it less apt to crack.

When a little clay is added to mortar, it acquires the important property of hardening under water; so that it may be employed by the farmer in those edifices which are constantly exposed to the action of water. Limestone is found not unfrequently mixed with clay; and in that case it becomes brown by calcination, instead of white. These native limestones are employed for making water mortar; but good water mortar may be made by the following process : Mix together 4 parts of blue clay, 6 parts of black oxide of manganese, and 90 parts of limestone, all in powder. Calcine this mixture to expel the carbonic acid; mix it with 60 parts of sand, and form it into a mortar with a sufficient quantity of water. The best mortar for resisting water is made by mixing lime with puzzolano, a volcanic sand brought from Italy. Morveau informs us that basaltes, which is very common in this country, may be substituted for puzzolano. It must be heated in a furnace, thrown while red-hot into water, and then passed through a sieve.

MOSSES, in common language, are any minute, small-leaved, cryptogamic plants. Thus, club-moss is a lycopodium; Iceland and reindeer mosses are lichens; and the numerous species of Jungermannia are all comprehended under the same term. But in systematical botany no plants are considered mosses, except such as belong to the natural order, Bryacere or Musci. Such plants are simpleleaved; without spiral vessels or stomata; with a distinct axis of growth; and with the sporules, or reproductive matter enclosed in cases called sporangia or thecæ, covered by a cap or calyptra. It is not a little singular that such plants should have cases called staminidia, containing powdery matter; among which are found animalcules, not distinguishable from such as are called spermatic, and which swim about freely in water. None of the mossey are of any known use, except for the purpuse of packing plants, and surrounding their roots when they are sent to a distance. They are bad conductors of heat, and might be employ. ed, instead of straw, to guard delicate-growing plants from the influence of frost.

MOSS LAND. Land abounding in prat moss, but not so much saturated with water as to become peat bog or morass. Many remedies have been prescribed for the destruction of moss. A good scarifying or harrowing, with short, sharp tines, succeeded by a top dressing of salt or soot, is probably the most efficacious: lime in any form is less nowerful, though (especially when combined with sand) it remarkably promotes the growth of trefoil tribes and other grasses, highly palatable to cattle, but does not avail to the exclusion of moss. Mr. Bishop of Perthshire, who has ob. tained from the Highland Society of Scotland a prize for an essay "On the Management of Pasture in regard to the Destruction of Musci," suggests as the most certain remedy, that a great portion of the summer's grass should remain unconsumed on the ground until the following winter, when the barer it is eaten before the new growth of spring, the finer will be the following summer's grass. Breaking up the land, and sowing appropriate grasses after a course of culture, is a certain remedy. but often a very inconvenient one. Mr. W. Bell gives an account of certain experiments which he carried on very successfully for converting moss into manure by the application of whale oil.

Mr.A. Blackadder, speaking of the manures for decomposing moss, says: Adjacent rcci strata ought to be carefully explored, as in general they have each their corresponding earthy covering, more or less adapted to the purposes of vegetation. Where the rocks are of the primitive class, or of the coal formation, their disintegrated portions, and oftimes their superficia! covers, are of inferior value as a soil; but even the rock-earth of the latter, as also of clay-slate, fime, or even the old red sandstone, though not previously mingled nor superim. posed in the moss, are yet valuable as ingredients of composts for top-dressing, as are also those of the finer sandstone, greenstone, and sea-sand containing calcareous matters in a state of decomposition, or even where these are absent. While sand laid over moss pro duces rapid decomposition, and consequent vegetation, no such effect is produced by the purer clays. Putrescent matters, whether animal or vegetable, possess the most powerful influence. Lime, unless in compost, seems " have no such effect on simple mosses; and its effects on mixed mosses, or those in a state of partial decomposition, must depend on the quantity of foreign matter and other circumstances. The value of moss greatly depends on local circumstances, and particularly with regard to the supply of operatives at the com. mencement of improvements: access to putrescent manures: markets for the sale of the produce; snils affording materials for top. dressing; and turf suitable for wedge-drairo 
or for drain-tiles, or stone for drains, or clean gravel, if found preferable, the expense at which these can be laid down at the moss must enter into the calculation. Or, again, if the moss is to be entirely removed, whether an adequate supply of water can be obtained, with access to a river or to the sea, into which it may be floated off. Nothing adds more to the intrinsic value of moss than mixtures of other soils during the progress of its formation, either by means of the winds carrying drift sand, or by water transporting earthy particles. When, again, a considerable quantity is thus superimposed, the soil ceases to be a moss, properly so called, and is an alluvial soil upon a moss subsoil. In either case, little more is required than thorough drainıng, in order to the production, by the ordinary means, of the best crops; and such is the description of the greater part of the mosses hitherto successfully improved in Scotland. The same writer furnishes some causes of the failure in moss improvements.

MO'IH. Clothes-moth, Fur-moth, Grease-moth, \&c. The various kinds of destructive moths, found in houses, stores, barns, granaries, and mills, are mostly very small insects; the largest of them, when arrived at maturity, expanding their wings only about eight-tenths of an inch. The ravages of some of these little creatures are too well known to need a particular description. Among them may be mentioned the clothes-moth (Tinea vestianella), the tapestry-moth or carpet-moth ( $T$. tapetzel$(a)$, the fur-moth ( $T$. pellionella), the hair-moth ( $T$. crinella), and the grain-moth ( $T$.granella), with some others belonging to a group, which may be called Tineans (Tineada); also the pack-moth (Anacampsis sarcitella), which is very destructive to wool and fabrics made of this material, and the Angoumois grain-moth (A. cerealella), both of which are to be included among the Yponomeutians. In the cabinet of the Boston Society of Natural History, the cases, containing the large and beautiful collection of shells, were formerly lined with fine white flannel. In this some moths soon established themselves, multiplied very fast, and, in the course of a few years, did so much damage that it became necessary entirely to remove the moth-eaten linings. In their winged state these moths were of a light buff colour, with the lustre of satin, and had a thick orangecoloured tuft on the forehead; the wings were deeply fringed, and the first pair were lanceshaped, and expanded rather more than half an inch. This species agrees very well with the description given, by the old naturalist, of the Tinea fiavifrontella, or the orange-fronted tinea, and with Wood's figure of Tinea destructor, the destroyer. Should it prove to be different from these, it may be named the satin-buff moth. Objects of natural history are very apt to be injured by another moth, closely resembling the foregoing, and differing from it chiefly in being somewhat smaller, and in having the hind-wings tinged with gray. Chocolate, as Réanmur has remarked, is devoured by another lirica, whose little silken cases are often seen between the cakes, and I have also found them in chucolate put up in tin cases. Other articles .f lood are also devoured by some of these tinex, and even our books are not spared by them.

Habits of Moths, and Means of preserving Clothes, \&c., from their Attacks. - The tineans, in the winged state, have 4 short and slender feelers, a thick tuft on the forehead, and very narrow wings, which are deeply fringed. They lay their eggs in the spring, in May and June, and die immediately afterwards. The "ggs (according to Latreille and Duponchel, from whose works the following remarks are chiefly extracted) are hatched in $\mathbf{1 5}$ days, and the little whitish caterpillars or moth-worms proceeding therefrom immediately begin to gnaw the substances within their reach, and cover themselves with the fragments, shaping them into little hollow rolls and lining them with silk. They pass the summer within these rolls, some carrying them about on their backs as they move along, and others fastening them to the substance they are eating; and they enlarge them from time to time by adding portions to the two open extremities, and by gores set into the sides, which they slit open for this purpose. Concealed within their movable cases, or in their lint-covered burrows, they carry on the work of destruction through the summer; but in the autumn they leave off eating, make fast their habitations, and remain at rest and seemingly torpid through the winter. Early in the spring they change to chrysalids within their cases, and in about 20 days afterwards are trans. formed to winged moths, and come forth, and fly about in the evening, till they have paired and are ready to lay their eggs. They then contrive to slip through cracks into dark closets, chests, and drawers, under the edges of carpets, in the folds of curtains and of garments hanging up, and into various other places, where they immediately lay the foundation for a new colony of destructive mothworms.

Early in June the prudent housekeeper will take care to beat up their quarters and put them to flight, or to disturb them so as to defeat their designs and destroy their eggs and young. With this view wardrobes, closets, drawers, and chests will be laid open, and emptied of their contents, and all woollen garments, and bedding, furs, feathers, carpets, curtains, and the like, will be removed and exposed to the air, and to the heat of the sun, for several hours together, and will not be put back in their places without a thorough brushing, beating, or shaking. By these means, the moths and their eggs will be dislodged and destroyed. In old houses, that are much infested by moths, the cracks in the floors, in the wainscot, around the walls and shelves of closets, and even in the furniture used for holding clothes, should be brushed over with spirits of turpentine. Sheets of paper sprinkled with spirits of turpentine, camphor in coarse powder, or leaves of tobacco, should be placed among the clothes, when they are laid aside for the summer. Furs, plumes, and other small articles, not in constant use, are best preserved by being put, with a few tobacco leaves, or hits of camphor, into bags made of thick brown paper, and closely sewed or pasted up at the end. Chests of campher wood, red cedar, or of Spanish cedar. 
are found to be the best for keeping all articles from moths and other vermin. 'The cloth linings of carriages can be secured forever from the attacks of moths by being washed or sponged on both sides with a solution of the corrosive sublimate of mercury in alcohol, made just strong enough not to leave a white stain on a black feather. Moths can be killed by fumigating the article containing them with tobacco smoke or with sulphur, or by shutting it in a tight vessel and then plunging the latter into boiling water, or exposing it to steam, for the space of 15 minutes, or by putting it into an oven heated to about 150 degrees of Fahrenheit's thermometer.

Stored grain is exposed to much injury from the depredations of two little moths, in Europe, and is attaclied in the same way, and apparently by the same insects, in the United States. See Conn-Moth, Grarn-Wenvil, and Insects.

MOTH MULLEIN. See Muluein.

MOTTLED. In botany, signifies marked with blotches of colour of unequal intensity, passing insensibly into each other. It is synonymous with maculated; as, for instance, in the stems of common hemlock (Conium maculatum).

MOULD. A general name for the finely divided earthy substance that forms the upper stratum or surface soil of land, and in which all kinds of vegetables strike root and thrive. See Anatrsis of Sorls, Earths, and Humus.

MOUl.D-BOARD. See Plougr.

MOULD ON HOPS. A vegetable disease, which is liable to affect the hop plant, in the more advanced periods of its growth, and produce much mischief to the crop. See Mrunew and Hops.

MOULDEBAERT. This implement of Flemish husbandry resembles a large square maltshovel: it is strongly prepared with three bars of iron on the lower side, secured by 12 bolts, and is drawn by a pair of horses with swirgletrees. It is used for transporting compost, mould, \&c., from one spot to another. Its usual dimensions are as follows: breadth across, 3 feet 6 inches; lengih, 3 feet; height of back, 1 font 6 inches; length of handle, 4 feet. The person who drives, with long reins, by pressing moderately on the handle as the horses go forward, collects and transports about $5 \mathrm{cwt}$. of earth to the place where it is to be laid down, which is done in the most expeditious manner, by his letting go the handle; this causes the front edge of the implement to dip and catch against the ground, whereby it is at once turned over and emptied of its load. 'The extremity of the handle, to which a rope is affixed, by this upsetting strikes against, and rests upon, the swingle-tree bar, and in this manner the mouldebaert is drawn along towards the heap of earth or compost; the driver then, by taking up the rope, draws back the handle, collects his load as before, proceeds to the spot which is to receive it, and the horses are never for a moment delaved.

MOULTING. The fall of the plumage of birds. It may be either partial or total: the complete moult generally takes place annually; the partial moult occurs at the change of plumage 0 which some species of birds are subject at the breeding season. The moult is al ways accompanied by the developement of a new plumage, which may be of a different colour from that which is lost.

MOUNTAIN ASH. See Rowas Tres.

MOUN'TAIN EBONY (Burhinia; in memo. ry of John and Caspar Bauhin, botanists of the sixteenth century). A genus of showy and interesting evergreen shrubs, which will suc. ceed well in a mixture of sand, loam, and peat.

MOUNTAIN LAUREI. See Kalma Lat?FOLIA.

MOUNTAIN MAHOGANY (Betula lenta).

Black Birch. See Brrcн.

MOUSE-EAR CHICKWEED. See CrrckWEED.

MOUSE-FAR SCORPION-GRASS. See Scorpion-Grass.

MOW. A pile or heap of corn, straw, or hay placed together for the purpose of being kept dry. See Stack and Rick.

MOW-BURNT. A term applied to such substances as are over-heated in the mow by the process of fermentation.

MOWING. The act of cutting down corn, grass, \&c., by the scythe.

MOWING MACHINES. See Rraping MA. CHINES.

MUCILAGE. A turbid, slimy fluid, produced by treating some vegetable substances with cold water, others with hot. It resembles gum, but is distinguished from it by not forming a thick curd with the solution of Goulard's extract. See Starch, Lifseed, Mansh MalLow, \&c.

MUCK. A farming term for any sort of material, such as dung, straw, \&c., that is moist, or in a fermenting or decomposing state.

MUD. The mechanically suspended matters of water deposited at the bottom of rivers, ponds, ditches, \&c. As much of this kind of material should be collected as possible, and be thrown up into heaps in order to become mellow. It contains much carbonaceous matter, and is an excellent manure, either in the simple or com. pound state, mixed with composi, or with a bushel of lime or salt to each cubic yard.

MUDWORT (Limosella; from limos, mud, in allusion to the habitation of the species; whence, also, the English name). The common mudwort (L. aquatica) is an English annual subaquatic plant, growing in muddy spots, where water has stagnated during winter. The herb is diminutive and quite smooth.

MUGWORT (Artemisia vulgaris). This species of Artemisia grows very common about English hedges, in waste ground, and the rough borders of fields. This species is weakly aromatic, and bitterish; and has, from remote antiquity, been esteemed an active warm medicine in decoction.

MULBERRY TREE (Morus; from the Celtic word mor, signifying black, in allusion to the colour of the fruit). The species of Morus, or mulberry, grow from 10 to 30 feet high. A moist situation and loamy soil, with a free ex posure to the sun, suit them best.

1. The common mulberry ( $M_{0}$ nigra) is is general cultivation for the sale of its fruih which is well known. 
2. The white mulberry (M. alba) is extensively cultivated in many countries for its leaves, which form the chief food of silkworms.

The mulberry tree may be propagated by layers, cuttings, or grafting. The principal use of the fruit of the black mulberry is for the dessert: but from its cooling and laxative properties, its juice, diluted with water, is sometimes used as a beverage in fevers. It is also employed in the form of syrup for medicinal purposes, chiefly to colour other fluid medicines. The juice is also used to give a dark tinge to liquors and confections. When properly fermented and prepared, the fruit yields a pleasant vinous liquor, known under the name of mulberry wine. In the cider counties they are sometimes mixed with apples, to form a beverage known as mulberry cider. The bark of the root has an acrid bitter taste, and is a powerful cathartic; hence it has been successfully used as a vermifuge, in doses of a scruple, in powder. The wood of the tree is yellow, tolerably hard, and may be applied to a variety of uses in turning and carving. It is, however, necessary to steep it in water before it is worked, in order to remove the tough and fibrous bark, which is capable of being con. verted into strong cordage, ropes, and brown paper.

Linnæus has enumerated seven species of the mulberry known in his day, all which are employed to feed silkworms, except the Tinctoria and Indica, of which the first named furnishes the well-known dyeing substance called fustic.

The species of mulberry found growing wild in the United States, is the Morus rubra of botanists, the berries being of a round and oblong form, and red, or dark purple, the pulp enveloping numerous small seeds. When perfectly ripe they are pleasant and wholesome.

'The varieties of mulberry employed in Evrope for feeding the silkworm form a long ist. They have usually been multiplied by engrafting the finer kinds on the stalks of the common white Italian mulberry. Hence, the fine, large, and firm-leaved kind called the Rose of Provence, Rose of Lombardy, \&c. The exertions made to improve the tree and increase the size of the leaf by repeatedly sowing the seed of the best kinds, has resulted in the greatest success, and now the Moretta, Elata, and other varieties, are obtained from seed, with leaves sufficiently large to render grafting unnecessary.

Besides these long-known varieties of mulberry used for feeding silkworms, comparatively few of which have been employed in the United States, there are two cthers, namely, the Multicaulis and the Chinese, which have been very greatly multiplied, especially the former. The Chinese is usually produced from seeds imported from Canton. Its growth is exceedingly vigoruns. and its leaves heart-shaped, flat, and very large. The Multicaulis is always propagatef from cuttings or layers, and is more hardy than the Chinese, with larger leaves, which are always hollow and uneven. Even where the severe winter frosts of the Northern States rause the Multicaulis to be cut down, the suck- ers spring up from the old roots so as o afford in good season an abundance of foliage. Of late years, a hybrid variety of mulberry has been produced in France by shaking the pollen of the Moretta flowers over the flowers of the Multicaulis. The seed of the Multicaulis produced by this mixture, produces a hybrid variety with more valuable qualities than the parent, and nearly as great a capacity for propagation by layers and cuttings. 'The hybrid Multicauiis has large flat leaves, like those of the Chinese or Canton seedlings. 'They are firm, and much relished by the worms. They endure frost equally well with the white mulberry, and are exceedingly well adapted to the silk-culture, both from their great precocity of growth, hardiness, and valuable qualities for feeding the worm and making good silk.

MULE. This is the well-known offspring of the ass and the mare, or of the she-ass and the horse. In the latter case, the produce is called a jennet, and is much less hardy, and therefore rarely bred. The term mule is generally applied in the animal creation in the same sense with hybrid in the vegetable world, signifying the intermixture of two distinct species. Mules are very hardy animals, and therefore much used in warm climates, where they are preferred to horses, either for the purposes of draught or carriage. Considerable numbers are likewise employed in Ireland, and in some of the northern counties of Britain, on account of their great strength and durability. Nu animal is more sure-footed or more hardy; but the pace of the mule is disagreeable to those unaccustomed to its action. The diseases to which the mule is liable are few. He attains double the age of the horse, and is much more easily maintained. The mules of the south of Europe are frequently very fine animals, 16 or 17 hands in height, active, handsome, and peculiarly patient of labour; but very inferior in beauty to the horse, particularly about the head and tail. The importation of Spanish asses into England has tended greatly to improve its mules, many of which, when bred with care, are sufficiently thick-set and heavy for all those purposes in which our largest draught-horses are employed.

To have large and handsome mules, the mare should be of a large breed, well proportioned, with rather small limbs, a moderatesized head, and a good forehead; and the ass should be of the large Spanish breed.

MULI,EIN (Verbascum; said to be from bar bascum, bearded, in allusion to the bearded filaments). The English species of Verbascum are strong, robust-growing plants, producing an abundance of showy yellow flowers, and on that account they are well adapted for planting in the garden at the back of flower borders, or in shrubberies. They grow freely in any soil, and are readily increased by seeds ; some of the perennial kinds by divisions of the root. (Paxton's Bot. Dict.) There are as many as 6 wild species common to Britain, viz, great mullein, or high taper ( $V$. thapsus); white mellein ( $V$. lychnitis); yellow hoary, or Norfolk mullein ( $V$. pulverulentum); dark or black 
mullein ( $V$. nigrum) ; large-flowered primroseleaved mullein (V.virgalum); and moth mullein ( $V$. blatlaria). The dark black mullein is a perennial, the moth mullein annual, and the rest are biennial in habit. They mostly grow to the height of 3 to 5 feet, in fields and waste places, on chalky and gravelly soils. The species of mullein common in the United States, in the fields of slovenly farmers, is the Verbascrem thapsus of botanists.

MUNJEE'T. A kind of madder grown in the East Indies.

MURIATIC ACID, called also Hydrochloris. acid; anciently Marine acid, and Spirit of seasalt.

MURICATE. In botany, implies covered with short, sharp points.

MURRAIN. A contagious, malignant epidemic, which frequently prevails in hot, dry seasons among cattle, carrying off vast numbers. It once used to sweep off the horned stock of whole districts, and there are few years in which it is not now seen in some part of the kingdom. It principally appears in marshy and woody districts, or where under-draining has been neglected, or the cattle have been exposed and half-starved. The disease is known by the animals hanging down their heads, which are swollen, by short and hot breathing, cough, palpitation of the heart, staggering, an abundant secretion of viscid matter in the eyes, rattling in the throat, and a slimy tongue. The early stage of murrain is one of fever, and the treatment should correspond with this: bleeding and small doses of purgative medicine will be serviceable. The peculiar fetid diarrhœa must be met.with astringents, mingled also with vegetable tonics. In combating the pustular and gangrenous stage, the chloride of lime will be the best external application; while a little of it, administered with the other medicines inwardly, may possibly lessen the tendency to general decomposition. Above all, the infected animal should be immediately removed from the sound ones. (Youatt on Cattle, p. 379.)

MUSCLE (Fr. muscle; Sax. murcula). Fleshy fibres, susceptible of contractions and relaxaiions. They constitute what is commonly called flesh, the most nutritious species of auimal food. See Fresh and Gexatir.

MUSHROOMS (Fr. mouscheron; Lat. Agaricus, from Agaria, a city, or Agarus, a river of Sarmatia, now Malamonda). A more exten. sive genus than this is not known in the whole vegetable kingdom. Some species, as the common mushroom, $\mathcal{A}$. campestris, $\mathcal{A}$. vaginatus, \&c., are well known for the wholesomeness of the food which is prepared from them. Others, as A. muscarius, $A$. necator, the whole genus $A m a-$ nitu, and many others, are very dangerous poisons: indeed, the latter quality exists more or less in so many species, and these resemble those that are wholesome so nearly as to ren. der it advisable to be exceedingly cautious in the use of fungi, for the most dreadful effects are well known to have resulted from want of caution in this respect.

The edible mushroom ( $A$. campestris), is nearly inodorous, but has a grateful flavour. The crows or hat is at first hemispherical, then convex, and at last Aat; neshy; about 2 to 5 inches broad; white, or very light-brown, slightly scaly, the scales soft and fibrous; gills pink, changing to fuscous black; the flesh, when divided, usually changes to a reddish hue. The use of the mushroom, as an article of diet, was known to the ancients. See Fungr.

To produce mushrooms artificially, beds variously constructed are employed; and, from the numerous modes which have been invented and adopted for their production, sume accompanied with extraordinary expense, it is obvious that this "voluptuous poison" is with us, as it was with the Romans, in high estimation.

MUSSELS, or MUSCLES (Mytilis edilis). A species of shell-fish which abound on the rocky shores on the borders of the sea in many parts of the British islands, adhering to the rocks. Muscles are also found in immense beds, both in deep water and above the low water-mark, in the British seas. Where they can be collected in large quantities they may be made use of as an excellent manure, either alone or in the state of compost, with earthy substances.

MUST. A term applied to new wine and wort before it is fermented. It is also given to the saccharine juice of several fruits susceptible of the vinous fermentation, and particularly to the expressed juice of the grape before its conversion into wine.

MUSTARD (Fr. moutarde; Lat. Sinapis; from $\sigma / v \iota \pi t$, on account of its making the eyes water,

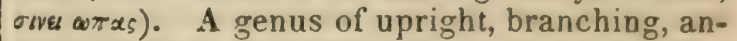
nual or biennial herbs, often hairy or bristly. There are five wild species common to the British islands :-

1. Wild mustard (S. arvensis). A very troublesome annual weed in corn-fields; also abundant in waste ground newly disturbed. The seeds serve as an inferior kind of mustard, or rather, to adulterate that made from the common mustard. See Chanzock.

2. White mustard (S. alba), 3. Common mustard ( $S$. nigra), are annuals, in general cultivation, but are also found wild on waste ground and by road-sides, \&c. See Cult. vaten Mustard.

4. Narrow-leaved wall-mustard (S. tenuifolia). This perennial species is found growing on old walls and heaps of rubbish about most ancient cities. The root is tapering, rather woody. Herb for the most part entirely smooth, and more or less glaucous all over: fetid when bruised. Sten bushy, erect, $1 \frac{1}{2}$ or 2 feet high, with numerous round, leafy branches, occasionally besprinkled with a few hairs.

5. Sand mustard (S. muralis). This annual species flourishes on sandy, barren ground near the sea. 'The root is small and tapering

MUS'TARD, CULTIVATED. The species of Sinapis generally grown in the kitchen garden for domestic purposes are the white mus. tard (S. alba), and the common or black mus tard (S. nigra). The first is the one grown iot salads; but the seed of both is employed in the manufacture of mustard.

The soil they succeed in best is a fine, rich, mouldy loam, in which the supply of moisture 
is regu.ar; it may much rather incline to light ness than tenacity. If grown for salading, it need not be dug deep; but if for seed, to full the depth of the blade of the spade. In early spring, and late in autumn, the situation should be sheltered; and, during the height of summer, shaded from the meridian sun. For salading, the white may be sown throughout the year. From the beginning of November to the same period in March, in a gentle hotbed appropriated to the purpose, in one already employed for some other plant, or in the corner of a stove. From the close of February to the close of April, it may be sown in the open ground, on a warm, sheltered border; and from thence to the middle of September, in a shady one. Both the white and black, for seed, may he sown at the close of March, in an open compartment.

For salading, it is sown in flat-bottomed drills, about half an inch deep and six inches apart. The seed cannot well be sown too thich. 'The mould which covers the drills should be entirely divested of stones. Water must be given occasionally in dry weather, as a due supply of moisture is the chief inducement to a quick vegetation. The sowings are to be performed once or twice in a fortnight, according to the demand. Cress (Lepidium sativum), is the almost constant accompaniment of this salad herb; and as the mode of cultivation of each is identical, it is only necessary to remark that, as cress is rather tardier in vegetating than mustard, it is necessary for the obtaining them both in perfection at the same time, to sow it five or six days earlier. See Cress.

It must be cut for use while young, and before the rough leaves appear, otherwise the pungency of the flavour is disagreeably increased. If the top is cut off, the plants will in general shoot again, though this second produce is always scanty, and not so mild or tender. For the production of seed, whether for manufacture of mustard or future sowing, the insertion must be made broadcast, thin, and regularly raked in. When the seedlings have attained four leaves, they should be hoed, and again after the lapse of a month, during dry weather, being set 8 or 9 inches apart. Throughout their growth they must be kept free from weeds, and, if dry weather occurs at the time of flowering, water may be applied with great advantage to their roots. The plants flower in June, and are fit for cutting when their pods have become devoid of verdure. They must be thoroughly dried before thrashing and storing. For forcing, the seed is most conveniently sown in boxes or pans, ever if a hotbed is appropriated to the purpose. Pans of rotten tan are to be preferred to pots or boxes of mould. But whichever is employed, the seed must be sown thick, and other restrictions attended to as for the open-ground crops. The hotbed need only be moderate. Air may be admitted as abundantly as circumstances will allow. (G. W. .Tohnson s Kitchen Garden.)

MUS'TARD, FLOUR OF. The seeds of both slack and white mustard are employed in making the ordinary flour of mustard for dietetical ise. In the dry state, mustard is inodorous, 838 and, were it possible to taste without the aid of moisture in the mouth, it would also be tasteless; the principle of its odour and taste not existing ready formed in the mustard, but requiring water for its developement. The principles which exist in the mustard are two: one an acid, which has been named myronic acid, and is a compound of carbon, sulphur, hydrogen, nitrogen, and oxygen; the other a sub. stance resembling vegetable albumen, which has been named emulsin, or myrosyne. When the myrosyne and the myrenic acid, which is united with potassa in the form of a myronate of potassa in the mustard, act upon each other by the aid of water, the volatile oil of mustard is formed, and odour and pungency given to the mustard. It is the volatile oil which red. dens and blisters when mustard poultices are used; and it is important to know that vinegar checks the acrimony of the poultice, and should not be used. Tepid water only is required.

MUT'TON (Fr. mouton). The flesh of the sheep. Although, by recent extensive improvements, the breed of sheep have been diminished in size, yet the smallness of bone and symmetry of form which the animals have thus acquired, have considerably decreased the quanti ty of offal, and added largely to the dead weight of marketable flesh. Before that time the mutton of those coarse sheep rarely amounted to more than one-half of their live-weight; whereas now, the common average is more than twothirds; and Dishley wethers, when well fattened, are said to be in the proportion of an ounce of bone to a pound of flesh. The best and most nutritive mutton is that of sheep which are at least three, but not more than six years old, and which have been reared on dry, sweet pastures. The meat afforded by such as have been fed on salt marshes, or near the sea-coast, is likewise sweet and wholesome; for they have acquired both firmness and a fine flavour from the saline particles abounding in such situations.

A sheep, to be in high order for the palate of an epicure, should never be killed earlier than when five years old, at which age the mutton will be found firm and succulent, of a dark colour, and full of the richest gravy; whereas, if only two years old, it is flabby, pale, and savourless. To ascertain the age of multon, Mr. Ellman directs: "To observe the colour of the breast-bone when a sheep is dressed, that is, where the breast-bone is separated: which in a lamb, or before it is one year old, will be quite red; from one to two years old, the upper and lower bones will be changing to white, and a small circle of white will appear round the edge of the other bones, and the middle part of the breast-bone will yet continue red; at three years old, a very small streak of red will be seen in the middle of the four middle bones, and the others will be white; and at four years old, all the breast-bones will be of a white or gristly colour." South Down wether mutton, in point of delicacy and flavour, is thought equal to any that is killed; and in summer as preferable to some other fine-flavoured breeds, especially Norfolk mutton. This circumstance is attributed to the closeness of the giain, or the specific gravity 
being greater, rendering it more impermeable to the air than coarser and looser fleshed mutton, which is, of course, more subject to putridity. The olter the mutton, the finer the flavour.

It is alm:j: innecessary to remark, that wether-multon is always considered so far preferable to that of the ewe, that the flesh of the latter, although more commonly kept to a mature age, always sells at an inferior price. Connoiseurs, however, assert that a spayed or maiden ewe, kept until five years old before she is fattened, produces inutton superior to that of any wether.

The live-weight, with the offal, of a large, fat wether, and the joints when cut up for market, were as follows :-

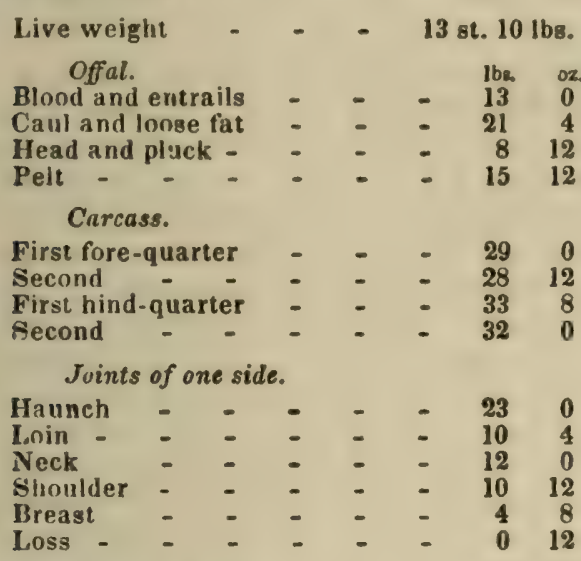

See Mrat and SuEer.

MUZZLE. The nose of a horse or other animal. It also signifies a kind of halter put upon the nose of a horse or mule, to prevent eating or biting.

MUZZLE OF A PLOUGH. A term sometimes applied to the copse or part to which the draught is attached. See Plougr.

MYRRH. See Swetr Cicelt.

MYRTLE (From myros, perfume; myrtos of the Greeks, myrtus of the Dutch, and of almost e very other European language). The myrtle, from the delightful perfume, the delicacy of its blossoms, and the glossy green of its perpetual foliage, is a favourite and well-known genus of plants, which grow well in sandy loam and peat; and cuttings, if not too ripe, will root freely either in sand or soil under a glass. There are nearly a dozen distinct species, besides numerous varieties. The myrtus pimenta yields the allspice or Jamaica pepper.

The common European myrtle ( $M$. communis) is a native of the south of Europe, growing 5 or $\mathbf{6}$ feet high, with very fragrant leaves, and blowing small white flowers in summer. Being a tender shrub, this myrtle should have a southern or southwestern aspect, with provection in winter.

MYRTLE BILBERRY. See WhortıeBERRY.

M YRTLE, THE DUTCH, or SWEET GALE (Myrica gale; from myrio, to flow, being found on the banks of rivers). This, in England, is an ornamental, aromatic, indigenous shrub, growing wild in bogs and marshes, especially on a gravelly soil. The stem is upright, bushy, 3 or 4 feet high, with numerous aiternate branche 3. It bears berries which are very small, covered with resinous dots, exhal. ing a delightful fragrance when rubbed letween the fingers. The leaves are aromatic from the same cause. This plant, perhaps one of the more innocent substitutes for hops, is used for brewing by the poor in 8 weden. I.innarus says the berries boiled in water yield wax like those of the candleberry mvrtle (M. cerifer $u$ ). See Caxulebentr Mratez.

\section{N.}

NAG. A provincial term applied to a horse, of a small size for the saddle; such a horse is very useful for many purposes, where light labour is required.

NAPIFORM. Formed like a turnip, tuberous.

NARCISSUS (from narke, stupor, on account of the effects produced by the smell upon the nerves). This is an old and very popular flower of great beauty, and some of the species are highly fragrant.

NARCO'TIC (Fr. narcotique). Substances having the double property of exciting in the first instance, and afterwards stupifying and producing sleep or torpor. In medicine the term comprehends opiates, anodynes, and other drugs which induce sleep and allay pain.

NAS'TUR'TIUM (from nasus, the nose, and tortus, tormented). The acridity of $N$. officinalis affects the muscles of the nose. Few of these plants are worth cultivating; they are of the simplest culture. The seed of the annual kinds has only to be sown in the open ground in spring. See Crass.

NAVE OF A WHEEL. The short, thick block in the centre of the wheel which receives the end of the axletree, and from which the spokes radiate: it is bound with hoops, called nave-bands, to strengthen it. It has likewise in each end of the hole through which the axletree passes, a ring of iron called the washer, which saves the nave from wearing.

NAVEL-ILL. See Calf, Disfases of.

NAVEL-WORT, Cotyledon (from kotyle, a cavity; in allusion to the cup-like leaves). A numerous and rather ornamental genus of succulent herbs or shrubs, with very thick, juicy, alternate, simple, entire, or jagged leaves. In England, the native species are two in num. ber: both are perennial in habit, flowering about June and July.

NAVEW. The common wild navew (Brassica campestris) belongs to the cabbage tribe, and is an annual plant, found in corn-fields, marshes, and about the banks of ditches and rivers. The root is tapering; stem erect, 2 feet high, leafy, branched, glaucous; rough in the lower part, with small bulbous spreading bristles; smooth upwards. Radical leaves lyrate, toothed, and jagged, rough; stem-leaves smooth, clasping, oblong, partly pinnatifid all somewhat glaucous. Flowers blowing in June and July, yellow, corymbose, almost as large as those of the turnip. Pods on longish stalks. $1 \frac{1}{2}$ inch long, nearly cylindrical, beaked. The roots are nourishing, containing a sweet juice, which is sometimes domestically used in coughs and asthma. 
NAVICULAR. A botanical phrase, signifying boat-shaped.

NEAT CATTLE. See Catrle.

NECTARY, in botany, is applied to those parts of a flower which secrete honey.

NECTARINE (Aniygdulus Persica, var. Nertarina). A variety of the common peach, from which the fruit differs only in having a smoother rind and finer pulp. The culture is in every respect the same as the peach. The varieties of nectarines are numerous, nearly 70 being described in the catalogue of the Horticultural Society of London. Forsyth recommends for a small garden the following sorts:-Fairchild's Early, Eldridge's Scarlet, Newington, Red Roman, and Temple's. Nectarines, like peaches, are subdivided into free-stones and cling-stones.

\section{NEP. See Catmint}

NERVES. In botany, the strong ribs upon leaves or flowers, which are bundles of vessels, chiefly spiral. Besides conveying the sap to the leaf, and returning the proper juice to the bark, they often afford distinctive characters to the leaf.

NETTED. A botanical term, implying that the veins or membranes are reticulated on the leaf, or variously intersected.

NETTLE, Urtica (from uro, to burn; in reference to the stinging properties of most of the species). An extensive genus of herbaceous or shrubby plants of little beauty, and which are justly looked upon in the eyes of the agriculturist as mere weeds. The herbage in all the species is copiously armed with venomous perforated bristles, each of which has a bag of liquid poison at its base. This liquor, by the slight pressure required to pierce the skin, is transmitted into it, causing great irritation. Many of the numerous exotic species have not this stinging property; but the sting of common nettles is not to be compared with that of some of the Indian species grown in the gardens cf Europe. These are, however, all surpassed in virulence by one which in Timor is called duoun setan, or devil's leaf, the effects of which are said by the natives in many cases to cause death. In England, the indigenous species of nettle are three; viz. 1. Roman nettle ( $U$.pilulifera), an annual plant, growing in waste ground amongst rubbish, chiefly near the sea. The herb is armed all over with peculiarly venomous stings. The stem is branched, leafy, bluntly quadrangular, often purple, about 2 feet high. 2. The small nettle (U.urens) is found to be in all cultivated ground a troublesome weed, especially on a light soil. It is annual in habit, flowering from June till October, smaller than the last, and of a much brighter green; iis copious stings hardly less virulent. The several parallel ribs of the leaves form its distinguishing character. The whole plant being refused by every kind of :attle, should be carefully extirpated from pastures. 3. The common or great nettle (U.dioica), which is a noxious perennial weed, growing almost everywhere, and flowering in July and August. The root is branching and creeping, with flechy roots, and many fibrous radicles. Tire herb is of a duller green than the last, rect, 3 feet high, with less irritating stings. 840
Leaves large, heart-shaped, spreading, pointed strongly serrated, veiny. The leaves are employ ed for feeding poultry, especially in the winter; when boiled, they are said to promote the lay. ing of eggs. Asses devour-nettles eagerly, but all other live-stock refuse them, unless they are dried. In the western islands of Scotland, a rennet is prepared by adding a quart of salt to 3 pints of a strong decoction of nettles; a tablespoonful of which is said to be sufficient to coagulate a bowl of milk. The young tops of the common and smaller nettles may be boiled as potherbs during spring, and eaten as a substitute for greens; being not only nourishing, but mildly aperient. The tough fibres of the stem may be manufactured like hemp, and are often found in winter naturally separated and bleached. The roots are astringent and diuretic. See Dean-Netre.

NETTLE-HEMP. See Hemp-Nettle.

NETTI.E TREE (Celtis). This is an ornamental genus of trees and shrubs, varying in height from 6 to 50 feet. The most of them do very well in any common garden soil, and are suitable for the back of shrubberies and plantations. They are increased by seeds or layers.

NETTLE TREE, AMERICAN (Celiis orcidentalis). Sugar-berry. This American tree, Michaux says, if not rare, is little multiplied in comparison with the oaks, the walnuts, and maples. As it is scattered thinly through the forest, it is difficult to fix the point at which it ceases towards the north, but it is believed not to extend beyond the Connecticut river. In the Middle, Western, and Southern States, it bears the name of nettle tree, whilst the French call it bois inconnu, or unknown wood. On the Sa. vannah river trees are found 60 or 70 feet high, and 18 or 20 inches in diameter. In the Middle States it seldom grows above 10 or 15 feet in height. It is similar in its foliage and general appearance to the European nettle tree. The flowers are small and white, and open early in spring. The fruit consists of small berries disposed on stems singly, of a dull red colour, purplish when mature, and of a sweetish taste. (Michaux.)

NICKING. In farriery, an operation performed on the tails of horses to make them carry them well.

NIGH'TSHADE (Solanum). A very numerous, principally tropical genus of shrubs or herbs, more or less narcotic; though in some cases rendered eatable by cookery, as in our common potato. Some of the genus are very dangerous and highly virulent poisons. Two species only are indigenous to England,-1. The woody nightshade (S. dulcamara). See BitTERSWEET.

2. The common or garden nightshade ( $S$. nigrum). This is common everywhere, in waste as well as cultivated ground. The root is fibrous, annual in habit, occasionally perennial. Herb fetid, narcotic, bushy, with numerous angular or winged leafy branches. Stem herbaceous, without thorns. Leaves undivided, ovate, lengthened at the base, smooth. Umbels from the intermediate spaces between the leaves, lateral, drooping, solitary, stalked, simple, downy. Flowers white with a musky scent. The berries globular, b'ack; some 
times, as it is reported, yellow. A grain or two of the dried leaf has sometimes been given to promote various secretions. Both its poisonous and medicinal powers depend on an alkaline principle, which can be procured in a separate state, and has been called solunia. It is a powerful narcotic, and the poisoning principle of the solanums.

NIGHTSHADE, DEADLY, or DWALE (Atropa belladonna). A plant with narcotic and dangerous qualities, found growing in hedges and waste ground on a calcareous soil, frequently about ancient ruins. The root is fleshy and creeping. Stems herbaceous, annual, 3 feethigh, round, branched, leaty, slightly downy. Leaves lateral, mostly two together of unequal size, ovate, acute, undivided. Flowers solitary, stalked, drooping, dark dull purple in the border, paler downwards, about an inch long. Berry of a shining violet black, partially enveloped in the calyx, which is persistent, the size of a small cherry; sweetish, and not nauseous, so that children have often been tempted to eat it to their own destruction. The poisonous principle is an alkali named atropia.

NIGHTSHADE, ENCHANTER'S. See

\section{EvchaNten's Nighrshade.}

NIGHT-SOIL. In agriculture, a powerful manure. This valuable fertilizer has not been employed in England to the same extent as on the continent, although it is certainly one of the most valuable of the organic manures; and to this neglect many causes have contributed. Its disagreeable odour, certain vexatious fiscal regulations with regard to its removal, and erroneous modes of applying it, either in excessive quantities, or mixed with other composts in such proportions that its powers could not be distinguished in the mass; its semifluid nature requiring for its removal carriages of a peculiar construction, the extent and completeness of the sewerage of our large cities, and several other minor obstacles, have rendered its use not nearly so extensive as, even in a national point of view, is desirable. Davy, however, described it, 25 years since, as "a very powerful manure, and very liable to decompose: a part of it is always soluble in water; and, in whatever state it is used, whether recent or fermented, it supplies abundance of food for plants." (Lectures, p. 229.) "The disagreeble smell," he adds, "may be destroyed by mixing it with quicklime; and if exposed to the atmosphere in thin layers in fine weather, and mixed with quicklime, it speedily dries, is easily pulverized, and, in this state, may be used in the same manner as rape-cake, and delivered into the furrow with the seed."

Night-soil is a mixture of urine and foces; and these have been found to contain the following substances. Foces were analyzed by M. Berzelius: the products were-

Water

Vegetable and animal remains

Bile -

Albumen - : - - - -

Peculiar and extractive matter

Salts

Elimy matter, insoluble residue, \&c.
'The salts detected in this analysis, equal to 1.2 parts, were carbonate of soda, muriate of soda, sulphate of soda, ammonia, phosphate of magnesia, and phosphate of lime. (Gerileris Journal, vol. vi. p. 536.) 'To the same great chemist we are indebted for an analysis of hilman urine. He found 1000 parts to contain-

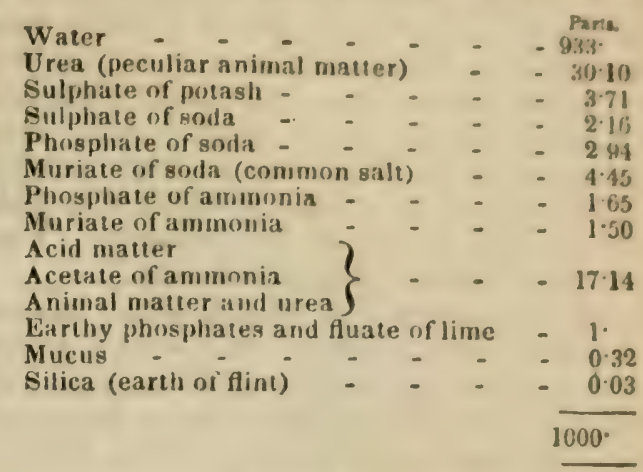

(Annals of Philos. vol. xi. p. 423.)

The chemical composition of urine shows, that it abounds in animal and mineral constituents which must afford a copious supply of food to plants.

According to very recent experiments reported by I. C. Nesbit, the excretions of one person were found, from actual daily weighings long continued, to average 7 to $8 \mathrm{oz}$. avoirdupois of solid matter, and $3 \frac{1}{2}$ lbs. of urine. This would make the annual amounts $170 \mathrm{lbs}$. of fæces, and $1277 \mathrm{lbs}$. of urine. But when these are perfectly dried, there remains only $45 \mathrm{lbs}$. from the solid matter, and $35.7 \mathrm{lbs}$. from the urine, making the annual amount of dry matter in both, about 80 lbs. From a comparison with other manures in the English market, the actual value of this 80 lbs. of dry matter is computed by Mr. Nesbit at $\$ 2.50$. This appears to be a lower estimate than that made by Boussingault, who considers the excrements of a single adult during a year sufficient to produce $14 \frac{1}{2}$ bushels of wheat; an estimate which agrees better with the views of the Chinese, who reckon the ordure of even a superannuated or disabled person as of sufficient fertilizing value to compensate for his bread. The odour of night-soil may be destroyed by any means which will dry it: such as additions of dry mould, peat, powdered charcoal, or plaster; also by sprinkling with a saturated solution of copperas in water, or oil of vitriol diluted with 10 parts of water.

Davy's plan of destroying the smell of nightsoil by the addition of quick-lime, may answer very well to correct a nuisance; but the agricultural value of the manure produced, would be lessened, since the addition of caustic lime to animal matters drives off their ammonia, the most fertilizing portion.

The account of eastern customs, furnished by modern travellers, illustrates very remarkably the notices of the sacred historians. "In Arabia, says Niebuhr (vol. i. p. 91), "the dung of asses and camels is chiefly used for fuel, because these are the most numerous and common. Little girls go about gathering dung in the streets, and in the highways; they mix it with cut straw; and of this mixture make cakes, which they place along the walls, or upon the declivity of some neighbouring eminence, to dry them in the sun." Tourn. $4 \mathrm{~B}$ 
fort, speaking of Georgia, says, "All this fine country yields not a single tree; and they are forced to burn cows' dung." (Tournefort, vol. iii. p. 137.) And again, when speaking of Ezeroon, he says, "You see neither tree nor bush, and their common fuel is cows' dung." And Ire Bruyn speaks of the same custom as occurring in Persia:- "Wood is very dear, and is sold by weight; whence it is that they are obliged to make use of turf made of camels' dung, cows' dung, sheeps' dung, horses' dung, and asses' dung. They use it more particularly for heating of ovens, in which they bake most of their meats in this country. They even apply human dung in this way."

Long experience has taught many nations the value of this manure. In China it is preserved with the greatest care, mixed with a fat marl; and, according to Sir George Staunton, made into cakes, which, after being dried in the sun, constitute a regular article of traffic between the citizens and the cultivators of that singular empire. The same useful practice is carried on in Belgium. What we throw into our rivers the more thoughtful Belgians turn to account; what is a nuisance in London is a source of revenue at Brussels. To a report of my friend, Dr. Granville, I am indebted for a pretty copious account of the value assigned to this manure in the northern states of the continent; and this I will give chiefly in his own language. When describing a continental tour, made chiefly for the purpose of examining the mode of employing this description of manure in Germany, he says, "The kingdom of 'W ürtemberg is so overstocked with population, and land, consequently, is of such value, that every inch of it is progressively brought into a state of culture by dint of labour and manuring, no matter how ungrateful the soil, or its situation, may at first sight appear.

"The cultivation of the vine is one which requires, in certain arid and mountainous soils, a liberal use of the human manure. Wishing to ascertain this fact from my own observation, I undertook a journey through the principality of Nassau, and along both banks of the Rhine, examining many of the vine districts, as I descended that river for the purpose of visiting Holland. On my return, I took French Flanders in my way, looking particularly to the great flax districts of Tournay, Lille, Valenciennes, and Cambray, where the surprising results obtained from the application of human manure, like those obtained in Belgian Flanders by similar means, have induced agriculturists, within tre last few years, to give to that species of manure the name of 'Flemish Manure." "

And, when speaking of the little care taken in England of this fertilizer, he continues:"In no part of France, Würtemberg, Bavaria, Bohemia, Prussia, Saxony, the Confederated States of Germany, Holland, and Belgium, is -here a city in which, as in London, the general mass of filth, of every description, created by a vast population, is firsi allowed to enter the river which may happen to traverse that city, and is then returned, diluted with the wator of that river, to the houses of the inhabit842 ants, to be used either for domestic or culinary purposes; although, by avoiding the latter disgusting alternative, foreign cities are less free from unpleasant smells than London is. In this respect, it may be truly said that foreigners smell the filth of their cities, but do not swallow it; whereas the Londoner swallows it, but seldom smells it.

"In no large city of that part of Europe which I have recently visited, possessing a river, is any portion of the contents of closets and cesspools suffered to find its way, or to be emptied into it, except at Amsterdam, Antwerp, Brussels, Stuttgard, and Leipzig; and even there only in a partial manner. In Paris the Seine is contaminated by one large drain only, conveying the urine from the large reservoirs of night-soil at Montfauçon, and by 2 smaller ones proceeding from cesspools. $\mathrm{T} O$ convey generally, or to empty even partially any such matter into the river, is a practice against which the laws have provided by heavy fines and incarcerations. And such is the present feeling of all the governments on that subject, even in the great cities I have just enumerated as exceptions, that the superior authorities are seriously engaged in devising plans for preventing in future every possible infraction of those laws; not because it is desirable to preserve pure the water of such rivers (since no domestic use is made of it), but on account of the loss of a material, deem. ed most valuable, which such infractions must necessarily entail.

"Night-soil is husbanded in every part of the Continent I have visited, without exception, with a jealousy and care which prove how valuable it is considered by the people. In most of the cities of the second order, and the smaller capitals, night-soil is a source of profit, first, to the householder, next to a middleman, and, thirdly, to the farmer, who is the last purchaser, and employs it.

"In all the towns of the Grand Duchy of Baden, of the kingdom of Würtemberg, of Bavaria (except Munich and Würtzburgh), of the province of Salsburg, of Bohemia (except Prague), of Saxony (except Dresden), in some of the minor cities of Prussia, in all the confederated principalities, in all the cities on both banks of the Rhine, particularly Strasburg, Mayence, Coblentz, Bonn, Cologne, Dusseldorf, Nimeguen, \&c., the householder disposes of the contents of his cesspool for a certain sum of money, hesides getting the operation of emptying it performed gratuitously. By comparing the returns of the different prices paid in those cities for the commodity in question, one year with another, and equalizing them by an average price, the inhabitants appear to be benefited to the amount of 4 francs a head yearly, and the middlemen to al least 40 per cent. more on the sum he pays to the original seller. I will cite Strasburg as an example, since most of the other cities of the same extent (on the Rhine, and in many parts of Germany), and a few cities even larger presented the strongest analogy to the case I have selected. At Strasburg, a company of middlemen engage to empty the cesspools, of $w^{2}$ every house has at least two (built air 
water-tight), once a year for nothing, and pays, moreover, 6 francs per churelle, containing 96 baquels, of the capacity of 4 gallons each. 'This quantity the company sells afterwards to the armers for ten francs. (The capacity of the tharelle being to that of a ton as 28,772 ounces are to 35,840 , it follows that the price of a ton at Strasburg would be $10 \mathrm{~s}_{\text {. }}$ ) Now, as there are 14,000 houses in Strasburg, 10,000 of which aave cesspools affording the soil in question (which is always semi-liquid), supposing the atter to be emptied only once a year, and to urnish each 3 charettes only, at six francs, we have $10,000 \times 6 \times 3=180,000$ francs, which he company pays yearly to the inhabitants of town having a population of 70,000 souls. But as the company resell to the farmer the aid soil fur manuring purposes, at ten francs er charette, it follows that this article of traffic roduces yearly at Strasburg 300,000 francs, r just about $4 \frac{1}{4}$ francs for each inhabitant."

The high prices paid for this manure by the Continerital farmers betrays the estimation in which they hold it. "The contractor at Brusels, M. Champon," says Dr. Granville, "sells his manure for $13 s .4 d$. per ton-400 florins, or 33l. 6 d. for a barge-load of 50 tons. M. Smet, he greatest trafficker, perhaps, in this material n East Flanders, gets for some of his 10 s., and or the best and larger portion of it $15 \mathrm{~s}$. per on; while the contractor at Antwerp disposes of all he has of Flemish manure at 52 florins he $p u t$, or 624 florins the barge-load, equal to 52l., or 1l. 10s. $9 d$. per ton. But if we look to what takes place every day at Montfaucon, zear Paris, where 200 cart-loads of the conents of the cesspools are daily deposited, to be converted into poudrette, we find the latter (a hry and compound manure made from night oil) to fetch a much higher price than all the rest.

"But by far the most important point of ractical knowledge in this matter, put forward y the same great authorities, and the truth of which was afterwards confirmed to me by nore than one great farmer in East Flanders, $\mathrm{s}$, that while the manuring with human soil ias produced 14 times the quantity sown, where horse-dung has only yielded 10 , the proyortion of the human or Flemish manure emloyed was, to that of the horse-dung, as 1 to 5 nly; so that with 1 ton of the Flemish a arger produce is obtained than with 5 tons of table manure." See MANuREs APPLICABLE BY ire DRILL.

In Sweden the value of night-soil has been ong well understood by the farmers. Nearly alf a century since the Baron de Schulze, then writing to Sir John Sinclair, observed, They have now ceased to spoil the fine harour of Stockholm with nuisances of every ind. The contents of the privies are now ollected, by undertakers, in barrels, of which ley are obliged to have a double quantity to eplace those deposited in the reservoirs, from rhence they are carried to the country. My Idest son, who has changed the sword for the loughshare, has particularly attended to this anure, heing favourably situated on the Lake Ialar, 48 English miles from the capital; he onveys it in a covered boat, each loading of which is sufficient to diess about 3 acres of spring corn, aud between 4 and 5 of winter corn and meadow ground. This manure, by the motion of the boat, becomes inore liquid; and it is conveyed from the hold of the vessel by a bucket at the end of a lever, through a spout into a close cart on shore diawn by two oxen. These carts are provided with a mova. ble funnel, and with a strainer so regulated, by means of a pole, that the manure can be administered at pleasure by the driver, without further attention to spreading. That the land may not be overdunged, and the crop consequently lodged, care must be taken not to lay above 40 such cart-loads on the Swedish acre for spring corn; each cart containing $180 \mathrm{gal}$ Ions English, or 1920 lbs. Except that other powerful manure produced by the refuse of the herring oil-works, none can come into competition, for richness, with the contents of the privy mixed with urine. 'The effects of this manure, no doubt, diminish gradually; yet its operation may be plainly perceived in the fourth successive crop. When clover is meant to be sown with the spring corn, this species of manure is unsuitable; for although the seed be diminished to one-third, the straw becomes so thick and strong as to choke the clover. A mixture of lime is sometimes recommended for this manure, in order to dry it and correct the smell; but, besides that lime is not plentiful here, the process would be found to require a considerable time and expense. A little addition to the wages of the labourers or cottagers soon reconciles them to the inconvenience of the smell, and it becomes still less offensive to them if they are allowed to use part of it on their own little fields. If any particular impediment occurs, such as harvest work, this manure is then from the vessel conveyed to great pits, to be, after a mixture with other substances, driven to the field at a more convenient season." (Com. Board of $A g r$. vol. i. p. 326.) The prejudice which some English labourers entertain against the employment of night-soil is readily overcome by a little management. The stream which flows through the village of Eastbourn, in Sussex, had become, a few months since, much contaminated through the night-soil which had been deposited in it from the adjoining cottages, and it was in vain that their orvners were advised to use it for their gardens; until an excellent lady of the place, who is ever ready to promote the comfort of her poorer neighbours, desired her bailiff to go round and propose to purchase it of them. His offer was, however, rejected, universally rejected; and ever since they have no longer suffered the contents of their privies to be wasted, but have carefully applied them, and with the best results, to their own gardens; remarking, that if it was worth a farmer's while to buy it of them, it must be worth more to them for their gardens.

"By this term, night-soil," remarked the indefatigable Arthur Young, "at London, is to be understood the collections there made of what a French marquis calls 'l'espèce de fumier que la politesse empêche de nommer;' from which trait of him one would not have expected he should know so much of the value of it as be 
really did. An Englishman says, 'tis more decent and better to let it alone; but as I conceive it perfectly decent and efficient, I shall consider human ordure as the very best manure that can be procured. But here, I shall first consider the farmer's conduct at home, where his great object is to raise as much manure as possible without being obliged to depend on purchases, which are only to be made in certain situations. If the farmer manages his necessary-house in such a manner as to suffer nothing to run off from it, and frequently throws malt-dust, saw-dust, fine mould, or sand into it, he may, every year, manure from 1 to 2 acres of land.

"If the farmer is within reach of any confiderable town, and there are scavengers or people who will collect this manure and keep it separate, the farmer can hardly purchase it at too high a price. In the last century, the ordure of the galley-slaves at Marseilles was all saved, and sold to the farmers as a dressing for grapes, olives, and figs; the last of which produced by it were the best in the world. At Nice it sells high, and every peasant has a house of office for passengers. In China it seems to be a manure, of all others, in the most request; and in Italy they are well acquainted with its value. At London it sells at from $3 s$. to $6 s$. a load; at 17 miles distant, with turnpikes and all expenses, it costs 25s. a wagonload; yet it answered greatly. It should be laid by the scavengers in very light swamps (not too deep) in a grass field, and in summer trenches cut through it to drain; and then being thrown in heaps, it is of very light carriage. Three wagon-loads, or from 240 to 300 bushels, are enough for an acre of grass land, upon which I think it answers best; but mixed with marl, loam, turf, or dry pond mud, its use for that application is excellent. I have compared it with all other manures, and found that none of them I could procure equalled it by many degrees. It is a vulgar error to imagine that manuring a field with this substance will give a bad taste to plants. I dressed part of a pasture with it, fed the whole of that year with horses, cows, and young cattle, and I remarked to various gentlemen that saw it how close into the ground that part was constantly eaten, while there was much longer grass, \&c., in every other part of the field."

"On October 20th, 1772," adds Arthur Young, "I marked divisions each of 4 square perches on a summer fallow; the soil a poor blue pebbly gravel, and manured these compartments as follows:-

\section{Produre of Wheat per Acre.}

Soil, simple

Bushels of night-soil

Do

Do.

Aubic yards of farmyard compust

Do. and 1 cubic yard of chalk

-
-
-

Bushels. $12 \frac{1}{6}$ $320 \quad 37 \frac{1}{2}$ $240 \quad 321$ $6031 \frac{1}{4}$ 6025 $30 \quad 23$ i

"The effect of nigat-soil," he continues," - was prodigious; it just trebles the produce. In all tre experiments I have made with this manure, I h2" ever found this result almost uniform." (Annals of Agr. vol. iii.p. 79.) It is evident, also, from the experiments of Arthur 844
Young, which are entirely confirmed by those of the Essex farmers, and my own, that nightsoil is an excellent manure for potatoes. The following table contains the results of Arthur Young's trials. The soil on which these experiments were made was a poor gravelly loam.

Produce per Acre.

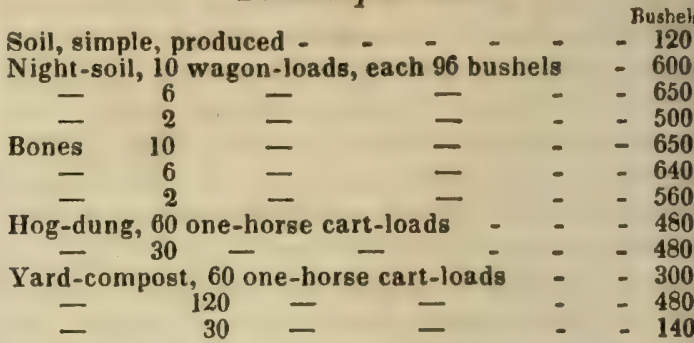

These experiments are useful, as indicating the comparative value of each fertilizer, although the quantities employed were evidently excessive. Mr. Hewitt Davis, of Spring Park, near Croydon, finds 6 tons of night-soil, mixed with peat, to be amply sufficient for an acre of ground. He thinks this manure the best for turnips. Night-soil is, however, in spite of all the obstacles of prejudice and inattention, much more extensively used in the neighbourhood of the large manufacturing towns of the north of England than it was formerly. Mr. Dixon, of Hathershaw, in Lancashire, thus describes his mode of using it. "For the conveyance of night-soil and urine, we have the largest and strongest casks, such as oils are imported in; the top of each is provided with a funnel to put the matters through, and the casks are fixed on wheels like those of a common dung-cart. I am fully aware that there are many localities where neither peat nor night-soil can be readily obtained; but it is worth a farmer's while to go even more than 20 miles for the latter substance, provided he can have it without deterioration: the original cost is often trifling. On a farm where turnips or mangel-wurzel are cultivated to some extent, the system here recommended will be almost incalculably advantageous. A single horse is sufficient for one carriage; mine holds upwards of a ton each; 6 tons of this manure in compost with peat, or, if that is not convenient, any other matters, such as ditch-scourings, or high headlands which have been properly prepared and laid dry in a heap for some time, would be amply sufficient for an acre of turnips or mangel. This manure is by far the most invigorating of any I have ever yet tried. Bones in any state will bear no comparison as a help for any crop ; but it must be remembered that I write on the supposition that it has not been reduced in strength before it is fetched."

There have been various patents granted in France for the preparation of manure from night-soil, several of which have proved very successful. The poudrette, or dried night-soil, first prepared by $\mathbf{M}$. Bridet, was found, after repeated trials, to be it very powerful dressing for land; $240 \mathrm{lbs}$. of this powder producing effects equal to 8 loads of stable manure. This substance has been recently examined by Professor Hermstadt, who reports it to be a perfect substitute for common dung; that it is most 
efficacious in wet seasons; and that in dry seasons it is less useful upon sandy soils than apon greasy c.ays. There is no doubt but hat very exc.lent composts may be made rom night-suis; and, in fact, several are now orepared in London, on a very bold scale, for he service it the farmer; but the success of hese is usually impeded by the preparers proessing that their preparations may be used in juantities much too small. Then, again, one or two patents have been taken out in England or artificial manures, by persons who were evidently very grossly ignorant of what they orofessed to understand. (Johnson on the Ferilizers, p. 92.) See Farm-Yand ManuRe; MArones applicable bT the Drill; Urine.

NIPPERS. A term applied to the four teeth in the fore part of the horse's mouth, two in he upper and two in the lower jaw : they are out forth between the second and third years. Nippers, in farriery, are the pincers which the miths use in shoeing.

NITRATES OF POTASH AND SODA. Two salts lately much employed in agriculure. The first (nitrate of potash) is known n commerce under the name of saltpetre, and s principally procured from the East Indies, where it is found on the surface of the ground, especially in the district of Tirhût, in Bengal. it also abounds in Ceylon, Persia, Egypt, and even in Spain; but that which is hrought to England comes chiefly from India in an impure state, and contains about 70 per cent. of pure aitre. It, however, varies in quality; but the average loss in the purification is generally about 15 to 20 per cent. Nitre is also formed y artificial composts in various parts of Europe. When pure, nitre is composed of nitric acid 54.15 parts, or 1 equivalent; and potash $\mathbf{1 7 \cdot 1 5}$ parts, or 1 equivalent; or 52.9 per cent of acid $+47 \cdot 1$ of alkali $=100$.

Nitrate of soda, which is known as cubic petre s obtained chiefly from Peru, where it is found $n$ a thick stratum, at an elevation of 3500 feet above the level of the Pacific Ocean. (Darvin's Researches, p. 443.) It is sold, it seems, at he ship's side on the coast of Peru, at $14 \mathrm{~s}$. per wt. It is composed of nitric acid $62 \cdot 1$ parts, and potash $37 \cdot 9$ parts.

It is only in modern days that saltpetre has oeen extensively employed as a fertilizer; for $t$ is not long that the nitre of commerce has veen produced in quantities sufficiently large and reasonable to enable the farmer to profitaoly use it as a manure. That the knowledge of its enriching qualities, however, is not a modern discovery, is too self-evident to be loubted. Virgil (Georgics, lib. i. v. 193, 195) recommends it to the Italian farmers as an excellent addition to the dregs of olive oil, to form a steep to cause the seed-grain to swell and regetate with vigour; and from his days to our own, hardly an agricultural writer has omitted to notice its powers. 'The very first English author who wrote upon husbandry, in 1532, Sir Anthony Fitzherbert, describes it as having the power to insure to the farmer the minst abundant crops. And in 15\%, a learned Jerman cuunsellor, Heresbaschius, in his Trea. ise upon Rural Affairs, describes the use of this salt as not an uncommon dressing in his time for coleworts. A century afterwards, Evelyn, in his Discourse on Earth, told the farmers of his age that if they could but obtain a plentiful supply of saltpetre, they would " need but liule other compost to meliorate their ground." And even Jethro T'ull, in the early part of the last century, who denied very zealously the necessary use of manures of all kinds-even Tull placed nitre at the head of his list of throse substances which he deemed to be the essential food of plants.

Saltpetre, therefore, must not be regarded as a modern introduction into agriculture; for it has long been used in limited quantities by previous generations of cultivators, who, like us, were content to notice the effects which it produces, without being able to exactly com prehend its mode of action.

It is idle to merely substitute words in explanation of unknown effects, and to say that saltpetre is a stimulant, or that it yields nitrogen to the plant; and there is little evidence of its entering into the composition of any of the more commonly cultivated crops: there is, therefore, but a slight probability of its being a direct food of the plants to which the farmer usually applies it The only common exception is that of barley, in which a minute portion of cubic petre (nitrate of soda) is found to exist.

But although these nitrates have not been detected in the farmer's crops, yet they are known to exist in many plants, most likely as essential ingredients. Thus saltpetre is found in the common horse-radish, in the nettle, and the sunflower. M. Chevalier discovered it in the Chenopodium olidum; M. Vauquelin in the deadly nightshade. Dr. John found it in the Mescmbryanthemum crystallinum; M. Chevreul in woad. The growth of the sunflower is materially promoted by watering it with a weak solution of this salt. It languishes in soils which do not naturally contain it; but when the salt is added to the earth, then it immediately makes its appearance in the plant in the usual proportions.

And although we are not aware of its existence in the ordinary field-crops, yet still it may beneficially exist in them, and exert a considerable influence at certain periods of their growth, although in minute proportions: and, notwithstanding we have no direct evidence of the fact, it is not unlikely that its presence may tend to vary, in the vegetable world, the essentially present combinations of nitrogen, in a way which the skilful investigations of the chemist have not yet succeeded in tracing. Such researches, however, have already proved that nitrogen (of which, with oxygen, the acid of saltpetre is formed) performs a much more important part in vegetable economy than was once supposed; and many facts are aiready apparent which should encourage us io persevere in the examination. For instarce, it has been observed by the farmer that these two nitrates (the base of whose acid is nit:ogen) have a very powerful effect in adding to the deep green colour of plants. Now, this is precisely the effect produced by other fertilizers, which also contain nitrogen; such as gelatine, urine, oils, blood, soot, fish, \&c. In fact, I am not aware 
of any manure producing this rapid, darklygreen, luxuriant growth, from which nitrogen is absent. Saltpetre is naturally generated on the earth's surface under favourable circumstances, and in situations much more frequent than the farmer is wont to suspect. Wherever ammonia is copiously generated, as in stables, farm-yards, \&c., and wherever the nitrogen, which forms a component portion of ammonia, at the moment of its extrication has access to potash or calcareous matter, there saltpetre is usually formed. This is naturally done so copiously, in some of those situations in which the farmer is placed, as to form fine crystalline exudations on the walls; and it is in such places that those plants which abound in saltpetre, as the nettle, the horse-radish, \&c., commonly flourish with uncommon luxuriance. It has been proved by those who gather the saltpetre from the earth's surface in southern Africa and Hindostan, as well as by those who prepare the artificial saltpetre beds in Spain from the sweepings of the streets of Madrid, that nothing more is requisite for the formation of saltpetre in these beds of earth, than the presence of a certain proportion of decomposing animal and vegetable matters, with some potash, and calcareous matter. Now all these essentials for the formation of saltpetre must in many situations be afforded by the farmer's own soils. There are, in fact, many lands in the cultivator's possession where, especially in dry summers, the formation of saltpetre in minute proportions is continually taking place; where the putrefaction of animal matters must in small proportions be productive of ammonia; and where an abundance of potash is already existing in the soil to neutralize the nitric acid produced, and form with it nitrate of potash or saltpetre. For it has been ascertained that if, at the moment when nitrogen is evolved, it is presented with oxygen gas, that it combines with it, and forms nitric acid. Here, then, we have explained to us the origin of the acid of the nitre, and we know that its base, or potash, is to be found in some form or other in all cultivated soils. And if we armit that this must in some instances be the case, then we shall be furnished with a ready explanation of many of the difficulties and discordant results which have attended the recent very general application of these two nitrates, since the fact that saltpetre has commonly been found to produce the least results upon those deep, rich, alluvial soils which must abound in decomposing organic matters, in some degree conntenances the conclusion, as does the smallness of the quantity of saltpetre applied; for, if once we concede the possibility of the soil, under favourable circumstances, being able to generate this salt, then it will be allowed that one $c w t$ per acre is not a large crop for the soil to prisuce. That in this way it is generated in some of the richest soils of the East, to such an extent as to cover the surface with a white incrustation, is known to every oriental traveller. To a still greater extent is the land in those countries impregnated in many situations with the nitrate $:$ lime, a salt which, possessing the same acid as nitre and cubic nitre, has lime instead of potash or soda for A16 its base; and from some experiments which I have made, I have little doubt but this nitrate, which is of much less cost than either the nitrates of potash or soda, will be found a valuable agent for the use of the cultivator. For its excessive deliquescent or moistening properties, which render it so unmanageable for many manufacturing purposes, make it more valuable to the cultivator of the poor, dry, thirsty soils, where artificial fertilizers are most in request. If nitrate of lime was imported at a reasonable rate, the farmer could readily, if he wished, make his own cubic petre, at a very low price, by mixing the nitrate of lime with glauber salts (sulphate of soda), by which means a rapid decomposition takes place, the result of which is nitrate of soda (cubic petre) and sulphate of lime (gypsum). The inferior, impure. refuse glauber salts, made by the cotton bleachers in the preparation of their bleaching powder, would answer for this purpose very well.

My experience of the enriching powers of saltpetre extends over several years. My earliest experiments were made in the kitchen and flower garden, in which I found very considerable advantage in increasing the beauty and in prolonging the bloom of several of the tenants of the latter; and in the former I found excellent results from applying it at the rate of $2 \mathrm{cwt}$. per acre to $\mathrm{my}$ beds of horse-radish, and in very small proportions, as one-eighth of an ounce per gallon, to the water with which I watered, to prevent mildew, \&c., my early and late crops of pease, wall-fruit trees, \&c. My experience with it as a field crop has been principally confined to the gravels of Essex and the chalks of Hampshire and Berkshire, in which, especially upon grass, I have obtained results exceedingly satisfactory. In 1840, I tried it upon the old clay grass soils of Knitbury, in Berkshire, with various other manures; 1 st, at the rate of $1 \mathrm{cwt}$. per aere; $2 \mathrm{~d}$, nitrate of soda, $1 \frac{1}{4} \mathrm{cwt}$. per acre; $3 \mathrm{~d}$, Poittevin's manure, 14 bushels per acre; 4 th, gypsum, $1 \frac{1}{2} \mathrm{cwt}$. per acre; 5 th, nitrate of soda, $1 \frac{1}{2} \mathrm{cwt}$., and gypsum $1 \frac{1}{2} \mathrm{cwt}$. per acre. These were all applied by hand in the month of April; but although they all produced a better crop than the soil simple, yet the extreme dryness of the season operated very materially against the success of almost all artificial dressings, and the produce of the whole plot was much below an average crop. Nos. 1, 4, and 5 were decidedly the best, producing at the rate of rather more than 2 tons of hay per acre; while the produce of the soil simple was less than $22 \mathrm{cwt}$. per acre. The grasses were of the ordinary kinds tenanting the upland pastures, mixed with a considerable portion of nearly worn-out roots of lucern, which, in the plot No. 4, gypsum alone, and in No. 5, gypsum and cubic petre mixed, was revived by the application to a very remarkable degree; its plants nearly doubling in height any other portion of the land.

In some experiments, at which I was present, on the barley and wheat land of the chalk formation in the neighbourhood of Wincliester, the effect of the saltpetre was excellent; the green colour of the crops was iendejod much 
more deep, and the increased produce far more than compensated for the expense of the saltpetre. And the same success altended its ap. plication to both red clover and sainfoin on the down lands; but when I tried saltpetre at the same rate per acre on the lawn of a rich old garden, whose earth was also principally chalk, there was no perceptible effect produced, even in the colour of the grass. This soil abounded in decomposing organic matters, was within reach of the soot and other ammoniacal matters of the city of Winchester, and, I have little doubt, in minute proportions already contained saltpetre. In fact, almost all the successful experiments with saltpetre have been made on light, poor land. Those of $\mathrm{Mr}$. Lightfoot were on the gravels of Hertfordshire, which have a substratum of chalk; and yet he produced with $1 \mathrm{cwt}$. per acre of saltpetre effects more than equal to those produced by folding the land with sheep. And when Mr. Beadel, of Witham, tried it on the Essex clays, it produced hardly any effect, except increasing the colour of the wheat; but when he used the same quantity ( $1 \mathrm{cwt}$. per acre) on his light barley land, after Swedish turnips, the increase was 15 bushels of barley and $640 \mathrm{lbs}$. of straw per acre; and on a sandy field of oats, the increase from its application was 20 bushels of oats and half a load of straw. The successful experiments of Mr. Kimberley, of 'Trotsworth, on clover, in which he produced with $1 \mathrm{cwt}$. per acre of nitre results fully equal to that from 25 cubic yards of horse-dung, were upon the sandy lands of Surrey, "of moderate quality." Mr. Everitt, of North Creake, bears out entirely these conclusions, when he applauds its nse "upon all light, warm soils," but predicts that, " on cold clay land, on an average of seasons, it will not more than repay the outlay;" and yet this excellent farmer had no reason to be dissatisfied with his success, having obained from an application of $1 \mathrm{cwt}$. of saltpetre to "good light land," an increase of $6 \frac{1}{2}$ bushels of wheat. The experiments of Mr. R. Harvey, of Harlstone, entirely confirm those of Mr. Everitt; and in the Report of the Harlstone Farmers' Club, in 1839 , it is stated to be " the unanimous opinion of the meeting," that saltpetre was excellent in its effects on heavy clover layers, but that on light land it was highly beneficial to "wheat, clover, and other layers and tares."

One of my neighbours, too, an excellent farmer of Essex, in 1839, found on the fine, light barley soils of his farm the following results from top-dressing his barley with $1 \mathrm{cwt}$. per acre of saltpetre, compared with the soil undressed, dressed with night-soil, with sprats, and with farm-yard manure:-

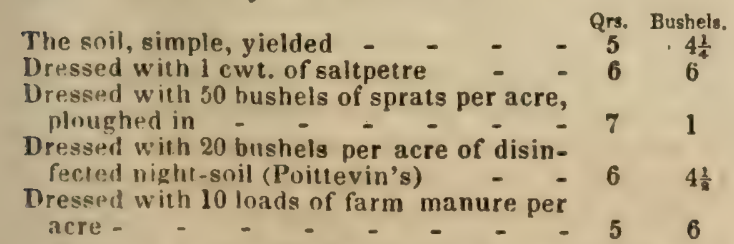

I have noticed, also (and the same remark applies to cubic petre), that the effect of saltpetre is the soonest apparent when it is finely powdered. and spread on the land in moist weather. The explanation of this must, per. haps, be found in the supuerior rapplity with which, in such seasons, it mixes with the soil. The cultivator will remember that moist weather is also the best adapled for the application of other top-dressings, such as gypsum and soot. I have found in the application of crushed bones to grass lands, that they never produce such good effects as when rolled into the soil by a heavy roller, when the ground is softened by wet weather. The Staffordshire farmers will readily attest the same fact. If long-continued dry weather succeeds the application of the nitrates to clover, the leaves of the grass, wherever the powdered nitrate has fallen, become covered with yellowish spots.

The application, too, of either nitre or cubic nitre to grass renders it much more attractive to live-stock, who, if turned into a grass field only partially dressed with either, will almost invariably resort to the portion of the land dressed with the nitrates. 'This is one argument in favour of the conclusion that these salts are in minute proportions absorbed by the crops to which they are applied. We know that this is the case with other saline manures, such as gypsum (sulphate of lime) and common salt; and every cultivator who has dressed his grass with either salt or gypsum will attest how decidedly his live-stock prefer the grass so treated to every other portion of the same field.

The effect of cubic petre as a fertilizer for heavy soils, seems to be rather more favourable, as far as my observations extend, than that of saltpetre; and in this I am confirmed by the observations of many of my neighbours. Yet still I am of opinion that, in the great majority of instances, both the cubic petre and the saltpetre will be found much more valuable top-dressings for light lands than for the heavier soils; and I am not much inclined to alter my opinion from the results of many of the carefully observed experiments of the very dry season of 1840 ; for in such periods it is almost hopeless to expect that any kind of topdrescing will produce results such as may serve to guide us in our future practice. Thus, in seasons such as the last, I have repeatedly witnessed the failure of top-dressings of all kinds; not only of the salts, such as lime and salt, gypsum and soot, and malt coombs, but even of the richest manure. My neighbours in Essex know very well that if a dry summer follows the application of their sprats (perhaps the most powerful of all animal manures), the application is entirely useless. In my own experiments with nitrate of soda I have inva. riably found the most excellent effects produced by its application to barley at the rate of $1 \frac{1}{3} \mathrm{cwt}$. per acre, sown broadcast, as finely divided as possible, soon after the young plants were beginning to show themselves above ground. The soils on which these experiments were made were the barley soils of Hampshire and Essex; and the same increase to the green colour of the crop, and a similar large increase to the produce of seed which my neighbours experienced, resulted from my own experiments. The clover also, which was somn with the barley in most instances, seemed to derive a considerable benefit from the dressing; anr? 
I have noticed on more than one occasion, the advantage of sowing the cubic petre in moist weather. In the dry summer of 1840 , the effect of the cubic petre was very inferior to that produced by it on similar land and crops in 1838 and 1839 -an effect which entirely supports my conclusions with regard to the inefficacy of all top-dressings in periods of long-continued dry weather. Of this opinion, too, is a very excellent and extensive farmer of Surrey.

Mr. Hewitt Davis noticed too the effect on some of the clays as well as the sands of Surrey in 1840 , - that the effect of cubic petre upon young wheats at the rate of $1 \frac{1}{4} \mathrm{cwt}$. per acre was excellent, not only in producing a very deep green colour, but in inducing a very considerable rankness of growth. But then, in his experience and observations, he has noticed that the wheat thus dressed has a stronger tendency to blight than that growing on the adjoining lands. On his farms, however, this rankness of growth is not felt as an evil; for on all soils, heavy as well as light, he practises an excellent system of thin sowing, the effect of which, as I can attest, is excellent in producing most abundant crops; either on the poor, hungry, black gravels and sands of Addington in Surrey, or on the tenacious clays of Sussex, he never drills more than 5 pecks of seed wheat per acre at intervals of 12 inches. It is true that by this plan the appearance of the wheat during the winter months is not so vigorous as many farmers would at first sight approve; but the plants gradually get together, stool out very abundantly, have all their ears of a uniform length; the produce is abundant, the sample generally excellent, and rarely subject to blight.

These valuable experiments of $\mathrm{Mr}$. Davis entirely confirm those which I have been induced to make on several occasions, and may, in a great measure, perhaps, serve to explain some of the discordant results of the recent extensive, and, in the majority of instances, successful experiments, with nitrate of soda and saltpetre, as a top-dressing for wheat, barley, and oats. For in a great many instances where the cubic petre has failed to produce advantageous results, the seed has been sown in rather large quantities; the corn, therefore, by the action of the salt becomes darkly green, grows with great luxuriance-is perhaps too thick on the ground; and the farmer, as a natural consequence, finds that the nitrated corn has a tendency to mildew. In the first number of the second volume of the Journal of the Royal Agricultural Society of England, there is a mass of valuable information, collected by Mr. Barclay, which illustrates very considerably these observations on the advantages of thin sowing; such as the experiments of Mr. Barker, Mr. Hyett, and others. And although I am not prepared to contend that the effects of these two powerful salts will be in all cases the most apparent on thin-sown corn, yet I am much inclined to think that the farmer will find that this is very often indeed the case.

In most soils there is to be found a certain proportion of carbonate of potash, and in many it exists in sufficient quantity to decompose the 848 nitrate of soda, and form nitrate of potash and carbonate of soda. This may, perhaps, serve to account, in some instances, for the varying results obtained in some apparently similar soils from the application of the nitrate of soda, and may be one reason amongst others why moisture is found to be so essentially necessary for the beneficial action of cubic nitre; for it is a chemical axiom, that to produce any chemical action between two substances, one of them must be in a fluid state, perfectly dry substances hardly ever producing any chemical action on each other.

Such, then, are the results of the long-continued experiments and observations upon nitre and cubic nitre which I have been able to make, and to suggest to others to re-examine and verify; and such, too, are, I think, the reasonable conclusions to be derived from our united experience.

In pursuing a path so novel, and so extensive, it need hardly astonish us that there are yet several sources of error to be avoided, deceptive appearances to be scrutinized, and additional experiments needed, before we can expect to arrive at the knowledge of the best and most economical modes of applying these two valuable nitrates. The soils to which they are best adapted, and the causes of their not a]ways producing even on apparently similar soils the same powerful effects, are amongst the objects of inquiry to which $I$ have alluded in this paper. The advocates, however, of these saline manures have no need to complain of the progress which they have made; for admitting that on some soils they have apparently produced but trifling effects, and on other soils hardly any, yet still in the multitude of instances they have amply repaid the farmer for his outlay. There is no other instance, perhaps, of such a rapid introduction of a saline manure into agriculture, as that of the modern, extensive, and increasing use of cubic petre by the farmers of Great Britain; and if we only pause to remember the difficulties of experimental researches like those, exposed, as all examinations of the process of vegetation of necessity are, to innumerable sources of error, we shall find no reason to complain of the success of its introduction, or of the talent and enterprize with which the farmers of England have conducted their valuable experiments.

There are many experiments with these two salts to be met with in the agricultural journals of the last few years.

1. Memorandum of saltpetre, nitrate of soda, and common salt, used as top-dressings in the south-east garden park, of a lightish land, well drained, 11 th A pril, 1840, on pasture laid down with grain in 1839: one acre sown with $1 \frac{1}{2} \mathrm{cwt}$ of nitrate of soda, measured and marked as such; then a piece of one rood, without any dressing; again, one acre sown with $1 \frac{1}{2} \mathrm{cwt}$. of saltpetre; next to this half an acre dressed with three-fourths of a $\mathrm{cwt}$. of common salt.

Result.-In little more than a fortnight after this, having had some favourable showers, there was an extraordinary change on the two distinct acres dressed with saltpetre and nitrate of soda, as compared with the rest of the field. The grass continued to grow on these divisions 
much stronger, close, and of an infinitely richer and darker colour; and the cattle lying much upon it, seemed very fond of it. 'This superior appearance continued through May and June, and perhaps later. The grass was, after this, eaten so close that no difference could be noticed, if any existed; it was particularly and frequently observed in September, October, November, and now, 8 th December; and no difference was then, or is now, perceptible between the ground dressed with saltpetre and what was not so dressed. The pasture seemed equally benefited by the nitrate of soda as by the saltpetre; and as the latter cost in proportion to the former as $30 \mathrm{~s}$. to $20 \mathrm{~s}$. per cwt., there can be no question of preferring the nitrate of soda. No improvement could be perceived to have taken place from the dressings of com. mion salt.

2. Another trial was made on pasture of the second year, in the lawn, on light land and dry, 14th April, 1840; one acre, measured and marked, sown with $1 \frac{1}{2} \mathrm{cwt}$. of saltpetre; adjoining this, one acre sown with $1 \frac{1}{2} \mathrm{cwt}$. of commion salt; and next, one acre, measured and marked, sown with $1 \frac{1}{2} \mathrm{cwt}$. of nitrate of soda.

Result.-Every remark applicable to the experiments in the south-east garden park applies equally to this. In both, in the different breadths sown by the cast of the hand where the two breadths joined, and the ground had got an extua y!uantity, the grass was richer and darker, showing that $1 \frac{1}{2} \mathrm{cwt}$. per acre is not an overdressing, whether of saltpetre or of nitrate of soda.

3. Memorandum of dressings of saltpetre, cummon salt, and of nitrate of soda, on the 16 th of April, on oats already brairded in Stott's Fauld, partly on well drained, dry, and partly on light land; one acre and fifteen falls, measured and marked, sown with saltpetre at the rate of $1 \frac{1}{2} \mathrm{cwt}$. per acre; next to this, one acre and fifteen falls, dressed with common salt in the same proportion; next to this, one acre and fifteen falls, sown at the same rate with the nitrate of soda.

Result.-It was long before any effect was perceived on any of the oats dressed as above. About the end of June a difference was perceived on the acre and fifteen falls sown with saltpetre, which had previously shown worming, and then came away darker and stronger, and became a heavy crop of oats and straw. 'The acre and fifteen falls dressed with nitrate of soda never seemed to be benefited by the dressing Being an inferior, light, sandy soil, with a red, irony bottom, it was injured by the early drought, and never recovered; the salt here, as on the pastures, seemed to have no eflect.

4. Memorandum of dressings of saltpetre and nitrate of soda, in Laughlan Glenfield, principally strong clay, thorough-drained, and subsoil-ploughed, 26th April, 1840, on red clover, \&c., for green cutting : one acre, measured and marked, sown with saltpetre, at the rate of $1 \frac{1}{2}$ cwt. and $23 \mathrm{cwt}$. of nitrate of soda, were sown here in the same proportion.

Resulı.-The clover, \&c., seemed equally benefited by the saltpetre and by the nitrate of soda: and, compared with what was not dressed, the improvement was very perceptible in about a fortnight, and it became a much darker, stronger, and heivier curp than in that part of the field not dressed, and it was ready for cutting fully ten days earlier. It was not weighed, but it is believed there was from onethird to one-half more on the ground dressed than where it was not. The second cutting did not show a better crop than where it was not dressed. Nearly an acre was dressed with nitrate of soda after the first cutting, on the 10th of August, where one had before been applied, but it did not seem to do much good.

5. Memorandum of dressing of saltpetre and nitrate of soda on some winter-sown wheat in Bridge Park, on clay land, thorough-drained, and subsoil-ploughed, 20th A pril, 1840.

First Lot.-Twenty falls, measured ana marked, dressed with $28 \mathrm{lbs}$. of nitrate of srda Produce: Wheat 7 bushels, $17 \frac{1}{2}$ lbs, or per acre (by an acre a Scotch acre is meant throughout and a Scotch acre is about one-fifth longer than a statute acre; and by "a fall," a perch of land), 58 bushels, 26 lbs.; straw 64 stones, 18 lbs., or per acre 518 stones. Weight of wheat per bushel, $157 \frac{1}{2} \mathrm{lbs}$. Sold to baker for $28 \mathrm{~s}$.

Second Lot.-Twenty falls, measured and marked, sown with $28 \mathrm{lbs}$. of saltpetre. Produce: Wheat 6 bushels, 38 !bs., or per acre 52 bushels, 24 lbs.; straw 95 stones, 12 lbs., or per acre 764 stones. Weight per bushel, 58 lbs. Sold to baker for 28 s.

Third Lot.-Forty falls adjoining, measured and marked, without any dressing. Produce Wheat 11 bushels, 1 lb., or per acre 44 bushels, 4 lbs.; straw 79 stones, or per acre 316 stones Weight $59 \mathrm{lbs}$. Sold for seed at 35 s. per boll.

Fourth Lot.-A small quantity of oats adjoining to this winter wheat was dressed with saltpetre, which produced a great effect on the strength and colour of the oats; but the produce was not weighed or measured after being cut.

Fifth Lot.-Trial of nitrate of soda on six drills of potatoes, at the rate of $1 \frac{1}{2} \mathrm{cwt}$. per acre, sown over the stems when 5 inches long, on 10 th June. Result: The shaws (tops) seemed much finer and richer than those not thus treated; but the potatoes being sold, the comparative produce was not ascertained.

Six drills of Swedish turnips, dressed at the same rate, 10th June, on a healthy braird, fol. lowed by fine showers and warmth. Piesuit: Both shaws and turnips much improved, as compared with those near them not thus dressed; in appearance improved by several tons to the acre, but no comparative weights were taken.

In the trial with nitrate of soda, in the same proportions, on mangel-wurzel and carrots, Walls, the overseer, could not observe any difference between those so dressed and those which were not; and saltpetre and cubic petre were also mixed in small proportions with the compost from an old hotbed, and used in the garden for turnips, spinach, carrors, caulifiow ers, asparagus, and onions, but without any apparent advantage.

Mr. S. Martin, of Warbleton, in Sussex, has given, in the Sussex Express, the following details of his experiments with nitrate of soua as a top-dressing for corn, on a four-acre field io 
his occupation:- "The soil of the field selecled is a thin, gravelly loam, with a substratum of sandstone, and was a rye-grass ley, fed with sheep and beasts until the last week in May, 1839, when it was ploughed up, and afterwards twice stirred and harrowed, and manured with 120 bushels of lime per acre, previously to its being sown with the wheat "golden drop" in the autumn. In the last week of April, this year, I applied $1 \mathrm{cwt}$. of nitrate of soda per acre over the whole field (with the exception of two lands in the middle of the field); in the second week in May, I applied to two lands adjoining those upoli which none had been sown an additional 1 civt. per acre. Previously to the application of the nitrate, the plants had a very sickly appearance, getting yellow in patches, and looking, as we call it here, "speary;" but in a very few days subsequent, its appearance was much altered, it having (with the exception of the two lands on which none had been sown, and which remained in a very sickly state) changed from a faint yellow to a luxuriant green; the iwo lands upon which the $2 \mathrm{cwt}$. per acre were sown were much darker in appearance than the other, and easily distinguishable from the remainder at a very considerable distance.

"At harvest I measured off" exactly 8 rods if each, and had it reaped (leaving a stubble about 16 inches high), and carted and thrashed separately; the result was as under: -8 rods vithout soda produced 1 bushel, 3 galls. 1 pint, : 27 bushels, 6 galls. 4 pints per acre; weight, i1 lbs. per bushel; straw 89 lbs., or 49 trusses, 16 lbs. per acre: 8 rods with $1 \mathrm{cwt}$. of soda per acre, 2 bushels, 1 gall., or 42 bushels, 4 galls. per acre; weight, $60 \frac{3}{4}$ lbs. per bushel; straw, 155 lbs., or 86 trusses, 4 lbs. per acre: 8 rods with 2 cwt, of soda per acre, 2 bushels 2 galls. 7 pints, or 47 bushels, 1 gall. 4 pints per acre; weight, $60 \frac{1}{2}$ lbs. per bushel; straw, 156 lbs., or 86 trusses, 24 lbs. per acre.

"On another piece of land, soil very thin and gravelly, sown with Talavera wheat in the autumn, I applied $1 \mathrm{cwt}$. per acre in the first week in May, and the result was equally satisfactory, the produce good, and weighed $64 \mathrm{lbs}$. per bushel.

"In an adjoining field of precisely the same lescription of soil, but which had been in hops for 11 years previously, and amply manured every year, I sowed on two rods at the end of one of the lands nitrate equal to $1 \frac{1}{2} \mathrm{cwt}$. per acre, which had a very prejudicial effect; the part with nitrate of soda being much mildewed sind totally unfit for bread, while the straw on ihe remainder of the field was very bright and dean, and the grain full and handsome. I also used nitrate of soda on a meadow, $1 \mathrm{cwt}$. per acre, applied the last week in April; produce very trifling.

"As far as my experience goes, and from the effect of nitrate of soda on my neighbours' lands, I am of opinion that it is a very valuable manure for their light soils, exhausted by repeated croppings, particularly in districts where the arable lands have been repeatedly manured with lime; but I have great doubts whether it would answer for wheat on newly nroken up $n$ r other land in a high state of cul'ration and full of manure. In my experi$\sin$ ment on the old hop ground, although the straw was much longer, with a blade broad and flaggy, the yield was miserably deficient, both in quantity and quality, compared with the rest of the field.

"In respect to its effect on the second crop, I can only observe, that a very thin, wornout field of 18 acres, with wheat in 1839 , on which $1 \mathrm{cwt}$. per acre was used (one land of which had a double quantity), was sown this year half with oats and half with seeds, that both oats and seeds were fully equal to any I ever grew on that field; and that the land where the $2 \mathrm{cwt}$. per acre was sown produced fully as many plants, with longer straw and more grains, and was, as far as I could judge from appearances (I did not keep it separate), much superior to the other."

\section{NITRIFICATION. See Eremacausis.}

NODI. In botany, the knots or swelled articulations of stems; the place where one joint is articulated with another.

NONE-SO-PRETTY. One of the names of the London-pride Saxifrage. See Saxifrage. NONESUCH, or Brack Medick. See MeDICK.

NOONINGS. A term provincially used to signify working during dinner-hours.

NORFOLK PI,OUGH. See Ploughs.

NORT HER N L I G H T S, or AURORA BOREALIS. See Lights, Northers.

NOSE-BAND. That part of the head-stall of a bridle which comes over a horse's nose. It is sometimes termed maserole.

NUCLEUS (Lat). Literally, any thing round which matter has accumulated, or to which it is affixed. In botany, it is used in various significations: -1 . The central, fleshy, pulpy mass of an ovule. 2. That part of a seed contained within the testa, and consisting of either the embryo and albumen or of the embryo only. 3. In lichens, the disk of the shield, which contains the sporules and their cases. 4. In the language of the older botanists, what is now termed by gardeners a clove; that is, the secondary bulb of a bulbous plant.

NUISANCES, in English law, are of two kinds: public or common, which annoy the king's subjects in general; and private, which are defined "any thing done to the hurt or annoyance of the lands, tenements, or heredita. ments of another." A nuisance may be defined to be any act done which renders the lives of the neighbours less comfortable than they were before. The remedies allowed by the law are in some cases summary, as when a gate is erected across a public highway, or cattle trespass on the land; and in which cases the passenger or owner of the land is justified in removing the nuisance : or in other cases, the general legal remedies are, indictment or presentment, for public nuisances; or by an action on the case for damages, for private nuisances. Indictable Nuisances. - of the number of public nuisances which are punishable by indictment are setting spring-guns and mantraps, which, by the $7 \& 8 \mathrm{G} .4$, c. 18 , is declared to be a misdemeanor; but the act allows such to be set "from sunset to sunrise in dwelling. houses for the protection thereof." Other indictable nuisances are for erecting a privy ur 


\section{NURSERY.}

placing putrid carrion near a highway, or keeping hogs, and feeding them with offal near to a street; for keeping a dangerous bull in a field through which there is a public pathway (if the bull or other dangerous animal is purposely placed there to stop a disputed path, and death ensues, it is a murder); for keeping unmuzzled a ferocious dog; for baiting on the queen's highway a bull, \&c. The punishment in any case of nuisance is fine or imprisonment, or both; and the court may order the defendant to pay the prosecutor his costs. It is no defence to prove that the nuisance has existed for a number of years; but in some cases the facts of the case may be taken into consideration by the jury, who are to determine whether the benefit derived by the public exceeds the annoyance. But in indictments for obstructing the highway by placing on it for a length of time carriages while loading and unloading, it is no defence to show that space was always left for two carriages to pass and repass on the other side of the street. 'The non-repair of a road or a bridge are also well-known nuisances, which are indictable.

Nuisances on which an Action on the Case is maintainable. - Accidents from the negligent use of loaded guns; placing baited traps so near to the premises of another, or the highway, that dogs are attracted into them and injured. For an injury by a vicious bull; and it is no defence by the owner of an animal that he has had notice of having done an injury, and has taken every precaution to prevent it doing so again. No action, however, lies for an injury by a dog let loose on the owner's closed premises at night for their protection; or on land on which the injured party has no right to go. If a person harbour a dog, or allows it to resort to his premises, he is liable for any damage it may cause. And the owner of a dog that destroys or injures sheep is, of course, liable to their owner. If the owner catch the dog in the act of worrying his fowls or sheep, he is justified in shooting him; but he must not follow the dog some distance, and then shoot hirn; nor may he shoot a dog merely trespassing; but he may if the dog is chas. ing deer in a park. And if any man do any thing on his own soil which is a nuisance to another, as by stopping a rivulet, and so diminishing the water used by him for his cattle, the party injured may enter on the soil of the other and abate the nuisance; and this right of abatement is not confined merely to nuisances to a house, to a mill, or to land.

NURSERY. In horticulture, a piece of land set apart and appropriated for rearing and pre. serving young plants and trees of different kinds, with a view to supply both gardens and plantations. The situation ought to be open and airy, and the soil of an average quality, neither too heavy nor too light, so as to be adapted to the majority of plants; but in a complete nursery there ought also to be shady borders for plants requiring shade, and beds or compartments of peat soil or other peculiar earths, for such plants as are not readily increased and grown in ordinary soils. Where tender plants are propagated, or where hardy $n$ ts are to be raised from seeds or struck
OAK.

from cuttings, which are not easily germinated or rooted in the open ground and in the ordi. nary manner, hotbeds, frames, and handglasses are also requisite. Every private gardes of any extent requires a nursery to raise and bring forward young plants, as a reserve tor supplying failures by disease or accident in the general garden; and in every country where private gardens or plantations of trees are frequent, public or commercial nurseries are formed by persons who adopt nursery garden. ing as a business.

NU'T, BLADDER. See B LañIE-NUt.

NUT, THE EARTH. See EAтти-Nuт.

NUTRI'TION. The matter by which an ani$\mathrm{mal}$ or plant is supported, and its growin increased. See Foon and Meat, Gases, Eantus, SALTS, WATER, \&C.

NU'TS (Lat. nux). In botany, seeds covered with hard shells; but in the general acceptation of the word, signifies the fruit of different species of hazel (Coryli).

NYMPH. See PuPA.

\section{O.}

OAK (Ger.eiche; Dut. eik; Dan. eeg; Sw. ek; Lat. Quercus; from the Celtic quer, fine, and cuez, a tree; others derive it from the Greek word choiros, a pig; because those animals feed on the acorns).

The oak is indigenous throughout Britain, and in former ages, before the clearing away of the forests had commenced, appears to have covered a very large portion of its surface; for, even in districts where the natural or self-sown oak is now rarely seen, the remains of noble and gigantic trees are frequently met with, sometimes in the alluvial deposits on the mar gins of rivers, or in boggy places covered with a layer of peat-moss, which has been generated around them by the stagnation of the water caused by their fall.

A fine oak is one of the most stately and picturesque of trees; it conveys to the mind associations of strength and duration, which are very impressive. The oak stands up against the blast, and does not take, like other trees, a twisted form from the action of the winds. Except the cedar of Lebanon, no tree is so remarkable for the stoutness of its limbs ; they do not exactly spring from the trunk, and thus it is sometimes difficult to know which is stem and which is branch.

English oak warps and twists much in drying, and in seasoning shrinks about $\frac{1}{3} \frac{d}{3}$ of $i t s$ width. This wood is more durable than any other timber in water; and in a dry state it has been known to last nearly 1000 years. The more compact it is, and the smaller the pores are, the longer it will last; but the open, porous, and foxy-coloured oak, which grows in Lincolnshire and some other places, is not near so durable. The bark, leaves, and fruit of all the species abound in astringent matter, and in tannic acid. The bark in the spring contains more tannic acid, and is more easily separated, than at any other season: hence oaks are usually barked in May, June, and the beginning of July. When separated. the bark is dried by being set up in ranges, which are called loftes 
In the greater part of North America, as well as in Europe, there is no tree so generally useful as the oak, which seems to have been multiplied in proportion to its utility.

Linnæus, in the third edition of his Species Plantarum, published in 1774, described 14 species of oak, of which 5 only are natives of the New World. Since then, owing to the labours of those indefatigable naturalists, Humboldt, Bonpland, and especially Michaux, the father, the number of American species of oak has been increased to no less than 44, all of which are comprised between the 20th and 48 th degrees of North latitude. In the Old Continents, only 30 species are enumerated, and these are scatsered on both sides of the equator. The species and varieties of the oak added to those described by the Michaux, are chiefly found in the extreme Southern States, Texas, and Mexican possessions.

The following classification of American oaks was made by the elder Michaux, who includes in it three European species:

\section{First Division.}

Fructification annual.

First Section-Leaves lobed.

1. White oak (Quercus alba).

2. Common European oak (Quercus robur).

3. European white oak (Quercus robur pedunculata).

4. Mossy-cup oak (Quercus olivøformis).

5. Over-cup white oak (Quercus macrocarpa).

6. Post oak (Quercus obtusiloba).

7. Over-cup oak (Quercus lyrata).

Srconn Sxction.-Leaves toothed.

8. Swamp white oak (Quercus prinus discolor).

9. Chestnut white oak (Quercus prinus palustris).

10. Rock chestnut oak (Quercus prinus monticola).

1. Yellow oak (Quercus prinus acuminata).

12. Small chestnut oak (Quercus prinus chincapin).

\section{Seconn Diviston.}

Fruclification biennial; leaves mucronated (except in the 13th species).

First Sfction.-Leaves obtuse or entire.

13. I,ive oak (Quercus virens).

14. Cork oak (Quercus suber).

15. Willow oak (Quercus phellos).

16. Jaurel oak (Quercus imbricaria).

17. Upland willow oak (Quercus cinerea).

18. Running oak (Quercus pumila).

\section{Second Section.-Leaves lobed.}

19. Bartram oak (Quercus heterophylla).

20. Water nak (Quercus aquatica).

21. Black Jack oak (Quercus ferruginea).

22. Bear oak (Quercus banisteri).

Tніку Sвстіол. - Leaves multifid or many-clefled.

23. Barren scrub oak (Quercus Catesbai).

24. Spanish oak (Quercus falcata).

25. Black oak (Quercus tinctoria).

26. Scariet oak (Quercus coccinea).

2\%. Gray oak (Quercus ambigua).

28 Pin oak (Quercus palustris).

29. Red oak (Quercus rubra). 852
The most valuable species of the American oaks is the white oak, which is found as far north as the small town of Trois Rivières, in Canada, lat. $46^{\circ} 20^{\prime}$, and the lower part of the river Kennebec, in Maine, and thence south on both sides of the Alleghanies down to the 28th degree of latitude. Its vegetation is repressed in the Northern States by the severity of the winters. In the lowermost Southern States it is found only on the borders of swamps, with a few other trees, which likewise shun a dry and barren soil. The white oak is observed to be uncommon on lands of extraordinary fertility, like those of Tennessee, Kentucky, and Genesee, and in all the spacious valleys watered by the western rivers. One may travel whole days in those states without seeing a single stock, though the few that exist, both there and in the Southern States, exhibit the most luxuriant vegetation.

The white oak abounds chiefly in the Middle States and in Virginia, particularly in that part of Pennsylvania and Virginia which lies between the Alleghanies and the Ohio. East of the mountains this tree is found in every exposure, and in every soil which is not extremely dry or subject to long inundations; but the largest stocks grow in humid places. In the western districts, where it composes entire forests, the face of the country is undulated, and the yellow soil, consisting partly of clay with a mixture of calcareous stones, yields abundant crops of wheat.

By the foregoing observations it appears that the severity of the climate, the fertility of the soil, its dryness or humidity, are the causes which render the white oak so rare over threequarters of the United States that it is inadequate to supply the local demand, though the country contains but a small proportion of the population which it is capable of supporting.

Among the American oaks this species bears the greatest analogy to the European oak, especially to the variety called European white oak, Quercus pedunculata, which it resembles in foliage and in the qualities of its wood. The American white oak is 70 or 80 feet high, and 6 or 7 feet in diameter; but its proportions vary with the soil and climate.

The excellent properties of the white oak for the construction of houses, ships, and almost innumerable other purposes, are too well known to need any particular description in this place.

Great black oak (Quercus tinctoria). The wood of this tree is of a coarser grain than that of the white oak, and of a reddish colour. Between every year's growth, also, it appears porous, yet when dry and seasoned, it becomes strong and durable. The bark has, for a long time, been in great repute for tanning, and for the very excellent yellow dye which it affords. Dr. Bancrof, of Iondon, learned the use of the bark as a dye, when in this country, during the revolutionary war; and introduced it in the manufactories of England, to which country many ship-loads of the article, ground, have been annually shipped, under the name of Quercitron bark. 
Syanish oak (Quercus falcala, of Michaux); the bark of this species is somewhat rough, and light-coloured. The leaves are deeply and obtusely sinuated, and end in several acute, bristly points : the foot-stalks are pretty long. The timber is generally worm-eaten, or rotten at heart; but the bark is preferred to ail other for tanning, and is much dearer.

Live oak (Quercus virens). This species is confused to Georgia, South Carolina, and Florida. The tree is of uncommon magnitude, and singularly beautiful. The moss hangs in lengths of several yards from the large branches of the old trees, and waving with the wind, gives the tree a venerable appearance. The wood is proverbial for its durability, when cut at a proper season, and is much used for ship timber. See Aconns, Drx Rot, and PrantaTIONS.

OAK-APPLE. This is not to be confounded with those beautiful little excrescences so common upon the underside of the leaves of the oak, and known by the name of galls and spangles; they are the nidi of different species of Cynips, produced by the puncture of the ovipositor of the female, upon the different parts where they are found. The oak-apple is also formed by the puncture of a cynips, upon the twigs of $Q$. pedunculata. It rises rapidly, is usually spheroidal, in size about 1 to 2 inches in diameter. Its texture is spongy. It has some resemblance to the Bedeyuar of the $\mathbf{E g}$ lantine, but is not so rough and fibrous on the surface. The oak-apples are very astringent, containing tannic acid, and may be used in dyeing, making ink, and staining.

'The largest galls or oak-apples, found in the United States, grow on the leaves of the red rak. They are round and smooth, and measure from $1 \frac{1}{2}$ to 2 inches in diameter. This kind of gall is green and somewhat pulpy at first, but, when ripe, it consists of a thin and brittle shell, of a dirty drab colour, enclosing a quantity of brown spongy matter, in the middle of which is a wondy kernel about as big as a pea. A single grub lives in the kernel, becomes a chrysalis in the autumn, when the oak-apple falls frorn the tree, changes to a fly in the spring, and makes its escape out of a small round hole which it gnaws through the kernel and shell. This, says Dr. Harris, is probably the usual course, but I have known this gallfly to come out in October. The name of this insect is Cynips confluentus. Its head and thorax are black, and rough with numerous little pits and short hairs; the hind-body is smooth, and of a shining pitch colour; the legs are dull brownish-red; and the fore-wings have a brown spot near the middle of the outer edge. Its body is nearly one-quarter of an inch long, and its wings expand five-eighths of an inch.

Clusters of three or four round and smooth galls are often seen on the small twigs of the white oak. They are nearly as large as bullets, of a greenish colour on one side, and red on the other. They approach in hardness to the Aleppo galls, and perhaps might be put to the same use. Each one is the nest of a single insect, which turns to a fly and eats its way out in June and July, having passed the winter as a chrysalis, within the gall, lodged in a clay- coloured, egg-shaped case, about three-twentieths of an inch long, and with a brittle shell. These little cases appear to be cricons, but are not made of silk or fibrous matter. Similar cocoons are found within many other galls, and I have some which were discovered under stones, and were not contained in galls, but produced gall-flies, the insects having left their galls to finish their transformations in the ground. The gall-fly of the white oak varies in colour. Sometimes it closely resembles the gall-fly of our oak-apple, differing from it only in size, and in wanting the brownish spot and dark-coloured veins on the fore-wings; and sometimes it is of a dull brownish-yelluw colour, with a brown spot on the back. It is threetwentieths of an inch long, and its wings expand three-tenths of an inch. It is the Diplolepis, or more properly Cynips oneratus of Dr. Harris's "Catalogue."

Galls of the size and colour of grapes are found on the leaves of some oaks. Each one contains a grub, which finishes its transformations in June. The winged insect is the Cynips mubilipennis, or cloudy-winged Cynips, so named from the smoky cloud on the tips of its wings. Excepting in this respect, it closely resembles the dark-coloured variety of Cynips onerutus, and very little exceeds it in size.

One of our smallest gall-flies may be called Cynips seminator, or the sower. She lays a great number of eggs in a ring-like cluster around the small twigs of the white oak, and her punctures are followed by the growth of a rough or shaggy reddish gall, as large sometimes as a walnut. "When this is ripe, it is like brittle sponge in texture, and contains numerous little seed-like bodies, adhering by one end around the sides of the central twig. These seeming seeds have a thin and tough hull, of a yellowish white colour; they are egg-shaped, pointed at one end, and are nearly one-eighth of an inch long. The gall-insects live singly, and undergo their transformations within these seeds; after which, in order to come out, they gnaw a small hole in the hull, and then easily work their way through the spongy ball wherein they are lodged. 'They are less than one-tenth of an inch long, are almost black, or of the colour of pitch, highly polished, especially on the abdomen, and their mouth, antennæ, and legs are cinnamon-coloured.

It has been observed that no tree in Europe yields so many different kinds of galls as the oak. Those described are not all that are found on oaks in the United States, and they seem to be sufficiently distinct from the galls of European oaks. (Harris.)

OAK BARK. The cortical layer stripped from the oak tree. Oak bark is preferred to all other substances in the tanning of leather, and in $\mathbf{E u}$ rope brings a high price afterwards as a manure. The exhausted bark is used by gardeners to produce a slight equable heat by its fermentation, and may be advantageously used as a manure. The tan-balls, or muddy sediments of tan-pits, are used for summer fuel. The bark contains different quantities of tannic acid, according as it is near to or distant from the wond. Thus, the inner part, or liber, according to Sir H. Davy's experiments, yields $3 \mathrm{C}$ 853 
about 77 per cent. of tannic acid; the cellular layer, lying upon the liber, yields only 56 per cent; and the cuticle little or none. Dr. Higgins obtained 108 parts of tannic acid from the bark of an oak felled in the spring, and only 30 from an oak felled in winter. When the bark is set up to dry, the air, aided by moisture, acting upon the tannic acid, converts a portion of it into gallic acid, which is not originally a constituent of oak bark. See BArk and $\mathrm{T}_{\mathrm{A} \text {. }}$.

OAK PRUNER. The ground beneath black and white oaks is, says Dr. Harris, often observed to be strewn with small branches, neatly severed from these trees, as if cut off with a saw. Upon splitting open the cut end of a branch, in the autumn or winter after it has fallen, it will be found to be perforated to the extent of six or eight inches in the course of the pith, and a slender grub, the author of the mischief, will be discovered therein. In the spring this grub is transformed to a pupa, and in June or July it is changed to a beetle, and comes out of the branch. The history of this insect was first made public by Professor Peck, who called it the oak-pruner, or Sienocorus (Elaphidion) putator. See Pl.16, 1. In its adult state it is a slender, long-horned beetle, of a dull brown colour, sprinkled with gray spots, composed of very short close hairs; the antennæ are longer than the body, in the males, and equal to it in length in the other sex, and the third and fourth joints are tipped with a small spine or thorn; the thorax is barrel-shaped, and not spined at the sides; and the scutel is yellowish-white. It varies in length from four and a half to six-tenths of an inch. It lays its eggs in July. Each egg is placed close to the axilla or joint of a leafstalk or of a small twig, near the extremity of a branch. The grub hatched from it penetrates at that spot to the pith, and then continues its course towards the body of the tree, devouring the pith, and thereby forming a cylindrical burrow, several inches in length, in the centre of the branch. Having reached its full size, which it does towards the end of the summer, it divides the branch at the lower end of its burrow, by gnawing away the wood transversely from within, leaving only the ring of bark untouched. It then retires backwards, stops up the end of its hole, near the transverse section, with fibres of the wood, and awaits the fall of the branch, which is usually broken off and precipitated to the ground by the autumnal winds. 'The leaves of the oak are rarely shed before the branch falls, and thus serve to break the shock. Branches of five or six feet in length and an inch in diameter, are thus severed by these insects, a kind of pruning that must be injurious to the trees, and should be guarded against, if possible. By collecting the fallen branches in the autumn, and burning them before the spring, we prevent the developement of the beetles, while we derive some benefit from the branches as fuel.

Cak trees are also subjected to the attacks of insects, which destroy the leaves, deposit their eggs in the branches which they destroy, and others which devour the solid wood. See Beetrfis, Borers, Catehpilinas, Locusts, \&c. 854
OAT (Russ. owes; Pol. owies; Dutch, haver Fr. Avoine; Lat. avena). A very valuable cereal grass, of which several varieties are cultivated for their seeds : the chief of these are-1. The Avena sativa, or common oat. Pl. 3, e. 2. The A. orientalis, or Tartarian oat, $f$. 3. A. strigos a or bristle-pointed oat. 4. A. brevis, or short oat. 5. A. nuda, or naked oat.

The common oat is far the most important of these species. Its spikelets contain two or three seeds. Its florets are sometimes furnished with awns, and at other times are awnless. The oat is a native of cold climates: it flourishes in the temperate latitudes, but it degenerates, and at last refuses to yields profitable crops as it approaches the equator. It is, however, cultivated with success in Bengal, as low as the $25^{\circ}$ of latitude. It flourishes remarkably well in Ireland and in Scotland, and constitutes the principal food of the inhabitants. In England it is cultivated to a very considerable extent in the fen districts of the eastern counties, as well as - in the northern border districts, in which last the oats are considered to be very superior. By cultivation, difference of soil and climate, and other causes, the common oat ( $A_{\text {. sativa }}$ ) has produced several varieties, which have been divided by some authors into three classes, the black, the gray, and the white. Those of the first class are commonly hardy, have small seeds, become early ripe, and are hence well adapted for cold hungry soils, such as those which are usually found on cousiderable elevations.

The gray, or dun-coloured oats, although possessing more valuable qualities than the black oat, are still inferior in quality to the white, but on some soils yield very remunerative crops.

The third and most valuable class of oats is the white. "The most improved of these," says Professor Low, "are without awns. They are the least hardy kinds, but they are of the greatest weight to the bushel, and the most productive of meal. In this class the potato oat is that which has possessed the greatest reputation for a time in the districts where it is cultivated. It is not so well suited to inferior soils as some of the other white and darkercoloured kinds: it is also less productive of straw, though the grain is more plump, weighs heavier, and yields a greater weight of meal. The hardier kinds, however, are better suited to certain situations than the finer, just as the hardier red wheats are better suited to certain situations than the thin-chaffed and white varieties. The potato oat was the discovery of accident, and the produce of a single plant. It has, in many cases, shown a tendency to degenerate, by the husks becoming thicker and the body less plump, and by the partial appearance of awns."

The Poland oat is another valuable cultivated variety of the white oat. It comes early to maturity, and is a prolific bearer. Its defects are a tendency to be deficient in straw, and a liability to shed its seeds.

Besides these there are several other varie. ties of the white oat, as the Dutch, or Friesland oat, the Hopetoun oat of East Lothian, \&c.

The Hopetoun oat was produced in 1824 , by 
M. P. Sherriff, of Mungo's well, in the way he thus describes. "Having frequently had occasion to pass the gateway of a crop of potato oats, in the summer of 1824 , a stalk of remarkable height attracted my attention. When the crop was reaped, the grains supported by this stalk, and those upon a short one proceeding from the same root, were gathered and sown in the following spring. The crop from the grains of the gigantic stalk was again conspicuously tall, and after the crop of 1827 the new variety established its superiority." In some comparative trials by Mr. Boswell, "on a good free black soil," the Hopetoun exceeded the potato oat in produce, as, in some experiments by Mr. Forsyth, of Elgin, "on a rich loam," it exceeded the late Angus oat, and in those of $\mathbf{M r}$. Howden, at Traprain, in East Lothian, it proved superior to the gray Angus, the potato, and the early Angus oats.

The early Angus oat is well known for its early ripening, and the late Angus, says $\mathrm{Mr}$. Sherriff, is also well known for its fine straw and grain; and although late in ripening, is the most esteemed species of oat in the early districts of Scotland, such as East Lothian and Morayshire. There is a difficulty, however (Mr. Sherriff very justly adds), of ascertaining the merits of different varieties of grain by experiment, from the many contingencies affecting the results, the most powerful of which is the nature of the season. Some kinds of oats grow rapidly in the early part of the season, and some attain their full height, such as the Polish and Georgian oats, both of which are stunted. Others grow slowly, and are later in arriving at their full height, such as the potato, Flemish, and early Angus oats, which are also short. Others continue to grow through the season, and are still later in arriving at their full height, as the Hopetoun and late Angus oats, which are taller than the others. When the early part of the summer proves wet, and is followed by drought, the Polish and Georgian oats have an advantage over other kinds, as they attain their full height before the drought commences. When the early part of the summer is very dry, and moisture succeeds, the Hopetoun and Angus oats benefit by the moisture, while the others mentioned do not. When the season proves wet throughout, and the different oats in consequence reach an extreme height, the smaller species have frequently an advantage over the larger in grain produce, in consequence of the straw of the latter becoming too luxuriant.

The Cumberland early oat, so named from being raised from a single head by a Cumberland gentleman, is of a longish grain, more like the early Angus variety than the potato; colour dark and dull. It is as much earlier than the potato oat as the latter is earlier than the Hopetoun, being ripe nearly a fortnight sooner than the Hopetoun.

Red Oat.-There is a peculiar variety of oat (classed with the gray oats), called the red oat, which is a favourite in some districts, and is thus described by the celebrated William Dawson, of Frogdon, in 1791:- "Happening to be at Linton, in $\Gamma$ weeddale, which is about the highest land kept in cultivation in the south of Scotlami, I found the farmers complaining much of the loss they had by late harvests. and I asked if they had tried the Dutch oats, which were so much earlier than the common kinds. They told me that they had tried the Dutch oats, but that they had a kind in their own country which were as early as the Dutch, and were superior in several respects; they were not so apt to shake even as the common oat; they suited every sort of suil if in good condition, and they yielded well in meal; that they had been sown in that country for fifty years, but no one knew where they came from. Upon this information I commissioned a boll for a trial, and found them answer so well that I have sown no other sort for several years. They do not produce much straw, but what they do produce is very good. I saw a second crop of these oats upon the same land last year, which was good. I have found that they answer the character given of them at Linton fully. That they answer best upon land in good condition, but that they produce very little straw upon poor land; yet the produce of corn is not even in these situations inferior to any other oats. 'These properties give them a great superiority over every other kind known in this country, and grown in high situations, and cold climates and soils." They are a kind of oat much relished by horses, who, if used to them, do not readily take to other, even richer kinds. Carters accustomed to them give them a decided preference.

The Gerrgian Oat was introduced about the year 1824, but it has not made much progress. In 1826, Mr. Wilson, of Preston, reported the following comparative trials between it and the potato oat (Trans. High. Soc. vol. i. p. 153), upon 2 English acres of equal land. The quantity sown upon an acre was 6 bushels, and of the potato 4 bushels. The Georgian was reaped 10 days earlier than the potato, but they might have been 14 days. The appearance of the Georgian was by far the most luxuriant during the summer, till the end of July, when the potato shot out considerably longer in the straw. They were carefully cut down, stacked, and thrashed in March, 1826; the result was, in-

Weight of straw of the potato oats per acre $-317 \mathrm{stones}$ Weight of straw of the Georgian oats per acre $238 \quad 12$

The produce of the potato oats per acre was 69 Winchester bushels, and the Georgian 68.

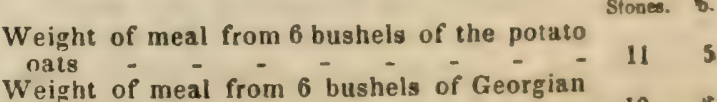

eats

106

The Tartarian Oat is cultivated to some extent in England, but much more extensively in some portions of the Continent. "Its fascicle" is contracted, and nods to one side, which distingaishes it from the common oat. The colour of its corolla is generally dark, but the plant improves by culture in a good soil, losing its awns, and that darkness of colour which ap. pears to distinguish the oat in its less improved state." The breadth of this oat annually cultivated in England has much increased within the last few years. It is the best description 
for the poorest exhausted soils, producing the most straw on those sorts of any other variety. The oat can be profitably cultivated upon, perhaps, a greater variety of soils than any other of the cereal grasses. It may be grown, too, successfully with less preparation of the soil, and less manure. The oat plant, however, succeeds best in fresh soils, in newly broken up o.d pastures, and in those abounding in organic matters.

The organic manures by which the oat crop is best nourished, appear to be green manures; fish, especially those like sprats, abounding in vil, and, in fact, all those of a readily decomposable description. Recently-drained marshes, peaty soils after being dressed with lime, newly enclosed commons after being chalked, all usually yield large crops of oats.

The land intended for oats should be ploughed, if possible, especially on clay soils, in the previous winter, or at least as early in the spring as possible: this is a practice almost always adopted by the best farmers of our island. A still more common course of cropping is to sow oats after turnips, or other green crops, and especially on the four-shift system with grass-seeds.

A miserable custom still prevails in some parts of England, of taking two crops of oats in succession, or an oat crnp after wheat or barley. Arthur Young long since denounced this as bad husbandry. After observing that white vats should be sown in March, in preference to any other season, he remarked, that "in the general conduct of them the farmer should by all means avoid the common error of sowing after other corn crops, by which they exhaust the land. They should always receive the same preparation as barley, nor ought a good husbandman to think of their not paying him as well for such attention as that crop. It is a very mistaken idea to suppose it more profitable to sow barley on land in good order than oats. He was, from divers experiments, inclined to think that oats will equal, and in many cases exceed, barley. The superior quantity of the produce will ever be found to more than counterbalance the inferiority of the price; which, however, sometimes exceeds that of barley."

Oats are commonly sown from March to April, but it is very probable that they might he advantageously sown much earlier in many situations, and when on grass leys generaily broadcast: from 4 to 6 bushels per acre seed is the ordinary quantity. By the drill, after turnips, a much less quantity will be sufficient. I have known from 10 to 11 quarters per acre grown year after year from only 2 busnels of seed.

They are usually cut in the south by the scythe-in the north and western portions of IBritain by the sickle; and they should never be allowed to become perfectly ripe before they are cut. The usual produce varies from 25 to tio bushels per acre. In the fens of Lincolnshire, and in Essex and Suffolk on land previously dressed with 35 or 40 bushels of sprats fuer acre, the yield is usually much more considerable.

The weight of a bushel of oats varies from 856
35 to 45 pounds, and 14 pounds of oats commonly yield about 8 pounds of meal.

The following table will show the quantity of meal that is usually extracted from certain weights of oats; and though different results may be obtained by various qualities and seasons, yet the progressive ratio of the produce will generally be found nearly similar.

Weight per Bushel. Produce in Meal.

\begin{tabular}{llllr} 
ight per Bushel. & Produce in Meal. & \multicolumn{2}{c}{ Produce of Husl. } \\
$42 \mathrm{lb}$. & $25 \mathrm{Ib} .2 \mathrm{oz}$. & $16 \mathrm{lb}$. & $14 \mathrm{oz}$ \\
40 & 23 & 6 & 16 & 10 \\
38 & 21 & 12 & 16 & 4 \\
36 & 20 & 3 & 15 & 13 \\
34 & 18 & 11 & 15 & 5 \\
33 & 17 & 5 & 14 & 11 \\
30 & 16 & 1 & 13 & 5
\end{tabular}

Oatmeal is a well-known article of food; it is the flour from which, in the northern portion of Great Britain, the bread of the working classes is partly procured. The oat-seed was examined by Sir H. Davy; he found in 1000 parts of Scotch oats 743 of soluble or nutritive matter, composed of 641 mucilage or starch, 15 saccharine matter, and 87 gluten or albumen. In 100 parts of oats from Sussex, 59 parts of starch, 6 of gluten, and 2 of saccharine matter, 33 husk.

The principal demand for oats in Great Britain is for horses. Its use for bread is chiefly confined to the northern districts. Meal is employed also for various domestic purposes, feeding pigs, dogs, \&c.; and it has been used in brewing ale, and in the malt distilleries; but for this purpose its value is much inferior to that of barley.

The seeds were analyzed by Schraeder; he found in 227.8 grains of ashes, obtained from $2 \mathrm{lb}$. of oats-

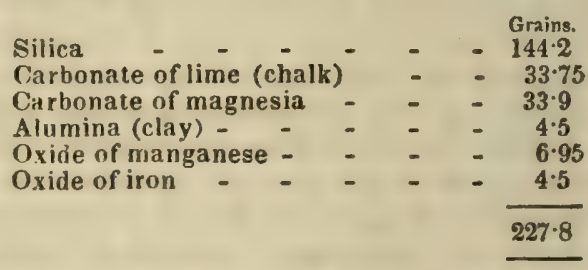

The analysis, of M. Vauquelin rather differs from this; he found in 100 parts of the ashes of the oat-

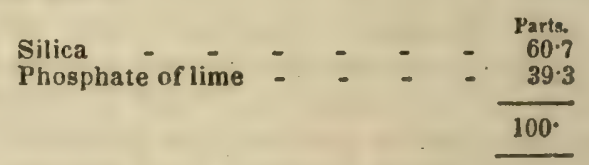

But by burning the whole plant, stalk and seed together, he obtained a residuum composed of-

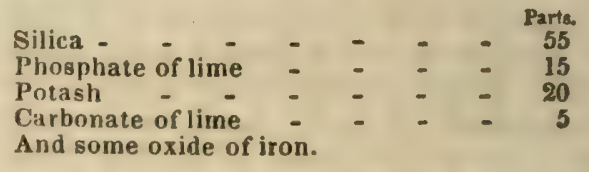

M. Saussure obtained from 100 parts of the ashes of the seeds of the oat-

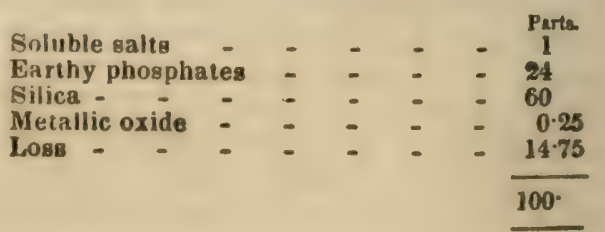


OAT-GRASS.

Average price of oats in England, per Winchester quarter :-

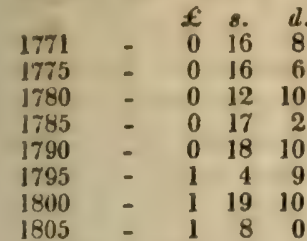

$\begin{array}{lllll} & & £ & 8 & d \\ 1810 & - & 1 & 9 & 4 \\ 1815 & - & 1 & 3 & 6 \\ \text { Per Imperial } & \text { Quarler. } \\ 1820 & - & 1 & 4 & 9 \\ 1825 & - & 1 & 5 & 8 \\ 1830 & - & 1 & 4 & 5 \\ 1835 & - & 1 & 2 & 0 \\ 1840 & -\end{array}$

The account, in imperial quarters, of the iureign oats and oatmeal entered for home consumption every five years since 1815 , was-

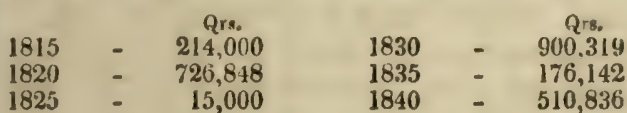

The annual average of oats, in Winchester quarters, imported into England from 1801 to 1825 was, from-

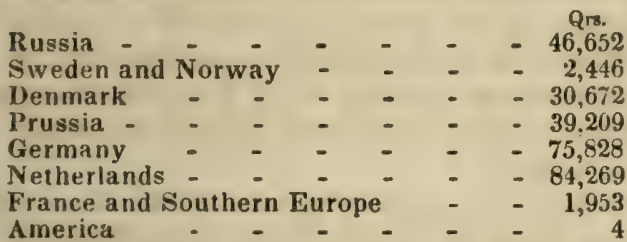

From Ireland were imported into this country, of oats and oatmeal, in Winchester quarters-

\begin{tabular}{|c|c|c|c|c|c|}
\hline & & Qrs. & & & Qrs. \\
\hline $\begin{array}{l}1810 \\
1815\end{array}$ & - & $\begin{array}{l}493,231 \\
597,537\end{array}$ & $\begin{array}{l}1825 \\
1830\end{array}$ & - & $\begin{array}{l}1,629,856 \\
1,471252\end{array}$ \\
\hline 182 & - & 916,250 & 1835 & - & $1,822,766$ \\
\hline
\end{tabular}

Table showing the average Price of Oats per Bushel in the Philadelphia Market, for the 1st, $2 d, 3 d$, and 4 th Quarters of the following Years:

\begin{tabular}{|c|c|c|c|c|}
\hline Year. & 1st Quarter. & 2d Quarter. & 3d Quarter. & 4th Quarter. \\
\hline 1833 & 36 cts. & $\frac{40 \text { cts. }}{30}$ & $\frac{30}{30}$ & 35 cts. \\
1834 & 27 & 31 & 30 & 33 \\
1835 & 36 & 38 & 38 & 40 \\
1836 & 50 & 42 & 38 & 50 \\
1837 & 50 & 49 & 45 & 36 \\
1838 & 33 & 37 & 41 & 41 \\
1839 & 44 & 53 & 32 & 33 \\
1840 & 28 & 27 & 25 & 26 \\
1841 & 26 & 37 & 47 & 46 \\
1842 & 43 & 37 & 23 & 25 \\
\hline
\end{tabular}

Oats raised south of Philadelphia usually bring about 3 cents per bushel less than those raised in Pennsylvania and still further north, which are generally much heavier.

OAT-GRASS. See Avena.

OATMEAL. The meal or flour of the oat is used in Great Britain to make porridge, gruel, bread, and poultices. In the mealing process, the oats, after being previously dried in a kiln, are made to pass through the mill-stone to divest them of their coarser husks or "shealings" before being ground. The kernels are then named "grits" or "groats;" and are next ground over again into a coarse, rough meal, varying in its fineness according to the custom of different districts. This is afterwards either baked upon a heated iron, called a gridle in Scotland, into thin, flat cakes, or made up with water in to loaves, and baked. When gradually stirred into boiling water, and boiled into a thick consistence, it forms the porridge of Scotland. It is eaten either with skimmed milk, butter, molass as, or ale. It is thus very
OKRA.

generally used as the cummon porridge fur breakfast and supper of the greater portion of the peasantry of the northern parts of England, Scotland, and Ireland, and forms a very nutritive and healthy food. It is, however, apt to prove acescent in some stomachs, and to cause cutaneous diseases. See Gronts.

OCHRE. See Fulrem's Earth.

OFFSETS. In gardening, young radical bulbs, when separated or taken off from the parent roots, are so called. One of the chie? methods of propagating plants is by offsets.

OIL-CAKE. The marc which remains after the oil has been expressed from the seeds of flax and rape. See Colza, Lissegd Cake, Palma Christi, Rape.

OILS (Ger. oel; Lat. oleum). This term cum. prehends two substances that have very distinct properties, namely, volatile and fixed oils; but, in general language, the term oll is :ndicative of the latter. Fixed oils are unctuous, fluid bodies, which, when dropped upon paper, sink into it, and make it semi-transparent, or give it what is called a greasy stain. They are composed of carbon, oxygen, and hydrogen. Train oil has been sometimes used as a manure, and is a powerful fertilizer. See FIsн. Linseed oil is a common food for live-stock. See Linseed Oil.

The following results of analysis show the variations in the proportions of elementary sub. stances in olive and train, or fish oil, 100 parts of each :Hydrogen. Oxygen. Carbon.

Olive oil, $13.36+9.9 x+437+77 \cdot 213=100$ parts. Train oil, $16.1+15.03+68.87=100$ parts.

The numerous uses to which unctuous oils obtained from the seeds of various plants are applied, for food, burning, soap-making, \&c. \&c., give great importance to their production and preparation. The proportions yielded by 100 parts of many seeds, are as follows:-

Palma Christi, 62 per cent.; garden cress, 56 to 58 ; poppy, 56 to 63 ; oily-radish, 50 ; sesamum or bene plant, 50 ; cabbage, 30 to 39 ; wild mustard, 30 ; weld, 29 to 36 ; gourd, 25; hemp, 14 to 25 ; flax, 11 to 22 ; black mustard, 15 ; white mustard, 36 to 38 ; rape, colewort, and Swedish turnip, $33 \frac{1}{2}$; colza, 36 to 40 ; rape, 30 to 36 ; euphorbium or spurge, 30 ; sunflower, 15; stramonium, 15; ground-nut with shells, 21; cotton, 16 ; the kernels of walnuts and hickorynuts, 40 to 70 ; hazel-nuts, 62 ; sweet almonds, 40 to 54 ; bitter almonds, 28 to 46 ; beech mast, 15 to 17 ; plum, $33 \cdot 3$; grape stones, 14 to 22 ; horse chestnuts, 12 to 18 .

'The excellent oils expressed so abundantly from the seeds of the poppy and sesamum or bene plant, are largely substituted in commerce for olive oil.

OKRA (Hibiscus esculentis). This plant is cultivated extensively in the West Indies, from whence it has been introduced into the United States. The pods are gathered green, and used in soups. They form an important ingredient in the celebrated Gumbo soup of New Orleans and other southern places. The pods are filled with seeds and a mucilage of a bland and highly nutritious quality. Hence the okra is frequently recommended to persons afficted with dysentery and other bowel complaints either eaten boiled, or made into soup. Wher 3 c 2 857 
buttered and spiced, they afford a rich dish. and with vinegar, they make a good pickle. The plant comes to maturity in the Middle States, and the pods are abundant in the Philadelphia market. Those who become once accustomed to this wholesome vegetable, contract a great fondness for its peculiar flavour.

In Louisiana and other southern states, a dinner is scarcely considered complete without okra cooked in some way or other, and the poor consider it one of their greatest blessings. Mr. Legare, editor of the Southern Agriculturist, has furnished the following recipe for making okra soup, after the celebrated method pursued in Charleston. The pods, he says, are of proper size when 2 or 3 inches long, but may be used as long as they remain tender. If fit for use, they will snap asunder at the ends, but if too old and woody, they must be rejected. One peck of the tender pods are to be cut crosswise into very thin slices, not exceeding one-eighth of an inch in thickness. 'To this quantity add about one-third of a peck of tomatoes, previously peeled and cut into pieces. The proporlion of tomatoes may be varied to suit the taste. A coarse piece of beef (a shin is generally made use of) is placed in a pot or digester with about $2 \frac{1}{2}$ gallons of water, and a very small quantity of salt. This is permitted to boil a few moments, when the scum is taken off and the okra and tomatoes thrown in. With these ingredients in the proportions mentioned, the soup made is remarkably fine. Still, some think it improved by additions of green corn, Lima beans, \&c. The most essential thing to be attended to is the boiling, and the excellence of the soup depends almost entirely on this being done faithfully. For if it be not boiled enough, however well the ingredients may have been selected and proportioned, the soup will be very inferior, and give but little idea of the delightful flavour it possesses when well lone. A properly constructed digester is decidedly the best vessel for boiling this or any other soup in; but where such a utensil is not at hand, an earthenware pot should be pre ferred; but on no account make use of an iron one, as it would turn the whole soup perfectly black, instead of the proper colour, namely, green, coloured with the rich yeilow of tomatoes. The time usually required for boiling okra soup is about 5 hours, during which it should be occasionally stirred, and the ingredients mashed. When taken off, the original quantity will be reduced to about one-half, and the meat "done to rags;" the whole forming a homogeneous mass, of the consistence of thick porridge.

OLEANDER (Nerium, from neros, humid; ailuding to the habitat of the plants). This is a genus of noble evergreen shrubs, of easy culture, and flowering freely the greater part of the year. $N$. oleander and its varieties bear forcing remarkably well; and, although treated as green-house plants, yet they will not flower well unless they are kept in the stove. They grow well in any rich, light soils, and young cuttings root in any soil, if kept moist. The leaves of $N$. oleander contain tannic acid, and the leaves and bark of the $\operatorname{root}$ of $N$. odorum are app.ied externally as powerful repel- lants by the Indian practitioners. N. tinctorium yields indigo. (Paxton's Bot. Dict.)

OLIVE (Olea). This is a very important genus of plants, on account of the oil, \&c., which is obtained chiefly from the 0 . Europaca.

It is an evergreen, small tree, with lanceolate leaves, of a deep-green on the upper, and nearly white or hoary on the under surface. The flowers are small and white. The fruit is an elliptical drupe, of a bluish-purple colour when ripe. The tree lives to an extreme old age, and continues to bear good olives. It is also much admired for the fragrance of its flowers, which render it worthy a place in every green-house collection. They grow well in loam and peat; ripened cuttings root readily in sand, under a glass. They may also be increased by grafting on the common prive The unripe fruit of the olive, preserved in salt and water, is a well-known article for the dessert

With regard to the capacity of a portion of the Southern United States to produce the olive, the following extract from a communication of John Couper, Esq., will give interesting information:-

"I had a very pretty grove of 200 olives, im ported about 10 years since, their stems from 8 to 12 inches diameter, and perhaps averaging 20 to 25 feet high to the top; they have borne fruit for some years. I had also near 600 trees, or plants, from 11 to 5 years old. From comparisons between the olive and orange, in previous severe frosts, where the orange was much hurt, the olive was uninjured. I have, there. fore, no hesitation in believing the olive is well adapted to, and will succeed on our sea-coast, of both Carolina and Greorgia.

"I have been personally acquainted with sour-orange trees, both on St. Simon's and Je$\mathrm{kyl}$, for 58 years, and believe they were planted near 100 years since; and have never been killed by frost until last February, when they were all destroyed. I therefore conclude, that since the first settlement of Georgia the olive would have succeeded. It occurs to me that, notwithstanding the immense value of the olive in France, they have been cut down in some severe frosts.

"The olive and orange seemed so completely destroyed, even to some depth under ground. that I cut them down, and planted corn in their place; on examination about a month since, the lower roots still appearing fresh, I concluded that opening the ground around them might encourage vegetation; and have now the satisfaction to see the olives pushing out abundance of fine, strong shoots, not one failing. The oranges are doing the same, though some appear dead, not yet decided; by returning the earth to the olive shoots, they will throw out roots, and furnish fine plants. In fact, I am better satisfied respecting the success of the olive than I was before the severe frost." (Farmer's Register, vol. iii. p. 246.)

OLIVE, THE AMERICAN (Olea Americana). This American tree belongs exclusively to the Southern States, the Floridas, and Louisiana. Like the live-oak and cabbage-tree, it is confined to the sea-shore. "It is so little multiplied," says Michaux, "that it has hitherto re. ceived no name from the inhabitants of the 


\section{ONIONS,}

sountry, except on the banks of the river $\mathrm{S}_{3}$ vannah, where it is called Devil wood.

"This tree grows in soils and exposures extremely different: on the sea-shore it springs with the live-oak in the most barren and sultry spots; and in other places it is seen with the big laurel, the umbrella tree, the sweet leaves, \&c., in cool, fertile, and shaded situations.

"This tree, or, to speak more accurately, this large shrub, is sometimes 30 or 35 feet high, and 10 or 12 inches in diameter: but this size is extraordinary; it commonly fructifies at the height of 8, 10, or 12 feet. The leaves are 4 or 5 inches long, opposite and lanceolate, entire at the edge, smooth and brilliant on the upper surface, and of an agreeable light-green. 'They are evergreen, or at least are partially renewed only once in 4 or 5 years. The fertile and barren flowers are on separate trees: they are very small, strongly scented, of a pale yellow, and axillary, or situated between the petiole of the leaves and the branches. The season of flowering, in the neighbourhood of Charleston, is about the end of April. The fruit is round, and about twice as large as a common pea. When ripe, it is of a purple colour, approaching to blue, and consists of a hard stone thinly coated with pulp. As it remains attached to the branches during a part of the winter, its colour forms, at this season, an agreeable contrast with the foliage.

"The bark which covers the trunk of the devil wood is smooth and grayish. The wood has a fine and compact grain, and, when perfectly dry, it is excessively hard and very difficult to cut or split; hence is derived the name of devil wood. It is, notwithstanding, neglected in use. On laying bare the cellular integuinent of the bark, its natural yellow hue changes instantaneously to a deep red, and the wood, by contact with the air, assumes a rosy complexion. Experiments should be made to detect the nature of this active principle in the bark, which causes it to change colour so suddenly by exposure to the air.

"From the temperature of the native skies of this tree, we may conclude that it is capable of resisting a greater degree of cold than the common olive: it becomes, then, on account of its beautiful foliage, its odoriferous flowers, and its showy fruit, a valuable acquisition." (Michaux.)

ONIONS (Allium cepa). Of this genus, there are eight individuals that demand the gardener's care.

They all require a rich, friable soil, on a dry substratum; a situation enjoying the full influence of the sun, and entirely free from trees, which are very inimical to them, especially to those which have to stand the winter. If the soil be poor, or exhausted, abundance of dung should be applied in the preceding autumn or winter, and the ground thrown into ridges. By these means it becomes well decomposed and incorporated with the soil ; for rank, unreduced dung is generally injurious, engendering decay, and indricing maggots; if, therefore, the application of manure is neglected until the spring, it should be taken from an old hotbed, or other source whence it is to be had in a thoroughly putrescent state, and turned in only

\section{ONIONS.}

to a moderate depth. Sea-sand, particulariy if the ground is at all tenacious, is advanta geously employed; coal-ashes, and especially soot, are applied with particular benefit. In digging over the ground, small spits only should be turned over at a time, that the texture may be well broken and pulverized. A considerable degree of attention is required from the difficulty of giving the requisite degree of firmness to light soils, which, if rich, are well suited to the growth of these vegetables. Old, solt, or light, sandy soils, Mr. A. Gorrie, of Rait, re. commends to be dug rough in October, and about January to have a top-dressing of cowdung applied and left on, to have its fertilizing matters washed in until the time of sowing then as much as can be is to be raked off, and, without digging, the seed sown, trod in, and covered with earth from the alleys. By this management, soils will produce good crops which before were annually destroyed by the maggot. Onions for pickling, as well as those to stand the winter, should be grown on light, poor soils, which cause the first to be small in the bulb, and the latter, not growing so luxuriantly, to withstand the winter better.

There are 14 distinct varieties of this vegetable, as appears from the description given by Mr. C. Strachan, gardener to the Horticultural Society of London.

1. Silver-skinned onion. 2. Early silverskinned. 3. True Portugal. 4. Spanish. 5. Strasburg. 6. Deptford. 7. Globe. 8. James's keeping onion. 9. Pale-red. 10. Yellow. 11. Blood-red. 12. Tripoli. 13. Two-bladed. 14. Lisbon.

In England the onion is raised from seed, which may be sown for the first main crop towards the close of February, if dry, open weather, otherwise only a small portion, in a warm, dry situation. The principal crop, however, must be sown during March, it being kept in mind that the close of February is to be preferred, for the earlier the seed is inserted, the finer will be the bulbs: main crops may even be inserted as late as the beginning of April, and, at its close, a small sowing to draw young in summer, and for small bulbs to pickle; again in July and early in August for salads in autumn; and, finally, in the last week of August, or early in September, to stand the winter for spring and beginning of summer. The seed is sown thinly, broadcast, and regularly raked in. An ounce of seed is abundantly sufficient for a rood of ground, especially for the main crops, as they should never be allowed to grow to a size fit for salads without thinning. No other seed ought to be sown with it; for the practice of stealing a crop is detrimental to both crops, without the slightest advantage to compensate. The beds should be divided by narrow a'leys into portions about four feet wide, for the convenience of cultivation. In about six weeks after sowing, the plants will be of sufficient size to allow the first thinning and small hoeing, by which they are to be set out about 2 inches apart; if this is performed in dry weather, it will keep the beds free of weeds for six weeks longer, when they must be hoed a second time, and thinned to 4 inches apart; and now, where they have 
falled, the vacancies may be filled up by transplanting sorxe of those thinned out into the places; the best time for doing this is in the evening, and water must be given for several successive nights. In transplanting, the root only is to be inserted, and no part of the stem buried; for there is very good reason to believe that naturally the bulb grows entirely upon the surface, and that growing within the mould is a great cause of their not keeping well. After the lapse of another month they must be thoroughly gone over for the last time, the weeds eradicated, and the plants thinned to 6 inches asunder; after this they in general only require to be weeded occasionally by hand; they must, however, be kept completely free from weeds, and the stirring of the surface which the hoe effects is very beneficial. In order to prevent their running too much to blade, it is a good practice early in July, before the tips change to a yellow hue, to bend the stems down flat upon the bed, which not only prevents the rapid growth of the blade, but causes the bulbs to become much larger than they otherwise would be. The bend should be made about 2 inches up the neck.

About the close of August the onions will have arrived at their full growth, which may be known by the withering of the foliage, by the shrinking of the necks, and by the ease with which they may be pulled up. As soon as these changes appear, they must be taken up, the bed being frequently looked over; for, if the whole crop is waited for, the forwardest, especially in moist seasons, are apt again to strike root. They should be spread on mats, $\& c$. , in the sun, frequently turned, and removed under shelter at night. In 2 or 3 weeks, when the roots and blades are perfectly withered and void of moisture, and the bulbs become firm, they are fit for storing, being housed in dry weather, and carefully preserved from bruising: previous to doing this, all mould and refuse must be removed from them, for these are apt to induce decay, and spread contagion to all near them. To prevent this as much as possible, all faulty ones should be rejected: in the store-house they must be laid as thin as may be, and looked over at least once a month. Notwithstanding every precaution, many will decay, and more sprout, especially in mild winters; therefore, to preserve some for late use, it is useful to sear the roots and the summits with a hot iron, care being taken not to scorch the bulb.

For the winter standing crop the only additional directions necessary are, to tread in the seed regularly before raking, if the soil, as it ought to be, is dry and light. They must be 'rept constantly clear of weeds, as well as of the fallen leaves of trees, which cause them to spindle and become weak, but they need not be !hinned, as they serve as protections for each other. Early in spring they are to be weeded, and, as may be necessary, transplanted for bulbing. 'There are several modes of cultivation lately introduced or revived, which proluce onions of superior size and goodness. The great obstacle to the production of fine unions in England is the want of a sufficient continuance of warm weather; or, at least, the

860 inclemency of the early part of the year prevents the insertion of the seed until so late, that the most genial season to vegetation passes away whilst the plants are in their infancy; it is the obviating this unfavourable circumstance that causes the superiority of the several plans hereafter detailed.

It is a practice that originated in America, and which has met with the decided approval of Mr. Knight and others, to sow in May; to cultivate the plants as in the other crops; and, in October, the bulbs, being of the size of nuts, are to be taken up, dried, and housed, as directed for the full-grown bulbs. About the middle of the following March they must be planted out in rows 6 inches apart each way, and afterwards cultivated in the same manner as the other crops. If sown earlier than May, they run to seed when transplanted. Another mode nearly as efficacious, and which, I understand, has been practised for a great length of time in the south of Essex, is to sow in the latter part of August, to stand the winter, and in March, early or late, according to the forward growth of the seedlings, to be planted out in rows at the before-directed distance, and cultivated as usual.

In Portugal they sow in a moderate hotbed during November or December, in a warm situation, with a few inches of mould upon it; and the plants are protected from frost by hoops and mats; in April or May, when of the size of a swan's quill, they are transplanted into a light, rich loam, well manured with old rotten dung, to bulb.

It would seem, from the practice of Mr. Macdonald, gardener to the Duke of Buccleugh, at Dalkeith, that transplanting alone is of great benefit. "His soil," he says, "is not very favourable to the growth of the onion, being light and thin; and it was not until after many experiments he was able to obtain fine bulbs, and which he at length accomplished by sowing in the end of February, and about April transplanting them at the usual distance in drills, first dipping the root into a puddle, consisting of 1 part soot and 3 parts earth, mixed with water; the work being performed in moist weather." The puddle, as is observed by Mr. Sinclair, can be of no other use than to assist the rooting of the plants.

To obtain seed, some old onions must be planted during February, or early in March. The finest and firmest bulbs being selected, and planted in rows 10 inches apart each way, either in drills or by a blunt-ended dibble, the soil to be rather poorer, if it differs at all from that in which they are cultivated for bulbing. They must be buried so deep that the mould just covers the crown. Early in spring their leaves will appear. If grown in large quantities, a path must be left 2 feet wide between every 3 or 4 rows, to allow the necessary cultivation. They must be kept thoroughly clear of weeds, and when in flower have stakes driven at intervals of 5 or 6 feet each side of every 2 rows, to which a string is to be fastened throughout the whole length, a few inches below the heads, to serve as a support, and prevent their being broken down. The seeds are ripe in August, which is intimated by the 
nusks becoming brownish: the heads must then be immediately cut, otherwise the receptacles will open and shed their contents. Being spread on cloths in the sun, during the day, and taken under cover every night and during inclement weather, they soon become perfectly dry, when the seed may be rubbed out, cleaned of the chaff, and, after remaining another day or two, finally stored. It is of the utmost consequence to employ seed of not more than one year old, otherwise not more than 1 in 50 seeds will vegetate.

The goodness of seed may be easily discovered by forcing a little of it in a hotbed or in warm water, a day or two before it is employed: a small white point will soon protrude if it is fertile.

Onions are raised in large quantities, in the town of Weathersfield, Connecticut, for exportation to the West Indies and Southern States. The business is there reduced to a perfect system. Early in spring the land is manured, by ploughing in fine manure from the stable or barn-yard, in the proportion of about 10 loads to the acre. That of neat cattle is preferred, as that of horses is considered to be of too heating a nature. It is then well harrowed and laid out into beds of 5 feet wide, by turning a furrow towards them each way; this raises the beds above the alleys, and allows the surplus water to run off. They are then well raked with an iron-toothed or common hay rake, and the alleys suffered to remain as left by the plough.

As early as the season will admit, the seed is sown in the following manner. A rake, with teeth a foot apart, is drawn crosswise of the beds, and drills made for the reception of the seed; it is then sown with the thumb and fingers and covered witl the hand, allowing 10 or 12 Ibs. to the acre. After the plants are up, they are kept clean of weeds, which generally requires four weedings, using a hoe of suitable width to pass between the rows, which saves much labour. When ripe, they are pulled, and the tops cut off to a suitable length for tying them to the straw in roping. Three and a half pounds are required by a law of the state to be put in each rope; and the ordinary crop is from 6 to 8000 ropes to the acre.

Onions inay be raised in the same way in the Middle and Southern States, though the more common practice is to grow them from small bulbs raised from seed the previous year, by sowing thickly in rows, about 9 or 10 inches apart, about the middle of spring; if sown too early, they are apt to run to seed when transplanted. Cultivate and preserve as for full-grown bulbs. Plant early in spring, in well manured ground, in rows about 6 inches apart, and 5 inches in the row, allowing about 18 inches after every fifth row as an alley for convenience in weeding.

If the land is at all light, it is a good practice to tread or roll well before sowing or transplanting, and be careful to disturb the bulbs as little as possible in weeding.

Potato, or under-ground Onion.-This species of allium has received the above appellations, on account of its producing a cluster of bulbs or offsets, in number from 2 to 12 , and even more, uniformly beneath the surface of the soil.
From being first introluced to public notice in Scotland, by Captain Burns of Edinburgh, it is there also known as the Burn union. 'There evidently appear to be two varieties of this vegetable, one of which bears bulbs on the summit of its stems, like the tree onion, and the other never throwing up flower-stems at all. One variety is much larger than the other, and this vegetates again as soon as ripe.

Both varieties are best propagated by offsets of the root, of moderate size; for if those are employed which the one variety produces on the summit of its stems, they seldorn do more than increase in size the first year, but are prolific the next; this also occurs if very small offsets of the root are employed.

They may be planted during October or November, or as early in the spring as the season will allow, but not later than April. In the west of England, assisted by their genial climate, they plant on the shortest and take up on the longest day. They are either to be inserted in drills, or by a blunt dibble 8 inches apart each way, not buried entirely, but the top of the offset just level with the surface. Mr. Maher, gardener at Arundel Castle, merely places the sets on the surface, covering them with leaf mould, rotten dung, or other light compost. The beds they are grown in are better not more than 4 feet wide, for the convenience of cultivation.

The only cultivation required is to keep them clear of weeds. The practice of earthing the mould over them when the stems have grown up is unnatural, and by so doing the bulbs are blanched and prevented ripening perfectly, on which their keeping depends. So far from following this plan, Mr. Wedgewood of Betley recommends the earth always to be cleared away down to the ring whence the fibres spring, as soon as the leaves have attained their full size and begin to be brown at the top, so that a kind of basin is formed round the bulb. As soon as they vegetate, they intimate the number of offsets that will be produced, by showing a shoot for each.

They attain their full growth towards the end of July, and become completely ripe early in Sepiember: for immediate use they may be taken up as they ripen, but for keeping, a little before they attain perfect maturity, which is demonstrated by the same symptoms as were mentioned in speaking of onion.

ONION, THE WELSH, or CIBOULE. This is a perennial, which never forms a bulb, but is sown annually, to be drawn young for salads, \&c.: on account of its strong taste, it is greatly inferior to the common onion for this purpose; but from its extreme hardiness in withstanding the severest frost, it may be cultivated with advantage as a winter standing crop for spring use. In France two varieties are in cultivation, the white and the red; the first of which is the one in .... ral use in England. As it may be sown at a:: times, in common with the onion, and is similarly cultivated, except that it may be sown thicker, and only thinned as wanted, the directions given for that vegetable will suffice. The blade usually dies away completely in winter, but fresh ones ar thrown out again in February or March. 
To obtain seed, some of the roots must be planted out in March, 6 or 8 inches asunder. Jhe first autumn they will produce but little seed; in the second and third, however, it will be produced abundantly. If care is taken to part and transplant the roots every two or three years, they may be multiplied, and will remain productive for many years, and afford much better seed than that from one-year old roots. There is good reason for concluding, as Mr. T. Milne, of Fulham, ingeniously explains, that by a confusion of names, arising from similarity of appearance, this vegetable is the true scallion of Miller and others, whilst the hollow leek of Wales is the true Welsh onion; for the description of scallion, as given by Miller, accords exactly with that of the Welsh onion; and as he describes it as a distinct variety, we are reduced to the dilemma of receiving this explanation, or considering the variety as lost; for from Miller's known accuracy it is impossible to consider that he was deceived. At present all onions that have refused to bulb, and formed lengthened necks and strong blades in spring and summer, are called scallions.

ONION, THE TREE, or CANADA ( $A l$ lium Canadense). This, which is a very hardy perennial species, like the ciboule, is without a bulbous root, but throws out numerous offsets. Its top bulbs are greatly prized for pickling, being considered of superior flavour to the common onion for that purpose, as well as others in which that species is employed.

It is propagated both by the root offsets, which may be planted during March and April, or in September and October, and from the top bulbs, which are best planted in spring, and not before the latter end of April. The old roots are best to plant again for a crop of bulbs, as they are most certain to run to stems. If the bulbs be planted earlier than as above directed, they are apt to push up the same season, and exhaust themselves without producing either good offsets or bulbs; but on the other hand, by planting the old roots in the previous autumn, or early in the spring, they will produce good bulbs the same year. They must be inserted in rows 12 inches asunder, in holes 6 inches apart and 2 deep, a single offset or bulb being put in each. Those planted in autumn will shoot forth leaves early in the spring, and have their bulbs fit for gathering in June, or the beginning of July; those inserted in the spring will make their appearance later, and will be in production at the close of July or early in August: they must not, however, be gathered for keeping or planting until the stalks decay; at which time, or in the spring also, if only of one year's growth, the roots may be taken up and parted if required for planting; but when of two or three years' continuance, they inust at all events be reduced in size, otherwise they grow in too large and sprindling bunches; but the best plan is to make a fresh piacitation annually with single offsets. The unly cultivation necessary is to keep them ulear of weeds; and when the stems run up, I1, give them the support of stakes.

The bulbs, when gathered, must be gradually und carefully dried in a shady place; and if kept perfectly free from moisture, will continue 862 in good state until the following M.g. (G.W Johnson.)

OPEN. A term frequently applied to ecws or heifers, signifying that they are not in calf.

OPEN CUTS. Such drains or gutters as are made in land by the spade, and left without being covered in. They are used in draining lands in particular cases. Open cuts, if effectual, are the best of all for forest draining, as they cannot be inconvenient, from the plough not being employed after the trees are planted. Cuts of this sort are frequently found useful in the practice of irrigation or watering of land.

oPHTHALMIA. See Sheep, Diseases of.

ORACHE (Atriplex; from atir, black). A genus of herbaceous or shrubby straggling plants of little beauty, and the simplest culture and propagation. There are in England several native species.

The $A$. hortensis is cooked and eaten in the same manner as spinach, to which it is much preferred by many persons, although it belongs to a tribe whose wholesomeness is very suspicious. It flourishes best in a rich, moist soil, and in an open compartment. Those, however, of the autumn sowing, require a rather drier soil. It is propagated by seed, which may be sown about the end of September, soon after it is ripe, and again in the spring, for succesşion; the sowing to be performed broadcast, the seeds being scattered thin. The plants soon make their appearance, being of quick growth. When they are about an inch high, they must be thinned to 4 inches asunder; and those removed may be planted out at the same distance in a similar situation, and watered occasionally until established. At the time of thinning, the best must be thoroughly cleared of weeds, and if they are again hoed during a dry day, when the plants are about 4 inches high, they will require no further attendance than an occasional weeding by hand. For early production, a sowing may be performed in a moderate hotbed at the same times as those in the natural ground.

The leaves must be gathered for use whilst young, otherwise they become stringy and worthless. To obtain seed, some plants of the spring sowing must be left ungathered from, and thinned to about 8 inches apart. The seeds ripen about the end of August, when the plants may be pulled up, and when perfectly dry, rubbed out for use.

ORANGE, OSAGE (Maclura aurantiaca). 'This is an American deciduous tree, which grows wild in Arkansas and Louisiana, where it attains the height of a tree of the second or third class, but in the Middle States it seldom grows higher than 15 or 20 feet. It is very branching; each branch being armed with numerous sharp thorns. The wood is remarkably tough, and said to be very durable. The male and female flowers are on separate trees. The fertile or female tree bears fruit abundantly in a very few years. These are round, rough, and greenish-coloured, resembling somewhat an orange, and weighing from 12 to 18 ounces, containing from 100 to 250 seeds.

Recently this thorny tree has received very considerable attention, with a view to making it useful in the construction of live fences, 
which purpose it is extensively cultivated in / cherry; and wherever wheat can be ripened in nurseries. "Its great merit," says Mr. T. S. the plains, these fruits will arrive at perfection Pleasants, of Virginia, "consists in the spreading manner of its growth, the denseness of its branches, and the armature with which they are furnished. Planted in hedge-rows, the maclura would never become unmanageable on account of its size; at the same time its growth is sufficiently vigorous to make a fence in 3 , 4 , or at most 5 years, from the seed. It may be asserted with safety, that on land of tolerable fertility, the labour and expense of perfecting a system of hedges would not be greater than to keep ordinary enclosures in good condition for the time required to construct them.

"The Osage orange trees are readily raised from the seed, which, unlike those of the common thorn, require no preparation. On the contrary, they vegetate with certainty in 2 or 3 weelss after planting. With tolerable care the seedlings will grow 2 or 3 feet in beight the first season; after which they are to be re. moved from the nursery rows to the place designed for the hedge. Fifty of the large orange-shaped berries yield at least a pound of seed, or from 8 to 10,000 grains. It is the usual practice to place the sets from 12 to 15 inches apart, in a single row." (Farmers' Register, vol. 5, p. 86.)

'Though originally from a southern locality, the Osage orange is so hardy as to stand the winters not only of the Middle, but of the East-ern States.

ORANGE TREE (Citrus). The genus to which the orange tree belongs consists of ornamental species of fruit trees, growing from 3 to 15 feet high. The leaves are on more or less dilated and winged footstalks; the flowers are large, white, and odoriferous, existing at the same time as the fruit, which is too well known to require description. Orange trees thrive best in a good loamy soil, mixed with a quantity of rotten dung. The different kinds are procured by budding or grafting on common stocks. Stocks for working upon are raised from any oranges, lemons, \&c. They are sometimes raised from cuttings, in which case they produce fruit when very small plants. The flowers of the orange tree yield, by distillation, a fragrant volatile oil, known by the name of oil of Neroli. The fruit of the bignaroll or bitter orange makes one of the best preserves which can be eaten, namely, Scotch marmalade. The unripe fruit is used for flavouring the liquor called curacoa. The ripe fruit is wholesome, and a useful refrigerant in fevers.

ORANGE, WILD See Cherry, WiLd

ORCHARD (Gr.). In horticulture, an enclosure devoted to the culture of fruit trees. In England the surface of the soil in orchards is generally kept under pasture; which, while it prevents the earth from being washed away by rains, is favourable to the running of the roots immediately under the surface, by which they are sooner called into action by heat in spring, and sooner thrown into a torpid state by cold in autumn. The principal fruits grown in orchards of this description in Great Britajn are the apple, the pear, the flum, and the on declivities exposed to the south and southeast.

ORCHARD-GRASS (Dactylis glomeruta) Called in England cock's-font. It is an imper fect perennial, native to the United States. Bee Cock's-Foot, and Grasses.

ORCHIDACEA (Orchis, one of the genera). A natural order of herbacenus endogens, inhabiting all parts of the world, excepting thuse climates situated upon the verge of the frozen zone, or remarkable for their exceeding dryness. They are well known for the singular form of their flowers. Some of them grow in the earth, others inhabit rocks and the branches of trees, and a few appear to be true parasites. They all belong to the class Gy. nandria of Linnæus, are often very agreeably scented, and sometimes produce an aromatic fleshy fruit, as in the case of the vanilla, which contains a large quantity of benzoic acid. The nutritious substance called salep is prepared from the amylaceous tubers of the male orchis, merely drying them in ovens. They become semi-pellucid, and when pulverized, form a mucilage with boiling water. They are usually grown in the frame or hothouse, and thrive best in a mixture of loam, peat, and chalk, broken small. They can only be increased from seeds. It would be quite impossible to describe the characters of each species.

The species indigenous to England are1. Butterfly orchis (O. bifolia). 2. Pyramidal orchis (O.pyramidalis). 3. Green-winged meadow orchis (O.moris). 4. Early purple orchis (O. mascula). 5. Dwarf dark-winged orchis (O. ustulata). 6. Great brown-winged orchis (O. fusca). 7. Military orchis (O. militaris). 8. Monkey orchis (O. tephrosantos). 9. Lizard orchis (O. hircina). 10. White cluster-rooted orchis (O. albida). 11. Frog orchis (O.viridis). 12. Marsh palmate orchis (O. latifolia). 13. Spotted palmate orchis (O. maculata). 14. Aromatic palmate orchis (O. conopsia). Mos: of the native species of orchis inhabit meadows and pastures, and hilly, chalky downs. The roots are doubly tuberous, fleshy; leaves chiefly radical; flowers numerous, spiked, purple, crimson, or whitish-in some highly fragrant. (Smith's Eng. Flor. vol. iv. pp. 8-24).

OREGON ALDER (Alnus Oregona). A species of the alder genus, which, like the European alder, attains the height of 30 or 40 feer. (Nuttall's Supplement to Michaux.)

ORGANIC CHEMISTRY, is that portion of the science of chemistry which relates to animal and vegetable substances. "The object of organic chemistry," says M. Liebig, "is to discover the chemical conditions which are essential to the life and perfect developement of animals and vegetables, and generally to in. vestigate all those processes of organic nature which are due to the operation of chemica. laws." In this article I shall confine myself principally to the results obtained by the analy? sis of vegetable and animal substances. Under the heads Aтrosphers, Earths, Gases, TemPERA.URE, WATER, \&c., will be found an ar count of their respective uses to vegetation 


\section{ORGANIC CHEMISTRY.}

There is no branch of chemistry more diffcult, and yet more interesting, than that of organic chemistry; for in this the chemist finds, added to his ordinary difficulties, and to his many sources of uncertainty, the presence, and very often the controlling influence, of a living principle, which in some instances seems to neutralize and overcome even the most powerful chemical affinities. "I would warn, therefore, the reader," to use the words of Dr. Thomson, "not to expect complete information in this branch of science: the wonders of the vegetable creation are still but very imperfectly explored; many of the organs of plants are too minute for our senses, and scarcely a single process can be completely traced. The multiplicity of operations continually going on in vegetables at the same time, and the variety of different and even opposite substances formed out of the same ingredients, and almost at the same time, astonish and confound us; the order, too, and the skill with which every thing is conducted, are no less surprising; no two operations clash; there is no discord, no irregularity, no disturhance; every object is gained, and every thing is ready for its intended purpose. This is too wonderful to escape our observation, and of too much importance not to claim our attention. Many philosophers, accordingly, distinguished equally by their industry and sagacity, have dedicated a great part of their lives to the study of vegetation. But hitherto their success has not been equal to their exertions. No person has been able to detect the formative agent in plants, nor even the principle which is always so busy in performing such wonders, nor to discover him at his work; nor have philosophers been much more fortunate in their attempts to ascertain the instruments which he employs in his operations." A great variety of curious and interesting facts, however, have been discovered. These I shall attempt to collect and arrange, to point out their dependence on each other, and to deduce such consequences as obviously result from the discoveries which have been bitherto made.

The farmer will, upon reflection, be able to call to mind many circunstances, showing the influence of the living principle upon the chemical substances of organic matter. He will remember, for instance, that the living substance flourishes in the very same position, and under the very same circumstances, where, when dead, it rapidly putrefies. Every plant growing on the soil, or on a dunghill, testifies to the fact. The living plants which flourish in the same solution of a salt in which they are dissolved, when dead, prove the same thing in another way; and these proofs may be multiplied viry easily on very slight reflection. And as regdrds animal life, the very same results are obtained; the very gastric juice which the living stomach holds for an age, dissolves that stomach wnen dead. Animals can sustain a temperature considerably greater than that where the putrefaction of animal substances rapidly proceeds; and men even can exist for a comsiderable period in an atmosphere heated considerably above the boiling point of water.

In this sketch of organic chemistry, I shall 864 principally confine myself to the vegetable branch of it, and briefly follow the progress of a plant through its several stages of germina. tion, its growth, and its decay, leaving the reader to refer to other heads of this work for the information he may need.

Germination. That all plants arise from seeds is now, I believe, undisputed by every person, notwithstanding the very many puz. zling phenomena which occasionally occur; such as the profusion of some of the grasses, occasioned by the application of certain manures. Thus, "by dressing certain soils with bones and wood ashes, the white clover, which contains this salt, appears in great quantities. Now, phosphate of lime abounds in bones and in the ashes of wood; other plants, it is probable, require the same food. Thus, after the great fire of London, says Mr. Playfair, large quantities of the Erysimum latifolium were observed growing on the spots where a fire had taken place. On a similar occasion, the Blitum capilatum was seen at Copenhagen, the Senecio viscosus in Nassau, and the Spartium scoparium in Languedoc. After the burnings of forest pine in North America, poplars, according to Franklin, grew on the same soil. (Liebig's Org. Chem. p. 152.)

Seeds, therefore, the farmer may rest assured, are essential to the production of plants. Now, the first movement of the seeds towards the production of plants is denominated their germination. To this certain requisites are essentially necessary; such as moisture, moderate heat, and oxygen gas. That all seeds require a certain degree of moisture before they will vegetate, is known to every one: where there is no moisture, there can be no germination. This, however, varies according to the nature of the plant. Some of the mosses, for instance, will germinate on walls and other places where the supply is very limited; others, such as the water plants, will only grow immersed in water. The rice of Hindostan is grown in swamps abounding with water, which would be destructive to all the grain crops of the English farmer. The water-meadow grasses of our own country illustrate the same position. The plant, too, has the power of decomposing water, and assimilating its hydrogen in the formation of its own substances. Water is composed of hydrogen and oxygen, and these substances are always essential ingredients in vegetables.

Heat is also necessary to germination: thus few plants will vegetate below the freezing point of water; nevertheless, this low temperature does not destroy their vitality, for every farmer is aware that frozen seeds will vegetate after they have been thawed. As, however, there is a peculiar degree of moisture on which every plant vegetates with the greatest advantage, so there is a temperature peculiarly favourable to the growth of every plant. The ivy, the elder, and the honey-suckle, for instance, invariably produce their leaves long before any other English plant has felt the warm reviving influence of spring.

And, again, if the seed is not supplied with oxygen gas, the most favourable supplies of moisture and heat will not induce it to germi 
nate. Ray tried this in the vacuum of an airpump with some lettuce seed; they did not germinate in vacuo, but they grew very well when the atmospheric air (which contains 21 per cent. of this gas) was admitted. It is for this reason. that the farmer is careful not to bury his seed-corn so deep in the ground as to be out of the influence of the oxygen of the atmosphere. Beyond a certain depth, which varies with different plants, no seeds, in fact, will vegetate. Seeds have been buried deep in the earth for centuries, and when, afterwards, they have been accidentally thrown upon the surface, have vegetated. There is reason for believing that it is not the entire atmospheric air, but only its oxygen, which is essential to germination. In the experiments of M. Saussure, the quantity of oxygen consumed by various plants during their germination varied very considerably in amount. Wheat and barley, weight for weight, consumed less oxygen than peas; and peas less than beans and kidney-beans. The oxygen consumed by wheat and barley amounts to beiween $\frac{1}{10}$ th and $\frac{1}{20}$ th of their weight, while that consumed by beans and kidney-beans may amount to $T^{\frac{1}{n}}$ th part of their weight. The nxygen absorbed by the seed is in all probability combined with the carbon of the plant, and emitted during its germination, in the state of carbonic acid gas. This gas is composed entirely of carbon and oxygen, in the proportion of 6.12 parts of the former and 16 of the latter; and the quantity of it emitted is exactly equal in amount to the quantity of oxygen absorbed by the seed that should unite with the carbon of the plant, to form the carbonic acid gas, and a certain quantity of carbon is always lost by the seed during vegetation.

When once a plant has vegetated, its growth proceeds with more or less rapidity; none that I am aware of remain stationary; indeed, it cannot remain stationary, and live. They increase in size, require a supply of various substances as food, and the examination of the nature of this nutriment constitutes one of the most valuable branches of organic chemistry; for under this head are included the assistance afforded to plants by the gases, the earths, and by water. In the examination of the food of plants will also be illustrated the important questions of rotation, of fertilizers, and of various other important questions, which in this work will be found treated of under their respective heads; and it will be useless to repeat what I have there at some length endeavoured to illustrate. That the atmosphere yields its carbon and its oxygen; the soil its silica, alumina, and magnesia, with various saline matters; and that water yields both hydrogen and oxygen for the service of the plant, is pretty well established by many valuable experiments which I have there given: and it is impossible to observe the results of the analysis of a perfect plant without being struck with the number of its ingredients, and perceiving at once the probable sources from whence it drew its supply. Take, for instance, the analysis by M. Cadet of the solid matters or ashes of the common garlic. From 172 parts of these he obtained of

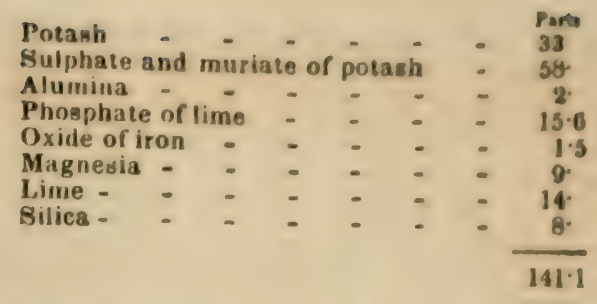

All these substances, there is litcle doubr, were absorbed by the plant from soil in which it grew; but in the fresh or unburnt garlic these are combined with about eight times their weight of mucilage, albumen, sulphur, vegetable fibre, and water. Now the three first of these must have been formed during the growth of the plant, from either the atmosphere or from water : the first (the atmosphere) being composed of oxygen, nitrogen, and car bonic acid; and the latter (water) of hydrogen and oxygen. Mucilage was found by M. Ber zelius to be composed of

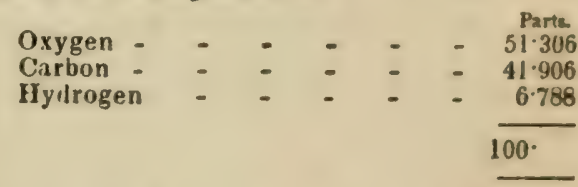

Albumen contains, according to the analysis of MM. Gay Lussac and Thenard,

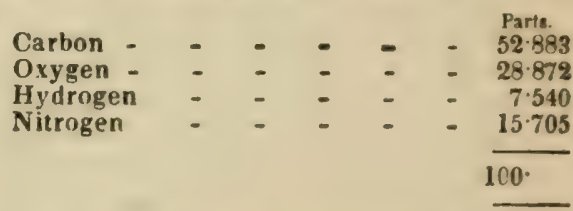

The same excellent chemists have shown woody fibre to be composed of

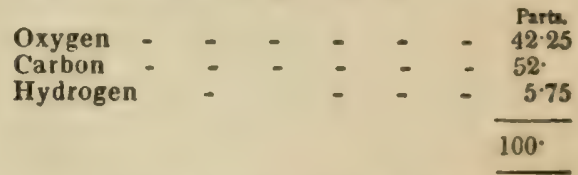

The chief vegetable matters of the garlic, therefore, the student will remark (and the same conclusion applies to other vegetables), are composed entirely of two or three principal ingredients. The composition of all plants is, in fact, much more similar than is commonly supposed. For instance, all the vegetable acids, such as vinegar (acetic acid), sugar, gum, starch, woody fibre, \&c., are composed of three substances, viz., carbon, oxygen, and hydrogen, arranged in different proportions, as may be seen from the following table:

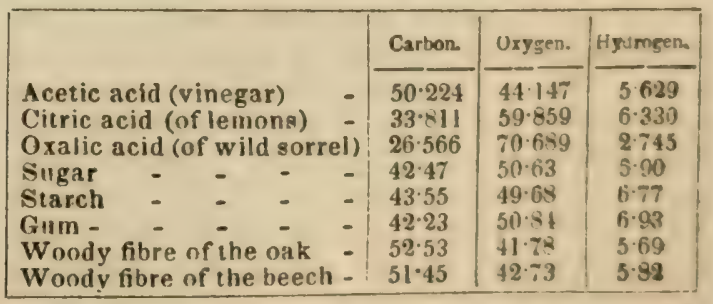

The decomposition of vegetable substances.-All dead vegetable substances, when left to them. selves, under favourable circumstances, speedi. ly decay, or decompose, and are resolved inus their constituents. This is commonly effected in two ways, either by fermcntation or by putro$4 \mathrm{D}$ 86.5 
faction, to this last phenomenon several requisites are necessary ; moisture must be present, and the temperature must not be below $32^{\circ}$ of Fahrenheit: in fact, it proceeds with extreme slowness at a temperature below $45^{\circ}$. It is retarded in its progress by the absence of the atmospheric air, but its presence is not essential : when water, however, is entirely absent, putrefaction cannot proceed.

The disagreeable odour which is emitted during putrefaction is owing to the gaseous substances which are generated. Those plants which contain nitrogen emit ammonia : onions produce phosphuretted hydrogen. By all of them carbonic acid gas and carburetted hydrogen gas are emitted in considerable quantities. 'l'hese gases, being, when presented to the roots and leaves of plants, exceedingly invigorating, are one of the causes of the increased luxuriance of all crops manured with green vegetable rnatters. When the putrefaction of the vegetable substance is at an end, the carbon, hydrogen, and oxygen, of which it is composed, are gone, and nothing remains but the earths and salts with which the purely vegetable matters were once combined in the plant. The ashes which are left when putrefaction ceases, are in fact nearly the same as those left after combustion. See Putrefaction.

Animal substunces.-The analysis of animal substances is attended with all the difficulties to which I have alluded as attendant upon the examination of vegetable substances; and the progress of chemical philosophy has not yet succeeded in demonstrating the composition of any great proportion of the many substances met with in the animal world. The great mass of animal matters contain nitrogen, and this is the chief general chemical difference between animal and vegetable substances; hence, when animal substances putrefy, ammonia is disengaged, for this alkali is composed of nitrogen and hydrogen.

The following analysis of several animal natters will show how generally present is nitrogen in this class of substances:-

\begin{tabular}{|c|c|c|c|c|}
\hline $\begin{array}{c}\text { Gelatin (glue, } \\
\text { isingla8s), \&c. }\end{array}$ & $\mathbf{4 7 \cdot 8 8 1}$ & $\mathbf{2 7 \cdot 2 0 7}$ & $\mathbf{7 \cdot 9 1 4}$ & 16.998 \\
$\begin{array}{c}\text { Albunen (white } \\
\text { of egg), \&c. }\end{array}$ & 52.883 & 23.872 & 7.540 & 15.705 \\
$\begin{array}{c}\text { Fibrin (fibre in } \\
\text { clots of blood) }\end{array}$ & 53.360 & 19.685 & $7 \cdot 021$ & 19.934 \\
$\begin{array}{c}\text { Urea (found in } \\
\text { urine) - }\end{array}$ & $20^{\circ}$ & 26.66 & 6.66 & 46.66 \\
\hline
\end{tabular}

These are the chief animal substances of which most others are compounded. Thus the principal solid matter of animal muscle is fibrin. The outer skin or cuticle of animals is composed of from 93 to 95 per cent. of albumen. 'The solid matter of the blood is chiefly composed of the same substance. Under the heads Animal Minures, Fish, Bones, Geratin, \&c., the reader will find all the animal chemistry vearing upon farming and rural affairs, with which I am acquainted. The relative proporvions of the inorganic constituents of vegetable substances forms a topic of great interest; and Professor G. F. W. Johnston's lectures upon the subject, just published, will be read with satis866 faction. See Let IX., on the Application of Che mistry and Geolog? to Agriculture.

ORNITHOLOGY (Gr.). The science which teaches the natural history and arrangement of birds.

OSIER. The name given to various species of willow or salix, chiefly employed in basketmaking. Although under the heads $\mathbf{S}_{\text {allow }}$ and WILlow are noticed most of the species of this genus, it may be well to describe in this place, a few of those which are more generally known under the name osier. Osiers differ from sallows in their long, straight, flexible, and mostly tough twigs; thin, generally sessile germens, and elongated styles and stigmas. The osier forms a hardy and useful hedge for excluding boisterous winds; and as it flourishes in wet situations is frequently planted with a view to prevent the banks of rivers being washed away by the force of the current. Osiers are divided into two classes: the first is known by their blunt and downy or mealy leaves, which in the other are more pointed, smooth, and green, re. sembling the myrtle.

The common osier (S. viminalis) is one of the most abundant species. This tree is found growing in wet meadows, osier-holts, the banks of rivers, and other moist situations. The branches are straight, erect, wand-like, very long and slender, round, polished, downy when young, with fine silky hairs. Leaves on short foot-stalks, almost upright, about a span long, and half an inch wide. The value of the common osier for various kinds of basket-work is universally known. 'There is a variety much esteemed, called the velvet osier, in which no external difference is discernible, but the twigs are said to be more pliant. There are also various species as well as varieties comprehended under the name of osiers, some of which, having smonth leaves, are noticed under the articles SxLLow and Wirlow.

The silky-leaved osier (S. Smithiana) is a shrub found growing in meadows and osier grounds, the branches of which are brittle and unfit for basket-work. It is therefore important for cultivators of osiers to distinguish carefully between this and the velvet osier; for while the latter is, for some kinds of work, greatly esteemed, the silky-leaved osier proves of no utility.

The auricled osier (S. stipularis) is a common species in osier-holts, hedges, and woods, and is easily known at first sight by its coarse, tall habit, and conspicuous stipules, but not worthy of cultivation for any economical purpose. The twigs are upright, tall, soft, and downy, of a pale reddish-brown, brittle, and of little or no use as an osier.

The fine basket osier (S. Forbiana) is a shrub grown in the meadows and osier-holts of the eastern part of England. The stem is erect, bushy, with upright, slender, smooth twigs, very nexible and tough, of a grayish-yellow, not purple hue, highly esteemed and much cultivated for the finer kinds of basket-work.

Green-leaved osier (S. rubra). This is a small tree, with long, upright, smooth, grayish or purplish, more frequently tawny branches, very tough and pliant, this being one of the 
nost valuable osiers when cut down annually. The very long and narrow leaves of this rather rare species agree in shape with the common osier (S. viminalis), but want its dense white pubescence.

In the fens of the east of England many holts (as they are provincially called) or plantations of osiers are raised, which beautify the country, keep the stock warm in the winter, and provide much useful wood for baskets and all kinds of wicker-work. The mode of planting is very simple; it is, first, to dig the land from 6 to 12 inches deep, and then to prick down cuttings of 4 years' growth, and 18 inches long, at about 3 feet distance from each other. The soil may be moor or clay, or any that is low and wet.

These holts or osier plantations must be fenced round, either with dikes, which are most common, or with hedges. The proper season for making them (they seldom fail of zrowing at any time), is from the fall of the leaf till very late in the spring.

OSIER, GOLDEN, or YELLOW WILLOW. See Willow.

OUZE. A deposit made by the sea.

OVEN. A domestic furnace used for baking bread, pies, tarts, \&c. Ovens are generally constructed of brick-work in a semicircular form, with a very low roof, and the bottom of which is laid with stone: in the front is a small aperture and door, by the shutting of which the heat is confined while the bread is baking. They are usually heated by means of dry faggots, wood, \&c. As these ovens, however, are wot calculated for small families, on account of the quantity of fuel they consume, others have been contrived, on a more diminutive scale: these are usually formed of cast or hammered iron, and may be heated by the same fire which serves for the cooking of other provisions; but for baking bread these ovens are inferior to the brick ovens.

OVERLAND FARM. A provincial phrase usually applied to a parcel of land without any building or house attached to it.

OVER-REACH. See Cuxcking.

OVER-YEARS. A country term applied to such bullocks as are not finished fattening at three years old when home-breeds, or the first winter after buying in; but kept through the following summer to be finished the next winter.

OVIPOSITOR (Lat. ovum, an egg; and pono, I place). In entomology, is the instrument by which an insect conducts its eggs to their appropriate nidus, and often bores a way to it: the same instrument is in some genera used as a weapon of offence, whence it is called the " aculeus." In the gall insect, and some others, the ovipositor is furnished at its root with a sac containing an acrid secretion, which is deposited in the wound made by the ovipositor at the same time as the eggs.

OWLING. In law, so called from its being generally commitled during the night. An offence consisting in conveying sheep or wool to the sea-side, in order to export them clandestinely. The offence was formerly capital, particularly if the offender neglected to surrender after proclamation made for that purpose.

OWLS. A tube of reptorial birds, including those which fly by night, and have the eyes directed forwards. The owl, although frequently held in disrepute, should never be destroyed by the farmer, to whom he is a great friend; for his diet consists chiefly of field-mice, of which he consumes large numbers. 'The owls are usually arranged into two principal groups: one in which all the species exhibit two tufts of feathers on the head, which have been called horns, ears, and egrets; in the second group, the heads are smocth and round, without tufts.

OX. Synonymous with the generic name Bos; in a more restricted sense, it signifies the castrated male of the domestic variety. See Cattre.

OXALIC ACID. See Acins.

OXALIS CRENATA. A perennial orna. mental plant, native of Chili, lately discovered by Mr. Douglas. The flowers are beautiful, of a yellow colour, and in umbels; the stalks and leaves are succulent, of an acid taste, and useful as salads; the roots or tubers are produced in clusters; their taste, when boiled, somewhat resembles a chestnut. They are raised from the tubers, are extraordinarily productive, as easily cultivated as the potato, and decidedly superior in flavour. They require a rich soil, and, like the potato, are stored during winter in cellars. (Kenrick.)

OX-BOOSE. Provincially, a stall or place where oxen stand in the winter to be fed or fattened.

OX-EYE (Chrysanthemum, from chrysos, gold, and anthemum, a flower; alluding to the colour of some of the flowers). The great white oxeye maudlin-wort, or moor daisy (C. leuccinthemum), $\mathrm{Pl} .10, w$, is very common in pastures, fields, and by way-sides. 'The flavour of the whole plant is herbaceous, slightly, not ple. santly, aromatic. Its properties are not important; like many other herbs, mixed with grasses, it makes a part of the hay crop. The root is branched, tough, and woody, with many fibres. Stem erect, simple, or branched, accurding to the soil, from one to two feet high. Leaves deep-green, clasping the stem, oblong, obtuse, cut, pinnatifid at the base; radical ones obovate, stalked. Flowers large, terminal, solitary, not inelegant, with a broad yellow disk, and brilliant white radius. See Dirsx.

Another wild indigenous species, the yellow ox-eye ( $C$. segetum), has already been noticed under the head Cons Marigozn.

OX-FEET. A term applied to the feet of horses when the horn of the hind feet cleaves just in the middle of the fore part of the hoof, from the coronet to the shoe: they are not common, but very troublesome.

OX-HARROW. A term applied to a very large sort of harrow, called in some counties of. England a drag.

OX-LIP. See Cowsur.

OXYGEN GAS. A simple or undecompounded substance, discovered in 1774 by Dr. Priestley. It constitutes 21 per cent. of the atmosphere, and it is that portion of it which supports animal life and combustion. It is emitted by plants growing in the light, and is absorbed by them during the night. It is found in combination with hydrogen and carbon, and 
'ess often with nitrogen, in all vegetable and animal substances. It unites with various bases, and forms alkalies, acids, and metallic oxides. It is tasteless, and soluble in water, which at a temperature of $60^{\circ}$ absorbs about $\frac{1}{2}$ of its bulk. One hundred cubic inches of this gas weigh about 34 grains. See Gases, their Uses to Vegetation.

OYSTER SHELLS. As a manure, the use of crushed oyster shells has never been so extensive in England as in Ireland. Though consisting mainly of carbonate of lime, they contain a very minute proportion of phosphate of lime, $1 \frac{1}{2}$ to $2 \frac{3}{4}$ per cent., with a small proportion of magnesia. They are consequently not nearly so valuable as bones, which contain the phosphate of lime in so much greater quantity; and, unless pulverized, are not sufficiently quick in their effects to encourage the farmer to use them unbro. ken. In England they have been, therefore, little employed, even in districts, such as the clay and sand formation, where, from the absence of carbonate of lime in the soil, the calcareous matter supplied by oyster shells would be a very valuable addition. In Ireland, which is almost entirely destitute of chalk, the use of the broken oyster shells has been more considerable than in England; and in Dublin the parish authorities, in hard seasons, are glad to set the paupers to work to collect and break the shells which are thrown away as rubbish; and I am informed that the money received for the powdered shells affords a very tolerable remuneration for the labour bestowed in their preparation. The mother-of-pearl with which the oyster shells are lined is similar in composition to the outer shell or crust. This has been analyzed by $\mathbf{M}$. Merat Guillot, who found in 100 parts of motherof-pearl, -

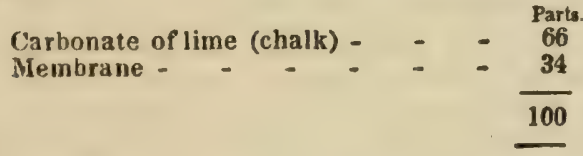

Powdered oyster shells should always, if possible, be drilled in with the seed; for, by thus coming into close contact with the plant, all the volatile and earthy constituents of the decomposing shell are absorbed by its roots and leaves with the greater readiness, from being placed more immediately in contact with them. In this way they have been found to answer very well on the light, sandy soils of Norfolk, when drilled in with the turnip seed; as will be seen from the following account of Mr. Blakie, in a letter to Sir John Sinclair, dated Sept. 18, 1818:- "Oyster shells pounded or bruised (without having been burned) were first used upon Mr. Coke's farm as a manure in the year 1816. In the summer of that year, the experiment was tried upon a hungry, light, sandy soil, which had been cleaned for turnips. The oyster shell dust, or powder, was drilled ir. ihe usual way, upon 27 -inch ridges, at the rate of 40 bushels per acre (without any other manure), was slightly covered with earth, and the turnip seed sown upon it. Another part of the same field, quality of land equal, was manured with farm-yard dung, at the rate of tons per acre, put into the same sized ridges, 868 and sown with turnip seed as before described, no other manure having been applied. The turnips proved a good crop on both pieces: nor was there any perceptible difference in the bulk, but the produce was not weighed. The turnips were all eaten upon the ground by sheep; and the succeeding crop, barley, was good on both, and apparently equal, but the produce was not thrashed separate. 'The seeds or layer crop of clover, in the present season, 1818, is a good plant, and appears equally so. In this experiment, so far as it goes, it appears that 40 bushels of oyster-shell powder are equal in virtue as a manure to 8 tons of farm-yard dung, at least for the purpose to which it was applied.

"In the autumn of 1816, powdered oyster shells were tried as a manure for wheat, in competition with rape-cake powdered. The experiment was apon a one year's clover layer; the wheat sown after one ploughing; the soil a kind, light, gravelly loam. Oyster-shell powder, at the rate of $4 \mathrm{cwt}$. per acre, was drilled with the wheat seed on one part of the field; and on another part, of the same quality, rapecake dust was drilled with the wheat at the same rate per acre as the shell powder; no other manure was applied to either part. The crop of wheat was good, nor was there any perceptible difference upon the ground; but the produce was not thrashed separate. A similar experiment was tried upon the same wheat field, the manure applied at spring; the operation as follows: the wheat seed was sown without any manure in the autumn of 1816 , and in the spring of 1817 rape-cake dust, at the rate of 4 cwt. per acre, was drilled between the rows of wheat; at the same time an equal weight of shell powder was applied in like manner to another part of the field. The result of this was similar to the autumn experiment, viz., there did not appear to be any difference in the crop produced upon the shell manure from that on the rape cake. The field on which these experiments were tried is now in turnips, a good crop, and exhibits no difference where the manure, as before stated, had been applied for the wheat crop. These experiments are satisfactory, so far as they go, but certainly not conclusive; because the produce was in no one instance either weighed or measured. This I very much regret; but it appears to be almost impossible to conduct such experiments with a requisite degree of accuracy upon a farm establishment of such magnitude as that of Mr. Coke at this place. For, during the hurry incident to collecting the harvest, the farm manager has so many important concerns to attend to, that he cannot devote any portion of his time to superintending experimental objects; and were he to depute the management of such concerns to the labourers, it is not to be expected that they would pay the attention requisite. The oyster shells are here broken to pieces by passing them through the oil-cake crusher; or are bruised by repeatedly drawing a heavy iron roller over them when spread upon a stone or hard-burned brick or edge floor. I give it as an opinion, that oyster. shell manure is likely to answer for gardens, particularly to rake in with onions and other 
small seed. I also think it may prove beneficial as a top-dressing for grass plants, to destroy moss, and prevent worms from casting.

Mr. Livingston, of New York, says (Annuls of $A g r$. vol. xx. p. 87), "In A pril, 1791, I strewed 7 bushels of ground oyster shells over half an acre of rye, growing on a very poor soil, and 3 bushels of gypsum on another half-acre adjoining; sowed $10 \mathrm{lbs}$. of red clover seed over both. The rye was not better than the rest of the field; the clover seed being bad, came up but thinly; that, however, dressed with oyster shells, much better than that manured with gypsum."

It is certain, therefore, that oyster shells, when powdered or crushed, are an excellent manure; and, in many parts of England, where they can be obtained in considerable quantities, I have every reason to believe that they will be found very useful to the farmer. (Johnson on the Fertili:ers, p. 368.)

\section{P.}

PACANENUT. See Hrckor.

PACE. In horsemanship, the peculiar manner of motion, or progression, in the horse or other animal. The natural paces of the horse are, a walk, a trot, and a gallop, to which some add an amhle, as some horses have it naturally. See Canter, Gallop, \&c.

FACK RAG-DAY. A provincial term in England signifying the day after Martinmas day, the time of changing farm servants.

PADDLE-STAFF. An implement used by ploughmen to free the share from stubble, earth, \&c.

PADDOCK. A small field or enclosure. It also signifies a large toad.

PAIL. A wooden bucket in which milk, water, or other fluids are commonly carried.

PAII-BRUSH. A hard brush, furnished with bristles at the end, to clean out the angles of the ressels more fully.

PALM. An ancient measure of length taken from the extent of the hand. The English palm is understood to be three inches.

PALMA'TE. In botany, divided so as to resemble a hand spread open.

PALMA CHRIsTi. See Castor Or Plant. The cake left after the expression of castor oil is very advantageously applied to land as a manure for wheat and other crops. An interesting communication upon this subject may be found in the first volume of the Farmer's Register, from T. G. Peachy, Esq., of Williamsburg, Va., the results of whose experiments show the great value of the article. In one experiment he applied from 50 to 60 bushels per acre on $7 \frac{1}{2}$ acres of land sown with 10 bushels of wheat, and the product was 26 bushels of wheat per acre. In this case the land was so poor that not over 5 bushels could be expected from it without the dressing. He recommends about 40 bushels as an ordinary dressing. $\mathrm{Mr}$. Peachy does not think the common impression correct, that the chief efficacy of the cake resides in the portion of oil which it retains. IIis press, he says, "is a very powerful one, and leaves a very small portion of oil in the cake. There is, moreover, other refuse matter in such an establishment as ours, which contains a vast deal more oil than the cake, which I have used as manure, and been uniformly disappointed in its effects. Accident has enabled me, I think, to solve the difficulty, and to declare my belief that the fertilizing qualities of the oil-cake reside chiefly in the farina it contains. Some time last year a vessel laden with flour was stranded near Jamestown, and the flour ruined. Mr. John Mann, who owns a farm in the neighbourhood, took two or three of the barrels and top-dressed a small portion of his wheat with it. I was not an eye-witress of its effects; but I was informed it produced as great an increase of that portion of his crop as my oil cake would have done.

"By experiment, I find that 50 bushels of the cake will weigh $1800 \mathrm{lbs}$; and of this quantity I have discovered that $1 \frac{1}{1}$ is farina or flourequal to 5 barrels of flour. The cotton seed, I fancy, contains mure farina, in proportion to the oil, than the castor bean, and, I believe, would produce as great an effect after being deprived of its oil, as it would do in its original state. I should be much obliged to you to give us your opinion on this subject." See Linseed Cake, Rape Cake, \&c.

PALMETTO (Chamaops palmetlo). Cabbage tree. This American tree belongs to the genus of the palms, and is found farther north than any other species in America. From its lofty height it is reckoned in the United States as a tree. It is first seen about Cape Hatteras, in the 34 th degree of latitude, from which it spreads to the extremity of the Florida peninsula, and thence around the Gulf of Mexico. In the extreme south the palmetto is not entirely confined to the immediate vicinity of the sea. Its stem or trunk is erect, and rises 80 or 90 feet, embellished at top by a globe of plumed leaves, each somewhat like a large fan, and plicated in the same manner, each frond, with its stipes or stem, 30 feet in length; the frond, or expanded part of the leaf, 15 feet over. There are six species of the palm in Carolina and Florida, all of which have flabelli-formed leaves or fronds.

It is the central part of this vast plant at top which stands erect, like a sharp cone or sugarloaf, surrounded by the expanding leaves, which is eaten roasted or boiled, like cabbage; and consists of the young frond, rudiments of fronds, with all the succeeding appendages of the future growth, involved together, white and tender as a curd, as rich, and of the like pleasant flavour.

A well grown palm stands perfectly erect, on a shaft or column of 60 or 80 feet high, its base 3 feet diameter, having 3 or 4 rings and circular mouldings, 3 or 4 feet upwards; from thence upwards to the top it diminishes almost imperceptibly, forming a model of a pillar for the architect, almost inimitable. A tree produces but one cabbage, and as soon as that is cut off, this glorious production of nature perishes. But, though the tree dies, yet it ceases not to be useful; the exterior ligneous part, of three-fourths inch thickness, is as hard as bone when dry, and the interior 
spongy consistence being rotted out, or devoured by worms, it makes excellent trunks ur conduits for draining off water, being almost incorruptible under ground. These shafts also, split in two, and set upright in the ground, inake strong and durable palisades; and we are informed that they answered a very good purpose in South Carolina, at the time of the revolutionary was, particularly at Sullivan's Island. The ramparts of the fortifications being lined with the trunks of the cabbage tree, split in two, and set upright against the wall; their smooth, firm, and elastic surface, together with their spongy interior, united to repel the shot of their assailants.

The stems are also used in Charleston, S. C., for the facing of wharfs, as the salt-water worm never touches them. Pieces of the spongy part of the stem afford a very good substitute for scrubbing-brushes, and are even preferred for whitening floors.

The leaves of the smaller species afford excellent and durable thatch for covering barns and out-houses; and the younger leaves of the cabbage tree are manufactured by the negroes into beautiful, light, and durable hats, called Bermudian hats. The repent caudex of the saw-palmetto, being torn from the surface of the earth, cut into proper lengths, dried, and burned to ashes, produce the greatest quantity of potash of any known vegetable. And the drupes, or large berries of this species, which are of the size and figure of dates, and as sweet, afford good and nourishing food to the Indians and hunters. They are not palatable in white people till they become accustomed to them.

PALMS. A natural order of arborescent endogens, chiefly inhabiting the tropics; distinguished by their fleshy, colourless, six-parted Uowers, enclosed within spathes; their minute enibryo lying in the midst of albumen, and remote from the hilum; and rigid plaited or pinnate inarticulated leaves, sometimes called tronds.

Falms is a common name for the male flowirs of the willow.

PALSY. In the horse this nervous disease is usually confined to the hinder limbs. Old carriage-horses, and horses of draught of every kind, although not absolutely paralyzed, have often great stiffness in their gait, and difficulty of turning. These are evident injuries of the spine. Bleeding, physicking, antimonial medicines, and stimulating embrocations are the most likely means of cure for palsy. See Sheep, Diseases of.

PAMBINA. A species of North American bush cranberry, discovered on the Columbia river.

PAN. A term applied to the bed or flooring ripon which the cultivated soil lies or is placed. See Moorhani Pan.

PANIC-GRASS (Prnicum). This is a very extensive genus of large, coarse grasses, mostly annual in Europe, of no agricultural use: the inflorescence spiked or panicled; the seeds in some instances used for food. There are three indigenous species: the rough, the green, and the loose panic-grass ( $P$. verticillatum, viride, and Crus-galli). See Mrrzer Gaıss.
PANICLE. In botany, a form of inflores. cence in which the primary axis developes secondary axes, which themselves produce tertiary; or, in other words, a raceme bearing branches of flowers, in place of simple ones.

PANNAGE. An old manorial term applied to the food which swine consume in woods, as acorns, and the mast of beech. It also signifies the money taken by the king's agistors, for the privilege of feeding hogs in the king's forest.

PANSY. A term applied chiefly to the garden varieties of Viola tricolor, and others which are usually cultivated under the name of heart'sease. See Violet.

PAPAW (Anona triloba). An American plant, which, though most frequently appearing in the form of a shrub, sometines attains the size of a tree of the third order. By the French of Upper Louisiana the papaw is called Assiminier. It is not found north of the Schuyl. kill river, in the vicinity of Philadelphia; and it appears to be unknown, or extremely rare, in the low and maritime parts of the Southern States. "It is not uncommon," says Michaux "in the bottoms which stretch along the rivers of the Middle States; but it is most abundan: in the rich valleys intersected by the western waters, where, at intervals, it forms thickets exclusively occupying several acres. In Kentucky, and in the western part of Tennessee, it is sometimes seen also in forests where the soil is luxuriantly fertile; of which its presence is an infallible proof. In these forests it attains the height of 30 feet, and the diameter of 6 or 8 inches, though. it generally stops short of half this elevation.

"The leaves are borne on short petioles, and are alternate, 5 or 6 inches in length, and of an elongated form, widening from the base to the summit. They are of a fine texture, and the superior surface is smooth and brilliant. The flowers, which are attached by short peduncles, are pendent, and of a purple hue.

"When the fruit is ripe, which takes place towards the beginning of August, it is about 3 inches long, and $1 \frac{1}{2}$ inches thick, of a yellowish colour, and of an oval form, irregular and swelling into inequalities. Its pulp is soft, and of an insipid taste, and it contains several large, triangular stones. It is never brought into the markets, and is sought in the woods only by children. At Pittsburgh some persons have succeeded in making from it a spirituous liquor; but, notwithstanding this experiment, very feeble hopes can be entertained of cultivating the tree with profit for this purpose.

"The trunk of the papaw is covered with a silver-gray bark, which is smooth, and even polished. The wood is spongy, extremely soft, destitute of strength, and applicable to no use in the mechanical arts. I have noticed that the cellular integument of the bark, and par. ticularly that of the roots, exhales in summer a nauseous odour, so strong as to occasion sickness if it is long respired in confined air. (Michaux's Am. Sylvu.)

The papaw belongs to the custard-apple genus, which in the tropics produces several kinds of fruit highly esteemed. Among these is the 
celebrated Cherimoyer (Anona cherimolia) found in perfection in Mexico, Peru, and Brazil; the Alligator pear ( $A$. palustris), the Sweet sop ( $A$. squamosa), all esteemed West India fruits, about as large as a middle-sized apple, and filled with a soft, rich, delicious pulp.

PA PILIONACEOUS PLANT'S include many of the most common and valuable plants supplying food to man and animals, such as pulse, beans, peas, tares, sainfoin, \&c. The papilionacre take the name from the resemblance borne by their flowers to the butterfly, as is seen in the blossom of the common pea. The fruit forms a pod called a legume, and such plants are hence named leguminous.

PARASITICAL PLAN'TS are those which grow into the tissue of other species, and feed upon their juices. Of this kind are the misseltoe, the broom-rape (Orobanche), the Lathroa, \&c. Such species have no proper roots. 'The term parasitical is, however, often applied to mosses, Orchidaceous plants, 'Tillandsias and the like, which are mostly epiphytes, growing upon the bark of trees, but deriving their food from the air, by means of their own roots.

PARING AND BURNING. This wellknown operation of agriculture, once much more extensively practised in England than at present, consists in paring off the turf to a depth of two or three inches, generally with a breast-plough worked by a labourer, or by a turf-paring plough drawn by a horse; allowing it to dry, and then burning it in heaps. It is commonly best performed in the months of April and May. It is a practice now rarely adopted on sandy or calcareous soils, although productive of good results on peat, and some kind of clay soil; but even there it is very doubtful whether it is the best mode of treating the land.

The practice is certainly as old as the days of Virgil, who mentions it in the first book of she Georgics. Endless have been the theories brought forward to account for its operation. Dr. Home thought it dispelled "a sour juice" from the land. (Prin. of $A g r$.) Dr. Darwin considered it produced "a nitrous salt" in the ashes. "Many such obscure causes," says Davy, "have been referred to for the purpose of explaining the effects of paring and burning, but I believe they may be referred entirely to the diminution of the coherence and tenacity of clays, and to the destruction of inert and useless vegetable matter, and its conversion into a manure. All soils that contain 100 much dead vegetable fibre, and which consequently lose from one-third to one-half of their weight by incineration, and all such as contain their earthy constituents in an impalpable state of division, such as the stiff clays and marls, are improved by burning; but in coarse sands, or rich soils, containing a great mixture of the earths, and in all cases in which the texture is already sufficiently loose, or the organizable matter sufficiently soluble, the process of torrifaction cannot be useful. All pure silicious sands," adds Davy, "must be injured by it;" and here practice is found to accord with theory. Arthur Young found "burning injured sand:" and an intelligent farmer in Mount's
Bay told me that at had pared and burued a small field, several years ago, which he had not been able to bring again into good condition. I examined the spot; the grass was very poor and scanty, and the soil a silicious sand.

'The process of paring and burning, therefure, seems to be most adapted for peaty or clay lands; for, as Davy continues, "the process of burning renders the suil less compact, less tenacious and retentive of moisture; and when properly applied, may convert a matter that was stiff, damp, and in consequence cold, into one powdery, dry, and warm, and much more proper as a bed for vegetable life."

Davy examined three specimens of the ashes from different lands that had undergone paring and burning. (See Asuss, antè, p. 115.) "The great objection," he adds, "to this operation is that it destroys vegetable and animal matter, or the manure in the soil: but in cases in which the texture of its earthy ingredients is permanently improved, there is more than a compensation for this temporary disadvantage. And in some soils where there is an excess of inert vegetable matter, the destruction of it must be beneficial; and the carbonaceous matter remaining in the ashes may be more useful to the crop than the vegetable fibre from which it was produced." (Agr. Chem. p. 344.)

Liebig thinks that all the benefit of burning the soil is attributable to its thus obtaining increased powers for the absorption of aminonia. He says, "Soils which contain oxides of iron, and burned clay, must absorb ammonia, which is favoured by their porous condition; they further prevent the escape of the ammonia once absorbed by their chemical properties. The ammonia absorbed by the clay, or ferruginous oxides, is separated by every shower of rain, and conveyed in solution to the soil. Powdered charcoal possesses a similar action, but surpasses all other substances in the power which it possesses of condensing ammonia within its pores, particularly when it has been previously heated to redness. Charcoal absorbs ninety times its volume of ammoniacal gas, which may be again separated by simply moistening it with water." (Organic Chem.)

And it is evident, from the experiments which Liebig gives, that charcoal powder is a very fertilizing application to some plants. The practice, however, of paring and burning is evidently one whose advantages the farmer and the chemist admit with reluctance. And it is very probable, that by other means, such as the use of lime, \&c., most soils may be cultivated with more advantage to the farmer by the avoidance of this expensive and destructive process. "My practice," remarks Mr. Pearson, "in the use of turf for various, purposes, convinces me that all lands must be injured by paring and burning, save those lands, which are few and far between, that possess ton much inert vegetable matter; or, in other words, lands that grow their crops to such a state of luxuriance, as to prevent the desired intent of the cultivator. Those lands which possess too much inert vegetable matter might also be improved by having part of their 
sulisoils burned; but not by surning the tarf even here, for that is the only thing that can be commended on the spot that will cause fermentation in the soil when it is ploughed in." See Peat Sorls.

PARK. A considerable extent of pasture and woodland, surrounded or adjoining the country residence of a man of wealth, devoted to purposes of recreation or enjoyment, but chiefly to the support of a herd of deer, though sometimes to cattle and sheep. Parks were origivally nothing more than portions of forest scenery appropriated by the lord of the soil for the exclusive use of animals of the chase; but this is now become, in many cases, a secondary consideration, and the chief uses of a park are as indications of wealth and extent of territory, and as grazing ground for domesticated animals.

PARSLEY, CUITIVATED (Apium petrosilinum). There are two varieties of this wellknown plant, the common plain-leaved, and the curly-leaved. It is somewhat singular that the first should be most cultivated, notwithstanding the superior beauty of the latter, as well as by reason of its curled leaves rendering it more easily to be distinguished from the Elhusa, or fool's parsley, a variety of the hemlock, often occurring in gardens: it requires much care in saving the seed, otherwise it degenerates into the plain-leaved. Parsley is raised from seed, which is recommended usually to be sown annually; but if never permitted to run to seed, and the stalks are cut down as often as they rise, it will last for several years. It may be sown from the close of February until the middle of June, and this is repeated about the middle of September, for the supply of winter and spring; but this is unnecessary if the plants are not allowed to seed. The seed is to be inserted moderately thick, in narrow drills barely an inch deep, 12 inches apart if in a bed by itself, or in a single one round the edge of a bed; the mould being raked level, and the stones immediately over them gathered off. The plants will not make their appearance in. less than three or four, and sometimes six, weeks. When two or three inches high, it may be gathered from as required. In early June, when the plants make a show for seed, the stems should be cut down close to the bottom, and again in September, if it has acquired a straggling, rank growth; this will cause it to shoot afresh, and acquire a strong growth before the arrival of severe weather. On the approach of frost, if protection is afforded to the plants by means of haulm wr reed pannels, so supported as not to touch them, it will preserve them in a much better state for use in winter and spring. To save seed, nothing more is necessary than to allow some of the plants to run up in June; they sbcild not, however, be allowed to stand nearer than 18 inches to each other. The seed ripens in early autumn, and, when perfectly dry, may \&c beaten out, and stored.

PARSLEY, THE COW. For rough cowparsley, see Crcelx. Smooth cow-parsley, see Chervil.

PA RSLEY, THE FOOL'S. See Foo''s PARSLEY. 872
PARSLEY, THE HEDGE. See HEDGParsLeY.

PARSLEY, HAMBURGH (Apium lalifolium). This esculent is likewise known by the name broad-leaved and large-rooted parsley. It is cultivated for its root, which attains the size of a middling parsnip, boiling exceedingly tender and palatable. It is eaten both as a sauce to flesh-meat and in soups, \&c. It is propagated by seed, which may be sown at monthly intervals from February until the middle of June. It is sown either thinly in drills, 9 inches apart, or broadcast and raked in. The plants appear in about a month after sowing, and when of tolerable growth require to be thinned to 9 inches asunder, and cleared from weeds either by hand or the hoe; which latter opera. tion being performed as often as weeds appear, is the only cultivation required. By the end of July or during August, the earliest sowings will have acquired a sufficient size for occasional use; but they seldom attain their full growth until Michaelmas; and the latest crops not until the following year. On the arrival of frost some of them must be taken up, and after the removal of the superfluous fibres, decayed leaves, \&c., buried in sand, in a dry situation, under cover.

To obtain seed, some plants must be left where grown, and allowed to run in May; their produce will ripen in July or August, when it must be cut, and, when perfectly dry, beaten out and stored.

PARSLEY-PIERT. See Ladies' Mantle.

PARSLEY, SMALLAGE, or WILD CELERY (Apium graveolens). This wild plant, the seeds and herbage of which in its native ditches are acrid and dangerous, with a peculiar strong taste and smell, by culture becomes the mild and grateful garden celery, for which and its name we are indebted to the Italians, and which has now supplanted our native Alexanders. It is biennial, and flowers in August and September. The root is tap-shaped, and the herbage smooth and shining. The plant grows in ditches and marshy ground, especially towards the sea. The stems are widely spreading or floating, long, branched, furrowed. Leaves bright-green, pinnate, or ternate; leaflets wedge-shaped, entire at their base, but variously notched above. Flowers in terminal and lateral umbels, small, numerous, greenish-white. Fruit almost globular, with permanent, wide-spreading, straight styles.

PARSNIP (Pastinaca, from pastinum, a dibble, in allusion to the form of the root). The common wild parsnip ( $P$. sativa) is the well-known culinary root; the other species are unworthy of cultivation. The original is a biennial plant, and found in England growing wild about the borders of fields, on hillocks, and dry banks, in a chalky soil, the root being spindle-shaped, white, aromatic, mucilaginous, and sweet, with a degree of acrimony, which it loses by cultivation. The stem reaches to a yard high, erect, branched, deeply furrowed. Leaves oblong, simply pinnate, downy beneath; leaflets serrated and cut, bright-green. Umbels terminal, erect, of several unequal, angular, downy rays. Flowers small, yellow, appearing in July. Fruit large, pale-brown when quite ripe 


\section{PARSNIP.}

The Field Culture of the Parsnip.-Colonel the Souteur describes this valuable field crop as thriving in any deep land, whether stiff or light. It succeeds in the island of Jersey admirably on soil resting on granite or sienite, or argillaceous schistus, on red clay, or on a gravelly bottom; on almost pure sand, if mixed with a light coating of earth, and on soils derived fiom pudding-stones, or white and red felspar. 'This includes most of the British islands, exclusive of the chally or limestone ranges. Sume persons cultivate it on poor black heath soil, not above 7 or 8 inches deep, and by rieans of heavy dressings of manure raise a good crop; but the parsnip in such situations forms a large shoulder, and forks away into fingers when near the hard subsoil, whereas, in very deep land, it will run down a foot or two of a good size.

An old grass lay is broken up by some persons in September, by others just before the parsnip seed is sown; the former I consider to be the best mode. When the turf is well rolled, 20 tuns per acre of stable manure are spread over the land. A trench is then opened through the centre of the field between 2 and 3 feet wide, and where the soil will admit of it, from 1 foot to 18 inches deep. A small two-horse plough then turns the manure and about 3 inches of soil into the trench, and is imme. diately followed by a large trench plough, with 3 or 4; and, in many cases, with 8 or 10 horses, which turns a foot or more of clean soil upon the manure and scurf when the land has been recently skim-ploughed. The soil is then harrowed, and the parsnip seed, which should be new, is sown at the rate of 3 or 4 pounds to the acre. The plants, when they are an inch high, are weeded, and are thinned out to 6 inches apart, and, according to the soil, should be again thinned out to 9 inches or more at the second hoeing. In September, when the fine aftermath begins to appear, some of this erop may be taken up for milch cows; as from 12 to 25 pounds of them given at milking-time will have a surprising effect on the cream, and produce fine yellow butter, which will keep admirably, if properly salted and prepared, preserving an excellent and superior flavour.

They are taken up with a fork, or ploughed up in October or November. The average produce, per statute acre, is 9 to 11 tons. The dry leaves of the parsnip are given to cows. The parsnip will fatten pigs (or poultry if boiled) in an extraordinary manner, and it is certainly one of the best preparatory crops for wheat. It will keep in store until April, and it is advisable to remove the leaves before the roots are stored. The parsnip being a very hardy vegetable, the frost does not injure the seed or the young p-aut; and, if thought desirable, the former may be sown as soon as they are ripe in autumn. There are only 1 or 2 varieties of parsnips, of which the common species is the best for fieid culture. 1000 parts of the parsnip yielded Davy 90 parts of saccharine miatter, and 9 parts of mucilage.

Garden Culture.-The soil in which the parsnip succeeds best is a rich, dry, sandy loam, and the deeper the better. The most inimical to $t$ are gravel or clay. It is always beneficial to trench the ground 2 spades deep, a little ma. nure being turned in with the bottem spit. If the soil is suitable to them, they are not much benefited by the general application of manure at the time of sowing, but often injured in consequence of numerous fibres being induced. Dr. Macculloch says, that in the island of Guernsey, which has long been celebrated for the fineness of its parsnips, sea-weed is the manure chiefly employed. Of excrementitious manure, that of pigeons is the best. Drcayed leaves are also very favourable to its growth. The situation cannot be too open.

It is propagated by seed. 'The usual time for sowing is from the end of February to the beginning of April, but the earlier the better. It has been recommended in field cultivation to sow them in September; in the garden, when sown at this season, they also obtain a finer flavour, but many of them in general run to seed. In the isle of Guernsey they regulate their time of sowing according to the soil; in the most favourable soils they sow in January; or if the soil is wet or stiff, they do not insert the seed until the latter end of March.

The seed is sown broadcast, rather thin, and well raked in. The compartment being laid out in beds, not more than 4 feet wide, for the convenience of weeding, \&c. When the seedlings are $\mathbf{2}$ or $\mathbf{3}$ inches high, they are carefully thinned to 10 inches apart, and the wceds removed both by hand and small-hoeing. The beds require to be frequently looked over to remove all seedlings that may spring up afresh, as well as to be frequently hoed, until the plants so cover the ground as to render it impracticable. The roots may be taken up as wanted, in September, but they do not attain maturity till October, and which is intimated by the decay of the leaves. In November, part of the crop may be taken up, and the tops being cut close off, laid in alternate layers, with sand, for use in frosty weather. The remainder may be left in the ground, and taken up as required, as they are never injured by the most intense frost, but, on the contrary, rendered sweeter. In February or March, however, any remaining must be extracted, otherwise they will vegetate. Being preserved in sand, they continue good until the end of April or May.

For the production of seed, some of the finest roots are best allowed to remain where grown; or else, being raised in February; planted in a situation open, but sheltered from violent winds. Seed should never be employed that is more than a twelvemonth old, as it has generally lost its vegetative power when of a greater age.

PARSNIP, THE COW. See Cow-Parsyip. PARSNIP, THE SEA, or PRICKLY SA.M PHIRE.

PARSNIP, THE WATER. See WATERPARSNIP.

PARTERRE (Fr.). In gardening, a system of beds of different shapes and sizes, in which flowers are cultivated, with intervening spaces of gravel or turf for walking on.

PARTURITion. See Anontion, Cacriso of Cows, Gestation, Paggaycr, \&c.

PASSION-FLOWER (Passiflora, from passio, passion; and flos, a flower; in allusiun to 
the filamentous appendages or rays bearing a resemblance to the cross; the emblem of the passion of Christ). The species of this inte. resting and elegant genus are admirably adapted for stove and green-house climbers, being of easy culture, free growers, and, if allowed plenty of room, producing abundance of beauiful flowers. Many of the kinds produce fruit freely, from which, through impregnation, several fine hybrids have been raised. The iruit of some, as $P$.edulis, $P$. laurifolia, and $P$. quadrangularis, or granadilla, are eaten: the succulent pulp which surrounds the seeds is found to be fragrant, cooling, and pleasant, agreeably acid, and admirably adapted for allaying thirst in hot climates.

All the species will thrive well in a mixture of loam and peat, and are easily increased by cuttings planted in sand. The hardy kinds should be planted in sheltered situations.

PASTERN OF A HORSE. The distance that intervenes between the joint of that name and the coronet of the hoof.

PASTURE (Fr.). Ground on which cattle feed. I have, under the head Grass, gone at some length into the question of the grasses oest adapted for different soils. The pastures of England and Ireland exceed in extend and productiveness those of any other country of similar extent. "The excellence of pastures," observes the author of The British Husbandry, vol. i. p. 478, "depends greatly both upon their position and the different species of animals for whose support they are intended. Thus, uplands which are elevated, open, and dry, are the best adapted for the feeding of sheep; while a heavy stock is fed with more advantage upon ground which is lower in point of situation, as well as better enclosed. The soil of uplands, particularly if it be of a chalky nature, bears a sweet, though a short bite of grass, which is so favourable to the pasturage of the smaller breeds of sheep, that although it will support but a scanty stock, it yet produces the finest species of mutton. These flocks of sheep, too, by the folding system, keep in cultivation many a poor, thin soil, which would otherwise be worthless. There is an excellent paper, by Mr. Magillivray, on the natural pastures of Scotland, in which he traces the natural grasses which are found on the highest elevations down to the valleys and sea-shore. "The bleak summits of these mountains," he remarks, "exposed to the depressing influence of a low temperature, boisterous winds, and abundant rains, covered for a great part of the year with snow, and presenting either bare rock ir a shallow, gritty soil, produce few plants of any description, and hardly a dozen of those which are selected by sheep as their food. 'These latter consist of $\mathbf{3}$ or $\mathbf{4}$ carices or hard grasses, 1 or 2 junci or rushes, some tufts of the common club-rush, together with the Festun: viviparu, and 1 or 2 other grasses. The exireme heights scarcely present any other vegetation than Silene acaulis, Salix herbacea, and Statice armeria. Farther down the mountains, extending downwards to about $3000 \mathrm{feet}$ above the level of the sea, we find a vegetation still poor and stunted, but by no means defirient in beauty, and perhaps affording better 874 pasturage than some of the lower grounds. We here find irregular patches of verdure, consisting chiefly of Carices and Scirpus crespitosos, which, however, are also eaten by sheep; by the streamlets are several species of Alpine plants. Farther down the mountains, Aira flexunsa grows in tufts, and of a large size. Several carices form a tolerable sward in many places; the Agrostis vulgaris, \&c., occasionally occurs. Calluna vulgaris, or common heath, first makes its appearance. As we proceed downwards, and arrive at the places where the mountains begin to expand, we enter upon a region, the predominant feature of which is the Calluna vulgaris, mingled with Erica cinerea (the gray-leaved heath); the vegetation becomes more vigorous; various grasses present themselves. The valleys of this region, in which flow the streamlets, are generally more verdant than the open ground. The heaths are less abundant, and the pasturage consists chiefly of carices and graminez, intermingled with many of the plants of ordinary pasture ground, such as Lotus corniculatus, Polygala vulgaris, \&c. The general aspect of the vegetation, however, is heaithy, and continues so until we reach the vicinity of the river." For every information, however, relating to the formation of pastures, and the cultivation of the grasses, the farmer cannot consult a better authority than the Hortus Gram. Woburnensis of the late Mr. George Sinclair.

In feeding pastures, it is usual with those fields which are shut up from stock at Candlemas, to graze them in the succeeding May. Those which are fed until April may, after being shut up, be grazed again at Midsummer. If it is intended to feed a pasture during the winter, it should be allowed to rest in the months of October and November. See Mravow and Grassrs.

PEA, THE (Pisum sativum, Fr. pois, Span. pe soles. The English is evidently a corruption of the Latin name). This valuable plant is supposed to be a native of the south of Europe, and was cultivated by the Greeks and Romans. It is said by Acton to have been brought to England in 1548. There are only one or two kinds of pea: the gray pea ( $P$. arvense), and the pea cultivated as a vegetable in gardens ( $P$. sativum). Of the last, however, the varieties are endless.

Of field peas, the varieties are distinguished as the early and the late ripening. The com. mon early are small and dark-coloured. The gray pea of this class is the most common.

The later sown varieties are generally similar in their characters to garden peas; they differ, however, from them in having usually purple flowers. The most common kinds are the white, the early Charlton, and the pearl. Field peas, especially where there is a considerable demand for them, as in the neighbourhood of large towns, are a very profitable crop to be gathered green, since there is time after the peas are gathered, in the month of June, to prepare the land for a crop of turnips.

Where they are grown for their seeds, the white peas are those generally cultivated for the pur. pose of boiling, the gray as food for animals. 
The pea will succeed pretty well on both heavy and light soils; but it certainly does best on the latter, especially if the land abounds with carbonate of lime. It is an excellent crop to interpose between corn crops, for it affords considerable facilities to the cleansing of the land, and is not otherwise an exhausting crop. In many parts of England a pea crop is dibbled on the clover and grass leys, and afterwards a corn crop is taken with great advantage. In others a crop of oats is taken, and then a crop of peas. When this latter mode is adopted, the land is commonly ploughed in the autumn, and by cross-ploughing and harrowing in the spring, brought into some degree of tilth, and then the seed may be sown with the ordinary drill. The quantity of seed employed is about 3 bushels per acre, and the rows are usually from 9 to 27 inches apart. There is every facility aforded for the use of the horse-hoe. This instrument, with the early and occasional use of the hand-hoe, will cleanse the land; to which end the crop of peas will, as they approach maturity, materially assist, by overpowering and stifling the weeds.

Peas are usually one of the most uncertain of the English farmer's crops. 'They are subject to many casualties-to blight or mildew; to the attacks of a variety of insects, such as the grub, which devours the roots; lice, aphides, \&c., which haunt the leaves; and a small beetle, the Bruchus granarius, lays its eggs in the green pods, which produce a grub that devours its seeds. Then, again, it is frequently injured by the weather, in very dry, or in continued wet, or late harvests; and hence in the east of England it is often designated by the farmers as "a gentleman farmer's crop." This crop, however, is too often mismanaged in the way to which Arthur Young so well alluded, when he told the careless farmers of his day that they were "too apt to sow this pulse when the land would yield nothing else. They have a proverb among them," he adds, "which signifies that the season does as much for peas as good husbandry; and they from thence take care that good crops shall be owing to season alone. Hence arises the general idea of peas being the most uncertain crop of all others. This is owing to their being scarcely ever sown on land that is in good order. Let," he continues, "the good husbandman lay it down as a maxim, that he should sow no crop on land that is not in good order; not merely in respect of fine tilth at the time of sowing, but also of the soil being in good heart, and clear of weeds. He would not, however, here be understood to rank all these crops together; because beans and peas will admit of cleaning while they grow. On that account, if a farmer comes to a field which his predecessor has filled with weeds, a horse-hoed crop of beans will be expedient, when a barley crop would be utterly improper; and, after land has yielded one crop of barley, certainly another should not be sown, but one of pulse substituted. If these ideas are well executed, the peas and beans, in every course, will find the land in teurt enough for barley, the soil will always be clean, and the crop good. Peas, when manage $\downarrow$ in a spirited manner, will not have the reputation of being so very uncertain a crop, which character has, he thinks, in some mea sure been owing to ill conduct."

Peas do not need any particular dressings with manure; in fact, few crops require it so little; and in many situations manure produces the ill effect of rendering the plant too luxuriant. Von Thaer found, by several experiments, that the dung applied to the pea crop is the most profitable when used as a top-dress. ing. And, moreover, he contends that on sandy loams it produces in this way a much better effect in the succeeding crop. Lime and soot are, perhaps, the best dressings for peas; and these may operate to some degree by killing the insects of the soil, which might otherwise prey upon them; besides, the pea plant seems to delight in every situation where it can have access to calcareous matter. The crop is commonly cut with a hook at the end of a staff, or the half of an old scythe set in a bandle. By these the peas are severed, and made up into small bundles, called wads or wisps, and these remain on the ground until they are sufficiently dry to be carried. The straw of peas is very useful for the stock of the farm-yard: cows eat it, when it has been well gathered, with considerable avidity. See Haulm.

1000 parts of peas grown in Norfolk afforded Davy 501 parts of starch, 22 of saccharine matter, 35 of albuminous matter, and 16 paris of extract. The ashes obtained by burning the pea plant in flower and when ripe were examined by M. Saussure: he found in 100 parts of these ashes, procured from the Pisum sativum in flower, of soluble salts 49.8 parts, of earthy phosphates $17 \cdot \% 5$, earthy carbonates 6 , silica $2 \cdot 3$, metallic oxides 1 , and loss $24 \cdot 65$ parts. And from the ashes of the ripe plant, soluble salts 34.25 parts, earthy phosphates 22 , earthy carbonates 14 , silica 11 , metallic oxides $2 \cdot 5$, and loss $\mathbf{1 7 \cdot 2 5}$ parts.

The average price of peas in England, per Winchester quarter, was in

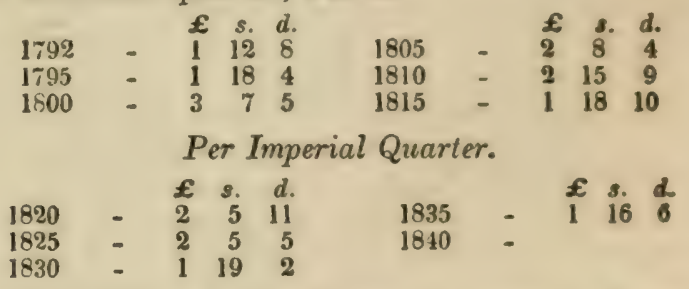

The amount of the imperial quarters of peas and beans entered for home consumption in England every five years, from 1815 to 1835 , was, according to Mr. M·Culloch :

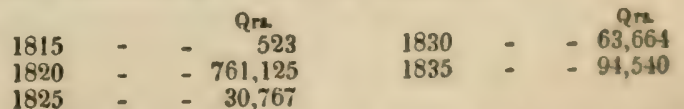

The annual average of peas and beans, im ported into England from 1801 to 1825, in Win chester quarters, was, from

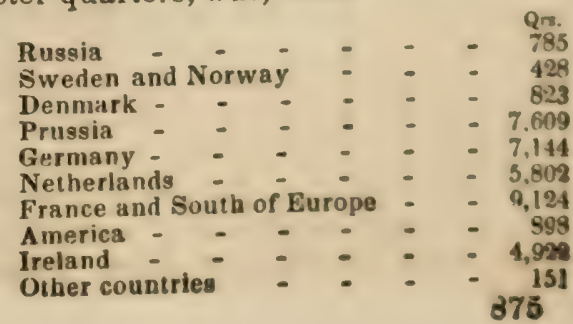


Garden Culture of the Pea.-Of the numerous varieties, which differ much in their hardiness, yield, height, \&c., we may enumerate the following:-Cormack's early dwarf-pea, early Charlton, early golden Charlton, early Nichol's golden Charlton, common Charlton, Reading hotspur, early single-blossomed, early Warwick, early dwarf frame, early double-blossomed frame, dwarf marrowfat, tall marrowfat, green or Patagonia marrowfat, early green nonpareil, Knight's marrowfat or wrinkled pea, Spanish moratto, imperial blue, Prussian blue, egg, white Rouncival, gray Rouncival, green Rouncival, blue Rouncival, tall sugar (the sugar-peas are eaten like kidney-beans), crown or rose, Leadman's dwarf, dwarf sugar, dwarf Spanish, sickle pea.

$\Lambda$ soil moderately rich and mouldy is best suited to this vegetable; rather inclining to aluminous for the lofty growers and main crops, but for the early and late ones, light and dry; if naturally otherwise, rendered so by the admixture of drift-sand with the earth of the drills. Dwarf varieties will grow on poorer and lighter soils than the others. In an extremely rich soil they grow luxuriant but unproductive. They are rather injured than benefited by the application of unreduced dung at the time of sowing. Road dirt and rotten leaves form the best compost for them. For the early and late crops, that is, from October until the close of January, and during June and July, the sowings must be performed in sheltered situations, as south borders. In December, the rows are best drawn parallel with and within a foot of the fence. At other seasons their site cannot be too open.

They are propagated by seed, the sowing of which commences with the year. In January they may be inserted in sheltered borders, and large supplies in an open compartment, and thence continued throughout February and until July, once every two or three weeks. During this last month, and in the first week of August, the last sowings must be made for production the same year. For the first production in the following year, a small sowing may be performed at the close of October, and repeated about the middle of November and December, though it often happens that these are scarcely a week forwarder than those inserted in the following February. The necessary extent of the various sowings may be determined with inlerable exactness from the experiments of Bradley; he found on the average that 3 rods of ground, containing 18 double rows, afforded 36 quarts of shelled peas.

The seed must be inserted in drills, or by the dibble, in rows at a distance proportionate to the height to which the variety grows, as well as according to the season.

When the plants have advanced to a height of 2 or 3 inches, they are to be hoed, the weeds cleared away, and earth drawn round the stems. This should be performed twice or three times gradually as they ascend, previous to the sticks being placed. It should be performed in dry weather, and the leaves never covered, or in wet weather they decay. For the winter standing crups it should be especially attended to, as it protects thein greatly from frost. Peas are 876 always best supported by sticks; if it is neglected, even for the dwarf varieties, they not only produce less, but sooner decay, are inconvenient to cultivate and gather from, and never so fine. Sticking is not required until the plants are 6 inches in height, or show their tendrils. If, during the time of blossoming, or swelling of the fruit, continued drought should occur, water may be very beneficially applied, it being poured between the rows, if they are in pairs, or otherwise in a shallow trench on one side of each. Watering the leaves is rather injurious. Failures in the rows of the earliest crops, whether from mice or other causes, may be rectified by transplanting. This is best performed in March; the plants thus removed must be watered until they have taken root, and also shaded, if the weather is hot. It is a good practice to nip off the top of the leading shoots of the early and late crops as soon as they are in blossom, as it greatly accelerates the setting and maturity of the fruit. Too much care cannot be taken when the pods are gathered, not to injure the stems. I have heard it stated from lengthened experience, that if the pods are cut off with scissors, the plants produced one-fourth more than when roughly gathered from. Bradley makes nearly a similar observation. From the main crops, or where there is no necessity for precipitation on account of bringing them to table early, the pods should not be gathered until the peas have become plump and moderately firm, yet green and tender. The more regularly the plants are gathered from, the longer they continue in production, as the later pods never attain maturity if the earlier ones are allowed to grow old before they are gathered.

In very severe weather the winter standing crops require the shelter of litter or other light covering, supported as much as possible from the plants by means of branches laid between the rows. Mr.J.Laird, gardener, at Portmore, N. B., employs straw ropes or twisted bands for this purpose, which he fixes along each side of the rows with wooden pins, driven into the ground. Whichever mode of shelter is adopted, it must be always removed in mild weather, otherwise the plants will be spindled, and rendered weaker. For the imperial blue, frame, and other dwarf varieties, the sticks need not be more than 3 feet high; for the Prussian blue, hotspur, and other middle-sized varieties, about 5; for the Knight's marrowfat, and other tall ones, at least 7; and for the $\mathrm{Pa}$. tagonian, not less than 8 . The best wood for this purpose is the brush, or fan-shaped branches of the hazel, \&c. Before they are employed, the ends that are thrust into the ground should be charred, or moderately burnt, which effectually preserves them from decay. If this is attended to, and, when no longer required, the sticks, if thoroughly dry, on a fine day are stored in a dry shed, they will last for three or more years.

For the production of seed, leave some rows that are in production during July, or sow purposely in March. Care must be taken, however, that no two varieties are in blossom near each other at the same time, but a lapse of at least three weeks should occur, otherwise no 
perfect variety zan be obtained. We are much in want of observations on this point. If hotspurs and marrowfats are sown on the same day, the latter will not bloom for nearly four weeks after the first. If the frame variety and the moratto are similarly inserted, the latter will succeed the first in about five weeks. The plants intended for seed ought never to be gathered from. When in blossom, all plants which do not appear to belong to the variety among which they are growing should be removed. They are fit for harvesting as soon as the pods become brownish and dry. When perfectly free from moisture, they should be beaten out, otherwise, if hot, showery weather occurs, they will open and shed their seed. Seed-peas preserve their power of germinating for eight or ten years.

Forcing commences in December, in the early part of which month they may be sown in a hotbed to remain, or thick, to transplant during the succeeding month into others for production. 'These may be repeated in January, and the transplanting take place in February. It is also a common practice to sow in a warm border during October, and the plants being cultivated as a natural ground crop, are removed into a hot-bed during January.

'The temperature employed in forcing may be either progressive, beginning at $40^{\circ}$ and $50^{\circ}$, for the extremes, at the time of sowing, rising to $52^{\circ}$ and $66^{\circ}$ when in blossom, and to $55^{\circ}$ and $70^{\circ}$ while the fruit is swelling; or the temperature may be uniformly kept up throughout their growth, having $50^{\circ}$ for the minimum and $70^{\circ}$ for their maximum.

In New York and some other of the Northern and Eastern States, the pea forms a highly valuable crop, not only for its intrinsic value, but as useful in preparing the land for the reception of wheat, and other grain, for which purpose it is considered on a par with the turnip and other root crops of England. The soil best adapted to the pea is one that is good for wheat, and where that grain is certain, peas may be considered so. The preparation of the soil demands nothing peculiar; it must only be made in good order for seed, in the manner required for other spring crops, by being well ploughed, harrowed, and if necessary, manured. If manured too highly, however, the vine or haulm is apt to be too abundant, and the pea itself inferior in quantity and quality. In this, as in most other cases, ton great a growth of vine or straw is incompatible with great crops of pulse or grain. Lime in all countries has been found an essential ingredient of pea or wheat soils; and where it does not naturally exist in them, should be applied previous to attempting the culture of these crops.

'The kinds of pea most usually cultivated as a field-crop, are the small yellow pea and the marrowfat. We prefer the latter; as it is equally certain with the other, is excellent for the table as well as for feeding, is as nutritious for animals, and generally more productive. In some situations, or in exhausted soils, the small yellow pea may however be preferable. From 30 to 40 bushels per acre is not an uncommon crop, and this highest amount is often exceeded. The quantity of seed required per acre may be stated at $2 \frac{1}{2}$ bushels, although some use only 2, and some put on 3 bushels per acre. For covering the pea the cultivator is a very good implernent, as it gives them more earth than the harrow and less than the common plough. The ground should be lef smooth by the roller or otherwise, as the ease of gathering is greatly depending on the state of the surface.

In harvesting the pea, some farmers hook them up with a scythe, some rake them by hand with the common hay-rake, but the most expeditious method by far, is to use the horse. rake in gathering this crop. In whatever way peas are gathered, it is necessary they should be ripe, and of course, if very dry at the lime, there will be some loss by shelling, but not perhaps more by the horse-rake than by the other methods, and four-fifths of the time required by the two first methods is saved. This, where the land is to be put into wheat, is frequently of great consequence. Once gathered, there is no crop so easily thrashed and prepared for market as the pea, and few that better reward the cultivator.

There is no plant cultivated which will bring pigs forward more rapidly than the pea, if the feeding is commenced as soon as the peas begin to harden, and the whole plant is fed out tc them. When gathered and hard, two methods of feeding have been adopted, both of which are far preferable to the barbarous practice of giving swine the pea without any preparation. The first is to soals and swell the pea in milk, if it can be had, if not, in water, and feed it to them in that state. The second is to grind the pea, either alone or with other coarse grain and feed it to animals in that way. This is preferable to feeding whole, as in corn or any other food, the finer it is made the more readily it will be assimilated, and in all cases, if cookec? into pudding the advantage will be decisive In England, where corn cannot be grown, a mixture of peas and barley is considered superior to any other food for making pork; here, closing the process of fattening with Indian corn, as giving more firmness to the pork, is preferred.

In the Southern States, a kind of pea, called there the Cow Pea, is cultivated for the purpose of making into hay, and for being ploughed under as a fallow crop, like clover.

PEA-BUG or BEETLE. In the spring of the year we often find, among seed-peas, many that have holes in them; and, if the peas have not been exposed to the light and air, we see a little insect peeping out of each of these holes, and waiting apparently for an opportunity to come forth and make its escape. If we turn out the creature from its cell, we perceive it to be a small oval beetle, rather more than onetenth of an inch long, of a rusty black colour, with a white spot on the hinder part of the thorax, 4 or 5 white dots behind the middle of each wing-cover, and a white spot, shaped like the letter $T$, on the exposed extremity of the body. This little insect is the Bruchus Pisi of Linnæus, the pea-Bruchus, or pea-weevil better known in America by the incorrec name of pea-bug. The original meaning of 
the word Bruchus is a devourer, and the insects to which it is applied well deserve this name, for, in the larva state, they devour the interior of seeds, often leaving but little more than the hull untouched. They belong to a family of the great weevil tribe called Bruchide, and are distinguished from other weevils by the follow. ing characters. The body is oval, and slightly convex; the head is bent downwards, so that the broad muzzle, when the insects are not eating, rests upon the breast.

The habits of the Bruchians and their larvæ are similar to those of the pea-weevil, which remain to be described. It may be well, however, to state here that these beetles frequent the leguminous or pod-bearing plants, such as the pea, Gleditsia, Robinia, Mimosa, Cassia, \&c., during and immediately after the flowering season; they pierce the tender pods of these plants, and commonly lay only one egg in each seed, the pulp of which suffices for the food of the little maggot-like grub hatched therein.

Few persons, while indulging in the luxury of early green peas, are aware how many insects they unconsciously swallow. When the pods are carefully examined, small, discoloured spots may be seen within them, each one corresponding to a similar spot on the opposite pea. If this spot in the pea be opened, a minute whitish grub, destitute of feet, will be found therein. It is the weevil in its larva form, which lives upon the marrow of the pea, and arrives at its full size by the time that the pea becomes drv. This larva or grub then bores a round hole from the hollow in the centre of the pea quite to the hull, but leaves the latter and generally the germ of the future sprout untouched. Hence, these buggy peas, as they are called by seedsmen and gardeners, will frequently sprout and grow when planted. The grub is changed to a pupa within its hole in the pea in the autumn, and before the spring casts its skin again, becomes a beetle, and gnaws a hole through the thin hull in order to make its escape into the air, which frequently does not happen before the peas are planted for an early crop. After the pea-vines have flowered, and while the pods are young and tender, and the peas within them are just beginning to swell, the beetles gather upon them, pierce the pods, and deposit their tiny eggs in the punctures. This is done only during the night, or in cloudy weather. Each egg is always placed opposite to a pea; the grubs, as soon as they are hatched, penetrate the pod and bury themselves in the peas; and the holes through which they pass are so fine as hardly to be perceived, and are soon closed. Sometimes every pea in a pod will be found to contain a weevil-grub; and so great has been the injury to the crop in some parts of the country, that the inhabitants have been obliged to give up the cultivation of this vegetable. These insects, as Mr. Deane has jherved, diminish the weight of the peas in whirh they lodge nearly one-half, and their leavings are fit only for the food of swine. This occasions a great loss, where peas are raised for feeding stock or for family use, as they are in many places. Those persons who eat whole peas in the winter after they are raised, run the risk of eating the weevils also; but if the peas are kept till they are a year old, the insects will entirely leave them.

The pea-weevil is supposed to be a native of the United States. It seems to have been first noticed in Pennsylvania, many years ago; and has gradually spread from thence to New Jersey, New York, Connecticut, Rhode Island, and Massachusetts. It is yet rare in $\mathbf{N e w}$ Hampshire, and I believe has not appeared in the eastern parts of Maine. It is unknown in the north of Europe, as we learn from the interesting account given of it by Kalm, the Swedish traveller, who tells us of the fear with which he was filled, on finding some of these weevils in a parcel of peas which he had carried home from America, having in view the whole damage which his beloved country would have suffered, if only two or three of these noxious insects had escaped him. They are now common in the south of Europe and in England, whither they may have been carried from this country. As the cultivated pea was not originally a native of America, it would be interesting to ascertain what plants the pea-weevil formerly inhabited. That it should have preferred the prolific exotic pea to any of our indigenous and less productive pulse, is not a matter of surprise, analogous facts being of common occurrence; but that for so many years a rational method for checking its ravages should not have been practised, is somewhat remarkable. An exceedingly simple one is recommended by Deane, but to be successful it should be universally adopted. It consists merely in keeping seed-peas in tight vessels over one year before planting them. Latreille and others recommend putting them, just before they are to be planted, into hot water for a minute or two, by which means the weevils will be killed, and the sprouting of the peas will be quickened. The insect is limited to a certain period for depositing its eggs; late sown peas therefore escape its attack. The late Colonel Pickering observed that those sown in Pennsylvania as late as the 20th of May, were entirely free from weevils; and Colonel Worthington, of Rensselaer county, New York, who sowed his peas on the 10th of June, 6 years in succession, never found an insect in them during that period. (Harris.)

PEA; COW. The plant called by this com. mon name in lower Virginia and the Carolinas. is there extensively cultivated. In some parts of Virginia it is called the Yeatman pea, from the person by whom it was introduced from the Eastern Shore. The pea is of a yellowish colour, is very productive both in vine and seed, unusually hardy in remaining uninjured by rain, after becoming ripe, and for table use is much esteemed. But it is chiefly cultivated, in common with several varieties of Indian peas, in fields, to plough under for the benefi: of successive crops, as a substitute for clover, buckwheat, and other plants not so well adapted to southern culture. The vines of this and the varieties of the Indian pea, all make exce! lent long forage for common work-horses, oxen, milch-cows, or sheep. The curing of the vine is sometimes difficult, as it requires a longer time than most other forage plants. Some stack it away with layers of dry straw, 
as is practised in the moist climate of England with clover.

PEA, EVERT.ASTING. See Eveunatro Pra and Iothrüs.

PEAS and OAT'S. These, in the Eastern and Northern States, are often sown together broad-cast, producing a mixed crop called Meslin. The common proportions are onefourth of peas to three-fourths of oats. The pea commonly sown is the green pea from Canada, which ripens about the time of the oats, and for which, while growing, the oats act as supporters. Peas and oats are usually ground together as feed for their fatting cattle, and are deemed valuable, though not so good or so much relished as Indian meal without mixture. Forty bushels of peas and oats per acre would be regarded a large crop. This has been produced, however, on nine acres, in Deerfield meadows. Some farmers sow at the rate of one-third peas and two-thirds oats.

PEA, PAR'TRIDGE. The Cassia Chamacrista of Beck; a native of the Middle and Southern States, where it goes by the common names of Sensitive pea and Magothybay bean. The stem is 1 to 2 feet high, rather erect, firm, and much branched, downy, and often purplish. Leaflets 3,10 , or 12 pairs, $\frac{1}{2}$ to $\frac{3}{4}$ inch in length and 2 to 3 lines wide. Petals of the flowers, deep bright-yellow, obovate, 2 or 3 of them with a purple spot at base. Stamens 10 , unequal, all fertile; anthers very long, 4 of them yellowish and 6 purple. Legume about 2 inches long and $\frac{1}{4}$ to $\frac{1}{3}$ of an inch wide, with a short, abrupt, nblique acumination, hairy along the sutures. See Wiln Sensitive Plant.

PEACH (Fr. pêche; Lat. Amygdalus, derived from amysso, to lacerate, in allusion to the fissured shell). The tall and coarse portion of the ornamental, early flowering plants, of which the peach forms a species, may be advantageously disposed of in large plantations, and the dwarf kinds in small shrubberies at the front of the large ones. In England the common way of increasing them is by budding on the plum stock or the bitter almond. Rich mould is a proper medium for them. 'They are most valued for producing their showy pink blos. soms early in the season, sooner than almost any other shrubs. The peach is now one of the most esteemed fruits: nearly 200 varieties are enumerated in the London Horticullural Society's Catalogue.

Although the peach is raised in the open air, in every part of the United States, it succeeds best in. the states of New Jersey, Delaware, Maryland, Virginia, and some of the Western States in similar latitudes. The flavour of the peaches of the United States is far superior to that of the same kind of fruit in Europe. In the vicinity of the large cities, or where facilities of quick transportation to these are furnisherl, the culture of the peach is a source of great profit.

Mr. Thomas Hancock, a very intelligent nurseryman, near Burlington, New Jersey, gives the following description of the mode practised by him in planting and managing peach orchards. "When it is intended to plant out a good orchard of trees, we generally select an elevated position, entirely unprotected by any timber or shelter of any kind; if a situation can he selected near the bank of a river, the crop is more certain, as the trees better withutand the frosts, which occasionally do much damare.

"Plough, and put the land in gord condition for corn or vegetahles, and plant the trees 20) feet apart each way; continue to till the land, taking off a crop of peas, beans, priatoes, or something that does not grow tno high: wiheat, rye, and oats are very injurious, and should not be planted. The land must not remain without tillage, as the trees would soon be injured: indeed, nothing will destroy a fine peach or. chard sooner than to let it lie in sward.

"The trees should be 2 years old on the stock from seed, and 1 year from the bud, the year after budding. This is considered as the best age for transplanting. If the water stands near the surface of the soil, or if the land has springs near the top of the ground, I should not deem it advisable to plant with the expectation of very certain crops. I have lost two orchards planted in this manner, while in an adjoining field, where the land, or a part of it, was high, with a dry subsoil, the trees flourished and produced abundant crops.

"Light sandy soil, or light loam, we consider the most preferable for planting out peach orchards, and I should judge that on many of the elevated knolls, in the vicinity of Boston, the peach might be cultivated to good advantage, particularly the earlier varieties. It is at least well worthy of trial." (Orchardist's Companion.)

The peach crop is, however, limited in a great degree by the destruction of the trees effected by a worm which attacks the inner bark of the root about the crown, and by a disease of uncertain origin, generally termed the yellows. In some parts of the country where the peach was formerly very extensively raised, the culture has been abandoned in consequence of the destruction of the trees from these two causes. Mr. Samuel Reeve, of Salem, New Jersey, very advantageously known as a nurseryman, says that the attacks of the peach-worm may be obviated or the insect de. stroyed by frequently examining the root at the surface of the ground while the tree is in a state of vegetation, removing the insects, as far as possible, and then washing the tree at the earth's surface with strong soap-suds, every week or two. Rubbing the trunk and main branches with soap-suds several times a year, is also highly conducive to keeping the tree in a healthy state. The ground should be kept loose around the peach tree. (Orchardist's Companion.)

The application of a mixture of common salt and saltpetre has been recommended by a gentleman in Maryland, as successful in pre. serving peach trees against the attacks of worms. The proportions are, 1 part of saltpetre to 8 parts of common salt. Half a pound of this mixture to a tree of 7 years old and upwards, is to be strewed upon the surface of the ground around and in immediate contart with the trunk of the tree. The mixture $1 \mathrm{~s}$ also recommended to be sown over the orchard in the proportion of 2 bushels to the acre By this means, it is said, the fruit is improved 
in size and flavour, the worms destroyed, and the yellows prevented.

The Yellows. The immediate cause of this fatal disease with which the peach tree is so often attacked, is still a matter involved in great obscurity. The following observations, by Mr. Robert Sinclair, of Clairmont Nursery, near Baltimore, Maryland, contains the views of a person of great intelligence and experience, in regard to the disease in question.

As I have, for about 30 years, occasionally had my attention drawn to this subject, I am willing, says Mr. Sinclair, to throw in my mite of experience. I am fully satisfied that the complaint exists. Some persons say that the worm at the root is the cause of the yellows. I acknowledge that any disorder that destroys the trees will cause the leaves to turn yellow; but the complaint I call the yellows will kill a whole orchard, without any visible wounds, on or before the third or fourth full crop. I think where any neighbourhood abounds with peach orchards, it will be nearly impossible to keep clear of the disease.

On planting out young peach trees on the site of a peach nursery, two years after the nursery was removed, and although the ground was in other respects well suited for the growth of the peach tree, yet by the next autumn many of them were dead, and the balance so sickly that I had them all dug up, and there was no sign of the worm at their roots. From this, and other similar experimerts, I think the disease may be generated by planting too near where a nursery or orchard of peach trees has been, or where the latter is; consequently, where a neighbourhood abounds with peach trees, there is danger of its becoming overspread with disease, without greater care than is usually taken to prevent it.

I think I have seen evidences of its being in some degree contagious. Richard Cromwell, the respectable and worthy peach raiser, near Baltimore, has for upwards of 30 years supplied that city with peaches of the best quality, on a large scale. Some time since, when I was walking with Mr. Cromwell through his peach orchard, when the trees were hanging full of ripe fruit: he pointed out a tree that he said had the yellows, having a full crop upon it, at that time worth one dollar per peck, and to me it appeared healthy; but he observed to me, "as soon as I take the fruit from the tree, I shall dig it up, in order to prevent the disease spreading any farther, for I expect the side of the adjoining trees next to it will be affected next season." I had occasion to pass through $\mathrm{Mr}$. Cromwell's orchard the next fruiting time, and the sickly tree had been dug up, but, as had been predicted, parts of the four neighbouring trees were evidently much affected, but only the sides next to the diseased tree, which made it the mort striking, and convincing of the contagion, if this is a proper term.

On another occasion, I had a favourite early purple peach, before I had a nursery, that I suspected was partially affected by the yellows, and being desirous of preserving the variety, I cut the healthiest branch I could get, and I had 12 buas inserted in healthy peach stocks; but when they had grown about 3 feet, they showed 880 the disease so plainly, that in order to preven it from spreading, 1 pulled up all the trees and had them burnt.

From these cases, it seems to me the disease may be generated by planting old peach orchards or nurseries too soon after the removal of the old trees, and also by planting too near those already affected with the disease; and if cuttings or scions are taken from disease 1 trees, their product will be also diseased. I also think the yellows may be communicated to young trees by planting seeds taken from diseased peach trees. (Hovey's Magazine of Horticulture.)

Drying Peaches. Several modes of effecting this are pursued. When done in-doors, furnaces should be placed in the cellar from which the heated air may rise into the building suitably provided with shelves, \&c.

In some of the Southern States, says Mr. Kenrick, the process is facilitated by a previous scalding. This is effected by immersing baskets of the fruit a few minutes in kettles of boiling w zter. They are afterwards halved, the stone separated, and being laid with the skins downwards, the drying is effected in the sun in three days of good weather. 'They then may be stored in boxes.

In France, as we are informed, peaches and other fruits are thus dried whole. The peaches or other fruits, being pared, are boiled for a few minutes in a syrup consisting of 1 pound of sugar dissolved in 3 quarts of water, and after being drained by being laid singly on board dishes, they are placed in the oven after the bread is taken out, and when sufficiently dry they are packed in boxes. The following is the mode of drying practised by Mr. Thomas Bellangee, of Egg Harbour, New Jersey. He has a small house provided with a stove, and drawers in the sides of the house lathed at their bottoms, with void intervals. The peaches should be ripe, and cut in two, not peeled, and laid in a single layer on the laths, with their skins downward, to save the juice. On shoving in the drawer, they are soon dried by the hot air produced by the stove. In this way great quantities may successively, in a single season, be prepared, with a very little expense in the preparation of the building, and in fuel.

PEACH TREE BORER. Pl. 16, fig. 8. The following interesting descripition of the peach tree worm, with a mode of protecting against its ravages, is from Dr. Harris's Treatise on Destructive Insects.

The pernicious borer, which, during many years past, has proved very destructive to peach trees throughout the United States, is a species of Egeria, named cxitiosa, or the destructive, by Mr. Say, who first scientifically described it in the third volume of the Journal of the Academy of Natural Sciences of Philadelphia, and subsequently gave a representation and account of it in his American Entomology. In the fifth volume of the New England Farmer, I have given the history of this insect, have mentioned the principal authors who have noticed it, and recommended pre ventive measures, which have been found effectual in protecting the peach tree from its most serious attacks. The eggs, from wrich 
these borers are hatched, are deposited, in the course of the summer, upon the trunk of the iree near the root; the borers penetrate the bark, and devour the inner bark and sap-wood. The seat of their operations is known by the castings and oum which issue from the holes in the tree. When these borers are nearly one year old, they make their cocoons either under the bark of the trunk or of the root, or in the earth and gum contiguous to the base of the trees; soon afterwards they are transformed to chrysalids, and finally come forth in the winged state, and lay the eggs for another generation of borers. The last transformation takes place from June to October, most frequently, however, during the month of July, in the state of Massachusetts. Here, although there are several broods produced by a succession of hatches, there is but one rotation of metamorphoses consummated within a year. Hence borers, of all sizes, will be found in the trees throughout the year, although it seems to be necessary that all of them, whether more or less advanced, should pass through one winter before they appear in the winged state. Under its last form, this insect is a slender, darkblue, four-winged moth, having a slight resemblance to a wasp or ichneumon-fly, to which it is sometimes likened. The two sexes differ greatly from each other, so much so as to have caused them to be mistaken for two distinct species. The male. which is much smaller than the female, has all the wings transparent, but bordered and veined with steel-blue, which is the general colour of the body in both sexes; the palpi or feelers, the edges of the collar, of the shoulder-covers, of the rings of the abdomen, and of the brush on the tail, are pale yellow, and there are two rings of the same yellow colour on the shins. It expands about 1 inch. The fore-wings of the female are blue, and opake, the hinc-wings transparent, and bordered and veined like those of the male, and the middle of the abdomen is encircled by a broad orange-coloured belt. It expands $1 \frac{1}{2}$ inch or more. This insect does not confine its attaclis to the peach tree. I have repeatedly obtained both sexes from borers inhabiting the excrescences which are found on the trunks and limbs of the cherry tree; and moreover, I have frequently taken them in connection on the trunks of cherry and of peach trees. They sometimes deposit their eggs in the crotches of the branches of the peach tree, where the borers will subsequently he found; but the in. jury, sustained by their operations in such parts, bears no comparison to that resulting from their attacks at the base of the tree, which they too of en completely girdle, and thus cause its premature decay and death. The following plan, which was recommended by me in the year 1826, and has been tried with complete success by several persons in this vicinity, will effectually protect the neck, or most vital part of the tree, from injury. Remove the earth around the base of the tree, crush and destroy the cocoons and borers which may be found in $i t$, and under the bark, cover the wounded parts with the common clay composition, and sulround the trunk with a strip of sheathing paper 8 or 9 inches wide, which should extend 2 nches below the level of the suil, and be se cured with strings of matting above. Frest mortar should then be placed around the root, so as to confine the paper and prevent access beneath it, and the remaining cavity may be filled with new or unexhausted loam. This operation should be performed in the spring or during the month of June. In the winter the strings may be removed, and in the following spring the trees should again be examined for any borers that may have escaped search before, and the protecting applications should be renewed.

PEACOCK (Pavo cristatus.) The peacock need scarcely be mentioned as a bird of economical use. Pea-hens and pea-chickens, indeed, are occasionally used for food, but this splendid creature is, and ought to be, regarded solely as an object of beauty. The advantages to be derived from rearing it for food are not to be thought of. See Fow , тив PEa.

PEARL-WORT (Sagina; from sagina, fatness; in allusion to its presumed nourishing qualities for sheep). These are hardy annual weeds, growing in any soil. There are in Eng. land three indigenous species.

PEAR TREE (Pyrus, from piren, the Celtic word for pear). Like other species of cultivated fruits, there are now a very great number of varieties, more than 600 being enumerated in the Horticultural Society's catalogue. A deep, rich loam is necessary for pear trees. They are increased by seeds, or by budding and grafting, which is the more common method, upon stocks of their own kind, or upon the quince. The established kinds are inultiplied by grafting the choicer on the common kinds. Almost the same treatment is required in pruning and training the pear as the apple. When we reflect on the labours of the horticulturists, who have by cultivation made the pear tree forget its natural thorus, and instead of an acerb berry, produce us a fruit so fair and nectareous, we find our warmest gratitude an insufficient return.

The wild pear tree ( $P$. communis) is a tall, handsome tree, growing in woods and hedges, with thorny branches, and simple, ovate, ser. rated leaves; downy beneath, and fringed with soft, white hairs. The flowers are copious, terminal, in corymbs, snow-white, with pink anthers. Fruit obovate, generally hard and aus. tere, but liable, even in a wild state, to many varieties, and sometimes eatable. The wood is light, of a fine grain, and tolerably hard. It is used by turners to make joiner's tools and picture-frames to be dyed black, and is also frequently stained and substituted for ebony. The white wild pear tree $(P$. aria), we have already noticed under the head Braм Trak. The expressed juice of the pear, when fermented in the manner of cider, constitutes the wellknown beverage, perry.

Grafting and Inoculnting.-In Europe it is very common to set the pear on a quince stock for clayey and light soils, whilst for trees. intended for sandy and calcareous soils, the free stock pear is preferred. Grafted on the white thorn (which, lize the quince, renders them dwarfish), pears come very early into bearing, continue prolific, and, in respect tes soil, will thrive 
well on a strong clay, which is considered unsuitable to those on quinces and wildings. But they are supposed to have an unfavourable influence upon the fruit, in rendering it small and hard. The following observations relating to the pear tree, its fruit, diseases, and insect enemies, are from the New American Orchardist, by Mr. Kenrick, whose list of fruits is valuable.

By grafting or inoculating on the quince, pear trees come much sooner into bearing, their productiveness is increased, the good quality of the fruit is not changed, but the size and longevity of the tree are diminished. Such pear trees are termed dwarfs. This mode is extensively adopted in France; but all kinds of pears will not grow on the quince stock. Those dwarfs trained in the form of a distaff, are called in that country Quenouilles.

The pear tree is of an extreme hardihood, exceeding that of the quince, and is seldom annoyed by the borer. The quince, when exposed, is liable to danger from the borer in the same degree as the apple tree. Their attacks always commence in the parts exposed above ground, or at the surface of the earth, and never beneath. In transplanting the pears, therefore, the quince stock must always be completely buried more than an inch beneath the soil. 'Thus situated and protected, the quince stock, from its nature, will strike root suddenly, new and numerous roots being produced on all sides, quite to the junction of the pear. Such is the mode adopted in practice by S. G. Perkins, Esq., and by other experienced cultivaars, for the complete protection of the quince stock from all dangers of every kind.

Soil and Distance.-The pear flourishes in rich soils and gentle declivities; they will succeed in the most common, deep, dry soil, and throw out numerous lateral shoots. But they do not flourish in moist situations; in a cold, strong, moist soil, with a clayey subsoil, they throw out very few lateral roots, the fruit is not so fair, or of so good a quality, and the trees are not so long-lived. They will even grow in poor soils, and in the clefts of rocks.

With respect to distance, the same observa. vions to be found under the head of AppLE may here apply. But the pear, from its pyramidal form, requires much less space. 20 feet, in suitable soils, is a good distance; but less answers in poorer soils. Quenouilles are found to answer even at 4 or 5 feet distance, producing large crops; and, as they occupy but litile space, and come suddenly into bearing, they are, for profit, extensively cultivated in France. The specimen pear trees at the Jardin du Roi, or Garden of Plants at Paris, in the autumn of 1840, were under the paricular care and management of Mons. Dalbret, the pupil of Thouin, and himself the autho- of a most valuable work on pruning. These trees were kept in the most perfect Quevouill or pyramidal form, from the summit quite down to the ground, by the system of short or spur pruning; and although at the distance of but about 7 feet asunder, yet they appeared to have ample space, and bore most abundant crops. But M. Dalbret then stated that 10 feet was the most suitable distance. In the climate 882 of the United States, and with more heat and sunshine, and finer skies, less distance might suffice. Pears produced on quince stocks are found to be much improved in flavour; all but some particular winter kinds, which are said in some cases to become worse.

The young, luxuriant shoots of the pear tree, by being bent downwards, generally produced the finest possible bearing wood for the second year; and, by grafting on the quince, and bending the branches, fruit may be produced from a seedling pear in the third or fourth year from the seed, which, in the common course, would require from 7 to 14 years. That system of rendering trees productive is fully described in Mr. Kenrick's Orchardist. He believes it to be the best system of all others.

As to standards, very little other pruning is necessary, except taking out those few limbs that interfere in keeping the tree well balanced.

The blight, or, as it is sometimes called, fireblight, is a malady which sometimes affects the pear tree during the months of June and July, causing the tree, or a portion of its branches, suddenly to turn black, with a mortal affection; its leaves wither at once, as by a stroke of the sun, and in a few hours become of a brown or black colour. Mr. Lowell is of opinion that this disease is caused by an insect called the Scolytus pyri. He observes, "On the first appearance of this disease, I instantly sawed off all the limbs affected, and proceeded to exa. mine them. I found at last the enemy, not at the point where death ensued, but some inches below it. The insect was very small, and apparently incapable of such extensive mischief but the effect was certain, and the manner of producing that effect was obvious. It had eaten a complete circle of the alburnum, or sap-wood, not exceeding the size of a knitting-needle, so as completely to intercent the passage of the sap." This insect was shown by Mr. Lowell to the late Professor Peck, and in the account of the insect which was soon after published in the Massachuselts Agricultural Repository, the professor observed, that the mischievous effects of this insect may be observed in June and July, and that the dead part of the branches should be cut off without delay and burned. Mr. Lowell has stated (New England Farmer, vol. v. p. 2), that by steadily pursuing the system of cutting off the limbs many inches below the apparent injury, and burning them, the insects have been extirpated from his estate.

The account of Professor Peck was repuhlished in the New England Farmer, vol. ii. p. 42. Some writers have attributed this disease to a stroke of the sun; others attribute it to manur. ing too high; some to excessive moisture at the roots, and too much pruning, which is sup. posed to cause a surfeit and produce a stagna. tion. But all agree that the only remedy is to saw off the limb. (Kenrick's $A m$. Orchardist.)

Some years ago, it was ascertained that a species of Agcria inhabited the pear tree in the State of Massachusetts, and it is said that considerable injury has resulted from it. An infested tree may be known by the castings thrown out of the small perforations made by the borers 
which live under the bark of the trunk, and subsist chiefly upon the inner bark. They make their cocoons under the bark, and change to chrysalids in the latter part of the summer. The winged insects appear in the autumn, having, like others of this kind, left their chrysalis skins projecting from the orifice of the holes which they had previously made. In its winged form, this . Egeria is very much like that which inhabits the currant-bush; but it is a smaller species. It was described by Dr.Harris in the year 1830, under the name of Egeria pyri, the pear tree $\mathbb{A g}$ eria ; and his account of it will be found on the second page of the ninth volume of the New England Farmer. Its wings expand rather more than half an inch; are transparent, but veined, bordered, and fringed with purplish black, and across the tips of the fore-wings is a broad, dark band, glossed with coppery tints; the prevailing colour of the upper side of the body is purple-black; but most of the under-side is golden-yellow, as are the edges of the collar, of the shoulder-covers, and of the fan-shaped brush on the tail; and there is a broad yellow band across the middle of the abdomen, preceded by two narrow bands of the same colour. (Harris.)

Drying Pears.--When dried in ovens, the fruit will keep for years. This mode of preserving is common in France. Bosc has described two modes of drying pears, and adds, that, in some of the cantons of that country, the cultivators annually preserve, by these means, supplies of subsistence extremely agreeable and wholesome during winter and spring. He invites cultivators not to neglect this resource. In this mode of drying, those varieties of middle size, melting and sweet, are preferred. After the bread is drawn from the oven, they are placed on the swept hearth, or on hurdles or boards. This operation is repeated a second, a third, and even a fourth time, according to their size and the degree of heat. The heat must not be so great as to scorch, and the fruit must not be dried to hardness. Lastly, they are placed in bags, and preserved in a dry place. 'The second mode of preserving is practised chiefly on the Rous selets and finest-flavoured varieties. Bosc states that he has tried them after three years' preservation, and found them still good; but they are better during the first year. They are gathered a little before their maturity, and after being half-boiled in a small quantity of water, they are peeled and drained. They are next carried on hurdles to the oven, after the bread is drawn, or the oven is heated to a suitable degree; here they remain twelve hours; after which they are steeped in the syrup, to which have been added sugar, cinnamon, cloves, and brandy. They are again returned to the oven, which is now heated to a less degree than at first. This operation is thrice repeated, until they are sufficiently dried, or of a clear brown colour, and firm, transparent flesh; and finally they are packed in boxes lined with paper. (Kenrick's Orchardist.)

PEAT. A collection of vegetable remains, commonly collected together in considerable masses, either on the surface of the earth, or in strata, at various depths. Owing to the changes which the plants composing it have undergone, it contains much tannic acid, which preserves the vegetable matier from further decomposition. It contains elements for the formation of the richest manure when substances are added to it to decompose the tannic acid, and hasten the decomposition of the vegetable matters, such as lime or marl. Peat has been found, when used alone as marure, not to possess any fertilizing qualities, as might be expected from its nature; but it has been advantageously employed as a mixture with compost. See Fan-Yan Mavine.

It often happens that in extensive agricultural districts at a distance from cities and other places from which they might obtain supplies of animal manures, the domestic resources of the farm-yards are entirely inadequate to preserve the fertility of the extensive fields. It becomes a question of deep interest whether it be possible to enrich barren fields without the aid of animals and the resources of the farm-yard. Under the head of FAr Yarn Mavures it will be seen that by Lord Meadowbank, Mr. Dickson, and other English agriculturists of high reputation, one load of dung has, by judicious mixture with peat and other matters, been made into six loads of manure, possessing equal fertilizing power.

The regular peat formation of geologists, so extensive in Britain, can hardly be said to exist in the United States. But a substance is found in abundance in bogs and marshes throughout the Union, sufficiently analogous in composition to answer most, if not all, the valuable purposes of European peat.

Dr. Samuel L. Dana, of I_owell, Massachusetts, has published a work of the highest interest to agriculturists, under the title of $A$ Muck Manual for Farmers. After treating of the various matters relating to soil, its elements, and the agencies brought to act upon it, he introduces, under the head of Artificial Manures, chiefly consisting of geine, the subject of swamp-muck, mud, or peat.

Peat, he states, is the result of a spontaneous change in vegetable matter, which ends in the production of geine, a term which he applies to designate humus and humic acid. Among manures, consisting chiefly of geine, peat, he says, is what bone-dust is among manures, consisting of animal matter. Peat is highly concentrated vegetable food. Under the general name of peat, Dr. Dana comprises several varieties, distinguished as, 1st. Peat, the compact substance generally known and used as fuel, under this name. 2d. Turf, or swamp muck, by which is to be understood the paring removed before the peat is dug. It is a less compact variety of peat, common in all meadow swamps, and includes the hassocts or tussacks. It includes also the mud of salt marshes. 3d. Pond mud, the slushy material found at the bottom of ponds when dry, or in low grounds, the wash of higher lands. This seldom contains more than 20 per cent of geine. These varieties comprise probably a fair sample of all the peat, and swamp muck, and pond mud, which occur in the various parts of the country. Dr. Dana has given analyses of 12 specimens representing the different va 
rieties, the average of the 10 best being per 100 parts, dried at a temperature of $300^{\circ} \mathrm{Fah}$ renheit,-by which process it loses 73 to 97 per cent. of water:- soluble geine, $\mathbf{2 9 . 4 6}$; insoluble geine, 55.03 ; total geine, $85 \cdot 39$; salts and silicates, 15.59 . The poorest varieties of pond mud gave only 5 to 8 per cent. soluble geine, 6 to 9 per cent. insoluble geine, or about 14 per cent. total of geine, and 85 of salts and silicates.

When fresh-dug peat, of average quality, is analyzed in its wet state, it is found to contain :-

\begin{tabular}{l} 
Water - $-\quad-\quad-\quad-85^{\circ}$ \\
Salts of lime -50 \\
Silicates - -50 \\
Geine - -50 \\
\hline $100^{\circ}$ \\
\hline
\end{tabular}

It is an interesting fact that this result differs very little from the result of the analyses of fresh cow dung, so far as the proportions of geine, water, and salts are concerned.

When allowed to drain as dry as it will, pond-mud still contains about two-thirds of its weight of water. It shrinks from two-thirds to three-fourths of its bulk, a cubic yard wet becoming one-fourth to one-third of a yard when dry.

A cord of pond mud weighs, when dug, 6117 lbs., and contains solid matter, $3495 \mathrm{lbs}$.; com. posed of geine, $495 \mathrm{lbs}$; of silicates and salts, 3005 lbs.

The salts and geine of a cord of peat are equal to the manure of one cow for three months. It is certainly a very curious coincidence of results, that nature herself should have prepared a substance, whose agricultural value approaches so near cow dung, the type of manures. The power of producing alkaline action on the insoluble geine, is alone wanted to make peat good cow dung:

The great question comes, how is to be given to peat, a substance which in all other respects is so nearly allied to cow dung, that lacking element, ammonia, without which cow dung would be no better than peat, nay, not so good, since in peat nearly one-half of the geine or humus is already in a soluble state. It is well understood that the various matters used as manure, either solid or liquid, from whatever source derived, all possess a common property of generating ammonia. Peat in its ordinary state contains traces of ammonia, which is evolved freely on the addition of caustic potash or common ashes. Peat, then, is a source of nitrogen, since this with hydrogen constitutes ammonia. Without going into all the nice chemical reasoning of which Dr. Dana avails himself, we will simply state his main conclusion, namely: that by the addition of alkali to peat, it is put into the state which ammonia gives to dung.

With regard to the quantity of alkali required to be added to swamp-muck or peat, in order to. bring it to an equality with cow dung, "It in found," says Dr. Dana, " that

52 parts of ammonia are equal to 58 parts of soda, or white ash, or to

72 parts of 1st quality pot or pearlash, or

A6 paris of 2 d quality pot or pearlash. 884
For all agricultural purposes, it may be con. sidered, that salts of hartshorn, or carbonate of ammonia, and white or soda ash, are equal, pound for pound, and that pots and pearls may be taken at one-half more.

"If all the nitrogen in dung becomes ammonia, then each $100 \mathrm{lbs}$. affords $2 \mathrm{lbs} .2 \mathrm{oz}$. Hence, if to $100 \mathrm{lbs}$. fresh-dug peat, there are added 2 lbs. of soda ash, or $3 \mathrm{lbs}$. of pot or pearl ashes, all the good effects of real cow dung will be produced. Peat or muck thus requires 2 per cent. of soda ash, or 3 per cent. of potash.

"A cord of green peat weighs 9216 lbs.; 2 per cent. is 184 lbs. Hence, a cord requires that amount of soda ash, or $276 \mathrm{lbs}$. of potash. But if the peat is quite dry, so as to have lost $\frac{3}{4}$ of its bulk, then 736 lbs. of soda ash, or $1104 \mathrm{lbs}$. potash will be necessary. Two per cent. of alkali seems enormous. It is stated, in the hope that it may lead to experiments on the free use of alkali. But as it will be hereafter shown, that this is to be reduced by mixing with loam or other matter, this quantity, even if applied to one acre, will probably produce very good effects.

"There are other practical facts, which may help to a solution of the question, how much alkali is to be added to a cord of peat. According to the experience of Mr. Phinney, of Lexington, an authority which may not be questioned, a cord of green dung converts twice its bulk of peat into a manure of equal value to itself-that is, a cord of clear stable dung, composted with two of peat, forms a manure of equal value to three cords of green dung. Indeed, the permanent effects of this compost, according to Mr. Phinney, exceed those of stable dung. On this fact, $2 \mathrm{lbs}$. of ammonia in $100 \mathrm{lbs}$. of cow dung, should convert $200 \mathrm{lbs}$. of fresh-dug peat into good cow dung. The equivalents of these, as has been shown, are $2 \mathrm{lbs}$. of soda ash, or $3 \mathrm{lbs}$. of potash. Allowing the gaseous ammonia to be divided equally among the 300 lbs. of dung and peat, this is in proportion of $10 \frac{2}{3} \mathrm{oz}$. of soda ash, or $1 \mathrm{lb}$. of potash to $100 \mathrm{lbs}$. of fresh peat. Now this calculation, deduced from actual experiment, confirms the theoretical proportions, supposing only $\frac{1}{3}$ of the nitrogen acts, though that was made before the author met with the statement of Mr. Phinney."

Dr. Dana furnishes another striking evidence of the favourable results from applying artifcial manure. "Mr. George Robbins, of Watertown," he says, "is an extensive manufacturer of soap and candles, and of starch, and, still better, a man who employs the refuse of those trades in enriching and gladdening his land. For four years (and it is believed his crops will compare with any of the best cultivators around him) he has not used a spoonful of manure made by any animal, walking either on two legs or on four. He keeps 11 horses, 4 cows, 100 hogs; he uses not a shovelful of their manure, but, selling that, he uses peat and swamp-muck, mixed with his spent barilla ashes. The proportions are, 1 part of spent ashes to 3 of peat, dug up in the fall, mixed in the spring. After shovelling two or three times, it is spread and ploughed in. The effect is 
imediate, and, so far, lasting. The effects of this spent ashes alone on sandy loam, are excellent; it makes the whole quite 'salvy."

"In the preparation of manure," says Dr. Dana, "price is every thing. Let the cost be estimated per cord, of artificial manure, prepareil in the proportions stated. Peat or muck may be called worth 50 cents per cord, and the labour of digging, say $\$ 1$.

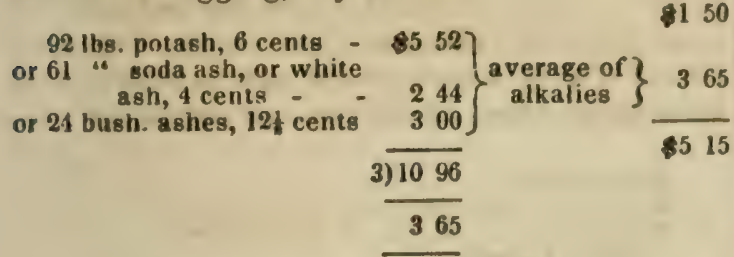

"Were they really good hard wood-ashes, about 16 bushels would be sufficient, but an excess here is allowed, to compensate for variation in quality. But this may appear a very high price; but it is to be remembered, that its value is to be compared with that of a cord of clear cow dung. What is the value of cow dung? It appears from the barn account of the Merrinack Manufacturing Company, that for 94 years, ending October, 1838, a bushel of clear cow dung costs $21 \frac{1}{3}$ cents. During the same time dung of inferior quality was delivered at the printworks, by the neighbouring farmers, at 20 cents per bushel. Clear dung is delivered at the printworks in Dover at $12 \frac{1}{2}$ cents per bushe!, and at several of the printworks in Rhode Island, ai 16 cents per bushel, giving an average of $\mathbf{1 7 \cdot 4 5}$ cents per bushel, and as a cord contains, in round numbers, 100 bushels, its price is

Doduct from this the price of an artificial cord,

$\$ 1745$

$\$ 1230$

"It is hence evident that an artificial cord is only about one-third of the price of a natural cord, and if the last may be mixed with two parts of loam or swamp-muck, so may the first, which will reduce the price of a cord of artificial manure to $\$ 271$. Now this is equal, according to all experience, cord for cord, to stable manure; the value of that may be estimated at $\$ 5$, so that an artificial cord costs only about one-half. The best plan for preparing the artificial manure, would be to dig the peat or swamp-muck in the fall; in the spring of the year let this be mixed in the proportion of 30 lbs. of potash, 20 lbs. of soda ash, or 8 bushels of common house-ashes, to every cord of freshdug peat, estimating this by the pit dug out, and allowing nothing in the spring for shrinking. If ashes are used, they may be mixed in at once with the muck, but if soda ash or potashes are used, they must be dissolved in water and the pile evenly wet with the solution. The pile is then to be well shovelled over, and used as is other manure. But it has been found by experience, that the peat may be dug in the spring, immediately mixed with the alkali, and used forthwith. If spent ashes are used to prepare this muck, add one cord of spent ashes to three cords of peat or swamp muck.

"There are other sources of alkali, for converting peat into soluble manure.

of these the chief is animal matter. Her, we have an. monia produced. It has been actually proved by experiment, that a dead horse can conver 20 tons of peat into a valuable manure, richer and more lasting than stable dung; a barrel of alewives is equal to a wagon load of peat The next great and prolific source of ammonia is the urine. The urine of one cow for a winter, mixed up, as it is daily collected, with. peat, is sufficient to manure half an acre of land with 20 loads of manure of the best qua. lity, while her solid evacuations and litter, for the same period, afforded only 17 loads, whose value was only about one-half that of the former.

"It need only be added in corsfirmation of all that has been advanced, that those who have had the prudence to fill their yards and hogpens with ineadow-mud which has thus he. come saturated with ammonia, have in no wise lost their reward. If they have been satisfied with their prac:ice, perhaps they will be no less firm in their belief of success, when science offers them a reason for the faith that is in them. (Muck Manual.)

PEAT SOILS. The improvement of peat soils is a subject ci very considerable agricul tural importance in England, where it involves not only the permanent improvement of large estates, but these peat soils include a very large proportion of several counties in the United Kingdom.

The deep peat mosses, or bogs, which are naturally the most difficult to bring into culti vation, often extend to a depth of ma.xy feet, contain but little earth, are usually tolerably level, and consist of a mass of light vegetable fibres. 'This peat, even in the midst of summer, is commonly saturated with wate.; at other periods semi-fluid, and very often a trembling, dangerous quagmire. Its soil, if I may call it such, is usually of a dark brown, chal.g. ing to a blackish colour when thoroughly drit d by a gentle heat. In this state the peat is easily inflammable, is commonly used for fuel, and has been occasionally employed by the gas manufacturer, the lime-burner. the charcoa! maker, and even the iron-smelter.

The common masses of peat existing on the earth's surface in England are the products of the decay of the mosses, common heath-plants coarse grasses, and the sedges which often accompany them. But the varieties of peat are numerous, according to their age and situ ation. 'There are some of the peats which are found beneath the soil, in the lower portions of the valley of the Thames, which are evidently the remains of considerable masses of under wood, and contain sulphate of iron. Many others, dispersed over the coast of Fssex and in Ireland, abound with the remains of large forest trees, and were most probably produced by some great convulsion of the earth in a dis tant period. In the southern counties, except in those of the banks of the Kennett and the Thames, the depth of the peat has not often exceeded a few inches; but in the places mentioned, and in those in the northern countics. the depth generally extends to severai feet.

The formation of bog-moss is first com menced in very many instances liy the rapid 


\section{PEAT SOILS.}

growir.g broad-leaved bog-moss (Sphagnum latifolium), a plant of very curious habits, whose growth under favourable circumstances (and it is strictly an aquatic) extends from an inch in leugth to $\mathbf{2}$ or $\mathbf{3}$ feet. In dry situations, or in those nnly periodically flooded, its progress is not rapid; but when it vegetates always immersed in the water of low, stagnant situations, there it increases with great vigour. It is true that this plant is an annual; but it sheds an abundance of hardy seeds, producing seedlings, which vegetate and easily support themselves in the water, with a slight assistance from the mere remains of their preceding generation. Their thread-like stems remain on the surface of the water till the seed is ripened; they then fall to the bottom and form distinct layers, which, in some specimens of peat, may be distinctly traced. The bog-moss thus commenced, gradually gets mixed with a variety of lichens, mosses, and scirpi, which annually add to the depth of the accumulating peat; and as the moss becomes firmer, other plants gradually establish themselves, such as several varieties of the rushes and sedges. It is only when the peat-moss is raised by the graduallyaccumulated remains of these peats from beneath the surface of the stagnant waters, that the heaths, the cranberry, the bilberry, and the grass-weeds make their appearance. The few plants which commorly tenant peat moors and bogs are of the most worthless kind, such as all live-stock commonly refuse. Besides the common heath-plants there are various rushes (Juncus), sedges (Carex), rush-grasses (Schoenus), club-rushes (Cyperus), cats'-tail rushes (Typha), bur-weeds (Sparganium), \&c.

Amongst the few specimens of the common grasses which are found in such places, strugg!ing, as it were, for existence, are the marshbent (Agrostis palustris), the awnless brownbent (Agrostis canina). This is a very common grass in bogs whose winter waters are deep. The awned creeping-bent ( $A$. stolonifera var. aristuta), the small-leaved creeping-bent ( $A$. sto. ung.), the black couch-bent ( $A$. repens), the white bent $(A . a l b a)$, the flote fescue (Glyceria fluitans), tall fescue (Festuca elatior), turfy hairgrass (Aira cospitosa), knee-jointed fox-tail grass (Alopecurus geniculatus), water hair-grass (Aira aquatica), water meadow-grass ( $P$ oa uquatica), long-leaved cotton-grass (Eriophorum polystachion), and the sheathed cotton-grass (E.vaginatum).

It is of primary importance that the farmer should clearly understand the chemical composition of the peat with which he has to contend, and that of the watery solution with which it is usually saturated. The common varieties of peat, when died by a moderate heat, lose a very considerable portion of their weight, and are materially reduced in bulk. The dry mass consists chiefly of woody fibrous remains of a dark-brown colour, of which a very inconsiderable portion is soluble in water; and even by exposure to the unassisted action of the sur and air, under the most favourable ircumstances, it decomposes with extreme lowuess. When burnt to an ash, the solid frrculuct thus obtained, varies commonly in its inmposition with the nature of the stratum of $\times 86$ earth on which the mass of peat rests. If th is of a gravelly or argillaceous nature, the ashes are generally composed chiefly of silex, and a small portion of alumina, oxide of iron, with some carbonate of lime and sulphate of iron: if, however, the substratum immediately under the peat is calcareous, then the ashes commonly yield a considerably larger proportion of carbonate of lime, the sulphate of iron (green vitriol) is absent, and the sulphate of lime (gypsum) abounds in its place. 'The celebrated Dutch ashes, which are productive of such large crops of clover, are composed of-

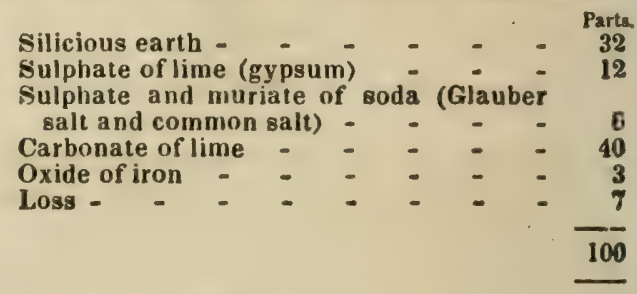

The liquid with which peat is usually soaked is also equally varying in its composition. It almost always contains a very small portion of brown vegetable extract, a quantity of the red oxide of iron, and when pyrites (sulphur and iron) are contained in the gravelly or other substrata, these are gradually, by the action of the water and the oxygen of the at mosphere, converted to sulphate of iron, whice. dissolves, and is found in the water. When however, this solution comes in contact with chalk or other calcareous matter, the lime decomposes the green vitriol, the iron is precipitated, and sulphate of lime, so enriching to some of the artificial grasses, is very com. monly found with red oxide of iron, dissolved in the peat-water.

The chemical composition of peat soils of course varies in the proportion of their constituents. The following analysis of a specimen of an entirely barren peat moss, in a perfectly dry state, will give the farmer a tolerable idea of their general composition:-

\begin{tabular}{|c|c|c|c|c|c|c|}
\hline Fine silicious & sand - & - & - & - & - & $\begin{array}{l}\text { Parta } \\
29\end{array}$ \\
\hline Inert vegetab & e matter & - & - & - & - & 289 \\
\hline Alumina. & $-\quad-$ & - & - & 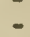 & 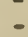 & 14 \\
\hline Oxide of iron & - & - & - & - & - & 30 \\
\hline \multicolumn{7}{|c|}{ Soluble vegetable matter, with some sul- } \\
\hline phate of pot & ash - & 3 & - & - & - & 11 \\
\hline \multirow{2}{*}{$\begin{array}{l}\text { Sulphate of lin } \\
\text { Loss - }\end{array}$} & me (gypse & & - & - & - & 12 \\
\hline & - & & - & - & - & 15 \\
\hline
\end{tabular}

Such is the composition of a barren peat moss. The analysis of an active or fertile peat moss, with which it will be well to compare it, gave the following results, after being also dried in a gentle beat:-

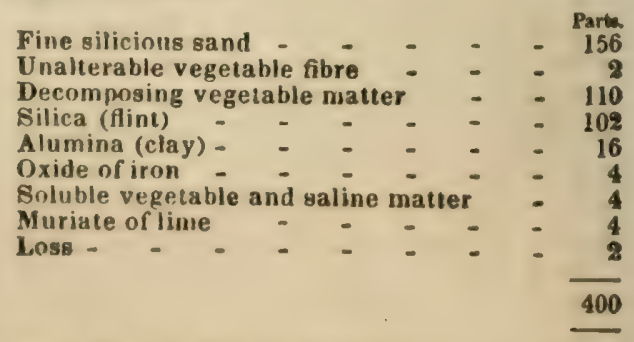

Such is the usual chemical composition of peat. This, however, is occasionally varied 
by the presence of other substances, but the above sketch will afford a tolerably correct view of its ordinary properties; and this kind of knowledge will very materially aid the farmer in proceeding to examine the mode in which the composition of such soils may be altered so as to be rendered tenantable by useil varieties of plants.

The must common delusion in which the possessors of peat soils are apt to indulge, is the belief in the possibility of rendering them permanently productive withotiteither previous drainage or the application of earth. The melancholy attempts of this kind which I have witnessed on the peat land of various parts of England, especially in timber planting, can only excite the pity of those who witness the effects of such misspent time and money. The young trees too, which are most commonly employed in these ill-judged attempts, are usually of the fir tribe, precisely the kind the least adapted to prosper in a bog of water and peat. Common reflection would suggest that, if any kind of trees could be expected to vegetate with even moderate vigour in soils such as these, composed as they are often of merely a mass of hard inert vegetable matters, saturated with a weak solution of green vitriol-if any kind of plantations would progress, it would be the alder, the willow tribe, or the hardy birch tree, tenacious of life, which can endure more moisture and subsist on poorer soils than most other plants. After the slightest consideration we should hardly decide upon placing on such swamps trees which delight in dry upland slopes, as the Scotch fir and the larch; yet we can hardly traverse a single line of railway, driven as their constructors have too often been to take for their line of country the most trembling, dangerous bogs, the most worthless heaths, without being struck with the ludicrous appearance of bright yellow-topped larches and ragged, sickly-looking Scotch firs, soaking in bog-water-and that too not in mere patches, but over hundreds of acres. I do not confine these observations to the north of England-to Lancashire and Yorkshire-but the remark applies to many of the southern counties: for instance, by the road-side between Wareham and Poole, in Dorsetshire, may be seen similar wet, peaty, heath plantations of Scotch firs.

In effecting the underdraining of peats, the first error to be carefully avoided is placing the drains too near the surface. I have invariably found in deep peats, that where the drains cannot be placed beneath the peat, they should be canstructed at least at a depth of from 4 to 6 feet or even more; and this is not adding materially to the expense, for the peat-owner will find that one drain at the depth of 5 or 6 feet will produce more powerful and far more permanent good effects than three drains at a depth of three feet. The good results of depth in peat-land drainage will be found by the farmer years after the soil is reclaimed-for, as the peat is dried and its upper portion decomposed and rendered solid by cultivation, the mass of peat gradually and very materially sinks, and this too in deep peats for a lengthened period. And as this contraction is chiefly confined to the upper portion of the peat the resu.t is that the improving soil of the surface gradually approaches the drairs, and that in some varieties of the softer kinds of peat in a very injurious extent. Such too is the porous. spongy nature of most peat soils, that it is difficult to remove entirely the water from those portions of them lying on a level with the sides of the drains, and in consequence the roots of many cultivated crops are apt to penetrate, under the shallow-drain system, into the corrosive water of the peat, which they never do without material injury.

For let me again remind the farmer, it is no: the mere presence of too much water which renders the peat moss sterile, but the noxious. astringent, irony quality of that water.

In the reclamation of peat soils, the necessary drainage being effected (see Dnaisivo) the next important object is to furnish the soil with a sufficient quantity of earthy matter to support vegetation, and this may be done in several ways: that by paring and burning, so common in various parts of Cambridgeshire and Lincolnshire, I consider the worst of all modes; for it merely furnishes the soil by an expensively rapid progress with the freed earths of the peat, which its gradaal decomposition would by other modes more profitably and steadily effect.

The first operation after the water has been drained off is to break up as deeply as possible, by the common and the subsoil-ploughs, the surface of the peat; and then, if good wellburnt lime can be procured, there is no earthy addition so rapid and so powerful in dissolving and rendering pliable the peat as this. A few ploughings, assisting the combined operations of the atmosphere and the lime, will, in a few weeks, bring the soil into such a state as to enable it to bear a first crop. The quantity of lime should be about 250 or 300 bushels per acre; but the quantity of necessity must vary with the readiness with which the lime is procurable; where it is very expensive, the cultivator is obliged either to reduce the quantity, or mix it thoroughly with a proportion of clay or marl before he spreads it over the surface of the peat. Where limestone is to be obtained in the immediate neighbourhood, and other fuel is not to be readily procured, peat may be employed in many cases in the process of lime-burning without much difficulty, it chiefly requiring that the peat should be thoroughly dried previous to its being used. For a first crop on the thus so far reclaimed peat soils, I have found no other crop equal to potatoes. These are best planted in ridges; the horse hoe-plough can then be easily kept at work, which not only considerably promotes the decomposition of the peat, by facilitating the in troduction of the moisture and gases of the at mosphere, but this very operation adds very materially to the vigour and produce of this valuable root, than which no other plant more delights in fresh soils, such as that produced by well-drained, fresh earth-dressed peaty lands.

It is well to avoid for a year or two all attempts to produce grain crops on 'and like that I am describing. The course of crapping which the farmer will almost always find the most profitable, is to follow the potatoes with 
peas, then turnips, oats, grass-seeds, peas, wheat. In all cases, ton, he must remember in what small proportion some of the essential ingredients of his crops are at first existing in this peaty soil, and how valuable even a slight dressing of clay or marl will be found in supplying such deficiencies.

And, again, it is here that the services of the manure-drill are available to an invaluable cxtent in applying bone-dust, or any kind of organic or even earthy manure, especially tc the young land's earliest crops. For the natural results of the progress of cultivation, the gradual decomposition of the soil and tough vegetable remains, the accumulation of more easily decomposable vegetable matters, the application of the ordinary farm-yard compost, finally sufficiently enrich the ground with those salts of lime and of potash which form the essential ingredients of all fertile land.

To expedite the accumulation of decomposing soluble matters in the soil, several expedients may be adopted. For instance, if the farmer has access to night-soil, an admirable compost may be made by mixing this seven or eight weeks previous to its employment with the peat itself. I know of no other compost so powerful on peat soils as a compost of wellputrefied peat and night-soil: 4 or 5 cubic yards of the night-soil is an ample dressing per acre with 12 or 15 cubic yards of peat. If the farmer has not access to night-soil, let him substitute farm-yard compost with the peat in a rather larger proportion, or even urine, or the drainage from his farm-yard. This plan, first, I believe, successfully adopted by the late I,ord Meadowbank, is well described by $\mathrm{Mr}$. Dixon, of Heathershow, in an essay for which a prize was awarded to him, in 1839 , by the Royal Agricultural Society of England.

The farmer must, to derive the maximum benefit from this plan, avoid certain errors, which will else materially deteriorate the richness of the compost. He must be careful to have the peat he intends to use dug for some time previously, and exposed in spits to the drying influence of the sun and winds. The peat, in fact, can hardly be employed too dry; and the farmer will find that, if he makes the compost in the dry, warm weather of summer, he may then use more peat in proportion to his farm-yard dung or night-soil, than if he makes the mixture when the temperature of the air is less. In the warm weather of the spring and summer months, the cultivator will find 1 cubic yard of fresh, good farm-yard compost sufficient for 3 or 4 cubic yards of peat; but in colder weather the proportion of peat must be decreased. The farmer will find that the tresher and richer the animal manure, the larger will be the proportion of peat with which it may be successfully mixed. Thus, with the rich semi-fluid mixture from the slaughter-houses of London, with 1 cubic yard of this, 6 or 7 cubic yards of peat may be mixed; and I have found, on several occasions, every reason to agree with Lord Meadowbank and others who have employed peat in this way, that it is very desirable not to mix mure than half the intended proportion of peat 889 at first, but to wait until the fermentation of the mass is somewhat advanced, and the temperature of the peat increased, before the last half is added to the heap. Some persons recommend the addition of a portion of lime to this compost; but this is a plan I do not consider either advantageous or harmless: for the lime combines with, and even partially decomposes, some of the richest portions of the animal matters of the manure; and I have on some occasions suspected, from certain appearances, that it retarded, when thus used, the dissolution of the peat. In 8 or 9 weeks the compost will be ready for use; the peat and dung will be thoroughly mingled together, and the whole heap will have the colour of a dark garden-mould. Of the nourishing quality of this mixture of peat with night-soil or yardmanure, or urine, the farmer will readily convince himself by the fertile effects which it produces; and, when drilled with turnip-seed, the roots of the young plants will be found to encircle the lumps of it, just as they do in the case of crushed bones.

If the possessor of a peat soil cannot well prepare a compost of either night-soil or farmmanure with the peat, he may still furnish his soil with a valuable dressing, by mixing hot lime and peat together, at the rate of 1 cubic yard of the former with 3 or 4 cubic yards of the latter. In this case it is not necessary to dry the peat previously, for the lime readily absorbs the water contained in it, and in the course of 7 or 8 weeks the entire mass is reduced to the state of mould. From some experiments which I have made on a small scale, I have found that the addition of a portion of common salt to the lime, not exceeding 1 part of salt to 3 parts of lime, will still more increase the fertilizing powers of this peat com. post; but my experiments on this head require repetition betore I can confidently recommend this plan for the farmer's adoption.

When once the peat is well drained, a very thin covering of earth will produce much greater effects in forming a solid soil than the farmer may imagine possible: the facility with which roads are made across the extensive deep Scotch peat-mosses and the great Irish bogs, in some degree illustrates the same fact: the bog, when once dried, is found to require only a thin layer of gravel to make an excellent road. It is true that these are apt to tremble pretty considerably under the feet of the plough-horses, but they bear the heaviest carriages with perfect safety, even in places where the bog of peat is of a depth of from 20 to 40 feet.

Peat-moss lands are commonly divided by the deep ditches or channels by which they are drained.

A valuable account of the practice of Eng. lish farmers in the improvement of peaty ground, by Ph. Pusey, Esq., more especially those of Lincolnshire, is contained in the Journ. Roy. Agr. Soc. vol. ii. p. 390.

PECK. A measure of capacity containing 2 gallons, or the fourth of a bushel. The imperial peck contains 554.55 cubic inches. Besides the standard peck, there are in England 
local pecks, which are extremely various: thus he Lancashire peck contains six gallons; but in other counties it is much less.

PEE-TSEE. A species of water chestnut, which grows in the southern provinces of China, in shallow rivers and ponds, with leaves ike a bulrush, and hollow like the stalk of an onion. Its fruit is in the capsule of the root, like the husk of a chestnut.

PENNYROYAL (Mentha pulegium). English pennyroyal. This well known perennial plant is found growing wild in England on wet commons, and about the margins of small brooks. It has a strong acid, and very peculiar smell, and is stimulant and tonic, but less grateful than peppermint. The stems are somewhat procumbent, or quite prostrate. Leaves ovate, scarcely half an inch long, full of pellucid dots. Flowers whorled. Flowerstalks purplish, clothed entirely with very short, dense, hoary pubescence.

Pennyroyal is cultivated in Europe for its use in culinary and pharmaceutical preparations. There are two varieties - the trailing, which is usually cultivated, and the upright. These plants are best grown on a tenacious soil: even a clay is more suitable to them than a light silicious one. It should be moderately fertile, entirely free of stagnant moisture, and consequently on a dry subsoil, or well drained. A wet soil makes them luxuriant in summer, but insures decay in winter.

'They are propagated by parting the roots in February or March, September or October, and by slips or offsets at the same season. The mints likewise may be increased, by cuttings of the annual shoots in May or June, as well as by cuttings of the roots either in spring or autumn. For production of green tops throughout the winter and early spring, the spearmint is often planted in a hot-bed; and more rarely pennyroyal, every three weeks during October and three following months.

The pennyroyal indigenous to North America is the Hedeomu pulegioides, an aromatic annual plant, very different in its habits from the European pennyroyal. It grows in all parts of the country, preferring dry grounds and pastures, where it often scents the air to a considerable distance. (Flora Cestrica.)

PEPPER-BRAND. A disease in grain. See MrLdew.

PEP PE R - G R A S S (Lepidium sativum). rongue-grass. A kind of cress, possessing very pleasant and refreshing qualities, and generally cultivated in the United States for the table. 'The Virginia lepidium, or wild pepper-grass, is an annual commonly found in fields and along road-sides. One or two other species are known in the United States. (Flora Cestrira.)

1'EPPERIDGE. An appellation improperly applied by the descendants of the Dutch in New York, to the tupelo or black-gum. The name more appropriately belongs to the common barberry.

PEPPE R M I T (Mentha piperita). This species differs from the common spear or green mint chiefly in the intensity of its taste and dark colour of its foliage. It is only cultivated for distillation; the essential oil or distilled 112 water enters into various cordial and medical preparations.

PEPPERS. See Capricum.

PEPPER-SAXIFRAGF (Cnidum, the ancient name of orach). These are worthless herbaceous plants.

The meadow pepper-saxifrage (C. silnus) is an indigenous perennial species, with smooth dark-green herbage. The ront is spindleshaped; stem erect, furruwed, sulid, tough, from 1 to 2 feet high. Flowers yellowish or greenish-white, blowing in August and Sep. tember. The whole plant being fetid when bruised, is supposed, in some parts of Norfolk, Eng., to give a bad flavour to milk and butter; but cattle certainly do not eat it, except accidentally or in small quantities. When this herb abounds in pastures, it may be found partially cropped, though generally left almost entire.

PEPPER, THE WALL. See SToxecrop. PEPPERWOR'T (Lepidium, from lepis, a scale, in allusion to the shape of the pods, which appear like little scales). Most of these plants are uninteresting, and none of them are pretty. L. sativum is the well-known garden cress. There are, in England, four indigenous species.

PERCH. In land measure is the fortieth part of a rood, or equal to $30 \frac{1}{4}$ square yards. Perch is also sometimes used as a denomination of long measure, when it signifies the same thing as a rod or pole, being $5 \frac{1}{2}$ yards or $16 \frac{1}{2}$ feet.

PEREN N I A L (Lat. perennes, lasting throughout the year). In botany, those herbaceous plants, the roots of which remain alive more years than two, but whose stems flower and perish annually. Gardeners generally call them herbaceous plants.

PERIWINKLE (Vinca, probably from vinculum, a band; in allusion to the suitableness of the shoots for making bands). These plants are well adapted for covering naked ground in shady situations. Any common soil suits them, and they are readily increased by separating the rooted trailing shoots. The two species indigenous to England are called the greater and the lesser periwinkles.

PERSIMMON (Diopyros Virgmana). This American tree grows in the Southern and Middle States to the height of 6 or 70 feet. The French call it Plaqueminier. It produces an abundance of excellent fruit, abounding in sugar: and somewhat resembling the date.

PHLEUM PRATENSE. See Cat's-tail.

PHOSPHATES. Substances in which piosphoric acid is united with some other matter, such as lime, magnesia, potash, soda, iron, \&c. See Acros. Within a few years past, a class of manures in which phosphate of lime is the most active fertilizing agent, have acquired very great agricultural importance. It includes bones, and the superphosphate of lime prepared from them, urate, guano, \&c., among organic substances, and a mineral called aputite. Phosphoric acid is found in some soils but not in others, its deficiency corresponding with different degrees of sterility. In three specimens of soil analyzed by Mr. Gyde, he detected in 1000 parts of one fertile without inanure, $4 \frac{1}{2}$ parts; in another fertile with manure only $1 \frac{1}{4}$ parts, whilst in the 
third specimen, from a naturally barren soil, he could not detect any phosphoric acid.

Under the hearls of Bones and Acins, will be found much valuable information relative to the important influence excrcised by phosphoric acid upon the growth and fullest developement of plants, with statements of the proportions in which phosphates exist in different grains and other agricultural crops. The extent of the demands made upon the soil for the phosphate of lime, by growing animals kept upon it, have been estimated by $\mathrm{Mr}$. Hayward, a skilful chemist. He calculates the amount of phosphoric acid annually abstracted by the live stock from a farm of 100 acres, to be equal to $413 \mathrm{lbs}$., requiring to produce it $1491 \mathrm{lbs}$. of bones. His estimate is as follows:-

In the bones and flesh of 110 lambs, of $25 \mathrm{lbs}$. each, at 6 weeks old

In 40 year-old sheep, of $90 \mathrm{lbs}$. each

In 4 calves, at 5 weeks old, weighing together $500 \mathrm{lbs}$.

In 4 young cows, forming $135 \mathrm{lbs}$. flesh and $35 \mathrm{lbs}$. of bone each per annum In 2 young horses, gaining the same as the linst

$\begin{array}{cc}\text { Acid. } & \text { Bones } \\ 145 & 537 \\ 210 & 777 \\ 21 & 77 \\ 16 & 23 \\ 21 & 77\end{array}$

Phosphate of lime consists of 59 parts phosphoric acid, and 47 parts lime. The phosphates of magnesia, potash, and soda, are found mueh less extensively in agricultural products than the phosphate of lime, which last seems indispensable to fertility. The chief modes in which the farmer has long been accustomed unconsciously to return this salt to the soil has been, by the use of oil cake for his stock and of crushed bones for manure. In a more recent period the use of guano, of urate, \&c., has been in fact a similar operation. It has been found by Professor Johnston (Trans. High. Soc. 1845, p. 470), that turnips grown upon land dressed with guano contained a considerably larger proportion of phosphate of lime than the turnips grown in the adjoining soil, dressed in the ordinary way, the ashes of the turnips grown with the ordinary farm-yard dung containing $7 \cdot 73$ per cent. of phosphoric acid, whilst the turnips produced on the land manured with guano yielded $19 \cdot 39$ per cent.

Perhaps the most economical plan by which phosphoric acid can be introduced into the soil is through the application of superphosphate of lime, the process of preparing and applying which will be found described under the head of Bones. Of bone-dust, 40 lbs. to an acre, Liebig considers sufficient to furnish the necessary supply of puos phates to 3 crops of wheat, clover, \&c.

(bil or linseed cake is not only valued by Finglish farmers as food for stock, but, as we have rreviously stated, as a dressing for land. It has been usual to attribute its good effects in promoting the growth of plants mainly to the oil; but as this exists in small proportion, and as the effects of oily manures, such as blubber, fish, \&c., only last a single year, whereas those of linseed cake endure for several years, its fertilizing effects must depend upon some other ingredient. In 3 specimens of linseed cake analyzed by $\mathrm{Mr}$. Gyde, he found respectively $12 \cdot 4,10 \cdot 5$, and 8 per cent. only of fatty matters. The ashes or solid portions of 3 varieties of oil cake, examined by Mr. Fromberg, were found to contain per cent. of earthy phosphates: 1st, Gold of pleasure, 40.56 ; 2d, Fnglish cake, 47.67 : and $3 d$, American cake, $38 \cdot 28$, whe ashes constituted of the 890 1st cake 689 , of the $2 \mathrm{~d} 7 \cdot 25$, and of the $3 \mathrm{~d} 6.35$ per cent. of the entire cake.)

The phosphates of lime, marnesia, soda, \&c., which abound in the urine of man, the swine, and other omnivorous and carnivorous animals, are not met with in that of the ox or horse, which last discharge all their phosphates with the solid excrements. The superpliospluate of lime, as prepared for sale, ought to contain, when genuine, in 100 parts, according to Mr. Pusey, phos. phate and biphosphate of lime 35 to 40 ; Sulphate of lime or gypsum 20 to 25 ; animal matter 20 ; water 20 parts. It has often, however, other substances mixed with it which reduce its value, and of these plaster of Paris is one of the most common. Its price in England is about 7 shillings, or $\$ 1.75$, for $112 \mathrm{lbs}$.

In an experiment where about $6 \mathrm{cwt}$. of superphosphate of lime was applied to wheat, ploughed in at the time of sowing, the produce on the acre was over 53 bushels of $61 \mathrm{lbs}$. each; whilst an acre sown with 400 lbs. Peruvian guano, the ensuing spring yielded 40 bushels, and the soil without any dressing, about 29 bushels per acre. Hence it appears probable, that weight for weight, it is fully equal as a fertilizer to the best guano.

PIGEON (Columba). All the numerous varieties of this domestic bird, such as tumblers, carriers, powts, \&c., come from one common species - the stock-dove-which derives its name from building in the stocks of trees.

PIGEON'S DUNG. See Dove-Cote and Guano.

PIGGERY. A collection of small sties where hogs or swine are lodged. See SwinE.

PIKE. A word of various signification in different districts. In some counties it is applied to a prong, or what is generally called a fork, used for carrying straw, \&c., from the barn, cocking of hay, \&c. In others it signifies a sort of stacklet or load, cock of hay, \&c. In the midland districts of England it means to glean.

PILE. A sharpened beam of wood driven down into the ground to protect the banks of rivers, or for other similar purposes. Pile is also provincially applied to the breaking off the awns of thrashed barley, and to a blacle of grass.

PILING-IRON. A tool used in breaking off the awns of barley, and sometimes the tails of oats, an operation which with the farmers is called piling barley. See Hummeller.

PILEWORT CROWFOOT. See Crowfoot.

PILLWORT (Pilularia, from pilula, a pill; shape of the heads containing the reproductive organs). The creeping pill-wort, or peppergrass $(P$. globulifera), is in Englanci an obscure little plant, found in dark meadows among grass, especially where they have been overflowed with water during winter. It is perennial in habit, putting forth brown fowers in June and July.

PIMPERNEL (Anngallis). A genus of very pretty, interesting nlants, of easy culture.

PINE TREE (Pinus, from pinos; a Greek word used hy Theophrastus, to designate a nine tree; and some authors derive it from the Celtic pin or myn, a mountain or rock. alluding to the habitat of the tree). This much-esteemed and well-known genus, belonging to the gymno. spermous division of exogens, contains some of the trees of most universal use in civilized society, and which form a very important article 
commerce, both in Europe and America. he genus Pinus is distinguished from the firs, the leaves being needle-shaped and grouped pairs, or in three, four, or five together; held, it were, together by a sheath at their base. ost, if not all of the species, are highly derving of culture, being very ornamental and autiful in every stage of their growth. They ill succeed on almost any kind of soil, but to ing the timber to its greatest state of perfecn, a somewhat loamy surface soil and a cool bsoil are requisite. Young plants may be tained by a variety of methods. All the spees may be propagated by layers, by inarching nearly allied kinds, and by herbaceous afting; many may also be increased by cutigs, but the speediest way is by seed, and hich process I shall briefly notice. In some the species the cones attain their full size e first year, but in most not till the end of the cond autumn. The cones of the Scotch pine . sylvestris), and those allied to it, open of emselves shortly after being gathered from e tree, and spread out in the sun; but the nes of $P$.pinaster, $P$. pinea, and similar kinds, not, though treated in the same manner; and en their scales only after several months. ae seed should be sown on a finely-prepared ther sandy soil, in March or April. The seeds the most common kinds are always sown beds, and after being gently beaten down e slightly covered with light soil.

There are upwards of fifty species of pines d the appearance of the tree, as well as the ality of the timber, varies with the species d with the situation in which each grows. enerally speaking, the timber is hardest and st in exposed cold situations, and where its owth is slow. See Fin Tres.

PINE, THE GROUND. See Bugle.

PINK (Dianthus; from dios, divine; and thos, a flowcr, in reference to the fragrance the blossoms and the unrivalled neatness of flowers). A truly beautiful and ornamental nus, containing some of the most prized wers we possess, on account of the beauty $d$ fragrance of their blossoms, and their foge, which is as green and vivid in winter as is in summer. The genus is divided into those th solitary and those with aggregate flowers.

PIP. A disease among poultry, consisting a white thin skin, or film, growing upon or der the tip of the tongue, which hinders the eding. It is supposed to arise from the drink$g$ of foul water, or eating filthy meat; it is ually cured by pulling off the film with the gers, and washing the part with a solution of mmon salt.

PIPE-CLAY. A species of clay abounding Devonshire and other parts of England, emoyed in the manufacture of earthenware. Mixture of Sorls.

PIS'TIL. In botany, the columnar body in e centre of a flower, consisting commonly three parts; viz., the ovary, styles, and stigas. It is one of the essential parts of the wer; and when it is absent the flower is erile. It receives the pollen, and communiites its stimulus to the ovules; without which e seeds are imperfect, and do not germinate. PITCH (Ger. pech). In commerce, the resi- duum which rell.ains on inspissating tar, of boiling it down to dryness. It is a black sulid substance, with a shining fracture, softens at $90^{\circ}$, and becomes liquid in boiling water. It is extensively used in ship-building, and for other purposes. Large quantilies are manufactured in Great Britain, but not sufficient to supply the great demand. 'The duty on importation is 10 d. percwt. In husbandry, pitch signifies a fork-full of hay, corn, or straw, or as much as is raised to the load, stack, or mow, at one time.

PI,ANER TREE (Planera ulmifolia). "Ken tucky, Tennessee, the banks of the Mississippi, and the Southern States, are, says Michaux, the only parts of the American republic where my father and myself have found the planer tree.

"I have more particularly observed the planer tree in the large swamps on the borders of the river Savannah in Georgia. It is a tree of the second order, and is rarely more than 35 or 40 feet high, and 12 or 15 inches in diameter. Its bloom is early and not conspicuous. Its minute seeds are contained in small, oval, inflated, uneven capsules. The leaves are about $1 \frac{1}{2}$ inch long, oval-acuminate, denticulated, of a lively green, and a little like those of the European elm, to which this species bears the greatest analogy.

"The wood of the planer tree is hard, strong, and seemingly proper for various uses; it is probably similar in its characters to the analogous species in the north of Asia, the Siberian elm; but the tree is rare and the wood is neg. lected." (N. A. Sylva.)

PLANKS (Ger. planken; Dan. planker; Fr. planches). Thick strong boards cut from various kinds of wood, especially oak and pine Planks are usually of the thickness of from one inch to four. They are imported in large quantities from the northern ports of Europe, and from several ports of North America. Those employed for making sheds or farm out-houses should be tarred, or steeped in corrosive sublimate.

PLAN'T. In natural listory. See Accrixatation, Botayx, Earths, Gases, Organic Chemistrt, Teyperature, Water, \&c.

PLANTS IN Closely GLazed cases. By the recent discovery of $\mathrm{Mr}$. Ward, of London, that certain plants will grow when enclosed in glazed cases, the most forbilding local circumstances may be overcome, and any person, whether inhabiting the most humble or the most splendid dwelling, provided they are exposed for a few hours every day to the sun's light, has it in his power to rear and cultivato a miscellaneous collection of plants, to enjoy the beauty of their appearance, and to watch their progress through all the stages of their growth, at an expense so insignificant as to be within the means of every one, even in very moderate circumstances; in short, to enjoy, even in rooms heated with anthracite coal, w parlour green-house.

To do this an apparatus must be provided, consisting of a box and a glass roof, such as are used for raising cucumbers, for instance, or more ornamental, as may be desired. The box should be lined in the bottom with zinc to pre vent leakage. The whole should be close, u 
prevent evaporation, and may be painted to represent any description of wood; a hole or holes should be left in the bottom, through the zinc and board, to carry off any extra water, if you find there is too much for the health of the plants enclosed. At the upper edge of the box a groove is sunk to receive the lower edge of the glass roof, which rests tightly upon it.

The frame-work cover should be glazed with good glass, with a door on one side made to fit close, and which may be opened to remove dead branches, for trimming, and the addition or subtraction of plants. Along the top of the roof, hooks or brass rods may be placed, from which small pots may be suspended with brass wires; twine will soon decay in the continued dampness. The whole of the frame-work should be well fitted, so as to preclude, as far as possible, all interchange between the air in the case, and that in the room.

Lay the bottom of the box with pieces of broken earthenware, as an open subsoil. Next lay a stratum of turfy loam, one inch deep, and fill in the remainder of the space with soil, composed of equal portions of peat and loam, mixed with about one-twentieth part of rough white sand, free from iron. The artificial garden plot is now ready to receive the plants. Plant these in the usual manner, and then shower over them, with a fine rose wateringpot, sufficient water to saturate the soil, till the liquid begins to run off by the opening in the bottom. After draining thus for 24 hours, cork up the hole or holes, place the glass case on the box, and the operation will be finished.

The most remarkable part in the economy of the case, thus closed up, is the preservation of atmospheric purity. To all who reflect, for the first time, on this subject, it will seem incomprehensible how the plants can possibly thrive and blossom, without the occasional interchange of fresh air with the atmosphere. This certainly does appear extraordinary, yet it is ascertained by experiment, that no such reinvigoration is requisite; to account for the phenomenon it will be necessary to explain the constitution of atmospheric air, and the means adopted by nature for its purification.

Air consists of three gases in close mechanical union, nitrogen, oxygen, and carbonic acid, in the proportions of about 79 of nitrogen, 20 oxygen, and 1 of carbonic acid, in 100 parts of pure air. In this mixed composition, the essential element for the support of respiration in both animals and plants, and also for combustion, is the oxygen, the nitrogen being little else than a diluent to modify the strength of the oxygen. It was long believed by men of science, that plants possessed the power of exuding oxygen, and so formed a prime agent for restoring vitiated air to purity. Later investigations, however, by French chemists, have made it evident that plants have no such power, unless when placed under the influence of the sun's rays, or, in other words, that solar light is the grand cleanser of the atmosphere, and without which, both plants and animals languish and die. With respect to plants in particular, it is ascertained, that while inhaling oxygen, and expiring carbonic acid, their leaves nos sess the remarkable property, in conjunction $8 ! 12$ with the sun's light, of retransforming the c bonic acid into oxygen. At night, when light of day has departed, the expired carbo acid may be detected in the neighbourhood plants, and hence, one cause of injury to hea by breathing night-air; but when the morn sun again bursts upon the scene, a great $c$ mical process commences in the atmosphe the carbonic acid is decomposed, oxygen evolved, and all nature rejoices in re-creat of its appropriate nourishment.

A question will here readily occur-W species of plants are best adapted for these mestic green-houses? This has been answe ably by $\mathrm{Mr}$. Ellis, in a paper read before Edinuurgh Botanical Society in 1839. Acco ing to this gentleman's statement, the pla most suitable are "those which partake larg of a cellular structure, and possess a succul character, and especially those which h: fleshy leaves; whilst on the contrary, the c tinued humidity is unfavourable to the de lopement of flowers of most exogenous plar except such as naturally grow in moist : shady situations." Plants, therefore, wh grow naturally, and bloom in cavernous : moist situations, or in moist and warm mates, are best adapted for these cases; wit. this class of vegetables there are many bea ful and luxurious plants, which it would be small pleasure to contemplate. We name a few which have eminently succeeded. specimen of this mode of culture may be se in the possession of Mr.J. J. Smith, Jr., Lib rian of the Philadelphia Library, which is e nently successful.

Crocuses, and winter aconite; joy; lyco dium; the various cactuses; aloes; primros the fairy roses; begonias; all the ferns; a mone; musk plants; myrtles ; jasmines, \&

All the vacant spaces in the case may employed in raising salads, radishes, \& "and I think," says Mr. Ward," "that a m would be a bad manager who could not, in course of a twelvemonth, pay for his case of its proceeds."

Sir W. J. Hooker, in a letter to Mr. Wa says, "Splendid as is the hot-house and gre house collection at Woburn Abbey, I do whether that gives more pleasure to the no proprietors and their numerous visiters th the beautiful little collection in $\mathrm{Mr}$. War case, that occupies a table in the library, a flourishes without requiring the skill of gardener in its cultivation." Once prope watered, these cases have remained for sev years without any additional moisture.

The uses to which this discovery of Ward's has led, are important to man; es cially so in the transmission of plants fr one country to another by sea. So admira does il answer to thus enclose plants for s voyages, that few instances of failure have curred in their transmission, where care been taken to renew the glasses, if broken, a to expose the cases to the action of the su rays on deck in fine weather. But, even m important than this, it will enable the chem to make observations strictly comparative the effects of different soils, manures, \&c. determine the powers possessed by plants 


\section{PLANTAIN.}

orbing, and selecting various substances by $r$ roots; to ascertain the existence and naof the deleterious excretions from the $s$; the poisonous character of these excre$\mathrm{s}$, if they exist, being rendered very pronatical by the circumstance of plants, in a e of nature, occupying the same situations ages; to prove the effects of poisons on ats; to test the influence of light in proing plants from the effects of low tempera; and, lastly, by means of these cases the entific naturalist will be assisted in explorthat debatable ground on the confines of animal and vegetable kingdoms, where it ften impossible to determine the point at ch one ends and the other begins.

LAN'TAIN (Plantago; derived from planta, sole of the foot; resemblance in the leaves). enus of plants, the greater number of the cies of which are mere weeds: they are erally almost stemless, and for the most perennial. There are in England five naspecies :-

Greater plantain, or way-bread ( $P$. major), $\mathrm{ch}$ is very common in meadows, pastures, waste and cultivated ground, perennial, in flower all summer. The root consists nany long, stout fibres. The leaves are ical, numerous, broad, with seven or nine , on channelled, ribbed stalks, often longer themselves; margins wavy or toothed. wers on long spilses, small, whitish, with lish anthers, very numerous; the spikes, h on a simple, naked, radical stalk. The Is, which are angular, in a membranous sule, are the food of small birds. The roseped variety and the panicled one are often ivated in gardens for the sake of curiosity, afford remarkable instances of vegetable isformation. This species, like the whole us, in general, is mucilaginous, and someastringent, qualities which render it not gether a useless rustic medicine. Cows horses do not relish this plant, but it is en by sheep, goats, and swine. 'This peren-rooted plant is extensively naturalized in United States, and is remarliable, says Dr. lington, for accompanying civilized man, wing along his foot-paths, and flourishing und his settlements. From this circumace, the American Indians call it by a name ich signifies "the white man's foot."

- Hoary plantain ( $P$. media). 'This species ws abundantly in chalky or gravelly hills. root is rather woody. The leaves are te, downy, all pressed close to the ground, ry, entire, with five or seven ribs. The ry plantain, a great and lasting nuisance in grass-plats, is best killed by a drop of vilic acid on the crown of the root, which it er long survives. Its medical qualities are the former.

Ribwort plantain, or rib-grass ( $P$. lanceo), is also a very common species in meavs and pastures. Pl. 9, $i$. The leaves are nerous, erect, deep-green, acute, each taperat the base into a broad, flat, ribbed foot. $1 k$, accompanied at its insertion with large is of soft, white, woolly fibres. Flowerlks taller than the leaves, likewise woolly at base, five-angled, with intermediate fur-

\section{PLAN'TATIOV.}

rows, nearly smooth, twisted. Spike ovate, an inch long, with black imbricated bractes, ccca. sionally leafy at the base. This species makes a part of most meaduw hay, and has been cultivated as a crop, but seems to be now disused. Cattle are said not to eat it willingly, at least by itself. The total absence of rib-grass in marshy lands is a certain criterion of their in different quality: and in proportion as such soils are improved by draining, this plant will flourish and abound.

4. Sea plantain ( $P$. maritima). This grows in muddy salt-marshes, and about the mouths of large rivers. It is perennial, and flowers in August and September. The root is long and cylindrical; herb various in luxuriance. The leaves are all radical, numerous, from four to twelve inches long, dull-green, linear, channelled, hairy, nearly entire. Flower-stalks round, longer than the leaves, erect, smooth. Spikes cylindrical, slender, many-flowered, dense, with fleshy keeled bractes, not longer than the calyx. Sheep appear to be very fond of this species.

5. Buck's-horn plantain, or star of the earth ( $P$. Coronopus). This is an annual species, which flourishes on dry, sandy, or gravelly ground, flowering from June to August. The root is tapering; leaves pale, hairy, in pinnatifid, pointed segments. Spikes numerous, dense, cylindrical, varying greatly in length, on spreading hairy stalks.

The White, or Virginia Plantain, is a native of the United States, where it is commonly found in barren old fields and stony hills. It has a biennial root, leaves 2 or 3 inches long and from 1 to 2 wide, the whole plant being covered with a gray pubescence or down. Nine or ten additional species of plantain are enumerated in the United States.

PLAN'TAIN, WHITE, see Cunwen.

PLANTA'TION. In England this term is applied to a piece of ground planted with trees for the purpose of producing timber or coppice wood; and the term is also applied to a collection of trees or shrubs placed in the ground for their beauty or usefulness.

For the correct consideration of the best mode of forming plantations of timber trees, several circumstances must, of necessity, be taken in to the planter's account, of which the principal are-1st, The composition of the soil; idly, The trees to which that soil is best adapted; 3dly, The elevation, or inclination of the land: an inattention to these three primary questions has been the source of much waste of time, of labour, and of capital.

In this, as in all researches where vegetation is concerned, nature is ever our best guide and instructor. We find indigenous on the chalks, the beech, the birch, and the ash; the oak tenants the clay formation, the elm delights in rich alluvial bottoms, and in warm, sheltered situations. To the sand is left the fir tribe. the ash, and the birch, whic! last most picturesque tree will endure a c:inate, and vegetate on soils, far too cold and too barren for any other to exist in. On the warm gravels, and on deep, light loams, we find the Spanish chestnut located; and if, on even the peat, we only occasionally meet with a few straggling 
PLANTATION.

mountain ash and Scotch firs, it is not because the composition of the soil is too poor to sustain a better description of timber tree, but that the soil is usually saturated with water, too much impregnated with the salts of iron for any plants to be successfully planted till that corrosive moisture is removed.

Then, again, as regards the temperature best adapted to the tree, much too little attention is commonly paid. The fir tribe are found to delight in dry, cool elevations, whilst attempts to make the larch grow in warm, rich bottoms, generally fail.

These facts should be more carefully attended to by the planter: he should consider the inequalities of his land and the habits of his trees, and distribute them accordingly. Leaving the natives of a temperate climate to the southern and western slopes, he should devote to the northern declinations the natives of a colder clime; to them consign the larch and the Scotch fir, the ash and the birch.

This last-mentioned tree will, in fact, grow at a greater elevation above the sea, and in a more northern latitude, than any other. As we approach the Arctic regions, it is the last tree that remains to us. Long after all others have departed it still flourishes: in Greenland there is no other tree.

Then, again, as in all other questions where plants of any kind are to be made to vegetate, the chemical composition of the soil is a tolerably certain criterion, when compared with that of the wood of trees, to guide us in our selection of the species to which that land is the best adapted: the earths found in them by the chemist are sure to indicate the soils on which they will flourish. Thus, the ashes of the perfect wood of the oak contain more than 38 per cent. of soluble salts, and only 2 per cent. of silica (flint); that of the fir (Abies), grown on granite, only 16 per cent. of soluble salts, and 19 per cent. of silica. Now the fir flourishes very well on the poorest silicious sands, but the oak will not grow on such soils without a dressing of other earths. Car'Jonate of lime (challs), when in excess in soils, is less prejudicial to the growth of trees than an excess of any other earth. Now the carbonate of lime is precisely that earth which is most commonly found in timber trees, and in the largest proportions. The ashes of the wood of the oak, for instance, contain about 22 per cent. of the earthy carbonates, the poplar 29, the hazel 22, the hornbeam 26 per cent.; and that of the beech a still larger proportion. And so almost universally does carbonate of lime and silica exist in wood, that M. Einhof, an able Prussian chemist, came to the conclusion that the plant had the power of forming these earths when growing on soils that did not contain them: they certainly, however, are found to absorb the largest proportion of carhonate of lime and silica on soils in which those earths abound. Thus M. Saussure found in the ashes of the fir, growing on a soil which contained 1.74 per cent. of carbonate of lime, 16.34 per cent. of this earth; but in the ashes of the same wood, produced from a soil conraining 93 per cent. of carbonate of lime, he found 63 per cent. of that earth. And $r$ hen the 894 soil contained $75 \cdot 25$ per cent. of silica, the tim ber growing on it contained 13.49 per cent. but when the soil was entirely free from th earth, it was equally absent from the wood.

The observations of the planter confirm en tirely those of the chemist. Thus, on the poor hungry, heath lands, such as those of Norfolk Surrey, and the north, which contain hardly trace of carbonate of lime, they find that b dressing land intended for planting with chall or marl, the growth of the trees is very mate rially increased; and more recently, as in th forest of Darnaway, in Scotland, the planter have found the greatest advantage from placin only a handful of lime (about four bushels pe acre is sufficient) in the soil under the plants by this means the young trees, they say, ar forced forward, that is, they are supplied wit the carbonate of lime at the very pericd of thei growth when their roots, from want of exten and vigour, are least able to absorb from th soil the portion of this earth so essential fo their healthy growth. And it is precisely suc heath soils as those to which I have alluded a being so materially benefited by the applica tion of lime, chalk, or marl (which also con tains chalk), that are found when examined, their natural state, to be nearly destitute 0 carbonate of lime.

It is for the same reasons that, in the earl state of their growth, timber plantations ar benefited so materially by being manured wit organic matters, a fact well known to thos who plant for merely ornamental purposes and it is because all timber trees contain phos phate of lime in very considerable proportion that crushed bones are found to be so exceller a fertilizer for them; and hence one reaso why it has been long a well-known fact, tha by burying dead animals under trees nearl exhausted for want of nourishment, those tree will almost invariably be considerably revive and send out their shoots with unusual vigour and how essential the presence of phosphat of lime is to their growth, may be judged 0 from the fact, that this salt constitutes 4.5 pe cent. of the ashes of the oak, 35 in those of th hazel, 16.75 of the poplar, 23 in the hornbean 12 per cent. in those of the fir.

These chemical examinations naturally suf port the conclusions to which I have long com in my own experiments, that in all plantation of timber trees, both on the score of profit an of ornament, it is in almost all situations de sirable to assist the growth of the young trees b a small addition of manure. On a large scal this must be chiefly confined to the use of th earths, either lime, chalk, or marl, accordin to their respective local value; and for thi purpose a smaller proportion per acre of an kind of manure is of much greater value tha is commonly supposed. In Scotland they hav found about 4 bushels of lime an abundant ac dition, since they merely mix a handful of thi earth in the soil under each plant; and in th fine woods produced by Mr. Withers, of $\mathrm{H} n$ by spreading a poor marl over his hungr black, heath soil, and then ploughing them very deeply, he merely added about 20 cubs yards per acre.

In preparing the land for plantations, th 


\section{PLANTATION.}

ame chemical examination of its composition vell illustrates the advantage derived by the lant from merely previously stirring the soil, ince it is evident that when the constituents of the young trees are contained in it in only rery limited proportions, in such case the more asily their roots are enabled to penetrate in earch of that necessary nourishment, the more apid will be their growth. Previous trenching f the soil also conduces to the healthy growth f trees in more ways than one. It renders hem less subject to injury from want of moistre in the heats of summer; the atmosphere nore freely finds access to their roots, and not nly yjelds its watery vapour in the warmest veather for their service, but its gases, so ssential to their very existence, are also in a imilar manner more readily absorbed.

$I$ have had many occasions to notice the adantages of deeply stirring the land for timber rees. In my early plantings, my larch and ther timber trees made but little progress, for merely placed them in holes dug in the soil; neither manured, nor in any way prepared he soil. An experiment, however, which I ade some years since-in which, by merely enching the soil with the fork in a clump of arch, Scotch firs, and birch, to the depth of bout 20 inches, the growth of the trees, which ad for several years been extremely slow, was the succeeding years exceedingly vigorousonvinced me of the truth of the observations tade by Sir Henry Steuart, Mr. Withers, and thers, of the great advantages of trenching the oil, either by the spade or by the common or se subsoil plough.

The opinions and explanations given by the bouring woodmen of the cause of the occainial very luxuriant patches in extensive oung plantations accord with these concluions. They tell you that those favoured trees re on a dece, tender piece of land.

'The last branch of the investigation - that the best mode of planting and of expensenow to be considered. Too little attention usually paid by planters in the choice of their lants, the manner in which they have been eared, and in the care of their removal: inead of attending to the acquired habits of the ee, it is a very common practice for the plants be bought of some nurseryman, who has eared them in a warm, rich bottom, and then, s a natural consequence, when the trees are ansplanted to a cold, poor, hungry, exposed oil, a large portion of them are sure to perish, r, if they live, many become stunted or stageaded. That all these evils may be avoided ith only ordinary care, is proved by the exerience of the best planters, who are careful - procure their seedlings from land at least thetter than that on which they are intended be placed; and is further evidenced by the ct that, when the soil is prepared by either ep digging or manuring, or both, then the ortality amongst the plants is very small ined,-they need no further attention, they ually set at defiance the extremes of heat d cold, are very rarely diseased, and shoot th uncommon vigour. This attention to the ry acquired habits of the plant is not entirely imodern observation-the early Italian plant-
ILAN'T'ATION.

ers were careful in replacing the tree in the same position as regards the cardiual points that it occupied in its early growth. (Kirgil, Geo. ii. 269.)

There are other very common errors, of which I have long noticed the ill effects; for instance, the want of care with which the ronts of the young trees are deposited in the earth, and the unnecessary length of time which is suffered to elapse between the period when the plant is taken from the nursery and replanted. I have always found the after good effect of causing the roots of the young plant to be carefally arranged, and spread out before the earth is thrown in upon it; the usually heedless way in which the roots are thrust into the hole, and perhaps broken or materially bruised in the act of treading in the earth upon them, is of necessity very prejudicial to the young plant; and then, again, a still more negligent practice, that of ploughing in the young trees, is too often adopted on a large scale, by which the plants are still more hastily deposited in the soil, and are neither fixed with sufficient firmness in the ground, nor even placed in an upright position. From these causes I have witnessed some very decided failures; and there is certainly no economy in this hasty mode of planting; the trees perish in great numbers; they linger for years without vigour; have to be replaced at a considerable expense; and in the mean time the owners lose'all the advantages which might have been insured from a more skilfully obtained rapidity of growth.

The grouping or mixture of trees is a question which rarely engages the attention of the planter, although it is certain that, like the commonly cultivated crops of the farmer, some trees grow better when mixed with other kinds than when vegetating in plantations of the same species; that they have certain secretions, and excrete matters, both by their roots and leaves, which are noxious to other trees, is certain. Thus the ash, and more particularly the locust, are very obnoxious to most trees. Then, again, the grouping together of certain trees is particularly grateful to them all. Thus, the larch is a very good neighbour; the Scotch fir, the birch, and the Spanish chestnut grow very luxurianlly with it; the oak, the elm, the hazel, and the hornbeam are evidently good neighbours. The Roman planters had remarked this habit of trees. Thus, they believed that the elm was particularly grateful to the vine; and they were so convinced of the existence of what they called the sympathy between them, that they called the elm the husband of the vine. It was invariably their custom to plant them near each other; and as we are indebted to them for the introduction of the vine into England, so hence, in all probability, came with them our first elm trees.

The expense of these different modes of planting is next to be ascertained; it is an inquiry which will well repay the planter. The favourite mode, that of digging a small hole and inserting the tree, is, apparently, attended with the least outlay of money; in some in. stances it has been done for $4 \%$ or $5 \%$ per acre. or even less; but such plantations are veri rarely profitable, - the plants die, or bara! 
vegetate for years, have to be renewed again and again, and the general appearance of the plantation, overrun with weeds, or heath-moss, or furze, is very melancholy. About 40 s. per acre more, bestowed in deep ploughing or subsoiling, will make a strange difference in the rapid growth and consequent early profit of the plantation, and, moreover, save materially the axpense of the trees; for the number of them which perish in land thus prepared for their reception is very small.

In a still greater degree are these good results obtained by the addition of say 20 cubic yards per acre of marl, or clay, or a still less quantity of chalk, according to the nature of the soil, or lime, which may usually be procured for an outlay of less than 30 s. per acre; or of 2 or 3 tons of well putrefied farm-yard manure, a shovelful under each tree, in the manner I have before described. Now, supposing that even all these preparations of the soil are made, the expense per acre will then, in many situations, stand as follows, -

Ploughing deeply 20 cubic yards of marl or clay, or 10 of chalk - $\begin{array}{rr}1 & 10\end{array}$ 3 cubic yards of dung, at $6 s$. - - - 0180

Trees, ploughing, \&c. - - - - - 600

Subsoil ploughing will cost from $24 s$. to 30 s. per statute acre.

If the manure is omitted, as well as the earth and the ploughing, the outlay of 5 s. per acre in lime, in the way I have noticed, will not be without decided advantage. I am quite convinced, therefore, that if all planters were to confine their operations to a less extent of land, and prepare and plant that ground well, they would reap a much earlier and richer harvest from the money expended than they now do from a much greater extent of illplanted, exhausted soil. Such are the facts which I have noticed, in my own practice and that of others, as most necessary to be attended to in rearing profitable, luxuriant plantations of timber trees, on the poorest lands of England; hardly any of whose soils, however, are so barren or so elevated as not to be able to produce, with only reasonable care and expense, an ample return for the capital of the planter. It is a pursuit which is, in more respects than one, worthy of the attention of the landed proprietor, since he not only by his plantations adds to the beauty and income of his own estates, but at the same time yields to the community at large great and important services; its barren wastes are made to produce timber and underwood, the soil is gradually rendered fertile, profitable supplies of labour are afforded, its health is promoted, the very climate by a general system of plantations is ameliorated, for its bleak hills are clothed, its stagnant swamps are drained.

There is an excellent paper "On collecting and preparing the seeds of Forest Trees, the mode of sowing them," \&c., by Mr. Adam, and other planters. (Trans. High. Soc. vol. iii. p. 329.) He advises Scotish planters to collect the seed of tne white larch (Pinus larix) in November, Irom trees of 20 to 40 years of age, at an eleraturn not exceerling 400 feet; that the seed896 bed should be manured with cow dung, wel: mixed with the soil for some time previously to sowing the seed, which should be in April and May; the beds to be 42 inches in breadth, with intervals of 18 inches. The seed should be sown so that each square yard of ground may produce 2000 plants, which in the first year should reach to a height of 5 or 6 inches. Onethird of the plants may be drawn and pricked out in rows at a distance of 10 inches, and the remainder left for another year. The autumn, Mr. Adams thinks, is the best time for forming plantations.

The seed of the Scotch fir (Pinus sylvestris) is gathered in the same way, and, to separate the seeds from the cones, it is necessary to kiln-dry them; about $11 \frac{1}{2}$ quarters of cones produce about $112 \mathrm{lbs}$. of seed. The Scotch fir must stand 2 years in the seed-bed. Oal e are to be sown early in February: the best acorns are to be had in Kent, the brightest and heaviest being the most valuable; they keep very well spread on a deal floor; and may be placed in drills a foot apart, 2 inches deep, to be planted out when 2 or 3 years old. Ash keys are gathered in December or January, and laid in heaps mixed with one-third of their bulk of sand under cover; they should be turned over once or twice in the following year, and thus, after resting for 12 or 14 months, are ready for sowing in March, in drills a foot from each other, and $1 \frac{1}{4}$ inches deep. The seed of the Scotch elm is ripe in June, and should be sown soon after; that of the beech is gathered in September, and sown in the following March or April, in drills $1 \frac{1}{2}$ inches deep. The seeds of the Spanish chestnut are best procured from Spain: they may be sown in February, in drills 4 inches deep. The horse-chestnut seeds are to be sown in October: those of the weeping birch should be sown as soon as gathered, and covered with earth half an inch deep. Those of the lime should be gathered and sown in October. Poplars are propagated by cuttings.

For a description of the advantages of preparing the land for plantations, I would advise the young planter to consult the works of $\mathrm{Mr}$. Withers, the excellent Planter's Guide of Sir Henry Steuart, and the Journal of the Royal Agricullural Sociely of England. And for those who wish to plant in the most simple way at an expense of only 10 s. per acre, see a paper by Mr. Grigor. (Trans. High.Soc. vol. iii. p. 363.)

By this mode, which consists of merely mak. ing a hole, or raising the turf of the ground sufficiently to put in the plants, the estimate is for a Scotch acre (which is equal to 6150 square yards) -

\begin{tabular}{|c|c|c|c|}
\hline 500 one-year transplanted larc & hes & - & \\
\hline 1500 two-year seedling, do. & & - & -3 \\
\hline 500 nne-year transplanted Sco & tch fir & rs & -0 \\
\hline 1000 two-year seedling, do. & - & - & -1 \\
\hline Carriage of plants to the mour & - & - & -1 \\
\hline Expenses of planting 3,500 & - & - & -2 \\
\hline xpens & re & - & -10 \\
\hline
\end{tabular}

See Elm, Fir, Forest, Lanch, OAK, Pine, dec. FLANTING. In arboriculture, the art of forming plantations of trees. Also the art of inserting plants in the soil by the spade, dibble, trowel, or by other means in use in agricu!'ure 
PLANT-LICE.

and gardening. As in the preceding article have gone very fully into the particulars of planting trees, I shall only add in this place the following useful table, showing the number of plants required for one acre of land, from 1 foot to $21 \mathrm{fcet}$ distance from plant to plant.

\begin{tabular}{cc}
\multicolumn{2}{c}{ Distance. } \\
$F t$, & III. \\
1 & 0 \\
1 & 6 \\
2 & 0 \\
2 & 6 \\
3 & 0 \\
3 & 0 \\
4 & 0 \\
4 & 6 \\
5 & 0 \\
5 & 6 \\
6 & 0 \\
6 & 6 \\
7 & 0 \\
7 & 6 \\
8 & 0
\end{tabular}

$\begin{array}{cc}\text { Ii. } & \\ 0 & - \\ 6 & - \\ 0 & - \\ 6 & - \\ 0 & - \\ 6 & - \\ 0 & - \\ 6 & - \\ 0 & - \\ 6 & - \\ 0 & - \\ 6 & - \\ 0 & - \\ 6 & - \\ 0 & -\end{array}$

Number.
43,560
19,360
10,890
6,960
4,840
3,556
2,722
2,151
1,742
1,440
1,210
1,031
889
775
680

\begin{tabular}{rr}
\multicolumn{2}{c}{ Distance. } \\
Ft. & In. \\
8 & 6 \\
9 & 0 \\
9 & 6 \\
10 & 0 \\
11 & 0 \\
12 & 0 \\
13 & 0 \\
14 & 0 \\
15 & 0 \\
16 & 0 \\
17 & 0 \\
18 & 0 \\
19 & 0 \\
20 & 0 \\
21 & 0
\end{tabular}

Number.

PLANT-IICE. See Aphimins.

PLASHING. A mode of repairing or modifying a hedge by bending down a portion of the shoots, cutting them half through near the ground, to render them more pliable, and twisting them among the upright stems, so as to render the whole effective as a fence, and at the same time preserve all the branches alive. For this purpose the branches to be plashed or bent down must not be cut more than half through, in order that a sufficient portion of sap may rise up from the root to keep alive the upper part of the branches. Where hedges are properly formed and kept, they can very seldom require to be plashed; but this mode of treating a hedge is most valuable in the cases of hedges abounding with hedge-row trees, when from neglect, or from any other cause, the hedge has become of irregular growth. See Heners.

PIAASTER OF PARIS, or GYPSUM. One of the common names of the sulphate of lime or plaster stone, which is found abundantly near Paris. When burnt and reduced to powder, and then mixed with water, it forms a firm, sonorous substance, admirably adapted for forming models and casts.

Plaster of Paris or Grpsum, as a MaNunE. It is useless to search in the works of the early agricultural writers for any notice of the employment of gypsum as a manure. It is true that Virgil speaks of the value of a very impure variety of it, when he is commending the use of ashes to the Roman farmers. The early inhabitants of Britain thus used it; the farmers of Lombardy did the same; but ages elapsed before even chemists were able to distinguish this salt from limestone, or other calcareous matter. Its uses, in its simple state as a manure, were first noticed, according to Kirwan, about the middle of the 18th century, by a very able German clergyman, of the name of Meyer, who tried with success various experiments with a mineral substance found in his neighbourhood, which was long afterwards shown to he an impure sulphate of lime. The name of plaster of Paris, by which this substance is commonly known, arose from its abounding in the neighbourhood of that capital, where it was burnt into a powder, and used as a stucco. The composition of sulphate of lime, when pure, is-
PLASTER OF PARIS.

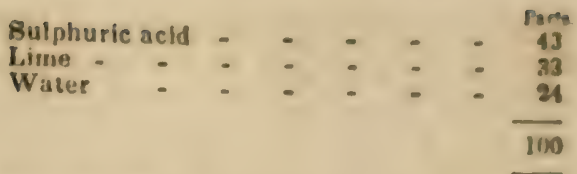

But the gypsum of commerce is usually united with a portion of silica and carbonate of lim:. It is thus combined in its native state. $\mathbf{A c}$ cording to Chaptal and Buchholz, gypsum consists of -

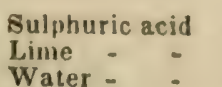

$$
\begin{aligned}
& \text { Parts } \\
& 32 \text { or } 43 \\
& 30 \text { or } 33
\end{aligned}
$$$$
38 \text { or } 21
$$

There is, perhaps, no artificial manure so decided in its effects upon some soils, so readily obtainable by the farmer, and so plentiful, as gypsum. Its mode of action, too, is now easily understood. It acts as a direct food for some plants. There are five commonly cultivated crops which contain gypsum in sensible proportions, and to which, in consequence, it is a direct food, viz., lucern, sanfoin, red clover, rye-grass, and turnips. Now, these are precisely the crops to which the farmer finds, on most soils, gypsum to be a fertilizing topdressing. Wheat, barley, oats, beans, and peas, do not contain a trace of this salt; and the farmer tells you that gypsum is of little or no service to these crops, however the application may be varied. That it does not operate by its attraction for atmospheric moisture, I some time since determined by my own experiments; for 1000 parts, previously dried, when exposed to air saturated with moisture for 3 hours, only gained 9 parts, wile under the same circumstances a good as able soil, worth 2 guineas per acre, gained 14 parts; and when compared with other manures, the disproportion is still greater: thus soot gained 36 parts, and horse-dung 145 parts. That it is not a promoter of putrefaction, I have ascer. tained by mixing this salt with various animal and vegetable substances; it seemed, in every case, rather to retard than promote the spontaneous decomposition of them all. The housewives consider hard water, which commonly owes its properties to the presence of this salt, to be a greater sweetener of tainted food than soft water. Davy, also, in some experiments with minced veal, thought that the addition of the gypsum rather retarded putrefaction.

There is no reason to believe that the proportion of sulphate of lime found in certain plants is as essential to their growth as the presence of the other earthy salts and pure earths. Thus, those plants which yield this salt never grow well on lands which do not contain it; those in which carbonate of lime is found never flourish in soils from which this salt is absent. Plants which abound with nitrate of potash (saltpetre), such as the sunflower and the nettle, always languish in soils. free from that salt; but when watered with as weak solution of it, their growth is very materially promoted, and the saltpetre is then formout in them, as shown, upon analysis, in very sensible proportions. The same remarks apply to the growth of those plants which contain common salt, or phosphate of lime; tha effect is the same, the result invariable. 
Liebig contends that the nature of gypsum consists in its giving a fixed constitution to the nitrogen, or ammonia, which is brought into the soil, and is indispensable for the nutrition of plants. He says, that $100 \mathrm{lbs}$. of gypsum give as much ammonia as $6250 \mathrm{lbs}$. of horses" arine would yield it: $4 \mathrm{lbs}$. of gypsum, he affirms, increase the produce of the meadow 100 lbs. The decomposition of gypsum is slow, which, he says, explains the reason why the action of gypsum lasts for several years. See Ammoxia.

I have noticed, in applying gypsum to grasses, that the weather, at the time of spreading it, has a very material influence upon the result of the experiment. Its effects are never soon apparent when it is sown in dry weather; but if the season is damp, so that the white powdered gypsum adheres to the leaves and stalks of the young grass, the good effect is then immediate. This observation was made many years since by Arthur Young, by Mr. Smith, and by the American farmers: it is a well-known fact with the sainfoin growers, of the Berkshire and Harnpshire chalk formation; the cloter cultivators of the gravels and loams of Surrey and Kent; and on the lucern grounds of the alluvial soils of Essex and Middlesex. The farmers of the United States, when dressing their clover or turnips with gypsum, always found it answer best when spread in rainy weather.

The result of the analysis of the clover and sainfoin grasses shows that an ordinary crop of these usually contains from $1 \frac{1}{2}$ to $2 \mathrm{cwt}$. per acre of sulphate of lime. Now, this is precisely the proportion of gypsum which the best cultivators find to be attended with the maximum benefit; those of Kent and Hampshire find it useless to apply more; but then they all agree that the annual repetition of the dressing, as long as the grass is suffered to remain on the ground, is attended with renewed benefit. It is here again that the experiments of the chemist and the farmer mutually confirm and illustrate each other; the very quantity of sulphate of lime which the first shows to be carried off the land in the clover, is precisely that which the latter returns to it in his dressings with gypsum.

One of the chief reasons why gypsum has not been universally employed by all cultivators of the artificial grasses, arises perhaps from the fact that many good soils naturally contain sulphate of lime in sufficient abundance for the service of the plant; and, in consequence, to such lands the application of gypsum is useless-it is an attempt to supply a deficiency which due not exist. I have invariably found in those soils to which gypsum is not a manure an abundance of this salt. It is not, however, necessary for the farmer to have his soil analyzed to determine the probable advantages of applying gypsum to his clover and other grasses; there are several easy observations which will readily indicate to him the nature of the case. Thus, when he finds that those fields which once produced luxuriant crops of res? clover or sainfoin will no longer yield them in abundance; if he notices that the voung plants soring up very numerously, but 898 die awa as the summer advances; if he finds that his fields will only grow clover success. fully once in 8 or 12 years, and that his neighbours tell him his land is tired of clover, or "clover-sick ;" if he notices that even the application of farm-yard compost hardly adds to the luxuriance of his grasses; he may then safely con. clude that his crops have gradually exhausted his land of sulphate of lime; and he may, with every confidence of success, apply a dressing of gypsum, at the rate of $2 \mathrm{cwt}$. per acre, taking care to choose a wet morning for the application; and this may be done at any season of the year, but it is best either in April or the first days of May. These facts I can attest from the results of my own observations and experience. In an old grass paddock, of about 70 acres, in the vale of Kennett, in Berkshire, the grass had for many years gradually become less and less productive, and this in spite of all kinds of applications; the earths (such as clay and chalk), farm-yard compost, \&c., had been liberally and repeatedly spread, without producing any thing like a luxuriant crop: but it was found at last that the peat ashes of the banks of the Kennett, when spread at the rate of about 40 bushels per acre, produced the very best results, an excellent crop, both in weight and in colour; certainly more than a ton of hay per acre beyond what the soil yield. ed before. The fact was now evident that it was gypsum that the soil needed; for as these peat ashes contain about $12 \frac{1}{2}$ per cent. of sulphate of lime, more than $2 \mathrm{cwt}$. of gypsum was conveyed into the land in them; it constitutes, in fact, by far the chief fertilizing ingredient in these peat ashes, the remainder being about 40 per cent. of sand, and the rest chalk, red oxide of iron, and a small quantity of common salt.

If this conclusion, therefore, was correct, as to the gypsum being the only valuable portion of the peat ashes, it was certain that an application of $2 \mathrm{cwt}$. per acre of gypsum to the same land would produce similar beneficial resalts; and, upon a trial, it was found that benefits fully equal to any yielded by the application of the peat ashes resulted. $2 \mathrm{cwt}$. per acre of gypsum, in fine powder, was spread on a portion of the grass with the most excellent effect: the grass not only grew with greatly increased vigour, but a quantity of white clover and other grasses made their appearance on the portion dressed, in so marked a manner as to attract the attention of the tenant to the fact. The soil on which these experiments were tried consists of -

\begin{tabular}{|c|c|c|c|c|c|c|}
\hline Organic matter, & chiefly & ve & etable & - & - & $\begin{array}{r}\text { Parta, } \\
3.5\end{array}$ \\
\hline Soluble matters & - & - & - & - & - & $3^{\circ}$ \\
\hline Cirbonate of lim & e and & ma & nesia & - & - & $19^{\circ}$ \\
\hline Oxide of iron - & - & - & - & - & - & $2 \cdot 75$ \\
\hline Alumina - & - & - & - & - & - & $8 \cdot 5$ \\
\hline Band and gravel & - & - & - & - & - & 62. \\
\hline & & & & & & $98 \cdot 75$ \\
\hline
\end{tabular}

This is about 10 inches deep, and it rests on a thin stratum of gravel and thin chalk.

There is another fact which clearly supports these conclusions, viz., the great use of common coal-ashes as a top-dressing to clover, sanfoin, and lucern; there is no manure uni- 
versally in the possession of the farmer, in fact, equal to them for immediate effect upon those grasses. Now, coal-ashes usually contain about 10 per cent. of sulphate of lime; and, therefore, a dressing with 50 bushels of coal-ashes per acre is equal to an application of about 5 bushels of gypsum; the remaining portion of the ashes consists principally of about 10 per cent. of lime and sand, and a small portion of red oxide of iron and alumina: so that the gypsum is here again evidently the active ingredient-the other constituent parts being nearly inert substances. My own experiments and observations have been confirmed by many others within the last two years, for gypsum is evidently creeping gradually into use as a manure for the grasses.

In England, the expense of the application of the gypsum is about 7s. per acre; this substance being usually sold in London for about 2l. 10s. per ton-at Reading and Southampton at 1 s. 9 d. per bushel. In the midland counties it may be had at a still more reasonable rate; thus, in Derbyshire, it is so plentiful that the farmers' cheese-room floors are commonly formed with it; it abounds, too, in the north of England. The comparative produce of the gypsumed over not-gypsumed land is very great; it of course varies in amount. I have seen it double the produce of clover hay, and give an equally copious crop of lucern; but this last I invariably cut green for soiling.

Mr. Smith, of Highstead, found still greater benefit from the use of gypsum to his clover leys; for where the simple soil produced 1 ton only per acre of hay, the portion of the same soil to which 5 bushels per acre of gypsum had been applied yielded 3 tons; the first yielding only $20 \mathrm{lbs}$. of seed, while the latter produced 105 lbs. Mr. Smith, too, first noticedwhat my own observations have confirmedthat cattle, horses, \&c., always prefer the grass growing on the gypsumed portion of the field to any other. 'The same remark is made by those who spread coal-ashes on their grass leys: the peat-ashes of Berkshire produce the same effect.

The general introduction, then, of gypsum, as a top-dressing for the artificial grasses which I have mentioned, is certainly an object of no mean interest to the farmer, especially if he cultivates the poor inland soils of England, where artificial manures are scarce, and the carriage of even the must portable is expensive; for gypsum possesses, in this respect, two advantages combined, which do not belong to any other, even of the saline manures : its first cost is trifling, and its carriage light, since a wagon will convey sufficient gypsum to dress 30 acres of grass.

PLASTER FOR TREES. See CANkER.

PLASTIC CLAY. Clay used in the manuracture of pottery.

PLATYPHYLLUM CONCAVUM, or KA'T'DID. A kind of grasshopper found in the United States. Dr. Harris, who was the first to give a scientific description, has called it Platyphyllum concrivum. The front of its head is obtuse, body of a pale-green colour, the wing-covers and wings being somewhat darker. Its thorax is rough like shagreen. The musi- cal organs of the male consist of a pair of taborets, formed by a thin, transparent mem. brane, stretched in a strong half-oval frame in the triangular overlapping portion of each wing-cover. During the daylime these insects are silent, and conceal themselves among the leaves of trees; but at night, they quit their lurking-places, and the joyous males begin the tell-tale call with which they enliven their silent mates. This proceeds from the friction of the taboret frames against each other when the wing-covers are opened and shut, and consists of two or three distinct notes, almost exactly resembling articulated sounds, and corresponding with the number of times that the wingcovers are opened and shut; and the notes are repeated, at intervals of a few minutes, for hours together. The mechanism of the taborets, and the concavity of the wing-covers, reverberate and increase the sound to such a degree, that it may be heard, in the stillness of the night, at the distance of a quarter of a mile. At the approach of twilight the katydid mounts to the upper branches of the tree in which he lives, and, as soon as the shades of evening prevail, begins his noisy babble, while rival notes issue from the neighbouring trees, and the groves resound with the call of "katy did, she did," the live-long night. From the head to the end of the wing-covers, this insect measures rather more than $1 \frac{1}{2}$ inch, the body alone being 1 inch in length. The piercer is broad, laterally compressed, and curved like a cimeter; and there are, in both sexes, two little thorn-like projections from the middle of the breast between the fore-legs. It is found in the perfect state during the misths of September and October. (Harris.)

PLEASURE-GROUND. That purtion of ground adjoining a dwelling-house in the country; and which is exclusively devoted to ornamental and recreative purposes. In the ancient style of gardening, the pleasure-ground was laid out in straight walks, and regular or symmetrical forms, commonly borrowed from architecture; but in the modern style, it is laid out in winding walks, and in forms borrowed direct from nature. A portion of lawn or smooth grassy surface may be considered as essential to the pleasure-ground under both styles. See Garnexivg, Laws, and Parterre.

PLOUGH. (Sax. Plou; Dan. Ploegh.) A well-known, perhaps the most ancient, certainly the most valuable of all agricultural implements. There are traces of it in even the earliest of all written authorities, and, judging of its importance in agriculture, we can hardly imagine it possible to carry on extensive systems of cultivation in any period or country without its assistance. By consulting the sacred records, we find, that in very early times they ploughed with two oxen (Deut. xxii. 10), that their plough had a coulter and ploughshare (1 Sam. xiii. 20), and that they were early aware of the advantages of a wir:er's fallow (Prov. xx. 4). It is certain that heir ploughs were long since furnished with wheels; a fact which is proved by the urawings on the early Greek ploughs which have escaped to us

Hesiod (Works and Days, p. 50_41) adviseil the Greek farmers to have a spare plough, tha: 
an accident might not interrupt the work; and he also enforces the advantages of careful and skilful ploughing.

The ploughs of Rome were of the most simple form, as may be inferred from ancient drawings. See Agriculture.

Rivalling these in simplicity and rudeness of form, are the never altered or improved ploughs of the Hindoos and the Chinese, from whose implements it is probable the shape of those of Rome was borrowed.

The object sought to be effected by means of the plough, is exactly the same as that accomplished in the primitive ages by the spade. The addition of cattle to force the plough in the operation of breaking up the ground, leads to complexity. But although the spade is an implement of such great simplicity, the act of digging with it exacts a great deal of individual exertion, almost every muscle of the body being called into play in alternately pushing and lifting. In this respect the modern improved plough possesses great advantages in being propelled by animals and directed with very little individual muscular exertion.

It is curious to trace the progress of ploughmaking in England. Those of the early cultivators were of necessity rude and imperfect, for in those days the ploughman made his own plough. A law of the early Britons in fact directed that no one should guide a plough antil he was able to make one. The driver was, by the same law, to make the traces by which it was drawn, and these were to be formed of withes of twisted willow; a long-exploded custom; many of the olden terms of which, however, are still retained by the rustic ploughmen. Thus the womb-withy is yet called the vambtye or wantye. Withen trees are denominated witten trees, or whipple trees, \&c.

It is uncertain whether the early British ploughs had wheels; some of those of the Saxons were certainly furnished with them. Yet it is pretty certain that they used ploughs of a form rivalling those of modern India in simplicity; a rude sketch of one of these is given in a \$axon MS. (Harl. MS. 603), from which it would seem that our Saxon forefathers were wont to fasten their horses to the plough by their tails; a barbarous custom, which certainly was formerly practised in Ireland to such an extent that the legislature interfered in 1634 , and declared by the 11 \& 12 Car. II.c. 15 (Irish Parl.), entitled "An act against ploughing by the Tayle, and pulling the Wool off living Sheep," that "in many places of this kingdome there hath been a long time used a barbarous custome of ploughing, harrowing, drawing, and working with horses, mares, geldings, garrans, and colts by the taile, whereby (besides the cruelty used to the beasts) the breed of horses is much impaired in this kingdome. And also divers have and yet do use the like barbarous custome of pulling off the wool yearly from living sheep, instead of clipping or shearing of them." These wretched practices are then declared illegal, and to be pun:shable with fine and imprisonment.

The Norman plough was also furnished with wheels, and it was usual for the ploughmen to eaury a hatchet to break the clods, as is de900 picted in an ancient picture from whence the sketch at page 41 is engraved.

It is pretty certain that the ox was at first, and for a lengthened period, the only animal employed to draw the plough. Thus, although the plough and oxen are so frequently mentioned in conjunction in the Bible, the horse is never alluded to for such an occupation: an old British law forbade the use of any animal except the ox for this purpose. The first representation, of which I am aware, observes Mr. J.A. Ransome, of a horse employed in the plough, is that given (A.D. 1066) in the tapestry of Bayeax.

There are evident traces in the early English agricultural authors of the importance which they ascribed to the improved construction of the plough. This implement, however, was long drawn entirely by oxen in Britain.

Fitzherbert, in his Boke of Hisbandrye (1532), speaks in a manner that shows that even in his day plough-horses were not generally employed; he observes, "a husbande may not be without horses and mares, and especially if he goe with a horse-plough." Worlidge, in his Mystery of Husbandry, describes (A.D. 1677) very clearly the first rude attempt to construct a sub-soil plough : he tells us, p. 230, "of an ingenious young man of Kent, who had two ploughs fas. tened together very firmly, by the which he ploughed two furrows at once, one under another, and so stirred up the land 12 or 14 inches deep. It only looseneth and lighteneth the land to that depth, bat doth not bury the upper crust of the ground so deep as is usually done by digging." When Heresbasch wrote $(\mathbf{1 5 7 0})$, it was not uncommon in some of the warmer parts of Germany and Italy to plough during the night, "that the moisture and fattness of the ground may remain shadowed under the clodde, and that the cattell through overmuch heate of the sunne be not diseased or hurt." (31 b.) Jethro Tull, more than a century since, paid considerable attention to the plough; he had even searched into the early history of this implement, and concluded that it was "found out by accident, and that the first tillers (or ploughers) of the ground were hogs." (Husb. p. 131.) The ploughs which he describes, and of which he gives drawings, were evidently (although rudely and heavily constructed) superior in several respects to all that had preceded them.

It is not necessary to do more than thus slightly advert to the various notices which are to be found in the early, histories and pictures of this invaluable implement; for, in fact, for ages the plough was little more than a rude, clumsy instrument, which served only to rake the surface, instead of making furrows in the land sufficiently deep for the seeds to be luried. It was not brought to any thing like a perfect tool for the purposes required till the close of seventeenth centary.

The plough, being the fundamental implement of agricultare, common to all ages and countries, its primitive form is almost every where the same. The forms used by the Greeks and Romans (see Agricelture) seem to have spread over Europe, and undergone no change till probably about the sixteenth century, when 
they began to be improver by the Dutct and Flemish. In the seventeenth century the plough underwent further improvement in England; and it was greatly improved in that following, in Scotland. 'There are now a great variety of excellent forms, the best of which, for general purposes, is, in Britain, universally allowed to be what is called the Scotch plough, and in Scut and the improved Scotch plough. In speaking of the implement we shall adopt the latter term, because the unimproved Scotch plough differs little from sume old forms of the implement common to Eurnpe from the time of the Romans. As the operation of ploughing, like many other operations in practical husbandry, must often vary in the manner of its being performed, it is evident that no one particular sort of plough can be superior to all others, in every season, and under every variety of soil or inclination of surface. The Scotch plough, however, and the variations of which it is susceptible, render it perhaps the most universal tillage implement hitherto invented or used.

In Britain ploughs are classed into two kinds: those fitted up with wheels, and called wheelploughs; and those without wheels, called swing ploughs. The latter are the lightest of draught, but require an experienced and attentive ploughman to use them; the former work with greater steadiness, and require much less skill in the manager: some sorts, indeed, do not require holding at all, excepting at entering in, and turning on and off the work at the ends of the ridges. On the whole, taking ploughmen as they are, and ploughs as they are generally constructed, it will be found, that a district ploughed with wheel-ploughs will show greater neatness of work than one ploughed with swing ploughs: but, on the other hand, taking a distriet where the improved form of swing ploughs is generally adopted, the ploughmen will be found superior workmen, and the work performed in a better manner, and with less expense of labour, than in the case of wheelploughs.

In the construction of ploughs, whatever be the sort used, there are a few general principles that ought invariably to be attended to; such as the giving the throat and breast, or that part which enters, perforates, and breaks up the ground, that sort of long, narrow, clean, tapering, sharpened form that affords the least resistance in passing through the land; and to the mould-board, that kind of hollowed-out and twisted form, which not only tends to lessen friction, but also to contribute greatly to the perfect turning over of the furrow-slice. The beam and muzzle should likewise be so contrived, as that the moving power, or team, may be attached in the most advantageous line of draught. 'This is particularly necessary where a number of animals are employed together, in order that the draught of the whole may coincide.

Land, when properly ploughed, must be removed from a horizontal position, and twisted over to a certain angle, so that it may be left in that inclining state, one furrow leaning upon another, till the whole field be completely plougbrd. 'The depth and width of the furrows which is most approved of by farmers, and commonly to be met with ir the best-ploughed fields, are in the proportion of 2 to 3 ; or, if the furrow be 2 deep, it must be 3 wide, and left at an angle of 45 to 46 degrees.

Various forms have been given to the different parts of the plough, by ingenious persons. according to their different fancies, in order 8 diminish the weight of the draught, and to turn over the furrow, and leave it in its proper position, without tearing or breaking it.

'To have the line of draught at right angles to the horses' shoulders is of great importance in the formation of a plough; a circumstance of which the greatest part of the plough-makers are totally ignorant, although it is well known to every one that has the least knowledge of mechanics. If we take the angle that the horses' shoulders make with a perpendicular from the horizon, and continue another line at right angles to it, or parallel to the draught chain ; the length of this line from the horses' shoulders to where it meets or crosses the coulter, at half the depth of the furrow, will be 13 feet 2 inches for ordinary sized horses.

Length of beam.-If the plough be properly made, the line of draught should pass through the middle hole of the plough bridle at the poin: of the beam. This requires the beam to be 7 feet long, to give it a proper height at the bridle.

Left side plane. - That part of the plough next the solid land should be made a perfect plane, and run parallel to the line of draught; whereas some of the common ploughs are completely twisted in that part, and deviate more than 2 inches from the line of draught; this throws the plough to the left, and causes the hinder part of the mould-board to press hard against the furrow, and crush and break it, besides increasing the labour of the cattle.

The position of the coulter must not deviate much from an angle of $\mathbf{4 5}$ degrees: for, if we make it more oblique, it causes the plough to choke up with stubble and grass roots, by throwing them up against the beam; and, if less oblique, it is apt to drive the stones or other obstacles before it, and make it heavier to draw.

The mould-board, for all free soils, and for working fallows, is generally most effective when it has a considerable concavity; but for breaking up clover leys, pasture, or any firm surface, and also for clayey soils, it is found to clean itself better and make neater work when it approaches nearer to a plane, and in very stiff clays, is formed with a concave surface. The lower edge of the mould-board, on the most improved forms, is in a separate piece, which, when it wears, can be taken off and renewed. 'The technical name of this slip of iron is the wearing-piece.

The materiuls with which ploughs are constructed is, generally, wood for the beam and handles, cast iron for the head, side-plates, mould-board, and sole, and wrought iron for the share, coulter, and muzzle. But of late years, in consequence of the dearness of timber, and the cheapness of iron in Britain, they have been constructed whom; of the latter material, and with considerable advantage in point of 
strength and durability, and some also in poin! of convenience. Among the conveniences may be mentioned, the facility which they afford of bending the left handle to the right of the straight line first introduced by Mr. Wilkie of Uddingston (who, if not the inventor, may certainly be considered the greatest improver of iron ploughs,) by which means the ploughman is permitted to walk with ease in the bottom of the furrow. The stilts or handles may also be joined to the body of the plough, in such a way as to admit of taking off and packing for a foreign country, or raising or lowering the points of the handles according to the size of the ploughman, as in Weatherley's plough.

A wooden Scotch plough with iron mountings, says Mr. Stephens, usually weighs 13 stones imperial, and an iron one for the same work 15 stones. The cost of a wooden one is $3 l$. 16s., capable of being serviceable, with repairs, for the currency of a lease of 19 years ; that of an iron one $4 l .4 s$., which will last a lifetime, or at least many years. Some farmers, however, still prefer the wooden one, alledging that it goes more steadily than the iron. Whatever of prejudice there may be in this predilection for the wooden plough, it must be owned that the iron one executes its work in a satisfactory manner. There is, I believe, no great difference of economy in the use of the two kinds of ploughs. (Stephens.)

Of swing ploughs, says Loudon, by far the best is the implement known in England as the Scotch plongh. It is almost the only plough used in Scotland, and throughout a considerable part of England; it is drawn with less power than wheel-ploughs, at least, those of the old construction, the friction not being so great; and it probably admits of greater variations in regard to the breadth and depth of the furrowslice. It is usually drawn by two horses abreast in common tillage; but for ploughing between the rows of the drill culture, a smaller one draw $\mathrm{n}$ by one horse is commonly employed. A plough of the swing kind, having a mouldboard on each side, is also used both in forming narrow ridges for turnips and potatoes, and in laying up the earth to the roots of the plants, after the intervals have been cleaned and pulverized by the horse and hand-hoe. This plough is sometimes made in such a manner that the mould-board may be shifted from one side to the other when working on hilly grounds; by which means the furrows are all laid in the same direction.

Swing ploughs, similar to the Scotch plough, have been long known in England. In Blythe's Improver Improved we have engravings of several ploughs; and what he calls the "plain plough" does not seem to differ much in its principal parts from the one now in use. Amos, in an Essay in Agricullural Machines, says, that a person named Lummis (whom he is mistaken in calling a Scotchman) "first attempted its construction upon mathematical principles, which he learned in Holland; but having obtained a patent for the making and vending of this plough, he withheld the knowledge of these principles from the public. However, one Pashley, plough-wright to Sir C harles Turner 902 of Kirkleathem, having a knowledge of those principles, constructed upon them a vast num. ber of ploughs. Afterwards his son established a manufactory for the making of them at Rotherham. Hence they obtained the name of the Rotherham plough ; but in Scotland they were called the Dutch or patent plough." Plate $17, a$, represents a Rotherham plough constructed chiefly of wood. The Americans have claimed the priority of the invention; and President Jefferson, of the United States, presented the principles for the construction of a nouldboard, first to the Institute of France, and next to the Board of Agriculture in England.

The Scotch plough was little known in Scotland till about the year 1764, when Small's method of constructing it began to excite attention (Small's Treatise on Ploughs and Wheel Carriages, 1784; and Lord Kaimes's Genileman Farmer). This ingenious mechanic formed the mould-board upon distinct and intelligible principles, and afterwards made it of cast iron. His appendage of a chain has been since laid aside. It has been disputed, whether he took the Rotherham, or the old Scotch plough, for the basis of his improvements. The swing plough has been since varied a little, in some parts of Scotland, from Small's form, for the purpose of adapting it more completely to particular situations and circumstances. Since 1810 , this plough has been very generally made entirely of iron. In Northumberland, the mouldboard is made less concave than in Berwickshire, and in Berwickshire it is even less concave than in Small's plough. Different degrees of concavity in the mould-board suit different soils : soft and sandy soil requires most, and a loamy or clayey soil least concavity. The following are the principal varieties of the improved Scotch plough at present in use in the most improved districts of the north, and among scientific farmers in all countries.

Small's plough.-The mould-board is more concave than in most other varieties, and this may be considered its characteristic as compared with these varieties. It is sometimes drawn by a chain proceeding from the muzzle to the head, in order to lessen the strain on the draught-beam, and in that case it is called Small's chain-plough. It is commonly made of wood and iron. Pl. 17, $b$. For a design of the East Lothian plough, or Small's improved, see Pl. 17, $c, d$, the figures representing two views.

In this plough the proper lines of the body on the land-side lie all in one plane, which, in working, should be held in the vertical position, or very slightly inclining to the left. The coulter slightly oblique to the land-side plane, the point standing towards the teft, the rake of the coulter varies from $55^{\circ}$ to $65^{\circ}$. In the mould-board the vertical sectional lines approximate to straight lines, giving the character of apparent concavity, and it is truncated forward. Share pointed, with a feather or cutter standing to the right, having a breadth of at least $\frac{3}{3}$ the breadth of the furrow, the cutting edge of the feather lying nearly as low as the plane of the sole. The neck of the share is prolonged backward, joining and coinciding with the curve of the mould-board, which curvature is also carried forward on the 
back of the father. The character of this plough is to take a furrow of 10 inches in breadth by 7 inches in depth, cut rectangular, leaving the sole of the open furrow level and clean. 'The resistance to the draught is generally below the average of ploughs, and this plough is employed for every kind of soil. The improved English swing plough, as made by Ransom, is represented in Pl. 17,e.

The Northumberland plough, and the Berwirkshire plough, are very nearly the same implenient; differing from Small's plough in having the mould-board less concave.

Wilkie's swing plough, which Loudon says is the best iroll swing plough in Scotland, is formed entirely of iron, except the points of the handles. Its characteristic, in point of form, is a longer mould-board with a greater twist in it, the object of which is to reverse the furrow more completely in light or highly pulverized soils.

Finlayson's iron ploughs are, as he informs us (British Farmer, p. 9), constructed in imitation of those of Wilkie, but with improvements and modifications adapted for particular circumstances.

The heath or self-cleaning plough, or rid plough, is formed with the beam so curved vertically, or divided and curved horizontally, as to leave no resting-place for stubble, heath, or other vegetable matter, at the top of the coulter, where in rough grounds, with ploughs of the ordinary construction, it gets entangled and stops the work.

Finlayson's Kentish skeleton self-cleaning plough $(\mathrm{Pl} .17, f)$ is intended as a substitute for the common Kentish turn-wrest plough. "The soil, in great part of Kent, is of a peculiarly adhesive clay. When this soil is between the wet and dry, it adheres to the body of the plough like glue, by which the draught is increased probably double or treble." By substituting 3 or 4 iron rods for the mould-board, the soil is prevented from adhering, while the operation of ploughing is at the same time performed in an equally perfect manner with two horses as with four. This is accounted for "by the whole surface of this plough not being more than one-third or one-fourth the surface of other ploughs." In like manner, when it is necessary to dig or trench very strong clayey soil between the wet and the dry, the operation is performed with much greater ease by a two-pronged fork. It is important to agriculturists to know the opinion and experience of a man of so much science and extensive practice as the late Mr. Finlayson, who says, "from my own experience I have no hesitation in saying that the most adhesive land may, with ease, be ploughed by the skeleton plough and one pair of good horses."

Finlayson's line plough is characterized by a rod which proceeds from the sheath of the plough to the muzzle, which is put on when the plough is drawn by horses in a line-a very disadvantageous manner, but yet common in many parts of England.

The Sumerville swing plough is known by its mould-board, a part of which is rendered movable by hinges; the advantage of this is, that the furrow can be laid more or less flat at pleasure. 'Tnis plough, however nas bee. b'st little used, and dnes not seem to meet the approbation of the best cultivators.

Turn-wrest swing ploughs are such as admu of removing the mould-board from one sifle (n another at the end of each furrow, for the rur. pose of throwing the earth removed al wars (o) one side. Their principal use is in ploughing across steep declivities, in order that th. furrow-slice may always be thrown down. Wherever it is practicable, however, it is bes? to plough obliquely up and down such dechvities; because the other practice soon refider the soil too rich and deep at bottom, and (ur) thin and poor at top.

Gruy's turn-wrest swing plough is one of the most scientific implements of the kind. The beam, head, and sheath, must always be placed in the direction of a line passing along their middle; and the two handles must be placed equidistant on each side of that line. There are two mould-boards and two coulters, and a mould-board is produced on either side, at pleasure, by moving a lever between the plough handles from the one side to the other. The line of draught can be shifted with equal ease and expedition, and at the same time one of the coulters raised up clear of the land, and placed along the side of the beam, whilst the other is put down, and placed in a proper position for cutting off the furrow-slice from the furrow-ground. All this is performed at once, without the ploughman changing his position, by means of two levers.

$A$ skim-coulter (Pl. 17, $m, m$ ) may be added to any plough, and may be useful in turning down green crops and long dung, as well as in trench ploughing. But in most instances it is thought a preferable plan, where the soil is to be turned to an unusual depth, to make two common swing ploughs follow each other in the same track; the one before taking a shallow furrow, and the other going deeper, and throwing up a new furrow upon the former.

The double share plough is distinguished by having one share fixed directly over the other. It is made use of in some of the southern dis. tricts of England with advantage, in putting in one crop immediately after ploughing down another; as by it a narrow, shallow furrow is removed from the surface, and another from below placed upon it, to such depth as may be thought most proper,-it being capable of act. ing to 10 inches or more. In this manner many sorts of crops, such as rye and other green crops that have much height of stem, may be turned down without the inconvenience of any of the parts sticking out through the seams of the furrow-slices, by which the farmer has a clean surface of mould for the reception of the grain.

The mining plough, or trenching plough, is sometimes employed for the purpose of loosening the soil to a great depth, without bringing it up to the surface; a mode of operation which 15 particularly useful for various sorts of tay rooted plants, as well as for extirpating the roots of such weeds as strilie deep into the ground. For these purposes it may be entployed in the bottom of the furrow after the common plough. It is constructed in a vert 
strong manner, having a share, but no mouldboard. The share raises the earth in the bottom of the furrow, and, passing on under what it has raised, leaves the soil where it was found, but in a loosened state. See Subsorl Plavgh.

Somerville's double-furrow plough is obviously advantageous in performing more labour in a given time, with a certain strength of team, than other sorts of ploughs, as producing two furrows at a time. It has been found useful on the lighter sorts of land, where the ridges are straight and wide, though some think it more confined in its work than those of the single kind. 'The saving of the labour of one person, and doing nearly double the work with but little more strength in the team, in the same time, recommend it for those districts where four-horse teams are in use. This plough has been brought to its present degree of perfection by Lord Somerville, especially by the introduction of movable plates at the extremities of the mould-board, as in his lordship's single plough. But, as observed by an excellent authority, "with all the improvements made by Lord Somerville, it can never come into competition, for general purposes, with the present single-furrow ploughs." Iord Somerville admits, that it would be no object to invade the system already established in well-cultivated counties; though, where large teams are employed, with a driver besides the ploughman, it would certainly be a matter of importance to use this plough, at least on light, friable soils. "Their horses," he says, "will not feel the difference between their own single furrow, working one acre, and the well-constructed two-furrow plough, with two acres per day; here is no system deranged, and double work done." This plough is also of particular value for ploughing up and down steeps.

The Argyleshire plough differs from Small's, or any single swing plough, in having no coulter fixed in the beam, but, in lieu of this, a fin or lnife rising from the left side of the share, which serves the purpose of slicing off the furrow as well as a coulter. This fin or feather must be placed at the same angle as the coulter, and should terminate in a lance-like shape, in order to furnish the least obstruction to stubble, weeds, or stones. This plough is not liable to be choked by stubble, or thrown out by catching small stones between the points of the coulter and sock. In point of draught it is precisely the same as the common plough.

The double mould-board plough is a kind of plough often used with advantage in clearing out furrows, in setting potatoes, cabbages, and nther similar crops, and in earthing up such as are planted in wide rows. Those whose mould-boards move on hinges. and may be set wide or narrow at pleasurc, are the most convenient. A variety of this plough, made by Weir of London, admits of removing the mouldtwards, and hxing in curved coulters and hoes, tur cleaning between drilled turnips and similar crops.

The binnt is almost the same thing as the deruble mould-hoard plough, and the one is summonly sold for the other, with no loss to the purchaser. It has two mould-boards, one on each side of the beam. It is used in some soils in forming a ribbed or ridged bed for wheat or other grains; by which means, when the grain is sown over the ribs or ridgelets in the broad cast manner, as it falls for the most part into the furrows, or is harrowed into them, it comes up in rows. It is also used in earthing up crops; and sometimes in Flanders, but never by the best cultivators in England, in giving the first furrow to stubbles.

The marking plough is used in straightening and regulating the distance of ridges where the drill system is practised. Any plough with a rod fixed at right angles to the beam, and a short piece depending from this rod, will trace a line parallel to the furrow drawn by the plough, which line will serve for a guide as to the width of ridges, \&c.

Clymer's plough is a recent modification of the implement, formed entirely of iron, and chiefly remarkable for the absence of the coulter, or rather its attachment to the breast, and for the share, mould-board, and other parts which move under ground, being composed of distinct pieces of cast-iron. This is considered as cheaper to commence with and easier to repair, because any one part may be renewed of the same material without deranging the rest; whereas renewing or repairing wrought. iron shares, mould-boards, or coulters, is found in many districts both difficult and expensive. It has never come into use in England.

Slothard's plough is characterized by a perforated mould-board. The holes may be in any form or dimensions; and their object is to allow the air to pass through, and thereby prevent the adhesion of wet earth, which it is contended adheres in ordinary ploughs with such a degree of tenacity as greatly to increase the friction, and diminish the speed of the horses.

Morton's trenching plough has two bodies, the one working 4 or 6 inches deeper than the other. The first cuts or pares off the surface to the required depth, say 5 inches, and turns it over into the furrow, 10 or 12 inches deep, made by the main body. The second body generally works from 10 to 12 inches deep, but might be. made to work to the depth of 13 or 15 inches; upon its mould-board is formed an inclined plane, extending from the back part of the feather of the sock or share to the back part of the mould-board, where it terminates about 6 inches above the level of the sole. This inclined plane raises the soil from the bottom of the furrow, and turns it over on the top of that which has been laid in the bottom of the previous furrow, by the body going hefore.

Draining ploughs are of various kinds, but none of them are of much use; the work can always be done better, and generally cheaper, by manual labour.

Wheel ploughs are of two kinds: by far the most common, are those where the wheel or wheels are introduced for the purpose of regulating the depth of the furrow, and rendering the implement more steady to hold; those less common are where a wheel is introduced for the purpose of lessening the friction of the sole or share. This last description of wheel plough 


\section{PLOUGII.}

is scarcely known, but it promises great advantages. The former is of high antiquity, having been used by the Romans.

Ploughs with wheels for regulation and steadiriess vary considerably in their construction in different places, according to the nature of soils and other circumstances; but in every form, and in all situations, they probably require less skill in the ploughman. Wheels seem, indeed, to have formed an addition to ploughs, in consequence of the want of experience in ploughmen; and in all sorts of soil, but n: re particularly in those which are of a storg and stubborn quality, they afford great assistance to such ploughmen, enabling them to perform their work with greater regularity in respect to depth, and with much more neatness in regard to equality of surface. From the friction caused by the wheels, they are generally considered as giving much greater resistance, and consequently demand more strength in the team that is employed; and, besides, are more expensive in their construction, and more liable to be put out of order, as well as more apt to be disturbed in their progress by clods, stones, and other inequalities that may be on the surface of the ground, than those of the swing kind.

With regard to wheel ploughs, those more especially in which the wheel is placed in the heel of the plough, the following extract from Mr. Stephens's Book of the Farm, will explain both the philosophy and practical effect:

'The application of a wheel in the heel of a plough, does not come under the same mode of reasoning as that under the beam, the former becoming a part of the body, from which all the natural resistance flows; but in viewing it as a part of that body only, we can arrive at certain conclusions which are quite compatible with careful experiments.

The breadth of the whole rubbing surface in the body of a plough, when turning a furrow, is on an average about $17 \frac{1}{2}$ inches; and supposing that surface be pressed nearly equal in all parts, we shall have the sole-shoe, which is about $2 \frac{1}{2}$ inches broad, occupying $\frac{1}{7}$ part of the surface; and taking the entire average resistance of the plough's body, as before, at $336 \mathrm{lb}$., we have $\frac{1}{7}$ of this, equal to $48 \mathrm{lb}$., as the greatest amount of resistance produced by the sole of the plough. But this is under the supposition that the resistance arises from a uniform degree of friction spread over the whole rubbing surface of the body; while we have seen, on the contrary, that the coulter, when acting alone, presents a resistance equal to the entire plough. It is only reasonable, therefore, in absence of further experiments, to conclude, that the fore-parts of the body, the coulter and share, yield a large proportion of the resistance when turning the furrow-slice; but since we cannot appreciate this with any degree of exactness, let the sole have its full share of the resistance before stated, namely, $48 \mathrm{lb}$. If a wheel is applied at or near the heel of a plough, it can only bear up tine hind-part of the sole, and prevent its ordinary friction, which, at the very utmost, cannot be more than half of the entire friction due to the entire sole. A wheel, therefore, placed here, and acting under every 114 favouring circumstance, even to the supposed extinction of its own friction, could not reduce the resistance by more than $24 \mathrm{ltws}$., heing the half of that due to the entire sole, or it is if of the entire resistance. But we cannot imagine a wheel so placed to continue any length of time, without becoming clogged in all dirrctions, thereby greatly increasing its own friction; and when it is considered that the neces. sarily small portion of any wheel that can be so applied will sink into the subsoil, to an extent that will still bring the sole of the plough into contact with the sole of the furrow. It will thus be found that the amount of reduction of the general resistance will be very much abridged, certainly not less than one-half, which reduces the whole saving of draught to a quantity not exceeding $12 \mathrm{lb}$., and even this will be always doubtful, from the difficulty of keeping such wheels in good working condition. 'This view of a wheel placed at the heel has been confirmed by actual experiments, carefully conducted, wherein Palmer's patent plough with a wheel in the heel, as patented many years ago (but in this case it was applied on the best principles), gave indications of increased resistance from the use of the wheel, as compared with the same plough when the wheel was removed; the difference having been $1 \frac{1}{2}$ stone in favour of no wheel. I hesitate not, therefore, to say; that in no case can wheels be of service towards reducing the resistance of the plough, whether they be placed before or behind, or in both positions, and the chances are numerous that they shall act injuriously. 'That the use of wheels may, under certain circumstances, bring the implement within the management of less skilful hands than is required for the swing plough, must be admitted; but, at the same time, there may be a question whether, even with that advantage, the practice is com. mendable. I should be wanting in candour if, for myself, I answered otherwise than in the negative.

Having, says Mr. Stephens, in a general way desciibed the construction of the frame-work and the acting parts of the wheel plough, there remains for me to say a few words on the wheels with which it is furnished. I have already adverted to wheels, as they appear to me to affect the draught of ploughs, and have expressed myself in sufficiently distinct language to show that, in my opinion, they must in all cases be injurious, and tend to increase the resistance of the plough to which they are appended, whether they be applied within the body, or under the front, or any other part of the beam. That wheels may be of advantage for the working of a plough in the hands of an unskilful ploughman may be true; but if this advantage is acquired by a certain additiona? expenditure of horse-power, which, however much the proprietor of the team may blint himself to, will ultimately, though probably unheeded, tell on his profit and loss account, there will be no gain, but an ultimate loss It must be admitted, even by the adrocates of the wheel plough, that though they may be handled with perfect regularity in ploughing along ridges, whether tive hulder be an experienced ploughman or not, yet in cross-ploughing they 1 . 2 905 


\section{PLOUGH.}

sannot by any means be brought so handily to follow the undulations of the surface. In leaving one ridge, the share will pass too shallow, and in entering on the brow of the next, it will go too deep, or at least deeper than the average of the ploughing. There is also the element of time, which in all farming operalions is an important one; and here wheel ploughs are found to come short by about 25 per cent. as compared with swing ploughs. Mr. Pusey, in his paper on the draught of ploughs, incidentally observes: "While the work of our ploughing teams is at best but $\frac{3}{4}$ of an acre upon strong ground (and sometimes as much as one acre upon the lightest), the daily task performed by 2 Scotch horses upon strong land is $1 \frac{1}{4}$ acre." This deficiency of effect cannot be attributed to want of power in the horses, for English horses are at least not inferior to those employed in Scotland for agricultural purposes, neither can it be from unskilfulness in the ploughmen, for even the most skilful seem to come short in this respect, by not being able to plough more than $\frac{3}{4}$ of an acre in a day, while with the swing plough almost any ploughman will turn over his acre a day. From the remarks of the same writer, it is to be inferred that a Scotch swing plough was incapable of being drawn through a certain clay soil by 2 horses, while the wheel ploughs were found to perform the work with tolerable ease, though still a heavy draught. There may be such cases; but from the conditions of this particular case, where the draught that baffled the horses in the swing plough seems not to have exceeded 52 stones, there is an ambiguity in che matter that leads to doubts of the accuracy on the part of the observers of the experiment. We know well that in working the Scotch swing plough in an 8 or 9-inch furrow on stiff land, the draught is not unfrequently as high as $7 \mathrm{cwt}$. or 56 stones; but 2 good horses never shrink from the task; and how a less draught, whatever be the soil, should have baffled the exertions of 2 good horses in a swing plough, even in the Oxford clay, requires some further investigation to be satisfactory.

Among agricultural writers, it seems, says Mr. Stephens, to be a prevalent opinion, that land when ploughed receives a curvature of surface; whereas, correct ploughing, that is, making the furrow-slices on the same ridge all alike, cannot possibly give the surface any other form than it had before it was ploughed. If the former surface were curved, then the newly ploughed surface would also be curved; but if it were flat, the new surface will be flat also. A thoroughly good ploughman, and I have known a few, but only a few of such valuable men, avoids so objectionable a practice, and ploughs always a true, sound furrow, making it larger or smaller as the particular state of the work may require.

Without putting much value on the informat1on, it may serve as a fact to refer to, in case it should be wanted, to state the weight of earth turned over in ploughing. If 10 inches are taken as a fair breadth for a furrow-slice, there will be 18 such slices across a ridge of 15 feet in breadth; and taking 7 inches as a proper lepth for such a furrow-slice, a cross section 906 of the slice will have 70 square inches. A cubic foot of earth is thus turned over in every $24 \frac{1}{2}$ inches and a little more of length of such a slice; and taking 2.7 as the specific gravity of ordinary soil, every $24 \frac{1}{2}$ inches and a fraction more of such a slice will weigh 12 stones 1 lb. imperial.

The usual speed of horses at the plough may be ascertained in this way. A ridge of 5 yards in breadth will require a length of 968 yards to contain an imperial acre; and to plough which at 9 bouts, of 10 -inch breadth of furrow-slice, counting no stoppages, will make the horses walk 97 miles, which in 10 hours gives a speed of $1742 \frac{1}{2}$ yards per hour. But as ridges are not made of 968 yards in length, and as horses cannot draw a plough that distance without being affected in their wind, and as allowance must be made for time lost in turning at the ends of the ridges, as well as for affording rest to the horses, that speed will have to be considerably increased to do that quantity of work in the time. By experiment it has been found, that 1 hour 19 minutes, out or 8 hours, are lost by turnings while ploughing an acre on ridges of 274 yards in length, with an 8-inch furrowslice. Hence, in ploughing an acre on ridges of 250 yards in length, which is the length of ridge I recommend as the best for horses in draught, in 10 hours, with a 10-inch furrow-slice, the time lost by turnings is 1 hour 22 minutes. I presume that the experiment alluded to does not include the necessary stoppages for rest to the horses, but which should be included; for however easy the length of ridge may be made for draught, horses cannot go on walking in the plough for 5 hours together (one yoking) without taking occasional rests. Now 250 yards of length of ridge give nearly 4 ridges to the acre, or 36 bouts; and allowing a rest of 1 minute in every other bout, 18 minutes will have to be added to the 1 hour 22 minutes lost, or very nearly $1 \frac{3}{4}$ hour of lost time, out of the 10 hours, for turnings and rest. 'Thus 18,000 yards will be ploughed in $8 \frac{1}{4}$ hours, or at the rate of 1 mile 422 yards per hour. I think this result is near the truth in regard to the ploughing of lea in spring; it is too little in ploughing red land in summer, and perhaps too much in ploughing stubble land in winter; but, as leaploughing is the criterion by which all others are estimated, this result may be taken as a near approximation to the truth.

The comparative time lost in turning at the ends of long and short ridges may be seen from the following table, constructed from data furnished by the experiment above alluded to:

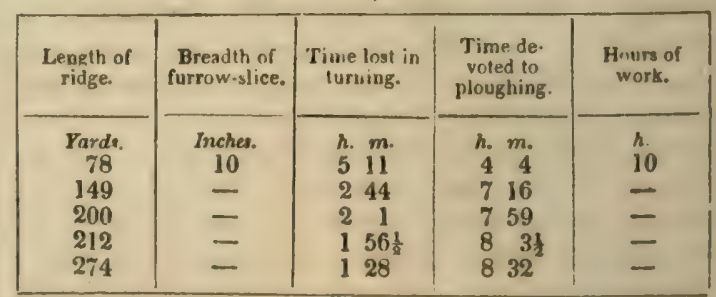

Thus it appears that a ridge of no more than 78 yards in length requires 5 hours 11 minutes of time to turn at the landings, to plough an acre in 10 hours, with a 10 -inch furrow-slice; whereas a ridge of 274 yards in length only re. 
quires 1 hour 28 minutes for the same purpose, making a difference of 3 hours 43 minutes in favour of the long ridge in regard to saving of time. Consequently, in the case of the shortest ridge, only 4 hours 49 minutes out of the 10 can be appropriated to ploughing, whereas in that of the long ridge, 8 hours 32 minutes may be devoted to the purpose. Hence, so very short ridges require double the time of long ones to plough, and are thus a decided loss to the farmer. This is a subject well worth your experimenting on, by ascertaining the time usually taken in ploughing and turning and resting on ridges of different lengths, in the different seasons, and in different soils. A watch with a good second-hand to mark the time will be required, and the observations should be made unknown to the ploughmen, at their usual rate of work ; for if you be constantly in the presence of the men, more than the usual work will be done, and less than the usual rests taken.

The whole value of ploughing, scientifically speaking, depends upon its having the effect of lonsening the texture of the soil, and thus permitting a free circulation of air and moisture through its interstices, for the double purpose of increasing the rapidity of the disintegration of its stony portions, and of re-reducing to powder what had formerly been pulverized, but which, from the joint action of pressure, and the binding effect of root-fibres, had become agglutinated together.

However well you may manure your land, however thoroughly you may drain it, you will never obtain the crops it is capable of yielding, unless you pulverize it; nay, so important did Jethro Tull think this, that he felt firmly persuaded that if you pulverized your soil well, you need not manure at all. I need hardly tell you, that we shall prove hereafter Jethro Tull to have carried his conclusions too far; but still so direct and unqualified a statement, from such a writer, should have its full influence upon all who wish to learn thoroughly the art of agriculture. Always bear in mind that the impalpable powder is the active part of soil, and that no other portion has any direct influence upon vegetation, and you will then, at all times, be sufficiently impressed with the necessity of thorough ploughing, harrowing, \&c.; indeed, you may rest assured that, except upon some few very light sands, you cannot pulverize the soil too much-economy alone must fix the limit of this useful operation.

Tempering, \&c.--A good ploughman will have his plough so "tempered," or its different parts so regulated or adjusted, that it will neither have a tendency to take more or less earth, or, in other words, go deeper or more shallow than is necessary. The width of the furrow-slice will be at the same time regulated, so that neither more nor less land be taken than is requisite. Some ploughmen, says Mr. Stephens, habitually make the plough lean a little over to the left, thus giving it in effect less land than it would have, were it made to move upon the flat of the sole; and to overcome the consequent tendency of the plough to make a narrower furrow-slice chan the proper breadth, they move the draughtbolt a little to the right. The ploughing with a considerable lean to the left is a had custorn, because it makes the lowest sile of the furrow. slice, when turned over, thinner than the upper side, which is exposed (1) view, thereby deluding you into the belief that the land has all been ploughed of equal depth; and it causes the horses to bear a lighter dratight than those which have turned over as much land in the same time, with a more equal and therefore deeper furrow-slice. Old ploughmen, becoming infirm, are very apt to practise this deceptive mode of ploughing. The plough should always move flat upon its sole, and turn over a rectan. gular furrow-slice; but there are certain ex. ceptions to this rule, depending on the peculiar construction of parts of cerlain forms of ploughs.

None assume the habit of leaning the plough over to the right, because it is not so easy to hold it in that position as when it moves upon the sole along the land-side.

Other ploughmen, especially tall men, prac. tise the habit of constantly leaning hard upon the stilts, or of steeping; and as this practice has the tendency to lift up the fore-point of the plough out of the ground, they are obliged, in order to keep it in, to put the draught-bolt farther from the ground than it should be. A little leaning of the hands upon the stilts is requisite at all times, in order to retain a firm hold of them, and thereby have a proper guidance of the plough.

A good ploughman will use none of these expedients to make his plough go steadily, nor will he fall into any of these reprehensible habits. He will temper the irons so as there shall be no tendency in the plough to go too deep or too shallow into the ground, or make too wide or too narrow a furrow-slice, or cause less or more draught to the horses, or less or more trouble to himself, than the nature of the work requires to be performed in the most proper manner. If he have a knowledge of the implement he works with-I mean, a good practical knowledge of it, for a knowledge of its principles is not requisite for his purpose,he will temper all the parts, so as to work the plough with great ease to himself, and, at the same time, have plenty of leisure to guide his horses aright, and execute his work in a creditable manner. I have known such ploughmen, and they invariably executed their work in a masterly way; but I never yet saw a ploughman execute his work well, who had not acquired the art of tempering the irons of his plough. Until he learns this art, the best-made plough will be comparatively worthless in his hands.

The state of the irons themselves has a material effect on the temper of the plough. If the cutting edge of the coulter, and the point and cutting edge of the sock, are laid with steel, the irons will cut clean, and go long in smonth soil. This is an economical mode of treating plough-irons destined to work in claysoils. But in gravelly and all sharp soils, the irons wear down so quickly, that farmers prefer irons of cold iron, and have them laid anew every day, rather than incur the expense of laying them with steel, which perhaps would not endure work much longer in such soil than iron in its ordinary state. Irons are now seldom 


\section{PLOUGH.}

\section{PLOUGH.}

if ever steeled; but whether they are steeled or not, they are always in the best state when sharp, and of the proper lengths.

An imperfect state of the mould-board is another interruption to a perfect temper of the plough. When new and rough, it accumulates the loose soil upon it, whose pressure against the turning furrow-slice, causes the plough to deviate from its right course. On the other hand, when the mould-board is worn away much below, it is apt to leave too much of the crumbled soil in the bottom of the furrows, especially in ploughing loose soils. Broken side-plates, or so worn into holes that the earth is easily pressed through them into the bosom of the plough, also cause rough and unequal work; and more or less earth in the bosom affects the balance of the plough, both in its temper and draught. These remarks are made upon the supposition that all ploughs are equally well made, and may, therefore, be tempered to work in a satisfactory manner; but it is well known that ploughs sometimes get into the possession of farmers, radically so ill-constructed, that the best tempering the irons are capable of receiving will never make them do good work.

When all the particulars which ploughmen have to attend to in executing their work, -in having their plough-irons in a proper state of repair, in tempering them according to the kind of ploughing to be executed, in guiding their horses, and in ploughing the land in a methodical way-when all these particulars are considered, it ceases to surprise that so few ploughmen should be first-rate workmen. Good ploughmanship requires greater powers of observation than most young ploughmen possess, and greater judgment than most will take time to exercise, in order to become familiarized with all these particulars, and to use them all to the best advantage. To be so accomplished, implies the possession of talent of no mean order. The ship has been aptly compared to the plough, and the phrase "ploughing the deep" is as familiar to us as ploughing the land: to be able to put the ship in "proper trim," is the perfection aimed at by every seaman; so, in like manner, to "temper a plough" is the great aim of the good ploughman; and to be able to do it with judgment, to guide horses with discretion, and to execute ploughing correctly, imply a discrimination akin to sailing a ship. (Stephens.)

Plough Handles.-The handles should be sufficiently wide apart to allow the ploughman to walk in the furrow, and long enough to give him a full command of the plough, so that he can lift or depress it readily in work, guide it to the right or left hand, and swing it round at the land's end out of the furrow into another.

Plough-beam.-The beam should be of such a length, that its end, commonly called its head, shall cut at the point of draught, upon a line drawn from that part of the collar to which the traces are attached, to the share or that part of it where it first raises the soil. On the right arrangement of the point of draught in the structure of the plough depends much of its steady working at its proper depth. It is from 908 the principle of balancing from a point ad justed to the line of draught, that the plough takes its name of swing, in contradistinction to the names of foot and wheel ploughs.

The beam should be curved upwards at the coulter and throat of the plough, to clear itself of rubbish which sometimes accumulates, and should be inclined slightly from the land, or, in other words, towards the furrow, because its tendency is to yield towards the loosened land, and it therefore requires this counteraction in the line of draught to keep it in a right line. This is supposing a pair of horses to be harnessed abreast ; if they be harnessed at length, the beam should be still more inclined; for as neither horse then walks on the "land," the direction of the force towards the land-side is still further decreased.

Plough-head.-The cross-head of the plough forms a ready means of increasing or decreasing the inclination last spoken of, and the hake, or draught-iron, which moves in th arc of a circle along the cross-head, has notches by which the depth of the plough can be regulated in unison with the line of draught. There are various contrivances for these purposes, most of which involve the use of a screw as a means of adjustment; but the plan of pins and notches is sufficiently accurate, and not liable to be out of order. Sketches of two, the one English, $h$, the other Scotch, $i$, are given in Pl. 17.

Plough-share.-The plough-share is the apex of the sole, as the hind part is called the heel. It varies in shape for different purposes. On stony lands it is best with a point, as figured Pl. 17, $k$. But where the land is free from stones, the wing is best when angular, and the cutting edge in a line, or nearly so, as figured in $\mathrm{Pl} .17, \mathrm{l}$.

For different work, "hard lands" and "summer lands," shares of a greater " dip" or "pitch" are requisite. A common plan is to use new shares on hard lands, and to wear them a day or two, and then lay them aside for summer lands.

Mould-board.-The upper part over the box of the share should form the first part of the rise of the mould-board. After the coulter and share have made the vertical and horizontal cuts for the depth and width of the furrow-slice, the mould-board has to complete the work by turning it over and leaving it in its proper position. On the precision with which this part of the plough performs its work, much, indeed nearly all, of the beauty of the ploughing depends: hence the importance of discovering its true form for the land on which it has to be used. Desirable, however, as this is, there does not as yet appear to be any precise rule for the formation of the mould-board, that has met with so uniform an approval under the test of practice, as would lead us to speak with entire confidence of it. We have looked at the mechanical principles laid down by Small, Bailey, Gray, Amos, Jefferson, Clymer, and other's, but are not aware of any plough-makers of the present day who strictly adhere to either the one or the other; and so long as the mould. board cannot be used on even the same farm 
under circumstances always similar, as its operation will necessarily be affected by the weather, the state of the land, with the varying depth and width of the plough, it is not an easy matter to determine which form is best for general purposes. It is clear that different soils, as, for instance, light sand and heavy clay, require mould-boards almost the opposite of each other; and such they are. The Norfolk mould-board is short, with rather a hollow or concave surface, whilst that used in the hundreds of Essex is long and convex.

Lord Western, many years ago, improved upon the form of the heavy land mould-board in use in that part of the county of Essex where he resides, by cutting away a considerable portion of the lower and hinder part of the figure, and by making it in a straight line lengthwise from the nose to the hind part.

Were the circumstances always the same, there can be no question but that one mathematical form of the mould-board would be preferable to all others; but, under circumstances so various, the plan hitherto adopted has been to prove, by experience and from practical operation, the forms best suited to different lands under an average depth and width of work, keeping as nearly as possible to the principle of the wedge, as necessary for the proper lifting, turning, and laying over the soil. Provided the mould-board be made so that the work, while in operation, goes on as it should do, a good practical criterion as to its figure will be found in the evidence of friction it has undergone, and this, with the fine cast metal now in use, can be determined to a nicety. If, on a given soil, the mould-board becomes brightened uniformly -if the mould appears to slip with light friction and with the same pressure from one end of it to the other, it cannot be far, if any thing, out of its proper shape for the purpose intended. And yet, if the same mould-board be used on some other lands, it will immediately show its inapplicability to them by the soil adhering to it in parts, not slipping well through it, and thus evidencing a want of uniformity in its general friction. Therefore, considering that neither depth nor width of furrow is always the same, and that scarcely one circumstance affecting its use is unvarying, it is difficult to find a rule which shall aptly suit these changes. At the same time it is not presumed that such will not or cannot be found; and the theory which most accords with our view, is one which has recently been laid down by the Rev. W. L. Rham, rector of Winkfield, Berkshire, a gentleman whose scientific and agricultural knowledge entitles his opinion to considerable deference. His theory is, that the mould-board should be composed of straight lines in the direction of its length, with continually increasing angles to the line of the furrow : these last lines being either straight, convex, or concave, horizontal sections of the mould-board.

Coulier.-Simple as the coulter may appear to be, it is a very important part of the plough, and much depends upon its being properly formed and fixed for the work it has to perform in the operation of ploughing. It should be made of iron and steel, and of sufficien: sub. stance to stand firmly to the position in which it is set for its work, not bending esther to the right hand or to the left. 'The blade or cutting part should be about $2 \frac{1}{2}$ inches wide, and formed by the meeting of two curves, as this shape cuts the land easier than when the edlye is either in a straight line or curved for warl. The land side of the coulter should be flat, and the opposite side a gradual taper from the edge to the back: the thickness must be dete'mined by the strength of the work it has to perform.

The angle at which the coulter is usually set, is about forty-five degrees from the plane of the ground; but in summer lands it requires to be placed in a more slanting position, and to take the lead of the share about three-quarters of an inch, to prevent the grass or rubbish driving in a heap, as it otherwise might do. On the contrary, when used for ploughing up hard fallows, it requires to be fixed ir a more upright position, and rather more backward than the point of the share. It should be placed about half an inch above the share, and a quarter of an inch to the land side of it. Every good ploughman has his own notions on the subject of setting the coulter, but the above directions are given from practical observation.

The usual mode of fixing the coulter in the socket of the frame or beam, is by means of wood or iron wedges driven above or below the socket, or by a coarse cut screw-bolt, which turns into the side of the scket and presses against the coulter-stalk. Each of these modes is defective, there being a complication in the details of all that appears not quite adapted to the class of workmen who have to use them.

Skim Coulters.-Skim coulters are sometimes used for the purpose of burying the surfacegrass or rubbish. Sketches of two kinds are given in pl. $17, m, m$. 'The usual plan is to fix the skim about six inches before the common coulter.

Wheel Coulters are used in the fen lands, and are useful when ploughing up turf. One of these coulters is represented in pl. 17,n. The cutting-disk should be made of steel, with a nave sufficiently long for it to be steady, and the box should be bored true, and revolve on a well-fitted steel pin, as on the perfect fitting of the box and axle the correct worling of the disk, and consequently the effective operation of the plough, depends.

Swing Ploughs.-The advantages attributed by Mr. Ransome to the swing plough are as follow's :-

1. It admits of being set into its work at a given depth, either shallower or deeper, by the alteration of the draught iron at the point of draught, or by increasing or decreasing the distance at which the power of the horses is applied.

2. The ploughman has also the power of regulating, in some degree, the depth of the work, by either lifting or bearing upon the handles.

3. It is a plough of more simple construc. tion than any other, and less expensive in its first cost.

4. A skilful workman can plough acrosis ridge anil furrow at very nearly a uniform 


\section{PLOUGH.}

\section{PLOUGH.}

depth; he can work with it on almost all lands, and in all weathers when ploughing can be done at all.

The Wheel Plough (with high Gallowses).-This derives its name from having the appendage of a carriage and wheels. The body of the plough is essentially the same as that of the swing plough, and notwithstanding the different form of its beam, the point of draught should be the same as that of the swing plough, namely, to cut a line drawn from the horse's shoulder to the share or point of resistance.

In the Report to the Board of Agriculture from the county of Leicester, published in 1808, it is stated, "that more than thirty years ago, wheels were first applied to the fore-end of the beam, and it was found by 'pitching' the plough a little deeper, and setting the wheels so as to prevent its drawing too deep, the wheels were a sufficient guide, and the plough required no one to hold it except in places of difficulty." If properly adjusted, a lad of 14 years of age can manage it easily; and the writer of this article once saw, at a ploughing match, a lad having a plough of this sort-the only one in the field-walking leisurely beside it, to the great astonishment of the other competitors, and from whom, to their still greater astonishinent, he carried away the prize. This lad had been taught ploughing only a few months.

When one wheel only is attached to the plough, some persons give the preference to a small one to run upon the unploughed land, as it is less likely to clog up, and requires no alteration towards the end of the furrow; but nthers prefer a larger wheel which runs in the furrow, as it has an even bottom to travel over, and correctly regulates the width of the furrowslice. It also more effectually facilitates the iurning round at the headland, particularly if the horses have to go to the right hand. The larger wheel to run in the furrow, therefore, is best for general purposes, and, with a lever attached to it, is rendered very easy of adjustment.

In the use of a gauge for the depth of ploughing, whether of two wheels, one wheel, or a foot, the plough should be so regulated as to press but lightly on the ground when passing over it; thus admitting as little of the counteracting force between the wheel and share as possible.

In the Prize Essay by Henry Handley, Esq., the advantages of wheels are clearly set forth, and his arguments in favour of their use have since been very strikingly confirmed by the trials made under the directions of Philip Pusey, Esq.

The silver medal of the Royal Agricultural Society of England was awarded to John Clarke, of Long Sutton, Lincolnshire, for the invention of a plough (see Jour. of Roy. Agr. Sor., vol. i. p. 66) for the purpose of ridge cullure; by an easy transition of shape, which is accomplished in a very simple manner, this inplement becomes,

1. A double tom or ridge plough.

2. A moulding plough.

3. A herse-hoe, or cleaning plough.

4. A skeleton, or broad-share plough.

rubsoil Ploughs. - At the thought of a subsoil 910 plough, says Mr. Ransome, our minds turn at once to James Smith, of Deanstone, as the gentleman who has opened a very interesting and important view of tillage, by the system of subsoil ploughing, and thereby breaking the under soil without turning it up to the surface. His practical knowledge has long been devoted to the interests of agriculture, and the results have been most beneficial. The plough he invented for the purpose is too well known to need a description, though we should consider our Essay incomplete without a sketch of it. See pl. 17, o; also $g$.

Following the invention of James Sinith, of Deanstone, was another of a different and much lighter description, the invention of Sir Edward Stracey, Bart., Rackheath, and the plough is called by the latter name. It answers the purpose of deep ploughing, that is, from 10 to 16 inches below the surface, and when preceded by the common plough, which is plan recommended, the depth below the - ro face-ground is just as much again as the $\ldots$. plough effects.

This plough answers admirably for underploughing grass lands, and is made into a subturf plough by changing the wheel gear in front, to that of a carriage and two wheels.

P. Pusey, Esq., in an interesting paper in the Eng. Agr. Soc. Journ. (vol. i. p. 434), gives an account of a plough, made to his order by Charles Hart, of Wantage; at the hinder part of this plough was fixed a strong tine, something like those on Biddel's scarifier, for the purpose of under-ploughing the soil. This tine was made to rise or lower at pleasure; and from the description of its use and operation, given in the above paper, we should think it a valuable invention, as it may be easily attached to a plough of the common sort, and removed when not wanted.

Skcleton, or Cleaning Ploughs, are often the transformations of common ploughs for that purpose, by taking the mould-boards and shares off, and substituting for the shares subsoil or cleaning shares, with prongs. See Pl. 17, $f$.

The plan of laying furrows in one direction, so as to have neither ridge nor water furrows, has within the last year attracted more than common attention in Britain. It has led to a careful inquiry in to the the system of ploughing pursued in Kent, and there seems to be a disposition among many first-rate agriculturists to try the plan, provided lighter implements can be furnished for the purpose, not exceeding the power of two horses' draught. 'To this object some eminent practical farmers have turned their attention, and a plough, made under the direction of Mr. William Smart, a farmer of great respectability and experience at Rainham, in Kent, bids fair to open a new and very important view of the mechanical principles of the turn-rest plough, which he has remodelled; and it may be made equally applicable to the power of two or four horses.

This gentleman, after many trials, arrived at the conclusion that, inasmuch as the work of the turn-rest plough depended on its wedge. like construction, its form could only be correct in proportion to its approach to the perfect wedge; and this form, obtained by straight 
lines in the direction, first, from the point of the share to the throat of the plough, to produce the effect of elevating the furrow-slice; and, second, from the edge of the coulter to the heel of the rest, to effect the turning of the flag, is that which he has adopted; making these lines tend to an angle of 15 degrees. With the assistance of an ingenious ploughwright in his own neighbourhood, several ploughs on this principle were constructed, and these have been the basis upon which still further improvements in the detail have been carried out. They are now so constructed that the ploughman can readily shift his coulter by means of a lever, which reaches the bottom of the handles, and also his rests or mould-boards from side to side, without leaving his station between the handles of his plough, they being so arranged that, by withdrawing a small pin and pressing the projecting rest towards the body of the plough, the mould-boards on either side become alternately the land side when not in work.

Ploughs for the purpose of turning the furrows all in one direction, and laying the slices at an angle with the horizon, as is done by the common plough, have been within the Last year or two brought before the public, but we cannot learn that they have been generally adopted.

In going thus at length into the subject of the plough, we have shown the present state of agricultural mechanics as respects those in general use. To have gone more fully into the description of those out of the common routine of farming, would have carried us beyond what we imagine to be the proper limit of this portion of the work. At the same time it must be observed, that there are a variety of purposes for which ploughs of a particular form, different from any already described, are required; such as paring ploughs, draining ploughs, drill ploughs, \&c. \&c. On each, indeed on all of which, a considerable amount of judgment and ingenuity has been expended.

Ploughs even for common purposes have been long in arriving at their present state; and there are doubtless many improvements that may yet be accomplished.

In the construction of ploughs, the first object to be borne in mind is the proper performance of the work to be done; the next, that this should be effected with the least expenditure of animal power, and with the greatest economy; and, lastly, that they should be made as simple as possible in reference to the ploughman who will have to use them. The circumstance of repairs, which will be continually required as the parts wear out, should also be kept in view, and the whole require to be made on an accurate plan, so as to insure every part fitting properly; the workman may then fix them on the spot as readily as a mechanic at his manufactory. Nor should it be forgotten that quality of materials and workmanship are main points in economy, and that to dispense with either is to pave the way to dissatisfaction and trouble to all parties concerned.

It is difficult to suggest alterations on the present implements, which appear adapted to the purpose, and likely to agree with the description of the requisites just given; but there is no doubt that the plough, in its varius forms, is capable of great improvement; and amongst the points to which attention may be usefully directed are the following:-

Amount of draught that different forms of mould-boards and shares require, in order to determine those best suited to the purpose.

A mould-board that will best turn the work on either side of the plough, so as to admit of its being changed from one to the other, after the plan of the Kent turn-rest.

A ready means of altering the depth or pitch of the swing plough while in motion, without stopping the horses, so that it may be accom. modated to any difference in the nature of the soil, or inequalities on its surface, which the plough may meet with.

The same as respects the wheel plough, with out placing any of its forces in opposition to each other.

Many papers on ploughs and ploughing are contained in the best modern agricultural pe. riodicals. Wilkie's turn-rest plough is described in the Trans. High. Soc. vol. vi. p. 484. Mr. Heathcote's steam plough, Ibid. p. 72. Mr. Laidlaw "On the general advantages of Twohorse Ploughs," Quart. Journ. of Agr. vol. ii. p. 712. "On the Plough of Palestine," Ibid. vol. iii. p. 373. "On Small's Plough as a Drill Plough," Ibid. p. 854. "On the Mathematical Construction of the Plough," by Mr. Amos, Com. Board of $A g r$. vol. vi. p. 437. "On Whee! and Swing Ploughs," by Mr. Handley, Journ. Roy. Agr. Soc. vol. i. p. 140. "On Draught in Ploughing," by Mr. Pusey, Ibid. p. 219. "On Subsoil Ploughing," by Sir James Graham, Ibid. p. 245. "On the Rackheath Subsoil Plough," by Sir E. Stracey, Ibid. p. 253. "On the Charlbury Subsoil Plough," by Mr. Pusey, Ibid. p. 433. "On the Rackheath Subturf Plough," by Sir E. Stracey, Ibid. vol. ii. p. 37 ; and "On a Light Subsoil Plough, adapted for two Horses," by Mr. Gabell, Ibid. p. 421.

The Plough in the United States.-Whilst in Europe, and particularly in Great Britain, the plough has been so much improved, American intelligence and ingenuity have been rewarded with great success in the same pursuit. The implement which the pioneer is obliged to make use of in first stirring and partially turning up the soil filled with roots and stones, is necessarily very rude, sometimes almost equal in this respect to those of the primitive ages of husbandry. One of these rough contrivances is, in New England and the Northern States, familiarly called the Bull plough. The several improvements on the plough in the United States seem to have progressed, for the most part, with little or no reference to European plans or models, and to have been almost exclusively confined to swing-ploughs, wheel-ploughs being scarcely ever seen. Sintplicity and economy seem to have been kept in view by all who have undertaken to improve or modify the implement. As the various sertions of the Union present varieties in the con. ditions of the soil, the ploughs are constructer with reference to these conditions, so that " 
the Northern, Eastern, Middle, and Western States, different ploughs are vaunted for their excellence. It has been observed as a singular circumstance, that to the celebrated author of the Declaration of Independence the United States should be also indebted for the first theory of the plough formed on mathematical principles. President Jefferson's letter to Sir John Sinclair, president of the British Board of Agriculture, addressed in 1798 , is published in the Transactions of the Am. Philosophical Society, vol. iv. p. 314. It describes the mould-board, and the principles upon which it is properly constructed. (See American Farmer, vol. ii. p. 185, and Domestic Encyclopedia, vol. iii. p. 113.)

In England the most complete set of experiments yet made to ascertain the particular merits of different ploughs, are those instituted by Mr. Pusey, president of the Royal Agricultural Society, and described by him in the $3 \mathrm{~d}$ No. of the Journal of that Society. A condensed view of the objects and results of these experiments may be found in the Cultivator, (vol. viii. p. 10), together with the results obtained with American ploughs at the Worcester ploughing match in 1840 .

The points embraced in the English experiments were:

1. 'The comparative lightness in draught, of wheel and swing ploughs.

2. The lightest plough absolutely, of whatever kind.

3. 'The effect of different soils upon the qualities, and chiefly on the draught of the plough.

4. The comparative tenacity of different soils.

5. The power of two horses to plough the strongest or clay soil.

Ten ploughs, embracing some from the most celebrated makers in England, the highly famed Sotch swing plough, and several of those in common use in the different districts of the kingdom, were selected by Mr. Pusey for his experiments, and he was aided by the presence and advice of some of the most distinguished agriculturists in the country. The ploughs were worked by skilful ploughmen; and, as much interest was attached to the experiment on the Scotch ploughs, a Clydesdale span of horses and a ploughman accustomed to the plough were sent up by Lord Moreton to manage that part of the trial. The Scotch plough has obtained considerable celebrity from the strong praise bestowed upon it by Mr. Loudon, who declares the improved Scotch plough to be superior to any similar implement known in England. They are constructed on the principles laid down by Mr. Jefferson, in his celebrated Report on the true shape of the mould-board, addressed to the French Institute, which, he showed from mathematical data, shotid be in the form of a gentle hollow curve; other ploughs constructed more full and short, not raising the earth gradually like a wave, but throwing it over at once. In condensing Mr. Pusey's experiments, we shall select, as sufficient for the present purpose, frcm the list given by him, three ploughs-1st, ihe improved Scotch plough made by Fergu- son, and entirely of iron-2d, a one-wheeled plough of wood, with an iron breast, by Mr. Hart, but commonly known as the improved Berkshire plough; and $3 \mathrm{~d}$, an old-fashioned plough made of wood, and such as is in general use in many parts of England, where it is called the old Berkshire plough. Some previous experiments had convinced Mr. Pusey that the Hart plough was of easy draught, and the ones now instituted showed that his impressions were correct.

The Clydesdale horses were much admired in their work; and it was the opinion of the bystanders that such land, usually worked with four horses in line, might be ploughed with two such horses abreast; though it was said it would cost as much to keep two horses in that condition, as to support the four in their usual working state. On this ground, where the horses had a firm footing, they worked with perfect ease.

In summing up the trials, Mr. Pusey remarks that the plough requiring the least draught was Hart's, though in the last trial it was beat by Ransome's two-wheel plough; and that of all modern ploughs the Scotch swing plough was the heaviest, "out of the question on a light soil, and by no means the best on a heavy one." The following table shows the average draught of all the ploughs on the several soils in which the experiments were made:

Trial 1. Sandy loam

2. Clay loam -
3. Loamy sand -
4. Strong loam -
5. Clay loam -
6. Moory soil -

$-\quad-\quad-17 \frac{7}{4}$ stone.
$-\quad-\quad-47 \frac{1}{4} 6$
$-\quad-\quad-16 \frac{1}{2} 6$
$-\quad-\quad-31 \frac{3}{3} 6$
$-\quad-\quad-28 \frac{7}{6} 6$

A drawing of Hart's improved Berkshire one-wheel plough is given in the Cultivator, (vol. viii. p. 10.)

The trials at the Worcester ploughing match in 1840 , were made to determine the award of two premiums offered by the Massachusetts Agricultural Society, of $\$ 100$, and $\$ 75$, for the best ploughs, one for lapping furrows and the other for laying them flat. The following remarks by the reporting committee will enable the reader to understand the experiments, whilst the list of ploughs will show the num. ber of inventors and improvers whose implements have acquired most celebrity in the eastern portion of the United States.

The power required to turn over a given quantity of earth by a plough is a very important consideration. This power can be measured with great accuracy; greater than many of the committee supposed, before they witnessed the operation. "The dynamometer, inserted between the plough-beam and the chain, measures with greal accuracy the strength exerted by the team. Suppose the strength applied be the same that would be re. quired to raise $336 \mathrm{lbs}$. over a single pulley; suppose also that the depth of the furrow is $6 \frac{1}{2}$ inches with a width of 13 inches. Multiply 13 by $6 \frac{1}{2}$, and you will have 84 with a fraction. Now, if $336 \mathrm{lbs}$. of power will take up and turn over 84 inches of earth, then $112 \mathrm{lbs}$. will turn 28 inches. Tried in this way, the ploughs exhibited showed the following results. The power in each case is $112 \mathrm{lbs}$. 


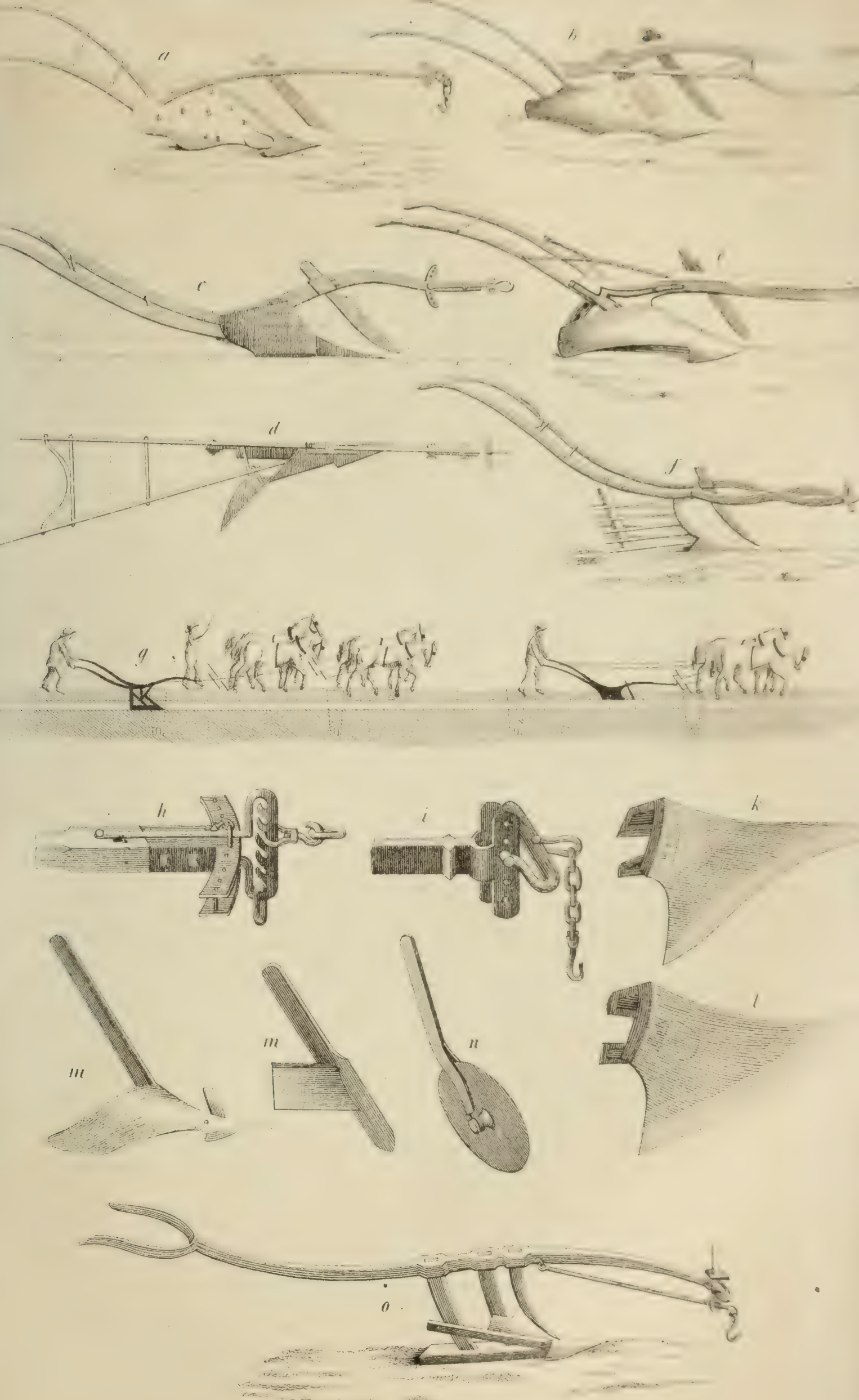



Finst Triac.-Ploughs for lapping furrows.

By Charles IIsward - - 29! inches.

Kuggles, Nourse \&c Mason - 24 "“

John Wilson - - - 21$\}$ “

Stephens' plough - - ough) 198 of

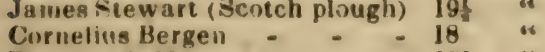

Barnahy \& Mcoers : - : 178 "

E. G. Whiting - -

Second Triac.-For flat furrows.

Prouly \& Mears - - - 27t “

Charles lloward - - 25 "

Ruggles, Nourse \& Co. - -24 “

Barnahy \& Mooers - - - 18t

E. G. Whiting prouty \& Mears 14 "

Another plough by Prouty \& Mears 26 "

Do. do. Charles Howard 25

The terms used in this experiment are different from those adopted in the English one; but those who choose may easily compare them with each other by remembering that 112 lbs. is 8 stone, and making the furrow-slice to correspond, which in the American experiment was 84 inches, and in the English one 45 ; or 61 by 13 , to 5 by 9 . When this is done, the experiments will be found to correspond remarkably well, and the general results of both may be considered as establishing many important truths, some of which have been already pointed out. Thus it will be seen that in the same soil, and under the same circumstances, one plough will work 100 per cent. easier than another, or that one horse will perform the work of two, or two that of four, with the same ease. Could horses speak, they would doubtless direct a vote of thanks to the men who have invented, and the farmers who use, implements by which one-half of the severest labour the horse performs is done away. We very much question whether our farm-horses on our heavy wheat lands do not often perform much more severe labour than the highest rate named by $\mathbf{M r}$. Pusey (52 stone, or 728 lbs.), as we have seen them day after day showing more exertion and evident distress in ploughing than when drawing a ton a day over hard roads. Whatever may be the obduracy or tenacity of the soil, or the toughness of the sward; only one pair of horses is used, where, under the same circumstances, four would be used abroad, and the question is never asked whether the plough is of a construction so defective as to require $5 \mathrm{cwt}$ to move it, or whether it works with ease, with a force of $2 \mathrm{cwt}$. applied. Mr. Pusey estimated the fair draught of the Clydesdaie horse at 16,8 Ibs. or 12 stone, and that of a common Eng!sh farm-horse at 112 lbs. or 8 stone.

At a fair held by the New York Agricultural Society, at Syracuse, in 1941. the first of the regular premiums, $\$ 30$, was awariled to the plough made by Howard Delano of Moitsville, the second premium of $\$ 20$ to E. G. Hulliday, for his plough, favourably known as the I,augh. lin plough. The Wisconsin and other ploughs attracted considerable notice; but the double mould-board plough of Barnaby and Mooers. from the excellence and novelty of its construction, the facility with which it would operate on side hills as well as on level land, and its ease of draught, rendered it deservedly a fit. vourite implement, and the honorary premium was deemed well awarded. It was supposed by many very good judges of ploughing, that the resistance offered by the land-side share would increase the draught sensibly, but the result showed that such was not the case.

The trial of ploughs which took place under the direction of a committee of the American Institute, at New York, was very well conducted; and although the number of ploughs on the ground was not as great as at Syracuse the trials with the dynamometer were more satisfactory. It is to be regretted that some of the favourite Massachusetts ploughs had nnt been present for competition, as a full investigation and understanding of the matter renuires repeated and careful comparison of ploughs ir. the same soils, and as near as possible under the same circumstances. We believe that such will hereafter be the case. The manner in which the report of the trials of ploughs last year at Worcester was presented, renders a comparison of the actual draught used there and at New York, difficult; but as the mode was adopted at New Yurk that English experimen!ers have used, a comparison between the ploughs of England and Scotland, and those of this country, is more easily made. The fol. lowing table, which we find prepared at our

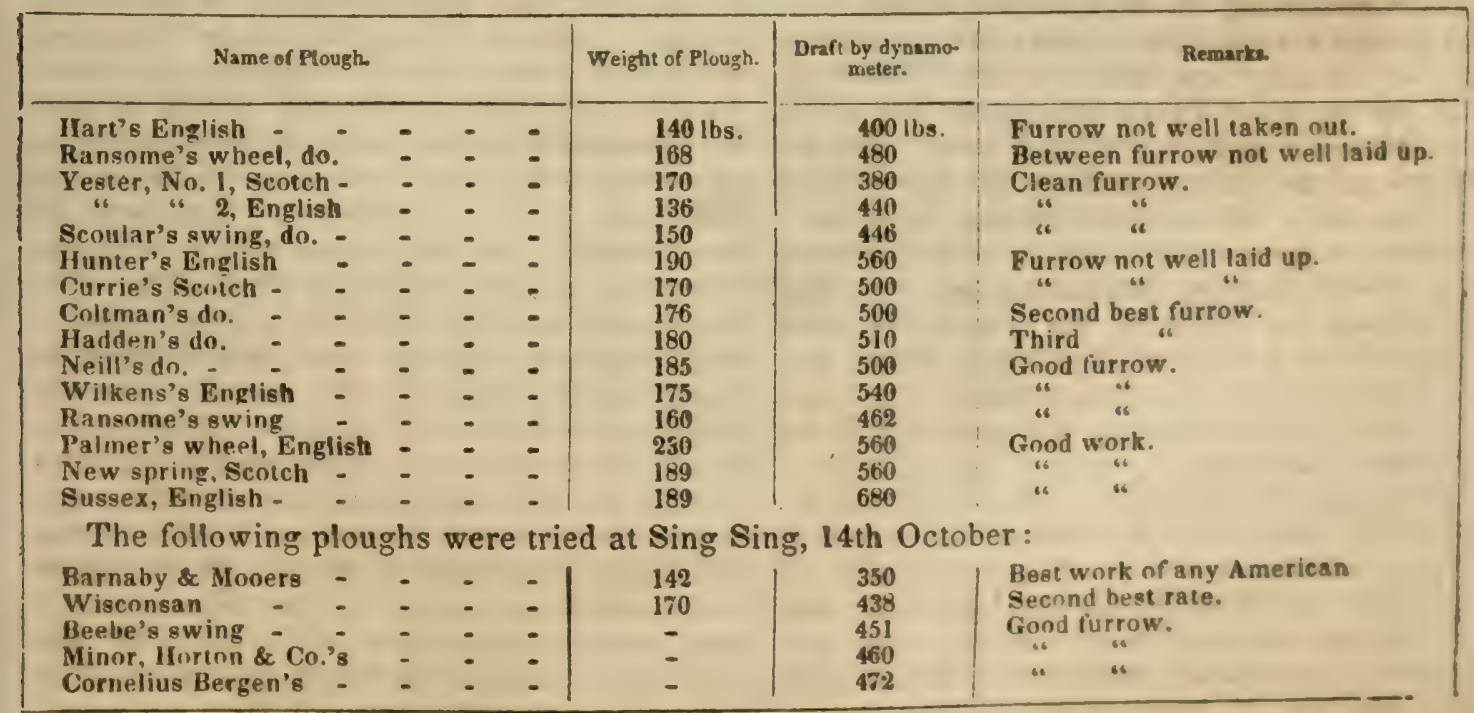




\section{PLOUGH.}

hand in an uccount of the New York trials, given in the Brooklyn Siar, we transfer to our columns with pleasure, merely remarking that we have verified the correctness of the foreign results, by reference to the reports in the Journals of the English Royal Agricultural Society, and the Scotch Highland Agricultural Socicty, from which they were taken. The reader will see that the best British plough, Yester No. 1, weight 170 lbs., draught $380 \mathrm{lbs}$., removed a furrow-slice of only 10 inches by 6 , while the best American, Barnaby and Mooers' double mouldboard side-hill plough (the same that received the premium at Syracuse), weight 142 lbs., draught 350 lbs., removed a furrow-slice of 12 inches by 8 , or nearly twice as large. We are gratified to learn that this plough, which re. ceived the premiums at Syracuse and New York, has been presented by the Institute to the Royal Agricultural Society, and that doubtless it will be subjected to comparison with the ploughs of that country. In examining the list of English agricultural implements, we have often remarked the fact, that English ploughs range in prices from $\$ 20$ to $\$ 30$, while the best improved American ones do not cost more than from $\$ 10$ to $\$ 15$. The table will be understood without further explanation.

In a report of a committee appointed to superintend a trial of ploughs near Baltimore, in 1842 , the following results are stated.

\begin{tabular}{|c|c|c|c|}
\hline $\begin{array}{l}\text { Plough. } \\
\text { Barnaby \& Moners' }\end{array}$ & $\begin{array}{l}\text { Depth of } \\
\text { furrow. } \\
5 \text { 2-0 in. } \\
6 \text { 6-9 }\end{array}$ & $\begin{array}{l}\text { Width of } \\
\text { furrow. } \\
12 \text { in. } \\
131-6\end{array}$ & $\begin{array}{l}\text { Force. } \\
\mathbf{3 5 0} \text { lbs. } \\
562\end{array}$ \\
\hline $\begin{array}{l}\text { Prouty \& Mears' cen- } \\
\text { tre-draught plough, }\end{array}$ & & & \\
\hline Boston - & $51-9$ & $12 \perp-6$ & 500 \\
\hline
\end{tabular}

5. The Davis Plough. This plough worked well, but was withdrawn before trial with the dynamometer.

The committee remark, "the task to the committee, of deciding where such excellence was to be found in each of the implements contending, was one of difficulty, and would have been more so, but for the various purposes to which the Barnaby and Mooers' plough is adapted, it heing in fact a plough of all work, and from the fact of its executing its work with so murh less draught than either of the others."

In commenting on the qualities of the several ploughs submitted to trial, the committee say of Barnaby and Mooers' side-hill plough, the one used:- "There is a peculiarity about this plough which is worthy of note. On the hottom of the furrow, and on the land side, it cuts out fully $12 \frac{1}{2}$ inches of the earth, so as to reduce resistance to the turning of the succeeding furrow, thereby facilitating, not only that (peration, but insuring the exactitude with which it is performed, leaving a clean and broad furrow behind, in which the furrow-horse can walk, and preventing the treading of the groitnd in turning."

Although the trials made at the various ex. hibitions have thus far resulted so much in favour of the double mould-board plough of Barnaby and Mooers, still has this been less extensively adopted than it would appear to Heserve. Associated with its great merits, there may yet remain some obstacle to its general nse, of easy removal. The objection from great
PLOUGH.

weight requiring unusual exertion in throwing out and turning, might possibly be obviated by the addition of a wheel or some other device.

The price of this plough varies from $\$ 4$ for No. 3, a 7 inch seeding plough, to $\$ 10$ for No. $8 \frac{1}{2}$, a heavy two or three horse, 12 inch plough.

The following is a summary notice of the ploughs best known to the farmers of the Middle States. The order in which they are men. tioned is not intended to express the precise dates of their invention or their relative merits.

Beech's Self-sharpening Plough has a concave mould-board. Its price varies with the size, from $\$ 6$ to $\$ 10$, the average price being $\$ 8$.

Miles's Plough, known also by the name of Dickson's, has the bar-share, land-side, and lockcoulter of wrought iron. They cost about \$13. This plough still retains precedence in the old counties of Pennsylvania, its execution being excellent, and its strength enabling it to contend successfully against obstacles met with in stony ground and tough swards.

Peacock's Plough.-This has been long known and is still extensively used. It has a barshare and lock-coulter, and is best adapted to soils of a light texture, where shallow work will answer. It does not turn a sod so well as is desirable.

Wiley Plough.-One of the oldest of the cast-iron ploughs still in use is that of B. H. Wiley. The share of this has two points capable of being turned once. It is adapted to stubbles, but does not perform so well in tough sward.

Woodcock's Plough.-For the last few years this has been in extensive use in Lancaster county, Pennsylvania, and Newcastle county, Delaware. It is a self-sharpening implement, with a slightly concave mould-board. A castiron angular cutter supplies the place of a coulter. It is sometimes constructed so as to have the mould-board on either the right or left side, thus adapting it to the habits of a few old farmers who retuin a partiality for ploughs turning the furrow-slice to the left hand.

Prouty and Mears's Centre-draught Plough.-One of the chief late improvements on American ploughs consists in lengthening or extending the mould-board, and still retaining the centredraught principle, a construction which enables the instrument to turn a sod or furrow-slice so as merely to lap, or to lie completely flat, at the discretion of the ploughman. The cost of these ploughs, which possess high merits, varies, according to size, from $\$ 7$ to $\$ 12$. The larger sizes are provided with a small wheel to each, attached near the beam, a rare thing in America, but which in the present instance serves to render it more easy for the plough to follow the horses with proper steadiness, thus serving to ease the ploughman as well as the horses, the tendency to sink too deeply into the soil being completely checked. With regard to the wheel to ploughs, it is worthy of remark that there is a disposition heginning to be ma. nifested in the United States in favour of at least one such appendage.

Subsoil Ploughs, now so extensively used in 


\section{PI,OUGHING.}

Great Britain, are rapidly coming into use in the United States, where various sizes are made, the largest being a heavy tug for four horses, whilst the smallest may be worked by two mules or one stout horse. Those made by Prouty and Mears are very efficient implements, the prices varying from $\$ 8$ for the single horse, and $\$ 10$ to $\$ 12$ for the larger sizes. A more simple and cheaper subsoil plough, which has proved very successful on trial, has lately been made in the city of New York, adapted to one or more horses. These consist of a common plough from which all the upper portion of the mould-board has been cut away, so as to leave the mere skeleton, which strikes deep and stirs up the subsoil very effectually. The price of these varies from $\$ 4$ to $\$ 6$, according to size. \&c. They may be had in New York at most of the agricultural implement stores, and in Philadelphia, of E. Chandler, agricuitural implement maker, 196 Market street. See Subsoll Plovghina.

PLOUGHING. The art of turning over the soil by means of the plough. There are various kinds of ploughing. Trench ploughing is effected by the plough passing twice along the same furrow: the first time for the purpose of throwing the surface soil into the bottom of the furrow, and the second time for raising a surrow-slice from under that which had been already turned over, and raising it up, \&c. turning it upon the first furrow-slice, by means of which the surface soil is entirely buried, and a stratum of subsoil laid over it: thus effecting in the field what trenching with the spade does in the garden. Trench ploughing can only be employed with advantage where the subsoil is naturally dry and of good quality, or where it has been rendered so by draining and subsoil ploughing; for bad subsoil brought to the surface, unless considerably altered in composition and texture, would be unfit for receiving seeds or plants.

To excel in the art of ploughing, the ploughman should take a pleasure in his work, and not rest satisfied till he can make his furrows in a straight line, and lay the slices as much as possible at the same angle from the bottom of the furrow. He should open his first furrow in a uniform manner, and proceed with regularity of width and depth of the furrow-slice, and "shut up" clean at last.

Ploughing matches, which of late years have been so general, have given a very increased interest to ploughmen and ploughboys. The face of the country is in many parts strikingly improved by the change which sound plough. ing has effected, and much of this may be traced to the lively interest which has been paid to this part of tillage by agricultural so. cieties and by practical farmers. I never knew a ploughing-match meeting established in any rural district without very beneficial effects being produced on the character of the peasantry. It never fails to elevate the ploughman in his own opinion; it induces him to strive to excel in his honourable vocation, to please his employer, and to stand well in the estimation of his richer neighbours. The very assemblage of the neighbouring farmers and gentry to wit-

\section{PLOUGHING.}

ness the trial of skill, brings ont all the latent pride of the roughest ploughman. 'The flowers in his horses' bridles, the network on their ears, the new, gay-coloured tape with wh ch their manes and tails are braided, betray the little feelings of honest pride in the ploughman's bosom. When at a recent meeting I noticed the air of triumph with which the victor in the field of Langley, in Buckingham. shire, after having had the queen's prize of five guineas awarded to him, marched his sleek, well-fed plough-horses off the field, with a sprig of laurel in their bridles, I could not but admit that the effect of that meeting would be felt, not only amongst the contending ploughmen there assembled, but through the adjoining hundreds. The triumph, too, was not confined to the ploughman; his master, nay, his parish, shared in the honour; and I will engage that many an honest ploughman, between one year's meeting and the next, as he ploughs "his acre," thinks of the field of meeting, and of the best means of securing a prize. Such meetings, moreover, teach even the most ignorant the importance of such affairs; that there is a great difference in the neatness, style, and profit to the farmer where the ploughmen execute their work properly; and they are pretty sure to convince even the most listless that there is more skill required in a ploughman than many persons would readily believe.

I believe it admits of no doubt, says $\mathrm{Mr}$. Stephens, that, since the institution of ploughing matches throughout the country, the character of our farm-servants as ploughmen has risen to considerable celebrity, not but that individual ploughmen could have been found before the practice of matches existed as dexterous as any of the present day, but the general diffusion of good ploughing must be obvious to every one who has been in the habit of observing the ploughed surface of the country. This improvement is not to be ascribed to the institution of ploughing matches alone, because superior construction of implements, better kept, better matched, and superior races of horses, and superior judgment and taste in field labour and in the farmer himself, are too important elements in influencing the conduct of ploughmen, to be overlooked in a consideration of this question.

But be the primary motive for improvement in the most important branch of field labour as it may, there cannot be a doubt that a properly regulated emulation amongst workmen of any class, proves a strong incentive to the production of superior workmanship, and the more generally the inducement is extended, the improvement arising from it may be expected to be the more generally diffused; and on this account the plough medals of the Highland and Agricultural Society of Scotland, being open for competition to all parts of Scotland every year, have perhaps excited a spirit of emulation amony ploughmen, jy rewaraing those who excel, beyond any thing to be seen in any other country. Wherever 15 ploughs can be gathered together for competition at any lime and place, there the ploughman who obtains the first premium offered by those interested in the 
exhibition, is entitled to receive, over and above, the Society's plough medal of silver, bearing a suitable inscription, with the gainer's name. About $\mathbf{4 0}$ applications are made for the medals every year, so that at least 600 ploughmen annually compete for them; but the actual number far exceeds that number; as, in many instances, matches comprehend from 40 to 70 ploughs, instead of the minimum number of 15 . The matches are usually occasioned by the welcome which his neighbours are desirous of giving an incoming tenant to his farm, and its heartiness is shown in the extent of the assistance which they give him in plonghing a field or fields at a time when he has not yet collected a working stock sufficient for the purpose.

Ploughing matches are generally very fairly conducted in Scotland. They usnally take place on lea ground, the ploughing of which is considered the best test of a ploughman's skill, though I hold that drilling is much more difficult to execute correctly. The best part of the field is usually selected for the purpose, if there be such, and the same extent of ground, usually from 2 to 4 ridges, according to the length, is allotted to each portion of ground to be ploughed. A pin, bearing a number, is pushed into the ground at the end of each lot, of which there are as many marked off as there are ploughs entered in the competition. Numbers corresponding to those on the pins are drawn by the competing ploughmen, who take possession of the lots as they are drawn. Ample time is allowed to finish the lot, and in this part of the arrangements $I$ am of opinion that too much time is usually allowed, to the annoyance of the spectators. Although shortness of time in executing the same extent of work is not to be compared to excellency of execution, yet it should enter as an important element inio the decision of the question of excellence. Every competitor is obliged to feer his own lot, guide his own horses, and do every other thing connected with the work, such as assorting his horses, and trimming his plough-irons, without the least assistance.

The judges, who have been brought from a distance, and have no personal interest in the exhibition, are requested to inspect the ground after all the ploughs have been removed, having been kept away from the scene during the time the ploughs were engaged.

The primary objects of the institution of ploughing matches must have been to produce the best examples of ploughmanship ; and by the best must be understood that kind of ploughing which shall not only appear to be well done, but must be thoroughly and essentially well done. In other words, the award should be given to the plough that produces not only work of a proper surface finish, but which will exhibit, along with the first, the propertv ; inaving turned up the greatest quantity of soil and in the best manner. (Book of the Farm.)

The following will be found a useful table, showing the distance travelled by a horse in ploughing or scarifying an acre of land; also the quantity of land worked in a day, at the rate of 16 and 18 miles per day of 9 hours.

\begin{tabular}{|c|c|c|c|}
\hline $\begin{array}{l}\text { Breadth of } \\
\text { Furrow-8lice } \\
\text { or Searifier. }\end{array}$ & $\begin{array}{l}\text { Space travelled } \\
\text { in ploughing } \\
\text { an acre. }\end{array}$ & $\begin{array}{l}\text { Extent ploughred pe } \\
\text { rate of }\end{array}$ & r dey at the \\
\hline loches. & Miles. & 18 Miles. 1 Acres. & 16 Miles \\
\hline 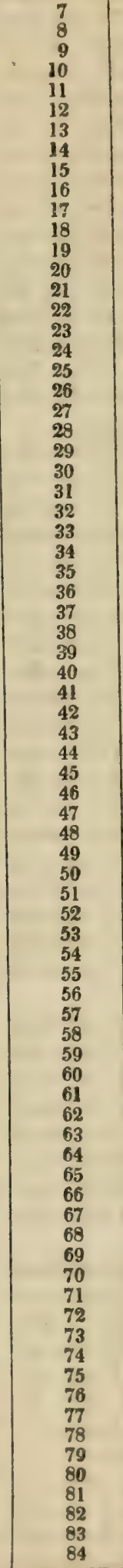 & 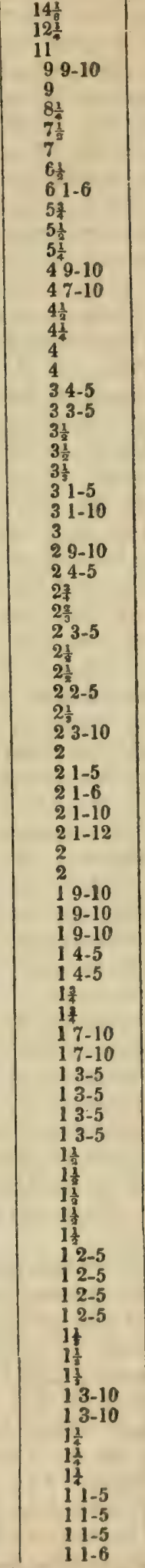 & 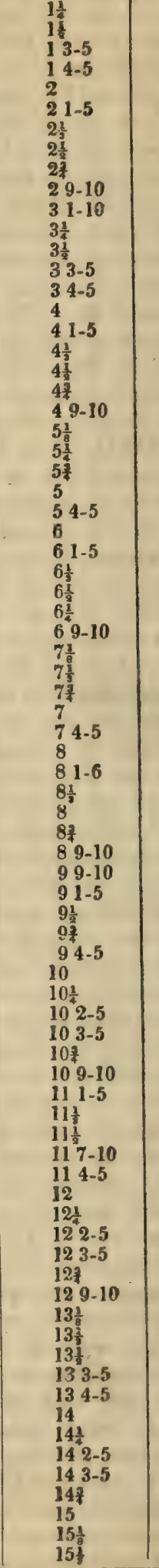 & 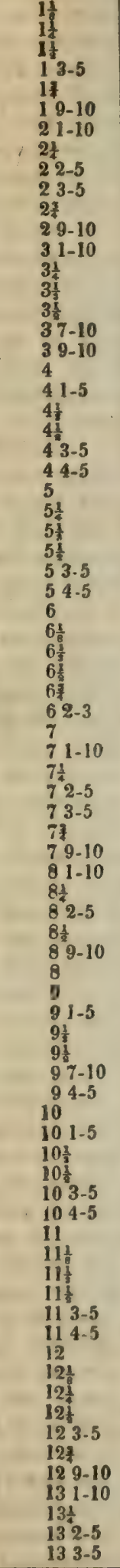 \\
\hline
\end{tabular}

PLUM (Prunus, from prune, its Greek name) A genus of trees and shrubs, several of which are indigenous to Britain. Having already noticed the bird cherry ( $P$. padus), the wild cherry tree ( $P$. cerasus), the wild bullace tree ( $P$. insititia), the black thorn or sloe ( $P$.spinosa), 
under their several heads, it only remains to speak in this place of the wild and cultivated species of plum tree. The wild plum tree ( $P$. domesticn) is a moderate sized tree, without thorns, found growing sometimes in woods and hedges, flowering in May. The fruit is rather oblong, seldom quite globular, its colour and flavour very variable. "Whether all our cultivated plums have originated from this species, or from the wild bullace tree" ( $P$. insititia), says Sir J. E. Smith, "its thorns having disappeared by culture like those of the pear tree, is a question which perhaps no botanist can ever solve." As to its varieties, Gerarde declares that "to write of plums particularly would require a peculiar volume, and yet the end not be attained unto, nor the stock or kindred perfectly known, neither to be distinguished apart." He adds that each country has an abundance of its own peculiar varieties. All the kinds of plum grow well in any common soil, and are increased by seeds or suckers, or by grafting or budding to perpetuate the particular kinds. There are 274 varieties named in the catalogue of the Horticultural Suciety. As a choice selection for a small garden, Mr. Nicol recommends the following twelve varieties: Jaune Hâtive, Wilmot's Orleans green gage, red magnum-bonum, white ditto, Coe's golden drop, Caledonian, mussel, damson, wine-sour, white bullace, blue impératrice.

The best plums for cultivation may be thus classed-

a. Purple Roun D.-Shoots smooth.-Purplegage; nectarine plum; Kirkes; virgin; queenmother.

Shoots downy.-Royal native; Orleans; early Orleans; Coxe's fine late red; winesour.

b. OnLong.-S'loots smooth.-Blue impératrice; Inkworth impératrice; Cooper's large red. Shoots downy.-Blue perdrigon; Shropshire damson.

a. Pale Round.-Shoots smooth-Green gage; Knight's large green drying; Lucombe's nonsuch.

Shoots downy.-Drap d'or; Mirabelle; Washington.

b. Овцоля.-Shoots smooth.-Coe's golden drop;

St. Catherine; White magnum bonum.

Shoots downy.-Gumaraen; White perdrigon.

If plum trees are much pruned, they grow too luxuriant to produce fruit, and often gum and spoil. The choice varieties of plums are much esteemed for the dessert; the more common sorts are used for pies, tarts, preserves, \&c. The wood is employed for turnery and cabinet work, and for the manufacture of $\mathrm{mu}$ sical instruments.

The following information relative to the cultivation and management of plum trees, is from a communication made by $\mathrm{Mr}$. S. Reeve, of Salem, N. J., to that valuable American work, Hoffy's Orchardist's Companion.

Plum trees, like other fruit trees, when first transplanted, and for a few or several subsequent years, should be managed and cultivated alike; but when the plum tree has arrived to maturity and ready to bear, the soil around it should be thrown into a hard texture, for in. stance, of the consistency of a kravel walk.

A pig and poultry yard which remains uncultivated, and never suffered to become a sward, is also very appropriate, from the circumstance of its being promenaded over constantly by bipeds and animals so as to preclude the possibility of grass growing.

In a soil of this description, owing to its teing compact and consequently remaining drier, the trees do not grow so fast as in cultivated grounds, the beneficial result is, that the sap centres itself more in the fruit; whereas, when the sap is too abundant, it is more apt to flow past the fruit into the branches, and thus ultimately, from a want of nourishment, the plums drop off in profusion, owing to their starved condition, and not so much, as it is often supposed, from the bore or sting of the curculio, of which it is frequently found divested when picked from the ground.

From a compact position or nature of soil as before described, another important advantage arises: although not operating as a perfect antidote to the attacks of the curculio, it is nevertheless a great preventive to its depredations, from the circumstance that this insect, when the fruit does fall, not meeting with a surface or soil such as sward, garden ground, \&c., in which to take shelter until the following spring, when it hatches and assumes the winged form, and again commences its destructive attacks upon the fruit.

Mr. Reeve submits it therefore as his opinion, that it would fully repay any person for his trouble or expense in removing (which should only be done when vegetation is checked) from the plum tree, when it has arrived to the age of 8 to 10 years, all the rich subsoil from around the tree in a circumference of from 10 to 12 feet down to the clay soil, and fill up the space again with poor earth, sand, or gravel, so as to check the growth of the tree for the benefit of the fruit, in accordance with the first principles stated in this article.

PLUM TREE WEEVIL. It is now well known that the falling of unripe plums, apricots, peaches, and cherries, is caused by little whitish grubs, which bore into these fruits. The loss of fruit, occasioned by insects of this kind, is frequenily very great; and, in some of our gardens and orchards, the crop of plums is often entirely ruined by the depredations of grubs, which have been ascertained to be the larvæ or young of a small beetle of the weevil tribe, called Rhynchonus (Conotrachelus) Nenuphar, the Nenuphar or plum-weevil. "I have found the beetles," says Dr. Harris, of Boston, "as early as the 30th of March, and as late as the 10 th of June, and at various intermediate times, according with the forwardness or backwardness of vegetation in the spring, and havi frequently caught them flying in the middle vi the day. They are from three-twentieths t", one-fifth of an inch long, exclusive of the curved snout, which is rather longer than the thorax, and is bent under the breast, between the fore-legs, when at rest. Their colnur is a dark-brown, variegated with spots of white. ochre-yellow, and black. The thorax is un

$$
4 \text { н } 2 \quad 917
$$


even; the wing-covers have several short ridges upon them, those on the middle of the back forming two considerable humps, of a black colour, behind which there is a wide band of ochre-yellow and white. Each of the thighs has two little teeth on the under side. They begin to sting the plums as soon as the fruit is set, and, as some say, continue their operations till the first of August. After making a suitable puncture with their snouts, they lay one egg in each plum thus stung, and go over the fruit on the tree in this way till their store is exhausted; so that, where these beetles abound, not a plum will escape being punctured. The irritation arising from these punctures, and from the gnawings of the grubs after they are hatched, causes the young fruit to become gummy, diseased, and finally to drop before it is ripe. Meanwhile the grub comes to its growth, and, immediately after the fruit falls, burrows into the ground. This may occur at various times between the middle of Jure and of August; and, in the space of a little more than three weeks afterwards, the insect completes its transformations, and comes out of the ground in the beetle form. The history of the insect thus far is the result of my own observations; the remainder rests on the testimony of other persons."

In an account of the plum-weevil, by Dr. James Tilton of Wilmington, Delaware, published in the Domestic Encyclopadia, (article Fruit, ) and since republished in the "Georgical Papers for 1809" of the Massachusetts Agricultural Society, and in other works, it is stated, that peaches, nectarines, apples, pears, quinces, and cherries are also attacked by this insect, and that it remains in the earth, in the form of a grub, during the winter, ready to be matured into a beetle as the spring advances. These statements, says Dr. Harris, I have not yet been able to confirm. It seems, however, to have been fully ascertained by Professor Peck, Mr. Say, and others, in whose accuracy full confidence may be placed, that this same weevil attacks all our common stone-fruits, such as plums, peaches, nectarines, apricots, and cherries; Dr. Burnett has recently assured me that he has seen this beetle puncturing apples; and it is not at all improbable that the transformations of some of the grubs may be retarded till the winter has passed, analogous cases being of frequent occurrence. 'Those that are sometimes found in apples must not be mistaken for the more common appleworms, which are not the larvæe of a weevil. The Rev. F. V. Melsheimer remarks in his catalogue, that this insect lives under the bark of the peach-tree. Professor Peck raised the same beetle from a grub found in the watery cxcrescence of a cherry tree, and from this circumstance named it Rhynchonus Cerasi, the cherry-weevil. The plum, still more than the cherry tree, is subject to a disease of the small limbs, which shows itself in the form of large irregular warts, of a black colour, as if charred. firuhs, apparently the same as those that are t.und in plums, have often been letected in these warts, which are now generaliy supposed .o be produced by the punctures of the beetles, and the residence of the grubs. Professor 918
Peck says, that " the seat of the disease is in the bark. The sap is diverted from its regular course, and is absorbed entirely by the bark, which is very much increased in thickness: the cuticle bursts, the swelling becomes irregular, and is formed into black lumps, with a cracked, uneven, granulated surface. The wood, besides being deprived of its nutriment, is very much compressed, and the branch above the tumour perishes." The grubs found by Professor Peck in the tumours of the cherry tree, went into the ground on the 6th of July, and on the 30 th of the same month, or 24 days from their leaving the bark, the perfect insects began to rise, and were soon ready to deposit their eggs in healthy branches.

In speaking of the difference between the grub of the plum-weevil and apple tree caterpillar, Dr. Harris observes, "It must be borne in mind that this plum-weevis, an insect unknown in Europe, when arrived at maturity, is a little, rough, dark-brown or blackish beetle, looking like a dried bud, when it is shaken from the trees, which resemblance is increased by its habit of drawing up its legs and bending its snout close to the lower side of its body, and remaining for a time without motion and seemingly lifeless. In stinging the fruit, before laying its eggs, it uses its short curved snout, which is armed at the tip with a pair of very small nippers; and by means of this weapon it makes, in the tender skin of the young plum or apple, a crescent-shaped incision, similar to what would be formed by indenting the fruit with the finger-nail. Very rarely is there more than one incision made in the same fruit; and in the wound, the weevil lays only a single egg. The insect hatched from this egg is a little whitish grub, destitute of feet, and very much like a maggot in appearance, except that it has a distinct, rounded, light-brown head. By means of the microscope I have satisfactorily ascertained that the grubs from the fruit and from the warts were exactly alike, and that both were without feet. It appears, furthermore, that the tumours on plum and on cherry trees are infested not only by these insects, but also by another kind of grub, provided with legs, and occasionally by the wood-eating caterpillars of the Ageria exitiosa, or peach tree borer. When the grubs of the plum-weevil are fully grown, they go into the ground, and are there changed to chrysalids of a white colour, having the legs and wings free and capable of some motion; and finally they leave the ground in the form of little beetles, exactly like those which had previously stung the fruit. Further obseryation seems to be wanting before it can be proved that the cankerous warts on plum and cherry trees arise from the irritating punctures of the plumweevils, and of the other insects that occasionally make these warts their places of abode; although it must be allowed that the wellknown production of galls by inseets on oak trees and on other plants, would lead us to suppose that those of the plum tree have a similar origin. In addition to the means already recommended for preventing the ravages of plum-weevils, I would observe that wall-fruit can be perfectly secured by a screen of milli net or close netting, which should be put on as 
soon as the fruit is formed, and should remain till it begins to ripen.

'The following, among other remedies that have been suggested, may be found useful in checking the ravages of the plum-weevil. Let the trees be briskly shaken or suddenly jarred every morning and evening during the time that the insects appear in the beetle form, and are engaged in laying their eggs. When thus cisturbed they contract their legs and fall ; and, as they do not immediately attempt to fly or crawl away, they may be caught in a sheet spread under the tree, from which they should be gathered into a large, wide-mouthed bottle or other tight vessel, and be thrown into the fire. All the fallen wormy plums should be immediately gathered, and after they are boiled or steamed, to kill the enclosed grubs, they may be given as food to swine. The diseased excrescences should be cut out and burned every year before the last of June. The moose plum tree (Prunus Americana), which grows wild in Maine, seems to escape the attacks of insects, for no warts are found upon it, even when growing in the immediate vicinity of diseased foreign trees. It would, therefore, be the best of stocks for budding or engrafting upon. It can easily be raised from the stone, and grows rapidly, but does not attain a great size. For further suggestions and remarks, the account of this insect by Dr. Joel Burnett, in the 18th volume of the New England Farmer, may be consulted. (Harris.)

Plums, nectarines, and apricots have been saved after being stung, by extracting the stung part. 'This may be done with the point of a linife or nippers properly adapted to the purpose. The wounds heal and the fruit grows and attains to perfect maturity.

POA (From poa, signifying grass or herbage). The meadow-grass. A genus of grasses of considerable extent, and very abundant in the pasturages of Europe. This genus contains some valuable hay and pasture grasses, succeeding well in rich loamy soil; some of the species are aquatic, growing only in water, or in very moist situations; and increased by seeds or divisions of the roots. Poa annua, pl. $6, c$, is the most common of all grasses. P. trivialis and $P$. pratensis are sown extensively as a part of the artificial grasses for pastures and lawns, which are now commonly made with picked grasses instead of "hay seeds." In general these grasses appear to be nutritious and agreeable to cattle. There are, in England, nine indigenous species, besides severa varieties.

1. Flat-stalked meadow-grass ( $P$. compressa), pl. 7, h. This is a very common species in dry, barren ground, flowering from June to September.

The root is moderately creeping, with downy fibres; stems obliquely ascending in the lower part, then erect and often crowded together, from 1 to $1 \frac{1}{2}$ foot high, remarkably compressed, by which this species may readily be known, as also by a sudden contraction where the panicle begins. Leaves short, narrow, roughish, especially at the edges, with long compressed sheaths, and a short obtuse stipule. The whole plant is more or less glaucous.
Florets from three to eight or nine, connected at the base by a mass of white fulded threads. as fine and soft as a spider's web, which may be drawn out to a considerable length. This grass, though not succulent, is eaten by all cattle, but cannot be cultivated in moist or manured ground. It never forms a close turf, and although it possesses superior nutritive powers, its produce anywhere is far from abunçant.

A variety of this species ( $P . c_{0}$ var. erect $\left.\alpha\right)$ i; mentioned by Sinclair, which differs from the last, in having culms more upright, less com. pressed, and produced in greater quantities. It grows closer, forms a pretty good sward, and the roots are less inclined to creeping. But II is nevertheless inferior in point of early growth. and the produce of the foliage. See $B_{L U E} G_{\text {nass. }}$

2. Alpine meadow-grass ( $P$.alpina), pl.6, L This species is chiefly confined to alpine regions and lofty mountains.

3. Wavy meadow-grass (P.laxa). This species grows in some of the Highlands of Scotland. It possesses no agricultural merit.

4. Bulbous meadow-grass ( $P$. bulbosa). This species tenants the sandy sea-shore, and other dry, barren ground. It is perennial, and flowers in April and May.

5. Roughish meadow-grass ( $P$. trivialis), $\mathrm{pl}$. 5, $i$. This is a very common species, in meadows and pastures, especially such as are rather moist. Perennial, flowering from June to October. The root is fibrous, and tufted the stems several, about eighteen inches high, erect, leafy, with several knots, the naked part cylindrical, roughish to the touch, as are the edges and backs of the flat, slightly spreading, lax, linear, deep-green leaves. In their long compressed sheaths also a slight roughness is sometimes perceptible. Panicle large, spread. ing with half-whorled, horizontal, wavy, angular, rough-compressed, linequal branches. Mr. Curtis, deeply versed in the practical economy of grasses, declares this to be one of the most valuable for pasturage and hay, yielding abun. dantiy, though not particularly early; and of the most excellent quality. Mr. G. Sinclair, another practical authority on the grasses, alsu observes, "The superior produce of this Poa over many other species, its highly nutritive qualities, the seasons in which it arrives at perfection, and the marked partiality which oxen, horses, and sheep have for it, are merits which distinguish it as one of the most valu. able of those grasses which affect moist, rich soils and sheltered situations: but in dry, exposed situations it is altogether inconsiderable: it yearly diminishes, and ultimately dies off, not unfrequently in the space of four or five years. Its produce is always much greater when combined with other grasses than when cultivated by itself; with a proper admixture. it will nearly double its produce, though on the same soil, so much does it delight in shelter. Those spots in pastures that are closely eaten down, consist for the most part of this grass."

6. Smooth-stalked meadow-grass ( $P$. prater sis), pl. $5, h$. This is a very common species in all meadows and pastures. It is perennial. flowering in May and June. The root is strong and creeping, with horizontal run'ters. The 
general aspect of the plant is very like the last, with which it has usually been confounded; but the stems and leaves betray no roughness when drawn through the hand. Spikelets fourflowered; florets lanceolate, ribbed, connected by a web. But the clear and essential mark of this species, compared with the last, consists in its very short, abrupt, pointless stipule, which in every leaf of every variety proves constant and invariable.

As an object of agriculture, this species is not less valuable than the $P$. trivialis, especially for permanent pasture. It is earlier in leaf, and will thrive with less moisture, though the rough-stalked meadow-grass produces, at last, a better crop. Mr. Curtis, and several other able botanists, have rendered great service to the farmer in directing his attention to such objects; and it is undoubtedly worth his while io be select in seeds for grass lands. But, after all, Nature is supreme in the accommodation of particular grasses to certain soils and situatiuns, and whatever we may sow, unless we have well studied her laws, she finally triumphs. The great objection to this grass is the property of the creeping roots to scourge the soil.

Mr. Sinclair notices, in his experiments on the grasses, two varieties, the short blue meadow-grass ( $P$. pratensis subcærulea) and the narrow-leaved meadow-grass ( $P$. pratensis angust $i$ folia), pl. $6, e$, which requires some notice here.

The discriminating characters of the firstnamed are as follows:-Panicle diffuse ; spikelets oval, generally three-flowered; the culms shorter, and somewhat glaucous; and the leaves much shorter and broader than those of the Poa pratensis. It may be further distinsuished by its delicate sky-blue or glaucous colour. Frorn its creeping roots and other demerits, this is evidently one of the inferior grasses. Although the botanical characters of the narrow-leaved meadow-grass ( $P$. angusiffolia) are not sufficient to constitute it a distinct species, its agricultural merits cause it to differ from $P$. pratensis, to which it is much superior. Its spring produce is considerable, and its properties of early growth and great nutritive matter would rank it with the most valuable grasses, but for its powerful creeping root. The culms are most valuable for the manufacture of the finest straw-plait, in imitation of the celebrated "Leghorn." See BuvE Girass.

7. Annual meadow-grass, Suffolk-grass ( $P$. (innua), pl. 6, c. This is an exceedingly commor species everywhere, as well in waste as cultivated ground, flowering from April to November. The root is ficrous. Stems pale, very smooth, oblique, compressed, 3 to 12 inches long. Leaves of a fine light-green, spreading, linear, bluntish, flaccid, roughish at the edge only. Panicle small, widely spreadıng. Sukelets ovate, five-flowered; florets a little remnte, five-ribbed, without a web.

'This is a good grass for fodder, abundant in proportion to the richness of the soil, easily raised, but not durable. The diminutive size of the plant, however, renders its cultivation unprofitable, compared with that of any other uf the pasture grasses. It is the most trouble920 some weed that infests gravel walks, stone pitchings, and the like. The most effectual way to extirpate it in such situations is to sprinkle salt on it; some recommend boiling water and a layer of litter, \&c.

This grass, which Dr. Darlington calls meadow-poa, in the Middle States goes by the name of green grass, spear-grass, and meadow-grass. Although it is styled an annual, it has a perennial root. This species varies considerably, in size and appearance, when growing in different soils and situations. In our best soils, the radical leaves are very long and luxuriant, - when it is known by the name of green grass. This has by some botanists been made a distinct species, under the name of $P$.viridis: but it is probably nothing more than a variety. It is, indeed, as Muhlenberg terms it, "optinıum pabulum;" being decidedly the most valuable of all the grasses known in our pastures. It has not been found necessary to cultivate it, by sowing the seed; for when the land is duly prepared by lime and manure, it soon takes possession of the soil,-or comes in, as the farmers term it; and supersedes the artificial grasses. In very poor land, it deteriorates so much that it would scarcely be recognised as the same plant. It is generally believed by the hotanists to be a naturalized foreigner in the United States.

8. Glaucous meadow-grass ( $P$.glauca). This species is found on the mountains of Wales, Scotland, and the north of England.

9. Wood meadow-grass ( $P$.nemoralis). This is a very common species in some districts in groves and woods, especially on chalk soils. The whole plant is very slender and delicate, $1 \frac{1}{2}$ or 2 feet high. Stems several, slightly compressed, smooth, striated, leafy, with 4 or 5 joints. Leaves almost all on the stem, grassgreen, narrow, flat, more or less rough, tapering to a fine slender point. Mr. George Sinclair speaks favourably of a variety of this species, which he names $P$. nemoralis, var, angusifolia. Although the produce is inconsider. able compared to that of many others equally nutrient, yet the early growth of this grass in the spring, and its remarkably fine, succulent, and nutritive herbage, recommend it strongly for admission into the company of the superior permanent pasture grasses. It flowers in the third week of June, and ripens the seed in the end of July.

The $P$. aquatica, Pl. 5, $m$, or water meadowgrass, of some botanists, is the reedy sweetgrass (Glyceria aquatica) of Smith. The decumbent meadow-grass ( $P$. decumbens) is the decumbent heath-grass (Triodia decumbens) of Smith's English Flora. The reflexed meadowgrass ( $P$. distans) of Sinclair is the reflexed sweet-grass (Glyceria distans) of modern botanists. The Glyceria fluitans is also sometimes zalled the Poa fluitans.

One or two exotic species are mentioned in Sinclair's work on the grasses, viz.,

The soft meadow-grass ( $P$. cenisia). This alpine species is a native of Germany, and attains to a greater size than most others of the same class. 'The root is filurous. Panicle diffuse, nodding. Its nutrient properties, as indicaled by the quantity of nutritive matter is 
contains, are not superior to those of several other grasses, which afford a greater abundance of herbage throughout the season.

The fertile meadow-grass ( $P$. fertilis). It produces flowers about the first and second weeks of July, and seeds in the second week of August. This grass, which is also a native of Germany, seems to be allied to the Poa nemoralis. It differs in having the panicle more loose and spreading, and less attenuated. The spikelets are more oval, and nerved. The culm rises from a foot and a half to 2 feet in height, and sometimes more, ascending at the base, afterwards erect, somewhat compressed. The root is slightly creeping. In regard to early growth, this grass stands next to the meadow fox-tail, cock's-foot, and tall oat. The herbage is more nutritive than that of either of those grasses; and from its agricultural merits it deserves a place in the composition of rich pastures, and ranks with the superior grasses of irrigated meadows. It flowers in the beginning of July, and the seed is ripe towards the end of the month.

The nerved meadow-grass ( $P$.nervata). This species is a native of North America. Panicle upright, often half a foot or more in length, with slender branches, pressed close and subdivided. Spikelets small, of a green colour. Valves of the blossom smooth, having five raised nerves on each valve. Leaves in two rows, resembling a fan, somewhat rough. Culm a little compressed. This grass is remarkably hardy, and possesses many very excellent properties: it will be found a valuable ingredient in permanent pastures, where the soil is not too dry, but of a medium quality as to moisture and dryness. The root leaves are produced on a shoot, and stand in two rows after the manner of a fan. This shoot, which is formed by the union of the base of the leaves, is very succulent, and contains a greater proportion of nutritive matter than the leaves, which accounts for the superior nutrient qualities of the lattermath. It flowers in the third week of June, and the seed is ripe in the last week of July.

POCKET. A large kind of bag in which hops are packed up.

POD. A term used to express the siliqua and silicula of botanists. A seed-vessel of some plants, consisting of two valves, separated by a linear receptacle, along each of the edges of which the seeds are alternately ranged. The wall-flower affords an example of the siliqua, which differs from the silicula merely in being oblong instead of being short and round. The satin-flower, or honesty, bears a pouch or silicula.

POISON (Fr.). Any substance which in small quantity disturbs, suspends, or destroys one or more of the vital functions. Poisons are classified by Orfila under the four heads of irritants, narcotics, narcotico-acrids, and putrefiants, or septics, and, we may add, sedatives. The same poisons which affect men usually affect horses, cows, and dogs; but goats and ,wine eat many things that are virulent poisons $n$ other animals. Sweet almonds and aloes are poisonous to dogs; sugar is poison to pigeons, parsley to parrots, and pepper to hogs. I cies.
On the other hand, hogs derour Nux vomica and henbane with impunity; goats browse on Aconile, Cicula virosı, and Arnica monlana, harmless; and sheep eat cominon hemlock without suffer-

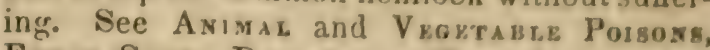
Fungt, Silezp, Disuasme op, Yew, \&c.

POI'T'TEVIN'S MANURE. A compound or. ganic and earthy manure powder, well adapted for the use of the drill. See Maneras aprl.

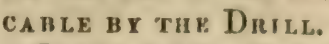

In three experiments with this manure, tried in 1840 , on turnips against bones, the following are the results.

First, on the stony goil. Toms Cwr

24 bushels of Poittevin's - $\quad$ - 92

16 bushels of bones - - - - 101

Second, on a sandy anil.

21 bushels of Poittevin's - $\quad$ - 1510

16 bushels of bones - $-\quad-\quad-\quad 1510$
Third, on a sandy soil with Swedes.

13 bushels of Poittevin's - - - 110

12 buahels of bones - $\quad \ldots$

This manure answers best on light soils; it is generally used too sparingly.

POLE. A measure of length equal to $16 \frac{1}{2} \mathrm{feet}$.

POLLARD. A name given to a tree that has been frequently polled or lcpped, and its top taken off, or headed down to the stem, for the purpose of fire-wood or small poles for hurdle-wood and other similar uses, as well as for hop-poles, \&c. The term is most com. monly in use in the southern and eastern dis tricts of Great Britain. Pollard is also applied to the fine bran or inner husk of wheat. It is a substance much used in feeding hogs and different domestic animals.

POLLEN. In botany, the pulverulent substance which fills the cells of the anthers of a plant, consisting of a multitude of little hollow cases, filled with a fluid holding very minute molecular matter in suspension. The latter is eventually discharged by the grains of pollen through their hollow tubes, and is supposed to be the spermatic fluid of a plant. When the pollen alights on the stigma of the plant, the membrane lining the shell is protruded to a tube, which enters the stigma, and lengthens until it reaches the ovule, into which it empties the impregnating fluid. The pollen grains vary in form and magnitude, being globular, angular, compressed, simple, and compound. Pollen is also a provincial name given to the hen-roost. It is sometimes written hen-pollen.

POI_L-EVIL. An accident which sometimes occurs to horses, from the animal's rubbing or striking his head against the lower edge of the manger, or hanging back in the stall and bruising the part with the halter. Such injuries are serious in their nature and difficelt of treatment, and will usually require the skill and anatomical knowledge of the veterinary surgeon.

POLYPODY. (Polypodium, from poly, many and pous, a foot; having numerous root-like feet. This is an extensive genus of very ornamental ferns. The hardy kinds are well adapted for ornamenting rock-work, or they may be grown in pots, in light loamy soil. All the species may be readily increased by dividing the roots, or by seeds.

There are in England four indigenous srye 
POMEGRANATE (Punica, from punicus of " Carthage," near which city it is said to have been first found; or from puniceus, scarlet; alluding to the colour of the flowers). A beautiful, hardy, deciduous shrub, growing from 12 to 15 feet high. There is no tree more showy than the pomegranate. $P$. granatum, and its varieties, produce their splendid flowers and fruit very plentifully from July to September, when planted against a south wall. They all grow well in a light, rich loam, and strike root freely from cuttings or layers; the rarer varieties are sometimes increased by grafting on the common kinds. The pomegranate requires shelter from frost. The pulp of the fruit is of an agreeable acid, and the rind is highly astringent.

POPLAR (Populus; some derive the word from paipallo, to vibrate or shake; others suppose it obtained its name from being used in ancient times to decorate the public places in Rome, where it was called Arbor populi, or the tree of the people). Most of the species of poplar are very ornamental, more especially in early spring, when the catkins of the males are produced. Their favourite place of growth is in moist soil, near a running stream; but they do not thrive in very marshy situations. All the species are readily increased by cuttings or layers, and some by suckers. There are in England four indigenous species of poplar: the white poplar, already noticed under the head Abele Tree; the gray or common white poplar ( $P$. canescens); the trembling poplar (See Aspex); and the black poplar ( $P$. nigra).

The black Italian, or necklace-bearing poplar ( $P$. monilifera), appears to have been first introduced in to Britain from North America, in 1772. Of all the poplars hitherto introduced, it is by far the most valuable, looking to it in the light of a useful and profitable timber tree, as it grows with astonishing rapidity, and produces a timber of large scantling and excellent yuality, equal, if not superior, to that of any other of its genus. The wood is of a grayish-white colour, tough when seasoned, and, if kept dry, very durable; its great size renders it fit for the largest buildings, and as flooring for manufactories and other erections, nothing can surpass it; for, in addition to the property of not splitting by percussion, it possesses the peculiar advantage of not easily taking fire, and, even when ignited, burning without flame or violence. $\Lambda$ s an ornamental tree, it well deserves a place in extensive grounds, its spiry height and pyramidal form, before it becomes aged, being well calculated to break long horizontal lines, or the monotonous effect of roundheaded trees: it also in a great measure, from its semi-fastigiate growth in the young state, supplies the place of the Lombardy poplar in such scenery, either of wooded landscape or in combination with buildings, as is improved by the presence of that tree.

The Lombardy poplar ( $\boldsymbol{P}$. fastigiata). In its clcse fastigiate growth and cypress-like form, whicn seems to be retained during the whole of its existence, the Lombardy poplar is too conspicuous not to be immeuiately recognised and readily distinguished from all other species of the genus. As a useful and profitable 922 timber tree it is greatly inferior to some of the species already described, the twisted and deeply-furrowed trunk, even of the tallest and largest trees, cutting to much waste, and affording boards of only a moderate size when sawn up. The wood is also softer and more spongy than that of the black and the black Italian poplars, and rapidly decays unless kept perfectly dry. In Britain, therefore, it is cultivated almost exclusively as an ornamental tree, for which its towering height and spire-like form eminently qualify it.

The Athenian poplar (P. Graca) as an ornamental tree is superior, in many respects, to the aspen (to which it is closely allied). It grows rapidly, young trees often making shoots in one season of 5 or 6 feet in length, and, though a slender-stemmed tree, it has the valuable property of resisting the wind, and is never seen, even in the most exposed situations, but an erect and perpendicular trunk.

The bark of all the poplars is more or less antiperiodic and tonic, containing an alkali, which can be procured separate, and is known by the name of Salicina. It may be used for curing agues in the same manner as Quinine, an alkaloid got from Peruvian bark.

There are many North American species of poplar, among which is the tulip tree (Liriodendron tulipifera), ane of the most majestic trees of the $\Lambda$ merican forests, but which has been improperly classed among the poplars. See Tulip Trek.

The other and more genuine species is the Carolina poplar $(P$. angulata). The lower part of Virginia, says Michaux, is the most northern point at which this species is found.

In the shape of its leaves and other characteristics, it bears a very strong resemblance to the cotton tree. The two species may, however, be readily distinguished by their buds, those of the Carolina poplar being short, of a deep green, and destitute of the resinous, aromatic substance which covers those of the cotton-wood, and of which the vestiges remain till late in the season. The wood of the Carolina poplar is white, but so very soft as to be of little value.

The Cotton-wood ( $P$. Canadensis). - I have found this tree, says Michaux, in the upper part of the State of New York, on the banks of the Genesee, in some parts of Virginia, and on several islands in the Ohio, always on a fat, alluvial soil.

The leaves of this tree are trowel-shaped, approaching to heart-shaped. The seeds are surrounded with a beautiful plume which has the whiteness of cotton, and the young buds are covered with a resinous, aromatic substance of an agreeable odour. In the Atlantic States this poplar is rare, and has received no specific name.

American poplar ( $P$. Ihousonica).-This species, Michaux says, he found only on the banks of the Hudson, above Albany, where it attained a height of 30 or 40 feet, with 12 to 15 inches in diameter. Several large poplars of this kind grow in and near the city of New York, where it is usually called American black poplar.

Virginia poplar ( $P$.monilifera).-This species 
was not found by the Michaux, but has been ong cultivated in Europe as a North American ree. It is also called the Swiss poplar, and is confounded with the cotton-wood.

Colton tree ( $P$. argentia). This species is scattered over a great extent of country comorising the Middle, Western, and Southern States; but it is so rare as to escape the noice of the greater part of their inhabitants. It s called cotton-wood on the Savannah in reorgia, where it is confounded with the $\mathrm{Ca}$ olinian poplar.

Tacumahaca or Balsam poplar ( $P$. balsamica). This species belongs to the northern regions f America, being very abundant in Canada, n the districts watered by the river Sagney, etween the 47 th and 49 th degrees of latitude, where, notwithstanding the severity of the winer, it rises to the height of 80 feet, with a dianeter of 3 feet. In the spring, when the buds egin to be developed, they are abundantly oated with a yellowish, glutinous substance, f a very agreeable smell.

Heart-leaved balsam poplar (P. candicans). In he Northern and Eastern States, this tree, which Michaux says is a genuine balsam, is ommonly seen growing before the houses in own and country. In spring, a fragrant reinous balsam exudes from its buds; but it liffers from the Tacamahaca, its leaves being hree times larger and more heart-shaped.

American aspen ( $P$. tremuloides). See Aspen, IMrican.

American large uspen ( $P$. grandidenta). 'This pecies belongs rather to the Northern and Viddle than to the Southern States. It is larger hat the preceding species, with which it is isually confounded.

POPPY (Papaver, from papa, pap, or thick nilk; the juice of the poppy was formerly sed in children's food to make them sleep). These plants succeed best in a light, rich soil. The perennial kinds are increased by dividing the roots. All the species are narcotic. In Ingland there are six indigenous species of oppy, which are nearly all annuals. They re arranged under two sections:-1. Those vith bristly capsules; 2. Those with smooth capules.

The 1st section contains the round, roughreaded poppy ( $P$. hybridum), which grows in andy or challiy fields. This is not a hybrid, is its name implies, but a true permanent pecies.

Long, rough-headed poppy ( $P$. argemone). This grows in grain fields and thin borders, lso on gravelly or sandy soils. It is annual, ind flowers in June and July. The herbage esembles the preceding, but the bristles are ess closely pressed to the stem, and the segnents of the leaves are somewhat broader. 'etals pale-scarlet, black at the base, soon alling, often jagged.

The $2 \mathrm{~d}$ section contains the long, smoothreaded poppy ( $P$. dubium). This species is ound in cultivated fields, especially on a light oil. Annual, and flowering in June and July. $t$ is of a stouter, more luxuriant habit than the oregoing, with broader leaves. The stem is lothed with spreading hairs; the flower-stalks with close-pressed bristles. Petals broader than they are long, of a light-scarlet, the margin mostly crenate.

Common red poppy, or corn rose ( $P$. rheas) See Coun Porpr. 'This is the only officinal species of the British poppies; but it is used in medicine merely as a colouring agent.

White poppy (P. somniferum). 'This species appears to grow wild on sandy ground in the neighbourhood of some of the fron lands. But it is probable that in places where it is fourul apparently wild, the seed from the cultivated poppy has been deposited by birds. The somniferous poppy is a native of Asia and Figypt. It is cultivated in Hindostan, Persia, and Egypt, on account of its opium; in Germany for the oil expressed from its seeds; and in England for the capsules, which are used in medicine. It is universally known in our gardens as an ornamental flower, and is much cultivated in the vicinity of London. 'The whole herb is glaucous, and generally smooth, though the flower-stalks now and then bear several rigid, spreading, bristly hairs. The stem is $\mathbf{3}$ or $\mathbf{4}$ feet high, erect, branched, leafy. Leaves broad, wavy, lobed, and bluntly notched, clasping the stem with their heart-shaped base. Flowers 3 inches broad, white or bluish-white, with a broad violet spot at the base of each petal. In gardens, double varieties of every shade of purple, scarlet, crimson, and even green mixed with white, are common, though nothing can be more liable to change. 'The capsule is nearly globular. Seed small, whitish-brown, oily, sweet, and eatable. There are two varieties, namely, $P$. album and $P$. nigrum, chiefly distinguished by the foramina under the stigma being absent in the former, and present and open in the latter. The milky juice of the capsules, when abstracted by transverse incisions and inspissated, forms opium, which, as Haller well observes, is far more potent and dangerous in hot countries than in our cooler climates. The capsules boiled afford a mild, narcotic decoction, more generally used for fomentations in inward pains, and for making a syrup, which is misused by lazy nurses, who administer it to restless infants, and sacrifice them to their own love of ease. Nothing is more to be condemned than the indiscriminate use of syrup of poppies. No opium, except as experiment, is made from poppies in England; and, could it be made, both it and the foreign opium should never be employed except by the advice of those who alone ought to direct its use.

Yellow poppy ( $P$. cambricum). 'This is a perennial species (and the only indigenous one) which fluurishes in moist, rocky situations in Wales and Westmoreland. It flowers in June. The herbage is tender, brittle, of a light, slight. ly glaucous green; its juice lemon-coloured. Stem a foot high, many-flowered, thinly covered with upright hairs, leafy, branched. Flowers of a most elegant, full lemon colour, deliciously fragrant.

Field poppy (Papaver dubium), bastard poppy. This foreign annual, says Dr. Darlington, has made its appearance in some of the cultivated grounds of Pennsylvania and other parts of the United States, and, if neglected, may become a troublesome weed.

POPPY, THE HORNED. See Hor red Popp 
POPULATION. As very erroneous notions with regard to over-population are often entertained, and as many of the most philanthropic men in England have, at considerable personal trouble and cost, promoted emigration, to avert the evils of war, pestilence, and famine, from what Mr. Malthus supposes to be the tendency of mankind to excessive population, it may be well for the public to peruse a paper (Quart. Journ. Agr. vol. iii. p. 89), which, in detail, ably examines and refutes many of Mr. Malthus's data, calculations, and conclusions. Mr. Malthus states, from data derived through a variety of sources, that the average births from each marriage are-

\section{In Europe .}

England -

- -2 ond in $1829-4136$

Russia - - 4.110

America (in towns) according to $\overline{M r}^{-}$. Barton 4.500

America (in town and country average) - 5.000

But, from returns made to government, it appears that the average births in England and Wales, during the 30 years ending 1820 , fell considerably under 4 from each marriage; and of these, from personal deformity, and a hundred other causes, a considerable portion of women must remain unmarried.

But supposing every woman, married or single, who lived to 18 years of age, should have 7 children, and the rate of mortality as favourable as at Carlisle, the population would require more than 26 years to double itself; and 25 years is the lowest rate of increase $\mathrm{Mr}$. Malthus has contemplated. But, supposing one-tenth part of all the women who attain 20 to remain in a state of celibacy, and the rest were to bear each $3 \cdot 66$ children, which is stated by Mr. Sadler to be the average prolificness in England, and the mortality continued as at Carlisle, the population would remain entirely stationary. In the rich and fertile country of France, the population is nearly stationary, and in Ireland, population increases faster than in England; which can only be accounted for by the institutions which encourage increased forethought before entering on the married state. Amongst barbarous nations, the period of marriage is almost always early; but as countries becume civilized, a portion of early life is devoted to labour of mind and body; and the desire of distinction in some, and, amongst all, the pursuit of gain, delays marriage; and, happily for mankind, nothing is less consistent with universal experience than the terrible succession of evils Mr. Malthus fears from over-population. Natural evils, and the more dreadful effects of misrule, have, indeed, spread death and desolation; but the consequences have not been ir.creased plenty to the survivors: on the contrary, the page of history shows that, in the fairest portions of the habitable world, poverty and want have followed decreasing numbers.

Whereas the wiser the laws, and, consequentIr. the more secure person and property, the slower men are to marry till they have secured for themselves and families, in a habitation of their nwn, the conveniences they were used to under heir paternal roofs; and, consequently, the eis tendency to the excessive multiplication 924 of mankind; and we refer to Scotland, France, \&c., as existing proofs.

No society, well governed, we repeat, has been known to outgrow, or tend to outgrow, its means of subsistence. When, in our own coun. try, one of the most populous in the world, we see how far the earth is yet from producing al that labour, well-directed, can bring forth, wher we look at the tracts lying waste or half-culti vated, we must see how little it is to be fearec as a possible evil, that our population will eve increase beyond the means of supplying itself with food. We have only to look to what $\mathrm{mi}$ nute care can effect in multiplying the produce of the earth, to feel in what a prodigious ratic it may be multiplied. A piece of heath lan the most worthless, converted into a cottager' garden, yields a return of food exceeding tha of the richest land of the cultivated fields. Anc nothing prevents the increase of this species 0 . culture but the want of hands to cultivate an of mouths to consume. Every vegetable tha grows, and is consumed, affords new material for fertilizing the earth, and increasing its pro ductions; and thus every increase of the num ber of consumers is a means of calling nev food into existence.

The introduction of a single plant fron another hemisphere has more than double the power of this and of every country in Eu rope to support their inhabitants. An acre o potatoes will supply food sufficient for the sup port, in healthful existence, of a family of 6 hu man beings for one year; a square mile of lan producing potatoes, therefore, will support 334 persons for the same time. But the produc of the potato is as nothing to that of the banan: and other plants of the tropical regions. No does the produce of the potato in our field show the full power of the earth to produc food. By the minute cares of the gardener successive crops of vegetables may be pro duced from the same surface, and in the sam season. Our present knowledge of agricultur shows us, that throughout the whole kingdon the productions of the earth may be prodi giously multiplied; but what our present know ledge of this art is in comparison with what $i$ may become, we know not. What other plant are yet to be applied to the support of anima life, what other means of fertilizing the eartl are yet to be discovered, what other application of mechanical power may yet take place in ai of human labour, we know nut; nor need we with relation to our present subject, be tor curious in inquiring. It suffices that, with ou present means and knowledge, limited as the are, we can multiply our means of subsistenc in a degree to furnish food for increasing num bers for more generations of men than the cares of the living race need extend to.

And if such be the case with a long-people country, what must we think of the fear tha the entire world will be over-peopled? The richest regions of the globe have yet beer scarcely trodden by the foot of the hunter; great part of Europe is still a desert; and long desolation has overspread lands that once were the seats of nations, and which only de mand security that they may be blessed witl abundance again. Such as Asia Minor, Syria 


\section{POPULATION.}

nd Greece, and such the long-desolated shores Northern Africa. It is not Nature that is arren of her gifts, but it is man that has bused them all; and, in the climates and the ands where we might look for the verdure of n eternal spring, we find only the moving countains and interminable tracts of the deert.

It is unnecessary, perhaps, to enlarge upon his statement, but one or two facts will surely onvince the most incredulous that we are not et nearly arrived at the maximum available roduce of the earth. Even as regards the aving in the seed-corn, we have witnessed in ur time that the drill has done much, and the ibbling system still more; but, by transplantig, greater things may yet be done. I will lustrate this position by only one or two facts ut of many of a similar kind that I am acuainted with. At the Battle Horticultural how (in 1837), $\mathbf{R}$. White received a prize for 1 fine ears of wheat growing from one grain, hich are deposited at the apartments of the abourer's Friend Society in Exeter Hall, and nother prize at the Society for Encouragement f Arts, \&c., in the Adelphi, and similar preiums are again offered there and elsewhere. - Brown raised that year 345 roots, with 4250 ars, from one grain, since June, 1836, the lants having been divided three times; and it recorded in the Philosophical Transactions for 768 , that in the same space of time, one grain i wheat produced 21,109 ears, containing 76,840 grains, or nearly a bushel of clean rain; thus, an acorn cup would hold seedbeat enough to raise plants for an acre of ind, and full 10,000,000 bushels of seed-wheat right be saved on the 4,000,000 acres under heat in England and Scotland; which quanty, allowing 8 bushels to each person, would upport 1,250,000 persons, who, if employed in reeding the crops, would double the produce, $s$ is shown by the increased crops raised by he tenants under the allotment system.

And again, as regards manuring the soil, griculture is yet only in its infancy; crushed ones, now so extensively employed, were unnown as fertilizers 25 years since; gypsum, hich abounds in England, is only slowly com$\mathrm{ig}$ into use; and millions of tons of the richst manure are now annually wasted in our ities and towns-suffered to putrefy in cessools, or poured into the sea through a thouand sewers; "and yet," says the Thames Imrovement Company, "strange as it may apear, England is almost the only nation in urope, notwithstanding its advance in agriultural knowledge, which suffers the peculiar nanure in question to be wasted and cast way; while all the other nations on the Connent, and even China, husband it, and treaure it up for their lands, make it an object of xtensive and lucrative traffic, and some exort it to their colonies. The principal Lonon sewers have been carefully gauged, and re found to convey daily into the river hames 115,608 tons of mixed drainage."

By these and other certain improvements, ve may safely conclude that, as regards the ultivation of the most barren tracts, the driftng sands of Norfolk, the heath lands of the north of England, and even the shingle of uts sea-coast, hardly a tithe has yet been effectrd in the way of cultivation. At the suggestion of the Archbishop of Dublin, an acre of shingle at East Bourn was covered with 3 , 4 inches of clay, at a cost of only 1 fid. 'T'his has formerl a plate to retain what mould, \&c., the tenant has added, who has hired this ground for fourteen years at 40s. per acre. So no land is hopelessly barren. Let such improvements proceed; let science go hand in hand with the farmer; let the naturalist find new cultivata. ble vegetables, or new varieties of those already known; let the chemist yield his magic aid to demonstrate the best mode of promoting their growth and increasing the fertility of the soil; and then, I fearlessly assert that many times the present inhabitants of Britain may be amply supported by the produce of the lanil of our birth.

POPULA T IO N, AGRICULTURAL, OF THE UNI'TED S'TATES. By the census of 1840 , it appears that the number of all the males, of 10 years old and upwards, in the United States and Territories, exclusive of the naval service, was 5,907,752. The whole population of the Union was $17,069,453$, of which the number engaged in agricultural pursuits is more than a fifth part of the whole population. When this is compared with the proportions engaged in some other pursuits, we find the next most numerous class com prised of those engaged in the various manufactures and trades, which, in the non-slaveholding states and territories, amounts to 1 in 17 , and in the slave states to 1 in 40 -averaging, in the whole Union, 1 to 22 of all the inhabitants. The largest proportion of manufacturers is in Rhode Island, where it constitutes about four-fifths of all the males above 20 years of age; next in Massachusetts; next in Connecticut; next in New Jersey; next in New York. The proportion employed in commerce comprises, in the free states, 1 in 122 , and in the slave states 1 in 197-the average in all the states being 1 in 146 of the whole population. 'The largest proportion is in Lou. isiana, which contains the great depôt for the commerce of the Mississippi Valley. The next largest is in Wisconsan Territory, and the next in Rhode Island. The proportion employed in ocean navigation is greatest in Massachusetts, where it amounts to 27,153, being 1 in 31 of the whole population of the state, and nearly one-half of all those engaged in the same pursuits in the whole Union, viz., 56,021 , or 1 in 305 . The next greatest is in Maine, where it amounts to 10,091 , being 1 in 49.72 of the state population. New York has 5511, Connecticut 2700, and Pennsylvania 1815, employed in ocean navigation. The proportion engaged in the learned professions, including engineers, amounts to 45,162 , or 1 in 217 of the whole population of the free states. and 20,093 , or 1 in 361 , of the whole inhabitants of the slave states.

PORES. In botany, apertures, more or less visible, in the cuticle of plants, through which transpiration takes place. They may exist on the cellular tissue; and when there they are the organs of insensible perspiration of the 
plant: they may exist as cortical pores; or on the leaf as stomata or breathing pores. Pores also exist in some kinds of anthers, through which the pollen is ejected; as in the potato (Solunum tuberosum).

PORK. The flesh of swine killed for culinary purposes. See BAcos, HAM, Meat, Sw INE, \&c.

PORTER. A well-known malt liquor. See Ale, Bere, and Brewing.

POTASH, or POTASSA. The name of one of the alkalies, composed of $39 \cdot 15$ parts of peculiar metal called potassium, 8 parts of oxygen, and 9 of water. It derives its common name from being first obtained from the ashes of vegetable substances which had been burned in iron pots, hence named pot-ashes. Potash is found in almost all land plants, in combination with the tartaric, citric, or other vegetable acid. The potash in these is no doubt an essential food or constituent of vegetation, and there is no fertile soil which does not, in some form or other, contain this alkali. It exists, however, in plants in varying proportions. See Arkatr. 'The potash of commerce is ar. impure carbonate mingled with salts of lime and other substances. In its separate or pure state, free from carbonic acid, it is a white salt, powerfully attracting moisture from the air, very soluble in water and in alcohol, corroding animal substances, consequently destroying the skin when applied to it. But potash usually means the carbonate. The quantity procured from different plants varies. Fumitory yields 79.0 in 1000 parts, wormwood $73 \cdot 0$, young wheat-stalks $47 \cdot 0$, thistles $35 \cdot 0$, vetch $27 \cdot 5$, common nettle $25 \cdot 3$, the sunflower $\mathbf{2 0} 0$, bean-stalks $\mathbf{2 0 \cdot 0}$, barley straw $\mathbf{5} \cdot 8$, vine-shoots $5 \cdot 5$, wheat-straw $3 \cdot 9$, and flax $5 \cdot 0$. The younger a plant is, if full-grown, the more potash it yields.

"The perfect developement of a plant," says Jiebig (Organic Chem. p. 104), "according to this view, is dependent on the presence of alkalies, or alkaline earths, for when these substances are totally wanting, its growth will be arrested, and when they are only deficient it inust be impeded. In order to apply these reinarks, let us compare two kinds of trees, the wood of which contain unequal quantities of alkaline bases, and we shall find that one of these grows luxuriantly in several soils, upon which others are scarcely able to vegetate. For example, 10.000 parts of oak wood yield 250 parts of ashes, the same quantity of firewood only 83 , of linden wood 500 , of rye 440 , and of the herb of the potato plant 1500 parts. Firs and pines find a sufificient quantity of alkalies in granitic and barren, sandy soils, in which oaks will not grow, and wheat thrives in soils favourable for the linden tree, because the bases which are necessary to bring it to complete maturity exist there in sufficient quantity. The accuracy of these conclusions, sn highly important to agriculture, and to the cultivation of forests, can be proved by the most evident facts. All kinds of grasses, the equisetacex, for example, contain, in the outer parts of their leaves and stalks, a large quantity of silicic acid (silica), and potash in the form of acid silicate of potash. The proportion of this 926 salt does not vary perceptibly in the soil of corn-fields, because it is again conveyed to them as manure, in the form of putrefying straw. But this is not the case in a meadow; and hence we never find a luxuriant crop of grass on sandy and calcareous soils, which contain little potash, evidently because one of the constituents essential to the growth of plants is wanting. Soils formed from basalt, grauwacke, and porphyry, are, cæteris paribus, the best for meadow land, on account of the quantity of potash which enters into their com. position."

In the experiments of the Rev. E. Cartwright with various manures applied to potatoes, wood-ashes, which contain potash, were found to produce very superior effects to several others : thus, where the soil, without any dresse ing, produced 157 bushels per acre, the land dressed with 60 bushels of wood-ashes yielded 187 ; with 60 bushels of malt-dust, 184 bushels; with 363 bushels of decayed leaves, 175 bushels; with 363 bushels of saw-dust, 155 bushels; with 121 bushels of lime, 150 bushels per acre. (Com. Board of $A g r$. vol.iv. p. 370.) See Gneer SaND, Alralis, and Salts.

POTATO (Solanum tuberosum). A valuable, well-known root, first imported from America into England by Sir Walter Raleigh, and first grown at Youghall, in Ireland. In many parts of England this tuberose plant is very extensively cultivated, both in the field and in the garden; but, in districts removed from large towns, or convenient markets, its cultivation is of necessity restricted to the garden, or for the consumption of the live-stock of the farm. As regards the field management of the crop, a writer in a popular journal remarks, when speaking of the preparation of the ground-

"It is, I know, customary, upon a large scale, to plough the land and make it tolerably fine before potatoes are planted; but if it is ploughed 5,6, or 7 inches deep, and made fine and mellow, still at the bottom of such ploughing the land is hard and smooth; and as the potato is a root that sends out fibres not only near the surface, but deeply, if possible, it can never porduce such a crop as where the land is broken 18 inches to 2 feet. The potato, like the cucumber, only enjoys itself in deeply pulverized soils, which causes them to flourish so much in well-managed sandy land.

"I should therefore recommend that, in all land where potatoes are to be grown, if the land be springy, or otherwise damp, that it be drained deep enough to take off all springs or surface water. When this is done, the land should either be fully trenched, or bastardtrenched, by the spade or plough, but I prefer the spade. The width of the drills from each other must depend entirely upon the goodness of your soil : the richer the land, the wider apart must be your rows and sets in your rows; say, in ordinary land rows, at 2 feet from each other, and 12 inches from set to set may do; but if your land be very rich, 3 feet from row to row, and 18 inches from plant to plant, will not be too much."

In preserving your sets, always select the largest and finest potatoes you can procure: do not use the small refuse or middling-sized, 
the plant and produce from the latter being much inferior.

The potatoes most valued in field culture are the ox-noble, yam, champion, purple-red, roughred, hundred-eyes, kidney, and Moulton white. The nutritive qualities of these were examined by Mr. George Sinclair, with his usual accuracy. "The yam," he observes, "is a very productive variety, attains to a large size, but is often hollow, and less nutritive than most others; 64 drachms afford of nutritive matter 190 grains, which consist of starch 164 grains, and saccharine and albuminous matters 31 ."

The ox-noble is a productive potato, adapted for stock; and 64 drachms of it contain 194 grains of nutritive matter, consisting of starch 164, and saccharine, mucilaginous, and albuminous matters 31 .

The purple-red is smaller than the ox-noble, but well-flavoured, and very prolific in light, moist soils: 64 drachms afforded 200 grains of nutritive matter, consisting of starch 169 , and albuminous and saccharine matters 31 grains.

The hundred-eye is very prolific on dry loams ; 64 drachms afford 218 grains of nutritive matter, composed of 170 grains of starch, and the rest albuminous and other matters.

The rnugh-red produces plentiful crops on soils or climates of a moister nature than that adapted for the hundred-eyed variety: it is well-flavoured; 64 drachms afford 250 grains of nutritive matter, which is composed of 199 starch, and 46 mucillage, sugar, and albumen.

'The champion grows to a moderate size; is very productive, and little subject to the disease called curl.

It is, hence, of great importance, in choosing seed potatoes, to consider the nature of the soil and climate; thus some of our finest varieties, which yield abundantly when planted in suitable soils and moist situations, will yield but inforior returns when planted in drier situa$\mathrm{u} u \mathrm{~s}$.

\begin{tabular}{|c|c|c|c|c|}
\hline $\begin{array}{c}\text { In 7000 grains, or 1 pound } \\
\text { of the bread-fruit pota- } \\
\text { lo, 1 found hy carefui } \\
\text { and repeated trials }\end{array}$ & $\begin{array}{c}\text { Soluble } \\
\text { matter. }\end{array}$ & Starcb. & Fibre. & Water. \\
- the Barbadoes potato & 980 & 548 & $\mathbf{4 7 7}$ & 5000 \\
- black kidney potato & 970 & 695 & 616 & $\mathbf{4 7 3 7}$ \\
\hline
\end{tabular}

The soluble matters consisted of gum, or mucilage, extractive, and saline matters.

The potato, although a tender plant, is grown in nearly all parts of the world, from the equator to Norway; and although it is usual to plant it early in the spring, yet it is possible, by choosing a quick-ripening variety, to plant it successfully even as late as July.

The best manures for the potato crop are common farm-yard compost, only partially decomposed, decayed leaves, sea-weed, the potato haulm, and any organic manures, that, while they afford nutriment, have a tendency, by rendering the soil lighter, to facilitate the extension of the roots. Lime is injurious to it. Pond mud or ditch scrapings, to each cubic yard of which, a month previously, a bushel of bacon salt, or other refuse common salt, has been mixed, is excellent. The soils best adapted fur the cultivation of the potato are of the light, dy, drained, peaty, or loamy description. It delights in fresh soils; those of a newly broken-up meadow, old woodlanils, or the site of old yards or buildings, are excellent. It does not do well on wet clays.

Potatoes are readily consumed by liresstrok in their unboiled state; but, generally speak. ing, they are best when steamed and mixer? with chaff.

The cultivation of the potato is thus described by Mr. George Johnson; and although his remarks were intended for the gardener, yet they apply in a great measure to the field culture of this valuable root.

The varieties of the potato are numerous, and continually increasing, as well as becoming extinct; the number, however, is very largely increased by local names for the same variety being classed distinct.

For forcing, or first crop in the open ground: - there are Broughton Dwarf, Early Warwick, Ash-leaved Kidney; Fox's Seedling, Early Manly, Early Mule, earliest for general cultivation, Earley Kidney, Nonsuch, Early Shaw, Goldfinger.

For main crops, the varieties are ranged in this class, according to their forwardness in ripening:-Early Champion, Ox Noble, Rednose Kidney, Large Kidney, Bread-fruit, Redstreak or Lancashire Pink-eye, Black Skin, Purple, Red Apple, Rough Red.

No inhabitant of the garden varies more in quality in different gardens than the potato; for a variety will have a strong, unpleasant flavour in one soil, that has a sweet, agreeable one in another. In a heavy, wet soil, or a rank black loam, though the crop is often fine and abundant, it is scarcely ever palatable. Silicious soils, even approaching to gravel, though in these last the tubers are usually corroded or scabby, are always to be planted in preference to the above. A dry, mouldy, fresh, and moderately rich soil is unquestionably the best for every variety of the potato; and, for the earliest crop, it may be with advantage more silicious than for the main ones. The blackskinned and rough red thrive better than any in moist or strong, cold soils. If manure is necessary, whatever may be the one employed, it is better spread regularly over the surface previous to digging, rather than put into the holes with the sets, or spread in the trench when they are so planted. Stable dung is, perhaps, the best of all factitious manures: sea-weed is a very beneficial addition to the soil, as is salt. Coal-ashes and sea-sand are applied with great benefit to retentive soils: but calcareous matter should never be used. The situation must always be open.

It is propagated in general from cuttings of the tubers, though the shoots arising from thence and layers of the stalks may be en ployed. New varieties are raised from seed. Planting in the open ground of the early kinds may commence towards the close of February, in a warm situation, and may thence be continued until the same period of March; and it is only during this latter month that any con. siderable plantation should be made, as the late frost are apt to injure, or even to destroy the advancing plants. In the course of Apri:. 
the main crops for winter's use should be inserted; for although in favourable seasons they will succeed if planted in May or even June, yet it ought always to be kept in mind that the earliest planted, especially in dry soils, produce the finest and most abundant crops.

Of the preparation of the sets, there is a great diversity of opinion. Some gardeners recommend the largest potatoes to be planted whole; others, these to be sliced into pieces, containing two or three eyes; a third set, to cut the large tubers directly in half; a fourth, the employment of the shoots only which are thrown out, if potatoes are kept in a warm, damp situation; and a filth, that merely the parings be employed. Cuttings of the stalks, 5 or 6 inches in length, or rooted suckers, will be productive, if planted during showery weather in May or June; and during this last month, or early in July, it may be propagated by layers, which are formed by pegging down the young stalks when about 12 inches long, they being covered 3 inches thick with mould at a joint. These three last modes are practised more from curiosity than utility, whilst at the same time none of the first five mentioned plans can be individually followed to advantage, without modification. For the main crops, it is evident, from experiment, that moderatesized sets, having two healthy buds or eyes, are most advantageously employed; middling-sized whole potatoes are the best, from which all but the above number of eyes have been removed, but especially having the crown, which is a congeries of small eyes always present, first removed; for from these proceed an equal number of little spindled stalks, which are comparatively worthless, and injure the main stem.

For the early crops, almost the very contrary to the above is the most advantageous to be practised. 'The set should have the crown eye, which is one growing in the centre of the congeries of small ones above mentioned, preserved. Some potatoes have two such eyes, but the generality only one. This is always the most prompt to vegetate; and if not known by this description, may bo evinced by placing iwo or three potatoes in a pan of moist earth, near the fire; if the earth is kept moist, the crown eye will be in a state of vegetation in five or six days. Again, as Mr. J. Knight remarks, although abundant crops of late varieties may be obtained from very small sets, by reason that tubers are not produced until the stem and roots become capable of supplying them with nourishment; yet, to obtain early crops, where tubers are rapidly formed under a diametrically opposite state of the plant, large jets $m$ ist be ernployed; in these, one or two eyes, at most, should be allowed to remain. Mr. Knight plants the largest undivided tubers, which, from experiments, evidently support the plants, and finally produce the earliest and largest produce he ever obtained. Another remark, which he makes, restrictively for the early crops. but may well be attended to for all, is, that it the sets are placed with their leading buds upwards, few and very strong early stems will be produced; but if the position is reversed, many weak and later shoots will arise, and not only the earliness, but the quality of the produce be depreciated. For the earliest crops, there are likewise several modes of as sisting the forward vegetation of the sets. These should be prepared in November, by removing every eye but one or two; and being placed in a layer, in a warm room, where air and light can be freely admitted, with a cover. ing of straw, they soon emit shoots, which must be strengthened by exposure to the air and light as much as possible, by taking off the covering without injuring them. During cold weather, and at night, it must always be renewed. The leaves soon become green, and tolerably hardy. In early spring they are planted out, the leaves being left just above the surface, and a covering of litter afforded every night, until the danger of frost is passed. The only modification of this plan that is adopted in Cheshire, where they are celebrated for the early production of potatoes, is, that they em. ploy chaff or sand for a covering instead of straw. The most preferable mode of inserting them, is with the dibble, in rows, for the early crops, 12 inches apart each way; and for the main ones 18. The set should never be placed more than 4 inches beneath the surface in the lightest soil, but in the more tenacious ones, 3 is the extreme. The potato dibble is the best instrument that can be employed; one person striking the holes, and a second dropping the sets, the earth being afterwards raked or struck in with the spade. There are several other modes of insertion, as opening a small hole with a narrow spade, and the set being dropped in, it is covered by the earth taken out in form. ing the next hole: or, at the time of digging over the ground, a second person follows the one so employed, and places the sets in the trench he opens in the pursuance of his work; but both these modes are open to numerous obvious objections.

The compartment may be laid out level and undivided, if the soil is mouldy and favourable; but if a heavy one is necessarily em. ployed, it is best disposed in beds, 6 or 8 feet wide. If the staple of the soil is good through. out, the alleys may be 2 feet wide, and dug deep, otherwise they must be made broader, and only one spit taken out, the earth removed being employed to raise the beds. If the land is low and wet, it is still further of advantage, after the beds, which should not be more than 4 feet wide, have been thus raised, if they are dug in parallel ritges, and the sets inserted along their summits. Some gardeners, on such soils, without digging the surface, lav some long litter on the intended beds; upon this the sets being placed, some more litter is thrown regularly over them; the earth is then dug from the alleys, and turned to the requisite depth over the whole. As soon as the plants are well to be distinguished, they should be perfectly freed from weeds; and, of the early crops, the earth drawn round each plant, so as to form a cup, as a shelter from the cold winds, which are their chief enemy at that season; but the main crops need not be earthed up until the plants are 6 inches in height. It is contended by some that this practice is immaterial in its effect. If the earth is brought so as to be of 
considerable depth about the stems, it must be even injurious; but if properly performed, it is certainly beneficial. 'Throughout their growth they should be kept perfectly clear of weeds. It is very injurious to mow off their tops, as is sometimes recommended. The foliage ought to be kept as uninjured as possible, unless, as sometimes occurs on fresh ground, the plants are of gigantic luxuriance, and, even then, the stems should be only moderately shortened. It is, however, of considerable advantage to remove the fruit-stalks and immature fowers as soon as they appear. 'This has been demonstrated by the experiments of President Knight, and others; indeed, that such would be the case is a reasonable expectation, since it is known that the early formation of tubers prevents the production of blossom. It is also worthy of notice, that a potato plant continues to form tubers until the flowers appear, after which it is employed in ripening those already formed.

The very earliest crops will be in production in June, or perhaps towards the end of May, and may thence be taken up as wanted, until October, at the close of which month, or during November, they may be entirely dug up and stored; or, at all events, before the arrival of any severe frost. Their finness to be taken up for keeping is intimated by the decay of their foliage, which generally loses its verdure with the first frosts. The best instrument with which they can be dug up is a three-flat-pronged fork, each row being cleared regularly away. The tubers should he sorted at the time of taking them up; for as the largest keep the best, they alone should be stored, whilst the smaller ones are first made use of. The most common mode of preserving them throughout the winter is in heaps or clamps, sometimes called pyeing them. These are laid in pyramidal form, on a bed of straw, and enveloped with a covering 6 or 8 inches thick, of the same material, laid even, as in thatching, and the whole enclosed with earth, in a conical form, a foot thick, taken from a trench dug round the heap, well smoothened with the back of the spade. Potatoes should not be stored until perfectly dry, nor unless free from mould, refuse, anu wounded tubers. It is a good practice to keep a hole open on four different sides of the heap, entirely through the mould and straw, for a week or two after the heap is formed; for in proportion to its size it always ferments, and these orifices allow the escape of the vapours, and perfect the drying. An equally good mode, and much more convenient, is to have them heaped in a dry shed, and covered thick with straw, as opportunity is given to look over them occasionally for the removal of decayed tubers, shoots, \&c. If carefully preserved, they. conrinue in perfection until late in the following summer. A variety of the potato is generally considered to continue about 14 years in perfection, after which period it gradually loses its goou qualities, becoming of inferior flavour and unproductive. Fresh varieties must therefore be occasionally raised from seed. For doing this there are two modes; the first of these, about to be detailed, is, however, the one usually pursued.
The berries or apples of the old stock having hung in a warm room throughout the winter, the seed must be obtuined from them by wash. ing away the pulp during February. 'This is thoroughly dried, and kept until A pril, and then sown in drills about half an mch drep, and 6 inches apart, in a rich moully srill. The plants are weeded, and earth drawn up (n) therr strms when an inch in height; as soon as this has increased to three inches, they are muved ints a similar soil, in rows 16 inches apart each way, and during their future growth earthed up 2 or 3 times. Being finally taken up in the course of October, they must be preserved until the following spring, to be then repianted, and treated as for store crops. (Dr. Hunler? Georg. Essays.)

Some gardeners sow in a moderate hot-bed, very thin, in drills, the same depth as above, and 9 inches apart. Water is frequently and plentifully poured between the rows, and eurth drawn about the stems of the seedlings, until they are a few inches in height. 'They are then transplanted into rows, water given, and earthing performed as usual. The only additional advantage of this plan is, that as the seed can be sown earlier, the tubers attain a rather larger size the first year.

It is to be remarked, that the tubers of every seedling should be kept separate, as scarce 2 will be of a similar habit and quality, whilst many will be comparatively worthless, and but few of particular excellence. If the seed is obtained from a red potato, that flowered in the neighbourhood of a white-tubered variety, the seedlings in all probability will in part resemble both their parents, as a cross fecundation may take place; but seldom or never does a seedling resemble exactly the original stock. At all events, only such should be preserved as are recommended by their superior size, flavour, or fertility. It may be stated as an indication before these qualities can be positively ascertained, that President Knight remarks, that the rough, uneven surface of the foliage, which in excess constitutes the curl, appears to exist as, and form a characteristic of every gond variety; for he never found one with perfectly smooth and polished leaves which possessed any degree of excellence, though such are in general more luxuriant and productive.

The early varieties, on account of their never flowering, were, until 1807, obtained by chance from plants that might now and then be produced from seed of the late kinds. In that year, Mr. Knight discovered that the cause of their deficiency of bloom was the preternatural early formation of the tubers. His mode of causing them to produce seed is to plant the sets on little heaps of earth, with a stake in the middle, and when the plants a.e about 4 inches high, being secured to the stares with shreds and nails, to wash the earth away from the bases of the stems, by means of a strong cul: rent of water, so that the fibrous riots only enter the soil, and these being perfectly dis. tinct from the runners that furnish the tubers. and which spring from the base of the stem none of these are produced, and the effect is, that blossoms appear and perfect seed.

There are numerous valuable communic: 
tions with regard to the potato dispersed through the agricultural journals, among which is one "On the Manures best adapted for Potatoes," by the Rev.E. Cartwright. He remarks, "The soil on which my experiments were tried is a ferruginous sand, brought to a due texture and consistence by a liberal covering of pondmud. Of this soil, in its improved state, I mean by the accession of pond mud (for, having been used merely as a nursery for raising forest trees, previous to these experiments, the nurseryman had not thought it necessary to make use of any other manure), the following is the analysis $\mathbf{4 0 0}$ grains gave:

Of silicious sand, of different degrees of fineness Finely divided matter. Loss in water

"The finely divided matter contained-

Carbonate of lime

Oxide of iron -

Loss by incineration (probably vegetable decomposing inatter)

"The remainder, principally silex and alumina. There were no indications of either gypsum or phosphate of lime.

"On the 14th of April, 1804, a portion of this soil was laid out, in beds 1 yard wide and 40 in length, and were manured as in the following table. On the same day the whole was planted with potatoes, a single row in each bed, and that the general experiment might be conducted with all possible accuracy, each bed received the same number of sets. On the 21 st of September the potatoes were taken up, when the produce of each row was, in succession, as follows:

Manures in bushels, per acre

1. No manure

2. Salt 8 bush., soot 30 bush.

3. Chandler's graves $97 \mathrm{cwt}$.

4. Salt 8 bush,, wood-ashes 60 bush.

5. Salt 8 bush., gypsum peat 363 bush., lime 121 bush.

6. Salt 8 hush., lime 121 bush., dung 363 bush.

7. Salt 8 bush.

8. Salt 8 bush., graves $92 \mathrm{cwt}$.

9. Sont 30 bush.

10 Fresh dung 363 bush.

11. Salt 8 bush., malt-dust 60 bush.

12. Wond-ashes 60 bush.

1 Salt 8 bush pent

5. Mitt-rinst 60 bush.

16. Sialt 8 bush., lime 121 bush., peat 363 bush.

17. Falt 8 bush., saw-dust 363 bush.

18. Salt 8 bush., peat 363 bish., bone-dust -

19. Decryed leaves 363 bush.

20. Salt 8 bush., lime 121 bush., sulphuric acid

21. Salt 8 bush., peat 363 bush.

22. Salt 8 bush., lime 121 bush.

23. Peat 363 bush.

24. Sa w-dust 363 bush.

25 lime 121 bush.

Producr.

$15 \%$

220

217

201

199
198
195

192

87

184

183

180

175
175
171

167

159

155

'The following experiments upon potatoes are extracted from Mr. George Sinclair's Communication to the Board of Agriculture, February 25 th, 1820. These experiments were made upon a soil composed of three-fourths silicious sand, ii! plots of 36 square feet.

1. Pianfed without any kind of manure

2. Twelve cubic inches of salt with the seed

I fix cubic inches of ralt with the seed

- Twelve cuhic inches of salt mixed with the soil 9:30
" $\mathrm{Th}$ werght of the crop of potatoes was $\mathrm{n}$. taken. The superior size of the roots produced by No. 4, left no room to doubt of the advantage of 13 bushels of salt per acre, ap. plied to the soil previous to planting, over the other modes of application; still the superiority was not very great." "I may notice here," observes Dr. Holland, "a practice pur. sued at Weston, near Frodsham, in the culture of potatoes, which seems deserving of attention. At this place, situated close to the iunction of the Mersey and Weaver, sea mud is used as a manure for crops of potatoes; 20 loads being the quantity usually laid on an acre. The ground thus manured not only gives a larger produce of potatoes, but is in a state of excellent preparation for a succeeding crop of either wheat or barley. The adoption of this practice has increased very greatly the value of land about Weston."

There is also a paper by Mr. Knight "On the advantages of employing large Tubers for Seed." "The good effects," he observes, "which I have proved to arise from planting large tubers of the potato plant, obviously spring from the large accumulation of fecula in them. Fed by means of this, not only a large breadth of foliage is produced, and exposed to sight more early in the year, but that foliage contains much disposable organizable matter, which once formed a part of the parent tuber." Knight thought that the ordinary produce of potatoes might be very materially in. creased. He remarks, "My opinion is, that more than a thousand bushels of potatoes may and will be obtained from an acre of ground."

Potatoes are fermentable, and are conse. quently employed along with barley by the Scotch distillers; and, also, by the London bakers in the manufacture of bread. The fecula is also separated and sold as arrow-root: it is a good and sufficiently pure starch; but it is less nutritive than the potato itself, owing to the separation of the saccharine matter and the albumen.

POTATO-FLY or BEETLE. The green cantharides, or Spanish-flies, as they are com. monly called, are found in the south of Europe, and particularly in Spain and Italy, where they are collected in great quantities for exportation. In these countries they often appear in immense swarms on the privet, lilac, and ash, which are quickly stripped of their foliage by these leaf-eating beetles. In like manner the American species of cantharides devour the leaves of plants, and sometimes prove very destructive to them, especially to those of the potato. Four native species of the cantharides found in the United States, have been tried and ascertained to be as effectual in raising blisters as the imported species. The kind found on the potato is the striped cantharis (Cantharis vittata). It is of a dull, tawny yellow or light yellowish-red colour above, with two black spots on the head, and two black stripes on the. thorax and on each of the wing-covers. The under-side of the body, the legs, and the antennæ are black, and covered with a grayish down. Its length is from five to six-tenths of an inch. In this and the three following spe cies the thorax is very much narrowed before 


\section{POTATO-FLY.}

and the wing-covers are long and narrow, and cover the whole of the back. The striped cantharis is comparatively rare in New England; but in the Middle States it often appears in great numbers, and does much mischief in potato-fields and gardens, eating up not only the leaves of the potato, but those of many other vegetables.

The most destructive kind of Cantharis, found in Massachusetts, is of a more slender form than the preceding, and measures only from five and a half to six-tenths of an inch in length. Its antennæ and feet are black, and all the rest of its body is ashen gray, being thickly covered with a very short down of that colour. Hence it is called Cantharis cinerea, or the ashcoloured cantharis. When the insect is rubbed, the ash-coloured substance comes off, leaving the surface black. It begins to appear in gardens about the 20th of June, and is very fond of the leaves of the English bean, which it sometimes entirely destroys. It is also occasionally found in considerable numbers on potato-vines; and in Cambridge, Massachusetts, it has repeatedly appeared in great profusion upon hedges of the honey-locust, which have been entirely stripped of foliage by these voracious insects. They are also found on the wild indigo-weed. In the night, and in rainy weather, they descend from the plants, and burrow in the ground, or under leaves and tufts of grass. Thither also they retire for shelter during the heat of the day, being most actively engaged in eating in the morning and evening. About the 1st of August they go into the ground and lay their eggs, and these are hatched in the course of one month. 'The larvæ are slender, somewhat flattened gruhs, of a yellowish colour, banded with black, with a small reddish head, and six legs. These grubs are very active in their motions, and appear to live upon fine roots in the ground; but I have not been able to keep them till they arrived at maturity, and therefore know nothing further of their history.

About the middle of August, and during the rest of this and the foliowing month, a jet-black cantharis may be seen on potato-vines, and also on the blossoms and leaves of various kinds of golden-rod, particularly the tall goldenrod (Solidago altissima), which seems to be its favourite food. In some places it is as plentiful in potato-fields as the striped and the margined cantharis, and by its serious ravages has often excited attention. These three kinds, in fact, are often confounded under the common name of potato-flies; and it is still more remarkable, that they are collected for medical use, and are sold in our shops by the name of Cantharis vittata, without a suspicion of their being distinct from each other. The black cantharis, or Cantharis atrata, is totally black, without bands or spots, and measures from four-tenths to half of an inch in length. I have repeatedly taken these insects, in considerable quantities, by brushing or shaking them from the potato-vines into a broad tin pan, from which they were emptied into a covered pail containing a little water, which, by wetting their wings, prevented their flying out when

\section{POULTRY.}

the pail was uncovered. The same methoo may be employed for taking the other kinds of cantharides, when they become truublesome. and destructive from their numbers; or they may be caught by gently sweeping the plants they frequent with a deep muslin bag-net. They should be killed by throwing them into scalding water, for one or $(w 0)$ mirnutes, after which they may be spread out on shri:is of paper to dry, and may be made profitalile by selling them to the apothecaries for medical use.

A species of the genus Mrloe (ungustirollzs), or narrow-necked oil-beetle of Say, about an inch long, and of a dark indigo-blue colour, is very common on butter-cups in autumn, and is also found on potato-vines.

POTATO MURRAIN. Since the year 1815, when the great destruction of potatoes in Great Britain and Ireland took place, with the consequent famine, this disease has been the subject of most active and earnest investigation. It would be vain to attempt giving even an epitome of the various views put forth on the subject. At present we will only refer to a single fact, which seems to afford the best clue towards determining the origin of the disease, as well as suggesting the best means of preservation and cure; namely, that the proportion of water, always large in the healthy potato, is greatly increased, say 6 to 8 per cent., in those about to become diseased. One of the best remedies is said to be planting in the fall; even partially diseased tubers planted in autumn have yielded good sound potatoes the succeeding season.

POULTICE. An external application employed for soothing pain and abating inflammation, and where this is advanced, promoting suppuration in gatherings, \&c. 'The best for animals are prepared of yround flax-seed, or rye-meal. The main object is to have the poultice large enough to continue long moist and soft : a hard and dry poultice is much worse than none at all. In renewing poultices, the parts should always he previously well fomented with warm water. To remove unpleasant smells, mashed carrots and powdered charcoal will be found to make a gooù poultice.

PUULTRY. A general term including every kind of domestic fowl, which is reared abou: the house or farm-yard, as cocks and hens, ducks, geese, turkeys, \&c. Poultry constitutes a part of every farmer's stock, but the rearing of it in England is not often productive of any pecuniary advantage; for though fowls are considered chiefly as an article of luxury, and sold at high prices in the market, they seldom or ever repay the value of the corn which they have consumed, especially if such grain must be purchased. Indeed, where profit is the object of the husbandman's labours, no poultry should be admitted into the vicinity of barns, unless for the purpose of picking up scattered grain; though, in genera!, it cannot be denied, that they acquire their fat substance from the corn left in the straw by negligent thrashing. The poor villager may, however reap, in some cases, benefit from poultry, as the fowls are able to shift for themselves the greatest part of the year, by feeding on insects, corn, or any thing of that nature.

There are many different breeds of this sort 
of live-stock; but those best known are the gume breed, the white or English breed, the black or Poland breed, the Dorking breed, the large or Shakebag breed, and the Malay breed. The two first are much smaller breeds than the others. This kind of stock affords profit in the eggs, as well as the chickens; therefore such as are the best layers and sitters should be chosen, which are in general the game and Poland breeds, but the other breeds have probably the advantage in respect to the size of the eggs: as food, the game and the white breeds are said to be the most delicate.

The care and management of the poultryyard usually devolves upon the farmer's wife, and the industrious housewife will do well to see to their food and rearing, \&c., herself, and not trust too much to servants. For the most economical methods of keeping and managing poultry, \&c., I refer the reader to the different heads of Dovecotr, Ducks, Fowls, Goose, Turkey, \&c. See also Eggs, Feathers.

The comparative value of the keep for domestic fowls is as follows: geese $\mathbf{5}$ per cent., ducks $7 \frac{1}{2}$ ditto, pigeons 10 ditto, dunghill fowls 40 ditto, turkeys and Guinea fowls $\mathbf{5 0} 0$ ditto. From a series of observations made on the diseases of domestic poultry, Mr. Flourens makes the following conclusions:-1. In these animals cold exercises a constant and determinate action on their lungs. 2. The effect of this action is the more rapid and more severe, the younger the animal is. 3. When cold does not cause acute and speedily fatal inflammation of the lungs, it produces a chronic inflammation, which is pulmonary consumption itself. [This, however, is a mistake, as pulmonary consumption is the deposition of tubercles in, not inflammation of, the lungs.] 4. Heat always prevents the attack of pulmonary disease: when the latter has taken place, heat suspends its progress, and even sometimes arrests it entirely, and effects a complete cure. 5. Pulmonary consumption in any stage is never contagious: fowls affected with that disease were not only all day along with the healthy fowls, but at night roosted in the same places, without communicating their disease to them. 6. Lastly, the action of too long confined air exposes these animals to abscesses of the cornea, and inflammation of the ball of the eye. These abscesses and inflammations are also caused in a still more cruel manner by cold, especially when accompanied with moisture. (Annales des Sri. Nat.) The reader will find an interesting essay by Mr. England on the rearing and management of domestic poultry, in the fourth volume of the Trans. of the Highl. Soc., to which a premium was awarded. There is also a paper on the same subject in the eighth volume of the Quart. Journ. of $\mathcal{A g r}$. p. 509 .

FOUND. In law, a place where cattle and goods which have been distrained are to be lodged and kept until redeemed. The common meaning in the United States is, a place where sattle are enclosed and kept. See Distness.

POVERTY GRASS, or Forked Aristida; frequent in the Middle States, on dry, sterile soils.

PREGNANCY. In cattle, the state of being writh young. Under the heads Aвонтіox, 932
Calving, Gestation, \&c., I have gone very fully into this subject. 'The following excellent observations by Mr. Youatt, on the detection of pregnancy in the mare and the cow, are highly practical and useful.

Among healthy animals, the impregnation of the female rarely fails to be the result of an intercourse between the sexes. The assurance, however, of this having taken place, is, occasionally, an affair of considerable interest, and of no little difficulty; and the value and the destiny of the female may very much depend on the decision of the question. A certain time having elapsed, the thing will speak for itself; but are there any symptoms or circumstances that will warrant the veterinary surgeon, or the agriculturist, in giving a decided opinion on the case in an early period of supposed preg. nancy?

It occasionally happens that the fifth or the sixth month arrives, and, even to the practised eye, there are few or no indications of conception having taken place. There are, also, but somewhat unfrequently, diseases which very closely simulate this natural process. Can the veterinary surgeon or the breeder dccide? The answer is in the affirmative, and plainly and unequivocally. This is one of the boons which the veterinary art can now confer on the agriculturist. The altered character of the female is regarded, and very properly, as a circumstance of no little weight. She is comparatively calm and quiet; her appetite returns, and she regains her former condition and her former habits. Five or six weeks pass, and there is no outbreak of any kind. The owner concludes, and he is not often wrong, that she is impregnated. He, however, has had little to do with mares or with cows who has not witnessed the return of the most furious œstrum, after a much longer period of time has elapsed. I have known more than 3 months pass in this delusive quietude, and then a salaciousness worse than at first has indicated that no actual impregnation had taken place. On the other hand, the cestrum, but not with all its former fury, has returned, 2 , and 3 , and 4 months after the connection; and yet, as the result finally shows, impregnation had taken place at their first intercourse.

Many circumstances may cause the owner to be anxious to know the truth of the matter. He may wish to sell her, or he may be unusually desirous to breed from her. Let the animal be examined per vaginam. Let the hand be slowly and cautiously passed up the vagina until it reaches the os uteri. Let there be no attempt to penetrate farther. No information can be gained from introducing the fingers into the uterus. It is simply wished to ascertain the character of the os uteri. In its natural and unimpregnated state it will be closed; but it will not be tightly or spasmodically so, and the contraction of the mouth of the womb will form a kind of cup, with the base towards that viscus. If she is impregnated, the entrance to the uterus will be more firmly closed, and the protrusion will be towards the vagina. This is the only exploration per vaginam which I would allow; it is easily made, and it will be satisfactory. If an exploration of this kind is 
attempted when half or more than half of the period of pregnancy has passed, it is not at all unlikely that so much irritation of the parts will ensue as to cause the expulsion of the fetus.

I will suppose that 2 months have passed since the supposed impregnation. 'I'he fetus is still remaining in the pelvic cavity. The heart has begun to beat, and the blood to circulate through its little veins. It will be situated immediately below the rectum. I introduce my hand into that intestine. I have not occasion to pass it very far up. I feel the little substance; for it then is small in proportion to its after growth. I feel it under my hand. I am certain that I am pressing upon the uterus and its contents. I cannot perhaps detect the pulsation of the embryo; but if I had delayed my examination until the fetus was 3 months old, I should have assurance that it was there by its now increased bulk, while the pulsation of its heart would tell me that it was living.

For 2 months from this period in the cow, and for 3 in the mare, I should have no other indication of the presence of the fetus, nor of its life and growth, except from the gradual enlargement of the abdomen of the mother; and, by that time, the little one would have increased in size and strength, and would have begun to take occasional exercise in its first domicile, and then would become the more evident, but not more satisfactory proof of the life of the fetus; its motion strong enough to be seen through the integument.

I might, perhaps, wish to give this assurance of the life of the fetus to some curious spectator, or to some intended purchaser. I would not gallop the mare in order to effect this: I would not so far disturb her or the young animal that she bore within her. Much less would I give her cold water to drink, and which she usually would drink until she annoyed the fetus, and the unborn animal told us how much we annoyed him by endeavouring to shift his quarters and get away from the action of the cold. I would not run the hazard of giving her the colic, and perhaps destroying him or her by this unscientific and somewhat cruel method of exploration; but I probably should give a tap or two on the outer wall of his dwelling, just sufficient to rouse him from his slumbers, and induce him to express his anger at the annoyance by a tolerably distinct plunge or kick.

Most certainly, if it was a cow that I was exhibiting, I would not give, nor would I suffer any one else to give those terrible punches in the right flank which I have no doubt are the cause of much unsuspected injury, and, occasisnally at least, connected with, or the origin of a difficult or a fatal parturition.

I may here observe that the fetus of the mare, from the beginning, occupies nearly the centre of the belly. In the early stage, Mr. Mogford generally found it "lying across the pelvic cavity, the spine being immediately under; the head on the left side, and the tail on the right side." In the latter portion of its fetal state its motions are pretty equally distributed on either side, and the beating of the fetal heart is most plainly heard at the very base of the abdomen.
The fetus of the cow is hucklled up on the right side of the belly. There its muturns are must seen, and the bealings of its heart best heard. The enormous paunch, lying principally on the left side, presses every other viscus, and the uterus among the rest, into the right flank. This also explains a circumstance familiar to every breeder. If the cow should happen in carry twins, they are crowded logether in the left flank, and one seems absolutcly to lie upon the other. Whenever the farmer notices the kicking of the fetus high up in the lank, he at once calculates on twins.

To return from this digression. If half the period, or more, of utero-gestation had passed, and I could not get the little stranger to move by my gentle tapping, and it was a cow with which we had to do, and a quiet one, I would have her carefully held by the cowherd, while I stooped and applied my ear flat upon the flank, and then slowly and with gentle pressure upwards and downwards, and forwards and backwards, over the flank and the lower part of it, until I heard-and which I should do in a great majority of cases - the pulsations of the fetal heart. I should recognise it by their quickness, the pulsations of the fetus being double or more than double those of the other.

If it was a mare, I would have a halter put on her, and an assistant should hold up one of her legs, while some person interested reached under, or perhaps knelt under the belly of the mare, and passing one ear along an imaginary line from between the teats to the chest, and deviating a little from one side to the other, he would then also recognise the quick pulsation of the fetal heart.

These observations are addressed to practical men, and will be speedily put to the test by them. The object of the author is to get rid of the vulgar and inefficient methods of detecting pregnancy which are now in general use, and to introduce others that are founded on a surer and more scientific basis.

'This subject has been treated of by others, and Dr. J. C. Ferguson, of King's College, London, has published an Essay on Auscultation, as the only unequivocal Evidence of Pregnancy. Auscultation is the method employed by physicians to determine the healthy or diseased condition of the lungs and other internal parts, by means of the ear and stethoscope.

PRICKING. In hunting, the tracing of a hare, where her footing can be perceived. In farriery, the term is used to signify the driving a nail into the soft or quick part of a horse's foot, so as to cause temporary lameness.

PRIMROSE (Primula, fron primus, the first; in allusion to the early flowering of the plants). This is an extensive genus of small, but very pretty and desirable plants. All the species of primrose succeed best in a mixture of loam and peat, and increase readily by seeds, or by dividing the plants, which should be done as soon as they have flowered. There are in England five indigenous species.

1. The common primrose ( $P$. vulgaris), grows common everywhere in England, adorning the groves, hedges, and waste grassy places in spring; flowering from March ic June. Flowers numerous, large su phis 
soloured, with a darker radiating spot in the middle; their scent agreeable; though slight. There are cultivated varieties, white, purplish, or brown, single or double, of which the double sulphur-coloured is peculiarly elegant.

2. Oxlip primrose ( $P$. clatior). This is a less common species, found in woods and pastures, but rare. It is perennial, and flowers in April.

3. Common cowslip, or paigle ( $P$. veris). See Cowsur.

4. Bird's-eye primrose ( $P$. farinosa). This species is found growing in wet pastures and by rivulets, on mountains in the north of England as well as in Scotland. It flowers later than the preceding species, in June and July, and is only about half the size of the cowslip. It is distinguished by the white mealiness of the flower-stalks and backs of the leaves, whose upper sides are green, smooth, and even, as well as by the beautiful rose-coloured flowers, whose mouth is surrounded with a notched, yellow, glandular border.

5. Scoltish primrose ( $P$. Scotica). This species is met with occasionally in the north of scotland, and is near akin to that last described.

PRIMROSE PEERLESS, or NaRcISSUS.

PRIVE' (Ligustrum, from ligare, to tie; in allusion to the very flexible branches). The common privet, print, or prim-print (L.vulgare), is a hardy shrub, growing from 6 to 8 feet in height, in its wild state tenanting rather moist thickets and hedges, on a gravelly or chalky soil: but it grows well in any situation, and in all soils. It may be propagated by seeds, layers, or cuttings. These plants are well suited for rnaking cut-hedges in gardens, especially the evergreen varieties of the common privet. 'The branches are straight, filled with pitch, and the wood is hard.

PROPAGA TION OF PLANTS. The greater number of plants are propagated naturally by means of seeds; but, in addition to these, many plants are extended over the surtace on which they take root by the production of runners, or lateral shoots, which spread along the surface, and root at the joints or buds, from which they send up new plants, by suckers, or side shoots from the roots, by bulbs, by tubers, rhizomes, and by varions other natural means. Artificially, plants are propagated by seed, by runners, suckers, offsets, dividing the tubers, layers, cuttings, grafting, budding, inarching, \&c. Seeds are gathered when mature, and sown on recently-stirred soil, and covered to different depths according to the size of the ;eed, the nature of the soil and situation, and other circumstances. The plants formed by iunners are separated from the parent plant by cutting through the runner, and removing the young plant, in order to plant it elsewhere. Suckers, slips, or side-shoots from the roots are separated from the parent plant by being slipped town, or cut off, so as to carry with them a portion of fibrous roots; and they are afterwards planted in suitable soil, \&c. Offsets are small bulbs which are produced round the hase of larger ones, or on stems, in the axilla if the leaves, and, being taken off and planted, becnme plants. Tubers are underground itcms containing leaf-buds; and these may be 934 separated and planted entire; or cut into as many pieces as there are buds, in either of which cases new plants will be formed. Layers are branches or shoots of either woody or herbaceous plants, which are bent down, and a portion of their length buried a few inches in the soil; that portion having been previously wounded by cutting, bruising, or twisting, which, by checking the descent of the sap, gives rise, after a certain period, to the production of roots.

After these roots are formed, the portion of the layer which has produced them is separated from the main stock or parent plant, and planted by itself.

Cuttings are portions of shoots, either of ligneous or herbaceous plants, and they are made of the young shoots with the leaves on, or of the ripened wood, either with or without its leaves; and after they have, either in an herbaceous state with the leaves on, or with the wood mature, and with or without the leaves, been properly prepared and planted, they form roots at the lower extremity, each cutting becoming a perfect plant. In general, cuttings should be taken from those shoots of a plant which are nearest the soil; because, from the moisture and shade there, such shoots are more predisposed to emit roots than those on the upper part of the plant.

The young, or last-formed shoots, are to be taken in preference to such as are older, as containing more perfect buds in an undeveloped state, and a bark more easily permeable by roots; and the cutting is to be prepared by severing its lower extremity across at a joint, the lenticells, or root-buds, being there most abundant. When the cutting is planted, the principal part of the art consists in making it quite firm at the lower extremity, so as com. pietely to exclude the air from the wounded section. Cuttings emit roots at this section, either in consequence of the action of the accumulated sap in the cutting, as in the case of the ripened wood in deciduous trees and shrubs; or in consequence of the joint action of the accumulated sap and of the leaves, as in the case of cuttings of soft wood with the leaves on, and in a living state. A few plants are propagated by cuttings of the leaves, the petiole of the leaf being slipned off from the parent plant, and probably containing the latent embryos of buds. Grafting, inarching, and budding, are processes which have been already explained. See Bunding, Graftina, LAYERTNG, \&c.

PUCCOON (Batschia Canadensis). A plant in the United States with an extremely red root, called American Alkanet.

PULSE. A term applied to all leguminous plants, as peas, beans, tares, vetches, lupins, \&c. All the species of pulse afford excellent manure when turned into the soil in a green state. The custom of ploughing in green suc. culent plants of this kind is very ancient. All the Roman agricultural writers commend it highly. Columella, particularly, advises lupins as a manure, which, if cut down and turned in while green, will have as good effect as the best and strongest dunging whatever. They may be sown upon poor land about the middle of 
Acptember, and be ploughed in before they attain their full growih. In gravelly soils they should be cut down after they have put forth their second flower; and in strong lands, where a little more advanced. In the former of these grounds they are turned in while young and tender, that they may quickly rot; and in the latter, are let stand till they grow stronger, that they may produce a better effect on the stiff clods of earth, and render them more mellow and friable. This practice is still extensively followed in northern Italy.

Peas, beans, lupins, vetches, and other succulent plants, have also been strongly recommended by the older writers on husbandry, as excellent manures, especially for sandy ground; these plants enriching the earth greatly if ploughed in, either green, or when in bloom. In strong land they are advised not to be turned down till the pods begin to harden. See Green Crops, Leguminous Plants, Peas, Rotation or Crops, \&c.

PUMPKIN (Cucurbita pepo). The pumpkin is extensively cultivated in the United States, where there are many varieties, some of them attaining the enormous size of 2 feet or more in diameter. But such large ones are not so highly esteemed. The better sorts are often used at table, affording the celebrated pumpkin pie of New England; and the coarser varieties are esteemed for feeding stock. When growing in the vicinity of squashes, the fruit of this is liable to be converted into a hybrid, of little or no value. Crops of pumpkins have been totally spoiled by that cause, the fruit becoming very hard and warty, unfit for the table, and unsafe to give to cattle. Flora Cestrica.

PURGATIVES. In farriery, such medicines is tend to evacuate the crudities of the bowels by stool, and which are sometimes called cathartics. See Purging.

The purgatives most frequently employed for horses and cows are sulphur, jalap, aloes, gamboge, Rhannus catharticus, and calomel. Saline purgatives are not often required; but when they are, Epsom salts (the sulphate of magnesia), is adequate for every purpose.

PURGING is necessary in a variety of cases, for different sorts of animals, particularly in diseases of the inflammatory kind, swellings in the extreme parts. Aloes is the best form of physic; but Epsom salts, linseed, and olive oil, are sometimes used on certain occasions as laxatives with great propriety and benefit, and in gross, full horses, in some disorders of the stomach, liver, \&c., but it should always be directed with caution.

Violent purging or scouring, attended with inflammation, will sometimes arise when a horse is worked hard upon green meat. The remedy is change of diet or less labour. Astringents should be used with much caution. It is probably an effort of nature to get rid of something that offends. A few doses of gruel will assist in effecting this purpose, and the purging will cease without astringent medicine. See Alors, Balls, Drenches, Linsfed $\mathrm{O}_{1}, \mathrm{E}, \mathrm{Ec}$.

PURSLANE (Portulaca; from porto, to carry, and lac, milk; juicy nature of the plants). purslane is now but liit: noticed as a garden flower, but in Britain is still cultivated as a salad and potherb. 'The species usually growa in the kitchen garden are the green or garden purslane ( $P$.oleracea), and the golden purslane (P. sativa).

PUTREF $\triangle$ CTION (Lat. Putrefactio). The spontaneous decomposition of animal and vegetable substances, attended by the evolution of fetid gases. The putrefactive fermentation of animal substances is usually attended by more fetid and noxious exhalations than those arising from vegetable products. 'This appears principally referable to the more abundant presence of nitrogen in the former; and, hence, those vegetables which abound in nitruginiferous principles, such as most (if not all) of the cruciform plants, exhale peculiarly nauseous effluvia; hence, also, such animal products as are destitute of nitrogen, are either unsusceptible of what is commonly called putrefaction, or suffer it slowly and imperfectly. The formation of ammonia or of ammoniacal compounds is a characteristic of most cases of animal putrefaction; while other combinations of hydrogen are also formed, especially carburetted hydrogen, and sulphuretted hydrogen, together with complicated and often highly infectious vapours or gases, in which sulphur and phosphorus are frequently discerned. These putrefactive effluvia are, for the most part, easily decomposed, and resolved into new and comparatively innocuous compounds by the agency of chlorine; hence the importance of that body as a powerful and rapidly acting disinfectant. The rapidity of putrefaction and the nature of its products are, to a great extent, influenced by temperature, moisture, and access of air; they do not ensue below the freezing point, nor in dry substances, nor under the entire exclusion of oxygen; and hence various means suggest themselves of retarding or preventing putrefaction, as well as of modifying its results. A temperature between $60^{\circ}$ and $80^{\circ}$, a due degree of humidity, and free access of air are the circumstances under which is proceeds most rapidly. The most effective antiputrefactives, or antiseptics, are substances which either absorb or remove a portion of the water or moisture, and enter into new combinations with the organic matter. The astringent or tannic principle of vegetables is also a powerful preserver of most organic tissues; it enters into chemical combination with the albuminous and gelatinous membranes and fibres; and the resulting compound, of which leather furnishes a characteristic example, is comparatively little prone to change, although the tanning material itself, as well as the animal principles with which it unites, are separately liable to decay. Among saline substances, the antiputrefactive powers of salt are commonly known: when a piece of flesh is salted, brine runs from it, in consequence of the energy with which the salt abstracts the component water of the muscular fibre; the flesh becomes indurated, and its susceptibility to putrefactive changes is greatly diminished; but it becomes at the same time less easy of digestion as an article of food. Corrosive sublimate is a far more powerful preservative than common sals and it appears to act not by the mere abstrar 


\section{PYROLIGNEOUS ACID.}

tion of water, but by entering into chemical union with the fibre. Sulphate of copper and several other metallic salts are similarly efficacious; but their poisonous nature prevents their employment in the preservation of articles of food.

The inhabitants of northern climates avail themselves of freezing to prevent the putrefacvion of their food, and the supplies of game and other articles in the Russian markets are retained in a frozen state. Our fishmongers resort to the same expedient for the preservation of their unsold fish, which is daily removed to the ice-house, after having been exhibited in their shops; salmon is packed in ice for the purpose of transport and preservation. See Decomposition, Dry Rot, Fermentation, MAnunes, Orgayic Chemistri, \&c.

PYROLIGNEOUS ACID. This term is generally applied to the acid liquor which passes nver along with tar and gaseous products, when wood is subjected to destructive distillation. This acid liquor is an impure vinegar, from which acetic acid is obtained. It has in its impure state a powerful smoky odour, not unlike that of Westphalia ham. The acid is purified by converting it into acetate of soda, and decomposing that salt by means of sulphuric acid. This acetic acid, after distillation, is in a high state of concentration; but it differ's from concentrated acetic acid, by being neither combustible nor crystallizable. It is usually lowered by the addition of water. If intended for the table or for domestic use, as a substitute for other forms of vinegar, it is usually coloured with a little burned sugar. This manufacture of vinegar is now carried on upon a very large scale, and the greater part of the vinegar used for domestic purposes and in the arts, in many of which it is largely consumed, is derived from this source. Ordinary vinegar, besides containing acetic acid and water, contains also sulphate of lime, some ethereal matter, a portion of sulphuric acid, and a colouring principle. See VINEGAR.

\section{Q.}

QUAKING GRASS (Briza; named from brizo, to nod, on account of the quaking character of the spikelets). A genus of grasses of which some species are pretty and interesting, as $B$. minor, B. rubra, and $B$. clusii; but the greater portion are mere weeds. The whole are of easy cultivation. Two species are indigenous to Britain, the smaller quaking grass (B. minor), and the common quaking grass ( $B$. medict, pl. 6, n. See Briza.

QUARRY. A pit or drift from which stones, cravel, slates, or some other similar material is raised.

QUARTER. The fourth part of any thing, as of a carcass. As a term of weight it denotes the fourth of a hundred weight, or $28 \mathrm{lbs}$; as a dry measure it signifies the fourth of a chaldron. Quarter is also a measure of grain containing 8 bushels: it is the common measure by which grain is sold in the southern districts of England, especially when in large nuantities.
QUARTZ. A German term, now universally adopted in scientific languages, and commonly applied in mineralogy to the purer varieties of silica, especially to rock crystal. Quartz oc. curs also in beds : it is usually granular, white, sometimes mixed with mica.

QUICKS. The young sets of the white thorn used in planting hedges. The term is also applied to couch-grass in some places. See Quickset.

QUICKSANDS-Are sandy spots of soil which contain water in such a proportion as to form a sort of shaking quag at certain times.

QUICKSET. A term applied to the white or hawthorn, the sets or young plants of which are raised by the nursery gardeners for sale for this purpose. See Fence, Hawthore, and HEDGE.

QUINCE (Cydonia). A well-known genus of fruit trees. C. vulgaris is the species generally cultivated for its fruit. It is a native of Candia; but cultivated over most parts of Europe and North America. It belongs to the natural order Pomacea. The fruit, or quince, is of a roundish, somewhat pyriform shape, and contains ovate-pointed, plano-convex seeds, yielding to boiling a large quantity of mucilage, which is employed in medical practice as a demulcent. The quince will thrive in any soil, and may be multiplied by suckers. $C$. japonica is one of the handsomest hardy shrubs, producing its beautiful scarlet or white flowers in great abundance. The Portuguese quince is reckoned the best. Quince-marmalade is greatly admired by those who are fond of the fruit, and all good housewives know its value in adding richness of fiavour to apple-pie.

QUINOA, or PERUVIAN RICE (Chenopodium quinoa). Humboldt speaks of this plant as one of the few cultivated in the highest and coldest regions of the Andes and the Mexican Cordilleras, where it ranks in utility with the potato, Indian corn, and wheat. Whilst young, the leaves are used as spinach, oxalis (sorrel), or common greens, whilst the seeds are boiled in soups and used as a substitute for rice. The plant is an annual, and resembles French spinach, or its kindred Lamb's-quarter (Chenopodium album), which is so widely diffused throughout the United States. The seeds are small, about the twelfth of an inch in diameter, yellowish-white, flat, resemble those of millet, and are easily pulverized. The plant attains about 3 feet in height, and produces greenish flowers about the lst of August. Mr. Gideon B. Smith has raised the quinoa at Baltimore, and found it very productive. (Am. Farmer, vol.13.) There are a great many species of chenopodium, many of which are enumerated under the head of goose-foot. In Peru, it would seem the quinoa is subjected to a process of scalding or part-boiling, before it is disposed of by the cultivator, whether for the purpose of assisting in its preservation, or to prevent its cultivation in other countries, is not ascertained. To this fact may probably be ascribed the failure of all previous attempts to cultivate it. Having, says Mr. Smith, eaten the quinoa, prepared in several ways, we are of course enabled to speak of its qualities from experience. Gentlemen who have eaten it in Peru, sposk 


\section{QUITTER.}

of it in the highest terms of praise. It has a very pleasant flavour, although this is peculiar and may not at first be relished. The taste more resembles that of oat-meal than rice. The grain is chiefly composed of a grain or sprout of the young plant, closely coiled, and imbedded in farina. In boiling, this spiral germ is detached, and the dish presents the appearance of being full of skippers, something similar to a dish of boiled beans. The description of the mode of sowing and cultivating the quinoa in Peru, together with the seed, was furnished Mr. Smith by I,ieut. Fitzhugh, U. S. N. From this it appears that it is sown broadcast, and gathered in the same seasons as wheat. When ripe, the grain shells off very easily, and to prevent loss, $i t$ is cut carefully and gathered in on cloths of cotton or linen.

QUITTER. In farriery, an ulcer formed between the hair and hoof, usually on the inside quarter of a horse's foot; it often arises from treads and bruises, sometimes from gravel, which, by working its way upwards, lodges about the coronet; if it is only superficial, it inay be cured by cleansing dressings, bathing the coronet every day with spirits of wine, and dressing the sore with lime-water, or a detergent application, such as red precipitate.

\section{R.}

RABBIT. (Lepus cuniculus). A well-known animal, resembling the hare, smaller in size, belonging to the order Rodentia. The rabbit has shorter hind-legs than the hare, and the ears are more thinly covered with hair. Rabbits abound in England, and are in many cases preserved in warrens. They are very prolific, and begin to breed at six months old, and have several broods in a year, and from five to seven young ones in a brood. The young are blind at birth, and nearly naked. Their fur, in a wild state, is of a brown colour; but varies when domesticated It constitutes a principal article in the manufacture of hats. Owing to its slight conducting power, it is, next to hare's fur, an excellent thing to wear over the shirt for those predisposed to consumption.

RACEME (Lat. racemus, a bunch of grapes). In botany, a form of inflorescence, in which the flowers are stalked along a common unbranched axis, as in the hyacinth.

RACHIS (Gr.). A branch which proceeds in nearly a straight lirre from the base to the apex of the inflorescence of a plant. It is also applied to the petioles of the leaves of ferns.

RACK. A railed convenience formed above the manger in a stable for the reception of the hay. It should be constructed with openings at the bottom for the seed or dust to pass through.

RADICLE. In botany, that portion of an embryo which eventually becomes the descending axis or root. It is the lowest of the two opposite cones of which an embryo plant consists.

RADISH, CULTIVATED (Raphanus satious). There are two kinds of cultivated radish, the fusiform, or spindle-rooted, and the globular, or turnip-rooted; and these again are di-

\section{RADISH.}

vided in to the spring and autumn varieties. As for the designation of short and long top, by which the old gardeners divided the varueties, I perfectly agree with Mr. Strachan, the gardener of the London Horticultural Sicciety, in considering it as giving importance to a difter. ence that is by no mears permanent. The first may be sown at all times of the year; but the last, requiring a greater length of time to perfect their roots, can only, as the name im. plies, be obtained during the latter part of the year.

Spring Varietics.-Fusiform-rooted: 1. Ioung white, called also the white transparent, white Italian, and Naples radish. 2. White Russian, probably the Raphanus salivus of Gerard. 3. Twisted radish of Mons. 4. Scarlet or salmon, or scarlet-transparent radish. 5. Purple, formerly called exclusively the shorttopped. 6. Red-necked white.

Turnip-rooted: 7. White turnip is the only one noticed by Gerard, as the Raphanus orbiculatus. 8. Early white turnip. 9. Pink, rose. coloured, scarlet, and crimson turnip. 10. Purple turnip. 11. Yellow turnip.

Autumn and Winter Varieties.-These are all of the turnip-rooted kind; and in the following list they are described in the order they follow in coming into use. 1. Yellow turnip. 2. Round brown. 3. White Spanish, is Miller's Raphanus albus orbicularis. 4. Oblong brown. 5. Black Spanish. 6. Large purple winter, or purple Spanish.

The soil best suited for this vegetable is a mouldy loam, rather silicious than otherwise, and moderately fertile. It should be dug a full spade deep, and well pulverized. The subsoil is best to be rather hard. Manure should not be applied at the time of sowing, if avoidable, as it is apt to cause the roots to be fibrous. If employed, it should be in a finely-divided, putrescent state. The situation should always be open ; but for early and late crops, warm and sheltered. Radishes are propagated by seed, which may be sown at all times throughout the year. For the earliest productions, during December, January, and February, in a hot-bed; and in the open ground once a month during winter, and every fortnight during the other seasons of the year.

'The time of drawing radishes is by no means indifferent. They eat in the greatest perfection if pulled in the morning before the sun has attained any power, and laid in a cool, damp place until wanted. The bed should have a plenteous watering the morning before that on which they are taken, but noile afterwards until subsequent to the drawing. In November, those wanted for winter must be taken up during dry weather, and preserved in sand.

Forcing.-A moderate hot-bed is required for this crop, of a length according with that of the frame to be employed; the mould, about eight inches deep, on the surface of which the seed is to be sown as soon as the violent heat is abated, and an additional half inch of mould sifted over it. The seedlings are in general up in less than a week, and in six they will be ready to draw. Throughout thrir grow th air must be admitted as freely as is allowable. 'The glasses, however, must be closed on the 


\section{RADISH, THE HORSE}

approach of evening, and mats or other covering put on in proportion to the severity of the season. When the mould appears at all dry, a light watering must be given during noon. The plants must not stand nearer than two inches to each other The temperature required is from $50^{\circ}$ to $70^{\circ}$; and it must be kept to this heat by moderate coatings as required.

If there is a deficiency of frames, hoops and mats may be employed, a frame of boards being formed round the bed, light and air being admitted as freely and as often as possible. If seed is sown within a frame without any bottom heat, the plants will be two or three weeks forwarder than if sown in the open ground.

RADISH, 'THE HORSE. See Horse-RADISH. RADISH, THE GREA'T WATER. See Criss.

RADISH-MAGGOT. Radishes, while growing, are very apt to be attacked by maggots, and rendered unfit to be eaten. These maggots are finally transformed to small, ash-coloured dies, with a silvery-gray face, copper-coloured eyes, and a brown spot on the forehead of the females; they have some faint brownish lines on the thorax, and a longitudinal black line on the hind-body, crossed by narrower black lines on the edges of the rings. They vary in size, but usually measure rather more than one-fifth of an inch in length. They finish their transformations, and appear above ground, towards the end of June. 'The radish-fly is called. $A n$ thomyia Raphani, in my "Catalogue," from the botanical name of the radish, on the root of which its larvæ feed. It closely resembles the root-fly (Anlhomyia radicum) of Europe. (Dr. Harris.)

RADISH, WILD (Raphanus Raphanisticum). $\Delta$ troublesome weed found in arable lands. See Charlock.

RAG. A torn piece of cloth of any sort: when of the woollen kind, they are used as manure. Woollen rags are almost entirely composed of animal matter: they are found to contain a very large proportion of albumen, (a substance similar in appearance to boiled white of egg), minute portions of lime and silica, and traces of various salts. They form, therefore, an excellent manure, by slowly decomposing in the soil ; and are found to remain dissolving in it, and forming soluble and elastic matters for the service of plants, when applied at the rate of 1200 weight per acre, for periods varying from two years on the heavy clays, such as those of the hop-grounds of the Weald of Kent, to three or four on the light, chalky soils of the ralley of the Kennet, in Berkshire. The lightness of carriage, and its readiness, as well as cleanliness of application, render it peculiariy -ligible as a fertilizer; it keeps, too, for any iength of tine, until the farmer is ready to ipply it to his ground, and is much more slowly decomiposed and consumed than either blubber, rape-cake, train-oil, or bone dust.

The consumption of these rags by the Berkshire and Oxfordshire farmers, and especially in Kent for the hop grounds, is very considerable. I ain informed by an extensive dealer in these rags, that at least 20,000 tons are annunlly consumes by the farmers of the south of 938
RAIN.

England. My informant himself has a sale of more than 500 tons per annum, which he delivers free on board a vessel, at any of the London wharves, for 5 guineas per ton. 'The custom of the farmer is, to cut the woollen rags, by means of a chopper and block, into shreds about the size of a crown-piece, and then spread them on their fields by hand, out of a common seed-basket, as evenly as they can ; they find that this manure is admirably adapted for hops, wheat, turnips, \&c., and that the beneficial effect is as great the second year as the first. It appears that one farmer in Kent, Mr. Ellis, of Barming, purchases annually 4 or 500 tons of these rags, almost exclusively for his hop grounds. The farmers of Kent think the application of the rags "warms" the ground, as they slowly putrefy in the soil; they certainly afford nourishment to the crop, for wool is com. posed almost entirely of a peculiar animal sub. stance, with a slight portion of phosphate of lime, or earthy matter of bones.

RAGWEED (Ambrosia elatior). See HoG WEED.

RAGWORT (Senecio). A portion of the species of this extensive genus has already been noticed under the head Growndser; lut there are in England four or five species of ragwort, properly so called. These belong to that section of the genus which have flowers with spreading rays and pinnatifid leaves; the others to that with undivided leaves and radiant flowers.

RAIN (Ger. regen). In meteorology, water falling from the clouds.

As the effects of rain upon vegetation are so highly important, it will be useful to ascertain the quantity or depth of rain that falls annually in various places, and the difference in the effects which are produced by it, more especially for the formation of reservoirs for agricultural purposes. To use the words of Mr. G. Tatem:-Although "fully aware, that little reliance can be placed upon any theory founded on data so uncertain as the quantities of rain that fall in different years, I am convinced that something might be done towards establishing rules for the guidance of agricul. turists and botanists, if observations were made at the same place for a series of years, and the results recorded." The average quantity of rain which falls in a year at 2 ny given place, materially affects the prod'sctiveness of the soil, and is necessarily influenced equally with the climate by a variety of general circumstances and local causes; such as latitude, proximity to the sea, elevation of the region, configuration of the country and of the mountain ranges, exposure to the prevailing winds, \&c.

Near the foot of high hills a greater quantity commonly falls than over a level country; the currents of the atmosphere in their course meeting with a hill, are forced to ascend, ant gaining a higher, and of course colder situation, the vapour is condensed into clouds, and even into rain, so that a deposition in showers very frequently follows. Hence the reason why clouds are so often observed on the sides and tops of mountains, which have been in. correctly supposed to attract them. The quan- 
tity that falls, and the manner in which it falls, Lancashire, according to Mr. Whistlecraf, are the circumstances to be attended to. A great number of rainy days are more injurinus to the soil, even where the quantity is not great, than heavy falls at distant intervals of time; the ground, in the first case, being constantly over-saturated, its fertility is much lessencd; in the other, the superfluous mosture beirg soon drained off, only the portion necessary for the nourishment of plants is left, which is gradually given out in dry weather, during which the ground for a time is in its most productive state.

In general, more rain falls in the north of England than in the south. The east and southeastern counties have usually the driest seasons and years. The fall of rain is various, however, at any period of the year, as may be seen from the annexed tables. 'The mean quantity falling annually in England is reckoned to be 32 inches, or, according to Dalton, $31 \cdot 3$; but this is unequally distributed. The annual amount in Westmoreland and following table:-

\begin{tabular}{|c|c|c|c|c|c|c|c|c|c|c|c|c|}
\hline Months. & & $\begin{array}{c}\text { Manches- } \\
\text { ter, 33- } \\
\text { years. }\end{array}$ & $\begin{array}{l}\text { Liverpool, } \\
18 \text { years. }\end{array}$ & $\begin{array}{c}\text { Chats- } \\
\text { worth, } 16 \\
\text { years. }\end{array}$ & $\begin{array}{l}\text { Lancaster. } \\
20 \text { years. }\end{array}$ & $\begin{array}{l}\text { Kendal, } \\
25 \text { years. }\end{array}$ & $\begin{array}{l}\text { Dumfries, } \\
16 \text { years. }\end{array}$ & $\begin{array}{l}\text { Glasgow, } \\
17 \text { years. }\end{array}$ & $\begin{array}{l}\text { London, } \\
40 \text { years. }\end{array}$ & $\begin{array}{l}\text { Paris, } \\
15 \text { years. }\end{array}$ & $\begin{array}{l}\text { Viviers, } \\
40 \text { yeara. }\end{array}$ & $\begin{array}{l}\text { General } \\
\text { avernge. }\end{array}$ \\
\hline January & - & $\begin{array}{l}\text { Inches, } \\
2 \cdot 310\end{array}$ & $\begin{array}{l}\text { Inches. } \\
2 \cdot 177\end{array}$ & $\begin{array}{l}\text { Inches. } \\
2 \cdot 196\end{array}$ & $\begin{array}{l}\text { Inches. } \\
3 \cdot 461\end{array}$ & $\begin{array}{l}\text { Inchea. } \\
5 \cdot 299\end{array}$ & $\begin{array}{l}\text { Inches. } \\
3 \cdot 095\end{array}$ & $\begin{array}{l}\text { Inches. } \\
1.595\end{array}$ & $\begin{array}{l}\text { Inches, } \\
1.464\end{array}$ & $\begin{array}{l}\text { French in. } \\
1.228\end{array}$ & French in. & Inches. \\
\hline February & - & 2.568 & 1.847 & 1.652 & 2.995 & $5 \cdot 126$ & $2 \cdot 837$ & 1.741 & 1.250 & 1232 & 1.700 & 2295 \\
\hline March & - & 2.098 & 1.523 & $1 \cdot 322$ & 1753 & $3 \cdot 151$ & $2 \cdot 164$ & $1 \cdot 184$ & 1.172 & $1 \cdot 190$ & 1.927 & $1 \cdot 7+8$ \\
\hline April - & - & $2 \cdot 010$ & $2 \cdot 104$ & 2.078 & $2 \cdot 180$ & $2 \cdot 986$ & $2 \cdot 017$ & 0979 & 1.279 & 1.185 & 2.686 & 1.950 \\
\hline May - & - & $2 \cdot 895$ & $2 \cdot 573$ & $2 \cdot 118$ & $2 \cdot 460$ & $3 \cdot 480$ & $2 \cdot 568$ & 1.641 & 1.636 & 1767 & $2 \cdot 931$ & $2 \cdot 407$ \\
\hline June. & - & 2.502 & $2 \cdot 816$ & $2 \cdot 286$ & 2.512 & $2 \cdot 722$ & 2974 & $1 \cdot 343$ & 1.738 & 1.697 & $2 \cdot 562$ & $2 \cdot 315$ \\
\hline July - & 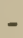 & 3.697 & $3 \cdot 663$ & $3 \cdot 006$ & $4 \cdot 140$ & 4.959 & 3.256 & $2 \cdot 303$ & $2 \cdot 448$ & 1.800 & 1.882 & $3 \cdot 115$ \\
\hline August & - & $3 \cdot 665$ & $3 \cdot 311$ & $2 \cdot 435$ & 4.581 & $5.0 \times 9$ & $3 \cdot 199$ & $2 \cdot 746$ & 1807 & 1.900 & $2 \cdot 347$ & $3 \cdot 103$ \\
\hline September & - & $3 \cdot 281$ & $3 \cdot 654$ & $2 \cdot 289$ & 3.751 & $4 \cdot 874$ & $4 \cdot 350$ & $161 \%$ & 1.842 & 1. 550 & $4 \cdot 140$ & $3 \cdot 135$ \\
\hline October & - & 3.922 & 3724 & 3.079 & $4 \cdot 151$ & $5 \cdot 439$ & $4 \cdot 143$ & $2 \cdot 297$ & 2.092 & 1780 & $4 \cdot 741$ & 3.537 \\
\hline November & - & $3 \cdot 360$ & 3.441 & 2.634 & 3.755 & $4 \cdot 785$ & $3 \cdot 174$ & 1.904 & $2 \cdot 222$ & 1720 & $4 \cdot 197$ & $3 \cdot 120$ \\
\hline Decernber & 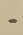 & 3832 & $3 \cdot 288$ & 2.569 & 3.955 & 6084 & $3 \cdot 142$ & 1981 & 1.736 & 1600 & $2 \cdot 397$ & 3.058 \\
\hline Annual & - & $36 \cdot 140$ & $34 \cdot 121$ & $27 \cdot 664$ & $39 \cdot \tau 14$ & $53 \cdot 944$ & 36.919 & $21 \cdot 331$ & 20.686 & 18.649 & $33 \cdot 977$ & \\
\hline
\end{tabular}

The greatest depth of rain which has been registered at any place in a year, is at Maranham, lat. $22^{\circ} \mathrm{S}$., and which is stated by Humboldt to be 277 English inches. But this is greatly above the average, and, indeed, more than double the annual quantity which has been observed at any other locality. At St. Domingo, the annual fall is estimated at 120 inches; at Cayenne, 116 inches; at the $\mathrm{Ha}$ vana, 91 ; at Calcutta, from 76 to 118 ; at Bombay, from 83 to 96 ; the island of Martinique, 87 inches; and at Sierra Leone, 86. Of European countries, Portugal appears to be the most humid, 123 inches having been observed at Coimbra in a year.

Although winter usually produces more rainy days than summer, the quantity of rain which falls is greater in the latter season. Dr. Dalton has ascertained that the first six months of the year may be regarded as dry, and the last six as wet months. Another ingenious author has inferred, from long observation, that in spring it rains oftener in the evening than in rain, estimated for 5 years (1838 to 1842 in- usually ranges from above 40 to nearly 70 inches, while that noted by the gauge in Fissex and Suffolk is as low as from 14 to 32 inches: seldom, however, does it exceed 25 inches. It may, indeed, be fairly inferred, that these two parts of England produce extrerues.

Mr. Howard gives the annual average at Londcin equal to 24.9 inches; Professor Phillips at York 25.7; and Mr. Adie at Edinburgh 25 inches.

At Keswick, in Cumberland, the depth on an average of 7 years was found to be 67 inches; at Baverstock, near Salisbury, during the same period, 323 inches; and at Plymouth, in De. vonshire, 45 inches. In the western parts of Scotland the depth is from 30 to 35 inches, which is from 6 to 10 inches more than that on the east coast.

The mean monthly and annual quantities of rain at various places, deduced from the average for many years, by Dalton, is given in the

\begin{tabular}{|c|c|c|c|c|c|c|c|c|c|c|c|c|c|c|c|}
\hline & & & Jan'y. & Feb'y. & March. & April. & May. & June. & July. & Angust. & Sept'r. & October & Nov'r. & Dac'r. & $\begin{array}{c}\text { Anoual } \\
\text { meas. }\end{array}$ \\
\hline \multicolumn{2}{|c|}{ Rain in inches } & - & $3 \cdot 687$ & $2 \cdot 574$ & $3 \cdot 224$ & $\overline{4 \cdot 600}$ & $\overline{4.290}$ & $4 \cdot 669$ & $4 \cdot 785$ & 5.581 & 3.555 & 3.698 & 3399 & 4083 & $48 \cdot 145$ \\
\hline Wind & North - & - & $2 \frac{1}{8}$ & 2 & 3 & $1 \frac{1}{5}$ & 1 果 & $1 \frac{1}{3}$ & 2 & 4 & 2 & $2 \frac{3}{3}$ & 2 & $2 \frac{1}{3}$ & $26\}$ \\
\hline 6 & Northeast & - & 5 & 4 & 6 & $\begin{array}{l}15 \\
5 \frac{9}{3}\end{array}$ & $4 \frac{1}{3}$ & $2 \frac{3}{5}$ & 2 & $5 \frac{8}{3}$ & 6 & $5 \frac{3}{3}$ & $1 \frac{9}{3}$ & 5 & $5 \div \frac{1}{3}$ \\
\hline 6 & East - & - & $\frac{2}{3}$ & $\frac{3}{8}$ & $\frac{9}{3}$ & $1 \frac{9}{3}$ & 2 & $2^{5}$ & 1 & $1 \frac{3}{2}$ & 1f & $1 \frac{9}{3}$ & + & t & 13 \\
\hline 66 & Southeast & - & 1 & $\frac{1}{3}$ & $1^{3}$ & 2 & 2 & $1 \frac{2}{3}$ & 2 & 3 & $2 \frac{1}{3}$ & 18 & $\frac{1}{3}$ & it & $17 i$ \\
\hline 6 & South - & - & 2 & $2^{3}$ & $2 \frac{x}{2}$ & 21 & 3 & $3 \frac{1}{3}$ & $3 \frac{?}{3}$ & 4 & $1 \frac{i}{3}$ & 2 & 1 & 1 & $28 \%$ \\
\hline 66 & Snuthwest & - & 8 & 7 & 6 & $7^{\circ}$ & $7 \frac{1}{5}$ & $8 \frac{1}{2}$ & $11 \frac{8}{3}$ & $6 \frac{1}{3}$ & 9 & $5 f$ & $7 \frac{2}{3}$ & 6 & $90^{\circ}$ \\
\hline 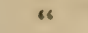 & West - & - & 5 & $4 \frac{1}{3}$ & 3 & 3 & $4^{3}$ & $5 \frac{1}{3}$ & $3 \frac{5}{5}$ & 3 & 3 & 5 & $5^{\circ}$ & 61 & 59 \\
\hline 6 & Northwest & - & $7 \frac{1}{3}$ & 8 & 9 & 7 & $6 \frac{8}{3}$ & $4 \frac{2}{3}$ & 5 & 3t & $4 t$ & 7 & 8 & $9^{3}$ & ร91 \\
\hline
\end{tabular}


clusive), together with the number of days in each month during which certain winds prevailed, the last being the results of three observations each day.

RAIN-GAUGE. An instrument for measuring or gauging the quantity of rain which falls at a given place. It is also known under the se reral names of ombrometer, udometer, pluviameter, and hytetometer. Its principles and construction are of the simplest nature; but it is made in a variety of shapes.

A convenient form of the instrument is that where the rain which enters a funnel of certain size, is collected in a bottle or other vessel, and afterwards measured in a graduated cylindrical glass tube, the marks on which not only represent the tenths and hundredths, but even the thousandth part of an inch of water. The height is read immediately on the scale.

It is requisite to be particular in the situation of the instrument. The gauge is best placed about 3 or 4 feet from the ground. In all cases an open space, free from trees, shrubs, or buildings, must be chosen.

RAKE. A tool of the toothed kind, of various sizes and forms, made use of in garden. ing, and for different agricultural purposes. There are several others used for field operations, some of which are worked by horses.

The drag-rake, in its simplest form, is merely a long cross-head, with a row of teeth placed in it: in some these are straight; they are, however, generally bent, with their points projecting forward. A very excellent and light instrument, having the teeth of steel, and made with screws, so as to admit of their being easily replaced in case of accident, is well known in England as Badgley's improved drag-rake. These rakes had, from time to time, increased in length and weight, till they became too large to be balanced by the hand. Two small wooden wheels were then added, which rendered them manageable by women or boys. Further additions having been made to them, they are now sufficiently strong to be worked by a horse. Used on fallows when foul, to remove the couch-grass, they act as a harrow, to get together the rubbish; or in harvest-time they act as a rake to collect the loose corn which may have escaped from the scythe or sickle. In order to clear them readily, there are different contrivances. One of the most simple and efficierit is an arrangement which, by lifting the handle, causes the teeth to be raised and brought between two iron bars, which constitute part of the framing; by this means all the rubbish is stripped off from the teeth of the rake.

In "Wedlake's Horse Hay-Rake," the weight of the rake is balanced upon the carriage by two heavy balls projecting in front of it; so that a slight lifting power applied to the handle will raise it from the ground, and disencumber it of the hay or stubble it may have gathered. This rake obtained the commendations of the Committee on Implements, at the meeting of the Royal English Agricultural Society at Cambridge.

The East-Lnthian Stubble-Rake is a machine not so well known in England as its merits deserve. Its advantages over those previously 940 described are as follows:-It has each tooth placed in a separate head, which, working upon a centre like the levers of a drill, adapt them selves to any inequality in the ground. To the handles, a bar the length of the harrow is firmly fastened, and from this bar each lever is sus. pended by a few links of chain. When it is necessary to clear the rake, these handles, on being elevated, lift all the levers between a framing of light iron rods.

An ingenious practical farmer, John Sayer, of Bodham, in Norfolk, made considerable im. provement upon this rake, by altering the form of the teeth to avoid tearing the land; and in order to effect more work without increasing the width of the rake, the naves of his wheels were made to project inwards, so that two additional levers could be introduced, working quite close to the spokes.

But within the last few months a very improved implement of this character has been introduced and patented by J. C. Grant, of Stamford, which obtained the prize of the Royal Agricultural Society of England, at its meeting at Liverpool. Its advantages consist in the adaptation of a compound lever, by which the whole row of tines may be instantly raised, and as quickly allowed to resume their position, while the form of the teeth being such as to describe part of a circle, the centre of which is the axis of the separate levers to which they are attached, each portion of the curve is successively brought into a vertical position, thus rapidly disengaging the teeth from the material collected, so that, without stopping the horse, the process of collecting is resumed, leaving no interval beyond what is requisite for the deposit of the hay, corn, or stubble previously collected.

Several minor improvements are included in the patent, but as these mainly refer to modes of construction, it will not be necessary here to particularize them.

$\mathbf{A}$ hay-making machine invented by Robert Salmon, of Woburn, and patented in 1816, consists of a series of rakes revolving upon two skeleton frames, to which motion is communicated by cog-wheels attached to the naves of the wheels in which it travels. It has undergone considerable improvement by $\mathrm{R}$. Wedlake, an ingenious manufacturer, residing at Hornchurch. These improvements consist in form. ing the cylinder in two parts, each of which has motion independent of the other, and in placing the tines or rake-teeth upon a bar, which, being supported by a spring, will yield to any obstruction caused by sudden unevenness of the surface of the ground, and return again to its original position. Its object is to spread the hay, and by thoroughly separating its parts, continually to expose them to the sun and wind, which it so thoroughly effects as to render the hay fit to cart much earlier than by the common process of shaking it by the hand. To the practical agriculturist, it will not be necessary to remark on the advantages accruing from the ability to hasten, if only by a few hours, the process of hay-making; but it will be valuable to know, that the universal testimony of all with whom we have conversed is. 
that this implement is a time-saving machine, and therefore one of the greatest value.

Americun Revolving Hay-rake.-This rake is drawn by one horse; and it can be made to go either along or across the ridges, as may be required. It can carry between 100 and 200 Ibs. of hay; and when that quantity is upon it, the hay can be deposited, by a simple revolution of the instrument, in rows, or at any fartıcular place required, without stopping the horse.

The common horse-rake, much used in the United States, especially in the North, is described and figured in the Cultivator, vol. vii. p. 89. It is made of a piece of strong scantling, 3 inches square, and 10 feet long, into which about 15 teeth are inserted horizontally, and made of strong white ash or other tough wood. The teeth should be about 22 inches long, and 1 inch by $1 \frac{3}{4}$ at the place of insertion, and tapering on the under side, so as to give them a slight turn upward at the point, to prevent their running into the ground while using. The draught-ropes are attached to the end of 2 projecting pieces of wood parallel to the teeth at each end of the rake. These projecting pieces should be about one-third of the length of the teeth. Those unskilled in the use of the rake sometimes attach the ropes at once to the ends of the head; in this way, it becomes almost entirely unmanageable. The forward ends of the draught-ropes are to be fastened to the horse's collar, leaving space enough between the horse and rake for the collecting hay. Handles are to be inserted in the head near the middle, for guiding the teeth and lifting the rake from the ground when necessary.

In using this rake, instead of the teeth moving onward upon their points, as in the common hand-rake, they run along flat upon the ground, passing under and collecting the hay; when full, the handles are thrown forward, the rake emptied, and lifted over the winrow for another load. The rake thus passes backwards and forwards across the field, always emptying opposite the last heap, and thus forming regular winrows at right angles with the path of the rake. A few hours' practice will enable any one to use this rake without difficulty, the only skill required consisting in keeping the points of the teeth just so low as to pass under all the nay, and yet not run into the ground. When small obstructions occur, the handles are depressed, thus causing the teeth to rise, and the rake passes freely over. Large obstructions, as stumps and stone-heaps, require the rake to be lifted from the ground.

The chief recommendation of this kind of rake, is its cheapness and simplicity. A good one need not cost more than \$2. It may also be used on rougher ground than the revolving rake, as it is more easily lifted over obstructions. Where the ground is very uneven, the teeth should be much shorter. When one becomes well accustomed to the use of it, work may be done nearly as fast with this, as with a revolving rake, though much more laborious. Twelve acres of hay, part of it yielding nearly 3 tons to the acre, on a meadow of the writer, werc raked into winrows, by means of one of these rakes, in about 6 hours' working time.
It possesses another advantage over the revolving rake-it may be used for scraping the winrows into heaps for drawing, and if the hay is stacked in the field, for drawing the hay to the stack. A man with a rake and horse not only raked the hay, but drew it at the same time to the stack, a distance of from 10 to 21) rods, as fast as an active man could pitch with a fork. A hand-rake need scarcely ever be used on the meadow, as all the scattered hay may be raked up in a short time after the rest of the hay has been drawn off.

The horse-rake is very useful in raking stubble of wheat, and eminently so in pulling and gathering peas.

Shafts, instead of ropes, have been attached to the head of the rake, and have been strongly recommended; but they diminish the simplicity of. the rake, and appear to possess no ad. vantage on the whole, and for gathering and drawing hay, are positively detrimental.

RAMPIONS, or RAMPION BELL-FLOW. ER (Campanula rapunculus). 'The esculent roots of this vegetable are far more delicate than turnips or radishes. They are long, white, and in the shape of a spindle. Like the radish, it is eaten raw, having a nut-like, pleasant flavour. The plant rises to the height of 2 feet, with blue flowers.

It is propagated by seed, which may be sown during March, April, and May; the plants from sowings in the two first months, soon, however, run up to seed. 'The insertions may be performed either in drills 6 inches apart, or broadcast; in either mode the seed to be buried $\frac{1}{2}$ an inch deep, effecting it in the latter by sifting mould over it; for, if the seed is raked in, from its minuteness, it is apt to be buricd too deep. The plants are to remain where sown; though, in case of any deficiency, those which are taken a way in thinning the crops may be transplanted successfully. The best time for performing the removal is of an evening. 'They are fit for thinning when about 2 inches in height, they must be set at a distance of 6 inches apart, being hoed at the time, and the same operation repeated two or three times, which, if performed in dry weather, will keep them free from weeds until used.

The plants of the sowings during the two first mentioned months will be fit for use at the close of August, or early in September, and continue throughout the autumn. Those of the last one will continue good throughout the winter, and until the following April. 'The soil, throughout their growth, must be kept muist, effecting; it in dry weather by giving frequent but moderate waterings through the fine rose of a watering-pot.

The root, for which it is cultivated, either to be sliced, together with its leaves, in salads, or eaten as the radish, as well as to be boiled like asparagus, is most palatable when drawo young, and eaten fresh from the ground.

For the production of seed, a few of the winter standing plants are left unmoved. These shoot up in the spring, towering in July and August, and ripening abundance of seed in early autumn. (G. W. Johnson's Kitch. Gard.)

RANUICULUS (From rana, a frog, several of the species being found in moist places fro. 
quented by that reptile). Many of the plants belonging to this extensive genus are well worth the cultivator's care, and they have long been favourites with the florist. The aquatic kinds require to be grown in water. The grumose-rooted species will thrive in any common soil and situation; they are increased by offsets from the roots, or by seeds. These plants are acrid, and most of them poisonous. See Crowfoot and Sprarwort.

RAPE. A plant of the cole kind, greatly cultivated in Flanders for the sake of the seed, but extremely valuable also as green food for cattle and sheep in winter and spring. "The plants," says Mr. Low, "usually cultivated under the name of rape, are the fusiform varieties of the following species of brassica. Cole or rape (B. napus), colza (B. campestris), fusiform common turnip (B. rapa), and early cole (B. precox)." 'There are different modes of treating this plant, according to the uses for which it is designed. 'The whole plant is of great service in feeding cattle; and after the seed is thrashed, the straw and chaff, on being burnt, afford ashes equally valuable as the best potashes. Wheat yields an excellent crop after rape, and the plant is grown with great advantage on bog plant, where paring and burning has been practised. Rape is very hardy, and with fair treatment it never fails on any soil. Cattle are so successfully fattened with it, that many farmers prefer it to turnips. See Cols.

For garden culture, rape is propagated by seed, and, like mustard, and other small salading, may be sown at any period of the year, when in request; being allowed a separate bed. For the production of seed, some plants of a sowing which has been made about the middle of July, must be thinned to about 18 inches apart: they will survive the winter in England, and flower in May and June of the next year. The seed, which is produced in great abundance, ripens in July and A ugust, and must then be cut and laid upon cloths to dry, as it is very apt to shed.

In England, rape (Brassica napus sylvestris) is frequently called coleseed, and in France navette. In both countries it is highly prized, not only for the value of the oil expressed from the seed, but for the cake left after pressure, which is extensively used for feeding cattle, its qualities for this purpose resembling those of the oilcake left after pressure of flaxseed in making linseed oil. Rape belongs to the cabbage or :urnip family, but it never heads, like the former, and its roots are of little value compared with the latter. Of the two kinds most commonly cultivated, one is biennial, sown one summer and harvested the next, whilst the other is a spring or summer crop.

Rape. though but little known in the United states, has been tried in various parts, and found to stand the winters even in New York and New England. Whenever, therefore, a demand shall be made for this valuable production of the soil, or its near kindred of the cabbage family, colza, the United States can yield them abundantly, in almost every part.

According to Loudon, the place which rape ascupies in a rotation, is between two culmi912 ferous or grain crops. On rich soils it may be succeeded to the greatest advantage by wheat, as it is found to be an excellent preparation for that sort of grain; and by its being taken off early, there is sufficient time allowed for getting the land in order for sowing wheat.

In Notes on the Agriculture of Germany, by Mr. Carr, an English gentleman, he says the after course is as follows:-

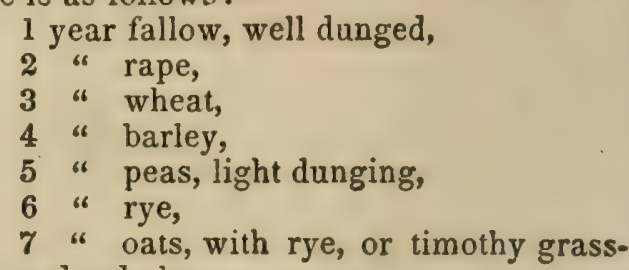
seeds, and red clover.

The clover and peas plastered in May. The clover is mown twice for hay, and left two years for pasture, when it is heavily manured, fallowed, and again sown with rape. "The rape-seed is sown broadcast in the last of July or first of August. This crop is greatly benefited the following spring by dusting gypsum over it, about $100 \mathrm{lbs}$. to the acre. In July the seed is ripe, and as the weather is generally fine, is trodden out by horses very expeditiously on large canvass sheets in the field. The oil of this seed pressed out, when purified, is without smell, gives a brilliant, clear-burning flame, and is universally used all over Germany, in the saloon of the rich, and the cottage of the poor. The value of the crop is somewhat precarious, because it is subject to so many contingencies; the turnip-fly and caterpillar prey upon it when young, and when in flower, a small beetle (Haltica nemorum) often eats away the blossom-bud, or lays its minute larvæ in the petals, ultimately furnishing every seed-pod with a maggot which either eats the seeds away, or, forcing the pod open when nearly ripe, causes it to fall out. When spared these calamities, it is, however, a very remunerating crop, worth from $10 l$. to $20 l$. an acre, especially if there is a foreign demand. The straw is generally burned, and the ashes scattered over the field; it is sometimes sold to the soap-makers, who prize it highly. Two furrows are now given for wheat sown broadcast in September."

Mr. Blackie, in his Essay on the Improvement of small Farms, says, that the produce of rape, when well manured, is beyond any thing almost that can be imagined, if let stand until it gets into blossom. Manure, he adds, makes the stalk tender and juicy, which would otherwise be hard and dry, so that if cut into small pieces for the purpose of feeding green to cattle, not a bit will be lost, and it grows to a height of 6 feet. I am, he says, almost afraid to say, that I believe, with the addition of some straw, an acre will keep 30 head of cattle in full milk for a month.

RAPE, edible-rooted. This name may be applied to a variety of the rape mentioned by Mr. Dickson, one of the vice-presidents of the Horticultural Society. Its root is white, and carrot-shaped, about the size of the middle finger. It is much more delicate in flavour than the turnip, like which root it is cooked, only that it is not peeled, but scraped, its skin being re- 
markably thin. It has been cultivated for a great length of years on the continent, and for about 30 years in England, but only by one person, as far as Mr. Dickson is aware. It is propagated by seed, which, for the main crop, may be sown from the middle of July to the end of August, or even later: these will supply the table until April; and, if wanted throughout the year, a little may be sown in the latter end of October, the plants from which will be fit for use, if they succeed, during April and May: the last crop to be inserted from the middle of January to the middle of February, which will come in at the end of May and during June. On a north border, and if the soil is sandy and moist, it is possible to have them sweet and tender during the whole summer, to effect which the seed must be sown at the close of March and May. They require the same modes of cultivation and treatment as turnips. In dry weather the beds must be watered regularly, until the plants have got three or four leaves. One great advantage attending the cultivation of this vegetable is, that it requires no manure. Any soil that is poor and light, especially if sandy, is suitable to it. In rich manured earth it grows much larger, but not so sweet and good. For the growth of seeds, Mr. Dickson recommends, in February or March, some of the finest roots to be transplanted to 2 feet asunder; but it would, perhaps, be a better practice to leave them where grown.

RAPE-CAKE. The refuse or marc remaining after the oil has been expressed from the rape or cole-seed. (See Linsend Cakr.) The use of rape-cake as a manure is pretty extensive in some parts of England, and its effects are so immediate and powerful, that its expense alone retards its more general employment. It contains a large quantity of mucilage, sume portion of albuminous matter, and a small proportion of oil. It should be kept dry, and used when recently made. It answers admirably for turnips. When first recommended as a fertilizer, it was used in the proportion of half a ton per acre; but by pulverizing it, and drilling it in with the seed, about half that quantity has been found suffcient. Rape-cake produces, when ploughed in with wheat, excellent crops. It has been found exceedingly noxious to the wireworm, and other field vermin, and when applied in compost, with 30 times its weight of farm-yard dung, it forms a very excellent manure.

Rape-cake, in common with all fertilizers of an oily nature, is much more decided in its effects in wet than in dry seasons. In Yorkshire and Lincolnshire the quantity applied is about 16 bushels per acre. It is more serviceable on clays and other moist lands than on dry soils; its benefit extends to only one crop, although there have been occasional instances of its extending to two. It may be either drilled with the seed or spread on the land before it is ploughed. See Livsenn, OruCakn. Palma Christi, \&c.

The practical benefits which are capable of being derived from a correct knowledge of the mode in which green manures operate, are consiterable. It should teach the cultivator to carefully bury in the soil every portion of either animal or vegetable matter he can command; for every weed, every fragment of straw he thus employs, will again, under judicious management, be returned to him in new forms of beauty and usefulness.

RASPBERRY (Rubres idous). This shrub, in its wild state, is found growing in our mountainous woods and thickets: flowering in May and June. The root is creeping. The stems are biennial, erect, 3 or 4 feet high, branched, round, pale or purplish, more or less besprinkled with small, straight, slender prickles, frequently rather resembling bristles than prickles, and sometimes altogether absent. Leaves primate, of five or three ovate, rather angular, lateral leaflets, serrated or cuc and angular, green, and nearly smooth above, very downy beneath, and a larger terminal leaflet. The footstalks are furrowed, downy, and prick. ly, with narrow lateral stipules. 'The flowers are small, white, or pinkish-white, pendulous, in drooping terminal clusters. Fruit crimson, of numerous juicy grains, beset with the permanent styles, and highly fragrant, with a very deliciously perfumed sweet and acid flavour, more exquisite in the wild state, in general, than when cultivated.

The wood of the raspberry bush produces fruit but one year, therefore that should be carefully cut down below the surface of the earth, and the young shoots should be shortened to about 2 feet high; and not more than three or four shoots should be left to each root, as these will produce a greater number of berries, and larger fruit, than would be obtained if twice that number of suckers were left. The middle or end of October is the proper time for this pruning. 'The fruit is produced from young branches out of the last year's shoots or suckers. The plants raised by layers are much preferred to those taken from suckers; they should also have plenty of room, for when there is not space for the air and light to pass between the rows, the fruit will be small, and not ripen well. They require a fresh, strong loam, deeply trenched and well manured in the first instance, for in warm, light ground they produce but little fruit.

The following selection is recommended for a small garden:-Barnet, Cornish, Double. bearing red Antwerp, Williams's preserving yellow Antwerp.

This fruit is employed for the dessert; it is also in very general use for jams and tarts. and is converted into wine and vinegar, which is a refreshing beverage, when diluted with water, in fevers. The young and fresh leaves of the common raspberry are eagerly eaten by kids. (See Bramele.)

RAT. The name of a large, destructive, and very prolific species of the genus Mus, the brown, or water-rat (Mus decumanus, Linn.), introduced into the British islands from Asia, not, as is commonly believed, from Norway. It has spread over all the country, and multiplied at the expense of the old British species. called the "black rat" (M. ratins, Linn.).

Of all the four-footed animals (says the au thor of Brit. Husb.) included in the rank of vermin, rats and mice are the mos? pernicivus. 
for they build their nests under the floors and in the roofs of barns, nor are even the stacks exempt; and are so prolific that, if not destroyed, they occasion incalculable mischief. It therefore behooves every farmer to use all possible means to check the evil, and one might suppose that every exertion was invariably made for that purpo:se; yet we constantly find homesteads overrun with these pests, without any other pains being taken than an occasional rat-hunt by farm servants, aided by a terrier, which, though not to be neglected, is a very ineffectual remedy. The best is, unquestionably, the construction of the barn-floor and roof in such a manner as to prevent them obtaining a permanent harbour in the building. The next is, before the entire clearance of the barn, while yet a little corn remains to prevent them from quitting it, to close every part of the barn, by carefully covering any holes there may be with sacks and tarpaulings, so as to prevent all access of the outward air, leaving only the door for a few minutes open while the process is going on. This done, some common iron chafing-dishes, which may be purchased for a trifle, should be placed upon the floor, and in the bags; or, if they cannot be had, build up a few bricks, clay, or any rubbish that will secure a fire from spreading, leaving a cavity in the centre, and filling it up with charcoal. 'Then light the charcoal from the bottom, and when the heaps are all burning, quickly strew a good quantity of broken brimstone upon the top; retire immediately, shut the door fast, and ceave the building entirely closed during a couple of days following. On opening it, the greater portion of the rats and mice will be found dead around the charcoal; and, aithough some may have been suffocated while in their holes, and if not discovered will occasion an unpleasant smell until their remains are dried up, yet it will not last long. The operation should be again repeated just previous to harvest, and if any opening be found into the barns while they are full, by the burrowing of the rats, brimstone matches should be inserted into them before they are stopped up. Traps and poisons are only partially efficient; but an effectual mode of trapping is detailed in a small pamphlet, published some years ago hy $\mathbf{M r}$. B. Broad, of Thurton, under the sanction of the Hereford Agricultural Society, which ought to be in the hands of every farmer in the kingdom.

The ferret is a decided enemy to the rat, and if kept in a hutch or cage, and only occasionally used, will be found very serviceable: but .xe should be well fed to induce him to return, or otherwise he will escape and become destructive to poultry. A cat or two should also always be reared about a barn. In new barns and outhouses, the entrance of rats is effectually prevented by steeping the joints, rafters, and flonring in a solution of corrosive subliinate. If \& rat or a mouse attempt to gnaw wood so prepared, their saliva moistens the sublimate, they take it into the stomach, and are so destroyed by it. See Mrce and Venmin.

REAPING. Cutting down wheat or other corn, grain, or pulse with a sickle, hook, or xcythe, or by a reaping-machine. These opesations are more advantageously performed when the corn or pulse is not quite ripe, than when it is thoroughly ripe; because, in the latter case, the seeds are apt to drop out in the process of handling, turning, and drying.

Mr. Hannum enters into some elaborate calculations on the advantages of reaping wheat a fortnight before it is ripe, from which he deduces the following results; that, independently of a gain of 4 per cent. on the value of the grain, we have, lst, straw of a better quality; 2dly, a better chance of securing the crop; and, 3 dly, a saving in securing it. (See Whеат.) The smaller the sheaves are, the better, especially in a wet harvest: in general, the diameter of the sheaf should not exceed 30 inches. It is of some importance, also, not to tie the sheaves too near the ears. In making the shocks, they should be placed across the furrows, in order to procure a free circulation of air around them.

In some districts in England, the scythe has of late years been partially employed for the purpose of reaping, but with no satisfactory result; and in Berwickshire the scythe-hook is now generally used in preference to the toothed sickle of our fathers. Cutting corn with a sickle of some sort is, however, considered preferable to mowing it with a scythe, unless the crop stands up well, and time presses. Barley and oats may be frequently mown with advantage; but wheat, which requires immediate and clean binding, and is too valuable to admit of any irregularities or wastefulness in harvesting, should be reaped. The mode of reaping called bagging, and practised a good deal about London, and part of the west of England, is thus executed:-The left leg being pushed into the standing corn, and the straw inclined with the left hand over the left foot. is then cut close to the bottom with a stroke fium the right hand. The increase of straw, where this is valuable, renders this a good method of reaping.

In England the mode of reaping varies with the nature of the crop. Barley and oats are generally cut with the scythe, beans with the sickle; peas with what are called fagging. hooks, which rather tear up than cut; and tares in the same way.

Reaping is a great part of the expense of a crop. The average price in England is from 12 to 15 s. an acre. See BANDS, Barlex, $\mathrm{H}_{\mathrm{AR}}$. VESTING, WHEAT, \&c.

REAPING-HOOK. An implement used to cut down corn. It is one of the oldest instruments employed in husbandry. There are two kinds of hooks; that which is principally used by the British labourer has a smooth blade of wrought iron and steel, about 25 inches long, and curved nearly to a semicircle; the other, which is universally preferred by the Irish reaper, has a finely serrated edge, and towards the lower point recedes from the curved direc. tion to nearly a straight line. The real action of the reaping-hook is that of a saw, consequently the serrated edge is an advantage. See SickLE.

REAPING MACHINE. A contrivance for the purpose of reaping grain by means of animal labour. With this view, and to facilitate an operation of such importance to the farmer. 


\section{REAPING MACHINE.}

different attempts have been made to construct machines, so as to despatch the work in a rapid manner by the assistance of hcrse labour, but the success with which they have been attended in England has hitherto been far from complete.

Many contrivances have also, of late years, been resorted to for supplying the place of the reaping-hook, but hitherto none have proved effectual, nor are the difficulties arising from roughness and irregularity of surface likely soon to be surmounted. No one will dispute the great utility and advantages of an efficient reaping machine, if it could be carried into operation, as these advantages are universally acknowledged. In England, such an implement is the more required now that the agricultural labourers are greatly reduced in number by emigration, and harvest work has become more expensive. There is now a much greater quantity of corn to cut down, and most of the grain ripens about the same period. In 1815, Mr. Smith, of Deanston, invented a reaping machine, which, in some experimental trials, appeared to perform its work exceedingly well; but, upon longer trial, it has not answered the favourable expectation formed of it. Since that period, another invention of a similar nature, by Mr. Patrick Bell, has attracted considerable attention, but does not appear to be of sufficient merit to have come into general use. The original cost of these machines, $40 l$. or $50 l$, must, in many instances, preclude their employment.

An excellent article on the advantages of a reaping machine will be found in the first volume of the Quart. Journ. of $A g r . p .137$; and Mr. Bell's machine is figured and described at p. 217 of the same volume.

American ingenuity has been active in the invention of machines for harvesting wheat and other grains. Among those which have been brought into the field, "Wilson's Mowing Machine, or Grass and Grain Cutter," is highly commended by some who have tried it. It has been most in use along the Hudson river, and is cousidured an improvement of Smith's English reaping machine.

But the machine that is perhaps best entitled (1) the notice of farmers, is the one invented by Obed Hussey, which is recommended for its simplicity, durability, and the great regularity and cleanness with which it performs its work. Even when the grain is too much lodged to be cradled, it will cut at the rate of two acres per hour, nearly as clean as if it had been standing. It can be adapted to the inequalities of the surface of a field, and has been so improved by its original inventor as to operate with great facility on stony land. This machine has received the most unqualified approbation of nearly all farmers who have tried it, or witnessed its operation. The Board of Trustees of the Agricultural Society for the Eastern Shore of Maryland, in their Report, made in 1836, say, "We deem it a simple, strong, and effective machine, and take much pleasure in awarding unanimously the meritorious inventor of it (Mr. O. Hussey) a handsome pair of silver cups."

The committee appointed by the Philadel119

\section{RED-ROOT.}

phia Society for Promoting A rriculture, to su. perintend the operation of $\mathrm{Mr}$. Mussey's machine, make a very favourable report, recom. mending it to the attention of the suciety and the agricultural community generally. They state that it was put in operation in a pince of several acres of heavy wheat, considerably lodged, and, contrary to their expectations, it performed remarkably well.

"The committee estimate the ordinary per. formance of the machine at from ten in twelve acres per day; although they fully believe, that on an emergency, it would accomplish twice this amount of work. In confirmation of this they would state, that it cut, on this occasion, 630 square yards in 2 minutes, doing its work in the most perfect manner." The cost of the machine is \$150. (See Farmer's Cabinet, vols. ii. and iii., Cultivator, and other American agricultural periodicals.)

$M$ 'Cormick's Reaping Machine is used in Virginia, and spoken of very favourably by the editor of the Southern Planter, who has furnished a cut and explanation of it in the number of that excellent periodical for January, 1843. It is said to cut 15 acres per day without leaving a single stalk in the field, and some think the wheat saved in harvesting a large crop will more than repay the first cost of the machine. It weighs about 600 lbs., rests upon two wheeis, and is drawn forward by two horses. The cost of the machine is $\$ 100$.

A machine for harvesting grain has been invented by G. G. Carpenter, of Caledonia, New York, which not only reaps the crop, but thrashes it out. In speaking of his machine and its merits, Mr. Carpenter observes, - "The great saving in grain and labour is in finishing the work without laying the grain on the ground. It may be gauged to cut as high as the grain will admit, and the 9 -feet swath streams from the cradles to the thrasher so evenly, that no more power is required to finish 15 to 20 acres a day than is necessary to drive a cummon thrasher, which only thrashes say 200 bushels in a day, with many hands in attendance." This machine costs $\$ 600$. The hands required to attend it are, one to drive the team, and one to take care of the machine. (See Cultivator, vol. vii.)

Other labour-saving contrivances for harvesting grain have been invented in the United States of late years, descriptions of which may be found in various agricultural periodicals.

RED BAY (Laurus Caroliniensis). An American species of the laurus genus found in the Southern States. (See Michaux's North American Sylva, vol. ii.p. 15.0.)

RED BUD. See Jüas TreE.

RED GUM. A disease of grain, a kind of blight. See BLiger.

RED-ROOT (Lithospermum arvense). S'uneweed. A worthless plant which has been 11. troduced into the United States, where it has spread itself extensively, especially in some parts of New York, where it is considered even a worse pest of the fields than the Canada thistle. Dr. Darlington describes the plant as being hispid, or beset with brislle-like and rather short hairs; the root annual; stem 12 (1). 19 inches high, generally much branched from 
the root, and often branched near the sumin:... l.eaves 1 to 2 inches long, and $\frac{1}{4}$ to $\frac{1}{3}$ wide, without stems, narrowed at the base, and spearshaped flowers, which show themselves in May in the Middle States, have yellowish or milkwhite and rather small corollas. The seed nuts are ovoid, with tapering points, rough, wrinkled, and brown, when mature. When this formidable weed, which is the pest of the northern wheat-crops, first appears in a field, it may be removed by carefully pulling it up while in flower, and thus preventing it maturing seed and propagating itself. Where it once gets possession, it is exceedingly difficult to destroy, as the seeds will lie many years in the soil without coming up, in this respect resembling those of charlock or the wild radish and mustard. One of the best methods of treating it, says the editor of the New Genesee Farmer (vol. i. p. 92), is to harrow, or lightly plough the wheat-stubble immediatcly after harvest, to cause the fallen seeds to vegetate, and destroy the young plants the next season by summer crops, which should be repeated for a year or (wo, when the land may be summer fallowed for wheat. Successive crops of buck wheat are said to be advantageous.

Rev-Root (Ceanothus Americanus). New Jersey tea. A plant with a large, red, perennial root, found in the United States. The stem grows 2 to 4 feet high, and is branched. It possesses considerable astringency, and during the revoIntionary war the leaves were substituted for tea.

Red-Roor (Sanguinaria Canadensis). The generic name is derived from the colour of the sap, which resembles blood. This American plant, which abounds in the forests, is variously called puccoon root, turmeric, and Indian paint. The rcot is perennial, with fibres attached to a reddish, horizontal stem, about 2 or 3 inches long and $\frac{1}{2}$ an inch thick, growing under ground. It possesses emetic and other mediciral properties. It is the only species of its genus.

RED SPIDER (Acarus). A well-known pest of gardens. It may be destroyed by application to plants of whale-oil soap, in the manner directed in the destruction of plant-lice. See ApHIs.

\section{RED TOP. See Hern's Grass.}

RED TOP, TALL (Tricuspis Seslerioides). A perennial grass, found in the Middle States, on dry banks and sterile fields, flowering in August and seeding in September. It has an erect, jointed culm or stem, 3 or 4 feet high and very smooth. Pursh calls it "a most excellent grass," and says he has seen "most excellent crops" of it, in the mountain meadows of Pennsylvania, where they mow it twice a year. Such crops may possibly pass for "excellent" in mountain meadows; but, observes Dr. Darlington, they would be not so considered in Chester county. If Mr. Pursh lias not misapprehended the fact, he is certainIy mistaken in the character of the plant; for it is a dry, rigid grass, with unusually hard culıns, and altogether unfit for making good hay. It is the only species of the genus in the Enited States. (Flor. Cest.)

RFD-WATER. In Britain, a well-known dis"ase in carree. "The disease commonly called 9.11 red-water, brown-water, black-water, moor-ill, \&c.," says Mr. R. Thompson, of Auchterarder, " is most prevalent in old, foggy pastures. It is seldom seen in hill pastures, or in new-sown pastures, in which there is abundance of clover; but it sometimes happens at the stall, where the animal has no other allowance than straw, turnips, and potatoes. It usually makes its appearance after a few days of rain, followed by cold, dry weather. As the disease appears at times in all situations, it is difficult to trace its existing cause, which may be the nature of the pasture, or the state of the weather, or both combined. It attacks every breed and kind of cattle.

"The first symptom is the appearance or something like blood mixed with the urine. So trifling is the complaint in some instances, that no inconvenience seems to be felt by the animal, who eats and drinks as usual, chews the cud, and is free of the disease in a few days. In such cases a natural diarrhoa comes on, to which the cure may be attributed. In general, however, the disease is not observed until the animal refuses food, separates from the rest of the herd, appears dull and heavy, and manifests great langour and apathy. The ears droop, the urine is of a reddish or brownish colour, and if it be a milch cow, the milk is often similarly tinged. The pulse ranges from 60 to 70 ; there is obstinate constipation of the bowels; the urine is discharged in moderate quantity, and apparently without pain. If relief is not afforded by some brisk purgative, at the period when the urine changes colour from red to brown, the pulse begins to sink, and if a little blood be drawn at this time, its surface assumes a brownish colour; the eye appears of a yellowish-brown tint; the urine acquires a darker hue; the animal refuses to rise; the pulse sinks; the legs, tail, and horns turn cold; and the animal dies, to all appearance perfectly exhausted, although it has manifestly no symptoms of acute pain during the course of the disease.

"Purgatives of any kind, if given in large quantities of water, are found to be the best medicines that can be employed. Medicines given to cattle that have lost the power of chewing the cud, generally pass into the first and second stomachs, and if a good draught of water is not given to wash them from thence, if the animal dies, the greater part of the medicines will be found in these stomachs; and upon this principle, common salt, if properly managed, will be found among the best. Dissolve the quantity to be given in as much water as will enable it to pass freely from the bottle or drenching horn, and let the animal have plenty of water to drink afterwards. Should it refuse to drink, no time should be lost in drenching it profusely with water. Without a plentiful dilution, there is no certainty of purging cattle that have lost their cud. If purging does not comr:ence in from 12 to 24 hours, a second dose should be given. Injections of soap and water should also be tried, if the case is obstinate, and when they operate, a pint of linseed oil should be given as a laxative. So obstinate is the constipation in some cases, that the salt acts only as a diuretic, 
causing a plentiful discharge of urine. Diuretics and astringents combined seem only of service when the bowels are open, and their improper administration often causes inflammation of the bowels and kidneys. If, after purgation, the bowels are kept open by laxatives, such as linseed infusion, the disease will gradually disappear without their use. In the last stage of the disease, when the urine assumes a dark-brown or black colour, no remedy seems to have any efficacy; the animal is sunk beyond recovery, the bowels lose their action, suppression of urine follows, the animal stretches itself out and dies, as if perfectly exhausted.

"There are two diseases which in their symptoms bear some resemblance to red-water in cattle, viz., inflammation of the kidneys, and inflammation of the mucous membrane of the bladder or the urethra, which often happens at calving. In these cases the urine, which is discharged with pain, is mixed with blood, but not so intimately so as the coloured urine in red-water, and it has generally more or less mucus mixed with it. Inflammation of the kidneys in cattle is comparatively rare. I have seen only one well-marked case, which terminated fatally. The animal experienced considerable pain upon pressure being applied to the region of the kidneys. The urine was small in quantity, and nearly as thick as blood; and pulse ninety and very hard. As the dis. ease advanced, the urine became black and fetid. The animal all along exhibited symptoms of excruciating pain, until death terminated its sufferings. Post-mortem examination disclosed extensive inflammation of the peritonæum. The abdominal cavity contained a large quantity of dark-coloured, fetid fluid; the fat surrounding the kidneys, as well as the kidneys themselves, was in part gangrenous; and the fat generally exhibited a yellow colour, as is usual in cases where death terminates inflammatory diseases." (Trans. High. Sac. vol. ix. p. 9.)

REED (Arundo). A genus of aquatic plants, in most instances mere weeds, infesting boggy low lands or meadows on the sides of rivers.

The best method of destroying reeds, is by draining the land; for if the drains be cut deeper than their roots, it will take away their nourishment, and consequently destroy them. Common salt, ashes, or soot, will likewise sometimes kill them; and so will ploughing up the land, and laying it in high ridges. Reeds always indicate a deep, good, moist soil, as a bad one will not nourish or support them. See Arundo, Aromatic Reen, and Bent or STARR.

The term reed is sometimes provincially applied to the straw of wheat, rye, \&c., that has not been bruised.

REED-GRASS. See Canary-Grass.

RENNET, or RUNNET. The prepared inner membrane of the calf's stomach, which has the property of coagulating the albumen of milk, and converting it into curd and whey. The maw is cleaned, salted, and suspended in paper bags. Previously to its use, the salt is extracted by washing the rennet; which is then soaked in hot water during the night; and in the morning the infusion is poured into the milk to coagulate it. This is the result of the gastric juice, which is acid; and acts upor. the caseous part of the milk, in the same man ner as other acids. It sometimes happens that no rennet sufficiently good for curdling milk can be procured; hence various plants have been advantageously substituted for this pur pose. The principal of these are the flowers of the yellow ladies' bedstraw (Galium verum), used in England, and the cardoon (Cynara cardunculus), in Spain. A strong infusion is made of the down of the latter vegetable in the evening, and on the succeeding morning $\frac{1}{2}$ a pint is poured among $\mathbf{1 4}$ gallons of new milk, which is thus effectually coagulated, and in consequence produces a delicious cheese. See Chese and Cheese Rennet.

RENT (Redditus; from redeundo). The sum of money or other consideration issuing yearly out of lands and tenements paid by the occupier to the owner. This, in Britain, has gradually taken the present form of payment in money, from a very different original tenure; for, in former days, the land was generally held of the superior lord, by certain services rendered, of either a military or servile nature, such as carrying out the lord's manure on to his land; certain days of ploughing, digging, or cutting the corn, \&c. of the landlord; the general adoption of a fixed rent or money pay ment in lieu of these arbitrary and rexatious tenures, was an advance of modern days.

RESERVOIR. A conservatory of water. 'The husbanding of water is now becoming a subject of peculiar interest to the English agriculturist. This arises from its scarcity in many districts, in consequence of the improved drainage of the land, and from the many uses to which machinery may be applied in farming operations by the agency of water power. The construction of reservoirs must resolve itself into the following heads:-

First, where a sufficient quantity of water can be diverted directly from the channel of a stream or river.

Second, where the supply is to be obtained from drainage, which maintains a stream during part of the year, but which stream fails during the summer months.

Third, where there are grounds affording a favourable situation for the construction of a reservoir, but through which there is no natural stream passing. See Povns and Tarks.

RESINS. Peculiar vegetable substances of allied properties, composed of carbon, hydrogen, and oxygen; the most common of which is the rosin of commerce, or residue after the distillation of turpentines, in order to obtain the volatile oil. When no water is used in this process, an empyreumatic, brownish-yellow, semi-transparent substance remains, namely, colophony or fidler's rosin; when water is used, the residue is the opaque yellow substance called yellow rosin. When every particle of water is evaporated from the last, and it is kept in a state of fusion at a moderate temperature, and then allowed to cool slrevly, the best resin is procured. It is translucent, brutlit, fusible at a moderate heat, inflammable, and soluble in spirits of wine, volatile oils, awd 
also fixed oils and fat, when aided by heat. The mineral acids convert it into artificial tannin; the alkalies into soap. Resin in combination with wax, a little oil of turpentine and wax, forms a good polish for furniture. Resin contains oxygen $13.3 .5 \%$, carbon $75 \cdot 944$, hydro. gen 10.719. The chief of the other resinous substances are elemi, copal, mastic, sandarac, lac, iabdanum, amber, \&c. They are almost all soluble in alcohol.

REST-HARROW (Ononis, from onos, an ass, and onemi to delight; some of the species are said to be grateful to asses). All the plants belonging to this genus are of easy cultivation, and several of them are rather handsome when in flower. The common rest-harrow or cammock (O.arvensis), is a native plant, with a woody, tough, and strong root, resisting the harrow's prongs, whence the English name. The stems are annual, though often considerably woody, or shrubby, various in length, hairy. Leaves generally simple, entire towards their base. Flowers mostly solitary, large, and handsome, of a brilliant rose colour. See Pl.x.k.

RHIZOMA (Lat. Rhiza, a root). A term applied to roots which spread under ground, like those of the iris.

RHODODENDRON (From rhodo, a rose, and dendron, a tree, because of the appearance of the terminal bunches of flowers). The rhododendron is decidedly one of the finest of all known genera, containing some of the most handsome, elegant, and showy shrubs; all of which are admirably adapted either for ornamenting the green-house or shrubbery, or for planting singly on lawns. Peat soil is most suitable to these plants, but they may also be grown in very sandy or vegetable mould. They are propagated by layers or seeds. The smallwooded kinds may be also increased very freely by young cuttings, planted in sand, under a glass.

'The species found in the United States are, the Rhododendron nudiflorum, or naked-flowered rhododendron, commonly called the wild honey-suckle, a beautiful American shrub found in the Middle States, frequent in woodlands and thickets, where it blooms from April to May. The flowers are of various shades, from very pale to bright purple. There are apparently several varieties of this beautiful flowering shrub. The leaves are subject to large green excrescences, produced by the puncture of insects. See Azalea.

Rhododendron viscosum, cla mmy rhododendron, or sweet white honeysuckle, a fragrant, pretty species, with very clammy white flowers, found in rocky woodlands in the Middle States, flowering in June. 'The stems grow to the height of 4 or 6 feet, with numerous short and crooked branches. See Azatea.

The Rhododendron maximum, or dwarf rose bay, forms a magnificent ornament of the American mountain forests. It generally presents itself in the form of a shrub, of less than 10 feet in height, although it occasionally attains an elevation of 20 to 25 feet, with a diameter of 4 or 5 inches.

RHUBARB (Rheum rhaponticum, from $p s e n$, to spread, and Rheum hybridum). A hardy perennial plant, a native of Asia. The leaves are very broad, and 2 feet long. Their petioles or stallks are large, and these only are used. They are agreeably acid and vinous, very wholesome, and much admired, whether stewed alone with sugar for tarts, and puddings, and pies, or com. bined with other fruits. Its use with us is fast increasing, and although its introduction to the London market did not take place, it is said, till 1815, yet now, we are told, a thousand cartloads are there annually sold. The soil best suited to these plants is one that is light, rich, deep, and moderately moist. A poor heavy or shallow soil never produces them in perfection.

It may be propagated by cuttings, but the mode almost universally practised in England is by seed. This should be sown soon after it is ripe in September or October, for if kept out of the ground until the spring, it will often continue dormant for twelve months; if the danger of this, however, is risked, it must be inserted early in February or March. The seeds are best inserted in drills 3 feet apart and an inch deep, the plants to remain where raised; for although they will bear removing, yet it always checks and somewhat lessens their growth. When they make their appearance in the spring, and have been thoroughly cleared of weeds, they may be thinned to 6 or 8 inches asunder, and the surface of the ground about them loosened with the hoe. Towards the con clusion of summer, when it can be determined which are the strongest plants, they must be finally thinned to 3 or 4 feet, or the hybrid to 6 . They must be continually kept clear of weeds. In autumn, when the leaves decay, they are removed, and the bed being gently turned over, a little well-putrefied stable-dung added, and some of the earth applied over the stools. In the spring, the bed may be again dug, previous to the plants making their appearance; and as the stalks, when blanched, are mach less harsh in taste, require less sugar to be rendered palatable, and are greatly improved in appearance, at this period a trench may be dug between the rows, and the earth from it laid about a foot thick over the stool. This covering must be removed when the cutting ceases, and the plants allowed to grow at liberty. As the earth in wet seasons is apt to induce decay, the covering may be advantageously formed of coal-ashes or drift-sand, which are much less retentive of moisture. Those plants produce the seed in greatest perfection that are not gathered from, but on no account must they be subjected to the process of blanching. Two year old plants often produce seed, but in the third year always. It must be gathered as soon as ripe, and great care taken that none is scattered over the beds, for the plants then produced often spring up and greatly injure the old plants by growing unobserved amongst them.

Varieties.-1. Buck's new early Scarlet Rhubarb. -A new and beautiful variety, and very early. The stalks and the juice are of a beautiful red colour, and quite as high-coloured as the juice of red currants, and of excellent flavour. Fit for use, in our climate, in April.

2. Tobolsk.-A new and very superior variety; the earliest of all the early, not excep:ing, perhaps, Buck's Early Scarlet. 'Tte stalks 
RHUS.

are of a beautiful pink colour, and of excellent havour. Originated in England by Mr. Youle, and fit for use here in April.

3. Dulley's Goliah.-A new variety, which grows to a very large size.

4. Dulley's Adonirul. - A variety of a still more recent date, and remarkably large.

5. Elfort Rhubarb (Var. Undulala).

6. Giant Rhubarb.-A new and large species.

7. Wilmot's Early Red.-Early and fine, with red stalks.

8. Myalt's Victoria.-A magnificent production, with leaves and stalks of enormous size, exceeding, in this respect, all other varieties. New, and of excellent quality.

9. Australian Rhubarb (Rheum Australe).A new variety and valuable acquisition; later in its vegetation than any other kind: it also continues to grow vigorously, and to furnish a supply of leaves long after all other varieties are gone, or till hard frosts. By protection and a frame, it lasts till January. The flavour of Rheum Australe resembles apples; and, though thought by some to be more medicinal in its effects than other sorts, yet those who have used it for years have never found it prove injurious.

Young seedling plants only need to be protected the first winter by soil. Rhubarb may be forced very early, by being covered with boxes or barrels, surrounded by horse-manure at the top and sides. The rhubarb is highly deserving of cultivation by every family.

Rhubarb Wine.-The leaf-stalks of green-coloured rhubarb, being cut in pieces as for tarts, and bruised with a mallet to extract the juice, will make a delicious wine, quite equal to green gooseberry wine, and very closely resembling Champagne. Of the red rhubarb a fine red wine is made.

Rhubarb Jam and Jelly.-A superior jam or jelly is thus made from the tender leaf-stalks af rhubarb, equal or superior to that from currants, and of excellent tlavour. To one pound of the stalks, cut as for tarts, add one pound of loaf or brown sugar; boil till the ingredients acquire a proper consistence. Unground ginger and lemon peel added to the jelly have been found a decided improvement. Buck's early scarlet rhubarb has a preference in point of colour, which is beautiful red; it is also of fine flavour, though not, perhaps, superior in this respect to other varieties. Rhubarb will answer for jelley three months before the currant is ripe. An excellent preserve is also made of rhubarb. For this purppse the stalks are cut into inch pieces, and preserved in the asual way with sugar. (Kenrick.)

RHUS (Derived from rous, in Greek, which is from rhudd, a Celtic word, signifying red; alluding to the colour of the fruit and leaves of some species in autumn). The hardy kinds are rather ornamental, and well fitted for shrubberies; some are propagated by cuttings of the roots, and others by cuttings and layers. The juice of $R$. radicans, poison or swamp sumach, and $R$.toxicodendron, poison vine or poison oak, is milky, stains black, and is extremely poisonous. $R$. coriaria is powerfully astringent, and is used in tanning Turkey or Moracen leather.

\section{RICE.}

RIB-GRASS. See Plantais.

RIBBON-GRASS (Phalaris). The variety of the genus Phalaris called picta, from its striped leaves, is found in garclens and yards as an ornamental plant. From its tendency to strike deep roots and spread, it oftun becumes troublesome to eradicate. The speecies called reed-like or American Phalaris, is common in swampy places in the Middle and Northeru States. When, says Dr. Darlington, the panicles of this plant first appear, they have sume resemblance to those of orehard grass; but he thinks it far inferior to the orchard grass, and too much of an aquatic for regular culture. Another species, the Phalaris cunariensis, or wild canary grass, is particularly naturalized in some of the Northern and Eastern States, where it produces crops of the greatest luxuriance. It is perennial, spreads rapidly, and may be easily propagated by transplantation.

RICE (Oryzu, from the Arabic word êruz, the Greeks coined their word cguc $\iota$, and the various modern nations of Europe their rice, riz, reis, \&c.). O. sativa, the common rice, has the culm from 1 to 6 feet in length, annual, erect, simple, round, jointed. Leaves subulate-linear, reflex, embracing, not fleshy. Flowers in a terminating panicle. Calycine leaflets lanceolate. Valves of the carolla equal in length; the inner valve even, awnless; the outer twice as wide, four-grooved, hispid, awned. Style single, two-parted.

O. mutica, the dry or mountain rice, cultivated in Ceylon, Java, and of late in Hungary, has the culin 3 feet high, and more slender. Fruit longish, with awns the longest of all. It is sown on mountains and in dry soils; rots with a long inundation, and perishes with sea-water.

The varieties of rice, as of other cultivated grain, are as numerous as the different soils, climates, and other physical circumstances, in which it is cultivated: besides the dry rice, the chief sorts, by some considered species, are the 0 . procox, or early rice, and the 0 . glutinosa, or clammy rice, both cultivated in irrigated laisds.

The native place of rice, like that of the other sorts of grain in common use, is unknown; it is cultivated in great abundance all over India, where the country will admit of being flooded; in the southern provinces of China, in Cochin China, Cambodia, Siam, Japan, \&c. In Japan it is very white, and of the best quality. It has also been introduced into cultivation in the southern kingdoms of Europe, Italy, Spain, the south of France, and within a few years into Hungary and Westphalia. In Carolina it has long been a staple commodity. Houghton's account of its introduction there is, that Ashby was encouraged to send a hundred pound bagful of rice to that province, from which, in 1698, 60 tons were imported into England. Dalrymple says, that rice in Carolina is the result of a small bag of paddy, given as a present from Dubois, treasurer of the East India Company, to a Carolina trader. A Dutch vessel also, from Madagascar, brought rice into the same province; and to this is attributed their having two kinds.

In the hilly parts of Java, and in many of the Eastern islands, the mountain rice is planted

4 I 
upon the sides of hills, where no water but rain can come; it is, however, planted in the beginning of the rainy season, and reaped in the beginning of the dry season. The natives call it Paddy Gunung, which signifies mountain rice. It is entirely unknown in the western parts of India, but it is well known in Cochin China, where it thrives in dry, light soils, mostly on the sides of hills, not requiring more moisture than the usual rains and dews supply, neither of which are frequent at the season of its vegetation.

There is a kind of hill rice which is hardy enough to grow on the edge of the Himalayan snows. This, it may be expected, will, at some future time, prove an acquisition of value to the European and American cultivators.

Rice is extensively cultivated in the East Indies and China, chiefly on low grounds near large rivers, which are liable to be annually inundated, and enriched by the deposition of mud. According to Sir Genrge Staunton's account, the Chinese obtain two crops of rice in a year from the same ground, and cultivate it in this way from generation to generation on the same soil, and without any other manure than the mud deposited by the water of the river used in overflowing it. After the waters of the inundation have withdrawn, a few days are allowed for the mud to get partially dry; then a small spot is enclosed by a bank of clay slightly ploughed and harrowed, and the grain, previously steeped in dung, diluted with animal water, is then sown very thickly on it. A thin sheet of water is immediately brought over it, either by a led stream, or the chain-pump. Thus a seed-bed or nursery is prepared, and, in the mean time, the remainder of the tract is preparing for being planted. When the plants are 6 or 7 inches high, they are transplanted in furrows made by the plough, so as to stand about a foot apart every way; water is then brought over them, and kept on till the crop begins to ripen, when it is withheld; so that when harvest arrives the field is quite dry. It is reaped with a sickle, threshed with a flail or the treading of cattle, and the husk taken off by beating it in a stone mortar, or passing it between two flat stones, as in a common meal mill. The first crop being cut in May, a second is immediately prepared for by burning the stubble, and this second crop ripens in October or November. After removal, the stubble is ploughed in, which is the only vegetable manure such lands can be said to receive from man. In Japan, Ceylon, and Java, according to Thunberg, Davis, and Raffles, aquatic rice is cultivated nearly in the same manner. Mountain-rice is grown much in the same way as barley.

In Lombardy and Savoy rice is sown on rich lands, the sower often wading to the knees in water: one crop a year only is obtained; but four crops are often taken in succession. In America a similar practice obtains.

In Westphalia, and some other parts of the south of Germany, rice has long been cultivated; there it is sown on lands that admit of irrication ; but the water is not admitted till the seei has germinated, ard it is withdrawn, as in Itals, when the crops mes into flower. From long cuiture, in a comparatively cold country. the German rice has acquired a remarkable degree of hardiness and adaptation to the climate; a circumstance which has frequently been alluded to as an encouragement to the acclimating of exotics. It is found, Dr. Walker remarks (Essays on $\mathrm{Nat}$. Hist.), that rice seeds direct from India will not ripen in Germany at all, and even that Italian or Spanish seeds are much less early and hardy than those ripened on the spot.

In Hungary rice has not been long cultivated: the mountain sort has chiefly been tried, and that in the manner of our barley or summer. wheat.

In England a crop of rice has been obtained near Windsor, on the banks of the Thames.

By far the best imported rice is that from Carolina : it is larger and better tasted than that of India, which is small, meager, and the grains frequently broken. As an article of diet, rice has been extolled as superior almost to any other vegetable: but whatever it may be in warmer climates, where it is a common, and to many persons almost their only food, it does not appear so well calculated for European constitutions as the potato; for we find that the poor constantly reject the use of rice when potatoes are to be had; and whilst these can be obtained, we may venture to predict, that rice will always be considered, in Britain, rather as a dainty, to be eaten with sweet con diments, spices, fruit, \&c., than as ordinary food. Loudon's Ency. of Plants.

The mountain rice has been raised in Mary. land by Mr. Bordley, on dry sandy land. The following comprehensive directions respecting the water culture of rice, were furnished by one of the most successful cultivators in South Carolina:

Begin to plant about the 25th March, trench shallow and wide, and scatter the seed in the row ; make 72 or 75 rows in a task, and sow 2 bushels to an acre.

1. Hoe about the end of April or beginning of May, when the rice is in the fourth leaf; then flood, and clear the field of trash. If the planting be late, and you are likely to be in grass, flood before hoeing; but hoeing first is preferable. The best depth to flood is $\mathbf{3}$ or 4 inches. It is a good mark to see the tops of the rice just ont of the water : the deep places are not to be regarded; the rice will grow through in 3 or 4 days. Observe to make a notch on the frame of the trunk, when the water is at a proper depth: if the rains raise the water above the notch, or it leaks out, add, or let off accordingly. This is done by putting a small stick in the door of the trunk, about an inch in diameter: if scum or froth appear in 8 or 10 days, freshen the water, take off the trunk doors, run off the water with one $e b b$, and take in the next flood; then regulate as before. Keep the water on about 15 or 17 days, accord. ing to the state of the weather; that is, if a hot sun, 15 days; if cool and cloudy, 17 days, counting from the day the field is flooded; then leak off with a small stick for 2 days, then run off the whole, and keep the field dry. In 4 or 5 days after, hoe the second time, stir the ground, whether clean or not, and comb up the fallen 
rice with the fingers. Keep dry and hoe through the field. Hoe the third time and pick clean. This will be about the beginning of July. 'Then flood as you hoe. Let the water be the same depth as before. If any grass has escaped, it must be picked in the water after it shoots out. This is called the fourth hoeing, but the hoe is never used except for some high places or to clean the dams. If the rice is flaggy and likely to lodge, flood deep to support it, and keep it on until fit to harvest. (Domestic Encyclopedia.)

If land is well drained and in good order, it is calculated that 5 acres of rice and 1 or $1 \frac{1}{2}$ of provisions may easily be cultivated to the hand.

Rice was formerly almost altogether exported in the form of clean rice, but at present the largest amount of that taken to England is in the husk or rough state, called paddy or cargo rice. The rice crop for 1842 has been estimated by Mr. Ellsworth at 94,007,484 pounds.

The following statement shows the annual quantities and value of rice exported from the United States at different periods:

\begin{tabular}{|c|c|c|c|c|c|}
\hline $\begin{array}{l}\text { Years. } \\
1791\end{array}$ & . & - & . & $\begin{array}{l}\text { Exports in Tierces. } \\
-96,980\end{array}$ & Value. \\
\hline 1792 & - & - & - & 141,762 & \\
\hline 1803 & - & - & - & 81,838 & $\$ 2,455,000$ \\
\hline 1816 & - & - & - & 137,843 & $3,555,000$ \\
\hline 1818 & - & - & - & 88,181 & $3,262,697$ \\
\hline 1836 & - & - & - & 212,983 & $2,548,750$ \\
\hline 1838 & - & - & - & 71,048 & $1,721,819$ \\
\hline 1841 & - & - & - & 101,617 & $2,010,107$ \\
\hline
\end{tabular}

(Hunt's Merchants' Magazine, July, 1843.)

RICE WEEVII. See Grain Wertil.

RICE, WILD (Zizania). Nuttall mentions three species of aquatic grasses, called wild rice, found in the United States, viz.: the Zizania aquatica (Pl. 4, c); Z. miliacea; and the Z. fluitans. This last is very small and easily confounded with other aquatic grasses. He found it around Savannah in Georgia.

The Z. aquatica is found in almost every part of the Northern and Middle States, where it goes by the names of water oats, Indian rice, and reed. The seeds resemble those of Polish millet. It is exceedingly prolific. The root is perennial. It grows in swampy places, and in deep water at the edges of ponds and sluggish streams. Stock of all descriptions are fond of the plant when green, or cured as hay. It resembles, at a distance, slender shoots of Indian corn. The stems are jointed, and as large as the little finger. The panicle or head is a foot or more in length, and the seeds blackish, smooth, narrow, cylindrical, about three-quarters of an inch long, white and farinaceous within. Gilleland's Ohio and Mississippi Pilot contains the following interesting details relative to wild rice: "Among the vegetable productions of the Western Territory north of Illimois and west of Green Bay, on the Ouisconsin and Fox rivers, the wild rice, called Folle avoine by the French, and Menomen by the Indians, claims particular attention. It grows in inexhaustible abundance, through all parts of the territory, in almost every one of the innumerable lakes, ponds, bays, rivers, and creeks. It is said to be as palatable and as nourishing as common rice, and if so, it wll be incomparably more valuable. It grows where the water is from 4 to 6 feet deep, and where the bottom is not hard or sandy. It rises above the surface of the water from 4 to 8 feet, and is often so tnick as almost to preven: ranues from passing through or among it. The otialk is soft like the bulrush, but grows in joints like reedcane, which it much resembles. It is usual for the Indians to force their canoes through it, just before it ripens, and tie it in large bunches for the purpose of preventing the will ducks and geese from breaking it down and destruying it. When fully ripe, they pass through 4 again, and, spreading their blankets in the inside of their canoes, they bend the branches of the wild rice over them, and thresh off the grain with sticks; an operation which requires little time, and is generally performed by the women. After drying it in the sun, they put it into skins, for future use. Every autumn anc spring the wild ducks and geese resort to th: wild rice lakes in flocks incredibly numerous. It is thought by many that the Zisania aqualicu will some day be an object of culture, which may afford a means of bringing into use large tracts of inundated land."

RICK. A pile of corn, hay, straw, \&c., regularly heaped up in the open air, and sheltered from wet by thatch. See Sтаск.

RIDDLE. A sort of sieve used to separat: dust and the seeds of plants from corn. They are made of various sizes for different uses.

RIGGIL. An imperfect male sheep, having only one or no testicle in the scrotum.

RIME. A hoary or white frosty appearance, sometimes on the ground in the autumnal, winter, and early spring mornings. See DEw and Frost.

RING-BONE. In farriery, a callus growing in the hollow circle of the little pastern of a horse, just above the coronet. It has its name from the resemblance to a ring.

RINGS, FAIRY. See FAIn R Ring.

RIPPLE GRASS. A popular name of the English plantain ( $P$. lanceolata).

ROADS. See High ways.

ROARING. In farriery, a disease well known to jockeys and horse-dealers, which usually accompanies or precedes broken wind. It is generally the result of long-continued or violent exercises. It is connected with dilatation of the air-cells of the lungs, and is incurable. See Broкes Wiñ.

ROCHAMBOLE. See Garlc.

ROCK CRESS. See Cuess, Wart.

ROLLERS. An implement of simple construction, like the roller, the main object of which is to render smooth the surface of arable lands. would not seem to admit apparently of much variety in its construction. Nevertheless, it is an implement in which greater diversity of form is found to exist than in most other agriculturai machines. Rollers are of all sizes, weights, and lengths; and the material of which they are made is nccasionally iron, sometimes stone. but most commonly wood. Of these, the first is undoubtedly the best, and particularly for the jointed roller, by which the operation of turning at the ends of the ridges is materially facilitated, and the slading of the earth which would otherwise take place on the head-lands. not only to their great detriment, but to the nc: small increase of labour to the horses, is there by prevented.

An ingenious gentleman. int ate George 
Booth, Esq., of Allerton, near Liverpool, who to a great love of farming added a very tolerable share of mechanical skill, and to both ample means to carry out his various devices, constructed a roller, or rather a nest of rollers, on the lever principle. He contended for a very small diameter as the most effective in crushing the clods, and throwing the greatest possible weight on the surface of the ground. We regret being only able to give an idea of his invention from memory; but do not think his roller was more than a foot in diameter at the outside. It consisted of five cylinders or rollers, arranged in such manner that three hind ones, separated from each other, have the two spaces overlapped by two cylinders placed in front.

Drill rollers.-These are made of rings adapted to a shaft. They are not by any means of modern invention, having been well known to the English farmers of Norfolk and Suffolk for the greater part of a century. The only improvement they have undergone has been to render each ring independent of its nejghbour, so that the process of turning at the end of the field is facilitated, as in the case of the jointed roller. The modern drill rollers in other respects have not improved, if the doctrine of Mr. Booth, already noticed, be correct, that a small diameter is better than a large one. 'The arill roller is used for the double purpose of crushing clods on rough lands, and making grooves ready to receive the seed of wheat or other grain soun broadcast on light soils. It is a capital tool for either purpose. In the first case it is followed by a harrow, of sufficient weight to lighten up the surface; in the other, the fine, short-toothed harrow, or even a mere bush-harrow, will be found sufficient. The less such land is disturbed after sowing the better, and the more distinct will be the several rows or grooves of corn.

Heovy rollers.-The heavy roller is a very effective implement. It is formed of 3 separat. cylinders, about 2 feet in diameter, and of the same length; the axis of each being independent of the other. On turning, they consequently revolve in different directions, and thus "slading" at the land's end is avoided.

The double-jointed barley roller is a very useful implement. It is so constructed that the two sides, being separate rolls or distinct irames, may revolve at opposite angles; and, wnen required, one may be placed behind the other. A plan has for many years been in use in Norfolk, of constructing them with twisted joints, so that the under end of one roll shall work behind the end of the other, thus leaving no seam between the roller.

Crosskills" clod-crusher is, under many circumstances, a valuable implement. It is composed of a series of iron rings, with notched edges, set apart from each other about 3 or 4 inches. small cross-bars or knives are placed at frequent intervals on the faces of these, and near their outer notched rims, so as to intersect every portion of land over which it passes. Its construction, combined with its great weight, renders it very effective for the purpose which its name denotes. Indeed, as an old farming 952 bailiff once aptly remarked, it is a roll and a harrow combined. The roller is an implement which requires some judgment as to the time of its use, and this remark applies with increased force to the one under consideration.

Seam or land-presser.-If a drill is so effective an implement, far more so is the seam or landpresser, inasmuch as its whole force and weight is directed to each individual furrow, as it is turned over by the common plough. The seam-presser is in fact an abstract of a drill roller, consisting of but two cylinders of cast-iron, which, following in the furrow, press and roll down the newly turned-up earth, and it is more particularly useful when applied to clover stubbles intended for wheat. (Ransome on $\operatorname{Ag} r$. $\operatorname{Im} p$.)

In the United States the roller is constructed of wood, stone, or cast-iron, according to convenience or the purposes for which it is used. In American husbandry we have yet no reason to expect, or perhaps desire, any but those made of wood, and such as any farmer, who has a moderate degree of mechanic shill, and the carpenter's tools which every farmer ought to keep, may readily construct himself. A good, sound, oak log, with the frame and shafts appended, makes a good roller. They are made of different lengths and sizes, varying from 15 to 30 inches in diameter. The lighter kinds are made in one piece, but the larger and heavier kinds are advantageously made in two pieces, with an iron rod passing through the centre of both, and upon which they revolve. English farmers construct the frame so as to rise above the roller, upon which a box is fixed, either to contain stones to add to the pressure of the roller, or to receive small stones and rubbish, collected on the field while at work, which are to be carried off. Their shafts, when at work, are generally horizontal. We think the roller is more easily drawn when the draught is on a right line from the collar or yoke of the team to the point of resistance. This may be done, and the advantages of the bo $x$ retained.

The uses and advantages of the roller are many and important, and no farmer should be without one. They are particularly important in the seeding process, to break down the clods, pulverize and smooth the surface, and to press the earth to the smaller seeds, which otherwise often fail to germinate for lack of moisture. This is particularly the case with oats, barley, and the grass seeds. In autumn the roller is sometimes passed over winter grain, with a view to counteract the effects of frost the following winter. In spring $1 t$ is advantageously passed over winter grain, as soon as the ground is so solid and dry that the feet of the cattle will not poach the surface. It renders light ground more compact; presses the soil to the roots of the grain, and thus promotes their growth; and upon all soils closes the innumerable cracks and fissures which abound on the appearance of dry weather in spring, and, by partially burying the crown, causes grain to tiller better, that is, send up more seed-stalks. Finally, the roller is of great advantage to grass lands in the spring, by reducing the in. 
equalities of surface, and pressing down the plants or earth which have been thrown up by the frost.

There are also rollers for other purposes, viz., the spiked roller, which is used for pulverizing stiff soils, preparatory for wheat. This is formed by inserting several rows of spikes, or cast or wrought-iron darts, in a common hardwood roller. The concave or scalloped roller is adapted to the form of ridges, and is often attached to the turnip drill. (Cultivator).

ROI.LING. In agriculture, the action or operation of drawing a roller over the surface of the ground, with the view of breaking down the clods, rendering it more compact, and bringing it even and level; or for only levelling the surface, as in grass lands. This is a practice that becomes necessary both upon the tillage and grass lands, and which is of much utility in both sorts of husbandry. In the former case it is made use of with different intentions, as for the purpose of breaking down and reducing the cloddy and lumpy parts of the soil in preparing it for the reception of crops. It is also of great use in many cases of light soils, in rendering the surface more firm, even, and solid, after the seed is put in.

ROOT. In botany, that part of the central axis of a plant which is formed by the descending fibres, and whose function is to attract liquid food from the soil in which it is mingled. It differs from the stem in not having leaves or buds upon its surface, and in its tendency to burrow under ground, retreating from light; nevertheless, some kinds of roots are exclusively formed in air and light, as in the ivy and other such plants; but these are to be regarded as prehensile organs, to support the plants, rather than as roots, or nutritious organs. The root-stock or rhizome is a prostrate, rooting, thickened stem, which yearly produces young tranches or plants. Ginger and orris-root are common instances of it. It is often confounded with the root. There are many appendages to the roots, namely, tubers, bulbs, \&c., which are mere reservoirs of food for the lateral progeny of the plant. See Burb, Rhizome, Tuber, \&c.

ROSE (Lat. Rosa, from the Celtic rhod, red, in reference to the prevailing colour of the 1. ivers). In botany, the English name for the well-known and universally cultivated flower of the genus Rosa. It is an extensive family, but all of the species love a stiff soil. No roses will thrive in shallow, poor ground. Standard roses are obtained by budding them upon vigorous stocks raised from the seed of the hedge or dog-rose, managing the stocks in the same way as fruit-stocks. Their heads must be pruned occasionally to prevent their rambling. The dvarf roses in flower borders should be pruned in January, down to a foot high, cutting out the old and dead wood. They will produce finer flowers. Roses bear their flowers upon wood of the last year. Only the China roses flower upon the shoots of the same year. Roses continue blowing a long time, if the fading Howers are cut off instead of being allowed to seed.

Nearly a dozen species of the wild rose are found in the United States, among which are 120 those familiarly known as the swamp, rock, dwarf, wild, \&c.

ROSE BAY, or MOUNTAIN LAUREI.

See Rhononenmov Maximum.

ROSE-CHAFER, or ROSE BUG, is a diurnal or day-flying beetle of the Melolonihian genus. Dr. Harris states that this insect, which is cornmon in the vicinity of Boston, is, or was a few years ago, unknown in the northern and western parts of Massachusetts, New Hampshire, and Maine. The natural history of the rosebug, one of the greatest scourges with which American gardens and nurseries are afficted, was for a long time involved in mystery, but is at present fully cleared up.

For some time after they were noticed, says Dr. Harris, rose-bugs appeared to be confined to their favourites, the blossums of the rose; but within 30 years they have prodigiously increased in number, have attacked at random various kinds of plants in swarms, and have become notorious for their extensive and deplorable ravages. The grape-vine, in particular, the cherry, plum, and apple trees, have annually suffered by their depredations; many other fruit trees and shrubs, garden vegetables and corn, and even the trees of the forest and the grass of the fields, have been laid under contribution by these indiscriminate feeders, by whom leaves, flowers, and fruits are alike consumed. The unexpected arrival of these insects in swarms at their first coming, and their sudden disappearance at the close of their career, are remarkable facts in their history. They come forth from the ground during the second week in June, or about the time of the blossoming of the damask rose, and remain from 30 to 40 days. At the end of this period the males become exhausted, fall to the ground, and perish, while the females enter the earth, lay their eggs, return to the surface, and, after lingering a few days, die also. The eggs laid by each female are about 30 in number, and are deposited from 1 to 4 inches beneath the suriace of the soil; they are nearly globular, whitish, and about one-thirtieth of an inch in diameter, and are hatched 20 days after they are laid. 'The young larvæ begin to feed on such tender roots as are within their reach. Like other grubs of the Scarabrians, when no: eating, they lie upon the side, with the body curved so that the head and tail are nearly in contact; they move with difficulty on a level surface, and are continually falling over on one side or the other. They attain their full size in the autumn, being then nearly threequarters of an inch long, and about an eighth of an inch in diameter. 'They are of a yellowishwhite colour, with a tinge of blue towards the hinder extremity, which is thick and obtuse nr rounded; a few short hairs are scattered on the surface of the body; there are six short legs: namely, a pair to each of the first three rings behind the head; and the latter is covered with a horny shell of a pale rust colour. In October they descend below the reach of frost. and pass the winter in a torpid state. In the spring they approach towards the surface, and each one forms for itself a little cell of an oval shape, oy turning round a great many times, so as to com. press the earth, and render the inside of the $c_{a}$
$4 \times 2$
95.3 
vity hard and smooth. Within this cell the grub is transformed to a pupa during the month of May, by casting off its skin, which is pushed downwards in folds from the head to the tail. The pupa has somewhat the form of the perfected beetle; but it is of a yellowish-white colour, and its short, stump-like wings, its antennæ, and its legs are folded upon the breast, and its whole body is enclosed in a thin film, that wraps each part separately. During the month of June this filmy skin is rent, the included beetle withdraws from it its body and its limbs, bursts open its earthen cell, and digs its way to the surface of the ground. Thus the various changes, from the egg to the full developement of the perfected beetle, are completed within the space of one year.

Such being the metamorphoses and habits of these insects, it is evident that we cannot attack them in the egg, the grub, or the pupa state; the enemy, in these stages, is beyond our reach, and is subject to the control only of the natural but unknown means appointed by the Author of nature to keep the insect tribes in check. When they have issued from their subterranean retreats, and have congregated upon our vines, trees, and other vegetable productions, in the complete enjoyment of their propensities, we must unite our efforts to seize and crush the invaders. They must indeed be crushed, scalded, or burned, to deprive them of life, for they are not affected by any of the applications usually found destructive to other insects. Experience has proved the utility of gathering them by hand, or of shaking them or brushing them from the plants into tin vessels containing a little water. They should be collected daily during the period of their visitation, and should be committed to the flames, or kiiled by scalding water. The late John Lowell, Esq., states that, in 1823, he discovered un a solitary apple tree the rose-bugs " in vast numbers, such as could not be described, and would not be believed if they were described, or, at least, none but an ocular witness could conceive of their numbers. Destruction by hand was out of the question" in this case. He put sheets under the tree, and shook them down and burned them. Dr. Green, of Mansfield, whose investigations have thrown much light on the history of this insect, proposes protecting plants with millinet, and says that in this way only did he succeed in securing his grape-vines from depredation. His remarks also show the utility of gathering them. "Eighty-six of these spoilers," says he, "were known to infest a single rose-bud, and were crushed with one grasp of the hand." Suppose, as was probably the case, that one-half of them were females; by this destruction 800 eggs, at least, were prevented from becoming inatured. During the time of their prevalence, rose-bugs are sometimes found in immense numbers on the flowers of the common whiteweed, or ox-eye daisy (Chrysanthemum leucanthemum), a worthless plant, which has come to us irom Europe, and has been suffered to overrun our pastures and encroach on our mowing lands. In certain cases it may become expedient rapidly to mow down the infested whiteweed in dry pastures, and consume it, with the sluggish rose-bugs, on the spot.
Our insect-eating birds undoubtedly devour many of these insects, and deserve to be cherished and protected for their services. Rosebugs are also eaten greedily by domesticated fowls; and when they become exhausted and fall to the ground, or when they are about to lay their eggs, they are destroyed by moles, insects, and other animals, which lie in wait to seize them. Dr. Green informs us that a species of dragon-fly, or devil's needle, devours them. He also says that an insect, which he calls the enemy of the cut-worm, probably the larva of a Carabus, or predaceous ground-beetle, preys on the grubs of the common dor-bug. In France the golden ground-beetle (Carabus auratus) devours the female dor or chafer at the moment when she is about to deposit her eggs. I have taken one specimen of this fine ground-beetle in Massachusetts, and we have several other kinds, equally predaceous, which probably contribute to check the increase of our native Melolonthians. (Harris.)

ROSE-LICE. See A pHIs.

ROSEMARY (Rosmarinus officinalis; from ros, dew, and marinus, of the sea, on account of its maritime habitat. Poetically implying "the dew of the ocean"). There are 3 varieties-the green, golden-striped, and silverstriped. The first is the one in general cultivation.

ROSE-SLUG. See Sudg.

ROSIN. See Resin.

ROT. In farriery, a disease in sheep and other animals, in which both the liver and lungs are affected, and there is commonly a dropsical tendency. Its ravages are chiefly, however, confined to sheep, and it is most commonly closely connected with excess of moist food, or placing these animals in low, wet situations, every way foreign to their natural habits ; for sheep, in a state of freedom, seek the most elevated, dry, and heathy situations-an instinct which long imprisonment and domestication has not yet eradicated: every farmer is aware with what tenacity his sheep adhere to the very highest portions of a field. It is only when we force them to inhabit low grounds, and situations foreign to their habits, that they thus become diseased. In a state of nature, too, they browse upon the heath plants, and seek with avidity at certain periods salt springs and salt exudations, facts which have not entirely escaped the notice of modern flockmasters. Thus the argali or wild sheep of Siberia, which are the presumed origin of all our domestic sheep, are found about the size of the fallow deer, on the immense chain of mountains reaching through the middle of Asia to the Eastern Ocean. They are found in small flocks, ranging over the highest elevations. As the winter approaches, they move downwards into the plains, and exchange their food from the mountain plants to grass and other vegetables. They are so partial to salt, that they scrape away the earth in considerable quantities in the neighbourhood of saline places in order to procure it. All animals in fact seek salt with the greatest avidity. In Flanders, sheep owners deem its use an effectual prevention of the rot, and there is very considerable reason to believe that by the use of this valuable con. 
diment, the ravages of this dreadful disease might either be very materially modified, or perhaps entirely prevented.

Many years since, Ellis, in his Practical Husbandry, recommended the use of salt, mixed with wort, in which had been boiled sage, pennyroyal, wormwood, shepherd's purse, comfrey, \&c., as a prevention of the rot; 7 or 8 spoonfuls was the dose, once a week after April, whenever the weather was wet.

More than three centuries since, Fitzherbert, the earliest of the English agricultural writers, alluded to this dreadful disorder in his Boke of Husbandry, and in his section entitled What thynges rotleth Shepe, he says, "It is necessary that a shepherde shoulde knowe what thynge rotteth shepe, that he myghte kepe theym the better. There is a grasse called sperewort, and hath a longe narrow leafe lyke a spere heed, and it wyll growe a fote hyghe, and beareth a yellowe floure in lowe places where the water is used to stande in wynter. An other grasse is called peny grasse, and growethe lowe by the erthe in a marshe grounde, and hath a leafe as brode as a peny or two pence, and neuer beareth floure. All manner of grasse, that the lande floudde runneth ouer, is very evylle for shepe, bycause of the sande and fylthe that stycheth uppon it. All moorish grounde and marsche grounde is yll for shepe. The grasse that groweth upon falowes is not good for shepe, for there moche of it wede, and ofte tymes it commeth uppe by the rote, and that bryngeth erthe with it, and they eate buth, \&c. Myldewe grasse is not good for shepe, and that ye shall knowe two wayes: one is by the leaves on the trees in the morninge, and specially of okes; take the leaves and putte thy tongue to them, and thou shalt fele like hony uppon them. And also there will be many kelles uppon the grasse, and that causeth the myldewe, wherefore theye may not well be left out of the folde, tyll the sonne have domination to drye them awaye. Also hunger rotte is the worst rotte that can be, for there is neither goode fleshe nor goode skynne, and that comethe for lacke of meate, and so for hunger they eate suche as they can fynde, and so will not pasture shepe, for they seldom rot but wythe myldewes, and than wyll they have much talowe and fleshe, and a good skyn. Also white snailes be yll for shepe in pastures, and in falowes there is an other rotte whiche is called pelte rotte, and that commeth of greatte wete, speciallye in woode countryes where they cannot drye."

The symptoms of the rot, and of some of its most decided remedies, have been thus described by Dr. Brown, of Boston (Mag. of Nat. Hist. vol. v. p. 98), "It cannot, I conceive, be demonstrated that in this disease the bile is thrown back upon the system, and mingles with the circulating fluid; for in the eariy stages there is no obstruction to the bile; and in the latter, what little is secreted is intercepted by the flukes on the hepatic side of the gall-bladder. The eye, which some persons take to be an index to the bilious condition of the system, has really not that 'tinge of yellow and jaundiced-like appearance' at the commencement of the disease. On the contrary, the peculiar whiteness of the eyes is the first ymptom which guides the shepherd to the un welcome truth. If the bile ducts be carefully examined in the earliest stage of the complaint, there will be found a few flukes in the duct which conveys the bile from the gall-bladder to the intestine, but none in the gall-bladiter, and none beyond it, a sound liver, no 'tulerercles," no 'abscesses,' and withal a fine, fat, healthylooking carcass. If it be in the latest stare when the examination is made, the gall-bladder will be found filled with flukes instead of bile: and the animals will be seen making their way up those channels which cunvey the bile from the liver to the gall-bladder, arresting it in its course, and pressing forward and enlarging the biliary tubes. Thus, when but few of these animals have possession of this viscus, its function is not materially impaired; the parenchyma, or substance of the liver, is unaltered in appearance; the mucous channels, which convey the bile to the gall-bladder, and from the gall-bladder to the intestines, have not yet felt their presence, and the bile itself is secreted apparently unaltered in quality or quantity: but here, as they live in a medium of perpetual nourishment, they multiply to an extent incredible, and impede the natural action of the liver and subordinate organs of the body. They at length completely block up the conduits of the bile, devouring the bile as fast as it is secreted; spreading irritation and dis ease from the vessels in which they live to the whole mass of the liver itself; and in some in stances they carve their way through the mem. brane which encircles them, and escape by myriads into the cavity of the abdomen; thus completing the destruction of an important organ, and with it the life of the animal. These extreme states are generally associated with dropsy and a total degeneracy of the muscular tissue; the blood is deficient in quantity, very serous, and almost destitute of fibrin. A cor. respondent inquires the class and family of the fluke, in hopes of finding a remedy for a disease so fatal. He will find it in the class Vérmes, and order Intestina, and it is the Fasciola hepa. tica. Contemplating it, as it is, as a variety of exotic worm, it occurred to me that vermifuges, destructive to other species, might be employed with advantage against this. But in instituting experiments on the living animals, I discarded those popular remedies which have only a mechanical action, and which could never reach the iiver, for those which operate by a wider range of influence. What I have observed is, that there are in this class of remedies those which have little or no effect when brought in contact with the living fluke; and there are others which destroy the animal immediately. To the first of those which are inert, belong solutions of vegetable bitters, spirits of tar, and several others, which need not be enumerated. To the second, or to those which destroy the animal, belong solutions of mercury and the spirits of turpentine. For example: a little calomel suspended in water, and dropped upon the animal, quickly deprives it of life; and a drop of the spirits of turpen tine kills it in a few seconds. The oil or tur. pentine is a deadly poison to the Auke. The next consideration is. how far th way be safe 
to administer this medicine to the living sheep, and what probability there is of its disturbing an animal inhabiting the liver. With regard to the first exception, there can arise no diffculty. The spirit of turpentine is borne readily by children, and has been given to adults in doses of a quarter of a pint; it is likewise applied externally to blistered surfaces, and as a styptic to the bleeding mouths of ruptured blood-vessels. There can be as little doubt with regard to the second exception, when we consider the penetrating nature of this drug; when we know that the mere immersion of the hand in it is sufficient to impregnate the urinary secretion; nor can we doubt that its influence will be acknowledged by an organ approximating and communicating with the stomach, and by the worm inhabiting that organ."

The outward symptoms of this disease were many years since well described by Dr. Harrison of Boston, Lincolnshire, when he said, "If in warm, sultry, and rainy weather, sheep that are grazing on low and moist lands feed rapidly, and some of them die suddenly, there is reason to fear that they have contracted the rot: this suspicion will be further increased, if in a few weeks afterwards the sheep begin to shrink, and become flaccid in their loins. By pressure about the hips at this time, a crackling is sometimes perceptible. Now or soon afterwards the countenance looks pale, and upon parting the fleece, the skin is found to have parted its vermilion tint for a pale-red, and the wool is easily separated from the pelt; as the disorder advances, the skin becomes dappled with yellow or black spots. About this time the eye loses its lustre, and becomes white and pearly, from the red vessels of the tunica adnata and eyelids being contracted or entirely obliterated. To this succeeds debility and emaciation, which increase continually till she sheep die, or else ascites or perhaps general dropsy supervene before the fatal termination."

Such are the symptoms and the most powerful known remedies for this disease ; an equally important research is its origin, its predisposing circumstances, or immediate cause. In this, however, in common with most other diseases of animal and vegetable life, difficulties nccur at every turn, of a nature almost entirely inexplicable. We must be content to do little more than merely trace its symptoms and the course in which it commonly runs. No flockmasters are perhaps more anxiously alive to the disease, or more often its victims, than the owners of the noble water-meadows of the south of England, such as those of the valleys of the Kennett, the Itchen, and the Wiltshire Avon.

These excellent farmers have noticed, that the first crop of spring water-meadow grass never imparts the rot to sheep; but that the second crop, which they therefore make into nay, is almost certain to do so. They notice, *.so, that the worst rotting-time is from Midsummer to Michaelmas; that almost all meadow land, if chanre flooded in summer, that is, if covered by the overflowing of rivers, so as

$n$ be covered with their muddy waters, is 956 almost certain to rot the sheep; that gravelly botlomed water-meadows, like those between Marlborough and Hungerford, never rot the sheep fed on them, in any season or period of the year. This would appear to confirm the very common suspicion that it is not the grass which rots the sheep, but the gaseous or aqueous vapours which emanate from such places, more copiously as the weather becomes warmer in the summer; but, then, against such a conclusion we have the fact, well known to owners of the water meads, that when sheep are soiled even upon fine dry elevated soils (such as never render sheep rotten), with the second crop of grass from water-meads-that then the sheep become as equally rotten as if they had been pastured on the very meadows from whence the grass was carried. It would seem, therefore, that there are more watery matters, or other sources of disease in the second crop than in the first.

That the grass of the second crop varies very materially in its chemical composition from that of the first, has been clearly shown by the analysis of the late Mr. George Sinclair. He found that rye-grass (Lolium perenne) at the time of flowering, taken from a water-meadow that had been fed off with sheep till the end of April, afforded of nutritive matter 72 grains. The same grass from the meadow that had not been depastured in the spring, afforded 100 grains. The same weight of this grass, taken from a rich old pasture that had been shut up for hay about the same time, afforded of nutritive matter 95 grains. That from the rich pasture that had not been depastured, afforded 120 grains. (Hort. Gram. Wob. p. 384.) And in the great majority of instances, the aftermath of the upland grasses is considerably less rich in nutritive matters than that of their first or spring crop.

Such, then, are the supposed causes, symp toms, and treatment recommended for the cure of this disease. For the cure, both turpentine and common salt seem to have sometimes been successfully used. But the effect of salt seems to be much more decided when employed as a prevention, rather than a cure. As a preventive, too, the use of aromatic vegetable substances seems to be excellent. It is the kind of prevention also which might be supposed to be efficacious from following the order of nature, and observing the habits of the sheep in their wild state, browsing as they invariably do upon the aromatic plants, and the shoots of moun. tain shrubs; and never descending to live upon the rank and watery grasses of the valleys, until compelled by the severity of the weather. Every farmer is aware with what avidity they consume such domestic herbs-the parsley, for instance-as abound in essential oils. An attempt has indeed been recently made to cultivate this herb in the fields as feed for sheep; and I have little doubt that if some attention were paid to the cultivation of such plants (if the parsley will not bear the browsing of the sheep, they might be occasionally soiled with it), by way of condiment or change; if the flock were allowed, at all times and seasons, access to common salt (and this might be mixed, if necessary, with aromatic suhstances 


\section{ROT IN TIMBER.}

grateful to the sheep); and, lastly, if some care were taken in supplying them, when feeding on watery plants, with a little hay, corn, or oil-cake, that then the destruction caused by this melancholy scourge of the flock-master would be either entirely prevented or very materially reduced. See Fruk.

RO'T IN TIMBER. It has been noted, that wood saturated with common salt is never subject to this disease. Mr. Bethel has proposed a plan for its prevention, by saturating the wood with coal-tar. Mr. Ryan uses for the same purpose a solution of corrosive sublimate (muriate of mercury). Sir W. Burnet employs a solution of muriate of lime. See DRY-Rot.

ROTATION OF CROPS. The order in which different crops are made to succeed each other. It was only towards the middle of the last century, that the importance of a scientific rotation of crops began even to attract the farmer's attention. Previous to that period we search in vain in the works of agricultural authors for the slightest notice of such a theme. The writers before those days, as Arthur Young noticed, recited courses of husbandry, good, bad, and execrable, exactly in the same tone as matters not open to praise or censure, and unconnected with any principles that could throw any light on the arrangement of the farm, or its more successful cultivation. And yet it is on this difficult part of the farmer's business being scientifically pursued, that much of the profits and advantages which he is to derive from his land for a course of years must depend. Arthur Young, the most popular and the most rapid of observers, saw the importance of this difficult inquiry in its true light: he correctly enough told the farmers of his day, that whenever very good or very bad husbandry is found on arable land, it is more the result of a right or wrong arrangement of crops than of any other circumstance; that no district is well cultivated under bad rotations, while it is extremely rare to find any badly cultivated under such as are good. More accurate and more generally diffused observations have long since, however, led the present race of cultivators to assign to the inquiry its proper value. The importance in fact of the investigation no modern farmer will for a moment doubt. It may not be a useless mode of conducting the research, if we inquire, as we proceed in our proposed examination, into the few yet valuable lights which chemical and entomological investigations have shed upon this important, yet, from the endless variety of soils and situalions, somewhat intricate and laborious theme.

In regard to the general principles, as it has been well observed, on which the proper cropping of land depends, it is now perfectly under. stood, that some kind of crops deteriorate or exhaust the land to a much greater degree than others; that some by their capability of being consumed on the farm (though they do exhaust the soil) return, in such consumption by livestock, as much or perhaps rather more to the soil than they draw from it, during the period of their growth. And again, that other crops, by admitting of profitable tillage and cleansing ihe land during their growth, aid very much in

\section{ROTATION OF CROPS.}

the essential destruction of werts, insects, \&ce. and in ameliorating the land for the succeeding crop; while, on the other hand, different crrps, by not permitting such cultivation, and being great exhausters when following in immediate and rapid succession, not only deteriorate the soil, but fill it with weeds and grubs. Hence it follows in practice, that by suitable arrange. ments of these different crops in rotation, most kinds of land may, without lying idle, tre constantly preserved in a clean and productive condition. In the management of rotations. however, much careful attention and discrimination is requisite in the cultivator, to profitably adapt them to the nature of the soil, and the other circumstances under which he is placed. Above all, the farmer must remember, that as different kinds of plants require different kinds and proportions of nutritious materials to be drawn from the earth for their increase and perfect growth, so also they need different situations and conditions of soil for their most profitable development.

The farmer, too, is well aware that certain crops never prosper well two or more seasons together in the same land; that they in fact commonly exhaust or "tear out" the soil to such an extent, that every lawyer's clerk is aware of and notices it in some restraining $\mathrm{co}$ venant of "the lease."

Even the gardener, aided as he is by the most copious supplies of enriching composts, always avoids as much as possible planting a tree where one of the same species has preceded it.

Now it is of primary importance that we should endeavour to understand, if possible, the cause of this phenomenon. This question, therefore, has long engaged not only the attention of the most sagacious farmers, but of many distinguished chemical philosophers. By these it has been regarded in chiefly two points of view. First, it has been contended, that as each plant has peculiar excretory matters, which it constantly deposits in the soil in which it is placed-matters which are found to be particularly noxious to other plants of its own species-that in consequence, until these are decomposed and removed from the earth by other plants, or by the gradual effects of decomposition, the same crop cannot advantageously prosper in the soil. And in support of this doctrine is adduced the well-known fact, that the excretory matters deposited or diffused through the water in which bulbs or other roots have been cultivated, will not well support other bulbs; yet still that such impure water is found to be more grateful than clear water to vegetables of another species.

And, again, that certain plants and trees are well known to be excellent and mutua fertilizing neighbours, - a knowledge indeed as old as the days of Rome under her emperors; for at those periods the Italian farmers cummonly planted the elm as the companion, or "husband," as they called it, of the vine: and every farmer is aware, amongst other facts of a similar nature, that the corn-flower can be found only amongst his corn crops-it is in vain to search for it elsewh sre. The gardener also well knows, that it is almost useless w 


\section{ROTATION OF CROPS.}

replant old orchards with the same trees, or to replace old quick-hedges with young quick plants, yet an old orchard or the site of an old hedge-row are proverbial for their fertility, when planted with other crops. There is considerable importance I think to be attached to this mode of accounting for the facts of the case, but it is by no means so complete an explanation as is desirable. There are some soils, for instance, which would seem (if this were the sole cause of the phenomenon) to defy all the excretory powers of the plant. Some of the newly-enclosed lands of the United States of America, for instance, have produced excellent wheat crops for even 20 years without interruption. Some of the alluvial soils of the lower portion of the valley of the Thames have yielded alternate crops of wheat and beans from time immemorial; and by the addition of manure, the potato grounds near London yield abundant crops for a series of years. There are other observations too, of a similar kind, which will readily be remembered by the intelligent farmer, which do not seem to assimilate entirely with this mode of removing the difficulties of the case.

The other way of explaining the reluctance with which a crop follows another of the same description is, by supposing that each kind of plant has some peculiar and essential ingredient which it absorbs from, and in a great degree exhausts the soil, and that it is, therefore, only after a lapse of some time, when that ingredient or those ingredients are restored by the application of manure, or by other modes, that the same plants can be again profitably cultivated. To a great extent this theory is not only a very plausible but a very probable and reasonable explanation of the difficulty. Thus the farmer is well aware that certain soils on which red clover formerly grew very successfully once in 4 years, will now only yield any profitable degree of produce of the same plant once in 8 or once in 12 years. The excretory powers of the plant in this instance, therefore, are useless in explanation of the difficulty; for according to that theory, the excretory matters which long were successfully dissipated or absorbed by other plants in the course of 4 years, should do so in our age just as well as in a former period. But if we admit what has been not only sometimes, but very often clearly proved to be the case, that the soils which are thus reluctant to produce red clover, are now totally exhausted of sulphate of lime (gypsum) - that, moreover, every fair average crop of this valuable grass contains from 100 to 200 pounds weight per acre of this salt-and that by dressing the laind with this manure, in almost exactly the same proportion and quantity as that which is contained in the clover, that then the land will again grow the very same crop once in 4 years; when these and other similar facts are proved, the very strong probable conclusion to which we must arrive is apparent, viz., that the clover had gradually exhausted the land of an essential ingredient which only needed to be restored to it, to enable the clover again to flourish with its wonted vigour. And this is not a solitary instance: inu s. marine plants will only grow successfully 958

\section{ROTATION OF CROPS.}

in inland situations, where common salt is added to the soil. The sun-flower and the nettle need in an equal degree the assistance of salt. petre. The presence in the soil of phosphate of lime (the earthy salt of bones) is equally essential to the vigorous growth of almost all the grain crops.

Then, again, there are other facts of a different nature well known to the farmer, which appear to lead us to the same conclusion; for instance, every cultivator is aware that by cutting his crops green, his land is not nearly so much exhausted as when the same crops are allowed to ripen their seeds. And if, in explanation of this observation, it can be shown that the plant, when ripe, contains a larger proportion of any peculiar saline or earthy ingredient than it does when in a growing, unripe state, this will further tend to establish the truth of the last-named theory-that it is the abstraction from the soil by the plant of some peculiar substance, which thus exhausts and indisposes it to support the same crop. Now this, according to chemical investigations, seems, at least in many instances, to be the case. Thus, M. Saussure, in his chemical researches, has shown by the results of his analysis, that the ashes of the plants of peas (Pisum sativium), when green and in flower, contain only $17 \cdot 25$ per cent. of phosphate of lime, but that, when ripe, they yield 22 per cent. And, again, that the ashes of plants of vetches (Vicia faba), which yielded only 13.5 per cent. of the same salt when in flower, contain $17 \cdot 75$ per cent. when they are ripe. The same result was obtained from other plants : the Solidago vulgaris, for instance, which yielded 8.5 per cent. of phosphate of lime when first in flower, contained 11 per cent. when ripe. The turnsole (Helianthus annuus), which afforded only 6 per cent. when flowering, contained 22.5 per cent. when ripe. The wheat plant, which held $10 \cdot 75$ per cent. in flower, contained 11.75 when ripe. The ashes of the straw of wheat were found to yield only $6 \cdot 2$ per cent. of this essentially present salt, but its sceds held 44.5, and its bran 46.5 per cent. of it. M. Vauquelin obtained a result somewhat similar in his examination of the ashes of the oat plant; the seeds affording him 39.3 per cent. of phosphate of lime, but when he burnt the whole plant, seed and stalk together, he then found only 15 per cent.

The evidence, therefore, in favour of the $a b$ sorbent theory, is certainly rather stronger than that in support of the excretory mode of ex. plaining the phenomenon. Yet, in all proba bility, both causes may contribute to produce the effect. Davy, the chief of modern chemists, adopted the former mode of explaining the reluctance with which a crop grows for 2 years successively on the same land. (Lectures, p. 357.) Changes of all kind seem, in truth, ever to be grateful to vegetation-change of soil, of seed, of the course of cropping, of manure, \&c. "Peas and beans," said Davy, " in ali instances, seem well adapted to prepare the ground for wheat; and in some rich lands, as in the alluvial soil of the Parret, and at the foot of the South Downs, in Sussex, they are raised in alternate crops for years together. Peas and beans contain a small quantity of a 
matter analogous to albumen (hard white of egg); but it seems that the nitrogen which forms a constituent part of this matter is derived from the atmosphere. The dry bean leaf, when burnt, yields a smell approaching to that of decomposing animal matter; and in its decay in the soil may furnish principles capable of becoming a part of the gluten in wheat.

"Though the general composition of plants is very analogous, yet the specific difference in the products of many of them, and other well ascertained facts, prove that they must derive different materials from the soil; and though the vegetables, having the smallest systems of leaves, will proportionately most exhaust the soil of common nutritive matter, yet particular vegetables, when their produce is carried off, will require peculiar principles to be supplied to the land in which they grow. Strawberries and potatoes at first produce luxuriantly in virgin mould, recently turned up from pasture, but in a few years they degenerate and require a fresh soil; and the organization of these plants is such as to be constantly producing the migration of their layers. Thus, the strawberry, by its long shoots, is continually endeavouring to occupy a new soil; and the fibrous radicles of the potato produce bulbs at a considerable distance from the parent plant. The most remarkable instance of the powers of the plant to exhaust the soil of certain principles necessary to its growth, is found in certain fungi. Mushrooms are said never to rise in two successive seasons on the same spot; and the production of the phenomena called fairy rings, has been ascribed by Dr. Wollaston to the power of the peculiar fungus which furms it, to exhaust the soil of the nutriment necessary for the growth of the species. The consequence is that the ring annually extends, for no seeds will grow where their parents grew before them, and the interior part of the circle has been exhausted by preceding crops; but where the fungus has died, nourishment is supplied for grass, which usually rises within the circle, coarse, and of a dark-green colour." "When cattle," adds Davy, " are fed upon land not benefited by their manure, the effect is always an exhaustion of the soil: this is particularly the case where carrying-horses are kept on estates; they consume the pasture during the night, and drop the greatest part of their manure during their labour in the daytime. The exportation of corn from a country, ...'ess some articles capable of becoming maare introduced in compensation, must u unately tend to exhaust the soil. Some of the spots, now desert sands in northern Africa and Asia Minor, were anciently fertile; Sicily was the granary of Italy, and the quantity of corn carried off from it by the Romans is probably a chief cause of its present sterility."

The same theory is also supported by $\mathbf{M}$. Liebig: in his excellent work on Organic Chemistry, p. 158, he remarks, "It is evident that iwo plants growing beside each other will mutually injure one another, if they withdraw the same food from the soil. Hence, it is not surprising that the Matricaria chamomilla and Spartium sioparium impede the growth of grain, when it is considered that both yield from 7 to $7 \cdot 43$ per cent. of ashes, which contain six-tenths of carbonate of potash. The darnel and the Erigeron acre blossom and bear fruit at the same time as the wheat; so that, when growing min. gled with it, they will partake of the compo. nent parts of the soil, and, in proportion is the vigour of their growth, that of the corn must decrease; for what one receives the uthers are deprived of. Plants will, on the contrary, thrive beside each other, either when the substances necessary for their growth, which they extract from the soil, are of different kinds, or when they themselves are not in the same stages of developement at the same time. On a soil, for example, which contains potash, both wheat and tobacco may be reared in succession, because the latter plant does not require phosphates, salts which are invariably present in wheat, but requires only alkalies and food containing nitrogen. According to the analysis of Posselt and Reimann, 1000 parts of the leaves of the tobacco plant contain 16 parts of phosphate of lime, 8.8 parts of silica, and no mag. nesia; whilst an equal quantity of wheat-straw contains $47 \cdot 3$ parts; and the same quantity of the grain of wheat $\mathbf{9 9 . 4 5}$ parts of phosphates."

The late George Sinclair took a similar view of the cause of the exhaustion of soils. "If." he says, "a plant impoverishes a soil in proportion to the weight of vegetable matter it produces on a given space of ground, the following will be the order in which the under-mentioned plants exhaust the ground, being the proportion they bear to each other with respec to weight of produce :-

\begin{tabular}{|c|c|c|c|c|c|}
\hline Mangel-wurzel & - & - & - & - & - \\
\hline Cabbages - & - & - & - & - & - \\
\hline White turnip & - & - & - & & - \\
\hline Potatoes & - & - & - & - & - \\
\hline Kohl-rabi (bulb & -8 & e & & e) & - \\
\hline Swedish turnip & - & - & - & - & - \\
\hline Carrots & - & - & - & - & - \\
\hline
\end{tabular}

But when we take the weight of nutritive matter which a plant affords from a given space of ground, the results are very different, and wili be found to agree with the daily experience in the garden and the farm.

The following figures represent the proportion in which they stand to each other with respect to the weight of nutritive matter per acre, and in exhausting the land:-

$\begin{array}{lllllll}\text { Potatnes - } & - & - & - & - & - & 63 \\ \text { Cabbages - } & - & - & - & - & - & 42 \\ \text { Mangel-wurzel - } & - & - & - & - & 28 \\ \text { Carrots - } & - & - & - & - & - & 24 \\ \text { Kohl-rabi - } & - & - & - & - & 17 \\ \text { Swedish turnip - } & - & - & - & - & 16 \\ \text { Common turnip - } & - & - & - & - & 14\end{array}$

Change of crops also prevents very mate rially the increase of the predatory grub anci insects which also more or less prey upon the farmer's crops. The parent of the English wire-worm, for instance, which is the larva of a small beetle, the Elater segetis, may be seen in the summer months depositing its eggs or lays or meadows abounding with the cerea. grasses; for instinct teaches it to place its iggs where the young wire-worm will meet with its natural food, which are the cereal grasses. Change of crops, therefore, not only checks the deposit of the eggs, but, by removing the naiu ral food of the young vermin, it materially pro. 


\section{ROTATION OF CROPS.}

vents increase, or even their continuance; which otherwise, as is the case, for instance, with the wire-worm, might for 4 or 5 years be a pest to the soil. See Bretre.

The ordinary course or rotation of crops under which the light lands of England are commonly cultivated, is either on what is denominated the four-course or shift system, or the five-course or shift.

The four-shift system commonly consists of failow, manured; 1, turnips, fed off; 2, oats or barley; 3 , grass seed; 4 , wheat.

The five-shift system, which is in many situalions a much more advantageous course of husbandry, is commonly fallow: 1, turnips; 2 , oats, or barley; 3 , clover; 4 , peas; 5 , wheat.

On clays the course varies: on some kinds of heavy clays it is usually fallow, with mauure; wheat; beans; wheat, manured; clover; oats, or wheat.

On other clays the system pursued is fallow, with manure; wheat, or oats; clover; beans; wheat.

The variations, however, are of necessity exceedingly various. Thus, on some of the inferior adhesive clays of the midland counties, they adopt the four-course system.

Another system of moderately heavy soil husbandry is :-

1. Turnips -
Fallow -
2. Barley -
Oats -
3. Seeds -
Tares fed off -
4. Wheat -

\begin{tabular}{|c|c|c|c|c|}
\hline & & & & Acres \\
\hline - & - & - & - & 20 \\
\hline- & - & - & - & 20 \\
\hline & - & - & - & 20 \\
\hline & - & - & - & 20 \\
\hline & - & - & - & 20 \\
\hline 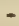 & - & - & - & 20 \\
\hline & - & - & 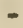 & 40 \\
\hline
\end{tabular}

There are endless variations, however, of this system, varying in their course from that practised in some of the heavy, rich Essex soils, of a two-shift system; viz., 1, wheat; 2 , beans; 3 , wheat; with an occasional fallow. And that more extensively used in the hundreds of that great agricultural county, of a five-shift system of fallow: 1 , oats; 2 , clover, dunged; 3 , wheat; 4 , beans; 5 , wheat. To the nine-shift system of husbandry, sometimes practised, which is about the longest course with which I am acquainted, viz.:

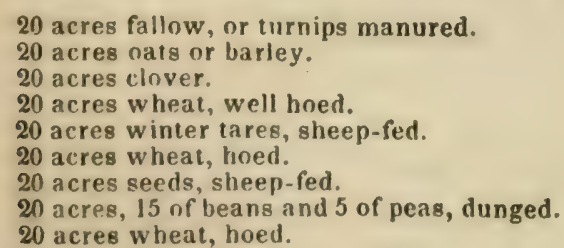

The following course, which takes in every valuable crop, without in any instance violating the rules that science directs, seems to me the best, and is recommended by a Norfolk farmer for most clays not too wet. Say for a fal'm of 350 acres -100 acres of green crops, such as cabbages, turnips, rape, and tares, adapting the green crops to the nature of the land; 50 acres of peas or beans; 50 acres of harley or oats, laid down with clover; and 100 acres of wheat.

You will by this course have every year 200 icres of wheat and other corn, 50 of clover, and 100 of green crops, thus saving your land 960

\section{ROTATION OF CROPS.}

from exhaustion by too frequent repetition of crops of the same genus. And white crops will in no instance succeed each other. The wheat stubbles are in this way sown with green crops, to be followed by $\mathbf{5 0}$ of barley and $\mathbf{5 0}$ of beans or peas; the barley sown with clover and followed by wheat, which will thus be $\mathbf{5 0}$ acres on clover, and 50 on the bean or pea stubble, taking care that the 50 acres of green crops, followed by beans or peas, when next coming in course for green crops, shall be sown with barley and clover, as by this means the clover comes only once in 7 years.

In whatever point of view, therefore, the farmer examines the rotation of crops best adapted to his land, the more highly interesting does the investigation appear. Long observation and the practice of ages have convinced the best English cultivators that sooner or later the soil is tired of or exhausted of something essen. tial to its luxuriant produce by a repetition of the same crops; that the richest meadows gradually decrease in their produce; other soils become "clover-sick;" and it is now even pretty generally suspected that the land is in many districts gradually getting tired of turnips. To the examination, therefore, of this greatquesti i, let every farmer contribute his mite of practu. I observations: it is a theme whose investigation has long yielded a rich harvest to English agriculture; for amongst its fruits must be numbered the introduction of turnips, of mangel-wurzel, and other green crops ; its exami. nation led to the adoption of the four-shift system, and the banishment of that which for ages rested on the miserable plan of one crop and a fallow. It is idle, therefore, to contend that nothing more is to be effected by change of crops; for the experience of all periods is against so indolent and so erroneous an assumption. Let the farmer only remember what has been accomplished by the mere in. troduction of the turnip plant; what thousands of acres have been brought into cultivation by its means, and how many mouths are fed by the increased fertility of the land produced by the adoption of that four-shift system of rotation of which it is the first crop. Let him bring to mind what superior crops are now produced by the adoption of new seeds and novel courses, to those which a century since tenanted the lands of merry England; and he will then see abundant reason for hope, and for an energetic perseverance in a course of discovery, which has already rendered such an abundant harvest to the excellent cultivators of our soil. See M. Bonsingault on the "Rotation of Crops," Quar. Jour. Agr.vol. x. p. 251; Liebig's Organ. Chem. of $A g r ., \& c$.

To prevent the depreciation of soil and improve its productive capacity, a proper rotation of crops is indispensable. The same general principles upon which these objects may be most judiciously accomplished will apply to all countries, but the manner of car. rying out these principles must vary with localities and peculiarities of climate and soil.

It was once thought that, after cuilure, it was necessary to allow the land to reniain for ane or more years at rest and idle, or fallow and 
unused, in order that the soil might thus have its strength renovated. It has, however, been found that with judicious management land need never be suffered to lie idle, but cultivated every year in one or more crops with profit, and even with improvement of the soil. In other words, the system carried out on a small scale in gardens may be extended to farms. A 14rge portion of Europe is at present cultivated without naked fallows, which are unknown in the vast productive agricultural operations of China.

In the United States, the rotations of crops vary considerably in different sections. In Massachusetts, one of the oldest settled portions of the Union, and the usages of which may perhaps represent those prevailing throughout the New England States, it would appear from Mr. Colman, that little of what may be called systematic husbandry prevails, the succession of crops being dictated rather by accident or convenience than by any well-considered principles. The following details from his 4 th Report on Agriculture, will show how things are managed in different parts of Massachusetts.

The rotation of crops in Franklin county is very limited, as the crops cultivated are few. In Buckland, the first year the land is broken up, corn is planted and manured: the second year, oats are sowed without manure, and the iand laid down to grass. It is continued in grass five years and then broken up, and the same course repeated. 'The first year of grass the produce is about two tons per acre, and when it yields not more than 1500 lbs. it is considered proper to break it up again. In Shelburne, on one of the best farms in the state, the course is, first year, Indian corn on green sward, manured; second year, spring wheat, and laid down to grass; the grass-seed sown with the wheat; one peck of herd's grass and one of red-top to the acre. The land remains in grass ordinarily five years. The average yield of grass is estimated at three tons to the acre, which I think must be an over-estimate, -and the cost of getting the hay at $\$ 2$ per ton. For spring wheat, in the second year of the course, is sometimes substituted rye, or oats, or oats and peas, or oats and wheat.

In Whately, first year, Indian corn; second year, oats, and laid down with herd's grass (timothy) and clover, and remains in grass three years.

On much of the meadow land in Deerfield, the first year the land is in corn; the succeeding year peas and oats, and so on continually. The corn is manured in the hill. The land, after the corn is gathered, is sometimes sown with winter rye.

In some parts of Deerfield, the usual rotation is, first year, corn, usually manured in the hill; the second year, spring wheat, or wheat and oats, or peas and nats, or rye with southern clover; third year, clover; and then plough again.

The best farmers universally advise to sow the southern or June clover with grain, to be ploughed in with the stubble where the land is not to remain in grass, with a view to enrich the land. If the grain is winter grain, the clover is usually sown in the spring before the snow has left the ground, at the rate of a bushel of clover chaff or clover-seed not cleaneal. or else at the rate of 6 or 7 lbs. of clearied seed. One of the most experienced farmers in the town has been accustimed (n) sow rye and clover together on the same land for a succession of years; in which case the cliver and stubble were always ploughed in together for the purpose of enriching the land for the succeeding crop, and in this process he states that the condition of the land was continually growing better. The crops, however, at best were not large.

I think proper here to mention the statement of another farmer, a man of much intelligence and experience, in confirmation of the experience of two other farmers referred to in a former report, that it is much better that the clover should be withered or dead when it is ploughed in, rather than in a green or succulent state.

In some instances, as in Sunderland, for example, broom-corn is repeated several years in succession on the same land, and, as it is stated, without a diminution of product. In these cases, the crop is manured in the hill every year; and the corn-stalks, after the brush is gathered, are burnt upon the land.

In the oldest cultivated sections of Pennsylvania, the rotations seem to have been conducted with much good judgment, as is evinced by very successful results generally obtained. These, as well as the system highly approved by many of the most judicious far. mers, are set forth in the following communication in the Farmers' Cabinet (vol. v. p. 94).

The example to which I refer, says the correspondent, is that of an old, practical, hard. working farmer, who commenced in the world as a day-labourer, and who is now worth at least $\$ 100,000$, not taking in the account many heavy pecuniary losses he has, at various times, sustained. This man, when 30 years of age, by the avails of his industry, added to a small legacy, was enabled to purchase and pay, in part, for a farm of 130 acres of land, 100 of which was under cultivation, but in a very low state. This farm is altogether upland, with a soil composed of lime, clay, and sand, in the chief of which the latter preponderatas, the former being least considerable. When he commenced farming, he adopted a particular system of rotation, to which he has implicitly adhered from that time to the present; which is 40 years, and his success is the best comment on the worth of his experiment. His mode was as follows: having divided his farm into oight fields of equal size, as nearly as possible, three of these fields are sown with wheat each year, one with rye, one planted with corn, two in clover, and one an open fallow, on which corn had been raised the year previous. One of the two clover-fields is kept for mowing, the other for pasture, both of which are ploughed as soon after harvest as possible, and prepared for wheat in the fall. All the manure which is made on the farm for one year is hauled, in the spring, on the fieid intended for open fallow. which is then ploughed, and after one or 140 $4 \mathrm{M}$ 
cross-ploughings through the summer, is also sown with wheat in the fall. The field on which rye is sown, is that from which a crop of wheat had been taken the same year, and which had yieldel three crops of wheat, alternating with crops of clover. Corn is planted on the field from which rye had been gathered the year previous, the stubbles of which are ploughed down in the fall. Clover-seed is sown early in the spring on two of the wheat fields, those which have been most recently manured. By this method, each field yields three crops of wheat, two of clover, one of rye, and one of corn, every eight years. Each field, in the mean time, has lain an open fallow, and received a heavy dressing of manure, perhaps at an average of 15 four-horse loads per acre. His crop of wheat is seldom less than 1500 bushels, but often much more. His average rye-crop is about 450 bushels, and his corn crop, annually, about 500 bushelsall which grain, at the present low prices, would amount to more than $\$ 2000$ annually, and at former prices to double that amount; and his farm is withal very highly improved.

This system corresponds very nearly with that of which a tabular statement is presented in the same volume, by Mr. W. P. Kintzer, of Pequea, Lancaster county, Pennsylvania, as successfully practised by himself. It is as follows :-

\begin{tabular}{|c|c|c|c|c|c|c|c|c|c|c|c|c|}
\hline & & & & & Field No. 1. & Field No. 2. & Field No. 3. & Field No. 4 . & Field No. 5. & Field No. 6. & Field No. 7. & Field No. 8. \\
\hline lst & Year & - & - & - & Wheat & Rye & Wheat & Clover & Corn & Wheat & Clover & Oats \\
\hline $2 d$ & " & - & - & - & Rye & Clover & Corn & Wheat & Oats & Clover & Wheat & Wheat \\
\hline $3 d$ & 66 & - & - & - & Clover & Wheat & Oats & Rye & Wheat & Wheat & Corn & Clover \\
\hline 4 th & $"$ & - & - & - & Wheat & Corn & Wheat & Clover & Clover & Rye & Oats & Wheat \\
\hline 5th & $"$ & - & - & - & Corn & Oats & Clover & Wheat & Wheat & Clover & Wheat & Rye \\
\hline 6 th & $"$ & - & - & - & Oats & Wheat & Wheat & Corn & Rye & Wheat & Clover & Clover \\
\hline 7th & $" 6$ & - & - & - & Wheat & Clover & Rye & Oats & Clover & Corn & Wheat & Wheat \\
\hline $8 \mathrm{th}$ & "6 & - & - & - & Clover & Wheat & Clover & Wheat & Wheat & Oats & Rye & Corn \\
\hline
\end{tabular}

In the county of Montgomery, where agriculture is in a very flourishing state,-the crops consisting of the ordinary grains and haygrasses, - a five-shift rotation, from the division of the farm into five fields, is very much pursued. Commencing with Indian corn, the sod, which has been top-dressed with lime the previous season, is ploughed in the fall or spring. The corn is followed by oats, which being harvested, the stubble is turned under, manure spread upon the ground and wheat sown, with timothy-seed in the fall and red clover in the spring. The wheat has thus the important advantage of immediately succeeding two cleansing crops, and the ground, after harvesting the wheat, is left in fine condition for the hay grasses. The first year after the wheat is harvested, the grass is mown, the second year pastured, after which the sod is again turned under for corn, and the rotation recommences.

What is known in Pennsylvania as the old York and Lancaster system, corresponds with the one last described, so far as the succession of grain crops and sowing of the grass-seeds are concerned, but differs in allowing the haygrasses to occupy the field five years. The first two years are most productive in red clover, which, being a biennial and the root dying out, leaves the ground in possession of the timothy and other perennial grasses.

The following interesting view of the former and present Virginia modes of conducting rotations, and the improvements introduced and suggested, is from the able editor of the Farmers' Register (vol. vii.).

The first and most humble attempt at a rotation in this country, and the one which formerly was general on the greater part of most farms, and is even now in extensive use, is the two-shift; which, however, short as it is, had various grades of bad quality. This usually followed the continual cultivation of the land, in its newer cundition, in tobacco, while rich enough for the crop, and afterwards in *orn, every year.

The two-shift was most usually this: 962
Ist year, corn-

wheat-or oats, if on land too light or $2 \mathrm{~d},\{$ too poor for wheat-

after harvest, grazed closely until next spring, when ploughed for corn again.

When too poor to bear any small grain crops, that part of the course was omitted on such poorer spots of the field, and afterwards on all; thus changing the rotation to

\section{1st year, corn-}

$2 d$ " natural cover of weeds, grazed.

When not grazed the second year, as was sometimes the case, for want of separate fencing, or some other cause, this rotation made a nearer approach to alternate and improving husbandry. It was then-

lst year, corn-

$2 d$ " weeds not grazed, and which (if not burnt off, as was done most usually) formed a very poor manuring crop.

The celebrated Eastern Shore rotation is of two shifts or fields, but of three crops in the two years. This is-

\section{Ist year, corn-}

2d, $\left\{\begin{array}{l}\text { first crop, oats- } \\ \text { secondary crop, Magothy bay bean- }\end{array}\right.$ a spontaneous and close cover immediately succeeding the oats, and which remains mostly or entirely untouched by the grazing stock, and is ploughed under for the next crop of corn. The interposition, by nature, ard not by the design or industry of the cultivators, of this leguminous and manuring crop, is a most valuable feature in a rotation which otherwise would be altogether exhausting and destructive. 'The moisture of the air, no less than the sandiness of the soil, and the cleanness from other plants, give vigour to this bean, and make one-third of the whole course meliorating, to two-thirds of exhausting crops. The same moisture also nourishes the oats, and prevents that crop exhausting so much, as in dryer regions-and also by its greater bulk of straw, furnishing more materials for manure. These circumstances render this rotation, severe and barbarous as it is, less exhaust. 
ing (or more improving, if much attention is paid to manuring) than the ordinary three-shift rotation. Except in the chance-made addition of the spontaneous bean crop, this rotation affends against every principle and rule which ought to govern.

The three-shift rotation was the next step in the supposed march of agricultural improvement, and even yet is that which many remaining two-shift or no-shift cultivators aspire to reach, as the limit of their farming and improving ambition, and their ne plus ultra of mild cultivation. This was

Ist year, corn-

2d " wheat, and afterwards the spontaneous grass and weeds grazed-

$3 d$ " pasture, closely grazed.

The severity of the second year was generally moderated on the poorer parts, by the wheat being there necessarily omitted, which of course gave to those parts two years rest from tillage, in three; and, while the wheat was growing, a cessation from grazing also. $W$ ith very few exceptions, such was the general system of the best cultivated farms in lower Virginia, when Taylor wrote; and it is on this kind of three-shift rotation that his denunciations were so deservedly cast. This rotation violates every sound principle and rule, and certainly deserved to be treated without mercy; but many have continued to denounce the three-shift rotation, even when rendered comparatively mild, as if the evil was in the number three, and not in circumstances more im. portant than the mere number of shifts.

But, taken in the aspect above described, and which was the best then that was exhibited, the three-shift rotation had no merit whatever. It had no other than fibrous-rooted plants; no other than narrow-leaved crops; no root, leguminous, or even grass crop; for the close grazing merely served to prevent the scanty weeds and grass from growing; and while every year's crop was exhausting, the system furnished but small resources and materials for manure. For the grazing animals were as many as the land could keep alive, and scarcely any were fattened (by grazing alone) for home consumption or market; and their support served to diminish, instead of adding to, the fattening or manuring of the land. At that iime it would have been difficult for a reading farmer to comprehend this undoubtedly sound maxim of English writers, "the more cattle kept, the more grain and other crops produced." But the English farmer keeps no animal except for the profit it will yield; and all that are so kept, give their rich and abundant products of manure, as an additional profit to the soil. But when a stock of cattle, sheep, and hogs, can barely make out to keep alive through the year, and never fatten, except by stall and grain feeding, then keeping them certainly yields no clear profit to their owner, and their close grazing of the fields takes away more of fertilizing materials than their dung can possibly replace. An English or French farmer would be no less at a loss to comprehend the object (or even to believe in such a general practice) of keeping a large stock of animals which no net profit was obtained, or even hoped for; and he would justly think that it would not be more absurd for a farmer to tend a crop of grain, and then leave it to rot on the field, than to give all his grass through summer to animals, and then lose the flesh so acquired, by starvation through the winter. Indeed, the general cattle management of this country would scarcely be believed in any good grazing or farming region. On the farms under the usual three-shift rotation, say of 400 acres of arable land, there would be from 40 to 60 head of grazing cattle, which furnished annually to the owner, at most, about as much milk and butter as two well-kept cows might supply, one or two passable beeves, with the aid of grain feeding, a few poor calves for veal, and a pretty large supply of hides from deaths by starvation in the spring. There were hogs enough to furnish the year's supply of bacon; but only by means of grain feeding, which alone was admitted to cost nearly or quite as much as the market price of the meat. A flock of poor sheep were on some farms also, of which, before shearing-time, half the wool of many was hanging on the briers, and the remaining fleeces filled with burs. This sort of grazing system accompanied the old three-shift rotation; and, inveterate as were old habits, and patient as we are of long-borne grievances, this evil was so great, that none could deny but that the mere expense of the dividing fences, necessary to keep the cattle from the fields of grain, cost more than all the returns from the grazing animals.

The four-shift rotation, recommended and practised by Col. Taylor, was-

1st year, corn-

$2 d$ "wheat, and clover sown-or if too poor for wheat, left at rest, and not grazed-

3d " clover (or weeds), not mown or grazed-

4th " clover, not mown or grazed.

This rotation, as before stated, was the first introduction of manuring fields by their own vegetable cover, and this practice, and the admission of the opinions on which the new practice was founded, was a prodigious step towards agricultural improvement. It is true that even this rotation is opposed to the rules of good husbandry in most respects. But the giving of two and a half years out of four for vegetables to grow, that were to die and decay on, and be finally ploughed into the land, was a feature that compensated for every fault, and made the rotation decidedly meliorating, if on land capable of being enriched by the mere application of vegetable matters.

In the first of these numbers, it was stated incidentally to other matters why this rotation became of less benefit and more objectionable, in proportion to the time, and to the effect with which it operated; and if it improved the productive power of any land, that it also greatly increased the labours of tillage, and the destruction of products, by increasing weeds and noxious insects. In consequence of this objection, very few disciples of the great introducer of and advocate for this rotation, have continued long to pursue it strictly.

The four-shift and clover fallow rotation differs 


\section{ROTATION OF CROPS.}

widely from that of Col. Taylor. This has been, and I believe still is pursued with great success by Hill (Yarter, of Shirley, John A. Selden, of Westover, and has been on some other of the best lands on James River, where it has since, in other hands, been either neglected or abandoned, for some modification of the threeshift rotation. 'This four-shift system is

Ist year, corn-

$2 d$ "wheat, and clover sown, and not grazed-

$3 d$ "clover, not grazed, and ploughed in deeply in August and September, and the field sown in wheat-

4 th " wheat, to be followed by corn, in recommencing the rotation next year.

A sufficient standing pasture was kept on other land. Mr. Carter, for a considerable length of time, substituted oats for corn in the first year.

The farmers above named (whose accounts of their systems and their products were reported at length in vol. i., Far. Reg.), and others also, undoubtedly made great crops, and great improvement of land, under this very severe rotation. But those results were due more to the excellence of their general management than to their rotation. None but admirable executive farmers can possibly overcome the great difficulties which accompany this rotation. He who, in our dry climate, on a stiff or even medium soil, can plough every August and September one-fourth of all his arable surface, to the depth of 8 or 10 inches, and turn in and cover effectually a heavy coat of cloverand this without failing in any year-shows ihereby alone his ability to execute the most arduous unaertakings, and to do well every thing which he may make a part of his general plan of operations. This rotation, in such hands as have directed it, has some admirable features; but it must be executed in the most perfect manner, or these best features are lost, and there will remain only the great evil of three fibrous-rooted, narrow-leaved, and exhausting grain crops, in succession.

The great merit of the four-shift rotation, in general, and considering it as embracing both of these very different varieties, is its easy adaptation to more mild or more severe cultivation, without any different arrangement or number of fields. Thus, Taylor's rotation may be rendered still milder (as is needed on the poorest lands) by omitting the wheat crop; and as the land improves, the richer spots may be thrown under the more severe cultivation of the other four-shift system, as practised by Mr. Carter or Mr. Selden. But, in any form, the rotation still remains objectionable, for the succession of grain crops (if there are even Iwo in the course), as well as for other things, in one or the other variety, which have been ilready stated.

Every rotation yet known in Virginia is more (rr less objectionable, upon one or more of the following grounds :

The adoption of certain usual crops, without regard to the various qualities and the wants of the soils, or even to the demand of the markel. Thus every farmer is sure to make

\section{RUBBING-POST.}

corn and wheat (or oats) his principal, if not his only crops. Thus, the fields are deprived universally of the most improving culture of roots, which dip intc and draw from the soil deeply: and of pea crops, which feed on the air, and give the product to the soil as manure; and of all annual green manure crops, which would cleanse the soil by their getting in, their growth, and ploughing under, as well as manure it; and the store cattle and hogs suffer for the want of roots and other succulent food, and those which are necessarily well fed consume grain calmost exclusively. Besides these and other objections, which any good practical farmer, or sound theorist, would make, I would further object to the great defect of the preparatory crop not serving to destroy the weeds which will obstruct, and the insects which will prey on the succeeding crop. Two great exceptions to this last general fault are presented when wheat follows clover, or tobacco, both of which are plants of the broad-leaved kind, unlike in all respects to the succeeding crop, and of such unlike conditions also, that it may be presumed that the growth of either has served well to destroy many of both the weeds and insect depredators, which are injurious to wheat. Accordingly, these two crops are the best forerunners of wheat; which after them always is an excellent crop for the land and the season.

Every well-informed farmer will agree to the importance of there being more meliorating crops introduced in our rotations-more grass, peas, roots, and broad-leaved vine crops. But the objection always is to making crops for which there is no sale or market demand. But suppose there is no direct sale and money profit made from hay or roots, they will yield as much profit by being used to feed and fatten (not merely to keep alive) the necessary farm-stock, and thus allow to be sold the corn and other grain which would be otherwise consumed by the animals, with less relish and less benefit.

While roots are totally wanting in our rotations, one important office is left unfilled, that is, the deep piercing of the soil and thorough opening of it by tap-rooted and tuberous-rooted plants. Another thing wanting, is the ploughing under of pea or other annual green crops, to cleanse, as well as to manure the soil. These properly introduced, and the grain crops separated by green crops, would produce rotations far more improving to the land than any yet known, and probably as much better for early annual income as for improvement of the land, the farmer's best capital.

ROWAN TREE (Pyrus aucuparia). The quicken tree, or mountain ash, as it is sometimes called, is a handsome tree, of slow growth, with a tough, cross-grained, not very hard wood, indigenous to our mountains, woods, and hedges. The leaves are pinnate scarcely a span long, composed of leaflets, uni form, serrated, smooth. The fruit is globose scarlet, very juicy, sour, and bitter. They are eagerly devoured by birds of the thrush kind The fruit, also, when the bitter is exiracted by soaking it in water, may be made into a preserve.

RUBBING-POST. A stone pillar or post set up in a field for cattle, hogs, or other animals 
to rub against, and for the protection of the gates, trees, and fences themselves.

RUDDLE or RADDLE. A kind of red earthy ochre, or ironstone, very easily reduced to powder, which is found in several parts of England, especially in Derbyshire; and is used in marking sheep.

RUE (Ruta graveolens). Rue thrives best in a poor brick earth, in which a portion of calcareous rubbish has been mixed. It will not endure the application of dung or a rich soil, for although this causes a luxuriant growth in summer, death is as certainly produced by severe frosts. It is propagated by slips and cuttings as well as from seeds; the first two modes being usually practised as being the most easy. It may be planted or sown any time during the spring.

RUNCINATE. A botanical term, applied to the Jobes of leaves: a leaf is said to be runcinate when it is irregularly lobed, the lobes gradually diminishing to the base, and hooked backwards. The leaf of the dandelion (Taraxacum) is a good example of the runcinate leaf.

RUN'T. A name given to a small kind of black cattle brought from Wales and Scotland. See CAtruf. It is also a term applied to the weak and stunted pigs of a litter; also several species of pigeons; as the Leghorn, Spanish, and Friesland runt.

RUSH (Juncus; Linnæus derived the name from jungo, to join; in allusion to the first ropes being made from rushes). This is an extensive genus of coarse plants, many of them aquatics, which are common on most wet lands. Rushes always intimate a deep, rich soil, and thrive best in land which is too cold and wet for other plants. The growth of these plants may be easily prevented by under or surface draining, which will prevent the stagnation of water on the soil; and by the application of saline or calcareous top-dressings, such as sand, lime ashes, and road-scrapings. All the species of rush do best cultivated in a moist situation, some of them entirely in water, and others in a peat soil; they may be increased by seeds, or dividing the roots. In Japan they cultivate the soft rush (J.effusus) for making floor-mats.

Sir J. E. Smith, in his English Flora, enumerates 23 indigenous species of rush. (Paxton's Bot. Dict.; Smith's Eng. Flor.)

Of the scirpus genus of plants, which includes the rushes, about 40 species have been found by botanists in the United States. Among these are the club-rush, or marsh scirpus; the bull-rush, which is also called tall club-rush or lake scirpus, which grows so luxuriantly along. the shores of the Delaware; and the brown cotton-grass, or wool-bearing scirpus.

The species of club-rush commonly met with in the United States are the Scirpus palustris, S. obtusis, S. tenuis, which, with the common bull-rush, S. Lacustris, are all worthless occupants of low, wet grounds. (Flora Cestrica.)

\section{RUST. See MiLnew.}

\section{RUTA BAGA. See Turnips.}

RYE (Secale cereale; Germ. roggen dut rog). This species of grain is much more hardy, but incalculably less va! uable in every respect than wheat. It has been cultivated from time immemorial, and is supposed to be a native of the Caspian Caucasian desert. In England it is very little used as an article of food compared with wheat and oats, though in the north of Europe, and in Flanders, it furms a principal article of human subsistence, but generally mixed with wheat, and sometimes also with barley. The grains consist of 6.5 .6 of meal, 24.2 of husk, and 10.2 of water. The preparation and culture of rye are essentially the same as for wheat; but the same quality of soil is not equally suited to each. Rye grows most luxuriantly for feeding when sown on hazel mould, but any poor, dry, sandy soil is fit for its production. It is sown either broadcast or in drills, in the autumn or spring; but the spring variety is that most hardy and most generally cultivated. The proportion of seed is about two or three bushels per as :e when required for a crop, and three bushels and a half when it is intented to be fed off. 'The meal of rye is considered second only to wheat; it is often used alone or mixed with a proportion of wheat floul to make bread and gingerbread. In those unaccustomed to its use, it is apt to cause an acescent state of stomach and diarrhœa. Rye is liable to a disease called ergot, which depends on a fungus, which attacks and alters the character of the grain. It becomes long, of a deep violet hue externally, and pinkish-white within. The odour of the ergotted grain is fishy and fetid, il.e taste slightly acrid. Ergotted or spurred rye is poisonous, when it is baked into bread. It causes febrile symptoms, great debility, often paralysis, tremors, abscesses, gangrene, and death. Sorne of the epidemics which have occasionally nearly depopulated the north of Europe, have been traced to the use of the spurred rye. As green food for sheep, rye is not only valuable for its early produce, but as producing a flow of milk in the ewes. The straw is highly esteemed for Dunstable work, for thatching and litter; and is also used to stuff horse-collars. See Eratot.

RYE-GRASS or RAY-GRASS (Lolium perenne), pl. 5, a. There has been much difference of opinion respecting the merits and comparative value of rye-grass. It produces an abundance of seed, which is easily collected and readily vegetates on most kinds of soil under circumstances of different management; it soon arrives at perfection, an 1 produces in its first year of growth a good supply of early herbage, which is much liked by cattle. Theso merits have no doubt upheld it ull the present day in practice, and will probably for some time to come continue it a favourite grass with many farmers. But the latter-math of ryegrass is very inconsiderable, and the plant im. poverishes the soil in a high degree, if the culms, which are invariably left untouched by cattle, are not cut before the seed advances towards perfection. The spike of the Lolium perenne is awnless; calyx shorter than the spikelets; floret lancenlate. The varieties of this species are very numerous, such as the slender rye-grass (var. tenue); compound or broad-spiked rye-grass (var. compositum); $\mathbf{P a}$ cey's rye-grass (v zr. ramosum); Russell's graws

4. 2 
(Russellianum); Whitworth's grass (Whitworthiensis); Stickney's grass (Stickneiensis): panicled rye-grass (paniculatum); double-flowered rye-grass (monstrosum): viviparous rye-grass (viviparum): all the varieties have a strong tendency to vary their form when sown on different soils. The annual species are common only to land under cultivation, under the alternate husbandry.

Rye-grass appears to have been cultivated previous to the year 1677 (Woldridge's Husb. 1st ed.), besides which, red clover, spurrey, trefoil, and nonsuch were the only plants then cultivated as grasses, or termed such; and it is only of late years that any other species of the natural grasses has been tried as a substitute for it in forming artificial pastures. One peck of rye-grass, with fourteen pounds of clover, per acre, is generally considered sufficient for sowing artificial pastures. Rye-grass, when not more than three years old, flowers in the second week of June, and ripens the seed in about 25 days after: as the plants become older they flower much later, sometimes so late as the beginning of August. See Grasses.

A variety called the Italian rye-grass was some time since brought prominently into notice, and is well spoken of. One species of rye-grass, the bearded darnel (Lolium temulentum) is poisonous. Pl. 7, $c$. It is an annual, and nowers in July. The root is downy and fibrous; the culm leafy, smooth, about two feet high, with leaves of a bright-green, rough in the under disk. The spike is a span long, and roughish. The calyx of the flowers linear, flattish, many-ribbed, rising above the spikelets. The florets are six, with the outer valve of the corolla elliptical, concave, with a dorsal awn. The seeds are elliptical, flattened, and furnished with a furrow along its upper side. See Darsex.

\section{S.}

SACCHARINE. A term applied to such substances as contain sugar. The plants in which this substance is abundant are in general highly nutritious and useful in the fattening of animals. See Molasses and Segar.

SACKS. The term sack, in the sense of a bag, is found in all the European and many Asiatic languages.

SAFFRON (Crocus sativus). The stigmata of this purple crocus are of a deep orange colour, and when in quantity have a peculiar and very characteristic odour; they are used in xnedicine, chiefly as a rich yellow or orangecoluaring matter. Saffron is now chiefly im. ported from the south of Europe, especially Spain; it was formerly much cultivated in England in the vicinity of Saffron Walden, in Cambridgeshire.

Saffron is often largely adulterated with the netals of other plants, especially with those of the marigold. The English saffron is superior to that brought from Spain. It should never be compressed into cakes, but the stigmata left 'n a dry, shrivelled state, or, as it is termed, hay affron. Where the stigmata are pale, the saf966 fron is bad. Saffron, as a medicine, is of little value. See Carthamus and Crocus.

SAFFRON, THE MEADOW. See Cor. CHICUM.

SAGE, GARDEN (Salvia officinalis; from salveo, to be safe, on account of the sanative properties with which it was supposed to be fraught). Sage is now used principally in culinary preparations. There are several varieties, as, 1. The common green. 2. Wormwood. 3. Green, with variegated leaves. 4. Red, with variegated leaves. 5. Painted, or particoloured. 6. Spanish, or lavender-leaved. 7. Red. A dry, moderately fertile soil, is best suited to their growth, in a rather sheltered situation. If the soil is rich, or super-abounding in moisture, they grow luxuriantly, but are apt to perish in winter. Sage is propagated by cuttings of the young shoots from the sides of the branches, sometimes also by rooted offsets, and likewise by seed. See Crarr.

SAGE, THE WOOD. See Germandrr.

SAGO (Malay and Jav. sagu). A specios of fecula or starch obtained from the cellular substance of a palm tree-the Sagus farinifera, Gærtn; Sagus Rumphii, Wild. In the early writers it is called sagu, suga, and zaga. In Java the word signifies bread. The sago which is procured from the above palm, and six other species of the same family, is the pith of the trunk. When the tree is of suffcient age it is cut down, split, and the pith extracted and reduced to powder, which is mixed with water and strained through a sieve. The sago is deposited from the fluid, and after two or three washings it is fit for use, and is called in this state, when dried, sago-meal. For the European market it is made into a paste and granulated, and is known in the trade under the name of pearl sago. The consumption of sago has undergone an almost incredible increase within the last twenty years, which is wholly ascribable to the reduction in the interval of the oppressive duties by which the article was formerly loaded. Sago has latterly been brought prominently into notice as food for domestic animals usually reared upon the farm, particularly horses and calves. Experience having decided in favour of its wholesomeness and economy, it will no doubt very soon become a general and staple article of food on all farms that rear young stock. From its emollient and nutritive properties, it ap. pears to be admirably adapted for calves while on milk; for cows sometimes before and after calving; for young horses in winter, instead of much dry corn, or none at all, as is too frequently practised; and for young pet lambs, whose mothers have either died or forsaken them, in which events a serious encroacliment is apt to be made on the milk intended for the calves. Sago seems peculiarly well adapted for horses for fast work, and for sporting dogs, since it is found to leave the wind unaffected; and with regard to fowls, the whole class of them might be rendered by it much more white in flesh and delicate for the table, than the food usually allowed them on farms.

Sago is most commonly used in a gelatinous state, and it is easily reduced to that state by boiling water. 
As a drink for horses, after a severe run or burst in the field, sago gruel, consisting of about a pound of the mucilage or jelly, completely dissolved in two or three gallons of warm water, is found to be superior to any other kind of drink. For cows, the jelly should also be given in the shape of drink. Sago jelly mixed with new milk forms an excellent food for calves. Dogs should have the jelly poured over biscuit, bread, or potatoes. To pigs sago should be administered in the shape of drink, from 2 to 3 pounds being given to each pig once a day; and the jelly for fowls should be in warm balls, mixed up with barley meal.

Sago has been sometimes used as an ingredient of household bread, in the proportion of 1 part of sago to 3 of wheaten flour. It forms an excellent pudding for the convalescents from acute diseases. It is only moderately nutritious, consisting chiefly of starch; yet it is the bread, and may be termed the staff of life of natives of the Molucca islands.

SAINFOIN or SAINTFOIN (Hedysarum onobrychis). The Bourgogne or Esparette of the French. Pl. 8, g. Having been first introduced to the farmer from France, this plant brought its French name of saint-foin along with it; and cock's-head, by which it was before known as a native of England, is become obsolete. The stems of sainfoin are recumbent, 2 or 3 feet in length; leaves pinnate, nearly smooth; flower-stalks axillary, ascending, longer than the leaves, each bearing a dense tapering spike of handsome variegated crimson flowers. The fruit is a legume, erect, single-seeded, toothed at the margin and ribs. Sainfoin is a well-known object of cultivation as fodder for cattle, on dry, barren, especially chalky or marly ground, in open situations. From its not thriving well except the soil or subsoil be calcareous, sainfoin is not generally met with in England; it is most extensively cultivated on the Cotswold Hills, and on the chalk soils of Surrey, \&c. Its nature, qualities, and treatment are similar to those of $\mathrm{LU}^{-}$ CERN, which see.

SAINT JOHN'S-WORT. See JoH N's-Wort. SAINT PETER'S-WORT. See JoHx'sWorT.

SALAD, CORN. See CoHs SALAD.

SALAL BERRY. A new fruit from the valley u: the Columbia river. It is about the size of a c.oum mon grape, of a dark purple colour, and possesses a sweet and pleasant flavour.

SALLOW. The common name of several species of Salix, which, unlike those known under the name of osiers, are not flexible, but form large trees or rough bushes, which grow in moist, marshy woods and hedges, in various parts of England. Sallows generally yield the best kind of charcoal for the manufacture of gunpowder, though all the species of salix are burnt for the preparation of this substance. Sir J. E. Smith particularizes, in England, nearly a dozen different native species of sallow. See Osier and Wrllow.

SALLOW-THORN (Hippophüe, from hippos, a horse, and phao, to destroy; in reference to the supposed poisonous qualities of the seeds). The species are mostly ornamental trees or shrubs, growing in any common soil, and may be readily increased by layers or cuttings of the roots. The common sallow-thorn or sea. buckthorn (H. rhamnoides) is a bushy, rigid shrub, 5 feet or more in height, with hard wood, and straight, spreading, leafy branches, each terminating in a thorn. 'T'he shı ub is a native, being found growing wild on sanday cliffs on the eastern coast of England. The leaves are linear-lanceolate, scattered, decidu. ous, $1 \frac{1}{2}$ inch long, on short stalks, dark-green on the upper side, minutely dotted, beautifully silvery as well as scaly beneath.

SALSIFY (Tragopogon porrifolius). An ornamental plant, which, when grown in the kitchen garden, succeeds in any common soil. It is sown and treated in the same manner as carrots; the flavour of the root is mild and sweetish. When properly cooked, it has a flavour much resembling that of oysters, from which it often goes by the name of oyster plane.

SALSILLA (Edible alstrameria). A very herbaceous plant, a native of Peru. Its roots are eaten like the potato. It is cultivated in the West Indies, and may answer well in many parts of the United States. (Kenrick).

SALT, COMMON, as a manure (Germ. salz; It. sale). This salt is a compound of chlorine and a metal, the base of soda, called sodium; or, in chemical language, salt is a chloride of sodium. It is too well known to require description; but it may be proper to state that it dissolves equally well in cold and in hot water.

It would be, perhaps, difficult to name any other substance in the catalogue of modern fertilizers, whose powers have been so often and so warmly disputed as common salt: and for this controversy many reasons may be assigned. It has been generally employed with little scientific accuracy, and in far too loose a manner for any reliance to be placed upon the majority of the reports which have been furnished to us : and for many years a prohibitory duty in England rendered it inaccessible to the farmeran impost which has not very long been removed, and which yet was the occasion of a great variety of blundering trials, miscalled experiments. The duty on salt was, indeed, one of long continuance. It originated as a war tax, in the ninth year of the reign of William III., and was not removed until after many an arduous debate, in the end of that of George III. The price of salt, in consequence of the duty, was raised from $6 d$. a bushel to more than $20 s^{\text {; }}$; and was, therefore, during the continuance of the tax, too expensive a fertilizer to be employed by the English farmer; and it was only after being for a century and a haif lost to agriculture, that it was again presented, in 1823 , unshackled with duties, to the notice of the agriculturist. During that long interval, salt, as a manure, was known only in the tra. ditions of the English farmers. Through these they learned, that it was formerly used to kil. worms, and to destroy weeds; that it cleansed fallows, increased the produce of light, arable soils, and was good to sweeten grass. These reported advantages were rendered an re probable by certain facts that had been forced, as it were, upon their attention. The gardener was well aware that the brine of the pickling tubs, when poured over his beaps of weeds, not 
only killed every weed, every seed, and every grub, but that these heaps were then converted irto so many parcels of the most fertilizing manure; the good effects of which, especially upon potatoes and carrots, were very decided. It was well known, too, that a single grain of salt placed upon an earthworm speedily destroyed it; that if brine were poured upon the lawn, all the earthworms were immediately ejected from that spot; and that if it were sprinkled about over a portion of the grass, to this salted portion all the deer, sheep, or the horses of the park constantly repaired, in preference to any other part of the field. Salt evidently, therefore, destroyed weeds and worms, and rendered grass more palatable to livestock; and, upon consulting the old agricultural writers, it was found that the notices of salt as a manure were many and important; and that salt had been employed in various agricultural operations from a very early period. Thus it is referred to in St.Luke, xiv. 34. Virgil reprobates a salt soil. Cato, 150 years B.c., commends it for cattle, hay, straw, \&c.; as does Virgil, lib. 3, v. 394. The early German farmers knew of its value for sheep; and for the same purpose, in Spain, it has been employed from the earliest ages. In 1570, Conrad Heresbach commends it as being a certain prevention of the "murrain or rotte." In 1653 , Sir Hugh Platt speaks of salt as a fertilizer in his usual visionary manner, and details the result of a very successful experiment on a "patch of ground" at Clapham; from which some late writers upon the uses of salt have led their readers into great blunders, by stating that this experiment was performed on an acre of land.

The use of salt by the cultivator, since the repeal of the duties in 1823, has been considerable, however, in many districts of England, in spite of these blundering instructions, ill-contrived experiments, and ignorant conclusions. If to this be added the natural difficulty of obtaining correct results in any experiments in which vegetable life is concerned, we need no longer be surprised that many contradictory statements have been made with regard, not only to salt, but to all other fertilizers.

Common salt is composed of 35.42 parts of chlorine, and 23.3 of sodium. This is not the place to enlarge upon its almost universal presence in almost all waters, soils, and situations, nor of the masses with which our country is endowed. Its fertilizing properties, when applied to land, may be described as five in number.

1. In small proportions, it promotes the decomposition $n$ f animal and vegetable substances -a fact first ascertained by Sir James Pringle and Dr. Macbride. Salt, therefore, promotes the rapid dissolution of the animal and vegetable remains contained in all cultivated soils. The recent discoveries of $\mathbf{M}$. Macaire, with regard to the excretions of vegetables, impart considerable information as to the use of common salt in promoting the putrefaction of vegetable substances in the soil; since it has been shown by this gentleman that the brown excretory matter of a plant is extremely noxious to 968 those of its own species; the salt, therefore, by its presence in the soil, promoting the putre faction of the excretion, naturally assists in removing the offending matter; and, in so doing, the excretion, as it decomposes, certainly affords nourishment to the plant which produced it. We are fully aware that this hypothesis may be disputed: we therefore offer it merely as an hypothesis. But it is true that salt, properly used, enables land which has been deteriorated by one crop to bear another with advantage.

2. It destroys vermin and kills weeds, which are thus converted into manure. 3 . It is a direct constituent or food of some plants; and it has been clearly ascertained, that if salt is applied to a soil, the vegetables afterwards growing on that land are found to contain an increased proportion of common salt. (Mr. George Sinclair, Prize Essay on Salt as a $M a$ nure.) All marine plants contain it in considerable proportions. 4. Salt acts on vegetable substances as a stimulant. Dr. Priestley tried various experiments, all supporting this supposition. He added to phials, containing an ounce and a half of water, various proportions of common salt, from 1 to 12 grains, and in the solutions placed various sprigs of mint and other vegetables. In those solutions which contained more than 12 grains, the plants died immediately, and the rest died in their order, except that which contained 3 grains of salt, which seemed to grow as well as plants growing in simple water. It was remarkable, however, that this plant, as well as all those that died in the stronger solutions, seemed to flourish at first more than those which were growing in simple water, and that that which had 3 grains of salt, and that which had 1 grain only, continued to live after the plants in simple water were dead. (Nat. Philos. vol. i. p. 106.) That vegetable substances are capable of being stimulated by chemical solutions, is well known. A solution of chlorine in water will make certain seeds vegetate which would otherwise rot in the earth; and a mixture of camphor, \&c., has been found to be very beneficial in restoring vitality to cuttings of various exotics too long delayed on their passage. 5. Salt preserves vegetables from injury by sudden transitions in the temperature of the atmosphere. That salted soils do not freeze so readily as usual when salt is applied to them, is well known; and that salt preserves crops of turnips, cabbages, \&c., from injury by the frost, is equally well established. (Johnson's Essay on Salt, pp. 6-68.)

6. Salt renders earth more capable of absorbing the moisture of the atmosphere-a property of the first importance, since those soils which absorb the greatest proportion of moisture from the atmosphere are always the most valuable to the cuitivator. "It affords," said the illustrious Davy, "one method of judging of the productiveness of land." ( $A g r$. Chem. p. 184.) See Earins.

The impure picking of scalings of the salt. makers is usually to be obtained by the farmer at a very low rate, and from its being a mixture of common salt and gypsum (sulphate of lime), it is excellently adapter? a! a manure for the 
grasses, such as clover, lucern, sainfoin, \&c.; and, as such, I will give the chemical analysis, for the information of the cultivator, of the refuse of the marine and fossil salt-makers. The pan scale of the Lymington marine saltmakers consists, according to the analysis of Dr. Henry, of-

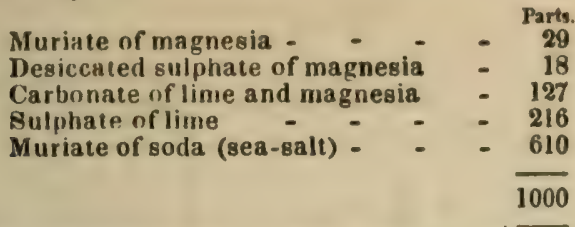

Of the pan scale of the fossil salt-refiners of Norwich, two specimens were examined by Dr. Henry; the first was composed of-

\begin{tabular}{|c|c|c|c|c|}
\hline Common salt & - & - & - & - \\
\hline Carbonate of lime & - & - & - & - \\
\hline Sulphate of lime & - & - & - & - \\
\hline
\end{tabular}

The second variety was composea of-

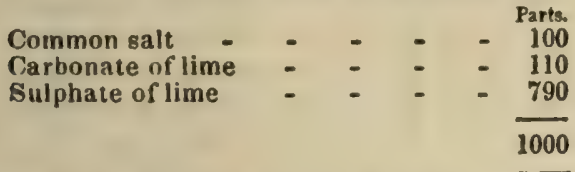

Salt, it should be remembered, rarely causes the wheat plant to grow larger or taller, but it fills up the ear better, and brings the weaker plants forward. Mr. Sinclair informs us, that "salt appears to lessen the produce of straw, and increase the weight of grain." I have never been able in my experiments, nor in any $I$ have witnessed (with salt alone), to observe any increased quantity of straw, even in cases where there was an increased produce, by means of salt, of 6 bushels of wheat per acre. The salt should be applied some time before sowing the seed, not less than 10, and not more than 20 bushels per acre. In my own experiments upon a light gravelly soil, at Great Totham, in Essex, the use of this quantity of salt per acre (in 1819) produced an increase of $5 \frac{1}{2}$ bushels per acre. The following statement of the result of some trials in 1820 , on a light and gravelly soil, will show how important may be the result to the country at large by its judicious application. I regret that incessant employment of a very different nature has hitherto prevented my continuing these experiments.

$$
\text { Produce per Acre. }
$$

No. 1. Soil without any manure for 4 years - 13 rashels.

2. Soil manured with stable dung to the previous crop (potatoes) - -

3. Soil with 5 bushels of salt per acre, and no other manure for 4 years $\quad-\quad 26 \quad 12$

The testimony of a plain Essex farmer corroborates these results. "The soil," says Mr. James Challis, of Panfield, "that I described to you to be of rather a loose, hollow description, had a dressing of salt in November, after the wheat was sown, about 14 or 15 bushels per acre: it produced at the rate of 6 bushels per acre more than that which was not dressed, and it may be stated to be $1 l$. per load of 40 bushels better in quality." (Essay on Salt, p. 45.)

It is a custom in most counties of England, to apply salt and water as a steep to prevent the ravages of the disease in wheat, called smut; the value of this is known to almost every farmer. Recent experiments have s:ug. gested that it may even be of use, when employed in larger quantities, as a preventive of mildew ; the most dreadful of the numeroum diseases to which the cultivated grassos are exposed. The experiments of the late Rev. $\mathbf{E}$. Cartwright strongly evidence, that when salt and water are sprinkled with a brush upon diseased plants, it effects a complete mire, even in apparently the most desperate cases. (My Essay, p. 49.) "The proportion, one pound in a gallon of water, laid on with a plasterer's brush, the operator making his casts as when sowing corn, is instant death to the fungus." The time and expense are trifling. It appeared, in the course of some inquiries made by the Board of Agriculture, that a Cornish farmer, Mr. Sickler, and also the Rev. R. Hoblin, were accustomed to employ refuse salt as a manure, and that their crops were never infected with the rust or blight. See Minnew.

Experiments demonstrate the efficacy of salt on barley and oats. In 1820, on a good alluvial soil, at Heybridge, in Essex, in a field of barley, the results of two experiments were-

1. Soil dregsed with 6 bushels of sait per acre, Boshol 20 loads of earth and stable dung, at turniptime, produced per acre

2. Soil dressed with 20 loads of dung and earth - 60

In the same year, at Sproughton, in Suffolk, on a sandy, barley soil, belonging to Mr. Ransome:-

1. Soil without any manure produced, per acre
2. Soil dressed with 16 bushels of salt per acre
in March -

The following table contains the resulis of fourteen experiments, made in 1819 , by the late Mr. George Sinclair, at Woburn, on the uses of salt to the barley crop. The soil had, the previous year, carried a crop of turnips, and was composed of three-fourths silicious sand:-

\begin{tabular}{|c|c|c|c|c|}
\hline \multirow{2}{*}{$\begin{array}{c}\text { Eind of Manure, and Mode of } \\
\text { applying it. }\end{array}$} & \multicolumn{2}{|c|}{$\begin{array}{l}\text { Quantity per } \\
\text { Acre. }\end{array}$} & \multicolumn{2}{|c|}{ Produce. } \\
\hline & $\begin{array}{l}\text { Bushels } \\
\text { of } \\
\text { Salt. }\end{array}$ & $\begin{array}{l}\text { Bushels } \\
\text { of } \\
\text { Lime. }\end{array}$ & Bush. & $\begin{array}{l}\text { Weight } \\
\text { per } \\
\text { Busbel. }\end{array}$ \\
\hline BARLEY. & & & & \\
\hline $\begin{array}{c}\text { Soil without manure of } \\
\text { any kind }\end{array}$ & - & - & 12 & $\begin{array}{l}\text { Ibe. } \\
434\end{array}$ \\
\hline Salt sown with the seed - & 55 & - & 20 & $43+$ \\
\hline Salt sown with the seed - & $5 \frac{2}{9}$ & - & 20 & $42 \%$ \\
\hline Salt applied before sowing & $33^{2}$ & - & $28 \frac{1}{3}$ & $44 \frac{1}{4}$ \\
\hline Salt applied before sowing & 11 & - & 287 & $43^{4}$ \\
\hline Salt applied before sowing & $5 \frac{1}{8}$ & - & $23 \frac{1}{3}$ & 43 \\
\hline $\begin{array}{l}\text { Lime and salt applied be- } \\
\text { fore sowing - }\end{array}$ & 33 & 60 & 9 & $42\}$ \\
\hline $\begin{array}{l}\text { Lime and salt applied be- } \\
\text { fore sowing - }\end{array}$ & 11 & 60 & 22 & $42 \frac{1}{6}$ \\
\hline $\begin{array}{l}\text { Lime and salt before sow- } \\
\text { ing }\end{array}$ & $16 \frac{1}{6}$ & 30 & $13 \xi$ & 43 \\
\hline Lime mixed and sown with & & & & \\
\hline seed - - - & - & 60 & $18 \frac{1}{4}$ & $43 \hat{z}$ \\
\hline $\begin{array}{l}\text { Lime mixed with soil pre- } \\
\text { vious to sowing }\end{array}$ & & & & \\
\hline vious to sowing - & - & 60 & 107 & $43 \frac{1}{6}$ \\
\hline $\begin{array}{l}\text { oATs. } \\
\text { Sown withnut any manure }\end{array}$ & - & - & 297 & 33 \\
\hline Salt with the seed - & 44 & - & $17 \frac{1}{4}$ & $30\}$ \\
\hline Salt mixed with the snil - & 44 & - & 27 & 27 \\
\hline
\end{tabular}

In these experiments upon oats, the quanuty of salt applied was evidently too great. Mr. Legrand states, that in his experiments upon barley, "it gradually advanced in its effects 16 bushels, and as gradually diminished bushels, when regetation was stopped." 
The following table contains the results of the experiments made at Woburn, 1818-19, by the late Mr. George Sinclair, with his usual scientific accuracy. I would direct the farmer's attention to this table, as containing a mass of valuable information.
The soil on which these experiments were made was sandy, and the plots each contained 36 square feet; the Talavera wheat was drilled into the soil November 5th, and reaped August 2d, 1818.

\begin{tabular}{|c|c|c|c|c|c|c|c|c|}
\hline \multirow{2}{*}{\multicolumn{2}{|c|}{ Kind of Manure, and Modo of applying ic }} & & \multicolumn{4}{|c|}{$\begin{array}{l}\text { Manures, omitting Fractiona } \\
\text { Quantity per Acre. }\end{array}$} & \multicolumn{2}{|c|}{ Produce. } \\
\hline & & & $\begin{array}{c}\text { Dung in } \\
\text { Tons. }\end{array}$ & $\begin{array}{c}\text { Salt in } \\
\text { Buahels. }\end{array}$ & $\begin{array}{l}\text { Lime in } \\
\text { Bushels. }\end{array}$ & $\mid \begin{array}{c}\text { Oil- } \\
\text { Cake in } \\
\text { Bushels. }\end{array}$ & Bushels. & $\begin{array}{l}\text { Weight } \\
\text { of a } \\
\text { Busbe! }\end{array}$ \\
\hline Spit manure applied previous to sowing the seed & - & - & 45 & 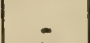 & - & - & 49 & $\begin{array}{l}16 \mathrm{~s} \\
577\end{array}$ \\
\hline Salt and spit manure dug in salt mixed with seed & - & - & 45 & 44 & - & - & 75 & 58 \\
\hline Salt mixed with soil 4 inches deep before sowing & - & - & - & 44 & - & - & 91 & 59 \\
\hline Salt ditto ditto ditto & - & - & - & $5 \frac{1}{8}$ & - & - & 77 & 59 \\
\hline Salt sown with seed - & - & - & - & $5 \mathbf{i}$ & - & - & 73 & 57 \\
\hline Salt combined with manure, dug in 4 inches deep & $\because$ & - & 45 & $5 \frac{2}{6}$ & - & - & 75 & $52\}$ \\
\hline Salt and manure: salt sown with seed, manure du & g in & - & 45 & $5 \frac{1}{8}$ & - & - & 95 & 59 \\
\hline Salt and manure : salt applied to the surface & - & - & 45 & $5 \frac{1}{8}$ & - & - & 82 & $57 \frac{1}{4}$ \\
\hline Salt simply applied to the surface - & - & - & 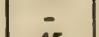 & $5 \frac{2}{9}$ & - & - & 60 & 55 \\
\hline Salt and manure : salt applied to the surface & - & - & 45 & 44 & - & - & 55 & $53 \geq$ \\
\hline Salt simply applied to the surface - - - & - & - & - & 44 & - & - & 77 & 56 \\
\hline Salt and line mixed, and applied with the seed & - & - & - & $5 \frac{2}{8}$ & 121 & - & 66 & $.56 \frac{3}{3}$ \\
\hline Salt and lime mixed, and applied before sowing & - & - & - & $5 \frac{1}{9}$ & 120 & - & 68 & 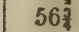 \\
\hline Salt and lime mixed, and applied on the surface & - & - & - & $5 \frac{1}{3}$ & 120 & - & 64 & $566^{\circ}$ \\
\hline Lime applied with the seed - - - & - & - & - & - & 120 & - & 53 & $52 \frac{1}{6}$ \\
\hline Lime applied to the surface - & - & - & - & - & 120 & - & 57 & $54 \frac{1}{2}$ \\
\hline Salt, lime, and dung mixed, and applied as manure & - & - & 90 & $5 \frac{2}{2}$ & 120 & - & 62 & $56 \frac{2}{9}$ \\
\hline Long dung dug in as manure - & - & - & 41 & $=$ & - & - & 71 & $56 \frac{2}{4}$ \\
\hline Salt and Iong dung mixed, and applied as manure & - & - & 41 & 22 & - & - & 71 & 56 \\
\hline Lime and long dung mixed, and applied as manure & - & - & 41 & - & 120 & - & 54 & 57 \\
\hline Salt and long dung mixed, and applied as manure & - & - & 41 & 44 & - & $\therefore$ & - & 56 \\
\hline Oil-cake mixed, and applied with the seed & & - & - & - & - & $5 \frac{2}{2}$ & 48 & 56 \\
\hline Oil-cake applied as common manure & - & - & - & - & - & $5 \frac{2}{8}$ & 73 & 60 \\
\hline Oil-cake and lime applied as common manure - & - & - & - & - & 120 & $5 \frac{1}{9}$ & $74 \frac{1}{4}$ & 567 \\
\hline Salt and oil cake mixed, and sown with the seed & - & - & - & $5 \frac{1}{8}$ & - & $5 \frac{1}{8}$ & $60 \frac{1}{4}$ & \\
\hline Salt and oil-cake mixed, and applied as manure & - & - & - & $5 \frac{2}{3}$ & - & $5 \frac{1}{6}$ & $74 \frac{3}{2}$ & 58 \\
\hline Salt, oil-cake, and manure, applied as manure & & $-{ }_{-}^{-}$ & 90 & $5 \frac{i}{9}$ & - & & $74 \frac{1}{8}$ & 58 \\
\hline $\begin{array}{l}\text { Salt, oil-cake, and manure; the salt and oil-cake } \\
\text { seed, manure previously dug in - }\end{array}$ & & n with the & 90 & $5 \frac{2}{8}$ & & & $55 \frac{1}{3}$ & \\
\hline Salt, oil-cake, and lime, applied as manure & - & - & - & $5 \frac{1}{8}$ & 120 & $5 \frac{1}{2}$ & 71 & $\begin{array}{l}50 \frac{1}{2} \\
51 \frac{1}{4}\end{array}$ \\
\hline Sait, oil-cake, and lime, sown with the seed - & - & - & - & $5 \frac{1}{8}$ & 120 & $5 \frac{1}{9}$ & $55 \frac{1}{6}$ & $55 \frac{1}{6}$ \\
\hline Salt, oil-cake, and lime, applied to the surface & - & 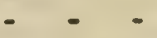 & - & $5 \frac{1}{3}$ & - & $5 \frac{1}{2}$ & 66 & 58 \\
\hline Salt applied to the soil in the preceding spring & - & - & - & 62 & - & - & $44 \frac{1}{4}$ & 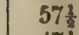 \\
\hline Salt applied to the soil in the preceding spring - & - & - & - & 31 & - & - & $26 \frac{1}{9}$ & $47 \frac{1}{8}$ \\
\hline
\end{tabular}

As a Manure for Grass Land, Meadows, \&c., salt has been used in all parts of England, with varying success. It al ways, however, sweetens the herbage. It has been employed at the rate of 6 to 16 bushels per acre, and where the primary object has been the destruction of the old turf, even 30 to 40 bushels have been successfully employed on the same extent of land. It has the effect of completely preventing wormcasts on lawns, \&c.

In a letter with which I was favoured from Mr. Collyns, of Kenton, Devonshire, 1826, he says-" One of my neighbours writes me, 'In using salt as a manure on grass land, $I$ have found the salted portions not to be affected by severe frosty nights, when every blade of grass on the unsalted portions has been in a frozen state. I observe, too, that it is destructive to every kind of grub and worm; and I am convinced, where it has been used with judgment, that it has not failed.' Another intelligent neighbour," continues Mr. Collyns, "whose farm is almost entirely a light black sand, writes, I have found salt answer my most sanguine expectations for barley, oats, potatues, and turnips, both as to the increased quantity and improved quality of the crops, of which I can now give ocular demonstration: my barley and oats, which used to yield me only 15 to 20 bushels per acre, now yield from 10 to 45 . My wheat is certainly much im970 proved in quality, but I expected more in quantity. I have had $\mathbf{3 5}$ bushels of wheat from an acre dressed with 10 bushels of salt; and from the same field last year, after the same quantity of salt, 140 bags of potatoes per acre. This year again, dressed with 10 bushels of salt, I have not more than 20 bushels of wheat per acre, but the quality very superior indeed, and the root of clover in it very fine and luxuriant In every field I have salted, I find the grass very much superior to any produced before the use of salt.' I have since," adds Mr. Collyns, "gone over his farm, and am astonished at the verdant pasturage, in what used to be coarse and rushy meadows. In this arable land, he never got more than 10 bushels of wheat per acre until he used salt; so that this is also a decided improvernent."

In Suffolk, according to a statement furnished to me by Mr. Broke, of Capel, near Ipswich, "In the month of April, 1821, 6 bushels of salt manure were applied to half an acre of red clover; the soil good turnip land, not sharp: extent of the field 10 acres. The salted clover at first looked very yellow, and apparently injured, but it soon began to recover, and when mown, the increased produce was, at the very least, $10 \mathrm{cwt}$. per acre; and the aftermath proportionally good; the cattle eating it down closer, and in preference to any other part of the field." 
With potatoes.-There have be on various experiments made with salt as a manure for potatoes. The author of this work, in 1817, on a gravelly soil, at Great Totham, in Essex, made the following trials :-

1. Soil simple, produce per acre

2. Soil with 20 bushels of salt in Septembe

3. Soil with stable manure, 20 loads in the opring of the year

4. Soil with 20 loads of manure and 20 bushels of salt -

5. Soil with 40 bushels of salt alone -

6 . Soil with 40 bushels of salt and 20 loarts of manure

The Rev. Edmund Cartwright, of Hollenden House, in Kent, in 1804, made various important trials of salt as a manure for potatoes. The soil on which the experiments were made consisted of three-fourths sand. See Potatoes.

"Of ten different manures," said this agriculturist, "salt, a manure hitherto of an ambiguous character, is (one only excepted) superior to them all. The effect of the mixture of salt and soot is remarkable." The writer of this witnessed the same result on carrots, at the rate of 16 bushels of each per acre.

Vermin.-With regard to the destruction of vermin by means of salt, we may safely assert, that there is, perhaps, no agricultural use of common salt more undoubted. The effect, too, is direct, and the result immediately apparent. For this purpose, from 5 to 10 bushels per acre are sufficient. The agriculturist need be under no apprehension that the salt will destroy his crop, for 20 bushels of salt per acre may be applied to young wheat with perfect safety: I have seen even 25 bushels used with advantage. See Insects.

In reference to Weeds. - Salt has been of late years used at the rate of from 20 to 40 bushels per acre, to kill weeds and to cleanse fallows, with great advantage; it also, in the large proportion we have named, will destroy coarse, sour grass, \&c.; and though, for a time, all vegetation is destroyed, yet, in a short period, a much superior turf is produced. If the cultivator can collect weeds, parings of turf, ditches, banks, \&c., of the most foul description, and spread evenly on the surface of the heap half a bushel of salt to every ton of the collection, he will find every weed, in the course of a few weeks, killed and dissolved away. This plan I have long followed myself, on a light, gravelly soil; and upon spreading this salted mixture, at the rate of 14 or 15 loads per acre, its beneficial effects can be traced to an inch. I have principally used it as a dressing for turnips and oats.

In the Garden.-Salt has been employed by the gardener for many purposes; most commonly on lawns, at the rate of 10 bushels per acre, to prevent worm-casts; and on gravel walks in a larger proportion, to kill weeds; it may be employed, however, as a fertilizer in gardens with decided advantage. I have witnessed the results of the following experiments made by my brother, Mr. George Johnson, at Great Totham; and I the more readily give them a place here, from knowing with what care they were made:-

The soil was composed of -
Gtonea and eraval.

Vegetable fibre

Soluble matter

Carbonates of lime and magnesta

Oxide of iron

Animal and - -

Animal and vegetable matter

Alumina

Silica

Loss

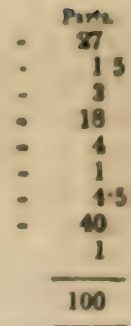

Windsor beans were sown on it-

Soil.treated with 20 bushels of salt per acre,

bushels

Soil simple

Onions-

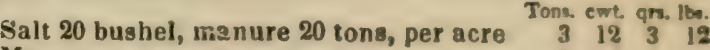
Manure - - - - - 210210

Carrots -

1. Soil without any manure - - - 13400 2. Soil with 20 tons of manure - -2218028

3. Soil with 20 bushels of salt - $\quad 18200$

4. Soil with 20 bushels of salt, and 20 tons of manure _ _ _ - 23

Parsnips-

1. Soil with 20 tons of manure, and 20

2. Soil with 20 tons manure - $\quad-\quad-\quad 6150010$

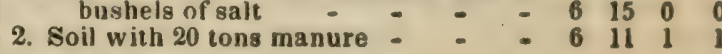

Early potatoes-

1. Soil simple

$-\quad-\quad-\quad 308$

Beets-

1. Soil simple

Tons. $\mathrm{ewt}$ qre.

Soil with 20 bushels of sait - $\quad-\quad 483$

3. Soil with 20 tons of salt, and 20 tons of manure

700

4. Soil with 20 tons of manure - - - 6100

In preventing clubbing in the roots of some of the brassica tribe, Mr. Johnson found salt highly useful; he states, in some observations on this disease read to the Horticultural Society of London, October 16, 1821 :- "Sume cauliflowers were planted upon a light silicious soil, which had previously been manured with well-putrefied stable manure, and over one. third of the allotted space was sown salt, at the rate of 20 bushels per acre, immediately before planting in July, 1821. The previous crop had been broccoli. Fifty-four plants were set on the two-thirds unsalted, and 26 on the one-third salted: the result has been, that of the 54 unsalted, 15 have been diseased and unproductive, but of the 26 salted only 2."

There is little doubt, but that salt might b much more extensively employed by florist than at present. A very small quantity of sal added to the water in which flowers are placed, adds considerably to their duration. There are inany bulbous-rooted flowers which flourish best in the immediate vicinity of the sea. Mr. Edwin Greville remarked, in 1824, that some common salt applied at the rate of 16 bushels per acre to a portion of a bed of stocks, in his garden at Wyaston, in Derbyshire, made them grow most decidedly stronger and finer, and bloom much more perfectly than those growing in the same bed unsalted. "There was nc possibility of error or doubt on the subject." said my intelligent informant. I have given the experiments of Dr. Priestley upon various plants vegetating in salt and water. He found 
that the use of salt materially protracted the existence of the plant. It is a common custom with the importers of exotic plants, to dip cuttings in salt-water. Before the adoption of this plan, they almost invariably perished in the passage.

Among the many excellent communications with which I have been favoured on the use of salt in the cultivation of plants, was one from an eminent florist, near Paddington, Mr. Thos. Hogg. "From the few experiments," he observes, "that I have tried with salt as a garden manure, I am fully prepared to bear testimony to its usefulness. In a treatise upon flowers, published about 6 years since, I remarked, that the application of salt, and its utility as a manure, was yet imperfectly understood. It is a matter of uncertainty, whether it acts directly as a manure, or only as a kind of spice or seasoning, thereby rendering the soil a more palatable food for plants. The idea that first suggested itself to my mind arose from contemplating the successful culture of hyacinths in Holland. This root, though not indigenous to the country, may be said to he completely naturalized in the neighbourhood of Haerlem, where it grows luxuriantly in a deep, sandy, alluvial soil; yet one great cause of its free growth, I considered, was owing to the saline atmosphere: this induced me to mix salt in the compost; and I am satisfied that no hyacinths will grow well at a distance from the sea, without it. I am also of opinion, that the numerous bulbous tribes of amaryllidaceæ, especially those from the Cape of Good Hope, ixias, alliums, which include onions, garlic, shalots, \&c., anemones, various species of the lily, antholyza, colchicum, crinum, cyclamens, narcissus, iris, gladiolus, ranunculus, scilla, and many others, should either have salt or sea-sand in the mould used for them. I invariably use salt as an ingredient in my compost for carnations; a plant which, like wheat, requires substantial soil, and all the strength and heat of the summer, to bring it to perfection; and I believe I might say, without boasting, that few excel me in blooming that flower."

In the inundations of the sea, as in Friesland, for instance, in 1825, various curious effects were produced by the salt-water. The oak, the mulberry, pear, peach, and others with deep roots, did not suffer; neither did the asparagus, onions, celery, \&c., for they were never finer, or more luxuriant. But the vines and gooseberries contracted a salt taste; and the apricots, apples, cherries, elms, poplars, beech, willows, \&c., could not bear the over-dose of sea-water. They pushed out a few leaves, but speedily perished. (Turner's Sacred Hist. p. 117.) Similar results were noticed, after an inundation of the sea, in the garden of the late Richard Gower, Esq., near Ipswich, in Suffolk, in November, 1824. In this instance a portion of the garden remained 24 hours under the seawater. The asparagus beds were materially improved in their produce. The cherry trees, in the following year, produced a numerous crop of cherries, which tasted, however, so very salt that they could not be eaten, although very fine in appearance. These trees all died in the following year, 1826. (Jolinson on the Fertilizers, p. 374.)

Salt, with other Manures.-Sult and Lime. With a mixture of salt and lime, a manure is gradually formed of a most powerful description. It promises now, through the successful example of Mr. Bennett and Sir C. Burrell, to be very generally adopted. It is difficult to account for the neglect of this manure, on any other ground than the difficulties which were so long thrown in the farmer's way, by the longcontinued tax upon salt. That it is not a novel plan for enriching the land is quite certain. Glauber, a celebrated German chemist, one of the last of the alchemists, described it in the jargon of his craft nearly two centuries since, when he said "The Sal mirabilis (common salt), as it is of itself, is, by reason of its corroding virtues, which it as yet retains, plainly unfit for the multiplication of vegetable, for that being so used would prove more hurtful than profitable. Upon this account it is necessary that to one part of it be added two parts by weight of the best calyx vine (lime), which being moistened with water and made into balls, are to be well heated red-hot for an hour, that so all the corrosivity being introverted, the sal mirabilis may be alkalizated, and used to vegetables for an universal medicine: for it conserves its attracting force, and loseth it not in the heating red-hot." (Glauber's Works, by Packe, pp. 2, 47.)

Christopher Packe, who, in 1688, published in English Glauber's folio volume, dwells at considerable length in his preface upon this mixture of salt and lime; "for the enriching of poor and barren land, it is the cheapest of all mixtures, and is most easy to be done; for any ploughman having but once seen it done may be presently able to manage it."

Salt and lime was used as a manure by $\mathrm{Mr}$. Mitchell, of Ayr, many years since, and he, not knowing what others had done with this fertilizer before his time, considered himself to be the discoverer. He thus described his process:-Take 32 bushels of lime, and slack it with sea-water, previously boiled to the saturated state. This quantity is sufficient for an acre of ground, and may be either thrown out of the carts with a shovel over the land in the above state, or made into compost with 40 loads of moss or earth, in which state it will be found to pay fully for the additional labour, and is sufficient for an acre of fallow ground, though ever so reduced before. Its component parts are muriate and sulphate of lime, mineral alkali, in an uncombined state, also muriate and carbonate of soda. All the experiments have done well with it, but especially wheas and beans; and it has not been behind any manure with which it has been compared. There is one instance in which it was tried in comparison with 72 cart-loads of soaper's waste and dung; and although this was an extraordinary dressing, yet that with this salt and lime manure was fully above the average of the field. Mr. Mitchell calculates that 3000 gallons of sea-water, boiled down to about 600 gallons, will slack 64 bushels of shell lime. (These 3000 gallons of sea-water will contain about 


\section{SALT, COMMON.}

1bs. of common salt.) A quantity sufficient fur 2 acres. The expense of carrying the water from the sea, the evaporation, \&c., he adds, will cost 20s. The 64 bushels of limestone cost him 408 ., or $3 l$. for 2 acres.

The use of this mixture of salt and lime was also noticed in the year 1800 , by $\mathrm{Mr}$. Hollingshead, of Chorley, in Lancashire, who observes: "Lime prepared for manure should be slacked with salt-springs or salt-water : lime so slacked will have a double effect." And in 1816, Mr. James Manley, of Anderton, in Cheshire, when giving his evidence before a committee of the House of Commons on the salt duties, mentioned, that in getting marl (which is a mixture of carbonate of lime, alumina, and silica), he had found that, by mixing it with brine instead of water, the portion of the field on which the brined marl was used yielded 5 bushels of wheat per acre more than that portion on which the watered marl was employed; and it may be well to remember, that the celebrated salt sand of Padstow Harbour is composed of 64 per cent. of carbonate of lime; and that, in the experiments of the late Rev. Edmund Cartwright, upon potatoes, of 25 manures, or mixtures of manures, salt and lime were found superior in their product of potatoes to 19 others.

Every farmer has it in his power, even in the most inland situations, to procure this most excellent manure for the use of his farm, by means of a mixture of two parts of lime and one part of common salt, and suffering it to remain incorporated in a shady place, or covered with sods, for 2 or 3 months; a plan which I suggested some years since. (Essay on Salt, p. $32,3 \mathrm{~d}$ ed.) By this process a gradual decomposition takes place, muriate of lime and soda are formed, the whole mass speedily becoming encrusted with alkali. There is another advantage to be derived from the adoption of this process, besides the formation of soda, viz., that the muriate of lime is one of the most deliquescing or moisture-absorbing substances, with which we are acquainted; and, in consequence, whenever it exists in a soil, the warmth of the sun has, in summer, much less influence on it than it would otherwise have.

I would especially warn those who try the effect of a mixture of salt and lime, to attend carefully to the directions I have given, and not, as some farmers have done, to use the mixed salt and lime immediately, before any decomposition has taken place. After it has been well mixed together in a dry state, it should be allowed to remain 2 or 3 months undisturbed, and then applied at the rate of from 35 to 60 bushels per acre, either by sowing it out of a seed-basket, or mixed with earth, and spread in the usual way. It is necessary to give the mixture time, since the decomposition proceeds very slowly, and is not to be hastened by any simple process. See Limk.

Salt and Soot.-Salt has never been employed with other substances so extensively as it might. I have used it for potatoes, mixed with earth, ditch-scrapings, and with soot, with the most decided success; the places where it has been thus applied being much superior, both in appearan'e and in produce.
SALTS.

The mixture of salt with sont produces the most remarkable effects, especially when trenched into ground prepared for carrots. Mr. G. Sinclair found that when the soil, unmanured, produced twenty-three tons of carrots per acre, the same soil, fertilized with a mix. ture of only six bushels and a half of salt, and six and a half of soot, yielded forty tons per acre. Mr. Belfield describes the mixture as equally beneficial for wheat. And Mr. Cartwright found, that when the soil, without any addition, yielded per acre 157 bushels of potatoes, that, dressing the same land with a mixture of thirty bushels of soot and eight bushels of salt, made it produce per acre 240 bushels. (Johnson on Fertilizers.)

SALTS, their uses to vegetation. That peculiar saline substances exist in almost all vegetables, was an early observation made by the natural philosopher. The saline and alkaline taste perceivable in the ashes obtained by the combustion of these substances, very plainly indicated the fact. And although the skill of the chemist did not at first enable him to accurately discriminate between the salts, the alkalies, or even the earths contained in plants, with even tolerable accuracy, yet the progress of science has long since surmounted a mass of difficulties, and has detected a strange variety of salts in plants. A salt, he it remem. bered, is a substance produced by the combination of an acid with a base, that is, with an earth, an alkali, or a metallic oxide: the class of salts, therefore, is exceedingly numerous (they have been estimated at about 2000), and includes many substances which at first sight do not appear entitled to such a name; thus the union of the carbonic acid with the earth lime, which is an oxide of a metal, forms the salt carbonate of lime, or chalk, marble, \&c. Sulphuric acid and lime form the salt sulphate of lime (gypsum), with phosphoric acid, phosphate of lime (earthy matter of bones), and many other earthy salts look to the mechanical eye as little like salts as these.

The farmer must avoid, in entering into this examination, the common error of supposing that the saline substances found in plants are not their essential constituents or food, but are merely there by chance; that their presence is unattended with benefit, and their absence totally unproductive of injury; for such is a most erroneous conclusion. Not only are certain salts, the phosphate and sulphate of lime, and the carbonate of potash, for instance, invariably present in certain plants, but without those salts are present in the soil in which they grow, they will not maintain a healthy vegetation. Under the head Earths, Gases, Watra, I have endeavoured to show how essential those substances are to vegetation, and what a great part they perform in the support of the farmer's crops ; but still it will be found, that when a soil is carefully composed of all the pure earths discovered in plants, watered in abundance with pure water, and supplied with all the gases of putrefaction and of the atmosphere, that still all these are not sufficient by themselves to support a single ordinarily cult. vated crop; but then it is found that where such a soil is supplied with various saline sub. 
stances (for instance, with the various saline matters draining from a dunghill), that then every difficulty is removed. Neither must the cultivator suppose, that when saline substances are mixed with the soil, that then the plant growing upon it absorbs those salts as a matter of necessity, united with the moisture contained in that soil, without having the power of rejecting or separating it from its solution; for such an assumption has been proved to be contrary to the fact by several very accurate experiments. M. Saussure, for instance, found that plants had the power, when placed in saline solutions, foreign to their habits, of separating them from the water in which they were dissolved. These are researches fraught with instruction to the cultivator. He dissolved the following salts in water, in such proportions that each solution contained $\frac{1}{100}$ part of its weight of the salt-muriate of potash, muriate of soda (common salt), nitrate of lime, sulphate of soda (Glauber salt), muriate of ammonia (sal ammonia), acetate of lime, sulphate of copper (blue vitriol). In each of thesse solutions he put plants of Polygonum Persicaria, or of Eidens cannabina, furnished with their roots. The Polygonum grew for five weeks in the solution of muriate of potash, nitrate of lime, muriate of soda, and sulphate of soda, and its roots increased in them as usual. It languished in the solution of sal ammoniac, and the roots made no progress. It died in 8 or 9 days in the solution of acetate of lime, and in less than 3 days in the solution of sulphate of copper. When such a number of plants of Polygonum were put into the solutions as to absorb one-half of each in 2 days, the remaining half was found to have lost very different proportions of the salt which it had originally contained. Supposing the portion of salt at first in solution to be 100 , the following table exhibits the quantity of each which nad disappeared when one-half of the liquid was absorbed-

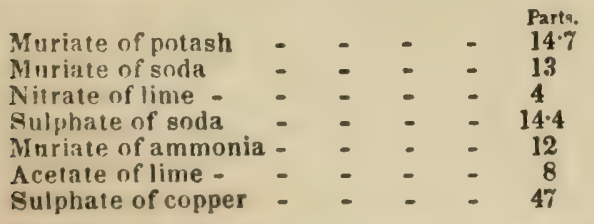

The Bidens absorbed pretty nearly the same proportions, but in general did not vegetate so long as the Polygonum.

When various salts were dissolved at once in the same solution, and plants made to vegetate in them, it was found that different proportions of the salts were absorbed. The following table exhibits the results of these trials, supposing, as before, the original weight of each salt to have been 100 , each solution contained $\frac{1}{0} \overline{0}$ part of, its weight of each salt-

1. Sulphate of soda

1. $\{$ Muriate of soda

$\{$ Sulphate of soda

\{ Muriate of potash

3. $\{$ Nitrate of lime

Muriate of a mmonia

$\{$ Acelate of lime

4. $\left\{\begin{array}{l}\text { Aulphate of copper } \\ \text { Sulate }\end{array}\right.$

5. Acetate of lime 974
6. $\{$ Nitrate of lime

6. $\{$ Sulphate of copper

Sulphate of soda -

7. Muriate of soda

Acetate of lime

These experiments succeeded nearly equally with other plants, as the Mentha piperita and the Scotch fir. When the roots were cut or removed, the plants absorbed all solutions in. discriminately; on examining the plants, the salts absorbed were found in them unaltered. It being thus clearly established that plants possess a discriminating power, and that they do not absorb saline solutions merely because they happen to be dissolved in the soil, it next becomes an object of interest, as an illustration and guide for the operations of agriculture, to ascertain what salts are found by the researches of the chemist in commonly cultivated plants. And if, at the conclusion of our examination, we find that certain salts are found in abundance only in certain plants, and that these saline substances exist in them in. variably in all soils and situations, and that without their presence the plant languishes and merely supports a sickly existence, we shall be almost driven to the conclusion, that these are as essentially the food of plants, as any of the other substances with which they abound.

For a lengthened period, the vegetable alkaline salt, carbonate of potash, has been obtained from plants. Procured at first by their combustion, in iron pots, it hence obtained its name. Dr. Thomson has given a table of the quantity of potash obtained from 100 parts of the ashes of various trees and plants. See Alkali.

In general, says Dr. Thomson, three times as much ashes are obtained from shrubs as from trees. An equal weight of the branches of trees produce more ashes than the trunk, and the leaves more than the branches. Herbs arrived at maturity produce more ashes than at any other time. Green vegetables produce more ashes than dry. The salt which is obtained by the combustion of plants, although chiefly composed, does not consist wholly of potash: there are many salts mixed with it; these are usually sulphate of potash, muriate of potash, sulphate of lime, phosphate of lime, \&c., but these bear in general but a small proportion to the potash.

Perhaps the most copious table of the alkaline and other salts obtained by the combus. tion of various plants has been given by $\mathbf{M}$. Saussure in his chemical researches on vegetation. He obtained from 100 parts of the ashes of the -

Leaves of oak (Quercus Robur), May 10 Do., September 27

Wood of a young oak, May 10 - $\quad 7$

Bark of do.

Perfect wood of oak

Albumen of do.

Bark of do.

Cortical layers of do.

Extract of wond of do.

Soil from the wood of do.

Extract from do.

Leaves of poplar (Populus nigra), May 10

Do., Septeinber 12

Leaves of hazel

Do., washed in cold water.

Leaves of do., June 22 .

Do., September 20 


Wood of hazel, May 1 -
Bark of do.

M. Vauquelin found 20 per cent. of potash in the ashes of the oat; and from his experiments it is probable that potash exists in plants in combination with the acetic and carbonic acids.

The mineral alkali soda, or carbonate of soda, is found in almost all the plants which are found growing in the sea, or on the shore, within reach of its influence. The amount of alkali which these produce, is considerably greater, in proportion to that produced hy plants natives of inland places. Thus, 100 parts of the salsola soda yield 19.921 parts of ashes, and these contain 1.992 parts of soda and common salt. Many plants, the vegetable marrow and the vine, for instance, derive great benefit from the application of soda to their roots. Soap-suds are used as an excellent liquid manure by many gardeners.

Sea-weed, kelp-soda, barilla, and the common washing-soda of the shops, have all been used successfully as saline manures; and the well-known fertilizing mixture of salt and lime, after it has remained undisturbed for some time, contains chloride of lime and soda in abundance. Sea-weed abounds with a strange mixture of alkaline salts, and there is no green manure more powerful in its effects than this, especially when it is ploughed in as fresh as possible. Mr. Gaultier de Claubry found in the Fucus saccharinus and in the Fucus digitatus (which is much used in Scotland as a manure) the following substances-saccharine matter, mucilage, vegetable albumen, oxalate of potash, malate of potash, sulphate of potash, sulphate of soda, sulphate of magnesia, muriate of soda, muriate of potash, muriate of magnesia, carbonate of potash, carbonate of soda, hydrindate of potash, silica, phosphate of lime, phosphate of magnesia, oxide of iron, oxalate of lime. In the islands of Guernsey and Jersey they employ the ashes of the sea-weeds, which they call vraic. Half a bushel strewed over a perch of ground in winter, or the beginning of spring, is sufficient. It gives a full ear to the corn, and prevents it from being laid.

Phosphate of lime, which is composed, according to the experiments of $M$. Berzelius, of phosphoric acid 100 parts, and lime 81.59 , abounds in vegetable substances. It forms the basis of bones, from which, for the purposes of experiment, it is commnnly procured. Obtained in this way it is always in the form of a white powder, without either taste or smell ; is insoluble in water, and unaltered by exposure to the atmosphere. Phosphate of magnesia is composed of phosphoric acid and magnesia; is a salt soluble in 15 times its weight of water. These two salts have been found in a variety of vegetable substances by MM. Vauquelin, Saussure, and other able chemists. See Boxes.

There is little doubt but that these salts are absorbed from the soil by the plants. Almost all cultivated soils contain them in some form or other; and of the value of their addition to the soil in almost every form, there is considerable evidence. Thus, phosphate of lime abounds in all the richest animal manures, such as in bone-dust and the richest excrements of animals; and, again, it is found by the Cheshire graziers, that the earthy salts of bones obtained from the size-makers, after most of the oily matters are removed by the action of steam, and hardly any thing but the salts of lime remain, are quite as fertilizing to their pastures as when used in their fresh state, abounding with animal matters.

Sulphate of lime, or gypsum, is another salt, which is invariably found in and promotes the growth of certain plants.

It must, I think, be regarded as one of those salts which constitute the food or constituents of plants. It is always present in the clover, lucern, and sainfoin, and in smaller proportions in the potato and the turnip. See PLAster of Paris.

That it is a food for plants, was the opinion of Sir Humphry Davy. He remarked, when speaking of gypsum and the allialies, "It has been generally supposed that these materials act in the vegetable economy in the same manner as condiments or stimulants in the animal economy; and that they render the common food more nutritive. It seems, however, a much more probable idea, that they are actually a part of the true food of plants, and that they supply that kind of matter to the vegetable fibre, which is analogous to the bony matter in animal structures. Thus, those plants which are most benefited by the application of gypsum, are those which always afford it on analysis. Clover and most of the artificial grasses contain it, but it exists in very minute quantity only in barley, wheat, and turnips." (Ag. Chem. p. 19.) And it is noticeable, that most of these remarks apply to the phosphate of lime (which can hardly be re garded as a stimulant), since it is not even soluble in water; it is also worthy of observation, that the same salts of lime (the phosphate and the carbonate) which Davy thus supposes to be placed in plants to add to their strength and solidity, are precisely those salts which for that very purpose are placed in the bones of ani. mals. They thus, as it were, mutually nourish each other. The very phuiphate of lime, which in the dissolving bone-dust is absorbed by the plant, again becomes, in the food of animals, a material for the formation of other bones. 
The carbonate of lime, in some of its forms of chalk, limestone, marl, \&c., is the most universally present of all the salts contained in vegetables. It is, in minute proportions, soluble in water, and more so if the water is saturated with carbonic acid gas, hence it is readily absorbed by the roots of plants. It exists in vegetables in very varying proportions; thus, the ashes of the perfect oat plant, straw and seed together, were proved by M. Vauquelin to contain more than 5 per cent. of this earth. (Ann. de Chem. vol. xxix.p. 19.) In 32 ounces of seeds of wheat, M. Schraedar found 12 grains of carbonate of lime; and in the same quantity of seeds of rye 13.4 grains; 24.8 grains in seeds of barley; 33.75 in those of the oat; and 46.2 in the same weight of the straw of rye. It is most cornmonly, although not always, found in vegetables with carbonate of magnesia. These were found together by $\mathbf{M}$. saussure in the ashes of the following different substances. He obtained from 100 parts of the ashes of the-

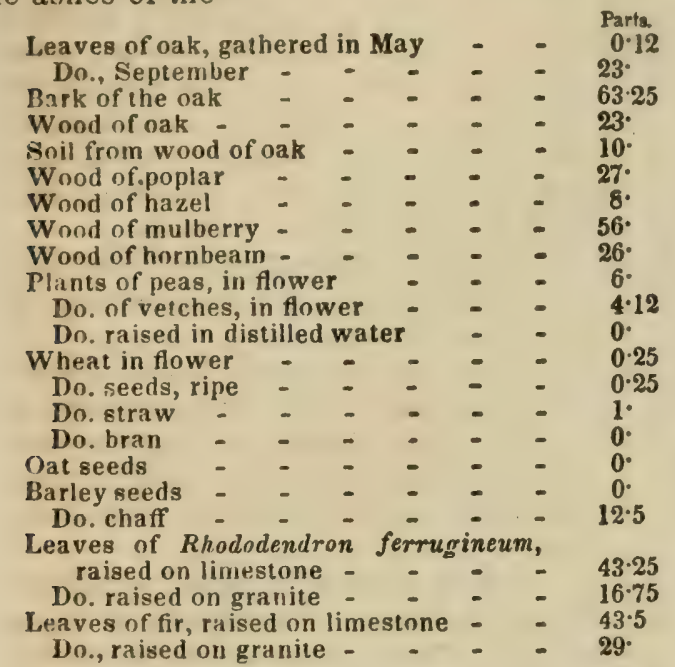

Now, these two soils (the granite and the limestone) contained carbonate of lime in the following proportion:-

\begin{tabular}{|c|c|c|c|c|c|c|}
\hline Carbonate & of lime & - & - & - & $\begin{array}{c}\text { Granite. } \\
1.74\end{array}$ & $\begin{array}{l}\text { Limestone } \\
98 \text {. }\end{array}$ \\
\hline Alumina & - $\quad-$ & - & 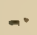 & - & $13 \cdot 25$ & 0.625 \\
\hline Silica - & - & - & - & - & $75 \cdot 25$ & \\
\hline Petroleum & - & - & - & - & & 0.25 \\
\hline \multirow{2}{*}{\multicolumn{2}{|c|}{ Iron and manganese }} & - & - & - & 9. & 0.25 \\
\hline & & & & & $99 \cdot 24$ & $99 \cdot 275$ \\
\hline
\end{tabular}

Carbonate of lime has also been detected in the sap and white matter of the ulcer of the elm by M. Vauquelin; in the ashes of wormwood (more than 50 parts in 100), by Kunsmuller; in the flowers of the arnica, by $M$. Chevalier ; in the potato, by M. Einhof; in the red bark of St. Domingo, in Peruvian bark, and in the wood of the quingania, by M. Fourcroy. Existing, therefore, so universally in plants, there can be no doubt of the fact that this salt is fulfilling, then, some wise and salutary purpose ; not fortuitously, but with design; not by chance, but by the regulation and arrangement of their Divine Architect.

Few if any saline fertilizers act so well alone, as when mixed with others, or with ordinary manures. As a general rule, the more fertilizers are mixed the better they operate unon plants.

Nitrate of potash, which is composed of ni976 tric acid $54 \cdot 34$ parts, and potash $45 \cdot 66$ parts, enters into the composition of a few plants, it is true, but in the greater number, even in those of the farmer's crops, on which on some soils its application produces such luxuriant effects, its presence cannot be detected, even in minute proportions. Some plants, however, do contain it in considerable quantities. Thus it has been found in the common nettle, the horse-radish, and the sunflower. M. Chevalier found it in the Chenopodium olidum; M. Vauquelin in the leaves of the deadly nightshade; M. Chevreul in woad; Dr. John in the Mesembryanthemum crystallinum. M. Boullion Legrange made various plants, such as the sunflower, vegetate in soils which did not contain any saltpetre: upon examining them, no traces of saltpetre were discernible, but upon watering them with a weak solution, it made its appearance in them as usual. (See Nitrates.) The presence of cubic petre (nitrate of soda), which is composed of nitric acid $62 \cdot 1$, and soda $\mathbf{3 7} \cdot \mathbf{9}$, is still more rare in plants; it has only been detected in barley.

The salts formed with the vegetable acids existing in the juices of plants are rather numerous. Oxalate of potash, for instance, exists in the Oxalis acetocella, and several others; oxalate of lime in rhubarb, parsley, fennel. squills, tormentilla, deadly nightshade, and spinach. Nitrate of lime is contained in the onion, malate of lime in the houseleek, wake-robin, mignionette; and malate of potash in rue, the garden purslane, nasturtians, lilac, madder, \&c.

There is, perhaps, no saline substance that exists to so great an extent in marine plants, and which has been used for so long a period and to such an extent for those growing in inland situations, as common salt. (See SALT.) A substance which not only abounds in all plants growing on the sea-shore, but always exists in smaller proportions in many of those growing in upland districts. 'Thus, Mr. G. Sinclair obtained from 1450 grains of wheat-chaff from Bedfordshire, ashes 50 ; common salt $2 \frac{3}{4}$ : from 1450 parts of the seed, ashes 10 ; common salt $\frac{1}{6}$. But from the same crop, which had been dressed with 44 bushels of common salt per acre, he obtained from 1450 parts of the chaff, ashes 40 ; common salt 4: and from 1450 parts of the seed, ashes 10 ; common salt $\frac{1}{4}$.

Common salt is found generally in minute proportions in most cultivated soils. Davy detected in 400 grains of a good silicious soil from a Tonbridge hop-garden, nearly 8 parts of common salt.

Besides being in small proportions a direct food for plants, common salt also seems to perform several other services to vegetation, and the same remark probably applies to other salts; for instance, when applied to the soil in small proportions, it certainly promotes the putrefaction of its organic matters. See $\mathbf{S}_{\mathbf{A} \text { LT. }}$

And again, salt, in common with several others, appears to excite or stimulate the plant, when applied to it in proportions not too excessive; a fact first noticed by Dr. Priestley.

Another use of common and other salts to vegetation is, the preservation of the plant from injury by sudden transitions in the temperature of the atmosphere: salted soils only 
freeze in intense frosts. I have repeatedly witnessed in the case of culinary vegetables, such as cabbages, broccoli, \&cc., that, while the produce of the unsalted portions of the ground were half-killed by the frost, the salted portions have totally escaped. Many salts have also the property of retarding the evaporation of the moisture of the soil; others absorb it from the atmosphere, or are of the class of deliquescing salt; such are the common salt, chloride of calcium, chloride of magnesia, cubic petre, or nitrate of soda, \&c., which, in consequence, when they are used as fertilizers, they increase this property, so valuable and so essential to all cultivated soils. Thus I found by some experiments upon a rich soil near Maldon, in Essex, worth $42 \mathrm{~s}$. per acre, that 1000 parts, dried at a temperature of $212^{\circ}$, absorbed in 18 hours, by exposure to air saturated with moisture at a temperature of $62^{\circ}, 25$ parts. But 1000 parts of the same field, which had been dressed with 12 bushels of marine salt per acre, under the same circumstances gained 27 parts; and 1000 parts of the same soil, which had been dressed with 6 bushels per acre, gained 26 parts. The attraction of some saline substances for the moisture of the atmosphere is very considerable. I found that 1000 parts of refuse salt manure, dried at $212^{\circ}$, absorbed in 3 hours, by exposure to air saturated with moisture at $60^{\circ}, 49 \frac{1}{2}$ parts. 1000 parts of the sediment or pan-scratch of the salt-makers, gained 10 parts; 1000 parts of Cheshire crushed rock-salt, 10 parts; 1000 parts of gypsum, 9 parts. Chloride of calcium is so powerfully deliquescent, that it absorbs sufficient moisture from the air to dissolve in it and form a solution. Dr. Marcet found that 288 grains in 124 days absorbed 684 grains of water. 288 grains of nitrate of lime, a salt found in some of the richest alluvial soiis of the East, absorbs in 147 days 448 grains. Carbonate of potash, another saline fertilizer, also absorbs moisture. Now, it is worthy of the farmers' notice, that chloride of calcium is the very salt which is produced in such abundance by the decomposition of common salt by lime, in the way so successfully recommended first, by the old German chemist Glauber, by Mr. Hollingshead, Mr. Bennett, and Sir Charles Burrell (See SALT and LIME); for, by the slow action carried on for three months by these substances on each other, this salt and soda are produced by the decomposition; and it is not improbable that when these salts are present in the juices of plants, that by this means the attractive powers of their leaves and roots for aqueous vapour may be increased. Davy alludes to these essential, yet too little understood powers of absorption possessed by vegetables, when he says (Lectures, p. 207), - "In very intense heats, and when the soil is dry, the life of plants seems to be preserved by the absorbent power of their leaves; and it is a beautiful circumstance in the economy of nature, that aqueous vapour is most abundant in the atmosphere when it is most needed for the purposes of life, and that when other sources of its supply are cut off, this is most copious."

Of the salts of ammonia, as I have in another place remarked, carbonate of ammonia has 123 been detected in the Chenopodium olidum by Messrs. Chevalier and Lasseigne; and it probably exists in other plants which are distinguished for their powerful disagreeable odour. Muriate of ammonia has been found in woad by $M$. Chevreul. The salts of ammonia are in general exceedingly fertilizing in their effects upon vegetation. Soot owes part of its efficacy to the ammoniacal salts it contains. The liquor produced by the distillation of coal contains carbonate and acetate of ammonia, and this liquid of the gas-makers is a very good manure. "In 1308," says Davy, "I found the growth of wheat in a field at Roehampton assisted by a very weak solution of acetate of ammonia." The experiments of Mr. Robertson with soot clearly show the fertilizing effects of the soluble por. tion of it. He mixed logether, in order to form a liquid manure, six quarts of soot in a hogshead of water. "Asparagus, peas, and a va. riety of other vegetables," says this intelligent horticulturist, "I have manured with this mixture, with as much effect as if I had used solid dung." Care must be taken, however, in using this and all other liquid fertilizers, not to make the solutions too strong: it is an error into which all cultivators are apt to fall in their early experiments. Even Davy was not an exception, since, from making his liquids too concentrated, he obtained results which widely differed from his later experiments. There is no doubt but that the salts of ammonia, and all the compound manures which contain them, have a very considerable forcing or stimulating, or, perhaps, from their decomposition, nourishing effect upon vegetation. In the experiments of Dr. Belcher upon the common garden cress, by watering them with a solution of phosphate of ammonia, the plants were 15 days forwarder than plants growing under similar circumstances, but watered with plain water; and he also describes the experiments of $\mathrm{Mr}$. Gregory, who, by watering one-half of a grass field with urine, nearly doubled his crop of hay. Other testimonials in support of the fertilizing powers of the salts of ammonia are furnished by Mr. Handley.

Of the mode in which ammonia operates upon plants, a late valuable work on organic chemistry, by M. Liebig, abounds with observations, with some of which I cheerfully and cordially agree. To understand these remarks, however, the farmer must remember that ammonia is composed, according to the analysis of Davy, of hydrogen 74 parts, and azote or nitrogen 26 parts. "The nitrogen of putrefied anima!s," he observes, "is contained in the atmosphere, as ammonia in the furm of a gas, which is capable of entering into com. bination with carbonic acid, and forming a volatile salt. Ammonia in its gaseous form. as well as all its volatile compounds, are of extreme solubility in water. Ammonia, there. fore, cannot remain long in the atmosphere, as every shower of rain must condense $i$, and convey it to the surface of the earth: thence, also, rain-water must at all times contain ammonia, though not always in equal quantity. It must be greater in summer than in spring or in winter, because the intervals of time between the showers are greater; and, where tween the showers are greater; and, 
severa vet days occur, the rain of the first must contain more of it than the second. The rain of a thunder-storm, after a long-protracted drought, ought, for this reason, to contain the greatest quantity which is conveyed to the earth at one time. But all the analyses of atmospheric air hitherto made have failed to demonstrate the presence of ammonia, although, according to our view (says M. Liebig), it can never be absent. If a pound of rain-water contains only one-fourth of a grain of ammonia, then a field of 40,000 square feet must receive annually upwards of $80 \mathrm{lbs}$. of ammonia, or 65 lbs. of nitrogen; for, by the observations of Schubler, which were formerly alluded to, about 700,000 lbs. of rain fell over this surface in 4 months. This is much more mitrogen than is contained in the form of vegetable aibumen and gluten in 2650 lbs. of woad, 2800 Ibs. of hay, or $200 \mathrm{cwt}$. of beet-root, which are the yearly produce of such a field; but it is less than the straw, roots, and grain of corn which might grow on the same surface would contain. Experiments made in the laboratory of Giessen, with the greatest care and exactness, have placed (continues Liebig) the presence of ammonia in rain-water beyond all doubt. It had hitherto escaped observation, because no one thought of searching for it." See Ammovin.

I cannot recommend the farmer to adopt the able conclusions of M. Liebig without considerable caution: hardly any thing retards the progress of science more than erroneous theories. Fortunately, however, the farmer can in all cases patiently and successfully examine and apply the valuable facts of the skilful chemist without mystifying himself with not always intelligible doctrines. It is very probable that plants have the power of decomposing ammonia, and of assimilating the nitrogen which it contains, in the same way as there is little doubt the hydrogen of water is assimilated by them; but we have no direct evidence of the facts, and the best course, therefore, will be to regard them not as absolute chemical truths, but merely as of the class of what may be perhaps denominated scientific probabilities.

Some of the other compounds of chlorine, the old class of chlorides of the chemist, have been tried as fertilizers, with very doubtful success; for although at first the seeds which had been steeped in them germinated with a considerably increased rapidity, yet they speedily seemed to suffer by this additional stimulus. Davy tried solutions of chlorine, and sulphate of iron (green vitriol): he says, "Though the plume was very vigorous for a time, yet it became at the end of a fortnight weak and sickly, and at that period less vigorous in its growth than the radish sprouts which had been naturally developed, so that there can be scarcely any useful application of these experiments. Too rapid growth and premature decay seem invariably connected in organized structures, and it is only by following the slow operation 3 of natural causes that we are capable of making imp: ovements." Oxymuriate of lime, or, properly speaking, chloride of calcium, however, appears to be beneficial to ogetation: this was ascertained in 1795 , by 978
Ingenhouz; and I have given in my work On $_{n}$ Fertilizers, p. 367 , the result of some trials by Mr. Fincham with this chloride that were highly successful: he says, "Half of some turnipseed were steeped for 36 hours in a solution of chloride of calcium, composed of 1 part chloride of calciam, and 48 parts water; this was sown under precisely similar circum. stances of soil and aspect with the other half unsteeped. The first came up much sooner, was never attacked by the fly, and the produce was half as much again, and the tops made more luxuriant. He attributes the failure of Davy to his having used the chlorine, uncombined with the base lime.

Mr. Owen Mason, of Providence, Rhode Island, has computed the saline contents of the crops raised from a field near that place, during 8 years' cultivation, as follows :-

\begin{tabular}{lrr|rr} 
& & Ibs. & Ibs. \\
Potash &. & 424.92 & Sulphuric acid 113.88 \\
Soda &. & 131.92 & Phosphoric acid 108.12 \\
Lime . &. & 532.88 & Chlorine . & 58.64 \\
Magresia &. & 64.08 & & \\
Alumina &. & 5.96 & Total & 1830.50 \\
Silica . . & 590.40 & &
\end{tabular}

"It is doubtful," Mr. Mason observes" "if the cultivator ever suspected that he carried to his barn two casks of potash, one cask of soda, two casks of lime, a carboy of oil of vitriol, a large demijohn of phosphoric acid, and a variety of other matters contained in his fourteen tons of fodder, which were as certainly stowed away in his mows as if they had been conveyed thither in casks and carboys." This statement will perhaps serve to give some idea of the enormous quantities of saline matters that are removed from the soil by the crops ordinarily raised. When the crops are eaten on the farm, and the manure produced therefrom is returned to the soit, there is established a continued circulation of those ingredients which would be lost if the crops were removed and the stock sold. See Sorrs.

SALTPETRE (Germ. and Fr. salpetre). See Nitrates and Satts.

SALTWORT (Salsola, from salsus, salt; in allusion to the saline properties of the species). A genus of plants which inhabits the sea-coast, especially abundant on the coast of the Mediterranean, where they are extensively gathered and burnt for the manufacture of barilla and soda. See KELP.

SALT-MARSH CATERPILLAR. See $\mathbf{C}_{A}$ TERPILLAR.

SALVING or SMEARING sheep is resorted to in various districts, for the purpose of preserving the fleece from the effects of weather, destroying injurious insects, and preventing cutaneous diseases. A mixture of damaged butter, hog's lard, resin, and Gallipoli oil, is found to be the most efficacious salve. Tar stains and spoils the colour of the wool. See SHEEP.

SAMPLE. A small quantity of a commodity exhibited at public or private sales, as a specimen. Wool, wine, corn, seeds, and indeed most species of agricultural produce and merchandise that can be conveyed in small bulk, are sold by sample. If an article be not at an average equal to the sample by which it is sold, the buyer may cancel the contract, an 
return the article to the seller. (M'Culloch's Com. Dirt.)

SAND (Germ.). Finely divided silicious matter constitutes common river and sea-sand: particles of other substances are often blended with it, and sometimes it becomes calcareous from the prevalence of carbonate of lime.

Sand is often employed as a manure by the cultivator of the poor, hungry clays, especially if he can obtain calcareous sand. See Елатнs, Mixtuhe of Solls.

SANDWORT'. See Сигск wevd. (Arenaria, from arenc sand; referring to the sandy situation in which most of the species are found.) This is an extensive genus of herbs, of humble growth, with numerous slender stems, opposite, mostly narrow, entire, undivided leaves, and small, white or reddish, inodorous flowers, with coloured anthers. This succulent vegetable bears a great resemblance to samphire, and considerable quantities of it are pickled and sold for that plant.

SANICLE (Sanicula, from sano, to heal.) The wood sanicle (S. Europea) is a mere perennial weed, growing in woods and groves abundantly, about a foot high, flowering in May. The root is tufted, with fleshy fibres. The leaves are chiefly ridical, simple, with deeply cleft lobes, veiny, ar.d of a deep shining green. Flowers cream coloured, in capitate umbels, in an irregular, ? wice compound, partly umbellate panicle. The herb is bitter, with an acrid, somewhat aromatic pungency. Its reputed vulnerary qualities are no longer believed.

SAP. In bofar.y, the fluid which is absorbed by the rooto from the earth, and undergoes the first action of the vital chemistry of the plant, is called the sap. It is formed as the absorbed fluid ascends upwards into the stem. It is afterwaris conveyed to the leaves, where it is exposed to the influence of light and air, loses a large portion of its water, undergoes a chemical change, and, being returned to the branches and stem, it is analogous to the blood in animals; all the secretions being furmed from it. Changed in the leaf into proper juice, it is assimilated to the various parts of the plant. In its crude state it consists of little except water, holding earthy and gaseous matter in solution, especially carbonic acid; but as it rises through the tissue of the stem, it dissolves the secretions it meets with in its course, and thus acquires new properties, so that by the time it reaches the leaves it is entirely different from its state when it first entered the root. The course taken by the sap in its passage through the stem, is by the whole of the tissue included within the bark, provided it is all permeable; but as, in many plants, the central part of the stem becomes choked up with solid matter deposited in the tissue, it usually happens, especially in trees, that the course of the sap is confined to the outer part of the wood, hence called sapwood. It is not certainly known through what kind of tissue the upwarit motion of the sap takes place, but it is probable that it is carried on wards through all the tubes and vessels of the wood, and their intercellular passages. The dotted vessels of the wood seem more especially destined to fulfil this office when the sap is in rapid mo tion; but as they afterwards become empty, while the ascent of the sap contimues, there can be no doubt that the woody tubes or pleuren. chyma offer the most constant means ly which the sap is conveyed. See Arниити.

SAP-SAGO. A kiud of cheese made in Switzerland, having a dark olive-green culour and agreeable flavour, derived chiefly, if not entirely, from the addition of mellilot. See Cheige and ZAHZIEGR.

SAVIN. See JunipER.

SAW-DUST. The refuse or waste powder obtained from saw-pits, after any wood or limber has been separated or cut asunder by the saw. If fresh oak saw-dust be scattered on gravel walks it effectually prevents the growth of weeds, and when mixed with blood and quicklime it forms an excellent manure for the garden. This substance has lately been brought prominently into notice as an adjunct to other manures. 'There can be no doubt of its usefulness when made into compost with putres. cent manures, saline substances, and organic matters. A compost of this kind, which has been well mixed and decomposed, and turned over with the spade at proper time, will produce an excellent crop of turnips.

SASSAFRAS (Laurus sassafras). This, on account of its sensible qualities, and real or supposed active medical virtues, was among the first American trees which became known to Europeans. In the United States, the neighbourhood of Portsmouth, New Hampshire, in latitude $43^{\circ}$, may be assumed as one of the extreme points at which it is found towards the northeast. But here it is only a tall shrub, rarely exceeding 15 or 20 feet in height, whilst in the Middle States it attains a height of 50 or 60 feet, being still more stately farther south. It is found in the Western and extreme Southern States, and in the low, maritime parts of Virginia, of the two Carolinas, and of Georgia. The sassafras is observed to grow of preference about plantations and in soils which have been exhausted by cultivation and abandoned. The old trees give birth to hundreds of shoots which spring from the earth at little distances, but which rarely rise higher than 6 or 8 feet. Though this tree is common on poor land, and blooms and matures its seed at the height of 15 or 20 feet, yet it is never of very ample dimensions except in fertile soils, such as form the declivities which skirt the swamps, and such as sustain the luxuriant forests of Kentucky and West Tennessee. About New York and Philadelphia the sassa. fras is in full bloom in the beginning of May, and six weeks earlier in South Carolina. The wood stripped of its bark is very durable, strong, and resists worms, \&c. It forms excellent posts for gates. Bedsteads made of it are never infested with bugs. It is, however, only occasionally employed for any useful purpose, ano never found in the lumber-yards of large towns. The pith and dried leaves of the young branches of the sassafras contain much mucilage, resembling that of the okra plant, and are extensively used in New Orleans to thicken potage, and make the celebrated gumbo soup. In Virginia and other Southern States, the inhabitants make a 
beer by boiling the young shoots of the sassafras in water, to which a certain quantity of molasses or sugar is added, the whole being left to ferment. The beer is regarded as a wholesome and pleasant drink during summer. So is an infusion of the bark of the roots, which is much drunk for the cure of cutaneous and other disorders.

SAW-FLIES. The names of above 60 species of saw-flies, natives of the United States, and found in Massachusetts, are given in Dr. Harris's Catalogue. Some of these are very interesting in their caterpillar state. One of the largest flies is called Cimbex Ulmi, because it inhabits the elm. The female of this species, at first sight, might be mistaken for the hornet. (The name Cimbex was originally given by the Greeks to certain insects resembling bees and wasps, but not producing honey.) The elm saw-fly measures an inch in length, the wings expanding about 2 inches. It appears in the Eastern States from the last of May to the middle of June, during which the female lays her eggs upon the common American elm, the leaves of which serve as food for the young caterpillars hatched out. These come to their growth in August, and then measure from $1 \frac{1}{2}$ to 2 inches in length. Like all false caterpillars of the genus Cimbex, this insect, when handled or disturbed, betrays its fears or its displeasure by spirting out a watery fluid from certain little pores situated on the sides of its body just above its spiracles. The false caterpillars of other saw-flies prove very destructive to pines and other fir trees. They crawl down the trees and weave cocoons which are concealed in the leaves, \&c. In the following spring the insects burst their chrysalids and come forth as winged flies.

No means, says Dr. Harris, for the destruction of the caterpillars of the fir saw-fly have heen tried here, except showering them with soap-suds, and with solutions of whale-oil soap, which has been found effectual. They may also be shaken off or beaten from the trees, early in the morning, when they are torpid and easily fall, and may be collected in sheets, and be burned or given to swine. For other means to check their depredations the reader may consult the articles on the pine and fir saw-files of Europe, contained in Köllar's Treatise.

Dr. Harris has described a kind of saw-fly (Selundria vitis), which attacks the grape-vine. It is of a jet-black colour, except the upper part of the thorax, which is red, the legs being a pale-yellow or whitish. The body is about 4 of an inch long. The false caterpillars proceeding from the eggs of these flies may be found in swarms of various ages on the lower sides of the leaves, some very small and others fully grown. When fully grown they measure about $\frac{5}{8}$ ths of an inch in length. The body is a light-green, the legs and tip of the tail being black. After the first moulting they become almost entirely yellow, and then leave the vine to burrow in the ground. They come out again from their chrysalis state in about a fortnight, pair and lay eggs for a second brood. The young of the second brood are not transformed into flies until the succeeding spring, remain- ing in the ground in their cocoons through the winter. "For some years previous to the pub. lication of my Discourse," says Dr. Harris, "I observed that these insects annually increased in number, and, in the year 1832, they had become so numerous and destructive that many vines were entirely stripped of their leaves by them. Whether the remedies then proposed by me, or any other means, have tended to diminish their numbers, or to keep them in check, I have not been able to ascertain, and have had no further opportunity for making observations on the insects themselves. At that time, air-slacked lime, which was found to be fatal to these false caterpillars of the vine, was advised to be dusted upon them, and strewed also upon the ground under the vines, to insure the destruction of such of the insects as might fall. A solution of one pound of common hard soap in five or six gallons of soft water, is used by English gardeners to destroy the young of the gooseberry saw-fly ; and the same was recommended to be tried upon the insects under consideration.

"All the young of the saw-flies do not so closely resemble caterpillars as the preceding; some of them, as has already been stated, have the form of slugs or naked snails: Of this description is the kind called the slug-worm in this country, and the slimy grub of the pear tree in Europe. So different are these from the other false caterpillars, that they would not be suspected to belong to the same family. Their relationship becomes evident, however, when they have finished their transformations; and accordingly we find that the saw-flies of our slug-worms and those of the vine are so much alike in form and structure, that they are both included in the same genus. Moreover, there are certain false caterpillars, intermediate in their forms and appearance between the slimy and slug like kinds and those that more nearly resemble the true caterpillars; thus admirably illustrating the truth of the remark, that nature proceeds not with abrupt or unequal steps; or, in other words, that amidst the immense variety of living forms, wherewith this earth has been peopled, there is a regular gradation and connection, which, in particular cases, if we fail to discover, it is rather to be attributed to our own ignorance and short-sightedness, than to any want of harmony and regularity in the plan of the Creator. In considering the resemblances of species, we cannot fail to admire the care that has been taken, by almost insensible shades of differ ence among them, or by peculiar circum. stances controlling their distribution, their habits of life, and their choice of food, to prevent them from commingling, whereby each species is made to preserve forever its individual identity.

"The saw-fly of the rose, which, as it does not seem to have been described before, may be called Selandria rosa, from its favourite plant, so nearly resembles the slug-worm sawfly as not to be distinguished therefrom except by a practised observer. The caterpillars of these perform their appointed work of destruction in the autumn; they then go into the ground, make their earthen cells, remain there- 
in throughout the winter, and appear, in the winged form, in the following spring and summer."

During several years past, these pernicious vermin have infested the rose bushes in the vicinity of Boston, and have proved so injurious to them, as to have excited the attention of the Massachusetts Horticultural Society, by whom a premium of $\$ 100$, for the most successful mode of destroying these insects, was offered, in the summer of 1840. Showering or syringing the bushes with a liquor, made by mixing with water the juice expressed from tobacco by tobacconists, has been recommended; but some caution is necessary in making this mixture of a proper strength, for if too strong it is injurious to plants; and the experiment does not seem, as yet, to have been conducted with sufficient care to insure safety and success. Dusting lime over the plants when wet with dew has been tried, and found of some use; but this and all other remedies will probably yield in efficacy to $\mathbf{M r}$. Haggerston's mixture of whale-oil soap and water, in the proportion of two pounds of the soap to fifteen gallons of water. For particular directions to use this, see ApHines.

For a species of minute saw-fly, destructive in the turnip crops in England, see FLY IN ToRnips.

SA W-GRASS. See Bog-Rush.

SAXIFRAGE (Saxifraga; from saxum, a stone, and frango, to break; in allusion to its reputed merical qualities in that disease). This is a very extensive genus of beautiful alpine plants, the greater part of which are particularly suitable for ornamenting rock-work, or growing on the sides of naked banks. They are all readily increased by seeds or divisions. These herbs are, for the most part, perennial, various in habit, often in some degree hairy and glutinous, with stalked, simple, undivided or lobed leaves. Flowers either panicled, rarely solitary, on a long naked stalk, or corymbose at the top of a round leafy stem; erect, white, yellow, or purple, frequently spotted, inodorous. Dr. Darlington describes two American species under the names of Virginia or Early Saxifrage, and Pennsylvania or Tall Saxifrage. Canada and Labrador have some species.

SAXIFRAGE, BURNET. See BurNET.

SAXIFRAGE, GOLDEN. See GoldeN SAXIFRAGE.

SCAB. A contagious disease incident to sheep, which, like the mange in cattle, horses, and dogs, and the itch in the human subject, is the effect of certain minute insects belonging to the class Acari; at least these insects always are present in this disease. In the human subject the itch insect obtains its food from the pustules of the disease. The cure of scab, however, is supposed to be in the destruction of this insect. Washes, whether infusions of tobacco, hellebore, or arsenic, appear to be objectionable, and a safer and more effectual method of curing the disease and benefiting the wool is the application of a mercurial cintment. The ointment should be made of two strengths. That for bad cases should consist of common mercurial or Trooper's oint- ment, rubbed down with three times its weight of lard. 'The other, for ordinary purposes, should contain five parts of lard wo one of the mercurial ointment. (Youalt on the Sheep, p. 536.) See Shrep, Disgasis or.

SCABIOUS (Scabiosa, from scabies, the itch: the common kind is said to cure that disorder). Some of these plants are well adlapted for ornamenting the flower-border. The herbaceous species are readily increased by division at the root, or by seed. 'The seeds of the annual kinds merely require sowing in the open border. There are three indigenous species, all perennials; viz., the devil's-bit scabious ( $S$. succisa), which is common in grassy, rather moist pastures, flowering from August in October (see Devin's-Bit Scanious); the field scabious (S. arvensis), growing in corn-fields and pastures, with a bristly stem a yard high. The radical leaves are lanceolate, serrated, stalked, the rest pinnatifid and quite sessile. The flowers, which appear in July, are large and handsome, of a fine pale purple. Sheep and goats are said to eat this herb; but its bitter and nauseous flavour is not agreeable to domestic cattle. The small scabious (S. columbaria) is a less common species, attaining to the height of twelve or eighteen inches. The leaves and flowers are smaller and more delicate than the last.

SCALD CREAM. Provincially, cream raised by heat, or clouted cream. See DArnr, Milk, Butter, Lactometer, \&c.

SCALLION. See Orion.

SCAPE. In botany, a stem rising from the roots, more frequently from a rhizome or underground stem, bearing nothing but the flowers. The iris is an example.

SCARIFIER. A tillage implement for stirring and loosening the soil, without bringing up a fresh surface. Under the same head may be included the grubber, the cultivator, and the scuffler, all of which act on the combined principles of plough and harrow at the same time. Some of these implements have wheels, by the raising or lowering of which the tines or prongs may be made to sink more or lese in to the earth. See Hanrow.

Amongst the earliest of the many varieties of this implement that I am acquainted with (says Mr. J. A. Ransome, in his work upon the Implements of Agriculture), is one which the late T. Couke used, attached to the framework of his drill, the coulters and apparatus of which, being removed, gave place to a bar, or head, suspended by joints to the axle, on which a row of strong tines was fixed. Bee Pl. 14, fig. 2.

On a similar plan to this, but working on a plough-carriage, another invention by Robert Fuller, a practical farmer of Ipswich, came into operation, and worked exceedingly well.

Biddell's Scarifier and Extirpator (Pl. 15, fig. 3 ) is held in deservedly high repute in Suffoll (where it originated) and the eastern and misland counties, where it is now in very general use. It is an implement of immense power, and well calculated to supersede the extensive use of the plough, otherwise indispensable in the cultivation of strong Jand, and we are in clined to believe with betrer effect. There cau 
be no question that in a general way a finer tiith may be obtained with Biddell's scarifier than with any plough; and, for this reason, strong and tenacious clays and even many of the better loams, though dry at the surface and apparently in good order for ploughing, frequently turn up coarse and "loamy." In the early part of the spring, the combined action of frost and the atmosphere may probably in time effect what a scarifier would do at once, viz., reduce the clods to a comparatively fine mould, without which the hope of a good barley crop is but slender. There is no reason why the process of scarifying should not prove equally beneficial to the turnip or any other crop. Indeed, some are of opinion that what is usually called a stale furrow, in contradistinction to a newly ploughed one, is more favourable to the germination and after-growth of a plant like the turnip than a sowing on soil freshly turned up.

A great improvement on Fuller's extirpator, was Finlayson's Patent Self-cleaning Harrow. Pl. 15, fig. 5. This well-known implement may be called the parent of several of the same description, which, in improved forms, have subsequently come into use. It is formed of iron, and, according to the inventor, has the following advantages:-1. From the position in which the tines are fixed, their points ( $a a a a a)$ hanging nearly on a parallel to the surface of the land, it follows, that this implement is drawn with the least possible waste of power. 2. From the curved form of the tines, all stubble, couch, \&c., that the tines may encounter in their progress through the soil, is brought to the surface, and rolled up to the face of the tines; when it loses its hold, and is thrown off (at $b \quad b \quad b \quad b \quad b$ ), always relieving itself from being choked, however wet or foul the land. 3. The mode by which this harrow can be so easily adjusted to work at any depth required, renders it of great value; this is done as quick as thought by moving the regulator $(c)$ upwards or downwards between the lateral spring (de); and by each movement upwards into the openings $(f g h i k)$, the fore-tines $(l l l l)$ will be allowed to enter the soil about $1 \frac{1}{2}$ inch deeper by each movement into the different spaces, until the regulator is thrown up to $(e)$, when the harrow is given its greatest power, and will then be working at the depth of 8 or 9 inches. Also the axletree of the hind-wheels is moved betwixt 0 and $p$, a space of 7 or 8 inches, by a screw through the axletree, which is turned by a small handle $(g)$, so that the nind part of the harrow, by this simple mode, is also regulated to the depth at which it is found necessary to work. 4. When the harrow is drawn to the head or foot lands, the regulator is pressed down to $d$, and the fore-wheel $(m)$ is then allowed to pass under the fore-bar $(n)$, by which the nose of the harrow is lifted, and the points of the fore-tines $(l l l l)$ will then be tairen 2 or 3 inches out of the soil, which affords the means of turning the harrow with the greatest facility. 5. Being made of malleable iron, its durability may be said to be endess; whereas, if made of wood, the prime cost would be entirely lost at the end of every 5 or a vears. Lastly, the mode of working is so easy, that any boy of 10 or 12 years of age is perfectly qualified to manage it. Next to Wilkie's brake, we consider this the most valuable of pronged implements, and think that, like Wilkie's implement, it might be substituted for the plough, after drilled green or root crops, $c$ a light soil generally. Some account of the astonishing powers of the implement, as exem. plified in breaking up Hyde Park, London, in 1826, will be found in the Gardener's Magazine, vol. ii. p. 250.

Wilkie's Parallel Adjusting Brake is very nearly allied to the implement last mentioned; its chief improvement consists in the triangular adjustment of the teeth or prongs, and the facility with which they may be completely thrown out of work; whereas, with Finlayson's harrow this can only be partially done, the hindteeth of the latter still retaining some hold of the ground, even though the first row be lifted up. This we are aware has been represented as an advantage, inasmuch as the slight hold retained by the back-row of tines prevents the implement from running on the horse's heels, when turning at the ends of the stetches on hilly ground. We see but little in this as an argument in favour of any implement of the kind. Indeed, we are rather disposed to give the preference to one like Wilkie's brake, which, by a parallel movement of the frame in which the tines are fixed, can, either at the turnings or while in action, be elevated or depressed en masse.

Kirkwood's Grubber in its operation somewhat resembles those last described, but is superior to them in working. The leverage that is obtained by pressing on the handles or stilts of the machine, whether in action or rest, is so simple, and yet so powerful in its effect, as to regulate the depth of the tines to the greatest nicety; or, in cases of obstruction, to throw them out of work altogether. It is an admirable implement, and well deserving the high commendation which has been bestowed on it.

SCORE. A term signifying $20 \mathrm{lbs}$, in speaking of the weight of cattle or swine.

SCORING. A provincial term signifying the glossing or making the furrow-slice in ploughing or turning land up, by the plough acting as a trowel. It is sometimes written scowering.

SCORPION-GRASS (Myosotis, from myos, a mouse, and otos, an ear; fancied resemblance in the leaves.) All the perennial species of this genus are very beautiful, especially the well-known Forget-me-not (M. palustris). They grow best in moist places, or by the edges of ponds or ditches; they may also be grown in pots among alpine plants. The annual species like a dry, sandy soil; most of the perennial kinds may be increased by divisions of the roots, and all by seeds. Sir J. E. Smith describes seven species of scorpion-grass indigenous to England, two of which are annuals, the rest perennials. Besides the $M$. palustris and $M$. arvensis, there are one or two other species found in the United States.

SCOTCH FIR. A common but improper name for the Scotch pine (Pinus sylvestris). See Pine and Fin.

SCOURING. See Pungisa. 982 
SCRAPER. See Moúnва RT.

SCUFFLER. An implement of somewhat the same kind as the scarifier, but which is mostly lighter and employed in working after it. See Hannow.

SCLLL-CAP (Sutelluria). There are several species of this plant found in the United States. The common hairy scull-cap (S. pilosa) has a perennial root, and stem 12 or 18 inches high, inore or less hairy, and often purplish. The flower is a purple-blue colour, and opens from June to August. There are several varieties of this species. The large-flowered or entire-leaved scull-cap (S. integrifolia) is distinguished for its handsome, large, bluish flowers, which bloom in June. It is intensely bitter to the taste. The lateral-flowered scullcap (S. laterifolia), has acquired the name of mad-dog scull-cap, from its having acquired much notoriety some years ago as a supposed remedy for hydrophobia. "Like its numerous predecessors of the same pretensions," says Dr. Darlington, "it had its day of importance among the credulous, and then sank into the oblivion which necessarily awaits all such specifics." Several other species of scull-cap are enumerated in the United States.

SCURVY-GRASS (Cochlearia). A genus of plants of little interest, with the exception of horse-radish ( $C$. armoracea), and the common scurvy-grass ( $C$. officinalis). Besides these there are three other indigenous species: the Greenland scurvy-grass, the English scurvygrass, and the Danish scurvy-grass. They are either annual or biennial herbs, and were once celebrated as antiscorbutics, but have lost their reputation. The plants are mostly smooth and rather succulent, with branched, spreading stems, and simple leaves, the radical ones stalked and most entire. Flowers white, or pale-purplish.

The common scurvy-grass is cultivated in gardens for its leaves. It flourishes best in a sandy, moist soil, but will succeed in almost any other, especially if abounding in moisture. The situation must always be as open as possible. It is propagated by seed, which should be sown as soon as it is ripe in July or June, for if kept from the ground until the spring, they will entirely lose their vegetative power, or produce plants weak and unproductive. The sowing is performed in drills 8 inches apart, and half an inch deep.

SCYTHE. This implement for mowing grass has been latterly much used for cutting grain crops, and with great success, when it has been properly mounted with a rake or cradle, and put into expert hands.

Drummond's iron-handled scythe is considered in Scotland very effective. A good mower will cut down with it from an acre and a half to two acres in the day, and with this scythe he can either cut out from the standing corn when upright, or cut in, as he may deem the better way at all times.

The common grass-scythe will cut oats and barley also very well when upright, but the mower will perceive his inability to lay down evenly and at right angles with the standing corn, for the convenience of the binders, a heavy crop of wheat with this scythe, even if furnished with a bow.

The Hainault or Flemish scythe, the favourite Belgian implement for severing corn, appears to be a very efficient instrument, but although all the trials made with it in Scutlad and England report favourably of it, it has not come into use even partially; prejudice and the results of habit and custom rendering the old sickles, scythes, and reaping-hooks mure popular. See Hay-Making, Reapisib-Hoox, SICKLe, \&c.

SCYTHE AND CRADLE. The well-known American implement called the scythe and cra. dle used in the United States for harvesting wheat and all other kinds of small grain, is much preferable to the Hainault scythe. 'The cradle is made with 5 long teeth extending the full length of the scythe, and bent to the same shape. These teeth are generally made of the strong and pliant ash, shaved down so as to be as light as is consistent with the necessary strength. The handle is bent in such a manner as contributes greatly to the convenience of using the implement. It is slowly becoming introduced into England.

SEA-BUCKTHORN. See Sallow-Thor.

SEA-HOLLY. See Enyrao.

SEA-KALE. See KALE.

SEA-LAVENDER. See Trвiтt.

SEA-MUD or OUSE. This rich saline deposition from salt-marshes and the sea-shores is found to possess very enriching properties, and to be a useful addition to the soil where it can be obtained in any quantity. See Arce. VIUM, MARSH-MUd, and WARPING.

SEAM. A provincial term applied to any fatty substance, as tallow, grease, or lard. A seam of corn is also a quarter or 8 bushels, and a seam of wood a horse-load, or about $3 \mathrm{cwt}$.

SEA-MILKWORT (Glaux, from glaukos, gray, in allusion to the colour of the leaves). The common sea-milkwort, or black salt-wort (G. maritima), is in England a pretty little indigenous perennial plant, growing abundantly in inuddy salt-marshes.

SEA-SHELL. All marine shells, where they can be obtained in sufficient quantity, form a durable and lasting addition to the soil. See Orster-Shells.

SEA-WARE. A term frequently applied to the weeds thrown up by the sea in many situations, and which is collected and made use of as manure and for other purposes. It consists principally of the Quercus marina, and various species of $F u c i$, and has often the names of sea-wrack, ore-weed, sea-tangle, \&c. See KELP.

SECHIUM (Sechium edulis or Siegos edulis). A new vegetable from South America; in size and form resembling a very large bell-pear: the skin smooth, of a pale-green colour; the flesh solid. For the table it is prepared in a manner similar to the squash, and is stated to be of a more delicate flavisur. It has but one single flat seed, which is larger than a Lima bean. A new vegetable, imported by Mr. Buist, of Philadelphia, and altogether unlike any thing before known or cultivated here.

SEDGE (Carex, from careo, to want, the upper 
spikes being without seeds). This is a very extensive genus, the species of which are uninteresting; part of them are natives of marshy situations, while a few thrive on dry, sandy eminences; they seed freely, by which they are increased. The roots are, perhaps without exception, perennial, mostly creeping; sometimes fibrous and tufted only; herbage grassy; stem simple, generally with thin, finely serrated, and sharply-cutting angles, without knots or joints. Leaves linear, pointed, flat, roughish, with similarly cutting edges; their bases more or less tubular and sheathing, membranous at the summit, often auricled, the upper ones becoming bractes. Sir J. E. Smith enumerates and describes no less than 62 species of Carices indigenous to Great Britain. There are a great many species of sedge found in the United States.

SEED is the reproductive part of a plant, resulting from a change effected in the ovules by the process of impregnation: it contains the embryo or rudiment of a future plant.

For the preservation of the seed from insects and decomposition, and for food for the embryo, seeds contain fecula, saccharine, oily, and gummy matter within their coverings, and somelimes acrid, poisonous principles. In their coverings they alșo contain mucilage, oil, both fixed and volatile, and other principles which man makes subservient to his use, either as diet or condiments, or for other purposes. Seed is a form of reproductive matter peculiar to flowering plants, its equivalent in flowerless plants being the sporuli. It is commonly and very justly remarked, that, as the seed is the part intended by nature to multiply the races of plants, in this respect it resembles the egg, and, like it, long retains its vitality.

The choice of the seed intended to be sown is an object of greater importance than many farmers seem to imagine. It is not sufficient that the finest grain be chosen for this purpose, unless it be likewise clean from weeds. In procuring seed, it should be a rule with the farmer to purchase or reserve such as is the most full, plump, sound, and healthy, whatever the kind may be, as it is perhaps only in this way that crops of good corn can be insured. And this practice is still more obvious from the circumstance of its being in some measure the same with plants as with animals, that the produce is in a degree similar to that from which it originated. See Barler, Grasseg, OAts, Temperature, Wheat, \&c.

The usual quantity of seed applied per acre for the ordinary crops of the English farmer, when either broadcast, drilled, or dibbled, is as follows :-

\begin{tabular}{|c|c|c|c|c|c|c|}
\hline & & Time of sowing. & & Broadcast. & Drill. & Dibbled. \\
\hline Wheat - & - & September to Dec & ember & $2 \frac{1}{6}$ to $3 \frac{1}{2}$ bushels. & 2 to 3 bushels. & 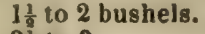 \\
\hline $\begin{array}{l}\text { Oats : - } \\
\text { Barley - }\end{array}$ & $=-$ & February to April & & 4 to 6 & $3 \frac{1}{2}$ to $4 \frac{1}{9}$ & \\
\hline Rye - & - & $\begin{array}{l}\text { February to May } \\
\text { August and Septe }\end{array}$ & - & $\begin{array}{l}3 \text { to } 4 \\
2 \frac{1}{2} \text { to } 3\end{array}$ & $2 \frac{1}{2}$ to $3 \frac{1}{8}$ & \\
\hline Beans - & - & November to Mar & $\begin{array}{l}\text { moer - } \\
\mathrm{ch} \text { - }\end{array}$ & 3 to 4 & $\begin{array}{l}2 \text { to } 3 \\
2 \frac{1}{8} \text { to } 3 \frac{1}{9}\end{array}$ & 2103 \\
\hline Peas - & - & January to March & - & $3 \frac{1}{2}$ to $4 \frac{1}{2}$ & 3 to 4 & \\
\hline Tares. & - & August to March & - & $2 \frac{1}{3}$ to 3 & 2 to $2 t$ & \\
\hline Buckwheat - & - & May & - & 2 to $2 \frac{1}{3}$ & & \\
\hline Clover, Red - & & March and April & - & 12 to $16 \mathrm{lb}$, & 10 to $14 \mathrm{lb}$. & \\
\hline Trefoil & Mixed & $\begin{array}{l}\text { Do. : } \\
\text { Do. }\end{array}$ & - & $\begin{array}{l}3104 \\
2\end{array}$ & & \\
\hline Red Clover & ${ }^{8} l$ & 1). - & - & & & \\
\hline Rye Grass & - & Do. - & - & 1 peck & & \\
\hline Turnips & - & May to August & - & 2 to $3 \mathrm{lb}$. & $1 \frac{1}{6}$ to $2 \mathrm{lb}$. & \\
\hline Mangel-wurze & - & April and May & - & & & \\
\hline Potatoes & - & March to June & - & - & 20 to 25 bush. & \\
\hline
\end{tabular}

The quantities here given are those common throughout the island. But from the general custom in Flanders, and from the extensive practice which I have witnessed on the farms of Mr. Hewitt Davis and other excellent farmers, I am inclined to think that these quantitues may be considerably reduced. As in most cases it is usual to have on the land many more seedling plants than the soil can properly mature, thinner sowing has the effect of producing stronger, healthier, and more prolific neads; and I am still inclined to this opinion in favour of thinner sowing, notwithstanding I am aware that such excellent agriculturists as Lords Leicester and Western practise, and strongly recommend, thick sowing.

As to the season for sowing, only general directions can be given. It is a highly imporrant subject, much too little attended to in geutral. In the north of England they are frecuently sowing weeks earlier than in the south.

SEED-LIP. A sort of basket in which the sower carries the seed he is about to scatter over the ground.
SEEL. A term provincially applied in England to time or season in respect to crops, as hay-seel, or hay-time, and barley-seel, or barley-seed time, bark-seel, barking-season, \&c. It is sometimes written seal.

SENNA, WILD (Cassia Marylandica). 'This plant, which is abundant in the Middle States, is quite ornamental, and often introduced into gardens. It has a perennial root and erect stem, growing to the height of 3 or 4 feet, and branching. The leaves resemble those of the imported senna (also a species of cassia), for which they are a good substitute, the medical properties being nearly similar. Its flowers are yellow and in clusters, followed by a seed. pod or legume 3 or 4 inches long.

SENSITIVE PLANT, WILD, commonly called Twinkling Cassia (Cassia nictitans). This plant is found in the Middle States, on roadsides, \&c. Its root is annual, and the stem grows 6 to 12 inches long, mostly oblique, slender, branching, and roughish-hairy. It produces yellow flowers in August, succeeded by seed-pods an inch to an inch and a half long, and two or three lines wide. 
§EPTA. In botany, the partitions which divide the interior parts of a fruit.

SERRA'TE. A botanical term, implying notched, or cut like the teeth of a saw.

SERVICE TREE (Pyrus). There are in England two species of this tree, the wild service tree ( $P$. torminalis), and the true service tree $(P$.domestica). Both are indigenous trees, often of considerable size, of extremely slow growth, and the wood is very hard. The service tree is still occasionally to be met with in the hedgerows in Kent, and in the wealds of Sussex, as also in the north of England and Wales. The leaves of the wild service tree are darkgreen, deciduous, simple, somewhat heartshaped, serrated, seven-lobed, on long stalks. Flowers white, numerous, in large, terminal, irvmbose, downy panicles. The umbilicated fruit, which is not larger than that of the haw! $\quad$, becomes agrecably acid and wholesome the frost has touched it, or when, like the medlar, it has undergone a kind of putrefactive fermentation. Ray prefers its flavour to the true service, which latter is now become obsolete. See June BerRy.

SESSILE. A botanical term, applied to leaves without footstalks, which are seated close apon the stem.

SETACEOUS. In botany, implies shaped like bristles.

SETON. In farriery, a small cord constitnted of a number of threads laid together and passed through the skin by a proper needle, for the purpose of keeping open an issue.

SHALOT or ESCALOT (Allium ascalonicum). Having a stronger taste than the onion, yet not leaving, as it is said, the strong odour on the palate which that species of Allium is accustomed to do, the shalot is often preferred, and employed instead, both in culinary preparations and for eating in its natural state. Each offset of the root will increase if planted in a similar manner to its parent. The planting may be performed during October or November, or early in the spring, as February, March, or beginning of April. The first is the best season, especially if the soil lies dry, as the bulbs become finer; but otherwise the spring is to be preferred, for excessive moisture destroys the sets. Mr. Henderson supports the practice of planting in autumn, and says, "if the smallest offsets are employed for planting, they never become mouldy in the ground, and are never injured by the most intense frosts." They are to be planted 6 inches asunder each way, in beds not more than 4 feet wide, being usually inserted in drills, by the dibble, or with the finger and thumb.

SHAMROCK. The national emblem of Ireland. The term "shamrock" seems a general appellation for the trefoils, or threeleaved plants. There has been much dispute as to what is the true Irish shamrock; it has generally been considered to be the clover or Trifolium repens. A writer in the Journal of the Royal Inst. No. 3, advances abundant testimony in proof of the wood-sorrel (Oxalis acetosella) being the true shamrock.

SHARE OF A PLOUGH. That part which cuts or breaks the ground. See Provak.
SHAW. A country term applied a wood that encompasses a close.

SHEARING: OF SHEEP. The cperation of cutting off the fleece or coat of wool with a pair of shears.

This is performed in different ways, but the best mode is that of the circular or rnund the sheep, instead of the longitudinal, which is now mostly in use in Britain. Shearing is usually performed about June or July, according to situation and season, but should not be done either too early or be too long protracted, as injury and inconvenience may attend either extreme. A good clipper is capable of clipping from 14 or 15 to 20 or 25 sheep in the day, and more are frequently done by very expert persons. Great care should be taken not to cut or prick the animals; but where this accident happens, in the northern parts of the kingdom, they touch the part with a little tar or sheepsalve; and in Sweden it is often done with train. oil and resin melted together. After shearing, the sheep should be turned into a warm, dry pasture. See SHép.

SHEARLING. The name given to a sheep that has been once shorn.

SHEARS. A name appliad to some instrumenis employed in agriculture. The shears used for sheep-shearing are of very ancient origin: they were termed forfex by the Romans; and it appears that no improvement has been made on the instrument. In a collection of antique gems at Berlin, called the Stosch collection, is a gem bearing a representation of a newly shorn sheep, and the shears, which are exactly the same as those now used. Shears are also employed for clipping hedges.

SHEATH. In botany, the lower part of the leaf that surrounds the stem.

SHEEP (Ovis aries, nat. ord. Ruminantia). Of the original breed of this invaluable animal, which is in modern English farming almost equally important for furnishing the farmer with a dressing of manure, and the community at large with mutton, clothing, and other almost necessaries of life, nothing certain is known. Several varieties of wild sheep have, by natu. ralists, been considered entitled to the distinction of being considered the parent stock. Of these are, 1. The musmon (O. Musimon), still found wild in the mountains of the larger islands of the Mediterranean and in European Turkey. 2. The argali (O.Ammon), or wild Asiatic sheep, which are the tenants of the highest mountains of central Asia, and the elevated, inhospitable plains of its northern portions. 3. The Rocky Mountain sheep ( $O$. montana), which is found on the mountains of North America; and, 4. The bearded sheep of Africa (O.tragelaphus), found in the high lands of Egypt, and in Barbary. It is doubtul whether sheep are indigenous to Britain, but they are mentioned as existing there at very early periods. The Romans established a woollen manufactory at Winchester, at which city the first guild of fullers was established. The natural habits of the sheep attach it to the highest ground, to the upland slopes, where the heath and other aromatic plants abound. Nature never intended this aninal to occurv 40 985 
the deep alluvial turnip lands of our rich arable farms, or to consume the succulent grasses of our water-meadows: every shepherd is aware that their natural instinct, after being for ages domesticated, still leads them invariably to the elevated portions of the field in which they are placed. All these facts tell the farmer in very intelligible language that it is change bf food, of pasturage, and, if possible, the giving them occasionally aromatic food, that will best conduce to the prosperity of his flock. With this view parsley has been successfully cultivated. Then, again, the wild sheep are found to frequent all those places where saline exudations are to be found. In common with the deer and other ruminating animals, they lick the salt clay of some of the American uplands to such an extent, that these places are denominated licks. Some of the most skilful of the English flock-masters never allow their sheep to be without salt. The female sheep goes with young twenty-one weeks, produces one, and rarely more than two at a birth; her milk yields abundance of strong-tasted cheese, but a very limited quantity of cream. The sheep, in temperate climates, is clothed with wool, which is annually renewed, but in warmer countries the animal is furnished with hair. In its wild state it has generally horns, but these have nearly disappeared in most of the breeds of domestic sheep. The domesticated sheep is known in England by different names, according to its age or sex. "The male," says Mr. Youatt, "is called a rum or tup. While with his mother he is denominated a tup, or ram lamb, a heeder, and in some parts of the west of England a pur lamb. From the time of weaning until he is shorn he has a variety of names; being called a hog, a hogget, a hoggerel, a lamb hog, a tup hog, or a teg; and, if castrated, a wether hog. After shearing, when probably he is a year and a half old, he is called a shearing, a shearling, a shear hog, a diamond, or dinmont ram or tup, and a shearling wether when castrated. Atter the second shearing he is a two shear ram or tup or wether: at the expiration of another year he is a three-shear ram, \&c., the name always taking its date from the time of shearing. In many parts of the north of England and Scotland he is a tup lamb, after he is salved and until he is shorn, and then a tup hog, and after that a tup, or if castrated, a dinmont or wcdder. The female is a ewe or gimmer lamb until weaned, and then a gimmer hog or ewe hog, or teg, or sheeder ewe. After being shorn she is a shearing cwe or gimmer, sometimes a theave or double-toothed ewe, or teg; and afterwards a twoshear or threc-shear, or a four or six-tooth ewe or theave. In some of the northern districts, ewes that are barren or that have weaned their lambs are called eild or yeld ewes." (Youatt on Shern, p. 2.)

The teeth of the sheep are in number the same as those of the ox, viz., eight incisor or vitting-teeth in the lower jaw, and six molar teeth on each side, and in each jaw.

When the lamb is born he has either no incisor teeth or only two, but before he is a month old he has eight. The two central teeth of these are shed, and again at two years old at986 tain their full growth: when between two and three years of age, the two next incisors are shed; at three years old, the four central teeth are fully grown; at four, he has six complete teeth. That the primitive breed of sheep were horned, we have direct evidence. (Gen. xxii. 13; Joshua vi.6.) Immense flocks of this animal have in all ages of the world been kept by man, but more universally for their wool and skins than for their flesh: for that is yet to many nations by no means a favourite meal. The Calmucs and Cossacks still prefer that of the horse and the camel; the Spaniard who can procure other flesh rarely eats that of the Merino; to many North Americans it is still an object of dislike. Englishmen, perhaps, consume more mutton than the people of any other country, but the taste for this is certainly of modern origin. It has rapidly extended, as better breeds and sweeter kinds of mutton have been produced.

My limits will not allow me to describe the great variety of breeds of sheep which belong to various countries; I shall, therefore, confine myself to a brief notice of those which tenant the British islands, referring those of my readers who need further information on the valuable work of Professor Youatt On the Sheep, and to Professor Low's Illustrations of the Breeds of Domestic Animals, from whence this article is chiefly taken; there is also an excellent essay upon the sheep by Mr. Ellman in Baxter's Library of Agriculiural Knowledge. Class I.-Sheep without Horns.

The new Leicester Sheep, says Mr. Youath, which comprehends the most excellent of Bakewell's own breed, and of Culley's variety or improvement on it, is precisely the form for a sheep provided with plenty of good food, and without any great distance to travel or exertion to make in gathering it. It should have a head hornless, long, small, tapering towards the muzzle. Eyes prominent, with a quiet expression; ears thin, rather long, directed backwards; neck full and broad at its base, gradually tapering towards the head, particularly bare at the junction with the head; the neck seeming to project straight from the chest, so that there is, with the slightest possible deviation, one continued horizontal line from the rump to the pole. The breast broad and full; the shoulders broad and round, no uneven or angular formation, no rising of the withers, no hollow behind the situation of these bones. The arm fleshy throughout, even down to the knee. The bones of the leg small, standing wide apart, no looseness of skin about them, and comparatively bare of wool. The chest and barrel deep and round; the ribs forming a considerable arch from the spine; the barrel ribbed well home; the carcase gradually diminishing in width towards the rump; the quarters long and full; the legs of a moderate length; the pelt moderately thin, soft, and elastic, covered with a good quantity of white wooh not so long as in some breeds, but considerably finer. The principal recommendations of this breed are its beauty, and its fulness of form: in the same apparent dimensions greater weight than any other sheep; an early matu- 
rity and a propensity to fatten, equalled by no other breed; a diminution in the proportion of offal, and the return of most money for the quantity of food consumed. (Culley on LiveSluck; Marshall's Midland Counties; Youalt on Sheep, p. 111. )

For Bakewell's views, when engaged in improving sheep, see Dishuex BrezD.

The Teeswater Sheep was bred originally on the banks of the Tees; it came from the stock of the old Jincolnshire, and, like them, it is nearly extinct. It was a tall, clumsy animal, polled, and with white face and legs; they were crossed by the Dishley sheep, because a smaller and a better breed, and few traces are now to be found.

The Lincolnshire Sheep.-Culley described the old breed of Lincolnshire sheep, half a century since, as having "no horns," white faces, long, thin, and weak carcasses; the ewes weighing from 14 to $20 \mathrm{lbs}$. per quarter, the three year old wethers from 20 to $30 \mathrm{lbs}$; thick, rough, white legs, large bones, thick pelts, and long wool, from 10 to 18 inches, and weighing from 8 to $14 \mathrm{lbs}$. per fleece, and covering a slowfeeding, coarse-grained carcase of mutton. Culley, however, ran into the opposite extreme; if the Lincolnshire farmers bred only for the wool, he regarded only the mutton. A cross between the two produced a very profitable and much improved animal.

The Cotswold Sheep have been long celebrated for the fineness of their wool. In 1467, a flock of these sheep were carried into Spain by license from Edward IV. Gervas Markham, in the time of Queen Elizabeth, describes them "as long-woolled and large-boned breed." Few of the original Cotswold breed, however, now remain; they have been gradually improved by crossing with the Leicester sheep, and it is this half-bred Cotswold and Leicester which now chiefly tenants the Gloucestershire and Worcestershire farms. The old Cotswold sheep are described by Mr. Youatt, as being taller and longer than the improved breed, comparatively flat-sided, deficient in the forequarter, but full in the hind-quarter, not fattening so early, but yielding a longer and heavier fleece. (Youatt on Sheep, p. 340.) The mutton of this breed is well described by Mr. Ellman, as fine-grained and full-sized, but capable of great improvement by proper crossing. "The Cotswold," he adds, "differ from the South Down in several particulars; the skin of the Cotswold is much thicker than the South Down; the head.long and thin; ears wide and not too thin, having no wool but a tuft on the poll; wool below the hock considered objectionable. On the Cotswold they never allow two rams to ran together." $\mathrm{He}$ thinks twin ewes have much more to do with getting twins than twin rams; both, however, should be attended to, as well as a still more important particular, their keep. (Baxter's Lib. of Agr.)

The Dartmoor Sheep.- "The short or rather middle-woolled sheep of Devonshire," says Mr. Youatt, "a few of which are still seen in South Devon, and on the greater part of the hills in the northern district, but most numerously on :he forests of Dartmoor and Exmoor, are everywhere of nearly the same character, and betray on a smaller scale a great affinity with th. Dorsets; have white faces and legs; some with and some without horns; small in the head and neck, and generally small-toned; carcase narrow and flat-sided, weighing when fat from 9 to 12 lbs. per quarter; the lleece 3 or $4 \mathrm{lbs}$. in weight in the yolk; wuol short, with a coarse and hairy top."

The South Down Sheep.-The remarks of Mr. Ellman of Glynde, in Sussex, who has done more than any one to improve the race of South Down, are so practical and clear, that what he has done so well it is useless to give in any other language; he says, when speaking of this valuable breed, "the head should be neither too long nor too short, the lip thin, the neck neither too long nor too short, but thin next the head, and tapering towards the shoulders. South Down breeders object to a long, thin neck; it denotes delicacy. The breast should be wide and deep, projecting forward before the fore-legs; this indicates a good constitution, and disposition to feed. The shoulders should not be too wide between the plate-bones, but on a level with the chine; if the shoulder. blades are wide on the top, the animal generally drops behind the shoulders. The chine should be low and straight from the shoulders to the tail; the ribs should project horizontally from the chine, for the animal will then lay its meat on the prime parts; the sides high and parallel; the rump long and broad; the tail set on high, and nearly on a level with the chine; the hips wide; the ribs circular, and barrel-shaped; the legs neither very long nor very short; the bones moderately fine." (Baxter's Lib. of Agr p. 570.)

Romney Marsh Sheep.-Towards the begin. ning of this century, Mr. Price described "the pure Romney Marsh bred sheep as distin guished by thickness and length of head, a broad forehead with a tuft of wool upon it, a long and thick neck, and carcase flat-sided; chine sharp, tolerably wide on the loins, breast narrow and not deep, and the fore-quarter not heavy nor full; the thigh full and broad, the belly large; the tail thick, long, and coarse, the legs thick, feet large, the muscle coarse, bone large. Wool long and not fine; have much internal fat, much hardihnod; requiring no artificial food during the hardest winter, except a little hay." (Youatt on Shecp, p. 334.) With all these good properties, however, the old Romney Marsh sheep has been nearly obliterated by occasional crossings with the Leicester sheep; which, by judicious managemen! (taking care not to render the breed too tender by the introduction of too much of the Leicester), has produced a sheep possessing sufficient hardiness for these bleak marshes, yet produc. ing more symmetry of form, with earlier maturity, and greater propensity to fatten.

The Cheviot Sheep are a peculiar breed, which are kept on the extensive range of the Cheviot Hills. They are described as having "the face and legs generally white: the eye lively and prominent; the countenance open and pleasing; the ear large, and with a long space from the ear to the eye; the body long; and hence they are called 'long sheep,' in distinc. tion from the black-faced breed. They are full 
behind the shoulder, have a long, straight back, are round in the rib, and well-proportioned in the quarters; the legs clean and small-boned, and the pelt thin, but thickly covered with fine, short wool: they possess very considerable fattening qualities, and can endure much hardship, both from starvation and cold. He is fit for the butcher at three years old, and at two when crossed with the Leicester." (Youat on Sheep, p. 2S5; "On crossing the Mountain and Cheviot Sheep," by Mr. Hogg, Quart. Journ. Agr. vol. i. p. 175.)

Class II. Hornen Sheep.

The Dorset Sheep._- "Most of these," says Mr. Youatt, "at least of the pure breed, are entirely white; the face is long and broad, and there is a tuft of wool on the forehead; the shoulders low and broad; the back straight; the chest deep; the loins broad; the legs rather beyond a moderate length, and the bone small. They are, as their form would indicate, a hardy and useful breed. They are good folding sheep; their mutton well-flavoured, averaging, when 3 years old, from 16 to 20 pounds a quarter. Their principal distinction and value is the forwardness of the ewes, who take the ram at a much earlier period of the year than any other species, and thus supply the market with lamb at the time when it fetches the highest price. These sheep are principally bred within a circle of 12 miles round Dorchester, where a considerable quantity of house lamb for the London market is produced. In other parts of Dorset the South Down breed prevails; except in Portland and on poor, sandy, heath soils near Warebone and Poole, where a poor smallhorned breed prevails, with black muzzles, well adapted for this locality. Their meat is tender."

The Norfolk Sheep._- "A peculiar variety of heath sheep," says Mr. Youatt, "has been found in the localities of Norfolk and Suffolk from time immemorial. The carcass was long and slender; legs long; face and legs black or mottied; face long and thin; the countenance lively and expressive of mingled timidity and wildness: taken altogether, there was more resemblance to the deer in the Norfolk sheep than has been observed in any other species. They were attempted to be improved by being crossed with the South Downs; but at length the pure South Down was generally preferred to the pure Norfolk, and, in consequence, the race is now nearly extinct."

The Merino Sheep.-This celebrated breed are, in Spain, divided into the estantes, or stationary, and the transhumantes, or migratory. 'The first are those which remain during the year in one place or farm: the last travel some hundred miles every year in search of pasture. They are thus described by Mr. Low in his excellent Illustrations of the Breeds of Domestic Animals.

"The stationary sheep consist partly of the larger sheep of the lower country, partly of unixed races, and partly of pure Merinos, which do not differ in any respect from the migratory sheep of that name, except in the method of sreatment. The stationary Merinoes are reared where the district or farm affords them sutficient food during the whole season. They are most numerous in the central countries, where the pastures are less apt to be scorched by the 988 heats of the summer, as in Segovia, and the mountain ranges to north of Madrid.

"The migratory sheep have been reckoned to amount to ten millions, which is probably equal to half the whole number of the sheep of Spain. They may be divided into two great bodies: those which are to pass further to the eastward, to Soria, or even beyond the Ebro. These vast hordes of sheep break up from their winter cantonments, south of the Guardina, about the 15th of April, and proceed chiefly northward. The rams having been admitted to the ewes in the month of July, the lambs are born in November. In the course of their journey northward, they are shorn in large buildings erected for that purpose. The western, or Leonese division, crosses the Tagus at Almaray. The eastern, or Sorian division, crosses the same river further to the eastward, at Talavera, and in its course approaches the city of Madrid. Having reached their destination, they are pastured until the end of September, when they recommence their journey southward. Each of these journeys, of several miles in length, occupies about 6 weeks in travelling. The older sheep, it is said, when April arrives, know the time of setting off, and are impatient to be gone. In the ten or twelve latter days, increased vigilance is required, on the part of the shepherds, lest the sheep should break out. Some of them do so, and pursue their accustomed route, often reaching their former year's pastures, where they are found when the main body arrives; but, for the most part, these stragglers are carried off by wolves, which abound along the course which the migratory flocks pursue.

"These migratory sheep are divided into flocks of a thousand or more, each under the charge of its own mayoral, or chief shepherd, who has a sufficient number of assistants under his command. It is his province to direct all the details of the journey. He goes in advance of the flock; the others follow with their dogs, to collect the stragglers, and keep off the wolves, which prowl in the distance, migrating with the flock. A few mules or asses accompany the cavalcade, carrying the simple necessaries of the shepherds, and the materials for forming the nightly folds. In these folds the sheep are penned throughout the night, surrounded by the faithful dogs, which give notice of the approach of danger.

"When the sheep arrive at the esquilcos, or shearing-houses, which is in the early part of their journey northward, a sufficient number of shearers are in attendance to shear a thousand or more in one day. The esquilcos consist of two large, rude rooms, and a low, narrow hut adjoining, termed the sweating-house. The sheep are driven into one of the large rooms, and such of them as are to be shorn on the following day are forced into the long, narrow hut as close as it can be packed, where they are kept all night. They undergo in this state a great perspiration, the effect of which is to soften the hardened unctuous matter which bas eollected on the fleece. They are then shorn without a previous washing, and the wool is left in the esquilcos, where it is sorted, and made ready for sale. By this arrangement 
1000 sheep, ar more, are shurn with only the delay of a day.

"The shepherds employed in tending these sheep amount to 50,000 , which, supposing there to be $10,000,000$ of sheep, is at the rate of 200 to each shepherd. 'The number of dogs is calculated at 30,000. These shepherds form a peculiar class of men, strongly attached to their pursuit, and living in a state of great simplicity. Their food is chiefly black bread, oil, and garlic. They eat the mutton of their sheep when they die or meet with accidents. In travelling they sleep on the ground, wrapping themselves in their cloaks; and in winter they construct rude huts to afford shelter. They seldom, it is said, marry, or change their calling.

"The whole of this extraordinary system is regulated by a set of laws; and an especial tribunal, termed the mesta, exists for the protection of the privileges of the parties having the right of way and pasturage. These parties claim the right of pasturage on all the open and common land that lies in their way, a path of 90 paces wide through the enclosed and cultivated country, and various rights and immunities connected with the pasturage of the flocks. The system is opposed to the true interests of Spain. A change of pasture may be required for the flocks in the drier countries at ertain seasons, but the periodical migration of so vast a body of sheep cannot be necessary to the extent to which it takes place. Enormous abuses are committed on the cultivated country as they pass along. A fourth part of the year consumed in travelling must be prejudicial to the health of the animals in a greater degree than the benefits they derive from a change of pasturage. A prodigious mortality accordingly talkes place among these sheep; and more than half the lambs are voluntarily killed, in order that the others may be brought to maturity. The sale of the lambskins, which form a subject of export to other countries, is indeed a source of profit, but nothing equal to what the rearing of the animals to their state of maturity would produce. That these extensive migrations are necessary to preserve the fineness of the wool is conceived to be an error. Attention to breeding and rearing would more certainly produce this effect than a violent change of place. In Spain itself there are numerous flocks of stationary Merinos, whose wool is of all the fineness required; and in other countries of Europe, where the sheep are never moved off the farms that produce them, wool is produced superior to that of the migratory flocks of Spain. The system is of great antiquity, and is so riveted in the habits of this ignorant and intractable people, that it is likely to be one of the last of those ancient abuses which will yield to the desire of change which at this moment agitates the feelings of men in this distracted country. The Spaniards long preserved the monopoly of this race of sheep with jealous care; but other countries at length were able to carry off the Golden Fleece of Spain, and the Merino race is now spread over a great part of Europe.

"The Merino breed, which had extended to so many countries, was at a period more recent introduced into the British Islands. George
III., a zealous and patrintic apriculturist, re solved to make a trial of this celebrated breed on his own farms, and means were laken to obtain a small Merino flock. This was done clandestinely; the animals were selereed from the flocks of different individuals where they could best be got; were driven through Portugal, and embarked at Lisbon. They were safely landed at Portsmouth, and conducted to the king's farm at Kew. 'The fluck was bad; the selection had been carelessly or ignorantly made; and the animals being taken from different flocks, presented no uniformity of cha. racters. It was then resolved to make direct application to the Spanish government for permission to export some sheep from the best flocks. The request was at once complied with; a small and choice flock was presented to his majesty, by the Marchioness del Campo di Alange, of the Negretti flocks, esteemed to be the most valuable in Spain; and in return his majesty presented to the Marchioness eight splendid coach horses. This flock arrived in England in 1791, and was immediately transferred to the royal farms, while all those previously imported were disposed of or destroyed. "On the first change of these sheep to the moist and luxuriant pastures of England, they suffered greatly from diseases, and, above all, the rot, which destroyed numbers of them ; and from foot-rot, which affected them to a grievous extent. By a little change of pastures these evils were remedied; and, after the first season, the survivors became reconciled to their new situation, and their progeny seemed thoroughly naturalized, and remained as free frum diseases as the sheep of the country. The wool was from year to year carefully examined; that of the original stock remained unaffected by the change of climate, while in that of their descendants little degeneracy could be detected either in its felting propensities or its fineness.

"The most distinguished breeders of Merinos at this time in England are Lord Western and Mr. Bennet, M. P. for Wiltshire. Lord Western's stock is either Saxon, or has been crossed by Saxon rams; Mr. Bennet's is pure Spanish, and has undergone progressive improvement by selection of individuals of the same blood. The number of his flock amounteci at one time to 7000 ; it was subsequently reduced to 3500 . It was treated in the ordinary manner of sheep in England. Lord Western's, it is believed, is managed more in the Saxon manner, with respect to protection from the weather. Mr. Bennet's fine flock, notwithstanding it had been thus acclimated, perished in great numbers in a severe winter some years ago, proving that the race had not yet lived sufficiently long in England to be perfectly inured to its cold and variable climate. Other gentlemen have imported Merinos direct from Saxony, and thus obtained at once the highest perfection of the fleece; but there is little reason to believe that their experiments will be more successful than those previously made. Merinos have lately been carried in some numbers to Ireland, and may perhaps prove more advantageous than some of the existing breeds; but this will not show the great value of the Merinos, but the 
comparatively little value of the races which they have supplanted."

The first impression (says Mr. Youatt) made by the Merino sheep on one unacquainted with its value would be unfavourable. The wool, iying closer and thicker over the body than in most other breeds of sheep, and being abundant in yolk, is covered with a dirty crust, often full of cracks. The legs are long, yet small in the bone; the breast and the back are narrow, and the sides somewhat flat; the fore-shoulders and bosoms are heavy, and too much of their weight is carried on the coarser parts. The horns of the male are comparatively large, curved, and with more or less of a spiral form. The head is large, but the forehead rather low. A few of the females are horned, but, generally speaking, they are without horns. Both male and female have a peculiar coarse and unsightly growth of hair on the forehead and cheeks, which the careful flock-master cuts away before shearing-time: the other part of the face has a pleasing and characteristic velvet appearance. Under the throat there is a singular looseness of skin, which gives them a remarkable appearance of throatiness, or hollowness in the pile: the pile, when pressed upon, is hard and unyielding; it is so from the thickness with which it grows upon the pelt, and the abundance of the yolk detaining all the dirt and gravel which falls upon it; but, when examined, the fibre exceeds in fineness, and in the number of serrations and curves, that which any other sheep in the world produces. The average weight of the tleece in Spain is 8 pounds from the ram and 5 from the ewe: when fatted, these sheep weigh from 12 to 16 pounds per quarter. The excellence of the Merino consists in the fineness and felting quality of their wool, and the weight yielded by each sheep; the ease with which they adapt themselves to the climate, the readiness with which they take to the coarsest food, their genlleness and tractableness. Their defects are their unprofitable and unthrifty form, voracity of appetite, a tendency to barrenness, neglect of their young, and inferior flavour of the mutton. (On Sheep, p. 148; Dr. Parry on the Merino sheep, Com. Board of $A g r$ vol. v. p. 337 ; Sir Joseph Banks on ditto, Ibid. vol.vi. p. 269 ; Mr. Downie on ditto, Ibid. vol. vii. p. 61.)

The Irish Sheep have been much improved by the importation of English rams. Culley describes them as ugly and ill-formed. Bodies large. Legs long, thick, crooked, and of a gray colour. Faces gray. Heads long, large flagging ears, sunken eyes. Neck long, and set on below the shoulders. Breast narrow, short, and hollow; flat-sided.

The Shetland Sheep are described by Mr. Wilson (Quart. Jour. Agr. vol. ii. p. 557) as small and handsome; hornless, seldom exceeding 40 pounds in weight; hardy, feeding on even seaweed: wool soft and cottony.

The Hebridean Sheep is described by Mr. Wil son as the smallest of its kind. Shape thin and lank. Face and legs white. Tail short. Wool of various colours, bluish-gray, brown, or deep russet. Even when fat, this sheep weighs only 20 pounds: the wool rarely weighs *ore than 1 pound.
With regard to the profitable management of sheep, it is only possible to offer general suggestions to assist the farmer. I have alluded already to the advantages of varying the food of sheep, and I shall refer at the end of this article to various important testimonials in favour of the superior profit derived from keeping sheep dry and warm. In every case they should have access to dry food, and, if possible, occasionally to those lands where heath and other plants which are indigenous to upland soils are to be found: in all cases, too, they should have access to common salt.

The importance of salt to the general health of sheep is now, in fact, generally admitted. Every farmer observes that his cattle, horses, \&c., are remarkably fond of licking the salt earth of the farm-yard, stables, \&c. In Spain, they give their sheep salt with great regularity: $112 \mathrm{lb}$. in 5 months to 1000 sheep. I subjoin the statement of the late $\mathrm{Mr}$. Curwen. $\mathrm{He}$ employed salt to his live-stock daily for years:

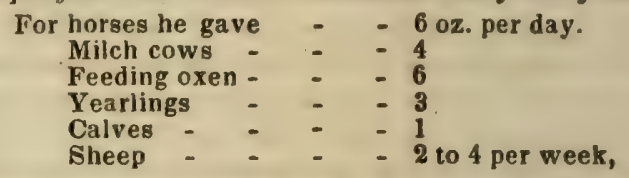

if on dry pastures; but if they are feeding on turnips or coles, then they should have it without stint. Some give it to the live-stock on a slate or stone, some lay lumps of it in the cribs or mangers. It is an asserted fact, that if sheep are allowed free access to salt, they will never be subject to the disease called the rot. Some recent experiments also lead me even to hope that I shall one day or other be able to prove it to be a cure for this devastating disease. I have room but for one fact. "Mr. Rusher, of Stanley, in Gloucestershire, in the autumn of 1828 , purchased, for a mere trifle, 20 sheep decidedly rotten; and gave each of them, for some weeks, an ounce of salt every morning. Two only died during the winter; the surviving 18 were cured, and have now," says my informant, "lambs by their sides."

The late Mr. Butcher, of Brook Hall, in Essex, for years employed salt for his cattle and sheep on his farm near Burnham, in Norfolk. One of his fields was so very unfavourable for sheep, that before he used salt he had lost 10 and 12 sheep in a night, when feeding on the turnips; but after he had adopted salt, he never lost one. He used to let the sheep have the salt without stint; and he remarked, that the sheep always consumed four times the salt on this particular field than when feeding on any other on the farm. Mr. Butcher one year let this field of turnips to a neighbour, who did not use salt; and consequently, after losing 10 sheep the first night, gave up the field in despair.

There are several points in the management of sheep to which I can only briefly allude. Coupling the male and female is too rarely attended to; and yet, by an attention to this important point, properties are added in one sex which may be deficient in the other; but extreme care is necessary in arranging this, not to introduce other points which may be still more objectionable than those attempted to be ro moved. Mr. Ellman is of opinion that twis 
getting is hereditary: "Experience," he says, "has satisfied me that a ram which may be a twin would get double the number of twin lambs than other rams." He advises that, just previous to lambing-time, the ewes should not be kept too well, but that their food should be increased a few days after parturition. Cleanliness in the lambing-yards he very properly deems to be of the greatest importance. Lambs are best castrated at from 8 to 12 days old. In the performance of this operation it is calculated that, when properly performed, the deaths do not average 1 in a 1000. Mr. Ellman recom. mends 80 to 100 ewes to each ram, or, when lamb rams are empioyed, only 40 ; and that they should remain with the ewes $\mathbf{3}$ weeks, in separate lots.

Slatistics.-The number of sheep in Great Britain has long been gradually on the increase, with the demands of an enlarging population. To this the introduction of turnips and other better supplies of winter food, which much increased the facilities for their keep, has mainly contributed. In 1698, Gregory King calculated that there were $12,000,000$ sheep in Great Britain; in 1741 the number had increased to $16,640,000$; in 1774, according to Arthur Young, the number was $25,589,754$; in 1801 , Mr. Luccock estimated them at 26,148,463. Mr. M·Culloch, in 1834, states the number to be $32,000,000$; the value of the wool 7,000,000l.; and that of the manufactured woollen articles $21,000,000 l_{\text {. }}$; and the number of persons employed in the manufacturing of these goods about 332,000 . (Youatt on Sheep; Low's Prart. Agr., and Breeds of Dom. Animals : Baxter's .Agr. Lib. ; M'Culloch's Com. Dict.)

Of the many valuable papers upon sheep dispersed through the British agricultural periodicals, I can, in this place, only give a brief catalogue. There is a letter by Mr. T. Es. court, Com. to Poard of Agr. vol. iv. p. 294, "On keeping Sheep warm when feeding," which shows very clearly the advantages of sheep being kept dry and warm when feeding, a subject not nearly so well understood as is desirable; see also "On Sheep Stells (Timber Clumps)," by Dr. Howson, Trans. High. Soc. vol. vi. p. 332 ; "On Rain-proof Feeding Troughs," by Mr. Buist, Quart.Journ. of $\mathcal{A g r}$. vol.ii. p. 114; "On Canvass Sheds for Sheep," by Mr. Munro, Ibid. vol. xii. p. 290; "On Shed-feeding," by Mr. Childers, Journ. Roy.Agr. Soc. vol.i.p. 169407; "On the Improvement of the fine-woolled Breed," Com. to Board of $\mathcal{A g r}$. vol. vi. p. 65 ; the Rev. Edmund Cartwright "On feeding Sheep on Muscovado Sugar," Ibid. p. 405; "On the Braxy in Sheep,"Trans. High. Soc. vol. i. p. 43 ; "On the Flesh Fly and Maggot," by Mr. Hogg, Ibid. p. 325, and by Mr. Mather, Ibid. vol. iv. p. 221, and Quart. Journ. of $\mathcal{A g r}$. vol. i. p. 210. "On Salving Sheep," by Mr.J. Graham, Ilid. vol. ii. p. 243; this salve is composed of $7 \mathrm{lb}$. of rosin, $17 \mathrm{lb}$. of butter, $16 \mathrm{lb}$. of nalm oil, 2 chopins of fish oil: and by $\mathrm{Mr}$. Harkness, Ibid. vol. iv. p. 125. "On the Loupingill," by Mr. Tod and Mr. Laing, Ibid. vol. iii. p. 73; "On the Foot Rot," by Mr. Hogg and the Rev. H. Riddell, Ibid.p. 307; by Mr. Dick, Quart. Journ. of $A g r$. vol. ii. p. 852, and by Mr. Back, Ibid. vol. iii. p. 654; "On Blindness in
Sheep," by Mr. M'Farlane, Trans. Migh. Sor. vol. iv. p. 393; "On Rabies," by Mr. Dickson, Ibid. vol. vi. p. 261; "On certain Dismases of Sheep (the Pining, Scab, \&c.)," by Mr. Hogg, Quart. Journ. of $\Lambda g r$. vol. ii. p. 6.97; "On the Origin and Natural History of the Sheep," by Mr. Wilson, Ibid. p. 354-536; "On drafing Sheep," Itoid. vol. iii. p. 1005; "On the acnte Dysentery," by Mr. Dick, Ibid.vol.p. 411; "On the Rot," Ibid. p. 503; and vol. vi. p. 117; "On the Physiognomy of Sheep," It/id. vol. x. p. 298; "On different Breeds, and on feeding and dressing Tups," by Mr. Hogg, Itid. vol. xi. p. 105-108; "On a peculiar Affection of the Liver in Ewes," by Mr. Buckley, Journ. Roy. $\mathcal{A g r}$. Sor. vol. ii. p. 116. See Foon, MaAt, Mct. ToN, Woor.

All the best varieties of sheep known in Europe have been introduced into the United States, where the raising of sheep, both for the profits of carcass and wool, is a highly productive branch of agriculture. The num. ber of sheep in the United States, in 1840, was estimated at about 20,000,000. Immense num. bers of these are raised in the high and cool districts in Northern Pennsylvania, New York, and the Eastern States. Various American agricultural periodicais contain valuable observation in regard to sheep in the United States. Jonathan Roberts, Esq., a veteran farmer of Montgomery county, Pennsylvania, who has taken much interest in this kind of stock for the last half-century, has favoured us with the following valuable observations:

"Many of the diseases which prevail among sheep in Britain are little known in this part of the United States, where the air is drier. Such air, associated with a broken and even mountainous country, seems best adapted to the breeds of this animal. Farly in my experience I witnessed the renovation of a flock of what we call country sheep, that had been too long propagated in the same blood. This was about the year 1789. An imported ram from England, with heavy horns, very much resem. bling the most vigorous Spanish Merinoes, was obtained. The progeny were improved in the quality of fleece and in vigour of constitution. On running this stock in the same blood for some 12 years, a great deterioration became apparent. A male was then obtained of the large, coarse-woolled Spanish stock; improvement in the vigour of the progeny was again most obvious. A Tunis mountain ram was then obtained, with a result equally favourable. In this process, fineness of fleece or weight was less the object than carcass. In 1810, a male of not quite pure Merino blood was placed with the same stock of ewes; and a change of the male from year to year, for some time, produced a superior Merino stock. Wool of a* marketable quality for fine cloths was now the object, and it was not an unprofitable husbandry, when it would sell in the fleece unwashed, from 86 cents to $\$ 1$. The Saxon stock then became the rage, and the introduction of a tup of that country diminished grcally the weigh. of the fleece, without adequately improving its fineness. A male of the Spanish stock would! give sometimes $9 \mathrm{lbs}$, and the marsh graziers say that they went so high as 15 lbs. Sarnn maja. 
scarcely exceed $5 \mathrm{lbs}$, and the ewes $2 \frac{1}{2} \mathrm{lbs}$. By running in the same blond, and poor keeping, the fleece may be made finer, but it will be lightened in proportion, and of a weak and infirm texture. There are few stock-keepers who have mixed the Spanish with the Saxon breeds but what either do or will have cause to regret it. In this part of the country a real Spanish Me. rino is not to be obtained. Sheep-raising has ceased to be a business of any profit nearer to the maritime coast than our extensive mountain ranges, whether for carcass or fleece. I sold, the last season, water-washed wool of very fine quality; for 30 cents per $1 b$. At such a price for wool, land near our seaports can be turned to better account, even in these dull times, than wool-growing. Stock-sheep do best in stony and elevated locations, where they have to use diligence to pick the scanty blade. Sheep on the seaboard region should be kept more for carcass than fleece: and feeding more than breeding, ought to be the object for some 100 miles from tide-water. It is now a well ascertained fact, that health and vigour can only be perpetuated by not running too long on the same blood. The evils I have witnessed were due to a want of care on this head more chan to any endemical quality in our climate. Sheep kept on smooth land and soft pasture are liable to the foot-rot. I have found this readily relieved by a little spirits of turpentine or salted grease and tar, or tar only. The hoofs of the Merino require paring occasionally, for want of a stony mountain-side to ascend. It is no longer a problem that this is to be a great wool-growing country as well as a wool-consuming one. There is, in our wool-growing country, land in abundance, held at a price that will enable the wool-grower to produce the finest qualities at 30 cents per lb., the cloths to be manufactured in proportion, and the market to be steady. I have seen Merino wool since 1810 range from $\$ 1$ per $l b$. to $18 \frac{3}{4}$ cents, though I do not recollect selling below 22 cents. The best variety of sheep stock I have seen, putting fineness of fleece aside, was the mixed Bakewell and South Down, imported by Mr. Smith, of New Jersey. The flesh of the Merino has been pronounced of inferior flavour. This, however, does not agree with my experience, as I have found the lambs command a readier sale than any other, from being preferred by consumers."

In regard to the particular distribution of sheep through the several states, we find, according to the returns accompanying the census of 184.0 , that there were in Maine, 649,264; New Hampshire, 617,390; Massachusetts, 378,226; Rhode Island, 90,146 ; Connecticut, 403,162; Verinont, 1,681,819; New York, 5,118,777; New Jersey, 219,285; Pennsylvania, 1,767,620; Delaware, 39,247; Maryland, 257.922 ; Virginia, 1,293,77\%; North Carolina, 538,279; Tennessee, 741,593; Kentucky, 1.008,241; Ohio, 2.028,4.01 ; Indiana, 695,982 Lilinois, 395,672; Missouri, 348,018.

SHEEP, DISEASES OF. Apoplexy.-Bleed coniously; then give 2 ounces of Epsom salts in a quarter of a pint of water.

Blackuater.-Keep the bowels open with Ep-

som salts; and give a tea-spoonful of elixir of vitriol, or sulphuric acid, diluted with 7 parts of water, in an infusion of oak bark.

Blackmuzzle.-Mix an ounce of verdigris (acetate of copper), 4 ounces of honey, half a pint of vinegar; simmer them together over a fire for 10 minutes in an earthen pipkin. Apply it to the mouth on a piece of rag.

Cough, or Cold.-Bleed; give a solution of Epsom salts.

Diarrhad. See Calves, Diseases or.

Dysentery. See Diarrнé.

Fly.-Fly powder: Two pounds of black sub phur, half a pound of hellebore; mix them together, and sprinkle the sheep from the head to the tail with a dredging-box. Sheep wash: The farmer will find this an excellent recipe : Half a pound of powdered white arsenic (arsenious acid), $4 \frac{1}{2}$ pounds of soft soap. Beat these for a quarter of an hour, or until the arsenic is dissolved, in 5 gallons of water. Add this to the water sufficient to dip $\mathbf{5 0}$ sheep. The quantity of arsenic usually recommended is too large.

Foot Rot.-One drachm of verdigris (acetate of copper), 1 drachm of blue vitriol (sulphate of copper), 1 drachm of white vitriol (sulphate of zinc), 2 ounces of water, 2 drachms of nitric acid, 2 drachms of butter of antimony; pare away the horn, and apply the lotion upon a feather to the part affected.

Redwater. See ReDWATER.

Rot. See Rot.

Scab, or Schab.-Apply a lotion formed of 1 ounce of corrosive sublimate, 4 ounces of sal ammoniac, dissolved in 4 quarts of rain-water. This is a powerful stimulant, and must be used with caution.

Ticks. See Fry.

Wounds.-Wash the part, and apply a lotion formed of vinegar 1 pint, spirits of wine 1 ounce, spirits of turpentine 1 ounce, Goulard's extract 1 ounce. If the wound be a recent one, it is better to stitch it up with separate liga. tures, which can be easily withdrawn, and dress with cold water.

SHEEP-FOLD. A yard or other contrivance for the purpose of confining and keeping sheep during the nights or in bad weather, in order to afford them protection and shelter. They are sometimes fixed, being constructed of any convenient sort of light material, so as to enclose a space in proportion to the number of sheep, which is kept constantly well littered with some dry substance, such as stubble, refuse straw, dry sand, \&c., during the time the sheep are folded and foddered in them, in order that as much manure may be raised as possible. In some cases, also, for the more perfect protection of the sheep, they have sheds all around them, under which the sheep may lie without injury from rain, snow, or any sort of moisture. These usually are termed standing folds, and are either formed about the homestead or on some dry, rather elevated situation on the farms, having the bottoms well laid with some sort of material that is capable of keeping the sheep dry and clean. See Foun, Ford. ING, and HuRDer.

SHEEP-HOUSE. A slight wooden building constructed for the purpose of containing and protecting sheep in bad weather, \&c Houses 
of this kind are usually made low for the sake of warmth in the winter, being mostly a thirr part longer than they have breadth: they should also be sufficiently large for the quantity of sheep that they are to contain. The side should be lined with boards, and the bottoms be laid in an even manner with stone or some other material, that the litter may be well impregnated with the urine of the sheep. The sides exposed to the sun should be lined with movable hurdles, that when it shines the whole may be laid open, to give due refreshment and afford the sheep an opportunity of feeding upon the pasture wherein they stand. They should be well and securely covered with some sort of proper material upon the tops. They are sometimes fixed in particular situations; but in other cases, which is the more improved method, so constructed as to be capable of being removed as they may be wanted.

SHEEP-PENS. The divisions made by the small movable gates or hurdles which are set up to keep sheep in some particular spot. They are usually formed on a dry place about the corners where different enclosures of the pasture meet, so as to be convenient for the whole. Pens are useful for examining and selecting the sheep, being divided so as to contain about 3 dozen sheep each, as by this means they are always at the command of the shepherd for any purposes he may have in view. The bottoms should be firm and dry, so that the sheep may not be soiled.

SHEEP-S'TEALING. By the 7 W. 4 , \& 1 Vict. c. 90, every person convicted in England of stealing any horse, mare, gelding, colt, filly, bull, cow, heifer, ram, ewe, sheep, or lamb, is liable to be transported for a term not exceeding 15 years, nor less than 10 years; or be imprisoned for any term not exceeding 3 rears.

SHEEP'S SORREI، (Rumex acetosella). perennial species of dock, which in England is found growing abundantly in dry, gravelly fields and pastures. The herb is acrid, with some astringency. The root is creeping. The stem wavy, slender, often decumbent. The flowers are diœcious, smail, separate, in numerous whorled leafless clusters. The leaves lanceolate-hastate above, but hastate in the lower part of the stem. The acid which they contain is the oxalic, combined with potassa, as a binoxalate; but it is less used than its fellow-species R. aretosa. See SorREI.

Dr. Darlington informs us that there are in the United States 10 or 12 additional species of sorrel, but it is difficult to say how many of these are indigenous.

SHEPARDIA, SILVER-LEAVED. See BvFFALO BERRY.

SHEPHERD. The person who has the care and management of a flock of sheep. Mr. Bannister says, that it is necessary to have for this employment " a person who is well skilled in the nature and management of sheep, and hath been brought up in that employment from his infancy; who is sober, diligent, and good-natured; qualities essentially necessary in a shepherd, who, although he may seem to lead a life of indolence, when contrasted with the more laborious servants of the farm, need rarely to have a minute's time hang heavily on his hands, if he will be altentuve 16 his business. which will furnish him with stsfle: rent ein p! wy. ment throughout the day, particularly in the lambing season, or where there are two folls a: work; nor will he want opportunily fur the exercise of his patience and gond temp.r. in his attendance on the sheep, which is by nature an animal of great obstinacy and perversenes. and hath often paid the forfeit of its life to thes. innate qualities, where the shepherd was a man of a morose and surly disposition."

SHEPHERD'S NEEDLE (Scandex Peclen Veneris). This is a troublesome annual weed. very common in cultivated fields in England. The root is tapering. The fruit is nearly smooth, with a bushy edge, having a beak from 1 to 2 inches long; whence the specific name.

SHEPHERD'S PURSE (Thlaspi, from thlao, to compress; the seed-vessels are compressed). In England this is a genus of worthless plants, the principal species of which is the common shepherd's purse ( $T$. bursa pastoris), which occurs in almost every part of the globe. It is an annuai plant, with a tapering, whitish root, having a peculiar smoke-like scent. 'The herbage is rough, with prominent hairs. Stem branched, leafy, from 6 to 12 inches high. Ra. dical leaves deeply pinnatifid. Flowers small, corymbose, often tinged with purplish-brown. Pouch inversely heart-shaped, somewhat triangular. Seeds about 5 or more in each cell. Small birds eat the seeds and flowers.

SHEPHERD'S S'TAFF. See TrasEL.

SHERARDIA (named by Dillenius in ho. nour of his patron, W. Sherard, LL.D., consul at Smyrna). This is a genus of uninteresting plants. One species, the blue sherardia, or little field-madder ( $S$. arvensis), is indigenous to England, where it grows in fallow fields, or among corn, on a light or gravelly soil. The plant is annual; herbage generally hairy; stems several, branched, spreading, mostly decumbent, 3 to 6 inches long. Leaves whorled, pale-green. Flowers pale purplish-blue, in a sessile terminal umbel.

SHERDS. In gardening, fragments of earthen pots, \&c., employed to drain the soil supplied to potted plants, and also as under-draining for gravel walks.

SHIFTS. See Rotatyon of Crops.

SHIM. A tonl of the tillage kind, used in breaking down and reducing the more stiff and heavy sorts of land, as well as culting up and clearing them from weeds. They are made of different forms and constructions, to suit different purposes.

SHOCK. See SHuck.

SHOREWEED (Littorella, from liltus, the shore, in allusion to its place of growth). The plantain shoreweed (L. lacustris) is a prettr little perennial sub-aquatic, indigenous to England, flowering in June. It has no stem; but the root, which is fleshed and tap-shaped, throws up many long, linear, channelled leaves. The flowers are whitish-green.

SHOR'T-HORNS. See CatrL.

SHRUB. A small, low, dwarfish, wody plant, resembling a tree, which. instead of one single stem, frequently puts forth from the 
same root several sets or stems. The most hardy, indigenous shrubs are the box and ivy, which resist the severest winters. Next, in point of hardiness, are the holly, juniper, and furze; but there are besides numerous ornamental shrubs, well calculated to diversify parks and lawns.

SHUCK. A husk or shell. In husbandry, it also signifies a shock or stouk of 12 sheaves of corn set up together in the harvest field. See Reaprag.

SHY. In norsemanship, the starting suddenly aside of a horse.

SICKLE (Sax. ricol; Dutch sickel; from Lat. secale). A hook with which corn is reaped. See Reaping-Hook, Scythe, \&c.

SILICA. The name of the earth which forms almost the entire substance of common sand or silex, and also of quartz and flint. Potash renders silex soluble in water, and capable of entering into the sap of plants. Hence one of the great advantages of potash as a fertilizer, especially adapted to wheat, which demands much silica, as well as potash, in the soil. Silica enters into the composition of all plants, forming the shining outer coating of straw, corn-stalks, reeds, grasses, \&c. See Earths; Mixture of SorLs; ANaLYsis.

SILK CULTURE. The United States being, like China, situated on the eastern side of a sreat continent, offer peculiar advantages for the production of silk. From the general predominance of westerly winds in extra-tropical regions, the eastern sides of continents in these possess a dry and warm summer climate, peculiarly adapted to the prosperity of the silkworm. In Europe, the region of the silk-culture is confined to the southern portions, and comrnences at a distance from the sea, on the eastern side of the mountain ridge of the Cevennes. These mountains offer a barrier to the moisture borne far inland by the prevailing westerly winds sweeping from the Atlantic. In the United States the prevalence of the same winds keeps off a large amount of the moisture from the sea, and leads to a comparatively dry atmosphere. So far as this characteristic of climate is concerned, the culture of silk may be extended to the very shores of the Atlantic. At various times attempts have been made to introduce it into the United States, but it is only within a very few years past that the subject has received the attention which it merits as an important and most valuable agricultural resource. Among other obstacles which have tended to prevent the developement of the silk culture, the comparatively tardy growth of the ordinary kinds of mulberry trees cultivated for feeding the silk-worm has been not the least, since where immediate sources of profit exist in other products of the soil, few will engage in enterprises, the profits of which have to be so long anticipated. The introduction of a new kind of mulberry, the Morus Mulicaulis, a tree of rapid developement, having in a great measure removed the obstacle referred ii), the silk culture has, to a greater or less degree, been introduced from one end of the sountry to the other. Strange as it may seem, the Eastern States, with a comparatively rigor:994 ous cliriate, have heretofore been almost the sole prolucers of domestic silk as an object of profit. In some of the townships of Connecticut and Massachusetts, silk has for many years been an object of domestic culture; but this was carried on to great disadvantage, the cocoons having been usually wound off upon common wheels, and spun into sewing silk. No such thing as a regular filature for converting co. coons into reeled silk, and thus preparing it for being woven into different fabrics, existed in the Eastern States; so that, instead of using only the refuse cocoons in making sewings, the very best were thus appropriated. The introduction of suitable reels for winding off silk and placing it in the best form for mercantile purposes, has been comparatively slow, owing in a great degree to the introduction of many contrivances intended to curtail labour by wind ing immediately from the cocoons and twisting by the same process into sewing silk. Most or all such contrivances have proved very unprofitable, and have yielded, or may be expected to yield, to the simple but effective operation of the Piedmontese recl, the most perfect of all devices for taking silk from the cocoons, and placing it in the best forms for market. Many very skilful reelers have been made in various filatures in the United States. Although in every part of the Union the mulberry can be reared, and the silk-worm successfully fed, still it cannot be doubted that the southern portions of the Middle, and all the Southern States, afford peculiar advantages to the silk culture. An agricultural resource, which in France and other countries is so highly appreciated and fostered with so much zeal by the government, by the establishment of model filatures, and the zealous attentions of men of skill and science, should be regarded as well worthy the protection of the general and state governments of the Union. Many states already allow liberal premiums for cocoons and raw silk produced within their borders, and these inducements to individuals should be continued until the silk culture becomes fairly established as a regular branch of rural labour; after which it will, like most other branches of industry once fairly set on foot, take care of itself.

Large crops of cocoons were last year produced in Pennsylvania, Ohio, Kentucky, Tennessee, and Indiana. The comparatively small cost of conveying to market an article so highly valuable as silk, should encourage its culture in districts from which the heavy and bulky products of agriculture cannot be transported so as to leave a fair profit to the producer. In Ohio many thousand yards of silk stuffs were woven in 1842 , the manufacturers paying for the cocoons about $\$ 4$ per bushel. The culturists find their advantage in having the silk reeled from the cocoons into organzine, instead of the formerly unprofitable mode of turning the most valuable silk into sewings. American raw silk, when properly reeled, is superior to that generally produced in Europe: A person who had been many years engaged in weaving silk in different establishments in London, having had (as he says) for 15 years from 250 to 300 lbs. of the raw material, of 
every grade and name, passing through his hands weekly, expresses the following opinion relative to silk produced in the United States:

"I am qualified to affirm, from various experiments I have tried, that the silk is superior to any I have seen from Italy, China, France, Piedmont, or Valencia, where the worms are fed upon multicaulis, or Italian. Its brilliancy, strength, and scent are superior. I am aware that an exposure to the saline air, in the passage across the ocean, may be the cause of the loss of fragrance to imported silk; but the brilliancy is peculiar to American silk, if reeled in a proper manner, with cleanliness.

"I am confident that the mammoth sulphur. worm is the pure Fossam brown. To try this, I had about $3 \mathrm{lbs}$. of silk reeled, and enclosed it in an air-tight box for 3 weeks. When I took it out it had the fragrance of the Fossam brown stronger than any that I ever smelt in England, which convinced me that the mammoth sulphur is the identical silk which is always from 5 to 8 shillings per pound higher than ordinary silk. The mammoth white and the peanut white is a Novi, and superior to any I have seen in England. The yellow or orange I cannot, satisfactorily to my own mind, yet define, but am trying experiments in order to ascertain. I am strongly persuaded it is a Bergam. Should this be the case, it will prove a great acquisition to manufacturers of silk velvet. Some have supposed the pea-nut white is the Piedmont, but they are mistaken. The Piedmont cocoon is lily-white, very diminutive, with a sharp point."

Where legislative patronage has been exiended in the allowance of bounties on cocoons and raw silk, the state treasuries may be referred to as criterions showing the increase or diminution of the silk crop with great precision. The treasurer of Massachusetts has furnished the following report, indicating how the matter stands in that state:

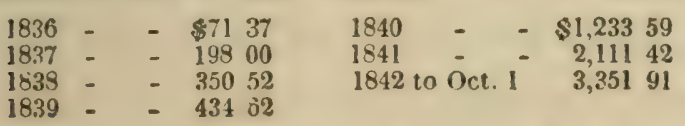

"Another consideration, calculated to urge the business forward," says the Northampton Silk Convention, "is found in the fact that all our present agricultural staples are now extremely depressed, and are likely to remain so. The market is completely glutted. Our farmers must take up something new, or their sufferings will be prolonged indefinitely. In this crisis, silk comes to their aid. In the production of this article they cannot glut the market for one whole generation, most assuredly."

Without desiring to excite undue expectations, it is a question which deserves serious consideration, whether much more may not be realized from the prosecution of this business than has hitherto been? The little town of Mansfield, in Connecticut, by a persevering devotion to it, undiscouraged by the ill-success of others, has been enabled to derive therefrom a good profit; and it appears from the last census that, with a population of 2276 , not less than $\$ 20,000$ is annually received from this business.

The bounty paid in Ohio, in 1841, amounted io \$2681 76; in Pennsylvania \$1418 55. In 1842 there was paid as bounty, in Ohio, $\$ 6699$ 61. The whole amount of rer!ed silk produced in Ohio is set down at 3000 prounds. One person sold 300 pounds of reeleil silk for $\$ 1600$. The whole aggregate of the silk crop throughout the United States, for 1842, is given in a tabular view, by Mr. Ellsworih, at 244,124 pounds of cocoons. (Ellsuorth's Rrpore to Congress.)

Under the head of Murnsanx, some observations have been made in relation to the varieties of the tree best adapted to the silk culture in the United States. Besides the numerous communications to be found in most of the American periodicals devoted to agriculture, and some specially to the silk r,ulture, many excellent original treatises have been written upon the same subject. Among the last we may name the essay published under the auspices of P.S. Duponceau, Esq., of Philadel. phia, one of the greatest champions of the legitimate silk culture that the Union has produced. By legitimate silk culture, is meant the employment of the Piedmontese reel, the use of which is absolutely necessary to give the product of the cocoonery its proper value. The work thus referred to is a duodecimo printed in Philadelphia, and bears the name of M. d'Homergue. It is particularly useful in relation to the subject of the Piedmontese reel. A summary of the principal Chinese treatises on the culture of silk, \&c., was published, in 1838, by P. Force, Esq., Washington. An excellent Treatise on the Mulberry Tree, and the Production and Manufacture of Silk, was published in Philadelphia, in 1839, by $\mathrm{Mr}$. John Clarke. Several Manuals on the silk culture, furnishing abundant information, embracing the most minute details, have been published by Roberts, Cobb, Kenrick, Comstock, Clarke, \&c., \&c. Among the periodicals specially devoted to the subject, the Silk Culturist, edited by F. G. Comstock, of Hartford, Connecticut, in 1835-6, and the Burlington Silk Record, by E. P. Morris, may be mentioned. In the latter are given the interesting views of Mr. Morris, with a description of his newly invented and valuable feeding-shelves, together with the results of many experiments in raising worms upon an extensive scale.

SILK-GRASS or BEAR-GRASS. See YUCCA.

SILK-WEED. See Cotros, Wird.

SILLS. A country name for the shafts of a cart, \&c.

SILVER BELL. See Haresia.

SILVER FIR. See Fir and PIYs.

SII.VER-WEED, or WILD 'TANSEY ( $P$ o tentilla anserina). An indigenous perennial plant, which, according to Linnaus, indicates clay under the surface. Although it is foutnd frequent in osier holts and spongy meadows, it grows most commonly upon cold, stiff land, and is a sure mark of the sterility of the soil. Flowers large, bright-yellow, the calyx hairy; and each on a long, simple stalk, mostly erech blowing all the summer. See Crrecsforl.

SINCLAIR, GEORGE. An able and sue cessful writer and experimentalist on the aru ficial and other grasses. He carried on a to 
ries of valuable researches on these in the grass garden at Woburn Abbey, under the direction of the Duke of Bedford, the results of which he gave to the world, in his justly celebrated work, the Hortus Gramineus Woburnensis. $\mathrm{He}$ also edited a fragment of a work of $\mathrm{Mr}$. Holdich on The Wecús of Agriculture. He died in 1835 , in the $52 d$ year of his age.

SI'T-FAS'T. In farriery, an ulcerated sore in which a part of the skin has turned horny; if it cannot be dissolved and softened by rubbing with mercurial ointment, it must have a mild blister applied, which will cause it to separate. It generally proceeds from a warble or little tumour resulting from the pressure of the saddle. See Bacr-Sore and Galls.

SIZE. See Glue.

SKEGS. A kind of oat, sometimes cultivated as a crop in Nottinghamshire. It is the Avena stipiformis of Linnæus. See OATs.

SKEP. A coarse, round, farm-basket. It is also provincially used to signify a bee-hive.

SKID. The chain by which the wheel of a wagon is fastened, so as to prevent its turning round, upon descending a steep hill. See Drat.

SKIM COUlter. See Plough.

SK UN K-C A B B A GE ; Swamp-cabbage ; Skunk-weed. Familiar names applied to a plant common in 1ow grounds in the United States. It is the Symplocarpus fotida of some botanists, and the Pothos fotida of others. It has a perennial root, and very large leaves, often, when fully grown, measuring 2 feet long and 1 foot wide. "This plant," says Dr. Darlington, "is notorious for the pole-cat-like odour which it emits, when wounded; and is said to possess some medicinal virtues, as an antispasmodic. The root, when chewed, produces a tingling or pricking sensation in the mouth. It is the only species of the genus in the United States: Dr. Barton, however, describes a pretty distinct variety, near Philadelphia."

SLATE. A well-known, neat, convenient, and durable material for the covering of the ruofs of buildings. There are many varieties of slate, and it likewise differs very greatly in its qualities and colours. In some places it is tound in thick lamina or fiakes, while in others it is thin and light. The colours are white, brown, and blue. Slate is so durable in some cases as to have been known to continue sound and good for centuries.

SLAUGHTER-HOUSE. See Aватton.

SLEET. See Svow.

SLOE. The American species of sloe belong in the viburnium family, and are not to be confounded with the black hedge thorn. See

BrackTHORY.

SI,OUGH-HEAL. See Serf-heal.

SLUG. A genus of molluscous animals, or naker snails, comprehending several species, which differ only in colour. Slugs infest gardens and fields, and are very injurious to the growing srops; hence it becomes essential to destroy inem. Dry lime and slacked lime have been recommended, which, being dissolved by the dew and moisture of the atmosphere, act as a poison to these animals. But pulverized lime is not suitable to all soils, and may even prove injurinus to some crops. Lime-water appears to be preferable. But as many husbandmen may not have an opportunity of liming their fields or gardens, or of keeping a sufficient stock of geese, fowls, ducks, \&c., to turn in and devour the slugs, common salt will be found an effectual cure; and tar-water or other refuse of gas-works will prove destructive to them, if sprinkled on the land. See Insects and Svails.

The disgusting slug infesting pear and cherry trees in the United States is a slimy false caterpillar, the nature and characteristics of which, and the parent-fly, are particularly described by Professor Peck and Dr. Harris. See SAW-FLIES.

SMALLAGE PARSLeY. See Cerent, WILD.

SMITHFIELD. The principal market for the sale of live cattle in the United Kingdom. It is very inconveniently situated in the heart of the metropolis. The numbers of cattle slaughtered have been more than double dur-

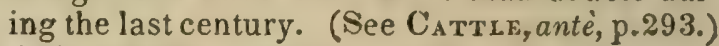
Although this increased consumption is scarcely proportioned to the increase of population, it should be remembered that a very differen description of cattle are now slaughtered to what were then killed. The present average dead weight of the bullock is about $656 \mathrm{lbs}$., of the calf $144 \mathrm{lbs}$, of the pig $96 \mathrm{lbs}$, and of the sheep and lamb $90 \mathrm{lbs}$; ; approaching to double the weight of these animals in 1730. This renders the number of cattle slaughtered in the metropolis, and the increasing number of the inhabitants, a little more proportionate. From this estimate, and the number of cattle sold in Smithfield market in the year 1830 , we may now form some not very inaccurate idea of the amount of this branch of the provision trade in London.

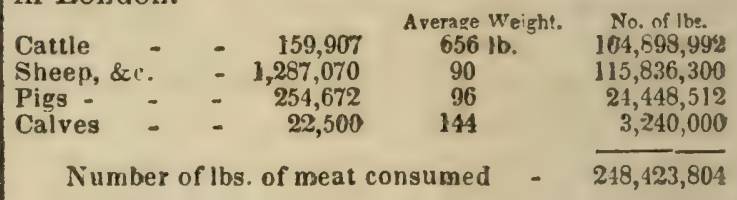

This, estimated at the average price of $6 d_{0,}$ would be $6,210,595 l_{\text {. }} 2 s_{0} 0 d_{\text {. }}$; at $8 d_{\text {. }}$, it would produce $8,268,293 l .9 s .4 d$., exclusive of bacon, hams, and all salted provisions brought from a distance (the importation of Irish bacon and hams into Great Britain is 500,000 cwt.), and also fish and poultry. 'This calculation will enable us to determine another curious question,-what is the average quantity of meat consumed by each individual in the course of a year? If we divide the gross number of pounds, $248,423,804$, by $1,450,000$, the estimated number of inhabitants in London and its environs, the quotient will be 170 , or each individual consumes nearly half a pound of meat every day. This is a very high calculation compared with that of Paris, where each person is supposed to consume but 80 pounds in the year; and Brussels, where 89 pounds form the allotinent of each; but the English is a meat-eating poprlation, and composed chiefly of Protestants; and when we remember that this includes the bones as well as the meat, half a pound a day is not too much to allow to each person.

Cattle are sent from every part of the king. 
dom to Smithfield market, but many more from some districts than from others. The farmer has personally little to do with the sale of his cattle, but custom and interest induce him to consign them to a salesman, who is acquainted with all the butchers and dealers of the district, and with the contractors. He sees at a glance what is the state of the market; he can tell whether it is likely to rise or fall; and comparing the lot which is intrusted to him with others, and with the market generally, he knows what they ought to fetch. The salesmen are generally honourable men; they procure for the owner the value of his cattle under all the circumstances of the market, and although it may not always be so much as the grazier had expected, it is more than he could have got himself, and he is always sure of receiving his money. See Pourtri, Sherp, Swink, \&c.

SMU'T. A disease affecting almost every species of corn, the grains of which become filled with a fetid black powder, instead of containing farinaceous matter. Wet seasons, an imalculx, organic weakness, deficiency of the parts of generation, and other circumstances, have been assigned as the primary causes of this disease, but all the results of experience are against the opinion that these are more than contingencies which aggravate the symptoms, and accelerate the progress of the infection. That the smut does not arise from a deficient fecundity is apparent, because it affects and destroys the grain long before the sexual organs are fully developed. Fogs, exposure to intense sunshine when moist, or other atmospheric influences upon the ear after it has been protruded, have been assigned as causes; but these cannot be productive of the mischief, for the disease has been observed during an early stage of the vegetation of the ear, and long before it has escaped from the leafy enrelopes; this also dismisses the opinion entertained by some that the disease occurs after the grains are fully formed. It does not arise from the too abundant moisture of the soil, because I have universally observed that the driest parts of a field are as liable to bear an infected grain as the most wer; and we all know that an infected plant stands surrounded by others entirely untainted. Some persons have thought that insects are the origin of the disease; but the most accurate observations have refuted this opinion, and shown that the diseased grains may be an agreeable nidus for the larva, but that these always appear after the disease is matured. Upon examining some of the diseased grains, Mr. R. Somerville found upon them a minute insect, in form like a wood-louse, which I know from observation to be a species of the acarus, and these he considered the cause of the disease. But this is a conclusion unwarranted by observation, for similar vermin are found upon the roots of the Brassica tribe that are infected with anbury; and, indeed, this genus of insects is invariably found upon decaying vegetable matter; it is their habitat.

Other persons have thought that the grains injured by the process of thrashing are most liable to the disease; but this is refuted by the fact that it appears in some years, and is scarcely to be detected in others. The Rev Dr. Ilales bruised numerous grains of wheas of different sizes with a hammer, but the resuls convinced him that this opinion is crruneous. Wolfins thought it arose from a monstrosity of the embryo; but M. Cymen has shown that the male nowers of some plants suffir froin smut as well as the female, and the furmer we know have no embryo.

Some farmers have considered thit pigeons. dung induced the disease, but general experience is against this idea. Nur is the disease the consequence of any defect of the sap, for all the parts except the ear are healthy; and there are some plants, observes M. Cymen, having perennial roots, and which are vigorous, yet their seeds ire annually attacked with this disease.

Having thus disposed of the several causes which have been erroneously assigned, I will now proceed to detail the more correct knowledge that has heen accumulated respecting this plague of our corn crops.

This disease is severally termed smut, dustbrand, blighl, burnt corn, \&c. In France it is commonly known by the names of charbon and nielle volante. Botanists, aided by the microscope, have discovered that the cause of smut is a parasitical fungus, which preys not only upon the sap, but destroys the very organic structure of the grain and chaff upon which it fixes. 'The majority of naturalists agree in distinguishing the fungus by the title of Uredo segetum; but as it has oiher synonymes, these, and the authors who have employed them, may be usefully enumerated. Uredo segetum, Pursh, n. 27; Chaos ustilago, Lin. Syst. Nat. 1326, n. 4; Réiculaire des blés, Bulliard's Fungi, vol. i. p. 90 , plate 472, f. 2. Reticularia segetum, Withering, iv. p. 388. Churbon, Tessier, Des Maladies des Grains, 299. Bulliard describes this fungus as globular, extremely fine, and attached to a tine elastic thread. They are exceedingly numerous, enveloping the seed and chaff of the plants they affect, and are, as well as their nun still more minute seed, of an intense black colour, having a disagreeable fetid smell, which has been not inaptly compared to stale lobsters. Mr. Kirby tells us that Mr. Lathbury examined the dust of this fungus under a powerful magnifier, and found it consisted of numerous minute particles, uniform in shape and size, much smaller and blacker than those of the pepper brand, and less easily separable: they seemed to be contained in little irregular cells. This dust or seed is the food of a small, shining, black insect, the Dermestes ata of Marsham.

Chemical analysis has demonstrated tha? this fungus effects an entire decomposition of the vegetable particles of the grain it infects. the saline constituents remaining nearly un altered in the grain. Parmentier, Cornet, Girot, Chantians, Fourcroy, and Vauquelin, have successively examined it, and the resuli of their researches is, that smutted grains of wheat are composed, Ist, of about nne-third their own weight of a green, butyracesus, fetid and acrid oil; $2 \mathrm{~d}$, nearly one-fourth of a vegetoanimal substance, perfectly similar 0 that which comes from putrid glu'en; $3 \mathrm{~d}, \mathrm{a}$ black coal, one-fifth of their weight, similar to thai 
which is found in all remnants of putrefied organic compounds; 4 th, free phosphoric acid, amounting scarcely to more than 004 of the smut; 5th, phosphates of ammonia, magnesia, and lime, in the proportion of a few thousandths. "We must remark," say MM. Fourcroy and Vauquelin, "that in one examination of putrefied gluten, we found characters very similar to those of the smut of wheat; and that the products of the one are so like those of the other as to render it difficult, in certain cases, not to confound them together. It requires a man to be well practised in chemical experiments to discern the slight differences that exist between these two putrefied matters, because the differences are only delicate shades, not easily discernible. The contagion attacks especially the gluten, and precedes, indeed prevents, the formation of the starch; since we know positively that this fecula, no traces of which are found in the smut of wheat, suffers no alteration from the septic process which so powerfully attacks the glutinous substance." The ravages of this disease are chiefly, though not exclusively, confined to the cereal plants. Mr. Kirby says it is common to wheat, oats, barley, and rye; and that he has seen the flote fescue (Glyceria fluitans), and some other grasses, affected with it. Barley and oats are more frequently affected by it than wheat, which may proceed from the latter being usually steeped before sowing. Wildenow, who, in his Principles of Botany, $\$ 331$, describes the smut under the name of "Ustilago," and as being a small fungus, says, "This singular variety of gangrene occurs most frequently in the species of Graminex, rarely in other plants, sometimes in Scorzonera, Tragspogon," \&c. The ear of corn which is attacked is in general totally destroyed, but sometimes the same ear contains sound as well as smutty grains; and even one end of the same grain has been found diseased and the other end sound. However, as all the grains in an ear are usually infected, so, when one stall is smutty, it generally happens that all the ears from the same root are so too. In March or April, upon carefully opening the hose or blade (folium vaginans) which covers the ear, and examining the young ear, although it was not above one-sixth part of an inch long, and almost close to the roots, M. Du Hamel found this embryo already black and distempered; a fact confirmed by the researches of Mr. Kirby. When the diseased ear comes out of the above-mentioned envelope, it looks lank and meager. About half an inch of the upper part of its stalk is commonly not quite straight. If cut asunder at not more than a quarter of an inch below the ear, it will be found nearly solid or filled with pith; the circulation above is therefore obstructed. The next most important point for consideration is, from whence is the infection cismmunicated; and the following experiments will be found to have demonstrated that it is capable of being conveyed to the plants by the agency of the parent seed. These experiments are satisfactory and decisive; for, although they are only in acrordance with the most prevalent opinions of farmers upon the point, yet prevalent opinions are not always in accord- ance with truth, and are never to be implicitly received until sustained by evidence, which is independent of prejudice, and more accurate than surmise.

Mr. R. Somerville, in a paper published in the Communications to the Board of Agriculture, details experiments fully substantiating the fact, that the disease is communicable to the crop from the parent seed. He mixed some smutted grains with others perfectly healthy, and kept them in a box for two months; after which, previously to sowing, he rubbed them together between his hands. The sample was then divided into two equal parts, one of which was well washed with clear water three or four times, and then sown in a drill in his garden. The other half was sown similarly, but without being washed or otherwise prepared. The blades appeared above the surface at the same time, and during the first two months of their growth there was no visible difference in their appearance. Soon afterwards many of the plants from the unwashed seed were observed to have a darker and more dirty green hue than those from the seed that had been cleansed with water. This difference of colour by degrees became more striking, and increased until the grain was protruded from the blade, at which time roany of the dark-coloured plants evinced symptoms of decay; and the whole of them, when fully developed, were found to be completely destroyed by the smut. The plants from the washed seed produced scarcely a single diseased ear. These results were not fortuitous, for the experiment afforded a similar testimony when repeated the next season.

The experiments of $\mathrm{Mr}$. Harrup agree with the preceding. In these, wheat, consisting half of sound and half of smutted grains, was sown without being previously at all prepared, and this produced a crop of which nearly twothirds were smutted. Similar wheat, soaked for twelve hours in a saturated solution of common salt, and then mixed with quicklime, produced on the same soil, in the same situation, and in the same season, a crop in which not a smutted ear could be found.

Similar, but more extended, and even more accurate experiments, were completed by $\mathrm{Mr}$. Bevan, and are recorded in the ninth volume of The Agricultural Magazine. They give the result of his trials with various liquids as steeps for seed-wheat. The wheat was grown on a sandy soil, at Leighton in Bedfordshire. The columns in the accompanying table which are marked $\mathbf{A}$. contain the results from the sound grain that was sown; and those marked B. are the results from smutted samples. (See Table at top of the next page.)

The conclusion from these and many other accordant experiments is, that washing the seed is effective in preventing the communication of the disease to the crop to which it gives birth. If the washing was frequently repeated. or the cleansing made complete, by passing a continual stream through the seed for some hours, it is probable that simple water might be employed for this purpose as effectually as any saline solution. But as this would require mure labour than is dnsirable, and as the salts, 
\&c., employed are beneficial in other ways, by |ing to the future vigour of the plants, steeps an protecting the seed from vermin, and minister- generally and very properly adopted.

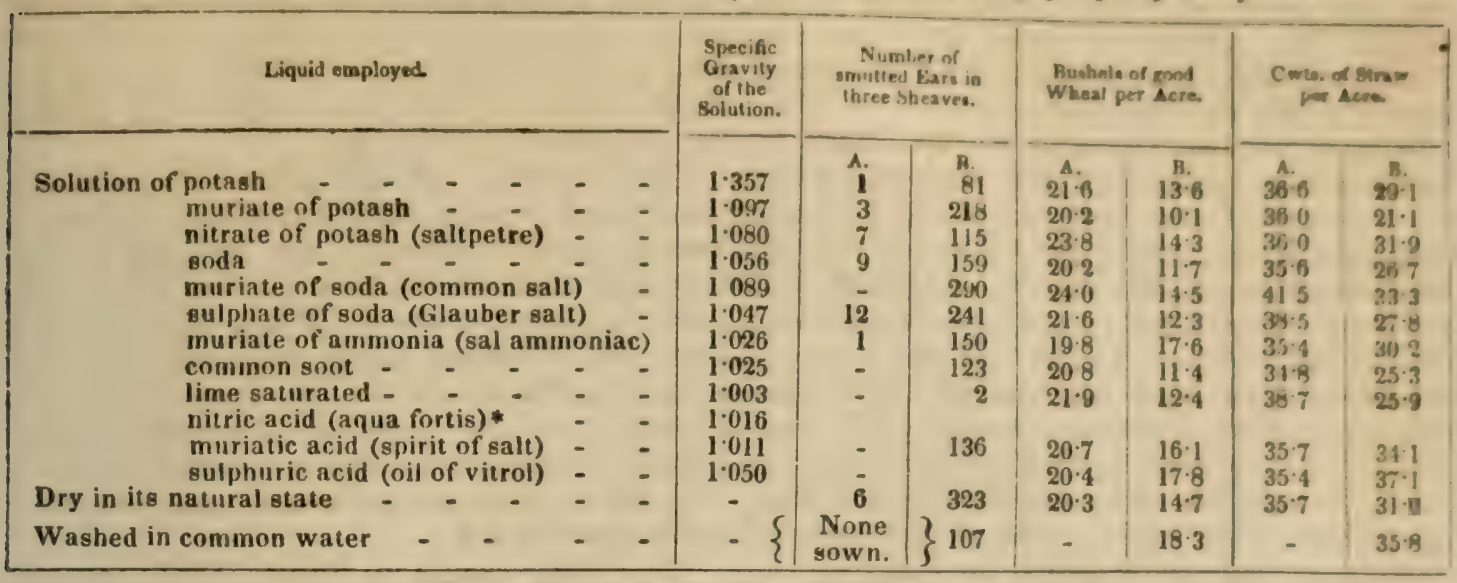

* The seed treated with this acid did not vegetate.

The experiments of Mr. Bevan indicate that lime-water is the most effective of these preparations; and, if this be adopted, it may be prepared by mixing 1 pound of fresh lime with 3 gallons of boiling water, and the clear liquor then to be poured off and immediately used. In this liquor the wheat should be soaked for 12 hours, stirred twice or thrice during the time, and then mixed upon a floor, with the powder made by pouring $\mathbf{3}$ gallons of boiling water upon 4 pounds of lime. I have had no experience of the effects of lime-water as a preventive of the smut; but with stale urine, and a solution of common salt, I have witnessed numerous and extensive experiments. The results, without exception, were favourable and nearly similar; and this being the case, a preference is to be given to common salt, as being decidedly the most cleanly and the least disgusting. The mode which I have observed to be the most effective is, to wash the seed with pure water, pouring this off with all the floating grains, and then allowing the seed to soak for 12 hours in a solution of common salt, having a strength or specific gravity sufficient to float a hen's egg. I have no doubt that lime, like common salt, is effectual against the disease, by reason of its powerful action upon the texture of the fungus tribe. Every housekeeper knows how completely mushrooms dissolve away when sprinkled with salt; and in experiments I have made upon the Urego segetum, I found that the effect of common salt upon this fungus is not less remarkable.

Mr. Tull, MM. de Lignerolle, Douat, and others, agree in recommending that the seed to be sown upon any farm should be frequently obtained from other soils; but, however beneficial this may be for securing other desired effects, I do not understand how it can prevent the occurrence of smut unless the seed is obtained from a crop and a district notably free from the disease. There is little doubt but that the method in which the disease is imparted to the plant is by its root imbibing the extremely minute seeds of the Uredo along with the moisture of the soil. This opinion is confirmed by the observation that the disease is most prevalent when the winter has been mild and the spring wet; for, in such seasons, the abundant moisture passing through the soil is most likely to convey the seeds to the mouths of the piants radicle fibres.

I remember trying some experiments, the full details of which I have accidentally lost, in which I buried some of the Uredo segetum about an inch below the surface of the soil, in a garden pot in which some wheat was grow. ing, supplying those plants, during their after growth, plentifully with water poured upon the surface of the soil. Not one of these plants escaped infection.

A nother garden pot, in which wheat from the same sample was growing, and similarly treated in every respect, but to which moisture was supplied solely by means of the saucer in which it was placed, both pots being sheltered entirely from the rain, produced plants which were not at all infected. Although it is very apparent that the smut is generally imparted to a wheat crop by the agency of the seed sown, yet I ain by no means of opinion that this is the only source of infection. I have kept ears of wheat that were covered and destroyed by the Uredo during more than twelve months in a situation where they experienced the vicissitudes of temperature during all the seasons, unprotected by more than the paper envelope in which they were suspended in an outhouse. Yet when the Uredo that had been thus exposed was mixed with healthy wellwashed seed-wheat, this produced diseased plants in a triplicate proportion more numerous than that not so mixed. This experiment de. monstrates that frost and drought, acting in concert with a damp atmosphere, do not destroy the vegetating power of the Uredo's seed. Stch being the fact, why may not this seed remain in the soil ready to impart the plague? We know that, owing to its extreme lightness, the seed floats buoyantly in the air, and may be carried by winds to distant soils, which in the autumn of the same year, before any extremity of cold has been endured, will have to bear the wheat crop for the following harvest. The opinion that the soil is one source of infertion. is sustained by the fact that fields in the vicinity of the sea are rarely injured, and never extensively, by the ravages of the smur. Such soils are impregnated more than any other with common salt, and the effect of this saline compound upon the Ureau nas beer. 
noticed already. These considerations suggest that applications to the soil as well as to the sced are necessary for the banishment of the disease; but a more full notice, and some curious particulars upon this point, will be found detailed under the head Minnew.

I have frequently examined the roots of wheat plants affected by the smut, but have never perceived that they had a diseased appearance; a fact which I find confirmed by the researches of $\mathrm{Mr}$. Kirby. Although the root is not affected, yet I have invariably found the smutted plants of a form and habit much less robust than those undiseased. The average result of Mr. Bevan's experiments is, that smulted wheat produces stiaw in the proportion of only 30 to $36 \cdot 75$, when compared with wheat unattacked by the smut. This is not a result contrary to that which might be anticipated; for in plants, as well as animals, an organic affection so serious as this is usually accompanied by a general emaciation of the frame. so decidedly is this effect produced upon wheat, that a practised eye can at once detect by its appearance, before the diseased ear is protruded, a plant that is thus distempered. 'The stem and leaves look upright, thin, and stiff, wearing the aspect that is best described, to those who know the appearance, by the term s:aring. I cannot conclude without remarking that these facts strengthen the analogy I am so fond of tracing between plants and animals. The atrophy exhibited by both, when under the influence of disease, is strikingly illustrative of their close relationship; and this is further carried on by their being equally liable to the ravages of parasites. The skin of every ani$\mathrm{mal}$ is liable to be infested by vermin, as its inicstines and other viscera are by worms and various other creatures. So plants are not only subject to invermination, but, like animals, they are preyed upon by various genera of their own race. Their barks are assailed by numerous lichens and fungi, whilst internally they are a prey to the Uredo I have just described, and to several others of the fungus iribe. Animals have their larger parasites, as the tick, \&c., and vegetables similarly bear the misseltoe, dodder, and others. This repeated urging that plants are closely allied to animals in every particular is not without its use. Every year's experience convinces me that it is not less beneficial to cultivate plants with the least possible injury to their various parts, than it is to treat our farming stock with genteness and an attention to their comfort; and it is by demonstrating the analogy between the two great divisions of created beings, that the reason of the cultivator is to be drawn to regulate his practice.

Finally, I will observe, that the farmer is much too prone to regard the diseases of his crops as of trivial importance. In such cases as where the curl destroys whole fields of his potatnes, or the mildew reduces the produce of each acre of wheat to a few bushels, he is miserably sensible of the injury he has sustained: but if, within the circle of corn-ears around him, as he survers his crops, he only sees ? sprinkling of tho.se affected with the ranut, he lonks upon this as of insignificant 1000 consequence. Yet, in the experiments of Mr. Bevan, in the instances where only two smutted ears occurred in three sheaves, the weight of the straw was reduced nearly one-third, and that of the grain three-sevenths. (Essay by G. W.Johnson, Quart. Journ. Agr.vol.ix.p.45.) See Bright and Mildew.

SMUT-MILL. Of late years the millers in the United States avail themselves of contri. vances called smut-mills, the passage of the wheat through which clears it very effectually from the offensive dust. Wheat affected with smut was formerly much objected to by the grain merchants and millers, but since the introduction of the machines referred to, is so readily cleansed that smut is scarcely objected to in the sample, and the market price reduced but little, if at all.

An inquiry made, in March, 1842, into the merits of a smut-mill invented by $\mathrm{Mr}$. Wm. C. Grimes, of Yurk, Pennsylvania, by a committee of the Franklin Institute of Pennsylvania, war ranted them in recommending the machine to the notice of millers, as capable not only of making good white flour from wheat so badly smutted as to be generally considered unmerchantable, but which will also improve the general quality of flour, by the removal of cheat, and of the down or furze which covers one end of the grain, and of most other accidental foreign matters which tend to injure the quality of the flour. (Jour. of the Franklin Inst. of Penn. vol.iv., third series, p. 32.)

SNAILS (Helix-Helicide). A well-known genus of molluscous animals, comprising a great many species. They live throughout the winter in a torpid state, in cavities in the earth, which are covered over with a calcareous kind of wall, partly formed with its mucous secre tion. The animal escapes from its cell in April, bursting its operculum, and again breathes as before its hybernation. The species of shellsnails are very extensive. In the garden, snails do much damage to the vegetables in cultivated grounds, biting off pieces of the leaves by means of a semicircular, dentated, horny plate which is affixed to the upper lip. 'To extirpate them, it has been recommended to strew the ground with lime and ashes, or salt. Snails seldom annoy farmers, unless it be under the hedges; and if they venture out into the middle of a field, the roller is a certain destructive implement to their fragile coverings. The red, or great vine-snail (H.pomatia), formed one of the luxuries of the tables of the ancient Romans, and by peculiar feeding and other treat ment was brought to attain an immense size. It is still an article of food in certain cantons of Switzerland and France, and some of the provinces of Spain and Portugal. This species of helix was brought to England by the Howard family, and placed on the grounds in the neighbourhood of Box-hill, where it is still found; but it does not attain to the size it often displays in Italy. It is supposed to be a good article of food for the consumptive.

SNAKE-ROOT. Several plants in the United States go under this appellation. The Virginia snake-root (Aristolochia serpentaria) is the wellknown fibrous root, noted for its intense bitterness, and extensively employed in medicine as 


\section{SNOW.}

as a tonic. It is found in rich woodlands, in the Middle States. The root is perennial.

SNOW. This well-known precipitation from the atmosphere serves to defend winter graincrops and all other vegetables from the severity of frosts; for, being a very bad conductor of heat, it prevents the internal warmth of the earth from being carried off through the surface of the land, and consequently ameliorates the soil. 'The plants being thus sheltered, shoot forth in the spring with renewed vigour; and, cherished by the genial rays of the sun, vegetate with increased luxuriance. As ammonia and other saline matters, possessing fertilizing matters, have been detected in snow, it not only cherishes vegetation by the protection it affords, but by the direct influence of the fertilizers referred to.

SODA. See Kelp; Salts, their uses to vegecation, \&c.

SOD BURNING. See Paring and Burning. SOFT-GRASS. See Holcus.

SOIL. The upper surface of the earth which furnishes a medium or basis for the growth of plants. Prof. Johnston, in his Elements of Chemistry, has remarked, that the earthy part of the soil is not, as some have supposed, a mere substratum, in which the plant may so root itself as to be able to maintain its upright position against the force of winds and tempests, but it is a storehouse of food also, from which the roots of the plant may select such earthy substances as are necessary or fitted to promote its growth. And the young farmer, when he is endeavouring to understand the true theory of the food of plants, and the operation of fertilizers, must discard from his mind all suspicion that these earthy and saline substances, found in the substance of his crops, are merely there by accident, or absorbed by their roots accidentally in the moisture of the soil; for, on the contrary, it has been shown that these substances are always found in the plant, and that they vary in amount at different stages of its growth. Thus, to give a single instance, Mr. J. P. Norton (Trans. High. Soc. 1845, p. 321 ; Farmer's Almanack, vol. iii. p. 19) has shown that the ashes of the stalk of the unripe potato-oat contained

\begin{tabular}{|c|c|c|c|c|}
\hline & June 4 & June 18 & July 2 & July 16 \\
\hline Potash and soda & $24 \cdot 94$ & $26 \cdot 49$ & $36 \cdot 25$ & $42 \cdot 43$ \\
\hline Common salt & $32 \cdot 66$ & $24 \cdot 94$ & 11.62 & $4 \cdot 46$ \\
\hline Lime . . & $2 \cdot 40$ & $3 \cdot 74$ & $2 \cdot 64$ & $4 \cdot 12$ \\
\hline Magnesia & $0 \cdot 88$ & $2 \cdot 20$ & $1 \cdot 17$ & $1 \cdot 47$ \\
\hline Oxide of iron & $0 \cdot 39$ & $0 \cdot 40$ & $0 \cdot 88$ & 0.62 \\
\hline Sulphuric acid & $6 \cdot 15$ & $8 \cdot 51$ & $7 \cdot 98$ & $7 \cdot 84$ \\
\hline Phosphoric acid & $16 \cdot 15$ & $12 \cdot 55$ & $2 \cdot 21$ & $6 \cdot 31$ \\
\hline Silica . . . & $16 \cdot 29$ & 20.41 & $36 \cdot 64$ & $34 \cdot 85$ \\
\hline
\end{tabular}

It is true that the amount of these fixed or inorganic substances varies in the same species of plant grown on different soils; but, although the proportions vary, the ingredients do not alter; and so closely is the proportion preserved in which they exist, that Professor Johnston has been able to determine pretty accurately the general amount of the inorganic ingredients carried off the soil, per acre, by the ordinary rota: tion of the four-course system. As the basis of this calculation, he supposes the turnips to consist of 25 tons of bulbs, and 7 tons of tops; the barley, of 38 bushels of $63 \mathrm{lbs}$. each, and 1 ton of straw; the clover and rye-grass, of 1 ton of each in hay; and the wheat crop to be composed of 25 bishels of $60 \mathrm{lbs}$., and $1 \frac{3}{4}$ tons of straw. 126
SOII.

These, he calculatus (lilements of Chomiat y, po. 51 ), will contain and carry away from the soil (supposing none of them (o) be ruten on the land) -

\begin{tabular}{|c|c|c|c|c|c|}
\hline Potash & & & $\begin{array}{l}\text { lby. } \\
. \quad 2 y()\end{array}$ & Sulphurace arid & lin \\
\hline Soda & & 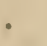 & - 150 & Phomplionse ared & (16) \\
\hline Lime & - & - & 212 & Chalormue: . & 39 \\
\hline Magnesi: & & - & 50 & & \\
\hline Silica & . & - & - 318 & Tuial & 1280 \\
\hline
\end{tabular}

So that, if we carry off the entire prouluce, and add none of it again in the shape of manure, we ought every fourth year to add to the sril rem acre, if we wish to restore it to its original condition,

Pearl or potash

Crystallized carbonate of

$$
\text { sonda }
$$

Common salt

Gypsuin

Lime

Epsom suits (sulphate of magnesia) Bone-dust

$$
\text { Total }
$$

390 lbs. at.a cost of $f 3$ gi) 0
$500 \%$

$65 "$

60

$250 "$

360

$\overline{1785}$

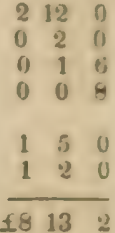

$\pm 813:$
We may safely, then, adopt the conclusion of Liebig, when he tells us (Organic Chemistry, $p$. 63) that "many of these inorganic constituents vary according to the soil in which the plants grow, but a certain number of them are indispensable to their developement. All substanees in solution in a soil are absorbed by the roots of plants, exactly as a sponge imbibes a liquid, and all that it contains, without selection. 'The substances thus conveyed to plants are retained in greater or less quantity, or are entirely separated when not suited for assimilation."

The results of these chemical researches it will be found very serviceable to bear in mind, in the investigation of the composition and uses of all fertilizers.

The chief cultivated soils with which the farmer has to encounter, although in reality mixtures of sand, clay, and lime with various saline and organic matters, may, for the convenience of something like a classification, be arranged under the heads of sand, clay, and lime. These, it must be remembered, are fertilizing according to the proportions in which they are blended together; and, as a general rule, it may be taken that, whenever any one of these earths is deficient in a soil, the addition of such earth will add to its fertility; and hence they all, in some situation or other, are found to be useful additions or fertilizers to soils in which the added earth naturally exists in insufficient piopor. tions.

In burning a piece of wood or any other vegetable substance, a small portion of it remains behind, called the ash or inorganic par: - which is a compound substance consisting of various $\mathrm{mi}$ neral substances, gases, \&c., that have served as the food of the growing plant or tree, and which it is the proper function of soils to supply. Such are silica or flint; alumina, or the basis of clay; potash, soda. lime, magnesia, nxide of iron. chlorine united with the soda in the form of common salt, sulphuric acid, phosphoric acid, carbonic acid. The portions of the wood or othes vegetable matter lost or dispersed in the burning are termed the organic constituents. Sand, clay, and lime, although they compose sich a laris amount of the innrganic constituents of soils, have associated with them many other substances $482 \quad 100$ ? 
which exert important influences upon the growth of plants, and the ratios of which it is of the highest importance to the practical farmer to understand. The presence of the substances constantly found in fertile soils in their due proportions, however small these may appear, is just as necessary to maintain fertility, as that of the substances existing in the largest proportions. All the essential ingredients of a good soil must be present to secure a good crop, although they need not always exist in precisely the same proportions. Any one of these primary constituents of soils in superabundant quantity wili lessen or destroy fertility. Too much potash, salt, magnesia, iron, lime, or clay, will ali impair or entirely destroy productiveness in soils, until these have had the superabundance washed away by rains. The barrenness of a soil may arise from its containing too small or too large a proportion of one or other of the essential ingredients. The proportions of the several inorganic substances required by plants which are the most common objects of cultivation in England, are presented in the following table from Prof. Johnston's Lectures.

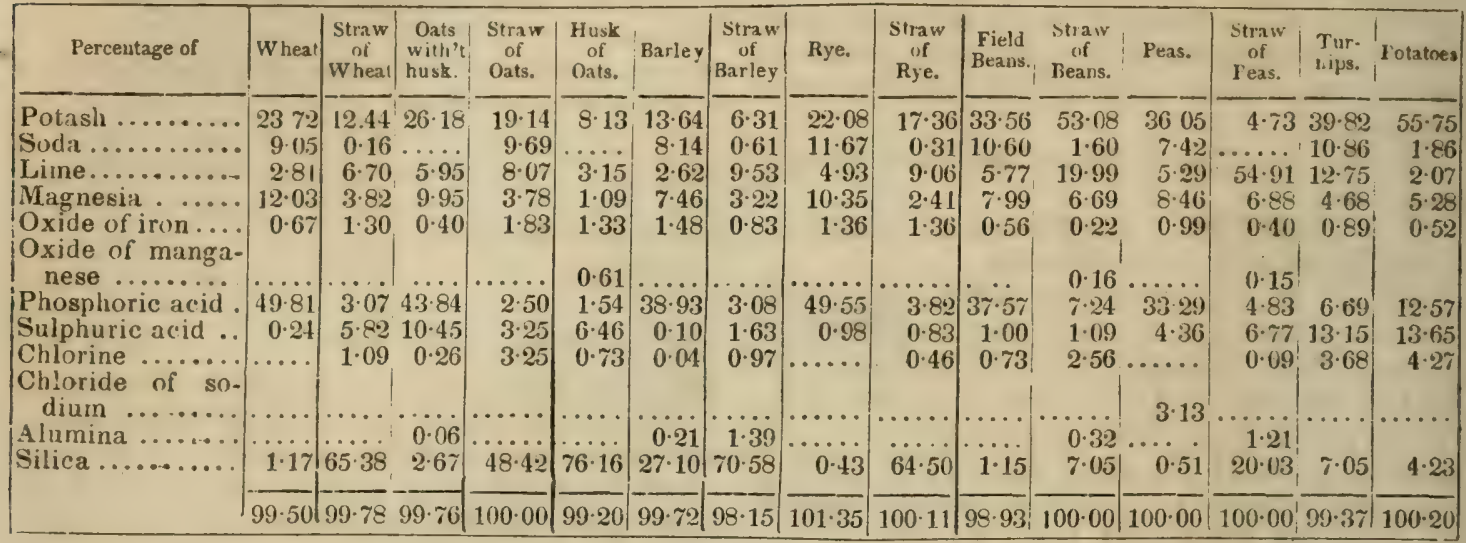

Although some of these substances make up a comparatively large amount of the ashes of plants, potash composing 23 per cent., and phosphoric acid nearly one-half the ash of wheat, oats, barley, and rye, the proportion of these in the soil appears exceedingly small, compared to the whole bulk. How eagerly then must such substinces be solight after by the roots of plants and appropriated as food! Straw contains but a very small quantity of phosphoric acid. The potash taken up by Indian corn, is in very much the same proportion as that abstracted by wheat. The phosphoric acid ascends into the grain, whilst the silicious matter lodges in the straw or stalk, giving these strength to support the ears. In the potato more than half the ash consists of potash, whilst the proportion of phosphoric acid is very small. Thus do plants of various kinds and families differ materially in their demands on the soil for sustenance. Even different parts of the same plants require various proportions of the nutritious substances. How is it possible for the delicate fibrous roots of plants to derive any nourishment from such hard materials as flint, limestone, shells, bones, \&c.? The answer is that these hard substances must all undergo solution in water before they can be absorbed by delicate roots and circulated through the infinitely minute sap-vessels. The perfection of refined agriculture consists in knowing how to adapt with precision the elements requisite as food and the modes of culture necessary in different soils to favour in the highest degree the growth and fullest developement of plants of various descriptions. One of the most importaut points connected with practical farming is to be able to specify what particular plants take from the soil, and what must be applied in order to restore the deficiency with least expense.

Professor J. F.W. Johnston has given the following tabular view of the composition of mils of different degrees of fertility.
The soil, of which the composition is given in the first column, had produced crops for 60 years without manure,-and still contained a sensible quantity of all the substances required by plants. That in the second column produced good crops when regularly manured,-it was in want of three or four substances only, which were given to it by the manure. The third was hopelessly barren,-it was in want of many substances which ordinary manuring could not supply.

\begin{tabular}{|c|c|c|c|}
\hline & $\begin{array}{l}\text { Fertile, } \\
\text { without } \\
\text { Manure. }\end{array}$ & $\begin{array}{c}\text { Fertile, } \\
\text { with } \\
\text { M:inure. }\end{array}$ & Barten. \\
\hline Organic matter........ & 97 & 50 & 40 \\
\hline Silica (in the sand and clay) & 648 & 883 & 778 \\
\hline Alumina (in the clay) .... & 57 & 51 & 91 \\
\hline Lime................ & 59 & 18 & 4 \\
\hline Magnesia ................ & $8 \frac{1}{2}$ & 8 & 1 \\
\hline Oxide of jron ............ & 61 & 30 & 81 \\
\hline Oxide of manganese ...... & 1 & 3 & $\frac{1}{8}$ \\
\hline Potash $\ldots \ldots \ldots \ldots \ldots$ & 2 & trace & trace \\
\hline $\left.\begin{array}{l}\text { Soda } \\
\text { Chlorine, }\end{array}\right\}$ chienly as c'm. salt & $\left\{\begin{array}{l}4 \\
2\end{array}\right.$ & & \\
\hline Sulphuric acid........... & 2 & $\frac{3}{4}$ & \\
\hline Phosphoric acid .......... & $4 \frac{1}{2}$ & $1 \frac{3}{4}$ & \\
\hline $\begin{array}{l}\text { Carbonic acid (combined } \\
\text { with the lime \& magnesia }\end{array}$ & 40 & $4 \frac{1}{2}$ & \\
\hline Loss $\ldots \ldots \ldots \ldots \ldots \ldots$ & 14 & & $4 \frac{1}{8}$ \\
\hline & 1000 & 1000 & 1000 \\
\hline
\end{tabular}

Soils generally have in them some of the elements of fertility so locked up by strong union with other substances, that plants cannot appropriate them to their uses, unless something be added which has the power to destroy the natural combination, release the fertilizers, and render them accessible to the wants of vegetables. Under such circumstances, the application of lime will unlock potash where granite or felspar and mica exist, and the freed potash will in turn render silex soluble. [See Silex, Lime, Salts.]

Heavy and stiff clays, which cannot be cultivated in grain crops to profit, will often pay well for grazing purposes. 
SOILING. The practice of supporting animals in the summer season, with green food, cut daily and given to them in their houses, stalls, or yards. A number of different plants and grasses are resorted to for this purpose, particularly those which have a quick and luxuriant growth; as lucern, sainfoin, tares, clover, maize, turnips, \&c,

Soiling appears to be highly advantageous, in a variety of ways, by the food being consumed with much less waste, by the great increase of good manure that is produced, and by the stock feeding with less interruption and inconvenience, from their being more effectually shaded from the excessive heat of the sun, and better protected from the attacks of Hies and other insects. In all these respects it would seem to have a great superiority over that of letting the animals range indiscriminately in the pastures or other grass lands.

Soiling has been found, by the most careful experiments, to answer perfectly both with horses, neat cattle, and swine; and with cows it has been found very beneficial in the trials of Mr. Curwen and several others.

By an extensive and judicious use of soiling, the farmer may derive benefit in being enabled to have a considerably larger extent of land both under the states of tillage and grass, from the considerable increase of manure that is produced.

That a great saving of food is effected by keeping cattle and other stock in pens, yards, or stables, and supplying them with fresh-cut green herbage, is undoubted. Many say that three, and some assert even four animals can be well kept upon the produce of land where soiling is practised, more than the same land would sustain if pastured. Besides the very great advantage of enabling double or treble the stock to be kept on a given number of acres, soiling offers another in the greatly increased amount of manure, which is far beyond what would be supposed by persons unacquainted with the practice. Where proper arrangements are made and care taken, all the manure of animals may be saved, instead of being scattered and partially lost, as is the case with a large proportion dropped in the lanes or fields. It gives the farmer an opportunity of applying all his straw and coarse litter to the best advantage, by spreading and using it as an absorbent for the less solid portions of the excrements of his animals. A good supply of litter is indispensable in order to derive the fullest advantages from soiling. By such means, and properly arranged gutters leading to tanks or cisterns, the farmer has the power of saving nearly all of the liquid or best portion of the manure of his cattle, his main dependence for keeping up the productiveness of his lands. (See Liquid Manure, and Nigut-Soil.)

Another advantage derived from soiling-and a most important one, too-is the saving of fencing in the interior of farms.

Among the objections urged against the practice, are the great amount of labour required for cutting and carrying the feed for a large stock, and the difficulty of getting a supply of green food fit to mow sufficiently early in the season. It has also been asserted, that cows soiled will not give so much milk as when grazed; but the experience of others shows results entirely contrary, and that, by judicious feeding and management, the amount of milk may be regulated almost at pleasure. The success of the plan depends almost as much upon securing to the animals proper ventilation, cleanliness, and com- fort, as upon the nature of the formi. Whatever system of soiling may the adopted, it would seem of great importance that the animals should, for the promotion of their health, be oecasion. ally turned out into the open air, during some portion or portions of the day. As this catuot be done in many large dairy establishments in or adjacent to large cities, cows are often kopt tied up in their stalls for weeks, and many for months together, to the great injury of thoir health, and deterioration of their milky secretwons. In an interesting report made by the Commissioners on the State of Health in Large T'owns in England, the following observation occurs: "It is known that tubercular consumption is very prevalent among the cows which supply milk to the inhabitants of some large towns, where they are immured during part of every year in dairite perfectly closed; and which, being too small for the number of animals which they contain, soon become filled with heated, vitiated air, for the removal of which no provision is made. This is remarkably the case with the cows belonging to the milkmen of Paris, which are annually carried off by consumption in considerable numbers. A confirmation of the influence of this cause is afforded by the exemption of the horse from consumption, although frequenly placed in the same circumstances with the cows, but with intervals of exposure to fresh air, and the enjoyment of exercise. Where a number of horses, however, are collected together in ill ventilated stables, they may become consumptive. A discovery of this kind was lately made, as to the influence of defective ventilation on the cavalry horses in some of the government barracks in England; and it is stated that a saving of several thousand pounds per annum was effected by an easy improvement of the ventilation of the barracks near the metropolis." (See Ventilation.)

In feeding cows, it must be remered that they are very capricious in their appetites, and do not like to be kept constantly on the same kind of food. A variety should therefore always be resorted to, when practicable. The food may be given to them several times a day, never less than three times, viz. early morning, noon, and night, and oftener when convenient. Water should be allowed morning and evening, and salt must be at hand, so that they can help themselves at pleasure.

SOLAR INFLUENCE. See Tempera Ture, Light, and Atmosphere.

SOOT is very extensively employed in the east of England, as a powerful manure, and produces, when used at the rate of 12 or 20 bushels per acre, most luxuriant crops of wheat and other grain. This valuable fertilizer is composed of a mixture of charcoal, an oil, salts of ammonia, some muriatic acid, lime, magnesia, silica, and other foreign substances; but the charcoal is by far the largest ingredient, and has a powerful influence on vegetation; and, according to Liebig, it can "completely replace vegetable mould or humus. Plants thrive in powdered chareoal, and may be brought to blossom and bear fruit if exposed to the influence of rain and the atmosphere." (Organ. Chem. p. 61.) All the substances contained in soot are the natural food of vegetables; the carbon gradually combines with the oxygen of the atmosphere, and is converted into carbonic acid gas, which is readily absorbea by the roots and leaves of plants. 
In Essex, the chief employment of soot is for wheat, and it is generally applied by the chimney sweepers to the land, out of a basket, in the same manner that seed is sown. This is usually done in the spring of the year, in March, April, or May. Wheat so treated speedily assumes a very deep green, and on some soils grows with greatly increased luxuriance. Soot was employed by the Rev. E. Cartwright as a manure for potatoes, both by itself and in combination with various other fertilizing substances. The experiments were made on a portion of the same soil as that described in the article Asurs. The following were the results obtained:

1. The soil, without any manure, yielded bushels oi potatnes

2. Soot 30 bushels

3. Soot 30 bushels, salt $\overline{8}$ bushels -

Per Acre.

Various agriculturists have noticed the good results from mixing salt and soot. Mr. George Sinclair, in his prize essay On Salt as a Manure, mentions it as "remarkable" in the case of carrots. Mr. Belfield of Elford has done the same with regard to wheat.

In Mr. Sinclair's experiments upon carrots, Per Acre. Tons, cwt. lbs.

The goils without any manure produced carrots -

Soil with $6 \frac{1}{2}$ bushels of salt dug in -

Soil with $6 \frac{1}{3}$ bushels of salt, and $6 \frac{1}{2}$ bushels soot

In both the liquid and solid state, it has been employed by Mr. John Robertson of Kilkenny, with graat success. "On meadows," he says, "I have used soot with great advantage in substance; and though sown by the hand, one dressing gave me always heavy crops of hay for two successive seasons. But this is a wasteful mode of applying it, a great portion of its ammonia, one of its most active ingredients, being volatilized, and dissipated in the atmosphere: when dissolved in water, there is no waste,-it is all available; and for horticultural purposes I have mostly used it in that state, mixing it up in the proportion of about six quarts to a hogshead of water. Asparagus, peas, and a variety of other vegetables, I have manured with it, with as much effect as if I had used solid dung; but to plants in pots, particularly pines, I have found it admirably well adapted; when watered with it, they assume a deep, healthy green, and grow strong and luxuriant." Mr. A. Main makes some pertinent remarks on soot as a top-dressing to crops, and describes a machine for distributing it, in the sixth volume of the Trans. of the Highland Soc. p. 535.

SORREL (the genus rumex, from the shape of the leaves in many of the species, resembling a pike or spear). There are in England several indigenous species of sorrel, some of which have already been described. The common English sorrel (Rumex acelosa) is a perennial plant, met with almost everywhere in meadows and pastures, flowering in June. The root is long and tapering, astringent, and somewhat woody. The herbage is smooth, powerfully and agreeably acid. Stem from 1 to 2 feet high, erect, simple, leafy, striated. 'eaves oblong, arrow-shaped. Flowers dice1004 cious, with permanent tuberculated petals. The acidulous taste of sorrel depends on binoxalate of potassa and tartaric acid: the astringency on tanuic acid.

The flavour of the wood-sorrel (Oxalis acelosella) is much more grateful, and the leaves are more juicy, than those of the common sorrel ( $R_{\text {. acetos } a)}$ and the French or Roman sorrel ( $R$. scutatus). The acid is merely the oxalic, free and also combined with potassa and ammonia. It likewise contains some saccharine matter. The garden cultivation required by them is identical. The leaves are employed at all seasons of the year, in salads, sauces, \&c. The wood-sorrel requires a silicious, yet moist and moderately fertile soil, in a shady situation, as beneath a hedge with a northern aspect. The garden sorrel thrives best in any mouldy garden soil that tends to lightness rather than tenacity, and is not too poor. The situation must be open. French sorrel is most healthful in a light, dry soil, that is tolerably fertile, in an open compartment. The rumexes are propagated by seed, and all of them by parting the roots, both which modes may be practised from the middle of February until the same period in May, and by the latter also in September and October. The finest plants are raised by seed, but those from portions of the roots are soonest in production.

Sheep-sorrel, or field-sorrel ( $R$. acetosellu), is abundantly diffused throughout the United States, and often forms a great pest to the farmer. The best way to subdue it is by means of liberal dressings with lime. This has been disputed by some, but where the application has been made in large quantity, it will seldom or ever fail. Of this genus two other species, troublesome to farmers, have been already mentioned. These are the sour or curled dock (R. crispus), and the bitter or broad-leaved dock (R. obtusifolius). See Docк.

SORREL TREE (Andromeda arborea). This is the only species of andromeda, which rises to a sufficient height to be ranked among forest trees. It begins to appear on the Alleghanies in Virginia, and is found to their termination in Georgia. In the fertile mountainous regions of North Carolina, it attains a height of 50 feet, with 12 or 15 inches in diameter. The name is derived from the acidity of the leaves, which in drying become black. When sumac is noi to be obtained, these leaves are used as a substitute in dyeing wool. The tree will endure much cold, and grows well in the vicinity of New York. It has small, white flowers, formed into spikes 5 or 6 inches long. These render the tree a very pretty ornament to gardens, \&c. SOUTHERNWOOD (Absinthiusn). 'The field southernwood (A. campestris) is a rather rare species. It is perennial in habit. The whole herb is without any aromatic or bitter flavour. Stems at first prostrate, becoming more or less upright as the flowers appear, branched, leafy, straight and wand-like, smooth, often reddish, near 2 feet high. Leaves irregularly and doubly pinnatifid, in many linear; blunt segments. Flowers drooping, small, ovate, yellow with a purplish calyx, forming numerous slender leafy clusters at the ends of the stems and branches. See Wormwoon. 
SOWING. See SEF,

SOWING MACHINE. See DurL.

SOW-THIS'TLE (Sonchus, from somphus, hollow; the stems being hollow). A rather large genus of annual or perennial plants, rarely shrubby, generally tall. They have hollow stems, and more or less pinnatifid or lyrate leaves, toothed or prickly at their edges. The surface of the herbage is usually smooth, that of the inflorescence hairy or glandular, often viscid. They contain a bitter white juice, and are plants of easy culture in any common soil. The herbaceous species are increased by division; the seeds of the annual and biennial kinds only require to be sown in the open grourd. There are in England three indigenous perennial species: the blue sow-thistle (S. caruleus), the tall marsh sow-thistle (S. palustris), one of the largest herbaceous plants, growing from 6 to 8 feet high; and the corn sow-thistle (S. arvensis). The most common native species is annual in habit, viz., the common sow-thistle (S. oleraceus), which is found almost everywhere, in cultivated and waste ground; flowering from July to September. Hares and rabbits are very fond of the herbage, which, like the root, is milky and bitter. The leaves are sometimes dressed and eaten among other culinary herbs, and the roots have occasionally been converted in to bread.

SPADE HUSBANDRY. There are many situations in which, from the small size of the enclosures, or the want of sufficient power for the easy working of the common or the subsoil plough, the cultivator may prefer the employment of manual labour with the spade; and it is fortunately found by experience that the difference in the expense of deep-digging, or spade husbandry, is not materially different from that of the subsoil plough. A great mass of information on this head was collected by the late Dr. Yelloly; not, however, so much with the view of showing the increased fertility of the soil by deep-stirring, as with the intention of demonstrating the immense field which is thus opened for the profitable labour of a teeming and increasing population. (See Di. Yelloly on Spade Husbandry; also Eritish Farmer's Magazine.)

The trials which have been hitherto made of spade husbandry, in various parts of the kingdom, have been insufticient, in point of extent, to afford any adequate criterion of the general applicability of that practice. Such trials, indeed, have been usually regarded either as matters of speculation and experiment, or as charitable efforts adopted by the benevolent to give employment to the poor, without reference to pecuniary expediency.

In most parts of Biscay and the north of Spain, the fields are commonly cultivated by the spade: great crops of potatoes and turnips are raised by these means." (Sinclair, p. 394; Brit. Husbandry, vol.ii. p.571.) See Fraxdrns, HUSBANDRY OF.

SPANISH NEEDLE (Bidens). See BunMarigoln.

SPAN-WORMS. A common appellation applied to those caterpillars called also loopers, and geometers. In New England they are called canker-worms.
The caterpillars of the Geomutras of lin nxus, earth-measurers, as the term umplics, or geometers, span-worms, and loopers, liave received these several names from their precu'iar manner of moving, in which they seerm to measure or span over the ground, step by siep, as they proceed. Most of these caterpillars have only 10 legs; namely, 6 , which are join? and tapering, under the fore-part of the turly, and 4 fleshy proplegs at the hinder extremity; the 3 intermediate pairs of proplegs being wanting. Consequently, in creeping, they arch up the back while they bring forward the hinder part of the body, and then, resting on their hindlegs, stretch out to their full length, in a straight line, before taking another step with their hindlegs. They have the power of letting them. selves down from any height, by means of a silken thread, which they spin from their mouths while falling. Whenever they are disturbed they make use of this faculty, drop suddenly, and hang suspended, till the danger is past, after which they climb up again by the same thread. These span-worms are naked, or only thinly covered with very short down; they are mostly smooth, but sometimes have warts or irregular projections on their backs. They change their colour usually as they grow older, are sometimes striped, and sometimes of one uniform colour, nearly resembling the bark of the plants on which they are found. When not eating, many of them rest on the two hindmost pairs of legs against the side of a branch with the body extended from the branch, so that they might be mistaken for the twig of the tree; and in this position they will often remain for hours together. When about to transform, most of these insects descend from the plants on which they live, and either bury themselves in the ground, or conceal themselves on the surface under a slight covering of leaves fastened together with silken threads. Some make more regular cocoons, which, however, are very thin, and generally more or less covered on the outside with leaves. A very few of the span-worms fasten themselves to the stems of plants, and are changed to chrysalids, which hang suspended, without the protection of any outer covering.

In their perfected state these insects are mostly slender-bodied moths, with tapering antennæ, which are often feathered in the males. Some of the females are without wings, and are distinguished also by the oval and robust form of their bodies. These moths are most active in the night; but some of them may be seen flying in thickets during the daytime. They are very short-lived, and die soon after their eggs are laid.

It was formerly supposed that the canker. worm moths came out of the ground only in the spring. It is now linown that many of them rise in the autumn, and in the early part of the winter. In mild and open winters I have seen them, says Dr. Harris, in every month from October to March. They begin to make their appearance after the first hard frosts in the autumn, usually towards the end of October, and they continue to come forth, in greater or smaller numbers, according to the mildness or severity of the weather after the frosts have

1005 


\section{SPAN-WORMS.}

begun. Their general time of rising is in the spring, beginning about the middle of March, but sometimes before, and sometimes after this time; and they continue to come forth for the space of about 3 weeks. It has been observed that there are more females than males among hose that appear in the autumn and winter, and that the males are most abundant in the spring. The sluggish females instinctively make their way towards the nearest trees, and creep slowly up their trunks. In a few days afterwards they are followed by the winged and active males, which flutter about and accompany them in their ascent, during which the insects pair. Soon after this, the females lay their eggs upon the branches of the trees, placing them on their ends, close together, in rows, forming clusters of from 60 to 100 eggs or more, which is the number usually laid by each female. The eggs are glued to each other, and to the bark, by a grayish varnish, which is impervious to water; and the clusters are thus securely fastened in the forks of the small branches, or close to the young twigs and buds. Immediately after the insects have thus provided for a succession of their kind, they begin to languish, and soon die. The eggs are usually hatched between the first and the middle of May, or about the time that the red currant is in blossom, and the young leaves of the apple tree begin to start from the bud and grow. The little canker-worms, upon making their escape from the eggs, gather upon the tender leaves, and, on the occurrence of cold and wet weather, creep for shelter into the bosom of the bud, or in to the flowers, when the latter appear. Where these insects prevail, they are most abundant on apple and elm trees; but cherry, plum, and lime trees, and some other cultivated and native trees, as well as many shrubs, often suffer severely from their voracity. The leaves first attacked will be found pierced with small holes; these become larger and more irregular when the canker-worms increase in size; and, at last, the latter eat nearly all the pulpy parts of the leaves, leaving little more than the midrib and veins. A very great difference of colour is observable among canker-worms of different ages, and even among those of the same age and size. It is possible that some of these variations may arise from a difference of species; but it is also true that the same species varies much in colour. When very young, they have 2 minute warts on the top of the last ring; and they are then generally of a blackish or dusky brown colour, with a yellowish stripe on each side of the body; there are 2 whitish bands across the head; and the belly is also whitish. When fully grown, these individuals become ash-coloured on the back, and black on the sides, below which the pale yellowish line remains. When fully grown and well fed, they measure nearly or quite 1 inch in length. They leave off eating when about 4 weeks old, and begin to quit the trees; some creep down by the trunk, but great numbers let themselves down by their threads from the branches, their instincts prompting them to get to the ground of the most direct and easiest course. When thus descending, and suspended in great numlers under the limbs of trees overhanging the $10 n_{B}$ road, they are often swept off by passing car. riages, and are thus conveyed to other places. After reaching the ground, they immediately burrow in the earth, to the depth of from 2 to 6 inches, unless prevented by weakness or the nature of the soil. In the latter case, they die, or undergo their transformation on the surface. In the former, they make little cavities or cells in the ground, by turning round repeatedly and fastening the loose grains of earth about them with a few silken threads. Within 24 hours afterwards, they are changed to chrysalids in their cells. The chrysalis is of a light brown colour, and varies in size according to the sex of the insect contained in it; that of the female being the largest, and being destitute of a covering for wings, which is found in the chrysalis of the males. The occurrence of mild weather after a severe frost stimulates some of these insects to burst their chrysalis skins and come forth in the perfect state; and this last transformation, as before stated, may take place in the autumn, or in the course of the winter, as well as in the spring; it is also retarded, in some individuals, for a year or more beyond the usual time. They come out of the ground mostly in the night, when they may be seen struggling through the grass as far as the limbs extend from the body of the trees under which they had been buried. As the females are destitute of wings, they are not able to wander far from the trees upon which they had lived in the caterpillar state. Canker-worms are therefore naturally confined to a very limited space, from which they spread year after year. Accident, however, will often carry them far from their native haunts, and in this way, probably, they have extended to places remote from each other. Where they have become established, and have been neglected, their ravages are often very great. In the early part of the season the canker-worms do not attract much attention; but in New England it is in June, when they become extremely voracious, that the mischief they have done is ren. dered apparent, when we have before us the melancholy sight of the foliage of our fruit trees and of our noble elms reduced to withered and lifeless shreds, and whole orchards looking as if they had been suddenly scorched with fire.

In order to protect our trees from the ravages of canker-worms, where these looping spoilers abound, it should be our aim, if possible, to prevent the wingless females from ascending the trees to deposit their eggs. This can be done by the application of tar around the body of the tree, either directly on the bark, as has been the most common practice, or, what is better, over a broad belt of clay-mortar, or on strips of old canvass or of strong paper, from 6 to 12 inches wide, fastened around the trunk with strings. The tar must be applied as early as the 1st of November, and perhaps in October, and it should be renewed daily as long as the insects continue rising; after which the bands may be removed, and the tar should be entirely scraped from the bark. When all this has been properly and seasonably done, it has proved effectual. The time, labour, and ex pense attending the use of tar, and the injury 
that it does to the trees when allowed to run and remain on the bark, have caused many persons to neglect this method, and some to try various modifications of it, and other expedients. Among the modifications may be mentioned a horizontal and close-fitting collar of boards, fastened around the trunk, and smeared beneath with tar; or four boards, nailed together, like a box without top or bottom, around the base of the tree, to receive the tar on the outside. These can be used to protect a few choice trees in a garden, or around a house or a public square, but will be found too expensive to be applied to any great extent. Collars of tin-plate, fastened around the trees, and sloping downwards like an inverted tunnel, have been proposed, upon the supposition that the moths would not be able to creep in an inverted position, beneath the smooth and sloping surface. This method will also prove too expensive for general adoption, even should it be found to answer the purpose. A belt of cotton-wool, which it has been thought would entangle the feet of the insects, and thus keep them from ascending the trees, has not proved an effectual bar to them. Little square or circular troughs of tin or of lead, filled with cheap fish-oil, and placed around the trees, 3 feet or more above the surface of the ground, with a stuffing of cloth, hay, or sea-weed between them and the trunk, have long been used by various persons in Massachusetts with good. success; and the only objections to them are the cost of the troughs, the difficulty of fixing and keeping them in their places, and the injury suffered by the trees when the oil is washed or blown out and falls upon the bark. Mr. Jonathan Dennis, Jr., of Portsmouth, Rhode Island, has obtained a patent for a circular leaden trough to contain oil, offering some advantages over those that have heretofore been used, although it does not entirely prevent the escape of the oil, and the nails, with which it is secured, are found to be injurious to the trees. These troughs ought not to be nailed to the trees, but should be supported by a few wonden wedges driven between them and the trunks. A stuffing of cloth, cotton, or tow, should never be used; sea-weed and fine hay, which will not absorb the oil, are much better. Before the troughs are fastened and filled, the body of the tree should be well coated with clay-paint or white-wash, to absorb the oil that may fall upon it. Care should be taken to renew the oil as often as it escapes or becomes filled with the insects. 'These troughs will be found more economical and less troublesome than the application of tar, and may safely be recommended and employed, if proper attention is given to the precautions above named. Some persons fasten similar troughs, to contain oil, around the outer sides of an open box enclosing the base of the tree, and a projecting ledge is nailed on the edge of the box to shed the rain; by this contrivance, all danger of hurting the tree with the oil is entirely avoided. In the Manchester Guardian, an English newspaper, of the 4 th of November, 1840, is the following article on the use of melted Indian ubber to prevent insects from climbing up trees. "At a late meeting of the Entomolo-? gical Society [of Iondon], Mr. J. IT. Fennel] communicated the following sucesstul mode of preventing insects ascembag the trunks of fruit trees. Let a piece of Intian rubter be burnt over a gallipot, into which it will gradu ally drop in the condition of a viscid juice, which state, it anpears, it will al ways retain ; fur Mr. Fennell has, at the present lime, some: which has been melted for upwards of a year, and has been exposed to all weathers withrut undergoing the slightest change. Having melted the Indian rubber, let a piece of cord or worsted be smeared with it, and then tied seve. ral times round the trunk. The melted sut. stance is so very sticky, that the insects will be prevented, and generally captured, in their attempts to pass over it. About 3 pennyworths of Indian rubber is sufficient for the protection of 20 ordinary sized fruit trees." Applied in this way it would not be sufficient to keep the canker-worm moths from getting up the trees: for the first comers we uld soon bridge over the cord with their bodies, and thus afford a passage to their followers. To insure success, it should be melted in larger quantities, and daubed with a brush upon strips of cloth or paper, fastened round the trunks of the trees. Worn-out Indian rubber shoes, which arc worth little or nothing for any other purpose, can be put to this use. This plan has been tried by a few persons in the vicinity of Boston, some of whom speak favourably of it. It has been suggested that the melted rubber might be applied immediately to the bark without injuring the trees. A little conical mound of sand surrounding the base of the tree is found to be impassable to the moths, so long as the sand remains dry; but they easily pass over it when the sand is wet, and they come out of the ground in wet as often as in dry weather.

Some attempts have been made to destroy the canker-worms after they were hatched from the eggs, and were dispersed over the leaves of the trees. It is said that some persons have saved their trees from these insects by freely dusting air-slacked lime over them while the leaves were wet with dew. Showering the trees with mixtures that are found useful to destroy other insects, has been tried by a few, and, although attended with a good deal of trouble and expense, it may be worth our while to apply such remedies upon small and choice trees. Mr. David Haggerston, of Watertown, Massachusetts, has used, for this purpose, a mixture of water and oil-soap (an article to be procured from the manufactories where whaleoil is purified), in the proportion of 1 pound of the soap to 7 gallons of water; and he states that this liquor, when thrown on the trees with a garden engine, will destroy the canker-worm. and many other insects, without injuring the foliage or the fruit. Jarring or shaking the limbs of the trees will disturb the canker. worms, and cause many of them to spin down, when their threads may be broken off with a pole; and if the troughs around the trees are at the same time replenished with oil, or the tar is again applied, the insects will be caugh. in their attempts to creep up the trunks. In the same way, also, those that are coming dow $n$ 
he trunks to go into the ground will be caught and killed. If greater pains were to be taken to destroy the insects in the caterpillar state, their numbers would soon greatly diminish.

Even after they have left the trees, have gone into the ground, and have changed their forms, they are not wholly beyond the reach of means for destroying them. One person told me that his swine, which he was in the habit of turning into his orchard in the autumn, rooted up and killed great numbers of the chrysalids of the canker-worms. Some persons have recommended digging or ploughing under the trees, in the autumn, with the hope of crushing some of the chrysalids by so doing, and of exposing others to perish with the cold of the following winter. If hogs are then allowed to go among the trees, and a few grains of corn are scattered on the loosened soil, these animals will eat many of the chrysalids as well as the corn, and will crush others with their feet. Mr. S. P. Fowler thinks it better to dig around the trees in July, while the shells of the insects are soft and tender. He and Mr. John Kenrick, of Newton, Mass., advise us to remove the soil to the distance of 4 or 5 feet from the trunk of the trees, and to the depth of 6 inches, to cart it away and replace it with an equal quantity of compost or rich earth. In this way, many of the insects will be removed also; but, unless the earth, thus carried away, is thrown into some pond-hole, and left covered with water, many of the insects contained in it will undergo their transformations and come out alive the next year. (See Yankee F'armer, of July 19, 1840, and New England Farmer of June 2,1841 , for some valuable remarks by Mr. Fowler.)

Canker-worms are subject to the attacks of many enemies. Great numbers of them are devoured by several kinds of birds, which live almost entirely upon them during their season. They are also eaten by a very large and splenlid ground-beetle (Calosoma scrutator), that appears about the time when these insects begin to leave the trees. These beetles do not fly, but they run about in the grass after the cankerworms, and even mount upon the trunks of the trees to seize them as they come down. The latter are also stung by a four-winged ichneuinon-fly, which deposits an egg in every canlier-worm thus wounded. From the egg is liatched a little maggot, that preys on the fatty substance of the canker-worm, and weakens it so much that it is unable to go through its fuIure transformations. I have seen one of these ilies sting several canker-worms in succession, and swarms of them may be observed around the trees as long as the canker-worms remain. Their services, therefore, are doubtless very c. unsiderable. Among a large number of canlser-worms, taken promiscuously from various trees, I found that nearly one-ihird of the whole were unable to finish their transformations, because they had been attacked by internal enemies of another kirid. These were little maggots, that lived singly within the bodies of the canker-worms, till the latter died from weakness; after which the maggots underwent a shange, and finally came out of the bodies of Hear victims in the form of small two-winged 1008 cuckon-flies, belonging to the genus Tachina. Mr. E. C. Herrick, of New Haven, Connecticut, has made the interesting discnvery that the eggs of the canker-worm moth are pierced by a tiny four-winged fly, a species of Platygaster, which goes from egg to egg, and drops in each of them one of her own eggs. Sometirnes every canker-worm egg in a cluster will be found to have been thus punctured and seeder for a future harvest of the Platygaster. The young of this Platygaster is an exceedingly minute maggot, hatched within the canker-worm egg, the shell of which, though only one-thirtieth of an inch long, serves for its habitation, and the contents for its food, till it is fully grown; after which it becomes a chrysalis within the same shell, and in due time comes out a Platygaster fly, like its parent. 'This last transformation Mr. Herrick found to take place towards the end of June, from eggs laid in November of the year before; and he thinks that the flies continue alive through the summer, till the appearance of the canker-worm moths in the autumn affords them the opportunity of laying their eggs for another brood. As these little parasites prevent the hatching of the eggs wherein they are bred, and as they seem to be very abundant, they must be of great use in preventing the increase of the canker-worm. Without doubt, such wisely appointed means as these were once enough to keep within due bounds these noxious insects; but, since our forests, their natural food, and our birds, their greatest enemies, have disappeared before the woodman's axe and the sportsman's gun, we are left to our own ingenuity, perseverance, and united efforts, to contrive and carry is to effect other means for checking their ravages.

Apple, elm, and lime trees are sometimes injured a good deal by another kind of spanworm, larger than the canker-worm, and very different from it in appearance.

Probably more than one hundred different kinds of geometers may be found in Massachusetts alone. Seventy-eight are already known to me. Some of these are small, and are not otherwise remarkable; some are distinguished for their greater size and beauty in the moth state, or for the singularity of the forms and habits of their caterpillars. None of them, however, have become so notorious on account of their devastations as the species already described. (Harris's Treatise.) See Lime Tree, Insect Enemies.

SPATTLING POPPY. A name sometimes applied to chickweed.

SPAVIN. In farriery, a disease in horses, consisting of a swelling in or near some of the joints, by which a lameness is produced, and of which there are three kinds; the blood-spavin, the bog-spavin, and the bone-spavin.

SPAYING. 'The operation of castrating or extracting the ovaries of the females of different kinds of animals, as sows, heifers, mares, \&c., in order to prevent any future conception, and promote their fattening.

SPEAR GRASS. The American name for the great smooth-stalked meadow-grass. See Poa Pratensis.

SPEARMINT (Mentha viridis). This species of mint is employed in sauces and salads, as 
well as dried for soups in winter. There are two varieties, the broad and narrow-leaved, equally good. See Mint.

SPEEDWELL (Veronica). An extensive genus of herbaceous or somewhat shrubby plants, with annual or perennial roots.

Common or male speedwell (Officinal veronica), called by the French 'The d'Europe, is a common plant in the Middle States, found on dry banks, woodlands, and commons, flowering in June and July, and ripening its seed in August and September. Water speedwell, or long-leaved brooklime, is also occasionally found along the muddy margins of rivulets, and also the scull-cap speedwell, or shield-like Veronica, with some other species. (Dr. Darlington's Flora Cestrica.) See Brnn's Ere.

SPELT. A species of coarse wheat. It will afford to be cropped once or twice in its early growth, affording excellent pasturage. Compared with wheat, its weight, with the hull on, is as 42 to 76 . See WHEAT.

SPICEWOOD (Laurus Benzoin). An American shrub or small tree, called also in the United States by the common names of wild allspice, fever bush, and Benjamin tree. The stems grow to the height of 8 or $10 \mathrm{feet}$, and are branched, the wood being very brittle, and when broken giving out a very pleasant aromatic odour. It is found in moist low grounds. An infusion of the branches is often used medicinally, more especially in the spring of the year, as a drink for horned cattle. See Launus. SPIGNEL. See FENNEL.

SPIKENARD, PLOUGHMAN'S (Conyza, from konis, dust; because it was supposed to have the power of driving away flies; whence also one of the common names, flea (fly) bane. The genus Erigeros is, however, the real fly-bane; some of its viscid species, dipped in milk, being used in the south of Europe to catch the various little winged insects so troublesome in warm climates). This is a numerous herbaceous or shrubby genus, of which the only British species ( $C$. squarrosa) is the type. This is a perennial plant, growing in chalky or lime-store countries, frequent in woods, or a marly soil. The root is tapering, fleshy, much branched; the herbage soft and downy, bitter, somewhat aromatic, with a portion of mucilage. The stem is upright, angular, leafy, 2 or 3 feet high, terminating in a corymbose, leafy panicle of numerous dull yellow flowers. The radical leaves bear some resemblance to those of foxglove, but when rubbed are readily distinguished by their aromatic scent.

\section{SPIKE ROLLER. See RoLler.}

SPINACH (Spinacea oleracea. From spina, on account of its prickly seed). There are two varieties, the round-leaved or smooth-seeded, and the triangular-leaved or prickly-seeded. The first being the most succulent, and consequently less able to endure a low degree of remperature, is employed for the spring and summer crops, and the latter for autumn and winter. For the round-leaved variety, a rich, moist, and mouldy loam, in an open situation, is preferable; but for the triangular-leaved a light, moderately fertile, and dry one, which may likewise be an open compartment, but a sheltered border is most conducive of a continued supply throughout the winter. The earth should always be well pulverized at the time of digging, as a tine tilth is one of the greatest inducements to its vigour. It is propagated by seed. The first sowing of the round-leaved variety may take place at the close of January. in a warm situation, to be repeated in larger but still small breadihs at the commencenent and end of February; and thrnce in be continued, as the plants rapidly advance to srepes, every 3 weeks until the middle of A pril, when, as this affection increases, it must be perturmed once a week until the close of May, when it may be reduced to once a fortricht, and $s(1)$ practised until the end of July. With Augus?, the sowing of the triangular-leaved variety commences, the main crop of which should be sown during the first 10 days of that month. The sowing may be repeated, after intervals of 3 weeks, until the early part of September.

The sowings may be performed broadcast and regularly raked, which is the mode generally practised for the principal crops, and for the winter-standing always, or in drills an inch deep and a foot apart; in either mode the seed being scattered thin.

Tetragonia, or New Zealand spinach (Tetragonia expansa), is much admired as a substitute for summer spinach, being of more delicate flavour, and not so liable to run to seed. It is propagated by seed, which is sown, in the seed vessel, as gathered the preceding autumn, at the latter end of March, in a pot, and placed in a melon-frame. The seedlings must be pricked while small singly into pots, and kept under a frame without bottom heat until the third week in May, or until the danger of frost is past.

SPINAGE, WILD. See Goosefoot.

SPINDLE TREE (Euonymus Europœus.) This shrub or small tree grows wild in English hedges and thickets. The very hard and finegrained wood is preferred for spindles and for skewers. It is fetid in every part when bruised, and esteemed poisonous. The branches are smooth and even angular when young; afterwards round, with a green, smooth, not warty bark. Lueaves ovate, pointed, finely serrated, about 2 inches long, furnished with awl-shaped stipules. Flowers fetid, small, greenish-white, mostly four-cleft. The capsules usually of a fine rose colour: seeds orange-coloured.

SPINDIE-WORM. These American insects are fatal to the plants attacked, the greater part of which, however, are without value to the farmer. Indian corn must be excepted; for it often sufiers severely from the depredations of one of these Nonagrians, known to our farmers by the namp of the spindle-worm. This insect receives its common name from its destroying the spindle of the Indian corn; hut its ravages generally begin while the corn-stalk is young, and" before the spindle rises much abore the tuf of leaves in which it is embosomed. The mis. chief is discovered by the withering of the leaves, and, when these are taken hold of, they may often be drawn out with the included spindle. On examining the corn, a small hole may be seen in the side of the leafy stalli, near the ground, penetrating into the soft centre of the stalk, which, when cut open, will be foun 1 is 
be perforated, both upwards and downwards, by a slender, worm-like caterpillar, whose excrementitious castings surround the orifice of the hole. This caterpillar grows to the length of an inch or more, and to the thickness of a goose-quill. It is smooth, and apparently naked, vellowish, with the head, the top of the first and of the last rings black, and with a band across each of the other rings, consisting of small, smooth, slightly elevated, shining, black dots, arranged in a double row. With a magnifying glass, a few short hairs can be seen on its body, arising singly from the black dots. This mischievous caterpillar, says Dr. Harris, is not confined to Indian corn; it attacks also the stems of the dahlia, as I am informed both by Mr. Leonard and by the Rev. J. L. Russell, both of whom have observed its ravages in the stems of this favourite flower. The chrysalis, which is lodged in the burrow formed by the spindle-worm, is slender. It is shining mahogany-brown, with the anterior edges of four of the rings of the back roughened with little points, and four short spines or hooks, turned upwards, on the hinder extremity of the body. The moth produced from this insect differs from the other Nonagrians somewhat in form, its fore-wings being shorter, and more rounded at the tip. It may be called Gortyna Zea, the corn Gortyna; Zea being the botanical name of Indian corn. The fore-wings are rust-red; they are mottled with gray, almost in bands, uniting with the ordinary spots, which are also gray and indistinct; there is an irregular tawny spot near the tip, and on the veins there are a few black dots. The hind-wings are yellowish-gray, with a central dusky spot, behind which are two faint, dusky bands. The head and thorax are rust-red, with an elevated tawny tuft on each. The abdomen is pale-brown, with a row of tawny tufts on the back. The wings expand nearly one inch and a half.

In order to check the ravages of these insects, they must be destroyed while in the caterpillar state. As soon as our corn-fields begin to show, by the withering of the leaves, the usual signs that the enemy is at work in the stalks, the spindle-worms should be sought for and killed; for, if allowed to remain undisturbed until they turn to moths, they will make their escape, and we shall not be able to prevent them from laying their eggs for another brood of these pestilent insects.

Treatise.)

SPINES. In botany, branches that, being imperfectly formed, lose their power of extension, become unusually hard, and acquire a sharp point. They are very different from aculei, or prickles, which are a kind of hardened hair. In leaves they are processes formed either by an elongation of the woody tissue of the veins or by a contraction of the parenchyma: in the former case they project beyond the surface or margin of the leaf, as in the holly; in the latter case they are the veins themselves indurated, as in the palmaled spines of Berberris vulgaris.

SPIINT. In farriery, a hard excrescence growing on the shank-bones of horses. It appears first in the form of a callous tumour, and afterwards ossifies. If the splint interfere with the action of some terdon or ligament, the 1010 hair should be removed, a little strong mercu. rial ointment be rubbed in for two days, and then an active blister applied. (Youatt on the Horse, p. 244.)

SPRING WHEAT. See WheАT.

SPRUCE PINE (Pinus Canadensis). Hemlock spruce. A tree which abounds in the northern parts of Pennsylvania, New York, and the Eastern States. Ste Fins.

SPUD. An implement used advantageously in cutting up weeds. It consists of a chisel. formed tool, about 2 inches wide on the cutting edge, inserted into a handle of some 4 or 6 feet in length; it is often made use of by the far. mer as a useful substitute for the walking-cane, affording an opportunity of destroying weeds with the utmost facility whilst walking over his grounds. Every farmer ought to own a spud.

SPURGE (Euphorbia; Linnæus named this genus after Euphorbus, a physician to Juba, King of Mauritania). This is an exceedingly variable and a very extensive genus of plants, comprising a number that are entirely unworthy of cultivation. The hardy perennial species thrive in any common garden soil, and in. crease by divisions of the roots or by seeds. The hardy annuals and biennials merely re. quire sowing in the open ground. The tender kinds must be sown in the hot-house or in a hot-bed frame, and, when potted off, must be set with other tender annuals and biennials. The root of $E$. ipecacuanha is said to be equal to that of the true ipecacuanha. E. untiquorum, E. canariensis, and some other fleshy species, produce the drug "euphorbium," which is the inspissated milky juice of such plants. There are in England 13 indigenous species, but the only one necessary to be noticed is the lesser spurge ( $E$. lathyris). It is a biennial, flowering in June and July. The stem rises from a strong, fibrous root to the height of 3 to $4 \mathrm{feet}$, purplish, smooth, round, hollow. The leaves opposite, spreading, in fours, sessile, oblong, acute, entire, and glaucous. The flowers are in a terminal, solitary umbel, consisting of 4 repeatedly forked branches, furnished with cor. date, entire bractes: the flowers are variegated with yellow and dark purple. Capsules are large and smooth, and, when half-ripe, are pickled as capers. 'The seeds, when pressed between moderately heated iron plates, yield a fixed, acrid oil, which might be advantageously substituted for castor oil. See Mole Tree.

SPURGE-LAUREL (Daphne laureola.) A British evergreen shrub, growing in woods, thickets, and hedges, flowering in March. The stem is 2 or 3 feet high, with round, pale, smooth, brown, upright, tough, and pliant branches, crowned with tufts of evergreen leaves, elegantly drooping in all directions, and about 2 or 3 inches long, on short footstalks. The flowers are deep-green, in axillary clusters, with orange anthers. Their scent, resembling saffron, with an overpowering sweetness, is perceptible in an evening only. The berries, which are oval and black, are poisonous to all animals except birds. Every part of the plant is very acrid, producing, like the mezereon, a burning heat in the mouth and throat. The bark of its root is commonly ase 1 
instead of mezereon. It is powerfully excitant and diaphoretic. 'The bark of the stem, soaked in vinegar and beaten out flat, forms an excellent agent for keeping blisters open.

SPURGE, OIIVE. See Mвzиноn.

SPURREY (Spergula, from spargo, to scatter, because it expels its seeds.) A genus of herbaceous, annual, or perennial plants, with slender linear leaves and white flowers. There are in England four indigenous species, the most common of which is the rough-seeded corn spurrey (S. arvensis), an annual plant, which grows in sandy corn-fields, and flowers from June to August. (See Pl. 9, b.) The stems are spreading, lax, 6 inches to 2 feet long, moderately branched, jointed, leafy, angular, and hairy and viscid in the upper part. Leaves whorled, linear, narrow, fleshy, downy, obtuse, with short stipules. The flowers are white, on slender, downy flower-stalks. The roughseeded spurrey is a common weed in sandy soils, and is in Scotland called yarr, and in Norfolk pick-purse. It is devoured with avidity by all cattle, and appears to be conducive to their health, while it remarkably tends to increase the milk of cows, and to fatten sheep. Hence a large, smooth-seeded variety of this weed (S. sativa) is industriously cultivated in Flanders, because it is so far superior to other pasture grasses that it continues green till a late period of autumn, and often throughout the winter. Its seeds afford on expression a good lamp oil; the flour obtained from them, when mixed with that of wheat or rye, produces wholesome bread, for which purpose it is often used in Norway and Gothland. Poultry eat spurrey greedily, and it is supposed to make them lay a great number of eggs. Whether given as hay, or cut green, or in pasture, Von Thaer observes that it is the most nourishing, in proportion to its bulk, of all forage, and gives the best flavoured milk and butter. It has been recommended to be cultivated in England, but it is not likely that such a plant can ever pay the expense of seed and labour in that country, even on the poorest soil; or, at all events, as Professor Martyn observes, we have many better plants for such soils.

SQUASH (Cucurbita). Of this plant there are many varieties, distinguished by peculiarities of shapes, colours, \&c. The young fruit is a rich and excellent vegetable for boiling, stewing, or baking. The common round kind (Cucurbila malopepo) is also called Cymbling (and by the French Bonnet de Prêtre). The warty or long squash (C. verrucosa), is said by Mr. Nuttall to be cultivated by the Indians of the Missouri to its source. Mr. Kenrick, of Boston, notices the following varieties:

1. Early orange; 2. Early long warted; 3. Early scallop; 4. Acorn; 5. Canada crook neck; 6. Long yellow crook neck; 7. Commodore Porter's Valparaiso; 8. Autumnal marrow; 9. Scarlet summer.

'The early orange is a new summer variety, very early, and of superior quality. 'The Canada crook neck is, without doubt, far superior to any and all others, for the late or main crop. It is fine-grained, mealy, and of a sweet, excellent flavour. By being kept in a dry and suitable temperature, they may be preserved till the following summer. Sow in April or May, as soon as the frosts are over, and the earth be. comes warm ; the early or summer varieties in hills 6 feet asunder; the winter varieties in hills 8 feet asunder, and 4 plants may remain in a hill.

Autumnal marrow squash (Cucurbila succado), introduced to notice by John M. Ives, Esq., of Salem. A fine, new variety, of an ovate form, pointed; the skin extremely thin, of a creamcolour; the flesh orange; the grain duicate, flavour excellent; seeds large, pure white. Average weight, 8 pounds. It keeps well in winter.

The scarlet summer squash is a new and beautiful flat variety, from France, of the acorn species, of a fine scarlet colour.

The Valparaiso squash, the seeds of which were brought from the Pacific by the late Com. modore Porter, is a splendid vegetable, without any neck, in shape and size somewhat resembling a long watermelon, flattened, and of a rich citron or orange colour. Mr. Comfort, of Bucks county, near Philadelphia, has raised some weighing 100 lbs., which have been greatly admired at agricultural and horticultural exhibitions. This vegetable possesses all the good qualities of the common kinds of pumpkin and squash, of which it would seem to be a hybrid variety, very superior to either. Being neither watery or stringy, it makes a delicious pje, far more rich and delicate than that of the ordinary pumpkin. It is also served up at table with meat, like the common squash, either boiled, or baked like a loaf of bread or sweet potato: containing a large amount of saccharine and other nutritious properties, they are also excellent food for farm-stock, especially milch cows. They are cultivated like other vegetables of the same family, but much care must be observed to keep them at a considerable distance from other varieties, with which they have a strong tendency to mix, thus leading to depreciation. They keep well in winter.

SQUASH.BUG. The common American squash-bug (Coreus tristis), so well known for the injurious effects of its punctures on the leaves of squashes, is one of the most remarkable insects belonging to the natural division, which includes bed-bugs, fruit-bugs, and various other fetid bugs (Hemiptera). It was first described by De Geer, who gave it the specific name of tristis, from its sober colour, which Gmelin unwarrantably changed to moestus, having, however, the same meaning. Fabricius called it Coreus rugator, the latter word signifying one who wrinkles, which was probably applied to this insect, because its punctures cause the leaves of the squash to become wrinkled. Mr. Say, not being aware that the insect had already been three times named and described, redescribed it under the name of Coreus ordinatus. Of these four names, how ever, that of tristis, being the first, is the only one which it can retain. About the last of October squash-bugs desert the plants upon which they have lived during the summer, and conceal themselves in crevices of walls and fences, and other places of security, where they pass the winter in a torpid state. On the return of warm weather, they issue from 
winter-quarters, and when the vines of the squash have put forth a few rough leaves, the bugs meet beneath their shelter, pair, and im mediately afterwards begin to lay their eggs. This usually happens about the last of June or beginning of July, at which time, by carefully examining the vines, we shall find the insects on the ground or on the stems of the vines, close to the ground, from which they are hardly to be distinguished on account of their dusky colour. This is the place where they generally remain during the daytime, apparently to escape observation; but at night they leave the ground, get beneath the leaves, and lay their eggs in little patches, fastening them with a gummy substance to the under-sides of the leaves. The eggs are round, and flattened on two sides, and are soon hatched. The young bugs are proportionally shorter and more rounded than the perfect insects, are of a pale ash-colour, and have quite large antennæ, the joints of which are somewhat flattened. As they grow older and increase in size, after moulting their skins a few times, they become more oval in form, and the under-side of their bodies gradually acquires a dull ochre-yellow colour. They live together at first in little $s$ warms or families beneath the leaves upon which they were hatched, and which, in consequence of the numerous punctures of the insects, and the quantity of sap imbibed by them, soon wither, and eventually become brown, dry, and wrinkled; when the insects leave them for fresh leaves, which they exhaust in the same way. As the eggs are not all laid at one time, so the bugs are hatched in successive broods, and consequently will be found in various stages of growth through the summer. They, however, attain their full size, pass through their last transformation, and appear in their perfect state, or furnished with wing-covers and wings, during the months of September and October. In this last state the squash-bug measures six-tenths of an inch in length. It is of a rusty black colour above, and of a dirty ochre-yellow colour beneath, and the sharp lateral euges of the abdomen, which project beyond the closed wing-covers, are spotted with ochre-yellow. When handled, and still more when crushed, the latter give out an odour precisely similar to that of an over-ripe pear, but far ton powerful to be agreeable.

In order to prevent the ravages of these insects, they should be sought and killed when they are about to lay their eggs; and if any escape our observation at this time, their eggs may be easily found and crushed. With this view the squash-vines must be visited daily, during the early part of their growth, and must be carefully examined for the bugs and their eggs. A very short time spent in this way every day, in the proper season, will save a great deal of vexation and disappointment afterwards. If this precaution be neglected or deferred till the vines have begun to spread, it will be exceedingly difficult to exterminate the insects, on account of their numbers; and if at this time dry weather should prevail, the vines will suffer so much from the bugs and drought together, as to produce but little if any

isua. Whatever contributes to bring forward 1012 the plants rapidly, and to promote the vigour and luxuriance of their foliage, renders them less liable to suffer by the exhausting punctures of the young bugs. Water drained from a cowyard, and similar preparations, have, with this intent, been applied with benefit.

The leaves of the squash are also preyed upon by another insect of a very different description, namely, the Coccinella borealis (See P1. 16, fig. 11). Although the genus of insects to which this belongs destroys Aphides, there are, as Professor Halderman, of Pennsylvania, observes, a few exceptions, among which is the species named, which may be found, both in the larva and perfect state, eating the leaves of the squash.

SQUAW-ROOT (American orobranche).

SQUILL (Scilla, from skylla, to injure, the bulbs being poisonous). An extensive genus of interesting bulbous plants. A light soil is most suitable for them; and they are readily increased by offsets from the bulbs. The leaves are radical, linear. The flowers in clusters, blue, purplish, or white. There are four indigenous species, the vernal squill ( $S$. verna), the two-leaved squill ( $S$. bifolia), the autumnal squill ( $S$. autumnalis), and the harebell squill, or wild hyacinth (S. nutans). The bulb of the wild hyacinth contains much mucilage, which can be readily separated from an acrid principle which is conjoined with it. It is much employed by calico-printers.

SQUITCH-GRASS. See Bert and Coucu. ST. JOHN's WORT. See John's Wort.

STACK. Corn in the sheaf, piled up in a circular or rectangular figure, brought to a point or ridge at the top, and afterwards thatched to protect it from the influence of the weather, and more especially from rains. The term is also sometimes applied to hay piled up in the same manner, which, however, in most places is called a rick. The foundation of a corn stack is commonly made on a platform of wood or iron, raised on props to protect it from the moisture of the soil, and also from rats and mice; in which respect stacks of corn difier from ricks of hay, which are built always on the ground. It is of great advantage to soak the props in corrosive sublimate, which not only preserves the wood, but also destroys vermin. Stacks are of various forms and dimensions, according to circumstances; but for grain those of a long, narrow, square shape are probably the most advantageous, where the quantity of corn is considerable; as they are found to stand more firmly, have a better appearance, are more conveniently and readily built, and preserve the grain better than those of any other form. And they have the great advantage of requiring less thatch as well as labour in putting it upon them than the round stack. But where the corn is only in a small proportion, the round or oblong shape may be more proper and suitable, as being more readily drawn up in the roof; but the circular, with a conical top and cylindrical body diverging a little at the eaves, is esteemed the best form by some. For hay, the form of the rick or stack is a matter of still less consequence; the long square or oblong shapes are perhaps the mosi safe and convenient, especially when not ton 
uroad, as they admit the air most fully, and are besides the most convenient to cut from in trussing hay for sale at the market.

STAG. A term applied provincially in England to a young horse. Also to the male of the deer kind. See DEER.

STAGGER-BUSH (Andromeda Mariana). This American plart grows in the Middle States, with a stem 2 to 3 and 4 feet high. It is very abundant in New Jersey, where the farmers are of opinion that it is destructive to sheep, when eaten by them, producing a disease called the staggers.

S'TAGGERS. See A poplexy.

STALL-FEEDING. The process of fattening cattle in the stall. The best practice in this mode of fattening is probably that of wholly confining them to the stalls, as by this means they are kept quiet, and free from interruption, and of course feed more quickly and with greater regularity, which seem to be points of great importance in this system of management. There are, however, many other meihods adopted in different situations and circumstances.

In regard to the sorts of food that may be employed in the way of winter-fattening animals, they are very numerous, but the principal succulent kinds are carrots, parsnips, potatoes, Swedish turnips, cabbages, common turnips, grains, \&c.; and of the more dry sorts, oil-cake, oats, barley-meal, rye-flour, bean and pea-meal, and others of the same nature, with different kinds of straw cut into chaff by means of machinery, or hay cut in the same manner. It is usual with some to employ the different meals in a state of mixture in nearly equal proportions, except bean-meal, which, from its heating quality, is mostly mace use of in smaller quantities. But on the principle of fresh kinds of food having a more powerful effect on the systems of animals when first applied, it may be more beneficial to have them given in alternation, or at distant intervals, as their effects may in this way be more fully experienced.

In respect to the cut straw and hay that is made use of in this way, the first should be prepared from that which is fresh thrashed out. The hay, instead of being of the inferior kind, should be the best that the farm affords, and such as is not in the least injured in the smell or taste by keeping. The more inferior kinds of hay have, however, by the addition of a very small proportion of common salt, been made to be preferred to the best when not prepared in that way. See CAtthe, Folning, Foon, Sorling, and Ventilation.

STANDARDS. The young trees reserved at the felling of woods, for the growth of timber. It also signifies such fruit trees as are intended to grow in an open exposure, and not to be hacked and mangled with the knife, as the dwarf trees and those planted against walls are.

S'TARR, or BENT. See Arundo and ELyMos.

STARCH (Germ. stärke). One of the common proximate principles of vegetables. It is characterized by its insipidity, and by insolubility in cold water, in alcohol, and in ether. The term "starch" is commercially applied to that obtained from wheat, which for this manu. facture is ground and diffused through rats of water, where it remains two or mure weeks, and undergoes a slight fermentation, and accquires a peculiar sour smell. The sour liquaur is drawn off, and the precipitate washed in sieves. through which the impure starch passes with the water. It is afterwarils passed through other waters, drained through boxes lined with linen or canvass, and ultimately stove-dried in paper. When drying, it cracks int, the prismatic pieces, resembling miniature basalh, which is its usual form. Starch may be obtained from many other grains, and from pota. toes and several esculent vegetables. Arrow. root is the starch.of the Maranta arundinace, British arrowroot that of the root of Arum mucu. latum; sago, of the Sagus faranifera, an East Indian palm tree; and tapioca and cassava, of the Jairopha manihot. In the process of germination, and by various chemical agents, starch may be converted into a species of gum and sugar. Pure starch is white, tasteless, and inodorous. It consists of two distinct substances, that are readily recognised under a good magnifying lens, namely, a membrane called amylin, and a gummy semifluid matter named amiolin; the one the husk, the other the contents of the granules. In cold water, unless triturated in a mortar, the grains do not burst, but remain entire and insoluble; but in boiling water they burst and form a mucilage. Starch is a compound of 42.8 parts of carbon, 6.35 of hydrogen, and 50.85 of oxygen in 100 parts. Starch is much less nutritious than wheat flour, or the farina of any grain which contains gluten; and on this account the starch of arrowroot, sago, \&c., is used as a diet for the sick. Starch is detected from other mucilages by forming a blue colour with iodine, when the mucilage is cold. Starch in England is charged with a duty of $3 \frac{1}{4} d$.per lb., and its manufacture is consequently placed under the control of the excise.

STAR OF BETHLEHEM. See BETHLEHEM, Stan OF.

STAR-THISTLE. A name applied to some species of Centaurea, viz. Jersey star-thistle ( $C$. isnardi), the common star-thistle (C. calcitrapa), and the yellow star-thistle, or St. Barnaby's thistle (C. solstitialis). The first is a perennial weed, the others are annuals. See BLUE-BotTLE, KNAPWEEN, \&c.

STARWORT (Aster, a star; whence also the cammon name, the flowers resembling little stars from the rays of their circumfereuce). Many species of this extensive genus are stately and handsome plants. The swellings or galls as large as a walnut, so often found on the stems of some American species of starwort, or aster, are caused by the punctures of a fly.

STARWORT, THE WATER (Callitriche named by Pliny from kalos, beautiful, and thrix, hair). Annual aquatic plants, which grow in ditches, ponds, and lakes.

STEAM. Water converted into an elastic fluid by the application of heat. It woult be foreign to our subject to go into any detail of the various mechanical uses and improve ments to which steam has been applied wit 4 Q 2 1013 
30 much success. Latterly, however, a spirit of inquiry has led to an investigation into the application of steam to purposes of husbandry, such as engines for ploughing, draining, \&c.; and, though there are obstacles in the way of their successful operation, there is little doubt that eventually the spirit of research and improvement will overcome these difficulties, and create a singular revolution in the practical operations of agriculture, whereby a vast amount of animal power will be saved, and an increased impetus be given to production. A series of very able papers on this subject appeared a few years ago in the Quart. Journ. of $A g r$ vols. v., vi., vii.

STEAMING FOOD. The advantages to be derived from boiling or preparing the food of live-stock are now very generally understood and appreciated; although it is still a question whether it always compensates for the extra labour and time consumed. We have already gone into this subject under the head Foop, and merely revert to it now to call attention to some articles describing apparatuses for steaming food, which will be found in the Quart. Journ. of $A g r$. in vols. iv-vi. Steaming is also popularly treated of and explained in the first volume of Brit. Husb. p. 129, and has been frequently discussed in American periodicals.

S'TEARINE (Gr.). That part of oils and fats which is solid at common temperatures. Both in fats and in fixed oils it is associated with a fluid principle, which cannot be rendered solid at the lowest known temperatures. Stearine is only found in animal fats; or, at least, is rarely present in those of a vegetable origin. See FAT.

STEELYARD. A well-known balance, by which the weights of bodies are determined by means of a single standard weight.

STEEN KROUT (Lithospermum arvense). Stone Seed, Wheat Thief. See RaD WEr.D.

S'TEEPING. See Brining of Grain and Smur.

STEPPES (Russ). The name given to the vast extent of plains peculiar to Asia; synonymous with the prairies of North America, and the llanns of South America. The steppes of Russia are not unlike the heaths of Germany; being in part susceptible of cultivation, and affording pasturage for numerous herds belonging to nomadic tribes.

STITCHWORT (Stellarin, from stella, a star; the flowers are star-like). A genus of herbaceous plants which are mere weeds. Some are annual, the others are perennial. See Chickwend.

S'TIGMA. In botany, the upper extremity of the style without a cuticle, in consequence of which it has almost uniformly a humid and papillose surface. It is the part upon which the pollen falls, and where it is stimulated into the proluction of the pollen tubes, which are indispensable to the act of impregnation.

S'TII.ES. A well-known contrivance for the admission of foot-passengers, without permitting the stock of the enclosures to escape. stiles are made in very different forms and manners in different districts, according to the materials, situations, and ourposes for which ohro are intended

1014
STINGERS and PIERCERS. A class of insects embracing bees, wacps, ants, saw-flies, ichneumon-flies, \&c.

STIPULES. In botany, small scales or ap. pendages situated on each side at the base of the petioles or leaf-stalks, most commonly of a less firm texture than the latter, and having a subulate termination.

STOCK-NUT. See HAzEL.

STOLONIFEROUS. Bearing runners which root at the joints.

STOMATA. In botany, orifices through the epidermis of plants, chiefly of the leaves, having the appearance of an areola, in the centre of which is a slit of various form and size, that opens or closes, according to circumstances, and lies over a cavity in the subjacent tissue. They are universally regarded as spiracles, or breathing pores. In leaves of trees and plants exposed to the air they usually oc. cupy the under disk; on those that lie upon the surface of water, the upper disk.

STONE. An English common weight estimated at $14 \mathrm{lbs}$.

S'TONECROP (Sedum). A genus of herbs, with alternate, very succulent, either flat, cylindrical, or tumid leaves. Root mostly perennial. Flowers yellow, white, or reddish, usually cymose, rarely axillary. There are, in England, ten indigenous species, which inhabit, for the most part, old walls, roofs, and dry sandy ground. See House-LeEk and Onpixe.

STONE-PARSLEY (Athamanta). These are chiefly weeds.

STONE PINE. See Fins.

STONE WEED (Field Lithospermum). See RED-RoOT.

STOOKING. The Scotch term for setting up sheaves of corn in stocks or shocks. 'The operation is performed soon after the corn is cut, it being previously tied into bunches or sheaves.

S'TOOL. The root of a timber tree, which throws up shoots. Coppice wood consists chiefly of the shoots sent up by the roots of stools, or trees or shrubs which have been cut over by the surface. In general, all dicotyle. donous trees are endowed by nature with the property of sending up shoots from the stumps or stools; but this is not the case with most of the gymnosperms or coniferous trees. A wood of pines or firs, therefore, when once cut down, can never be renewed, except by seeds. It is a curious fact that the shoot, however large the stool may be, can be traced to the pith, and therefore appears to have been originally a shoot of the first year's growth of the plant. That its growth has been impeded is evident; but when the tree is cut down, and the whole sap is thrown into a small space, the latent, yet vital gum is stimulated, and a twig thence produced.

S'T'ORK'S-BILL (Erodium, from erodios, a heron; the carpels resemble the head and beak of that bird). This is an extensive genus of plants of considerable beauty: they thrive well in any common soil with the usual treatment.

STRAINS. In farriery, accidental injuries arising from over-distension of the muscles or tendons, in consequence of which the animals suffer great pain, and are generally lamed. 
STRANGI,ES. In farriery, a disease which is principally incident to young horses ; usually appearing between the fourth and fifth year, and oftener in the spring than at any other season. It is preceded by cough, and is a disease tn which all horses are subject, but it never returns. A blister will be found the best application to hasten the formation and suppuration of the tumour under the jaw, which, from its situation, has probably given the name to this disease.

STRATH, in Scotland, is generally understood to signify a valley of considerable size, whose appellation is determined by some river running through it, or some particular characteristic.

STRATUM. When different rocks lie in succession upon each other, each individual forms a stratum. See Geologr.

STRAW. 'The stalks or culms on which corn and other grasses grow, and from which the grain has been separated by thrashing. When chopped or cut small, it affords a whole. some provender for horses and oxen, especially if it be mixed with green food. (See CинғF and Cuaff Engines.) When not allowed to be carried off the premises, the chief value of white straw for farm purposes lies in its conversion into manure; for although it may carry store cattle through the winter, it will neither fatten them nor enable any animal to work; and its intrinsic worth for the uses of litter and of occasional feeding has been estimated by experienced farmers in England at 20s. to 30 s. the ton. See Haulm.

STRAWBERRY (Fragaria, from fragrans, fragrant; the perfumed fruit of the strawberry is well known). The strawberry is our earliest fruit, and as the harbinger of the fructus hrrai, its appearance is as welcome as its flarour agreeable. The cultivation and propagation of this plant is so familiar to every one, as are the wholesomeness and deliciousness of the fruit, that neither need be particularized here. 'Three species of strawberry found wild in the United States are enumerated by $\mathrm{Mr}$. Nuttall: 1. F. vesca, in the state of Ohio, near Lake Erie. 2. F.Virginiana. 3. F. Canadensis, both common in the Southern, Middle, and Northern States. The species indigenous to Britain are two, the wood strawberry ( $F$. vesca), and the hautbois strawberry ( $\boldsymbol{F}$. elatior). The covering of strawberry plants with sea-weed in the winter has been found to increase the size of the fruit to a prodigious degree. This is much practised in the island of Jersey.

STRA WBERRY-LEAVED CINQUEFOIL. See Cinaueforl.

STRA W-CUTTER. See Chaff-Engtas.

S'TRAW-YARD. The yard into which straw is thrown in thrashing. Also the enclosure in which cattle are confined in winter, for the purpose of being foddered on straw. There ought to be open sheds for shelter in the straw-yard; for though pure air is essential to the health of store and working cattle, cold winds and rain are highly injurious to them. The great use of a straw-yard is for the accumulation of manure, which cannot be rich unless the cattle get some food besides straw to support them.

STREET DUNG. The mixture of anima and vegetable matters, comminuted particles, \&c., swept up from the streets of large touns, which is found to be an excellent fritulizr ; is is composed of a mixture of horse ding. débris of the paving stones, soot, lime, atsd metallic particles.

S'IRENGTH, in mechanics, is used in the same sense as force or power. Thus, strength of animals is the muscular force or energy which animals are capable of exertung: strength of materials is the resistance which bodies oppose to a force acting upon them. It is obviously a matter of much importance ?, be able to estimate with tolerable accurary the efforts which an animal of the averacre stren: employed in labour is capable of exerting, anil, accordingly, very numerous observations have been made on the subject; but this species of force is subject to variation from so great a number of circumstances, both physical and mechanical, that the results given by different authors present very little agreement with each other, though they are of great value as affording data for determining the modes in which animal labour is most advantageously employed.

Of all animals employed as first movers, the horse is, beyond question, the most useful, and that whose labour is susceptible of the most numerous and varied applications. For the purpose of determining his muscular power, the dynamometer may be conveniently used; but, as the action of the animal is very quickly reduced by continued exertion, it is mure usual to estimate it according to the amount of daily labour performed. Desaguliers and Smeaton estimate the strength of a horse as equivalent to that of 5 men; the French authors have commonly stated it as equal to 7 men; and Schulze makes it equal to that of 14 men in drawing ho. rizontally. According to Desaguliers, a horse's power is equal to $44 \mathrm{lbs}$. raised 1 foot high in 1 minute. Smeaton makes this number 22.916 , Hachett 28, and Watt 33. The last estimate is commonly understood by the term horsepower as applied to steam-engines. The quantity of action which a horse can exert diminishes as the duration of the labour is prolonged. Tredgold gives the following table, showing the average maximum velocity with which a horse unloaded can travel according to the number of hours per day :-

\begin{tabular}{|c|c|c|c|}
\hline $\begin{array}{c}\text { Time of } \\
\text { March in } \\
\text { Hours. }\end{array}$ & $\begin{array}{c}\text { Greatest Velocity } \\
\text { per Hour in Miles. }\end{array}$ & $\begin{array}{c}\text { Time of } \\
\text { March in } \\
\text { Hours. }\end{array}$ & $\begin{array}{c}\text { Greatest Velocity } \\
\text { per Hour iu Mica }\end{array}$ \\
\hline 1 & $14 \cdot 7$ & 6 & $6 \cdot 0$ \\
\hline 2 & $10 \cdot 4$ & 7 & 5.5 \\
3 & $8 \cdot 5$ & 8 & $5 \cdot 2$ \\
4 & $7 \cdot 3$ & 9 & $4 \cdot 9$ \\
5 & $6 \cdot 6$ & 10 & $4 \cdot 6$ \\
\hline
\end{tabular}

The useful effect a horse is capable of pro. ducing, depends much upon the manner ic which his strength is applied. See CARTE. Drxamometer, Horse-Poweh, Thrashrye Ma. CHINE.

Strength of Materials.-There are four different ways in which the strength of a solid body may be exerted: first, in resisting a longitudinal tension, or force tending to tear it asun der; secondly, in resisting a force tending 10 break the body by a transverse strain; thirdly in resisting compression, or a force tending tc crush the body; and, fuurthly, in resisting a 
force tending to wrench it asunder by torsion. $\mathrm{Mr}$. Hodgkinson gives the following results of his experiments on the resistance of a crushing force of short pillars of some of the most common descriptions of wood, the force being applied in the direction of the fibres.

\begin{tabular}{|c|c|c|c|c|c|c|c|}
\hline \multicolumn{6}{|c|}{ Description of Wood. } & \multicolumn{2}{|c|}{$\begin{array}{l}\text { Strength per square Inch } \\
\text { in lbs. }\end{array}$} \\
\hline Alder & - & - & - & - & - & 6831 to & 6960 \\
\hline Ash & - & - & - & - & - & 8683 & 9363 \\
\hline Bay & - & - & - & - & - & 7518 & 7518 \\
\hline Beech & & & - & - & - & 7733 & 9363 \\
\hline Englis & 1 birch & & - & - & - & 3297 & 6402 \\
\hline Cedar & & : & - & - & - & 5674 & 5863 \\
\hline Red de & & - & - & - & 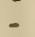 & 5748 & 6686 \\
\hline White & deal. & - & - & - & - & 6781 & 7293 \\
\hline Elder & $-\quad$ & - & - & - & - & 7451 & 9973 \\
\hline Elun & - & - & - & - & - & & 10331 \\
\hline Fir (sp & ruce) & & - & - & - & 6499 & 6819 \\
\hline Maliog & any & & - & - & - & 8198 & 8198 \\
\hline Oak & Quebes & & - & - & - & 4231 & 5982 \\
\hline Oak & Englisk & & - & - & - & 6484 & 10058 \\
\hline Pine & pitch) & & - & - & - & 6790 & 6790 \\
\hline Pine & red) & - & - & - & - & 5395 & 7518 \\
\hline Poplat & & - & - & - & - & 3107 & 5124 \\
\hline Plum & (dry) & & - & - & - & 8241 & 10493 \\
\hline Teak & & & - & - & - & & 12101 \\
\hline Waln & & - & - & - & - & 6063 & 7227 \\
\hline Willo & & & - & - & - & 2898 & 6128 \\
\hline
\end{tabular}

(Brande's Dict. of Science; Barlow's Treatise on the Strength of Timber.)

S'TUBBLE. The root ends of the culms of corn left in the field, standing as they grew, after the corn has been reaped by the sickle or scythe. In some parts of England only a small portion of the straw is cut off with the ears of corn, and the stubble in that case is a foot or 18 inches in length; but in others the corn is cut as close to the surface as possible, in which rase the stubble is quite short. In general, .nng stubble is a symptom of bad farming, because a quantity of straw is in this case left to waste in the field, which might have been carried home and rotted into manure.

STYLE. In botany, is that elongation of the ovarium which supports the stigma. It is an extension of the midrib of the carpellary leaf, or is formed by the rolling up of the attenuated extremity of the latter.

SUBSOIL-PLOUGH (Pl. 17, o, g). See Prover and Subsolz-Ploughing.

SUBSOII,-PLOUGHING. In farming, the operation of breaking the substratum by means of a plough constructed especially for that purpose. Considerable discussion has taken place with regard to the advantages of subsoil-ploughing; a difference of opinion which appears to have been principally caused by an inattention to the chemicaleffects produced by the subsoil, or Deanstonizing system of tillage, so named from being first employed, or at least first brought into general notice, by Mr. Smith, of Deanston, in Stirlingshire, when he was examined, in 1836 , before ine Agricultural Committee of the House of Commons. By this system, by means of a subsril plough, of which there are several kinds, the subsoil, or under crust of earth, is merely broken and pulverized, say to the depth of from 14 to 20 inches, without being brought to the surface, or mixed with the upper soil; after a iapse of 4 or 5 years, a portion of the previously disturbed substratum is found, by experience, in a state to be advantageously (by deep ploughing; hrough: to the surface; it being in this lol6 time, by the action of the atmosphere, and perhaps by a partial mixture with the surface. mould, rendered sufficiently friable and fertile. It is of necessity a consequence of this subsoilploughing, that the permanent drains of all lands thus cultivated must be constructed rather deeper in the soil than is usual with farmers; the top of those at Deanston are placed at a depth of 22 inches from the surface, so as to be completely out of the way of the subsoil which the plough has turned over.

As the description of this valuable plough cannot be too generally circulated, I will here introduce it in Mr. Smith's own words:-

"The subsoil-plough has been constructed on principles appearing the best fitted to break up the subsoil completely to a depth sufficient for thorough cultivation, say 14 to 16 inches, whilst the active soil is still retained on the surface; to be of the easiest possible draught in reference to the depth of furrow and firmness of the subsoil; to have strength and massive weight sufficient to penetrate the hardest stratum; to resist the shocks from fast stones, and to throw out all stones under $200 \mathrm{lbs}$. in weight. All this has been accomplished and practically proved at Deanston, over an extent of at least 200 acres of various soils; and also in various parts of England, Scotland, and Ireland, during several seasons. The plough requires 4 good horses, an active ploughman, and a lad to drive the horses and manage them at the turnings. Six horses, yoked three and three abreast, may be necessary in some very stiff or stony soils. A common plough, drawn by two horses, goes before the subsoil-plough, throwing out a large open furrow of the active soil; the sub. soil-plough following, slits up thoroughly and breaks the subsoil, and the next furrow of active soil is thrown over the last opened furrow of the subsoil; the stones brought to the surface by the subsoil-plough being thrown aside on the ploughed part of the land by a lad: thus the work proceeds until the whole field is gone over. The lad should carry a bag of wooden pins, that he may mark the site of the large fast stones which the plough cannot throw out, and which must afterwards be dug out with the pick, and perhaps blasted.

"The charge of subsoil-ploughing a Scotch acre may be estimated at $24 s$. or $30 s$. per statute acre, being one-fifth of what a similar depth with the spade would cost, and, upon the whole, as effectually done. When land which has been opened up by the subsoil-plough shall have undergone the first rotation of cropping, several inches of the subsoil may be taken up by the plough to mix with the active soil; and in proportion as the subsoil is ameliorated, so may the greater depth be taken up with advantage. In the richer subsoils it is sometimes expedient to plough to the whole depth of the moved subsoil on the first application of the trench-plough. The trench-plough recommended for this process should be made in the form of Wilkie's plough, having all its dimensions made of double size; or, what is found to answer fully as well, by a plough in the fashion of the old Scotch plough, but also of double dimensioni. Such ploughs require six horses, yoked three and three abreast, with one man to 
hold the plough, and another to manage the horses, to do the work effectually. This operation should be performed in turning over the winter furrow preparatory to a green crop, and the sooner the work is performed after harvest the better. In estimating the expense of this operation, the horses may be charged at $4 s$. each, to cnver all expenses, tear and wear, \&c., which will amount to $24 s$; two men, $2 s_{\circ}=4 s_{s}$; and an attendant lad to pick out stones, $1 \mathrm{~s}$.; in all 29s. As the work is heavy, the motion of the horses is necessarily slow, and it will, in general, take 8 hours' working to accomplish one statute acre. 'The expense of this operation may appear alarming; but when it is considered that one such ploughing will be more effectual in killing weeds, and in exposing the soil to the air, than two ordinary ploughings, we may deduct the cost of two such $=20$ s., leaving 9 s. to be charged against the deep working.

"When land has been thoroughly drained, deenly wrought, and well manured; the most unpromising sterile soil becomes a deep, rich loam, rivalling in fertility the best natural land of the country; and from being fitted for raising only scanty crops of common oats, will bear good crops of from 32 to 48 bushels of wheat, 30 to 40 bushels of beans, 40 to 60 bushels of barley, and from 48 to 70 bushels of early oats per statute acre; besides potatoes, turnips, mangel-wurzel, and carrots as green crops, which all good agriculturists know are the abundant producers of the best manure. It is hardly possible to estimate all the advantages of dry and deep soil. Every operation in husbandry is thereby facilitated and cheapened; less seed and less manure produce a full effect; the chances of a good and early tid (a Scotch term for that slate of the ploughed soil which is most suitable for receiving the seed, neither too moist nor too dry) for sowing are greatly increased, a matter of great importance in our precarious climate; and there can be no doubt that even the climate itself will be much improved by the general prevalence of land dry."

In this instance, as in most other novel agricuitural efforts, the zeal of its promoters has sometimes carried them too far; they have even confidently contended that in most situations subsoiling will render draining unnecessary; a result which would hardly have been arrived at by the most sanguine subsoiler, if he had paused to recollect that deepening the soil, however it may promote the absorption of atmospheric moisture, can in few situations enable land-springs and stagnant waters to escape. The objects to be attained by these operations are, in fact, diametrically opposite. The one is adopted to increase the gradual healthful supply of food and moisture by the earth to the roots of the crop, in the degree the most grateful to its habits. The other expensive practice is to remove that moisture when (from any cause) it becomes too abundant for healthful vegetation; this removal can only be obtained in very peculiar situations by the mere use of the subsoil-plough, and then to a very limited extent; such, for example, as when the crust or subsoil is of such a degree. of thinness as to be completely penetrated by the plough, and thus the upper soul bruught, by breaking up the separatung crust, into immediate contact with a substratum of earth of greater absorbent properties than the pan-crust which has hitherto separated them.

The farmers of the chalky soils of Sussex, Dorsetshire, Wilts, and Ilampshire, very advantageously raise the substratum of chalk ex. isting under their lands, and spread it in considerable quantities on the surfice. I'huse of Essex and Suffolk in many places do the same with the under-stratum of clay or marl on which their surface-soils immediately rest; and they find this a very profitable practice, because the earths which constitute all fertile snils being also the necessary constituents of the commonly cultivated grasses, are gradually and incessantly carried off from thence by continual cropping, and consequently in time an advantageous opportunity is afforded for their being replenished with the earths, perhaps contained in the subsoil, in which they may have become deficient.

The chemical effect of pulverizing anil brealsing up a subsoil is certainly advantageous to the plant in two ways, besides others with which we are very likely at present unacquainted; first, it renders the soil penetrable to a much greater depth by the roots, or minute fibres of the plant, and consequently renders more available any decomposing matters, or earthy ingredients, which that substratum may contain; and, secondly, it renders the soil much more freely permeable by the atmosphere, rendering, in consequence, a greatly increased supply, not only of oxygen gas to the roots of the plants, but also yielding more moisture, not only from the soil, but from the atmospheric air; which moisture, let it be remembered by the cultivator, is in all weathers as incessantly absorbing by the soil as it is universally contained in the atmosphere, abounding most in the latter, in the very periods when it is most needed by the plants - that is, in the warmest and driest weather.

It is, perhaps, needless to prove, that the roots of commonly cultivated plants will pene. trate, under favourable circumstances, much greater depths into the soil, in search of moisture, than they can, from the resistance of the case-hardened subsoil, commonly attain. Thus the roots of the wheat plant in loose, deep soils, have been found to descend to a depth of 2 or 3 feet, or even more; and it is evident, that if plants are principally sustained in dry weather by the atmospheric, aqueous vapour absorbed by the soil, that that supply of water must be necessarily increased, by enabling the atmospheric vapour and gases, as well as the roots of plants, to attain to a greater depth; for the interior of a well-pulverized soil, be it remembered, continues steadily to absorb this essential food of vegetables, even when the surface of the earth is drying in the sun.

And by facilitating the admission of air th the soil, another advantage is obtained, that of increasing its temperature. The earths are naturally bad conductors of heat, especially downwards; thus it is well-known, that, at the siege of Gibraltar, the red-hot balls employed

1017 
by the gurrison were readily carried from the furnaces to the batteries in wooden barrows, whose bottoms were merely covered with earth. Davy proved the superior rapidity with which a loose, black soil was heated compared with a chalky soil, by placing equal portions of each in the sunshine; the first was heated in an hour from $65^{\circ}$ to $88^{\circ}$, while the chalk was only heated to $69^{\circ}$. (Elements of $A g r$. Chem. p. 178.) This trial, however, must not be regarded as absolutely conclusive, since the surface of the black soils naturally increases more rapidly in temperature when exposed to the direct rays of the sun than those of a lighter colour. A free access of air to all soils also adds to their fertility, by promoting the decomposition of the excretory matters of plants, which otherwise would remain for a longer period, to the annoyance of plants of the same species.

In a recent communication to the secretary of the English Agricultural Society, Sir E. Stracey has given some of the results of his experience with the Rackheath subsoil-plough, and they are of a description which cannot be too generally known:- "On my coming," he remarks, " to reside on my estate at Rackheath, about 6 years since, I found 500 acres of heath land, composing 2 farms (which had been enclosed under an act of parliament about 40 years), without tenants; the gorse, heather, and fern, shooting up in all parts. In short, the land was in such a condition, that the crops returned not the seed sown. The land was a loose, loamy soil, and had been broken up by the plough to a depth not exceeding 4 inches, beneath which was a substratum (provincially called an iron pan) so hard, that with difficulty could a pickaxe be made to enter in many places; and my bailiff, who had looked after the land for 35 years, told me that the lands were not worth cultivation-that all the neighbouring farmers said the same thing-and that there was but one thing to be done, viz., to plant with fir and forest trees; but to this I paid but little attenlion, as I had the year preceding allotted some parcels of ground, taken out of the adjoining lands, to some cottagers; to each cottage, about one-third of an acre. The crops on all these allotments looked fine, healthy, and good, producing excellent wheat, carrots, peas, cabbages, potatoes, and other vegetables in abundance. The question then was, how was this done? On the outside of the cottage allotments all was barren. It could not be by the manure that had been laid on, for the cottagers had none but that which they had scraped from the roads. The magic of all this I could ascribe to nothing else but the spade; they had broken up the land 18 inches deep. As to digging up 500 acres with the spade, to the depth of 18 inches, at an expense of $6 l$. an acre, I would not attempt it. I accordingly considered, that a plough might be constructed so as to loosen the soil to the depth of 18 inches, keeping the best soil to the depth of 4 inches, and near the surface, thus admitting air and moisture to the roots of the plants, and enabling them to extend their spongioles in search of food; for air, moisture, and extent of pasture, are as necessary to the thriving and increase of vegetables as of a nimals. In this attempt I succeeded, as $: 018$ the result will show. I have now broken up all these 500 acres, 18 inches deep. The process was by sending a common plough, drawn by two horses, to precede, which turned over the ground to the depth of 4 inches; my subsoil-plough immediately followed in the furrow made, drawn by four horses, stirring and breaking the soil 12 or 14 inches deeper, bu: not turning it over. Sometimes the iron pan was so hard, that the horses were set fast, and it became necessary to use the pickaxe to release them before they could proceed. After the first year, the land produced double the former crops, many of the carrots being 16 inches in length, and of a proportionate thickness. This amendment could have arisen solely from the deep ploughing. Manure I had scarcely any, the land not producing then stover sufficient to keep any stock worth mentioning, and it was not possible to procure sufficient quantity from the town. The plough tore up by the roots all the old gorse, heather, and fern, so that the land lost all the distinctive character of heath land the first year after the deep ploughing; which it had retained, notwithstaniing the ploughing with the common pioughs, for 35 years. Immediately after this subsoil-ploughing, the crop of wheat was strong and long in the straw, and the grain close-bosomed and heavy, weighing full 64 pounds to the bushel. The quantity, as might be expected, not large (about 26 bushels to the acre), but great in comparison to what it produced before. The millers were desirous of purchasing it, and could scarcely believe it was grown upon the heath land, as in former years my bailiff could with difficulty get a miller to look at his sample. Let this be borne in mind, that this land then had had no manure for years, was run out, and could only have been ameliorated by the admission of air and moisture by the deep ploughing. This year the wheat on this land has looked most promising; the ears large and heavy, the straw long; and I expect the produce will be from 34 to 36 bushels an acre : the wheat, the "golden drop." My Swedish turnips on this land this year are very good; my pudding and sugar-loaf turnips failing in many parts, sharing the fate of those of my neighbours, having been greatly injured by the torrents of rain which fell after they had shown themselves above the ground. Turnips must have a deep and well-pulverized soil, in order to enable them to swell, and the tap-roots to penetrate in search of food. The tap-ro tt of a Swedish turnip has been. known to penetrate 39 inches into the ground."

Sub-turf Plough.- "Being on the subject of the sub-soil plough," says Sir Eamund Stracey, "I may as well tell you I have contrived another plough, from the use of which the greatest benefit has been derived by my park land. I call this my 'sub-turf plough.' It is used to loosen the turf about $10 \frac{1}{2}$ inches deep below the surface, without turning over the flag; loosening the soil underneath, consequently, admitting the air and the rain, and permitting the roots of the herbage to spread in search of food. There are no marks left by which it can be known that the land has been so ploughed, except from the straight lines of the coulter, at 
the distance of about 14 inches one from another. In about three months from the time of ploughing these lines are totally obliterated, and the quantity of aftermath, and the thickness of the bottom, have been the subject of admiration of all my neighbours. Another advantage from this subturf-ploughing is, that, before that took place, water was lying stagnant in many parts (after heavy rains), especially in the lower grounds, to a great depth: now no water is to be seen lying on any part, the whole being absorbed by the earth." (Journ. of Eng. Agr. Sor. vol. i. p. 253.)

And for heavier soils, the evidence in favour of subsoil-ploughing is equally valuable. In the year 1838, an experiment was made by Sir James Graham, which is important in several respects. It was on a field of about 8 acres, of the poorest and wettest land. "The surface-soil is about 5 inches deep of black earth, of a peaty quality. The subsoil is a weeping retentive clay, with sand and rusty gravel intermixed. This clay extends to the bottom of the drains, which are of tile, laid 30 inches deep in every furrow. This field was rented by the out-going tenant at $4 s .6 d$. per acre. It was in pasture of the coarsest description, overrun with rushes and other aquatic plants. After draining, on one-half of this field I used Mr. Smith's subsoil-plough. On the other half I trench-ploughed to the depth of 10 inches, by two ploughs following in succescion. In the first part, not mixing with the surface any of the subsoil; in the last part, commingling the surface and the subsoil in nearly equal proportions. The whole field was heavily, but equally manured, and planted with potatoes; and though the potato crop, even on good land in this neighbourhood (Cumberland), was below an average, yet the crop in this field exceeded an average, and yielded about 12 tons per acre. The field is equally drained in every part. The crop was so equal throughout the field, that I am unable to pronounce positively which part was the best, but I am inclined to give the preference to that portion where Mr. Smith's subsoilplough was used."

SUBSTRA'TUM. A stratum lying under another stratum. The term subsoil is generally applied to the matters which intervene between the surface soils and the rocks on which they rest; thus, clay is the common substratum, or subsoil, of gravel.

SUCCORY. See Curccorr.

SUCCULENT. A botanical term, signifying fleshy, or filled with juice.

SUCKER. A young twig or shoot from the root of a plant. See Propagatron.

SUDORIFIC. Having the power of producing perspiration.

SUET. The fat situated about the loins and kidneys, which is harder and less fusible than that from other parts of the same animal. That of the ox and sheep is chiefly used; and, when melted out of its containing membranes, it forms tallow, and is largely used in the manufacture of candles and the ordinary soaps. Beef and mutton suet, when fused, concrete at a temperature of about $100^{\circ}$. Like other kinds of fat. it is a compound of cartom, hydeogen,

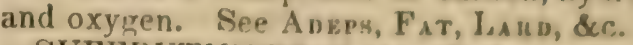

SUFFRUTICOSE (I,at. mufruter, an urdershrub). Any plant which is not exartly either a shrub or an herbaceous plant, that is, wich has not hard woody twigs and complete buds, like the one, nor perishable, succulent leaves and shoots, like the other, is so termed. Isavender is an instance of a suffruticose plant.

SUGAR (Fr. sucre; Germ. zucker'). The great commercial demand for sugar is almost exclusively supplied from the sugar-cane (Arundo saccharifera), which contains it in greater quantity and purity than any other plant, and consequently affords the greatest facilities for its extraction. Cane sugar is cumbined, in the juice of the plant, with a number of other substances. The following analysis of $\mathrm{M}$. Avequin shows the nature and proportions of these: -0.46 albumen, 0.81 gum, 101.2 crystallizable sugar, 41.6 uncrystallizable sugar, 0.85 chlorophyle and oil, 0.75 stearin, 1.28 resin, 3.58 salts, and 700.8 water, in 1000 parts. The juice, after expression, is freed from some acid which it contains, by means of lime, and then concentrated by boiling; after which, as soon as brown grains form, the syrup is purified, and allowed to crystallize. The crystals are next separated from the molasses, or uncrystallizable sugar, by dripping. This forms muscovado or brown sugar, which is afterwards purified. The purest raw sugar comes from Demerara. Pure sugar is a compound of 44.44 of carbon, $6 \cdot 18$ of hydrogen, and $49 \cdot 78$ of oxygen, in 100 parts. Sugar is nutritive, demulcent, and powerfully antiseptic. Grape sugar undergoes fermentation more readily than cane sugar. A large quantity of sugar, identical to cane sugar, is contained in the sap of the American maple (Acer saccharinum), that of the cocoa-nut (Cocos nucifera), and in the juice of the beet-root (Beta vulgaris), from each of which it may be economically obtained: it has also been extracted from grajes or raisins, and, as is well known, is contained abundantly in many ripe fruits and esculent vegetables. It is, however, in these seldom so pure or in such quantity as to admit of ready separation, or crystallization. The total average quantity entered annually for home consumption in England, is, in round numbers, nearly 4,000,000 cwts. See Marze, Maple, Molassrs, \&c.

The sugar-cane, under the name of the sugar-reed, is mentioned in the oldest recurds of antiquity as a product of the Eastern world. It would also appear, that the sugar-cane was found growing luxuriantly in Hispaniola, when Columbus first discovered America, according to the account given by Peter Martyr, written during the second voyage of Columbus. There are many varieties or species of the reedy grass producing sugar, both cultirated and growing wild on the banks of rivers and meadows, in both the Indies, China, Africa, the South Sea Islands, and America. The commou sugar-cane (Saccharum officinarum), Plate iv. d, is a perennial-rooted plant, very susceptible to frost, and therefore restricted in $\mathrm{jts}$ cultivation to a belt or zone extending from $35^{\circ}$ to $40^{\circ}$ on each side of the eytator. In the Southern 1019 
United States the cultivation cannot be carried on advantageously higher than about the $32 \mathrm{~d}$ degree of latitude, and here the cane dies down annually, unless cut in time to escape the effects of frost. It attains the height of 7 or 8 feet, or more, and its broad leaves, and large, silky panicles, give it a beautiful aspect. The stems are jointed, very smooth, shining, and filled with a spongy pith: the flowers of the sugarcane are small, and very abundant, being clothed externally with numerous silky hairs. But, in the regular course of cultivation, it never lowers in Louisiana, and but rarely in the West Indies. Consequently, seed is difficult to be procured, short of Otaheite or China. It is well known that where the plant is allowed to go to seed, this natural process interferes with the developement of the saccharine materials. In the West Indies, it is propagated by cuttings from the main stalk, planted in hills or trenches in the spring or autumn. The cuttings root at the joints under ground, and send up shoots, which, in 8,12 , or 14 months, are from 6 to 10 feet long, and fit to cut down for the mill. A plantation lasts from 6 to 10 years, but in Louisiana the planting has to be renewed every 2 or 3 years.

The juice of the sugar-cane is so palatable and nutritive, that, during the sugar harvest, every creature which partakes freely of it, whether man or animal, appears to derive health and vigour from its use. The meager and sickly negroes exhibit at this season a surprising alteration; and the labouring horses, oxen, and mules, though constantly at work, yet, as they are allowed to eat, almost without restraint, of the refuse plants and scummings from the boiling-house, improve infinitely more than at any other period of the year. The sugar-cane is now cultivated in all the warm parts of the globe. The variety from Otaheite has lately, in the West Indies, superseded all other kinds of cane, and succeeds in soils too poor for the common varieties. The qualities of the sugar are also very superior.

Sugar is now cultivated to considerable extent in the United States. On the northern coast of the Gulf of Mexico, for the distance of about 300 miles, the sugar region is almost entirely embraced within the limits of Louisiana. Here, the soil being all alluvial and of the richest description, the cane is forced by its exceeding fertility, together with the warmth of the long summers, to a state of maturity which enables it to yield sugar in the greatest abundance, and of the finest quality. Thus, the natural strength of the soil and warmth of the summer compensate in a great degree for other defects of the climate. The extent of lands in this portion of the United States admitting of the profitable culture of sugar, is sufficient not only to supply the entire amount required for home consump. tion, but for large exportation. From 1835 to 1816, sugars imported into the United States paid duties of $2 \frac{1}{2} \mathrm{cts}$. per $1 \mathrm{~b}$. on muscovado or brown, white havannas 4 to $4 \frac{1}{2}$ cts., and refined 6 to $12 \mathrm{cts}$. per $1 \mathrm{~b}$. according to quality. This protection of the planter was reduced by the tariff of 1816 , to only 30 per cent. ad valorem in all kinds.

Varieties of the Cane. There are five varie1020 ties of cane mostly planted in the West Indies and Louisiana. The Otaheite cane is, as has been before observed, more extensively cultivated at present in the West Indies than any other. It will grow better on the lighter and older cultivated soils, and has several peculiar advantages over the Brazilian or Creole canes in former use, but now generally superseded. The last narred is more delicate and requires more culture than any other variety, but produces sugar of the finest quality. The varieties most extensively cultivated on the rich lands of Louisiana, are the Bourbon, Red-Ribbon and Blue-ribbon, the last being the most luxuriant. All the varieties "rattoon," that is to say, produce a growth from the roots two and sometimes three successive years in Louisiana. The consumption of England now amounts to upwards of $400,000,000$ pounds, which gives an average of about 30 pounds for each individual. That of the United States is about $250,000,000$ lbs, per annum, which, considering the population, gives a larger individual rate of consumption than any other country in the world.

In an interesting communication in the Farmers' Register, vol. iii., Mr. Macrae, a Florida sugar planter, speaks of the sugar culture in that region as profitable, but still, he thinks, too uncertain, from the effects of frost, to be depended upon to the exclusion of other southern crops. The season for manufacturing, he observes, may not admit of the saving of 500 acres of cane; but it assuredly admits of 100 acres being profitably saved, with 50 effective hands, and the requisite machinery; and that, too, without any serious sacrifice of cotton, or great loss of labour. The opinion there generally maintained, that the manufacture of a sugar crop will essentially interfere with and diminish the cotton crop, he regards as erroneous. In the proportion of one-fifth cane, he says there need be no such interference-admitting that the earliness and severity of frost is such as to compel the immediate ser. vice of all other labours to the security of the cane. "Your 50 hands will mattress it (100 acres) in from 3 to 5 days, where it may lie for a month. Half your force, with tried machinery, will then manufacture it in a fortnight, without any extra labour; and your other remaining half of labourers will certainly, at that season, save all the cotton that is liable to fall. It is not, however, one year in ten, that the season would compel this entire disposition of your labourers; and certainly your chance of revenue from two crops, not liable to the same disasters (for none can deny that the cotton plant has nearly as many risks to run before its fruit is saved, as the cane), is more than equivalent to a moderate loss by a heavy blow of cotton. No one should attempt the cane cultivation as a source of revenue, with a less force than 50 effective hands; and I attribute the heretofore failures of sugar here, in a great measure, to overcropping, and a poverty of labourers."

The operation termed " mattressing," consists in piling the cane which is cut, to prevent injury from frost, in rows in the field. The plan recommended by $\mathrm{Mr}$. Macrae, is to cut the cane down close to the ground, and 
throw three rows into one, thus forming windrows across the field, taking care to place the foliage of one stool of cane over the bults of the previous one, and laying them to the height of 3 or 4 feet, like a thatched roof. In this way the cane can be kept several weeks for grinding and pressing. "Mattressing" the cane for a limited period, even after the frost, so far from injuring its product, will, he says. increase it in Florida. Mr. Macrae says, that in Florida, no prudent man will under any circumstances attempt a sugar crop alone, and he advocates the sugar culture only in connexion with cotton. In the West Indies from 3000 to 6000 pounds of sugar are produced to the acre, whilst in Louisiana about 1000 lbs. of sugar per acre is considered an average yield. The crop in that state in 1847-48, was 240,000 hogsheads, each estimated at 1000 lbs. gross, with 20 gallons of molasses, and sold at the very low price of $2 \frac{1}{2}$ to 5 cts. on the plantation. It is calculated that $\$ 300$ capital is required for the production of each hogshead of sugar and barrel of molasses. The expenses of working an estate, including wear and tear of machinery, have been stated at $\$ 60$ to $\$ 75$ for each slave employed. The average product 5 hogsheads to the hand, or about 10 per cent. profit upon the capital. Mr. Forstall, in his communication to the Commissioner of $\mathrm{Pa}$ tents (1847), estimates the profits at 5, and some years only $2 \frac{1}{2}$ per cent. He says that when sugars average $4 \frac{1}{2}$, and cotton $6 \frac{1}{2}$ cents, the results per slave are nearly the same, with the advantage in favour of the cotton crop of requiring only $\frac{x}{4}$ less cost of machinery. The slaves employed in the sugar culture increased from 1828 to 1844 , from 21,000 to 50,670 ; the total capital from $\$ 34,000,000$ to $\$ 60,000,000$. The report of the Commissioner of Patents for 1848, contains much highly valuable information relative to the sugar crop, especially the article, with drawings, by C. I.. Fleischman.

Whilst the crop of cane sugar is increasing annually at the South, that from the maple is becoming greater in the Northern and Western States. The amount of sugar made in 1840 , from both sources, has been reported at $155,100,809$ pounds. In Michigan alone, there is said to be no less than 30,000 acres abounding with the maple. These trees have been estimated at an average as worth to the farmer, for the purpose of sugar-making alone, from 2 to 3 dollars each. The proportion of sugarmaples per acre in the sugar districts has been computed at 30 . See MaPLE.

Under the head of $M_{A} i z_{\text {r }}$ reference is made to the proposed manufacture of sugar from Indian corn, one acre of which, of luxuriant growth, has been estimated to produce from 600 to 1000 pounds and more of good sugar. The manufacture of sugar from the beet, so extensively carried on in France, Germany, and other European countries, has never been successfully introduced into the United States. To succeed fully, the manufacture must be carried on upon a large scale, with ample capital. Many excellent essays upon the subject may be found either separate or published in various agricultural periodicals.

Chemical composition of Sugar.-The progress of modern chemistry in ascertaining the precise elements of various substances, has de- veloped some highly interesting facts relative to sugar, showing the very slight difference between its composition and that of many other matters to which it apparently bears not the least resemblance, such as starch, sa $w-1$ lust, or common woody fibre, linen rags, \&ce., which by slight additions have been actually converted into sugar. By some chemists, and particularly Prout, starch is considered as sugar partly organized, containing but a small quantity of carbon and hydrogen more than sugar, the excess however being sufficient 10 prevent crystallization or conversion by nature into sugar. The following table, prepared from the statements of Berzelius, Raspail, and Dumas, by Dr. Prout, shows in a curious and interesting light, by what mere shades of difference in their constituent atoms, substances, which to the sense appear as far apart as the zenith from the nadir, are separated. Water is composed of definite and well-ascertained proportions of oxygen and hydrogen, and in the formation of sugar, starch, acetic acid, and lignin, or the pure woody fibre of trees and plants, these two materials are found united in the same proportions as in water; the only ingredient added for their completion being carbon. These substances, sugar, acetic acid, starch, and lignin, may therefore be considered as composed of carbon and water in the proportions here given.

Sugar.-100 parts of sugar from starch contain

Carbon. Water.

From honey - - - - 3636

From East India moist - _ _ $40.88 \quad 59.12$

From beet-root and maple - $42 \cdot 10 \quad 57.90$

From English refined - - $42.05 \quad 58.05$

From sugar candy, pure $\quad-\quad 42.85 \quad 57 \cdot 15$

Acetic Acid - - - - - - 47.05

52.95

Starch.-Arrow root in its ordinary state

$36 \cdot 04$

63.06

From wheat in its ordinary state

From wheat iried $212^{\circ}$

Lignin.-In its ordinary state of dryness From willow dried $212^{\circ}$

$37 \cdot 50$

62.50

$5 \pi \cdot 20$

42. $5: 30$

$50.00 \quad 50.00$

Dr. Prout, in his Bridgewater Treatise, remarks, "that both starch and wood can by different artificial processes be converted into sugar or vinegar. But we are unable to reverse the process, and convert vinegar into sugar, or starch into wood." The chemist Braconnet has ascertained that a pound of linen rags yields rather more than a pound of sugar.

Mr. Guthrie of Sackett's Harbour, in his attempts to make sugar from potatoes, produced large quantities of molasses, but with all his skill was unable to crystallize or grain it, without the introduction of some deleterious substance, lead, for instance; and consequently all his was used in a liquid form, of the consistence of thick syrup, or rather honey. The potatoes were first converted into starch, and then, by boiling in sulphuric acid, diluted, fpr some hours, into sugar. The directions in the Encyclopedia Americana for this process are, 2000 parts of starch, 8000 parts of water, and 40 parts strong sulphuric acid-the mixture $\omega$ boil some 36 hours in silver or lead; but Mr. Guthrie accomplishes the conversion by the use of steam in about 6 hours. The produc tion of sugar or molasses is possible from a great variety of materials provided by nature, such as the cane, maple, beet honey-all plants 
that afford starch, or substances that by chemial process can be converted into gum, as flax, linen rags, \&c.; still none have yet been found, which can successfully enter into competition with the cane.

SUGAR BEET. The white beet already mentioned under the head BEET. As it is not probable that this root will soon be brought into requisition for the production of sugar in the United States, where so many other sources exist from which this may be readily procured, we shall confine our observations to it as an article of food for farm-stock.

The following information relative to the beet culture, \&c., is from Mr. Colman's Fourth Report upon the Agriculture of Massachusetts:

"Beets are often a very profitable crop. They are raised in considerable quantities; are packed in barrels and shipped to the south. One dollar and a half is a common price for a barrel containing $2 \frac{1}{4}$ bushels. The farmer giving this statement has often produced 600 bushels to the acre. They are planted on ridges about 4 feet apart, in double rows; and the intermediate spaces are often sown with turnips. The ridge planting is decidedly preferred here for all vegetables of this kind. In my opinion, and so far as my own experience goes, which has not been small, it would be better to make the ridges about 27 inches apart, plant the beets in single rows, and cultivate them with a plough. A very useful machine for planting beets is a wheel, set like that of a wheel-barrow, with pins projecting from the rim 2 inches, and placed 8 inches apart, which is passed along on the top of the ridge, and the seeds dropped by hand into the holes marked by the pins. They may then be covered by drawing a rake-head along the top of the ridge. Too much care cannot be taken to perform all operations in planting, where the vegetable is afterwards to be cultivated, in straight lines. "The work is by this means greatly facilitated."

A crop of sugar beets was raised at Nahant, in 1840, by Mr. Frederick Tudor, of 42,284 lbs. on 93 rods, or at the rate of 36 tons $746, \frac{63}{100} \mathrm{lbs}$. net weight per acre, being about 1300 bushels per acre, allowing $56 \mathrm{lbs}$. per bushel. One of the roots cropped and cleaned, weighed $31 \mathrm{lbs}$. The ground was trenched to the depth of 20 inches, and well manured, the stones removed being all laid at the bottom of the trenches. Allowing the beets worth $\$ 5$ a ton, this would give $\$ 180$ to an acre, leaving the land in high tilth for further rich crops. The expenses of cultivating an acre of sugar beets in the New England States, have been thus stated by the editor of the Yankee Farmer.

Use of an acre of land well prepared for beets, and manured, or managed in the previous crop

Ploughing -

Cultivator-ing, horse, cultivator and hand, two

hwice more before sowing - - - - -

Harrowing - - - -

Seed $\$ 225$, sowing with a machine 75 - -

First hoeing

Second hoeing, thinning, and transplanting to supply deficiencies

Iloeing again, and loosening the ground with machines

llarvesting
This we think a high estimate. Still, it must be admitted that the cost of cultivating an acre of sugar beets much exceeds that of an acre of Indian corn. In some places the proportional expense of a root over a corn crop is double, in others treble. The following observations upon the mode of cultivating the beet crop, are also taken from the Yankee Farmer.

Make the rows 2 feet 4 inches apart, and then a cultivator can be used in hoeing. If the beets stand one foot apart in the rows, and weigh $2 \frac{1}{4}$ lbs. each, the yield will be 20 tons. In rich ground, at that distance a great number will weigh 4 or 5 lbs. each; 20 tons is a good crop, but not extremely large, for in some cases 25 or 30 tons to the acre have been raised in this country. At the above expense of $\$ 40$ to the acre with a yield of 20 tons, the cost would be $\$ 2$ per ton. We make this estimate, to show how cheap beets may be raised under favourable circumstances, such as good land at a fair price, convenient machinery and implements, and the most prudential management in the culture, with labour at a moderate price, and a favourable season.

Supposing we reckon the produce only twothirds as much as above, say $13 \frac{2}{3}$ tons, and the cost $32 \frac{1}{2}$ per cent. more, which will be $\$ 5333$; then the cost of the beets will be only $\$ 4$ per ton, one-fifth less than Mr. Bosson reckoned in his calculation on the cost of beet sugar. If we reckon $50 \mathrm{lbs}$. to the bushel, $13 \frac{1}{2}$ tons per acre would be only 533 bushels, which would be no more than a middling crop; not half as much as has been raised in a number of cases that have been named.

In estimating the value of sugar beets for feeding stock, \&c., Mr. P. Diehl, of Pennsylvania, says that in his neighbourhood, persons feeding the beet to cows, readily procure 2 cents per lb. more for their butter than their neighbours who do not use the beet. His hngs are wintered entirely on beets and kitchen slop, and kept in fine condition. He states that he has fattened solely on sugar beets, beeves, which when sold, were pronounced by the butchers the best they had killed for many years before. In contrasting the probable amount of profit to the farmer, per acre, of a crop of corn and a crop of beets, he says: Al. lowing for the average crop of beets $1000 \mathrm{bu}$ shels per acre, which is moderate, this quantity will fatten 11 head of steers in 90 days, at one bushel per day for each steer. Allowing the average corn crop to be 50 bushels per acre, which is very large, this product will fatten only $1 \frac{1}{2}$ head, in the same time, feeding at the usual rate of $1 \frac{1}{2}$ pecks per day. This leaves a balance in favour of beets, fractions aside, of about 800 per cent. (See Cultivator, vol. viii.
$\$ 1200$ 400 p. 119.) There is perhaps no food which wil contribute in winter so much to increase the quantity and quality of the dairy products as the sugar beet. But it should be used along with good hay, fodder, and other dry provender.

Under the head of MANGEL WURzEL, a tabular view is given of the comparative nutritive materials in several of the roots most usually cultivated for agricultural purposes. From this it will be seen, that in saccharine matter as 
well as in the total amount of soluble matter, the beet transcends all the other roots taken into the estimate. See table, Art. Foov, p. 499.

SULPHATES. A class of concentrated fertilizers, in which sulphuric acid is combined with different substances, as with lime to form gypsum; See Plaster of Paris. Ammonia, to form sulphate of ammonia, a new fertilizer of great power, enjoying high repute in England, costing about $\$ 5$ per $100 \mathrm{lbs}$., and used at the rate of 100 to $150 \mathrm{lbs}$. per acre as a top-dressing or otherwise. Sulphuric acid with soda, forms the well known Glauber's Salts, also used as a fertilizer at the rate of $100 \mathrm{lbs}$. to $200 \mathrm{lbs}$. per acre, and costing in England about $\$ 35$ per ton. Copperas, or sulphate of iron, has been mentioned as a great destroyer of disagreeable odours when added to putrid animal substances. See NigHTSorl.

SUNDEW. A most singular and beautiful genus of plants, having leaves ornamented with red glandular hairs, discharging at their ends a thick acrid juice resembling dew. The hairs are irritable when touched, and contract upon insects.

SUNFLOWER (Helianthus, from helios, sun, and anthos, a flower; on account of the brilliant colour of the flowers, and from the erroneous idea that the flowers always turned towards the sun). A highly ornamental and extensive genus of plants; and from their tall growth they are particularly adapted to the back of flower-borders or the front of shrubberies, in which situations they make a splendid appearance in autumn: they grow well in any common garden soil, the tender kinds being protected in winter. It appears to possess far more profitable qualities than were hitherto supposed, and, besides forming a beautiful nbject in a bed of flowers, it may be cultivated with advantage, and applied to many useful purposes. An acre of land will contain 25,000 sunflower plants, 12 inches distant from each other. The produce will be according to the nature of the soil and mode of cultivation; but the average has been found to be 50 bushels of the seed per acre, which will yield 50 gallons of oil. The oil is excellent for table use, burning in lamps, and for the manufacture of soaps. The marc, or refuse of the seeds after the oil has been expressed, made into cake, will produce $1500 \mathrm{lbs}$, and the stalks, when burnt for alkali, will give 10 per cent. of potassa. The green leaves of the sunflower, when dried and burnt to powder, make excellent fodder for milch cows, mixed with bran. From the ease with which sunflowers are produced in gardens (for they seem to flourish in any soil, and to require no particular care), we may safely say that an acre of land will yield a considerable return. Poultry are very fond of the seeds.

SUNFLOWER, WILD or FALSE. Sneezeueed (Helenium autumnale). A plant with a biennial root found in the United States.

SW AMP. Ground habitually so moist and soft as not to admit of being trod by cattle, but at the same time producing particular kinds of trees, bushes, and plants. A swamp differs from a bog and a marsh in producing trees and shrubs, while the latter produce only herbage, plani., and mosses. In autumn and sprirg, the exhalations fiom swamps are pro- ductive of agues, conserquent'y it is impertam? to fill them up or drain them.

SWAN (C'ygnus). (of thre nutie webefiried birds so called there are three $B_{1}$ uluth species: the Hooper, or Bewick's; the wild, and the tame swan. The wild swan and If ingmer culcht, perhaps, to be regarded as the only true na? species. The tame swan $(C$ whir $)$ is superior in bulk to either of the wild sper.m, and is at once distinguished by a large, blark, cailous knob on the base of the bill. ()ur remarks in this place will be exclusively directod to the domesticated swan. These graceful hirls are rarely dressed for the table; they are cronci. dered too ornamental to destroy. They are nut destructive to fish, and they keep the waine free from weeds. Mr. Main, who long studied their habits, in his work on Domestic Pouliry, says the tame swan is herbivorous and granivorous; that is, they feed upon weeds and grain. They love also bread, vegetables, \&c., which they eat greedily from the hand.

The swan lays from 5 to 8 eggs in the summer, and breeds only once in the year. They love an islet to breed their young upon, for the sake of its quiel; and a little straw deposited there is all they require for making their nest. The swan sits a month, but if the weather is bad, they are known to remain longer before they hatch. The cygnets, or young swans, remain a year with their parents; but when the breeding season approaches, the old cob or male bird drives them away. This is the period to sell; and if the birds have paired, they fetch a higher price in the market. Swans are not in full plumage till the third year. These birds often take flight at the fall of the year, therefore the old birds should have the first joint of one wing removed, which would pre. vent their roving. Two pair of swans will seldom agree together upon the same piece of water. The cob, or male swan, is larger than the female, and bolder. They require feeding in very severe winters, and the ice should be broken for them to swim about. At other times tikey feed on weeds growing in the water, op herbage on the banks of it. Swans and cygnets are caught most easily with a swan-hook, which is a long pole of 10 or 12 feet, with a blunt hook 10 inches in length, bent at right angles to the pole; the angle should be turned like a ring, and open in the inner side, to let in the neck of the bird. The swan has a peculiar kind of snort, but no voice. They hiss when angry.

SWARD. Green turf; that is, the surface of land under pasture grasses. A fine sward may be called the characteristic feature of British landscape, not being found in the same degree of perfection in any other country, not even in Ireland.

SWEAL. To singe or burn off the hair, a in hogs.

SWEET-BRIER. See Eglatiys.

SWEET FIAG. See Acones and ARova. TIC REEN.

SWEET-GRASS (Glyceria, from glukrus. sweet, alluding to the herbage; whence alst: the common name). A genus of grasses of which some of the species are aquatics. Dr. Smith emumerates 6 species indigenous is 10:2: 
Lingland: viz. the reedy sweet-grass (G. aquatica), the floating sweet-grass ( $G$. fluitans), the reflexed sweet-grass ( $G$. distans), the creeping sea sweet-grass (G. maritima), the procumbent sea sweet-grass (G. procumbens, ) and the hard sweet-grass ( $G$. rigida). The only species which have been thought worthy of trial by Mr. Sinclair and other experimental cultivators of grasses are :-

1. The floating sweet-grass (G. fluitans). Marona grass. The panicle is oblong, branched, divaricating. Spikelets close pressed. Florets numerous, obtuse, seven-ribbed, with short intermediate ribs at the base. Nectary obtuse, tumid. This species appears capable of being cultivated as a permanent pasture grass. The seed will not vegetate unless kept very moist. It flowers from the first or second week of July till the end of summer. Birds are fond of the seeds, and generally strip the panicle ere the seeds are all perfected. Schreber informs us that it is cultivated in several parts of Ger. many for the sake of the seeds, which are esteemed a delicacy in soups and gruels. When ground into meal, they make bread, very little inferior to that from wheat. The bran is given to horses that have the worms; but they must be kept from water for some hours afterwards. Fish, particularly trout, are said to be very partial to the seed.

2. The reedy sweet-grass (G. aquatica). In this species the panicle is erect, repeatedly branched, spreading. Florets numerous, obtuse, with seven ribs. Nectary cloven, acute. This grass is common on the banks of rivers, and frequent on the margins of standing pools. On the banks and little islands of the Thames, where it is generally mown twice in the year for hay, it affords abundant crops of valuable winter fodder. Mr. Curtis informs us that in flat countries, which do not admit of being sufficiently drained, it is almost the only grass for hay and pasturage. In the fens of Cambridge, Lincoln, \&c., immense tracts which used to be overflowed and produce useless aquatic plants, and still retain much moisture, though drained by mills, are covered with this grass, which not only affords rich pasturage in summer, but forms the chief part of their winter fodder. Its powerful creeping roots make it a dangerous and troublesome weed in ditches, where, with other aquatic plants, it soon chokes them up. In the fens of the Isle of Ely this grass grows to the heigh: of six feet, and proves excellent fudder for milch cows, though horses are not fond of it. 'The nutritive matter of this grass contains a greater proportion of sugar than exists in any of the superior pasture grasses. The best manner of propagating it is by planting the roots either in autumn or spring. It flowers about the second and third weeks of July, and the seed is ripe in the second week of August.

SWEET POTATO (Convolvulus battatus). Carolina potato. 'The fine, esculent, tuberous root of this species of low-creeping vine or convolvulus, is perennial. It flourishes in the Middle and Southern States-to which last it is native-wherever the soil is light and sandy, refusing to grow and perfect itself on clay or stiff loam soils. The plant is propagated by planting the tubers in beds early in the spring, from which the young sprouts are subsequently planted out in hills 5 or 6 feet apart. The trailing vines must not be allowed to strike root. The long roots are of different colours, being rich yellow, red, or white, and attain a large size, from a few ounces to several pounds in weight. When boiled, baked, or roasted, they have a sweet and very agreeable taste, and are very nutritious.

SWEET SCENTED SHRUB (Calycanthus Floridus), Carolina Allspice. An American spicy shrub, the flowers of which are extremely odoriferous, the perfume resembling that of the strawberry. The wood and especially the root are strongly camphorated, and may, $\mathrm{Mr}$. Nuttall thinks, probably produce this drug as abundantly as the Laurus camphora. By cutting off the terminal leaf-buds after the usual season, it is said that a succession of flowers may be obtained throughout the summer, every leafbud so extracted being constantly succeeded by two flowers. The flowers of the Calycanthus rarely produce seed, even in its native moun. tains of Carolina.

SWINE (Genus Sus). The hog has been generally described as a creature of gross habits and unclean tastes, as having the senses of touch and taste obtuse, and even as being so insensible that mice may burrow in his skin without his seeming to feel. But these opinions are most unjust and incorrect. Far from being unclean, nature has furnished him with powerful organs of digestion, enabling him to derive sustenance from a variety of substances, and his voracity is only the result of the extent and perfection of his digestive and respiratory organs. Although one of the pachydermatous, or thick-skinned animals, the hog feels blows acutely, and manifests his suffering by loud cries. Indeed, the inference that his sense of touch is dull, because of the thick layer of fat with which his body is enveloped, is most erroneous, for it is well known that the plexus of nerves which gives sensibility to the body is exterior to this fatty layer. So far from being insensible to pain, the hog even suffers under the irritation arising from the punctures of gnats, musquitoes, and other small insects, and endeavours to protect himself from their persecution by rolling in moist places and covering himself with mud.

Natural History of the Hog.- "The hog (says Prof. Low) is subject to remarkable changes of form and characters, according to the situa. tions in which he is placed. When these characters assume a certain degree of permanence, a breed or variety is formed; and there is none of the domestic animals which more easily receives the characters we desire to im. press upon it. This arises from its rapid pow. ers of increase, and the constancy with which the characters of the parents are reproduced in the progeny. There is no kind of live-stock that can be so easily improved by the breeder, and so quickly rendered suited to the purposes required; and the same characters of external form indicate in the hog a disposition to arrive at early maturity of muscle and fat as in the ox and sheep. The body is large in proportion to the limbs, or, in other words, the limbs are 
short in proportion to the body; the extremities are free from coarseness; the chest is broad, and the trunk round. Possessing these characters, the hog never fails to arrive at earlier maturity, and with a smaller consumption of food, than when he possesses a different conformation."

The wild boar, which was undoubtedly the progenitor of all the European varieties, and also of the Chinese breed, was formerly a native of the British Islands, and very common in the forests until the time of the civil wars in England.

The wild hog is now spread over the temperate and warmer parts of the old continent and its adjacent islands. His colour varies with age and climate, but is generally a dusky brown with black spots and streaks. His skin is covered with coarse hairs or bristles, intersected with soft wool, and with coarser and longer bris!les upon the neck and spine, which he erects when in anger. He is a very bold and powerful creature, and becomes more fierce and indocile with age. From the form of his teeth he is chiefly herbivorous in his habits, and delights in roots, which his acute serise of smell and touch enables him to dis. cover beneath the surface. He also feeds upon animal substances, such as worms and larvæ, which he grubs up from the ground, the eggs of birds, small reptiles, the young of animals, and occasionally carrion; he even attacks venomous snakes with impunity.

The female produces a hitter but once a year, and in much smaller numbers than when domesticated. She usually carries her young for 4 months, or 16 weeks.

In a wild state the hog has been known to live more than 30 years; but when domesticated he is usually slaughtered for bacon before he is 2 years old, and boars killed for brawn seldom reach to the age of 5 . When the wild hog is tamed, it undergoes the following amongst other changes in its conformation. The ears become less movable, not being required to collect distant sounds. The formidable tusks of the male diminish, not being necessary for self-defence. The muscles of the neck become less developed, from not being so much exercised as in the natural state. The head becomes more inclined, the back and loins are lengthened, the body rendered more capacious, the limbs shorter and less muscular; and anatomy proves that the stomach and intestinal canals have also become proportionately extended along with the form of the body. The habits and instincts of the animal change: it becomes diurnal in its habits, not choosing the night for its search of food; is more insatiate in its appetite, and the tendency to obesity increases.

The male, forsaking its solitary habits, becomes gregarious, and the female produces her young more frequently, and in larger numbers. With its diminished strength and power of active motion, the animal also loses its desire for liberty. These changes of form, appetites, and habits being communicated to its progeny, a new race of animals is produced, better suited to their altered condition. The wild hog, after - t has been domesticated, does not appear to 129 revert to its former state and habits; at least the swine of South America, carried thither by the Spaniards, which have escaped to the woods, retain their gregarious habits, and have not become wild brars.

In its wild state the hog has 6 incisor teeth in the upper, and 6 in the lower jaw; but when domesticated the number is reduced to 3 in each jaw, and this number is not cy mstanc. The vertebræ of the back vary from 14 to 15 in number; the lumbar and the sacral from 4 to 6 ; the caudal from 2 to 3 or 4 , the tail being often rudimental in the domesticated races.

Mr. T. E. Eyton (Trans. of Zool. Soc., Feb. 1837), amongst other osteological differences in the races of hogs, points out the following as applicable to the number of vertebræ:-

\begin{tabular}{|c|c|c|c|c|c|}
\hline \multirow{7}{*}{$\begin{array}{l}\text { Cervical } \\
\text { Dorsal - } \\
\text { Lumbar } \\
\text { Sacral - } \\
\text { Caudal }\end{array}$} & $\begin{array}{c}\text { English } \\
\text { male. }\end{array}$ & $\begin{array}{l}\text { African } \\
\text { male. }\end{array}$ & $\begin{array}{c}\text { Chinese } \\
\text { male. }\end{array}$ & $\begin{array}{l}\text { Wild } \\
\text { Boar. }\end{array}$ & $\begin{array}{c}\text { Domealie } \\
\text { Hrag. }\end{array}$ \\
\hline & 7 & 7 & 7 & 7 & 7 \\
\hline & 15 & 13 & 15 & 14 & 14 \\
\hline & 6 & 6 & 4 & 5 & 5 \\
\hline & 6 & 5 & 4 & 4 & 4 \\
\hline & 21 & 13 & 19 & 20 & 23 \\
\hline & 55 & 44 & 49 & 50 & 53 \\
\hline
\end{tabular}

The hog family includes several species, but these have us:ually been divided into three genera.

1. The true hig, which is the most diffused and important class, comprehending the wild boar (Sus aper) of Europe, Asia, and Africa; the babiroussa (Sus babirussa) of the islands of the Eastern Archipelago, which is of lighter form than the common wild hog; the Papuan hog (Sus papuensis) of New Guinea, and the wood swine, or masked African boar (S. larvatus), of Southern Africa and Madagascar.

2. The wart-bearing hogs of Africa (Phacochares).

3. The peccaries of America. Of these there are two species, the collared peccary (Dicotyles torquatus) and the white-lipped peccary (D. labiatus), both inhabiting the countries of the Atlantic from Guiana and Paraguay. extending into the northern continent, being common on Red River. The peccaries are rather smaller than the common swine of Europe: they are covered with stiff bristles, very long upon the neck and spine, which they erect when irritated, are nearly destitute of tail, and are further characterized by a glandular opening in the back, whence the generic term dicotyles, signifying a double navel.

The true hog does not appear to have been indigenous to America, but was taken over by the early voyagers from the old world, and it has now spread and multiplied throughout the continent.

The first settlers of Canada, the British North American settlements, and the United. States, carried with them the swine of the parent country, and a few of the breeds still re. tain traces of the old English character. From its nature and habits the hog was the most pro. fitable and useful of all the animals bred by the early settler in the distant clearings. It was his surest resource during his first years of toil and hardship. It arrived earlier at maturity. required less care, sought ont, for the mose part, its own fond. was be least subject in ac4 \& 2 
cilents and diseases in a new situation, and therefore best repaid any portion of attention bestowed on the breeding and rearing it.

'Their widely extended foreign commerce afforded the Americans opportunities of procuring the varieties from China, Africa, and other countries. The large consumption of pork in the United States, far exceeding the consumption of any other country, has also contributed mainly to the improvement of the breeds, by causing the Americans to pay considerable attention to the rearing of swine, which have thus become one of the most important articles of commerce, and a source of considerable profit to the breeder on a large scale.

Breeds.-The various breeds which have been reared by crosses bctween those procured from different countries are so numerous, that to give any thing like a detailed description of all would fill a volume instead of an essay. I shall, therefore, confine myself to a short notice of those which are either considered as the origin of some peculiar race, or most generally bred for their fattening or other profitable qualities. The celebrated English breeder, Culley, only distinguishes four breeds, the Berkshire, the Chinese, the Highland, and the Irish species.

The principal breeds of England have been usually named after the particular counties or localities where they have been, for the most part, reared. 'Thus, we have the Berkshire, the Hampshire, the Essex, the Suffolk, and a dozen others, each supposed to be distinguished by a certain set of common characters. Those approved on account of their superior size, and therefore usually reared for the purpose of making bacon, are the Berks, Hants, Hereford, Salop, Norfolk, and Chester breeds. The breed best adapted for table pork is the small white Chinese. There are, however, particular breeds preferred by individuals.

The Berkshire Breed. This was one of the earliest improved of the English breeds, and it is now the most widely distributed, as it is the most superior, of the numerous varieties of England. It is a breed which is distinguished by being, in general, of a tawny white, or rufous-brown colour, spotted with black or brown; head well placed, large ears, generally standing forward, though sometimes hanging over the eyes; body thick, close, and well made; legs short, small in the bone; coat rough and curly, wearing the appearance of indicating both skin and flesh of a coarse quality. Such, however, is not the case, for they have a disposition to fatten quickly: nothing can be finer than the bacon, and the animals attain to a very great size, averaging from 50 to 60 stone, although they have not uncommonly reached to the prodigious weight of 100 stone and upwards.

The county of Berkshire has long been celebrated for its famous breed of swine, and the breed has, by frequent and judicious crossing, been much altered for the better. The original breed was of the larger race of swine, and is e.escribed as being long, and rather crookedsnouted, with uncouth, heavy ears; body long and thick, though not very deep; legs short,

s. much bone; although slow feeders, they 1026 always made great weights. The character of the true Berkshire seems to indicate that one of the earliest means employed to improve them was a cross with the wild boar. The improved breed is lighter in the head and ear, shorter in the carcass, with somewhat less bone, and higher in the leg: in colour generally dark spotted. They have little offal, thin rind and hair, and few or no stout bristles. The native breed is still occasionally crossed, either with the pure Chinese or the Tonquin race; and it is asserted, on good authority, that if not crossed once in 6 or 7 years with the Asiatic breed, they will degenerate in shape and quality. The improved Berkshires will be found excellent in all respects, but particularly as a cross for heavy, slow-feeding hogs. The unqualified approbation which this breed has obtained, renders it incumbent on every breeder who wishes to improve his stock of swine to obtain a cross with that race. Al. though hardy and thrifty in its nature, the Berkshire hog requires constant good keep, or it will decline fast.

The old Enylish Breed.-The original native breeds of Great Britain may be arranged into two general classes; but between these extremes there are so many varieties, that numbers cannot be reduced to either class.

1. Those of small size, with the ears erect, or partly so, of which the most marked are those of the Highlands and islands of Scotland. They are hardy creatures, usually of a dusky-brown colour, having an arched back, with coarse bristles on the neck and spine; and approximate closely in character and habits to the wild hog. They are, for the most part, left to provide for themselves, ranging at large over the heaths and moors, grubbing up roots and destroying the eggs of birds, and even newlyborn lambs, when they come in their way. These hogs are usually very meager and thin; flesh coarse and fibrous; but it is greatly improved when the animals are confined and properly fed. When roaming at large on the sea-coast, their flesh, from feeding on shellfish, sea-weed, and the bodies of fish which are cast up by the tide, acquires a rank and unctuous taste.

2. The second class comprises those of a larger body, with long, pendent ears.

Although their colour varies considerably, they are, for the most part, white, or white spotted with black. The characteristics of this old race, where it exists without intermixture with foreign blood (which is not often the case in the present day), are a huge, uncouth form, large bones, long limbs, arched and narrow back, low shoulder, and long snout, with the ears large and flapping, covering the greater part of the face. 'They consume much food, are slow feeders, and their only recommendation is that of being prolific breeders, and attaining to a large size when fattened at the age of two or three years. 'The old English breed, and many other once celebrated local races of that country, have all had their distinctive cha. racters more or less effaced by crossing.

The Chinese or Siamese breed.-The varieties of this widely-extended race which are the most common in England, were brought to 
America and England from Canton and other Indian ports, for the most part as sea-stock, by the vessels employed in the tea trade, \&c. Owing to the much larger consumption of pork by the Chinese than of any other animal food, they pay great attention to the rearing and fattening of their swine. It is said they even use the milk of the sow for domestic purposes. The pure Chinese breed is too delicate and sensible of cold to be of much value in climates liable to frequent changes of temperature. It is chiefly, therefore, by intermixture that its value is recognised; and it is for this reason that its introduction has proved so beneficial in England, by correcting the coarseness of form, quieting the restless disposition, and adding a greater tendency to mature quickly and fatten kindly. The flesh of the Eastern hogs is more suited for pork than for bacon. Mr. Culley subdivides the Chinese breed into seven varieties, but there appear to be only two distinct species-the white and the black; the former better shaped than the latter, but less hardy and prolific. Both are, however, small-limbed; ears and head thin and transparent, small and fine; neck thick; the body close, compact, and well formed; legs very short; flesh delicate; round in the carcass, thin-skinned, and the head so embedded in the neck that, when quite fat, the end only of the snout can be seen. They are rather difficult to rear; the sows are bad nurses; and, from their small size, they scldom reach to a greater weight than from 10 to 12 stone when one year old, and 16 to 18 stone when two years old.

'The black race, from their valuable properties of fattening on a small proportion of food, being very thrifty, and prolific breeders, notwithstanding their inferior size, have been advantageously crossed with other breeds.

There is a mixed tawny breed, or patched with black and white, which is valuable for breeding sows and roasters.

Hampshire breed.-This is a very large breed, which is longer in the neck and body, but not so compact in form as the Berlishire. They are mostly of a white colour, or spotted, and are well disposed to fatten, coming up to a great weight when properly managed in respect to food. The goodness of the Hampshire hog is proverbial; it is principally fattened for large hams and bacon.

The Shropshire breed is large and coarse; but these hogs are found profitable where the keep is in sufficient abundance for their support; hence they are held in estimation in England by distillers, and are commonly fed to 30 score weight and upwards. They are neither so well formed as those of the Berkshire breed, nor do they equal them in their disposition to fatten and thrive on cheap food. 'The standard colour of the Shropshire hog appears to be white, or brindled with black, and sometimes sandy patches. The breed may be described as flatboned, deep and flat-sided, harsh or rather wiryhaired, the ears large; head long, sharp, and coarse; leg too long, low, although very substantial, yet not sufficiently wide, considering the great extent of the whole frame. Within the last 15 or 20 years this breed has been much improved by a cross with the Berkshire, which has reduced the leneth both of their legs and carcass, and rendered the head lighere.

The Rudguicle breed. - Thus is the mine enoto mous breed in Great Britain, and is roared about the neighbourhood of a village on the borders of Sussex and Surrey, whence it take: its name. They feed to an extraurlinary size without any peculiar care, and weigh, at iwo years old, on an average, full 70 stone, which is nearly double what other kinds will wrigh at the same age. 'The Rudwick snu's are accounted good mothers, very prolific and hardy, and are particularly noted as being an extremely large sort, having been known to weigh from 80 to 116 stone, $8 \mathrm{lbs}$. to the sinne. Indeed, some have reached to the extraordinary weight of 182 stone. As large breeds pay the farmer the best in many cases, such a breed as the Rudgwick deserves to be attended to in the system of hog management.

The Suffolk and Norfolk breeds have been long in repute as hardy and prolific species, and when crossed with either the Dishley or the Berkshire hog, produce animals which are held in very general esteem.

The Norfolk breed.-This is described as being a small, short set-eared, thin-skinned porking sort, various in colour, white, bluish, striated; generally an inferior kind. But on the Lincoln side of the county there is a large spotted variety of very good form and quality.

The Suffolk breed is a small, delicate, white race, which has for many years been held in good estimation. They are shorter and more pug-formed than the Norfolks; and by their dish face and pendent belly, it is to be pre. sumed that the variety proceeded originally from the white Chinese breed. Their defects are, that they are great consumers in proportion to their small bulk, and that they produce little flesh.

The Woburn breed.-This is a large, hardy, well-formed, and very prolific variety, introduced by the late Duke of Bedford, which is generally white, spotted with various colours, round in the carcass, small-limbed and headed, and so kindly disposed to fatten, that they are said to attain about twice the size and weight of other sorts of hogs within the same given period of time.

The Tonkey or Tonquin breed is a cross be. tween the Berkshire and the Chinese, which has produced a species possessing very many good points.

The Dishley breed, reared by the celebrated cattle-breeder, Bakewell, are remarkably fineboned and delicate, besides possessing considerable beauty, and are said to lay on a larger quantity of meat, in proportion to bone and offal, than any other kind known. When fat, they are nearly equal in height, length, and thickness, their bellies almost touching the ground, the eyes being deep-set and sunk from fat, and the whole carcass appearing to be a solid mass of flesh. As a set-nff to these good qualities, are the defects of their being slow of growth, tender constitutioned, bad nurses, not very prolific, and requiring more food in fai tening than the larger hogs. By a cross with a Dishley boar, several of the native breeds of the different Eaglish counties have been mucb 
improved. A roundness has been given to the Irame, with a proportionate depth of body; the legs have been shortened, a finer bone produced, with a better appearance when growing as a store, and a disposition to feed quicker and more kindly in the sty.

Small while English breed.-This breed of small hogs is met with in several districts, but prevails most in the northern parts of England. It is of a white colour, thick, compact, and well made in the body, short in the leg; the head and neck well formed, ears slouching a little downwards; hardy, and well disposed to fatten.

The Essex breed.-The original Essex breed was not held in much repute. Their peculiar character was a long, sharp head roundbacked; carcass flat, long, and generally high upon the leg; bones not large; colour white, or black and white; bare of hair; quick feeders, but great consumers, and of an unquiet disposition. A variety known as the Essex half-blacks, which were introduced some years ago by the late Lord Western, as descendants from the Berkshire, have now justly acquired such very great celebrity, as to be considered by many good judges superior to most breeds in the kingdom. They are described in the Essex Report as black and white, short-haired, thin-skinned, with smaller heads and ears than the Berkshire, but feathered with inside hair, which is a distinctive mark of both; having short, snubby noses, very fine bone, broad and deep in the belly, full in the hind-quarters, but light in the bone and offal. They feed remarkably quick, grow fast, and are of an excellent quality of meat. The sows are good breeders, and bring litters from 8 to 12 ; but they have the character of being bad nurses.

The Willshire Breed.-Originally this was a long-bodied, low hog, hollow about the shoulders, and high on the rump; with middling large pointed ears; round bone; and light in colour. But of late years this breed has been advantageously crossed with the pig and Berkshire sorts, and a smaller and better variety produced.

The Gloucester, the Yorkshire, the Northampton, and the Hereford breeds, call for little notice. The Hereford appears to be a descendant of the Shropshire, and is a large, useful race; but the others are very inferior kinds, possessing few good points.

In reviewing the various breeds of swine, a brief survey of the principal continental varieties and distinct races may not be out of place. I shall therefore give a slightly altered abridgment of a diffuse article which some time since appeared in the Quart. Jour. of $\mathcal{A g}$. vol. iii. p. 49.

France.-In the time of Buffon, the greater portion of the hog 3 of Vivarez and the north of France were white; while in Dauphiny, I.anguedoc, and Provence, they were all black: black pigs still prevail both in Spain and Italy. The variety known in France under the name of porc de nobles appears to be derived from the improved English breed, which originated in a cross between an Anglo-Chinese sow and an $\because$ mancipated American boar. The French nreets if swine are in general bad, but excel1028 lent hams are sent from Bretagne from h.gs reared on acorns and fatted off with maize. The principal breeds of France at the present time are-

1. The race of the Pays d'Auge, in which the head is small and sharp, ears narrow and pointed, body long, legs broad and strong, hair coarse, white, and bones small. It attains to the weight of $800 \mathrm{lbs}$.

2. The race of Poitou. - The distinguishing characters of which are, head long and thick, with the point projecting, ears large and pendulous, body long, bones large, but broad and strong, bristles coarse. Its weight seldom exceeds 500 lbs.

3. The race of Périgord. - Neck thick and short, body broad and compact, hair black. This race, crossed with others, has produced the pied swine, so common in the south of France.

4. The race of Champagne.-These do not fatten well, they are of large dimensions, with long, flat sides, broad, pendent ears, and coarse white hair.

5. The race of Boulogne are also of considerable size, and disposed to fatten quickly; ears very broad, general colour white. This breed has sprung from a cross between the larger English breed and one of the common races of France.

The French pigs, although they have excited many facetious observations from travellers, and not unfrequently been compared to greyhounds, may be fattened, we are assured, at a small expense; and the method of doing this is now beginning to be understood. The Chinese and English breeds are also getting into use for crossing. The fact that $4,000,000$ pigs are killed yearly in France, shows of how great importance they are to the small agriculturist. (For. Quart. Rev.)

Other European BReds.-In some parts of Hungary the breed of swine is excellent. In Germany swine are common, but the breed is everywhere indifferent. Of the other continental races only a very few require particular notice.

The Jutland swine, which are of a large size, and form an important branch of Danish commerce, have the ears large and pendent, body elongated, back somewhat curved, legs long.

The Swedish swine.-The most peculiar and characteristic breed of Sweden are supposed to contain a cross of the wild boar, and have the head broad, turned upwards; ears unusu. ally erect, body lengthened, legs long.

The Polish and Russian pigs are generally small, and of a reddish or yellowish colour.

Race of the Cape of Good Hope.-This breed is somewhat less in size, but else approaches closely to the Siamese pig, and is nearly identical with the breed of the South Sea Islands. It probably originated in India. The hair is black or deep chestnut, hard, and thinly scattered; the ears are straight, and tail pendent and terminated by a tuft of bristles. This race is now very generally distributed; it has been propagated extensively in Australasia, and now occurs not only in Southern Africa, but in several parts of South America.

The smooth or short-legged swine, a breed derived from the Chinese, are bred in Spain, Por- 
tugal, Savoy, and the north and south of Italy. This pig is of small size, very productive, and a ready fattener; it is usually of a copper colour, but sometimes occurs of a bright fiery red. The head is unusually short, the jaws thick, the forehead stunted; the skin falls in folds above the eyes; the ears are short, pointed, and almost erect; the neck is thick and strong, the chest very vigorous, the body round and lengthened, the legs short and strong, the skin very thin, and the bristles short and slender.

The Zealand hog is of a mixed Chinese race, and weighs from 160 to $240 \mathrm{lbs}$. about the end of its second year. It has the ears erect, body short, back strongly bristled, tail small.

The Turkish hog fattens in half the time required by many of the larger and more common breeds, and weighs from 300 to $400 \mathrm{lbs}$. It prevails throughout European Turkey, and a great portion of the Austrian dominions. Ears straight and pointed; legs short and fine; body scarcely longer than high, and covered all over with slender frizzled bristles, of a gray colour, more or less deep, approaching to rufous brown.

The pig of Guinea (not the Guinea pig) is a remarkable variety, which is little known. The back is bare; head small; ears long, slender, and much pointed; tail long, naked, reaching to the ground; hair short, red, shining, finer and softer than that of any other known race.

In Asia only Europeans and the low Hindoos eat pork. Wild hogs are abundant, and do so much injury to the rice fields that it is a material part of the ryot's business to watch them, which he does night and day, on a raised platform of bamboos.

of the Mediterranean breeds there are several, which are approved and held in much estimation; among these are the Maltese, the Neapolitan, \&c., and hogs are occasionally brought from the sea-ports of Turkey and Spain.

The Mallese breed was at one time in great favour in England; it was of small size, of a black colour, nearly destitute of bristles, with an aptitude to fatten readily. A breed from the country near Naples has been recently introduced, which is extensively employed as a cross with the existing native breers. This Neapolitan breed is very similar to the Maltese breed already alluded to. Their flesh is good and delicate, but the animals are not hardy, and quite unfit for general use. The duchy of Parma is said to produce the best hogs of Italy, which possess all the good qualities of those about Naples. They are also more hardy, and of larger size.

In Mexico they have a very fine race of hogs, which are regarded as an important article of commerce. They are kept very clean, and often given a cold bath, as the breeders find from experience that cleanliness contributes mainly to their rapid growth, upon less food. This is fully corroborated by the following experiment, which was recently made by a gentleman from Norfolk. Six pigs of nearly equal size were put to keeping at the same time, and treated the same as to food and litter for seven weeks. Three of them were left to shift for themselves as to cleanliness; the other three were kept as clean as pussible by a inan employed for the purpose, with a currycomb and brush. The last consumed in seven weeks fewer peas by five bushels than the other three yet weighed more when killed by two stume and four pounds upon the average.

Bullock informs us that the Mexicans arr very curious in rearing and feeding swime, a and that an essential requisite in a Mexican swile. herd is an agreeable voice, in oriler that he may sing or charm the animals into peace. when they quarrel and fight, and lull them to sleep at proper times, to promote their faltetiing. (Travels, 1824.) There are many wild swine in Paraguay.

Characteristics of a good hog.-There is evidently much diversity in swine in different circumstances and situations. Like other descriptions of stock, they should be selected with especial reference to the nature of the climate, the keep and the circumstances of the management under which the farm is conducted. The chief points to be consulted in judging of the breeds of this animal are the form or shape of the ear, and the quality of the hair. The pendulous or lop ear, and coarse, harsh hair, are commonly asserted to indicate largeness of size and thickness of skin; while erect or prick ears show the size to be smaller, but the animals to be more quick in feeding.

In the selection of swine, the best formed are considered to be those which are not too long, but full in the head and cheek; thick and rather short in the rieck; fine in the bone; thick, plump, and compact in the carcase; full in the quarters, fine and thin in the hide; and of a good size according to the breed, with, above all, a kindly disposition to fatten well and expcditiously at an early age. Depth of carcass, lateral extension, breadth of the loin and breast, proportionate length, moderate shortness of the legs, and substance of the gammons and forearms, are therefore absolute essentials. These are qualities to produce a favourable balance in the account of keep, and a mass of weight which will pull the scale down. In proportion, too, as the animal is capacious in the loin and breast, will be generally the vigour of his constitution; his legs will be thence properly extended, and he will have a bold and firm footing on the ground.

For head and ears, the small Berkshire or Oxford pigs are good models; and for true shape, the improved Shropshire, Hereford, and Gloucester. If colour deserve any consideralion, perhaps the light, sandy, and yellow spotted are to be preferred, as these appear to afford by far the most delicate meat when dead.

Procreation.-The sow generally goes with young four lunar months, but the perind of gestation in different species varies considerably. According to the experiments of M. Teissier on the gestation of animals, it appears that the extreme periods of 25 sows were 109 to 143 days, which would lead to the inference that they go on an average 127 day's from the time: of taking the boar until they farrow; but experience proves that they most commonly farrow within little more than 16 weeks, althongh they occasionally go with young 20 weeks. Buin 
the sexes manifest a desire for coition at 7 or 8 months old; and although frequently brought logether at a still earlier age, it is more freferalle to restrain them until they have attained to the age of 12 months, as a larger and stronger litter will be produced. The boar should not commence serving until at least a year old, and he may be considered in his prime at 2 years old. He should not be strained by being allowed to serve ton many sows; from 12 to 14 being sufficient. The sow should rarely be put to the boar before 8 months old. See Gistation.

The animals when collectively spoken of are usually either termed swine, hogs, or pigs; but when distinctively named, the young gelded male is called a "barrow," the male when not castrated is called a "boar," and the female a "sow," or "shoot;" their progeny when very young being styled "sucking pigs," and when advanced somewhat larger in size, "porkers."

There is much difference of opinion as to the best age for breeding sows. Some considers that sows at 3 years old throw their stock much larger and stronger than when of a less age; while others are of opinion that they are never such good breeders as at the age of from a year and a half to two years and a half old; after which they throw the pigs unevenly.

Regarding the sex of the progeny, it is asserted in a recent French work on the subject of generation (Giron, sur la Réproduction des Animaux Domestiques), that among females those which receive the male first produce generally more males than females. This is not a matter of much consequence in swine; but in horses and cattle it is a question of some moment: and if this theory is borne out by experience, the hint thrown out may prove useful to breeders. The sow will produce two litters in a year (occasionally five in two years), and from 8 to 12 pigs in each farrow. The number of pigs to be kept will be easily indicated by the number of teats which the mother has; and on no account should more be atsempted to be retained than nature has thus provided for.

"The choice of a boar," says a modern writer, "depends so much upon fancy, or local prejudice, in favour of a particular breed, and is so little governed by either soil or climate, that no other general rule can be laid down upon the subject, than to avoid an animal which is not small-headed, deep and broad in the chest, the chine rather arched, the ribs and barrel well rounded, and the haunch falling full down nearly to the hock. He should also be more compact in his form and rather smaller than the sow; for, if she be coarse, her progeny will be improved in form and flesh by the cross, and the more roomy she is, the better chance will she afford of producing a large and healthy litter." (Brit. Husb. vol. ii. p. 511.) "The boar cannot be too well kept; but the sow should not be highly fed before taking the boar.

The plan or custom of breeding in and in from close relations is a most injudicious course, and seems to bring on degeneracy in the offspring. In selecting both sows and boars, a ilte regard inust be paid to the object for in: 0 which the progeny are designed. Small bone is desirable in stock reserved for breeding, as this description produces the least offal.

Uses. -4 pig, for its size, is one of the most useful animals in the whole creation, inasmuch as he is food from top to toe, and there is no part of him which cannot be turned to account. His fat is made into lard, which is used in medicine, as well as by housekeepers, confectioners, and others. That about the loins is the firmest and the most dense. For ordinary use it must be separated from the membranes, which is effected by melting it over a slow fire and straining through cloths. It should be stirred as it cools, to prevent the separation of the solid part or stearine from the eluine or oily part. The flesh is either eaten fresh when young, or of the adult animal, bacon hog, salted in brine or with dry salt, and then either kept moist, as pickled pork; or merely dried, white bacon; or cured, dried, and smoked, bacon; that of the hind legs, ham, equally nutritive, but less easily digested; the collar and head of the old boars are made into brawn; the skin or rind is eaten with the flesh, if not smoked, and is also tanned for saddle-seats, shoes, covers for pocketbooks, \&c.; the bladders are prepared as ox bladders. The bristles clean our teeth and brush our clothes: those of superior quality from Russia, fetch $14 l$. to $26 l$. the cwt.; the second quality, from $5 l$. to $10 l$. The abdominal fat is used; as also the blood for food, and it yields a bezoar, principally from a morbid con. cretion in the stomach of the wild hog. Even the intestines are used for chitlings, and converted into an inferior kind of lard, by being cut open and washed clean, and (after the water is well pressed out of them) melted in the same way as lard: this substance is very useful for making common candles, greasing wheels, and other general purposes. To sum up all, the hog multiplies his species in a degree proportioned to his usefulness.

The flesh of the hog, when fresh, is easy of digestion and nutritive; but it is not a food capable of being eaten for a length of time with impunity. It is apt to cause derangements of the mucous membrane, and diseases of the skin.

Bacon.-In Great Britain the curing of bacon, as an article of commerce, prevails most in the counties of York, Hants, Cumberland, Northampton, Dumfries, Galloway, and the northern and other ports of Ireland.

For bacon flitches, the larger breeds, such as will weigh, when killed, from 18 to 22 imperial stone, are always preferred, from being the most profitable to the farm and readily taking the market. In selecting pigs for this purpose, the sow should be of a large, deep carcass; head long, with deep ears, straight chine, and of equal symmetry from the shoulders to the tail; of fine skin, which shows an aptitude to fatten, and the boar should be of a thicker and closer make than the sow.

Small hogs for bacon will be ready for the knife in 12 weeks, and the larger from 16 to 20 weeks. The girth of fat bacon hogs is about as follow' :-When ten score, 4 feet 1 inch; twelve score, 4 feet 4 inches; fourteen score, 4 feet 7 inches; sixteen score, 4 feet 11 inc hes; eighteen score, 5 feet 2 inches; twenty 
score, 5 feet $\gamma$ inches. (IIillyard's Pruct. Furm. p. 51.)

"In Hampshire, and some adjoining counties, after the hog is killed, they first swale him, or singe off the hairs, by kindling a fire round him, which is far preferable to scraping off the bristles with warm water, as the latter mode softens the rind, and injures the firmness of the flesh. He is then cut into flitches, which are well rubbed with common salt and saltpetre mixed, and are laid in a trough, where they continue for three weeks or a month, according to size, and are often turned. They are then taken out, suspended in a chimney, over a wood or turf-fire, or in regular curing-houses, till they are quite dried. In Kent they are dried before a slack fire, which requires a similar method and time to that employed in salting. They are hung up or deposited on racks for use. Somersetshire or Wiltshire bacon, which is the best in England, is cured as follows:The sides of the hogs are laid in large wooden troughs, sprinkled with bay salt, and left unmoved for 24 hours, to drain off the blood and juices. Then they are taken out, and wiped quite dry, and some bay salt, previously heated in an iron fryingpan, is rubbed into the flesh, till enough of it is absorbed. This is continued for four suceessive days, during which the fitches are turned every second day. With large hogs, the flitches must be kept in brine for 3 weeks, and must be turned every other day, after which they are dried as usual. In these methods the hide or skin is left on; but in some counties there is a different practice, which has been recommended abroad as preferable, because it affords an opportunity of converting the skin into leather, while the meat takes the salt and is cured as well as in the former mode. The hides of swine have long been made into shoes in China. Where the consumption of bacon is very rapid, the last-mentioned practice may be adopted; but it is certain that bacon will in a short time become rusty, and consequent loss be incurred, if it be not cured with the rind, and kept in a dry room." (The Complete Grazier.) See Bıcos.

Pork.-In England, mess or table pork, or that for the London market, is generally cured near the principal sea-ports, and along the coast, from whence it can easily be shipped to the metropolis. If the object of breeding hogs is for pork and hams only, it is evident that pork from a hog of 25 to 35 stone ( 8 pounds to the stone) is by far more profitable than those from 35 to 50 stone; in which case a cross between the Chinese and Essex will be found to answer very well, as the progeny come to early maturity. (Baxter's Agr. Lib.)

The middle-sized hogs, such as the Northumberland, the Berkshire, the Suffolk, and Oxford breeds, are those generally preferred for this purpose, and their ordinary weight will be from 8 to 10 or 12 imperial store.

For delicate pork for tamily use, the smaller kindly-feodirg pigs are chosen. The Berksnire and the Suffolk breeds, when not too large, will be the best for this purpose. The Chinese will answer well at 6 or 8 months old, when it. will weigh 4 to 8 imperial stones. By higher feeding it may be made, when a little

older, to attain to double this weight; but the meat will then be fiurd coarse. Weanings are generally falled in a very short pertial. A pig of 5 or 6 months old will falten, if in gorod condition, in 8 or 10 weeks.

The fat of the hog is neither mixed with the flesh nor collected at its extremeties, but covers the animal all over, and forms a thick, distinc: and continued layer beneath the integuments. and in this respect may be said to resemble th. whale and other cetaceous animals. It is termed lard, and differs in chemical composition and properties from the fat of the ruminating animals. It more readily imbites sale than any other kind of fat; and the same prioperty being possessed by the flesh, there is in animal food better suited than pork for preservation by salting. See $L_{A} \mathrm{nn}$.

Statistics.-The number of swine sold in Smithfield market in 1830 was 254,672 , which. it the average weight of 96 lbs. each (a very moderate computation), gives the number of pounds of pork consumed annually at 24,448,512. (Youatt on Caltle.) The swine sold in Glasgow market in 1822 were 6539 . The exports of swine from Ireland in 1825 , were 65,919; in 1835, 376,191. Estimated value in the latter year, 893,839l. Increase between these two periods, 310,272 .

In the United States of America a very large number of hogs are reared; and latterly much attention has been paid to the improvement of the breed by judicious crosses. 'The piggeries are on an extensive scale; and it is no uncom. mon thing in some of the Western States for a drover to have from 3000 to 4000 pigs. In a letter written from Michigan city, dated IIth September, 1841, the writer, a farmer, states that he had then $\mathbf{3 5 0 0}$ pigs up to fatten! The bountiful crops of Indian corn raised on the fertile Western lands afford greater advantages than any other part of the world for the rearing of this kind of stock. Corn-fed bacon is proverbially excellent.

Swine in the British North American colonies, and the United States:-

\section{Upper Canada}

Lower Canadi

New Brunswick

Nova Scotia and Cape

Breton

Prince Edward's Island

Newfousdland and Labradur

Inited States

$\begin{array}{rr}1832, * & 1836 \\ 220,000 & 250,0 \\ 350,000 & 400,00 \\ 65,000 & 80,000 \\ 98,214 & 100 \\ 30,000 & 22,00 \\ 16,000 & 20.0\end{array}$

18.41.

$50 ? .000$

00,000

80,000

100000

22,000

3 หร2 21

The states producing most swine are-Tennessee, 2,926,607; Kentucky, 2,310,533; Ohio, 2,099,746; New York, 1,900,065. Viroinia, $1,992,155$; North Carolina, 1,4,4,716; Indiana, $1,623,608$; Pennsylvaria, 1.503,964; Illinois, 1,495,254; Georuia, 1,457,755; Mississippi. ?71,16?. The swine in the whole six Eastern

tes, according to the census returns of $1840^{\circ}$ numbered only 851,698 .

Diseases.-This subject has been so much neglected by practical men, that but little is known in the way of cure in the absence. therefore, of scientific prescriptions, it will be most advisable to study prevention rather than hazard a trial of the numerous recipes recom.

* M'Gregor's North America, 2d ed. vol. ii. p. 589

+ Martin's British Colnnies. 
mended as cures. The diseases of swine are generally the result of want of care and cleanliness, or arise from injudicious and irregular feeding; from their being kept in loathsome and uncomfortable situations, inhaling the most noxious vapours, and at one time overfed, and another stinted in their supply of food. Is it to be wondered at that they become subject to internal and cutaneous diseases? Fortunately they will generally eat when even sick; and salis ( 1 to $2 \mathrm{oz}$.), sulphur ( 2 to 3 drachms), an. timony, and such like aperients, may be mixed with their food for measles, and other disorders arising from an impure state of the blood. If they will not eat, there can of course be no cure applied.

In swine-pox, sulphur and madder may be administered in small quantities, with treacle, in the wash; fresh brewer's grains, or pollard, may also be given. Madder and sulphur will also be found the best alterants in foulness of the skin or habit. Salt, mixed with ground ivy, leeks, or other similar vegetables, is one of the best applications for the sores of swine. But for cutaneous diseases in general, an ointment formed of equal parts of mutton suet and tar, with the addition of a little sulphur, will be found beneficial. Strong beer and peaporridge are recommended as tonics.

In cases of surfeit, indigestion, or injury from eating slightly poisonous matter, swine will refuse their food, constantly lie down, and have the stomach distended. In this case, two heads of garlic, mixed with $6 \mathrm{oz}$. of fresh butter, will afford relief, given every 6 hours. Soap-suds are said to have the effect of emptying the stomach.

The most formidable of the diseases to which swine are liable, is inflammation of the lungs, and other internal parts. This disease has been known to destroy a fourth of the hogs in a distillery in the course of a few weeks. The chief indications of the disease will be the distressing cough, the heaving of the flanks, and the refusal of all food. Bleeding must be promptly resorted to, and moderate purges cautiously administered. The safest aperients are castor oil or Epsom salts, after which the following sedative powder may be given : foxglove (digitalis) 2 grs., antim. powd. 2 grs., nitre half a drachm.

In cases of murrain, a species of leprosy, which prevails chiefly in hot seasons, the best advice that can be given is to keep the animal cool, and not suffer carrion or portions of animal food to be given.

The health of swine is to be estimated by their cheerfulness, by the gloss upon their coats, their skin being wholly free from eruption. If pigs snort on being disturbed, it is an excellent sign of sound health and good keep. The state of the excrenrent or digestions will generally indicate pretty correctly the thriving condition of the aninal, for unless these are of a firm consistence, the hog will not fatten rapidly. If store or stock-pigs are kept well and in good condition, it will prevent most of the diseases to which the animals are subject, and they will also thrive and fatten at half the expense when shut up for that purpose. From the confinement of the hog, and the nature of 1032 his food, a description of dyspepsia takes place, a superabundant acid is formed in the stomach, and, the skin sympathizing, cutaneous eruptions display themselves; one of the best prophylactics in such a condition of the animal are cinders or charcoal. It operates as a most salutary tonic, and improves the general powers of digestion. Hogs are so fond of cinders, that when a handful of them is thrown into a sty, the animals tight for them.

Wearing.-If the young pigs have been well fed, they may be weaned after six weeks, and in all cases in two months. In their after treatment, when separated from their mother, they should be regularly fed 3 times a day, and their food should at first consist of warm liquid food, such as whey, milk, or the refuse of the dairy and kitchen, \&c., raised to the temperature of the mother's milk by the addition of a little warm water. They will soon learn to partake of more solid substances.

The rearing and fattening of the hog presents little difficulty, for this animal is reared equally well on a small or a large scale; by the cottager, from the wash and refuse of his house and garden, or by the extensive breeder, who has more abundance and variety of food at command.

As the situation, climate, crops, and other local circumstances must to a great extent regulate the breeding and feeding of swine, it is quite impossible to lay down rules of general application, or to describe a practice which necessarily varies in almost every district. I shall content myself, therefore, with noticing a few of the substances upon which the animals are usually fed and found to thrive best.

It constitutes the principal value of swine, that they can be maintained on almost any kind of aliment. In America, Indian corn or maize is largely used. In the West Indies, the cane tops, refuse trash from the cane after the juice has heen expressed, and the washings of the sugar-coolers, boilers, distillery vats, \&c., furm their principal food. In Newfoundland, Labrador, and other parts where fish is plentiful, they are freely fed upon the waste refuse from the fisheries; and although they thrive well upon this food, their flesh is coarse and strong.

Where the farmer or breeder has a rich piece of grass or clover unemployed, hogs which are not put up for feeding may be turned into it with advantage; but there is an objection to this on the score of the manure which is lost. When the field is so situated that the hogs can return at night to the well-littered sties, the practice may then be found beneficial.

But roots, rather than herbage, is their natural food, such as earthnuts, the roots of couch grass, \&c.: acorns, chestnuts, beechmast, hazel-nuts, and other dry seeds and fruits, are eagerly consumed by them; and hence, in the countries in the south of Europe, in the neighbourhood of forests where these abound, they are frequently suffered to range at large and collect their own food. Hogs are also very partial to juicy and pulpy fruits, such as the grape, the orange, the refuse of apples, pears, olives, \&c., after the juice has been expressed. Although hay and dried fodder is not adapted 
. the feeding of swine, if these substances are chopped and boiled they will not refuse them.

Moist, succulent, green food, such as clover, tares, lucern, sainfoin, buckwheat, succory or chiccory, cabbage, lettuce, \&c., is more suited to their taste. Every kind of farinaceous substance, such as oat-meal, barley-meal, bran, maize, inillet, pease or beans bruised, and indeed the seeds of all gramineous and leguminous plants, are the most fattening substances that can be given to them. 'They will feed greedily, and thrive surprisingly, on most kinds of roots and tubers, such as carrots, turnips, beets, potatoes, the Jerusalem artichoke, \&c., particularly when prepared by boiling. It may be taken as a general rule, that boiled or prepared food is more nutritious and fattening than raw or cold food; the additional expense and labour will be more than compensated by the increased weight and quality. Thus cabbage, turnip and potato tops, the husks of peas and beans, and even many green weeds, such as nettles and thistles, fatten; and others, void of poisonous qualities, will be found very fattening if boiled and mixed with other food, and given, as most food should be, lukewarm. The refuse of the kitchen, garden, and dairy, the grains and wash or liquid refuse of breweries, distilleries, and sugar manufactories, where they can be obtained, the sweepings of barns and granaries, will all be found exceedingly fattening. Animal substances, particularly fish, should, however, be seldom or never given as fond, since they will necessarily impart a strong and disagreeable flavour to the meat. A little salt should be generally added to all their victuals, which will create thirst, and induce the animals to consume a greater quantity of food. Fermented wash is found to fatten swine much quicker than fresh food.

Ringing. - The practice of ringing swine, which was usually performed at the time of weaning, is growing into disuse, and the ringing is not advisable, inasmuch as it not only proves painful to the animal, but troublesome to the owner; for it frequently happens that the ring breaks, or is worn out; the cartilage gives way, and the ring has to be as often replaced by a fresh operation. A more preferable and lasting process is now adopted, which consists in either cutting the two strong tendons of the snout (the cartilaginous and ligamentous prolongations) about an inch and a half from the nose, by a slight incision with a sharp knife, or else to shave or pare off the gristle on the top of the nose, which may be done without prejudice to the animal, when about two or three months old. The place heals over in a short time, and the animals are thus prevented from grubbing or tearing up the ground. (Prize Essay on Swine, by P. L. Simmonds; Wilson "On the Hog," Quart. Jour. of Agr. vol. iii. p. 38; Low's Illustrations of the Breeds of Dom. Animals.)

SWINE'S CRESS. See Wart-Cress.

БWINGLE-TREE. See Plough.

SWING PLOUGH. See Plodgr.

SYCAMORE. See ButTonwoov.

SYTHE. See Scх'тн.

\section{'T.}

'TACAMAHAC:A. See Porran.

TAG. $\Lambda$ term applied to a young slieep of the first year. See Survip.

'TALI.)W (Germ.lulg). The fat ritlanes by melting the suet of the $n x$ and sheep, and straining it so as to free it from membrane. When pure, it is white, tasteless, and turarly insipid; but the tallow of cummerce has usually a yellow tinge, and is divided, accririt. ing to the degree of its purity and comsistrice, into candle and soap tallow. T'allow consists of stearine, eluine, margarin, and traces of hircin. According to Chevreul, its ultimate components are 78.996 of carbon +11.7018 of hydrogen $+0 \cdot 304$ of oxygen in 100 parts. I is used in medicine as an emollient and at demulcent. Tallow is an articie of great importance. It is manufactured into candles anil soap, and is extensively employed in the drew. ing of leather and in various processes of the arts. Besides the supplies of native tallow, a very large quantity is annually imported into England, principally from Russia. 'The expor: of tallow from Petersburg amount, at an average, to between $3,500,000$ to $4,000,000$ poods. of which the largest portion by far is l)rought to England. (M'Culloch's Com. Dict.)

'TAMARISK (Tamarix). 'This is a genus of very elegant shrubs. The hardy indigenous species, or French tamarisk (S. Gallica), is we!? suited for ornamenting shrubberies: it will grow in any soil or situation, and is freely increased by cuttings planted in the open ground. in spring or autumn. Sheep feed greedily on this species for the salie of its salt taste. The stem is slender, with abundance of long. drowping, smooth, red, shining branches. Leaves minute, lanceolate deciduons, spurred, acure. Lateral cylindrical clusters of numerous, nearly sessile, reddish or white bracteated flowers, without scent.

TANK. In gardening, a cistern or reservoir made of stone, timber, or some other material. Tanks are used for collecting and preserving water during a scarcity or drought. They are sometimes built in the ground, and lined with lead or cement. Where wells cannot be sunk. and water is scarce at some seasons, tanks are necessary appendages to a house.

A tank, 12 feet by 7 feet, has been found sufficient to supply with water a large family and 6 horses: this was surrounded by only $4 \frac{1}{2}$ inch brick-work, resting solid against the sides. in consequence of being, like a decanter. smaller at the bottom than higher up; and the dome is constructed on the Egyptian plan, by projecting horizontally each row of materials one-third of their length beyond those below by filling up the back with earth as it pmceeded, to balance the weight of this projecting masonry.

At the Eastbourne work-house for 14 parishes, a tank has been made 23 feet deep by 11 wide, of the roughest materia!s, boing only flint stones, and though they require more mortar than if they had been regularly shaped, orily 90 bushels of lime were allowed, inciuding ?

$$
4 \mathrm{~S} \quad 1033
$$


ccats of plaster, and the workmanship is executed like field walls at 10 s. per 100 square teet; the only essential being that no clay be used (which worms in time bore through), and that the lime, or Parker's cement, be good.

A current of air is said to promote the purity of water in tanks, which is easily effected by the earthenware or other pipe which conveys the water from the roof being of 6 or 8 inches in diameter, and an opening left for the surplus water to run away; and where the prevailing winds do not blow soot and leaves on the house, the water remains good, even for drinking, without clearing out the rubbish more than once a year; but, in some cases, filtering by ascension may be found useful, and effected by the water being delivered by the pipe at the bottom of a cask or other vessel, from which it cannot escape till it has risen through the holes in a borard covered with pebbles, sand, or powdered charcoal. See Reservoms, Ponds, \&c.

'TANNER'S BARK. The bark of oak, chestnut, willow, larch, and other trees, which abounds in tannic acid, and is used by tanners for preparing leather. After being exhausted of the tanning principle by being chopped into small pieces, or bruised and steeped in water, it is laid up in heaps to dry, and sold to gardeners for the purpose of producing artificial heat by fermentation in pits or beds, in barkstoves or other out-houses. See Bark and Farm-Yarti Mavelia.

TANNIC ACID. This terin has been especially applied to a substance obtained by Pelonge, by acting upon bruised galls by common unrectified ether, in a long, narrow funnel or percolater. Tannic acid is a white uncrystalline powder, very astringent, little soluble in water, and reddening litmus. When moistened and exposed to air, it attracts oxygen, is decomposed, and is converted into gallic acid. It is extremely astringent, and appears to be the active principle of tanning substances (tannin) in general. Its ultimate elements are 30 atoms of carbon, 18 of hydrogen, and 24 of oxygen.

TANNIN. A word synonymous with tannic acid, the pure astringent principle upon which their power of converting skin into leather depends. Its leading character is its property of producing a dense whitish precipitate in a strong solution of animal jelly, such, for in- stance, as isinglass; and on this account it condenses the gelatin of animal hides, and, renderins them impermeable to water, converts them into leather. It may be obtained tolerably fare by infusing bruised grape-seeds in cold water, or more circuitously by adding acetate of copper to filtered infusion of galls, washing the precipitate, and decomposing it (diffused through water) by sulphuretted hydrogen. On evaporating its solution, it is ubtained as a pale yellow extract of a strong astringent taste. The action of astringents upon persalts $c_{-}^{f}:->n$ has given rise to its distinction into two varieties, the first changing them to deep blue or black, the second to green. The tan of galls, oak, bark, grape-seeds, \&c., possesses the former property; that of catechu and tea, the latter. (Brande's Dict. of Science.)

TANNING. The art of preparing leather from raw skins and hides so as to render them 1031 more pliant, durable, and impermeable to water. The processes employed for this purpuse are various, every tanner adopting some peculiar or favourite method.

A discovery has recently been made which seems likely to revolutionize the tanning trade. By means of a tanning machine, or pair of horizontal rollers fixed over a tan-pit, between which is fixed a band or beit of hides attached by ligatures to each other, to the number of 50 to 100 , and by which the rollers are constantly fed or supplied, the hides are lifted out of the pit on one side of the machine; as they pass between the rollers, the exhausted ooze or tanning liquid is pressed out of them, and they are deposited in folds in the pit on the other side of the machine, where they absorb another supply of fresh tannin. The first hide having been inserted between the rollers, the others follow in succession, and upon arriving at the end of the band the motion of the roller is reversed, and the belt is returned through the machine to receive another squeeze. This alternating motion is constantly repeated, the pit being replenished from time to time with fresh solutions of tan, till the operation is completed. The effects produced by this simple plan, are1. The shortening of the time of tanning to one-fourth of that generally required. 2. 'The production of a considerable increase of weight. 3. The leather tanned by this method resists water longer than that tanned by the old process. 4. The new method is cheaper than the old. 5. It is applicable to the existing tanyards, at a comparatively trifling expense, with a capability of working in rounds or series, and of expending tan or liquor. 6. That it is availa. ble for all sorts of leather.

TANSY (Tanaretum). The species of tansy are not possessed of much beauty. The hardy kinds succeed in any common soil, and are readily increased by rooted slips of the fibrous creeping root. They increase freely by cuttings. Withering asserts that if meat be rubbed with the leaves of tansy, the flesh-fly will not touch it. In England the only indigenous species is the common tansy (T. vulgare). Every part of the herb is bitter, with a strong but not unpleasant scent. 'The qualities are esteemed of a tonic and cordial nature, expelling intestinal worms, and strengthening the digestive powers. The plant, however, does not agree with every stomach. There are two varieties of this species, the variegated, and the curled or double tansy, which is kept for use in gardens, as being more wholesome or milder than the wild sort; but in England tansy pudding is out of fashion.

TAPE-GRASS or EEL-GRASS. See VALESNEMTA.

'TAPIOCA. A white, edible substance, consisting of very pure starch, obtained from the root of a tropical plant called manioc (Jatropa manihot) or cassava.

TAP-ROOT. A root which penetrates decp and perpendicularly into the ground without dividing, and has few lateral fibres. In shape it resembles a spindle; hence it is botanically termed a fusiform root. But the main trunk of any root that penetrates vertically deep into the ground is called the tap. 
TAR. A dark brown, viscid liquor, obtained by charring the wood of the fir tree; it consists of resin, empyreumatic oil, and acetic acid. When inspissated by boiling, it is converted into pitch. The manufacture, which is carried on in the pine forests of Northern Europe, is simple. A conical hole, usually in the side of a bank, being made, roots and fillets of pine are let into the cavity, and the whole is covered with turf, which is beat firmly down above the wood. The wood being kindled, a slow combustion takes place. A cast-iron pan at the bottom of the cavity receives the fluid, and has a spout which projects through the bank and carries the tar into barrels. As quickly as the barrels are filled, they are closed with bungs, when the material is ready for exportation. This manner of preparing tar has been derived from the earliest ages. Tar is a very compound substance; it contains modified resin, and oil of turpentine, acetic acid, charcoal, and water. Tar is used in medicine as well as in the arts. It is an excellent topical stimulant, when made into an ointment with lard, in dry skin diseases. These two substances, tar and pitch, are of extensive use in the arts.

Tar may be found useful as an application for cuts in sheep by clipping, and also to the parts affected by the fly. It is also of great use in some cases for applying as a paint to boarding, \&c.; but in this use a little tallow or other coarse fat should be melted with it, as by this means it goes farther, and resists the weather more effectually. Large quantities of tar are made from the abundant pine forests of North Carolina. See also Gas-Tan.

TARE EVERLASTING. See Lathyts and Vктchling.

TARES (Ervum, from ervo, tilled land; some of the species are a pest on cultivated ground). The word tare is frequently applied to what is properly the common vetch (Vicia sativa). There are in England two indigenous species of tare, which are troublesome annual weeds.

1. Smooth tare (E. tetraspermum, PJ. 10, c), which grows in corn-fields, hedges, and thickets, particularly such as are rather moist. 'The root is small and tapering. The herbage is besprinkled with fine, soft hairs, especially the flower-stalks and calyx. Stem weak, quadrangular, branched from the bottom, leafy, climbing to the height of $\mathbf{2}$ or $\mathbf{3}$ feet. Flowers mostly in pairs, small, drooping, pale gray; the standard streaked, and the keel tipped with a deep blue. Legumes pendulous, oblong, bluntish, smooth. Seeds most generally 4 .

2. Hairy tare (E. hirsutum), which is in habit much like the foregoing; the flowers are in clusters of 5 or 7 , very small, pale blue, or almost white, with two dark spots on the keel. Legumes short, dark brown, besprinkled with hairs, to which the specific name alludes. Seeds two in each legume, large and promi. uent. See Lathxrus, Sorling, Vetch, VetciLINe, \&c.

TARO. A bulbous-rooted plant of the genus Arum, a native of the valley of the Columbia river. It is planted on hills, and cultivated in the manner of rice, on ground so situated as to be partially flooded with water. It comes to maturity in 8 or 10 months from the time of planting. To prepare them for food, they are roasted; they then become a substitute for bread; or they are made into pui, ly pulveriz. ing and converting them into a paste.

'TEAM. A number of horses ur oxen draw ing at once in the same plough, cart, or other carriage.

It has been long a disputed point among farmers whether horses or oxen form the most economical and advantageous team for the purpose of the cultivator in performing his work. The question remains still undeciled, though many intelligent farmers in England now incline to the side of horse teams, except in particular circumstances and situations.

TEASEL, or TEAZI.E (Dipsacus, supposed to be derived from dipsuo, to thirst; in consequence of the leaves holding water). It is a curious genus of plants: some of the species are pretty flowering plants, especially the small teasel. They grow well in any common soil, and are readily increased by seeds. 'There are in England three native species, all biennial.

1. 'The manured or fuller's teasel ( $D$. fullorum), although growing about hedges, can scarcely be considered wild. This species is extensively cultivated in the west of England, the dried heads of which furnish the teasel used by fullers in dressing cloth. 'The root is fleshy, branched, and tapering. Stem 5 to 6 feet high, erect, strongly furrowed, prickly, leafy, branched at the top. The leaves sessile, combined, serrated, with prickly ribs. Flowers whitish, with pale purple anthers, very numerous, in a close, obtuse, conical head, the intermediate scales bristly at the edges; rigid and hooked at the points, by which they are rendered serviceable for teazing woollen cloth, being fired in several rows in wooden frames with handles adapted for that purpose. The scales are just strong enc ugh to raise the wool, giving way before they $\mathrm{c}$ an injure the cloth. Many mechanical inventions have been attempted to set aside the teasel, but without success, all of them having proved inefficient or injurious. The dressing of a piece of cloth consumes from 1500 to 2000 teasels. They are repeatedly used in different parts of the process. Some esteem this but a luxuriant variety of the following, as it requires a very richly manured soil to preserve its characters and useful properties.

2. Wild teasel (D. sylvestris). In England a very common species about moist hedges and by road-sides, less robust than the foregoing: about 4 feet high. Leaves opposite, serrated. Scales of the receptacle straight. Common caly $\mathrm{x}$ inflexed, longer than the head.

3. Small teasel, or shepherd's staff (D. pilu sus). This species grows in moist, shady places, on a challiy or limestone soil. This is ? useless weed, but not troublesome to the farmer

TEATHING. Provincially, the practice of eating turnips off, upon young wheat crops, in the early spring months, by live-stock, as sheep and bullocks. It is often written tathing.

TEETH. See AgE of Avivals.

TEMPERATURE. See Atrosphers, Alertune, Chimate, Earths, Elevation, Meteo. oLorit.

TENANT (Tenens, from the Latin encre, (1) 1035 
hold). In law, one who holds or possesses lands or tenements by any kind of right, either in fee for life, for years, or at will. See Lease.

TENDRILS. The curling, twining organs of prehension, by which some plants lay hold of others.

TEN-O'CLOCK. A troublesome perennial plant and weed, with a bulbous, fibrous root, difficult to destroy, as it will grow even years after the tops are cut off. Fields must not be ploughed. This foreigner has escaped from the gardens, and has become a grievous nuisance on many farms. Although it rarely perfects its fruit, the bulbs are propagated laterally with great rapidity; and are extremely difficuit to extirpate. One native species has been found in the United States, on the Rocky Mountains. (Flora Cestrica.)

TETHERING. The practice of confining to precise limits or pasturage any kind of stock, by means of light chains or ropes fastened to iron pins (with swivel rings) driven into the ground. For the small farmer with indifferent fences, or for gentlemen with limited and ornamental lawns, this practice, which secures shrubs and pleasure-grounds from injury, is obviously often an advantageous system; and indeed a rich lawn immediately in view of a house is the fittest situation for tethering, as an impoverished field would disappoint, and demand a too frequent and therefore troublesome change of tether. The practice is almost universal throughout France, even in common farms.

THATCH. Straw, or any other dry vegetable substance, laid on the top of a building, rick, \&c., to keep out the wet.

There are many different sorts of materials that may be made use of as thatch, but the straw of wheat and rye, when well laid, forms the neatest and most secure covering for general purposes.

The reed is a highly valuable article for the purpose of thatch, where a lasting roof is required; but is much too expensive at first, although it is cheapest in the end. Reed is also thought to be too stubborn for common purposes. Fern is also occasionally used. See Fern.

THERMOMETER (Gr.). An instrument for measuring variations of heat or temperature, too well known to need description. See ATmosphere, Climate, Meteonologx, \&c. See also Table in next column.

THISTLE. A well-known prickly weed, common in corn-fields and pastures. Whereever thistles grow naturally it is a sure sign that the land is strong, and of a tolerably good quality; but they are at the same time a great annoyance to every plant intended to be cultivated.

By an excellent regulation in France, a farmer may sue his neighbour who neglects to thistle his land at the proper seasons, or may umploy people to do it at the other's expense: and it were to be wished that a similar law was in force here, to prevent the wide-spreading inischief occasioned by the seeding of this pernicious weed; among which may be reckone?, besides its choking the young corn, that if wheat in particular be not well thistled, the 1036

Table exhibiting the degrees of the Centigrade an? Fahrenheit's Thermometers corresponding to those of Reaumur's Thermometer.

\begin{tabular}{|c|c|c|c|c|c|}
\hline Reaum. & Cent. & Fahr. & Reaum. & Cent. & Fahr. \\
\hline 80 & $100^{\circ}$ & 212 & 29 & $36 \cdot 25$ & $97 \cdot 25$ \\
\hline$x$ & $98 \div 75$ & givy.75 & 28 & $35^{\circ}$ & $95^{\circ}$ \\
\hline 78 & $97 \cdot 5$ & $207 \cdot 5$ & 27 & $33 \cdot 75$ & $92 \cdot 75$ \\
\hline 77 & $96 \cdot 25$ & $205 \cdot 25$ & 26 & $32 \cdot 5$ & 90.5 \\
\hline 76 & 95. & $203^{-}$ & 25 & $31 \cdot 25$ & $88 \cdot 25$ \\
\hline 75 & $93 \cdot 75$ & $200 \cdot 75$ & 24 & $30^{\circ}$ & 86 \\
\hline 74 & $92 \cdot 5$ & 198.5 & 23 & $28 \cdot 75$ & $83 \cdot 75$ \\
\hline 73 & $91 \cdot 25$ & 196.25 & 22 & $27 \cdot 5$ & $81 \cdot 5$ \\
\hline 72 & $90^{\circ}$ & $194^{\circ}$ & 21 & $26 \cdot 25$ & $79 \cdot 25$ \\
\hline 71 & $88 \cdot 75$ & $191 \cdot 75$ & 20 & $25^{\circ}$ & 77 \\
\hline 70 & $87 \cdot 5$ & 189.5 & 19 & $23 \cdot 75$ & $74 \cdot 75$ \\
\hline 69 & $86 \cdot 25$ & $187 \cdot 25$ & 18 & $22 \cdot 5$ & $72 \cdot 5$ \\
\hline 68 & $85^{\circ}$ & $185^{\circ}$ & 17 & $21 \cdot 25$ & $70 \cdot 25$ \\
\hline 67 & $83 \cdot 75$ & 182.75 & 16 & $20^{\circ}$ & $68^{\circ}$ \\
\hline 66 & $82 \cdot 5$ & $180 \cdot 5$ & 15 & $18 \cdot 75$ & $65 \cdot 75$ \\
\hline 65 & $81 \cdot 25$ & $178 \cdot 25$ & 14 & $17 \cdot 5$ & $63 \cdot 5$ \\
\hline 64 & $80^{\circ}$ & $176^{\circ}$ & 13 & 16.25 & $61 \cdot 25$ \\
\hline 63 & $78 \cdot 75$ & 173.75 & 12 & 15 & $59^{\circ}$ \\
\hline 62 & $7 \% \cdot 5$ & 171.5 & 11 & $13 \cdot 75$ & $56 \cdot 75$ \\
\hline 61 & $76 \cdot 25$ & $169 \cdot 25$ & 10 & 12.5 & $54 \cdot 5$ \\
\hline 60 & $75^{\circ}$ & $16 \%$ & 9 & $11 \cdot 25$ & $52 \cdot 25$ \\
\hline 59 & $73 \cdot 75$ & $164 \cdot 75$ & 8 & $10^{\circ}$ & $50^{\circ}$ \\
\hline 58 & $72 \cdot 5$ & $162 \cdot 5$ & 7 & 8.75 & $47 \cdot 75$ \\
\hline 57 & $71 \cdot 25$ & $160 \cdot 25$ & 6 & $7 \cdot 5$ & $45 \cdot 5$ \\
\hline 56 & $70^{\circ}$ & $158^{\circ}$ & 5 & $6 \cdot 25$ & $43 \cdot 25$ \\
\hline 55 & 68.75 & $155 \cdot 75$ & 4 & 5. & $41^{\circ}$ \\
\hline 54 & $67 \cdot 5$ & 153.5 & 3 & $8 \cdot 75$ & $38 \cdot 75$ \\
\hline 53 & 6625 & $151 \cdot 25$ & 2 & 2.5 & $36 \cdot 5$ \\
\hline 52 & 65 & $149^{\circ}$ & 1 & $1 \cdot 25$ & $34 \cdot 25$ \\
\hline 51 & $63 \cdot 75$ & $146 \cdot 75$ & 0 & 0 & 32 \\
\hline 50 & $62 \cdot 5$ & 144.5 & 1 & $1 \cdot 25$ & $29 \cdot 75$ \\
\hline 49 & $61 \cdot 25$ & $142 \cdot 25$ & 2 & 2.5 & $2 \% \cdot 5$ \\
\hline 48 & $60^{\circ}$ & $140^{\circ}$ & 3 & $3 \cdot 75$ & $25 \cdot 25$ \\
\hline 47 & $58 \cdot 75$ & $137 \cdot 75$ & 4 & 5. & $23^{\circ}$ \\
\hline 46 & $57 \cdot 5$ & $135 \cdot 5$ & 5 & 6.25 & 20.75 \\
\hline 45 & $56 \cdot 25$ & $133 \cdot 25$ & 6 & $7 \cdot 5$ & $18 \cdot 5$ \\
\hline 44 & $55^{\circ}$ & 131. & 7 & $8 \cdot 75$ & 16.25 \\
\hline 43 & $53 \cdot 75$ & $128 \cdot 75$ & 8 & $10^{\circ}$ & $14^{\circ}$ \\
\hline 42 & 52.5 & $126 \cdot 5$ & 9 & $11 \cdot 25$ & $11 \cdot 75$ \\
\hline 41 & $51 \cdot 25$ & 124.25 & 10 & 12.5 & $9 \cdot 5$ \\
\hline 40 & $50^{\circ}$ & 122 & 11 & 13.75 & $7 \cdot 25$ \\
\hline 39 & $48 \cdot 75$ & $119 \cdot 75$ & 12 & $15^{\circ}$ & 5. \\
\hline 38 & $47 \cdot 5$ & $117 \cdot 5$ & 13 & $16 \cdot 25$ & $2 \cdot 75$ \\
\hline 37 & $46 \cdot 25$ & $115 \cdot 25$ & 14 & $17 \cdot 5$ & 0.5 \\
\hline 36 & $45^{\circ}$ & 113. & 15 & $18 \div 5$ & $1 \cdot 75$ \\
\hline 35 & $43 \cdot 75$ & $110 \cdot 75$ & 16 & $20^{\circ}$ & $4^{\circ}$ \\
\hline 34 & $42 \cdot 5$ & 108.5 & 17 & $21 \cdot 25$ & $6 \cdot 25$ \\
\hline 33 & $41 \cdot 25$ & 106.25 & 18 & $22 \cdot 5$ & $8 \cdot 5$ \\
\hline 32 & $40^{\circ}$ & $104^{\circ}$ & 19 & $23 \cdot 75$ & $10 \cdot 75$ \\
\hline 31 & $38 \cdot 75$ & $101 \cdot 75$ & 20 & $25^{\circ}$ & $13 \cdot$ \\
\hline 30 & $37 \cdot 5$ & $99 \cdot 5$ & & & \\
\hline
\end{tabular}

reapers take up the grip so tenderiy, lest they should prick themselves, that, by their loose handling of them, they sometimes leave upon the ground corn enough to sow the whole field. There are no plants over which the economical farmer ought to keep a more watchful eye than the thistle tribe, as they are not only useless, but occupy much ground, and, being furnished with winged downy seeds, are capable of being multiplied and carried almost to any distance: besides, they do much mischief by impeding the work both in handling hay and corn crops. It is, of course, a matter of much consequence to be well acquainted with the qualities of each kind, in order to enable us to judge with certainty how far and by what means their destruction may be effected in the most certain and ready manner.

There are in England many sorts of thistles, but those which chiefly deserve the attention of the farmer are either of the annual, biennial, or perennial kinds.

The annual species of thistle are the muskthistle (Carduus nutans), the milk-thistle ( $C$. marianus), the welted or curled thistle (C.acanthoides), the slender-flowered thistle ( $C$. tenuiflorus), the common sow-thistle (Sonrhus olera- 
seus). The principal biennial thistles are the spear or bull-thistle (C. lancelatus), the marshthistle (C. palustris), and the cotton-thistle (Onopordum acantheum). The perennial species are two, the common sow-thistle (Sonchus arvensis), and the common or field-thistle (Cnicus arvensis), or Canada thistle. The dwarf or stemless thistle ( $C$. acaulis), the star-thistle (Centaurea calcitrapa), and the common carlinethistle (Carlina vulgaris), are more frequently found to infest dry sandy pastures and calcareous soils than loamy or damp grass-lands. Where they prevail to a great extent, there is no remedy like breaking up the land and taking a course of crops; for palliative remedies are of little avail. Hand-weeding, when the weeds are confined to local spots, and are only just beginning to spread generally over the soil, will be found effectual; but when once the pasture becomes generally infected with the seeds and roots of these plants, no time should be lost in using the plough, harrow, and horse-hoe, and a judicious course of cleansing crops before returning the land again to permanent pasture.

Among the species of pasture-weeds that generally prevail in loamy soils, and are also prevalent in clayey and damp soils, are the marsh or red plume-thistle (Cnicus palustris), the meadow or small purple plume-thistle (Cnicus pratensis), and the melancholy plumethistle (Cnicus heierophyllus). In crops of artificial grasses, such as sainfoin, lucern, \&c., where the dwarf plume-thistle (Cnicus acaulis) prevails, and when it is impracticable, under such circumstances, to draw out this weed without injuring the crops, a good remedy will be found in the use of common salt. Children may be employed to apply the salt by hand to the crown of the weed. If the least part of the root of the thistle be left, it springs up season after season. Besides possessing this principle of vitality in the root, its seeds are so winged with down as to render dissemination, even to a great distance, by means of the wind, almost certain.

It is obvious that the annual and biennial species of thistles may be readily removed by preventing their running to seed and disseminating themselves, which is best effected by carefully eradicating them, or frequently mowing them over close to the surface, and rolling. But in the perennial kinds, from their roots continuing in the earth, increasing and throwing out new shoots or stems every year, there is much difficulty in extirpating them, and they perhaps can be no other way destroyed than by rooting them out of arable land by deep ploughing and frequent harrowings, or by fallowing or laying the land down to pasture; the annual species seldom appear in pasture-lands. But for destroying the common thistles the best method is by weeding-pincers, or the finger and thumb when in loose land, cutting them over in the bleeding season frequently by weedingknives, and applying salt to the cut stalk.

The most common thistle found in the United States is the $C$. lanceolatus, a biennial. The most troublesome pest, the $C$. arvensis. (See Canada Thistue.) Dr. Darlington thinks the yellow thistle a fcreigner introduced into the
United States. It is the most prickly of al! the tribe, and hence called by botanists Cordum spinosissimus, and Cnicus horriduus. The roos of this is considered by some bienuial, by others perennial. 'The tall or tallest thistle ( $($. al'usse mus), is common along fencerows, \&c., in the Middle and other States. 'The dwarf carduuy (Carduus Pumilus), is common in J'ennsylvania and other Middle States, growing in r.j firlis. \&c., from 1 to 2 feet high, with flowers of a pa!e? reddish-purple, and quite fragrant. The heads are handsome, and the largest of any other American species. Several other species of thistle are found in the United States. See

Canama Thister.

THISTLE, PLUME' (Cnicus). This is a separation from the genus Cardurs made by Sir J. E.Smith. They are prickly, herbaceous plants, and differ chiefly in the down being evidently feathery, not merely rough. 'The biennial species may be readily destroyed by mowing before the flowers form seed. There are in England nine indigenous species of plume thistle. Some of which are common in waste ground, moist meadows, \&c. Those which give most trouble to the farmer are, the

Marsh plume-thistle (C.palustris), a biennial, growing plentifully in moist meadows or pas. tures, and watery spots by road-sides. Stem from 3 to 6 feet high.

Creeping plume-thistle ( $C$. arvensis). A very troublesome perennial weed in cultivated fields and by way-sides, from its flesny root, which is very tenacious of life, creeping deeply into the earth to a great extent. Stemi 3 or 4 feet high.

Branching bog plume-thistle (C. Forsteri). A perennial, flowering in July and August, with a tapering root.

Woolly-headed plume-thistle (C.eriophorus) A large and conspicuous perennial plant, grow ing in waste mountainous ground, and by road sides, on a limestone or chalky soil.

Melancholy plume-thistle ( $C$. heterophyllus). A perennial, growing in moist mountain pastures in the north.

Meadow plume-thistle (C. pratensis). A perennial, growing in low, wet meadows and pastures, especially among trees. Root fibrous.

Dwarf plume-thistle ( $C$. acaulis). A perennial, growing on chalky and gravelly soils. Root woody, running deep into the ground Stem entirely wanting. The large bright-greer leaves, spreading close to the ground, in a circle near a foot in diameter, chole all other herbage.

THORN (Cratagus). A name given to several indigenous shrubs and rmall trees. See Brack-Thors, Bгсктиолу, Hawthors, White-Thor , \&c.

Of this genus of shrubbery trees so valuable" in an agricultural point of view, there are many species and varieties. Dr. Darlington describes the following as found in Chester county, Pennsylvania: 1. The Newcastle or cockspur thorn (C.crus galli). Two varieties of this exis" the most common of which is much employed in making the fine hedges for which Newcastle county, Delaware, is celebrated. Dr. Darlington thinks that, with proper manago ment, this kind will ultimately make a more 4 s 2 
durable and effective hedge than the Washington thorn (C. cordata), which is now generally used in Chester county. It is a more rugged plant, and seems to be less liable to disease, or to be injured by insects, than the Washington thorn. (Flora Cestrica.)

2. The small-leaved thorn (C.parvifolia), a rugged little bush abundant in New Jersey.

3. 'Thorn-bush or dotted cratægus (C. punctatu), a red-fruited variety. The fruit is large, half to two-thirds of an inch in diameter, mostly three-seeded, red, sometimes yellow when mature, dotted and esculent.

4. Black-thorn (C. Alava), yellow cratægus, an apparent misnomer. The fruit is pearshaped, large (about half an inch in diameter), three or four-seeded, greenish-yellow, with a tinge of dark red when mature, esculent, but rather insipid.

5. White-thorn or crimson cratægus ( $C$. coccinea). This is the most common species in Chester county, Pennsylvania. The thorns have more resemblance to the cock-spur, than those of the real crus galli or Newcastle thorn. 'T he fruit is one-third to half an inch in diameter, and bright purple when mature.

6. The Washington thorn ( $C$. cordata). This species, says Dr. Darlington, was introduced into Chester county from the neighbourhood of Washington city, and is now extensively used in hedging. It grows fast in favourable situations, under good management, and will make a handsome hedge in about 10 years from the time of planting. It does not succeed well on dry, rocky banks, and especially in the red shale districts. The young branches are also subject to disease from the puncture of insects. "I have used this thorn," says Dr. Darlington, "to a considerable extent, and have succeeded in obtaining some pretty fair hedges; but I am now strongly inclined to the opinion that the C. crus galli, or cock-spur thorn, is entitled to the preference, for that object. One important fact, however, applies to every sort of thorn, and should be remembered by all persons who may undertake hedging, which is, that if they are not carefully attended to, and skilfully managed, the hedges will become a nuisance and a source of vexation, rather than a benefit, and had better never be attempted. With due care and skill, they make a valuable and ornamental enclosure.

7. Hawthorn or English thorn (C. oxyacantha), sharp-thorned cratægus. This species (of which there are several varieties in Europe) was introduced many years ago, and is apparently naturalized in a few localities; but does not seem to extend itself much. It is said to be the favourite thorn for hedging in England; but is rarely applied to that use here. Some 10 or 12 additional species have been enumerated in the United States; but the genus stands greatly in need of a careful revision. (Flora Cestrica.)

Many species of the thorn genus are highly ornamental. Of these the most beautiful of all thorns when in bloom, is the $C$. oxyacantha rosea superba, with deep crimson flowers and small red fruit. The sweet-scented thorn ( $C$. ndoratissima) has very large, pale red fruit. The large tansy-leaved thorn (C. Leeana), has 1038 large pale red fruit. The small black-fruited thorn (C. Oliveriana), bears very profusely, but matures late. The new double-scarlet is a most beautiful variety of the $C$. oxyacantha rosea superba, just mentioned.

THORN-APPLE (Dalura). An ornamental genus, but chiefly composed of plants possessing very deleterious qualities. One species indigenous to England, is the common thornapple (D. stramonium), an annual, which grows in waste grounds and dung-hills. It is a bushy, fetid herb, 2 or 3 feet high, of a narcotic quality, and greatly in repute as a remedy for the asthma, being smoked like tobacco. The leaves are ovate, smooth, sinuated. The flowers are axillary, erect, white, sweet-scented, especially at night, about 3 inches long. Fruit as big as a walnut in its outer coat, very prickly. Seeds black. In the United States it goes by the name of Jamestown weed, doubtless from the place where it was first naturalized, in Virginia.

THRASHING, or THRESHING. The act of beating out the corn from grain or other crops. The flail was the implement formerly used for thrashing corn, and which separated the grain from the straw and husks very effectually and expeditiously; but as it is now become expensive, and always bruises a great many seeds, it has been attempted to avoid these inconveniences by proper machines provided with a number of flails, or other parts answering the same purpose, made to move by the power of water, wind, or horses. By this means the business of thrashing is found to be performed cheaper, more expeditiously, and with less damage to the health of the thrasher, which is frequently thought to be injured by the dust, \&c., which arises in the common way of thrashing, as well as by the extreme laboriousness of the work. Various machines for effecting the purpose of thrashing have been lately invented. See Frair, and ThrashingMachine.

THRASHING-MACHINE. To the farmer on an extensive scale, the thrashing-machıne is absolutely necessary. He cannot wait for the tedious operation of the flail to prepare a delivery of corn for a given day, or pressing purpose; nor can he, without the risk of pilfering and imposition, keep his barn constantly open for thrashers. The flail, however, is still the implement in general use among all who farm on a scale not sufficiently extensive to require any of the complex machinery which modern skill has invented. The advantages of the flail are, its simplicity, the power of giving employment to the labourers in the barn during wet days, and the convenience of having fresh straw for fodder every day.

'The following description of the thrashingmachine is chiefly derived from the valuable essay On Aricultural Implements, by Mr. J. Allen Ransome, of Ipswich, England.

In ancient times various modes of thrashing out grain were resorted to, and we read of "the bruising with the cart-wheel," " the sharp thrashing instrument having teeth," "the trampling under the feet of the unmuzzled ox," or "the rollers plain or fluted" mentioned in the later practice of continental argicustare. But of all these the Aaii a rone remains in use 
in England; and it is with this instrument, preserving very nearly its original form, by which till very lately the entire growth of corn and seeds in this kingdom were thrashed.

'That the flail may be made thoroughly to effect, though at great cost of labour and time, the purpose of clearing the grain without damage either to the corn or the straw, is a point none will be inclined to dispute. But the disadvantages attending its use are not confined to waste of labour and time; for, though it may be granted that the operation, if properly performed, may be perfect, how difficult it is to secure its proper performance, every agriculturist whose journeys to his barn have from time to time interrupted his surveys of other not less important agricultural operations, can fully testify. It is evident that the latter part of this operation will require much more labour to produce a given quantity than its earlier stages; and hence the straw is frequently passed away partially thrashed, in order to procure a greater bulk in a given time. Nor are these disadvantages all with which we have to contend: constant inspection may, perhaps, to some extent, remedy them; but no attention will altogether suffice to remove the temptation to pilfer, which is continually presented where large quantities of grain are ever under the eye and in the power of those to whom a small portion is of great importance; and hence arises, even when undetected, and often indeed when not committed, a cause of painful temptation on the one hand, and injurious suspicion on the other.

' $\mathrm{To}$ overcome these evils, prejudicial not only to the true economy of the farm, but to those feelings of confidence which, justly to sustain the social bond, should ever exist in the relation between the labourer and his employer, the attention of our enterprising neighbours in Scotland was first directed to the construction of machinery; and in 1732, Michael Menzies, a gentleman of East Lothian, invented and patented a machine for thrashing grain. We regret that, as nothing but the bare record of this invention is enrolled in the Patent-nffice, we have not been able to learn more of this, the germ of thrashing-machine invention, than that it was a contrivance by which a series of thails were made to revolve upon a cylinder; but we are pleased to be able in some degree to redeem it from the "condemnation of fain $t$ praise," with which we find its memory generally accompanied, by reference to the report of a cornmittee appointed by the Society of Improvers in Scotland, to inspect its operation, and determine upon its merits. This committee, after various trials, reported it to be "their opinion that the machine would be of great use to farmers, both in thrashing the grain clean from the straw and in saving a great deal of labour; for one man would be sufficient to manage a machine which would do the work of six." They further recommended the society " to give all the encouragement they could to so beneficial an invention, which, being simple and plain in the machinery, might be of universal advantage." 'The society approved of the report: and acted upon the recommendation.
During the next period of twenty y a ass we are not aware of aty cuher allempes lis carry out the object of thrashing by nachinery; fust in 1753-8, Michael Sterling, a farmer in the parish of Dumblane, Peith, ajpliend the princi. ple of the mill in common use for huling flax to this purpose. 'This mill had a renteril hat: with 4 cross arms enclused in a cylindrical case, 3 feet 6 inches high, and abnut 8 feet in diameter. The shaft was made to lurn at considriable velocity, and the sheaves were gradually let down from an opening at the top; the grain and straw, after being subjected to this beating. were then pressed through an opening in the floor, where rakes and fanners completed the separation of the grain from the straw and chaff. It was, however, found that this machine broke off the ears of barley and wheat instead of clearing them of the grain, and that at best it was only fit for oats.

It is curious to trace the various plans by which the desideratum of thrashing by machinery was attempted to be accomplished; a few of these we shall venture to bring before our readers, and a slight sketch of them will suffice satisfactorily to show that in following out the principles which distinguish Meikle's machine (hereafter to be mentioned), little of value has been lost to the public of those which have fallen into desuetude. In 1772 , two gen. tlemen residing in Northumberland, Alderton and Smart, invented a machine, by which the sheaves were carried round between an in. dented drum of 6 feet diameter and a number of fluted rollers, which, pressing by means of springs against the fluted concave, rubbed out the corn from the ears; and in 1785, Wiliiam Winlaw, of Mary-le-bone, patented an invention which he denominated a "mill for separating grain from straw."

This mill was made on a principle similar to the coffee-mill, but was found to exceed the simple object proposed in the specification, by grinding the grain as well as separating it from the straw. Other machines upon the plan of rubbing out the corn were also tried, but, on account of the damage done to the grain, were discarded. In addition to the mill invented by Winlaw, a machine was in 1792 patented by Willoughby, of Bedford, Notts, the principle of which appears to have been somewhat similar to that of Menzies; how nearly so, we regret we have not the opportunity of judging. It comprised a series of loose flails made to act upon a grated floor, and turned rapidly round by means of a horse-wheel. The straw was presented by hand to the action of the fails.

In 1795 , an individual of the name of Jubb, residing at Lewes, obtained a patent for an invention of which the principal feature was the passing the straw between two rapidly revolv ing beaters, under which it was held by iwo feeding rollers, whence the corn fell into a winnowing-machine.

The inventive talent of the Americans was at this time brought to bear upon this important subject. James Wardrop, of Ampihill, Virginia, invented a machine, which was introduced into England about 1796, to be worked by two men; it was made with flails or elastir rods 12 feet in length, of which 12 were atlache 1039 
in series, each having a spring requiring a nower of 20 pounds to raise it 3 feet high at the point; a wallower shaft, with catches or teeth, in its revolution successively lifted each flail in alternate movements, so that three of the flails were operated upon by the whole nower, viz., 20 pounds. 'The flails beat upon a grating to which the corn is introduced by hand.

In 1785, Andrew Meikle, an ingenious mechanic of 'Tyningham, East Lothian, first introduced to the public, through the medium of a gentleman of the name of Stein, of Kilbogie, the invention whose principle has been the basis upon which the machines in use in Britain up to the present time have been mainly constructed. It appears that, his attention having been long turned to the subject, he discovered that the plan of rubbing would never be otherwise than attended with the disadvantage before alluded to; and his son George agreed with the gentleman above named to erect a perfec machine, and in 1786 he completed the first that was ever made, adopting the plan of introducing between two rollers the corn, which was then thrashed out by four beaters fixed upon a revolving drum, each striking, as it tevolved, the corn held between the rollers. The machine alluded to was erected, and found to work exceedingly well. A patent was accordingly applied for, and, after some opposition from a party not concerned in the invention, obtained.

In the trials between the erection of the original machine and the obtaining the patent, a new principle appears to have suggested itself, viz., that of stripping off the corn from the ear by a comparatively sharp edge, or, as termed by him, "scutching out the grain," instead of beating it by a flat surface. The difference has been partially illustrated by supposing a handful of straw with the corn in the ear to be held in the hand, while with the flat sides of a twofeet rule the ears should be struck or beaten; this is the operation of the common beater. If, instead of striking the ears with the flat side, a sharp blow be given with the thin edge of the rule in the direction of the ear where the rule touches, it will strip the corn from the ear with less labour and with greater certainty. This may be called the scutching principle to which Meikle's beaters in his patent were applied.

It will not be uninteresting to learn, upon the authority of Sir John Sinclair, "that the inventor of this important machine was rendered cumfortable in his old age, and enabled to provide for his family after his death, by the voluntary donations of his grateful countrymen." Not less gratifying is the testimony of Professor Low, in his admirable treatise on the Elements of Practical Agriculture, that "to Andrew Meikle, beyond a question, belongs the honour of having perfected the thrashing-machine. Changes and improvements have indeed been made on certain parts of the original machine; but in all its essential parts, and in the principle of its construction, it remains as it came from the hands of its inventor."

By the drawings and specification of Meikle's machine, it appears that, at the time of taking vut this patent, the plan of shaking the straw 4) means of circular rakes had not been sug. gested; and in the report drawn up for the consideration of the "Board of Agriculture" for the county of Northumberland, we find that, in 1789, the first machine having a circular rake attached, and with fanners below, to perfect the cleaning of the grain, was erected. Although it is not there stated, we have good reason to believe that this important improvement, occasioning the addition of but one light wheel to the machine, was the invention of $\mathrm{J}$. Bailey, the enterprising occupier of Chillingham, one of the gentlemen appointed to draw up the report alluded to.

We have thus far traced carefully, and, we trust, correctly, the progress of the invention of the thrashing-nachine used in Scotland, till it has arrived at very nearly its present perfection. Various combinations of mechanical powers, and many contrivances, have doubtless been since added to produce particular effects, which have progressively tended to its improvement and ultimate perfection.

It will be difficult, within the limits to which this article must necessarily be confined, to enter minutely into detail, or adequately to set forth the merits of the various inventions and improvements on this machine, for which in the course of the last half-century no fewer than 25 patents have been obtained; besides several awards from the Bath and West of England Society and the Society of Arts. But we should do injustice to the subject, did we not here mention the name of Lester, whose mechanical talent and skill as an engineer have not a little contributed to the establishment of a higher style of excellence in 2 gricultural mechanics than was coincident with the then taste of the age in that much neglected department.

The machines now in general use throughout the eastern counties of England are, with few exceptions, portable. They are frequently the property of individuals who, itinerating from farm to farm, thrash at a certain price per quarter; the farmer finding horses, and, with the exception of the proprietor, who feeds the machine, the necessary complement of men. They are simply thrashing instruments, having neither circular rakes nor fanners attached. The beaters, 4,5 , or 6 in number, are so placed round the drum that their beating edge shall radiate from the centre. These strike upon the straw, which is passed along a feeding-board placed at an inclination of about $30^{\circ}$, tending to a point equidistant from the centre and upper part of the circumference of the drum. The concave describes the third part of a cir cle, and is formed alternately of iron ribs and open wire-work in segments, so placed that its inner surface may be brought into near contact with the edges of the revolving beaters, and susceptible of adjustments by screws to increase or diminish the distance. The usual plan is to place it with about $\frac{3}{4}$ of an inch space at the feeding part, and gradually to increase the distance to $1 \frac{1}{4}$ or 2 inches at the lower end, where the straw is delivered upon a fixed harp or riddle, through which such part of the grain as is not driven through the wired part of the concave falls, while the straw is removed by forks. 
The thrashing part, commonly called the barn work, occupies a space of 6 feet by $4 \frac{1}{2}$ feet, and, together with the apparatus by which motion is communicated (which is made either for 2, 3, or 4 horses' power), may at pleasure be elevated upon a pair of wheels and axle, and thus removed by two horses.

Many of these machines are made by persons who possess little claim to any mechanical knowledge, and who, purchasing the unfitted castings, by the help of village artisans, produce an imitation of those which are considered good. As the perfection of these machines must depend upon mathematical accuracy in the adjustment of all their parts, and in the truth and precision of their fitlings, it is unreasonable to expect that this can be accomplished where no facilities exist beyond the forge and the work-bench; and hence arises a degree of discredit, which is unfairly thrown upon the principles upon which the machine is constructed.

With these machines, properly constructed, barley may be thoroughly thrashed with as little or less damage than with the flail, and wheat straw need not be so broken as materially to diminish its usefulness even for the purpose of thatching. We cannot, with Sir John Sinclair, reckon the circumstance of breaking the straw one of the advantages of thrashing by machinery, as we do not think it desirable that any slovenly performance of the thrashing-machine should trench upon the legitimate occupation of the chaff-engine; and we repeat our opinion that all disadvantages from the above-mentioned causes may, by a well-constructed machine and a competent manager, be entirely remedied.

The latest patent which is at present in operation is one taken out by Joseph Atkinson, of Braham Hall, Yorkshire, which appears to be of American origin. The thrashing or beating-out process is obtained by means differing from any previously mentioned; the drum being surrounded by a series of pegs, so arranged as in its motion to pass similar rows of pegs placed at intervals in a concave, surrounding nearly one-half of the circumference of the drum. This machine is not at present so fully introduced in to England as to afford opportunity for fairly testing its comparative merits; and it would be unfair to give, upon slight evidence, an opinion which may have any tendency to increase the difficulty of the introduction of a new article. We can therefore say little more than that while such trials as have fallen under our own inspection have not convinced us of its superiority, we are inclined to the belief that the principle is not so defective as to prevent its being carried out to advantage, under such modifications as may be suggested upon further trials.

We have now to draw the attention of our readers to a machine in operation upon Jord Ducie's example-farm at Whitfield, of which it is probable, in a forthcoming report of that interesting establishment, that a full account, accompanied by the necessary drawings, will be given. Through the kindness of the manager, John Morton, in accordance with whose suggestions it was constructed, we have been favoured with an opportunity of witumbsing its performance, and with the following descrip. tion, which we give in his own wurds :-

"This machine is worked ly a sloam-engine of six horse power. The corn is limomehe from the stack upon wagons running along a trams. road upon an inclined plane, to the duors of the building, whence, sheaf by sheaf, it is thrown by children into the buckets of an elevator, which, in its rotation, carries them to the feeding-board. This feeding-board is placed at a tangent from the drum parallel with its top; and, as in Lee's machine, and the portable machines in Suffolk and Norfolk, the foedingrollers are dispensed with, an endless wet, gradually carries the unthrashed straw to the feeding-mouth, from which the revolving scutches rapidly convey it to the concave.

"The drum and concave, being the part on which the separating of the corn or thrashing principle depends, we shall first describe:The drum is about 18 inches diameter, formed of sheet-iron strained round a cast-iron skeleton accurately turned; upon this the beaters, or rather scutches, formed of angle-iron with its edges planed, are so placed as to describe an angle with the surface of the drum, pointing for ward in the direction of its motion; these project about seven-eighths of an inch. The screen or concave encloses the drum to the extent of about one-third of its circumference, and consists of 4 or 5 arched pieces of grating, 3 inches wide, jointed together. It is made of cast-iron bars, having a square section placed so that every one shall present an edge to the passage of the straw, uniting (as is not uncommon in other machines) the fluted concave of the Scotch machine with the wired grating of the English ones; the screen is supported on iron bolts, so that it approaches to within about oneeighth of an inch of the edge of the scutcher. Spiral springs surround these bolts, which permit the bars of the concave to yield when too much pressure may at any time occur between them and the revolving drum. The grain is thus separated, most of it passing through the screen of the concave; but in order that no grain shall be allowed to pass away with the straw, it is thrown upon the shaker below.

The motion given to the siraw by this shaker is the most perfect we can conceive; the blows occasioned as each series of spars strike it from beneath, effectually remove every particle of loose grain, while the shaker rapidly carries forward the straw, and at its termination deposits it in the straw-house, while the corn sifted out by its action falls before the blast of a fanner (the construction of which is peculiar); and all the light grain and short straws thrown out by the first winnowing into the light corn spout is then taken up by another elevator, deposited again upon the feeding-board, and passed a second time through the drum, in order effectually to separate any that may remain. After passing through another win nower, the thoroughly cleaned corn is taken up by a third elevator, and dropped into a hopper, through which it passes into a sack. which is placed on a weighing machine, and $i$ : is there weighed and left thoroughly fit for

market.

1041 
We have introduced at length the description of this machine, or rather series of machines, as being the most complete of any that have fallen within the range of our observation; the most comprehensive in its design, performing every operation, from receiving the sheaf at the barn-door to depositing its grain in a clean state weighed up in the sacks, and excellent in the greater part of its detail, which is carried out, both as regards ingenuity and workmanship, in a style very superior to the general character of agricultural machines.

With regard to the moving power most advantageously connected with the thrashingmachine, it may be observed, that where the locality admits of the use of a water-wheel, this power is most economical and easily managed; but the advantage is limited to peculiar situations.

Where the quantity of work to be performed is sufficient to repay the interest of outlay, expense of wear and tear, \&c., a steam-engine would be most advantageously employed on the farm. Of its economy, as compared with either horse or manual labour, there need be no question. But as few farms in England at present have these appendages, the question for consideration is narrowed to the comparison between horses and manual labour. On the authority of Dr. Gregory, the dynamic power of a horse at a dead pull may be calculated in the main as equivalent to that of six men, or to $420 \mathrm{lhs}$., if exerted in a direct line; but the result of experiments made by Tredgold tend to prove that sustained effort at the rate of three miles per hour must not be calculated at more than equivalent to $120 \mathrm{lbs}$. drawn over a pulley. This, taking six hours of labour per diem as the utmost he would recommend, would be the maximum of useful effect. Under the circumstance of any deviation from a straight line, this must be materially reduced; and in describing a circle of 18 feet radius, the cramped position of the horse will probably prevent his power from being advantageously exerted to the extent of much more than half. It will, therefore, be seen that a very large proportion of dynamic effort is wasted; and this not only arises from the constrained position of the horse's movement, but from the friction of the mill by means of which motion is communicated to a machine.

It is aftirmed by Emerson that a man of ordinary strength, turning a roller by the handle, can act for a whole day against a resistance equal to $30 \mathrm{lbs}$. weight; and if he works 10 hours a day, he will raise this weight through $3 \frac{1}{2}$ feet in a second, or about $2 \frac{1}{2}$ miles per hour.

Animal power is, however, so varied by the character of the exertion, that it is difficult to arrive at a correct calculation. The late Robertson Buchanan ascertained that in the action of working a pump, of turning a winch, of ringing a bell, or rowing a boat, the dynamic results were respectively as the numbers 100 , :67, 227, and 249. See Strexgtr.

Having cavsed a machine with beaters to be ronstruci-1, wrrked by 4 inen whose force thotrid be exerted as in the manner of rowing a boat, the results, as compared with a machine requiring the force of 4 horses in a circle 1042 of 18 feet radius, we found might be taken on an average as 5 to 12 . It was thought the continuous effort might be for an equal length of time exerted by 6 men relieving each other at intervals, as by the same number of horses relieved in the same way.

We have not yet had opportunity to repeat the experiment; and we instance this only show that, although advantage may be on the side of horse-labour for large quantities, manual force is not so inapplicable to this object as most writers have represented it to be; and we are of opinion that, on small farms, handmachines may with great advantage be used. A simple and effective hand thrashing-machine, which was exhibited at the Royal Agricultural Society's meeting at Liverpool, obtained the commendation of the judges (vide their report). It is worked by 4 men, and the moving power being obtained by means of a lever on the one side, and by a crank handle on the other, the men working it may relieve each other by change of motion. It requires one man to feed the machine, and the number of hands necessary to bring the sheaves and remove the straw will depend upon the distance it has to be conveyed. When the straw is short, and the wheat of average yield and in good condition, it will thrash at the rate of 12 to 16 bushels per hour.

In England the cost of the thrashing-machines of former days varied considerably, and their performances were very unequal. It may not be uninteresting to compare them with those of the present day. The following are extracted from the Agricultural Reports :-

In the reports of Roxburgh and Selkirk, in 1796, R. Douglas states that 25 or 30 bolls, inills by water, or with 4 horses, or from would do great execution. In the report of Norfolk, in 1804, Arthur Young gives an account of machines which belonged to the fol. lowing parties:

Droziers, Reedham, built by Wigfull, $40 \mathrm{co}$. wheat. cost $120 l$., worked by 7 persons and $\{50 \mathrm{co}$. barley. 6 horses. 150 to 180 bush.

Farrow, Shibidham, built by Wigfull, $\{20 \mathrm{co}$. wheat worked by 7 persons, and by $4,5,\{30 \mathrm{co}$. barley. or 6 horses.

Beck, Castle Rising, built by Wigfull, 32 co. wheat.

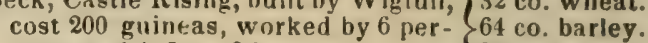
sons, and 4,5 , or 6 horses.

Whiting, Tring, built by Fordyce, $24 \mathrm{co}$. wheat. from Scotland, cost $200 l$., worked $55 \mathrm{co}$. barley. by 6 persons and 6 horses. Bevan, Riddlesworth, engineer from $40 \mathrm{cn}$. Wheat. Leith, cost $100 l$., worked by $10,40 \mathrm{co}$. barley. men and 8 horses.

Coke, Holkham, cost $600 \mathrm{l}$, worked 64 . co. wheat. by 12 men and 8 horses. Reeves, Heverland, built by Assby, $\{30 \mathrm{co}$. wheat. Blyboro', cost 100 guineas, worked $32 \mathrm{cn}$. barley. with 2 or 3 horses. $\quad 40 \mathrm{co}$. peas.

Styleman, Smithsham, cost $300 l .,\{80 \mathrm{co}$. wheat. worked by 10 persons and 8 horses. $120 \mathrm{co}$. barley,

In the report of Kent, $\mathbf{R}$. Boys, in 1805 , remarks on the only thrashing-mill then in Kent, which, by a number of improvements, and after 24 qrs. wheat. many alterations, he funds to an- 32 qrs. barley. swer extremely ivell; and he states 40 qgrs. oats. that it requires 4 horses and 12 men tn work it.

In Sir John Sinclair's Syslem of Hus bandry, pahlished in 1812, we find 50 holls, or abous an recoint of R. Kerr's machine, $\} 300$ bishels of which, with 6 horses, 4 men, and 4 wheat. women, would thrash 
Considerable improvements have since been effected. In the statements of the trials of im. plements at the Royal English Agricultural Society's meeting at Cambridge, in 1841, the quantity of wheat thrashed by two four-horse portable machines manufactured by J.R. and A. Ransome, of Ipswich, and R. Garrett and Son, Leiston, was respectively 61 bushels and $\frac{3}{4}$ of a peck, and 61 bushels and $\frac{1}{4}$ of a peck per hour; and the corn was clean thrashed and uninjured.

This must not be taken as a criterion on which to found an average, as it was doubtless the result of stimulated exertion; but it is not unusual with machines of this construction, with reaped wheat in fair condition, to thrash $100 \mathrm{co}$. or 400 bushels in a day of 10 hours, and the same quantity of mown barley.

It should, however, be observed, that these, having neither rakes nor fans, the work of which is done by hand, would require 8 men and 5 boys, and a change of horses in the day.

Thrashing-machines are now very generally used in the United States, to get nut the crops of wheat, \&c. Before their introduction flails were employed in the Northern and Eastern States, whilst in the Middle and Southern States, treading with horses and catlle was the customary mode of thrashing. The cost by employing the flail was generally estimated at 10 bushels out of every 100 , which, when wheat was a good price, proved very expensive. The employment of horses, though expeditious, is very objectionable, the grain being rendered gritty and filthy, so as to lessen its value in the market. The practice, too, of setting horses at sur is hard and peculiar work in hot weather pro\%ed injurious and often destructive to them.

The notice furnished in this article of the successive improvements made in Britain, in contrivances for thrashing out grain, will show the efforts there made and the results obtained. Ingenuity would seem to have been still more actively employed in the same pursuit in the United States, where, within a few years past, more than 100 patents have been obtained for inventions and improvements of the thrashingmachine. These have nearly all involved two main principles: 1st, a beater consisting of bars; and, 2 dly, a cylinder furnished with spikes instead of bars. This last may perhaps be called the American principle, par excellence. Where bars are used, the machine requires an increased velocity equal to 300 revolutions per minute, over what is requisite where the cylinder is furnished with spikes. It is for this reason chiefly, that the spike machines have been so much more generally used. It must, however, be observed, that where the beater is composed of bars, the force required to work the machine is about one-third less in performing the same amount of work. In Eams's patent, the bars are of wrought or cast-iron, notched on the edges.

Pitts's Thrasher and Separator is considered a machine by which a great saving of labour is effected over the ordinary machines, the operations of thrashing and cleaning being performed at the same time. The bundles are fed to the machine at one end, and the clean seed, without a kernel being scaltered, taken from the other. Its weight is about 700) Itis., and it occupies a space alcout 8 feet by 2 feet 1 inches. The whole machinery is durable, and easily kept in repair. It thrasties and cleans all kinds of grain in the best manner, perfurming the work at the rate of from 25 to 50 bushels per hour. Four hands are required (n) tend the machine when in operation, viz.-(ine to forward the bundles, one to feed, one (1) meisure and put the grain into bags, and one (1) pitch the straw away as it comes from the machine. It can be easily moved from place to place, and attached to any horse power, and can be used in the field as well as on the thrashing-foor, there being no loss or scattering of grain after it is once fed into the machine. The late Judge Buel considered this machine as the best adapted to the purpose of any he had ever seen.

Horse Power.-The power almost universally employed to propel thrashing-machines in the United States is that adapted to horses. These are generally of a description which admits of transportation along with the machine from place to place. They are of two kinds, one called the sweep power, in which the horses attached pass round in a circle; the other called the endless chain or tread power, where the horse or horses move as if walking or trotting, but in consequence of the rotation of the endless chain of bars on which they are placed, always remain in the same place. Mixe's cast iron portable sweep power is generally considered the best now in use, in the Middle States at least. Its weight is from 700 to $1000 \mathrm{lbs}$, and the price $\$ \$ 0$ for a two-horse, and $\$ 90$ for a four-horse power.

The endless chain or tread power is coming into very general use, being specially adapter to farms where there is much barn or shedroom, admitting of the thrashing being done under shelter; whereas, with the sweep power, the operations require the open yard.

The tread power, called Pitts's, is now in high repute. These, as well as all uther kinds of machinery used in thrashing, are extensively manufactured in Wilmington, Delaware, by Hollinsworth \& $\mathrm{Co}$., and may also be had of Mr. Chandler, manufacturer of agricultural implements, 196 Market street, Philadelphia, as also at most of the numerous depots for agricultural implements in that and other cities in the United States. The price of the onehorse endless chain power is $\$ 75$; of the two. horse do., \$85. It is said that a two-horse tread power is equal to a four-horse sweep power.

THREAVE. A quantity of grain, consisung of 24 sheaves. It is sometimes written thrave.

THRIFT (Statice, from statizo, to stop: in allusion to the powerful astringency of some of the species). The species of thrift ought to be in every garden, on account of their lively little flowers. There are three indigenous species of thrift or sea-lavender, all perennial, viz:-

1. The common thrift, or sea gilliflower ( $S$. Armeria), which is a common ornament of rus. tic gardens, where it serves for edgings of flower-beds; nor does this plant suffer muct: 
from the smoke even of London. The flowers are numerous, rose-coloured, inodorous.

2. Blue spiked thrift, or common sea-lavender (S. limonium), which grows plentifully on muddy sea-shores, and about the mouths of large rivers. The root is woody and tough. Leaves leathery, glaucous, usually 2 or 3 inches long. Panicle of spikes of imbricated, upright, fine blue flowers.

3. Matted thrift ( $S$. reticulata), growing on muddy sea-shores, chiefly on the eastern coast of England. (Smith's Eng. Flor.vol. ii. p. 115.)

A kind of A merican sea-lavender, S. Caroliniana) is described by Nuttall as apparently a mere variety of the S. linonium. The flowers are of an elegant blue.

THRIPS. The Thrips, or vine-fretter, as it is often called, is a very minute, light-coloured or spotted fly, exceedingly active in all its motions, and appearing to leap rather than fly. They live on the buds, leaves, and flowers of plants, being so small as readily to escape notice, unless particular attention is directed to them. They are generally found by observing the effects of their apparently poisonous bites which produce deformities in the leaves or blossoms, causing these often to swell or curl up. The peach tree occasionally suffers severely from their attacks, as well as from those of the plant-lice, to which family of insects they are allied. (Harris on Destructive Insects.)

A remedy for thrips will be found, with the mode of using it, under the head of Aphis.

A new disease of the plum tree, occasioned by thrips, is described by Dr. Harris, in Hovey's Horticultural Magazine.

THYME, GARDEN (Thymus vulgaris, from Iunós, courage, being considered a reviver of the spirits; or from vivw, to sacrifice, being employed as incense). The varieties are,the broad-leaved green, narrow-leaved green, variegated, and lemon-scented. The variegated is grown almost solely on account of its ornamental foliage. A poor, light, and dry soil is best suited to it. In moist or rich ones, it becomes luxuriant, but deficient in its aromatic qualities, and generally perishes during the winter. 'The situation cannot be too open.

Thyme is propagated both by seed and rooted slips. Sowing may be performed from the middle of March until about the beginning of May. Slips may be planted from the beginning of February until the close of May.

The seed must be sown neither thin, nor raked in more than half an inch below the surface. It is sometimes sown in drills of a similar depth, six inches apart, or as an edging to a bed or border. The seedlings must be kept clear of weeds, and, if the season is dry, watered moderately twice a week. When of about six weeks' growth, or when 3 or 4 inches high, they require to be thinned to 6 inches apart, unless grown as an edging, when they must be left thick. Those removed may be pricked out to a similar distance, if required. Water is required occasionally until they have taken toot. The plants may be left in the situations they are placed in at this season, or be finally plariced out in September or October, or in the early spring of the following year. To obtain wlips, some old stools may be divided into as 1044 many rooted portions as possible, or layers may be obtained by loosening the soil around them, and pegging the lateral shoots beneath the surface. They must be planted out at distances similar to those raised from seed, water and weeding being similarly required.

In autumn the decayed stalks should be cleared, and a little fresh earth scattered and turned in among the stools.

Although this herb is perennial, yet after 3 or 4 years it becomes stunted and unproductive, consequently requiring to be raised periodically from seed. For the production of seed, some plants should be allowed to run up without being gathered from in early summer. The seed is ripe during July, and must be cut immediately it is so, and laid on a cloth to dry, otherwise the first rain will wash it out of the seed-vessels.

THYME, WILD (Thymus). A genus of aromatic, pungent, branched, somewhat shrubby plants, belonging to the natural order Labiata. They are often diffuse in England, and of humble growth: in some instances annual. The common wild thyme ( $T$. serpyllum) is plentiful almost everywhere, particularly on heaths and dry mountainous ground. The odour of the plant is gratefully aromatic. Bees are fond of the flowers. Whether, as alleged, the quality of mutton is improved by the sheep feeding on this plant, or on fine, short grasses which usually accompany it, is still a matter of great doubt. See Basil, Calamint, and Thym.

TICKS. See Shenp, Diseases of.

TILLER. A term applied to the branching of the stems of wheat, \&c., from the roots.

TILTH. The condition of the earth after ploughing, \&c.; or the state of the soil in respect to tillage as relating to manure.

TIMBER (Germ. zimmer; Du. timmerhout). The term used to express every large tree squared, or capable of being squared, and fit for being employed in house or ship-building.

TIMBER TREES. See Trees, PlantaTrovs, and the several indigenous trees, under their alphabetical heads.

TIMOTHY GRASS (Phleum pratense). See Cat's-Tair Grass.

TINE. A tooth or spike placed in any $\mathrm{jm}$ plement, but especially in the harrow kind. See $\mathrm{H}_{\text {an now. }}$.

TOAD (Rana bufo.) A well-known and much dreaded, though perfectly innoxious reptile of the frog genus, which feeds on insects, flies, ants, \&c. It is preyed upon by owls, buzzards, snakes, \&c.; otherwise the toad attains to a considerable age, some remarkable instances of which have been recorded.

Dr. H. Storer, in some remarks upon reptiles furnished by him to Professor Hitchcock, and published in the Zoological Survey of Massachu selts, observes:-Great errors also exist with regard to the order Batrachia. The acrid secretion found upon the skin of the Hyla versicolor, the toad, and several species of efts and newts, has caused them to be considered venomouswhich is incorrect. Every species of this order is inoffensive, and, when better known. will undoubtedly be found beneficial to man.

In some countries, the flesh of the different Rane, frogs, is an article of food. With us, 
the nabits of the Bufo Americanus, or common toad, are becoming better understood, and the horticulturist, instead of destroying, carefully preserves it on his grounds, for the benefit it affords him, by feeding upon noxious insects. In the same way are our springs and wells rendered the purer by the presence of the carnivorous salamander.

TOAD-FLAX. A name applied to two perennial species of Antirrhinum. 1. The creeping, pale blue toad-flax ( $A$. repens) is a rare species, growing on chalky banks or rocks near the sea. The herbage is smooth and glaucous, stem panicled, leaves linear, scattered, partly whorled; flowers sweet-scented.

2. Common yellow toad-flax (.9. linaria), which is common about hedges and the borders of fields. The leaves are linear-lanceolate, crowded; stems erect; spikes terminal; flowers terminal, inodorous. (Pl. 10, x, x.) See Fuueluig and Sivap-Dragon.

Common linaria is found in the Middle States, where it bears the names of toad-flax, butter-andeggs, and Ramstead-weed. It is a foreigner, frequenting fence-rows and pastures, where it is a showy but very obnoxious weed. (Flora Cestrica.)

TOAD-FLAX, BASTARD. See Bastand Toan-Frax.

TOBACCO. Botanists have given this wellknown American plant the generic name of Nicotiana, from John Nicot, of Nismes, in Languedoc, ambassador from the King of France to Portugal, where he procured the seeds from a Dutchman who had derived them from Florida. The first plant was said to have been presented by Nicot to Catharine de Medicis, whence the former French name, Herbe à la Reine, or the queen's plant. The name tobacco, which has superseded all others, is an appellation acquired from the place from whence it was originally most generally derived, namely, the island of Tobago, in the West Indies. According to Linnæus, tobacco was known in Europe as early as 1560. It was taken to England from the West Indies or Mexico by Ralph Lane in 1586, but only the herb for smoking, a practice introduced into England by Sir Walter Raleigh, who acquired it from Captain Lane. In the house in which he lived at Islington are his arms on a shield, with a tobacco plant on the top. Smoking has consequently been common in Europe for upwards of two centuries. It is a powerful narcotic, and also a strong stimulant with respect to the whole system, but especially to the stomach and intestines, to which, in small doses, it proves emetic and purgative. The smoke thrown up the anus acts as a glyster: an infusion of the leaves forms a powerful lotion for obstinate ulcers. The decoction, powder, and smoke of tobacco are used in gardening to destroy insects, and in agriculture for the same purpose, and to cure cutaneous eruptions in domestic animals.

Botanists have identified many different species of tobacco, and Loudon, in his Encyclopadia of Plants, makes the following list of those enumerated under the generic head of Nico. tiana, with the places from which they were derived:-

\begin{tabular}{|c|c|c|c|}
\hline Speenes. & Cammin Name. & \multicolumn{2}{|c|}{ Gugen smd Dale. } \\
\hline cotiana labacum & Virginiasn & Amortea & 1578 \\
\hline macrophylla & I.arge-lonved & A merica & 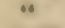 \\
\hline fruticona & Stirubby & C. Huลa & 1000 \\
\hline undulata & Rwoet-ncented & $\therefore \approx w$. & $\ln (x)$ \\
\hline rustica & Common-green & A mirries & 1570 \\
\hline paniculata & Panicled & Peru & $17: 32$ \\
\hline glutinosa & C:Anumy & Peru & 1790 \\
\hline plumbaginifolia & Cirled leaved & A mepua & 1816 \\
\hline pusilla & Primroge-lenved & Veras Cirnz. & $173 \%$ \\
\hline quadrivalvis & Four-valved & N. A nuerira & 1811 \\
\hline nal & Dwurf. & N. America & 1423 \\
\hline Langsdorffii & Langedorft's & Chill & 1819 \\
\hline cerinthoides & Honey wort & 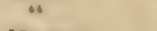 & |k21 \\
\hline repanda & IIavaurah & Ilavans & 1023 \\
\hline
\end{tabular}

In the 4 th plate there are representations of the species known as Virginia tobacco (Nicotiana tabacum, $f$ ), common green tobacco $(N$. rustica, g), Havana repanda $(h)$, of which the fine and fragrant cigars are made; the Quadrivalvis, or four-leaved tobacco (i), and the Nana, or dwarf species (k), both of which last are used by the Indians of the Rocky Mountains.

'Tobacco is cultivated in Europe as farnorth as Sweden, and is also grown in China, Japan, and other eastern and hot countries. The sort most generally preferred is the Virginua species, a very beautiful plant. The cu nmon green kind ( $N$. rustica), is also frequentl, cultivated, especially in Europe, it being considered hardier than the Virginian sort. Parkinson says he has known Sir Walter Raleigh, when prisoner in the Tower, prefer it to make good tobacco, "which he knew so rightly to cure." Tobacco has been successfully cultivated and cured in England, but its growth is prohibited as a crop, and it is now only grown for curiosity as a border flower, or by gardeners for the destruction of insects. In Germany and other northern countries, most families who have gardens grow enough of $N$. rustica for their own use; but as they do not know how to cure it properly, it is not much valued, and is never made into chewing tobacco or snuff, but used for smoking.

Although tobacco, an annual ylant, may be brought to maturity in almost every country, even in Russia and Sweden, with their transient summers, still will the plants, under such unfavourable circumstances, be small, and their flavour weak. In long, moist, and not very warm summers, such as those of Ireland, the plants may attain a very large size, but they will not have that superior flavour which can only be derived from abundance of clear sunshine, and free, dry air. The fragrant tobacco of Havana and Luconia may retain pre-eminence for smoking, but for all other purposes the peculiarly high and rich flavour of the tobacco of Maryland, Virginia, and neighbuuring states must always give it preference, both at home and abroad.

It will be seen from an estimate furnished Congress by Mr. Ellsworth, Commissioner of Patents, of the agricultural products of the United States in 1842 , that tobacco, though cultivated in every State of the Union, constitutes a staple crop in comparatively few, namely, Virginia, Maryland, North Carolina, Kentucky, Tennessee and Missouri. The crop of the year mentioned, was below the average, and in Virginia not over two-thinls of the regular crop, being both light and of bad quality. I. was distributed as follows :-

$4 T$

1045 


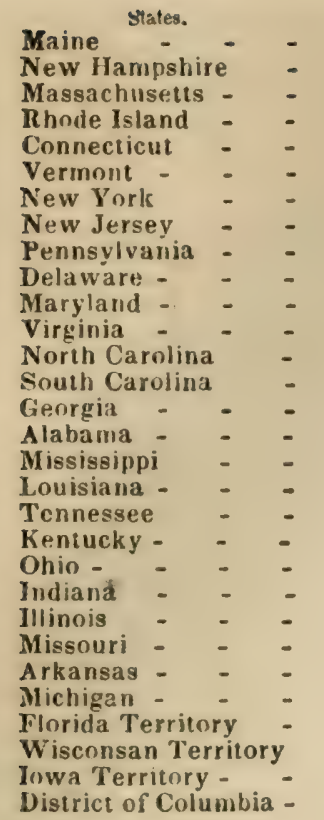

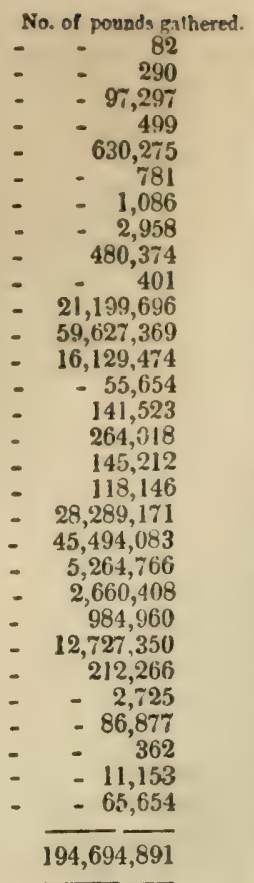

Iucreased attention has been latterly paid to the culture of tobacco in Illinois and even in some of the New England States. The following statement would seem to show, that, notwithstanding the vast amount of tobacco raised in the Union for home consumption and exportation, there is yet no reasonable ground for apprehending an over-stock of the market. In a letter of the Secretary of the Treasury relative to the amount of home consumption and exports of tobacco, with a great variety of other particulars, it is stated that the whole amount supplied elsewhere than in the United States, is about $150,000,000$ pounds; the amount of possible consumption of American tobacco is put at not less than $1,000,000,000$ pounds. So that were only one-half of this quantity actually consumed, it would be four times more than our present export, which, in value, is only second to that of cotton.

In almost every country in Europe the most vexatious restrictions in the forms of excessive duties and imposts are levied upon tobacco. In general, the governments, such as France, Spain, Italy, \&c., take possession of all the tobacco imported or raised, and farm or let out to great capitalists for immense sums, the privileges of vending to manufacturers and retailers. In this way the cost of tobacco in Europe is usually extremely high, and governments manage to derive from their subjects vast sums of money by exactions in the shape of imposts upon the tobacco they consume. In France the revenuc thus annually derived, is $\$ 10,000,000$, and all this from a reduced importation of srime 0000 or 7000 hogsheads. It wou! indeed seem to be a favourite object for excessive taxation in nearly every government. At a great meeting of tobacco planters held in May, 1840, it was shown from authentic documents, that on an export of 100,000 hogsheads, valued here at $\$ 7,000,000$, a duty was paid by the consumers in the various countries of Eu"ope, of more than $\$ 30,000,000$. "As a matter if interest to many of our readers," says the -ditor of the Cultivutor, "we copy or condense from the report of that body, the amount of tobacco exported to the European countries respectively, or the mos: prominent ones :

\begin{tabular}{|c|c|c|c|c|c|c|c|}
\hline \multicolumn{2}{|l|}{ Countries. } & \multicolumn{4}{|c|}{ Export of Tohacco in hhds. } & \multirow{2}{*}{\multicolumn{2}{|c|}{ Tax per th. }} \\
\hline Russia & - & - & - & 358 & & & \\
\hline Holland & - & - & - & 3,300 & - & - & 13 \\
\hline Belgium & - & - & - & 6,000 & - & - & 24 \\
\hline Great Brita & ain & - & - & 28,772 & - & - & $72 \frac{7}{4}$ \\
\hline France & - & - & 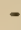 & 12,000 & & & \\
\hline Spain & - & - & - & 5,700 & & & \\
\hline Portugal & - & - & - & 363 & & & \\
\hline Italian Sta & tes & - & - & 2,000 & & & \\
\hline Austria & - & - & - & 4,000 & & & \\
\hline
\end{tabular}

The remainder of the 100,000 hogsheads is distributed through the German States, Sardinia, Hungary, \&c. \&c. We have been unable to ascertain the precise duties paid in all cases, but the enormous rates of those ascertained, and the fact that the tobacco import is in most of the countries of Europe farmed out for a stipulated sum, renders it certain, that while none are below what is here named, some of the highest much exceed the almost prohibitory imposts of Great Britain. A duty of 800 per cent., such as England imposes on our tobacco, is an anomaly in the history of trade; and which, under all circumstances, may be deemed positively unjust." This excessive duty, however, is imposed merely for revenue purposes, not for protection to agriculture, like the duty on wheat; as, excepting a few plants for private use, for medicinal purposes, \&c., it is prohibited to be grown.

"The culture of tobacco is every year extending itself in the Western States, and promises to become a most important article of export from the rich districts north and south of the Ohio. That tobacco can be grown in Indiana, Ohio, Kentucky, and Tennessee, with a profit greater than that attending the culture of wheat and corn, seems certain; and we doubt not. that as the cultivation progresses, and the better methods of curing are adopted, the tobacco of the new States will rival in quality and celebrity that of the old. The plants on new land grow more luxuriantly than on soils cultivated for any considerable time; but experience proves that the quality is not so fine. The best tobacco in any country is grown on lands in good condition, but not extravagantly rich, or highly manured."

Many facts connected with the history of the first production and exportation of tobacco in America are highly interesting. Some of these were collected by an intelligent investigator a few years ago, from which we extract the following. In a letter still extant, of the Governor and Council of Virginia, dated James' City, January 20,1622 , it is stated, that there was not then above $60,000 \mathrm{lbs}$. of tobacco made in the colony. In 1639, however, only 17 years afterwards, the Grand Assembly passed a law which recites, that, "Whereas, the excessive quantity of tobacco of late years planted in the colony, has debased the quality," and enacts, "that all the tobacco planted this present year, and the two succeeding years, in the colony of Virginia, be absolutely destroyed and burned, excepting and reserving so much in equal proportion to each planter, as shall make in the whole just the quantity of 120,000 Ibs. of tobacco, stripped and smoothed, \&c. In consideration whereof, the creditors of the 
planters were compelled to "accept and re. ceive 40 lbs. of tobacen so stripped and smoothed, in full satisfiction of every $100 \mathrm{lbs}$. now due them." It is not important to ascertain whether this law was re-enacted at the end of the 3 years named in it; for we find in an official report to the commissioners, that the yearly exports of tobacco for ten years ending in 1709, were 28,868,666 lbs., of which $11,260,659$ lbs. were annually consumed in Great Britain, and $17,598,007$ lbs. in other countries of Europe. In 1744-1776, the average annual exportation was $40,000,000 \mathrm{lbs}$, of which 7,000,000 lbs. were consumed in Great Britain, and 33,000,000 lbs. in other European countries. The annual average exportation from 1768 to 1770 , both inclusive, was 67,780 hhds. of about 100 lbs. each, or $67,780,000 \mathrm{lbs}$. As we have now approached the period when the exportation of tobacco arrived at a point from which it has vibrated, (sometimes a little above or below it,) we subjoin a statement of the exportation for the years 1772-1775, inclusive, which will furnish the remarkable fact that (compared with any succeeding four years since that period) the annual exportation of tobacco just before the Revolution, was about the same that it has been at any time since, in our most prosperous periods. For although 1790-1792 were three years of very heavy exportations, they fell off in 1793 nearly one-half, making the annual average exportation not materially, different from $1772-1775$ :

Statement showing the quantity of tobacco exported from the United Colonies from 1772 to 1775 , inclusive.

\begin{tabular}{|c|c|c|c|}
\hline Years. & Pounds exported. & $\begin{array}{l}\text { Pounds consumed } \\
\text { or remaining on } \\
\text { hand in Great } \\
\text { Britain. }\end{array}$ & $\begin{array}{l}\text { Pounds consumed } \\
\text { or remaining on } \\
\text { hand in other } \\
\text { countries of k'u } \\
\text { rope. }\end{array}$ \\
\hline & & & 7,4 \\
\hline 177 & 100 & 3, & 96,776 \\
\hline 1774 & $97,397,2$ & 18,6 & $78,676,9$ \\
\hline \multirow[t]{2}{*}{1775} & $101,828,617$ & $2 \pi, 623,451$ & $74,205,166$ \\
\hline & $397,497,139$ & $147,609,157$ & $249,665,982$ \\
\hline
\end{tabular}

Total exportation for the 4 years, $397,497,139$ lbs., or an annual average of $99,374,785 \mathrm{lbs}$. This brings up to the period of the Revolution. The following will exhibit the exportation of the article during that period.

Statement showing the quantity of tobacco exported from the United Colonies, from 1776 to 1782 , inclusive.

\begin{tabular}{|c|c|c|c|}
\hline Years. & Pounds exported. & $\begin{array}{l}\text { Pounds consumed } \\
\text { or remaining on } \\
\text { hand in Great } \\
\text { Britain. }\end{array}$ & $\begin{array}{l}\text { Pounds consumed } \\
\text { or remain ng on } \\
\text { hand in other } \\
\text { countries of Eu. } \\
\text { rope. }\end{array}$ \\
\hline $\begin{array}{l}1776 \\
1777 \\
1778 \\
1779 \\
1780 \\
1781 \\
1782\end{array}$ & $\begin{array}{r}14,498,500 \\
2,441,214 \\
11,961,533 \\
17,155,907 \\
17,424,267 \\
13,339,168 \\
9,828,244\end{array}$ & $\begin{array}{c}{ }^{*} \\
7 \\
7,520,550 \\
10,982,899 \\
11,474,791 \\
7,600,296 \\
6,364,813\end{array}$ & $\begin{array}{r}14,498,500 \\
2,441,214 \\
4,440,783 \\
6,173,008 \\
5,950,176 \\
5,738,872 \\
3,463,431\end{array}$ \\
\hline & $86,649,533$ & $43,943,349$ & $42,705,984$ \\
\hline
\end{tabular}

* This year Great Britain exported to the Continent nearly $26,000.000 \mathrm{lbs}$. of old stock.

+ Great Britain exported this year to the Continent $6,000.000 \mathrm{lbs}$. of former stock.
Total exportation for the 7 years, $86,6,83,5883$ Ibs., or an annual averaege of $12,35 \times, 508$ liss. Of the total 7 years' expurtation, 33,974,949 lbs were captured by the Britush diurng the war.

The following table rexhibuts the exports of tobacco from the United States, fior the years $1787,1788,1789$, immediately proceding the adoption of the present Constitution.

Statement showing the quinutity of tolurero experied from the United States, from 1787 to 1789, in clusive.

\begin{tabular}{|c|c|c|c|}
\hline Years. & Younds exported. & $\begin{array}{l}\text { Pounds erinsumes } \\
\text { or remalas } \\
\text { hand in on } \\
\text { Brilain. }\end{array}$ & 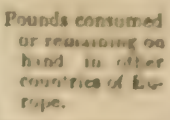 \\
\hline \multirow{4}{*}{$\begin{array}{l}1787 \\
1788 \\
1789\end{array}$} & $99,041,000$ & $45,379,795$ & $44,661,205$ \\
\hline & $88,595,000$ & $39,600,401$ & $45,(x) .5,1=6$ \\
\hline & $88,675,000$ & $48,831,232$ & $39,>13,785$ \\
\hline & $267,311,000$ & $133,811,431$ & $133,500,159$ \\
\hline
\end{tabular}

It may be proper to remark, that the weight of a hogshead of tobacco is much greater now than formerly. Originally, tobacco being less compactly pressed, the hogsheads averaged only $600 \mathrm{lbs}$., but they gradually increased, and in 1770 , reached 1000 lbs. average. At this time Kentucky averages about 1300 lbs. per hogshead, and the average of all kinds (Kentucky, Virginia, Maryland, and Ohio) we have estimated at 1200 lbs. per hogshead, which we believe to be very nearly right. The annual average exportation for the last 21 years, from 1815 to 1835 , inclusive, is within a fraction of 82,760 hogsheads. Taking our estimate of 1200 lbs. per hogshead to be the true weight we shall thus have $99,313,000$ lbs. as the annual average for the last 21 years; and we have seen that the annual average exportation for the four years ending in and including 1775, was $99,374,785$ lbs., which establishes the remarkable fact, that the exportation of leaf tobacco has remained stationary for a period of 60 years.

On a careful examination of the foregoing statements, it appears, that when our exports of leaf tobacco, for two or three successive years, much exceed $100,000,000 \mathrm{lbs}$; for some succeeding years they are proportionably reduced below that standard. It is also evident that the revolutionary war gave a check to the exportation of leaf tobacco from which it has never recovered; for until that period, as may be seen by reference to the preceding statements, the annual average exportation increased regularly and steadily. It was $37,780,000 \mathrm{lbs}$. greater for the years 1763 to 1770 , than for the years 1744 to 1746 ; and for the years 1772 to 1775 , it was $31,594,785$ lbs. more than the annual average for the years 1763 to 1770. In other words, for the 31 years immediately pres ceding the revolution, our exports of leaf tobacco annually increased very nearly $2,328,000$ lbs., and for the 60 years since that period, it has remained stationary, except when interrupted by wars or other commercial embarrassments. The reason is apparent. Before the revolution, all Europe depended on us for supplies of the article; but, being cut of from the supplies by the war. Europeans turned their attention to growing it for themselves, and 
S'atement exhibiting the number of hogsheads of tobacco exported from the Uniled States from 1790 to 1835, inclusive, and the average price per pound, and gross value from 1802 to 1835, inclusive. Also the number of pounds of manufactured tobacco and snuff exported from 1791 to 1835, inclusive, and gross value from $1817^{\circ}$ to 1835 , inclusive.

\begin{tabular}{|c|c|c|c|c|c|c|}
\hline Years. & $\begin{array}{l}\text { No. of hhds. Leaf } \\
\text { Tobacco. }\end{array}$ & $\begin{array}{l}\text { Average price } \\
\text { per } 1 \mathrm{lb} \text {. }\end{array}$ & Total value. & $\begin{array}{l}\text { Manufactured To. } \\
\text { bacco-lbs. }\end{array}$ & Snuff. & $\begin{array}{l}\text { Value of manufac- } \\
\text { tured S' aff. }\end{array}$ \\
\hline $\begin{array}{l}1790 * \\
1791 \\
1792 \\
1793 \\
1794 \\
1795 \\
1796 \\
1797 \\
1798 \\
1799 \\
1800 \\
1801 \\
1802 \\
1803 \\
1804 \\
1805 \\
1806 \\
1807 \dagger \\
18081 \\
1809 \\
1810 \\
1811 \\
1812 \\
1813 \\
1814 \\
18159 \\
1816 \\
1817 \\
1818 \\
1819 \\
1820 \\
1821 \\
1822 \\
1823 \\
1821 \\
1825 \\
1826 \\
1827 \\
1828 \\
1829 \\
1830 \\
1831 \\
1832 \\
1833 \\
1834 \\
1835\end{array}$ & $\left.\begin{array}{r}118,460 \\
101,272 \\
112,428 \\
59,947 \\
72,958 \\
61,050 \\
69,018 \\
58,167 \\
68,567 \\
96,070 \\
78,686 \\
103,758\end{array}\right\}$ & \begin{tabular}{|c|} 
Average price \\
per Ib. not \\
ascertained. \\
\\
\\
\\
$6 \frac{5}{6} \mathrm{c}$. \\
6 \\
$5 \frac{7}{6}$ \\
$7 \frac{2}{3}$ \\
$6 \frac{1}{4}$ \\
$7 \frac{1}{3}$ \\
$7 \frac{1}{2}$ \\
$5 \frac{7}{6}$ \\
5 \\
5 \\
5 \\
5 \\
$6 \frac{1}{4}$ \\
8 \\
$15 \frac{1}{4}$ \\
$12 \frac{1}{3}$ \\
10 \\
$10 \frac{1}{2}$ \\
8 \\
$7 \frac{3}{4}$ \\
$6 \frac{1}{3}$ \\
$5 \frac{3}{6}$ \\
$5 \frac{1}{3}$ \\
$6 \frac{7}{6}$ \\
$6 \frac{7}{8}$ \\
$5 \frac{7}{4}$ \\
$4 \frac{3}{4}$ \\
$5 \frac{5}{6}$ \\
$5 \frac{1}{8}$ \\
$4 \frac{3}{4}$ \\
$4 \frac{3}{4}$ \\
$5 \frac{3}{4}$ \\
$6 \frac{1}{4}$ \\
$7 \frac{1}{4}$ \\
\end{tabular} & \begin{tabular}{|c} 
Total value of \\
Leaf Tobacco \\
ascertained. \\
\\
\\
\\
$\$ 6,220,000$ \\
$8,230,000$ \\
$6,000,000$ \\
$6,341,000$ \\
$6,572,000$ \\
$5,476,000$ \\
838,000 \\
$3,774,000$ \\
$5,048,000$ \\
$2,150,000$ \\
$1,514,000$ \\
319,000 \\
232,000 \\
$8,235,000$ \\
$12,800,(00$ \\
$9,230,000$ \\
$10,241,341$ \\
$8,874,167$ \\
$8,188,188$ \\
$5,798,045$ \\
$6,380,020$ \\
$6,437,627$ \\
$5,059,355$ \\
$5,287,976$ \\
$5,347,208$ \\
$6,816,146$ \\
$5,480,707$ \\
$5,185,370$ \\
$5,833,112$ \\
$4,892,388$ \\
$5,999,769$ \\
$4,755,968$ \\
$6,595,305$ \\
$8,250,577$ \\
\end{tabular} & 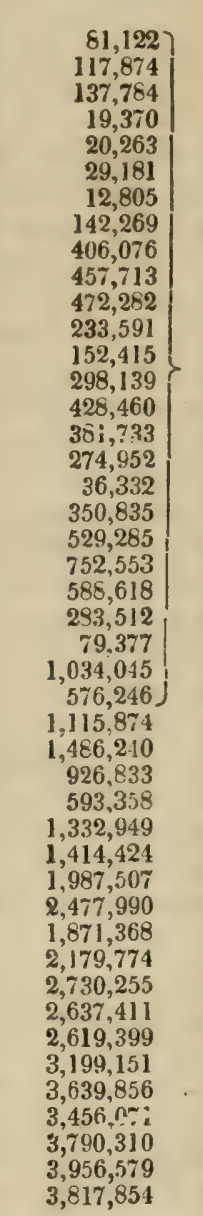 & $\begin{array}{r} \\
5,080 \\
5,513 \\
13,710 \\
4,996 \\
44,552 \\
44,602 \\
36,684 \\
45,174 \\
53,920 \\
61,801 \\
45,812 \\
85,655 \\
19,509 \\
29,425 \\
27,967 \\
31,175 \\
13,453 \\
57,826 \\
36,471\end{array}$ & $\begin{array}{r}\$ 281,509 \\
373,875 \\
237,192 \\
149,589 \\
149,083 \\
157,182 \\
154,955 \\
20,789 \\
172,353 \\
210,134 \\
239,024 \\
210,747 \\
202,390 \\
246,747 \\
292,475 \\
295,771 \\
288,973 \\
328,409 \\
357,611\end{array}$ \\
\hline
\end{tabular}

have continued to cultivate it all over the conlinent.

It will be observed that the exportation of manufactured tobacco and snuff has increased more than 44 fold since 1791, and more than 3 fold since 1817 ; but the gross value has not proportionably increased, at least since 1817 .

From a review of the subject, as above detailed, it will be perceived, that, if it were in our power 10 furnish a precise statement of the exports of each description of tobacco, and the countries to which it was exported (although very desirable on many accounts), it would not furnish satisfactory evidence that the consumption of tobacco generally, or of any particular description, had increased or diminished in Europe, without knowing what they gron, as well as what we export. We have devoted much labour and attention to this part of the subject; but, although we can learn generally that the production of it in Europe keeps pace with the increased consumption, yet our researches have not enabled us to lay before you any useful statement, either as to the quan. Lity or the qualities grown, except for 3 years in France, as follows:

1048
Statement showing the quantity of Tobacco grow in France for the years 1818-1820.

\begin{tabular}{|c|c|c|c|}
\hline Years. & Kilogrammes. & Pounds. & $\begin{array}{c}\text { No. of hhds. esti- } \\
\text { mated at 1,200 } \\
\text { lbs. per hhd. }\end{array}$ \\
\hline 1818 & $7,418,000$ & $18,545,000$ & 15,454 \\
1819 & $10,360,000$ & $25,900,000$ & 21,583 \\
1820 & $13,155,000$ & $32,887,500$ & 27,406 \\
\hline
\end{tabular}

This shows an increased production of nearly double in the 3 years.

It will strike you with surprise, as it did us, that the consumption of tobacco has increased so much in our own country as to carry off the very large surplus grown beyond the foreign demand. Formerly, when all the tobacco was grown in Virginia and Maryland, we exported as much as we do now; and now, in addition to those states, which produce nearly, or quite as much as they did then, Ohio, Kentucky, and Tennessee, together with Connecticut, Pennsylvania, Indiana, and Missouri. produce as much more. We must, therefore, consume more than the quantity required for exportation.

Remarks.-If the preceding statements may be relied on as correct, it appears that there 
has been a very surprising increase of the use of tobacco in this country, and that the annual consumption now amounts to upwards of 100,000,000 lbs.:-giving about 7 lbs. to every man, woman, and child. 'The sum annually paid ly the consumers of this quantity of tobacco in its manufactured state, has been computed by a writer in The Portsmouth Journal, at $\$ 20,000,000$. (Nutional Gazeite, Philadelphia, Oct. 6, 1836. Republished in Farmer's Register, vol. vi. 1833.)

Cullure of Tobacco.-The following concise directions for the cultivation and management of tobacco are chiefly taken from a communication drawn up by Mr. J. F. Edmunds, of Mecklenburg, Virginia, and originally published in the Farmer's Register.

Raising the Plants.- The land for the plantbed is usually selected in a warm exposure on the south or southeastern side of a hill in a wood, new ground being always preferred. From this the roots should be grubbed, the rubbish cleared away and the old leaves raked off. Brush of pine or other wood is then to be piled on until from 2 to 3 feet thick all over the bed, and this is to be set on fire. As the beds should be prepared for seeding immediately after the frost is ont of the ground, the brush should be collected and put in place some time during the winter. Instead of burning over the whole bed at once, a part may be fired for an hour or so at a time, proceeding thus over the entire bed. The place is then to be broken up with hoes, and sometimes with coulters drawn by horses or oxen, and the work repeated until the earth is made perfectly fine, being careful to avoid turning under the surface. All the roots should then be extracted, and the land laid off in beds (slightly elevated if dry, and more if moist or wet) 4 feet wide. And to 16 square yards, a common pipe-bowl of seed is sown. The bed is then trodden or pressed with hoes, and well covered with brush to protect the plants from frosts. When the plants have come fully out, they should be slightly manured with strong manure made fine; this should be repeated frequently, and in larger quantity, as the plants increase in size and are able to bear it.

When the plants have attained a good size, and there is no longer danger of frost, the covering of brush is removed, and the bed weeded with the hand, those employed in this duty taking great care to avoid bruising the tender plants. The beds require frequent picking to keep down the weeds.

Preparation and Planting.-The plants will be generally ready for removal about the last of May or first of June. They are to be drawn out after a rain and transplanted in good ground previously well prepared for their reception.

Soil and Season.-In Virginia and the other states, the best tobacco is grown in rich, light, alluvial, loamy land, or such as has been recently cleared and brought into cultivation. Tobacco requires a mild and warm season, and can never be worth growing in situations elevated much above the level of the sea, in northern exposures, or in wet and springy land.

Field Cullure.-The land for tobacco should 132 be of the best quality, either newly clenreil and virgin soil, or old ground highly mamured and well pulverized, or goul clover fallow, phoughed in the fall, manured and cross-ploushed in the spring, just before planting, wel! harrowed, and then laid off with a plough in rows 3, 3y. or 4 feet apart each way. Every square thus made is to be scraped with the hure sin as (1) form a hill in which one plant is to be set. In case the plants die from drought, or are destroyed by worms, a very cominun wccurrence. others must be set in their places.

Culivation.- 'The culture is very much like that usually adopted for Indian corn, the plough, cultivator and hand-hoe being freely used ic keep down weeds and loosen the earth.

It is important to the early growth of the plant to plough and work deep once or twice, so that when it is ripening, the ground will be broken deep and fine. ('The coulter is preferred for this operation.) 'This should be effected without much interference with the roots, as that would check the growth, and prevent the plant from attaining its proper size. And hence the advantage of greater distance between the rows than the common distance of $3 \frac{1}{2}$ feet-because the wide rows can be ploughed, and worked with less damage to the roots. In this, as in all other crops, if we wish a good return, "we must speed the plough" and hoe, before the roots run out. On our high lands we should endeavour, by deep and horizontal ploughing, to counteract the bad effects of drought. On our flats, we should aim to prevent the collection of water by drains dis. charged at the lowest point.

The bed is best for high land, because it retains more moisture where it is generally needed. The hill, retaining less moisture, is best for flat land, where there is commonly a superabundance.

Priming, Topping, Suckering, and Worming.As the tobacco plant grows and developes, a blossom-bud puts out from the top, which is termed buttoning. This top must be pulled off along with such of the upper leares as are too small to be of any value. The plants are thus left usually about 2 or 3 feet high. The plants also shoot out suckers from every leaf, which must be broken off, care being taken not to break the leaf from the main stem. This causes the leaves to spread.

The most regular topping is performed by measure. The topper carries in his hand a measure 6 inches long, by occasionally applying which, he can regulate the priming with great accuracy; and as the remaining leaves are numbered, this governs the operation, and gains the object of even topping. The topper should always carry this measure in his hand, as it serves to prevent excuses for negligence and uneven topping. Prime six inches, and top to eight leaves. We have found, by experience, that this is the best ave. rage height. We sometimes, but sellom, vary from this general rule. If the land is poores than common, or if, from the backwardness of the plant, and the advanced state of the season, we apprehend frost, we do not prime as high: (say 4 inches.) If we have an uncommonly rich spot, and there is danger that the wy 4 T 2

1049 
leaves will come to the ground, we should rise in the same proportion. 'The crop should be wormed and suckered, at least once a week.

Cutting and Housing.-In about 3 months after setting out, the plants assume a spotted and yellowish appearance, indicating that they have attained sufficient maturity for cutting and housing. This stage of the tobacco culture is generally reckoned the most difficult and delicate part of the whole business, and the planter, if he wishes to be successful, must give it all his attention, as the profit of a whole plantation, for the year, greatly depends upon the diligence and skilful management exercised during the few days of cutting. He should therefore be well prepared for this state of the crop, by having the barns close, carts and wagons in good order, and every thing arranged to despatch business as much as possible, since it is hard work he has to encounter. To save a heavy crop in the best manner requires both energy and activity. The most judicious hands should be selected for cutters. The plants are cut with a knife near the ground, and suffered to lie in the sun for a few hours, to cause them to "fall" or wilt. When the field is a pretty large one, a middling or average hand should count the whole number of plants he cuts, so that, allowing each cutter the same number, we may arrive at nearly the whole quantity cut. We should never cut more nor less than will fill the contemplated barn; otherwise there is labour lost in attending to a barn not full, or the overplus is injured for want of firirg. The tobacco, after it has "fallen," or becomes sufficiently limber, is carried to the barn in carts or wagons, being from 6 to 10 plants on a stick, and stowed away for firing. It is also of great importance to be particular in the arrangement of the sticks. 'The equal and general circulation of heat throughout the house depends on the manner in which this is done. Our barns commonly have three firing tiers above, and three below the joists. We commence arranging the sticks on the most elevated tier in the roof, to which we give five inches distance; and on each tier, as we descend, we gain one inch; so that on the lowest tier, nearest the fire, the sticks are placed eleven inches apart. This disposition of the sticks, I have ascertained by late experiment, is important. The sticks of tobacco being wider apart, next o the fires, gives a freer circulation, and, consequently, a more equal temperature, than the usual way of equal distance from bottom to top. The heat having more space to ascend, must be more equal and generally diffused, and will give a more uniform house of tobacco.

esteem this a considerable improvement; and if we have house-room, and make a greater difference in the proportionate distance between the sticks, it will be a still better arrangement.

Curing.-We commence our warming or preparing fires, says Mr. Edmunds, the day after nousing. We prefer what is commonly called the "bed logs" of green, and the "feeding" of dry or seasoned wood. By this arrangement the fires are rendered more governable. The bed logs should be nicely fitted to 1050 the barn floor, two lengths to reach across, the large ends placed outwards, to guard against the tendency of heat to the centre. We keep up our warming fires from 36 to 48 hours, the mercury ranging from $100^{\circ}$ to $115^{\circ}$. This will generally bring the leaf to the drying state; the tail, or end of the leaf, now begins to curl handsomely, and then the planter must be on the alert. If he is careless, and his fires are made too hot, the aromatic oil passes off with ine sap and smoke, and he has a house of red or dark inferior tobacco. If his fires are kept too low, his tobacco gets into a clammy sweat, and the oil escapes. There is much more danger of the former than of the latter evil. There is more tobacco injured by too much heat than by the want of a sufficiency. The fires should now be kept steady and regular, with a gradual increase of heat, so that in 48 . hours the mercury will stand $150^{\circ}$ to $160^{\circ}$. It must be kept at or about that temperature until the tobacco is cured.

Siripping, Prizing, \&c.-After the plants become sufficiently dried, known by the stems getting hard, which will be in about 2 months after housing, the leaves are stripped from the stalks. For this operation a moist time in the spring or late in winter is chosen, to prevent the leaves from crumbling. They are divided by select hands into three classes for stripping: 1st, that which is of the best colour and quality; 2dly, that which is somewhat inferior, comprising the balance of the leaf; $3 \mathrm{dly}$, lugs, or ground leaves. Some planters make still more classes, but this requires more attention and discrimination than can be generally bestowed, at least by ordinary hands. After sorting, the leaves are neatly tied up in bundles called "hands," consisting of 4 leaves in each bundle of the first class, or 6 of the second and third classes. The hands are next "put down to condition," as the process is commonly termed. This consists in putting it in large bulks and subjecting it to pressure from weights, in which state it undergoes a sweat. It must be watched during this process, and as soon as it is observed beginning to heat, taken out and hung up to dry. After drying thoroughly, it must be again taken down and put into bulk, a damp spell being chosen so as to prevent the leaves from breaking or crumbling. In Mr. Edmunds' instructions he observes, that, "at the close of each day's stripping, and oftener if the weather is drying, we bulk down what has been stripped, being careful to pack straight. It is left in this situation until we wish to commence prizing, and then hung, from 12 to 15 bundles on a smooth stick, and hoisted in the barn, the sticks placed 6 inches apart, the hoister carrying a measure in his hand. It is important to measure, as the order will be more uniform. It should remain until the stems are perfectly dry; after which it should be taken down for prizing, as dry as it can be handled without breaking. It remains in this state a few days, until the leaves are pressed together, and we have soft weather for packing. Each bundle is then carefully straightened, repacked, and heavily weighted. It is then ready for prizing. We should prize in weather when the order of the tobacco will 
not change. Each bundle should be straight, and closely packed in hogsheads in the usual way."

Some very excellent views upon the culture and subsequent management of tobacco will be found dispersed through the different southern agricultural periodicals, and especially the first volume of the Farmer's Register. One of the communications in this last work, signed Frederick Oronoko, is very full of information upon every branch of the subject. The writer states that two great errors are generally committed in topping and priming. On rich land the plants are topped too low, which, with planting too far apart, causes the leaves to grow too large, coarse, and curly. On such lands, instead of making 10 leaves, at least 12 should be made by topping to about 16 , and not finishing priming with the topping, but commencing again when the four top leaves get about half-grown. If the seasons be favourable to a rapid growth, some of the high top suckers shoula be indulged a while, which in a wet summer will prevent the leaves from growing coarse. Nothing, he says, is easier than to keep down the size of the leaves, and prevent them from getting too large, if you will only top high and indulge the suckers to a proper extent in the early part of the summer, when the seasons are favourable to rapid growth. Sucker and prime judiciously, as the rains subside and dry weather sets in. By turning out a superabundance of leaves, it enables one to speculate on the weather in this crop with more certainty than can be done with any other. The four top leaves are always the richest, if ripe, and of much the best and most useful shape. In a plant of 10 leaves, he thinks, in general, they are worth more than the other six, although the four are not so large, and do not usually weigh more than half as much as the six. The same rules, he thinks, are also applicable to the culture of tobacco on thin land, such as can just barely produce a crop, although he is opposed to the culture of such poor land. One-third to one-half of the Virginia crop is made upon such land as does not pay for the labour. It is a general impression that much of the fine, high-priced tobacco has been made on poor land. It will, he says, "be well to correct this error, as it has caused much injury, and great loss of labour, and final destruction and death to a great deal of thin land, either poor originally, or in the last stage of consumption by the Virginia-killing mode of cultivation. It is true, however, to a notorious degree, that several poor counties have of late been very conspicuous, and, perhaps, meritoriously celebrated, for making fine, high-priced tobacco; but the fine tobacco was not made on poor land, when the land was actually poor; it was made on the richest, liveliest spots that could be picked out in those poor counties. Many of those who have not rich land, have resorted to the necessity of picking the best spots of thin land with only a meager coat of soil, and that coat nearly all composed of vegetable matter, scraped into hills, which causes them to be tolerably rich, active, and productive for one or two years, as this is generally new ground. In this way a part of the fine, high-priced tobacco has been made, but much the greater part has leen producad by the rich land, with the aid of the art of high curing, with but little or no fire."

Another great error dwelt upon hy the same writer is that of cutting before the plant gets entirely ripe, which is the chief cause why so much is detective in flavour, colour, and sub. stance; and why so much feels rich ard thicis without being so. The oduriferums qualitues of most aromatic plants are acquired in ureas. est perfection during the last stages of their growth, and some are never fully developerl till they get through the process of curing. which is peculiarly the case with tea, coffere and tobacco. Much of the substance as well as weight are therefore sacrificed by premature cutting, which also prevents the plant from curing with a good, lively, healthy colour. A dull, dingy hue will inevitably be the aspect of all that is cut green, cure it as you may. Any bright colour given to it artificially by the process of curing will fade away. "I hazard nothing in the declaration that every rich plant cut in perfection, fully ripe, whether on rich or thin land, bottom or high land, may be cured of good colour and flavour, that will be lasting and delicious to the taste and smell. And although good colour and flavour constitute the chief value, yet no more than about one-tenth of the Virginia crop has ever come to market with these great advantages.

"Many incorrect and erroneous opinions have gone into circulation respecting colour. Impressions have been extensively made in the country that yellow is a favourite hue. A bright, lively colour is invariably admired by the purchasers who give the highest prices. But neither brown, red, nor yellow will do. A rich mixture of red and yellow on the under side of the leaf is desirable; such a mixture as is to be found in fat lightwood, and brilliant, rich, bright mahogany. The dull brown and dark, dingy colours are very objectionable. The next best colour to the favourite one just described, is a rich, deep yellowish-green, or rather the fat lightwood colour, with a slight admixture or tinge of green, but it is so much the worse of the green, in the ratio that it contains that shade, which lessens the fine flavour, and detracts from the value.

"A similar colour, in a faint and feeble degree, can be given to the poor, thin tobacco, and is certainly a handsome dressing for it in the new state, and is well calculated to take with superficial judges. But as such a dressing injures the stamina, and increases the fading in going through the sweat, either on land or at sea, it should never be attempted, as it is an injury, and will never take with any com. petent judge."

The dapple, or pieball, is very much admired by many purchasers who are esteemed good judges, but the writer thinks those variegated colours a disadvantage, and the results of elther too rapid curing, or bruising in pressing. A competent juige, he says, had rather have the under side of the leaf, stem, and fibres, all of one colour, of the fat lighwood appearance; and this uniformity in colour proves the maximun. and is the best evidence of rich, well-cured tobacco, in its highest perfection. 
The same writer thinks that firing has been carried to great excess, very much to the injury of tobacco, of late years, both in smoking it too much, and parching and curing it too rapidly. The smoke is a very objectionable flavour, and the excessive parching makes the leaf too crisp, and destroys the valuable elasticity. I should be well cured, with as little fire as possible. Some cure it very well without fire.

Several years ago, a great number of planters took up the impression, that the purchasers were fond of hard-fired tobacco, from the erroneous opinion of some of them, who said they liked to smell the effects of fire, because it was an evidence that it was well cured; but they have since discovered their error, and no one is now fond of the smell of smoke, which is a great objection in every market in Europe as well as in America.

The following additional observations relative to curing tobacco, are furnished by the same authority.

Sunning the tobacco is very necessary after cutting; but it should not be kept in the field any longer than to kill and make it sufficiently limber for removal to hang on sticks upon a scaffold at the tobacco-house, where it should hang in open airy order, at first letting in the sun well upon the stalks. In this way the buttend of the stalks and big ends of the leaves and stems will get a great deal of the sun's heat, which they require in curing. And as fast as the leaves contract and draw up from heat, and in drying, the plants should be moved up nearer to each other, in closer and closer order, to prevent the lower parts of the leaves from being exposed to the sun.

It would be a great advantage to split the stalks, as it facilitates the curing very much. They should be split from the top down within 2 or 3 inches of the cutting point. The plants thus split should straddle the sticks, and the sticks should range north and south, so that the morning's sun will shine on one side of the stalks, and the evening's on the other. In this manner it should take the sun and open air night and day, until it becomes well cured, and until the stalks, and stems, and leaves get dry. Showers of rain, and even heavy showers, in this situation, while the leaf continues green, are of little disadvantage; because they only wet a small part, viz.: the under side of the leaves, which are now uppermost. Nearly all of the rich ingredients are concentrated on the upper side of the plants as they stand growing.

But hot, sultry spells of rainy or very damp weather, of many days continuance, will mould, mildew, rot, or wash it to destruction, particularly after a considerable progress in curing. And when the winds come from the eastward, preceded by several damp, cloudy days, you may count upon a long spell, and then you should commence housing before the rain sets in, or much falls; and use fire as the weather may require.

The firing should be in close houses; the closer the better. And the more windows, the conter, all with tight shutters, to shut out the daınp in long wet spells, and let it in when vanted to bring the tobacco in order. No toin.52 bacco can be finally well cured without coming and going frequently. You cannot have any command of your tobacco as regards weather, without close, tight houses, which are of very great importance.

Five fires dispersed are enough for a room 20 feet square; and they should not be large, but burn free, steady, and gradual, and would be the better of never going entirely out, if you intend curing by this destructive mode. But why make fires in the house at all? As smoke is now so very objectionable, why not do the little firing that may be necessary in very long wet or damp spells, to prevent mould, mildews, \&c., in the manner that plank is steamed and dried at saw-mills?-by stoves, or by running a ditch or two through the house, and covering this with flat slabs of rock, or arching it over with brick, and making the fire at one end, out of doors. The heat and smoke thus procured will be enough in a close house, with the windows all shut, to prevent mould, mildew, \&c.

Those who cure without firing, or with as little as possible, let it remain after it turns yellow until the stalks and stems as well as the leaves get dry, in the open air and sun, if the weather permits, or in the house by the aid of fire, if necessary. But if the stalks, stems, and leaves get dry before the leaves get suffciently yellow, let the tobacco hang until it becomes very high indeed from wet or damp weather, and bulk it in this damp, soft, high order, in very large bulks, in a very close room, and cover well with straw, \&c., with heavy weights on the top, and let it remain till it gets warm; examine it every three to four hours night and day, and as soon as it yellows sufficiently, hang it up in the house, if the weather be wet or very damp, and fire it moderately and gradually until dry.

The best kinds of woods to use are those which make the most heat and weakest smoke. The kinds best for smoking bacon are the worst for firing tobacco, since the smoke flavour has become objectionable.

Another correspondent of the Farmer's Register shows, by observations of the thermometer, the precise degrees of heat to which the tobacco is subjected in the different stages of firing. He has also furnished valuable information in relation to other points connected with the curing process. In warm weather, says this writer, we hang from 8 large plants to 10 small ones on each stick; the sticks should be carried immediately into the house, and placed 8 or 9 inches apart. The sticks having been regularly arranged throughout the house, the process of curing then comes on.

My practice for several years, with but little variation, has been to regulate the sticks, the day after cutting and next morning. Com. mence with small fires, so as to raise the thermometer to $90^{\circ}$; this heat should be continued from 36 to 48 hours, which we call the warming or preparatory fire: (the small yellow tobacco, when cut, requiring a shorter preparation than large, thick, green tobacco; ) the heat should then be raised gradually $10^{\circ}$, and continued 4 or 5 hours-thus continuing to raise 
the heat throughout the whole process $16^{\circ}$ every 4 or 5 hours, until the thermometer reaches $150^{\circ}$, which is called a curing heat. The continuation of this heat depends much on the state of the atmosphere, as well as on the size of the plant: it should, however be continued until the whole plant is thoroughly cured. As soon, then, as the tobacco comes in order to handle, you may remove it to some other house, hanging it as thick as you can conveniently press the sticks together, where it will remain in perfect security until you are ready for stripping.

In the month of November you may safely begin to strip; and much care should be used in making the different qualities, as well as tying the different bundles; the "tie leaf" should be stemmed, which looks much better than to have one-half of the leaf hanging down the bundle. A good hand will tie from 700 to 1000 bundles in the day The tobacco stripped during the day, can be easily packed down in bulk at night, on a platform raised 18 or 20 inches from the flcor, where it may remain until winter is nearly over, when it must be rehung in order to get it in prizing order.

Much depends on the order for prizing. The stem must be perfectly dry: never strike or take down tobacco for prizing, unless the wind is at some southern point; and it should be taken down as dry as you can possibly handle without very much breaking it. When down, it should be well covered with fodder or leaves; if the "season" continues, you may pack it in bulk as straight as possible for prizing; the hogshead weighing from 16 to $18 \mathrm{cwt}$. The following are a few extracts from notes taken last summer during the curing season.

"15th Sept. 1833. First barn-tobacco very ripe-weather hot and dry-cut Friday-commenced firing Monday morning-thermometer $90^{\circ}$ at $9 o^{\prime}$ clock-12 o' clock $106^{\circ}$ - process too rapid-half past $30^{\prime}$ clock, $110^{\circ}$-fired all night - Tuesday 9 o'clock, $120^{\circ}-3$ o'clock $150^{\circ}$ fired all night-Wednesday $150^{\circ}$ _fired all night-Thursday $150^{\circ}$-Friday $150^{\circ}$-fires kept up irregularly, and stopped in the evening, High wind each day-thermometer at back side of the house." When this tobacco came in order to be examined, I discovered that a small portion was somewhat injured by the fires being too strong in the commencement, as seen above.

"16th Sept. 1833. Second barn-tobacco ripe-but not very ripe-weather hot and drycut Saturday-commenced firing Mondaysmoked all day at $90^{\circ}$ - Tuesday the same half day-Tuesday evening thermometer $100^{\circ}$ Wednesday morning leaf half cured on the lower tier-heat $140^{\circ}$ - fired half night-Thursday $146^{\circ}$-Friday $146^{\circ}$ - fired half night-handsumely cured-thermometer 3 feet from the door and 5 feet high-windy each day.

" $22 \mathrm{~d}$ Sept. Third barn-dry weather-cut Saturday-not very ripe-commenced firing Monday morning $90^{\circ}-$ continued all night at same-Tuesday 9 o'clock $110^{\circ}$-tails curlingtobacco looks very well--Wednesday $120^{\circ}$ at 0 o'clock-lower tier leaf nearly curer-Thurssay $150^{\circ}$ - fired all night-Friday $160^{\circ}$--fired till bedtime." This house, on craminalinr. was very well cured.

I forgot to mention in the proper place that my barns are made as tight and clowe as pos. sible. I do not, however, think that the rone should be very close; my harns are coverol with oak boards, and are generally open mon $_{0} \cdot h_{1}$ to let off the smoke and vapour as last as they are formed. Some of my neighbours have win. dows made just under the comb of the hrouse.

As the essential properties of the hinarco plant are very volatile, the writer mainfinus that the sooner it is well cured and presserl ims hogsheads the better, and the horghearl cannol be too tight. If the crop comes in early, sil as to admit of being cured in autumn, it will tre all the better. It should not, if possible, be al. lowed to remain out of the hogsheads all winter. He tells the planters of Virginia not to fear tha? they will ever overstock the world with fin tobacco, and thereby reduce the price. The finer it is made, the less will be made in Europe and other countries not so favourable to the perfection of its qualities. The low, dull state of the markets for common and inferior tobacco, is not the result of too much, but a consequence of its indifferent quality, which causes it to be little if any better than that which is made on the continent of Europe, with which it comes in competition.

In Maryland and Virginia it is estimated that one good hand can manage 6000 plants, which, allowing a yard to each, would cover about an acre and a quarter. A hogshearl weighing $1350 \mathrm{lbs}$. (some weigh 1800) is considered a good yield for one hand. On the fine rich lands of Kentucky, from 1000 to 1500 lbs are raised per acre. In Virginia the leaves of 4 good plants are estimated to make $1 \mathrm{lb}$. ci cured tobacco.

Some of the diseases, accidents, and enemies to which tobacco is exposed, are, in the language of the planter, worm-holes, ripe-shot or sun-burnt, moon-burnt, stunted, forn by storms of hail and wind, injured or killed by frost, house-burnt.

Toвacco, Chemistry sf. Under the head of Amovra it has been observed that the juice of fresh tobacco leaves contains ammoniacal salts. The existence of the volatile alkali in cured tobacco, is shown by the action of the smoke of a cigar upon blue vegetable flowers or vegetable colours, turning the reds to purple, and the purples to green.

When the leaves of the tobacco plant are subjected to distillation with water, a weat ammoniacal liquid is obtained, upon which a white, fatty, crystallizable substance swims which does not contain nitrogen, and is quite destitute of smell. But when the same plant, after being dried, is moistened with water, tied together in small bundles, and placed in heaps, a peculiar process of decomposition talies place. Fermentation commences, and is accompanied by the absorption of oxygen; the leaves now become warm and emit the characteristic smell of prepared tobacco and snufr. When the fermentation is carefully promo:el and too high a heat avoided, this smell in creases and becomes more 1 elicate; and a.fe: 1053 
the fermentation is completed, an nily, azotizeri. volatile matter called nicotine is found in the leaves. This substance, nicotine, which pos- sesses all the properties of a base, was not present before the fermentation. The different kinds of tobacco are distinguished from one another, like wines, by having very different odoriferous substances, which are generated along with the nicotine.

On a soil which contains potash, both wheat and tobacco may be reared in succession, because the latter plant does not require so much of the phosphates, salts which are invariably demanded largely in wheat, but requires only alkalies, and food containing nitrogen.

According to the analysis of Posselt and Reimann, 10,000 parts of the leaves of the tobacco plant contain 16 parts of phosphate of lime, 8.8 parts of silica, and no magnesia; whilst an equal quantity of wheat straw contains $47 \cdot 3$ parts, and the same quantity of the grain of wheat 99.45 parts of phosphates.

Now, if we suppose that the grain of wheat is equal to half the weight of its straw, then the quantity of phosphates extracted from a soil by the same weights of wheat and tobacco must be as $97 \cdot 7: 16$. This difference is very considerable. The roots of tobacco, as well as those of wheat, extract the phosphates contained in the soil, but they restore them again, because they are not essentially necessary to the developement of the plant. (Liebig's Organic Chemistry.)

Tobacco is a plant that contains much mineral matter. An acre yielding 800 lbs. would contain about $160 \mathrm{lbs}$. of mineral matter, most or all of which is carried off from the soil. Hence in exhaustion of land from this crop is greater than that from grain crops, provided their straw be duly returned to the fields, as in this case the loss would be confined to the phosphates and other mineral matters removed with the grain, which in a four years' rotation would amount to mly about 83 lbs. per acre, instead of about 600 lbs. carried off by the tobacco in the same time. The following analysis furnished by Professor J. F.W. Johnston of the ashes of tobacco leaves, grives the mineral constituents, with their proportions per cent :

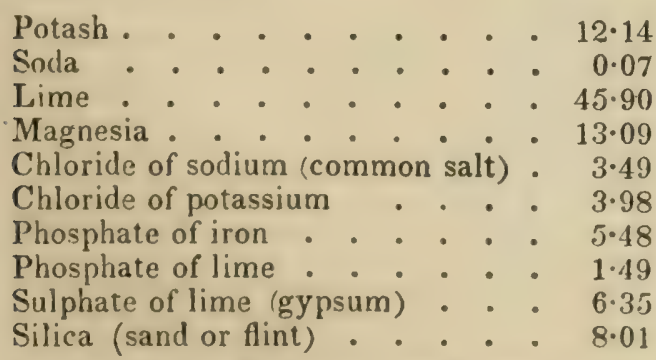

From this view of the mineral constituents of tobacco, the soil most favourable to its growth may be readily recognised. The proportions of the several articles removed by every $100 \mathrm{lbs}$. is not difficult to estimate, with the additions of the special manures required to prevent the exhaustion of the soil. Among these it will be observed, the largest amounts are lime, magnesia, potash, iron, and silica.

Some successful results are reported in the Albany Cultivator, of the culture of tobacco in Massachusetts. The variety produced there is called the "Connecticut Seed-leaf," and it usually hrings domble the price, and sometimes even nore, of Virginia and Kentucky tobacco. For 1054 a profitable crop, rich land is necessary, though sandy soils manured at the rate of 10 or 20 twohorse-loads per acre, will produce well. With good management, the yield is from 1500 to 2000 lbs. per acre, of marketable tobacco, capable of bringing an average price of $8 \mathrm{cts}$.

The Massachusetts growers believe that, with proper attention, instead of injuring the soil, tobacco may be made an ameliorating or improving crop, the liberal manuring required favouring the after crops; wheat and other grain, and also grass crops, flourishing better when tobacco forms a part of the rotation, than where it does not. Where $\$ 36$ worth of manure was put upon 1 . acre and 100 rods, a ton of tobacco was raised, worth $\$ 160$. The same piece of land, sown immediately afterwards in wheat, yielded 30 bushels. The following crop being grass, produced 4 tons of hay at two cuttings. One farmer in South Hadley had 17 acres planted in tobacco.

A long and instructive account of the mode of cultivating tobacco in $\mathrm{Cuba}$ is given in the Report of the Commissioner of Patents for 1847.

'IOMATO, or LOVE-APPLE. (Solynnm (ycopersicum; Lycopersicum esculatum.) Several varieties of this plant are found in our gardens and fields, some of which are red and others yellow; among the reds are, 1 st, the common large; $2 \mathrm{~d}$, the small; $3 \mathrm{~d}$, the pear-shaped; 4 th, the cherryshaped. Of the yellow there are, 1st, the large yellow; $2 \mathrm{~d}$, the small or cherry-yellow.

The tomato is a native of South America. It forms a rich vegetable sauce, and an excellent addition to soups. With sugar it makes a very valuable preserve. In the Middle or Northern States, the seed may be sown in April, in a hot-bed; or in May, in a warm situation, and transplanted as soon as the season will admit. A middling soil produces more fruit and less vines than a very rich soil.

Tomatoes remaining on the vines late in the season, and which, if left out, would be destroyed by frost, may be preserved for many weeks by simply pulling up the vines and hanging them up, with the fruit upon them, in some house or sheltered situation. Those not ripe when the vines are pulled mature afterwards.

Cows are said to thrive well and give an increased quantity of milk of improved quality when fed upon tomatoes. They may not take them kindly at first, but are said to grow fond of them soon.

TOMENTOSE. In botany, means covered with dense, close, white hairs, or down.

TOP-DRESSING. A term applied to such manures as are laid upon land without being turned in: and also to the practice of dressing the surface of grass land, or other crops, with some kinds of highly reduced manure, that can be evenly spread out or sown equally over them by the hand.

A great variety of substances are in use for this purpose, such as soot, ashes, guano, and the dung of pigeons and other birds, rape dust, lime, gypsum, \&c., the benefits of which are noticed under their respective heads.

TORMENTIL (Tormentilla, alluding to a supposed efficacy in toothache, as well as to a belief that it could cure diseases of the bowels). The British species are two; both parennial. They are now regarded as belonging to the genus Potentilla, and the natural order Rosarea.

1. In Fngland common tormentil or sept-foil ( $l$. oficinalis or tormentilla) grows in barren pas. 
tures, heaths, and bushy places. The stem is slender, ascending, branched. 'The woody red roots are so astringent as to be used in the western isles of Scotland for tanning leather, for which purpose they are superior even to oak bark. 'The root is likewise one of the most efficacious of English indigenous aromatic astringents, and may be used with great effect in cases where medicines of this class are proper; namely, in chronic purgings. It is usually given in decoction, but is best arministered in powder.

2. Trailing tormentil (T.reptans). This species grows sparingly about the borders of fields and hedges. The stems are 2 feet long, hairy, prostrate, but not creeping; the leaves composed of 5 leaflets, obovate, strongly serrated, bright green, on long hairy footstalks. Flower of a full yellow, twice the size of the foregoing. Stipules undivided. It is also astringent, but less so than its congener.

TOUCH-ME-NO'T. See Balsay.

TOWER-MUSTARD (Turritis, from turris, a tower; the foliage is so disposed on the stems as to give them a pyramidal form, and for the same reason the plants are called tower-mustard). The species are hardy annuals: one, the smooth tower-mustard ( $T$. glabra), is indigenous, and grows wild on banks and by roadsides, in a dry gravelly soil. 'The flowers are numerous, closely corymbose, pale sulphurcoloured. Pods very long and slender, on short stalks. Seeds about 60 in each cell, very small.

TRaCtion. See Carts, Horse, Roal), Strength, \&c. The reader may also consult a very able essay "On Draught" in Professor Youatt's work on The Horse, of which our space will not allow us to give even an outline.

TRANSPLANTING. The act of removing either cuttings, layers, roots, or entire plants, from one soil into another. See Plaxisiva and Propagation.

TRAPA NATANS. This plant grows in ponds, and is eaten like the chestnut. 'The canal of Versailles is covered with the plant, and the root is sometimes served up at table.

TRAVELLER'S JOY. See Clematis.

TREACLE-MUSTARD (Erysimum, from erion, to draw and cure: it is popularly reckcned a cure for a sore throat, and is also said to draw and produce blisters). An extensive genus of plants, possessing warm and pungent qualities. The leaves are simple, often lanceolate, and nearly entire. Flowers corymbose, yellow, sulphur-coloured, or white. Pods in very long upright clusters. There are in England three indigenous annual species. 1. The worm-seed treacle-mustard ( $E$. cherianthoides) : 2. The garlic treacle-mustard (E. alliaria), known also under the local names of Jack-bythe-hedge, or sauce-alone. 3. Hare's-ear treacle-mustard ( $E$. orientale). The second is the most common. The whole herb is smooth, shining, deep green, and exhales, when bruised, the smell of garlic; and the seeds are stronger than the other parts of the plant. 'The stem is a foot high, somewhat branched. The leaves stalked, cordate, acute, veiny, and broadly serrated. The flowers are white. The pods erect, sinooth, on a spreading stalk. The peasantry eat the young leaves with bread and butter. See Mrun Mistan.

'TREES are divided naturally into two principal classes, namely, fruit and tumbor trees: the former includes all such as are raised chiefly, or entirely, for their edible fru:t, an ace count of which, together with their moles of cultivation, the reader will find in alpha! itical order, and also in the articles Furr, Oncuann, Puvina, \&c.

The second division comprehends those trees, the wood of which is empliyed in shipbuilding, machinery, or for other useful purposes, such as the oak, elm, larch, \&er, the culture of which has been discusind under those respective heads. For the diseaues of trees, see Americas Bligut, Casken, MizDEw, \&c.

By timber, in English law, is intended only such trees as are considered fit and proper by the custom of the country to be employed in building or repairing houses; and timber trees are those which are of 20 years' growth. The custom of the country naturally varies with regard to the kind of trees which are considered to be timber. The oak, the elm, and the ash are universally deemed to be such: beech is con sidered so in Buckinghamshire, birch in Yorkshire, because it is generally used for buildings of an inferior kind. Thus the chestnut, walnut, lime, and others may, under similar customs, be considered timber. If pollards are sound, it seems that they must be considered as timber: this was the opinion of Chancellor King.

According to English common law, the property of the tree is in the owner of the soil on which it grows; and though its roots may extend into two estates, yet it belongs to the owner of the land on which it was nriginally planted or sown. Nurseries of young fruit trees, raised for filling up orchards, cannot be removed by the tenant, but a nurseryman may do so.

The tenant for life, without impeachment of waste, of an estate, may cut down timber in a husbandlike manner. But the Court of Chancery will restrain such tenant from cutting down underwood of an insufficient growth, or ornamental or sheltering trees. But this shel. ter or ornament is not to be construed to mean extensive woods.

By custom, but not by common lasr, the trees growing on a copyhold estate may belong to the lord. The copyholder is not guilty of waste if he cut timber merely for necessary repairs. Timber trees growing on the estates of ecclesiastical corporations are to be devoted to the repair of the church. And consequently neither they nor their lessee can fell limber for their own use. Neither can a mortgagor cu down timber if the land without it is a scanty security. But the Court of Chancery will not restrain a mortgagor from cutting iimber, unless the security is insufficient without it Though the timber of the estate belongs to the landlord, and also such trees as are lilie!; ic become timber, yet the general property is bushes and trees not timber is in the tenant, and, therefore, the landlord cannot maintain an action of trespass against a stranger, for cui. 105; 
ting bushes and thorns growing in a herge, if the tenant afterwards assented. The tenant or lessee has no right to cut timber; and in an action for waste the defendant cannot give in evidence, even in mitigation of damages, that the timber was cut for the purpose of necessary repairs; or, that after it was cut the timber was exchanged with the lessor's consent for timber more fit for the purpose intended. But he may cut timber without waste which has been cut within 20 years; and in Kent they are in the habit of cutting trees of 26 or 28 years' growth. Windfalls belong to the lord, and the Court of Chancery will, if necessary, order it to be preserved for him who has the first estate of jnheritance in the land. See Bark, Forests, Nursert, Timber, \&c.

TREFALLOW. A local term, signifying to plough land the third time before sowing.

TREFOIL (Trifolium, from tres, three, and folium, a leaf. All the species have trifoliate leaves. The French call it trefle, and the English trefoil, or clover). An extensive and wellknown genus of herbaceous plants, natives of cold or temperate climates, either perennial or annual. Many of the species are highly important as food for cattle, either fresh or in the state of hay, often acquiring a fragrant scent in drying. The white, red, and yellow clover are amongst the most valuable herbage plants adopted in European agriculture.

Lucern has been recommended as superior to clover and sainfoin, and various other leguminous plants have been highly extolled; yet the red clover for mowing, and the white for pasturage, far excel all other plants in these respects. All the species thrive in common garden soil, and many of them being very showy are well suited for ornamenting the flower border. The perennial kinds are readily increased by dividing the plants at the roots in spring, or by seeds. See Brnn's-Font Trafoil, Clover, and Melinot.

TREFOIL, THE MARSH. See Buck-Bian.

TRENCH PLOUGH. See Plodgr.

'TRenching. See Subsoil Ploughing.

TRIFOLIUM INCARNATUM. A well-

known and much esteemed species of trefoil.

See Crover and Tueforl.

TRITICUM. See Wheat-Grass.

TRUFFLE (Tuber cibarium). A round fungus growing under ground in many parts of Southern Europe, destitute of roots and leafy appendages. It absorbs nutriment at every point on its surface. The truffle is composed of globular vesicles, destined for the reproduction of the vegetable, and short, barren filaments, called by Turpin tigcllules; and the reproductive bodies, trufinelles. Each globular vesicle is fitted to give origin to a multitude of reproductive bodies, but a few of them only perfect the young vegetable. The parent dies; the trufinelles are nourished by its dissolving substance, and the cavity it originally filled becomes the abode of a multitude of young iruffles; but many of them die, the stronger starving the weaker. $\Lambda$ s truffles spread over a large space, it is difficult to say by what means they progress. The truffle is one of the most wholesome and nutritive of the esculent fongi, and is generally discovered by means of 1056 dogs, which are taught to scent it; so that, on smelling the truffle, they bark and scratch it up. 'Truffles are highly esteemed at the tabies of the luxurious, where they are served up, either roasted in a fresh state like potatoes, or they are dried, shred, and dressed as ingredients in soups and ragouts. See Tuсканок.

TRUSS. A bundle of hay, straw, \&c. It may be observed that in England a truss of hay must contain $56 \mathrm{lbs}$. or half a cwt.; a truss of straw 36 lbs.: 36 trusses make a load. In June, July, and August, a truss of new hay must weigh $60 \mathrm{lbs}$. See $\mathrm{H}_{\mathrm{A}} \mathrm{T}$ and Straw.

TUCKAHOE. This curious vegetable is sometimes known by the name of Indian bread, or Indian loaf. It is found in the Southern States on the Atlantic, and even as far north as Kent county, Del. It is a natural production, the origin of which has greatly perplexed naturalists, as it is commonly found several feet under the surface, and, like the truffle of Europe, has apparently no stem orleafy appendage connecting it with the external atmosphere. They are generally found through the instrumentality of hogs, whose acute sense of smelling enables them to fix upon the spot where they lie buried. They are usually of a globular or flattened oval shape, and rather regular surface, the large ones resembling somewhat a brown loaf of coarse bread. The size varies from that of an acorn to the bigness of a man's head. Clayton, the celebrated botanist, was the first naturalist who has mentioned the Tuckahoe. He gave it the Latin name of Lycoperdon solidu. (See his Flora Virginica.) In May, 1817, Dr. Macbride, of Charleston, S. C., communicated a memoir on the subject to the New York Philosophical Society. Although the tuckahoe is quite common in the Southern and one or two of the Middle States, its natural history is still involved in much obscurity. Its name in the Indian language is said to designate bread, and is applied to certain edible roots. Though sometimes found emerging from the earth and exposing a small part of the surface, it is generally met with 2 or 3 feet below the soil. When first dug up, it is soft enough to be easily cut with a knife, and of an acrid taste. Its colour internally is white, like that of the meat of the cocoa-nut, and its texture compact and homogeneous. It is covered with a tough substance, strongly adhering to the white parenchyma, of a dark brown colour, and somewhat wrinkled. When dried, the internal substance becomes hard and loses its acrimony, possessing very little taste or smell, and capable of being reduced to powder without difficulty. When examined by the microscope, the tuckahoe exhibits no fibres or pores or any other indications of organization, so easily detected in roots and other vegetable productions of ordinary growth. Its substance breaks as easily in one way as another, like a lump of starch or chalk. From these characteristics, together with the peculiar nature of the bark or external covering, it has been classed among the fungus tribe. In those parts of the country, however, where the tuckahoe most abounds, it is generally supposet: :o be the root of a species of Convolvulus (Pandura(tus), called "the man of the earth." But both 
Dr. Macbride and Mr. La Conte, after much attentive examination in its native state, are decidedly of the contrary opinion, the roots of the Convoluulus being unlike those of the tuckahoe. Most of the southern botanists regard it as a fungus. (See Medicul Repository, vol. vi.) Dee TIUUFLe.

TULIP (Tulira). A genus of celebrated and much-prized florists' flowers. They succeed well in rich loam and sand, and are increased by offsets; new varieties are obtained from seed. The choicer kinds require to be taken up and dried after they have ceased flowering, and planted again in the autumn. 'They should be slightly protected in very rainy or frosty weather, as they are very liable to rot. One species, the wild tulip ( $T$. sylvestris), is indigenous to England, growing about old chalkpits. It bears sweet-scented, bright-yellow, somewhat drooping lowers in April. Although the Tulipomania, which rose to such an absurd height in Holland in the 17 th century, is long since extinct, yet the rage for producing fine tulips still exists. The finest tulips are reared at Haarlem. The principal florists have their favourite breeders. A breeder is a seeding tulip, 8 or $\mathbf{9}$ years from the seed, but still vigorous. If the stem be tall; the petals of the flower blunt at the apex; if the flower be selfcoloured, or of an equal, uniform colour on both surfaces of the petals; if the base be pure white or bright yellow; and the anthers and stigmas dark or black, it is highly esteemed as a breeder. The bulb is planted deep in a sheltered, sunny place, and care is taken to prevent the leaves being injured by wind or hail; the stem is propped, and the flower carefully secured from the hot rays of the sun, as well as from wind and violent rain. The seed is carefully collected, and from it many fine tulips are anticipated. The varieties at Haarlem are very numerous; they are chiefly varieties of the Tulipa Gesneriana and T. Suaveolens.

TULIP POPLAR (Liriodendron tulipifera). This tree, the only one of its genus, is found in great abundance in the Middle United States, where, on the rich woodlands in the alluvials bordering the Delaware and other bays, it attains a growth which makes it the most majestic tree of the American forest. Trees are frequently found from 100 to 140 or 150 feet in height, and 6 or 8 feet in diameter, the trunk being sometimes 60 or 80 feet perfectly straight and without a knot or branch. This stately tree, when its wide-spreading branches extend from the ground to the summit, loaded in May writh its tulip flowers, has been referred to in the article on the Bres, as the most magnificent of floral productions. The wood, which is very soft, is highly valued for building, and also for many purposes to which it is applied by the cabinet-maker and other mechanic artists. The varicty called yellow poplar is generally preferred. It is known by its thicker and more deeply furrowed bark. The bark, which is very thick and spongy, is also a valuable aromatic bitter; and has been successfully used in intermittents.

TULL, JETHRO. The science of agriculture, although the first in inportance to mankind, is yet remarkable for the few great names whose discoveries or general abilities adorn its history. Fur an explanatuon of this fart, we must in some measure te contented wuh the comamon observation that its advances, us inforotements, are so slow, as to be almost impercieptible; are dependent upon much more tedions experiments thas any other scsence: for instance, it is true that many, very many of the processes, daily witnessed and carried un by the cultivator, are based upon chemical prificilo ples, and may be illusrated, and very materially assisted, by chemical experiments : bus those who have studied the science the most carefully are fully aware that no experiments upon the laws of dead matter even nearly equal in difficulty those upon living substances, for these last, in many instances, seem endow: ed with powers which completely neutralize and overcome the very principle of chemical attraction and repulsion. Such experiments, too, are not, like those made in the philosopher's laboratory, secure from interruption, and carefully and readily guarded from every source of error; on the contrary, those of even the most scientific, the most careful cultivators, are of necessity liable to many accidents, are ever the sport of the winds and the weather, require months to complete, and often the duration of a life to repeat and firmly establish. Then, again, to add to the difficulty of such investigations, there are hardly two soils to be found, in England or elsewhere, whose compo. sition and conditions are even nearly the same. All differ either in the proportion of some ingre. dient, in climate, in declination, or in the nature of their substrata; the variations in their treatment, therefore, must often be as different as their numerous varieties. Thus, encircled with difficulties, requiring for the attainment of considerable eminence the union of both practical experience, patient and long-continued research, and scientific knowledge, we need hardly feel surprised that those who have made important improvements in agriculture have been but few in number, and that these illustrious exceptions to the general rule have appeared at very distant intervals. The farmer, too, however skilful and successful in his business, however industrious and talented, is but rarely induced to describe the improvements he has caused, or the implements he has improved or invented; he is too often content with the profit derived from his own ingenuity, and too frequently lets others reap all the honours of dis coveries to which he is more justly entitled.

In the list, however, of distinguished Englisi farmers, Jethro 'Tull presents us with a highly honourable exception to the general rule; for, utterly regardless of all selfish considerations, he not only made great and successful efforts for the promotion of agriculture, but he made those valuable researches, publicly known in. a work entitled the Horse-hoeing Husbandry, which will hand him down to all after-ages as one of the chief of English farmers; as a pa triot who, undaunted by the natural difficulties of the attempt, altained great anit important advances in the cultivating and increasing the fertility of the land, and in enlarging the resources of the followers of a business to which he was not originally bred; fur, as we shall
\[ 4 U \] 
presently see, Tull became a farmer not from inclination, but from the effects of a sickly constitution and diseased frame.

The life of Jethro 'Tull will, indeed, well repay the careful and often-repeated study of the English farmer in more ways than one; will afford not only instruction, but encouragement to him who has to contend against the poorest soils, the most adverse of circumstances; for, if such a cultivator holds a poor, thin, hungry soil, so did Jethro Tull; -if he farms in a remote and desolate district; if he has ignorant and obstinate labourers; if he is visited by sickness; if he is almost driven from his proiession by even incurable diseases, so, let him be assured, was that great farmer whose labours are the subject of this memoir. The dauntless intrepidity and perseverance, too, of Tull, should always be remembered to his honour. Knowing, as he did, the correctness of the principles for which he so nobly contended, he never relaxed in his endeavours to induce their general adoption; and if it was only after the lapse of many years, when Tull had long been in his grave, that those principles and those mechanical inventions for which he so energetically contended were commonly adopted, the fault was not Tull's, but must be attributed to the ignorance and the apathy of the age in which he made his important, his ill-requited discoveries.

The debt of gratitude which all modern farmers owe to Tull is, indeed, a large one; he was the first who boldly and zealously contended for the adoption of improved machinery in all agricultural operations; the ploughs which he depicts in the engravings which accompany his Horse-hoe Husbandry, have not been very materially improved in the last century. He invented several varieties of hand and horse-hoes. He was very nearly, if not quite, the first who produced a practically useful drill. He shared the fate of all those who, as discoverers, have the temerity to disturb old systems. He was regarded by the bulk of his contemporaries as an idle, restless innovator. He was ridiculed, thwarted, and opposed in every way, not, as might have been reasonably expected, by the most ignorant, but by those who either did know, or ought to have known, better things. His neighbours regarded him as almost a lunatic; and the tradition of the neighbourhood of Shalborn still is, that he was even wicked enough to attempt to banish the flail from his farm, and that he had a machine in his barn at Prosperous, which worked a set of sticks so readily as to thrash out his corn without the assistance of the labourer. This, there is little doubt, was an attempt to construct a thrashing-machine; and that it was, in ihose quiet days for agriculture, regarded as a wonder, is proved by the existence of the tradition. When thus located in a remote rural parish, on the borders of the counties of Berks, Hants, and Wilts, Tull wrote his Husbandry, a book which is not nearly so well known as it ought to be; for, though the progress of science has rendered a considerable portion of Tull's writings obsolete, yet much, very much, remains nnaltered by the progress of discevery, 1058 to aur. ply repay the farmer for a careful and often repeated perusal.

'Tull wrote with all the modesty and diffdence of genius: he tells us, in the preface to his Husbandry, that be knew that he had undertaken a task of which he was incapable, and that it was produced during a long confinement within the limits of a lonely farm, in a country where he was a stranger. And when we remember that he was, through life, an invalid,-obliged to abandon his sedentary profession of the law, and seek for health by foreign travel and by country pursuits, - when we think of these things, we cannot but still more admire the energy of mind he betrayed, and the difficulties he overcame. He feelingly alludes to some of these, when he says, with regard to his great work-"Tis no wonder that the style is low as the author, or as the dust that is here treated of, since the whole was written in pains of the stone, and other diseases as incurable and almost as cruel; but fine language will not fill a farmer's barn." Every thing connected with the history of this great benefactor of agriculture must be interesting to the cultivators of this and all other countries. I regret that, with some industry, I have not been able to obtain for the farmer more information with regard to him. He was born in Oxfordshire, on his paternal estate. He was educated for the legal profession, became a member of Staple Inn, and was called to the bar on the 11 th December, 1693, by the benchers of Gray's Inn, and not at the 'Temple, as is commonly asserted in the bingraphical dictionaries. He was aflicted soon after his call to the bar with a pulmonary disorder, and, in consequence, abandoned his Oxfordshire farm, and for some time travelled on the Continent. He was for a considerable period at Montpelier, in the south of France. Returning to England, he took into his own hands the farm called Prosperous, at Shalborn, in Berkshire, where, again resuming those agricultural efforts which he had commenced in Berkshire, he wrote his Horse-hoe Husbandry.

During his tour on the Continent, Tull carefully compared the agriculture of France and Italy with that of his own country, and omitted no occasion to observe and note every thing which supported his own views and discoveries. He particularly, on more than one occasion, in his work, alludes to the similarity of the practice followed by the vine-dressers of the south of Europe, in constantly hoeing or otherwise stirring their ground, and his own horse-hoe husbandry. Finding that they did not approve of dunging their vineyards, Tull readily adduced the fact in favour of his own favourite theory, that manuring a soil is an unnecessary operation.

After 'Tull's decease, his lands in Berkshire found their way into Chancery, and were sold, by order of the court, in 1784, to Mr. Blandy, the father of the present owner. It consists of about 70 acres of freehold land, but 'Tull held about 130 acres in addition, by a different te. nure. The house in which he dwelt has bcen modernized, but the old-fashioned brew-house yet remains as ' $\Gamma$ ull had it; and when I visited 
Prosperous, in July, 1840, was still in very gond condition. Of the out-houses, 'Tull's granary and his stables are yet in existence, though fast verging to destruction; and at the end of this granary, which Tull built, is an old well in which, when cleared out some years since, was found, deeply buried in the accumulated mud of nearly a century, a threepronged hoe, which there is no doubt belonged to Tull, and is now in the museum of the Royal A rricultural Society of England. Into this well it was most likely thrown by his men, who, adopting the use of his new tools with the utmost reluctance, annoyed him in many ways. Against these he declaims with much bitterness: "Tis," he says, "the most formidable objection against our agriculture, that the defection of servants and labourers is such, that few gentlemen can keep their lands in their own hands, but, rather than make nothing of them, they let them for a little to tenants who can bear to be insulted, assaulted, kicked, cuffed, and bridewelled, with more patience than gentlemen are endowed with." "This burst of feeling would very clearly intimate the probable truth of the case-that Tull was energetic and irritable-that his servants pillaged and annoyed him, and that he did not submit to their impositions without struggling against them in a way which his legal education should have taught him to avoid.

Such was the spirit of enterprise, and such was the genius of 'Iull, that no difficulties, however formidable, stopped him in his researches. His experiments, carried on in his garden and in his house, with regard to the food and the habits of plants, some of which he gives in the first pages of his work, betray the thirst for knowledge, the industry, and tact, which he possessed.

The tradition of his neighbours is, that, when confined to his room and to his couch by his incurable maladies, he yet managed to carry on his experiments on vegetation, by having large boxes and garden-pots of earth placed in his room, and before his windows, where he sowed his seeds, and watched their progress under different modes of cultivation, with all the zeal of a martyr, and the enthusiasm of an inventor. He is still spoken of by the old labourers of that district, as being a man whom it was impossible to oppose, in any of his plans, with eventual success. He was evidently the wonder of his neighbours, who would, perhaps, have regarded him as a magician, if the age of witcheraft had not then been nearly, if not quite, over. It would seem, from what Tull says (p. 50), that it was in 1701 that he constructed his first drill for planting sainfoin. And the occasion of his doing so he thus describes in his preface: "It was very difficult to find a man that could sow clover tolerably; they had a habit (from which they could not be driven) to throw it once with the hand to two large strides, and go twice on each cast; thus, with 9 or 10 pounds of seed to the acre, two-thirds of the ground was unplanted, and on the rest it was so thick that it did not prosper. To remedy this, I made a hopper, to be drawn by a boy, that planted an acre sufficien:ly with 6 pounds of seed; but when I added to this hopper an exceedingly light plough, that made 6 channels 8 inches asunder, into which 2 pounds of sered to an acre being drilled, the ground was as well planted. This drill was easily drawn by a man, and sometimes by a boy."

Jethro 'Tull's great improvements in tillage consisted in the use of his drill, and in the aloption of such wide intervals between his rows of turnips (several feet, 3 to 6 ), that the horsehoe could be easily and constantly employed. He ridiculed, very justly, the delusions under which the farmers then laboured with regard to the unvaried advantages of thick sowing. He told them that they "did not grudre to bestow three or four pounds in the buying and carriage of dung for an acre, but that they thought themselves undone if they afforded an extraordinary eighteen-pennyworth of earth to the wide intervals of an acre, not considering that earth is not only the best, but also the cheapest entertainment that can be given to plants." And again, in another place (p. 32), he told the thick-sowing, broadcast cultivators of those days, what must have not a little astonished them, "that every row of vegetables to be horse-hoed ought to have an emply space or interval of 30 inches on one side of it at least, and of nearly 5 feet in all sorts of corn;" and he was very justly suspicious that what he was going to advance "would seem shocking to them before they have made trials."

Tull was the first English farmer who advo. cated to its fullest extent the decided advantages of constantly pulverizing and stirring the soil, to illustrate which almost all his experiments were directed. His explanations, how. ever, of his own discoveries were not always so good as the object he had in view, although there is little to find fault with in his theory of the advantages of tillage. "I have had," he says (p.24), "the experience of a multitude of instances, which confirm it so far, that I am in no doubt that any soil, be it rich or poor, can ever be made too fine by tillage; for one cubical foot of this minute powder may have more internal superficies than a thousand cubical feet of the same or any other earth tilled in the common manner; and I believe no two arable earths in the world do exceed one another in their natural riches twenty times; that is, one cubical foot of the richest is not able to produce an equal quantity of vegetables, celeris paribus, to 20 cubical feet of the poorest; therefore, it is not strange that the poorest, where. by pulverizing, it has obtained 100 times the internal superficies of the rich, untilled land, should exceed it in fertility; or, if a foot of the poorest was made to have 20 times the superficies of such rich land, the poorest might produce an equal quantity of vegetables with the rich. Besides, there is another extraordinary advantage when a soil has a large internal superficies in a very little compass; for then the roots of the plants in it are better supplied with nourishment, being nearer to them on all sides within reach than it can be when the soil is less fine, as in common tillage, and the ronts in the one must extend much farther than in the other to reach an equal quantity of nourishment; they must range and fill perhape 
above 20 times more space to collect the same quantity of food. But, in this fine soil, the most weak and tender roots have a free passage to the utmost of their extent, and have also an easy, due, and equal pressure everywhere, as in water."

He did not confine his attention to the advantages of thoroughly pulverizing the land: he was also an advocate for much deeper ploughing than was usual in his time, and in one or two places laments the supineness of the farmers in this respect, and the idleness of the ploughmen, in only half-penetrating the soil, for fear of injuring the appearance of their horses; and he illustrated the advantages of his proposed mode of ploughing by the best means in his power, not only by general observation, but by also appealing to several very ingeniously-contrived little experiments upon the habits of plants.

Tull saw very clearly that this theory of the advantages of pulverizing and deepening soils would be strongly supported if it could be shown that the roots of the commonly cultivated grasses would, under favourable clrcumstances, penetrate to more considerable depths than the ordinary shallow soils of the farmer allowed them. He paid, therefore, considerable attention to the roots of plants, not only in his small experimental glasses and pots, but in his fields. He found, by some observations on the roots of some wheat plants growing in a deeply loosened soil, that their roots had penetrated to inore than double the depth of the commonly ploughed land of the farmer; and all this I can support from my own observations on the roots of the crops growing on the edge of chalk and loam pits, and in other situations where the soil has been loosened to great depths. Tull, two, noticed the very considerable and rapid extension of the roots of trees growing near 10 old dunghills, sewers, \&c., and he hence adduced another argument in favour of the advantages which are derived from assisting, in the best ordinary way then known, the roots of plants to penetrate deeper into the soil. Had Tull lived in our days, he would have been an ardent advocate for the subsoil and subturf ploughs: he would not then have confined his efforts to the increased use of the common plough and the trenching-spade.

A century has now elapsed since Jethro Tull thus earnestly endeavoured to draw the attention of the farmers of England to the importance of deepening, pulverizing, and mixing their soils. Tull, unfortunately for himself, lived an age or two too soon: had to encounter the ignorance and the obstinacy of his workmen, the apathy of his neighbours, the ridicule of those who understood him not, and the anger of the indolent. 'The principles, however, which he inculcated have survived and overcome all these obsiacles; are yearly more prized, bec ause better understood. Tull thought that the carth, and the earth alone, did every thing for vegetation; astonished at the effects which were produced by merely deepening and pulverizing, he allowed his enthusiasm to carry him too far. "Every plant," he tells us, "is earth, and the growth and true increase of a flant is the addition of more earth " and in 1060 another piace he adds, "too much nitre sorrodes a plant, too much water drowns it, too much air dries the roots of it, too much heat burns it; but too much earth a plant never can have." Thus impressed with the value and the all-sufficient powers of earth to support vegetation, it need hardly surprise us that Tull soon came to the conclusion that, under a proper management of the plough and the scarifier (for a rude instrument of this kind was known in Tull's days), the land might be so pulverized and deepened as to bear its crops without the addition of any decomposing manures.

Tull deceived himself, in this instance, by not attending to the quantity of finely-divided, slowly decomposing substances, which all cultivated soils contain in some shape or other. By ploughing and pulverizing, the progress of the putrefaction of these organic matters was accelerated, they were rendered more soluble, and then the succeeding crop was, by their decomposition, sufficiently nourished. But these operations could not be long continued; at each repetition of the experiment the amount of the stubborn, slowly decomposing matters of the soil became reduced, and, in consequence, the crops produced under the system became less. Tull's farm at Shalborn was well adapted to try the effect of this theory; it is situated on the crown of a rising ground, whose thin-skinned soil is a light loam mixed with gravel, resting on chalk; of such a soil the organic matters, of necessity, are speedily exhausted by cropping and pulverizing. Tull soon found this out; he struggled hard against the necessity, but he finally had recourse tc the employment of manures; he found at last. that, however valuable good tillage is to the application of fertilizers, it is utterly incapable of supplying their place. The failure of Jethro Tull, therefore, in this great effort was complete; but it was the failure of a man of genius. He tardily admitted the value of dunging the land; but he still explained its operation in such a way as to refer all the benefit to the earth, when he told the farmers of those days, "its use is not to nourish, but to dissolve, that is, divide the terrestrial matter which affords nutriment to the mouths of vegetable roots." To a very considerable extent Tull was correct in this explanation of the mode in which common manure operates irs rendering the soil more fertile; for it renders the land more pervious to the atmospheric gases and vapour, and, in consequence, all vegetation growing upon the land is better nourished. But the benefit, as Tull imagined, does not end here; the organic matters of the compost, as they slowly dissolve in the soil, gradually give ous a considerable proportion of various gases, such as carburetted hydrogen and carbonic acid gas, all of which are absorbed by the plant at the moment of their extrication, enter into new combinations, and promote its vigorous growth. That this is not a merely mechanical advantage is proved in several ways; for instance, the benefit of the application of the de. composing compost is proved to be just as advantageous in some instances to the crop where it is not even mixed with the soil. This is shown by the effect (known to every gar- 
dener) which is produced by placing the manure in a chamber beneath the soil, so that the roots of the plants neither mix with, nor does the soil even touch the compost. 'The gases of putrefaction, however. arise and mix with the soil, and the most luxuriant effects are produced without any division of "the terrestrial matter," which Tull imagined to be so cssential to the explanation of the phenomenon. We need not search in the works of Tull for any attempts to use the drill for the application of fertilizers, for all Tull's efforts were directed to cultivate the earth without manure of any kind. He admitted the necessity of using it at all only with extreme reluctance; he told his readers, 7 years before his death, that "the particular scheme of raising constant annual crops of wheat without dung or fallow is as yet only upon probation; but, by six crops I have had in that manner, I see nothing against their being continued. This, it is true, requires greater care in their management than any other branch of the husbandry; but he who can do this without dung or fallow, may easily do it with one or both of them; and there may be such wet, clayey land which the plough cannot well pulverize without help of the ferment or dung."

Tull, in fact, let no opportunity escape him to decry the ill effects of employing manure. Modern gardeners would be astonished at his zeal when he contends for its banishment from the kitchen garden. "There is," he says ( $p$. 18), "much more reason to prohibit the use of dung in the kitchen garden, on account of the ill taste it gives to esculent roots and plants, especially such dung as is made in great towns. It is a wonder how delicate palates can dispense with eating their own and their beasts' ordure, but a little more putrefied and evaporated, logether with all sorts of filth and nastiness, a tincture of which those roots must unavoidably receive that grow amongst it. Indeed, I do not admire, that learned palates, accustomed to the gout of silphium, garlic, and mortified venison, equalling the stench and rankness of this sort of city muck, should relish and approve of plants that are fed and fattened by its immediate contact. People who are so vulgarly nice as to nauseate the modish dainties, and whose squeamish stomachs even abhor to receive the food of nobles, so little different from that wherewith they regale their richest gardens, say, that even the very water wherein a rich garden cabbage is boiled stinks; but that the water wherein a cabbage from a poor undunged field is boiled has no manner of unpleasant savour; and that a carrot bred in a dunghill has none of that sweet relish which a field carrot affords. Dung not only spoils the fine flavour of these our eatables, but it spoils good liquor. The dunged vineyards in Languedoc produce nauseous wine; from whence there is a proverb in that country, that poor people's wine is best, because they carry no dung to their vineyards." Our author, however, had a better opinion of vegetable manures than those of animals, for he says, "Vegetable dung, unless the vegetable be buried alive in the soil, makes a much less ferment in it, and, consequently, divides it less than animal dung does. But the dung of vege- tables is much more wholesume fur the use of edible rocuts and plants than that of anima!s."

Jethro Tull, according (1) Chalmers, clied at his house at Prosperous, January 3, 1740. Of his works and inventions of agricultural ma. chinery I have already spoken. Five chispters of his only work that I am acquainted with, The Horse-hoe Husbandry, were published in folio in 1731, the chief volume in 1733; and in the same year some additions were printed which are not found in many of the cropies of that year, or even in that of 1751. Cobsell. however, was careful to add it to an octavo edition which he printed in 1829. In this, he omitted only the plates of the ploughs and other agricultural implements; but he added an introduction, in which he did litule except laud Tull, and vituperate those who had adopted Tull's plans, without acknowledging the source of their obligation; not remembering that many a Tullian improvement has been often made since our author's time, by plain, practical farmers, who never even heard the name of 'Tull mentioned.

Tull, as I have before remarked, published his "addenda" to his Husbandry in the same year that the first edition appeared; in these he takes more notice than was perhaps necessary of certain attacks which had been made upon his book, by the members of a certain "equivocal society," amongst whom was the celebrated Stephen Switzer, the most talented seedsman, gardener, and horticultural author of his day. It appears, too, that a society of gentlemen in Dublin had, without his leave, reprinted for distribution his five "specimen chapters," all of which annoying circumstances evidently irritated him; besides these controversial notices, and certain corrections of the errors made by the printer, the long addenda do not contain any thing very valuable. Time has sctlled pretty well the respective merits of the contending parties; the fame of 'Tull is steadily increasing, while the name and works of even the classical, the elegant Switzer, are much too little known amongst modern cultivators.

Twenty-four years after the death of Jethro Tull, a paper appeared in the Gentleman's Magazine, vol. xxxiv. p. 522, dated at Hungerford. about 4 miles from the farm where he lived and died, and signed with the initials D. Y., which details almost all that is known of the life of the great introducer of the drill system. Ii was written by one of his neighbours, who had known and associated with him, and ralued very properly his services in the cause of agriculture. He describes in that essay the sensation produced by the unheard-of attempts of Tull. He says, "Novelty always excites curiosity-many gentlemen came from differen? parts on the fame of this new method of farming, some of whom were persuaded by the weight of Mr. Tull's arguments, tc go hand in hand with him in the course of his experiments, while others, who thought themselves more, 0 ise and more discerning, touk every occasion of ridiculing the practice, and of representing it as a fanciful project, that, after a great expense, would end in nothing but the ruin of the proprietor. In jeneral, the whos

$4 v^{2}$ :061 
body of farmers and husbandmen pronounced the man as a conjuror, who, by sowing a third part of his land, would make it produce a quantity equal to that of sowing the whole."

The farm of Jethro 'Iull will ever be an object of interest to the lover of agriculture. Arthur Young made a pilgrimage to Prosperous (Annals of Agr. vol. xxiii.p. 173), and William Cobbett did the same. More persons would visit it if they knew where it was to be found. To such it will be interesting to know that the rural parish of Shalborn is situated under the Coomb Hills, about 4 miles south of Hungerford; that the roads are tolerable, and the present holder of the farm obliging, and not insensible of 'Tull's great merits. If Tull was deceived in his beliet of the powers of the plough to render the soil fertile without the assistance of manure, he was yet fully justified in almost every thing that he predicted, with regard to the advantages of thoroughly pulverizing and increasing the depth of the soil.

"The difference betwixt the operation of the spade and that of the common plough," he observes, "is only this, that the former commonly divides the soil into smaller pieces, and goes deeper ;" and he adds, "how easy and natural it is to contrive a plough that may equal the spade, if not exceed it, by going deeper, and cutting the soil into smaller pieces than the spade commonly does." The explanation, too, which Jethro Tull gave to the advantages or theory of deep ploughing was excellent, considering the chemical knowledge of his days; for the modern cultivator must remember, that, in his time, the composition of the atmosphere was almost entirely unknown. T'ull could not have known any thing of the three gases, nitrogen, oxygen, and carbonic acid,-of which it is now found to be constituted; and of the existence of its insensible aqueous vapour he was equally unacquainted; he did not know how important these are to the roots of plants, and how the access of them all is naturally promoted by pulverizing the land on which they vegetate. But though Tull did not know these things, yet it is certain that he had carefully observed many facts which proved that vapour vas absorbed by the soil, and that this absorption was promoted by pulverization. "To demonstrate," he says (pp. 27, 28), "that dews moisten the land when fine, dig a hole in the hard, dry ground, in the driest weather, as deep as the plough onght to reach; beat the earth very fine, and fill the hole therewith; and after a few nights' dews, you will this fine earth become moist at the bottom, and the hard ground all round will become dry. Till a field in lands: make one land very fine by frequent deep ploughing, and let another be rough by insufficient tillage alternately; then plough the whole field crosswise in the driest weather, whicn has continued long, and you will percesve, by the colour of the earth, that every fine land will be turned up moist, but every rough land will be dry as powder from top to bottom. In the driest weather, good hoeing procures moisture to roots; though the ignorant and incurious fancy it lets in the drought, and therefore are afraid to hoe their plants at such times."

1062
TL:ese enlightened observations of Tull have been verified and illustrated by the progress of agricultural discovery, by the improved modes of practice adopted by modern farmers, and by the march of chemical philosophy. Evelyn had observed the advantages of continually keeping the ground of fruit orchards hoed or dug. Sir Henry Steuart attests, with Sir Walter Scott, Withers, and a hundred others, the same fact, as applicable to timber plantations. The farmers of even the most sandy soils of Norfolk, on the very same principle, keep the ground between their rows of turnips constantly stirred, just as Tull proposed and practised a century since. And when, long after Tull was in his grave, Dr. Priestley discovered the oxygen gas of the atmosphere, it was soon found that its presence was essential to the growth of plants; that it was highly grateful to the roois of plants, either when applied to them in its simple state, or when combined with the aqueous matters of the atmosphere; and that this application was very sensibly indeed promoted, in either form, by increasing the finely divided state of the soil; and, further, that without this division of its particles, the earth was totally incapable of absorbing either the necessary gases or the watery vapour.

The subsoil-plough of Mr. Smith of Deanston, and the subturf-plough of Sir Edward Stracey, which have both proved so successful in our days, only illustrate the truth of Tull's principles and Tull's sagacious observations Tull was an advocate for deep ploughing, and for internal pulverizations: he did not, it is true, see the necessary limits, on ordinary soils, and with common ploughs, to the realization of this theory: he forgot that the inert nature of many substrata would render it impossible to bring them at once to the surface; but though he omitted to take this into his calculation, yet still he argued correctly enough, when he so strenuously urged his brother farmers to increase the depth of their soils by every practicable means, to let in the air to the roots of their crops, and to give every facility possible to the growth of the roots of the plants; for, by so doing, he very plainly told them they derived benefits which exclusively belong to the vege. table world. "There is yet," he said (p.28), "one more benefit hoeing gives to plants, which by no art can possibly be given to animals; for all that can be done in feeding an animal is, to give it sufficient food at the lime it has occasion for it; if you give an animal any more, it is to no manner of purpose, unless you could give it more mouths, which is inpossible; but, in hoeing a plant, the additional nourishment thereby given enables it to send out innumerable additional fibres and roots; so that hoeing, by the new pasture it raises, furnishes both food and mouths to plants."

'To every agricultural operation, in fact, of a mechanical nature, Tull's genius was admirably adapted; his ploughs, his hoes, his drills, were all of a description far superior to those of the rest of the farmers of those days. It was only where he attempted to reason upon the habits and food of plants, involving chemical truths, that Tull made great blunders. Thus, 
believing, as he did, that earth, ard earth alone, was the sole food of plants of all kinds, he ridiculed the opinion of Dr. Woodward, that all the constituents of plants were conveyed to them through the agency of water. Woodward thought, very justly, "that water is only the agent that conveys the vegetable matter to the bodies of plants, that introduces and distributes it to their several parts for their nourishment." This theory seemed absurd to Jethro 'Iull, who believed that all plants fed upon the same kind of food, and that that food was earth, and only earth. It is true that ' $T$ ull had a very indistinct idea that something else was requisite for the food of plants, and that "certain materials contribute in some manner to the increase of plants." And he then specifies five substances, at the head of which it is not a little singular that he places saltpetre or nitre. But how this salt operated as a fertilizer was not at all more clear to 'Tull than to any who have succeeded him in the investigation. "Nitre," he says, (p.10), "is useful to divide and prepare the food, and may be said to nourish vegetables, in much the same manner as my knife nourishes me, by cutting and dividing my meat; but when nitre is applied to the root of a plant, it will kill it as certainly as a knife misapplied will kill a man. Nitre is, in respect of nourishment, just as much the food of plants as white arsenic is the food of rats." Tull, however, had a high opinion of the powers of common salt, when used as a steep for seed-corn, to prevent the smut in wheat; and he gives ( $p .66$ ) this account of the origin of the practice. "Brining of wheat, to cure or prevent smuttiness, was accidentally discovered about 70 years since, in the following manner: A shipload of wheat was sunk near Bristol in autumn, and afterwards at the ebb-tide all taken up, after it had been soaked in sea-water; but it being unfit for making of bread, a farmer sowed some of it in a field, and when it was found to grow very well, the whole cargo was bought at a low price by many farmers, and all of it sown in different places. At the following harvest, all the wheat in that part of England happened to be smutty, except the produce of the brined seed, and that was all clean from smuttiness." He then gives the farmer directions for drying the brined seed, by rolling it in quicklime, just as is now commonly practised by the farmer.

Water, Tull thought, was not a food for plants, because it commonly contains earth, to which he attributed the origin of the common opinion that water is a food of plants. And as to air being their food, which it certainly is, Tull considered this as a complete "phantasie," -quite an "riry hypothesis." In common with many of the learned of his days, Tull here strangely confused himself, by not attending to observations and experiments with regard to flants, and to these only. The merit, however, of Tull, amid his occasional mistakes, was enhanced by his modesty; and it is impossible for us, when we reflect upon the difficulties he had to encounter in the prosecution of his researches, and in the production of his bonk, to be insensible to his appeal, where he tclls us, at the conclusion of his preface, "One cause that made the three parts of this book (that is to say, the theory, or speculative part, the prac. tical part, and the description of the (min) s, the more defective was, that all three were (m) many for me to make perfect at once, and iwo would have been useless without the thir! therefore, it was better to give but a slimb of all than to have made any two of thrm never so full and perfect, leaving out the other."

Such was the modesty, such were thro meril. of this great father of the drill and the hursehoe husbandry, to whose memory sumethring, I hope, will one day be erected-sume memorial to indicate the agriculturist's gratitude, worthy of the English farmer. Tull lies buried without even a stone to indicate that such a benefactor of agriculture reposes beneath it. His grave is even doubtfully placed. If Tull dieis at Shalborn, as Chalmers asserts, he wis rirt buried there. There is no trace of him in the parish register; the tradition of the old people of the neighbourhood is, that he died and was buried in Italy. His deeds, his triumphs, it is true, were of the quiet, peaceable kind, with which the world in general is little enamoured; but their results, their value to the land of his birth, were of no mean order. His drill, his horse-hoe, have saved his country, in seed alone, the food of millions; and when used as a distributer of manure, it has done, and it will hereafter accomplish, still greater things. It has brought into cultivation thousands of acres of the barren craig, the wolds of Lincolnshire, of the deep sands of Norfolk; and its powers are not yet nearly exhausted, for, as fresh fertilizers are discovered, the drill evenly and economically distributes them; and as improvements in its construction are continually taking place, there is evidently much yet to be achieved by its use. The same remarks apply, in a great measure, to his hoe, and to his system of attempted cultivation without manure; for, although the last was a complete failure. yet even this bold attempt was not unattended with benefit to agriculture; for the farmer was hence taught, that, although by deep ploughing and complete pulverization of the soil the use of manure could not be entirely avoided, yet that by these means a much smaller quantity was sufficient than under the old and indolent mode of tilling the land. The efforts, too, of 'Tull were productive of advantage in other and in indirect ways;-his researches, his successes, his example, excited a spirit of inquiry, which since his days has hardly ever entirely slumbered. He was certainly the first who dared to boldly quit the beater track, which had been used by the farmer for ages, and follow a way of his own. And although he has been well followed and imitated by succeeding cultivators, who have availed themselves of new discoveries and machinery of which Tull had not the assistance, yet there have been none who have since excelled, or perhaps equalled him, in the boldness and originality of his conceptions, or in the energy with which he realized them. (Quart.Journ. of Agr. vol. xi. p. 342.)

TUMBREL. A sort of dung-cart, conveniens for many purposes.

TUMBRII. A machine employed chiefly in the county of Lincoln, for the purpose of sivios 
hay to sher zuring the winter. It resembles the basket fish-pots used by fishermen, and consists of a circular cage or crib, which may be made of osiers, willows, or other pliant brushwood of any kind. The whole 1 s about 10 feet in circumference, and closely wattled to the height of about one foot, above which it is left open for the space of 18 inches; it is then wattled again to the height of 8 or 10 inches, and an opening, about 18 inches in breadth, is left at the top, for putting in the roots or other food, whether green or dry. The staves which form the skeleton of it are 10 inches asunder, so that 12 sheep may feed at the same time in each tumbril.

TUPELO. Under this name Michaux describes three species of the genus Nyssa found in the United States. One of these, the Nyssa aquatica, has already been described with the Black gum, with which it is commonly confounded where both grow together. (Michaux, vol. iii. p. 40.)

TURF. A term often applied to the green surface or sward of grass lands. Also the name given to peat, which is used in several parts as fuel. It varies much in its nature in different places, being sometimes hard and of a dark or black colour, while in others it is soft and spongy. It is a substance very useful in burning calcareous stones into lime. See Lime, Moss, Peat.

TURKEY (Meleagris gallo-pavo). A wild fowl, originally introduced into Europe from America. They require care in their infancy. The black turkey is the best sort, both for size and delicacy. 'Turkeys are particularly clean birds, loving sweet food and delighting in air. 'They prefer roosting in trees, for which reason an evergrecn, such as a yew tree, spruce fir, $\& c .$, is a great advantage, planted in the centre of' a ponltry-yard. Turkeys and pea-fowl hop up gradually from the low branches, and are sheltered from frost. But where this is not the case, the turkey-house must be dry and warm in winter, and cool in summer; it must be kept free from vermin, and the dung and litter of feathers, \&c., should be often swept away. The perches must be large for their talons to grasp; and there should be plenty of ventilation, by gratings or holes bored in the Aloor.

Turkeys seek quiet places to lay in, and often stray far from home. Their nest must be watched, and the newly laid egg exchanged for one made out of challs every day. The turkey-hen lays from 12 to $20 \mathrm{eggs}$; and when she desires to sit, place her in the turkey-house on her eggs, and coop her up with them, if she is unwilling to remain, till she becomes settled. Do not disturb the hen while sitting, or attempt to assist the chick in piercing the shell. When the young ones are born, keep them in the nest for some time, as they love warmith, but do not handle them. Keep them warm and dry. When the red colour of the head appears, they are considered safe from the diseases of their infancy. Do not allow a turkey to sit twice in a scasun; the young ones never succeed unless they are full feathered before Michaelmas. Feet young turkeys three or four times a day, and let the food be a thickish paste, made of fine barley-meal, mixed with finely chopped onions, netles, and pot-herbs. The French give their turkeys plentiful supplies of nettles, of which they are very fond; it is a warming and nutritious herb. Let the food be given fresh every day, and place it on a board with a shallow pan of water. Coop the hen while the young ones feed, or she will eat it herself. When the chicks begin to follow the turkey into the poultry-yard, do not let them out till the dew is off the ground. Vetch and marrowfat peas are poisonous to young turkeys; lettuce brings on looseness; and hemlock and henbane should be destroyed near all poultryyards.

'Turkeys love oats, boiled potatoes mashed with the meal of buckwheat, barley, or beans or plain barley, like other fowls. Let the water always be sweet and clean. A turkey is six weeks fattening; if possible, feed two or three together, as they do pot love solitary confinement. Let them eat as much as they like, but let the food be fresh every day, and let it be the paste above mentioned, softened by melted lard. Cramming turkeys is a cruel practice, and is not often done. They will feed well enough and fast enough if plenty of sweet food is placed before them, and if they are allowed some little space to move about in. It is a curious fact, that turkeys in America feed on the caterpillars that are found on the tobacco plant with impunity.

Turkey eggs are very good in pastry, and mixed with hen eggs they improve omelets. Turkey's dung, properly mixed with other com. posts, makes a valuable manure.

TURNIP (Brassica rapa). No vegetable has had such influence in advancing the husbandry of Great Britain as the turnip. By whom and at what period turnips were first used in England as the food of cattle, however, does not appear; but from various accounts, their culture and uses were known in the Low Countries as far back as there are any records. The ancients ap. pear to have been well acquainted with the value of this root; Columella, speaking of the several kinds of vegetables adapted for the farm, recommends the cultivating of rapa in plenty, because, says he, those roots that are not wanted for the table will be eaten by the cattle. Worledge, in his Mystery of Husbandry, \&c., printed in 1669-81, says, that "although turnips be usually nourished in gardens, and be properly a garden plant, yet are they, to the very great advantage of the husbandman, sown in his fields in several places in England, not only for culinary uses, as about London and other great cities, but also for the foou of cattle." Again, he says, "that in Holland they slice their turnips with the tops, and rape-seed cakes and grains, \&c., and therewith make mashes for the cows and give it them warm, which the cows eat like hogs." He likewise complains of the very great neglect and deficiency of English husbandry in this particular. Some time since, a very excellent paper "On the Cultivation of the Turnip Crop on Light Soil, by Mr. M. Milburn," appeared in the Transacions of the Yorkshire Agriculiural Society, from which this paper is chiefly extracted.

It is generally supposed that the cultivation 
of turnips as a field crop was introduced into Norfolk by I,ord Townshend; but there is still further evidence that they were known as such some time before the date assigned for their introduction. They are mentioned in HoughIon's Collection of Papers, vol. i. p. 213, as food for sheep, in 1684. Since that period considerable improvements in their cultivation have taken place, and a great variety of very inferior soils have been made capable of growing considerable crops of them, by judicious management and proper selection of manure.

On the value and importance of the turnip crop to England, it is unnecessary to expatiate. Not only does it enable the farmer to supply the consumer with fresh meat during the winter, instead of the salted food upon which our ancestors had almost exclusively to depend, but also partially supplies the place of a fallow; it imparts to the land a degree of fertility which ensures, under proper management, a succession of crops for the fullowing years of the rotation. It is indeed the sheet-anchor of light soil cultivation, and the basis of the alternate system of English husbandry, to which every class of the community is so much indebted.

Preparation of the Soil.-Turnips generally succeed a crop of wheat. In some cases, on very poor soils, the clover leys are broken up for turnips; and, on others, a crop of winter tares, either mown or depastured, are taken off between the wheat crop and ploughing for turnips. As a regular system, the former cannot be pursued; for the frequent recurrence of the turnip and clover crops would operate injuriously, and defeat the object of the cultivator; and the latter is only applicable to soils quite free from root weeds, of a superior staple, or in a very high state of cultivation.

As soon as the grain crop is secured, and the stock have passed over the stubble, it is desirable to have it ploughed, to subject the soil to the ameliorating influence of the frosts of winter. In all cases the plough should be below the couch-grass, which is usually most abundant on inferior soils, but seldom below the mould. In ordinary cases, nothing is more necessary than to prevent the water from standing in any part during the winter; where the land is intended for Swedes, an effort should be made to have it partly or entirely cleared of weeds before the winter

When the land is free from weeds, the crossploughing may be begun as soon as the dryness will admit of it. It may take place in February with advantage; inasmuch as it exposes a new and more extensive surface to the action of the frosts which generally succeed. If allowed to remain a month or two longer, it may advantageously be crossed with Finlayson's harrow. Where the couch-grass, however, is abundant, it is positively injurious to cross-plough early, as the operation breaks the roots, and renders the clearing of the land afterwards tedious and difficult. Where very abundant, the operation should be delayed until the soil is dry, even if it should be the latter end of April or the beginning of May; more will be effected by one ploughing in this case than by two under different circumstances.

When the dryness admits of it, usually in two or three days, the land should be harrowed across; first with the patent or hinge harrows. and subsequently with the loose harrows, which separate the rubbish mure effectually from the soil; and then the werils should be raked wir, which is generally performed hy women.

As soon as the couch-roots, \&ie, are fienared off, either by carting into large, or burning in small heaps, the land may be dragged with Fin. layson's or any approved drag; and the same course followed alternately, so lone as any roots remain. When they are unable in rake them off, they should be hand-mathered, ard no dependance whatever should be placed on the destruction of any by the sun's rays, until the 25 th of June, a time when, on most soils, the sowing should be concluded. It is drsirable that the land should lie a week or ten days before the last ploughing is given to it, as it adinits of the germination of such seeds of weeds as may be lying dormant in the soil, and is likewise favourable to the accumulation of moisture in a dry season. The turnip-seed should be sown immediately, however, after the last ploughing.

Manure-In treating of the manures with which the turnips should be dressed, farm-yard manure stands the foremost, because it is what every farmer possesses, and, with the excep. tion of the calcareous soils in the East Riding of Yorkshire, is almost invariably employel in the cultivation of turnips. In general, it never will, and never can be superseded; and, though every deference is due to the practical knowledge of the East Riding farmers, there can be no doubt that, if their straw were mure curefully made into manure, and applied to the turnip crop in conjunction with bones, it would be decidedly advantageous. It is unnecessary to say that house-made manure, and by fattening cattle, especially such as are consuming artificia! food, is the best; and that of horses, cows, pigs, \&c., should be mixed as intimately as possible, the hot character of horses' dung neutralizing the coldness of that of the cow, and vice versâ. It is desirable to cart this mixture to the fields intended for turnips in January and February, during the frost, or at such other times as convenience may dictate; but the ear. lier the better. About three weeks before used it should be turned over, the sides of the mixen being carefully turned into the middle. Without entering in particular into the much disputed question of the fermentation of dung being useful or otherwise, thus much every farmer will know well the truth of, that oin light soils. and for turnips, well rotted dung is indispensable, where it is used at all. When fermentation is progressing so fast as to induce destructive heat, or mouldiness, it may be checked by treading the mixen and covering it with scill; and when it is sluggish. it may be excited by turning and watering.

For sandy or gravelly soils, farm-yard manure is an almost necessary ingredient in producing a crop of turnips. The rapid decom. position of vegetable matter which takes place on such soils requires that there should be a supply for that succulent crop; and, as before stated, there can be no doubi of its utility u calcareous soils; hut for peaty Jescriptions

1065 
where there is abundance of vegetable matter, it is less useful.

The time for laying on the manure depends on the method of sowing adopted, and clearness of the land from weeds. If the ploughdrill be used, it is desirable to immediately precede the plough; if the Norfolk, or large drill, it is beiter to lay it on a week or two before sowing, to allow it to mix intimately with the soil, especially if other manure is intended to be used, and the soil pretty free from weeds. The quantity to be applied will vary with circumstances: 12 to 14 tons per acre may be stated as an average, and more if the soil be poor and no other manure intended; while less may be used in proportion as other manures are applied.

Lime stands next in importance, as a dressing. The object of all manure is to supply some deficiency, remedy some mechanical inconvenience, or correct some detrimental agent in the soil. When dung, for instance, has been applied for several successive crops, a quantity of undecomposed vegetable matter accumulates, which the natural soluble properties of the soil cannot dissolve, and it remains inert. A dose of lime will correct this, and bring every particle of such inert matter, with which it comes in contact, available as food to the plants. It also assists in the intimate pulverization of the soil, as well as corrects any acidity which may exist in it, from causes which the agriculturist can seldom foresee, nor correct, except by its use. It is also destructive to weeds in the soil, and hence exceedingly valuable; for every farmer knows that weeds, being indigenous, are much more ready to grow in the soil than his crops, which are artificial, and often exotic. For peaty soils, an occasional dressing of quick lime is invaluable, especially if there is an addition of clay, road scrapings, \&c., to give the requisite firmness to the soil. It should be laid on as soon as convenient after bringing from the kiln, and in as hot a state as possible. The time for laying on lime is a few weeks before the sowing, in order that the subsequent ploughings may mix it thoroughly with the soil, and thus its effects be more immediate after the sowing. The quantity per acre entirely depends upon the character of the lime in the locality. Two to four chaldrons per acre are used; but as it is applied for turnips generally in conjunction with other fertilizers, the former may be stated as the better quantity. If dung is also applied, they should be used at as great a distance of time between each other as circumstances will admit of, and the latter not long before the sowing.

Bones form one of the most valuable manures for turnips on all light soils, on account of their portable and stimulating character; they are least useful on a gravelly or loamy soil. They have converted barren moor lands into rich, fertile, and productive farms, luxuriating in every valuable product of the earth. Their value is beyond all praise. The East Riding of Yorkshire affords a specimen of what they have effected; and they require only

? be known to be extensively applied. I 1066 many cases they are used alone; in others, in conjunction with farm-yard manure, with ashes, and with lime. Ashes are sometimes drilied with them as a substitute, by diminishing the quantity of the bones. Lime is a valuable auxiliary, on "old going land," or soil which has been long under cultivation. On pea:y soils, having a substratum of sand, they have produced wonderful crops, by supplying them with the necessary animal matter. The quantity varies from 12 to 30 bushels per acre. Sixteen bushels per acre will produce a fair crop, on average soils; and some farmers say that more than that quantity is waste. It is desirable to mix them with a quantity of ashes, when they are drilled in the above quantity. This facilitates the early progress of the plants, and supports them until the bones become available. English bones are generally preferred to foreign; but from experiments made by the writer, he prefers foreign to Englict and also to recent bones; for, although thlatter have more of their juices than the former the former sooner decompose; and the fat and animal juices require considerable chemical changes before they are available as food for the plants. A mixture might be judicious, but he has not tried it, nor is he aware of the trial having been made.

Other manures of a miscellaneous character are used for turnips. Pigeon's dung is most valuable; rape dust has been used successfully; and animalized carbon has also been advantageously employed. Sixteen bushels per acre, when drilled, is the quantity generally applied. Malt eulms are useful as a top-dressing. (Trans. York. Agr. Soc.)

A machine for sowing turnip-seed with bonedust is described in the second volume of Trans. High. Soc. p. 205; and the results of some experiments with different manures is given, Trans. High. Soc. vol. i. p. 66, 72, vol. iv. p. 233.

Weir's Manuring one-row Turnip Drill, is described and figured by Loudon, and said to be a remarkable improvement on the Northumberland implement. It has a manure hopper, and a seed hopper, the same as the others; but the manure, in place of being dropped along with the seed, is deposited in a deep gutter made by the coulter which goes before; this manure is covered by a pronged coulter which follows the other: next comes the coulter which forms the gutter for the seed, which are deposited 1 inch above the manure. (See Loud. Ency. of Agr.)

Varieties.-There are numberless varieties and sub-varieties of turnips, which arrange themselves under four heads:-1. Swedish turnips, or Ruta buga; 2. Yellow and white turnips; 3. Yellow turnips; and 4. White turnips. Professor Low has divided them into three classes, distinguished by their form:-1. The round, or globular; 2. The depressed; and 3. The fusiform. These may be considered as types, to which the different cultivated kinds more or less approach. Many varieties are cultivated which are more fanciful ihan useful. For the main particulars of the following list I am chiefly indebted to an interesting Essay on 


\section{TURNIP.}

Turnips published by Dr. William Ellis of Caistor, Lincolnshire, and to Messrs. Lawson's excellent Agricullurisl's Manual.

Swnisu Tunnps.-The Ruta Raga, or Swedish turnip is hardier and more nutritious than any of the common sorts, and in addition to its being more esteemed as food for horses throughout the turnip season, is better adapted for spring feeding generally. It, however, requires a somewhat deeper and superior class of soils, logether with a greater allowance of manure. Swedish turnips are generally sown from about the middle to the end of May, and 2 to $2 \frac{1}{2} \mathrm{lbs}$. of seed per imperial acre are, under ordinary circumstances, considered sufficient. They possess an advantage over the others in being easily transplanted, so that the blanks in the rows, either of the Swedes or other sorts (when they occur), are by that means easily filled up.

Skirving's new improved Purple-topped Swede.Mr. William Skirving of Walton Nursery, near Liverpool, who has for many years directed his attention to the improvement of agricultural roots and plants, introduced last season for the first time the above variety. From comparison with every known variety of turnip, which Mr. Skirving has been at pains to collect from all quarters, both in England and on the continent, it appears to have shown itself to possess all the good qualities of a turnip, and gives a greater weight per acre of sound nutritive bulb: it is also hardier, and keeps longer than any other variety. The leaves of Mr. Skirving's Swede appear to partake considerably of the character of those of the common turnips, being less smooth and more serrated at the edges, and deficient in that glaucous bloom which distinguishes the lcaves of the genuine Swedish turnip, which leads me to suspect that he has attained the size by hybridizing with some of the larger varieties of yellow turnips.

Bullantyne's new improved Purple-topped Swede. -This improved variety for symmetry of shape, equality of size, and for the uniform deep purple colour of its top, is unsurpassed by any other variety which has come under our notice.

Scott's Prize Purple-topped Swede.-This is oxheart shaped, purple above ground, and yellow fleshed, with a small top.

Laing's new Pu'ple-topped Swede is a decidedly distinct variety. It has a leaf something like that of a lettuce. The leaves are so inserted in the top of the turnip as to give it much the appearance of that of a pine-apple. It grows to a good size, keeps well, and bears a very high character among the agriculturists of Berwickshire and Northumberland, where it is extensively cultivated. The crop has a most beautiful appearance when in full leaf.

Green-topped Ycllow Swede.-This variety is of longer standing than the purple-topped, since the introduction of which less attention has been bestowed by cultivators in procuring improved stocks of the green-topped Swede, which has on that account fallen somewhat in the estimation of growers; but, where the same care is taken in selecting the roots grown for seed, the green-topped may be considered as being equal in merit to the purple.

Scott's Prize Green-topped Yellow Swede is an im] roved variety of the above. The purple-
TURNIP.

topped Swedes are at present nore pupular, as we before mentioned; but where, as is the case with Mr. Scott's, equal care has lieen bestow wed on the selection of stocks, and in the subsequent management, the green is in no way inferior to the purple-topped varimy.

Hillyard's Thorpeland S'wede.-This has the appearance of a true Swedish turnip, and is said io be more nutritive, bulk for bulk, than some of the larger varieties, which may or may not be the case. Its dwarfish size, and the impossi. bility of raising any great weight of food per acre from it, must, notwithstanding its other merits, be a great obstacle to its making its way among the larger sorts which now invite the attention of cultivators.

Cox's new Imperial Swerle.-This variety may be considered as intermediate in colour between the purple and green-topped sorts; its roots often attain a large size, but are rather irregular, and of a some what coarse-like quality.

White Swede.-The roots of this turnip are very irregularly shaped, with numberless fangs: they are white under the surface of the ground, and greenish above. It is impossible to say what improvement may do for even this kind, but at present we are acquainted with no variety of white Swede worthy of cultivation.

Yellow and Whi'e Tervips.-Common turnips are divided into two important classes, viz. the white and yellow-rooted; the former comprehending those which are most tender and arrive soonest at maturity, and which are best fitted for using during the earlier part of the season; and the latter, with trifling $\in$ xcep. tions, such as from their hardiness and period of arriving at perfection, are intermediate between the white sorts and the Swedes, and, like the latter, require a somewhat superior suil and an additional allowance of manure. The period of sowing common turnips should be regulated according to the length of time that the variety to be grown requires to arrive at maturity; for when allowed to remain in the ground in what may be termed growing weather, or before winter sets in, after they attain to a full size, they become soft, spongy, and of inferior quality. A general rule, however, is, to commence with the yellow sorts about a fortnight after the Swedes, or about the beginning of June, and to follow with the white sorts from the middle till towards the end of that month.

YELLow Tursips. - Altringham Yellow.This turnip-although from its being rather below the medium size attained by yellow turnips in general, it is more particularly snited for garden culture-is also in good repute in some quarters as a field turnip. It is recommended for its fine globular shape, and the superior solidity of its flesh. It has a light greenish top, very small neck, and tap-root.

Aberdeenshire Sugar Iellow.-This is a very hardy turnip; it buries jtself considerably in the ground, is highly nutritious, and one of the most approved of the varieties ately introduced.

Border Imperial Purple-toppea Yellow.-The following particulars, respecting this vanetr. are given by Mr. Hogg:- "This turnip possesses all the qualities of the Swedish, with the advantage of being a much freer grower 
It produces a larger crop than the white globe, is a good feeder, and stands the winter better than any of the common yellows. It is in full perfection for using in February, and continues for as long a period as the Swedes; and should the latter fail, the border imperial being sown as late as the month of June, will yield a crop equal, if not superior, to what might have been expected from the Swedes, had they succeeded."

Green-topped Bullock Yellow.-This turnip attains a medium size. Its shape is globular, or somewhat flattened, with a very small tap-root; it is an old variety, and is held in deserved estimation.

Purple-topped Bullock Yellow.-This variety differs from the former chiefly in the colour of the top; the size, shape, and quality of the roots being pretty nearly the same. It is also highly esteemed, and is considered by some to come nearest to the Swedes in hardiness and solidity of texture.

Skirving's Improved Purple-topped Bullock Yellow.-This improved variety of the above obtained for its introducer-Mr. Willaim Skirving, of Liverpool--the medal of the Highland Society of Scotland. It has been generally grown for a number of years by the first agriculturists in Lancashire and the northwestern counties.

Green and Purple-topped Yellow Scotch differ but little in any of their essential properties from green and purple-topped bullock yellow. The roots are flatter, and grow more in the ground.

Ox-heart Yellow is an excellent turnip; although it comes early to maturity, and attains a considerable size, it is by no means deficient in hardiness.

Yellow Globe.-This is a superior turnip, both for field and garden culture. Its roots are of medium size, globular, and always nearly under the surface of the ground; top greenish, leaves rather small and spreading.

Yellow Sone.--This variety differs from the last in growing more out of the ground, and having a greener top; in other respects it is pretty similar.

Brown-topped Tankard Yellow.-Root bright yellow, with a purple or brownish top, of a somewhat irregular long or tankard shape. This variety is in great repute in Aberdeenshire. A sub-variety, of not so very long a shape, is preferred by some growers. They are both excellent turnips.

Green-topped Tankard Yellow differs from the above chiefly in the colour of the top. Of this there is also a sub-variety, of a flatter shape.

Large Laurencekirk Yellow Tankard, introduced by Mr. Robert Scott, of Laurencekirk, resembles Dale's hybrid in many particulars, like which it grows a good deal out of the ground, but is distinguished by its more oblong and more uniformly shaped roots. It arrives early at maturity, but is generally considered as rather less hardy, although it yields an equally bulky crop.

Dale's Hybrid.-This highly esteemed variety -s a cross between the green-topped Swede and white globe, procured by repeated impregations. Its most distinguishing characteristics 1068 are as follow:-foliage strong and luxuriant roots of a large size, oblong shape, and of a lightish yellow colour, with light green top, having also a small neck and tap-root. The form of the root, however, although generally oblong, is rather apt to vary, being sometimes almost globular; but its more material characteristics, of large size and luxuriance of growth, are always the same. Compared with any other of the yellow field sorts, it is found to arrive sooner at maturity, and consequently may be sown at a later period of the season; while at the same time it is equally hardy, or at least has been found sufficiently so, to withstand the severest winters which have occurred since its introduction.

Gordon's Yellow.-This very superior variety is of a rather oblong shape, deep green colour on the top, which is generally very slightly tinged with red. It is very nearly allied to Dale's hybrid, being a cruss between the Aber. deenshire bullock yellow and the Swede. Sir F. A. Mackenzie, Bart., upon whose extreme accuracy as an experimentalist the utmost reliance may be placed, grew last year a considerable number of the most approved kinds of turnips, on his farm at Conan Mains, near Dingwall, in Ross-shire, with the view of selecting such as might be found most worthy of being kept in cultivation as best suited to the soil and climate of Ross-shire. The result of his experiments was, that of Swedes, Skirving's is decidedly the best, Gordon's yellow the best of the yellow-fleshed, and Scott's purple-topped hybrid and the old white globe, of the white-fleshed kinds.

Hood's New Large Yellow is a very superior, large, globular-shaped, hardy turnip, remarkably perfect in symmetry, with rather a lightish green top.

Pollexfen Yellow.-This turnip derives its name from its introducer, Thomas Pollexfen, Esq., of Cairston. From his peculiar method of selecting and transplanting the bulbs, as well as of stacking and preserving the seed, the turnip-seed of Mr. Pollexfen's growth has long been held in deserved estimation in Scotland, and has commanded the highest prices. The insular situation of Orkney, although in latitude $59^{\circ}$ north, renders its climate less exposed to the extremes of heat and cold than in more continental situations farther south, the winters being mild, and the frost so gentle that the ice is seldom sufficiently strong to sustain the weight of a man. Its climate is on that account peculiarly favourable to the growth of turnips, and turnip-seed grown in Orkney is accordingly highly prized by the Scotch farmers. The Pollexfen yellow is a green-topped turnip of a large size, rather flattish in shape, skin very smooth and thin; the flesh is firm and nutritious, being slightly impregnated with the green topped Swedish. It is adapted for winter and spring feeding, and is not liable to injury from frost. This turnip obtained the prize at the meeting of the Highland and Agricultural Society of Scotland, held at Inverness in 1836 , in the report of which it is highly commended.

White Turrips. - White Globe.-Roots globular; skin smooth, and perfectly white; neck 
and tap-root small. Although the above description embraces the principal characteristics of the white globe turnip, yet there is a considerable variety in those to which the name is applied, arising from the degree of care and attention bestowed by growers in selecting their seed-roots; and the shape is often not a little affected by the kind and state of the soil in which they are grown. Thus globes of any kind, and particularly the variety here mentioned, when grown on a very superior rich soil, may be said to be forced beyond their natural size, and thereby acquire somewhat of a monstrous or overgrown appearance, losing in a great measure their natural symmetry of shape.

Pomeranian Globe.-This variety was introduced some years since from Pomerania, and may be considered the most perfect globe turnip in shape, as well as the most regular or uniform grower. Its skin is of a smooth white, and somewhat shining or transparent-like in appearance; leaves smoothish, of a dark green colour, with whitish nerves.

Green Globe.-Roots of a fine globular shape, with a small neck and tap-root; very white beneath, and green above the surface of the ground, of medium size, hardy and firm of texture, but scarcely so much so as the green round, although it arrives at maturity rather earlier.

Stone Globe.-This is considered to be the hardiest of all the entire white globe turnips. It grows naturally deeper in the soil than the others, and has stronger and darker green foliage.

Red Globe-Roots medium-sized, globularly shaped, and firm in texture. This is an old, and, in some districts, a pretty extensively cultivated variety. It is medium early, and generally allowed to be particularly well suited for light soils and exposed elevated situations.

White Round is known in Lincoln by the name of spring white. It is the largest of the round turnips, and, at the same time, the softest and most irregular in shape. It is generally hollowed towards the neck, and, being so, is apt to be injured by retaining moisture, which renders it unfit for using, except in the beginning of the winter season.

Green Round.-The round turnips are all of a peculiar flattish shape, rather hollowed towards their neck, as also on their under side; and, when grown to a large size, they become more or less of an irregular round, or somewhat cornered shape. The green-topped variety possesses these characters in a less degree than the former, and is generally of a pretty, regular, round shape, flattened, but not much hollowed, on the upper and under surface, the former of which is of a green colour, and the latter white. It is also the hardiest of the round turnips.

Red Round.-This sort is inferior in size to the two former, but rather firmer in texture, and more regular in shape. It should also be used in the early part of the season.

White Tankard.-The tankards, like the three preceding kinds, are unsuitable for winter feeding, not so much on account of their softness, as from their standing mostly above ground, and being thereby much exposed to frost. They are generally earlier in arriving at maturity than the others. The white tankard has its roots more than half out of the ground, oblong, or tankard-shaped, but often bent or crooked. It is the lareest of the tan. kards, but is also softer in texture than eithrep red or green; its leaves are large and luxuriant: it is the earliest in maturing of any, ?' $2 t$ will not stand the frost.

Green Tankard.- The roots of this specios are also more than half above ground; of a greenish colour, except on the uniler surface, which is white.

Red Tankard.-In size, form, and texture, this variety may be considered as occupying an intermediate place between the white and green tankard. It is of a bright red colour on the upper surface, and white on the under.

Lawton Hybrid.- Harly, ana possessed of more solidity and firmness than most of the white sorts.

Scott's improved Purple-topped IIybrid.-For a white-fleshed turnip is remarkably solid, and attaining a great size.

Lewisham Green-iopped Ox.heart.-An excellent variety, grown in some of the southern districts of England and Scotland.

The short seasons of growth allowed the turnip in the American climate, renders most of the preceding varieties unfit for culture. Mr. Buist of Philartelphia, recommends the two following preferable to the most superior of the European sorts.

Red or Purple-topped. (American,) shape flat and round, with purple top; very hardy and keens well. Sow about the end of August, or not later than the 8th of September.

White or Flat Dutch; often called strap-leavea' White, is in form, size and qualities, very similar to the preceding; it is more generally cultivated in the United States than any other kind of turnip.

Lewisham Green-topped Ox-heart.-This is an excellent variety, grown in some of the southern districts of England, and in Scotland. It acquired this name from having been first introduced by Messrs. Willmot \& Co. of Lewisham.

Aluiumn, Siubble, or Six Weeks.-Roots much above ground, rather large, of an irregular globular shape, or in form between the white globe and white round, and rather soft. This sort arrives sooner at maturity than any of the others, the tankard turnips perhaps excepted: and from its natural softness of texture should always be sown late, and used before the severe frosts set in. As descriptive of its forwardness, it has received the above names, being suited for sowing in early situations in autumn after the corn crop has been removed, and it is also valuable for making up blanks in turnip fields, where the first sowing may have partially failed.

The comparative nutritive powers of the different varieties of turnips appear to be as follow :-

Graiss of

64 drachms of the Swedish turnip afford

Stone or garden turnip

Norfolk white turnip.

Common or white loaf

Tankard or loug-rooted 
Methods of sa ving.-The modes of sowing are various; but the general principle to be attended to is, to get the seed into the nearest possible connection with the manure used, so that it may have all the advantage of its fertilizing influence in the earliest stage. This is forestalling, because, it decides the drill method to be the most valuable, before we describe the others; but it is a principle so necessary and obvious as to strike every reflecting person at the outset. The old broadcast plan was, to spread on the manure, plough it in, and then very carefully sow the seed with the hand. This practice is almost everywhere abandoned, nor can it be justified or recommended in any case.

The plough drill is used where farm-yard manure only is employed. The manure is spread on the ground, and the plough follows with the drill, being fixed to the right-hand side of the plough, and thus deposits the seed immediately in the seam made by the plough, and directly upon the manure just covered by the plough. The plough-drill is only useful where very bulky manure alone is applied. See Drite.

The ridge or Scotch method is used with success, especially on inferior and thin soils, and has its decided advantages. The ridges are made either with a single cast of the double mould-board plough, or a double one of the common or ribbing plough, and from 20 to 28 inches apart. A cart with manure follows, and women are generally employed to drop the manure into the seams made by the plough. The plough again follows, and closes the ridges, covering the manure; and the drill succeeds, drawn by one horse, and sows one ridge at a time. A light roller goes over the sown ridges to cover the seed, and sometimes the ridges are rolled before the sowing. This plan takes more time and labour to effect it, but the turnips generally succeed; and if they should be destroyed by the flea-beetle, they can be resown with more probability of success than by any other method.

The general and most expeditious way is by the large drill. 'This is constructed to deposit the bones, ashes, \&c., with the seed, upon the level surface, drilling 6 or 7 rows at once. It is drawn by 3 horses, and will drill 12 acres per day. The seed does not run down the same funuel as the bones, but has a separate apparatus immediately behind the latter, and the coulters of the drill generally cover the whole. A pair of light harrows are usually passed over once after the sowing; and should much heavy rain succeed, it is desirable to give it another furn with the harrows immediately before it is dry, to prevent it from scarping. The quantity of seed sown by each of these methods, is from 2 to 3 pounds per acre.

After Culture-When the turnip plants are of about 3 weeks' growth, they require to be thinned, and the weeds destroyed. This is usually performed by hand-hoeing; but in some cases Swedes are hand-thinned by woinen, and subsequently horse-hoed, which can be tone in all cases where they are sown in ridges, and is a considerable saving of labour. 1070
No two plants should be left together at the first hoeing, but they should be thoroughly singled; and a second hoeing must take place about 2 or 3 weeks afterwards, to destroy the weeds. For ordinary crops, they should be left 7 to 12 inches distant, according to the richness or poverty of the soil; if the latter is the case, they should be at shorter distances, as they will grow to a smaller size. The whole of the ground should be gone over, as it loosens the earth, and promotes the growth of the plants. The double operation is usually performed for from $6 s$. to $7 s$. per acre. Sometimes the crop requires hand-weeding in the autumn, especially if the soil is infested with charlock.

Diseases.-The extensive and repeated culture of the turnip has fostered the rapid increase of its natural enemies; and after all the pains, labour, and expense of the cultivator, he often sees his crop entirely destroyed, or seriously injured. The remedies he can apply for many of these can only be termed palliative; but still he has much in his power; and as the knowledge of natural history and field-entomology advances, he may expect more and more assistance. See Irsects.

The turnip flea-beetle (Haltica nemorum) is one of the worst enemies which attack the turnip plant, which it does when in its seedleaf state, and often destroys a crop, and even the second and third sowings. Various steps have been taken in order to prevent its attacks, and several steeps for the seed used, but without success; top-dressings of a saline and astringent character have been applied, but have failed; machines have been invented, but none of these have succeeded. The only directions which can be given are: sow plenty of seed; use stimulating manure, to excite the plants to vigorous growth in their first stages, and secure a sufficiency of moisture in the soil at the time of sowing; especially keeping seedlings in turnip fields clear of charlock, which nurses the flea. See Fly is Turnips.

The black caterpillar, larva of the Athalia centifolic, also preys upon the leaves in a more advanced stage, appearing on the plants when they are about 3 weeks old. See $S_{A W}-F_{L Y}$.

Another disease to which the turnip is liable, is vulgarly called "fingers and toes." See AxBURY.

The wire-worm is a sad enemy. (See WireWorm.) The swarms of aphides, or plant lice, severely injure the turnips; and, from the smallness of their size, are often unobserved. In 1836 they committed terrific ravages. They suck the juices of the plant, and appear in countless numbers. They are both oviparous and viviparous, and increase with amazing rapidity. Happily they are always followed by swarms of lady-cows, which feed on them, as well as insectivorous birds, which destroy vast numbers. No remedy can be applied with any probability of success. Every farmer should carefully protect swallows, red-breasts, \&c., which are great destroyers of the aphides.

Slugs are, especially on newly ploughed soils, great devourers of the turnip plant in all its stages. Ducks will devour them, but always injure the plants. Three bushels of quick 
lime per acre, scattered over the plants early in the morning, when the slugs are active, is a certain method of destroying them. Perhaps the very best preservative from ail the above diseases may be stated to be-liberal manuring, adapted to the soil; thorough clearing of the land from weeds; and, in short, pursuing the steps above detailed for securing a full crop. The vigour of the plants in such cases, and their rapid vegetation, often enable them to overcome many serious attacks.

Sloring.-There are different modes of performing this useful practice. The common way is to take up the turnips, choosing dry weather, cutting off the leaves and taproots (provincially called topping and tailing), which operation should be performed with as much exactness as possible, so as not to wound the bulb, as this would cause the turnip to rot; nor yet to leave much of the leaves, as this would make the turnip vegetate on receiving a slight degree of heat; after this the turnips are placed in a well-aired situation, adjoining to the feeding byre, in a narrow tapering ridge, similar to potato pits, and this is covered with straw and secured with ropes. The situation chosen for the store should be as dry as possible. The heaps must not be covered with earth, like potatoes; for this would cause the turnips to heat and completely destroy them.

But as this practice of storing is only adaptod for the Swedish and yellow varieties, the white globe variety possessing too much water ( $)$ be preserved for any length of time, another method is often practised by. what is called yluring. The tap-roots being taken off, the bulbs, with the leaves, are placed close together in the position they grew, upon some dry place near to where they are to be consumed. In this way they will keep longer than if they had been left in the field, as they are not so apt to run to seed.

But even the placing system has its objec:ions; for if a tract of dry weather set in, the turnips, from being merely on the surface, become soft and shrivelled, and not so palatable to the cattle, and will even continue so for a considerable time, although the weather should be rainy, until the fibres begin to take hold of the soil; and another objection is, that if the turnips are not placed near the steading, the destruction from game, hares, wood-pigeons, \&c. is very great, particularly if the turnip be Swedish.

In order, therefore, to remedy these objections, another method has been adopted, which has been found to answer every purpose iniended. The turnips are brought from the tield, without either "topping or tailing," to a piece of dry ground near the straw-yard; then a man with one horse in a plough makes a straight furrow; the turnips are then placed in the furrow quite close together, till the whole is filled from end to end; then the man with the plough moves round to where he commenced, drawing another furrow just as close to the turnips as to enable him to cover them, and so on alternately, the men making the furrow and covering the turnips, while the women and girls lay in the turnips. By this method the turnips keep as fresh, preserving all their natural juice and are as well relished by the cattle as though they were taken from the field: thus allowing the land to be suw w with wheal

'The report of the Harlesum Farmers' Pilub for 1839, affirms that the lesst mollind of preserving roots during the wibter, is by clamprong them, both as regards protection from frust and maintaining their quality; and that the follow: ing is a very effectual method of makifig the clamps:-Select a convenient and dry silna. tion, and pack the ronts carefully, with their crowns outside, in a row about 6 frot wide at the bottom, and terminating in a narrow ridge at the top; then dig a trench, commencing imnmediately at the edge of the runt-, 2 freet wide and $l$ deep, turning the mould from the heap: thatch the latter carefully with straw, commencing in the trench, so that all the rain may drain off the heap into it. The clamp may be left two or three weels in this state, that the evaporation from the roots may escape; the mould already taken out of the trench is then to be laid on the straw, commencing at the bottom of the thatch, and covering the heap 12 inches thick throughout, finishing with a sharp edge. Half the trench originally made will, of course, by this plan be filled up with straw and mould: the other half will remain as a channel for the water falling off the heap; and, as sufficient mould will not have been raised from the original excavation, it will be advis. able, in procuring more, to make the channel left round the heap a few inches deeper, as well as wider. If the roots are stored late in the season, and the probability of frost setting in renders it necessary to cover the heap with mould as soon as it is made, it would be better to leave the top uncovered for a week or ten days longer, that the heat may escape. There is no objection to the roots being wet and dirty when they are clamped: the tops should be cut off; but not too close to the crown; the roots and fibres should be left on.

In England, the turnip crops cultivated with so much care and at so much cost, yield a most abundant supply of vegetable matter, most of which, owing to the comparatively mild winters, is left on and in the ground to be eaten off by sheep. This adds great fertility to the soil and prepares it for producing those astonishingly luxuriant crops of wheat of 40 , 50 and 60 bushels to the acre. The profits of the turnip crop, either direct or indirect, must be very great, to authorize a tenant on land loaded with taxes, to go to an expense of nearly $\$ 50$ per acre in putting in his root crop, as may be seen in the article Appraisemert, where the details of expenditures in putting in only 17 acres of Swedish turnips are estimater at $£ 11715$ s. sterling, equal to nearly $\$ 900$, of federal money, a sum actually paid for the crop in the ground by an incoming tenant. The root crops of Britain which form the basis of her agricultural prosperity, can only be partially carried on in the United States, owing (o) the severity of the winter, by which every thing on or near the surface of the ground is bound in early and enduring frust. But then, where cold thus opposes a barrier, a high summer heat opens a new resource, and where nature obstructs the way in one direction, she ppens: others to agricultural thrift. One of these is 
the Indian corn crop, denied to Europe, except in a small space on or near the Mediterranean. The value of this crop, far transcending that of any other staple, is referred to under the head of Marze. In reference to the agricultural value of the turnip and other roots, $\mathrm{Mr}$. Nicholas Biddle in an aduress before the Philadelphia Agricultural Society in 1842, made the following interesting observations:-

"It is strange how things so lowly acquire national importance. The best farming is that which will give the greatest mass of sustenance to animals-since the less land required for animals, the more can be given for the maintenance of human beings. That fine farming region, England, had reached the limit of its power of supporting animals-since it turned to the root culture it more than doubled or quadrupled its power-and now, odd as the mingling of such dissimilar notions may seem, it is scarcely an exaggeration to say, that England's power is based upon its iron, its coal, and its turnins. Then, that beet, which the commercial jealousy of Napoleon endeavoured to raise to the dignity of the sugar-cane, which at this moment yields to France more than 60 millions of pounds of good sugar, and has now become so incorporated into the French agriculture as to divide the government of France between the encouragement of the foreign sugar-cane and the domestic sugar beet. 'To us the question is unimportant, since sugar is so cheap in this country as to leave to us the sugar beet as an excellent food for our cattle."

Although the excessive frosts in the United States interfere with the English plan of feeding the turnips from the ground during winter, still there is no question that great advantages may be derived by the American farmer from the cultivation of the turnip, the Swedish especially, to lay up as green and succulent food for stock, to be used conjointly with hay and other kinds of provender. Very satisfactory experiments have demonstrated the value of turnips appropriated in this way, for an account of which the reader may consult Buel's Farmer's Instructor, Coleman's Reports, the Cultivator, and other Am. agricultural periodicals.

The insects which attack turnips in America will be found described under the heads CATERPILlan, Flea-Beetle, Fly in Turnips, \&c.

TURNIP CART. This is an ingenious adaptation of the disc turnip cutter to the turnip cart. The disc is put in motion by a facewheel fixed upon the nave of the cart-wheel, which, as it revolves communicates by means (If cog-wheels with the axis of the cutlingplate. It offers a very convenient mode of feeding sheep on pastures or lawns, and was introduced about the year 1834, by Arthur Biddell, farmer, of Playford, the inventor of the well-known scarifier, which bears his name.

'TURNIP CUT'IERS. Although there are steral kinds of turnip cutters, the principles upon which they are constructed do not emlirace much variety: setting aside the simple application of the knife with a lever handle, the others may be divided into two classes; first, those which have their knives placed on a disc; and secondly, those with their cutting edges arranged on a cylinder.

1072
As the object to be effected is simple, and involves litule mechanical contrivance, a short description will suffice.

Gardner's Patent Turnip Cutter, is pronounced the best known in England. In Ransome's Barrow Turnip Cutter, Gardner's machine is used, the disc of which is attached to the side of a barrow, which serves as a hopper; the knife is nearly the length of the radius, and when required to cut the turnip in slices is alone used; if it be necessary to cut small slices for sheep, the small cross-knives are, by a simple contrivance, adjusted to dissect the slice; and in this case the barrow is useful, as it is easily moved from trough to trough, into which the small slices may be made to fall.

It is intended to cut into small slices for sheep, and is generally acknowledged to be the best implement for the purpose that is at present in use in England.

TURPENTINE. A transparent, oleo-resinous substance, which exudes naturally, but is chiefly obtained by incision, from various species of pine. There are several kinds of turpentine, namely, common, Bordeaux, Canadian, Strasburg, Venice, and Americ:an white. The Chian turpentine is the production of the Pistachia terebinthus; but all of them possess the same general and chemical properties.

TUSSER, THOMAS, a celebrated agricultural writer. Five-and-twenty years after the publication of the first English work upon agri culture (Fitzherbert's Boke of Husbandrye), appeared (in 1557) the One Hundred Points of Good Husbundry, by Thomas Tusser. Thi celebrated work must be regarded more as a series of poetical good farming, and domestic direclions and axioms, than as a regular treat ise upon agriculture. All that is known of the author of this curious production has been collected by Dr. Mavor, in his able edition of Tusser's book, and by my brother, Mr. George W. Johnson, in his History of English Gardening; and both these authors have been obliged to content themselves chiefly with Tusser's own account of himself; for Tusser did what few men ever attempt-he wrote his own life, and in a manner still more rare, in verse. $H$ is life was full of adventure; for he evidently had all the restlessness of genius, with the unsettled habits too commonly confirmed by continued change of occupation.

He was born about the year 1515, at Riven. hall, a village on the high-road between the towns of Witnam and Keldevon, in Essex, of a family allied by marriage to the higher ranks of society.

He was buried in the church of $\mathbf{S t}$. Mildred in the Poultry, according to Stowe, with this epitaph:

"Here, Thomas Tusser, clad in earth, doth lie,

That sometime made the Points of IJushandry:

By him then learn thou may'st; here learn we must, When all is done, we sleep, and Iurn to dust:

And yet, through Christ, to heaven we hope to go:

Who reads his books, shall find his faith was $60 . "$

In whatever capacity he at various rimes lived he acted with ability, yet never so as to benefit his fortune. That he excelled as a chorister,-to which he was originally educated, though strongly against his inclination, 
-is certain; for none but those of more than ordinary powers are admitted into the royal choir. As a courtier he was unfrowned upon till the disgrace of his patron. As a farmer it is evident that he possessed a correct knowledge, from his work upon the subject. The same book testifies that, as an author and a poet, he was far above mediocrity. Fuller, in his Worthies of Essex, describes him, in his usual quaint manner, as " a musician, schoolmaster, serving-man, husbandman, grazier, poet; more skilful in all than thriving in any vocation. He spread," he adds, "his bread with alı :orts of butter, yet none would stick thereon.' The testimony of Fuller to the excellent private character of 'Tusser is valuable as coming from one who must have been the contemporary of many persons who well remembered our author. "I hear," says Fuller, "no man to charge him with any vicious extravagancy or visible carelessness." The true reason of his ill success in life is to be found, perhaps, in the verses of a poet almost his contemporary. Peacham, in his Minerva, a book of emblems, published in 1612 , has a device of a whetstone and a scythe, with this beneath:

\section{"They tell me, Tusser, when thou wert alive, And hadst for profit turned every stone, \\ Where'er thou camest thou couldst never thrive, \\ Though hereto best couldst counsel every one; As it may in thy Husbundry appear, Wherein a fresh thou livest among us here. \\ So, like thyself, a number more are wont To sharpen others with arlvice of wit, \\ When they themselves are like the whetstone blunt."}

Tusser's work first appeared in 1557, enritled "A Hundreth Good Pointes of Husbandrie:
"A hundreth good points of hushandry
Maintaineth good household, with huswifry.
Housekeeping and husbandry, if it be good,
Must Inve one another like cousinnes in blood.
The wife, too, must hushand as well as the man,
Or farewel thy husbandry do what thou can.

Imprinted at London, in Flete strete, within Temple barre, at the sygne of the hand and starre, by Richard Totell, the third day of February, An. 1557. Cum priviligio ad imprimendum solum."

A copy of this edition, which Dr. Mavor considers to be unique, is in the British Museum. It consists of only 13 quarto leaves.

The Book of Huswifry, it is supposed, was at first printed by itself; it was afterwards added to the editions of the Husbandry.

Editions of this work appeared in 1561, 1562; and another, "newly corrected and amplified," 1570,1571 (Watts). To these succeeded an enlarged edition and several reprints, the last of which is that edited by Dr. W. Mavor in 1812,4 to and $8 \mathrm{vo}$, with many notes and additions.

'To this Book of Husbandry, says Weston, is often joined The Booke of Regarde, containing the Castle of Delight, the Garden of Unthriftinesse, the Arbour of Virtue, and the Castle of Repentance. Another work is ascribed by Haller to the pen of Tusser, viz. Tractatus de Agriculiura Versibus Anglicis. Iondon, 1638-72. Both these lastmentioned works are extremely rare.

Tusser dedicated his book first to Lord William Paget, in an acrostic, and after his death to "the I.ord Paget of Beaudesert," his son and heir. From this we find that 'l'nogr shared au author's very common fitte, fur her wils us-

$$
\begin{aligned}
& \text { "By practice and ill sperding. } \\
& \text { These lessons harl theetr broeding, } \\
& \text { Aid not by hearsay or rendling. } \\
& \text { As some abroal have blow n ; } \\
& \text { Who will not thun bellege ure } \\
& \text { So much the more they grieve ine } \\
& \text { Because they grudge in give mo. } \\
& \text { What is of right mule own? }
\end{aligned}
$$

Its price, when first published, as described in his prefatory address to the reader, was only $4 d$. or $8 d$. He says,

$$
\begin{aligned}
& \text { "What is a groat } \\
& \text { Or twain to note, } \\
& \text { Once in the life, } \\
& \text { For man or wife r" }
\end{aligned}
$$

The style in which Tusser wrote his book is plain, and sometimes rather hobbling; but at the same time it is a metre easily remembered: and verse is well adapted to impress upon the memory the mass of useful truths and rural directions contained in the work. In the rhyming preface, "to the buyer of this book" (for Tusser seemed to do every thing in verse), he says, -

\section{"What look ye, I pray you ghew what \\ Terms pointed with rhetorick fine? \\ Gond husbandry seeketh wnt that, \\ Nor is't any meaning of mine.'}

His tenth chapter consists of a series of 63 excellent "Good Husbandry Lessons, worthy to be followed of such as will thrive." He omitted no opportunity to give occasion for seasonable reflections:

\section{"As bud, by appearing, betnk'neth the apring. And leaf, by her falling, the contrary thing; Sn youth bids us labour io get as we can. \\ For age is a burden to labouring nan."}

He comments the system of moderate cornrents, and was evidently no enemy to the sports of the field:

\section{"To hunters and hawkers take heed what ye say \\ Mild answer with courtesy, drives them away \\ So where a man's better will upen a gap, \\ Resist not with rudeness, fur fear of mishap."}

He begins his monthly husbandry with September, for that was then the period, as now in England, when arable land was commonly entered upon by the farmer. He says, in his opening stanza, -

"At Michaelmas lightly, new farmer comes in,

New husbandrv forcelh him; new to begin:

Old farmer, still taking, the time to him given,

Makes August to last untill Michaelmas even."

In furtherance of his object, that of giving some very minute directions to the incoming tenant, he even gives a catalogue of farming implements in verse, in which he manages with some adroitness to include several apparently impracticable names, such as,-

"A hand-barrow, wheel-burrow, shnvel, and spade. A curry-comb, mane-comb, and whip for a jade."

It was the approved practice in 'Tusser's days to "sow timely thy white wheat, sow rye in the dust." They were used also to put rye meal into their wheat-flour:

"But sow it not mired tn grow sin nn land,

Lest rye tarry wheat till it ghed as it stand "

Thick and thin sowing had even then sor.. respective advocates:

$4 \times 2$ 
Though beans be in sowing; but scattered In, Yet wheat, rye, and peason, I love not ton thin Sow barley and dredge with a plentiful hand, Lest weed, stead of seed, overgroweth thy land.

It is evident that in those days the farmers were not able to grow their grain on many soils where the modern holders find no obstacles. Thus he speaks of the difficulty they found in producing barley in the parish of Brantham, in Essex, where he farmed some land; and, again, he tells us, what will surprise the modern skilful suffolk farmers, -

"In Suffolk, again, whereas wheat never grew, Good husbandry, used, good wheat land I knew."

And he adds,-

"As gravel and sand is for rye and not wheat."

He mentions several varieties of wheat then grown by the farmers of the reign of good Queen Bess, such as white and red rivet, white and red pollard, Turkey and gray. But of this last he says,--

"Oats, rye, or else barley, and wheat that is grey,

Brings land out of comfort, and soon to decay."

The land, however, was evidently farmed with little skill :

" Two crops of a fallow, enricheth the plough,

Though t'one be of pease, it is land good enough:

One cron and a fallow some soil will abide,

Where, if ye go further, lay profit aside."

He warns the farmers to beware of corn stealers, and to keep their soil in good heart; to manure their land with the earth from headlands and old banks; he commends the use of night-soil for gardens; and recommends the manure of the farm-yard to be laid up "round on a hill." And he had the wisdom to perceive the advantages of shed-feeding live-stock:

"The houseing of cattle, while winter doth hold,

It is gond for all such as are feeble and old

It saveth much compass and many a sleep,

And spareth the pasture for walk of thy sheep."

Grazing has, since Tusser's days, been more and more on the decline, as soiling has been better appreciated. A distinguished modern, witty divine, in a letter to a friend, thus zealously denounces the grazing system: "Grazing is an absolute barbarism; it is just the same as if you desired your servants to trample and roll over your bread and butter."

For faint cattle he recommends the use of bay-salt; and in his February's husbandry gives some directions for the management of their dung, which betrays a deplorable want of knowledge in its economy:

"Wholayeth on dung, ere he layeth on plow.

Fuch hushandry useth, as thrift doth allow:

One month ere ye spread it, so still let it stand,

Ere ever to plow it, ye take it in hand.

Place dung heap alow, by the furrow alnng, Where water, all winter-time did it such wrong: Sn inake ye the land to be lusty and fat.

And corn thereon sown, to be better for that."

In another place, however, he recommends the farmer to use the mud from ditches and ponds as a dressing for their land.

They harvested their corn, it seems, then, much after the same manner as at the present lay. They reaped their wheat and mowed heir stubbles; and this they carried as we do i) $\mathrm{w}$. as sron as possible after harvest:

1074
"For fear of destroying with cattle or rain. The sooner ye load it more profit ye gain."

And as to barley, Tusser says,-

"The mowing of barley, if barley do stand,

Is cheapest and best, for to rid out of hand :

Some mow it, and rake it, and set it on cocks

Some mow it, and bind it, and set it on shocks."

They let out, at the period when Tusser wrote, it seems, the harvest-work either by the acre or by the day; of which modes of getting in the corn he seems to prefer the latter:

"By great will deceive thee, with ling'ring it out,

By day will despatch, and put all out of doubt."

His directions to the farmer with regard to the treatment of his harvestmen and the poor gleaners, and his warm hopes for the farmer's success, betray the excellent benevolent spirit with which he was actuated. He says, -

"Corn carried, let such as be poor go and glean, And after thy cattle, to month it up clean; Then spare it for rowen till Michel be past, To lengthen thy dairy, no better thou hast.

In harvest-time, harvest-folk, servants and all, Should make altogether, good cheer in the hall: And fill out the black bowl of blythe to their song, And let them be merry all harvest-time long.

Once ended thy harvest, let none be beguil'd; Please such as did help thee-man, woman, and child. Thus doing, with alway, such help as they can; Thou winnest the praise of the labouring man.

Now look up to God-ward, let tongue never cease In thanking of Him for his mighty increase, Accept my good will, - for a proof go and try ;

The better thau thrivest the gladder am I."

Having commenced his directions with the outgoing tenant, his last stanza concludes with a reference to the incoming:

"New farmer he thinketh each hour a day,

Until the old farmer be packing away."

"Thus endeth and holdeth out A ugust's Husbandry till

Michaelmas Eve. Tho. Tusser."

The Book of Husbandry of Tusser is also in. teresting from the information it gives us with regard to the customs and habits of the farmers of more than two centuries and a half since. It is evident that they then lived very much upon salt fish, for in his directions for the farmer's diet, he mentions for Lent herrings and salt fish-at Easter they had veal and baconat Martinmas, beef-before the feast of St. John, mackerel--fresh herrings at Michaelmas -at Hallowtide, sprats and spurlings-for Christmas fare they seemed to have all the modern standing dishes, -

\section{"Good bread and good drink, a good fire in the hall,}

Brawn-pudding and souse, and good mustard withal; Beef, mutton, and pork, shred pies of the best,

Pig, veal, gonse, and capon, and turkey well drest."

They evidently, however, lived generally very frugally :

"Where fish is scant, and fruit of trees,

Supply that want with butter and cheese, Quoth Tusser."

They bought, in Tusser's time, such stocks of salt fish as would amaze a modern farmer in these protestant days, when, by the increase of green winter food, cattle and sheep are kept easily through the winter, and fresh meat is always to be had. Few farmers would now think of undertaking a journey to buy fish yet he directed the farmer of the sixteenth century, - 


\section{TUSSER, THOMAS.}

" When harvest is ended, take shipping or ride, Ling, salt fish, and herring for Lent to provide; Get home that is bought, and go stack it up dry, With pearse-straw between it, the safer to lie."

They had a rude way of measuring time, it seems :

"As huswives are teached, instead of a clock,

How winter nights passeth by crowing of cock."

The care of the garden evidently fell to the wife's share, who had also to see to the feeding of the household. It seems that the labourers had then a great fondness for porridge, for Tusser tells us, -

\section{"No spoon-meat, no bellyfull, labourers think."}

In other days, too, it is evident that spinning was no mean part of the mistress's avocation, for it is here said,--

"Wife, pluck fro thy seed hemp the fimble hemp clean; This looketh more yellow, the other more green.

Use t'one for thy spinning, Michell the t'other,

For shoe-thread and halter, for rope and such other:

Now pluck up thy flax for the maidens to spin."

Tusser never seems to have forgotten, on any occasion, to recommend to the landholder the payment of his just dues; even the question of the tithes, once so obnoxious to the farmer, was not overlooked by him. He advised his farming brethren to

\section{"Tithe duly and truly, with hearty good will,}

That God and his blessing may dwell with thee still; Though parson neglecteth his duty for this,

Thank thou thy Lord God, and give ev'ry man his."

The Points of Huswifery, united to the Comfort of Husbandry, by Thomas Tusser, Gentleman, was, it is concluded, first published with The Husbandry in 1561 or 1562 . It is written in rather a more lively style than the former, and has an epistle dedicatory, "to the right honourable, and my especiall good lady and mistress, the Lady Paget," which he thus commences:

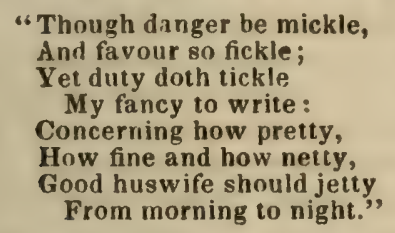

This work contains an abundance of directions, in his usual style of versification, for the conduct of household duties. He directs the servants, before breakfast, to be set to work:

"Let some to peel hemp, or else rushes to twine, To spin, or to card, or to seething of brine."

At breakfast time the wife was, in those days, the carver for the farm servants:

"Let huswife be carver, let pottage be heat,

A mess to each one with a morsell of meat."

In the cookery department the now nearly extinct race of turnspits were indispensable attendants upon the cook:

"Good diligent turnbroche, and trusty withal."

In his washing section he is rather more ierse than gentle in his conclusion:

"Maids, wash well, and wring well, but beat, ye wot how,

If any lack beating, I fear it be you.

In his directions for malt-making he alludes to the use of straw and wood, but does not mention the modern fuel, coke, or cinders. They used, it seems to dine at noon:

\section{UDDER.}

"By noon, see your dinner be ready and neat:

Let meat tarry aervant, not wervant his meat."

The mistress of the house then made, as now in some parts of England, her own candles, it seems :

"Provide for thy tallow, ere froat cometh in,

And make thine own candle, ere wuter begin."

Twice a week, Sundays and Thursdays, the ploughmen were entitled to roast meat for sup. per; and to a harvest goose when the corn was gathered in. At harvest-home the mistress was enjoined,-

"Remember thou, therefore, though I do it not,

The seed-cake and pasties, and furmety pot.",

In Tusser's time a very un wholesome custum prevailed, in the absence of carpets, of strewing the citizens' houses with rushes, and those of the country with flowers. He gives, there. fore, a list of "strewing flowers of all sorts," in which we find only the common sorts of flowers now cultivated, such as cowslips, daisies, lavender, roses, sage, tansy, violets, \&c.

Such were the works of Tusser, writings which were long in the hand-book of the Eng. lish country gentleman. That they were popular is evidenced by the rapid succession of copious editions which fell to their lot; that they were read with delight is shown by the way in which he is commonly quoted by the farmer of all grades. If he had spoken in prose, as has been sometimes suggested, he might certainly have been more instructive to the few, but he would not have been read by the many.

The popular details and histories of all nations escaping from rudeness are commonly written in verse; and multitudes can learn these by heart who never were taught to read. Tusser, therefore, is deserving of the gratitude of the English farmer, for his labours tended to improve, to refine, to elevate the profession he celebrated in his verses. The attempt at any thing like a systematic treatise on farming had not, when Tusser died, been deemed possible. (Quart. Journ. Agr. vol. xil. p. 69.)

TWAYBLADE (Listera; named in honour of Martin Lister, M.D., a famous English physician and naturalist; best known as a conchologist and entomologist). A genus of curious little native plants, growing wild in shady places. They may be grown in a mixture of peat and loam, and are increased by divisions of the roots.

T W I G-R US H (Cladium, from klados, a branch or twig, referring to the appearance of the plant). This is a genus of hard, harsh, rushy, often prickly-edged plants, whose stems, whether round or triangular, are more or less clothed with alternate sheathing leaves or scales.

TWITCH. See Couch.

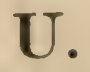

UDDER. The glandular organ of a cow, mare, ewe, or other animal which is destined for the secretion of milk. There are four teats, each of which consists of two granular lobatec glands, comprebending bloodvessels, nerves 1075 
and milk dusts, all of which first unite into eight or ten principal ducts, and these again into one, which perforates the skin of the teat at its apex. The granular part is the secreting organ.

UMBEL. In botany, a particular arrangement of the flowers in certain plants, of which the carrot is a familiar example; the peduncles and pedicles spring from a common centre, and rise till they form a somewhat flat tuft. The umbel is a loose inflorescence, the primary axis of which is short, and the secondary long; and the umbel becomes compound when the secondary axes are developed, in the same manner as the primary. Both the primary and the secondary umbel is generally furnished with bractes at the point of its divergence. The secondary umbel is termed umbellule. The -ifference between an umbel and a corymb is, hat in the latter the flowers form a flat head, the secondary axes arising alternately from different points of the primary, not, as in the former, springing from a common centre. See INFLORESCENCE.

UMBELLIFEROUS PLANTS (Umbelliferc). An extensive group of useful plants, including those well-known garden vegetables parsley, celery, carrots, fennel, caraway, coriander, dills, anise, lovage, angelica, eryngo, samphire, hemlock. The name of the class was given from a fanciful resemblance to some parts of an umbrella or parasol. The flower-stem divides at the top into a number of short, slender branches, which all run from a common point or centre like the rays of an umbrella from the ring sliding up and down the stick. The class, though containing so many useful plants, has many possessed of extremely poisonous qualities, such as hemlock, the fool's parsley (Ethusa cynapium, Pl. $10, \mathrm{~g})$, dropwort, \&c. The blossom of the elder resembles at first sight those of umbelliferous plants, to which, however, the elder does not belong, because the rays of the flower do not proceed from a common point, some being higher and some lower.

UNDERWOOD. A term applied to coppice, or any wood not accounted timber. See Coppice, Fonfest, and Plantation.

URINE. A saline fluid secreted from the blood of animals by the kidneys, collected in the urinary bladder, and emitted by the canal of the urethra. Urine differs in different animals, and varies in its characters, according to the kind of food employed. The usual salts contained in it are, sulphates, phosphates, and chlorides, all of which are fertilizing substances. The urine also of oxen and horses is alkaline; it undergoes decomposition less rapidly than that of carnivorous animals: it contains hippurates, but no lithic acid, that substance which forms red gravel in man. Hippuric acid contains 7 per cent. of nitrogen. Urine, therefore, is of much use as a manure, improving most kinds of soil. Columella has asserted that, stale, it is excellent for the roots of trees. And Hartlib commends the Dutch for preserving the urine of cows as carefully as they do the dung, to enrich their ands.
It is a fluid capable of being employed with great benefit both on meadows and on arable land. See Lreuin Manurn and Night-sorr.

URITH. Provincially the etherings or bindings of hedges.

USTILAGO (from ustus, scorched appearance). A genus of fungi, parasitical, which are found preying upon the cereal and other grasses. See Smux.

\section{V.}

VALLESNERIA (Spiralis). This plant grows very abundantly from the bottoms of fresh water rivers and lakes over the whole United States, where the flow of water is not very rapid. It goes by the different names of eelgrass, tapegrass, and channelweed. It is upon the roots of this grass, or a native spe. cies of vallesneria, that the canvass-back duck feeds, and to which its peculiarly delicate flavour is ascribed, by Wilson, the ornitho. logist.

VALUATION. See Appraisement.

VEGETABLE CHEMISTRY is that branch of the science of chemistry which relates to vegetable substances. Under the heads Analysis, Chemistry, Organic Chrmistry, Gases, Earths, Water, Salts, \&c., I have endeavoured to include all the facts supplied by this important science for the assistance of the farmer with which I am acquainted; I shall, therefore, merely insert in this place the chemical analysis of the inorganic substances found in several of the commonly cultivated crops of the farmer; and this I take from p. 318 , of the valuable Lectures on Agricultural Chemistry and Geology, by J. F. Johnston; see also Liebig's Organic Chemistry.

Besides the elements of the organs of plants, other substances, obtained from inorganic nature, are necessary for certain organs destined to special functions peculiar to each family of plants. In the ashes of the plants left after burning them, these substances are found Almost all plants contain acids, in combination with soda, potassa, lime, alumina, or magnesia. The quantity of these salts varies at different periods of the growth of the plant: thus unripe grasses contain more bitartrate of potassa than the ripe, and the potato more potassa before it blossoms than afterwards. The nature of a soil, as has already been detailed, alters the quantity of salts found in plants. The Salsola kali, raised from seeds of plants near the sea, in an inland garden, contains both potassa and soda; but the plants from the seed of this contain potassa only. But these facts are detailed under the head SALrs, \&c.

In examining the results of these analyza. tions, the farmer must remember, that the acids and their bases do not exist in plants in an uncombined state, but in combination with each other; that is, as salts.

1. Of the Ash of Wheat.-According to the analysis of Sprengel, 1000 lbs. of wheat leave 11.77 lbs. and of wheat straw $35.18 \mathrm{lbs}$. of ash, consisting of- 


\begin{tabular}{|c|c|c|c|c|c|}
\hline \multirow[b]{2}{*}{ Potash } & \multirow[b]{2}{*}{ - } & \multirow[b]{2}{*}{ - } & \multirow{3}{*}{ - } & \multirow{2}{*}{$\begin{array}{l}\text { Grain of } \\
\text { Wheal. } \\
2 \cdot 25 \text { lbs. }\end{array}$} & \multirow{2}{*}{$\begin{array}{l}\text { Sitraw of } \\
\text { Wheat. } \\
020 \text { Ibs. }\end{array}$} \\
\hline & & & & & \\
\hline Bnda - & - & - & & $2 \cdot 40$ & $0 \cdot 29$ \\
\hline Lime - & - & - & - & 096 & $2 \cdot 40$ \\
\hline Magnesia & - & - & - & $0 \cdot 90$ & 0.32 \\
\hline \multicolumn{4}{|c|}{ Alumina, with a trace of iron } & $0 \div 6$ & 090 \\
\hline Siliea - & - & - & - & $4 \cdot 00$ & $28 \cdot 70$ \\
\hline Bulphuric a & cid & - & - & 0.50 & 0.37 \\
\hline Phosphoric & acid & - & - & 0.40 & $1 \cdot 70$ \\
\hline \multirow[t]{2}{*}{ Chlorine } & - & - & - & $0 \cdot 10$ & 030 \\
\hline & & & & $11.77 \mathrm{lbs}$. & $35 \cdot 18 \mathrm{lbs}$. \\
\hline
\end{tabular}

2. Of the Ash of Barley.-A thousand pounds f the grain of barley (two-rowed, Hordeum dischon) leave $23 \frac{1}{2} \mathrm{lbs}$., and of the ripe dry straw $2.42 \mathrm{lbs}$. of ash. This ash consists of -

\begin{tabular}{|c|c|c|c|c|c|c|}
\hline \multirow[b]{2}{*}{ Potash } & \multirow[b]{2}{*}{ - } & \multirow[b]{2}{*}{ - } & \multirow[b]{2}{*}{ - } & \multirow[b]{2}{*}{ - } & Grain. & Straw. \\
\hline & & & & & $2.78 \mathrm{lbs}$. & $1.80 \mathrm{lbs}$ \\
\hline Soda - & - & - & - & - & $2 \cdot 90$ & $0^{-48}$ \\
\hline Lime - & - & - & - & - & $1 \cdot 06$ & 5.54 \\
\hline Magnesia & - & - & - & - & 1.80 & 076 \\
\hline Aluunina & - & - & - & - & 0.25 & 1.46 \\
\hline \multicolumn{2}{|c|}{ Oxide of iron } & - & - & - & a trace. & 0.14 \\
\hline \multicolumn{2}{|c|}{ Oxide of mangan } & lese & - & - & - & 0.20 \\
\hline Silica - & - & - & - & - & $11 \cdot 82$ & $38 \cdot 56$ \\
\hline \multicolumn{2}{|c|}{ Sulphuric acid } & - & - & - & 0.59 & $1 \cdot 18$ \\
\hline \multirow{3}{*}{$\begin{array}{l}\text { Phosphoric } \\
\text { Chlorine }\end{array}$} & acid & - & - & - & $2 \cdot 10$ & $1 \cdot 60$ \\
\hline & - & - & - & - & $0 \cdot 19$ & 0.70 \\
\hline & & & & & $23.49 \mathrm{lbs}$. & $52.42 \mathrm{lbs}$. \\
\hline
\end{tabular}

3. Of the Ash of Oats.-In 1000 lbs. of the rain of the oat are contained about $26 \mathrm{lbs}$., nd of the dry straw about $57 \frac{1}{2}$ lbs., of inorganic aatter, consisting of-(see next column)

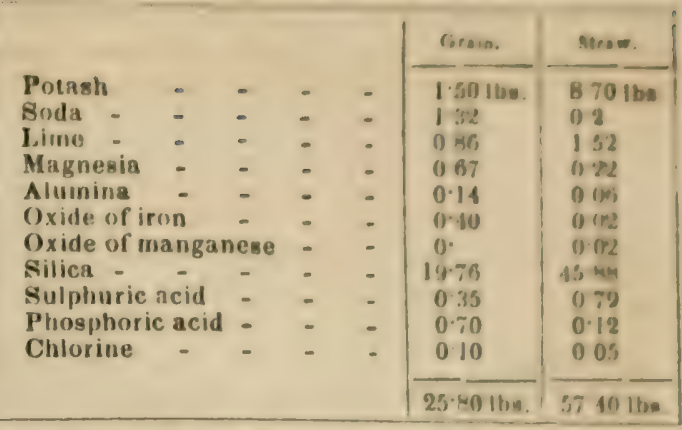

4. Of the Ash of Rye.-The weight of ash contained in $1000 \mathrm{lbs}$. of the grain of rye is $10 \frac{\mathrm{l}}{\mathrm{lbs}}$. and of the straw $28 \mathrm{lbs}$. 'This ash consists of -

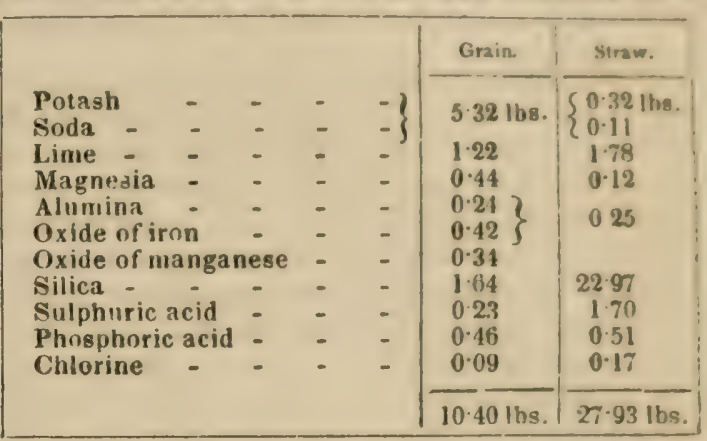

5. Of the Ash of Beans, Peas, and Vetches.-The ash of the seed and straw of the field bean, the field pea, and the common vetch (Vicia sativa), dried in the air, contains in 1000 lbs. the several inorganic compounds in the following proportions :-

Pot:

\section{Lime}

Magnesi

Alumina

Oxide of iron

Oxide of manganese

Silica

Sulphuric acid

Phosphoric acid

Chlorine

\begin{tabular}{|c|c|c|c|c|c|}
\hline \multicolumn{2}{|c|}{ Field Bean. } & \multicolumn{2}{|c|}{ Field Pea } & \multicolumn{2}{|c|}{ Common Vetch. } \\
\hline Seed. & Straw. & Seed. & Straw. & Seed. & Siraw. \\
\hline $4 \cdot 15$ & 16.56 & $8 \cdot 10$ & $2 \cdot 35$ & $8 \cdot 97$ & $18 \cdot 10$ \\
\hline $8 \cdot 16$ & 0.50 & $7 \cdot 39$ & - & $6 \cdot 22$ & 052 \\
\hline $1 \cdot 65$ & $6 \cdot 24$ & 0.58 & $27 \cdot 30$ & $1 \cdot 60$ & 1955 \\
\hline $1 \cdot 58$ & $2 \cdot 9$ & $1 \cdot 36$ & $3 \cdot 42$ & 1.42 & 3.24 \\
\hline $0.3 t$ & 0.10 & .20 & 060 & 0.22 & 0.15 \\
\hline - & 0.07 & ). 10 & 020 & 0.09 & $0 \cap 9$ \\
\hline$\therefore$ & 0.05 & - & 007 & 0.05 & 0.08 \\
\hline $1 \cdot 26$ & $2 \cdot 20$ & $4 \cdot 10$ & $9 \cdot 96$ & $2 \cdot 00$ & 4.42 \\
\hline 0.81 & 0.34 & 0.53 & $3 \cdot 37$ & 0.50 & 1.22 \\
\hline $2 \cdot 92$ & $2 \cdot 26$ & $1 \cdot 90$ & $2 \cdot 40$ & $1 \cdot+0$ & $2 \cdot 80$ \\
\hline 0.41 & 0.80 & 0.38 & 0.01 & $0-43$ & 081 \\
\hline $21 \cdot 36$ & $31 \cdot 21$ & 2464 & $49 \cdot 71$ & $22 \cdot 90$ & $51 \cdot 01$ \\
\hline
\end{tabular}

6. The Ash of the Turnip, Carrot, Parsnip, and |from the field, contain respectively in 10,000 otato.-These 4 roots, as they are carried|lbs.-

\begin{tabular}{|c|c|c|c|c|c|c|c|c|c|c|c|c|c|c|c|c|}
\hline \multirow[b]{3}{*}{ Potash } & \multirow[b]{3}{*}{ - } & \multirow[b]{3}{*}{ - } & \multirow[b]{3}{*}{ - } & \multirow[b]{3}{*}{ - } & \multirow[b]{3}{*}{ - } & \multirow[b]{3}{*}{ - } & & \multirow[b]{3}{*}{ - } & \multirow[b]{3}{*}{ - } & \multirow[b]{3}{*}{ - } & \multicolumn{2}{|c|}{ Turnips. } & \multirow{2}{*}{ Carrots. } & \multirow{2}{*}{ Parsnip. } & \multicolumn{2}{|c|}{ Pitaloce } \\
\hline & & & & & & & & & & & Roots. & Leaves. & & & Rounte. & Tope. \\
\hline & & & & & & & & & & & 23.86 & $32 \cdot 3$ & $35 \cdot 33$ & 2079 & $40 \cdot 28$ & $81 \cdot 9$ \\
\hline Soda & - & - & - & - & - & - & - & - & - & - & 10.48 & $22 \cdot 2$ & 922 & $7 \cdot 02$ & $23 \cdot 24$ & 0.9 \\
\hline Lime & - & - & - & - & - & - & - & - & - & - & $7 \cdot 52$ & $62 \cdot 0$ & 6.57 & 4.68 & $3 \cdot 31$ & $129 \%$ \\
\hline Magnesia & & - & - & - & - & - & - & - & - & - & $2 \cdot 51$ & 5.9 & $3 \cdot 84$ & $2 \div 0$ & 324 & 1700 \\
\hline Alumina & & - & - & - & - & - & - & - & - & - & 0.36 & 0.3 & 0.39 & 0.24 & $0 \cdot 50$ & A. 4 \\
\hline Oxide of $i$ & iron & - & - & - & - & - & - & - & - & - & 0.32 & $1 \cdot 7$ & 0.33 & 0.05 & $0 \cdot 32$ & 0.2 \\
\hline Oxide of $n$ & $\operatorname{man}$ & gan & & - & - & - & - & - & - & - & - & - & 0.60 & & & \\
\hline Silica & - & - & - & - & - & - & - & - & - & - & $3 \cdot 88$ & $12 \cdot 8$ & $1 \cdot 37$ & $1 \cdot 62$ & 0.84 & $49 \cdot 4$ \\
\hline Sulphuric & $\mathrm{c} \mathrm{aci}$ & & - & - & - & - & - & - & - & - & 8.01 & $25 \cdot 2$ & $2 \cdot 70$ & 1.92 & $5 \cdot 40$ & 42 \\
\hline Phrsphor & ic a & cid & - & - & - & - & - & - & - & - & 367 & $9 \cdot 8$ & $5 \cdot 14$ & 1. & $4 \cap 1$ & 127 \\
\hline \multirow[t]{2}{*}{ Chlorine } & & - & - & - & - & - & - & - & - & - & $2 \cdot 39$ & $8 \cdot 7$ & $0 \% 0$ & 1.78 & 160 & $5 \cdot 0$ \\
\hline & & & & & & & & & & & $63 \cdot 3$ & $180 \cdot 9$ & $66 \cdot 19$ & $41 \cdot 80$ & 82.83 & $308 \cdot 4$ \\
\hline
\end{tabular}

7. Of the Ash of the Giasses and Clovers.-The / sive use. I have also calculated the weights ollowing table might have been much en- given below for these plants in the state uf hay arged. I have thought it necessary, however, only, as the succulency of the grasses-that is. to introduce in this place only those species the quantity of water contained in the sreen of grass and clover which are in most exten- crop-varies so much that no correct estimate 
could be made of the quantity of inorganic matter present in hay or grass, from a knowledge of its weight in the green state only. The annexed quantities are contained in 1000 lbs of the dry hay of each plant:

\begin{tabular}{|c|c|c|c|c|c|c|c|c|c|c|c|c|c|c|c|c|}
\hline \multirow[b]{2}{*}{ Potash } & \multirow[b]{2}{*}{ - } & \multirow[b]{2}{*}{ - } & & & & & & \multirow[b]{2}{*}{ - } & \multirow[b]{2}{*}{ - } & \multirow[b]{3}{*}{ - } & \multirow{3}{*}{ - } & \multirow{2}{*}{$\begin{array}{c}\begin{array}{c}\text { Rye-grass. } \\
\text { Hay. }\end{array} \\
8.81\end{array}$} & \multirow{2}{*}{$\frac{\begin{array}{c}\text { Red } \\
\text { Clover. }\end{array}}{19 \cdot 95}$} & \multirow{2}{*}{$\begin{array}{c}\begin{array}{c}\text { White } \\
\text { Clover. }\end{array} \\
31 \cdot 5\end{array}$} & \multirow{2}{*}{$\frac{\text { Lucern. }}{13 \cdot 40}$} & \multirow{2}{*}{$\frac{\text { Sainfoin. }}{20.57}$} \\
\hline & & & & & & & & & & & & & & & & \\
\hline Soda & - & - & - & - & - & - & - & - & - & & & 3.94 & $5 \cdot 29$ & 5.79 & $6 \cdot 15$ & $4 \cdot 37$ \\
\hline Lime & - & - & - & - & - & - & - & - & - & - & - & $7 \cdot 34$ & $27 \cdot 80$ & $23 \cdot 48$ & 4831 & $21 \cdot 95$ \\
\hline Magnesi & - & - & - & - & - & - & - & - & - & - & - & 0.90 & $3 \cdot 33$ & $3 \cdot 05$ & $3 \cdot 48$ & $2 \cdot 88$ \\
\hline Alumina & - & - & - & - & - & - & - & - & - & - & - & 0.31 & $0 \cdot 14$ & 1.90 & $0 \cdot 30$ & 0.66 \\
\hline Oxide of & & - & - & - & - & - & - & - & - & - & - & - & - & 063 & 030 & \\
\hline Oxide of & angar & ese & - & - & - & - & - & - & - & - & - & & & & & \\
\hline Silica & & - & - & - & - & - & - & - & - & - & - & $27 \cdot 72$ & $3 \cdot 60$ & $14 \cdot 73$ & $3 \cdot 30$ & 5. \\
\hline Sulphuri & cid & - & - & - & - & - & - & - & - & - & - & 3.53 & $4 \cdot 47$ & 3.53 & 4.04 & 3.41 \\
\hline \multirow{3}{*}{$\begin{array}{l}\text { Phospho } \\
\text { Chlorine }\end{array}$} & acid & - & - & - & - & - & - & - & - & - & - & $0 \cdot 25$ & 6.57 & 5.05 & $13 \cdot 07$ & $9 \cdot 16$ \\
\hline & - & - & - & - & - & - & - & - & - & - & - & 0.06 & $3 \cdot 62$ & $2 \cdot 11$ & $3 \cdot 18$ & 1.57 \\
\hline & & & & & & & & & & & & $52 \cdot 86$ & $74 \cdot 78$ & $91 \cdot 32$ & $95 \cdot 53$ & 69.57 \\
\hline
\end{tabular}

VEGETABLE PHYSIOLOGY is that science which treats of the vegetable kingdom, its habits, properties, and organization, in the most comprehensive manner. Its objects have been clearly stated by Mrs. Marcet, in her excellent Conversations on Vegetable Physiology, when describing the lectures of M. Decandolle on this science; and what she has so well described, it is needless for me to give in other words. "So far from confining himself to the classifiation of plants, the physiologist examines the regetable kingdom in its most comprehensive and philosophical point of view. In describing the structure, he investigates the habits and properties of plants, and shows, not only how wonderfully they have been formed to fulfil the purposes of their own multiplication and preservation, but how admirably they answer the high purpose which nature has assigned to them, of ministering to the welfare of the animal creation, and more especially to that of man. He turns his attention particularly to point out the means by which the science of botany can promote that with which it is most intimately and importantly connected-agriculture. He makes ready the soil and sows the seed for the husbandman; he extracts the healing juices and the salutary poisons for the physician; he prepares materials for the weaver, colours for the dyer: in a word, as he proceeds, there is scarcely an art on which he does not confer some benefit, either by pointing out a new truth, or warning against an old-established error." From this description of the objects of the science of vegetable physiology, the reader will see that almost all its different branches are treated of separately in articles which are dispersed through this volume. It is only, therefore, a few scattered fragments which I propose to gather together in this place. See Accumation, Botaxy, Eanths, Gases, Light, Putrefaction, Salts, TempenATURE, WATER, \&c.

The description of the cambium for the descending sap of plants was omitted in its prorer place, and the effect of gravity or attraction upon plants was referred to this head. The sap having ascended in to the leaves, and being in its course gradually altered into a fuid suitable for the nourishment of the plant, descends principally through the liber, or inner layer of bark, but a small portion also descends through the young wood, or alburnum. This movement, esperially through the plants with 1078 pendent branches, is materially facilitated by motion, as by the action of the wind. "Mr. Knight," adds Mrs. Marcet, "has made a va. riety of interesting experiments on this subject. He confined both the stem anci branches of a tree in such a manner that it could not be moved by the wind. The plant became feeble, and its growth much inferior to that of a similar tree growing in its natural state. He confined another tree so that it could be moved only by the north and south winds, and obtained the singular result of an oval stem, the sides accessible to the wind growing more vigorously than those sheltered from its influence. Every species of restraint, and especially such as tend to render plants motion. less, impedes their growth. Stakes by which young trees are propped, nailing them to walls or trellises, green-houses, or confined situations where the air has not free access, check and injure the vigour of vegetation, and render plants diminutive and weakly. The cambium descends almost entirely through the liber or most internal and youngest layer of the bark; if, therefore, a ring is cut completely through the bark, this fluid is arrested in its course, and, accumulating around the upper edge of the intersected bark, will cause an annular protuberance. The descent of the cambium thus being obstructed, it will accumulate in that part of the tree above the intersection, afford it a superabundance of nourishment, creating a proportional vigour of vegetation, and a corresponding excellence and profusion of produce." This operation, or ringing, is often performed on the non-productive branches of fruit trees.

The effect of gravitation or attraction upon plants is of the highest.importance to their germination and their growth. From the very nature, however, of this essentially present power, a principle known only to us by its effects, the research is surrounded with diffculties. Mr. Knight, the late excellent president of the Horticultural Society, described some of the effects of gravity upon plants in his usual happy manner, when, in addressing the fellows of the Royal Society, he observed, "It can scarcely have escaped the notice of the most inattentive observer of vegetation, that in whatever position a seed is placed to germinate, its radicle invariably makes an effort to descend towards the centre of the earth, while the elongated germen takes precisely the oppo- 
site direction; and it has been proved by $\mathrm{Du}$. hamel, that if a seed during its germination be frequently inverted, the points both of the radicle and germen will return to the first direction. Some naturalists have supposed these opposite effects to be produced by gravitation; and it is not difficult to conceive that the same agent, by operating on bodies so differently organized as the radicle and germen of plants are, may occasion the one to descend and the other to ascend." The hypothesis of these naturalists it was the intention of Knight to examine by certain experiments, which he thus proceeds to describe: "I conceived that if gravitation were the cause of the descent of the radicle and the ascent of the germen, it must act either by its immediate influence on the vegetable fibres and vessels during their formation, or on the motion and consequent distribution of the true sap afforded by the cotyledons; and as gravitation could produce these effects only while the seed remained at rest, and in the same position relative to the attraction of the earth, I imagined that its operation would become suspended by constant and rapid change of the position of the germinating seed, and that it might be counteracted by the agency of centrifugal force. Having a strong rill of water passing through my garden, I constructed a small wheel, similar to those used for grinding corn, adapting a wheel of a different construction, and formed of very slender pieces of wood, to the same axis.

"Round the circumference of the latter, which was 11 inches in diameter, numerous seeds of the garden bean, which had been soaked in water to produce the greatest degree of expansion, were bound at short distances from each other. The radicles of these seeds were made to point in every direction, some towards the centre of the wheel, and others in the opposite direction; others at tangents to its curve; some pointing backwards and others forwards, relative to its motion, and others pointing in opposite directions in lines parallel with the axis of the wheels. The whole was enclosed in a box and secured by a lock, and a wire-grate was placed to prevent the ingress of any body capable of impeding the motion of the wheels. The water being then admitted, the wheels performed something more than 150 revolutions in a minute, and the position of the seeds relatively to the earth was as often perfectly inverted within the same period of time, by which I conceive that the influence of gravitation must have been wholly suspended. In a few days the seeds began to germinate; I soon perceived that the radicles, in whatever direction they were protruded from the position of the seed, turned their points outward from the circumference of the wheel, and in their subsequent growth receded nearly at right angles from its axis. The germens, on the contrary, took the opposite direction, and in a few days their points all met in the centre of the wheel. Three of these plants were suffered to remain an the wheel, and were secured to its spokes to prevent their being shaken off by its motion. The stems of these plants soon extended beyond the centre; but the same cause which frst occasioned them to approach its axis still operating, their points returned and miet agaso at its centre. The motion of the wheel ienn in this experiment vertical, the radicle and ger men of every seed occupied during a mumbe portion of time in each revolution precisely the same position they would have assumerl has the plants vegetated at rest; and as gravitatum and centrifugal force also acted in lines parallel with the vertical motion and surface of the wheel, I conceived that some slight objections might be urged against the conclusions I felt inclined to draw. I therefore added to the ma. chinery I have described another wheel, which moved horizontally over the vertical wher:ls: and to this, by means of multiplying wheels of different powers, I was enabled to give many different degrees of velocity. Round the cir. cumference of the horizontal wheel, whose diameter was also 11 inches, seeds of the bean were bound as in the experiment which I have already described, and it was then made to perform 2.50 revolutions in a minute. By the rapid motion of the water-wheel, much water was thrown upwards on the horizontal wheel, part of which supplied the seeds upon it with moisture, and the remainder was dispersed in a light and constant shower over the seeds in the vertical wheel, and on others placed to vegetate at rest in different parts of the box.

"Every seed on the horizontal wheel, though moving with great rapidity, necessarily retained the same position relative to the attraction of the earth, and therefore the operation of gravity could not be suspended, though it might be counteracted in a very considerable degree by centrifugal force, and the difference I had an. ticipated between the effects of rapid vertical and horizontal motion soon became sufficien. ly obvious. The radicles pointed downwards about 10 degrees below, and the germens as many degrees above, the horizontal line of the wheel's motion, centrifugal force having made both to deviate 80 degrees from the perpendicular direction each would have taken had they vegetated at rest. Gradually diminishing the rapidity of the horizontal wheel, the radicles descended more perpendicularly, and the germens grew more upright, and, when it did not perform more than 80 revolutions in a $\mathrm{mi}$ nute, the radicle pointed about 45 degrees below, and the germens as much above, the horizontal line; the one always receding from, and the other approaching to, the axis of the wheel.

"I would not, however, be understood to assert that the velocity of 250 or 80 horizostal revolutions in a minute will always give accurately the degrees of depression and elevation of the radicle and germen which I have mentioned; for the rapidity of the motion of my wheels was somewhat diminished by the collection of fibres of confervæ against the wire grate, which obstructed in some degree the passage of the water; and the machinery having been the workmanship of myself and my gardener, cannot be supposed to have moved with all the regularity it might have done, had it been the work of a professed mechanic. But I conceive myself to have fully proved that the radicles of germinating seeds are made 10 de. scend, and their germens in ascend. hy suan 
external cause, and not by any power inherent in vegetable life; and $I$ see little reason to doubt that gravitation is the principal, if not the only, agent employed in this case by nature." Mr. Knight has endeavoured to point out the means by which he conceives the same agent may produce effects so diametrically opposite to each other.

It has, however, been objected by Duhamel (and the greatest deference is always due to his opinions) that gravitation could have little influence on the direction of the germen, were it, in the first instance, protruded, or were it subsequently inverted, and made to point perpendicularly downwards. To enable myself, says Mr. Knight, to answer this objection, I made manoy experiments on trees of the horsechestnut and of the bean, in the box I have already described; and as the seeds there were suspended out of the earth, I could regularly watch the progress of every effort made by the radicle and germen to change their positions. The extremity of the radicle of the bean, when made to point perpendicularly upwards, generally formed a considerable curvature within 3 or 4 hours when the weather was warm. The germen was more sluggish; but it rarely or never failed to change its direction in the course of 24 hours; and all my efforts to make it grow downwards by slightly changing its direction were invariably abortive.

As trees possess the power of turning the upper surfaces of their leaves and the points of their shoots to the light, and their tendrils in any direction to attach themselves to contiguous objects, it may be suspected that their lateral roots are by some means directed to any soil in their vicinity which is best calculated to nourish the plant to which they belong; and it is well known that much the greater part of the roots of an aquatic plant which has grown in a dry soil, on the margin of a lake or river, have been found to point to the water, whilst those of another species of tree which thrives best in a dry soil have been ascertained to take an opposite direction: but the result of some experiments I have made is not favourable to this hypothesis; and I am inclined to believe that the roots disperse themselves in every direction, and only become more numerous where they find most employmenr, and a soil best adapted to the species of plant.

A tree growing upon a wall at some distance from ine gruund, and consequently ill supplied with fond and water, has also been observed to adapt its habits to its situation, and to make very singular and well-directed efforts to reach the soil beneath by means of its roots. During the period in which it is malsing such efforts, little addition is made to its branches, and almost the whole powers of the plant appear to be directed to the growth of one or more of its principal roots. To these much in cor.sequence is annually added, and they proceed perpendicularly towards the earth, unless made to deviate by some opposing body; and as soon as the ronts have attached themselves to the soil, the branches grow with vigour and rapidity, and the plant assumes the ordinary abits of its species.

In some other experiments of Knight to illus 1080 trate these highly interesting habits of plants pieces of alum, and of the sulphate of iron (green vitriol), blue vitriol (sulphate of copper), were placed at small distances perpendicularly beneath the radicles of germinating seeds of different species, to afford an opportunity of observing whether any efforts could be made by them to avoid poisons; but they did not appear to be at all influenced except by actual contact of the injurious substances. The growth of their fibrous lateral roots was, however, obviously accelerated when their points approached any considerable quantity of decomposing vegetable or animal matter; and when the growth of the roots was retarded by want of moisture, the contiguity of water in the adjoining mould, though not apparently in actual contact with them, operated beneficially: but I had reason to suspect that the growth of roots was, under these circumstances, promoted by actual contact with the detached and fugitive particles of the decomposing body and the evaporating water.

The way in which plants establish themselves in opposition to the various obstacles they have to encounter, as, for instance, in withstanding violent winds, is very remarkable. The growth and forms assumed by the roots of trees of every species are, to a great extent, dependent upon the quantity of motion which their stems and branches receive from winds; for the effects of motion upon the growth of the root and of the trunk and branches are perfectly similar. Whatever part of a root is moved and bent by winds or other causes, an increased deposition of alburnous matter upon that part soon takes place, and consequently the roots which immediately adjoin the trunk of an insulated tree in an exposed situation become strong and rigid, whilst they diminish rapidly in bulk as they recede from the trunk, and descend into the ground; by this sudden diminution of the bulk of the roots the passage of the descending sap through their bark is obstructed, and it, in consequence, generates, and passes into many lateral roots, and these, if the tree be still much agitated by winds, assume a similar form, and consequently divide into many others. A kind of net-work, composed of thick and strong roots, is thus formed, and the tree is secured from the danger to which its situation would otherwise expose it. In a sheltered valley, on the contrary, where a tree is surrounded and protected by others, and is rarely agitated by winds, the roots grow long and slender, like the stem and branches, and comparatively much less of the circulating fluid is expended in the deposition of alburnum beneath the ground; and hence it not unfrequently happens that a tree in the most sheltered part of a valley is uprooted, whilst the exposed and insulated tree upon the adjoining mountain remains uninjured by the fury of the storm.

All such investigations as these are fraught with instruction to the cultivator of the earth. They not only illustrate the every-day opera. tions of the farmer, but they guard him against the adoption of specious novelties and unscientific efforts to increase the fertility of the soil. Such researches, too, will bardly fail tc 
instruct and elevate the character of the tiller of the earth in more ways than one. They will teach him, as M. Mirbel long since well remarked, that every operation " is connected in the vast system of the globe, and that order emanates from the equipoise of conflicting phenomena. Animals carry off the oxygen of the atmosphere, replacing it by carbonic acid gas; and are thus at work to adulterate the constitution of the air and render it unfit for respiration. Vegetables take up carbonic acid gas, retain the carbon, and give out oxygen; and are thus purifying the air tainted by animals, and re-establishing the necessary proportions between its elements. In Europe, while our vegetables, stripped by the severity of the season of their foliage, no longer yield the air contributing to life, the salutary gas is borne to us by trade winds from the southernmost regions of America. Breezes from all quarters of the world intermingle thus the various strata of the atmosphere, and keep its constitution uniform in all seasons and at all elevations. The substances which are produced by the dissolution of animal and vegetable matter are absorbed by plants, and constitute a portion of the nourishment by which they are maintained; plants, in their turn, become the food of animals, and these again the prey of others which subsist on flesh. Yet, in spite of this perpetual state of war and destruction, nothing perishes, for all is regenerated. $\mathrm{Na}$ ture has ordained that the two great divisions of organized beings should depend the one upon the other for support, and that both the life and death of individuals should be equally serviceable in preserving the harmony of the universe."

If we come to consider vegetation as it regards ourselves, we shall find that this great agent of nature, subjected in a certain degree to the control of man in a state of society, is the main source of his prosperity or of his misery. How many countries have the greedy ambition of princes, and the degradation and ignorance of the people, made barren! Recollect what Asia Minor, Judea, Egypt, the provinces at the foot of Mount Atlas, have been, and behold what they are at this day. Recollect Greece, once the country of science and of liberty, now that of ignorance and slavery; she can be only recognised in her ruins, and her monuments of the dead. Man had denied his labour to the earth, and the earth her treasures to man: all vanished with agriculture. The traveller who passes that country of so great renown, finds, in the place of the fine forests that crowned its mountains, of the rich harvests reaped by twenty busy nations, of the numerous flocks that enriched its fields, only naked rocks and sterile sands, with here and there a miserable village. He seeks in vain for several rivers recorded in history; they are gone! Thus the rage of conquest and of rule not only overturns cities, depopulates whole countries, and brings back barbarism, but it dries up the very springs from which the natural riches of the earth have flowed. To these melancholy resuits of our passions we might oppose the more cheerful ones of our industry; but they are more properly within the province 136 of the arts of cultivation than of vegetable physiology.

VEGE'I'ABI.E. MARROOW ('ururben we forn). This fruit of the succada gourd is uniformly of a pale yellow colour, and of an ellimis:oblong shape, the surface having irrmular. longitudinal ribs, uniting into a projecturfe apex. When full grown it is about 9 ituchury in length and 4 in diameter, and is by far the best adapted for culinary purposes of any spe. cies of the gourd tribe. It is of recent intro duction into Europe, having been bruught from Persia. It is useful for culinary purposes in every stage of its growth; when very youum it is good if fried with butter; when larese, w about half-grown, it is excellent either when plain, boiled, or stewed with rich sauce: for either of these purposes it should be cut in slices. The flesh has a peculiar tenderness and softness, from which circumstance it has received its name, much resembling the buttery quality of the beurré pear, and this property remains with it till it is full-grown, when is is used for pies. It is in its intermediate state of growth that it is likely to be most approved. Compared with all the other vegetables of the same family, its superiority is decided. I consider the vegetable marrow without a rival.

"We have grown the true vegetable marrow two seasons," says the editor of the Cultivator, "and although we have not used it in the intermediate state of its growth, as recommended by Mr.Sabine, we esteem it among the best varieties of the cucurbita for boiling and for pies. It is cultivated like the common pumpkin or squash, and will ripen in the U. S. in a high latitude."

VEGE'TABLES. The observations of vegetable physiologists and the researches of chemists have mutually contributed to establish the fact, that the growth and developement of vegetables depend on the rejection of oxygen, which is separated from the other compouent parts of their nourishment.

In contradistinction to vegetable life, the life of animals exhibits itself in the continual absorption of the oxygen of the air, and its combination with certain component parts of the animal body.

While no part of an organized being can serve as food to vegetables, until, by the processes of putrefaction and decay, it has assumed the form of inorganic matter, the animal organism requires, for its support and developement, highly organized atoms. The food of all animals, in all circumstances, consists of parts of organisms.

Assimilation, or the process of iormation and growth,-in other words, the passige of matter from a statc of motion to that of rest,goes on in the same way in animals and its vegetables. In both, the same cause determines the increase of mass. 'This constitutes the true veretable life, which is carrieci on without consciousness. (Liehig's Animal ('hemis!ry.)

VENISON. The flesh of deer. See Drsa and Mrat.

VENTILATION. The injurious effects of close and dirty stables, and other places where stock are often kept, and the great advantages derived from securing a proper ventilation or continual supply of fresh unbreathed air to $+\mathrm{Y} \quad$ 1051 
animals, are matters which have received, of late, a great deal of merited attention. The owner of horses or other stock, intent upon protecting these from the wet and cold, and placing them in the most favourable position to take on fat, often exposes them to the most injurious effects induced by the breathing of impure air. "We generally find," says an able writer upon this subject, "that the unhealthiness of the atmosphere in which stabled horses and cattle are placed, increases with the value of the animal; this is especially the case with the horse. The groom finding no mode so easy in his endeavours to procure for his horses a fine coat, as that of keeping them in a high temperature, is pretty sure, if not restrained, to effect this by excluding from his stable every breath of air by which its temperature may be lowered, or its purity preserved. It results then (often, it is true, by slow degrees) that the animal, from the breathing an atmosphere surcharged as a certain consequence with the carbonic acid gas emitted from the lungs of the horses in the stable, and with fumes of ammonia from the decomposing urine with which the floor is saturated (a decomposition accelerated by the warmth of the place), becomes tender and diseased. That to this source must be attributed the majority of those diseases of the lungs by which so many valuable horses are annually carried off, there is no reason to doubt. 'The temperature of the stable,' says Professor Youatt, in his excellent treatise on the horse, ' should never in winter exceed ten degrees above that of the external air, and during the rest of the year should be as similar to it as possible.' And he adds a fact which is far too little known to the owners of live stock: "The return to a hot stable is quite as dangerous as the change from a heated atmosphere to a cold and biting air. Many a horse that has travelled without injury over a bleak country, has been suddenly seized with inflammation and fever when he has immediately at the end of his journey been surrounded with heated and foul air.' 'And,' he adds in another place, 'of nothing are we more certain, than that in the majority of the maladies of the horse, those of the worst and most fatal character, directly or indirectly are to be attributed to the unnatural heat of the stable.' The evil, then, being certain, the remedy merely consisting in the better and more regular ventilation of the stable, can I urge upon the horse's owner a more reasonable or a more profitable improvement than this? My own experience tells me that a warm box, well ventilated and constantly kept clean, is by far the best and the most healthy medium in which a horse can be placed. Both cleanliness and ventilation must, of course, go together; for it is easy to lose the advantages of ventilation by a disregard to the cleanliness of the stable.

"With regard to the stall-fed cow and the ox, the same erroneous mode of treatment is too constantly adopted: warmith and quiet, and an absence of light, it is true, have all been determined to be highly conducive to the rapid progress of the animal to maturity, but no sensible farmer ever yet concluded that the purity or the foulness of the air in which the animal is placed, is a matter of perfect indifference : and yet in now many instances are such cows, such fattening oxen, stall-fed, in an atmosphere in which the lungs of the animals must be weakened, their 1082 health endangered? How commonly do we see them placed in low close stables, into which a breath of fresh air rarely enters? It is idle to contend that to confine them in such an atmosphere does them no injury. It has been found that the same kind of impure air which these animals are too often made to endure, is certain death to the smallcr animals; and, that the mortality increases as the size of the animal decreases, has been well shown by many curious and valuable inquiries. I will give a few only of these, being quite sure that to many of my readers they will afford matter of grave and useful reflection, when they are considering the ventilation not only of the stables of their live stock, but of the cottages of their labourers, and the rooms which the farmer is himself inhabiting. Let us commence our inquiries, then, with the effects of bad air upon the smaller tribes of birds, and proceed afterwards to the larger animals. 'It is well known,' says Dr. Arnott (Report of Commissioners upon the Health of Towns, p. 61), "that a canary bird suspended near the top of a curtained bedstead in which people have slept, will generally, owing to the impurity of the air, be found dead in the morning; and small, close rooms, in the habitations of the poor, are sometimes as ill-ventilated as the curtained bedstead.'

"Mr. Edwin Chadwick, the excellent Secretary to the Poor-Law Commissioners, in his able supplementary report upon the sanatory condition of the labouring classes, gives some striking facts in illustration of the ill effects of bad smells upon the health of small birds. He says (p. 10), 'In the course of some inquiries which I made with Professor Owen, when examining a slaughterman as to the effects of the effluvia of animal remains on himself and family, some other facts were elicited illustrative of the effects of such effluvia on still more delicate life. The man had lived in Bear Yard, near Clare Market, which was exposed to the combined effluvia from a slaughter-house and a tripe factory. He was a bird fancier, but he found that he could not rear his birds in this place. He had known a bird, fresh caught in the summer time, die there in a week. He particularly noted, as having a fatal influence on the birds, the stench raised by boiling down the fat from the tripe offal. He said, 'You may hang the cage out of the garret window, in any house round Bear Yard, and if it be a fresh bird it will be dead in a week.' He had previously lived for a time in the same neighbourhood, in a room over a crowded burial. ground in Portugal Street. At times, in the morning, he had seen a mist rise from the ground, and the smell was offensive. That place was equally fatal to his birds: He had removed to another dwelling-house in Vere Street, Clare Market, which is beyond the smell from this particular place, and he was now enabled to keep his birds. In town, however, the ordinary singing birds did not actually live more than about eighteen months. In cages, in the country, such, birds were known to live as long as nine years or more, on the same food. When he particularly wished to preserve a pet bird, he sent it for a time into the country; and by repeating this removal he preserved them much longer. 'The fact of the pernicious effect of offensive smells on the small graminivorous birds, and the short duration of their life in close rooms and districts, 
was attested by a bird-dealer. In respect to cattle, the slaughterman gave decided reasons for the conclusion, that, whilst in the slaughterhouse, they lost their appetites and refused fool, from the effect of the ethluvium of the place, and not, as was popularly supposed, from any presentiment of their impending fate.' 'The spread of the knowledge of the fact that animals are subject to typhus, consumption, and the chief of the train of disorders supposed to be peculiarly human,' remark the Commissioners in another place, 'will, it may be expected, more powerfully direct attention to the common means of prevention.' (Report, p. 103.)

Epizoor: diseases, are such as prevail amnng a large number of animals at the same time, just as epidemics do in the human species. ' The epizootie are, in many respects, less serious than the epidemics: nevertheless, as they often affect the animals which serve for the nutriment of man, and that, apart from this consideration, they may have grave consequences for the public health, they have constantly engaged the care of the Council. In 1834 an epizootie was reported to the Administration, which prevailed amongst the cows of the communes round Paris, and which caused a great mortality. The researches of the Council established that this epizootie was only a chronic disease, a true pulmonary phthisis, to which has been given the name of pommelière, and by which the greater part of the cows had been attacked which fill the stables of the milkmen of Paris and its environs. According to the Council, the principal cause of the evil was to be attributed to the vicious regimen to which this animal is subjected. It is known that they pass a part of the year in stables perfectly closed, in which the space is not proportioned to the number of inmates, in which the vitiated air renews itself with extreme difficulty, and in which the heat is sometimes suffocating. It is known, also, that they pass suddenly from the food of the stable to pasture, and that in this change they go from the hot and humid atmosphere of the stable to a sudden exposure to the continued variations of the external air. This alternation of food, and of heat and cold, operates as a powerful cause of disease. But as the evil does not announce itself in a violent manner, as its progress is not very rapid, as there is even a period in the disease in which the animal is disposed to get flesh, the cow-feeder, who knows to what point to keep her, sells her when she is ready to calve. It is in a radius of thirty leagues from the capital that cows of this kind are purchased by the jobbers, who supply the milkmen of Paris. With these last they still hold out a certain number of years, if they are properly cared for; but in general they are kept in stables which are neither sufficiently large nor sufficiently airy, where they are exposed to the same causes which gave birth to the malady. The phthisis arrives insensibly at its last stage, and carries off every year, from Paris and its neigbourhood, a great number of these cows.'

"6 A similar discovery was only lately made as to the effect of defective ventilation on the cavalry horses in some of the government barracks in England; and it is stated a saving of several thousand pounds per annum was effected by an easy improvement of the ventilation of the barracks near the metropolis. An agriculturist had a large number of sheep housed to feed them on mangel wurzel, but a great number of them sickened and died, and he supyon of 1 , : : sas the food which had killed them. A seler mary surgeon, however, who happormal in l, a ware of

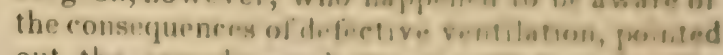
out the remedy-a lecter venfilation for the over-crowded sheep. Thedelecet was reuredied; the sheep throve will."?

In adopting means for the removel or extruetion of foul air, in dwellings for man, as well as in stables, dairies, and even sho..pr-culs and pigpens, when these are made rlose, live sentilator, or holes for its escape, should al ways be placed at the highest part of the ceiling. Withdrawing the foul air from the bottom of buildings, on the supposition that, as carbonic acid gas is heavier than common air, it must necessarily subside to the lowest portion of the interior, though plausible in theory, is found to be allugether erroneous in practice. For it has been ascertained that this heavy gas, as it comes from the lungs combined with heat and moisture, is lighter than common air, as we see by the rising of the breath in frosty weather. In the ventilation of stables, cow-houses, \&c., the supply of air will require to be of larger amount than for buildings intended for human beings. About 400 cubic inches per minute is the usual allowance of air breathed by an adult person; but for horses and cows, three times as much is required.

The one or more openings for the escape of the foul air, have their sizes or areas calculated according to the following rule. Multiply the number of horses the stable is to contain by 12 , and divide the product by 43 times the square root of the height in feet from the ceiling to the floor, and the quotient is the area of the ventilation tube or tubes in feet. (Burn on Practical Ventilation.)

No foul air can by any possibility be extracted from the interior of a building, however well arranged it may be, unless an ample supply of pure air is admitted, because it is the force of the entering air that causes the vitiated to be expelled.

The fresh air should be admitted by apertures in the walls, made close to the floor under each window. Where this can be done, and supposing there were six windows, and the fresh-air ducts required to be 6 square feet, six openings should be made, each equal to one square foot. All the openings should have valves fixed on the outside, to regulate the admission of air. In stables, \&c., well supplied with the means of admitting fresh air and withdrawing the foul air, the doors and windows may be made as tight as possible, yet the interior will smell sweet and clean.

Dairies cannot be too well supplied with pure fresh air; to secure which, they should not be situated in the vicinity of any source of contamination. (See Burn's Treatise on Practical Ventilation, for further details.) See Sorurvg.

Animal Heat.-Recent researches made by chemists have developed many wonderful phenomena of life hitherto regarded as inexplicable mysteries. Among these is that relating to the source of animal heat, and the kinds and proportions of food necessary to maintain it. This being a subject intimately connected with the practices of sheltering and feeding cattle and other stock, it of course demands the close con sideration of the intelligent farmer, to whom we present the results recently obtained through the investigations of Dr. Playfair :-

"The average temperature of the bodies of 
our cattle is about $100^{\circ}$, or more than $40^{\circ}$ higher than the ordinary temperature of the climate of England. Hence there must be some provision in the animal body to sustain the heat, which is absolutely necessary for the performance of the organic functions. The air, being so much colder than the body, must constantly withdraw from it heat, and tend to lower its temperature. Whence, then, comes the fuel for the production of the heat?

"The fuel consists of those ingredients of food from which nitrogen is absent; they all contain carbon and the elements of water. We know that oxygen is continually inhaled in the air we breathe, and that it is never again expired as such. Expired air consists of carbonic acid, a gas composed of carbon and oxygen. In the body, therefore, the oxygen has united with carbon; or it has produced the very gas which is obtuined by burning a piece of charcoal in the open air. Now the heat generated by the combustion of the carbon in the body must be exactly equivalent to that produced by burning the same amount in the atmosphere."

Experiments have taught us, that the average quantity of carbon in the food of an adult man amounts to 14 ounces daily. By the combustion of this quantity $197,477^{\circ}$ of heat are produced, and this is amply sufficient to account for the heat of the human body.

The experiments of Boussingault show, that a cow breathes out about 70 ounces of carbon daily, and from this we calculate that $987,385^{\circ}$ of heat must be produced in the body of a cow in the space of twenty-four hours. These calculations will at once prove that there is little difficulty in accounting for the heat of the animal body.

But, as the heat of the animal body is the same in all regions, it is obvious that the quantity of fuel (food) necessary to sustain the constant temperature of the body must vary according to the nature of the climate. Thus less food is required for this purpose in India, where the temperature of the external air equals that of the body, than in the polar regions, in which it is very many legrees lower. But a beneficent Providence has arranged the produce of different countries so as to meet the exigencies of the climate. The fruits, upon which the inhabitants of warm countries love to feed, contain only 12 per cent. of carbon, while the train-oil enjoyed by the inhabitants of arctic regions contains above 70 per cent. of the same element.

It has been shown that the food of various countries is more or less combustible, according to the temperature of the climate; and proofs were adduced that the amount of the food consumed varied also according to the temperature. The animal body is a furnace which must be kept up to a certain heat in all climates. This furnace must, therefore, be supplied with more or less fuel according to the temperature of the external air. If then in winter we wish to retain the vital functions of our cattle in a pro. per degree of activity, we must keep up the heat of their bodies. This we may do in two ways. We may either add more fuel (food) to the furnace, or we may protect their bodies from the cold. Warnth is an equivalent for food, which may thus be economized. As a proof of the view I have now given, I will cite the following experiment, which was made by the Farl of Ducie at Whitfield farm.
One hundred sheep were folded by tens in pens, each of which was 22 feet in length by 10 feet in breadth, and possessed a covered shed attached to it of 12 leet in length by 10 feet in breadth. They were kept in these from the 10th of Octo. ber to the 10th of March. Each sheep consumed on an average $20 \mathrm{lbs}$. of swedes daily. Another hundred were folded in pens of a similar size, but without sheds attached. They were kept during the same time, and their daily consump. tion of swedes amounted to $25 \mathrm{lbs}$. each. Here the circumstances were precisely similar with respect to exercise, the only difference being that the first hundred sheep had sheds into which they might retire, and thus be partially protected from the cold.

This partial protection was equivalent to a certain amount of food, and consequently we find that the sheep enjoying this protection consumed one-fifth less food than those sheep which were left entirely exposed to the cold. In the last case the consumption of the additional food arose wholly from the necessity of adding more fuel (food to the furnace of the body, ) in order to keep up its normal temperature. This was proved from the circumstance, that those sheep which enjoyed the protection had increased 3 Ibs. each more than those left unprotected, although the latter had consumed one-fifth more food.

The influence of warmth in reducing the consumption of food has been examined experimentally by other farmers, who pretty well agree in the conclusion, that warmth is, to a considerable extent, a substitute for food. It is true, that in the experiments with sheep the results have been somewhat discordant, but, as I have elsewhere had occasion to remark, this has arisen in many cases from inattention to other injurious influences to which these animals were exposed. Warmth is not only essential to their health and fattening progress, but this must be a dry and a wholesome warmth. To confine the sheep, as is sometimes done, over putrefying masses of fold, shed, or farm-yard dung, in an atmosphere saturated with fumes of ammonıa and the gases of putrefaction, is to substitute one drawback upon the health and comfort of the animal for another, which produces a greater evil than cold. The sheep, in a state of nature, carefully avoids all these things; it leaves to the ox the deep rank-growing grasses of the damp lowland pastures. It carefully seeks its food and its habitation on the highest elevations, amid dry rocks and heath-producing soils, far away from all great masses of decomposing organic matter. The domestic sheep of our enclosed lands, by always occupying the most elevated portions of the field, clearly indicates that its natural instinct in this respect is still unchanged by all the efforts of the breeder. Follow, then, the sheep from his upland pastures, in the clear, dry, warm climate of Asia, and view him placed in our cold temperature, in a warm shed it is true, but with the floos of that shed covered for a depth of many inches with a mass of putrefying dung, and then let us ask ourselves, "Is this the way fairly to test the advantages of shelter and of warmth to the domestic sheep? Is this the way to fairly try the economy of raising the temperature of the atmosphere in which it is placed?" The Rev. A. Huxtable saw this in its true light, when be commenced his trials. He tells us, in his valua- 
ble little paper Jour. R. A. S. vol. vi.p. 212, "Having observed that sheep in wet weather on our downs always select the most beaten roads for their bed, it occurred to me that not only when under sheds should they lie on boards, according to your own experiment, but also that the courts to which they have daily access whilst their houses are being cleaned should be covered, not with soft litter, but with hard chalk or sand, or other materials to form a solid bottom. My little yards attached to the sheds are floored with a sort of asphalte made of chalk beaten small, covered with gas-tar and sand. In constructing sheds for my sheep I have kept in view the strictest economy; and I venture to send these minute details, which I hope will serve to prove that the protection of sheep from the inclemency of the weather is within the reach of every tenant farmer. Fach of these sheds contains about 50 sheep. They are erected on a very simple plan : a couple of fir poles, 1\% feet long, are nailed together at the top; their extremities, at a distance of 15 feet, are driven into the ground; another couple, 10 feet distant, are united with this, and held firm by a ridgepole nailed into and lying between the tops of the fir poles. Side pieces are nailed parallel to the ridge-pole, and small hazel-wood is interlaced so as to support the thatch, which a labourer ties on with tar-twine. The thatch in front and behind reaches to about 3 feet from the ground; behind, a bank of turf is raised to meet the thatch; the front is guarded by a hurdle, moveable at pleasure, to allow the sheep to go into the court, which is of the same size as the shed. It is important that both ends of the shed should be protected with bavins only, which will secure a free ventilation, yet keep out rain. My sheds, about 50 feet long (not charging the straw), cost about $41 s$, each.

"These sheds are floored with 1-inch boards, separated (each strip from the other) by $\frac{3}{4}$ inch intervals. The cost of the timber and mode of preparing the floor were as follows:- White pine timber was used for its cheapness, being 1s. $3 d$. the cube foot, which would therefore give eleven 1 -inch boards. On account of the particular width of the logs which I bought, the board was sawn into pieces 7 inches broad and 1 inch thick. These, for economy, are handsawn into three parts, and are nailed upon joists at a distance of $\frac{3}{4}$ inch. By this plan nearly onethird of timber is saved; so that each sheep, requiring 9 feet of space, lies actually on 6 feet of 1-inch board. The cost of timber for joists, nails, and carpenters' work, raises the total expense of placing the sheep on boards to $1 s .4 d$. per head. Instead of sleepers I used small blocks, 6 inches thick, to keep the rafters from direct contact with the manure. The boards are put together into frames about 10 feet by 4 , so that they may easily be taken up by one man. Beneath the boards the floor, excavated 8 or 9 inches, is puddled and made water-tight, and govered with 6 inches of sawdust, burnt clay, or good dry mould. This receives and absorbs the manure which falls, or is swept below twice a day. The boards, after sweeping, are watered with a solution of $3 \mathrm{lbs}$. of sulphate of iron (copperas), which instantaneously removes the odour not only of the ammonia, but of the more offensive sulphuretted hydrogen. The boards should be laid perfectly flat, to prevent the sheep slipping about. The sheep are fed under the sheds, not in the conrts. Ther remules of this arren ecment

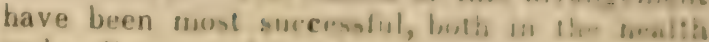
and well duing of the sheep.

"It is true that I have. lost four head, whir!s seem to have died from apoplexy; lut I lostile same number in the flock which were at largo, and treated in the usual manner. Though i have had more than 300 Southdowns so sheelderd? some of them longer than five months, yet i have never seen any instance of lanueness, er.h in the least degree.

"'Their food consists of turnips, for the last fortnight only of swedes; half a pint per day (never more) of oats or peas; with straw cue into clafi", over which ground linseed has bee a poured, mixed with boiling water.

"I regret that I cannot send the important statistics of weight and improvement under this regimen. During one month the sheep werc weighed, and found to have iricreased a vout 3 lbs. per week on an average; that is, trin were selected and weighed which seemerl fairly to represent the flock, and they had made this improvement. The illness of my bailiff stopped these calculations; but the general issue will be allowed to be satisfactory, as more than half have been sold which in twelve weeks have paid $13 s$. a head.

"Leaving out of the account both the injury which in bad seasons my clay-lands would have sustained by the treading of the sheep, and the value of the rich manure saved under shelter (its gases fixed by the sulphate of iron and gypsum strewed daily over the boards), I consider that the whole expense of boards and sheds was saved in the first month."

In the stall feeding of cattle, the application of these just principles can hardly be too systematically regarded. Of this opinion, too, is Mr. George Dobito, who, in his prize "Essay on fattening Cattle," (Jour. R. A. S. vol. vi.p. 78), remarks, "Cleanliness, warmth, and quiet, are the great points I insist upon, of course coupled with good feeding; but many tons of oilcake are annually wasted, because the comfort of the arimals is not more attended to."

The subjects of air and food are so closely allied as to be viewed to most advantage together. That vegetable substances contain animal matters ready formed, was a suspicion which was entertained in a confused shape by more than one of even the early Greek philosophers, but it was reserved for the modern chemist to prove the truth of the supposition. This has been thus explained by Dr. Lyon Playfair (Jour. R. A. S. vol. iv. p 216 :-

"All vegetable food has been found to contain a peculiar substance, which, though it differs in appearance and in form, according to the source from whence it is obtained, is in reality the same body. It has received the name of gluten or albumen, and is precisely identical, in chemi. cal composition, with the albumen obtained from the white of an egg. This substance is invariably present in all nutritious food. Chemis's were surprised to discover that this bo!y nper varies in composition; that it is exaely the same in corn, beans, or from whateser plant it is extracted. But their surprise was much in creased when they remarked that it is quite identical with the flesh and blool of arimals. I: consists, like the latter, of carbon, lighrogen, nitrogen, and oxygen, and in the very same pro. portion in $\mathbf{1 0 0}$ parts. By identity in composit.ou 
is not meant a mere similarity, but an absolute identity; so much so, that if you were to place in a chemist's hand some gluten obtained from wheat flour, some dry albumen procured from the white of an egg, a fragment of the flesh of an ox or of a man, or some of their dried blood, and request him to examine their difference, he would tell you, strange as it may appear, that they are precisely the same, and that with all the refinements of his science he was unable to detect any essential difference between them. There is much difference, indeed, in external appearance and in structure, but in their ultimate composition there is none." To render this more obvious, I subjoin the composition of these various substances, as obtained by different chemists, who executed their analyses without any knowledge of the results obtained by the others :-

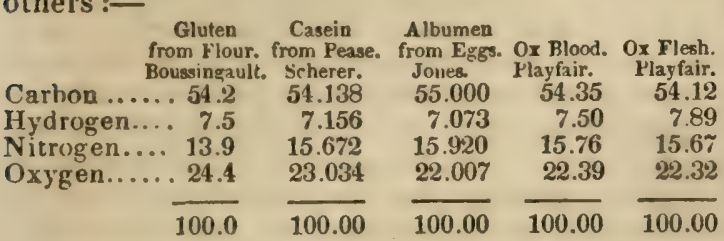

These analyses do not differ from each other more than the analyses of the same substance usually do. Thus we are led to the startling conclusion, that plants contain within them the fesh of animals ready formed, and that the only duty of animals subsisting upon them is to give this flesh a place and form in their organism. When an animal subsists upon flesh, we find no difficulty in explaining its nutrition; for the flesh being of the same composition as its own body, the animal, in a chemical point of view, may be said to be eating itself; nor, with a knowledge of this identity of vegetable albumen with flesh, is there any difficulty in comprehending the nutrition of vegetable feeders.

Plants, then, in reality, form the flesh of animals; and the latter merely appropriate it a place in their organism.

It follows, then, as a conclusion, that the analysis of any vegetable substance pretty accurately indicates its nutritious powers. "It has been shown by many laborious chemical researches," to use the words of Dr. Playfair, "that there are two kinds of food. The first, which contains nitrogen, is exactly of the same composition as the principal tissues of the human body, and is the only substance which can supply the waste of these tissues. The second kind of food is that destitute of nitrogen, such as starch, gum, and sugar, all of which are destined for the support of respiration and consequent heat of the animal. The latter kind of food, when in excess, is converted into fat, but never into muscle. The increase of flesh in an animal consists in two changes of the matter of the food, without any alteration in its composition. The albumen or nitrogenous constituent of the food is first converted into blood, without decomposition, and the blood is afterwards converted into flesh. In order to show that the transformation is actually effected without change, we have only to refer to the following results of the analysis of vegetable albumen, of ox blood, and of flesh :-

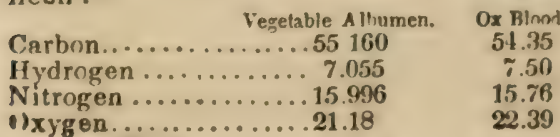

"As muscle then is formed only by the albumen or gluten of the food, which albumen is in reality flesh itself, we can ascertain the comparative value of food, as far as the production of muscle is concerned, by estimating the exact quantity of the nitrogenous constituent of the food. The following table," continues Dr. Playfair, "contains the approximative, though not perfectly accurate, information relative to the value of food for the support of respiration and production of fat :-

\begin{tabular}{|c|c|c|c|c|c|}
\hline \multirow[b]{2}{*}{100 lbs. } & \multicolumn{2}{|c|}{ Unazotized } & & \multicolumn{2}{|c|}{ 'nazotized } \\
\hline & $\begin{array}{l}\text { Albumen. } \\
\text { lbs. }\end{array}$ & $\begin{array}{c}\text { Matter. } \\
\text { Itss. }\end{array}$ & $100 \mathrm{lbs}$. & $\begin{array}{c}\text { Albumen. } \\
\text { los. }\end{array}$ & $\begin{array}{c}\text { Matter. } \\
\text { fbs. }\end{array}$ \\
\hline Flesh & . 25 & 0 & Oats & 11 & 68 \\
\hline Blood & 20 & 0 & Barleymea & 114 & $68 \frac{2}{2}$ \\
\hline Beans & . 31 & $51 \frac{1}{8}$ & Hay & 8 & $68 \frac{1}{2}$ \\
\hline Peas. & . 29 & $51 \frac{1}{2}$ & Turnips & 1 & 9 \\
\hline Lentils & . 33 & $48^{2}$ & Carrot & 2 & 10 \\
\hline Potatoes & 2 & 25 & Red-beet & $1 \frac{1}{8}$ & $8 \frac{1}{6}$ \\
\hline
\end{tabular}

That fat exists ready formed in various vege table substances, has been proved by careful chemical examination. Thus, according to Liebig, hay contains 1.56 per cent., and maize 4.67 per cent. of fat. Braconnot found 1.20 per cent. in peas, while Fresenius got $2 \cdot 1$. per cent.; and in lentils 1.3 per cent. Vogel obtained 2.00 per cent. of fat in oats; Liebig 0.3 per cent. in dry potatoes; and Braconnot $0 \cdot 13$ per cent. in rice, although, in another variety, Vogel states that be detected 1.05 per cent. The substance here called fat is in reality a waxy or resinous body, and not tallow, except in a few instances.

[Food.] An animal requires, to sustain its body in good condition, supply heat, and make up for daily waste, about 1-60th part of its own weight. If the object be to increase the size, enable it to work, or give milk, a still larger proportion of food must be given. Thus, to feed for milk twice the quantity of food named will be required. If muscle for labour be needed, food containing gluten must be given, and as peas and beans contain gluten in the largest quantity, they constitute exceedingly valuable food for working horses. Wheat contains 35 to 40 per cent of the gluten out of which muscle is formed. Cabbage is rich in gluten, and the flower of the caulifiower contains more gluten than any other garden regetable we raise for food. When fat is required, or a good coat, give substances containing oil, such as Indian corn, oats, linseed-cake, as well as rape-cake and poppy-seed cake. Farmers generally prefer those substances which unite the muscle and fat-giving qualities. The milkman desirous of quantity and little regarding quality, gives his cattle grains from the brewery-and various kinds of watery slops. But where the dairyman wants butter or cheese, then quality is to be considered. In order to make butter, the milk must be rich, and he has it in his power to add largely to the ordinary produce of the dairy, by the selection of food rich in oil. In England oil-cake is given, but not much at a time, as it gives an undesirable taste to the butter. A skilful dairyman can, however, often manage, by giving a large quantity of oilcake, to get a far better quality of milk than by giving any other kind of food. If the object be to make cheese, food is given rich in the material to produce curd - which is precisely that furnishing the flesh or muscle, already referred to. To feed with cabbage would produce a poor cheese, which contains little fat, but a large proportion of the curd or muscle-forming material. Where milk to make butter or rich cheese is 
required, more fatty fond must be furnished; and of all subsiances for effecting this object, linseed. cake, and maize are perhaps the best.

It is of great inportance to allend to the state in which food is introduced into the stomach of animals. Indian corn, for example, given without mixing with other food, will not be so readily digested. The proper preparation of food for animals is a branch of agricultural knowledge which has been found highly profitable to the farmer. By mixing different kinds of food, the requirements of the animal are best met. Cut straw or chaff is an admirable substance with which to mix other more nutritious materials, rendering these more readily digested and nourishing, besides making the food go further. Malt is often employed with great advantage, mixed with other food. Other influences, such as warmth, shelter, ventilation, and quiet, exert a great effect in promoting the thrift and welfare of animals.

The amount of nutriment found in different varieties of the food consumed by the farmer's live stock, has been referred to under the head Food, where some interesting facts will be found, chiefly derived from the researches of Davy. It is a subject to which still more recent investigations have given additional interest. The proportions in which the several elementary substances exist in 100 parts of some of the most commonly cultivated grains and products of the farm, are represented in the following table from Prof. J. F. W. Johnston's Lectures.

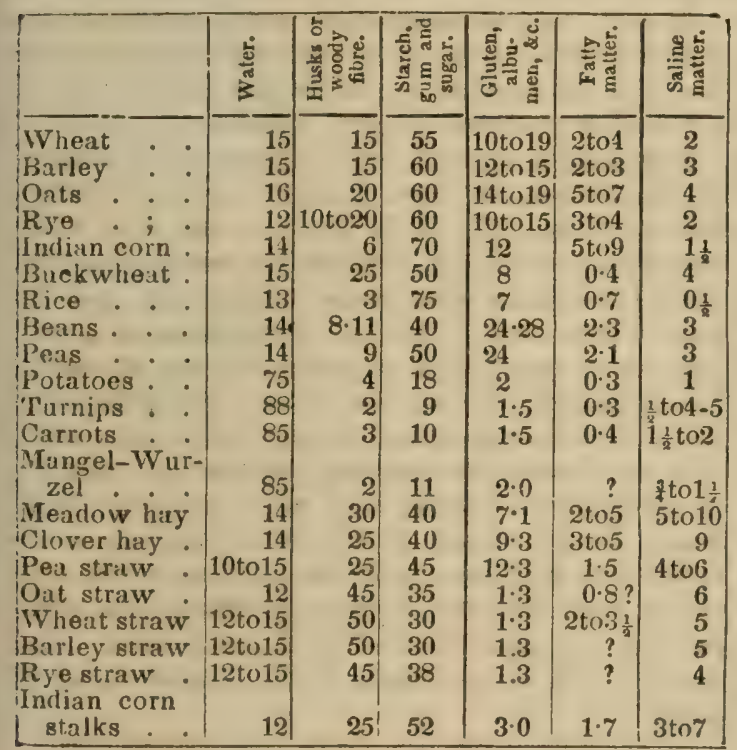

Some of the numbers in the above table are given as mere approximations, especially those referring to buckwheat and fatty matter, which last is very uncertain.

It hence appears that water enters into the composition of every vegetable product, wheat containing 15 per cent., the turnip 88 to 90 per cent., exhibiting the strong contrast between grains and roots. The second column represents woody fibre, straw and husks, parts of plants which animals cannot digest, and from which they consequently derive no nourishment. In wheat and other grains, the proportion of this varies from 10 to 20 per cent. In the column designating the proportions of starch, gum, and sugar, the grain of wheat exhibits about 55 per cent., Indian corn 70 per cent., Indian corn stalks 22 per cent., rice 75 per cent., \&c. All grains likewise contain a substanee called gluten, bue in quantities varying very mun h, ws way bes soen

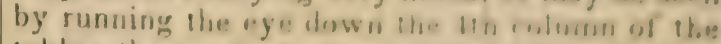
table; the greatest proportion of this and albumen being fond in brams, whin he girains throg highly nutritious qualities. Even pea-straw is very rich in these materials, which trakes them valuable provender, where ofher himls of sprat are almost worthless. Of oil or fally materep, wheat and barley have very little, whilst in oats and Indian corn, oil abounds. The rone crops and straw's have very little. Planis lake in, through their leaves and roots, tire carbonic acid and other materials, the changr.; in which produce the starch, gluten, and fat to be found in them all, and which go to nourish animals.

It forms, says Mr. Karkeek, in his "Essay on Fat and Muscle" (Jour.R.A.S. vol.v. p.219), a curious and interesting subject for the feeder to ascertain the respective quantities of the fleshing and fattening properties contained in an acre of the different crops commonly used in the rearing and feeding of stock. The following acreable table of mutrition has been constructed chiefly from Professor Johnston's calculations; the proportions of gluten, \&c., from Boussingault's ana. lysis, which indicate the fleshing properties; and the proportions of starch, gum, and sugar, the fattening properties :-

\begin{tabular}{|c|c|c|c|c|c|}
\hline One Acre of & $\begin{array}{c}\text { Produce } \\
\text { per } \\
\text { Acre. }\end{array}$ & $\begin{array}{l}\text { Weight } \\
\text { of Grain } \\
\text { per } \\
\text { Bushel. }\end{array} \mid$ & $\begin{array}{l}\text { Wt. of } \\
\text { Glufen, } \\
\text { Albu- } \\
\text { men, \& } \\
\text { Caseine. }\end{array}$ & $\mid \begin{array}{c}\text { Wt. of } \\
\text { Starch, } \\
\text { Gum, } \\
\text { Sugar, } \\
\text { and } F \text { at. }\end{array}$ & $\begin{array}{l}\text { W'eight } \\
\text { of Water } \\
\text { per Acre. }\end{array}$ \\
\hline Field beans. & 25 busly & $\begin{array}{l}\text { lbs. } \\
64\end{array}$ & $\begin{array}{l}\text { lbs. } \\
450\end{array}$ & & $\begin{array}{l}\text { lbs } \\
256\end{array}$ \\
\hline Peas. & $25 \quad 66$ & 66 & 380 & 845 & 208 \\
\hline Oats & 50 & 42 & 290 & 1,1 & 336 \\
\hline Hay & 3 tons & . & 480 & 2,790 & 752 \\
\hline Potatoes & 126 & . & 600 & 3.330 & 20,250 \\
\hline Carrots & 25 & .. & 1,120 & 5,800 & 47,600 \\
\hline Turnips. & 30 & 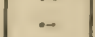 & 800 & 6,700 & 56,950 \\
\hline Wheat straw & 3,000 llos. & 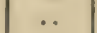 & 40 & 910 & 450 \\
\hline Oat straw & $2,700 \quad 66$ & .. & 36 & 97 & 324 \\
\hline Barley straw & $2,100 \quad$ i6 & . & 28 & 646 & 252 \\
\hline
\end{tabular}

Another table showing the nutritive properties per acre of the ordinary crops of the farmer has been given by Mr. Hyett, and will be found at the head of the next page.

The tables just given from analyses marle by Prof. J. F. W. Johnston, and other eminent chemists, show the proportions of water, with those of the several dry organic constituents, as well as the ashes or saline matters contained in many of the articles of food with which the farmer is most familiar. From these it may be seen that it is very important for the economical management of live-stock to know the amount of water as well as of the organic and nutritive ingredients which each kind of food contains. Thus we find that in giving a pig $100 \mathrm{lbs}$. of potatoes, we actually give it about $75 \mathrm{lbs}$. of water. But in giving it $100 \mathrm{lbs}$. of Indian corn, we contribute only about 14 lbs. of water, nearly all the remaining $86 \mathrm{lbs}$. being nutritious matter. As already observed, the table just given from Professor J. F. W. Johnston shows the proportion of woody fibre freed from the nutritious substances, well known to be contained in greater or less proportion in husks, straw, \&e. This woody fibre, as it cannot be digested by animals. must therefore be deducted from the amsunt of nourishment. It constifutes half the amount of wheat and rye straw, whilst it makes but 30 pep cent. of ordinary mearlow grass hay, and only 2 ? per cent. of clover hay. 


\begin{tabular}{|c|c|c|c|c|c|c|c|c|c|}
\hline & & & $\begin{array}{l}\text { Assumed } \\
\text { A veraze } \\
\text { per Acre. }\end{array}$ & & Taken at & & $\begin{array}{l}\text { Ave: age } \\
\text { per acre in } \\
\text { lus. }\end{array}$ & $\begin{array}{c}\text { Equivalents } \\
\text { of } \\
\text { Nourishent. }\end{array}$ & $\begin{array}{l}\text { Re!lative } \\
\text { Nourishnear per } \\
\text { Acle. }\end{array}$ \\
\hline Wheat . & . & - & 32 bush. & 60 lbs. & per bushel & $=$ & 1,920 & $\div 41$ & $46 \cdot 8$ \\
\hline s6 straw & - & • . & $30 \mathrm{cw}$. & 66 & 66 & $=$ & 3,360 & $\div 450$ & $7 \cdot 46\}$ \\
\hline Peas & - & . . & 20 bush. & 66 & 6 & $=$ & 1,200 & $\div 45$ & 26.6 \\
\hline straw & - & - . & & 66 & 66 & $=$ & & $\div 125$ & \\
\hline Barley . & . & . & 40 bush. & $48 \quad 66$ & 66 & $=$ & 1,920 & $\div 54.5$ & $35 \cdot 2$ \\
\hline 66 straw & . & . & $20 \mathrm{cwt}$. & 66 & 6 & $=$ & 2,240 & $\div 300$ & $7 \cdot 4$ \\
\hline Oats . & . & . & 50 bush. & 4066 & 66 & $=$ & 2,000 & $\div 55$ & $36 \cdot 3$ \\
\hline "6 straw & & & $40 \mathrm{cwt}$. & 66 & « & $=$ & 4,480 & $\div 300$ & $14 \cdot 9$ \\
\hline Beans . & . & . . & 32 bush. & 60 66 & 66 & $=$ & 1,920 & $\div 61.5$ & $31 \cdot 2$ \\
\hline 66 straw & - & - & $40 \mathrm{cwt}$. & 66 & 66 & $=$ & 4,480 & $\div 450$ & $9 \cdot 97$ \\
\hline Clover hay & . & & $30 \mathrm{cwt}$. & 66 & 66 & $=$ & 3,360 & $\div 90$ & $37 \cdot 3$ \\
\hline Ordinary hay & - & . & $20 \mathrm{cwt}$. & $\ll$ & 66 & $=$ & 2,240 & $\div 100$ & $22 \cdot 4$ \\
\hline Fotatoes & . & . & 100 bags & 290 lbs. & per bag & $=$ & 28,000 & $\div 200$ & 140 \\
\hline Cabbage & . & . & 20 tons & 66 & 66 & $=$ & 44,800 & $\div 250$ & $179 \cdot 2$ \\
\hline Carrots. & - & . . & 25 tons & 66 & 68 & $=$ & 55,000 & $\div 275$ & 200 \\
\hline Beet. . & , & & 25 tons & 66 & 6 & $=$ & 55,000 & $\div 397$ & $138 \cdot 5$ \\
\hline Green clover & ? & . & 6 tons & "6 & 66 & $=$ & 13,440 & $\div 475$ & $28 \cdot 29$ \\
\hline Turnips & . & . & 25 tons & “6 & 66 & $=$ & 55,000 & $\div 500$ & 110 \\
\hline
\end{tabular}

And in the same economical point of view, it becomes an important question to ascertain, provided the result of modern experiments relating to the formation of flesh and the generation of heat is correct, and calculating from the data which they furnish, the relative value of each description of food. This has been attempted by Dr. Playfair, with a result which he thus describes (Jour R. A. S. vol. vi.p. 560: "All food then has two distinct purposes, the formation of flesh, and the sustenance of animal heat. The substances in vegetables destined for the formation of flesh are perfectly identical with it in composition, and are known by the names of gluten, albumen, fibrin, or casein; those which are suited for the support of animal heat are not at all similarly composed to flesh, and consist of starch, gum, sugar, \&c. Knowing these facts, it becomes a money question as to the value of particular kinds of food for the support of the frame. We know how much of flesh-giving principle each variety of food contains, and therefore we can at once estimate how much of each it will be necessary to consume to obtain one pound of real nutriment, and what the cost of that pound will be to the consumer. The following table is constructed on this principle, but as prices vary in different localities, these may be altered to suit the peculiar case : in the table, they are given at tbe rate at which the respective substances might be purchased in London under favourable circumstances.

Quantity of Food necessary to produce $1 \mathrm{lb}$. of flesh, and the Money-Cost of its production. $25 \mathrm{lbs}$. of milk furnish $1 \mathrm{lb}$. of flesh, $\boldsymbol{t} . \mathbf{s}$. $d$.

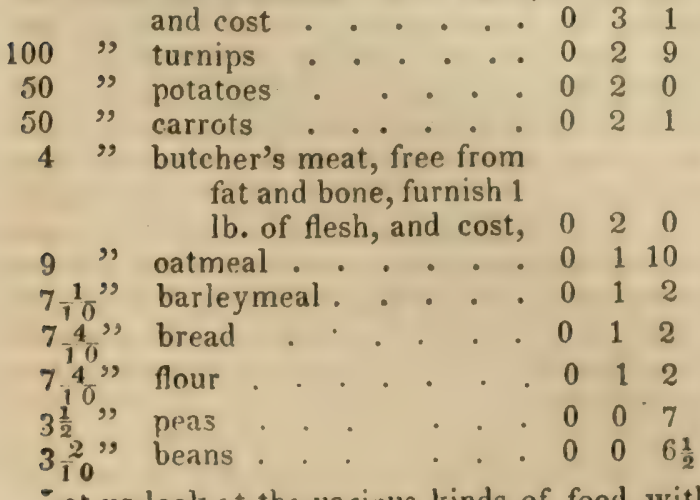

wet us look at the various kinds of food with

reference to ILeir value as fuel, and we shall 1088 perceive the potato takes its proper rank. $1 \mathrm{lb}$ of carbonaceous fuel to sustain animal heat would be furnished by different weights of the following articles at the English prices named: $4 \mathrm{lbs}$. of potatoes, $2 \frac{1}{2} d$.; $10 \mathrm{lbs}$. carrots, $2 d$.; $1 \frac{1}{2} \mathrm{lb}$. flour, $28-10 d . ; 1 \frac{1}{2} \mathrm{lb}$. barleymeal, 2d.; 11 1-10 lb. turnips, 2d.; $1 \frac{1}{2}$ lb. oatmeal, $3 \frac{3}{4} d . ; 19-10 \mathrm{lb}$. beans, $3 \frac{3}{4} d . ; 19-10 \mathrm{lb}$. peas, 3 8-10d.; $2 \mathrm{lb}$. bread, $4 d . ; 119-10 \mathrm{lb}$. milk, $1 \mathrm{~s} .5 d$. These estimates must, however, be considered as rough approximations.

It will not be unattended with benefit if we contrast these valuable scientific researches upon the cost of production with the results of the trials of a practical Scotch farmer.

From some careful experiments of Mr. Bruce, of Waughton, in East Lothian (Trans. High. Soc. 1846 , p. 375), with linseed cake and other substances in sheep feeding, he concludes that "mutton can be producea at a lower rate per lb. upon liberal use of foreign keep along with turnips, than upon turnips alone, taking of course the increased value of the manure into account ;" that of this foreign keep "linseed is the most valuable, and beans the least so; but that the mixture of both forms a useful and nutritious article of food. In his trials 95 Cheviot ewes were divided into five lots, and enclosed, and fed witt: turnip tops and the following substances, upon portions of equally sheltered grass land. Lot A consisted of 15 ewes, B, C, D, and E, of 20 each.

\begin{tabular}{|c|c|c|c|c|c|c|}
\hline & \multicolumn{2}{|c|}{ Weight. } & \multicolumn{2}{|c|}{$\begin{array}{c}\text { A verage Consumption } \\
\text { of each Sheep per } \\
\text { W eek. }\end{array}$} & \multicolumn{2}{|c|}{$\begin{array}{c}\text { Cost of Production } \\
\text { per } 1 \mathrm{~b} .\end{array}$} \\
\hline Lot. & & & & " & & \\
\hline A & & & $\begin{array}{r}0 z \\
56 \frac{1}{2} \\
4 \frac{1}{4}\end{array}$ & $\begin{array}{l}\text { Linseed. } \\
\text { Beans. }\end{array}$ & 46. & Linsee \\
\hline B & 1 & 2603 & $113 \frac{1}{4}$ & Lins'd cake. & 101 & Lin \\
\hline C & 2382 & . & $95 \frac{i}{x}$ & $\begin{array}{l}\text { Beans and } \\
\text { Linseed. }\end{array}$ & 59 & $\begin{array}{l}\text { Beans and } \\
\text { Linseed. }\end{array}$ \\
\hline & & 2657 & $157 \div$ & Poppy & 106 & cake. \\
\hline$D$ & 2104 & 2557 & 113 & Bea & $133 i$ & Ben \\
\hline $\mathbf{E}$ & 2417 & $2 \pi 36$ & 100 & $\begin{array}{l}\text { Boins and } \\
\text { Linseed. }\end{array}$ & $56 \frac{1}{4}$ & $\begin{array}{l}\text { Beins and } \\
\text { I.inseoci. }\end{array}$ \\
\hline
\end{tabular}

See Organic Chemistriy, Food, Gelatin, Ve. gatable Chemistr $x$, and other heads relating (, these subjects.

VERBFNA. See VERVAIN.

VERJUICF. An acid liquor, prepared from the twigs of the vine, or from grapes or apples that are unfit to be converted into wine or cider. It is also made from the wild crab apples. 
VERMIN. A general name for all birds, animals, insects, \&c., which prey upon or prove injurious to the cultivator's crops, and to his live-stock.

The insects, \&c., comprise the most extensive and fearful class of depredators. Among these are the aphides, caterpillars, ants, beetles, and their grubs, wire-worms, slugs, earthworms, \&c.

VERNAL GRASS. See Antuoxanthom.

VERSATILE. In botany, sigrifies swingirg lightly on the stalk, so as to be continually changing direction. It is illustrated in the leaves of the aspen.

VERTICILLATE. Disposed in a whorl.

VERVAIN (Verbena; said to be derived from its Celtic name Ferfaen). This is a genus of extremely beautiful ornamental plants while in flower, either when grown in pots in the green-house or when planted out in the flower garden; and they will all succeed well in the open ground during the summer months. The flowers of $V$.tencrioides have a delightful jasminelike odour. They all flourish well in a light loamy soil, with careful drainage when kept in pots. The herbaceous perennial kinds increase rapidly by cuttings, planted in sand under a glass; the green-house kinds in a little heat. The annuals and biennials should be raised on a gentle hot-bed.

One species is indigenous to England, the common vervain ( $V$. officinalis), a perennial which grows by road-sides and in dry waste grounds, or pastures about villages. The root is woody, somewhat creeping. Stem ascending, $1 \frac{1}{2}$ foot high, leafy, roughish, with minute prickles or bristles. Leaves deeply cut. Spikes slender, several composing a sort of panicle of small, bluish, inodorous flowers. This species has scarcely any aromatic or other sensible quality. The root worn about the neck with a string is an old superstitious remedy or charm for the king's evil.

A great many species of vervain or verbena are found in various parts of the United States. Nuttall enumerates 10 in this country, and altogether 20 American species in the two hemispheres.

VESICLES. In botany, inflated, hollow excrescences, like bladders or blisters.

VETCH (Vicia, from vincio, to bind together, because the species have tendrils by which they encircle other plants). Some of the species of this genus are well worth cultivating in the flower-border for the beauty of their flowers. They are of the easiest culture in any common garden soil. The perennial kinds may be readily increased by dividing the root or by seeds. The seeds of the annual kinds only require to be sown in the open border in spring. $V$. sativa and its varieties are extensively cultivated, and well known by the common name of vetch or tares; they are used in England as early fodder for all kinds of cattle, and are allowed to be more nutritive and profitable than hay or any other herbage. The seeds also form the food of pigeons. There are in Britain 10 indigenous species of vetch, the principal of which are the tufted vetch, wond vetch, common vetch, and bush vetch. Of all the different vetches (says Sinclair) that were submitted to experiment. the winter tare or common velch (Ir. satirise var.) afforded the must nutritive matter: 64 drachms of the herbage, cut at the ume of flowering, afforded 4 drachms 4 grains of nutritive matter; while spring lares only yielded 3 drachms 3 grains, which confirms the justice of that preference which practice has given $w$ the former.

1. The tufted vetch ( $V$. crarcu), is a peren. nial, very common in England in a wild state in hedges, thickets, osier grounds, and bushy. low meadows. The stems are 2 or 3 feet high. furrowed, rather downy, climbing by uneans of their long, many-branched tendrils, by which they choke and overtop other herbs. Flowers numerous, in dense clusters, beautifully varie. gated with tints of bright violet-blue, and some purple. Legume scarcely an inch long, smooth, with 4 or 5 dark, globular seeds, the size of a lentil. This vetch is said to be nutritious foou for cattle, but it has not come into use, proba. bly from the difficulty of gathering, or of cultivating, so pertinacious a climber. Dr. Plot, in his History of Staffordshire, says that this and the Vicia sylvatica advance starved or weak cattle above any thing yet known; and Dr. Anderson, in his Essuys, speaks highly of this plant. It is inferior to the wood vetch, or common tare ( $V$. sylvatica), in the quantity of nutritive matter it affords, but contains much less superfluous moisture. This must give it a su. periority, in regard to nutrient properties, over tares which contain an excess. But it has a strong, creeping root, that will always prevecí its admission to arable lands. It might be best cultivated on tenacious soils, and used after the manner of lucern, to which it is much superior in nutritive qualities, though greatly de. ficient in the weight of crop. Forty-three grains of nutritive matter consisted of-

Saccharine matter, or sugar

Mucilage

Insoluble and saline matter

Gram.

11

The tufted vetch flowers about the middle of July or the beginning of August, and the seed is ripe at the beginning of September.

2. The wood vetch (V.sylvaticu) grows in woods and hedges, chiefly in the more mountainous parts of Britain, and is one of our most elegant wild plants, well worthy to decurate shrubberies, or to be trained over a trellis or bower. The habits of this vetch are similar to those of the species last described, but it seems more impatient of exposure, and thrives best where it has the support of bushes. The root is creeping, perennial; herbage smooth. Stems numerous, much branched, climbing to the height of 6 or 7 feet, and spreading widely, decorating the bushes which support them with a profusion of delicate flowers, elegantly variegated with blue and white, streaked with gray. Legume the size of the last, bright brown, minutely dotted. When transplanted to open situations, the produce is inconsiderable compared with that of the tufted vetch or the bush vetch. though in its natural place of growth the pro. duce is six times that of either of these species: it is likewise superior in the quantity of nutritive matter it affords. Horses, cows, sheen. and the South American llamas, ate this vetch 1059 
with more eagerness than they did the other vetches or natural grasses that were on several trials offered to them. The wood vetch fowers in July and August, and the seed is ripe in September.

3. The common vetch or tare ( $V$. sativa, $\mathbf{P l}$. $7, r$ ) is an annual plant, which is in general cultivation, and therefore too well known to need description; 3000 grains of the green herbage of the common vetch consist of-

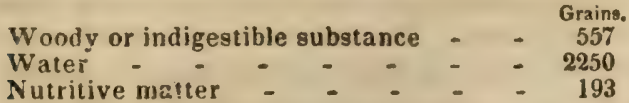

Hence 1,135 grains of the woody fibre of tares are combined with $27 \frac{1}{2}$ grains of saline matter.

In England vetches are very commonly sown upon a wheat stubble, and no crop better repays the addition of any organic fertilizers.

The bush vetch ( $V_{\text {. sepium }}$ ) has been already noticed. See Busa Vетсн.

The other British species of vetch or tare are the narrow-leaved crimson vetch ( $V$. angustifolia), spring vetch ( $V$. lathyroides), rough-podded yellow vetch ( $V$. lutea), hairy-flowered yellow vetch $(V$. hybrida), smooth-podded sea-vetch ( $V$. lovigata), and rough-podded purple vetch ( $V$. bithyrica). These call for no detailed description. A few species of the vetch family are found in the United States and Territories. 'The species called tufted vetch ( $V$. cracca), is common on the borders of woods and meadows, and troublesome in some gardens in the southern parts of Pennsylvania and other Middle States. Mr. Nuttall says it is smaller than the European plant described under the same name, but Dr. Darlington does not feel satisfied of its being a native of the United States.

The species enumerated by Mr. Nuttall are, 1. V. pusilla. 2. Sativa. 3. Americana. 4. Sylvatica, inhabiting the alluvial banks of the Missouri as far north as Fort Mandan. Leaflets a little more obtuse than usual. 5. Cracca. 6. Caroliniana. See TARE and Vetchlivg.

VETCH, THE BITTER (Orobus, from oro, to excite, and bous, an ox ; the orobos of Theophrastus was the name of a plant used for fattening oxen). 'The plants of this genus deserve to have a place in every flower-border, on account of their very elegant papilionaceous blossoms. Any soil suits them, and they are readily increased by dividing the plants at the roots in spring, or raised by seeds. There are in Eng. land two native species, both perennials.

1. The common bitter vetch, or heath pea (O. tuberosus), grows in elevated or mountainous pastures, thickets, and woods. 'The root is creeping, externally blackish, swelling here and there into oblong knobs. Herbage smooth, darkish green. Stems simple, erect, a foot high, compressed and winged. Leaves alternate. Flowers in loose, long-stalked, axillary cluslers, elegantly variegated and veined, with purple, crimson, and shades of blue and flesh colour. Legumes pendulous, long, cylindrical, black when ripe. The roots have a sweetish caste, and afford some luxuries and refreshments to the hardy independent Highlander. There is considerable elegance in the flowers, and in the plant altogether. 2. Wood bitter vetch ( $O$. sylvatirus). In this/erected: a gentleman of superior abilities has 1090

species the root is woody and tough, deeply fixed in the ground. The stems are numerous, spreading or recumbent, 1 to 2 feet long, hairy, more or less branched. Clusters of numeroils flowers, which have a hairy calyx, are cream coloured, streaked, and tipped with purple. The legumes are ovate-oblong, smooth, compressed, and shorter than usual in the genus.

VETCH, KIDNEY. See KInNEY-V ғтсн.

VETCH, MILK. See MiLK-VETCH.

VETCHLING (Lathyrus.) A numerous herbaceous genus of annual or perennial plants. The flowers are stalked, axillary, either solitary, in pairs, or in clusters; either crimson, purplish, blue, or yellow. The herbage commonly affords good fodder; the seeds are scarcely used for any purpose. There are seven indigenou: species of vetchling, or everlasting pea ; the yellow vetchling ( $L$. aphaca), the crimson vetchling or grass-vetch ( $L$. nissolia), the roughpodded vetchling ( $L$. hirsutus), the yellow meadow vetchling, or tare everlasting ( $L$. pratensis), narrow-leaved everlasting pea ( $L$. sylvestris), broad-leaved everlasting pea ( $L$. latifolius), and the blue marsh vetchling ( $L$. palustris): most of these species have been already noticed under the heads Evercasting Pea and Lathy. Rus. The latifolius is that species usually cultivated in gardens on account of the beauty of the flowers. It has been recommended for field cultivation, but the advice has not been followed. Bees procure much honey from the flowers.

VETERINARY COLLEGE. The Highland Society of Scotland have instituted a veterinary school in connection with their establishment, which is under the management of Professor Dick. By diffusing generally a practical knowledge of veterinary medicine, it cannot fail to be attended with the happiest consequences to the community at large. A veterinary college has long been established in London; and that useful periodical, the Veterinarian, edited by Professor Youat, has added much valuable information to our stock of knowledge on the diseases of animals. See FARrierY and HippoPATHOLOGX.

The London Veterinary College was first established in the year 1792, at St. Pancras. Mr. Boardman, in his Dictionary of the Veterinary Art, remarks, that "the public are indebted for this national foundation to the exertions of the Agricultural Society of Odiham, in Hampshire. The first professor was M. St. Bel, a Frenchman, who had previously signalized himself in this country as a veterinary anatomist, by dissecting the famous race-horse Eclipse. This college is supported by public subscription. The annual contribution is 2 guineas, but payment of 20 guineas at once constitutes a subscriber for life.

"The views and objects of the college appear in the following statement, printed by the authority of the governors. The grand object, they observe, is the improvement of veterinary knowledge, in order to remedy the ignorance and incompetency of farriers, so long univer. sally complained of. For this end, a range of stables, a furge, a theatre for dissections and lectures, with other buildings, have been 
bee appointed professor, with other requisite officers.

"The anatomical structure of quadrupeds, as horses, cattle, sheep, dogs, \&c., the diseases to which they are subject, and the remedies proper to be applied, are investigated and regularly taught; by which means enlightened practitioners of liberal education, whose whole study has been devoted to the veterinary art in all its branches, may be gradually dispersed over the kingdom, in whose skill and experience confilence may be securely placed.

"Subscribers have the privilege of sending their diseased animals to the college, without further expense than that of their daily food, and these in general form a sufficient number of patients for the practice of the professor and pupils. On fixed days, the professor prescribes for animals belonging to subscribers who find it inconvenient to spare them from home, provided the necessary medicines be furnished and compounded at the college; subscribers' horses are also there shod at the ordinary prices."

VILLOUS. A term in botany, signifying covered with soft, close, long, loose hairs, resembling shag.

VINE (Vitis, from the Celtic gwid, signifying the best of trees. Wine is derived from the Celtic word gwin). A valuable genus of plants. The common grape vine ( $V$. vinifera), with its very numerous garden varieties, is in general cultivation for its much-esteemed fruit. None of the other species are worth cultivating. The acids of grapes are chiefly the tartaric and acetic; but malic acid is also present in them. Mr. I.oudon, in his Encyclopredia of Gardening, thus botanically describes the vine: - "The grape vine is a trailing, deciduous, hardy shrub, with a twisted irregular stem, and long flexible branches, decumbent, like those of the bramble; or supporting themselves, when near other trees, by means of tendrils, like the pea. The leaves are large, lobed, entire, or serrated and downy, or smooth; green in summer, but when mature, those varieties in which the predominating colour is red constantly change to, or are tinged with, some shade of that colour; and those of white, green, or yellow grapes as constantly change to a yellow, and are never in the least tinged with purple, red, or scarlet. The breadth of the leaves varies from 5 to 7 or 10 inches, and the length of the footstalks from 4 to 8 inches. The flowers are produced on the shoots of the same year, which shoots generally proceed from those of the year preceding; they are in the form of a raceme, of a greenish-white colour, appearing in the open air in England in June; and the fruit, which is of the berry kind, attains such maturity as the season and situation admit by the middle or end of September. The berry or grape is generally globular, but often cvate, $v$ val, oblong, or finger-shaped; the colours are green, white, red, yellow, amber, or black, or a variegation of two or more of these colours. The skin is smooth; the pulp and juice of a dulcet, poignant, elevated, generous flavour. Every berry ought to enclose five small heart ar pear-shaped stones; but as they are parlially abortive, they have seldom more than three; and some varieties, as they attain certain age, as the $A$ scalon or Aultana raisin, have none. The weight of a berry depends not only on its size, but on the thickness of its skin, and texture of the flesh, the lighterst be ing the thin-skinned and juicy sorts, as the sweel-water or Muscadine."

Although we presume the excellent treatise of Mr. Clement Hoare on the C'ullure of the Vine is in the hands of most of our reaclers, yet, as there is no other standard work of reference on this subject, we must necessarily draw upon this for our extracts.

of all the productions of the vegetable world (observes this experienced cultivator) which the skill and ingenuity of man have rendered conducive to his comfort and to the enlargement of the sphere of his enjoyments, and the increase of his pleasurable gratifications, the vine stands forward as the most pre-eminently conspicuous. Its quickness of growth, the great age to which it will live,--so great, in. deed, as to be unknown; its almost total exemption from all those adverse contingencies which blight and diminish the produce of other fruit-bearing trees; its astonishing regetative power; its wonderful fertility, and its delicious fruit, applicable to so many purposes, and agreeable to all palates, in all its varied shapes, -combine to mark it nut as one of the greatest blessings bestowed by Providence to promote the comfort and enjoyments of the human race.

From the remotest records of antiquity, the vine has been celebrated in all ages as the type of plenty and the symbol of happiness. The pages of Scripture abound with allusions to the fertility of the vine as emblematic of prosperity; and it is emphatically declared, in describing the peaceful and flourishing state of the kingdom of Israel during the reign of $\mathrm{S}_{\mathrm{O}}$ lomon, that "Judah and Israel dwelt safely, every man under his vine and under his fig tree, from Dan even to Beersheba." The source of enjoyment thus mentioned to record the happy state of the Jewish nation may be, with reference to the vine, literally possessed by the greater portion of the inhabitants of Great Britain.

The native country of the vine is generally considered to be Persia. The finest grapes in the world are those of Shiraz and of Casvin. The latter city, says M. Morier, is environed by vineyards and orchards, and the former yield a grape which is celebrated throughout Persia. It is along the line of mountains that stretch from the Persian Gulf to the Caspian Sea, that the best vine districts are sitmated; but the grape vine has been found wild in America, and has now become naturalized in all the temperate regions of the world. In the northern hemisphere it forms an importau branch of rural economy, from the 21 st to the 51 st parallel of latitude; and by an improved method of culture very fine grapes may be annually grown on the surface of walls, in the open air, as far north as the 54th parallel, and even beyond that in favourable seasons. The vine is supposed to have been introduced into Britain at the commencement of the Christian era. It certainly did not exist before the 
man invasion, as neither Cesar, Pliny, nor Tacitus notice it in the description of Great Britain. Bede informs us, that in the commencement of the eighth century the cultivation of the vine had made some progress in Great Britain : vines are mentioned in the laws of Alfred. History, indeed, amply proves, that for a long series of ages vineyards were common in the southern parts of England, and that the quantity of wine produced from them was so great as to be considered one of the staple products of the land. Lambarde (Topographical Dictionary of England) informs us, that at Halling, near Rochester, the bishop's vineyard yielded such excellent wine, that a present of it was sent to Edward II. when he was at Bakingfield. There was a royal vineyard at Rockingham, in the fifth year of King Stephen; and William of Malmsbury, speaking of the vale of Gloucester, says, "this district, too, exhibits a greater number of vineyards than any other county in England, yielding abundant crops, and of superior quality." The same author also says, that in the isle of Ely the soil is "covered with vines, which either trail along the ground or are trained on high, and supported on poles." In the time of Richard II.. also, the vine grew so plentifully in Windsor Little Park, that part of the wine made there was sold for the king's profit. From some cause or other, however, the cultivation of the vine has fallen into general neglect, although good grapes might be grown on vines trained as espaliers, or in the same manner as in the vineyards abroad, from which excellent wine could be made, at a cost that would not exceed that of moderately strong beer. Why vineyards should have so completely disappeared, it is difficult to say, since there are many thousands of acres of poor land that are of little value in an agricultural point of view, but on which vines would flourish, and produce abundant crops of grapes, and yield thereby a most profitable return.

Fruit-bearing Powers of the Vine-From a long course of experiments, Mr. Hoare has computed the following scale of the greatest quantity of grapes which any vine can perfectly mature, in proportion to the circumference of its stem measured just above the ground.

\begin{tabular}{|c|c|}
\hline Circum & \\
\hline 3 & - \\
\hline 4 & - \\
\hline 4 & - \\
\hline 5 & - \\
\hline 5 & - \\
\hline 6 & - \\
\hline 6 & - \\
\hline
\end{tabular}

\begin{tabular}{r|rr} 
Ib. & \multicolumn{2}{|c}{ Circum. } \\
5 & \multicolumn{2}{|c}{7 inches } \\
10 & $7 \frac{1}{6}$ & - \\
15 & 8 & - \\
20 & $8 \frac{1}{2}$ & - \\
25 & 9 & - \\
30 & $9 \frac{1}{8}$ & - \\
35 & 10 & - \\
40 & &
\end{tabular}

No vine should be suffered to ripen fruit until its stem measures 3 inches in girt. In general, vines are allowed to bear a much greater quantity of grapes than the above scale represents, but in all such cases it will be found that they are not perfectly ripened; and moreover, by producing a superabundance of iruit, the plants are crippled for many years.

Aspect.-The warmer the aspect, the greater perfection does the grape attain in the climate of England, provided all other circumstances are alike; and if the greatest quantity of the sun's rays shining on the surface of a wall 1092 were alone to be considered as constituting the best aspect, there would, of course, be no difficulty in naming a due southern one as better than any other. But warmth alone is not sufficient; shelter from the withering influence of the wind is equally necessary. The best as. pects are those that range from the eastern to the southeastern, both inclusive. The next best are those from southeast to south.

Soil.-The natural soil which is Inost congenial to the growth of the vine, and to the perfection of its fruit in this country, is a light, porous, rich, sandy loam, not more than 18 inches in depth, on a dry bottom of gravel, stones, or rocks. A strong argillaceous soil is injurious to the vine : it checks the expansion of the roots, and retains too much moisture. In calcareous soils the vine always flourishes, especially if the bottom be stony or gravelly. No subsoil can possess too great a quantity of these materials for the roots of the vine, which run with eagerness into all the clefts, crevices, and openings in which such subsoils abound In these dry and warm situations, the fibrous extremities, pushing themselves with the greatest avidity, and continually branching out in every possible direction, lie secure from that excess of moisture which frequently accumulates in more compact soils; and, clinging like ivy round the porous surfaces of their retreats, extract therefrom a species of food, more nourishing than that obtained by them under any other circumstances whatever. All borders, therefore, made expressly for the reception of vines, ought to be composed of a sufficien quantity of dry materials, such as stones and brickbats, broken moderately small, lumps of old mortar, broken pottery, oyster shells, \&c. to enable the roots to extend themselves freely in their search after food and nourishment; to keep them dry and warm by the free admission of air and solar heat, and to admit of heavy rains passing quickly through, without being retained sufticiently long to saturate the roots and thereby jnjure their tender extremities. The sweepings obtained from a turnpike road, or from any other high road kept in a good state of repair by the frequent addition of stones, and on which there is a considerable traffic of horses or other cattle, is the very best compost that can be added to any border intended for the reception of vines. Its component parts, consisting chiefly of sand, gravel, pulverized stones, and the residuum of dung and urine, afford a greater quantity of food, and of a richer and more lasting nature, than can be found in any other description of compost that I have ever seen or heard of being used for that purpose. Borders in which vines are planted should never be cropped nor digged.

Manure.-The best species of manure for the vine are those which afford a considerable degree of nourishment, but at the same time slowly decompose in the soil. Such are bones, whole or crushed, the horns and hoofs of catthe, the entire carcasses of animals, cuttings of leather, woollen rags, feathers, and hair, and the leaves of the vines themselves. Liquid manures are also valuable, and forcing in their effect; of this class the most powerful are urine, soot-water, blood, the drainings of dung 
heaps, and soap-suds. It should, however, alwavs be recollected, that the more manure is used, the poorer the wine procured from the grapes. As a top-dressing, and to be forked into the border, night-soil, refuse fish, stable manure, and the excrements of all birds and animals, will be found highly enriching substances as fertilizers, and their nutritive and stimulating properties have been frequently alluded to in the progress of this work; but if rich manures are used, they should be mixed with turf and sand. In the Alto Douro is a law which prohibits the vine being "littered;" as this operation, though it considerably augments the produce, tends to deteriorate the quality of the wine.

On the Construction of Walls.-No general rule can be laid down as to the height of the wall, which must necessarily vary under different situations and circumstances. Mr. Hoare states, that in unsheltered situations and exposed aspects he has never seen fine grapes produced much higher than 8 feet from the ground.

But, in favourable situations, height is no consequence. If built for the express purpose of rearing grapes, low walls of not more than 6 feet are to be preferred, as more convenient for pruning and training the vines. Brick walls are undoubtedly the best, the surface being smooth and even. A considerable heat is obtained by blackening the wall.

Propagation.-Vines are propagated in the open ground by layers and by cuttings. The former is the most expeditious mode, provided the shoots be laid down in pots, and planted out the same summer. The latter mode is much the best. To provide cuttings to be planted at the proper season, select at the autumnal pruning a sufficient number of shoots of the preceding summer's growth. Choose such as are well ripened, of a medium size, and moderately short-jointed. Cut them into convenient lengths of 6 or 8 buds each, leaving at the ends not less than a couple of inches of the blank wood for the protection of the terminal buds. Stick these temporary cuttings about 9 inches in the ground, in a warm and sheltered situation, where they will be effectually protected from the severity of the winter. The best time to plant them out is about the middle of March, but any time from the 1st of that month to the 10th of April will do very well.

Pruning and training are so closely connected together, and so mutually dependent on each other, that they almost constitute one operation. The judicious pruning of a vine is one of the most important points of culture throughout the whole routine of its management. The object is to get rid of all the useless and superabundant wood, for those shoots of a vine which bear fruit one year never bear any afterwards. There are three methods of pruning vines in practice amongst gardeners; namely, the longpruning, spur-pruning, and the fan or fruit tree method. The first is considered to be the most eligible method, and is that which is practised and recommended by Mr. Hoare. As the sole object in view in pruning a vine is to increase its fertility, the best method to accomplish this is w leave a sufficient supply of bearing shoots on the least possible proportiona $t$ quantity of old wood.

Long-pruning appears to recommend itself by its simplicity; by the old wood of the vine being annually got rid of; by the small num ber of wounds inflicted in the pruning; by the clean and handsome appearatuce of the vine. and by the great ease with which it is managert, in consequence of its occupying but a small portion of the surface of the wall.

Mr. Hoare lays down the following practical general rules for the guidance of the pruner:-

Ist. In pruning, always cut upwards, and in a sloping direction.

2d. Always leave an inch of blank wood beyond the terminal bud, and let the cut be on the opposite side of the bud.

$3 d$. Prune so as to leave as few wounds as possible, and let the surface of every cut be perfectly smooth.

4th. In cutting out an old branch, prune it even with the parent limb, that the wound may quickly heal.

5th. Prune so as to obtain the quantity of fruit desired on the smallest number of shoots possible.

6th. Never prune in frosty weather, nor when a frost is expected.

7 th. Never prune in the months of March, April, or May. Pruning in either of these months causes bleeding, and occasions thereby a wasteful and an injurious expenditure of sap.

8 th. Let the general autumnal pruning take place as soon after the lst of October as the gathering of the fruit will permit.

Lastly, use a pruning-knife of the best de. scription, and let it be, if possible, as sharp as a razor.

Training.-To train a vine (Mr. Hoare goes on to observe) on the surface of a wall is to regulate the position of its branches, the principal objects of which are, to protect them from the influence of the wind; to bring them into close contact with the wall, for the purpose of receiving the benefit of its warmth; to spread them at proper distances from each other, that the foliage and fruit may receive the iull effect of the sun's rays, and to retard the motion of the sap, for the purpose of inducing the formation of fruit-buds. The flow of sap, it must be remembered, is always strungest in a vertical direction, and weakest in a downward one. For this reason, the method of serpentine training may be considered preferable to every other, being calculated in a greater degree to check the too rapid ascent of the sap, and to make it flow more equally into the fruiting shoots, and those intended for future bearers. On walls that are much less than 5 feet high, a portion of the shoots must be trained hori: zontally.

Varieties of Grapes.-The following 12 sor:s of grapes are those best adapted for culture on open walls in England:-

1. Black Hamburgh. As a splendid table: fruit, this is, in every respect, one of the mos valuable grapes that can be grown on open walls. It is a prolific bearer, hardy in its na. ture, and under judicious culture will ripeu with as small a portion of direct solar het as any grape we have. 
2. Black Prince. This is a very fine grape, and nearly if not quite equal to the black Hamburgh; both of these sorts ripen in a southeastern aspect, about the middle of October.

3. Esperione. The Esperione vine is very hardy, extremely prolific, and ripens its fruit perfectly in any season, however unfavourable.

4. Black Muscadine. This is also a prolific bearer, but it requires a good aspect to ripen it perfectly.

5. Miller's Burgundy. 'This is a very hardy and prolific grape, and ripens perfectly in any season. Its leaves, which are very thick, distinguish it from every other sort, being covered on both sides with a hoary down, which, when they are young, is nearly white; hence it is called the "miller's" grape.

6. Claret grape. 'This is a very fine wine grape. It requires a good aspect. Early in the summer its leaves change to a russet red, and die in the autumn of a deep purple blood colour.

7, 8, 9. Black, grizzly, and white Frontignan. The flavour of these three sorts is so extremely delicious, that no good vine wall should be without them. They ripen well in favourable aspects, and where the soil is very dry; but, being thin-skinned, and constitutionally disposed to decay after they become fully ripe, they cannot be kept long on the vine, particularly if the wall against which they are growing be destitute of a projecting coping.

10. White Muscadine. This is an exceedingly fine grape, and a prolific bearer; and from its hardy nature, and the certainty with which it ripens in any season, it may be considered as the best white grape that can be grown on open walls.

11. Malmsey Muscadine. This resembles the preceding, except that the berries are smaller, and the branches not so regularly formed; but the juice is sweeter, and possesses a higher flavour.

12. White sweetwater. This is a delicious grape; but, owing to its tenderness when in blossom, the berries sit very unevenly on the branches.

If it be desired to have a very early sort, to the preceding may be added the early black July; which, though the branches and berries are smaller, and the latter in general unevenly set, is a very sweet and also a well-flavoured grape. (Hoare on the Cultivation of the GrapeVine on open Walls, 3d edition; Phillips's Hist. of Fruits, p. 177.)

The work of Mr. Hoare is so full of details that it is scarcely necessary to add any thing to the directions contained in his work; and we shall therefore confine ourselves to a statement of a few general truths in regard to the cultivation of the vine in the United States, the results of much observation and some experience.

1. The vine is a native of America, as it is of Asia, while it was an exotic in Eumpe. There is nothing, therefore, in the soil or climate of America uncongenial to the vine, and, in fact, there are few parts of the United States where the forests are not filled with grape-vines rrowing with the greatest exuberance. therefore, the cultivation of the ine has made comparatively little progress, it is mainly because other fruits and other crops have offered greater attractions. But as the country has advanced, and the population is concentrated in large towns, the grape has become an object of more interest, and we think it would now reward the industry of our farmers.

2. This cultivation would have two objects, the making of wine, and the supply of grapes for the table. As to the first, we have no doubt that wine can be made of an excellent quality and at not unreasonable prices in the United States. In fact, we know that cultivators on a large scale, such as Mr. Rapp, at Harmony, Mr. Long worth, in Ohio, Mr. Geo. Sheaff, and Mr. N. Biddle, both of Pennsylvania, have succeeded in making wine-good, sound, palatable wine, which would require only the wine-dealers' arts to place it on a footing of equality with some of the best wines of Europe. But so long as the wines of France and of the old-established wine countries of Europe can be produced so cheaply, and imported with scarcely any duty, the competition of the foreign wine-makers is difficult to withstand, and it is mainly, therefore, when raised for the table that grapes will repay the labour of the farmer; and this, we think, they certainly would do. The importation of grapes and raisins into the United States will afford the best evidence of the consumption of those articles, and their cost to us.

We happen to have before us two returns of importations for different years, from which we make the following extracts.

In the year 1834 the importation stood thus-

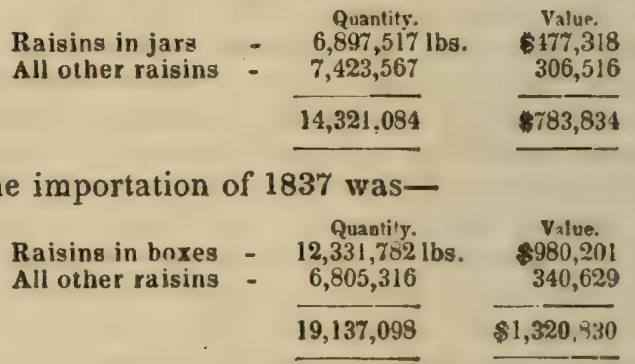

We have not at hand any more recent statements, and therefore do not know how these importations have been sustained. But these tables show an efficient demand for grapes, fresh and dried, of no less than 1,320,000 dollars in a single year. Such an object is worth contending for. These imported grapes are generally not of the best kind, even in their own country, being selected mainly on account of their hard skins and their ability to bear the long voyage. They are gathered before they are fully ripe, and, being packed in sawdust, they retain too much of the flavour of that material. Now, if these grapes were met on their arrival by grapes grown here, and plucked from the vines within a few hours instead of a few months before they are brought on the table, the preference could not fail to be given to the native fruits.

Such fruits might be furnished from vineries covered with glass, or raised in the open fields.

For raising grapes under glass, we do not think it necessary to give any directions, sinen whoever proposes it will find ample instrur. 
tions in the works of M'Intush and other gar deners. Of the kinds of grapes best adapted for culture under glass we may speak with some confidence. 'These kinds are very numerous-great varieties of Chasselas-great varieties of Muskats-many of Frontignac. But we think that the labour and time are best rewarded by the black Hamburgh, which, for its excellence and its abundant bearing, may perhaps be placed at the head of all the grape family; by the Muscat of Alexandria, the flarour of which is of surpassing richness, though an uncertain and scanty bearer, and by one or two varieties of the Frontignac. 'These are at the head of their respective kinds, and none of the imported grapes can be placed in any sort of comparison with them.

The cultivation of grapes in the open air is of course cheaper and easier to farmers.

The best kind of foreign grapes, such as are above enumerated, may be successfully grown in city gardens with much shelter and care, and there are few gardens in which they would not prosper. But as yet the foreign grape has not succeeded in field cultivation, and accordingly for this purpose we must employ other varieties, which, though of inferior quality, are either natives, civilized by cultivation, or foreigners gradually acclimated. The sorts which are most considered are the Scuppernon, a vine of doubtful origin, which thrives well and bears abundantly in North Carolina, but as yet has made little progress to the north, though worthy, we believe, of more extensive experiments. Those most known to field cultivation in the Middle States are the Alexander, the Isabella, and the Catawba; and on these our markets will probably rely for some time. 'They may be cultivated in rows exactly like Indian corn, with the plough and the hoeharrow; they do not require even as much trouble as a field of Indian corn, and, instead of being renewed and replanted every year, the plants will last for many generations of men. They require no covering in winter, but will stand unharmed the severest frosts and snows.

On the whole, what we think should come next in the progress of American farming is, that every farm-house should have its patch of grapes as well as of peas or beans, of the improved native grapes, and that by degrees the highest kinds of foreign grapes should be acclimated, so as to form a part of field cultivation. 'J'his we believe entirely practicable, and to this we invite the attention of farmers.

Of foreign grapes two kinds are well known in Virginia and other Southern as well as Middle States, namely, the Summer sweetwater and the White sweetwater. Highly interesting communications upon the subject of the vine culture in the United States will be found in the American Farmer, Farmer's Register, and many other valuable periodicals.

Among the various species of grape-vines found wild in the forests of the United States, the following have been described by botanists.

1. Fix-grape (Vuis labruska or Vitis vulpina). The berries of this luxuriant vine grow in short clusters, and are about half an inch and often more in diameter, varying a maturity from near- ly black 2o dark amber or copper colour and greenish-white. The flavour is inusty and strong. "All kindsof this grape," says Bartrain, "posseps. a strong, rancid smell and taste, have a thick coriaceous skin, and a tough, jelly-like pulp or tegument which encloses the seeds. Brtwren this nucleus and the skin is a sweet, lively juice, but a little acerb or stinging in the in'suth if pressed hard in eating them. There is as. other property of this grape which alone is sufficient to prove it to be the $V$. vulprina, that is, the strong, rancid smell of its ripe fruit, very like the effuvia arising from the body of the fox, which gave rise to the specific name of this vine, and not, as many have imagined from its being the favourite food of the animal for the fox (at least the American species) sel. dom eats grapes or other fruit if he can get animal food." "In the wild state," says Dr. Darlington, "we find varieties in the fruit, and in our gardens and vineyards we have grapes under several names, which appear to be nothing more than varieties of this-(or possibly some of them may be hybrids)-such as the Isabella grape, the Schuylkill (called also Alexander's and Tusker's grape), the Calawba grape, and Bland's grape. The two former of these are nearly black, the two latter copper or amber coloured-with less of the musky flavour than the others. The Schuylkill and Catawbr varieties have been cultivated with the most success in Chester county." (Flora Cestrica.)

2. Little summer grape ( $V$. astivalis), called also the Common blue grape and Bunch grape. In this most common of all American wild grapes the berries are round and small, generally about one-fourth of an inch in diameter. of a deep blue or nearly black colour, covered when ripe with a thick bloom or powder. Their flavour when mature, which is generally after the first frost, is of an agreeable sprightly acid. "This species," says Dr. Darlington, "presents several varieties; some of them with a larger fruit, which is much esteemed, and well worthy of culture. It sometimes attains to a great height in rich woodlands; the upper branches sustaining it by clinging to the limbs of tall trees, and gradually ascending, whilst the older branches below die and drop off, leaving the stem naked and suspended, somewhat resembling a topgallant halyard, belayed at the root."

3. Chicken grape ( $\boldsymbol{V}$. cordifolia and $\boldsymbol{V}$. lubrusca of Marsh, and $V$. serotina of Bartram), also called Winter grape and Bermudian grape. This kind has very small berries, not so large as currants. They are very late in ripening, and, when mature, are nearly black, and possessed of so much acerbity, that even birds will not eat them until they have undergone melioration from autumnal frosts. This vine. is remarkable for its sweet flowers. It mounts to the top of trees, and its stems and twigs are more hard and woody than those of the preceding variety, or Summer grape.

4. Bull or Bullet grape ( $V$. taurina of Bartram, and $V$.vulpina of Linnæus and Waiter). This excellent grape is a native of the Southera States, and in the Carolinas, Georgia, and the Floridas is called the Bull grape. It is pro nounced by Bartram and others a distinet variety from that whirh it w: embles in external 
appearance, called Fox grapes from Pennsylvania to Florida. The Bullet or Bull grape is described by Bartram as having "A stiff, ligneous, smooth stem, of pale ash colour, and mounts to a great height by climbing up trees. The leaves are cordated and serrated, thin, and both surfaces naked or smooth. The racemes or fruit bunches short, containing 15 or 20 grapes at a medium. The berries or acini are large, near ihe size of a rifle ball; of a black colour when ripe; having a bluish nebule over them, which being rubbed off they appear of a deep blood colour. In figure they approach to an ellipsis or prolate spheroid; however, at a little distance they appear black and round. This species is deservedly esteemed the best native yrape in America, and would make a rich and delicious wine. The juice is sweet, rich, and lively, and there is but little of the tough, jelly-like substance enclosing the seed. The skin of the grape is rather thick, yet there is a sweet, melting pulp within, which mixes with the saccharine juice when eaten. This undoubtedly is the first American grape which merits attention and cultivation for wine. It thrives in every soil and situation, from the sea-coast to the mounlains; it even thrives and is fruitful when growing in the barren sandhills of Carolina and Florida."

After describing these distinct varieties of grapes found in the United States, Mr. Bartram inentions several others which he considers derived from a commixture of those described, as Alexunder's or Tasker's grape; Bland's grape; Rucoon grape. Other varieties, possessing still superior properties, have since been added, such as the Isabella, Powell, Catawba, Scuppernon, \&c., already mentioned.

Although so short a time has elapsed since the previous observations relative to the grapes and ineir culture in the United States were written, vineyards have become an important branch of husbaudry in various parts of the United States, especially in the valley of the Ohio.

An interesting publication, made in 1850 by R. Buchanan, Esq., of Cincinnati, furnishes in a sma1l space, a very great amount of instructive information relative to this culture and wine making, as carried on in the vicinity of Cincinnati, where the general intelligence and capital of the Americans is seconded by the practical experience of the very numerous German settlers.

'The soil where these vineyards are mostly planted gives, on analysis, from 3 to 4 per cent. of carbonate of lime, with oxide of iron from 2 per cent. to 0.30 ; vegetable matter, 10 to 13 per cent.; sand and clay, about 80 per cent.

Mr. B. gives, from his own experience, the following estimate of the cost of a vineyard of 6 acres, containing 14,400 vines; the details are highly interesting, as showing the several operations to be performed, and cost of each.

'Trenching, two feet deep, \$65 per acre........ \&39n.0() Sndding avenues.......................60.(1) Cont of 30,000 cuttings, at $\$ 2.50$ per thousand....75.0() Pl inting ................................

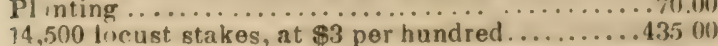
Setting 14,500 stakes......................55.0

Cost of attending the first yenr-vine dresser, \$216, and a hand for one month, 815 , (and bont themselves)

Secund year-vine dresser, $\$ 216$, and a hand fo two months, at $\$ 15$ per month...........256.0

Cuttings, after first year, to replace failures, $s a y, 20.00$ 1096
Hauling, cartirg, \&c...................68.06 Contingencies, \&c..................... 150.00

A verage cost, say, $\$ 300$ per acre........... $1,800.00$

In this instance the vineyard was on a gentle declivity, not requiring terracing or benching; nor was there much stone to remove, both of which would have added much to the expense. "By proper economy," Mr. B. says, "a man may have a vineyard of several acres in a few years, without feeling the expense to be burthensome. Commence by trenching with the spade 2 or $2 \frac{1}{2}$ feet in the fall or winter, and planting out in spring. Next year another acre, and so on for five or six years. After the third year he will have his own cuttings from the first acre, and also grapes enough to pay the cost of planting the succeeding additions to his vineyards. 'The stakes can be got out in winter at little cost in money, and in this way a vineyard of six acres might be established at one half the cost of the estimate just given."

Mr. B. estimates the cost of vineyards in trenched ground at $\$ 200$ to $\$ 350$ per acre-according to situation and condition of the soil, and the judicious economy displayed in the management.

The expenses of attending a vineyard will be comparatively small where there are workers in the family. But where hired hands have to be employed, in Ohio a vineyard of 6 acres will cost for a vine dresser, who boards himself, $\$ 240$ per annum ; assistants in pruning, $\$ 25$; assistance in the spring culture, $\$ 40$, and summer culture, $\$ 55$; in all $\$ 360$, or at the rate of $\$ 60$ per acre. Where the cuttings can be sold for $\$ 2$ to $2.5 \mathrm{C}$ per 1000 , it will reduce the sum about $\$ 100$.

The vineyard should be laid off with a line, so as to make rows $5 \frac{1}{2}$ to 7 feet apart, with the vines 3 to 4 feet asunder. The more level the ground, the farther apart should be the vines, so as to give freer access to the sun and air. Mark with a stick about 15 inches long, every place where a vine is to grow, digging a hole a foot deep in which two cuttings are to be placed in a slanting position, separated 6 or 8 inches at the bottom, and one inch at the top of the hole. Cover with a shovelful of rich vegetable mould from the woods, leaving the top eye of each cutting even with the surface, or, if the weather be dry, covered with the light mould half an inch or an inch. If both cuttings grow, one should be removed or cut off the following spring, leaving but one to each stake. To preserve and prepare the cuttings, the trimmings pruned from the vines should be buried in the earth; about the last of March or first of April, the proper time for planting, cuttings may be made, having each 4 eyes or joints, taken from ripe wood; and if some of the old wood is left on, so much the better. Cut them off close below the lower joint, and about an inch above the upper. Some have recommended planting with roots 2 years old, but experience seems to be in favour of planting cuttings, as the most thrifty vines are those which have never been transplanted or disturbed.

Treatment of the Young Vineyard.-The first yeur, keep the ground clean and free from weeds, with the hoe; many use the plough as being more expeditious and economical, but the more careful vine dressers who can afford it, never cultivate with the plough, using only the two-pronged German hoe, made especially for the purpose. 
The earth should be stirred around the young rines, two or three times during the season, to rromote their growth; superfluous shoots must be pulled off, leaving but one or two to grow, at first, and but one eventually.

In the spring, cut the young vine down to a single eye, or bud; at first, if two are left for greater safety, take off one, afterwards; drive a stake 6 or 7 feet long firmly to each plant. Locust nा cedar is preferred, but oak or black walnut, charred at the end, driven into the earth, or roated with coal tar, will, it is said, last nearly as long. Keep the young vine tied neatly to the stake, with rye or wheat straw-pick off all stickers, and let but one stalk or cane grow. 'The vineyard must be kept clean of weeds, and the young vines hoed as before.

The second spring after planting, cut down to iwo or three eyes, or joints, and the third year to four or five; suckering, tying up, and hoeing the vines as recommended above.

Re-plant from the nursery, where the cuttings have failed to strike root in the vineyard.

The third year, the vines will produce a few grapes, sometimes enough to pay the expenses of attending them.

Train two canes to the stake this year, take off suckers, and keep well hoed.

The vineyard having now commenced to bear, may be considered as fairly established; and for the fourth and successive years, the following treatment is generally adopted.

Spring Pruning. - This is usually done from the middle of February to the first week in March. Some prune in January, and Mr. Schuman has recommended November and December, as the proper time.

No serious injury to the vines, by winter pruning, has yet been discovered.

Pruning, the fourth year, requires good judgment, as the standard stem, or stalk, has to be established.

Select the best shoot or cane of last year, and cut it down to 6 or $\delta$ joints, and fasten it to the adjoining stake in a horizontal position, or bend it over in the form of a hoop or bow, and tie it to its own stake. The ties should be of willow. This is the bearing wood. The other cane, cut down to a spur of two or three eyes, to make bearing wood for the next season.

Mr. Schuman remarks in his treatise, "There are various methods of training adopted. Some tie the shoot up to the stake with two or three ties at proportionate distances.

"The greater part of the German vine-planters make circular bows with three ties, and another mode is to make half-circle bows. I recommend the latter as the best, and proceed to describe it.

"Give the shoot the first tie on the stake 9 inches from the ground, and the second 9 inches above it; then bow it over to the neighbour ing stake in a horizontal position, and give it the third tie to that stake, at the top of the vine."

In the succeeding, and all subsequent years, cut away the old bearing wood, and form the new bow, or arch, from the best branch of the new wood of the last year, leaving a spur as before, to produce bearing wood for the coming year, thus keening the old stalk of the vine down to within 18 to 24 inches, from the ground. The vine is then always within reach and control.

Should a vine be lost after the vineyard is in bearing, it can be replaced by a layer from the adjoining vine, which is a much letper mode than planting a young vine. The layers mav be put down late in summer, but spring is pro. ferred.

Cultivate the yellow, and the osior willow, to make ties for the spring pruning. They will grow in any wet place.

Summer Pruning consists in removing suck. ers, and pinching off all lateral shous, feaving but two stalks or caries to be trained for bearilin wood the ensuing year, and pinchins off it.. enis of the bearing branches, about the time of bis. soming, some two or three jaints beyond, or above the last blossom bunch; pull no laves of the bearing branches, and bui very few from any other. As the vines grow, tie them neatly to the stakes, with rye straw, (some use grass), and when they reach the top, train them from one stake to the other, until the fruit has nearl; matured; the green ends may then be broken off. If this is done too early, there is danger of forcing out the fruit-bearing buds for the next year, and of injuring the grapes in ripening.

Mr. Longworth cautions American vine grow. ers against a common European practice of shortening the leading branches intended to produce the next year's crop, heading in the short branches and thinning out the leaves for the purpose of exposing the fruit to the sun and air to promote its ripening. This method, though sometimes advantageous where there are cold summers, he says will, in the hot American climate, where some shade is necessary, prove highly injurious, if not entirely destructive to the grapes. No more lateral branches should be taken from the main shoots intended for next year's fruit, then to give them the necessary length. A large crop is often occasioned by leaving too much bearing wood. This should always be avoided; for even if the crop ripens thoroughly, too much of the sap is taken by the fruit, and too litcle left to produce good young wood for the next season's crop.

Cu? ture.--The vineyard must be kept perfectly clean from weeds and grass, and should be horit twice during the spring and summer.

The cultivator or the plough is less expensive, but the vines and roots are in danger of bring injured by that mode of culture; thereforp the hoe is preferred by those who can afford it. It has been recommended by some writers, to cut off the roots of the vines near the surfice of the ground, and 4 or 5 inches under, that the roots, when the vines are young, may be well established at a proper depth below.

By others, this plan is thought to be injuricias. The majority, however, prefer cutting off the surface roots for the first three or four years.

About every third year, put in manure, by opening a trench the width of a spade, and four or five inches deep. Above and near each row. throw in two or three inches of well rotted manure, and cover up with the earth.

Another plan adopted, is to run a furrow with the plough, put in manure, and cover over, either with the plough or hoe.

Others, again, scatter manure over the surface. and dig it in.

An intelligent cultivator, J. A. Corneau, remarks: "High manuring is generally admitted to be injurious to the vinous quality of the grape; or, in other words, it accelerates a lareer growib. of wood, and a more attractive-looking fruit $4 \mathrm{z} 2$ 
while the more essential qualities of the grape for wine making, are very much deteriorated. No substance should ever be used which has a tendency to ferment, or which, in undergoing a chemical change in the soil, would form an acid or a salt of a highly stimulating nature. Vegetable manures, bones, \&c., may be used to advantage." Well rotted stable-yard manure has been used moderately, by the writer, with good effects to the plants and the fruit, and without any perceptible injury to the "vinous quality of the grape."

Diseases, Insects, and Frosts.-The " rot," as it is termed, is the great evil, especially in cultivating the Catawba.

This takes place usually in the latter end of June or early in July, Dr. Warder says, "about the period of stoning," or "hardening of the seed," after continued heavy rains, and hot sweltering suns.-It strikes, something like the rust in wheat, suddenly, and with the same disastrous effect to the crop. Various modes of prevention. have been recommended, but none yet tried have proved always effectual.

The cause is supposed to be an excess of water about the roots of the vine, in any clay subsoil retentive of moisture; sandy soils with a gravelly substratum, are generally exempt from this disease.

The opinions of Mr. Elliott, Mr. Longworth, and the Fruit Committee of the Cincinnati Horticulural Society, on this subject, are quoted.

Mr. Elliott, in the Horticulturist, Vol. 2, p. 314 , says the rot for the past three years has followed excessive rains in July and August. Dr. Flagrg, two years since, found a small part of a vineyard where the rot was very slight. This had not been worked after the spring, and the ground was in such a state, that most of the rains passed off on the surface. Vines planted in rows eight feet apart, in one instance were found to be affected with rot, but very slightly.

In the same article, Mr. Longworth says: "It is of late years only, that the rot has been so destructive among our grapes; one thing is certain, if we had little or no rain after the grapes are fairly forward, we should see but little of the rot; certain it is, that continued rains iollowed by a hot sun, cause us to look out for the appearance of the rot."

He also refers to instances where, in seasons when the rot prevailed extensively, crops escaped although raised upon a stiff clay sub-soil. In such cases the ground had been left without hoeing, and become so hard baked on the surface as to prevent the riin-water from penetrating to the roots. Underdraining will doubtless be found of the greatest advantage to vineyards on soils retentive of moisture. See Draining.

In the able report of Dr. Mosher, Mr. Ernst, and $\mathrm{Mr}$. Kidd, the Fruit Committee of the Society for 1818 , it is remarked, "some vineyards were injured by the wet weather in July, causing the grapes to rot and fall off; this however, seems to have been confined to situations where the air had not a free circulation, allowing fogs and vapours to remain too long upon the vines in hot weather, as well as to a tenacions clayey soil ; on dry and moreairy situations, and where the ground was thoroughly drained, the crop has been fine and fair."

H. W. S. Cleveland, of Burlington, N. J., who has a vintyard of two to three acres, and who, $\mathrm{Mr}$. Downing says, is orie of the most reli1098 able horticulturists in the State, recommands covering the whole surface of the vineyard with shavings, leaves, or coarse grass, to prevent the ravages of insects, and diseases of the fruit-see Horticulturist, Vol. 3, p. 113.--In the same Vol. p. 121, "A Jerseyman," in summer pruning, put the leaves and young stems in a trench at the root of the vines-sprinkled gypsum on them, and covered over with earth. This was done at the suggestion of Mr. Downing, who strongly recommends it to the vine dressers on the Ohio, with a request that upon trial they "report progress."

And at page 161 , of the same Vol., "B.," " of Chester Co. Pa." recommends "special manures," as a certain specific-having tried with success, a mixture of guano, gypsum, and wood ashes.

Mr. Downing says to " J. D. Legare, Aiken, S. C." in the same Vol. p. 255, "We note your experiment with ashes to prevent rot, but you must not decide against it with one year's trial. -It has been found effectual here at the north, when used along with gypsum."

Two years ago, the writer of this treatise tried ashes on a small scale, but witlout sypsum; a trench was dug above two rows, the width of a spade, some four inches deep, and two or three inches of leached ashes put in and covered over with earth. No beneficial effect was perceived. The two rows were slightly affected by the rot, as were those adjoining.

Hoeing in autumn, and not stirring the ground at all in the spring and summer, but keeping the weeds cut down, and the surface smonth, that the water may not sink, but pass off rapidly, has also been spoken of as a probable remedy against rot.

Some persons even recommend letting the weeds grow : to say the least of it, this would be slovenly culture.

With a view to test the advantages of wide planting and high training, in preventing the rot, Mr. Werk has planted on his farm near Cheviot, eleven acres in the Catawba grape, twenty feet apart in the rows each way, and the vines are trained to locust stakes twelve feet high. Last year they produced fruit for the first time, and were entirely free from rot. But here it must be remarked, that the first crop from young vines, is generally but little affected by that disease. Mr. Werk also cultivated the ground between the rows, for other purposes.

The "mildew" comes earlier in the season, when the grapes are about one fourth grown, blighting occasionally a few bunches, and sometimes only the lower end. It is neither common nor destructive.

The "speck," by some persons mistaken for the rot, and by others called the bitter rot, is a large circular spot on the side of the grape, looking as if caused by the sting of an insect, and extending to the seed on one side of the berry, whilst the other is uninjured; but owing to this wound, or speck, the juice will be bitter. This has been attributed to the action of the sun on the fruit when covered with rain or dewdrops.

The vine is so remarkably healthy, and of such luxuriant growth in almost any proper soil, that diseases at the root are almost unknown here. Mr. Schuman states that a white worm resembling the peach tree worm, is sometimes found eating off the young roots of the vine, and found eating off the young roots of the vine, and 


\section{VINEGAR.}

Mir. Mottier has also found and destroyed it but it is rarely met with in vineyards.

The Insects found most annoying, are a green vourm that feeds on the vines just as the fruit buds appear, and before they blossom, eating off the tender bunches, and doing great mischief if not promptly destroyed. The Canker, or Measuring Worm (of which the above may be a variety) is sometimes found on the leaves and young shoots. The Curculio, so destructive to the plum, has occasionally been found on the grapes; they can be readily shaken down on a sheet, by a sudden blow on the stake, and destroyed. If ever permitted to get domesticated in a vineyard, this insect would be immensely destructive.

The Rose-bug, Dr. Shaler says, has been observed in some vineyards in Kentucky, but it is rarely met with here.

A large brown beetle, or bug, will frequently sting the young tender branches of the vine in summer, making a wound that subjects the branch to be broken off by strong winds. They can be watched and picked off, late in the evening, or early in the morning. All horticulturists are familiar with the spring and the early fall caterpillar, and of course, would not permit either to get a foothold in the vineyard.

Frost.-Late spring frosts have some years, but not often, been highly injurious, especially to vineyards near small streams of water, damp woods, or in cold situations. The most severe within the memory of $\mathrm{Mr}$. Buchanan, occurred on the 9th of May, Tth of May, and 15th of April, of three successive years, when the buds had so far put out, that their loss was not replaced by the pushing out subsequently of the latent, or twin bud, which partially overcame the loss of the first bud in the latter year, $18 t 9$.

In warm and sandy lands, with a gravelly substratum, the buds are in some years pushed forward prematurely by warm autumns, so as to be killed by the severe frosts in winter. See WINE.

VINEGAR is the acetous and acetic acids of the chemist, containing a variety of foreign admixtures, some colouring matter, and an ethereal substance or spirit, which gives it a grateful aroma. Vinegar has been known from a very early age. It was by far the earliest known acid of commerce. That it was drunk in remote periods, diluted with water, by the labourers and soldiers, is very certain. It is repeatedly mentioned in the Old Testament. But then they had several descriptions, one of which, a kind of small wine, which they called pesca or sera, is supposed to be that offered to Ruth (Ruth, ii. 14), and to our Saviour by the Roman soldiers (Matt. xxvii. 48). The strunger variety of vinegar is alluded to in another place (Prov. x. 26). They mixed it also with nitre, or, properly speaking, natron, which was an alkali that, by neutralizing, destroyed its sharpness. "As vinegar upon nitre, so is he that singeth songs to a heavy heart." (Prov. xxv. 20.) They made it in those days from wine. (Numb. vi. 3.) It is known to every one, that when wine or beer is exposed to the influence of the atmosphere, it becomes sour or acid; now this acid is the acetic. In the wine countries it is chiefly made from the produce of the vine, weak or low wines; the shoots of the vine, \&c., being also employed for that purpose. It may be readily made from merely sugar and water.
VINEGAK.

That of commerce in Fingland is watily made from wort from malt liquor or culder. Virwegar is of a yellowish or reddish colour, an acid laste, and pleasant odour. Its specific gravity is commonly between 1.0135 and 1.0251 . It usually holds in solution various foreign substances, such as colouring matters, sulphate of lime, muelage, sulphuric acid, and the ethereal spirit almady mentioned. Vinegars differ greafly in strengeth and in purity. The best known in Engtand for domestic purposes is the French white wine vinegar; but the Vinaigre d'Orleans, made from the red wine of the Orleanois, is that most esteemed in France; and that imported from Bourdeaux, although named Champagne vinegar, is often made from red wine. The density of French vinegars varies from $10 \cdot 14$ to $10 \cdot 22$. The free sulphuric acid in British vinegar is permitted by the English excise law's to the amount of one part in one thousand, but it is often added to four times that amount.

Vinegar is readily purified from its impurities by distillation, and in this form is the transparent distilled vinegar of commerce. But even then it is united with a considerable portion of water.

The specific gravity determines this point. Thus, at $10 \cdot 14$ it contains 10 per cent. of real acetic acid, at $10 \cdot 2215$ per cent., at 10.2518 per cent., at 10.3526 per cent, at 10.6050 per cent., and so on, until it reaches 10.635 , which is the strongest liquid acetic acid.

When deprived of all impurities and water, by chemical means, pure acetic acid is composed, according to the analysis of M. Berzelius, of -

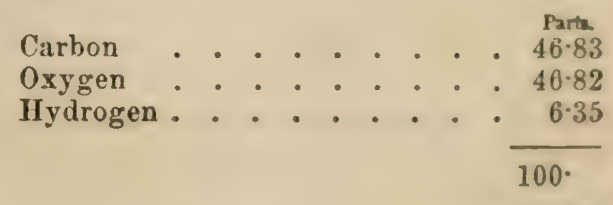

Some plants contain acetic acid naturally. M. Vauquelin found it in the sap of various trees, and in the chick-pea. Scheele detected it in the elderberry. It has been found also in the date palm tree, and in several others; and few plants exist in which acetic acid in the form of salts, such as the acetates of lime or potassa, is not found.

In England, for domestic purposes, it is prepared in several very considerable manufactories from a mixture of barley or malt with water, by keeping the wash exposed in open vessels to the influence of the atmosphere. in rooms heated to a particular temperature. The formation of the acetic acid in this manner is in these works promoted by the addition of a certain small proportion of acetic acid.

An excellent vinegar for domestic purposes may be readily made by exposing a mixture of one part of brown sugar by weight with seven parts of water and some yeast, in a cask whose bung-hole is only slightly covered over (as by a piece of gauze pasted down to keep out insects), for some weeks to the action of the atmosphere and the sun. The acetic fermentation and the goodness of the vinegar are promoted by the ad. dition of vine leaves.

Although vinegar is familiarly used in small quantity as an agreeable and useful addition to food, yet in large quantities it interrupts digestion, and induces emaciation. In combination 
with water, it is an exccllent cooling and invigorating substance when employed for sponging the body, especially in febrile conditions of $i:$ : its vapour inhaled with the vapour of hot water relieves hoarseness; and, when moderately diluted, it forms an excellent gargle in inflamed or sore throats. See Acrns and Prholigneous Acin.

VIOLET (Viola). Al] the species of this genus deserve to be cultivated, either for the beauty or the scent of their flowers. The species natives of America thrive best in vegetable mould or peat, and are readily increased by parting the roots or by seeds. There are 8 native species of violet in England, and, according to Schweinitz, 29 in the United States.

VIOLET, AMERICAN (Erythronium Americanum). Sometimes called Dog's-tooth violet. This very pretty plant is found throughout the Atlantic States on the lowest alluvial banks of streams, and in most moist places, where it puts forth its beautiful violet flowers in April and May. It has a perennial bulbous root, rather deep in the ground. Among other American species of the violet enumerated by botanists, is the white violet (E.albidum), found throughout the Western States and Territories, in Upper Louisiana, and on the banks of the Missouri, where no other species appears to exist. There appears to be a yellow-flowered species confounded with this white species, and nearly allied to it.

VIPER's BUGLOSS. See Honer, Ciniak.

\section{W.}

WAGES. The price or hire paid to labourers or servants for performing different sorts of farm work.

These differ greatly in different districts and situations, and according to the character and employment of the workmen, but in all they are considerably increased within the last 15 or 20 years. They may perhaps be stated as varying, in England, under different circumstances, from $9 s$. to $18 \mathrm{~s}$. by the week, and from $9 l$. to $15 l$. or $18 l$. by the year.

WAGON. A wheel-carriage, of which there are several varieties, accommodated to the different uses which they are intended to serve.

In the business of husbandry, wagons constructed in different forms, and of various dimensions, are made use of in different districts or parts of the kingdom; and mostly without much attention to the nature of the roads, or the articles which are to be conveyed by them; being in general heavy; clumsy, and inconvenient. There is, however, a wagon much employed in Berkshire, England, which is constructed on a more simple and convenient principle than those mostly met with in the other southern parts of the island, not having the height or weight of them, while it possesses sufficient strength, and is easy in the draught.

Wagons require more power in the draught than carts, which is certainly an objection, though they carry a much greater load, and are far from being so handy and convenient; and $\mathrm{Mr}$ Parkinson is of opinion, that more work 1100 may be done in any particular time, with the same number of horses, by carts than by wagons, in the general run of husbandry business, especially where the distance is small between loading and unloading; a fact which has long been known and attended to in Scotland.

Where wagons are used for husbandry, they should be made wide and low. Manures may be carried in this sort of wagon almost as well as in carts. Broad wheels are improper for passing and repassing upon tillage lands; for, if in fallow, they press the land too much, and make it so hard as to prevent its being ploughed till wet comes; but on grass land broad wheels are proper for all uses, as there they operate as rollers.

Wagons are probably the best conveyances for different sorts of heavy loads to a distance; but for home business, especially harvest and other work, which requires to be speedily performed in the field, carts with proper shelving will be found preferable. See CART and HIGHWAY.

WAIN. A name applied to an ox cart, without any side rails, or ladders, in some dis tricts in England; but in others shelvings are added, and the body is large and open. They are rarely met with at present. In Gloucestershire they adapt them to harvest work by fixing ladders and rathes on them. In the lower part of the vale they are called dungpots; but in the forest districts, where drawn by oxen, wains.

WALNUT TREE (Juglans, from Jovis glans; literally the nut of Jove). All the species of the ornamental genus to which the well-known walnut tree belongs are tall, stately-growing trees, well adapted for parks and lawns. They grow freely in any rich loamy soil, and are raised from seeds. This deciduous tree was formerly held in great esteem in England for its wood, which is often very finely veined; but, on account of its aptness to be wormeaten, it has long since given place to the mahogany. As a fruit tree, independent of its timber, which is still of much value, it merits attention, and it is also useful as an ornamental tree. There are several species capable of being cultivated with advantage both for their wood and fruit; as the common walnut, the white walnut, and the black walnut tree.

The common walnut ( $J$. regia) is a very large and lofty tree, which has strong spreading boughs. The leaves are pinnate, with a very strong but not unpleasant smell; the leaflets 3 pairs (sometimes 2 or 4 ), nearly equal, except that the odd one is largest; they are entire, smooth, and shining. The male flowers are in close, pendulous, subterminating filaments; the females scattered, frequently 2 or 3 together. Fruit an ovate, coriaceous, smooth drupe, inclosing an irregularly grooved nut, which contains a four-lobed, oily, eatable kernel, with an irregular knobbed surface, and covered with a yellow skin. This tree is a native of Persia.

It has been noticed by Martyn, "that as they all vary again when raised from the seed, and that as nuts from the same tree will produce different fruit, those who plant the walnut for its fruit should make choice of the trees in the 
nurseries, when they have their fruit upon them."

The conımon walnut has several varieties, as the oval walnut, the round walnut, the large walnut, the small-fruited walnut, the double walnut, the early walnut, the late walnut, the tender thin-shelled walnut, and the hard thickshelled walnut.

There are two other species, the hickory-nut, or white walnut (J.alba), and the black walnut (J.nigra). Both these are natives of Virginia; but they are seldom cultivated in Britain, except as timber trees.

The best manure for the walnut is ashes, spread in the beginning of winter, the land having been first ploughed or trenched over in an effectual manner.

The length of time in which the English walnut bears well from the nut is about 20 years.

Mr. Knight has suggested that this tree will bear much sooner when raised by grafting, with bearing branches, by approach. But where the trees are intended for timber, it is a good practice to plant them out at once where they are to grow, as they thrive faster, and form better trees, by that method of raising them.

These trees should not be planted nearer together than 40 feet, and even more distant, if they are designed for fruit. They delight in a firm, rich, loamy soil, or such as is inclinable to chalk or marl; and will thrive very well in stony ground, or on chalk hills, as is evident from those large plantations near Leatherhead, Godstone, and Carshalton in Surrey, where great numbers of these trees planted upon the downs produce annually large quantities of fruit, to the no sinall advantage of their owners.

In order to preserve this fruit, it should be left upon the tree till it is thoroughly ripe, and then, as it would be exceedingly troublesome to gather it by hand, it may be beaten off, but not with such violence as is commonly used, from a mistaken notion that the tree is improved thereby; for most certainly it cannot be benefited by that rough way of forcing off the young wood upon which this fruit grows.

The fruit is used in two different stages of its growth: as when green, to pickle; and when ripe, to eat the kernel. For the first purpose, the young green walnut, when about half or near three parts grown, before the outer coat and internal shell shall become hard, is most excellent, for which they are generally ready in July or the following month, and should be gathered by the hand, choosing such as are as free from specks as possible. But the fruit is discovered to be fully ripe by the outer husk easily separating from the nut, or by the husks sometimes opening at the valve, and the nuts dropping out, which occurs usually about the latter end of September.. In trees of considerable growth, it is commonly beaten down with long poles; for, as the walnuts grow mostly at the extremity of the branches, it would, in very large spreading trees, be troublesome and tedious work to gather them by hand. As soon as gathered, they should be laid in heaps a few days to heat and sweat, to cause their outer husks, which closely adhere, to separate from the shell of the nuts; after which throy should be cleaned from the rubbish, and deprisited it a dry room for use, covering liem over close with dry straw, a foot thick, where they wil: keep 3 or 4 months. They always commanil a ready sale at market in large lowns, where. at their first coming in, they are hought wi:h their husks on, and sold by the sack, or hushel, but afterwards cleaned, and sold both ty meassure and by the thousand.

Plantations of these trees in England ar. therefore profitable, in their annual crops of fruit, while growing, and in their timber when felled or cut down.

It is stated in the Glouceslershire Report, that "it will grow almost in any soil, wants no pruning nor care, and in less time than the vak it will make a large tree. The wood is ton valuable to apply to the usual purposes of tim. ber trees, but is always used either in cabinet work or for gun-stocks; for the latter, indeed, so great has been the demand for a few years past, from the Birmingham gun-malers, that the county has been ransacked for this wood, and high prices have been held out to tempt the sale of it. In consequence of this, the stock has been much diminished, and, with very few exceptions, only here and there is a solitary walnut tree seen growing. In the parish of Arlingham there are more, perhaps, than in many other parishes combined."

Were it only for the oil that these nuts afford, the trees which produce them would be worth some care. It has been abserved by Evelyn, that one bushel of them will yield $151 \mathrm{lb}$. of peeled kernels, and that these will yield half that weight of oil, which, the sooner it is drawn, is the more in quantity, though the drier the nut, the better is its quality. He adds, that the lee, or marc of the pressing, is excellent for fattening hogs. Certainly it would be good manure for land; as are the cakes of linseed. rape, \&c., after the oil has been squrezed ou of them. The green husks boiled, without any mixture, make a good colour to dye a dark yellow-brown. The kernel being rubbed upon any crack or chink of a leaking vessel, stops it better than either clay, pitch, or wax. (Phillips's Fruits, p. 342.)

In the variety of trees which compose the vast forests of North America east of the Mississippi, the walnut, says Michaux the younger, ranks after the oak, among the genera whose species are most multiplied. In this particular, the soil of the United States is more favoured than that of Europe, to no part of which is any species of this tree indigenous. 'This ardent student of nature has designated 10 species of walnut in the United States, including the hickories, and thinks others may yet be discovered in Louisiana. There is, he alls, room to think that species may be discover. ed, susceptible, like the pacanenut hicliory, of speedy melioration, by the aid of grafting and attentive cultivation. Some weight is given this consideration, by an observation of Michaux the father, that the fruit of the common Eu. ropean walnut, in its natural state, is harder than that of the American species just mentioned, and inferior to it in size and quality. To the members of agricultural societies in 


\section{WAI.NUT TREE.}

the United States it belongs to extend their observations and experiments on this subject, after the example of our ancestors, to whom we are indebted for a rich variety of fruits, equaliy salutary and beautiful.

The walnuts of North America appear to present characters so distinct as to require their division into two sections. These characters consist principally in the form of the barren aments or catkins, and in the greater or less rapidity of vegetation in the trees. The first section is composed of walnuts with single aments, and includes two species, the black walnut and the butternut; to which section is added the European walnut. The second section consists of such as have compound aments, and comprises the 8 species already described under the name of Hickory.

The black walnut (Juglans nigra), is known by no other name in all parts of the United States where it grows. East of the Alleghany mountains, the most northern point at which it appears, is, says Michaux, about Goshen in the state of New Jersey, in the latitude of $40^{\circ}$ $50^{\prime}$. West of the mountains, it exists abun. dantly $2^{\circ}$ farther north, in that portion of Genesee which is comprised between the 77th and 79th degrees of longitude. This observation, as I shall have occasion to remark, is applicable to several other vegetables, the northern limit of whose appearance varies with the ciimate, and this becomes milder in advancing towards the west.

This last observation of Michaux in respect to the amelioration of climate in going west, has been ascertained, from exact thermometrical observations, to be applicable only to those sections of country situated sufficiently near the Lakes, and to the eastward of them to be influenced by the greater equality of temperature maintained by bodies of water than by land. The proximity of those great internal seas have a similar effect in modifying climate to that manifested on the Atlantic border, where many trees and plants creep up several degrees higher than they can be found further in the interior. (See Climate of the Uniten States.)

The black walnut is multiplied in the forests about Philadelphia, and, with the exception of the lower parts of the Southern States, where the soil is sandy, or too wet, it is met with to the banks of the Mississippi, throughout an extent of 2000 miles. East of the Alleghany mountains in Virginia, and in the upper part of the Carolinas and of Georgia, it is chiefly confined to the valleys, where the soil is deep and fertile, and which are watered by creeks and rivers: in the western country, in Genesec, and in the states of Ohio and Kentucky, where the soil in general is very rich, it grows in the forests, with the coffee tree, honey-locust, red mulberry, locust, shellbark-hickory, black sugar maple, hackberry, and red elm; all which trees prove the goodness of the soil in which they are found.

It is in these countries, says Michaux, that the black walnut displays its full proportions. On the banks of the Ohio, and on the islands of that beautiful river, I have often seen trees of 3 or 4 feet in diameter and 60 or 70 feet in height. It is not rare to find them of the thick1102 ness of 6 or 7 feet. Its powerful vegetation clearly points out this as one of the largest trees of America. When it stands insulated, its branches, extending themselves horizontally to a great distance, spread into a spacious head, which gives it a very majestic appear ance.

The leaves of the black walnut when bruised emit a strong aromatic odor. They are about 18 inches in length, pinnate, and composed in general of 6,7 , or 8 pair of leaflets, surmounted by an odd one. The leaflets are opposite and fixed on short petioles; they are acuminate, serrate, and somewhat downy. The barren flowers are disposed in pendulous and cylindrical aments, of which the peduncles are simple, unlike those of the hickories. The fruit is round, odoriferous, of rather an uneven surface, and always appears at the extremity of the branches: on young and vigorous trees, it is sometimes 7 or 8 inches in circumference. The husk is thick, and is not, as in the hickories, divided into sections; but when ripe it softens and gradually decays. The nut is hard, somewhat compressed at the sides, and sulcated. The kernel, which is divided by firm ligneous partitions, is of a sweet and agreeable taste, though inferior to that of the European walnut. These nuts are sold in the markets of New York, Philadelphia, and Baltimore, and served upon the tables. The size of the fruit varies considerably, and depends upon the vigour of the tree, and upon the nature of the soil and of the climate. On the banks of the Ohio, and in Kentucky, the fruit with the husk is 7 or 8 inches in compass, with the nut proportionally large: in Genesee, on the contrary, where the cold is intense, and in fields exhausted by cultivation, where these trees have been preserved since the first clearing of the land, it is not of more than half this bigness. Some variations are observed in the form of the fruit, and in the moulding of the shell; but these I consider as merely accidental differences. Indeed, there is no genus of trees in America, in which the fruit of a given species exhibits such various forms as in the walnut; and doubtless this circumstance has misled observers, who, being acquainted only with the small number of trees existing in European gardens, have described them as distinct species.

The bark of the black walnut is thick, black ish, and on old trees deeply furrowed. When the timber is freshly cut, the sap is white and the heart of a violet colour, which after a short exposure to the air assumes an intenser shade, and becomes nearly black: hence probably is derived the name of black walnut. There are several qualities for which its wood is principally esteemed; it remains sound during a long time, even when exposed to the influences of heat and moisture; but this observation is applicable only to the heart; the sap speedily decays. It is very strong and very tenacious: when thoroughly seasoned it is not liable to warp and split; and its grain is sufficiently fine and compact to admit of a beautiful polish. It possesses, in addition to these advantages, that of being secure from worms. On account of these excellencies, it is preferred and suc- 
cessfully emplnyed in many kinds of work, chiefly in cabinet-making.

'I'he husk of the fruit yields a colour similar in that which is obtained from the Furopean walnut. It is used in the country for dyeing woollen stuffs.

This tree has been long since introduced, in England and France, into the gardens of the lovers of foreign culture. It succeeds perfectly and yields fruit abundantly. Though differing widely from the European species, it bears a nearer resemblance to it than any other American walnut. By comparing the two species as to their utility in the arts and in commerce, it will appear that the wood of the black walnut is more compact, heavier, and much stronger; that it is susceptible of a finer polish, and that it is not injured by worms; qualities which, as has been seen, render it fit not only for the same uses with the European, but also for the larger works of architecture. These considerations sufficiently evince that it is a valuable tree, and that it is with great reason that many proprietors in America have spared it, in clearing their new lands. On highroads, I am of opinion that it might be chosen to succeed the elm; for experience has proved, that to insure success in the continued cultivation of trees or herbaceous plants on the same soil, the practice must be varied with species of different genera.

Nuts of the European walnut and of the black walnut have been planted at the same time in the same soil; those of the black wal nut are observed to shoot more vigorously, and t) grow in a given time to a greater height. By grafting the European upon the American species at the height of 8 or 10 feet, their advantages, with respect to the quality both of wond and of fruit, might be united. (Michaux.)

The second species of walnut, properly so called, has been described under the head of Butteñut.

WARBLE. See Back-sore, Galls, and SITFAST.

WARP. A slimy deposit or ooze left upon land by the receding sea tides in particular situations. See Aleuvium and Warping.

WARPING OF LAND. A mode of fertilizing and improving tillage lands practised in particular situations on the borders of large rivers and waters into which the sea tides flow, and where the level of the ground is such as to admit of their being flooded with great facility. The practice is, for the most part, confined to the districts situate on the coasts of Lincolnshire and Yorkshire. The water of the tides that come up the 'Trent, Ouze, Dun, and other rivers which empty themselves into the great estuary of the Humber, is muddy to an excess; insomuch that in summer, if a cylindrical glass, 12 or 15 inches long, be filled with it, it will presently deposit an inch, and sometimes more, of what is called warp: a circumstance which renders them so fertile.

The fertility of Egypt, of the land bordering cn the shores of the Ganges, and some of the large American rivers, I have already shown to be attributable to the periodical overfowing of the waters which are surcharged with a large quantity of earthy sulistances which they hold in solution.

"The effect of warping is very diffrereqt from that of irrigation; for it is not the water that works the effect, bat the deposituon of the mush so that in floods the businmss crises, as also in winter; and the object of this practice is nor to manure the soil, but to creatr it. 'The gua. lity of the land intended to be warpen is not of the smallest consequence; a brig, clay, sand, peat, or a barn floor, are all one: as tire warp raises it in one summer from 6 to 16 ifuchers thick, and in the hollows, or low places, 2, 3 , or 4 feet, so as to leave the whole piece level. 'Thus a soil of any depth you please is formerl. which consists of mud of a vast fertility, though containing not much besides sand."

'This is a practice which is begun in the month of July, and is proceeded with during the summer season; and as it can only be performed at that period, every occasion of having it executed should be embraced, by having the work in perfect repair, that every tide may be made to produce its full effech With regard to the advantage of doing this work in the summer months, it may be remarked that at these times the lands not only become the soonest dry, a circumstance which must always fully take place before the process of cultivation can be carried on, but the tides are less mixed with fresh water, in which situation they are constantly found the most cffectual.

The method of executing the work is thus described, in the Agricultural Survey of the West Riding of Yorkshire, by Lord Hawlie:-

"The land to be warped must be banked round against the river. The banks are made of the earth taken on the spot from the land: they must slope 6 feet, that is, 3 feet on each side of the top or crown of the bank, for every foot perpendicular of rise: their top or crown is broader or narrower, according to the impetuosity of the tide and the weight and quantity of water; and it extends from 2 to 12 feet: their height is regulated by the height to which the spring tides flow, so as to exclude or le them in at pleasure. In these banks there are more or fewer openings, according to the size of the ground to be warped, and to the choice of the occupier; but in general they have only two sluices, one called the flond-gate, to admit, the other called the clough, to let off the water gently; these are enough for 10 or 15 acres. When the spring tide begins to ebb, the floodgate is opened to admit the tide, the clough having been previously shut by the weight of the water brought up the river by the flow of the tide. As the tide ebbs down the river, the weight or pressure of water being taken from the outside of the clough next the river, the tide water that has been previnusily admitted by the flood-gate opens the clough again, and discharges itself slowly but completely through it. The cloughs are walled on each side, and so constructed as to let the water run off between the ebb of the tide admitted and the low of the next; and to this point particular attention is paid. The flood-gates are placed sc high as only to let in the spring tides when 1103 
opened. They are placed above the level of the common tides.

"Willows are also occasionally planted on the front of the banks, to break the force of the tides, and defend the banks by raising the front of them with warp thus collected and accumulated; but these willows must never be planted on the banks, as they would destroy them by giving the winds power to shake them."

It is stated that in England the first cost of a sluice for warping, that is, 5 feet in height and 7 feet in width, may be estimated at from $400 l$. to $500 l$; and that such a sluice will in general be adequate to the warping of 50 acres annually, and, where the soil is contiguous to the river, for $\mathbf{7 0}$ or more.

The following is given as the substance of a note by a commissioner employed in warping: - "Warpleaves one-eighth of an inch every tide on an average; and these layers do not mix in a uniform mass, but remain in distinct layers.

"If only one sluice, then only every other tide can be used, as the water must run perfectly off, that the surface may incrust; and if the canal be not empty, the tide has not the effect.

"As a new soil is created by this practice, it is of little consequence what the original nature of the land may be, almost all kinds being improved by it. But at the same time it may be the most beneficial in such light soils as are very open and porous, and such stiff ones as are defective in calcareous matter, and which require substances of this kind to render them less tenacious. Land, when once well warped, will continue for a vast length of time in a good state of fertility; but still it is suggested by some experienced warpers as a better practice to apply a small portion of warp whenever the land is in the state of fallow, which will be about every 5 or 6 years, as by this means the farmer will be more secure of having good crops. The depth to which the lands are covered by the tiaes must be regulated according to their levels, and the height of the tide in the rivers from which they proceed. It may be admitted to the height of 3 , or 4 , or more feet; but the deposit of sediment is in some measure proportionate to the height of the water, though the same effects may be obtained from much smaller quantities of water by continuing the process a great number of tides."

The expense of this mode of improving lands must necessarily differ much in different cases, according as the circumstances of situation and distance vary; but, according to $\mathrm{Mr}$. Young, it can seldom exceed $12 \%$. or $15 l$. the acre, and in most instances it must be greatly below such estimates.

Warped lands are found capable of growing most kinds of crops in great plenty, but particularly oats, beans, wheat, flax, potatoes, and grass-seeds.

WARRANTY. In horsemanship, \&c., a term applied to the assurance of the animal's being sound when purchased. See Buring and SELLing.

WARREN. A franchise, or place privileged, pither by prescription or grant from the king, to keep beasts and fowls of warren in ; as rabbits, hares, partridges, pheasants, \&c.

1104
By statute $21 \mathrm{Edw} .3$, a warren may lie open, and there is no need of closing it in, as there is a park.

In the forming a warren, great caution is to be used for the fixing upon a proper place and a right situation. It should always be upon a small ascent, if possible, and exposed to the east or the south. The soil that is most suitable is that which is sandy; for when the soil is clayey or tough, the rabbits find great difficulty in making their burrows, and never do it so well; and if the soil be boggy or moorish, there would be very little advantage from the warren; for wet is very destructive to these animals. See RAввгт.

WASP (Vespa). An extensive genus of insects, of which three species are common to

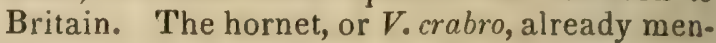
tioned; common wasp, or $\boldsymbol{V}$. vulgaris, which makes its nest in the ground; the small wasp, or $V$. coaretata, the nest of which is a kind of paper made of woody fibre and suspended to the boughs of trees.

Of the wasps most commonly known in the United States there are two species, namely, the large, fierce, stinging insect which builds its flat paper nest in bushes, \&c., and the more harmless blue-winged mud-wasp, commonly called the mason, from its plastering its nest with mud against the walls of houses, \&c. These nests are composed of cells, each one of which contains a single egg, together with a considerable number of living spiders, caught and imprisoned therein solely for the purpose of affording the little mason's young a ready supply of fresh provisions. In noticing this characteristic of the mud-wasp, Dr. Harris also refers to the habits and nests of some other tribes of the same family, such as the holes of the stump-wasp, stored with hundreds of horseflies for the same purpose; the skill of the leaf-cutter bee in cutting out the semicircular pieces of leaves for her patchwork nest; the thimble-shaped cells of the ground-bee, hidden in clusters under some loose stone in the fields, made of little fragments of tempered clay, and stored with bee-bread, the work of many weeks for the industrious labourer; the waxen cells made by the honey-bee, without any teaching, upon purely mathematical principles, measured only with her antennæ, and wrought with her jaws and tongue; the water-tight nests of the hornet and wasp, natural paper-makers from the beginning of time, who are not obliged to use rags or ropes in the formation of their durable paper combs, but have applied to this purpose fibres of wood, a material that the art of man has not yet been able to manufacture into paper. These are only a few of the objects deserving of notice among the insects of this order; many others might be mentioned, that would lead us to observe with what consummate skill these little creatures have been fashioned, and how richly they have been endowed with instincts, that never fail them in providing for their own welfare, and that of their future progeny. (Treatise on Des. Insects.)

Wasps are not only destructive to grapes, peaches, and the more delicate kinds of fruit, but also to bees, the hives of which they attack and plunder, frequently compelling these in- 


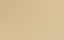




\section{Plate 10.}

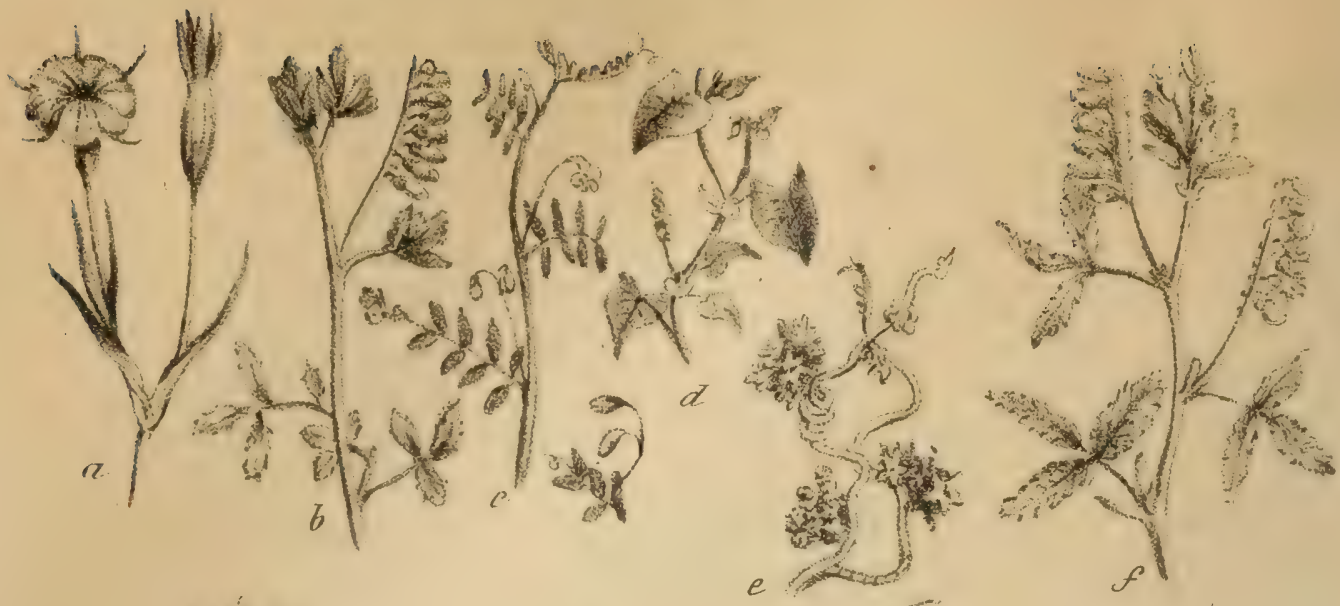

a
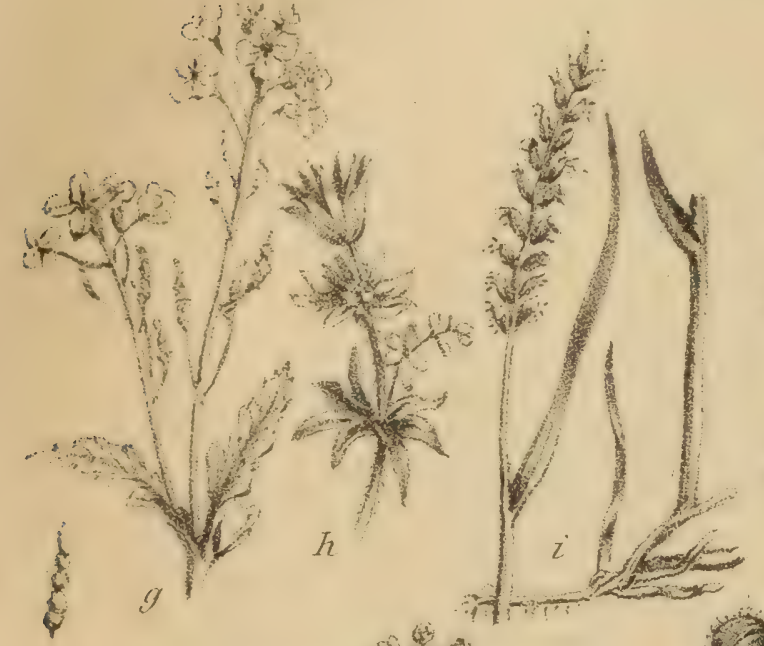

$$
14 \div
$$

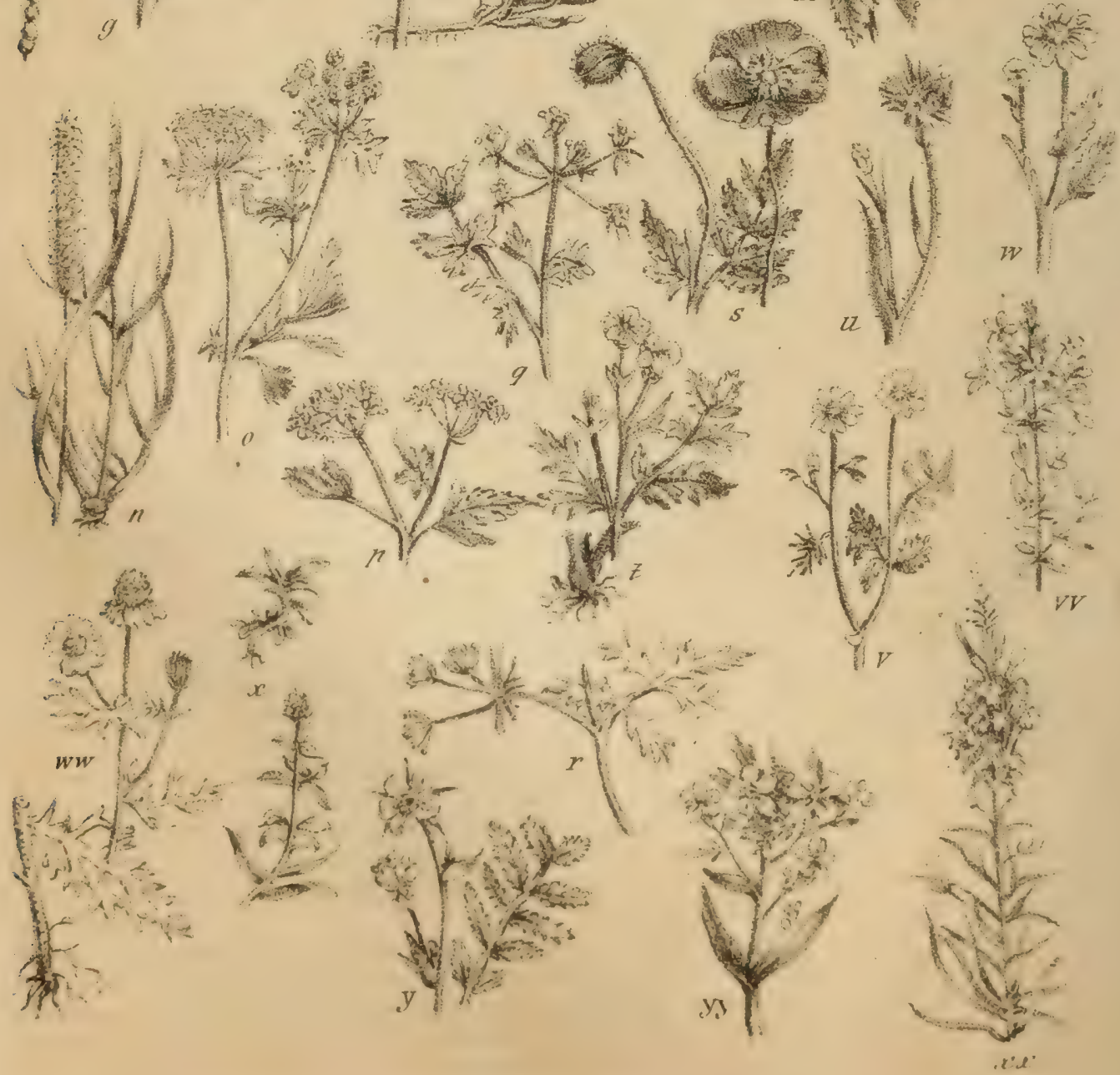


dustrious insects to change their habitation. 'The nests of those wasps which build in the earth may be destroyed with hot water or oil; those on trees are best suffocated by lighted brimstone. (Kollar on Insects, p. 79.)

Wasps are much affected by cold; so that when winter begins to set in they become less bold and savage, and they all perish, except a few females, as soon as the frost begins. This is a wise provision of nature; for, did they survive the winter, they would soon rival the locust in their destructive depredations.

WASTE LAND. The following is an account of the quantity of land uncultivated and waste in the British dominions, including Scotland, Ireland, and the British islands, according to the evidence of $\mathrm{Mr}$. Cowling before the Emigration Committee in 1827:--

\begin{tabular}{|c|c|c|c|}
\hline & & $\begin{array}{l}\text { Uncultivated } \\
\text { Acres. }\end{array}$ & $\begin{array}{l}\text { Unprofitable } \\
\text { Acres. }\end{array}$ \\
\hline England & - & $3,454,000$ & $3,256,000$ \\
\hline Wales - & - & 530,000 & $1,105,000$ \\
\hline Scotland & - & $5,950,000$ & $8,523,930$ \\
\hline Irelaud & - & $4,900,000$ & $2,416,664$ \\
\hline \multirow[t]{2}{*}{ British Islands } & - & 166,000 & 569,469 \\
\hline & & $15,000,000$ & $15,871,463$ \\
\hline
\end{tabular}

WATER. A well-known, universally diffused substance, which in ordinary temperatures is fluid, but is solid when cooled down to $32^{\circ}$ of Fahrenheit's thermometer. It rises into vapour at all temperatures, even below the freezing point, and at $212^{\circ}$ expands suddenly into steam. It is composed, by weight, of oxygen 8 parts, and hydrogen 1 part.

Water is one of the most useful elements in the arts and manufactures, as well as in rural and domestic economy. The extensive utility of water for imparting motion to machinery, and for domestic purposes, is too well known to require explanation; and as we have already treated of its beneficial properties for irrigating land, under this head we shall have principally to confine ourselves to its uses to plants.

Its Uses to Vegctation.-The value of water to vegetation very early attracted the attention of mankind. In the most ancient of all books, Genesis ii. 10, we are told that "a river went out of Eden to water the garden." And the earliest of the Greek and Egyptian philosophers, astonished and confused by the magic effects which water produced upon the rank and luxuriant lands of the warm eastern climates, were loud in their praises of the unaided powers of water to support vegetation. They not only regarded it as one of the four elements of which the world was composed, but Hippocrates considered it to be the substance which nourishes and supports plants and animals. Theophrastus even considered that all metals were produced from water. 'The opinion that pure water, and water only, was able to support vegetation, was in succeeding ages long the opinion of many philosophers distinguished for their laborious investigations and their ardent love of truth. Amongst these may be named Van Helmont, Bonnet, Duhamel, Tillet, and the illustrious Boyle. These great men deceived themselves, however, by not sufficiently attending to the purity of the water 139 with which they experimented, or puariting with rigid accuracy agiluse nfleer sureers of error. $O f$ the many researches which they institutrol to determine this point, none was inne apporenlly conclusive than that of the weti-known willow tree experiment of Van Helmont, which long deceived, from its apparent arcuracy, the philusophers of that age. This celefirated ex. perimentalist planted a willow which wropheil $5 \mathrm{lbs}$. in a common earthen vessel filled with 200 lbs. of soil, which had been previrusly thoroughly dried in an oven, and then mustened with only rain-water. 'This earthen vessel he placed in the earth in a garden, cuvering it over in such a manner that all access of dust, \&c., was prevented. For five years this willow continued to grow, although moistened only with either rain or distilled water. At the end of that period, it was found to weigh $169 \frac{1}{1 b s}$. although the earth in which it was planted, when again dried and weighed, was found to have lost only two ounces of its original weight. Here, then, said the contemporaries of Van Helmont, is an increase of $164 \mathrm{lbs}$, and yet the only food the willow had was water; it is evident, therefore, that pure water, and water only, is quite sufficient to support vegetation.

Various sources of error were, however speedily discerned to prove that this experiment was totally insufficient to decide this question. The illustrious Bergman, in 1773, showed that the rain-water employed by $\mathrm{Van}$ Helmont, so far from being chemically pure, contained sufficient earthy matters to supply the whole of that found in the willow iree. And, in addition to this, it was afterwards shown that unglazed earthen vessels readily imbibe and transmit the moisture of the soil in which they are placed: now this moisture abounds with a variety of solid matters, both organic, earthy, and saline. (Thomson, vol. iv. p. 313.)

Still more accurate experiments have been since instituted with water chemically pure, with very different results. In this way all attempts to raise plants have in every instance totally failed, although, as I have in another place had occasion to remark, I have fruilessly varied the attempt in several ways. See Liquid MANURE.

Although, however, it is, from the result of these laborious researches, pretty clearly proved that water is not the sole food of plants, yet it must be evident to the most casual observer what an indispensable food this universal fluid is to vegetation. To all vegetation. in fact, it is an indispensable necessary of life. although almost every species of plant requires to be supplied with it in varying prom portions: some, such as the aërial epidendron, and other Oriental plants, being able to supply themselves from merely the aqueous portion of it which always exists in the atmosphere: while some, such as the rice plant, and the aquatics, cannot prosper without being sup. plied with it in such copious quantities as would be destruclive to the ordinary crops of the farmer. In some proportion or other, however, they all require it, and all altempls have been in vain made to cause plants to grow in situations where moisture was ahsolutely

$$
5 \text { A } \quad 1105
$$


removed both from the earth and their surrounding atmosphere.

M. Berthollet was of opinion that the leaves of plants have the power of decomposing water when exposed to the light of the sun. 'The oxygen gas, according to this distinguished philosopher, which is always emitted under these circumstances, is derived partly from the decomposition of the water. "Indeed," adds Dr. Thumson, "If we consider the great quantity of hydrogen contained in plants, it is difficult to conceive how they should obtain it, provided the water they absorb does not contribute to furnish it." (System of Chem. vol. iv. p. 349.) These views open a field for future and highly interesting researches, which will probably lead to the establishing of new facts highly important to the cultivator. And as Davy, the chief of chemists, well said, "We can only reason from facts. We cannot imitate the powers of composition belonging to vegetable structures, but at least we can understand them; and as far as our researches have gone, it appears that in vegetation compound forms are uniformly produced from simpler ones; and the elements in the soil, the atmosphere, and the earth, absorbed and made parts of beautiful and diversified structures." (Lec:ures, p. 314.)

Pure water, therefore, is certainly not capable of entirely supporting vegetation. Yet, although it cannot produce effects so extensive as these, yet its uses are many and important, and it is more than probable that it is decomposed by plants, its oxygen partially evolved, and its hydrogen assimilated with carbon and oxygen into a variety of vegetable substances, most of which contain hydrogen in some form or other: thus

Sugar is composed of -

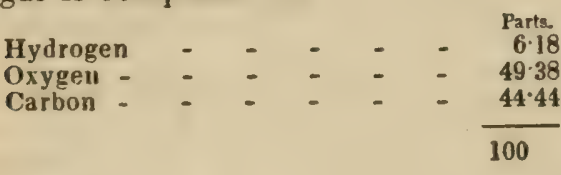

Gum, of -

Hydrogen

Oxygen -

Carbon

$-$

$\div$

$\begin{array}{r}-\quad 6.43 \\ -\quad-\quad 51.46 \\ \hline 100 \\ \hline\end{array}$

Starch, of-

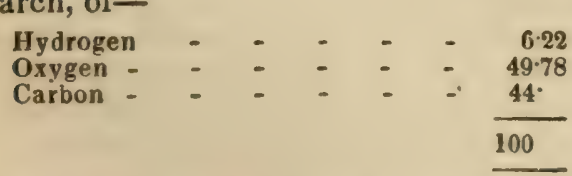

It would be difficult indeed to account for the large proportion of hydrogen present in vegetable substances, without we allow that in some instances water is decomposed by the plant. "All the hydrogen," says Professor Iliebig, rather ton sweepingly, "necessary for the formation of an organic compound is supplied to a plant by the decomposition of water. (Organ. Chem. p. 66.)

That plants have a strong attraction for wainr is evident from a variety of circumstances; thus by their leaves and roots they separate the aqueous vapour of the atmosphere from the gases in which it is contained, and that too 1106 in all ordinary temperatures. This unvaried presecce of aqueous vapour in the atmosphere is not less remarkable by the immense importance it is to vegetation; for without the assistance which the farmer's crops derive from it in dry weather, the warmth of the sun would too often in the summer months wither and destroy them. This beautiful arrangement of creative wisdom did not escape the attention of Davy, who noted too the variations in its quantity according to the changing demands of vegetation. The quantity of water, he remarked (Elements of Agr. Chem. p. 207), which exists in air as vapour, varies with the temperature. In proportion as the weather is hotter the quantity is greater. At $50^{\circ}$ of $\mathrm{Fah}$ renheit's thermometer, air contains about onefiftieth of its volume of vapour; and as the specific gravity of vapour is to that of air nearly as 10 to 15, this is about one seventy-fifth of its weight. At $100^{\circ}$, supposing that it has a free communication with water, it contains about one-fourteenth part in volume, or one twentyfirst in weight. It is the condensation of vapour by the diminution in the temperature of the atmosphere which is probably the principal cause of the formation of clouds, and of the deposition of dew, mist, snow, or hail. The leaves of living plants appear to act upon the vapour likewise in its elastic form, and to absorb it. Some vegetables increase in weight from this cause when suspended in the atmosphere, and unconnected with the soil; such are the house-leek, and different species of the aloe. In very intense heats, adds Davy, and when the soil is dry, the life of plants seems to be preserved by the absorbent power of their leaves; and it is a beautiful circumstance in the economy of nature, that aqueous vapour is most abundant in the atmosphere when it is most needed for the purposes of life, and that when other sources of its supply are cut off, this is most copious.

And, again, when water is combined with saline substances, the roots of plants separate it from them in a very remarkable manner. Some curious experiments of this kind were made by M. Saussure. See Salts, their Uses to Vegetation.

That plants have the power, when nourished only with pure water, of decomposing the carbonic acid gas of the atmosphere, has been shown by some very careful experiments of M. Saussure. He found that some sprigs of peppermint, when supplied with pure water only, and allowed to vegctate for some time in the light, nearly doubled the portion of carbon which they originally contained. The quantity of water which, under ordinary circumstances, plants absorb, is very considerable; thus, Dr. Hales ascertained that a cabbage transmits into the atmosphere, by insensible vapour, about half its weight of water daily ; and that a sunflower, 3 feet in height, transpired in the same period nearly 2 lbs. weight. (Veg. Statics, vol. i. p. 5, 15.) Dr. Woodward found that a sprig of mint, weighing 27 grains, in 77 days emitted 2543 grains of water. A sprig of spearmint, weighing 27 grains, emitted in the same time 2558 grains. A sprig of common nightshade, weighing 49 grains, evolved 
3708 grains, and a. lathyrus of 98 grains emitted 2501 grains.

In a previous page of this Encyclopadia, I have endeavoured to show the various uses of the earths to vegetation. (See Eanтнs.) The cultivator will observe how many of their chief fertile properties are connected with their attraction for the aqueous vapour of the atmosphere, their powers of absorption, their capability of retaining it. It is in vain, indeed, by any contrivance to attempt to make plants of any description vegetate in absolutely dry earth, or in air from which the aqueous vapour is entirely withdrawn. It is true that some of the flowering roots of the East, and some of the mosses of our own country, almost appear to do so; but such plants support themselves by absorbing a certain degree of moisture, even when suspended, as in oriental countries, by a silken cord from the ceiling of the room, or from apparently dry brick walls; for when by chemical means the moisture is entirely removed from them, even these hardy plants cease to vegetate.

Various foreign substances have been supposed to exist in minute proportions in rainwater, to which its fertilizing effects have been chiefly ascribed: thus ammonia is believed by Professor Liebig to exist in rain-water. Nothing, however, is more likely to lead to erroneous general conclusions than the detection of minute foreign substances in water. Such hasty generalizations have often deceived the most excellent philosophers: thus the great Boyle, by digesting pure water for a lengthened perind in glass vessels hermetically sealed, found that it deposited a minute quantity of flint in powder; and hence he was led to conclude that water was in this way converted by long boiling into silica, an error which several other philosophers adopted, until the celebrated Lavoisier and Dr. Priestley proved that the flint deposited arose from the water having, by long boiling, partially dissolved the glass. In the same way even Davy, the most cautious of experimentalists, once thought that chlorine and soda might, by the influence of the voltaic pile, be obtained from water absolutely pure; but more careful and rigid experiments soon convinced him of the extreme difficulty of procuring entirely pure water, the vessels in which the water was procured communicating, with every apparent caution, sundry impurities; and this difficulty, I think it very likely, the skilful chemists of Germany have not successfully escaped.

Water exists in all cultivated land in some proportion or other. The quantity, however, necessary to be present in the farmer's soils to obtain the maximum advantage varies with their nature, the climate, and the crop. For instance, the rice-fields of India require a degree of moisture which would be utterly destructive to the grain crops of the English farmer. The most porous, sandy land in a rainy climate will be prolific, when the same soil in a dry, warm country will be absolutely barren. Even the drifting sands of Arabia, for instance, if placed under the incessant rains of the American Andes, would certainly be speedily covered with vegetation. Some of the richest water- meadows of the south of England and of Sentland are formed on subsoils of liroken fints, gravels, and the roughest shingle. And, agann, the meadow-lands often need such copious supplies of moisture as would be the means of destroying the grain crops. The surface water which tenants many uncultivated sonls is generally surcharged with a variety of foreign substances, very commonly with vergetable matters. That in the gravelly soils is usually sur. charged with oxide of iron; that resing on calcareous soils, with sulphate of line (gypsum); whilst those from peat lands commonly abound with sulphate of iron, or the red nxide of the same metal.

In most of the soils which the farmer has to bring into cultivation, the removal of these waters is his first care; for such an abundance of moisture is not only pernicious, from the usual bad quality of the land water, but from the quantity being far too great for the habits of the plants which the farmer intends to cultivate; such waters, too, dissolve, and sometimes carry off from the soil, in their imperceptible drainage, all the soluble richest portion of the soil. For many reasons, therefore, draining has been long very justly held to be the foundation of all agricultural improvements; since its good effects are not confined to the low marsh land, but its beneficial influence is extended to the most upland soils. It removes the land springs, and dries the surface of thousands of acres of even the most elevated of the English gravels.

Almost to an equally beneficial extent has the addition of water to plants for a lengthened period been carried on by the cultivator in a variety of modes; by the gardener, either in steam in his conservatories, or by the wateringpot in the open ground. Almost endless, indeed, are the varieties of artificial irrigation, from the minor applications of the gardener to the more gigantic efforts of the managers of the water-meads. It is this branch of the investigation of the uses of water to vegetation which is the most interesting to the farmer, and to the head In aigatios I must refer the reader. In regarding the uses of water to regetation in this manner, however, the cultivator must remember that it is not pure water that he is thus using for his crops, but, as I have before remarked, water surcharged with a variety of earthy, saline, and organic matters, to whose presence a chief portion of the fertilizing effect of such streams must be attributed; for it is found that the most foul and impure waters are much the best for the purposes of irrigation: thus the water of a river below a town is found to be much more fertilizing than the sane water before it has been mixed with the contents of the sewers. These are facts well known, for instance, to the owners of the fine water meadows of the valleys of the Itchen, the Kennet, and the Avon. That of the Thames above the influence of the tide is not nearly so valuable to the grazier as it is after it has had mixed with its waters the huge mass of impure matters from the Iondon sewers. Then, again, by far the richest irrigating waters, because the very foulest of all, are those of the sewers of the city of Edinburgh, which produce such singu. 
larly luxuriant crops of grass on the Craigintinny meadows. This observation is not confined to the English graziers: those of the duchy of Milan long since made the same remark. Half a century since, Mr. Songa, when describing the meads of the banks of the Brembo, says, "That water is found excellent which passes through the fosses of the town of Treviglio, and discharges itself irom them uy forming a canal of 8 or 10 feet broad, and 1 foat or $1 \frac{1}{2}$ foot deep. The lands irrigated with this water seem to receive every time the advantage of a dunging, and on this account sell from a third to a half dearer than any other of an equal quality of soil." (Young's Annals, 1793, p. 182.) Watering the land to add to its ferlility is a very ancient practice.

Such, then, are a few of the well-ascertained facts with regard to the application of water to vegetation, uses which are so valuable when well understood by the farmer. In all his operations this universal fluid will be found to influence his arrangements; and in a due and regular supply of it to his crops consists, in fact, the success of most of his efforts. If, for instance, a farmer would judge of the value of a particular field from merely a specimen of its soil, the attraction of the previously dried earth for the moisture of the atmosphere will afford a very tolerable indication of its comparative value; those soils which attract the most water being commonly those which obtain the highest rents.

All researches like these, in many obvious and indirect ways, are attended with considerable advantage to the cultivator. For, the inore he becomes acquainted with the uses and properties of water, the more readily will he be able to avail himself of every opportunity which may present itself for extending its sphere of usefulness. It is idle to conclude that every thing possible has been effected with regard to the agricultural uses of water; for, saying nothing of the inferior extent of our water meads to those of even the banks of the Italian rivers, much still remains to be accomplished in rendering available, not only the liquid drainage of our large towns, but in the use of the steam-engine for the purposes of irrigation; an agent to which I have in this work already alluded, and for obtaining whose magic assistance the farmers of no other country are sn well situated as those of our own island. 'To the cultivator, therefore, an examination of the powers and properties of water will in many ways be attended with benefit; for if the farmer once seriously contemplates the powerfully invigorating and enriching qualities of the waters near to which he is very often placed, the abundance of organic matters which they contain, and the advantages to be derived from their judicious application, he will speedily devise some means or other by which he may avail himself of this too often neglected agent. The finely divided earthy and organic matters which now so copiously pollute the waters of our rivers are in fact the only great Arawbacks upon the otherwise gradually increasing productiveness of the land. (See $A_{L}$ rovirm and Warpine.) These, be it remembered, are ever quietly yet incessantly acting 1108 as drains upon the fertility of the land; they never cease the work of impoverisiment; and it is only by the efforts of the merchant, the fisherman, and the irrigator, that any portion of these finely divided matters ever return again to the cultivated soils of our country. Sce InniGation and Rair.

WATER-ALOE, or WATER SOLDIER (Stratioles aloides; from strulos, an army, in allu. sion to its long sword-like leaves). In England, an ornamental native aquatic, which fills the ditches in summer with a close phalanx of sword-like leaves, and increases so fast in the ponds where it is planted as to become almost a troublesome weed. In its wild state it inhabits deep ditches and pools, and is a stoloniferous, smooth, floating herb, with numerous radical leaves, and a solitary central flower-stalk, but no stem. The parent plant sinks to the bottom after flowering, and sends out long simple runners, each terminating in a leaf, bud, or young plant, which first takes root in the mud, by several long fibres, and in the following summer rises to the surface of the water, blossoms and then again subsides to ripen its seeds and throw out fresh runners, each tuft of leaves flowering but once. The leaves are a span long or more, acute, highly vascular, fringed with very sharp saw-like teeth. Flowers white, large and handsome, the stall firm, stout, two-edged, much shorter than the leaves.

WATER-CARPET. A name in Pennsylvania for the Golnen Saxifrage, which see.

WATER-COWBANE. See CownaN

WATER-CRESS. See Cress.

WATER-DROPWORT. See DRoPWort.

WATER-ELDER. See Gueldir Rosk.

WATER-FARCY. See Farcr.

WATER-HEMLOCK. See Cownasr.

WATER-LLLY, THE FRINGED. See BUCKBEAN.

WA'TER-LILY, YELLOW.-See LILr, WATER.

WATER-LILY, WHITE. See LIIT, WATER.

WATER-MELON. The following directions for cultivating water-melons for an early markei, are given in the Southern Agriculturist.

Select a high and dry soil for the purpose. Plough it up well, and harrow it. Check off the spot thus treated at distances of 10 feet each way. Dig out each check with a hoe or spade, and into the same place 5 or 6 quarts of cotton seed; or if this cannot be procured, fill the place with stable manure, partly decomposed. Haul over this the earth before dug from the hole, and mix it well with the manure. If you have used cotton seed, in the spring, it will have sprouted a week or two after being put into the hole; and must now be killed by chopping up the same well, and mixing it with the soil. This being lone, you may now haul up the manure and earth as before directed, into hills, on the top of which you must place about a peck of sand, taken from some street or weil-travelled road. Your hills will be now ready for planting. I should, however, state that the hills must, instead of being made high, be made flat and broad.

Soak your seed over night in millr-warm water, and plant them out the next morning, placing from 5 to 6 seed to each hill. The 


\section{WATER-PEPPER.}

seed must not be covered more than 1 or 2 inches under ground. Water the hills for a few days until the seed has sprouted, and then leave the plants to run.

As soon as the plant has got 6 leaves, take off the centre plant with a sharp penknife, and when the lateral shoots are 6 inches or a foot long, take off all but three. When the shoots, thus left, begin to run to the ground between the hills, stake them down with a small crossstick.

As the vines begin to branch, at every 3 or 4 feet, where the vine branches, put a shovelful of rich earth over the same, and press it down lightly with the foot. Wet weather should be selected for this operation, and by so doing the vines will never fail to take where they have been set. The spaces between the hills should be kept free of grass-and by following the above directions, large melons will be produced.

From a quarter acre of land thus treated, more melons will be made than from four times the amount as usually cultivated. See Melon, Water.

WATER-PEPPER (Polygonum punctatum). A plant found in the Middle and other States, possessing very acrid qualities, causing obstinate ulcerative inflammation when applied to the skin.

WATER-PLANTAIN (Alisma, from the Celtic alis, water). A genus of pretty little, aquatic, perennial, smooth plants, with simple, entire leaves, and nurnerous, stalked, white, yellowish or purplish, panicled or umbellate inodorous flowers. In England, there are four native species; viz.:

1. The greater water-plantain, or thrumwort (A. plantago), which is very common in pools, ditches, and about the margins of rivers. The root is fibrous. Leaves all radical, on long stalks, erect, ovate, acute, ribbed, in deep or running water lengthened out more or less. It has been recommended in hydrophobia; but, like many other wonder-working remedies, it is worthless.

2. Star-headed water-plantain ( $A$. damasoni$\boldsymbol{u} \mathrm{m}$ ), found in ditches and pools on a gravelly soil, but not common. The root consists of many long pale fibres. The leaves all radical, floating, bluntish or oblong, heart-shaped at the base. Footstalks very broad, with many ribs, and a membranous border, tapering upwards. Flower-stalks scarcely a span high, bearing 1 or 2 whorls of white flowers, yellow in the middle. Capsules six, spreading in the form of a star, half-ovate.

3. Floating water-plantain (A.naluns). This species frequents the lakes of North Wales and Cumberland.

4. I.esser water-plantain (A. ranunculoides). This grows in swamps and turfy bogs, but is not a very common species.

5. Creeping water-plantain (A. repens). This has only been found on the margins of some of the lakes in North Wales.

WAX (Germ. wachs). A solid concrete abounding in the vegetable kingdom, whence it is erroneously supposed that it is collected by bees. Bees' wax is a secretion in the body of the bee, and is accumulated in what are
WAY-GOING CROP.

called the wax-pockets. Buers confined in a hive, and fed merely on sugar, form wax. It constitutes the partitions of the cells in which they store their honey. It is obtained by melt. ing the comb. Wax, when pure, is of a whir ish colour; it is destitute of taste, and has scarcely any smell. Bees' wax, indeed, has a pretty strong aromatic odour; but this smoms chiefly owing to some substance with which i: is mixed; for it disappears almost completely by exposing the wax, drawn out inti) thin ribands, for some time to the atmosphere in blanch, frequently changing the surface thus exposed, by remelting it, and reducing it again to thin flakes. By this process, which is called bleaching, the yellow colour of the wax disarpears. White wax is principally used in making candles, and in white ointments, for the sake of its colour. Wax is insoluble in water: nor are its properties altered though kept under that liquid. When heat is applied to wax, it becomes soft; and at the tenaperature of $142^{\circ}$ if unbleached, or of $155^{\circ}$, if bleached, it melts into a colnurless transparent fluid, which concretes again, and resumes its former appearance, as the temperature diminishes. If the heat be sill further increased, the wax boils and evaporates; and if a red heat be applied to the vapour, it takes fire and burns with a bright flame. It is this property which renders wax so useful for making candles. Wax coinbines readily with fixed oils when assisted by heat, and forms with them a substance of greater or less consistency, according to the quantity of oil. 'This composition, which is known by the name of cerate, is much employed by surgeons.

According to the experiments of Gay-Lussac and Thenard (Rech.Physico-Chim.vol.ii.p.316), 100 parts of wax are composed of-

\begin{tabular}{|c|c|c|c|c|c|c|c|}
\hline Oxygen & - & - & - & - & - & - & 5.54 \\
\hline Hydrogen & & - & - & - & - & - & 12.67 \\
\hline \multirow[t]{2}{*}{ Carbon } & - & - & - & - & - & - & $81 \cdot 78$ \\
\hline & & & & & & & 100 \\
\hline
\end{tabular}

Wax is sometimes adulterated with the white oxide of lead to increase its weight, with white tallow, and with potato starch. The first is detected by melting the wax in hot water, when the oxide falls to the bottom undissolved; the presence of tallow is indicated by the wax being of a dull opaque white, and wanting the transparency which distinguishes pure wax: and starch may be detected by applying strong sulphuric acid to the suspected wax, as the acid carbonizes the starch without acting on the wax.

Notwithstanding the large supply of wax produced in England, a considerable quantity is imported from abroad; but it is subject to the high duty of $11.10 s$. per $\mathrm{cwt}$. The price raries, duty included, from 5l. to 10l. per ew (Thomson's Chem. vol.iv. p. 103; Thomson's $D_{6}$ pensatory: Mreullocli's Com. Dice)

WAX-MOTH. See B.в-Moти, and Pl. 16, \&.

WAY-BRE.ID. One of the common name: of the Common or Great Plantain.

WAYFARING TREE. See Germen Rose.

WAY-GOING CROP. That which is taker from the land the year the tenant leaves a farr $5 \wedge 2$ 1109 
W AY, FRIVATE RIGHT OF. This may arise either from grant or by prescription and usage from time immemorial, for this is in law supposed to arise from a grant. According to English common law, a right of way may be to a particular person to go over the grantor's land to church, to market, or to any particular cluse. Such a special permission is, however, to be construed strictly: the grantee cannot, under such a grant, justify going beyond the place specified in the grant; nor can he take any other person with him; neither can he assign over this right,-it dies with him. And a grant for agricultural purposes does not authorize the grantee to use the road for commercial or general purposes; neither does a prescriptive right of way for all kind of carriages, prove a right of way for all manner of cattle. If a grantor convey a piece of ground in the middle of his own land, the law will presume that he also granted a way to it. "When," said Lord Kenyon, in this case, "they made the conveyance, it must be taken for granted that they intended to convey some beneficial interest ; but he can derive no benefit whatever from the grant unless he has a right of way to the land." But if by purchasing other land, or new circumstances afterwards arise by which he can approach the public road, then the right of way ceases with the necessity. And if a private way is granted, that does not justify a person for going over the land by the side of it, even if the road is overflown with water from an adjoining river. Lord Ellenborough, C. J., said, in this case, "It is a thing founded in grant, and the grantor of a private way does not grant a liherty to break out of it at random over the whole surface of his close."

By the $2 \& 3$ W. 4 , c. 71 , it is enacted, that in all claims for right of way by prescription, where it has been enjoyed for 20 years, such right shall only be defeated or destroyed by showing that such right was first expired at any time previous to such 20 years; and where it has been erijoyed for full 40 years, the right shall be absolute and indefeasible, unless it shall appear that the same was enjoyed by some consent or agreement by deed or writing.

WEANING. The means employed to reconcile a young animal to the loss of its mother's milk, and habituate it to take common food. Under the head FoAx we have already given directions for their management during and after weaning. The process of weaning calves is variously managed by different farmers. When not let run with the cow, the most advisable mode, as it regards the calf, is to place it loose in a crib, and to suckle it by hand with the mother's new milk, of which it will consume for some time not more than about four quarts per day : the quantity, however, must then be gradually increased, as it will. in the course of a few weeks, require as much as three gallons. If the weather be fine, it should be, within a fortnight or three weeks, turned nut daily in the orchard, or some wellshel:ered enclosure of sweet herbage; and, as it will in the course of 10 or 12 weeks have ac quired soine relish for the pasture, it may be r.'gularly weaned by gradually diminishing the 1110 quantity of milk, and then substituting the skimmed for the new. Calves may, however, be reared with skimmed milk and meal, with. out any portion of new milk, except the first few days' biestings, and many persons give them nothing but water-gruel and hay-tea within a fortnight after they have been removed from the cow. Sago and linseed jelly are also very nutritious, and calves may be weaned on them without any other food. (British Husb. vol. ii.p. 441.)

The time of weaning lambs differs materially, according to the locality of the farms and the quality of the pasture. Four months old is about the period usually selected.

The lambs should be turned into somewhat better pasture than that to which they had been accustomed, in order to compensate for the loss of the mother's milk. Many farmers are very fanciful as to the provision for the weaned lambs. The clover or the sainfoin, or the aftermath, are selected by some; others put their smaller and more weakly lambs to weed the turnip crops; but there can be nothing more desirable than a fresh pasture, not too luxuriant, and yet sufficient to maintajn and increase their condition. (Youatt on Sheep, p. 516.) For directions as to weaning pigs, see SWINE.

WEASEL-SNOUT (Galeobdolon luteum). The weasel-snout, yellow archangel, or dead nettle, is a pretty, indigenous, perennial plant, found abundantly in most parts of England,in marshy, shady places. The root is somewhat tuberous, moderately creeping. The stems are 18 inches high, simple, leafy, covered with close deflexea hairs. Leaves stalked, ovate, acute, serrated, slightly hairy, bright green, various in breadth. Whorls numerous, each composed of many large, handsome, inodorous yellow flowers, whose lower lip is spotted with red, the middle segment stained with orange-colour. The flowers afford to bees an abundant supply of honey.

WEATHER (Sax.). A term applied to denote the state or disposition of the atmosphere, with regard to heat and cold, drought and moisture, fog, fair or foul, wind, rain, hail, frost, snow, \&c.

A knowledge of this is of vast importance to the farmer, as the securing of his produce in a perfect manner greatly depends upon it ; and as it is in and by means of the atmosphere that plants are nourished, and animals live and breathe, any alteration in its density, heat, purity, \&c., must, of course, necessarily be attended with proportionable effects on organization.

The great but regular alterations a little change of weather makes in many parts of inanimate matter is fully shown in the common instances of barometers, thermometers, hygrometers, \&c.; and it is owing partly to our inattention, and partly to other causes, that man, like other animals, does not feel as great and as regular ones in the tubes, chords, and fibres of his own body.

In order fully to establish a proper theory of the weather, it would be necessary to have registers carefully kept in different parts of the giobe for a long series of years, whence we 
might be enabled to determine the directions, breadth, and bounds of the winds, and of the weather they bring with them; with the correspondence between the weather of divers places, and the difference between one sort and another at the same place; and thus, in time, learn to foretell many great emergencies; as extraordinary heats, rains, frosts, droughts, \&c. But hitherto very few, and only partial, registers or accounts of the weather have been kept. The Meteorological Society of Great Britain, and the British Association for the Advancement of Science, have latterly done much towards increasing our stock of meteoric knowledge, and have collected an immense body of facts and registers, from which many useful inferences have been drawn, and some important theories deduced. The general conclusions that have been drawn from the experiments that have been made on this subject are -that barometers generally rise and fall together, even at very distant places, and a consequent conformity and similarity of weather; but this is the more uniformly so, as the places are nearer together, as might be expected;that the variations of the barometer are greater as the places are nearer to the pole: thus, for instance, the mercury at London has a greater range by 2 or 3 lines than at Paris; and at Paris, a greater than at Zurich; and at some places near the equator there is scarcely any variation at all; - that the rain in Switzerland and Italy is much greater in quantity for the whole year than in Essex; and yet the rains are more frequent, or there are more rainy days, in Essex than at either of these places ;that cold contributes greatly to rain, apparently by condensing the suspended vapours, and so leading to their precipitation; thus, very cold months or seasons are commonly followed immediately by very rainy ones, and cold summers are always wet ones. High ridges of mountains, and the snows with which they are covered, not only affect the neighbouring places, but even distant countries often partake of their effects.

The science of meteorology, or the study of the changing phenomena of the atmosphere, \&c., has from the earliest periods occupied a greater or less share of attention from the tiller of the soil, the gardener, and those engaged in the pasturage of animals. 'To no individual (the mariner, perhaps, excepted) is a foreknowledge of the probable future state of the weather of more consequence and importance than the agriculturist; for on this must mainly depend the progress and success of his field operations, his seedtime and his harvest, and the greater or less return afforded by his crops.

It may not comport with the dignity of the man of science, or the elevated learning of the erudite philosopher, to have his eyes and ears open to the plain and simple rules and guides which nature lays out before him. Perhaps he has little of leisure to note the every-day phenomena which the atmosphere and all animate and inanimate nature hold up to observation, as in a glass, where all who use their eyes may read as they run. The companions of his study are the more costly and elaborately pre- pared phisosophical instrumens: hou musth. however, might their value be enhanced by a careful and comparative observation of the "skyey influences," as the puet teruns thern? But to these closel companions, the husbasudman, the shepherd, the traveller, the fisherman. and the mariner have rarely accers, white en. gaged in the busy out-of-dour occupaturns of their several avocations. Those who tull the land, or who go down to the sea in ships, of all others, are they who become, by habits of observation and reflection, most conversant with the signs and changes of the heavens : the sun, the moon, and the stars are (1) them monitors and instructors, whose warning voices meet a prompt and ready response. 'The ripple of the wave, the curl of the smoke, the pase. ing shadow of the cloud, the budding of the tree, the arrival and departure of the migratory birds, the frolicsome gambols of animals, every leaf that quivers in the sunbeam, every plant that drinks the dew of heaven, the myriads of insects, and creeping things innumerable, that inhabit each leaf and opening flower, are all fraught with instruction and information to the experienced and watchful observer.

Around, above, beneath, all animate and inanimate creation, animals, vegetables, the elements, a thousand objects in a thousand direc. tions, in every recurring season, furnish their quota of information towards our stock of meteoric knowledge, and foretell the approaching variations of atmospheric phenumena. The ex. perienced fisherman and the watchful and wary mariner will predict the coming storm, by the tiny cloud and other unerring criteria which frequent and attentive observance of the sky has rendered familar, long before its approach is visible to the ken of the ordinary and inat. tentive observer.

It has been well remarked, that "the shepherd, whose sole business it is to observe what has a reference to the flock under his care, who spends all his days and many of his nights in the open air, under the wide-spread canopy of heaven, is obliged to take particular notice of the alterations of the weather; and when he cares to take a pleasure in making. such observations, it is amazing how much progress he makes in them, and to how great a certainty he arrives at last, by mere dint of comparing signs and events, and connecting one observation with another. Every thing in time becomes to him a weather-gauge: the sun, the moon, the stars, the clouds, the winds, the mists, the trees, the flowers, the herbs, and almost every insect, animal, and reptile with which he is acquainted-all these become, to such a person, instruments of real knowledge."

To the farmer, a careful study of the weat ther, and of the inferences to be drawn from precedent, and from natural and artificial data. come fraught with numerous and important considerations. Lilie the angler, the husbandman "must observe the wind, sun, and clouds by day; the moon, stars, and wanes of the air by night." Few are so entirely dependent on the caprice of the weather, for the commonest routine operalions of the farm, as the agrica: 
turist. And how soon may his fairest crops be blighted by adverse and unfavourable seasons, or by the baneful effects of scorching and arid winds, of severe frosts, of heavy rains. Some winds come fraught with disease and death; murrain, malaria, and epidemics, in hot, dry seasons, commit fearful ravages among his live-stock; and these are frequently to be attributed to some mysterious atmospheric agency: other winds bring swarms of noxious insects and predatory birds to our shores; the lightning and the whirlwind level his plantations or fire his ricks; the hail-storm, and the frost, and excess of rain, damage and destroy his growing crop, or that to which he has looked for reward and profit for all his toil and outlay.

The various casualties and diseases to which his crops are liable are frequently attributable to, and certainly much aided by, the state of the weather and conditions of the atmosphere. Information relative to many of the important phenomena connected with the atmospheric states and changes, will be found dispersed through this work under various heads, such as Atmosphene, Altitude, BArometer, Chimate, Dew, Fogs, Frost, Hoar Frost, Lightina, Rain, Srow, Moow, Influence of, \&c.

As means of prognosticating the future states of the weather, data, either natural, artificial, or both combined, are usually referred to. In the natural data are included those of -

1. 'The vegetable kingdom; many plants shutting or opening their flowers, contracting or expanding their parts, \&c., on approaching changes in the humidity or temperature of the atmosphere.

2. The animal kingdom; most of those familiar to us exhibiting signs on approaching changes, of which those by cattle and sheep are more especially remarkable.

3. The mineral kingdom; stones, earths, metals, salt, and water of particular kinds, often affording indications, of approaching changes.

4. Appearances of the atmosphere, the moon, the general character of seasons, \&c. The characters of clouds, the prevalence of particular winds, and other signs, are very commonly attended to.

The artificial data are the various meteorolugical instruments, as the barometer, hygrometer, pluviometer, and thermometer, \&c., which are all extremely useful aids to the farmer.

It is a very common error to predict the future state of the season from some single appearance in the commencement of it, as an early bee, an early bud or blossom, the premature appearance of a swallow; but this is both unphilosophical and fallacious.

In England a moist autumn, succeeded by a mild winter, is generally followed by a dry and cold spring, in consequence of which vegetation is greatly retarded. Should the summer be uncommonly wet, the succeeding winter will be severe; because the heat or warmth of the earth will be carried off by su?h unusual evaporation. Farther, wet summers are mostly attended with an increased quantity of fruit on the white-thorn (Mespilus oxycantha) and dog1112 rose (Rosa ranina); nay, the uncommon fruir fulness of these shrubs is considered as the presage of an intensely cold winter.

A severe winter is supposed to be indicated by the appearance of birds of passage at an early period in autumn; because they never migrate southward till the cold season has commenced in northern regions. Great storms, rains, or other violent commotions of the clouds, produce a kind of crisis in the atmo. sphere; so that they are attended with a regular succession either of fine or of bad weather for some months. An unproductive year mostly succeeds a rainy winter, as a rough and cold autumn prognosticates a severe winter. Very cold months or seasons are commonly followed immediately by very rainy ones, and cold summers are always wet ones.

Plants.-The sensitive indications afforded us by many plants first claim attention, and will be found amply to repay the time that may be bestowed upon the singular properties inherent to them.

Very many of our most common plants are unerring guides for the foretelling rain and other atmospheric changes. The opening and shutting of some flowers depends not so much on the action of the stimulus of light as on the existing state of the atmosphere, and hence their expansion or contraction betokens change.

The common chickweed or stitchwort (Stellaria media) may be considered a natural barometer; for if the small, white, upright flowers are closed, it is a certain sign of rain; while during dry weatner they expand freely, and are regularly open from nine in the morning till noon. After rain they become pendent, but in the course of a few days they again rise.

The purple sandwort (Arenaria rubra) is another example of a true prophet prior to a coming shower. 'The beautiful pink flowers expand only during sunshine, and close at the approach of evening or before rain.

The pimpernel (Anagallis arvensis) has been very justly named "the poor man's weatherglass." This little plant blooms in June in our stubble-fields and gardens, and continues in flower all the summer. When its tiny brilliant red flowers are widely expanded in the morning, we may generally expect a fine day; on the contrary, it is a certain sign of rain when its delicate petals are closed.

The goat's-beard (Tragopogon pratensis) will not unclose its flowers in cloudy weather. From its habit of closing its flowers at noon. this plant has received the common name of "Go-to-bed-at-noon," and in many districts the farmers' boys regulate their dinner-hour by the closing of the goat's-beard.

It is stated in Kcilh's Botany, that if the Siberian sow-thistle shuts at night, the ensuing day will be fine; and if it opens, it will be cloudy and rainy.

When the African marigold remains closed after 7 o'clock in the morning or evening, rain may be expected. If the trefoil and the convolvulus contract their leaves, thunder and heavy rain may be expected. Lord Bacon tells us that the stalks of the trefoil swell and grow more upright previous to rain. 
The dark and lovely gentianella opens its blue eyes to greet the midday sun, but closes its petals against the shower.

The germander speedwell (Veronica chamadrys), so universal a favourite in every hedgerow, closes its blue corolla before rain comes on, opening again when it ceases. The red campion (Lychnis diurna) uncloses its flowers in the morning. The flowers of the white cainpion (Lychnis vespertina) open and expand themselves towards the approach of night. The wood sorrel (Oxalis acetosellu, "la Petite Oseille," or Suselle, of the French), an unobtrusive, elegant little inhabitant of the moist, shaded bank, as soon as night approaches, as it is of too delicate a structure to bear the storm, closes up its curious triple leaves, hanging its flowers towards the earth, thus preserving the more tender parts from injury; but as soon as the morning sun arises, these expand and regain their beauty. Most of the Hieraciums, or hawkweed tribe, also open their flowers with the morning light, going to sleep again in the afternoon. The clear, bright, and gay flowers of the succory (Cychorium intybus) foretell the commencement of the daylight. Another of the components of Flora's clock which deserves a passing word, is the common daisy (Bellis perennis), opening at sunrise, and closing its flowers at sunset: hence by Chaucer called the "Eie of Day." The great white oxeye (Chrysanthemum leucanthemum), foretelling the coming storm, closes its flowers. The flowers of the alpine whitlow grass (Draba alpina), the bastard feverfew, the winter green (Trientalis Europaa), all hang down in the night as if the plants were asleep, lest rain or the moist air should injure the fertilizing pollen. The common nipplewort (Lapsana communis), that lovely gem, the white water-lily (Nymphaa alba, "the naiad of the river,") and several of the diadelphous tribe of plants, in serene, calm weather expand their leaves in the day-time, and contract them during night.

Animals.-Among quadrupeds the following are believed to indicate, by their restlessness and peculiar actions, a foreknowledge of approaching changes of weather. When horses stretch forth their necks, neigh much, snuff the air with distended nostrils, and assemble in the corner of a field with their heads to leeward, rain may be expected.

Sheep are seen running to and fro, jumping from the ground, and in their gambols apparently fighting, previously to a change of weather. Fine weather may be expected to continue when cattle lie in the open field or in the courts instead of the sheds; when sheep take up their lair for the night on the brow of a knoll; when pigs lie down for the night without covering themselves up in litter. Bad weather is said to be prognosticated when asses hang their ears forward, or rub themselves against walls or trees. Swine also become uneasy, restless, grunting and squealing loudly, and return to their sties. Before rain dogs are apt to grow very sleepy and dull, and to lie all day before the fire, showing a reluctance to food, except grass. When cats lose their vivacity, remaining within doors, wet or windy u :ather may be expected. Finally, when rats and mice are more than usually resulese, for. saking the fields and ditches, appruachung rain may he anticipated.

Fallow deer, and many othrr animals, becoming restless from the uneasiness thr.y freel owing to the altered conditum of the atron sphere, prognosticate the approach of rain. If frogs croak more than usual-if twals issue from their retreats in great numbers-if earthworms come forth from their holes-if moles throw up the soil more than usual-if pios shake and spoil the stalks of the curn-if oxen lick their forefeet-all these sirns are saul (n) indicate rain.

It may be remarked that, in summer, when sheep rise early in the morning, it is a sure. sign of either rain or a very hot dav; and that in all seasons when they jump and play about it is a sign of rain or wind (but generally both) in the summer, and very stormy weather in the winter.

In winter, when the sheep lie under a hedge, and seem loth to go off to pasture, and bleat, it is considered a sign of a storm.

When rabbits come out to feed early in the evening, it is a sign of rain in the night in summer, and of either rain or snow in winter; and when it is likely to be a bad night, they will be apt to return to their burrows before it is dark.

Next, with respect to birds: there is an old saying that "when swans fly it is a sign of rough weather," and the correctness of this saying would appear to be proved. A late writer states that he had invariably found that when the swan flies any distance against the wind, however fine the weather may be at the time, so sure will a wind, alınost amounting to a hurricane, arise within 24 and generally 12 hours after the bird has taken flight. The early appearance of woodcocks, snipes, fieldfares, and other birds of passage, \&c., are prognostics of severe winters. When owls hoot and screech during bad weather, it is a sign of coming fine weather. The missletse thrush (Turdus viscivorus) frequently sings particularly long and loud before rain, and sometimes even during severe storms: hence it is termed the "storm-cock." The blue macan is said to be a true indicator of the changes of the weather. Dr. Thornton is stated to have had one some years ago whose blue feathers assumed a greenish hue in rainy weather, or gray in clear weather, if likely to change for wet.

When cranes fly exceedingly high, in silence. and ranged in order, it is said to indicate fine weather; but if their flight is in disorder, and they speedily return with cries, it foretells wind. If fowls roll themselves in the sand more than usual, it denotes rain; also when the cocks crow in the evening, or at unusual hours. When peacocks cry at night, rain may shorly be expected. When peacocks ronst on the tops of hotries, when the raven sails round and round high up in the air, and when the song. birds carol late in the evening, the weather will continue fair.

The croaking of crows is said to indicate fuc weather. When ducks and geese fly backwards and forwards, and frequently plunge into the water, or send forth cries; or when pigeons return slowly to their houses, the probabilit 1113 
.s that the succeeding day will be rainy. It is a sign of rain or wind when sparrows chirp a great deal; if the redbreast be seen near houses; or swallows fly near the ground, or brush the surface of the water. When sea-fowl and other aquatic birds retire to the sea-shore, or more inland, it generally indicates a change of weather. If larks or kites soar high, and continue so for some time, it is generally a sign of fine weather. If the kingfisher disappear, expect fine weather. If swallows and martins fly lower than usual, foul weather may be expected.

Mr. Yarrell, in his History of British Birds, vol. iii. p. 117 , records an instance of instinct, showing how useful an attention to the movements of animals, \&c., might occasionally prove:-" I am indebted to the kindness of Lord Braybrooke for the following account of a female swan, on the small stream at Bishop's Stortford. This swan was 18 or 19 years old, had brought up many broods, and was highly valued by the neighbours. She exhibited, some 8 or 9 years past, one of the most remarkable instances of the power of instinct that was ever recorded. She was sitting on four or five eggs, and was observed to be very busy in collecting grass, weeds, \&c., to raise her nest; a farming man was ordered to take down half a load of haulm straw, with which she most industriously raised her nest and the eggs $2 \frac{1}{2}$ feet; that very night there came down a tremendous fall of rain, which flooded all the malt-shops, and did great damage. Man made no preparation; the bird did. Instinct prevailed over reason; her eggs were above, and only just above, the water."

The same author, in his account of the green woodpecker (Picus viridis), known in some localities as the "rain-bird," from being very vociferous when rain is impending, alludes to the probable means by which birds and some other animals become cognisant of approach ing changes in the weather. The following is the rationale referred to:-

"It is highly probable that no change takes place in the weather without some previous alteration in the electrical condition of the atmosphere, and we can easily understand that birds, entirely covered as they are with feathers, which are known to be readily affected with electricity, should be susceptible of certain impressions, which are indicated by peculiar actions; thus, birds and other animals, covered only with the production of their highly sensible skin, become living barometers to good observers." (Yarrell's British Birds, vol. ii. p. 136.)

Insects, being very sensible of every change in the atmosphere, are good weather guides.

When gnats collect themselves before the setting sun, and form a sort of vortex in the shape of a column, it announces fine weather. 1. they play up and down in the open air near sunset, they presage heat; if in the shade, mild and warm showers; but if they sting those passing them, cold weather and much rain may De expected.

If garden spiders break off and destroy their webs, and creep away, expect continued rain and showery weather.

If spider webs (gossamer) fly in the autumn, nxpect fine weather.
The following curious observations on the singular foreknowledge possessed by the spider are extracted from a little work entitled The Pocket Buromeler. This despised insect oftentimes indicates a coming change in the weather 10,12 , or 14 days previous to its taking place. The following directions will be a guide to the curious in their observations of this insect:If the weather is likely to become rainy, or windy, spiders fix the terminating filaments on which the whole web is suspended unusually short. If the terminating filaments, on the contrary, are very long, the weather will be serene, and continue so for 14 days. If spiders be totally indolent, rain generally ensues: though their activity during rain is a certain proof of its short duration, and that it will be followed by fine and settled weather. Spiders usually make some alteration in their webs every 24 hours. If this take place between the hours of 6 and 7 P. M., it foretells a clear and serene night.

The weather is about to become cloudy and change for wet, when flies sting and are more troublesome than usual. Most insects become torpid when their temperature is much reduced. When it approaches the freezing point, they fall into a lethargic state, and require no food. Ants present a remarkable exception to this rule; for they are not benumbed till the thermometer is $27^{\circ}$ of Fahr., or $5^{\circ}$ below freezing point. When bees do not range abroad as usual, but keep in or about their hives, it is a sign of rain.

In the summer season much information relative to the change of the weather may be gained from watching the movements of ants. The finer the day, the more busily are they employed, as they never bring out their corn to dry but when the weather is clear and the sun very hot. A celebrated naturalist relates the following curious anecdote:- He one day observed these little creatures, after having brought out their corn at eleven in the forenoon, removing the same, contrary to their usual custom, before one in the afternoon. The sun being very hoi, and the sky remarkably clear. he could perceive no reason for it; but balf an hour after, his surprise ceased-the sky began to be overcast, and there fell a shower of rain, which caused all this bustle, no doubt, among these active little creatures: they evidently foresaw rain, and provided accordingly; and were we minutely to examine in to the economy and management of these wonderful artificers, many other similar and equally curious facts might be gleaned relative to the weather.

The leech also possesses the peculiar property of indicating approaching changes of the weather in a most eminent degree. In fair and frosty weather it remains motionless and rolled up in a spiral form at the bottom of the vessel; previous, however, to rain or snow, it will creep to the top, where, should the rain be heavy, or of leng continuance, it will remain for a considerable time,-if transient, it will descend. Should the rain or snow be accompanied with wind, it will dart about with great velocity, and seldom cease its evolutions until it blows hard. If a storm of thunder or light. ning be approaching, it will be exseedingly 
agitated, and express its feelings in violent convulsive starts at the top of the glass. It is remarkable, that however fine and serene the weather may be, and to our senses no indication of a corning change, either from the sky, the barometer, or any other cause, yet, if the leech shifts its position, or moves about slug. gishly, the coincident results will undoubtedly occur within 26 hours.

Signs of Rain.-Although we have incidentally glanced already at some of these indications, it may be well to sum them up in a body, as being more easy of reference.

A white mist in the evening over a meadow or a river dispersed by the sun next morning, indicates that the day will be bright. Five or six fogs, successively, portend rain. Where there are high hills, and the mist which hangs over the lower land draws toward the hills in the morning, and rolls up to the top, it will be fair; but if the mist hangs upon the hills, and drags along the woods, there will be rain soon. A general mist before the sun rises is a sign of fair weather.

Against much rain, the clouds grow bigger and increase very fast, especially before thunder. When the clouds are formed like fleeces, but dense in the middle, bright towards the edge, with the sky bright, they are signs of a frost, with hail, snow, or rain. If clouds breed high in the air, in the white train like locks of wool, they portend wind, and probably rain. When a general cloudiness covers the sky, and small black fragments of clouds fly underneath, they are sure signs of rain, and probably it will be lasting. 'Two currents of clouds generally portend rain, and in summer thunder.

If the dew lies plentifully on the grass after a fair day, it is a sign of another fine day. If not, and there is no wind, rain will follow. A red evening portends fair weather; but if spread too far upward from the horizon in the evening, and especially morning, it foretells wind or rain, or both. When the sky in rainy weather is tinged with sea-green, the rain will increase; if deep blue, it will be showery.

If there be a haziness in the air, which fades the sun's light, and makes the orb appear whitish or ill-defined; or at night, if the moon and stars grow dim, and a ring encircles the former, rain must follow. If the sun appears white at setting, or goes down into a bank of clouds in the horizon, bad weather is expected. If the moon looks pale and dim, we expect rain; if red, wind; and if the natural colour, with a clear sky, fair weather. If the setting sun appears yellow or gold colour, and particularly if accompanied with purple streaks, the following day will be fine.

If the wind veers about much, rain is pretty sure. If, in changing, it follows the course of the sun, it brings fair weather; the contrary, foul. Whistling or howling of the wind is a sure sign of rain.

'The aurora borealis, after warm days, is generally succeeded by cooler air. Shooting stars are supposed to indicate wind.

Before rain, swallows fly low; dogs grow sleepy and eat grass; waterfowls dive much;

h will not bite; flies are more troublesome; toads crawl about; moles, ant: lires, and man insects, are very busy; birds fly low fir unsec:s: swine, sheep, and calle are unrasy, abd even the human body.

"The air, when dry, I believe, refracts more red or heal-making rays; and as ilry aif is noo perfectly transparent, they are again reflected in the horizon. I have generally otherved a coppery or yellow sunset to furetell rain; but, as an indication of wet weather approarhing. nothing is more certain than a halo roumd the moon, which is produced by the precipitated water; and the larger the circle, the nearer the clouds, and consequently the more reasly to fall." (Sir H. Davy.)

To turn now to the atmosphere: the bulk of our most valuable meteorulogical observations are, of course, deducible from its electrical condition, and the precise kind of electricity present; from the power of evaporation exercised, from the state and direction of the wind, from a careful examination of the clouds; in fact, the phenomena of the atmosphere are wellnigh endless. But, though endless in the variety of their forms and consequences, and for the most part uncertain in the time of their occurrence, yet they are successively the same in their nature to parts and properies, and are all the production of simple causes. The principal agents in producing these phenomena have already been noticed under the head METEоноцоg. I need not enlarge further upon the advantages to science in general derivable from the accurate and careful investigation of meteorological researches, aided by the excel. lent instruments that are now attainable, and at a moderate expense. From the accumula. tion of a multitude of such facts can we alone hope at some future time to derive that accu. rate knowledge and insight into the secret springs that would appear to be the movers of these phenomena. This may not be too much to effect from the analogies of the seasons and the results of experience; and this, we may venture to predict, will be the crowning reward of meteorological research. (Trans. of Met. Soc. vol. i. 1839.) See Mons, Influence of.

Clouds.-The following definition of the descriptive terms now employed by meteorologists to define various clouds, may prove useful to those in the habit of consulting meteorological registers, which are occasionally published in newspapers and scientific journals It is taken from Ure's Chemical and Miner. Dicts article "Cloud," p. 338.

A cloud is a mass of vapour, more or less opaque, formed and sustained at considerable heights in the atmosphere, probably by the joint agencies of heat and electricity. The first successful attempt to arrange the diversified forms of clouds, under a few general modifications, was made by Luke Howard, Esq We shall here give a brief account of his ingenious classification.

The simple modifications are thus named and defined-1. Cirms; parallel, flexuous, or diverging fibres, extensible in any or in all directions. 2. Cumulus; convex or conical heaps, increasing upwards from a horizontal base. 3. Stralus; a widely extended, continuous hor zontal sheet, increasing from below. 
The intermediate modifications which require to be noticed are-4. Cirro-cumulus; small, well-defined, roundish masses, in close horizontal arrangement. 5. Cirro-stratus; horizontal or slightly inclined masses, attenuated towards a part or the whole of their circumference, bent downward, or undrlated, separate or in groups, consisting of small clouds having these characters.

The compound modifications are-6. Cumulostratus; the cirro-stratus blended with the cumulus, and either appearing intermixed with the heaps of the latter, or superadding a widespread structure to its base.

7. Cumulo-cirro-stratus, vel Nimbus; the rain cloud, a cloud or system of clouds from which rain is falling; it is a horizontal sheet, above which the cirrus spreads, while the cumulus enters it laterally and from beneath.

The cirrus appears to have the least density, the greater variety of extent and direction, and to appear earliest, in serene weather, being indicated by a few threads pencilled in the sky. Before storms they appear lower and denser, and usually in the quarter opposite to that from which the storm arises. Steady high winds are also preceded and attended by cirrus streaks running quite across the sky in the direction they blow in.

The cumulus has the densest structure, is formed in the lowest atmosphere, and moves along with the current next the earth; a small irregular spot first appears, and is as it were the nucleus on which they increase. The lower surface continues irregularly plain, while the upper rises into conical or hemispherical heaps, which may afterwards continue long nearly of the same bulk, or rapidly rise into mountains: they will begin in fair weather to form some hours after sunrise, arrive at their maximum in the hottest part of the afternoon, then go on diminishing, and totally disperse about sunset. Previous to rain the cumulus increases rapidly, appears lower in the atmosphere, and with its surface full of loose fleeces or protuberances. The formation of large cumuli to leeward in a strong wind indicates the approach of a calm with rain; when they do not disappear or subside about sunset, but continue to rise, thunder is to be expected in the night. The stratus has a mean degree of tensity, and is the lowest of clouds, its inferior surface commonly resting on the earth or water. This is properly the cloud of night, appearing about sunset. It comprehends all those creeping mists which in calm weather ascend in spreading sheets (like an inundation of water) from the bottom of valleys and the surfaces of lakes and rivers. On the return of the sun the level surface of this cloud begins to put on the appearance of rumulus, the whole at the same time separating from the ground. The continuity is next destroyed, and the cloud ascends and evaporates, or passes off with the appearance of nasient cumulus. This has long been experienced as a prognostic of fair weather.

The cirrus having continued for some time increasing or stationarv, usually passes either to the cirro-cumulios or the cirro-stratus, at the same time descending to a lower station in the atmosphere. This modification forms a very beautiful sky, and is frequent in summer, as an attendant on warm and dry weather. The cirro-stratus, when seen in the distance, fre. quently gives the idea of shoals of fish (a mackerel sky). It precedes wind and rain; is seen in the intervals of storms, and sometimes alternately with the cirro-cumulus in the same cloud, when the different evolutions form a curious spectacle. A judgment may be formed of the weather likely to ensue, by observing which modification prevails at last. The solar and lunar halos, as well as the parhelion and paraseline (mock sun and mock moon), prognosiies of foul weather, are occasioned by this cloud. The cumulo-stratus precedes, and the nimbus accompanies rain.

When there are small round clouds, of a dapple-gray colour, with a north wind, it may be concluded that there will be fair weather for 2 or 3 days, but that large clouds like rocks are a sign of great showers. And when small clouds increase, it is a sign that there will be much rain, but if the large clouds are seen to lessen, there will be fair weather.

In summer or harvest, when the wind has been suuth 2 or 3 days, and it grows very hot, and clouds are seen to rise with great white tops like towers, as if one were on the top of another, and joined together with black on the lower side, it may be considered a sign that there will be thunder and rain sudderily. When two such clouds rise, one on each hand, it is time to make haste to shelter.

When a cloud is seen to rise against the wind or side wind, it is a sure sign that when the cloud comes up near you, the wind will blow the way that the cloud came. It is the same with the motion of a clear place, when all the sky is thick except one edge.

At all times, when the clouds look black in the west, it is sure to rain, or if raining, it is sure to continue, whatever quarter the wind may be in; and, on the contrary, if it breaks in the west, it is sure to be fair.

It is often observed, on those clear sunny mornings which occur in summer and autumn, that it is very likely, if not certain, to rain before evening; and there is frequently much truth in the remark. The reason is, that when moisture accumulates in the air, before it begins to be precipitated, it imparts to it a higher refractive power; and it becomes, in consequence, more bright and transparent. (British Almanac, 1830.)

The gradual diminution of clouds, till they are no longer observable, is a sign also of fine weather. So, likewise, is the continuance or abundance of dew upon the grass, after a serene day.

During winter, fleecy clouds being thick and close in the middle, and very white at the edges, the surrounding sky being remarkably blue, indicate hail or snow, or cold, chilling, showers of rain.

Where the clouds appear moving in two opposite currents, and the lowest is wafted rapidly before the wind, it is a certain sign of rain; and if this occurs during summer, or generally in hot weather, ii announces a thunder-storm.

It may be a useful piece of information for agriculturists, or those concerned in getting in 
their crops, to describe the appearance of a small cloud, which, from its rapid formation and disappearance, is likely to escape the observation of most persons, but which, from m own experience, I have found a very faithful forewarner of foul weather. It appears mostly in the mild weather of spring, summer, and autumn, when its warning token becomes most acceptable. It is a small, delicately soft, thin, white, curved cloud, formed suddenly upon the summit of those fine heaped clouds (termed cumuli) which often prevail in warm weather, and appear to tower up to a prodigious height. It is necessary to keep a watchful eye upon the summit of the cumulus. When this little film, which I term "the storm cap," appears, it lies closely over the rounded summit, like a white silken web; in a very few seconds it will disappear, sinking, I suppose, into the cumulus; but in a little time, and when heavy foul weather threatens, the film again appears, disappearing as shortly as before. (Mag. Nat. Hist. vol. iv. p. 444.)

The following indications have been recorded, as shown by the predominance of certain of the prismatic colours of the rainbow, but they are perhaps too fanciful to be deserving of much credence.-1. Red; if this colour be very predominant, wind, or wind and rain, may be expected. 2. Orange; when the orange colour appears strong and very full, it generally indicates approaching rain. 3. Yellow; when yellow is more conspicuous than the other colours, it foretells dry weather. 4. Green; approaching rain may be expected when the green is very predominant. 5. Blue; fine weather may be expected when the blue is particularly full. 6. Purple; if the purple be a very full colour, wind and rain may be expected. 7. Violet; the violet, when very clear, generally indicates approaching fine weather. See Rarñow.

The Wind.-The earth is surrounded to the extent of 60 miles with an atmosphere, on which all nature mutually depends for life. This aërial ocean revolves with our earth round the sun, is very susceptible of motion, and some parts of it is constantly in restless commotion. These commotions are called winds, and are principally caused by heat from the rays of the sun, which, rarefying the air, causes it to ascend; and the vacuum thus formed is filled up with a colder air from the north and south.

Wind has been explained in the following manner:- Heated air has a tendency to rise, and cold air rushes in to supply its place. 'Thus the heated air of the equatorial regions rises and gives place to a current sent from the polar regions, which is a process that serves to equalize the temperature of the world. But the polar countries lying near to the axis of the sphere, the air from those regions has not received so much motion as that about the equator, or grealest distance from the axis; wherefore it arrives at the equator, where the motion of the earth is greater. If it had no motion before, an east wind would be the consequence, and the force of that wind would be as the difference between the motion of the earth where the air came from, and that where it arrived: but then, in the northern hemisphere, it has a motion to the south: for it is rushing into a vacuum left by the air which rises; so that the wind will not be from the east, but northeast; and the number of derrees north of the east from which it will blow will depend upon the comparative force of the cur. rent of air from the north to the difference between the earth's motion at the equator and al the polar region, whence the air comes. As there must be a corresponding efflux freas the equator higher up, according to this theor, the wind should every where be northeast ur scichwest, but it blows in very differer.t disections at different times and places, owirz chiefly to circunistances connected with the distribution of land and water, and the variatiors in tem. perature at different times and places.

From observing the wind a fair idea of the coming weather may oftentimes be drawn; and yet, as Solomon observes, "he that corsiders the wind shall never sow;" that $i . j, b=$ thas busies himself too much about the wind wil: become superstitious. The iudiraticis to be drawn from observing the direction and shanges of the wind must vary in uiffsen: countries, according to the relative positions of these in regard to the sea, la.kes, plains, or mountains covered with sncw. iror an explanation of some of the phenomena of cimate and weather, the reader is referred to preceding articles, under the hoads of Banometer, Cinste o THE UNited STATES, \&c.

In ail countries, therefore, particular winds are noted for being accompanied with either wet or dry weather. Thus the south and southwest winds bring much moisture into Britain, while those from the north and northeast ar. cold, dry, and penetrating. Heirce the old Eng lish proverb-

\section{"When the wind's in the socth,} It's in the rain's mouth."

Not only does this arise from the immense surface of ocean over which thr, se wirds sweep south of the equator, the evapura'ior. from which must be prodigiots; but írorn tiese southerly winds being of a bigher temperziure, whereby they hold a greaier quantity of vapour in suspension or solutica, the conciensation of which must be proporticially greater on arriving in this colder cirmate. Accordingly, it has been observed tha: the wiad will turn from the north to the south ruie:iy and without rain; but on returning from ihe south to the north, will blow hard and bring much rain. Again, if it begin to rain from the south, with a high wind for 2 or 3 hours, the wind falls; but if the rain continues, it is likely to rain for 12 hours or more, and does usually rain until a strong north wind clears the air. For the same reasun, winds from the west and southwest are in England considered to bring with them wet weather. (Chambers' Information for the People, No. 58, New Series.)

A change in the warmth of the weather is often followed by a change in the wind. Thus, the northerly and southerly winds, though commonly accounted the causes of cold and warn weather, are really the effects of the cold $n$ warmth of the atmosphere. 
Mr. Towers (Quart. Jour. of Agr. vol. ix. p. 39) relates the case of a person in Somersetshire who had been hay making nearly 40 years, and had hardly in one instance failed to carry in good condition. He had observed that in the month of June, earlier or later, there are three or more days wherein the wind blows from the northeast, and that period is invariably dry. When that wind first occurred, he seized the opportunity of cutting his grass and carrying the crop before the wind veered to the south. This theory holds good as respects the southwestern counties, where the wind from any quarter between north and east is the sure concomitant of dry weather.

The following predictions of the weather are met with in the Holy Sciptures; and, applying with equal correctness in the present day as at the time they were written, I subjoin them:A south wind, or great heat in summer, portends a whirlwind. (Job xxxvi. 9.) Cold or fair weather is indicated by the north wind, which drives away rain. (Ibid. xxxvii. 9, 22.) A red sky in the evening foretells fair weather; in the morning, foul. "When it is evening ye say, It will be fair weather, for the sky is red. And in the morning, It will be foul weather today, for the sky is red and lowering." (Matt. xvi. 2, 3.) "When ye see a cloud rise out of the west, straightway ye say, There cometh a shower; and so it is. And when ye see the south wind blow, ye say, There will be heat; and it cometh to pass." (Luke, xii. 54,55.)

It results from observations made by $M$. Schow, that in the north of Europe the western winds are more frequent than the eastern. This rule is without exception; but the western winds diminish more and more as we approach the centre of the Continent, being more frequent in England, Holland, and France than in Denmark and the greater part of Germany; and more frequent in these latter countries than in Russia and Sweden. At London, the east wind is to the west as 1. to 1.7; at Amsterdam, as 1 to 1.6 ; at Copenhagen, as 1 to 1.5 ; at Stockholm, as 1 to $1 \cdot 4$; at Petersburg, as 1 to 1.3. The west winds seem to incline the more to the south according to the propinquity of the Atlantic sea; towards the interior of the Continent they incline more to the northwest. The north winds appear to increase towards the east. Amongst the winds which come from the west, that of the southwest predominates in England, Holland, and France; that of direct west in Denmark and the greater part of Germany; at. Moscow the northwest predominates; at Petersburg and Stockholm the north wind is much more frequent than in the western parts of Europe. In the western and middle districts of northern Europe, such as England, France, Denmark, Germany, and Norway, the west winds are much more frequent during the summer than during the winter or spring. This does not appear to be the case in Sweden and Russia. During the winter the west winds are more southerly; during the summer more direct and more northerl; iJahrb. der Phys. und Chemie, 1828.)

With regard to the supposed influence of the moon upon the conditions of the weather, and 1118 the strong evidences to prove that this satellite exerts no infuence in controlling the atmosphere, so far as wet and dry weather are concerned, see Moox, Inftunce or.

Under the head of Barometen it has been observed that changes of weather are indicated, not by the actual height of the mercurv, but by its change of height. One of the most general, though not absolutely invariable, rules, is, that where the mercury is very low, and, therefore, the atmosphere very light, high winds and storms may be expected.

In winter the rising of the barometer presages frost; and in frosty weather, if it falls three or four divisions, there will follow a thaw; but if it rises in a continued frost, snow may be expected.

The mercury generally rises very fast after great storms of wind, when before it was very low. In England it has been observed to rise an inch and a half in six hours, after a longo continued storm of southwest wind.

The words on the plate of a barometer are not strictly to be adhered to, though they will in general agree; for a fluctuating and unsettled state of the mercurial column indicates uncertain or changeable weather. The height of the mercury does not so much indicate the weather as its motion up and down : to know, therefore, whether the mercury is actually rising or falling, observe-

1st. If the surface of the mercury is convex (or stands high in the middle), it is then rising.

$2 \mathrm{~d}$. If the surface is concave (standing low in the middle), it is then falling.

$3 d$. If the surface is plain, or a little convex, it may be considered as stationary.

4 th. A small tap on the barometer case, by shaking the tube will sometimes bring the mercury to its approaching height.

The greatest heights of the mercury are on easterly and northeasterly winds; and its lowest station on southerly winds.

If the weather is about to be cold, frosty, or foggy, it rises pretty high; but if going to be windy or tempestuous, it will then sink very low, and, as soon as the first storm is over, it will rise again apace.

The domestic barometer would become a much more useful instrument if, instead of the words usually engraved on the plate, a short list of the best established rules, adapted to the particular locality in which it was situated, accompanied it, which might be either engraved on the plate, or printed on a card. It would be right, however, to express the rules only with that degree of probability which observation of past phenomena has justified. There is no rule respecting these effects which will invariably hold good.

In the following table the mean temperature, mean highest, and mean lowest, have been calculated from observations made on regis. tering thermometers, hung on a post 2 feet 8 inches from the grass, facing the north, and in no way sheltered. The barometer is in a vestibule. No corrections of any kind have been made in registering the barometer. (Johnson's and Shaw's Farmer's Almanac, vol. i p. 157.) 
WEEDS.

Tables calculated from Atmospherical Observations, made in the Parish of Cobham, Surrey, England, during the Eight Years from 1833 to 1840.

THE RMOMFTER.

\begin{tabular}{|c|c|c|c|c|c|c|}
\hline Month. & \multicolumn{2}{|c|}{$\begin{array}{l}\text { Utmost } \\
\text { Range. }\end{array}$} & \multirow{2}{*}{$\frac{\text { Mean. }}{3 y \cdot 38}$} & \multirow{2}{*}{$\frac{\begin{array}{c}\text { Mean } \\
\text { Highent. }\end{array}}{526}$} & \multirow{2}{*}{$\frac{\begin{array}{c}\text { Mean } \\
\text { Lowest. }\end{array}}{14 \cdot 6}$} & \multirow{2}{*}{$\begin{array}{l}\text { Diff-rence, } \\
\text { nr Solar } \\
\text { Variation. } \\
38 \cdot 0\end{array}$} \\
\hline January - & 60 & 10 & & & & \\
\hline February & 60 & 14 & $30 \cdot 84$ & $54 \% 7$ & $20 \cdot 6$ & $34 \cdot 1$ \\
\hline March & 66 & 16 & $42 \cdot 02$ & 60.1 & $20 \cdot 5$ & 396 \\
\hline April & 85 & 17 & $46 \cdot 25$ & $71 \cdot 3$ & $23 \cdot 0$ & $48 \cdot 3$ \\
\hline May & 86 & 23 & $55 \cdot 25$ & $79 \cdot 8$ & $30 \cdot 3$ & $49 \cdot 5$ \\
\hline June & 93 & 33 & $61 \cdot 31$ & $88 \cdot 5$ & $37 \cdot 8$ & 50.7 \\
\hline July & 98 & 33 & $63 \cdot 00$ & $89 \cdot 2$ & 39.2 & $50 \cdot 0$ \\
\hline August & 94 & 32 & $61 \cdot 83$ & $85 \cdot 8$ & $36 \cdot 7$ & $49 \cdot 1$ \\
\hline Septembe & 82 & 27 & $56 \cdot 32$ & 76.0 & $32 \cdot 3$ & $43 \cdot 7$ \\
\hline October & 79 & 21 & $49 \cdot 87$ & $68 \cdot 4$ & $25 \cdot 8$ & $42 \cdot 6$ \\
\hline Novembe & 66 & 16 & $43 \cdot 64$ & $58 \cdot 8$ & $21 \cdot 8$ & $37 \cdot 0$ \\
\hline December & 63 & 4 & $38 \cdot 98$ & $57 \cdot 5$ & $18 \cdot 8$ & $38 \cdot 7$ \\
\hline
\end{tabular}

BAROMETER.

\begin{tabular}{|c|c|c|c|c|c|c|}
\hline Month. & Uimost & Range. & Mean. & $\begin{array}{c}\text { Mean } \\
\text { Highest. }\end{array}$ & $\begin{array}{c}\text { Mean } \\
\text { Lowest. }\end{array}$ & $\begin{array}{l}\text { Differ- } \\
\text { ence. }\end{array}$ \\
\hline January - & $30 \cdot 83$ & 28.97 & $29 \cdot 986$ & 30.59 & $29 \cdot 17$ & 1.42 \\
\hline February & $30 \cdot 62$ & $28 \cdot 62$ & $29 \cdot 819$ & $30 \cdot 44$ & $29 \cdot 01$ & $1 \cdot 40$ \\
\hline March & $30 \cdot 68$ & $28 \cdot 70$ & $29 \cdot 915$ & $30 \cdot 47$ & $29 \cdot 24$ & $1 \cdot 23$ \\
\hline April & 30.53 & $29 \cdot 02$ & $29 \cdot 999$ & $30 \cdot 41$ & $29 \cdot 34$ & 1.07 \\
\hline May & $30 \cdot 62$ & $29 \cdot 42$ & $29 \cdot 960$ & $30 \cdot 42$ & $29 \cdot 54$ & 0.88 \\
\hline June & $30 \cdot 42$ & $29 \cdot 29$ & 30.008 & $30 \cdot 35$ & $29 \cdot 55$ & 0.80 \\
\hline July & 30.47 & $29 \cdot 37$ & 30.039 & $30 \cdot 36$ & $29 \cdot 57$ & 0.79 \\
\hline August - & $30 \cdot 48$ & $29 \cdot 11$ & $30 \cdot 023$ & $30 \cdot 35$ & $29 \cdot 42$ & 0.93 \\
\hline September & 30.58 & $28 \cdot 99$ & $31 \cdot 182$ & $30 \cdot 34$ & 2926 & 1.08 \\
\hline October - & $30 \cdot 71$ & $28 \cdot 98$ & $29 \cdot 997$ & $30 \cdot 50$ & $29 \cdot 24$ & $1 \cdot 26$ \\
\hline November & $30 \cdot 48$ & $28 \cdot 67$ & $29 \cdot 822$ & $30 \cdot 38$ & $29 \cdot 00$ & $1 \cdot 38$ \\
\hline December & $30 \cdot 66$ & $29 \cdot 04$ & $30 \cdot 038$ & 30.50 & $29 \cdot 28$ & $1 \cdot 22$ \\
\hline
\end{tabular}

Tables showing the mean temperature in most sections of the United States, and also at many noted places in Europe and Asia, will be found under the heads of Атмоsphere and Chimate.

WEEDS. A weed has been aptly defined "a plant out of place." The clearing of all kinds of crops, and keeping them free from weeds, is an essential part of cultivation: if this be omitted, neglected, or but partially performed, a portion of the crop will be lost, in proportion to the prevalence of such weeds, from defective preparation or partial extirpation. The nourishment drawn from the ground by the roots of all vegetables being somewhat similar, where that nourishment is suffered to be drawn by weeds, it is lost to the intended crop, which will therefore be reduced in produce in proportion as it has been deprived of nutriment from the soil, and prevented from occupying its whole extent of ground. The same observation will apply to pastures, to hedges, and plantations, and to all parts of the earth's surface reclaimed, occupied, and cultivated for the use of man; for therein the growth of noxious or useless plants will be injurious to the success of the useful ones, and in proportion as the former abound, the latter must prove defective.

The clearing of crops from weeds must be effected in two ways: 1 . In the preparation; and, 2. During the growth of the crop. In the preparation, attention must be given to distinguish root weeds from seedlings, as their destruction must be effected upon different principles. In the spring of the year particularly, attention should be paid to hoeing and weeding.

And old 'Tusser's advice may be followed with ad:rntage :-
WEEDS.

'In May get a weed-hook, a rentrh, and a glove.

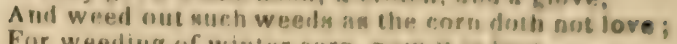

For weediug of winler corn, now it is lased.

But June is the betlep for woeding the romt.

The. May-weed doth burn, and the thistle doth fret

The fitches pull downward hrstls rye and the wheal,

The brake and the cockle be noratime ton much,

Yet like unto bondle no weed thore in sucl.

Slack never thy weeding, for dearth nor for cheap,

The corn shall reward it, ere ever ye rualo;

And specially where ye do trust fir tin ared.

Let thist be well used, the better in specd."

The plants we term weeds, considered as respecting mankind, are not totally useless; many of them have valuable medical qualities, and some of them may be applied to use. ful purposes, so as to pay something towarils the expense of clearing them from the ground. Thus, sow-thistles (Sonchus) afford food for rabbits or hogs; the hog-weed, or cow-parsnip (Heracleum sphondylium), is good for either swine or cattle; horses and asses are fond of young thistles when partially dried, and the seed may be prevented from spreading by gathering the down, which makes good pillows; however, there is some danger of trusting them to this stage of growth, as a high wind would, and frequently does, disperse them over a whole country. Charlock, or wild radish, when drawn, may be given to cows, which are very fond of it, particularly of the smooth kind; and, in the Oxford Report, it is stated that it can be converted into good hay. Nettles, fern, and the more bulky hedge-weeds, are, in Staffordshire, collected annually about midsummer and burned; their ashes being afterwards formed into balls, which are of considerable value, being used in composing a ley for scouring and cleaning linen and other clothes.

It is said that pigeons are of use in picking up the seeds of many weeds that would otherwise vegetate; and I have no doube but that a prodigious quantity of the seeds of weeds are eaten by small birds, particularly of most of the snake-weeds (Polygonums), of the spurry (Spergula), and, in severe weather, of the different sorts of charlock (Sinapis, Brassica, and Ruphanus), and of many other kinds. It has been observed that bees have not thriven so well in England since the extirpation of weers has been more attended to. In China and Japan, it is said, not a weed is to be seen, and that they only make use of night-snil as a manure, partly with a view of preventing any rise of weeds.

Weeds, like all other vegetables, may be distinguished into annuals, biennials, and perennials, according to their term of duration.

Annuals are those which continue only one year, the plants dying after perfecting their seeds: these are generally very prolitic in seed. Biennials are those which continue two years. and die after perfecting their seed: these also produce an abundance of sced. Perennials are those which continue many years: some of these perfect their seeds every year, and others, being very tenacious of growth by their roots, and having the faculty of reproducing themselves in this way, are less prolific in seeus; but many of them increase both by seeds and roots.

The weeds of agriculture are very numerous but by far the greater part are underlings, ari 
are little noticed; these are comparatively innocent, and a very great portion of them have no local or cummon names. Mr. William Pitt, in his essay On the Extrrpution of Weeds (Com. to Board of $A g r$. vol. v. p. 233), enumerates 55 weeds, and the list might have been greatly extended; but few farmers, whose knowledge is bounded by the soils they respectively cultivate, would think themselves troubled with more than a dozen to twenty; that is, four or five which trouble them in their fallows; four or five, the seeds of which infest their samples of corn; and a few besides, which are locally prevailing and obtrusive, but (as seems to have been too generally considered) not very hurtful.

The fact was, that, before the improved agriculture became so generally known, those weeds which did not hurt the samples the farmers cared little about; not considering how much they hurt the crops: and hence it has been, that on the different soils corn poppy, charlock, blue-bottles, corn marygold, Mayweed, \&c., have been suffered to abound.

The weeds of agriculture may be divided into, 1. Those which infest samples of corn; 2. Rooted or fallow weeds, and such others as are hard to destroy; 3 . 'Those which are principally objectionable as they encumber the soil; 4. Underling weeds, such as never rise with the crop or come into the sickle. Under their respective heads, in alphabetical order, we have already treated of the deteriorating qualities and mode of destruction of each weed; but, following the above arrangement, we shall classify them, and add such :urther remarks as may be required.

1. Weeds which infest Samples of Corn.-In England the weeds of this description do not exceed ten in number, and it very rarely happens that more than two sorts are found associated in one sample of wheat. They vary as to soil so much, that some of the worst weeds in fens and marshes are not known at all on clay, cold soils, and are but very little seen on any sort of dry turnip land. Light loams and teep, loose soils generally have most weeds by nature. The weeds which infest the sample are, darnel, cheat, or chess (Bromus secalinus and mollis), cockle (Agrostemma Githago), tares (Ervum telraspermum and hirsutum), melilot (Melilotus officinalis), wild oats (Avena fatua), hariff (Galium Aparine), crow-needles, or shepherd's needle (Scandix pecten Veneris), black bindweed (Polygonum Convolvulus), annual snake-weed (Polygonum lapathifolium), and craarlock seeds in barley sometimes.

Of these ten weeds, whose seeds infest samples of corn, five are principally injurious to wheat; the others are partial, and more common in barley and oats.

2. On Fulluw Weeds.-The objects of a fallow are, and always were, first, to eradicate root weeds, and cleanse and open the soil to the fibres of future crops; second, to pulverize and break down the texture of clay soils, and mix them with manure, in order to bring the land periodically into a mild and fertile condition. Seedling weeds are destroyed incidentally; and good fallows, with good seasons, kill a great many, though it be not the object of fallowing 1120
The English fallow weeds are principally the following: couch, including Triticum re. pens, Agrositis rejuens, Holcus mollis, and Poa pratensis, rest-harrow (Ononis arvensis), saw-wort, the common way-thistle, or pasture-thistle (Carduus arvensis), curled dock (Rumex crispus), tall oat-like soft-grass (Holcus avenaceus), colt'sfoot (Tussilago Farfara), corn bindweed (Convolvulus arvensis), corn mint (Mentha arvensis), surface-twitch (Agrostis stolonifera angustifolia), black foxtail-grass (Alopecurus agrestis), common knot-grass (Polygonum aviculare), wild carrot (Doucus Carota), hedge parsley, or dill (Torilis infesta), common fool's parsley (Ethu sa Cynapium), spingel or fennel (Meum Fænicu lum).

3. Weeds which are principally objectionable as they nncumber the Soil, or whose Roots are annual, and whose Seeds pass the Corn-sieve.-Of this class of weeds, the following deserve particular notice: charlock (several species), corn popny (Papaver Rhøas), blue-bottle (Centaurea Cyanas), stinking May-weed (Anthemis cotula), corn marigold (Chrysanthemum segetum).

To extirpate these weeds, clean corn-seed must be used, not a single plant of these weeds must be suffered to perfect seed in the hedgerows, and a judicious rotation of crops adopted, so as to admit of the unsparing use of the horse-hoe, as well as of the hand, in weeding; by which means these noxious and disgraceful pests of corn-fields will be overcome, and banished from the soil.

The corn-poppy particularly accumulates upon gravelly soils of low quality, also on dry sandy soils, and generally on all dry and shal low lands which are overcropped and neglect. ed. But much better soils, as loamy gravel, \&c., are infested with it; only here the crops are generally good enough to keep it under, and being less abundant, it is much easier subdued by weeding. But the corn poppy is never so triumphant as in a hot and dry season, in which case many fields, which should have been corn, are wholly covered with it. One of three things must be done by way of remedy: $1 \mathrm{st}$, the soil must be clayed or marled; $2 \mathrm{~d}$, or it must be fed with much larger quantities of farm-yard dung or compost; 3d, if neither of these be easily practicable, the rotation must be changed.

4. Of the Weeds called Underlings, or such as never rise in the Crop, nor come inlo the Sickle.These are groundsel or Simson (Senecio vulgaris), annual meadow-grass (Poa annua), chickweed (Stellaria media), shepherd's purse (Thlapsi bursa pastoris), spurry (Spergula arvensis), camomile feverfew (Matricaria Chamomilla), fat hen or wild spinach (Chenopodium album), corn salad, or lamb's lettuce (Fedia olitoria), flixweed (Sisymbrium Sophia), common fumitory (Fumaria officinalis), and sand musiard (Sinapis muralis).

Land may be rendered inert or unfertile from an excess of manure, as well as from the want of it; severe and avaricious cropping, long persevered in, being understood in both cases. Over-stimulus, as in the first instance, wears out, or renders inert, the principle of fertility in the land; and, in the latter instance, the want of stimulus produces the same effect 
Plate 2.
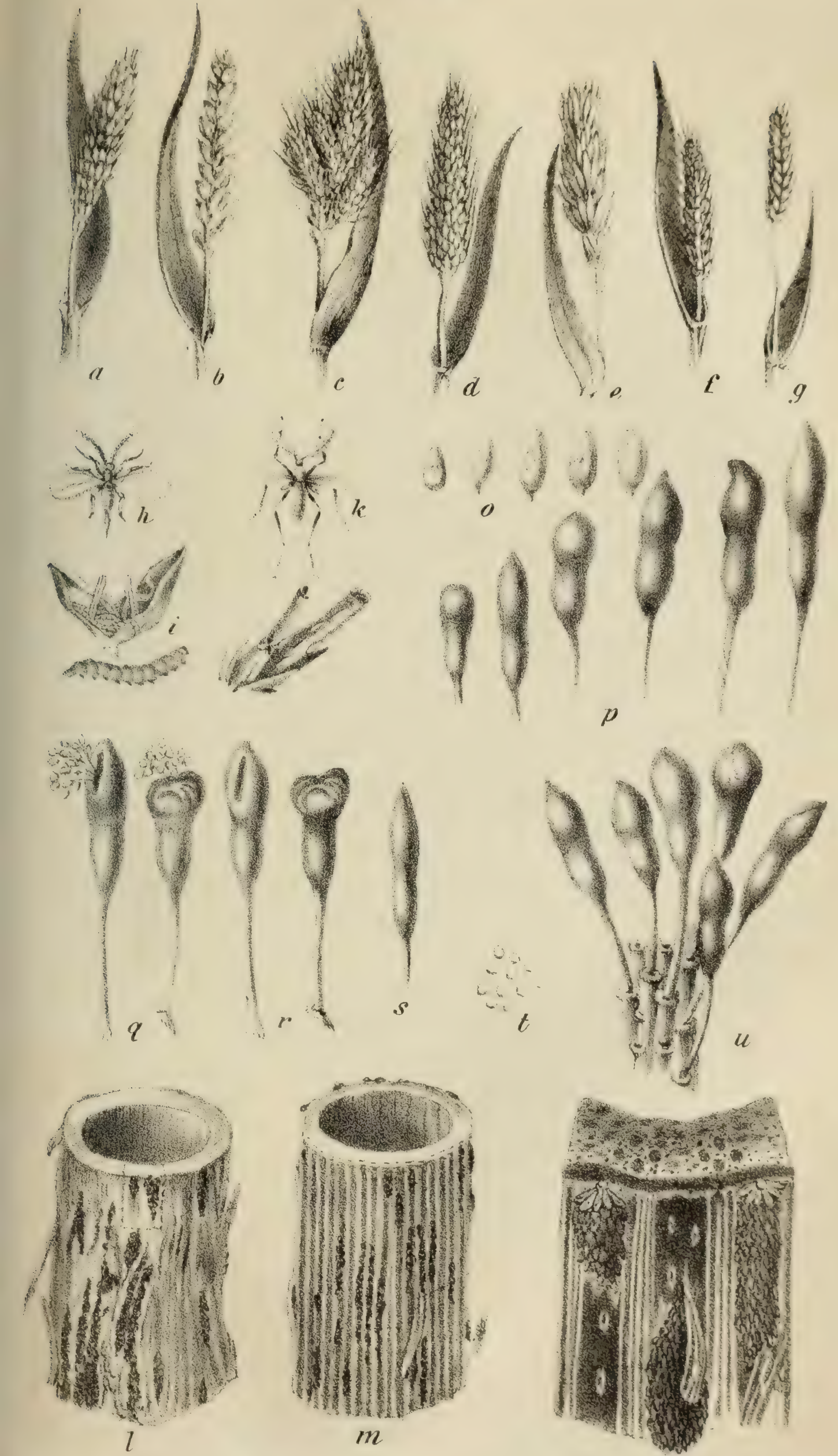

larvelice of Ithent with the

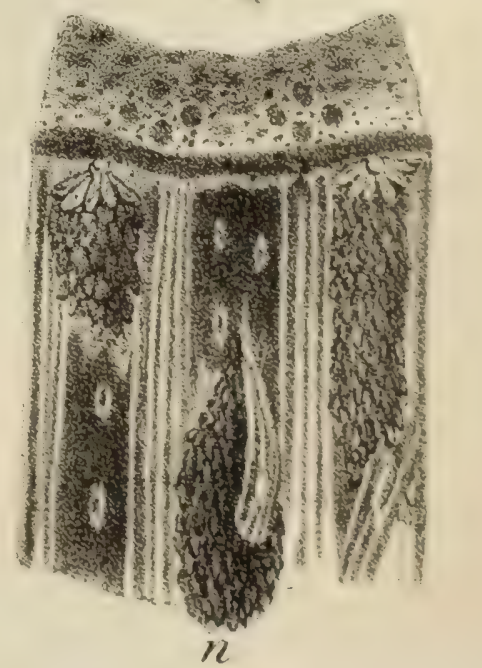



The underling weeds, above mentioned, flourish and prosper under this state of the land, brought on by either cause. The remedy is therefore obvious, viz., rest, or a clear-out summer fallow: and if in the first mentioned case (which is to be met with in deep fen land and in old garden mould), apply a dressing of lime, and sow down with the superior pasture-grasses and clovers, to remain for not less than five years. In the latter case, or when the fertility of the soil is worn out by injudicious cropping, and a niggardly supply of manure, joined to the naturally thin and poor staple of the soil, then a full application of manure, or marl and manure, the latter consisting as much as possible of cow-dung, should be given, and the land sown down with the superior permanent pasture-grasses suited to the soil, with a due admixture of clover.

5. Pasiure Weeds.-Some farmers seem to suppose that if they keep the weeds subdued in the growing crops, they have performed wonders (and too many have reason to congratulate themselves if they do this), while all kinds of nuisances in the shape of weeds disfigure and overrun their pastures. But thisiles, milkweed, everlasting, John's-wort, sweet elder, \&c., flourish undisturbed, and fill the earth with seeds or roots in readiness to spread and grow whenever the earth is moved for their reception. Any plant not wanted on a farm, or not required in course of cultivation, should never be allowed to perfect its seeds on any part of it; if they are, the farmer will find, to his sorrow, that he has suffered an enemy to steal a march upon him, one which it may require much time and labour to subdue. Allow, then, nothing to go to seed on your farm you do not mean to cultivate; dig them up root and branch, or, if this is not practicable, take your scythe and cut them at once.

The following weeds are more frequently found to infest dry, sandy pastures, and calcareous soils, than loamy or damp grass lands. Dwarf-thistle (Carduus acaulis), common camomile (Anthemis nobilis), ox-eye daisy (Chrysanthemum leucanthemum), great fleabane, or ploughman's spikenard (Conyza squarrosa), cheese refrning, or yellow ladies' bedstraw (Galium verum), longrooted hawk-weed, wild thyme (Thymus serpyllum), sheep's sorrel (Rumex Acelosella), knot-grass, or snake-weed (Polygonum aviculare), yellow rattle (Rhinanthus cristagalli), common Carline thistle (Carlina vulgaris).

Where these are found to prevail to a great extent, there is no remedy like breaking up the land and taking a course of crops, for pallialive remedies are of little avail. The thisiles, sheep's sorrel, and knot-grass, are the most formidable. Hand-weeding, when the weeds are confined to local spots, and are only just beginning to spread generally over the soil, will be found effectual; but when once he pasture becomes generally infected with he seeds and roots of these plants, no time thould be lost in using the plough, harrow, and corse-hoe, and a judicious course of cleansing zrops, before returning the land again to permajent pasture.

The pasture wreds which generally prevail n loamy soils, anit such as are prevalent in clayey and damp soils, are principally as fo: lows:-yellow goat's beard ('Tragopogon pratensis), marsh, or red thistle (Carduus palustris), melancholy plume-thistle (C'ncius helerophyllus), meadow plume-thistle (Cardurs pratensis), common butter-bur (Tussilago Petasites), ragwort (Senecio Jucobcea), common daisy (Bellis perennis), black knap-weed, or matfellow (Centaurea nigra), broadleaved dock (Rumex obtusifolius); several species of orchis, common cow parsnip, or hog-weed (Heracleum Sphondylium), and sedge (Carex).

The means to be adopted for the extirpation of these noxious weeds in pastures must be regulated by the nature of the soil and the comparative prevalence of the weeds. In good pasture land, where, from accident or neglect, these weeds, in part or wholly, have insinuated themselves, hand-weeding may most advan. tageously be had recourse to; and particularly for the larger weeds, such as thistles, rag-weed, docks, and knapweed, it will be found the best temporary remedy. Should the coarseness of the pasture have been occasioned by too fre. quent haying, then depasturing closely for two or three years, with a good top-dressing of dung compost applied in the early part of the spring or late in the autumn, with strict attention to hand-weeding, will be found effectual to recover the pasture and extirpate the weeds. Fre. quent top-dressings are of the greatest use in effecting the above improvements on deteric. rated thin pasture lands, as regards the destruction of weeds, as well as of improving the quality of the pasture. When the sedges, marsh-thistle, pestilent wort, \&c., prevail in meadows, then recourse must be had to other means than that of hand-weeding, viz., draining, paring and burning, liming, and a judicious rotation of crops under the horsc-hoe husbandry, until every vestige of the seeds and roots of these noxious weeds disappear. The ground may then be laid down to permanent pasture, with the seeds of the most valuable species adapted to the soil, and, where water can be commanded, converted to water meadow, by which the value of the land will be considerably increased. (Holdich's Weeds; Pitt's Essays on Weeds.) See Cavana Thistie, Charlock, Covch, \&c., \&c.

WEEVILS. In the winged state, the insects thus called are hard-shelled beetles, which, says Dr. Harris, are distinguished from other insects by having the forepart of the head prolonged into a broad muzzle or a longer and more slender snout, in the end of which the opening of the mouth and the small horny jaws are placed. The flies and moths produced from certain young insects, called weevils by mistake, do not possess these characters, and their larvæ or young differ essentially from those of the true weevils. The latter belong to a group called Rhynchophorida, literally, snoutbearers.

Among insects of this class is the Pales weevil, Curculio (Hylohius) Pales. See P1. 16, 6. This is a beetle of a deep chestnut-brown colour, having a line and a few dots of a yellow. ish-white colour on the thorax, and many small yellowish white spots sprinkled over the wing covers. All the thighs are toothed beneata 
and the snout is slender, cylindrical, inclined, and nearly as long as the thorax. On account of the len th of the snout this insect has been placed in the genus Rhynchonus by some natu. ralists; but the antennæ are implanted before the middle of the snout, and not far from the sides of the mouth. This beetle measures from two to three-eighths of an inch in length, exclusive of the snout. It may be found in great abundance, in May and June, on boardfences, the sides of new wooden buildings, and on the trunks of pine trees. I have discovered them, in considerable numbers, under the bark of the pitch pine. The larvæ, which do not materially differ from those of other weevils, inhabit these and probably other kinds of pines, doing sometimes immense injury to them. Wilson, the ornithologist, describes the depredations of these insects, in his account of the ivory-billed woodpecker, in the following words. "Would it be believed that the larvæ of an insect, or fly, no larger than a grain of rice, should silently, and in one season, destroy some thousand acres of pine trees, many of them from 2 to 3 feet in diameter, and 150 feet high? Yet whoever passes along the highroad from Georgetown to Charleston, in South Carolina, about 20 miles from the former place, can have striking and melancholy proofs of the fact. In some places the whole woods, as far as you can see around you, are dead, stripped of the bark, their wintry-looking arms and bare trunks bleaching in the sun, and tumbling in ruins before every blast, presenting a frightful picture of desolation. Until some effectual preventive or more complete remedy can be devised against these insects and their larvæ, I would humbly suggest the propriety of protecting, and receiving with proper feelings of gratitude, the services of this and the whole tribe of woodpeckers, letting the odium of guilt fall to its proper owners." (American Ornithology, vol. iv. p. 21.) Some years ago Mr. Nuttall procured, near the place above mentioned, specimens of the destructive insects referred to by Wilson. They were of three kinds. Those in greatest abundance were the pales weevil. One of the others was a larger, darker-coloured weevil, without white spots on it, and named Hylobius pirivorus, by Germar and Schönherr, or the pitch-eating weevil; it is seldom found in Massachusetts. The third was the white pine weevil. It is said that these beetles puncture the buds and the tender bark of the small branches, and feed upon the juice, and that the young shoots are often so much injured by them as to die and break off at the wounded part. But it is in the larva state that they are found to be most hurtful to the pines. The larva live under the bark, devouring its soft inner surface, and the tender newly formed wood. When they abound, as they do in some of the pine lorosts of the United States, they separate large pieces of luark froin the wood beneath, in con:equanim of which the part perishes, and the iree itscif soon languishes and dies.

The white pine weevil, Rhynchanus (Pissodes) Strobi, of Professor Peck, unites with the two preceding insects in destroying the Ameriran pines, as above describet. But it em- ploys also another mode of attack on the white pine, of which an interesting account is given by the late Professor Peck, the first describer of the insect, in the 4 th volume of the Massa. chusetts Agricultural Repository and Journal, accompanied by figures of the insect. The lofty stature of the white pine, and the straightness of its trunk depend, as Professor Peck has remarked, upon the constant health of its leading shoot, for a long succession of years; and if this shoot be destroyed, the tree becomes stunted and deformed in its subsequent growth. This accident is not uncommon, and is caused by the ravages of the white pine weevil. This beetle is oblong-oval, rather slender, of a brownish colour, thickly punctured, and variegated with small brown, rust-coloured, and whitish scales. There are two white dots on the thorax; the scutel is white; and on the wing-covers, which are punctured in rows, there is a whitish transverse band behind the middle. The snout is longer than the thorax, slender, and a very little inclined. The length of this insect, exclusive of its snout, varies from one-fifth to three-tenths of an inch. Its eggs are deposited on the leading shoot of the pine, probably immediately under the outer bark. The larvæ, hatched therefrom, bore into the shoot in various directions, and probably remain in the wood more than one year. When the feeding state is passed, but before the insect is changed to a pupa, it gnaws a passage from the inside quite to the bark, which, however, remaining untouched, serves to shelter the little borers from the weather. After they have changed to beetles, they have only to cut away the outer bark to make their escape. They begin to come out early in September, and continue to leave the wood through that month and a part of October. The shoos at this time will be found pierced with small round holes on all sides; sometimes 30 or 40 may be counted on one shoot. (Harris.) See Cohn Wefila, Curculio, Grain Wrevil, Pea Wefitu, Plum Trew Wervil, \&c.

WEIGH. In England, a weight of cheese, wool, \&c., containing $256 \mathrm{lbs}$. avoirdupois. Of corn, the weigh contains 40 bushels; of barley or malt, 6 quarters. A weigh of cheese or butter in Suffolk is 256 lbs, and in Essex 336 lbs.

WEIGHTS AND MEASURES. The proportions or quantities by which various sorts of agricultural or other produce are disposed of. In Britain they vary greatly in different districts, and even in different places of the same district or county.

In a general sense the term measure is applied to that by which any thing is compared in respect of quantity. Thus we have measures of extension, if weight, time, force, resistance, temperature, \&c.; in short, of every thing of which greater or less can be predicated; and it frequently happens that the unit or measure is not taken in the thing or pro perty which is the immediate subject of consideration, but in something else which depends on it, or is proportional to it. Angular space, for example, is measured by an arc of a circle; time, by the rotation of the earth upon its axis, or its revolution around the sun; force. 
by the quantity of motion it impresses on a body; degrees of heat, by the expansion of metals or other substances; muscular strength, by the resistance of a spring. See DrNamo-

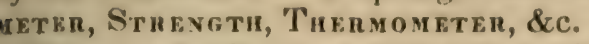

By measure, in an absolute sense, is understond the unit, or standard, by which we measure extension. We have, therefore, measures of length, of superficies, and of volume or caacity; but, as the two latter may be deduced $\mathrm{n}$ all cases from the former, it is only necesary to establish a unit, or standard of length. The choice of such a standard, and the different multiples and parts of it taken for the uses f society, form a metrical system, or system of metrology.

As no precise notion can be formed of the magnitude of a line in any other way than by comparing it with another line of a known ength, the necessity of having recourse, for he interchange of ideas, to measures not enirely arbitrary, but fixed by nature and inteligible alike to all mankind, seem to have been erceived in the earliest ages. Hence origiated the foot, the cubit, or length of the arm rom the elbow to the tip of the middle finger; he ulna, arm, or yard; the span; the digit, or inger; the palm; the fathom, or space from he extremity of one hand to that of the other, when they are both extended in opposite directions; the pace, the harley-corn, the hair's breadih, and other denominations of measure taken from parts of the human body, or from natural objects, which, though not of an absolute and invariable length, have a certain mean value sufficiently definite to answer all the purposes required in a rude state of society. $\mathbf{B u t}$ as civilization advanced, the necessity of adopting more precise standards would be felt, and the inadequacy of such measure as the foot the cubit, \&c. (referred only to the human body), to convey accurate notions, would be rendered most apparent in their application to itinerary measures, or the estimation of great distances.

English System of Livical Measurcs.-The unit of lineal measure in England is the yard, all other denominations being either multiples, or aliquot parts of the yard. The yard is divided into 3 feet, and the foot subdivided into 12 inches. The multiples of the yard are the pole or perch, the furlong, and the mile; $5 \frac{1}{2}$ yards being a pole, 40 poles a furlong, and 8 furlongs a mile. But the pole and furlong are now scarcely ever used, itinerary distances being reckoned in miles and yards.

The relations of these different denominations are exhibited in the following table:-

\begin{tabular}{r|c|c|c|c|c|}
\hline Inches. & Feet. & Yards. & Pol 2s. & Furlongs. & M les. \\
\cline { 2 - 6 } 12 & 0.083 & 0.028 & 0.00505 & 0.00012626 & 0.0000157828 \\
36 & 1 & 0.333 & 0.06060 & 0.00151515 & 0.00018939 \\
198 & 3 & 1 & 0.1818 & 0.004545 & 0.00056818 \\
7920 & 660 & 5.5 & 1 & 0.025 & 0.003125 \\
63360 & 5280 & 220 & 40 & 1 & 0.125 \\
\end{tabular}

Of the different measures of length used in Measures of Superficies.-In square measure Guropean countries, the foot is the most unirersally prevalent. We subjoin the relation etween the foot of different countries and the inglish foot.

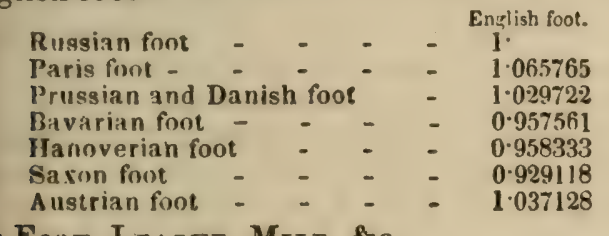
the yard is subdivided, as in general measure, in to feet and inches; 144 square inches being equal to a square foot, and 9 square feet to a square yard. For land measure the multiples of the yard are the pole, the rood, and the acre; $30 \frac{1}{4}$ (the square of $5 \frac{1}{2}$ ) square yards being a pole, 40 poles a rood, and 4 roods an acre. (See Acns.) Very large surfaces, as of whole countries, are expressed in square miles.

The following are the relations of square

measure :-

See Foot, League, Mile, \&c.

\begin{tabular}{|c|c|c|c|c|}
\hline Square Feet. & Square Yards. & Poles. & Rools. & Acres. \\
\hline $\begin{array}{c}1 \\
9 \\
2 \approx 2 \cdot 25 \\
10890 \\
43 ; 60\end{array}$ & $\begin{array}{c}0 \cdot 1111 \\
1 \\
30.25 \\
1210 \\
4840\end{array}$ & $\begin{array}{r}0.00367309 \\
0.03305798 \\
1 \\
40 \\
160\end{array}$ & $\begin{array}{l}0 \cdot 001091827 \\
0 \cdot 000526448 \\
0.025 \\
1 \\
4\end{array}$ & $\begin{array}{l}0.000022957 \\
0.000206612 \\
0.00625 \\
0.25 \\
1\end{array}$ \\
\hline
\end{tabular}

Land is usually measured by a chain of 4 oles or 22 yards, which is divided into 100 inks. Three chains in length and one in readth make an acre, which equals 169 square erches, or 4840 square yards.

Land Measure.

\begin{tabular}{|c|c|c|c|c|}
\hline Countries. & & $\begin{array}{l}\text { Land } \\
\text { Measure. }\end{array}$ & $\begin{array}{c}\text { English } \\
\text { Square } \\
\text { Yard. }\end{array}$ & $\begin{array}{l}\text { No. equal to } \\
10 \text { Enzlish } \\
\text { Acres. }\end{array}$ \\
\hline Encland & - & Acre & 4840 & 10000 \\
\hline Scritland & - & - & 6150 & $7 S 60$ \\
\hline Ireland - & - & - & 7840 & 6173 \\
\hline France - & - & Hectare & 11960 & 4016 \\
\hline Prussia - & - & Morgen & 3053 & 15853 \\
\hline Hainburg & - & - & $115+5$ & 4192 \\
\hline Amsterdam & - & - & 9722 & 4978 \\
\hline Dantzic - & - & - & 6650 & 7278 \\
\hline
\end{tabular}

Measures of Volume.-Solids are measured by cubic yards, feet, and inches; 1725 cubir; inches making a cubic foot, and 27 cubic feet a cubic yard. For all sorts of liquids, corn, and other dry goods, the standard measure is declared by the act of 1824 to be the imperial gallon, the capacity of which is determined immediately by weight, and remotely by the standard of length. See Galrox.

The parts of the gallon are quarts and pints, 2 pints being a quart, and 4 quarts a gallon. 
Its multiples are the peck, the bushel, and the quarter; the peck being 2 gallons, the bushel 4 pecks, and the quarter 8 bushels. The following are the rotations :-

\begin{tabular}{|r|r|l|l|l|l|}
\hline Pints. & Quarts. & Gallons. & Pecks. & Bushels. & \multicolumn{1}{|l|}{ Quarters. } \\
\hline 1 & 0.5 & $\frac{0.125}{0}$ & 00621 & 0.0115625 & 0.001953125 \\
2 & 1 & 0.25 & $0 \cdot 125$ & 003125 & 000390625 \\
8 & 5 & 1 & 0.5 & $0 \cdot 125$ & 0015625 \\
16 & 8 & 2 & 1 & 0.25 & 0.03125 \\
64 & 32 & 8 & 4 & 1 & 0.125 \\
1512 & 256 & 46 & 32 & 8 & 1 \\
\hline
\end{tabular}

Cubic or Solid Measure.

1728 cubic inches make $-\quad-1$ cubic font.
27 cubic feet - -1 cubic yard.
$\left.\begin{array}{l}40 \text { feet nf rongh timber } \\ 50 \text { feet of hewn timber }\end{array}\right\} \quad-1$ load.

This comprehends length, breadth, and thickness.

And 108 solid feet, that is, 12 feet in length, 3 feet in breadth, and 3 feet deep, or commonly 14 feet long, 3 feet 1 inch broad, and 3 feet 1 inch deep, are a stack of wood.

And 128 solid feet, that is, 8 feet long, 4 feet broad, and 4 feet deep, are a cord of wood.

Grain Measures.

\begin{tabular}{|c|c|c|c|c|c|}
\hline \multicolumn{3}{|c|}{ Countries. } & \multirow{2}{*}{$\begin{array}{c}\text { Rushels. } \\
1000\end{array}$} & \multirow{2}{*}{$\begin{array}{c}\text { No. of equal } \\
\text { to English } \\
\text { Quarters. }\end{array}$} & \multirow{2}{*}{$\begin{array}{l}\text { Name of } \\
\text { Measure. }\end{array}$} \\
\hline England & - & - & & & \\
\hline Scotland & - & - & 1022 & 7827 & \\
\hline France & - & - & 4427 & 1307 & Setier. \\
\hline Holland & - & - & 3157 & 2534 & Mudde. \\
\hline Prussia & - & - & 1479 & 5409 & Scheffel. \\
\hline Spain - & - & - & 1599 & 5003 & Fanaga. \\
\hline Poland & - & - & 1451 & 5513 & Korzee. \\
\hline
\end{tabular}

(Loudon's Encyc. of Agr. p. 20.)

English Corn Measures.

\begin{tabular}{|c|c|c|c|c|}
\hline & & & & \\
\hline 4 gills & $=$ & 1 pint & $=$ & $34 \frac{1}{3}$ cubic in. \\
\hline 2 pints & $=$ & 1 quart & $=$ & $69 \frac{1}{3}$ \\
\hline 4 quarts & $=$ & 1 gallon & $=$ & $277 \frac{i}{4}$ \\
\hline 2 galtons & $=$ & 1 peck & $=$ & $544 \frac{1}{2}$ \\
\hline 8 gallons & $=$ & 1 bushel & $=$ & $2218 \frac{1}{3}$ \\
\hline 8 bushels & $=$ & 1 quarter & $=$ & 10) cubic ft. \\
\hline 5 quarters & $=$ & l load & $=$ & $51 \frac{1}{5}$ \\
\hline
\end{tabular}

See Busher, Peck, Quarter.

The Winchester quarter is more than the Imperial quarter, being in the proportion of 1 to 0.96945 . The English Imperial quarter, in estimating weight, means the $\frac{1}{4}$ of a ton of 2240 lbs. $=560 \mathrm{lbs}$. or 1 quarter.

English Measures of Wood and other Fuel.Cord-wood, being the bigger sort of fire-wood, is measured by a cord or line, whereof there are two measures; that of 14 feet in length, 3 feet in breadth, and 3 feet in height. The other is 8 feet in length, 4 feet in height, and 4 feet in breadth. This last is generally adopted in the United States.

Weights.-Weights are used to ascertain the gravity of bodies, a quality depending partly on their magnitude and partly on their density. The determination of the gravity or weight of different bodies supposes the invention of the balance. Nothing is known of the steps which led to its introduction; but it was used in the remotest antiquity. Weights have frequently been derived from grains of corn. Hence in England, and in some other European countries, the lowest denomination of weight is a grain; and 32 of these grains are directed, by the ancient statute, called Composirio Mensurarum, to compose a pennyweight, 1124 whereof 20 make an ounce, 12 ounces a pound and so upwards.

Tables of Weights and Measures according to th Imperial Standard.

\begin{tabular}{|c|c|c|c|}
\hline \multicolumn{3}{|c|}{ Avoirdupois Weight. } & nea. \\
\hline & $1 \mathrm{drachm}$ & & $\begin{array}{r}1.771 \\
98.346\end{array}$ \\
\hline 16 drachms & 1 ounce & $=$ & $28 \cdot 346$ \\
\hline $\begin{array}{l}16 \text { ounces } \\
28 \text { pounds }\end{array}$ & 1 pourd & $\equiv$ & 453.544 \\
\hline $\begin{array}{l}28 \text { pounds } \\
4 \text { quarters }\end{array}$ & quariercw & $=$ & 12699 kilagrai \\
\hline $\begin{array}{l}4 \text { quarters } \\
20 \text { cwt. }\end{array}$ & l cwt. & $\overline{=}$ & $\begin{array}{r}50.790 \\
1015.920\end{array}$ \\
\hline
\end{tabular}

In England the stone is generally 14 lbs avoirdupois weight, but for butchers' meat of fish it is $8 \mathrm{lbs}$. Hence the cwt. equals 8 stone of $14 \mathrm{lbs}$, or 14 stone of $8 \mathrm{lbs}$.

Hay and straw are sold by the load of $3 i$ trusses. See HAr and 'T'russ.

The custom of allowing more than 16 ounce: to the pound of butter used to be very genera in several parts of England.

Wool Weight.-Like all other bulky articles wool is weighed by avoirdupois weight, but th divisions differ thus,

7 pounds
2 cloves
2 stone
$6 \frac{1}{2}$ tods
2 weys
12 sacks

$$
\begin{array}{ll}
= & 1 \text { clove. } \\
= & 1 \text { stone. } \\
= & 1 \text { tod. } \\
= & 1 \text { wey. } \\
= & 1 \text { sack. } \\
= & 1 \text { last. }
\end{array}
$$

Cheese and butter.

$$
\begin{array}{lll}
8 \text { pounds } & = & 1 \text { clove. } \\
32 \text { cloves } & \equiv & 1 \text { wey in Esex. } \\
42 \text { cloves } & \equiv & 1 \text { wey in Suffolik. } \\
56 \text { pounds } & = & 1 \text { firkin of butter. }
\end{array}
$$

Miscellaneous Information relative to Weight and Measures.-Specific gravity is determine by weighing the substance first in air, and the in water at the temperature of $60^{\circ} \mathrm{F}$ ahrenhei In the latter case the substance loses of it weight a quantity precisely equal to the weigh of its own bulk of water. The total weight $i$ : air is then divided by the loss of weight in wates and the quotient is the specific gravity. Thi is either over or under that of pure wates which is the standard of comparison. Th standard of weights is, the cubic inch of dis tilled water, weighing 253.458 Troy grains the Troy pound, 5760 grains, or 22.8157 inches The same standard of 7000 Troy grains make the pound avoirdupois, $27 \cdot 7274$ cubic inches 10 of which, or 277.274 , being the imperia gallon, or a quart 69.32 ; and a gill of 5 ounce of water, equal to $8 \cdot 664$.

The specific gravity of water being 1.000 that of alcohol, pure, is 0.829 ; beer, 1.034 cider, 1.018; milk, 1.032; linseed oil, 0.94 vinegar, 1.025; sea-water, 1.026; ox bone 1.666 ; brass, $7 \cdot 824$; brick, $2 \cdot$; cork, 0.24 ; gold 19.2587; granite, $2 \cdot 728$; bar-iron, $7 \cdot 68$; lead 11.352 ; lignum vitæ, 1.33; mahogany, 1.06 marble, 2.716; mercury, 13.58; oak, 1.17 platina, 20.722 ; silver, 10.474 ; clay-slate, 2.67 tin, 10.717; limestone, 1.386 ; elm, 0.671 ; ho ney, 1.45. (Treasury of Knowledge.)

A cubic foot of loose earth or sand weigh: $95 \mathrm{lbs}$.

A cubic $\mathrm{ft}$. of common soil weighs 124 lbs.

$\begin{array}{llll}\text { " " } & \text { " clay, } & 127 & \text { " } \\ \text { " } & \text { mason's work " } & 205 & \text { " } \\ \text { " } & \text { distilled water, } & 62.5 & \text { " } \\ \text { " } & \text { cast-iron, } & 450 \cdot 15 \text { " } \\ \text { steel, } & 4 & 489.8 \text { " }\end{array}$




\section{WEIGHTS AND MEASURES.}

\begin{tabular}{|c|c|c|c|c|c|}
\hline A cubic & $\mathrm{ft}$. & lead, & weighs & 709.5 & lbs. \\
\hline " & “ & platina, & $\because$ & $1,218 \cdot 75$ & “6 \\
\hline " & " & copper & “ & $486 \cdot 75$ & "6 \\
\hline " & $"$ & cork, & $"$ & 15 & 6 \\
\hline$"$ & “ & tallow, & 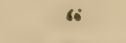 & 59 & “ \\
\hline 16 & " & oak, & " & $73 \cdot 15$ & "6 \\
\hline " & " & brick, & as & 125 & 66 \\
\hline " & “ & air, & “ & $\cdot 075$ & 3 " \\
\hline
\end{tabular}

The American quintal is $100 \mathrm{lbs}$. The ton 2240 lbs.

The weight of a cubic inch of distilled water, in a vacuum, is 252.722 grains, and in air, is 252.458 grains.

The Turkish pound is 7578 grains; the Danish, 6941 ; the Irish, 7774 ; the Neapolitan, 4952; the Scotch pound Troy, 7620.8.

The imperial gallon contains 10 lbs. avoirdupois of distilled water, weighed in air at $62^{\circ}$, with the barometer at 30 inches. Two gallons are equal to a peck, 8 gallons to a bushel, and 8 bushels to a quarter.

Heaped measure, per bushel, is $2815 \frac{1}{4}$ cubic inches clear.

The Winchester bushel is $18 \frac{1}{2}$ inches in diameter, and 8 inches deep, containing 2154.42 cubic inches.

1000 ounces of rain-water are equal to about $7 \frac{1}{2}$ gallons wine measure, or to a cubic foot.

Seven lbs. avoirdupois is a gallon of flour.

A chaldron of coals is $58 \frac{8}{3}$ cubic feet.

Twelve wine gallons of distilled water weigh i00 lbs. avoirdupois.

The imperial dry bushel, when not heaped, is 2218.192 cubic inches; the peck, 554.548 ; gallon, $2 \% 7 \cdot 274$, and quart, $69 \cdot 3185$. The bushel is 8 inches deep, and 18.8 wide, with a heap 6 inches high.

A bushel of wheat is $60 \mathrm{lbs}$; rye, $53 \mathrm{lbs}$; barley, 47 lbs.; oats, 38 ; peas, 64 ; beans, 63 ; clover-seed, 68 ; rape, $48 \mathrm{lbs}$.

A Scotch pint is equal to 4 English pints. A Scotch quart is $208 \cdot 6$ cubic inches.

'I'here are $545,267,000$ cubic yards in a cubic mile.

According to usage in Philadelphia and other parts of the United States, building-stone, when piled, or "perched," as it is usually termed, is measured by allowing 25 cubic feet to the perch. But when placed in the wall, only 22 feet are allowed to the perch. In measuring stone wall, 14 inches of thickness is usually allowed. When the thickness of the wall exceeds 14 inches, the extra thickness is estimated and made an additional charge. This is the common rule when the walls have only one face. In double-faced walls, there is commonly an allowance of about one-third more. Three pecks of good lime will generally suffice to lay one perch of stone wall. About 2 one-horse loads of sand are allowed to malie mortar for 3 perches of stone wall.

To convert cubic feet into perches, divide by 25 ; or, what is still more easy, multiply by $\cdot 04$.

In brick-work, 14 bricks are usually allowed to the cubic foot: sometimes only 13 are allowed. To convert cubic feet into cubic yards, livide by 3 , and the product by 9 .

Lumber Measure.-In estimating the number - $f$ feet in a board, the length in feet is to be maltiplied by the width in inches, and the re-
WEIGIITS AND MEASIJRES.

sult, divided by 12 , shows the contents in feet When boards are more than I inch thick, all over is added. A board 12 feet long and 11 inch thick, would of course be estimated to contain one-fourth more than a board only 1 inch thick.

A bill passed by the legislature of Pennsylvania, in 1833, for the regulation of weights and measures in the state, provides for procuring and preserving standards, which are to conform to those of the United States, when established; the linear standard to be the yard, with the customary multiples allowed.

Superficial Measure.-Acre defined to be 4840 sq. yards.

Capacity Measures.-Wine gallon 231 cubic inches. Beer gallon 282 cubic inches. Bushel 2150.42 cubic inches. Lime bushel 131 inches diameter at bottom, 15 inches at top, and 13.47 inches deep. A cord of wood to contain 128 cubic feet. A hogshead of cider 110 wine gallons.

Weights.-Troy pound to be equal to that of the United States mint, and the avoirdupois pound to bear to it the ratio of 7000 to 576

$60 \mathrm{lbs}$. of wheat to pass for a bushel.

58 - rye.

48 - buckwheat.

47 - barley.

32 - oats.

85 - coarse salt (foreign).

70 - ground salt.

62 - fine.

80 - anthracite coal, 112 lbs. to make 1 cwt., and $2240 \mathrm{lbs} .=1 \mathrm{ton}$.

If the square of the diameter of a circle be multiplied by 7854 , the product is the area. If the diameter of a sphere be cubed and mul tiplied by 6236 , the product is the solidity; and the square of the diameter, multiplied by $3 \cdot 14159$, is the surface of the sphere.

To find the contents of a cask, add double the square of the bung diameter to the square of the head diameter, and multiply this sum by the head of the cask; then divide the product by 1077 for ale gallons of 280 cubic inches each, or by 882 for wine gallons of 231 cubic inches each.

Method of ascertaining the Weight of Cattle while living.-This is of the utmost utility for all those who are not experienced judges by the eye, and, by the following directions, the weight can be ascertained within a mere trifle. Under the head Catru: we have already given a useful table on this subject; but the annexed rules will be found of service. Take a string, put it round the beast, standing square, just behind the shoulder-blade; measure $c n$ a footrule the feet and inches the animal is in circumierence, this is called the girth; then with the string measure from the bone of the tail, which plumbs the line with the hinder part of the buttock; direct the line along the back to the fore-part of the shoulder-blade; take the dimensions of the foot-rule, as before, which is the length, and work the figures in the following manner; - Girth of the bullock. 6 feet 4 inches; length, 5 feet 3 inches; which, multiplied together, make 31 square superficial feet; that again, multiplied by 23 (the number of 
pounds allowed to each superficial foot of all cattle measuring less than 7 and more than 5 feet in girth), makes 713 lbs.; and allowing 14 lbs. to the stone, is 50 stone $13 \mathrm{lbs}$.; and where the animal measures less than 9 and more than 7 feet in girth, 31 is the number of pounds to each foot. Again, supposing a pig or any small beast should measure 2 feet in girth, and 2 feet along the back, which, multiplied together, make 4 square feet, that multiplied by 11, the number of pounds allowed for each square foot of cattle measuring less than 3 in girth, makes 44 lbs.; which, divided by 14, to bring it to stones, is 3 stones 2 lbs. Again, suppose a calf, sheep, \&c., should measure 4 feet 6 inches in girth, and 3 feet 9 inches in length, which, multiplied together, makes $16 \frac{x}{2}$ square feet; that multiplied by 16 , the number of pounds allowed to all cattle measuring less than 5 feet and more than 3 in girth, makes 264 lbs.; which, divided by 14 , to bring it to stones, is 18 stones $12 \mathrm{lbs}$. The dimensions of the girth and length of black cattle, sheep, calves, or hogs, may be as exactly taken this way as it is at all necessary for any computation or valuation of stock, and will answer exactly to the four quarters, sinking the offal, and which every man who can get even a bit of chalk may easily perform. A deduction must be made for a half-fatted beast of 1 stone in 20 from that of a fat one, and for a cow that has had calves, 1 stone must be allowed, and another for not being properly fat.

The last act of Parliament on the subject of weights and measures, is the $5 \& 6$ W. 4 , c. 63 , which contains some important provisions. It abolishes all local or customary measures under a penality of $40 s$. for every sale made by them; it prohibits the mischievous practice of selling by heaped measure; it enacts that coals shall in all cases be sold by weight; that with the exception of the preciotis metals, jewels, and drugs, all other articles sold by weight shall be sold by avoirdupois weight only; and that a stone shall in all cases consist of $14 \mathrm{lbs}$. avoirdupois; a hundred weight of eight such stones, \&c. Lead and pewter weights are not to be stamped. It enacts that the Winchester bushel, the Scotch ell, and all local or customary measures shalt be abolished; and every person who shall sell by any measure other than one of the imperial measures, or some multiple or aliquot part thereof, shall be liable to a penalty not exceeding $40 \mathrm{~s}$. for every such sale. That the use of heaped measure shall be abolished, and all bargains, sales, and contracts made after the passing of this aet, by heaped measure, shall be null and void.

Articles sold by heaped Measure, hou to be sold. -Whereas some articles heretofore sold by heaped measure are incapable of being stricken, and may not be conveniently sold by weight; it is enacted, that all such articles may henceforth be sold by a bushel measure, corresponding in shape with the bushel prescribed by the 5 G. 4, c. 74, for the sale of heaped measur or by any multiple or aliquot part thereof, filled in all parts as nearly to the level of the brim as the size and shape of the articles will adsait; but nothing herein shall prevent the sale 1126 if weight of any article heretofore sold by heaped measure.

All coals, slack, culm, and cannel of ever description shall be sold by weight and not by measure.

All articles sold by weight shall be soid by avoirdupois weight, except gold, silver, platina diamonds, or other precious stones, which may be sold by Troy weight, and drugs, which, wher sold by retail, may be sold by apothecaries weight.

The stone, hundred weight, \&c.-From and aftel the passing of this act, the weight denominater a stone shall, in all cases, consist of 14 stand ard pounds avoirdupois, the hundred weight of 8 such stones, and the ton of 20 such hundrec weights; but nothing herein shall prevent any bargain, sale, or contract being made by any multiple or aliquot part of the pound weight.

Fiar prices.-In Scotland, from and after the passing of this act, the fiar prices of all grain in every county shall be struck by the imperial quarter, and all other returns of the prices of grain shall be set forth by the same, withou any reference to any other measure whatso ever; and any sheriff-clerk, clerk of a market or other person offending against this provision shall forfeit not exceeding $5 l$. See FIAR.

Penally on price lists, \&c.-From and after the 1st of January, 1836, any person printing, or clerk of any market or other person making any return, price list, price current, or any journal or other paper containing price list or price current, in which the weights and measures quoted or referred to denote or imply a greater or less weight or measure than is denoted or implied by the same denomination of imperial weights and measures under the provisions of this act, shall forfeit and pay not exceeding 10 s. for every copy of every such return, price list, price current, journal, or other paper which they publish. (Brande's Dict. of Science; M'Culloch's Com. Dict.)

The following observations relative to the weights and measures of the United States are derived from a correspondent of the Farmer's Cabinet.

The subject of establishing by the Congress of the United States a uniform standard of weights and measures for the whole confederacy, is a matter of great importance to the agricultural and commercial interests. Most of the states, perhaps all, have legislated on this very interesting, important, and difficult subject, and it is obvious, from the results of their disjointed labonirs, that there is still room for the exercise of the skill, judgment, and science of the most learned men in the nation, to reduce the chaos to order, and to prepare a uniform system, founded on scientific principles, for the use of the whole nation. Much confusion and loss must be sustained by the great discrepancies which exist in the weights and measures in use in the different states which are in habits of constant conmercial intercouse.

On an examination of the learned and able report made by John Quincy Adams to the Senate of the United States in 1821, and that made by F. R. Hassler to the same body in 
1832, on this subject, it does not appear that the bushel in any two states contains the same number of cubic inches, and some of them differ materially from each other; the weights also are variant, and the measures do not always correspond with each other. In Pennsylvania the Winchester bushel, 18.5 inches in diameter and 8 inches deep, and containing 2150.42 cubic inches, is understood to be the standard dry measure; one-eighth of this, or 268.8 inches, is a gallon, and $67 \cdot 2$ cubic inches the quart, dry measure. The ale gallon is 282 cubic inches, and the quart 70.5 inches; and this is understood to be the quart by which dry articles are measured. The wine gallon, which is also the measure of all spirituous liquors, contains 231 cubic inches, and the quart $57 \cdot 75$ inches. The reason for these differences is not sufficiently apparent to be recognised by any person of ordinary understanding, but they are calculated to produce much embarrassment, and not a little fraud, for there are always persons who are disposed to sell by the smaller rather than the larger measure. In England, whence we obtained all our standards of weights and measures, a better system has of late years been adopted, by which the pint, quart, and gallon, for wine, ale, beer, and grain or corn, measure the same with regard to magnitude; 8 of these gallons make one bushel; and one gallon contains $\mathbf{2 7 7 \cdot 2 7 4}$ cubical inches, or 10 pounds of distilled water at a temperature of 62 degrees; and the imperial bushel 2218.192 cubic inches, or 80 pounds of water at 62 degrees.

From the above it appears that the English bushel at present in use contains 67.772 cubic inches more than the standard bushel of Pennsylvania.

WELD (Reseda luleola). The dyer's weed, yellow rocket, or yellow weed, is in England an indigenous annual plant, growing in waste ground, especially on a chalky soil, as well as in fallow fields, and on walls. The root is tapering. 'The stem wand-like, striated, leafy, somewhat branched, smooth, like the rest of the herb; 2 or 3 feet high. The leaves are sessile, of a darkish green, linear-lanceolate, obtuse, entire, single-ribbed. The flowers are in terminal clusters, erect, many-flowered, dense, pointed. The flowers themselves, which blow in July, are small, greenish-white, without much scent. Weld is cultivated for the sake of its stalks, flowers, and leaves, which are employed for dyeing wool and other substances yellow, or, mixed with indigo, green. The whole plant is fetid when bruised. When it has attained maturity, which is about the time of flowering, it is pulled, and made into bundles and dried, in which state it is used as a dye-stuff. Weld is preferred to all other substances for giving the lively green lemon-yellow: but, to render the yellow permanent, the wool must be previously prepared with a mordant of alum and tartar. Being an exhausting crop, and liable to failure from many causes, the cultivation of the dyer's rocket is only partially carried on in Essex and a few other places in England.

Weld will grow on any soil, but fertile loams produce the best crops. Loudon gives the fol- lowing directions for sowing and masaging weld.

The soil being brought to a fine tilih, the seed is sown in April or the beginning of May, generally broadcast. 'The quantity of seed is from two quarts to a gallon per acre, and it should either be fresh, or, if two or three years old. steeped a few days in water previously to being sown. Being a biennial, and no advantage obtained from it the first year, it is sometime. sown with corn crops in the manner of clover. which, when the soil is in a very rich state, may answer, provided also, that hoeing, weeding, and stirring take place as soon as the corn crop is cut. The best crops, however, will obviously be the result of drilling and cultivating the crop alone. The drills may be a foot asunder, and the plants thinned to 6 inches in the row. In the broadcast mode it is usual to thin them to 6 or 8 inches distance every way; often, when weld succeeds corn crops, it is never either thinned, weeded, or hoed, but left to itself till the plants are in full blossom.

The crop is taken by pulling up the entire plant, and the proper period for this purpose is when the bloom has been produced the whole length of the stems, and the plants are just beginning to turn of a light or yellowish colour; as in the beginning or middle of July in the second year. The plants are usually from 1 to $2 \frac{1}{2}$ feet in height. It is thought by some advantageous to pull it rather early, without waiting for the ripening of the seeds, as by this means there will not only be the greatest proportion of dye, but the land will be left at liberty for the reception of a crop of wheat or turnips; but in this case a small part must be left solely for the parpose of seed. In the execution of the work, the plants are drawn up by the roots in small handfuls, and set up to dry after each handful has been tied up by one of the stalks, in the number of 4 together in an erect position against each other. Sometimes they, however, become sufficiently dry by turning without being set up. After they have re. mained till fully dry, which is mostly effected in the course of a week or two, they are bound up into larger bundles, that contain each 60 handfuls, and which are of the weight of $56 \mathrm{lbs}$. each: 60 of these bundles constituting a load. These last, in places where this kind of crop is much grown, are tied up by a string made for the purpose, and sold under the title of weld cord.

The produce of weld depends much on the nature of the season; but from half a load to a load and a half is the quantity most commonly afforded, which is usually sold to the dyers at from $5 l$. or $6 l$. to $10 l$. or $12 l$. the load, and sometimes considerably more. It is mostly bought by persons who afterwards dispose of it to the dyers occasionally as they find it convenient. 'The demand for it is sometimes very little, while at others it is so great as to raise the price to a high degree. It is sometimes gathered green, and treated like woad or indigo; but in general the dried herb is used by the dyers in a state of decoction.

The use of wold in dyeing is for giving a yellow colour to cotton, woollen, mohair, silk, and linen. Blue cloths are dipped in a decoction of it, which renders them green; and the ye? 
-ow colour of the paint called 1)utch pink is obtained 1.om weld.

To save seed, select a few of the largest and healthiest plants, and leave them to ripen. The seed is easily separated.

The chief disease of weld is the mildew, to which it is very liable when young, and this is one reason that it is often sown with other crops.

W'ELI. (Sax.). A term sometimes applied to a chimney or vent-hole left in a rick or mow of hay, or other similar materials, to prevent its overheating.

WHEAT (Triticum). This is undoubtedly the most important genus of the order Graminec; for wheat is that species of grain which is more generally cultivated than any other, and, from the universal demand and high price it obtains, best repays the European farmer's toil and outlay.

The flour of wheat is the most nutritious and palatable of all the cereal grasses used as the food of man. Linnæus comprehended all the different varieties of wheat known in his day under six species; but modern botanists enumerate about 30 species, and some hundreds of sub-varieties brought in to existence by continued cultivation. It has been well observed that for mere practical purposes it is sufficient to have two general classes, namely, white and red, and the varieties distinguished by their spikelets, as the smooth or bearded, the woodychaffed or the hairy-chaffed. There are some varieties characterized, also, as spring or winter (Lammas) wheats, though these are frequently apt to lose their distinguishing characters, and to accommodate their habits to the season in which they are sown.

"It is to be presumed," says Colonel le Couteur, "from the passage "In the sweat of thy face shalt thou eat bread,' (Gen. iii. 19), that wheat was coeval with the creation; and that upwards of a thousand years before the Christian era, some improvement in its culture and some knowledge of a superior variety had been attained, by the circumstance of its being stated that "Judah traded in wheat of Minnith." (Ezek. xxvii. 7.)

Columella, who wrote about the time of our Lord, makes some interesting remarks on wheal:-

"The chief and the most profitable corns for men," he observes, "are common wheat and bearded wheat. We have known several kinds of wheat; but of these we must chiefly sow what is called the red wheat, because it excels both in weight and brightness.

"The white wheat must be placed in the second rank, of which the best sort in bread is deficient in weight.

"The trimestrian shall be the third, which husbandinen are mighiy glad to make use of; for when, by reason of great rains or any other cause, the early sowing has been omitted, they have recourse to this for relief; it is a kind of white wheat." Pliny says that "this is the most delicious and the daintiest of any sort of wheat, exceeding white, but without much substance or strength, only proper for moist tracts of land, such as those of Italy, and some parts of fiaul; that is ripens equally, and that there is no sort of corn that suffers delay less, be cause it is so tender that such ears of it that are ripe presently shed their grains; but in the stalk it is less in danger than any other corn, for it holds its ear always upright, and does not contain the dews which occasion blasting and mildew." (This description of Pliny's seems to accord with the spring wheat of the present day, which, be it remembered, came to us from Spain.)

"The other sorts of wheat are altogether superfluous," continues Pliny, "unless any man has a mind to indulge a manifold variety, and a vainglorious fancy. But, of bearded wheat, we have commonly seen four sorts in use; namely, that which is called clusinian, of a shining bright white colour; a bearded wheat which is called venuculum; one sort of it is of a fiery red colour, and another sort of it is white, but they are both heavier than the clusinian. The trimestrian, or that of 3 months' growth, which is called halicastrum; and this is the chief, both for its weight and goodness. But these sorts, both of ordinary common wheat and of bearded wheat, must, for these reasons, be kept by husbandmen; because it rarely happens that any land is so situated that we can content ourselves with one sort of seed, some part of it happening, contrary to our ex. pectation, to be wet or dry. But common wheat thrives best in a dry place, and bearded wheat is less affected by moisture."

Hence it appears that Romans were aware of the propriety of selecting their wheat, and that it was then believed that winter or beard. less wheat was best suited to dry uplands, and bearded wheat to low or moist lands. In addrtion to the winter wheats, some of which he states to be bearded, he distinctly alludes to the trimestrian or spring wheat, of which I shall speak hereafter. In the edition of Gerard's Herbal, printed in London in 1660 , only 5 kinds of wheat are enumerated; and, although this was the leading botanical work of the day, these are most indistinctly described.

Modern writers generally are equally vague; they merely designate a number of varieties; but no attempt appears to have been made to class them correctly, or to ascertain their rela. tive values by comparison.

In Sinclair's Hortus Gramineus Woburnensis, 42 of the cultivated varieties are enumerated as winter or spring wheats, according to the arrangement of Linnæus, which this illustrious writer has merely given as a sort of botanical classification.

The Muison Rustique for 1835 , enumerates 39 varieties; and, although a short notice is given of them, it is by no means sufficient, as their farinaceous qualities are not explained. Mr. Paxton, in his Botanical Dictionary, enumerates 25 distinct species, besides several varieties.

A classification of wheat is much required, pointing out the relative value of varieties, in their quantity of meal, the weight of bran and pollards, with the weight of straw of each, and their adaptation to soils. That this is a cleside. ratum no one, I imagine, will deny; but that it requires time, attention, and perseverance, to make such discoveries, will also be conceded, when it is stated that I already possess up. 
wards of 150 varieties or sub-varieties.

\section{Couteur on Wheat.)}

The most popular description of the different species of wheat which admit of cultivation for their seed is that given by Professor L,ow, in his work on the Elements of Agricullure, and I shall therefore avail myself of his scientific description.

Sperific character.-The calyx of wheat consists of 2 valves or glumes, enclosing several florets. In each of these florets there are 2 valves, forming the corolla, and enclosing the seed. Sometimes the corolla encloses a perfect seed, and sometimes the seed is not perfected. Each calyx, with the florets which it encloses, is termed a spikelet. 'The part to which the spikelets are attached is termed the rachis or shaft, and the spikelets placed one above the other, on each side of the rachis, form the ear or head. The rachis is jointed, and the spaces between the joints are termed the internodii.

Species.-1. Spring or summer wheat ( $T$. astivum) $\mathrm{Pl} .2, a$, has awns both on the calyx and corolla. Each spikelet has usually 5 florets, of which 2 are barren. The grain is too tender to bear the frosts of the winter, but as quick in progress from its first shout to ripeness as barley, oats, or any other spring corn. It requires a shorter period to complete its vegetation than any of the other kinds. Summer wheat is the prevailing species of warmer countries, and is cultivated in many parts of Europe. It is much used in France, where it is called ble de Mars, from the season in which $\mathrm{it}$ is usually sown, and in some provinces bleds tremois, from the time it takes between seedtime and harvest. In Spanish it is called trigo de margo; in Portuguese trigo tremes; and in German sommer waitzen, all which names mark distinctly the difference between this and winter corn. It does not appear from the older books on husbandry, that it was at any period much cultivated in England; the more modern ones are, in general, silent on the subject of it; they mention, indeed, under the name of spring wheat, every kind of winter wheat which will ripen when sown after turnips in February. This is probably the reason why the real spring wheat has been so little known; agriculturists in general conceiving themselves to be actually in the habit of sowing spring wheat, when, in reality, they were substituting winter wheat in its place, have been little inclined to inquire into the properties of the true spring wheat when they had an opportunity of so doing.

Its grains are, for the most part, small, and ine produce of the straw is less than that of some other species, when cultivated under the same circumstances. Professor Low says, that "the trials which have been made with it in this country have shown it to be inferior in productiveness and quality to the better kinds of winter wheat. The advantage which it possesses is the earlier period of its ripening, on which account it may be sown so late, even in this climate, as the beginning of May." The Board of Agriculture being desirous of bringing spring wheat into general cultivation, in 1805 offered large premiums to those who should, in the spring of that year, sow the greatest quantity of land with spring wheal In one of the communications made to the Board, Sir Joseph Banks states that "in the countries best acquainted with its culture, spring wheat is preferred to all other corn for raising a crop of seeds. 'This is owing to the small quantity of leaf it bears, less, perhaps, than any other corn, and to the short duration of the leaf, which fades and falls down almost as soon as it has altained its full size.

"In cases where red wheat has been damaged by the wire-worm, a mischief which seems of late years to have increased in Great Britain, spring wheat appears to hold out an easy and simple remedy. In the first week of May the ravages of the worm have somewhat abated; if then the seed of spring wheat is at that time dibbled, or only raked with a garden rake, into the naked spots left by the worm, though it will not attain the growth at which the worm begins to prey upon it till he has changed his state for that of a winged beetle, it will certainly be ripe as soon as the winter wheat, and may be thrashed out and sold with it; or, if it is preferred, may be reaped separately, as the appearance of the ears, which, in the Lincolnshire sort, have longer beards or awns than the rivet or cone wheat, will point it out to the reapers in such a manner that no great error can happen in separating it from the Lammas." (Com. to Board of Agr.vol.v p. 181.) To the miller this mixture of grain can be of no consequence; but it wcrld be scarcely safe to employ the produce as seed.

From the analysis of Sir H. Davy it may be inferred that bread made of the flour of spring wheat is more nutritious than that made of winter wheat, because the former contains a larger proportion of gluten or half-animalized matter. He found that

\begin{tabular}{|c|c|c|c|}
\hline & Gluten. & Starch. & $\begin{array}{l}\text { Insoluble } \\
\text { Matter. }\end{array}$ \\
\hline $\begin{array}{l}100 \text { parts of the best Sicilian } \\
\text { wheat contained }\end{array}$ & 21 & 75 & 5 \\
\hline 100 parts of spring wheat of & 21 & 70 & 6 \\
\hline $\begin{array}{l}100 \text { parts of gond English } \\
\text { wheat of } 1803 \text { - } \\
100 \text { parts of blighted wheat of }\end{array}$ & 19 & 77 & 4 \\
\hline $1804-$ & 13 & 52 & 44 \\
\hline
\end{tabular}

2. Winter, or lammas wheat (T. Lyburnum), Pl. 2, $b$, is distinguished from the last by its appearance, being much more vigorous in the stem, more erect and thick in the ear, by hav. ing no awns upon the calyx, and only short awns upon the corolla, near the summit of the spike. But the awns not being a good botanical character, many botanists have conceived the species to be the same. The characters, however, of either kind being permanent and remaining under given circumstances unchanged for an unknown period, they may be regarded as species. The winter wheat has usually 5 or 6 florets, of which 2 are barren.

Winter wheat is that which is the most important with relation to its cultivation in Northern Europe. It is, in England, generally sown in autumn, or previously to the winter months, and ripens its seed in the following summer: but it is an annul plant, and may be sown in spring.

$5 \mathrm{C}$

1129 
"Silght varieties of this species are exceedngly common in different localities, and are probably attributable to some peculiarities in the mode of culture. 'The common varieties of winter wheat are distinguished from each other according to the colour of the tunic enveloping the grain, and the difference observable in their chaff. The colours are usually divided into white and red, the latter of these including many different shades of brown. Red wheat is commonly said to be more hardy than white; it is therefore thought better suited for cultivation in bleak and upland districts. The plant is, however, not so productive as the white, and the flour which it yields is seldom of so desirable a quality." (Baxter's Lib. of Agr. p. 640.)

3. Compact wheat (T. compactum) is allied to the two last-named species, and may be merely a variety of them. In it the internodii of the rachis are very short. It is partially produced in different parts of Europe. "I have received specimens of it," says Professor Low, "from France and Sweden, and have cultivated them without observing any change of characters. Whether, however, the characters which distinguish it are sufficiently permanent to entitle it to be regarded as a species, has not been determined. In the mean time, following the authority of Host (Icones et Des. Gram. Aust.), I have placed it amongst the species."

4. Egyptian, or many-spiked wheat ( $T$. compositum), Pl. 2, $c$, is distinguished from the others by its branched or compound spike, which no other species tends, under any circumstance, to produce. Its seeds are numerous, and the produce abundant. It requires a good climate and a fertile soil, for in unfavourable situations the branches of the spike are not evolved, and then it assumes the appearance of ordinary wheat. It is cultivated in Egypt and the east, as it is in the south of Europe and different parts of Italy. It was known in Germany about 240 years ago, and in France it is said to have been cultivated for about 80 years, having been brought from the east under the name of wheat of Smyrna. In England it has been partially cultivated as the subject of experiment. It is uncommonly fruitful, and the straw is very strong and tough, whence it has received the name of reed wheat.

The grains, however, do not yield so large a proportion of flour or meal as any of the other species and their varieties, and the flour is scarcely superior to that obtained from the finest barley. Egyptian wheat will bear great degrees of heat and drought without harm, so that it is found to yield abundantly in situations where other kinds would be greatly injured, if not destroyed; a circumstance which points it out as admirably adapted to the arid lands whereon it is chiefly cultivated. It would be more cultivated in England, if its form did not cause $\vdots:$ to hold the wet at harvest-time, and hence it is verv liable to be laid.

5. Turgid wheat (T.turgidum), Pl. 2, d. In this species the corolla is awned, but not the ialyx; the spikes are covered with soft hairs, and in some varieties change to a dark colour, and the awns drop off as the seeds become 1130 ripe, in which respect it differs from sumn.er wheat. It is known in different localities under the several names of gray wheat, duck's bill wheat, gray pollard, rivet, pole rivet, cone, pendulum, \&c. This species grows very tall, with a thick and rigid stem. The spikes are large and heavy, and nod to one side as the grain increases in weight. 'The kinds or minor varieties are distinguished by the farmer from their qualities of earlier or later ripening, and greater or less productiveness. One of the most esteemed of these is cone wheat, so named from the conical form of its spike. The turgid wheats are productive in corn and straw, but the grain is coarse and hard, and the flour much browner and of an inferior quality. They are chiefly suited to the inferior clays, upon which in England they are extensively cultivated. They are valued under such circumstances for their productiveness in grain and their large growth of straw; but being inferior to the winter wheats in the quality of their produce, the cultivation of them is not likely to be extended in that country.

6. Dark-spiked wheat (T. atratum) is allied to the last species, if it is not rather to be regarded as a variety of it. It has merely been made the subject of experiment, but not of extended cultivation. It is not superior in productiveness to the turgid wheats in common use.

7. Barley-like wheat ( $T$. hordieiforme), so named from its peculiar form, resembling that of barley, seems, like that last described, to be derived from Africa. The florets are awned, and the calyx and corolla become dark as the seeds ripen. But it resembles the class to be next referred to, termed spelt-wheat.

8. Far $(T . z e a)$ is one of the class of speltwheats. It is distinguished by the distance of its spikelets from one another. The straw is rigid; the calyx and corolla adhere closely to the seed, and the spikelets again so closely to the rachis, that they cannot be separated from the rachis without breaking it. This wheat is cultivated in some parts of Europe on inferior soils.

9. Spelt-wheat (T. spelta), $\mathrm{Pl} .2, f$, is distinguished like the last by its snikelets being firmly attached to the rachis, and by its rigid calyx and corolla closely enveloping the seed. Spelt is much cultivated in the south of Europe. It is grown extensively in the southern provinces of France, in Switzerland, Italy, in several parts of Germany, and in Airagon, Catalonia, and other parts of Spain, as well as in the north of Africa, and at the Cape of Good Hope. Spelt could be raised in England with facility, and it is probable on soils low in the scale of fertility. It has been cultivated in Scotland, 600 feet above the level of the sea. It is said that spelt-wheat is better adapted than any of the more delicate kinds for culture in Australia, and probably it will be found the more preferable sort in all the more southern wheat-growing countries.

There are two distinct varieties of spelt, distinguished as the awned and the awnless: the latter is perhaps the most naked of all the cerealia. The grains of this are large, but the ear contains only a small number of them. as 
a portion of the flowers prove barren. It is generally, if not always, a spring-sown crop; grows strongly, and its stalks are nearly solid. Bread made of its flour is said to be of a dry quality. It is well known in commerce that the incomparable Nuremberg and Frankfort starch and flour are solely obtained from speltwheat. 'The grain cannot be divested of its husks by thrashing, and therefore requires to be passed through a mill. It should however be sown or drilled with the husks on.

10. One-grained wheat, or St. Peter's corn (T. monocrocum), Pl. 2, g, is readily distinguished from all the other wheats by its general appearance, in which it resembles barley. Its spikelet consists of three or four florets, one of which only is for the most part fertile, and hence its name of one-grained wheat. The fertile floret has a long awn. The stem of this species of wheat is slender and rigid; and, from being both hard and fine, the straw is excellent for thatching. It is allied to the spelts, with which it was classed by some of the older botanical writers. This species is principally cultivated in the mountains of Switzerland and other elevated regions of Europe, and in barren soils. In consequence of its containing less gluten than common sorts, it answers better for being boiled into gruel and for being baked into bread. The four-sided form of the ripe ear is so regular, that it has the appearanee of being carved in ivory. It has never formed an object of cultivation in this country, and does not appear to possess properties to entitle it to be introduced.

11. Polish wheat ( $T$. polonicum), Pl. 2, e. This species has long awns, and is distinguished from all the others by its long and leafy calyx and corolla. It is cultivated in Germany, in Poland, and in Spain. It was brought into notice, and partially cultivated, in some of the counties of England, in the latter part of the seventeenth century; and it is said to have been valued on account of its productiveness of flour. But, although it may be possessed of this quality, its florets are often infertile, and it does not merit a more extended culture in this country. Unless sown sparingly, it is apt to lodge, in consequence of which the quality of the corn is impaired.

Varieties.-The minor varieties of any species of wheat are not permanent in their character, though, under given conditions, they will remain unchanged for an indefinite period. Under other circumstances, however, they degenerate; and herice particular kinds that were once valued have now ceased to be so. The best advice that can be given, therefore, in the choice of varieties and sub-varieties, is to select those which the practice and experience of the principal farmers of the neighbourhood have stamped as the best. Colonel Le Couteur, one of the best authorities on the culture of wheat, has given us the result of his experiments and great experience, upon four of the best pure and improved varieties of wheat lately introduced into England. (Journ. Roy. Eng. Agr. Soc. vol. i. p. 113.)

1. White downy.-This excellent variety is believed to be the same that is so well described by Boys in his General View of the Agri- culture of Kent, as the "Hoary White," or "Velvet-eared," said by him to have been much prized by the millers, but then entirely lost The seed after being washed and steeped was sown in drills 7 inches apart, at the rate of two bushels or a little more to the acre. The wheat was carefully hand-hoed in the month of May, which caused it to tiller freely. The preceding crop was potatoes. This wheat will withstand the most severe weather. The season 1837 to 1838 was a very trying one, both as to wetress and severity of cold, the thermometer having fallen to $18^{\circ}$ below freezing; but the crops of this wheat raised by my neighbours were perfectly insensible to it, and of great produce. This wheat is not remarkable for its early maturity, though it cannot be called a tardy variety. It is not subject to degenerate, and if attention is paid to sowing the seed pure, and annually, or even occasionally, varying the manure intended for it, it is possible that it may never degenerate. The only objection to it is the huskiness or velvety ear, which in damp weather is retentive of moisture; and in snatchy seasons the grain is more apt to sprout than the smooth-chaffed varieties. It is not much affected with dust-brand; and when pickled and limed, has never been found with smut-balls. It is little liable to shed, even when over-ripe, and will resist very heavy gales without being laid or broken.

2. Jersey Dantzic.- The seed is described as having been raised from a single ear, originating from seed procured from Dantzic, selected from the finest "high mixed." It is, however, suspected to be identical with some excellent sorts, called in Sussex, Kent, and some parts of Surrey, the "Chittums;" in other parts "Pegglesham;" in Berkshire, "Trump;" in Essex, "Hardcastle;" in some counties, "Old Suffolk," in Scotland, "Hunter's White;" and assuming several other names. This wheat is not quite so hardy as the "hoary;" it is, nevertheless, considered sufficiently so to succeed throughout the kingdom, excepting the northern parts of Scotland. In rich soils it tillers amazingly, and produces a longer straw than the hoary, nor is it so liable to sprout in a moist climate from being smooth-chaffed: in very severe, moist, and stormy weather, it will be laid sooner than the hoary.

It ripens a week earlier at least than the varicty last described, and should be reaped while the grain can be marked by pressure from the thumb-nail, as it is rather liable to shed if over-ripe, a disadvantage which the hoary is peculiarly free from, as it is tenacious to the ear. In the dry season this wheat will afford a beautiful, clean, white straw, fit for. bonnet-making, or any purpose of thatching: it is firm and tenacious. In wet seasons it is rather subject to rust. which, under such circumstances, almost all wheat suffers from.

3. Whittington Wheat.-The seed was obtained from Mr. Whittington himself, and was a very fine, pure sample. The grain is large, full, and plump, rather of a whitish-red cast, and a little thick-skinned. The seed was washed, pickled, drained, and limed, then sown in drills seven inches apart, about three bushels to the acre. When the seed is large, it is con 
sidered prudent to add half a bushel or more to the acre. I consider this to be a very hardy wheat, affording much herbage and straw, very fit for being eaten down by sheep in the spring when sown early in the fall. The Whittington is rather a late wheat, ripening a week or ten days later than the Jersey Dantzic before described, though it was in bloom on the same day. From the purity of the seed, and the uniform appearance of the crop, it does not appear likely to degenerate, nor does it seem more liable to disease than other wheats. The straw is brittle, and many ears break off. I am of opinion, from what I have witnessed, that the value of this description of wheat is much overrated: the millers dislike it, and in certain situations it is apt to blight.

4. Bellevue Talavera.-This admirable variety is invaluable where it is adapted to the soil and climate. 'The seed being large, a greater quantity of it should be allowed than usual. This wheat has succeeded in the north of Scotland, and is sufficiently hardy to withstand the winter in its grassy state, but it is otherwise more valuable as a spring crop: without doubt it may be sown as late as the first week in February in all the milder parts of England, with a prospect of reaping quite as good an average crop from it as from any other wheat, but with a certainty of obtaining more flour than from most. There is no tendency to degenerate observable in this wheat, as far as the experience of tive or six years goes; nor, from its early habits, is it at all likely to become intermixed by fecundation from other varieties, though sown about the same period, as it will, in such cases, flower a fortnight or three weeks before them. It is not more liable to disease than ordinary white wheats, and affords a very fine, clear, white straw: it is, indeed, one of the Italian bonnet-making varieties. There is, however, one disadvantage in it, which is, that the ear is so heavy that it is apt to break down, though not break off, when swept by a gale about the period of ripening; but it has a countervailing good quality, of ripening the grain equally well though bent down; as is the case with spring wheats, which ripen their seed well though quite laid, which with winter wheats is doubtful. Another peculiarity is the tenacity of the chaff to the ear, more remaining on it after passing through the thrashing. machine than any other variety I am acquainted with.

The following sorts I have also grown experimentally, but, not having raised them in quantities sufficient to warrant a positive opinion, which probably might only tend to mislead, they are merely named.

The "golden drop" is one of the best red wheats, affording great produce in coru and straw, and a larger quantity of flour than some white wheats.

"Hickling's prolific red" is a productive variety, but rather coarse. The properties of this wheat are, straw long, stout at the bottom, and tapering at the head; head short, thick, close, and heavy; kernels four in the row across the ear, and red in colour, with the chaff white; in sample the wheat is short, pluinp, thin-skinned, and looks as if it would flour well: colour dark orange-red.

Brown's "ten-rowed chevalier," or prolific, is well named, where it suits the soil and climate: it is, when pure, a very fine variety.

"Gale's Hampshire" is a very enormously productive sort of bearded wheat. "Essex red," a very good variety. "The duck's-bill" wheat is very productive, but shedding greatly, and not very farinaceous.

In order to present the particular points of comparison between the four principal varieties above-described, the results are appended in a tabular form:-

\begin{tabular}{|c|c|c|c|c|c|c|c|c|c|c|c|c|c|}
\hline \multirow[b]{2}{*}{ Varieties. } & \multirow[b]{2}{*}{ Soil. } & \multirow[b]{2}{*}{ Manure. } & \multirow[b]{2}{*}{$\begin{array}{l}\text { Quantity } \\
\text { of Seed } \\
\text { per Acre. }\end{array}$} & \multirow[b]{2}{*}{$\begin{array}{l}\text { Tirne of } \\
\text { Sowing }\end{array}$} & \multirow[b]{2}{*}{ Harvested. } & \multicolumn{4}{|c|}{ Produce per Acre. } & \multicolumn{2}{|c|}{$\begin{array}{c}\text { Produce per } \\
\text { Acre in }\end{array}$} & \multirow{2}{*}{ 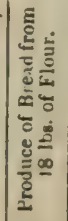 } & \multirow{2}{*}{ 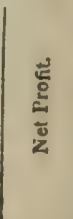 } \\
\hline & & & & & & है & 竧 & 沊 & 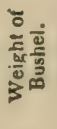 & 尊 & 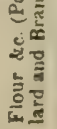 & & \\
\hline $\begin{array}{l}\text { White } \\
\text { Downy }\end{array}$ & $\begin{array}{l}\text { Argillaceous } \\
\text { schist, light } \\
\text { and rich. }\end{array}$ & $\left\{\begin{array}{c}\text { Kelp ashes, } 9 \\
\text { qrs. }\end{array}\right\}$ & 2 bushels. & $\operatorname{Ian} .29$. & Aug. 16. & $\begin{array}{c}\text { bush } \\
48\end{array}$ & $\begin{array}{c}\text { lbs. } \\
4557\end{array} \mid$ & $\begin{array}{l}\text { lbs. } \\
315\end{array}$ & $\begin{array}{l}\text { lbs. } \\
62\end{array}$ & $\begin{array}{c}\text { lbs. } \\
2402\end{array}$ & $\begin{array}{l}\text { lbs. } \\
542\end{array}$ & $\begin{array}{l}\text { 1bs. } \\
25\end{array}$ & $\begin{array}{l}\text { L. S. d. } \\
749\end{array}$ \\
\hline $\left.\begin{array}{l}\text { Jersey } \\
\text { Dantzic }\end{array}\right\}$ & Ditto. & Ditto. & Ditto. & Ditto. & A ug. 12 & $43 \frac{1}{2}$ & 4681 & 430 & 63 & 2161 & 606 & $25 \frac{3}{4}$ & $\begin{array}{l}599 \\
9\end{array}$ \\
\hline$\underset{\operatorname{ton}}{\text { Whitting- }}\{$ & $\begin{array}{l}\text { Do. on a } \\
\text { red clay } \\
\text { bottom. }\end{array}$ & $\begin{array}{l}2 \mathrm{hhds} \text {. of lime. } \\
6 \mathrm{qrs} \text {. lime ashes. } \\
5 \text { qrs. kelp ashes. }\end{array}$ & \} 3 bush. & Jan. 8. & Aug. 24. & 33 & 7786 & 483 & 61 . & 1454 & 524 & $23 \frac{?}{?}$ & 276 \\
\hline $\left.\begin{array}{l}\text { Bellevue } \\
\text { Talavera }\end{array}\right\}$ & Ditto. & Ditto. & Ditto. & Feb. 3. & Aug. 17. & 52 & 5480 & 282 & 61 & 2485 & 626 & 25 & 8129 \\
\hline
\end{tabular}

N. B. - In the estimate of profit, in the last column, the calculation is not made with relation to the respective values of the wheats as to their productiveness in flour, which it might be, but according to the ordinary uarketable value of good wheat ; the straw is valued as intended for manure.

The following is an excellent account of an experiment on the relative values of several varieties of wheat by Mr. John Morton, which I have extracted from the first volume of the Journ. of the Fng. Agr. Soc., p. 39. It is from practical and careiully carried out experiments, such as these, that we shall be able to arrive st the pronortionate value of different species and new varieties of wheat, and from which we may be enabled to select the good and reject the bad kinds.

$113^{\circ}$
The profits of farming, whether the land be pasture or arable, and the tenant be a feeder of stock or a tiller of the ground, may be increased in two ways. The stock-farmer knows very well that the return he obtains from his cattle depends, not only on the kind of food given to them, and the manner in which it is supplied, but also on the feeding quistities of the breed to which they belong; and he increases his chance of profit as much when, on purchasing from the brecder, he selects with 
judgment, as when he adopts an improven mode of feeding. The intelligent farmer of arable land, again, expects a greater crop, the more he has been able to improve the texture of the soil, and the better the nature and state of the manure which it contains. He expects it, because he knows that it depends on the nature of the food given to the plants, and the manner in which they are provided with a constant supply of it. 'The crop does not, however, depend only on this: for as two beasts, fed in exactly the same manner, may not be equally. profitable, owing to a difference between them regarding the quantity and quality of the meat they afford, so two different kinds of wheat, though sown on land precisely similar, and in equally good condition, may give unequal returns, owing to a difference between them regarding the quantity and quality of the flour they afford. Hence the importance, too often overlooked by farmers, not only of preparing the land for the crop in a good and sufficient manner, but also of selecting that kind of seed which experience has pointed out as being most valuable and productive. It was with a view, not only of ascertaining the relative value, hardiness, and other properties of several of the most commonly planted wheats, but also of effecting an improvement in the best of them, that the following experiment was commenced on the Ist of November, 1837. To insure accuracy in the results, it was necessary that the seeds of each variety should be planted so as to have them all at equal distances. To effect this, two boards were used, each 6 inches wide, 9 feet long, and $\frac{1}{2}$ inch thick. Along the centre of each board was a row of holes, 3 inches apart and 1 inch in diameter.
A dibble was made to fit into the holes, having a shoulder at the distance of $2 \frac{1}{2}$ inches from the point.

When the board was placed on the ground, and the dibble put through each hole in succession, a series of holes was thus made, 2 inches deep, and 3 inches apart from centre to centre.

After this had been done through the sist board, the second, which was touching it, and parallel to it, was served in the same way; and then the first was taken up, and placed on the other side of the second. By proceeding thus, the whole ground was finished, and then one grain of wheat was dropped into each hole. The rows were thus exactly 6 inches apart, and the grains in the rows were 3 inches from one another. The regularity with which the planting was performed was thus mathematically accurate. The ground planted lies on the lower edge of the great oolite formation, and the soil is a stone brash, about 10 inches in thickness. Crops of potatoes had been taken off it for a succession of eight years; and it had been manured every alternate year with a compost of equal bulks of stable-dung and earth, at the rate of about 20 cubic yards per acre. It was 67 feet in length; and 3 rows of each variety of wheat were planted, except the first and last numbers, of which there were 4 rows. The outer row of each of these, however, was not taken into account, because their roots had a much greater extent of ground for their growth than the others, whose roots touched one another all round. The end plants of each row were also rejected for the same reason. Sixty-six feet in length of ground were thus taken up, and three rows of each variety occupied in width $1 \frac{1}{2}$ foot: the ground occupied by each variety was thus 99 square feet, the 440th part of an acre:

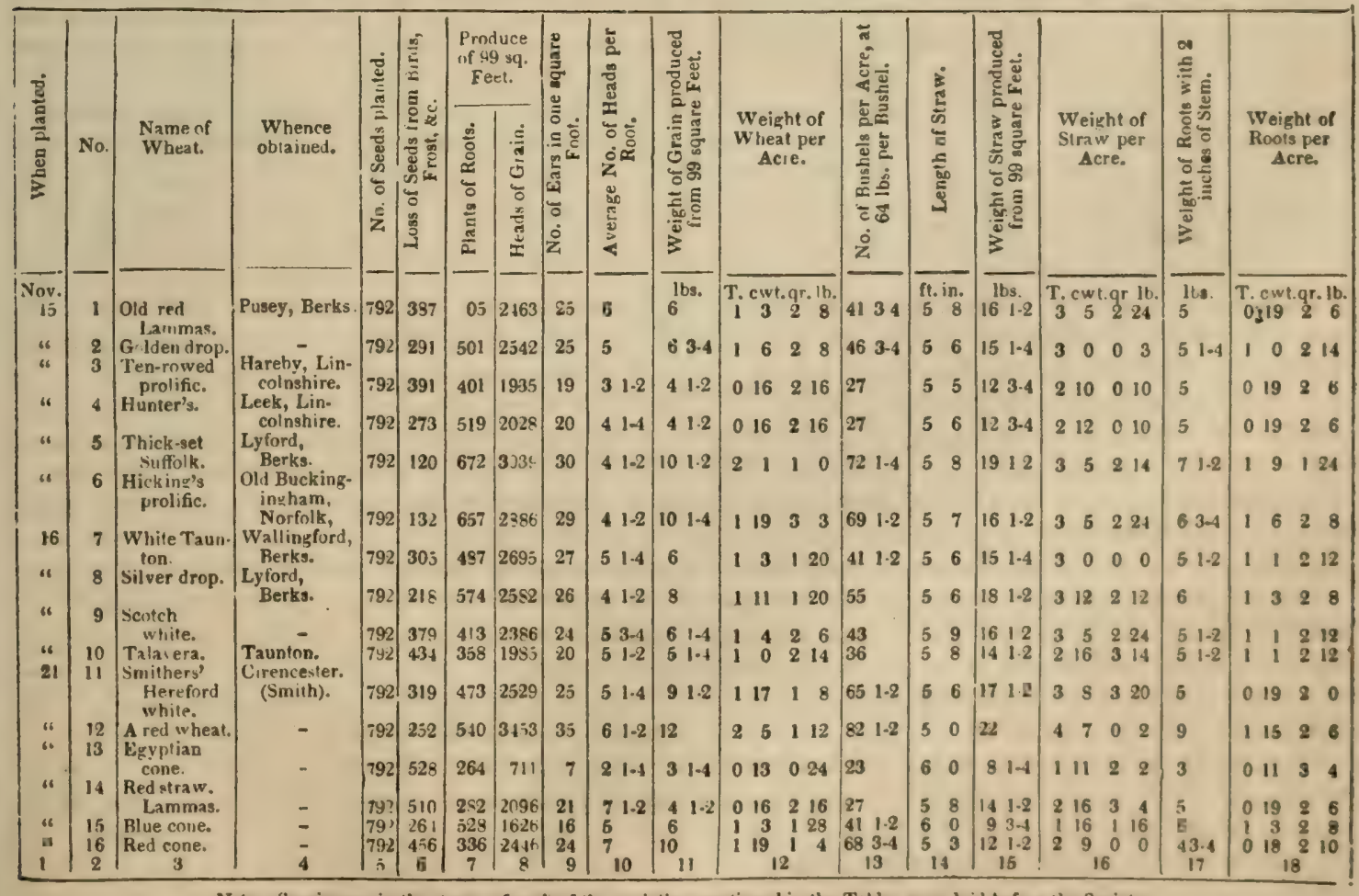

Note-Specimens, in the straw, of each of the varieties mentioned in the Table, were laid before the Socieiy.

Athough the tabular form in which this ex- it. The seed from which the first ten varieties periment is detailed explains itself by the headings of each column, yet it is considered necessary to give a somewhat fuller account of were raised was carefully selected from specimens of each obtained in the ear. The others were from samples, and here, also, the greatest 
care was taken that the seed from which each was raised should be the best and plumpest that could be obtained.

The first five columns need no explanation beyond what is given at the head of each; the sixth shows the number of grains lost from casualties. If the frost had been the only agent in the destruction of so many of the seeds, this column might have been considered as a very accurate index of the relative hardiness of each variety. This, however, is not the case; for the havoc which the birds made must also be taken into account. It was thought at the time that more injury was sustained from the latter cause by those varieties planted on the $21 \mathrm{st}$ than by any of the others; but this does not appear to have been the case, for, if the great loss sustained by these had been wholly owing to the havoc committed by the birds, it is evident that the varieties marked Nos, 12 and 15 would not have been so slightly injured, while Nos. 11, 13, 14, and 16 suffered so severely. The figures in this column may, therefore, be said to indicate with tolerable accuracy the relative ability of each variety to withstand the effects of a severe and changeable winter, such as that during which the experiment was made.

The number of plants of each variety which came to perfection is placed opposite the name of each in the seventh column. This was ascertained by pulling each as they respectively lipened, and counting the plants of each before proceeding to the others. In this way, by a simple subtraction, the numbers contained in the sixth column also were ascertained.

When all the plants of any variety had been pulled, the number of ears also belonging to them was counted, and the results are placed in the eighth column.

By dividing these by 99 , the number of square feet which each variety occupied, we obtain the number of ears in each square foot; and this is placed opposite the name of each wheat, in the ninth column.

The average number of ears to each root, ascertained by dividing the number of ears by that of the roots, is placed in the tenth column. 'This column shows the degree in which each species possesses the important property of spreading and shooting out stems, or, as it is technically termed, of tillering; and it will be seen that they vary in this respect greatly.

After having been pulled and dried, the wheat was carefully rubbed out; and, after the light and imperfect grains had been separated, the weight of the remainder was taken, and placed opposite each sort, in the eleventh column.

The thirteenth column contains the number of bushels per acre raised from each variety. As the quantity produced was so small, there was some difficulty in obtaining the particulars which this column contains.

The mode adopted was this: The average weight of several of the varieties was ascerlained, by weighing 8 pints of each, to be at the rate of $64 \mathrm{lbs}$. per bushel, some being rather more and others less. The number of bushels were then obtained from the weight of wheat per acre, by dividing it by 64 .

The weight of straw, which is placed in the

fofesnth and sixteenth columns, was ascertainJ134 ed after the roots had been cut off, and after it had remained out sufficiently long to dry it perfectly.

- After the earth had been removed from the roots, which had been cut off with about two inches of the stem, they were weighed, and the result placed in the seventeenth and eighteenth columns. The object of this was to ascertain the amount of vegetable matter left in the soil after the wheat crop has been removed, and the result greatly exceeds any conception of it that had been previously entertained.

The inferences which, it is presumed, may be drawn from the above details, are the following:-

1st. With regard to the hardiness of the varieties, which, as we have already said, may, to a certain extent, be deduced from the particulars contained in the sixth column, that they may be placed in three classes. Nos. 5, 6, 8, $12,15,4$, and 2 being the hardiest; Nos. 13, 14, 16 , and 10 being the most delicate; and Nos. $1,3,7,9$, and 11 occupying an average station. $2 d$. With regard to the property of tillering, of which we have already spoken, that Nos. 12, 14,16 , and 1 possess it in the greatest degree; that Nos. $3,13,4,5,6,15,8$, and 2 possess it in the least; and that Nos. 7, 9, 10, and 11 hold a medium rank.

$3 d$. 'That with respect to the relative value of each variety mentioned in the table, No. 12 is undoubtedly the best of any, in productive. ness, and in being sufficiently hardy; that No. 13 is as undoubtedly the worst of any, as will be seen by a reference to any of the columns; and that the others vary greatly, some possessing nearly three times the productiveness of others.

'These 16 different sorts of wheat, with the exception of Nos. 13, 15, 16, which are beard. ed, are merely varieties of one species of the genus Triticum; and the circumstance of differences existing among them, some possessing three times the value of others, shows that any variety is capable of improvement. This, indeed, is shown by many other plants besides the wheat. 'The originals of the potato, the carrot, and the turnip, were comparatively in. significant and useless in their application as food, and it was only by careful and repeated cultivation that they were at length brought to their present condition, and made to hold such an important rank among the many nutritive. plants cultivated for the food of man and beast. It is supposed, then, and where it has been tried experience shows it to be a fact, that, by first ascertaining the best of many varieties of wheat, and planting the finest and plumpest seeds selected from the best sample that could be obtained of it, the last of a succession of crops, the first of which was raised in this manner, and all the others from seeds selected out of the produce of the preceding harvests, would, at length, afford a wheat of a more productive and valuable kind than has hitherto been used by the farmer. The experiment here detailed is, then, merely the first slep in the process; it merely points out the best of the varieties which were tried. The improvement of these by repeated cultivation still remains to be effected.

During the growth of the wheat, a journal 
was kept, an extract from which is given here, as it refers to an insect which was observed after the blossorning of the plants, and to which the destruction of many of the seeds was owing.

Observations of this kind might be easily and generally made, and they would be useful as information regarding the nature and habits of the insects which attack wheat; and answers to the how, when, and where, on the subject, which would thus be obtained, afford the only guide to the invention of means for their destruction.

1838.

\section{Extract from Journal.}

July 5th.-All the wheat is in blossom, except Nos. 13 and 15 .

14th.-Very rainy and windy weather. Whether will this be found to injure or improve the quality of the grain?

16th.-Since the rain of the $14 \mathrm{th}$, an orangecoloured substance, like rust, has been observed in the seed-vessels of some of the ears, as if the rain had got in and rotted the pollen. A very small fly has been observed about the ears in the evening. Many of the ears are filling rapidly; some are already full, and others are only in blossorn.

19th. - In the ears of wheat, which were before-mentioned as having abortive grains, owing, as was thought, to the pollen having been rotted by the rain, I now find small orange-coloured grubs, about the tenth of an inch long, doubtless the offspring of the small fly observed about a week ago.

Aug.4th.-All these grubs have disappeared.

27 th.-Nos, 4, 10, and 11 , are ripe and pulled.

28 th.-Nos. 3,5 , and 6 , are ripe and pulled. 29 th.-Nos. 7,8 , and 9 , are ripe and pulled. 30 th.-Nos. 2, 12, and 16 , are ripe and pulled.

Sept.1st.-Nos. 1 and 14 are ripe and pulled. 2 d.-Nos. 13 and 15 are ripe and pulled.

The account of this experiment is thus finished, and there now remains but to state what will have already occurred to the reader, especially if he be a practical man, that it is not one nor many experiments, if conducted on a small scale, which will accurately determine the point this tends to ascertain.

Soil.-Although wheat can be cultivated on any soil, yet heavy loams, strong clays, and marls are considered to be the best wheat soils, and the larger the proportion of alumin in the soil, the heavier will be the grain, and the more productive the crop.

Sandy soils (says a modern writer) are unfavourable to the growth of wheat, for they are deficient in that degree of firmness which is necessary to support the roots of the plants. It is therefore a crop which should never be sc vn on such land; or if grown, it should only be upon one ploughing of a clover ley, and then afterwards folded by a flock of sheep. (Brit. Husb. vol. ii. p. 140.)

Very fine descriptions of wheat are grown on gravelly, chalky, and finty soils, which have a dry subsoil.

In England the cultivation of wheat varies in different districts, and according to the nature of the soil. Upon heavy clays, the course of cropping is commonly a twelvemonth's fal. low, with from four to six ploughings, \& $\&$., and a dressing of manure or lime, or both. On this description of land, wheat also very cum. monly follows beans, which have been carefully cleaned; and, thirdly, is sown extensively upon clover-leys. On lighter soils, a crop of turnips or rape sown in May, and fed off by sheep early in the autumn, is frequently substituted with advantage instead of a year's naked fallow. And, again, a practice, but which I strongly condemn, is still followed in several parts of England, of sowing dressed or folded rye-grass leys with wheat. (See Rots. Tron of Crops.) On soils adapted for turnips, and where the drill and horse-hoe are employ. ed, a course I much approve from the ley's return, from a small expenditure, consists of : 1 st, turnips; $2 d$, oats or barley; $3 d$, clover ; 4 th, beans or peas; and then, 5 th, wheat.

'The quantity of seed varies considerably; and, although I have witnessed large crops grown from one bushel of seed drilled per acre, the rows at foot intervals, yet the general practice may be taken at from two to three bushels per acre. The time of sowing is from September to March; the winter varieties should be in the ground by the end of November, and the spring varieties as early as the season will admit. For the diseases of wheat see Fly in Wheat, Mindew, and Rust. And I may observe that, although subject to several diseases, yet upon the whole it is the hardiest of the cereal grasses, and flourishes under a greater variety of seasons and climate.

Sowing.-Wheat is either sown broadcast, or by the drill or dibble. Drilling is the most preferable mode. When it is sown in drills, the usual distance between the rows is from 9 to 12 inches; but it is conceived that the larger intervals are the better, and that they may in most cases be even more than 12 inches. The best period of sowing, it has been said, is from about the middle to the end of September. The early part of October, however, is well suited to the sowing of wheat, and it may be continued till the middle of November.

The proportion of seed that is necessary must depend upon and be regulated by a variety of different circumstances, but in general from two to three bushels, according to the state of the soil, the nature of the climate, and the period in which it is put into the ground, may be the most suitable proportion for soils of a medium state of fertility, under the broadcast method of husbandry; but where the drill or dibble system of culture is practised, a considerably less quantity may be sufficient for the purpose. See SErD.

In the case of summer-fallow the quantity of seed need not exceed two bushels to the acre. When the sowing takes place in spring, the quantity may be extended to three bushels. rather less than more.

The cultivation of wheat is rerv rapid hr 


\section{WHEAT.}

either of the following methods : 1. By selecting the grains of superior ears and dibbling them in a seedling bed, 4 inches apart every way. 2. By dividing and transplanting the roots.

The same weight of Rostock and Dantzic flour from wheat grown in the Baltic, made only 23 pounds of bread, very light and good, but not so white by many shades or well-flavoured as that made from the two first varieties of home growth.

These experiments having been made in my own presence, may be relied on. The dough was worked in the French mode, not pushed down, turned and worked with closed hands, but drawn up into long strings, and repeatedly lifted, in order to expose it to the action of the air as much as possible, which tends greatly to improve the bread, by rendering it more light and easy of digestion. See Bread.

The superiority of the hoary variety of wheat, which furnished three pounds more bread on a baking of 18 pounds of flour, or an increase of one-sixth over the Dantzic and Rostock, which was also a very fine sample of flour, is thus clearly established. (Le Couteur on Wheat, p. 44.)

Securing the crop.-I have already briefly adverted under the head REApING to the advantages to be derived from harvesting the grain before it is fully ripe, but have reserved to this place some further experiments and details corroborative of the benefit and profit resulting therefrom, by Mr. John Hannam of North Deighton, near Wetherby. This gentleman remarks,-

"Having selected a field of "old square-headed red wheat' for the experiments, on August 4, 1840 , I cut a sheaf. At this time it was quite green, $i, e$. both straw and ears were in full vigour, and full of sap. Though the grain appeared perfectly formed, the chaff still adhered so firmly to it that it was scarcely possible to separate them by friction in the hands. When separated it was large and plump, but so full of milk, that the slightest pressure reduced the whole to a juicy consistency or pulp.

"This sheaf stood in the field fur a fortnight, when it was housed. On the same day, A ugust 18, I cut another. The wheat was, of course, yet 'green,' speaking positively, or 'not ripe,' if we speak negatively, - being what farmers commonly term 'raw.' This is, the straw, though appearing at a distance green, when examined closely, was of a hue fast apprcximating to yellow; while, for about a foot itpwards from the ground, it was quite yellow. The ears, too, were more open, the chaff tinged with various shades of yellow and green, and the grain itself, when separated, soft and pulpy, but not near so full of fluid as before. The judgment of the farmer will, however, best tell him the conditions of the wheat, both at this and at the preceding cutting, when I say, that in another fcrtnight the whole field was ripe. At the end of this fortnight, (September 1,) I housed the sheaf cut on August 18, and which had remained exposed to the weather in the interval, and cut a third. This I have said was 'ripe;' but by the term I don't mean that degree of ripeness when the straw breaks, the 1136 ears curl, and the grain shakes out; lut that condition in which it is customary to commence reaping it - when the straw, from the roots to the ear, is uniformly yellow, and has lost all symptoms of vivid health.

"On the 14th of September the third sheaf was taken from the field and carefully preserved, along with the other two, till the 1st of November, when, out of each sheaf, I selected 100 ears, and put each parcel into a separate bag. The straw from each of these parcels of ears was preserved carefully.

"The ears in one bag (No. 1, or that cut very green) were now thrashed, the chaff carefully separated, and the gross weight of the corn yielded ascertained by an extremely accurate balance. The weights of a fixed measure of a certain number of grains were next found. To avoid error, this was, repeated several times.

"No. 2 (cut raw) and No. 3 (ripe) underwent the same process: for the results of which see the following table:-

Comparative Weights of Wheat reaped at different periods.

\begin{tabular}{|c|c|c|c|}
\hline Time of reaping, and Condition. & $\begin{array}{c}\text { Gross } \\
\text { Produce. }\end{array}$ & $\begin{array}{c}\text { Equal } \\
\text { Measure. }\end{array}$ & $\begin{array}{c}\text { Equal } \\
\text { Number of } \\
\text { Grains. }\end{array}$ \\
\hline No. 1. Aligust 4 (very & & & \\
green - - & 576 & 568 & 198 \\
No. 2. August 18 (raw) & 736 & 580 & $23 \frac{1}{4}$ \\
No. 3. Sept. 1 (ripe) - & 650 & 570 & $22 \frac{7}{7}$ \\
\hline
\end{tabular}

"As this table is merely comparative (the weights used being in parts, and decimal parts of the same, for the convenience of minute experiments), it may not be unnecessary to give the following table of the absolute weights of each sample in ounces, drachms, scruples, and grains Troy:-

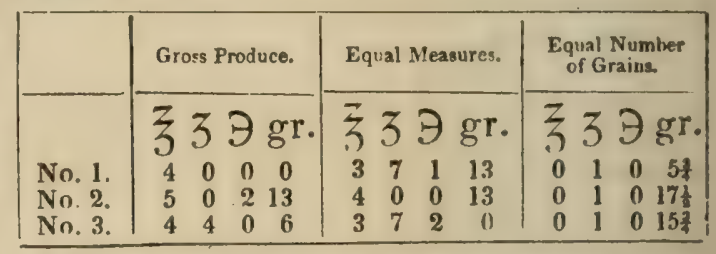

"The straw belonging to each sample was now weighed (all the parcels having previously been made of the same length, commencing from the bottom of the ear), when the following was the result:-

Comparative Weights of 100 Straws of an equal length, belonging to the samples Nos. 1, 2, 3.

$$
\begin{array}{lll}
\text { No. 1. (green) } & = & 550 . \\
\text { No. 2. (raw) } & = & 475 . \\
\text { No.3. (ripe) } & = & 450 .
\end{array}
$$

"The next thing to be ascertained was the quality of the produce, or the comparative worth of each description. Believing in the old saying, that,

"The proper value of a thing

Is just as much as it will bring,'

on the 5th of November I attended market, and asked the opinion of an extensive corn-grower as to the values of the respective samples, according to the prices of the day. His opinion was,

No. 1.

No. 2.

61s. per quarter.

64s. do.

62s. do. 


\section{WHEAT.}

Putting the same samples into the hands of an extensive corn-factor and miller, his opinion of its value, and what he would give to buy, was for

No. 1. - - - - 61s. perquarter.
No. 2. - - $\quad$ - 63 s. do.
No. 3. - - 61s. do.

Adding these values respectively together, and taking the mean price of each (by which we shall obtain as near an approximation to the truth as possible), we have

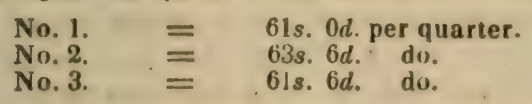

"The loss or gain on these samples, by reaping at different periods, will be best seen from the following

Table of the relative Weights and Value of Wheat cut August 4, August 18, and September 1 ; that cut last (or ripe) being taken as the standard, and unity assumed as its value in each column.

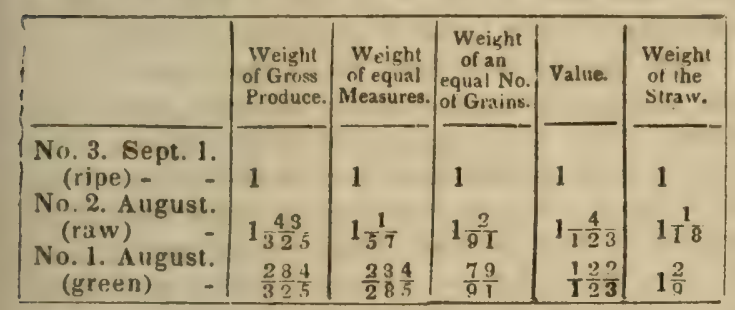

"According to this table, it is evident that the wheat reaped a fortnight before it was ripe has the advantage of the ripe in every point:

1st. In weight of gross produce $\frac{43}{325}$, or $13 \frac{1}{5}$ per cent.

$2 d$. In weight of equal measures $\frac{1}{5}$, or nearly $\frac{1}{2}$ per cent.

$3 \mathrm{~d}$. In weight of equal number of grains $\frac{2}{01}$, or nearly $2 \frac{1}{5}$ per cent.

4 th. In quality and value $\frac{4}{12} \overline{3}$, or above $3 \frac{1}{4}$ per cent.

5 th. In weight of straw $\frac{1}{18}$, or above 5 per cent.

On the other hand, that reaped $a$ month before it was ripe, has an advantage of 22 per cent. in weight of straw, compared with the ripe, but in every other point has the disadvantage: thus,

1st. In weight of gross produce $\frac{37}{3 \frac{7}{5}}$, or $11 \frac{5}{13}$ per cent.

2d. In weight of equal measures $\frac{-1}{2} \frac{1}{3}$, or rather more than $\frac{1}{3}$ per cent.

$3 d$. In weight of equal number of grains $\frac{13}{3}$, or better than $13 \frac{l}{6}$ per cent.

4 th. In quality and value $-\frac{1}{2} \overline{3}$, rather more than $\frac{4}{5}$ per cent.

"It may be here necessary to mention that the sample No. 3 (ripe) was very bold, but rather course, feeling rough in the hand; while No. 2 (raw) was quite as bold, but very fine and thin in the skin. No. 3 (green) was also a good and clear sample, but much smaller than either of the others. This will account for the apparently anomalous fact of there being scarcely any difference in the marketable value of the green compared with the ripe, while there is a difference of 13 per cent. in favour of the ripe in weight of equal numbers of grains; for the sample being dry and good, the buyer lost little by this inferiority in the size of grain, as the weights of equal measures were the same,
WHEAT.

- The difference of $\frac{1}{2} g$ scarcely making 6 in the sack.

"Before venturing to draw any deductions from these experiments, let us put their results in a still more practical point of view.

"Suppose we have 3 acres of wheat, 1 of which, reaped when ripe, yields us 30 bushels of corn and 1 ton of straw: what will be the gross value of the same? And what the value of the other 2 acres, according to the data furnished by the foregoing experiments, supposing each acre to be exactly equal in crop, and the one reaped a fortnight and the other a month before the ripe.

"Before answering this, we must fix a value for the straw-say $2 d$. per stone, which, taking into account that used by the farmer himselfand many cannot sell any -is as much as it is actually worth. Whence we have, for the acre of ripe,

30 bushels of wheat, at 61 s. $6 d$. per quarter (the price of sample No.3.) - - - 1110 \% 1 ton of straw, at $2 d$. per stone - $\quad-\quad-1108$

Gross produce $-\overline{£ 12} \overline{173 \frac{1}{8}}$

"Let us next take the acre cut 'raw.' Before we can come to its value, we must first resolve the question, How much, in measure, will the acre produce us, supposing it to produce 30 bushels, if cut when ripe?

"In solving this, as we must assume each crop to be exactly equal if cut at the same time, it is obvious that, if we would determine the difference caused by reaping at an earlier period, we cannot found our calculations upon the gross weight of the two samples (Nos. 2 and 3 ) ; for, although there is no doubt but that this weight was materially affected by the condition of the wheat at the time of reaping (indeed, the difference in the weight of equal numbers of grains proves the fact), it is possible that, in selecting the 100 ears from the sheaf, I might take out of one sheaf ears with a greater number of grains in them than those taken out of the other. This, then, would affect the total or gross weight; and, therefore, it cannot be taken into account in the present case, where both acres are supposed to have an equal number of grains.

"To the weights of equal measures, and of equal numbers of grains, both the result of many careful trials, this objection cannot be urged; and they are amply sufficient to enable us to tell the produce of an acre of 'raw,' when that of the 'ripe' is 30 bushels. Thus, in the first table, we have,

No. 2. (raw)

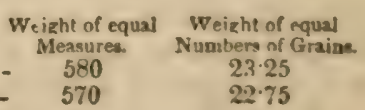
No. 3. (ripe)

Now put $m=$ this measure, and $n=$ the num. ber of grains weighed of each sort; then $n: 22 \cdot 75:: 1: \frac{22 \cdot 75}{n}=$ the weight of one grain of No. 3., whence

$$
\frac{22 \cdot 75}{n}: 1:: 570: \frac{570 n}{22 \cdot 75}=\text { the number of grain. }
$$
of No. 3 in the measure $m$.

Again, similarly, $n: 23 \cdot 25:: 1: \frac{2325}{n}$, we:gn

of one grain of $\mathbf{N o} .2$, and 


\section{WHEAT.}

$\frac{23.25}{n}: 1:: 580: \frac{580 n}{23.25}=$ the number of grains of No. 2 in the measure $m$.

And $m \div \frac{570 n}{22 \cdot 75}=\frac{22 \cdot 75 m}{570 n}=$ the space occupied

by one grain of No. 3 (ripe); and

$m \div \frac{580 n}{23 \cdot 25}=\frac{23 \cdot 25 m}{580 n}=$ the space occupied by one

grain of No. 2 (raw).

Now, as there are the same number of grains upon each acre, and as the acre of ripe yields 30 bushels, we have

$\frac{23 \cdot 75 m}{570 n}: \frac{23 \cdot 25 m}{580 n}:: 30$ bushels : $30 \cdot 1307313$ bush$\mathrm{els}$, the produce of one acre cut a fortnight before the ripe.

Again, by reference to the second table, we have 1 and $1_{T}^{1}$ as the relative weights of the straw No. 3 and No. 2; whence, as No. 3 is supposed to produce one ton,

1: $1 \frac{1}{18}:: 160$ stones : $168 \%$ stones, the weight upon the acre reaped when raw. And for the whole produce of the acre, we have

$30 \cdot 1307$ bushels of wheat, at 63 s. $6 d$. per quarter

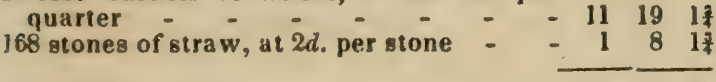

$£ 1 3 \longdiv { 7 3 \frac { 1 } { 2 } }$

Adopting the same course for the produce of the acre cut first, $i$. e. a month before the ripe, and which corresponds with sample No. 1, we get

$\frac{568 n}{19 \cdot 75}=$ the number of grains of the green in the measure $m$; whence $\frac{19 \cdot 75 m}{568 n}=$ the space occupied by one grain of green.

But (vide above), $\frac{22 \cdot 75 m}{570 m}=$ space by one grain of the ripe; whence $\frac{22 \cdot 75 m}{570 n}: \frac{19 \cdot 75}{568 n}:: 30$ bushels: 26.1356 bushels, the produce of the acre cut $a$ month before the ripe. And (vide "Table of relative weights," \&c.

$1: 1 \frac{2}{9}:: 160$ stones : $195 \frac{5}{9}$ stones of straw, the produce of the same; whence we have

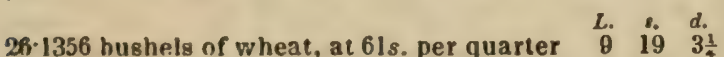
1955.9 stones of straw, at $3 d$. per stone - 1127

\section{£I1 $1110 \frac{1}{4}$}

The total products of the three acres stand thus :-

$\begin{array}{lllll}\text { No. 3. Reaped when ripe } & L & \text {. } & \text { d. } \\ \text { No. 2. Reaped a fortnight earlier } & - & 12 & 17 & 3 \frac{1}{4} \\ \text { No. 1. Reaped a month before the ripe } & 11 & 7 & 31 & 10 \frac{1}{2}\end{array}$

Showing a loss of $11.5 \mathrm{~s} .5 \mathrm{~d}$., or about 10 per cent., by cutting very green; and a gain of 10s. per acre, or nearly 4 per cent., by reaping in a raw state, or a fortnight before it was ripe.

"From the above details, it would appear that it is the farmer's interest to cut his wheat before it becomes thoroughly ripe. Many, no doubt, will be disposed to doubt deductions of such importance, drawn from such limited experiments. This objection the writer anticipates, because it is a natural one, which he felt himself, when he considered the most important conclusions which resulted; when, however. he retraced, step by step, his investigasions, without any variation in that result, he could !135 no longer refuse to believe it true till he proved it untrue. $\mathrm{He}$ is aware that there are other points of consideration in this subject-that there are peculiarities in the nature of land, of seed, or of season, and that there is, as in all man's investigations, a possibility of error; any of which circumstances might materially affect the result of experiments upon so limited a scale as the present one; and for this reason he will, if all be well, give the subject a trial in the ensuing harvest, on a much more comprehensive scale. That the results of these experiments will be corroborative in the main points, he has no doubt, and for this cause he feels no hesitation in laying the preceding 'details' before the agricultural world: moreover, as he has in no case given a deduction without the grounds upon which it rested, the degree of 'acceptation' which the reader may give it rests with himself. The most skeptical, he, however, flatters himself, will think it ' worthy of being tested, if of nothing more.

"In testing, however, the conclusion which the foregoing experiments warrant, there are some other advantages which strengthen that conclusion, which must not be forgotten. That they have not been considered in the preceding pages, is not because they are of no import, but, on the contrary, because they are of such consequence, that the writer could not assign them an adequate momentary value. And had he attempted to do so, he would have at once made the details of his experiments valueless by mixing the real results of practice with the imaginary ones of opinion. Before the sub. ject, however, can be thoroughly sifted, they must be considered. The circumstances are these :-independently of the 4 per cent. gain (according to the foregoing experiments) by reaping our wheat a fortnight before it is ripe, we have,

"1st, Straw of a better quality.

" $2 \mathrm{~d}$, A better chance of securing the crop; and,

" $3 \mathrm{~d}$, A saving in securing it.

"1st, 'Straw of a better quality.' This is easily demonstrated, both for the purpose of food and manure.

"As an article of food, the value of any vegetable depends upon the gross quantity, or upon the combination of certain substances termed soluble, from their entering into union with water. This rule applies particularly to the grasses which are used for the purpose of feeding stock. The substances generaily found in these grasses are saccharine matter or sugar, mucilage or starch, and gluten or albumen, and bitter extract and saline matters. Of these the sugar is, no doubt, the most, and the extractive matter the least, nutritive; the latter having been found, by experiment, to come away in the dung of the animal consuming it, while the other matters were absorbed by the body.

"Now, wheat is a species of grass, and the value of the straw, as an article of food, depends upon the quantity of nutritive matter contained in it. 'This nutritive matter nust be very small in straw, as now generally used,' the practical farmer will say, 'for straw per se is but poor food, and scarcely able to sustain life.' 
This is true; "from $\mathbf{4 0 0}$ grains of dry barleystraw,' says Sir H. Davy, 'I obtained 8 grains of matter soluble in water, which had a brown colour, and tasted like mucilage. From 400 grains of wheaten straw I obtained 5 grains of a similar substance.' With this paucity of nutritive matter in the straw before us, how can we account for the fact that, in the sap of wheat, the straw, and in all succulent plants, there is naturally a great proportion of mucilaginous and succharine matter? The answer is this: in all grasses and succulent plants, the greatest proportion of this is present before the flower is dead ripe. So in wheat, when we allow the straw to remain till thoroughly ripe, a portion of the sugar is converted, by the action of light, heat, \&c., into mucilage, and a great proportion of the nutritive powers of the grass absorbed by the atmosphere, or lost in some manner; for, as Mr. Sinclair observes in his Report of Experiments of Grasses, 'there is a great difference between straws or leaves that have been dried after they were cut in a succulent state, and those which are dried (if I may so express it) by Nature while growing. The former retain all their nutritive powers, but the latter, if completely dry, very little, if any.'

"As a manure, too, the straw cut 'raw' is equally superior to the ripe; for, as it is an agricultural axiom, that the better the food of an animal is, the better the manure from it; the manure from a stock consuming thi.s straw, containing a fair proportion of nutritive matter, must be more valuable than that from stock consuming the ripe with scarcely any in it.

"But a great proportion of the farmer's straw is converted into manure without undergoing the process of mastication and digestion. For this purpose the unripe straw is equally preferable, as all unripe vegetables are manures without preparation; the soluble and nutritive extracts which they contain, being the principal agents in forming vegetable manure; as they not only combine to render the process of decomposition the more rapid, by breaking down the woody fibres, \&c., in the manure heap, but are also, in their pure and separate states, stimulants to vegetation.

"It may be urged, that the increased value of the straw is more in favour of that cut very green (No. 1) than that cut a fortnight later (No. 2). This is true; but to produce this increase of value, if we cut our wheat so early as No. 1, we have a desiccation of the grain to such an extent as to diminish the measured produce above 12 per cent.; while, by reaping with No. 2, we are, so far from injuring either sample or measure, actually improving both, and at the same time gaining above 5 per cent. in the weight, and at least as much in the quality of the straw. For the increase of weight in the latter is not produced by a greater produce, but by the presence of a greater portion of those soluble substances which are alike necessary to animal and vegetable life-are alike the nutritive part of food and the quickening principle of manure.

" $2 \mathrm{~d}$, We come now to the second advantage, the 'better chance of securing the crop.'

"This is self-evident. We gain a fortnight at the commencement of harvest. If the weather be good, we can secure a great portion of our wheat before we should scarcely have begun upon the old system. If not, we can wait; so, under any circumstances, our chances of securing the grain must be greater. Moreover, if we take a retrospect of the harvests for a number of years, we shall find that nearly all the early harvests have been what we term 'good' ones, i. e. good as regards weather and the condition in which the grain was secured. When the peculiarities of our climate, its general fickleness, and its still greater liability to change as the autumn advances, are considered, this will require no explanation.

"If we look, too, at the later harvests, we shall, I venture to say, find, that in nine cases out of ten, the grain which was first cut was secured in the best condition. As an example of this, the crop of 1839 will suffice. The crops were late, the beginning of reaping the same, and the result was, that in the North of England full 75 per cent. of the whole wheat crop was damaged. And full 75 per cent. of that which was uninjured, I will also venture to say, was that which was cut the first. In Yorkshire this was especially seen; for the earliest wheat was, with the greatest difficulty, secured. In this village (North Deighton) not a sheaf was in stack till the day before, and on some farms, the very day on which the rainy weather set in.

"The frequent recurrence of such years as this, will teach the value of even a fortnight, better than any thing that can be said here. And that they will recur is beyond a doubt. What has happened once may happen again, but what has frequently happened (as this sort of harvest has), with the same causes in operation, we are warranted in saying will happen again, and oflen.

" $3 \mathrm{~d}$, The saving in securing the crop is a double one. In the first place, there is less waste in moving or reaping, and no danger of 'shaking' or 'necking' in strong winds. In the second place, there is an absolute economy in the expense of reaping the crop, which may be thus illustrated.

"The busy period of harvest with the farmer generally extends over four or five weeks. In this month a certain portion of his work is done by his own hands, $i$. e. by the regular labourers and servants of the farm; therefore, by beginning a fortnight sooner, and extending the season of harvest over six weeks instead of four, it is evident that these regular servants would cut a much greater proportion of his crop-in fact, one-half more. By this he is rendered less dependent on those extraneous 'helps' or 'takers' who, in the seasons of hurry and anxiety, fix their own terms.

"To assign a value for these advantages is, as has been said before, for the furmer himself; and it will not be an insignificant one. For if beginning harvest a fortnight earlier enables him to save a crop from spoiling once in a lifetime,-if the improved quality of his straw as food for his stock allows him to plough out an acre more, or to pasture another acre of clozer with feeding-stock, instead of mowing it for his lean stock, every grain saved, every extra bushel 
of corn produced, and every extra head of stock fed, is a benefit to the whole community as well as to himself,-is so much added to the gross produce and wealth of the country: there being, in fact, an increased return without an inc"eased oullay." (Quart. Journ. of Agr. vol. xii. p. 24.)

In a recent obliging communication, with reference to this important subject, made to me (March 1842), by Mr. John Hannam, he observes in reference to the experiments above detailed, "At the time I wrote you last I stated that the bulk of the wheat reaped by me during the present harvest was unthrashed. I could therefore only give you an idea of the quality of the raw and the ripe by public opinion from a sample sheaf. Since then the various cuttings (for I made several) have been thrashed and ground. The result of which was, $3 \frac{1}{2}$ bushels of the ripe gave 10 st. 11 lbs. of good flour, 1 st. 9 lbs. of seconds (technically termed 'sharps'), and 2 st. 5 lbs. of bran: $3 \frac{1}{2}$ bushels of raw gave $12 \mathrm{st}$. $6 \mathrm{lbs}$. of flour, $12 \mathrm{lbs}$. of sharps, and 2 st. $1 \mathrm{lb}$. of bran. From which it appears that the raw cut wheat gave $6 \frac{4}{7} \mathrm{lbs}$. of flour to the bushel more than the ripe gave, while the latter gave $3 \frac{1}{7} \mathrm{lbs}$. more sharps and $1 \frac{1}{8} \mathrm{lb}$. more bran than the former per bushel.

"Your question as to the effect of early reaping upon the vegetative powers of the seed I have not answered, because I can give no answer but what depends more upon opinion than fact. I have never seen a practical trial made of wheat, as seed, in the various conditions necessary to warrant a final and definite conclusion. An American writer, commenting upon my experiments, while he coincides with iny conclusions as incontrovertible, says that it is 'equally indisputable' that the ripe wheat is preferable for seed. For all this, I am not disposed to assent blindly to any such doctrine, because I have seen early cut wheat used with perfect success as seed many times."

The editor of the Cultivator, in noticing these facts, remarks:- "A farmer friend of ours, growing wheat extensively, found last season that one of his fields of wheat, then in a very raw or green state, was badly struck with rust. He determined to cut it at once, and did so, amid the laugh or pity of his neighbours, who thought him little better than crazy. The adjoining fields suffered little from rust, and stood ill fully ripe; yet, at thrashing, the wheat first cut gave the finest wheat and the best yield." Mr. Hannam mentions a similar instance, in which it was remarked of a farmer who was cutting his wheat earnestly, that he "had cut grass, and stacked muck;" when thrashed it yielded four bushels per acre more than it had been estimated at, and was sold for the highest price in the market. In this country, the same reason, arising from bad weather or a late harvest, does not exist for early cutting, as in England; but there are others which render the subject of little less interest here than there ; and the agricultural public of both countries are certainly much indebted to Mr. Hannam for the skill and perseverance with which he has pursued these investigations in all their parts.

The editor of the Cultivator proceeds to no1140 tice the experiments reported by Mr. Hannam, and in so doing exhibits the results in a man. ner calculated to be more striking than the statements recently presented in detail. It appears, says the editor, that J. Hannam, Esq. a farmer of Yorkshire, England, made an experiment in cutting wheat by reaping at five different times from the same crop, with the following results as to the time of cutting and value of the produce of an acre, which he sets down at 28 bushels :

No. 1 was cut a month before fully ripe.

No. 2 was cut 3 weeks before fully ripe.

No. 3 was cut 2 weeks before fully ripe.

No. 4 was cut 2 days before fully ripe.

No. 5 was cut when ripe.

'Taking 100 lbs. of grain, he found it to yield flour as follows :-

$\begin{array}{cc}\text { No. } & \text { Flour. } \\ 1 & 75 \mathrm{ibs} \\ \mathbf{2} & 76 \\ 3 & 80 \\ 4 & \mathbf{7 7} \\ \mathbf{5} & \mathbf{7 2}\end{array}$

Seconds.
7 Ibs.
7
5
7
11

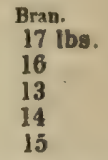

"It thus appears," says Mr. Hannam, "that No. 3 (cut two weeks before it was fully ripe) is superior to all other varieties; giving more per bushel than No. 5 (cut when fully ripe) by $6 \frac{1}{2} \mathrm{lbs}$. of flour, and again of about 15 per cent. on the flour of equal measure of grain. $100 \mathrm{lbs}$. of wheat of No. 3 makes $80 \mathrm{lbs}$. of flour; while 100 lbs. of No. 5 yields 72 lbs.; showing an average of 8 per cent. in favour of grain cut raw. In grinding, it was found that No.5 ground the worst-worse than No. 1. In No. 5 were a greater quantity of flinty particles, which would not pass the bolt, than in any of the others. The bran from No. 5 was coarse and heavy; while that from No. 3 was 'thin as a bee's wing." "

Mr. Hannam extended his experiments to some length, and sums up the advantages of cutting wheat two weeks before it is fully ripe, as follows: first, there is a gain of $\mathbf{1 5}$ per cent. of flour upon equal measures; second, a gain in the weight of straw of 14 per cent.; third, a gain of about 163 in the value of every quarter of wheat; and, fourth, a gain of about 583 upon every acre producing 28 bushels. These calculations are founded upon the price of wheat in England, at the time the experiments were made. The flour produced from No. 3 was of a far better quality than that produced from the grain cut at any other times.

Produce.-The fair produce of wheat (as is well observed by the author of British Husbandry) varies so miach upon different kinds of land, and is so much governed by climate and mode of cultivation, that it is difficult to form any acreable estimate of the amount or average quality in ordinary seasons and under the common course of management; it may, however, be fairly calculated at 3 quarters, or, perhaps, 28 bushels per imperial acre. To produce the latter quantity, circumstarices must, however, be favourable, and any thing beyond that may be considered large, though on some land 4 to 5 quarters are not unusual. The weight may average $60 \mathrm{lbs}$. per bushel. The straw is generally reckoned to be about double the weight of the grain; an acre producing three quarters of wheat of the 
ordinary quality may therefore be presumed to yield about $26 \mathrm{cwt}$.

The use to which the grain is applied is almost exclusively that of food in its various preparations, and chiefly in that of bread, though a considerable quantity-but generally of an inferior or damaged kind-is employed in the manufacture of starch. This preference is due, not only to the superiority of its nutritive properties, but also to their peculiar nature; for "more water is consolidated in bread made from barley, and still more in that from oats; but the gluten in wheat being in a much larger quantity than in any other grain, seems to form a coubination with the starch and water which renders it more digestible than any other." (Lectures on $A g r$. Chem. p. 121.)

Since the Western States have become thickly settled, and so much of their rich lands been brought under tillage, especially since the completion of numerous canals and rail-roads have opened ready markets in the commercial cities, they have poured into these such vast quantities of wheat as have reduced the price and tended greatly to lessen the profits of husbandry in the old Atlantic States. At present, more than a third of the whole wheat crop in the Union is produced west of the mountains, and the proportion is every year rapidly increasing. By reference to the tabular statements of crops (art. AgRICULTURE) it appears that Ohio stands at the head of the wheat-growing states; her product in 1839 having been estimated at over 16,500,000 bushels. Pennsy]vania stands next, having furnished that year upwards of $13,000,000$. The produce of New York is estimated at over $12,000,000$; and of Virginia, 10,000,000 for the same time. These four large states raised upwards of $52,000,000$ of the total amount of $84,823,272$ bushels produced that year in the whole United States. The aggregate of the wheat crop of the United States for 1842, has been estimated at 102,317,540 bushels. (Ellsworth's Rcport to Congress.) The
Governor of Ohio, in his message, computes the wheat crop of that state in 1842, at no less than $24,000,000$ bushels, of which, he thinks, $14,000,000$ may be allowed for exportation, after deducting 10,000,000 for domestic consumption. Some idea of the rapidity with which the wheat crop increases in the Western States, may be formed from the fact, that, in 1840 , the amount of wheat shipped from Chicago to Buffalo amounted to only 20,000 bushels, whilst, in the following year, 1841, it amounted in the sarne period to no less than 200,000 bushels.

The United States present almost boundless facilities over an immense extent of fertile territory for raising wheat. But, great as the aggregate crop at present appears from the preceding statements, it scarcely exceeds that of the comparatively insignificant limits comprehended by the United Kingdom of Great Britain. Notwithstanding her im. mense domestic product of wheat, England is compelled to import annually many millions of bushels from other countries, for only a small portion of which is she indebted to the American farmers, who have for so long a period worn her cloths and tilled their ground with implements of British manufacture. In 1841, when the imports of foreign wheat into the kingdom amounted to $21,604,840$ bushels, the proportion received from her greal customer the United States, only amounted to 2,528,600 bushels.

In June, 1840, Lord Palmerston, the British prime minister, caused letters to be addressed to the British consuls in various parts of Northern and Southern Europe, from which wheat is extensively exported. These letters contained certain queries relating to points connected with the grain-growing countries and their markets. A great many highly interesting facts were elicited in the answers to these circulars, many of which have been condensed in the following tabular form.

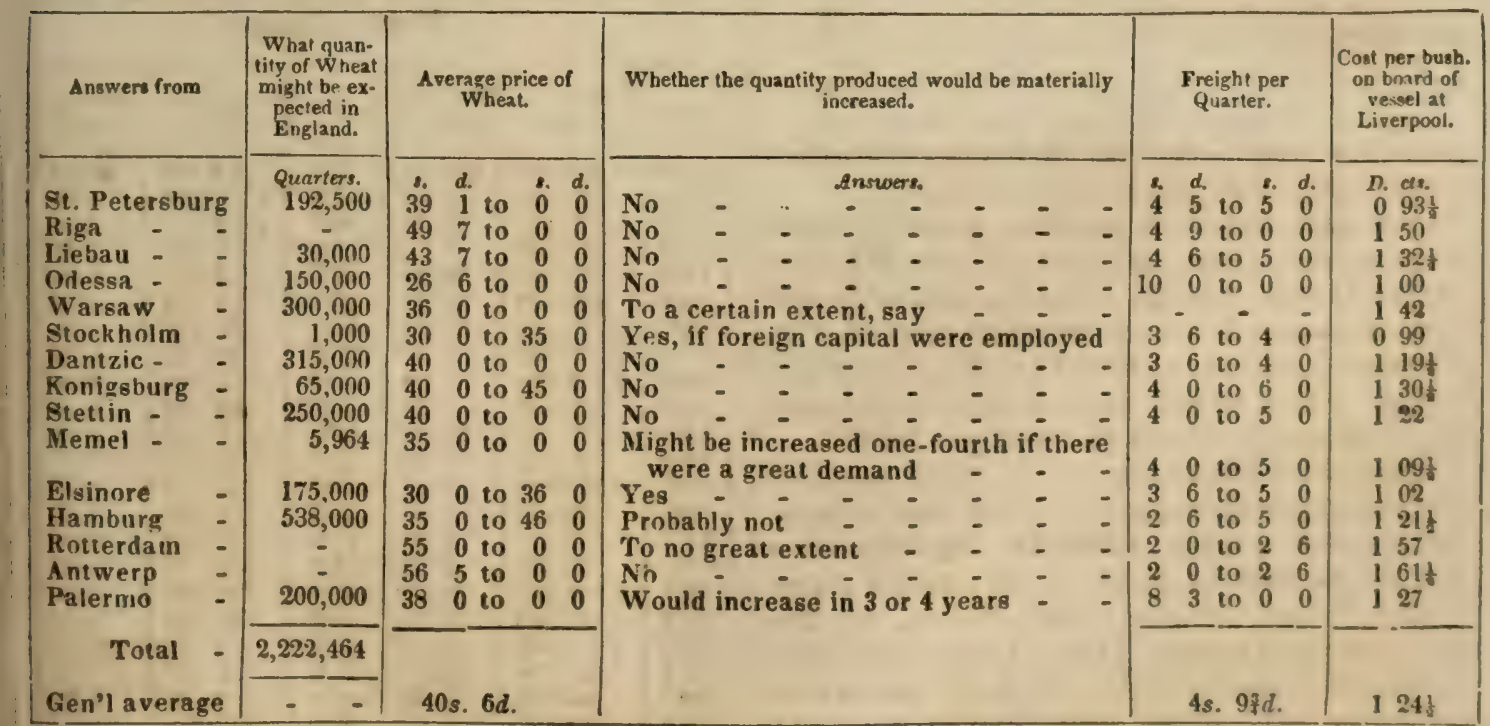

Other facts elicited by these inquiries with / already been extensively tilled, and cannot be respect to other countries competing with the agricultural interests of the United States, mav be interesting. Among these are the following:

It appears that in the grain-growing districts in Europe, the soil contiguous to seaports has pushed further without the aid of artificial manures, while the bad roads from the interior shut them out from a competition with this and other countries more favourably situated.

Thus in Russia: The corn districts are (me 
remote from the seaports for the grain to be ready, in season, for exportation; the rapid increase of manufactures has withdrawn from tillage, \&c.

In Poland, there is a deficiency of manure, and scarcity of hands, and want of skill in cultivation.

From Odessa, the report is that the crops are precarious, on account of drought; tillage is defective, and improvement difficult ; distances great; no roads; the rivers unnavigable; the landholders impoverished, and no improvements to be expected.

It may also be gratifying to some to compare the transportation of flour, \&c., from Poland (one of the greatest grain-growing districts) and the United States to England.

From Poland to Dantzic, the grain is chiefly brought from the interior in flatboats of the rudest construction, similar to those in use on the western waters of the United States, at an expense of 25 cents per bushel, open to the weather, \&c. During the voyage the wheat sprouts, and forms a thick mat or covering for the bulk. On reaching Dantzic, the boat is broken up and sold, the wheat taken out and dried in the fields, then stored in the ware. houses at an expense of 6 cents per bushel. From Dantzic to England the freight, \&ce, not including the duty, is nearly $8 d$. - - equal to about 15 cents per bushel; making in all about 46 cents per bushel. From Illinois to Liverpool the whole freight would be 14s. per quarter, or 1s. 9d.-equal to 38 cents per bushel; being about 8 cents in favour of Illinois. There are costs and charges also, in both cases, which would probably be in favour of our export.

In this connection, it may be interesting to compare a detailed estimate of the exports of wheat from Illinois to England, both by New Orleans and Canada.

\section{Illinois wheat, viu Neu Orleans to Liverpool. \\ Wheat, 4 z bushels, at 50 cents, is - Grinding and harreling (with offal) Freight in New Orleas Freight do Liverpool

which is a little less than 90 cents per bushel. Charges would be alike in both cases.

View the matter in another point of light. Suppose the wheat or flour of the Western States carried through Canada, and, after the 5 th July, to pay 3 s. on an imperial quarter, viz., ( 8 bushels), which is about $8 \frac{1}{3}$ cents per bushel: Foreign wheat would have to pay, at the present sliding rule, about 60 cents per bushel.

The United States, therefore, could succeed with the greatest competitor; but that compelitor cannot supply $1,500,000$ bushels-less than the surplus of some of the smaller states of this Trion produce: and, indeed, all Europe could not supply England with more than $18,000,000$ bushels, under the most favourable circumstances-about three-fourths as much its the state of Ohio now furnishes.

It may be remarked, too, that the crops on the continent are far more precarious than those of the United States; and hence the conlinental governments find it necessary, and are careful to reserve large granaries, to guard 1142 against such a misfortune as a failure of the usual harvest. Exportation thence is also for. bidden in certain cases, but in the United States no such prohibition exists.

While, therefore, we may look with confidence to advantages in our favour in the British market, we must remember that we have to compete against almost unpaid labour, and cannot expect a great profit on our culture, unless the very cheapest mode of production is studied. Labour (as we have before remarked) must doubtless fall very considerably in agricultural districts, or else farmers and planters cannot hire. (Ellsworth's Report.)

With regard to the different kinds of wheat cultivated in the United States, some are best adapted to one latitude and soil, some to another. The fine varieties which succeed so well in England and other parts of Northern Europe, very often fail in the United States, and the most common difficulty with them arises from the circumstance of their tardy habit of maturing, which exposes them to rust and mil dew. Seeds from the southern parts of Eu. rope and shores of the Mediterranean, are those which seem best adapted to the climate of the United States, since these mature very early. A fine red variety, now commonly known as the Mediterranean wheat, is being very extensively cultivated. It seems to have improved under culture in the United States in the essential quali. ties for making flour, since the millers, who at first objected to it and would only purchase at a reduced price, now pay the same as for other red wheat. This wheat has been already mentioned as resisting the attacks of that great American scourge of wheat crops, the Hessian fly.

For the following valuable table, showing the exports of flour from the United States, during a long series of years, with the prices per barrel, we are indebted to Hunt's Merchant's Magazine.

Exports of Flour from the United States, and Price, from 1795 to 1843.

\begin{tabular}{|c|c|c|c|c|c|}
\hline Year & $\begin{array}{l}\text { Flour. } \\
\text { Barrels. }\end{array}$ & $\begin{array}{l}\text { Price per } \\
\text { Barrel. }\end{array}$ & Year. & $\begin{array}{c}\text { Flour. } \\
\text { Barrels. }\end{array}$ & $\begin{array}{c}\text { Price per } \\
\text { Barrol. }\end{array}$ \\
\hline 1795 & 687,369 & $\$ 1200$ & 1819 & 750,660 & $\$ 800$ \\
\hline 1796 & 725,194 & 1600 & 1820 & $1,177,036$ & 537 \\
\hline 1797 & 515,633 & 1000 & 1821 & $1,056,119$ & 425 \\
\hline 1798 & 567,558 & 700 & 1822 & 877,867 & 700 \\
\hline 1799 & 519,265 & 1000 & 1823 & 756,702 & 775 \\
\hline 1800 & 653,052 & 1000 & 1824 & 996,792 & 662 \\
\hline 1801 & $1,102,444$ & 1300 & 1825 & 857,820 & 537 \\
\hline 1802 & $1,156,248$ & 900 & 1826 & 868,690 & 525 \\
\hline 1803 & $1,311,853$ & 700 & 1827 & 837,385 & 800 \\
\hline 1804 & 810,8118 & 775 & 1828 & 860,809 & 550 \\
\hline 1805 & 777,513 & 1300 & $\mathbf{J} 829$ & $1,227,434$ & 550 \\
\hline 1806 & 782,724 & 750 & 1830 & $1,806,529$ & 725 \\
\hline $180 ?$ & $1,249,819$ & 825 & 1831 & 864,919 & 568 \\
\hline 1808 & 262,813 & 600 & 1832 & 955,768 & 587 \\
\hline 1809 & 846.247 & 750 & 1833 & 835,352 & 550 \\
\hline 1810 & 789,436 & 825 & 1834 & 955,768 & 500 \\
\hline 1811 & $1,445,012$ & 1050 & 1835 & 779.396 & 909 \\
\hline 1812 & $1,443,492$ & 1075 & 1836 & 505,400 & 750 \\
\hline 1813 & $1,260,942$ & 1300 & 1837 & 318,719 & 1025 \\
\hline 1814 & 393,274 & 1450 & 1838 & 448,161 & 950 \\
\hline 1815 & 869.739 & 925 & $1 \times 39$ & 923,121 & 675 \\
\hline 1816 & 729,053 & 737 & 1810 & $1,897,50 !$ & 500 \\
\hline 1817 & $1,4 \pi 9,198$ & 1475 & 1811 & $1,032,011$ & 650 \\
\hline 1818 & $1,157,697$ & 102.5 & 1842 & - & 450 \\
\hline
\end{tabular}

From these tables it appears that, during the period 1795 to 1810 , which embraced the European wars, and when the populatium of the United States averaged $5,000,000$, the export 
of flour averaged nearly $1,000,000$ barrels per annum, at near $\$ 10$ per barrel, or an export of 1 barrel to every 5 inhabitants. During the non-intercourse, from 1807 to 1811 , the price fell very low; and in 1812 the export was resumed, and was so large that the rates again rose very high, so high as to check the export. Under the high successive tariffs of 1824-28-33, the export of flour declined, and with that decline prices fell; until after 1834, when debt and state stocks were exported in return for foreign goods, instead of the legitimate export of produce, and the rage of speculation, by checking agriculture, produced actual scarcity, which again brought up prices. The revulsion drove people to work, and the large crops of 1839, assisted by a scarcity in England, caused a great export, which, with the $1,000,000$ barrels sent forward in 1841, raised the value of the whole crop $\$ 150$ per barrel, or 25 per cent. in that year. 'The surplus of those two years may be estimated at 2,500,000 barrels. Ac. cording to the census, there were produced in 1839 , in round numbers, $8,000,000$ barrels of flour, and the product of 1840 was estimated at $12,000,000$ barrels, worth $\$ 60,000,000$. The export of one-sixth part, or $2,000,000$ barrels, raised the price to $\$ 650$ in 1841 , or the value of the crop to $\$ 78,000,000$; making a difference, in favour of the farmer, equal to $\$ 18,000,000$ or 30 per cent. (Hunt's Mag.)

The average price of wheat may be estimated pretty correctly from that of flour, by adopting the miller's rule of computing the price of a bushel of wheat weighing $60 \mathrm{lbs}$. as one-fifth the price of a barrel of flour. Bee Bread, Flour, Fly ix Wheat, Grain, Graix FLY, \&cc.

\section{Partianentari Paperg nelating to Wheat and othen Gratx.}

Statement of the Quantities of each kind of Grain imported into England from 1828 to 1841.

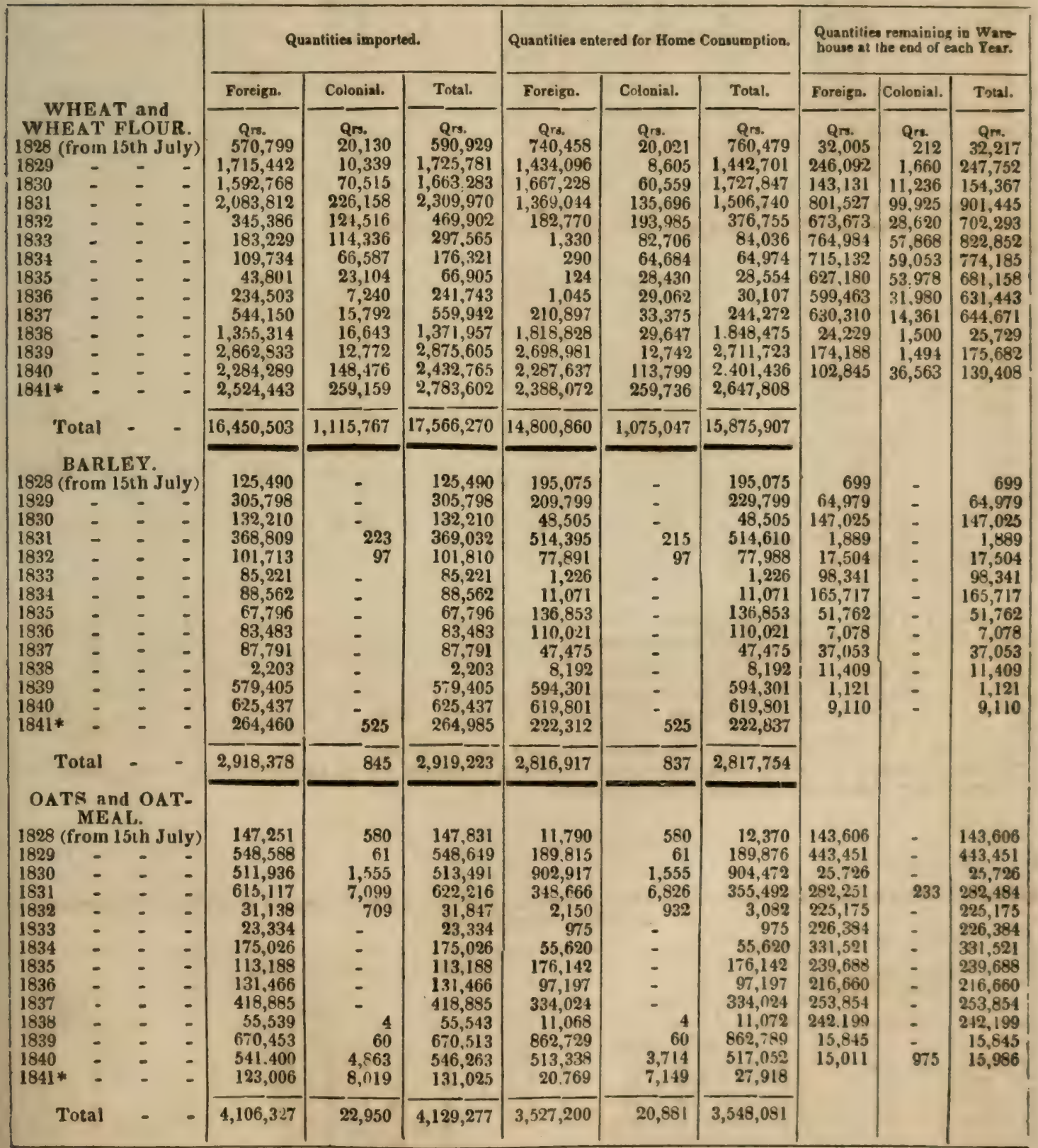

- Tha Returns for 1841 will be liable to alteration (although not to any considerable extent) when the Accounts of that year shall have been finally adjusted. 
WHEAT.

WHEAT.

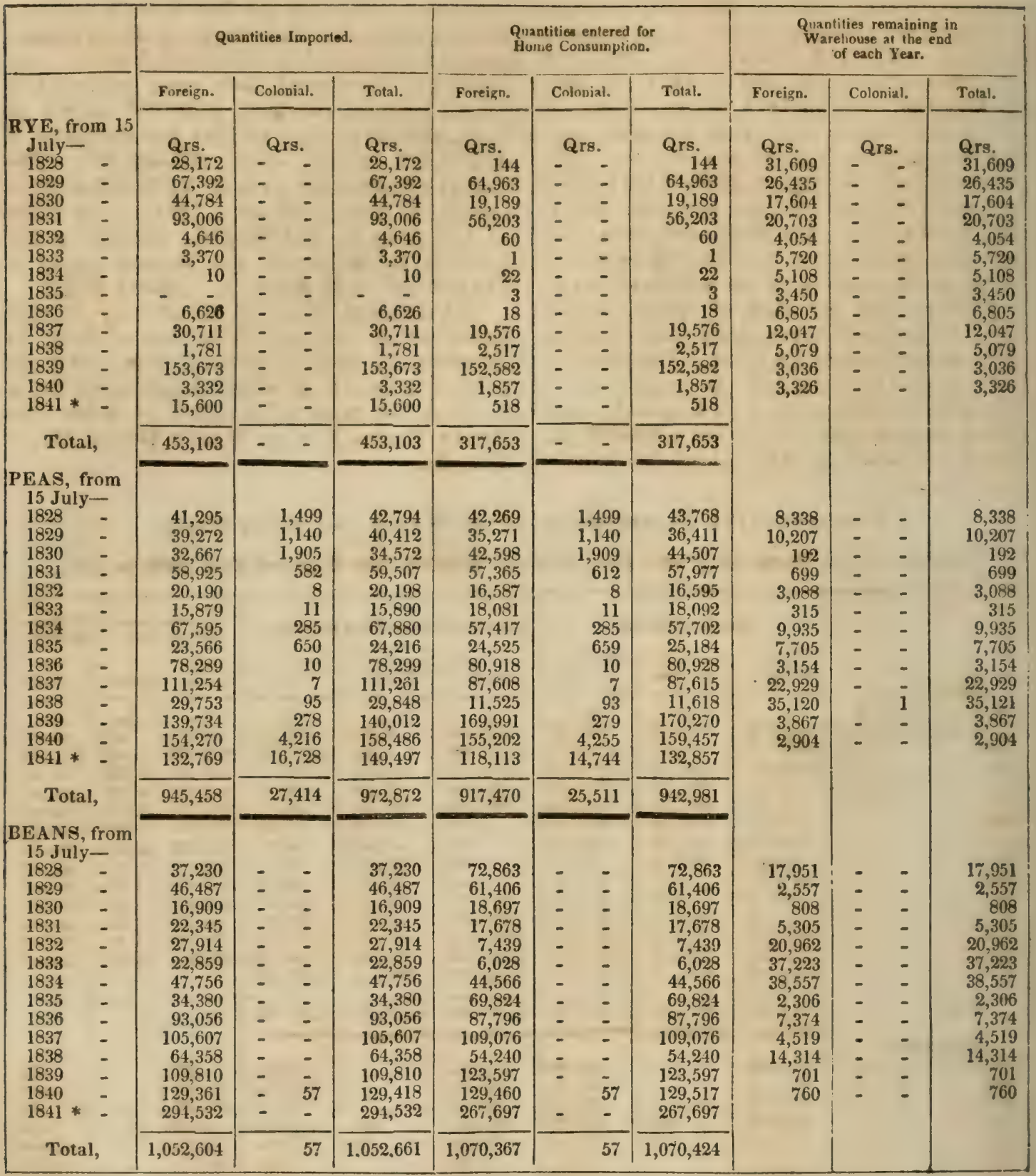

Previously to 1833 , the monthly returns of the importation and consumption of foreign and colonial corn were collected together, in annual periods, commencing on lst January, and terminating on 3îst December. From 1833, downwards, they have been made up, like the other accounts of this department, in periods, commencing on fith January in each year, and terminating on 5th January, in the year succeeding. This circumstance is necessary to be noted, inasinuch as it explains why the aggregate imports and consumption of the several years, from 1828 to 1832 inclusive, as exhibited in the present statement, will be found to differ, to a small extent, from the quantities shown in other accounts, which have been compiled, not, as in this case. from special monthly returns of the corn trade, but from the ordinary records of the general commerce of the country.

* Note. - The returns for 1841 will be liable to alteration (although not to any considerable extent) when the accounts of that year shall have been finally adjusted.

Statement of the Septennial Prices of each kind of Grain, as prepared for the Purposes of the Tithe Commission, in each Year, from 1835 to 1841 .

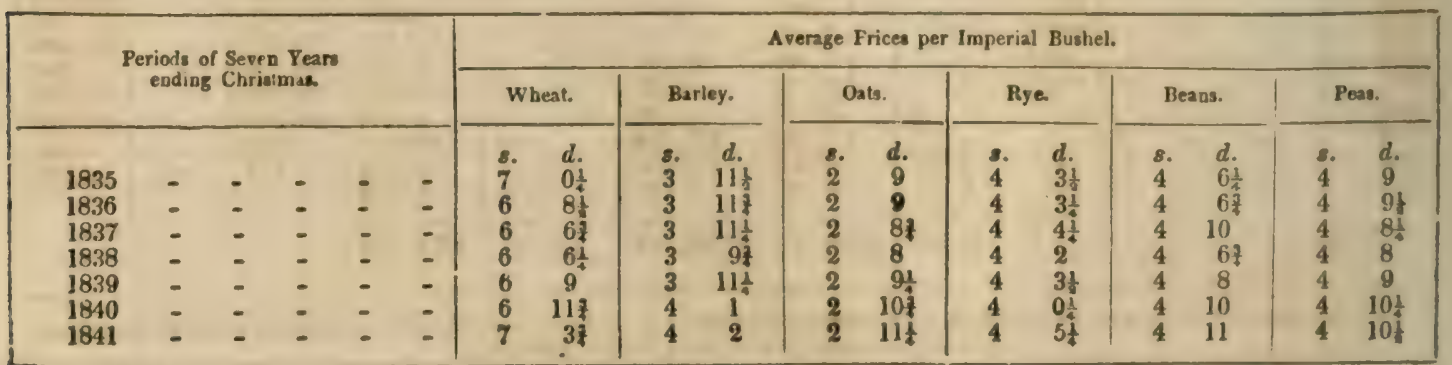


Sistement of the Total Quantities of Wheat and Wheat Flour imported into, and exported from, Great Brilain, in each Year, from 1697 to 1841.

\begin{tabular}{|c|c|c|c|c|c|c|c|c|}
\hline Yeara. & Iinporied. & Exported. & Years. & Imported. & Exported. & Years. & Impinrted. & Expories. \\
\hline 1697 & $\begin{array}{l}\text { Qrs. } \\
\quad 400\end{array}$ & $\begin{array}{l}\text { Qrs. } \\
14,698\end{array}$ & 1746 & Qrs. & $\begin{array}{l}\text { Qr8. } \\
\text { 131,105 }\end{array}$ & 1795 & $\begin{array}{c}\text { Qrs. } \\
313,793\end{array}$ & $\begin{array}{l}\text { Qrs. } \\
18,830\end{array}$ \\
\hline 1698 & 1,689 & 6,886 & 1747 & - $\quad-$ & 270,191 & 1790 & 879,200 & 21,679 \\
\hline 1699 & 486 & 557 & 1748 & 6 & 545,240 & $1 \% 97$ & 461,767 & 54,525 \\
\hline 1700 & 5 & 40,057 & 1749 & 382 & 631,007 & 1793 & 396,721 & 59,782 \\
\hline 1701 & 1 & 98,324 & 1750 & 280 & 950,483 & $1 \% 99$ & 463,185 & 39,362 \\
\hline 1702 & - & 90,230 & 1751 & 3 & 662,957 & 1800 & $1,264,520$ & 22,013 \\
\hline 1703 & 50 & 106,615 & 1752 & - & 430,117 & 1801 & $1,424,765$ & 28,406 \\
\hline 1704 & 2 & 90,314 & 1753 & - & 300,754 & 1802 & 647,663 & 149,304 \\
\hline 1705 & - & 96,185 & 1754 & 201 & 356,781 & 1803 & 373,725 & 76,580 \\
\hline 1706 & 77 & 188,332 & 1755 & - & 237,466 & 1804 & 461,140 & 63,073 \\
\hline 1707 & $-\quad-$ & 174,155 & 1756 & 5 & 102,752 & 1805 & $920,83\lfloor$ & 77,955 \\
\hline 1708 & 80 & 83,969 & 1757 & 141,562 & 11,545 & 1806 & 310,312 & 29,566 \\
\hline 1709 & 1,552 & 71,618 & 1758 & 20,353 & 9,234 & 1807 & 401,916 & 25,113 \\
\hline 1710 & 400 & 16,607 & 1759 & 162 & 227,641 & 1808 & 81,889 & 99,005 \\
\hline 1711 & - & 80,911 & 1760 & 3 & 393,614 & 1809 & 455,987 & 31,278 \\
\hline 1712 & - & 148,539 & 1761 & - & 441,956 & 1810 & $1,567,126$ & 75,785 \\
\hline 1713 & $-\quad-$ & 179,969 & 1762 & 56 & 295,385 & 1811 & $3 \approx 6,131$ & $9 \%, 765$ \\
\hline 1714 & 16 & 180,665 & 1763 & 72 & 429,538 & 1812 & 290,710 & 46,325 \\
\hline 1715 & $-\quad-$ & 173,237 & 1764 & 1 & 396,857 & 1813 & 559,000 & $\{$ Records \\
\hline 1716 & - & 75,876 & 1765 & 104,547 & 167,126 & & & castroyed. \\
\hline 1717 & - & 25,637 & 1766 & 11,020 & 164,939 & 1814 & 852,567 & 111,477 \\
\hline 1718 & - & 74,381 & 1767 & 497,905 & 5,071 & 1815 & 381,475 & 227,917 \\
\hline 1719 & 20 & 130,533 & 1768 & 349,268 & 7,433 & 1816 & 332,491 & 121,611 \\
\hline 1720 & - & 84,343 & 1769 & 4,378 & 49,892 & 1817 & $1,089,855$ & 317,524 \\
\hline 1721 & - & 82,748 & 1770 & 34 & 75,449 & 1818 & $1,691,261$ & 58,668 \\
\hline 1722 & - & 178,915 & 1771 & 2,510 & 10,089 & 1819 & 625,638 & 44,689 \\
\hline 1723 & - & 158,082 & 1772 & 25,474 & 6,959 & 1820 & 996,479 & 94,657 \\
\hline 1724 & 148 & 247,162 & 1773 & 56,857 & 7,637 & 1821 & 707,384 & 199,816 \\
\hline 1725 & 12 & 211,175 & 1774 & 289,149 & 15,928 & 1822 & 510,602 & 160,499 \\
\hline 1726 & - & 143,626 & 1775 & 560,988 & 91,037 & 1823 & 421,019 & 145,951 \\
\hline 1727 & - & 31,030 & 1776 & 20,578 & 210,664 & 1824 & 411,591 & 61,680 \\
\hline 1728 & 74,574 & 3,935 & 1777 & 233,323 & 87,686 & 1825 & 787,606 & 38,796 \\
\hline 1729 & 40,315 & 18,993 & 1778 & 106,394 & 141,070 & 1826 & 897,127 & 20,054 \\
\hline 1730 & 76 & 91,530 & 1779 & 5,039 & 222,261 & 1827 & 711,868 & 57,323 \\
\hline 1731 & 4 & 130,650 & 1780 & 3,915 & 224,059 & 1828 & $1,410,300$ & 76,489 \\
\hline 1732 & - & 202,612 & 1781 & 159,866 & 103,021 & 1829 & $2,190,09 j$ & 75,097 \\
\hline 1733 & 7 & 427,425 & 1782 & 80,695 & 145,152 & 1830 & $2,205,751$ & 37,149 \\
\hline 1734 & 7 & 493,747 & 1783 & 584,183 & 51,913 & 1831 & $2,86 i, 860$ & $65,8 \div 5$ \\
\hline 1735 & 9 & 155,280 & 1784 & 216,917 & 89,288 & 1832 & $1,254,351$ & 289,558 \\
\hline 1736 & 18 & 118,218 & 1785 & 110,863 & 132,685 & 1833 & $1,166,457$ & 96,212 \\
\hline 1737 & 32 & 466,071 & 1786 & 51,463 & 205,466 & 1834 & 931,456 & 159,482 \\
\hline 1738 & 3 & 588,284 & 1787 & 59,339 & 120,536 & 1835 & 750,808 & 134,076 \\
\hline 1739 & 23 & 285,492 & 1788 & 148,710 & 82,971 & 1836 & 861,156 & $2: 6,978$ \\
\hline 1740 & 5,469 & 54,391 & 1789 & 112,656 & 140,014 & 1837 & $1,109,492$ & 308,420 \\
\hline 1741 & 7,540 & 45,417 & 1790 & 222,557 & 30,892 & 1838 & $1,923,400$ & 158,621 \\
\hline 1742 & 1 & 295,698 & 1791 & 469,056 & 70,626 & 1839 & $3,110,729$ & 42,512 \\
\hline 1743 & 3 & 375,979 & 1792 & 22,417 & 300,278 & 1840 & $2,526,645$ & 87,242 \\
\hline 1744 & 2 & 234,274 & 1793 & 490,393 & 76,869 & 1841 & $2,923,189$ & 30,390 \\
\hline 1745 & 8 & 325,340 & $1 \% 94$ & 327,902 & 155,048 & & & \\
\hline
\end{tabular}

Note.-This Account includes the Trade with Ireland. 
Statement of the Quantities of the several kinds of Grain and Meal imported from each Country, and likeurse of the Quantities re-exported from the Warchouse to each Country, in each Year, from 1828 to 1840 , (omitting 1829 and 1831.)

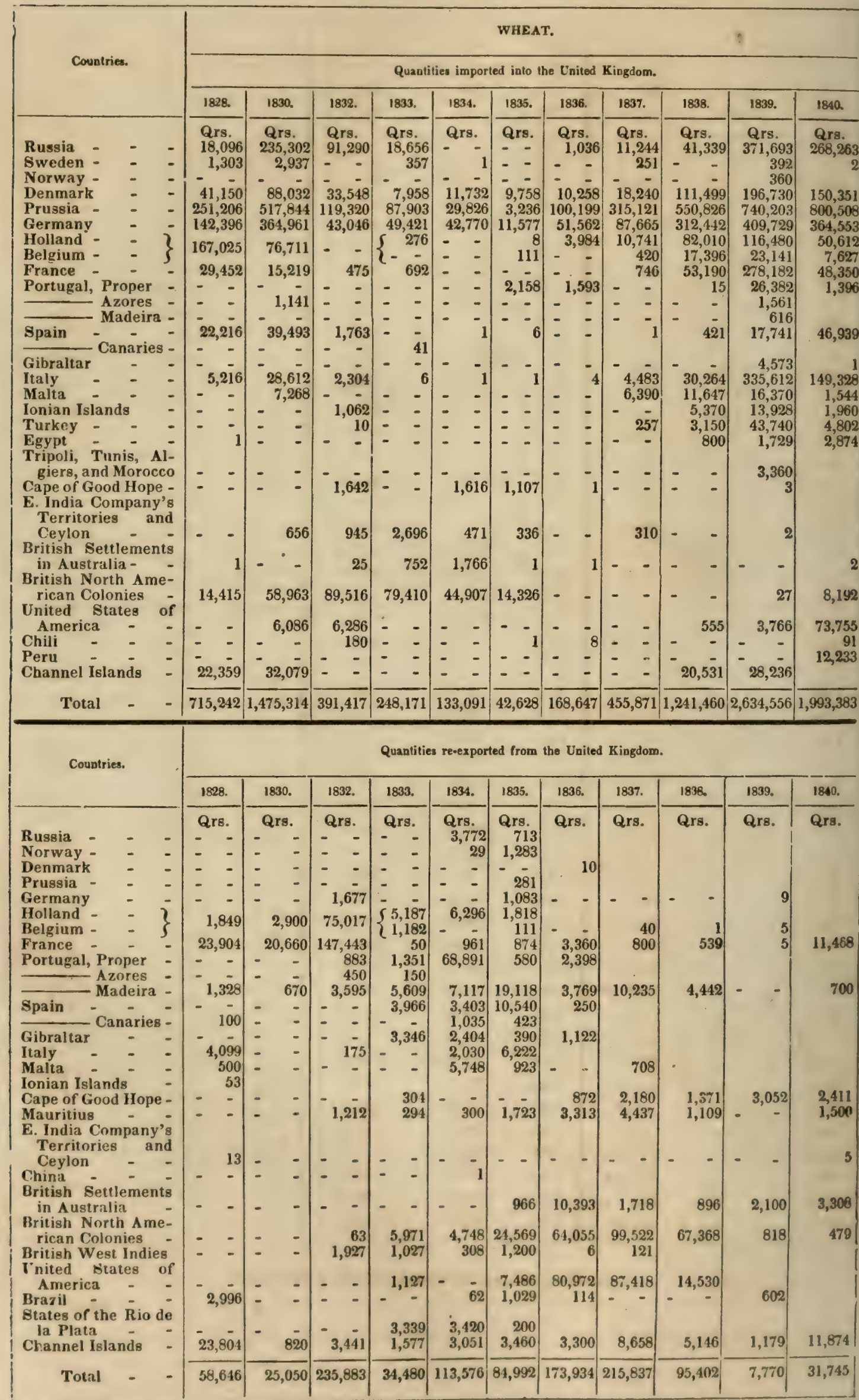


WHEAT.

WHEAT.

Statement of Quantities of Grain and Meal imporled, and Quantities re-exporled, in each Year, from 1828 to 1840 -Continued.

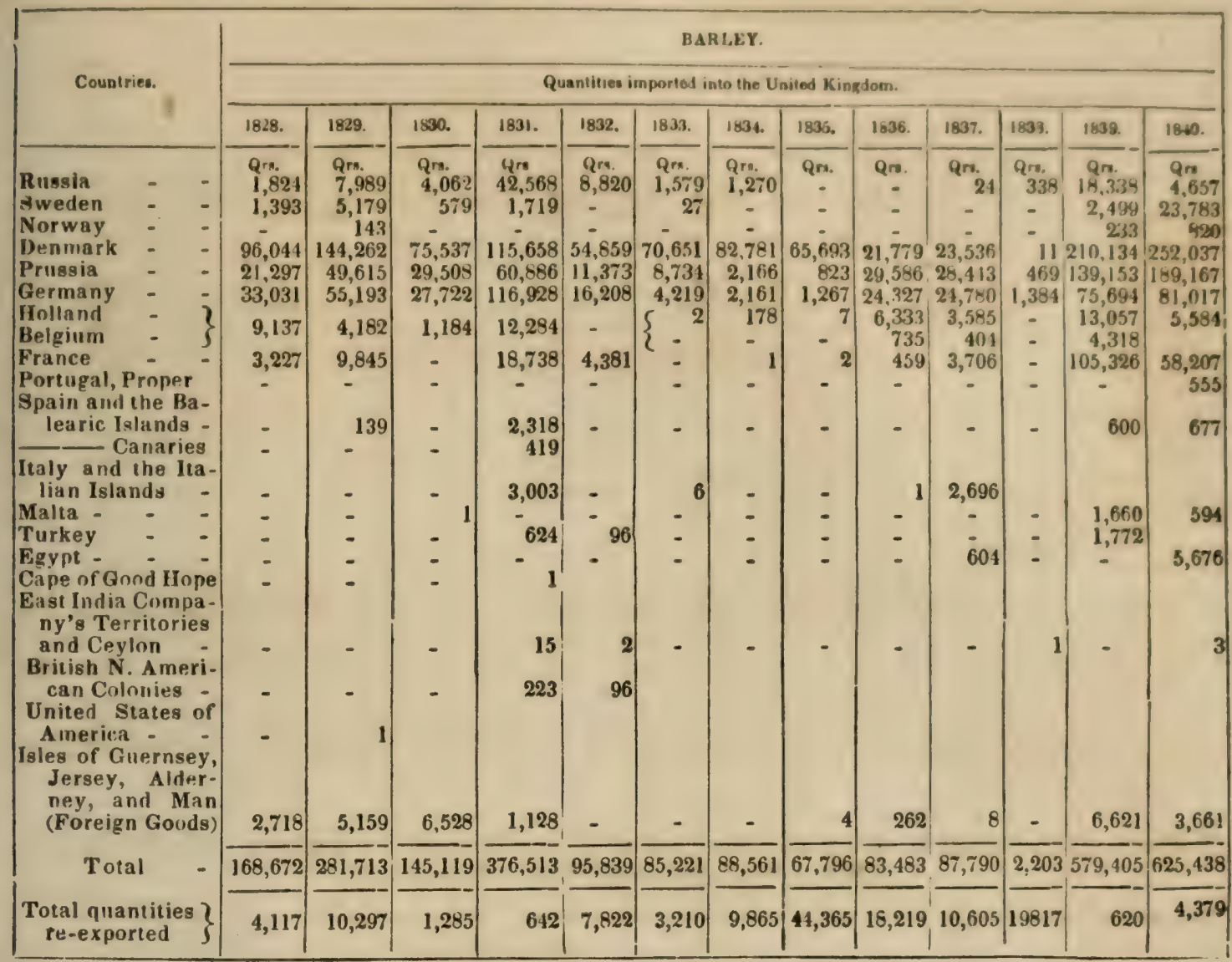

Statement of Quantities of Grain and Meal imported, and Quantilies re-exported, in each Year from 1828 to 1840 (omitting 1829)-Continued.

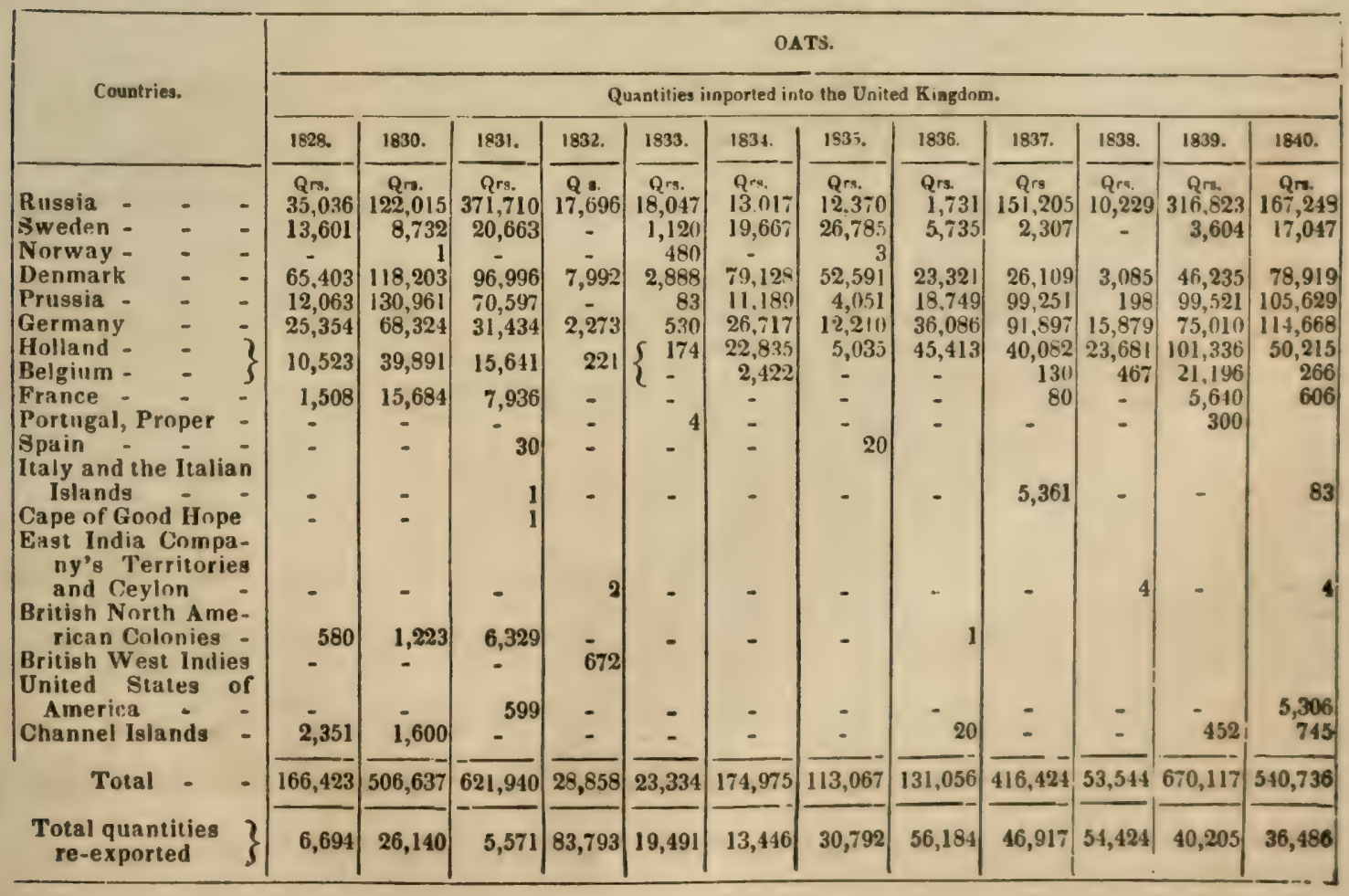

Note. - Of the Oats re-exported, by far the largest amount went to the British Colonies, especially to those te the West Indies. 
Statement of Quantities of Grain and Meal imported and Quantities re-exported, in each Year, from 1828 to 1840 - Continued.

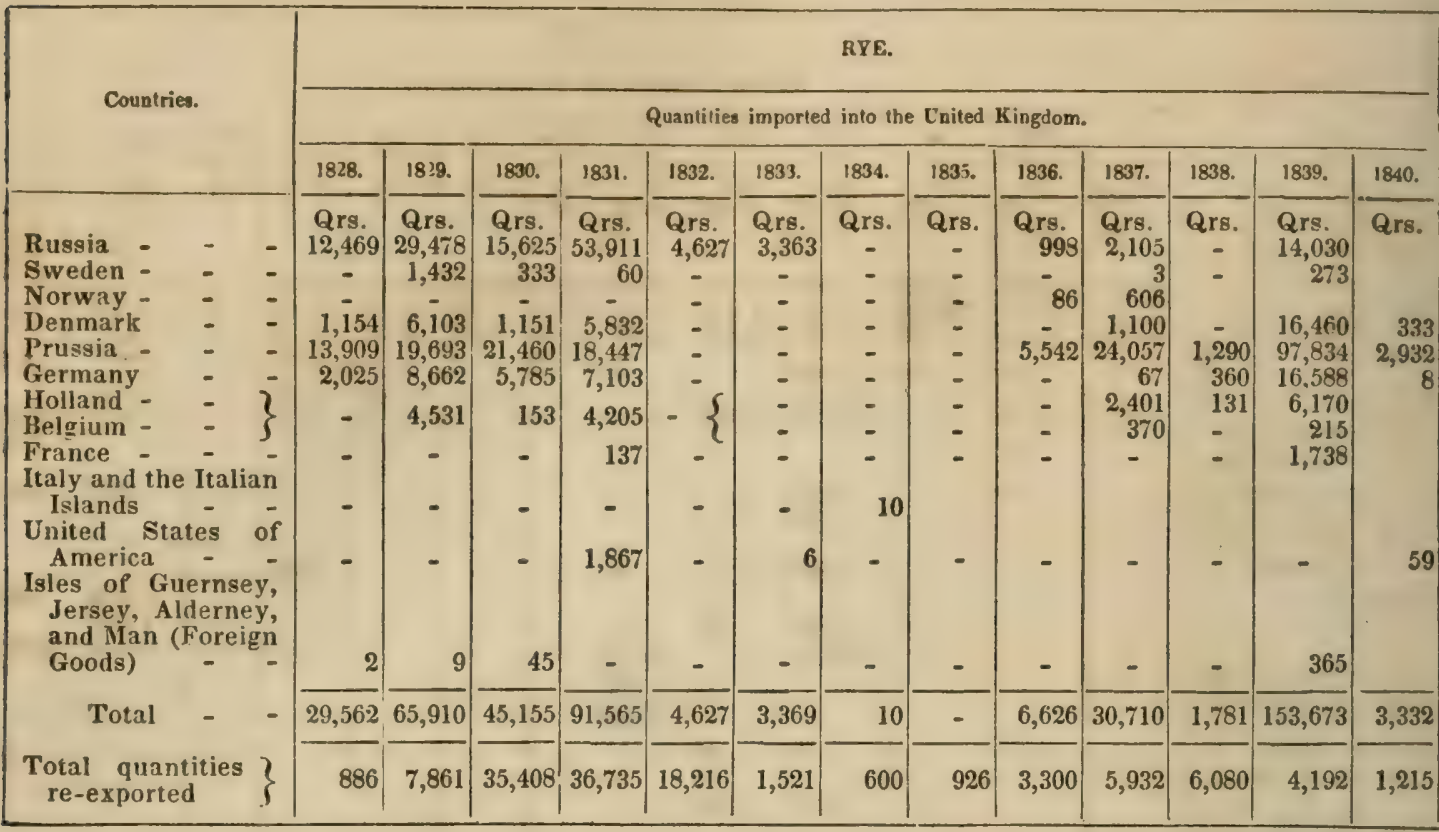

Note.-Of these re-exportations the largest amount went to Holland and Belgium, and in the years 1836, 1837, and 1838 to the United States.

Statement of Quantities of Grain and Meal imported and Quantities re-exportea, in each year, from 1828 to 1840, (omitting 1829)-Continued.

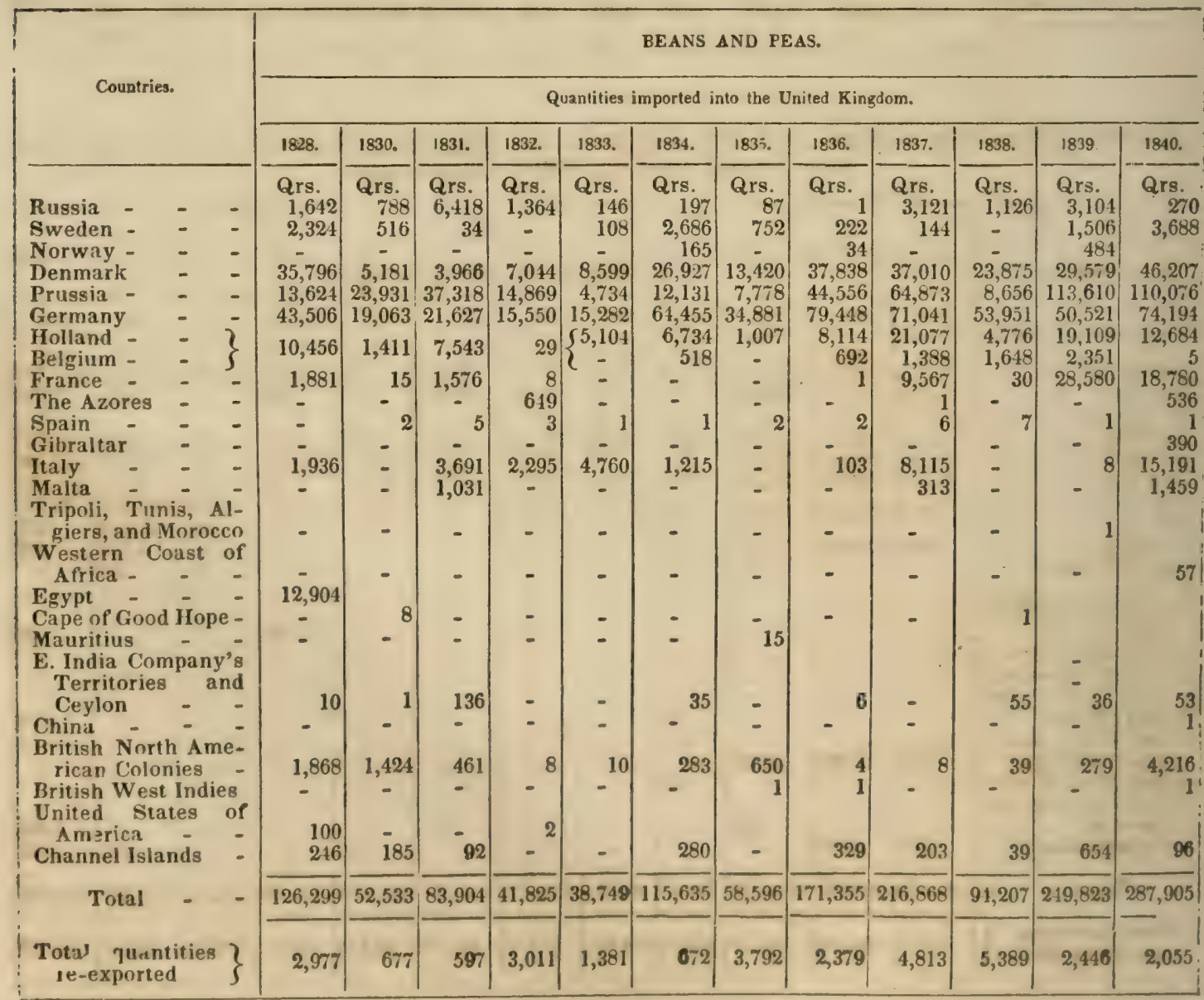

Note.-Of these re-exportations of Beans and Peas, many went to the British North American, but by tar the mrgent went to the West India colonies. 


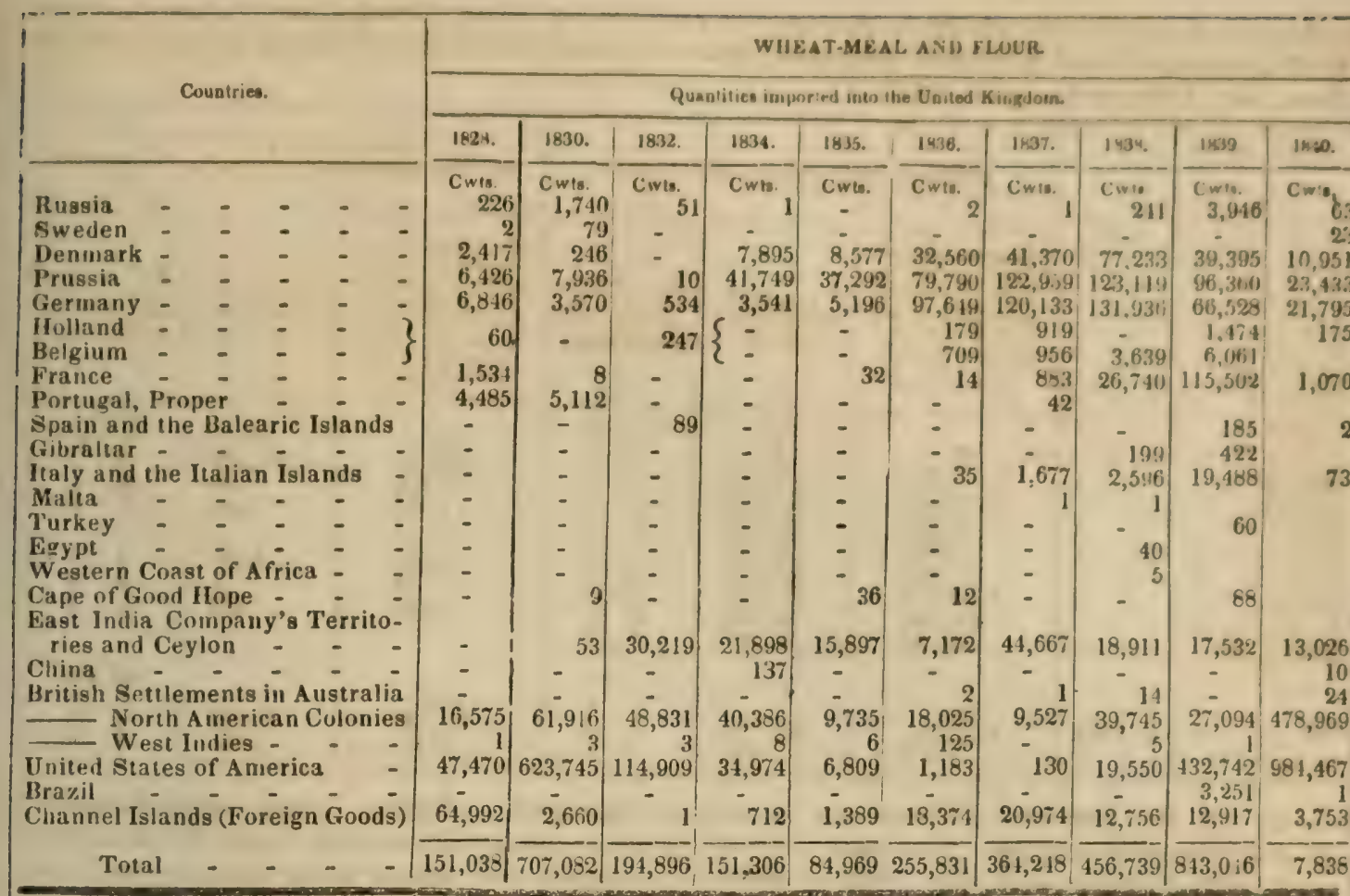

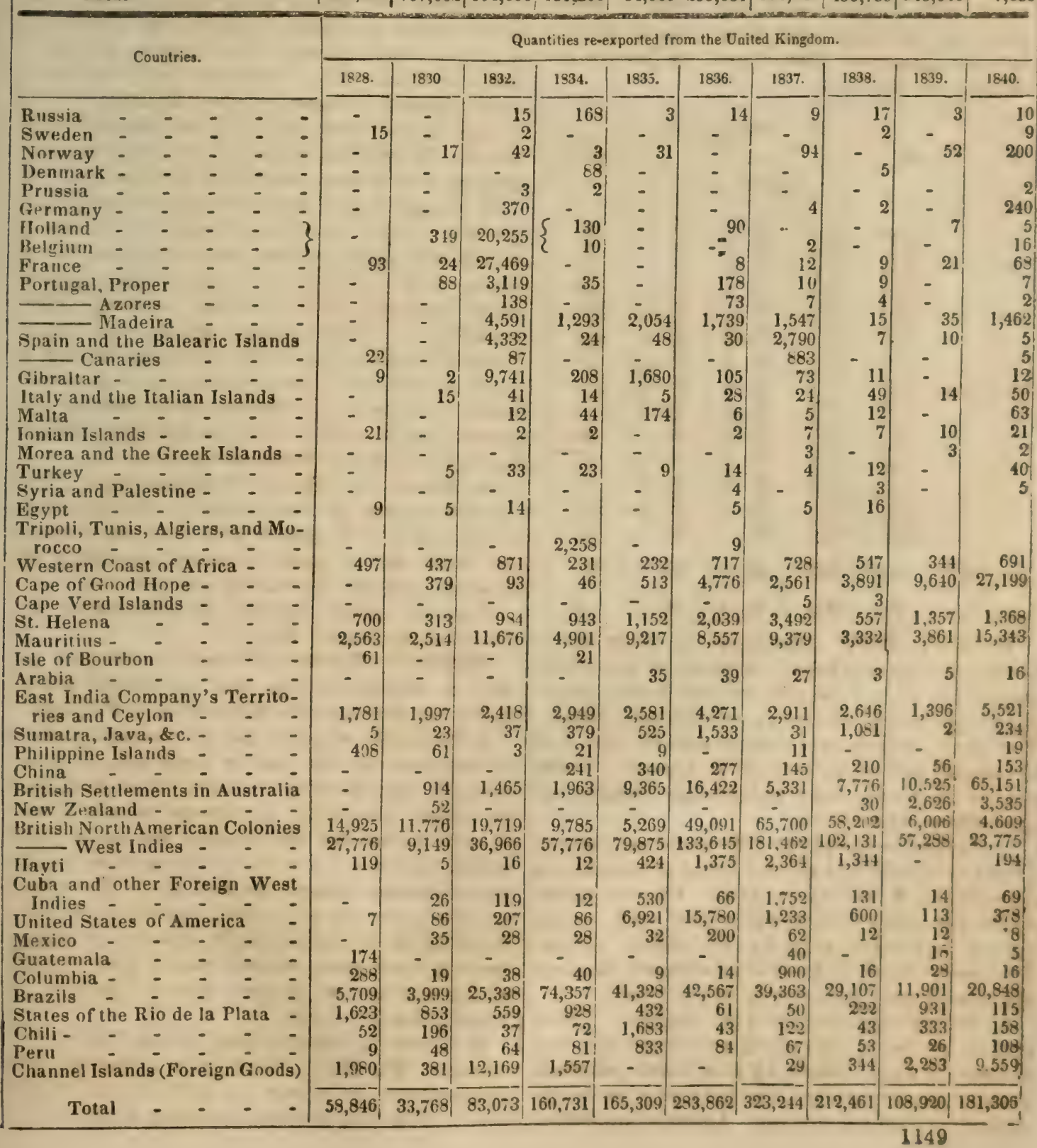


An Account of the total Quantities in England of each kind of Grain, Foreign and Colonial, with the total Amount of Duty paid upon earh kind, and the average Rate thereof during the whole Period from July, 1828, to December, 1841.

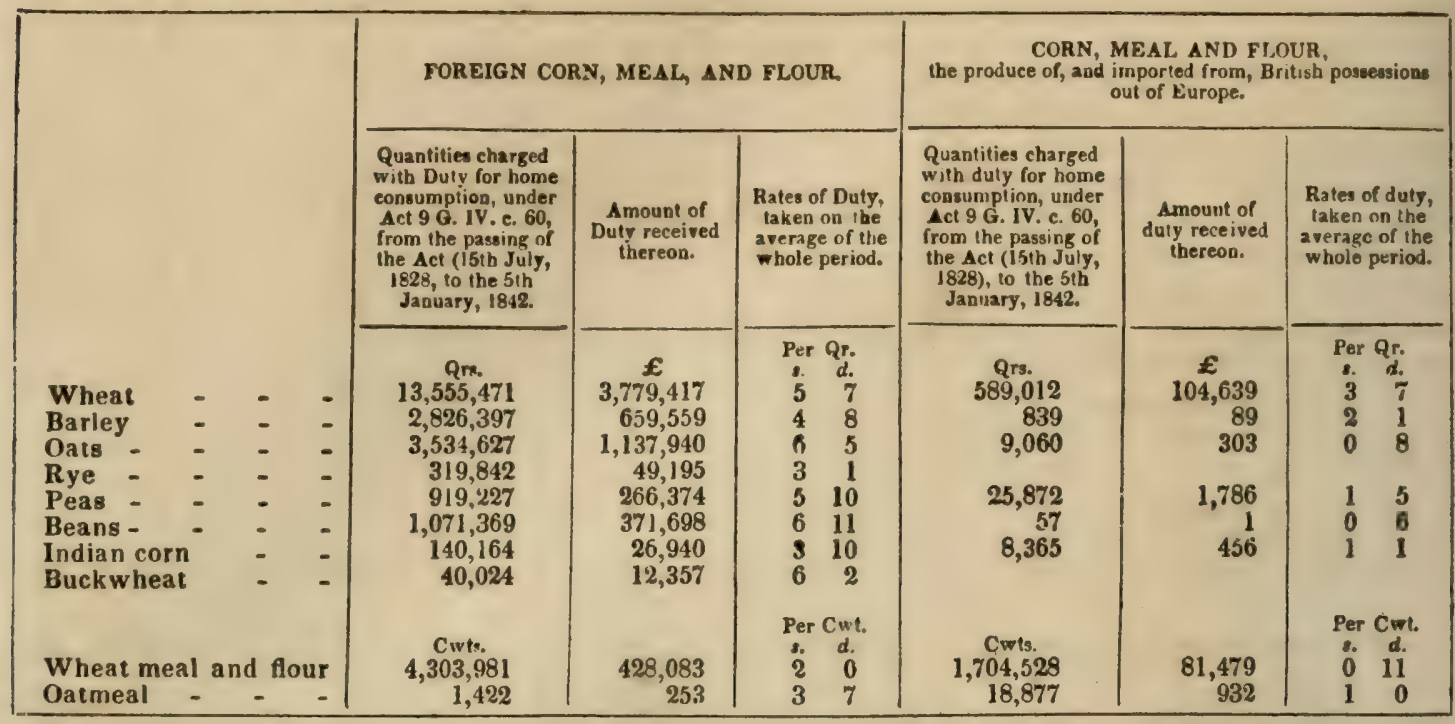

Statement of the Decennial Fluctuations in the rough-edged. Spikes long, many-flowered.

Price of Wheat in England, from 1646 to 1815 ; from 1816 to 1828; and from 1829 to 1841 ; exhibiting the highest and lowest annual Average in each Decennial Period and the per-centage Amount of Difference.

\begin{tabular}{|c|c|c|c|c|}
\hline \multirow{2}{*}{\multicolumn{2}{|c|}{ Periode. }} & \multicolumn{2}{|c|}{$\begin{array}{l}\text { Annual Average } \\
\text { Price. }\end{array}$} & \multirow{2}{*}{$\begin{array}{r}\text { Per cent. } \\
\text { Difference }\end{array}$} \\
\hline & & Highest. & Lowest. & \\
\hline Ist period & 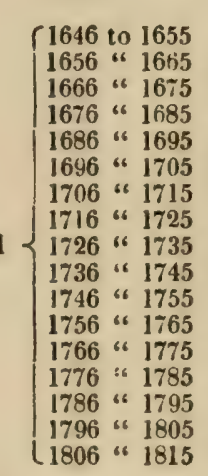 & $\begin{array}{rr}3 . & d . \\
77 & 10 \\
67 & 9 \\
62 & 10 \\
55 & 0 \\
61 & 11 \\
65 & 0 \\
71 & 11 \\
44 & 5 \\
49 & 11 \\
46 & 5 \\
40 & 10 \\
55 & 0 \\
59 & 1 \\
54 & 3 \\
75 & 2 \\
119 & 6 \\
126 & 6\end{array}$ & $\begin{array}{rr}33 & d . \\
23 & 9 \\
37 & 1 \\
33 & 0 \\
34 & 9 \\
23 & 0 \\
26 & 11 \\
23 & 9 \\
31 & 9 \\
24 & 4 \\
22 & 9 \\
29 & 8 \\
27 & 7 \\
41 & 10 \\
34 & 8 \\
40 & 0 \\
51 & 10 \\
65 & 7\end{array}$ & $\begin{array}{r}227^{\circ} \\
82^{\circ} \\
90^{\circ} \\
58^{\circ} \\
169^{\circ} \\
141^{\circ} \\
202^{\circ} \\
40^{\circ} \\
105^{\circ} \\
104^{\circ} \\
37^{\circ} \\
99^{\circ} \\
41^{\circ} \\
56^{\circ} \\
87^{\circ} \\
130^{\circ} \\
92^{\circ}\end{array}$ \\
\hline $2 d$ period & -1816 “ 1828 & 9611 & 447 & 117. \\
\hline 3d period & - 1829 “ 1841 & 708 & 394 & 79. \\
\hline
\end{tabular}

WHEAT, COW (Melampyrum, from melas, black; and pyros, wheat). A genus of branched, spreading, annual, nearly smooth herbs, growing to the height of twelve or eighteen inches. The seeds, which resemble grains of wheat in shape and colour, turn black in drying. There are, in England, four indigenous species of cow-wheat, namely:-

1. Crested cow-wheat ( $M$. cristatum), which grows in woods and thickets, and sometimes in corn-fields, flowering in July. Flower rather small, not quite closed, variegated with cream colour and light purple; the palate yellow. The seed-vessel is a crescent-shaped capsule, cortaining two large seeds in each cell.

2. Purple cow-wheat (M. arvense). This species grows in corn-fields on a light soil, and flowers in July. Stem $1 \frac{1}{2}$ foot high, purplish, arintely quadrangular; the branches more upright than in the foregoing. Leaves lanceolate, Bractes loosely spreading, deeply pectinated or pinnatifid, the upper ones entirely, and the lower ones partially, coloured of a delicate purplish rose colour. The flowers are large and scentless. The seeds are two or three in each capsule, but one is often abortive. This is one of the most beautiful of English wild plants. It will grow from fresh seeds in a dry garden, and is well worthy of cultivation.

3. Common yellow cow-wheat ( $M$. pratense). Pl. 7, q. This is a very common species in woods and bushy places, especially on clay or loamy soil. It flowers in July and August. Stem smooth, with several wide-spreading branches. Leaves bright green, lanceolate. Flowers axillary, solitary, opposite, turned in pairs to one side. The capsules have a curved point. Cows are reported to be fond of this plant; and Linnzus says the best and yellow. est butter is made where it abounds.

4. Wood cow-wheat ( $M$. sylvalicum). This species grows in alpine woods, especially in forests of fir. It agrees with the last in general habit, but is rather smaller, especially the flowers, and the capsule is less pointed.

Two or three species of cow-wheat are found in the United States.

WHEAT-GRASS (Triticum). Of this genus, to which belongs our cultivated wheat, there are five species indigenous to England.

1. Sea rushy wheat-grass ( $T$. junceum), which is frequent on the sandy sea-coast, is a perennial, and flowers in July. The root, with its widely creeping, numerous woolly fibres, is well calculated for binding the loose sand, which purpose it serves in common with Ely. mus arenarius, Arundo arenaria, \&c. The whole plant is glaucous and rigid, like those grasses. Stem 12 or 18 inches high, simple, inclining, smooth, even and polished, tinged with a bright violet hue below, striated above. Leaves involute, sharp-pointed.

2. Creeping wheat-grass, or couch-grass ( $T$. repens). Pl. 10, $i$. This is a common pest everywhere, in waste as well as cultivated land. The long-jointed, creeping root-stock, or 


\section{WHEAT-GRASS.}

rhizome, strikes so deeply and widely as to be verv difficult of extirpation. It is, in fact, an underground stem, vivacious, and consequently shooting up stems and leaves at every joint. The stem above ground is slender, 2 feet high, and leafy. Leaves linear, flat, of a dull, somewhat glaucous green, most numerous on the lower part of the stems. But the plant is so well known that it requires no description. Forking out the roots after the plough is doubtless the best mode of extirpating this noxious weed; but the process must not be discontinued while a particle of the root-stock is suspected to remain in the soil, as the least portion will grow, and the land being so much broken and loosened by the operation, gives double encouragement for the rapid growth of the plant. It does not thrive well when combined with other grasses, but is naturally more common in hedges. The root-stock contains a large proportion of nutritive matter; it is esteemed abroad for feeding horses. At Naples the rootstocks are collected in large quantities for this purpose, and brought to market. The nutritive matter from the leaves contains an excess of bitter extractive and saline matters. Dogs eat the leaves, and also those of the Holcus avenareus, to excite vomiting; hence it is sometimes called dog's grass, and in other places bears the name of quitch or quicks. See Coucr.

3. Fibrous-rooted, or bearded wheat-grass ( $T$. caninum). This differs essentially from the common couch-grass last described, in having the root fibrous, without a rhizome. It grows in woods and shady hedges on a chalky or limestone soil. The stems are 2 feet high, very smooth. Leaves nearly upright, lanceolate, taper-pointed, thin, flat, bright green, rough on both sides. As this grass yields a large supply of early spring herbage, and produces a sufficiency of seeds, which vegetate quickly on all soils except such as are tenacious or retentive of moisture, it might be cultivated to advantage on soils of an inferior quality instead of rye-grass. But for soils of the best quality it does not, as yet, uphold a sufficient claim, the awns of the spike being objectionable, and the produce of the latter-math very inconsiderable.

4. Crested wheat-grass ( $T$. cristatum), a native of Scotland. The roots of this species consist of several long, strong woolly fibres, suited to a sandy soil. The culms are ascending, 12 or 18 inches high, simple, rigid, slender, leafy; hairy at the top. This grass seems well adapted, from its comparative merits, for culture on light heath soils; the produce of early herbage in the spring being superior to most of the alpine grasses, or those which affect sandy dry soils. The latter-math is productive, and very nutritious. It flowers about the second week of July, and the seed is ripe about the end of August.

5. Dwarf sea wheat-grass ( $T$. loliaceum). This is an annual sfecies, growing on the sandy sea-coast, flowermg in June and July. The root is formed of many long downy fibres. Stem rigid and wiry, branched from the bottom, generally 2 or 3 inches high, but various in luxuriance, leafy, very smooth, and polished,
WHEEI.

erect or decumbent. Leaves linear, acute, nearly smooth, involute when dry.

WHEEI. A circular piece of wood, metal, or other substance, that revolves on an axis. It consists of three principal parts, the nave, heel, or the centre; the spokes or radii, and the periphery or ring. The strength of the wheel depends much on the framing and the arrangement of the spokes, every one of which should stand perpendicularly to the nave. In England and other parts of Europe, the elm is considered the best wood for making naves, as it bears the cutting of the mortices truer than any other. See ELM. In making wheels, after they are loosely put together, they are either left to season in a current of air for some weeks, or they are exposed to a heat of $140^{\circ}$ Fah. in a kiln. After this they are exa. mined, and if every thing is correct, the tire or iron hoop is put on, whether made of one hoop or separate pieces. Some years since a patent was taken out in England by Mr. T. Jones for making iron wheels, many of which are now in use. These wheels are not conical, nor what is termed dished, but cylindrical, which enables them to run lighter and also prove less destruc. tive to roads. They are not heavier than wooden wheels, they require less draught, and are more durable, Some improvements have been made on Mr. Jones's wheel by Mr. Wil. liam Howard, but the merits of this have not yet been fully proved.

The utility of wheels to carriages may be said to be twofold; namely, by diminishing or more easily overcoming the resistance or friction from the carriage, and more easily overcoming obstacles in the road. In the first the friction on the ground is transferred, in some degree, from the outer surface of the wheel :o its nave and axle, and in the latter they serve easily to raise the carriage over obstacles and asperities met with on the roads. In both these cases the height of the wheel is of material consideration; as the spokes act as levers, the top of an obstacle being the fulcrum, their length enables the carriage more easily to surmount them, and the greater proportion of the wheel to the axle serves more easily to niminish or to overcome the friction of an axle, as has been shown by Jacob in his work on Wheel Carriages.

Carriages with four wheels are much more advantageous than carriages with two wheels, as carts; for with two wheels, it is plain, the tiller horse carries part of the weight in one way or other; in going down hill the weight bears upon the horse, and in going up hill the weight falls the other way and lifts the horse, which is still worse. Besides, as the wheels sink into the holes in the roads, sometimes on one side, sometimes on the other, the shafts strike against the tiller's sides, which destroys many horses; moreover, when one of th. wheels sinks into a hole or rut, half the weight falls that way, which endangers the overturn. ing of the carriage.

With respect to the utility of broad wheet. in amending and preserving the roads, it ha.i been so long and generally acknowledged as t) have occasioned the legislature to inforce their 
ase. At the same time the proprietors and drivers of carriages seem to be convinced, by experience, that a narrow-wheeled cart is more easily and speedily drawn by the same number of horses than a broad-wheeled one of the same burden: probably because they are much lighter, and have less friction on the axle.

WHEEL-PLOUGH. See Plougr.

WHEY. A provincial term applied to the serous part of the milk, from which the curd has been separated.

Whey, when new and of a pale green colour, forms an agreeable beverage, and with catmeal makes an excellent gruel or porridge. I left till it gets sour, it undergoes the vinous fermentation as readily as buttermilk. Anong the Tartars and Scythians a spirituous liquor is prepared from milk which has undergone fermentation.

Whey is divided into two sorts, green and white; the former escaping readily from the curd, while the latter is freed from it by means of pressure. There are different methods of extracting the whey. In some dairies the whole whey, when taken from the cheese-tub, is put into pails or other yessels, where it remains for about 24 hours; when it is creamed, and the whey is applied to the use of calves and pigs, which are said to thrive as well on it after the cream has been taken from it as before. The cream, when skimmed off the whey, is put into a brass pan and boiled, and afterwards set in pans or jars, where it remains till a sufficient quantity for churning is procured, which in large dairies happens generally once, but sometimes twice, in the week. In Ayrshire whey is given to horses. See Darrx and MiLK.

WHEY BLTTER, as its name implies, is butter made from the whey which is taken from the curd, after the milk is coagulated for the manufacture of cheese. It is chiefly made in those counties where cheese is manufactured, and where it forms no inconsiderable part of the profits of the dairy. In the county of Derby, more butter is said to be made from whey than from the cream of milk, or from milk churned altogether. A similar preparation in the United States goes under the names of cottage cheese, schmeer case, \&c.

WHIN, or GORSE. See Furze.

WHISKY. A spirit obtained by distillation from corn, sugar, or molasses, though generally from the former. Whisky is the "national spirit," if we may so term it, of Scotland and Ireland; but that distilled in the former is generally reckoned superior to that of the latter.

WHITE CROPS. A term used in England to designate crops of grain, such as wheat, barley, oats, \&c.

WHITE-RO'T (Hydrocotyle ; from hydor, water, and cotyle, a cavity; in reference to the plants growing in moist situations, and the leaves being hollowed like cups). One species only is indigenous, the common white-rot or marsh penny-wort (H.vulgaris), which grows very frequent on moist heaths, boggy comm.uns, and the margins of little clear rivulets. It is perennial in habit, flowering in May or June. 'The roots are fibrous; stems creeping !152 to the exteni of 2 or 3 feet, slender, smooth, often subdivided, quite prostrate. Leaves solitary or aggregate, on upright, simple foot-stalks, 2 or 3 inches high; orbicular, peltate, smooth, cloven at the base. Umbels very small, of diminutive white or reddish, nearly sessile flowers. Fruit somewhat wrinkled, compressed. This herb is acrid, and, probably, like others of the umbelliferous tribe growing in wet places, poisonous. But whether it causes the rot in sheep, and, indeed, whether these animals ever touch it, is doubtful. Too moist a pasture is known to produce that disease, and there the Hydrocotyle is generally to be found. See Rot.

WHITE-THORN. See HAWTroRx,

WHITE-TOP (Agrostis alba). See Hend's and Yellow-'Top.

WHITLOW-GRASS (Draba, from drabe, acrid, biting; alluding to the taste of the leaves). Some of the species of this genus are very pretty, being well adapted for ornamenting rock-work or growing in pots among other alpine plants. A mixture of loam and peat suits them best; and they increase with facility, either by dividing at the root or by seeds. There are in England five native spe. cies: the common whitlow-grass ( $D$. verna); the yellow alpine whitlow-grass ( $D$. aizoides); the simple-haired whitlow-grass (D. hirta); the twisted-podded whitlow-grass (D. incana); and the speedwell-leaved whitlow-grass ( $D$. muralis). The leaves are undivided; the flowers either white or yellow.

WHORTLEBERRY (Vaccinium). A genus of shrubs mostly of very humble growth, with simple, alternate, evergreen, or deciduous leaves. Flowers stalked, solitary or aggregate, reddish or white, very elegant. Berries blue, black, or red, acid and eatable. The ge. nus is chiefly American, and the foliage turns red in decay. All the species are well worth cultivating, some of them for the sake of their fruit, some for curiosity, and others for ornament. The different kinds of whortleberry and bilberry succeed well in peat soil or very sandy loam. Some of them grow best in moist situations, and others in dry. They may be raised from root suckers, creeping roots, trailing rooting stems, or from seeds. There are four indigenous species, namely :-

1. In England the black whortleberry or bilberry (V.mirtyllus), is a shrub growing on stony heaths, and in woods where the soil is turfy, chiefly in mountainous countries, abundantly flowering in May. 'The stem is bushy, from 1 to 2 fee! hish, with irregular, smooth, green, leafy, angular branches. Leaves stalked, ovate, serrated, about an inch long, bright green, smooth, thin, delicate, and veiny; deciduous. Flowers on simple, axillary, solitary, drooping stalks. Corolla ovate, bright red, with a waxy transparency. Berries bluish-black, of 5 cells, acid, but not agreeable nor wholesome except when dressed. They are, nevertheless, eaten raw in some countries with boiled cream and sugar. The leaves contain a good deal of tannic acid, and have been substituted for those of Uva ursi。 as an astringent medicine, but are very inferior to them.

1. Bog whortleberry or great bilberry ( $V$ 


\section{WIIORTLEBERRY.}

uliginosum), grows on boggy, mountainous heaths, and is common in the Highlands of 'Scotland. It flowers in May. 'Taller than the preceding, with round branches. Leaves obovate, entire, smooth, deciduous. Flowers several together, flesh-coloured. Berries large, bluishblack, less acid, and less wholesome than the former.

3. Red whortleberry, or cowberry ( $\boldsymbol{V}$. vitis idaca.) This species grows on dry, stony, turfy heaths, or in mountainous woods, in many parts of Scotland, Wales, and the north of England. It is plentiful in Derbyshire. It is an evergreen, flowering in June. The roots are creeping; stems erect, 3 or 4 inches high, with a few irregular, wavy, leafy, downy branches at the summit. Berries globose, deep red, astringent, and acid, with much bitterness, which they lose by immersion for some hours in water before they are made into pies, rob, or jelly. In the latter state this fruit is excellent for sore throats, as well as for eating with venison or other roast meat, as is practised generally in Sweden. The leaves of this species are often mistaken for those of Uva ursi. They contain much astringent matter, and are little inferior to Uva ursi as a medicine.

4. Marsh whortleberry, or cranberry ( $V$. axycoccus). This species grows in clear, watery, turfy bogs, among mosses. The roots are creeping, with many long fibres. Stems slender, wiry, trailing, and creeping, with numerous leafy branches. Leaves ovate, entire, smooth, revolute, acute, perennial. Flowers very elegant, drooping, on simple red stalks, several together at the end of each branch. Berries spotted in an early state, finally deep red, very acid, highly grateful to most people in tarts or other preparations with sugar; though in Sweden they serve only for the acid liquor to boil silver plate in, to eat away the minute external particles of the copper alloy.

Mir. Nuttall enumerates twenty-five species of whortleberry, or huckleberry, natives of the United States, 17 of which are deciduous, and 8 evergreens. The following is his enumeration:

\section{Leaves deciduous.}

1. Vaccinium stamineum. Berries large, partly pyriform, and green when ripe; bitter and scarcely edible. 2. album. 3. arboreum. The largest species of the genus in North America; branches divaricated; flowers partly as in $V$. stamineum; berries rather dry but sweet, with a granular pulp. 4. dumosum. Very low, and running profusely; berries perfectly black to appearance, conspicuously crowned by the persistent calyx. 5. frondosum. Berries and under side of the leaves glaucous; fruit large and rarely copious; agreeable, but quickly deliquescent, and subject to be infested by the larva of insects. 6. pallidum. 7. resinosum. Flowers reddish, angular. Fruit not much esteemed. 8. corymbosum. Fruit subacid, and agreeable, as well as that of the following. 9. amoenum. 10. virgatum. 11. fuscatum. 12. galezans. 13. ligustrinum. 14. tenellum, some. times called sugar-huckleberries, small and rather too saccharine, but a very agreeable fruit, brought in great quantities to the Phila- delphia market. 15. uliginosum. The European whortleberry. 16. myrlilloides. 17. raypulisum.

\section{Lentes sempersirent.}

18. Vilis idac. Berries scarlet, farinaceous, and insipid. A small subalpine species, indi. genous also to the north of Europe. 19. myrtifolium. 20. crassifolium. A variety probably of the following. 21. nitidum. Branches procumbent and repent. From Virginia to Georgia. 22. myrsinites. 23. buxifolium. 24. ovatum. 25. obtusum. These two last are indigenous to the northwest coast.

Vaccinium is a North American genus, with the exception of 3 species in Europe, 1 in $\mathrm{Ja}$ maica, 1 in the island of Taheiti, in the Pacific, 1 indigenous to Madeira and Cappadocia, and 3 in Japan.

The species first named by Mr. Nuttall, is what is commonly called in the Middle States squaw huckleberry and deerberry, the stems of which are low. The 5 th species, or leafy vaccinium, is commonly called blue huckleberry, and blue. tangles. The stems grow from 2 to 5 feet high. The large and dark blue berries of this species are a very agreeable fruit. The 7 th species, or resinous vaccinium, is commonly known in the Middle States by the appellation of black huckle. berry; the fruit of this has larger seeds than the species last described, and, though pleasant, is not so much esteemed. 'The 8 th species, or corymbose vaccinium, is what is known in the Middle States as the swamp, or tall huckleberry, a stout shrub, growing from 5 to 10 feet high, yielding abundantly large berries, one-third of an inch in diameter, purplish-black when ripe. Some other species, especially the $V$. fuscatum, and $V$, amoenum, are confounded with this by some naturalists. The 14 th species is also called the Pennsylvania vaccinium, and commonly the sugar-huckleberry. The stem of this is from 1 to 2 feet high, and much branched. The berries are middle-sized and covered with a little silvery powder or bloom when mature. The product is very abundant and the fruit sweet and pleasant.

In Kent county, Delaware, a new species or variety of whortleberry has been recently discovered, the fruit of which is of a beautiful rich white colour with a yellowish tinge. 'The flavour is extremely pleasant, and free from the least harshness or acerbity. They are of course exempt from the objection to the common kinds, that of staining the teeth and lips.

In the valley of the Columbia river a new species of bushberry has been discovered, called Pambina.

WIKES. A provincial term in England, signifying temporary boundaries or marks, set up to divide swath, to be mown, such as boughs in the common fields, or meadows. Also boughs set upon haycocks for tithes, \&c.

WILD OATS. A name given to the tall oat-like soft grass (Holons avenaceus). A noxious weed in arable lands. See Holcus.

WILD PEAR TREE. See Jty BERr.

WILLOW (Salix: from sul, near, and lis, water (Celtic); in allusion to the place of its growth: or from salire, to leap, because of the rapidity of its growth). An extensive genus of well-known useful and ornamental trees $5 \mathrm{E} \quad 1153$ 
and shrubs. They all delight to grow in swampy places, and are increased by cuttings, though some of the more rare alpine kinds root with difficulty. There is no tribe of trees of such various magnitude as the willows, from th,e large white willow to the minute Salix herbacea, six of which may be placed between two leaves of a duodecima, roots, stems, leaves, and flowers. Many of the species of willow, under the names of osier and sallow, are extensively grown for the manufacture of basketrods; the best sorts for which are the great rourd-leaved sallow (S. caprea) and the common osier (S. viminalis). The branches of some of the species are used as stakes, poles, handles to rakes, hoes; and a great variety of economical purposes. Loudon (Arb. Brit.) says, "In the north of Europe the bark of $S$. alba is used for tanning leather, and for dyeing yarn of a cummon cinnamon colour; and the leaves and young shoots are given to cattle in a green state, or dried like the twigs of the birch, and laid up for winter fodder." The bark, however, is less valuable than that of some of the other species. The leaves of the least willow (S. herbace $($ ), soaked in water, are employed in Iceland for tanning leather. (Paxton's Bot. Dict.) The arrangement of the species of willows is a matter of considerable difficulty, as well as their technical discrimination. Among the numerous species of willows there are only a few which are cultivated for farm purposes: of these we shall enumerate and describe the following:-

1. The long-leaved triandrous willow ( $S$. triandra). This tree is very common in wet woods, hedges, and osier grounds. It is of an upright form, rising naturally, when not injured, to the height of 30 feet; towards autumn casting the bark of its trunk and larger branches in broad, solid portions, cracking angularly asunder, like the plane tree. The young branches are erect, long, tough, and pliant, smooth, leafy, brownish, somewhat brittle at their joint or insertion. Leaves linear-oblong, serrated, smooth, rather unequally sloping at the base. The narrower-leaved willows generally come under the denomination of osiers, of which this is one of the most valuable. It is cultivated for white basket-work, producing rods 8 or 9 feet long, tough and pliant, even when stripped of their bark, and very durable. They are cut down every year. There are several varieties of this species; one, called the French willow, is cultivated in Sussex and in the eastern parts of England; it is more slender in form, and only about 12 or 15 feet high.

2. Bedford willow (S. Russelliana). When this tree was first recommended for cultivation, by the name of the Leicestershire, or Dishley willow, it was regarded with scorn as "only the cracls willow" (S. fragilis), a sort notoriously useless. This ignorance and prejudice are now removed, and this willow is found the most profitable for cultivation of any species of the genus, for the value of its timber as well as bark, the rapidity of its growth, and the handsome aspect of the tree. This spe. cies of willow was first brought into notice by the late Duke of Bedford, who engaged an 1154 able chemist, Mr. Biggin, to make experiments upon it. It was found to contain in its bark more of the tanning principle than any other tree of England, except the oak. The bark also contains the largest quantity of salicina, a salt which has been found useful as a substitute for the quinia and cinchona in agues, and which is much less liable to excite irritation in the stomach than the salts of the cinchona It is of great importance that the distinctions between this willow and the crack willow ( $S$. fragilis) should be clearly pointed out, on account of the wide difference in their qualities and value. This tree is more handsome than the crack willow in its mode of growth, as well as altogether of a lighter or brighter hue. The branches are long, straight, and slender, not angular in their insertion, like $\boldsymbol{S}$. fragilis; and the trees, when stripped of their leaves, may al ways be distinguished by these marks. They are polished, very tough, flexible, round, and smooth. Leaves lanceolate, tapering at each end, serrated throughout, and very smooth. Those of $\boldsymbol{S}$. fragilis are ovate-lanceolate; the foot-stalk, also, is longer than the scale, whilst in S. fragilis it is so short that the leaf is nearly sessile. In both it is glandular or leafy.

3. Bitter purple willow (S. purpurea). This is a shrub growing in low meadows, about the banks of rivers and ditches, bat not common. The trunk is 3 or 4 feet high, with long, slender, very smooth branches, spreading widely, and, if not supported, trailing on the ground, of a rich and shining purple, with a somewhat glaucous hue. Leaves partly opposite, obovatelanceolate, serrated, very smooth, narrow at the base. This is a very valuable osier for fine basket-work, but more especially for platting into low, close fences, to keep out hares and rabbits; the leaves and bark being intensely bitter, those animals will not touch either. 'The twigs, moreover, are so long, tough, and flexible, that they may be interwoven into any shape, and kept very close to the ground, as they always retain their horizontal mode of growth. Such a fence is scarcely inferior to one made of wire, and is, perhaps, more dura. ble, as continually producing young shoots, to supply the place of those that decay. It is important to distinguish this useful and elegant willow from that to be next described. The bark contains much salicina.

4. The rose willow ( $\boldsymbol{S}$. helix) grows in marshes, osier holts, and about the banks of rivulets. It is a tree of humble growth, erect, about 10 feet high, smooth in every part, altogether of a lighter hue than the last. The bramehes not trailing, but upright, smooth, and polished, of a pale yellowish or purplish ash colour, tough, and pliable, less slender and elongated than the foregoing species, though useful for the coarser sorts of basket-work. Leaves partly opposite, oblong-lanceolate, pointed, slightly serrated, very smooth, linear towards the base. Their colour a light, rather glaucous green, turning blackish in drying. The leaves and twigs are less bitter than the former, and the greater size of the trunk, as well as branches, renders this species fit for several purposes which that is not. It also 
WILLOW.

makes a better figure in plantations, and the roots give more solidity to the banks of rivers or ditches.

5. Common white willow (S.alba). This is a tall tree, whose bark is thick, full of cracks, useful for tanning; and, as yielding much salicina, good also for the cure of agues, though inferior in quality to that of the true Bedford, or Huntingdon willow. The bark is called cortex salignum, and anglicanum by some writers. The branches are numerous, spreading widely, silky when young. Leaves all alternate, ellip. tic-lanceolate, pointed, serrated, silky on both sides; the lowest serratures glandular. There is a variety which is very superior in the value of the wood and bark, and the rapid growth as well as handsome aspect of the tree, to the original species. See Osisr and SAlLow.

The willow genus contains more than 130 species, chiefly distributed over the northern parts of Europe and America. Many of the species are alpine. Only 4 have as yet been found indigenous to South America, whilst in North America botanists enumerate upwards of 25 indigenous kinds. Some of these are mere shrubs.

The black willow (S. nigra) is the most common of the American willows, and the most analogous to that of Europe. It is less multiplied in the Northern and Southern than in the Middle and especially in the Western States. It is found on the banks of the great rivers, such as the Susquehanna and the Ohio, and is called black willow, or simply willow.

The black willow is rarely more than 30 or 35 feet high and 12 or 15 inches in diameter. It divides at a small height into several diverzent but not pendent limbs, and forms a spacious summit. The leaves are long, narrow, finely denticulated, of a light green, and destitute of stipulæ. In the uniformity of its colouring the foliage of this species differs from that of the European willow, the lower surface of which is glaucous.

Upon the trunk the bark is grayish and fine$1 \mathrm{y}$ chapt; upon the roots it is of a dark brown, whence may have been derived the specific name of the tree. The roots afford an intensely bitter decoction, which is considered in the country as a purifier of the blood, and as a preventive and a remedy for intermittent fevers.

The wood is white and soft, and the branches are easily broken from the tree. Neither the wood nor the twigs are applied to any useful purpose. (Michaux.)

Michaux describes two other species of American willow. One, from being found on the shores of Lake Champlain, he calls Champlain willow (S. ligustrina). It grows 20 to 25 fect high, with 7 or 8 inches diameter, and very much resembles the black willow, except that the leaves are longer and narrower. The other is the shining willow (S.lucida), so called on account of the brill:ancy of its foliage. This Michaux found only in the Middle and Northern States. It is found in moist but open grounds, and is more common on the edges of the salt meadows than in the interior of the forests; it is also seen on the islands, not co-
WILLOW-HERB.

vered with wonds, in the rivers, and near the shores of the lakes.

This species is easily distinguished by the superior size of its leaves, which are nvalacuminate, denticulated, and sometimes 4 inches in length.

The shining willow attains the height of 18 or 20 feet; but its ordinary elevation is 9 or 10 feet. Baskets are made of its branches, when those of the European willow, which are preferable, cannot be obtained; but it possesses no property that recommends it to attention.

Many species of willow are found in the United States and in Canada, the greater part of which are susceptible of no useful employment. The three species described are distinguished only by their superior height; but even these are greatly inferior to the $\mathbf{E u}$ ropean willow in size and in the properties of their wood. In the Northern and Middle States, particularly in Pennsylvania and in some townships in the lower part of New Jersey, great numbers of the European willow have been planted, of which light baskets are fabricated for the market of Philadelphia. This tree furnishes the charcoal for the manufacture of gunpowder. (Michaux.)

The common yellow willow is the $S$. vitellina of botanists. It is also frequently called golden willow, and by some egg-yolk willow. The French call it Le Saule. This, says Dr. Darling. ton, was early introduced here as a shade tree, and has become partially naturalized in many places. I think I have never seen any but the pistillate plant. A variety with paler bark (perhaps the S. alba of authors) is also occasionally to be met with. The handsome $S$. babylonica, or weeping willow, is more generally preferred as an ornamental shade tree, and the pistillate plant of that species is extensively propagated about houses, but it can hardly be said to be naturalized.

WILLOW-HERB (Epilobium, from epi, upon, and lobos, a lobe; the flowers have the appearance of being seated on the top of the pod). Many of the species of this genus are very ornamental, as $E$. angustifolium; while a few others, such as E. montanum, are mere weeds. They all grow well in any common soil, and are either increased by seeds or by dividing the roots. The indigenous species are nine, namely, the rosebay willow-herb ( $E$. angustifolium), the great hairy willow-herb (E. hirsutum), the small-flowered hoary willow-herb (E. par viflorum), the broad smooth-leaved willow-herb (E. montanum), pale smooth-leaved willow-herb (E. roseum), square-stalked willow-herb (E. tetragonum), round-stalked marsh willow-herb (E. pahestre), chickweed-leaved willow-herb. (E. alsinifolium), and the alpine willow-herb (E. alpinum).

These are all perennial herbs, with simple, generally toothed, leaves; flowers mostly purple, in terminal leafy clusters or spikes, with. out scent. The most common of these are-

1. The rose-bay willow-herb ( $E$. angustifolium), which grows wild in meadows and moist, shady places, chiefly in the north of England. The root is creeping, fleshy, with numerous buds, stems from three to six feet high, erect, roundish, leafy, smooth, reddish, seldom oranch- 
ed. Leaves scattered, numerous, nearly sessile, linear-lanceolate, acute, various in breadth, veiny, smooth. Flowers crimson, inodorous, very handsome, numerous, in long terminal upright clusters. This is a very ornamental flower, common in gardens, where it increases but too rapidly: thriving, like many mountain plants, even in the smoky air of London. There is a white variety. 2. The great hairy willowherb (E. hirsutum). This species is very common in England in all watery places, ditches, and the margins of rivers; among reeds, coarse grasses, and willows. It has an extensively creeping root. The whole herbage is downy, soft, and clammy, exhaling a peculiar but transitory acidulous scent, justly compared to the flavour of boiled codlings and cream. Stems four feet or more in height, round, leafy, copiously branched, and bushy. Leaves half, clasping the stem, ovate-lanceolate, hairy. Flowers in leafy corymbose clusters, large, of a delicate pink. Of this genus, which is most multiplied in the North of Europe, there are $\mathbf{8}$ species enumerated in Nuttall's Genera as indigenous to North America.

WILLOW-LICE. See Aphiprans.

WILLOW-WEED. In England, a name applied in the fens to the snake-weed, or paleflowered persicaria (Polygonum lapathifolium), an annual plant, which grows very freely on all loose and deep soils, and on marshy lands, though it be scarcely known to any of the cultivators of clay, and it is as rarely to be seen on any sort of turnip land. This plant grows commonly from 18 inches to 2 feet; its stalks are tender and succulent, pale, spotted, or reddish; the joints much swollen. The plant branches most when it has free growth, and produces a great number of crowded spikes of seeds. The leaves resemble those of the willow, but are charged with dark spots in the middle. The seeds are very bright and heavy, highly nutritious, and therefore very grateful to birds, especially partridges. Those who keep decoys for catching wild ducks will buy the seeds to feed and entice the fowl. Pigs will do well on them, if boiled. These seeds very much infest samples of fen corn, whether wheat, oats, or barley. As a weed in fen soils, this plant is the most ramping and cumbersome of any weed that grows.

WIND. See Wrather.

WIND-FLOWER. One of the names of the marsh gentian. See Gextrax.

WIND, in HORSES. See BrokeN WiND and RoAring.

WINDMILL. A well-known contrivance for grinding corn or raising water, which is put in motion by the action of the wind upon its sails or vanes. They are of two kinds, vertical and horizontal, but the former is generally preferred. Since the extensive introduction of improved horse power, hand, and steam machinery, windmills are becoming much less common throughout the country; and from depending entirely upon the caprice of the weather, they are only suited to elevated or exposeü situations, where they will catch every passing breeze; and are much less useful than water-mills, which can generally be kept at work continuously, or for a much longer 1156 period. A set of arms and sails might be ad. vantageously used in some situations for pump. ing up water from a well into a trough or cistern for cattle, or for the purposes of irrigation. In the West Indies, a simple apparatus of this kind is usually attached to the pump cr well in the farm-yard. The velocity of the sails of a windmill, in a moderate wind, was calculated by Mr. Ferguson to be thirty miles an hour.

WIND-PLANT. Wood or Grove Anemone (A. nemorosa). An American plant, with a perennial root, found in the moist woodlands and thickets of the Middle States, flowering in April and May. Flowers white, often tinged with purple.

WINDROW. A term signifying in England the green parts, or borders of a field, dug up, in order to carry the earth on other land to mend it; so called because it is laid in rows, and exposed to the wind. It is also applied to a row of peats or a line of hay exposed to dry, and also to turfs cut up in paring and burning.

WINE (Vinum, Lat.; vin, Fr.; vino, Ital. and Span.; vinho, Portu.; usein, Germ.; wïn, Dutch; win, Swed.; vün, Dan.; vino, Russ.) A well-known agreeable, and, when moderately used, wholesome liquor, prepared from the juice of the grape, and that of some other fruits. The invention of wine is involved in the obscurity of the earliest ages. The sacred writings, however, lead us to believe that it must have been known before the deluge; for we are informed that the patriarch Noah, immediately after that overwhelming event, "began to be a husbandman; and he planted a vineyard; and he drank of the wine, and was drunken" (Genesis, ch. ix. v. 20, 21), a suffcient reason for supposing that it was a fermented liquor, and not merely the simple juice of the grape. It is, indeed, natural to imagine, that in those countries where the vine is a native, the spontaneous fermentation of the juice of the fruit, when it was expressed, either purposely or accidentally, and not immediately used as a beverage, would have naturally led to the invention of making wine at a very early period. It is, nevertheless, certain, that until modern times the preparation of wine was purely empirical.

The history of wine is of great interest, but it would be impossible to attempt even a very brief sketch of it in an article of this descrip tion, and therefore we shall confine our remarks upon that part of the subject to some account of the wines used in England, our object being rather to treat of the general rules to be followedein making and preserving wine, and to explain its dietetic qualities, than to trace its history.

Wine, at a former period, was made in England for sale, and most of the large abbeys were supplied with it from grapes raised in their own vineyards; but at no time was it considered equal in quality to foreign wine; and certainly no stronger reason for the neglect into which wine-making in England fell need be stated. Soon after the Norman conquest, much encouragement was given to the importation of the wines of Anjou and of Poitou; and in the time of Henry III. we find those the 
Moselle and St. John, probably an Italian sweet wine, were added to the imports. But for a considerable period the foreign wines were not drunk in their genuine form, but were mixed with honey, sugar, orange juice, and even opium. Chaucer, in the Knight's Tale, speaks of

\section{"A clarrie (claret) made of certain wine,} With narcotise and opie of Thebes fine."

These mixed wines received different names, according to the nature of the wine employed. When made with Burgundy or Bordeaux, the mixture was called Bishop; when with old Rhenish, its name was Cardinal; and when with Tokay, it was dignified with the title of Pope. In the reign of Edward II. the taste for sweet wines prevailed; and consequently we find the wines which Alsace then furnished, which were chiefly sweet, were much used. In the time of Elizabeth, the profusion and diversity of wines displayed on the tables even of the citizens of the metropolis, and the inhabitants of the southern provinces, almost exceed belief. Harrison, in his account of the mode of living in England in that reign, states, that there were upwards of eighty-six different wines in use ; "whereof," he adds, "Vernage, Cate-piment, Raspis, Muscadell, Romnie, Bastard, Tire, Oseie, Caprike, Clareie, and Malmeseie are not least of all accompted of, because of their strength and valure." (Hollinshed's Chron. p. 167.) Sack, with which all are familiar who have read the works of our immortal dramatist, was a dry Spanish wine; but sugar was often added to it, with the view, as Venner informs us, to lessen the hot and penetrative quality of the wine. In truth, the best sack (for there were several kinds in use) was of the growth of Xerez, or in other words sherry. In Pasquil's Palinodia, published in 1619 , this is stated in the following lines:-

$$
\begin{aligned}
& \text { To nive me sacke, old sacke, boys, } \\
& \text { The life of mirth, and the joy of earth, } \\
& \text { Is a cup of good old sherry." }
\end{aligned}
$$

The Spanish wines still retained the first place on English tables, at the commencement of the seventeenth century. After this time, the preference was given to the Canary wines, more of which, Howell (Familiar Letters, part ii. 60) informs us, "was brought into England than to all the world besides." Champagne appears to have been unknown in Britain until a present from Louis XIV. of two hundred hogsheads of wine, consisting of Champagne, Burgundy, and Hermitage, was sent to the king of England; but it was long after this time unknown to those not connected with the court, and, therefore, it was regarded, as Venner terms it, "a regal wine." Even at this period, however, although much wine was drunk, yet few persons kept a stock of it in private cellars; the chief consumption was in taverns.

The war with France in 1689 introduced the use of the wines of Portugal, particularly the red wine, or port, as a substitute for the growths of Bordeaux; and the celebrated Methuen treaty, which obliged us to receive the wines of Portugal in exchange for our woollen inanufactures, and at one-third less rate of the duty levied on French wines, confirmed the taste of Englishmen for this strong and intoxicating beverage, a taste which is again happily, as respects health and longevity, on the decline.

From the foregoing sketch it is evident that the English taste in wine has varied considerably at different periods. For five or six cen. turies, the light wines of France and the banks of the Rhine, and the rich sweet wines of the Mediterranean and the Archipelago, were in high estimation. Then came the dry Spanish wines; and at the close of the seventeenth century the red growths of the Bordelais were in most frequent demand; which, however, owing to the wars with France, were given up, and the rough wines of Porlugal substituted for them. But, as we have already said, the use of these is now on the decline, and our growing intercourse with the continent has revived the taste for light wines. (Henderson's History of Wine.)

As far as concerns what is denominated home-made wines, there is in England scarcely any, if we except the gooseberry (intended to imitate Champagne) and raisin wine, that merit any notice. Indeed, it is an incontrovertible fact, that grapes ripened on walls and trellises are in general unfit for the manufacture of wine; and, in England, those cultivated under glass are too valuable for the dessert and other purposes, in their recent state, to be employed for making wine. Still, however, to make home-made wine forms one of the occupations of the wife of a farmer, and tolerable wine may be made with a mixture of raisins and grapes cultivated in the open air, in favourable seasons. The principles of wine-making are the same, whatever kind of fruit is $\mathrm{cm}$ ployed: in knowing, therefore, the manufacture of grape-wine, it is easy to modify the process, so as to render it applicable to every other description of wine.

The juice of the grape, when chemically analyzed, is found to consist of a considerable portion of sugar and water, mucilage, tannic acid, bitartrate of potassa, tartrate of lime, phosphate of magnesia, chloride of sodium, sulphate of potassa, and a mucososaccharine principle, on which the fermentative process productive of the wine depends. Thenard, a distinguished French chemist, assures us that this substance excites the vinous fermentation by abstracting a portion of oxygen from the sugar, by means of its carbon, forming carbonic acid gas, whilst its hydrogen and the remaining oxygen and carbon of the sugar are converted into alcohol, the basis and exciting principle of all wines. When the must, or expressed juice of the grape, is exposed to a temperature. of $65^{\circ} \mathrm{F}$ ahr., this chemical change or fermentation commences; an intestine motion takes place in the liquor; bubbles are evolved, which buoy up the grosser matter, increasing the bulk of the mass, and forming a scum upon the surface. An augmentation of temperature now takes place; the must loses its saccharine taste; it acquires a deeper colour than before, and a vinous flavour, which increases with the advancement of the process. After a few day: . the fermentation gradually subsides, the mass returns to its original bulk, the scum sinks to

$$
\begin{array}{ll}
5 \text { E } & 1157
\end{array}
$$


the bottom of the vessel, the liquor becomes transparent, and it is now wine. The constitution of the must is liable to be greatly influenced by the quality, the variety, the climate, and the culture of the grapes, as well as the nature of the seasons. In a cold year, owing to the deficiency of the saccharine matter, the wine is weak, harsh, and acescent; in wet seasons it is devoid of a competent quantity of spirit: high winds and fogs are also injurious.

In England, the mode of training the vine high upon walls is a disadvantage for making the fruit into wine. In the best wine countries, it is never allowed to grow more than 3 or 4 feet high; and it is found that the bunches nearest to the soil, if they do not touch it, are always the richest. It is a mistake to suppose that sweet wines are the most susceptible of decomposition; on the contrary, they can be kept for almost an indefinite length of time without undergoing any deleterious change. All wines continue to suffer a certain degree of fermentation after they are racked off and ut into casks; and as long as the saccharine matter is supplied to maintain this slow fermentation, the wine remains gond; but, when that is exhausted, the acetous fermentation begins, and the wine is converted into vinegar.

Admitting, however, the goodness of the fruit, and the wine to be made consequently expected to be excellent, many circumstances may destroy that hope, for the process does not proceed in the regular manner above described, unless certain rules be strictly observed: these are the following:-1. The grapes should be well and equally bruised or trodden; for the juice that first flows contains little mucososaccharine matter, and consequently does not ferment freely. That substance is contained chiefly in the insoluble organized parts and the skin, which also contains the greatest part of the acid, the resinoas extractive, and the colouring principle. 2. 'The fermentation should be conducted at a temperature of $60^{\circ}$ to $65^{\circ} \mathrm{Fahr}$., below which it languishes, and above which it proceeds too violently. When it progresses too slowly, that evil may be remedied by the addition of a little boiling must. 3. The contact of air is essential in the commencement; and this affords another reason for the good bruising of the fruit, as much air is absorbed in that stage of the process. But after the fermentation is established, the air should be excluded, for the sake of preserving the aroma; and to secure this, the French chemist, Chaptal, who paid much attention to the manufacture of wines, recommends the vats to be covered with boards and linen cloths. 4. The greater the bulk of material, the more perfect the wine. 5. When the wine is perfected and racked off, it should be sulphured by burning sulphur-matches within the casks intended to contain it, in order to restrain, within a certain degree, the further fermentation.

When gorod wine is actually produced, much of the alvantage expected from the possession of it depends on the future management and preservation of it; for every wine contains within itsels the sources of both improvement and decline. The chief points to be attended to are guardıng against vicissitudes of tempera1158 ture and the contact of air. Wines in the cask or wood, as the term is, are liable to become sour, either by a sudden transition from cold to heat, or the reverse; and the same susceptibility to acescency is favoured by defect of proper fining; but this process should not be frequently repeated, as it impairs the flavour and the body of the liquor. Wines are mellowed by the slow precipitation of the tartar, which carries down with it the colouring matter and the salts of lime; and this occurs in the ratio of the evolution of the alcohol, during the continued gradual fermentation which goes on even after the wine is bottled. This would strengthen wine in the cask, were it not balanced by the evaporation of the alcohol through the sides of the cask. Old Rhenish wines kept in the barrel lose nearly one-half of their original alcohol; yet it is an undoubted fact, that wine in bottles, not corked, but tied over with a bladder, becomes stronger:-that membrane permitting water to pass through it, but not spirit. Another curious fact, however, must not be forgotten, namely, that whilst the wine becomes weaker when kept in cask, it becomes much improved in its other qualities; a fact which is illustrated by the transportation of Madeira to India, or keeping it in a warm place.

The adulteration of wine is too comprehensive a subject to be here fully treated of; but, independent of this evil, every foreign wine sent to Great Britain, except the best of the Rhenish wines, contains much uncombined brandy, which tends not only to render them unwholesome, but impairs their original flavour, and risks their partial decomposition. Were home-made wines free from this evil, it would tend greatly to encourage a new branch of trade which has lately sprung up in Scotland, chiefly at Edinburgh, Leith, and Glasgow. From a parliamentary return, we find that 24,848 gallons, equal to nearly 150,000 bottles, were sent to England in 1839 , and $23,089 \mathrm{gal}-$ lons in 1840 . Of the 24,848 in 1839 , about 13,000 gallons were shipped from Leith, and 11,000 from Glasgow; and of the quantity in 1840 , about 14,700 gallons went from Leith, and 7,000 from Glasgow.

In the present day, when temperance has made so favourable an impression on the habits of all classes of society, some remarks on the dietetic properties of wine become essential in an article devoted to its other qualities. Were technical phraseology allowable, we should say that wine is stimulant and salutary in small, narcotic and poisonous in large quantities. This opinion, however, neither implies that it is necessary as an ordinary article of diet, nor that it is deleterious even in the largest doses, as a medicinal agent. Wine, moderately used, in the artificial state of modern civilized society, is not at all essential for the healthy, however occupied, except under exposure to unusual fatigue. But were this principle of necessity to guide the regulation of diet and beverage, the art of cookery would be annihilated; and the growth of wine, as well as the manufacture of every spirituous liquor, under whatever name it is known, ardent spirits, cider, or malt liquor, would cease to exist 
In notlcing, therefore, the dietetic properties of wine, we must take society as we find it, not as it ought to be constituted. The stimulant operation of wine is exerted on the nerves of the stomach, and the secreting powers of that organ are influenced by these; and thus a beneficial effect results when the digestive powers are depressed. This, in a great degree, depends on the alcohol contained in the wine; yet it is a fact, that the same quantity of brandy diluted with water, to the strength of wine, will cause intoxication more speedily than when it is taken in the form of wine, especially if the wine contains no uncombined alcohol. 'The stimulant power of wine, however, depends on the quantity of alcohol in its composition; but this power is much greater in those wines that contain adventitious and imperfectly combined spirit. On this account, Port-wine is more apt to derange the stomach, and to cause intoxication, than Sherry of the same strength; and Claret or Rhenish less than either. But besides the evils arising from wines containing uncombined brandy, those wines that contain much acid are usually deleterious to persons of sedentary habits, or who have weak stomachs. Indeed, the daily use of the best wine can only be supported with impunity by those who take much exercise in the open air. But, if we admit that wine is a necessary article of life for the healthy, there can be only one opinion respecting the superiority of the better kinds of Borileaux. Whatever wine is taken, it should not be conjoined with other sorts, as nothing impairs digestion more than mingling several sorts of wine at one meal.

Such are the general effects of the moderate use of wine; its abuse is so well known, both in reference to mind and body, that it is unnecessary to make a single remark, in this place, upon the subject, except to caution those who feel no immediate injurious effects from a pint of Port, or indeed of any wine, daily, not to rely too confidently upon their apparent powers of resisting its evil influence; for a foundation may be slowly formed for maladies, that, when they appear, are always difficult of cure, and often altogether irremediable.

With respect to the comparative value in reference to the wholesomeness of different wines, a few remarks may be necessary, before concluding this article. Among the brisk wines, Champagne is the least noxious, even when it is drank to excess, the excitement is of shorter duration, and the subsequent exhaustion is less. It is said to be hurtful to the gouty; but gout is almost unknown in the province where it is made: and more of the evil said to be caused by Champagne is due to the variety and the nature of the dishes, and the period of the day at which they are eaten, than to the wine itself. The red wines of Burgundy are strong, heating, and consequently intoxicating, and they should only be taken in very small quantity. The Bordeaux wines, as we have already stated, are the safest for daily use. They certainly do not excite inebriety so rapidly as most other wines. The wines of Oporto abound in astringent matter, and in uncombirsed brandy. They are unfit for weak stomachs; they tend to cause sleep rather than to elevate the spirits, and they are the most pernicious as daily beverage. The spanish wines, especially Sherries, are less objectionable, but they should never be drunk without dilution with water, unless for medicinal purposes. The same opinion may be hazarded with respect to Madeira; and perhaps no wine is more suited for the dyspeptic, if hypuchon driasis be absent. The best light wines of the Rhine and the Moselle are, of all others, the most wholesome. They contain little alcohol, and that little is wholly combined. They prove, in many instances, refrigerant, and have a tendency, from the nature of the acid which they contain, the tartaric, to diminish obesity. Lastly, all sweet wines are apt to disorder the sto. mach; and when used freely they intoxicate as readily, and cause as deleterious subsequent effects as the stronger wines. But, after all, we must revert to the opinion, that wine is an un. necessary article of diet for all who are healthy and robust; and must truly be regarded, beyond certain limits, either as a medicine or a poison. (Henderson's History of Ancient and Modern Wines; Maculloch on Wine-making.) See Alcohol and Vins.

Account of the Quantity of Foreign Wine retained in England for Home Consumption, in Wine Gallons, from 1789 to 1836.

\begin{tabular}{|c|c|c||cc|c|}
\hline \multicolumn{2}{|c|}{ Years. } & Gallons. & \multicolumn{2}{|c|}{ Years. } & Gailons. \\
\cline { 1 - 5 } $1789-$ & $5,814,665$ & 1823 & - & $4,845,060$ \\
1790 & - & $6,492,313$ & 1824 & - & $5,030,091$ \\
1792 & - & $8,082,249$ & 1825 & - & $8,009,542$ \\
1794 & - & $6,799,220$ & 1826 & - & $6,058,443$ \\
1796 & - & $5,732,385$ & 1827 & - & $6,826,361$ \\
1798 & - & $4,760,657$ & 1828 & - & $7,162,376$ \\
1800 & - & $7,728,871$ & 1829 & - & $6,217,652$ \\
1802 & - & $6,355,749$ & 1830 & - & $6,434,445$ \\
1804 & - & $4,840,719$ & 1831 & - & $6,212,264$ \\
1805 & - & $5,936,235$ & 1832 & - & $5,965,542$ \\
1810 & - & $6,805,276$ & 1833 & - & $6,207,770$ \\
1815 & - & $5,968,435$ & 1834 & - & $6,480,544$ \\
1520 & - & $5,019,960$ & 1835 & - & $6,420,342$ \\
1822 & - & $4,975,159$ & & - & \\
\hline
\end{tabular}

Acrount exhibiting the Quantities of the different Sorts of Wine imported into and exported from the United Kingdom in the Year ending the 5th of Junuary, 1840, and the gross Revenue accruing thereon.

\begin{tabular}{|c|c|c|c|}
\hline Species of Wine. & $\begin{array}{l}\text { Quantities } \\
\text { imported into } \\
\text { the United } \\
\text { Kingdom. }\end{array}$ & $\begin{array}{l}\text { Quantiries } \\
\text { exported from } \\
\text { the United } \\
\text { Kingdons. }\end{array}$ & $\begin{array}{c}\text { Groes a mount } \\
\text { of revenue } \\
\text { rece ved } \\
\text { thereon. }\end{array}$ \\
\hline $\begin{array}{l}\text { Cape - } \\
\text { French - } \\
\text { Madeira - } \\
\text { Portugurse } \\
\text { Spanish - } \\
\text { Rhenish - } \\
\text { Canary - } \\
\text { Fayal } \\
\text { Sicilian and } \\
\text { other wines }\end{array}$ & $\begin{array}{r}\text { Gallons. } \\
723,740 \\
508,329 \\
267,047 \\
3,272,206 \\
4,130,753 \\
82,910 \\
341,225 \\
202\end{array}$ & $\left.\begin{array}{r}\text { Gallons. } \\
3,520 \\
121,525 \\
162,527 \\
299355 \\
989776 \\
13,350 \\
292,779 \\
90 \\
170,163\end{array}\right\}$ & $\begin{array}{c}\boldsymbol{f} \\
73,596 \\
109,820\end{array}$ \\
\hline Total - & $9,908,722$ & $2,053,085$ & $1,915,648$ \\
\hline
\end{tabular}

American Wine Making.-For their efforts to introduce the grape culture into the United States, great credit is due to the German vine dressers. But for the first demonstration that good wines resembling those of the Rhine and Moselle can be made on this side of the Atlantic, we are indebted to Mr. Longworth, of Cincinnati, whose zeal, intelligence, liberal expenditures, and final triumphant success, entitle biun 
to the lasting gratitude of his countrymen. This gentleman, who now owns in the vicinity of Cincinnati $122 \frac{1}{2}$ acres in vineyards, cultivated by 27 tenants-says, "I have for 30 years experimented on the foreign grape, both for the table and for wine. In the acclimation of plants, I do not believe; for the White Sweet Water does not succeed as well with me, as it did 30 years since. I obtained a large variety of French grapes, from Mr. Loubat, many years since. They were from the vicinities of Paris and Bordeaux. From Madeira I obtained 6000 vines of their best wine grapes. Not one was found worthy of cultivation in this latitude, and were rooted from the vineyards. As a last experiment, I imported 7000 vines from the mountains of Jura, in the vicinity of Salins, in France. At that point the vine region suddenly ends, and many vines are there cultivated on the north side of the mountain, where the ground is covered with snow the whole winter, from 3 to 4 feet deep. Nearly all lived, and embraced about twenty varieties of the most celebrated winegrapes of France. But after a trial of five years, all have been thrown away. I also imported samples of wine made from all the grapes. One variety alone, the celebrated Arbois wine, which partakes slightly of the Champagne character, would compete with our Catawba. If we intend cultivating the grape for wine, we must rely on our native grapes, and new varieties raised from their seed. If I could get my lease of life renewed for twenty or thirty years, I would devote my attention to the subject, and I would cross our best native varieties with the best table and wine grapes of Europe. I have heretofore wanted faith in the doctrine of French horticulturists, that to improve your stock of pears, you must not select the seed of the finest fruit, but of the natural choke-pear. I am half converted to their views. The Catawba is clearly derived from the common Fox grape. In raising from its seed, even white ones are produced, but I have not seen one equal to the parent plant; and in all, the white down on the under side of the leaf, and the hairs on the stalk, common to the wild Fox grape, are abundant."

The Catawba, which has led the way in America to the production of wines calculated to compete with the finer vintages of Europe, at present stands without a rival as a wine grape. It makes an excellent sparkling wine, resembling sparkling Moselle, and also a good, dry Hock. Its colour varies from almost clear water to straw colour and pink, and it possesses a fine fruity flavour, and most grateful aroma. It requires no sugar in fermentation when the grapes are well ripened. It is but justice to one of the most persevering pioneers in the grape culture and wine making in the United States, Major Adlum, of the District of Columbia, to say that he had long since entertained the most exalted views in regard to the valuable qualities presented by the Catawba grape. In a letter to Mr. Longworth he says"In bringing this grape into public notice, I have rendered my country a greater service than I would have done, had I paid off the National Debt;" and Mr. Longworth expresses his concurrence in this enthusiastic estimate.

In regard to the present cost of making wine in the valley of the Ohio, Mr. Buchanan states, from his own experience, that when done by hired labour, the gathering, pressing, and filling the juice into casks, comes to an average of $\$ 25$ to $\$ 30$ per acre. It is the German emigrants who make wine to greatest profit, as the most of the work is done by their wives and daughters. The largest profits will accrue to those who bring into requisition the most intelligence and skill, who take care to have the fruit gathered when fully ripe, the green and decayed berries picked out, (from which by the addition of 8 or 10 ounces of sugar to the gallon, wine of an inferior quality may be made,) who use a clean press, clean casks, a cool cellar from which the external aur can be excluded, who, during the period of fermentation, which continues from two to four weeks, attend to keeping the casks filled to within four or five inches of the bung, (which last must be put on loosely,) and racking off at the proper time in spring, always keeping the casks after fermentation, full and air-tight, never bottling till 4 or 5 years old, and finally selling without their names in seasons. when wine is not of the best quality.

The great secret, for such it has been generally kept among wine-makers - of producing an effervescing wine, consists simply in mixing the wine of the new vintage with wine of the previous vintages, half and half.

Although 400 and even over 600 gallons of wine per acre have been occasionally obtained from Ohio vineyards in some very favourable seasons and situations, Mr. Buchanan sets down the average produce of an acre (containing 2420 vines, planted 3 by 6 feet apart), in fair seasons at 300 to 400 gallons. A probable average for 8 or 10 years, with but little rot, would be 250 gallons. And with a reasonable allowance for loss by rot, frosts, \&c., 200 gallons might be set down as a fair average.

A bushel of grapes on the stem will yield from 3 to $3 \frac{1}{2}$ gallons of juice. Some have yielded 4 gallons, but this is rare. In measuring, the bushel is "heaped," or liberally rounded on the top. A recapitulation of Mr. Buchanan's statements would give the costs and profits of an Ohio vineyard as follows:

\section{Cost of the vineyard per acre, say $\$ 250$,} interest per annum

Cost of attendance per acre

15.00

Cost of making the wine

Probable average annual product: 200 gals. of wine, at, say $\$ 1.00$.

$\$ 100.00$

Supposed profit per annum

$\$ 200.00$

A press capable of expressing from 160 to 300 gallons per day, will cost $\$ 60$ to $\$ 150$ - the vessels $\$ 10$ to $\$ 15$, and the casks from 4 to $8 \mathrm{cts}$. per gallon, according to size and quality. The loss in quantity in making the wine, by fermentation, lees in racking, and by evaporation, is about 10 per cent. See VINe.

The experiment of letting the grapes, after being mashed, ferment in the skins slightly before pressing, has been found to afford some advantages. The mashed grapes are allowed to stand in large open hogsheads, for 24 to 30 hours, or until they begin to ferment, and the grapes rise to the surface. They are then pressed. Too much fermentation in this state would be injurious, and give a bitter, astringent taste to the wine; but a slight fermentation adds to the colour and aroma. 
Mr. Longworth states that it is a very great pros in wine making, to have the grapes gathrred too soon, and before the saccharine principle is lully developed. The richness of the wine is estimated by the weight of the must or fresh juice, the average of the least being $95 \mathrm{deg}$. on the scale of the Hydrometer. He states that in the neighbourhood of Cincinnati he found some from well matured fruit which weighed 101 , whilst that of other vineyards weighed only from 65 to 80 . He says that he would rather pay 75 cts. per gallon for must weighing 95, than $5 \mathrm{cts}$. for that which weighs only 75 .

Fermentation.-The casks are to be filled up till within 3 or 4 inches of the bung, and this is to be put in loosely. The gas escapes without the wine running over. Usually in 2 to 4 weeks the fermentation ceases, and the wine becomes clear; then fill up the casks and tighten the bungs.

In February or March, rack off the wine into clean casks. A second but moderate fermentation will take place late in the spring, after which the wine becomes clear and is ready for sale. If the casks are kept well filled, and the bungs tight, it will improve for many years. Use no brandy or sugar if the grapes are sound and well ripened.

It was a long time disputed whether alcohol existed already formed in the wine, or whether it was developed through the application of heat in distillation. Gay-Lussac succeeded in extracting alcohol from wine in a vacuum at the temperature of $59 \mathrm{deg}$. Fahrenheit, thus demonstrating that it was not developed by the heat used in distillation.

When it is necessary to add sugar to grape juice, experience has proved in France that glucose, or the sugar made from starch, is to be preferred, since it more resembles that of the grape than the sugar made from the cane or the beet. Sugar ought, however, never to be added except with the greatest caution and judgment, being apt to make the wine thick, flat, and acid. Although it may increase the proportion of alcohol, the quality of the wine will never equal that of good seasons, when sugar can be dispensed with. Some add alcohol instead of sugar to the fermenting must. But although this may furnish the wine with strength, it will never be equal to that in which sugar has been used.

The safest way of keeping the wine is in buttles well corked and sealed, and placed on their sides. The fewer rackings it receives, and the less exposure to the air, the sweeter and better it will keep. The bottling may take place one year after racking, although better deferred till the lapse of 2 years. Never bottle before the second fermentation, which takes place in the spring succeeding the vintage, unless it is where the sparkling quality is desired, which, as has been already stated, is imparted by mixing the wine of the new with that of an old vintage. The fining of wine can be done to the greatest perfection by bottling or racking off during the very coldest weather in winter, at which time it will of course deposit most of its soluble materials. This was an important secret, kept and practised upon with great success by a celebrated Philadelphia wine merchant.

Consumption of Wines in Great Britain and the United Slates.--The importations of wine into tl:3 United Kingdom of Great Britain in
1819 , amounted to $7,970,0157$ galls., and the increase in the home consumption, conupared with the previous year, was 115,315 galls. The pro. portions in which the various wunes were consumed in England in the year 18.9, are stated as follows : Of the total amount drank, Cape constituted 3.87 per cent. ; French, 5.30 ; Portugal, 42.36 ; Spanish, $39 \cdot 16$; Madeira, 1.14 ; Rhenish, 0.74 ; Canary, 0.32; Sicilian and other sorts from the Mediterranean, $7 \cdot 11$; total, $100 \cdot 00$.

As nearly all the wine imported in the United States is consumed at home, the following statement will show the proportions of various wines consumed, and consequently exhibit the American taste.

The values of the different wines imported into the United States in one year, namely, from July 1st, 1817 , to July 1st, 1848 , were as follows:

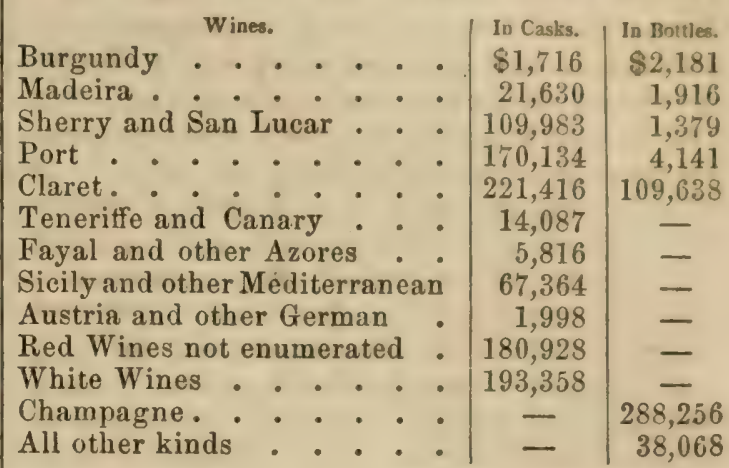

Thus it appears that the English taste runs mainly upon Port and Sherry, which constitute $81 \frac{1}{2}$ per cent. of all the wines they drink. Their consumption of French wines, or Claret and Champagne, amounts to only 5.30 per cent., and of Madeira to only 1.14 per cent. In the United States, on the contrary, the French wines, including Champagne and Claret, constitute over 56 per cent. of the value of all the wines consumed, Port and Sherry 19, Madeira about $1 \cdot 64$, and Claret and other red wines alone, 36.

WINE-PRESS. The one most commonly used near Cincinnati is made somewhat like a "Screw Cider Press." The screw, which is of iron, and about 3 or 4 inches in diameter, is placed either in a strong upright frame, or coming up through the centre of the platform, the last plan being the cheapest and most simple. A strong, tight, box platform, 6 or 7 feet square, made of 2 or 3 inch plank 6 or 8 inches high at the sides, is wedged into heavy timbers, and, in this, a box of $1 \frac{1}{4}$ inch boards, 5 or 6 feet square, perforated with holes near the lower edge, 8 or 10 inches high at the sides (marle so as readily to be taken apart), is placed to contain the grapes. Boards to fit loosely inside of this box, and lie on top of the pile of mashed grapes (or the "cheese"), and pieces of scantling, to lay across to receive the pressure, complete the press. The pressing power is applied by a strong lever attached to the nut or female screw, and the juice runs out through a hole.

WINNOWING-MACHINE. A contrivance employed for separating, by an artificial current of air, the chaff from the grain, after it has been thrashed out of the straw. Various are the accounts (remarks Mr.J. A. Ransome in his Treatise on the Implements of Agriculture) given of the introduction of this machine, and many of the claimants for the credit of having been the first maker of this piece of mechan- 
ism in England or Scotland. All, however, agree that the idea, design, or model was originally furnished from Holland, earlier, however, than the date of any of these by at least a period of twenty years. We learn from the papers of Robert Somerville of Haddington, that in 1710, pursiant to articles of agreement between himself and Fletcher, laird of Saltoun, James Meikle (father to Meikle of thrashingmachine memory) visited Holland for the purpose of learning "the perfect art of sheeling barley," in order to the introduction of the barley-mill. The same authority, 1805, states, "that on Meikle's return he made the first fanners which were seen in Britain;" and that these were in use only a few years before that date at the Saltoun barley-mills. That the machine was not made public till many years afterwards may be attributed to a clause in the above-mentioned agreement, by which Meikle was bound, on leaving Saltoun's service, "not to profit any more by this mill, nor communicate the arts he had learned to any other." In $173 \%$, through the medium of Rogers of Cavers and others, it was brought into more general use; and in 1768, A. and R. Meikle obtained a patent for a machine of this kind. Although a very considerable advantage over the plan of dressing by hand, these still appear to have been but very imperfect, the corn having to be passed through them twice or thrice, in order to be perfectly separated. And in 1798, R. Douglas, in his Agricultural Survey of Roxburghshire, remarking upon these defects, mentions an improvement invented by one Moodie of Lilliesleaf, "in which he had happily combined some properties of other fans, so that the grain at one operation could be both separated from the chaff and lighter seeds, and completely riddled of all sorts of refuse."

Other patents had been taken out which do not appear to have involved much real improvement, till, in 1800 , I. Cooch of Northampton patented the machine which has since been known by his name, and has obtained deserved commendation, being in use and approved beyond most at the present day. This machine dresses all kinds of seeds, and its work is performed in a perfect manner: its principle involved more mechanical combinations than were at that time generally understood by the class for whose use it was intended; and this, together with its then cost, retarded its more general adoption.

In 1812, John Elmy obtained a patent for improvements in winnowing-machines, and produced a very efficient implement; the arrangement of its various parts were simple, and greater effect was obtained from the blast. Comparing this with the drawings and description of one we find in the Edinburgh Journal of Agriculture, and with that described by Professor isow, we have little doubt of their general Jdentity with this, the model upon which the machines in general use are now made.

In $1839, T$. F. Salter obtained a patent for a machine for winnowing and dressing corn and seeds, which at the R. A. S. E. meeting at Cambridge was exhibited, and obtained the silver nedal.

In this invention are combined the princi1162 ples of Grant's hummelling machine, described in British Husbandry, vol. xi. p. 204, and of Hall's smut machine (Loudon's Ency. of $A g r . p$. 439 , fig. 403), with the operations of the common winnower.

The undressed grain from the hopper passes through a cylindrical sieve, having within it a rotary spindle, upon which short blunt arms are arranged in a spiral direction; these agitate the grain as it passes along, and thus separate the small dirt and dust as well as the awns of barley, which fall through in a closed box or cupboard. The cylinder is placed in a slanting direction, and is provided at each end with slides, which regulate the quantity and speed with which the grain shall pass. Through the slide aperture at the lower end the grain is introduced upon other sieves, which, having a backward and forward motion, distribute it equally over their surface, when it is subjected to the blast of the fan, driving obliquely through the sieves; this carries the chaff out of the machine; the grain falls on a screen, which, having a similar motion to the sieves, separates from it all small seeds, and the dross corn is carried away in a division formed for the purpose. The grain, dross, corn and chaff are thus all thoroughly separated from each other, and the dust, dirt, and small seeds, having fallen in an enclosed box from the cylinder, may be entirely removed.

We have heard this machine highly approved by many, and when pains are taken to separate the corn from the short straw, \&c., previously to submitting it to the machine, we believe it to be very effective; but as there is some degree of complication in its details, it is chiefly suited to those to whom a high degree of excellence in the manner of "making up their corn" is a matter of more importance than the time or labour it may require.

We now come to the description of the winnower used in combination with the thrashing apparatus at Whitfield, in which the principal feature is the improvement of the fan or blower. Having noticed that the ordinary form and position of the fans, which are flat boards, radiating from the centre, tended to keep the air contantly whirling within the casing, rather than to force it forwards; and that if, instead of being flat, they were curved forward in the direction of their motion, they would draw the air in from the tube and force it out at the sides, J. Clyburn of Uley, the engineer by whom the machinery at $W^{\top}$ hitfield was executed, constructed a blower, in which, by a certain curvature of the fans, and a different arrangement of the chamber in which they revolve, the tendency to form a vacuum is considerably increased, and greater force is consequently obtained from the blast.

We are not disposed to leave this part of our subject without some allusion to an invention for still further carrying out the process of cleaning corn, known as 'Tuxford's reeingmachine. This consists of a series of sieves, to which a rotatory motion is given : the grain is by this means separated from any small dust and dirt, which passes through the wires of the sieve, while all the lighter rubbish is by the motion brought to the top, whence it is re- 


\section{WINTER CHICKWEED.}

moved by hand. This implement is more, perhaps, adapted for millers ; and its cost presents, in its present form, a bar to its general introduction. If it could be reduced to the power of being worked by hand, it would be a very valuable assistant to the proper preparation of the grain for market.

The American machines for cleaning grain are commonly designated Fans, Grain Funs, and in the Eastern States, Winning Mills. Their construction differs materially from such as are used for similar purposes in Europe, being much more simple, and not having more than half the machinery. The old "Dutch Fan," formerly used, and which had no shaking screen, is now superseded by highly improved fans. The principal modern improvement in these consists in the application of a screen attached to the shaker, which more effectually rids the grain from cockle and dirt that cannot be blown out. The ordinary size of an American an is about 5 feet in the frame or boarding, $3 \frac{1}{2}$ feet in height, and about 2 feet 4 or 6 inches in width. The blower or fan is about $2 \frac{1}{2}$ feet in diameter. Screens and ridd'es from 18 to 20 inches square, from 3 to 6 riddles accompanying each fan. The most simple arrrangement for working a shaker is a small crank attached to a rod leading from the side of the fan to the riddle-frame or shaker.

A fan of the dimensions described will clean from 40 to 60 bushels of wheat per hour. English farmers who have come to the United States, say that these simple winnowing-machines do far more work than the English, which last are complicated with much machinery, for cleaning smut, \&c. (See Sxut-Milx.) The English winnowing-machines cost from $\$ 40$ to $\$ 60$, whilst the American are made for $\$ 16$ to $\$ 24$, according to the size and number of screens; at which prices they are furnished, among other places, at No. 196 Market street, Philadelphia, by Mr. Chandler, agricultural implement maker.

WINTER CHICKWEED. See ChIC KWEed, EURopfan.

WIN'TER-CRESS (Burbarea, on account of its being formerly called the herb of $\mathrm{St}$. Barbara). There are, in England, two indigenous species; 1 . The bitter winter-cress, or yellow rocket (B. vulgaris), a perennial, which is common in rather moist waste ground, about hedges, or in marshy meadows. The root is tapering, somewhat woody; stem about 2 feet high, simple or branched, leafy, stout, angular, and furrowed. Lower leaves lyrate, the terminal lobe roundish; upper obovate, toothed, strongly ribbed, of a fine texture, quite smooth. Flowers bright yellow, in round-headed corymbose clusters. Pod quadrangular, about an inch long. The whole herb is nauseously bitter, and in some degree mucilaginous. A double-flowered variety, with innumerable petals produced in long succession, and turning white as they fade, is frequent in gardens. 2. Early winter-cress (B. precox). This biennial species is found in watery, grassy places, or on the banks of ditches. Stems, one or more, erect, $1 \frac{1}{2}$ or 2 feet high, smooth, a little branched, tinged at the bottom with a violet hue. Lower leaves lyrate: upper deeply pinnatifid, with linear, oblong, entire segments; flowers fewer,
WIRE-WORM.

smaller, and paler than those of $B$. vulgari. Pods thrice as long as in that species, exactly square, smooth. 'I'his species propagates itself abundantly by seed, hut the root is not perennial. It may be eaten like water-cresses, with which it agrees in flavour, except being rather more pungent.

WIN'TER-GREEN (Pyrola, from the leaves being similar to those of the pear tree). A genus of very pretty plants, rather difficult to cultivate. A shaded peat border appears to suit them best, and they are readily increased by divisions or seeds. The whole genus is astringent and tonic. There are, in England, five native species, all perennials, as follows :1. Round-leaved winter-green (Pyrola rolundifolia). 2. Intermediate winter-green (P.media). 3. Lesser winter-green $(P$. minor $)$. 4. Serrated winter-green $(P$. secunda) ; and, 5. Single-flowered winter-green ( $P$. uniflora). They all inhabit alpine wooded localities; the flowers are white or reddish, often highly fragrant. $P$. uniflora is one of the most curious and elegant of British flowers.

Winter-Green, Amrrican (Pyrola umbellata), Pipsissiwa. The Chimaphila umbellata of Nuttall. This plant is very abundant in cool situations in the United States. It has a long creeping root, and ascending stem 3 to 6 inches long, leafy at the top. The leaves are of a deep green and very glossy, possessing a peculiar flavour, some bitterness, and a moderate degree of astringency. Under the Indian name of Pipsissiwa, this plant has been long noted as a popular medicine. It has doubtless some virtues, but its properties are very often misapplied in its empirical use.

The Spotted Winter-Green (Pyrola maculata) is also a common plant in the United States erroneously called Pipsissiwa by Pursh. Its properties are similar to those of the first. named species, though weaker. Five or six additional species of the Pyrola genus are found in the United States.

WINTER-PROUD. A term provincially applied to wheat which in winter puts on a more green and luxuriant appearance than it is able to support in the following summer; or in which the ramifications become too numerous to be kept up, or brought to maturity, from the previous over-exertion of the soil. In these cases the crops decline during the spring and summer, and at harvest yield imperfectly, falling much below other crops which had a more backward appearance in the winter.

WINTER-WEED. A name given, in Nor. folk and other parts, to the ivy-leaved speedwell (Veronica hederifolia). See SPEFnwelt.

WIRE-WORM (Elaler segetis). These are larvæ of that tribe of insects named Elateride, or click-beetles, which are readily known by having the sternum produced behind into a strong spine fitted to enter a groove in the abdomen situated between the intermediate pair of legs. By bringing these parts suddenly into contact, the insects are enabled to spring to some height into the air, and thus recover their natural position, when they happen to fall on their backs, which they frequencly do, when dropping from plants to the ground. A special provision of this kind is rendered 
necessary, in consequence of the shoriness and weakness of their legs. The wire-worms have a long, slender, and cylindrical body, covered by a hard crust, which has obtained for them the above name. They are composed of twelve segments fitting closely to each other, and are provided with six conical scaly feet, placed in pairs on the three segments next the head. The latter is furnished with short antennæ, palpi, and two strong mandibles or jaws.

Upwards of sixty different species of these insects occur in Britain, and it is probable that a considerable proportion of them feed upon the most valuable cultivated plants. The same species of larva does not appear to confine itself to one kind of food, but attacks indiscriminately the roots of grain and other grasses, as well as esculent roots, such as turnips, carrots, radishes, \&c. But it is at the same time deserving of notice, that as a strong similarity prevails among larvæ specifically distinct, it is probable that different kinds may often have been confounded, and a more correct knowledge may prove them to be more restricted in their choice of food than is at present supposed: this, at least, is rendered not unlikely by what is observed in analngous cases. We are as yet acquainted with the metamorphoses and habits of a very small number of these insects; and it is, therefore, highly desirable that whenever a destructive species of wireworm prevails, it should be traced to the perfect condition. 'This, however, is attended with considerable difficulty, owing to the length of time they continue in the larva state, extending, in many instances, to several years.

This insect nccurs in considerable plenty throughout the country in grass fields and pasture lands, and is usually found creeping among the herbage, or lying at the sides of stones; it is scarcely ever observed on the wing. The extent of the injury they sometimes occasion may be estimated from the fact, that a single worm has been observed to bite from 8 to 20 plants in a very short time; and they are occasionally so abundant, that from 4 to 8 have been turned up by the spade in a space of 4 square feet. The depredations of the wire-worm in England being principally confined to wheat sown upon clover leys, old pastures recently broken up, pea and bean stubbles, \&c., we may suppose the general average of the injury to amount to about a twentieth part of what is sown upon this description of lands. This may be deemed a very fair and moderate calculation.

When the fields lie fallow, these insects continue to feed on the grass and other weeds, which are frequently allowed to overrun the surface; whereas, if the soil were kept clean, they would either die for want of tood, or be compelled to remove to some other place. As these larvæ invariably live beneath the surface of the soil, every plan suggested for their destruction must be founded on this consideration.

Without adverting to this fact, many superficial applications, such as strewing the surface with quicklime, soot, \&c., have been tried without effect. The most obvious remedy is to saturate the soil with some fluid which has been previously ascertained to destroy the in- sects without injuring the plants; that is, if the latter be of a kind which it is necessary to preserve, as will usually be the case. In a fallow field, this precaution need not be observed, as a double benefit would ensue from the de. struction of both insects and weeds. More carefully conducted experiments, and on a more extensive scale than any that have yet been undertaken, will be necessary to show what kind of liquid is best adapted for this purpose. Probably, different substances will be found most useful in different situations, according to the nature of the soil and the chemical ingredients which enter into its composition. The latter consideration should be particularly attended to in all experiments on the subject, as most likely to suggest the most appropriate remedy; and it might even happen that the fluid employed to destroy the insects might be so managed as to produce a most beneficial change in the chemical qualities of the soil. If a strong saline solution, for exam. ple, should be found to kill the insects, as it is very likely to do, there are few soils which would not derive benefit from such an applica. tion. Of course, many substances prove speeuily fatal to these insects, and among these the choice would have to be determined by cheapness and ease of application. Beirkander, a Swedish observer, who has investigated their habits, found that they lived among-

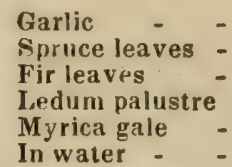

$\begin{array}{rrrrr} & & & \text { Days. Hour } \\ - & - & - & 9 & 0 \\ - & - & - & 0 & 14 \\ - & - & - & 0 & 12 \\ - & - & - & 0 & 9 \\ - & - & - & 0 & 2 \\ - & - & - & 4 & 0\end{array}$

He suggests that such of these plants as proved most speedily fatal should be mixed with the manure. He also considers it of great advantage to cause children to follow the plough, and pick up all that happen to be turned up. He states that in this way he has scen $35 \mathrm{l}$ wire-worms collected in a field nor exceeding 600 feet by 56 .

Sir Joseph Banks suggested a very simple plan for alluring the wire-worms from the plants, and collecting them that they might be destruyed. This consisted merely in burying slices of potato, stuck upon skewers, near the seeds sown. As the larvæ are very fond of this root, they leave the young plants and fix upon it. These slices require to be examined every day, and the wire-worms collected upon them destroyed. Mr. Tallant affirms that he has frequently freed fields entirely from wire-worms by sowing a crop of white mustard-seed. The experiment he has tried so frequently, and in circumstances so) well calculated to demonstrate its effects, that he is perfectly satisfied that the remedy is efficient. "Encouraged," he observes, "by the results of my former trials, I sowed a whole field of 42 acres, which had never repaid me for 19 years, in conse. quence of nearly every crop being destroyed by the wire-worm; and I am warranted in stating that not a single wire-worm could be found the following year; and the crop of wheat throughout, which was reaped last hare vest, was superior to anj I bad grown for 21 years. I am, therefore, undor a strong persua- 
Bion that the wire-worm may be successfully repelled and eradicated by carefully destroying all weeds and roots, drilling white mustardseed, and keeping the ground clear by hoeing." (Brit. Farm. Mag. 1831.)

Nature herself has taken means to check their superabundant increase by making them the prey of a small ichneumon, which searches out their retreats, and deposits its eggs in their bodies, which are consumed by the parasitical larvæ as soon as haiched." (Mr. Duncan, Quart. Journ. of Agr. vol. viii. pp. 96,348.) (See Issecrs.) Under the head Bretre, at page 174, the American wire-worms have been described as materially differing in structure and habits from those of Europe.

WISP. A term applied to a small bunch of hay or straw, when used in rubbing down horses or cattle.

WITHY. A name sometimes given to the flexible boughs of willows and osiers.

WOAD, DYER'S (Isatis tinctoria). This is a biennial plant, growing wild in cultivated fields and about borders in England, but rare. As the ancient Britons are reported to have painted their bodies with the blue colour obtained from this plant, which is still used in dyeing, the woad is most probably an original production of England; though what occurs now and then about cultivated fields is supposed to have escaped from the crops occasionally raised, chiefly in the middle part of the island. The naturalized plants are less perfectly smooth, and far less luxuriant than the cultivated ones. This plant has a tapering and fibrous root. The stem rises 2 or 5 feet high, wand-like, slightly glaucous, leafy, panicled at the top. Panicle of many compound racemose branches, beset with diminished lanceolate leaves, all of a yellow hue as well as the stalks. Flowers numerous, small, bright yellow.

Woad has been cultivated in France from time immemorial. In England its culture is mostly confined to Lincolnshire, where it is a common practice to take rich flat tracts near rivers, at a high price, for the purpose of growing it for 2 or 4 years. Those who engage in this sort of culture form a sort of colony, and move from place to place as they complete their engagements. It is sometimes, however, grown by stationary farmers. The leaves are the parts of the plant used, and it is considered as a severe crop.

There is a variety of woad, called the Dalmatian, described by Miller, and also a wild sort, but only the common is cultivated in England.

The soil for woad should be deep and perfectly fresh, such as those of the rich, mellow, loamy, and deep vegetable kind. Where this culture is carried to a considerable degree of perfection, as in Lincolnshire, the deep, rich, putrid, alluvial soils on the flat tracts extending upon the borders of the large rivers, are chiefly employed for the growth of this sort of crop; and it has been shown by repeated trials that it answers most perfectly when they are broken up for it immediately from a state of sward.

The preparation of the soil, when woad is to be grown on grass land, may either be effected by deep ploughings, with the aid of the winter's frost; cross-ploughing and harrowing in spring: by deep ploughing and harrowing in spring; by paring and burning; or by trench-ploughing or spade-trenching. 'The first mode appears the worst, as it is next to impossible to reduce old turf in one year, and even if this is done, the danger from the grub and wire-worm is a suf. ficient argument against it. By ploughing deep in February, and soon afterwards sowing, the plants may germinate before the grub is able to rise to the surface; by trench-ploughing the same purpose will be more effectually obtained; and, best of all, by spade-trenching. But a method which is equally effectual with the first, more expeditious, and which has a superiority over it in more completely destroying grubs, insects, and other vermin, which are apt to feed on the plants in their early growth, is that of paring and burning. 'This is, however, chiefly practised where the sward is rough and abounds with rushes, sedge, and other plants of the coarse kind, but might be had recourse to on others with benefit.

The time of sowing may be extended from February to July. Early sowing, however, is to be preferred, as in that case the plants come up stronger, and afford more produce the first season.

The mode of sowing is generally broadcast, but the plant might be most advantageously grown in rows and cultivated with the horse-hoe. The rows may be 9 inches or a font apart, and the seed deposited 2 inches in depth. "The quantity of seed for the broadcast method is 5 or $6 \mathrm{lbs}$. to the acre; for the drill mode, 2 lbs. are more than sufficient, the seed being smaller than that of the turnip. New seed, where it can be procured, should always be sown in preference to such as has been kept for some time; but when of the latter kind, it should be steeped for some time before it is put in to the ground.

The after-culture of the woad consists in hoeing, thinning, prong-stirring, and weeding, which operations may be practised by hand or horse-tools, as in the culture of teazle.

In respect to the business of gathering the crops, with the spring-sown ones, the leaves will generally be ready to be gathered towards the latter end of June or beginning of July, accord. ing to the nature of the soil, season, and cli mate; but for those put in at a later period ik. the summer, they are often fit to be gathered earlier. This business should, however, constantly be executed as soon as the leaves are fully grown, while they retain their perfect green colour and are highly succulent, as, when they are let remain till they begin to turn pale, much of their goodness is said to be expended, and they become less in quantity, and of an inferior quality for the purposes of the dyer. In the execution of this sort of business, a number of baskets are usually provided in proportion to the extent of the crop, into which the leaves are thrown as they are taken from the plants, which is effected by the hand, by grasping them firmly and giving them a sort of a sudden twist. In favourable seasons, where the soils are rich, the plants will often rise to the height of 8 or 10 inches; but in other circumstances they seldom attain mere than 4 or 5 ; and where the lands are well ma. 
naged in the culture of the plants, they will often afford two or three gatherings, but the best cultivators seldom take more than two, which are sometimes mixed together in the manufacturing of them. It is necessary that the after croppings, when they are taken, are constantly kept separate from the others, as they would injure the whole if blended together, and considerably diminish the value of the produce. It is said that the best method, where a third cropping is either wholly or partially made, is to keep it separate, forming it into an inferior kind of woad.

The produce is mostly from about a ton to a ton and a half of green leaves. The price varies considerably; but for woad of the prime quality it is often from $25 l$. to $30 l$. the ton, and for that of an inferior quality $6 l$. or $7 l$, and sometimes much more.

To prepare it for the dyer, it is bruised by machinery to press out the watery part; it is afterwards formed into balls and fermented, reground, and fermented in vats, where it is evaporated into cakes in the manner of indigo. The haulm is burned for manure or spread over the straw-yard, to be fermented along with straw-dung.

The use of woad in dyeing is as a basis for the black and other colours.

To save seed, leave some of the plants undenuded of their leaves the second year, and when it is ripe in July or August, treat it like turnip-seed.

The only diseases to which the woad is liable are the mildew and rust; when young it is often attacked by the fly, and obliged to be resown, and this even on winter-ploughed grass lands more than once. (Loudon.)

WOLF'S-BANE (Aconitum). A genus of ornamental, tall, free-flowering, very hardy plants, succeeding well under the shade of trees; increased by division or by seeds. All the species are to be dreaded, being of a poisonous quality, highly narcotic, and acid. 'The aconite has, however, become of great service as a narcotic in many very troublesome disorders. One species, the common wolf's-bane or monk's-hood ( $A$. napellus), is a native of Greece, but now grows wild in this country in watiry places. It is perennial in habit. Root fleshy, tapering; stem erect, simple, leafy, clothed with minute, close hairs, and terminating in a solitary, simple, upright, spike-like paricle of large, dark-blue, helmeted flowers, without scent. The nectaries are full of honey, and form the spur of the flower. Leaves deeply five-cleft, cut, with linear segments, furrowed above, and of a deep green, but pale beneath. See Aconite.

WOOD. The fibrous or ligneous substance of which the branches, trunks, and roots of trees are principally composed. In vascular trunks, the hardest wood is always in the centre. See Bark, Liber, Lrgnin, Timber, 'TrREs, \&c.

\section{WOODBINE. See Hoversuckre.}

WOUD-RLSH (Euroua, from the Gramen Luzulæ, or glow-worm grass of Bauhin). These plants are nearly related to Juncus, from which they are at once distinguished by their flat leaves. They possess little beauty, and are of 1166 the easiest culture. There are seven indigenous species, all of which are described in Smith's Eng. Flor. vol. ii. p. 177.

WOODSIA (named in honour of Josenh Woods, F. L. S., an excellent practical British botanist, who first illustrated our native species of Rosa). A genus of small ferns, of which two species only have hitherto been discovered:-the oblong Woodsia ( $W$. ilvensis), and the rounded-leaved Woodsia ( $W$.hyperborea). These ferns grow best in peat and loam mixed, and are increased by division, or by seed. 'Their roots are fibrous; fronds tufted, erect, stalked, pinnate, pinnatifid, clothed with simple hairs, or narrow-pointed scales. (Smith's Eng. Flor. vol. iv. p. 322.)

WOOD-SORREL (Oxalis, from oxys, acid; the leaves have an acid taste). Most of the plants of this genus deserve cultivating on account of their very pretty blossoms, which are produced in great abundance. The hardy species should be planted in a shady border, where they will grow and flower very freely. The seeds of the hardy annual species may be sown in the open border in spring. There are in England two wild native species,-1. The common wood-sorrel ( $O$. acetosella), which grows abundantly in groves and shady places. Stalks radical, single-flowered. Leaves ternate, inversely heart-shaped, hairy; root of many scaly joints. Leaflets of a delicate bright green, often purplish at the back, drooping at night, on long, hairy, radical, purplish font-stalks. Flowers solitary, drooping, bell-shaped, either white or purplish, always streaked with fine branching purple veins. When ripe, the blackish shining seeds are projected to a distance on the slightest touch or motion, by their elastic tunics, which remain contracted and wrinkled in the capsule. This herb is powerfully and most agreeably acid, making a refreshing and wholesome conserve with fine sugar; its flavour resembling green tea. Few of our wild flowers are more elegant.

2. Yellow procumbent wood-sorrel ( 0 . corniculata). This species is annual, growing in shady, rather moist waste ground. The root is fibrous, and it has become almost a weed in gardens. Stems branched, procumbent. Flower stalks in small umbels of yellow flowers.

Several species of oxalis have been found in the United States, among which are the following, enumerated by Nuttall. 1. O. acelosella. 2. violgcea. This species appears often to flower again late in the autumn, and is then destitute of leaves. 3. Lyoni. Рн. 4. Corniculata. 5. Stricta. 6. Dillenii. These two last are scarcely distinct species.

This genus of more than 100 species is, with a few exceptions in Europe and America, peculiarly indigenous to the Cape of Good Hope. The leaves of all the species are more or less sensitive and nictitant. (Paxton's Bot. Dict.; Smith's Eng. Flor. vol. ii. p. 323.) See Sonnez.

WOOD-WASP. See SA W-Fr.

WOOT)-WAXEN. See GreEN Wrad.

WOOL (Germ: wolle; Dutch, wol; Rus. $w o \ln a)$. The soft, hairy, or downy substance which forms the covering of sheep, and is found in smaller proportion on many other animals. It is an article which has continued 
from the earliest period down to the present day to be of primary importance, having always formed the principal part of the clothing of mankind in most temperate regions. Authors have seemed to imagine that the production of wool was confined to the sheep; practical men, however, know that there is a numerous list of animals, on whom, at some season of the year at least, wool is found.

M. Chevreul, who has long devoted himself to the examination of wool, has proved that wool contains three or four different substances. The following is the result of an examination of 100 parts of a merino fleece :-

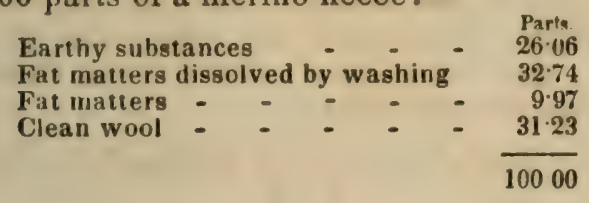

A consideration of the most important properties of wool cannot be better introduced than in the words of one to whom the agriculturist, whatever department of husbandry may chiefly occupy his attention, is much indebted. - "Fine and coarse," says Arthur Young, "are but vague and general descriptions of wool; all fine fleeces have some coarse wool, and all coarse fleeces some fine. I shall endeavour, for the information of my readers, to distinguish the various qualities of wool in the order in which they are esteemed and preferred by the manufacturer. First, fineness with close ground, that is, thick-matted ground. Second, fineness. Third, straight-haired, when broken by drawing. Fourth, elasticity, rising after compression in the hand. Fifth, staple not too long. Sixth, colour. Seventh, what coarse is in it to be very coarse. Eighth, tenacity. Ninth, not much pitch-mark; but this is no other disadvantage than the loss of weight in scouring. The bad or disagreeable properties are,-thin, grounded, toppy, curly-haired, and, if in a sorted state, little that is very fine, a tender staple, no elasticity, many dead white hairs, very yolky. 'Those who buy wool for combing and other light goods that do not want milling, wish to find length of staple, fineness of hair, whiteness, tenacity, firmness, elasticity, and not too many pitch-marks." (Annals of Agriculture, vol. xviii. p. 329.) The fineness of the wonl differs greatly on the different parts of the sheep. That running down the side of the neck, and covering the shoulders, the ribs, and the back, is the finest; the next covers the superior parts of the legs and the thighs, and extends up to nearly the haunch and the tail, and a still inferior portion runs along the upper part of the neck, the throat, the breast, the belly, and the lower part of the legs. There is considerable variation in this respect in different breeds, and in individuals of the same breed; and although a fleece, taken generally, may be said to be adapted to a particular use, yet a portion of it may be employed in the manufacture of a much more valuable article; and at the same time, a greater quantity will t.e thrown aside as not sufficiently fine for the originally intended purpose. The influence of temperature on the growth of wool is very considerable. Sheep in a hot climate will yield a comparatively coarse wool, and those in a cold climate will carry a finer, but, at the same time, a eloser and a warmer fleece. The natural instinct of the sheep would seem to teach the wool-grower the advantage of attending to the influence of temperature on him. He is evidently impatient of heat. In the open dis. trict, and where no shelter is near, he climbs to the highest parts of his walk, that if the rays of the sun must still fall on him, he may nevertheless be cooled by the breeze; but if shelter is near, of whatever kind, every shaded spot is crowded with sheep. Pasture has a very great influence on the fineness of the fleece. The staple of the wool, like every other part of the sheep, must increase in length or in bulk when the animal has a superabundance of nutriment; and, on the other hand, the secretion which forms the wool must decrease, like every other, when sufficient nourishment is not afforded. Connected with fineness is trueness of staple-as equal a growth as possible over the animal-a freedom from the shaggy portions, here and there, which are occasionally observed on poor and neglected sheep. These portions are always coarse and com. paratively worthless, and they indicate an irregular and unhealthy action of the secretion of wool, which will probably weaken or render the fibre diseased in other parts. Soundness and elasticity are also very important properties in wool.

If the pile is sound, there are few qualities in wool of so much consequence as softness. Fashion has done much in effecting this. Softness of the pile is evidently connected with the presence and quantity of yolk. There is no doubt that this substance is designed, not only to nourish the hair, but to give it richness and pliability. Bad management, neglect, exposure, starvation, impair the pliability of the woolly fibre, but chiefly so because they arrest the secretion of the yolk, or change its properties. The colour of the fleece is of minor, and yet of no trifling importance. The alteration of the colour was the first recorded improve. ment of the sheep; and its purity, its perfect whiteness, should never be lost sight of by the sheepmaster of the present day. To a certain extent, the fleece is frequently stained with the colour of the soil on which the animal grows. In some parts of Gloucestershire the wool acquires an orange colour; in Hertfordshire and Warwickshire it is of a brownish red; and in the fens of Lincoln and Cambridge it has a dark blue tint.

In some districts, and particularly in the west of England, the farmer needlessly uses a considerable quantity of ochre or ruddle, either in the composition of his salving niixture, or to gratify a foolish fancy. The tar gives consistence to the oil or butter, and although it is often with considerable difficulty washed away, yet while it remains on the fleece, it gives a permanency to the smearing process; noi one plea, however, can he offered in favour of the ruddle. See Salvivi.

It is not necessary (nor, indeed, would our space permit it) to go into the construction of wool, as seen through the microscope. We shall pass on, therefore, to point out the differ. 
ence between hair and wool. The fibre of / a single fleece; and if the besi wool of one wool is crisped or curled, the curls increasing fleece be not equal to the finest sort, it is thrown according to the fineness and felting property to a $2 \mathrm{~d}, 3 \mathrm{~d}$, or 4 th, or to a still lower sort, of an of the wool: hair is often disposed to curl, but equal degree of fineness with it. The bes' in an inferior degree. The distinction, there- English short native fleeces, such as the fine fore, between these substances is more in de- Norfolk and Southdown, are generally divided gree than intent. Wool is decidedly crisped by the wool-sorter into the following sorts, all and serrated; hair is sometimes curled, but to varying : $\mathrm{n}$ fineness from each other:-viz. an inferior degree, and the irregularities of its 1. Prime; 2. Choice; 3. Super; 4. Head; 5. edge, in some few cases, assume the form of Downrights; 6. Seconds; 7. Fine Abb; 8 . slight serrations. Wool will felt; hair will Coarse Abb; 9. Livery; 10. Short coarse, or only entangle and harle to a limited extent. breech wool. The relative value of each va. See Fret and Hair. ries, according to the greater demand for coarse,

The old and apparently simple division of fine, or middle cloths." (Youatt on Sheep; wool was into long and short, or, according to Bakewell's Observations on Wool; Luccock on the purposes to which it was devoted, "comb- Wool; Anderson on Wool.) See Alpaca, Frfieck, ing" and "clothing wool" "but there was con- LAMB-Skiss, and SHEEP.

siderable difficulty in arranging some fleeces which were of intermediate lengths, and convertible to either purpose. A third subdivision, that of " middle wool," has recently been added. These are again divided into subordinate classes, according to the fineness of the fibre. "In sorting wools," says Mr. McCulloch, "there are frequently eight or ten different species in Price of Suthdown Wool in England, in different Years.

An Account of the Quantity and declared Value of British Woollen Manufactures exported from the United Kingdom in the Year 1841. (Parl. Paper, No. 23, Sess. 1842.)

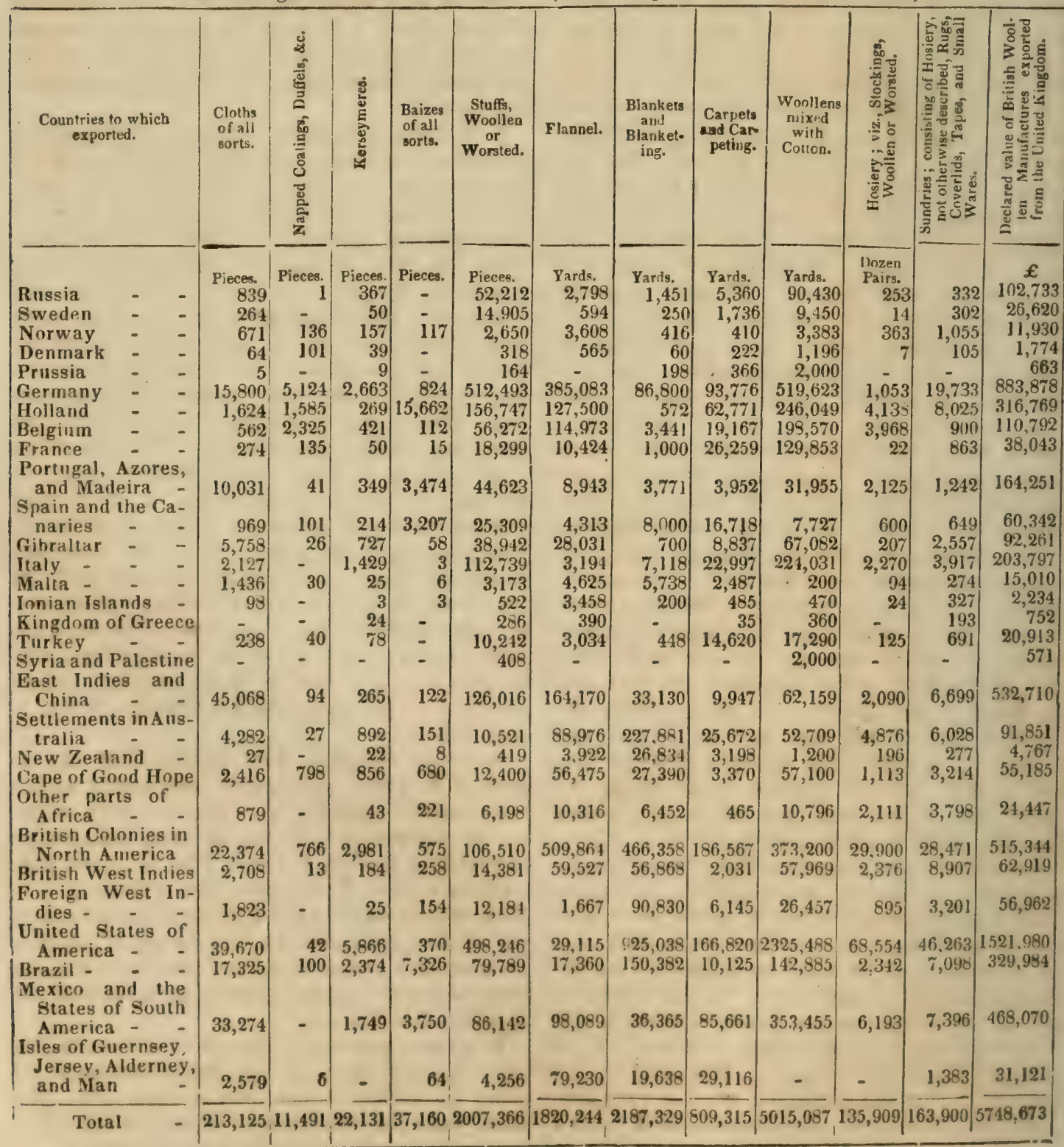


An account of Sheep and Lambs' Wool imported into Great Britain in the undermentioned Years. (McCulloch's Con. Dict.)

\begin{tabular}{|c|c|c|c|c|c|}
\hline \\
\hline In 1810 & & & & & - $\quad 10,914,137$ \\
\hline 182 & & - & & - & $9,799,0$ \\
\hline 18 & & - & - & - & - $\quad 43,795,2$ \\
\hline 18 & & - & & - & - $\quad 32,313$ \\
\hline & & - & & - & $-38,076,41$ \\
\hline 1839 & & - & & - & - $\quad 57,379,92$ \\
\hline 1841 & & - & & 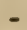 & -56170 \\
\hline
\end{tabular}

An Account of the Quantity of Sheep and Lambs' Wool imported into the United Kingdom in the Year 1841 ; specifying the Countries from which it came, the Quantity that paid a Duty of One Penny per Pound, and the Quantity that paid a Duty of One Halfpenny per Pound; of the Quantity of Foreign Wool re-exported during the same period, and the Countries 10 which it was sent; and the Quantity remaining warehoused under Bond on the 5th day of January, 1842. (Parl. Paper, No. 237, Sess. 184\%.)

Quantity of sheep and lambs' wool imported .n :o the United Kingdom:-

From Russia

Russia
Sweden and Norway
Denmark

Lbo.

- 4,131,652

- $\quad 15,424$ 165,125

- 20,958,775

121,061

- $\quad 300,862$

- $\quad 14,659$

679,071

- $1,088,200$

25,678

- 1,502,254

124,989

447,563

$\begin{array}{r}70 \\ -\quad 85.250 \\ \hline\end{array}$ $1,079,910$

3,008,664 $7,993,060$ $3,597,531$

48,590

$$
759,909
$$$$
\begin{array}{r}
-\quad 272 \\
-\quad 4,881
\end{array}
$$

4,881

5,014

58,791

318

$5,105,637$

923,832

$3,144,462$

$$
\begin{aligned}
& \text { Foreign wool - - - 56,170,974 } \\
& \text { Produce of the Isle of Man - } \quad \text { - } 8,667
\end{aligned}
$$

Quantity of foreign sheep and lambs' wool retained for home consumption :-

Charged with duty at $1 d$. per lb. Lbs. 22,051,796 Do. - at $\frac{1}{2} d$. do. - - - 14,495,002 Do - at $6 d$. do, being red wool 4,306 Duty-free, being the produce of British possessions $16,310,916$

Total quantity retained for home consump-

tion - - - _ - - 52,862,020

Quantity of foreign sheep and lambs' wool re-exported :-

To Germany -

Holland -
Belgium -
France -

Lbe.

67,517 $1,094,636$ 846,460

Portugal - - - - - - - $\quad$ - $\quad 3,927$
United States of A merica

Islands of Guernsey, Jersey, and Man : $\quad 1,971$

Total quantity re-exported - $\quad-\quad \overline{2,554,455}$ lows :-

147
5 F 2

Quantity of foreign sheep and Inmbs' wan! remaining warehoused under bond on sth January, 1812 . _ _ _ _ 6,912,060

An Account of the quantity of British Sheep und Lumbs' Wool, and Woollen Yurn, exporled from the United Kingdom in the Year 1841; sperify. ing the Countries to which they were sent. (Parl. Paper.)

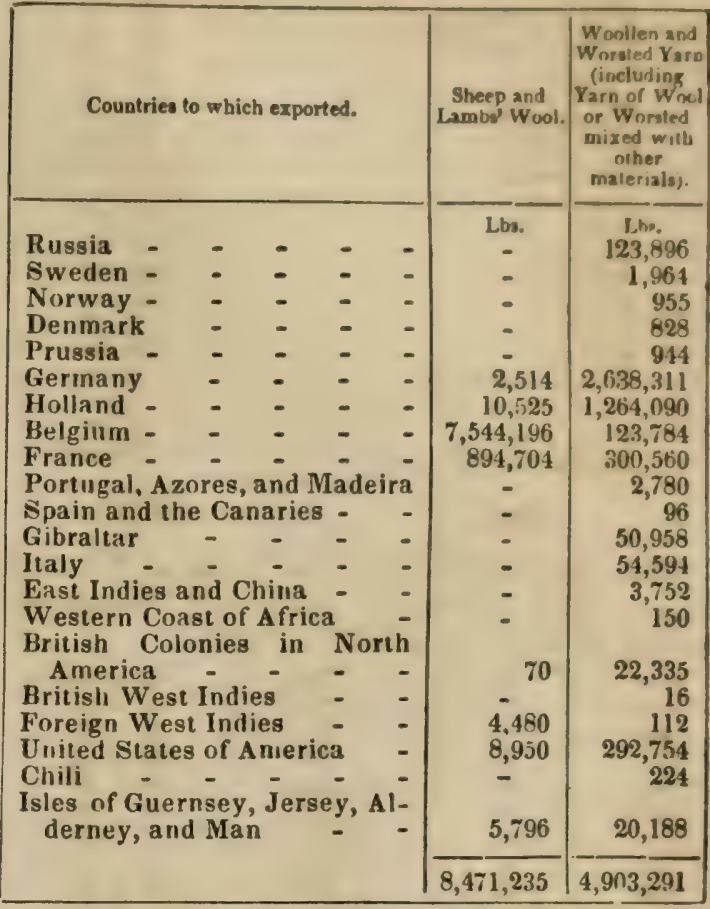

Account of the Pieces of Woollen Cloths, Cuatings, and Kerseymeres, exported in the Years 1820, 1830 , and 1840 .

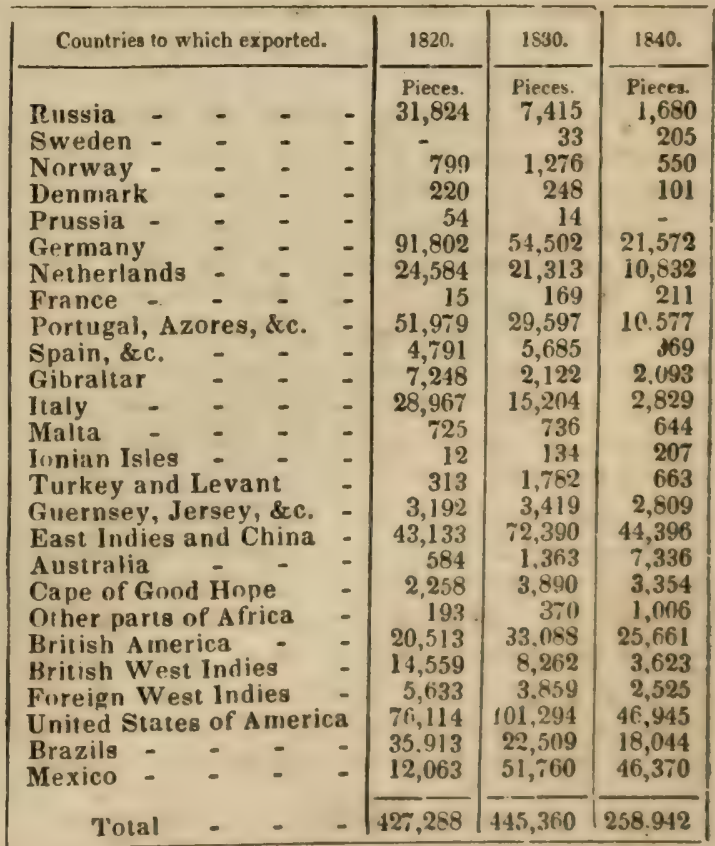

(Leeds Times, Aug. 1841.)

Under the head of Agnicurteral Products of the United States, the gross amount of wool for 1839 was stated. The proportions furnished by individual states were as $\mathrm{fo}^{\prime}$

1169 


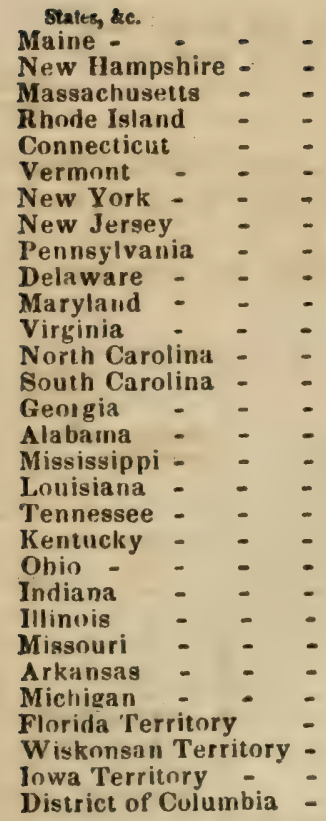

Total -
Pounds of $W$ ool.

- 1,465,551

$1,260,517$

941,906

183,830

889,870

$3,699,235$

9,845,295

397,207

- 3,048,564

64,404

488,201

$2,538,374$

625,044

299,170

371,303

220,353

175,196

49,283

$1,060,332$

$1,786,847$

$3,685,315$

$1,237,919$

650,007

562,265

61,943

153,375

7,285

6,777

707

- $35,802,114$

The following statement from a Vermont paper, (the Burlington Democrat,) shows the prices of wool from 1821 to 1843 .

\begin{tabular}{|c|c|c|c|c|}
\hline 1821 & 55 to $85 \mathrm{cts}$. & 1831 & - & 45 to $70 \mathrm{ct}$ \\
\hline 1822 & $33-65$ & 1832 & - & $42-63$ \\
\hline 1823 & $35-65$ & 1834 & - & $43-60$ \\
\hline 1824 & $25-70$ & 1835 & - & $55-65$ \\
\hline 182 & $25-70$ & 1836 & - & $60-80$ \\
\hline 18 & $25-65$ & 1838 & - & $45-47$ \\
\hline & $25-50$ & 1839 & - & $45-60$ \\
\hline & $30-50$ & 1840 & - & $43-44$ \\
\hline & $25-45$ & 1843 & - & $25-30$ \\
\hline & $38-68$ & & & \\
\hline
\end{tabular}

An interesting view of the foreign wool trade and the check upon this effected through the protection received from Congress, is exhibited in the following account derived from the columns of the New York Journal of Commerce, (for Sept. 1843.)

In a communication to the Middlebury People's Press, dated 10th July last, and signed by the Hon. William Slade, late a member of Congress from Vermont, some interesting facts are stated as to the operation of the new Tariff upon the importation of wool from foreign countries. By information received from the Register of the Treasury, it appears that during the 1 st half of the present fiscal year, which commenced on the 1st of October last, about a month after the new Tariff went into operation, there was imported into the United States, of wool costing 7 cts. a lb. or under, only 881,568 ¿bs. and of wool costing over $7 \mathrm{cts}$. a lb., only 175,962 lbs. Making a total of only $1,037,530$ lbs. of all descriptions of wool in 6 months! This is a most extraordinary falling off, compared with the importations of previous years, as will be seen from the following schedule:

$\begin{array}{llllll}\text { Year. } & & & \text { Uader 8 ets. } & & \text { Over 8 cts. } \\ 1835 & - & - & 5,543,626 & - & 388.830 \text { Ibs. } \\ 1836 & - & - & 11,033,010 & - & 806,370 \\ 1837 & - & - & 9,480,195 & - & 703,276 \\ 1838 & - & - & 6,551,126 & - & \mathbf{4 4 5}, 478 \\ 1839 & - & - & 7,398,519 & - & 527,620 \\ 1840 & - & - & 9,303,992 & - & 675,009 \\ 1841 & - & - & 11,404,764 & - & 981,281 \\ 1842 & - & - & 10,558,993 \text { Ibs. } & 351,384\end{array}$

Making, on an average of 7 years, something nver $9,000,000 \mathrm{lbs}$. per annum, $\frac{1}{13}$ ths of which, at the piace whence imported, cost less than 8

cts. a lb. The new Tariff makes the minimum 7 cts. per lb. instead of 8 cents, and levies a duty of 5 per cent. on wool not above that $\mathrm{mi}$ nimum, whereas under the old Tariff such wool was duty free. But these changes are so slight, that they are not at all sufficient to account for the immense decrease in the amount imported. Lest such should be the inference of the woolgrowers, Mr. Slade tel!s them that through the efforts of the Vermont delegation in Congress, the word "coarse" was inserted in connection with cheap wool, so that now, in order to be admitted at the low duty of 5 per cent. (which cannot exceed $3 \frac{1}{2}$ mills per $1 \mathrm{~b}$.), wool must not only have been bought at $7 \mathrm{cts}$. a $\mathrm{lb}$. or under, but must also be coarse: and he adds, "I have no doubt that with a careful and thorough execution of the coarse wool provision, according to its true intent and meaning, the reduction [in the quantity of wool imported] would have been still greater." To illustrate this point, he states the following particulars:

"It appears from the Custom House returns that 1101 sheep, of the aggregate value of $\$ 10,565$-averaging $\$ 960 \mathrm{each}$, and therefore presumed to have been merino bucks-were exported from the United States to Buenos Ayres in the years 1837 and 1838. The quantity of wool, the product of the crossings of these merino with the native South American sheep, imported into the United States at and below the value of $8 \mathrm{cts}$., cannot, of course, be ascertained. The importations from that country of wool costing $8 \mathrm{cts}$. and under, were greatly increased in the succeeding years; embracing, as is well known, much fine wool, and therefore presumed to have been the product of the crossings referred to. That increase will appear by the following statement of the importations of wool costing $8 \mathrm{cts}$. and under, from Buenos Ayres, during the years 1839, 1840, and 1841 , compared with the previous 3 years.

$$
\begin{aligned}
& \text { In } 1836 \quad \text { - } \quad \text { - } \quad \text { - 2,256,887 pounds. } \\
& 1837 \text { - } \quad \text { - } \quad-2,108,582 \\
& 1838 \text { - - - - - 2,515,883 } \\
& \begin{array}{l}
1839-\div \quad-\quad-\quad-\quad-683,535 \\
1840-566,468
\end{array} \\
& 1841 \text { - } \quad-\quad \text { - 8,870,799 }
\end{aligned}
$$

"The French blockade of Buenos Ayres in 1839 and 1840 diminished the exports of those years, and consequently swelled those of 1841 when the blockade was raised. The annual average of the 3 years was $3,373,600 \mathrm{lbs}$. That of the preceding 3 years was $2,293,784 \mathrm{lbs}$; making an excess of the average of the last 3 , over that of the first 3 years, of $1,079,816 \mathrm{lbs}$. -an increase of about $\mathbf{4 7}$ per cent.

"It was the extraordinary quantity of fine wool thus cheapened in the market of Buenos Ayres, and thrown, in large quantities, upon our own, that suggested the necessity of the introduction of the word 'coarse' into the clause in question. Its intended effect was, to subject to the higher duty all wool not coarse, though costing less than 7 cts."

This higher duty, which applies to all wool costing over $7 \mathrm{cts}$. a $\mathrm{lb}$, and, according to Mr. Slade's construction, to all wool not coarse, whatever may be its cost, is $\mathbf{3} \mathrm{cts}$. a lb. and $\mathbf{3 0}$ per cent. ad valorem. Hence the duty on wool costing 10 cts. at the place whence imported, is $6 \mathrm{cts}$. a lb.; and on wool costing $20 \mathrm{cts}$., 9 
cts. a 1b. This is a large per centage, we admit; but not so large as that established by the Tariff of 1832, which on all wool over 8 cts. a lb. levied a duty of 4 cts. a pound and 32 per cent. ad valorem. On wool costing over $8 \mathrm{cts}$., the duties during all the years embraced in the second of the above tables, except a part of 1842, were, on an average, as high as they are now. We wish this fact to be particularly noted; for it affords conclusive evidence that the smallness of the importations of wool since the new Tariff went into operation, is not occasioned by that Tariff. It is occasioned, in part, by the market having been over-stocked with coarse wool during 1841 and 1842 (nearly $17,000,000$ lbs. having been imported during those 2 years from Buenos Ayres alone),partly by the prostration of carpet manufacturing in this country for the last year or two, on account of low prices and the scarcity of money,-and partly by the cheapness of wool grown in the United States. This last is what is going, very soon, to nullify the Tariff, and importations too, so far as wool is concerned. We have no doubt that in 10 years-perhaps lesswe shall become a wool-exporting country to such an extent that protection against imported wool will be as effective as it now is against imported cotton;-and no more so. [We still lay a duty of $3 \mathrm{cts}$. a pound on cotton, which does neither hurt nor good.] The great west is coming, with her immense prairies, admirably adapted to sheep,-and she will soon deluge the country with wool and sheep-skins, as she now does with hogs, bacon, pork, lard, lardoil. snap, \&c.

WUOLLEN RAGS. See $\mathbf{R}_{A G}$.

WORK. See LAвоUR.

WORLIDGE, or WOOLRIDGE, JOHN. An ear.y English agricultural writer. But little more is known of his history, than that he was a gentleman who was a great lover of rural affairs and gardening. Of his works I am only acquainted with the following:-1. Systema Agricultura; The Mystery of Husbandry discovered and laid open, 1669-77-81, 1687, folio, 1716, 8vo. 2. Treatise on Husbandry, 1675, folio. 3. Systema Horticultura; or, The Art of Gardening, 1677. 4. Vinetum Britannicum, 1678-91, 8vo. 5. The most easy way of making Cyder, 1678. 6. Apiarium, 1691, $12 \mathrm{mo.}$

The Systema Agriculturce was the most bulky folio volume on agriculture that had yet ap. peared, and its comprehensive themes are all set forth in its first page. The authors of those days seemed to consider it essential that their readers should have, in the title-page of a book, a complete summary of its inviting contents. Woolridge was evidently of this opinion, for his title-page announces that this was the "Systema Agriculturæ, or the Mystery of Husbandry discovered; treating of the several new and most advantageous ways of tilling, planting, sowing, manureing, ordering, improveing, of all sorts of gardens, orchards, meadows, pastures, corn-lands, woods, and coppices; as also of fruits, corn-grain, pulse, new hays, cattle, fowl, beasts, bees, silk-worms, and fish, with an account of the several instruments and engines used in the profession; to which is added, Kalendarium Rusticum, or the husbandman's monthly directions; also the prognosticks of dearth, scarcity, plenty, sickness, heat, cold, frost, snow, winds, rain, hail, thunder, \&c.; and Dictionarium Rusticum, or the interpretation of rustick terms; the whole work being of great use and advantage to all that delight in that most noble practice." It is dedicated to the gentry and yeomanry of England, and opens with a preface laudatory of agriculture.

Notwithstanding, however, the ill aspect of this heavy title-page, the book contains more useful and more enlightened observations on many points of husbandry than any which had preceded it. He was a warm friend to the enclosure of commons and other waste land, and he suggested, what in fact he appears (p.21) to have carried into effect in 1665 , at Wilton, the erection of water-works for the purpose of flooding meadows, an improvement of which I think not nearly so much has been made as is possible in this land of steam and steamengines. He was evidently well acquainted with the management of water-meads, and his directions with relation to them are practical and sensible. He advises that sandy meadows should be chalked, and ashes applied to sour rushy grasses. When speaking "of several new species of hay or grass," he enumerates clover-grass, trefoyle, St. Foyn, La Lucern, ray-grass, \&c. He also recommends the deep ploughing or digging of land, and on all occasions seemed alive to any improvement in the implements of agriculture. After giving an account, at some length, of the rude and clumsy contrivance of Gabriel Platte, for a dibblingmachine, he elaborately and earnestly advocates the use of a drill, an engraving of one of which, primitive enough, it is true, in its appearance, he gives in his work. "To remove," he says, "all manner of ecrors or inconveniences that can be found in setting or hoeing of corn, I shall here give you a plain and perfect description of an easy and feasible instrument that shall disperse your corn, grain, or pulse, of what kind soever, at what distance, and in what proportion you please." The farmer may be curious to know the construction of this drill of a century and a half since. It had a coulter, a pipe, a hopper, wheels, and axletrees. He was the first English author, I believe, who suggested the use of the manure. drill, for, when speaking of the drill, he says (p. 52), "By the use of this instrument also, you may cover your grain or pulse with any rich compost you shall prepare for that purpose, either with pigeon's dung, dry or granu. lated, or any other saline or lixivial substance made disperseable, which may drop after the corn, and prove an excellent improvement; for we find experimentally, that pigeon's dung, sown by the hand on wheat or barley, mightıly advantageth it by the common way of husbandry; much more might we, therefore, expect this way, where the dung, or such like substance, is all in the same furrow with the corn, where, in the other vulgar way, a grea. part thereof comes not near it. It may eithes. be done by having another hopper, on the same frame, behind that for the corn, wherein the compost may be put, and made to drop suc. ce:sively after the corn, or it may be sown 
with another instrument to follow the former, which is the better way, and may both disperse the soil, and cover both soil and seed."

Woolridge was evidently an observer who was able and willing to think for himself. $\mathrm{He}$ advocated change of seed "from dry, hungry, barren land, to rich and fat land; also from land inclining to the south, to land inclining towards the north, and the contrary;" all of which, he well adds (and the reader must remember that Woolridge was writing when chemistry existed only in name), "are manifest signs that there is some particular thing wherein each seed delights, which if we did but understand we might properly apply it, and gain riches and honours to ourselves; but because we are ignorant thereof, and are content so to remain, we must make use of such soils, dungs, composts, and other preparations and ways of advancement of the growth of vegetables as are already discovered and made use of." (p.57.)

He extols the use of steeps for seed-corn, mentions with approbation for this purpose nitre, common salt, as well as urine, and gives a recipe for making a kind of liquid manure with sheep-dung ( $\frac{1}{2}$ bushel), saltpetre ( $\frac{1}{2}$ lb.), and common salt (1 lb.), boiled together for ten minutes in water ( 20 quarts), and this he commends very highly as a steep; and I am inclined to believe that something of this kind of rich liquor, more especially if the seed was afterwards dried by being sprinkled with some of the very fine manure powders at present proposed, such as the urate of the London Manure Company, the composition of M. Poittevin, the guano, gypsum powder, \&c., might be used more profitably by the cultivator than at first sight he may be inclined to believe. He was in favour of paring and burning on some soils, and had the good sense to discern the advantages capable of being derived from the permanent improvement of the soil by the use of earthy manures. He devotes, therefore, a chapter to the soils and manures taken from the earth (p. 65); notices the uses, for this purpose, of chalk, lime, marl, clay, fuller's earth.

The value of sand as a fertilizer did not escape our author's attention. He notices the value to some soils of that of the calcareous shores of Cornwall, and of the Suffolk craig formation, and of that which he advises the farmer to lay under his farm-yards and sheeppens.

The excrements of fowls were strongly recommended by Woolridge as a fertilizer. He describes those of pigeons and hens as "incomparable,-one load is worth ten loads of other dung;" commends the use of "all marrowbones, fish-bones, horn, or horn-shavings ;" but he fell into the error with regard to those which it required a century and a quarter to remove, viz., he fancied that all the enriching qualities of the bones were to be attributed to the grease they contained, instead of to their phosphate of lime. He advocated the mixture of peat, saw-dust, and tanners' refuse bark with dung-heaps, - a plan which is even now not nearly so extensively adopted as its merits deserve. Indeed, as honest John Woolridge corcludes his section (p. 85), "The well-pre1172 paring of dung-mixt is a piece of husbandry not to be slighted, on which point of good or ill husbandry depends the rise and fall of the rents or values of many farms in this king. dom."

Every account of live-stock given by the earlier agricultural writers betrays the total want of attention then paid by the farmers to the breeding of stock, or if they do mention the points to be commended in an ox or a sheep, they are precisely those which a modern breeder endeavours to avoid. For instance, the chronicler Hollingshed commends the Eng. lish cows for their largeness of bone, and even Woolridge, writing centuries after him, although very elaborate on most points of husbandry, treats of the farmer's live-stock in a manner that clearly indicates that in those days, to use a Norfolk phrase, "a cow was a cow, and a sheep a sheep." 'Thus all the instruction he gives the breeder with regard to the selection of a cow is, that "the best sort is the large Dutch cow, that brings two calves at one birth, and gives ordinarily two gallons of milk at one meal." His account of sheep I will also give, without abridgment, for its facts will sound still more novel to a modern farmer: - There are divers sorts, some bearing much finer wool than others: as the Herefordshire sheep about Lemster bear the fairest fleeces of any in England. Also they are of several kinds as to their proportion: some are very small, others larger. But the Dutch sheep are the largest of all, being much bigger than any I have seen in England, and yearly bear two or three lambs at a time. It is also reported that they sometimes bear lambs twice in the year." This seemed to convince Woolridge, and very naturally, too, of their value, for he adds, "It may doubtless be of very good advantage to obtain of those kinds and also of Spanish sheep that bear such fine fleeces."

The scientific modern breeder, when he smiles at this negligence and folly of a by-gone race of farmers, must remember, however, the difficulties under which they laboured, not only from lack of knowledge, but also of the means to improve at a reasonable rate their illshaped, large-boned, and slow-feeding race of oxen. He should reeollect that they had not had the advantage of a Bakewell, a Culley, or a Collings, to labour during a lengthened period for their improvement, - the days of the Smithfield Club, and of the Highland Society, were yet far distant. They had not even a suspicion of what improved breeding would effect; and if they were ignorant, as they evidently were, that their breeds were inferior, we can hardly wonder that they were content to labour on, since the very first step to improvement, a belief in greater excellence being possible, was wanting.

The opinions, however, of Woolridge with regard to plantations of timber-trees were evidently more enlightened; for although he lived a century before the days of our modern extensive planters-of such men as the Lords Athol, Devonshire, and Fife, and of Sir Henry Steuart-yet he earnestly advised the planting of the poorer soils of our island; he asked the landowners of his time, after describing to 
them the profit they might derive from such foresighted enterprise, "What can be more pleasant than to have the bounds and limits of your own property preserved, and continued from age to age by the testimony of such growing and living witnesses, in the spring yielding a reviving cordial to your winter-chilled spirit, giving you an assurance of the approaching summer by their pregnant buds and musical inhabitants? In the summer, what more delectable than the curious prospect of the variety of greenness, dark shades, and retirement from the scorching sunbeams?" He well knew, too, what some of my northern friends are only now proving to be practically the case, that "woods also finely refrigerate the air in the summer's parching heats, and qualify the dry and injurious winds, both in winter, spring, and autumn." He devotes a long chapter to the profits and pleasures of fruit trees, and ridicules very quaintly the objection too commonly made to such plantations, viz., "that their fruit would be stolen." "When," he says, "they become more common, they will be little regarded by these filchers, or if they do borrow a few sometimes in their pockets, or to make a few apple-pies withal, yet that is a poor discouragement to an ingenious spirit, and much like that rustick humour of one that would not improve a very good piece of ground for that purpose with fruit trees, hecause the parson would have the decimation of it, and so denied himself the nine parts, because the parson should not have the remainder."

Of the ploughs employed 150 years since, he mentions the double-wheeled or Hertfordshire plough, the turnwrest or Kentish plough, "which surpasseth for weight and clumsiness" the one-wheeled plough, the plain plough, and the trenching plough.

Woolridge gives also sundry directions for angling, fowling, bird-catching, horse-breeding, and sundry other rural affairs, and finally he winds up with a Kalendarium Rusticum. In these he gives various monthly directions, of which one specimen will suffice, of the mode of farming then commonly adopted. In May he directs the farmer " to kill ivy, to feed down or mow rank corn; to sow barley, buckwheat, pease, hemp, and flax, clover-grass, St. Foyn, and other French grasses; to pare and burn land, and wean lambs." He every month, as if in rivalry of the almanac-makers of former generations, treated the farmer to some poetry. often of a most absurd description; thus, in the month of March, after having told them that "this month ushers in the most welcome season of the year," and that "now gentle Zephyrus fans the sweet buds, and the crelestial drops water fair Flora's garden," he could not help adding some of his own poetry, telling them what must have been indeed novel information, that now

"The Infty mountains standing on a row,

Which hut of late were perriwigg'd with snow, Doff their old coats, and now are daily seen To stand on tiptoes all in swaggering green. Meadows and gardens are prankt up with buds, And chirping birds now chant it in the woods

Woolridge labo red hard, however, in spite of occasional absurdities of expression, to ele. vate the science of agriculture; and that it was deemed a science in the 17 th century, is evi. dent in this opening address to the farmer, when he says, "Agriculture hath been (not undeservedly) esteemed a science that principally teaches us the nature and divers properties and qualities, as well of the several soils, earths, and places, as of the several productions or creatures, whether vegetable, animal, or mineral, that naturally proceed or are artificially produced from, or maintained by, the earth." "This he promises the husbandman he will do "after a plain and familiar method." He soon, however, begins to illustrate his "plain and familiar method," by talking of the "secret, mystical, and mechanick indagations of nature, the universal spirit, or spirit of mercury and of salt;" and gives us but a mean opinion of his natural philosophy, by gravely telling us that "soon will horse-hairs receive life lying in rain-water but a few cays in the heat of the sun in spring-time."

But in spite of these occasional mistakes, the book of Woolridge was perhajs the most practical, and therefore the most useful book which had yet appeared treating of agriculture and rural affairs. The very publication of such an expensive folio, of 326 pages, betrays the increasing thirst for knowledge of the cul tivators of those days, and the same remarks apply generally to those of Platte and of Hartlib; in truth, both agriculture and agricultura! writers could hardly fail to keep pace with the rapid increase to the general stock of know ledge which the age in which they flourished received to so remarkable an extent; and this improvement was not, as my brother, Mr. George Johnson remarks (Hist. of Gard.), in only one branch of knowledge, but in the whole circle of the arts and sciences. The reformation was not confined to religion. By deliver. ing the human mind from servile thraldom; and teaching man, instead of bowing blindly to custom, merely on account of its antiquity, to have a self-dependence, it gave an impulse to improvement which no tyrant opposition of either bigotry, indolence, or self-sufficiency could check. Such men as Bacon, Peiresc, and Evelyn arose, and whilst the first traced the path which men of science should tread, the two latter lent their talents and their wealth to sustain them in the pursuit. Bacon, it has been truly observed, was the first who taught men that they were but the servants and inter. preters of nature, capable of discovering truth in no other way than by observing and imitating her operations; that facts must be collecied instead of speculations formed. and that the materials for the foundations of true sistems of knowledge were to be discovered, not in the books of the ancients, not in metaphysical theories, not in the fancies of men, but by care. ful, and laborious, and patient experiments and observations in the external world. Peiresc was a munificent man of letters; his advice, his purse were open to the votaries of every art and every science; his library was stored with the literature of every age and nation, his garden with the rarest and most useful exotics, and these last he delighted to spread over the 
country. When, indeed, we cast our eyes over a list of the men of science and literature of all kinds that adorned this age, especially in chemistry and in botany, the two sciences perhaps of all others the most important to agriculture, we need not be surprised to find how rapidly it was rising from being a mere art of empiricism; and when we note how rapidly the thirst for foreign research was prevalent, we can easily perceive how improved modes of culture and new plants were acquired to agriculture. Cavendish, but especially Kaleigh, by their visits for lucre as well as fame to the Spanish settlements of America in 1580-8, led the way in a path which Lancaster and Raymond followed in 1791, and laid the foundation of that anomalous copartnership of commercial monarchs, the East India Company. Annual fleets now returned from the east and west, laden with the curiosities of both the animal and vegetable kingdoms; of these the potato, tobacco, and tea need alone be in. stanced; and although the views of men were not yet liberal enough to prompt them to voyages of discovery, with an unmixed desire of ettending the field of science, or an enlarged wish to benefit mankind, yet new plants, in common with other hitherto strange natural products, attracted their attention, and, though at first imported as novelties, soon became by degrees to be desired and sought for as the luxuries and necessaries of life. (Quart. Jour. $A g r$ vol. xii. p. 460.)

WORM. See Cút-worm, Earth-worm, WIRE-WORM, \&c.

WORM-SEED (Chenopodium). See GoosEFoo'r.

WORMS, INTESTINAL. A troublesome sort of vermin found in the intestines of horses and other animals. There is, perhaps, nothing so destructive to the bealth and appearance of the horse as worms. When they have obtained a settlement in the intestines, neither the labour of the groom nor the liberality of the master will prove of any avail towards improving the animal's condition: for as fast as the chyle is formed from the aliment, which ought to be converted into blood, these numerous guests first satiate their craving appetites, and leave but a scanty supply for the exhausted system of the horse, so that a double allowance of corn would not preserve a healthy state; because the digestive organs cannot exert an extraordinary power for any length of time, without producing such a state of debility as to render them incapable of performing afterwards their proper office.

In these animals, the most common kinds are the following:-1. Bots, which many young horses are subject to in the spring; 2. 'Those that resemble earth-worms, and which, by physicians, are called lumbrici; 3. Those that are about the size of the largest sewing-needles, with flat heads, called ascarides; 4 . That species of worm called tania, or tape-worm. See Bors, FLUKF-Work, \&c.

WORMYOOD (Artemisia, so named in honour of Artemisia, wife of King Mausolus, or

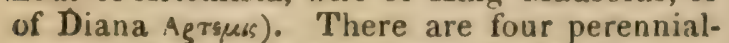
rooted bitter aromatic herbs included under ibis name, and cultivated solely for medicinal

$$
1174
$$

purposes:-Common wormwood (A. ab sinthium) is a native of almost every part of Europe, and in England is found by road-sides on heaps of rubbish, \&c. It is an erect under shrub, with hoary tri-pinnatisert leaves. 'The flowers in small, globose, nodding, racemose panicles. The same remarks apply to the drooping sea-wormwood ( $A$. maritima), which is found on salt marshes and the sea-coast. Roman wormwood ( $A$. pontica) is a native of Iraly; and Santonicum or Tartarian wormwood ( $A$. Santonica), which is a mere variety of $A$. maritima, of Persia and Siberia. The soil best suited to the growth of these plants is one that is dry, light, and poor, otherwise they become luxuriant, and are defective in their medicinal qualities, as well as in their power to withstand the rigour of the winter. Any situation will suit the common and the seawormwoods that is open and unconfined; but the exotic species require to be sheltered from the severe aspects. In a severe winter, the Tartarian can only be preserved under a frame. The sea-wormwood seldom flourishes from the want of a genial soil; the application of salt would undoubtedly be beneficial.

They are all propagated by seed, as well as slips and cuttings, the first of which may be sown in March or April, and the latter planted during June, July, and beginning of August. The seed is sown thinly broadcast, and when the plants arrive at a height of 2 or 3 inches, are weeded and thinned to 6 inches asunder; and those taken away pricked out at a similar distance, water being given if the weather is at all dry. The slips and cuttings are planted in a shady border, about 8 inches apart, and water given regularly every evening until they have taken root. They are all to be transplanted finally early in the following spring, by whichever mode they are raised, setting the plants at last 18 inches apart. See Mugwont, and SouthenNwoon.

WOUNDWORT (Stuchys, from stachys, a spike, alluding to the mode of flowering). A genus of rather weedy-looking plants, hardly worth cultivating for ornament. 'They all succeed in common garden soil. The perennial kinds are easily increased by dividing the roots in spring or autumn. The seeds of the annual kinds should be sown in spring, in the open border. As a vulnerary these plants have no power. There are five indigenous species: the hedge woundwort (S. sylvaticu); the ambiguous woundwort (S. ambigua); the marsh woundwort (S. palustris); the downy woundwort (S. germanica); and the corn woundwort (S. arvensis). The marsh woundwort has a fleshy root, creeping extensively; throwing out in autumn a number of tuberous shoots, which render it, in low, wet ground, very difficult of extirpation. 'This, therefore, should be attempted in summer before these kuobs are produced, when the flowers are appearing.

Several species of wonndwort, or hedgenettle, are found in the United States. One, called S. sylvatira, is found on the banks of the Ohio, on the skirts of thickets, giving out the same fetid odour as the European species. The flowers are, however, paler. (Nuttall.) 


\section{Y.}

YAM (Dioscorea sativa). A climbing plant, cultivated in the East and West Indies, Its roots are very large, flattened, sometimes palmated. It is boiled or roasted like the potato, and is wholesome, palatable, and nutritious. The flour is also used for puddings and bread. The $D$. aluta is equally cultivated; its root is 3 feet long, and often weighs $30 \mathrm{lbs}$. Of both kinds there are numerous varieties.

YARD-DUNG. See Farm-Yand Manure.

YARD OF LAND. A quantity of land which in some counties in England signifies 15 acres, in some 20 , and in others 24,30 , and 34 acres.

YARROW (Achillea). A genus of showy, free-flowering plants, succeeding well in any common soil, and readily increased by dividing the roots. The species are possessed of aromatic, bitter, tonic, and stimulating qualities. In England the following are indigenous perennials :-

1. Sneezewort yarrow, or goose-tongue ( $A$. ptarmica), which grows in wet hedges, or about the banks of rivers, flowering in July and August. The root creeps widely, and is difficult of extirpation where the soil is moist. Stems upright, about 2 feet high; corymbose at the top. Leaves sessile, linear, pointed, equally and sharply serrated, and of a glaucous green. Flowers numerous, small, milk-white in the disk as well as in the radius, with an irregular number of ligulate florets. The whole plant has a pungent flavour, provoking a flow of saliva, and this flavour renders it acceptable, as Schreber asserts, to sheep, who delight especially in saltish food. The sneezing caused by the dried and powdered leaves is rather owing to their little, sharp, marginal prickles. Its name is derived from this property of causing sneezing.

2. Serrated yarrow ( $A$. serrata). This is a much less common species, in which the root is fillrous, leaves linear, lanceolate, downy, deeply serrated. Flowers of a yellowish-white or buff colour, not half the size of the foregoing. The whole herb has a powerful aromatic scent and bitter flavour, somewhat like tansy.

3. Common yarrow or milfoil ( $A$. millifolium), $\mathrm{Pl} .9, k$. This species grows abundantly in English meadows and pastures. The root is creeping, with smooth, reddish, subterraneous shoots, which are warm and agreeably pungent, partaking of the flavour and salivating quality of the pellitory of Spain ( $A$. pyrethum). Stems furrowed, erect, about a foot high. Leaves doubly pinnatifid, hairy; segments linear, toothed, pointed. Flowers numerous, white, occasionally reddish or purple. The whole herb is astringent, and weakly aromatic. Although considered a bad weed in pasture and arable lands, in consequence of its creeping root, Dr. Anderson and others have recommended it for cultivation; but its productive and nutrient properties are very inferior to many other plants equally adapted to light soils; 64 drachms of the leaves and stems, cut when in flower, afforded 98 grains of nutritive matter. Linnæus says that its properties are vulnerary and styptic. An essential oil is ex- tracted from the flowers; and as ointment made of the leaves is reckoned good against the scab in sheep. A. moschulu, an exotic species, a native of Italy, is sudorific and acrid, and makes a wholesome fond for cattle.

4. Woolly yellow milfoil, or yarrow ( $\mathcal{A}$. to mentosa). 'This species grows about dry hilly pastures in Scotland and Ireland. 'The root is wondy, slightly creeping, with many long fibres. Stems scarcely a foot high, curved at the base, then erect. Leaves doubly pinnatifid, woolly, segments linear, crowded, acute. Flowers densely corymbose, on woolly stalks, of a bright golden yellow. 'The whole herb, as well as the flowers, has an aromatic scent when rubbed. It serves to decorate rock-work in gardens, but will not bear wet or shade.

YEARLINGS. A term applied to calves, colts, and other young stock, when they have completed their first year.

YEAST. The froth or scum which rises on beer during the act of fermentation. (See Brewing and Fermentatios.) It contains a variety of components; among others, carbon, acetic and malic acids, alcohol, potassa, lime, a saccharine, mucilaginous extract, gluten, and water.

Yeast is an article of the greatest importance in domestic economy, forming a necessary ingredient in the manufacture of bread, which would otherwise become heavy and unwholesome. When put in contact with saccharine matters, at a temperature of between $50^{\circ}$ and $60^{\circ}$, it causes fermentation, and changes the sugar into alcohol and carbonic acid. Yeast may be dried and yet retain its properties, but a temperature of $212^{\circ}$ destroys it.

The yeast prepared by the Hungarians will keep for a whole twelvemonth. During the summer season they boil a quantity of wheaten bran and hops in water; the decoction is not long in fermenting, and when this has taken place they throw in a sufficient portion of bran to form the whole into a thick paste, which they work into balls, that are afterwards dried by a slow heat. When wanted for use they are broken, and boiling water is poured upon them; having stood a proper time, the fluid is decanted, and in a fit state for leavening bread. See Brean.

"The substance called yeast or ferment, derives its name from the power it possesses of causing fermentation in sugar, or saccharine vegetable juices. It possesses," says Liebig, "all the characters of a compound of nitrogen in the state of putrefaction and eremacausis.

"Like wood in the state of eremacausis, yeast converts the oxygen of the surrounding air into carbonic acid, but it also evolves this gas from its own mass, like bodies in the state of putrefaction. (Colin.) When kept under water, it emits carbonic acid, accompanied by gases of an offensive smell (Thénard), and is at last converted into a substance resembling old cheese. (Prousl.) But when its own putrefaction is completed, it has no longer the power of inducing fermentation in other bodies. The presence of water is quite necessary for sustaining the properties of ferment, for by simple pressure its power to excite fermentation is much di minished, and is completely destroyed by drv 
ing. Its action is arrested also by the temperature of boiling water, by alcohol, common salt, an excess of sugar, oxide of mercury, corrosive sublimate, pyroligneous acid, sulphurous acid, nitrate of silver, volatile oils, and, in short, by all antiseptic substances.

"The insoluble part of the substance called ferment does not cause fermentation. For when the yeast from wine or beer is carefully washed with water, care being taken that it is always covered with this fluid, the residue does not produce fermentation.

"The soluble part of ferment likewise does not excite fermentation. An aqueous infusion of yeast may be mixed with a solution of sugar, and preserved in vessels from which the air is excluded, without either experiencing the slightest change. What then, we may ask, is the matter in ferment which excites fermentation, if neither the soluble nor insoluble parts possess the power? This question has been answered by Colin in the most satisfactory manner. He has shown that in reality it is the soluble part. Before it obtains this power, the decanted infusion must be allowed to cool in contact with the air, and to remain some time exposed to its action. When introduced into a solution of sugar in this state, it produces a brisk fermentation; but without a previous exposure to the air it manifests no such property.

"During the fermentation of sugar by yeast, both of these substances suffer decomposition at the same time, and disappear in consequence. But if yeast be a body which excites fermentation by being itself in a state of decomposition, all other matters in the same condition should have a similar action upon sugar; and this is in reality the case. Muscle, urine, isinglass, osmazome,* albumen, cheese, gliadine, gluten, legumin, and blood, when in a state of putrefaction, have all the power of producing the putrefaction or fermentation of a solution of sugar. Yeast, which by continued washing has entirely lost the property of inducing fermentation, regains it when its putrefaction has recommenced, in consequence of its being kept in a warm situation for some iime.

"If we consider the process of the fermentaiion of pure sugar, in a practical point of view, we meet with two facts of constant occurrence. When the quantity of ferment is too small in proportion to that of the sugar, its putrefaction will be completed before the transformation of all the sugar is effected. Some sugar here remains undecomposed, because the cause of its transformation is absent, viz., contact with a body in a state of decomposition.

"But when the quantity of ferment predominates, a certain quantity of it remains after all the sugar has fermented, its decomposition proreeding very slowly, on account of its insolubility in water. This residue of ferment is still able to induce fermentation, when introduced into a fresh solution of sugar, and retains the same power until it has passed ihrough all the stages of its own transformation.

"Hence a iertain quantity of yeast is neces-

* An extractive animal matter on which the peculia hovour of broth is supposed to depend; hence its nume, from the Greek for odour and broth. sary in order to effect the transformation of certain portion of sugar, not because it acts by its quantity increasing any afinity, but because its influence depends solely on its presence, and its presence is necessary, until the last atom of sugar is decomposed.

"We have seen that ferment or yeast is a body in the state of decomposition, the atoms of which, consequently, are in a state of motion or transposition. Yeast, placed in contact with sugar, communicates to the elements of that compound the same state, in consequence of which, the constituents of the sugar arrange themselves into new and simpler forms, namely, into alcohol and carbonic acid. In these new compounds, the elements are united together by stronger affinities than they were in the sugar, and therefore under the conditions in which they were produced further decomposition is arrested.

"We know, also, that the elements of sugar assume totally different arrangements, when the substances which excite their transposition are in a different state of decomposition from the yeast just mentioned. Thus, when sugar is acted on by rennet or putrefying vegetable juices, it is not converted into alcohol and carbonic acid, but into lactic acid, mannite, and gum.

"Again, it has been shown, that yeast added to a solution of pure sugar gradually disap. pears, but that when added to vegetable juices which contain gluten as well as sugar, it is reproduced by the decomposition of the former substance.

"The yeast with which these liquids are made to ferment, has itself been originally produced from gluten.

"The conversion of gluten into yeast in these vegetable juices is dependent on the decompo. sition (fermentation) of sugar; for, when the sugar has completely disappeared, any gluten which may still remain in the liquid does not suffer change from contact with the newly deposited yeast, but retains all the characters of gluten.

"Yeast is a product of the decomposition of gluten; but it passes into a second stage of decomposition when in contact with water. On account of its being in this state of further change, yeast excites fermentation in a fresh solution of sugar, and if this second saccharine fluid should contain gluten, (should it be wort, for example,) yeast is again generated in consequence of the transposition of the ele. ments of the sugar exciting a similar change in this gluten.

"After this explanation, the idea that yeast reproduces itself as seeds reproduce seeds, cannot for a moment be entertained." (Liebig.)

YELLOW-BEAR. See Caterpillar.

YELLOW-TOP (Agrostis alba). A variety of Herds. Called also, in the New England states, White-top.

YELLOW-WEED. See Wrin.

YELLOW-WOOD (Virgilia lutea). This tree, says Michaux, is confined to that part of West Tennessee which lies between the 35 th and 37 th degrees of latitude, where it is com. monly designated by the name which is here adopted. 
This tree grows of preference on gentle de?livities, in a loose, deep, and fertile soil, and is usually accompanied by the red mulberry, coffee tree, sweet locust, black walnut, and other species whose presence evinces the richness of the land. It rarely exceeds 40 feet in height and 1 foot in diameter, and in general it does not attain even these dimensions. Its trunk is covered with a greenish bark, which is smooth instead of being furrowed like that of most other trees.

The leaves of the yellow-wood are 6 or 8 inches long on old trees, and of twice this size on young and thriving stocks. They are composed of two rows of leaflets, smooth, entire, nearly round, and about an inch and a half in diameter. The leaflets are 3,4 or 5 on each side, borne by short petioles, and surmounted by an odd one, which is supported by the common footstalk. As in the button wood, the lower part of the footstalk contains the bud, which becomes visible in plucking the leaf.

The flowers form elegant, white, pendulous bunches, a little larger than those of the locust, but less odoriferous.

The seeds of the yellow-wood also nearly resemble those of the locust, and are contained in pods that differ only in being a little narrower. The seeds are ripe in the vicinity of Nashville about the 15th of August.

YEOMAN. A term applied to the first or highest degree of cultivators in England. The yeomen are properly freeholders, and such as cultivate their own lands. This term has been derived from various words by different authors. Dr. Johnson seems to incline to the word geman, Frisick, a villager; Fortescue derives it from gemen, or yemen, Saxon for a commoner. Sir Thomas Smith's definition of a yeoman is, "a free-born Englishman who may lay out of his own free lands in yearly revenue to the sum of 40 s."

YEW TREE (Taxus). A genus of ornamental evergreen trees, well adapted for underwood, as they thrive under the shade and drip of other trees; they are also very ornamental when planted to form hedges. They will grow in any moist soil, but succeed best in loams and clays. They are chiefly propagated from seeds, which should be sown as soon as ripe; but can also be increased by cuttings formed of either one or two years' wood, and planted in a shady border in the beginning of April or end of $\Lambda$ ugust. In England the common yew tree (T. baccata) is the only indigenous species. The trunk is straight, with a smooth deciduous bark. Leaves two-ranked, crowded, linear, flat, about an inch long, dark green. Fruit drooping, consisting of a sweet, internally glutinous, scarlet berry. The leaves are fetid and very poisonous, and prove speedily fatal to cattle accidentally tasting them when young and tender. The berries have a sweet mawkish taste, and may be eaten without danger. The wood of the yew tree, being of extremely slow growth, is hard and tough, formerly highly valuable for making bows, but now chiefly used for fine cabinet-work or inlaying. It makes handsomer chairs than many exotic wonds.

YOKF. A 1 -ame of wood fixed with bows 148 over the necks of oxen, whereby they are coupled together, and harnessed to the plough, \&c. It is sometimes written "yoak," and is composed -1 . of a thick piece of wood that passes over the neck, and is strictly called the "yoke;" 2. of a bow, which encompasses the neck; and 3. of the "wreathings," or "stitchings," that serve to connect the whole. Besides these parts, there are employed a ring, denominated the "yoke-ring," and a chain for securing the traces.

YOKE of land. In England, the quantity of land which a yoke of oxen can plough in a day. Hence, in some parts of Kent, a little farm, from its only requiring a yolie of oxen to till it, is called a "yokelet."

YOLK. See EgG, and Woor.

YOUNG, AR'THUR. A celebrated agricultural writer and farmer; perhaps the mosi popular author on rural affairs that England or any other country has produced. His characteristics were great zeal, enterprise, and energy, with a copious flow of plain and intelligible language, which the meanest capacity could readily comprehend; and although he possessed few claims to be ranked as a scientific farmer, yet he succeeded by his labours in exciting a general love of agriculture in the up. per classes of his countrymen, which has, since his day, never materially subsided. And this feeling, although attended, through a want of practical information, with considerable in. dividual loss, has yet produced great public advantages. It has been remarked, indeed, of the writings of Arthur Young, that they pro. duced more private losses and more public benefit than those of any other author. A memoir of this extraordinary man was published soon after his death by Dr. Paris, his friend and medical attendant.

His services to agriculture were important, and they would have been still more valuable if he had confined himself to the improvement of the science of agriculture, and avoided all those many political and party themes of which he was ever too ready to be the champion. This morbid feeling he carried with him to the Board of Agriculture; and, in consequence, both Arthur Young and the board of which he was long the chief spirit, experienced the same fate,-they obtained the support of only a section of the farmers of England, and they much too often laid themselves open to the charge of being more intent upon the advancement of the interests of their party than of thuse of practical agriculture. Thus the very first sentence of the first volume of the Annals of Agriculture, published in 1790, is as follows ;- "The parties of one country and the debility of another having at last extinguished the torch of discord;" and the entire essay comprehends hardly any thing else than a political survey of the state of the kingdom, and its possessions, fisheries, \&c. It speaks with much zeal of the French Revolution, union with Ireland, customs, exports, tonnage, produce of the taxes, population, national debt, West Indian plantations of Great Britain; indulge- : all kinds of visions; gives a statement of what the editor would do if he were made a king, \&c. \&c.; and hardly a page is reserved for practical $5 \mathrm{G}$ 1177 


\section{agriculture, of which his work was to be "the annals."}

Arthur Young was the descendant of a respectable family, who had resided on their estate at Bradfield Combust, near Bury St. Edmund's, in the county of Suffolk, for more than two centuries; he was born in I,ondon, on the 7th of September, 1741. His father, the Reverend Arthur Young, rector of Bradfield, had three children; John, and a daughter Elizabeth; the third was Arthur, the subject of the present memoir, who was educated at Lavenham, a school about six miles from Bradfield Hall.

Arthur Young was brought up for mercantile pursuits, in a merchant's counting-house at Lynn, where, at the age of 17 , he commenced his literary career by writing a political pamphlet, entitled The Theatre of the present War in North America; and then four novels-The Fuir American, Sir Charles Beaufort, Lucy Watson, and Julia. Benson, or the Innocent Sufferer. In 1763 he returned from the residence of his uncle in London to his mother at Bradfield Hall, without any prospect of a pursuit, profession, or employment. His whole income, during the life of his mother, arising from a copyhold farm of 20 acres, and producing only as many pounds, she was anxious that he should reside with her; and, as the lease of her farm of 80 acres would shortly expire, she urged him to undertake its cultivation, a scheme so much in unison with his taste and wishes, that he did not long hesitate in accepting her proposal, and he embarked as a farmer. Young, eager, and totally ignorant, as he then was, of every necessary detail, it is not surprising, as he used to say, that he should have squandered large sums, under golden dreams of improvements, especialIy as he had a thirst for experiment, without a knowledge of what is demanded for its success. In this year (1765) he married Miss Martha Allen, of Lynn, and in the year 1767 undertook the management of the farm of Samford Hall, in Essex, which consisted of about 300 acres of land. Various unforeseen circumstances, and embarrassments from the want of capital, soon induced him to give 100\%, to a farmer for taking the estate off his hands; and this farmer, by the advantages of capital, realized a fortune upon it. It was here, uniting the plough with the pen, that he wrote his work entitled, Political Essays on the Present State of the British Empire, but which was not published until 1772, in 1 vol. 4 to. He now advertised for another farm, and the knowledge which resulted from viewing the different estates that were on this occasion presented to his notice, furnished him with the materials for his tour, which he called The Six Weeks' Tour through the Southern Counties. By the advice of his Suffoll bailiff, he hired a farm of 100 acres in Hertfordshire; and, from viewing it in an uncommonly favourable season, they were both deceived in the nature of the soil. "I know not," said Young, "what epithet to give this soil; sterility falls short of the idea; a hungry, vitriolic gravelI occupied, for 9 years, the jaws of a wolf. A nabol's fortune would sink in the attempt to raise good arable crops, upon any extent, in such a country: my experience and know!adge aad increased from travelling and from prac1178 tice; but all was lost when exerte $I$ upon such a spot. I hardly wonder at a losing account. after fate had fixed me upon land calculated to swallow, without return, all that folly or im. prudence could bestow upon it." It will be here naturally asked, why he did not go to land decisively good? He answers the question very satisfactorily. "It was on account of the houses; for, although I saw numerous farms that would have suited well, they had wretched hovels on them."

Finding, about the year 1783 , that his income was barely sufficient to meet his expenditure, he engaged to report the parliamentary debates for the Morning Post; this he continued to perform for several years; and after the labours of the week, he walked every Saturday evening to his farm, a distance of 17 miles from London, from which he as regularly returned every Monday morning. This was the most anxious and laborious part of his life: ". I worked," says he, "more like a coal-heaver, though without his reward, than a man acting only from a predominant impulse." In 1774 . he published Political Arithmetic, a work which met with high consideration abroad, and was immediately translated into several languages. Mr. Young has left a memorandum which states that he received for his different writings, in the interval between the years 1766 and 1775 the sum of $3000 l$.

In 1784 he commenced the publication of his Annals of Agriculture, in which he appeared in the double capacity of editor and author, a work which he continued to the period of his blind. ness; it extends to $45 \mathrm{vols} .8 \mathrm{vo}$, and presents a vast store of information upon subjects of agriculture and political economy. The plan upon which it was conducted was one which ought to have ensured for it more extensive and profitable patronage, for, instead of recording anonymous correspondence, it refused admittance to any paper that had not the name and address of its author; it can accordingly boast of communications from the most exalted and enlightened characters in Europe, at the head of whom stands our late most gracious sovereign, who transmitted to Mr. Young for publication an account of the farm of Mr. Ducket, the able cultivator of Petersham, which is recorded in the 7th volume of the Annals, under the signature of "Ralph Robinson." During the progress of this work he travelled (and he published a popular description of his travels) over most parts of England, into Ireland, and in France.

In 1793, animated as he always was by the spirit of adventure, he could not resist an opportunity that occurred for realizing the favourite speculation he had so long entertained-that of cultivating a large tract of waste land. He accordingly completed the purchase of 4,400 acres of waste in Yorkshire. But his fates had decreed other things for him. The Board of Agriculture was established in the August of 1793, and he was immediately appointed its secretary. An individual is rarely appointed to an official situation on account of his possess. ing in an eminent degree those qualifications which its duties require; but in the instance of Mr. Xoung this was undoubtedly the facl; 
his general and profound knowledge in agriculture was the only circumstance that marked him as the most proper person to fill a situation in every respect so important and honourable. "The gratification," says he, "of being elected into so respectable a situation, in which opportunities of still giving an humble aid to the good cause of the plough could scarcely fai. of offering, would not permit me to decline the appointment; although, to a person established in the country, the salary, with the residence annexed, was not that pecuniary object which has been represented; and I must have improved on bad principles indeed, if it would not, in a few years, have turned out a more profitable speculation. (The salary was $400 \%$. per annum, with a house free from all charge.) What a change in the destination of a man's life! Instead of entering, as I proposed, the solitary lord of 4,000 acres, in the keen atmosphere of lofty rocks and mountain torrents, with a little creation rising gradually around me, making the desert smile with cultivation, and grouse give way to industrious population, active and energetic, though remote and tranquil ; and every instant of my existence making two blades of grass to grow where not one was found before-behold me at a desk, in the sinoke, the fog, the din of Whitehall. 'Society has charms;' true, and su has solitude to a mind employed. The die, however, is cast, and my steps may still be, metaphorically; said to be in the furrow."

At the Board Arthur Young continued, to his ifath, zealously employed on all occasions as its secretary, in the service of agriculture :old age at last crept on; he became blind, and afflicted with the complaint which caused his death. He was attended (concludes Dr. Paris) by Mr. Wilson, Mr. Chilver, and myself; and although the incurable nature of his disease defied every hope of permanent relief, yet his sufferings were greatly palliated by the resources of art, and he died without entertaining the least suspicion of the malady under which he suffered. Pious resignation cheered him in his illness, and not a murmur of complaint was heard to escape his lips. On the 12th of April, in the year 1820, at his house in Sackville street, after taking a glass of lemonade, and expressing himself calm and easy, he expired. His remains were conveyed to Bradfield, and deposited in a vault in the church-yard.

I have thus offered a brief sketch of the principal labours of Arthur Young, a man who filled a large space in the public eye for a long series of years, but whose name and talents appear to have commanded still greater notice and respect in foreign countries than in his own. That he reflected lustre on the age and the country in which he lived can be hardly denied. Of what other philosopher can it be said that at one time he entertained, under his humble roof, pupils of seven different nations, each of whom had been sent to him, for is structions in agriculture, by his respective government? I was lately informed by his daughter, that the late Duke of Bedford breakfasted at Bradfield on one of the mornings of a Newmarket race-meeting, and was met by pupils from Russia, France, America, Naples Poland, Sicily, and Portugal. His numerous: works are distinguished by vivacity of thought. quickness of imagination, bias to calculation, and fondness for political speculation; and had they been less successful, posterity might per. haps have regarded these traits of genius as fatal defects, and as pregnant sources of fallacy and disappointment.

YUCCA (commonly called Adam's needle) An American genus of plants found on the sandy sea-coasts of the Southern States and tropical regions, several of which are made is subserve valuable purposes. Nuttall gives the following description of the characters of the genus and individual species:-

Proper stem none; caudex inconspicuous or assurgent and shrubby; leaves comose (or crowded and terminal), ensiform, spiny at the point, sometimes with a sphacelate filamentiferous margin; flowers in a terminal, irregular panicle, each protected by two spathes; corolla white, roundish campanulate.

Species. 1. Y. filamentosa. 2. Angustifolio Sternless; leaves glaucous, long, linear, anc mucronate, margin filamentose; capsules large and dry, oblong-obovate. Habitat on the banks of the Missouri, from the confluence of the river Platte to the mountains. Flowers large and white; leaves scarcely half an inch wide.

3. Recurvifolia. In sandy fields, North Carnlina. 4. Gloriosa. Capsule internally fillert with a sweetish pulp of a purple colour. This plant is called petre by the Mexican Spaniards, and used for cordage, ropes, \&c., as well as for packing-cloth, and is extremely durable. 5. Aloifolia. There is also a 6 th species of this genus, discovered by the late Mr. John Iyons, improperly called $Y$. angustifolia by the gardeners around London; it is nearly allied to $Y$. filamentosa, but has much narrower leaves; with its specific characters I am unacquainted.

The soil and climate of East Florida are believed to be well adapted to the culture of these and many other plants, the fibres of which are converted into fabrics and cordage of greats value. The general government, a few years since, granted a large tract of land in that territory to the late Dr. Perrine for the purpose of encouraging the introduction of the Sisal hemp. and other filamentous plants and tropical productions. The recent melancholy massacre of this gentleman and his family by the Indians have frustrated these attempts, for a time at least. See HEMP.

ZAPZIEGER, or SAP-SAGO, a kind of cheese made in Switzerland. See Chersz and SAP-SAGO.

THE END. 





\section{Old Books}

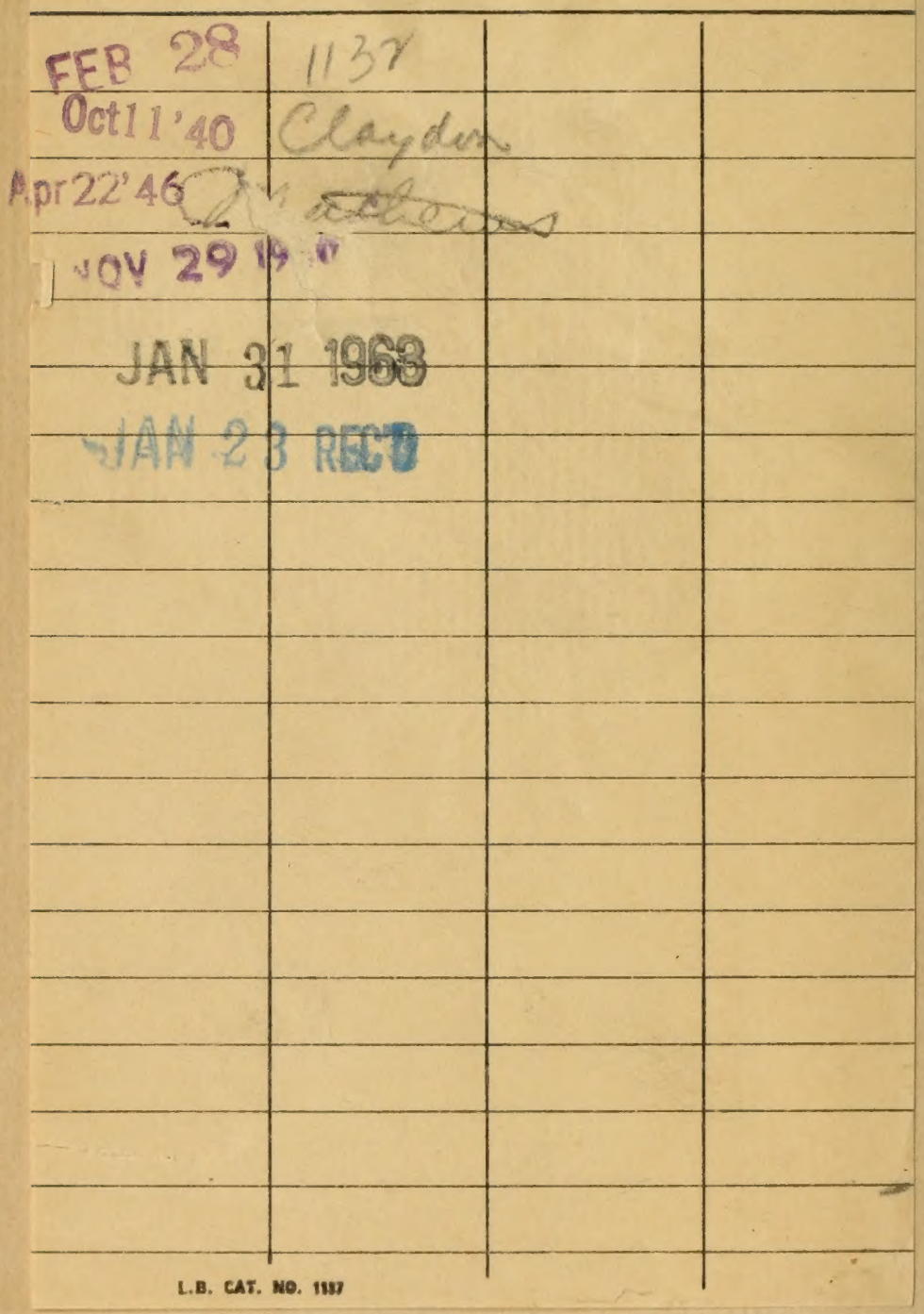




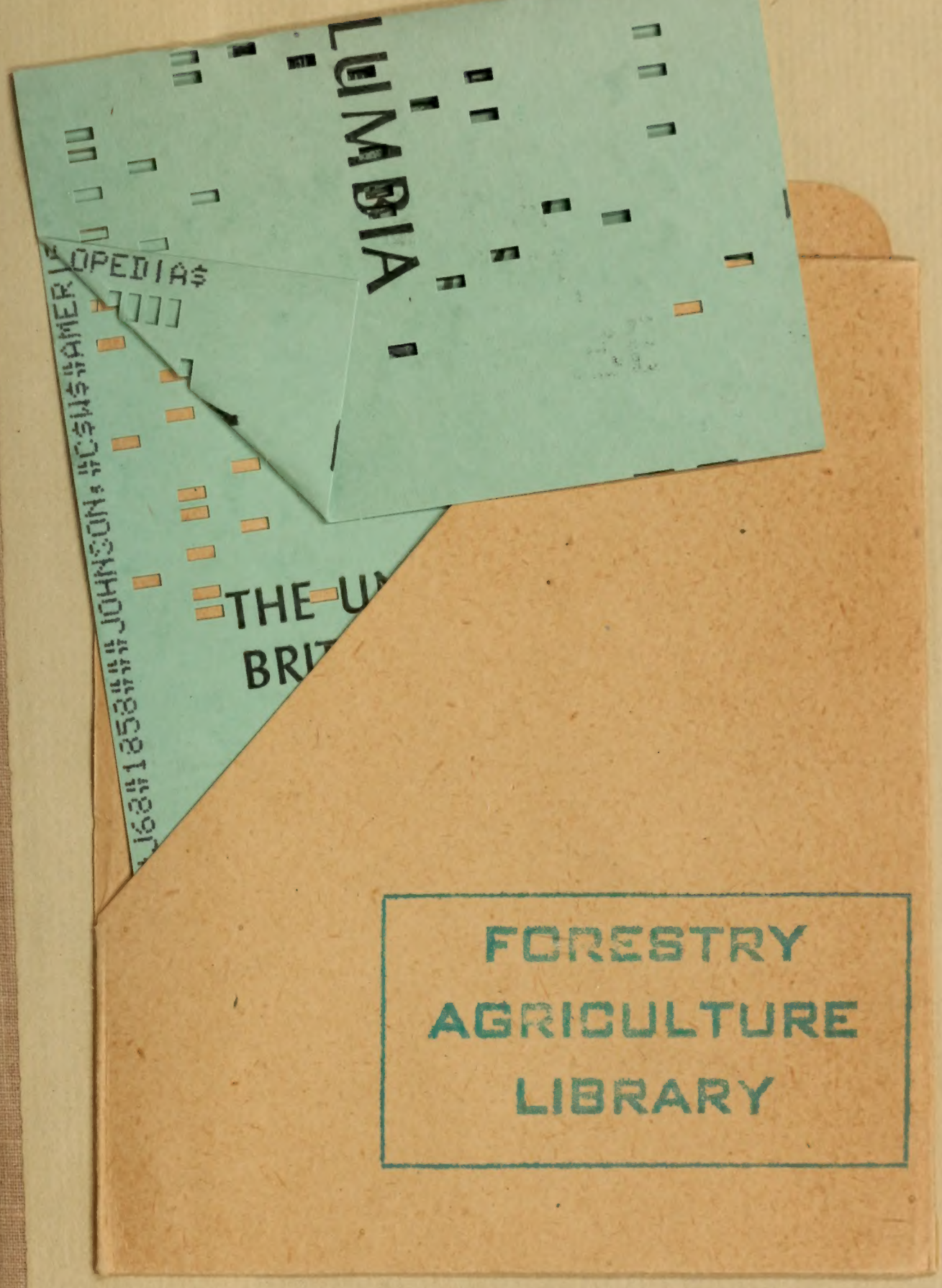


